bin - 190.

20.

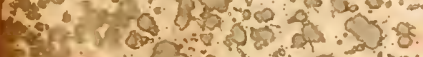

c. 8 . (2)

T. 3.50 .

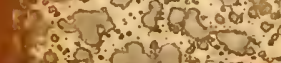

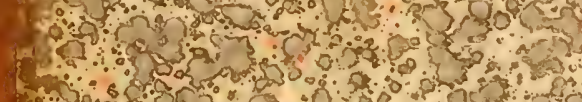

$$
\text { 3in }
$$

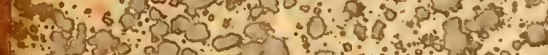

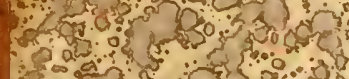

का को 0 .

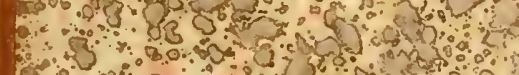

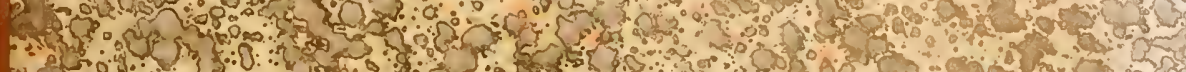

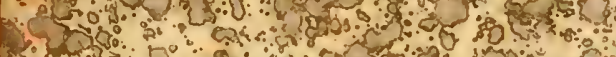

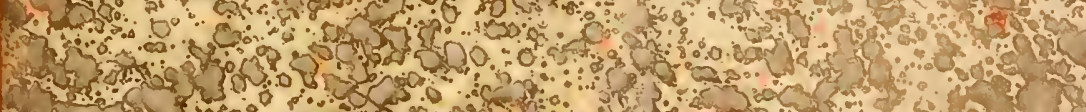

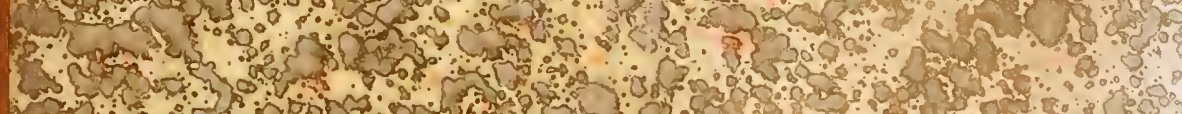
and of a. Hon a

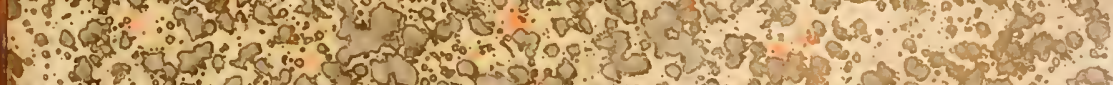

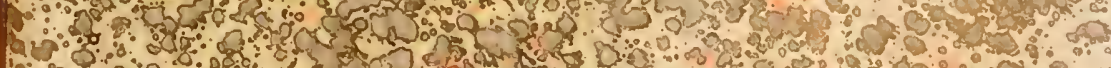

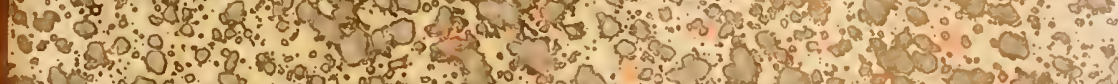
3.8.5. 130 Pि 3 a - 103 b

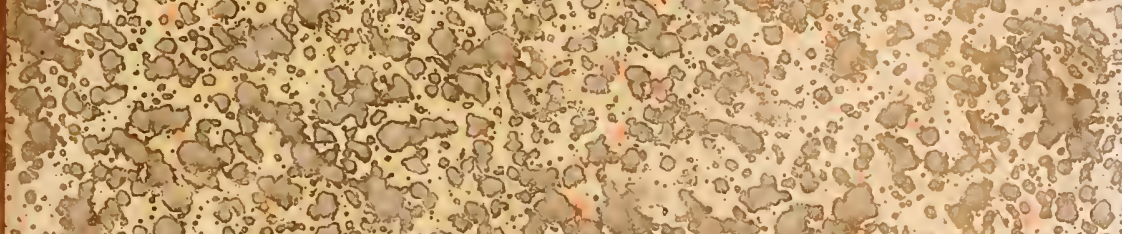
$\therefore$ -

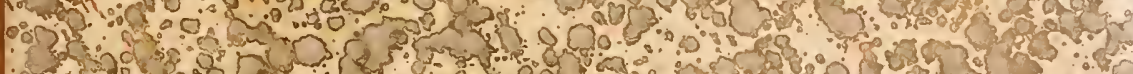

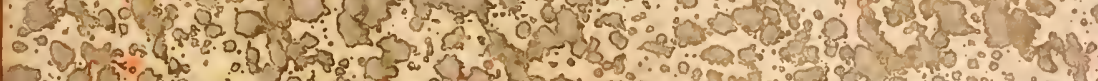

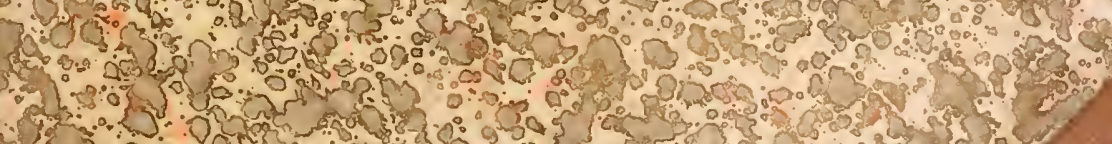

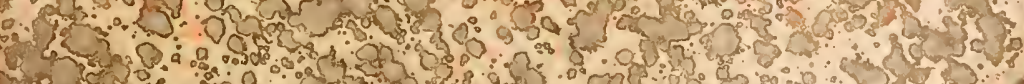







\section{ZOOLOGISCHES ZENTRALBLATT}

UNTER MITWIRKUNG VON

PliOF. ITR. O. BÜTSCHLI UND PROE. DR. B. HATSCHEK IN HEIDELABRG

IN WIEN.

HERAUSGEGEBEN YON

DR. A. S C H U B ER G

A. O. PROFESSOR IN HEIDEI,BERG

X. JAHRGANG

1903

\section{E I P Z I G}

VERLAG VON WILHELM ENGELMANN 
Druck der Kg]. Universitätsurnckerei von H. Stürtz in Würzburg. 


\section{Inhalts-Verzeichnis.}

(Alle Ziffern beziehen sich auf die Nummern der Referate.)

\section{Geschichto und Literatur.}

Ehlers, E., Göttinger Zoulogen. - (O. $\mathrm{B}$ ü t s chli)

Fickel, J., Literatur über dio Tierwelt des Königreichs Sachsen. - $(H$. Simrot h)
Köppen, Th., Gustav Ivanowitsch Radde. (N. v. Ade l ung) . . . . . . . 809 Szilády. Z., Ungarische zool. Literatur $1891-1900$ - (A. Gorka) . . 810

\section{Methodik und Technik.}

Programme und Anweisungen zu Beobachtungen und zum Anlegen von
Sammlungen im Gebiet der Naturwissenscliaften. - (N. v. A d elung) 98

\section{Anstalten und Unterricht.}

Hagmann, G., Zoologischer Garten des Huseu Goeldi in Pará (Brasilien). (F. R ömer) Biennial Report of the Illinois State Laboratory of Natural History. - (F. Zschok ke) . . 574
Petersen, C. H. J., Report of the Danish Biological Station to the Board of Agriculture. 1899 and 1900. (F. Zschokke). . . . . . . 744

Richard, L. J., Musée océanographique de Monaco. - (F. Zschokke) . . 746

\section{Lehr- und Handbücher, Sammelwerke.}

Gardiner, J. St., Unit of Classification for Systematic Biology. - (W. May) . . . . . . . . . . . 402

Haller, B., Lehrbuch der vergleichenden Anatomie. 1. - (J. W. S penge l)

Matzdorif, C., Tierkunde für den Unterricht an höheren Lelıanstalten I-IV. - (H. Simroth).
Nalepa, A., Naturgeschichte des Tierreiches. - (H. Simroth) . . . . 739

Schultz, E., Zoologie. Populäre Vorlesungen. - (E. Schultz) . . . 811

Sherborn, C. D., Index Animalium. $1758-1800$. - (E. H a r t e r t) . . 357

\section{Zellen- und Gewebelehre.}

Beard, J., Germ-Cells. I. Raja batis. - (R. Fick). . . . . . . 358

— Germ cells of Pristiuris. - (R. F i ck) 359

- Numerical law of the germ cells. - (R. Fi ck)
Beard, J., Determination of Sex in animal development. - (R. F i c k) 361, 362

Bergmann, W., Eibildung bei Anneliden und Cephalopoden. - (R. F i c k) 296 
Boveri, M., Mitosen bei einseitiger Chromosomenbindung. - (R. S. Bergh) 440

Boveri, Th., Mehrpolige Mitosen als Mittel zur Analyse des Zellkerns. (R. S. Bergh)

Delage, Yves, Théories de la Fécondation. - (R. Fick)

Friedmann, H., Chromosomen als Trä ger der Vererbungssnbstanzen. (R. Fick)

- Physiologie der Vererbung. - ( $\mathrm{K}$. Fick)

Häcker, V., Elterliche und grosselterliche Kernanteile. - (R. Fick) . . 366

Hertwig. R., Tesen und Bedentung der Befruchtung. - (R. Fick).

- Korrelation von Zell- und Kerngrösse. - (R. Fick)

Lubosch, Wilh., Eireifung der Metazoen. - (R. F i ck)

Hesse, R., Organe der Lichtempfindung bei niedern Tieren. VIII. - (R. Hesse)

Lee, A., Bolles, Nebenkern et régression du fuseau caryocinétique. - (R.Gold$\mathrm{sch} \mathrm{mid}$ )

Meves, F., Richtungshörperbildung in der Sperniatogenese. - (R. Gold$\mathrm{sch}$ midt).

Rohde, E.. Untersuchungen über den bau der Zelle. I. Kern u. Kernkörper. - (R. Cioldscli midt)
Rhumbler, L., Aggregatzustand und physikalische Besonderheiten des lebenden Zellinhaltes I. - (A.P ït te r) - Aggregatzustand und physikalische Besonderheiten des lebendenZellinhaltes. II. - (A. P ïtter).

- Nechanische Erklärung der Ähnlichkeit zwischen magnetischen Kraft. liniensystemen und Zellteilungsfiguren. - (R. G olds chmidt) . . . 572

Rouget, Ch., Phagocytose et Leucocytes hématophages. -- (J. C. H. de Meijere).

Saint-Hilaire, K., Stoffwechsel in der Zelle und in den Geweben. I. - (E. S cluct z) .

Schuberg, A., Zellverbindungen. Vorl. Ber. - (A. Sc huberg). . . . . 505

- Zellverbindungen. I. - (A. S c hu berg). . . . . . . 506

Stauffacher, Hch., Einiges äber Zellund Kernstrukturen. - (R. Goldschmidt). . . . . . . . . 573

Strassburger, Ed., Befruchtung. -

(R. Fick) d. . . $\cdot$ in Heredity.
Sutton, W., Chromosomes in - (R. Fick).

Vejdovsky, F., und Mràzek, A., Um. bildung des Cytoplasma während der Befruchtung und Zellteilung. -- R. Golds ch midt)

Ziegler, H. E., Experimentelle Studien über die Zellteilung. - (R.S. lie r gh)

\section{Vergleichende Morphologie. Physiologie und Biologie.}

Driesch, Hans, Neue Antworten und neue Fragen der Entwickelungsphysiologie. - (R. S. B ergh)

Fischel, A., Entwickelnng und OrganDifferenzierung. - (R.S. B ergh) . $44 t$

Fürth, 0. v, Vergleichende chemische Physiologie der niederen Tiere. (A. Pütter)

Korschelt, E., und Heider, K., Vergleichende Entwickelungsgeschichte der wirbellosen Tiere. - (R.S. B ergh) 445

Lenhossék, M. v., Problem der geschlechtsbestimmenden Crsachen. (A. P üt ter) .

Loeb, J., Arbeiten über die Dynamik des tierischen Wachstums. - (R.S. Bergh)

Marshail, W., Gesellige Tiere. I-IV. - (A. s chuberg) . . . . 812-815

Ostwald, W., Neve theoretische Betrachtungsweise in der Planktologie. -- (F. Z schokke)

- Theoretische Planktonstudien. I. F. Zschokke)
Pfeffer, W.. Pflanzenphysiologie. (A. Pütter).

Rádl, Em., Phototropismus der Tiere. - (A. Piitter).

Roux, W., Selbstregulation der Lebewesen. - (R. S. Bergh) . . .

Schimkewitsch, Wl., Direkte Teilung: unter kïnstlichen Bedingungen. -(R. S. Bergh)

Schultze, Bernh. S., Problem der geschlechtsbestimmenden Ursachen. (R. Fi c k) .

Schultze, Oskar, Ursachen männlicher und weiblicher Geschlechtsbildung. - (R. Fick).

Simroth, H., Ursprung der Wirbeltiere, der Schwämme und der geschlechtlichen Fortpflanzung. - (R. Fick) 132

Stolc, A., Versuche betreff. die Frage, ob sich auf ungeschlechtlichem Wege die durch mechanischen Eingriff oder das Milieu erworbenen Eigenschaften vererben. - (R. S. Bergh)

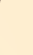


Verworn, Max, Biogenliypotliese. (A. Pütter).

Webster, R. W., Absorption of Liquids by Animal Tissues. - (A. Piitter) 448
Wedekind, W., l'arthenogenese und Sexualgesetz, - (R. Fick) . . . 372

- Junge oder Mädchen! - (R. Fick) 373

- Rudimentäre Funktion. - (R.Fick) 446

\section{Deszendenzlehre.}

Döderlein, L., Beziehungen nahe verwandter "Tierformen " zueinander. (F. v. Wagner)

Korjinsky, S., Heterogenese und Evolution. - (t). Schultz).

Pauly, A., Wabres und Falsches an Darwins Lehre. - (F. v. W a g n e r) 671
Wettstein, R. v., Neo-Lamarckismus und seine Beziehungen zum Darwinismus. - (F. v. IV a gner) . . 508

Ziegler, H. E., Derzeitiger Siand der Descendenzlehre in der Zoologie. (F. v. Wagner)

\section{Faunistik und Tiergeographie.}

Adams, Ch. S., Southeastern United States as a centre of geographical distribution of flora and fauna. (J. M e is e n heimer).

- Postglacial origin and migrations of the life of the north-eastern United States. - (J. Meisenheimer).

Amberg, 0., Biologische Notiz über den Lago di Muzzano. - (F. Zschok ke) 401

- Anhang zur vorstehenden Abhandlung über den Lago di Muzzano. (F. Z / scliokke).

Brehm, V., Zusammensetzung, Verteilung und Periodicität des Zooplanktons im Achensee. - (F.Zschokke) 284

Buffa, P., Condizioni fisiche e biologiche di taluni laghi alpini del Trentino. - (F. Zschokke)

Chun, C., Aus den Tiefen des IVeltmeers. - (F. Zs chokke).

Daday,E.v., MikroskopischeSüss wasserfauna aus Kleinasien. - ( $\mathrm{k}$. Zschokke)

- Mikioskopische Suisswassertiere der Umgebung des Balaton - $(\mathrm{k}$. Zschokke).

Davenport, C. B., Animal Ecology of the Cold Spring Sand spit. - (J. Uleisen heimer)

Erlanger, C. v., Zoogeograplie ind Ornithologie von Abyssinien. - (J. Me isen lie ime r)

Gadeau de Kerville, Recherches sur les Faunes Marine et Maritime de la Normandie. I. u. III. - (F. Zs schokke) 337

Galvagni, E., Fauna einiger dafmatinischer Inseln. - (J.M e is en he i me 1) 868

Häcker, V., Zoologische Reiseeindrïcke aus Norwegen. - (J. Il eisenhe imer)

Knipowitsch, N., Untersuchnngen an der Murman-Küste. Bd. I. - (E. Selultz)

Kobelt, W., Verbreitung der. Thierwelt Lief. 9-12. - (J. M eisen heimer) 279
Kükenthal, W., Zoologische Ergebnisse einer Reise in den Mlolukken und in Borneo. - (J. Me is en he rmer)

Kuhlgatz, Th., Fauna des Betula nanaHochmoores im Culmer Kreise in Westpreussen. - (J. M e i s e n h e i mer) 280

Lo Bianco. S., Pelagische Tiefenfänge der Maja in der Nähe ron Capri. (F. Zschok ke)

- Le pesche abissali esegnite nelle adiacenze di Capri. - (F.7s chokke) 674

Lohmann, H., Reichtum des Meeres an Plankton. - (F. Zs chok ke)

- Tier- und Ptlanzenwelt sowie Bodensedimente des Nordatlandischen Ozeans. - (Fr. Zscllokke)

Marsson, M., Fanna und Flora des verschmntzten IV assers. - (F. Zschokke) . . . . 406

Mokrzetzki, S. A., Schïdliche Tiere und Pflanzen im Gouvernement Tau. rien. - (N. v. A delung)

Monaco, Alb. Prince de, Quatrième campagne de la Princesse Alice II. - (F. \%schok ke)

Monti, R., Condizioni fisico-biologiche dei Laghi Ossolani e Valdostani. (F. Zschok ke)

Mrázek, Al., Fauna der Warmhäuser. (J. Meisenlieimer).

Oberhummer, E., Insel Cypern. - $(0$. II a s). . . . . . 452

Preble, E. A., Biological Investigation of the Hudson Bay Region. - (J. Ne is enhe imer).

Richard, J., Campagne scientifique du Yacht "Prinzesse Alice" en 1902. (F. Zschokke)

Römer, F., Meeresfauna von Spitzbergen. -- (J. Meisenheimer) . 872

Sauerwein, M. Ch., Océanographie. (F. Zschokke)

Scharff, K. F.. Attantis-problem. (J. Meisenheimer) . . . . 453 
Schnee, Tierwelt in der Jaluit-Lagune. - (J. Neisen heinter)

Schuster, W., Eingebürgerte Fremdlinge im Mainzer Becken. - (J. M e issenhei $\mathrm{mer}$ )

Shitkow, B., u. Buturlin, S., Im Norden Russlands. - (C. G revé

Thilenius, G., Ergebnisse einer Reise Jurch Oceanien. - (J. Meisen. heimer)

Voigt, M., Zooplankton des kleinen Uklei- und Plussees bei Plön. - $\mathrm{F}$. $\mathrm{Zschokke)}$

Weber, Max, Indo-australischer Archipel und die Geschichte seiner Tierwelt. - (J. Meisen he im e r)

Wesenberg-Lund, C., Faume relicte dans le lac de Furesö. - (F. '/ s c lı ok ke) 340 Zacharias, 0.. Biologische Charakte- ristik des schwarzsees bei kitzbühel in 'T'rol. - (F. Zs schok ke). . 287

Zacharias, 0., Plankton des Achensees in Tirol. - (F. Zschokke) . . . 288

- Biologische Charakteristik des Klinkerteichs zu Plön. - ( $\mathrm{F} . \mathrm{Zs} \mathrm{chokke)} 410$

- Niedere Flora und Fauna holsteinischer Moorsümpfe.- (F.Zschokke) 411

- Färbung der Gewässer durch die Anwesenheit mikroskopischer Organismen. - (F. Zs chokke) . . 41:3

- Beobachtungen an der sog. ,Stadtpfütze" zu Hohenmölsen. - (F. $\mathrm{Zschokke)......} \mathrm{.} \mathrm{.} \mathrm{.}$

Zykoff, W.. Winterplankton der Wolga bei Saratow. - (F. Zs chokk $\theta) \quad .576$

- Planktou der Altwässer des oberen Jenissees. - (F. Z schok ke) . . 74

\section{Paläontologie.}

Arnold, Ralph, Paleontology and Stratigraphy of the Varine Pliocene and Pleistocene of San Pedro, California. - (A. Tornquist)
Boili, F., Famna der Pachycardientuffe der Seiser Alp. - (A. Tornquist) 750

\section{Parasitenkunde.}

Scott, Th., Parasites of Fishes. - (F. Zs chokke)

\section{Invertebrata.}

Leon, N., Trophysema IIacckelii. - (R. v. I. endenfeld)

\section{Protozoa.}

Argutinsky, P., Malariastudien. (VI. L ii he) . . . . . . . . .577

- Malariastudion II. - (II. L üh e) .578

- Tropicaparasit (Plasmodium praccox Gr. u. Fel.) - (M. L üh e) .

Awerinzew, S., Struktur der Kalkschalen mariner Rhizopoden. - (L. Rhumbler)

Berestneff, N., Über einen neuen Blutparasiten der indischen Frösche. (M. lü ü e) . . 676, 677

Bertrand, L. und Klynens, J., La malaria. - (M. L ï h $\mathrm{e})$

Blanchard, R., Les coccidies et leur rôle pathogène. - (M. L ì h $\theta$ ) . .603

Bonnet-Eymard, G, Évolution de l'Eimeria nova. - (M. Lühe) . . . . 634

Burchardt, E., Amphioxus lanceoletus. V. Branchiocystis amphioxi. - (M. Lühe) . . . . . .

Chatin, J., Altérations nucléairos dans les cellules coccidiées. - (M. I ü he) 606
Cuénot, L., Legerella testiculi. - (M. Lüh $\mathrm{e})$. . . . . 607 Drago, U., Coccidium scyllix. - (M.L is he) 608 Durham, H. B., Drepanidium in the 'T'oad. - (M. L ïh e) .

Entz, Geza, Patagonische Protozoen. - (A. Gorka) . . . . . . . 374 - Variation der Infusurien. - (A. (rorka) . . . . . 375

Giglio-Tos, E., Coccidie parasite dans les thrombocytes de la grenouille. (II. L ül h e)

Gram, Christ., Malaria aestivo-autumnalis mit Halbmonden olne intraglobuläre Parasiten. - (M. L ü $\mathrm{h} \mathrm{e}$ ).

Grassi, B., Malaria, Nachtr. z. 2. Aufl. - (M. Lü he)

- Trasmissione della malaria umana. (II. L ü he) . . . . . . . . . 680

Gray, G., Quartan showing Cyclic Variation of Parasites. - (M. L ü li e) . 10 
Gray, St. Geo, The Malaria Parasite. Greely, A. W. Artificial P'rortuction of Spores in Monas. - (A. Piitter) . 751

Grunow, A., Protozoen - (Coccidien-?) Hrkrankung des Darmes. - (M. L ̈̈h e) 610

Holmes, S. J., Phototaxis in Volvox. (A. Pit ter)

Jacquemet, M., Coccidies des Céphalopodes. - (N. L ij he)

Jennings, H. S., Reactions to stimuli in unicellular Organism. IX. - (A. $P$ üt ter)

and $\mathrm{Cl}$. Jamieson, Reactions to stimuli in unicellular Organism. X. -- (A. $P$ ü t t e r)

Kerschbaumer, Fr., Malaria. - (M. L üh e).

Lankester, E. Ray, Terminology for the Various Stages of the Malaria Parasite. - (MI. Lüh e) . . . 579-582

Laveran, A., Altérations cellulaires produites par les coccidies. - (M. L ïl e).

- Hémogrégarines des Ophidiens. (M Lühe)

Laveran. A. et F.Mesnil, Coccidie trouvée dans la rein de la linenre cosulcutr.

( M. L Lïl l e)

- Coccidies intestinales de la Rana csculenta. - (N. T, ̈̈h e )

- Protozaires parasites dune Tortue. - (M. J ï h e)

- Protozoaires parasites d'une 'Tortue d'Asie (Damonia recresii).-(M.I. Iii lı e) 682

- Hématozoaires des Poissons marins. - (II. L ïh e)

Lazear, Jesse, W., Structure of the Malarial Parasites. - (N. L üh e) .

Léger, L. Éléments sexuels et fécondation chez le Stylorhynchus longicollis F. St. - (R. Fi ck)

- Classification des Coccidies. - Mi. Lï li $\theta$ )

- Coccidie coelomique chez Olocrates abbrcviatus. - (M. L ï he)

- Eimcria. -- (M. L ï he)

- Genre Eimcria. - (M. L ï he)

Léger, L., et O. Dubosq, Eléments sexuels et fécondation chez les Pteroccphelus. - (R. Fick)

- Grégarines et épithélium intestinal chez les Trachéates. - (M. L üh e)

Lühe, M., Die Coccidien-Literatur der letzten vier Jahre. (Zus Übers.) 603-649 Neuere Sporozoenforschung. - (M. L ïh $\theta$ ) 621,622

- Schrotausschlag der Schweme und Coccidium fuscum. - (II. L ̈̈̈le)

- Gattungsuamen Eimeria und Coccidium. - (H. L ühe).

- Befruchtungsvorgänge bei Proto. zoen. - (M. I i ï li e).
Maier, H. N.. Bau der IVimperapparate der Infusorien - (A. Schuberg) 589

Marceau, F., Karyolysus lacertarum, parasite endoglobulaire du sang des lézards. - (M. Lii he)

Maurer, G., Malariaparasiten. - (M. L $\ddot{u} \mathrm{he}$ ). . . . . . . 12 586 - Malaria perniciosa. - (M. L üh e) 684

Mesnil, F., Coccidies et paludisme. (M. L ühe)

- Classification et origine des sporozoaires. - (M. L ï li e)

- Nom générique Eimeria - (I Lü he) 628

Metzner, R., (ocridium cuniculi I. (M. L i h he)

588 Minkiewicz, R., Les Protozoaires de la Mer Noire. (E. Schulz) . .816

11 Moussu, G.. et G. Marotel, Coccidiose du monton. - (II. L ii he)

- Coccidiose intestinale du mouton. (M. L ü he)

- Coccidiose du mouton et son parasite. - (M. I, ӥ he

612 Neresheimer, E. R., Histologische Differenzierung bei heterotrichen Ciliaten. - (A. s' cluberg) . . . . 590

Pérez,Ch., Adelca mesnili. - (M.Lühe) 633

- Cycle évolutif de l'Adelea mesnili. - (M. L üh e)

Pianese, G., Coccidie oviforme. - (II. L ï he)

- Protozoon des Meerschweincliens. (M. l, üh

Ross, R. and Fielding-0uld, Life history of the parasites of malaria. - (M. I, ii he)

Ruge, R., Studium der Malariakrankheiten. - (M. L ïh e)

- Syphilis und Malaria. - (M. L ü h $\theta$ )

- Das deutsche Proteosoma. - (M. Lii he)

- Protcosomr in Ciemany - (M. hii he)

ITalariaforschuno - (II. L ü he)

Sambon. L. W., Remarks concerning the nomenclature, etiology, and propliylaxis of the intermittent fevers. (M. I, ïh e)

Schaudinn, Fritz, Studien über kranklreitserregende Protozoen. II. - (M. I. ï h e)

Generationswechsel der Coccidien und Hämosporidien. - (MI. Lü ü e) . 637

- Cienerationswechsel bei Coccidien. - (M. Lü he)

- hrankheitserregende Protozoen. I. - (M. Liih e)

Schoo, H. J. M., Over Mlalaria J. (M. L ӥ he) . . . . . . . . . 17

Sergent. E.. Coccidie du Caméléon. (II. L ü lie)

Siedlecki, M., I' Herpetophrya astoma n. g. n. sp. - (A. Schuber g). 
Siedlecki, M., C'ycle évolutif de l'.Idelea ovata. - (M. Lïh e).

- Cycle évolutif de la Caryohopha mesnilii. - (II. L ii lı e)

Siegel. C., Geschlechtliche Fintwicklung von Hacmogregarina stepanovi im Rüsselegel Plarobdella eatenigera. (M. L ii h e)

Simond. P. L., Coccidium Kermorganti. - (M. I i i he)

- Coccidium Legeri. - (M. L ïhe)

\section{1}

642

644
Stiles. Ch. W., Eimeriellu. - (M. I, ii he) 647 Thomas, J. J., Coccidia oxilormia. (M. L ii h e)

Voirin, V., Cocridium oxiforme und Coccidium fuscum, - (M. L ï he) . . . 648

Wasielewsky, C. v., Verbreitung und künstliche Übertragung der Vogelmalaria. - (H. L i î $\mathrm{e}$ ) . . . . . 689 Impfversuche mit Haemarnocba spec. ine. (Syn. Protesoma) Vorl. Mitt. (M. L, ii he)

\section{Spongiae.}

Baar, R., Hornschwämme aus dem Pacific. - (R. v. Lend en feld) . 752

Cotte, J., Gemmules de Suberites domuncula. - (R. v. Le nd enfeld)

- Choanocytes de Sycandra raphanus. - (R. v. Le nd en f eld)

- Désassimilation chez les Spongiaires. - (R. v. Lendenfeld)

- Tyrosinase chez suberites domuncula. - (R. v. Le ndenfeld)

- Manganèse et Fer chez les Éponges. - (R. v. Lendenfel d)

- Les Éponges élaborent - elles de l'amidon? - (R.v. Le ndenfeld) 512

- Nutrition chez les Spongiaires. - (R. v. Lendenfeld)

ljima, J., Walteria lenckarti Ij. - (R. v. Lendenfeld)........ . .

- Hexactinellida. III. - (R. v. Lendenfeld).

Kirkpatrick, K., South A frican Sponges. - (R. v. Lendenfeld)

- South African Sponges. II. - (R. v. Le nd enfeld)

Lendenfeld, R. v., Sipongille fragilis Leidy. - (R. v. Le n d enfeld).

- Tetraxonia. - (R. v. Lendenfeld)

Preiwisch, J., Kalksclı̈ämme aus dem Pacific. - (R. v. Lendenfeld)

Schrammen, A., Systematik der Kieselspongien. - (R. v. Le nd enfeld). 135

- Horizont der Therosiphonia nobilis

Roem. - (R. v. Lendenfeld).
Sclulize, F. E., Chaulophacus arcticus (Armauer Hansen) und Chalycosoma gracile F. E. Sch. nov. spec. - (R. v. Lendenfeld). . . . .

Sollas. Ig. B. J., Sponges collected during the "Skeat Expedition" to the Malay Peninsula. - (R. v. Lendenfeld).

- On Haddonella Topsenti, gen. et sp. n. - (R. v, Lendenfeld).. . 874

Thiele, J., Kieselschwämme von 'T'ernate. II. - (R. v. Le ndenfeld) $1 \times 6$

- Unzureichend bekannte monaxone Spongien. - (R. v. Le n d e n f el d) 754

Topsent. E., Spongiaires des côtes d'Algérie. - (R. v. L en d enfeld) 137

- Éponges nonvelles des Açores. (R. v. Lendenfeld) . . . .

- Orientation des Crinorhiza. - (R. v. Lendenfeld) .. . . . .

- Larves curassées de Thoosa armata. - (R.v. Lendenfeld)... .

Urban. F., Dermalepithel der Kalkspongien. - (R. v. Lenden feld) 516

Vosmaer, G. C. J., and J. H. Vernhout, Porifera of the Siboga-Expedition. - (R. v. Lendenfuld) . . . .

Whitelegge, Th., Lendenfelds types described in the Catalogue of Sponges in the Australian Museum. - (R. v. Lendenfeld . . . . . . 459

Wilson, H. V., Sponges collected in Porto Rico in 1899. - (R. v. Liendenfeld).

\section{Coelenterata.}

\section{Hydrozo:}

Aders, W. M., 'T'eilung von Protolydi'a Lcuckarti. - (R. Goldsehmidt) .592

Cerfontaine, P. Regeneration et Heteromorphose chez Astroides calycularis et Pennarin cacolinii. - (R.S. Bergh) 100

Dendy, A., Free-swimming Hydroid, Pelagohydre mirabilis n. gen. n. sp. - (C. Hartlanb)
Gast, R. und E. Godlewski, Regulationserscheinungen bei Pennaria Carolinii. (R. S. B e r g h)

Godlewski. E. jr., Regeneration in Tirbulrria. - (R. S. Bergh) . . . . 101

King, H. D., Further Studies on Regeneration in IIydra viridis. - (R. S. Bergh).

Morgan, T. H., Some Factor's in the Regeneration of Tubularia. - (R. S.
Be $r(\mathrm{~g} h$ ) 
Schydlowsky, A., Polypes liyilraires des mers arctiques. - (E. Selultz) \$17

Stevens, N. M., Regeneration in Antennularia ramosa. - (R. S. B ergh) 415

\section{Acalepha.}

Friedemann, 0., Postembryonale Entwicklung von Aurelia aurita. (0. Ma a s)

Hein, W., Entwicklung von Cotylortiza tubrreulata - (O. Ma a s) . . . 462

Maas, 0., Scyplomedusen der SibogaExpedition. - (O. M a a s).

\section{Anthozoa.}

Bernard, H. M., Madreporarian corals in the British Iluseum. IV. - (IV. $\mathrm{Nay}$ )

Duerden. J. E., Boring algae as Agents in the Disintegration of Corals. (W. May).

- West Indian Madreporarian Polyps. - (IV. May)
Felix, Neue Korallengattungen aus deu ostalpinen Kreideschichteı. - (IV. M a $y$ )

Gardiner, J. Stanley, South African Corals of the Genus Flabollum. (W. M a y) .

- Variation and Protandry in Flrtbellum rubrum. - (IV. M a y).

- Coral islands of the Maldives. (IV. M a y)

Hazen. P., Regeneration in the Anemone Sagarlialuciae. - (R.S. Bergh) 811

Hickson, S. J., Alcyonaria of the Maldives. I. - (IV. N a y)

Kiikenthal, W., Nepbthyidengattung aus dem südatlantischen Ozean. (IV. May) .

- Revision der Alcyonarien. II. Nephthyiden. 1. -- (W. II a y)

Lendenfeld, R. v., Arbeiten von Agassiz über die Korallriffe der Fidschiinseln. - (IV. M a y)

Moroff, Th., Octocorallien. - (W. Ma y) 418

Pratt, E. M., Mesogloeal cells of Aleyonium. - (TV. Ma y) . . . . 467 Alcyonaria of the Maldives. II. (IV. II ay).

\section{3}

\section{Echinoderna.}

Bell, F. J., Echinoderma. - (H. L udwi g)

- Echinoderms of the Maldive and Laccadive Islands. - (H. Lud wig)

Grieg, J. A., Nordlige Norges echinodermer. - (H. Lu d wig)

Hérouard, Edgard. Anatomie comparée des Echinodermes. - (H. Ludwig)

Rankin, W. M., Echinoderms collected on the IVest Coast of Greenland. (H. Lud wig)

Russo, A., Echinodermi. - (H. L i dwig) .

\section{Asteroidea.}

Delage, Yves, Parthenogenese artificielle chez lsterias glacialis. - (R. S. $\mathrm{B} \in \mathrm{r} g \mathrm{~h}$ )

Döderlein, L., Japanische Seesterne. (H. L u d w i g)

Hartmann, M., Studien am tierischen Li. - (R. Fick)

Loeb, J., Eireifung, natürlicher 'Tod und Verlängerung des Lebens beim unbefruchteten Seesternei. - (R. Fick)

Russo, A., Apparato madreporico di Antedon. - (H. L u d w ig).

\section{Ophinoide:}

Döderlein, L., Japanische Euryaliden. - (H. Lud wigr)
Koehler, R., Ophiures nouvelles. (H. Ludwig)

\section{Echinoislea.}

Ariola, V., Partenogenesi nell' $A$ bacia pustulosa. - (H. L, u d w ig)

Boveri, Th., Einfluss der Samenzelle auf die Larvencharaktere der Echiniden. - (R. S. B e r $g$ h)

Herbst, Curt, Zur Entwicklung der Seeigellarven notwendige anorganische Stoffe. - (R. S. B e r g h $)$

Loeb, J., Eggs of a Sea-Urchin Strongylocentrotus purpuratus, fertilized with the Sperm of a Starfish (1stericts ochracea). - (R. S. Bergh)

Meijere, J. C. H. de, Echiniden. (H. Lud wig)

Morgan, T. H. (iastrulation of the Partial Embryos of Sphaerechinus. - (R. S. B e r $\mathrm{gh}$ ).

Stevens, N. M., Eggs of Eehinus microtuberculatus. - (R. S. B ergh)

Teichmann, E., Beziehung zwischen Astrosphären und Furchen. - (R. S. B e r g h)

\section{Holothuriojeleal.}

Barthels, Pl.. Cuvier'sche Orane der Holothurien. - (H. Lud w i g) 
Clark. H. L. North Pacific Holothurians. - (H. Ludwig)

Euriques, P., Digestione, circolazione e assorbimento nelle Oloturie. (H. L udwig)

Hérouard, E., Holothuries provenant

\section{Vel'mes.}

Rizzo. A., Fauna elmintologica dei rettili nella provinzia di Catania. (M.Bra u n)

\section{Plathelminthes.}

Shipley, A. E., Parasites from the Soudan. - (M. Braun)

\section{Turbellaria.}

Bardeen, Ch. R., Heteromorphosis in Planarians. - (R. S. B erg h) .

Child, Ch. M., Studies on Regulation. I. Fission and Regulation in Stenostoma. - (R. S. B e r g h $)$

- Studies on Regulation. II. FormRegulation in Zooids and Pieces of Stenostoma. - (R. S. Bergh)

Curis, W. C., Life history, normal fission and reproductive organs of Planaria maculata. - (E. Bress la u)

Graff, L. V., Vorl. Mitteil. über Rhabdocoeliden I - (E. Bresslau)

- Vorl. Mitteil. uiber Rhabdocoeliden II. - (E. Bresslau)

Markow, M., Turbellarienfauna der Ungegend von Charkow. - (E) Bresslau)

Sabussow, H., Tricladenstudien. IV. - (E. Schult z)

Schockaert, R., Rijpwording van het ei van Thysanozoon Irorchi. - (R. Fick)

- Orogénèse chez Thysanozoon Brocchi. I. - (R. Fick)

- Ovogénèse chez le Thysanozoon Broc. rhi. II. - (R. Fick)

Stummer - Traunfels, R. v., Suisswasser-Polyklade ans Borneo. - (E. Bressla u)

Thacher, H. S. Regeneration of the Pharynx in Planeria marulate. (R. S. Bergh)

Zacharias, 0. , Neue Turbellarienspecies (Stenostome turgidum). - (E. Bresslau)

Trematodes.

Ariola, V., Monogratia dei Didymozoon. (i1. Britun). des campagues de la "P'rincesse Alice". - (H. Lud wig) . . . . . . .

Östergren, H., Holothurioidea of Northern Norway. - (H. Ludwig) . 14.2

Perrier. R., Holothuries. - (H. Lu dwi g).
Bossuat, E., Helmintles dans le foie. - (V. Braun)

Cohn, L., Zwei neue Distomen (I. Braun) . . . . . . . . 520

Goldschmidt, R., Zoogonus mirus Lss. - (M. Bra un)

Gronkowski, Const. V., Zum feineren Bau der Irematoden. - ( M. B ra u n) 849

Haswell, W. A., Remarkable Sporocysts. - (M. Braun) . . . 850

Hollack, J, Sexuelle Amphitypie bei Dicrocoeliinen. - (M. B ra u n) . .522

Janicki, C. v., Furchung des Eies von Gyrodactylus elegans von Norden. - ( $\mathrm{K} \mathrm{F} \mathrm{i} \mathrm{ck)}$

Johnston, G. J., Australian entozoa. II. - (.I. Braun) . . . . . 851

Looss, A., Distomen - Unterfamilie der Haploporinae. - (M. B ra un) . .

- Trematodenfauna des Triester Hafons. II. - (M. Brau n)

- Notizen zur Helminthologie. V. (M. Br a un)

Markow, M., Nouveau représentant du genre Prosthogoninitus. - (M. Braun) . . . . . . . 524

Paronae Monticelli, Generi Placunella e Trochopus. - (MI. Bra u n) . . . . 525

Rátz, I. v., Ungarische Egel. - (A. Gorka) . . . . . . 818

Stafford, J.. American Representatives of Distomum cygnoides. - (M. Bra uu)

American Representatives of Disto. mum variegatum. - (M. B rauı) . 856

Zschokke, F., Dipylidium caninum (L.) beim Menschen. - (E. Riggen. bach)

\section{C'estodes.}

Boas, J. E. V., Triplotaenia mirabilis. Cohn, L. Renus Wagrneria Nonticelli. (E. Riggen bach) . . . . .

Curtis, W. C., Crossobothrium laciniatum. - (E. Riggenbach) . . .876

Fédorov, N., Anémie bothriocéphalique. (E. Riggenbach) . . . 46r

Galli-Valerio, K., Bothriorephalus lutns Brems, chez le chat. - (E. Rigge e u b a c h) 
Haswell, W. A.. Cestode from Cestracion. - (E. Riggen bach)

Kholodkovsky, N., Ténias des Ruminants. - (E. Rigg en bach)

Linstow, 0. v., Echinococcus alceolaris und Plerocercus lachesis. - (E. Riggen bach)

- 'T'aenien aus Ceylon. - (E. Riggenbach)

Lühe, M., Nomenclatorische Berichtigung betr. die Cestodengattung Amphitrctus R. Bl. - (L. Riggen bach) 471

\section{Nemertini.}

Bergendal, D., Nordische Nemertinen. - (E. Bresslan) 6.58

- Studien über Nemertinen. iI. (E. Bresslau).
Bergendal, D.. Angaben, den hopf einiger Heteronemertinen betreffend. - Nemertinengattung Callinera Bgdl. - (E. Bressla u).

Coe, W. R., Nemertean Parasites of Crabs (Carcinonemertes). - (E. B ressla u)

- Genus Curcinonemertes. - (E. Bresslau)

Kostanecki, Ras., Reifung und Be. fruchtung des Eies von Cercbratulus muryinatus. - (R. Fick) . . . .4i2

- Abnorme Richtungskörpermitosen in befruchteten Eiern von Cere. lratulus marginatus. - (R. F'i ck) . 473

Wilson, E. B.. Cleavage and Lokalisation in the Nemertine-egg. $-\langle\mathrm{R} . \mathrm{S}$. $\mathrm{B} \theta \mathrm{r}, \mathrm{gh}$ ).

\section{Nematlelminties.}

Camerano, L., Nuova specie di Chordodes del Congo. - (O. v. Lin stow) 755 - Gordiens nouveaux ou peu connus. - (0. v. Linst ow $)$

Giard, A., Evolutions métamorphiques chez les Ascarides des Poissons. - (O. v. Linstow) .

Jerke, Parasitische Anguillula des Pferdes. - (O. v. Linstow) $\cdot$. Paraten Linstow, 0. v., Parasiten aus Siam. - Helminthologische Beobachtungen. - (O. v. Linstow) Loos, A.. Einwanderung der Ankylo. stomen von der Haut aus. - (O. v. Linstow)

Low, G. C., Filaria perstans. - $(0$. v. Linst ow)

Martini, E., Furchung und Gastrulation bei Cucullanus elegans Zed. (R. S. Bergh).

\section{Chatopoda.}

Attems, C. Graf, Anatomie und Histologie von Scololepsis fuliginosa Clap. - (J. W. Spengel)

Bretscher, K., Wasserbewohnende Oligochäten der Schweiz, - (K. Bretscher).

- Tiergeographisches ïber die Oligochäten. - (K. Bretscher) . . - Oligochäten aus Graubünden. (K. Bretscher) Oligochäten der Schwoiz. - $(K$. Bretscher) Crossland, Cyril. Marine fauna of Zanzibar. Polychaeta. I. - (J. W. S pengel)
Montgomery, T. H., Organisation of laragordius rarius (Leidy). - (O. v. Linstow)

Noè, G., Filaria labiatopapillosa Alessandrini. - (O. v. Linstow)

Shipley, A. E., Nematodes parasitic in the earthworm. - 0 . v. Linst ow

- Parasites from the Sudan. - (O. 1. Linstow)

Stiles. C. W., Hookworm disease (Uncinariosis, or Anchylostomiasis) in man. - (O. v. Linstow)

Tretiakow, D., Entwicklungsgeschichte von Gordius aquatirus Vill. - (E. Schultzl

Weinland, E., Energiegewinnung durch Zersetzung von Kohlehydrat ohne Sauerstoffzufuhr bei Ascaris lumbricoides. - (O. v. Linstow) . . 758

Zykoff, W. P. v., Wolga-Fauna. - (O. v. Linstow)

Annelides.

Fauvel, P., Annélides Polychètes de la Casamance. - (J. IV. S penge l) 305

- Annélides polychètes de la Casa. mance. - (J. W. Spengel).

- Otocystes des Annélides Polychètes. - (J. W. SpengeI)

- Tube des Pectinaires - (J.W.Spen. gel) .

Foot, K., et E. Church, Cocoons of -1llolobophora foetida. - (R. Fick). 301

- Spermatozoa of Allolohophora foctilla. - ( $\mathrm{k}$. F i ck)

Gravier, Ch., Classification des Néréidiens de Quatrefages (Lycoridiens Grube) - (J. W. S p engel)

- Nouvelles espèces du genera Ly. 
costis Savigny. Aud. et Ew. rev. (J. IV. Spengel) .

Gravier, Ch., Capitellidien d'eau donce. - (J. W. Spengel)

- Annélides polychètes d'eau donce. - (J. W. Spengel)

Janda, Victor, Regeneration des zentralen Nervensystems und Mesoblastes bei Pihynchelmis. - (R. S. bergh)

Johnson, H. P., Collateral budding in Ammelids of the genus Trupanosyllis. - (J. W. Spengel)

Oppenheimer, A., Certain sense organs of the Proboscis of the Polychaetous Annelid Rhunchobolus dibranchiatus. - ( . IV. S̈pengel)

Pratt, E. M., Polychaeta from the Falkland Islands. - (J. IV. Spen • $\mathrm{g}$ el)
Pratt, E. M., Polychaeta from the Falkland Islands. - (J. W. Spengel) 706

Treadwell, A. K., ,Artificial Parthenogenesis" in the Egg of P'orlarkc obscura. - (R. S. Bergh).

\section{Echiurida.}

Torrey, J. C., Development of the Mesublast in Thulassema. - (R. S. Bergh)

\section{Hir udinea.}

Bürger, 0., Entwicklungsgeschichte der Hirudineen. Clepsine. - (R. S. Be r $r(1)$

Sukatschoff, B., Entwicklungsgeschichte der Hirudineen. - (R. S. Be r g $\mathrm{l}_{1}$ )

\section{Prosolygria.}

Bratchiopoda.

Cumings, E. R.. Morphogenesis of Platystrophiat. -- (A. 'J'o r'nyu ist)

\section{Enteropneusta.}

Menon, K. R., Enteropneusta from Madras. - (J. W. S pengel)

\section{Arthropoda.}

\section{Crustacea.}

Eutomostraca.

Bigelow, M. A., Derelopment of Lepas. - (R. S. Berg $\mathrm{h}$ )

Brian, A., Sostituzione di nome al nuovo genere di Crostaceo Lerneide: Silvestria mihi ( $=$ Leptotrachelus. mihi). - (F. Zschokke)

Daday, E. v., Neue Cladoceren-1 rattung aus der Familie der Bosminiden. (F. Zschokke)

van Douwe, C., Süsswasser-Harpacticiden Deutschlands. - (F.Zs chok ke) 594

- Freilebende Siisswasser-Copepoden Deutschlands: Cyclops crassicutulis Sars. - (F. Zs chokke)

- Copepodenfauna Bulgailens. - (F.

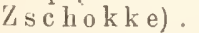

Ekmann, S. von, Phyllopodenfamilie Polyartemiidae. - (F. Zschokke) 306

- Cladoceren und freilebende Copepoden aus Ägypten und dem Sudan. - (F. Zschok ke)

Ishikawa, C., Furchungslinie bei Atycplive compressa de Hann. - (R. S. Bergh)
Lerat, $\mathbf{P}$. . Ovogénèse et spermatogénèse dı Cyclops strenuus. - (R. Fick

Meissner, W., Niedere Crustaceen des Wolga-Flusses bei Saratow. - (F. Zscllokke) . . . . . . . . 307

Merkel, F., Über Limnadia gigas (Hernann), Limnadia hermanni Brongniart. - F. Z s chokke) . . . 766

Petrunkewitsch. Alex., Reifung der parthenogenetischen Eier von Artemia salina. - (R. Fi ck) . . . . 381

Samter, M. und Heymons, R., Variationen bei Artemia salina Leach. (E. Z s chok ke)

Sars, G. 0., New South American Plyyllopod, Eulimnadia brasiliensis, G. (). Sars. - (F. Z s chokke) . 346

- On the Polyphemidae of the Cas. pian Sea. - (F. Z s cllokke) . .662 763 Scott, Th., Crustacea collected during the year 1901. - (F. Z / s chok k e) 345 - Some new and rare Crustacea. (F. Kschokke). 761 
Sharpe, R. W., Fresh-Water Ostracoda of the United States National Mnseum. - (E. Z s ch o k ke)

Zacharias, 0 ., Jahreszeitliche Variation von Hyclodaptinia kahlberyensis Schoedl. - (F. Zschokke)
II a lacostraca.

Holmes, S. J., Death - Feigmng in terrestrial Amphipods. - (A. P iitter) 597

Neher, E. M. Eye of Palaemonetes antrorum. - (R. H esse)

\section{Palaeostraca.}

Schmidt. Fr., Revision der osthaltischen silurischen Trilohiten. V. Asaphiden. II. (E. S'chultz)

Myriopoda.

Berlese, A., Acari, Myriopoda et Scorpiones hucusque in Italia reperta. XC1II.-XCVI. Myriopoda. - (K.Verho eff).

Bouin, P. v. M., Réduction chromatique chez les Myriopodes. - (R. Fick) 382

Saussure et Zehntner. Myriopodes de Madagascar: - $(\bar{K}$. Verho eff $)$
Silvestri, F.. Acari, Myriopoda et Scorpiones hucusque in Italia reperta. Ordo Pauropoda. - (K. Verho eff)

28 Verhoefi, K.. Diplopoden. J. - (K. Verho eff)

Arachinila.

Croneberg, A., Hydrachnidenfauna der Umgegent von Moskau. - $(\mathrm{R}$. Piersig).

- Hydrachnidenfauna Central-Russlands. - (R. Piersig)

Froggat, W. W., Fowl Tick. (Aigas remericnmus Packard). - (R.Piersig)

Kobert, R., Beiträge zur lienntnis der Giftspimnen. - (A. P iitter) .

Koenike, F., Acht neue Lebertir-Arten, eine Arrhenurus- und eine AtractidesArt. - (R. Piersis)

- Hydrachniden aus dem Schwarzwald. - (R. Piersig) .

Michael, A. D., British Tyroglyphidae. - (P. Piersig)

Ondemans, A. C., Sonderbare Art von Üborwinterung einer Milbe. - $(\mathrm{R}$. Piersig)

Ribaga. C., Acari sudamericani. $-(R$. Piersig)

Binnenthal, F., Richter v., Rosenschädlinge ans dem 'T'ierreiche. - (WV. MI a y)

Felt, E. P., Crude Petroleum as an Insecticide. - (W. Ma y)

Froggatt. W., Limitations of Parasites in the Destruction of Scale Insects. - (A. Hand irs ch)

- Typical Insects of Central Australia. - (N. v. Adelung)

Gross, J., Histologie des Insektenovariums. - (R. He y mons)

Needham, J. et C. Betten, Aquatic
Schtschelkanowzew, S, Anatomie der Pseudoscorpione. - (E. Sebultz) 34.

Soar, C. G., Living Hydrachnid Larvae in the stomach of a 'lrout. - (R. Piersig) .

Thor, Sig., Systematik del Acarinenfamilien Bdellidae. - (R. Piersig) 311

- South African Hydrachnids. - ( $R$. Pi ersig).

- Sperchon-Arten und itumes-Art aus der Schweiz. - (k. Piersig)

- Haut verschiedener dickhäutiger Acarina, - (R. Piersig) .

Trägårdh, J., Litorale Arten der Gattung Bulle Latr. - (R. Piorsig)

Wasmann, E., Myrmecophile Antennophorts. - (R. Piersig).

Wolcott, H. Rob., North-American species of Curripes. - (R. Piersig) 196

Insecta.

Insects in the Adirondacks. - (N. v. A de lung

Plateau, F., Attraction des insectes par les étoffes colorées et les objects brillants. - (K.W. v. D a 11 a T orre) 726

- Rapports entre les insectes et les fleurs. III. - (K. W. v. Dalla T'orre) 727

Rübsaamen, E. H., Mitteilung über die von Bornmuiller im Oriente gesammelten Zoocecidien. - (W. M a y) 703

Skottsberg, C., Einige bliitenbiologische Beobachtungen im arktischen Teil 
von schwedisch Lappland. 1900. (K. IV. v. Dalla Torre)

17 il Report of the State Entomologist. - (W. M a y)

Verhoeff, K., Coxalorgane und Genitalanhänge der 'I'racheaten. - (K. V e r' hooff) .

Zehntner, L. Insectenplagen bij de Cacaocultnur op Java. - (4. Handlirs ch)

- Proefstation voor Cacao te Salatiga.

-. (A. H a nd lirs c li

\section{Aptergota.}

Silvestri, F., Caratteri morfologici di Projapyx. - N. v. A d elung)

- Nuovo genere di Projapygidae ('Thysanura). - (N. v. A d e lung) 770

- Anajapyr resiculosus Silv. (Projapygidae, 'Thysanura.) - (N. v. A d e l ung)

Willem, V., Collemboles recueillis par l'Expédition antaretique belge. - (N. v. A de lung)

\section{() rthoptera.}

Azam, J., Orthoptères recueillis dans l'île de Chypre. - (N. v, A delung)

Baumgartner, W. J., Spermatid Transformations in Fryllus assimilis.

( R. Goldschmidt)

Burr. M., Forficularia of the Hungarian National-Museum.-(N. v. A d el ung) 107

- Earwigs of Ceylon. - (N. v. A del ung) 108

- Arrida Stål (- Trualis Fabr.). (N. v. A d e l $n 11 \mathrm{~g}$ )

Caudell, A. N., Arizona Acridiidae. (N. v. A d e $1 \mathrm{nng}$ )

Cholodkowsky, N., Speicheldrüsen von firyllus doncsticus L. - (N. v. A d e $l$ ung)

Finot, A.. Genre Euthymia. - (N. v. A d $\theta$ l u $1 \mathrm{~g}$ )

Hancock, J. L., Tettigidae of North America. - (N. v, A d elu n g)

Jacobson, G. G. und V. L. Bianchi, Gradflügler und Scheinnetzfliogler des rnssischen Reichs. - (N. v. A d e l u n g)

Krauss, H., Orthopteren Dentseh.Siidwestafrikas. - (N. v. A de l $\mathrm{ng}$ ) . 112

- Orthosterenfauna der Sahara. (N. v. Ad $\theta] u n g$ ) . 11 :

- Orthopteren aus Australien. - (N. v. A d e l u $n g$ )

Morse, A. P., New North American Ortloptera. - (N. v. A d e l u n g)

- Xiphidini of the Pacific Coast. (N. v. Adelung) .

- New Xiphidium from Florida. (N. v. A delıng)
Rehn, J., Mexican Orthoptera. - (N. v. A delung) . . . . . . . .

- Remarks on some Mexican Orthoptera. - (N. v. Adelung) . . . 40

- North American Orthoptera. - (N. v. A $d \theta l u n g$ )

Scudder, S. H., Four new species of ITippiscus. - (N. v. A d e l ung).

- Myogryllus in the United States. (N. v. A d e l u n g)

- Species of Ciryllus on the Pacific Coast. - (N. v. A delung) . .

- The Species of Diapheromera. (N. v. Adelung).

- Nortl American Orthoptera. - (N. v. A d e l $u n g)$

Stscherbakoff, A. M., Acridiodea und Locustodea von Kieff u. 'Tschernigoff. - (N. v. A d e lung)

Sutton. W. S. Chromosome Group in Brachystola magna. - (R, F ick) .663

Verhoeff, K., Nerven des Metacephalsegmentes und die Insektenordnung Oothecaria. - (K. Verhoeff). Stellung von Ilemimems. - (K. Verhoeff)

Vosseler, J., Faunistik und Biologie der Orthopteren Algeriens und Tunesiens. - (N.v. Adelu $\mathrm{ng}$ )

$$
\text { I'soudonameptera. }
$$

Child, C. M. and A. N. Young, Regeneration of the Appendages in Nymphs of the Agrionidae. - (N.v. A de J ung) 773

Enderlein, G., Europäische Psociden. - (N. v. Adel u ng) . . . . 774

- Amerikanische Psociden. - (N. v. A del u $\mathrm{n}$ ) . . . . . . . 775

Hinds, W. E., T'hysanoptera inhabiting North America. - (N. v. A d el un g) 819

Needham, J. G. and Ch. A. Hart, Dragon Flies. (Odonata) of lllinois I - (N. v. A d e l ung)

Ribaga, C., Anatomia del Tichopsocus dalii Mc. Lachl. - (N. v. A delung) 859

Silvestri, F., Termitidi e Termitofili dell' America meridionale. - (K. Escherich) . . . . . . . 482

Sjöstedt, Y., Termiten Afrikas. - (K. Escherich)

Trägårdh, J., T'ermiten ans dem Sudan. (N. v. Adelung) . . . . . . 776

Wasmann, E., Bemerkungen zu $Y$. Sjöstedts "Monographie der Termiten Afrikas". (K. Escherich) . . 481

Williamson, E. B., Indiana List of Dragon-Flies. - (N. v. Adelung) 777

$$
\text { Neuroptera. }
$$

Banks, N., New genus of Myrmeleonidae. - (N. v. Adelung) . . 50 
Banks, N., Neuropteroid Insects from Mexico. - (N. v. A d el ung) . .

\section{Rhyllchota.}

Breddin, G., Hemipteren von Celebes. - (A. H and lirs c h)

Cholodkorsky, N. A., Biologie der Blattläuse. II. - (N. v. A d el ung) 117 - Hermaphroditismus bei ChermesArten. - (A. Hand lirsch) . . 534

- Biologischer Cyclus von Chermes - viridanus Choldk. - (A. Handlirs ch)

Distant, W. L., Fauna of British India. Rhynchota I. - (A. H and lirsch)

Froggatt, W. Australian Hemiptera I. u. II. - (A. H a nd lirs ch) . . 587

- Australian Psyllidae. II. - (A. $\mathrm{H}$ a $n$ d lirs c h)

Gadd, G., Darmkanal bei den Larven von I I hrophora spumaria L. - (E. Schult $z$ )

Gossard, H. A., Two Peach Scales. - (A. Hand lir s c li)

Hijeber. Th., Catalogus Insectorum Faunae Germanicae: Hemiptera Heteroptera. - (A. H and d irs e h)

Kellogg. V. L., and S. J. Kuwana, Mallophaga from Birds. - (A. Ha udlirseh)

Kirkaldy, G. W., Hemptera. Ha nd lirs c lı)

Kuwana, S. J., Coccidae from the tialapagos Islands. - (A. II a n dlirsch)

- Coccidae of Japan. - (A. Ha ind. lirsch)

Matsumura, S., Jassinen 'Japans. (A. Hand I r s c h)

Melichar, L., Acanaloniiden und Flatiden (Homoptera). - (A. H a ndlir'sch)

Pantel, J., et R. de Sinéty, Évolution de la spermatide chez le Notonecta glanca. - R. Golds ch midt)

- Évolution de l'acrosome dans la spermatide du Notonecte.- (R. G o l d$\operatorname{sch} \mathrm{mid} t)$

- Origine du Nebenkern et les mouvements nucléiniens dans la spermatide de Notonecta glauca. - (R. (ì olds ch midt)

Reh, L., Amerikanische Obst-Schildläuse, - (A. H and lirsch)

Smith, J. B., The Rose Scale. - (A. Han di irs ch)

\section{Diptera.}

Banks, N., Eastern Species of Psychoda. - (J. C. H. de Me ijere) . 778
Becker, Th., Plıoriden. - (.I. C. H. de We jjere) . . . . . . 779

Giard, A., Ethologie des larves de Sciare medullaris. - (J. C. H. de Meijere) . . . . .

Goeldi, E., Os Mosquitos no Pará. - (J. C. H. do Meijere)

Grimshaw, P. H., Fauna Hawaiiensis (Diptera). - (J. C. H. de M eijere) 782

- und P. Speiser, Diptera (Supplement). - (J. C. H. de Meijer $\theta$ ). 788

Hendel, Fr.. Paläarktische Sciomyziden. - (J. C. H. de Meijere) .784

535 Kellogg, V. L., Extraordinary new Mari-

time Fly. - (J. C. H. de M eijere) 785

- Life-History and Structure of Blepharocera capitata Loew. - (J. C. H. de Meijere)

- Net - Winged Midges (Blepharoceridae) of North - America. - (J. C. H. de Meijere)

- Larve of the Giant Crane Fly. IIolorusia rubiginosa. - (J. C. H. de M eijere) .

Histoblasts (lmaginal Buds) of the wings and legs of the Giant CraneFly, Holomsia mbiginosa. - (J. C. H. Meijere)

786

Kertész, K., Dipteren. - (J. C. H. de Meijere)

Kohaut, R., Flöhe Ungarns. - (A. (Gorka)

Lósy, J. Biene und Bienenlaus. (A. Gork as)

Melander, A. L., Gynandromorphism in a new species of Hilara, - J. C. H. de $\mathrm{M}$ e ijere)

Metalnikofi, S., Anatomie und Physiologie der Mückenlarve. - (E. Sclultz) .

Nuttall, G. H., and A. E. Shipley, Structure and Biology of Anopheles. 1. u. II. - (J. C. H. de M e ije re) 892 547

Pergande, T., 'The ant-decapitating Fly. - (K. W. v. Dall a 'T'orre) 725

Portschinsky, J., Oestrides du Genre Oestromyia. - (N. v. A de I ung) . 144

Shipley, A. E., and E. Wilson, Stridulating organ in the mosquito. (II. L üh e)

Smith, J. B., Salt - Marsh Mosquito. - (J. C. H. Meijere)

Thomas, Fr., Dipterocecidien von Iaccinium uliginosum. - J. C. H. d e Meijere).

Trägårdh, Ivar, Dipterenlarven. I. (K. Es c heri ch)

Wagner, J., Aphanipterologische Studien. V. - (N. v. A d e l u $\mathrm{ng}$ )

$$
\text { Lepidoptera. }
$$

Agassiz. G., Coloration des ailes des papillons. - (M. v. Linden) 490 
Bachmetjew, P., Sclmetterlinge Bulgariens. - (N. v. $A \mathrm{de}$ i ung)

Bolle, J., und M. Richter, Schlafsucht der Seidenraupe - (M. v. Li nden) sfi

Cholodkorsky, N., Variations artiticielles du Papillon de l'Ortic (Iranesar urticae). -- (M. v. Linden)

Farcas, K., Energiewechsel der Seidemraupe. - (A. Gorka)

Froggatt, W. W.. The Codling Moth. (Carpocapsa pomonella Linn. - (M. v. Linden)

Giard, M. A., Évolution d'Acherontia atropos. - (M. v. Linden)

Grünberg, K., Keim- und Nihrzellen in den Hoden und Ovarien der Lepidopteren. (Vorl. Mittlg.) - (R. Gold$\mathrm{sch} \mathrm{mi}(\mathrm{t})$.

- Keim- und Nährzellen in den Hoden und Orarien der Lepidopteren. (R. Fick)

- Lieim- und Nährzellen in den Hoden und Ovarien der Lepidopteren. (R. He y mo ns)

Grum-Grshimailo, Gr., Lepidoptera nova vel parum cognita regionis palaearcticae. I. - (N. v. Adelung) 148 Lepidopteri. II. - (N. v. A delung)

Heath, E. F., Lepidoptera of 1901 in Southern Manitoba. - (M. V. T,illde n)

Hermes, 0., Naclitschwärmer in Rovigno. - (M. v. L i in d e n)

Hirschler, Jan, Regenerationsvorgänge bei Lepidopterenpuppen. - (il. v. Linden)

Hormuzaki, C. Frhr. v.. Lepidopterologische Beobachtungen in der Bukowina. - (M. v. Linden)

- Varietäten eniger in der Buko. wina einheimischer Grossschmetterlinge. - (M. v. Linde n)

- Schmetterlinge (Lepidoptera) der Bukowina. - (M. v. L $1 n d \mathrm{e} n$ )

- Melitaeengruppe Athalia Ratt., Aurelia Nick. und Parthenia Borkh. (M. v. Linden)

- Neuere Macrolepidopterenfunde aus Rumänien. - (M. v. Lin d en)

Krulikowsky, L., Lepidopterenfauna des Gouvernements Jarosslawlj. - (N. v. A de $\operatorname{lu} \mathrm{ng}$ )

Levrat, M. M. D., et A. Conte, Co. loration naturelle des soies de Lépidoptères. - (M. v. Linde n)

Linden, M. v. Farben der Schmetterlinge und ihre Ursachen. - (H. v. L i inde 11$)$

- Pigmente der Lepidopteren. - (M. v. Linden)

Mokrzetzki, S. A., Der WViesenzünsIor Phyctaenodes stictiralis L., Eury- creon (Botys) sticticalis L. - (N. v. A d el $1 \mathrm{ng})$. . . . . . 15:

Portschinski. J. A., Bekämp̧ung schärllicher Schmetterlinge. - (N. v. A d e lung)

- Getreidemotte (Sitotioga cerculclla Oliv.) und das einfachste Mittel zu ihrer Vernichtung. - (N. v. Adelung)

Schenk, 0., Antennale Hautsinnesorgane einiger Lepidopteren und Hymenopteren. - (II. v. Linden) .

Smith, J. B. New Noctuids and Notes - (M. v. Linden) . . . 554

- New Noctuids from British NorthAmerica. - (M. v. Linden)

- Acronycta and Types. - (M. v. Lind en)

- Three new Noctuids from British North America. - (M. v. Linden) 557 312 - New Species of Noctuidae for 1902 - (M. v. Linden). . .

Tichomiroff, A., Künstliche Parthenogenese heim Seidenspinner. - $(\mathrm{E}$. Selultz)

\section{( 'oleoptera.}

Csiki, E., . Inophthalmus-Arten des russischen Reiches.-. (A. Gorka) . . 388 Coleopteren. - (K. Escheric h) . 3×9

Felt, P., E., Elm Leaf Beetle in New York State. - (IV. M I ay) . . 351 - Grapevine Root Worm. - (W. II a y) $43 t$

Ganglbauer, L., Systematisch-coleopterologische Studien. - (K. Esche rich)

Glasunow, D., Revisio specierum bicolorium generis Nebriae Latr. Carabidae). - (N. v. A d e lung) . . . 154

- Sphenoptera de la région ethiopienne (Buprestidae). - (N. v. A delung) 15,6 - Sphenoptera paléarctiques du sousgenre Dcurlora B. Jak. (Buprestidae). - (N. v. Adelung).

Holmgren, Nils., Exkretionsorgane des Apion Haripes und Dacytes niger. (K. E's che rich)

Jakowleff, B. E., Genre Sphenoptera Sol (Coleoptera, Buprestidae). - (N. v. Ad el ung)

Jaquet, M., Faune de la Roumanie. Coleoptères. - (N. v. A d elumg).

- Faune de la Roumanie. IIarpalus.

Petri, K., Coleopteren.'Tribus Hyperini.

-. (K. Esclie richj
Ponerantzev, D., Hainbuchensplintkäfer. - (N. v. A delung) . . Exo

491 Porta, A., Apparato di secrezione e secreto della Coccinclla 7-punctata. L. - (K. Esclierich)

Funktion der Leber bei den lnsek. ten.- (K. Fischerich) 
Rossikow, K. N., Bekämpfung der Laubkäfer. - (N. v. A d elung) . . .

Semenov, A., Pédoncule mésothoracique chez certains Coléoptères. - (N. v. A d e lung)

Stuhlmann, Franz, Über den Kaffeebolirer in Usambara. - (IV. M ay) 711

Tschitschérine, T., Tribu des Harpalini. (N. v. Adelung)

- Reitters Bestimmungs.'Tabellen der Harpalini. - (N. v. A delung). . - Hąrpalini des régions paléarctiques et paléanarctiques. - (N. v. Ad e$\mathrm{l} u \mathrm{ng})$ Ilarpalini (Coleoptera, ('arabidae.) - (N. v. Adelung)

- Platysmatini du Muséum d' Histoire Naturelle de Paris. VI. - (N. v. A del un $\mathrm{n}$ ) Platysmatini de la région Malgache. - (N.v. A delung) Sous-genre Bothriopterus Chand. (genre Platysma Bon. 'T'sch.) - (N. v. A delung)

- Nouvelles espèces de la tribu des Platysnatini. - (N. v. A d el ung) Platysmatini de l'Australie. - (N. v. $A d \theta l u n g)$

Verhoeff, K., Zirpvorrichtung von (ientrupes. - (K. H s cherich)

Voinov, D. N., Spermatogénèse chez le Cybister lioeselii. - (R. Gold$\mathrm{sehmidt}$.

\section{H y menoptera.}

Adierz, G., Myrmekologiska studier IV. (K. Es cherich)

André, E., Femelle probable de l'Anomma niyricans. - (K. Escherich)

Bethe, A., Psychische Qualitäten an Ameisen. - (K. Escherich)

- Heimkehrfähigkeit der Ameisen und Bienen. - (K. Escherich)

Buttel-Reepen, H. v., Stammesgeschichtliche Entstehung des Bienenstaates. - (H. E. Zi egler)

Cholodkovsky, N., Spinnapparat der Lyda-Larven. - (N. v, A d el ung)

- Interessanter Ameisen-Instinkt. -

(K. E s cherich)

- Spinnapparat der Lyda. - (K. W. v. Dalla 'T'orre) .

Cobelli, R.. Senso del gusto nel Lasius emarginatus Oliv. - (K. Es cherich) - Lasins emarginatus Ol. - $\mathrm{K}$. Escherich)

- Senso del gusto nel Lasius emarginatus Oliv. - (K. W. v. Dalla Torre)

- I veleni ed il Lasins cmarginatus Oliv. - (K. W. v. D a ll a To r re) 714

Dahl, Fr., Leben der Ameisen im Bismarck-Archipel. - (K. Escherich) 219
Dalla Torre, C. G. de, Catalogus $\mathrm{Hy}$ menopterorum III, 1 u. 2. - (Fr: Fr. Kohl)

Dedekind, A., Altägyptisches Bienenwesen. - (K. W. v. Dalla Torre) 715

Dickel, Ferd., Geschlechtliche Differenzierung im Bienenstaat. - (K. W. v. Dalla To r r $\theta$ )

Ducke, Adf, Stachellose Bienen (Melipona III, ) von Para. - (K. WV. v. Dalla $\mathrm{T}$ or r e) .

- Blütenbesuch, Erscheinungszeit etc. der bei Para vorkommenden Bienen. (K. WV. v. D a l I a T'o r.re) .

Emery, C., Larve di alcuni Formiche. - K. Escherich)

- Ameisenlarven. - (K. Escherich) 221

- Genere Eciton. - (K. Es cherich) 222

- Végétarisme chez les fourmis. (K. Escherich)

- Polimorfismo delle Formiche. (K. Escherich)

- Metamorfismo e metamorfosi nel genere Dorylus. - (K. Es cherich) 225

- Formiciden von Celebes. - (K. Escherich)

- Note sulle Doryline. - (K. Es che rich)

- Geschlechtspolymorplismus der Treiberameisen. - (K. Es cheri ch)

Escherich, K., Biologie der Ameisen. Zus. Übers.

- Ameisenpsychologie. - (K. Es ch erich)

Nordafrikanische MyrmerorystusArten. - (K. Es cherich)

Field, A. M., Study of an Ant. - (K.

Escherich)

- Further Study of an Ant. - (K Escherich)

- Notes on an Ant. - (K. Es che rich)

Forel. A., Fourmis de l'Amérique du Nord. - (K. Es cherich)

- Nordamerikanische Ameisen. - (K. Es cherich)

- Fourmis du Japon. - (K. Es s h e ri ch)

- Sensation des Insectes I-V. (K. Es cherich)

- Psychische Fähigkeiten der A meisen. - (K. Es cherich)

- Geruchsinn bei den Insekten. (K. Escherich)

Fourmis termitophages. - (K.

Escherich)

- Variétés myrmécologiques. - (K.

Escherich)

- Quatres notices myrmécologiques.

(K. Escherich)

- Variétés myrmécologiques. - (K. Es cherich)

- Phylogenetische Wirkthgen und Rückwirkungen bei den Insekten. (K. Es cherich) 
Forel, A., Fommis d'Algérie. - (K. Escherich)

- Bethe und die lnsckten-Psychologie. - (K. Escherich)

- Sitten und Nester einiger Ameisen der Sahara. - (k. IV. v, Dalla 'Torre)

- und Dufour, H., Emptindlichkeit der Ameisen für [ltraviolett und liontaen-Strahlen. - (K. Escherich) 247 and Dufour, H, Empfindlichkeit der Ameisen für Uitraviolett und Röntgencche Strahlen. - (K. W. V. D a ll a 'T o r res

Frohawk, J. W., Attitude of Hylernating Wasp. - (K. W. v. Dalla '1'orre)

Gounelle, E., Bruits produits par les Fourmis of les 'lermites. - k. Esclierich)

Harrington, Ernest, Nale Was]' with Female Antemmae - (k. II. v. Dalla 'I'orre).

Höppner, Jos., Biologie nordwestdeutscher Hymenopteren. - (K. IV v. Dalla Torrel

Janet, Ch., Nymphes nues dans les nids de Latsins Harus. - (K. Escherich)

Kohl, Fr. Fr., Hymenopterengruppe der Sphecinen. II, - (K. W. v. I) all a Torre)

Frontale Gynandromorphie bei Ammowhila abbrevintr. - (K. IV. v. Dalla 'T'orre

Kokujew, N., Symbolae ad cognitionem Braconidatum Imperii Rossici ef Asiae Centralis. 11. - (N. v. A de lung) Celor semenomi, gen, et sp. nov. Ichneumonidae). - (N. v, A d e I un g) 169

Kulagin. N. Entstehung der Geschlechter hei don Bienen. - (N. v. A d e l u $\mathrm{n} \mathrm{g})$

Lagerheim, G., Lasius fuliginosus. - (K. Fis cher i ch)

Lameere, A., Fourmis du sahara. (K. Es cher i cli

Marchalı. P., Cycle évolutif du Polygnotus minutus "(Linden). - (J. C. H. (te Meijere)

Mayr, G., Südafrikanisclie furmiciden. - (K. Es c lier i c h)

Meisenheimer, J., Geistige Făhigkeiten der Ameisen und Bienen. - ( $K$. (Hischerich)

Moscáry, A., und V. Szépligeti, Hymenoptera. - (K. W. v. Dalla 'T'orre)

Muckermanı, H., Life-history of Ants. (K. Escherich)

- Nests of some North American species of Formica. - (K.Esch e r i ch) 27 g

Nielsen, J. C., Biologische Studien über einige Grabwespen und solitäre Bienen - (K. W. v. Dall a T orre) 723

Oudemans, J. Th., Nester von Lasius fuliginosus latr. - (K. Escherieh) 274

- Merkwiirdiges Nest von I'espa vulgaris L. - (K. W. v. Dalla Torre)

Petrunkewitsch, A., Die Richtungskörper und ihr Schicksal in befruchteten u. unbefuchteten Bienenei. - (R. F i c k)

- Das Sichicksal der Richtungskörper im Drolmenei. - ( $\mathrm{R}, \mathrm{Fick})$

Plateau, F., Phénomène de la constance chez quelques Hyménoptères. - (K. W. v. Dalla T orre)

Prowazek, St., Ameisenheobachtungen. - (K. Es clierich)

- Pteromalidenlarven in Schildläusen. - (K. W. v. Dalla 'Torre)

Reichenbach, H., Parthenogenese bei Ameisen. - (K. Esclie rich)

7.0 Reichenbach, W., Parthenogenese bei Ameisen. - (K, W. Y. D a llir Torre)

Robertson, Ch., Flower visits of oligotropic Bees III. - (K. W. v. Dalla 'Torre)

Ruzsky, M., Ameisen der Umgebung des Aral-Sees. - (N. v. A delung) Nene Ameisen aus Russland. (K. IV. v. D a lla Torre). Ameisenfauna der Astrachanischen Kirgisensteppe. - (N. v. A del ung) 798

Schäffer, C., Geistige Fähigkeiten der Ameisen. - (K. Kischerich) .

Schrottky, C., Biologische Notizen solitärer Bienen von St, Paulo (Brasilien). - (K. W. v. D a ll a T o r re) $7: ; 2$

Silvestri, Fil., Meliponidi del bacino del Rio de La Plata. - (K. W. v. Dalla Torre)

Sladen, F. W. L., A recent producing organ in the worker of ipis mellifica. - (K. W. v. Dalla Torre) . 799

Sternander. R., Verbreitungsbiologie der skandinavischen Pflanzenwelt. (K. Escherie h)

Tutt. J. W., Lasins americanus und Aphis pmenicola. - (K. Escherich)

Ule, E., Ameisengärten im Amazonagebiet. - (K. W. v. Dall a T orre) 800

Viehmayer, H., Zurückfinden von Ameiserl zu ihrem Nest. - (K. Es cherich)

Wasmann, E., Seelenleben der Ameisen. - (K. Escheruch) . . . . - Orientierungsvermögen der Ameisen. -_ (K. Es c he ri cll)

- Zusammengesetzte Nester der Ameisen. - (K. Escherich)

- Bethes Reflextheorie. - (K. Es c herich) 
Wasmann, E., Gastverhältnisse (Symphilie) bei den . Imeisen und Termitenyästen. - (K. Escherich) E : Wheeler, W. M., remale of Eciton
sumichasti Norton. - K. Escherich)

- Texan Ponerinae - (is Esche rich)

- Ponera and stimmatomina. - (K. Escherich)

- Fommis mexicaines. - (K. Es c herich)

- Nests of American Ants. - (K. listlerich)
Wheeler, W. M. . New agricultural Ant from T'exas. - (K. Escherich)

- Erebomyrma. - (K. Es cherich). 277

- and W. H. Long. Males of Some

'T'exan Ecitons. - (K. Es s h e r i ch) 267

- and J. F. Mc Clendon, Dimorphic Queens in an American Int (Lusizis latipes Walsh.) - (K. Escherich) 278

Yung, Em., Combien y-a-t-il de fourmis dans une foumiliere. - $(K$. Escherich)

\section{Mollusca.}

\section{Imphinem:a.}

Thiele, Joh., Systematische stellung der solenogastren und P'hylogenie der Mollusken. - (H. Sim roth) . 20

\section{liastropostat.}

l'rosobranchia.

Drummond, J. M., Development of Preludina rivipara. - (J. Meisonhe imer)

Hoffmann, R. W., Emährung der kimbryonen von Nassa mulabiles Lam. - (J. Meisen lheimer)

Robert, A., Development des 'Troques. - (J. Me isen beimer)

\section{P'ulmonatia.}

Ancel, P., Glande hermaphrodite d' IIelic pomatio, (I.) - (R. liold$\mathrm{s}(\mathrm{ch} \mathrm{mid}$ )

Frandsen, P., Reactions of Limax: maximus to directive stimuli. - (H. S i m r o th)

Nordenskiöld, E., 'T'rockenzeitanpassung eines Ancylus. - (H. Simroth) . $82 t$

Cinhaloporlat.

Schweikart, A., Nikropyle und Chorion hei den Cephalopoden. - (R. Fick) 494

Lamellihranchia.

Frech, Fritz, ticrilleia. (A. 'T'o r' quist).

\section{Tunicata.}

foldschmidt, R., lintwickelung der Appendicularien. - $(0$. Seeliger $) 495$

Hartmeyer, R., Holosome Ascidien. (O. Seeliger)

Heine, P., Herz der salpen und der Ciona intestinctis. - $(0$ Seeliger $) 827$

Herdmann, W. A., Tunicata. -10 . Seeliger) . . . . . . . . . . Isert, A.. Drïsenanhänge des Darmes bei den Monascidien. - (O. Seeliger) 801
Magnus, R., Bodeutumy des (iandions bei Ciona intestinalis. $-(0.5$ o el ig e r) 497

Van Name, W. G., Ascidians of the Bermuda Islands. - (0. Fe eliger) $80 \%$

Riedlinger, R., Bau vour styelopsis grossulariu. - (O. seeliger) . so:

Salensky, W.. Etudes anatomiques sur les Appendiculaires. 1. - (E. schultz)

\section{Vertebrata.}

Boulenger, G. A., Fishes, Batrachians and Reptiles collected in Mashonaland. - (F. W e r n er)

Döderlein, L., Erwerbming des Flugvermögens bei Wirbeltieren. - ( F. v. W a g $n$ e r)

Fatio, V., Deux petits vertébrés nouveaux pour la Suisse. - (F. R ö me r)
Fïrbringer, M., Norphologische streitfragen. I. 1. II. - (B. R a witz) .562 198

Jaquet, M., systeme nerveux sympatique cervical dans la série des vertébrés. - (B. R a witz)

Lenhossék, M. v., Entwicklumg des Glaskörpers. - (R. Hesse) . . \$16 
Levaditi, C., Le Leucocyte et ses Granulations. - (B. R a w it $z$ ) 563

Marceau, E., Structure du coeur chez les vertébrés inférieurs. - (B. R a witz)

Meves, Fr., Zur Struktur der roten Blutkörperchen bei Amphibien und Säugetieren. - (B. R aw it $z$ ) . van Pée, P., Origine du corps vitré. - (R. Hesse) .
Rabl, C., Entwicklumg des tilaskörpers. - (R. Hesse).

Schauinsland, H., Entwicklungsgeschichte und Anatomie der Wirbeltiere I, II, III. - (H. L. Ziegler) 565

Steinach, E., und K. H. Kahn, Echte Contraktilität und motorische Innervation der Blutcapillaren. - (A. Püt ter)

('yelostomi.

Giacomini, E., Capsule surrenali nei Ciclostomi. -- (B. Rawitz) . . .

- Glandule salivari dei Petromizonti. - (B. Rawitz)

- Sul paucreas dei Petromizonti. (B. R awitz) 127
Haack,W., Mundhöhlendrüsen bei l'etromyzontell. - (B. Rawitz) . . . 886

Plate, L., Studien über Cyclostomen. I. - (H. C. Redeke) . . . 436

\section{Pisees.}

Bühler, A., Rückbilduug der Eifollikel bei Wirbeltieren. I. Fische. - (R. Fick)

Gorjanovic-Kramberger, K., Palaeoichthyologische Beitrige. - (A. 'T'orn q 11 is t)

Nordquist, 0., Distribution of Freshwater-Fish in Finland. - (F. Zschokke)

Reibisch, J., Einfluss der Temperatur auf die Entwicklung von FischEiern. - (J. M e is en h e ime e $r^{\circ}$.

Schneider, G., Ichthyologische Beiträge. II. -- (H. C. Redeke)

Tower, R. W., The Gas in the SwinBladder of Fishes. - (N. Lühe) . 600

Zenneck, J.. Reagieren die Fische auf Töne? - (A. Pütter)

\section{Chondropterygi.}

Beard. J., Origin and Histogenesis of the Thymus in liaja batis. - (B. R awitz)

Giacomini, E., Corpo interrenale e corpi soprarenali dei Selaci. - (B. R a w itz)

Retzius, G., Spiralfaserapparat am Kopfe der Spermien der Selachier. - (R. Goldschmidt)

Studnicka, F. K., Epithel der Mundhöhle vou Chimaera monstiosa. - (b. Rawitz)

$$
\text { Ganoidei. }
$$

Budgett, J. S., Structure of the larval Polyptcrus. - (J. M eisenh eim er) 292

Schreiner, K. E., Occipitalıegion von
Limia und Ispidostens. - (.T. Ma isen. lie imer) 31

$$
\text { 'Teleostei. }
$$

Boeke, J., Entwicklungsgeschichte der Teleostier. I. - (.J. M eisnnh e imerl. Citrosoma im Befrucltungsmomente bei den Salmoniden. - (R. Fick)

Eigenmann, C. H., and C. Kennedy, Unılateral Coloration with a Bilateral Effect. - (H. C. Rede cke) . . . 4!!!

Giacomini, E., Capsule surrenali dei Teleostei. - (B. Rawitz) . .

His, W., Zellen- und Syncytienl,ildnng. studien am Salmonidenkeim. - (J. Ml eisenheimer) . . . . . . . . .

- Protopiasmastudien am Salmonidenkeim. - (J. M e is en le eimer) . . 883

- Lecithoblast und Angioblast der Wirbeltiere. - (J. Me is en hein er) 884

Kopsch, Fr., Künstliche Befruchtung der Eier von Cristicips argentutus. - (k. Fick)

— Entstehung des Dottersackentoblasts bei verschiedenen Knochenfischen. (J. M e ise uhe in er)

Lampert, R., Nahrung der Bachforelle und des Bachsaiblings. - (H. C. Redeke).

$$
\text { bipnoi. }
$$

Kerr, G. J., Development of Lepridosiren paralora. III. - (J. Me is enli e i $\mathrm{m}$ er) 
Brewster, W., Birds of the Cape Region of Lower-California. - (t). Hartert)

Bryan, W. A., Key to the birds of the Hawaiian group. - (E. Hartert).

Giacomini, E., 'Terminazioni nervose nelle capsule surrenali degli Uccelli. - (B. Rawitz)

Giglioli, H. H., Strange case of Athem ehiaradiac. - (E. Hartert)

Grant, W. K. 0., and H. 0. Forbes, Burds of Sokotra and Abd-el-Kuri. - (E. Hartert)

Hartert. E.. Birds collected in the Kiknyu Mountains. I. Laniidae. - (F. Hartert).

- Birds from Pahang Eastern Malay Peninsula. - ( $\mathrm{E}$. Harte $\mathrm{r}^{\mathrm{t}}$ )

- Birds of North. IVest-Eenador. (E. Hartert)

Heinroth, 0., Ornithologische Ergebmisse der I. Dentschen Südsee-Expedition von Br. Mencke. - (N). Har. $\mathrm{t} \in \mathrm{rt}$ )

Henshaw, H. W., Birds of the Hawaiian islands. -- (E. Hartert)

Kunz, H., Otis tetrar, die Zwergtrappe. - (E. H artert)

Marceau, E., Fibres musculaires cardiaques chez les oiseanx. - (B). liawitzl

Mudge, Geo. P., Myology of the Tongue of Parlots. - (B. Rawitz) . 35
Oates, E. W., Silver-Pheasants of Burma. - (E. Hartert)

New Silver-Pheasant from Burna. - (E. Hartert)

Oberholser, H. C., Larks of the cents Otwerris. - ( H. Hartert)

Pycraft, W. P., Pterylogranhy of I'hotodilus. - (H. Hartert)

Richmond. C. W. Generic terms froposed for birds during the years $1890-1900$. - (E. Hart ert)

Rothschild, W.. and E. Hartert, Collection of birds made on Ysabel in the solomon group. - (E. Hartert) 210

Salvadori, T., Onitologia delle Isolo del golfo di fininea. 1. - (li. Har. t e r t)

- Ornitologia delle Isole del fiolfo di Guinea. II. - (E. Hartert) . . 400

Schuster. W., Vogel und Mensch. (fi. Harte $\mathrm{r}$ t)

Sharpe, R. B., 'I'urdidae. - (W. H ar'. te r t;

Silantieff, A. A., Schliissel zur Bestimmung der europäischen Vögel. - (N. r. A delung)

Suschkin, P., Norphologie des Vogelskelettes. - (E. Schultz) . . .

Svenander, G., Schlund und Magen der Vögel. - E. Lö $\left.\mathrm{n} n \mathrm{~b} \in \mathrm{r}^{\circ} \mathrm{g}\right)$.

Tschusi zu Schmidhoffen, V. V., Palatearktische Formen III. (Weidensperling) - (E. Hartert)

\section{Mammalia.}

Bensley, R. R., Cardiac Glands of Manmals. - (B. Rawitz)

Bolk, L., Affen-Anatomio. IV. Ḱleingehirn der Menschenaffen. - (B. Rawitz)

Büchner, E., l'rzewalkis P'ferd in der Bearbeitung des Akademikers IV IV. Salensky - C. (†revé)

Carlsson, A., Systentische Stellung von Eupleres youdoti. - (F. R ö mer)

Cohn, Franz, Histologie und Histogenese des Corpus lutem. - (R Fick) . 003

Daffner, Fr., Wachstum des Menschen. - (A. Püt ter)

Fish, P. A., Cerebral Fissures of the atlantic IValrus. - (B. R a w itz)

Grönberg, G., Ontogenese eines niederen Sängergehirns nach Untersuchungen an Erinaceus europaeu. - (B. R a. witz)

Hammar, J. Aug., Entwickelung des Vorderdarms. II. - (B. R awitz) , 17s

Jakobi, A., Ziesel in Deutschland. (IV. M a y)

Kaschtschenko, N. Th., Siugetiere, gesammelt von P. G. Ignatows Altaiexpedition. - (C. Grevé) .
Kastschenko, N., skelet eines Manmuilis. - (E Sehultz)

Keibel, Franz, Entwicklung des Relies bis zur Anlage des Mesoblast. (li. F $1 \mathrm{ck}$ )

Kennel, J., Stummelschwänzige Haus katze und ihre Nachkommenschaft. - (E. v. W a guer)

Limon, M., Glande interstitielle de l'ovaire. - (R. Fick) . . . . Vacuoles de la Granulosa des follicules de de Graaf. - (R. Fick)

Loewenthal. N., Beziehungen der T'aenia semicircularis. - (B. R a witz) 179

Loweg. Th., Integmment des Erethionn dorsatus. - (F. Rö mer)

Mc Clure. Ch. F. W., Venous system of Didelphys marsupialis I. I. - (B. Rawitz)

Marceau, E., Fibres cardiartues des mammiferes. - (B. Rawitz) . . 126

Palacky, J.. Verbreitung der Meeressäugetiere. - (F. R öm e r)

Peiser. A., Drüsen des menschlichen Verdaunngsapparates. - (B. Raw it $z$ 
Rabi, C. Entwickelung des Gesichts. (F. $R \ddot{0} \mathrm{~m} \otimes \mathrm{r}$ ).

Retzius. G.. Spermien des Menschen und einiger Säugetiere. - (R. Gold$\mathrm{sch} \operatorname{midt}$ ) 504

Ruge, G., Leber bei den Primaten. IlI. - (B. Raw it z)

Salensky, W., Eques Przeralskii l'ol. - (H. Scliultz)

Satunin. K. A., Neue Nagetiere atus Centralasien. (C. (irevé) . . 6699 Schimkewitsch. W., Uber einen kall von Heterotopie der Haare - (F. (R ö $\mathrm{m}$ e r)

Schlosser, Max, Fossile Sängetiere Chinas. - (A. 'T orn quist).
Schmid, Joh., Untersuchungen über' die Ohrmuschel verschiedener Säugetiere. - (F. Rïmer)
Schreiner, J. Th., Maulwurf (Talpaeuropaea. - (N. v. A d elung) . . 213

Van der Stricht, 0., Pseudochromosomes dans l'oocyte de chauvesouris. Comm. prél - (R. Fick) . 83. i

- Spermatozoïde dans l'oeuf de chauve-souris. ( $\mathrm{T}$. nncfula). - (R. Fick) . . . . . . . . 401

Szakáll, Gyula, Spalax typhlus Pall. - (A. Gorka). . . . . . 437

- Gehörorgan der ungarischen Blindmans. - (1. Gorka) . . . 835

181 Weinberg, R., Fossile Hirnformen. 1. Anchilophus Desmaresti. - (B. Rawitz). . . . . . . 569

Zürn, J., Retina und Area centralis der Haussängetiere. - (R. Hesse) 336

Antorem-Register.

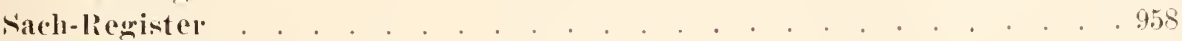

Geompaphisches legrister . . . . . . . . . . . . . . . . . . . . . 962

Systemat isches liogister . . . . . . . . . . . . . . . . . . . . . 964

Genus- und Familien-Reginter. . . . . . . . . . . . . . . . . . . 975

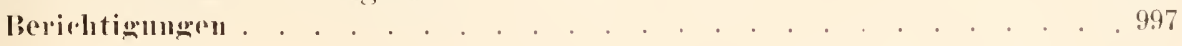





\section{Zoologisches Zentralblatt}

unter Mitwirkung von

Professor Dr. O. Bütschli and Professor Dr. B. Hatschek

in Heidelberg

herausgegeben von

in Wien

Dr. A. Schuberg

a. o. Profeseor in Heidelberg.

Verlag von Wilhelm Engelmann in Leipzig.

\section{Jahrg.}

27. Januar 1903.

No. 12 .

Lu beziehen durch alle Buchhandlungen und Postanstalten, sowie durch die Verlagsbuehhandlung. Jährlich 26 Nummern in Umfang von 2-3 Bogen. Preis für den Jahrgang 11.30 . - Bei direktor Zusendung jeder Nummer unter Streifband erfolgt ein Aufschlag von M. 4.- nach dem Inland und von M. 5. - nach dem Ausland.

\section{Referate.}

\section{Geschichte und Literatur.}

1 Ehlers, E., Göttinger Zoologen. In: Festschrift zur Feier des hundertjährigen liestehens der Kïnigl. Gesellsch. d. Wissensch. zu Göttingen. Berlin 1901. pag. 393-494.

Obgleich es der Zweck dieser Zeitschrift verbietet, nüher auf die sehr verdienstliche und interessante Studie des Verfs. über die PHege und Förderung der zoologischen Wissenschaften durch so zahlreiche hervorragende Männer in Göttingen einzugehen, so ist es doch geboten, hier auf die sorgfältige Arbeit hinzuweisen. Wer sich für HistorischBiograplisches interessiert, wird in ihr cine erwinschte biographische Zusammenstellung über jene Männer finden: sowie vielfache Belehrung über ihre Bestrebungen, ihre Erfolge und die bedingenden Umstände für beides. Wir können hier nur andeuten, über welche Persönlichkeiten die Schrift näheren Aufschluss bietet. Von A. r. Haller an, welcher die Göttinger Gesellschaft der Wissenschaften organisierte, werden folgende Männer behandelt. Der Sonderling C. W. Büttner (1716-1801), der hauptsächlich deshalb Beachtung verdient, weil er Blumenbach "den Weg bahnte". - I. C. P. Erxleben (1744-1777), nicht ohne Verdienst um die Systematik ler Sängetiere. J. Fr. Blumenbach (1752-1840), dessen naturgemäß sehr eingehend gedacht wird, da er ein langes Menschenleben hindurch eine Leuchte der Universität war, dessen Bedeutung und Einflıss auf die biologische Forschung seiner Zeit ihm auch eine sehr herrorragende Stelle unter den Göttinger Zoologen sichert. - Chr. W. Gatterer. - B. Nerrem (1761-1824; 1781-1784 Priv.-Doc. in G., später Marburg), verdient um 
die Erforschung der Vögel, besonders aber der Reptilien und Amphibien. - W. Josephi (1763-1845; später Professor in Rostock). Der früh verstorbene F. A. A. Meyer. - J. L. C. Gravenhorst (1777-1857; später Professor in Breslau), namentlich als Entomologe von Bedeutung. - Lor. Oken, über dessen „Bedrängnisse“ als Privatdocent in Göttingen $(180 \check{-}-1807)$ mancherlei Interessantes mitgeteilt wird. - F. G. Herbst. - Ed. Stromeyer. - J. C. A. Kräner. - Der Sammler F. A. Schlotthauber. - A. A. Berthold(1803-1861), der sich namentlich um die zoologische Sammlung erhebliche Terdienste erwarb und als Anatom ınd Plhysiologe für Göttingen längere Zeit Wichtiges leistete. - Eine sehr eingehende Würdigung erfährt natürlich Rud. Wagners Lebensarbeit (180.̃-1864), die für die Universität und die Königliche Gesellschaft (1840-1864) von hoher Bedeutung war. - Als Schüler und Mitarbeiter dieses hervorragenden Mannes, die in Göttingen vorübergehend wirkten, werden C. Bergmann (1814-1865, später in Rostock), R. Le uckart (1812-1898), H. Frey (1822-1890, später in Zürich) und G. Meissner (geb. 1829) eingehender gewürdigt. - Auch W. Keferstein (1833-1870) begann noch unter Wagners Anregung als Assistent am physiologischen Institut. Ehlers gibt uns eine pietätvolle, doch gerechte Würdigung der bedeutsamen Leistungen seines ihm und der Wissenschaft allzıfrüilı entrissenen Freundes, dessen Bemühnnngen auch die Anregung für eine würdige Entwickelung der Sammlungs- und Institutsräume zu danken ist.

Als Kefersteins Schülem wird ferner E. Selenkas, H. Grenachers und R. r. Willemoes-Suhms gedacht. - Kefersteins Nachfolger, C. Claus, weilte nur 3 Jahre in Göttingen ${ }^{1}$ ); ihm folgte dann der Verf. der vorliegenden Schrift.

Wir fügen noch zu, dass Verf. auch iiber die allmähliche Entwickelung der Hilfsmittel, als Sammlungen und Institute, ausführlich berichtet, und in den Belegen und Zusätzen von einer Anzahl der aufgeführten Gelehrten Schriftenverzeichnisse gibt.

Am Schlusse fasst Ehlers sein Urteil in folgendem Satze zusammen: „Fragt man aber, wer ron Göttingen aus diese Wissenschaften“ (Physiologie, vergl. Anatomie und Zoologie) „anr wirksamsten gefördert hat, so kann die Antwort nur lauten: der junge Blumenbach."

O. B ï ts chli (Heidelberg).

1) Unter den Schülern von Claus gedenkt Verf. F. Richters als des Verfs. von "Untersuchungen über die Entwickelungsgeschichte des Flusskrebses". Hier ist ihm jedenfalls ein Irrtum unterlaufen, der einzige übrigens, den Ref. bemerkte; denn es dürfte wohl sicher Reichenbach mit Richters verwechselt sein, ein Irrtum, der durch die fast identische spätere Lebensstellung beider Forscher nahe gelegt war. 


\section{Lehr- und Handbücher. Sammelwerke. Vermischtes.}

2 Haller, B., Lehrbuch dervergleichenden Anatomie. Lief. 1. Jena (Gustav Fischer) 1902. VI, 424 pag. 412 Fig.

Wenn ein Verfasser, der sich seit 20 Jahren auf verschiedenen Gebieten des Tierreiches als Forscher betätigt und sich einen wohlbekannten Namen gemacht hat, ein Lehrbuch der von ihm gepflegten Wissenschaft veröffentlicht, so wird man mit um so höhern Erwartungen an dasselbe herantreten, wenn das Bestreben offenkundig zutage tritt, ein Originalwerk ron eigenartigem Gepräge zu schaffen, wie es einst Gegenbaurs ..Grundzüge" waren. Das in seinem, die sog. Wirbellosen - oder, wie Verf. vorzieht zu sagen, die Achordaten - behandelnden ersten Teil hier vorliegende Buch liefert uns indessen den schlagendsten Beweis, dass zur Abfassung eines brauchbaren Lehrbuches Eigenschaften, Fähigkeiten und Kienntnisse erforderlich sind, die nicht jedem, der sich als Forscher bewährt hat, zu Gebote stehen. Verf, deutet selbst im Vorwort an, dass er mit gewissem Zagen an die schwierige Aufgabe herangetreten sei. Dass er es trotzdem gewagt hat, kann ihm leider nicht zum Verdienst angerechnet werden, denn in weniger vollkommener Weise hätte das Werk wohl kaum gelingen können.

Es ist zunächst - um mit Geringfügigerm zu beginnen aufs tiefste zu bedaueru, dass der Verf, der zwar deutscher Abstammung, aber doch der deutschen Sprache nicht völlig mächtig ist, sein Manuskript und die Druckbogen nicht ron einem deutschen Freunde hat durchsehen lassen. Jetzt starrt das Buch in solcher Weise ron Verstössen gegen die elementarsten Regehn der deutschen Sprachlehre, ron falschen Artikeln, falschen Endungen, Präpositionen mit falschem Kasus, inkongruenter Bildung ron Satzteilen, gänzlich undeutschen Wendungen und Ausdrücken, unerhörten sprachlichen Neubildungen usw. usw, dass es schon deshalb als Lehrbuch unbrauchbar erscheint. Manche Sätze sind olne jeden Zusammenhang und ganz unverständlich, z. B. pag. 13: .. Doch kann durch beschleunigte Entwickelung des Nesoderms, in diesem Falle Mesenchym genannt, sich zumeist nur ron Ektoderm, noch vor der Gastrulation erfolgen." Vieles wäre offenbar vermieden worden, wenn der Verf. auf die Korrektur mehr Sorgfalt rerwendet hätte. Es wimmelt in dem Buch geradezu von Druck- und Schreibfehlern, die z. T. in bedenklichstem Maße sinnstörend sind, so wenn pag. 343 von den Anschlïssen der Skorpioniden an die silurischen Euryali d en statt Eury],teriden geschrieben wird, oder wenn es auf pag. 345, wo vou den Beziehungen der Crustaceen und Xiphosuren zu Tri- 
lobiten die Rede ist, dreimal statt Trilobiten Belemnit en heisst ${ }^{1}$ ). Manche Fehler der Art führen sich augenscheinlich auf Unkenntnis des Verfs. in den altklassischen Sprachen zurück, so wenn er hartnäckig Xyphosuren, Hypolyte, Hyppocrane, Acrocrymus, Bathycrynus, Chilusdarm etc. etc. schreibt. In den krklärungen der 412 Figuren finden sich allein etwa 50 falsch geschriebene Tiernamen, Batrachoceps statt Batrachoseps, Mitirocoma statt Mitrocoma usw., neben anderen Fehlern wie Sinusepithel statt Sinnesepithel, verstümmelte Autornamen wie D'elage, Staden statt Sladen, oder Fowler statt Tower. Er sagt das Ocellus, das Imago u. dgl.

Bedenklicher als diese formalen Fehler, durch welche übrigens die Brauchbarkeit des Buches in hohem Grade beeinträclitigt wird, ist die vielfache Schwerfälligkeit und Unklarheit der Darstellung, die sich oftmals in einem Grade steigert, dass nur das Fremdwort "konfus" dafür zutreffend erscheint. Bleibt manchmal der mit den Tatsachen vertraute Fachmann im Zweifel, was der Verf. meint, so kann man unmöglich erwarten, dass der Lernende, fuir den das Buch bestimmt ist, den Sinn verstehe. Fin paar beliebig herausgegriffene Beispiele dafür: pag. 420 „Unter den Apterygoten sind die Tracheen bei den Thysanuren, his auf die drei letzten Abdominalsegmente, die ron den Tracheen des drittletzten Segmentes versehen werden, und den drei Thoraxsegmenten segmentweise angeordnet. Im Thorax vereinigt gelangt das Stigmenpaar im zweiten Segment zu mächtiger Ausbildung und iibergreifend auf das erste Segment, den Kopf, dann das dritte Segment und erste Abdominalsegment, macht alle andern Tracheenpaare überflüssig. Es rückbilden sich diese dann bis auf ein Rudiment im dritten Segment. Das Übergreifen der Tracheen auf andere Segmente gelangt bei den Thysanuren zur Geltung; und Anastomosen mit den Tracheen dieser ist ein Moment von grosser Bedeutung, denn es führt hinüber zur Finheitlichkeit des ganzen 'Tracheensystems." Pag. 14: ..Durch die Differenzierung von Tentakeln, Fangarmen etc., dann der Darmhöhle und Keimdrüsen in der Richtung der Nebenachsen hin, ändert sich deren Gleichwertigkeit, indem abwechselnd einzelne ron ihnen, entsprechend jener Differenzierung länger, beziehentlich liürzer werden wie die auf sie folgenden. Legrt sich eine oblonge Gastrula entlang ihrer Längsachse auf den Boden und schiebt sich in dieser Lage von Stelle zu Stelle, so erfolgt an dieser den Boden berührenden Wand eine Abplattung. Infolgedessen gelangen zwei Nebenachsen zur Ausbildung. Die eine daron ist die Dorso-

1) Wer errät wohl in Polyphorus (pag. 373) Tclyphonus, in Ophiophelus (pag. 120) Ophiopholis, und was Iysscus, eine angebliche Stammform der Poriferen, sein soll, habe ich nicht ermitteln kömnen. 
ventralachse und rerbindet Bauch und Rückenfläche; die andere, die Querachse, die beiden Seitenflächen. Während dann in der Querachse der frühere Zustand sich erhalten hat, ist durch die Ausbildung der Dorsoventralachse die bilaterale Grundform erreicht worden. Die senkrechte Ebene, welche entlang der Hauptachse gelegt würde, trennt dann die Grundform in zwei spiegelbildlich gleiche Hälften. Die oberhalb oder unterhalb der horizontalen, durch die Querachse gelegenen Ebene gelegene Stücke sind Gegenstücke oder Antimeren." Ich denke, kein Leser wird in dem Wort "konfus" einen zu harten Ausdruck für diese einem grundlegenden Begriff gewidmete Darstellung erblicken, und dabei enthält sie auch noch einen schweren sachlichen Irrtum, denn der Ausdruck Antimeren dient bekanntlich nicht zur Bezeichnung der Rïcken- und Bauchhälfte, sondern der rechten und linken Hälfte eines Tieres.

Wir liommen damit zu der wissenschaftlichen Seite des Buches. Der Verf. stellt sich berechtigterweise voll und ganz auf den Standpunkt der Descendenzlehre, wie ja schon darin angedentet ist, dass er sein Buch Ernst $\mathrm{Haeckel}$ gewidmet hat. Aber die Art und Weise, wie er phylogenetische Bezielıungen konstruiert und statuiert, ist in hohem Grade anfechtbar und kann vielfach nur als eine Karrikatur phylogenetischer Betrachtungsweise bezeichnet werden. Gelegenheit dazu bieten ihm ror allem die allgemeinen Übersichten, mit denen die Schilderung jedes einzelnen Metazoenstammes eingeleitet wird. Lesen wirz. B., was der Verf. über die Cölenteraten sagt (pag. 77): .Nach erfolgter totaler Furchung entsteht eine einschichtig langgestreckte Blastula, die alsbald, an dem aboralen Pole beginnend, in der Furchungshöhle Zellen abschnürt und die Larve dann zu einer zweischichtig oblongen form, der für die Cölenteraten höchst charakteristischen Planula, wird. Die leitet sich jedoch von einer am Urmunde sekundär unvollkommen sich schliessenden Gastrula (Aurelia) ab und somit ist diese Planula ein sekundär erworbener Zustand ron untergeordneter allgemeiner Bedeutung. Die durch Flimmerung des Ektoderms sich bewegende Planula setzt sich mit dem oralen Pole fest und der aborale Pol beginnt sich einzustülpen. Es trennt sich die Körperwand an der Mitte des eingestülpten Blattes durch, und am freien Rande sind somit Ektoderm und Entoderm mit einander verwachsen. Hierdurch kommt durch einen sekundären Prozess nach Festsetzung der Larve eine sekundäre oder sessile Gastrula zu stande. Eine ähnlich phylogenetisch wichtige Ausgangsform, wie der Olynthus für die Poriferen, ist der aus der festsitzenden sekundären Gastrula sich entwickelnde einfache Polyp bei den Cölenteraten. Lr ist gleich wie jener unter den Askonen unter der ursprünglichsten Abteilung der 
Cölenteraten, den Hydrozoen, recent. Es rergegenwärtigt die Gattung Hydra den primären Polypen." Der Leser möge diesen Abschnitt, in welchem die Ontogenie der Scyphozoen der Phylogenie der Hydrozoen zu grunde gelegt wird, zugleich als ein Beispiel für des Verfs. lichtrolle Darstellungsweise gelten lassen. Aus der allgemeinen Übersicht über die Würmer hebe ich nur folgenden Passus hervor (pag. 153): „Ursprünglich ("ölomaten, ist das Cölom bei einem Teil der Würmer in Wegfall geraten, während es bei den anderen melır oder weniger sich erhielt. Da jedoch der Wegfall des Cöloms nicht monophyl erfolgte, so kann der Nangel oder das Vorhandensein eines Cöloms umsoweniger für alle als Einteilungsprinzip gelten, als gewisse Acölomier, die Rotatorien nämlich, mehr Beziehungen zu Amneliden als zu den anderen Acölomaten bieten." Trotzdem werden die Würmer eingeteilt in Plathelminthen (ohne Cölom), Rotatorien (ohne Cölom) und Cölhelminthen, charakterisiert durch ... das gut erhaltene, einheitliche, doch immer angepasste - durch die Metamerie abgeteilte - Cölom". Obgleich stark divergierend sollen diese, d. h. Chätognathen, Nemathelminthen und Anneliden .. eine einheitlichere Gruppe wie die Plathelminthen" sein. Besonders charakteristisch aber ist die Behandlung der Bryozoen, pag. 220. „Die Bryozoen sind eine direkt ron der Trochophora ableitbare Abteilung. Es dreht sich die Längsachse der Endoprokten-Trochophora in der Weise um $180^{\circ}$, dass der frühere dorsale Wimperschopf mit dem Scheitelorgan nach unten zu liegen kommt. Es nähert sich dann der After dem Mund und verbleibt für immer innerhalb des Wimperkranzes, der später zum Fühlerkranze wird. Bei den höchst entwickelten Phoroniden sind schon im Larvenleben insofern sekundäre Zustände eingetreten, als der Füblerkranz sich zu einem, zum Balancieren der Larve dienenden Organe gestaltete, später aber den Mund umwächst, wodurch der After ausserhalb des T'entakelkranzes zu liegen kommt. Bei den meisten ektoprokten Formen stellt sich im Larvenleben ein stark cänogenetischer Zustand ein ... Das Resultat ist aber immer dasselbe: es setzt sich die Larve mit dem Wimperschopfe fest und darnach gestaltet sich die weitere Entwickelung. Es liegt dann jedesmal jedo von den beiden Nephridien, am After mündend, zwischen diesem und Mund, ober ihnen das Centralnervensystem. Es geht daraus hervor, dass das Ganglion einem konzentrierten Bauchmark und keinem (erebralganglion entspricht." Wie ist Verf. zu dieser gewiss originellen Auffassung des Bryozoenkörpers gekommen? Indem er 1. in ganz grundloser Weise die sog. Fussdrüse der Pedicellina-Larve für deren Scheitelorgan erklärt und 2. nicht weiss, dass nach $\mathrm{H}$ armers sorgfältiger, in Korschelt-Heiders Lehrbuch genau referierter 
Untersuchung die Larve sich nicht mit der Fussdrüse, sondern mit dem ent gegengesetzten Körperpol anheftet.

Dieser Fall führt uhs auf die Literaturkenntnis des Verfs., die ähnliche sehr empfindliche Lücken an vielen Stellen aufweist. Auch dafür nur ein schlagendes Beispiel. Z Zu der Behauptung (pag. 175): ..Bei den Rotatorien ist bisher überhaupt nur das Scheitelganglion der Trochophora zur Beobachtung gelangt", konnte der Verf. nur kommen, wenn ihm die wichtigsten Arbeiten über Rotatorien-()rganisation, die in der Zeitschr. f. wiss. Zoologie erschienenen Arbeiten Zelinkas, besonders die ïber Discopus synaptue, dessen höchst kompliziertes Nervensystem dort aufs eingehendste beschrieben ist, unbekannt geblieben waren. In andern Fällen hat er allerdings die neueste Literatur benutzt, so \%. B. die Arbeit von Hesse iiber die Augen der Polychäten; doch gibt er deren Ergebnisse vielfach falsch oder in ganz unzutreffender Weise wieder. In noch anderen Fällen hat er sich offenbar damit begnügt, einige Abbildungen anzusehen und ohne Beruicksichtigung des Textes sich eine Vorstellung zu bilden, die sich dann gelegentlich in wahrhaft ergötzlicher Weise von den 'Tatsachen entfernt; so wenn er unter bezug auf eine nach Moniez kopierte Abbildung (Fig. 163, pag. 159) erklärt, die Saugnäpfe der Cestoden ...werden von einem sehr hohen Epithel gebildet, an dessen Basalmembran sich Muskeln ansetzen". Auf der Keichnung sieht es allerdings ungeführ so aus, allein es sollte doch wohl selbst einem Anf:ïnger in der Zoologie bekannt sein, dass die Saugnäpfe der Trematoden und C'estoden muskulöser Natur sind. Statt der Abbildungen werden gelegentlich Präparate in ähnlicher Weise benutzt und die Organe ohne jede Berïcksichtigung der Literatur nach dem (intdiinken des Verfs. gedeutet. So wird bei Simunculus (Fig. 185) aus einem der beiden Vorderdarmgefässe eine Vorderdarmdrïse, aus dem ins Ende des Nitteldarms einmündenden Blindsack eine Enddarmdrïse, den Nieren (Segmentalorganen) wird am Hinterende ein nicht existierender Trichter angezeichnet, dem Darmnerren ein do. Ganglion und dem hinteren Körperende eine do. "Aboraldrüse“. Auf den Gebieten, wo der Verf. selbständig gearbeitet hat, werden seine eigenen Befunde in ganz ungebührlicher Breite wiedergegeben, die übrige Literatur mehr oder weniger rollständig ignoriert (Mollusken). Auf einem Missverständnis literarischer Angahen wird es wohl beruhen, wenn Verf. den dipneumonen Spinnen ausser dem Lungenpaar noch „Tracheen mit vier Paar ventralen Stigmata" zuschreibt (pag. 422), dass er die Stigmen aber, noch dazu in einem Medianschnitt (Fig. 387), in die Abbildung von Epeira einzeichnet, ist - stärker!

Endlich passieren dem Verf. in bezug auf ganz elementare und 
fundamentale Dinge die gröbsten Irrtümer. So müssen wir pag. 393 lesen, dass durch die Ostien des Arthropodenherzens das Blut nach aussen gelangt, jag. 399. dass die Rhizocephalen Nahrung durch die Körperobertläche aufnehmen; pag. 400 wird der Kraumagen der Malakostraken als ein Teil des Magens erwälint, pag. 402 die thorakalen Darmblindsäcke der Spinnen den Mitteldarmdrüsen (= Leber) der Skorpione an die Seite gestellt, ihre Leber aber als „Abdominaldarmdrüisen" aufgeführt, pag. 414 heisst es von den Crustaceen: „Die kurzen Ovidukte mïnden, gleich den oft sehr lingen und in zwei Abschnitte, Samenleiter und Ductus ejaculatorius, differenzierten Ausfiihrgängen [des Hodens] am Basalglied des letzten Thorakalfusspaares, wobei auch bei ibnen das betreffende Beinpaar jederseits in ein Kopulationsorgan $(f)$ umgewandelt ist". In der $\mathrm{Ab}$ bildung ron Sepia (Fig. 260 B) ist einer der beiden 'Tentakel mit $h c=$ Hektocotylus bezeichnet. Über diesen geht der Verf. im 'T'ext mit folgenden Worten hinweg: "Ausserdem gelangen bei den männlichen Dibranchen bei den meisten Formen ein seltener zwei Arme zu spezieller Ausbildung für die Verwendung beim Begattungsakte. Ein solcher Arm leisst Helitocotylus" (pag. 262). Der I'luteus ist die Larvenform der Ophiuren und Crinoiden (pag. 110). I)ie Kalk- oder Hornskelette der Anthozoen ,sind von peridermalen Gebilden insofern zu trennen, als sie stets subektodermal im Mesoderm lagern. Sie dienen somit auch dafür zum Beweise, dass Skelettgebilde im Nesoderm nicht unbedingt dort entstehen miissen " (pag. 108). Diese Liste mehr oder weniger grober Schnitzer liesse sich fast nach Belieben vergrössern.

J. W. Spengel (Giessen).

\section{Zellen- und Gewebelehre.}

3 Rhumbler, I., Der Aggregatzustand und die physilialischen Besonderheiten des lebenden Zellinhaltes. I. Teil. In: Zeitschr. f. allgem. Physiol, Bd. 1. 1902. pag. 279-38s. 31 Textfig.

Fiir eine mechanische Inalyse der Tätigkeiten der lebenden Zelle, wie sie jetzt vielfach in Angriff genommen wird, ist die Frage nach dem Aggregatzustand des lebendigen Zellinhaltes von fundamentaler Bedeutung; denn die Mechanik flüssiger Substanzen ist fast in jeder Hinsicht verschieclen ron derjenigen fester Körper.

$\mathrm{Rl}$ lu $\mathrm{mbler}$ hat es num in der vorliegenden Arbeit unternommen, in systematischer Weise einerseits die Kongruenzen zwischen dem Verhalten des lebenden Zellinlıaltes und leblosen Flïssigkeiten festzustellen, andererseits aber die Inkongruenzeu, die sich zwischen leblosen hom og enen Fliissigkeiten und lebendiger Substanz ergeben, 
darauf hin zu prüfen, ob sie im stande sind, die Lehre vom flüssigen Aggregatzustand der lebendigen Substanz zu widerlegen.

Als flüssig bezeichnet der Verf. in Anlehnung an die früher geltende Definition in der Physik jede Substanz, die a) ohne innere Elastizität ron messbarer Grösse, b) ohne merkbare Kompressibilität (bei gewöhnlichen Drucken), c) den Kapillargesetzen unterworfen ist.

Der Mangel messbarer innerer Elastizität wird durch eine ganze Reihe von Beobachtungen erwiesen, deren interessanteste wohl die über die Verschiebbarkeit der Teilchen bei der sogenannten Plasmaströmung sein dürften. As Objekt dienen Prothalliumzellen von Chara foetida, die besonders rasche Rotationsströmungen zeigen. Durch einfache Beobachtung und experimentelle Eingriffe zeigt R h u m bler, wie ausserordentlich hochgradig die einzelnen Konstituenten des Zellinhaltes verlarert, entmischt und durcheinander gemengt werden können, ohne dass das Zeichen des Lebens, die Plasmaströmung erlischt.

Die zweite Eigenschaft, welche der lebende Zellinhalt zeigen muss, wenn wir ihm flüssigen Aggregatzustand zuerkennen sollen, ist die Inkompressibilität bei gewölnnlichen 1)ruckkräften. I'm diese Eigenschaft demonstrieren zu können, hat Rhumbler sich einen . Depressor" konstruiert, der es ermöglicht, durch genau abstufbaren Druck auf das Deckglas eine darunter befindliche 'Zelle unter einen I) ruck bis zu 7 Atmosphären zu setzen. Eine grosse Reihe von Versuclien zeigen, dass der auf der Zelle lastende Druck keinen nachweisbaren Einfluss auf die Plasmaströmung ausübt, dass ror allem die Geschwindigkeit der Strömung nicht vermindert wird, wie man es erwarten müsste, wenn die strömende Substanz ein Gerüstwerk ron auch nur geringer Festigkeit besässe. Lag ein 'T'eil der Zelle unter dem Deckglas und so unter bedeutendem Druck, der andere niclit unter dem Deckglas, so war nie eine gesetzmäßige Differenz in der Strömungsgeschwindigkeit beider Abschnitte zu konstatieren, der Druck pflanzte sich also in der Zelle gleichmäßig nach allen Seiten fort, wie er dies eben in einer Flüssigkeit tut. Gelang der Nachweis, dass die lebendige Substanz sich in bezug auf die beiden ersten Punkte der Definition wie eine Flüssigkeit verhält, relativ leicht, so bieten ihre viel verwickeltern Beziehungen zu den Kapillargesetzen erhebliche Schwierigkeiten.

Das erste Kapillargesetz verlangt von den Fliissigkeiten, dass sie sich in einem frei beweglichen Nedium infolge ihrer Oberflächenspannung mit Minimalflächen unkleiden. Dass diese Eigenschaft sowohl der Zelle als Ganzes wie auch isolierten Bestandteilen der Zelle zukommt, ist bekannt. Besonders die Beobachtungen von Berthold, 
Driesch, C. He rbst und anderer sprechen unzweideutig dafür: der isolierte, keinen hindernden Kräften unterworfene Zellinhalt nimmt Kugelgestalt an. Aber dieser Nachweis reicht nicht aus, um zu beweisen, dass die Zelloberfläche wirklich dem ersten Kapillargesetz folgt; denn auch eine Flüssigkeit, die von einer elastischen gespannten Hülle umgeben wäre, würde dieselben Erscheinungen zeigen. Da nun in vielen Fällen der Zellkörper tatzächlich von einer elastisch gespannten Haut (vgl. Turgor der P'flanzenzellen), der Zellmembran, umgeben ist, so muss zunächst die Frage entschieden werden, ob sie es ist, die das Streben der Kellen nach Ninimalt1ächen bedingt, oder ob es sich um wirkliche Oberflächenspannung infolge des Flïssigseins der Zelloberfläche handelt. Die l'rüfung ergibt hier „die erste mechanische Inkongruenz zwischen leblosen Flüssigkeiten und lebenden Zelloberflächen. Die Oberflächenteilchen einer einheitlichen fiüssigkeit lassen sich innerhalb der Oberflächenschicht ebenso gut wie im Innern ad libitum verschieben, während das in keinem Falle mit den Oberflächenteilchen der lebenden Kelle geschehen kann."

In ein Hïssiges Medium eingesenkte, mit dem Medium nicht mischbare leblose Flüssigkeitstropfen lassen sich durch vorbeiziehende Strömungen stets in ihrem Innern in konforme Strömungen versetzen. Ebenso verhalten sich auch abgestorbene \%ellen, z. B. die, zu diesen Experimenten besonders benutzten der Amoeba blattae. Ganz anders die lebende Zellen; selbst die so leichttlüssig erscheinende Amoeba blattae lässt sich durch Vorheiführen äusserer Ströme nie in Innenströmung versetzen; eher reisst sie, wemn sie der Unterlage anhaftet, in Stücke, als dass sie die Aussenströmung in ihrem Innern wiederholt. Ganz ebenso verhalten sich isolierte Blastomeren von Frosch und Molch.

Erklärt sich diese Differenz zwischen Fliissigkeitsoberflächen und Zelloberflächen wirklich durch die Anwesenheit einer feinen elastisch gespannten \%ellhaut? Das ist nach Rhumblers weiteren Ausführungen nicht der Fall; es spricht gegen eine solche Annahme besonders 1. die unbegrenzte Kriechfähigkeit der Amöben, die mit mathematischer Bestimmtheit erheischt, dass stets Substanzen aus dem Innern an die Oberfläche treten und auch ständig solche in entgegengesetzter Richtung absinken, ein Vorgang, der bei flüssigem Aggregatzustande zwanglos verständlich ist, aber auch nur bei diesem! 2. Die Fähigkeit der Amöben, feste Nahrungskörper aufzunehmen, olne dass bestimmte Mundöftinungen in der hypothetischen Nembran vorhanden wären. Endlich 3. die Schalenbildung der Diftlugien, bei der die Bausteinchen der Gehäusewand aus dem Zellimnern an die Oberfläche 
treten. Es liesse sich nicht begreifen, wie sie durch die Oberfläche der Amöbe auf die Aussenseite derselben kommen sollten, wenn die Amöbe ron einer festern Membran umgeben wäre; , dlagegen erklärt der Hüssige Zustand der OberHächenschicht nicht bloss die Möglichkeit des Durchkommens der Steinchen auf die Aussenfläche, sondern auch die Entstehung des dichten Mauergefüges, das die Difflugien anszeichnet".

Nusste die Annahme einer festen Hülle, die die Zellen ganz allgemein umgeben sollte, entschieden abgewiesen werden, da sie nicht iul stande war, den Beobachtungstatsachen gerecht zu werden, so wäre doch noch die Möglichkeit zı diskutieren, dass ein Hüssiger Hüllmantel die Zelle überzöge und ihre Widerstandsfähigkeit gegen Aussenströme bewirkte. Aber auch diese Annahme wird, obgleich einige Gründe sich wolıl für sie ins leld führen liessen, aus rerschiedenen Erwägungen als im höchsten Grade unwahrscheinlich abgelehnt.

Halten wir also daran fest, dass, wie oben gezeigt, liein Geriist von irgend welcher Festigkeit in der Zelle vorhanden ist, und erinnern wir uns, dass beim Absterben der Zelle, olne Finwirkung von Reagentien, sich ein zäheres Gerinnungsgerüst in einer selı dïnnen Flüssigkeit niederschlägt, so müssen wir annehmen, dass diese beiden Substanzen intra vitam in einer Weise verteilt sein mïssen, die eben bewirkt, dass das Gemisch die erwähnten mechanischen Eigentümlichkeiten zeigt. „Es gibt aber nur eine Mischungsart ronzwei "Flüssigkeiten“, welche bei Anfrechterlualtung der inneren Verschiebbarkeit die Oberfläche der Mischung soweit unverschiebbar maclut, dass äusserlich vorbeigeführte 'Tangentialströme nicht analoge innere Rotationsströme in der Mischung erzeugen. Diese einzig mögliche Misclungsart, d. h. diejenige, die allen seither festgestellten mechanischen Eigentümlichkeiten der von uns behaudelten Zellinhalte gerecht wird, ist die Schaummischung oder, wie wir mit Bütschli sagen kömmen, die "Wabeustruktur".

An einer Mischung ron $\ddot{O}$ l in einer Lösung von Gummi arabicum zeigt Rhumbler, wie die bis dalin ohne weiteres auftretenden Wirbelströme auf äusserliches Anblasen sofort aufhören, wenn man soviel Öl der Gummilösung zumischt, dass sich die aneinander gedrängten Öltropfen gegenseitig abplatten und so das Gummi als Trennungswände zwischen siclı nehmen, d. h. also in dem Augenblick, wo die Mischung Wabenstruktur angenommen lat. So widerstandsfähig ein solclies Schaumsystem gegen äussere Strömungen usw. ist, so leicht finden in ihm bewegungen statt, wenn eine Änderung der chemischen Zusammen- 
setzung und damit der Molekularattraktion bezw. der ObertlächenEnergie erfolgt; 'T'emperaturdifferenzen, elektrische Einflisse usw., können diese Kräfte in hohem Maße beeinflussen. Das Bewegungsgesetz der Schaummassen formuliert Rhumbler in den Worten: .. Die Bewegungen der Schaummassen geschieht leicht durch solche Inderungen im System, welche die Molekularkräfte der den schaum komponierenden Substanzen beeinflussen; sie geschieht schwer oder gar nicht. Durch solche Inderungen im system, welche die Molekularkräfte der im Schaum gemischten Substanzen unberïhrt lassen und die Schankomponenten nur als Massen (mit ihrem Trägheitsmoment [1/2 $\left.\mathrm{mr}^{2}\right]$ ) a ngreifen." Diese Wabenstruktur, die eine "innere" Spannung der Zelle, eine "Schaumspanmung“ zur Folge hat, ist ron hoher mechanischer Bedeutung für das Verlialten der Yelle im Zellverbande. Sie bewirlit auch das eigentiunliche Verhalten der lehendigen Substanz gegen Druckwirkungen. Erleidet die Zelle Drucke von kurzer Dauer, so verhält sie sich ihnen gegenüber wie eine elastische Substanz: sie kehrt schnell wieder in ihre frühere Gestalt zurück. Gegenïber lang dauernden Druckwirkungen aber verhält sich die Zelle wie eine . knetbar plastisclıe "Masse, d. h. es findet eine Umordnung der Wabenwände statt im sinne einer Konsolidation der durch den Druck bewirkten Form. Hört der lange dauernde Druck auf, so gewinnt die Zelle gar nicht oder doch äusserst langsam ihre frühere Gestalt wieder, es hat eine Anpassung der Form an die neuen Druckverhältnisse stattgefunden. Auch hierfür liefert R. eine Reihe von Beobachtungen.

Die Wabenstruktur erklärt auch die zweite Inkongruenz zwischen dem Verhalten homogener Flüssigkeiten und der lebendigen Substanz, nämlich die Möglichkeit, welche für die Zelle besteht, andere als absolute "Ninimaltächen" zu bilden. Es ist ja ersichtlich, dass infolge sehr verschiedener Beschaffenheit des Alveolarwerkes an verschiedenen Stellen der Zellobertläche, der Anomogenität der Zelloberfliche (Roux), hier auch sehr verschiedene Obertlächenspannungen herrschen müssen, welche dann die Ijildung von Flächen gestatten, die wesentlich grösser als die mathematischen Vinimalfïchen, also nur ,relative Minimaltlächen" (Driesch) sind, olme dabei die Allgemeingültigkeit des ersten Kapillargesetzes in Frage zu stellen.

Die weiteren Ausführungen über die Geltung der Kajpillargesetze für die lebendige Substanz verspricht $R$ humbler in einer weitern Arbeit, auf die wir, nach den hochinteressanten Ergebnissen der ersten, nit Recht gespannt sein dürfen. A. Pütter (Breslau). 


\section{Descendenzlehre.}

4 Korjinsky, S., Heterogenese und Evolution. Zur Theorie

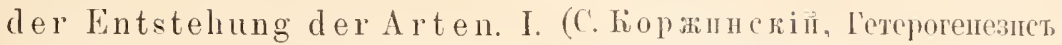
и әволюція. Ііт теоріп пропсховденія впдвь.) In: lém. Acad. imp. sc.

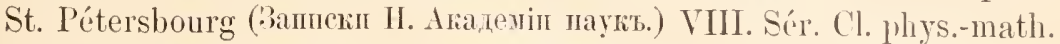
Vol. IX. Nr. 2. 1899. pag. 1-94 (russisch).

Obgleich sich rorliegende Schrift des bekannten, leider zu frïh verstorbenen Botaniker's hauptsächlich auf botanisches Gebiet erstreckt, so ist doch die Frage ron so allgemein biologischem Interesse und fiir die Zoologie so anregend, dass sie, besonders bei dem stetig steigenden Interesse fuir die Mutationstheorie, eine eingehende Besprechnng verdient. Verf. klagt über die geringe $/ a$ ahl von Tatsachen im Verhältnis zu den theoretischen Erörterungen anf dem Gebiete des eigentlichen Darwinismus und erzählt von den Enttäuschungen, die er auf seinen Reisen durch Russland und Sibirien erlebte, wenn er bemüht war, die Ursache der Entstehung neuer Formen aufundecken. Deswegen, da er bei wilden Gewächsen keine Lösung fand, wandte er sich zum Gartenbau. Hier fand er, (lass I) a r w ins Vorstellung von der Entstehung der Kulturrassen auf filscher Lrklärung der Tatsachen beruhe, dass nie ein Gärtner zur Erlangung einel nenen Rasse mit individuellen Eigentiimlichkeiten operiert hat, und dass nie eine Summierung dieser Eigentümlichkeiten beobachtet wurde. Alle neuen Varietäten, deren Entstehung bekannt ist, sind anf dem Wege plötzlicher $\Lambda$ bweichungen hervorgegangen. Iliese plötzlichen sprungweisen Abweichungen nennt der Verf. im Anschluss an Koelliker "Heterogenese".

Der rorliegende I. Teil der Arbeit soll die Heterogenese selbst charakterisieren, der II. 'T'eil der Arbeit, der leider nicht zu Ende gelangte, sollte die Rolle der Heterogenese bei der Entstehung der Arten behandeln. Verf. glaubt, dass die Heterogenese durchaus nicht so ungemein selten ist, wie man glauben möchte, und führt eine Menge Beispiele gut bekannter lälle ans der Pflanzenzucht an. Nach diesem Materiale zu urteilen, sind die Eigentümlichkeiten plötzlich durch Heterogenese neu entstandener Rassen sehr konstant und werden unverändert ron Geschlecht zu Geschlecht rererbt. Solche Formen lassen sich nicht durch Atarismus erklären, oft weisen sie im Gegenteil progressive Eigentümlichkeiten auf, wenn anch atavistische Eigentümlichlieiten manchmal gleichfalls zum Vorschein kommen können. Viele teratologische Formen stehen heterogenen Formen durch die Art ihrer plötzlichen Entstehung sowohl, als auch durch ihre Vererbbarkeit nahe, doch lassen sich lange nicht alle Veränderungen, die durch Ileterogenie entstehen, auf Missbildungen zurïckführen. Durch Heterogenese wird nicht nur irgend ein Organ verändert (gegen Godron), 
sondern viele. In den zwanziger nud dreissiger . Tahren war die Gartenbaulitteratur besonders reich an Besclireibungen solcher, durch Heterogenese neu entstandener Arten. Hier finden wir V'ariationen in der (rrösse: Zwergformen (Nanismus) und Riesenformen (Géantisme), die plötzlich inmitten normaler Exemplare, die in gleichen Bedingungen in guter Gartenerde aus Samen gleicher Herkunft wachsen, entstehen. Das Fehlen der für Fragaria so charakteristischen Ausläufer bei einer 1811 plötzlich entstandenen Rasse, die darauf durch Samen weiter rerpflanzt wurde. Bedeutende Veränderungen entstehen auf gleiche Weise auch in der Krone: so 'I'rauereichen und Formen mit hängenden Zweigen, so pyramidale Formen. Heterogene Variationen der Blätter bestehen bald in Vereinfachung des Blattes, bald im Komplizierterwerden desselben. Variationen in der Farbe der Blätter und Bliiten entstehen gleichfalls durch Heterogenese, ebenso Abreichungen in der Form der lilüte, in der \%eit des Blïhens, in den Früchten. Für alle diese Erscheinungen werden sehr viele Beispiele angeführt, für die wir aufs Original verweisen müssen. Aus ihnen kommt Verf. zu dem Schlusse, dass die Heterogenese ziemlich vielseitige Veränderungen hervorzubringen imstande ist. Das Bild der Heterogenese stellt sich so dar, dass aus Samen ron normalen Exemplaren irgend einer Art unter tausenden Pflanzen ein Individuum herrorwächst, welches sich durch eine oder viele Eigentümlichkeiten scharf von allen übrigen unterscheidet. Heterogene Eigentümlichkeiten zeigen immer mehr oder weniger scharfe Abweichungen, während individuelle durch kleine Abweichungen sich unterscheiden: "Alle individuellen Variationen sind in den Grenzen des Typus eingeschlossen, die heterogenen dagegen treten aus diesen Grenzen hinaus und bilken eine Störung des Typus". Die vorliegende Erscheinung muss anch ron Hybridation scharf unterschieden werden. Für jede Art genommen ist die Heterogenese doch eine ältere Erscheinung: so wurde Erythrius crista-galli 1771 kultiviert, und 1844 erst trat ihre erste Variation auf; Begonia semperflorens, 1829 kultiviert, gab erst nach 50 Jahren die erste Abart. Wenn man von einigen Variationen behauptet, dass sie öfters aufgetreten sind, so muss man es so verstehen, dass nicht zweimal dieselbe Form auftrat, aber nur eine gewisse Eigentünlichkeit derselben; auch sind leicht Irrtiimer möglich, und den Berichten der Gärtner, die oft nach dem plötzlichen Auftreten einer Variation behaupten, auch sie hätten dieselbe erzielt, ist nicht zu trauen, wenn man nicht weiss, woher der Samen genommen wurde. Der Vert. behauptet, dass ihm kein wirklich bewiesener Fall bekannt ist, wo eine Variation in nehr als je einem Exemplare gleiclıeitig entstanden ist. Die Ursache der Heterogenese ist nicht in den äussern Wachstums- 
bedingungen zu suchen, da diese sich ja auf mehrem Exemplaren äussern müsste. Die Veränderungen beim Ïbergang aus dem wilden Zustande in eine Kulturpflanze kann nicht die Ursache der Heterogenese sei, da die Pflanze erst nach vielen Jahren der Kultivierung plötzlich eine Variation giebt. Eine gute Ernährung und I'llege scheint das Auftreten der Heterogenese zu begünstigen, doch ist hier auch die Erklärung möglich, dass auf schlecht genährte und folglich wohl vernachlässigte Zuchten schlecht geachtet wird, so dass eine Variation leicht unbeachtet bleiben kann. Die Heterogenese ist sowohl in regressiver; als in progressiver Richtung möglich, doch bieten regressive Formen grössere Abweichungen. Die Fruchtbarkeit heterogener Formen ist oft herabgesetzt, oft aber gar nicht gestört; eine zuerst wenig fruchtbare Variation wird in der nächsten Generation, je mehr sich ihr Charakter fixiert, fruchtbarer. Alle durch Heterogonie entstandenen Abweichungen sind nicht nur bei vegetativer Termehrung konstant, sondern vererben sich anch. Am sonderbarsten ist das Faktum, dass einige lıeterogene Variationen ron Anfang an keine Mischrasse gaben und sich augenscheinlich gleich so sehr von ihrem Ausgangstypus unterschieden, dass sie keine Befruchtung mehr mit demselben eingingen. Was die Tendenz zur Variation betrifft, so tritt sie nicht konstant zu Tage, muss aber während vieler Generationen gleichsam Kräfte sammehn, um die Macht der Vererbung zu brechen und eine neue Rasse zu schaffen. Wir mïssen annehmen, dass die Veränderungen in der Samenknospe zu suchen sind und während oder nach der Befruchtung auftreten; wolcher Art aber diese Veränderungen sind, weswegen sie nur in einer und nicht auch in der benachbarten Samenknospe auftreten, .. ist unklar, wie vieles andere in diesem geheimnisvollen I'rozesse".

\section{E. Schultz (St. Petersburg).}

\section{Faunistik und Tiergeographie.}

5 Mokrzetzki, S.A., Schädliche Tiere und Pflanzen im Gouvernement Taurien im Jahre 1900 mit Angabe der Nittel zu ihrer Bekämpfung. (С. А. Могіжещкій, Вредныя жинотныя и Растенія въ Таврщческой Туб́ерніп по наблюденіяуь 1900 года. ('ъ указапіемъ мұръ борьбы.) Simferopol 1901. 97 pag. 1 Taf. (Russisch).

Der erste Teil des vorliegenden Berichtes enthält das durch Anfragen bei 261 Landwirten erhaltene statistische Material über die im Jahre 1900 im taurischen Gour. beobachteten Schädlinge und die durch sie angerichteten Beschädigungen. Alle Angaben über schädliche Pflanzen sollen hier weggelassen werden. Es muss bemerkt werden, dass das betreffende Jahr wegen Trockenheit und aus andern 
Ursachen, kein günstiges für die Kulturen war. Unter den ungïnstigen Faktoren nahmen die Insekten samt Pilzkrankheiten nach der Trockenheit die erste Stelle ein, indem etwa ${ }^{1}$ \& der Ernte durch sie zu Grunde ging. Als Schädlinge sind zu nemnen: Anisoplia austriaca Hbst. (zerstörte bis zu ${ }^{2} / 3$ der Saaten), Brachycolus korotneri Mordw. (diese Blattlaus erschien während der Älrenbildung und liess in einzelnen Ähren nur :3--4 Körner zurn̈ck); Cecidomyia destructor Say (schadete nur friilien Wintersaaten). Athous niger L., Agriotes lineatus L., Aphtona enphorbiae F., Emycreon sticticatix, Entomoscelis adomidis Pall., Epicometis hirta P'. (vernichtete stellenweise den halben bis ${ }^{3 / 4}$ Obstertrag), Eriocampa adumbrala Kl., Carpocapsa pomonella F., Polyphylla fullo L. (die Larven vernichteten bis zu 30\% der frischgepflanzten Reben). V'on Säugetieren schadeten Zieselmäuse, Feldmäuse und Hamster.

Der zweite T'eil enthält eigene Beobachtungen des Verfs.

A. Schädling eder Felder und Gemüsegärten. Irachyrolus liorotnerri Mordw. trug in erster Linie zur Missernte der Gerste bei. Diese erst 1901 von Mordwilko beschriebene Blattlaus erscheint Ende Mai; Anfang Juni sind die befallenen Pflanzen niedrig, vertrocknet, noch ohne Ïlnrenbildung. Unter dem obersten, röhrenförmig zusammengerollten Blatt am C̈hrenstiel sitzen die ungeflïgelten Läuse und saugen bis Ende Juni. wo nur noch wenige, kranke Läuse und zahlreiche Häute sowie Exkremente zu finden sind (letztere machen das Stroh untauglich zum Füttern). Anfang Juni erscheinen gefligelte Individuen, welche in ungeheuren Scharen (Wolkenbildung) davonfliegen. Yon Feinden dieser Blattlaus sind zu nennen: Imagines und Larven von Corcinella septempunctata L., Adalia bipunctata L., Exochomus 4-pustulatus L., E. reisei Retow. und Adoniu rariegata Goeze (welche ebenfalls in enormen Mengen auftraten), Larven ron Syrphiden, Cecidomyiden (Bremia Rübs.), Chrysopiden, ferner als Entoparasiten: Braconiden. Alle diese Feinde bewirkten die fast völlige Vemichtmng der Blattläuse, von denen im folgenden Jahre nur wenige mehr anzntreffen waren. Ein ähnliches massenhaftes Auftreten war schon früher mehrfach bei Siphonophora cerectis Kalt. in Südrussland beobachtet worden. Mittel zur Bekämpfung: tiefes Umpfliigen der Stoppeln znr Vernichtung der Wintereier, Verbrennen der Stoppeln, Bestellen der befallen gewesenen Felder mit Wintersaat oder mit anderen Getreidearten, möglichst frühe Saat des Sommergetreides. Ausserdem schadeten noch die Blattlïuse Pentaphis triviatis Pass. und Parratetus cimiciformis Heyd.

Anisoplia austriaca Hbst. schadete vorziiglich in den geraden .Jahrgängen (1900, 1898 usw.) Als Parasiten sind zu erwähnen Tiphia femorata 
T.morio F. (Hymenoptera) und Dexia mstica F., Microphthalmus longifacies R. (Diptera). Als wirksame vorbeugende Mittel sind zu empfelılen der öftere Fruchtwechsel, das Brachliegenlassen der Felder, öfteres Pfligen, Wintersaaten. Ist der Käfer einmal erschienen, so lat die Ernte möglichst bald zu erfolgen (selbst bei nicht völliger Lieife); das Einsammeln der Käfer muss mit Hilfe ron Netzen oder mit Karren geschehen, an welchen eine lange Stange mit Drahtkamm und darunter ein Sack befestigt sind. Nach letzterer Methode können zwei Mann täglich etwa 400 Kilogr. Käfer einsammeln.

Von Drahtwürmern schadete am stärksten die Larve von Athous niger L. Die Käfer erscheinen ron Juli an, es überwintern halb erwachsene Larven, welche im nächsten Frühjalır (April bis Mitte Juni) hauptsächlich an T'abakspflanzen (Krrim) grossen Schaden anrichteten. Walzen der bestellten Felder (Herbst und Frülıjalır), Düngen mit Chile-Salpeter oder Kochsalz, Brachliegenlassen, lruchtwechsel, Vergiften der Käfer mit in Pariser Grün getauchten Kleebüscheln oder Sammeln der Larven mittelst zerschnittener Kartoffeln als Lockspeise erwiesen sich als erfolgreiche Mittel gegen den Schädling. Auszusäende Samen (Weizen, Mais, Ficheln u. s. w.) können erfolgreich zuror in Kinpfervitriol, Tabakslauge oder Petroleum eingeweicht werden.

Die Raupe von Agrotis abesa P. richtet bedeutenden Schaden in den Tabaksplantagen an; die Raupen vergraben sich tagsüber in der Erde und fressen nachts die äusseren T'eile der Pflanzen (können sie diese nicht erreichen, so werden zuror die Stiele durchgebissen); Mitte Mai gehen die liaupen in die Erde, wo sie sich im Juli verpuppen, wälırend der Schmetterling von August an austliegt. Kommt in Südfrankreich (wo sie den Reben schadet) und in Siidrussland (var. scythica Mphr.) vor; das Weibchen legt 250 runde hellgelbe Eier, aus denen Angust--September die Raupen ausschliipfen. Empfohlen wird ein giftiger Köder aus Weizenkleie, Sirup und Pariser Grün.

C'ledeobir moldacica E. Die liampe schadet den Futtergräsern Festuca orina L. und Stipa, indem sie deren Stengel in der Erde fressen. Die Biologie dieses Schädlings wird erstmals beschrieben: Verpupung Anfang Mai in vertikalen, mit Gespinst ausgekleideten Gängen, in welchen die Larven eine Zeitlang leben; der Cocon bestelıt aus undurchsichtigem grauen Gewebe, ist flaschenförmig, der Halsteil mit 5-6 Paaren dachziegelartig angeordneter Scheidewände, deren Bedeutung nicht sicher aufgeklärt wurde (vielleicht erleichtern sie das Ausschlïplen). Die ersten Puppen wurden den 5. Mai¹), die

1) Die Daten sind hier alle nach dem alten Stil, also um 13 Tage zurück, angegeben. 
ersten Schmetterlinge den 17. Mai, Haupthug rom 20.-31. Mai, Eiablage Ende Mai, Ausschlüpfen der Larven in der zweiten Hältte des Sommers, Überwintern der Larren ron November ab in der Erie. Diese Art trat friiher nur 1879 massenhaft auf. Durch lertilgung ler Raupen machen sich einige Vögel nützlich.

Gegen die Raupen der Motte Eurycreon sticticalis L. empfiehlt der Verf. verschiedene Mittel, welche an anderer Stelle besprothen werden sollen.

Gegen die Larven von Dorcadion piyrum Sch., welcher die Halme der Gerste durchnagt, empfiehlt der Verf. tiefes Umptligen nateh der Ernte (bevor der Käfer ausschlüptt), Fanggräben.

Entomoscetis adonidis L'all. schadet nur Kreuzblütlern (Raps, Ribbenarten), Aphtona enphorbicte I: frühen Leinsaaten (I'ariser Grïn!), Pentodon monodon F. dem Mais, Etiella sinquenella 'Tl'. Akaziensamen und Bohnenarten.

Weitere Schärllinge waren Tumymecus palliatus F.. Tylenchus, der Pilz Septoria gramimm I)esm., Bufo riritis Lam. (welche vielleicht junge Getreideschösslinge aussaugt!)

B. Scliärlinge in Gärten, Weingärten und Wäldern. Die Larve von Thaynchites bacchus L. kamm nach den Beobachtungen des Verfs. aueh in den von Pilzen (Monitia) befallenen, mumifizierten und noch am liame hängenden Frïchten sich entwickeln ${ }^{1}$ ) (obgleich nur langsam) und in solchen Frichten überwintern. Die Stiche des Rüsselkäfers begïnstigen die Entwickelung und Verbreitung des P'ilzes in hohem Maßje, wallrend dieser letztere die Frucht für die Entwickelung der Larve geeignet macht (eine drt Symbiose). Sammeln der vom I'ilz befallenen Frïchte und deren Vernichtung!

Carpocapsa pomonella L. hatte in einem Somner zwei Generationen, von denen die eine von Mitte Mai bis Mitte Juni, die zweite von Vitte Juli an Hiegt. Zur Bekämpfung wird empfohlen, an den bäumen Ringe aus Keitungspapier anzubringen, unter welche Sägespäne gestopft werden, in welch letztern sich die Rampen zu Hunderten rerstecken und welche alle zwei Wochen remichtet werdeu mïssen. Über diese Motte wird eine spezielle Schrift in Aussicht gestellt. In Gärten wurlen ferner beobachtet Diloba caeruleocephala L. und Rhynchites populeti L.

In Weinbergen richtete namentlich der Sauerwurn (Cochylis ambiguella) grossen Subaden an. Zur Bekänpfung emptiehlt der Verf. 1. Vernichtung der P'uppen durch Sammeln oder Kratzen der Stämme, 2 Bespritzen der ersten Generation (während der Rebenblüte) mit dem Dufoursehen Inseliticid (Neife + persisches Insekten-

1) Solche befallene Früchte fallen nicht ab. 
Pulver in Wasser) rermittelst der Vermorelschen Spritze, 3. Bespritzen der latbreifen Trauben mit Bordeanxscher Flüssigkeit noch während des Fluges der zweiten Generation. Ein weiterer Schädling an Trauben war Dactylopius longispinus Targ., - an Himbeeren Lasiopteicu mbi Heid.

In Waldkulturen schadete namentlich Lina tremulae F. an Weiden, welche zur Befestigung des Flugsandes an Dnjepr angepflanzt wurden; gegen diesen Blattkäfer wird Abschüttehn im Frühling und Herbst und Bespritzen nit lariser Grün + Kalk empfohlen.

Gegen Feldmäuse empfiehlt der Verf. mit Arsenik vergiftete Weizenkörner, welche in die Mäuselöcher gestreut werden; die Körner können in kochende Arseniklösung gelegt und später mit Methylengrïn gefärbt werden; dieses Mittel gab auch ausgezeichnete Resultate gegen Hamster und Zieselmäuse.

$$
\text { N. v. A delung (St. Petersburg). }
$$

\section{Protozoa.}

6 Marceau, F., Note sur le Karyolysus lacertarum, parasite endoglobulaire du sang des lézards. In: Arch. Parasitol. T. IV. Nr. 1. 1901. pag. 135-142, arec : (46) tigs.

Verf. fand die im Titel der Arbeit genannte Hämosporidien-Art bei 25 Exemplaren von Lacertu muralis konstant, nie dagegen bei Lacertu riridis. Seine Untersuchungen hat er ausschliesslich an Präparaten angestellt, welche in der üblichen Weise fixiert und mit EosinMethylenblau gefärbt waren. Seine Schilderung läuft in der Hauptsache auf eine Bestätigung der Angaben von Labbé linaus, ohne wesentlich neue Gesichtspunkte beizubringen. Insbesondere unterscheidet der Verf. wie Labbé zweierlei Vermehrungscysten: Makrosporozoitencysten mit wenigen und grossen lieimen und grössere, seltener zu beobachtende Mikrosporozoitencysten mit zahlireichen und kleinen Kieimen. Worauf dieser Unterschied beruhen könnte, wird jedoch nicht erörtert. Auch tritt derselbe in den Abbildungen, welche allerdings sehr stark schematisiert sind, insofern nicht recht hervor, als die Grösse der Cysten und der Sporozoiten, sowie die Zahl der letzteren variabel und die Extreme durch kontinnierliche Übergänge miteinander verbunden erscheinen. Einen Restkörper hat Verf. in den Cysten „nicht immer" beobachtet; aber auch hier beschränkt er sich auf kurze Anführung dieser Tatsache, ohne sich über deren Bedeutung den Kopf zu zerbrechen.

M. Lühe (Königsberg i. Pr.).

7 Bertrand, Léon et Jos. Klynens, La malaria. Paris (J. B. Baillière et fils) 1903. $8^{0}$. $\mathrm{V} ; 184$ pag. 4 planches et 50 figs.

- Nr. 5-7. - 
Bertrand und K lynens haben die Ergebnisse der neteren MalariaForschung ähnlich wie Ruge (vgl. Nr. 15) in Gestalt eines Leitfadens zusammengestellt, hierbei jedoch die morphologisclien, bezw. allgemeiner gesprochen, die zoologischen Gesichtspunkte sehr viel mohr in den Vordergrund gestellt. Ihr Buch gliedert sich, abgesehen von einer kurzen Einleitung ron 3 Seiten, in 5 Teile, deren erster (pag. 4-8) die Systematik der Protozoen belıandelt, d. h. die Einteilung derselben in Klassen und die weitere Einteilung der Sporozoen in Ordnungen.

Der zweite Teil (pag. 9-44) enthält eine Besprechung der Coccidien und zwar wird mit besonderer Ansführlichkeit (auf pag. 9-29), im Anschluss an die bekannte Arbeit ron Sch a u dinn, der Zeugungskreis von Coccidium schubergi Schaud. behandelt. Diesem folgt damn nur eine kurze Besprechung einiger anderer Coccidien und zwar der anderen Coccidien aus Lithobius, sowie der Coccidien des Kaninclıens, des Rindes, der Maus und des Menschen, ferner eine kurze allgemeine Besprechung der Bedentung des Generationswechsels und des Befruchtungsvorganges (letzterer im Anschluss an Ma u pas' I'ntersuchungen über die Konjugation der Infusorien) und endlich ein Abschnitt über die Untersuchungstechnik (im wesentlichen im Anschluss an Schaudinn).

Der dritte Teil enthält dann die Besprechung der Malaria-Parasiten des Menschen (pag. 45-106). Nachdem zunächst die Frage der Ein- oder Mohrzahl der Arten menschlicher Malariaparasiten besprochen ist, folgt die Srhilderung ihres Entwickelungscyklus mit besonderer Berücksichtigung der in dem Anopheles erfolgenden Sporogonie. Hierauf wird die Schizogonie noch eimmal ausfïhrlicher und für jede der ron den Verff. wie ron der Mehrzahl der Malaria-Forscher angenommenen drei Arten menschlicher Malaria-Parasiten gescndert besprochen; das letzte Kapitel dieses Teiles behandelt die bei der Blutuntersuchumg anzuwendende Technik, während ein Anhang noch eine kurze und nicht erschöpfende liesprechung der bei Tieren beobachteten endoglobulären Parasiten bringt.

Der vierte Teil des Buches (pag. 107-154) ist den Mücken gewidmet und behandelt 1. deren Äusseres, 2. den Verdauungshanal, 3. die Unterscheidung des Geschlechts und der Arten, 4. die Eier, Larven und Puppen, sowie die Dauer der Metamorphose, ò. die Lebensweise der Mïclien und endlich 6. wiederum die anzuwendende Intersuchungstechnik. I)er fünfte und letzte 'Teil des Buclıes entlält schliesslich noch eine Besprechung der Malaria-Prophylaxe. Besondere Herrorhebung verdient die treffliche Ausstattung des Buches. Zahlreiche Textabbildungen, darunter ein nicht ganz merheblicher Prozentsatz Originale sollen das Verständnis des Textes erleichtern und 
dem gleichen Zwecke dienen die am Schlusse des Werkes befindlichen 4 Tafeln, von welchen nur die letzte Kopien enthält (Mikrophotogramme von Oocysten des Malariaparasiten nach Ross). Tafel 1 enthält 4 Mikiophotogramme von "Coccidium schubergi" (Fig. 1 und 3 glaubt Ref. allerdings auf Coccitim lacazei anstatt auf C. schubergi beziehen zu müssen). Tafel 2 und 3 endlich bringen eine Anzahl guter (nur leider etwas schwach vergrösserter) farbiger Abbildungen endoglobnlärer Malaria-Parasiten, welche mit zwei Ausnahmen zur Illustration des Entwickelungsganges des Tertian-Parasiten dienen.

M. L ï lı e (Königsberg i. Pr.).

8 Gram, Christ., Ein Fall von Malaria aestivo-autumnalis mit Halbmonden ohne intraglobuläre Parasiten. In: Nord. med. Arkiv. Bd. XXXIV. 3. Följd Bd. I. 1901. Afd. 2. Inre Medicin, Háft 1. Nr. 2. pag. 1-6 mit 3 Fig. u. 1 Fieberkurve. Vorliegende kasuistische Mitteilung ist insofern auch von morphologischem Interesse, als Verf. angibt, dass die (allein gefundenen) Halbmonde den Erythrocyten nur ,angeheftet" waren, ,oft in solcher Weise, dass man annehmen könnte, sie seien mit dem Aussaugen der betreftenden Blutkörperchen beschäftigt" (! Ref.).

\section{L ü he (Königsherg i. I'ro.).}

9 Grassi, B., Die Malaria. Studien eines Zoologen. Nachtrag zur 2. vermehrten Auflage. Jena (G. Fischer) 1903. 40. 19 pag. Mk. 2,00 .

Im Anschluss an die Referate $\mathrm{Nr} .631-633 \mathrm{im}$ vorigen Jahrgange des Zentralblattes sei hier der sneben erschienene Nachtrag zur deutschen Ausgabe von G rass is Malaria - Werk erwälnt, obwohl derselbe keine lagen von speriell zoologischem Interesse behandelt. Wie bereits in den eingangs erwälnten Referaten bemerkt, ist die italienische Ausgabe der 2. Auflage gegenüber der deutschen Ausgabe um vier Zusütze vermehrt, voll denen zwei sich auf Epidemiologie, zwei auf Therapie und I'rophylaxe beziehen. Vorliegender Nachtrag bringt die beiden epidemiologischen Zusätze in Übersetzung (1. über „Paludismus olme Malaria“, d. h. iiber Gegenden mit Anophelen aber ohne Malaria und 2. die epidemiologischen Untersuchungen des Prof. Dionisi) und anstatt der beiden anderen auf Grund neuerer Erfahrungen des Verfs. einen ,kurzen Bericht über den zu Ostia in Jahre 1901 mit der chemischen Prophylaxe gemachten Versuch gegen dic Malaria-Infektion". Vergl. hierzu die italienischen Publikationen: Grassi, B., Per la lotta contro la Malaria. (Policlinico, sezione pratica, 1901. - Im S.-A. 12 pag. 8".) und Grassi, B. (in colla- 
borazione coi Dottori C. Barba Morrihy, G. Pittaluga, G. Noé e col Preparatore G. Riccioli) Relazione dell' espirimento di profilassi chimica contro l' infezione malarica fatto ad Ostia nel 1901. gr. $8^{\circ}$. 143 pag. Nilano 1902. (Supplemento alla Rivista Medica). Es sei dem Ref. gestattet, bei dieser Gelegenheit zu bemerken, dass die Zahl der epidemiologischen, prophylalitischen 1. dgl. MalariaArbeiten, welche in letzter Zeit erschienen sind, eine ausserordentlich grosse ist. Es liegt jedoch nach Ansicht des Ref. nicht in der Aufgabe des Zoologischen Zentralblattes, über alle diese Arbeiten zu berichten. Ref. hat die rorliegende P'ublikation lier nur besprochen, weil sie ihrem Titel nach sich als ein Nachtrag zu einer friher bereits zum Referat gelangten darstellt, beabsichtigt jedoch in diesem Zentralblatt prinzipiell nur solche Malaria-Arbeiten zn referieren, welche nicht nur medizinisches, sondern auch zoologisches Interesse darbieten. Bezïglich all der zahlreichen anderen Malaria-Arbeiten muss ein für allemal auf medizinische Zeitschriften, namentlich auf Ba umgartens Jahreshericht verwiesen werden.

II. L ïh e (Königsberğ i. I'ro).

10 Gray, G. Douglas, A Case of Cuartan showing Cyclic Variation of Parasites. In: Journ. of Tropical Nedicine. Vol. IV. Nr. 7. 1901. pag. 110-111, mit 1 Fieberkurve.

Gray berichtet über einen Fall ron Quartana, der um deswillen ron Interesse ist, weil rom 3. Fieberanfall ab Zählmngen der Parasiten rorgenommen wurden. Es fanden sich kurz nach dem genannten Anfall durchschnittlich 500 Parasiten pro cbmm, nach dem vierten 446 , nach dem fünften 627 , nach dem sechsten 302 . Es müssen also stets in jeder Generation eine sehr grosse Zahl der jungen Parasiten zu grunde gegangen sein. Drei Tage nach dem sechsten Fieberanfall fanden sich, nachdem inzwischen Chinin gegeben worden war, immer noch 210 Parasiten pro cbmm. Daun aber erfolgte ein sehr rasches Sinken der Zahl; denn abermals drei Tage später wurten nur noch 35 Parasiten pro cbmm festgestellt und noch später waren nur noch so vereinzelte Parasiten nachweishar, dass eine Schätzung der Zahl nicht mehr möglich war.

NI. L üh e (Königsberg i. P.).

11 Kerschbaumer, Fritz, Ma laria. Ihr Wesen, ihre Entstehung und ihre Verhütung. Wien u. Leipzig (W. Braumïller) 1901. $8^{0}$. VII. 170 pag. 12 Taf. Kr. $8,00=$ II. 7,00 .

Vorliegendes Werk gliedert sich in drei Abschnitte, welche .. Wesen der Malaria“, „Entstehung der Malaria“ und "Verhiitung der Malaria" betitelt sind. Schon hieraus geht hervor, dass dasselbe sich in erster 
Linie an Mediziner und nicht an Zoologen wendet. Es enthält jedoch eine Reihe von Angaben, welche auch für den Zoologen von Interesse sind und zwar speziell in dem dritten der genannten Abschnitte, in welchen man dies seinem Titel zufolge am wenigsten erwarten sollte. Über die Malaria-Parasiten selbst freilich und über die ron ihnen hervorgernfene Krankheit bringt der Verf. nichts Nenes bei, er beschränkt sich vielmehr darauf, die neueren Forschungs-Ergebnisse in übersichtlicher Form zusammenzustellen. Hierbei wird die Stellung der Malaria-Parasiten im zoologischen System und die Schizogonie in dem Abschnitt iiber das "Wesen der Malaria“, die Befruchtung und die Sporogonie in demjenigen iiber die .Entstehung der Malaria“ abgehandelt. Hierbei bespricht Verf. anch die bedauerliche Vielgestaltigkeit in der Benennung der verschierlenen Entwickelungsstadien der Nalaria-Parasiten, grösstenteils in Anlehnung an des Ref. ..Ergebnisse der neueren Sporozoenforschmng". In seinel diesheziiglichen Erörterung hat er freilich diese Benennung ron Entwickelungsstadien und die Namen für die Gattungen und Arten nicht auseinander gehalten.

Ausgedehnte eigene Untersuchungen hat Kerschba umer über die Lebensweise der für die nenere Malaria-Forschung so wichtigen Culiciden angestellt und zwar speziell in der Umgegend von Rorigno. Der Bericht über diese Untersuchungen und die dabei errielten Ergebnisse, welcher in dem Abschnitt über die .Verhütung der Malaria“ niedergelegt ist, bildet den Haupt-Inhalt des Buches, indem er ungefähr $2 / 3$ desselhen einnimmt. Dieser Bericht ist es auch, der in dem vorliegenden Werke rornehmlich das Interesse des Zoologen fesselt. Verf. teilt ausserordentlich zahlreiche und sorgfïltige beobachtungen iiber die Biologie der Culiciden mit und versucht auch bereits, einige allgemeine Schlussfolgerungen aus seinen Einzelbeobachtungen zu ziehen. Die dem Verf. selbst wichtirste unter diesen allgemeinen Schlussfolgerungen besagt, dass als Brutplätze der Anophelen niemals Gewässer dienen, die tiefer als ein Meter sind - und gerade diese Schlussfolgerung ist inzwischen bereits ron Schaudinn in seiner Arheit über den Tertian-Parasiten als verfrüht und nicht allgemein gültig bezeichnet worden. Um so wichtigeres Material für eine zukünftige zusammenfassende Bearbeitung der Culiciden-Biologie bilden des Verfs. eigene Beobachtungen, welche dauernden Wert behalten werden und auch den Hauptwert des Buches ausinachen. Die Ablage der Eier, die Lebensweise der Larven, Puppen und ausgebildeten Mücken, die Lebensdauer, die Zahl und Aufeinanderfolge der verschiedenen Generationen innerhalb eines. Jalures sind rom Verf. in gleicher Weise berïcksiehtigt worden. Die Tafeln bringen ausschliesslich Abbildungen zur Erläuterung der vor den Mücken ent- 
worfenen Schilderung. Eier, Larven, Puppe und Imago von Culex pipiens und Anopheles claviger sind nach eigenen Beobachtungen abgebildet worden. Besonders hervorgehoben seien die Figuren, welche die Verteilung der soeben oder vor einigen Stunden in Aquarien abgelegten Eier von Anopheles veranschaulichen sollen.

M. L ïh he (Königsberğ i. P.).

12 Lazear. Jesse W.. Structure of the Malarial Parasites. In: Johns Hopkins Hospital Reports. Vol. X. Nos. 1.-2. Baltimore 1901. pag. 1-10. pl. 1.

Lazear liefert eine kurze Schilderung der drei Arten der menschlichen Malaria-Parasiten, welche durch eine farbige Tafel mit 36 (ieider meist sehr kleinen) Figuren erläutert wird. M. Lüh e (Königsberg i. Pr.).

13 Maurer, (r., D i e Ma la r i a p ras iten. In: Hünchen. med. Wochenschrift. XLVIII. Jahrg. 1901. Nr. 9. pag. 337-342. 17 F'ig.

II a urer gibt eine kurze, aber alles Wichtige herrorhebende Schilderung der Stadien der Schizogonie der drei verschiedenen Arten der menschlichen Nalaria-Parasiten. Beim Perniciosa-Parasiten (Verf. zieht ebenso wie auch Ref. den Namen „Perniciosa" für die relativ bösartigste Form der Malaria der nicht allgemein zutreffenden Benennung "Tropenfieber" und der nur für Südeuropa gïltigen Bezeichnung "Sommer-Herbstfieber" vor) wird auch der Halbmond und seine Bedeutung für das Auftreten ron Rezidiven besprochen. Ausser praktisch-medizinischen Fragen wird auch die Färbetechnik der Malariaparasiten erörtert. Yon den Text-Abbildungen soll eine die Herstellung von Ausstrich-Präparaten erläutern, wobei Verf. wie mancher andere Malariaforscher die Anwendung ron Objektträgern emptiehlt. Die übrigen Abbildungen sind Darstellungen der Malariaparasiten selbst und zur Veranschaulichung der Unterschiede der drei Arten recht instrultiv - besser jedenfalls (weil weniger schematisiert) als irgend welche andern bisher existierenden Textabbildungen von den Malariaparasiten.

M. Lüh e (Königsberg i. Pr.).

14 Ross, Ronald and R. Fielding-Ould, Diagrams illustrat ing the life history of the parasites of malaria. In: The Thompson Yates Laboratories Report. Vol. III. Lart. II. Liverpool 1901. pag. 183-188, with 2 plates. (Reprinted from the Quart. Journ. of Mierose. Sc.)

Die Verff. geben eine kurze Zusammenfassung des Entwickelungscyklus der Malariaparasiten, welche im wesentlichen wolıl nur einen erläuternden Text zu den beiden Tafeln darstellen soll. Diese ent- 
halten 67 Abbildungen, welche jenen Entwickelungscyklus illustrieren sollen. Dargestellt sind die in der Blutbahn lebenden Stadien (Waclistum und Vermehrung durch Schizogonie, sowie herangewaclisene Gametocyten) von allen drei Arten der menschlichen Malaria-Parasiten, sowie ron Proteosoma und Halteridium, ferner die Reifung der Gameten, Kopulation und Sporogonie rom Perniciosa-Parasiten. Die Abbildungen sind, entsprechend der Bezeichnung als "Diagrams", ziemlich stark schematisiert. Dies zeigt sich am stärlisten bei dem röllig kngelig gezeichneten und ringsum mit Sporozoiten wie mit einem gleichmäßigen ('ilien-Mantel umgebenen isolierten Sporoblasten in Fig. 60 sowie bei der Darstellung der Einwanderung der Kopula in die Darmwandung des Anopheles in Fig. 52-55. Nach diesen Figuren scheint es nïmlich, als wenn der befruchtete Makrogamet sich bereits innerhalb des Darmlumens durch Abrundung und Abscheidung einer Hülle zur Oocyste umwandle und als wenn dann im Darmepitlel eine weite Öffnung sich bilde, welche den Durchtritt der Oocyste gestattet und sich alsbald hinter derselben wieder schliesst. M. Lüh he (Königsberg i. Pr.).

1) Ruge, Reinlold, Einführung in das Studium der MalariaKrankheiten, mit besonderer Berücksichtigung der Technik. Ein Leitfaden für Schiffs- und Kolonialärıte. Mit zwei photographischen sowie einer lithographisehen Tafel, 19 Abbildungen und 27 Fieberkurven im T'ext. Jena (G. Fischer) 1901. $8^{0}$. 139 pag. MIls. 4,00.

Die grossen Fortschritte, welche die Malaria-Forschung in den letzten Jahren gemacht hat, und die ebenso grosse praktische Bedeutung dieser Fortschritte haben es zur Folge gehabt, dass, namentlich in den letzten beiden . Jahren, eine sehr grosse Zahl ron Publikationen erschienen ist, welche nicht die Absicht haben, die Wissenschaft weiter zu fördern, sondern nur dazu dienen sollen, die erzielten Fortschritte, im ganzen oder unter rorwiegender betonung dieses oder jenes Gesichtspunktes, diesem oder jenem Leserkreise mundgerecht darzustellen. Soweit es sich hierbei um kurze, in Zeitschriften erschienene Artikel handelt, dïrfte sich eine Besprechung in diesem Zentralblatt erübrigen. Das Rugesche Buch dagegen verdient Erwälnnung, obwohl es sich seinen Leserkreis unter den praktischen Ïrzten sucht. In denı 1. Kapitel (Ätiologie: I)ie Malariaparasiten und die Stechmücken) wird nicht nur der Entwickelungsgang der Malariaparasiten hesprochen, sondern in vergleichsweise grosser Ausführlichkeit auch die Morphologie der Culiciden, sowie die bei Untersuchung der Anophelen auf Malariaparasiten anzuwendende Technik. 
Selır instruktiv und nachahmenswert ist die Eintragung des ParasitenBefundes in die Fieberkuren, welche im 3. Kiapitel die .,Symptomatologie" erlïntern sollen. Des weiteren ist fiir den Zoologen noch das (;. Kapitel (.. Diagnose und Differentialdiagnose") ron Interesse, da in diesem die bei der Untersuchung der Malariaparasiten anzuwendende Färbetechnik abgehandelt wird. Der übrige Inhalt des Buches ist dagegen lediglich ron medizinischem Interesse. Die mikrophotographischen Abbildungen ter Malariaparasiten auf Taf. I zeichnen sich, wenigstens zum Teil, durch relative Sclı̈rfe vor manchen ähnlichen Abbildungen rorteilhaft aus; die anf tlemselben Wege hergestellten Abhildungen ron Culer mimens und Anopheles dariger auf Taf. II sind jedoch nur Schattenbilder - für diese Abbildungen wären Zeichnungen den Mikrophotogrammen entschieden vorzuziehen gewesen. I)ie dritte Tafel enthält farbige Zeichnungen des Tertianparasiten.

M. I. ï he (Königsberg i. Pr.).

16 Ruge. Reimholl, Syphilis und Malaria. Fine parasitologische Hypothese. In: ('entr.-I31. t. Bakter. otc. Bi. XXXII. Originale. $\mathrm{Nr}$. 8/9. 1902. pag. 596 -601.

Terf. vergleicht die beiden im 'Titel genannten Krankheiten miteinander mit bezug auf klinischen Verlauf, Neigung zu Rezidiven, Wirkmngslosigkeit iler spezifischen Heilmittel (Quecksilber bez. ('hinin) gegenüber den Spätformen u. dgl. und kommt daraufhin zu dem Schluss, dass wahrscheinlich auch die Syphilis ähnlich wie die Malaria durch ein parasitisches Protozoon hervorgerufen wird. Für die zoologische Forschung kann diese Annahmo jedoch nach Ansicht des Ref. erst dann bedeutung gewinnen. wenn wirklich einmal bei der Syphilis sollten Gebilde positiv nachgewiesen sein, deren ProtozoenNatur als walrscheinlich anerkannt werden kann.

M. L ühe (Königsberg i. P.).

17 Schoo, I. J. H., Over Malaria. I. Welke Temperatur is noodig roor de Amplhigonie van Plasmodium virax? In: Nederl. Tijdschr. voor Geneeskde. 1901. Deel. II. Nr. 24. pag. 1338 -1345. Mit 1 Fig.

Verf, ein holländischer, in Krommenie wohnhafter Arzt, hat Untersuchungen zur Malaria-Epidemiologie seiner Heimat angestellt und ist hierbei auch auf die Frage des Einflusses der Temperatur auf die Entwickelung des Tertian-I'arasiten im Körper der Nücken geführt worden. Die Resultate, welche er bei den diesbezüglichen Untersuchungen erhielt, lassen sich in folgende Sätze zusammenfassen: 
Bei einer konstanten Temperatur ron $25^{\circ} \mathrm{C}$. entwickeln sich die Sporozoiten in 12 Tagen und 2 Tage später sammeln sich dieselben in den Speicheldrüsen an. Eine Temperatur-Erniedrigung auf $15^{\circ}$ oder auch auf $10^{\circ} \mathrm{C}$. ist ohne schädliche Wirkung auf die Parasiten, wenn dieselbe erst 2 Tage nach der Infelition der Mïcken erfolgt und die Infektion selbst bei giinstigerer Temperatur stattfand. Erfolgt dagegen die gleiche T'emperatur. Enniedrigung bereits in den beiden ersten Tagen nach der Infektion, so ist dieselbe für die Entwickelung der Oocysten sehr schädlich uud kann dieselbe sogar ganz verhindern. Bei $18^{\circ} \mathrm{C}$. erfolgt die Entwickelung langsamer als oben angegeben, aber immerhin noch sicher in 18 'Tagen. I'mgekehrt erfolgt die Entwickelung bei $30^{\circ}$ C. viel schneller als bei $25^{\circ}$ C. Schliesslich sei auch noch angefülırt, dass nach dem Verf. bereits eine einzige vor dem Fieber-Anfall gegebene starke losis ron Chininum sulfuricum die Entwickelung der Gameten des 'T'ertian-Parasiten zu verhindern bez. die Gameten abzutöten sclıeint - eine Angabe, die mit anderen, hauptsächlich alierdings auf den PerniciosaParasiten bezüglichen Angaben niclit im Einklange steht und daher wohl noch der Berücksichtigung bedarf.

II. Lühe (Königsherg i. P.).

\section{Coelenterata.}

18 Dendy, A., On a f ree-swimm ing IIydroid, Pelagohydra mirabitis n. gen. n. sp. In: Quart. Journ. microse. Sc. Tol. 46. N. S. 1902. pag. 1-24. Pls. 1-2.

Whe ich auf die ausserordentlich interessante Abhandlung eingehe, in welcher das rom Verf. bei Neuseeland gefundene einzige Exemplar eines völlig neuen schwimmenden Hydroiden mit höchst anerkennenswerter Ausführlichkeit beschrieben wird, möchte ich, da die Literatur nicht genügend Berücksichtigung darin fand, einen kurzen Öberblick vorausschicken jiber diejenigen wenigen uns bekannten Hydroidpolypen, denen entweder nur eine geringe $\mathrm{k} r$ i e c h en de Beweglichkeit zukommt oder zeitweilig eine pelagische Lebensweise eigen ist. Von ersterer Gruppe kennen wir, wenn ich von dem ganz aberranten und noch wenig erforschten Süsswasserhydroiden Polypodium hydriforme Ussow ${ }^{1}$ ) absehen darf, bis jetzt nur zwei Arten aus rerschiedenen Gattungen. Eine derselben wurde erst ror einigen Jahren entdeckt. (I. M u rbach "Hydroida from Woods Holl, Mass." 1899.) Dieser "Hypolytus peregrimus" genannte Polyp ist ein Tubularia und Corymorpha ähnliches, solitär lebendes,

1) Morph. Jahrb. XII, 1887. 
$1^{1 / 2} \mathrm{~cm}$ grosses Tier, dessen Hydrocanlus von einer zarten Röhre umgeben ist und sich (der Corymorpha-Larve ähnlich) basalwärts zuspitzt. Der interessante Hydroid, der sich durch Querteilung am Basalende seines Hydrocaulus zu vermehren rermag, kann die leicht ersetzbare Sekretröhre, durch welche er voriibergehend festgeheftet wird, verlassen und wird dann gelegentlich pelagisch gefangen. - Dasselbe gilt wahrscheinlich für den andern, schon vor langer Zeit beschriebenen Hydroiden Acaulis primarius, Stimpson 18533, der Beziehungen zu den Pennariiden und zu Myriothela erkennen lässt. Lir wurde zuerst bei Grand Manan, dann 1873 von G. O. Sars bei den Lofoten und zuletzt (ein $2 \mathrm{~cm}$ langes Exemplar) von Lönnbero 1898 auf einem Zostera-Blatt im Öresund gefunden. Auch Acrutis hat ein zugespitztes Fussende und steckt in einer zarten schleimigen Röhre, mittelst deren der Polyp sich festheftet. - Murbach hat 1. c. die Bezielungen von Acrulis und Hypolytus nicht gewürdigt, sondern vielmehr Haleremita cumuluns Sch a ulinn als Parallele heran gezogen, einen Hydroiden, der in den hier zu besprechenden Formenkreis gar nicht hineingehört, sondern vielmehr der kürzlich ron H. F. I' e r kin s (1902, Johns Hopkins Un. Cire. XXI pag. 87), beschriebenen Cronionemus-Larre ähnlich ist. - Pela gis ch le be nd e oder richtiger ausschliesslich pelagisch gefangene Hydroiden kannten wir bis-

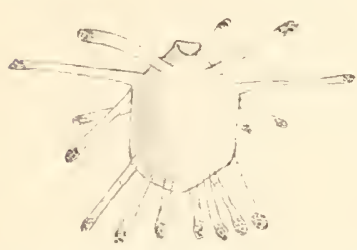

Fig. 1. Actinula-Larve von Margelopsis hacchelii Hartl., den oralen Pol nach unten ge. richtet. $50 \times$ vergr. her nur zwei, nämlich Margelopsis gibbesi (三Nemopsis giblesi, Mc. Crady 18533) und Margclopsis huechelii Hartl. (vgl. H a rtla ub. Zur Kenntnis der Cattungen Margelopsis und Temopsis; in: Göttinger Nachr. 1899) und Ref. hat diesen Sommer bei Roscoff (Küste (ler Bretagne) noch eine dritte Art entdeckt, die hier vorläutig Margelopsis stylostoma genannt sein inöge, obwohl sie streng genommen, wie wir sehen werden, nicht zu Margelopsis gehört. - Die drei Arten sind 1-2 mm grosse Actinulaartige ungestielte Hydranthen. Sie schwimmen oder schweben mit der Mundöffnung nach unten gerichtet und die langen Tentakeln weitauseinander gespreizt umher. Von M. gilbesi beobachtete Mc. Crady eine aktive, lebhafte Schwimmbewegung durch synchronisches Zusammenschlagen der Tentakeln. M. gibbesi und die bei Helgoland in Menge gefangene $\boldsymbol{M}$. hacckelii knospen zahlreiche frei werdende Medusen, während $M$. stylostoma wahrscheinlich sessilbleibende Gonophoren bildet. Die erwachsene Form der Meduse von $M$. haeckelii ist mit voller Sicherheit festgestellt. Sie teilt mit der Hybocodon Qualle die Entwickelung ron Actinulae am Manubrium und hat 
übrigens eine sehr ungewöhnliche Eigenschaft mit der Meduse der zu besprechenden Pelagohycha gemein. A m aboralen nach oben gerichteten Pole des Hydranthen befindet sich bei sämtlichen drei Arten ein knopförmiger Fortsatz mitnapfartiger Vertiefung. Die bisher rätselhafte Bedentung desselben, werde ich weiter unten einigermalien zu erklären versuchen. $\boldsymbol{M}$. sty-

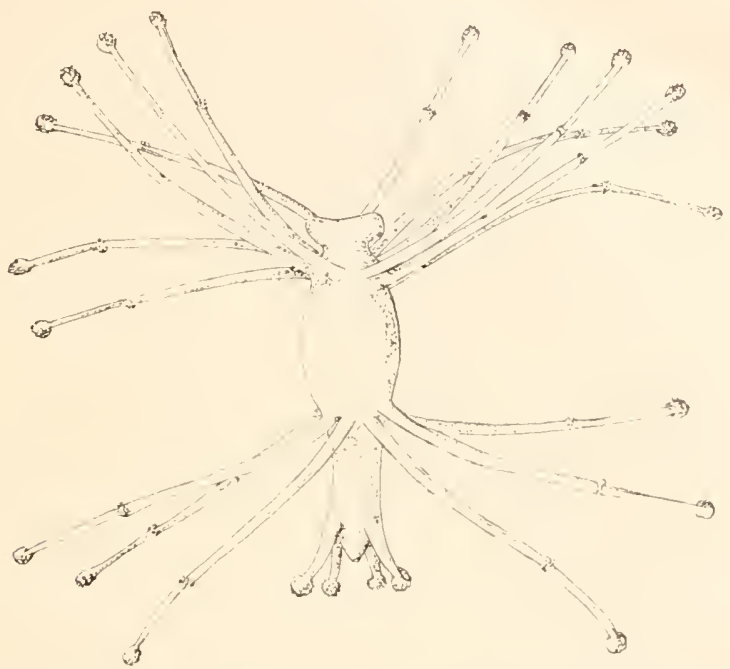

Fig. 2. Margelopsis stylostoma Hatt., walırscheinlich ein abgelöster, pelagisel lebender Hydranth von Tiarella singularis F. E. Schulze, sehr stark vergr.

lostoma hat, abgesehen ron den zwei Kränzen langer Tentakehn, noch vier kurze mäßig geknöpfte Mundgriffel (wie Tiarella singularis F. E. Schnlze) und alle andern T'entake!n tragen (wie bei Tiarella und auch an Hypolytus und Heterostephanus ammliconnis MI. Sars erinnernd) in ihrem distalen Verlaufe eine mehr oder minder ringförmige Nesselspange.

Die Eigenschaften der fünf besprochenen freien Hydroiden erinnern teils an T' ubulariden, teils an Pennariiden und teils an die Corymorphiden. I) Gattungen Myriothela. Heterostephame, Lampra, Monocaulus, Branchiocerianthus und Corymorpha stehen nicht nur morphologisch in Beziehung zn ihnen, sondern können, was ihre Befestigungsweise anlangt, als Übergänge zu den frei beweglichen Formen wie Acaulis und Hypolytus angesehen werden. Corymorpha hat ausserdem durch Veränderung ihres Hydrocaulus in ein der pelagischen Lebensweise dienendes Schwimmorgan, wahrscheinlich den phyletischen Ausgangspunkt gebildet für die von Dendy entdeckte Pelagohydra mirabilis. 
Pelagohydra wurde rom Verf. im Oktober 1901, augenscheinlich ron der Flut angespült aber noch lebend, am sandigen Strande von Sumner aufgefunden, einem Badeorte der Südinsel ron Neuseeland. Der mit Medusenknospen bedeckte und batl als Hydroid erkannte

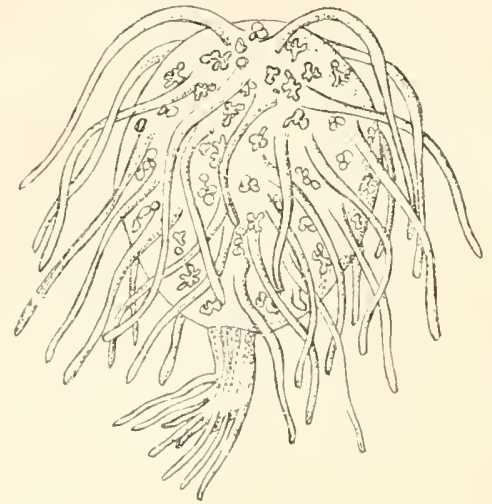

Fig. 3. Pelagohydia mirabilis Dendy, nov, gen. nov. spec. $2 \times$ vergr.

Organismus wurde eine kurze \%eit in einem Glase lebend beobachtet und dann mit Osmium konserviert. Seine Länge betrug im ausgestreckten Zustande ca. $4 \mathrm{~cm}$. Der Kürper zerfiel in zwei scharf getrennte Abschnitte, in den nach unten gerichteten Hydranthen (narrow proboscis like portion) und den darüber liegenden ballon-oder blasenförmigen Hydrocaulus (..float"). Als Verf. das Tier in ein Glas gebracht hatte. Hottierte es, wie die Margelopsis-Arten mit dem oralen Ende nach unten gerichtet, dicht unter der Oberfläche des Wassers, dann in eine Blechdose iibertragen und ins Dunkle gestellt, sank es in dieser zu Boden. Die Schwimmblase war formveränderlich, bald vertikal länglich bald rund und der Hydranth (ron Dendy als "proboscis" bezeichnet), war sowohl Hexibel als stark kontraktil. Die grosse Schwimmblase (Hoat) war äusserlich mit einer Menge fadenför'miger Anbïnge (,tentakles") besetzt, wie sie auch (papilliform processes Allman) dem Hydrocaulus ron Corymorpla eigen sind, und diese Anhänge, resp. viele derselben, führten gleichzeitig konvulsive, schlagende Bewegungen aus (, like gigantic Hagella"), so dass der Verf. zu dem Glauben neigt, sie möchten als Ruder gedient Laben. Zwischen diesen Anhängen der Blase sassen eine grosse Menge verzweigter Blastostyle (,stolons“) mit Medusenknospen auf allen Stadien der Entwickelung. Wir sehen also diese abweichend von Corymorpha rom Hydranthen auf den Hydrocaulus verlagert, und diese ilne Lage spricht wohl auch etwas für die schwimmende und nicht etwa mit dem Hydro- 
caulus im Sande oder in einer Röhre steckende Lebensweise des Tieres ${ }^{1}$ ). - Der ron der Schwimmblase äusserlich wie innerlich scharf getrennte Hydranth (,proboscis") hat eine mngewöhnliche, schmal cylindrische und nach dem Nunde zu lionisch rerjüngte Form. Nur die orale, untere Hälfte desselben trägt 'Tentakeln, und zwar stehen diese, nach unserer Auftassung der stark vergrösserten Ablildung Fig. 2 Taf. 46, in zwei, allerdings nicht deutlich getrennten, aber' doch zu unterscheidenden Kränzen, einem ganz oralen von hurzen und einem aboralen von längern Tentakeh. -. Die Schwimmblase und der Hydranth sind inmerlich durch ein dïnnes horizontales Septum rollkommen voneinander getrennt. Als verdauende Iiavität dient ausschliesslich der unterhalb des Septums gelegene, den Hyclranthen angehörige Hohlraum, dessen entodermale Auskleidung zahlreiche, in das Lumen rorragende Längsfalten bildet. I) urch eine Menge ron (j)fnungen, welche das sonst undurchbohrte Septum an Rande umgeben, liommuniziert die Gastralhöhle aber mit einem der Innenwand der Schwimmblase angehörigen netzförmigen Röhrenwerk, und diese Eutodermröhren, die offenbar denen in Hydrocaulus der Corymorpha homolog sind, kommunizieren ihrerseits mit dem Hohlraum der an der Blasenwand sitzenden Blastostyle. - Der Hohlraum der Schwimmblase ist durch ein System radiär verlaufender, selı diinner, durchsichtiger Stuitznombranen in zahlreiclıe Kammern geteilt; die Stïtzmembranen strahlen von einer zentralen, festeren (iewebemasse, die dem axialen Entoderm des Corymorphastiels entspricht, ans und befestigen sich peripher an der Blasenwand und am septum. Die 'Tentakeln des Hydranthen sind solide; zwischen dem axialen Gewebe der grösseren T'entakeln und dem Entoderm der Gastralhöhle besteht aber kein Zusammenhang, auch ist ein solcher für die kurzen oralen 'Tentakeln zweifellaft, die sich histologisch ron den grösseren Tentakelı unterscheiden. - Die geisselartigen Aulı̈̈nge der Schwimmblase sind histologisch identisch mit den grösseren T'entakeln des Hydrantlen; ihr axiales Gewebe bildet an der Trand der Schwimmblase einen in diese etwas rorspringenden P'flock (projecting plug). Bezüglich weiterer histologischer Details, die viele Übereinstimmung mit Branchiocerianthus imperator. (Allman) ergaben, sei auf die auch in dieser Hinsicht ausfülnliche Publikation selbst verwiesen. - Es bleibi noch zu bemerken, dass die Medusen nichit

1) Dass gewisse zarte Medusenknospen eine Entwickelung im Sande übrigens sehr gut vertragen, beweisen die Ammenpolypen von Tiara pileata (Perigonimus), die mit Vorliebe auf dem Rücken von Corystes cassivclaunus wachsen, einer Krabbe, die sich bis auf die Fühler und Augen in den Sand ëinwühlt und in dieser Pusition tagelang ruhig verhart. (Im Helgoländer Aquarium gemachte Beobachtung.) 
denen von Corymorpha gleichen (Steenstrupia), von deren vier Tentakeln drei verkiimmert sind, sondern auffallenderweise vielmehr denen ron Margelopsis. Wie bei dieser ron mir beschriebenen qualle trägt nämlich jeder der vier dicken Marginalbulben einc Gruppe von Tentakeln, die nicht wie bei den Margeliden in einer lieilie stehen. Auch abgesehen von diesem für eine Codonicle ganz mgewöhnlichen Charakterzug lierrscht im Bau der zwei (quallen grosse Ïhnlichkeit. Verf. beobachtete an den reiferen Knospen Kontralitionsbewegungen und hält das normale Freiwerden fuir sehr wahrscheinlich. - Terf. erklärt I'. miratitis für den einzigen bis jetzt bekannten, der pelagischen Lebensweise strukturell angepassten Hydroiden und schlägt ror, ihn als Vertreter einer neuen Familie der I'elagohydridae zu betrachten. Auf einen Vergleich mit Margelopsis $($, Nemopsis") und Acautis lässt er sich nicht ein, da er, nach Allmans beispiel, dieselben für abgelöste Hydranthen festsitzender Species hält. Wie weit er darin recht hat, möchte ich für Maryelopsis in einigen Schlussworten auseinander setzen. Jedenfalls hätte Dendy die Beziehungen zu Margelopsis etwas melı wïrdigen müssen; er scheint aber des Referenten Arbeit, in welcher die Mrargelopsis-Meduse zum ersten Male beschrieben wurle, nicht geliannt zu haben.

Die Margelopsis-Polypen, deren Bedeutung unaufgeklärt war und zu den verschiedensten Hypothesen Anlass gab, sind weder, wie $\Lambda 11$ man und andere vermuteten, Hydranthen, die nach Art von Tubulariaköpfen rom Hydrocaulus ahgerissen werden, eine Zeitlang noch pelagisch die an ihn knospenden Geschlechtspersunen verbreiten und dann zu grunde gehen, noch auch sind sie, wie ich in meiner Murgelopsis-Arbeit l. c. irrtumlich rertreten hahe, a usschliesslich pelagisch lebende Arten, sondern sie sind junge, schon Geschlechtsknospen treibende Hydranthen, die sich nach Beendigung. ihrer Entwickelung normal ron festsitzenden gestielten Hydroiden ablösen (z. B. Tiarella simgularis li. E. Schulze), an denen sie durch seitliche Knospung entstanden.

Durch die Entdeckung meiner $M I$. stylostoma, die ich am 3 . Juni bei Roscoff pelagisch erbeutete, und durch deren Thbereinstimmung mit jungen Tiardla-Hydranthen ist, wie ich glaube, in das Inunkel der Nemopsis-Frage mehr Licht gebracht. - Tiavella singularis $\left.{ }^{2}\right)$ ist ein solitär auf Cystosira lehender, 1875 bei Triest gefundener $2 \mathrm{~mm}$ grosser, gestielter Hydroid, der durch drei voneinander getrennte Tentakelkreise seines Hydranthen an Pemaria tiarella Me Crady erinnert, sich ron dieser aber dadurch unterscheidet, dass

1) Zeitschr. für wiss. Zool. XXVII. 
die zwei untern Kreise aus langen fadenförmigen, terminal geknöpften 'T'entakeln bestehen, die, was ganz einzig dastand, auch in ihrem Verlauf Yesselspangen besassen, ein Verhalten, das wir nur von Heterostephams kannten und später auch von Hypolytus peregrimus Murbach, dem oben schon erwähnten freibeweglichen $\mathrm{Hy}$ droiden, kennen lernten. Zwischen den zwei basalen Kräinzen erzeugt der Hydranth sessil bleibende, nicht an Blastostylen sitzende. medu-

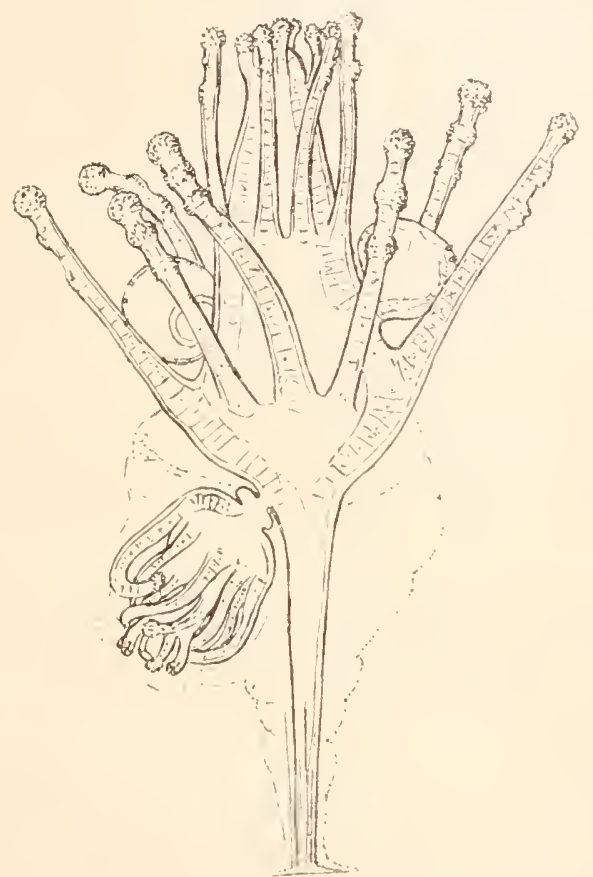

Fig. 4. Tiarelle singuleris F. E. Schulze 1876, stark rerge. (nach Schulze).

soide Gonophoren (wie P'emaria). Ausserdem vermelnt sich Tiarella ähnlich wie Hydra und seyphistoma dadurch, dass die Basis ihres Hydranthen junge Hydroid-Kinospen treibt, die sich nach Vollendung ihrer Ausbildung sofort vom miitterlichen P'olypen abschnüren. Diese, oft bereits mit Genitalgemmen versehenen jungen Hydranthen haben, wie F. F. Schulze schreibt, einen „dem basalen Pole ansitzenden scheiben-oder knopffömigen Anhang*, der als ,Basalscheibe“ bezeichnet wirl. "Wie ein hohler, dicker, flacher Knopf sitzt diese drehrunde und gegen das freie Ende zu leicht konisch verjüngte Basalscheibe mittelst eines ebenfalls drehrunden Stiels vom halben Scheibendurclimesser der halbkugelig abgerundeten Basalfläche des Hydranthen zentral auf. Ihre 
kolbenförmige Höhle anastomosiert durch einen im Stiel enthaltenen engen Verbindungsgang mit der weiten Magenhöhle des Hydranthen." - Dieser Fortsatz des aboralen Hydranthenendes findet sich sowohl bei M. stylostoma als bei MI. giblesi und $\boldsymbol{M}$ haertielii. Welche Bedeutung er für sie hat. ist einstweilen unaufgeklärt. Möglicherweise ist er ein für die pelagische Lebensweise wichtiges Organ. Wüssten wir, ob die Margelopsis-Arten dauernd pelagisch sind oder ob sie sich nach einiger Zeit festsetzen, so wïrden wir in dieser Frage bedeutend klarer sehen. Ist das letztere nämlich der Fall, sn ist anzunehmen, dass die Basalscheibe der Margelopsis zur Fusscheibe des Tiarella-artigen festsitzenden Hydroiden wird. Sehr wohl denkbar ist aber auch, dass die ungeschlechtlich entstandenen Margelopsis-Hydroiden eine dauernd pelagische Generation bleiben, und dass die zu ihnen gehörige sessile Hydroid-Generation ausschliesslich aus den geschlechtlich erzengten I'lanulae herrorgeht. Da aber Margelopsis stylostoma von Roscoff, anch was Stellung. Form und Zahlenverhältnisse der Tentakeh betrifft, mit der jungen abgelösten Tiarella-Kinospe iibereinstimmt, andererseits den zwei anderen Margelopsis-Arten im wesentlichen gleicht, so können wir nicht nur die völlige Identitiit der $M$. stılostoma und Tiarella für hochwahrscheinlich ansehen, sondern auch für die zwei andern Margelopsis (Nemopsir Mc. ('rady) die gleiche Entstehungsweise roraussetzen. Hoffentlich gelingt es bald, die zu M.haeckelii gehörigen festsitzenden Hydroiden bei Helgoland aufzufinden.

\section{Hartla ub (Helgoland).}

\section{Vermes.}

\section{Yemathelminthes.}

19 Tretiakow, 1). Entwickelungsgesch ichte von Gordius aquaticus Vill. (1. Третьявов'. Змпріональное развитіе Gordins aquaticus Villat). In: Trav. Soc. Imp. Natur. St. Pétersbourg. Vol. XXXII. Livr. 1. Compt. rend. des séances N. 1. 1901. pag. 19—22 (russisch mit deutschem Resumé).

Die Furchung ist eine totale und äquale. Es entsteht eine Blastula aus 16 gleichgrossen Blastomeren. Darauf dringen einige Kellen - Verf. nennt sie "Urmesodermzellen" — in die primäre Leibeshöhle, teilen sich und erfüllen die ganze Höhle. Darauf bildet sich eine Einwucherung am hintern Ende - die Anlage des Darmes. Der Embryo streckt sich in die Länge. Ton den Seiten bildet sich das Nervensystem. Das vordere Ende der Darmanlage erweitert sich in eine Blase. Ihr entgegen wächst ron rorne eine Entodermeinstiilpung, die mit der genannten Blase rerwächst. Die Zellen des 
Darmes linter der blasenförmigen Erweiterung ziehen sich zusammen und das Darmlumen schwindet. Die Wände der Einstülpung verdicken sich und liefern die primäre Muskulatur der Larve. Die ganze Entwickelung hat sehr wenig Ïhnlichkeit mit derjenigen der Nema. toden. Überhaupt klärt sich ja die Stellung ron Gordius als eine sehr gesonderte auf. Die referierte Mitteilung ist leider sehr kurz gefasst und bietet einige Unklarheiten; der Ref. hielt es dennoch für notwendig, sie hier mitzuteilen, da der Terf, in nächster Zeit eine weitere Bearbeitung der Frage beabsichtigt und der Gegenstand jedenfalls von Interesse ist.

E. Schultz (St. Petersburg).

\section{Annelides.}

20 Gravier, Ch., Sur la classification des Néréidiens de Quatrefages (Lycoridiens Grube). In: Bull. Mus. Hist. nat. (Paris). Année 1901. Nr. 7. pag. 350-357.

Nach einer Besprechung der früheren Versuche, die sehr homogene Familie der Nereiden einzuteilen (Kinberg. II lmgren, Ehlers, Grube, de Saint-Joseph) gelangt Verf., indem er für die Abgrenzung der Gattungen hauptsächlich die Rüsselbewaffnung verwendet, zu einur durch folgenden Schlüssel ausgedrückten Klassifikation :

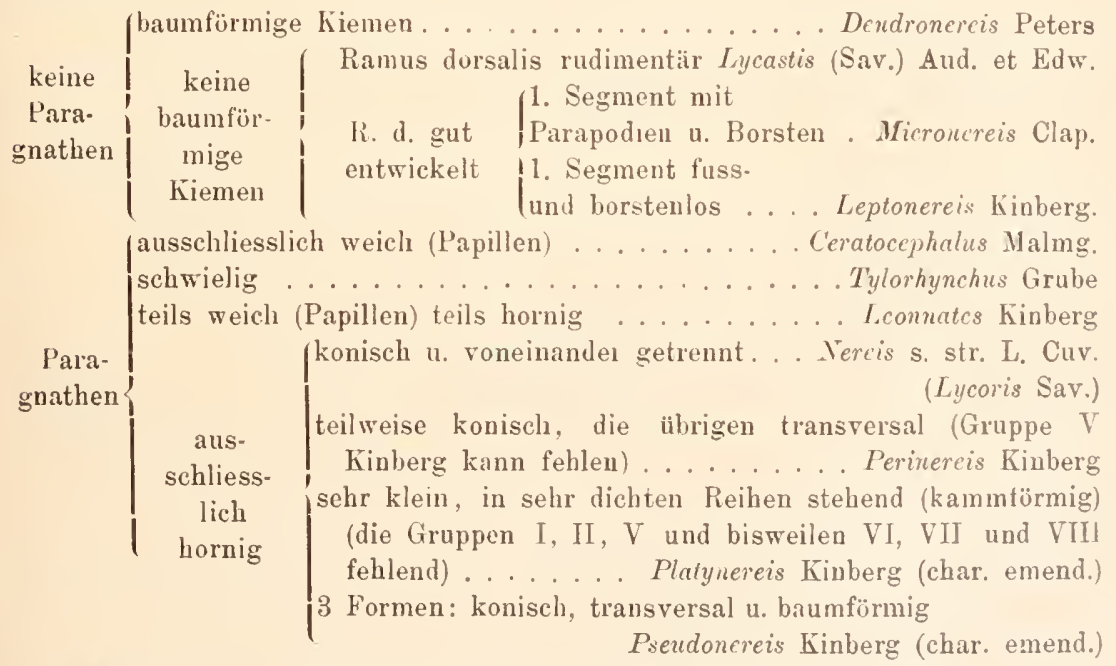

Auf diese 11 Gattungen verteilen sich die Arten folgendermałen:

1. Dendroncreis: D. arborifera Peters (Mozambique) und D. pinnaticirris Grube (Philippinen).

2. Lycastis: L. brevicornis Aud. et Edw. (französische Küste), L. quadraticeps Blanchard (Chile), L. littoralis F. Müller und L. abimua F. Müller (Brasilien), L. senegalensis de Saint-Joseph (Senegal), L. gueayi und L. ouanaryensis Gravier (Guayana). 
3. Mieronereis: M. variegata Clap. (franz. Küste).

4. Leptonereis: L. raillanti de Saint-Joseph (franz. Küste).

5. Ceratocephala: (keine Species angegeben).

6. 'Tylorhynchus: T. chinensis Grube (Shanghai).

7. Leonnates: 1. indicus Kinberg (Singapor), L. virgatus Grube (Philippinen), I. pusillus? Langerhans (Madeira), L. jousseaumei Gravier (Rotes Meer).

8. Veris: Diese Gattung wird folgendermaßen in vier Uutergattungen zerlegt:

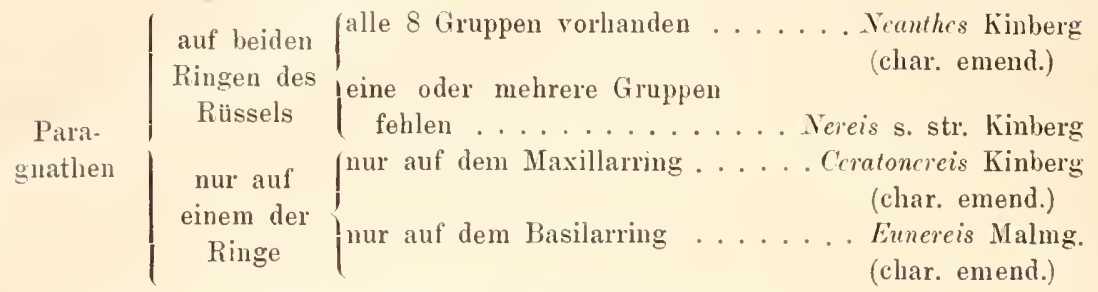

Die Untergattungen umfassen folgende Gattungen anderer Autoren:

Neanthes: Alitta Kinberg und Hediste Malmgren p. p.

Vereis: Mastigonercis Sccmarı, Thorsa Kinberg, Nereilepus Blainville, Nereis

Malmgren, Herliste Malmgren p. p., Praxithca Malmgren und Cirronereis Kin-

berg. Ferner folgende Arten: Noreis ehlirsiana Grube-Semper, N. Aavipes

Ehlers und $N$. tenuis Webster et Benedict.

Ceratonereis: dahin Nereis dcbilis Grube-Örsted.

Énereis: dahin Nereis ignota Quatref., N. articulata Ehlers, N. tridentata Webster etc.

9. Prinereis: umfasst die Gattungen Naumachins Kinberg, Lipcphile Malmgren,

Hcdyle Malmgren, Hediste Malmgren p. p. Stratonice Malmgren, Nereilepes:

Johnston und Arete Kinberg.

10. Platynereis: umfasst Leontis Mahngren, Ipinineris Malmgren, Pisenoe Kinberg.

11. Pseudoncreis: (keine Species angegeben).

.I. W. Spengel (Giessen).

21 Gravier, ('H.. Sur deux nouvelles espèces du genera Lyeastis Savigny, Aud. et Edw. rev., de la Guy ane française. In: Bull. Mus. Hist. nat. (Paris), Année 1901. Nr. 8. pag. 397-402.

Verf. beschreibt Lycastis ouanaryensis n. sp. und $L$. geayi n. sp. aus französisch Guyana, beide dadurch interessant, dass sie in Süsswasser leben; letztere wurde ausschliesslich darin gefunden, erstere auch in Brack- und Meerwasser.

J. IV. Spengel (Giessen).

22 Gravier. Ch., Sur un Capitellidien d'eau douce. (Eisigiellan. gen. ouanaryensis n. sp.) In: Bull. Mus. Hist. nat. (Paris). Année 1901. Nr. 8. pag. 402-404.

Verf. gibt folgende Diagnose der neuen Gattung Eisigiclla: 'Thorax aus 12 Segmenten bestehend; Segm. 1 borstenlos, die 11 übrigen ausschliesslich mit gesïumten Borsten; die Abdominalsegmente mit gekerbten Haken; weder Kopulationsapparat noch Kiemen noch Seitenorgane erkennbar; Genitalporen fehlend oder rudimentär. Die Art, von der nur ein einziges Exemplar vorlag, ist dadurch interessant, dass sie in Süsswasser lebt (vergl. Eisigs Versuche über die Gewöhnung von Capitella capitata an das Leben im Süsswasser; Monographie pag. 798).

J. W. Spengel (Giessen). 
23 Gravier, Ch., Sur les Annélides polychetes d'eau douce. In: Bull. Mus. Hist. nat. (Paris). Annie 1902. Nr. 1. pag. 25-30.

Verf. gibt eine Übersicht der bisher bekannt gewordenen Süsswasser-Polychäten. Dieselhen rerteilen sich folgendermafien auf 4 Familien:

1. Nereiden:

1 Art im See Palaeostom, Mingrelien (nach Czerniawsky).

1 Art auf Trinidad (nach Kennel).

Lycastis quadraticeps Blanchard, Chile (nach Ehlers bisweilen im Süsswasser).

L. grayi Gravier, franz. Guyana (nach (iravier).

L. oucharyensis Gravier, lesgl. (nach Grar i er im Neer-, Brackund Süsswasser).

Verschiedene andere Nereiden werden auch im Brackwasser getroffen.

2. Euniciden:

Lumbriconereis sp. auf Trinidad (nach Kennel).

3. Capitelliden:

Eisigiella oudnaryensis Gravier, franz. Guyana (nach Grarier).

4. Serpuliden:

Manaymkica speciosa Leidy, Vereinigte Staaten N.-A. (nach Leidy, Potts und Foulke).

Caobangia billeti Giard, Tonkin, in Melania-Schalen (nach Gi a r d).

Dyboroscella baictensis J. Nusbaum.

D. godlewskii Goriajeff, die heiden letztern nach ihren Autoren im Baikalsee.

J. W. Spengel (Giessen).

\section{Arthropoda.}

\section{Palacostraca.}

24 schmidt. Fr., Revision der ostbaltisthen silurischen Trilobiten. Abth. V. Asaphiden. Lieferung II, die Gattungen Asaphus sens.' str., Onchomctopus, Irolchus und Niobe enthaltend. In: Mém. Acad. Imp. Sc. St. Pétersbourg. (Запнекі И. Акад. пауцъ.) Classe phys.-math. Vol. XII. Nr. \&. (deutsch). pag. 1-110, 12 Taf. 64 Textfig.

Diese Fortsetzung der Beschreibung der Asaphiden enthält die oben genannten Gattungen init Tafeln der vertikalen und horizontalen Verbreitung der Arten. Vom Genus Asaphus sind 15 Arten und 11 Varietäten, von Isotelus 4 Arten, von Niobe 3, von Onchomctopus eine Art ausführlich besclnieben. Über die Hälfte der Arten und Varietäten (18) gehört den Autor.

E. Schultz (St. Petersburg). 


\section{Arachnida.}

25 Koenike, F.. Acht neue Lebertia-Arten, eine Arrenurus- und eine Atractides-A r.t. In: Zool. Anz. Bd. XXV. 1902. Nr. 679 pag. 610-616.

Die zuerst beschriebene Lebcrtia - Art, ein Männclien, hat eine Grösse von 1,36 mm. Die Epidermis ist durch Linien netzartig verziert, die einzelnen Maschen sind lang ausgezogen. Auf der Seitenwand des Capitulum am Grunde der grossen Fortsätze zieht sich eine Querrille hin. Das Hinterende des zweiten Hịiftplattenpaares ist doppelt so breit wie bei $L$. insignis Neum. Der Genitalhof ragt etwa ${ }^{1 / 3}$ aus der Genitalbucht hervor. Der Verf. benennt die ehen beschriebene Form nach ihrem Entdecker L. halberti.

Lebertia densa, ein Weibchen, zeichnet sich durch eine sehr fein und dicht punktierte Épidermis aus. Die Hautdrüsenböfe sind rotbraun und stark chitinisiert. Das zweite Epimerenpaar besitzt ein sehr breites Hinterende. Weiter bemerkt man, dass das Epineralplattengebiet einen auffallend starken, subkutanen Randwulst bildet. Körperlänge?

Lebertia rufipes wird $1 \mathrm{~mm}$ lang. Alle Chitinbildungen sind bei ihr hell rotbraun gefärbt, die Füsse haben eine rote Farbe. Auf dem Rücken zählt man 18 Flecken. Die Epidermis ist mit Längs- und Querstrichelung versehen, so dass sie beschuppt erscheint. Der Genitalh of tritt etwa ${ }^{1 / 3}$ aus der sogen. Genitalbucht hervor. Die Hinterende des zweiten Epimerenparres sind von mittlerer Breite. Das Weibchen ist noch nicht bekannt.

Auch Lebcrtia cognatı liegt nur als Männchen vor. Die Epidermis zeigt eine verworrene, in der Längsrichtung des Körpers verlaufende Liniierung. Auf dem Rücken zählt man 6 Flecken. Die Maxillartaster sind merklich schwächer als die benachbarten Glieder des 1 . Beinpares. Wie bei $L$. rufipes weist das Hinterende des zweiten Hüftplattenparares nur mittlere Breite auf.

Lebertia plicata, ein Männchen, ist nur $086 \mathrm{~mm}$ lang. Auf der Epidermis erkennt man eine deutliche Liniierung. Die Hautdrüsenhöfe sind gut bemerkbar. Auch bei dieser Art elreichen die Maxillartaster nicht gauz die Stärke der benachbarten Beinglieder. Die Endigung des zweiten Hüftplattenpaares ist sehr breit. Das äussere Geschlechtsorgan reicht nicht aus der von den Hüftplatten gebildeten Bucht heraus.

Lebertia maculosa 5 , nicht ganz $1 \mathrm{~mm}$ gross, zeichnet sich durch eine Epidermis aus, die mit kleinen rundlichen Papillen dicht besetzt ist. Auf dem Rücken zählt man 14 grosse Flecke. Wie bei $L$. plicata ist das Hinterende des zweiten Hüftplattenpares sehr breit. Der Genitalhof ragt nur wenig aus der Genitalbucht heraus.

Lebertia zschokliei $\sigma^{7}$, etwa $0,85 \mathrm{~mm}$ lang, besitzt eine Epidermis, die infolge ihres dichten Papillenbesatzes wie beschuppt aussieht. Auch bei dieser Art ist das Hinterende des zweiten Epimerenpares recht breit. Die Fusskralle gleicht annähernd jener voll Sperchon tenvipalpis Koen. Der Genitalhof tritt hinten nicht aus der Genitalbucht heraus.

Lebertia subtilis o?, $1 \mathrm{~mm}$ gross, hat eine völlig platte Epidernis ohne jedes Fleckenmerkmal. Das zweite Hüftplattenpaar endigt hinten ähnlich wie bei $L$. insignis Neum. Das Genitalfeld ragt kaum aus der Genitalbucht hervor.

Arrhenurus adnatus $\sigma^{7}$ erreicht eine Länge von $1,35 \mathrm{~mm}$ und eine Breite von $0,72 \mathrm{~mm}$. Der Körperanhang ähnelt demjenigen von A. stjördalensis Thor, doch bemerkt man, dass jeder Teil des Doppelhöckers am Hinterrande einen hyalinen Aufsatz besitzf. Der Anhang trägt keine Höcker. Auf der Innenfläche 
des zweiten Maxillartastergliedes stehen $\delta$ mäßig lange Borsten. Das vierte Glied des Hinterfusses hat einen Sporn.

Atractides subasper $\sigma^{7}$ ist nur $0,45 \mathrm{~mm}$ lang. Die Epidermis zeigt eine feine Querliniierung. Auf dem Rücken befindet sich ein grosser, spröder Chitinpanzer, der nur eine schmale. weichhäutige Randzone freilässt. Der Hinterrand des Panzers ist granuliert. Die freien Mündungshöfe der Hautdrüsen sind gross und porös. Das Endglied des ersten Beines weniger gekrümmt als bei A. spinipes C. L. Koch. Das P, ohne Rückenpanzer, wird etwa 0.7 m:n gross. Sämtliche Hautdrïsen sind mit grossem Chitinhofe ungeben.

\section{R. Piersig (Annaberg, Erzgeb.).}

Ribaga, C., Acari sudamericani. In: Zool. Anz. Bd. XXV. 1902. Nr. 675 pag. 502-508.

Der Verf. beschreibt eine Anzahl Hydrachniden und Ixodiden, die von F. Silvestri in Südamerika gesammelt wurden. Es befinden sich darunter eine neue Gattung, 12 neue Arten und 3 neue Varietäten. Die erste ist nahe verwandt mit der Gattung Arrhcurus Dug., und wird deshalb von Ribag a mit dem Namen Arrenurella ( $=$ Arrhenurellu) belegt. Als wichtigste Unterscheidungsmerkmale werden von dem Verf. die Aneinanderlagerung der zweiten und dritten Hüftplatte, die verlängerte Form der Genitallefzen, sowie die gäuzliche Abwesenheit von Genitalnapfplatten angeführt. Im übrigen entsprechen die Merkmale der neuaufgestellten Gattung denen von Arrhenurus. Das Endglied der Maxillartaster ist gegabelt. Die einzige hierher gehörige Art A. convexa Rib. orreicht eine Länge von $1,3 \mathrm{~mm}$. Der olivengrüne Körper ist oval und zeigt einen stark gewölbten Rücken. Das zweite Naxillartasterglied ist mehr als das doppelte so breit wie das erste; es besitzt vier Borsten. Das dritte Glied hat etwa die Stärke des Grundgliedes, doclı steht es ihm an Länge nach. Wio das vierte Glied trägt es zwei Haarborsten. Das fienitalfeld weist einen fast birnenförmigen Umriss auf.

Unter den neuen Arten befinden siclr zwei Vertreter der Gattung Limnesia. Die eine Species, L. minuscula Rib. ist ein Männchen, dessen Genitalhof breit birnförnig erscheint. Sein chitinisierter, reich bewimperter Aussenrand wird allseitig von gleichmäßrig verteilten, ovalen Genitalnäpfen umgeben. Die Maxillartaster sind mittelstark. Das zweite Glied besitzt auf dem stark verkürzten Rücken drei Borsten, während die Unterseite auf einem kleinen Höcker eine winzige Stachelborste trägt. Auf der Unterseite des etwa viermal so langen wie dicken Palpengliedes erheben sich nahe dem distalen Ende zwei auf sebr nieirigen Höckerchen eingelenkte, lange Borsten. Körperlänge des 'lierchens etwa $0,7 \mathrm{~mm}$.

Limnesia pauciseta Rib. liegt nur im weiblichen Geschlechte vor. Auch bei ihr bilden die Schamlefzen zusammen eine birnförmige Figur, deren Seitenrand keine chitinöse Verhärtung aufweist. Die nach der Mitte zu kleinern Genitalnäpfe sind am Hinterende des Geschlechtsfeldes stark zusammengerïckt. Man bemerkt zwischen ihnen nur wenige Börstchen. Auf der Unterseite des zweiten Gliedes der ziemlich kurzen Palpen erhebt sich eil kleiner beborsteter Vorsprung. Das vorletzte Glied ist am Vorderende der Innenseite nut drei Zähnchen und Härchen ausgerüstet. Körperlänge $1,70 \mathrm{~mm}$.

Die Gattung Arrhenurus Dug. ist in der Sammlung durch eine neue Art vertreten. Der Schwanzanhang ist ungefähr viernal so breit als lang. Der Petiolus ist konisch zugespitzt. Ein hyalines Häutchen scheint nicht vorhanden zı sein. Auf dem Rückenschilde erheben sich zwei ziemlich grosse Höcker, 
zwei wesentlich kleinere sitzen dich nebeneinander am mittleren Hinterende des Schwanzanhanges. Körperlänge 1,50 $\mathrm{mm}$.

Die Gattung Eulais (Eylai.) wird in der Sammlung durch sechs neue Species vertreten. Ausserdem werden auch noch zwei Varietäten aufgeführt. $E$. armata Rib. besitzt eine Augenbrille, die vorn wellig abgestutzt ist. Die beiden Augenkapseln sind von hinten her durch eine tiefe Einbuchtung bis zum kurzen Brückensteg voneinander geschieden. Das dritte Palpenglied weist auf der Innenseite sieb́en Fiederborsten und eine einfache Säbelborste auf, während das vorletzte auf der gleichen Seite neun an der Spitze gefiederte Borsten und über 20 Säbelborsten und auf der Anssenseite fünt dergleichen zählt. Körperlänge $5 \mathrm{~mm}$. - Eulais multispina Rib. hat eine Augenbrille, die vorn schwächer aus. gebuchtet ist als hinten. Das dritte Palpenglied trägt auf der Innenseite 16 Borsteu, von denen nur zwei gefiedert sin 1 , die mit vier glatten Borsten das Vorderende des Gliedes einnelmmen. Um das distale Ende stehen ausserdem noch 10 feine, kurze Härchen. Die Innenseite des vierten Palpengliedes ist mit zwei nach der Spitze zu schwach gefiederten Borsten und etwa 20 einfachen Säbelborsten ausgerüstet. Körperlänge $2 \mathrm{~mm}$. Die hierher gehörige Varietät E. v. brevipalpis Rib. zeichnet sich durch kürzere und stärker verdickte Maxillartaster aus. Auf der Innenseite des dritten Palpengliedes entspringen nur neun Borsten, vou denen nur zwei eine schwache Andentung von Fiederung erkennen lassen. Das vierte Glied zählt an der Innenseite und unten 11 einfache und vier gefiederte Borsten. Körperlänge $7 \mathrm{~mm}$. - Die Augenbrille vol Eulais montana Rib. ist in der Mitte stark eingeschnürt, so dass beide Kapseln fast voneinander abgetrennt erscheinen. Die kurzen Maxillartaster sind am inneren Vorderende des dritten Gliedes mit vier einfachen und vier gefiederten Borsten versehen. Das vierte Gilied am vordeln Beugeseitenende besitzt drei gefiederte und eine einfache Borste. Borstenkörperlänge 2,4-3 mm. - Euluis orthophthalma Rib. hat eine Augenbrille, deren Vorderrand in der Nitte schwach ausgerandet erscheint. Die hintere mittlere Einbuchtung ist tiefer. Drittes Palpenglied mit vier glatten und vier schwach gefiederten Borsten. Am Vorderende der Beugeseite des vorletzten Gliedes bemerkt man 11 einfache Haarborsten. Körperlänge $2 \mathrm{~mm}$. - Eulais perincisa Rib. zeichnet sich durch eine Augenbrille aus, deren Vorderrand schwach wellenförmig verläuft und in der Mitte des Steges einen unbedentenden Einschnitt aufweist. Die hintere Einbuchtung ist ungemein tief. Das zweite Glied der Maxillartaster trägt auf der innern Beugeseite drei einfache und drei gefiederte Borsten. Am vierten Gliede zählt man daselbst sieben gefiederte und drei einfache Bursten. Körperlänge $1,75 \mathrm{~mm}$. - Eulais colpoplthalma Rib. erreicht fast eine Grösse von $3 \mathrm{~mm}$. Der mittlere Vorderrand der Augenbrücke ist schwach vorgebogen. Die bintere Einbuchtung der Augenbrille reicht weit nach vorn. Auf der Innenseite des zweiten Palpengliedes nahe dem distalen Ende eutspringen drei gefiederte Borsten; auch die Unterseite trägt die gleiche Anzahl Fiederborsten und ausserdem noch eine glatte Borste. Die Innenfläche des vierten Palpengliedes besitzt vorn drei gefiederte und nach der Beugeseite zu 10 einfache Borsten. - Die Sammlung enthält auch ein Exemplar von E. protendens Berl, das jedoch in der Ausrüstung der Palpenglieder nicht ganz mit dem von Berlese beschriebenen Typus übereinstimmt. Der Verf. gibt ihm deshalb den Beinamen "distendens". Zwei Exemplare weichen noch stärker ab, so dass der Verf. sie als Varietät betrachtet $(E, p r$. var. ornatula Rib.) Als Unterscheidungsmerkmale führt or für diese Form an, dass dieselbe auf der Innenfläche des dritten Palpengliedes sechs gefiederte und einfache Borsten trägt, wïhrend das vierte Glied am Innenrande nur sechs Säbelborsten aufweist. 
Die Gattung Hydrachna wird durch zwei Arten vertreten: Hydr. miliaria Berl. und H. silvestri Rib., von denen die letztgenannte Form neu ist. Das einzige Exemplar, ein Weibchen, erreicht eine Länge von $2,7 \mathrm{~mm}$. Chitinüse Verhärtungen auf dem Vorderriicken treten nicht auf. Das hintere Innenende der vierten Hüftplatte springt stumpt abgerundet vor. A m ovalen Geschlechtsfelde tritt vorn eine tiefe Einkerbung auf, wahrend das Hinterende nur die Andeutung einer schwachen Einbuchtung aufweist.

Die Ixodiden der Sammlung umfassen nur zwei Gattungen. Die eine davon, Amblyomma, wird durch sieben Species vertreten: A. cajennense Koch, 1. americanum Koch (?), A. strialum Koch, A. dissimile Koch, A. sp. (Nph.), A. rotundalum Koch und A. neumanni Rib. Die zuletzt genannte Species ist neu. Der verschiedenfarbig marmorierte, abgeflachte Rumpf weist vorn eine schwache im hintern Drittel jedoch eine dichte Punktierung auf. Im Anblicke von oben ist sein Umriss fast länglich birnförmig. Die Coxa des ersten Beines ist vorn mit zwei kräftigen Dornen bewehrt, am Hinterende bemerkt man nur einen einzigen, aber stark verlängerten Stachel. Die Radula wird durch eine in der Mitte vertieften Längsrinne gekennzeichnet; sie ist mit drei Reihen deutlich voneinander geschiedenen Zälnnen ausgestattet. Das zweite Glied der kurzen Palpen ist niclıt längev als dick und erreicht kaụn die Länge des dritten Gliedes. Körperlänge $3,2 \mathrm{~mm}$.

Die zweite Gattung "Lhipicrphalus" ist nur mit einer Art: Fih. "nmulatus Say var. micropla Can. vertreten.

Bemerkt sei zum Schluss, dass die beigegebenen lateinischen Diagnosen für genaue Bestimmung und Festlegung der Arten unzureichend sind. Ob sich für späterhin die Aufstellung so zahlreicher Eulais-Arten auf Grund der Verschiedengestaltigkeit der Augenbrille und der Ausstattung der Palpen mit einfachen und gefiederten Borsten festhalten lässt, will dem lief. im Hinblick auf die so häufig auftretenden Übergangs- und Zwischenformen kaum glaublich erscheinen.

R. Piersig (Annaberg, Erzgeb.).

27 Trägårlh, Ivar, Zur Kenntnis der litoralen Arten der Gattung Bdella Latr. In: Srenska Ak. Handl. Bd. 27. Abt. 4. Nr. 9. Anhang. 1902. pag. 1-24. Taf. 1-2.

Der Verf. verbreitet sich zunächst eingehend über das (ieschichtliche von Acarus littoralis Linné. Aus dem Gegebenen ersieht man. dass die Autoren betreffs der Identifizierung dieser Milbe verschiedene Auffassung haben. J. C. Fabricius weist sie der Gattung Gamasus zu, während Trouessart in ihr ein Synonym von Riluyncholophus miniatus (Herm.) erblickt. Berlese vermutet, dass Acarus littoralis Linné der Gattung Bdella nahe stehe. Der Verf. tritt der Meinung des zuletzt genannten Forschers bei. Auf (irund der Angaben der älteren Forscher bezüglich der Grösse, Gestalt, Färbung, des Aufenthaltsortes sowie der geographischen Verbreitung dieser Acaride sucht er die Richtigkeit seiner Auffassung zu beweisen. Hierbei macht er auf die Tatsache aufmerksam, dass J. C. Fabricius in seiner zuletzt erschienenen Arbeit einen Gomasus littoralis L. beschreibt, der sich nicht deckt mit der von ihm unter dem Namen 
Acarus littoralis L. früher gekennzeichneten form. Träg a r dh vertritt die Ansicht, dass A. littoralis (1794) eine Bdella ist, während G. littoralis (1805) mit Rhyncholophus miniatus (Herm.) var. mbipes Berl. et Ttr. identisch sein diirfte. Nachdem der Verf. die Synonyma ron Bdella littoralis (L.) festgestellt hat, geht er zur nähern Beschreibung derjenigen Form über, für die er den ebengenannten Namen in Anspruch nimmt. In einem weitern Absclmitt biologischen Inhalts bestätigt der Verf. die Angaben Trouessarts und Miclıaels, dass die Bdelliden nicht, wie Karpelles behauptet, Ptlanzenfresser sind, sondern vom Raube leben. Nacl dem Bau der Mundteile gehören sie zu den Tieren, die ihre Bente aussaugen. Trägardh beobachtete, dass Bdella L. Vücken und kleine Fliegen zu diesem Zwecke überfiel.

Der nächste Abschnitt beschäftigt sich mit einer Rerision der bis jetzt beschriebenen litoralen Bdella-Arten, die vom Verf. in zwei Gruppen eingeteilt werden, von denen die eine alle diejenigen Formen zusammenfasst, welche auf ihren Mandibeln eine grosse Anzahl Haarborsten (mindestens S) tragen, während die andere an dem gleichen Gebilde nur zwei derselben anfweist. - Obgleich die Frage nach der Identität mehrerer in der Literatur beschriebenen Bdella-Arten schon von Michael erörtert worden ist, hielt es der Verf. doch für notwendig, derselben nochmals näher zu treten. Um sicher zu gehen, legte er seinen vergleichenden Untersuchungen die ihm zur Verfügung gestellten Typen zu grunde. Auf diese Weise konnte auch die Variabilität der als Artmerkmale angewendeten Charaktere näher untersucht werden. Das Resultat der gewissenhaften Prüfung sämtlicher Objekte befestigte in dem Vert. die Überzengung, dass alle die in der Literatur beschriebenen Bdella-Arten sich aller Walırscheinlichkeit nach auf nnr zwei Arten zurückführen lassen, nämlich auf Bdella littoralis (L.) und B. decipiens Thorell. Bdella littoralis (L.) stammt von der nicht litoralen $B$. capillata Kramer oder einer dieser nahestebenden Form ab, und B. capillata var. pullipes und B. capillata var. pallipediformis sind als Zwischenstufen in dieser Entwickelung anzusehen. Die postembryonale Entwickelnng ron B. littoralis bestätigt diese Annahme und zeigt auch, dass diejenigen Bdella-Arten, welche mehrere Borsten auf den Mandibeln besitzen, von Bdella-Arten mit zwei Borsten auf den Mandibeln abstammen. B. decipiens ist wahrscheinlich als eine Varietät von $B$. vulgaris anzusehen.

Der letzte Abschnitt der vorliegenden Arbeit bescliäftigt sich mit der geographischen Verbreitung der litoralen Bdella-Arten. Bdella littoralis (L.) kommt ïberall an den Gestaden der arktischen und subarktischen Gebiete vor. B. vulyaris rar. littoralis Noniez bewohnt 
die Küsten Frankreichs, $B$. decipiens diejenigen von Schweden, Sibirien und Spitzbergen. Für die Ufer des Mittelmeers ist das Auftreten von Bdella-Arten noch nicht festgestellt.

Die beigegebenen 'Tafeln illustrieren vortrefflich die Ausfïhrungen des Verts.

R. Piersig (Annaberg, Erzgeb.).

\section{Iyriopoda.}

28 Berlese, A., Acari, Myriopoda et Scorpiones hucusque in Italia reperta. Padua 1902. fasc. XCIII-XCVI. - Myriopoda. 38 Taf. nebst kurzer Erklärung.

F. Silvestri setzt dieses Werk fort. Die Mehizahl der Tafeln ist für die Erweiterung unserer Kenntnisse der Pa u ropoden und Symphylen wertvoll, während bei den Diplopoden imıner noch neben manchem Überflüssigen in den Tafeln die wichtigeren und komplizierteren Organe zu ungenau behandelt sind. Besonders gilt das für die Craspedosomiden, die ohne Beriicksichtigung der neueren Literatur bearbeitet worden sind. Immerhin sind inelirere bisher unbrauchbare Nova des Verfs. aufgeliärt worden. Die von A t tems gut beschriebene Gattung Prodticus hat jedenfalls die Priorität vor Anamastigona Sily. Sehr unangenehm ist es, dass verschiedenen Tafeln ïberhaupt kein Satz beigegeben ist.

$$
\text { K. Verhoeff (Berlin). }
$$

29 Silvestri, F., Acari, Myriopoda et Scorpiones hucusque in Italia reperta. Ordo Pauropoda. Portici. 1902. 74 pag. 56 Abbildungen.

Verf. hat mit diesem Zusatzhefte zu dem bekannten 'lafelwerke Berleses ein übersichtliches Handbüchlein dieser kleinen TracheatenOrdnung gegeben, indem er die wichtigsten Organisationsverhältnisse behandelt und eine systematische Ïbersicht gibt. Er erfreut uns darin auch mit manchen Dingen, die bisher wenig oder gar nicht bekannt waren, so dem innern Kopfgerüst. das einer Reihe von Muskeln zum Ansatz dient, ferner der Rumpf- und Beinmuskulatur ${ }^{1}$ ). Die wichtigsten Formen der Cuticulargebilde sind übersichtlich zusammengestellt. Eingehend sind die Kopfdrüsen behandelt und es verdient hervorgehoben zu werden, dass nach $\mathrm{S}$. die von Schmidt behaupteten Kopftracheen nicht existieren, sondern auf die Ausführungsgänge der Mandibulardrüsen zu beziehen sind. Im Kapitel über die Geschlechtsorgane wird auch die Spermatogenese geschildert. Iın allgemeinen sprechen Silvestris Schilderungen für den modifiziert degenerativen Charakter der Pauropoden²).

1) Der Trochanter ist allerdings irrtümlich aufgefasst. (Ref.).

2) Wie ihn auch Ref. in Nr. 500 des Zoolog. Anzeigers vertreten hat. 
Der systematische Teil enthält Familien- und rattungen-Schlüssel. eine I'bersicht der italienischen, und ein Verzeichnis aller bis jetzt bekannten Arten.

K. Verhoeff (Berlin).

30 Saussure et Zehnther, My riopodes de Madagascar. In: Hist. nat. de Malagaskar par Grandidier. Paris 1902. 204 pag. 3 Taf.

Ein zu diesem Werke gehöriger Atlas erschien schon 1897. Durch die Verzögerung des Textes sind gewisse kleine Mängel entstanden, welche die Terff. selbst anführen, die jedoch nicht verhindern können, dass uns mit diesem Buche eine wertvolle Basis für die Diplopoden Nadagaskars gegeben ist. Verschiedene Nachbarinseln haben ebenfalls Berücksichtigung gefunden. Die Diplopoden-Fauna Madagaskars lässt, wie auch andere Tierklassen, einen ge $\mathrm{m}$ is ch ten Charakter erkemnen, zeigt aber doch mehr Verwandtschaft mit dem afrikanischen Festlande als mit den indo-malayischen oder sonstigen Ländern.

Behandelt sind folgende Faunenangehörige: Boundlum n. g. 2, spharotherimm 28, Sphaeromimus 11. g. 1, Orhomorpha 2, Tuberaularimm 3, Phymatodesmms n. g. 1, Phimocricus 1, Spiromanes n. g. 3, Trigomiulus 11, Spirostrophus 11. g. 2, Spiromimus 2, Pygorton 1, Alloporus 1, Thyropygus 1, Spirostreptus 38.

Auffallend ist die geringe \%ahl (5) ron l'olydesmiden. Besonders wertvoll und teilweise von allgemeinem Interesse sind die Mitteilungen über die Spliaerotheriiden, indem uns hier zum ersten Male eine mit Zirpvorrichtungen reichlich ausgerïstete Diplopoden-Gruppe in dieser Richtung näher gerückt wird. Beide Geschlechter sind mit Zirpvorrichtungen rersehen, das o aber reichlicher und andersartig als das + . Eei den Männchen gibt es vier Arten von Stridulationseinrichtungen und zwar zwei am vordern und zwei am hintern Paar der Genitalanhänge. Die erste Art wird durch das erste und zweite Glied, die zreite durcl das zweite und dritte Glied der vorderen Genitalanhänge dargestellt, die dritte Art durch die Zange der hinteren Genitalanhänge. Eine vierte Zirpvorrichtung findet sich zwischen der Hinterfläche des zweiten Glierles der hintern Grenitalanhänge und der Innenfläche des "I'ygidium". Bei den Weibchen ist las Analschild jederseits mit einer Anzahl Leisten ausgerüstet, gegen welche der Hinterland des zweiten Ciliedes des letzten Beinpares mit kleinen Rauheiten gerieben wirl, während ihnen die andern Zirprorrichtungen fehlen, da ihnen die Genitalanhänge am Hinterende des Kï̈pers ahgehen. Die Zirprorrichtung der Weibchen nnd die erstgenannte der Männchen setzen sich aus kleinen harfenartigen Gebilden zusammen. deren Kielchen in Schwingungen ver- 
setzt werden, indem sie von den Hinterbeinen als Bogen angestrichen werden. Die anderen Zirpvorrichtungen der Männchen verhalten sich umgekehrt, d. h. die kleinen Harfen sind beweglich und streichen selbst gegen die feststehenden Bogen. Jede Species ist mit zwei oder drei solcher Instrunente rersehen, welche je nach der Art, in welcher sie das Tier beniitzt, rerschiedenartige Töne erzeugen. Bei allen madagassischen Sphaerotherien fanden die Verff. derartige Apparate. Sie kommen auch schon bei jungen Individuen ror', sind dann aber noch unvollständig. Zur Artunterscheidung sind sie gut verwendbar. Bei asiatischen Formen dieser Familie scheinen die Zirpvorrichtungen oft $7 u$ fehlen, doch kommen sie in anderen Fällen vor, \%. B. bei Sphaeropoens brandti und inermis ron C'eylon.

Bei den $S p h$ a ero theriiden sind die (ienitalanhänge, auch ahgesehen von den Zirpvorrichtungen. systematisch sehr wichtig. Es sind ihrer, ganz wie bei den Glomeriden, drei Pare, die noch stärker umgebildet sind wie bei diesen. was besonders für das rorderste, recht kleine Paar gilt, dis seiner schwäche halber nicht als Greifzange, sondern nur als Stridulationsorgan dienen kann. Das zweite Paar endet immer mit einer kräftigen Zange, während das dritte und hinterste eine pantof'elartige Höhlung enthält, in der die Verff. eine liörnige Spermamasse beobachteten. Mit liecht treten die Verff. jener unverständlichen, auch von Bourne wieder geäusserten Meinung entgegen, als seien die Genitalanhänge „Adrentivbildungen”, bloss deshalb, weil die Weibchen keine besitzen und besondere Ganglien nicht mehr ausgeprägt sind. Sie weisen darauf hin, dass die Genitalanhänge tatsächlich gegliederte Beine sind, die nur zu den besonderen Zwecken umgebildet wurden, dass die Glomeriden iiberdies in den vordersten Genitalanhängen den völligen Übergang zu Laufbeinen anfweisen und dass ron den Stammteilen der zugehörigen ehemaligen Segmente auch noch dentliche Therreste zu finden sind. \%. B. Pleurenplatten.

Die Arbeit enthält im weitern sehr dankenswerte Schlïssel für Gattungen und Arten, wobei namentlich bei den erstern teilweise recht anerkennungswerte Fortschritte zu verzeichnen sind. Die T'erff. waren sichtlich bemüht, die neuere Literatur zu berücksichtigen, weslalb man ihnen die etwas veraltete, allzuweite Gruplenfassung nicht weiter zum Vorwurf machen wird. Es ist zu wünschen, dass das treffliche Werk bald seinen Abschluss finden möge ${ }^{1}$ ).

K. Verhoeft (Berlin).

1) Auf pag. 108 uben muss es statt ,quelques Iulus" heissen Lysiopeialum! 


\section{$-46=$}

\section{Insecta.}

31 Needhan, J. Gro, and Cornelius Betlen, Aquatic Insects in the Adirondacks. A study conducted at the Entomologic field station. Saranac Inn X. Y. under the direction of Ephraim Porter Felt, State Entomologist. In: New York State Museum, Bull. 47. 1901, Albany, pag. 383-612. - Pl. 1-36. Abí. i. T. (Preis 45 cents).

Es war. wie dies ja auch rorausznsehen ist. den Amerikanern vorbehalten, die erste Stition zum Studium der Wasserinsekten zu errichten. Dass dies mit der nötigen Energie, Sachkenntnis und reichlichen Mitteln seitens der New Yorker Staatsuniversität in's Werk gesetzt wurde, beweist der vorliegende Band, bei welchem der reichhaltige und gediegene Inhalt mit der schönen Ausstattung wetteifern. Und doch soll dieser Bericht nur als ein erster Versuch aufgefasst werden, indem einmal nur eiu Teil der erzielten Resultate darin niedergelegt wurde ${ }^{1}$ ), ferner die gesamte Arbeitszeit sich nur über 10 Wochen erstrecken konnte. Nur jahrelang in gleicher Weise fortgesetzte Beobachtungen in verschiedenen Lokalitäten werden ein wirklich vollständiges Bild der wasserbewohnenden Insektenwelt eines grössern Gebietes geben kömnen. Dass eine l'ortsetzung des begonnenen Werkes nicht lange wird auf sich warten lassen, dafür bürgt der bekannte Unternehmungsgeist der Amerikaner, welcher sich auch auf wissen- . schaftlichem Gebiet (namentlich in der angewandten Entomologie) schon so glänzend bewährt hat.

Trotz der rerhältnismäßig kurzen Arbeitszeit sind die wissenschaftlichen Ergebnisse der Adirondackstation bedeutende zu nennen: die Entwickelung und Lebensweise von gegen 100 Species konnte mehr oder weniger genau festgestellt werden, die Fauna des Gebiets wurde wesentlich bereichert und 10 neue Species wurden entdeckt, welche die Aufstellnng zweier neuer Gattungen notwendig machten.

Der ganze Bericht zerfällt in 4 Teile, deren Inbalt hier kurz besprochen werden soll.

1. Entersuchung, Einrichtung, Objekte, Methoden und Resultate. Den Autoren war die Aufgabe gestellt worden: .. to collect and study the halits of aquatic insects, paying special attention to the conditions necessary for the existence of the various species, their relative ralue as food for fishes, the relations of the forms the each other, and their life histories". Die Fischereikommission

1) Für das nächste Jahr wird ein zweiter Bericht versprochen, in welchem die gezüchteten Chironomiden, die Unterordnung der Zygoptera (Odonata) und der Inhalt dex untersuchten Fischmägen (auch die Fischkultur soll berücksichtigt werden) zur Besprechung kommen sollen. 
des Staates New York stellte einen 'Teil ihrer Räume und ihrer Ausrüstung zur Verfïgung. Das Gebiet ist von einer Menge von Wasserläufen durchzogen und enthält eine bedeutende Anzahl von grössern oder kleinern Seen, so dass alle giinstigen Bedingungen zum Gelingen der gestellten Aufgahe vorlagen. Der Bericht enthält eine austührliche Beschreibıng der Lokalität, des Pflanzenwuchses auf derselben, der /uchtteiche mit ihrer Flora, der einzelnen Fang- und 'Zuchtplätze, des Zieles und Ganges der Arbeiten, der Apparate und Methoden. Die Ziele der Station waren sehr weit gesteckt: galt es doch nicht nur die Fauna und die Lebensweise der Wasserinsekten les gegebenen Gebietes genau zu erforschen, sondern auch die Vermehrungsfähigkeit der genannten Insekten zu studieren, die gegenseitigen Nahrungsverhältnisse der verschiedenen Bewohner der Gewässer (Insekten, Fische u. s. w.) festzustellen, und ausserdem die Sammlungen des Museums durch eine möglichst grosse Anzahl von Vertretern aller Tierklassen zu bereichern. In dem rorliegendeu Bericht ist naturgemäf hauptsächlich ron den beobachteten und erbenteten Insekten des Wassers die Rede, wälırend alle übrigen Materialien an anderer Stelle bearbeitet wurden. Ton neuen Formen werden hier beschrieben: Lenctra tenella (Plecoptera, erstmals wissenschaftlich beschrieben), Sisyra umbrata und Climacia Alictyona (Hemerobi idae), Gomphus descriptus var. boreatis (Odonata), die bisher nu' aus einem Bruchstiick bekannte Ephemeride Bactis pygmaea Hag., das q ron Lencorrhinia glaciatis Hag., ferner zwei Dipteren (durch I). W. Coduillett) Zabrachia nor. gen. (Stratiomyidae) polita nov. sp. und Roederiodes nor. gen. (Empididae) jmcta nor. sp., fünf parasitische Hymenopteren (durch R. A hsmead): Telenomms longicomis nor. sp. (Scelionidae), Brachystropha qmadriceps nov. sp. und Rhizarcha astigma nov. sp. (Aly siidae) Aphithius nigripes nov. sp. (Braconidae) und Atractodes sepedontis nor. sp. (in Puparien der Diptere Sepedon fuscipemis parasitierend), sowie zwei 'Tenthrediniden (durch A. D. Ma egillivray) Pachynematus corticosus nov. sp. und Traxoms imominatus nov. Sp.

2. Fauna des Little Clear Creek. Hier werden die in und an dem erwähnten Flusslaufe beobachteten Lebewesen aufgezählt (Amphibien, Mollusken, Crustaceen, Insekten, Yermes), die Zahl der Individuen einzelner Wasserjusekten (Larven) festgestellt und einiges iiber allgemeine biologische Terhältnisse mitgeteilt.

3. Lebensgeschichte der das Wasser bewohnenden Insekten. Hier finden wir die ausführliche Beschreibung von Tertretern der Ordnungen Plecoptera, Ephemerida, Odonata, Neuroptera, Trichopter a sowie kürzere Angaben über die ibligen 
Insektenordnungen. Es ist sowohl der systematischen wie der biologischen Seite Rechnung getragen, die Bibliographie und Synonymie berüicksichtigt, und es sind anschauliche analytische Bestimmungstabellen für die Familien, Gattungen und Arten beigegeben, welche durch Textabbildungen erläutert werden. Zur Besprechung kommen hier Ephemeridae: 7 gen., 7 sp.; Odonata (Anisoptera) 35 gen. (Helocordutia. Dorocordulia nov. gen.), 84 sp.; Sialidae: 3 gen., 5 sp.; Hemerobiidae; 3 gen., 3 sp.; 'Trichoptera: 13 gen. 26 sp. (viele umbestimmt gebliebene Gehäuse); I)iptera 7 gen., 7 sp.: Hymenoptera: 7 gen., 7 sp. Die auf dem biologischem Gebiet erhaltenen liesultate sind ganz bedentend. Die dem Bericht beigegebenen Tafeln sind von ausgezeichneter Ausfülnung; es soll namentlich auf die wunderschönen Phototypien nach lebenden Insekten lingewiesen werden.

N. v. A delung (St. Petersburg).

32 Willem. V.. Les Collemboles recueillis par l'Expédition antaretique helge. In: Ann. Soc. Eut. Belgique T. 45. 1901. pag. 260-262. Abb.i.T.

Es werden drei nette Collembolen beschrieben, welche in der Umgebung der Gerlachstrasse gesammelt wurden und zur Aufstellung zweier nener Gattungen geführt haben. Es sind dies Achorutoides nov. gen. (Neanurini Bürner, dem Vorfalnen nahestehend, von welchem .lumida und Aphmomma herzuleiteu sind) antareticns: nor. spec.; Cryptopyyus nov. gen. (Anurophorus nahestehend) antarcticus nov. spec.; Isotoma octooculate nov. sp. N. v. A delung (St. Petersburg).

33 Axam, J., Orthoptères recueillis dans l'île de Chypre. In: Bull. Soc. Entom. France Jhg. 1901. pag. 188-191.

Von Larnaea (Cypern) werdeu 3 Dermapteren, 3 Blattodeen, 2 Mantodeen (darunter eine Gonypeta s].), 10 Acridiodeen (darunter Stcnobothrus azami und Pyr(yomorpha cypria nn. spp.), 4 Gryllodeen und 4 Locustodeen mitgeteilt.

N. v. A d elung (St. Petersburg).

34 Cimclell. A. N.. On some Arizona Acrididae. In: The Canadian Entomologist. Vol. 33. 1901. pag. 102-106.

Es werden $11 \mathrm{sp}$. aus Arizona aufgeführt, von denen die eine neu ist, und einem neuen Genus angehört. Arcopteryx: nov. gen. (Amonic nahestehend, vou der es siclı durch die Gestalt der Stirnleiste, das rauhe Metanotum und längere Elytren unterscheidet) penclope nov. sp. Die übrigen Arten gehören den Gattungen Hippiseus (1 sp.), Trimerotropis (1 sp.), Anconic (1 sp.), Schistocerca (2 sp.), Hesperotetix (1 sp.), Melanoplus (4 sp.) an. N. v. Adelung (St. Petersburg).

35 C'holodkowsky, N., Kur Kenntnis der' Speiclreldriisen ron Gryllus domeslicus L. In: Allgem. Zeitschr. f. Entomol. Bd. 6. 1901. pag. $177-178$. Abb. i. 'T'.

Die beiden (nicht verwachsenen) Speicheldrüsen bestehen aus je einem pro-, meso- und metathorakalen Abschnitt, welche jeder aus drei Acinigruppen mit gemeinsamem Ausführgang musammengesetzt 
sind; ferner ist ein unpares Speichelreservoir vorhanden, dessen zwei Ausführgänge sich jederseits mit denen der Trüsen verbinden; der gemeinsame umpaare Endabschnitt des Kanals mündet mit einer trichterförmigen Erweiterung unter dem Hypopharynx.

Der histologische Ban ist nach dem Verf. derselbe wie bei den Blattiden.

X. r. I delung (St. Petersburg).

36 Morse, A. P., New North American Orthoptera. In: The Canadian Entomologist. Vol 33. 1901. pag. 129-131.

Es werden zwei neve Locustodeen und eine nene Acridiodee beschrieben. Odontoxiphidium nov. gen. (C o nocephalidae; Tiphidium nahestehend) apterum nov. sp., Scudderia (Phaneropteridae) cuncata nov. sp. und Hesporotettix (thela nopli) Horidensis nov. sp.

N. v. A delung (St. Petersburg).

37 Morne, A. P., The Xiphidiini of the Pacific Coast. In: The Canadian Entomologist. Vol. 33. 1901. pag. 201-205.

8 - A new Xiphictium from Florida. Ibid. pag. 236.

Die von dem Verf. gesammelten und mitgeteilten 4 Arten Tiphidim (Locustodea) sind die ersten westlich vom Felsengebirge bekannt gewordenen Xiphidiinen. Es sind dies Orchlimum agite, Xiphidium spinosum nov. sp., X. occidentale nov. sp. mit $X$. oceidentale cardotum und $I$. occidentale camurum nov. var. und $X$. vicinum nov. sp. In den beiden letztgenannten Species ist die Variabilität einiger Merkmale (Länge der Elytren und der Legescheide) im Zusammenhang: mit der geographischen Lage des Fundorts.

Tiphidium gracillimum nov. sp. wird aus Florida beschrieben.

N. v. A delung (St. Peterslurg).

39 Rehn, J., Notes on Mexican Orthoptera, with description of new species. In: 'Trans. Amer. Entom. Soc. Vol. 27. 1900-1901. pag. 85-99.

10 - Remarks on some Mexican Orthoptera, with descriptions of new species. Ibid. pag. 218-229.

11 - Random Notes on North American Orthoptera. lbid. pag. 331-337.

Die beiden Listen mexikanischer Orthopteren enthalten zusammen 14 neue Species; das Material wurde von O. W. Barrett in den Provinzen Guertero, Vera Cruz, Morelos, Tamoulipas nnd Distrito Federal gesammelt. Die erbeuteten Insekten verteilen sich wie folgt: Dermaptera: Apterygida 2 sp., Sparattia (Sp. dentifcra nov. sp.), Ancistrogaster 3 sp.; Blattodea: Thyrsocera 2 sp., Periplaneta $1 \mathrm{sp}$. (P. americana colorate nov. subsp.), Homocogamia $1 \mathrm{sp}$.; II a n to dea: Stagmomantis 1 sp., Theoclytes 1 sp., Vates $2 \mathrm{sp.} \mathrm{(} V$. annectens nor. sp.; der Vetf. weist nach, dass Theoclytes ein Synonym von I'ates ist); Phasmodea: Bacterie $1 \mathrm{sp}$. (das $q$. von B. trixlens wird beschrieben, indem das ron Westwood als solches mitgeteilte Exemplar nach Rehn zu B. striuta gehört. Gryllodea: Gryllus 2 sp. (Gr. barzctti nov. sp.), Oecanthus 1. sp.; Tettigonidae (= Locustodea): Stcnopelmatus 1 sp., Dichopetrla $1 \mathrm{sp}$. , Scudderia $2 \mathrm{sp.,}$ Phrixa 1 sp., Symmetropleura $1 \mathrm{sp}$. (Ph. tcocelac nov. sp.), Phylloptera $1 \mathrm{sp} .$, (Ph. annulata nov. sp.), Petaloptera 2 sp., Syntcehna 1 sp. (S. caudelli nov. sp.), Stilpnochlora 3 sp., Pyrgocorypha 3 sp., Conocephalus 2 sp., Tiphidium 1 sp., Capnobotes 1 sp. (C. imperfectus nov. sp.), Ciongrocnemis 1 sp. Acridiodea: Truxalis 1 sp., Syrbuta 2 sp. (S. eslavae nov. sp.; S. (Herus nov. subg.) valida nov. sp.), Orphuldlla $3 \mathrm{sp}$ 
(O. aculeate und neglecta $\mathrm{nn}$. spp.), Plectrotettix 1 sp., Sphenarium 3 sp., Machacrocera $2 \mathrm{sp}$., Irphia $1 \mathrm{sp}$., Tomonotus 1 sp., Lactista $2 \mathrm{sp}$. (L. incrmus nov. sp.) Trimerotropis 2 sp., Tacniopoda 2 sp., IIeliastus 1 sp., Rhomalea $1 \mathrm{sp}$., Schistocerea 5 sp., Aidemona 1 sp., Melanophes 4 sp., Perixerus 1 sp. (I'. laevis nov. sp.), Paratettix 1 sp., T'elmatettix 1 sp., Tettigidea 2 sp.

In einem weiteren Aufsatz gibt der Verf. ein Verzeichnis von Orthopteren aus der Sammlung der Akademie der Wissenschaften und der seinigen, welche zu den weniger bekannten gehören und über welche neuere Angaben erwïnscht sein müssen.

N. v. A d e lung (St. Petersburg).

42 Scudder. S. H., Four new species of Hippiscus. In: The Canadian Entomologist. Vol. 33, 1901. pag. 88-92.

Der Verf. teilt vier nene Arten der Gattung Hippiseus (Orthoptera, Acridiodea) mit, welche ihm seit Veröffentlichung seiner Monographie dieser Oedipodidengattung bekannt geworden sind. Es sind dies die nn. spp. II. (IFippiscus) citrinus von Alabama, H. (Xanthippus) glaucipes von Californien, H. (Tanthippus) croceus und H. (Tanthippus) ralidus, beide aus Idaho.

N. v. A delung (St. Petersburg).

43 Scudder, s. H., Niogryllus and its species in the United States. In: Psyche. Vol. 9. 1901. pag. 256-258.

44 - The species of Gryllus on the Pacific Coast. Ibid. pag. 267-270.

Die Gattung Miogryllus war bisher nur durch eine Art aus dem Gebiet der Vereinigten Staaten bekannt. ścudder veröffentlicht nunmehr fünf Arten für dieses Gebiet (alle von den südlichen Staaten) und zwar M. capitatus nov. sp. aus Texas, M. lincatus Scudd. (Arizona), M. saussurei Scudd. (Georgia, Floriảa), 11. transtersalis nov. sp. (Florida) und $M$. sicarius nov. sp. (San Diego).

Für vier nördlich von Mexiko, an der pacifischen Küste vorkommenden Gryllus-Arten stellt Scudder eine analytische Tabelle auf. Es sind dies (ir. integer nov. sp., Gr. meäis nov. sp., Crr. pennsyltanicus Burm. und Cir. assimilis Fabr.

N. v. A delung (St. Petersburg).

45 Scudder, $\therefore$. H., The species of Diapheromera (Phasmidae) found in the United States and Canada. In: Psyche. Vol. 9. 1901. pag. 187-189.

$\mathrm{Zu}$ den drei bisher für Nordamerika bekannten Diapheromera-Arten fügt Scudder zwei neue Arten (D) carolina nov. sp. von Nordcarolina und D. mesillana nov. sp. von Neu Mexico) linzu. Ausserdem wird die genaue Verbreitung aller fünf Arten mitgeteilt und eine analytische Tabelle zur Bestimmung der letztem mitgeteilt.

N. v. A d elung (St. Petersburg).

46 Stscherbakoff, A. M., Be itrag zur Fa una der Acridiodea und Locustodea der Gouvernements Kieff und Tschernigoff.

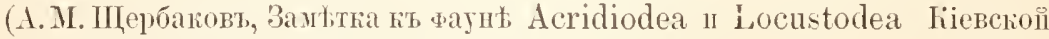
॥ Чернитовскої губериіiі.) Kieff 1900. (Nachrichten der Universität Kieff, 1901). 30 pag. (Russisch).

In Auftrage der Naturforschergesellschaft in Kieff sammelte der Verf. in den erwähnten Gouremenents Orthopteren, welche er in vorliegender Mitteilung aufzählt. Da bis jetzt noch wenig Angaben 
in der Literatur über die Orthopteren dieses (zweifellos an interessanten Formen reichen) Gebietes vorliegen, so war ein Verzeichnis derselben erwïnscht.

Die mitgeteilte Liste entlält aber fast nur Formen, welche mit Gewissheit rorauszusetzen waren, da sie überhaupt in Mitteleuropa gemein sind, dagegen hat der Verf. alle ,zweifelhaften oder schwer zu bestimmenden" Arten, also gerade diejenigen Formen, welche ron besonderem Interesse waren, in die Liste nicht aufgenommen. Fis ist zu hoffen, dass dieselben nachträglich veröffentlicht werden. Die Liste enthült $2 t$ Acridiodeen und 13 Locustodeen. Diagnosen lateinisch nach brunner.

N. r. A delung (St. P'etersburg).

47 Verhoeff, K., Ueber die Nerven des Metacephalsegmentes und die Insektenordnung Oothecaria. In: \%ool. Anz. Nr. 685. 1902. pag. 20-31. 9 Abb.

Das Ganglion des Kieferfussegmentes der Chilopoden ist mit dem Unterschlundganglion verwachsen, weshalb auch seine vier Nervenpare aus diesem herrorkommen. Verf. hat im Mikrothorax der Insekten ein Segment aufgefunden, welches hinter dem Kopfe und rorne am Thorax gelegen, dem Kieferfussegmente der ('hilopoden homolog ist. Er fand bei verschiedenen Insekten, namentlich Blattiden und Mantiden, auch noch 3-4 Nervenpaare hinten am Unterschlundganglion, welche den genannten Nerren der Chiloproden entsprechen and bisher meist übersehen wurden. Zwei einschlägige Nervenpare hat Verf. auch bei Käfern gefunden (Geotrupes). Blattodeen und Mantodeen wurden als Ordnung Oothecaria zusammengefasst und dureh eine vorläufige Charakteristik umschrieben, wobei verschiedene, bisher nicht verwertete oder äberhaupt nicht heachtete Merkmale verwendet worden sind.

k. Ver ir o eff (Berlin).

48 Verhoeff, K., Die verwandtschaftliche Stellung ron Hemimerus. In: Sitz.ber. d. Ges. nat. Fr. Berlin 1902. Nr. 4. pag. $87-90$.

Die in mehrfacher Richtung besonders interessante Gattung Hemimens war bisher hinsichtlich ihrer rerwandtschaftlichen Stellung immer noch nicht rollständig geklärt, da man schwankte, ob sie den Dermapteren oder Blattodeen zugezählt werden sollte. Verf. zeigt, dass Hemimerus entschieden zu den Dermapteren gehört, aber ein abweichender Zweig derselben ist, auf welchen die Unterordnung Dermodermaptera aufgestellt wird. Beide Geschlechter stimmen im Bau der Hinterleibssegmente in weitgehendem Malie mit den Dermapteren überein, so ist beim o tas 8. und 9. Abdominal- 
segment sehr schmal entwickelt und die Oripositoren fehlen, während beim $0^{7}$ zweigliedrige, längliche Parameren angetroffen werden, in der Paramerenzunge und den doppelten Präputialsäclien aber ganz weitgehende Übereinstimmungen mit den typischen Dermapteren vorliegen.

K. I erhoeff (Berlin).

49 Needham, J. (x. and $\boldsymbol{\Lambda}$. Ch. Hart, The Dragon-F lies (Odonata) of Illinois. Part I. Petaluridae, Aeschnidae and Gomphidae. In: Bull. Illinois State Laborat. Nat. Hist. Yol. VI. 1901. 94 pag. pl. I.

Das Material zu vorliegender Arbeit war ein sehr reichlialtiges, und da ausserdem die Biologie und Fangmethoden beriicksiclitigt sind und der systematische Teil sich durch reichliche Angaben über Morphologie und Literatur auszeichnet, so liegt ein Resultat vor, welches weit ïber den bäufig so eintönigen Sammellisten steht.

Die Arbeit beginnt mit einer allgemeinen Besprechung der Ordnung Odonata mit deren Familien und ihrem genetischen Zusammenlıang. darauf folgt eine kurze kritische Besprechung der einschlägigen Literatur und sodimn die Lebensgeschichte der Odonaten spez. der Anisoptera), wobei die Lebensweise der Jugendstadien und Imagines, die Standorte derselben sowie der Fang und die Präparation in klarer und anschaulicher Weise besprochen werden. Einer liurzen Angabe ïber die liauptsächlichsten morploologischen Merlsmale folgen Schlïssel zur Bestimmung der nordamerikanischen Familien und Gattungen, die Besprechung dieser letzteren und die Aufzählung und Beschreibung der einzelnen Arten.

Dem systematischen 'Teil entnehmen wir folgende Angaben über aus irgend einem Grunde wichtigere Funde: Nesincschna pentacantha Ramb. (die Nymphe vor allen andern Aeschniden durch den Besitz von abdominalen Dorsalhaken ausgezeichnet), Epiaeschna heros Fabr. (durch bedentende Grösse ausgezeichnet), Boyeria rinosa Say (die Nymphen zeichnen sich wie diejenigen der erstgenannten Art durch auffallende Anpassung an Aststückchen u. dergl. aus), Basiacschna janata Say, Acschna clepsydra Say (Nymphen mit seitichen Dornen am 5. Abdominalsegm.), Leschna californica Calv. (erstmals für Illinois), Lnax jumius Drury (die Nymphen dieser grossen Art nähren sich z. T. von Mollusken, Imnicola, und zeichmen sich überhaupt durch grosse Gefrässigkeit aus). Progomplus obscums Ramb. (erstmals für Illinois; die Nymphen dieser seltenen Gomphide sind durch grosse Nähe der mittleren Beine ausgezeichnet: Anpassung an reissende Ströme; hier ist eine analytische Tabelle zur Bestimmung der nordamerikanischen Gomphiden, Imagines und Nymphen, eingeschaltet), Diastatomma carolus Needl. (trotz der ungeheuren Menge von Nymphen ein höchst seltenes Objekt). Hagenius brevistylus Selys (dessen Nymplre eine ganz abweichencie Gestalt besitzt, indem sie sehr breit und ganz flach ist, so dass sie sich wenig von den Steinen etc., an welche sie sich klammert, abhebt, und so den Fischen entgeht), Lanthus parrulus Selys (erstmals für Illinois konstatiert; die kleine Nymphe hat die Gewohnheit 
sich tot zu stellen), Dromogomphus spinosus Selys; Gomphus (21 nordamerikanische Arten mit Schlüssel), G. abbrcviatus Hag. (sehr selten, aus N. York, die Nymphe wird erstmals beschrieben), (i. cxternus Sel. (deren Nymphe mit derjenigen von G. fraternus verwechselt wurde, Beschreibung beider), (t. spicatus Sel. (erste Beschreibung der Nymphe), ('. australis Needh. (erstmals für Illinois), u. a. m.

Im ganzen werden angeführt: Nasiaeschna Selys 1 sp., Epiaeschna Hag. 1 sp., Boyeria Mc. L. 1 sp., Basiaeschna Sel. 1 sp., Aeschna Fabr. 6 sp., Anax 1 sp., Aphylla Sel. 1 sp., Progomphns Sel. 1 sp., Diastatomma Burm. 4 sp., Hagenius Sel. 1 sp., Lanthus Neuh. 1 sp., Dromogomphns Sel. 1 sp., Gomphus Leach 21 sp.; ein 'leil der Species lag nur als Nymphe ror.

\section{N. r. Adelung (St. Petersburg).}

50 Banks, N., A new genus of Myrmeleonidae. In: The Canadian Entomologist Vol. 33. 1901. pag. 329-330.

Hagen hatte mehrere canadische Myrmeleoniden in die auf eine turkestanische Art basierte Gattung Marcacanda He Lachl. eingereiht. Banks weist nach, dass die obenerwähnten Arten generisch von Maracanda verschieden sind nnd einer neuen Gattung angehören müssen, für welche er den Namen Cryptolcon nov. gen. vorschlägt (Diagnose). N. v. A delung (St. Petersburg).

51 Banks, N. A List of Neuropteroid Insects from Mexico. In: Trans. Amer. Entom. Suc. Vol. 27. 1900-1901. pag. 361-371. Pl. XII.

Im ganzen werden 11 Pseudoneuropteren, 20 Neuropteren und 19 Trichopteren mitgeteilt, darunter 17 neve Arten. Diese interessante Liste ist das Resultat eimes mehrjährigen Sammelns, erschïpft aber lange nicht die bereits bekannten Neuropteroiden Mexikos. Auffallenderweise fehlen in der Fauna fast vollständig die Hemerobiiden; von den Trichopteren gehören die meisten Arten den Leptoceriden und Hydropsychiden an. Auf die Gattungen verteilen sich die erhenteten Aıten wie folgt: Termitidae: Calotemes 1 sp.; Perlidae: P'scudoperla 2 sp.; Psocidae: Pterodcla und Psocus je 1 sp.; Ephemeridae: Cellitroctis 2 sp., Boctis $3 \mathrm{sp}$ (undeterminiert), Tricorythus $1 \mathrm{sp}$; Sialidae: Corydalis $2 \mathrm{sp}$, Nerromus 1 sp., Sialis 1 sp. (S. mexicance nov. sp.); Coni opterygidae: Conioptery.t 1 sp.; Nantispidae: Hantispa $1 \mathrm{sp}$.; Chrysopidae: Crysopa 5 sp. (Chr. mexicana und tolteca nn. spp.), Leucochrysa $1 \mathrm{sp}$., Meleoma $1 \mathrm{sp}$.; M yrmeleonidae: Acanthactisis 1 sp., Mymelcon 1 sp., Brachynemumes 1 sp., Mieroleon nov. gen., durch seine einfache Nervatur ausgezeichnet (M. apicalis nov. sp.), Eremoleon nov. gen. für $E$. macer Hag.; A scalaphidae: Ulula 1 sp. (H. tuberculata nov. sp.), Haplogenius 1 sp.; Limnoplnilidae: Platyphylax 1 sp. (Pl. discolor nov. sp); Sericostomatidae: Eremopyche nov. gen., wahrscheinlich Lasiocephala nahestehend (für $E$. frontalis nov. sp.), Olemira 1 sp. (O. mexicena nov. sp.) Helicopsyche 1 sp. (H. mexicana nov, sp.); Leptoceridae: Leptocerus 1 sp., (L. mexicams nov. sp.), Leptocella $2 \mathrm{sp.}$ (L. dorsalis und gracitis nu. spp.), Heteroplectron $3 \mathrm{sp.}$ (H. maculatum nov. sp.); Hydropsychida e: IIydropsyche 1 sp. (II mexicana nov. sp.), Polycentropus $1 \mathrm{sp}$. (undeterminiert), Philopotamus $3 \mathrm{sp}$. (Ph. mexicanus und bicolor nn.spp.), Diplectrona 1 sp. (D. unicolor nov. sp.), Leptonema $1 \mathrm{sp}$, Macronema $1 \mathrm{sp}$.; Rhyacophilidae: Rhyacophila $1 \mathrm{sp}$. Die Tafel enthält Detailzeichnungen für die neuen und einige schon bekannten Arten.

N. v. A delung (St. Petersburg). 
52 Gadd, Gr., T'eber den Bau des Darmkanals bei den Larven

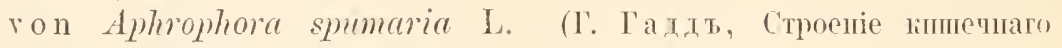

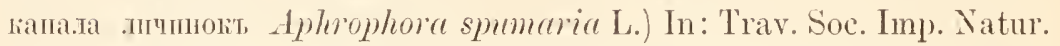

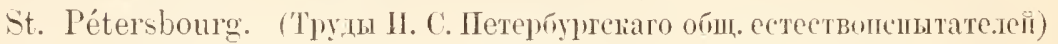
Vol. XXXII. livr. 4. 1902. pag. 65-95. 1 Taf. (Russisch mit deutschem Resumé.)

Anknüpfend an eine Mitteilung $\mathrm{X}$. Wagners aus dem Jahre 1868, untersuclite der Verf. den Darmkanal der Larven ron Aphophora spmaria. Er beschreibt die originelle Muskulatur der Gaumenplatte. Dic Basis der Bohrwerkzeuge hat die Gestalt einer Spirale. Die Speicheldrüsen besitzen Kerne ron ausserordentlich unregelmäBiger Gestalt. Der Magen besteht aus zwei Abschnitten; ron dem rordern geht der Diinndarm aus. Der interessanteste Teil der Arbeit besteht in der Beschreibung der Darmanhänge. Ausser den Malpighischen Gefïssen (zwei Paare), welche in den Darm selbst münden, sind noch zwei lange blinde Anhänge des Magens selbst vorhanden. Der eine mündet in den rordern Abschnitt des Nagens, der andere in den hintern. Der erste hat in seiner hintern Hälfte grosse Zellen mit Kügelchen, welche die Anwesenheit von Substanzen zu erkennen geben, die zur Guaningruppe gehören. Dis Epithel des zweiten Anhanges zeigt ganz andern (harakter; die Zellen haben lange Fortsätze. Beide Blind. säcke sind an den Enden durch Bindegewebe miteinander verlötet. Der eine Magenfortsatz hat demnach eine exkretorische Funktion, der andere die Funktion einer Drüse. Der Verf. erinnert daran, dass anch bei Arachnoideen und Amphipoden die Anhänge des Mitteldarmes eine exkretorische Funlition haben. Dieses scheint mir die viel umstrittene Frage um die Homologie der Malpighischen Gefässe bei Arachnoideen einerseits und Myriopoden und Insekten andererseits zu beleuchten und aufzuklären. E. Schultz (St. Petersburg).

53 Metalnikofr, S., Beiträge zur Anatomie und Physiologie der Mückenlarve. In: Bull. Acad. Imp. Sc. St. Pétersbourg (Ізвтстія II. Aкадемin naylis). T. XVII. Nr. 1. 1902. pag. 49-58. 2 Taf. (deutsch).

Der Verf. setzt die Untersuchungen A. Kowalevskys über den Prozess der Exkretion in den Perikardialzellen der Mückenlarven fort. Bekanntlich wird in den P'rikardialzellen der Arthropoden ammoniakalisches Karmin ausgeschierlen. Aber wie dasselbe in diese Zellen gelangt und aus ihnen wieder ausgeschieden wird, war noch nicht näher beobachtet worden. Zuerst gibt der Verf. eine ausführliche Beschreibung des Darmes der Culex-Larve. Im Darme der Larve wird das Karmin aufgelöst und ron den grossen Epithelzellen des Mitteldarmes auf- 
gesogen, wo dasselbe in den Vakuolen zu sehen ist und darauf durch die Darmwand in die Leibeshöhle ausgeschieden wird. Hier vermischt sich die Karminlösung mit dem Blute. Die Leukocyten nehmen am Prozesse keinen Anteil. Darauf nehmen die Perikardialzellen eine rosa Färbung an. Sie liegen an den Seiten des Herzens, zwei Paare in jedem Segmente, ausser dem ersten, welches nur ein Paar enthält; sie sind von einer dünnen Hiille umgeben. Nachdem diese Zellen das Karmin aufgenommen haben, beginnen sie zu zerfallen - werden kleiner und verschwinden, wahrscheinlich mit Hilfe der Lenkocyten. da in ihnen oft später Karminkörnchen zu finden sind. Zuletzt gibt der Verf. noch eine ausfiihrliche Beschreibung des Herzens und seiner Klappen, die er an lebenden Exemplaren beobachtete.

E. Schultz (St. Petersburg).

54 Cholodkowsky, N., Über den Spinmapparat der Lydu-Larven. In: Allg. Zeitschr. f. Entom. Bd. 6. 1901. pag. 17-19. Abb. i. T'

An dem Spinnapparat von Lyda erythrocephala L. fand der Verf. folgendes listologische Verhalten: Die Wandıngen der Driisenschläuche bestehen aus einer Lage Hacher Lpithelzellen unt einer darïberliegenden Schicht ron grossen secernierenden \%ellen, deren Sekret \%wischen den Hachen Zellen in den Hauptkanal mündet. Nach rorne zu rerschwinden die grossen Zellen erst auf einer Scite, dann ganz. Vor der Ausmündung an der Unterlippe nehmen die rerjüngten Hauptkanäle je einen Ansführgang der Filippischen I) rüsen auf, um sodam in einem kurzen mpaarigen Gang an der Spitze der Unterlippe nach aussen zı münden. I)ie Filippischen 1)rüsen haben ein sehr enges (gegen Pickel), mit dicker Cuticula ausgekleidetes Lumen. Ganz neu (auch für Tenthrediniden) sind zwei biischelförmige, durchsichtige zusammengesetzte tubulöse Drïsen (..glandulae multifidae“), deren Ausführgang neben denen der Hauptkanäle in das unpaare Endstïck mündet. Sie bestelıen aus (ylinderepithel.

Die Filippischen Irüsen bestehen aus einer Schicht grosser Epithelzellen mit von Vaknolen umgebenen Kernen; die Vakuolen könnten Reservoire für das Zellsekret darstellen.

$$
\text { N. v. Adelung (St. Petersburg). }
$$

55 Holmgren, Nils, Über die Exkretionsorgane des Apion faripes und Dacytes niger. In: Anat. Anz. XXII. 1902. pag. 225 -239 . Fig. $1-12$.

Dass unsere Kenntnisse über die Exkretionsorgane der Insekten noch recht unvollstïndig sind, zeigt wiederum die vorliegende Arbeit Holmgrens, nachdem in der letaten Zeit schon mehrfach von 
Möbusz, K a rawaiew und Sedlaczek (vgl. Zool. Zentr.-Bl. I, pag. 89, VII, pag. 208, IX, pag. 539) daraut hingewiesen worden war. Letzterer stellte hei den Borkenkäfern fest, dass nicht alle sechs Malpighischen Gefässe sich gleich verhalten, sondern dass nur vier davon frei enden, wäluend die zwei übrigen mit ihren distalen Enden nochmals mit dem Darn in Verbindme treten, so dass man auch eine rerschiedene Funktion für die beiden Gruppen annehmen müsse.

Öhnliches find Holmgren bei Apion flaripes (Curculionide); nnr ist hier die Differenzierung noch viel weiter geschritten, inden den vier normalen schlauchförmigen Malpighischen Gefässen zwei kurze blasenförmige ovale Drüsen mit dünnem röhrenförmigen Ausführgang gegenüberstelıen (vgl. Fig.). Auch histologisch unterscheiden sich die ungewandelten Malpighischen

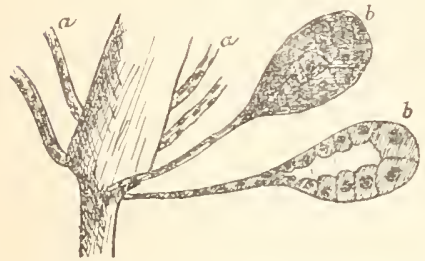

$a=$ normale Malpigh. Gefässe.

$b=$ umgewandelte Malpigh. Gefässe. Gefiisse von den normalen, einmal dadurch, dass bei den ersteren eine chitinöse Intina (Stäbchensaum) fehlt, und sodann auch durch die bedeutendere Grösse der Sekretionszellen, besonders der distal gelegenen, welche mitmnter einen kolossalen Umfang erreichen.

Das Sekret dieser acinösen Drüisen ist zweierlei Art, entweder feinkörnig oder aus langgestreckten Cylindern bestehend. Ersteres wird nur ron den \%ellen der Halsregion produziert, letzteres ron den grossen distalen Zellen. - Die feinen Exkretkörnchen sind C'hromatinkörnchen, welche nach teilweiser Auflösung der Kernmembran in die Kellsubstanz wandern. - Bei der zweiten Art der Exkretbildung beteiligt sich aber nicht allein der Kern durch Abgabe von ('hromatinkörnchen, sondern anch das Zellylasma. welches sich $11 \mathrm{~m}$ diese Körnchen ansammelt. So entstehen zunächst kleine Fxkretkugehn, welche eine Reilıe ron Verwandlungen durchmachen, bevor sie zu der definitiven Cylinderform gelangen.

Ausser Apron untersuchte Terf. auch noch einen Canthariden, Dacytes niyer, der wieder ganz eigentümliche Terhältnisse bezüglich der Fxkretionsorgane aufweist, insofern, als sich dieselben beim $q$ anders verhalten als beim . Bei letzteren finden sich lediglich sechs normale Malpighische Gefässe, beim q dagegen sind ausser diesen noch weitere sechs kurze kolbenfürmige exkretorische Anhänge vorlanden. Diese sind aber nicht, wie bei Apion, umgewandelte Malpighische Gefässe, sondern Nenerwerbungen, also accessorische Exkretionsorgane. Histologisch unterscheiden sie sich von den normalen Nalpighischen (iefässen ebenfalls durch das Fehlen einer Chitinintima 
und die Grösse der Drüsenzellen. Besonders am distalen Ende findet man zwei kolossale /ellen, welche auch den grössten Teil der Exkretbildung besorgen. Die Exkretionsprorlukte bestehen in kleinen, farblosen Kï̈gelchen, welche sowohl in dem wandständigen Kern als im Zellplasma gelegen sind. Interessant sind ferner die Angaben, wie diese Exkretstoffe in die Zelle gelangen: grosse Önocyten legen sich um die Spitze des Exkretionsorganes und geben die massenhaft in ihnen enthaltenen Kügelchen an die zwei grossen distalen Zellen des letzteren ab; zuerst gelangen sie hier in die wandständigen Kerne, rour da aus in das Zellylasma und endlich in das Lumen des Exkretionsorganes. Eine Anzahl Experimente (Einfühıung von verschiedenen Farbstoffen) bestätigten diese mikroskopischen Befunde in jeder Weise. K. Escherich (Strassburg).

5t Jarquet, M., Faune de la Roumanie. Coléoptères récoltés en 1899 et déterminés par Mr. E. Poncy. In: Bull. Soc. Sciences. Bucarest Jhg. X. 1901. pag. $483-496$.

57 - Faune de la Roumanie. Description de la nouvelle espèce de Harpalus, mentionnée plus lı at, ITarpulus (Erpeinus Mots.) Sticrlini Poncy. Ibid. pag. 496-497.

Die Liste der rumänischen Käfer wird fortgesetzt, wobei 2 Cicindeliden, 56 Carabiden, 8 Dytisciden, 3 Hydrophiliden, 10 Staphyliniden, 2 Silphiden, 1 Seaphidide, 3 Histeriden, "2 Dermestiden, 3 Fyrrhiden, 1 Parnide, 3 Lucaniden, 33 Scarabaeiden, 3 Buprestiden, 16 Elateriden, 1 Dascillide, 13 Malacodermide, 1 Lymexylonide, 1 Bostrychide, 13 Tenebrioniden, 2 Melandryiden, 1 Lagride, 1 Pyrochroide, 3 Anthiciden, 4 Mordelliden, 4 Cantlariden, 4 Oedemeriden, 2 Bruchiden, 1 Seolytide, 25 Cerambyeiden, 50 Chrysomeliden, 1 Endomychido und 1 Coccinellide mitgeteilt und eine neve Art Harpalus stirrlini nor. sp. heschrieben wird.

N. v. Adelung (St. Petersburg).

58 Porta, A., Ricerche sull' al'l'aratodi secrezione e sulsecreto della Coccinella \%-punctala L. In: Inat. Anz. XXII. 1902. pag. 177-192. Taf. TII.

59 - I) ie Funktion der Leber bei den Insekten. In: Allgem. Zeit. f. Entom. VII. 1902. jag. $417-429$.

Verf. beschäftigt sich mit der schon so oft behandelten Erscheinung des sogen. Blutens der Coccinellen, worüber immer noch verschiedene Ansichten geltend gemacht werden. Während die einen Autoren die aus dem Kniegelenk austretende Flüssigkeit für das Produkt besonderer Irïsen anfülıren, halten es andere für reine BlutHïssigkeit, die bei bestimmten Reizen durcl eine besondere öffnung an der Spitze des Schenkels austritt. Porta unterzog nun die fragliche Flüssigkeit einer eingehenden Untersuchung sorohl in chemischer als in spektroskopischer und mikroskopischer Beziehung, stellte dic Quantität fest, die cin Individum jedesmal abgeben kann 
(ca. 0,0026 g) und ermittelte ihre physiologische Wirkung auf rerschiedene kalt- und warmblïtige Tiere. Es ergab sich dabei, dass es sich um eine gallenartige Flïssigkeit handelt, welche auf Frösche, Kaninchen etc. eine entschieden giftige Wirkung ausübt. Die Frage, woher diese .Galle" kommt, beantwortet Porta dahin, dass sie ron Driisenfollikeln des. Mitteldarms stamme, welche in den Maschen der netzförmigen Muskularis gelegen sind. Demn diese Drüsenzellon ergaben dieselbe chemische Realition wie die obige Flüssigkeit und ausserdem zeigen sie als Inhalt dieselben Körperchen, welche in letzterer enthalten sind. Die Galle soll infolge liräftiger Kontraktion des Darmes durch die Wand desselben in die Leibeshöhle und von da durch die von $\mathrm{Lutz}$ beschriebene öffinung am Kiniegelenk nach aussen gelangen. Mit der Gallenflüssigkeit werden auch die zerfallenen und losgelösten I)rïsenzellen mit nacl aussen geschafft.

I)ass dieser Auffassung rerschiedene Schwierigkeiten entgegenstehen, betont Porta selbst und er versucht auch, die zwei hauptsächlichsten Einwände, die man dagegen erheben muss, zu entkräften: nämlich erstens, wie es kommt, dass die Galle sich nicht mit den Blut mischt und zweitens, wie es möglich ist, dass die Galle samt den zerfallenen Elementen durch die Wand des Darmes gelangen kann. - I)ie Erklärung, die er dafür gibt, dürfte noch eingehender zu beweisen sein, was ja wohl in der ausführlichen Arbeit, die Verf. in Aussicht stellt, geschehen wird. Auch die Flüssigkeit, welche Timarcha und die rerschiedenen Meloiden abgeben, ist nichts anderes als ein Gallensekret. - Intersuchungen an anderen Insekten ergaben ferner, dass überall Galle in Mitteldarm vorhanden ist. Die gallenbildende Funktion wird ron Irüsenfollikeln rerrichtet, welche entweder, wie bei Coccinella, zwischen den Bündeln der Muskularis, oder in den Blindsäcken oder \%otten des Mitteldarms gelegen sind. Diese Organe wälen demnach funktionell der Leber der ïbrigen Tiere gleichzustellen.

K. Escherich (Strassburg).

60 Verhoefi; K., I) ie zusammengesetzte \%irpvorrichtung von Geotrupes. In: sitzber, Ges. naturf. Fr. Berlin 1902. $\mathrm{Nr}$. 7/8. pag. $149-155$. 4 Abb.

Die Gentrupes-Arten bringen durch Reiben ihres Hinterleibes gegen IInterhüftfeilen ein zirpendes Geräusch lnervor, wie seit langem schon bekannt ist. Yerf. weist jedoch nach, dass das Zirpen nicht lediglich durch diese Hinterhïfteilen hervorgehracht wird, sondern dass sich am Rücken des Hinterleibes noch eine zweite Zirpvorrichtung in Gestalt mehrerer Haarfelder befindet, die ein etwas schwächeres zirpen bewirkt wie die Hinterhüfteilen. Gegen diese Haarfelder des 
Hinterleibsrückens, welche von zahllosen Häutungshauren gebildet werden, streichen die Hinterhülften der Flügeldecken. Felder von Häutungshaaren am Hinterleibsrïcken liommen auch bei vielen nicht zirpenden Käfern vor und hat Verf. auf deren Bedeutung schon früher aufmerksam gemacht. Er zeigt, dass bei den dem Zirpen dienlichen Häutungshaaren ein Funktionswechsel vorliegt: 1. Häutungshaare, nur der Häutung und dem allgemeinen Hautskelettschutz dienend, 2. besondere Haarfelder, dem Abschluss des die Fliigel enthaltenden Alarraumes dienend und der Zusammenlegung faltbarer Flügel, 3. dieselben Haarfelder, umgebildet als Zirpvorrichtungen; 4. komnten bei Voraussetzung des Zustandes Nr. 3 und der nickenden Abdominalbewegung auch an anderen Stellen, z. B. den Hinterhïften, wie bei Geotrupes, weitere verstärliende Zirpvorrichtungen entstehen und diese damn unter Umständen sogar die propygidialen an Bedeutung übertreffen.

K. I'erhoeff (Berlin).

\section{Mollusca.}

\section{Lamellibranchia.}

61 Frech, Fritz, Uber Cowilleia. In: Centralb]. f. Mineral., Geol. nnd Palateontol. 1902. Nr. 20. pag. 609-620.

Verf. betont die geologische Wichtigkeit der Gervilleien als Leitfossilien und die bisher geringere Beachtung derselben, im Vergleich zu Inoceramus in der oberen Ḱreide, und der für die Einteilnng der Wolgaschichten wichtigen Gattung Aucella. Als wichtigstes Merkmal für die Einteilung der Gervilleien in natiirliche Gruppen gibt Verf. den Zahnban an, der eine detaillierte lieschreibung erfährt; er teilt sie folgendermaßen ein: 1. Gruppe der Gerrilleia ariculoides; 2. Gruppe: Gerr. angusta; 3. Gruppe: Gerr. hatmani; 4. Gruppe: Gerr. solenoides und zwar mit a) subgenus: „Gerr. bovéi (Odontoperna) und b) subgenus: Hoemesia. Es folgt hierauf die eingehendere Beschreibung einiger Arten dieser Gruppen mit mehrern Abbildungen in Text sowie zum Schlnss mit der bildlichen Wiedergabe der Entwickelung des Zahnbanes ron Perna und die Endergebnisse: 1. die u. a. von E. Philippi befürwortete Einziehung von Batiercellia ist durchaus gerechtfertigt, weil sie in der Dyas und untern Trias die "direkten Vorläufer" von Gerrilleia umfasst. 2. Gerrilleia s. str. lässt sich in Jura und Kreide in vier natüliche Gruppen gliedern. 3. Absonderung von zwei liurzlebigen, selbständigen Seitenzweigen in der Mitteltrias, welche beide als Untergattungen mit besondern Namen (Hoemesia Laube, Odontoperna Frech) zu bezeichnen sind.

A. Tornquist (Strassburg i. E.). 


\section{Vertebrata.}

62 Futio, V., Deux petits vertébrés nouveaux pour la Suisse. In: Revue suisse Zool. Tom. 8. fasc. 3. 1900. pag. 467-476.

Als neu für die Schweizer Fauna werden mit verschiedenen Fundorten angeführt: Sorcr vulgaris Pall. und Ranagracea Boul. Ausserdem werden Fundorte genannt für Sorer vulyaris L. var. nigra Fatio, drvicole agrestis L., Rana esculcnta L. var., Triton cristatus Laur., subsp. meridionalis und $T r$. lobatus Otth. subsp. meridionalis. F. Römer (Frankfurt a. M.).

\section{Pisces.}

6.) Gorjanovic-Kramberger. Karl, Pal a e ichthyologische Beiträge. In: Mittheil. Jahrb. kgl. ungar. geol. Anstait. XIV. Band. 1. Heft. Budapest 1902. pag. 3-21.

Verf. teilt die Ergebnisse seiner eingehenden Untersuchungen mit über 8 Fischarten (davon 6 neue), welche 4 verschiedenen Lokalitäten angehören.

I. Uber einige Fische des ungarischen Tertiärs, und zwar aus der mittlern und obern Abteilung desselben. 1. Chuea hungarica Kramb. Gorj. aus Rákos bei Budapest in dortigen grauen pannonischen Tonmergel. 2. Clup. doljeana im sarmatischen Tripoli von Dolje bei Podsused nahe Agram in Kroatien zahlreich vorkommend. 3. Ciaclus (10rmua) lanceclatus ein fast vollständiges Exemplar aus dem Komitate Moson. 4. Caranx böckhi von dem Fundorte: Szt. Margita (Komitat Sopron) im dortigen Leithakalk.

1I. Über einen obermiocänen Lates aus Dolje bei Podsused, nahe Agram in Kroatien. 5. Lates croaticus klein, aber komplett erhalten und aus dem weissen sarmatischen 'Tripoli von Dolje herrïhrend. Das einzige Exemplar befindet sich im geol.-paläontologischen Nationalmuseum in Agram.

III. Über einen miocänen Spariden aus Steiermark.

6. Chrysophrys intermedius. Dieser Fischrest stammt aus der Zone der Leithaoder Lithothamnien-Kalke bei Cilli in Unter-Steiermark.

IV. Über zwei obercretacische Fische der Inseln Brazza und Solta in Dalmatien. 7. Enchodus longipinnatus aus Supetar auf der Insel Brač (Brazza) in Dalmatien. 8. Coclodus gasperinii Kramb. Gorj., ein prachtvoll erhaitener kleiner Fisch, dessen generische Stellung schwer zu fixieren war und vom Verf. auf Grund der Bezahnung der Gattung Coclodus Heckel zugeteilt wurde. Der Abhandlung sind vier prächtige Tafeln in Lichtdruck-Photographie und ausserdem noch fünf Textabbildungen beigegeben.

A. Tornquist (Strassburg i. E.).

Aves.

64 Arrigoni degli Oddi, E., Atlante Ornitologico. Uccelli Europei con Notizie d'Indole Generale e Particolare. Con 50 Tavole colorate. Milano 1902. I'ag. 1-165; I-XXV 1. $1-566$.

Das bisher beste, kurz, allgemein verständlich gehaltene und doch anch fïr den wissenschaftlichen ()rnithologen branchbare Handbuch der Vögel Europas. Die Tafeln, mit Ausmahme der letzten drei, sind nicht hervorragend, aber immerhin ganz brauchbar. Sie sind dem textlich ganz unwissenschattlichen Werke "Die Vögel Europas“ ron 
Arnold entnommen. Der erste Teil bildet eine rortreffliche Einleitung in das Studium der Tögel im allgemeinen, behandelnd die äussere Struktur, namentlich die Pterylographie und den Fussbau, die Mauser, die Farben, abnorme Fürhungszustände, Dimorphismus, die geographische Verbreitung, Nutzen und Schaden, die Wandermngen der Vögel, Stimme nnd Gesang, Eier und Fortpflanzung, Klassifikation, Vogeljagd und Togelfang in Italien, und namentlich ein sehr gutes. nach Ländern geordnetes Verzeichnis der Literatur über die europäischen Vögel. Der zweite T'eil enthält die spezielle Naturgeschichte der Vögel Europas, deren 565 Arten und viele Unterarten beschrieben sind. Die Ordnungen, Unterordnungen, Familien und Gattungen sind ausfülırlich gekennzeichnet. Bei den Arten sind keine Citate angegeben. Wenn es auch bei einem Werke wie das rorliegende lobend anzuerkennen ist, dass man nicht mit langen Listen ron Synonymen und Literatnrnachweisen belästigt wird, so hätte doch die jemalige erste Beschreibung mit Nutzen citiert werden können. Iie Beschreibungen sind kurz, aber genïgend. Unterarten werden in vielen Fällen unter besonderen Therschriften behandelt, in sehr zahlreichen Fällen aber wird nur im Text erwähnt, dass neuere Autoren - oder dieser oder jener Schriftsteller, je nachdem der Fall liegt - eine Anzahl Unterarten unterscheiden, und es sind meist die Unterschiede angegeben, ohne dass jedoch der Verf. sich entschieden darüber ausspricht, ob er diese Unterscheidungen für richtig liält oder nicht. Wenn man auch einwenden könnte, dass viele der nur im Texte erwähnten Formen ebenso gut wie andere unter besondern Überschriften hätten stelıen können, so muss doch anerkannt werden, dass in allen Fällen darauf aufmerksam gemacht worden ist. So bietet denn das vorliegende Werk ein zuverlässiges und vollständiges Nachschlagebuch über die Formen der Vögel Europas und steht bisler in seiner Art einzig da.

E. Il a r tert (Tring).

65 Berlepsch, If. and Jean Stolzmann. () n the ornithological researches of $\mathbf{H}$. Jean Kalinowski in Central-Perr. Part. II. In: Proceed. \%ool. Soc. Lond. 1902, vol. II, pag. 18-60.

Diese sorgsame Arbeit bildet den Schluss des Artikels in der gleichen Zeitschrift 1396, wo 294 Arten aufgezälılt und erörtert wurden. Hier werden nun weitere 189 Arten kritisch besprochen. Von Trochiliden allein sind 6 neue Unterarten beschrieben. 43 Arten dieser interessanten Familie wurden gesammelt. Ferner sind neu beschrieben: 2 Picidae, dann Momotus aequatorialis chlorolaemus, Mralacoptila futrigularis melanopogon, Penelope sclateri phumosa, Rallus nigricans humitis, Creciscus riridis subrufescens, Eury- 
myga major meridionalis, Troglodytes solstitialis macrourus und Aegialitis alticola. Ieider sind auch wiedertholt neue Formen ganz unauffällig im Texte bedingungsweise benannt, d. h. „in Falle sie sich später als neu erweisen", schlagen die Verf́. den Namen so und so vor. Ref. kann diese störende Gewohnleit nicht billigen. Namen dienen dazn. die als verschieden erkamnten Formen zu bezeichnen und sind zu unserer gegenseitigen Verstiudigung da; es kamn aber keinen Torteil bringen, sie bedingungsweise aufzustellen. Manche der schönsten neuen Formen sind schon zwischen 1894 und 1902 vorher beschrieben worden. Die Sammlungen stammen aus der Umgegend von Junin und den Tälern von ('hanchamayo und Vitoc und enthalten nicht weniger als 483 Vogelarten. I) a frühere Sammler noch 66 Arten erbeuteten, die Ka linowski entgingen, so liat jenes Gebiet die grosse Anzahl ron 549 Vogelarten aufzuweisen. E. Hartert (Tring).

66 Brewster. W., Birds of the C'ape Region of Lower California. With one map. In: Bull. Mus. Comparat. Zoolog. Harvard College. Tol. XLI. Nr. 1. September 1!02. pag. 1-241.

Die Grundlage zu dieser umfangreichen und gründlichen Arbeit bildet eine dem Verf. gehörende Sammlung ron 4400 Vögehn, die von N. A. Frazar innerhalb von neun Monaten zusammengebracht wurde, ausserdem wurde alle über jene Gegend bekannte Literatur und Exemplare in verschiedenen amerikanischen Museen benutzt. Im ganzen sind 255 rerschiedene Formen, nämlich 167 Species und ss Subspecies aufgezälılt. Iusser der auf das Gebiet bezüglichen Literatur hat Verf. auch kritische systematische Bemerkungen. sowie alle biologischen Angaben, die er finden konnte. und wertrolle Notizen über Nester und Eier gegeben. Totams melanolencus frazari, Megascops xantusi, Bubo virginiams elachistus und Tachycineta thalassina brachypteru sind neu beschrieben. 36 Arten sind zum erstenmal für das Gebiet nachgewiesen. Die Karte stellt Niederkalifornien und die umliegenden Gegenden dar, eine punktierte Linie grenzt das Gebiet, von dessen Vogelwelt die rorliegende Arbeit handelt, ab.

E. Hartert (Tring).

67 Richmond, C. W., List of the generic terms proposed for birds during tlie years 1890 to 1900, inclusire, to which areadded names omitted by Waterhouse in his, Index generum a rium". In: Proceed. U. S. Nat. Mus. IXIV. 1902. pag. 663-729.

Im Jahre 1889 erschien der "Index generum arium" von Waterhouse, ein Werk ron grosser Branchbarkeit für Ornithologen. Die 
vorliegende, mit bemerkenswertem l'leisse zusammengebrachte Liste enthält die seither hinzugekommenen und eine Anzahl von W a terhouse übersehener generischer Bezeichnungen. Lis sind - horribile dictu - nicht weniger als 675 Namen, die Velf. hier aufzälılt, mit genauem Citat, Angabe der Familie, des sogenannten Typus und anderen Details. Eine grosse Anzahl der neu limzugekommenen Namen sind leider von Heine. in Il eine und Reicllenow, Nomencl. Mus. Hei. Orn., 1890, lediglich als Ersatz unklassisch gebildeter oder sonst unschöner Namen gemacht, und somit nach heutigem Gebrauch alle unnütze Synonyme. Die zahlreichen, meist von Hitchcock, nach den Spuren (sic!) fossiler Vögel benannten, also undefinierten und nie wieder zu erkennenden Gattungsnamen sind (als wesenlose nomina nuda aufgefasst:) nicht mit aufgezählt.

\section{E. Hartert ('lring).}

\section{Mammalia.}

68 Kastschenko, N., Uas Skelet eines Mammuths mit Spuren der Verzehrung ainiger Theile dieses Thieres durch den ihm

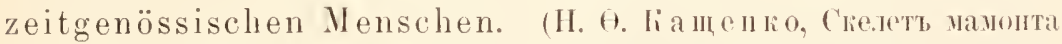

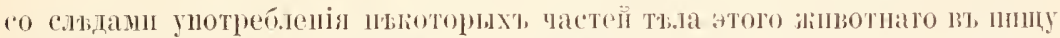

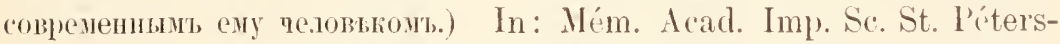
bourg. ('3annckir II. Ara, nayks.) VIII. série. ('lasse pliys-math. Vol. XI. Nr. 7. 1901. pag. 1-60. 'Taf. I-VIII (russisch).

Verf. fand in der Lmgebung von 'Tomsk ein rollstïndiges Mammutskelett im Löss eingebettet, umgeben ron Kiohlenresten. Interessant ist, dass unter den ausgegrabenen Kinochen auch zum erstenual die Hyoidknochen entdeckt wurden. Humerus und Femur sind aufgehauen, um das Mark zu erhalten. Die kippen und einige tlache Knochen sind an einigen Stellen angeschabt, was nur dadurch zu erklären möglich scheint, dass der Mensch das Knochenpulver selbst zu irgend emem Zwecke nötig latte. Daneben sind Steinwaffen gefunden worden, die an Ort und Stelle schnell hergerichtet zu sein scheinen, worauf zur Seite geworfene Überreste der für die Waffen benutzten Steine deuten. Auch einige Knochen scheinen zum Zwecke, Instrumente aus ihnen herzustellen, gesplittert und gebrochen worden zu sein. Einen neben dem Skelette, dessen Knochen ungeordnet umherlagen, gelegenen Balken deutet der Verf. als Watfe, mit welcher das Mammut vom Menschen erlegt worden sein kann.

\section{E. Schultz (St. Petersburg).}

69 Salensky, W., Equns Praewalstii Pol. - In: Wissensch. Resultate d. von Przewalski nach C'entral-dsien untern. Reisen, herausg. 
ron d. k. Akad. d. Wissensch.; Zool. Theil. Iil. I. Mammalia. Abth. 2 Ingulaten. Lief. 1. pag. 1-76. $\frac{1}{4}$ Taf. (russisch nud dentseh).

Diese neue, von Paljakoff auf Grund eines einzigen Exemplares beschriebene Art, wird rom Verf. num sehr ausführlich nach 13 Fellen, 9 Schädeln, einem mrollständigen Skelette und einigen lebenden Tieren beschrieben. Messungen wurden nach dem Schema ron $\mathrm{Na}$ thusius vorgenommen. Die Schädelmessungen werden mit solchen an nahestehenden Arten (gew. Pferd, Maul, Kulan, Kiang, Esel, Zebra, E. hurchelli u. a.) verglichen; aus ihnen ergibt sich, lass $I$. macualstivi in kranionetrischer Hinsicht einen besonderen Typus bildet, der sich mehr dem I'ferde, als dem Esel nähert; auch den Backenzähnen nach steht genannte Irt dem Hausperde sehr nahe. Die beträchtliche Grösse des Kopfes, Fehlen des Haarschopfes, aufrechte Mähne. Rückenstreifen und Schulterstreifen, Form des Schwanzes. Grösse der Ohren, Farbe des Rumpfes, Streifung an den Beinen sind heständige Merkmale der Art, die $E$. caballus am nächisten steht, aber durchaus selbstständig ist. Merkmale des Haispferdes sind hier mit Merkmalen des Halbesels gemischt. Die Art steht nach der Meinung des Verfs. der gemeinsamen Stammform der l'ferde, Esel und Halbesel nahe und darin besteht die grosse systenatische Bedentung von E.przewalstii. Die Frage, ob es dem Hauspferde den Ursprung gegeben, lässt Verf. noch offen.

E. Schultz (St. Petersburg).

70 Schlosser. Max. Die fossilen Säugethiere Chinas. In: Centralbl. Mineral., Geol., Palaeontol. 1902. Nr. 17. pag. 529-535.

Verf. veröffentlicht die Namen fossiler Säugetiere Chinas nach kurzem Vorwort in einer Tabelle und bemerkt, dass eine ausführlichere Arbeit wegen Herstellung zahlreicher Tafeln erst später erscheinen wird. Diese von Herru $\mathrm{K}$. Haberer in Schanghai, Tientsin, Itschang und Peking zusammengebrachte Sammlung umfasst Reste von 62 Pliocänarten und befindet sich im paläontologischen Museum in München. Verf. schildert die ausserordentlich grosse Reichhaltigkeit dieser Sammlung und erwähnt u. a., dass z. B. Accratherium blanfordi durch 100, Hipparion richthofeni durch nahezu 1000 Backenzähne vertreten ist, dass ferner mindestens $95^{\circ}$ o all dieser Säugetiere phocïnen Arten angehören; es sind Arten folgender Gattungen aufgeführt: Homo? - Uisus, Hyaenarctos? - Vulpes, Canide, Lutra, Melcs, Palhyacna, Iyacna, Machairodus, Felis, Siphneus, Dipoides, Elephas, Stegodon, Mastodon, Rhinoceros, Alelodus, Aceratherium, Tapinus, Chalicotherium, Inchitherium, Hipparion, Eques, Sus, Hippopotamus, Paracamelus, Camelopardalis, Alcicephalus, Sivatheriine, Cervarus, Palacomeryx, Cervus, Antilopinar, Gazella, Protetraccros, Palaeoreas?, Thagoceras, Plesiaddax, Strepsiceros, Paraboselaphus, Pseudobos, Bos, Bison und Bibos.

A. Tornqu ist (Strassburg i. E.). 


\section{Zoologisches Zentralblatt}

unter Mitwirkung von

Professor Dr. O. Bütschli and Professor Dr. B. Hatschek

in Heidelberg

herausgegeben von

in Wien

\section{Dr. A. Schuberg}

2. ग. Professor in Heidelberg.

Verlag von Wilhelm Engelmann in Leipzig.

X. Jahrg.

10. Februar 1903.

No. 3.

Lu bezzehen durch alle Buchhandlungen und Postanstalten, sowie durch die Verlagsbuehhandlung. Jalirlich 26 Jimmern im Umfang von 2-3 Bogen. Preis für den Jahrgang 31.30 . - Bei direkter Zusendung jeder Nummer unter Streifband erfolgt ein Aufschlar von 1l. 4.- nach dem Inland und vol $11.5 .-$ nach dem Ausland.

\section{Referate.}

\section{Wissenschaftliche Anstalten und Unterricht.}

71 Hagman, G., Der zoologische Garten des II seu Goeldi in Pará (Brasilien). Frankfurt a. M. 1901. (Mahlau und Waldschmidt). 55 pag.

Beschreibung des zoologisclien Gartens in Pará - seiner Entstehung, seiner Gebäude und seiner T'iere -, der von F. A. Goeldi, als er im Jahre 1893 von der Regierung des Staates I'ará den Ruf erhielt, das in Pará vorhandene NaturalienKabinett zu reorganisieren, neben dem Nuseum begründet wurde. In Anbetracht des prächtigen fedeilıens des, Museu Paraense "hat die Regierung dasselbe im letzten Jahre zu Ehren Goeldis in H useu Goeldi* umgetauft.

\section{F. Rö in er (Frankfurt a. M.).}

\section{Zellen- und Gewebelehre.}

72 Rhumbler, I.., Der Aggregatzustand und die physikalischen Besonderlueiten des lebenden Zellinlıaltes. II. Teil. In: Zeitschr. f. allgem. Physiol. Bd. 2. pag. 183-340. 1 Taf. und 80 'Textfig.

Der Schluss des ersten Teiles der vorliegenden Arbeit (s. Ref. Nr.3 auf pag. 8 dieser Zeitschrift) hatte zu der Erkenntnis geführt, dass die Oberflächen lebender Gebilde sehr lıäufig nicht ron absoluten, sondern nur von ,relativen" Minimalflächen begrenzt sein könnten. Die Annahne solcher Flächen war aber zunächst ganz hypothetisch und schien eine ganz mberechenbare Willkïr in die Frage der OberHächenentwickelung hineinzutragen. Der vorliegende Teil II bringt nun an erster Stelle den ausführlichen Beweis, dass tatsächlich in der Natur "relative Minimalflächen“ vorkommen.

Diese sowohl wie auch andere wichtige Eigenschaften des lebenden Zellinlıaltes demonstriert $\mathrm{Rhumbler}$ an den Schalen der Fora- 
miniferen. Diese interessanten Skelettgebilde geben zunächst den Nachweis der Gültigkeit des zweiten Ka pillargesetzes für die lebendige Substanz, oder besser für das ..lebendige System" (Jensen). Dieses Gesetz verlangt, dass eine Flüssigkeit bei Berührung mit einem festen Körper stets denselben konstanten Winkel, den sogen. Ranclwinkel mit ihm bilden soll. Ist die Sarkode der Foraminiferen eine Flïssiglieit, so muss sie beim Vortliessen zur Bildung von Schalenkammern stets einen bestimmten, für dieselbe Art konstanten Winkel mit den schon früher gebildeten Schalenwänden bilden. Dieses theoretische Postulat fand $R$ h u m ler durch eine grosse Anzahl von Messungen vollkommen bestätigt. Bei den Individuen einer und derselben species, mögen sie auch noch so stark variieren, wie z. B. Peneroptis pertusus, ist der Winkel, unter dem die neugebildete Kammerwand an die alte Schale ansetzt, also der Randwinkel, stets konstant. Entsprechend der schon aus dem ersten Teil der Abhandlung bekannten Anomogenität der lebenden Zellobertläche gibt es Formen, die zwei Arten ron Randwinkeln haben; dann sind aber stets die ,homologen" Randwinkel einander gleich, d. h. diejenigen, die dieselbe Lage zu der Linie haben, die die Kammermündungen verbindet, der sog. Mündungsachse. Es handelt sich bei dieser Kionstanz der homologen Randwinkel nicht etwa um eine "zweckmäßige" Einrichtung; denn es müsste dimn der Randwinkel, wenn er etwa ein Minimum von Materialaufwand bewirlien sollte, für alle Formen gleich sein, was nicht der Fall ist. Die Konstanz ist vielmehr die notwendige Konsequenz des flüssigen Aggregatzustandes der Sarkode und ihr Vorhandensein ist von $\mathrm{R}$ humble r a p riori gefordert und dann durch Beobachtung festgestellt.

Dass in der Tat Flüssigkeiten im stande sind, durch Abscheidungen an ihrer Oberfläche Gehäuse zu bilien, wie man sie bei Foraminiferen findet, das beweisen eine Reihe interessanter Experimente, in denen die einfachern Schalenformen aus den Familien der Rhabdamminidae und Ammodiscidae nachgeahmt werden ron den Niederschlagsmembranen, die in einer $5 \%$ igen Chromsäurelösung an der Oberfiäche von Quecksilbertropfen entstehen. Eine Asalyse der Vorgänge, die zu solchen Formbildungen fülren, ergibt eine Reihe wichtiger Übereinstimmungen in $\mathrm{mech}$ a $\mathrm{n}$ is che $\mathrm{r}$ Hinsicht; die prinzipiellen Unterschiede gegenüber den Vorgängen an lebenden Systemen hebt R hu mble r, um Missrerständnissen rorzubeugen, noch besonders hervor.

Flüssigkeiten bewegen sich auf ebenen, konkaven und konvexen Flächen mit sehr verschieden grossem Aufwande von Oberflächenenergie, sie bewegen sich am leichtesten, wenn die bei der Bewegung 
notwendig werdende Oberflächenvergrösserung möglichst gering ist. Ihre Oberflächen, die durchaus keine absoluten Minimalflächen sind, stellen also ,relative Minimalflächen" dar; und wenn sich der Nachweis erbringen lässt, dass die Sarkode beim Vorfliessen auf den schon gebildeten Schalenteilen denselben Gesetzen folgt, wie Flüssigkeiten, dann ist auch für sie der Nachweis der realen Existenz relativer II in imalflächen erbracht.

Dieser Nachweis, den Rhumbler mit aller Schärfe zu bringen vermag, fülırt ihn zu einer mechanischen Analyse des Baues der Foraminiferenschale ïberhaupt, ein Gebiet, anf dem er schon in der geistreichen Arbeit über die Doppelschalen von Orbitolits Grundlegendes geleistet hat. Es würde zu weit führen, alle die einzelnen feinen Züge dieses 'Teiles der Arbeit im Referat darzustellen: das Ergebnis ist, dass es sechs Faktoren sind, die durch ihr verschiedenartiges Ineinandergreifen die ganze Formenfülle der Foraminiferenschalen mechanisch verständlich machen (pag. 210):

1. „Die Anomogenitä in der Spannung der Oberfläche desjenigen Sarkodeteiles, der zur Zeit der Kammerbildung aus der Schalenmïndung herrorgetreten ist.

2. Das Gleichbleiben homologer Randwinkel.

3. Die Gestalt der Flussfläche, d. h. derjenigen ältern Schalentlächen, welche ron der hervorquellenden sarkode berïhrt werden.

4. Die Lage der als Austlussöfinung dienenden Schalen$\mathrm{m}$ ü $\mathrm{n}$ d $\mathrm{u} \mathrm{n} \mathrm{g}$...

5. Das Gesetzkleinsten (Oberflächenkonsumes.

6. Unter besondern Umständen auch die Menge der a usgeflossenen Sarkode.

Einen Spezialfall des "Randwinkelgesetzes" liess das Studium der Foraminiferenschale noch unberührt, dic Erscheinung der Ausbreitung einer Flïssigkeit an der Grenzfläche zweier anderer, für deren eine die Luft eintreten kann, also die Ausbreitungserscheinungen an der Grenzflïche Wasser-Luft. Wegen seiner grossen Oberflächenspannung zwingt das Wasser alle andern Flissigkeiten, sich an seiner Oberfläche auszubreiten, wie wir es etwa von einem ïltropfen kennen. Rhumbler stellt nun wieder ein Postulat anf: ist der lebende Zellinhalt fliissig, so muss er sich an der Wasseroberfläche ausbreiten. Beobachtungen lagen hierüber noch nicht vor, der theoretische Gedanke war der Vater des Experimentes, das R humblers Annahmen vollständig bestätigte. An Entwickelungsstadien des Frosches und an Amoeba limicola konnte Rhumbler die wichtige Tatsache feststellen, dass sie in dem Augenblick, in dem sie die Wasserobertläche berühren, 
auseinander gerissen werden und sich als feines Häutchen an der Obertläche ausbreiten. Bei Froschlarren geht diese Eigenschaft erst um die Zeit verloren, wo sie sich von der Gallerthïlle trennen, erst dann sind sie ,wasserspiegelfest". Die Eigenschaft, sich in dieser Weise auszubreiten, haben n u r Flïssigkeiten.

Dass der lebende Zelinhalt auch dem dritten Kiapillargesetz unterworfen ist, zeigt die Beobachtung des Aufsteigens in Kapillarröhren, das Rhumbler bei Eiern ron Rana und Triton sowie an den Plasmodien von Aethatium beobachten konnte.

Der Gang der Beweisführung ist somit durchgeführt und der Verfasser resumiert pag. 330: „Der lebendige \%ellinhalt 1. Protoplasmaströmung zeigender Zellen, 2. derjenige amöboider Zellen und 3. derjenige der Eier und früher Embryonalzellen besitzteinen flüssigen Aggregatzustand und hat die mechanischen Besonderheiten eines anomo gen komponierten Schaumgemenges".

Mancherlei allgremeine Erörter ungen lassen sich noch an R lıumb. lers Resultate knüpfen; es sei lier nur auf eine lingewiesen, die der Verf. schon in seiner Orfitolites-Arbeit betont hat: Die mechanische Analyse des Baues der Foraminiferenschale, die auch in der rorliegenden Arbeit einen breiten Raım einnimmt, fülırt für diese Formen zu einer Auflassung von, wie Ref. glauben möchte, fundamentaler Wichtigkeit. Wenn es erlutubt ist, den Gegensatz zwischen der landläufigen Auffassung und der Rlumblers in dieser Sache auf Schligworte zuzuspitzen, so möchte ich sagen: Die naive Betrachtungsweise fasst die grosse "Hhnlichlieit, vulgo ,Gleichheit“, der Schalenformen in einer und derselben Species als die Wirkung ron .. Vererbung" auf, die mechanisclie Analyse kommt zu dem Resultat, dass sie bedingt ist durch - .Konvergenz"! Nicht eine in der Art ihrer mechanischen Wirksamkeit ganz unvorstellbare mystische Kraft, die durch das Schlagwort „Erblichkeit“ uns ebensowenig näher gerückt wird, wie durch die Annahme einer "Autonomie der Lebensvorgänge", zwingt die Sarkode, ilure Schale in der für die Species typischen Form aufzubauen, es ist vielmehv eine Summe von mechanisch scharf bestimmbaren und für diesen Fall sclion jetzt bestimmten Faktoren, die stets in der gle i cli en We is e auf die Sarkode einwirken, und sie so zwingen, immer dasselbe Produkt zu liefern. Ändern sich die Faktoren, dann ändert sich die Form, die gebildet wird, die ja eben nur das Resultat einer bestimmten Kombination ron Bedingungen darstellt, wie das besonders demonstrativ aus dem Studium der Regenerationsprodukte und der spaltungsmonstra hervorgeht.

A. Puitter (Breslau). 


\section{Vergleichende Morphologie, Physiologie und Biologie.}

73 v. Lenhossék, M., Das Problem der geschlechtsbestimmenden Ursachen. Jena (G. Fischer) 1903. 99 pag. 2 Textfig. M. 2.-.

Das uralte Problem der Geschlechtsbestimmung hat zuerst von seiten der Statistik eine wissenschaftlicle Behandlung erfahren. Als ein "Gesetz der grossen Zahlen" hat die Statistik schon im 17. Jahrhundert, später genauer, das Verhältnis der Knabengeburten zu den Mädchengeburten festgestellt, es beträgt nach Bodio (1887-1891) 105,2 : 100 für Deutschland.

Die Bemühungen der Statistik aber, die Falitoren aufaufinden die bestimmend für das Geschlecht der Nachkommen sind, haben trotz der ungeheuern, auf diesen Punkt verwandten Arbeit zu keinem positiven Ergebnis geführt, so dass derselbe ganz der biologischen Forschung bleibt. Die grundlegende Anschauung, zu der Lenhossék in seinen Auseinandersetzungen gelangt, ist nun die, dass im Tierreich die Bestimmung des Geschlechtes ein Vorrecht des miitterlichen Organismus ist und dass diese Bestimmung schon vor der Befruchtung im Ei vollzogen erscheint. Eindeutig spricht, wenn man die angefuihrten Beispiele scharf betrachtet, eigentlich nur eines für Lenhosséks Anschauung: die Beobachtung Korschelts iiber den Dimorphismus der Eier von Dinophilus apatris, bei dem sich, aus den schon ovarial getrennten Eiern, stets die Männchen (Zwergmännchen) aus den kleinen lıellen Eiern, die Weibchen aus den grossen dotterreichen entwickeln. Das ist wirklich eine positive Instanz, ein Beweis, dass hier das Männchen keinen Einfluss auf die Geschlechtsbildung hat. Den iibrigen Beispielen kommt ein Beweiswert kaum zu, es lässt sich bei ihnen eigentlich nur zeigen, dass sie sich auch unter der Annahme, dass das Geschlecht des Eies schon vor der Befruchtung bestimmt sei, betrachten lassen. So ist der herrschenden Ansicht gegenüber, dass bei dem Wechsel in der Produktion von männlichen und weiblichen Individuen auf parthenogenetischem und zweigeschlechtlichem Wege, eben das Eintreten oder Ausbleiben der Befruchtung das ausschlaggebende Moment sei, Lenhosséks Deutung dieser Erscheinungen, auf Grund der Armalme, dass das unbefruchtete $\mathrm{Ei}$ schon geschlechtlich bestimmt sei, doch eben nur ein Deutungsversuch, der als solcher nicht im stande ist, der gegenteiligen Auffassung die wissenschaftliche Existenzberechtigung auch nur zu beeinträchtigen.

Pflügers Versuche hätten eine vortreffliche Stütze für Lenhosséks Theorie abgegeben, wenn ihnen nicht leider gerade, wie Lenhossék auch selbst anlentet, das Experimentum crucis fehlen würde. Pflüger fand bei Versuchen über künstliche Befruchtung von 
Fröschen, dass die Geschlechtsproportionen bei T'ieren verschiedener Standorte überaus verschieden waren, und durch die vielerlei Schädlichkeiten und ungiinstigen Bedingungen der kiinstlichen Befruchtung in keiner nennenswerten Weise rerändert wurdell. Frösche aus Utrecht zeigten als Verhälnis der Mämnchen zu den Weibchen 13,2:100 im Freien, 18,1:100 bei künstlicher Zucht, Frösche aus Königsherg datgegen im Fréien 46, $7: 100$, in der Zucht 48,5:100. Soll nun der Schluss, dass das Geschlecht der Eier schon vor der Befruchtung bestimmt gewesen sei, dass also die ron demselben Standort stammenden Spermatozoen ohne Einfluss darauf seien, zwingend erbracht werden, so muss doch der Nachweis erfordert werden, dass auch bei Befruchtung mit Spermatozoen von andern Standorten keine Veränderung in der Geschlechtsproportion eintritt; dieses ausschlaggebende Experiment fehlt aber.

Die Beobachtung endlich, dass eineiige mensehliche \%willinge ausnahmslos gleichgeschlechtlieh sind, enthält auch keinen Beweis fïr Lenhosseks Annahme, dass das unbefruchtete li schon bestimmtes Geschlecht habe, es zeigt rielmelı unzweideutig nur, hass nach der Befruchtung sogleich das Geschlecht bestimmt ist, so dlass jerle jetzt einsetzende Spaltung des Keimes nur zu gleichgeschlechtlichen Produkten führen kann. Dieser letztere Nachweis ist aber anch schon ein grosser Gewinn. Er wird vom Verf. noch weiter ausgebaut. Sein Hauptwert liegt darin, dass mit dem Xachweis geschlechtlicher Trennung in frïhesten Entwickelungsstadien jeder Versuch, durch äussere Eintlüsse während des embryonalen Lebens die Geschlechtsbildung zu beeinflussen, als verfehlt erscheinen muss; und in der Tat haben sich auch, wie L enhossék ausführlich darstellt, alle Angaben iiber positive Erfolge in dieser Hinsicht als irrig erwiesen.

So bestechend die Theorie Lenhosséks von der ovarialen Geschlechtsbestimmung der Nachkommen ist, so kann sie also doch lieineswegs als bewiesen angesehen werden.

Gleichriel, ob nan sie annimmt oder nicht, so bleibt noch immer die Frage bestehen: lässt sich das Geschlecht oder die Geschlechtsproportion der Nachkommen durch äussere Beeinflussung des elterlichen Organismus vor der Befruchtung verändern? Dies ist eine rein tatsächliche Frage, theoretisehe Bedenken oder Postulate werden durch den Ausfall nicht erregt oder negiert. Für Wirbellose existieren mehrfache unzweideutige Beispiele ron Beeinflussung der Geschlechtsproduktion durch Ernährungseinfliisse; was aber bei höhern Tieren, speziell beim Menselien, in diesel Richtung belıauptet worden ist, hält einer strengern Kritik nicht stand. 
Eine Abfertigung der Schenkschen Theorie, die ja auch nur in Laienkreisen Aufsehen erregen konnte, und die in ihrer gänzlichen Unwissenschaftlichkeit dargestellt wird, beschliesst den Hauptteil der inhaltsreichen Schrift, die wohl niemand ohne lebhaftes Interesse lesen wird, wenn auch manche Austührung, besonders in physiologischer Hinsicht, zu Widerspruch anregen mag, was vielleicht gerade als guter Erfolg hervorgehoben zu werden verdient.

In Parenthese sei nur erwähnt, dass ein paarmal (s. p. 18 u. 21) ein Lapsus calami untergelaufen und Hydatina senta als Strudelwurm (Turbellar) anstatt als Rädertier (Rotator) bezeichnet worden ist.

A. Pütter (Breslan).

74 Verworn, Max, Die Biogenhypothese. Eine kritisch-experimentelle Studie über die Vorgänge in der leben.digen Substanz. Jena (G. Fischer) 1903. 114 pag. M. 2.50.

Dass die Frage nach dem Wesen der Vorgänge, deren Ausdruck die körperlichen Lebenserscheinungen sind, nicht nur für den Physio-. logen Bedeutung hat, brauchte wohl nicht besonders herrorgehoben zu werden, wenn nicht viele zoologische Arbeiten so stark den Anschein erweckten, als sei es den Verfassern ganz aus dem Sime gekommen, dass tote Tiere nur insofern für uns Interesse haben kömnen, als wir uns aus den bei ihnen erhobenen Befunden ein Bild ron ihrem Zustand wïhrend des Lebens machen können. Und diesen selben Eindruck, dass sie nämlich mehr für die im Tode erstarrten Organismen gemacht seien, als für lebende, sich beständig verändernde Wesen, machen auch gar viele in der Zoologie entstandene Theorien. Da muss es denn für den Zoologen von grösstem Werte sein, von einem auf der Höhe der modernen Physiologie stehenden Forscher zu lı̈ren, wie er den Mechanismus oder vielleicht besser Chemismus des Lebens auffasst, welche grundlegenden Tatsachen bei jeder Theorie der Lebensvorgänge zu berïcksichtigen sind, unter welchem allgemeinen Bilde sich dieselben darstellen lassen. Einen Versuch dieser Art hat Verworn mit seiner Biogenhypothese gemacht.

Eine Darstellung des Werdens der Lehre von den Vorgängen in der lebendigen Substanz führt immer klarer zu der Grundvorstellung der Biogenhypothese, dass der Stoffwechsel der lebendigen Substanz, diese fundamentale Eigenschaft aller belebten Gebilde, "in letzter Hinsicht a uf dem fortwährenden Zerfall und der fortwährenden Neubildung einer sehr labilen chemischen Verbindung beruht".

An diese Grundauffassung knüpten sich dann eine Reihe ron Fragen, nach den speziellen Eigenschaften, die man auf Grund der 
Lebenserscheinungen den „Biogenen" beilegen, und den speziellen Vorgängen, die man beim Stoffwechsel der Biogene annelmen muss. Die Rolle des Sauerstoffes, die Dissociation des Biogens, die Regeneration des Biogenrestes, der Stickstoffumsatz, die Vermehrung der Biogenmenge werden auf Grund alter und never experimenteller Erfahrungen charakterisiert.

Von besonderm biologischen Interesse ist das Kapitel „Biogen und Zelle", in dem die Frage erörtert wird, wo man sich in der Zelle die Biogensubstanz lokalisiert zu denken hat. Dass diesellse in Protoplasma der Zelle enthalten ist, lässt sich sicher erweisen; fraglich erscheint dagegen ihre Anwesenheit im Kern, ja die Beobachtung, dass der Kern keine eigentliche Atmung, d. h. Sauerstoffverbrauch und Kohlensäurebildung hat, lïsst sogar die Annalıme, dass in ihm Biogensulstanz enthilten sei, in hohem Grade unwahrscheinlich erscheinen, ein Resultat physiologischer Forschung, das wohl verdiente, bei allen Spekulationen über die Bedeutung des Kerns berücksichtigt zu werden. Der Nachweis, dass ausser den bekannten, mikroskopisch nachgewiesenen Reservestoffen auch llepots für Sauerstoff in der Zelle existieren, in denen dieser chemisch gebunden ist und zwar 1 m so fester, je niedriger, um so lockerer, je liöher die Temperatur ist, sei als bemerkenswert herrorgehoben. In der Reizphysiologie ergibt sich aus der Annahme der Biogenhypothese eine ungemeine Verfeinerung und Vertiefung der Fragestellungen. Auch der Vorgang der Selbststeuerung des Stoffwechsels, der ron grösster Bedleutung für die Physiologie und Pathologie ist, stellt sich im Lichte der Biogenhypothese übersichtlich dar, wie derselbe auch in andern Fragen der Physiologie seinen Wert als erklärende und heuristische Hypothese bewährt. Was lie Biogenhypothese besonders wertvoll erscheinen lässt, das ist ihre Ausbaufähigkeit, die sie dadurch erhält, dass möglichst wenige spezielle Momente in sie aufgenommen sind, und diese nur auf Grund experimenteller Erfahrungen. Die Hypothese ist als "Arbeitshypothese" gedacht; sie repräsentiert nicht das wissenschaftliche Glaubensbekenntnis eines Forschers, der gewillt ist, alle Erfahrungen, die er oder andere noch machen werden, ummehr in den Rahmen der einmal ausgesprochenen Anschauungen hineinzupressen, sondern kritisch aufgebaut, hat ihr Verfasser mit ihr nur ein Bild rom Mechanismus des Lebens entwerfen wollen, wie es auf Grund der heutigen Frfahrungen möglich ist, bereit, jede neue Erfahrung mit einer entsprechenden Ïnderung der Arbeitshypotlese zu beantworten, durch sie selbst aber zu schärferer und tieferer Fragestellung anzuregen.

A. P iitter (Breslau). 


\section{Echinoderma.}

75 Bell. F. J., Echinoderma. In: Report on the Collections of Natural History in the Antarctic Regions during the Voyage of the "Southern Cross“. London 1902. pag. $214-220$. pl. $26-28$.

Bell berichtet über antarktische Echinodermen, die auf der Fahrt des Schiffes „Southern Cross" erbeutet wurdev, und macht dabei selır mit Recht darauf aufmerksam, dass Formol für Echinodermen ein höchst ungeeignetes Konservierungsmittel ist und von den Sammlern besser nicht angewendet würde. Die vorliegende Ausbeute enthält insbesondere eine lehrreiche Reihe von Variationen der Cycthra simplex und zwei neue Ophiuren-Gattungen: Ophiostcira (antaretica $\mathrm{n}$. $\mathrm{sp}$.), die sich durch fünf grosse kielförmige Platten auf dem Scheibenrücken auszeichnet, von denen eine jede sich zwischen zwei Radialschilder lagert, und Ophionotus (rictoriae n. sp.), die sich von Ophioglypha durch äberzählige Armplatten und Nangel der Einschnitte und Stachelkämme über den Arm. basen unterscheidet. Die beiden neuen F'ormen werden durch gute Abbildungen erläntert. Im übrigen enthielt die Ausbeute Cucumaria crocea, Thyone sp., Holothuria sp., Asterias neglecta, A. antartica, Odontaster meridionalis, Ophiactis sp., Ophiomusium (:) sp., Ophiozona incrmis, Echinus margaritaceus, Hemiaster carernosus.

H. L u d wig (Bonn).

76 Bell, F. J., 'T'he actinogonidiate Echinoderms of the Maldive and Laccadive Jslands. In: The Fauna and Geography of the Maldive and Laccadive Archipelagoes. Vol. I. Part. 3. London 1902. pag. 223-233.

Verf. zählt die von Gardiner auf den Korallenriften der Malediwen- und Lakediwen-Inseln gesammelten Crinoideen (10 Arten), Seesterne (13 Arten), OphiIrren (12 Arten, darunter die seltenen Formen Ophiopteron elegans und Ophioacthiops nnicolor) und Seeigel (15 Arten) mit näherer Augabe der Fundorte auf eine neue form ist nicht darunter.

H. Ludwig (Bonn).

77 (rrieg, James 1., Oversigt over det nordlige Norges echinoderme r. In: Bergens Mus. Aarb. 1902. No. 1. 38 pag. 1 Taf. 2 Fig. im Text.

Nach einer historischen Übersicht iiber die allmähliche Entwicklıng unserer Kenntnis der nordeuropäischen Echinodermenfauna und einem Vergleich derselben mit der arktischen, britischen, mittelmeerischen und nordamerikanischen Fauna gibt Verf. eine sorgfältige Zusammenstellung aller bis jetzt von Nordnorwegen (Nordland, Lofoten, Tromsï, West- und Ostfimmarken) bekannt gewordenen Arten, in welcher nur die Holothurien unberiiclssichtigt gelassen sind, weil die-

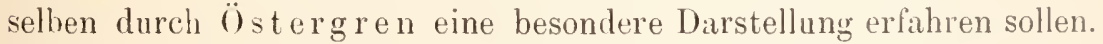
Bei allen Arten werden die Fundorte und Tiefen sowie die bisher bekannte geographische Verbreitung genau angeführt. Das Verzeichnis bezieht sich im einzelnen auf 2 Crinoidea, 26 Ophiuroidea, 26 Asteroidea, 12 Echinoidea. Bei mehreren Arten geht Verf. näher auf die Synonymik ein oder gibt genauere, ron Abbildungen unterstützte Beschreibungen, so namentlich bei Amphilepis norvegica, 
Ophiacantha spectabitis, Poraniomorpha rosen, Lasiaster hispidus, Solaster syrtensis.

H. Ludwig (Bonn).

78 héromard, Elgarl, Sur l'anatomie comparée des Echinodermes. In: Bull. Soc. zool. France. Tome 27. Paris 1902. pag. 131-138. 1 Fig. im Text.

Von den Ilolothurien ausgehend, unterscheidet Hérouard in der Körperwand aller Echinodermen drei bindegewebige Schichten, eine äussere, mittlere und innere, ron denen ausschliesslich die äussere und die innere im stande sind, Kalkkörper und grössere kalkige Skelettstücke zu liefern. Die mittlere stellt in ihrer Gesamtheit das unvollständig ausgefüllte und dadurch lakunär gebliebene Schizocöl (= Rest des Blastocöls) dar, dessen Liicken zum Teil zu bestimmt umgrenzten Blutgefässen werden. Während die Hyponeuralkanäle rom Enterocöl abstammen, sind die Epineuralkanäle ektodermalen Ursprungs.

H. Ludwig (Bonn).

79 Rankin. Walter II. Echiuoderms collected on the West Coast of Greenland by the PrincetonArctic Expedition of 1899. In: Proceed. Acad. Nat. Sc. Philadelphia. Vol. 53. 1901. pag. 169-181.

Verf. berichtet über Echinodermen von der Westseite Grönlands mit genauer Angabe der Fundorte und Tiefen sowie Bemerkungen über die geographische Verbreitung. Der Bericht bezielnt sich im einzelnen auf zwei Holothurien, eine Seeigel-Art, acht Seesterne, sechs Ophiuren und zwei Antedon. Die bisher von Grönland nicht bekaunte Asterias gumneri wird näher beschrieben.

H. Ludwig (Bonn).

Eo Russo, Achille, studii su gli Echinodermi. In: Atti dell' Accademia Gioenia Sc. Nat., Vol. 12 (Ser. 4, Vol. XV), Mem. 7, Catania 1902. 93 pag. 3 Taf. und 5 T'extfig.

In der Einleitung zu dieser abschliessenden und zusammenfassenden Abhandlung, die nanentlich in betreff der Holothurien und Crinoideen wichtige neue Beobachtungen enthält, legt Russo die Gesichtspunkte dar, nach welchen ihm für die Feststellung der natürlichen Verwandtschaftsbeziehungen der einzelnen Echinodermenklassen zueinander das Studium der allmählichen Aus- und Umbildung der Genitalorgane, des Madreporenapparates und des Lakunensystemes von grüsserer Bedeutung erscheint als das des Wassergefässystemes, des Nervensystemes und des Skelettes. Als wichtigstes Ergebnis seiner langjährigen Untersuchungen bezeichnet er die Auffassung, dass die Ophiuren, A sterien und Ech iniden einen wohlumgrenzten Hauptstamm der Echinodermen darstellen, dessen wichtigstes Merkmal der Besitz eines kreisförmig durch alle Radien und Interradien rerlaufenden, aus der primären Gonade entstandenen Genitalstranges ist, der aller- 
dings bei den Seeigeln sich sekundär in fünf getrennte Geschlechtsdrüsen auflöst, aber bei den Ophiuren und Seesternen dauernd fortbesteht, und dass andererseits die Holothnrien zusammen mit den Crinoideen einen zweiten urspriinglicheren Hauptstamm bilden, der dadurch gekennzeichnet ist, dass kein dem ringförmigen Genitalstrang der Ophiuren, Seesterne und Seeigel homologes Gebilde zur Entwickelung gelangt, vielmehr die primäre Gonade entweder zur definitiven Geschlechtsdrïse wird (Holothurien) oder einer Rückbildung anheimfällt und durch eine eigenartige Neuanlage ersetzt wird (Crinoideen). In allen Klassen aber tritt die primäre Gonade als ein Abköminling des Cölomepithels in demselben Interradius auf, in welchem der primäre Steinkanal liegt (= Interradius CD).

Im ersten Kapitel geht $R$ us s o nälier auf die Entstehung und das weitere Schicksal der primären Gonade in den einzelnen Echinodermenklassen ein. Sie liefert bei den Holothurien sowohl die Geschlechtsschläuche als anch den Genitalgang. Bei den Crinoicien wird sie, sobald bei der festsitzenden I arve von Antedon rosacea sich die Arme entwickeln, völlig rïckgelildet: dafiir haben sich, mnabhängig von ihr, zwei andere Gonaden angelegt, nämlich erstens das Axialorgan (= Genitalstolo, liein Homologon der ovoiden Drïse der Ophiuren, Seesterne und Seeigel) und zweitens eine periösophageale Gonade, die sich weiterhin einerseits mit dem Axialorgan verbindet und andererseits die Genitalstränge der Arme und Pimmulate entsendet. Bei den Ophiuren, Seesternen und Seeigeln entstelit die primäre Gonade unabliängig von der nur diesen drei Kilassen zukommenden oroiden Drïse und wächst zu einem ringförmig die Körpermasse umkreisenden Genitalstrang aus, der bei den Ophiuren und Seesternen fortbesteht und die Geschlechtsorgane des fertigen Tieres aus sich herausknospen lässt, bei den Seeigeln aber, nachdem er die Genitaldriisen auf gleiche Weise geliefert hat, in seinen radialen Abschnitten verkïmmert und sicl zu einer lilutlakune umbildet.

Das zweite Kapitel behandelt die Entstehung und Weiterentwicklung des aboralen sinus und der aboralen (= genitalen) Blutlakune und deren Beziehungen zu den benachbarten Organen. Beide Gebilde stehen in der Stätte ihres Ursprunges (Interradius CD) und in ihrem weitern Schicksale in engster Verbindung mit der prinären Gonade. I)er aborale Sinus ist eine Abschnürung der Leibeshöhle und die aborale Lakune bildet sich an seiner Wand. Bei den Holothurien wird aus dem Sinus der sog. problematische Kanal und die aborale Lakune setzt sich nachher mit den unabhängig davon entstandenen perioralen und intestinalen Lakunen in Zusanmenhang. Bei den Crinoiden werden aboraler Sinus und aborale Lakune rück- 
gebildet. Bei den Ophiuren und Seesternen wird aus der aboralen Lakune die den Genitalstrang in seinem ganzen Verlaufe umhüllende Lakune und aus dem aboralen Sinus der zugehörige Perihämalkanal. Bei den Seeigeln aber wird aus der aboralen Lakune das bei den erwachsenen Tieren als "driisiger Anhang der ovoiden Drüse" bezeichnete Gebilde, das also genetisch von der oroiden Driise versclieden ist, und der aborale Sinus wird rudimentär, während die Genitallakune aus einer Umbildung des Cenitalstranges und ihr Perihämalkanal als eine Neubildung entsteht.

Im dritten Kapitel werden Ursprung und Weiterentwicklung der Butlakunen des Darmrohres geschildert, wobei zwischen „absorbierenden Lakunen" und den Darm in seinem Verlaufe begleitenden "Darmlakunen" unterschieden wird. "Absorhierende Lakunen" stehen nit der aboralen Lakune oder ihrem Analogon in Verbindung, kommen in allen Klassen vor, werden aber bei den Crinoideen und bei den Seeigeln rïckgebildet. Die dorsale und die rentrale „Darmlakune“ sowie die periösophageale Lakune der Holothurien und Seeigel entstehen als selbständige Gebilde; auch die Crinoideen besitzen anfänglich diese drei Lakunen; später aber wird diese Anordnung verwischt durch die Ausbildung eines das Axialorgan umspinnenden Lakunengeflechtes. Ophiuren und Seesterne haben keine "Darmlakunen".

Das vierte Kapitel bezieht sich auf den Steinkanal, den Parietalsinus, die Ampulle, den Axialsinus, die ovoide Drüse und das gekammerte Organ. Holothurien und Crinoideen besitzen kein Homologon der ovoiden Drüse. Bei den Holothurien stellt die später rerschwindende bläschenförmige Aussackung des primären Steinkanals das Homologon des Axialsinus der Ophinren, Seesterne und Seeigel dar. Bei den Crimoideen entsteht aus der gleichen Aussackung der Parietalsinus, der nach dem Schwunde des nach aussen mündenden Abschnittes des primären Steinkanales in die Leibeshöhle durchbricht; in seinem primären Zustande ist der Parietalsinus homolog dem Bläschen am primären Steinkanal der Holothurien, sowie der Ampulle und dem Axialsinus der Ophiuren, Seesterne und Seeigel. An der Innenwand des Axialsinus bildet sich die ovoide Drüse.

In den folgenden Kapiteln stellt er seine Ergebnisse über die Homologien der untersuchten Organe zusammen, liritisiert dann die rerschiedenen bis jetzt aufgestellten Hypothesen über die phylogenetischen Beziehungen der Echinodermenklassen und trägt dann seine eigenen Ansichten darïber vor, wobei er auch auf strittige Punkte in der Organisation der Cystoideen und Blastoideen näher eingeht. Den Cystoideen glaubt er eine einzige Genitaldriise zuschreiben zu können, die sich wie bei den Holothurien aus der primären Gonade 
entwickelte, während bei den Blastoideen die primäre Gonade in Übereinstimmung mit den Crinoideen riickgebildet worden sei und die definitiven Geschlechtsdrüsen aus der selundären, periösophagealen Gonade ihre Entstehung genommen hätten. Er leitet daber die Blastoideen direkt ron den Crinoideen ab, welche ilrerseits ebenso wie die Holothurien ron Cystoideen abstammen, die selbst atus einer bilateralen Urform ilire Entstehung genommen luaben. Den Ursprung der Seesterne führt er durch Vermittelung der Edrioasteroideen auf die Blastoideen zurück und betrachtet die Seeigel als cinen Seitenzweig der Oplinuroideen.

Ein Anhang enthält teclnische Bemerkungen über Fixationsfliissigkeiten, Entkalkungs- und Färbungsmethoden.

$$
\text { H. Ludwig (Bonn). }
$$

81 Russo, Achille, Sullo sviluppo dell' a pparato madreporico di Antedon (a proposito di alcune ricerche paleontologiche di Otto Jakel). In: Zool. Anz. 24. Bd. 1901. No. 65̃1. p. $529-532$. 5 Fig. im T'ext.

Russo widerspricht auf Grund seiner entwicklungsgeschichtlichen Beobachtungen an Antedon rosacea der Deutung, welche Jaekel der vierten Kelchöffnung der C'ystideen gegeben hat. Sich stützend auf die von Russo ebenfalls bestrittenen Angaben von Seeliger (iiber Anterlon) und Mortensen (über Cucmmaria glacialis) sieht Jaekel darin die Öffinung des Parietalkanales und zugleich die Geschlechtsöffnung. Russo aber glaubt, dass sie lediglich eine Geschlechtsöffuung darstelle und mit dem ron seeliger irrtïmlich füc ein ron dem Steinkanal unabhängiges Gebilde gehaltenen I’arietalsinus (T'arietalkanal) nichts zu schaffen liabe. Das Fehlen der vierten (i)ffnung = Genitalöffinung bei Callocystites sucht er durch die Annahme zu erklären, dass bei dieser Forn die Genitalprodukte überhaupt nicht durch eine präformierte Öffnung, sondern durch Dehiscenz nach aussen entleert wurden.

H. Ludwig (Bonn).

82 Döderlein, L., J apan is che Seesterne. In: Zool. Anz. 25. Bd. 1902. Nr.669. pag. $326-335$.

Verf. beschreibt die von ihm an den japanischen Küsten gesammelten 17 Seestern-Arten. Neu sind Astroyonium pretiosum, Asterias nipon und A. satsumana, sowie die.Varietäten Astropecten kagoshimensis var. kochiana, Asterias volsatella var. sakurana und A. calamaria var, japonica. Die nordatlantische Cribrella sanguinolenta wird in ihrem Vorkommen bei Japan bestätigt. In Asterias temispina des Mittelmeeres wird eine geographische Varietät der A. calamaria vermutet.

H. Ludwig (Bonn). 
83 Döderleiu, L.. Jap an ische Euryaliden. In: Zool. Anz. 25. Bd. 1902. Nr. 669. pag. 320-326.

Von Japan waren bis jetzt keine Euryaliden mit verzweigten Armen bekannt. Verf. beschreibt davon sechs Arten aus der Kagoshima-Bai und aus der Sagami-Bai, die er alle für neu hält: Gorgonocephalus japonicus, sugamina, tubcrosus, Astrophyton pardalis, globiferum, coniferum. H. Ludwig (Bonu).

84 Koehler. R., Note préliminaire sur quelques Ophiures nouvelles provenant des campagnes de la „Princesse Alice“. In: Bull. Soc. Zool. France 1901. pag. 222-231. 8 Textfig.

Koehler beschreibt, unter Beigabe von Abbildungen, drei neue Ophiuren, die auf den Fahrten der fürstlich Monakoschen Yacht Princesse Alice 1896 und 1901 aus grossen Tiefen erbeutet wurden, nämlich zwei Ophioglypha-Arten und eine an Astrophiura permira Sladen erinnernde, aber damit nicht identische Form, auf die er die neue, mit Ophiomusium verwandte Gattung Opliophycis gründet. Anhangsweise fügt er einige Angaben über die schon früher beschriebene Ophioglypha thouleti hinzu.

H. Ludwig (Bonn).

85 Ariola, V., I.a natura della partenogenesi nell' Arbacia pustulosa. In: Bollett. mus. zool. e anat. comp. R. Tniversiti Genova. No. 111. 1901. 12 pag. 1 Taf.

Durch Nachprïfung der Loebschen Angaben iiber chemische Befruchtung an Arbacia pustulosa luat Verf. sich ïberzengt, dass die unbefruchteten Eier dieses Seeigels keineswegs durclı die Finwirkung der verschiedenen von Loeb angegebenen Salzlösungen zur Entwicklung schreiten, sondern das nur deshalb tın, weil sie an und für sich zur Parthenogenese befähigt sind. Die parthenogenetisch entstandenen Larven ron Arbacic unterscheiden sich deutlich ron den normalen, d. h. durch Befruchtung gelieferten, und kommen über ein Gastrula-älnnliches Stadium nicht linaus.

Loeb (Archir f. Entwicklungsmechanik 64. Bd. 1902. pag. 288 -289) hebt dagegen herror, dass A riola die verkehrten Lüsungen angewandt und deshalb keine kïnstliche l'arthenogenese habe hervorrufen können. (ob bei Arbacia die von Ariola behauptete natiorliche Parthenogenese tatsächlich vorkomme, unterwirft er dem stärksten Zweifel und vermutet, dass Ario la durch parasitische Larven anderer Tiere irregefülurt worden sei.

H. Lu dwig (Bomn).

86 De Meijere, J. ( $\because$ H. Vorläufige Beschreibung der neuen, dureh die Siboga-Expedition gesammelten Echiniden. In: Tijdschr. d. Nederl. Dierk. Vereen. (2) Dl. VIII. Afl. 1. 1902. pag. 1-16.

De Meijere beschreibt aus der Ausbeute der niederländisch-ostindischen Tiefsee-Expedition 21 neue Seeigel-Arten, nämlich 1 Porocilaris, 1 Phormosoma, 1 Dermatodiadema, 1 Hemipedina, 1 Mieropyga, 1 Astropyga, 1 Echinus, 2 Echinocyamus, 1 Fibularia, 1 Clypcaster, 1 Aphanopora n. g., 1 Neolampas, 1 Stercopncustes ฉ. g., 1 Sternopatagus n. g., 2 Palacopneustes, 1 Plesiozonus n. g., 1 Linopncustes, 
1 Homolampas, 1 Phrissocystis. Von den 4 neuen Gattungen ist Aphanopora mit Echinobrissus nalse verwandt, unterscheidet sich aber durch die fehlenden Ambulakralblätter und die ungepaarten Poren. In Stcrcopneusles liegt der erste rezente Vertreter der echten Ananchytiden vor, der sich jeduch von den fossilen Formen durch das Vorbandensein einer subanalen Fasciole und das sehr spezialisierte Meridosternum unterscheidet. Sternopatagus gehört zu den Pourta. lesiidae als deren primitivste Form und zeigt, dass dieselben von den Anancliytiden abzuleiten sind. Plesiozomus steht der Gattung P'alacopneustes nahe, ist aber durch die einander sehr genäherten Porenzonen und durch die Lage der eingeschlossenen Platten gekennzeichnet. Schliesslich macht Verf. noch auf die zweierlei Füsschen von Micropyga tubcrculata und deren Kalkkörperchen aufmerksam und teilt Beobachtungen über das Vorkommen und den Bau der Drüsenpedicellarien bei einer Reibe von Arten mit. H. Ludwig (Bonn).

87 Barthels, Philipp, Zur Histologie der Curierschen Organe der Holothurien. In: \%ool. Anz. 25. Bd. 1902. Nr. 671. pag. $392-395$.

Barthels hält gegenüber $R$ us so daran fest, dass der zentrale Kanal der Cuvierschen Schläuche mit seinem Epithel nicht atrophiert, sondern in den fertigen Organen dauernd fortbesteht, dass ferner die Ringmuskelschicht der Schläıche tatsächlich in Spiraltouren verläuft, und hebt die Irrtümlichkeit der Russoschen Ansichten vom Bau des Aussenepithels und seiner Verbindıng mit der Längsmuskulatur der Schläuche hervor. II. Ludwig (Bonn).

88 Clark, Hubert Iyman, Notes on some North Pacific Holothurians. In: Zool. Anz. 25. Bd. 1902. Nr. 677. pag. 562-564.

$\mathrm{Clark}$ berichtet über die geographische Verbreitung von sieben nordpacifischen Holothurien; darunter sind vier von Sifka, die frither von dort noch nicht bekannt waren.

H. L u d w ig (Bonn).

89 Hérouard, Elgard, Holothuries provenant des campagnes de la "Princesse Alice“ (1892-1897). In: Résultats camp. scientif. accomplies sur son yacht par Albert ${ }^{\text {er }}$ prince souverain de Monaco. Fasc. XXI. Monaco 1902. 4". 61 pag. 8 Taf.

In diesem prächtig ausgestatteten Werke bericlitet der Verf. ausführlich über die auf den Fahrten der "Princesse Alice" erbeuteten nordatlantischen Holothurien unter Beigabe von zahlreichen, zum Teil nach dem Leben gemalten Abbildungen. Er beschreibt 12 neue Arten (1 Stichopus, 1 Psendostichopus, 1 Paelopatides, 1 Paroriza, 2 Psychropotes, 1 Deima, 1 Panmychia, 1 Scotoplanes. 2 Folya, 1 Scotoanassa), ron denen eine zugleich eine neue Gattung der Synallactinen, Paroriza, repräsentiert; in derselben Unterfamilie trenut er die Mesothuria intestinatis, weil er ihre Fühler parweise von ungleicher Grösse fand, von den übrigen MLesothuria-Formen und 
grïndet darauf die neue Gattung Allantis. Von schon bekannten Arten werden namentlich Pseudostichoms villosus Théel und occultatus v. Marenz., Allantis (Mesothuria) intestinalis rar. revilli Théel und Mesothuria lactea (Theel) eingehend behandelt. In der Unterfamilie der Elpidiinen bringt er eine neue Abgrenzung der Gattungen in Vorschlag. - Bei Scotoplanes delagei n. sp. kommen in der Körperwand parasitische Sporencysten vor, die vielleicht zu irgend einer Sporozoenform gehören.

H. Ludwig (Bonn).

\section{Vermes.}

\section{Plathelminthes.}

90 Boas, J. E. V., Triplotaenia miralitis. In: Zool. Jahırb. Abt. f. Syst., Geogr. u. Biol. d. Tiere. Bd. 16. 1902. pag. 329-333.

Triplotaenia mirabitis ist ein höchst merkwürdiger Bandwurm. Von allen bis jetzt bekannten Cestoden unterscheidet er sich durch den Besitz eimer doppelten Strobila. An dem Skolex nämlich entspringen zwei vollständig gleich ansgebildete, etwa $150 \mathrm{~mm}$ lange Ketten. Jede entlält in den ältern Abschnitten zahlreiche Genitalapparate, jede zeichnet sich aus durch eine verschiedene Ausbildung der beiden Seitenränder. Der eine ist glatt, abgerundet, ohne Einschnitte, der andere hingegen mit zahlreichen Fransen geziert. In beiden lietten fehlt auch die Segmentierung. Es kommen keine Proglottiden zur Ausbildung; die Geschlechtsapparate liegen dicht aneinander gedrängt im Parenchym, ohne eine regelmäßige Anordnung zu zeigen, ganz in derselben Weise, wie es bei Fimbriaria fasciolaris der Fall ist. Die Genitalöffnungen liegen alle am wulstigen Rande, dem anch die Geschlechtsorgane so stark genähert sind, dass die Hälfte des Wurmkörpers am gefransten Rande leer bleibt. Auf die Einzelheiten des anatomischen Baues geht der Verf. nicht ein, es scheint jedoch, dass Triplotaenia mirabilis mit Fimlniaria fasciolaris anatomiseh viel Ähnlichkeit hat. Die reifen Embryonen sind von drei Hüllen umgeben. Die innerste ist ziemlich dick und liegt dem Körper der Oncosphäre eng an, die mittlere ist dünn und umgibt die innere nur lose. Die äusserste Hülle ist fest und dick.

Triplotaenia mirabilis scheint mit den Anoplocephalinen, speziell mit der Gattung Anoplocephala verwandt zu sein. Die eigentiimliche Ausbildung eines doppelten Bandwurmkörpers könnte zur Vermutung führen, es handle sich um eine abnorme Cestodenform. Allein es ist zu bemerken, dass beide Ketten am Skolex entspringen und in Gestalt und Bau vollständig gleichwertig sind, dass also von einer Hanpt- und einer Nebenkette, wie solche bei Abnormitäten gefunden werden, nicht die Rede sein kann. Ausserdem verfügt der Verf. über vier gleich 
gebildete Exemplare dieses seltsamen Wurmes. Sie stammen aus einem Felsenkänguruh. Ein mit diesen Exemplaren ganz iibereinstimmendes Bruchstück ist auch in einem zweiten Individuum derselben Wirtsart gefunden worden.

E. Riggenbach (Basel).

91 Galli-Valerio, B., Bothriocephalus latus Brems. chez le chat. In: Centralbl. Bakt., Parastkde u. Infektkr. I. Abt. Bd. XXXII. 1902. pag. $285-287$.

Die Frage, ob die in der Katze rorknnmende BothriocephalusArt identisch sei mit dem breiten Bandwurm des Menschen, ist bis jetzt unentschieden geblieben. Creplin war der Meinung, es handle sich um eine neue Art. Er benannte sie Bothriocephatus felis. Nach ihm hat auch Krabbe und verschiedene andere Autoren im Darm der Katze einen Bothriocephalus gefunden und geglaubt, in ihm wesentliche Unterschiede gegenüber $B$. latus zu erkennen. Zuletzt hat Ariola alle Katzenbothriocephalen unter dem Namen B. decipiens vereinigt. Die Bezeichnung stammt von Diesing und galt nur für die Bothriocephalen der wilden Feliden. Nun hat aber der Verf, einen Bothriocephalen, den er aus einer Katze erhielt, genau untersucht und mit Bestimmtheit nachgewiesen, dass dieser B. latus ist. Der ganze Unterschied zwischen dem Bandwurm der Katze und dem des Nenschen liegt in der Grösse. Aber, dass sich die Parasiten in ilırer Grösse nach derjenigen des Wirtes richten, ist bekannt. Der Grubenkopf der Katze kann also wohl kleiner sein als der des Menschen. Überdies findet man in letzterem nicht selten eine Varietät (B. latus var. tenella), die in bezug auf ihre Grösse dem Katzenbandwurm näher steht als den typischen B. latus. Durch die Untersuchung des Verfs. finden auch Brauns Beobachtungen volle Bestätigung. Es gelang diesem Forscher, durch Verfütterung von Larven des $B$. latus in der Katze den ausgewachsenen Wurm zu züchten. Die Exemplare erwiesen sich kürzer, sie hatten weniger Glieder und einen kleinern Kopf als diejenigen, welche sich im Verlauf desselben Zeitraumes im Menschendarm entwickelt hatten.

$$
\text { E. Riggen bach (Basel). }
$$

\section{Arthropoda.}

Arachnida.

92 Hichael, Albert D., British Ty roglyphidae. In: Ray Soc. 1901. Vol. I. pag. 1-291. Taf. A-C und 1-19.

Die vorliegende vortreffliche und erschöpfende Arbeit zerfällt in zwei in einem Bande vereinigte umfangreiche Teile, von denen der 
erste sich mit der Geschichte und Literatur, der systematischen Stellung und Anatomie sowie mit der Entwickelung der Tyroglyphen beschäftigt, während der zweite Abschnitt der ausführlichen Beschreibung und Kennzeichnung der Gattungen und Arten gewidmet ist. Das sehr ausführliche Kapitel über die Anatnmie beriicksichtigt zunächst den äussern Körperbau. Der Verf. bemängelt, dass in den meisten Lehrbüchern der vergleichenden Anatomie die Acarinen als Arachniden bezeichnet werden, deren Cephalothorax und Abdomen ohne sichtbare Abgrenzung in eine gemeinschaftliche Nasse verschmolzen seien. Das gelte wohl für die Gattung Sarcoptes und deren verwandte Sippen, im weitern Sinne auch noch für die Genera Chortoglyphus, Trichotursus, Hericia und Carpoglyphus sowie für einige Species der Gattung Glycyphagus, nicht aber für die meisten Vertreter aus der Familie der Oribatiden, Gamasiden, Trombididen und Phytoptiden und für einige Species der Tyroglyphiden, bei denen man eine deutliche Einschnürung des Körpers zwischen lem zweiten und dritten Beinpaare beobachten liann. Den ror dem Einschnitte gelegenen Teil des Rumpfes bezeichnet der Verf. in alter Weise mit Cephalothorax, den hinteren Abschnitt mit Abdomen. Er vermeidet also die neuerdings von $\mathrm{Oude-}$ mans vorgeschlagenen, entschieden neutraleren Bezeichnungen I'rosoma und Metasoma. Ehenso kann er sich nicht damit befreunden, dass Kramer und viele der neuern Acarinologen den die Mundteile umschliessenden Teil des Cephalothorax Capitulum nennen. Dieser Name könne zu der irrtümlichen Auffassung führen, dass der so benannte Körperteil homolog sei mit dem Caput der Insekten. Auch hier häit Michael an der alten Bezeichnung Rostrum fest, obwohl er nicht verkennt, dass dieselbe von den verschiedenen Autoren in rerschiedenem Sinne gebraucht wurde. Der die innere Anatomie der Tyroglyphiden behandelnde umfassende Abschnitt bildet eine wertrolle Ergänzung zu den Arbeiten Gnddens ${ }^{1}$ ) und Nalepas ${ }^{2}$ ). Während der erstgenannte Forscher seine mit den einfachsten Mitteln ausgeführten Untersuchungen auf Tyroglyphus siro L. beschränkte, ziehen $\mathrm{Nalepa}$ und Michael mehrere Formen in den Kreis ihrer Beobachtungen. Der zuerst genannte Forscher studierte die anatomischen Verhältnisse von Tyroglyphus longior und Carpoglyphus anonymus, II ich ael hingegen beschäftigte sich vorzugsweise mit dem inneren Bau von Glycyphagus platygaster, Hericia robini und Rhizo-

1) Beitrag zur Lehre von der Scabies. In: Würzburger med. Zeitschr. 1861. pag. 301 .

2) Die Anatomie der Tyroglyphen. In: Sitz.-Ber. Ak. Wien, Abt. 1. Bd. 90. 1884. pag. 1-32. Bd. 92. 1885. pag. 116-167. 
glyphus echinopus. Die Zeichnungen Guddens und Nalepas werden in der vorliegenden Arbeit des Vergleichs wegen mit herangezogen. Der Verf. beschreibt zunächst den Verdaungstraktus. Die typische Form des Pharynx bei den Acarinen besteht seiner Ansicht nach aus zwei mehr oder wenig stark chitinisierten Rinnen, die der Gestalt nach an Dachtraufen erinnern. Beide sind mit ihren Konvexitäten nach unten gerichtet und an ihren Rändern mehr oder weniger beweglich verbunden. Die untere Rinne ist nichts anderes als eine Fortsetzung der Ventralseite des Mundkegels. Die obere Rinne bildet das Dach des Pharynx. Durch eine Anzahl Muskeln (I evator tecti pharyngis) kam dasselbe von dem Boilen des Pharynx abgezogen werden, wodurch jene Saugwirkung entsteht, die die Mahrungsaufnalume ermöglicht. Andere Muskeln (Occlusor pharyngis) bringen die Pharyngealdecke in ilıre urspriingliche Lage zuriick. Da eine Art Kklappe oder ein Schliessmuskel den Wiederaustritt der Nahırung nach vorn zu verhindert, wird die letztere gewaltsam in die Speiseröhre bezw. in den Magen hineingetrieben. Der (O)sophagus weist an seinem hinter dem Schlundganglion (brain) gelegenen kürzern Teile eine Erweiterung auf, auch ragt er nicht selten ein wenig in den Magen linein, eine Einrichtnng, durch welche das Zurücktliessen der Nahrung verhüitet wird. Der Magen bildet bei Glycyphagus platygaster einen weiten Sack mit dicken Wänlen, der sich, ron der Seite gesehen, nach hinten melır oder weniger stark verbreitert. Diese lirscheinung tritt besonders stark bei Hericia rolimi auf. An jeder Seite setzt sich der Magen in je einem Blindsack fort, der bei Glycyphagus platygaster merkbar weiter ist als bei Hericia robini. Colon und Rectum entsprechen dem typischen Bau. Die sog. Malpighischen Gefässe bestehen aus einem Par blind endender Schläuche, die bei H. rolini länger als der Mastdarm sind. Bei G. platygaster konnte der Verf. die genannten Gebilde nicht auffinden. In einem Abschnitt ïber die Histologie und Physiologie des Ernährungstraktus bestätigt zunächst der Verf., dass die äussere Wand des letzteren auch bei den ron ibm genauer untersuchten Formen in einer mehr oder weniger strukturlosen Tunica propria besteht. Eine epitheliale Auskleidung

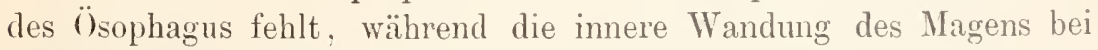
Glycyphagus platygaster sich aus grossen, mit deutlichem Kern versehenen Zellen zusammensetzt, die ursprünglich eine fast gleich starke Schicht bilden. Die einzelnen Zellen erreichen eine Länge und Breite vom $16-30 \mu$ und eine Dicke von $12-16 \mu$. Ihre Kerne haben einen Durchmesser von $10-13 \mu$, doch sind sie nur etwa $5 \mu$ dick. Während des Verdauungsprozesses übernehmen diese Zellen die Funktion der Aufsaugung der verflüssigten und assimilierten Nahrungs- 
stoffe mittelst Endosmose. Dabei wachsen dieselben immer mehr; sie schwellen am distalen Ende keulenförmig an. Schliesslich wandert die noch weiter verdaute Nahrung mittelst Exosmose durch die Tunica propria in die Leibeshöhle, wo sie sich mit dem Blute vermischt. Nach den Austritt des Nährsaftes schnürt sich der proximale Teil der Zelle ab und fällt in den Magenraum. Entweder sind diese losgelösten, kugeligen Zellen leer oder sie enthalten Exkretionsstoffe, die später kristallisieren und kleine Konkremente bilden, welche durch den After ausgeschieden werden. Aller Wahrscheinlichlieit nach enthalten diese weisslich durchscheinenden Ausscheidungsprodukte Harnstoffe. Letztere häufen sich jedoch auch in der Körperhöhle an. Während sie jedoch bei den Gamasiden, Trombidiiden und Hydrachniden durch die grossen, wohlausgebildeten Malpighischen Gefässe in vertlüssigter Form den Körper verlassen, bilden sie bei den Tyroglyphiden, bei denen ja die Maluighischen Gefässe verhältnismäßig klein oder gar mehr oder weniger verkümmert sind, Kristalle oder Konkremente, die anscheinend im Körper verbleiben. Bei alten Exemplaren von Histiostoma rostro-serratum und Hericia robini ist oft die ganze Leibeshöhle damit erfüllt. Bemerkenswert ersclieint, dass diese zwei Species Flïssigkeitsbewohner sind.

Die Zellen in der Nähe des distalen Endes der Blindsäcke sind bei $G$ l. platygaster gewöhnlich dicker als diejenigen des eigentlichen Magens. Sie zeichnen sich durch deutliche Kerne und Kernkörperchen aus. Im Colon ist der Zellenbau nicht ïberall gleich, rorn treten platte Zellen auf, die in ihrer Zusammensetzung an das Pflasterepithel erinnern, weiter hinten werden die Zellen kleiner aber dicker. Die Zellen des vorderu Teils des Rectums haben keulenförmige Gestalt; sonst ist der Mastdarm mit $21 \mu$ langen und $10 \mu$ dicken Zellen ausgekleidet.

Wie bei andern Milben treten auch bei Gl. platygaster zwei Paar sog. Speicheldrüsen auf, die, symmetrisch verteilt, dicht nebeneinander auf beiden Seiten des Cephalothorax liegen. Obschon listologisch einander ähnlich, sind beide Paare in der Gestalt sehr roneinander verschieden. Die grössere davon stellt ein abgeplattetes, fast nierenförmiges Gebilde dar, das aus sehr grossen, sternförmig angeordneten, beinahe dreieckigen Zellen sich zusammensetzt. Diese haben durchschnittlich eine Länge von $40-50 \mu$ und eine Breite von ungefähr $30 \mu$ und umschliessen je einen runden oder elliptischen, im Durchmesser $10 \mu$ grossen, durchsichtigen Kern mit mehrern Kernkörperchen. Der Ausführungsgang beginnt mit einer kleinen Erweiterung, im weitern Verlaufe wird er jedoch sehr fein. Am meisten erinnert die soeben beschriebene Drüse an die nierenförmige 
Drüse bei Thyas petrophilus Mich. und bei Bdella. Das andere Drüsenpaar besteht je aus zwei oder drei grossen Zellen. Es entspricht den ,,vordern Speicheldrïsen" bei Bdella. Auch hier werden die Ausführungsgänge ungemein fein und sind schwierig zu verfolgen.

Im Gegensatze zu Nalepa, der von der grossen Ähnlichkeit der Sexualorgane beider Geschlechter ïberzeugt ist, vertritt der Verf. die Ansicht, dass die Abweichungen im Bau derselben viel auffallender sind als z. B. bei den Oribatiden. Bei aller Übereinstimnuung in der Anordnung und Zahl der paarig auftretenden Geschlechtsorgane und ihrer Ausfïhrungsgänge sowie der Genitaldrüsen bei Männchen und Weibchen besteht doch der Unterschied, dass bei dem zuletzt genannten Geschlechte die weitverbreitete ringförmige Gruppierung der genannten Organe zur vollen Ausbildung gelangt ist, während man bei dem $\sigma^{7}$ fast jede Spur daron rermisst. Die männlichen Geschlechtsorgane bei Gl.platygaster und H. robini entsprechen im allgemeinen denen von Tyroglyplus longior, nur ist zu erwähnen, dass bei der zuerst genannten Art die Gestalt der Testes birnförmig ist, auch liegen sie beide weit hinten im Innern der Leibeshöhle. Die Vasa deferentia entspringen am schmälern Vorderende der Hoden; sie vereinigen sich erst kurz vor dem Penis. Der Ductus ejaculatorius bei Gl. platygaster ist kurz; er tritt durch eine Öffnung des chitinösen Gerïstes, welches den Penis stützt. Sein distales Ende erweitert sich zu einem ansehnlichen Hohlraum, der für gewöhnlich zusammengefallen ist.

Die accessorischen Drüsen, zwei an der Zahl, weichen in Form, Grösse und Struktur merkbar voneinander ab. Die eine davon, von Michael die gekammerte accessorische Drüse genannt (the chambered accessory gland), besitzt eine birnförmige Gestalt und mündet mit sehr kurzem, von der Drüse nicht scharf abgesetztem Gang in den Ductus ejaculatorius. Ziemlich ansehnlich an Grösse, liegt sie über den Testes und über der andern accessorischen Drïse. Letztere wird von dem Verf. „the receptacnlar accessory gland" getauft. Sie ist ausser dem Magen das umfangreichste innere Organ, dessen Gestalt man als verkehrt birnförmig bezeichnen kann. Auch bei ihr ist der in der Mitte des Vorderendes entspringende weite Ausführungsgang ungemein kurz. Der Penis besitzt bei Gl. platygaster an seinem proximalen Ende einen annähernd löffelförmigen Bulbus, dessen konvexe Seite nach unten gekehrt ist. Am distalen Ende des Bulbus verengt sich plötzlich der Penis und wird zu einer gekrimmten Röhre, die sich allmählich verjüngt. Auf der äussern Wandung nahe dem Rande der Genitalöffnung treten zwei Stachel auf, die 
möglicherweise bei der Begattung als Einführungsorgane dienen. Bei H. robini ist der Bulbus weniger scharf hervortretend und die Röhre weniger gebogen. Das Penisgerist von Gl. platygaster gleicht annähernd einem im Körver anfgerichteten grossen lateinischen 1, nur sind die Arme des Buchstaben nicht ganz gerade, sondern einander zugebogen, dabei nehmen sie nach unten zu an Dicke zu. Ganz abweichend hiervon ist der Bau des gleichen Organs bei H. robmi. Es besteht aus zwei Stücken, ron denen jedes ein dreitckiges Rahmenwerk chitinöser Stäbe mit einer untern Verlängerung bildet. An diese treten die Aufriclitungsmuskeln (the erector muscles) heran, während die Zuriickziehmuskeln sich an die obere Spitze des Dreieckes anheften. Wie bei den meisten Tyroglyphiden und Sarcoptiden treten auch bei Gl. platygaster auf beiden Seiten der Geschlechtsöffnung zwei sehr einfach gebaute Genitalnäpfe auf, die in einer durch eine einfache oder doppelte Hautfalte gebildete Tasche eingesenkt sind. Im Gegensatze $z u \mathrm{~N}$ a lepa und in Thereinstimmung mit Haller hält der Verf. diese Genitalnäpfe für Sinnesorgane unbekannter Funktion. Eigentümlicherweise fehlen dieselben bei Hericia und bei den Männchen von Trichotarsus. Die zu beiden Seiten des Anus auftretenden Begattungs-Saugnäpfe (copulative suckers) sind wirkliche Anheftungsorgane, die, wie ilu Name schon sagt, bei dem Cnitus in Wirksamkeit treten. Man findet sie bei den Männchen der Gattungen Maelia, Histiogaster, Alewrobius, lihizoglyphus, Tyroglyphus und Chortoglyphus, nicht aber bei denjenigen ron Glycyphagus und Hericia. Die Männchen weniger Gattungen (z. B. Tyroglyphus) besitzen ausserdem noch auf der Innenseite der 'Tarsen des vierten Beinpaares je eine saugnapfähnliche Pustel, die jedenfalls zum Festhalten des Weibchens dient.

Die weiblichen Geschlechtsorgane von Gl. platygaster ähneln denen anderer 'Tyroglyphiden-Arten. Die Orarien, zwei an der Zahl, sind annähernd birnförmig gestaltet. Sie stehen mit dem Receptaculum seminis durch je einen kurzen Gang in Verbindung. Die Befruchtung der Eier tiudet infolgedessen im Orarium statt. Die beiden Eileiter rereinigen sich und bilden gemeinschaftlich die Vagina, eine kurze Röbre, die rechtwinklig zum Genitalring steht. Ihr proximaler Teil besitzt dicke, muskulöse Wandungen, während das distale Ende weit diinner und biegsamer ist. Hier bildet die Scheide auch eine grosse, transversale Falte. die sich ausdehnt, wenn sie ein Ei in sich birgt, sonst aber zusammengelallen ist.

Bezüglich des Nervensystems teilt der Verf. mit, dass das Schlundganglion (the brain) im Sagittalschnitt fast keilförmig erscheint. Das untere Schlundganglion hat anf seiner dorsalen Ober- 
fläche eine rundliche Anschwellung, die unmittelbar neben der Durchtrittsöffnung des Ösophagus liegt. Bei Hericia robini findet sich diese Verdickung nicht, doch ist das Unterschlundganglion merkbar länger. Auch das Oberschlundganglion erscheint massiger als bei Gl. platygaster. Über den Ursprung der Nerven rertritt Michael eine andere Ansicht als Winckler und Nalepa. Er glaubt, dass vom Oberschlundganglion ausser dem unpaaren Pharyngealnerven nur drei Nervenpaare entspringen: die Mandibularnerven, die Sehnerven und zwei feine Nervenstränge, die zu den dorso-ventral verlaufenden Muskeln in der Nïhe des Rostrums gehen. Tom Unterschlundganglion dagegen sollen sieben Nervenpaare herkommen: die Maxillartastermerven, die Beinnerven (S), die Sexualnerven und ein Paar, das die dorso-rentral ausgespannten Muskeln in der Mitte des Leibes innerviert.

Von allen Sinneswerkzeugen sind bei den Ty roglyphiden die des Gefühls am meisten ausgebildet. Als solche dienen besonders gewisse lange Borsten, ron denen eine auf der Streckseite der Tibia des ersten Beines nahe dem distalen Ende sitzt. Ähnliche Haare, jedoch viel schwächer entwickelt, finden sich auch am vorletzten Gliede des zweiten Fusses, nicht selten auch an den Hinterfüssen. II ichael nennt diese Iaargebilde ..Tastborsten" (the tactile hairs). Auch den Maxillartastern schreibt der Verf. einen hochausgebildeten Tastsinn zu. Ausserdem sollen im geringern Maße die Hautborsten dem Gefühle dienen. Die- Tyroglyphiden besitzen mit einer cinzigen Ausinahme (Carpoglyphus anomymus) keine Augen oder andere, optischen Zwecken dienende Organe. Über Simnesorgane anderer Funktionen weiss der Verf. keine Auskunft zu geben.

In einem weitern Abschnitt beschäftigt er sich mit zwei drüsenähnlichen Gebilden, die bei den meisten, wenn nícht allen Tyroglyphiden auftreten und im hintern Teile des Abdomens liegen. Sie sind von ansehnlicher Grösse und enthalten eine stark lichtbrechende Flüssigkeit. Der Verf. nannte sie frïher „expulsory vesicles“, doch teilt er jetzt mit $\mathrm{N}$ alepa die Meinung, dass es sich bei ihnen um Öldrüsen handelt, deren Inhalt zur Einfettung der Körperoberfläche diente. Ganz eingehend behandelt der Verf. das Kapitel über die Muskeln. Er teilt die letzteren in sechs Gruppen ein: 1. Muskeln des Capitulum (of the rostrum and mandibles), 2. Dorso-rentralMuskeln, 3. Muskeln, die den Körper verkïrzen können, 4. Muskeln des Ernährungstraktus, 5. Muskeln des Genitalapparates und 6. Beinmuskeln. Die Beschreibung der Muskulatur ergänzt die von Nalepa an einer einzigen Species (Caroglyphus anomymus) angestellten Untersuchungen in vortrefflicher Weise. 
Wie die Betrachtung der anatomischen 'Tafel C ergibt, hat der Verf. besonders die drei Arten Gl. platygaster, Hericia robini und Rhizoglyphus echinopus berücksichtigt.

Im sechsten Kapitel seiner umfangreichen Arbeit schildert der Verf. in eingehender Weise die gesamte Entwickelung der Tyroglyphiden. Er unterscheidet dabei vier Stadien: das des Eies, der Larve, der Nymphe und des geschlechtsreifen, definitiven Tieres. Bei einigen Generationen erscheint das Nymphenstadium insofern verwickelt, als sich das seltsame Hypopus-Stadium einschieht, das man frïher als eine besondere Entwickelungsstufe aufzufassen geneigt war. Aus den Darbietungen Michaels sei folgendes kurz hervorgehoben: Die Eier der Tyroglyphiden sind gewöhnlich gross im Verhältnis zu ihren Trägern. Sie haben eine ovale oder länglich-runde Gestalt und eine glatte, weiche Schale ohne jeden Vorsprung. Da die letztere dehnbar ist, fällt bei den Tyroglyphiden das Deutorum-Stadium weg. Die sechsfüssigen Larven nähern sich in der Gestalt melır oder weniger der Nymphe oder dem adulten Tiere. Äussere Sexualorgane fehlen noch. Bei Tyroglyphus und den meisten andern Gattungen treten jene eigentümlichen Chitinstäbe auf, die von Claparède als "Bruststiele" bezeichnet werden. Sie fehlen bei Carpoglyphus und den dieser Gattung nahestehenden Genera. Die Larven der Tyroglyphiden sind gewöhnlich beinahe farblos und fast durchscheinend. Eine Ausnahme hiervon machten nur Hericia robini und einige andere Arten. Die Behaarung ist meist weit dürftiger als bei der Imago. Durch eine Häutung verwandelt sich die Larve in die achtbeinige Nymphe. Letztere macht ebenfalls eine mit einem Ruhestadium verknuipfte Häutung durch, so dass man von einer ersten und zweiten Nymple reden kann. Michael hat besonders eingehende Beobachtungen über die dabei sich abspielenden Vorgänge gemacht. Als Versuchstiere benutzte er Individuen von Tyroglyphus siro, Carpoglyphus anonymus und Histiogaster entomophragus, doch erwies sich die letztgenannte Species als am brauchbarsten für die angestellten Untersuchungen. Trotz zahlreicher Versuche konnte er bei ihr niemals ein Hypopusstadium feststellen. Die zuerst im Winter vorgenommenen Experimente ergaben die eigentümliche Tatsache, dass die in kleine Zellen eingeschlossenen Tierchen trotz normaler Zimmerwärme wohl zuweilen in einen lethargischen Zustand verfielen, nie aber sich häuteten. Dieser Prozess trat nur im Sommer ein.

Ein ausfiuhrlicher Abschnitt handelt dann von dem HypopusStadium, das der Verf. als den interessantesten Teil in der Lebensgeschichte der meisten Tyroglyphen bezeichnet. In seinen Ausführungen tritt er zunächst den Anschauungen Berleses entgegen, der 
mit Unrecht die rom Verf. unter dem Namen Disparipes bombi beschriebene Tar so nemide als einen Hypopus erklärt. Desgleichen kann sich Michael nicht mit der Ansicht Mégnins befreunden, der für Pterotichus falciger eine mundlose Hypopusform in Anspruch nimmt. Er ist vielmehr überzeugt, dass das Auftreten dieser gepanzerten Zwischenform nur bei den 'Tyroglyphiden vorkommt. Nachdem der Verf. einen geschichtlichen Überblick über die auf das HypopusStadium sich beziehende Literatur mit allen ihren Irrungen und allmählichen Fortschritten gegeben hat, kommt el schliesslich auf seine eigenen Untersuchungen in dieser Richtung zu sprechen. Seine Ansichten hat er in den folgenden Sätzen niedergelegt:

1. Die Hypopusform stellt nicht ein adultes Tier, sondern eine ungeschlechtliche Entwickelungstufe dar.

2. Die Hypopi sind die heteromorphen Nymphen von Tyroglyphus und einigen verwandten Gattungen wie z. B. Histiostoma, Rhizoglyphus, Histiogaster usw.

3. Nicht alle Individuen einer Art werden Hypopi, meist nur ein verhältnismäßig kleiner Teil, aus dem sich beide Geschlechter entwickeln.

4. Das Hypopusstadium liegt zwischen den zwei Häutungen der Nymphe.

5. Die Umwandlung in das Hypopusstadium wird nicht durch ungünstige Umstände wie 'Trockenheit verursacht, auch ist sie nicht ein blosser Ausnahmefall, sondern sie stellt eine weise Einrichtung der Natur dar zur Verbreitung der Arten. Sie erscheint ganz unerwartet unter oft ganz entgegengesetzten Bedingungen.

6. Bei dem gegenwärtigen Stand unseres Wissens können wir ebenso wenig sagen, weshalb eine Nymphe zum Hypopus wird und die andere nicht, wie, weshalb ein $\mathrm{Ei}$ sich zu einem Männchen oder Weibchen entwickelt.

7. Die Hypopus-Formen sind keine echten Parasiten; sie entnehmen ihrem Wirte keine Nahrung; sie gesellen sich vielmehr zu Insekten und andern Tieren olme Wahl, um sich nach andern Orten verschleppen zu lassen.

8. Das Chitinkleid des Hypopus befähigt diesen während des Transportes Hitze und 'Trockenheit erfolgreicher zu widerstehen als wie das im Nymphenstadium oder als adultes Tier geschehen könnte.

9. Bei Gl. spinipes ist der Hypopus röllig ausgebildet und fähig die Beine zu bewegen, doch kann er nicht laufen. Seine Haut wird nicht hart und dunkel gefärbt wie bei andern Hypopus-Formen. In der Regel verlässt er nicht die Haut der jungen Nymphe, sondern 
bildet sich in derselben zur zweiten Nymphe um. Erst die letztere verlässt die alten Häute.

10. Bei G7. domesticus ist die Entwickelung insofern eine unvollständige, als der Hypopus der Gliermaßen entbehrt und immer von der Nymphenhaut umschlossen bleibt.

11. Bei beiden obengenannten Species bildet die Haut der ersten Nymphe eine Art Gehäuse, das im Ausehen ganz wesentlich von einer einfach abgestreiften Haut abweicht.

Wie man sieht, teilt Michael nicht die Meinung Mégnins, der annimmt, dass die Umwandlung der Nymphe in die Hypopusform infolge ungünstiger Lebensverhältnisse stattfinde. Er stimmt vielmehr mit Severin Jensen ${ }^{1}$ ) überein, dessen Arbeit ihm allerdings anscheinend unbekannt geblieben ist.

Der nächste Abschnitt der Michaelschen Arbeit beschäftigt sich mit der Entwickelung der reproduktiven Organe. Der Verf. bestätigt die Beohachtungen Nalepas. Bezüglich eines auch von dem letztgenannten Forscher nicht völlig geklärten Punktes, ob die zweite Nymphe irgend welche Anzeichen von äusseren Sexualorganen aufweist, hat Michael sorgfältige Untersuchungen angestellt, wobei besonders Vertreter von Histiogaster entomophagus, Carpoglyphus anonymus und Tyroglyphus siro berücksichtigt wurden. Das Ergebnis war, dass niemals die Anlage äusserer Geschlechtsteile bemerkt wurde, obwohl die innern Genitalorgane mehr oder weniger deutlich durch die Körperhaut hindurch schimmerten. Während der letzten Häutung mögen die völlig ausgebildeten Geschlechtsorgane mitunter durch die noch nicht abgestreifte Nymphenhaut zu sehen sein und dadurch zuweilen zu einer irrigen Auffassung geführt haben.

Der zweite Teil des vorliegenden Werkes ist der Systematik der Tyroglyphiden gewidmet. In der gegebenen Diagnose der Familie ist die ron Berlese unter die Tyroglyphiden gerechnete Gattung Hemisarcoples nicht mit berücksichtigt, da der Verf. in Übereinstimmung mit Canestrini und P. Kramer die Ansicht vertritt, dass dieselbe in die Unterfamilie der Canestriniinae gehört. Die Tyroglypliden werden ron Michael in drei Unterfamilien eingeteilt, in die Lentungulinae (mit gestielten Ambulacra an den beiden vordern Beinpaaren), in die $\mathrm{H}$ is ti os to min a e (ohne gestielte $\mathrm{A}$., aber mit säge- oder messerförmigen Mandibeln) und in Tyroglyphinae (mit scherenförmigen Mandibeln). Die erstgenannte Unterfamilie umfasst nur eine Gattung mit einer Art. Auch die zweite

1) Jensen, Adolf Severin, En Tyroglyphide i Hesteiglens Ägkapsel. In: Vidensk. Meddel. fra den naturhist. Foren. i Kbhvn 1895. pag. 101. 
Unterfamilie wird von einer einzigen Gattung repräsentiert, die jedoch vier Arten zählt, von denen zwei als neu aufgeführt werden: Histiostoma spiniferum und $H$. pyriforme. Die zuerst genannte Form erreicht eine Länge von $260 \mu$ und eine Breite von $75 \mu$. Sie kennzeichnet sich ror allem durch ihren schmalen Körper und durch die grosse Länge der gebogenen Dornen anf dem Notogaster. Es wnrde nur ein Weibchen, eine Nymphe und ein Hypopus erbeutet. H. mriforme charakterisiert sich durch die langen "Flagella" an den Palpen, durch gezähnte Mandibeln und durch ein Abdomen, das weiler warzenartige Erhebungen. noch spatel- oder blattförmig verbreiterte Haargebilde auf dem Rücken aufweist. Am meisten nähert sich diese neue Form dem Histiostoma fimetarium Can. et Berlese, doch unterscheidet sie sich ron demselben durch seine gesägten Mandibeln, seine hiruförmige Gestalt, seine breite Abrundung des Hinterendes sowie durch das Auftreten von zwei Paar verbreiterten Haaren an den seitlichen Vorderecken des Abdomens. Ausserdem sind die vier Borsten am Hinterende merkbar grösser als bei der Vergleichsart. Es wurden Männchen, Weibchen, Nymphen und Larsen aufgefunden. Der erste Band der Michaelschen Arbeit üher. die Tyroglyphidae enthält nur eine Gattung der Unterfumilie der Tyroglyphinae: ,Glycyphagus". Es werden neun in England erbentete Arten eingehend beschrieben und bildlich dargestellt, doch befindet sich lieine neue Species darunter. Der Restimmungsschlïissel für diese Unterfamilie berïicksichtigt auch die in Fngland noch nicht aufgefundenen Gattungen Saproglyphes und Maclia. Der später erscheinende zweite Band wird die noch übrigen Gattungen der Ty roglyphinae behandeln. Es wird dadurch eine Monographie der englisthen Ty roglyphiden geschaffen, die sich würdig an die ron demselben Autor lierausgegebene, zweibändige Arbeit über die britischen Oribatiden anschliesst.

R. Piersig (Annaberg, Erzgeb.).

\section{Insecta.}

93 de Dalla Torre, C. G., Cat a logus Hym enopterorum. - Vol. III., Pars I. und II. Lipsiae (Sumpt. Guil. Engelmann). 1901/1902. gr. 8. prag. 1141. Mk. 56.

Vor einiger Zeit erschien die zweite Hälfte des 3. Bandes des Dalla Torreschen Hymenopterenkatalogs. Dieser unfasst in 1141 Seiten die Citate für die Familien: Trigonalidae, Megalyridae, Stephanidae, I chneumonidae, Agriotypidae, Evaniidae und Pelecinidae. Der erste Teil des 3. Bandes schliesst ab mit Vol. XXXY (1899) des Zoological Record und Vol. V (1900) der Bibliographia Zoologica (Vol. XXIII des Zoolog. Anzeigers), der z we ite 
Teil mit Vol. XXXYII (1900) des Zoological Record und Jahrg. XXIII (1900) des Zoolog. Anzeigers. Mit dem 3. Bande („IchneumonidenBande") hat nun dieses grosse, hochbedeutsame Katalogwerk, dessen 10 Bände seit dem Jahre 1892 in ungezwungener Reihenfolge erschienen sind, seinen Abschluss gefunden, insoweit es den eigentlichen Katalog betrifft. Wie verlautet, soll aber noch als Appendix zum Werke ein 11. Band erscheinen, welcher die ganze hymenopterologische Literatur verzeichnet. Ohne Zweifel würde der Hymenopterenkunde mit einem Literaturbande ein sehr grosser Dienst geleistet.

Es dürfte im Sinne der Besprechung liegen, wenn bei Gelegenheit des Katalog-Abschlusses das chronologische Erscheinen der einzelnen Bände in Erinnerung gebracht wird.

Vol. I. Tenthredinidae incl. Uroceridae. 1894 ( $1 \mathrm{lk} 20$ ).

Vol. II. Cynipidae. 1893 (.1k. 6).

Vol. III. (s. oben).

Vol. IV. Braconidae. 1898 (Mlk. 15).

Vol. V. Chalcididae et Proctotrupidae (Mk. 28).

Vol. VI. Chrysididae. 1892 (Mk. 5).

Vol. VII. Formicidae. 1893 (Mk, 13).

Vol. VIII. Fossores (Sphegidae). 1897 (11k. 33).

Tol. IX. Vespidae. 1894 (Mk. 8).

Tol. X. Apidae. 1896 (Mk. 28).

Ferner glauben wir in Erinnerung bringen zu sollen, dass der Dalla Torresche Hymenopterenkatalog zum vorteilhaften Unterschiede von andern ähnlichen Katalogwerken (z. B. Br. E. Harold und Gemminger "Catalogus Coleopterorum“) sämtliche Beschreibungen einer Art citiert, auch alle biologischen, anatomischen und physiologischen Angaben, alle Versetzungen in verschiedene Genera ersichtlich macht und dass sämtliche Citate aus erster Quelle geschöpft und nicht den rorhandenen Monographien entnommen sind, was ihnen den Wert der Ursprünglichkeit gibt. Dalla Torre hat sich mit seinem einheitlich durchgeführten Hymenopterenkatalog ein bleibendes Denkmal gesetzt, für das ihm die Wissenschaft Dank schuldet.

Fr. Fr. Kohl (Wien).

\section{Vertebrata.}

Amphibia.

94 Lebrun, Hector, La Cytodiérèse de l'œuf. La vésicule germinative et les globules polaires chez les batraciens. Sixième mémoire. Les cinèses sexuelles chez Diemyctilus 
torosus. In: La Cellule. 20. Band. 1901. 1. Heft. pag. 1-99. Taf. I-IV.

In der Einleitung betont Verf., dass er eigentlich beabsichtigt habe, die Untersuchung der Amphibien-Lireifung, nachdem er sie zwölf Jahre betrieben, abzubrechen. Nur der Umstand, dass er grelegentlich einer Reise nach Kalifornien sehr rollständiges Material einer nichteuropäischen Urodelen-Species, des Diemyctiüus torosus sammeln konnte, veranlasste ihn, nochmals dasselbe Gebiet zu behandeln. Das Material rerschaffte sich Verf. im März 1901 aus den Bergen bei Tocoloma in der Nähe ron San Francisco, da die Tiere in der Ebene zur Zeit des Aufenthaltes des Verfs. bereits abgelaicht hatten. Verf. rerarbeitete innerhalb acht T'agen iiber 1000 Weibchen. Er berichtete iiber die vorläufigen Ergebnisse der Untersuchung bereits am 15. Mai 1901 in der Mikroskopischen Gesellschaft San Franciscos und sandte den Bericht an Withman in Chicago zur Veröffentlichung im Biological Bulletin, was aber ohne seine Schuld unterblieb. Verf. vermutet, Whitman wolle die Monrve-Doktrin auf die amerikanische Fauna ausdehnen.

Der Ref. hält es für seine Pflicht, über diese abschliessende ${ }^{1}$ ) Arbeit Lebruns, der wohl als der beste Kenner der AmphibienEireifung bezeichnet werden muss, eingehend zu berichten.

IIethode: Diemyctilus gleicht Triton cristatus, laicht mehrmals im Frühjahr in mehrwöchentlichen Intervallen jedesmal etwa 30 Eier. Die Umarmung des Weibchens durch das viel kräftigere und grössere Männchen dauert mehr wie 12 Stunden. Gegen Fnde der Umarmung drehen sich Männchen und Weibchen die Kloakenöffnungen einander zu und das Männchen setzt einen Spermatophor in die weibliche Kloake. Verf. fand niemals Spermatozoen in den Eileitern, die Befruchtung erfolgt also offenbar beim Durchtritt des Eies durch die Kloake. Die Laichung findet 12-24 Stunden nach der Kopulation statt; Verf. lat die Ablage nie direkt beobachten können. Der Follikelsprung erfolgt stets erst bei Beendigung der Kopulation, denn Verf. fand niemals Bauchhöhleneier bei den in der Kopulation getöteten Weibchen. Eileiter und Eiwanderung entsprechen dem Verhalten bei unsern Tritonen. Bei der Fiablage verkriechen sich die Weibchen zwischen die Wurzeln von Bäumen an Bachufer'n. Y'erf. fand niemals abgelegte Eier ausser im Magen anderer Weibchen. Die Eierstocks- und Bauchhöhleneier liess Verf. mindestens ${ }^{1 / 4} 4$ Stunde in Gilsons Fliissigkeit, die aus den obern Eileiterteilen 1 Stunde, die aus dem untern Eileiterabschnitt 2 Stunden. Die Entbuilsung

1) Vgl. Zoolog. Zentr.-Bl. V. (1898) pag. 55 ff., V. pag. 433 ff., VII. (1900) pag. 174 ff., VIII. (1901) pag. 347 ff., IX. (1902) pag. 802 ff. 
der Eileitereier aus ihren Gallerthüllen gelingt ohne Beschädigung des Eies nur, wenn die Eier in der Gilson-lösmng gut gehärtet sind. Die Einbettung der Eier in Paraffin wurde wie früher ausgeführt. Die Färbung geschah nach neuer Methode durch starke DelafieldLösung, Ammoniak-Alkoholwaschung, Kongorotfärbnng, Differenzierung durch salzsauren Alkohol, Neutralisierung mit Ammoniakalkohol. Bei dieser Färbung wird das Nuclein tiefblau, das Protoplasma, die Dotterschollen und die achromatischen Figuren orangerot.

Eierstock und Eierstockei. Das Aussehen, die Grösse und Form der Eier sind identisch mit denen von Triton alpestris, ebenso das Pigment und seine Verteilung. Anch rler Ban des Ovars und die Anzahl der Fier und ihrer Generationen ist die gleiche. Nur die Zeit der Eiablage ist individuell verschieden. Verf. fand bei den einen das Ovar noch ganz gefüllt, bei andern waren nur noch die Eier für die letzte Ablageperiode darin enthalten. Verf. schiebt dies Verhalten auf das milde Klima Kaliforniens. 24 Stmonden vor dem Follikelsprung findet man das Keimbläschen am animalen Pol; sein Plasmanetz ist zwar stark nit Körnchen beladen, die offenbar von einer Nucleolenauflösung stammen, doch ist das Plasmanetz im Gegensatz zu den Tritoneiern dieses Stadinms noch deutlich zu erkennen. Das Keimbläschen zeigt im Innern bis 450 vakuolisierte Nucleolen, die eine nucleolenärmere, körnchenreiche Karyoplasmainsel unrahmen. Die kleinen Nucleolen dieser Insel sinı in fädiger Auflösung begriffen, sehen aus wie Clromosomen. Sie bilden meist Zwillingsschleifen (Rückerts .Chromosomenkonjugation“). Die fäligen Figuren erhalten sich nicht lange, sondern bilden Bürstenfignren. Die Entstehung (ler ersten Richtungsspindel findet bei Diemyctilus in der Regel in der Bauchhöhle statt, nur einmal fand Verf. den Beginn der Spindelbildung schon im Ovar. Andererseits fand Verf. in Bauchhöhleneiern bereits die zweite Richtungsspindel ausgebildet.

Verschwinden des Keimbläschens. Nach Vollendung der letzten Nucleolenauflösung ist das Plasmanetz des Keimbläschens so von Körnchen überschwemnt, dass man die Netzstruktur kaum nehr erkennt. Die Nucleinkörnchen lösen sich aber rasch auf; die enorme Nucleinmasse zieht nach des Verfs. Meinung aus dem Zellplasma gelöste Albumine an, so dass das Keimbläschen seine grösste Ausdehnung erreicht und grosse Vakuolen im Keimbläschen entstehen, durch die das Plasmanetz im Kern zu dicken Balken, die zwischen den Takuolen verlaulen, zusammengedrängt wird. Die Struktur sei aber nicht wirklich "wabig", sondern die "Wabenwände" bestïnden nur aus zusammengeschobenen Plasmanetzen. In diesem Stadium sind nur noch wenige, anscheinend regellos zerstreute Nucleolen vor- 
handen. Nun tritt ein merkwürdiger, bisher vom Yerf. noch nicht beobachteter (wol aber von O. Schultze, R. Fick vgl. unten) "Kiontraktionsprozess" im Keimbläschen ein, durch den die Vakuolenflüssigkeit aus dem Keimbläschen ausgepresst wird. Sie umgibt oft fast das ganze Kíeimbläschen als ein homogener, kongoroter Hof. Stets bleibt das Keimbläschen aber noch an einer oder der andern Stelle mit deu Dotter in Beruihrung. Das Exsudat bleibt nicht lange "homogen", sondern wird rasch vakuolisiert und sammelt sich an der vegetativen Seite des Keimbläschens an. Später trennt es sich ganz vom Keimbläschen und versinkt gegen den regetativen Lipol in der Dottermasse. Durch die Exsudation ist das Keimbläschen etwa auf die Hälıte seiner frühern Grösse geschrumpft und seime Struktur ist jetzt wieder dichtnetzig ohne Vakuolen. Verf. gesteht jetzt zu, dass diese seine neuen Ergebnisse mit den rom Ref. bestätigten Angaben von O. Schultze (und Goette 1869. Ref.), die er frïher lebhaft bekämpfte, übereinstimmen. Er glaubt, dass diese Vorgänge sehr rasch ablanfen und deshalb trotz deu Hunderttausenden ron Schnitten, die er untersucht hat, von ilm bisher nicht beobachtet bezw. anders (als besondere Form des "Nebenkerns") gedeutet wurden. Verf. glaubt, dass die Mehrzahl der ron den Autoren als Balbianis "Nebenkern" beschriebenen Bildungen solche ausgestossene Kerntrümmer sind. Diese Körper sind immer nur vergängliche Bildungen. $\mathrm{Zu}$ verschiedlenen Zeiten treten immer wieder neue solche Körper neben dem Kern auf. Terf. schliesst sich roll und ganz der von R. Fick 1899 (s. Zool. Zentr.-Bl. Jahr'g. VI. pag. 946) geäusserten Anschauung an, dass man nicht auf die Erhaltung der Individualität gewisser Zell- und Kernteile schliessen dïrfe, weil man zu verschiedenen Zeiten des Zellenlebens ähnliche Gebilde in ähnlicher Weise manöverieren sehe.

Während der Kernsaftausstossung hahen sich die der letzten Nucleolenauflösung entgangenen Nucleolen in der Mitte gesammelt und verschmelzen oft zu einer einzigen Masse. Während dessen hat sich auch die Kérnbläschenmembran aufgelöst, das Kiernplastinnetz strahlt in das Zellplasma aus.

Der geschilderte Hergang ist übrigens nicht die Regel. In der Regel sammeln sich die rerschmolzenen Nucleinmassen wie bei Bufo und den Tritonen im untern Teil des Keimbläschens, der ein besonders dichtnetziges Protoplasmafeld darstellt und vom Autor ,, Spindelfleck" genannt wird. Die Nembran löst sich dann zuerst am obern Pol des Keimbläschens und die Strahlung ist auf das Nucleolenkonglomerat zentriert.

Nun folgt ein Vergleich seiner Resultate mit denen von Helen 
K ing (s. Zool. Zentr.-Bl. Jahrg. IX. pag. 187 ff.). Verf. ordnet die Bilder Kings anders wie die Verfasserin. Die von King gefundene Tatsache, dass die in Wasser gelegten Ovarialeier ron Bufo sich zum Teil ganz gut weiterentwickeln, stimmt gut zu des Verfs. Befund, dass bei Bufo die Reifung sclion im Eierstock stattfindet.

Spindelbildung (pag. 34f. u. 36-38). Die Präparate ron Diemyctitus zeigen dasselbe, wie die der andern Species: Um den Spindelfleck bildet sich zuerst eine auf den ganzen Spindelfleck zentrierte Strahlung olne Centrosomen oder Sphären. Die Spindel selbst ist zuerst tonnenförmig und besteht aus knäuelartig iiber die Pole weg laufenden Fäden. Die äussere Strahlung verliert sich nach Ausbildung der Spindel. Verf. betont, dass die Spindel schon fertig sein könne, wenn die Chromosomen noch unfertig sind, d. h. wenn sie noch nicht die volle Zahl und die richtige Form zeigen, nämlich noch zum Teil von groben Chromatinbrocken vertreten werden.

Später bildet sich eine deutliche Polstrahlung aus, deren stärkste Strahlen sich im Äquator überkreuzen. Die Dotter- und Pigmentkörner drängen sich mehr und melrr gegen die Spindelfigur vor. Bald sind von der Polstrahlung nur noch die zum Äquator ziehenden Fasern (erentuell sogar nur auf einer Seite) vorhanden. Allmählich wird die Spindel spitzpolig und dichtfaserig, dann wird sie wieder oval, die Pole abgeplattet.

Ausarbeitung der Richtungschromosomen (pag. 28-34 u. 38-43). Diese Abschnitte schildern an der Hand vorzüglich klarer Abbildungen in einleuchtender Weise die allmähliche Ummodelung der endgiiltigen zwölf Richtungschromosomen aus den klumpigen Nucleolenkonglomeraten des aufgelösten Keimıläschens. Bei Diemyctilus ist die Variabilität noch grösser wie bei Rana. An ein und derselben Spindel sind die einzelnen Chromosomen anfänglich oft zum Teil noch Blöcke, zum Teil Stäbchen, Kreuze, Ringe, U-Schleifen, doppeltgekrümmt oder ..zopfartig“ (Ref.) gewunden. Erst allmählich

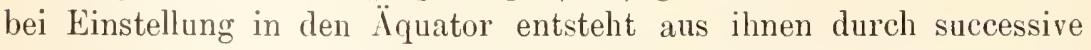
Teilung und Formumwandlung die richtige Zahl der definitiven U-förmigen Schleifen. Dabei kommt nach des Verfs. Meinung oft eine zweimalige Querteilung der Chromatinfäden vor, der aber nach Ansicht des Verfs. absolut nicht die von Weismann angenommene Bedeutung zukommt. Verf. bespricht eingehend die Formwandlung und Art der Anheftung an die Spindel von jeder der angegebenen Chromosomenform.

Im vollendeten Äquatorialstern liegen die U-Schleifen nur im Spindelmantel und ihre freien Enden sind nach der Peripherie gewendet. Die Spaltung der Chromosomen in die beiden Tochterschleifen 
findet (mindestens manchmal) erst im vollendeten Ïquatorialstern statt (s. Fig. 31). Die Spaltung ist bei manchen ('luromosomen eine Längsspaltung, bei andern ( . B. den Ringchromosomen) eine einfache oder doppelte Querspaltung. Terf. meint, diss manclimal vor der Wanderung der Chromosomen zu den I'olen noch eimmal eine V'erklebung der beiden Tochterhälften der Chromosomen im Ïquatorialstern stattfinde. In Fig. 33 bildet el einen solchen Ïquatorialstern mit ganz regehmäig geformten, noch nicht oder nicht mehr gespaltenen U-förmigen Chromosomen ab. Verf. betont, dass jetzt sogar in Flemmings Lager Carnoys im ,Jahre 1885 autgestellter Satz, dass keine einzige besondere Frscheinung bei der Karyokinese wesentlich, d. h, bei allen \%ellen gleich sei. ausser dem Endresultat der gleichmäßigen Chromatimhalbierung, bestätigt sei durch II eves' Arbeit über Paludina rivipara.

Bei der Wanderung der Chromosomen nach den Polen gehen die Schleifenwinkel voran. (Nach des Ref. Meinung stellt dieser Torgang z. B. eine der von F l emming hetonten koustanten, wesentlicher mitotischen Escheinungen dar.) Wenn die schleifen am I'ol angelangt sind, "tritt eine totale lerschmelzung derselben zu einem homogenen Chromatinklumpen ein, die lerf. anı zentralen l'ol der Richtungsfiguren hisher noch bei keiner andern Amphibienspecies beobachtet lat. - Während der Wanderung der Chomosomen zu den Polen verlieren sich an der Spindel anch die mächtigen, in Äquator sich kreuzenden l'olstralılen, die spindel wird zuerst länger und schmäler, bei Abschuürung der ersten Richtungszelle aber dann bedentend kiirzer. Im die Richtungsstelle lierum bildet sich ein dichter Pigmentring. - Die erste Richtungszelle ist anch hier nicht kuglig, sondern scheibenförmig. Die Chromosomen derselhen sind meist zu einem Kilumpen verschmolzen, manchmal erhalten sich aber einzelne. - \% weite Reifungsfigur. Dreimal fand Verf. Bauchböhleneier, die schon in der zweiten Reifungsteilung begriffen, sonst erfolgt sie stets erst im untern ${ }^{1}{ }_{3}$ des Eileiters, also kur\% vor der Eiablage. Verf. erklärt jene Ausnahme in ansprechendster Weise dadurch. dass diese Eier woll durch Darmschlingen rom Eingang in den Eileiter abgehalten worden seien. Nach der ersten Reifungsteilung tritt eine Verschmelzung der im Ei zurïckbleibenden Chromosomen der ersten Reifungsspindel ein, die Verf. als ein .Ruhestadium" bezeichnet. Bald findet aber wieder eine 'Trennung in 10-11 einzelne U-förmige Chromosomen statt, deren Schenkel, wie es scheint, doppelt gekriimmt und miteinander doppelt verklebt sein können. Das Stadium des Aquatorialsterns scheint lange Zeit bestehen zu bleiben. Spätere 
Stadien hat Verf. überhaupt nicht beobachtet. Bei einigen Chromosomen dieses Stadiums fand Verf. eine Körnelung ausgeprägt. Die Entstehung der zweiten Richtungs sp indel komnte Verf. nicht genauer verfolgen. Einmal fand Verf. auf dem Stadium des Äruatorialsternes deutlich kuglige „Sphären" und Polstrahlungen an beiden Polen der zweiten Reifungsspindel, sonst, aber niemals etwas ähnliches.

Ein besonderer Abschnitt (pag. 55-59) ist der Widerlegung der Angaben Helen Kings gewidmet; die Widerlegung stützt sich zum Teil auf dieselben Einwände, die Ref. (rgl. Zool. Zentr.-Bl. 9. Bd., pag. $187 \mathrm{ff}$.) gegen Kings Darstellung erhoben hat.

Die 2. Hälfte der Arbeit behandelt den Einfluss der Eruährung anf die Eireifung. Verf. sehickt voraus, dass er letztere Untersuchungen für hundertmal wertroller halte, wie alle Theorien von Weismann und seiner Schule; es sei viel zu viel Wert auf die Chromosomenzahl gelegt worden; dieselbe sei auch an der ersten Richtungsspindel nicht einmal bei derselben species konstant und von ganz bestimmten ..Redulitionen“ der (hromosomenzahl und Masse als den wesentlichsten Erscheinungen bei der Eireifung kömne gar keine Rede sein.

Einfluss der Ernährung auf den Zeitpunkt der Reifung; Verf. schiclit voraus, dass die Eier lü̈ufig gewissermaßen als Reservestoffbehälter dienen und bei Nahrungsmangel der Individuen mehr oder weniger vollständig aufgezelurt werden. (Degeneration der Eier bei gefangenen Fröschen.) Bei den Fröschen und Kröten erfolgt die Eiablage an den ersten warmen Tagen, also unmittelbar nach einer langen Hungerzeit. Die Tritonen legen ihre Eier später ab, wenn die Tümpel auszutrocknen beginnen und ihre Nahrung knapp zu werden beginnt. Ähnlich ist es bei Salamandra und Alytes, wo auch die Follikelberstung und Befruchtung naeh einer Hungerperiode erfolgt. Verf. setzt in ansprechendster Weise auseinander, die Kier stellten gewissermaßen nahrungaufspeichernde Parasiten dar, die bei Eintritt einer Hungerzeit dem Organismus lästig fallen und denen in solchen Zeiten die Verwendung als Reserve-Nährmaterial droht. Durch die plötzliche Veränderung des Stoffwechsels, der, statt ihnen Nahrung zuzuführen, plötzlich Stoffe entzielıt, wird die Re i i ung der Eier eingeleitet. Loeb und Budgett haben bei Eintritt von Sauerstoffmangel eine Auflösung der Kémmembran beobachtet. Verf. meint, auch die feste, Atmung behindernde Umarmung der Froschweibchen durch die Männchen müsse den Sanerstoffmangel im Weibchen rermehren. Ausser dem Ernälırungs- und Sauerstoffmangel soll auch die Entwässerung, die allmähliche Konzentrierung der Körpersäfte einen Reiz zur Reifung abgeben; Bataillons Versuche zeigten, dass bei Deshydratation 
Kernteilung ohne I'rotoplasmateilung eintrete. Terf. vermutet auch für die Samenreifung dieselben Ursachen.

Einfluss der Ernährung auf die Nucleinfiguren. Vert. glaubt, dass die Nucleolenverschmelzung, also die Konzentrierung des Nucleins auf den Eintritt eines Hungerzustandes hindeute, die Zerstreuung der Nucleolenauflösungsprodukte hingegen nur bei guter Ernährung stattfinde. Die Nucleolenumwandlungen vergleicht Verf. mit Kernteilungen. Das Keimbläschen sei ein grosses Syncytium mit kleinen wachsenden und sich teilenden Kernen; die Teilung erfolge mit allen wesentlichen Charakteren der Kinese. (? Ref.) Die Frnährung der Eierstöcke sei eine ïberreiche, weil sie nicht durch Nachbarzellen gehindert werde. Beim Hungerzustand der Amphibien wïrden nur die Keimblïschen-Nucleolen rom Sauerstoffmangel ergriffer und zur Teilung getrieben, nicht das Keimbläschen und die Eizelle selbst. An Schluse dieses Alschnittes spricht Terf. die Neinung aus, die Eireifung mit den Richtungsteilungen wïrden nur durch die mechanischen Insulte bei der Eiwanderung und durch die Wasserentzichung ron seiten der enorm hydrophilen Schleimhüllen bewirkt. Diese Theorie wird nach des Ref. Meinung allein schon durch die Tatsache, dass die Eier bei bufo vulgaris bereits im Eierstock rollständig reif werden, widerlegt.

Dis Kapitel über die Befruchtnng enthält u. a. Betrachtungen ïber L oebs und R. Hertwigs Ergebnisse und Anschauungen. In einem besonderen Abselmitt über die Individualität der Vorkerne wendet sich Vert. gegen die Annahme vieler Autoren, dass die Theorie Boveris vom Erlraltenbleiben der väterlichen und mütterlichen Chromosomen während der Furchung bei Ascaris, Crepidula u. a. bewiesen sei. Verf. bestreitet das auf Grund eigener Untersuchung an Ascaris und Conklins eigenen Abbildungen. In einem Schlussabschnitt über das Centros om protestiert Verf. gegen Bemerkungen Wilsons über Carnoys und des Verfs. Ascaris-Arbeiten. Verf. betont mit Stolz, dass allmählich immer mehr Autoren sich davon ïberzeugen, dass die Centrosomen nicht als dauernde Zellorgaue angesehen werden können.

R. Fick (Leipzig).

\section{Aves.}

95 Svenander, Gustar, Studien über den Bau des Schlundes und des Magens der Vögel. In: Kgl. Norsk. Vidensk. Selsk. Skrift. 1901. Nr. 6. Trondhjem 1902. (Inaugural-Dissertation a. d. Univ. Upsala 1902). 240 pag. 8 Taf.

In der vorliegenden Arbeit, die in dem Zoologischen Institut Upsala ausgefïhrt wurde. hat der Verf. sich bemüht, nicht nur 
den bau der Speiseröhre und des Magens zu beschreiben, sondern auch die Beziehungen zwischen den Strukturverhältnissen jener Organe und der Beschaffenheit der Nahrung darzulegen. Im speziellen Teil wird zuerst die makroskopische Anatomie der betreffenden Organe ron nicht weniger als 134 Vogelarten mehr oder weniger eingehend beschrieben (pag. 6-64), damn folgt eine Darstellung der mikroskopischen Strukturverhältnisse bei 47 Vögeln (pag. 64-153). In diesen beiden Abschnitten des speziellen Teils werden die besprochenen Vogelarten in je drei biologische Diät-(xruppen eingeteilt, nämlich 1. solche, welche sich von animalischer Kíst, 2. solche, welche sich sowohl von aninalischer als regetabilischer host und 3. solche, welche sich ron vegetabilischer Kost ernähren. Eine solche Einteilung lässt sich nutiurlich nicht ganz streng und konsequent durchführen, weil ja gewisse Vögel bald ron dieser, bald von jener Art ron Nahrung fressen, man kann deslatb vielleicht in gewissen Fïllen andere Ansichten als der Verf. hegen; da er sich jedoch atuf eigene beobathtungen stiitzt, darf man ihm nicht so viel widersprechen. Im allgemeinen Teil (pag. 15t-218) erliält man eine Zusammenstellnng der gewonnenen Resultate. Yon diesen sind besonders die folgenden zn erwähnen. Tei den von ilm untersuchten Vögeln konnte der V'orf. vier verschiedene liropftypen unterscheiden: 1. .Der Kropt' bestelit aus einer allseitigen spindelfömigen Erweiterung des (isophagus und ist etwa an der Mitte des Halses. demnach ein stiick oberhalb der Furcula gelegren. Wenn ant stärksten ansgebilutet, schiebt er sich in gefïlltem /ustande dorsalwärts an der rechten Seite des Halses rorbei, so diss er auf' der liückseite des Halses zu liegen kommt." Einen solehen Kropf fand der Verf. in höclister Entwickehng bei den Fringilliden, schwächer bei einigen sumpf- unı Schwimmrögehn, wie Machetes, thur. 2. .. ler Kropl besteht aus einer, an der Vorder-

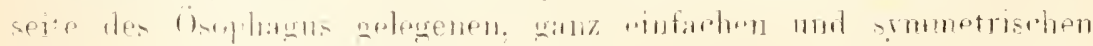

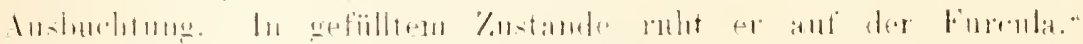

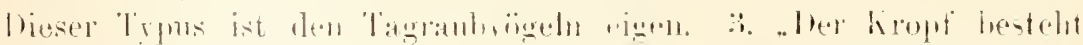
athe einer lach vorne sehr erweiterten schwach schlingentörmigen Partie des (i)sophagus und wird deshalb unsymmetrisch. In gefülltem Zustande ruht er auf der Fur'ula." Einen solchen Kropf besitzen die Papageien und Hühner. 4. „Der Kropf besteht aus einer etwas nach vorne, hauptsäthlich aber seitwärts, erweiterten Partie des Ösophagus und bildet infolgedessen zwei Seitentaschen, die beiderseits des Halses gelegen sind und auf der Furcula aufliegen." Einen solchen Kropf haben die Columbcte. Bei T'auben, Hiihnern und Papageien wird die Nahrung eine Zeit lang im Ḱropfe zurückgehalten, auclı wenn sie hungern, bei den anderen wird der Kropf nur angewandt, wem 
der Magen gefüllt ist. Kigentiimlich ist jedoch, dass bei den I'apageien im Kropfe und im Ösophagus oberhalb desselben Drüsen gänzlich fehlen. Bei den Tagraubvögeln (ausser Falco) dienen neben dem Kropfe auch Drïsen- und Muskelmagen zur Aufbewahrung grösserer Nahrungsmengen und bei Ardea und Phalacrocorax, die keinen Kropf haben, nur die letateren Organe. Bei Falco dient neben dem Kropf nur der Muskelmagen dazu. Bei anderen, den Kropf entbehrenden Vögeln haben sich andere Organe zur Aufspeicherung grösserer Nahrungsmengen besonders ausgebildet, 7. B. bei Cuculus, Caprimulgus und Striges nur ter Muskelmagen, bei Jynx. Picus muthes und ciridis nur der Drüsenmagen, bei Longipennes und 'T'ubinares Ösophagus nebst dem Drïsemnagen. Ias Epithel der Speiseröhre wechselt sehr betreffs der Mäclitigkeit. Im allgemeinen ist es am liräftigsten bei den Inselitenfressern entwickelt, unl der Verf. hat interessante Anpassungen in diesel Bezielnngg entdeckt. Gewöhnlich sind die Epithelzellen bei diesen Vögelı innen nicht geschichtet. Bei Cuculus scheinen the oberthathlichen \%ellen anzuschwellen und zu verschleimen. Rei Ameiscufressern wie Jymx. Picus rividis und martius findet man an der Obertliiche des ansserordentlich stark entwickclten Epithels eine Schicht von geschnumpten, zerstörten Zellen. dann eine lage ron grossen. klaren Zollen und zu nuterst lileinere, sich stärker fäbonde Matrixzellen, Interhalh des Fupthels liegt eine Bindegeweheschicht, dann folgt rine Iängsmusliclsehicht. welche der Verf. aut eine befriedigende Weise in Chercinstimunng mit (oppel

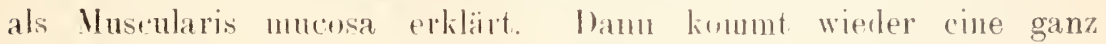
domne, hisweilun sogar fehlende Subnucosa, sowie Ringmuskeln, die bei verschiedenen Formen rershieden entwickelt sinl, am besten bei denjenigen, die grössere lingenstande verschlingen, wie Phalacrocorar, Larus etc. besser bei deu inselitenfressenten Passeles als bei den

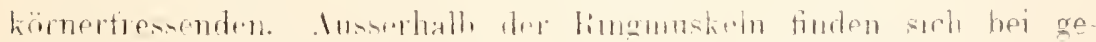

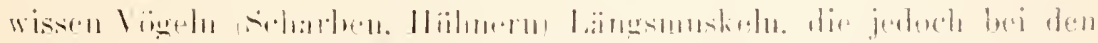

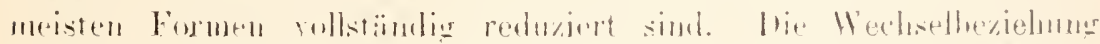
in der verschiedenen Entwiekelung des hroplés und der Magenabteilungen ist schon angedentet. Am besten wäre es ja, wenn ein Futterbehälter von nöten ist - was bei allen Vögeln, welche ihre Nahrung in grösserer Menge auf einer Stelle finden, der Fall ist dass der von grössern, zarten Irüisen freie Muskelmagen sich tiir diesen Zweck entwickelt lıätte. Dies kann aber nicht in solchen Fällen stattfinden, da dieser Magenabschnitt seine starke Muskulatur nicht aufgeben kann, weil dieselbe (immer oder nur bisweilen) für die Zerkleinerung der Nahrung notwendig ist. Deshalb begegnen wir einer solchen Anpassung bloss bei tenjenigen, die sich ausschliesslich von 
weicher animalischer Kost ernähren. Die inneren Strukturverhältnisse der beiden Magenabschnitte werden ausführlich besprochen. Der Muskelmagen z. B. liann inwendig eben oder mit Falten oder Leisten versehen sein. Oft tragen diese mehr oder weniger entwickelte Papillen oder stehen die Papillen auf einer ebenen Fläche. Die Sekretschicht, die den Muskelmagen anskleidet, wird teils von dem durch die schlauchförmigen Drüsen abgesonderten Sekret, teils durch die Tätigkeit des zwischen den Drüsen gelegenen Magenepithels gebildet. Das Sekret verhäit sich verschieden je nach dem Ursprųnge. Das der Druisen ist viel stärker und fester, das des Epithels weniger hart und mehr elastisch. Ia nun durch Falten- oder Papillenbildung oder beide zugleich die Epithelfläche zwischen den schlauchförmigen Driisen vergrössert wird, so folgt daraus, dass die Seliretschicht in einem Magen mit gefalteter Oberfläche elastischer wird, als in einem Magen, wo die Drüsen ganz dicht mit nur wenig /\%wischenraum stehen. Es erweist sich anch, dass bei besonders erweiterungsfähigen Magen die Falten- oder Papillenbildung besonder's ansgeprägt ist. Dies wird an zahlreichen Beispielen auseinander gesetzt. Aus den schlauchförmigen Drüsen Hiesst ein Sekret, das slüter erstarrt und aus den Drüsen selbst wie säulenförmige Bildungen herrorragt. Wenn es aber noch Hliissig ist, Hiesst es aus und breitet sich von einer Drüse zur anderen aus und verbindet die Sänlen mit gewölbeförmigen Brücken. Die Drüsenabsonderung ist intermittierend und wïhrend der Zwischenzeit bildet sich von dem Magenepithel, besonders demjenigen der Falten und Papillen, die oben erwähnte elastischere Zwischensubstanz, die oft Reste abgestorbener Epithelzellen enthält. Infolge dieser Unterbrechung der Absonderungen von den verschiedenen Partien des Magens und des verschiedenen Baues der Magentläche wird eine Schichtung der Sekretschicht hervorgerufen, welche oft undentlich und unregelmäßig ist, hisweilen aber ziemlich regelmäBig erscheinen kann. Übrigens finden sich eine Menge wertvoller Angaben über die Ausbildung der Muskeln, des Bindegewebes, der Drüsen, Leukocytenansanmmlungen etc. und in vier Tabellen wird die Mächtigkeit der verschiedenen Gewebeschichten im Ösophagus und in den Magenabschnitten sowie auch die Grösse der Drüsen etc. bei verschiedenen Vogelarten vergleichend dargestellt.

Eine nicht genug zu schätzende Leistung dieser Arbeit liegt auch darin, dass eine Menge Fehler früherer Autoren vom Verf. gewissenhaft richtig gestellt worden sind.

E. Lönnberg (Upsala).

\section{Mammalia.}

96 Loweg, 'Th.. Studien üb er das Integument des Erethizom dor- 
satu. (Erethizon dorsutum Cuvier). In: Jenaische Zeitsclu. fiir Naturw. Bd. 36. 1900. pag. 1-39. 2 Taf.

Verf. untersuchte die Hautgebilde eines $18 \mathrm{~cm}$ langen Embryos des nordamerikanischen Nagers Frethizon dorsatus aus der Familie der Kletterstachelschweine. Die Arbeit bildet eine I'arallelarbeit zu Römers Untersuchung an einen Embryo von Thryonomys (Aulacodus) rinderians Tem. und zeigt, dass die Finteihng der HautoherHäche in Schuppen wie bei Aulacodus nur eine scheinbare ist, die dadurch zu stande kommt, dass die Stacheln und Haare in charakteristischer Schuppenstellung gruppiert sind. Diese reigen auf dem ganzen Körper - auf dem Rücken die Stacheln, am Kopt, am Bauch und an den Seiten die Haare - dieselbe Anordnung, indem eine Anzahl Stacheln und Haare (meist 9) nebeneinander in einer leicht gebogenen Linie in altemierenden Reihen liegen und zwischen sich haarfreie Felder lassen, da sie nur an deren Hinterende hervortreten. In nun die Haut die Haare und Stacheln an ihrer Austrittsstelle wallartig umgreift und um das Haar eine kleine Vertiefung bildet, die in ihrer Zusammenwirknug in einer jeden Haargruppe wie ein dunkler Strich erscheinen, so wird der hintere, etwas ansteigende Rand einer Schuppe vorgetäuscht und man hat den Eindruck, als ol, der ganze Körper mit kleinen Schuppen bedeckt sei.

Die Schnitte durcl solche Hautstellen zeigen aber, dass eine grosse Cutispapille, welche einer einheitlichen schuppe üher einer jeden Haargruppe zu grunde liegen nuisste, nicht gebildet wird. Wohl erscheinen aut Schnitten durch den hintern liand einer vermeintlichen Schuppe zwischen den einzelnen Hatren Hache Erhebungen, welche Papillen ähnlich sehen. Aber sie enthalten keine besondern Wucherungen des Cutisgewebes und erheben sich kaum über das allgemeine Nivean der Haut. Sie sind nur scheinbare Papillen, die dadurch entstehen, dass die Haut die Hatre an ihrer Ausmündung wallartig umgreift.

Beim erwachsenen Tier findet sich anf der ()berfläche der Felder eine üppige Behaturung von feinen Wollhaaren, deren erste Anlage auf Schnitten durch die Haut des Embryos auch schon zu sehen sind, während die Stachehn und Hare unter dem hintern Rande schon voll atusgebildet sind und die Hant durchbrochen haben. Die histologische Untersuchung ergab ferner, dass die Stacheln nichts anderes als voluminös entwickelte Einzelhare darstellen und dass die Ĺnterschiede der drei Hautgebilde Haare, Borsten, stacheln nur in der rerschiedenen Stärke und Entwickelung zu suchen sind.

Die Stacheln des Erethizon schliessen sich an diejenigen des Igels und des Stachelschweines an, sie haben mächtig entwickelte 
Talgdrüsen und besondere Muskelfasern, welche das Aufrichten der Stacheln bewirken.

Bezüglich der phylogenetischen Deutung schliesst sich Verf. der Ansicht Römers an, dass die Hautfelder mit der charakteristischen Gruppierung der Stacheln und Haare die letaten Überreste eines ehemaligen Schuppenkleides sind, welches den Stacheln und Borsten ihre Stellung rorgeschrieben hat. Die Beziehungen zwischen beiden sind nur topographische gewesen. Die Haare können sich zunächst nur unter dem hintern freien Rande der schuppen entwickelt haben. Als darn späterhin die Schuppen immer mehr an Bedeutung verloren und schwanden, haben sich die Haare erst ihrer Plätze bemächtigt.

Denselben Vorgang sehen wir heute noch an dem Embryo ontogenetisch. Die Schuppen sind geschwunden, aber ihre Plätze sind noch vorhanden. An dem hintern Rande dieser Schuppenfelder entwickeln sich zunächst einige wenige stacheln und Borsten und erst später legt sich auf den Schuppenfeldern ein allgemeines Kleid ron feinen Wolthaaren an.

Der Embryo hat an jeder Körperseite, etwa $3 \mathrm{~mm}$ seitlich ron der Achselhöhle, aber gegen den Riïken hin verschoben eine Zitze mit gut entwickelter, in der Tiefe der ('ntis gelegener Milchdrüse. Sie ist von einer tiefen Mammartasche umgeben. Durch Ausstïlpen derselben kann die '/itze während der Laktationsperiode verlängert und dem .Jungen zwischen den Borsten und stacheln zugänghich gemacht werden. Ihre dorsale Lage (ähnlich wie bei Myopotamus) ist als eine Anpassung an das Baumleben anzusehen und behindert die Mutter in der Laktationsperiode am wenigsten.

$$
\text { F. Römer (Frankfurt a. M.). }
$$

97 Palacky. J.. Die Verbreitung der Meeressäugethiere. In: Zool. Jahrb. Abtheil. f. System. Band 15. 1901. pag. 250-266.

Fine Zusammenstellung und Vergleich der fossilen und recenten Arten hauptsächlich nach Trouessart und Zittel, für die Pinnipedien, Sirenen und Cet a ceen nach ihrer Anzah] der Arten und ihrer Verbreitung, die aber die newere Literatur nicht gebührend herücksichtigt (z. B. bei den Sirenen und Cetaceen nicht), mit unzusammenhängenden Gedanken und Fragen über die Abstammung und Verwandtschaft der verschiedenen Gruppen, woraus sich ergiebt, dass die Meeressäugetiere in Absterben begriffen sind, die ältere Verbreitung gleichmäßiger war als die jetzige und ein arktischer Ursprung ausgeschlossen erscheint.

F. Römer (Frankfurt a. M.). 


\title{
Zoologisches Zentralblatt
}

unter Mitwirkung von

Professor Dr. O. Bütschli

in Heidelberg

herausgegeben von and Professor Dr. B. Hatschek

in Wien

\author{
Dr. A. Schuberg \\ a. o. Professor in Heidelberg.
}

Verlag von Wilhelm Engelmann in Leipzig.

\section{Referate.}

\section{Allgemeine Methodik und Technik.}

98 Programme und Anweisungen zu Beobachtungen und zum Anlegen von Sammlungen im Gebiet der Naturwissen-

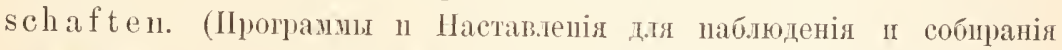
колтекцій по Естествениой Неторін.) Zusammengestellt von einer speziellen Kommission im Auftrage der K. Natf. Gesellschaft. 5. verbesserte und vermehrte Ausgabe. St. Petersburg. Selbstverlag der Gesellsch. 1902. 595 pag. 302 Ahb. i. T. (Russisch.)

Das rorliegende Werk ist speziell für den Gebrauch der Vorstände von naturhistorischen Museen der Gouvernementslandschaften, ferner aber auch für alle Freunde der Naturwissenschaften überhaupt bestimmt. Es umfasst nicht nur die reinen Naturwissenschaften, sondern ausserdem noch die Gebiete der Bodenkunde, Hydrologie, Meteorologie, Landwirtschaft, Photographie und der Bodenaufnahmen. Ton einer Reihe speziell hierfuir befähigter Fachleute bearbeitet, bieten die ,Programme und Anleitungen" eine Menge ausgezeichneter Anweisungen und Ratschläge für alle, welche sich mit dem Sammeln und Ordnen naturhistorischer Objekte beschäftigen. Die uns speziell interessierenden Abschnitte VI: ,Instruktionen zum Anlegen von Tiersammlungen und zu Beobachtungen des Tierlebens ${ }^{6}$ und VII: ,Einrichtung von Süsswasseraquarien und Terrarien und deren Instandhaltung" umfassen 370 pag. und sind mit vielen $\mathrm{z}$. $\mathrm{T}$. eigens für diese Ausgabe angefertigten sehr guten Abbildungen ausgestattet, welche sowohl typische Vertreter der einzelnen Gruppen, wie auch Methoden zum Sammeln, Präparieren und Aufbewahren darstellen. Der VI. Abschnitt enthält folgende Kapitel: Über das 
Anlegen der Sammlungen von Säugetieren und Vögeln (Erlegen, Präparation der Bälge, Behandlung der Eier, Beobachtungen der Lebenserscheinungen, Ausstopfen, Skelettieren) von A. M. Nikolsky u. a.; Sammeln von Reptilien und Amphibien; Sammeln von Fischen (dieses von H. A. Warpachowsky und J. D. Kuznetzoff bearbeitete Kapitel enthält genaue Angaben darüber, wie die verschiedenen Arten behandelt werden mïssen, welche Frscheinungen im Leben der Fische besondere Beachtung verdienen usw., und ausserdem 'Tabellen und Abbildungen (nach F. A. Smitt) zum Bestimmen der europäischsibirischen Salmo- und Coregonus-Arten); Sammeln, Aufbewahren und Verschicken von Insekten und das Beobachteu ihres Lebens ${ }^{1}$ ); Instruktionen zum Sammeln wirbelloser Tiere, exkl. Insekten (dieser von X. M. Knipowitsch redigierte Abschnitt enthält u. a. Angaben ïber die anzustellenden Beobachtungen der Lebenserscheinungen, Lebensbedingungen, klimatischen Verhältnisse u. dergl., Fang mit den verschiedensten Vorrichtungen für Süsswasser- und Neeresbewohner, Konservierungs- und Verpackungsmethoden, spezielie Angaben für die Behandlung der einzelnen Gruppen mit Abbildungen charakteristischer Vertreter); Beobachtung der in wirtschaftlicher Hinsicht schädlichen Insekten (dieses, wie auch die folgenden, von A. A. Silantjeff verfasste Kapitel bespricht die periodischen Erscheinungen im Leben der Insekten, die Parasiten und sonstigen Feinde schädlicher Insekten, die Einwirkung der Tätigkeit schädlicher Inseliten auf das Wachstum der Pflanzen): Anweisungen zum Sammeln und Konservieren von Proben durch 'Tiere beschädigter Pflanzen; Programm zum Studium des Lebens und der Tätigkeit ständig oder zeitweilig im Erdboden lebender Tiere (Höhlen und Gänge grabender Tiere, Zusammensetzung, Quantität der nach atussen beförderten Erde: Fintluss dieser Tätigkeit auf den Boden und die Gewächse). Das Kapitel über Aquarien enthält gute Ratschläge über Bau, Durchliiftung und Besetzung derselben. Überall ist der einschlägigen Literatur reichlich Rechnung getragen. Eine weitere Verbreitung des äusserst praktisch verfassten Werkchens wäre für Sammler, Reisende, Forstleute, Landwirte u. dergl. m. von grossem Nutzen.

N. v. A delung (St. Petersburg).

\section{Vergleichende Morphologie, Physiologie und Biologie.}

99 Schimkewitsch, W1. Über direkte Theilung un terkünstlichen Be dingungen. In : Biolog. Centralbl. Bd. 22. 1902. pag. 605-608. Verf. gibt eine Zusammenstellung der vorliegenden, ziemlich zahl-

1) Über dieses vortrefflich verfasste Kapitel wurde bereits (Zool. Zentr.-Bl. 1902, pag. 132) auf Grund einer Sonderausgabe referiert.

- $\mathrm{Nr} .98-99$ 
reichen Angaben über das Eintreten der Amitose anstatt der Mitose mnter verschiedenen künstlichen Bedingungen und fügt einen neuen Fall hinzu: durch Injektion verschiedener Stoffe in das Eiweiss der Hühnereier lïsst sich beobachten, "dass oft die Zellen der Embryonalscheibe begierig den Dotter zu verschlingen anfangen, und dass dieser I'rozess, der gewöhnlich in der Gegend des Randentoderms vor sich geht, sich auf das ganze Entoderm der Scheibe ausbreitet und dass sogar bei der danach folgenden Degradation der Scheibe die Zellen des Mesoderms und Ektoderms an diesem Prozesse teilnehmen und darin dem Randentoderm ähnlich werden. Zuletzt degeneriert der Embryo und die Scheibe erscheint als Syncytium mit Kernen und verschlungenen Dotterpartikeln; dabei tritt oft Amitose auf. Verf. hält es für wahrscheinlich, ,dass die Zelle, sobald sie in ungünstige Verhältnisse gerät, ehe sie der Degeneration anheimfällt, auf diese Verhältnisse durch erhı̈hten Stoffwechsel reagiert, welcher den Übergang des Kernes zur direkten T'eilung zur Folge lat."

R. S. Bergh (Kopenhagen).

\section{Coelenterata.}

100 Cerfontaine, P., Recherches expérimentales sur la Régénération et l'Hétéromorphose chez Astroides calycularis et Pennaria carolinii. In: Areh. de Biol. Bd. 19. 1902. pag. 245315. Taf. 8-9.

Verf. macht zunächst darauf aufmerksam, dass er schon im Jahre 1891 Beobachtungen über Heteromorphose bei Anthozoen (Astroides calycularis) veröffentlicht hat, die ganz unbeachtet geblieben sind, und die er nun wiederholt hat. Wird ein Polyp der erwähnten Art oberhalb des Kelches abgeschnitten, so bildet der am Platz gebliebene T'eil einen neuen Polypen, während das abgeschnittene Stïck am aboralen Ende einen neuen Polypen produziert; so entsteht also ein doppelköpfiges Tier ohne Skelett. Nur in einem Falle, in lem Verf. Sorge traf, dass das abgeschnittene Stück mit dem aboralen Ende angeheftet blieb, traf solches nicht ein; in diesem Falle wurde an der aboralen Fläche ein Kalkskelett (aus vier Stiicken bestehend) gebildet.

Verf. gibt weiter eine Übersicht des normalen Wachstums und der Konstitution der Kolonie von Pennaria cavolinii und beschreibt verschiedene zufällig aufgefundene UnregelmäPigkeiten in der Architektonik dieser Form (durch Atrophieen, Hypertrophieen und Beschädigungen verursacht).

In der Regeneration unterscheidet Verf. zwischen der normalen, jährlich eintretenden und der accidentellen oder experimentell 
erzeugten; letztere würden einfach dadurch zu stande gebracht, lass die Polypen in Aquarien gesetzt werden: dann findet eine rollständige Degeneration der Polypen mit nachträglicher Regeneration statt. In beiden Fällen weicht der Vorgang darin von dem normalen Wachstum ab, dass die Polypen ohne regelmäßige Ordnung zum Vorschein kommen (z. B. erscheinen die Polypen an der Spitze der Stämme und Zweige bei der Regeneration oft später als die weiter unten sitzenden, seitlichen, während sie bei dem normalen Wachstum immer zuerst erscheinen). Schliesslich kommt doch durch forgesetztes Wachstum die normale Architektonik zu stande. - Gelegentlich bemerkt Verf., dass bei Phoronis kowalevstii eine ähnliche annuelle spontane Regeneration rorkommt.

Von Heteromorphosen beschreibt Verf.: a) die Bildung von Hydrorhizen an der Stelle ron Stammgipfeln (oft sind die Hydrorhizen auch hier verzweigt, bilden ganze Netze; ein Eintluss des Geotropismus oder des Stereotropismus war nicht nachzuweisen); b) die Lrzeugung von Stämmen an der Stelle ron Hydrorhizen; c) die Erzeugung ron Hydrorhiza-artigen Verzweigungen an der Stelle ron sekundären oder tertiären Ïsten; d) Gonosomen an der Stelle, wo gewöhnlich Hydranthen sitzen, oder auch umgekehrt. Keine der Erscheinungen trat mit Konstanz auf und konnten die Bedingungen für das Auftreten der Heteromorphosen nicht festgestellt werden (im Falle b waren die Kolonien frei aufgehängt und durch Wasserströme in [passiver] Bewegung gehalten; aber anch hier war keine Konstanz in den Versuchsergebnissen).

Es folgt noch ein allgemeiner Teil, Betrachtungen rerschiedener Art über Regeneration und Heteromorphose enthaltend; Verf. hebt hervor, dass eines der wichtigsten bestimmenden Iomente für den Verlauf der betreffenden Vorgänge ist, dass die Möglichkeit, Nahrung zu erhalten, geschaffen werde; bisweilen übe das Nervensystem auch einen bestimmenden Einfluss aus. Zwischen der Regeneration und der normalen Vermehrung durch Kinospung existiert nach Verf. kein radikaler Unterschied. Den Begriff der Heteromorphose fasst Verf. in viel engerm sinne als lief. auf.

Endlich macht Verf. Nitteilungen über den Bau des Sporosacs von Pennaria und stellt fest, dass derselbe grosse Ähnlichkeit zeigt mit dem Bau von Sarsia (der Meduse von Symcoryne) nach F. E. Schulze. Die Unterschiede sind geringfügiger Art und durch die Lebensweise bedingt, indem die Ieduse sich frühzeitig (ror Ausbildung der (Geschlechtsprodukte) rom Hydroidenstamm ablüst, während der Sporosac höchstens (nach Trinchese) wohl in Ausnahmefällen, wenı 
ganz reif, sich spontan ablöst und schwache Schwimmbewegungen austïhren kann.

R. S. Bergh (Kopenhagen).

101 Godlewski, L. jr., Regeneration in Tubularia after longitudinal splitting. In: Bull. Acad. Sc. Cracovie. Cl. math-nat. 1902. pag. 387-396. 11 Textfig.

Verf. bemerkt, dass es schwierig ist, Tubularia-Stämme der Länge nach in ganz gleiche Hälften zu spalten, und er beschreibt den Verlanf der Regeneration, der recht rerschieden ausfällt, je nachdem das Stiick die Hälfte des Stammes oder mehr oder weniger enthält. In Stïcken, die grösser als die Hälfte sind, wächst über die offene Wunde von jeder Seite eine Zellmasse vor, so dass es schliesslich zur Vereinigung kommt. Diese Zellmassen bestehen anfangs nur aus Entoderm päter folgt das Ektoderm mit. In jenen (entodermalen) Zellwülsten tritt jederseits ein Lumen auf, und hier findet eine lebhafte Körnercirculation statt. - Sind die Stämme einigermaßen genau halbiert, so fängt der Regulationsprozess schon in ähnlicher Weise vie im vorigen Falle an; die vorwachsenden Wülste wachsen sich aber nicht unmittelbar entgegen, sondern biegen sich einwärts, um sich jederseits mit dem noch dem alten Perisark anliegenden Cönosark zu vereinigen; in dieser Weise wird das alte Lumen in drei Teile: ein mittleres, offenes und zwei seitliche, geschlossene abgeteilt; in diesen findet Körnercirculation statt. Später kommt es zur Verwachsung und Vereinigung aller drei Lumina. - In Stücken, die weniger als die Hälfte enthalten, tritt ein Solidwerden der ganzen Masse durch Verkürzung des Cönosarks und Anhäufung der Entodermzellen ein; erst später bildet sich eine neue Höhlung aus. So werden je nach der Grösse des Quersçhnitts verschiedene Modi der Regulation benuitzt.

Karyokinesen fand Verf. bei diesen Regulationen nicht.

Was die Anlage des Hydranthen betrifft, so erscheinen die Tentakelanlagen früher an dem alten Teil der Stammwandung als an der neugebildeten Verschlussmembran; der Hydranth geht unter rechtem Winkel vom alten Stammteil aus. Bisweilen entwickelt sich am aboralen Ende der Hydranth früher als am oralen (umgekehrt, wenn der Stamm nicht gespalten ist). Mitunter werden auch beide Hydranthen in der Mitte des Stammstücks angelegt und stehen sich hier gegenïber; das Verbindungsstück zwischen ihnen reisst dann, und es findet Durchbruch des Perisarks statt. Solche Hydranthen fallen nach 2-5 Tagen oft ab und kömnen noch einmal neugebildet werden.

R. S. Bergh (Kopenhagen). 


\section{Echinoderma.}

102 Delage, Yves, Nouvelles recherches sur la parthénogénèse artificielle chez Asterias glacialis. In: Arch. zool. expér. et génér. Sér. 3. Tom. 10. 1902. pag. 213-235̃.

Verf. macht auf die Unvollkommenheiten der bisherigen Methoden zur Erzeugung künstlicher Parthenogenese aufmerksam: nur eine gewisse, oft relativ geringe Zahl der Eier entwickelt sich, und selbst bei Anwendung desselben Agens macht sich dieser Übelstand geltend; dies hängt walırscheinlich $a b$ von der sehr verschiedenen Reife der Eier bei der kiinstlichen Entleerung aus den Ovarien. Auch sind die Embryonen und Larven ron viel geringerer Qualität als die aus befruchteten Eiern geziichteten; die schon von Loeb hervorgehobene Tatsache, dass die kïnstlich-parthenogenetischen Blastulae am Boden bleiben, ist nach Verf. nur eine Folge ihrer Schwäche. Verf. hat deshalb nach einem hesser wirkenden Agens gesucht und lat ein solches in der Kolılensäure gefunden; mit diesem Reagens gelingt es, fast $100 \%$ der Eier zur Furchung zu bringen und superbe „Auricularien" (Verf. nennt die Larre so, weil sie mit der typischen Holothurienlarve viel grössere Übereinstimmung zeigen als mit der Bipinnaria) mit allen Organen in voller Ausbildung zu erhalten.

Man präpariert "Selterswasser mit Meerwasser" und hebt die mit Kohlensäure gesättigte, sterilisierte Lösung bis zum Noment des Gebrauchs auf; Verf. gibt ausführlich die Vorsichtsmaßregeln, um Beimischung ron Spermatozoen zu verhüten, an. Der günstigste Moment für die Cberfühırung der Eier in die Lösung ist derjenige, wo das erste Richtungskörperchen sich in den am weitesten entwickelten Eiern zu zeigen anfängt. In der Lösung bleiben sie am besten eine Stunde, auch $1^{1}{ }_{2}-2$ Stunden Aufenthalt ist nicht schädlich : bei kürzerer Einwirkung ist der Prozentsatz der sich entwickelnden Eier geringer. Längere Einwirkung wirkt schädlich. In der Lösung scheinen die Eier in dem Zustand latenten Lebens zu sein: keine Spur von Entwickelung findet statt, und selbst angefangene Reifungsvorgänge stocken. Nach dem Zurückbringen in gewöhnliches Seewasser zieht sich das Protoplasma zusammen und hebt eine Membran ab; eine Furche bildet sich von einem bestimmten Punkt der Oberfläche aus, und die Furchung geht an. Fast nur solche Eier, welche noch ihr Keimbläschen ganz intakt hatten zur Zeit der Überführung in die Lösung, furchen sich nicht, und solche lassen sich auch nicht befruchten. Die Larven sind, soweit erkennbar, von ganz gleicher Qualität wie die aus befruchteten Eiern gezuichteten; es ist nach alledem nicht übertrieben zu behaupten, dass die Kohlensäure das 
Spermatozoon vollständig ersetzt hat; ja sie wirkt sogar in Falle künstlicher Entleerung der Ovarien zu einer in bezug auf die Eireife nicht allzu gïnstigen Jahreszeit stärker als die Spermatozoen; bei einer Gegenprobe mit künstlicher Befruchtung gelang es Terf. nur aus $30-40^{\circ} \%$ der Eier Larven zu zuichten. Die künstlichen parthenogenetischen Larven hielt Verf. 42 Tage am Leben (vom Anfang der Entwickelung an gerechnet); die Netamorphose hatte noch nicht angefangen; der Larvenzustand scheint bei der genannten Art sehr lange zu dauern.

Weiter erörtert Verf. die Frage, worauf die Wirkung der Kohlensäure als Entwickelungsförderer beruht. Nicht auf der einfachen, durch sie bewirkten Asphyxie; denn gekochtes Wasser bewirkt auch (durch die Abwesenheit des Sauerstoffes) Asphyxie und bringt keine Entwickelung zu stande. Auch nicht auf der Anästhesie; denn die andern Anästhetica (Chloroform, Chloral, Norphium usw.) in irgend welcher Dose zugesetzt, bleiben ohne entwickelungsfördernde Wirkung. Auch nicht auf der Aciditiat; denn keine andere Säure gibt entsprechende Resultate (am besten wirkt die Salzsäure, auch sie lässt sich aber der Kohlensäure nicht entfernt vergleichen). Schliesslich auch nicht auf der Erhöhung des osmotischen Druckes; denn wenn durch Zusatz von destilliertem Wasser die an sich schwache Erhöhung bis unter dem normalen Druck erniedrigt wird, erfolgt doch Entwickelung (bis zu einer gewissen Grenze wirkt der Zusatz von destil. liertem Wasser günstig auf die Entwickelungsfähigkeit der Eier). Zu sagen, die Wirkung der Kohlensäure sei excitierend oder sei eine katalytische (Loeb), ist zunächst keine Erklärung und ausserdem falsch; denn die Eier werden in den Lösungen im Gegenteil gehemmit, gelähmt und entwickeln sich erst nach dem Zurückbringen in ihr normales Medium. Die Vorstellung, die Verf. sich über diese Sache gebildet hat, ist diese; die Richtungskörperbildung ist eine so spezielle und seltene Art der Zellteilung, dass sie nur unter ganz besondern, „präzisen, sehr delikaten Bedingungen" stattfindet, und dass wenig dazu gehört, um an ihre Stelle die normale Zellbildung zu setzen. Während das Ei nun im Begriff ist, die Richtungskörper zu bilden, wird es plötzlich in einen Zustand der Lethargie versetzt; darnach erwacht es, findet sich im Zustand der Teilung, und anstatt nun die so spezialisierte T'eilung weiter zu fübren, schickt es sich zu einer normalen T'eilung an. Die Kohlensäure wirkt als ein temporäres Gift und zwar nicht als Excitans. Für seine Ansicht führt Verf. u. a. die oben erwähnte Tatsache an, dass Eier, die noch nicht in die Richtungskörperbildung eingetreten waren (die ihr Keimbläschen intakt hatten), sich nicht entwickeln, und dass $\mathrm{CO}_{2}$ ohne Wirkung ist 
auf die Eier von Strongylocentrotus, welche schon im Ovarium ihre Richtungskörper gebildet haben und also in einem Zustand der Ruhe in die Lösung versetzt werden. Auch die andern, Parthenogenese fördernden Agentia sind als temporäre Gifte aufzufassen, nur als weniger vollkommene in ihrer Wirkung.

Die Eier können sich also entwickeln, ob sje 0, 1 oder 2 Richtungskörperchen gebildet haben, wenn sie bloss nicht in den $\mathrm{Zu}$ stand der Ruhe übergegangen sind. Verf. meint, dass die Zahl der Chromosomen dieselbe sei, wie in den befruchteten Eiern, ohne sich übrigens hierüber ganz bestimmt auszusprechen.

Auf eine Vermutung von Loeb hin hat Verf. auch untersucht, inwiefern die von ihm frülıer nachgewiesene Tendenz zu natürlicher Parthenogenese einfach auf Schütteln zurückzuführen sei. Das Ergebnis war folgendes: die Tendenz ist jedenfalls schon da ohne Schütteln, wird aber durch schwächeres Schütteln erlıöht; starkes Schütteln wirkt tötend. Die natürliche Parthenogenese ergibt nur unvollkommene Larven und betrifft nur einen kleinen Prozentsatz der Eier.

Schliesslich macht Verf. darauf aufmerksam, dass die parthenogenetischen Larven von Asterias sehr stark phototropisch sind, trotzdem sie absolut kein Sehorgan besitzen.

R. S. Bergh (Kiopenhagen).

103 Ilerbst, Curt, Vorläufige Uebersicht ïber die Rolle der zur Entwickelung der Seeigellarven nothwendigen anorganischen St offe. In: Verh. naturhist.-med. Ver. Heidelberg. N. F. Bd. 7. 1902. pag. $367-394$.

Um die rom Verf. gestellte Aufgabe zu lösen, analysiert er die "Ausfallserscheinungen". welche beim Fehlen eines jeden der verschiedenen Stoffe im Seewasser sich einstellen; unklar bleibt dabei, ob die Wirkungen dieses Fehlens sich einstellen. Die Stoffe teilt er in zwei Kategorien: solche, die rom Beginn der Entwickelung an im umgebenden Medium rorhanden sein müssen, und solche, die erst auf spätern Stadien den Larven zur Verfügung zu stehen brauchen. zu jenen gehören: $\mathrm{Cl}, \mathrm{OH}, \mathrm{Na}, \mathrm{K}$ und $\mathrm{Ca}$, zu diesen $\mathrm{SO}_{4}, \mathrm{CO}_{3}$ und $\mathrm{Mg}$.

In Lösungen, in denen alles $\mathrm{NaCl}$ durch HCOONa und die übrigen Chloride durch Sulfate ersetzt sind, also in ganz Cl-freien Lösungen, beginnt nur die Furchung, hört aber sehr schnell auf, während in Lösungen mit Chloriden an Stelle der Sulfate und HCOONat an Stelle von $\mathrm{NaCl}$ Blastulae entstehen können. Dem Chlor muss demgemäß „eine allgemeine Rolle bei der Ontogenese“ zugeschrieben werden, „welche nicht auf einem einzigen Stadium der Entwickelung auszu- 
füllen ist, sondern sich auf allen wiederholt." "Worin jene holle besteht, ist zur Zeit noch unklar.

Die Rolle des Hydroxyls äussert sich in rerschiedener Weise. Zunächst wird bei ungeniigender Alkalinität des Seewassers die Befruchtnng verhindert und kann durch Zusatz einer geringen Menge $\mathrm{NaOH}$ ermöglicht werden (in demselben Wasser, dessen Alkalinität zur Befruchtung nicht ansreicht, können sich befruchtete Eier bis zun, Blastulastadium entwickeln). Ferner ist die Alkalinität von bedentendem Einfluss auf die regelmäßige Ausgestaltung der Larvenform ; in Wasser ron ungenügender Alkalinität entstelıen leicht knittrige und faltige Larven. Auch werden durch die Alkalinität die Dimensionen der Larven erheblich gesteigert, und endlich bildet jene eine notwendige Bedingung der Wimperbewegung. Verf. erörtert ferner die Frage, wie das Hydroxyl seine Rolle ansiubt. Er hat durch Indikatoren die Möglichkeit, dass seine Aufgabe sei, eine im Stoffwechsel produzierte stärkere Süure zu nentralisieren, geprüft; die Versuche fielen aber negativ ans, und Verf. glaubt (mit Loeb), dass seine Bedentung darauf beruhe, dass die Oxydationsprozesse durch Alkaliznsatz bedeutend gefördert werden (ebenso werden manche Fnzymwirkungen dadurch befördert).

In bezng auf das Natrium bekämpft V'erf. den Satz Loebs von seiner Giftigkeit in allgemeiner Fassung; denn ,wenn ein Stoff in irgend einer Weise unentbelrlich ist, darf man nicht allgemein von seiner Giftigkeit sprechen. Es kann dann höchstens in einem speziellen Falle schädlich wirken, wenn ihm in diesem Falle nicht andere Stoffe als Antagonisten entgegen arbeiten."

In reinen NaCl-Lösnngen lösen sich Kiemenepithelien von Fischen in einzelne Zellen auf (ob diese Wirkung sich auch an Seeigelkeimen wahrnehmen lässt, teilt Verf. noch nicht mit); das $\mathrm{Na}$ wirkt also in dieser Hinsicht als Antagonist des Ca. Dies ist der einzige Einfluss des Na, welchen Verf. ausfïhrlich erörtert. Sonst wird nur seine Unentbehrlichkeit auf jeden Zeitpunkt der Ontogenese nachgewiesen.

Was das Kalinm anbetrifft, so verhalten sich Echimus und Sphaerechims etwas verschieden, indem bei ersterem in K-freiem Wasser die Furchnng nicht zu Ende geführt wird, während bei letzterem kleine, trïbe Blastnlae entstehen. Das K spielt zunächst eine Rolle beim Wachstum (die Blastulae sind kleiner und die Bildung des Urdarms unterbleibt); da die bedeutende Volumenzunahme des Echinodermenkeimes rom Ei bis zum Pluteus ansschliesslich durch Wasseraufnahme zu stande kommt, muss das $\mathrm{K}$ bei der Wasseraufnahme eine hervorragende Rolle spielen. Die kleinen, trïben Sphuerechinus- 
Blastulae wimpern nicht munter im K-freien Medium, obwohl sie Wimperhare besitzen können; mit steigendem K-Gehalt (bis zu einer gewissen Grenze) nimmt die Lebhaftigkeit zn. Da die Lebhaftigkeit der Wimperbewegung vom Wassergehalt der Gewebe abhängig ist, so führt Verf. auch die obengenannten Tatsachen auf die Bedeutung des $\mathrm{K}$ für die Wasseraufnahme zurïck (auch bei der liontraktion spielt das $\mathrm{K}$ eine wichtige Rolle).

Die Rolle des Calciums ist zunächst, wie Verf. in einer frühern Arbeit nachwies, diejenige, den Zusammenhalt der Zellen zu bewirken: im Ca-freien Medium gehen Furchungs- und Epithelzellen (nicht Muskelzellen) auseinander; in Ca-haltiges Medium zurückgeführt, werden sie wieler zum Zusammenschluss gebracht, sofern sich die einzelnen Zellen noch punktuell berühren. Verf. vergleicht die Wirkung des Ca hierbei mit seiner Wirkung bei der Fibrinbildung; sie sei „,eine kompliziertere, von mehrern Komponenten abhängige Koagulation. “ Weiter ist das Ca für die Skelettbildung und für die Muskelkontraktion notwendig, nicht dagegen für die Wimperbewegung oder für die indirekte Zellteilung (weshalb Verf. den Vergleich der Spindelfasern mit Myofibrillen verwirft).

Die Sulfate spielen zunächst ilıre Rolle bei der Grössenzunahme der Larven (in $\mathrm{SO}_{4}$-freien Medium werden sie kleiner und fallen zusammen); weiter sind sie notwendig fuir die Ausgestaltung des Darmes (der Urdarm bleibt meist kürzer als normal und gliedert sich nicht), für die l'igmentbildung (die in $\mathrm{SO}_{4}$-freien Lösungen absolut unterdrückt wird), für die Skelettbildung (sie wird verzögert und anormal; die Skelettnadeln der Plutei enthalten ausser $\mathrm{CaCO}_{3}$ auch Sulfate, wie Verf. nachwies), und für die Architektonik der Larvenform; die Störung der Architektonik in $\mathrm{SO}_{4}$-freien Lösungen äussert sich sowohl in einer abnormen Lagerung der Kalkbildner und des Skelettes wie im Verlaufe des Darmkanales und in der Lage des Wimperringes; solche Larven erscheinen im Gegensatze zu den streng bilateral-symmetrischen normalen Larven als mehr weniger ausgesprochen radiär gebaut. "Die Sulfate des Meerwassers verhindern also das vorzeitige Auftreten des radiären Baues, sie erhalten dem Keime eine Zeitlang seine anfängliche bilaterale Struktur." Endlich bewirkt die Abwesenheit der Sulfate eine Hypertrophie des Wimperschopfes; diese kann noch gesteigert werden, indem man in dem Wasser ohne $\mathrm{SO}_{4}$ den Ca-Gehalt erhöht, und diese Steigerung kann so weit gehen, dass der Wimperschopf sich über die Hälfte, ja noch über einen grössern Teil der Larrenoberfläche ausdehmen kann; damit geht dann inmer Hand in Hand eine Redulition des Darmes. „Da die Hypertroplie des Wimperschopfes mit steigendem Ca-Gehalt steigt, so ist das 
Calcium als alitiver, positiv schaffender Stoff zu bezeichnen. Das $\mathrm{SO}_{4}$-Ion hat also nur die Aufgabe, diese Wirkung des Calciums auf das richtige Maf, zu beschräsken" (die umgekehrte Wirkung auf die Ausbildung der Keimregionen hat das Lithium).

Über die Bedeutung der Carbonate steht nur fest, dass sie beim Aufbau des Skeletts notwendig sind; die Seeigellarren nehmen das Calciumcarbonat direkt aus dem Meerwasser auf (gegen Steinmann).

Bei Asterias ist nicht nur Calcium, sondern auch Magnesium für den Zusammenhalt der Zellen der Keime notwendig: in Mg-freiem Medium kommen aus der Furchung keine geschlossenen Keime zu stande, und Bipinnarien, die in solche Lösungen hineingebracht werden, zerfallen in Zellen und Zellenlıaufen. Bei Echiniden spielt $\mathrm{Ig}$ eine bedeutende Rolle bei der Darmbildung (ohne Mg bleibt der Darm rudimentär, namentlich bei Sphaerechims), ferner auf die Skelettbildung (namentlich bei Sphaerechinus beim Feblen von Mg rudimentäre Skelettnadeln und Anomalieen), endlich anf die Wimperbewegung, die ohne $\mathrm{Mg}$ ausbleibt oder ganz schwach bleibt); für die Muskelkontraktion ist $\mathrm{Mg}$ dagegen nicht notwendig (bei Asterias hat $\mathrm{Mg}$ auf die Wimperbewegung nicht den genannten Einfluss; auch pathologische, trübe Larven der Seeigel können sich dem Einfluss des Fehlens von Mg entziehen).

Als Prozesse, welche von allen notwendigen Stoffen beeinflusst werden, führt Verf. schliesslich auf: die Entwickelungsgeschwindigkeit und die Grössenzunahme der Latrven und diskutiert die Arten der Beeinflussung, die dabei möglich sein können.

R. S. B ergh (Kopenhagen).

\section{Vermes.}

\section{Plathelminthes.}

104 Thacher, H. S., The Regeneration of the Pharynx in Planaria maculata. In: Amer. Natur. Vol. 36. August 1902. pag. 633-641. 8 Textfig.

Verfasserin wollte untersuchen, inwiefern die Regeneration des Pharynx im alten und neuen Gewebe (Morgan) verschieden sei, und inwiefern die Existenz resp. der Mangel der Fortptlanzungsorgane ron Einfluss auf die Regeneration sei. Zu dem Zweck wurden die Würmer zu rerschiedenen Jahreszeiten in drei Stïcke zerschnitten, die mittleren (mit dem Pharynx) weggeworfen, die übrigen auf die Bildungsprozesse untersucht. Fixierung in Sublimat-Essigsäure, Färbung in Hämatoxylin-Orange. Die Ergebnisse waren folgende.

In dem neuen Gewebe des vordern Stücks entwickelt sich der 
Pharynx folgendermalien: grössere, protoplasmareiche Zellen des Parenchyms teilen sich lebhaft und wandern der Schnittläche zu. In dieser Anhäufung ron Zellen bildet sich zunächst der Hohlraum der Schlundtasche, dann der Hohlraum der Pharynx selbst, und nun öfnet sich bald dieser einerseits in jenen, anderseits in den Hohlramm des alten Darms. I)ie Vorgänge im alten Gewebe des hintern Stïcks weichen nur in untergeordneten I'unkten ab (Verzögerung im Auftreten, Stellung zum alten Darm und Grösse). - Auch die Anwesenheit der (ieschlechtsorgane in der Region, wo sich der Pharynx regeneriert, indert die Vorgänge nicht in wesentlichen Punkten (Verzögerung im Auftreten findet statt); in keinem Falle wird der urspringliche Genitalporus - selbst bei Degeneration der Geschlechtsorgane - zum neuen Schlundporus. R. S. Bergh (Kopenhagen).

\section{Annelides.}

105 Trealwell, A. R.. Notes on the nature of , artificial Parthenogenesis" in the Egg of Pollarlie obscura. In: Biol. Bull. Mar. biol. Labor. Woods Holl. Vol. 3. 1902. pag. 235--240. 12 Fig.

Durch Einwirkung von KCl-Seewasser auf unbefruchtete Eier (mit nachfolgendem Zurückversetzen in normales Seewasser) ist es Verf. gelungen, bedeutende Veränderungen an den Eiern des genannten Chaetopoden zu verfoigen. Dieselben könuen sehr verschiedenartig ausfallen: teils finden Vorgänge statt, die Verf. als „PseudoFurchungen" bezeichnet; bei ihnen wird nur das Protoplasma und nicht der Kern zerteilt (das Chromatin liegt manclmal ganz unregelmäßig zerstreut, und es treten oft eine grössere Anzalıl von Astrosphären in der Zelle auf); teils finden wirkliche Furchungen (Kern- und Zellteilungen) statt; aber werler die wirklichen noch die falschen Furchungen verlaufen nach dem typischen Schema der normalen Furchung. Richtungskörper werden keine gebildet.

Wimpernde „Embryonen" können sowohl nach Furchung, wie ohne solche entstehen, und es bilden sich nicht nur Wimpern, sondern (selbst ohne Furchung) sogar ein Prototroch. - Verschmelzung ion Eiern und Embryonen kommt ror, nicht aber in so hohem Maße wie bei Chatopterns.

R. S. Bergh (Kopenhagen).

106 Biirger, otto, Weitere Beiträge zur Entwicklungsgeschichte der Hirudineen. Zur Embryologie von Clepsine. In: Zeitschr. f. wiss. Zool., Bd. 72. 1902. pag. 525-544. Taf. 30-32.

Verf. untersuchte hauptsächlich die Embryologie ron Clepsine sexoculata (Bergm.), vergleichsweise untersuchte er auch die weniger 
günstige Clepsine bioculata, sowie für ältere Stadien „Riesenembryonen einer Clepsine, die Schauinsland von der Urville-Insel mitgebracht hat." Fixierung in verdünnter Fle mming scher Flüssigkeit, heissem Sublimat oder $10 \%$ iger Salpetersäure; Färbung in Hämatoxylin und Eosin oder Fisenhämatoxylin (die Elemente des Keimstreifens traten an Schnitten von vergoldeten Embryonen sehr scharf hervor).

In bezug auf die Schichten des Keimstreifens schliesst sich Verf. Ref. genau an: innerhalb der Epidermis liegen im Querschnitt jederseits der rentralen Medianlinie vier Zellen, yon denen die innerste zur Neuroblastenreihe gehört und den Bauchstrang bildet, während die drei äussern Myoblasten sind und die Ringmuskulatur erzeugen („unbegreiflich" scheint Verf., dass Wh itman diese Zellen die Nephridien erzeugen liess). Noch tiefer liegt das zweischichtige sog. Mesoderm; in der tiefsten Schicht desselben machen sich frühzeitig segmental angeordnete, grössere Zellen, die Erzeugerinnen der Nephridien oder Nephroblasten bemerkbar (Wh itman hielt dieselben für die Mutterzellen der Hoden: möglicherweise lat er jedoch auch die wirklichen Erzeugerimen der Geschlechtsorgane gesehen, die mit den Nephroblasten leicht zu rerwechsehn sind, sie liegen etwas mehr lateral im zehnten und elften Segment und werden vom Verf. als Gonoblasten bezeichnet). Wenn Verf. gegen die Bezeichnung, innere Muskelplatten" (Ref.) anstatt „Mesoderm" opponiert, weil auch andere Gebilde als Muskeln daraus entstehen, so war dies Ref. selbstverständlich wohl bewusst. Das Entoderm wird anch als Darmdrüsenblatt bezeichnet, trotzdem sich auch die Chorda aus ihm bildet.

Die Leibeshöhle legt siclı in derselben Weise an, wie bei den Gnathobdelliden: zuerst entstehen die Seitenhöhlen (schon bevor die Spaltung eintritt, heben sich die kiinftigen Peritonealzellen durch stärkere Färbung ab); sie verbreitern sich zunächst ventralwärts und verschmelzen über dem Bauchmark; Septen sind in der so gebildeten Bauchhöhle kurze Zeit vorhanden, sie werden damn aufgelöst und lassen nur durch Abwechselung ron weiten und engen Abschnitten die Segmentierung erkennen; in die erstern münden die Seitenhöhlen ein. Die Rïickenhöhle entsteht in genau entsprechender Weise wie die Bauchhöhle; der Embryo, welcher bereit ist, das Muttertier zu verlassen, besitzt demnach zwei einheitliche Cölomkaritäten (Bauchund Pï̈ckenhöhle) und eine grosse Anzahl parriger, segmentał angeordneter, halbzirkelförmiger Kanäle, welche jene miteinander verbinden (Seitenhöhlen). Die genannten Hölılen sind identisch mit Okas Ventral-, Dorsal- und Zwischenlakunen (nebst ventralen und dorsalen Kommunikationslakunen). I)ie Rückbildung des Cöloms geht beson- 
ders auf Kosten der Seitenhöhlen vor sich und hat vor allem in der enormen Verstärkung der Septen seinen Grund.

Das Bauchgefäss cntsteht früher als das Rückengefäss. Letzteres wird von einer links- und rechtsseitigen Serie von Zellen oder Cardioblasten erzengt, welche (Mesodermzellen) sich in der Mittellinie vereinigen; der Vorgang erinnert sehr an die Herzbildung bei den Insekten und schreitet von vorn nach hinten fort. Das Bauchgefäss entsteht in ganz entsprechender Weise.

In dem Bothryoidalgewebe unterscheidet Verf. mit A. Graf Exkretophoren, Fettzellen und Stapelzellen. Erstere entstehen hauptsächlich in dem splanchnischen Blatt der Seitenhöhlen; die Fettzellen und Stapellzellen entstehen im Mesoderm zwischen den Myoblasten und dem somatischen Blatt des Peritoneums; schon in ältern Embryonen sind die Fettzellen durch ihre bedeutende Grösse leicht unterscheidbar; die Stapelzellen unterscheiden sich leicht durch ihren grobkörnigen Inhalt.

Die Entwickelung der Nephridien verläuft in folgender Weise: jeder Nephroblast teilt sich in eine kleinere, medial gelegene und eine grössere, lateral gelegene Zelle; erstere nennt Verf. Trichterzelle, letztere behält fortan den Namen Nephroblast. Beide Zellen erzeugen zunächst zusammen einen Zellstrang, welcher sich zwischen Trichterzelle und Nephroblast lagert (lebhafte mitotische Teilung); bei dem Wachstum des Stranges (Anlage des Schleifenteiles) werden die zwei grössern Zellen voneinander entfernt, d. h. die Trichterzelle verhar't in ihrer Lage, der Nephroblast verschiebt sich noch mehr lateral; schliesslich verschwindet letzterer, während aus der Trichterzelle schliesslich durch Teilung drei Zellen entstehen, eine mittlere (die Stielzelle) und zwei seitliche (die Kronenzellen); das Receptaculum oder die Nephridialkapsel entsteht aus dem proximalsten Abschnitt des Stranges (aus den letzten Teilungen des Nephroblasts entwickelt sich schliesslich jener Abschnitt des Schleifenteiles, welcher die Kommunikation mit der Endblase vermittelt. Das vierte Paar der Nephridien (d. h. dasjenige, welches auf die $q$ Gonoblasten folgt) entwickelt sich später und langsamer als alle ïbrigen.

Entwickelung der Geschlechtsorgane. „Die Gonoblasten teilen sich in zweifacher Weise. Erstens bilden sie infolge äqualer Teilungen einige ebenfalls auffallend grosskernige Zellen. Zweitens erzeugen sie infolge inäqualer Teilungen eine Anzahl kleinkerniger Zellen, welche die grosskernigen umhïllen. Die Bildung einer Kiapsel ist eine sehr frühzeitige Erscheinung." Diese Zellballen werden in die Septen eingeschlossen und wölben sich stark in die Seitenhöhlen vor. In Embryonen, die sich anschicken, das Muttertier zu verlassen, ja noch 
später unterscheiden sich die Produkte des o und $q$ Segmentes nicht im geringsten voneinander; erst später geht die I)ifferenzierung an. Die +-Organe werden mit all ihrem Zubehör von den Produkten der Gonoblasten des XI. Segmentes erzeugt. Die Kapseln der von diesem Gonoblastenpaar sich herleitenden Zellkörper entwickeln sich zu den Ovarialsäcken; die Zellballen, welche in den Kapseln enthalten sind, zu den Keimsträngen; in den sich später bildenden stielförmigen Auswüchsen der Kapseln, die sich unter dem Banchmark vereinigen. sind die jungen Produkte zu erblicken und die unpaare gemeinschaftliche Fortsetzung, die jene später ventralwärts nach aussen treiben, ist als Anlage der Vagina zu denten. Die ,fibrösen Fortsätze der Ovarialsäcke" (Brandes), die über dem Bauchmark eine Brücke bilden, verdanken Ausstülpungen der Kapseln ilıren Ursprung. - Die organe nehmen ihren Ursprung aus zwei rerschiedenartigen Anlagen: nur die Vesicula seminalis nebst dem Ductus ejaculatorius, der Spermatophorentasche und dem unpaaren Ausführungsgang werden von dem im X. Segmente enthaltenen Gonoblastenpaar erzeugt; die Hoden und Vasa deferentia entstehen aus ganz andern Anlagen, nämlich aus einer Anzahl Wucherungen, welche vom Peritoneum der Seitenhöhlen ausgehen (bei C'. sexoculata an der medialen, bei der exotischen Clepsine an der ventralen Wandung ihres hintern Abschnittes). Diese Anlagen höhlen sich frühzeitig aus und lassen ein Epithel und freie Zellen im Innern unterscheiden; aus let/tern entwickeln sich die Samenbildungszellen. In bezug aut die speziellere Ausbildung des Vas de-

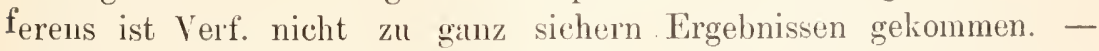
Zwischen den Produkten der Gonoblasten des X. und des XI. Segmentes existiert also der Unterschied, dass nur in letzterm ein Kieimstrang, d. h. der essentielle Teil einer Geschlechtsdrüse zur Entwickelung kommt. - Verf. berichtigt seine frühern Angaben über Nephelis, Hirudo und Aulastoma: auch bei diesen Formen finden keine Einstïlpungen der (definitiven) Epidermis als Anlagen der ausleitenden Gänge der Geschlechtsorgane statt, wie er sich bei einer Nachuntersuchung überzeugt hat.

Die Entwickelung der Clepsine weist - wie ihre Organisation grössere Übereinstimmung mit derjenigen der Chaetopoden auf als die der übrigen Hirudineen. Die Seitenhöhlen entsprechen den Ursegmenthöhlen der Chaetopoden; das sog. Rüickengefäss von Hirudo entspricht wahrscheinlich der Rückenhöhle von Clepsine. - Verf. luält die Nephroblasten und die Gonoblasten (als Urzellen der Ausfühungsgänge der Geschlechtsorgane) für homolog.

$$
\text { R. S. Bergh (Kopenhagen). }
$$




\section{Arthropoda.}

Insecta.

107 Bur. Malcolm, On the Forficularia of the Hungarian $\mathbf{N a t i o n a l}$ Museum of Budapest. In: Természetr. Fïz. XXV. 1902. pag. 1-12. T. XX.

108 - 'The Hal wigs of Ceylon. In: Journ. Bombay Nat. Hist. Soc. Vol. XIV. 1902. pag. 59-78 u. 316-336. Pl. A u. B.

Unter den 73 Species des Pester Museums fanden sich $6 \mathrm{mn}$. spp. (Spongiphora nigrorufa, Labia sicaria, Platylabia qualrata und Opisthocosmiabirr von NeuGuinea, Chartospania stella von Malacea und Apterygida lingua von Java); ausserdem gibt der Verf. Beschreibung ${ }^{*}$ und Abbildung des o"der sehr seltenen Tagalina grandiventi is Blanch. (Neu-Guinea).

Der Aufsatz über die Dermatopteren Ceylons ist zu dem Zwecke verfasst, $\mathrm{zu}$ weitern Arbeiten über diese Insekten für die gesamte orientalische Region anzuregen und demgemäß mit einer sehr zweckmäßigen Einführung versehen. Ferner teilt der Verf, analytische Tabellen zur Bestimmung der ceylonischen Gattungen und einiger Arten mit. Die Fauna enthält 1 Neolobophora Sc. $(N$. tamul sp. n.), 6 Pyyidicrenn Serv., 2 Diplatys Serv., 1 Platylabia Dohrn, 1 Echinosoma Dohrn, 1 Psalis Serv., 3 Labidura Leach, 4 Anisolabis Fieb. (A. kudayge sp. n.), 1 Brachylabis Dohrn (Br. philetas sp. n.), 1 Forcipula Bol, 3 Labia Leach, 2 Chelisoches Sc., 1 Carcinophora Se., 3 Apteryjida Westw., 4 Opisthocosmia Dohrn, (O. neolobophlioroides sp. n.).

Alle Gattungen und Arten sind ausführlich beschrieben (mit Literatur, die Abbildungen [z. T. in Farben] von sehr guter Ausführung).

N. v. A delung (St. Petersburg).

109 Burr, Malcolın, A Monograph of the genus Acrida Stal ${ }^{1}$ ) (= Truxalis Fabr.), with Notes of some allied genera, and descriptions of new species. In: 'I'rans. Ent. Soc. London 1902. part. II. pag. 149-187.

Burr hat sich der dankenswerten Mühe unterzogen, die Arten der Gattung Acrida kritisch zu sichten, was angesichts der hier früher herrschenden Verwirrung keine leichte Anfgabe war, unsomehr da der Verf. auf diesem Gebiet nur Bolivar als Vorläufer hatte. Sämtliche Arten werden nochmals charakterisiert und mit erschöpfender Synonymie und Bibliographie versehen. Ausserdem gibt der Verf. eine gute analytische Tabelle für die Arten der Gattung, sowie für die Gattungen Acrida Stål nebst einiger ihrer näheren Verwanden Achurum Sauss., Rhadinotatum Mc N., Golastorhinus Br. (diese Gattung wurde bisher zu der Acridiida e gezählt), IIyaloptery.x Charp., Truxalis Fabr., Calamus Sauss., Glyphoclonus Karsch, Odontomctus Bol., Amphieremna Karsch, Oxyolena Karsch, Amycus Stal, Machaeridia Stål.

Was die beiden europäischen Aıten der Gattung Acrida Linn. betrifft, so erhält die früher allgemein unter dem Namen Truxalis unguiculata Ramb. bekannte Art den Namen Acrida variabilis Klug (nasuta L. oder eximia Eichw. dürften die Priorität haben), wobei der Verf. A. miniata lilug und A. pharaonis King als Symonyme dieser Art auffasst; die frühere Tryalis nasuta Linn. behält bei Burr ilıren Speciesnamen bei, wäbrend Stal, Bolivar u. a. dem Namen $A$. turrita L. die Priorität geben. Der Gattungsname Acrida L. ist nummehr von der Mehrzahl der neuern Forscher endgültig angenommen worden.

Von neuen Arten beschreibt Burr. Acrida intercalata (Madagaskar), 1 . luyubris (Ostindien, Ceylon, Celebes), A. subtilis (Madagaskar), A. somalia (Somali),

1) muss heissen: Linné ! 
Crclastorrhinus sclache (Sikkim), G. lucius (Java), G. esox (Japan), Hyaloptcryx cxaygeratus (Chiquitos, Bolivia).

N. v. Adelung (St. Petersburg).

10 Hancock, J. I.., The T'ettigidae of North A merica. Chicago (Mrs. Frank G. Logan) 1902. 80. 188 pag. 11 Pl. 13 Abb. i. T.

Eine ausgezeichnete; sehr liübsch ausgestattete monographische Arbeit, welche die Klassifikation, Beschreibung und Lebensgeschichte der Tettigiden Nordamerikas (inkl. Zentralamerika, Mexiko und Westindien) enthältt. Die zahlreichen Mitteilungen über Entwickelung, Fortpflanzung u. dergl., welche zum grossen Teil auf eigenen Beobaclitungen beruhen, verleihen der $\mathrm{H}$ a n cockschen Monographie einen besondern Wert. Zu bedauern ist eine gewisse unübersichtliche Anordnung des Stoffes, indem ein und derselbe Gegenstand an rerschiedenen Stellen besprochen wird (z. B. die Eiablage).

Nachdem der Verf. die Herkunft des Namens Tettix sowie die unterscheidenden Merkmale der Familie besprochen hat, behandelt er ihre Verbreitung; vier von den sieben Bolivarschen Unterfanilien u. zw. die Cladonotinae, Metrodorinae, T'ettiginae und Batrachidinae sind in dem gegebenen Gebiet vertreten, von welchem drei Gattungen (Choriphyllum, Phyllonotus und Micronotus) auf Westindien, vier auf Nicaragua (Tylotettix, Chiriquia, Otumba und Platythorns), Ochechotettix auf Mexiko allein, Apotettix auf Mexiko und Texas, Plectronotus auf Zentralamerika, Clypeotettix auf Zentralamerika und Mexiko beschränlit sind; Nomotettix ist in den nordöstlichen Vereinigten Staaten sowie über Kansas, Nebraska, Illinois nach Süden, Tettix in der gemäßigten Region nach Norden zu (mit zwei südlichen Arten), Neotettix ausschliesslicl im Siiden, Puratettix im Norden, Nordosten und südlich bis Mexiko und Zentralamerika, Telmutettix im Westen und Süden der Vereinigten Staaten, Mexiko und nach Sïden, Tettiyidea über Nordamerika, Mexilio und Zentralamerika verbreitet; Allotettix und Scoria finden sich in Zentral- und Suidamerika; die Gattung Paxilla ist durch eine Species in Florida und Georgia vertreten.

Die Körperform ist bei den subtropischen und tropischen V'ertretern oft bis zu einem erstaunlichen Grade modifiziert, indem das Pronotum wie bei Choriphylhum blattförmig seitlich zusammengedrückt. deprimiert, verlängert $u$. dergl. m. erscheint. Kurz- und langgeflïgelte Formen einer Gattung treten bald räumlich getrennt, bald zusinmen auf. Dimorphismus und Polymorphismus in jeder form ist weit verbreitet; die Schutzfärbung einzelner Arten und Individuen ist dem ungebenden Medium (Untergrund) auf das Wunderbarste angepasst. Das Überwintern erfolgt in den gemäfigten Regionen, gewöhnlich in 
der Nähe von Gewässern, unter dürren Blättern, Rinde, Noos, in Erdritzen u. dergl. Zur Nahrung dienen in Zersetzung begriffene Pflanzenteile, Erde, Algen, Flechten, Moose, zarte Grassprossen, keimende Pflanzen usw., von denen grosse Quantitäten aufgenommen werden. Die Eiablage beginnt (Illinois) Mitte Mai, die Larven schlïpfen in 23-16 Tagen (je nach der Temperatur) aus; die Eier werden in runden Klumpen nebeneinander in die Erde, zwischen Moos usw. abgelegt, wobei die Eier einiger Arten durch ihre Gestalt usw. vor Feinden geschützt sind. Einzelne langgeflïgelte Arten unternehmen ausgedehnte Wanderungen. Die Paarungszeit beginnt früh und dauert einige Stunden bis Tage, die Vorrichtungen zum Festhalten der Weibchen sind wohl ausgebildet. Polyandrie ist namentlich bei den Gattungen ausgebildet, wo die Geschlechter kürzere Zeit beisammenbleiben (Tettix u. a.); hier finden wir anch die stärksten individuellen Farbenabweichungen. Der Paarungsakt wird für verschiedene Arten des Näheren beschrieben, desgleichen die Gestalt der Spermatozoen.

Wenn die jungen Larven ausschlüpfen, sind sie von weisser Farbe; die zuerst ausschliipfende Larve bahnt einen Weg nach der Oberfläche, den auch die übrige Brut einschlägt, worauf das Amnion gesprengt und abgeworfen wird; bei dieser Prozedur gehen manche Exemplare zu grunde. Spätestens ${ }^{1 / 2}$ Stunde nachher tritt die schützende Färbung der Larven ein. Die Zahl der. Häutungen beträgt 4-5, wobei das P'ronotum allmählich seine charakteristische Form annimmt, während die Flügel erst ganz zuletzt zum Vorschein kommen; das Lebensalter der Imagines beträgt mindestens zwei Jahre. Die Larvenstadien sind durch stärkere Ausbildung der Crista des Pronotums und grössere Zahl der Antennenglieder u. a. m. ausgezeichnet. Einige siidliche Formen behalten diese Charaktere als Inagines bei (Choriphyllum, eine ungeflügelte Form) und dürften den Stammeltern der Tettigiden näher stehen. Von Feinden dieser letztern sind Trombididen, Ameisen, eine Wanze (Galyutus oculutus). Spimnen, Fische, Frösche, Schlangen zu nennen.

Die äussere Morphologie der Tettigiden wird an der Hand zahlreicher Zeichnungen erläutert. Der systematische Teil enthält die ausführliche Beschreibung sämtlicher Gattungen und Arten, sowie die Bibliographie, Synonymie und biologische Bemerkungen.

Es sind dies: 1. Cladonotinae; Choriphyllum Serv. (3 sp., Ch. foliatum sp. n.), Phyllonotus gen. n. (3 sp.), Tylotettix Morse (1 sp.); 2. Metrodorinae; Chiriquia Morse (1 sp.), Otumba Morse (1 sp.), Platythorus Morse (1 sp.); 3. Tetti ginae; Nomotcttix Morse (8 sp., N. floridamus und $N$. arcnatus spp. nn.), Tettix Ch. (12 sp., T. blatchleyi sp. n.), Neotettix Hanc. (4 sp.), Micronotn.; gen. n. (1 sp.), Apotctix gen. 11. (3 sp., A. eurycephalus sp. n.), Merotettix Morse 1 sp., Ocheto. tettix Morse (2 sp.), Paratettix Bol. (9 sp., P. texamus, tubereulatus, morsei und ro- 
bustus spp. nn.), Clypeotctix gen. n. (1 sp.), Allotettix Hanc. (1 sp.), Telmatettix Hanc. $5 \mathrm{sp}$ (T. aridus und mimutus spp. nn.; 4. Batrachidinae; Paxilla Bol. (1 sp.), T'ttigidca Scudd. (18 sp.), Pletronotus Morse (1 sp.), Scaria Bol. (1 sp.).

Den Beschluss der Arbeit bildet die Liste der in den Sammlungen des Nationalmuseums enthaltenen Arten, sowie eine Rieilie Beobachtungen üher Lebensweise, Fortpflanzung usw., welche in Virarien angestellt wurden, femer ein Terzeichnis der einschlägigen Literatur. Die Abbildungen sind von sehr guter Ausführung.

$$
\text { I. v. A delung (St. Petersburg). }
$$

11 .Jacobson, G. G., und Y. T. Bianchi, Die Geradflibgler und Scheinnetzflüler des russischen Reichs und der angrenzenden I.̈̈nder'; nach R. T iimpel's, ,Die Geradflügler

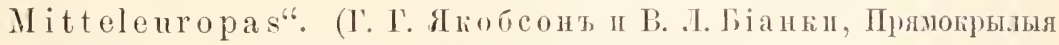

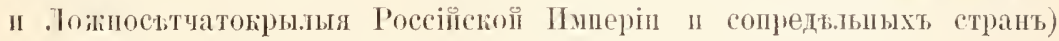
St. Petersburg (A. Devient). 1902. Lief. III und I I'1). lag. 161 - 352 Taf. X-XYII. (Russisch.)

Von Phasmodeen werden 7 Arten, welche den 4 Familien: L onchodidae, Clitumn idae, Cladomorplidae und Bacillidae angehören, aufgeführt; davon ist jedoch nur eine einzige Art, Gratillia bituberculata Redt., aus dem r'ussischen Reiche (Transkaspien, Turkestan) bekannt geworden. Es unterliegt wohl keinem /wweifel, dass in der Krim, in Kaukasus und in Kentralasien noch Bacilliden vorkommen liönnen, welche von den Sammlern bisher übersehen wurden; für den bekannten Bacillus rossii hat der Verf. den ältern Cy rilloschen Namen B. filiformis restituiert, da die Fabric iussche gleichnamige Art um drei Jahre später beschrieben wurde.

Die beiden neuen Lieferungen enthalten die Bestimmungstabellen der Acridiodeen und Locustodeen, und die Besprechung der' erstern. Die Acridiodeen sind durch die Familien der Tetrigidae, Chorotypidae (für Mastacidae, welcher Name auf dem präoccupierten Genusnamen Mastax beruhte; die älteste Gattung der Familie ist Chorotyms Serv.), Acrididae (fiur Tryxalidae), Oedipodidae, Phymateidae (für Py rgomorphidae; die älteste Gattung heisst Phymateus Thhog, woraus Stål mit Inrecht P hy matidae formte, welcher Name bereits in den Hemiptera-Heteroptera besetzt war und daher in Pyrgomorphidae geändert wurde), Pamplugidae, Acridiidae vertreten. Die Zahl der angeführten Arten ist eine ausserordentlich grosse, und eine um so mehr unerwartete, als gerade für diese Unterordnung bisher nur wenige zusammenfassende Arbeiten existierten.

1) Vergl. Zool. Zentr.-B1. IX. Jhg̣. 1902. pag. 370. 
In den Tetrigidae finden wir die Gattungen Cladonotus Sauss. 1sp., Criotettix Bol. 1 sp. Tctrix Latr. $10 \mathrm{sp}$. (davon 7 in Russt.)1) (T. tenuicornis Sahlb. ist identisch mit $T$. bipunctata Lin., T. bipunctata Sahlb. mit T. kraussi Saulcy), Paratettix $1 \mathrm{sp}$. (R.); die Chorotypidae sind durch die Gattung Gomphomastax Brunn.-Watt. mit $3 \mathrm{sp}$. (2 R.) vertreten; (r. mastax Krauss und F. kraussi Burr sind identisch mit $G$. (Chrysochraon) clarata Ostroumoff. Sehr zahlreich sind die Arten der Acrididae, welche bekanntlich fast alle auf Wiesen u. dergl. in Masse vorkommenden Feldheuschrecken umfassen. Wir liaben hier die Gattungen Acrida Linn. (für Tryxalis auct., welche nur für einige amerikanische Arten zu Recht bestehen bleibt; wird von den meisten neuern Autoren anerkamnt) $4 \mathrm{sp}$. (2 R.), Duronia Stảl 2 sp. (1 R.), Platypterna Fieb. (= Oehrilidia Stảl) $3 \mathrm{sp}$. (1 R.), Parapleurus Fisch.-Fr. 1 (R.) sp., Paraeinema Fisch.-Fr. 1 sp., Chrysochraon Fisch.-Fr. 5 sp. (4 R., wovon eine unbeschrieben), Stenobothrus Fisch.-Fir. " 36 sp, $(27 \mathrm{R}$. wozu noch 5 weitere ( $3 \mathrm{R}$.) ungenügend beschriebene Arten kommen dürften (in vorliegendem haben wir die erste Zusammenstellung einer so grossen Anzahl von Stenobothrus-Arten), (tomphoccms Thnb. $12 \mathrm{sp.}(10$ R.) und eine uubeschriebene Art; Phlocems Fisch.-Waldh. 1 (R.) sp.. Stutronotus Fisch-Fr. 7 (R.) sp., und eine unbeschriebene, Aryptcra Serv. (für Stethcophyma Fisch.-Fr.) $5 \mathrm{sp}$. (4 R.), hierzu wahrscheinlich auch die südrussische Oedipoda signata Fisch.Waldh. (von Brunner zu Ramburia hispanica Ramb. gestellt), Epacromia Fisch.. Fr. 4 sp. $(2 \mathrm{R}$.) und wahrscheinlich auch Oedipode neuroptere Fisch.-Waldh.; Mecostethus Fieb. 1 (R.) sp. An Arten reich ist auch die Familie der Oedipodidae, welche viele Steppenformen enthält. Hierher gelı̈ren die Gattungen Psophus Fieb. 1 (R.) sp., Pyigodera F.-W. 1 (R.) sp., Biunncrilla Sauss. 1 (R.) sp., Scintharista Sauss. 1 (R.) sp.. (Miroyesia Bol. 1 sp., Ptrmoscirta Sauss. 1 sp., Wioscyrtus Sauss. 3 (2 R.) sp., Cosmorhyssa Stal 2 sp., Ocdalcus Fieb. 4 (3 R.) sp., Pachytlyus Fieb. 3 (2 R.) sp., ( $I$. migratorius L. geht vereinzelt nördlich bis Abo in Finnland, St. Petersburg, Gouv. Olonetz; $P$. danicus L. $=P$. cinerascens Fabr. kommt in Russland nur in einigen südlichen Gouvernements sowie in den Kirgisensteppen häufig vor, doch ist der Verbreitungsbezirk dieser Art noch wenig bekannt, indem sie vielfach mit der erstern Art verwechselt oder identitiziert wurde); Hcteropternis Stal 1 sp., Celes Sauss. 1 (R.) sp., Pscudoceles Bol. 1 sp., Ptetica Sauss. 1 (R.) sp., Ocdipode Latr. part., Br.-W. (non Stal) 6 (5 R.) sp., dazu kommen vielleicht woch 6 ungenügend beschriebene Walkersche Arten aus Syrien und Nord-Arabien; Trilophidia Stàl 2 sp.; Bryodema Fieb. 8 (4 R.) sp. (Br. mongolicum Bol. und Br. bolirari sind Synonyme von Br. luctnosum Stoll. Br. roseipennis Krauss - ein Synonym von Br. barabense var. rhodopus Fisch-W.); Cosmorhipis Sauss. 1 (R.) sp., Thalpomena Sauss. 2 (1 R.) sp.; Conozoa Sauss. 1 sp. (nach Brunner v. W. = Mioscirtus wagneri); Acrotylus Fieb. 4 (2 R.) sp.; Leptoscirtus Sauss. 1 sp.; Egnatius Stảl 1 (R.) sp.; Charora Sauss. 2 (1 R.) sp. (die beiden letzten Gattungen gehören vielleicht in die Familie der Chorotypidae, subf. Gomphomastacini); Hclioscirtus Sauss. 1 (R.) sp.; Sphingonotus Fieb. 17 (10 R.) sp. (Auf Grund einer allerneusten Arbeit Vosselers muss diese Zahl um eine Species vermehrt werden, indem Sph. zinini Kitt. von Sph. octofasciatus Serv. spezifisch verschieden ist; Ref.); Leptopternis Sauss. 4 (2 R.)

1) In der Folge sollen die im Gebiet des russischen Reiches vorkommenden Arten mit R. bezeichnet werden. Es sei nochmals darauf aufmerksam gemacht. dass in dem vorliegenden Werk erstmals eine Zusammenstellung der Fundorte für die russischen Orthopteren versucht ist. 
sp.; (L. marrorlactyla Eversm. ist identisch mit L. hlausi Kitt.) Trinchus Fisch.-W. 2 (R) sp.; Strmiger Zub. 1 (R.) sp.; Haplootropis Sauss. 1 (R.) sp.; Cuenlligeru Fisch.-Fr. 3 sp. (die rmssische C. grandis Portsch. gehört nach Ansicht des Verfs. zn Tincthis s. u.); Crlyphonus 2 sp.; Tincthis Fieb., (für Eremobia Serv. 1839, welcher Name bereits 1829 für eine Käfergattung vergeben wurde; die Unterfamilie der Eremobiini muss nach der ältesten Gattung Batrachotetix Burm. 1839 Batrachotetrigini benannt werden), $18(10$ R.) sp.; Eremocharis Sauss. 4 sp.; Phymateidae; Chrotogonus Serv. 3 sp.; Ltractomorpha Sauss. 5 sp.; Pyngomorpha Serv. 5 (2 R.) sp.; Poceilocerus Serv. 1 sp. Pamphagidae: Niphocera Latr. (ist nach $\mathrm{Reh}$ u 1834 für eime Dipterengattung vergeben) $1 \mathrm{sp}$.; Tropidanclun Sauss. 2 (1 R.) sp.; Pamphagus Thunbg. 8 sp. (es unterliegt kaum eiuem Zweifel, dass eine dieser der östlichen mediterranen subregion angehörenden Arten auch für die russische Fauna, z. B. für Transkaukasien, nachgewiesen werden wird); Eunapius Stål 2 sp.; Nocarodes Fisch.-IV. 5 (4 R.) sp., wozu noch zwei von $\mathrm{F}$ ischer.W ald h. beschniebene vermuthiche Larvenformen kommen. Auch die Familie der Acrididae ist recht zahlreich und durch z. T. sehr merkwürdige Formen vertreten, von welchen einige hier durch selır gute Textfiguren erstmals alggebildet zu finden sind: I) crocorys Serv. (von Redtenbacher wurde der ursprünglich fehlerlafte Name Dericorys Serv. in Derocorystes statt Derocorysta umgeändert, daher muss der alte Name mit Abänderung des fehlerhaften Buchstabens mit Recht bestehen bleiben) 4 (3 R.) sp., von welchen eine in Farben sehr naturgetreu dargestellt ist, sowie zwei ungenügend beschriebene Fie be rsche Formen (die Gattung Derocorys scheint viel artemreicher zu sein als bisher vermutet wurde, wenigstens hat der Ref. eiue Anzahl neuer Arten dieser schönen und auffallenden Acridiodeen für Westasien konstatiert, welche demnächst veröffentlicht werden sollen); Oxya Serv. 2 sp., Dicxis Zub. 1 (R.) sp., welche anffallenden Sexualdimorphismus zeigt und erstmals abgebildet ist; Pezotettix Burm. part. 3 (1 R.) sp.; Conophyma Zub. (5 R.) sp., welche in letzter Zeit von Z abowsky beschrieben wurden (Abb.); Tropidopola Stal (für Opsomala [recte Ophomala] Serv. welcher Name nach stal amerikanischen Arten zukommt) 3 (1 R.) sp. und vielleicht noch T'mualis (?) japonica Motsch.; Acridium Latr. 3 (1 R.) sp. und vielleicht noch 4 von Walker wie gewöhnlich ungenügend beschriebene Arten; Schistoccrca Stål $1 \mathrm{sp}$. (Von Fischer.W. wurde eine neue Seh. aus den Kirgisensteppen beschrieben. welche wohl mit Sch. peregrina Oliv. identisch ist; diese einzige in der alten Welt weit verbreitete Art der amerikanischen Gattung wäre dann auch aus Russland bekannt); Podisma Latr. (der Verf. hat mit Recht gegen Scudder den Namen Podismini statt Melanopli beibehalten, dả der amerikanische Orthopterologe die Änderung nur aus dem Grunde vornahm, weil die amerikanische Gattung Melanoplus Stal mehr Arten zähle; dagegen ist mit Recht einzuwenden, dass die asiatische Fauna zu wenig erforscht ist um über die Zahl der Podisma-Arten urteilen zu können) 15 (5 R ) sp. (Abb.); (für P. primnoa Fisch.-W. ist das Subgenus Prmmna Motschoulsky beizubehalten, welcher seine Species P. viridis zwar gar nicht, das Subgenus dagegen wohl charakterisiert hatte; subg. Eupodisma Scudd. wird daher Synonym); Sphodromorus Stal 1 sp.; Calliptamus Serv. (nach den heutigen Regeln der Nomenklatur ist die von Burmeister vorgenommene Änderung dieses Namens in Caloptems nicht zulässig) 2 (1 R.) sp., dazu noch 3 ungenügend beschriebene russische Arten von Fischer. Waldh. und 9 Walkersche Arten; Paracaloptenus Bol. 1 sp.; Thisocectres is (4 R.) sp. (Abb.); Euprepocnemis Fieb. 1 (vielleicht 2) R. sp.; Pareuprepocnenis Brunm.-1 Watt, $1 \mathrm{sp.}$ 
Vergleicht man die Zahl der hier angeführten Gattungen und Arten mit den im Originalwerk angeführten (22 gen., 64 sp.), so wird man sich am besten ïber die Erweiterung des Planes der russischen Ausgabe orientieren können. Über die Locustodeen soll nach krscheinen der nächsten Lieferung gesprochen werden.

Die illuminierten Tafeln, auf deren Vermehrung schon früher aufmerksam gemacht worden ist, enthalten unter anderm folgende Orthopteren, welche in sonstigen Werken gar nicht oder ungeniigend in Farben abgebildet worden waren: Forficula tomis. Heterogamia aegyptiaca +, Gratidia bituberculata (eine schöne Phasmodee aus Transkaspien und dem russ. Turkestan), Gomphocerus sibricus ó, Derocorystes curvipes 5 . Die neu hinzugekommenen schwarzen und farbigen Abbildungen, wie bereits erwähnt von ausgezeiclneter Ausführung und Naturtreue, sind ron der Künstlerin O. M. Somina angefertigt worden.

Es sind noch einige wesentliche synonymische Ïnderungen für das Referat über die Blattodeen und Mantodeen nachzutragen: Ectobia lirida Fabr. ist synonym mit E. perspicillaris Herbst, welcher Name die Priorität hat; Aphlebia maculata Schreb. mit A. schaefferi Lin.; Heterogamia livida Brunner-W. wird in die Gattung Anisogamia ïbergefiilnt. Empusa eyena Charp. wird dem ältern Namen E. tricornis Götze untergeordnet.

N. r. A delung (St. Petersburg).

112 Krauss. H., Beitrag zur Kenntnis der Orthopteren Dentsch-Südwestafrikas. In: Verh. k. k. zool.-bot. Ges. Wien. 1901. pag. 281-293.

113 - Beitrag zur Kenutnis der Orthopterenfauna der Sahara. Ibid. 1902. pag. 230-254. 12 Abb. i. T.

Trotzdem die Gebiete Damara, Herero und Gross-Nama, welche das heutige Deutsch-Südwestafrika ausmachen, in ihrer Orthopterenfauna bereits durch Arbeiten von Stal und Karsch bekannt geworden sind, gelang es Krauss dennoch, in einer von Sander von der Walfischbai nach Windhoek gesammelten Ausbeute $6 \mathrm{ganz}$ neue und 9 Arten, welche aus dem Gebiet noch nicht bekannt waren, zu konstatieren; die übrigen 19 Arten waren bereits von den obengenannten Autoren beschrieben. Die neuen Arten sind eine Blattodee: Derocalymma stigmosa (ausgezeichnet namentlich durch die asymmetrische of Subgenitalplatte), eine Mantodee: Gomypeta noctixaga, 3 Acridiodeen: Pyrgomorpha sanderi, Orbillus namaqua, Calantops debilis; 1 Locustodee: Eurycorypha cuspidata nn. spp. Ausserdem werden von einigen früher bekannten Arten die fehlenden Geschlechter beschrieben. Wantis alliceps Schaum ist nach Krauss das $\bigcirc$ von Dystacta paradora Sauss., indem beide trotz der sonstigen grossen Verschiedenheit eine merkwürdige Zeichnung des Prosternums gemein haben; dis Stâl sche Gattung Chroicoptera muss mit Dystacta zusammenfallen. Cantanlops solitarins Karsch, eine eigentümlich gefärbte Acridiodee, wird ausführlich charakterisiert. Die als neu für das Gebiet mitgeteilten Arten waren früher aus Südafrika, Mozambique, 


\section{$-127-$}

Somali- und Kaffernland, Abessinien, Sansibar, Madagaskar bekannt, oder es sind weitverbreitete Arten.

Die zweite Arbeit behandelt die Orthopteren der algerischen Sahara, wo bis jetzt noch nicht gesammelt worden war (Biskra-Tougourt-Ngoussa-OurghaGhardaja-Guerrara-Biskra). Von den 44 beobachteten Arten sind 14 echte Wüstentiere, 21 Oasenbewohner, 3 beiden Gebieten gemeinsam; 10 Arten kommen ausser der Wüste auch im Mittelmeergebiet und im tropischen Atrika vor; für die Oasenbewohner sind 6 Arten charakteristisch für dieselben, die übrigen werden namentlich auch im Mittehmeergebiet gefunden. Die Mehrzahl der Arten gehören der paläarktischen Fauna, 5 Arten der ïthiopischen Region an; eine der letztern, die bekannte Schirocerca pregrina, ist, wie bekannt, der einzige altwelthiche Vertreter einer amerikanischen Gattung und wahrscheinlich aus Zentraloder Südamerika eingewandert. Die Liste enthält 9 neue Formen, wovon zwei neuen Gattungen angehören. Es sind dies die Acridiodeen Plaiypterna gracilis 11. sp., P. filicornis n. sp., Eremogryllus n. gen. (Truxalidae, Stcuronotus nahestehend, aber namentlich durch Fehlen der fast bej allen Acridiodeen vorhandenen Krallenpelotten ausgezeichnet) hammadac n. sp.; Votoplcura n. gen. (ebenfalls Stauronotns nahestelıend, aber mit kurzen breiten Antennen, dicken gekrümmten Cerci usw.) saharica n. sp., Sphingonotus vosseleri n. sp., Eremobia claveli Luc. var. nov, mozabitica, Sphodromerus crucntatus n. sp. und die Gryllodeen Gryllus palmetorum n. sp., Gr. hygrophilus n. sp. (lebt frei an feuchten Orten). Fast bei allen Arten finden sich Beobachtungen ïber Standorte, Schutzfärbung, Lebensweise, Lautäusserungen $u$. dergl.

N. v. A delung (St. Petersburg).

114 Kranss. H. A.. Orthopteren a us Australien und dem Malayischen Archipel, gesammelt von Prof. Dr. Richard Semon. In: Semon, Zool. Forschreis. in Anstral. u. d. mal. Archip. Jena 1902. 40. pag. 745-770. Taf. IXVII.

Die Ansbeute stanmt vom Gebiet des Burnettflusses (Queensland), von den Thursday-Inseln, von Britisch Neu-Guinea, von der Insel Amton (Molukken) und von Westjava; sie umfasst 132 Arten, von denen 20 neu für die Wissensclaft sind und welche sich wie folgt auf die einzelnen Gruppen verteilen: B l at to dea 1): Blatta L. (Bl. secura u. Bl. anceps nn. spp.), Epilampra Burm. 1 sp., Polyrosteriet Burm. (2 sp., P. ceratodi sp. n.), Stylopyga F.-W. (semoni sp. n.), Periplaneta Burm. (2 sp., P. spinosostylata sp. n., ausgezeichnet durch bedornte Styli!), Catara Walk. (minor sp. n., trägt die Eikapsel in einer Ausstiilpung der Vagina), Panesthia Serv. (2 sp, I. polita sp. n.) II antodea: Sphodroporla Stal (1 sp), Hicrodula Burm. (1 sp.), Rhombodera Burm. (1 sp. in neuer var.); Mantis L. (1 sp.) Phasmodea: Tropidoderus (irr. (1 sp.), Eurycnema Serv. (Eu, cercata sp. n.) Die Phasmodeen werden eingehender in der in Bälde zu erwartenden Monographie von C. Brunnerv. Wattenwyl und J. Red tenbacher behandelt werden. Acridiodea: Coptotettix Bol. (C. inflatus sp. n.), Desmoptera Bol. (1 sp.), Crancë Stâl (1 sp.), Gesonia Stål (1 sp.), Tauschira Stâl (T. Lucida sp. u.), Stropis Stål (1 sp.), Cirphuta Stal (C. sculpta sp. n.). Tritropis Br. (1 sp.), Bibracte Stâl (1 sp.), Catautops Sch. (1 sp.) Locnstodea: Elimaca Stal (1 sp.), nov. gen., Dicorypha (in der Nähe von Polichne Stål, D. furcifcra sp. n.), Phyllophora Thub. (1 sp.', Heteraprizm nom. nov. für Aprion Haan, Brunner, nec Serville!, H. brunneri sp. n.), Rhachi-

1) Der Verf. schreibt Blattidae usw. Es wäre zu wünschen, dass endlich eine Einigung betreffend der Schreibweise der einzelnen Gruppen erzielt würde! 
dorus O. Herm. (Rh. sentoni sp. 1.), (ryllocris Serv. (2 sp.), Gr. auriculata sp. n., durch die hervortretenden weichen Genitalteile ausgezeichnet). Gryllodea: Crymnogryllus Sauss. (1 sp.), Hcterotrypus Sauss. (H. mimulus sp. r.), Podoscirtus Serv. (1 sp.) Die Tafel enthält sehr schöne Abbildungen der neuen und einiger alten Formen.

N. v. A d elung (St. Petersburg).

115 Sculder. S. H., Index of the Nord American Orthoptera. In: Occasion. Papers of the Boston Soc. of Nat. Hist. VI. 1901. $436 \mathrm{pag}$.

Der vorliegende Index, die Frucht 40 jähriger Arbeit, enthält alle seit Linné bis zum Ende des vorigen Jahrlunderts gedruckten Angaben ïber Orthopteren, welehe in ganz Nordamerika (inkl. dem nördlichen Teil von Zentralamerika) und Westindien gefunden worden sind. Gattnngen (ohne Autorname!) und Arten sind alphabetisch angeordnet, letztere fiir jede Gattung. Eine jede Art ist unter allen Gattungen zu suchen, unter deren Namen sie jemals erwähnt worden ist; ebenso sind alle Synonyme von Speciesnamen an ihrer respektiven Stelle in der alphabetischen Reihenfolge verzeichnet, wobei nur in gewissen Füllen von einer Stelle auf die andere verwiesen wird. Bei dieser Anordnung ist es allerdings ebenso schwierig den wahren Autornamen einer Art, wie auch deren endgültigen Namen ausfindig zn machen. Dagegen kann der unbekannteste, älteste Namen einer Art stets mit Leichtigkeit anf nenere liezeichnung zurückgeführt werden. Wird z. B. der Name Acheta domestica aufgeschlagen, so finden wir neben einigen auf diesen Namen bezüglichen Literaturangaben den Verweis auf Gryllus (Achetus) domesticus und hier weitere Literaturangaben ohne Verweise; andererseits finden wir die Hausgrille aber an anderer Stelle auch unter dem Namen Gryllus domesticus ohne jegliche Verweise.

Jedenfalls bietet der Scuddersche Index ein ausgezeichnetes Iittel, sich in der ausserordentlich zersplitterten Literatur über amerikanische Orthopteren zurecht zu finden, was früher um so schwieriger war, als die nomenklatorischen Gebräuche einiger nordamerikanischen Autoren von den unsern einigermaßen abweichen. Sehr wertvoll ist auch das Verzeichnis der citierten Literatur, wobei natürlich auch die ausserordentlich zahlreichen Arbeiten über nordamerikanische schädliche Insekten Aufnahme gefunden haben. Ein durchgehendes alphabetisches Register aller Speciesnamen mit Angabe der Gattungen, bei welchen sie aufgeschlagen werden können, bildet den Beschluss des Werkes, welches für jeden Orthopterologen unentbehrlich sein wird, der sich mit der nordamerikanischen Fauna beschäftigt.

N. v. A delung (St. Petersburg).

116 Vosseler, J., Reiträge zur Faunistik und Biologie der - Nr. 114-116. - 
Orthopteren Algeriens und Tunesiens. In: \%wol. orahth. Abtl. f. Syst. Bd. XY1. pag. 337-404. Taf. 17 1. 18. \& Mbb. i. T. u. lid. XVII. pag. 1-99. Taf. 1-3. 5 lbb. i. 'T. - Separat. Jena. (G. Fischer) 1902. Mk. 1, ô ().

Die Arbeit Vosselers bietet in faunistincher wie in biologischer Hinsicht sehr viel Interesse; dazu kommt, dass der Vert. auch die klimatischen und die Bodenverhältnisse der erforschten Gebicte eingehend bespricht und im Inscluluss an biologische Erscleinungen auch morplologiscle und physiologischo Fragen beribht, so dass sein Boricht als ein wohlabgerundetes (ranze erselseint. Die lieobachtungen des Verf's. sind das Resultat zweier Iieisen in die betreffenden Crebiete. Derartige Arbeiten können nur mit Freude begriisst werden und wïrden auch für unsere europäische Fauna sehr am I'latze sein.

bie V osselersche Arheit zerfält in acht einzelne Kapitel, welche je einen spezicllen Gegenstand hehandeln, und lier in grösserer Kürze, als sie es verdicnen, besprochen werden müssen:

1. Übersicht über die plysikalischen Verhältnisse der untersuchten Gegenden; die Witterungsverhältnisse der die Reiseroute betreffenden Gebiete bieten in jeder Hinsicht das gïnstigste Verhältnis zu Beobachtnngen biologischer Fragen.

2. Die Rolle des Windes fïr die Verbreitung der Arten. Die starken stümme mnd namentlich die ron ilmen in biewegung gesetzten Sandmassen sind naturgemäß von grösster bedentung für die Existenz wie fü die Verbreitung der Ortlopteren. Wichtig ist die Beobachtung des Verf's., dass gute Flieger (Schistocerca, Stumonotws) sich vom Winde treiben lassen, andere Formen dagegen (Sphingonotus, Evemobia, ferner Myrmeleon, Eulen, Schwärmer) gegen denselben ankämpfen. Da ersteve Formen sich nu wenig über den Boden erheben, worden sie vom Winde an den das Gebiet begrenzenden Gebirgsketten abgeladen, wodurch hier ein grosser Reichtum an Formen bedingt wird. Die Hauptrolle spielen hierbei die Süd- und Nordwinde, während Westwinde nur im südlichen Tunesien Eintluss haben, indem sie Heuschreckensthwärme ins Meer treiben. Nahezn die Hälfte aller Arten und Gattungen ist fast oder ganz Hugunfihig und daher vor Verschleppung durch den Wind geschützt; dass anch sie trot\%dem eine weite V'erbreitung aufweisen, führt der Verf. auf Wandertrieb und grosse Anpassungsfähigkeit zurück.

3. Verzeichnis der gefundenen Arten. Die Reisen wurden je im . Iuni-Juli 1897 und 1901 ausgefülnt und beriilnten zum Teil noch nicht erforschte Örtlichkeiten. Im ganzen kamen etwa 5̃1 Arten (85̃ Gattungen) zur Beobachtung; für das gegebene Gebiet sind nummelr 220 Arten und 3 Varietäten, welche gs (rattungen an- 
gehören, bekannt; Finot (1895-1896) führte für dasselbe Gebiet 91 Gattungen mit 207 Arten auf.

Vosseler erbeutete folgende Formen: Forficulodea: Labidura 1 sp., Anisolabis 1 sp., Forficula 3 sp. Blattodea: Hetcrogamia 1 sp., Loboptcra 1 sp., Periplancta $1 \mathrm{sp}$. II a ntodea: Ercmiaphila $2 \mathrm{sp}$. (Beschreibung des wenig bekannten of von E. denticollis Luc.) Mantis $1 \mathrm{sp.,} \mathrm{Fischeria} 1 \mathrm{sp}$., Iris $1 \mathrm{sp.,}$ Idolomorpha ). sp. (die sehr seltene I. longifrons de Sauss.; hierzu wohl ein eigenartiges Fiernest, das abgebildet wird); Acridiodea: Paratcttix $1 \mathrm{sp.,} \mathrm{Acrila}$ 1 sp., Ochrilidia 1 sp., Duronia 1 sp., Epacromia 1 sp., Stcnobothrus 1 sp. . Stauronotus $2 \mathrm{sp}$. (St. genei Oesk. auf eng begrenzte ,Inseln" beschränkt), Erenogryllus 1 sp., Notopleura $2 \mathrm{sp}$. (N. pygraea n. sp.), Stethophyma $1 \mathrm{sp.,} \mathrm{Ocdipoda}$ 3 sp., Pachytilus 1 sp., Oedalcus 2 sp. (Oe. senegalensis Kr. neu für das Gebiet), - Lerotylus 2 sp., Egnatioides n. g. (E. striatus n. sp., von Finot als $q$ von Leptoscirtus ariculus S. beschrieben), IIelioscirtus 2 sp. (H. gracilis n. sp.; da das einzige frühere Charakteristikum zur Unterscheidung dieser Gattung von Sphingo. notus, die Verdickung der Flügelaxillaradern, auch bei den of of der letztern Gattung vorkommt, gibt Vosseler eine neue Charakteristik der Gattung IIelioscirtus, welche sich namentlich durch die Proportionen der Flügel von Sphingonotns unterscheidet. II. finotianus Sauss. wird in letztere Gattung verwiesen); Sphingonotus $10 \mathrm{sp.,} 1$ var. (Sph. descrtorum n. sp. identisch mit Sph. rosseleri n. sp. Krauss 1); Sph. diadematus n. sp.; Sph. balteatus Serv, neu für Algerien; $S p h$. mecheriae Kr. für Sph. cocrulans L. var. mecheriac Kr. und Sph. lucasii Sauss. für Sph. scabriusculus Stal var. Incasii Sauss.) ; auffallend ist die grosse Zahl der Sph.Arten, deren iiberhaupt nur etwa 26 bekannt sind.

Leptopternis $2 \mathrm{sp}$. (L. maculata lund calcarata $\mathrm{mn}$. spp.; die Gattung war frïher nur aus Turkestan, Astrachan, Granada und Ägypten bekannt), Ercmobia $1 \mathrm{sp}$. (die ausserordentlich grosse Variabilität der Arten dieser Gattung ist durch eine kolorierte Tafel erlüutert), Pyrgomorpha $3 \mathrm{sp}$., Ocncrodes $1 \mathrm{sp}$. (wegen der Unbeständigkeit der Nerkmale bei den Pamphagiden ïberhaupt, glaubt der Verf., dass die Zahl der Arten dieser Gattung bedeutend reduziert werden wird), Pamphayus 5 sp., 1 var ( $P$. expansus Br. gehört nach dem Verf. wohl mit $P$. algcricrs Br., $P$. simillimus Yers. nnd $P$. manritanicus Bol. zu P. tibialis Fieb.; P. marmoratus Burm. ist woll die Stammform von $P$. clephas $\mathrm{L}$., $P$. marmoratus var. nov. Iunctanus, $P$. djclfonsis n. sp.), Eunapins $2 \mathrm{sp}$., Platyphyma 1 sp., Dericorys (recte Derocorys!) 1 sp., Acridium 1 sp., Schistocerca 1 sp., Thisoicetrus 1 sp., Calopteuns 1 sp., 1 var. (C. italicus I. var. nov. descrticola); Locustodea: Odontura 1 sp., Rhacoclcis $1 \mathrm{sp}$., (Th. annulata Fieb. erstmals für Algerien), Decticus $1 \mathrm{sp}$., Ctenodecticus (Ct. vasarensis Fin. erstmals für Tunis), Platyclcis 2 sp., Ephippigera 6 sp. (E. compressicollis Fisch. neu für 'Tunesien, E. ncrii n. sp.), Platystolus 1 sp. (Die enorme Gefrässigkeit und Mordlust von Pl. pachygaster Luc. wird hervorgehoben), Eugaster 1 sp.; Gryllodea: Platyblemmus 1 sp., Gryllus 2 sp., Gryllomorpha 1 sp., Tridactylus $1 \mathrm{sp.}$

4. Vergleichung der algerisch-tunesischen Orthopterenfauna mit den äbrigen mediterran-paläarktischen; in einer 'Tabelle stellt der Verf. die Verbreitung von 224 Arten zusammen, aus welcher folgende Schlussfolgerungen zu entnehmen sind:

1) Vgl. Referat Nr. 113. Gleichzeitig von beiden Autoren beschrieben; doch wurde Vosselers Manuskript früher zum Druck eingesandt. 
Aus Algier sind 91 gen. und 199 sp., aus 'T'unesien 79 gen. und 135 sp. bekannt, während 73 gen. und 114 sp. beiden Ländern gemeinsam sind. Der geringere Formenreichtum Tnnesiens verteilt sich auf die ganze Ordnung. Aus der Vergleichung der nordafrikanischen mit der süd- und nitteleuropäischen (Tabelle) ergibt sich die grosse Annäherung an die sicilianische Fauna, dann an Spanien. Die grösste Verbreitung haben die Forficulodeen, Blattodeen, Mantodeen, die geringste die Pamphagiden und Ephippigeriden, wo wir nur für beide Faunen wenige gemeinsame Formen haben. Was die indigenen Formen betrifft, so sind $76 \mathrm{sp}$. und 8 gen. auf AlgerienTnnesien beschränkt, während 12 Gattungen den Steppen und Wüsten der tropischen und subtropischen '/one angehören und nur wenige Vertreter am sïdlichen Ufer des Mittehmeeres haben. 5 gen. sind Nordafrika und Spanien gemeinsan. Viele Vertreter der algerischtunesischen Fauna entstammen der äthiopischen Region (daron 4 zuerst rom Senegal beschrieben). Abgesehen ron diesen und andern Aftinitäten und Kosmopoliten bestehen doch nahe Beziehungen der nordafrikanischen zur mediterranen Fauna. Hervorzuheben sind noch einige Formen (z. B. Splingonotus octofasciatus, Scintharista wagneri), welche wir auch aus Sarepta und den Kirgisensteppen kennen.

Der Artenreichtum nimmt von Usten nach Westen zu. Dies Verhalten spricht scheinbar gegen Marshall. welcher eine Entstehung der paläarktischen Fauna ron Zentralasien aus annimmt; der Terf. erklärt diesen Widerspruch dadurch, dass in frühern Epochen der Zug der Orthopteren von Osten nach Westen durch geologische Vorgänge unterbrochen wurde, woranf die bereits im uördlichen Afrika angelangten Formen, ohne Nachschub zu erhalten, weiterwanderten, und sich westlich anhïufteu. Viele Arten sind durch lokale Anpassung entstanden, andere in der Ausgestaltung begriffen. Die grosse Zahl der flugunfühigen Acridiodeen und Locustodeen ist auf Anpassung (gegen Verschleppen durch den Wind) zurückzuführen.

Was die V'erbreitung der Orthopteren innerhalb des algerischtunesischen Gebietes betrifft, so ist hier eine Kuisten- und Wistenfauna zu unterscheiden; letztere hat nach Vosseler (gegen Erlanger) einen mehr äthiopischen Charakter.

5. Zeichnung und Aupassungserscheinungen bei Acridiern. Hier schickt der Verf. eine Besprechung der "Zeichnung" bei den Orthopteren iiberhaupt voraus. Hierbei wird aut den prinzipiellen Unterschied in Färbung und Zeichnung zwischen Vorder-und Hinterfliigel hingewiesen, ferner darauf. dass auf den Vordertlïgeln alle Arten von Zeichnungen von der vordern Radial- und der hintern 
Thararler beeinflusst werden. Die Lage der auf den Flügeln häufig auftretenden Querbinden ist annähernd festgestellt; InregelnäRigkeiten sind auf Ungleichheiten im Längenwachstum zurückzuführen. Bemerkenswert ist, dass bei Larven auf den Hinterflügeln die Färbung (primitive Längszeichnung) zuerst auf der obern Seite auftritt, welche bekanntlich bei der letzten Häutung durch Längsdrehung der Flïgel zur untern Seite wird. Die bei Acridindeen so lä̈ufigen (Yuerstreifnngen der Schenkel entsprechen den Querbinden der Elytren in der Ruhelige; sind letztere nit Längsstreifen versehen, so finden wir solche auch auf den Schenkeln. Was die allgemeine Körperfürbung betrifft, so konnte sich der Verf. an Ort und Stelle (gegen Finot) davon überzeugen, dass dieselbe, wenigstens in der Wüste, auf grössere oder geringere Anpassung an den Boden zuriickzuführen ist (Verbreiterung des Körpers, körnige Struktur der Haut, Färbung). Fortschritte in der Anpassung treten zuerst beim Weibchen anf. Die Schutzfärbung ist in vielen Fällen individuell, daher die Farbstoffe erst nach der Häutung entstehen können resp. in löslichem Zustande an die Haut herantreten, um das sich ansfärbende Tier der Umgebung anzupassen (ror der Häntıng verblasst die Färbung oft). Die Annahme einheitlicher, chemisch vielleicht komplizierter (irundsubstanzen (Melanine? und Lipochrome?) erklärt auch die nicht seltene Imwandlung der roten oder blauen Fliggel in blane resp. gelbe bei ein- und derselben Art. Zu bemerken ist noch, dass die Häutung stets am Tage (chemisch wirksame Strahlen!) ror sich geht. Der Verf. führt hier mehrere Beispiele für besonders auffallende mimetische Schutzfärbung und auch für scheinbare Ausnahmen von der Regel an, auf welche leider nicht näher eingegangen werden kann.

6. Häutung ron Engaster. Hier wird der interessante Ausfärbungsprozess einer mit Trutzfarben ausgeriisteten Locustodee geschildert.

7. Spermatophoren von Eugaster und Platystolus. Der Ban der Spermatophoren und der Spermatozoen wird geschildert und abgebildet; hervorzuheben ist Verlauf und Bau des Ausführungskanales bei Platystolus, welche von den gleichen Verhältnissen bei den übrigen Locustodeen wesentlich abweichen.

8. Die Verteidigungsäfteder Orthopterasaltatoria. Der Verf. schildert zuvor den Prozess des ..Blutspritzens“ einiger Locustodeen, welches schon frïher von Bonnet und Finot, Ancey, dem Verf. selbst und Cuénot beschrieben wurde, und fïhrt neute Beobachtungen an. Platystolus, welcher nach Cuénot kein Blut spritzen soll, besitzt auf der Mittellinie des Pronotum (hinter dessen Ausschnitt) eine Spalte, welche sich erst beim ersten Spritzen bildet; 
das Spritzen wird durch Kontration des Abdomens bewirkt; das ausgespritzte Blut schreckt andere kannibaliche Locustodeen nicht ab, wohl aber Eidechsen nsw. Emyastor yn!yomi Serv., welchen der Verf. schon früher daraufhin untersuchte, zeigt die löchste Ausbildung des Spritzapparates; die Poren liegen zwischen Coxa mud Trochanter und setzen sich mach innen in Gestalt eines Trichter's fort (Einstülpung der Haut). '/ux Verteidignng hebt das 'Tier den Körper, so dass die Pore frei nach aussen sielıt, durch die Streckung der Beine öfnet sich die spalte und das Bht wird durch Banchdruck nach ganz bestimmten, beabsichtigten Richtungen ausgespritzt (bis $50 \mathrm{~cm})$. Ein kleiner Muskel reguliert die (j)ffnung der I'ore, verhindert die Umstülpung des Trichters und bewahrt das Tier ror unnützem Blutverlust. Auch infolge innerer schmerzen (durch Gregarinen) erfolgt Blutspritzen.

Die Untersuchungen des Verfs. ergaben, dass zwischen dem Spritzsaft und dem Blut weder in der Beschaffenheit ihrer zelligen Bestandteile noch in deren Zahlenverläiltnissen ein Unterschier besteht, und dass zwischon beiden auch chemisch und physiologisch vollständige Übereinstimmung herrscht. (I)as Blut ron Eurgastor und Platystolus wird gena!l geschildert, die zelligen, recht verschiedenartigen Gebilde und deren Einschlüsse abgebiliet.)

Das Blutspritzen selbst fasst der Verf. nicht als eine reflektorische, sondern als eine willkürliche Handlung aut. Zum Schutze des Tieres dient (wie bei vielen (nthopteren) zunächst das zu einem Panzer ausgebildete und oft mit Stacheln versehene Pronotum, indem Eidechsen und Vögel ilue bente meist an der Brust zu ergreifen ptlegen; das Blutspritzen dient zur Verstirkung der Abwehr. Die Autotomie, welche bei Blutspritzern nie eintritt. bildet eine niederere Stufe des Schutzes, aus welcher das ökonomische Blutspritzen hervorgegangen ist.

Schliesslich beschreibt der Terf. noch den von ihm entdeckten

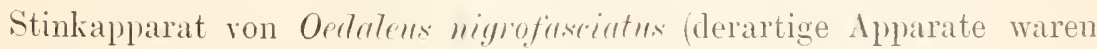
bisher bei den (Orthoptera saltatoria nicht bekamnt); dieser Apparat liegt im Pronotum, seine Ansmündung in der Hant zwischen Pro- und Mesonotum, hat die Gestalt eines dreieckigen säckchens mit verschiedenen Muskelsystemen und bildet eine Einstüloung des Integuments; in der Hypodermis finden sich \%ellen von dreierlei Typus, darunter grosse eimzellige 1)rüsen mit Vakuolen und feinem, in das Bläschen mündendem Ausführgang, welcher mit dem hern in Terbindung zu stehen scheint. Wie Wand der Stinkblase geht ohne Austiihrgang direkt in die äussere Körperlaut über; der dustluss des Sekretes erfolgt infolge Pressung der Blase und Blutdruckes; das sekret dient zweifelsohne dazu, auf die \%unge von Feinden zu wirken. 
Es soll zum Schlusse der Besprechung der so viel interessante biologische und physiologische Beobachtungen enthaltenden Arbeit Vosselers noch auf die schöne Ausführung der Tafeln, namentlich derjenigen, welche äussern Bau und Färbung betreffen, hingewiesen werden; die \%eichnungen sind von dem Verf. und Frl. M. M ïlberger ansgeführt.

X. v. A delung (St. Petersburg).

117 Cholodkorsky, N. A., II. Beitrag znr Biologie der Blattläuse mit compliziertem Entwicklungscyclus. (H. A. Xo.toд-

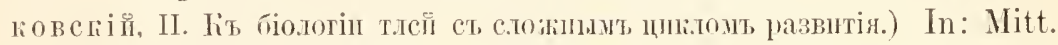
d. St. Petersburg. Forstinst. 1900. pag. 125̃-142. (Iıввьстія C. IÍ́. .Іьеного IIıетитута.) (Russisch.)

Der Verf. kommt auf Grund seiner an verschiedenen ChermesArten angestellten Beobachtungen ${ }^{1}$ ) (welche kurz resumiert werden) zu einigen Betrachtungen allgemeiner Natur. Die genanen Beobachtungen über den Lebenscyklus ron Chermes abietis Kalt. und C'h. Tapponims. Cholodk. schliessen nach Ansicht ('holodkovskys die Möglichlieit aus, dass hier Sexuales auftreten, diese Arten vermehren sich rielmehr sicher a ws chliesslich parthenogenetisch; die Erscheinung entspricht der Apogamie einiger Farne (Iteris cretica, Aspidium falcatum). Der Unsstand, dass beide genannten Chermes-Arten eine ganz bestimmte Verbreitung haben und sich gleichzeitig auch durch lionstante morphologische Merkmale von nahestehenden Formen mit geschlechtlicher Fortyflanzung unterscheiden, ist ron ganz besonderer Pedeutung. Doch kann man sich auch auf Grund des Entwickelungscyklus allein (bei Abwesenheit morphologischer Unterschiede) für die Selbständigkeit einer Art aussprechen (Chermes strobilobius. Kialt. und Ch. Tapponicus Cholodk.). Individuen, welche zu einer Species gehören, müssen einen gleichen Entwickelungscyklus durchlau fen. Im speziellen bezieht sich dies auf Blattläuse, bei welchen man nach dem Verf. nie einen Speciesnamen geben sollte, ehe alle Stadien der Entwickelung bekannt geworden sind. Nach frühern Beobachtungen des Verfs. diirfte Ch. riridams Cholodk. die ungeflügelten Exules bei der nahestehenden Ch. rividis Ratz. ersetzen (wo solche Exules fehlen); sollte dies der Fall sein, so liegt der Gedanke nahe, dass erstere Art ron Generationen der Ch. rividis abstammt, welche auf die Lärche ausgewandert sind und sich hier zu einer besondern Art ausgebildet haben. Ïhnliches trifft man auch bei Uredineen und bei Cecidomyia und Myclophilus. Der Verf. glaubt hieraus mit Sicherheit schliessen zu kömen, dass äussere Faktoren (namentlich Ernährungs.

1) Vergl. Zool. Zertr.-Bl. III. pag. 434; IV. pag. 453 и. 919. 
bedingungeul) eine tiefeingreifende verändernde Wirkung habenkönnen, woraus nichtnur Ernährungsmodifikationen (Nägeli), sondern auch stabile Formen hervorgehen können, welche nicht hinter, guten Arten" nnd, ,beständigen Varietäten" zur ïckstehen. Natürlich kamn eine derartige Veränderung nur dann vor sich gehen, wenn die äussern Faktoren die Eigenschaften des Idioplasmas beeinflusst haben.

$$
\text { N. r. A delung (St. Petersburg). }
$$

\section{Vertebrata.}

118 Giacomini, E., Contributo alla conoscenza delle capsule surrenali nei C'iclostomi. Sulle capsule surrenali dei Petromizonti. In: Monit. zool. ital. Anno Xill. No. 6. 1902. 21 pag. Taf. 2 u. 3.

119 - Brevi osservazioni intorno alla minutestrutturarlel corpo interrenale e dei corpi soprarenali dei selaci. In: Atti IR. Accarl dei Fisiocrit. Siena. Ser. IV. Tol. X. 1898. 11 pag.

120 - Sulla esistenza della sostanza midollare nelle capsule surrenali dei Teleostei. In: Monit. zool. ital. Anno XIII. No. 7. 1902. 7 pag.

121 - Sopra la fine struttura delle capsule surrenali degli anfibi. In: Processi verb. della li. Accad. dei Fisiocrit. Siena. 1898. 11 pag.

122 - Sopra la fine struttura delle capsule surrenali degli anfibi e soprai nidi cellulari del sympatico di questi vertebrati. Siena. 1902. St pag. 3 T'af. 1 Textfig.

123 - Sulle terminazioni nervose nelle capsule surrenali degli nccelli. In: Processi rerb. Ir. Accad. dei Fisiocrit. Siena. 1898. 8 pag.

Bei Petromyzon marims. (118) kommen die Nebennierenkapseln nit ihren beiden T'eilen, der Rinden- und der Marksubstanz, vor und sind in der ganzen Stammesregion bis einerseits in die Kopf-, andererseits in die Caudalregion vorhanden. In der mittlern (Nieren-) Region besteht die Cortikalsubstanz ans zahlreichen kleinen soliden Lobulis von epithelialem Charakter. Die Lobuli sind von einer Membrana propria ungeben. Die Marksubstanz besteht aus einem Gewebe ron epithelialem Aussehen, in welchem zuweilen sympathische (ianglienzellen vorkommen.

In der caudalen Region findet sich um die Vena caudalis ein Gewebe ähnlich der eben erwähnten Marksubstanz, und anch Cortikalsubstanz ist hier zu beobachten. In der prärenalen Region findet 
man ähnliche Bildungen wie in der mittlern. In der Regio cardiaca umgibt Marksubstanz die Arteria coeliaca, in der Regio cephalica die Jugularis; Rindensubstanz kommt hier nicht vor.

Bei J'otromyzon plampri sind die Lobuli der Cortikalsubstanz weniger zahlreich, die Marksubstanz ist weniger leicht nachweisbar als bei der vorigen Species; sonst sind keine Differenzen vorhanden.

Ammococtes. Auch hier triftit man im wesentlichen die gleichen Verhältnis c wie bei erwachsenen Tieren.

Die Corpora suprarenalia der Elasmobranchier (119) sind Homologa der Marksubstanz in den Nebennierenkapseln der Amphibien (rgl. später). Das Corpus interrenale zeigt bei Torpolo ocellata die Struktur der Cortikalsubstanz.

Bei Ammilla rulyuria (120) liegen die Markzellen längs der Vena cardinalis, und zwar hauptsächlich der rechten. Bei Esox lucius: finden sich in der cranialen lymphoiden Partie der Nieren an den Cardinalvenen zahlreiche Kellnester und Zellstraten vom Charakter der Markzellen. Cynrims carpio. Tinca rulyaris. Lenciscus albus und anla, sowie Burbus pletrejus zeigen im wesentlichen gleiche Verhältnisse.

Die unter No. 121 angeführte Arbeit des Vert's. ist nur eine vorläufige Nitteilung zu der unter 122 citierten Monographie; sie bedarf daher keiner besondern Besprechung mehr. Aus der Monographie ist folgendes hervorzulieben:

Die Untersuchungen wurden an folgenden species vorgenommen: Salamamalia maculose; S. atia: Salamamalina perepicillata; spelerpes fuscus; Thiton cristatus; T. taemiatus; T. alpestris; Empoctus platyceplatus; Rama exculenta; R. temporaria; Bombinator ignens; Bufo inlyaris; Rufo rividis: Hyla arborea.

Salamamar maculosa. Das System der Nebennierenkapseh erstreckt sich durch den ganzen Stamm rom hintersten Ende des Mesonephros bis zur Regio cardiaca, wobei es sich auf die Venae renales und deren Verzweigungen, auf die hintere Partie der Vena cava inferior und auf die hintern Cardinalvenen (Venae azygos) rerteilt. Zur bequemen Übersicht und zur leichtern beschreibung teilt Yerf. das System ein in einen vordern (cranialen) Teil - vom vordersten Ende des Mesonephros bis zur V'ereinigung der beiden Aortenwurzeln einen mittlern, den Genitalnieren entsprechenden und einen hintern, (caudalen), der längs der Beckennieren dahinzieht.

In der mittlern Region besteht die Cortikalsubstanz aus Epithelialkörpern, die solid sind und eine feine Membrana propria besitzen. Die Zellen dieser Gebilde enthalten eine fettige substanz in Form feinster 'Tröptchen, welche Produkte der sekretorischen 'Tätigkeit der 
Zellen sind. Indessen dürfen diese Tröpfchen nicht mit gewöhnlichem Fett identifiziert werden; wichtig aber sind sie deswegen, weil sie in den Zellen der Rindensubstanz der Nebenniere aller Säuger vorkommen. Häufig werden in den Zellen dieser Partien auch mitotische Figuren angetroffen.

I) Kellen der sogenannten Marksubstanz sind (wie dies in den Leferaten der frühern Arbeiten ebenfalls hervorgehoben wurde) von epithelialem Aussehen und liegen meist in einer Schicht, selten in mehreren.

Der Sympathicus mit seinen Ganglien liegt dorsal oder medial der Nebennierenkapsel und steht mit der Marksubstanz in engen Beziehungen. Verf. fand daher oft Ganglienzellen in der Nachbarschaft dieser Substanz und fand ausserdem isolierte oder zu Nestern vereinte (Zellnester) Markzellen, teils in den Ginglien teils im Stamm des Symphaticus.

Salamandra atra reigt sehr ähnliche Verhältnisse wie S. maculosa, nur finden sich in der mittlern und hintern Region des Systems die Zellen der Marksubstanz in viel beträchtlicherer '/ahl als bei der vorigen Species.

Mit Ausnahme der geringern Grössenverhältnisse stimmt Salamandrina perspicillata mit $S$. $m$. überein. Das Gleiche ist der Fall bei Speterpes fuscus.

Triton cristatus sowie die übrigen vom Verf. untersuchten und oben angeführten U rodelen zeigen ebenfalls in den Hauptzügen Übereinstimmung mit Salam. macul.; hinsichtlich der abweichenden Einzelheiten wird auf das Original verwiesen.

Die Beschreibung seiner Refunde an Batrachiern beginnt der Verf. mit:

Bufo vulgaris. Weder Membranen noch bindegewebige Stränge trennen die Nebennierenkapseln von der Nierensubstanz, der sie aufliegen. Die Cortikal-(Interrenal)-Substanz wird von Epithelsträngen gebildet, die von einer Membrana propria umgeben sind, sich ramifizieren und untereinander kommunizieren, wodurch sie ein Balkenwerk herstellen. Zuweilen findet man unter diesen Zellen mitotisch sich teilende. Die Marksubstanz besteht aus Kellen, die von denen der cortikalen Substanz sich scharf unterscheiden! Die Zellnester des Sympathicus finden sich in den Ganglien des Grenzstranges, in diesen selber und in den zur Niere und den Nebennierenkapseln gehenden Nerren. Die Zellen dieser Nester gleichen denen der Marksubstanz.

Bufo viridis zeigt, abgesehen von einigen Kleinigkeiten, gleiche Verhältnisse wie die vorige Species. 
Rara exculenta und Rana temporaria zeigen an die Elasmobranchier und Teleosteer erinnernde Zustände. Die Markelemente sind im cranialen Teile zahlreicher und umfänglicher als im caudalen. Die Zellnester sind sehr beträchtlich entwickelt.

Die Nebennierenkapseln von Bombinator igmeus erinnern mehr an die Zustände bei den Urodelen als bei den Anuren.

Hyla arborea endlich gleicht Rana.

Auf diese Spezialbesclireibung folgen allgemeine Betrachtungen über die Morphologie des Systems der Nebennierenkapseln, hinsichtlich deren auf das Original verwiesen wird.

Zur Feststellung der Nervenendigungen in den Nebennierenkapseln der Vögel bediente sich Verf. (126) der schnellen Golgischen Methode. Er untersuchte an Anas boschas, Meleagris gallopaio, Gallus domesticus, Columba domestica, Cypselus apus, Pica candata, Fringilla coelebs, Pusser italiae, Athene noctua. Stryx Hammea. Die Nervenendigungen zeigen eine völlige Übereinstimmung im Verhalten bei allen untersuchten Species. Die Nebennieren der Vögel sind sehr reich an Nerven. Diese verzweigen sich zum Teil in der bindegewebigen Umhïllung der Organe, zum Teil gelangen sie mit den Blut. gefäissen in das Innere. Die meisten Nervenfusern sind marklos, nur wenige sind markhaltig. Im Innern des Organes bilden die Nervenfasern einen grossen P'lexus, dessen einzelne Fasern in der Marksubstanz enden. Grosse sympathische Zellen finden sich spärlich im Urgan vor.

B. Rawitz (Berlin).

124 Marcealu, F., Note sur la structure du coeur chez les vertébrés inférieurs. In: Compt. rend. soc. Biol. (19. Juli) 1902. (pag. 5 - 7 des Sepr-Abdr.)

An Fischen (Tert. führt 5 Vulgärnamen auf) unterscheidet man an ausgedehnten Herzen eine kompalite periphere und eine spongiöse innere Zone. Am kontrahierten Herzen kann man kaum die weitesten Lücken im spongiösen Teile unterscheiden. Die Muskelfasern bilden voluminöse Bündel, die ein Netz von bald breiten bald engen länglichen Maschen herstellen. Die Fibrillen sind völlig kontinuierlich.

Bei Batrachiern finden sich vollkommen kontinuierliche Muskelfasern, die sogenannten Zellgrenzen sind an ihnen nicht zu sehen.

Bei Reptilien (Saurier und Ophidier) ist das Gleiche zu konstatieren.

B. Rawitz (Berlin).

125 Harceau, F., Note sur la structure des fibres musculaires cardiaques chez les o iseaux. In: Compt. rend. Soc. Biol. (20. Dezember) 1902. 3 pag. 
Die Untersuchungen des Verfs, erstreckten sich auf die Gattungen Anser, Anas, Gallus, Garmins und Camimulgus (Warum Verf. hierbei sich der nicht immer leicht verständlichen Vulgärnamen und nicht vielmehr der wissenschaftlichen Namen bedient, ist nicht einzusehen.)

Die Herzmuskelfasern der Vögel haben einen kreisförmigen oder elliptischen Querschnitt und sind Cylinder. Sie sind schwächer als die der Mammalia. Zu umfangreichen Bündeln gruppiert anastomosieren sie unter so geringem Winkel, dass dadurch ein Netz von sehr engen und langen Maschen entsteht. Sie gleichen den Muskelfasern im Herzen der niedern Wirbeltiere und der Säugetierembryonen. Sie bestehen aus einer mehr oder minder dicken fibrillären Rinde, welche eine cylindrische Sarkoplasmamasse einschliesst. Das Sarkolemma ist nicht gut zu sehen, lange nicht so gut wie bei den Mammalia.

Das Vogelherz ist im Verhältnis zum Körpergewicht stärker entwickelt als das der Säuger.

B. Rawitz (Berlin).

126 Marceat, F., Recherches sur le développement et sur les fonctions des traits scalariformes, zones de batonnets, points intercellulaires ou pièces intercalaires des fibres cardiaques des mammifères. In: Compt. rend. Soc. Biol. (14. Juni) 1902. 3 pag.

Bei der Geburt sind beim Menschen und vielen Säugern die Herzmuskelfasern absolut kontinuierlich. Im Laufe der nächsten Monate ändert sich dies, insofern die Stäbchenzonen innerhalb der Muskelfasern sich ausbilden.

B. R aw itz (Berlin).

\section{Cyclostomi.}

127 Giacomini, E., Sulle cosi dette glandule salivare dei Petromizonti. In: Annali della Facoltà di Medicina dell' Università di Perugia. Vol. XII. Fascicoli 3 und 4. 1900. 5 pag.

Die Angaben des Verfs. beziehen sich auf Petromyzon marims. Die beiden fraglichen Organe liegen rentral zwischen Mundöffnung und ersten Paar Kiementaschen und haben ovale Gestalt. Es handelt sich bei jedem Organ um eine grosse, mit Sekret gefüllte Höhle, von deren cranialem Ende der in der Mundöffnung auf einer kleinen Papille sich ötfinende Ausführungsgang abgeht. Umgeben ist der Drüsenkörper von einer Lage von Muskeln.

Man kann die Organe mit einer grossen, einfachen, alveolären Drüse vergleichen. Das secernierende Epithel besteht aus cylindrischen Zellen mit ovalen, basal gelegenen Kernen. Erstere enthalten zahlreiche Tröpfchen einer fettigen Substanz, die sich auch in dem den 
Drüsensack erfüllenden Sekret finden. Die sogenamnten Speicheldrïsen der Petromyzonten secernieren also keinen Speichel, sondern eine fettige Substanz.

B. Rawitz (Berlin).

\section{Pisces.}

128 Beard, John, The origin and histogenesis of the thymus in Raja batis. In: Zool. Jahrb., Abt. f. Anat. und Ontog. d. Tiere. Bd. 17. Heft 1-2. 1902. pag. 403-480. Taf. 5-10. 8 Textfig. Jede Thymusanlage wird zunächst durch eine kleine, gut umschriebene Platte von Hypoblastzellen dargestellt, die Verf., in Anlehnung an die Terminologie v. Kupffers für das Sinnesepithel, "Placode" nennt.

Bei einem Embryo von sechs Kiemenspalten zeigt sich in der Gegend der ersten an derdorsalen Wand eine Thymus-Placode. Auf einem weitern Entwickelungsstadium, bei bereits durchgebrochener Kiemenspalte ist die Placode als ein vierseitiges Gebilde erkennbar. Mit dem Durchbruche der Kiemenspalte richtet sich die Placode in einem Winkel von etwa $45^{\circ}$ dorsalwärts auf. Bei der weitern Entwickelung wandert die Placode nach auf- und auswärts infolge des Wachstums des Hypoblasts. Sie liegt jetzt in der Nähe des Notochords und ihre Oberfläche steht im Vergleich zu der des ersten Stadiums rechtwinkelig. Jetzt wachsen die Placoden etwas in die Dicke, aber nicht in gleicher Weise in die Länge. Auf einem Entwickelungsstadium von $34 \mathrm{~mm}$ Länge erscheint die Thymus-Placode jederseits dicker und baucht sich nach innen aus, aber auch jetzt noch hat sie an Längenausdehnung nicht gewonnen.

Da die Thymus, wie Koelliker zuerst nachgewiesen hat und was unzweifelhaft richtig ist, Leukocyten produziert, so unternimmt Verf. im 3. Kapitel der Arbeit den Nachweis, dass die Thymus als die Quelle der ersten Leukocyten zu betrachten sei, nachdem er im 2. Kapitel Histologen und Pathologen das Recht abgesprochen hat, auf Grund von Färbungsdifferenzen verschiedene Arten von Leukocyten zu unterscheiden.

Aus den Schnittbildern, welche die Embryonen von Raja batis liefern, geht unstreitig herror, dass die einzige Funktion der Thymus in der Produktion von Leukocyten besteht. Und da in der Embryologie dieser Species kein anderes Organ mit gleicher Funktion gefunden werden kann, so bleibt nur der logische Schluss übrig, dass die Thymus der einzige Sitz für die Bildung der Leukocyten ist. Um die schwierige Unterscheidung zwischen Lenkocyten und embryonalen Erythrocyten sich zu erleichtern, muss der Beobachter des Umstandes eingedenk bleiben, dass die Leukocyten einen exzentrisch, 
die Erythrocyten einen genau zentral gelegeneu Kern haben. Bis zu einer Embryolänge ron $17 \mathrm{~mm}$ bleiben die beiden vordern P'lacoden jeder Seite vollständig epithelial. Man trifft in diesem Stadium nirgends in den Organen Leukocyten an. Bei einem $20 \mathrm{~mm}$ langen Embryo dagegen kommen diese Zellen, wenn auch in geringer Zahl, im Blut und im Herzen vor. In der Thymus-Placode dagegen sind hier keine Lenkocyten zu treffen, weil die wenigen, die gebildet werden, ausgewandert waren. In einem andern Embryo der gleichen Grösse traf dagegen der Verf. ein oder zwei Leukocyten in der Placode. Die eben referierte Angabe modifiziert Verf, aber sofort, indem er mitteilt, dass er bereits in einem ungefähr $14 \mathrm{~mm}$ langen Embryo eines andern Jahrganges Leukocyten nachweisen konnte. Man kann sagen: fehlen die Leukocyten im Mesoderm und im Blut, so fehlen sie aucl in den Placoden. Und umgekehrt: sind sie dort vorhanden, so sind sie es auch hier. In Embryonen von 19-23 mm ist die Produktion von Leukocyten in den Placoden zwar nicht sehr gross, aber eine sehr schnell zunehmende; sind diese völlig ausgebildet, dann wandern sie einzeln aus der Placode aus.

Die Art, wie die Umwandlung der Epithelzellen in Leukocyten in der Thymus von Raja batis erfolgt, lässt sich am besten an Embryonen von 17-23 mm beobachten. Die Zellsubstanz der Placodenzellen wird zunächst stärker lichtbrechend, dann nimmt der Kern, welcher bisher oval war, eine rundliche Form an und schliesslich wird die ganze Zelle rund. Damit ist der Lenkocytencharakter erreicht, zumal die Lage des Kernes eine exzentrische geworden ist. Einzelne dieser so entstandenen Leukocyten wandern aus, andere bleiben in der Placode und letztere teilen sich öfters. Diese Um. wandlung der Placodenzellen nimmt allmählich an Umfang zu.

Auf den spätern Entwickelungsstadien - Embryonen von 37 bis $70 \mathrm{~mm}$ - kann man die Thymusanlage nicht länger als Placode bezeichnen, denn sie wird andauernd dicker und ragt von $42 \mathrm{~mm}$ Embryogrösse ab nach innen als ein birnförmiges Gebilde.

Die Spiracular-Placode der Thymus wurde von frühern Autoren als "Ventralfollikel des Spiraculum" bezeichnet, als Placode erst vom Verf. erkannt. Sie ist nicht auf der ventralen, sondern auf der dorsalen Seite der Spiraculartasche gelegen.

In gewissen Perioden der Embryonalentwickelung gehen Thymusund sensorische Placoden desselben Branchialbogens topographische Beziehungen ein.

Verf. gibt dann noch eingehende Notizen literarischer Art und tritt im letzten Abschnitte noch einmal den Beweis all, dass die Thymus die Geburtsstätte aller lymphoiden Strukturen und Leuko- 
cyten sei. Hierfiir wird auf das Original verwiesen. (Wenn die Meinung des Verfs. für alle Tertebratenklassen zuträfe. dann wïrde es sehr grosse Schwierigkeiten geben, pathologische Erscheinungen beim Menschen, wie die der Lenkämie, zu erklären, da diese erst nach dem Schwinden der Thymus beobachtet werden und eine Termelrung der Leukocyten innerhalb der Blutbahm beim Menschen nicht vorkommt. Es müssen daher zum mindesten auch Bildungsstätten für Leukocyten ausser der 'Thymus vorhanden sein.) B. R a w it z (Berlin).

\section{Mammalia.}

129 Schmidt, J., Yergleichend-anatomische Untersuchungen ïber die Ohrmuschel verschiedener Säugetiere. Berlin (Paul Parey) 1902, 46 pag. 10 Taf., 1 Textfig. Mk. 6.-.

Die Arbeit befasst sich mit dem Studium der äussern Gestaltung und feineren Modellierung des Ohres der Säugetiere im Vergleich zum Ohr des Menschen und wählt als Hauptrergleichsoljekt das Knorpelgerïst der Ohrmuschel.

Die Ohrmuschel der meisten T'iere ermöglicht nämlich ohne besondere Vorbereitungen ein genaueres Studium ilurer Formen nicht. Das dichte Haarkleid verdeckt die feinem Formen; die starke Wölbung der Muschel und die oft sehr enge Beschaffenheit der Cavitas conchae verhindern den Einblick in die Tiefe. Verfasser macht die Ohrmuschel der Entersuchung dadurch zugänglich, dass er sie des Haarkleides und auch des dunkeln Pigmentes entledigt, was am besten durch langsame Maceration zu erreichen ist, die eine Lockerung der Epidermis und der Haare bewirkt und die Ohrmuschel mit allen ihren Feinheiten blosslegt. Andere Methoden führten zu Schrumpfungen oder Aufquellungen. Die vergleichend-anatomische Untersuchung, die hauptsächlich auf der veterinär-anatomischen Literatur fusst, geht von einer Frörterung der Merkmale des menschlichen Ohres aus und stellt dann die Interschiede und Konformitäten mit den Ohren verschiedener Säugetiere (Affen, Halbaffen, Meerschweinchen, Pferd, Esel, Zebra, Tapir, Rind, Schaf, Ziege, Antilope, Hirsuh. Reh, Schwein, Hund und Katze) fest, wobei das intakte Ohr weniger als die der Haare und der Epidermis entledigte Ohrmuschel zum Vergleich herangezogen wird. Darnach ist die Ohrmuschel des Menschen als ein rudimentäres Organ anzusehen, das sich leicht zur tierischen Ohrmuschel rekonstruieren lässt, wenn man dem menschlichen Ohr eine solche Stellung gibt, dass das Tuberculum Darwinii, der Rest der Spitze des tierischen Ohres: den höchsten Punkt des Ohres einnimmt.

Die Ohrmuschel der Sängetiere lässt die am Ohr des Menschen 
festgestellten anatomischen Merkmale in ihren Einzelheiten mehr oder minder deutlich erkennen. Das Ohrläppchen ist kein dem Nenschen ausschliesslich zukommendes Gebilde, die Spina helicis kommt auch bei verschiedenen Tieren vor, dagegen werden die Plicae auriculares des Tierohres beim Menschen nicht beobachtet; kommen bei letzterem faltenartige Gebilde vor, so handelt es sich um Abnormitäten, welche die Anthelix betreffen. Ferner fehlt den Menschen infolge der starken Reduktion der Kopfohrmuskeln das Scutulum der Tiere, das als ein Frgänzungsknorpel für den komplizierten Bewegungsapparat der Muschel anzusehen ist.

Die Caniden und Feliden verfügen noch über eine besondere Hauttasche des äussern Ohrrandes, welche den andern Tieren und dem Menschen mangelt.

F. Römer (Frankfurt a. M.).

130 Daffner, Franz, Das Wachstum des Menschen. Anthropologische Studie. Zweite vermehrte und verbesserte Auflage. Leipzig (W. Engelmann) 1902. 475 pag. 3 Fig. im 'Text. Mk. 9.-.

Eine grosse Anzahlıl von Daten über Maß- und Gewichtsverhältnisse des menschlichen Kiörper's vom Beginn der Entwickelung bis zum Greisenalter hin, hat der Verf., zum T'eil auf Grund eigener Beobachtungen, zusammengestellt.

Die Inhaltsïbersicht gilt folgende Gliederung: Embryo und Fötus, Dauer der Schwangerschaft, das ausgetragene Kind, Zähne, P'ubertät, Bemerkungen zum Körpergewicht, Blut und Atmung, Hirngewicht und Geisteskraft, Kopfnaße beim Erwachsenen. Schädelmaße, Entwickelung der Körpergrösse und des Kopfumfangs, Wachstumszuund abnahme, Wachstum des Gesichts, Grössenverhältnisse zwischen Ober- und Unterkörper, Grösse, Gewicht, Kopf- und Brustumfang, Breiten- und Dickendurchmesser der Brust, Brustwarzenentfernung und Halsumfang, Brustkorb, Hand, Fuss, Farbe der Haare und Augen, Hautfarbe.

Schon diese Anordnung lässt völlig eine Gliederung nach einem einheithichen Gesichtspunkte rermissen, aber noch viel mehr macht sich dieser Nangel einer klaren Disposition in den einzelnen Abschnitten selbst, in störender Weise bemerkbar. So schiebt der Verf. \%. B. zwischen die Besprechung der Formverhältnisse des Embryos im dritten Monat und die Fötustabelle, über die Formverhältnisse der späteren Monate, eine, wie er sie nennt, „kurze Abschweifung" von 26 Druckseiten ein, in der von allen möglichen allgemein naturwissenschaftlichen Dingen die Rede ist, von Darwinismus und Descendenztheorie, zwei Begriffen übrigens, die Verf. durchaus nicht etwa scheidet, was ja bei Laien normal, bei einem Naturforscher aber doch 
einigermaßen befremdlicl erscheint, vom Kampf der Teile im Organismus usw. Tnd das alles in Form von Citaten, die mehr oder weniger zusammenhanglos, mit oder olme etwas Kitt eigener Worte aneinander gereiht sind. Diese, rom Autor selbst als Abschweifung bezeichnete Interpolation stelit aber immer noch in besserm Zusimmenhang als manche andere Ausführung, durch die man fast in jedem Abschnitt überlascht wird.

7. B. wird man wohl kaum erwarten, in einem Buch, das über das Wachścum des Menschen handelt, eine, fast zwei Druckseiten lange Auseinandersetzung darüber zu finden, ob es zweckmäßjig sei in der Pubertät, in der sich der. Stimmwechsel vollzieht, bei Knaben den Gesangunterricht fortzusetzen oder zu unterbrechen (entnommen aus Mackenzie). Auch die luetischen Geschwïre der Pharynxwand und des Gaumensegels sind ja ein Gegenstand, über den man noch wesentlich mehr zusammenschreiben kann, als die etwa fünf Druckseiten, die ihnen der Verf. in dem Kapitel . Pubertät" widnet, nur ist der Nutzen für das vorliegende Buch nicht einzuselıen. In wohl nicht ganz unberechtigtes Staunen versetzt es auch, wenn inan auf pag. 237, nur eine Seite nach der Kapitelïberschrift "Bemerkungen zum Körpergewicht", anf eine Auseinandersetzung über das erste Stehen und Gelıen der Kinder stösst; derartige Proben liessen sich noch in grosser Menge auffülren.

Auch die Berücksichtigung der Literatur lässt viel zu wünschen übrig, z. B. besonders in dem Kapitel Hirngewicht und Geisteskraft, das etwa so anmutet, als wäre es zur Blütezeit Büchners verfasst. Für diese mangelnde Vertrautheit mit neuern Fragestellungen liefert die an Weitschweifigkeit grenzende Ausführlichkeit, mit der massenhafte lange ('itate älterer und ältester Forscher gegeben werden, keinerlei Ersatz.

Gegenüber so fundamentalen Mängeln verlohnt es nicht, noch näher auf das Heer kleinerer sachlicher und formeller Finzelheiten einzugehen, die zu Ausstellungen herausforderu, und man wird selbst bei voller Anerkennung der Menge wertvollen Einzelmaterials, las dem Buch die Stelle eines, sicher sehr erwünschten, Nachschlagewerkes hätten erobern können, es doch als eine wenig geschickte Komplikation bezeichnen müssen, deren wissenschaftlicher Wert ebenso wie ihre praktische Brauchbarkeit nicht hoch angeschlagen werden kann.

A. Piitter (Breslau). 


\section{Zoologisches Zentralblatt}

unter Mitwirkung von

Professor Dr. O. Bütschli

in Heidelberg

herausgegeben von

Dr. A. Schuberg

a. 9. Profesgor in Heidelberg. in Wien

Verlag von Wilhelm Engelmann in Leipzig.

X. Jahrg.

10. März 1903.

No. 5.

Lu bezlehen durch alle Buchhandlungen und Postanstalten, sowie durch die Verlagsbuchhandlung. Jahrlich 26 Nummern in Umfang von 2-3 Bogen. Preis für den Jahrgang M. 30 . - Bei direkter Zusendung jeder Nummer unter Streifband erfolgt ein Aufschlag von j. 4.- nach dem Inland und $\nabla$ on H. 5. - nach dem Ausland.

\section{Referate:}

\section{Zellen- und Gewebelehre.}

131 Ire, A., Bolles, Nouvelles recherches sur le Nebenkernet la rógression du fuseau caryocinétinue. In: La Cellule. 'T. 20. 1902. pag. 181-217. 1 Taf.

Die Spindel der Spermatogonien von Helix pomatia besteht aus einem Strahlenbiindel, das im Innern von einem rakuolenartigen hyalinen Ciebilde, das sich schon im ruhenden Kern fand, dem Hyaloplast, durchzogen ist, der an seinen beiden I'olen ein stark färbhares, dornförmiges Gebilde, das A krosom² trägt. Während der Telophase verdoppelt sich der Spindelpol, indem Hyaloplast und Akrosom sich teilen. bie beiden Arme des Hyaloplasten rücken mit den P'olen unter der Obertläche der Zelle nm 181" auseinander und dann erst legen sich die Pole dem Kern an, der an diesen beiden Stellen eine Eimbuchtung erleidet, die nach Verf. nur eine Folge einer Kontraktion des den Kern durchziehenden Hyaloplasten ist. Die Spindelfasern sind währendlessen degeneriert und bilden eine centroplasmatische Masse 1 m die Pole, so dass das "Centroplasma“ der nächsten Generation, der Auxocyten, nichts anderes ist als ein Spindelrest. Auf die gleiche Weise entsteht der Nebenkern der Spermatiden, nur tritt hier keine Teilung des Poles ein. Bei der Umwandlung der spermatide nimmt die dem Akrosom naheliegende Spindelrestmasse allmählich die charakteristische Form des Nebenkerns an. Dieser ist also

1) Es ist durchaus zu vorwerfen, dass dieser Terminus, der sich in der spermatogenetisclien Literatur für ein ganz anderes Gebilde eingebiurgert hat, hier angewandt wird, zumal das hier so benannte Organ nichts anderes ist als ein Zentralkörper. (Ref.). 
kein permanentes Zellorgan und darf nicht mit einem besondern Namen (Idiozom) belegt werden. Die Richtigkeit dieser Darlegungen erscheint allerdings dem Ref. angesichts der I)arstellung von v. Ko r f f sehr zweifelhaft.

R. Goldschmidt (Nümberg).

\section{Vergleichende Morphologie, Physiologie und Biologie.}

132 Simroth, H., Über den Ursprung der Wirbeltiere, der Schwämme und der geschlechtlichen Fortpflanzung. In: Verh. d. deutschen Zool. Gesellschaft 1902. pag. 152-162. Verf. gibt in diesem Vortrag eine Weiterfülırung der Ideen seiner ror 11 Jahren erschienenen „Entstehung der Landtiere“. Verf. ist der Ansicht, dass die ersten Lebewesen nur Bakterien sein konnten, die als Hauptleibesmasse nichts weiter als Chromatin - oder Vererbungssubstanz seien. Bei den Bakterien habe sich die Konjugation als Vorläufer der geschlechtlichen Fortpflianzung, zigleich ein I'rodukt des Landlebens entwickelt. Das Bacterium mit Cytoplasma stellt bei der geschlechtlichen Fortpflanzung das Ei dar, das reine Bacterium in Spirillenform das erste Spermatozoon. bei den Infusorien zeigt die Kernsubstanz gewebliche Differenzierung in den "physiologischen Macronucleus und in den Micronucleus, den Vererbungskern". Hier ist die nur im Wasser mögliche, gleichmäßig fortschreitende Differenzierung zum Maxinum gediehen. Schon zeigt der Macronucleus hänfig Neigung zn weiterer Teilung (Rosenkranzform). Von hier scheint nur ein Schritt nötig zum Metazoon. Denkt man sich das Infusor anfs Land versetzt, so würde bei der viel schärfern physiologischen Trainierung des Landlebens jene Spaltung des Kernes nnmöglich, beide würden vereinigt bleiben, und damit würde vermutlich eine weitergehende Mitose eintreten, welche jeden histologischen Lestandteil seinem zugehörigen Kernabschnitt zufuihrte: das Infusor würde zum acölen Turbellar.

R. Fick (Leipzig).

\section{Spongiae.}

133 Cotte, J., Observations sur les Gemmules de Suberites domungula (laps. statt domuncula, der Ref.). In: Réunion biol. de Marseilie. Bd. 1. 1902. Nr. t. pag. 1493-1495.

In dieser Mitteilung veröffentlicht Cotte einige Beobachtungen über die Gemmulae von Suberites dommenla. Im Herbst finden sich auf Murex-Schalen, welche ron dem Weichtier selbst orler von einem später eingewanderten Pugurus bewolnt werden, entweder kleine, zarte Suberiten ohne Gemmulae, oder grössere Suberiten mit einer basalen, der Murex-Schale anhaftenden Gemmulae-Lage, oder die Gemmulae-Lage allein. Letztere kann entweder dick und mit Resten 
des Suberitrs, von dem sie gebildet wurde, vermengt, oder duinn und frei ron solchen Resten sein. Die Ciemmulae solcher dümner Schichten werden als nadelärmer als jene der dicken Schichten bezeichnet. Der Verf. behauptet, dass die Suberites-Gemmulae im stande seien, direkt neuerdings Gemmulae zweiter Generation zu erzeugen, und dass jene dünnen Schichten nadelirmer Gemmulae auf den Murex-Schalen solche Gemmulae zweiter Generation sind. Er sucht diese Behauptung durch die Ergebnisse einiger von ibm angestellter Versuche zu bekrïftigen und vergleicht diese Gemmulae der Hefeform der Schimmelpilze.

R. v. Lendenfeld (Prag).

134 Kirkpatrick, R., Descriptions of South African Sponges. In: Marine Investigations in South Africa. Cape of Good Hope. Dep. of Agriculture. Jhg. 1902. Kapstadt 1902. Nr. 4. pag. 219-232. Taf. 1-3.

In der vorliegenden Arbeit werden $2 \mathrm{Hexactinelliden} \mathrm{und} 6$ Tetractinelliden von den Küsten der liapkolonie und Natals beschrieben. 6 von diesen 8 Arten sind neu. Für eine Tetillide, deren Einströmungsporen auf eine grubenförmige Einsenkung der Oberfläche beschränkt sind, wird das neue Genus Spongocardium aufgestellt.

R. v. Lendenfelà (Prag).

135 Schrammen, A., Zur Systematik le Kieselspongien. In: Mitteil. aus dem Roemer-Museum. Nr. 19. 1903. 21 pag.

In der rorliegenden Arbeit behandelt Schrammen die Verwandtschaftsverhältnisse und die Systematik der Hexactinelliden und Tetractinelliden. Er nimmt die nene Schulzesche Einteilung der Hexactinelliden in Amplidiscophora und Hexasterophora an und ändert die von ihm friuher (siehe \%ool. Zentr.-Bl. Bd.9. Nr. 83) rorgeschlagene Einteilung in Hexactinosa, Lychniscosa und Stauractinophora derart ab, dass die Hexactinosa und Lychiscosa T'ribus der Hexasterophora bilden, während die Familien der Stauractinophora als incertae sedis in einem Anhange den Hexactinelliden beigefügt werden. In bezug auf die Lithistiden wiederholt er seine frühern Angaben (siehe \%ool. Zentr.-Bl. Bd. 7. Nr. 584). Er führt die Anomocladinidae und Rhizomorinidae (mit den vier Subfamilien Azoricidae, Scleritodermidae, Neopeltidae und Cladopeltidae) sowie die beiden neu aufgestellten Gamilien Megarhizinidae und Scolioraphinidae als Monactinellilen-Familien mit lithistidem Skeletthabitus auf. Die iibrigen, mit tetraxonen Nadeln ausgestatteten Lithistiden leitet er zum Teil ('Tetracladinidae) ron Pachastrelliden-ähnlichen Vorfahren, zum Teil (die andern) von Theneiden-ähnlichen Torfahren ab. R. v. Lendenfeld (Prag). 
136 Schrammen. A., Ueber den Horizont der Thecosiphonia nobilis Roem. In: Zentr.-BI. Min. Geol. Pal. Jhg. 1903. pag. 19-23.

Der Autor führt an der Hand der einschlägigen Angaben in der Literatur den Nachweis, dass Thrcosiphonia nobilis ein gutes Leitfossil der 'Turonschichten mit Inoccramus mieri ist. Aus dem etwas ältern Scaphiten-Pläner von Halberstadt beschreibt er als nen eine andere Thecosiphonia-Art, und er glaubt, dass T. nobilis aus dieser herrorgegangen sei. $\quad$ R. r. Lendenfeld (Prag).

137 Topsent. E.. Considérations sur la faune des Spongiaires des côtes d'Algérie. Fonges de la Calle. In: Arch. Zool. expér. Sér. 3. Bđ. 9. 1901. pag. 327-370. Taf. 13, 14.

Topsent hat ein beträchtliches Material ron algerischen spongien untersucht und bescheibt in der vorliegenden Arbeit eine Anzahl derselben. Dann wendet er sich der algerischen spongienfama im allgemeinen zu und behandelt ihren Charaliter nnd ihre Beziehnngen zu den Spongien anderer Teile des mediterranen Gebietes. Gcorlia canaliculata O. Schmidt geliört in ras Genus Isops. Die Frage, ob Erylus discophorus and E. mammilaris synonyme sind, wird einer eingehenden Kritik unterzogen. O. Schmidt beschrieb seinerzeit 74 algerische spongienarten. Da manche von diesen syezifisch nicht unterschieden sind, so reduzier't sich diese Zahl auf 64. Hier»u kommen 29 seither dort aufgefundene, so dass gegenwïrtig 93 algerische Spongienarten bekannt sind. 63 ron diesen sind auch am Nordufer des Mittelmeeres gefunden worden. 40 kommen auch ausserhalb des Mittelmeeres ror. 26 sind auf Algier beschrinkt. Von diesen diiften aber auch einige, ron 0 . Schmidt ungenügend heschriebene. mit extraalgerischen Formen identisch sein, wodurch die Zahl der auf Algier beschränkten Arten auf etwa ein Dutzend herabgesetzt wiurde. R. r. Lendenfeid (l'rag).

138 Topsent. E.. Éponges nouvelles des Açores (Deuxième série). In:

Mém. Soc. Zool. France. Bd. 14. 1901. pag. 448-466.

In der vorliegenden Arbeit werden fünf neue Hexactinelliden beschrieben und Bemerkungen über eine sechste gemacht Bei Eurcle alicei n. sp. wurden Amphioxe beobachtet, wie sie bei den andern Eurect-Arten nicht vorkommen. Aphrocallistes azoricus hat ausnehmend dünne Röhrenwände $(0,4-0.6 \mathrm{~mm})$ und sehr enge Kanalmündungen $(0,2-0.3 \mathrm{~mm}$. R. v. Lendenfeld (Prag).

139 'opsent, R.. Sur l'orientation des Crinorhisa. In: Compt. Rend. Ac. Sc. I’aris. 1402. 3 pag.

In dieser Mitteilung wird die Frage nach der natiurlichen Stellung der Crinorhiza-Arten elörtert und nachgewiesen, dass einige von ihnen, ähnlich wie Trichostemma, mit einer liegelförmigen Basis der Unterlage aufruhen. Die Papillen von Cladorhiza Tongipimna und Aximoterma mivabile werien als Wurzelausläufer angesehen.

$$
\text { R. r. I, endenfeld (Prag). }
$$


140 Vosmaer, G. C. J., and J. H. Vernhout, The Poriferia of the Siboga-Expedition. I. 'The Genus Placospongia. In: Siboga-Expeditie, Monographie VI a. Leiden 1902. 40. 17 pag. 5 Taf.

Die vorliegende Arbeit ist eine erschöpfende und reich illustrierte Mnnographie der Gattung Placospongia, in welcher die Iutoren drei Arten unterscheiden. Hie Gattung wird zu den spirastrelliden Chavuliua gestellt und als den bohrenden Vioen (Clionideu) remwindt angresehen. Sicheres über den Bau des austihrenden Kanalsystems. konnte nicht ermittelt werden. Die Autoren glauben aber annehmen zu können. dass die Ausströmungsöffnungen, ebenso wie die Einströmungsöff̈nungen, in jenen Membranen liegen. welche die Spalträume zwischen den Hautpanzerplatten überbrücken. lieziiglich des einfülırenden Systems wird bemerkt, dass die Kanäle desselhen innerhalb des Schwammkörpers anastomosieren. Die charakteristischen, Sterraster-ähnlichen Mikrosklere dieser Spongien, für welche der Ref. seinerzeit die Bezeichnung Pseudosterraster aufgestellt hat, werden Sterrospira genannt. In bezug auf den Bau dieser Nadeln und ihre Zugehörigkeit zu den Monaxonen stimmen die Autoren mit Keller, dem Ref. u. a. A. ïberein.

R. v. Lendenfeld (Prag).

\section{Echinoder'ma.}

141 Enriques, Paolo, Digestione, circolazione e assorbimento nelle Oloturie. In: Archivio zool. Vol. I. Napoli 1902. pag. 1-58. Taf. I-II.

Verf. schickt seinen vorzugsweise an Holothuria tubulosa angestellten Cntersuchungen über die Rolle, welche das lakunäre Blutgefässystem der Holothurien bei der Verdauung, Resorption und Circulation spielt. eine anatonische und histologische Beschreibung des Verdauungskanales und der Blutgefässe roraus. Den bisher als Magen bezeichneten Abschnitt des Holothuriendarmes nemnt er Kropf (ingluvies), den ersten absteigenden und den aufsteigenden Schenkel des Dïnndarmes zusammen Magen und nur den zweiten absteigenden D) ïnndarmschenkel Darm. Auch in der Benennung der Blutgefässe des Darmes weicht er, und zwar ohne jeden triftigen Grund, von der bisher iblichen durchaus ab: das ventrale (antimesenteriale) Darmgefäss bezeichnet er nämlich als dorsales Randgefüiss und das ventrale Quergefäss wird bei ihm infolgedessen zur dorsalen Queranastomose; dententsprechend nennt er dann weiter das dorsale (mesenteriale) Darmgefäss das ventrale und unterscheidet daran den Abschnitt, der dem ersten absteigenden Darmschenkel folgt, als linkes und den dem aufsteigenden Darmschenkel folgenden als rechtes Ventralgefïss. 
Das peritoneale Epithel der Wundernetz-Gefässe stellt nach ihm ein driisiges Organ, die Verdaumngsdrüse, dar, deren Sekret durch Amöbocyten aufgenommen und bis unter das „Magen“-Epithel verbracht wird, von wo aus es in das Lumen des Verdaumngsanales ergossen wird und im stande ist, Fiweisssubstanzen und Kohlehydrate zu lösen. Die Resorption der gelösten Nahrung geschieht nicht unmittelbar durch die Darmwand in die Leibeshöhle (Cohnheim), sondern durch Vermittelung der Blutgefüsse. Die grossen Darmgefässe besitzen die Fähigkeit rhythmischer P'ulsation und reranlassen dadurch zwar lieinen Kreislauf, wohl aber eine oscillatorische bewegung der gesamten Blutfliissigkeit.

H. Ludwig (Bonn).

142 Östergren, Hjalmar. 'The Holothurioidea of Northern Norway. In:

Bergens Museums Aarbog 1902. Nr. 9. 34 pag.

Östergren behandelt die nordnorwegischen Holothurien vom systematisclien und zoogeographischen Standpunkte und betont dabei insbesondere die Notwendigkeit, die arktische Region nicht im rein geographischen, sondern im hydrographisch-faunistischen sime zu begrenzen. In einzelnen gibt er ausser zahlreichen neuen f'undorten eine Fülle von kirgänzungen und Berichtigungen zn den Angaben des Ref. und anderer Autoren in betreff des Vorkommens und der Abgrenzung der Arten. Von Mesothuria intestinalis hält er die gleichfalls zwitterige 1I. verrilli mindestens als Varietät auseinander. Die Aufstellung der neuen Gattung Allantis Hérouard lehnt er durchaus ab und erklärt Stichopus richardi Hérouard für identisch mit Stichopus tremulus. Von Synapta inhaerens unterscheidet er scharf die damit bis jetzt gewöhnlich zusammengeworfne Art Labidoplax buski (M'Intoslı) (= Siynapta tencra Norman), tritt für die definitive Vereinigung der Gattung Orcula mit Phyllophorus ein und bezeichnet unter genauer Darlegung der unterscheidenden Merkmale den Myriotrochus vitreus (M. Sars) als eine von M. vinkii sicher verschiedene Art.

H. Ludwig (Bonn).

143 Perrier, Rémy, Holothuries. In: Expédit. scientif. du ..Travailleur" et du "Talisman" pendant les années $1880,1881,1882$, 1883. Paris 1902. pag. 273-5̄54. Taf. XII-- XXII. 14 Figuren im Text.

In diesem prächtig ausgestatteten Werke berichtet R. Perrier, nach mehrern vorläufigen Mitteilungen, in erschöpfender Weise über die Holothurien-Ausbeute der französischen Expeditionen im östlichen Teile des atlantischen Ozeans. Er schickt einen historischen Überblick über unsere bisherige Kenntnis der Tiefenformen des erwähnten Gebietes voraus, sowie tabellarische Übersichten ïber die Fundstellen und iber die vertikale und horizontale Verbreitung der Arten und unterlässt auch bei den einzelnen Familien und Gattungen nicht, auf deren geographische Verbreitung hinzuweisen. Bei der Peschreibung der einzelnen Arten wird auch die makroskopische Anatomie der innern Organe möglichst berïcksichtigt. Am reichsten an nenen 
Formen war die Ausbeute in den beiden Familien der Synallactiden und Psychropotiden. Im ginzen werden 5 neue Gattungen und 28 neue Arten geschililert.

Unter den Synallactiden sind neu die Gattungen Zygotharia (conncetens 11. sp.) und Bemhothuria (funcbris n. sp.). Bei Mcsothmin intestinalis fand er rudimeutäre Dorsalfüsschen, unterscheidet 1/csothuria verrillii als besondere Art, lehnt ebenso wie Östergren die rattung fllontis. Hérouard ab, beschreibt als neue Arten Mesothria maroceana und expectans und gibt eine Bestimmungstabelle sämtlicher Mesolhuria-Arten. Ebensolche Tabellen gibt er auch für die Zygothuriaund P'seudostichopus. Arten, zieht 'T'héels Holothuric lacta und thomsoni sowie Sluiters Mesothura marginata zu Zygothuria und beschreibt eine neue Pscurlostichopus-Art: atlanticus. Andere nene Synallactidae sind: Synallactes enucifera, Bathyplotes reptans, Pclopatides grisea.

Bei den Deimatidae hebt er das Vorkommen der Oneirophanta mutabilis im atlantischen Ozean hervor und gibt eine ausführliche Schilderung ihrer Kalkkörper, beschreibt die n. sp. O. altcrnata und in sehr eingehender Veise die Lactmogone violacea Théel sowie die Benthogone rosca Koehler.

Hinsichtlich der Elpidiidae setzt er seine Ansichten iiber eine natïlichere Abgrenzung und Anordnung der Gattungen auseinander und hildet daraus zwei Gruppen; zur ersten Gruppe stellt er Irpa, Kolga, Scotoplanes, P'eriamma und Achlyonice, zur zweiten Elpidia, P'arelpidia, Elpidiogonr, Peniagone, Scotoanassa und Enypniastes. Die neue Gattung I'criamma grinndet sich auf Arten, die Théel zu Scotoplanes und Peniagone gestellt hatte und welche Hérouard zu einer neuen, aber von Perrier nicht angenommenen Abgrenzung der Gattung Kolga veranlasst hatten; neu ist Periumma roseum. Während bei Elpidia nur die typische Art $E$. glacialis verbleibt, vereinigt er die vier Théelschen Arten: $E$. ambigua, rigida, verrucosa und incerta zur nenen Gattung Elpidiogone. Auch seine Definition der Gattung Peniagone ist nen; neue Arten: P'eniagono poreellus und verllum.

Die Familie der Psychropotidae erhält cinen Zuwachs von 7 nenen Arten: Euphronides auriculata, violacea, talismani, Psychropotcs buglossa, fucata, Benthodytes lingua, glutinosa.

Von Holothuriidae werden die vorhandenen Beschreibungen von Holothria mammata Grube (aus dem Mittelmeer), II. farcimen Selenka (von den Azoren) und Stichopus tremulus Gunner (= richardi Hérouard) ergänzt und eine interessante neue Gattung und Art: Gastrothuria limbata beschrieben, die zu den Synallactiden überleitet.

Neue Dendrochiroten sind Cncumaria incurvata (= Siphothuria E. Perrier) (verwandt mit C. tergestina Sars), C. compressa, Thyone gadeana (verwandt mit Th. fusus) und Psolus nummularis.

Zu den Rhopalodinidae stellt er die Gattung Sphaerothuria, für welche er aber den Namen Ipsilolluria festhält, und beschreibt eingehend die beiden von E. Perrier vorläufig anfgestellten Arten: $Y$. talismani und attenuata.

Bei den Molpadiidae liefert er Beiträge zur Kenntnis von Trochostoma blakei Théel, Tr. albicans Théel und Ankyroderma musculus (Risso), behauptet die Identität von Ankyroderma danielsseni mit der letztgenannten Art und beschreibt als neu: Ankyroderma maroccanum und loricatuu.

Aus der Familie der sy natidae wurde nur Protankyra abyssicola (Théel) erbeutet.

Aus seinen Erörterungen ïber das System und die Phylogenie 
der Holothurien ist am bemerkenswertesten, dass er die Molpadiidae (seine Anactinopoda) wieder näher an die s'ynaptidae heranrïickt und diese beiden Gruppen als Ordnungen zu einer Lnterklasse mit dem alten Namen Apoda wieder vereinigt. Was er aber dabei hinsichtlich meiner Abgrenzung der synaptidae als Paractinopoda (im liegensatze zu allen andern ron mir als Actinopoda bezeichneten Holothurien) vorbringt, geht von einer Auffassung der Paractinopoda aus, die ich, was er ausser Acht lässt, längst abgeändert habe; vergl. meine Bearbeitung der Holothurien in Bronns Klassen und Ordnungen 1902, pag. 447 und pag. 460. Der Ciegensat\% der Paractinopoda zu den Actinopoda liegt keineswegs nur in dem andern Ursprung der Fühlerkanäle, sondern ebensosehr und vielleicht noch mehr in dem gänzlichen Mangel von Radialkanälen des Wassergefässystems bei den erwachsenen T'Tieren, während sie bei den Molpadiidae wie bei allen andern Actinopoda rorlianden sind. Ferner übersieht er bei seiner neuen Benennung der Molpadiidae als Anactinopoda röllig; dass es bei ihnen, wie Gerould und Dendy: meinen Vermutumgen entsprechend, nachgewiesen haben, verkümmerte und umgestaltete Füsschen an den Enden der Radialkinäle gibt.

H. Lu d w ig (Bonn).

\section{Arthropoda.}

Insecta.

144 Portschinsky, J.. Sur les Oestrides du Genre Oestromyia et les larves cuticoles de la Saiga tatarica L. et de l'Antilope gutturosa Pall. (Т. По ор чи нскіиі, объ оводахь изъ рода Oestromуіа и о личинкахь оводовт изъ кожи сдйги и джейрана.) In: Ann. Mus. Zool. Ac. Sc. St. Pétersbourg. T. VII. 1902. pag. 205-222. Tab. VI. (Russisch.)

Der Verf. beschreibt zwei neue Imagines der Gattung Oestromyia Brauer, ron denen die eine, Oe.pallasi nov. sp., rom Altai, die andere, Oe. Koslowi nor. sp. - vom Gebirge Burchan-Budda (Zentralasien - stamnt. Erstere Art dürfte nach Ansicht des Verfs. vielleicht identisch sein mit Oe. leporims Pall. (von diesem Forscher aus dem Fell von Lagomys alpimus Pall. gezogen). Leider sind keine biologischen Angaben über die beiden neuen Vertreter dieser äusserst seltenen Gattung bekannt, ron welcher nur noch eine Art, Oe. sotymus Braner (Larven in Arricola aralis) beschrieben worden ist. Der Verf. gibt genaue Beschreibungen der neuen Arten; welche er ausserdem mit der erwähnten Brauerschen Art vergleicht. Ferner teilt er die Larven zweier Oestriden-Arten aus Zentralasien mit, von denen die eine aus der Haut der Saiga-Antilope bereits ron Pallas be- 
schrieben worden war, die andere, aus der Haut von Antilope guthrosa. neu ist; beide Larven gehören augenscheinlich verschiedenen fattungen an. Zu bemerken ist, dass zwar verschiedene ()stridenlarven, aber kein einziges erwachsenes Insekt aus Antilopen bekannt geworden sind. Von Interesse ist die Bestätigung dessen, dass nicht nur die Wirtstiere sich gegenseitig die Parasiten aushriicken und rerzehren, um ihren Durst zu löschen (die Larren sind sehr gross und saftig), sondern dass auch die Kinler der Tschuktschen die Larven ron Oedemagena tarandi als Leckerbisien betrachten. Die Tatel enthält schöne Abbildungen der Imagines und Larren, sowie letails der letztern.

N. r. d delung (St. Petersburg).

145 Bachmetjew, P., Die Schmetterlinge Bulgariens. (Il. Eax-

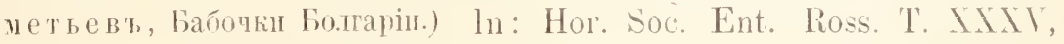
1902. pag. 356-466 (Russisch).

Der bereits durch seine experimentellen V'ersuche an Schmetterlingen bestens hekannte Terf. hat in der rorliegenden faunistischen Bearbeitung der Schmetterlinge semer Heimat ein Werk geliefert, das nicht nur durch seinen Gegenstand, sondern auch durch die grïndliche Beriicksichtigung aller auf die Fanna einwirkenden Faktoren besondere Beachtung verdient. Wir haben es hier mit dem ersten Versuch zu tun, der bis jetzt gemacht worden ist, die bulgarische Fauna einer Insektenlikasse unfassend zu bearbeiten, und doch hat dieses Land Eigentümlichkeiten aufzuweisen, welche wohl geeignet sind, die Zusammensetzung der Fauna zu einer eigenartigen zu stempeln. Nach den Untersuchungen bulgarischer Geologen hat Bulgarien keine eigentliche Kiszeit durchgemacht (Gletscher sind mit Sicherheit nur an (ler siidgrenze nachgewiesen), so dass das übrige Europa nach der Beendigung der Glacialperiole seine Fauna z. T. ans Bulgarien und Serbien erhalten hat. Eine wiclitige Rolle in faunistischer Hinsicht hat Bulgarien auch zu jener \%eit gespielt, wo statt der Dardanellenstrasse eine Landenge bestand, über welche die Inseliten ron Krleinasien nach Europa herüberwandern komnten. Die Anwesenheit eines hohen Gebirgszuges sowie die Nähe des Meeres geben der Fauna des liaum $100000{ }_{1} \mathrm{~km}$ messenden Gebietes ein eigenartig gemischtes Gepräge. Auch begünstigen die erwähnten Verhältnisse das Vorkommen auf gewisse Teile des Landes beschränkter (Lycaena zcph!) mes Fir. und Cosius balcunicus Led.) oder solcher Formen, für welche Bulgarien den äussersten Vorposten bei ilırem Vormarsch aus Asien nach Europa bildet (Lycaena balcanica Frz.).

Dem rorliegenden Verzeichnisse liegen zahhreiche Sammelberichte bulgarischer Entomologen (die betreffenden Objekte wurden fast durch- 
gehends ron dem Verf. oder von H. Rebel bestimmt), Angaben einiger ausländischer Reisenden sowie das eigene Material des Verfs. zu Grunde; doch gibt dasselbe nach den Worten des Verfs. keineswegs ein erschöpfendes Bild der Lepidopterenfauna Bulgariens, da zu einem solchen gegenwärtig noch kein genügendes Material vorliegt.

Von grossem Werte sind die dem Verzeichnis vorangehenden líapitel, welche die geographische Lage der hauptsïchlichsten Sammelorte in Bulgarien und namentlich die klimatischen Verhältnisse dieses Landes behandehn; ein weiterer Abschnitt ist dem Charakter der Flora gewidmet. Sehr umfassend sind die Literaturangaben, welche sich nicht auf die Lepidopterenfauna des Landes ( $40 \mathrm{Nr}$.) beschränkt, sondern auch auf floristische, geologische und meteorologische Arbeiten erstreckt.

Das Verzeichnis selbst enthält: Rhopolocera 32 gen., $235 \mathrm{sp}$. Sphinges 15 gen., 82 sp., Bombyces 53 gen., 139 sp., Noctuae 96 gen., 308 sp., Geometrae 63 gen., 217 sp.

Aus der Fassung der Liste kann man darauf schliessen, dass auch die Mikrolepidopteren ihre Bearbeitung finden werden. Bei dieser Gelegenheit wird eine ausführliche Besprechnng der faunistischen Facies namentlich mit Bezug auf die Nachbarländer hoffentlich nicht fehlen.

N. v. Adelung (St. Petersburg).

146 Cholodkovsky, N., Sur quelques rariations artificielles du I'apillon de l'Ortie (Taneswa urticae). In: Annal. soc. entomol. France. Vol. LXX. 1901. pag. 174-177. 1 Taf.

Es war bisher noch nicht gelungen, durch die Einwirkung monochromatischen Lichtes anf die Schmetterlingsraupen und Puppen irgend welche auffallendere Abänderungen in der Zeichnung der Falter zu erhalten. Solche Zïchtungsversuche unter farbigem Licht sind nun neuerdings wieder ron Cholodkorsky unternommen worden und zwar mit viel besserm Erfolg wie die bisherigen. Zu den Tersuchen wurden Raupen ron $I^{r}$. uticae verwendet, von denen ein Teil rotem, ein anderer blauem, ein dritter gelbem monochromatischem Licht ausgesetzt wurde, Eine weitere Anzahl Falter wurde im Sonnenlicht, eine andere unter dem Ausschluss ultravioletter Strahlen unter einem doppelwandigen Glasgefäss, dessen Doppehwandung mit Chininsulfatlösung erfüllt war, aufgezogen. Das Ergebnis der Versuche waren etwa 50 Falter, die in ihrer Farbe und Zeichnung kleinere Variationen zeigten, nur drei Exemplare waren wesentlich verändert. Von diesen war der eine unter gelbem Licht, die beiden andern unter bla ue m Licht aufgewachsen. Die Abünderungen betrafen bei diesen drei Faltern sowohl das Kolorit wie auch die Zeichnung der Flügel. Der 
unter gelben Lichtstrahlen entstandene Schmetterling zeichnet sich durch die fast gänzliche Abwesenheit der beiden dunkeln Flecken in den Seitenrandzellen vier und fünf der Torderflügel, durch Terdunklung des gelben Bandes zwischen dem zweiten und dritten schwarzen Vorderrandflecken und durch eine allgemeine Verdunklung seiner Crundfarbe aus. Auch die blauen Seitentandtlecken sind in Vordertlügel sehr reduziert, im Hinterflügel sogar gänzlich geschwunden. Im HinterHügel ist die Grundfarbe dunkler wie bei normalen Faltern (mehr rotbraun wie rotgelb) und statt der schwarzen seitenrand- und Wurzelzeichnung findet sich lier braune Beschuppung, die nur in den Seitenrandzellen drei bis vier durel eineu unbestimmt begrenzten rotgelben Fleck unterbrochen wirl. I) ie Grundfarbe der Flügelunterseite ist graubraun. Wiese Aberration hat sehr viel Ihnlichkeit mit den bisher gezüchteten Wärmeaberrationen, fïr die auch die Reduktion der schwarzen Seitenrandzellttecke, die Reduktion der blauen Randtlecken und bei extremen formen die Schwärung des Flügelvorderrandes charakteristisch ist.

Im Gegensat\% zu diesem, unter gelbem Licht entstandenen Falter findet sich die Vorderflügel-(irundfarbe der unter blauem Lichte erzogenen Schmetterlinge kaum rom Typus abweichend. Am meisten aberrieren hier die Hinterfliigel, die bei einem der Falter überhaupt nicht gezeichnet sind und haarförmige, schwargraue, etwas durchsichtige Schuppen tragen. Bei dem zweiteı, weniger stark abgeänderten Falter ist nur die eigentümliche Schuppenform hervorzuheben. Sehr deutlich entwickelt finden wir auf den Vordertlïgeln bei Nr. 2 und auch auf dem Hinterflügel des Falters die blauen Randflecken, die sonst besonders die in der Kälte gezüchteten Schmetterlinge auszuzeichnen ptlegen.

Diese Experimente, deren Wiederholung der Verf. in Aussicht stellt, sind von grösstem Interesse für das Verständnis der Wärmeund Kälteaberrationen und in letzter Linie für die richtige Deutung klimatischer Varietäten. Versuche, die die Ref. in letzter Zeit mit Lösungen des roten Schuppenfarbstoffes angestellt hat, haben iibrigens ganz ähnliche Resultate ergeben. In der IVärme, vorausgesetat, dass sie nicht zu linng einwirkt, tritt eine Verdunklung der Farblösung ein, unter roter und gelber beleuchtung ein Hervortreten der roten und rotbraunen Töne, unter violetter blauer und unter gr ïner Beleuchtung, wird die Farblösung dagegen ausgebleicht. Die bewirkende Trsache der Verfärbung ist also in einem Fall auf die Wärmestrahlen, im andern auf die chemisclı wirksanen Strahlen zurïckzuführen.

M. ron Linden (Bonn). 
147 Griuberg, K., Untersuch ungen über die Keim-nnd Nährzellen in den Hoden und Orarien der Lepidopteren. (Vorl. Mittlg.) In: Zool. Anz. Bd. 26. 1902. pag. 131-142. Textfigg.

Die Untersuchungen des Turfs. beziehen sich auf Bombyx mori L., Phatera bucephata L.. Gastropacha mbi L. Pieris brassicae L., und Iranesse io L., und beschäitigen sich zunächst mit der Versonschen Zelle, für die der Name ., l picalzelle der Insektenkeimdr ï sen" vorgeschlagen wird. Im Hoden ron Bombyr mori ist diese Zelle bereits beim Embryo rorhanden und als eine umgewandelte Keimzelle aufzutassen (gegen To y a ma). Unter ihrem Eintluss werden Spermatogonien aufgelöst, die sie assimiliert und zur Ernährung der andern Keimzellen verwertet. zu welchem Behufe sie auch teilweise selbständig Nährmaterial produziert. Im postembryonalen Leben wird sie datm allmählich rïckgebildet. Auch iu Orarium findet sich eine entsprechende Zelle, die aber funktionslos bleibt und ebenfalls degeneriert. lles weiteren werden Mitteilungen uiber die postembryonale Fintwickelung der Ovarien bei Lombyx mori und Pieris brassicae gemacht. In der Nähe des Eiröhrenstiels lagen bereits im embryonalen Orar eine Anzahl kleinerer Kerne. Diese rermehren sich, erfüllen den hintern Teil der jungen Eiröhre und ordnen sich dann nach Art ron Epithelzellen an den Wandungen der Eiröhre nebeneinander. Sie bilden die Follikelzellen, die somit nichts mit den Keimzellen zu tun haben. sondern schon embryonal geschieden sind. Aus den Oogonien entstehen nur Xährzellen und Eizellen, welche letzteren bei ihrer Entwicklung eine Kiemzone, eine Synapsiszone, eme Differenzierungszone (Differenzierung in Kein- und Xährzellen) und eine Wachstumszone (Bildung ron Ei- und Nährkammern) durchlatufen.

R. (roldsch midt (Nürnberg).

148 firmm-frimailo, Gr., Lepidoptera nova vel parum cognita regionis

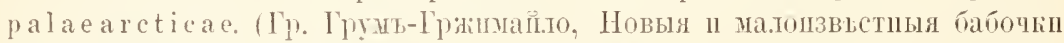

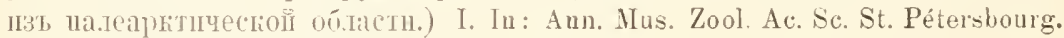
T. IV. 1899. pag. 455472.

149 - - II. Ibid. 'T. NII. 1902. pag. 191-204. (Russisch.)

Der Terf. beschreibt eine Reihe neuer Schmetterlinge, welche zumeist aus dem asiatischen Russland, Zentralasien, Persieu usw, also aus verhältnismälı̈g wenig eriorschten Gebieten stammen. Die Diagnosen und Fundorte sind lateinisch abgefasst. Es sind dies: C'olias hyperborea sp. n. (Nordostsibirien, Übergang zu den amerkanischen Arten), C. aquilonaris sp. n. (ebendaher), Earias turana sp. n. ('Transkaspien), Anctia serum sp. n. (Mongolei); Hyperborea gen. nov. (Aretia nahestehend), II. czekanouskii sp. n. (Nordsibirien); Newelshoia gen. nov. (Hypopta nahestehend) für Cossus albonubila Cräser (Wladiwostok, nördl. Mongolei), Zeuzera ariana sp. n. (Samarkand), Stygia dercetis sp. n. (Moabit), Hepialus uralensis sp. n. (Ural, Wilui, Irkutsk), Harpyio intercalaris sp. n. (Ostchina), H.syra sp.n. (Syrien), 
Teracohts semiramis sp. 1. (östl. P'ersien), Lycacna berezouskii sp. n. (Sze-tschuen), L. serica sp. n. (ebendaher), l, aricic sp. n. (ebendaher), Ino duskei sp. n. (üstl, Persien), Holcocerus mus sp. n. (östl. Persien), H sacerm sp. 1). (Transkaspien). H. zarudnyi sp. n. (sïdïstl. Persien). H. drangianicus sp. n. (östl. Persien), Mypopln zoronstres sp. n. (südöstl. Persien), S'tygia ahngeri sp. n. ('T'ranskaspien). Ausfordem werden mehrere neue Varietäten älterer und neuer Arten heschrieben.

N. v. Adelıng (St. Petersburg).

150 Krulikowsky. I.. Zur Kenntnis der Lepidopterenfauna des Gouver.

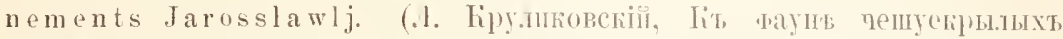

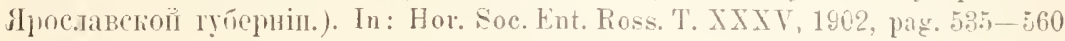
(Russisch).

Die gegebene Lokalität, welche bisher in lepidopterologischer Hinsicht nur ganz mangelhaft. untersucht war, liegt zwischen verhältnismäfig gut erforschten Gebieten; ein recht vollständiges Verzeichnis der Lepidopterenfauna des Jarosslawljschen Gouvernements füllt daher eine empfindliche Lücke. Der Verf. lualt sich in Anordnung und Nomenklatur an den neuen Katalog ron Staudinger und Rebel und enthält 2 Arten Papilionidae, 9 Pieridae, 34 Nymphalidae, 13 Lycaenidae, 9 Hesperiidae, 13 Sphingidae, 10 Notodontidae, 6 Lymantridae, 9 Lasiocampidae, 1 Saturniidae, 4 Drepanidae, 160 Noctuidae, 3 Cymatophoridae, 1 brephidae, 120 Geometridae, 1 Nolidae, 2 Cymbidae, 19 Arctiidae, 5 Zygaenidat. 3 Psychidae, 5 Sesiidae, 1 Cossidae, 4 He pialidae, 42 Pyralidae, 6 Pterophoridae, 37 Tortricidae, 2 Glyphipterygidae, 6 Yponommeutidae, 4 Plutellidae. 26 Gelechijdae. 12 Elachistidae. 2 Gracilatiidae, 1 Lyonetiidae, 12 T'ineidae, 1 Eriocraniidae. Im ganzen 586 Arten mit Angaben ïher frühestes und spätestes Auftreten.

N. v. Adelung (St. Petersburg).

151 Portschinski. J. I. Die Bekämpting einiger schädlicher Schnetterlinge mit Hilfe polyluger Parasiten nuter

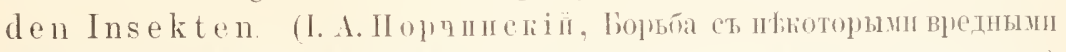

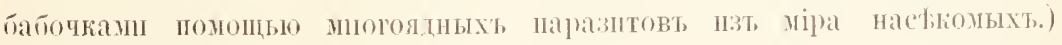
Ausg. d. Depart. f. Landwirthschaft. St. Petersburg 1901. 32 pag. (Russisch.)

Bereits in Jahre 189t hatte der Verf. bei Gelegenheit einer Besprechung der Mittel gegen die Tonne daranf hingewiesen, dass bei gleichzeitigen Auftreten der Nome mud des schwammspinners (Ocneria dispar L. $)^{2}$ ), gegen erstere, deren Eier nur sehr schwer zu rernichten sind, am wirksamsten durch die Vernichtung der leicht anffindbaren und erreichbaren Schwammspinnereier vorgegangen werden kamn, indem die Parasiten beider Schädlinge grösstenteils die gleichen sind und mach dem Verschwinden des schmammsininers notgedrungen zum weitans grössten Teil anf die Rimpen der Tonne

1) Dies ist der Fall in Nadelwäldern, welche einen bedeutenden Prozentsatz von Laubbäumen aufweisen, welch letztere dem Schwammspinner unentbelnrlich sind. 
ïbergehen werden: der auf solche Weise ungehener vermehrten Zahl von Parasiten wird es dann mit Leichtigkeit gelingen. diesen zweiten Schädling binnen kurzem zum Verschwinden zu bringen. In dem rorliegenden Aufsatz führt der Verf. diesen Gedanken weiter aus, indem er ihn auf andere Kombinationen gleichzeitigen Auftretens rerschiedener schädlicher Schmetterlinge (wie sie nach den dem Entomologischen Bureau des Departements zukommenden Berichten in rerschiedenen Teilen Russlands konstatiert werden) ausdehnt. Gleichzeitig bespricht der Verf, die Znsammensetzung der Parasitenschar eines jeden Schädlings, wobei er den Nachweis führt, dass die Mehrzahl dieser Parasiten polyphag ist: wenn auch bis jetzt nicht für jeden polyphagen Parasiten eines gewissen Schädlings nachgewiesen wurde, dass er mit Sicherheit gerade anch in bestimmten, gleichzeitig mit ersterm auftretenden Schädlingen rorkommt, so muss dieses letztere doch in vielen Fällen mit sicherheit angenommen werden, da die meisten polyphagen Ichneumoniden und Tachinen nicht wählerisch sind; eine Iiraconide. Apanteles liparidis z I3., parasitiert nachgewiesenermaßen in den Raupen von 33 Schmetterlingsarten; ansserdem sind unsere Kemntnisse ron den Parasiten schädjicher Insekten noch bei weiten nicht rollst:̈ndig zu nennen, und die Zahl der polyphagen Parasiten wird mit der Z'eit noch bedeutend wachsen.

Unter den olen erwähnten Kombinationen im gleichzeitigen Auftreten schädlicher Schmetterlinge sind ror allem folgende ron Wichtigkeit: 1. Yonne + Schwammspinner (Kubansches Gebiet); 2. Ringelspinner (Clisiocamua nenstria L.) + Goldafter (Porthesiu chrysorhoea L.) (ehendaselbst); 3. Ringelspanner + Baumweissling (Aporia cratuegi L.) (Kreis I'fa); 4. Ringelspinner + Schwammspinner (Woronesh). Bei der Kombination 2, welche in jungen Eichenwäldern auftrat, wäre die Vernichtung der Raupennester des (ioldafters leichter anszuführen als diejenige der Eierringel des Ringelspinners, bei 3 diejenige der Räupchen des Banmweisslings (welche im Kreise Ufa den Faulbeerbäumen [Prmus padus], deren Früchte einen bedentenden Handelsartikel bilden, ausserordentlich stark schadeten); bei 4 werden die grossen Eierklumpen des Schwammspinners zu vernichten sein. Tritt zu letzterer Kombination noch der Goldafter hinzu, so empfiehlt der Terf. ebenfalls das Ternichten der Goldaftereier. Zuu letzterer Kombination sei bemerkt. das ron 26 l'arasiten des Schwammspinners 14 sicher anch die beiden andern Schädlinge befallen. Es versteht sich ron selbst, dass bei jedem Auftreten ron Schädlingen deren Parasiten nach Art und Zahl genan studiert werden mïssen. Zur Vernichtung der Fier des Schwammspinners empfiehlt der Verf. 
das Bestreichen derselben (nittelst Malerpinsel) nit Naphtha, was ausgezeichnete Resultate gegeben hat; gut wirken auch Petroleum (mit 'Teer!) und Kreosot (teuer). Die interessinten, rorläufig mehr theoretischen Ausfïhrungen des Verfs. lassen weitere Berichte mit Spannung erwarten.

N. v. A delung (St. Petersburg).

52 Portschinski, J. A., Die Getreide mot te (Sitotioga cerealella Oliv.) und das einfachste Mittel zu ihrer Verniclitung.

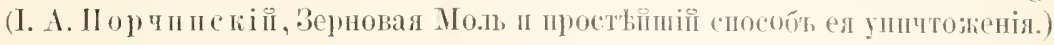
Ausg. d. Depart. f. Landwirthsch. St. Petersburg 1902. 14 parg. 8 Abb. i. T. (Russisch.)

53 Mokrzetzki, S. A., Der Wiesenzii nsler (Phlyctaenodes sticticalis L., Eurycreon [Botys] sticticalis L.), dessen Lebensweise und die Mittel zu seiner Bekämpfung. (C. A. Mokpqeцií, . Іуговой моты.гек, его жызи, и мұры борьбы ет нпмт.) Ansg. d. Depart. f. Landwirthsch. St. P'etersburg 1902. 23 pag. (Russisch.)

Die Getreidemotte, welche anch im westl. Europa und Nordamerika sporadisch schadet, hat in nenester \%eit mehrfach die gesamten Getreide- und Maisvorräte der Gemeindespeicher im Kaukasus und in Transkaukasien vernichtet. I ie Lebensweise und Entwickelung ist genügend bekannt. In den angeführten Gebieten überwinterte die Motte als Raupe, wind im Frülijahr mit dem Getreicle aufs Feld gebrackt, wo sie ihre weitere Entwickelung durchmacht: der ausschliipfende Schmetterling belegt die Körner der Winter- und Sommersaat mit Eiern und geht auch auf Mais über. Mit dem Getreide in die Schuppen verbracht, vollenden die Räupchen ihre Entwickelung und die Falter dieser Generation legen ihre Eier in das aufgespeicherte Getreile; ein 'Teil dieser Eier gerït mit der Wintersaat wieder aufs Feld, wo die Räupchen iberwintern, ein anderer Teil entwickelt sich in den Speichem (siehe oben). l)ie Motte kamn sich aber anch stetig in Getreide fortptianzen, welches jahrelang in Speichern liegt. Der Verf. hält die bisher angewendeten Mittel zur Bekämpfung für zu kostspielig oder kompliziert und befürwortet die Anwendung von Scliwefellohlenstoff in der Weise, dass die Desinfelition grösserer Portionen in entsprechenden, mit einem Deckel versehenen Gruben, kleinerer I'ortionen in Fïssern vorgenommen wird. Ileses bereits in Frankreich und in Amerika angewandte Verfahren ergab im Kaukasus die besten Riesultate. Das Getreide usw. wird durch den Schwefelkohlenstoff in seiner Qualität in keiner Weise beeinträchtigt. Als wirksamste Jahreszeit für die Desinfektion empfiehlt der Verf. die auf die Ernte folgenden Wochen, wo der Schädling im Stadium der Raupe ist. 
Der Wiesenziinsler scheint in Westeuropa als Schädling unbekannt zu sein ${ }^{1}$. Im enropiiischen mo asiatischen Russland hat derselbe schon rielfach nngehenem Schaden in Cremiisegärten. Feldern (namentlich Zuckerrüben) und Weinbergen angerichtet. Mokrzetzki hatte 1901 Gelegenlseit, diesen Zünsler im Gonv. 'Taurien zu beobachten und berichtet dariiber folgendes: Der Flug danerte rom Ende April bis zum November, wobei die stärkste Flugzeit der ersten Generation in die erste Hälfte des Mai (a. St.) fällt. An dritten Jage begann die Paarung mol die Eiablage an die Blätter niederer krautartiger PHanzen; ein Weibchen legt bis zn 100 Eiern in Hänfchen ron je einigen Eiern. Nach einex Woche krochen die Räupchen ans, begannen die Weichteile der Blätter (meist an ein und derselben Ptlanze) zu fressen, wobei sie eine grossartige Gefrässigkeit an den Tag legen. Bald war der ganze Bezirk (Steppe, Weide u. dergl.) kahl gefressen, die Räupchen sammelten sich zu ungehenern Scharen nnd wanderten (Fnde Mai) nach liultivierten Ländereien aus (Gemüsegärten, Kleefelder, Raps); am 10. Juni gingen die Räupchen dieser Generation zur Verpuppung in die Erde. Der $3 \mathrm{~cm}$ lange, $5 \mathrm{~mm}$ breite Cocon besteht aus weisslichem Gewebe mit anhaftenden Erdteilchen; die letzte Häutung erfolgt innerhalb des Cocons. Nach drei Wochen erfolgt der Flug der zweiten Generation, welcher Mitte Juli derartige Dimensionen annimmt, dass er nicht selten den Eindrnck eines Schneegestöbers herrornuft. Die Entwickelung der zweiten Generation erfolgt wie diejenige der ersten; die Raupen gingen am 20. Angust zur Verpuppring in die Erde, wo sie im Puppenstadium iberwintern. Die Raupe dieser Pyralide ist erstaunlich polyphag, indem sie fast alle Gewächse zur Nahrung benutzt; im allgemeinen remeidet sie nur Gräser (wohl wegen der in den Blättern enthaltenen Kieselsüure) und Solanaceen, greift in der Not aber auch diese (mit Ausnahme les Nachtschattens und der Tomaten) an: selbst Nadel- (Thuja) und Laubhölzer (nit Ausnahne weniger Arten) werelen nicht rerschont, wobei auch die weiche Rinde gefressen wird.

Die Angaben Mokrzetzkis weichen in mehrfacher Hinsicht von denen früherer russischer Autoren ab, erstens indem er nur zwei Generationen beobachtet hat, während früher bis drei Generationeu angenommen wurden, terner indem er die Verpuppung in lockerer Erde konstatierte (friihere Forscher hatten das Gegenteil angenommen)

1) Da in der einschlägigen westeuropäischen Literatur keine Angaben über diesen Schädling, welcher unter Umstäuden sich nach Westen ausbreiten könnte, zu finden sind, so möge dessen Lebensweise etwas ausführlicher besprochen werden; Ref. 
und nachweist, dass die Wanderungen der Raupen zum Teil auf der Suche nach solchem Boden beruhen.

Von Feinden der Raupen sind viele Singvögel, Carabiden (Calosoma denticolle Gebl.) und Ameisen, namentlich aber Braconiden zu nennen. Als Mittel zur Bekämpfung empfiehlt der Verf. laauptsächlich 1. das Umgeben der Gärten nsw. mit Kanälen, deren Wände oben schief zusammenlaufen und welche mit Wasser gefüllt sind oder auf deren Boden man Naphtharïckstïnde, Teer, Syrup oder ungelöschten Kalk schüttet: 2. um die Gräben herum Bespritzen der Gewächse mit Pariser Grün und Kalk: 3. in Gemüsegärten zeitweiliges Zuschütten der Pflanzen mit Erde; 4. Bestreuen der Raupenziige mit Kalk, Bespritzen mit Karbolemulsion u. dergl. (heisses Wasser unter $60^{\circ} \mathrm{R}$. niitzt bei diesen Raupen nicht); 5. Anbringen ron $40 \mathrm{~m}$ breiten, mit Grasarten besäten Schutzstreifen um Gärten u. dergl.; 6. Schutzringe ron Raupenleim an Obstbäumen; 7. Umptlügen aller mit Cocons besetzten Felder im llerbst und Frühling.

$$
\text { N. v. A delung (St. Petersburg). }
$$

154 Glasmow, D., Revisio specierum bicolorium generis Nebriae Latr. (Coleoptera, Carabidae) in Asia media habitantium. (1. K.

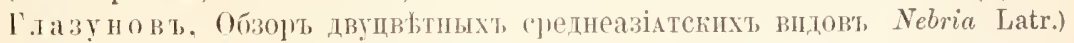
In: Horae Soc. Ent. Ross. T. XXXV. 1902. pag. 467-492. Taf. II. (Russisch.) Der Verf. bespricht die beilen Gruppen der mittelasiatischen zweifarbigen Nebria. Arten, von denen die erste, vollständig geflügelte (für die übrigen morphologischen und Farben-Unterschiede sei auf das Original verwiesen) eine weite geographische Verbreitung (fast das ganze asiatische Hochland) hat, die zweite, kurzflügelige, besonders in vertikaler Richtung in ibrer Verbreitung sehr beschränkt ist, und namentlich im Turkestan die europäische alpine Nebria-Gruppe ersetzt. Der einzige europäische Vertreter der ersten Gruppe, N. prammodes Rossi besitzt auf bejelen Seiten der Abdominalsegmente je eine, die asiatischen Arten je 2-3 borstentragende Grübchen. Zu dieser Gruppe gehören N. psammophila Solsky mit 1 subsp. und 4 Varietäten (nov. subsp. transeaspica n. var. oreophila, subalpina, humerosa), $\boldsymbol{N}$. limbigera Solsky mit 1 subsp. und 2 Varietäten (nov. s. bsp. kandshutica, nov. var. alaiensis, picta), N. kozlowi n. sp., N. sublivida Sem., N. grombczcwskii Sem.; zur zweiten Gruppe: N. ambigua n. sp., I. haberhaueri Heyd., N. perlonga Heyd. und $N$. grumi n. sp. Diagnosen, Fundorte und vergleichende Mafistabellen lateinisch.

N. v. Adelung (St. Petersburg).

155 Jakowleff. B. E. Études sur les espèces du genre Sphenopterca Sol (Coleoptera, Buprestidae). In: Horae Soc. Ent. Ross. T. XXXV. 1902. pag. $168-184$.

156 - Révision des Sphenoptera de la région éthiopienne (Coleoptera, Buprestidae). lbid. pag. $279-355$.

157 - Étude sur les Sphenoptera paléarctiques du sous-genre Deudora B. Jak. (Coleoptera, Buprestidae). Ibid. pag. 561-583.

In dem ersten Aufsatz werden 7 neue Sphenoptera-Arten (aus Zentralasien, Algier, Indien, Ägypten und Persien) beschrieben. Der zweite Aufsatz gibt den

Zoolog. Zentralbl. X. Jahrg.

- Nr. 153-157. - 
Versuch einer systematischen Übersicht der äthiopischen Sphenoptera-Arten (z. T. auf Grund der typischen Exemplare von Kerremans). Die Untergattung Sphenoptera sens. str. ist nur durch 3 Arten vertreten, darunter eigentümlicherweise die paläarktische Sph. antiqua Illig. var. variolosa Kerr., welche sogar in Nordafrika fehlt; die Untergattung Deudora nur durch eine einzige Species, die mediterrane Sph. rauca var. africana B. Jak.; das Fehlen spezieller afrikanischer Arten ist sehr auffallend (40 sp. im paläarktischen Gebiet!); dagegen ist die Untergattung Hoplistur vorwiegend afrikanisch (67 afrikanische, 15 paläarktische sp.); bemerkenswert ist, dass dieses Subgenus auch in Ostindien reich vertreten ist und ausserdem auf den zwischen beiden Gebieten zerstreuten Inseln gefunden wurde (neuer Beweis für das einstige Vorhandensein eines grossen, sich von Südafrika bis Ostindien erstreckenden Kontinents). Ausserdem sind noch die subgg. Tropeopcltis (nov. subg) Hoplandrocnema und Chrysoblcmma in Afrika vertreten. Im ganzen sind es 144 äthiopische Arten, vol denen nur 2 auch im paläarktischen Gebiet vorkommen.

Auf Grund neuen Materials gibt. Jakowleff eine vervollständigte analy. tische Tafel der paläarktischen Deudora-Arten ${ }^{1}$ ), sowie einen Katalog aller 49 Arten. Dabei erfolgt die Beschreibung von 7 neuen Arten (Turkestan, Transkaukasien, Bucharei, Kleinasien).

N. v. A delung (St. Petersburg).

158 Rossikow, K. N., Ueber die Bekämpfung der La ubkäfer. (К. H. Росспковь, О ириахь борьбы съ хрущанг.) Ausgabe des Departements f. Landwirthschaft. St. Petershurg 1901. 21 pag. (Russ.)

Der Verf, hat im Sommer 1901 im Auftrage des Entomologischen Bureaus genaue Lntersuchungen über Lebensweise, Entwickelung und Bekämpfung von Mololontha inlyaris Fabr. (A. $\left.)^{2}\right)$, M. himpocustani Fabr. (B.), Polyphylla fullo 1. (C.). Phizotrogus solstitialis L. (I).), Phyllopertha horticola L. (E.) auf einem Areal von etwa 6300 ha (Kiefernwaldung mit eingesprengten Laubwaldbezirken, Wiesen usw.) des Gouvernements 'lschernigow (Kleinrussland) ausgeführt. Für die Eiablage bevorzugen $\mathrm{A}$. und $\mathrm{B}$. keinen besondern Boden, aber lichte Bestände, C. dagegen tiefen feuchten Sand mit dünnem Graswuchs, D. wenig tiefen sand mit dünnem Graswuchs an ganz offenen Stellen, E. mit Gebüsch bedeckte Kahlschläge. Der Flug dauert bei A. und 1). von Ende April ${ }^{3}$ ) bis erste Hälfte . Tuni, bei C. zweite Hälfte Juni bis Anfang Juli, D. erste Hälfte .Juni bis Anfang Juli, E. Ende Mai bis erste Hälfte Juni. Die Zahl der Käfer war bedeutend: von A. und B. fing der Verf. auf einem Gebiet von etwa 100 qm unter drei Eichen gegen 5000 Käfer. Als Nahrung dienten A. und B. ausschliesslich Laubholz (vorzugsweise Birke und Eiche), C. nur Kiefernnadeln (Frass äusserst gering), 1). wie A. und B. Zwischen der

1) Vergl. Zuol, Zentr.-Bl. 1900. pag. 811.

2) Der Raumersparnis wegen bezeichnet der Ref. die einzelnen Arten mit Ordnungsbuchstaben.

3) Alten Stils. 
Paarung und der Eiablage erfolgt ein Zwischenraum bei A. und B. von 10 Tagen (experiment.), hei C. ron $8-9$ T. (natïrl.), bei D. von $6-7$ (exper.), 5-6 (natiirl.) T., Die Eiablage erfolgt in 2-3 Malen, bei A. und B. wurden 60-70 Fier (zu 3-25), bei C. 24-36 Eier (zu S-12), bei D. 32 Eier (zu 6-18) abgelegt. Das Ausschliipfen der Larven erfolgte bei A. und B. nach 12-14, bei C. nach 15-17, bei D. nach 10 Tagen. Nach dem Ausschlïpfen blieben die Larven 2-3 Nonate an denselben Stellen, C. am längsten, D. am kïrzesten. In den ersten Monaten nährten sich die Larven nur von Humus, später (im zweiten und dritten Jahr) A., B. und D. von Wurzeln der Bäume (wobei D. abgestorbene Wurzeln vorzogen), C. von Graswurzeln.

Was die Parasiten und Krankheiten der Larven betrifft, so waren $5 \%$ aller 3-4 jährigen Larven von A., B. und D. in allen Lagern von Flacherie befallen, bei C. betrug die Zahl solcher Larven $2-3 \%$, bei E. $30-40 \%$. 2-3\% der Larven aller Arten waren von Nematoden erfüllt, nur $1 \%$ der Larren von A., B. und C. waren von parasitischen Fliegenlarren, 40-50\% (an offenen Stellen bis zu $75 \%$ ) der D.-Larven von parasitischen Larven von Tifia femorata Fabr. befallen. Endlich waren $1-2^{0}$ o aller A. und B.-Larven krüppelhaft.

Von Mitteln zur Bekämpfung ergaben auf Grund ausgedehnter Versuche die besten Errebnisse: Zur Vorbeugung: das Bedecken der zur Kultur bestimmten und der schon bestellten Flächen während der Flugzeit mit Stroh, wobei kleine Räume frei bleiben, um zur Eiablage anzulocken; Vernichten der Brut an diesen Stellen. Mittel zur Vernichtung: 1. Begiessen der Brutstätten mit Schweinfurter Grïn, nach vorheriger Auflockerung des Bodens; 2. Bespritzen des Laubes der Futterbäume mit einer Mischung ron Schweinfurter Grün, Wasser und frisch gelöschtem Kalk. Der Verf. warnt vor dem Austreiben von Schweinen wegen der Echinorymchus gigas-Eier, welche nach Schreiner in den Engerlingen zur Entwickelung gelangen und dann wieder mit den letztern von den Scliweinen gefressen werden. N. v. A d elung (St. Petersburg).

159 Tschitschérine, T.. Mémoire sur la tribu des Harpalini. In: Hor. Soc. Ent. Ross. T. XXXIV. pag. 335-370.

160 - Einige Bemerkungen zu Reitter's Bestimmungstabelleu der H a r palini. Ibid. T. XXXV. 1901-1902. pag. 125-155.

161 - Genera des Harpalini des régions paléarctiques et paléallarctiques. Ibid. pag. 217-251.

162 - Bemerkungen ï ber Har palini (Coleoptera, Carabidae). Ibid. pag. 584-597.

Die Carabidentribus der Harpalini wird auf Grund von zum Teil neuen, hauptsächlich den Mundwerkzeugen und den Tarsen entnommenen Merkmalen in folgende Subtribus eingeteilt: Glyptini, Daptini, Ditomini, Harpalini 
sens. str. (Nesacinopus nov. gen.), Acupalpini, Trichopselaphini, Stenomorphini, Anisodactylini, Pelmatellini. Hs folgt eine analytische Tabelle für die paläarktischen und paläanarktischen Gattungen der Subtribus H a r pa lini s. str., Acupalpini (Idiomelas nov. gen.), A n is od a e ty lin i.

Die zweite der angeführten Arbeiten enthält eine kritische Besprechung der in dem XLI. Heft der Reitter'schen "Bestimmungstabellen der europäischen Coleopteren" enthaltenen Harpalini; der Verf. wendet sich gegen die analytische Anordnung und die Reihenfolge der Gattungen als nicht der systematischen Verwandtschaft entsprechend und kritisiert sodann die einzelnen Gattungs- und ArtMerkmale der "Bestimmungstabelle", wobei er seine, von denen Reitters abweichende Ansichten über Synonymie uıd systematische Stellung einzelner Gattungen und Arten mitteilt.

Der dritte Aufsatz bildet die Ergänzung des ersten; er enthält eine verbesserte analytische Tabelle der 9 Subtribus, und eine solche für die Gattungen der Subtribus Ditomini (Carterocarus, Eriocypas (nov. genera); die Tabellen der Subtribus Harpalinis. str. (Subgenera nov. Macrophonus, Eriophonus, Tachyophonus, Cephalotyspis, Typsiharpalus, Nicroharpalus der Gattung Harpalus.), Acupalpini (Liocellus, Pelagophilus nov. gen.) nnd Anisodactylini werden in etwas veränderter und vervollständigter Form wiederholt. Von neuen Arten sind zu erwähnen: Pentophonus anionowi (Transkaspien), Harpalus cous (Mandschurei, Japan), H. semenowi (Thibet) nn. spp

In dem letzten der Aufsätze des Verfs. werden einige neue Arten der Gattung Harpalus mitgeteilt: H. (.Mcgalophonus) phoenix, vermutlich aus syrier, $H$. (Ophonus) sulcifor aus Syrien, $H$. (Artabas) petri aus Nowotscherkassk; über einige ältere Arten werden verschiedene Angaben gemacht.

Die beiden auf die Klassifikation der Harpalini bezüglichen Arbeiten enthalten sehr viel in morplologischer und systematischer Hinsicht wichtige Neuerungen und sonstige bemerkenswerte Mitteilungen.

N. v. Adelung (St. Petersburg).

163 Thchitschépine, T.. Notes sur les Platysmatini du Muséum d'Histoire Naturelle de Paris. VI. In: Horae Soc. Ent. Ross. T. XXXIV, 1900, pag. 371-397; VII. Ibid. pag. 488-478; VIII. Ibid. pag. 509-516; IX. Ibid. pag. $534-540$; X. Ibid. pag. 666-775 1).

164 - Notes sur quelques Platysmatini de la région Malgache. Ibiel. pag. $570-576$.

165 - Révision du sous-genre Bothriopterus Chaud. (genre Platysma Bon. (Tsch.). Ibid. pag. $606-613$.

166 - Déscription de quelques nouvelles espèces de la tribu des Platysmatini. Ihid. T. XXXV, 1901-1902, pag. 1-16.

167 - Notes sur les Platy'smatini de l'A ustralie. I. Ibid. pag. 494 - 501.

Die Fortsetzung der Besprechung der im Pariser Museum enthaltenen Carabiden der Tribus Platysmatini enthält folgende neue Aufstellungen: Gen. Platysma (Bon.): nov. subgg. Mcraulax, Paranortes. Metamelanius, Eutanys (Pl. arctum und cxtcruntum spp. nov. aus Chili), Antarctobium, Chactauchenium, Plagioplatys, Hoplauchenium (Pl. minax sp. nov., Persien); Botinynopnoctus nov. gen. (B. mattoënsis n. sp. aus Brasilien); Eudromus ankatandrae n. sp. aus Madagaskar; Arsenoxenus nitescens n. sp. v. d. Sundainseln; Tropidocern. flavipes und dispar nn. spp., beide vom Senegal: Feroniola nov. gen. (F. famelica aus Patagonien n.sp.)

1) Vgl. Zool. Zentr.-Bl. VIII. 1901. pag. 31. 
Ferner werden einige neue Arten mitgeteilt, welche bereits hekannten Untergattungen von Platysma angehören, und zwar $P$. (pterostichus) harmaudi und dolens aus Sikkim, Pl. (Blennidius) fontainci aus Clile, Pl. (Argutoridius parens aus Brasilien und Pl. (Percosteropus iranicus aus Persien).

Von Madagaskar beschreibt der Verf. folgende neve Formen: Abacetus insularis, A. exul, A. micros, Eucamptognathus ikopac nn. spp. Der folgende Aufsatz enthält eine analytische Tabelle der Platysma-Arten aus del Untergattung Bothriopterus Chand. mit Angabe der Verbreitung.

Es folgt die Beschreibung neuer Gattungen und Arten exotischer Platysminen: Drimostoma planipenne n. sp. (Kamerun), Lobobrachus alternans n. sp. (Brasilien); Apsaustodon n. g. (eine ganz isoliert dastehende Form) segregatus n. sp. (Venezuela); Liopasa n. g. crrprra n. sp. (Queensland); Paranurus n. g. petri n. sp. (Torre-Strasse?), Homalosoma hecate 11. sp. (Australien), Platysma (Chalcochrous) hera n. sp. (Kap.).

Schliesslich werden 3 neue Formen aus Australien mitgeteilt: Platysma (Pterostichus) ixion, Pl. (Pt.) rhanis, Pi. (Eosteropus n. subg.) creperum n. sp.

Sowoll die Diagnosen als auch die analytischen Tabellen zeichnen sich wio auch in frühern Arbeiten des Verfassers durch Ausführlichkeit und Genauigkeit aus; die einschlägige Literatur ist in ergiebiger IVeise berücksichtigt.

N. v. A delung (St. Petersburg).

168 Kokujew, N.. Symbolae ad cognitionem Braconidarum Imperii Ros-

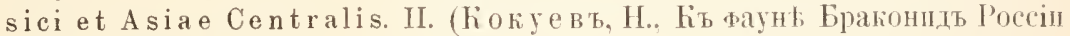
и Центра.ыної Азін.) III. Horae Soc. Ent. Ross. T. XXXIV. 1900. pag. 541 -569. (Russisch) 1).

169 - Celor semcnoui, gen. et sp. nov. (Hymenoptera, I chneumonidae). Ibid.

T. XXXV. 1901. pag. $210-216$. (Ruscisch.)

Die dritte Abteilung der "Symbolae" umfasst die Unterfamilie der Doryctinae (Braconida cyclostomata Wesın.), für deren 6 Gattungen (darunter 1 neue) eine analytische Tábelle gegeben wird. Hypodoryctcs nov. gen. (Doryctes Hal. nahestehend); ausserdem folgende neue Arten: Rhaconotus scabcr (Südrussland), Hypodoryctes sibiricus (Gouv. Tomsk), Doryctes strigatus (Gouv. Wjatka) nn. spp., ferner werden bereits bekannte Arten auf ihre Verbreitung hin besprochen und mehrere neue Varietäten aufgestellt. Sowohl die ausführlichen Diagnosen wie die analytischen Tabellen für Gattungen und Arten sind auch in lateinischer Sprache verfasst.

Eine von A. Semenow in Transkaspien aufgefundene Ophionide wird als Celor (A. Sem. in litt.) scmenowi n. sp. ausführlich beschrieben. Die neue Gattung steht Cicmastus Grav, nahe.

N. v. Adelung (St. Petersburg).

170 Kulagin, N., Die Entstehung der Geschlechter bei den Bien еп. (ћу тагпнь, Н., Пропсхожденіе пола у пчель.) Noskau 1901. 8 pag. (Russisch.)

Der Verf. hat die Versuche Dickels, Petrunkewitschs u. a. m. wiederholt, welche entscheiden sollen, ob das Geschlecht der Arbeiterinnen und Drohnen durch Befruchtung der Eier oder durch verschiedene Nahrung bedingt wird. Dabei ergaben die in Arbeiterinnenzellen

1) Vergl. Zool. Zentr.-Bl. VII. 1900. pag. 518. 
übergeführten Drohneneier stets Drohnen, und die mikroskopische Untersuchung von 100 Drohneneiern ergab keine Spur von Spermatozoen, womit also die Frage wiederum zu gunsten ersterer Annahme entschieden wird. Ferner unternahm der Verf. Versuche von kïnstlichen Reizungen des Eies: Schwefelsäure (spez. Gew. 1,014, während zwei Minuten) hatte keine Wirkung auf Drohneneier, welche stets Drohnen ergaben. Der Verf. schreibt die Entstehnng der Geschlechter dem Tmstande zu, dass die Königin die unbefruchteten Eier normal im Sommer, also bei erhöhter Ernährung, ablegt, und dass Wärme, Eunährung u. dergl. diesen Eiern einen Anstoss zur Entwickelung ron Männchen geben, wie dies im befruchteten Ei durch das Spermatozoon der Fall ist.

N. v. Adelung (St. Petersburg).

171 Ruzsky, II. Die Ameisen der Umgebung des Aral-Sees. (M. Pyncliii, Муравыи оврестиостей Ара.льскаго зория.) Taschkent, 1902. 80, 24 pag. (Russisch.)

Von dem Aralo-Kaspischen Gebiet waren bisher nur die Ameisen der Fedt. schenkoschen Ausbeute ('Turkestan) bekannt geworden, von denen 30 Arten aus dem östlichen Teil dieses Gebietes stammten. Hierzu kommen nunmehr eine Anzahl, von L. Berg am Aralsee selbst und auf dessen Inseln erbeuteten Arten, und zwar Camponotus muculatus F. (subsp. fedtschenkoi, turcestanicus und pallens), Myrmecocystus viaticus F., M. cursor F'onsc. (nov. var. caspicus), Formica rufibarbis F. (var. clara, n. var. subpilosa), $F$. nasuta Nyl., Lasius alienus Foerst., Plagiolepis pygmaea Latr., Tapinoma erraticum Latr., Myrmica bergi sp. n., Tetramorium caespitum L. (form. typica, f nov, reticulitentre, form. semilaere, inerme), Solenopsis orbula Em., Pheidole pallidula Nyl., Monomorium barbatulum Mayr., Carliocondyla koshewnikowi sp. n., Aphacnogaster barbara L., A. structor Latr., Crematogaster subdentata Mayr.

Die meisten dieser Formen sind der Wüste oder Steppe eigentïmlich, eine kommt ausserdem anch auf der Schwarzerde und in Kieferwäldern, eine andere in Laubwäldern, eine dritte fast überall vor. Die Mehrzahl der Aralameisen gehört der mediterranen Fauna an, vier Formen gehen bis in den Norden Westeuropas, 8 Formen sind endemisch (von diesen sind 5 Formen neu).

$$
\text { N. v. Adelung (St. Petersburg). }
$$

\section{Vertebrata. \\ Cyclostomi.}

172 Giacomini, E., Sul pancreas dei Petromizonti con particolare riguardo al Pancreas di Petromyzon marimus. In: Verhdlg. d. anat. Gesellsch. auf der XIV. Versammlg. in Pavia. 1900. pag. 44-52. 4 'Textfig.

Bei den Petromyzonten existiert ein drüsiges Organ, das sowohl nach seiner Lage wie nach seiner Struktur als ein wirkliches Pancreas betrachtet werden muss. Es besteht bei Petr. marims zum kleinen Teil aus drüsigen Follikeln, zum grossen aus wirklicher Drüsenmasse. Beide Partien besitzen beim erwachsenen Tiere keine Beziehungen zum Darmepithel, münden aber teils durch einen Ansführungsgang, teils durch einzelne öffnnngen in das Darmlumen. 
Die Hauptmasse des Pancreas findet sich in der Giegend der Spiralklappe und dringt zwischen die Leber ein, ohne mit dieser zu versclimelzen.

Die cylindrisch-prismatischen Zellen des Organes und der Follikel sind wie die Langerhansschen Zellen bezw. Blasen zu betrachten. Die Sekretion ist eine innere, d. h. bleibt zunächst in dem Organ und tritt erst sekundär aus ihm heraus. B. R awitz (Berlin).

\section{Pisces.}

173 Kopsel, Fr., Über die künstliche Befruchtung der Eier von Cristiceps argentatus. In: Sitz-Ber. Gies. Naturf.-Freunde Berlin. Jahrg. 1902. Nr. 2. pag. 33-36.

Verf. empfiehlt die grossen (Durchmesser $1,5 \mathrm{~mm}$ ) und sehr durchsichtigen Eier des Blenniiden Cristiceps argentatus zu entwickelungsgeschichtlichen Untersuchungen. Laichzeit in Neapel März-April. Die kïnstliche Befruchtung gelingt durch Eintauchen der in Seewasser ausgeschüttelten Ovarien in den Brei eines zerpuetschten Hodens. Die Dottermasse der Eier ist eigentïmlich mosaikähnlich aufgebaut, so dass die Eier schon vor der Befruchtung Furchungsbilder vortäuschen können.

R. F i ck (Leipzig).

\section{Amphilia.}

174 King, Helen Dean, Preliminary Note on the Formation of the first polar Spindle in the egg of Bufo lentiginosus. In: Anat. Anz. 21. Bd. Nr. 15. 1902. pag. 414-417.

Die Verfasserin hat an neuem Material ihre Eireifungs-Untersuchung (s. Zool. Zentr.-Bl. 9. Bd. pag. 187 ff.) wieder aufgenommen und gibt dankenswerterweise bereits jetzt eine Übersicht iiber die Hauptresultate ihrer erneuten Untersuchung. Sie macht in dieser Notiz aucl den ihr rom Ref. gemachten Vorwurf wieder gut, indem sie jetzt zu Carnoy-L ebruns Arbeiten Stellung nimmt. Die Resultate der Verf. stimmen mit Lebruns Arbeiten im wesentlichen überein, namentlich im Hauptpunkt, des vollkommenen Verschwindens aller Chromosomen während der Reifung und dem Fehlen jeder Spur von Centrosomen trotz Anwendung der verschiedensten Färbemetboden. Abweichend von Lebrun nimmt Verf. aber auch ein vollkommenes Verschwinden aller Nucleolen und eine voribergehende Ringbildung bei allen Chromosomen an, während sie Lebruns Entdeckung des ganz variabeln Aussehens der Chromosomen vor ihrer Einstellung im Äquator und der eigentiimlichen Umwandlungen der Kreuz- und Vögelchen-Chromosomen (s. Zool. Zentr.-Bl. Bd. 7, pag. 176, Ref.) bestätigt.

R. Fick (Leipzig). 
Aves.

175 Bianchi, V., Matériaux pour servir à l'ornithofaune du Gouverne-

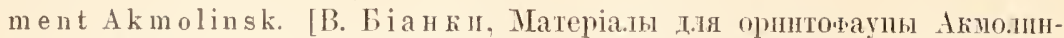
choü oú.1actir.] In: Ann. Mus. Zool. Ac. Sc. St. Pétersbourg. T. VII. 1902. pag. 10-30. (Russisch.)

Das Material zu vorliegender Liste stammt aus dem Gebiet Akmolinsk (Westsibirien) und bietet in faunistischer wie biologischer Hinsicht (genaue Daten, verschiedene Alterstadien) Interesse. Von den etwa 300 aus der Steppenzone bekannten Arten erbeutete Ignatow 88 Arten, während nach seinen Angảen noch etwa 10 weitere Arten beobachtet wurden. Die sperlingsartigen Vögel sind sehr schwach vertreten. Die Liste enthält Corvidae $1 \mathrm{sp}$., Sturnida e 1 sp., Fringil. lidae $4 \mathrm{sp}$., Alaudidae $4 \mathrm{sp}$. Motacillidae 4 sp., Laniidae 1 sp., Sylviidae 5 sp., Turdidae 5 sp., Hirundinidae 2 sp., Bubonidae 1 sp., Cnculidae 1 sp., Laridae 10 sp., Charadridae 19 sp., Glareolidae 1 sp., Otididae 1 sp., Rallidae 1 sp.. Phasianidae 1 sp., Falconidae 7 sp., Anatidae 10 sp., Plataleidae 1 sp., Ardeidae 3 sp., Phalacrocoracidae 1 sp., Podicipedidae 2 sp., Colymbidae 1 sp.

$$
\text { N. v. A delung (St. Petersburg). }
$$

176 Silantjeff. A. A.. Schlïssel zur Best immung der europäischen

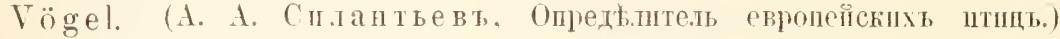
St. Petersburg. Verl. r. A. Devrient. S०. 1901. 128 pag. 75 Abb. i. T. (Russisch.)

Das vorliegende Buch bildet einen vervollständigten Auszug aus einem kïrzlich mit $\mathrm{N}$. C Cholodkowsky herausgegebenen grossen Werke .Die Vögel Europas" und beruht auf Beobachtungen, welche der Vert. während seiner langjährigen lehrtätigkeit über die dem Anfänger am leichtesten verständlichste Form, Anordumng und Wahl der Merkmale anzustellen Gelegenheit hatte; es ist daher ganz besonders für die Praxis geeignet, um so mehr, da der die 'Terminologie behandelnde Abschnitt besonders ausführlich behandelt und mit 70 Originalzeichnungen, welche die Merkmale charakterisieren, ausgestattet ist. Sehr praktisch erscheinen dem Ref, auch die in der Einführung mitgeteilten analytischen Tabellen zur Feststellung der verschiedenen Fussformen einzelner Ordnungen der Tögel, und die Erklärung der systematischen Bestimmungstabellen an der Hand von Beispielen. Letztere Tabellen dienen zum Bestimmen der Ordnungen. Familien, Gattungen und Arten. Den für Alter und Geschlecht eigentümlichen Merkmalen ist Rechnung getragen; das Fehlen der Autornamen bei den Gattungsnamen hätte vermieden werden sollen.

$$
\text { N. v. Adelung (St. Petersburg). }
$$

\section{Mammalia.}

177 Carlsson, Albertina, Über die systematische Stellung von 
Eupleres youdoti. In: Zool. Jahrb. Abth. f. Syst. Bd. 16. 1902. pag. $217-242$.

Über die systematische Stellung des madegassischen Eupleres herrschen verschiedene Ansichten. Doyère, welcher die erste Beschreibung von ihm gibt, rechnet ihn auf Grund der Beschaffenheit des Zahnsystemes zu den Insectivoren. Andere Forscher haben ihn für einen Virerriden angesehen und teilweise zu der Unterfamilie der Virerrinae, teilweise zu der der Herpestina gestellt. Blainville und Gervais bringen ihn nach Untersuchung des Skelettes in die Nähe ron Genetta.

Verf. untersuchte ein in Formol konserviertes junges Weibchen von $24 \mathrm{~cm}$ Lï.çe und kommt auf Grund der morphologischen Berücksichtigung des Skelettes, der Muskulatur, des Gehirnes und der V'erdaungsurgane zu dem Ergebnis, dass Enpleres goudoti, obwohl er in einigen Organen sekundär abgeändert ist - z. B. Reduktion der Zähne, Länge des Radius im Verhalten zur derjenigen des Humerus, Differenzierung des Condylus occipitalis — sich demnach durch den Besitz einer Anzahl ursprünglicher ('haraktere ror der Mehrzahl der Viverriden auszeichnet. Man kann demnoch Eupleres weder zur Unterfamilie der Viverrinae noch zu den Herpestinae stellen, sondern muss ihn als eine Form auffassen, welche noch Kennzeichen vereinigt, die sich auf beide Gruppen verteilt haben. Aussertem besitzt er Charaktere, welche man bei lieinen andern Viverriden ausser bei der ebenfalls abseits stehenden Nandinia antrifft.

F. Röm er (Frankfurt a. II.).

178 Hammar, J. Aug., Studien über die Entwickelung des Vorderdarms und einiger angrenzenden Organe. II. Abteilung: Das Schicksal der zweiten Schlundspalte. Zur vergleichenden Embryologie und Morphologie der Tonsille. In: Arch. f. mikr. Anat. und Entwicklgsgsch. Bd. 61. Hft. 3. 1902. pag. 404-458. Taf. XXI und XXII.

Im Kapitel 1 erörtert Verf. die Rückbildung der zweiten Schlundspalte beim Menschen.

Bei einem Embryo von 8,3 mm Länge ist, wie auch schon auf einem frühern Stadium, die Schlundtasche in zwei Abschnitte geteilt: einen medial gelegenen frontal gerichteten und einen lateralen sagittal gerichteten. Der Zusammenhang von Schlundtasche und Schlundfurche ist in seiner Ausdehnung auf die Hälfte gegen frïher reduziert, und zwar ist er durch das Zwischentreten von Mesenchymgewebe in der dursalen Hälite gelöst. Dadurch ist das Blindsäckchen, welches das Schlundspaltenorgan bildet, zu einem blinden Schlauch 
verlängert worden. Der der lateralen Körperwand angehörige Abschnitt der zweiten Schlundfurche ist gleichzeitig verwischt. Bei einem Embryo von 11,7 mm Länge bildet die Schlundtasche eine platte dreiseitige Spalte. die, hauptsächlich in der Transversalebene gelegen, ron der lateralen Schlundwand in rentrolateraler Richtung ausgeht. Die Schlundtasche mündet dorsal in der Vittellinie in den Schlund, ihre Mündung in den Sulcus praecervicalis ist ein kleines rundes Loch geworden. Von diesem aus geht dorsalwärts ein schmales Rohr ab, dits an einer Stelle kein lumen besitzt; wabrscheinlich ist dies der R a blsche Kiemengang. Das dorsale blinde Ende des Ganges, das frei ist, zeigt das Schlundspaltenorgan, abwärts mündet der Gang frei in den Sulcus praecervicalis; es handelt sich hier also um ein ektodermales Gebilde, den Rest einer Kiemenfurche.

Ein Embryo ron $11,8 \mathrm{~mm}$ lässt eine beträchtliche Reduktion des Kiemenganges erkennen, insofern sein mnteres Ende verschwunden ist. Diese Reduktion geht immer weiter, so dass an einem $13,4 \mathrm{~mm}$ langen Embryo von den ektodermalen Bildungen der zweiten Spalte, dem Kiemenstrange und dem Schlundspaltenorgan, nur noch ein kleines, aboralwärts der Schlundtasche gelegenes Bläschen übrig ist. Nicht minder stark ist die Rückbildung der Schlundtasche. Bei einer Embryolänge von $17 \mathrm{~mm}$ ist endlich der ganze Schlundfurchenkomplex verschwunden und ebenso ist die zweite Schlundtasche fast gänzlich atrophiert. Nur die dorsale Verlängerung der letztern ist noch deutlich und tritt jetzt sogar besser hervor als früher. An der ganz niedrigen Seitenwand des Schlundes, medialwärts ron ihr, findet sich sehr deutlich die Alveolo-Lingualrime, welche gleichzeitig eine mediane Grenze für die primäre Paukenhöhle abgibt. Laterahwärts von dem hintern Ende dieser Rinne ist an der rentralen Wand des Schlundes ein Höcker entstanden: der Tonsillenhöcker, Tuberculum tonsillare.

Wenn der Embryo 20,5 mm Länge erreicht hat, beginnt die Abtrennung der primären Paukenhöhle als tubo-tympanales Rohr. Der Rest der Schlundtasche erscheint hierbei als eine Ausbuchtung ventralwärts von der Pharynxmündung der Tube. Beim Embryo von $24,4 \mathrm{~mm}$. bei welchem sich eine relativ weit rorgeschrittene Gaumenbildung zeigt, geht die dorsale Verlängerung der zweiten Schlundtasche ungeteilt in die Tonsillenanlage, Sinus tonsillaris (Tonsillenbucht) iiber.

Das zweite Kapitel berichtet über die Entwickelung der Tonsille beim Menschen.

Bei dem zuletzt erwähnten Embryo von $24,4 \mathrm{~mm}$ Länge läuft an der Tonsillenbucht eine noch sehr schwache Falte, die Intra- 
tonsillarfalte, Plica intratonsillaris. Beim limbryo von $31 \mathrm{~mm}$ Länge ist der Unifang der Tonsillenbucht beträchtlicher geworden, indem sie sich besonders nach rorn und unten und zugleich lateralwärts rom Tonsillenhöcker ausgeweitet hat. Jetzterer ist dabei eine dünne Falte geworden, die mit einer aus dem vordern Gaumenbogen stammenden Falte zusammentliesst und so die mediale Wand der noch offenen 'Tonsillenbucht herstellt (Plica triangularis). IDie Intratonsillarfalte ist nur angedeutet, tritt aber mit den folgenden Stadien klarer hervor. Sie bewirkt beim Fötus von $70 \mathrm{~mm}$ Länge eine 'T'eilung der 'T'onsillenbucht in zwei Absclinitte; nur deren oberster Abschnitt bleibt ungeteilt. So sind der Recessus tonsillaris superior und inferior entstanden, die hinter der Intratonsillarfalte ineinander ühergehen. Beim Fötus von $110 \mathrm{~mm}$ ist der ober'e Recessus der grössere und schärfer begrenzte, während der untere kleiner ist und ohne scharfe Grenze in die Schleimlıat der Umgebung sich rerliert. Er wird gleichzeitig rom obern etwas verdeckt. Die Wände des obern Recessus sind meben, denn es gehen von ihm solide Epithelfortsätze seitlich und in die Tiefe ab; die Wände des untern Recessus sind ebener. In der Umgebung jener Fortsätze ist eine Zellanhäufung in Bindegewebe aufgetreten, die, einem lymphoiden Gebilde ähnelnd, durch eine Vermehrung der Bindegewebszellen entstanden ist. Allmählich wird auch der untere Recessus abgeschlossen (Fötus von $145 \mathrm{~mm}$ ) und anch von ihm gehen jetzt Epithelfortsätze aus. An den letztern treten Seitensprossen anf, die sich häufig abschnüren; in ihrem Innern findet man zuweilen verhornte Epithelperlen. Die Zellanhäufung im Bindegewebe um die Gesamtheit der Epithelfortsätze dokumentiert sich nummehr als die Anlage eines Tonsillenlobus; doch liandelt es sich dabei nicht um Lymphocyten, sondern un verästigte und miteinander anastomosierende Zellen. Die intratonsillarfalte zeigt auf einem spätern Stadium $(190 \mathrm{~mm}$ Fötus) in ihrem vordern Teile eine Rinne, die beide Recessus miteinander verbindet. Nach hinten und oben ron der Tonsille ist eine neue Aussackung entstanden, die nicht an der Tonsillenbildung beteiligt ist, aber die lymploiden Anlagen überlagert. Hierdurch entsteht eine Retrotonsillarfalte; die Aussackung selber nennt Verf. Retrotonsillarrinne. Es handelt sich hier um inkonstante Bildungen.

Beim Fötus von $235 \mathrm{~mm}$ scheint nur ein Tonsillarrecess vorhanden zu sein, doch kommen auch hier zwei Tonsillenlobi vor. Die Retrotonsillarfalte verlängert sich nach vorn in die Plica triangularis, so dass hierdurch die Fossa supratonsillaris entsteht. Beim $260 \mathrm{~mm}$ langen Fötus sind die Terhältnisse im wesentlichen die gleichen wie bei dem vorher erwähnten Fötus. Unter den Ab- 
weichungen sei das völlige Fehlen der Retrotonsillarfalte erwähnt. Beim reifen Menschenfötus sind die Tonsillarrecesse deutlich individualisiert und auch die Intratonsillarfalte ist gut ausgeprägt. Bei einem 8jährigen Nädchen ist die Zusammensetzung der Tonsillen aus zwei Lobi deutlich, von denen der kleinere hintere vom rordern grössern ïberlagert wird. An der Tonsille des Erwachsenen sind die Verhältnisse in mancher Beziehung geändert. Die Plica triangularis ist fast rudimentär; die Recessus sind zur Supratonsillargrube reduziert: die Lobi sind in Lobuli zerlegt.

Im Kapitel 3 gibt Verf. einige rergleichende Notizen über die Entwickelung der Tonsillen bei einigen Säugern.

Bei Lepus cumiculus führt die Intersuchung ron Embryonen, Föten und rom erwachsenen Tiere zu folgenden Resultaten: Aus dem Rest der dorsalen Verlängerung der zweiten Schlundtasche geht die Tonsillenbucht hervor. Diese wird zu einer platten Tasche, indem der 'Tonsillarhöcker in sie einwächst. Das lymphoide Gewebe tritt spät auf und bildet eine die Tasche (Tonsillenbucht) umgebende Scheide. Der 'Tonsillenhöcker beteiligt sich nur teilweise an der Bildung der Tonsille. Bei Erinaceus (Art nicht bestimmt, Ref.) und Sciu'us (Art nicht bestimmt, Ref.) liegen die Verhältnisse ebenso wie bei Lepus.

Bei Felis domestica (Verf. gibt nur die Vulgärnamen an, für die Ref. die wissenschaftlichen setzt) untersuchte Verf. 4 Föten und ein erwachsenes Tier. Die Tonsillenbucht wird durch einen rundlichen Tonsillenhöcker in eine platte Tasche verwandelt, die allmählich in die Länge wächst, wobei an ihrem Vorderende eine Abschnürung nach hinten eintritt. Diese Abschnürung ist ein Blindsack, um den herum eine Zellwucherung eintritt, die dann lymphoid wird. Bei Canis familiaris gleichen die Verhältnisse denen des Kaninchens. Im eiförmigen, mittelst eines spiraligen Bindegewebsstreifens am Boden der Tonsillenbucht befestigten Tonsillenhöcker hat sich hauptsächlich das lymphoirle Gewebe angehäuft.

Die bisher erwähnten Tiere stellen eine durch starke Entwicklung des Tonsillenhöckers charakterisierte Gruppe dar.

Bei Sus (species?) schwindet frühzeitig der Tonsillenhöcker, eine Intratonsillarfalte wird nicht ausgebildet, sondern die Tonsillenbucht geht ungeteilt in die Tonsillenbildung ein, denn das erwachsene Organ ist einlappig. Damit ist wiederum ein besonderer Bildungsmodus dargetan.

Bei Bos und Oris wird der Tonsillenhöcker angelegt, schwindet aber frühzeitig. Die Intratonsillarfalte tritt später auf, zerlegt die Tonsillenbucht in zwei Recessus und bleibt während des ganzen 
Lebens als Septum zwischen beiden Tonsillenlobi erhalten. Sekundäre epitheliale Verästelungen finden sich in reichlicher Menge bei Bos, nur spärlich bei Ovis.

Mus decumams besitzt, wie schon Rapp nachgewiesen hat, keine Tonsille. Dieser Mangel ist ein primärer, denn es werden im Embryo weder Tonsillenbucht noch Tonsillenhöcker ausgebildet, es fehlt also die Tonsillenanlage.

Das Kapitel 4 enthält Beiträge zur Histogenese der Tonsille. Verf. kommt 7.1 der Ansicht, dass die auch von andern Autoren (Stöhr, Kollmann) bestrittenen Angaben Retterers, wonach die Sekundärknötchen aus abgeschnürten epithelialen Sprossen entstünden, auch nicht für die Menschentonsille zutreffen. Die Zellanhäufung, die oben beschrieben wurde, hesteht ziemlich lange aus fixen Bindegewebselementen, aber nicht aus lymphoidem Gewebe, wie man bei Anwendung geeigneter Tinktionen und starker Vergrösserungen erkennt. Leukocyten treten vielmehr, wie Verf. im Gegensatz zu Stöhr betont, sehr spät im Mesenchymgewebe der Tonsille auf. Daher erscheint es Verf. fraglich, ob die lymphoiden Zellen wirklich eingewandert und nicht vielmehr autochthon entstanden sind. (Dann würden also Lymphocyten aus fixen Bindegewebszellen entstehen; mit Recht sagt Verf., dass die Lösung dieses I'roblems eine grosse Tragweite besitzt. Ref.)

Verf. gibt endlich noch eine Zusammenfassung seiner Ergebnisse, auf die nicht eingegangen zu werden braucht.

B. Rawitz. (Berlin).

179 Loewenthal, N., Beitrag zur lienntnis der Beziehnngen de Taenia semicircularis. In: Morplol. Iahrb. XXX. 1 u. 2. 1902. pag. $28-41$. 'Taf. II.

Verf. untersuchte das Gehirn des Igels, der weissen Ratte und des Meerschweinchens und liomint zu folgenden Ergebnissen: Die Taenia semicircularis reicht bis zu einem Kerne, dem S phenoidalkerne, der an der vordern Grenze des Lobus hippocampi und der Übergangsstelle zwischen diesem und dem 'Tuber olfactorium gelegen ist. Es stösst dieser Kern an die Rinde an, ist aber doch als cin in die Tiefe dringender Herd zu bezeichnen. Der Igel zeigt die stirisste, Cavia die schwächste Entwiclielung dieses Kernes. Die Taenia selber durchbricht nach hinten von ihrem Kerne die hintere, ventrale und innere Abteilung des Corpus striatum, indem sie sich der ventralen und hintern Fläche der innern Kapsel rähert. Die Taenia geht nicht in den vordersten, sondern in den hintersten 'Teil der vordeln Kom. missur über.

B. Rawitz (Berlin). 
180 Ruge, Creorg, Die äusseren Formverhältnisse der Leber bei den Primaten. III. I ie Leber der platyr hinen Westaffen. In: Morphol. Jahrb. XXX. 1902. pag. 42-84. 17 Texttig. In ersten Abschnitte dieser Abhandlung bespricht Verf. Übersicht über Gestalt, Impressio oesophagea, Ligamentum coronarium. Das Material bildeten fünt Lebern von Celus capucinu. und zwei Lebern von Ateles uter. Die Lebern zeigten nicht unerhebliche individuelle Schwankungen, die indessen nicht ïber eine gewisse Grenze hinausgingen, so dass die Grundform erkenmbar blieb. Die Flächen der Leber der Platyrrhinen stehen in Korrelation zur Einlagerung des Organs in die Zwerchfellkuppel, zu ihrer Anlagerung an die Bauchhöhlenwand und zu den Nachbarorganen. Die Leber der Platyrrhinen weicht ron der der Prosimier sehr bedeutend ab; sie ist gleichnäßiger in der Quere, in dorsoventraler und in senkrechter Richtung ansgebildet und gleicht einer Hachen Schale, deren Anshöhlung caudalwärts gerichtet ist. Aus den Maßen, welche an den Lebern genommen werden können, ergibt sich eine Tatsache, die für die ganze Primatenreihe von Bedeutung ist: nämlich dass der Querdurchmesser des Organs allmählich anf liosten des dorsoventralen zunimmt.

Im Unterschiede zu den Prosimiern zeigt die Platyrrhinenleber eine gleichuäßige Ausbildung der Höhe in den verschiedenen Durchmessern; das Organ ist im ganzen massiver geworden, stellt mehr ein geschlossenes Gebilde dar als bei den Prosimiern.

Die Grundform der Leber wird durch die sehr selbständig erscheinenden Lappen bedingt. Während die Leber ron Ateles glatt erscheint, zeigt die Leber von ('elur.s namentlich an ihrer intestinalen Fläche ein sehr mannigfaltiges Aussehen; letztere schliesst sich daher mehr an niedere Verhältnisse an als erstere.

Folgende Lappen sind stets an der Platyrrhinenleber zu unter. scheiden: Stammlappen = Lobus centralis; linker Seitenlappen $=$ Lobus lateralis sinister: rechter Seitenlappen $=$ Lobus lateralis dexter: dorsaler Lappen = Lobus descendens (= Lobus venae carae).

Der stammlappen wird in einen rechten und linken Abschnitt durch die Hauptlängsfurche eingeteilt, von denen der rechte bei Celus an der untern Fläche einen von der Gallenblase herrïhrenden Findruck besitzt. Bei Ateles dagegen liegt die Gallenblase an der Intestinalfläche des linken Stammlappens. Während bei den Prosimiern die Gallenblase oft tief in das Leberparenchym eindringt, zuweilen von ihm ganz und gar umschlossen wird, ist sie bei den Platyrrhinen nur oberflächlich eingelagert.

Die Seitenlappen werden durch eine (rechte und linke) tiefe 
Furche - Fissura interlobularis - vom Stammlappen getrennt. Die Furche dringt jederseits bis zur Leberpforte. liei ('furs finden sich an den untern Flächen der Stamm- und Seitenlappen zahlreiche Fortsatzbildungen

Der Dorsallappen liegt dorsal ron der Leberpforte, wird, ganz wie bei Prosimiern, von der Yena cara durchbohrt und besteht aus einem rechten und einem linken Abschnitte. Der linke, der Eindrücke rom linken Seitenlappen erkennen lässt, grenzt an die Fossa ductus renosi und ist mehr und minder warzenförmig. Er ist als ein massir gewordener Processus omentalis der Prosimier zu betrachten. Der rechte Abschnitt, der Hohlvenenfortsatz der Leber, ist der Lobus descendens. An ihm findet sich die Impressio renalis; im übrigen zeigt er sehr beträchtliche individuelle Differenzen.

Infolge der starken Ausdelmung des Lobus dorsalis nach rechts entfernt sich die Tunica serosa in der Richtung nach rechts von der ventralen und rechten Wand der Vena cara und bildet dabei ein ligamentäres seröses Moppelblatt.

Impressio oesophagea. Sie findet sich an der Dorsalwand des Lobus lateralis sinister und den Processus papillares des dorsalen Lappens. Von ihren Wandungen gehen Fortsätze der betreffenden Leberlappen aus, wodurch aus der Impressio eine Incisura oesophagea wird.

Das Ligamentum coronarium zeigt manche Anklänge an das Verhalten bei den Prosimiern. Der rechte Abschnitt geht auf die Dorsalthäche des Lobus descendens über und bildet bei Cebus ein wirkliches Doppelblatt. Lei Ateles, der ein höheres Stadium darstellt, sind die beiden Blätter des Ligaments nach den Seiten auseinander gewichen, so dass eine ron der Serosa nicht überzogene Fläche entstanden ist. Dies bedentet einen Fortschritt in der Organisation, da dadurch die Leber fester an die Rumperand geheftet und besser in der Bauchhöhle gelagert ist. Der rechte Schenkel des Ligamentun coronarium - dies lehrt die Ateles-Leber — zeigt bei den Primaten zwei ganz rerschiedene Zustände. Als Ligamentum hepato-caro-phrenicum, das in keiner I'rimatenabteilung fehlt, bei den Prosimiern allein vorkommt, zieht der betreffende Teil voll Diaphragna auf die Dorsalfläche der Vena cara inferior. Der andere Zustand ist eine Folge der Breitenentwickelung der Leber und ist beim Menschen repräsentiert durch den rechten Abschnitt des Ligamentum coronarium hepatis.

Im zweiten Abschnitte gibt Verfasser eine Darstellung der Einzelbefunde unter Berücksichtigung der genaueren Verhältnisse. Es sind dies die individuellen Abweichungen, die oftmals iiber die Genusgrenzen nach auf- und abwärts weisen. 
Bei Cebus capucinus ist die Fossa ductus renosi arantii wegen der in sie stattfindenden Einsenkung des Ligamentum hepato-gastricum offen. Die Fossa venae umbilicalis dagegen ist stets auf Strecken überhrückt. Die Darmfläche des Stammlappens ist mit vielen kleinern und grössern freien Läppchen wie hesät, sie crhält dadurch ein eigenartiges Aussehen. Die Gallenblase, welche bei manchen Prosimiern rechts gelagert ist, findet sich hier nach links abgewichen. Es ergibt sich daraus, dass bei den Säugern die Lage der Gallenblase keiner bestimmten Regel unterliegt. Am linken Seitenlappen tritt ein lappenartiger Fortsatz auf, der gewöhnlich einer dreiseitigen Pyramide gleicht und vom Verf. Processus pyramidalis genannt wird.

Bei Ateles ater fehlen sekundäre Läppchen oder Fortsätze des Stammlappens, die durch Incisuren entstehen, vollständig, da letztere nicht vorhanden sind. Das ist ein sehr grosser Unterschied gegen die Leber von Celuss. Ferner sind bei Ateles die Lobi papillares und L. descendens des L. dorsalis miteinander verschmolzen, während sie bei Celus eine völlige Trennung zeigen.

B. Rawit z. (Berlin).

181 Schimkewitsh, W., Über einen Fall ron Heterotopie der Ha a re. In: Verhandl. d. k. Naturforscherges. in St. Petersburg, Band 30. Heft 4. 1900. pag. 29-33, 1. 'Taf.

Beschreibung dreier Fälle ron heterotopischer Entwickhng der Haare, auf dem inneren dem Herzen anliegenden Blatt des Herzbeutels von einem 4jährigen Bock der kaukasischen Ziege (Ros sikow), auf dem äussern Herzbeutelblatt bei einem Embryo von Aegoceros pallasii und aut einem Kiefer desselben Tieres. Die ganze OberHäche des untersuchten Kieferstückes war dicht mit kurzen Härchen bedeckt, welche aus den feinen Öffnungen herrorragten, durch welche die Harers'schen Kanäle nach aussen münden. Ebenso war die Höhlung eines Zahnes mit Haarbüscheln angefüllt, welche, ron unten in die Pulpahöhle eintretend, den Zahnschmelz nicht zu durchdringen vermochten und in der Pulpahöhle selbst und dem Dentin endeten. Die Schnitte durch den allerdings trocken aufbewahrten Knochen zeigen, dass die Haare mit geschlossener Zwiebel frei in den Havers'schen Kanälchen liegen, die Haare mit offener Zwiebel aber in Vertiefungen der Knochensubstauz oder auf Vorsprüngen derselben sitzen. Die Einzelheiten des echten Haares sind gut zu erkennen.

F. Römer (Frankfurt a. M.). 


\section{Zoologisches Zentralblatt}

unter Mitwirkung von

Professor Dr. O. Bütschli In Heidelberg

herausgegeben von

Professor Dr. B. Hatschek

in Wien

\section{Dr. A. Schuberg}

a. Profesor in $\mathrm{Heidelberg.}$

Verlag von Wilhelm Engelmann in Leipzig.

\section{Referate.}

\section{Spongiae.}

182 Cotte, J., ('omment les C'hoanocytes de Syrandra raphumus absorbent-ils les particules alimentaires? In: C. R. Soc. Biol. Paris, Bd. 54. 1902. pag. 1315̃-1317 (Bull. mens. Réun. Biol. Marseille. Bd. 1. pag. 25-27).

Cotte hat Sycandren mit Karmin und Kohlenteilchen sowie auch mit Reisstärke und Bakterien gefüttert. Durch die Ergebnisse seiner Untersuchung werden die Angaben frïlerer Autoren ïber die Nahrungsaufnalnme der Spongien bestäigt und erweitert. Cotte glaubt aus seinen Beobachtungen schliessen zu können, dass die Kragenzellen an ihrer Scheitelliache Pseudopodien-artige Fortsätze bilden und mit diesen die von der Geissel lierangewirbelten Teilchen ertassen und nach Amöben-Art ins \%ellinnere hineinziehen. Grosse Stärliekörner, die an der Scheiteltläche liegen, werd'n von solchen For'säitzen zuweilen ganz zugedeckt und erscheinen wie ron einer Plasmamembran eingehüllt. Die Aufnahme ron Kohlenteilchen und derartigen inditfelenten Stoffen will Cotte nicht mit dem Ausdrucke ('hemotaxis bezeichnen, sondern schlägt für dieselbe die bezeichnung Thigmotaxis vor. Die höchstentwickelten Kragenzellen sollen eine Sullassche Membran besitzen.

R. von Lendenfeld (Prag).

183 Cotte, J., Note sur la nature des produits de désassimilation chez les Spongiaires. In: C. R. Soc. Biol. Paris. Bd. 54. 1902. pag. 1317-1318 (Bull. mens. Réun. Biol. Marseille. Rid. 1. pag. $27-2$ - $)$.

Cotte hat weitere Versuche uiber die chemische Natur del stickstoffhaltigen Ausscheidungsprodukte der Spongien an Sulwerites

Zoolog. Zentralbl. X. Jahrg. - Nr. 182-183. 
domuncula ausgeführt und kommt zu dem schon früher von ihm angedeuteten Ergebnis, dass dieselben ausschliesslich oder doch teilweise Amide sind.

R. von Lendenfeld (Prag).

184 Cotte, J., Sur la présence de la Tyrosinase chez Suberites domuncula. In: C. R. Soc. Biol. Paris. Bd. 55. 1903. pag. 137-139 (Bull. mens. Réun. Biol. Marseille. Bd. 2. pag. 3-5')).

('otte hat seine Untersuchungen der chemischen Bestandteile des Suberites domuncula-Saftes fortgesetzt und gefunden, dass die Bräunung desselben an der Luft durch eine Tyrosinase herbeigeführt wird. Er kommt zu dem Schlusse, dass Suberites dommonlla einerseits eine Tyrosinase $d$. i. ein tyrosinbildendes Ferment enthält und andererseits anch Kïrper, welche im stande sind, Tyrosin zu liefern. Letzteres findet sich im lebenden Schwamme jedoch nicht fertig vor: es wird ron den rerdauenden l'ermenten aus den albuminoiden Bestandteilen des Schwammes selbst oder aus andern Eiweisskörpern, die man dem Safte beifügt, erzeugt. Thymol beeinträchtigt oder verhindert die Tyrosinase, Chloroform übt keinen Finfluss auf dieselbe aus. Auch andere Spongien, wie Donatia (Tethya) lyncurium und Georlia cydonimm (Cydonium gigas) enthalten dieses Tyrosinferment. R. ron Lendenfeld (Prag).

185 Cotte, J., Sur la présence du Manganèse et du Fer chezles Éponges. In: C. R. Soc. Biol. Paris. Bd. 55. 1903. pag. 139-141. (Bull. mens. Réun. Biol. Marseille. Bd. 2. pag. 5-7.)

Cottes neuere diesbezügliehe Untersuchungen ergaben, dass Reniera 0,0097\% und Sulverites 0,0032\% (des Trockengewichtes) Mangan enthalten. Die Gemmulae von Suberites domuncula enthalten $0,02 \%$. Dieser besondere Manganreichtum der Gemmulae wird mit dem besonderen Manganreichtum lebhaft wachsender Pflanzenteile rerglichen. Cotte scheint, wie Bertrand, anzunehmen, dass das Mangan einen katalytischen Eintluss auf die Kellteilungsprozesse ausübe. Eisen, nach dem Cotte früher vergebens gesucht hatte, hat er nun in Donatia (Tethya) und Suberites gefunden. Die Angaben von Schneider, dass Eisen auch in Spongitla vorkäme, hält er, der Unverlässlichkeit der angewendeten Methode wegen, für bestätigungsbedürftig.

R. von Lendenfeld (Prag).

1) Bemerkung zu dem Referat Nr. 133 auf Seite 146 dieses Bandes des Zool. Zentralbl.: Der Titel jener dort referierten Arbeit sollte bibliographisch richtig folgendermaßen lauten:

"Cotte, J., Observations sur les Gemmules de Suberites domuncula. In: C. R. Soc. Biol. Paris, Bd. 54, pag. 1493-1495 (Bull. mem. Réun. biol. Marseille, Bd. 1, pag. 39-41) 1902." 
186 Thiele. I., Kieselschwämme von Ternate, II. (Kükenthal, Ergebnisse einer zoologischen Forschungsreise in den Molukken und Borneo). In: Abh. Senckenberg. nat. Ges. Bd. 25. 1903. pag. 933-967. Taf. 28.

In der vorliegenden Arbeit hat Thiele seine kritische Nachuntersuchung der früher von Kieschnick beschriebenen, ternatensischen Kieselschwämme weitergefïhrt und zum Abschluss gebracht. Kieschnick hatte 50 Arten aufgeführt, diesen stehen 80 von Thiele benannte gegenüber. Von letztern können nur ganz wenige mehr oder weniger sicher auf die Kieschnickschen bezogen werden. Die grosse Mehrzahl der von Kieschnick neu benannten Arten war ganz unkemutlich beschrieben und die allermeisten von den nicht neuen waren falsch bestimmt. Wichtiger noch als diese Richtigstellungen und die Beschreibungen neuer Arten sind die vortrefflichen, kritischen Ausführungen betrefis der anzuwendenden Gattungsnamen. Diesen ist zu entnehmen, dass bei Anwendung unserer Nomenklaturregeln sehr viele eingebürgerte MonaxonidenGattungsnamen durch andere werden ersetzt werden müssen. Auch die Neuaufstellung von Gattungen ist als notwendige Konsequenz aus dieser kritischen Untersuchung hervorgegangen. Für den Formenkreis des Coppatias distinctus wird das neue Genus Rhabdastrella aufgestellt. Die noch nicht für sich untergebrachten Axinelliden mit diactinen Nadeh werden in dem Genus Phyeopsis Carter zu vereinigen sein. Statt des Gattungsnamens Desmacella - in dem jetzt gebräuchJichen Sinne - ist Bicmma zu setzen. Cribiclla O. Schm. muss durch Hamigera Gray ersetzt werden. Für einige Ectyion in a wird das neue Genus Eehinochalina aufgestellt. Besonders unangenehm ist es, dass so bekannte und gebräuchliche Namen wie Esperclla und Tethya vor dieser Kritik nicht bestehen. Für Esperella wird Mycale Gray und für Tethya Donatia Nardo zu setzen sein. Der Name Tethya wird auf diejenigen T'etraxoniden angewendet werden müssen, welche gegenwärtig das Genus Crumiella ausmachen.

R. von Lendenfeld (Prag).

\section{Vermes.}

Plathelminthes.

187 Schockaert, Rufiu, Nienwe onderzoekingen over de rypwording van het e i van Thysanosoon Brocchi. In: Handelingen van het vierde V'laamsch Natuur- en Geneezkundig Congres gehouden to Brussel. 30. Sept. 1900. pag. 27-33. 10 lextfig.

188 - L'ovogúnise chez Thysanozoon Brocchi (premiere partie). In:

La Cellule. 18. Bd. 1. Heft. 1901. pag. 3t-137. 4 Taf. 68 Figg.

In dem nitderdeutschen Tortrag hrachte Terf. etwa dieselben Punkte zur sprache, wie in der Mitteilung im Anatom. Anzeiger (vgl. \%ool. \%entr.-Bl. 7. Bd. pag. 789). In der ausfiihrlichen Abliandlung gibt Verf. nicht nur eine genaue Beschreibung seiner Entdeckung der sichelförmigen Centrosomenvorläufer, sondern behandelt anch fist alle übrigen wesentlichen Fragen der Eireifungslehre, soweit sie sein Objekt berïhren. Fr teilt die Abhandlung sehr übersichtlich in acht Kapitel ein, deren jedes einem besondern Bestandteil des Eies gewidmet ist. Die Fixierung geschah nach Gilson, die Färbung mit Eisenhämatoxylin.

Das 1. Kapitel behandelt den Bau des Keimbläschens hei

$$
\text { - Nr. 186-188. - }
$$


den jüngsten Orocyten. Die Zählnng der Chromosomen in den letzteren int fast unmöglich. I)ie Chromatinschleifen sind zuerst kompakt, beim Heranwachsen der Ovocyten werden sie zu Doppelkörnerreihen, dann verschwinden die Chromosomenschleifen, es entstehen melı oder weniger voluminöse Massen aus ihnen, später tauchen wieder (hromosomen atuf und es zeigt sich auch ein grosser Nucleolus. Die crwähnte Längsspaltung ist also niclıt etwat eine friiluzeitige Spaltung der Richtungschromosomen. In diesem Stadium werden betrïchtliche Chromatinmassen aus dem Keimbläschen in Form grösserer Körner ausgestossen. Das 2. Kapitel ist dem Protoplasma gewidmet: Der Dotter wird ron einwandernden Follikelzellen und den auswandernden Nucleinmassen des Keimblïschens gebildet. Die Lotterkörner sind zuerst chromatophil, später nicht mehr. Manche Eier degenerieren vor der Richtungsteilung. Das erste Anzeichen dafür ist das Anftreten einer amorphen lomogenen Zone in der Peripherie der Eizelle. In 3. Kapitel wird der Nucleolus besprochen. Verf. sagt, der Nucleolus gehe beim Zerfall der Chromosomen ans einer die andern Chromosomentrüummer an Grösse überragenden Nucleinmasse hervor. Bald erscheine in ihm eine helle Vakuole, die zum Plastinnucleolus wird. Je nachdem diese Takuole in der Mitte oder seitlich im Nucleolus auftritt, sieht dieselbe ganz verschieden aus. Die Nueleincalotten, d. h. die Nucleinhüille der Vakuole, werden immer kleiner, der helle Teil wird zum "Iauptteil". In diesem treten kleine Nucleoluli auf, die ans dem Nucleolus austreten und ,sekundäre Nucleolen" darstellen. IDie Nucleolen nehmen keinen Anteil an der Bildung der Richtungschromosonen, sie rerblassen gänzlich, wie es R. Fick beim Axolotl beschrieben habe. Im 4. Kapitel spricht Verf. iiber die ('hromosomen („Nucleinelement"). Im Stadium des Auftretens der Centrosomen (s. unten) erfolgt eine Längsspaltung des, wie Verf. meint, bei seinem Auftreten kontinuierlichen Chromatinfadens, der daleei auch der Quere nach in eine Anzahl ron Chromosomen zerfällt. Ein Synapsisstadium fehlt. Der definitive Knäuel bilde sich dann durch Verschmelzung der Chromosomenenden. Auch bei seiner Bildung nimmt nicht die ganze Nucleinmasse des Keimbläschens teil. Er spaltet sich der ganzen Länge nach und fragmentiert sich schliesslich in die reduzierte Chromosomenzahl. Im 5. Kapitel finden wir genane Angaben über den "glatten Faden oder das Centrosomenstäbchen". Schon in sehr jungen Orocyten tritt ein nicht granulierter Faden auf, der sich wohl von den Nucleinfäden unterscheidet. Zuerst ist er bogenförniig, bald biegen sich seine beiden dïnn ausgezogenen Enden nach entgegengesetzten Seiten. Der Faten zerfällt oft der Quere nach in zwei 
Schwesterfäden. Sie verlängern und verdicken sich. Dann legen sie sich an einen der sekundären Nucleolen und werden so klein, dass sie nur noch als ein gefärbter Saum erscheinen, der den betreffenden Nucleolus teilweise umgibt. Zuletzt zeigen sie in ihrer Mitte eino kleine Auftreibung. Das 6. Kapitel behandelt das Centrosom. Das "glatte Fädchen" wird zum C'entrosom, indem es aus dem Kieimbläschen auswandert. Wenn sich nur 1 ,glatter Faden" im Keimbläschen gebildet hatte, erscheinen die Centrosomen ganz dicht bei einander an irgend einer Stelle der Keimbläschenperipherie, indem sie erst dort aus dem Fädchen durch Teilung entstehen. Waren schon im Kieimbläschen 2 "glatte Füden" vorhanden, so treten die Centrosomen gleich von Anfang an an entgegengesetzten Polen des Keimbläschenumfanges auf. Die zuerst sichelförmigen, abgeplatteten Centrosomen verlieren ihre ausgezogenen knden, werden zu einem runden Körperchen. Das Körperchen ist das motorische Zentrum für die Strahlung; bis zur Spindelbildung wächst es immer mehr heran. Wenn es seine endliche Grösse erreicht hat, entfärbt es sich oft und lässt in der Nitte eine Centriole erscheinen, die von einem amorphen Hof ("C'entrosplüre") umgeben ist; der Hof hat dieselbe Grösse und Form wie das vorherige ganze gefärbte „Centrosom“. Das Wachstum des ursprünglichen Kentralkörperchens scheint nicht eine Aufblähung desselben zu sein, sondern durch Anlagerung chromatophiler Kernsubstanzen ron aussen her zu stande zu kommen. Die c'entriolen sind daher als das alktive Zentrum zu betrachten, nicht die ganzen ('entrosumen. 7. Kapitel: Strahlung. I) Strahlung entsteht durch \%entrierung dec Zellprotoplasmabalken. '/uerst sind die Strablen in ihrer ganzen Länge homogen, später wird ihr zentraler T'eil heller. Diese Zone stellt dann die "Rindenzone" V' a Benedens und Van der Strichts dar. Verf. glaubt aber nicht, dass diese Zone aus dem ('entrosom entsteht, zu ihm gehört, sondern dass sie nur eine besondere lokale Umwandlung der Zellbalkenstrahlen darstellt. 8. Kapitel: Spindel. Es gibt bei Thysanozoon keine Zentralspindel im Sinne Hermanns. Die kleine extranucleäre Spindel, die sich manchmal zwischen beiden Centrosomen zeigt, kommt nur durch die Begegnung der beiderseitigen Strahlen zu stande und nimmt keinen Teil an der definitiven Spindelbildung. Die Spindel bildet sich lediglich aus Kernsubstanz, gleichviel ob die beiden Centrosomen nahe beieinander oder aber gleich an den beiden Polen erschienen. Terf. glaubt, dass zur Spindelbildung der zum Aufbau der Chromosomen nicht verwendete Nucleiniest unter Verwandlung zu Plastin verbraucht wird. Die Spindel besteht nicht aus Zentral- und Mantelfasern, höchstens aus einem unregelmäßjigen Ge- 
menge von Fasern, die mit den Chromosomen verbunden sind, und solchen, die ron Pol zu Pol laufen.

R. Fick (Leipzig).

189 Schockaert, Rulin, L'Ovogénèse chez le Thysunozoon Brockhi. (Deuxième Partie.) In: La Cellule. t. XX. 1. Heft. 1902. pag. 100-176. 4 Taf. 60 Figg.

Verf. schickt voraus, dass die Arbeiten von r. Klinkowström (s. Zool. Zentr.-B1. 5. Bd. 1898. pag. 401 ff.), Francotte (s. Zool. Zentr.-Bl. 6. Bd. 1899. pag. 473 ff.) und ran der Stricht (s. Zool. Zentr.-Bl. 6. Bd. 1899. pag. 50 ff.) in ihren Schlussfolgerungen iiber die Redultionsfrage allerdings zum seben Resultat kommen, dass aber die Beweise für die gezogenen Schlüsse ungenügend seien, wie auch schon van $\mathrm{Name}$ (s. Zool. Zentr.-Bl. 7. Bd. pag. $47 \mathrm{ff}$.) hervorgehoben habe. Die Arbeit zeichnet sich, wie die vorstehend referierte, durch übersichtliche Einteilung, klare Abbildungen und die Hinzufügung einer Übersicht über die Ergebnisse vorteilhaft aus.

I. Kapitel: Herkunft der Chromosomen. Die jiingsten Orocyten besitzen wohl 9 Kernschleifen, die wahrscheinlich durch Verlötung von 18 Schleifen nach der letzten Orogonienteilung entstehen. Die 18 Orogonienchromosomen sind aber vor der Bildung der 9 Ovocytenchromosomen erst in Körner zerfullen und ein Teil des Kernnucleins ist in das Protoplasma ausgewandert, so dass also keine morphologische Kontinuität zwischen den Ovogonienchromosomen und den Richtungscliromosomen besteht. Mit der Zahlenreduktion hat die Nucleinauswanderung in das Protoplasma nichts zu tun. „Nach dem Erscheinen der Centrosomen zerfällt der Nucleinfaden zum Teil in Köörner, die sich später auflösen und nicht an der Bildung der Richtungschromosomen teilnehmen. Die sich erhaltenden Fadenteile zeigen oft Längsspaltung, wie Verf. meint, als Vorbereitung fiir die zweite Reifungsteilung. Während der Auflösung der Nucleinreste (s. o.) verschmelzen die erhaltenen liörnigen Fadentrümmer zu einer Art dichtem Knäuel, dessen Elemente die Körnehung verlieren und homogen werden. Die Chromosomen der ersten Reifungsfigur sehen sehr verschieden aus. Verf. unterscheidet 3 verschiedene Hauptarten: 1. Ringe, 2. enge U-Schleifen, 3. weite V-Schleifen. Die beiden Teile dieser 9 Cllromosomen sind nicht etwa durch Längsspaltung der ? einfachen Ovocytenchromosomen entstanden, sondern durch R.fache Querteilung des ursprïnglich etwa eine einzige lange, etwa parallelschenkelige Schleife bildenden primitiven Nucleinfadens.

II. Kapitel: Frste Reifungsteiluug. Auch in der Metaphase der ersten Reifungsteilung hat Verf. eine grosse Anzahl verschiedener Chromosomenformen gefunden, die er auf 3 Hauptformen (Ringe, 
Haken und Stäbchen) zurïckführt. Die 3 Hauptformen selbst erklärt er durch verschiedene Anleftung der Spindelfasern an den im Prinzip immer aus 2 Schenkeln bestehenden Chromosomen. Bei der ersten Reifungsteilung kommt es stets zur Trennung der beiden primitiven Schenkel. Da die letztern rerschiedene Querteile des primitiven Fadens darstellen (s. o.), so ist die erste Richtungsteilung eine wahre Reduktionsteilung (im Weismannschen Sinn, Ref.). In die erste Reifungszelle gehen nur die Centrosphäre und die Chromosomen des peripheren Pols der ersten Reifungsspindel ein, dadurch werde bewiesen, dass die Centrosphäre nicht ein sellständiges ()rgan, sondern eine Differenzierung von Zellinhalt sei. Die Chromosomen des zentralen Pols der ersten Reifungsspindel spalten sich der Lüinge nach, schmiegen sich in der Anaphase aber so eng aneinander, dass ihre Form nicht mehr festzustellen ist.

III. Kapitel: Zweite Reifungsteilung. In der Centrosphäre des zentralen Pols treten statt der einen bald zwei (entriolen auf, ohne dass Verf. eine Teilung der ersten Centriole beobachten konnte. Eine Zentralspindel im Sinne Hermanns oder M. Heidenhains existiert auch hier nicht. Verf. komte vielmehr Mac Farlands fundamentale Beobachtnigen iiher die Neuentstehung zweier Strahlungen im Zentrum der sich zum Teil noch erhaltenden alten Strahlung (s. Zentr.-Bl. 5. Bd. pag. 94 ff.) bestätigen ${ }^{1}$ ). Die ('hromosomen zeigen dann wieder ihre gespaltene Form. In der zweiten Reifungsteilung wird die Trennung der beiden Schwesterbälften vollzogen; sie ist also eine Längsspaltung. In der Anaphase der zweiten Reifungsteilung treten auch wieder verschiedene Formen der Chromosomen (V, Kreuze und Stäbchen) auf. Die Centrosomen verschwinden schon vor Abtrennung der zweiten Reifungszelle vollkommen. Die zurückbleibenden Chromosomen bilden sich zu einem gelappten Kern nin. Es erhält sich keine spur einer Ei-Centrosphäre.

R. Fick (Leipzig).

190 Cohn, I., Zur Kenntnis des Genus Wageneria Monticelli und anderer Cestoden. In: ('entrbl. Bakt., Par., Infekt. Bd. XXXII. 1902. pag. 53-60.

Als eine neue Wageneria-Art hat der Verf. das ron Creplin in Squalins grisens gefundene Monostomum impudens erkannt. Im anatomischen Bau weicht die neue species nur soweit es den Verlauf des Uteringanges und die Ansbildung des Uterus anbetrifft, ron

1) Ref. hat bereits 1899 aus van der Strichts Abbildungen der 'luilung der Samenstrahlung diesen Modus bei Thysanozoon erkannt (vgl. Zool. Zentr. BI. 6. Bd, pag. 55). Ref. 
Wageneria porrecte ab. Ihr Uteringang ist kurz. Er legt sich ror dem Orarium in einige Schlingen und mündet in der Mittellinie in den Uterus. Dieser ist in den jungen Proglottiden ein fast geradlinig begrenzter Kanal, in ältern Gliedern treibt er Aussackungen, in den ältesten jedoch verstreichen diese wieder, so dass sich dann der Uterus als breiter sack in der Mittellinie der Proglottis ausdelınt.

Wryeneria impudens besitzt in seiner Cuticula kleine Hacken. Das ist insoweit vou Bedentung, als bis jetzt über die Oberflächenbeschaffenheit der Wagenerien verschiedene Ansichten bestanden. Nonticelli fand bei Wageneria proglottis kleine Stacheln, Lüh e bei Wageneria porrecta hingegen feine Härchen. Der Unterschied zwischen diesen beiden (utikularbesätzen liegt darin, dass die Hacken in die Haut eingesenkte selbständige Gubilde sind, während die Härchen nur als Fortsätze der Cuticula hetrachtet werden müssen. Nun zeigt aber ein Vergleich mit andern Helmintlen, „dass der Weg vou der glatten Haut bis zur Zerspleissung derselben in Spitzchen und dann bis zur Einlagerung von Hacken" kein weiter ist. Es könnten somit beide Autoren Recht haben. - Die Bestachelung der Proglottiden, welche den Cestoden im allgemeinen fehlt, ist keineswegs so selten bei den Selachierbandwïmern. Sie kommt bei diesen Formen nicht nur den freilebenden Glieder'n zu, sondern hie und da auch der Gesamtstrobila. Als Beispiel für beide Fälle können gerade die noch in der Irbeit behandelten Cestoden Merocestus foliiformis (Crepl.) und Prosobothium armigermm n. gen. n. spec. gelten.

Merocestus folifformix (Crepl.) aus Squalius grisens wurde von Creplin ats ein Jistomm betrachtet, da seine freilebenden Proglottiden in der Tat eine tänschende $̈$ hnlichkeit mit einem solchen haben. Die blattförmigen Glieder sind nach hinten zugespitzt. Das Vorderende ist verschiedenartig gestaltet, im Leben also wahrscheinlich sehr beweglicls. Als Haftlapren kann es jedoch nicht bezeichnet werden. I)ie cuticula ist wie hei Hragoneria impmatens mit Hacken bewaffinet.

('irrluus und Vagina münden wenig hinter der Mitte des Seitenrandes der Proglottis. Bis hierher reichen auch die zweischichtigen Hodenfelder, deren Sammelkanal, das Vas deferens, sich zu einer Vesicula seminalis erweitert und in einen langen und dicken (irrus übergeht. Die weiblichen Geschlechtsdrüsen füllen die hintere Gliedhälfte. Eigentümlich ist die Lagebeziehnng zwischen Vagina und Uterus. Der letztere bildet keinen ununterbrochenen Hollraum, sondern er wird ron einzelnen Parenchymbalken durchzogen. In einem dieser Bakken mun zieht die Tagina quer durch den Uterus hindurch. Wahrscheinlich strich anfänglich die Vagina nahe an der Uterusanlage 
vorbei. Als diese sich zum liruchthehälter ausgestaltete, bildete sie um das allzu nalıe Rohr einen Divertikel. Sie umwuchs also die Vagina und so gelangte diese, seheinbar den Uterus durchdringend, in sein Inneres.

Prosobothrim armigermm nov. gen. nov. spec. aus Squalius acanthics ist ein Tetrabothriide. Es wird bis $21 \mathrm{~mm}$ lang und bis $1,9 \mathrm{~mm}$ breit. Eigentümlich ist die starke Bestachelung der Strobila. Skolex und Anfangsteil des Halses sind nackt. Die Hacken sind scharf zugespitzt, etwas nach hinten gebogen. Sie haben eine lange hintere und eine knrze vordere Wurzel. Nit kräftigen gebogenen Hacken ist auch der Cirrus bewehrt. Er liegt in einem mächtigen (irrusbeutel, der etwas hinter der Gliedrandmitte nach aussen sich öffnet. Dicht hinter ihm liegt die Vagina. Die Genitalporen alternieren unregelmäßig. I 1 vordern T'eil des Mittelfeldes liegen die zahlreichen Hodenbläschen, dem Hinterrande genälıert ist das zweitlïgelige ()variun und auf die Aussenfelder beschränken sich die Dotterstöeke. Der Uterus ist ein dickwandiger gebuchteter Kanal.

$$
\text { E. Rigg en bacli (Basel). }
$$

191 Linstow, 0. von, Edhinucocens alreolaris und Plerocercus larhesis. In: \%ool. Anz. XXYI. 1902. pag. 162-167.

Lichinococcus: alveolaris hat schon rerschiedene Dentungen erfahren. Urspriinglich betracistete man ihn als eine Geschwulst und nannte ihn Alveolarkolloid. As man seine walure Natur erkannte, bezeichnete man ihn als eine Abnormität des gewöhnlichen BlasenEchinorncons. Später jedoch behauptete man, dass er cine von Échinococcus polymorphus. und Tamin echinocorcus spezifisch verschiedent Art sei.

Verf. hatte Gelegenheit, sowohl einen Alveolar-Lchinococcus als einen Echinococcus polymorphus zu untersuchen. Beide stammten aus der Leber des Schweines. Der erstere stellte einen aptelgrossen Tumor dar, der aus einem rötliehen Gewebe mit weisslichen Einsprengungen bestand. Er bot ganz das Bild eines alveolaren Sarkoms oder einer tuberkulösen Entartung dar und könnte auch leicht mit einem solchen verwechselt werden, wenn nicht im Gewirr der Bindegewebs- und Leberzellen sich die mikroskopisch kileinen Skoleces des Cestoden fänden. Allerdings sind es deren nicht viele. Slie tragen schlanke Hacken, die in 2 Kränzen angeordnet sind. Der Hackenast ist etwas gekrïmmt, der Wurzelast gerade und der Helelast liolbig verdickt. Die Länge der kleinsten Hacken verhält sich zur Länge der grössten wie 11:13. Die durchschnittliche Zahl der Hacken beträgt 26 . 
Der gleichzeitig untersuchte Echinococcus polymorphus war von der Grösse eines Strausseneies. Er enthielt tausende von bräunlichen Brutknospen, die die Innenwand der Mutterblase bedeckten. Die Skoleces hatten durchschnittlich 36 Hacken in 2 Kränzen. Das Längenverhältnis betrug 11:14. Die Form der Hacken ist dieselbe wie bei Echinococcus alveolaris.

Verf. hält Echinococcus alvcolavis für eine Abnormität des Echimococcus polymorphus. Er könnte dadurch entstehen, dass ein Echimococcus mit Blasenbildung nach aussen rom Lebergewebe nuwuchert wird, weil dieses rom Toxin, welches der Parasit ausscheidet, gereizt würle. Die Entartung gleicht einer tuberkulösen Wucherung.

Das Grundgewebe lles Alveolar-Echinococcus hat wenig Bhtgefässe. Es wird also nur dürftig ernährt. Daher kann es im menschlicheı Körper leicht rerläsen oder vereitern. Bei den Hanstieren wirl dies selten vorkommen, da sie wohl vorher schon geschlachtet werden. Die dürftige Ernährung mag auch schuld sein, dass Echinococcus alceolaris nur wenige oder gar keine Skoleces zur Ansbildung bringt.

Die Arbeit schliesst mit einer kurzen Notiz über Plevocercus lachesis aus dem Buschmeister Lachesir mutu: Daud. Fr lebt in der Peritonealhöhle seines Wirtes, wirł $140 \mathrm{~mm}$ lang und $0,82 \mathrm{~mm}$ breit. Torne ist er kolbig verdickt. Eine Gliederung fehlt. Der Skolex ist mit vier un einen Hohlraum gruppierten Sangnäpfen ausgerüstet. Das Parenchym ist äusserst reich an Kalkkörperchen.

F. Riggenbach (Basel).

\section{Arthropoda.}

192 Vexhoeff, K., Zur vergleichenden Morphologie der Coxalorgane und Genitalanhïnge der Tracheaten. In: Zool. Anz. Bd. 26. Nr.687. 1902. pag. 60-77. 15 Abb.

Bei manchen niedern Hexapoden, z. B. Machilis, lässt sich feststellen, dass die abdominalen Bauchplatten nicht einfach sind, sondern aus Sternit und abgeplatteten Hüften bestehen, worauf zuerst L. Ha ase hingewiesen hat. Verf. hält es für angemessen, die sekundären Bauchplatten des Insektenhinterleibes als Coxosterna zu bezeichnen. Das V'erhalten der Styli spricht ebenfalls für die Richtigkeit dieser Anschauung. Verf. unterscheidet bei Hexapoden innere und äussere (oxalorgane. Die den Coxalorganen der I)iplopoden annähernd homodynamen innern Coxalorgane der Hexapoden sind eingliedrige, durch Hüftmuskeln berregliche Hüftanhänge, welche sich endwärts an der Innenfläche der Hüften als Eustülpungen finden.

Die äussern (oxalorgane (die Styli oder Griffel) der Hexapoden 
sind eingliedrige, durch Hiiftmuskehn bewegliche Hiiftanhänge, welche sich endwärts an der Aussenfläche der Hüften als Ausstiulpungen finden.

Die Klarstellung der Hüftnatur der bauchwärtigen Seitenteile an den Hinterleibssegmenten von Machitis, Lepisma u. a. ist sehr wichtig für das Verständnis der vergleichend-morphologischen Natur der Genitalanhänge. Am 8. und 9. Abdominalsegment sind die Hüften noch besonders deutlich und Verf. betont ganz besonders die morphologische Einheit und Zusammengehörigkeit dieser Hüften und jener Genitalanhänge, die als vier ( $)$ oder drei ( Stäbe an diesen Segmenten bekannt sind. Sie hängen nämlich einmal am Grunde mit den Hüftteilen zusammen und befinden sich a uf (hinter) diesen, sodann werden sie durch Hüftmuskeln bewegt. Diese Teile bezeichnet Verf. in Übereinstimnung mit seinen Untersuchungen an Diplopoden als Coxite (Gonocoxite) und Telopodite, wobei auf die morphologische und physiologische Verschiedenheit dieser Teile Rïcksicht genommen ist, während die verschiedenartige Gliederung der Telopodite allein, als einer Frage fïr sich, vorläufig nicht in Betracht kommt, rom Verf, aber in einer Reihe friiherer Arbeiten schon erörtert worden ist. Insbesondere die l'ar a meren sind Telopodite am 9. Abdominalsegment solcher I’terygoten-Mämnchen, deren zugehörige Gonocoxite nicht als solche ausgeprägt, sondern in der unpararen Subgenitalplatte als einem Coxosternum enthalten sind. Die Dermapteren besitzen Parameren, welche im ganzen sehr an diejenigen vieler Käfer erinnern. Das unpaare innere Telopodit der männlichen Dermaptera-Monandria ist nicht atus der Verwachsung zweier entstanden, sondern durch stärkere Ausbildung eines derselben und Verkümmermng des andern. Die innern Telopodite der Diandria-Gonopoden können sogar dreigliedrig sein, indem die Grundglieder an die Parameren angedrüclit sind, die Endglieder frei bleiben und meist ein- oder beiderseitig zurückgeklappt werden. In diesen Endgliedern liegen die Präputialsäcke eingestïlpt und in diesen können die dritten Telopoditglieder vorkommen, die meist als Virga erscheinen.

Zum Schluss weist Verf, nachdem er das Schwinden der Stylusmuskeln bei Pterygoten angegeben, auf die Styli der ColeopterenWeibchen hin, die nach Wandollek von der allgemeinen Eingliedrigkeit in manchen Fällen abweichen sollten. Er zeigt, lass dies nur Schein ist, indem die die Styli tragenden (ronocoxite bei Formen mit langen Legeeinrichtungen sich sehr in die Länge strecken und dann an Ende ein Stück mehr oder weniger abschnüren können (Pseudostylus), so dass scheinbar zweigliedrige Styli entstehen. Es 
schnüren also nicht die Styli, sondern die Gonocoxite ein Cilied ab. \%u solcher Bildung tindet man Übergänge.

K. Verhoeif (Herlin).

\section{Iy riopoda.}

193 Verhoerr, K.. Ueber Diplopoden. I. Anfsatz: Formen aus Tirol, Italien und Cypern. In: Arch. f. Naturg. 1902. Bd. I. Н. 3. pag. 175-19:. 1 T'af.

Trimerophorclla $\mathrm{n} . \mathrm{g}$. ist nahe verwandt mit Trimerophoron hoth. und hin. sichtlich des sechsten Beimpares und der einfachen Stirn des $j$ ein schöner Vorläıfer dieser Gattung; doch zeigen sich die Gonopoden merklich weiter entwickelt, da die vordern eine ausgesprochene Rinne für das Pseudoflagellum besitzen. Hierin ist also umgekehrt Trimerophoron der prächtige Vorläufer voin Thimerophorclla, so dass sich diese Gattungen gegenseitig ergänzen. Verf. behandelt den sehr variabeln Formenkreis der Glomeris conspersa C. K. und führt die wenig bekannte subsp, undulata C. K. aus, auch erörtert er die Auffassung bei der Gattung Cilomeris. Er macht Mitteilung über die verschollene Gl. tirolensis Latzel, vermelırt die Kenntnis der Diplopoden-Fauna 'Tirols und gibt ein Verzeichnis aller bisher mit Sicherheit aus Tirol nachgewiesenen Doppelfüssler.

Diplopoden aus Italien: Verf. behandelt nach Gebieten die von ihm auf einer italienischen Reise gesammelten Diplopoden, wobei er über deren bisher sehr vernachlässigte Vorkommnisse und Lebensweise Mitteilungen macht, sowie einige Nova beschreibt.

K. Verho eff (Berlin).

\section{Arachuida.}

194 Croneberg, A., Beitrag zur Hydrachnidenfanna der Umgegend von Moskau. In: Bull. Soc. Imp. Nat. Moscou. 1899. Nr. 1. pag. 67--100. 'Taf. t. Fig. 1-48.

195 - Kur Hydrachnidenfauna Central-Russlands. 1902. Nr. 1-2. pag. 90-101. Taf. 12. Fig. 113.

Der durch seine anatomischen Untersuchungen über den Bau der Hydrachniden und über die Nundhöhle der Arachniden vorteilhaft bekannte Verf. beschäftigte sich in den letzten Jahren mit der Feststellung der Hydrachnidenfauna der engern und weitern Imgebung Moskaus. In den ersten Verzeichnis werden 49 Arten aufgeführt, doch hetont der Verf., dass die Iiste keinen Anspruch auf Vollständigkeit macht. In es sich hierbei hauptsächlich um bekannte Formen handelt, verzichtet er auf ausführliche Ieschreibungen und beschränkt sich anf die, besonders für die Synonymie notwendigsten bemerkungen. Im Interesse einer leichtern Identifizierung der Moskauer Arten hat der Verf. ron den meisten Formen eine oder einige Abbildungen beigefügt, die zwar etwas klein sind, aber infolge ihrer sauberu Ausführung völlig genügen. Fünf neue Species werden ausserdem noch eingehend beschrieben.

Die eine davon, Tiphys (Acercus) diaphanus Croneberg, von welcher ein Weibchen und zwei Männchen erbentet wurden, nimmt eine Mittelstellung zwischen 
T. (A.) cussidiformis Haller und T. (.1.) brripes (- T. mutulus) Piersig ein. Von der letztern Art unterscheiden sich beide Gesehlechter sofort dadurch, dass mu an den zwei vordern Fussparren die Endglieder kolbig verdickt erscheinen, während sie an dem dritten Fusse ganz normal gebildet sind. Von T. (.t.) cussiliformis, dem sie weit näher verwandt ist, weicht sie durch die stärkere Ausbihdung des Hinterendes der dritten Hüftplatte ab, die bei beiden Geschlechtern die Innenecke der vierten Epimere umschliesst und von der benachbarten dureh eine dentlicho Nahtfurche abgetrennt ist. Bei dem Männchen von T. (A.) cassidiformis Hliessen sämtliche Hüftplatten nach innen zu ohne Grenzen zusammen. Auch der nur als Weibchen bekamnte $T$. (A.) trianguluris Prersig kann nach der (iestalt der Genitalnapfplatten sowie wegen der Küurze der zweiten fjpimeren nicht mit der hier vorliegenden russischen Form identifiziert werden, denn bei dieser reichen die zugespitzten Hinterenden der eben erwähnten Gebille fast bis zur Genitalüffnung.

Arrhenurus quatratus Croneberg erinnert in der Körpergrösse nnd Färbung an 1. neumani Piersig. Der Körperumriss zeigt jedoch tolgende Eigentümlichkeiten: der Vorderteil des Rumpfes ist wenig verschmälert und ohrie deutliche Ausbuchtung zwischen den Augen. Letztere sind weiter auseinander gerückt. Der Anhang ist im Gegensatze zu der auffallenden Breite des Vorderkörpers schmal nnd kurz. Die äussern Ränder der Seitenhöcker (Seitenecken) divergieren nicht nach hinten, sondern sind vielmehr mit ihren kurzen, abgerundeten Spitzen leicht gegenemander geneigt. In der Seitenansicht erscheint der Körper stärker verkürzt unıl der Rürken höher als bei der Vergleichsart. Nach der Ansicht des Ref. handelt es sich möglicherweise um jugendliche, noch nicht ausgewachsene Exemplare, eine Vermutung, die noch gestiitzt wird durch den Umstand, dass die hier beschriebene Form in Gesellschaft von Arrh. numani erbeutet wurde.

Arrhenurus rufescens Croneberg steht dem A. affinis líoelı. sehr nahe. Er unterscheidet sich von demselben hanptsächlich durch die abweichende Gestalt des Körperanhanges der Männchen. Letzterer ist verhältnismälỉg länger mit ausgeschweiften Seitenrändern und massigen, abgerundeten, nur sehr wenig vorragenden Eckfortsätzen, zwischen denen der Hinterrand einen bedeutenden Vorspmng bildet. Die Seitenecken des hyalinen Häntchens treten dentlich hervor.

Iydrachna atrala Croneberg erreicht etwa eine Grösse von 2,5 mm. Das Männchen ist merkbar kleiner. Die Chitinbildungen des Vorderriickens bestehen bei beiden Geschlechtern aus vier sehr kleinen, untereinander nicht verbundenen und in Gestalt eines hohen 'Trapezes gelagerten Plättehen, dio bedentend kleiner sind als die Augenkapsehn. Die Haut ist mit dichtgestellten rundlichen Papillen beleckt. Ein medianer Augenfleck tehlt ganz. Epimeren und Genitalplatten zeígen grosse Ähulichkeit mit denen von $I$. leegri Koen., doch sind die Innenecken der beiden hintern Hiiftplatten läuger ausgezogen. Beim Männchen sind die beiden histern Enden der Genitalnaptplatte hinter der Geschlechtsöffnung verwachsen.

Eulais (Eylais) mosyuensis Croneberg ähnelt im Bau der Augenbrïcke und des Capitulums der Eulais undulosa Koen., unterscheidet sich aber von ihr durch den reichern Borstenbesatz des vierten Palpengliedes, das an der Innenseite eine Reihe von sechs Borsten trägt, von denen nur die erste unbefiedert ist und zu denen sich am distalen Ende noch fünf weitere gesellen. Die äussere Reihe besteht aus sechs längeren glatten Borsten. Am dritten Maxillartastergliede bemerkt man einen stark entwickeiten Beugeseitenfortsatz, der mit kurzen, z. T. schwach gefiederten Borsten besetzt ist. Die Pharynx ist hinten stark verbreitert und besitzt vor dem Ende eine kräftige Einschnürung. Die Körperlänge beträgt $4-5 \mathrm{~mm}$. 
In seinen kritischen Bemerkungen weist Croneberg daranf hin, dass Atax intermedius Koen. nicht, wie der Ref. in seinem Werke "Deutschlands Hydrachniden" irrtümlicherweise annimmt, mit $\mathrm{Kre} u \mathrm{dowskys}$ A. ypsilophoms identisch ist. Letzterer besitzt auf jeder Genitalplatte etwa 20 Genitalnäpfe und muss anf die von Bonz beschriebene Form zurückgeführt werden. Bei Cochleophorns (= Yeumania) spinipes äussert der Verf, Zweifel, ob auch die von $\mathrm{Ne} u \mathrm{~m}$ a $\mathrm{n}$ unter diesem Namen beschriebene Form hierher gelı̈rt. Nach Angabe des letztern, dass das erste Beinpaar viel licker sei als die folgenden und nur auf der Bengeseite des zweiten Gliedes lange, spiralig gerillte, auf Erhöhungen sitzende Borsten besitze, scheint eine andere Form vorzuliegen. Bezüglich C. (Neumania) triangularis meint der Verf., dass derselbe mit Nesaea (= Nermania) mirabilis identisch sei. Er stützt sich dabei anf die Färbung des Tieres, das ist jedoch wohl ungeniigend, denn wir haben zwei nahe beieinander stehende Arten, die einen fast durchsichtigen Körper mit dunkelbraunen, nach hinten verbreiterten Darmflecken und rötlich gesprenkelten Exkretionsorgan (Malpighisches Gefäss) besitzen, so dass man vom Tiere bei seinen Bewegungen im Wasser kaum mehr als den Darm in Gestalt eines dunklen gleichschenkeligen Dreiecks unterscheiden kann. Beide Formen ( $N$. triangularis [Piersig] und $N$. limosa [C. L. Koch]) weichen nur durch die Ausstattung des Geschlechtsfeldes sowie in ilren Jugendformen von einander ab. Welche von diesen beiden Species zu Nesaca (N.) mirabilis Neuman gehört. lässt sich aus der Beschreibung und den Zeichnungen des schwedischen Forschers nicht feststellen. Des weiteren weist Croneberg darauf hin, dass die von Krendowsky beschriebene Piona (= Nesaen) carnea nicht, wie der Ref, früher glaubte, zn der von C. L. Koch so genannten Art gehört. Abgesehen von der geringern Grösse $\left(\sigma^{\top}=1 \mathrm{~mm}, \tau=1,9 \mathrm{~mm}\right.$ l.) sprechen noch andere Angaben dagegen. So soll die Genitaltasche des Männchens eine breite kreuzförmige Öffnung aufweisen und die Genitalplatten je nur neun Näpfe besitzen. Das Endglied des dritten Beines ist sehr verkürzt und erreicht nur die halbe Länge des vorletzten. wie denn anch das distale Bengeseitenende des Greifgliedes nur drei Schwimmborsten trägt.

Bei Hygrobates longipalpis äussert der Verf. Zweifel, ob Krendowskys Nesaea $(H$.) dentata hierher zu reclnen ist, da der genannte Autor zwar die kleinen zahlreichen Zähnchen an der. Unterseite des zweiten und dritten Palpengliedes erwähnt, nicht aber den grossen konischen Zapfen des zweiten Gliedes.

Von Oxus-Arten führt Croneber gr nur O. strigatus (Müll.) an. Was $O$. ovalis Krendowsky anlangt, so vertritt er die Meinung, dass dieselbe in das richtige Genus gestellt worden ist. Dass keine Verwechslung mit irgend einer Lebertia-Art vorliegt, wie Ko enike vermutet (Zool. Anz., 1898, Nr. 566, pag. 468) erhellt schon aus dem besonders erwähnten Umstande, dass das letzte Beinpaar krallenlos und mit einer langen Borste bewaffnet ist. Cro neberg widerspricht dann weiter der Ansicht des Ref., dass Arrhenumus albator Krendowsky identisch sei mit A. bruzelii Koen. Nach den Angaben Krendowskys besitzt die genannte Form an der Basis des Anhanges einen nach vorn geneigten, mit zwei zugeschärften Spitzen versehenen Rückenhöcker. Ausserdem bemerkt man zwischen den Seitenecken des Anhanges keinerlei Erhöhungen. Diese Merkmale sind dem Ref. infolge Unkenntnis des in russischer Sprache verfassten Textes entgangell. Die Zeichnung aber erinnert lebhaft an 1. bruzelli Koen. Da der Ref. sich C ron ebergs Darlegungen nicht verschliessen kann, schlägt er für die Krendowskysche Form den Namen A. cronebergi Piers. vor. Diplodontus impressus Krendowsky ist nicht synonym mit Hydryphantes ruber de Geer, sondern nach der Form des 
Rückenschildes mit $H$. dispar Schaub. Bei Hydiachna globosu de Geer erwähnt der Verf, auch einige Exemplare, die ähnlich wie H. uniscutuln Thor, H. bohemen Thon und $H$. paludosa Thon zwei längliche, dreieckige Rückenschilder besitzen, deren Vorderenden unmittelbar vor dem medianen Augentleck durch eine schmale Chitinbrücke zusammenhingen. Es handelt sich nach der Ansicht des Ref. um eine Spielart, die er als $H$. globosa var. mosquensis Piersig bezeichnet wissen möchte.

In dem Verzeichnis der Hydrachnidenfauna Zentralrnsslands werden 33 Arten aufgeführt, von denen zwei als neu bezeichnet werden. Die eine davon gehört der Gattung Arrhenurus an. A. laenis Croneberg gleicht in Grösse und Färbung dem A. leuckarti Piersig, unterscheidet sich aber sofort durch die Form des Vorderkürpers, der Seitenhörner des Anhangs und die Abwesenheit eines Rückenhöckers. Nach den beigegebenen Abbildungen zu urteilen, liegt der Beschreibuug ein noch nicht völlig ausgebildetes Individuum zu Grunde. Diese Annahme wird auch noch durch die Angaben Cronebergs bekräftigt, dass die Haut an den Rändern des Anhangs und auf den Seitenhöckern in eine feine Granulierung übergeht. Enlais (Eylais) unisinualu, die zweite neue Species, erinnert in Form und Bewaffnung der Palpen an $E$. cmarginata Piersig. Die Augenkapseln werden durch eine kurze, aber breite Brücke in ihrer vordern Hälfte verbunden; der Vorderrand desselben bildet mit den Augenkapseln eine gerade Linie, die nur in der Mitte eine kleine Einbuchtung aufweist. Vor der Einkerbung ragt ein kurzer abgerundeter Zapfen hervor, der den Augenmuskeln zum Ansatz dient. Die Körperläuge beträgt $3-4 \mathrm{~mm}$. In einem Nachtrage erwähnt der Verf. noch, dass Arrhenurws bruzelii in Russland in einer roten und grauen Varietät auftritt.

R. Piersig (Annaberg, Erzgeb.).

196 Wolcott, II. Robert, The North-American species of Curvipes. In: Stud. Zool. Laborat. Univ. Nebraska. 1902. Nr. 5̃0. pag. 201-256. Taf. 29-33. Fig. 1-60.

Die vorliegende Arbeit beschäftigt sich mit einer grössern Anzahl Piona-(Curcipes-) Arten, die in Michigan, Massachusetts, Wisconsiu, Illinois, Nebraska, Colorado, Missouri und Louisiana gesammelt wurden. Auf Grund eingehender vergleichender Untersuchungen an zahlreichen Individuen konnte der Verf. feststellen, dass die charakteristischen Merkmale der einzelnen Arten sehr beständig sind. Diese Beobachtung veranlasst ihn, 13 neue Arten aufzustellen, so dass die Liste der bisher in Nord-Amerika aufgefundenen Piona-(Curipes-) Formen nunmehr 19 Arten anfweist. Da das Material aus den verschiedensten Gegenden stammt, war es oft sehr schwierig, die Männchen und Weibchen ein und derselben Species zu identifizieren. U'm eine Verquickung verschiedener Arten zu vermeiden, hat der Verf. die grösste Vorsicht walten lassen. In den meisten Filllen reigten die Palpen, die Haarhöcker auf der Beugeseite des vorletzten Tastergliedes, die Zahl und Verteilung der Schwimmborsten, die (xestalt der Beinglieder und des Geschlechtsfeldes genügend Ähnlichkeiten, 
dass die Verwandtschaft der Geschlechter leicht festgestelit werden konnte.

Im zweiten Ahschnitt bietet der Verf. eine erschöpfende Beschreibung der einzelnen neuen Formen.

Piona (Curvipes) coronis Wolc., nur durch ein $q$ in der Sannlung vertreten, kennzeichnet sich durch den Besitz zahlreicher (20-28) frei in die Körperhaut eingebetteter Genitalnäpfe, die jederseits der Genitalöfnung einen fast kreisförmigen Fleck in Anspruch nehmen. Sie bilden an der iussern Ungrenzung desselben einen fest geschlossenen Ring, während sie in der Mitte spärlicher verteilt sind. Die Maxillartaster des $1,25 \mathrm{~mm}$ grossen Tieres besitzen eine Länge von $0,82 \mathrm{~mm}$. Die Bengeseite des vorletzten und längsten Gliedes trägt einen selır langen und einen weiter zurückgerüickten kleinen Haarhöcker; am distalen Ende der Innen. fläche erhebt sich ein kleiner Chitinzapfen.

Piona (C.) cxilis Wolc. chatakterisiert sich hesonders durch die aussergewöhnliche Länge der Maxillartaster, deren vierte Glieder an der Basis ziemlich stark verjüngt erscheinen. Letztere tragen auf ihrer Beugeseite je zwei hintereinander gestellte kleine Haarhöcker. Der Chitinstift am Vorderende zeigt genan nach mten. Der Geschlechtsh of des besteht aus einer langen, seitlich von zwei gewölbten, gemeinschaftlich eine Ellipse darstellenden Lefzen verschlossenen Genitalöffnung und zwei flügelförmig gestellten, mit 40-50 gleichmäßig verteilten Genitalnäpfen bedeckten Sexualplatten. Beim o zeigt das Geschlechtsfeld eine Verschmelzung mit den Hinterrändern der vierten Epimeren. Die Genitalöffnung ist kurz und liegt in einer flachen Samentasche, die eine elliptische, glatte Umrandung aufweist. Wie bei den meisten Piona (Curripes)-Hännchen sind die Napfplatten hinter der Samentasche durch eine Briicke verschmolzen. Letztere ist hier so breit, dass sie auch die sogen. Analöfnung umschliesst. Jede Genital. platte reicht bis an die Hinterrandsecke der vierten Epimere heran. Auf dem Greifgliede bemerkt man vor und hinter der Aushöhlung der Bengeseite einige steife Borsten, während das distale Ende drei Sclıwimınhare aufweist. Die Körperlänge des beträgt 825 " , die des 7920 "

Piona (Curvipes). pugilis Wolc. ähnelt $P$.(r.) erilis in bezug auf die Gestalt und Ausstattung der Maxillartaster; sie unterscheidet sich von iln durch eine eigentümliche leichte Krümmung der äussersten Beinglieder der drei vordem Extremitätenpaare. Das mänuliche Geschlechtsfeld ähnelt demjenigen von $P$. (C.) exilis Wolc. ơ. Die Genitalöffoung ist kurz und liegt in einer länglich runden mäfig tiefen Samentasche, die nach hinten nur undentlich umrandet erscheint. Die beiden zungenförmigen Genitalplatteu sinı bei dem Männchen hinter der Vertiefung durch ein ziemlich breites Chitimband, das auch den sogen. After umschliesst, miteinander verbunden; beim Weibchen liegt an gleicher Stelle ein grosser, nicht gehärteter Zwischenraum. Jede Genitalplatte besitzt $60-70$ Näpfe. von denen zwei merkbar grösser sind als die übrigen. Das Weibchen misst $1,555 \mathrm{~mm}$, das Männchen $1,270 \mathrm{~mm}$.

Piona (C.) turgita Wolc. nähert sich der P. (C.) longipalpis Krend. und der P. (C.) nodata (Müill.), doch weist sie bedeutend mehr Genitalnäpfe anf jeder Geschlechtsplatte auf. Im Gegensatze zu der zuerst genannten Vergleichsform trägt sie auf der Beugeseite des vierten Tastergliedes vier Haarhöcker. Mit $P$. (C.) fallax 'Thon kann sie nicht verwechselt werden. da sie in der Form und Bauart des Genitalhofes, in der Länge der Beine und der Naxillarpalpen, sowie in der Ausstattung des dritten Fusses erhebliche Abweichungen erkennen lässt. 
Das Endglied des dritten Beines erinnert mit seinem verdickten distalen Ende und seiner schwach konkaven Beugeseite an das entsprechende Gebilde bei $P$. (C.) controversiosa Piersig ơ, doch ist die Krallembewaffnung eine andere. Was den Genitalhof des Weibchens anlangt. so bemerkt man am Aussenrande der Lefzen zahlreiche feine Börstchen, die in zwei oder drei Reihen geordnet sind. Die beiden zungenförmigen Napfplatten sind der hintern Hälfte der Vulva angelagert und stehen miteinander durch eine schmale, ebenfalls feine Börstehen tragende Brücke in Verbindung. Ton ganz besonders charakteristischer Gestalt ist die Öffnung der unfangreichen, schief nach hinten weisenden Samentasche des Männchens; der konvexe Vorderrand derselben ist in der Mitte breit eingebuchtet; er geht eckig gebrochen in den wellig gebogenen Hinterrand über. Nach der beigegebenen Zeichnung zu urteilen sind die beiden fast scheibenförmigen Genitalnapfplatten nicht miteinander verbunden. Jede derselben ist mit etwa 50 Näpfen besetzt. Das Greifglied trägt am distalen Beugeseitenende sieben Schwimmborsten. Die Körperlänge des Weibchens beträgt $2,3 \mathrm{~mm}$, die des Männchens $1,4 \mathrm{~mm}$.

P. (@) triangularis Wolc. of verrät grosse Ähnlichkeit mit $P$. (C.) nodata (Müll.) und $P$. (C.) turgida Wolc, von denen sie sich durch den abweichenden Bau der Maxillartaster und des Genitalhofes unterscheidet. Die Palpenglieder verhalten sich zusammen wie 9:25:12:34:20. Auf der Beugeseite des vierten Gliedes erlreben sich zwei lange, schiet nach vorn gerichtete Haarzapfen, von denen der innere etwa in der Nitte, der andere halbwegs zwischen Mitte und distalem Ende steht. Die Genitallefzen sind vorn und hinten mit nur je einer feinen Haarborste ausgestattet. Auf den hinter der Genitalöffnung nicht verbundenen Napfplatten zählt man je 25-30 Näpfe; zwei derselben sind etwas grösser als die übrigen. Die Körperlänge beträgt $920 \mu$.

$P$. (C.) constricta Wolc. steht der 1 '. carnca C. L. Koch am nächsten. Sie weicht jedoch im Bau der Maxillartaster und des Genitalhofes wesentlich von dieser Art ab. Ausserdem ist auch das Greifglied des Männchens anders gestaltet. Beim Männchen erreichen die Palpen etwa ${ }_{5}$ der Rumpflänge, beim Weibchen noch weniger. Die einzelnen Glieder veı halten sich wie $9: 32: 12: 28: 19$. Das zweite Glied besitzt beim Mämnchen annähernd die Breite der benachbarten Beinglieder, beim Weibchen ist es jedoch merklich schwächer. Auf der Beugeseite des verletzten (iliedes erheben sich schief bintereinander zwei mittelgrosse Haarzapfen. Das verkürzte Endglied des dritten männlichen Fusses hat die Gestalt einer Corucopia, dessen gestütztes distales Ende eine schmale, kurze, stark gekrümmte Kralle trägt. Das distale Ende der Beugeseite des Greifgliedes ist mit einer mittellangen Dolchborste und drei schwimmhaaren ausgestattet. Das Geschlechtsfeld des Männchens kennzeichnet sich durch eine mehr breite als lange elliptische Samentaschenöffnung, die nach vorn zu in der Mittellinie des Körpers eine zapfenförmige Verlängerung aufweist, die bis an die verschmolzenen Innenecken der vierten Epimeren heranreicht. Zu beiden Seiten dieser Öffnung befindet sich je eine Genitalplatte, die etwa 9-10 mittelgrosse Näpfe trägt. Der vordere Teil der Platten ist napffrei und nur mit einem feinen Börstchen ansgestattet. Die Verbindungsbrücke der Genitalplatten hinter der Samentaschenöffnung bildet eine sehr schmale Leiste, die den sogen. After nicht mit einschliesst. Die Genitalplatten des Weibchens sind :̈hnlich gestaltet wie bei $P$. (C.) fuscata Herm. Jede derselben umschliesst 10 Genitalnäpfe. Die Körperlänge des Männchen beträgt $920 \mu$, die des Weibchens $1,730 \mathrm{~mm}$.

P. (C.) spinulosa Wolc. gehört unter die kleinsten Vertreter seiner Gattung. 
Sie charakterisiert sich durch eine dürftige Beborstung der Beine. Die Palpen sind bei beiden Geschlechtern etwa ${ }^{2}{ }_{3}$ so lang wie der Körper. Die einzelnen Glieder verbalten sich zueinander wie 10:28:13:31:18. Auf der Beugeseite des vorletzten Palpengliedes bemerkt man zwei Haarhöcker, von denen der äussere etwa die Mitte des Gliedes einnimmt, während der innere um ein geringes weiter bach vorn gerückt ist. Beim Weibchen sind beide annähernd von gleicher Grösse, beim Männchen ist der zurückstehende äussere viel stärker entwickelt als der innere. Das Greifglied des rännlichen Hinterfusses trägt an distalen Ende drei Schwimmborsten. Wie bei den meisten Männchen besitzt der dritte Fuss ein gekreuztes Endglied mit umgebildeter Kralle; letztere ist lang, gerade und sehr spitz und erreicht fast ${ }^{2} / 3$ der Länge des letzten Gliedes. Der Geschlechtshof ist mit flügelförmig schief nach der Seite und hinten gerichteten Genitalplatten ausgestattet, von denen jede beim Männchen 25-30, beim Weibchen 20-25 Genitalnäpfe aufweist. Die Geschlechtsöffnung des Männchens liegt in einer flachen, undeutlich umgrenzten Mulde (Samentasche). Der Anus liegt ein wenig hinter dem Geschlechtshofe frei in die Körperhaut gebettet. Wahrscheinlich ist das Weibchen noch nicht völlig ausgewachsen, wie die Lagerung des Sexualfeldes am Hinterende des Abdomens beweist.

$P$. (C.) media Wolc. charakterisiert sich nach den Angaben des Verf. vornehmlich durch den Besitz zweier langer neben einander gelagerter Haarhöcker auf der Beugeseite des vierten Tastergliedes sowie durch mondsichelförmige Genitalplatten, deren jede zwischen $35-40$ Genitalnäpfe trägt. Sie ist also eine nahe Verwandte von $P .(C$.) disparitis Koen. und $P$. (C.) rolunda P. Kramer. Möglicherweise ist sie mit $P$. (C.) tardus Thon identisch. Da das Männchen noch fehlt, lässt sich die Zugehörigkeit zu dieser europäischen Form mit Sicherheit noch nicht feststellen. Die Körpergrösse beträgt $1,1 \mathrm{~mm}$.

$P$. (C.) debilis Wolc. wurde nur in einem einzigen männlichen Exemplare erbeutet. Thre Körpergrösse beziffert sich auf 841 ". Sie kennzeichnet sich be sonders durch die geringe Dicke der kurzen Maxillartaster und die Eigenartigkeit des Genitalhofes. Die einzelnen Palpenglieder verhalten sich zu einander wie 9:28:19:35:9. Die mäß3ig entwickelten, fast nebeneinander gelagerten Haarhöcker der Beugeseite des vierten Gliedes liegen etwa zwischen dessen Mitte und distalem Ende. Am schwach gekrümmten Endglied des dritten Fusses bemerkt man zwei Krallen, von denen die eine einen langen, dünnen und spitzen Hauptzahn und einen imnern kurzen Nebenzahn besitzt; ausserdem entspringt den Seitenwandungen der Krallenscheide nahe der Streckseite je eine lange Borste. Das Greifglied des vierten Fusses ist am distalen Ende der Beugeseite mit vier Schwimmharen ausgerüstet. Der Genitalhof erinnert hinsichtlich der Plattenform und der Ausstattung mit Genitalnäpfen an $P$. (C.) controversiosa Piersig. Die Öftnung der samentasche ist jedoch fast kreisrund.

$P$. (C.) reighardi Wolc. weist sehr nahe Verwandtschaft mit $P$. (C.) obturbans Piersig und $P$. (C) tarda Thon auf. Sie unterscheidet sich von der zuerstgenannten Art durch die grössere Gedrungenheit der Maxillartaster, besonders des zweiten Segmentes, durch die fast gleichmäßige Verjüngung des vierten Gliedes nach dem distalen Ende hin und durcl die Abwesenheit sogen. Nebenhaarhöcker auf der Beugeseite desselben Gliedes. Der Geschlechtshof zeigt wenig Unterschiede. Die Genitalplatten sind in der Form und Ausstattung sehr variabel. Von P. (C.) tarda Thon gliedert sich dis neue Form durch die kürzern Maxillartaster ab, deren Glieder übrigens ein anderes Längenverhältnis aufweisen. Ausserdem nimmt das Genitalfeld cinen grössern Raum ein und bietet kleine Ab- 
weichungen im Bau der Genitalnapfplatten. Beim Weibchen sind die Palpen halb so lang wie der Körper. Das Längenverhältnis der Glieder wird durch die Zahlenreihe 7, 26, 15, 34, 18 ausgedrückt. Die Haarhöcker auf der Beugeseite des vierten Gliedes stehen etwas weiter zurück als bei $I$. (C.) obturbans Piersig, auch entspringen sie einer weniger breiten Basis. Die kleinen Nebenhaarhöcker felılen gänzlich. Das Endglied trägt drei Nägel, von demen nur der mittelste schwach gekrümmt erscheint. Die Borsten des zweiten und dritten Gliedes zeigen keine Spur von Fiederung. In Gegensatz zu der oben angezogenen Vergleichsart ist der Schwimmhaarbesatz der Beinpare dürftiger. Das vierte und fünfte Glied des dritten Fusspaares ist mit 3-4 bezw. 5-6 Schwimmborsten ansgestattet; die entsprechenden Glieder des Hinterfusses tragen deren gar nur 3 bezw. 4. Auf den mondsichelförmigen Genitalplatten zählt man je 21-23 Genitalnäpfe; in der den Schamlefzen zugekehrten Ausbuchtung liegen 2-4 freie Näpfe, von denen einer die andern an Grösse merkbar übertrifft. Beim Männclien treffen wir eine lange Geschleclitsöffnung an, die vom vordern bis zum hintern binde des Genitalhofes reicht; sie liegt in einer seichten, elliptischen Samentasehe. Jede Genitalnapfplatte trägt 35 Näpfe. Das Weibchen besitzt eine Länge von $825 "$, das Männchen eine solche vou 600 ,1. - P. (C.) inconstans Wolc. nähert sich in mancher Beziehung der $P$. (C.) rufa (C. L. Koch), $P$. (C.) paucipora Thor und $P$. (C.) circularis Piersig, doch unterscheidet sie sich durch die Gestalt und Ausrüstung der Palpen und des Genitalhofes. Die Maxillartaster sind ziemlich kurz und noch nicht hảb so lang wie der Körper. Das Längenverhältnis der Glieder wird durch die Zahlenreihe 9, 28, 14, 31, 18 ausgedrückt. Die Haarhöcker auf der Beugeseite des vierten Gliedes sind klein; der äussere, etwas grössere, liegt annähernd neben der innern, etwa in der Mitte des Segmentes. Wie bei $P^{\prime}\left(C^{\prime}\right)$ circularis Piersig $q$ besitzt das Geschlechtsfeld jederseits der langen Geschlechtsöffnung zwei oder mehrere Genitalplatten und einige wenige freie Näpfe. Die Zahl der Näpfe jederseits beträgt 11-19. Aller Wahrscheinlichkeit nach haben wir es hier nur mit einer Spielart ron $P$. (C.) circularis Piersig zu tun. - $P .(C$. setigera Wolc. sieht der $P$. (C.) inconstans sehr ähnlich. Sie unterscheidet sich von ihr durch die ungewöhnliche Länge der Stirnborsten. Ausserdem ist die Zahl der Schwimmhare an den Beinparen weit bedentender, das Längeverhältnis der Palpenglieder ergibt folgende Zahlenreihe: $10,28,5,14,33,5,14$. Auf der Beugeseite des vierten Gliedes besitzt das Weibchen zwei sehr kleine Haarhöcker während das Männchen deren seclis aufweist, von denen die hintersten am kräftigsten ausgebildet sind. Am meisten erinnern die Palpen an das gleiche Gebilde von $P$. (C.) thoracifera Piersig $\sigma^{\top}$. Der Geschlechtshof des Männchens sowohl als des Weibchens sieht demjenigen von $P$. (C.) circularis Piersig ungemein ähnlich, sodass man auf die Vermutung kommt, dass beide Formen miteinander zu identifizieren sind.

$P$. (C.) crassa WVolc. gleicht in vielen Stücken der P. thoracifera Piersig. Die Haut ist wie bei dieser sehr dick und mit Leistchen von verschiedener Höhe ausgestattet, so dass in der Seitenansicht die Oberfäche wie mit niedrigen Papillen bedeckt erscheint. Die Maxillartaster sind gedrungen gebaut; sie erreichen etwa die Hälfte der Körperlänge. Das Längenverhältnis der einzelnen Glieder ist wie 10:31:16:27:16. Auf der Beugeseite des vierten Gliedes erheben sich beim Nännchen und Weibchen wie bei $P$. (C.) thoracifera Piersig $\sigma^{7}$ nnd $P$. (C.) con. globata Koch auf gemeinschaftlicher, erhöhter Basis sechs bezw. acht Haarhöcker verschiedener Grösse. Beim Männchen sind dieselben so geordnet, dass sie gleichsam eine Fortsetzung und Verbreiterung des distalen Vorderrandes nach unten dar- 
stellen. Die Endglieder der Beine sind bauchig verdickt. Das Greifglied des ó hat am distalen Ende zwei Schwimmborsten. Die Krallen des Samenüberträgers sind sehr klein. Wie bei $P$. (C.) thoracifera Piersig o reicht der Genitalhof mit seinen Napfplatten über die Hinterecken der vierten Hüftplatten weit hinaus. Eine Samentasche ist nicht vorhanden und die Genitalöffnung fällt durch ihre Kleinheit auf. Beim Weibchen bilden die beiden Genitalplatten zwei zungenförmig schief nach den Seiten und hinten gerichtete Flügel mit je 70 und mehr Genitalnäpfen; beim Männchen zählt man etwa 50-60 Näpfe. Die Körperlänge des Männchens beträgt $659 \mu$, die des Weibchens $793 \mu$.

Der Verf. bietet am Schlusse seiner ausgezeichneten Arbeit ausführliche Bestimmungstabellen für beide Geschlechter. In einer weitern Tabelle vervollständigt er den von dem Ref. seinerzeit gegebenen Bestimmungsschlüssel der Gattung Piona (Curvipes) C. L. Koch. Ob die dabei verwendeten Unterscheidungsmerkmale bei Aufstellung von Arten berechtigt sind, muss erst die Zukunft lehren. Allem Anschein nach treten auch bei der Gattung Piona (Curvipes) so viele Zwischenformen auf, dass es scliwer halten wird, Arten und Unterarten scharf auseinander zu halten.

R. Piersig (Annaberg, Erzgeb.).

\section{Insecta.}

197 Kohl, Fr. F., Die Hymenopterengruppe der Sphecinen II. Monographie der neotropischen Gattung Podium Fabr. In: Ablandl. zool. bot. Ges. Wien. I. Bd. Heft 4. 1902. gr. 80. 101 pag. 7 Taf.

Die vorliegende Arbeit schliesst sich als Il. Teil an eine vor mehr als 10 Jahren begonnene Monographie der $\mathrm{Sphecinen}$ an und behandelt die Gattung Podium Fabr., in welcher auch die früheren Gattungen Dymatus, Trigonopsis und Parapodium eimbezogen werden. Sie bewohnen in 33 wohlbeschriebenen Arten die neotropische Region, nur $P$. biguttatum Taschbg. und $P$. luctuosum Smith bewohnen Nordamerika (Texas und Carolina). Nach einer Geschichte des Gattungsbegriffes werden Bestimmungstabellen für Weibchen und Hännchen getrennt vorgelegt und folgen die ausfübrliclsen mit viel Kritik versehenen Beschreibungen der einzelnen Arten, denen die geographische Verbreitung und soweit als möglich die Biologie angefügt wird. Mehrere Arten werden als neu beschrieben. Die schön gezeichneten Tafeln sind eine hochwillkommene Beigabe zur Erläuterung der wertvollen Arbeit; neun Arten blieben unerklärt. Hoffentlich folgen die weitern Gattungen in gleicher Klarheit recht bald.

K. W. v. Dalla Torre (Innsbruck).

\section{Vertebrata.}

198 Boulenger. G. A.. A List of the Fishes, Batrachians and Reptiles collected by Mr. J. Folliott Darling in Mashonaland, with De. scriptions of new Species. In: Proc. Zool. Soc. London May 6. 1902. pag. 13-18. Taf. II-IV.

Ausser vier Arten von Fischen (Barbus trimaculatus Ptrs., Clarias gariepinus Smith und 2 nn. spp., Labeo darlingi und Barbus rhodesianus) wurden im Distrikt von Salisbury, Rhodesia bei Mazoë und zwischen Umtali und Marandellas noch eine grössere Anzahl von Reptilien und Batrachiern gesammelt, die bei dem Um. stande, dass die Fauna von Rhodesia noch sehr unvollkommen bekannt ist, gewiss nicht olıne Interesse sind. Von den 8 Batrachiern sind die meisten wohlbekannte und mehr weniger weitverbreitete Arten, nur eine (Rana darlingi) ist 
neu; dasselbe gilt für die 35 Reptilien, von denen eine Schildkröte (Homopus darlingi) und eine Eidechse (Ichnotropis lougipes) als neu beschrieben werdell, während von den übrigen nur der in Jahre 1896 nach einem Exemplare beschriebeno Pachydactylus affinis Blngr. der seltene Platysaurus gnttatus Snith und ein typisches Exemplar der Taia haie L. spezielleres Interesse beanspruchen können. Die neuen Formen sind von P. Smith in gewohnter trefflicher Weise auf drei Tafeln abgebildet.

F. W e rner (Wien).

\section{Reptilia.}

199 Boulenger, G. A., Reptiles of Socotra and Abd-el-Kuri. In: Nat. Hist. of Socotra and Abd-e]-Kuri. 1902. pag. 75-104. Figg. Taf. VIIT-XI.

Die Reptilienfauna der beiden Inseln ist in obigem Werke das erste Mal im Zusammenhang dargestellt; als Basis dienten die in frühern Jahren von balfou $\mathrm{l}^{\circ}$ und Riebeck, in letzter Zeit von Ogilvie-Grant und H. O. Forbes gemachten Aufsammlungen. Die neuen Arten, welche von den beiden letztgenannten Forschern gesammelt worden sind, wurden schon früher von Boulenger (Bull. Liverpool Mus. II. 1899) beschrieben, die vorliegende Arbeit zieren aber die von Green wit gewöhnlich musterhaft ausgeführten Abbildungen derselben, sowie des riesigen Phyllodactylus riebecki Ptrs. Von allen Arten sind eingehende Beschreibungen und in Fussnoten Angaben der Sammler über Vorkommen, Lebensweise und dergl. beigegeben. Auffallend ist die grosse Anzahl endemischer Arten auf beiden Inseln, während die luäufigsten Formen der beiden Nachbarküisten (Somaliland und Südarabien) vollständig fehlen; ebenso fehlen Batrachier vollständig. Die von Socotra bekannten Arten sind: Pristurus insignis Blanf., P. rupestris Blanf. (dieser nicht endemisch), Phyllodactylus ricbecki Ptrs., trachyrhynchus Blngr., Ilemidactylus homoeolepis Blanf., pumilio Blngr., granti Blngr., tureicus L., flaviviridis Rüpp. (die beiden letztern nicht endemisch) Pachycalamus brevis Gtlır., Eremias gutulata Licht. (nicht endemisch), Mabuia socotrana Ptrs., Parachalcides socotranus Blngr., Chamacleon monachus Gray. Typhlops socoranus Gthr., Glaueonia filiformis Blngr., macrura Blngr., Zamenis socotrac Gthr., Ditypophis vivax Gthr. und Echis coloratus Gthr. (diese nicht endemisch). Nur 4 Arten sind also weiter verbreitet, dagegen sind 3 Genera (Pachycalamus, Parachaleides und Ditypophis) auf Socotra beschränkt. - Varames, Testudo, Crocodilus soll einstmals auf Socotra gelebt haben, fehlt aber jetzt vollständig; Chelone imbricata L. kommt an der Südküste vor. - Auf Abd-el-Kuri, welche Insel vorher niemals zoologisch erforscht worden war, lebten neben dem auch auf Socotra vorkommenden Pristurus rupcstris zwei endemische Geckos, Ilemidactylus oxyrhinus Blngr. und forbesii Blngr. - Von Seeschildkröten kommt sowohl Chelone mydas wie imbricata und Thalassochelys caretta an der Küste der Insel vor.

F. Werner (Wien).

200 Hagmann, G., Die Eier von Caman niger. Zweiter Beitrag zur Kenntnis der Lebens- und Fortpflanzungsweise der brasilianischen Reptilien. In: Zool. Jahrb. Syst. XVI. Bd. Heft 2. 1902. pag. 405-410. Taf. 19-20.

Die kleine Mitteilung enthält mehr, als der Titel angibt, da in gedrängter Kü̈rze verschiedene biologische Angabell iiber Caiman niger darin sich vorfinden. Der Autor hatte während eines dreimonatlichen Aufenthaltes auf der Insel Mexiana im nördlichen 'Teile 
des Amazonas-Ästuariums Gelegenheit, ausser dem kleinern und weniger häufigern (V'erhältnis wie 1:10) Caiman sclerops auch die grosse schwarze Art näher kennen zu lernen. Wie enorm häufig dieselbe dort sein muss, geht daraus hervor, dass auf einem Grundstiick in wenigen Tagen über 2000 Exemplare getötet wurien, und auch der Terf. wohnte einer solchen śchlächterei bei, wobei in zwei Tagen 800 Stïck von $1-4,2 \mathrm{~m}$ Länge zur Strecke gebracht wurden. Die Eier sind $87-92 \mathrm{~mm}$ lang und $54-55 \mathrm{~mm}$ breit (Durchschnitt $90 \mathrm{~mm}$ bezw. $55 \mathrm{~mm}$ ), rein weiss, oft durch die fiulende Holzmasse des Nestes bräunlich gebeizt, besitzen wie die von $C$. sclerops eine rauhe Schale, hervorgerufen durch dünne, geschlängelte, fast millimeterhohe Kalkwände und Kalksäulchen. Durch gegenseitiges Reiben der Eier entsteht ein eigentümliches Geräusch, das von den Bewohnern der Insel zum ..Rufen der Mutter" beniitzt wircl. Der grosse Kaiman ..Jacaré-assu" hat seine Fortptlanzungszeit auf Mexiana im Oktober und Norember, C. sclerops dagegen im Mai und Juni. I)as Nest wird ausführtich beschrieben und die Beschreibung durch zwei sehr interessante photographische Aufnahmen ergänzt, ron denen die auf Tafel 19 den $q$ Caimun im Papyrusdickicht bei dem bedeckten Nest, die auf Tafel 20 aber das aufgedeckte Nest und die freigelegten Eier zeigt. Es findet, wie schon Go eldi angab, eine Brutpflege, bezw. Bewachung und Verteidigung des Nestes ron seiten der Mutter statt und es wird, wie bereits erwähnt, die Mutter durch das Reiben der Eier herbeigelockt. Die Kaimans antworten übrigens sofort auf ihren. durch eine menschliche Stimme nachgeahmten Ruf. Die Eier brauchen 5-6 Wochen bis zur Reife, je nach den örtlichen Verhältnissen, vielleicht auch noch mehr.

F. Werner (Wien).

201 Lampe. E.. und $\boldsymbol{W}$. A. Liullolm, Catalog der Reptilien-und Amphibien-Sammlung (Schlangen, Froseh-, Schwanz. und Schleichen. lurche) des Naturhistorischen M useums zu Wiesbaden. In: Jahrb. Nassauisch. Ver. f. Naturk. Jahrg. 55. Wiesbaden. 1902. pag. 66.

Der von E. Lampe verfasste und von W. A. Lindholm mit Aumer. kungen versehene Katalog der Wiesbadener herpetologischen Sammlung, über dessen ersten Teil bereits referiert wurde, ist nummehr abgeschlossen. Die Sammlung enthält einige interessante Arten vou Schlangen, wie Epierates angulifer Bibr., Tenodermus jaranicus Reinh., Polyodontophis sagittarius (Cant.) (Original zu Enicognathus braconnicri Jan.), Tropidonotus sancti-johannis Blngr., Simocephalus guirali Mocq. von Kamerun, Zamenis mexicanus DB., Dendrophis caudolineolatus Gthr., Calameria javanica Blngr. (neu für Sumatra), Leptodira septentrionalis (Kemn.), Dryophis fasciolatus Fisch., Hydrophis frontaiis Jan., Denisonia flagellum (Mc. Coy) u. a. und von ihnen, sowie zahlreichen andern Arten werden ausführliche systematische Angaben gemacht. Die Amphibiensammlung ist ohne Belang. Im Anhang wird eine n. sp. Prosymna bergeri Lindheim aus Rietmond, Bezirk Gibeon, 
Deutsch-Südwest-Afrika, beschrieben und genaue Fundorte der von Fuchs in Sumatra gesammelten Schlangen des Museums angegeben. F. W erner (Wien).

202 Nopesa, Franz Baron v., Über die Varame-artigen Lacerten Istriens. In: Beitr. z. Palaeontol. u. Geol. Oesterreich-Ungarns u. d. Orients. Bd. XV. Heft 1. 1903. pag. 31-42. Taf. V. VI.

Der Verf. hat die von Gorjanović-Kramberger in die beiden Gruppen der Aigialosauridae und Dolichosauridae verteilten $V a$ rams-ähnlichen fossilen Lacertilier eingehend studiert und erbringt nun, nach Revision der Genera Pontosaums, Actaeosaums, Adriosaums (besitzt lange Dornfortsätze an den Schwanzwirbeln), Dolichosumus, Opetiosanus, Carsosamus, Aigialosamms und Wesoleptos, den Nachweis, dass diese Genera in zwei Gruppen unterzubringen sind, von welchen die eine die langhalsigen Formen (Dotichosanms, Pontosamus, Actreosamus, Adriosam grossköptigen Formen (die übrigen 4 (iattungen) unfasst. Die beiden Gruppen werden folgendermaßen charakterisiert.

\section{A. Typus Pontosaumes.}

Schädel 6-10 mal kürzer als präsacrale Wirbelsäule, klein und leicht gebaut.

Quadratum vermutlich schlank.

Wirbelsäule 39 präsacrale Wirbel, wo. von 13 auf den Hals, 26 auf den Rücken entfallen.

Die Halswirbel nehmen gegen vorne an Grösse ganz bedeutend ab.

Die Rumpfwirbel sind ebenso breit wie lang.

Rippen verhältnismäßig sehr kurz und der Leib daher ausgesprochen walzenförmig gestaltet.

Ventralrippen (Sternal- und Zwischenstïcke) sind nicht vorhanden.

Vorderextremität sehr stark reduziert, ihre Länge ist in der präsacralen Wirbelsäule 5 mal enthalten und verhält sich zum Hinterfuss wie 1:2.

Hinterfuss nach B o u le nger von primitivem Typus.
B. 'Typus Opetiosauns.

Schädel 3-4 mal kürzer als präsacrale Wirbelsäule, robust gebaut.

Quadratum pythonomorph.

29 präsacrale Wirbel, von denen 7 Halsund 21 Riickenwirbel gezählt werden können.

Eine bedentende Abnahme der Grösse der vorderen Halswirbel ist nicht bemerkbar.

Die Rumpfwirbel sind läuger als breit.

Rippen verlıältnismäfig lang, wodurch ein mehr gedrungener Körperbau bedingt wird.

Ventralrippen sind sehr stark entwickelt.

Vorderextremität nur wenig reduziert, sie ist nur 3 mal kürzer als die präsacrale Wirbelsäule und verbält sich zum Hinterfuss etwa wie $1: 1$.

Hinterfuss mit varanider Modifikation des 5. Metatarsale.

Der Verf. nennt die erste Gruppe Dolichosauridae, die zweite Aigialosauridae, welche Namen sich mit den gleichen von Gorjanovié-Kramberger aber nicht decken.

Es werden auch die Beziehungen zu Pleurosaurus (keine wesentliche Ähnlichkeit, nur Konvergenz infolge gleicher - aquatischer - 
Lebensweise) zu den Varanidae, den Pythonomorplıa erörtert und schliesslich folgende Punkte festgestellt:

1. Die Pythonomorpha stammen von den A igialos a uridae.

2. Die Aigialosauridae zeigen bereits Anpassungserscheinungen an aquatische Lebensweise.

3. Aigialosauridae und Varanidae haben gemeinsame (jurassische) Ahnen, die als terrestrische Reptilien den Varaniden sehr ähnlich gebaut gewesen sein müssen. F. Werner (Wien).

203 siebenrock. F.. Zur Systematik der Gattung Sternothaerus Bell. In: Zool. Anz. XXVI. 1903. Nr. 691. pag. 191-199.

Die Revision der Stemothacrus-Arten, we]che die am meisten in Erscheinung tretenden Süsswasserschildkröten des tropischen Afrika vorstellen und von denen vier Arten auch regelmäßig lebend nach Europa in den Handel kommen, war schon ein dringendes Bedürfnis. Der Autor hat sich der verdienstlichen Arbeit unterzogen, die Valenz der bisher bekannten Arten zu prüfen, und er hat bei eingehendem Studium nachweisen können, dass die sechs in B o ulengers Catalogne of the Chelonians ete. (1889) unterschiedenen Arten aufrecht zu erhalten sind, dass aber Sternothaerus oxyrhinus Blngr. = St, niger DB., St. botterji Blngr. $=$ simuatus Smitl und St. stciudachneri Siebenr. $=S$. gabonensis A. Dum. ist. Es werden auch weitere, sehr gut brauchbare Erkennungsmerkmale der einzelnen Arten gegeben. St. simatus Smith wird mit Recht aufrecht erhalten, und ebenso mit vollem Recht die spezifische Selbständigkeit des St. derbianus Gray, der von nigricans Donnd. oft nur schwierig oder aber gar nicht (namentlich ohne Fundortsangabe) zu unterscheiden ist, angezweifelt, jedoch die Arr, welche lokal von nigricans getrennt ist, noch beibehalten.

F. IV erner (Wien).

204 Welner. F.. Reptilien (E. Galragni, Beiträge zur Kenntniss der Fauna einiger dalmatinischer Inseln.) In: Verh. Zool. bot. Ges. Wien. 1902. pag. 381-388.

Es wird eine zusammenfassende Aufzählung der Reptilien und Batrachier, die dem Verf. bis Ende 1901 von Arbe, Lissa, Lagosta, Polagosa grande und P. piccola, sowie Mellisello bekannt geworden sind, gegeben, wobei grossenteils Aufsammlungen von Galvagni und Ginzberger zur Grundlage dienten. Von Arbe wird Emys orbicularis L., Lacerta serpa Ref., Rana csculenta L. var. ridibunda Pall., Bufo vuigaris Laur. und vividis Laur.; von Lissa: Hemidactylus turciens L., Lacerta oxyecphala D.B., littoralis Wern. mit var. lissana Wern., Zamenis gemonensis Laur., Coluber quatuorlincatus Gmel., Tarbophis fallar Fleischm., Bufo virirlis Laur.; von Lagosta: ITemidactylus tureicus L., dieselben Lacerten wie von Lissa, Ophisaums apus Pall., Zamenis gemonensis L. var. caspius Iwan. (neu für Dalmatien und ganz Österreich), sowie Bufo viridis; von Pelagosa grande: Lacerto serpa Ref. var. pelagosae Bedr. und Zamenis gemonensis Laur. var. carbonarius; von Pelagosa piccola: L. scrpa var. alliatica n. (von der Form von der naheliegenden Insel Pelagosa grande durch dunklere, graugrỉne Färbung unterschieden); schliesslich von Mellisello: L. scrpa Ref. var. mellisellensis Braun (welche von einigen Zoologen irrtïmlich zu L. littoralis gestellt wird, aber in jeder Beziehung eine achte ScrpaForm vorstellt). Zum Schlusse wird eine tabellarische Übersicht der bisher von den grossen dalmatinischen Inseln (Solta, Brazza, Lesina, Curzola, Meleda, Lagosta und Lissa) bekannten Reptilien und Batrachier gegeben, woraus ersichtlich ist, dass bisher 1 Schildkröte, 6 Eidechsen, 8 Schlangen und 2 Froschlurche von den 
Inseln bekannt sind, was $60^{\circ}$ o der Reptilien und $25 \%$ der Batrachier des dal. matinischen Festlandes ausmacht. F. Werner (Wien).

\section{Aves.}

205 Bryan, W. A., Key to the birds of the Hawainangroup. In: Memoirs of the Bernice Pauahi Bishop Museum. I. Honolulu 1901. pag. 1-76. Taf. XVI-XXX.

206 Henshaw, H. W., Birds of the Haw a iian islands, be ing a complete list of the birds of the Hawaiian possessions, with notes on their habits. Honolulu 1902. pag. 1-146. (Preis \$1).

Beide vorliegende Arbeiten geben uns rollständige Listen der auf der hawaiischen, meist noch unter dem Namen der SandwichInseln bekannten, Inselgruppe vorkommenden Vögel. Bryan zählt die Arten in der zum Bestimmen so beliebten und recht praktischen Form analytischer Schlüssel oder Bestimmungstabellen auf, doch sind stets die verschiedenen Ḱleider, Geschlechter und Alterszustände beschrieben. Die Verbreitung im allgemeinen, sowie im besonderen die innerhalb der Inselgruppe, ist genau angegeben. Die Gattungsmerkmale sind bei den Passeres durch Textfiguren von Köpfen und Flïgeh erläutert. Die Tafeln enthalten die von den Iälgen im Bernice Pauahi Bishop Museum genommenen Photographien der auf der Inselgruppe heimischen Arten. Diese Photographien geben zwar dem Laien einen Begriff ron der allgemeinen Gestalt der Arten, aber viele der kleinern Vögel sind gar nicht zu erkennen. Photographien ron Vogelbälgen sind leider heutzutage noch selır mangelhaft, weil die Vögel nicht (wie die zum Photographieren so sehr geeigneten Schmetterlinge) eine Fläche bilden, auch die Bälge oft rauh und mangelhaft präpariert sind. Ein guter Index erhöht die Brauchbarkeit des Buches. In 53 Anmerkungen sind noch besondere Auseinandersetzungen gegeben. Von Einzelheiten möge folgendes bemerkt werden:

Es unterliegt kaum einem Zweifel, dass $D_{0}^{\circ}$ les Angabe von der Häufigkeit vou Demicgrelta sacra auf einer Verwechslung mit Tyeticorax nycticorax nacvius beruht; $D$. sacra sollte daher nicht unter den hawaiischen Vögeln aufgeziiblt werden. Verf. nimmt nur eine Art der Gattung Pennula an, die er $P$. ccaudata nennt. Sharpe, Rothschild und andere nehmen zwei Arten, $P$. sandwichensis und $P$. millsi an, während $\mathrm{Scott} W \mathrm{Wils}$ on (nach $\mathrm{Finsch}$ ) noch eine dritte, $P$. wilsoni, anerkennt. Wie schon Roths child nachgewiesen hat, kann es eine dritte Art nicht geben, man muss jedoch vorläufig zwei annehmen, obwoll es nicht feststeht, dass , $P$. sandwichensis" wirklich von den Sandwich-Inseln stammt. Der Name von King (Pallus ecaudatus) ist, ,nomen nudum" und kann auf keinen Fall angenommen werden. Die bezüglich ihrer systematischen Stellung viel umstrittene "Himatione parra" wird vom Verf. endgültig in die Gattung Chlorodre. 
panis gestellt und entschieden vou Orcomyza, namentlich wegen Gestalt der Zunge und Gewohnheiten, entfernt.

Das Buch von Henshaw trigt einen ganz andern Charakter. Es beginnt zunächst mit selu interessanten allgemeinen Kapiteln über den allgemeinen Charakter der Ornis des Landes. die Ursachen des Verschwindens indigener Arten, die faunistischen Höhenzonen, den Ursprung der Ornis und die Geschichte ibrer Eiforschung, von ihrer Entdeckung durch Cook 1779 bis auf die Gegenwart. Für das bekannte Aussterben vieler Arten macht Verf., wenn wir ihn recht verstchen, einen tatsächlich bestehenden Schwächezustand verantwortlich, entstanden durch den bei insulären Formen häufig bestehenden Mangel des Kampfes ums Dasein, infolge zu günstiger Bedingungen, dann unter andern Ursachen auch das plötzliche Zusammengedrängtwerden infolge grosser Waldverwüstungen, die unvermeidliche Inzucht bei selten gewordenen, auf kleine Gebiete beschränkten Arten, bei mindestens einer Art die zu eifrige Verfolgung wegen der bunten Federn, und das Verschwinden mancher Bamarten in Waldbeständen.

Den Hauptteil des Buches bildet die Liste der Arten. Es ist eine kurze, aber treffende Beschreibung gegeben, die Verbreitung angeführt, das Vorkommen, die Nistweise, Eier und Lebensgewohnheiten sind beschrieben. Bei Chlorodrepanis pora kommt Verf. zu denselben Resultat wie Bryan. Der grosse ausgestorbene Drepanide von Oahu ist logischerweise Hemignathus cllisianus genannt, während Bryan ihn wiedertum als $H$. lichtensteini anführt. Von Psillivostra psittacea oliva$c_{e a}$, der auf Oahu früher einheimischen Form, von der Exemplare z. Z. nur im Kieler und 'l'ringer Huseum bekannt sind, wird berichtet, dass sie 1893 und 1899 lebend geselıen wurde. (Es wäre zu wünschen, dass solche Überbleibsel einer dem Untergange geweihten Art nicht aus kindischer Sentimentalität ,geschont", sondern erlegt und der Wissenschaft gerettet wïrden. Ref.) Terf. ist im Unrecht, wenn er den "Status" von Rhodacanthis flaviceps anzweifelt. Wer die Exemplare zu Tring (andre sind nicht bekannt) untersuchen konnte, kann nicht daran zweifeln, dass sie einer von $R$. palmeri ganz verschiedenen Art angelı̈ren.

Das anziehend geschriebene Buch hat auch einen guten Index. Bryans und II enshaws Bücher enthalten zwar wenig neues, sind aber für die Tielen, die nicht imstande sind, die kostspieligen Prachtwerke ron Rothschild und Wilson über die Vögel der hawaiischen Inseln anzuschaffen, ein willkommener, brauchbarer und zuverlässiger Ersatz.

E. Hartert (Tring).

207 Hartert. E.. On the birds collected by William Doherty in the Kikuyu Mountains, near Fisarpment station, in British East Africa. I. Laniidae In: Novit.Zoolog. Bd. IX. 1902. pag. 620-625. Tab. IX.

Der berïhmte Reisende und Sammler Doherty sandte umfangreiche ornithologische Sammlungen von den Kikuyu-Bergen, wo er bei der Station ,Escarpment", 8000 engl. Fuss über dem Meere, zwischen Nairobi und Naiwascha, sein letztes Lager aufgeschlagen hatte, in dem er starb. Der vorliegende Artikel beginnt die Aufzählung der von ihm gesammelten Vögel, zunächst mit den La nii den. Vou europäischen Zugvögeln wurden Lanius minor und collurio gesammelt. Dryoscopus cubla suahclicus Neum. ist eine wohl zu unterscheidende Subspecies. In den Kikuyu-Bergen wurde nur der typische Laniarius acthiopicus gefunden, während ilın westlich des grossen ostafrikanischen Grabens die westliche Form L. acthiopicus major vertritt. L. acthiopicus und funcbris gehören in die Gattung Lani- 
arius, und nicht zu Dryoscopus. Die Abgrenzung der Gattungen dieser Laniiden im "Catalogue of Birds in the British Museum", Band VIII, ist ganz unhaltbal: DiA Gattungen Malaconotus, Chlorophoneus, Pelicinius, Laniarius, Dryosropus Ind Channonotus müssen unbedingt anerkannt werlen, aber Cosmophoneus ist als unnötige Belastung zu verwerfen, beziehungsweise mit Chlorophoncus zu vereinigen. Chlorophoneus dohertyi (Rothsch.) ist eine liervorragende nene Entdeckung und wohl die prächtigste Ait der bunten Gattung. Die Geschlechter sind glejch. Sie ist auf Tafel IX von Ke ulemans' Meisterhand abgebildet.

E. Hartert (Tring).

208 Hartert, E., On birds from Pahang, Eastern Malay Peninsula. In: Novit. Zool. IX. 1902. pag. 537-580.

Eine Liste ron 196 von John Waterstradt nit Hilfe eingeborener Jäger auf dem angeblich 10000 englische Fuss hohen Gunong Tahan und in den Ebenen des Sultanates Pahang im Osten der Malakkahalbinsel angelegten Vogelsammlung. Während die Vogelwelt der westlichen Hälfte der Malakkahalbinsel ziemlich gut erforscht ist, sind die Nachrichten von der Osthälfte bisher nur sehr sparsam geblieben. Die Menge der nun nachgewiesenen Arten erweitert unsere Kenntnis von der Verbreitung der malayischen Vögel daher bedeutend. Der Sammler war der erste Europäer, der den Gunong Tahan bestieg, erreichte aber auch keine bedeutenden Höhen, und es ist sicher, dass dort noch viel mehr zu entrlecken ist. Von besonderm Interesse ist das Vorkommen einer Anzahl ron Arten, die man bisher nur rom Gunong .Jjau und andern Höhen in Perak kannte, wie Jole tickelli peracensis, Grauculus larutensis, Trochalopteron peninsulae u. a. m. Ferner ist liöchst auffallend das Vorkommen einer lokalen Form des riesigen, dem Argusfasanen (Argusiamus argus) verwandten Theinardius ocellatus, der bisher nur aus Tonkin bekannt war. Die neue Form, Rheinardius ocellatus nigrescens Rothsch., wurde in len niedrigen Hïgeln von Ulu Pahang erbentet. Ton andern Neuheiten ist eine Gimpelart ohne rote Farbe, Pyrhula waterstradti Hart., am bemerkenswertesten. Ausser der anch in der allgemeinen Färbung und den weissen Kopfseiten ähnlichen Pyrrhula lencogenys von Luzon kannte man bisher keine echt tropische Pyrhula-Art und konnte die Gattung als rein paläarktisch betrachten, denn die im Himalaya lebende Art bewohnt dort nur grosse Höhen, und das paläarktische Faunengebiet reicht jedenfalls über Tibet bis auf die Höhen des Himalaya hin. Die nur von Borneo bekannte Eule Pisorhina Tuciae oder eine sehr ähnliche Form wurde, leider nur in einem Exemplar. erbeutet. Fine bisher nur nach einem einzigen Stiicke hekannt gewesene, irrtiimlicherweise als aus Sumatra kommend beschriebene Muscicapide, Cyomis sumatrensis (Sharpe), wurde wieder entdeckt. 
Eine Serie von Pericrocoti gab Veranlassung zu längern Auseinandersetzungen, die darin gipfeh, dass $P$. montums, wray $i$ und cinereigula Synonyme sind, und d:ss $P$. speriosus firaterculus als Subspecies aufrecht zu erhalten ist. In Cachar kommen Übergïnge ron speciosus zu fratesculus ror. Criniger tephrogenys und ochaceus sind zwei röllig verschiedene, bisher inmer vermengte Arten. Pycnonotus simplex ist häufig, aber die Verbreitung dieser Form erstreckt sich nur über Malakka, Sumatra und Borneo, während sie auf Java durch eine verwandte, aber leicht unterscheidbare Form, P'ycnonotus millwitzi Hart., vertreten ist. Tartimulus humei ist eine neue Art nahe T. exsul. Ferner sind noch als neu beschrieben: Sira strigula malayana, Suya waterstradti, Sittu frontalis saturation, Pteruithe tahanensis und Ploceus pusserime infortunatus. Die Formen der Gattungen Kittucincle und Dissemurus sind kritisch untersucht, und von beiden ist je eine neue Form be. schrieben.

E. Hartert (Tring).

209 Hartert. E.. Some further notes on the birds of North-West Ecua-. dor. In: Novit. Zoolog. Bd. IX. 1902. pag. 599-617. Tab. VIII.

Es ist keine vollständige Aufzählung der reichen, seit Jahren an das TringMuseum gelangten Vogelsammlungen ans den nordwestlichen Teslen von Ecuador, die hier geboten wird, sondern nur Untersuchungen über einige besonders interessante Formen, Berichtigungen früherer Angaben und Beschreibungen never Arten und Unterarten. Folgendes mag besonders hervorgeloben werden:

Von den seltenen Arten Cryptums berlepschi, Tinamus latifrons und Odontophon parumbae wurden Serien gesandt.

Rhynchortyx einctus und spodiosthetus sind nicht getrennte Arten, sondern Junge und Alte derselben Art. Columba goodsoni ist eine sehr interessante nene Taubenart. Exemplare von Piermmes olivaceus granadensis gaben Gelegenlieit, die drei Unterarten von $P$. olivacens (olivaceus, tlacotinchus und granadensis) klarzulegen. Mitrcphanes berlepschi, Phynehocyelus megacephala Aarotectus, Aulia tertia, Lathria unimfus castancolinctus und Hylophilus bulunensis, sowie die TyrannidenGattung Craspedoprion (Typus Craspedopion acquinoctialis) sind neu beschrieben. Myrmotherula viduata Hart. ist nur eine Unterart von M. fuhiventris und hat nichts mit M. menetriesii zu tun. Die vom Verf. früher als Pyriglena berlepsehi und Thamnophilus cachabiensis beschriebenen Vögel sind Geschlechter einer Art, die schwierig im System unterzubringen ist, aber an besten in die Gattung Cereomacra gestellt wird. Auf der Tafel ist das merkwürdige Pittasoma rufopileatum in beiden Geschlechtern abgebildet.

E. Hartert (Tring).

210 Rothschild. W.. and E. Hartert, List of a collection of birds made on Isabel in the Solomon group by Mr. A. S. Meek. In: Norit. Zool. Bd. IX. 1902, pag. 581-594. Tab. VII u. XI.

Obwohl schon die ersten Erforscher der Salomo-Inseln, die Naturforscher der französischen Schiffe Astrolabe und Zélée, viele Vögel auf Ysabel sammelten, und neuerdings, im ,Ibis“, 1894 und 1895, Tristram Vogelsammlungen von dort bearbeitete, war doch die Ornis dieser grossen Insel bisher noch sehr ungenügend bekannt. Meek elbentete 58 Arten, von denen Edoliisoma erythropygium 
saturatius, Pitta anerythra, J'odargus inexpcctatus, Cacomantis meehi, Ceyx meeki, Astur rufoschistaeeus und Pseudoptynx solomoncnsis als neu beschrieben wird. Ganz unerwartete Erscheinungen sind Pitta und Pscudoptynx. Pitta ancrythra hat keine nahen Verwandten, steht aber wohl der australischen Art, Pitta strepitans, noch am nächsten, doch fehlt ihr alles Rot. Die Gattung ist ganz neu für den SalomoArchipel. Noch ïberraschender ist das Vorkommen der grossen Eule, I'sendoptynx solomonensis, da sie den philippinischen Arten, P. gurneyi und P. philippinensis, auffallend nahe steht, und andre Gattungsgenossen bisher nicht bekannt sind. Auch Podargus inexpectatus ist von besonderm Interesse, da sie die einzige bekannte Form der Familie Podargidae in dem Archipel ist. Eine Serie des kleinsten aller Papageien, Nasitcrna nanina Trıstr., gab Gelegenheit, die bisher nur in einem ganz jungen Exemplar bekannte Art ordentlich zu beschreiben. Die von dem Verf. friiher als Nasiterna nanina angeführte Form der Insel Kulambangras ist verschieden und wird als Nasitema tristrami neu beschrieben. Von den übrigen Arten sind am bemerkenswertesten: Myzomcla lafargei (bisher in Sammlungen einer der seltensten Vögel), Zosterops metcalfci, Graucalus pusillus nigrifrons, Granealus welehmani, Macroeorax woodfordi regetus und Ninox jacquinoti. Auf den Tafeln sind Myzomela eichhomi und Hypochamosyna meeki von Kulambangra, Ceyx meeti und Pitta anerythra von Ysabel dargestellt.

E. H artert (Tring).

\section{Mammalia.}

211 Peiser, A., Über die Form der Urïsen des mensclilichen Verdau ungapparates. In: Arch. f. mikrosk. Anat. u. Entwickelungsg. Bd. 61. Heft 3. 1902. pasg. 391-403. 'Taf. XX.

Nur wenige Drüsen haben einen rein tubulösen oder rein alveolären Charakter; die grössere Zahl lässt vielmelı Übergangsformen zwischen beiden 'Typen erkennen, man trifft entweder alveolär-tubulöse oder tubulo-alveoläre Drüsen. Terf,, der an menschlichem Material arbeitete, bediente sich des Macerationsverfahrens, da die plastische Rekonstruktion nach Born wegen der anzuwendenden sehr starken Vergrösserungen auf technisch unüberwindbare Schwierigkeiten stösst.

Die Lippendrüsen bestehen aus verschieden langen, sich verästelnden Schläuchen, an deren Wandungen bläschen- oder sackartige Ausbuchtungen vorkommen. Hier findet sich also eine Zwischenstufe zwischen alveolärem und tubulösem Bau. Die serösen Drüsen der Zunge (Ebnersche Drüsen) sind dagegen rein tubnlös, denn sie werden von gewundenen, teilweise verzweigten Schläuchen gebildet. Die Sublingualis gleicht in ihrem Bau den Lippendrisen, sie besteht aus verzweigten Schläuchen verschiedenen Kalibers, an denen bläschenförmige Ausstülpungen sich finden. Die Submaxillaris, die aus einem mucinösen und einem serösen Abschnitte besteht, zeigt ein dementsprechend doppeltes Verhalten. Der mucinöse Abschnitt besitzt ramifizierte Schläuche mit bläschenförmigen, breit aufsitzenden Ausstülpungen. Der seröse Abschnitt hat einen dem rein tubulösen 
Charakter sich mehr nähernden Bau. Ähnliche Verhältnisse sind an der Parotis zu erkennen.

Während die Labdrüsen Typen tubulöser Gebilde sind, erscheinen die Pylorusdrüs en alveolïr-tubulös. Die Brunnerschen Jrüsen sind stark gewundene und verästigte Schläuche mit zahlreichen bläschenförmigen Ausstülpungen, zeigen also einen gemischten Typus. Jas Pancreas endlich lässt reine Tubuli erkennen und auch Schläuche, an denen runde, eiförmige oder ovale Bläschen sitzen.

B. Rawitz (Berlin).

212 Rabl, Carl, Die Entwicklung des Gesichtes. Tafeln zur Entwicklungsgeschichte der äusseren Körperform der Wirbelthiere. I. Heft: I) as Gesicht der Säugethiere (Kaninchen, Schwein, Mensch). Leipzig (W. Engelmann). 1902. 21 pag. Tafel 1-8. Mk. 12.—.

Verfasser will sein reiches Material an Wirbeltier-Embryonen, welches er schon seit vielen Jahren sammelte und zun grössten 'Teil zeichnete, zu einem grössern Tafelwerke vereinigen, das in vier Lieferungen erscheinen-und in 3-4 Jahren fertig sein wird.

Auf die Auswahl nur guter Embryonen und auf vorziigliche Konservierung derselben legte Verfasser grossen Wert. Die Embryonen der meisten Wirbeltiere sind im frischen Zustande so durchscheinend, dass sie sich nicht zur Untersuchung des Oberthächenreliefs eignen; um dies hervortreten zu lassen, miissen sie erst durch die Konservierung undurchsichtig gemacht werden. Aber nicht jede Art der Konservierung eignet sich hierzu gleich gut, da ausser der Erhaltung der Form für die Reprodulition auch die Farbe in Betracht komnt, welche die Embryonen dabei annehmen. Reine Sublimatlösung macht sie weiss und die Schatten erscheinen im auffallenden Licht verschwommen und matt. Verf. erzielte die besten Bilder bei Anwendung einer Platinchlorid-Sublimatlösung oder Pikrinsäure-Sublimatlösung; die Embryonen wurden dann ockerfarben oder citronengelb. Noch viel prächtiger wurden diese Bilder, wenn die in genamnten Lösungen fixierten Embryonen mit alkoholischem Boraxkarmin (nach Grenacher) gefärbt waren. Auch die Zeichnungen wurden mit grösster Sorgfalt angefertigt und ausgesucht, und manche Zeichnung aus älterer Zeit, als noch die nötige Übung im Sehen und das Verständnis für gewisse Details fehlte, durch bessere ersetzt.

Bei diesen holıen Ansprüchen, welche der Verf. selbst an sein Material und an dessen Wiedergabe stellte, konnte es nicht ausbleiben, dass die zur Darstellung gelangten Entwickelungsreihen von seltener Vollständigkeit sind und die Reproduktion derselben auf den acht Tafeln rorzüglich, gelungen ist. Alle Embryonen sind in zwei 
Stellungen, die meisten sogar in drei Stellungen, von vorne, von der Seite und halb ron der Seite abgebildet und ron ausfïhrlichen Beschreibungen begleitet.

Vom K $\mathrm{K}$ in $\mathrm{inh}$ en sind 17 Stadien bei 15 facher Vergrösserung auf 4 Tafeln gezeichnet; das jüngste ist 9 Tage und 3 Stunden alt. In diesem Stadium sind drei Kiemenbogen angelegt, die Scheitelwölbung ist noch wenig entwickelt, die Augenblasen sind von geringer Grösse und das Gehörbläschen ist noch weit offen.

Vom Schwein sind sechs Stadien bei 13 facher Vergrösserung auf 2 Tafeln wiedergegeben; das jüngste hat eine Nackensteisslänge von $8,8 \mathrm{~mm}$ und eine Scheitelsteisslänge von $7,7 \mathrm{~mm}$ und ist etwa 20 Tage nach der Begattung dem Uterus entnommen. In Beziehung auf die Ausbildung des Auges, der Nase, des Gehörbläschens und der Kiemenbogen entspricht dieser Embryo am meisten dem Kaninchenembryo des IX. Stadiums, ist aber in mancher Hinsicht weiter, in mancher weniger weit entwickelt. In grossen und ganzen können beide als korrespondierende Stadien angesehen werden; das Schwein erreicht also erst nach 20 Tagen einen Grad der Ausbildung, der dem eines Kaninchens von der ersten Fiälite des 12. Tages gleichkomunt. Das älteste abgebildete Stadium des Schweines (VI) hat eine Nackensteisslïnge von $15,0 \mathrm{~mm}$ und eine Scheitelsteisslänge von $16,0 \mathrm{~mm}$.

Vom Menschen sind sechs Stadien auf 2 Tateln abgebildet, das jüngste bei 20 facher, die übrigen bei 12 facher V'ergrösserung. Besonderer Wert wurde auf die Frmittelung des genauesten Alters gelegt.

Das jüngste Stadium ist 19-20 Tage alt und wurde erst bei der 20 Stunden nach dem Tode ausgeführten Obdulition konserviert, der Kopf des Embryos, der mitsamt den \%otten einen Durchmesser von $18 \mathrm{~mm}$ hat, war aber noch gut erhalten. Es sind an ihm drei Kiemenbogen entwickelt, die an Grösse rom ersten zum dritten abnehmen. Das zweite Stadium gehört dem 24. oder 25. Tage an und wurde 8 Stunden nach dem Tode dem Uterus entnommen. Die Entfernung der Nackenkriimmung von der Steisskrümmung betrug $4 \mathrm{~mm}$. Das dritte und vierte Stadium, die sich nur wenig in der Entwickelung unterscheiden, sind ans dem Anfange der fünften Woche, das Alter des fünften Stadiums (Zwillinge) beträgt 30-31 Tage und das Alter des sechsten 37-38 Tage. Alle vier Stadien sind sehr frisch, nur 1-2 Stunden nach dem erfolgten Abortus konserviert worden. Der älteste Embryo hat eine Nackensteisslänge von $12,6 \mathrm{~mm}$ und eine Scheitelsteisslänge von $14 \mathrm{~mm}$. Die Leberwölbung ist schon sehr stark, die Extremitätenanlagen stehen deutlich vom kumpfe ab und 
zeigen die Gliederung in ihre spätern Abschnitte. Die Angen stehen noch weit auseinander, treten aber schon deutlich zutage. Der Schwanzfaden ist noch gut entwickelt.

F. Römer (Frankfurt a. M.).

213 Schreiner, J. Th., Der M a lwurf (Talpa emropaea) und die hauptsächlichsten Mittel zu seiner Bekämpfung. (I. O.

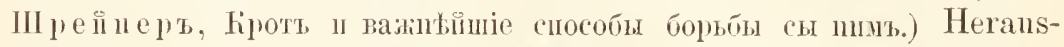
gegeben r. landw. Departm. d. Minist. d. Landw. St. Petersburg. 1902. 26 pag. 8 Abb. i. T. (Russisch.)

Der Verf. hat im rertlossenen Jahre in dem Wildpark der kais. Jagd in Gatschina Versuche zur Bekämpfung der Maulwürfe gemacht, wo diese Tiere sich ungeheuer vermehrt hatten. Gegen die Maulwïrfe kamen zur Anwendung: 1. Vertreiben derselben, indem man in die horizontalen Gänge Najhtlı, Petroleum, Naphthalin, faulen Fisch, Zwiebeln, Knoblauch usw. bringt, was die Tiere zum Verlassen der Gegend zwingt. 2. Ungeben eines bestimmten Rayons mit Kanälen, in welche gestossenes Glas usw., oder mit Löchern, in welche eine der obengenannten Substanzen verbracht wird. 3. Vergiften der Maulwürfe, indem man mit Arsenil behandelte Regenwürmer, Larven usw. in die Gallerien unterbringt; gefährlich und auf grössern Flächen schwer anwendbar. 4. Vernichtung durch Fallen; zur Anwendung kamen Fallen von Salomon, und hauptsächlich Webers Maulwurfszange, welche sehr gute Resultate gab. Mit 40 Fallen wurden während fünf Monaten 1445 Maulwürfe gefangen; nebenbei wurde namentlich das Vertreiben durch ïbelriechende Substanzen praktiziert. Mit diesen beiden Mitteln wurden die Maulwürfe auf dem sehr ausgedehnten Areal (mit Hilfe ron 3 Mann und 40 Fallen) so ziemlich vernichtet, was einen Kostenaufwand von etwa 750 Nark verursachte. Das Um. geben des Areals mit Gräben, welche mit gestossenem Glase usw. gefüllt werden (Brehm, Taschenbergra.) erwies sich als nutzlos, da die Maulwürfe entweder Gänge unter der Kanalsohle gruben oder an 'Tage über die Kanäle hinwegliefen.

N. v. Adelung (St. Petersburg). 


\title{
Zoologisches Zentralblatt
}

unter Mitwirkung von

\author{
Professor Dr. O. Bütschli and Professor Dr. B. Hatschek \\ in Heidelberg \\ in Wien
}

herausgegeben von

Dr. A. Schuberg

a. 9. Professor in Heidelberg.

Verlag von Wilhelm Engelmann in Leipzig.

\section{Jahrg.}

21. April 1903.

No. $7 / 8$.

Zu beziehen durch alle Buchhandlungen und Postanstalten, sowie durch die Verlagsbuchhandlung. Jahrlich 26 Nummern im Umfang von 2-3 Bogen. Preis für den Jahrgang M. 30. - Bei direkter Zusendung jeder Nummer unter Streifband erfolgt ein Aufschlag von il. 4.- nach dem Inland and von Y. 5. - nach dem Ausland.

\section{Zusammenfassende Übersicht. \\ Über die Biologie der Ameisen. \\ Übersicht über die neueren Arbeiten. \\ Von Dr. K. Escherich, Strassburg i. Els.}

214 Andre, Ern., Sur la femelle probable de l'Anomma nigricans Ill. In: Bull. Mus. Hist. Nat. Paris. T. 6. 1901. pag. 364-368.

215 Bethe, Albr., Noch einmal über die psychischen Qualitäten der A meisen. In: Arch. f d. ges. Physiol. 79. Bd. 1900. pag. 39-52.

216 - Die Heimkehrfähigkeit der Ameisen und Bienen, zum Teil nach nouen Versuchen. Eine Erwiderung auf die Angriffevonv. Buttel-Reepen und von Forel. In: Biol. Centr.-Bl. XXII. 1902. pag. 194 -224 ; pag. $234-238$.

217 Cholodkorsky, N., Eill interessanter A meisen-Instinkt. In: Ill. Zeit. f. Entomol. 4. Bd. 1899. pag. 363.

218 Cobelli, R., Il senso del gusto nel Lasius emarginatus Oliv. In: Verh. zool. bot. Ges. Wien. LII. 1902. pag, 254-257.

219 Dall, Friedr., Das Leben der Ameisen im Bismark-Archipel, nach eigener beobachtungen vergleichend dargestellt. In: Mitteil. Zool. Mus. Berlin. 2. Bd. 1901. pag. 1-70.

220 Emery, C.. Intorno alle larve di alcuni Folmiche. In: Mem. R. Ace. Sc. Istit. Bologna. Ser. V. T. VIII. 1899. pag. 3-10. Taf. I-II.

221 - Über Ameisenlarven. In: Verhdl. 71. Vers. deutsch. Naturf. u. Ärzte. 1900. 2 Th. 1. Hälfte. pag. $233-235$.

222 - Nuovi studi sul genere Eciton. In: Mem. R. Acc. Sc. Istituto Bologna, Serie V. T. VIII. 1900. pag. 511-526. 1 Taf.

223 1)-Le végétarisme chez les fourmis. In: Revue Scientif. (4). Т. 13. 1900. pag. $282-283$.

224 - Sul polimorfismo delle Formiche e particolarmente dei Dorilini. In: Monit. zool. ital. An. 11. 1900. pag. 47.

1) Mir nicht zugänglich gewesen. 
225 Emery. ('. Studi sul polimorphismo e la metamorfosi nel geuere „Dorylus". In: Mem. R. Acc. Sc. Istit. Bologna. Serie V. 'T. IX. 1901. pag. 415-433. 'Taf. I-II.

226 - Formiciden von Celebes. In: Zool. Jahrb. Syst. 14. Bd. 1901. pag. 565 -580 .

227 - Note sulle Doryline. In: Bull. Soc. entom. italiana. XXXIII. 1901. pag. $43-63$.

228 - Der Geschlechtspolymorphismus der Treiberameisen und die flügellose Urform der Ameisenweibchen. In: Naturw. Wochenschr. N. F. 1. Bd. pag. 54-55.

229 Escherich. K., Ame is enpsychologie. In: Beil. Allg. Zeitg. München. 1899. Nr. 100. (2. Mai).

230 - Zur Biologie der nordafrikanischen Myrmecocystus-Arten. In: Allg. Zeit. f. Entom. Bd. 7. 1902. pag. 353-359: 390-394. 2 Fig.

231 Field, Adele M.. A Study of an A nt. (Stenamma fulvum piceum). In: Proc. Acad. Nat. Sc. Phil. 1901, pag. $425-449$.

232 - Further Study of an Ant. lbid. pag. 521-544.

233 - Notes on an Ant. Ibid. 1902. pag. 599-625.

2:34 Forel. A.. Ébauche sur les maurs de fourinis de l'Amérique du Nord. In: Riv. di Sc. biol. An, 2. 1900. pag. 180-192.

235 - Über nordamerikanische Aneisen. In: Verhdlg. deutsch. Naturf. u. Ärzte. 1900. 2. T. 1. Hälfte. pag. 239-242.

236 - Fourmis du Japan. Nids en toile. Strongylognathus Huberi et voisins. Fourmilière triple. Cyphomyrmex Wheeleri (n. sp.) Fourmis importées. In: Mitteil. Schweiz. Entom. Ges. T. 10. 1900. pag. 267-287.

297 - Sensations des Insectes. 1-V. In: Rivista Sc. biolog. generale Como. Bd. II. 1900. pag. 562-602, 641-716. Bd. III. 1901. pag. 7-62, 241--282 und 401-460. 1 Taf. (Auch separat bei A. Reinhard in München.)

238 - Die psychischen Fähigkeiten der Ameisen und einiger anderer I usekten. In: Verhandl. V. internat. Zool. Kongr. Berlin 1901. pag. 141-169. 239 - Die Eigentümlichkeiten des Geruchssinnes bei den Insekten. Ibid. pag. $806-815$.

240 - Fourmis termitophages, Lestobiose, Atta tardigrada, Sous, Genres d'Euponera. In: All. Soc. entom. Belg. T. XLV. 1901. pag. 389-398.

241 - Variétés my rmécologiques. Ibid, pag 334-332.

242 - Quatre notices myrmécologiques. Ibid. 'T. XLVl. 1902. pag. 170 $-182$.

243 - Variétés myrmécologiques. Ibid. pag. 284-296.

244 - Beispiele phylogenetischer Wirkungen und Rückwirkungen beidenInstinkten und demKörperbau der Amejsen alsBelege für die Evolutionslehre und die psychophysiologische Identitäslelire. In: Journ. Pliysiol. u. Neurol. Bd. I. 1902. pag. 99-110.

245 - Fourmis d'Algérie récoltées par M. le Dr. K. Escherich. In: Ann. Soc. ent. Belg. T. XLVII. 1902. pag. 462-463.

246 - Nochmals Herr Dr. Bethe und die Insekten-Psychologie. In: Biol. Zentr.-Bl. XXIII. 1903. pag. 1-3.

247 - und H. Dufonr, Über die Empfindlichkeit der Ameisen für Ultraviolett und Röntgen-Strahlen. In: Zool. Jahrb. Syst. Bd. XVII. 1902. pag. $335-338$.

248 Gomelle. E.. Sur des bruits produits par deux espèces a mericaines de Fourmis et de 'Termites. In: Bull. Soc. Entom. France 1900. pag. 168. 
249 Janet, Ch., Sur la présence de nymphes nues dans les nids de Lasiue faves. In: Bull. Soc. Zool. France. T. 24. 1899. pag. 192-193.

250 Lagerheim. (i.. Über Lasins fuliginosus und seine Pilzzucht. In: Entom. Tidskr. Bd. 21. 1900. pag. 17-29. 7 Fig.

251 Lameere. Aug., Notes sur les moeurs des fourmis du Sahara. In: Ann. Soc. entom. Belg. Tome XLVI. 1902. pag. 160-169.

252 Meisenheimer, J., Neuere Forschungen ïber die geistigen Fähigkeiten der Ameisen und Bienen. In: Naturw. Wochenschr. N. F. Bd, 1. 1902. pag. 37-41. 6 Fig.

253 1) Prowazek, S., Ameisenbeobachtungen. In: Zool. Garten. 42. Bd. 1901. pag. $49-52$.

254 Schäffer, C., Die geistigen Fähigkeiten der Ameisen. In: Verh. Nat. Vereins Hamburg. 3. Folge IX. 1902. pag. 14-42.

255 1) Tutt. I. W., The Relations of Lasius americanus and Aphis prunicola. In: Eritom. Record. Vol. 11. 1899. pag. 78.

256 Viehmeyer, H.. Beobachtungen über das Zurückfindenvon Ameisen (Leplothorax unifasciatus.) z u ilırem Nest. In: Ill Zeit. f. Entomol. 5. Bd. 1900. pag. $311-313$.

257 Wasmamn, E., Vergleichende Studien über das Seelenlehen der Ameisen und der höheren Tiere. 2. vermehrte Aufl. Freiburg i. Br. 1900. $8^{\circ}$. VII, 152 pag.

258 - Zum Orientierungsvermögen der Ameisen. In: Allgem. Zeit. f. Entom. 6 Bd. 1901. pag. 19-21, 41-43.

259 - Neues über die zusammengesetzten Nester und gemischten Colonien der Ameisen. In: Allgem. Zeit. f. Entom. Bd. f. 1901 и. Bd. 7 1902. Separat 78 pag. 1 Taf.

260 - Noch ein Wort zu Bethes Reflextheorie. In: Biol. Zentr.-Bl. XXII. 1902. pag. $573-576$.

261 Wheeler. W. M., The female of Exiton Sumichastri Norton, with some notes on the habits of Texan Ecitons. In: Americ. Naturalist. XXXIV. 1900. pag. $563-574$. Fig. $1-4$.

262 - A Study of some Texan Ponerinae. In: Biolog. Bull. Vol. II. 1900. pag. 1-31. Fig. $1-10$.

263 - 'The habits of Ponera and Stigmatomma. Ibid. Vol. II. 1900. pag. 43 -69 .

264 - Notices biologiques sur les fourmis mexicaines. In: Ann. Soc. Ent. Belg. 45. Bd. 1901. pag. 199-205.

265 - The compound and mixed Nests of American Ants. In: Americ. Naturalst. Vol. XXXV. 1901. pag. 431-448, 513-539, 701-724, $791-818$. 20 Fig.

266 - A new agricultural Ant from Texas, with remarks on the known north-american species. In: Americ. Naturalist. XXXVI. 1902. pag. $87-100$.

267 - and W. H. Long, The Males of Soune l'exan Ecitons. In: Aneric. Naturalist. Vol. 35. 1901. pag. 157-173. 7 Fig.

268 1) Yung : Fin. . Combien y-a-t-il de fourmis dans une fourmilière? (Formica rufa?) - In: Revue Scient. (4). T. 14. 1900. pag. 269-272.

1) Mir nicht zugänglich gewesen. 
Die sozialen Insekten, und unter ihnen vor allem die Ameisen, erfreuen sich stets eines regen Interesses. Dafür zeugt die obige Liste, welche lediglich die biologischen Arbeiten aufzählt, die in den letzten zwei Jahren - nur ausnahmsweise führte ich einige Arbeiten von 1849 an - über Ameisen erschienen sind. Nicht nur Zoologen, speziell Fintomologen, sondern auch Physiologen und Psychologen beteiligten sich an der Erforschung des Lebens dieser sozialen Insekten. Ungeheuer zerstreut ist daher auch die Literatur; denn die Arbeiten sind nicht nur auf die zahlreichen zoologischen Zeitschriften der verschiedensten Länder beschränkt, sondern sie fanden auch in physiologische und psychologische Zeitschriften Eingang. Daher diurfte es vielleicht manchem willkommen sein, wenn ich in folgendem die Arbeiten der letzten Jahre im Zusammenhang darstelle.

I)er Übersicht halber versuchte ich die verschiedenen Arbeiten ihrem Inhalt nach in mehrere Kategorien einzuordnen, und wenn auch die Gruppierung nicht ganz einwandsfrei sein dürfte, so dürfte dieselbe doch aus praktischen Grïnden gerechtfertigt sein.

Im ersten Abschnitt sollen solche Arbeiten besprochen werden, welche einen allgemeinen Charakter besitzen, insofern sie das Leben der Ameisen ganzer Faumenbezirke im Zusammenhang behandehn, im zweiten Abschnitt werden die Arbeiten referiert, welche sich auf spezielle Gruppen oder einzelne Arten oder spezielle biologische Eigentïmlichkeiten beziehen; im dritten Abschnitt fasste ich alles, was über die Beziehungen rerschiedener Ameisenarten zueinander publiziert wurde, zusammen und der vierte Abschnitt endlich berichtet über den gegenwärtigen Stand der Ameisenspychologie.

\section{Allgemeines uiber das Ameisenleben in verschiedenen Fannenbezirken.}

Hier ist in erster Linie Dahls ziemlich umfangreiche Studie zu nemnen, welche das Leben der Ameisen im Bismarck. Archipel zum Gegenstand hat (219). Das Ziel der Arbeit ist, wie Verf. im Vorwort sagt, nicht etwa das, ein vollständig erschöpfendes Bild zu geben, sondern Terf. wollte das Wenige, was er während seines einjährigen Aufenthalts beobachten konnte, in einer form geben, welche auch Nichtspezialisten gestattet, auf einer gegebenen Grundlage systematisch weiter zu bauen. Und dieser Aufgabe ist I) ahl in der besten Weise gerecht geworden. Wie viel Arbeit und Zeitverschwendung wird dadurch den Reisenden erspart, wenn sie schon auf solche Weise orientiert ein Land betreten; sie laufen nicht (iefahr ihre kostbare /eit mit der Verfolgung schon bekannter Dinge zu verlieren, sondern wissen gleich, wo ihre Arbeit einzusetzen hat. 
Und das ist ein unschätzbarer Vorteil, der das Resultat der Reisen wesentlich beeinflussen muss. - Im folgenden seien die wichtigsten Ergebnisse D a hls mitgeteilt.

Die Schwärmzeiten der Ameisen sind im Bismarckarchipel keineswegs so scharf begrenzt wie bei uns; so scheinen z. B. einige Arten, Iridomymer cordutus und Camponotur muculatus das ganze Jahr hindurch zu schwärmen; doch dürfte die Hauptschwärmzeit der meisten Arten am Anfang der trockenen Jahreszeit liegen, da die liegenzeit für die Ameisen nahrungsreicher und deshalb für das Aufziehen del' grossen Larven geeigneter ist.

Bezüglich der Nester der $\Lambda$ meisen beobachtete Dahl im Bismarckarchipel eine ganze Anzalıl verschiedener Formen, welche übersichtlich in einer Bestimmungstabelle dargestellt werden. Natürlich passen in dieselbe nicht alle, sondern nur die Melrzathl der Nester hinein, da ja die Ameisen ihren Nestbau den äussern Bedingungen entsprechend vielfach modifizieren können. D ahl interscheidet im engen Anschluss an Forel acht Arten von Nestern: Erd-, Holz-, Mark-, Mörtel-, Blatt-, Spalt-, Röhren- und Kammernester.

Besonderes Interesse beanspruchen die „Marknester" des Camponotus quadriceps, welch letzterer mit einem Baum, Endospermum formicarium Becc., in ähnlicher Symbiose lebt, wie Azteca instabitis onit Cecropia adenopus in Amerika. Doch bestehen zwischen den beiden Fällen mehrere eingreifende Unterschiede; so sind bei Cecropia die Stengel von Anfang an hohl und mit Scheidewänden versehen, so dass die Aztecu ilıre Wohnung bereits fertig rorfinden, während die Stengel von Enfospermm ursprünglich mit Mark gefüllt sind und die Ameisen also erst ihre Wohnungen darin aushölılen müssen. Auch finden sich bei Endospermum keine präformierten diinnern Stellen in der Stengelwand wie bei dem amerikanischen Ameisenbaum, so dass es also Camponotus quadriceps auch in dieser Beziehung nicht so leicht hat wie Aztecu. - Für die kleinen Polsterchen am Blattstiel von Cecropia findet sich bei Enlospermum ein Seitenstiick in zwei kleinen glatten Kissen an der Wurzel jeder Blatttläche, welche wohl hauptsächlich des Nachts von den Arbeitern besucht werden. - Dass zwischen Endospermum und Camponotus eine Symbiose vorliegt, ist zweifellos, da kein Baum ohne Ameise getroffen wurde: doch ist die Anpassung des Baumes an die Symbiose nicht so weitgehend wie bei Cecropru. welch letztere einen kräftigen Schutz gegen die schlimme Atta nötig hat. Derartig gefährliche Feinde scheint Endospermum nicht zu besitzen; wenigstens kounte Dahl keine solche entdecken. Vielleicht wird ins die Zukunft diese noch kennen leliren. 
Unter "Mörtelnestern" versteht Terf. solche Hohlrämme, welche ron den Ameisen aus verkitteten kleinen Teilchen aufgebaut werden. Als "Blattnester" bezeichnet er diejenigen Ameisenbauten, welche durch ein papierartiges Gespinst zusammengehalten werden und sich stets im Laub lebender P'flanzen befinden, wobei die Blatttlächen einen Teil der Nestränder bilden. Es ist vor allem Oecophylla, welche solche Blattmester baut. Woher das Sekret für das Gespinst kommt, lässt Dahl unentschieden $\left.{ }^{1}\right)$. Oecophylla bietet noch mehr des Interessanten dar: so baut sie Ställe für Blattläuse, die eine bedentende Grösse (bis $40 \mathrm{~cm}$ im Durelımesser) erreichen können, und errichtet ferner auch .. Futterhäuser", das sind ,zeltartig ausgespannte, allseitig geschlossene Überdachungen einzelner Astteile" an solchen Stellen, wo Saft aus Verletzungen der Rinde austloss. Diese Dächer dienen dazu, den Saft vor Regen zu schützen, damit er etwas erhärten kann.

Als "Spaltnester" werden solche Nester bezeichnet, welche in schmalen spaltförmigen Hohlräumen, und als "Röhrennester" solche, welche in röhrenförmigen, von andern Insekten ausgenagten Höhlungen angelegt sind. Unter "Lammernestern" versteht Dahl ,die teils einkammerigen, teils in melırere Kammern geteilten rundlichen Räume, welche von Ameisen bewohnt, nicht aber von ilnen hergestellt sind". Hierher gehört die interessante Symbiose, welche zwischen der epiphytisch wachsenden Kinolle Mymecodia und Iridomymex cordatus besteht. In der genannten Kinolle befinden sich labyrinthartige Gänge, welche sich selbständig, ohne Zutun der Ameisen, entwickehn, und in diesen Gängen wohnen die Ameisen. Während nun Treub diese Gänge nit den Ameisen nicht in ursächliche Verbindung bringen, sondern sie als Durchlüftungsapparat der wasserreichen Knollen ansehen möchte, so hält Dahl dieselben (mit Schimper, Forel u. a.) für eine Anpassungserscheinung an die Symbiose. Allerdings gelang es Dahl nicht, einen ernstlichen Feind der Mymecodia aufzutinden und damit die Anwesenheit der Ameisen in dem Knollenlabyrinth zu erklären. Doch muss man sich, meint Dahl, ,nicht nur die Frage vorlegen, ob die P'tlanze durch die Ameisen vor einem wirklich vorkommenden Feinde, wie es für Cecropia in Amerika die Atta ist, gescliüzt werde, sondern man muss auch fragen, ob ohne den Schutz

1) Nach Chuns Angaben, welche Dahl noch nicht kannte, scheint es aber sicher, dass dasselbe von den Larven stammt; denn die Occophylla-Larven, welche Chun untersuchen liess, besitzen Spinndrüsen, ,welche an ungewöhnlicher Ent. wicklung alles überbieten, was wir von den gleichen Drüsen sonstiger Hymenopteren, speziell auch der Ameisenlarven, kennen!" Da die Ameisen selbst keine Drüsen besitzen, so dürften die Berichte früherer Autoren, wonach die Ameisen die Larven im Maul tragend als Spinnrädchen beniitzen, sich vollauf bestätigen. (Sieho Chun, Aus den Tiefen des Weltmeeres 1. Aufl. pag. 117.) 
der Ameisen vielleicht irgend ein Feind hätte erstehen können." Ferner lässt Verf. auch noch die Frage offen, ob nicht vielleicht die Ameisen die Samen verschleppen und dadurch die Wechselbestäubung vollziehen.

In einem weitern Kapitel gibt Verf. eine Übersicht der Ameisen nach der Lebensweise und zwar wieder in Form einer dichotomischen Tabelle. Bezüglich der Feinde der Ameisen im BismarckA rchipel stellt Dahl die Vögel obenauf; demn von den 90 erbeuteten Landrogelarten hatten nicht weniger als 28 Arten Teile ron Ameisen im Magen.

Zum Schluss stellt Verf. eingehende Vergleiche zwischen der Ameisenfauna des Bismarck-Archipels mitder Norddeutschlands, bezüglich der Lehensweise und der Arten- nnd Individuenzahl an, und kommt dabei zu folgenden Resultaten: Die Ameisenfauna des Bismarck-Archipels ist 5-6 mal reicher an Arten und $30 \mathrm{mal}$ reicher an Individuen als die Norddeutschlands. Die grössere Artenzahl ist besonders auf eine speziellere Anpassung an ganz bestimmte Lebensbedingungen zurückzufülıren, wie sich denn allgemein vom Pol nach den Tropen hin eine speziellere Anpassung zeigt. Dauernde Bewohner der Baumkronen, wie sie im LismarckArchipel sehr häufig sind, können in einem gemäßigten Kilima nicht existieren, weil das Nest vor der winterlichen Kälte geschützt sein muss. Andererseits fehlen im Bismarck-Archipel Nester mit Kíuppelbau und unter Steinen beinahe gänzlich, weil derartige Einrichtungen, welche die Sonnenstrahlen besser zur Wirkung kommen lassen, in dem stets warmen Klima iiberfluissig sind. - Wie bei uns sonnige, brachliegende Plätze mit sandigem Boden, so ist anch im BismarckArchipel das Grasland mit lockerm vulkanischem Boden am reichsten an Ameisen. Der Boden im Urwald ist verhältnismäßig arm an Ameisen, aber doch viel reicher als der mit Laub bedeckte schattige Boden unserer Wälder. Hier sind es die Laufkäfer und Nacktschnecken, welche das nahrungsreiche Gelände ausnützen und also die Stelle der Ameisen in den tropischen Wüldern vertreten.

In ähnlicher Weise zieht A. Forel (23t und 235) biologische Parallelen zwischen der Ameisenfauna Nord-Amerikas und der Europas, welche beiden auch in systematischer Beziehung sich ja sehr nahe stehen. Wie im Bismarck-Archipel, fällt auch in Nord-Amerika zunächst auf, dass man fast nirgends Ameisenhaufen sieht. Eine Ausnahme machen nur die ziemlich seltene, in Wällem lebende Formica exsectoides, sowie einige flache Erdhügel der Formica subsericea, die Forel dicht am Niagarafall, sonst aber nirgends von dieser Ameise angetroffen hat. Diese Erscheinung diirfte ihre Er- 
klärung in der kolossalen Sommerhitze dieses Landes finden, einer Hitze, welche ziemlich unvermittelt im Frühling einem iusserst kalten Winter folgt. Unsere Ameisen bewahren nämlich nur bei mittlern Temperaturen ihre Brut im "Hatufen" auf, bei extremen Plus- und Minustemperaturen aber bringen sie dieselbe in die Tiefe des Nestes. Da aber jene von Forel besuchten Gegenden von Nord-Carolina meistens nur solche extreme Temperaturen besitzen, so sind auch die „Haufen" überflüssig geworden. Die beiden oben genannten Ausnahmen bestätigen diese Ansicht, insofern ja sowohl in den Wäldern als auch dicht an einem Wasserfall weniger extreme Temperaturen herrschen, als in den unbewaldeten, der Sonne direkt ausgesetzten Lokalitïten.

Wie in Europa, so legen auch in Nord-Amerika die Ameisen ihre Nester wit Vorliebe auf Ostabhängen an, welche Erscheinung Forel also erklären möchte: Die Morgensonne weckt die Ameisen und treibt sie schon fribzeitig zur Arbeit, und Nachmittag ist es auch hier warm genug für sie. An Westabhängen dagegen verlieren sie einmal die ersten Morgenstunden, sodann haben sie im Sommer nachmittags zu heiss, und endlich liönnen sie Abend fast nichts mehr hereinbringen ron der verlorenen Arbeit, da ja die Nacht für die beiden Lagen ziemlich gleiclızeitig eintritt.

Auch darin stimmt endlicl die nordamerikanische Fauna mit der der Alten Welt überein, dass hie Gegenden mit kontinentalem Klima bedeutend ärmer an Ameisen-Arten sind als die Gegenden mit maritimen Klima (in gleichen geograplıschen Breiten). So besitzt der Westen ron Nord-Carolina, welchem der Ciolf-Strom ein besonders mildes maritimes Kilima verleiht, beleutend mehr Arten als der Osten mit seinen ausgesprochen kontinentalen Klima.

Ausser diesen allgemeinen Vergleichen gibt Forel (besonders in der ersten Arbeit) noch eine Anzahl kleinerer Details über die Biologie einzelner amerikanischer Arten und Gattungen, die zum Teil nur spezielles Interesse besitzen. Nur einige von diesen Mitteilungen, wie die Beschreibung des of ron Eciton carotinense, ferner die Angaben über einige gemischte Kolonien (Formica sangumea + subsericea, Dorymumex flarus + niger), und endlich die Angaben über die einzige pilzzïchtende Ameise Nord-Amerikas (Atta tardigrada Buckl.) diurften allgemeineres Interesse beanspruchen und werden unten (im II. und III. Abschnitt) noch näher besprochen werden.

Über die Ameisen ron Celebes berichtet C. Emery (226) einiges, jedoch melr in zoogeographischem als in ethologisclıem Sinne. El weist darauf hin, dass ron den 120 bis jetzt auf Celebes festgestellten Arten sich 58, also fast die Hälfte, auf den Sunda-Inseln 
wiederfinden; 27 kommen ferner auf Neu-Guinea und den Molukken ror, und 17 sind den beiden Gebieten gemeinsam. Daraus geht herror, dass der Ameisenfauna von Celebes ein hauptsächlich indomalayischer Charakter zugeschrieben werden muss. Im allgemeinen sind ja allerdings die Ameisen zur Lösung feinerer zoogeographischer Fragen weniger geeignet, indem die geflügelten $₹+$ der meisten Arten durch den Wind über nicht alizuweite Meeresstrecken gut transportiert werden können. Eine Ausnahme aber in dieser Beziehung machen die unterirdisch lebenden Dorylinen, deren $q$ q stets Hïgellos sind. Leider aber sind gerade über diese Gruppe unsere Kenntnisse noch recht mangelhaft. Nur 1 Dorylus-Art (laceigatus) ist bis jetzt mit Sicherheit auf Celebes festgestellt und dieser eine Fund spricht ebenfalls für den indomalayischen Charakter der Fauna, da die Gattung Dorylus der australisch-papnanischen Fauna fremd ist. - Auch die von den beiden Sarasin jüngst aufgestellte Ansicht, dass Celebes ron Borneo beständig getrennt, dagegen mit Java, Flores, den Molukken und Philippinen durch Landbrücken zeitweilig verbunden war, findet in der Verteilung der Ameisen über diese Inseln eine Bestïtigung.

İber die A meisen der Sah a ra endlich liegt eine kleinere Arbeit vor von $\mathrm{A} u \mathrm{~g}$. Lameere (251). Dieser Autor unternalin im Mai und Juni 1898 in Begleitung des Botanikers Jean Massart eine Exkursion in die algerische Saliara, welche ron der bekannten Oase Biskra aus in einem Halbkreis iiber Tougourt, El Oued, Quargla usw. nach Bou-Saada fuilute. Er konnte dabei bezüglich des Vorkommens der einzelnen Ameisen-Arten in der Wüste fünf verschiedene Faunenbezirke untersclieiden, nämlich: 1. 1) ie Oase mit kultiviertem, mehr oder weniger lehmigen Boden, der stets eine gewisse Feuchtigkeit besitzt. Hier ist vor allem Stenamma barbarum Herrscherin, welche die Getreidefelder pliindert, $u$ m alle Sorten von Körner in ihre Vorratskammern einzuschleppen. Neben dieser Ameise findet man in der Oase regelmäbig noclı einige andere, wie Tapinoma oraticum, Tetramorium caespitum, Camponotus maculatus, welche aber eine weit untergeordnetere Rolle spielen als die "Körnersanmlerin“. 2. Die nächste Umgebung der Oase, welche von verschiedener Beschaffenheit (sandig, steinig oder lehmig) sein kann, welche aber niemals gan'z trocken ist. Hier baut mit Vorliebe MIy mecocystus viaticus $v$ desertorum Forel sein Nest in die Eride. Unter Steinen findet man ausser Tapinoma und Tetramorium noch Pheidole pallidula und Plagiolepis mygmaea. 3. D ie sandige oder salzige Umgebung der Brackwaser, für welche der zierliche Acantholepis fiancmfeldi charakteristisch ist. 4. Die Steinw üste, 
welche teils lehmig, teils sandig ist und in welcher im allgemeinen grosse Trockenheit herrscht. Die hier lebenden Ameiseu sind deshall, gezwungen, tief in die Erde hinabzubauen, um die nötige Feuchtigkeit zu erlangen. Wir finden hier wieder Kïörnersammlerinnen, jedoch andere Formen (Stencmma aegyptiacum und striaticeps), ebenso auch andere Jagdameisen (Myrmecocystus albicans und riaticoides) und einen andern Camponotur (micans). 5. Die reine Sandw ïste, welche, den eigenartigen Lebensbedingungen entsprechend, auch eine ganz besondere Fauna besitzt. Dieselbe setzt sich zusammen aus zwei Körnersammlerinnen, Stenamma arenarium und Holcomyrmex chobauti, und zwei Jagdameisen, nämlich dem herrlichen, silberglänzenden und überaus wilden Myrmecocystus bombycims (siehe unten) und dem neuentdeckten Myrmecocystus lameerei Forel.

Diesen allgemeinen Angaben iiber das Vorkommen der SaharaAmeisen lässt Lameere noch eine ganze Reihe von Beobachtungsnotizen über die einzelnen Arten folgen, denen aber nur ein spezielles Interesse zukommen dürfte.

Dasselbe ist der Fall beziuglich der biologischen Notizen, die W. M. Wheeler (264) über die mexikanischen Ameisen gibt und auf die deshalb hier auch nicht näher eingegangen werden kann, sondern nur liingewiesen sein soll.

\section{Zur Biologie einzelner Gruppen oder Arten von Ameisen.}

Dorylinen. You jeher nahmen die Dorylinen das Interesse der Myrmekologen in besonderm Maße in Anspruch. Handelt es sich doch um Formen, die sowohl morplologisch als biologisch sich ganz eigenartig verlalten und einen entschieden primitiven Charakter bekunden. Es ist nocl gar nicht so lange (wenige Decemnien) her, dass man ron den Geschlechtstieren der genannten Ameisen noch nichts bestimmtes wusste, was um so auffälliger war, als doch zu den Dorylinen die so überaus häufigen Treiber- und Wanderameisen Afrikas und Amerikas gehören. Man hat zwar in den Zügen der "Treiber" (Anomma) schon frïher auffallend grosse geflïgelte Inseliten mit wandern sehen, doch hielt man dieselben, da sie durchaus kein ameisenähnliches Aussehen besassen, für Fremdlinge; nan liatte sie überdies bereits früher als Mitglieder einer besondern Familie beschrieben, und zwar unter dem Gattungsnamen Dorylus. Noch zwei weitere Gattungen wurden in diese Familie gestellt, nämlich Labidus und Aenictus.

Durch spätere Beobachtungen wurde nun erwiesen, dass Dorylus, Labidus und Aenictus keineswegs einer besondern HymenopterenF'amilie angehören, sondern dass sie lediglich die Männchen der unter 
dem Namen Anomma, Typhlopone, Eciton. Typhlatta usw. beschriebenen Treiber- und Wanderameisen darstellen, und es ist im Laufe der Zeit schon für eine ganze Anzahl Arten die Synonymie festoestellt. Neuerdings legte Emery (222) dar, dass nicht weniger als acht, von verschiedenen Autoren beschriebene Labidus-Arten als das Männchen von Eciton coecum Latr. aufunfassen sind. Und Wheeler und Long (267) machen uns ferner mit den labidiformen Männchen von Eciton schmitti und opacithorax bekannt, welche sie in grosser Anzahl in den Eciton-Nestern antrafen.

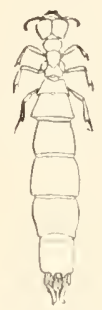

Fig. 1.

Anomma nigricans 111 . (nach André), stark verkleinert.

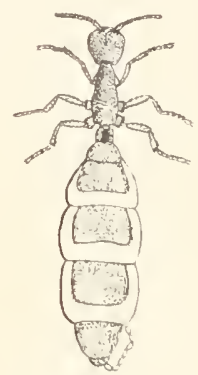

Fig. 2.

Eciton schmitti Emery, reifes 9 , (nach $W$ heeler), stark verkleinert.

Noch länger als die Männchen blieben die Weibchen der Dorylinen unbekannt. Das erste Weibchen wurde 1880 von 'T'rimen entrleckt, und zwar gehörte dieses der gemeinen Dorylus-Art des Kaplandes an. Es erwies sich als ein höchst merkwürdiges Hügelloses Tier, welches schon früher unter dem Namen Dichthatia beschrieben worden war (vgl. Emery 225). Das Weibchen der eigentlichen 'Treiberameise ist erst in jüngster Zeit entdeckt und ron E. André (214) beschrieben worden. Es ist ganz ähnlich dem $q$ der kapländischen Dorylus-Art (dichthadiiform), etwa $50 \mathrm{~mm}$ lang und rollkommen augen- und flügellos. - Emery (227) beschreibt ferner das o von Aenictus, einer ebenfalls afrikanischen Dory linen-Gattung; dasselbe ist illentisch mit dem von André früher als Alaopone abeillei beschriebenen Tier. Es weicht viel weniger von der Arbeiterform ab als das $q$ der obigen Dorylus, so dass es André sogar für eine Arbeiterform gehalten und auch als solche beschrieben hat.

Bezüglich der Weibchen der neuweltlichen Dorylinen, der Liciton, waren unsere Kenntnisse bis vor einigen Jahren gleich Null. „Nit einem Fragezeichen hatte André aus einer alten Sammlung unter dem Namen Pseudodichthadia ein fragliches Eriton-Weibchen be- 
schrieben: das war alles." Da entdeckte Forel (234 und 235) vor" drei Jabren in Nord-Carolina, bei Faisons, in einem norschen Föhrenstamme ein Nest ron Eciton carolinense, in welchem unter einer Anzahl Arbeiter sich das so lange gesuchte Weibchen befand. Dasselbe ist "gewaltig gross", augen- und flïgellos wie bei den altweltlichen I) oryliden; der Thorax ist ohne Spur ron Flïgelanlagen. "Ganz merkwiurdig ist die Tatsache, dass das o einen nur eingliedrigen Petiolus wie das ơ besitzt, während beim Arbeiter der Petiolus, gleich den Myrmiciden, zwei Abdominalsegmente in Anspruch nimmt. Bedenkt man, dass der Ameisenarbeiter einen Dinorphismus des o darstellt, dass bei den andern Dorylidengattungen der Petiolns des Arbeiters eingliedrig ist, und dass die Zahl der Petiolusglieder früher dazu diente, die Ameisen in Subfamilien zu teilen, so ist die sonderbare Abweichung des Ecitom-Arbeiters interessant genug und zeigt, wie leicht die gewïnschte natïrliche Systematik auf Irrwege geraten kann."

Kurz nach Forel beschreibt W. M. Wh eeler (261) das Weibchen einer andern Eciton-Art, welche er znerst für $E$. sumichastiv Mort. hielt, welche sich aber später als E. schmitti Emery herausgestellt hat. Dasselbe ist ganz ähnlich dem von Forel beschriebenen EcitonWeibchen und stimmt aucl bezüglicl des eingliderigen Petiolus mit ihm überein. Die zwei Exemplare, die Wheeler vorlagen und aus verschiedenen Kolonien stammten, wichen in mehreren Punkten voneinander ab, so in der Grösse (17 und 13,5 mm), Färbung usw. Verf. glaubt darin lediglich Altersunterschiede zu erblicken und nimmt also atn, dass das o nach der Metamorphose noch nachträglichen Veränderungen nuterworfen ist.

Ein Jahr später gibt Wheeler im Verein mit Long (267) in Anhang der hier citierten Arbeit die Beschreibung des $q$ einer dritten Eciton-Art, nämlich E. opacithorax, welches dem ${ }^{\circ}$ von $E$. schmitti überaus ähnlich ist. Das Exemplar, nach welchem die Beschreibung entworfen ist, wurde schon sieben Jahre früler, von liev. I'. Jerome Schm itt bei Belmont, Gaston County, N.-C. gefunden. - Endlich diurfen wir auch das $q$ ron Eciton coecum als beliannt annelmmen; denn nach Emery (222) ist es zweifellos, dass Pspudorlichthadia incerta André (siehe oben), wirklicl das 7 dieses Eciton darstellt. Und so liennen wir also heute bereits die Weibchen von vier EcitonArten: Ec. carolinense, schmitti, opacithorax und coecum. Ton den letztern drei kennen wir, wie oben gezeigt, ausserdem aluch die Männchen, so dass wir also jetzt ïber die drei Stände derselben unterrichtet sind.

Der Polymorphismus der Dorylinen-Gesellschaften ist aber mit 
den drei Ständen keineswegs erschöpft. Abgesehen daron, dass, wie Wheeler (261) zeigte, auch die Weibchen in zwei Formen auftreten können, besteht auch innerhalb der Arbeiterkaste noch ein ganz beträchtlicher Polymorphismus. Trennen wir zunäclist die grossköpfigen Soldaten von 10 bis $14 \mathrm{~mm}$ Länge, mit krummen spitzen Kiefern, von den iibrigen kleinern gewöhnlichen Arbeitern, so müssen wir auch unter diesen letztern wieder eine ganze Anzahl verschiedener Formen unterscheiden. Emery (225) hat nämlich gefunden, dass mit den Grössenunterschieden vielfach noch andere bestimmte Nerkmale verbunden sind. Die Grösse der Arbeiter variiert bei den meisten Dorylinen ganz kolossal, so z. B. bei Anomma wilererthi Em. zwischen 13 und $2,4 \mathrm{~mm}$, bei Dorylus affinis zwischen 11 und $1,7 \mathrm{~mm}$; Hand in Hand damit variiert auch die Form des Kopfes und der Fühler recht beträchtlich. Der Kof wird beim

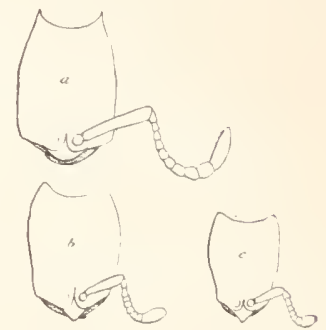

Fig. 3, a-c. Köpfe der kleinen Arbeiter von Anomma wilwerthi; a Fühler 11-gliedrig, $b$ Fühler 9- und $c$ Fühler 8-gliedrig (nach Emery).

Kleinerwerden des 'Tieres entweder breiter oder schmäler usw., gleichzeitig springt gewöhnlich der Clypeus weiter vor und wird vorne zngespitzt und - was an auffallendsten ist - die Kahl der Füllerglieder wird reduziert. Fün Beispiel davon soll hier angeführt werden: Anomma wituerthi (vgl. Fig. 3 a-c)

Körperlänge $13 \mathrm{~mm}$

\begin{tabular}{|c|c|}
\hline $\mathrm{mn}$ & \\
\hline $\begin{array}{l}10 \mathrm{~mm} \text {; Subapikalzahn der Man- } \\
\text { dibeln gut entwickelt } \\
6-3,5 \mathrm{~mm} \text {; Clypeus deutlich } \\
\text { vorspringend }\end{array}$ & $\begin{array}{l}\text { Kopf vorne deutlich } \\
\text { breiter als hinten; } \\
\text { Fühler 11-gliedrig. }\end{array}$ \\
\hline
\end{tabular}

$3 \mathrm{~mm}$; Fühler 9-gliedrig

$2,4 \mathrm{~mm}$; Fühler s-gliedrig

Kópf vorne schmäler als hiuten; Clypeus vorspringend u. zugespitzt.

Bei allen diesen Arten durchlaufen die Arbeiterformen von der grössten bis zur kleinsten zwei "kritische Zonen": eine obere, welche die Grenze zwischen den "Soldaten" und den mittlern Arbeitern, und eine untere, welche die Grenze zwischen letztem und den kleinsten Arbeitern, den Zwergen, angibt. Oberhalb und unterhalb dieser Zonen treten zu den Grössendifferenzen noch Unterschiede anderer Art linzu: „Diese Abänderungen sowie die Existenz der kritischen Zonen sind lediglich der Ausdruck allgemeiner oder spezifischer Wachstumsgesetze, welche verdienen, genauer studiert zu werden." (Emery 225, pag. 421). 
In derselleen Arbeit gibt Emery auch die Beschreibung einer Dorylus-Larve (D. affinis). Dieselbe ist weiss, ungefähr von cylindrischer Form und ist mit einfachen (nicht hakenförmigen oder verzweigten) Haaren besetzt; sie stimmt darin mit der Larve von Eciton und Accuthostichus, welche Emery (220) und andere schon früher beschrieben, überein. Andererseits weicht sie ron den letztern durch viel kleinere und schwächere Nandibehn $a b$ und ferner durch den Besitz von, wenn auch kleinen Antennenrudimenten. Die schwächern Mandibeln dürften darauf hindeuten, dass die Dorylus-Larven eine weitgehendere I'Hlege geniessen als die Eciton- und AcanthostichusLarven.

Yon den Ponerinen-Larven unterscheiden sich die Dorylinen-Larven vor allem durch den Mangel der für erstere charakteristischen warzenförmigen Anhänge. W. Müller, der die Larven der Eciton zuerst entdeckte ${ }^{1}$ ), hat zwar unter den normalen Formen auch einige mit Warzen bedeckte Larven gefunden, welche er den Männchen von Eciton zuschrieb: doch dürften diese Exemplare nach Emerys Ansicht (220), welcher sich anch Wheeler und Long (267) anschliessen, gar keine Eciton-Larven gewesen sein, sondern es diirfte sich hier viehmehr um Ponerinen-Larven gehandelt haben, welche ron den Ecitons geraubt und als Bente in ihr Nest eingetragen wurden.

Auch über die Lebensgewohnheiten der Eciton erfahren wir einiges durch die Arbeiten von F'orel (234, 235) und Wheeler (261, 267). Nach ersterm Autor tragen die Arbeiter ihre Larven und Puppen, wie Polyergus, zwischen ihren Beinen, sozusagen darauf reitend, indem sie das vordere Ende mit den Mandibeln halten. „Unglaublich ist die Fähigkeit dieser kleinen blinden Arbeiter, wenn man sie aus einem Sack nimmt und an einen ganz fremden Ort wirft, in weniger als 4 Minuten Reihen aneinander geordnet folgender Individuen zu bilden, die in allerkürzester Zeit irgend einen Erdspalt finden, wo sie in bester Ordnung ihre Brut hintragen." Darin uibertreffen sie alle übrigen Ameisen, sogar die Amazone, bedeutend (For el 235).

Auch Wheeler (261 und 267) fiel es auf, wie rasch sich die Arbeiter von Eciton schmitti in neuen Verhältnissen zurecht finden konnten. Die Kolonien dieses Eciton, die Wheeler bei Austin beobachtete, waren ïberaus volkreich und bestanden aus Tausenden von Individuen; sie befanden sich meistens unter grossen Steinen in Höhlungen, welche sie sich selbst zu banen scheinen. Hier hängen sie zu faustgrossen kompakten Schwärmen vereinigt. Nitunter

1) W. Müller, Beobachtungen von Wanderameisen (Eciton hamatum). In : Kosmos, Rd. XVIII. 1886. pag. 81-93. 
bilden sich auch lebende Ketten, welche an die Bilder der ..prehensiletailed monkeys crossing a stream" erinnern. - Während die EcitonArbeiter einen äusserst widerlichen Geruch besitzen, sind die $q$ q und $\delta \delta \mathrm{im}$ Gegenteil durch einen milden und angenehmen Geruch ausgezeichnet.

Wheeler setzte die zwei oben schon erwähnten Weibchen von Eciton schmitti in ein kïnstliches Nest (nach Janet) und zwar zu fremden Arbeitern. Sie wurden ron diesen sofort freundlich aufgenommen und adoptiert, und es dauerte nicht lange, so begannen sie Eier zu legen. Während dieses Geschäftes hielten sich stets einige Arbeiter bei der Hinterleibspitze des betr. \& auf, um jedes Ei, das erschien, sofort zu ergreifen und wegzutragen. Später verteilten sie die Eier in kleine Pakete, welche sie ununterbrochen im Nest herumtrugen. - Die Männchen sind fortwährend umgeben und bedeckt mit Arbeitern, welche wie vernarrt in sie sind und sie ununterbrochen belecken, am ganzen Körper, sogar an den Nandibeln und den Flügeln; selbst tote $\delta \delta^{\gamma}$ wurden noch eine Zeitlang liebkost. Wahrscheinlich ist es der angenehme Geruch, der so anziehend auf die Arbeiter wirkt. Oft sind die Männchen so schwer mit Arbeitern beladen, dass sie weder laufen noch tliegen können; lann versuchen sie auch, ihre zärtlichen Verwandten abzuschïtteln. Niemals nahmen die Männchen selbständig Nahrung zu sich, auch wurden sie niemals miteinander kämpfend gesehen, so dass die überaus grossen Mandibeln der $\sigma^{\curvearrowright} \sigma^{\curvearrowright}$ gleich den Hörnern mancher männliclıer Lamellicornier als sekundäre Sexualcharaktere aufzufassen sein diirften.

Ponerinen. - A uch über diese den Jorylinen so nahestehende Sub-Familie sind unsere Kenntnisse in den letzten .Jahren wesentlich gefördert worden, vor allem durch Wheeler, welcher mehrere Ponerinen beobachtet und zwei Arbeiten darüber veröffentlicht hat $(262,263)$. Die Kolonien, die der genannte Autor antraf, waren im Verhältnis zu andern Ameisen sehr volkarm; so bestanden die Kolonien von Leptogemys elongata aus etwa 10-50, die von Pachyrondyla harpax aus 15-100 und die von Odontomachus haematodes aus 100-200 Individuen. Die Nester dieser Ponerinen zeigen eine sehr primitive Bauart und bestehen aus einer Anzahl einfacher Gänge, ohne besondere Kammern, wie die höhern Ameisen, aufzuweisen. Bezüglich des Geschlechtspolymorphismus ist zu erwähnen, dass dieser in bedeutend geringerm Grade ausgebildet ist als bei den Dorylinen. Besonders die Weibchen sind nur ganz wenig von den Arbeitern verschieden und unterscheiden sich von den letztern eigentlich nur durch den etwas grössern Hinterleib, wie aus der beigegebenen Figur zu ersehen ist (Fig. 4). Das o ron Leptogenys ist stets fliigellos, weshalb 
es natürlich noch schwieriger ist, dasselbe unter den $\Varangle$ herauszufinden. Die o 9 von Pachycondyla harpax und Ponera coarctata sind dagegen geflügelt; bei ersterer finden sich übrigens sehr häufig auch ergatoide Weibchen, welche äusserlich ron den normalen Arbeitern gar nicht

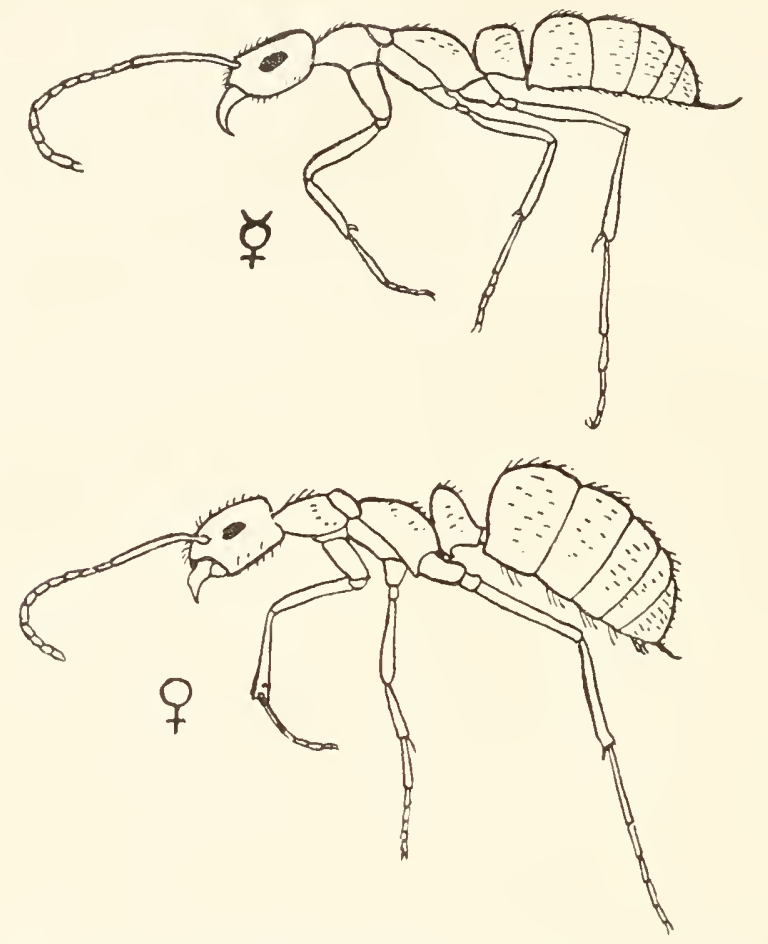

Fig. 4. Leptogenys clongata Buckl. ఫ̧ u. ㅇ (nach Wheeler).

zu unterscheiden und nur durch Untersuchung der Ovarien zu erkennen sind. - Die Männchen weichen gewöhnlich viel mehr von den Arbeitern ab als die 9 ㅇ, so ror allem durch die Form der Fühler, die Form des Kopfes, durch grössere Augen usw.

Un das Temperament und den Mut der Ponerinen zu erproben, setzte Wheeler verschiedene fremde Ameisen zu den Nestern, und da ergah sich, dass solche Fremdlinge, welche einer andern Art angehören, meist angegriffen und getötet wurden, während dagegen Artgenossen aus fremden Kolonien nach einigen Streitigkeiten oder auch sofort aufgenommen wurden. - Odontomachus nimmt fremde Artgenossen sofort auf; Leptogenys, Pachycondyla und Ponera dagegen balgen sich zuerst einige Stunden oder Tage, bevor sie in Frieden miteinander leben. Lange aber ror dem definitiven Frieden bringen sie schon die Larven der beiden Nester an einen gemeinschaftlichen 
Platz. Ebenso gut wie zwei, kann man allmählich 12 und mehr verschiedene Nester zu einer friedlichen Gemeinschaft zusammenbringen.

Ganz verschieden von den höhern Ameisen verhalten sich die Ponerinen auch bezüglich der Füterung ilser Larven. Sie reichen diesen nämlich nicht einen ausgehrochenen Futtersaftstropfen hin, wie bei jenen ibblich, sondern sie legen den anf dem Rücken liegenden Larven auf ihre thache bauchseite grössere und kleinere Nahrungsstücke, wie kleine tote Inseliten oder Stücke von grössern Inseliten, Myriopoden usw. Von hier holen sich nun die Iarren, deren Hals stark ventralwärts gekriummt ist, die Nahrung weg, mm sie aufzufressen. Sie bediirfen dazu natuirlich bedeutend stirkerer Mandibeln als die höhern Ameisenlarven, die mit Fliissiglieitstropfen gefüttert werden. Ind in der Tat zeichnen sich die l'onerinen-Larven durch die starke Ausbildung der Mandibeh vor allen iibrigen Ameisen. larven auffallend aus. Anch sonst zeigen die P'onerinen-Larven, wie Fin ery (220, 221) mid Wheeler (l. c.) zeigen, noch einige charaliteristische Merkmale. So besitzen sie nicht hakenförmige orler verzweigte Haare wie die höhern Formiciden, sondern einfache Haare, worin sie mit den Dorylinen übereinstimmen. Indererseits weichen sie aber ron diesen dadurch ab, dass sie mit warzenförmigen Anhängen versehen sind ${ }^{1}$ ), auf welchen dickere Borsten stehen (Fig. 5). Wheeler sieht in diesen borstigen Warzen eine Art "poils d'accrochage", welche dazu dienen, den Arbeitern einen festen Halt zum Angreifen darzubieten, und weist somit Biros Ansicht, nach welcher diese Warzen Verteidigungs- oder Schutzorgane darstellen sollten, entichieden zurück. - Zur Fig.5. Larve von Verpuppung spinnen die Larven einen Cocon in derselben Weise, wie bei den höhern Ameisen.

Bezüglich der Sorge um die Brut stehen die

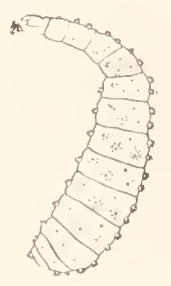

Leptogenys elongata Buckl. (nach Whe eler). Ponerinen den übrigen Ameisen kaum nach. Forel behauptet zwar (234), dass der Brutpflegeinstinkt der Ponerinen bedeutend schwächer ausgebildet sei, indem die Arbeiter bei Gefahr nur die Larven. nicht aber auch Puppen in Sicherheit brächten, doch stehen der einen Beobachtung Forels die Beobachtungen Wheelers gegenüber, wonach die Ponerinen ihre gesamte Brut einschliesslich der Cocons bei Störung des Nestes fortschleppten, allerdings in ihrer langsamen und tölpischen Weise.

1) Nur die Stigmatomma-Larven entbehren der Warzen; doch ist die Stellung von Stigmatomma zu den Ponerinen noch sehr fraglich.

Zoolog. Zentralbl. X. Jahrg. 
Die Königin einer Ponerinen-Kolonie geniesst bei weitem nicht das Ansehen einer der unsrigen Ameisenköniginnen; die Arbeiter widmen ihr kein besonderes Interesse und reichen ihr auch keine Nahırung dar. Sie muss also selbständig ihr Brot suchen und beteiligt sich ausserdenı auch an allen lı̈uslichen Geschäften (Reinigung des Nestes, Bruttransport usw.). Gewöhnlich findet sich nur 1 Königin in jeder Kolonie. Ihre lruchtbarkeit ist viel beschränkter als bei den andern Ameisen. Sie legt meistens nur 2 (oder nur wenig mehr) Eier auf einmal und wiederholt dies in Zwischenräumen von einigen Tagen oder Wochen. Deshalb sind, wie oben erwähnt, die Kolonien der Ponerinen stets volkarm.

Die Gründung neuer Kolonien hat Wheeler zwar nicht direkt beobachtet, doch schliesst er aus verschiedenen Gründen, dass dieselbe nicht durch das $q$ allein geschieht, sondern dass mit dem $q$, gleich dem Bienenschwarm, auch stets eine Anzahl Arbeiter ausziehen, um ihm bei dem überaus schwierigen Geschäft behilflich zu sein. Darnach würde also die Stanmkolonie sich jedes Jahr vollkommen auflösen in eine Anzahl Tochterkolonien.

Aus allen diesen Angaben geht deutlich hervor, dass die Ponerinen, was man ïlrigens schon vorher als sicher annahm, eine sehr primitive Stelle unter den heute lebenden Ameisen einnehmen und den einzellebenden Hymenopteren am näclısten stehen (vgl. auch Forel in Emery, 221). Wenn auch die lieutigen Ponerinen nicht schlechtweg als die Urameisen aufzufassen sind, so bleibt, wie Forel gegen Emery einwendet, ..die Tatsache doch bestehen, dass die Urameisen an die lentigen Ponerinen sich zunächst anlehnen“ (l. c.).

Ausser diesen, die beiden Sub-Familien der Dorylinen und Ponerinen behandelnden Arbeiten liegen noch eine Anzahl kleinerer Schriften aus der letzten Zeit vor, welche die Biologie rerschiedener einzelner Arten aus andern Gruppen und Gattungen betreffen.

Bleiben wir gleich bei Wheeler, so hat dieser noch interessante neue Beobachtungen über die körnersammelnden Ameisen aus 'Texas publiziert (266). Zunächst berichtet er einiges über die Biologie einer neuen Emte-Ameise, welche er bei Austin entdeckte und die er als Pogonomyrmer imbericulus beschreibt. Besonders interessant ist die Art der Nahrungsaufnahme dieser Ameise: sie sind sorrohl Fleisch- als auch Pflanzenfresser'; wenn ihnen Wheeler 
Fliegen rorsetyte, so frassen die Arbeiter davon und nachdem sie sich gesättigt, gaben sie kleinere Stiicke den Larven. War die Fleischkost zu Ende, so machten sie sich an die aufgesammelten Samenrorräte und fütterten auch damit ihre Larven. Dass die Arbeiter sich gegenseitig oder ihre Larven durch ausgebrochene Futtersaftstropfen ernährten, konnte Verf. niemals beobachten. Somit würden sich also die Pogonomyimex in dieser Beziehung ganz älnlich verhalten als die Ponerinen und die Dorylinen, die ja auch ihren Larven die Nahrung in Stiicken vorsetzen.

Im Anschluss daran teilt Wheeler die Resultate seiner zweijührigen Beobachtung über die beriihmte Ernte-Ameise Lincecums mit (Pogonom. barbatus v. molefaciens), welche nach letzterm Forscher innerhalb des Nestbereiches kein grünes Blatt, ausser einer einzigen Art von Gras (Ameisenreis, Aristida strictu) dulden und alle andern Iflanzen abbeissen und entfernen soll. Ja, diese Ameise soll die Aristida geradezu aussäen und kultivieren. - Nach Wheeler gehı̈rt aber diese Cieschichte, die nicht nur in alle populären Schriften, sondern auch in die Werke Forels und Lubbocks Eingang gefunden, in das Reich der Fabel. Denn es finden sich viele Pogonomyrmex-Kolonien ohne Aristida-Kulturen, ja weit entfernt von jeder Vegetation! Ferner würden auch die wenigen Aristidu-PHanzen keineswegs hinreichen, einer einigermaßen volkreichen Liolonie geniigend Nahrung zu verschaffen. Und endlich verschonen die Ernte-Ameisen bei ihrem Strassenbau nicht etwa die Aristida-PHanzen, sondern vernichten sie ebenso wie jede andere im Wege steliende Pflanze. Die Aristida-Kulturen, die man zuweilen antrifft, sind nach Wheeler lediglich ein zufälliges Tebenprodukt, welches dadurch entsteht, dass die Ameisen diejenigen Körner, welche bereits zu keimen beginnen, aus den Vorratskammern entfernen und vor das Nost tragen. Das Abgrasen des Bodens labe nur den Zweck, eine möglichst grosse Trockenheit zu erzielen, damit das Kieimen der Körner hintangehalten werde.

Mit den Lebensgewohnlieiten einer Myrmicine Stenamma fulcum Mayr, beschäftigte sich sehr eingehend Miss Adele Field (231, 232, 233). Eine ganze Menge einzelner Zïge aus dem Leben dieser Ameise werden da in den drei Arbeiten mitgeteilt ${ }^{1}$ ); nur einiges davon aber sei hier erwähnt. - Verfasserin konstatierte durch mehrfache Beobachtung, dass die A rbeiterinnen gar nicht selten das Geschäft der Eiablage übernehmen besonders in weisellosen Kolonien. Die aus diesen Eiern entschlüpften Nachkommen standen

1) Siehe auch v. Hansteins Referat hierüber in der Nat. Rundschau. 1902. pag. 198. 
an Grösse wesentlich hinter den normalen zurïck. Auch die Entwicklnngszeit dieser Larven währte bedentend länger, etwa 200 Tage, während die der normalen 20-97 Tage beträgt. Da auch Wheeler (26ō) das Eierlegen von Arbeiterimmen ziemlich häufig beobachtete, so scheint dies doch allgemeiner verbreitet zu sein als man bisher glaubte. - Verf. erzählt ferner ron eigentiimlichen ,Versammlungen, von dem merkwürdigen Benehmen eines t nach dem 'Tode des 0 . bringt Beispiele ron den Charakterverschiedenheiten der einzelnen Individuen, von dem Lernvermögen usw. - Auch über die Funktionen der Antennen und die Rolle, welche dieselben in dem geselligen Leben der Ameisen spielen, macht Terfasserin eine grosse Anzahl Experimente (232). Dieselben ergaben, dass die einzelnen Glieder der Geissel sich keineswegs gleich verhalten, sondern dass jedes cilied für sich eine besondere Funktion erfüllt, indem jedes einzelne Glied gewissemalen abgestimmt ist auf die Wahrnehmung dieses oder jenes ganz bestimmten Geruches. Miss Field unterscheidet drei Sorten von Gerüchen: 1. den Geruch, welcher den Fussspuren anhaftet, 2. den inherenten, angeborenen Geruch, welcher sich auf der ganzen Oberfläche des 'Tieres manifestiert und qualitativ für die und $8 \%$ einer Kolonie derselbe ist und welcher das Mittel zur Erkennung der Blutsverwandtschaft darstellt und 3. den Nestgeruch, welcher aus den Gerïchen aller Kolonie - Mitglieder gemischt ist und welcher die Unterscheidung des eigenen Nestes von fremden Nestern ermöglicht. - Den ersten, den Fussspurengeruch, sollen die Ameisen nur mit dem 10. Fïhler-Glied wahrnehmen, den zweiten mit dem 11. Glied und den Nestgeruch mit dem 12. Glied. - Solange das 5. und 9. Glied noch rorhanden sind, können die Arbeiter die Brutpflege noch ausïben; entfernt man aber auch diese beiden Glieder, so entfernt man damit auch die Liebe und Sorge für die Nachkommenschaft! Das harmonische Zusammenarbeiten des Ameisenstaates ist also "wahrscheinlich das Resultat der Reflexe, welche von den fünf Endgliedern der Fühler ausgehen". - Doch steht Miss Field keineswegs unbedingt auf dem Boden der Betheschen Reflextheorie (siehe unten), denn sie schreibt ja den Ameisen Gedächtnis, Associationsvermögen usw. zu. - Bezüglich der Wirkung der verschiedenen Lichtstrahlen auf die Ameisen kam die Verfasserin durch riele Experimente (233) zu dem Resultat, dass die Strahlen mit kürzerer Wellenlänge besser perzipiert werden als die mit längerer Wellenlänge. Wurde ein Nest mit roten, grünen und violetten Gläsern bedeckt, so flüchteten die Ameisen stets aus dem violetten Bezirk in die roten und grïnen, und zwar zweifellos deshalb, weil sie ihnen dunkler erschienen. Miss Field kam also in dieser Beziehung zu 
ähnlichen Resultaten wie L, ubbock, Graber und Forel (siehe unten).

Über pilzziichtende Aneisen handeln zum 'T'eil oder ausschliesslich die Arbeiten von Forel $(234,235,240,244)$ und Lagerheim (250). - Ersterer beobachtete in Nord-Carolina eine Kolonie von Atta tartigrarla, der einzigen pilzzüchtenden Ameise NordAmerikas. Die Tiere verteidigten ihr Nest nach Kräften gegen einen Haufen Crematogaster, welche Forel ilmen vorsetzte. Plötzlich kamen auch aus der 'Tiefe des Nestes Arbeiter hervor', welche eine graue Masse im Mund hielten und damit den Eingang verstopften. Diese Massen waren Stücke ihres Pılzgartens, der sich in einer grössern, tiefer liegenden rundlichen Höhlung lefand. Die línlonie liatte weit über 100 Einwohner und glich vollkommen denjenigen den andern kleinern Atta-Formen. Der Pilz erwies sich, wie Forel nachträglich (240) mitteilt, als derselbe, welchen auch die neotropischen Atta kultivieren, nämlich als lihozites yongylophor . Während Mac Cock behauptet hatte, dass Attr tardigioda 'T'annemnadeln für ihren Pilzgarten gebraucht, bezweifelt For e l diese Angabe, da keine Coniferen in der Nähe des beobachteten Nestes waren; er glaubt vielmehr, dass sie gar keine Blätter, sondern, andere näher liegende organisclie Substanzen" (Detritus, Exkremente usw.) als Nälırboden verwenden.

Pilzzïchtende Ameisen finden sich iubrigens nicht nur in Amerika, sondern auch bei uns. Schon seit längerer \%eit ist es beliannt, dass in den Nestern des glänzend schwarzen Lasins fuliginosus Latr. stets ein P'ilz sich findet, welchen Fresenius als Septoryorium myrmecophilum besclirieben lat. Num hat Lagerhein (250) wahrscheinlich gemacht, dass lieser Pilz tatsächlich von der Ameise gezüchtet wird. Das Nest von Laxius fuliginosus ist meistens in alten morschen Baumstämmen angelegt und enthält eine grosse Menge unregehmäfig gestalteter Gänge und Kammern, deren IVände aus fein zerkriimelten PHanzenteilcheı, Sand- und Erdjartikelchen, welche durclı ein Sekret zusammengehalten werden, bestehen. In diesen Wänden nun befindet sich der fragliche Pilz, und zwar derart, dass sein Mycelium in mannigfacher Verzweigung die Wand durchzielıt. Von diesem innerhalb der Wand wachsenden Mycel gehen lange, braune, harähnliche Hyphen aus, eine Art Flaum bildend. mit welchem insbesondere die "Kinderstuben" der Ameisen ausgekleidet sind.

Da in dem Lasiu-Nest ausschliesshich dieser eine Pilz angetroffen wurde, so scheinen die Lasius, gleichwie die Blattschneideameisen, es zu verstehen, das Aufkommen von .Unkraut", d. h. Schimmel und andere Pilze, zu verhindern. - Die Frage, ob der Lasius-Pilz auch ausserhalb der Ameisennester vorliomme, ist noch nicht mit Sicherheit 
entschieden; doch besteht grosse Wahrscheinlichkeit, dass er identisch oder wenigstens sehr nahe verwandt ist mit dem auf fanlendem Holze in Italien und Krain gefundenen Cladotrichum microsportom Sacc. In diesen Falle müsste also die Ameise den Pilz auf ihrer Wanderung gegen Norden mitgebracht haben. - Bezïglich der Vorteile, welche Lasins aus der Pilzzucht zieht, glaubt Lagerheim dieselben weniger darin erblicken zu müssen, dass der Pilz als Nahrung dient, als vielmehr darin, dass das Mycel den Kammerwänden eine grössere Festigkeit verleiht. „Das Vycelium, das nach allen Richtungen die aus zerkauten PHanzenteilen oder aus Sandkörnchen bestehende Wand durchwächst, hat vermutlich etwa dieselbe Bedeutung wie das Schilfrohr im Bewurf unserer Hauswände oder wie das Langstrolı im Lehm, nämlich zusammen mit dem ron den Ameisen gelieferten Mörtel das feine Baumaterial zusammenzubinden. “ Die schleimabsondernde Fähigkeit des Pilzmyceliums ist wohl ron Bedeutung beim Zusammenkitten des Baumaterials. - Der Nährboden les Pilzes dürfte wohl zum grössten Teil von der Ameise selbst geliefert werden, und zwar dürfte derselbe aus dem Sekret bestehen, durch wekhes das Baumaterial zusammengekittet wird.

Anch noch über andere Lasius-Arten liegen einige kur\%e biologische Mitteilungen ror: so prifte C'obelli (218) den Geschmacksinn von Lasius emaginatus durch Darreichung von verschiedenen Substanzen und kam zu dem Resultat, dass diese Ameise einen ziemlich schwach entwickelten oder wenigstens einen von dem unsrigen sehr verschiedenen Geschmack besitzt. - Ch. Janet (249) fand in einem Nest von Lasius. Alurus e ine Anzahl Puppen, welche nackt, d. h. ohne Cocon waren, was insofern Erwähnung verdient, als die Lasius-Puppen sonst stets nit einem Cocon umgeben sind. - Endlich liegt noch eine Arbeit über "Lasius americams und seine Beziehungen zu Aphis pruncicola" ron J. W. Tutt (255) ror, welche mir aber leider nicht zugängliclı war. - Über die Beziehnngen ron "Ameisen" zu Aphiden handelt auch die kleine Notiz ron Cholodkorsky (217). So oft letzterer die an der Rinde sangenden Lachms mit der Lupe beobachtete, zeigten die dabei sitzenden Ameisen sich sehr unruhig, nahmen eine Verteidungsstellung ein und spritzten dem Becbachter die Ameisensüure gerade ins Gesicht. Die Ameisen suchten dadurch offenbar den „Feind " zu vertreiben, um die Lachmus zu schützen.

Eine Anzahl kleinerer biologischer Notizen finden sich ferner noch in einigen neuern, sonst grösstenteils systematischen Arbeiten Forels (241, 242 u. 243). In der ersten dieser Arbeiten (241) macht Forel auf die Erscheinung aufmerksam, die er bisher nur in 
tropischen Gegenden angetroffen hatte, dass nämlich A neisennester in hohle Zweige und Stengel gebaut sind. Solche Nester fand er nun auch in der Schweiz und zwar in den trockenen kleinen İsten eines Nussbaumes. Nicht weniger als drei verschiedene Arten hatten sich hier häuslich niedergelassen, nämlich Dotichorterus quadripunctatus, Leptothorax affinis und Colobopsis truncata. Von ersterm fanden sich in dem Geäste des einzigen kleinen Baumes nemn Nester. von dem zweiten sieben und ron letzterer zwei Nester. Während nun die sieben Leptothorax wirklich sieben verschiedene liolonien darstellten, so schienen die Dolichoderus-Nester einer einzigen Kiolonie anzugehören, oder wie Forel sagt, eine "fourmilière polydome" zu bilden, denn sie verbanden sich nachdem sie zusammengebracht waren, bald zu gemeinsamer Arbeit. - In der zweiten und dritten Arbeit (24 u. 243) erzählt Forel die Geschichte eines befruchteten t von Camponotus Timmiperlus Ltr., welches mehrere Monate in Gefangenschaft gehalten wurde. Dasselbe bekam von August bis März keine Nahrung, sondern nur etwas Wasser und brachte es trotzdem fertig fünf Larven aufzuziehen, von denen drei sich rerpuppten. Womit das o die Iarven aufgezogen, ist nicht bestinnt zu sagen, aber es gibt nur zwei Möglichkeiten: entweder auf Kosten seines Körpers, d. h. mit Sekreten, mit Eiern usw. oder aber, indem die Larven mit dem dargereichten Wasser auch gelöste Nährstoffe, die sich beim Durchsicheru durch die Erde beimischten, einsaugten. Erst Ende März nahm das † Nahrung zu sich und zwar frass es eine seiner eigenen Larven auf. Nachdem im Mai eine Arbeiterin ausgeschlüpft, ist die Königin sehr lebhaft geworden, hat eine Galerie in der Erde ausgehöhlt und ist zmm erstemmal aus dem Gefängnis getlolien. Zwei Wochen später, nachdem die Arbeiterin gestorben, nahm sie zum erstenmal fremde Nahrung (Honig) zu sich. Bald darauf verliess sie das Gefängnis wieder und zwal auf Nimmerwiedersehen.

Öber die Geräusche, welche die Ameisen hervorbringen können, berichtet E. Gounelle (2+8), eine Beobachtung, welche er in Sïr-Amerika an Camponotus mus gemacht laat. Diese Ameisen leben in zusammengerollten Bambusblätern; sobald sie beunruligt werden, schlagen sie mit ihren Köpfen an die Wand. wodurch ein knarrendes Geräusch entsteht, welches an das Klappern der Klapperschlange erimnert und welches erstaunlich laut ist im Verlıältnis zu der Kleinheit der 'Tiere und der geringen Bewohnerzahl eines solchen Blattnestes. Gounelle lıält dieses Klopfen für ein Alarmsignal.

Eudlich seien noch knrz einige Beobachtungen, die K. Esclıerich an den nordafrikanischen Myrmecocystus-Arten gemacht hat, erwähnt (230). Allgemeineres Interesse dürfte hauptsächlich die 
Mitteilung über die Bedeutung der ..Soldaten" von M. bombycimns besitzen. Diese unterscheiden sich von den normalen Arbeiter-Formen durch die bedentendere Grösse, den mächtigen Kopf und vor allem durch die säbelfömigen linearen Mandibeln (Fig. 6). Trotz dieser körperlichen dusriistung scheinen aber die sogenamnten .Soldaten“ nichts weniger als solche, d. h. Verteidiger der Liolonie zu sem. Denn bei Angriffen und störungen hielten sie sich meist abseits von dem eindringenden Feinde und üherliessen es den normalen nittelgrossen nnd kleinsten Arbeitern sich demselben entgegenzastellen und das Nest zu rerteidigen. Verf. vermutet auf Grund längerer lieobachtung einer aus Biskra stammenden Kolonie im kïustlichen Nest,

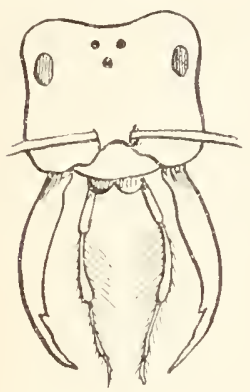
dass die grossköpfigen Formen mit linearen Mandibeln ..Anmenfunktion" besitzen, d. h. dass ihnen die I'Hlicht obliegt, die brut und vor allem die grossen C'ocons herumzutragen und bei Störungen in Sicherheit zu bringen. Die Ausbildung dieser Brutwärter dürfte damit zusanmenhängen, dass 1Y. bombycims nur in der ödesten Sandwüste rorkommt und infolgedessen die Beschaffung der nötigen Nahrung den gewöhnlichen Arbeitern so viel zu tun gibt, dass sie sich der Brut weniger amnehmen kounten. Lameere (251) hält dagegen die Soldaten des $\boldsymbol{M}$. bombycinms fiir umiitze Wesen, welche in Riückbildung begriffen sind. liese Ansicht ist aber entschieden zu verwerfen; denn wemn dieselben wirklich, ,Reste" wären, so miissten doch einige andere Myrmecocystus-Aiten ebenfalls derartige soldaten-Formen aufweisen. was aber bis jetzt bei keiner Art konstatiert rig. 6. Myrmecocystus worden ist. - Über die Beziehungen der Myrme-
bombycimus; aKopleines cocystıs-Arten zu einigen Käfern wurde frïlier „Soldaten“, $b$ Kopfeiner schon referiert (\%ool. \%entr.-131. 1902, pag. 8599). normalen Arbeiterin.

\section{Gemischte Kolonien und zusammengesetzte Nester.}

Nicht gering ist die Zahl der nenen Beobachtungen, welche in den letzten Jahren in bezug auf die Beziehungen verschiedener Ameisenarten zueinander sowohl als anch derjenigen ron Ameisen zu Termiten gemacht worden sind. Drei Autoren sind hier zn nennen: Forel $(236,240)$, Wasmann (25:1) und Wheeler (265).

Wasmann fasst in seiner nmfangreichen Arbeit alle neuern Beobachtnngen zı einem einheitlichen Bild zusammen, und so kamn 
ich mich in folgenden auf die Besprechung dieser Arbeit beschränlen, um so melur, als die Whe le r sche Abhandlung in dieser \%eitschrift schon frïher referiert worden ist (\%ool. Kentr.-Bl. 1902, pag. 256-260).

Wir sprechen von ,zusammengesetzten Nestern", wenn zwei oder mehrere Ameisenkolonien verschiedener Arten ränmlich so nahe beisammen wohnen, dass ihre Nester unmittelbar aneinander grenzen oder ineinander liegen. wobei jedoch jede der beteiligten Kolonien ilne eigene selbständige Haushaltung fïhrt. Wir sprechen voil... arten, welche heisamnen wohnen, anch zu einer einzigen gemeinsamen Kolonie verbunden sind: sie bewohnen in diesem ralle also nicht mehr getrennte 'Teile desselben Nestes. sondern schlechthin dasselbe Nest, und führen in demselben einen gemeinschaftlichen Haushalt.

Bezüglich der "gemischten liolonien“" welche zuerst behandelt werden sollen, sind auf rirund der Entstehungsweise drei verschiedene (iruppen zu unterscheiden: Ra ublolonien, Allianzkolonien und Adoptionskolonien. Die ersteren entstehen dadurclı, diss die "Herren" durch den Raub fremder Arbeiterpuppen in den besitz ilrer "Sklaven" oder . Hilfsameisen” gelangen. Solche Kolonien hestehen dementsprechend gewöhnlich aus den drei ständen

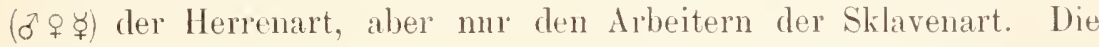
Allianzkolonien entstehen dadurch, dass sich die befruchteten Weibchen zweier versehiedener Arten oder liassen miteinander associieren, und die Adoptionskolonien endlich kommen dadurch zu stande, dass alte weisellose Kolonien ein befruchtetes $q$ einer andern Art adoptieren.

Wenn es mm auch in der Regel ganz bestimmte Ameisenarten sind, welche diese gemischten Kolonien bilden, so kommt es doch nicht selten vor, dass auch anclere Arten, welche für gewöhnlich in getrennten Kolonien leben, solche Verbindmngen eingelien, orler dass die Irt der /usammensetzung eine von der Regel abweichende ist, und wir unterscheiden demnach wiederum zwischen .normalen" und „anormalen gemischten liolonien”, und zwar in jeder der drei genannten Gruppen.

Was nun die Ra ubliolonien betriftt, so ist bei einer Anzahl der hierher gehörigen Ameisen das ,Rauben" nur fakultatir, so dass also die ..Herren" auch olnne Sklaven auskommen können; bei andern aber ist das Ramben obligatorisch, d. h. die Herren sind notwendig auf den Besitz von Hilfsameisen angewiesen und ron ihnen wesentlicl abhängig. Als „fakultative“ sklavenjäger kannten wir bis jetzt nur zwei Arten der Gattmug Formicr, nämlich smmpimer. Istr. in Europa, welche in Nord-Amerika durch eine Anzahl Subspecies und Varietiaten vertreten wird, und pergandei Fm. in Nord-Amerikir. 
Dazu kommt nun eine weitere nordamerikanische Art. Formica Ialiotemsis Em., welche nach den Beobachtungen zweier Kor'espondenten Wasm anns sich ganz ähnlich wie somguimea in Europa und deren Varietäten in Nord-Amerika verhält. F. dakotenvis ist gleich letzterer eine sklavenhaltende Ameise, bei welcher die Symbiose mit ihren Sklaven (Formica subsericea) nur eine fakultative ist: denn manche ilhrer Kolonien besitzen keine sklaven und zwar sind diese sklavenlosen Kolonien relativ noch liäufiger als bei sangminea. F. dakotemsis scheint also in noch geringerm Maße als diese an den Besitz von Hilfsameisen gebunden zu sein, so dass sie in dieser Beziehung möglicherweise eine pluylogenetische Vorstufe von $F$. sanguinea darstellt.

Auf einer noch tiefern stufe in dieser Hinsicht scheint $F$. exsectoides in Nord-Amerika zu stehen, welche nach den Beobachtmngen A. Forels (234) und Wheelers (265) gelegentlich sich auch die $F$. subsericea als Sklaven beilegt; wenigstens fand Forel sowohl als auch Whe eler in comnecticut je eine gemischte Kolonie exscctoides-subsericea; ausserdem wurden von anderer Seite in Pennsylvanien noch fünfmal solche angetroften. In allen diesen Fällen waren nur $q$ q ron exsectoides, nicht aber solche von subsericen in den Nestem vorhanden, was darauf hinweist, dass es sich tatsächlich mm Raubkolonien handelte.

Gehen wir nun ïber zu den obligratorischen Sklavenjägern, so sehen wir, dass hier der Instinkt des Sklarenhaltens bereits seinen Höhepunkt erreicht lat, dass sich aber andererseits auch schon Spuren der degenerierenden Wirkungen desselben zeigen. indem z. B. die Oberkiefer der .. Herren"-Arbeiter ganz einseitig, zu säbelförmigen Waffen ausgebildet sind. In erster Linie ist hier die PolyergusGruppe (Amazonenameisen) zu nennen, ron welcher bisher nur eine Art (rufescem Ltr.) in Europa und drei Rassen derselben in Nordund Mittel-Amerika bekannt waren. Jetzt beschreibt Wasmann noch eine vierte Rasse der Amazone aus Wisconsin, welche wegen ilner roten und schwarzen Färbung bicolor genannt wird. Sie hat eine Varietait unserer Formica fusca (var. subamescens Em.) als Sklaven, und zwar enthält jede Kolonie etwa $80 \%$ Sklaven. Auch bei unserer Amazone ist die Zahl der Sklaven $(F$. fusca) bedeutend grösser (wenigstens viermal so gross) als jene der "Herren", so dass sich also die neue Rasse auch in dieser Beziehung ganz ähnlich wie unsere rufescens verliält.

Ein weiterer ,obligatorischer" Sklavenjäger ist der nordische Tomognathus sublaeris Nyl. - Derselbe dringt in die Kolonien der naheverwandten Myrmiciden Leptothorar arevorum und muscormm. 
Nyl. ein, treibt die regelmäßigen Nestbesitzer in die Flucht und nimmt dann deren Nest samt der zurückgelassenen Brıt in Beschlag. Letztere zieht sie gemeinsam mit den eigenen Larven auf; daraus erklärt sich, dass in diesen gemischten Raubkolonien ausser den Arbeitern auch die Geschlechtstiere der Sklaven vorhanden sind. Während man früher nur das of von Tomognathus kamnte und man daher annahm, dass bei dieser Ameise eine unbegrenzte parthenogenetische Fortptlanzung stattfinde, wurde später (1896) von Adler auch das $\sigma^{7}$ entdeckt, welches dem o von Leptothorax so ähnlich ist, dass man es friilier übersehen hatte. Auch Nord-Amerika besitzt eine Tomognathus-Art (americums. Em.), welche bei Washington in einer gemischten Kolonie mit Leptothorax currispinosus entdeckt wurde.

Im Anschluss an Tomogmathus bespricht Wasmann die ,Säbelameise" Strongylognathms, welche in gemischten Kolonien mit der gemeinen Rasenameise, Tetramorium cuespitum L. lebt. Die ,Säbelameisen" sind insofer'n besonders interessant, als wir an den verschiedenen Arten derselben den Übergang von den Raubkolonien zu den Allianzkolonien sehen kïnnen. Der südenropäische Strongylogmathes huberi Forel und deren nordafrikanische liasse "ffe. Em. sind wahrschemlich noch Sklavenräuber: denn sie stimmen in der Kopfzahl der Kriegerimmen sowohl als anch in der Kampfestaktik und im Mut mit der Amazonenameise, der Sklavenräuberin par excellence, ungefähr überein. - Anders aber die in unsern Breiten vorkommende ,gelbe Sähelameise“" Strong. testacens)! Die Zahl derselben in den gemischten Kolonien ist nämlich meist eine so geringe im Verhältnis zu den Tetramorium $\left(1-20^{\circ} \%\right)$, dass sie ummöglich eine Beraubung der Tetramorimm-Kolonien unternehmen können, zumal sie auch nicht die Kriegstaktik und den nötigen Mut besitzen. In Rücksicht darauf nimmt Wasmann an, dass es sich hier nicht mehr um Raub. kolonien, sondern vielmehr um Allianzkolonien handelt. An Stelle des Instinktes Sklaven zu rauben, muss also bei der nördlichen Art sich allmählich die Neigung entwickelt haben, nach dem ParungsHuge die Nachbarschaft ron Tetramorium-Nestern antzusuchen und sich den von diesen ausgesandten Tctramorium $q$ q zuzugesellen. Möglicherweise ist diese Instinkts- ̈̈nderung auf die niedrigere Temperatur zurückzuführen, indem diese im Norden nicht mehr die zur physiologischen Auslösung des Raubzug-Instinktes nötige Höhe erreicht.

Ebenfalls auf friedliche Weise entstehen die gemischten Riolonien ron Anergates mit Tetramorimm. Anergates (die "Arbeiterlose") ist die einzige europäische Ameisenart, ron welcher nur of und $q$, aber keine Arbeiter existieren. Zudem sind die ofollig degenerierte 
Wesen, die eher einer Ameisenpuppe als einer Ameise älnlich sehen, während die befruchteten $q$ einen relativ riesigen Hinterleibsumfang erreichen. Statt der eigenen Arbeiterinnen dienen dieser Ameise die

der Rasenameise Tetrumorium caespitum als Hilfsameisen. Die Anergutes kommen, wie erwähnt, nicht durch Raub in den Besitz ihrer Helferinnen, sondern dadurch, dass ein befruchtetes o von Aurgates nach den l'arangsfluge in einer alten, weisellosen Tetramorium-holonie adoptiert wird. Es handelt sich also hier un eine Adoptionskolonie. Bewiesen wirl diese Annahme dadurch, dass in den betreffenden gemischten holonien niemals eine TetramoriumKönigin und niemals auch nur die Larren und Pnppen von Tetramorium-Arbeitem rorhanden sind.

Fin, wenn auch unolliommenes Seitenstïck zu diesen gemischten Kolonien besitzt die Nord-Amerikanische Ameisenfauna in den Kolonien Epoerus pergandei Em. + Monomorium minutum Buckl.; dem auch von Ejoecus hat man bis jetzt noch keine Arbeiterform kemnen gelernt: doch unterscheiclen sich diese Kolonien dadurch ron den vorigen, dass hier auch die Hilfsameise Monomorium of unt $q$ besitzt, während diese ja bei Tetramorium fehlen. Öber die Entstehungsweise und nähere Natur dieser Kolonien ist noch nichts bekamnt.

Ausser den bis jetzt besprochenen nor m a le n gemischten Kolonien wurden in den letzten Jahren auch noch einige interessante anormale Formen entdeckt. So fand Forel (236) im Kanton Wallis eine dreifach gemischte Kolonie, aus P'olyergus nufescens, Formica furcen und matensis bestehend. Dieselbe dürfte daturch entstanden sein. dass zunächst eine .. Allianz" zwischen einem befruchteten $q$ ron Polyergu. und einem solchen ron $F$. prutensix geschlossen wurde, indem dieselben nach dem Paarungstluge zufällig unter einem grossen Stein sich zusammengefunden. Die ron der Polyorgus-Kolonie abstammenten Amazonen raubten dann, ihrem Instinkt gemäb, die Arbeiterpuppen ron $F$. fisct, und damit war die dreifache liolonie fertig. Wir müssen also diese sonderbare Kolonie zur Hälfte als ..Allianz"- und zur Hälfte als ..Raubliolonie” auffassen. - Eine andere dreifach gemischte Kolonie fand $\mathrm{W}$ asmann bei Exaeten, und zwar bestand dieselbe ans Formica sanquinen + fusca + mratensis. Dieselbe kam, wie aus dem genanern Studium ihrer Geschichte sich ergab, dadureh zu stande, dass die normale Raublolonie senguinenfurcu nach Verlust ihrer letzten sunguincu-Königin eine junge fmatensisKönigin adoptierte. Wir haben es hier also mit einer .. Raub"- und zugleich .. Adoptionskolonie" zu tun. Ferner heschreibt Wasmann noch zwei anormal gemischte Kolonien For. fusca + rufiburbis, 
welche wohl auch als Adoptionskolonien aufzufassen sind. - Auch aus Nord-Amerika werden von Forel (23t) und Wheeler (265) noch einige anormale Kolonien beschriehen, die teils aus rerschiedenen Rassen ein und derselben Art, teils aus verschiedenen Arten bestehen. auf die jedoch nicht näher eingegangen werden kann.

Auch hezüglich der ,zus ammengesetzten Nester w. wurden unsere Kenntnisse in den letzten Jahren wesentlich gefördert. Wheeler (265) hat eine neue sehr interessante Ciastameise entdeckt, Leptothorax omer:soni, welche in Nord-Amerika bei Mymrea brerinodi. lebt. Obwohl jene als "echter Gast" bei letzterer lebt und sich auch aus deren Munde füttern lässt, so bewohnt sie doch ein selbständiges Nest, das allerdings mitten in dem Wirtsnest gelegen, aber durch hesondere Wälle ron ilım getrennt ist. So haben wir hier also gewissermaßen einen Übergang zwischen den gemischten líolonien nud den zusammengesetzten Nestern vor uns (siehe auch Kool. Zentr.-Bl. 1902 pag. 256). - Anch einige neue zu den Diebsameisen gehörige Formen wurden von Forel, Wheeler und Wasmann neuerdings beschrieben. Die Irebsameisen, welche bei uns durch die kleine gelbe Solmopsic fugax Ltr. repräsentiert werden, leben in der Nähe oder in den Nestern anderer grösserer Ameisenarten und zwar in ganz feinen Gängen, welche zwischen den Gängen und Kammem des Wirtsnestes angelegt sind, um von hier aus dem letzteren zum Zwecke des Puppenfrasses bequemere besuche alhstatten zu können. In Nordafrika ist Solenopsis fugar durch drei Arten vertreten (arbula Em., late Forel und oranionsis Forel), in Nord-Amerika durch eine Art. Solenopsis delitis Mayr. Letztere leht übrigens nicht ausschliesslich in den Nestern anderer Ameisen, sondern auch in menschlichen Wohnungen und bildet in Washington sogar eine häutige Hausplage, weshalb sie auch von einem spätern Autor (Say) als molesta bezeichnet wurde. Interessant ist auch die Mitteilung Wasmanns, dass bei der nordamerikanischen Solenopis debitis eine ganz ähnliche parasitische Proct ot rup i de vorkommt (Loxotrope califormicà Ashm.) wie bei der emropäischen S. fungr (Solenopsia imitatrix Wasm.).

Zu den Diebsameisen scheint ferner auch die Gattung Pheillole einen Vertreter zu stellen, wenigstens trat Wheeler eine Art, die er lamia nennt, mitten in einem Nest von Camponotur maculutus subsp. sansebeams Buckl. Auch manche Strumigenys-Arten, sowie ein Monomorium dïrften nach den Wheelerschen Beobachtungen ebenfalls als Diebe bei andern Ameisen leben.

Im Anschluss an diese Cruppe von zusammengesetzten Nestern bespricht Wasmann auch die verschiedenerlei Beziehnngen, welche 
in den tropischen Gegenden $\%$ wischen Ameisen und Termiten bestehen, und welche erst in der letzten Zeit etwas mehr beachtet wurden. Die Mehrzahl der ..termitophilen“ Ameisen führen eine ganz ähnliche diebische Lebensweise wie die letztgenannten myr'mecophilen Ameisen. Sie gehören sogar teilweise denselben Gattungen an; so wurden in Brasilien mehrfach Solenopsis-Arten und in Siidafrika, Madagaskar und Ceylon rerschietlene Momomorium-Arten in Termitenbauten angetroffen. - Übrigens tindet man bei den T'ermiten nicht immer nur je eine Art Ameisen. sondern nicht selten hausen zwei oder drei oder sogar noch mehr rerschiedene Ameisenarten in einem einzigen Termitennest.

Die hei den Termiten lebenden Ameisen sind aber nicht etwa alle heimtiickische $/$ werge und Diebe, sondern es gibt unter ihnen auch friedlichere Wesen ron grösserer Statur. So lebt eine Rasse der Crematogaster rictima stets in Gesellschaft ron Lutermes fulviceps und zwar in volliommenster Eintracht. In derselben friedlichen Weise leben auch gewisse C'amponotus-Arten mit T'erniten zusammen. C. punctulatus termitarins En. findet sich regelmäPig in den Bauten der südbrasilianischen Eutermes- und Anoplotermes-Arten, so dass man ihn sogar kurzweg als ..formiga de cupins", d. h. Termitenameise bezeichnet. Es scheint, dass die befruchteten Weibchen dieser Ameise nach dem l'aarungsfluge die Erdhügel der T'ermiten aufsuchen, um dort nene Kolonien zu gründen. Für die Termiten stellen die Ameisen wahrscheinlich eine Art Schutztrupe gegen andere karnivore Raubameisen dar. Dafür spricht unter anderem auch der Umstand, dass in allen den Fällen, in welchen der Camponotus vorhanden ist, niemals auch noch eine andere Ameisenart in dem betr. Termitenbau sich authält. Auf die verschiedenen „zufälligen Symbiosen" zwischen Ameisen und Termiten brauche ich hier nicht im einzelnen einzugehen. -

Der Schluss der Wasmannschen Arbeit ist meist theoretischer Natur. Vor allem wendet er sich gegen die zahlreichen Kínstausdrücke, die in letzter Zeit ron den verschiedenen Autoren eingefiihrt wurden und vielfach ganz unnötig seien und die höchstens das Verständnis erschweren. Iazu seien die neuaufgestellten Kategorieen oft keineswegs logisch koordiniert und entsprächen auch beziiglich ihrer Abgrenzung grösstenteils nicht den natürlichen Verhältnissen, was vor allem für die Wheelersche Einteilung, welche früher in dieser Zeitschrift kurz mitgeteilt wurde (Zool. Zentr.-Bl. 1902, pag. 256), zutrifft.

Da es für Fernerstehende nicht leicht ist, durch die vielen Namen und Kategorieen, die für die verschiedenen Formen der Symbiose zwischen Ameisen oder zwischen Ameisen und Termiten in der 
letzten Zeit anfgestellt wurden, hindurchznfinden, diirfte es das beste sein, die Übersicht, die Wasmann darüber gibt, hier in etwas abgekürzter Form anzuführen; dieselbe gestaltet sich folgendermaßen:

I. Die Symbionten wolnen beieinander, ohne zu einer Kolonie sich zu verhinden. Zusammengesetzte Nester. Die Komponenten derselben können zueinander in folgenden Beziehungen stehen:

1. Als Feinde (Echthrobiose). Die mehr oder minder gesetzmäßigen Formen nehmen meist die Form der Cleptobiose (Wlieeler) an, indem eine kleinere Art als I)iebsameise bei einer grösseren sich einnistet. Forels ,Lestobiose" (240) ist eine besonders feindselige Form der Cleptobiose.

2. Völlig indifferent, oft sogar ohne Scheidewände in den verschiedenen Teilen desselben Nestes: Forels ,Parabiose".

3. Die eine Art dient als Schutzwache der anderen: Phylakobiose. Nur zwischen Ameisen und Termiten bekannt.

4. Die eine Art wolınt als Gast im Neste der anderen: Gastameisen (,X $\mathrm{X}$ enobiose" Wh li e lers).

II. Die Symbioten verbinden sich zu einer Kolonie: gemischte Kolonieen" ,Herren" und ,Sklaven“" oder "Hilfsameisen".

1. Die ,Herren" gelangen durch Raub fremder Puppen in den Besitz der ,Sklaven": Raubkolonieen, Sklaverei (,D)nlosis" Wheelers).

a) Fakultative Sklavenhalter: Formica.

b) Obligatorische Sklavenhalter: Polyergur, Tomognathus, Strongylognathus huberi.

2. Die gemischten Kolonieen entstehen durch Allianz befruchteter Weibchen: Allianz-Kolonieen (,Allometrobiose" Forels).

3. Die gemischten Kolonieen entstehen durch Adoption eines befruchteten Weibchens durch eine weisellose Kolonie der Hilfsameisenart: Adoptionskolonieen, (,Kolakobiose" Wheelers).

Wie überall in der Natur, so sind auch hier die Grenzen nicht überall strikte einzuhalten; ausserdem sind nicht selten verschiedene der hier genannten biologischen Kategorieen miteinander kombiniert.

Auf die Bemerkungen zur Tierpsychologie, die Wasmann im letzten Kapitel der hier besprochenen Arbeit (hauptsächlich gegen Forel und Wheeler gerichtet!) macht, soll im nächsten Abschnitt eingegingen werden. 


\section{Psychologisehes.}

Die Polemik, die seit einiger Zeit um die Psychologie der Ameisen geführt wird, hat noch keineswegs zu einer Annäherung, geschwèige denn zu einer Einigung der daran beteiligten Autoren geführt. Das Kampfesobjekt ist nicht einfach, sondern sehr kompliziert, ebenso die Konstellation der Kämpfenden. Beziiglich des einen Punktes stehen Wasmann, Forel, Wheeler zusammen gegen Bethe, in einem andern l'unkt dagegen nähern sich Wasmann und Bethe, damn stehen wieder Forel und W asmann mit grundsätzlich verschiedenen Meinungen einander gegenïber usw.

Auf die Kontroverse zwischen Wasmann und bethe brauche ich nicht mehr näher einzugehen, da die hauptsächlichsten diesbezüglichen Arbeiten hier schon früher ron anderer Seite referiert wurden (vgl. Zool. Zentr.-131. 1898 pag. 273-275, 1899 pag. 672-675, 1900 pag. 705 u. 746$)^{1}$ ). Ilie später erschienene kurze Antwort Wasmanns (260) bringt sachlich nichts neues, sondern besteht ausschliesslich in persönlichen Auseinandersetzungen.

Forel (237, 238) ist bezüglich der Zuriickweisung der Retlextheorie Bethes röllig einig mit Wasm ann. Nach ihm besitzen die Ameisen nachweishich (iesicht-, Geschmack- ${ }^{2}$ ), Geruch- und einen Tastsinn; der Gehörsinn ist zweifelhaft; ein sechster Sinn ist nirgends nachzuweisen, und ein eigener Richtungs- und Orientierungssinn fehlt bestimmt. Die Orientierung der Ameisen im Raum beruht auf dem Geruchs- und Gesichtssimn verbunden mit dem Gedächtnis. Der Geruchssinn spielt dabei die Hanptrolle, jedoch nicht die ausschliessliche, wie Bethe meint. Die verschiedenen Ameisen verhalten sich in dieser Beziehung verschieden: die Lasius und Mymica, mit denen Bethe experimentierte, orientieren sich allerdings grösstenteils mit Hilfe des Geruchsinnes, andere Ameisen dagegen mindestens ebensoviel mit dem Gesichtssimn. Wasmann (258) berichtet Beispiele von $F$. sangumea, die dieses zweifellos machen; auch Leptothorax scheint nach den Mitteilungen ron Viehmeyer (256) durch Lichteindrücke sich leiten zu lassen. Überwiegend mit dem Gesichtssinn orientieren sich nach Forels beobachtungen (237) in Nord-Ameriki die grossäugigen Pseudomyrma, inden diese geradewegs im eiligsten Tempo auf ihr Ziel losstiirzen. - Der Geruchsinn der Ameisen ist übrigens von ganz anderer Beschaffenheit als der der Wirbeltiere, da derselbe in den beweglichen Fïhlhörnem seinen Sitz hat (hieher auch Field 232). Dalurch bekommen die Ameisen (wie auch die an-

1) Eine zusammenfassende Darstellung dieser Polemik findet sich in den Schriften von K. Esc le rich (229), J. Me is e nheimer (252) und C.Sch äffer (254),

) Betr, des Gechmacksinnes vgl. auch oben Cobelli (218). 
deren Insekten) die Fähigkeit 1. beim direkten Kontakt die chemischen Eigenschaften eines Körpers zu erkennen (Kiontaktgeruch) und 2. auch den Raum und die Form seiner Objekte, sowie anch die Form seiner eigenen Spur zu erkennen. Forel bezeichnet diesen qualitativ ron unserm Geruch doch recht abweichenden Simn den „topochemischen Geruchsinn." Mit Hilfe dieses Sinnes lässt sich auch die auffallende Erscheinung, dass die Ameise stets die beiden Richtungen ihrer Spur (zu und ron dem Nest) unterscheiden kann, unschwer ererklären, und brauchen wir daher nicht zu einer geheimnistollen Polarisation unsere Zufiucht zu nehmen. - Dass das Wegfinden der Ameisen nicht bloss auf einem Chemoreflex beruht, geht auch daraus hervor, dass manche Ameisen, wie z. B. die Formica-Arten, sich durchaus nicht genau an eine bestimmte Strasse halten, sondern jede für sich besondere Richtungen einschlägt. Bei solchen Ameisen kann man, wie Wasmann zeigte (258), auch ruhig den Boden ron ihrem Nest wegschaufeln, ohne stärkere Störungen zu reranlassen oder ihre Orientierung zin unterbrechen. Bethes Chemoreflex lïsst hier im Stich. Wir müssen vielmehr notwendig annehmen, dass die Ameisen Gesichts- und topochemische Geruchsbilder in ihrem Gehirn aufspeichern, und dass sie also einer Erinnerung fühig sind. Auch aus andern Tatsachen geht zweifellos hervor, dass die Ameisen ein Gedächtnis besitzen: manche Arten \%. B. können Freundinnen auch nach Monaten wieder erkennen. und die Amazonen (Polyergus) wissen genau, ob noch P'uppen in dem ansgeraubten Formica fusca Nest zurückgeblieben sind oder nicht. Im erstern Fall kehren sie am gleichen oder am folgenden Tag nochmals zum Raub zurïck, im letztern hingegen unteriassen sie dies (hierher auch Field 233).

Auch eine einfache, dem Ameisengehirn entsprechende form des Willens lïsst sich bei den Ameisen feststellen: besonders bei den geistig hochstehenden Formicta-Arten können solche Willensïusserungen deutlich beobachtet werden. .Stundenlang kann eine Ameise (Formica) eine Masse Schwierigkeiten überwinden, um zu einem Ziel zu gelangen, welches sie sich vorgesteckt hat. Dieses Ziel ist nicht genau instinktiv vorgeschrieben, da sehr viel Möglichkeiten vorliegen. und so kommt es oft vor, dass zwei Ameisen einander entgegenarbeiten." Wir mïssen hier unbedingt „individuelle Entschliisse " annehmen, allerdings „im Rahmen der Bahnen des Art-Instinktes."

Bezüglich des Gesichtssinnes der Ameisen ist noch zu erwähnen, dass dieser von dem unserigen insofern abweicht, als durch ihn auch die ultravioletten Strahlen perzipiert werden. Forel hat diese Erscheinung, die 1882 von Lub b o k entdeckt wurde, und über die er 1886 selbst eine Anzahl Experimente anstellte, neuerdings (247) 
im Verein mit dem Pligsiker Dufour unter Anwendung aller Kautelen nochmals nachgeprüft und wenigstens für Formica sanguinea mit Sicherheit bestätigt, dass sie die ultravioletten Strahlen zu sehen vermag (vgl. auch Field 233).

Auch die Morphologie des Ameisengehirns berührt Forel (238) kurz, indem er vor allem auf die verschiedene Ausbildung des den Sinnes- und Muskelzentren ïbergeordneten Nervenzentrums hinweist. Bei den Arbeitern ist dasselbe sehr gross, bei den Weibchen viel kleiner, und fast ganz verkïmmert bei den Männchen. Damit übereinstimmend sind auch die geistigen Fähigkeiten (Gedächtnis, Plastizität usw.) am höchsten entwickelt bei den Arbeitern, weniger bei den Weibchen und an schwächsten bei den Männchen, die „unglaublich dumm sind, die Freund und Feind nicht unterscheiden und den Weg zum Nest nicht finden können".

Aus allen diesen Momenten geht für Forel unzweifelhaft hervor, dass die Ameisen nicht bloss Reflexautomaten ohme Empfindung, sondern dass sie vielnehr empfindende Wesen sind und ein Modifikationsvermögen besitzen, mit Hilfe dessen sie ihre Handlungsweise nach frïhern Erfalırungen abändern und neuen Verlältnissen anpassen können. Zu demselben liesultat ist auch Wasmann gelangt. - Trotzdem aber lässt sich Bethe, wenn er auch mehrfach seine frühern Meimungen modifiziert hat, nicht ron psychischen Qualitäten der Ameisen ïberzeugen, wie aus seiner, ïbrigens recht persönlich gefärbten Antwort (216) an Forel zu ersehen ist. Er weist unter anderm darauf hin, dass seine .polarisierte Spur" nichts mystisches an sich habe, sondern dass die lezeichnung ,polarisiert" nur die qualitative oder quantitative Verschiedenheit der ,Hin". und ,HerSpuren" ansdrïcke. -- Auch rerwalıt er sich gegen den Torwurf Forels, dass seine Beobachtungen nicht exakt und einwandsfrei seien und fordert ihn auf, Belege dafür zu bringen. Forel führt nun in einer Erwiderung (246) an Bethe drei seiner Beobachtungen an, die sich als unexalit oder unrichtig erwiesen haben und macht damit, wie er sagt, Schluss der Polemik. Forel tut jedenfalls gut daran, dieselbe nicht weiter fortzusetzen, da sie doch niemals zu einen Ziele führen würde. Dazu ist der grundsätzliche Standpunkt der beiden zu rerschieden: Bethe leugnet die Berechtigung des Analogieschlusses in der Psychologie und damit einer wissenschaftlichen Psychologie ïberhaupt, während Forels (wie auch Wasmanns und Wheelers) ganze Aneisenpsychologie lediglich auf Analogieschliissen beruht.

Handelt es sich in dem Streit zwischen Forel und Bethe im Prinzip hauptsächlich um eine rerschiedene Bewertung der Methoden, 
so sind die Differenzen zwischen Forel und Wasmann fast ausschliesslich begrifflicher Art. Was ist Instinlit und was Intelligenz? Ist die Intelligenz ein Norum, welches allen Tieren fehlt und einzig allein dem Menschen zukommt, oder ist sie nur eine höhere Entwickelungsstufe der psychischen Qualitäten, die wir bei den Tieren antreffen? Forel bejaht letyteres, Wasmann verneint es. Forel sagt: „Sämtliche Eigenschaften der menschlichen Seele können aus Eigenschaften der Seele höherer Tiere abgeleitet werden, und sämtliche Seeleneigenschaften höherer Tiere lassen sich aus denjenigen niederer Tiere ableiten." Wasmann wendet dagegen ein (25̃9): „Die Vernunft .... ist ein Vorzug des Menschen, welcher die wesentliche Superiorität der Menschenseele über die tierische ausser Zweifel stellt." Diese Verschiedenheit in der Auffassung beruht im Grunde darauf, dass W a s man das, was F' o rel (und auch Wheeler u. a.) intelligent nennen, nämlich Modifikationsrermögen, einfaches Schlussvermögen aus Analogieen, Wahlrermögen etc., als ,instinktiv im weiteren Sinne" auffasst. Für Wasmann ist das Charakteristikum der Intelligenz ein $\log$ isches, formelles Schlussvermögen, welches auf einer wirklichen Einsicht in die Beziehungen zwischen Ursache und Wirkung, Mittel und \%week, beruht (257 u. 259). Und ein solches Schlussvermögen, ein solches /weckbewusstsein ist bei den Ameisen nirgends zu konstatieren; daher fehlt ihnen die Intelligenz. Auch Forel schreibe den Ameisen kein formelles Schlussrermögen zu, denn er spreche ja mehrfach ron ,instinktiven Analogieschlüssen". Diese seien aber nichts anderes, als neue, durelı Erfahrung erworbene Vorstellungsverbindungen, die durch das sinnliche Gedächtnis die Handlungsweise der Ameisen leiten. Der Ausdruck ,instinktiver Analogieschluss" sei zudem wenig glïcklich und enthalte einen inneren Widerspruclı; denn ein Analogieschluss sei seiner Natur nach stets intelligent, nieht instinktir.

Ganz ähnlich rerhalte es sich, wie Wasmann in der letzten Arbeit ausführt (259), mit dem, ,Wahlvermögen" (choice) der Ameisen, welches Wheeler (265) als Beweis für deren Intelligenz ins Feld führt. Auch hier müssten wir unterscheiden zwischen einer intelligenten und instinktiven Wahl; und da Wheeler den Ameisen ein eigentliches logisches Denkrermögen (ratiocination) abspricht, so könne es sich nur um eine instinktive Wahl handeln, welche aber ebensowenig wie Forels ,instinlitiven Analogieschlüsse“ für Vorhandensein einer Ameisenintelligenz beweisend sei.

Noch viel weiter aber weichen Forels und Wasmanns Anschauungen bezïglich der ersten und tiefsten Fragen der Psychologie voneinander ab. Forel vertritt die Lehre der psycho-physiologischen 
Identität oder des Monismus. I)arnach ist unsere Seele, ,die sich im Bewusstsein selbst reflektierende Tätigkeit des lebenden Gehirnes" (244, pag. 101). Körper und Seele sind also reell ein und dasselbe Ding und folgen daher auch genau denselben Gesetzen. Wirkungen mnd Rückwirkungen ron Körper auf Seele oder ungekehrt sind nichts anderes als Wirkungen und Rïckwirkungen einzelner Energien auf andere Energien und enthalten absolut nichts gegensätzliches zwischen Körper und seele, indem jede Fnergie ilır sogenanntes materielles substrat, d. h. ihre materielle und wahrscheinlich auch ihre mehr oder minder elementar seelische Erscheinungsseite besitzt. Er versucht dies an rerschiedenen Beispielen der Evolution bei den Ameisen klar zu machen (214). So ist die verschiedene Ausbildung des PilzgärtnereiInstinktes stets begleitet ron entsprechenden morphologischen Eigenschaften; ebenso sehen wir bei den sliavenjägern, den Diebsameisen usw. Körpergestalt und psychische Eigentïmlichlieiten stets harmonisch zusammenhängen und einander gegenseitig bedingen. Fragt man sich, ob die Körperbeschaffenheit der Atta. Formica usw. durch den Pilzgärtnerei- oder sklaverei-Instinkt oder letzterer umgekehrt durch erstern bedingt ist, so ..müssen wir diese Frage als falsch zurückweisen”. .Instinkt und Körperform sind der harmonische Ausdruck jener zahllosen in Tausenden ron Generationen wirksam gewesenen Wirkungen und Rückwirkungen."

W a mann als entschiedener D)ualist sieht dagegen in Seele und Leib zwei reell voneinander verschiedene. obwohl innig miteinander verbundene Kiomponenten des Menschen bezw. des Tieres. Forels Seelenlehre ist. wie Wasmann in seiner letzten Arbeit (25̃9) einwendet, genau betrachtet eine Seelenlehre ohne Seele, weil sie die eigene Realität der Seele leugnet. Denn die ..Psyche" ist ja nach forel ihrer Realität nach nichts weiter als eine summe materieller Gehirntätigkeiten, die man ron psychischer Seite betrachtet: zieht man nun ron dem ..Psyche* genannten Ding jene materielle Summe ab, so bleibt eine reine Null als Rest. - Und daher erscheint Wasmann Bethe, der die Berechtigung der Psychologie ïberhaupt leugnet, weit konsequenter; denn „wenn das Psychisclie gar keine eigene Realität besitzt, so soll man die Psychologie ruhig in die Rumpelkammer der leeren Abstraktionen rerweisen." 


\section{Nachtrag.}

Bei der Bearbeitmng der vorstehenden Übersicht sind mir einige kleinere Nitteilungen entgangen, welche zugleich mit den während der Drucklegung erschienenen Arbeiten hier noch nachträglich angeführt werden sollen. Es sind dies:

69 Adlerz, G., Myrmecologiska studier IV. Formira succica n. sp. Eine neue schwedische Ameise. In: Kongl. Vetensk.-Akad. Förhandl. 1902. Nr. 8. pag. $263-265$.

70 c'obelli, R., I veleni ed il Lasius emarginatus Ol. In: Terhandl, Zool. - Bot. Ges. Wien. 1903. pag. 18-20.

271 Mayr, G., Südafrikanische Formiciden, gesammelt von Dr. Hans Brauns. In: Amnal. Nat. Hof-IIus. Wien. Bd. XV1. 1901. pag. 1-30. Taf. I u. II.

272 Mnckemann. II.. A remarkable psychic contrast from the life-history of ants. In: Scientific American, Supplement Nr. 18.35. Jul. 19. 1902. pag. 22200.

273 - The structure of the nests of some Nortlr American species of Formica. In: Psyche. Juni 1902. pay. 355-360

274 Ondemans, J. Th.. Zwei merkw ïrdige Hymenopteren-Nester von Lasius fuliginosus Latr. und von Osmia rufa L. In: Allgem. Zeit f. Lintom. VI. 1902. pag. 179-181. 2 Fig.

75 Reichenlach, II., Über Parthenogenese bei Ameisen und andere Beobachtungen an Ameisenkolonien in künstlichen Nestern. In. Biol. Zentr.-Bl. XXII. 1902 pag. 461-465.

276. Stemander, R., Den Skandinaviska Vegetationens Spridningsbiologi. Zur Verbreitungsbiologie der skandinavisclen Pflanzenwelt. Upsala 1903. (Über die Verbreitung von PHanzen durch Ameisen, pag. $234-810,360-387,450-452,455$.

277 Whecler. W. M.. Erebomyima, a new genus of hypogaeic ants from Tex as. In: Biol. Bull. IV. 1903. pag. 137-148. 5 Fig.

278 - and VIc Clendon, J. F.. Dionorphic Queens in an American Ant (Lasins latipes Walsh..). Ibid. pag. 149-163. 3 Fig.

Adlerz (269) beschreibt eine neue Formica-Art aus Schweden, welche bisher nur auf der Insel Alnö im Bottnischen Meerbusen, unweit Sundswall, gefunden wurde. Da sie aber an dieser Lokalität in zahlreichen Kolonien rorkommt, so wird ihre Verbreitung wahrscheinlich eine weit grössere sein. Sie ist mit unserer Formica exsecta am nächsten verwandt, unterscheidet sich aber von dieser nicht nur morphologisch, sondern auch biologisch; so baut sie keine freistehenden Haufen, wie exsectu es tut, sondern höhlt ihre Kannmern im weichen Holze der morschen Baumstrünke usw. aus und bedeckt höchstens die Schnitttläche der letztern mit einen dünnen Lager von zusammengeschlepptem Material (Grasstengelchen usw.), durch welche Bauindustrie sie eher an $F$. trumcicola (Rasse von ruf $(u)$ erinnert. Cobelli (270) setzt seine Versuche (siehe oben 218) über den Geschmacksinn der Ameisen fort und prïft das Verhalten von Lasiu: emarginatus gegen verschiedene Gifte wie Belladonna, Cocain, Mor- 
phium usw. Dabei ergab sich, dass die genannte Ameise eine Abneigung gegen diese Gifte hat und dieselben nur dann aufnimmt, wenn sie mit Honig gemischt dargereicht werden.

G. Mayr (271) gibt eine Bearbeitung der von H. Brauns in Sïd-Afrika gesammelten Ameisen. Neben zahlreichen Beschreibungen neuer Gattungen und Arten teilt der Verf. auch einige Notizen über d ie K arton-Nester verschiedener Crematogaster-Arten mit. Crematogaster opaciceps Mayr baut sein Nest aus papierdïnnem Karton, welcher aus Holz- und Bastzellen, untermischt mit sehr kleinen Sandkörnchen, zusammengeklebt ist und etwa an durch Regen und Verwitterung verrotteten Rindermist erinnert. Das ganze Nest hat eine knollig-kugelige Form von 13-18 cm Durchmesser und hängt an Erica-Zweigen, welche teilweise im Innern des Nestes eingeschlossen sind. An einigen feinen, aus dem Neste heraustretenden Zweigen sassen Rindenläuse, über welche die Arbeiter des Crematogaster Schutzhüllen gebaut hatten. Des weitern beschreibt Verf. auch ein sehr grosses Kartonnest von Crematogaster peringueyi Em., welches Brauns in Port Elizabeth fand. Dasselbe ist eiförmig $(28 \mathrm{~cm}$ hoch, $22 \mathrm{~cm}$ breit) und stand unmittelbar über dem Erdboden aufrecht, festgehalten ron den Halmen eines Juncus, welche ron den Ameisen zur Fixierung benutzt wurden und innerhalb des Nestbaues diesem als Stützbalken dienten. Der Karton besteht aus einer ziemlich brüchigen Masse, welche aus humusreicher Erde, vermodernden Pflanzenzellen und sehr kleinen Sandkörnchen zusammengesetzt ist. Noch ein drittes (rematoyaster-Nest wird beschrieben, nämlich das des Crematog. hovo aus Madagaskar; dasselbe steckt in dem Geäste einer Myrtacee und erscheint von den Zweigen durchwachsen, ist eiförmig, hat $10 \mathrm{~cm}$ im Längen- und $6 \mathrm{~cm}$ im Querdurchmesser. Die OberHäche des Nestes zeigt 2-4 mm hohe, unregelmäbig gestellte kurze Wülste oder rundliche Erhöhungen. Das Material, aus welchem die papierdünnen Wände gehaut sind, hält die Mitte zwischen dem Nestmaterial des $C$. opaciceps und peringueyi, indem der humösen Masse ziemlich riel Pflanzenfasern beigegeben sind, so dass auch die Brüchigkeit dieses Nestes eine geringere ist als die des peringueyi-Nestes. Die drei Nester sind nach photographischen Aufnahmen vorzüglich dargestellt.

Auch Muckermann (273) beschäftigt sich mit dem Nestbau der A meisen und zwar mit dem der nordamerikanischen FormicaArten. Während Forel (siehe oben 221) für die nordamerikanischen Ameisen das Bauen von "Haufen" als eine Seltenheit hinstellt, weist Verf. darauf hin, dass diese Ansicht einer Modifikation bedarf, indem wenigstens in Wisconsin "Ameisenhaufen" gar nicht so selten 
vorkommen. Es gibt dort sogar mehrere Formica-Arten, welche normalerweise "Haufen" errichten, nämlich $F$. obsentipes und exsectoides. Allerdings sinil diese Haufen nur unbedeutend zu nennen im Verhältnis zu den Bauten der europäischen Ameisen; denn die „Haufen" von obscuripes erreichen höchstens eine Hölıe ron $40 \mathrm{~cm}$ und die von exsectoides sind noch niedriger, wälırend die europäischen Ameisenhaufen $1 \mathrm{~m}$ und noch höher werden können. - Andere Formica-Arten, wie daliotensis und rubirmala, bauen nnr selten; wieder andere, wie pergandei, nitidientris usw., bauen niemals "Haufen", sondern legen ilire Nester unter Steinen usw. an. - Sind nun auch die oberirdischen Banten der amerikanischen Formica-Arten im Verhältnis zu denen der europäischen recht unansehnlich, so sind die unterirdischen Anlagen um so gewaltiger. So fand der Verf. in einer Tiefe von $1,25 \mathrm{~m}$ noch ein f von $F$. rubicunde; und das Nest ron $F$. exsectoides scheint $2 m$ oder noch tiefer in die Fide zu gehen.

Dass in Wisconsin die Formica laäufiger Haufen bauen als in den von Forel bereisten siidlichern (regenden (Nord-Carolina) hängt zweifellos mit dem dort herrschenden gemäBigteren Kilima zusammen, und Verf. sieht daher in seinen Beobachtungen nur eine Bestätigung von Forels "theory of domes" (vgl. oben Forel 221). - Die andere von Forel l. c. ansgesprochene Ansicht, dass die Ameisen lieber auf ()st-Abhängen leben, fand $\mathrm{Huckermann}$ dagegen nicht bestätigt in Wisconsin, sondern er traf vielmehr auf den Ost- wie auf den Westabhängen Ameisen gleich zahlreich an.

Ebenfalls von dem Nestbau der Ameisen handelt die kurze Mitteilung von $\mathrm{Ou}$ de mans (274). Er beschreibt ein Nest von Lasius futiginosus, welches insofern interessant ist, als es in dem Strohdach eines dunklen Eiskellers angelegt und aus einem ganz ungewohnten Material, nämlich aus Torf, gebaut war. Dasselbe hatte infolgedessen auch eine schwarzbraune Farbe; in der Form glich es einem riesigen Schwamm, was auch die beigegebene Abbildung recht gut reranschaulicht.

Reichenbach (275) macht sehr interessante Mitteilungen über Parthenogenese bei Lasius niger. Er setzte im Frühjahr 1899 elf Arbeiter der genannten Ameise in ein kïnstliches Nest, und diese vermehrten sich derart, dass die Kolonie schon nach anderthalb Jahren etwa 200 Mitglieder aufwies. Und nicht nur ihresgleichen erzeugten die Arbeiter auf parthenogenetischem Wege, sondern es kamen auch Männchen zum Vorschein und zwar nur zur normalen Lasius-Schwärmzeit, also im Juli. - Weibchen dagegen sind trotz des raschen Aufblühens der Kolonie und der opulenten Fütterung 
keine entstanden. Die Frage, ob nach dem Auftreten der Männchen vielleicht eine Befruchtung der Arbeiter stattgefunden, lässt Verf. unentschieden, obwohl er die Möglichkeit einer solchen Begattung keineswegs für durchaus ausgeschlossen hält. - Im Anschluss an diese wichtigen Beobachtungen erzählt Verf. noch einige Beispiele aus dem Ameisenleben, welche dartun, dass die Ameisen nicht blind automatisch und reflektorisch handeln, sondern dass ilınen die Fähigkeit zukomme, auf Grund von gemachten Erfahrungen ihre Handlungen zu modifizieren. Nur so sei z. B. die mehrfach vom V'erf. gemachte Beobachtung zu erklären, lass die $F$. firsca-Arbeiter nicht mehr aus ilırem Nest herauskommen, sobald sie alle polyergus-Puppen eingetragen haben. - Sie müssen also ein Gedächtnis besitzen, welches ihnen sagt, dass draussen keine P'uppen mehr zu holen seien (vgl. auch oben Wasmann 259 und fiorel 238).

Über "Ameisenpsychologie" landelt auch die erste der oben citierten Nitteilungen Muckermanns (27•2). Verf. macht darin auf den gewaltigen Liontrast aufmerksam, der in der grossen Kriegstüchtigkeit der Amazonen und deren Unfähigkeit, selbständig Nahrung zu sich zu nehmen, gelegen ist; derselbe spricht ganz entschieden gegen das Torhandensein ron wahrer Intelligenz bei diesen Ameisen.

Sternanders Werk (276) über die Verbreitung der Ptlanzen wendet sich zwar in erster Linie an den Botaniker; doch dürfte dasselbe auch für den Myrmekologen einiges Interesse darbieten, insofern ein ziemlich umfangreiches Kapitel den Ameisen als V'erbreitern von PHanzensamen gewidmet ist. Es geht daraus hervor, dass die Ameisen durchaus keine geringe Rolle in der Verbreitungsbiologie der Pflanzen spielen. Verf. teilt alle die Samen und Früchte mit, die nach seinen mehrjährigen Beobachtungen von verschiedenen Ameisen transportiert worden sind. Auch eine Anzahl Experimente stellte Verf. an, die zeigen sollten, welche Samen ron den Ameisen transportiert werden, und welche Organisationserscheinungen der Samen (Anlockungsorgane) deren Aufsuchen bedingen. Je nach dem morphologischen Platz der Anlockungsorgane, d. h. ob letztere an dem Samen oder der Frucht, oder an der Blütenachse, oder ausserhalb der Bliite usw. sitzen, unterscheidet V'erf. vier Typen von myrmecophilen Synzoen. Die Anlockungsmittel bestehen meistens in ölführenden Anlängseln, Wülsten usw. Bezüglich der zahlreichen Einzelheiten sei auf das OriginalWerk, das mit einem deutschen Resumé versehen ist, verwiesen.

Endlich sollen noch zwei Arbeiten Wheelers $(277,278)$ besprochen werden, welche ganz kürzlich erst erschienen sind. - In der ersten Arbeit (277) beschreibt der amerikanische Myrmekologe 
eine neue Ameise (Erebonngrmu longi) aus l'exas, welche zu den Myrmicinen und zwar den Solenopsidii gehört, aber ron all den bisher bekannten Formen dieses Tribus so sehr ahweicht, dass eine neue Gattung aufgestellt werden musste. - Der Unterschied zwischen den Arbeitern und den Geschlechtstieren dieser nenen Art ist ganz enorm, und es verhält sich das Volumen des Arbeiters zu dem des $q$ etwa wie $1: 150$. - Die Arbeiter sind ferner fast blind, während die 00 und $q$ grut entwickelte Augen haben; endlich sind die erstern ganz blass gefärbt im Gegensatz zu den dunkler gefärbten Geschlechtstieren. Alle diese Momente lassen darauf schliessen, dass die neue Art eine wrösstenteils unterirdische Lebensweise führt und dass sie ferner rom liaub oder Diebstall anderer Ameisen oder 'Termiten lebt, denn sonst könnten die winzigen Arbeiter wohł kaum die vielen, enorm grossen Männchen und Weibchen aufziehen. Nach den Mitteilungen des Entdeckers I, ong scheint sie in der Tat lestobiotisch bei Termiten zu leben, was ja schon früher fïr verschiedene Solenopis-Arten festgestellt worden ist (rgl. oben Wasmann 259).

In der zweiten Arbeit (27 $s$ ) macht Wheeler im Verein nit II Clendon auf einen von ihnen mehrfach beobachteten I) imorphismus bei den $q$ v on Lasius latipes aufmerksam. Es fanden sich in verschiedenen Nestern an mehrern weit roneinander entfernten Lokalitiaten zwei Sorten ron $q \neq$, welche als $\alpha$ - $q$ 11. $\beta$ - $q$ bezeichnet werden. Die letztern, welche bisher allein als die $q\}$ von L. lutipes bekannt waren, zeichnen sich durch auffallend verbreiterte Beine besonders aus; die $\alpha$-q dagegen besitzen ganz normale Beine und unterscheiden sich ausserdem noch durch dunklere Färbung, dünnere Behaarung, schlankere Fühler u. s. w. von den $\beta$ - f. - Ein Vergleich mit den $q$ des nächstrerwandten L. dariger ergibt, dass das $\alpha$ - des latipes gewissermafen eine /wischenform zwischen ersterm und dem latipes $\beta=$ darstellt.

Bezüglich der Frage, wie dieser Dimorphismus zu deuten ist, sind vier Möglichkeiten zu berücksichtigen: entweder gehören die $\alpha$ - und $\beta$-Weibchen wirklich zwei verschiedenen Arten an, welche in einer Kolonie zusammenleben, oder 2. stellen die $\beta$-Weibchen krankhafte Formen dar (Elephantiasis, Acromegalie!) ; oder 3. ist der Dimorphisnus auf Kreuzungen zwischen latipes und dariger zuriickzuführen; oder endlich $t$. handelt es sich um einen wahren Dimorphismus. Die Verfasser halten letzteres für am wahrscheinlichsten. „Warum sollten wir nicht erwarten, dass anch unter den geflügelten of ein Dimorphismus vorkomnt, nachdem der Dimorphismus doch einmal im Blut der sozialen Hymenopteren liegt?.. . . Und warum 
sollte nicht L. latipes eine solche Art sein, bei welcher diese alte und tief eingewurzelte Tendenz in neuer Form zutage tritt?" Beistehendes Schema soll die immer weiter gehende Differenzierung veranschaulichen:

Ur-Weibchen

Steriles Weibchen (Arbeiter)

Kleiner Arbeiter Grosser Arbeiter

(Soldat)
Fruchtbares Weibchen (Königin)

$\alpha$-Weibchen $\overline{\beta \text {-Weibchen. }}$

Die Verf. erblicken in der Spaltung in $\alpha$ - und $\beta$-Weibchen eine liepetition des Vorgangs, welcher zur Differenzierung des ursprünglichen, gettügelten Weibchens in Königin und Arbeiter geführt habe. Sie wenden sich bei dieser Gelegenheit auch gegen die Ansicht Emerys, wonach die ursprünglichen Ameisenweibchen als ungeflügelt anzusehen seien, und die jetzigen geflügelten $q$ ihre Fliigel zum zweitenmal wiedererworben haben sollten. Eine solche Anschaung sei aus verschiedenen Grïnden unhaltbar und es sei jedenfalls viel richtiger, die Weibchen der Urameisen als geflügelt anzunehmen.

\section{Referate.}

\section{Faunistik und Tiergeographie.}

279 Kobelt, W., Die Verbreitung der Tierwelt. Lief. 9-12.1) Leipzig (Chr. H. Tauchnitz) 1902. gr. 80. pag. 419-576.

In den vorliegenden Schlusslieferungen des Gesamtwerkes führt Verf. uns eine Reihe rein biologischer krscheinungen vor Augen, zunächst den Winterschlaf und das Vorratsammeln der Tiere. In näherem Zusammenhange steht dieses Kapitel insofern mit der vorangehendén rein tiergeographischen Darstellung, als in derselben nur die gemäßigte Zone berücksichtigt wurde, und für die Bewohner derselben diese Erscheinungen als Mittel, dem Hunger und der Kälte zu entgehen, eine besonders hohe Bedeutung besitzen. Während die meisten Wirbellosen sowie riele Kaltbliiter sich im Winter in frostfreie Tiefen oder Schlupfwinkel zurückziehen und hier in einer Art von Erstarrungszustand verharren, suchen die Warmblïter auf andere Weise den Unbilden der kalten Jahreszeit standzuhalten. Kobelt

1) Vgl. Zool. Zentr.-Bl. IX. Jahrg. Nr. 304. pag. 307.

- Nr. 214-279. - 
unterscheidet in dieser Hinsicht vier verschiedene Gruppen, die indessen nicht scharf voneinander zu scheiden sind; die einen haben sich dem Winter völlig angepasst und trotzen demselben ohne besondere Vorkehrungen (Wiederkïuer, Hase), eine zweite Gruppe verschläft ihn (Bär, Dachs, Igel, Flerlermans), eine dritte sammelt sich Vorräte ein (Aricola oeconomus, Cricetus imlgaris, Arctomys marmotta usw.) und eine vierte endlich weicht dem Winter gänzlich aus durch einen Wechsel des Aufenthaltsortes. Auch eine ganze Reihe von Vögeln gibt es, die sich Futtervorräte für den Winter anhäufen; Verf. schliesst hieran eine interessante Erörterung der Beobachtungen, die für einen Winterschlaf von Vögeln (namentlich von Schwalben) in ursern Breiten zu spreclien scheinen.

Die eben erwähnte vierte Tiergruppe, welche dem Winter völlig ausweicht, führt Verf. über zu einer ausführlichen Besprechung der Tierwanderungen. Sorge wul die Nahrung und Sorge um das Wohl der Nachkommenschaft sind die beiden Hauptfaktoren, welche das Wandern der Tiere veranlassen. Es wird näher auf die verschiedenen Arten des Wanderns (Streichen, eigentliches Wandern, Yug) eingegangen, es werden ferner die Fälle aufgezählt, wo säugetiere diese Erscheinungen aufweisen, und sodann ein besonders weiter Raum der Darstellung des Vogelzuges gewidmet. Seine Erklärungsversuche, die Methoden zu seiner planmäBigen Beobachtung werden auseinandergesetzt, die bisher bekannten Hauptstrassen in Eurasien und Nordamerika näher geschildert und endlich eine Reihe von Spezialfragen des Vogelzuges, auf die im einzelnen hier nicht eingegangen werden kann, ausführlich besprochen. Neben dem Vogelzuge verdienen die Wanderungen niederer Tiere, namentlich der Insekten, besonderes Interesse. Solche wurden wiederholt beobachtet bei Wanderheuschrecken, Käfern, Schmetterlingen, Libellen (Fliegen! Ref.), auch sie finden unter besonderer Berücksichtigung der mannigfachen und zum 'Teil noch recht wenig aufgeklärten Ursaclien eine eingehende Würdigung. Ein letztes Kapitel dieses Abschnittes endlich behandelt die Wanderungen unserer Süsswasserfische, veranlasst hauptsächlich durch die Fürsorge für die Tachkommenschaft. Salmo salar und Alosa vulyaris steigen aus dem Meere in die Flüsse empor, den umgekehrten Weg nimmt Anguilla vulgaris, er wandert abwärts ins Meer, um hier zu laichen, während die junge Brut von neuem in die Flüsse zurückkehrt.

Einige rein biologische Kapitel über giftige Tierformen sowie über Höhlentiere bilden in einem Anhange vereinigt den Schluss des ganzen Werkes. Von giftigen Tieren kommen für die gemäßigte Zone in erster Linie die Schlangen in Betracht, von denen Deutscl- 
land drei Arten beherbergt, nämlich. Vivera ammodytes L., aspi. L. und berws L. In südlichern Gegenden und im Osten treten einige weitere Tipera-Arten hinzu, ferner die Cattung Cerastes, die NajaArten, Echis carinatu und Trigonocephutus. Die Wirkung des Schlangengiftes wird einer eingehenden Besprechung unterworfen. Z/u den giftigen Tieren sind weiter einzelne Skorpione Nordafrikas zn rechnen, übertrieben sind dagegen die meisten Angaben über sog. giftige Spinnen, allein Lathrodectes tredecimunttatus Rossi in Südr'ussland und der Kirgisensteppe ist als wirlich gefährlich zu be\%eichnen.

Ein letztes Kapitel endlich behandelt die Biologie der Höhlentiere, im wesentlichen im Anschluss an die Darstellungen Hamanns und einiger anderer Autoren. Näher geschildert wird das Leben des Protens anguimu. liervorgehoben werden die zilhlreichen echt troglobiiden Fische Nordamerikas (Amblyopsis, Typhlichthys, Chologaster, Lucifingu) und hingewiesen wird schliesslich auf die bedeutsame Rolle, welche speziell die Mollusken und Arthropoden (Ĺrebse, Spinnen, Tausendfüsse, Insekten) unter den Höhlenbewohnern spielen.

Wir sehen, dass dieser zweite Hauptabschnitt des vorliegenden Buches sich im wesentlichen mit biologischen Fragen beschäftigt, die mit der rein tiergeographischen Darstellung des ersten Abschnittes nur in einem mehr oder minder losen Zusammenhange stehen. Ihre Berechtigung finden diese biologischen Ausfiihrungen ror allem darin, das: das Buch fiir einen weiteren Leserkreis bestimmt ist, dem so eine wesentliche Ergänzung der Äusserungen des Tierlebens innerhalb der genüBigten Zone geboten wird.

J. M e is en he imer (Marburg).

280 Kublgatz, Th.. Torstudien über die Fauna des Betula nanaHochmoores im ('ulmer Kreise in Westpreussen. In: Naturwiss. Wochenschr. N. F. Bd. I. Nr. 52. 1902. pag. 613-619. 亏े Abildungen in Text.

Verf. stellte sich die Aufgabe, ein kleines Hochmoor Westpreussens, in welchem sich die Zwergbirke (Betula numa) als nordische Reliktenform noch in einem kleinen Bestande erhalten hat, faunistisch und biologisch zu untersuchen. Nach einer Darlegung der angewandten Fangmethoden hebt Verf. die auffallende Armut an Tieren hervor; es waren im wesentlichen nur Collembolen und Psociden reicher vertreten, erstere unter der Moosdecke des Moores, letztere auf der Zwergbirke selbst lebend. Aphiden fehlten vollständig, während von Cocuiden eine grössere Zahl erbeutet wurde. Auf den ron Wollgras bestandenen festeren Stellen des Moores fanden Ayalena 
Tabyrinthica, Ameisen sowie eine ganze Reihe anderer luseliten zusagende Existenzbedingungen.

J. Me isenheimer (Marburg).

281 Preble, Elward A., A biological investigation of the Hudson Bay region. North American Famna Nr. 22. Washington 1902. 140 pag. 14 Taf.

Die Abhandlung enthält die Ergebnisse einer zur famnistischen Untersuchung der Hudson-Bai-Länder unternommenen Expedition, eines Gebietes, dessen Erforschung im letaten Jahrhundert gegenüher den ïbrigen Teilen Nordamerikas stark vernachlïssigt worden war. Verf. brach im Juni ron Wimnipeg auf, durehunerte zunächst den Winnipeg-See seiner ganzen Ausdehnung nach, fulı damn mit einem Boot auf einem System kleiner Fliisse und Seen nordwärts bis zur York Factory an der Kü̈ste der Hudson-Bai und von hier mittels Segelbootes der Westliïste der Bai entlang bis Fort Churchill, ron wo noch ein Abstecher in das Gebiet der Barren Grounds unternommen wurde. Mitte August wurde die Heimreise anf dem gleichen Wege angetreten.

An diese kurze Beschreibung der Reiseronte schliesst Verf. eine genanere Schilderung des durchzogenen Landes in topographischer wie floristischer Finsicht unter lieifügung zahlreicher charakteristischer Photographien an und geht schliesslich etwas näher anf die Lebensbezirke des Gebietes ein. In den Bezirken von Winnipeg herrschen zwar in Flora wie Fauna canadische Elemente bereits ver, indessen ist das Gebiet als eine Art Clhergangsgebiet anzusehen, insofern ron südlichen Formen hier noch Querens macrocarpa. Acer neyzmdo und Utmus americams, weiter die Spitzmaus Blarina brericanda, sowie unter den Vögeh Zenaintura macroura und Icterus gallula vorkommen. Am Nordende des Wimnipeg-Sees sind diese Formen verschwmden und die Fauna ist rein canadisch geworden, wie das Auftreten von Mustela pemanti und americana, von Lynx canadensis, ron Parts. hudsonicus, Canachites canadensis usw. beweist. Noch weiter im Norden werden die canadischen Formen schliesslich durch hudsonische verdrängt, während zugleich zahlreiche südliche Bïume und Sträucher hier die Nordgrenze ihrer Verbreitung erreichen. Nördlich ron York Factory beginnen allmählich tundrenartige Gebiete aufzutreten und mit ilmen arktische Pflanzen- und Tierformen rorzuherrschen. Hier brïten Lagoms lagoms, Numenius hudsonicus, Limosa haemasticn, Plataropus Tobatus, Calcarius lapponicus, hier leben Tulpes Tagopus immitus, Dicrostmyx richardsoni (Lemming), und noch weiter im Norden Rangifer arrticus und Orithes moschatus.

An diese Darstellnng allgemeinerer Natur schliesst sich ein zweiter 
spezieller Abschnitt an, der neben einer ausfülırlichen Literaturzusammenstellung über das durchreiste Gebiet eine sorgfältige Aufzählung der Säugetiere, Vögel und Batrachier der canadischen Provinz Keewatin, in deren Gebiet die ganze Reiseroute gelegen war, nebst Angabe der Fundorte und biologischer Eigentümlichkeiten enthält.

J. Meis en lieimer (Narburg).

282 Thilenius, G., Ergebuisse einer Reise durch Oceanien. In: Zool. Jahrb. Abth. für Syst. etc. Bd. 17. Heft 3. 1903. pag. 425 $-4+3$.

Verf. gibt eine kurze Darlegung seiner auf einer Reise nach Neuseeland gemachten Erfahrungen. Einige allgemeine Bemerkungen betreffen zunäclıst den umgestaltenden Einfluss der Kultur auf die Zusammensetzung der Tierwelt der ozeanischen Inseln. Ausrottung und Auflösung der Wälder, Anlegung von Weide- und Kulturland, Verfolgung von seiten des Menschen und der eingeführten Raubtiere sind die hauptsächliclısten Faktoren, welche zur Vernichtung früher zalulreicher und weit rerbreiteter Formen führen können. Von speziellen Beobachtungen sei hervorgehoben, dass Hatteria, welcher in erster Linie die Reise galt, nur noch auf einigen abseits gelegenen unbewohnten Felseninselchen an der Kïiste von Neuseeland rorkommt, zusammenlebend mit Kolonien ron Seerögeln. Weiter erstreckte sich die Tätigkeit des Verfs. auf das Sammeln der Meeresfauna bestimmter Gebiete, sowie auf das Anlegen einer Vogelsammlung der Salomoninseln und Neuhebriden. Am Schlusse findet sich eine ausführliche Erörterung der Arbeitsmethoden auf wissensclaftlichen Reisen, der Fing- und Jagdgeräte, der photographischen Ausrüstung, der notwendigen Instrumente und Chemikalien, der жweckmäßigsten Verpackung und Versendung. J. Me is enheimer (Marburg).

z83 Weber, Max, I)er Indo-australische Archipel und die Geschichte seiner Tierwelt. Jena (G. Fischer). 1902. gr. 8. t6 pas. 1 Karte. Mlk. 1.-.

Nach einem kurzen geschichtlichen Abriss der tiergeographischen Durchforsclung des indo-australischen Archipels prüft Verf. in diesem zusammenfassenden Aufsatze, dem ein auf der letzten Naturforscherversammlung in Karlsbad gehaltener Vortrag zu grunde liegt, zunächst die Arbeitsmethode, deren sich der Zoogeograph zu bedienen hat. Drei Aufgaben treten an ihn heran, einmal die ozeanographische Untersuchung der Meerestiefen des betreffenden Gebietes, sodann die Erforschung seiner geologischen Vergangenheit und endlich das Studium seiner Fauna, wobei in gleicher Weise Landtiere, Süsswasser- und Meeresfauna Berücksichtigung finden müssen. 
In Anwendung dieser Methoden lehrt uns nun zunächst die Geologie, dass im Jura ein ansgedehntes, tiefes Meeresbecken das ganze Gebiet bedeckte, dass während der Kreidezeit, gefördert durch starke vulkanische Erscheinungen, die ersten Erhebungen über den Meeresspiegel stattfanden, und dass weiter im Tertiär die Tätigkeit dieser unterirdischen Kräfte noch zunahm und so neben ausgedehnten Landstrecken zugleich die tiefen Einsturzbecken entstehen liess, welche noch heute für den Archipel charakteristisch sind. Die Ozeanographie gestattet uns sodann einige genetisch eng zusammengehörige, grössere Bezirke schärfer zu uugrenzen. So liegen Sumatra, Java, Borneo und Bali auf einem submarinen Plateau von noch nicht $100 \mathrm{~m}$ Tiefe, und eine direlite Fortsetzung dieses Komplexes bildet die Inselreihe der kleinen Sundainseln ron Lombok bis Wetter. Fs besteht also auch keine bodenplastische Grenzlinie zwischen Bali und Lombok (Wallacesche Linie), keine tiefe Spalte trennt beide Inseln, sondern sie sind durch einen mäbig tiefen Rïcken miteinander verbunden, wie die Messungen der Siboga-Expedition nachwiesen. Einen abgeschlossenen, besondern Komplex bildet dagegen Timor mit den umliegenden Inseln.

Am tiefsten in die Vergangenheit des Archipels einzudringen gestattet uns indessen das Studium der Verbreitung seiner 'Tierwelt, ron der Verf. die Säugetiere als die nach ihren rezenten wie fossilen Vertretern am besten bekannte Gruppe roranstellt. Im östlicben Teile finden wir vorwiegend australische Sänger vor, im Westen asiatische und selbst eurasiatische Typen. Die Trennungshinie zieht durch die Molukkenstrasse nach Süclen, verläuft also in dem breiten C̈bergangsstreifen, in welchem die Grenzlinien der verschiedensten Tiergruppen sich kreuzen, und welche Celebes, die kleinen Sunda-Inseln nnd die Molukken umfasst. Das Schicksal der verschiedenen Inselkomplexe war nun im einzelnen ein recht mannigfaches. Die auf einem submarinen Plateau gelegenen drei grossen Sunda-Insehn waren als zusammenhängende Landmasse ursprünglich dem asiatischen Kontinente angeschlossen, von 176 Säugetieren kommen 68 auf dem benachbarten Festlande vor, während die übrigen grösstenteils durch nahe verwandte Arten vertreten sind. Das gleiclie Verhalten weisen Saurier und Süsswasserfische auf. Im einzelnen scheint Java sich zuerst losgelöst z!! liaben, blieb aber länger mit Sumatra in Zusammenhang als mit Borneo, am spätesten wurde Sumatra isoliert. Borneo erhielt ausserdem Bestandteile seiner Fauna aus dem Norden von Suidchina und den Philippinen. Diese asiatische Fauna der grossen Sunda-Inseln ging nach Norden hin auf die Palawan-Inseln über, verteilte sich weiter im Süden von Java aus ïber die kleinen Sunda- 
Inseln, wobei die Bali-Lombolistrasse weder für die Säugetiere, noch für die Cyprinoiden, die Weber auch auf Lcmbok nachwies, noch für die Land- nnd Süsswassermollusken ein Hindernis darbot. Diese Strasse ist nur insofern ron Bedeutung, als sie einen der ältesten Durchbriiche dieser Inselkette darstellt. Im allgemeinen ist die Fauna der kleinen sunda-Inseln infolge des jugendlichen Alters der ganzen Gruppe eine ärmliche zu nennen, neben javanischen Formen finden sich hauptsächlich noch Einwanderer ron Celebes ans ror, wie P. und F. Sarasin znerst nachwiesen. Auch die Geschichte der Insel Celebes rerdanken wir in eingehender Darstellung den letztgenamnten Forschern; Weber schliesst sich in wesentlichen ihren Ergebnissen an und betont nur stärker, im Gegensatz zu ihnen, den spezifisch asiatischen (harakter der Fauna dieser Insel, die er schon früher als eine .. verarmte indische Fauna" bezeichnet hatte.

Die Betrachtung der australischen Bestandteile des Archipels, die auf den kleinen sunda-In-eln und C'elebes schon vereinzelt auftreten (Phalanger) und mit der Annäherung an Neu-Guinea, welches bereits 39 Beuteltierarten besitzt, schnell an Kahl zunehmen, führt Verf. zunächst zu einer kurzen Erörterung der Entstehung der australischen Fauna überhaupt. Die Annalıme ciner Antarktis scheint ihm zu einer Ableitung derselben überfliissig, ja störend zu sein; für ihn sind die Wonotremen stark spezialisierte lielikten der mesozoischen Tierwelt, wïhrend die Benteltiere sich ïber eine vortertiäre asiatisch-australische Landmasse ron Eurasien über Australien verbreiteten und hier unter starken Anpassungen eine hohe Stufe ihrer Ausbildung erreichten. Bei dieser Annahme ist dann die Frage nur äusserst schwierig zu entscheiden, ob die australischen Formen des Archipels Relikten der alten zugewanderten Fauna sind, oder ob sie umgekehrt rezente Einwanderer aus Australien darstellen. Soviel ist jedenfalls al, sicher anzunehmen, dass Neu-Guinea einschliesslich der Arn- und Kei-Inseln in tertiärer Zeit mit Australien eine einheitliche Landmasse bildete, die zeitweise selbst bis zu den Molukken hinuiberreichte. Die erstern sind mithin dem australischen Faunengebiete zmzurechnen, während die eigentlichen Molnkken mit der C'eram-Gruppe eine Mischfauna australischer und asiatischer Formen beherbergen. Zum Schlusse fasst Weber seine Ergebnisse liurz folgendermaßen zusammen: In vortertiärer Zeit verband eine zusammenhängende, von eurasiatischen Formen bewohnte Landmasse Asien und Australien, erst im Eocän fand eine Zerstücklung statt, welche im Südosten ein einheitliches Gebiet, dass hentige Australien und Neu-Guinea, bestehen liess, im Norden ein seichtes Korallenmeer mit eingestreuten Inselkomplexen schuf. Dort entwickelten sich Monotremen, Beutel- 
tiere, Paradiesvögel und Kasuare, hier erhielten sich in spärlicher Zahl primitive Nager, Inselitivoren und rerwandte Formen. Im Miocän entstanden die tiefen Einsturzbecken, tauchte Celebes empor und erhob sich im Westen die Landverbindung mit dem asiatischen Festlande über den Meeresspiegel, so dass nummehr von neuem eurasiatischen Formen ein Zugang nach dem Osten lin offen stand. Veränderungen während des Pleistocäns endlich führten allmählich den heutigen Zustand des Archipels herbei, welcher somit tiergeographisch in drei Bezirke zu zerlegen ist, ein asiatisches Faunengebiet im Westen, ein australisches im Osten und ein Übergangsgebiet in der Mitte, das nach Osten hin an asiatischen Formen stetig ärmer, an australischen reicher wird.

J. M e is enheimer (Narburg).

4 Brehm, V.,Zusammensetzung, Verteilung und Periodicität des Zooplanktons im Achensee. In: Zeitschr. d. Ferdinandeums. III. Folge. Heft 46. Innsbruck 1902. 63 pag. 1 Karte. 6 Kurventafeln und 15 Abbildungen.

Verf. will durch seine Arbeit neues Vergleichsmaterial gewinnen, das zur allseitigen Würdigmng der vielfachen, in bezug auf das Süsswasserplankton sich erhebenden Fragen dienen könnte. Er zeigt durch das gut gewählte Beispiel des Achensees, wie die Planktonrerhältnisse unter dem Druck lokaler und temporaler Verhältnisse sich von Or't zu Or't verschieden gestalten und mit welcher Vorsicht deshalb gerade in diesem Gebiet bei der Aufstellung allgemeiner Gesetze vorgegangen werden müsse.

Der in den nördlichen Katkalpen $930 \mathrm{~m}$ über Meer liegende Achensee wird von $2000 \mathrm{~m}$ hohen Bergen umrahmt: er erreicht eine Maximaltiefe ron $138 \mathrm{~m}$, seine littorale Flora und Fauna entwickelt sich nur mäfig. Auch die pelagische Tierwelt zählt relativ wenig Arten, so dass ihr Bild übersichtlich bleibt.

In Betracht fallen vor allem: Asplanchna priodonta, Polyarthra platyptera, Anmaea cochlearis, Notholca longispina, Daphnin hyalina, Bosmina coregoni. Cyclops strenums. Ceratium hirmedinella und Peridinim spec. Dagegen fehlen die für alpine Seen so typischen Vertreter von Diaptomus und Triarthra und die weit verbreiteten Genera Bythotrephes und Leptodora. Die letzgenannten Polyphemiden bewohnen den vom Achensee durch keine Schranken getrennten Tegernsee. Ihr passiver Transport ron Gewässer zu Gewässer scheint sich aber nicht so leicht zu vollziehen, wie gewöhnlich angenommen wird.

Nach den gebräuchlichen Methoden - Fang mit dem Apsteinnetz, Stufenfänge in Intervallen von drei bis vier Wochen, Bestimmung des Rohvolumens, Zählung, Durchsichtigkeitsbestimmungen -

Zoolog. Zentralbl. X. Jahrg.

- Nr. $283-284$. 
wurde Aufschluss über die temporale Verteilung und vertikale Verbreitung des Planlitons und seiner Komponenten gesucht. Es ergibt sich im allgemeinen, dass sich der Achensee in mancher Beziehung biologisch wie ein hochalpines Wasserbecken verhält. Vorgänge, die sich im Plankiton der Seen des Flachlandes in Sommer einstellen, verschieben sich in dem untersuchten Tiroler Gewässer in den Herbst, solche, die in der Ebene den Monat Dezember charakterisieren, spielen sich in Bergsee gegen das Frühjahr ab.

Aus der Fülle der sorgfältig zusammengestellten Beobachtungen über das temporale Auftreten der pelagischen Organismen rerdient Beachtung, dass Daphnia hyalina im Achensee und Lanser Hoor ( $850 \mathrm{~m}$ ) bei Innsbruck sich im Norember und Dezember zweigeschlechtig fortpflanzt und Dauereier bildet, während dieselbe Art im Vierwaldstiadtersee in parthenogenetischer Generationenfolge perenniert. Im Bereich der ()stalpen und der benachbarten Gebiete (Iodensee) scheint sich I). hyalinu mehr der Dauereibildung zuzuneigen, im Westen dagegen sich melır parthenogenetisch fortzuptlanzen. Bosmina coregoni erzengt im Achensee keine Dauereier. Cyclops stremus schiebt sich in seinem Jahrescyklus rerbindend zwischen das Verhalten seiner Artgenossen der Ebene und der hochalpinen Gewässer ein.

Er erreicht im Acliensee zwei Vertretnngsmaxima im Juni und in September-(Oktober; in der Ebene liegen die beiden Maxima weit auseinander, das eine fällt in den Winter; hochalpin schieben sich beide zu einem einzigen Sommermaximum zusammen.

Als Leitform für die Wintermonate hat im Plankton des Achensees Perillinimm zu gelten, es tritt an die Stelle ron Ceratium, ohne dasselbe indessen ganz zu rerdrängen.

Deutlich konnte Verf. die nächtliche Planktonwanderung feststellen; er schildert dieselbe für die einzelnen in Betracht kommenden Tiere und erklärt sie durch die den betreffenden Organismen eigene Lichtscheu. Diese Leukophobie betrachtet er indessen als eine sekundäre, durch Stenothermie der tierischen Planktonten bedingte Erscheinung. Das Bedürfnis nach Kälte zwingt, nach Brehm, die Planktozoen die tiefen Meeresschichten aufzusuchen; Nahrungsmangel und Gasgehalt des Seegrundes veranlasst sie ron Zeit zu Zeit an die Oberfläche emporzutauchen, und zwar benützen sie zum Aufstieg die Nachtstunden, während welchen sich die obersten Wasserschichten abkühlen. Bei dieser Lebensweise wurde den wandernden Planktontieren die Dunkelheit durch Angewöhnung zum Lebensbeduirfnis. Zur Stütze dieser Ansicht werden eine Reihe ron Beob. achtungen anderer Autoren - Fehlen der Leukophobie bei Bytho- 
trephes der nordischen Seen, Auftreten von Tiefenbewohnern am Ufer hochalpiner Wasserbecken - herbeigezogen.

Im Achensee herrscht für das Plankton eine deutliche zonare Vertikalschichtung, die sich auch im Winter nicht ausgleicht. Im Sommer wenigstens scheint sich eine tiefliegende organismenlose Schicht zu bilden.

Mit dem Ref. stimmt Brehm darin überein, dass die Rotfärbung mancher Entomostraken, besonders der Copepoden, mit der Temperaturerniedrigung in engem Zusammenhange stehen. Auch die Schmuckfarben der Cladoceren dienen keinen sexuellen Zwecken. Die roten Farbstoffe möchte brehm als Kälteschutzmittel betrachten, die Schwingungszustände des $̈$ thers verändern und so Licht in Wärme umsetzen können. Er sucht seine Hypothese durch verschiedene Parallelbeobachtungen zu stützen.

Eine temporale Variation der I'lanktozoen fehlt im Achensee, wie in andern alpinen Becken. Dies findet seine Erklärung durch die Abwesenlieit nennenswerter Temperaturschwankungen und die dadurch hervorgerufene Gleichmäbigkeit des spezifischen Wassergewichts im Jahrestauf. Alle temporale Variation der Planktozoen kann nämlich mit Wesenberg-l,und als Kompensation aufgefasst werden für die durch T'emperatnrwechsel bedingte Veränderung im spezifischen Gewicht des Süsswasser's.

Dagegen spielt die lokale Variation und die Altersvariation letztere besonders bei Daphnia hyalina und Bosmina coregoni eine grosse Rolle. Die lokale Variation lässt sich auf den Einfluss verschiedenartiger Reize zurückführen; doch ist die Zahl der Variationsrichtungen beschränkt; rerschiedenartigste Reize lösen dieselben oder älnnliche Reaktionen aus. Manches weist deutlich darauf hin, dass die Plankton-Cladoceren unserer Seen, besonders in ihren sogenannten Sommerformen, degenerierte Nachkommen nordischer Kaltwassertiere seien.

Die Männchen ron Daphnia hyatina besitzen wahrscheinlich Wert für die Systematik der hyalina-longispina-Gruppe.

$$
\text { F. Zschokke (Basel). }
$$

285 Buffa, P., Sulle condizioni fisiche obiologiche di taluni laghi alpini del Trentino. In: Atti Soc. Venet.-Trent. Sc. Nat. Serie II, Vol. 4. Fasc. 2. Padova 1902. pag. 1-32.

Verf. bespricht acht stehende Gewässer - 6 Seen, 1 Teich, 1 Sumpf - der Trientiner Alpen hauptsächlich nach ibren geographischen, hydrographischen und physikalischen Eigenschaften. Besondere Notizen finder sich über Dımensionen, Ursprung, 'Temperatur, Niveauschwankungen, Farbe und Durchsichtigkeit der Seen.

Die Beobachtungen Horistischer und faunistischer Art fasst B. in Listen zusammen, welche gleichzeitig eimen Vergleich über das Vorkommen der gesammelten 
Pflanzen und Tiere in Italien gestatten. Als neu für Italien erwiesen sich die Rotatorien Gastroschiza truncata Levander, Distyla ludwigi Eckst., Brachionus bakeri Ehrbg., Polychaetus subquadratus Perty, Notogonia ehrenbergi Perty und Notholea labis Gosse.

Zwei der untersuchten Wasserbecken, der Lago di Lagorai $1858 \mathrm{~m}$ und der Lago delle Stellune $2140 \mathrm{~m}$ liegen hochalpin. Sie beherbergen Centropyxis aculcata Stein, Cyphoderic ampulle Leidy, Polyarthra platyptera Ehrbg., Amuraea tceta Gosse, Notholca labis Gosse, N. longispina Kellicott, Daphnia longispina Leidy, Alona quadrangularis O. F. M., Canthocamptus minutus Müll. und Salmo salvclinus L. Das für Hochgebirgseen bekannte faunistische Bild erfährt somit durch die vorliegende Arbeit keine wesentliche Veränderung.

Für die einzelnen Gewässer werden die ichthyologischen Verhältnisse etwas eingelıender berücksichtigt.

Ein biologischer Unterschied zwischen limnetischer und littoraler Region liess sich nur für den Lago die Caldonazza erkemen. $\quad$ F. Zschokke (Basel).

286 Lo Bianco. S.. Lie pelagischen 'T'iefenfänge der Maja in der Nähe ron Capri. Leipzig 1902. 85 pag. 1 liarte.

Terf. berichtet über den Erfolg der auf Veraulassung von F. A. Krupp in den an Capri angrenzenden Meeresabschnitteri unternommenen Tiefenfänge. Es handelt sich hauptsächlich un 17 mit verschiedenen Netzen ausgefuihrte Ziige, die Tiefen von 500 bis $1500 \mathrm{~m}$ erreichten und ïber Zusammensetzung und vertikale Verteilung des Oberflächen- und. Tiefemplanktons im Golf von Neapel eine lüulle von neuen Aufschliissen geben. Auch biologische und systematische Resultate fehlen nicht.

Der Reichtum und die Mannigfaltigkeit des Tiefenplanktons, das sich im April bis zu $1300 \mathrm{~m}$ Tiefe nachweisen liess, erwies sich als unerwartet gross; für weitere Nachforschungen bleibt in dieser Richtung offenbar noch ein weites Feld zu bestellen übrig $\left.{ }^{1}\right)$. Die meisten Planktonten gehören auch dem atlantischen Ozean an. Dies znsammengehalten mit ähnlichen Resultaten, die Lohmann für die Appendicularien ron Messina erhielt, spricht dafür, dass die Schwelle von Gibraltar für I'lanktonverbreitung kein Hindernis bildet.

Für die lienntnis der Lebensgeschichte des Aals ist es von Interesse, dass ein $70 \mathrm{~mm}$ langes Exemplar von Leptocephalus brevirostris in bedentender 'Tiefe, neun Kilometer vom Festland entfernt, erbeutet wurde. Vier für das Mittelmeer unbekamnte Scopeliden, ścopelus rissoi Cocco, S. crocodilus Risso, Chamliodus sloamii Bl. und Cyclothone microclon Githr., lionnten für die Nähe des Golfs festgestellt werden. Die letztgenannte Form, ein typischer Tiefentisch, scheint

1) Für den Golf und die angrenzenden Meeresabschnitte waren 33 Planktontiere und 6 Grundbewohner, für das Nittelmeer 23 Planktonten und 4 benthonische Arten nen. Unter $500 \mathrm{~m}$ Tiefe setzte sich das Plankton aus 22 Species zusammen. 
besonders häufig zn sein. Fs gingen von ihr 157 Exemplare in das Netz. Sie macht eine Metamorphose durch, wïhrend welcher der Körper an Länge verliert und sich vollständig pigmentiert. Wahrscheinlich ist Cyclothone microdon mit Gonostoma demudatum in dem Simne identisch, dass das letztere ein älteres Stadium der erstgenamnten Art darstellt.

Von pelagisch fiottierenden Fischeiern verdienen besonders diejenigen ron Lepidopus candatus Euphr. and Macrurus coelorhynchus Risso Erwähnung.

Unter den Tumicaten fellten die ron Chun in benachbarten Neeresbezirken gesammelten Arten von Stegosoma und Megalocercus; häufig waren dagegen Oikopleura cophocerca, O. Tongicanda. Fol. u. a.

Die Jungen ron Sepiola rondeletii Fér. leben pelagisch, bis sie eine bestimmte, indessen noch nicht definitive Grösse erreicht haben.

Wichtige Resultate zeitigten die Fänge für die Crustaceen und besonders für die Gruppen der Decapoden, Schizopoden, Isopoden und Hyperiden.

Hänfig war der prächtige Sergestide Sergia magnifica Chun, der sich durch die ungewöhnliche Lünge der änssern Fühler anszeichnet. $\mathrm{Er}$ lebt in Tiefen ron mindestens $1000 \mathrm{~m}$. Nit ihm identisch ist s. clausii König. Zum erstenmal im Gebiet des Golfs von Neapel wurde die abyssale oder bathybische Form Pasiphaea sicado Risso beobachtet. Von Amalopenaens elegans Smith liess sich der Lebenscyklus feststellen. Die bis jetzt aus dem Golf einzig bekannten Larvenstadien leben einige Meter unter dem Wasserspiegel; später suchen die jungen Tiere die grossen Tiefen auf, welche die natiirlichen Wohnstätten der erwachsenen Exemplare bilden.

Diaphoroms spec. und Oodeopus spec. sind für das Mittelmeer neue Decapodenlarven. Die erstgenannte Form stellt das Mysisstadium von Alpheus ruber M.-Edw, dar, während die zweite wahrscheinlich dem mediterran unbekannten Genus Calocaris angehört. In den ausgeführten Zügen fehlte Chuns Myersia clavigera; sie scheint sich zu einer sehr selten erbeuteten, noch nicht näher beschriebenen Art ron Morkippolyte zu entwickeln.

Vier Schizopoden erwiesen sich für das Mittelmeer als nen. Ton ihnen war Brutomysis vogtii Chun einzig ron Madeira, Nyctiphanes norvegica Sars einzig aus dem Norden bekannt. Nyctiphanes tritt im Golf ron Neapel während des Winters und Frühjahrs oft massenhaft auf; atmosphärische Störungen scheinen den Krrebs gegen die Oberfläche zu treiben. Unbekannt für das Mittelmeer waren auch Thysanopoda obtusifions Sars und Euphansia gibba Sars. Arachnomysis lencliartii Chun, von der Chun nur das Männchen kannte, 
charakterisiert sich durch eine Reihe sexueller Unterschiede. Die Eier der weit rerbreiteten Euphausia pellucida Dana schwimmen im Winter massenhaft unter der Oberfläche; ihre Larven, rom Nauplius bis zum $10 \mathrm{~mm}$ langen jungen Tier leben fast das ganze Jahr im Küsten- und Tiefenplankton; die reifern Tiere halten sich unter $500 \mathrm{~m}$ Tiefe auf. In den tiefern Schichten geniesst auch eine Art von Nematoscelis eine weite Verbreitung.

Wie Massenfänge es beweisen, leben gewisse Schizopoden der tiefen Wasserschichten zu Scharen rereinigt.

Unter den für das mediterrane Gebiet nenen Isopoden verdienen Erwähnung Eurydice pulchra Leach. Heterophryxus appendiculatus Sars, der auf Euphuria pellucida sitzt und sonst nur von den Capverden bekannt war, Branchiophryrus myctiphanae Caullery. B. spec. von den Kiemen von Eupharsia gibba und die durchaus nicht selten auftretende Gattung Microniscus. Auf welchen Copepoden dieselbe lebt, liess sich leider nicht entscheiden.

Von 22 gefangenen Hyperiden-Arten waren 8 neu für dis Mittelmeer. Hierher zählt die rom Challenger am Kap der guten Hoffnung gefundene Hyperia momontorii Stebb., H. luzoni Stebb. aus dem stillen Ozean und Eumonö̈ mimuta aus den siidlichen Meeren. Dagegen fing Lo Bianco nie Phronimella clongata, die Chun im Tiefenplankton des Golfs häutig antraf.

Zur Ausbeute gehörten eine Menge ron Copeporden, darunter das noch unbekannte Männchen ron Euchaeta spinosa Gsbrt., einer typisch abyssalen species. Die von W. M üller pelagisch gefundenen Ostracoden wurden alle erbeutet; ilıre einzehnen Arten charakterisieren die verschiedenen Tiefenzonen. Conchoccia magna darf ziemlich sicher als abyssale Form gelten. Manche C'opepoden, wie Eucalanus elongatus, Hemicalams longicomis und Setella gracitis leben in Schwärmen. Für das Mittelmeer wurde das Vorkommen einer nur aus dem atlantischen Ozean bekannten Cirripedienlarve nachgewiesen.

Auch die gesammelten Anneliden geben Anlass zu einer Reihe ron Bemerkungen. Mehrere derselben - Pedinosoma curtum Reibisch, Haliplanes isochaeta Reibisch, Nectochaeta grimaldii Mrzll. usw. - sind in die faunistischen Listen des Mittelmeer's neu einzutragen. Nectochaeta wurde im atlantischen Ozean bei $2000 \mathrm{~m}$ Tiefe entdeckt. An den Parapodien der männlichen Exemplare von Callizonella lepirlota rar. Krohnii Apst. fand Verf. Leuchtorgane. Die typische Gattung des Tiefenplanktons Tomopteris kommt im Golf in zwei Species ror.

In bestimmten Tiefen lokalisiert leben die Chatognathen; am tiefsten scheint sich Sagitta magna aufzuhaiten. 
Im Frühjahr verbreiten sich die grossen Siphonophoren von der Fläche bis in die tiefen Schichten. Diphyes sieboldii steigt bis zu $1300 \mathrm{~m}$ hinab. Selten sind die Ctenophoren.

Aulacantha scolymantha E. H. besucht den Golf oft in sehr bedentenden Mengen; sie lebt sowohl an der Meeresfläche, als in den grö̈ssten, durchfischten Tiefen.

Ein Netzzug förderte aus $1500 \mathrm{~m}$ Tiefe 6 Grundbewohner zutage; von ihnen sind der Fauna des Nittelmeers neu zuzufügen Apsendes grossimanus Norm., Rhachotropis grimaldii Chvrx., Echiuns spec. und die amerikanische Bitoculina sphaena d'Orb.

Die gewonnenen Einzelresultate geben dem Verf. Anlass zu einigen allgemeinen Betrachtungen ïber das Plankton des Golfs von Neapel. Er trennt voneinander das OberHächen- oder Litoralplankton und das Tiefenplankton.

Das Oberflächenplankton bält sich während des ganzen Jahres an der Fläche von Küstenregion und offenem Meer auf. Es reicht bis zu einer Tiefe von 20 bis $30 \mathrm{~m}$ und ist Temperaturdifferenzen von $13^{\circ}$ bis $26^{0}$ ausgesetzt. Verf. schildert Charakter und Zusammensetzung dieser, die obersten Wasserschichten nie verlassenden, biologischen Gemeinschaft. Von grössern Tieren gehören ihr nur wenige, wie z. B. Encharis multicornis, an. Durch das Vorherrschen gewisser Species erhält das Obertiächenplankton oft monotonen Charaliter. Pelagische Larven benthonischer Littoraltiere spielen besonders im Plankton der Küstenströmungen eine nicht unbedeutende Rolle. In Jahreslauf verändert sich dic Zusammensetzung des Oberflächenplanktons unter dem Einfluss biologischer und physikalischer Ursachen.

Das Tiefenplankton, das während des ganzen Jahres im Golf in Tiefen von 50 bis $1400 \mathrm{~m}$ und bei Temperaturen von 13 bis $20^{\circ}$ getroffen werden kann, erimnert durch äquivalente Zusammensetzung an das Plankton der grossen Ozeane. Es nimmt ebenfalls zu gewissen Zeiten monotonen Charakter an.

Während manche seiner Komponenten an bestimute Tiefen gebunden erscheinen, geniessen andere eine selır bedeutende, vertikale Verteilung.

Gegen Ende Herbst, im Winter und Frühjahr mischen sich durch Strömungen herbeigeführte Bestandteile des Tiefenplanktons mit dem Oberflächenplankton der Kü̈stenregion. Die dem kühlen, gleichmäßig temperierten, ruhigen Wasser der tiefen Wasserschichten angepassten Tiere erliegen dem Wechsel der Existenzbedingungen und gehen am Ufer zu grunde. Nur Tiere wie die autopelagische Encharis multicornis, die sich mit ihrem ungemein elastischen Körper den Bewe- 
gur,gen des Oberflächenwassers gewissermaßen anschmiegt, vermögen sich in Kïstennähe zu halten.

Das Phänomen der Vertikalwanderungen des Plankitons möchte Verf. zum grössten 'Teil als passive Erscheinung; zu der die durch physikalische Verhältnisse hervorgerufenen 'Tiefenströmungen Anlass geben, erklären. Er zeigt die Bedeutung der im Golf ron Neapel herrschenden Strömungsverhältnisse für die Planktonverteilung; Ströme, die Tiere an die Oberfläche emporbringen. mögen sich in jenem Meeresabschnitt bis zu etwa $1000 \mathrm{~m}$ erstrecken. Auch durch Beobachtungen in anderen Gebieten sucht Lo Bianco die Hypothese der passiven Migration zu stützen. Immerhin nimmt er, sich Chun anschliessend, an, dass auch biologische Bediurfnisse die Vertikalwanderung des Planktons bis zu einem gewissen Grad bedingen können.

$$
\text { F. Zschokke (Basel). }
$$

287 Zacharias, (). Zur biologischen Charakteristik des Schwarzees bei Kitzbühel in Tirol. In: Biolog. Centralbl. Bd. 22. 1902. pag. 701-703.

Aus dem Verzeichnis der Planktonorganismen (Rotatorien, Crustaceen und Flagellaten) des kleinen, alpinen Sees bei Kitzbüllel ist das limnetisch selten vorkommende Ccratium macroccos Ehrbg. hervorzulieben. Seine Gegenwart scheint sich auf alpine oder subalpine Wasserbecken zu beschränken, die es, wio z. B. auch den Schwarzsee, in Gesellschaft von C. hirundinella bevölkert. In dem Gewässer bei Kitzbïhel tritt als typische Schwebeform das dem Plankton sonst selten angehörende Infusor Trachelophyllum apiculatum auf. Es wird von einer dicken Gallerthülle umschlossen.

Pflanzliches Plankton belebte den See nur in geringer Nenge.

F. Z schokke (Basel).

288 Zaclarias. (). Mitteilungen über das Plankton des Achensees in Tirol. In: Biolog. Centralbl. Bd. 23. 1903. pag. 162-167.

Als Ergänzung zu den Darstellungen Brehms über das Plankton des Achensees (vgl. Nr. 284) führt Z acharias an, dass das genannte alpine Seebecken pelagisch weiter beherberge: Dinolryon sertularia Ehrbg., Anurctea aculeata Ehrbg., Anapus testudo Lauterb., Hastigocerca spec. und das Heliozoon Acanthocystis lemani Pénard. Die Gattung I'eridinium findet einen neuen Vertreter in P. alscissum n. sp. Zacharias möchte die Bosmina aus dem Achensee am ehesten zur B. corcgoni var. lariana $\mathrm{B}$ urch ard $\mathrm{cs}$ zählen, während sie Breh in der dollfusi- und ccresiancGruppe annähert.

Das Phytoplankton entwickelt sich im Achensee quantitativ und qualitativ schwach.

F. Zsclokke (Basel).

\section{Mollusca.}

\section{Gastropoda.}

289 Drummond, Ssabella I.. Notes on the development of Paludina viripara, with special reference to the urinogenital organs and theories of gasteropod torsion. In: 
Quart. Journ. microse. sc. N. S. vol. 46. pt. I. 1902. pag. 97-143. Taf. $7-9$.

Verf. bringt in der vorliegenden Abhandlung eine ausführliche Darstellıng ihrer in einer kurzen Mitteilung ${ }^{1}$ ) bereits veröffentlichten Untersuchungen iiber die Entwicklung von Paludina vivipara. Die Entwicklung der Urogenitalorgane verläuft auf den jüngern Stadien völlig entsprechend den Darstellungen v. Erlangers. Abweichungen davon findet Verf. einmal darin, dass die ursprünglich linke Niere sowie ihr von der Mantelhöhle gegen sie vorwachsender Ausführgang erhalten bleiben, und sodann in der Anlage der Gonade, die als Zellenwucherung an der dorsalen Wandung der linken Pericardhälfte auftritt. Diese Gonade steht mit der rudimentären linken Niere zunächst nur durch eine verdickte Zellenleiste der Pericardwand in Verbindung, bezieht diesen Zellenstrang aber bald in sich ein, bildet in ihrem Innern ein Lumen aus und tritt durch dasselbe schliesslich in direkte Kommunikation mit dem Lumen der ursprünglich linken Niere, welch letztere zugleich noch jetzt in Verbindung mit dem Pericard stehen kann. Der Zusammenhang zwischen Niere und ihrem Ausführgang wird dagegen erst später liergestellt. Es liefert also die urspriunglich linke Niere sammt ihrem Gange die Ausführwege der Gonade.

In erster Linie heschäftigen sich indessen die Untersuchungen der Verff. mit der Ausbildung der Torsion der Gastropodeu, weshalb im folgenden zunächst eine äusserst genaue Beschreibung der Veränderungen in den äussern wie innern Formverhältnissen des Embryos gegeben wird. Der auf den jüngsten Stadien völlig bilateral symmetrisch gebaute Embryo erfährt die ersten Störungen seiner Symmetrie durch das Auftreten des Mantels, dessen Anlage in Gestalt zweier ungleich grosser, später erst verschmelzender Vertiefungen erfolgt. Zugleich weist der Visceralsack eine geringe Neigung nach links von der Mittellinie auf, welche Neigung sich auf dem folgenden Stadium noch verstärkt und schliesslich zur Folge hat, dass Leber und Magen ganz auf die linke Seite des Tieres zu liegen kommen. Mantelhöhle und After haben dagegen eine starke Verschiebung nach rechts erfahren, welch letztere einem starken Wachstum der ganzen hintern Region des Visceralsackes sowie vor allem einer mächtigen Ausdehnung des Mantels nich rechts und unten zuzuschreiben ist. Weit stärker ausgeprägt sind diese Verhältnisse auf dem nächst ältern Stadium, wo die Vorwölbung der linken Seite von oben gesehen bereits deutliche Linkswindung erkennen lässt. Unter starliem Wachs-

1) Vgl. Zool. Zentr.-BI. 9. Jahrg. 1902. Nr. 719. pag. 700. 
tum aller Teile beginnt sodann der Eingeweidesack sicl mit seiner Spitze immer mehr rentralwärts zu wenden, wälrend zugleich die Mantelhöhle sich auch über die linke Seite hin ausdehnt, bis sclliesslich die Aufwindung in einer vollständigen Windung sich vollzogen hat und die Lagerung der Organe nunmehr im wesentlichen den Verhältnissen des erwachsenen Tieres entspricht. Auch die Kreuzung der Visceralkommissuren macht sich jetzt deutlicher als auf den jüngern Stadien bemerkbar, wobei der Ösophagus in seinen vordern Abschnitt enge Beziehungen zur Drehung derselben aufweist. - Terf. beschreibt schliesslich noch eine Reihe abnormer Bildungen. So fand sich ein Embryo mit umgekelurter Lagernng der Organe auf beiden Seiten. Ein zweiter, schon älterer Embryo wies noch vollkommen bilaterale Symmetrie auf, besass einen langausgewachsenen, an der Spitze nach vorn ungebogenen Eingeweidesack und zeigte starke Störmngen in Lagerung und Ausbildung seiner innern Organe. Auch die iibrigen, meist unregelmäßiger gestalteten Monstrositäten waren stets durch eine mehr oder weniger ausgeprägte, bilaterale Symmetrie ausgezeiclmet.

Diese tatsächlichen Beobachtungen werden num schliesslich einer kritischen Betrachtung der bisherigen 'Theorien üher die Torsion der' Gastropoden zu grunde gelegt. Dieselben zerfallen in zwei Klassen. Die erste umfasst diejenigen Theorien, welche die Torsion aus einer Torwärtsberegung des Palliallomplexes in einer Horizontalebene längs der rechten Körperseite abzuleiten suchen und diese Bewegung auf ein stärkeres Wachstum der linken Seite zurïckfführen (B ü tsclıli). Die Theorien der zweiten lilasse dagegen lassen zunächst eine ventrale Flexion eintreten und an diese eine vertikale Rotation des ganzen Eingeweidesackes sich anschliessen (P elsen e er, A ma u d r u t, Boutan). Die entwicklungsgeschichtlichen Untersuchungen ergaben nun ganz unzweifelhaft, dass eine Rotation der innern Organe um eine mit dem Ösophagus in der Richtung zusammenfallende Áchse tatsächlich stattfindet, insofern Nagen, Leber, Pericard, Niere und Mantelhöhle ihre gegenseitigen Lagebeziehungen durchaus beibehalten, in ihrer Gesamtheit aber im Laufe der Entwicklmg um $180^{\circ}$ rotieren, womit eine wirkiiche Drelıung des Ösopliagus rerbunden zu sein scheint. Es würden diese Tatsachen also durchaus zu gunsten der zweiten Klasse ron Theorien sprechen, ebenso wie die beobachtete exogastrische Einrollung der symmetrisch gebanten Monstrositäten. Andrerseits lüsst sich für die erste Kilasse dlis vorausgesetzte stïrliere Wachstum der linken Seite keineswegs mit Sicherheit aufrecht erlialten, ebensowenig ein asymmetrisclies Wachstum der Leber, wie es Plate versuchte. Was die eigentlichen mechanischen Ursachen der 
Torsion in phylogenetischer Hinsicht anlangt, so rermag die Embryologie hierüber keinen Aufschluss zu geben, ebensowenig wie wir über die Ursachen des ontogenetischen Geschehens eine Vorstellung besitzen.

J. M eis enheimer (Marburg).

Hoffmann, R. W., Über die Ernährung der Embryonen von Nassa mutalilis Lam. Ein Beitrag zur Morphologie und Physiologie des Nucleus und Nucleolus. In: Zeitschr. f. wiss. Zool. Bd. 72. 1902. pag. 657-720. Taf. 36-38. 12 Fig. im Text.

Die Embryonalentwicklung von Nassa mutabitis erfolgt wie diejenige fast aller Prosobranchier innerhalb eines ron einer eiweisshaltigen Flüssigkeit erfüllten Kiokons. In ilım macht der junge Embryo einen Teil seiner Entwicklung durch, um erst als Veligerlarve auszuschwärmen, und so lassen sich insgesamt drei Ernährungsperioden desselben muterscheiden. Die erste reicht rom ungefurchten Ei bis zum Durchbruch des Stomodäums, die Ernährung und der Aufbau des Embryos erfolgt während derselben allein durch Yerarbeitung des dem Ei ron der Nutter mitgegebenen Dotters. Die zweite Periode ist vom Durchbruch des Stomodäums bis zum Ausschwärmen der Veligerlarve zu rechnen, der Darm nimmt reichlich Eiweiss auf und führt so neue Nahrung dem jungen Embryo zu. Die dritte Ernährungsperiode endlich beginnt mit dem Ausschwärmen der Larve, die sehr bald fremde Nalırungskörper aufzunehmen und zu rerdauen vermag. Von der Darmentwickelıng ausgehend hat Verf. nun speziell der Dotterresorption während der ersten Ernährungsperiode seine Aufmerksamkeit zigewandt.

Die Furchung scheint sich durchaus dem für die bisher genauer untersuchten Prosobranchier gülthigen Typus anzuschliessen. Bemerkenswert ist besonders die ganz ausserordentlich umfangreiche Macromere D, welche sehr bald ihre Teilungsfähigkeit verliert. Ein von der Zellenkappe des Ektoblasts ausgeübter Druck drängt allmählich die drei kleinern Nacromeren nach unten auf die spätere Bauchseite des Embryos, und gleichzeitig verschieben sich die Kerne aller vier Macromeren in auffallender Weise nach der Ventralseite des Eies, eine Erscheinung, die Verf. auf eine Wirkung der Schwerkraft zurückführt, insofern im Laufe der Entwicklung das Ei sich im Kokon infolge einer Schwerpmnktsverlagerung umkehrt, und sodann die spezifisch leichtern Elemente der Kern- und Cytoplasmasubstanz ihre Lage ändern und emporsteigen müssen. Die kleineren Macromeren liefern unter starker Vermehrung ventrale und seitliche Wand des Mitteldarmes, während die grosse Macromere erhalten bleibt und mit einem Plasmafortsatz in eine ventrale Lücke der 
erstern hineinragt. Später scheint die grosse Zelle auch den Dotter der übrigen Macromeren in sich anzusammeln und bildet bis zu sehr späten Entwicklungsstadien einen der Dorsalwandung direkt eingeschalteten Teil des Darmkanals.

Verf. wendet sich nun speziell der oben erwähnten Verlagerung der Macromerenkerne nach der Ventralseite zu, die aufs engste mit der Verarbeitung des Dottermaterials zusammenhängt. Es zeigen nämlich die Kerne auf spätern Stadien ein höchst eigentümliches Verhalten. Bei den kleineren Macromerenkernen hat der Clıromatingehalt abgenommen, das Karyoplasma ist mit dunkeln Tröpffchen erfüllt, der Kiern selbst wie sein Nucleolus weisen unter Ausbildung von Fortsätzen Beziehungen zum Cytoplasma auf und sind ron einer dunklern Sekretmasse umgeben. Die Dotterkugehn, welche in der Nähe des Kernes einen nur kleinen Iurchmesser besitzen, nehmen mit der Entfernung von demselben stetig an Grösse zu. Toch auffallender ist das Verhalten des grossen Macromerenkernes. Sein feinkörniges Karyoplasma sendet eine Anzahl von Auslïufern nach dem Cytoplasmafortsatz aus, der in jenen ron den drei kleinern Nacromeren gebildeten Raum hineinragt, während der Nucleolus gleichzeitig Fortsätze in der entgegengesetzten Richtung nach den Dotterkömern lin anfweist. In dem Cytoplasma ventral ron den Karyoplasmafortsätzen liegt stets eine dunklere Sekretmasse. Das Kermplasma zeigt also Beziehungen zum Darmlumen und den rentralen Darmzellen, der Nucleolus dagegen zum Dotter. Und in der Tat scheint der Nucleolus aufs intensivste an der Aufnahme der Dotterelemente beteiligt zu sein, wie Verf. im einzelnen näher erörtert, während dagegen die Fortsätze des Kernplasmas der Ausdruck einer sezernierenden 'Tätigkeit sind.

Weiter geht Verf. nun im folgenden unter ausfiihrlicher Berïcksichtigung der Literatur auf die Bedeutung und Charakteristik der Nucleolen sowie auf die Beteiligung des Kernes an Stoffwechselvorgängen im allgemeinen ein und gibt im Anschlusse an diese Betrachtungen schliesslich eine schematische Darstellung der Vorgänge, wie sie sich bei der Resorption und Verarbeitung des Dotters im Keime von Nassa mutabilis abzuspielen scheinen. Der Kern nimmt zunächst unter teilweisem Schwinden der Kernmembran den Dotter in gelöstem Zustande in sich auf, welche Aufnahme im wesentlichen durch eine rom Nucleolus ausgeschiedene, den Dotter anziehende Substanz bewirkt wird. Das sehr fein rerteilte Chromatin verarbeitet sodann diesen aufgenommenen Dotter zu einem für die lebende Substanz assimilierbaren Körper, der nach der entgegengesetzten Richtung, nach der Ventralseite hin, abfliesst und dabei die Fortsatz- 
bildungen des Karyoplasmas hervorruft. Diese Assimilationsprodukte sammeln sich in der hier angehäuften Cytoplasmamasse an und werden schliesslich teils an die umgebenden Darmzellen, teils, namentlich später, direkt in das Darmlumen abgegeben.

J. Me is en heimer (Marburg).

Frandsen, P., Studies on the reactions of Limax maximu* to directive stimuli. In: Bull. mus. compar. zool. at Harvard College. Cambridge 1901. pag. 185-227.

Frandsens Experimente, mittelst deren er bei Limax maximus die Beziehungen zwischen äussern Reizen und der Bewegungsrichtung der Schnecke festzustellen sucht, bilden die Fortsetzung und Erweiterung jener Versuchsreihe, die Davenport und Helen Perkins vor einigen Jahren in gleicher Absicht unternahmen. Sie sind interessant genug, um ausfïhrlicher besprochen zu werden, wenn auch die Kritik in ähnlicher Weise herausgefordert wird, wie bei vielen modernen Arbeiten über Tropismen und Verwandtes, bei denen oft genug der Name den Nangel an wahrer Einsicht rerdecken muss. Nur zu oft werden unter dem Schein einer allgemeinen Subsumierung unter grössere, den exakten Naturwissenschaften, zumal der Physik, entlehnte Gesetze Erscheinungen in ihrer Bedeutung vergewaltigt, die bei einer eingehenden, auf das Wesen des einzehnen lieres gestiitzten Analyse ein ganz anderes Gesicht gewinnen. Am meisten dirrfte die generelle Behandhungsweise noch fuir die Ptanzen mit ihrer einfachern Ökonomie und füir die Hochseetiere, die unter besonders gleichmäßßgen Bedingungen leben, Geltung haben, am wenigsten für die in ihrer Ethologie wie in ihrem liörperbau am stärksten differenzierten Landtiere.

Das zeigt sich gleich im vorliegenden Falle beim ersten Kapitel, das der Thigmotaxis ron Limax gewidmet ist. Frandsen experimentiert so, dass er zunächst den rechten, ebenso den linken Ommatophor leise mit dem Finger beriihrt. Jedesmal weicht die Schnecke aus. Dann wird die Körperseite hinter dem Kopf erst rechts, dann links ebenso behandelt. Die Schnecke weicht wiederum aus. Daraus wird der Schluss gezogen: Limax ist negatir thigmotaktisch.

Ganz anders stellt sich die Sache, sobald wir zweierlei erwägen. Erstens hat die Schnecke, vom Munde abgesehen, nur e in Organ zur Befestigung an Fremdkörpern, das ist die Sohle mit ihrem derben Epithel, sie ist fast unter allen Umständen positiv thigmotalitisch. Zweitens bestehen die Nervenendigungen in der Haut fast ausschliesslich aus frei hervorragenden Härchen. Sie dienen teils chemischen Sinneswahrnehmungen, teils dem Getast, diesem letztern aber nur 
in zarter, äusserst empfindlicher Weise; ein eigentlicher Drucksinn, der auf Tastkörperchen unter der Obertläche wirkt, ist so gut wie ausgeschlossen.

Danach richte man das Experiment ein! Man lasse den Limax auf ebener Fläche oder an einem Zweig so weit kriechen, dass der Vorderkörper frei in die Luft hinausragt. Jetzt berühre man ebenso wie in den frühern Versuchen, einen Fühler. Die Schnecke wird ihn ebenso durch Retraktion der Spitze vor intensiverer Berührung schützen, aber sie wird gleichwohl den Vorderkürper nach der berührten Seite hinwenden und den Finger mit der Sohle zu erreichen suchen. Sie ist also in diesem Falle auch in bezng auf die Tentakelberülırung positiv thigmotaktisch. Sie wird es vermutlich ebenso sein, wenn wir statt des Fühlers die Körperseite hinter dem Kopf berühren. Die Thigmotaxis richtet sich also ganz nach den Umständen und es dürfte rerfehlt sein, das Tier schlechthin negativ thigmotaktisch zu nennen.

Ähnliche Bemerkungen, welche auf eine schärfere Beachtung der spezifischen Natur abzielen, gelten gleich für die Einleitung, in welcher dariber geklagt wird, dass der schnelle Abfall der Tiere in der Gefangenschaft und ihr Kannibalismus zu fortwährender Erneuerung des Versuchsmateriales zwingen, trotzdem die natürlichen Verhältnisse in dem Käfig mit Erde und Moos einigermaßen hergestellt waren. Der Fehler lag hier vermutlich in der Fütterung mit Kohlblättern. Freilich machen sich die Schnecken in den Gewïchshäusern oft genug lästig durch Vertilgung grïner Pflanzenteile, und das fällt um so mehr ins Gewicht, als es fast durchweg junge Blätter, namentlich Keimblätter sind, die gefressen werden. Doch ist auch das nicht die normale Nahrung, die vielmehr in Pilzen besteht. In den Glashäusern wird sichs zumeist um Schimmel und Moder handeln, im Freien rerzehrt Limax maximus fast nur grosse Pilze, und zwar das Mycel so gut als die Hüte, die Sporenträger. Wird in der Gefangenschaft diese Nahrung entzogen, dann wird eben das stärkere Eiweissbedürfnis durch Kannibalismus befriedigt.

Nit der verfehlten Verpflegung hängt wohl ein anderer Faktor zusammen, der in den Tabellen häufig genug die Gesetzmäßigkeit der Reizwirkungen unterbricht, die Ungleichmäßigkeit der Schleimabsonderung. In der Tat wird fast jedesmal bei einem Tiere, das sich irgend einer Regel nicht fügen will, seine Trägheit, die Zähigkeit des Schleimes, die Loslösung des Hinterrandes der Solıle rom Boden betont.

Dieser Faktor hat aber wohl noch eine viel wichtigere Beziehung als die zur Nahrung, nämlich die zur Fenchtigkeit. Auf die Sättigung 
der Luft mit Wasserdampf ist gar keine Rüicksicht genommen. Und doch wissen wir, namentlieh durch $K$ ün $\mathrm{kel}$, dass damit das Hauptlebenselement einer Schnecke, auf jeden Fall das eines Limax, vernachlässigt ist. Wie es unmöglich ist, einen Limax, dessen Wassergehalt unter eine bestimmte Grenze gesunken ist, zu irgend einer lokomotorischen Bewegung zu reizen, wie er bei bestem Futter verhungern muss, so lange wir nicht für l'enchtigkeit sorgen, so müssen alle Versuche unrollkommene Ergebnisse liefern, die auf den Feuchtigkeitsgehalt keine Rücksicht nehmen. Ich komme wieder darauf zurïck.

Die Ergebnisse des zweiten Krapitels, das die Geotaxis behandelt, sind die folgenden:

a) An einer geneigten Glasplatte zeigen alle Nacktschnecken eine geotaktische Reaktion (natürlich so gut als wir nicht mit einem Fuss im Rinnstein gehen oder auf die Dauer in der Horizontalen an einem Steilhang entlang. Die ausgesprochenen Klettertiere nur dürften hier eine Ausnahme machen).

b) Manche Nacktschnecken sind entschieden positiv, andere negativ geotalitisch. Wenige nur rerhalten sich ziemlich indifferent.

c) Die Geotaxis der Nacktschnecken schwankt in der Gefangenschaft nur wenig an rerschiedenen Tagen oder an verschiedenen Stunden desselben Tages.

d) Gelegentliche Abschweifungen bestimmter 'Tiere beruhen bis zu einem gewissen Grade auf thigmotaktischen und phototaktischen Eintliissen.

e) Die verschiedene geotaktische Realition bestimmter Individuen auf einer Glasplatte beruht hauptsächlich auf zwei Faktoren, auf der Beschaffenheit des Schleimes und auf dèn Längenverhältnis zwischen Vorder- und Hinterkörper, bei welcher Bestimmung das Hinterende des Mantels als Grenze genommen wird.

f) Ist das Verhältnis zwischen Vorder- und Hinterkörper 2:3 oder mehr, dann ist die Schnecke bei reichlichem und gutem Schlein positiv geotaktisch.

g) Ist das Verhältnis 3:5 oder weniger, dann wandert die Schnecke gewöhnlich aufwärts. Die negative Geotaxis wird um so stärlier, je mehr sich das Verhältnis dem Werte 1:2 nähert.

h) In der kleinen Zahl ron Schnecken, wo das Verhältnis zwischen $2: 3$ und 3:5 schwankt, hängt die Reaktion ron der Beschaffenheit des Schleims und andern Faktoren ab.

i) Alle Schnecken haben eine natürliche Tendenz sich zur Erde hinab zu bewegen. Die T'endenz wird bei den Tieren, die an einer Glasplatte negativ geotaktisch sind, markiert durch den Zug des schwereren Hinterkörpers nach unten. 
k) Die normale Abwärtsbewegung mag normaliter schwanken zu verschiedenen Tageszeiten, entsprechend der Gewohnheit, am Tage verborgen zu bleiben und nachts zu fressen.

Das Interessanteste an diesem Abschnitt ist die Feststellung der auffälligen Variation in den Körperproportionen, wenn es auch nicht allzu auffällig ist, dass bei einer Nacktschnecke der zuletzt umgewandelte Teil, der Hinterkörper, welcher den Intestinalsack aufgenommen hat, noch den meisten Schwankungen unterliegt. Hier liegt wieder ein Problem für weitere Untersuchungen vor, die Ursache der Variabilität betreffend. Es ist festzustellen, welches innere Organ die verschiedene Länge des Hinterkörpers bedingt.

Übrigens kann die positive Geotaxis schwerlich für den Limax maximus schlechthin gelten. Sie erscheint selbstrerständlich, insofern Limax eine Erdschnecke ist. Doch gibt es Exemplare genug, die fast in Mannshöhe unter der Rinde morscher Bäume den Tag zubringen, und das zwar, nachdem sie sich mit den aufgenommenen Pilzen den ersten Darmschenkel bis in den Hinterkörper beschwert haben.

Dass das Gewicht des Hinterkörpers die Kö̈perhaltung bedingt, kann wohl für alle Schnecken gelten, da der Vorderkörper mit dem weit kräftigern Spiel der lokomotorjschen Wellen die Hauptleistung übernimmt und den Rest nachschleppt. Und die Subsumierung der einen untersuchten Species unter allgemeine Begriffe hat doch wohl nur dann Sinn, wenn die Resultate eben zum mindesten für die Tiergruppe allgemeine Geltung haben. Da kann man dann in erster Linie den Limax arborum heranziehen. Bei feuchtem Wetter nimmt

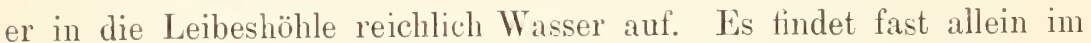
Hinterkörper Platz, schwellt und beschwert ihn und zwingt die Schnecke, negativ geotaktisch zu werden und nach oben zu kriechen, auf die Bäume oder Felsen hinauf. Bei trocknerem Wetter verliert die Schnecke das Wasser wieder, der Hinterkörper wird leichter, das Tier wird positiv geotaktisch und kehrt nach tiefer gelegenen, feuchteren Stellen zuriick. Hier harmoniert die wechselnde Belastung aufs beste mit der Lebensweise.

Die durchgreifendste negative Geotaxis zeigen, wenn man einmal den Ausdruck gebrauchen will, Gehäuseschnecken mit turmförnniger Schale. Diese luängt nach unten und zwingt die Schnecke, senkrecht nach oben zu steigen. So wird man z. B. Pupeen von der Form der Pupa avena niemals in anderer Stellung am Hechtenbewachsenen Felsen finden. Sie verlassen den Ort auch bei grellstem Sonnenschein nicht, wo sie sich in die Schale zuriickziehen. Ilır ganzes Leben bringen sie an derselben Stelle in derselben Körperhaltung zu 
oder steigen nur vom Ort ihrer Geburt an langsam aufwärts, bis sie etwa durch einen Zufall herabgeworfen werden und das Spiel von neuem beginnt. Solche Beobachtungen wird man aber nur in der freien Natur machen können.

Das dritte Kapitel behandelt die Phototaxis. Wiewoll die Experimente mit grosser Sorgfalt nach einer Normalkerze unter genauer Beobachtung des Lichteinfalls usw. angestellt sind, bleiben doch die Ergebnisse unsicher genug. Es sind die folgenden:

a) Limax ist dentlich phototaktisch.

b) Die Phototaxis zeigt individuelle Schwankungen.

c) Anf grelle Beleuchtung reagieren die Schnecken im Durchschnitt negativ.

d) Die Reaktion vermindert sich stufenweise mit der Abnahme der Intensität des Lichtes.

e) Rei einer gewissen Lichtstärke scheinen die Tiere weder positiv noch negatir zu reagieren. Sie mag der neutrale Reiz heissen.

f) Herabgehen der Lichtstärke unter den neutralen P'unkt verwandelt die negative Phototaxis in positive.

g) Die positive Reaktion steigert sich bis zn einer gewissen Lichtstärke.

h) Sie nimmt dann stufenweise ab mit der verminderten Belichtung, bis sie bei absoluter Dunkelheit Null wird.

i) Nacktschnecken reagieren auf Lichtreize in einem weiten Umfange der Intensität.

k) Wie Versuche mit Amputation der Ommatophoren ergaben, wird die Lichtwahrnehmung wahrscheinlich hauptsächlich durch das Ange vermittelt.

1) Die Reaktion ist unsymmetriscl auf der linken und rechten Körperseite. Die rechte Seite ist für Lichtreize weniger empfänglich als die linke. Die rechte Seite beschreibt im allgemeinen, went sie rom Licht getroffen wird, in 45 Sekunden einen etwas kleinem Bogen als die linke.

m) Im Dunkeln, wenn alle übrigen Reize eliminiert sind, beschreiben die Schnecken meist Spiralen ron allmälılich wachsendem Radius, manche rechts herum, manche nach links, wobei die erstere Richtung etwas überwiegt.

Wenn der Verf. für die Verschiedenheit der beiden Körperseiten irgend eine von frühen, unter andern Bedingungen lebenden Torfahren in der Rechts- und Linksdrehung ererbte Gewohnheit zur Erklärung heranziehen will, so brauchte er viehmehr nur an den unsymmetrischen Bau, an die rechtsseitige Lage der Genitalöffnung und an die entsprechende schraubenförmige Aufwindung bei der Copula zn denken.

Zoolog. Zentralbl. X. Jahrg.

- Nr. 291. -- 
Je mehr die distalen Genitalenden entwickelt sind, um so weniger wird die Schnecke sich nach links drehen. Und das verschiedene Verhalten der beiden Körperhälften unter l ist sicherlich diesem Umstand, nicht aber ihrer verschiedenen Empfänglichkeit für Lichtreize zuzuschreiben.

Die ganze iniihsame Versuchsreihe wird aber bestimmt umgestossen, sobald man die Tiere näher in der freien Natur kennen lernt. Hier zeigt sich ohne weiteres, dass die Phototaxis viel weniger in Frage kommt als die lieaktion auf Feuchtigkeit. Bei Regenwetter schweifen die Schnecken auch am Tage umher, bei Trockenheit nur in der feuchten Nachtluft. Der erste Somuenstrahl treibt sie in ihre Schlupfwinkel. Immerhin ist auch hier offenbar noch ein zeitweiliger Unterschied in der lieaktion auf Lichtreize; bei gutem Wetter kommen die Schnecken erst in tiefer Dämmerung heraus, während sie morgens erst von viel grösserer Helligkeit verscheucht werden, Beweis genug, dass in der Tat das Licht eine viel weniger direkte Wirkung ausuibt, als eine indirekte, insofern als rom Sonnenschein die relative Feuchtigkeit der Luft abhängt.

Übrigens regt die Frage, ob eine in der stets fenchten Gewächshausluft aufgewachsene Schnecke in ilıen Reaktionen von den freilebenden Formen abweicht, zu neuen Untersuchungen an.

Diese kritischen Bemerkungen wollen sich nicht gegen das Experiment im allgemeinen richten, sondern gegen seine nur zu leicht beliebte C̈berschätzung gegenüber dem streng zoologischen Studium der Natur. $/ u$ welchen Schliissen würden wir kommen, wenn wir uns denken, eine Anzahl Menschen der weissen Rasse würden plötzlich in eine tiefe Höhle gesteckt, in die ein schwacher Lichtschimmer dringt! Da sie der hellen Stelle zueilen werden, sind sie positiv phototakitisch. Sie werden aber negatir, wenn wir sie ebenso plötzlich auf eine von der Tropensonne beschienene Strasse versetzen, wo sie sich in den Schatten zurïckzielıen. Oder welchen Wert hat es, zu schliessen, dass wir beim Zubettgehen zumeist negativ phototaktisch werden?

Und endlich noch eines. Für Schnecken, die sich irgend einer Regel durchaus nicht fügen wollen, bringt Frandsen psychische Momente ins Spiel, Furcht, Eifer zu entfliehen usw. Abgesehen davon, dass mit Lichtwahrnelımung usw. namentlich auch Empfindungen, Vorstellungen und andere psychische Vorgïnge verbunden sind, kommt es doch wohl beim Experiment an niedern Tieren gerade darauf an, wenn man exakte Resultate haben, also die Lebenserscheinungen auf die exakten Naturwissenschaften zurückführen will, dass man nur 
mit mechanischen Bewegungsreaktionen reclmet, ihre psychische Analyse aber vollkommen ausschaltet.

H. Simroth (Leipzig).

\section{Vertebrata.}

\section{Pisces.}

292 Buigett, J. S., On the structure of the laval Polippterus. In: Transact. 'Lool. Soc. London. Tol. XVI. pt. 7. 1902. pag. 315342. Taf. 33-35. 5 Textfig.

Seinen frühern Darstellungen der äusseren Gestaltsverhältnisse einer Polypterus-Larve von $30 \mathrm{~mm}$ Länge fügt Verf. nummehr die Beschreibung einiger innerer Organsysteme, des Knorpelskelettes und des Urogenitalsystems, hinzu. Eine sorgtältige Untersuchung des auf diesen Stadium voll entwickelten knorpeligen P'rimordialcraniums führte dazu, in der allgemeinen Form eine beträchtliche $̈$ hnlichkeit mit den Selachiern, speziell den Scylliiden, feststellen zu können, während die Verteilung des Knorpels zugleich auf Beziehungen mit den Urodelen hinweist. Die Visceralbögen stehen hinsichtlich des Suspensorialapparates in der. Mitte zwischen Selachiern und Teleosteern, während zugleich ein wohl ausgebildetes Hyomandibulare und Palatoquadratum Polypterıs ron den Amplibien trennt. Es folgt sodann eine genauere Diustellung des Achsenskelettes, des Schultergïrtels, der Brust- und Bauchflossen, wobei der Verf. besonders den uniserialen Bau der Bauchflossen hervorhebt, dieselben also direkt mit den Flossen der Selachier in Beziehung bringen möchte.

Von dem Urogenitalsystem dieser jungen Larve ist die Pronephros noch erhalten, weist aber bereits alle Zeichen beginnender Rückbildung auf, während die Mesonepluos sich aut dem Wege zu ilırer vollen Ausbildung befindet. Letztere weist im vordern Körperteil in jedem Segment 2-5 Glomeruli und Kanälchen anf, weiter hinten beschränken sie sich auf die Einzahl. Im hintern Körperabschnitt tritt ferner nach aussen ron der Orarialankage eine Verdickung des Peritonealepitheles auf, welche die sich abschnürende Dorsalseite des spätern Oviduktes darstellt, und an der rom 24. bis 40. Segment je ein Peritonealtrichter ausmündet. Der weiblicle Ausführgang stellt somit bei T'olypterus keinen Miillerschen Gang dar, es liegen hier vielmehr ganz ähnliche Terhältnisse wie beim männlichen Urogenitalsystem vor, wo gleichfalls in eine den Genitalgang liefernde Falte der Cölomwand eine Reine von Nephrostomen einzumünden scheinen. Es würden also hier männliche und weibliche Geschlechtsgänge durchaus homologe Bildungen sein, ein Verhalten, wie es ausser den Crossopterygiern noch Cyclostomen, Ganoiden und 'Teleosteern zukommt, während bei allen übrigen Wirbeltieren der weib- 
liche Geschlechtsgang in dem Millerschen Gang eine Sonderbildung darstellt.

Zum Schlusse stellt Verf. die rerwandtschaftlichen Beziehungen von Polypterus zusammen. Die Entwickelung des Schädels, der Visceralbögen und der Brusttlossen weist ebenso wie eine Reihe anatomischer Eigentïmlichkeiten auf die El as m ob ran chi er hin, der Bau des Urogenitalsystems nähert Polypterus den Teleosteern und Amia, die Struktur der Hautknochen den fossilen Stegocephalen; die lebenden Crossopterygier stellen mithin Formen dar, die durch eine ganze Anzahl primitiver Merkmale mit den verschiedensten Gruppen verknïpft erscheinen. J. M e isenheimer (Marburg).

293 Kerr, Graham J., The development of Lepridosiren paradoxa. Part III. Development of the skin and its derivatives. In: Quart. Journ. microse. sc. N. S. Vol. 46. pt. III. pag. 417-459. Taf. $2 \tilde{o}-28$.

294 - The early development of inuscles and motor nerves in Lepidosiven. In: Rep. Brit. Assoc. Ailv. Sci. Section D. Belfast 1902. pag. 1-2.

Im Anschluss an seine frühern Untersuchungen iiber die Embryonalentwicklung von Lepidosiren bringt Verf. nummehr eine Darstellung der Entwicklung der Ektodermderivate, der Epidermis, der Nundhölle, der Hypophysis, des Zentralnervensystems und der Sinnesorgane.

Die Differenzierungen innerhalb des zunächst aus zwei Zellenlagen bestehenden Epiblasts beginnen mit einer Verdickung, die durch Teilungen der untern Zellenlage hervorgerufen wird, sowie mit der' Ausbildung von Drüsenzellen. Von letztern stellen besonders differenzierte Elemente das Cementorgan dar, das sich aus einer Verdickung der unteren Zellenlage des Ektoderms ableitet, die obere durchbricht und in seiner vollen Entwicklung aus hohen, frei an der Oberfläche liegenden Cylinderzellen besteht. Seine Rückbildung erfolgt in erster Linie durch die Tätigkeit massenhaft sich anhäufender Leukocyten. Die in Ektoderm auftretenden P'igmentzellen sind auf eine Einwanderung mesodermaler Elemente zurüclizuführen, ihre eigentümlichen Veränderungen und Verlagerungen bei Tag und Nacht, auf die Verf. schon in einer frühern Mitteilung näher einging, werden nochmals an einer Reihe histologischer Abbildungen näher erläutert.

Ein ektodermales Stomodaeum gelangt nicht zur Anlage, vielmehr entwickelt sich die Iundhöhle aus dem Teil der dotterreichen Darmzellen, der dem Ektoderm dicht anliegt. Die betreffende Stelle gewinnt zunächst durch Reduktion der Dotterkörner ein dem Ektodern 
ähnliches Aussehen, worauf ein Zerfall der innern Zellenelemente die eigentliche Höhlung entstehen lässt. Die erste Anlage der Zähnchen wird durch eine einheitliche, verdickte Leiste des Mundepithels gebildet, in welche eine Mesodermpapille hineinragt. Es kommt sodann zunächst zur Ausbildung einer Lage harter, kalkartiger Substanz, welche wahrscheinlich Schmelz darstellt, während erst später durch eine Umwandlung der nach aussen gerichteten Spitzen der Odontoblasten das Dentin entsteht, an welches sich schliesslich nach innen eine spongiöse Knochenmasse anschliesst. Nur die beiden letztern bilden den spätern Zahn, da Schmelzorgan und Schmelz nach dem Durchbruche der Zähnchen verloren gehen.

Die Hypophysis entsteht als keilförmige Einsenkung des Epiblasts, löst sich ron demselben los und legt sich als geschlossenes, mit einem weiten Hohlranm im Innern versehenes Bläschen dem Infundibulum an.

Das Gehirn, welches siclı in seinem anatomischen Verhalten nahe an dasjenige von Protopterus anschliesst, beginnt sich zunäclıst durch seine ansehnlichere Breite vom Rüickenmark abzugrenzen, eine leichte Einschnürung sondert sodann das Hinterhirn von den vordern Partien, und eine am Boden des Gehirns auftretende Querfurche bezeichnet die bald an Stärke zunehmende Gehirnbeuge. Eine parige Vorbuclitung zu beiden Seiten des primären Vorderhirns (Thalamencephalon) liefert die erste Anlage der Hemispliären. Die Trennung des Mittelhirns rom Vorderhirn erfolgt erst ziemlich spät, während zugleich die wichtigsten sonstigen Veränderungen, neben einer allmählichen Differenzierung der einzelnen Gehirnteile, in einem seitlichen Vorwachsen des mächtigen Hinterhirns nach vorn, sowie in einer starken Grössenzunahme der Hemisphären bestehen. Verf. geht sodann im einzelnen näher auf die Entwicklung der verschiedenen Gehirnabschnitte ein, vor allenı des primären Vorderhirns, dessen Trennung vom Mittelhirn sich dorsalwärts zuerst durch das Auftreten der Zirbeldrüse zu erkennen gibt. Letztere legt sich als Ausstülpung des Gehirndaches an, zeigt eine nur geringe Entwicklung und weist keinerlei Spuren eines rudimentären Auges in ihrer Umgebung auf. Von der Vorderwand des primären Vorderhirns entwickelt sich weiter als eine zweite Ausstïlpung die Paraphysis, wie sie auch bei den Urodelen beobachtet worden ist, sie bildet zunächst einen kleinen, zwischen den Hemisphären gelegenen Schlauch, wird aber bald wieder stark rückgebildet. Zu beiden Seiten der Paraphysis entstehen als parige Aılagen die seitlichen Choroidplexusse der Hemisphären, welch letztere selbst, wie schon erwähnt, seitliche Vorbuchtungen der Wandung des primären Vorderhirns darstellen. Am Boden des Gehirns legt 
sich das Chiasma an und dahinter bilden sich unter Beteiligung rölnenförmiger Drüsenschläuche Beziehungen zur Hypophyse aus.

Das Geruchsorgan entsteht als eine solide Einwucherung von Zellen der innern Epiblastlage, in der erst später eine kleine Höhlung im Innern auftritt. Unter Bildung der vordern Nasenöffinungen bricht dieselbe nach aussen durch, während dagegen die hintern Nasenłöcher erst viel später sich ausbilden. In der gleichen Weise vollzieht sich auch die Entwicklung des Gehörorgans als eine solide Ektorlermwucherung.

Über die Entwicklung der Augen wäre anzuführen, dass dieselben als solide Wucherungen zu beiden Seiten der Gehirnanlage auftreten, schon sehr bald indessen ein Lumen erhalten und später mit dem innern Raume des Gehirns rerschmelzen. Ihre Entwicklung zeigt im übrigen ebenso wie diejenige der Linse nur geringe Besonderheiten, besonders bemerkenswert ist der frühe Verschluss der Chorioidealspalte. Etwas näher geht Verf. sodann noch auf die histologische Struktur der Retina ein, speziell vor allem auf die Genese der Stäbchenzellen.

Betrefts der Entwicklung des peripheren Nervensystems machte Verf. die interessante Beobachtung, dass die motorische Nervenwurzel schon ausserordentlich früh Myotom und Rückenmark verbindet. Von dem Augenblicke an, wo die beiden letztern sich voneinander abheben, ist zwischen ihnen ein feiner Verbindungsstrang zu bemerken, der von der ventrolateralen Kiante des Nervenrohres ausgeht, an der Innenseite der Myotome sich festsetzt und mit der zunehmenden Entfernung beider Organsysteme immer länger auswächst, ohne seinen Zusammenhang nach einer von beiden Seiten hin je zu verlieren. Dotterreiche Mesenchymzellen legen sich dem zarten Nervenfäserchen zu seiner Ernährung seitlich an.

In einigen allgemeinen Bemerkungen bespricht Verf. zunächst die Einwirkung des Lichtes auf die Chromatophoren, welche durchaus eine direkte Reaktion der Zelle selbst hervorruft, bestehend in einem Einzielıen und Ausstrecken ron Pseudopodien. Ganz das gleiche gilt für die Pigmentzellen der Retina. Weiter wird sodann die Bedeutung des primären Vorderhirns (Thalamencephalon) als eines äusserst wichtigen und primitiven Gehirnabschnittes herrorgehoben, von dem erst sekundär die Hemisphären als paarige seitliche Vorbuchtungen sich ableiten. Übel die Bedeutung der Paraphysis lässt sich Sicheres bisher nicht feststellen, sie mag entweder der Rest eines alten Sinnesorgans sein oder einen Teil der urspriinglichen Verbindung des Gehirns mit der äussern Haut darstellen. Zum Schlusse endlich weist Verf. im Anschlusse an die oben mitgeteilten Beobachtungen über die 
Entwicklung der motorischen Nervenwurzeln darauf hin, dass diese Tatsachen zu gunsten der von Hensen aufgestellten Theorie sprechen, wonach die Nerven während der Entwicklung nicht selbständig nach ihren Endapparaten auswachsen, sondern ron Anfang an mit denselben verbunden sind und sich in stetem Zusammenhange mit denselben an die Peripherie verschieben.

Und hierauf geht Verf. auch in der zweiten, nur kurzen Mitteilung näher ein. Ausserdem finden sich aber in der letztem auch noch einige kurze Angaben über die Entwicklung der Myotome, welche insofern besondere Beachtung verdient, als sich hier sowohl inneres wie äusseres Blatt derselben an der Bildung von Muskelzellen beteiligen.

J. M e is en h e imer (Marburg).

95 Kopsch, Fr., Art, Ort und Zeit der Entstehung des Dottersackentoblasts bei verschiedenen Knochenfischen. In: Internat. Monatsschr. f. Anat. 11. Physiol. Bd. 20. Heft 1/3. 1902. pas. 101-124. 15 Textfignren.

Verf. gibt auf Grund eigener wie fremder Untersuchungen eine zusammenfassende Darstellung der Entstehung des mit verschiedenen Namen belegten Dottersackentoblasts (Parablast von His usw.) bei den Knochenfischen. Als typische Entstehungsart desselben ist bei allen bisher genauer untersuchten Formen ein Vorgang anzusehen, der eine Anzahl von Blastomeren ihre Individualität verlieren und zu einer Art Plasmodium verschmelzen lässt Als Entstehungsort sind bisher angegeben worden der Rand der Keimscheibe, ilıre Unterflïche oder beide zugleich. Ersterer Modus ist der häufigere und verbreitetste. Verf. erörtert denselben näher auf Grund von Beobachtungen am lebenden Objekt in Zieglers liompressorium bei Crenilabrus paro. Die beiden ersten Furchungsebenen stehen senkrecht aufeinander, die Teilungsmembranen der dritten Teilung rerlaufen der ersten Furchungsebene parallel, diejenigen der vierten dagegen der zweiten. Es entstehen so vier zentrale und zwölf peripher gelegene Blastomeren, von đenen die erstern allseitig abgeschlossen sind, die letztern dagegen als Randsegmente mit dem zentralen wie peripheren Protoplasma des Dottersackentoblasts zusammenhängen. Durch die fünfte Teilung wird der zentrale Teil der Keimscheibe zweischichtig, durch die siebente drei- und durch die achte vierschichtig. Von der neunten Teilung an bestelit das zentrale Protoplasma des Dottersackentoblasts nur noch aus einer dïnnen Lage, die mit der Dotterkugel und den Randsegmenten, deren Zahl nunmehr $1 \tilde{\partial}$ beträgt, in Verbindung steht. Bei der zehnten Teilung erhält jedes Randsegment zwei Kerne, insofern keine Protoplasma- 
scheidung mehr eintritt, und durch die elfte Teilung entstehen gleichfalls olıne nachfolgende Zellteilung zwei lieihen von Kernen im Dottersackentoblast. Alle Kierne desselben entstammen mithin den Randsegmenten, sein Protoplasma dagegen einmal dem zentralen wie peripheren Teil des Dottersackentoblasts und dann dem Protoplasma der Randsegmente. Ganz ebenso verhalten sich im wesentlichen die Eier von Gobius minutus, von Cristiceps argentatus, Belone acus und Labrax lupus. Ob eine Entstehung des Dotter'sackentoblasts an der Unterfläche des Keimes allein vorkonmt, muss bis auf weiteres zweifelhaft bleiben. Die dritte Entstehungsart am Rande und an der Untertläche der Keimscheibe findet sich bei Perca fluriatilis und bei den Salmoniden: Verf. schildert dieselbe näher von Trutta fario. Der Dottersackentoblast entsteht hier am Ende der elften Teilung, und zwar einmal am Rande und sodann an einem exzentrisch gelegenen Bezirk der Unterfläche. Eine Trennung allseitig abgeschlossener, oberer Zellen ron einer syncytischen, untern Lage von blastomeren erfolgt erst nach der fünften Teilung. Bei Beginn der neunten 'Teilung ist diese letztere noch an der ganzen Basis der lieimscheibe vorlanden. nach derselben tritt eine Sondermng ein, insofern sich eine zentrale, dickere Lage durch eine dïnne, ringförmige Zone ron den Randsegmenten scheidet. Die letztern liefern das Randsyncytium, erstere ein besonderes, stets etwas exzentrisch gelegenes, zentrales Syncytium. Der Dottersackentoblast entsteht durch die elfte Teilung, und zwar gleichzeitig am Rande und an der Keimbasis, wobei indessen Abfurchungen einzelner Zellen nach oben in dieser wie den nächstfolgenden Teilungen noch stattfinden kömmen. 1)ie Entstehungszeit des Dottersackentoblasts weist bei den verschiedenen Kinochentischen eine ausserordentlich grosse Übereinstimmung auf. Durch die zehnte T'eilung entsteht er bei Gobius mimutus, Crenitalous pavo und Belone acus, zum grössern Teile durch die zelnnte, zum geringern durch die neunte Teilung wird er bei Cristiceps argentatus gebildet, und durch die elfte endlich bei Trutta furio.

J. Me is enlieimer (Marburg). 


\section{Zoologisches Zentralblatt}

unter Mitwirkung von

Professor Dr. O. Bütschli

In Heidelterg and

herausgegeben von

\section{Professor Dr. B. Hatschek}

in Wien

\section{Dr. A. Schuberg}

a. Professor in $\mathrm{Heidelberg.}$

Verlag von Wilhelm Engelmann in Leipzig.

\section{Jahrg.}

5. Mai 1903.

No. 9.

Zu beziehen durch alle Bachhandlangen und Postanstalten, sowie durch die Verlagsbuchhandlung. Jährlich 26 Nummern im Umfang von 2-3 Bogen. Preis für den Jahrgang II. 30. - Bei direkter Zusendung jeder Nummer unter Stroifband orfolgt ein Aufschlag von M. 4.- nach dem Inland and von II. 5.- nach dem Ausland.

\section{Referate:}

\section{Zellen- und Gewebelehre.}

96 Bergmann, Willi, Untersuclungen ïber die Fibildung bei Anneliden und Cephalopoden. (Diss. Marbg. 1902. 26 pag.). In: Keitschr. für wiss. \%ool., 73. Bd., 2. Heft. 1902. 3 'laf.

Bei lihynchobolus convolutus, Stamocpphatus mulolphii, Siphonostoma diplochata bilden sich die Eier wie bei den marinen Anneliden allgemein ans dem Peritonealepithel der Dissepimente oder aus demjenigen an der Gabelung der Parapodien. Bei Omulhis tubicola aber zeigt die Ei- und Nährzellenbildung Besonderheiten. Ein eigentliches Ovarium ist hier nicht vorhanden, sondern es finden sich frei in der Leibeshöhle schwimmend spindelförmige Gruppen vou kleinen runden Zellen 60-100 an der Kahl, die einen kernfreien plasmaerfüllten Raum einschliessen. Diese schwimmenden Zellgruppen teilen sich nach vorangegangener Zellvermehıung. Die einzelnen Zellen der Gruppen wachsen zuerst gleichmäßig, mit I usnahme einiger peripherer Zellen mit ovalem Kern, die offenbar Follikelzellen darstellen. Bald jedoch übertrifft eine am einen Pol der Gruppe liegende Zelle ilure Nachbarn an Grösse, sie wird die Eizelle, während die ïbrigen die Nährzellen darstellen. Die Eizelle wäclst weiter, die Tährzellen nicht. Die Follikelzellen umhïllen nur die letztern, niemals die Eizelle. Um das Ei herum billet sich durch eine richtige Sekretion des Eies eine radiärstreifige Dotterhaut oder Zona radiata, die also nicht vom Follikelepithel gebildet wird, also kein "Chorion" ist. In der Peripherie des Keimbläschens liegen stark färbbare Brocken, im Innern zuerst ein einziger, später in fünf bis sieben zerfallender Nucleolus. Wenn die Eizelle grösser als die Nährzellgruppe geworden ist, werden 
die Nährzellen allmählich kleiner; die frei in der Leibeshöhlenflüssigkeit schwimmende Oocyte bedarf ihrer nicht mehr. Die Nährzellen fallen $a b$ und degenerieren.

Der zweite Abschnitt der Arbeit enthält die I'ntersuchung über die Eibildung in der Zwitterdrüse von Hesione sicula. Die Achse der Zwitterdrüse wird von einem Blutgefäss gebildet. Nach aussen wird das Blutgefäss vom Bauchhöhlenepithel bekleidet, dann folgen indifferente Zellen bezw. junge Ei- und Samenzellen, denen sich noch weiter aussen immer ältere Genitalprodukte anschliessen. Das ganze Gebilde wird von einem flachzelligen Epithel mit platten Kernen umschlossen. Die Ei- und Samenzellen zeigen namentlich auf Querschnitten gruppenweise Anordnung. In den ältern Eiern liegen die Keimbläschen meist dem Blutgefäss zu. Der Nncleolus des Keimbläschens zeigt oft eine dunklere und eine heller gefärbte Hällte. Selbst die das Peritonealepithel bereits vorbuchtenden Eier zeigen noch keine Spur einer Eihïlle.

Der dritte Abschnitt behandelt die Fibildung bei den Cephalopoden in specie den Decapoden. Bei Illex coindetii fand Verf. sehr klare Verhältnisse. Das bindegewebige Stroma ovarii enthält Oocyten verschiedenen Alters; es wird ron dem Hachzelligen Überzugsepithel der Leibeshöhle ïberzogen. Dieses Epithel ist die eigentliche Kieimstätte der jungen Oocyten. Bei einzelnen seiner Zellen wächst der liern, das Chromatin sammelt sich körnig an der Wand, so dass der Kern innen blasser erscheint. Damn entsteht im bläschenförmigen grossen Kém ein Nucleolus. Später löst sich das Ei rom Überzugsepithel ab und wandert in das Stroma ovarii ein, wo es seine Hïllen erhält. Ähnlich liegen die Verhältnisse bei Sepiola rondeletii. Verf. schildert das bei den verschiedenen Cephalopodenarten etwas verschiedene Verhalten der sich rakuolisierenden und auflösenden Nucleolen. Während der Ausbildung der Follikelfalten verschiebt sich das Keimbläschen, von einem Hof dichtern Protoplasmas umgeben, nach dem freiern spitzern Ende des Eies. Bei beginnender Rückbildung der Follikelfalten findet auch die Auflösung des Keimblïschens statt. Das Follikelepithel bildet sich aus den rom Überzugsepithel rom Ei mitgenommenen Peritonealepithelzellen durch lebhafte Vermehrung derselben. Die letztere geht soweit, dass das Epithel Falten schlägt, die in den Zellkörper des Eies eindringen und es schliesslich ganz durchziehen, was bereits lioelliker $184 t$ beschrieben hat. In die Follikelfalten dringen auch Gefiisse ein.

Die Eier drüngen sich über die Eierstocksoberfläche vor, so dass sie schliesslich nur noch durch einen Stiel mit dem Ovar zusammenhïngen. Zwischen das sie in diesem Stadium überziehende Follikel- 
und Eierstocks-Überzugsepithel hinein wuchert rom Stiel aus das Ovarialstroma und überzieht endlich als dritte, bindegewebige Hülle das Ei, auch an der vom Stiel abgewandten Seite. Wem die Follikelfalten sich zurïckzubilden beginnen, entsteht das „Chorion" in sehr eigentïmlicher Weise als Sekretion des Follikelepithels. Dieses sondert nämlich perlschnurartig sich allmällich aneinander legende mit Eisenhämatoxylin schwärzende Tröpfchen oder Körnchen ab, die sich dann durch Zusammenfliessen zu einer homogenen Membran vereinigen. Diese Haut umschliesst das Ei allein, wenn es sich vom Ovar ablöst, die übrigen Hüllen bleiben zurïck.

R. Fick (Leipzig).

297 Hesse, R., Untersuchungen ïber die Organe der Lichtemplindung bei niedern Tieren. VIII. Weitere Thatsachen. Allgemeines. In: Zeitschr. wiss. Zool. Bd. 72. 1902. pag. 565-656. 1 'Taf.

1. Weitere Tatsachen. A. Die Sehorgane von Stylaria lacustiv L. In einem aus pigmentierten Epithelzellen gebildeten Pigmentbecher, der rostral offen ist, finden sich, intraepithelial gelegen, die 5-6 grossen unpigmentierten Sehzellen des Ocells. Sie gehen jede in eine Nervenfaser über und enthalten in ilırem Plasma einen lïnglich ovalen, wohlumgrenzten Körper, der gegen die I'ignentwand zu liegt und vom Vert. als lichtrecipierender Teil der Zelle angesehen und mit dem Binnenkörper in den rermutlichen Sehzellen der Lumbriciden (vgl. Zool. Zentr.-BH. III, p. 721) gleich gesetzt wird (Verf. nennt diese Bildungen jetzt I'haosomen); ausserdem treten in dem Plasma der Sehzellen auf der rostralen Seite helle ,accessorische Vakuolen" auf, denen vielleicht die Hunktion zukommt, das Licht auf die eigentlich recipierenden T'eile der Zelle zu konzentrieren.

b. Die Sehorgane rou Spadrlla hexaptera. Sie sind invertierte Pigmentbecherocellen, deren I'igmentbecher gleichsam aus fünf Einzelbechern bestehend zu denken ist, welche mit ihren konvexen Seiten verklebt sind; vier von ihnen sind medial, die fünfte, grüsste lateral gerichtet. In jedem dieser Becher stecken die freien Enden einer Anzahl ron Sehzellen, welche eigentümliche stäbchenartige Bildungen tragen: jede Zelle ist von einer Neurofibrille durclizogen, welche sich nach einer knöpfchenartigen Anschwellung zu einem glockenförmigen "Stäbchenknauf" erweitert und in das stark lichtbrechende Stäbchen übergeht, das nur der gleichsam aufgequollene Endteil der Neurofibrille ist. Die basalen Enden der Sehzellen setzen sich in Nervenfasern fort, welche rostrad zum Gehirn ziehen.

C. Einiges über Gastropodenaugen: Der wesentlichste 
Inhalt dieses Abschnittes ist schon früher referiert (Zool. Zentr.-Bl. IX, Nr. 718).

2. Allgemeines: a) Die recipirenden Elemente in den Sehorganen. Man hat bisher stets primäre Sinneszellen, nie freie Nervenendigungen oder sekundäre Sinneszellen in den Sehorganen gefunden; als recipierende Elemente sind an diesen in den allermeisten Fällen freie Neurofibrillen-Enden nachweisbar, und zwar entweder in einer Zelle in grosser Zahl dicht nebeneinander stehend als „Stiftchensäume", oder nur eine einzige Fibrille, oder es finden sich zwischen diesen Grenzfällen C̈bergänge, Bündelchen von Neurofibrillen (,Neurofibrillenpinsel"). Der Unterschied zwischen diesen Befunden ist nur ein quantitativer, und zwar verhält sich die Zahl der Neurofibrillenenden in einer Sehzelle im allgemeinen umgekehrt wie die Zahl der Sehzellen in einem Selıorgan: bei wenigen Sehzellen trägt jede einen ausgedehnten Stiftchensaum, bei zalılreichen Selizellen finden sich nur eine oder wenige Neurofibrillen in einer Zelle. Die besondere Beschaffenheit dieser Neurofibrillenenden macht sich äusserlich oft in besonderer Verdickung und vermelırter Fürbbarkeit derselben geltend. - Als gemeinsame Bezeichnnng für die recipierenden Teile der Sehzellen wird der Ausdruck St:̈bchen beibehalten unter Hinweis darauf, dass ihm eine morphologische Bedeutung nicht zukommt, sondern jedesmal eine besondere Lrläuterung des Stäbchenbaues notwendig ist; „ein Stäbchen ist ein äusserer, anatomisch einfach abtrennbarer Teil der Sehzelle, der die recipierenden Endigungen enthält, ausserdem aber häufig noch andere Bestandteile umfasst wie lebendes Plasina oder Stritzgebilde." - Von dem geschilderten Verhalten machen nur die Sehzellen der $\mathrm{N}$ aideen und Lumbriciden eine Ausnahme, in denen bisher der Nachweis ron Neurofibrillenenden nicht geglückt ist; die Gebilde, welche Verf. hier für lichtrecipierende Elemente der Zellen ansieht, bezeichnet er als Phaosomen (im Anschluss an Ray L a n kesters Phaosphären).

b) Die Rolle des Pigments in den Sehorganen. Die Sehorgane sind bei niedern Tieren häufig nur infolge ihrer Pigmentierung aufgefunden (,Augenpunkte"), daher war bei allen bekannten Sehorganen Pigment vorhanden. Neuerdings jedoch kennt man nicht wenige Fälle, wo in zweifellosen Sehorganen das Pigment felılt: z. B. bei den verstreuten Sehzellen von Hirudo und denen von Pontobdella, bei dem Sehorgan ron Dialychone acustica (Zool. Zentr.-BI. VI, pag. 439), den Scheitelocellen der Phryganeen, den Augen von Ceratopsyllus u. a. Daher kann das Pigment eine wesentliche Bedeutung für die Lichtreception nicht haben (Jolr. Müller, Helmholtz, Hensen, Beer). l)as vorhandene Pigment liegt durchaus nicht immer in den Sehzellen, 
und häufig weit von den recipierenden Elementen derselben entfernt. Bei verwandten Formen kann die Verteilung des Pigments sehr verschieden sein: bei den Gastropoden z. B. sind teils die Sehzellen der Retina, teils die Stützzellen, teils beide pigmentiert. Nur funktionelle Verhältnisse sind maßgebend für die Pigmentverteilung; morphologisch ist es bedeutungslos, ob eine Zelle Pigment enthält oder nicht.

c) Versuch einer Klassifikation der Sehorgane. Die Einteilung der Sehorgane wird eine verschiedene, je nachdem man nach morphologischen oder nach physiologischen Rïcksichten rerführt (Hatschek). Die morphologische Einteilung fasst Verf. in umstehender Tabelle zusammen; für die nähere Begründung muss auf das Original verwiesen werden; es sei nur das eine erwähnt, dass primäre invertierte Augen sich sekundär zu vertierten umgestalten können (,Reversion"), so bei Hirudo, vielen Landplanarien'), den Skorpionen. - Von physiologischen Gesichtspunkten aus teilt Verf. die Sehorgane folgendermaßen ein:

I. Sehorgane ohne Bildreception-Photierorgane [Beer (Zool. Zentr.-Bl. VIII. Nr. 578)1.

1. Photierorgane ohne Pigmentschutz, oder besser ohne Lichtsonderung: \%. B. bei Dialychone.

2. Photierorgane mit Pigmentschutz oder mit Lichtsonderung: z. B. Pigmentbecherocell einer 'Turbellarie, Grubenauge von Patella.

II. Sehorgane mit Bildreception, Angen(Bildaugen)I d i erorgane [Beer].

1. Camera-Augen a) nicht accommodierbare, b) accommodationsfähige.

2. Musivische Augen: z. B. bei Branchiomma, Area; Komplexaugen der Arthropoden.

3. „Superpositionsaugen" Exners (Crustace en, Insekten), bei denen durch Zusammenwirken vieler Linsen mit Pigmentblendungen ein aufrechtes Bild entworfen wird.

d) Phylogenetisches über Sehorgane. Die Tabelle der morphologischen Einteilung der Sehorgane zeigt, dass bei verwandten Tieren im allgemeinen auch ähnlich gebaute Augen vorkommen. Vor allem fällt die weite Verbreitung der invertierten Pigmentbecherocellen (A $2 \beta$ ) auf, (ron denen aber die bei Aurelia aurita, bei Amphioxus

1) Die vom Verf. angenommene morphologische Einheit der Augen bei den Landplanarien, die v. Graff als invertierte Kolbenaugen und Retinaaugen unterschied, ist durch die Untersuchungen von A. Th. Schmidt aus v. Graffs Laboratorium (Zool. Centr.-Bl. IX. Nr. 868) gleichzeitig dargetan worden. 


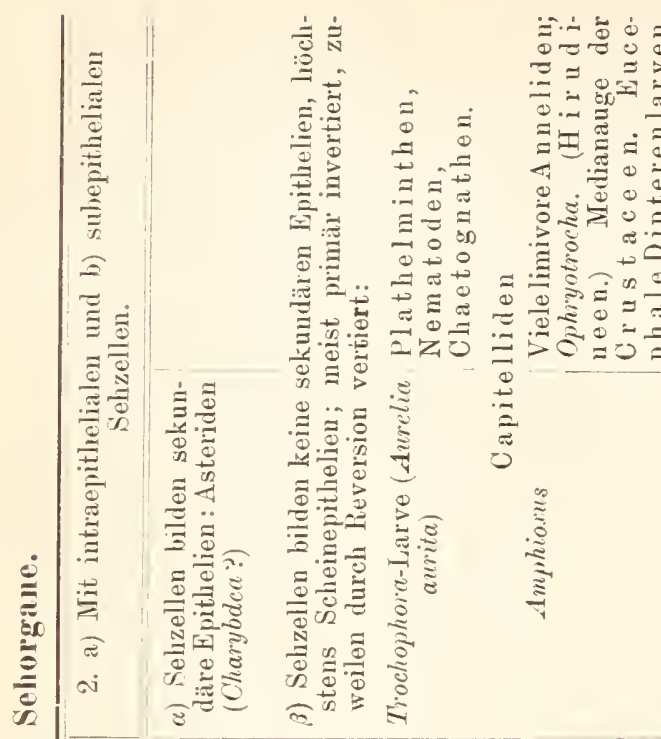

Ф)

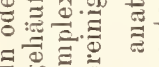

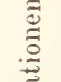

$=\quad 2$

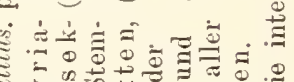

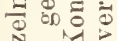

它

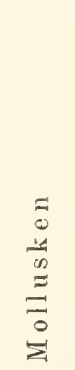

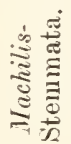


und bei den encephalen Dipterenlarven selbständige Bildungen sein dürften). Gleichsam abgelöst wird dieser Typus in der aufsteigenden phylogenetischen Reihe der Tiere durch die epithelialen Augen mit gesonderten Stäbchen, die ,Retinaaugen" (A $1 \beta$ ); auch die weniger verbreiteten Typen sind auf gewisse Verwandtschaftskreise beschränkt. - Im allgemeinen glaubt Verf., dass man in letzter Linie die Sehorgane nicht von schon spezialisierten, sondern von anelektiven Sinnesorganen ableiten muss. Mit der Spezialisierung für die bestimmte Reizart Hand in Hand geht wohl die ,Tendenz" der Sehzellen, sich von der Oberfläche zu entfernen (Übergang zu intra- und subepithelialer Lage, Einstülpung).

R. H esse (Tübingen).

\section{Protozoa.}

98 Léger, Iouis, Note sur le déreloppement des éléments sexuels et la fécondation chez le Stylorhynchus longicollis F. St. In: Arch. zool. expérim. et gén. Notes et Revue. Nr. $t$ u. 5. 1902. pag. $1-10$.

In einer Mitteilung des Verfs. rom rorigen Jahre (s. Zool. Zentr:Bl. 9. Br. pag. 109) gab Verf. an, dass die beiden Fregarinen in einer Gyste verschiedenen Geschlechtes seien. Die eine nennt er ,die männliche:, weil sie nur Spermatozoen, die andere, ,die weibliche": weil sie nur Eier erzeugt. Die Gieschlechtszellen bilden sich auf der Oberfläclie des (iregarinenkörpers oder der seiner Teilprodukte und vermehren sich rasch durch typische Karyokinese mit Centrosomen, während die Somazellen in Innern sich nur langsam durch atypische Mitosen vermehren. Die Somazellen scheinen aus dem grossen Primitivkern der Gregarinen zu entstehen, die Geschlechtszellen aus dem kleinen. Die Ei er zeigen gegenüber den noch nicht differenzierten Geschlechtszellen gar keine grossen Veränderungen. ,sie werden rund, ihr helles Protoplasma zeigt einige sehr spärliche Granulationen." Sie schnüren sich durch I'erdiinnung eines Stieles vom Muttertier ab, haben einen Durchmesser von etwa $6 \mu$, einen Nucleolus in einem kleinen Kern mit kurzen stäbchen- oder feinfadenförmigen Chromosomen. In einer kleinen Einbuchtung der Wand liegt dem Kern ein Doplelkörnchen mit hellem Hof als Centrosom an. Das Zellplasma zeigt einige grosse Vakuolen. Die Spermatozoen entstelien, wie bemerkt, aus den Gieschlechtszellen auf der Oberfläche der, ,männlichen Gregarine،. Die runden Zellen vergrössern sich, werden eiförmig, beladen sich allmählich mit Reservestoffkörnern. Der Kern rïckt an den peripheren Pol, d. h. an die dem Stiel der Zelle, der sie mit dem Soma verbindet, abgewandte Seite. Das Centrosom rückt 
umgekehrt an den Stielpol. Am peripheren Pol entsteht ein kurzer konischer Schnabel oder Spiess, der auch etwas Chromatin enthält. Tom Centrosom aus wächst ein diinnes Fädchen rïckwärts bis in den Stiel hinein. In umgekehrter Richtung wäclıst auch ein dünnes Fädchen nach rorn um den Kern lierum bis in den kleinen Sclınabel. Die Zelle zieht sich hinten zu einem dïnnen Faden aus, der sich rom Gregarinenleib ablöst und die ,Spermatide“ frei werden lässt. Der liern zeigt noch immer einen ziemlich grossen Nucleolus, der meist im untern Teil des liernes liegt und ron einem hellen Hof umgeben ist. Die Chromatinstäbclıen liegen peripher, das Centrosom ist doppelt und steht mit dem vordern und hintern Achsenfädchen in Verbindung. Ausser diesen ,Spermatiden", die die Befruchtung ausführen, gibt es aber auch noch weiter entwickelte Spermatozoen. Sie haben einen langen, schmalen Leib mit einem feinen Schwanz. Der Kern ist auch ganz rorn am Kopf, direkt hinter dem Schnabel. Das Nuclein ist auf drei oder vier grosse Brocken konzentriert, die Kernmembran ist unsichthar geworden. Der Nucleolus ist noch vorhanden. Der hintere Achsenfaden hat sich gespalten. Die Ansatzpunkte der beiden Fäden am Kerne können ziemlich weit voneinander abstehen. Im Schwanz vereinigen sich die beiden Achsenfäden wieder. Auch der Schnabel hat sich gespalten. Verf. glaubt, dass diese Samenelemente Weiterentwicklungen der ,Spermatiden" sind und aus solchen "Spermatiden" hervorgehen, die nicht zur Kopulation mit Eiern gelangt sind, weil sie während des Kopulationsstadiums noch nicht so weit entwickelt waren. Viele der weiter entwickelten Spermatozoen gehen zu grunde, in Ausnahmefällen bei Verlangsamung der Eireifung scheinen sie aber auch die Befruchtung vollziehen zu liönnen und zwar viel sclineller als die Spermatiden. - Die Befruchtung geschieht in der Weise, dass die Spermatiden sofort nach ihrer Ablösung rom mütterlichen Körper, offenbar durch eine Ausscheidung der Eizellen angezogen, die Kammer der weiblichen Gregarinen aufsuchen. Die Eizellen lösen sich sofort vom Körper ab und werden ron je einer Spermatide mittelst ihres Schnabels aufgespiesst. Daraufhin vereinigen sich die Zellenleiber beider Geschlechtszellen. Zuerst erkennt man aber noch beide Kerne, den Schnitbel und das Binnenfädchen. Bald wird aber die Copula etwa eiförmig, der Schnabel und Schwanz verschwinden. Die Kerne legen sich dann aneinander, die beiden Nucleolen stelten sich auch nahe aneinander, die C'entrosomen sind noch sichtbar, die Chromosomen liegen noch peripher. Dann verschmelzen beide Kerne und beide Nucleolen vollkommen miteinander. Der Kopulationskern ist jetzt intensiver färbbar. Wenn die Eiwand zur Sporocystenwand erstarrt, rerschmelzen schein- 
bar auch die männlichen und weiblichen Centrosomen zu einem einzigen, das sich dicht an die Kernwand anschmiegt. Die Centrosomenbeobachtung ist aber durch den Chromatinreichtum sehr erschwert, so dass Verf. die Verschmelzung nur als Hypothese aussprechen will. Es könnte sich aber auch so verhalten, dass die Centrosomen während der Nucleolenverschmelzung gänzlich verschwinden und sich erst aus dem Nucleolus wieder aufs neue bilden, denn Verf. hat nanchma ein chromatisches Körnchen aus dem Terschmelzungsnucleolus austreten sehen. Nach Vollendung der Kernverschmelzung werden die Copulae dickwandig und eirund und bilden Ketten. In diesem Stadium bildet das Chromatin einen langfädigen Knäuel, der Nucleolus ist ein kaum sichtbares Körnchen geworden. Das Centrosom, ein Zwillingskörnchen, liegt irgendwo der Kernwand an. Jetzt beginnt die mitotische Sporozoitenbildung, doch wird schon nach der zweiten Teilung die Spococystenwand so dick, dass man das Innere nicht mehr genau untersuchen kann. Wie bemerkt, kommen stets einige spät entwickelte "Spermatiden" oder meist auch die weiter entwickelten "Spermatozoen" nicht zur liopulation, ja es bleiben sogar stets auf der männlichen und der weiblichen Gregarine auch noch viele undifferenzierte Geschlechtszellen zurück. Vielleicht ist das der Ausdruck von Chromatin-Redulition. Noch zwölf Stunden nach der Kopulation schwärmen männliche sterile Sexualzellen herum, aber bald degenerieren sie.

R. Fick (Leipzig).

299 Léger, Lonis, et Octuve Dubosq, Les éléments sexuels et la fécondation chez les Pterocephalus. In: Compt. Rend. Acad. Science. Paris 20. T. 1902. 2 pag.

In vieler Beziehung fanden die Verff. bei Pterocephulus notilis A. Schn. von Scolopendra ähnliche Verhältnisse wie bei Stylorhymchus (s. vorstehendes Referat). Aber hier sind die Spermatozoen fast rein chromatische Körper ohne P'rotoplasma, während die Fier hier an einem Pol Kern und Bildungsplasma führen, in iibrigen Eiplasma grosse Iotterkörner. Die Spermatozoen sind sehr klein und schwer zu sehen, weil sie sehr durdscheinend sind. Sie besitzen auch einen Schnabel und Schwan\%, aber ausserdem eine Wellenmembran am ganzen Körper. Nach der lefruchtung bildet das Ei eine einfache oder doppelte Nembran und liefert durch dreimalige '/weiteilung acht Sporozoiten. Bei der liefruchtung stösst das Ei am vegetativen Pol ein kileines chromatinhaltiges Körperchen aus, das vielleicht ein Richtungskörperchen darstellt.

R. Fick (Leipzig). 


\section{Echinoderma.}

300 Hartmann, Iax, Studien am tierischen Ei. I. Ovarialei und Eire ifung ron Asterias glacialis. Aus dem Zool. Institut München. In: Zool. Jahrb. Abt. f. Anat. und Ontog. d. Tiere. 15. Bd. 4. Heft. 1902. pag. 793-812. 2 Taf.

Verf. beweist in dieser kurzen, aber äusserst inhaltreichen, a usserordentlich klar geschriebenen Abhandlung; dass die alte Anschauung O. Hertwigs, O. Schultzes u. a., nach der die Richtungschromosomen aus dem Keimfleck herrorgehen, richtig war, und dass die nenerdings ron Carnoy-Lebrun und ron R. Fick (s. Zool. Zentr.-Bl. 6. Bd. pag. 946) gemachten Angaben, die von manchen Autoren angefeindet wurden, offenbar vollkommen zu Recht bestehen. Verf. untersuchte die Ovarialeier in Villafranca, die Eireifungsstadien an Material ron R. Hertwig aus Messina. Er stellte fest, dass im heranwachsenden $\mathrm{Ei}$, auch bei ophiure lueris und Ophioglypha lacertosa sowie bei Phallithor bucephala, eigentiumliche periodische Chromatinauflösungen und liekonzentrierungen im Nucleolus stattfinden, die er als ,vegetative Kernveränderungen" bezeichnet und die, wie er meint, auch den Vorgängen im Amphibienei entsprechen. In den im Ovar zurückbleibenden Fiern tritt eine Verteilung des Chromatins im Kern und eine Bildung ron Yebennucleolen auf, die an grössern normalen Eiern nicht vorhanden ist. Am Schluss der Wachstumsperiode ist an normalen Eiern nämlich alles Clromatin und Plastin im Nucleohs rereinigt. Schon im lebenden Ei lassen sich zwei Teile unterscheiden. die heide aus feinwabig gebautem Plastin bestehen, deren einer aber ('hromatin eingelagert enthält, während der andere Teil daron frei ist. Die Waben sind am lebenden Objekt wahrzunehmen. C̈berhaupt ist das Objekt zur Cntersuchung ausserordentlich günstig, da man lurch die Beobachtung der lebenden Eier in den Stand gesetzt ist, genau die gewünschten Stadien zu konservieren. Nach dem Einlegen der reifenden Eier in Wasser entwickeln sie sich rasch. Das erste ist eine Fältelung ler Kieimbläschenmembran und eine Ausbreitung des ('hromatins im Nucleolus. Dann tritt ein Zentralkorn mit Strahlung zwischen der Eiwand und dem Keimbläschen auf, die Keimbläschenwand löst sich auf und der Nucleolus lässt aus seinem Innern Plastinmassen mit eingelagerten Chromatinlörnern austreten und in die Stralılung eintreten. Bald sind es einzelne Chromatinkörner, bald zu Kilumpen oder Reihen vereinigte, die sich aus dem Nucleolus ablösen, wobei der Nucleolus lappig erscheint. Wenn die genügende Chromatinmenge ausgetreten ist, rundet sich der Nucleolus ab; er enthält nur noch Spuren von 
Chromatin, wird allmählich immer kleiner und blasser und verschwindet zuletzt meist zur Zeit der Ausstossung der ersten Reifungszelle. Verf. macht darauf aufmerksam, dass die Angaben H a eckers und Obsts, wonach bei Äquorea bezw. Limax der neben der fertigen Spindel liegende Nucleolus seine frïhere zentrale ,Vakuole" verloren habe, ganz gut zu den jetzigen Befunden passe. Die ,zentrale Vakuole" sei offenbar niclits anderes als das an die Chromosomen abgegebene Chromatin. Auch Verf. hält durch die neuen Feststellnngen die Chromosomen-Individualitätshypothese usw. für erschüttert.

R. F i ck (Leipzig).

\section{Vermes.}

Annelides.

301 Foot, Katherine, and Ella Church Strobell, Further Notes on the Cocoons of Allolubophora fortida. In: Biol. Bull. 3. Bd. Nr. 5. Okt. 1902. pag. 206-213.

Die beiden Verfasserinnen haben interessante Beobachtungen iiber die Schleimröhren und Coconbildung bei Allolobophore gemacht, aus denen hervorgeht, dass die Coconbildung nicht nur während der Kopulation erfolgt, wie sie frïher geglaubt hatten, sondern auch an isolierten Exemplaren.

R. Fick (Leipzig).

302 Foot, Katherine, and Ella Church Strobell, The Spermatozoa of Allolobophora foctida. In: Americ. Journ. of Anat., 1. Bd. Nr. 3. 26. Nai 1902. pag. 321-327. 1 Taf'.

Die V'erfasserinnen geben Antotypiereproduktionen ron Mikrophoto-

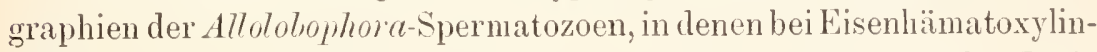
behandlung drei Pünktchen schwarz gefärbt sind. Eines an der Basis des vordern Spiesses, eines am vordern und ein ganz kleines am hintern Ende des Mittelstuickes. Sie glauben, dass das vordere Centrosom vielleicht den plasmatischen, Eintrittstrichter" R. Ficks und Foots und den , kometförmigen" Samenstern Lillies im Ei erzenge, das vordere Mittelstïckcentrosom den gewöhnlichen oder "hintern" Samenstern, das hintere Centrosom aber das Basalkörperchen der Geissel darstelle.

R. F i ck (Leipzig).

303 Johnson, Herbert Farlin. Collateral budding in Annelids of the genus Trypunosyllix. In: Amer. Naturalist. Tol. 36. 1902. pag. 295--315. 17 Fig.

Verf. liat an zwei Syllideen der pacifischen Küste Tordamerikas merkwürdige Knospungserscheinungen beobachtet, auf die er schon in einer vorläufigen Nitteilung (A new type of budding in 
Annelids, in: Biol. Bull. Vol. 2. 1901) hingewiesen hat. Eine der Arten, Trypanosyllis ingens n. sp., auf ein einziges, ohne die Gruppe ron Knospen $13 \mathrm{~cm}$ langes und $6 \mathrm{~mm}$ breites Exemplar gegründet, wurde bei Pacific Grove, Californien, gefunden; Verf. hebt in seiner Beschreibung die Existenz grosser pariger Divertikel des Darms hervor, die bei der ihr sonst nahe stehenden $T r$. gigantea (II. Int.) nicht erwähnt werden: Das Tier trug nahe dem Hinterende ein Büschel von etwa 30 Kinospen, die alle ungefähr anf der gleichen Entwicklungsstufe standen: Länge 5, Breite $2 \mathrm{~mm}$, Zahl der Somiten etwa 25. Parapodien ganz wie bei dem Stamm, nur das Endglied der Borsten mit einem dort fehlenden kleinen Zahn und feinen Einkerbungen an der konkaven Seite. Darmkanal rudimentär. Cölom mit Eiern prall angefüllt; keine im Stamm. Längsmuskulatur (auch im Stamm) nicht stark entwickelt, Ringmuskulatur fehlt. Rückenund Banchgefässe am Darm dicht anliegend. In jedem Segment ein Paar problematische Organe (Nephridien:). Zwei ventrale Nervenstämme der Epidermis anliegend, aber nicht mit ihr verschmolzen. Köpfe und Augen waren nicht aufzufinden.

Die zweite Art, in des Verfs. Abhandlung: The Polychaeta of the Puget Sound Region, in: Proc. Boston Soc. nat. Hist., Yol. 29, 1901, pag. 405, unter dein Namen Trypanosyllis gemmipara beschrieben, von Puget-Sund, wird $68 \mathrm{~mm}$ lang und $3 \mathrm{~mm}$ breit; etwa 300 Somite. Die hier vorhandenen linospen stehen auf den rerschiedensten Stufen der Entwicklung und bilden ein nahe dem hintern Körperende entspringendes Büschel, in dem die einzelnen Kinospen olıne jede erkennbare Ordnung oder Riicksicht auf bilaterale Symmetrie stehen. Die grössten (etwa 13 st.) hatten eine Länge von etwa 2,5 $\mathrm{mm}$ und bestanden aus 20-28 Somiten; ihre Parapodien glichen denen des Stamm-Individuums; ihre Analcirren länger und stärker als die Rückencirren. Das einer línospe sehr ähnliche Ende des Stamm-Individuums ist durch den Besitz eines kräftig bewimperten Enddarms und des Afters. ferner durch den Mangel der Kopfbildung von einer solchen unterschieden: es besteht aus 24 Somiten (incl. Pygidium). Die wie bei $T r$. ingens vorhandenen Darmdivertikel erstrecken sich nicht auf diesen Kïrperabschnitt. Die Kinospe besitzt kein Prostomium, sondern ist mit dem Stamm durch ihr die Augen und das Gehirn enthaltendes und mit Dorsalcirrus, Borsten und Acicula ausgestattetes erstes Segment verbunden. Die Augen, deren zwei vorhanden sind, weisen eine Linse, einen aus den Stäbchen zusammengesetzten „Glaskörper" und eine braun pigmentierte becherförmige Retina auf. Der Darmkanal ist nur durch einen dïnnen medianen Zellenstrang vertreten; Mund und After fehlen, ebenso Blutgefässe. 
Dissepimente und eine unvollständige mediane Scheidewand zerlegen den Körper in eine doppelte Reihe von Cölomräumen, die von unreifen. Samenmassen erfüllt sind. Die Parapodien besitzen Dorsal- und Ventralcirren, Borsten und ein Paar Acicula, ferner je eine grosse Parapodialdrüse, die wohl den von Trypanosyllis coeliaca und andern Syllideen bekannten "glandes pédieuses" ( Ma la qu in) entspricht. Ventral sind zwei starke Nervenstränge vorhanden, die vorn die Augen innervieren und dann in eine wahrscheinlich als Gehirn funktionierende ektodermale Zellenmasse übergehen. Ausser diesen grössern Kinospen ist ein Klumpen ron etwa 25 sehr jungen vorhanden, die noch keine Segmentation zeigen, aber mit den Anlagen ron je zwei Analcirren versehen sind. Diese Knospen sind in Längs- und Querreihen angeordnet. Sie entspringen ron einer Masse undifferenzierten Gewebes, das ron Muskelfasern durchzogen ist, die sich in die Längsmuskulatur der Knospen fortsetzen. Ïltere Kinospen, die sich anschliessen, lassen den Beginn der Segmentierung und das Auftreten der Fortpflanzungszellen erkennen. I'ubertätsborsten wie an den Knospen anderer Syllideen sind nicht rorhanden.

Die bei diesen zwei Arten beobachtete Ḱnospung ist im Gegensatz zu der bei den syllideen vorherrschenden Stolonenbildung als laterale Knospung aufzufassen und schliesst sich darin der Knospung von Syllix ramosu an, doch bestehen zwei wichtige Unterschiede dieser Art gegenüber: bei derselben ist der die Knospen mit dem Stamm verbindende Stiel segmentiert, und die Segmente tragen sogar rudimentäre Cirren; ferner enthalten die geschlechtlichen wie die ungeschlechtlichen Kinospen einen Ast des I)armkanals. Auch sind erstere mit grossen Augen und Schwimmborsten ausgestattet. Die. Knospen der hier beschriebenen T'rypanosyllis-Arten entbehren aber funktionierender regetativer Organe gänzlich und können daher wie der Palolo nur ein liurzes selbständiges Leben führeı. Sie sind nur lebende Maschinen zur Ausstreuung der in ihnen angesammelten Geschlech tsprodukte.

J. W. Spengel (Giessen).

304 Pratt, Edith M., A collection of Polychaeta from the Falkland Islands. In: Mem. Proc. Manchester liter. phil. Soc. Vol. 45. 1901. Nr. 13. 18 pag. pl. 4.

Verf. beschreibt eine kleine, Ende 1898 und Anfang 1899 durch Mr. Vallentin zusammengebrachte Kollektion von Polychäten von den Falklandsinseln mit Rücksicht auf die Bipolaritätstheorie. Die Sammlung unfasst fünf auf die arktischen und antalktischen Meere beschränkte (Eteone, Autolylus, Promenia, Bispira) und sieben kosmopolitische Gattungen (Platynereis, Goniada, Arenicola, Sabcllaria, Thelepus, Sabella, Spirorbis); vier extratropische Species (Goniada nonegica, Polyelora polybranchia, Arenicola claparedii, Bispira mariae) und eine kosmopolitische (Spirorbis borcalis). Eingehend beschreibt sie eine, vermutlich mit 
Goniada eximia Ehlers identische Form, welche sie als eine artarktische Varietät von Goniada norvegica Ürsted betrachtet. In bezug auf Sabellaria macropalea Schmarda $=$ S. armata (Kinberg) (s. Elılers, Die Polychäten des magellan. u. chilen. Strandes 1901, pag. 195). Neu für die Falklandsinseln sind Eteone spathocephala Ehlers (Magellanstr.), Autolytus simplex Ehlers (Nagellanstr.), Polydora polybranchia Haswell (Magellanstr., Sydney, Neapel), Arenieola elaparcdii - postlarvale Stadien pelagisch - (Neapel, Californien), Promenia jucunda Kinberg (Magellanstr.), Sabella ecratodaula Schmarda (Neuseeland), ? Bispira mariae Lo Bianco (Mittelmeer).

J. W. Spengel (Giessen).

305 Fauvel. P.. Annélides polychètes de la Casamance rapportées par M. A ug. Chevalier. In: Bull. Soc. Linn. Normandie (sér. 5). Vol. 5. 1901. (Caen, 1902) pag. 59-105. 55 Fig.

In der kleinen, nur 12 Species umfassenden Polychätensammlung von Casamance (Senegal) waren nicht weniger als elf verschiedene Familien vertreten und sieben newe Arten enthalten. Von den fün andern ist eine (Clycera africana Arvidson) rein afrikanisch, eine zweite (Loimia mcdusa Sav.) nur aus dem Roten Meer, die drei übrigen von den französischen Küsten (Ozean und Mittelmeer) bekannt (Marphysa sanguinca Mont., Diopatra neapolitana D. Cl., Cirratulus filiformis Kef. - letztere auch von Madeira, Cap. d. G. H. und Angra Pequena). Die neuen Arten sind: Nereis gravieri, Nephthys lycochacta, Nerinc perrieri, Aricia eheralieri, Armandia intermedia, Clymene monilis, Potamilla casamancensis. Von Diopatra neapolitana wird ein interressantes Regenerationsstadium beschrieben.

J. W. Spengel (Giessen).

\section{Arthropoda.}

\section{Crustacea.}

306 Vkman, S. von, Beiträge zur Kenntnis der Phyllopodenfamilie I'oly a rtemiidae. In: Bih. K. Svenska Vet.-Akad. Handling. Bd. 2S. Afd. IV. Stockholm 1902, pag. 1-38. Taf. 1-4. 1 Fig. im Text.

Die Gruppe der Polyartemiiden, die mit den Branchipodiden die Abteilung der an ostraken P'hyllopoden ausinacht, setzt sich einzig aus zwei Vertretern der Gattung Polyartemia zusammen. Beide bewolmen den hohen Norden, I' forcipata Fischer das schwedische Hochgebirge, Sibirien, Nordrussland, Finnmarken, $P$. hazeni Murdoch das nördlichste Alaska. Ein genaues anatomisches und histologisches Studium beider Arten erlaubte Verf. nicht nur die systematische Stellung der Polyartemiiden gegenüber den Branchipodiden festzustellen, sondern auch allgemeine Fragen, wie die über den Einfluss veränderter Lebensbedingungen auf die fortschreitende Differenzierung, zu streifen.

Die zwei Species unterscheiden sich besonders durch den Bau der Genitalorgane beider Geschlechter, durch die Morphologie der Greifantennen des männlichen Kopfs, sowie durch die Zahl der beintragenden Segmente, die bei $P$. forcipata 19 , bei $P$. hazemi 17 be- 
trägt. Hinter diesen Zahlen bleiben die iibrigen Phyllopoda anostraca mit 11 konstant auftretenden Thoracalsegmenten beträchtliclı zuriick. Die Vermehrung der Brustringe und damit der Extremitätenpaare gegenïber den Branchipodiden, sowie die gleichzeitig eintretende und heute immer noch weiter fortschreitende Reduktion in der Zahl der Abdominalsegmente deutet Terf. als einen sekundär eintretenden Entwicklungsprozess. In ähnlicher Weise lässt sich das Auftreten eines zweiten Exiten an den Beinen und die gegenüber Branchius und Artemia weiter vorgeschrittene Tereinfachung des Nervensystems in Kopf und Abdomen auffassen. Im Thorax stimnt die Ganglienkette mit den für die Branchipodiden bekannten Verhältnissen ganz überein, abgesehen von den durch die gesteigerte Segmentzahl bedingten Abweichungen. Vielleicht sind auch alle Antennenreste als sekundärer Erwerb zu betrachten; nur der basale Teil der alten Larvenantenne wiirde im reifen Tier weiterdauern.

Dagegen nähert sich dem primitiven Verhalten die Tatsache, dass ein Rudiment des Mandibulartasters während des ganzen Lebens bestehen bleibt, obwohl sein Umfang mit zunehmendem Alter abnimmt. Immerhin beginnt die Redulition des Tasters bei Polyartemu ebenso frühzeitig, wie bei den Branchipodiden, wo das Tasterrudiment bis heute vielleicht nur iibersehen worden ist.

Aus der genauen anatomisch-histologischen Beschreibung von $P$. forcipata sei nur noch weniges hervorgehoben. Die Schilderung betont besonders die Kigentümlichkeiten der Polyartemiiden gegenüber den Branchipodiden, sowie die neuentdeckten Verhältnisse; sie stellt auch ältere Angaben richtig.

Gegen eine besondere, respiratorische Funktion der Epipoditen oder „Kiemensäckchen" spricht ihr listologischer Bau. Auch die Exiten, wie Verf. nach älterm Vorschlag die an der Aussenseite des Beins, basalwärts rom Epipoditen sitzenden "Deckplatten" G. O. Sars' nennt, wirken nicht respiratorisch. Ebensowenig dienen dieselben dem Schntz der basalen Fussteile. Sie stellen vielmehr noch primitive, im Entstehen begriffene Schwimmorgane dar, die allmällich den typischen Borstenbesatz erhalten werden.

Die Unterlippe von Branchipus und Artemia fehlt der Gattung Polyartemia. Als ein Drïsenorgan in der allerfrühesten Entwicklungsstufe haben die beiden am Vorderende des Mitteldarms liegenden Blindsäcke zu gelten. Sie weichen histologisch vom Mitteldarm niclıt ab; nur ihre topographische Erscheinung und die Gegenwart eines Verschlussapparates gegen das Darmlumen liennzeichnet sie als besondere Organe.

An Branchipus schliessen sich die Verhältnisse der Exkretions- 
organe von Polyartemia an, sie entfernen sich, wie diejenigen der erstgenannten Gattung, in einigen I'unkten ron dem, was für Artemia gilt. Eine Antennendrüse tritt nur in den Larvenstadien auf.

Auch der Bau der weiblichen Genitalien weicht nur in Einzelheiten von demjenigen der Branchipodiden ab. Eine Vagina scheint zu fehlen, an der Grenze ron Ovidukt und Uterus entwickelt sich keine muskulöse Schliessvorrichtung; die schalenbildenden Driisen zeigen eine. andere Verteilung und Ausmiundung als bei Branchipus.

Erwähnung rerdient es, dass, im Gegensatz zu den übrigen Phyllopoda anostraca, die Hoden ron Polyartemia sich sehr weit in den Thorax ausziehen.

Männchen und Weibchen treten in beiden Arten ungefähr in derselben Zahl auf.

Polyartemia stellt gegenüber den Branchipodiclen ein weiter rorgeschrittenes, phylogenetisches Entwicklungsstadium der anostraken Phyllopoden dar. Ihre zwei species bewohnen gleichzeitig ausschliesslich arktische Gebiete, während die überwiegende Mehrzahl der Phyllopoden den gemäßigten und warmen Zonen der nördlichen und südlichen Hemisphäre angehört. Die Stammform der Ihyllopoden, mit Inbegriff von Polyartemia, entwickelte sich, nach Verf, zweifellos ausserhalb der Arktis. So sind die Eigentümlichkeiten der Polyartemiiden mit unter dem Drucke veränderter, äusserer Lebensbedingungen entstanden. Abänderung der umgebenden V'erhältnisse verïndert somit nicht nur die Organismen im allgemeinen, sondern beschleunigt auch ihre Entwicklung in einer zuror bestimmten Richtung.

F. Zs schoklie (Basel).

307 Meissner. W.. Notiz überniedere Crustaceen des Wolga-Flusses bei Saratow. In: Zool. Anz. Bd. 26. Nov. 1902. pag. 51-55.

Verschiedene Lokalitäten der Wolga bei Saratow beherbergen 36 Cladoceren, 12 Copepoden und 6 Ostracoden. Nach Vorkommen und Lebensweise lassen sich unter diesen Entomoktrasen Planktozoen, Bewohner des sandigen Ufers, der littoralen Wasserpflanzen und des Schlarnmgrundes unterscheiden.

In einer Bucht, die bei hohem Wasserstand mit den Strom in offener Verbindung stand, beim allmählichen Sinken des Wassers aber zum isolierten See und endlich zum teilweise mit Pflanzen durchwachsenen, schlanmigen Teich wurde, veränderte sich fortschreitend auch die qualitative und quantitative Zusammensetzung der Crustaceenbevölkerung. Das zuerst bestehende typische Potamoplankton verarmte im allgemeinen an Artenzahl.

Einen bedentsamen Einfluss auf das Flussplankton der Wolga und besonders auf die Nertretung der Copepoden in demselben übt die Schnelligkeit der Strömung aus. Quantitativ spielen folgende kntomostraken als Planktonten die grösste Rolle: Diaphanosoma brachyurum Liévin, Leptodora rintii Focke, Woina micrura Kurz und Bosminopsis zernowi Linko. Die letztgenannte, frïher als selten geltende Form trat in beiden Geschlechtern häufig auf. 
Auf andere Flüsse lassen sich die für die Wolga festgestellten faunistischen und biologischen Verhältnisse nicht ohne weiteres übertragen.

F. Zschokke (Basel).

08 Lerat, Paul, La première cinèse de maturation dans l'ovogenese et la spermatogénése du Cyclops stremus. Laboratoire de cytologie de l'Institut Carnoy Löwen. Note préliminaire. In: Anat. Anz. 21. Bd. Nr. 15. 1902. pag. 407-411. 4 T'extabbildgn.

Verf. kommt zu entgegengesetzten Anschauungen wie die bekannten Abhandlungen von Haecker und Rii ckert (s. Zool. Zentr.-Bl. 2. Bd. 1895. pag. 291 ff. u. 551 ff. Ref.). Verf. findet bei der ersten Reifungsteilung der Ovo- und Spermatogenese ganz ähnliche, von der Spindelfadenanheftung abhängige, verschieden geformte $Y$ und Doppel- $Y$, wie sie bei den Pflanzen, Amphibien und Insekten in jüngster Zeit beschrieben sind. Er glaubt daraus auf eine Längsteilung der Chromosomenpaare der ersten Reifungsspindel bei der Teilung schliessen zu müssen.

R. Fick (Leipzig).

99 Neher, E. II., T'he Eye of Palacmonetes antrorum. In: Proceed. Indiana Acad. Science for 1901. pag. 96-101.

Iei einer blinden Garneele, die aus den unterirdischen Gewässern der Gegend von San Marcos ('Texas) stammt und durch einen artesischen Brunnen zutage kommt, fand Verf. folgenden Bau des Auges: die Augenstiele sind vorhanden, aber im Vergleiche mit einer verwandten, am Licht lebenden Art verkïrzt; das Auge selbst ist zu einem kleinen Haufen von weniger als 350 Zellen reduziert, in deren Anordnung nichts an den Ban eines zusammengesetzten Auges erinnert; dagegen sind die optischen Ganglien gut erhalten. Bei jungen Exemplaren ist der Augenstiel zwar absolut kleiner, aber relativ grösser als bei den erwachsenen.

R. Hesse (Tübingen).

\section{Arachnida.}

10 Koenike. F.. Über ein paar Hydracliniden aus dem Schwarzwald nebst Beschreibung von Feltria minuta Koen. $\sigma^{7}$ a us dem Rhätikon. In: Mitteil. des Badischen Zool. Ver. Nr. 13-14. 1902. pag. 45-68.

Der Verf. beschreibt in dieser Arbeit zwei neue Feltria-Männchen, vonl denen das eine einer neuen Species angehört, während das andere der Feltria minuta Koen. zugehört. Beide Formen sowie die Nymphe der zuletzt genannten Art wurden von F. Zschokke im Heidenmuhr, einem Gebirgsbach im südlichen Schwarzwald, erbeutet.

Feltria armala Koen. $\sigma$ ähnelt in der Körperform der $F$. muscicola Piersig. Der in der Augengegend auftretende, mit einem feinen Haar besetzte Höcker des vordern Seitenrandes des Körpers tritt jedoch weniger stark hervor als bei der 
Vergleichsart. In Übereinstimmung mit Fcltria georgei Piersig ơ bemerkt man auf dem Rücken nur einen Panzer, der eine Form hat ähnlich wie die beiden Rückenschilde von $F$. muscicola Piersig $\sigma^{7}$ zusammen genommen. Das Maxillarorgan (Capitulum) besitzt an hintern Ende der untern Wandung nur einen einzigen Fortsatz. Der Maxillartaster ist merkbar stärker als die benachbarten Glieder des ersten Fusses, insbesondere gilt das vom zweiten Gliede, dessen Streckseite eine stark bauchige Auftreibung aufweist. Auf der Beugeseite besitzt er nur einen kräftigen Haarhöcker mit mäßig langer, naclı vorn gekrümmter Borste. Was die Hüftplatten anlangt, so ist zu bemerken, dass das stark lakig ungebogene Hinterende der ersten Epimere, wie es bei $F$. muscicola Piersig auftritt, fehlt. Die Beine sind kürzer als bei der Vergleichsart. Die Einlenkung des letzten Fussparres befindet sich niclıt wie bei $F$. muscicola Piersig $\sigma^{7}$ an der hintern Aussenecke der vierten Hüftplatte, souder'n etwa in der Mitte des Aussen. randes derselben. Das Endglied des dritten Beinpaares weist etwa in der Beugeseite desselben Abzeichen auf, wodurclı sich das Männchen der Vergleichsart auszeichnet, nur ist der auf niedrigem, aber kräftigem Höcker stehende Chitinstift erheblich länger als bei jener. Die Grundform des Genitallofes ist etwa eine querliegende Ellipse, die an der Hinterseite in der Mitte eine nur geringe Aushuchtung erkennen lässt. Die Körpergrösse beträgt $304 \mu$.

Das Männchen von $F$. minuta misst 320 "1. Der Körperumriss gleicht am Stirnrande bei Rückenlage fast völlig demjenigen von $F$. muscicola Piersig . Die Haut ist liniiert. Inter derselben befindet sich ein Panzer, der wie beim Weibchen schon bei geringerer Vergrösserung eine netzartige Felderung aufweist. Die Trennungsfurche zwischen Rücken- und Bauchpanzerplatte zieht sich am Seitenrande des Körpers hin. Das Hinterende des Capitulums besitzt wie F. musricola Piersig einen Doppelfortsatz, dessen Spitzen nach den Seiten umgebogen sind. Der Maxillartaster ist kräftiger gebaut als das erste Bein. Das vorletzte Glied zeigt auf der Beugeseite unweit des distalen Endes zwei kleine, nebeneinander gestellte Borsten. Das Endglied des vorletzten Fusses hat ebenfalls eine geschlechtliche Auszeichnung; auf seiner Bauchseite steht ein niedriger Höcker mit einem kurzen, daumenartig zurückgebogenen Chitinstift. Gleich deın Weibchen ist das Männcher durch einen ansehnlichen Genitallıof ausgezeichnet. Die völlig verschmolzenen Napfplatten haben einen flach gekrümmten Vorderrand, dessen Mitte eine winzige Ausrandung aufweist. Die Ausrandung des Hinterrandes ist stärker ausgebildet. In der Mitte der beiden gegenständigen Ausbuchtungen befindet sich die sehr feine Genitalöffnung.

Die Nymphe von $F$. minuta erreicht eine Länge voll etwa $256 \mu$. Die Körpergestalt sowie die Ausstattung und Bauart der Palpen und Beine erinnert an das Weibclien. Im Gegensatze zu den Verhältnissen bei der Nymphe von F. muscicola Piersig ninumt das Epimeralgebiet die halbe Bauchseite ein, auch ragt es vorn über den Stirnrand des Körpers linaus. Die vierte Hüftplatte endigt nicht in geraden, perpendikulär zur ventralen Mittellinie gerichtetem Rande. Die Genitalplatten sind ansehnlicher als bei der Nymphe von $F$. muscicola Piersig, auch trägt eine jede derselben efwa zwei Dutzend Genitalnäpfe.

Des weiteren gibt $\mathrm{K}$ oenike eine ausführliche Beschreibung von Hjartdalia runcinata Sig. Thor, einer Hydrachnide, die von drei Forschern (Thor, Protz und dem Ref.) an verschiedenen Stellen fast gleiclizeitig erbentet wurde. Der Verf. vertritt in Übereinstimmung mit Protz die Ansicht, dass dieselbe der Gattung Aturus P. Kraner zuzuzählen sei. Er bemängelt die von Thor und dem Ref. aufgestellten Diagnosen. Es sei unzutreffend, wenn in der Aturus-Diagnose von 
einem Mangel an Genitalplatten gesprochen werde. Er behauptet, dass A. scaber Kram., die zuerst aufgefundene Stammform, in Wirkliclikeit solche besitze, die allerdings leicht übersehen werden könnten. Der Ref. sagt in seiner Diagnose neigentliche Genitalplatten nicht vorhanden". Diese Behauptung muss er aucl jetzt noch als zu Recht bestehend aufrecht erhalten. Die Genitalnäpfe sind bekanntlich bei den Vertretern der Gattung Atums jederseits der Genitalöffnung in einer einfachen oder doppelten Reihe angeordnet, die sich bei den verschiedenen Arten mehr oder weniger weit nach dem Seitenrand des Rumpfes hinzieht. Da dieselben sehr dicht aneinander gerückt sind, bilden sie sehr häutig ein zusammenlängendes Band, für das man wohl kaum die Bezeichnung nGenitalplatte ${ }^{*}$ in Anspruch nehmen kam. Alle die von Koenike angeführten Merkmale (Körpergestalt, medianer Einschnitt am Hinterleibe, Stellung der Trennungsfurche, Mangel oder Vorhandensein der Genitalplatten) sind für sich allein gar nicht von dem Ref. als ausschlaggebend für Aufstellung einer Gattung erachtet worden. Bestimmend war vor allen Dingen, dass das Männchen am vierten Fusse nicht die charakteristischen Umbildungen zeigte, wie alle bekannten _1turus-Arten, sowie der Umstand, dass die Genitalnäpfe nicht auf besondern Genitalplatten, sondern auf dem allgemeinen Bauchschilde eingebettet sind. In zweiter Linie kommt noch die Ausstattung der Palpen mit Zapfen in Betracht. Dass Koenike selbst nicht so ganz von der Wahrheit und Zuverlässigkeit seiner Beweisführung über. zeugt ist, erhellt schon daraus, dass er die in Frage stehende Milbe als Typus einer Untergattung von Aturns gelten lassen will. R. Piersig (Annaberg, Erzgeb.).

311 Thor. Sig., Zur Systematik der Acarinenfamilien Bdellidae Kocl, 1842, Grube, 1859, Fi u odid ae Koch, 1842 und Cunaxidae Sig. Thor 1902. In: Verhandl. der K. K. Zool.-bot. Ges., Wien. Jahrg. 1902. pag. 159-165.

Inı ersten Abschnitt der vorliegenden Arbeit beschäftigt sich der Verf. mit der Revision der Gattungsnamen und mit der Synonymie einzelner Arten innerhalb der Familie Bdellida e C. L. Koch. Aus seinen Erörterungen geht hervor, dass nach dem Prioritätsgesetz gewisse Änderungen in der Penennung der einzelnen Gattungen und Arten vorgenommen werden müssen. Er stellt zunächst die Typen für die nach und nach geschaffenen Gattungen fest und bezeichnet als Stammform für das von Lat leille aufgestellte Genus Bdelle den Acarus longicornis L. Nach seiner Ansicht sind nun mit $B d$. longicornis L. identisch: Chelifer totus ruber Geoffroy, Scirus vulgaris Hermann, Bdella vulgaris und Bd. egregia C. L. Koch, Bd. arenaria P. Kramer und Bd. decipiens Thorell. - Als Typus für die von Hermann aufgestellte Gattung Scirus bezeichnet er Sc. longirostris Herm. Andere Arten derselben sind Brlella lapidaria P. Kramer, Bdclla virgnlata Can. et Fanz., Bdella capillata P. Kramer. Für die von v. H e yden gegründete Gattung Cyta (= Ammonia C. L. Koch) bezeichnet er Scirus sctirostris Herm. als Stammform. Eine andere hierher gehörige Art ist C. coernlipes (Dugès).

Der Name Cnnaxa v. Heyden wird für Scirus setirostris Herm. errichtet und muss als Gattungsname festgehalten werden. Für diese Gattung hat man seit Dugès in der Regel den Namen Scirus angewendet. Neben dem Typus C. sctirostris (Herm.) gehören noch hierher drei Kochsche Arten, zwei von Berlese und eine $(C$. taura) ron P. Kramer. -

Eine neue Abgliederung bewirkte C. L. Koch, indem er die Gattung und Art "Eupalus croccus Koch" schuf. - In neuerer Zeit stellte Berlese die neue Gattung Scimla mit einer Stammform: Sc. impressa Berl. auf. Trouessart errichtete die Untergattung Molgns, der er als 'Typus die Bdella sangninea Trouessart 
zuwies. Mit dieser sind wach seiner Meinung Bdella marina Packard und Bd. Bisteri (Johnston) synonym. Letztgenannte Art wurde später von ihrem Entdecker auf Acarus ( $B d$.) longicornis L. bezogen, eine irrige Auffassung, gegen die der Verf. polemisiert. Hierbei stellt er im Gegensatze zu den Behauptungen O'u deman s' fest, dass Acarus (Bd.) longicornis L. identisch sei mit Scirns vulgarrs Herm., nicht aher, wie der niederländische Acarinologe annimmt, mit Scinus longirostris Herm. Diese Form unterscheidet sich von dem Sc. rulgaris durch die Länge und cylindrische Form des fünften Palpengliedes, dessen distales Ende sich nicht verbreitert. Die beiden Endborsten sind schwach und kurz. Bei Sc. $(B d$.$) vulgaris Herm. erreicht das Endglied der Palpen nicht einmal die halbe$ Länge des zweiten Gliedes. Das stark verbreiterte distale Ende trägt zwei Endborsten, die kräftig und weit länger als das Glied selbst sind. Nach den Angaben Th ors lassen sich diese Merkmale an den Zeichnmngen Geoffroys deutlich feststellen, ausserdem deutet auch der Text darauf hin, wenn es heisst nantennis extremo bisetis“. Aus diesen Gründen können beide Formen nicht miteinander identifiziert werden. Die von G. Johnston beschriebene Art (Acarus longicomis nec L.) ist nach den Untersuchungen 'Thor's synonym mit Molgus arcticus (Thorell). Der Verf. bezieht auf diese Form nach folgende Species: Belclla litoralis Neumann, Bd. grandis C. L. Kocl, Bd. rillosa P. Kramer et Neum., Bd. marina Packard, Eupalus sanguineus Tronessart, Molgus sanguineus Trovessart, Bdella aretica Kramer und $B d$. aretica J. Trägårdh.

Der zweite Abschnitt verbreitet sich über die Gruppierung der Gattungen in Familien. Der Verf. erklärt sich damit einverstanden, dass Berlese und G. Canestrini die vou Koch den Schnabelmilben (Bdellides) zugewiesene Gattung Cheyletus aus dieser Familie ausscheiden. Ebenso stimmt er mit Trouessart überein, wenn dieser der Gattung Cunaxa (= Scimus) eine Sonderstellung zuweist und die Eupodidae als Unterfamilie (Eupodinae) mit den Bdellid e n vereinigt. $\mathrm{Ja}$, er geht insofern noch einen Schritt weiter, als er den Familiencharakter der Eupodidae festhält und dieselben mit den Bdellidae zu einer höhern Gruppe (Bdelloida) vereinigt wissen möchte. Aus diesem Verbande mussten dagegen folgende Gattungen ausgeschieden werden: 1. Cunaxa Heyden, 2. Eupalus Koch und 3. Scirula Berlese; denn die Bauart und Ausstattung der Palpen sei ganz verschieden von denen der Bdelliden. Da er diese Gattungen nicht mit den Trombidiidae vereinigen kann, schlägt er für dieselben deu Familiennamen Cu u axidae Sig. Thor vor. Zur Begründung seines Vorgehens kennzeiclınet er die wichtigsten Unterschiede der drei hier in Frage kommenden Familien wie folgt:

1. Cun axidae Thor, die drei- oder viergliedrigen Palpen mit zugespitztem oder klauenförmigem Endgliede. Mandibeln klauenförmig. Mit drei Paar Genitalnäpfen unter den Genitalklappen (Labia externa).

(Gattungen: Cunaxa, Eupalus, Scirula, ? Psendocheylus).

2. B dellida e Koch. Palpen lang, fünfgliedrig, seitwärts weit hervorragend und ellbogenförmig geknickt; Endglied cylindrisch oder gegen das distale Ende hin verbreitert, in der Regel mit langen Borsten versehen. Mandibeln scheren. förmig. Unter den Genitalklappen drei Paar Genitalnäpfe.

(Gattungen: Cysta, Bdella, Scirus, Molgus, ? Cryptognathus.)

3. Eupodidae Koch. Palpen kurz, viergliedrig, nicht seitwärts ellenbogenförmig geknickt; Endglied cylindrisch oder kegelförmig. Nandibeln scherenförmig. Nur zwei Paar Genitalnäpfe unter den Genitalklappen.

(Gattungen: Eupodes, Linopodes, Rhagidia (= Noerneria), Pronematus, Ereynetes, Penthaleus, Notophallus, Halotydeus,? Tydeus). 
Die Zugehörigkeit der Gattungen Nauorchestes, Alycus und Michailia Berlese scheint dem Verf. zweifelhaft. Da der Name Michaëlia schon früher vergeben ist (Michaëiia Trouessart, Nov. 1884 und Michaëlia Halle, 18. Dez. 1884), muss der Name Michaëlia Berlese, 29. Dez. 1884, verändert werden. Der Verf, schlägt für 11. angustana Berlese den Namen Bimichaëlia angustana (Berl.) vor.

R. Piersig (Annaberg, Erzgeb.).

\section{Insecta.}

12 Griuberg, Karl, Untersuchungen ïber die Keim-und Nährzellen in den Hoden und Grarien der Lepidopteren. Vorläufige Mitteilung. - Aus dem zool. Institut der Universität Marburg. In: Zool. Anz. 26. Bd. Nr.689. 15. Dez. 1902. pag. 131-142. Mit 4 Abbildungen.

Der erste Abschnitt handelt iiber die sog. Verson-Zelle, die Verf. "A picalzelle" zu nemnen vorschlägt, da sie immer an der Spitze der Keimschläucle auftritt. Sie kommt im Hoden und im Ovar vor. Sie entsteht aus einer Keimzelle und wird schon sehr früh (bei Bombyx mori schon im Embryo) angelegt. Im Hoden besorgt die \%elle die Ernährung der Keimzellen. Verf. unterscheidet dabei eine assimilierende Täitigkeit, nämlich die Aufnahme und Verarbeitung bereits vorhandener Stoffe (Auflösung von Spermatogonien und Aufnahme von Material aus der bindegewebigen Huille) und eine secernierende 'Tätigkeit, nämliclı die Produktion einer äusserst feinkörnigen, schwärzlichen Masse. Die letztere häuft sich dicht beim Kíern auf und wird durch das Plasma der Apicalzelle zu den Spermatogonien geleitet. Verf. meint, dass Verson die grössern Nahrungskörner, die wie kleine Kerne ausselıen, für junge, rom Kíern der Apicalzelle stammende Spermatogonien angesehen hat. Nach Vollendung ihrer Tätigkeit wird die Apicalzelle rückgebillet. In Orar bleibt sie im wesentlichen funktionslos und verfällt in spätern Stadien aucl der Degeneration.

Der zweite Abschnitt behandelt die postembryonale Entwicklung der Ovarien bei Bombyx mori und Pieris brassicae L. Terf. fasst seine Resultate dalin zusammen, dass die Differenzierung der Kíeimelemente sclıon in der Larvemperiode beginnt, dass die Oogonien nur Ei- und Nährzellen liefern, endlich, dass die Follikelzellen von den Zellen des Eirölırenstieles abstammen, die selbst von einigen Zellen stammen, die hereits im Embryo von den Keimzellen deutlich gesondert sind.

R. I i c k (Leipzig).

\section{Vertebrata.}

13 Biihler, A., Rückbildung der Eifollikel bei Wirbeltieren. 
I. F is che. In: Morphol. Jahrb. 30. Bd. 3. Heft. pag. 377-452. 1902. Nit 2 Taf. u. 2 Textabbildungen.

314 Bühler, A., Rïckbildung der Eifollikel bei Wirbeltieren. II. Amphibien. In: Morphol. Jahrb. 31. Bd. 1. Heft, pag. 85 -103. 2 Taf.

Verf. beginnt mit diesen Abhandlungen die Veröffentlichung einer auf breitester Basis ausgeführten Untersuchung des Schicksals der geplatzten und der ungeplatzten Follikel bei den Wirbeltieren, von den Fischen angefangen bis zum Menschen, die aufs wärmste zu begrüissen ist, da sie den so erbitterten Streit um die Entstehung der „gelben Körper" und der „atretischen Follikel“ endgültig zu schlichten berufen ist. In der Einleitung wendet sich Verf. gegen die Art des Referates ron Sobotta in Merkel-Bonnets Ergebnissen (1898) über diesen Gegenstand, der er Mangel an Sachlichkeit vorwirft. Auch auf die allgemeine Bedentung der Streitfrage geht Verf. ein. - Verf. bespricht sodam eingehend die ältere Geschichte unserer Kenntnisse über jene Bildungen, die auf Graaf zuriickgehen, und die Methode seiner eigenen Untersuchung. Gierade der Abschnitt iiber die Methode ist ausserordentlich interessant, weil er die Vor- und Nachteile der verschiedenen Arten genau abwägt. Verf. emptiehlt für die Entscheidung der meisten Fragen Formalin zum Härten, F'lemmings Lösung zum Nachfixieren und Eisenhämatoxylin zur Färbung. - Von Cyclostomen untersuchte Verf. Petromyzon planeri und Myxine glutinosa. Er schildert sehr klar den Ball des Eicrstockes, dessen Kenntnis für das Verständnis der beobachteten Vorgänge natürlich unerlässlich ist und deshalb hier ausführlich wiedergegeben werden muss. Das Orar stellt bei den Cyclostomen einen hohlen Sack dar mit vielen Lappen oder Ausbuchtungen. .Der Sack wird gegen das Cölom hin abgeschlossen durch eine dïnne Haut, die ich als oberflächliche Orarialplatte, Lamina orarii superfic. bezeıchne im (iegensatz zur Basalplatte, mit welcher das ganze Organ festsitzt. In hieser Oberflächenplatte des Ovariums sind die Follikel derart eingefügt, dass ihr grösster Teil in das Innere des Eies vorspringt". Das Innere des Ovars enthält in der Nähe der Basisplatte wenig lockeres Bindegewebe, der ganze übrige Teil erscheint hoht und wird nur von einzelnen schmalen Bindegewebsziigen, Trabekeln, durchsetzt. Im Hohlraum zirkuliert Lymphe „er ist also als Sin. lymphat. ovarii zu betrachten". Er zerfällt wie das Ovar in einzelne Buchten. Die OberHï̈chenplatte des Orars wird aussen vom Cölomepithel, innen von Sinusepithel (Innenepithel des Ovars bei Amphibien von O. Schultze) iiberzogen. Die gegen den Binnenraum des Ovars weit vorspringenden Eier sind rom Follikel ïberzogen. Dieser ist am reifen Ei kanm $2 \mu$ dick. Trotz aller 
Feinheit unterscheidet Verf. eine äussere, derbere $T$ h e ca ex terna mit ganz flachen und eine hellere innere Theca interna mit längsovalen Kernen. Die Theca int. wird durch eine feine, aber scharfe Linie, IIembrana propria, vom Follikelepithel getrennt. Dies besteht aus einer einfachen Schicht weit auseinander gezogener Zellen. Das Ei besitzt ein dickes $\mathrm{Oolemma}$, das aussen radiärstreifig, innen homogen erscheint. Der Dotter ist nocli durch eine besondere, feinste Haut, „Membrana vitellina der Autoren“, gegen das Oolemm abgegrenzt (bei Amphibien rom lief. als eigentliche Zellmembran nachgewiesen). Bei Myrine sind die Schichten dicker. Ton Teleosteern untersuchte Verf. eine frühlaichende Felchenart des Ziurichsees .Sommeralbeli“ genannt, die er Coregoms gäglingus bezeichnet. Dessen Ovar enthält glatte Muskelfasern, deren Mitwirkung beim Follikelsprung Verf. annimmt. Die Resultate an den Rundmäulern und Knochenfischen fasst Verf. dahin zusammen, dass nach der Eiausstossung fast nur eine totale liückbildung eintritt. Bei Coregoms atrophieren das Epithel und das Thecabindegewebe gleichzeitig und parallel. Höchstens im Anfang werden in der Theca einzelne grosse Bindegewebzellen gebildet. Beim Neunauge atrophiert die Theca erst nach dem Epithel. Das Epithel geht vollständig zu grunde, das Thecabindegewebe verbindet sich aber untrennbar mit der Oberflächenplatte des Eierstockes. Die Rissstelle des Follikels erhält sich bis ins letzte Stadium. Die Follikelatresie bietet ein wesentlich komplizierteres Bild, da es sich hier um die Bewältigung des ganzen Eimaterials handelt. Zum Teil geht die Resorption olme Einmischung ron fremden Zellen vor sich, indem der Eikern zerfällt, sich auflöst, ebenso Teile des Eiprotoplasmias. Die vertlüssigten Teile gelangen unter Mitnahme einzelıer Dotterkörner durch das Oolemm nach aussen. Dann beginnt das Follikelepithel seine auflösende und resorbierende Tätigkeit. Seine Zellen dringen beim Neunauge in kleineren, beim Hägling in grössern „Massen ins Ei ein (Verf. nennt sie .. Dotterzellen" Ref.) und machen daselbst das Dottermaterial durch Aufnahme und Zerkleinerung zur Wegschaffung geeignet. Vom Epithel übernehmen die Theca und die Gefässe mit ihren Leukocyten das so präparierte Material zum weitern Transport". Die Follikelhülle atropliert dann wie beim geplataten Follikel. Das Epithel und der Dotter verschwinden rollkommen, das Oolemm kann sich noch eine Zeitlang , in der zum Ovarialbindegewebe zurïckgekehrten Theca" erhalten.

In der zweiten Abhandlung berichtet Verf. zuerst über die Rïckbildung der geplatzten Follikel bei Bufo rulgaris und bei Triton, taeniatus. Auch bei den Amphibien tritt eine vollkommene Rückbildung der Eisackwand ein. Das Epithel geht rasch vollständig unter. 
Die Zellen der Theca interna nehmen hier aber „während längerer Zeit nach Form, Grösse und Färbung epitheloiden Charakter an, aktive Neubildung fehlt jedoch". Kuletzt tritt auch bei den Amphibien eine vollständige Verschmelzung der Thecawand mit den Oberflächenblatt des Ovars ein.

Die Follikelatresie hat Verf. nur an Bufo cinerea untersucht und kam dabei zum gleichen Resultat wie Ruge bei Axolotl und Salamandra. Der Torgang beginnt mit einer chromatolytischen Auflüsung des Keimbläschens und dem Eindringen von Follikelepithelzellen mit einigen Leukocyten in das Ei. Die Epithelzellen, die namentlich in die Aussenzone des Eies eindringen, nennt Verf. auch hier Dotterzellen. Sie beladen sich vollkommen mit Pigmentkörnchen, so dass man kaum oder gar nicht mehr ihren Kern erkennt. Später wachsen von der Theca Blutgefässe und Bindegewebszïge in den Eirest hinein. Die Dotterkörner werden vollkommen resorbiert, das Ganze schrumpft, das Epithel verschwindet und das Bindegewebe bildet schliesslich einen Teil des Ovarstromas. (Die rom Ref. 1899 bei Rana beschriebene und demonstrierte fettige Degeneration bei atretischen Follikeln erwähnt Verf. nicht. Ref.)

R. Fick (Leipzig).

315 van Pée, P., Recherches sur l'origine du corps vitré. In: Arch. de Biol. T'. XIX. 1902. pag. 317--385. 2 Taf.

316 r. Lenhossék, M., Die Entwicklung des Glaskörpers. Leipzig 1903 (F. C. W. Vogel). 107 S. m. 19 Abbild. u. 2 Taf. gr. 4. M. 12. -

317 Rabl, C.. Zur Frage nach der Entwicklung des Glaskörpers. In: Anat. Anz. 22. Bd. 1903. Nr. 25. pag. 573-581.

Zu den bisherigen Ansichten ïber die Entstehung des Glaskörpers im Wirbeltierange, der Bindegewebslehre, wonach Mesenchym die Grundlage für das Glaskörpergewebe bildet, und der Transsudationstheorie Kesslers, welche in der Glaskörpermasse eine aus den Blutgefässen des Auges stammende homogene Gallerte sehen wollte, ist durclı die Untersuchung ron Tornatola (vgl. Zool. Zentr.-Bl. VII, Nr. 291) eine dritte $\Lambda$ uffassung gekommen: der Glaskörper soll durch secernierende Tätigkeit embryonaler Retinazellen entstehen. In einer mehr beiläufigen Ïusserung hat C. Rabl ${ }^{1}$ ) und ausführlicher F is chel ${ }^{2}$ ), letzterer für das Salamanderange sich den Ausführungen To rnatolas angeschlossen. Aus neuester Zeit liegen weitere Ïusserungen vor,

1) C. Rabl, Über den Ban und die Entwicklang der Linse III. In: Zeitschr. f. wiss. Zool. LXVII. Bd. 1899. pag. 28. (Separatausgabe pag. 209).

2) A. Fischel, Über die Regeneration der Linse. In: Anat. Hefte 14. Bd. 1900. pag. 28. 
über welche hier berichtet werden soll: die eine erweitert die Angaben Tornatolas iiber den epithelialen Ursprung des Glaskörpers dahin, dass ausser der Retina auch die embryonale Linse an seiner Bildung beteiligt ist, und sucht diese Anschauung mit der bisherigen Annahme einer mesodermalen Herkunft zu vereinigen; die andere glanbt in der Linse die alleinige Ursprungsstätte des spezifischen Glaskörpergewebes erkennen zu sollen, und in Reaktion dagegen vertritt eine dritte wiederum den Standpunkt Tornatolas.

Die Untersuchungen van I'ées wurden an Schafembryonen gemacht, und nur betreffs der frühesten Stufen wurden Kaninchenembryonen zur Ergänzung herangezogen. An letztern stellt Verf. fest, dass die Bindegewebsschicht, welche anfangs zwischen der primären Augenblase und der Epidermis bei Sängern rorhanden ist, im Verlauf der Entwicklung bis auf einen geringen Rest verdrängt wird, sodass die beiden Epithelien für den grössten 'T'eil ihrer Erstreckung dicht aneinander liegen. An Schafembryonen von 5-6 mm Länge erweist sich die erste Anlage des Glaskörpers schon ans zwei Elementen rerschiedenen Ursprungs zusammengesetzt: einerseits aus spärlichen Mesodermzellen, die teils schon bei der Einstülpung in die sekundäre Augenblase gelangen, teils durch die Augenspalte eingewandert sind und eine fibrilläre Bindegewebslamelle bilden, welche mit dem extraoculären Bindegewebe in innigem Zusammenhange steht; andererseits aus fibrillären Elementen epithelialen Ursprungs, die teils von den Retina-, teils von den Linsenzellen abstammen und senkrecht zu der bindegewebigen Lamelle angeordnet sind; sie bestehen aus zahlreichen, stark lichtbrechenden radiär verlaufenden Fibrillen und entspringen ron der Spitze konischer Vorsprünge, die durch Verlängerung der epithelialen Zellen ron Netzhaut und Linse entstehen; den Ursprung der von der Retina ausgehenden Bildungen glaubt Verf. anf die M ïllerschen Stiitzzellen zurïckfuihren zu liönnen. Diese Fibrillen, welche sich teilen und untereinander kreuzen, bilden den Teil des Glaskörpers, welchen Verf. als epithelialen Glaskörper bezeichnet. Ijei etwas ältern Embryonen treten die ron den Linsenzellen ausgehenden liestandteile mehr und mehr zurück, und durch die Augenspalte sind spärliche Mesodermzellen und Gefässe eingewandert. Auch bei Embryonen ron $7-9 \mathrm{~mm}$ länge bleibt der Glaskörper noch ein fast ausschliesslich epitheliales Organ, in dem die Nesodermelemente durchaus eine Nebenrolle spielen. Bei Embryonen ron 10-11 mm jedoch dringen reichliche Mesodermzeilen in das Auge ein und bilden einen Filz feiner Fibrillen, die meist senkrecht zu den Fasern retinalen $\mathrm{Tr}_{\mathrm{r}}$ sprungs verlaufen und jetzt einen wichtigen Teil des Glaskörpers bilden, welchen Verf. mesodermalen Glaskörper nennt. Die Fasern, 
die von der Linse ausgingen, sind vollkommen verschwunden, und zugleich tritt auf der Linse eine glänzende Cuticula auf. Bei ältern Embryonen sind dann die mesodermalen Elemente gegenüber den epithelialen vorherrschend, welch letztere mit dem Beginn der Differenzierung der Netzhautschichten scheinbar abnehmen, aber immer noch deutlich erkennbar sind.

v. Lenhossék untersuchte lauptsächlich Kaninchenembryonen rom 10. bis 17. Tage in lückenloser Reihe, daneben, besonders für spätrre Embryonalstadien, Serien von Katzen-, Rinds- und Venschenembryonen. An Kaninchenembryonen rom zehnten Tage findet er die ersten Anlagen des Glaskörpers: in dem zur Linsenplatte verdickten Epidermisbereich verlängern sich einzelne Zellen basal zu einem faserig spitz auslaufenden Kegel; diese Basalkegel sind die ersten Anzeichen der beginnenden Bildung von Glaskörperfibrillen; am elften Tage, wo die stark verdickte Linsenplatte Andeutungen einer Einstiilpung zeigt, hat die Zahl dieser Kiegel bedeutend zugenommen, und einzelne von ihnen spalten sich T-förmig in zwei Fäserchen. Bei fortgeschrittener Einstïlpung der Linsenplatte ist diese dichotomische Teilung allgemein geworden, und die Ïstchen benachbarter Kegel anastomosieren miteinander zu meridional gerichteten lasern, den primären Meridionalfibrillen. welche die ersten Glaskörperfibrillen darstellen; senkrecht zu ihnen verlaufen feinste Fibrillen (.,Radiärfibrillen“) zur VorderHäche der Retinaanlage. Die primären Meridionalfibrillen behalten ihre Lage in der Nachbarschaft der Linse dauernd bei und bilden die Vordergrenze des Glaskörpers; sie ist ron der Linse durch einen spaltförmigen perilenticulären Raum ohne Fibrillen getreunt, der nur ron den Basalkegehn durchsetzt wird. Die Radiärfibrillen geben seitlich von Stelle zu Stelle wieder Ïstchen ab, welche siclı untereinander zu den sekundären Neridionalfibrillen verbinden, die konzentrisch mit den primären verlaufen. In diesem Fibrillengerüst liegen die spärlichen Mesenchymzellen, welche von Anfang an zwischen Augenblase und Epidermis vorhanden waren; sie stehen in lieinen direkten Beziehungen zu den Fibrillen, sondern nur in sekundärem liontalit. Auch die distale Wand des Linsenbläschens, welche bei weiterer Einstülpung desselben deutlich wird, trägt Basalkegel und entwickelt Glaskörperfibrillen, so dass später die ganze Obertläche der Linse von Glaskörpergewebe umhüllt erscheint. Dieser vordere, vergänghiche Abschnitt des Glaskörpers gibt uns die Erklärung dafür, dass die vordere Linsenfläche nie der Epidermis dicht anliegt; er wird allmählich durch einwncherndes Bindegewebe verdrängt. - Die Retinaanlage ist gegen den Glaskörperraum iberzogen ron einer ununterbrochenen Lamelle. die ein cutikuläres P'rodukt der Zellen der Augen- 
blase ist; diese "Cuticula retinae" ist die Anlage der Membrana hyaloidea, und ihre Anwesenheit in den frühesten Stadien der Glaskörperbildung würde schon allein genügen, $ı m$ die Annalıme zı widerlegen, dass die Retina an der Bildung des Glaskörpers beteiligt sei. Vom zwölften Tage an treten keine nenen Basalkegel auf; die Velmehrung der Glaskörperfibrillen geschieht nur durch Verästehung und reichere Entfaltung der schon vorhandenen. Viehmehr beginnt jetzt eine Rückbildung der Basalkegel, zunächst dort, wo ein Blutgefäss der Linse anliegt, dann auf der ganzen hintern und schliesslich auch auf der vordern Fläche der Linse. Hand in Hand damit geht die Entstehung einer cutikularen Bildung auf der Linsenoberfläche, der Linsenkapsel. Am 13. 'T'age ist las Fibrillengitter ganz von der Linse abgelöst und in seinem weitern Wacbstum auf sich selbst angewiesen; es wird jetzt dichter und gleichsam geflechtartig, indem zwischen den regelmäßig verlaufenden Faserkategorien eine Termehrung der unregelmäßigen Nebenästchen erfolgt ist. Die Gruppierung der Neridionalfasern wird später (16. Tag) unmittelbar vor der Netzhaut gedrängter: erster Anfang einer dichtern Rindenschichte. Gegen den Rand der Augenblase ist, ehenfalls infolge der Zunahme der Meridionalfasern, eine auffallende Verdichtung des Glaskörpers eingetreten, derart, dass ein kompaktes Bündel dieser Fasern am freien Rande der Retina mit dieser aufs engste verklebt erscheint. - Um die Arteria hyaloidea bildet sich durch Rïickwärtsbeugung und geflechtartige Anordnung der Meridionalfibrillen eine Grenzschichte, der "Glaskörpertrichter". - Ausser meridionalen und radiären Fasern findet man in spätern Stadien auch solche, welche den Linsenäquator zirkulär umkreisen. So ist also der Glaskörper weder Sekretkörper noch Bindegewebsgeflecht, sondern eine epitheliale Bildung, ausgehend ron den (nicht allen) Zellen der hintern Wand des Linsenbläschens; sein Fibrillenwerk ist ein richtiges dreidimensionales Netzwerk, nicht ein einfacher Filz frei auslaufender Faserverästelungen. Verf. vergleicht diese fibrillenbildende Tätigkeit der Linsenzellen mit der Pro-duktion des Ependymgerïstes durch die Epithelzellen des Medullarrohrs. - Die Zahl der im Fibrillengerïist des Glaskörpers vorhandenen Mesenchymzellen erscheint in spätern Stadien rermehrt; ein Einwuchern von Bindegewebe konnte jedoch Verf. nie beobachten, ebensowenig wie eine mitotische Teilung der anfänglich vorhandenen Mesenchymzellen; ob diese sich direkt teilen, lässt sich bei ihrev allgemein selır unregelmäßigen Zell- und Kerngestalt schwer entscheiden. - Die Beobachtungen an Katzen-, Rinds- und Menschenembryonen bestätigen die geschilderten Befunde. Speziell bei Katzen ist in dem Stadium mit noch nicht völlig abgeschnürten Linsen- 
bläschen der Glaskörper bedeutend umfangreicher, die Ausbildung der Gefässe jedoch viel weniger weit rorgeschritten als beim entsprechenden Stadium des Kaninchens, ein Beweis dafür, wie wenig begründet es ist, den Glaskörper in genetischen Zusammenhang mit den in das Ange eindringenden Blutgefässen zu bringen.

Rabl betont diesen Ausführungen gegenüber, dass sie sich auf einer sehr beschränkten Grundlage aufbauen, und weist die Auffassung des Glaskörpers als eines kernlosen Syncytiums, das sich von seinem Mutterboden abgelöst, dabei aber die Fähigkeit zu assimilieren und zu wachsen beibehalten habe, entschieden zurück. Im einzelnen führt er an, dass ausser bei den Säugern bei allen Vertebraten die Linse völlig scharf und deutlich abgegrenzt ist; Gebilde von der Art der Basalkegel hat er nur einmal bei Tropidonotus natrix an einem noch nicht völlig abgeschnürten Linsenbläschen an wenigen Zellen

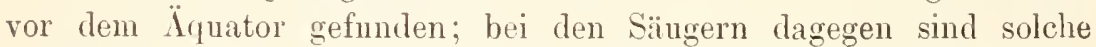
Fortsätze weit, ja man darf wohl sagen, allgemein verbreitet, und Verf. kann die Bildung des Fibrillennetzes von ihnen aus und die spätere Abtrennung dieses Netzes von der Linse bestätigen. Der perilenticuläre Faserfilz ist ebenso auf die Säuger beschränkt, wie das Rete vasculosum lentis, und Verf. nimmt einen innigen kausalen Zusammenhang zwischen beiden an derart, dass es die Aufgabe des Faserfilzes sei, das Kapillarnetz an der Linse festzuhalten. Für die Beobachtung der Glaskörperbildung von seiten der Retina ist gerade das Kaninchen ein ungiinstiges Objekt: bei Schwein, Schaf und Mensch ist es deutlich, dass das innere Blatt der sekundären Augenblase gegen den Glaskörperraum nicht durch eine gerade scharfe Linie begrenzt ist, dass vielmehr die basalen Enden der Zellen als spitze, konische Fortsätze rorspringen, von denen zarte Fasern radiär gegen die Linse ausgehen (wie ran Pée es rom Schaf dargestellt hat). Auch bei den Selachiern und Amphibien ist der Zusammenhang des Glaskörpers mit der Retina deutlich, nur bei den Sauropsiden gelang dem Verf. die Darstellung der ron der Retina ausgehenden Fibrillen noch nicht (doch hat sie Tornatola beim Huhn nachgewiesen). Schliesslich spricht sich Rabl gegen eine Beteiligung des Mesoderms an der Glaskörperbildung aus. Bei der Untersuchung zahlreicher Formen findet man, dass die Zahl der Mesodermzellen im Glaskörper sehr verschieden ist, auch bei nahe verwandten Tieren (z. B. unter den Selachiern sehr gering bei den Squaliden, recht gross bei den Rajiden; unter den Säugern bei Kaninchen und Schwein verhältnismäbig gering, bei Schaf und Mensch viel grösser), ja dass sie selbst in den beiden Augen des gleichen Embryos wesentlich verschieden sein kann. Somit kann das Mesoderm für die Entwicklung des Glas- 
körpers unmöglich die Bedeutung haben, die man ihm bisher zugeschrieben hat.

R. Hess e ('Tübingen).

\section{Pisces.}

18 Schreiner, K. E., Einige Ergebnisse über den Bau und die Entwicklung der Occipitalregion von Amia und Lepidosteus. In: Zeitschr. f. wiss. Zool. Bd. 72. 1902. pag. 467-524. Taf. 28 u. 29. 20 Fig. im Text.

An eine kurze Darlegung des Banes der Occipitalregion von Amia und Lepidosteus, welche in einen einheitlichen proximalen und einen wirbelkörperähnlichen distalen Abschnitt zerfällt, schliesst Verf. eine entwicklungsgeschichtliche Untersuchung dieser Teile an, um auf diesem Wege ihren morphologischen Wert näher zu bestimmen. Nach einer eingehenden Beschreibung aufeinander folgender Entwicklungsstadien beider Formen gelangt Verf. schliesslich zu folgenden Ergebnissen :

Bei Lepidosteus verschwinden ron allen zur Anlage gelangenden Myotomen die drei vordersten völlig, während die vier folgenden in den Bereich der Occipitalregion entfallen. Die beiden vordersten Myotome besitzen zu keiner \%eit irgendwelche Wurzeln eines zugehörigen Nerven, das dritte weist eine ventrale, später wieder verloren gehende Wurzel auf, und rom vierten Myotom an lassen sich stets dorsale und ventrale Wurzeln nachweisen, welche bis auf die dorsale Wurzel des rierten Myotoms auch später erhalten bleiben. Ganz ähnlich verhält sich Amia, nur konnte hier das erste Myotom infolge Mangels an entsprechend jüngeren Stadien nicht nachgewiesen werden, auch geht hier noch die dorsale Nervenwurzel des fünften ursprünglichen Myotoms zul grunde.

Was den Aufbau des eigentlichen Schädels anlangt, so liess sich nachweisen, dass bei Lepidosteus drei dorsale Bogenanlagen mit dem Occipitale laterale rerschmelzen, die ihrer Lage nach zwischen den 2.-5. Nerven des erwachsenen Tieres gelegen sind, während bei Amia nur der erste dorsale Bogen in das Occipitale laterale einbezogen wird, die beiden folgenden aber als I. und II. Occipitalbogen selbständig erhalten bleiben. Anch die Wirbelkörper dieser beiden Occipitalbögen werden noch deutlich erkemnbar angelegt, verschmelzen aber völlig mit dem Basioccipitale, und ebenso finden sich noch wohlausgeprägte ventrale Bogen vor, so dass hier sämtliche, einem Körpersegmente der Kinochenganoiden zugehörige Teile noch erhalten sind.

J. Meisen heimer (Narburg).

319 Reibisch, J., Über den Einf́luss der Temperatır auf die 
Entwicklung von Fisclı-Eiern. In: Wissenschaftl. Meeresuntersuch. N. F. 6. Bd. Abt. Kiel. 1902. pag. 213-232. Taf. IV.

Wie ron Heincke zuerst festgestellt wurde, ist das Produkt aus der Inkubationsdauer und der mittlern 'Temperatur bei der Entwicklung der Fischeier innerhalb gewisser Grenzen konstant, man spricht in der praktischen Fischzucht ron diesem Produkt als ron Tagesgraden. Bei der Bestimmung dieser Tagesgrade für irgend eine Fischart ist es num durchaus nötig, zunächst den Schwellenwert der lintwicklung festzustellen, von dem aus eine Konstanz der Tagesgrade erst möglich wird. Derselbe lässt sich aus einer Reihe von Einzelbeobachtungen durch einfache Rechnung ermittehn, er beträgt beispielsweise für Pleuronectes platessa - 2,40 C. Tom Schwellenwert ausgehend, lässt sich nummehr das arithmetische Mittel dieser Tagesgrade aufstellen und hieraus dann ziemlich genau entweder Tagesmittel des Ausschlïpfens oder Temperaturmittel bei einem gegebenen Faktor berechnen. Wichtig wird dies beispielsweise bei der Bestimmung des Zeitpunktes der Versendung angebriiteter Fischeier sein, falls dieselben zu einer bestimmten Zeit in einem Wasser ron bekannter' Temperatur ausschlüpfen sollen. Wenn man ferner, wie Verf. für Plenronectes platessa ansgeführt und durch eine Reihe ron Abbildungen erläutert hat, ron verschiedenen Entwicklungsstadien die Tagesgrade durch besondere Beobachtungen feststellt, so ist es möglich, von Fischeiern, die auf' hoher See treibend aufgefischt werden, zu bestimmen, wann dieselben abgelegt wurden, wofern die Temperatur der betreffenden Meeresteile für die in Betracht kommende Zeit bekannt ist. Es lassen sich also auf diese Weise Anhaltspunlte über Eiablage und Dauer des Laichgeschäftes gewinnen.

Als ... Schwelle" ist diejenige Temperatur anzusehen, unter welcher eine Entwicklung nicht mehr stattfindet: sie liegt bei den Siisswasserlaichem, speziell den Salmoniden, ziemlich genau auf $0^{\circ}$, während sie bei Seefischen in der Regel unter $0^{0}$ herabsinkt, was wahrscheinlich auf den tiefern Gefrierpunkt des Seewassers zurïckzuführen ist.

J. Meisenheimer (Marburg).

\section{Amphibia.}

320 Lauber, H., Anatomische Untersuchung des Auges von Cryptobrunchus juponicus. In: Anat. Hefte, 20. Bd. 1902. pag. 3-17. 1 Taf.

Die Beschreibung, welche R ejsek (rgl. Zool. Zentr.-Bl. VI, 1899, Nr. 250) rom Auge ron Cryptobranchus gibt, wird durch diese Arbeit bestätigt and in manchen Einzelheiten ergänzt. Ich erwähne nur die Bestätigung des bisher einzig dastehenden Vorhandenseins eines dichten liapillarnetzes in der Cornea.

R. Hesse (Tübingen). 
321 King, Helen Dean, The Follicle Saes of the Amphibian Ovary. In: The Biological Bulletin. III. Bd. 1902. pag. 245-25். Mit 6 Textabbildungen.

Die Verfasserin glaubt, dass der Follikelsprung durch die Vergrösserung des Eies hervorgerufen wird. Die Rissstelle schliesst sich sehr bald wieder. Das vorher einfache Follikelepithel schiebt sich durch die Faltung der Follikelwand nach der Ausstossung des Eies zu mehrern Lagen zusammen. Mitosen sind in ihm nicht zu finden. Sehr bald, im Mai - Juni, tritt eine Degeneration des Epithels und eine Obliteration der Follikelhöhle ein.

R. F i ck (Leipzig).

\section{Reptilia.}

322 Wetzel, G., Das Vorkommen von Kernen der Granulosazellen in den Ovarialeiern von Pelias berws. In: Verh. d. Physiol. Ges. Berlin Mr. 12-16. 27. VII. 1902. pag. 101-104. Verf. fand zahlreiche, dengrossblasigen chromatinarmen und wenige, den kleinen chromatimreichen Granulosakernen ähnliche Kerne in den Follikeln bei zwei Kreuzottern im Aiter von $1-2$ Jahren. Bei zwei andern Exemplaren fand er sie nicht. Verf. bespricht an der Hand der Literatur die möglichen Deutungen. Er meint, dass diese Kerneinwanderung eine früheitige Degeneration der Eier darstelle, sei nicht auszuschliessen.

R. Fick (Leipzig).

\section{Aves.}

323 Bowdich, B. S., Birds of Portorico. - In: Auk. vol. XIX. 1902. pag. 356 -366. Vol. XX. pag. 10-23.

Obwohl wir, vorzugsweise und grossenteils ausschliesslich durch den Hessen Gundlach, mit àer Ornis von Portorico wohl vertraut sind, sind doch Arbeiten über dieselbe in neuerer Zeit fast gar niclit erschienen, und jeder Beitrag ist daher willkommen. Verf. sammelte und beobachtete 90 Arten, alle vorher schon bekannt. Wertvoll sind die biologischen und nidologischen Beobachtungen, die den Schwerpunkt der Arbeit bilden. Über den seltenen kleinen Papagei Comurus maugei, von dem nur zwei Exemplare bekannt sind, erhalten wir leider keine genügende Auskunft. Es wird nur mitgeteilt, dass er in den Bergen bei Lares ziemlich häufig seiu soll, nach Aussage von Eingeborenen und Amerikanern, und dass lebende Exemplare mehrfach zum Kaufe angeboten werden, die anscheinend auf der Insel gefangen waren, aber vermutlich vom Verf. nicht erworben wurden. Am Schlusse ist ein Verzeichnis der 70 vom Verf. nicht gefundenen Arten gegeben, die ausser den 90 beobachteten noch - meist von Gundlach - auf Portorico beobachtet worden sind.

E. H a r t e rt (Tring).

324 Giglioli, H. H., 'The strange cas e of Athene chiaratice. In: Ibis. 1903. pag. 1-18. Tab. I.

Im Jahre 1899 wurde in Friaul eine merkwürdige kleine Eule 
gefunden, die sich von der dort so liäufigen Athene noctua durch dunkelbraune (nicht gelbe) Iris und sonstige sehr auffallende Merkmale unterschied.

Un die Aufmerksamkeit der Ornithologen und Sammler auf dieses merkwürdige Individuum zu lenken, benannte Giglioli es Athene chiaradiae (Giglioli: Intorno ad una presunta nuova specie di Athene trorata in Italia, in "Avicula" IV, fasc. 29--30, pag. 57, 1900). Diese Absicht blieb nicht unbelohnt, denn es wurden mehrere fernere Stuicke in den nachfolgenden Jahren gefunden, alle in derselben Gegend, nämlich bei Pizzocco, in der Provinz Udine. Da mehrere dieser Eulen mit ganz normalen Stücken ron Athene noctua im Neste gefunden wurden, ist die Möglichkeit, dass A. chiaradiae eine besondere Art darstellt, ron vornherein ausgeschlossen. Die Möglichkeit liegt vor, dass alle bekannten Exemplare von einem Elternpaare abstammen. Wenn dies der Fall ist, dürften weitere Individuen nicht wieder vorkommen, denn die übereifrigen Sammler, Signor Graziano Vallon und seine Leute, haben das Elternpaar der zuletzt gefundenen Athene chiaradiae gefangen, und es befindet sich jetzt ausgéstopft in Museum zu Florenz. Dies Elternpaar zeigt keine der Eigentümlichkeiten von Athene chiaradiae, sondern stimmt mit andern alten $A$. noctuc iberein. Einige ron Giglioli angegebene Verschiedenheiten sind besonderer Beachtung nicht wert, da man solche Variationen auch sonst bei $A$. noctua findet. Die mit grosser Energie rom Verf. zurückgewiesene Annahme, dass A. chiaradicue einen Bastard zweier Eulenarten darstelle, hätte nach Ansicht des Ref. gar nicht widerlegt zu werden brauchen, da für eine solche Annahme alle Gründe fehlen. Man kann also schliesslich nur zu dem Schlusse kommen, dass es sich nur um eine höchst auffallende, vielleicht nur in Friaul auftretende und merkwürdigerweise auch dort früher nie festgestellte Aberration handelt. Verf. betrachtet Athene chiaradiae als einen Fall von "Neogenesis" und knüpft Betrachtungen darïber an, ob sich aus solchen neogenetisch entstandenen Individuen nicht eine rollständig neue Art hätte entwickeln können. Zu einer solehen Bildung einer neuen Art ex abrupto würde nötig sein nicht nur die Paarung zweier $A$. chiaradiae, sondern anch eine erbliche Fortpflanzung ihrer so auffallend ron denen der Eltern abweichenden Charaktere! (Kann man eine solche billig erwarten, da die Charaktere der Eltern sich nicht in diesen - mit normalen Stïcken im gleichen Neste geborenen - fortgepflanzt haben? Ref.)

Wie dem nun auch sei, jedenfalls muss man dem Verf. recht geben, dass das Vorkommen dieser merkwürdigen Individuen ron grösserm Interesse ist, als manche neu entcleckte Art. (Unwillkür- 
lich muss man sich fragen, ob angesichts so auffallend von den Stammeltern verschiedener Stücke, die jeder Ornithologe olne nähere Kenntnis der Verhältnisse als neue Art beschrieben haben wïrde, nicht einige der seit langen Jahren entdeckten und immer noch als „Unica“" dastehenden Arten von Vögeln auch vielleicht auf eine auffallende Aberration rom Typus der Art zurückzuführen sein werden? Ref.)

E. Hartert (Tring).

25 Kunz, H., Otis tetrar, die Zwergtrappe, ein urdeutscher Brutvogel. In: Journ. f. Orn. 1902. pag. 28t-290.

Es wird ziemlich allgemein angenommen, dass die Zwergtrappe ein in neuerer Zeit aus Nordafrika in einige Gegenden Deutschlands eingewanderter Brutvogel sei. In Brehms Tierleben und andern Werken über unsre Vögel findet man angegeben, dass sie bis zum Jalıre 1870 nicht zu den deutschen Brutvögeh gerechnet werden konnte. Dies ist ein Irrtum. Otis tetrax ist ein uralter deutscher Brutrogel und ron den Ornithologen nur übersehen worden. (So mag es auch mit andern angeblich neuerlich eingewanderten Vögeln gehen. Ref.) Nach Kunz nistet und nistete er schon in frühern Zeiten von den östlichen Ausläufern des Harzes unter dem 52. Breitegrade bis nach Schlesien, ,überall“. Sein Aufenthalt aber sind Gegenden, in denen Ornithologen nichts erwarten, nämlich die ausgedehnten Getreidefelder jener Gegenden, wo ausser Rebhühnern und Lerchen kaum ein inderer Vogel nistet. Ausserdem liennen die Bewohner dieser Landstriche den Vogel nicht als Zwergtrappe, sondern nur unter dem Namen "Brachrogel", worunter die Ornithologen sonst bekanntlich etwas ganz anderes verstehen. Den in hochtönenden Worten im ,Zoolog. Garten" 1875 von Thienemann rorgebrachten Behatuptungen uiber die Einwanderung steht die exakte Forschung und sogar schon die ältere Literatur entgegen. 1849 berichtet Degland, dass otis tetrax in den Ebenen von Billay, Montreuil, Doué, in der Champagne und bei Troyes und Niort iiberall nistete. Döbel beschreibt 1854 in seiner ,„äger-Practica“ eine dritte Art Brachrogel; diese Beschreibung aber passt nur auf die Zwergtrappe. Klein erwälnt 1760, dass er im Jahre 1737 ein Weibchen mit legereifen Eiern erhalten habe, und dass die Eier sehr schmackhaft seien. Auch Bechstein beschreibt den Vogel 1805. Vor 50 Jahren war er nach Kunz ein regelmäßiger Brutvogel nördlich von Weimar, wo er damals schon Brachvogel hiess. E. Hartert (Tring).

326 Oates, E. W., On the Silver-Pheasants of Burma. In: Ibis. 1903. pag. $93-106$. 
327 Oates, E. W., On a new Silver-Pheasant from Burma. In: Ann. a. Mag. Nat. Hist. 1903, 2, pag. 231.

Durch das nummehr vorhandene, gegen frïher viel reichere Material im British Museum wurden ganz andere Ansichten über die Silberfasanen (Gemaeus) gewonnen. Nach Ansicht des Verfs. gibt es Arten, deren Männchen einander zum Verwechseln ähnlich sehen, während die Weibchen ganz verschieden sind, auf der andern Seite aber Arten, deren Männchen sehr verschieden aussehen, während die Weibchen sich kaum unterscheiden lassen. Keine von den vom Verf. anerkannten Arten sind einander aber in beiden Geschlechtern sehr ähnlich. Entweder die Männchen oder die Weibchen lassen sich leicht unterscheiden, in einigen Fäilen aber sind die Weibchen noch unbekannt. Mit Einschluss der in den ,Annals a. Mag. Nat. Hist.“ beschriebenen Art unterscheidet Verf. nun in Burma allein nicht weniger als 13 Arten. Die meisten derselben scheinen einander geographisch zu rertreten und dürften wohl nach Auffassung des Ref. und anderer Ornithologen nur als Subspecies aufzufassen sein, andere aber, wie Gennaens sharpii und rutipes, anscheinend auch G. nisbetti und affinis, sollen zusammen vorkornmen und müssen daher entweder wirklich als "Arten" aufgefasst werden, oder sind auf individuelle Eigentïmlichkeiten hin irrtïmlich gesondert. Das zu entscheiden dürfte noch mehr genau etikettiertes Material und eine eingehende Kenntnis der geographischen Verhältnisse ron Burma nötig sein.

E. Hartert ('l'ring).

328 Oberholser, H. C.. A review of the Larks of the genus Otocoris, In:

Proceed. U. S. Nat. Mus. XXIV. 1902. pag. 801-884, Tab. XLIII-XLIX.

Eine der fleissigsten Arbeiten, die man schreiben kann. Der Autor erkennt nur sechs Arten an: O. alpestris, O. allas, O. longirostris, O. bilopha, O. penicillala und $O$. berlepschi, kommt aber auf nicht weniger als 37 Formen, da er z. $B$. O. alpestris in 23 Unterarten, O. longirostris in 4, O. penicillata in 5 einteilt. Eine interessante Parallele findet sich in der Verbreitung der Formen von $O$. alpesiris und Melospiza in Nordamerika. Die grosse Ähnlichkeit zwischen Formen aus den entferntesten Gegenden ist auffallend, während näher zusammen wohnende viel verschiedener sind.

Der Name alpestris wird auf eine nordamerikanische Subspecies beschränkt, während die europäisch-nordasiatische Form Otocoris alpestris flava (Gm.) genannt wird. Sie soll sich von der typischen nordamerikanischen alpestris durch geringere Grösse und rötlicheren Nacken, Bürzel und Flügelrand unterscheiden. Eine ganze Anzahl von Unterartelı, aus der alten Welt sowohl wie aus der neuen, sind neu beschrieben und benannt. Für die im "Catalogue of Birds" $O$. brandii genannte Form wird Swinhoes Name sibirica $(O$. longirostris sibirica) angenommen. Die Tafeln entlialten photographische Aufnahmen der Wobnorte nordamerikanischer Formen sowie Weltkarten, auf denen die Verbreitung dargestellt ist. E. H a r tert ('Tring). 
329 Pycraft, W. P., On the Pterylography of Photoditus. In: Ibis 1903. pag. 36-48. Tab. II : mit mehrern Textfiguren.

Obwohl äusserlich an die Gattung Strix erinnernd findet sich nichts in der Pterylose von Photodilus (Phodilus), was auf eine nähere Verwandtschaft mit Strix hindeutet. Die ganze Pterylose weist auf die Unterfamilie A sioninae hin, worin Photodilus, mit Neigungen zur Gattung Asio, aber allerdings in vieler Hinsicht für sich allein Stehend einen l'latz finden muss. Ganz allein dastehend, von allen andern Eulen abweichend ist die Bildung des äussern Ohres. Sie stellt möglicherweise die primitivere Bildung dar, von der das liomplizierte Ohr der Gattung Avio abgeleitet ist. In die Unterfamilie As i o nin a e (Familie Asionidae) rechnet Verf. die Gattungen Asio, Symium, Photodilus, Bubo, Scops (Pisorthina), Ninor und Sceloglaur.

Eine pterylographische Übersicht derselben ist in Schlüsselform beigegeben.

E. Hartert (Tring).

330 Schuster, W., Vogel und Mensch: Die freundlichen und feindlichen Beziehungen $z$ wischen beiden und daras sich ergebende Besonderheiten in der Entwickelung und Verbreitung der Arten. In: Journ. f. Ornithol. 1903. pag. $1-40$.

Der interessante, anregende Artikel besteht aus einer Menge von Tatsachen, ohne aber neue Resultate zu ergeben. Dass die Kultur, namentlich die Verminderung der Wälder und die ungeheuere Ausdehnung des Ackerbaues in den Kulturländern, ebenso die Finführung vieler Baumarten und anderer Gewächse seit den Römerzeiten manche Arten vermindern und sogar vertreiben, andere vermehren und sogar anlocken müssen, liegt auf der Hand. Aber der Mensch verfolgt auch energisch Arten, die ihm (wie er annimmt) Schaden bringen, während er andere aus Egoismus begünstigt, weil sie ihm vermeintlich indirekten oder aber direkten Nutzen bringen. Ausserdem hat er für einige Vögel besondere Vorliebe, während andere ihm verhasst sind - solche Zu- und Abneigungen sind aber lokal verschieden: der Italiener baut dem Steinkäuzchen Niststätten an seinem Hause, während der deutsche Bauer die Eulen an das Scheunentor nagelt, der Vogelsberger Bauer freut sich, wenn sein Junge die Rabennester ausnimmt, der Rhönbauer lässt seinem Raben Schutz angedeihen, usw. Auch die Vögel verhalten sich dem Menschen gegenüber verschieden: einige freundschaftlich (? Ref.), andere geradezu feindlich, andere wieder indifferent. (Ref. ist geneigt zu glauben, dass man eher von Furcht und zutraulicher Furchtlosigkeit, als ron Feind- und Freundschaft sprechen kann, und dass es sich wohl stets darum handelt, ob die Nähe des 
Icnschen der Natur des betreffenden Vogels zusagt, ihın Nutzen oder Schaden bringt.) Aus der Fülle der mitgeteilten Tatsachen und Erwägungen möge folgendes erwähnt werden. Verf. ist der Ansicht, dass ,je seltener eine Vogelart wird, um so schener wird sie anch; die einzelnen Tiere verlieren das Gemeinschafts- unı dadurch anch das Sicherheitsgefülıl." Die Raubrögel sind in den Küulturlïndern alle mehr oder minder scheu, ebenso die Wat- und Schwimmrögel. Der Storch ist bei uns infolge ilm gewährter Schonung vertraut geworden. Wo die Vögel den Menschen nicht kennen, sind sie ohne alle Furcht, wie z. B. auf den Galápagos-Inseln und den Vogelklippen des Meeres. (Auf der Insel Laysan jedoch, wo alle andern Brutvögel ganz furclıtlos sind, ist die dort wohnende Ente schener. Die Procellariden sind meist nur an ihren Brutplätzen, und zwar anch da, wo sie den Menschen, der teilweise ron ihmen lebt, seit Jahrhunderten kennen, furchtlos! Ref.) Durch die Trockenlegung der Sümpfe werden die Collinago-Arten verdrängt, durch die leidenschaftliche Jagdansiibung (im Beginn der Brntzeit! Ref.) die Waldschnepfen bedenklich vermindert. Nicht nur durch den Eierraub, sondern auch durch die Eindänmung der sumpfigen Landstrecken und, weil er auf den Samen gewisser Sumpforgäser angewiesen ist" (" Ref.), nimmt der Kiebitz immer mehr ab.

Die Nachtrügel verhalten sich dem Menschen gegenüber meist indifferent, aus Mangel an Abschätzungsurteil, an Geistesfähigkeit. Strir flammea nistet fast nur in menschlichen Wohnungen. Verf. meint, dass sie ,fast von allen Vogelarten die meisten Albinos aufweist", was aber keineswegs allgemein gïltig ist! Ausserdem nisten die Schleiereulen in andern Ländern an Felswänden und in hohlen Bäumen. Die Hühnervögel sind alle scheu, die Mehrzahl der Singvögel wenig furchtsam. (Ref. glaubt, dass beim Beurteilen, ob ein Vogel furchtlos, zahm, zutraulich, oder furchtsam, scheu, vorsichtig ist, überhaupt das ganze Naturell desselben erwogen werden muss. Der Steppenrogel z. B., der mit weiten läumen rechnet und immer weite Strecken überschant und ïberfliegt, legt von selbst einen ganz andern Maßstab an, als der Heckenbewolner, dessen Reich ein Gebiisch, eine Hecke ist. Während jener auf hundert Schritte flieht, tut letzterer dies erst auf einen oder zwei Meter -- der eine aber mag darum nicht weniger vorsichtig sein, als der andere.)

Der Sperling lebt nur, wo Menschen wohnen. Wenu Verf. silgt, dass der Feldsperling rom Menschen unabliängiger sei, so gilt das nicht für die Länder des fernen Ostens, wo er ganz die Stelle unseres Haussperlings einnimmt.

Ruticilla tithys, ursprünglich und heute noch ein Bewohner der 
Felswände der Gebirge, hat sich im ganzen sïdlichen und mittlern Deutschland und anderwärts an Gebänden angesiedelt.

Acrocephalus streperus ist sicherlich ursprünglich ein Rohrbewohner, und ist es auch in allgemeinen geblieben, aber an manchen Orten hat er sich in Gärten und Feldern angesiedelt und wurite dann von unverständigen Ornithologen als .,A. horticolus" bezeichnet, olhe dass man das Gefieder untersuchte.

E. Hartert (Tring).

31 'ischusi zu Schmidhoffen, V. v., İ be palaearktische formen. III. Der Weidensperling (P'asser hispaniolensis Temm.) und seine Formen. In: Ornithol. Jahrb. Bd. XIV. 1903. pag. 1-21.

Vorliegender Artikel gehört zu den immer häufiger werdenden Arbeiten der neuern Richtung der systematischen Ornithologie, die. nicht das Hauptziel in der Unterscheidung der ,guten Arten" sieht, sondern sich mit dem sorossamen Studium der geographischen Verschiedenheiten innerhalb der be'sannten Arten beschäftigt. Zweifellos müssen wir diese Richtung als die vorgeschrittenere bezeichnen. Solche Forschungen sind natiirlich viel mïhsamer, als die blosse Unterscheidung der auffällig verschiedenen Arten. Es gehört dazı ,ein einigermaßen für Unterschiede empfängliches Auge" (was man zwar von jedem Systematiker verlangen sollte, aber leider nicht inmer findet, Ref.), vor allen Dingen aber ein grosses Material. Auffallende Arten können nach einzelnen Exemplaren unterschieden werden, die Subspecies der neuern Ornithologen nicht - dazu gehören Serien aus den verschiedenen Verbreitungsgebieten und Jahreszeiten.

Zu den Arten, um die man sich bisher in der systematischen Ornithologie im allgemeinen wenig bekümmerte, weil man annahm, dass sie innerhalb ihres Verbreitungsgebietes nicht wesentlich abänderten, gehörte Passer hispaniolensis. Erst 1902 (Novit. Zool. IX, 1902) unterschied Ref, eine Subspecies, die er Passer hispaniolensis maltae nannte. Verf. untersclreidet nun, nach Studium einer Serie ron 156 Weidensperlingen, sieben Formen: 1. Passer hispaniol. hispaniolensis: Spanien, Bulgarien, Türkei, Griechenland, N.-Afrika mit Ausschluss des N.-O., Kanaren und Kapverden. 2. P. hispaniol. arrigonii: Sardinien (? auch Corsica). 3. P. hispaniol. washingtoni: Ïgypten bis Kleinasien. 4. P. hispaniol. transcaspicus: Transkaukasien, Transkaspien bis N.-W. Indien(Punjab). 5. P. hispaniol. palaestinae: Palästina. 6. I. hispaniol. maltae: Malta, Sicilien. I'. hispaniol. brutius: Süd-Italien. Verf. setzt dann auch noch auseinander, dass I. hispaniolensis artlich ganz verschieden ist ron $P$. italiae, welch 
letzterer wohl als eine For'm von $I$ '. domesticus aufzufassen ist. Zu dem gleichen Resultate gelangte Ref. in Novit. Zool. 1902.

E. Hartert (Tring).

\section{Mammalia.}

332 Keibcl, Franz. I) Fe Futicklung des Rehes bis zur Anlage des Mesoblast. In: Arch. f. Anat. v. W. His. 1902. pag. 292 -314 . 2 'Taf.

Verf. berichtet ïber die interessinten Beobachtungen B is choffs, die ihn im Jahre 1854 dazu brachten, einen rollkommenen Stillstand der Lientwicklung im Winter anzunehmen Iem Verf. ist es ähnlich gegangen, s. Zool. Kentr.-Bl. VI. Bd., pag. 947 u. f. Schon auf dem Anatomenkongress in Bom konnte er aber darüber berichten, dass er jetzt loch ahgefurchte Eier, kleine Blastulae in den Rehuteri von Ende August an gefunden habe (s. Zool. Zentr.-Bl. IX. Bd., parg. 220\%. Verf. beschreibt die einzelnen Eier jetzt ganz genau in einer ansführlichen Figurenerklärung und berichtet auch iiber das genauere Verhalten der einzelnen Zellenlagen des Rehkeimes, unter berücksichtigung der neuen anderweitigen Befunde an den jungen embryonalen stadien. Er glaubt auch beim Reh eine besondere Embryotrophe (nach Bonnet) nachweisen za können.

R. Fick (Leipzig).

333 Limon, Manrice, Fitude histologique et histogénique de la Glande interstitielle de l'ovaire. Trarail du laboratoire d'Histologie de la fac. de Médecine de Nancy. Thèse Nancy 1901. pag. $1-63$. 2 Taf.

Verf. hat die Eierstöcke von Lepus cuniculus, Mus decumanus und musculus. C'aria cobaya, Tespertitio murimes, Talpa curopaea, Erinucens enropares untersucht. Er findet das interstitielle Gewebe durchaus nicht regellos im Eierstock verteilt, sondern in scharf umschriebenen Nestern und Zellanhäufungen, die meist radiär angeordnet sind. I)ie Zwischenzellengruppen billen offenbar Drüsen mit, ,innerer Sekretion", worauf ihre Anordinung zu den Gefässen schliessen lässt. Die Zellen sollen daher... $/$ w ischendriise des Eierstocks" genamnt werden. Die Zwischenzellen entstehen durch fettige Infiltration der imnern 'Thecazellen der' Graa fschen Follikel. Sie bilden zuerst die ,falschen gelben Körper", dann geben sie die zentrale Anordnung auf und bilden die \%ellgruppen. Die Zwischenzellen enthalten leicht lösliches Fett, kein Lutein, zeigen keine Mitosen, dürfen nicht mit den Marksträngen verwechselt werden.

R. Fick (Leipzig). 
34 Limon, M., Note sur les Vacuoles de la Granulosa des Follicules de de Graaf. In: Bibliogr. anat. Jahrg. 1902. Heft 3. Mit 17 'lextabbildungen. 7 pag.

Verf. beschreibt die Entstehung der, Epithelvakuolen" F'lemmings, der „Bläschenkörper von ( epithel des Kanincheneierstocks. Sie entstehen nicht durch Degeneration ron Granulosazellen, sondem durch eine Sekretion derselben, sind zuerst sternförmig, dann rund, ron radiär angeortheten Granulosazellen umgeben, finden sich oft in normalen reifen Follikeln mit grosser Höhle, andererseits auch in degenerierten Follikeln mit Höhlen, sind also jedenfalls nicht einfache Vorstufen der Höhlenentwicklung im Follikel.

R. Fick (Leipzig).

35 Vau der Stricht, 0., Les Pseudochromosomes dans l'Oocyte de Chauve-Souris. Communication préliminaire. In: Compt. Rend. Ass. Anatom. IV. session, Iontpellier 1902. 7. pag.

Verf. macht sehr interessante Angaben über eigentïmliche chromatopliile Körper, die in jungen Eiern ron $I^{*}$. noctula ror dem Dotterkern Balbianis auftreten, ihn damn ungeben, später aber ron ihm unabhïngig werden und den ganzen Dotter durchsetzen künnen. Zuletzt rerlieren sie die Färbbarkeit. Verf. meint, dass sie zur Dotterbildung Beziehung haben. Er fand sie auch an Furelungszellen bei Pristiurns. Verf. vergleicht sie auch mit den ,Centrophormien" von Ballowitz, mit den Chondromiten oder Mitochondrien von Czermak, Benda und Il eves und dem, „Ergastoplasma" Prenants und II. 1. P. Bouins. R. Fick (Leipzig).

36 Ziirn, J., Vergleichend histologische Untersuchungen ïber die Retina und die Areacentralis der Hassäugetiere. In: Arch. f. Anat. u. Physiol. Jg. 1902. Anat. Abt. Suppl.Bd. pag. $99-146$.

Die Untersuchungen beziehen sich auf die Retinae ron Pferd, Rind, Schaf, Ziege, Schwein, Hund und Katze. Es bestehn, bei allgemeiner Übereinstimmung, im einzelnen bezüglich des Baues der Retina zwischen diesen 'Tieren solche Unterschiede, dass schon die Betrachtung eines kleinen Netzhautstuickes, ja schon eines Zapfens rom Augenhintergrunde genügt zur Bestimmung der Zugehörigkeit. Die Pferderetina ist charakterisiert durch das geringe Dickemmafs ihrer Schichten (mit Ausnahme der Nervenfaserschicht), durch völliges Fehlen der kleinen amakrinen Zellen in der innern Körnerschicht, geringe Zahl der Sehzellen, maiskolbenähnliche Gestalt der Zapfen und stark entwickelte Radiärfasern. Für die Wiederkïulerretina sind 
charakteristisch: Ausgeprägte Zusammenlagerung der Fasern in ler Nerrenfaserschicht zu Faserbündeln, Menge kleiner amakriner Zellen in der innern Körnerschicht, schlank flaschenförnige Gestalt der Zapfen. Die Netzhäute von Schaf und Ziege unterscheiden sich von der der Rinder durch grössern Zellreichtum der Körnerschichten, sowie geringere Dicke und grössere Zahl der Zapfen. Beim Schwein treten die Körnerschichten gegen die plexiformen Schichten (besonders die auffallend dicke innere pl. Sclı.) stark zurück. In der Netzhaut des Hundes sind die plexiformen Schichten sehr dïnn, die äussern Körner zahlreich und die Zapfen durch pallisadenförmige Gestalt ausgezeichnet; letztere unterscheiden sich von den ähnlich gestalteten bei der Katze dadurch, dass sie kiürzer sind als die Stäbchen, dort dagegen ebenso lang. - Bei Pferd, Wiederkäuern und Schwein ist die Retina lateral (nach aussen-hinten) vom Sehnerv reicher nit percipierenden und leitenden Elementen ausgestattet als im Zentrum und in der medialen Hälfte. Pferd, Rind und Schwein besitzen eine streifenförmige Area centralis für das monoculare Sehen, in der die Zellelemente der Ganglienzellen- und innern lï̈rnerschicht vermehrt, die Sehzellen nicht vermindert sind. Ausserdem besitzen alle Haussäugetiere eine dem binocularen Selien dienende runde Area centralis, deren Analogie zur Fovea centralis des Menschen sich in einer Vermehrung der leitenden Elemente und einer relativen Zunahme der Zapfen (beim Schwein nur in ersterem) zeigt. Bei einigen, besonders scharfsichtigen Hunderassen (Rattler, Jagdhunde) findet sich innerhalb dieser Area ein ganz stäbchenfreies Gebiet, das histologisch der Forea centrailis gleichwertig ist und dem Zustande derselben beim sechsmonatlichen menschlichen Fötus gleicht. Im Bereiche dieses Gebietes ist die Limitans externa eingebuchtet. Ebenso findet sich aine solche Fovea centralis externa bei der Katze in der Mitte der Area centralis: die Zahl der Sehzellen ist hier nahezu auf die Hälfte reduziert. Eine Forea centralis interna wurde bei keinem der untersuchten Tiere gefunden.

R. Hesse (Tübingen). 


\section{Zoologisehes Zentralblatt}

unter Mitwirkung von

Professor Dr. O. Bütschli and Professor Dr. B. Hatschek

In Heidelberg

herausgegeben von

in Wien

Dr. A. Schuberg

a. 9. Profesor in $H e i d e l b e r g$.

Verlag von Wilhelm Engelmann in Leipzig. Jahrlich 26 Nummern im Umfang von 2-3 Bogen. Preis für den Jahrgang M. 30. - Bei direkter Zusendung jeder Nummer unter Streifband erfolgt ein Aufschlag ron \$1. 4.- nach dem Inland and von 11. 5.- nach dem Ausland.

\section{Referate:}

\section{Faunistik und Tiergeographie.}

337 Gadlea de Kerville, H., Recherches sur les faunes marine et maritime de la Normandie. $3^{\text {e }}$ Toyage; Région d'Omonville la Rogue (Manche) et fosse de la Hague, JuinJuillet 1899, suiries de quatre mémoires d'Engène Canu et A. Cligny, d'Edouard ('herreux, de Paul Mayer et du Dr. E. Trouessart sur les Copépodes, deux espèces nouvelles d'Amphipodes et les Halacariens récoltés pendant ce voyage et d'un supplément aux comptes rendus de ses deux précédents royages zoologiques sur le littoral de la Normandie. In: Bull. Soc. amis sciences nat. Rouen, $2^{e}$ sémèstre 1900. Paris 1901. pag. 14õ-276, 4 planches, 6 figures dans le texte.

Seit einer Reihe ron Jahren sammelte Gadeau de Kerville Materialien zur Zusammenstellung einer Fauna der Normandie. Das Gebiet seiner letzten Reise erstreckt sich über einen Teil der Küste des Departements La Manche mit dem Mittelpunkt Omonville la Rogue. In Betracht gezogen wurde ein Streifen der Littoralregion von etwa 12 Kilometer Breite mit felsigem, seltener kiesigem oder sandigem Untergrund, zahlreichen Klippen und sehr starken Strömungen. Die Tiefen reichten bis $60 \mathrm{~m}$ unter dem tiefsten Ebbestand. Besonderes Augenmerk widmete Verf. der Fauna einer ziemlich unfangreichen, bis zu $110 \mathrm{~m}$ tiefen Depression, der Fosse de la Hague. Doch wich die Zusammensetzung der Tierwelt dieser Lokalität durch nichts, als etwa durch Artenarmut, von derjenigen 
der gewöhnlichen Uferfauna $a b$. Abgesehen von den Copepoden lieferte die Fosse de la Hague 43 Tierformen.

Nach einer Beschreibung der beim Fang angewandten Methoden und Gerätschaften und einer Schilderung des Exkursionsgebiets, den auch Dünen und ein ron Süsswasserorganismen bewohnter, rom Meere abgeschnittener Teich angehören, folgt die systematische Aufzählung der gesammelten Tiere unter Berücksichtigung von Fundorten, Vorkommen, Hänfigkeit und Biologie. Einige Arten sind neu, andere waren für Frankreich oder für die Normandie unbekannt. In die Listen fanden auch die Bewohner von Süsswasser und Festland Aufnahme. Die Bestinmungen besorgten zahlreiche Spezialisten.

Aufgezählt werden 12 Arten und 1 Varietät von Spongien, 9 Hydropolypen, 1 Anthozoe, 8 Arten und 1 Varietät von Echinodermen, 117 Crustaceen, (35̃ Copepoden, 45 Amphipoden, 8 Isopoden, 1 Leptostrake, 4 Schizopoden, 24 Decapoden), 6 Pycnogoniden, 34 Arachniden, darunter bis $105 \mathrm{~m}$ tief hinabsteigende Halacariden, 5 Myriopoden, 112 Arten und 6 Varietäten von Inseliten, 23 Arten und 2 Varietäten von Bryozoen, 29 Polychäten, 2 Hirudineen, 11 Lamellibranchier, 2 Amphineuren, 55 Arten und 1 Varietät von Gastropoden, 2 Cephalopoden, 5 Tunicaten, 21 Arten und 1 Varietät von Fischen.

Canu und Cligny stellen die marinen Copepoden nach ilırem Vorkommen - Küstenformen der Oberfläche, des Untergrundes, Algenbewohner - zusammen. Neu ist vielleicht eine Art von Thalestris; unbekannt in der französischen Fauna war die Gattung Nitocra. die in einer, $N$. tau und $N$. oligochaeta nahestehenden Form gefunden wurde. Die beiden genannten Copepoden leben in den Algen der Gezeitenzone.

Zu der Amphipoden-Familie der Stenothoidae gehört die von Clu ev reux beschriebene Parametopa kerillei n. g., n. sp. Das Genus steht Stenothoe und Metopa nahe, unterscheidet sich aber von allen Verwandten durch die Grösse des Innenlappens der zweiten Maxille und durch die eigentümliche Ausbildung der Branchiallamellen. P. Na y er charakterisiert Caprella erethizon n. sp. und macht allgemeine Bemerkungen über die Art genügender Beschreibung ron Amphipoden. Seine Vorschläge wären auch für Bearbeiter anderer Tiergruppen beherzigenswert. Die Ausbeute an Halacariden war, nach Trouessart, wohl wegen der starken Strömungen, relativ arm. Immerhin erlaubte sie die bessere Beschreibung mancher Arten. Für Europa erwies sich als neu Halacurus lamellosus Lohmann, andere Species sind der Fauna des Kanals beizufiigen, die an Halacariden etwas ärmer ist als diejenige der Küisten des Ozeans. In den Zusätzen zu den Be- 
richten über die frühern Exkursionen des Autors wird die Diptere Onthocladius lervillei Kieft., die als Larve verlassene Austernparks bewolnt, beschrieben.

F. Zschokke (Basel).

338 Knipowitselı, N., Expedition für wissenschaftlich-practische Untersuchungen an der Murman-Küste. Bd. I. Unter Mitwirkung ron Jag od owskij und N. Shicharew. (Экспедигія д.я научнопромысловыхъ изсть,дованій у береговт Мурмана. Т. І.

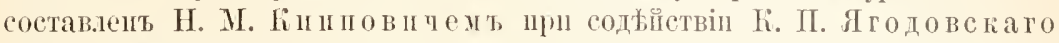
и Н. C. Sli ихарева.) Herausgegeben vom Comité für Unterstützung der Küsten-Bevölkerung des russischen Nerdens. (Foмптеть для помюц понорамь русскаго сівера.) St. Petersburg 1902. pag. 1 -605. 11 phototyp. Tafeln, Karten und Abbildungen im Text (russisch mit deutschem Auszuge).

Dieser I. Band der Berichte der Murmanexpedition enthält die Tätigkeit der vorbereitenden Expedition (1898/99) und des Expeditionsdampfers "Andrei Perwoswannyi" im Jahre 1900. Ein grosser Teil ist der Beschreibung der Organisation, des Schiffes und der Untersuchungsmethorlen gewidmet. Eine kleine Verbesserung am Batometer von Pettersson hat vielleicht Interesse, sowie mancher praktische Wink, was Dredgen, Planktonfang, Fischfang usw. betrifft. Eine bedeutende Anzahl von Beobachtungen ïber die Temperatur des Seewassers in verschiedenen Tiefen und zu verschiedenen Jahreszeiten liegt vor. Viele für die Murmansclie Küiste neue Fische sind teilweise in sehr grosser Zahl erbentet worden. Die tiefen Teile des Kola-lFord, Matowsky-Fjord und zum Teil des Varanger-Fjord sind von einer sehr reichen Crustaceen-Fauna bevölkert (Pandalus borealis $\mathrm{Kr}$.), die eine wichtige Rolle in der Biologie der Fische spielen. Ende Mai, wenn in der Nühe der Küste kein Fischfang stattfindet, findet man unter dem $71^{0} 14^{\prime} \mathrm{N}$ zahlreiche Fische. Kollektionen von Vögeln, Insekten und Pflanzen wurden auch auf dem Lande gesammelt. Auch Crasanalysen des Wassers wurden gemacht. Die Liste der gefangenen Fische enthält 61 Arten. Ihre Nahrung ist ausführlich an einem grossen Nateriale untersucht worden. Die Untersuchungen beleuchten vielfach die postpliocäne Periode dieser Gegenden. Viele Gebiete des Murmanmeeres sind überhaupt das erste Mal untersucht worden. Den Hauptinhalt des Werkes bildet das Journal, welches alle 378 Stationen und was auf denselben gefangen und untersucht wurde, enthält. Die spezielle Beschreibung der praktischen und wissenschaftliclien Resultate soll den II. Band füllen. Die Beschreibung der Kollektionen wird zum Teil in den Ausgahen der Akademie der Wissenschaften erfolgen.

E. Schultz. (St. Petersburg). 
339 Lohmann, H., Neue Untersuchungen über den Reichthum des Meeres an Plankton und über die Brauchbarkeit der verschiedenen Fangmethoden. $\%$ ugleich auch ein Beitrag zur Kenntniss des Mittelmeerauftriebs. In: Wissenschaftl. Meeresuntersuchung. herausgeg. r. d. Kommiss. zur Untersuch. d. deutschen Meere in Kiel und d. Biol. Anstalt auf Helgoland. Abteilung Kiel. N. F. Band 7. 1902. pag. 1-87. Taf. 1-4. 14 Tabellen.

Hensens Methode der Planktonforschung beruht auf zwei verschiedenen Voraussetzungen. Sie nimmt an, dass der Auftrieb innerhalb eines Gebiets gleichartiger Existenzbedingungen sich gleichmäßig verteile, so dass schon kleine Stichproben ein hinreichend zutreffendes Bild von den qualitativen und quantitativen Eigenschaften des Planktons geben können; und sie fordert, dass die Fangapparate frei ron nicht kontrollierbaren Fehlern seien.

Für die erste Voraussetzung haben die fortschreitenden Untersnchungen die rollste Bestätigung gebracht. Die Planktonverteilung wechselt räumlich in horizontaler oder vertikaler Richtung und in zeitlicher Folge immer genau gemäß dem Wechsel der Lebensbedingungen. Dies bewiesen Verf. besonders klar seine vor Syrakus in verschiedener Tiefe ausgeführten Fünge. Somit bleiben Stichproben zuverlässig. Ihre Grösse richtet sich nach der Dichtigkeit des Vorkommens der zu untersuchenden Organismen. Während für die quantitative Bestimmung der Bakterien die Filtration weniger ccm Wasser genïgt, kommen für Janthinen, Physalien, Acalephen usw. in der Regel Wassermengen in Betracht, die durch Auftriebnetze nicht mehr filtriert werden. Methoden und Werkzeuge sind daher bei der Untersuchung der verschiedenen Planktonwesen zu variieren.

Als den Fang- und Untersuchungsmethoden anhaftende Fehler haben zu gelten die Durchlässigkeit des Netzes oder des Filtermaterials und die Empfindlichkeit vieler Organismen gegen mechanische und chemische Eingriffe. In der Kieler Bucht machte Verf. die Erfahrung, dass die Fänge mit Müllergaze für einzellige Geschöpfe je nach Grösse und Gestalt der betreffenden Arten und nach der Menge des Gesamtauftriebs um $30-98,6 \%$ zu klein ausfallen. Sie sind somit durch mit genauer arbeitenden Apparaten ausgefülırte Fänge zu ersetzen.

Alle künstlichen Fang- und Konservierungsarten besitzen den gemeinsamen Fehler, einen Teil des Microplanktons chemisch oder mechanisch zu zerstören. Verf. fand indessen in den Fangapparaten der Appendiculariengehäuse ein äusserst sorgfältig wirkendes, natïr- 
liches Filtrationswerkzeug. Der Inhalt der Fangapparate setzt sich gerade aus denjenigen kleinsten und zartesten Planktonformen zusammen, welche durch kïnstliche Filter zerstört werden. Somit liegt in der Untersuchung der Appendiculariengehäuse die Möglichkeit, eine Fehlerquelle der quantitativen Planktonuntersuchung auszuschliessen.

Damit die Untersuchungen ihren wissenschaftlichen Wert behalten, miissen zwei Bedingungen erfüllt sein. Alle zu vergleichenden Grössen sind mit derselben Genauigkeit festzustellen, und die Fehler der Methode dürfen die in der Natur vorkommenden Schwankungen der untersuchten Verhältnisse nicht iibertreffen.

Verf. sucht daher durch Anwendung der verschiedenen Fangund Filtrationsmethoden den wirklichen Gehalt des Meeres an Auftrieb möglichst zu bestimmen und den beim Gebrauch der einzelnen Apparate eintretenden Verlust festzustellen. Als geeignetes Untersuchungsgebiet dient ihm das von Küsteneinfliissen fast ganz freie Mittelmeer bei Syrakus.

Eine vertikale Wassersäule von etwa $100 \mathrm{~m}$ Hölıe wurde in derselben Lokalität unmittelbar nacheinander durch Müllergaze Nr. 20, durch Papier und durch Seidentaffet filtriert. Der Vergleich der erhaltenen, konservierten und gezählten Fänge ergab die bei der Filtration durch Gaze und Papier erlittenen Verluste. Um das Vorkommen nicht konservierbarer Protozoen festzustellen, wurden Wasserproben von der Oberfliiche und aus verschiedenen T'iefen mit der M e y erschen Flasche, orler dem K r ü m m elschen Apparat geschöpft und durch Papier und Seide filtriert. Endlich gestattete die Untersuchung des Fangapparatinhalts frisch gesammelter Appendiculariengehäuse die Organismen zu erkennen, welche den mechanischen Einwirkungen der Papier- und Seidenfiltration erliegen. Aus der Betrachtung der beiden letzten Beobachtungsserien liess sich der Verlust der Seidentaffetfänge, die wahre Grösse des Verlusts bei Anwendung der andern Methoden und zuletzt eine Vorstellung vom wirklichen Gelialt des Meers an Auftrieb gewinnen. Verf. bespricht einlässlich die einzelnen Methoden, ihre Anwendung und die Vergleichbarkeit der erhaltenen Resultate. Er stellte auch Vergleichsfänge mit Netz und Pumpe an, um den Verlust an gefangenem Plankton infolge der Durchlässigkeit der Netzzenge und Filter abzumessen. Nicht alle Differenzen von Fängen, die an demselben Ort, zeitlich unmittelbar nacheinander ausgeführt wurden, hängen von der Unzulänglichkeit der Netzstoffe ab. Manche erklären sich durch UnregelmäBigkeiten in der Verteilung des Auftriebs und durch Fehler der einzelnen Methoden. Die Bedeutung der durch ver- 
schiedene Faktoren herbeigeführten Abweichungen für die Planktonforschung wird ausführlich erörtert.

Grösste Förderung finden unsere Kenntnisse über den Meeresauftrieb durch die vom Verf. ins Licht gerïckte Tatsache, dass die Appendicularien in ihren Gehäusen eigene Planktonfangapparate besitzen. Die betreffenden komplizierten Einrichtungen arbeiten so sorgfältig, dass die in ihnen aufgespeicherten kleinsten und skelettlosen Planktonorganismen in vorzüglicher Erhaltung, ja sogar lebend angetroffen werden. Sie entwickeln sich am höchsten bei den Oikopleurinen, deren Gehäuse gleichzeitig dem Schutz, der Lokomotion und dem Nahrungserwerb dienen. Eine gallertige Cuticulaausscheidung entsteht periodisch, entwickelt sich zum Gehäuse und wird nach höchstens sechs Stunden weggeworfen, um durch eine entsprechende Neubildung ersetzt zu werden. Umfangreiche, filtrierende, Gitterfenster dienen dem Wasser als einzige Eingangspforten. Sogar bei den grössten mediterranen Oikopleurinen bleibt die Maschenbreite der Gitter hinter derjenigen von Müllergaze Nr. 20 zurück, während die Maschenlänge erheblich grösser werden kann. Immerhin wirken die spaltförmigen Durchlässe der Fenster filtrierend bedeutend besser, als die fünfeckigen Löcher der Gaze; zudem ist der Verbrauch an Baumaterial erheblich geringer, als für ein gleich wirksames Gitter mit quadratischen Maschen.

Aus dem vorher filtrierten Wasser gewinnt die Appendicularie ihre Nahrung. Schon die Gegenwart ungeheuerer Mengen von Copelaten im Neeresauftrieb lässt auf die massenhafte Entwicklung der Nahrungstiere, d. h. des kleinsten, der Müllergaze entgehenden Planktons schliessen.

Im Gehäuse strömt das Wasser durch einen feinen Reusenapparat, der dasselbe zum zweiten Nale reinigt und zugleich die Nahrungskörper auf einen kleinen Raum zusammendrängt, so dass sie von der Oikopleura leicht aufgesogen werden können. Die im hintern Gehäuseteil gelegene Fangvorrichtung für das Microplankton, deren hohe Komplikation in Bau und Funktion Verf. eingehend beschreibt, setzt sich aus Filtrierapparat, Sammelkammer und Absaugrohr zusammen. In ihren "Reusengängen" sammeln sich die kleinsten Auftrieborganismen in grosser Zahl und vorzüghicher Erhaltung an. Der Inhalt besteht gerade aus dem zartesten, nackten Teil des Planktons, der sonst nicht zu erbeuten ist. Zudem lässt sich das natürliche zarte Filter leicht lospräparieren und mikroskopisch untersuchen.

Auch die gehäuselosen Fritillarien besitzen zum Planktonfang eine seltsam gebaute, aufblähbare Gallertblase. 
Bei der Verwertung der durch die Untersuchung der Fangapparate gewonnenen Resultate sind einige Einschränkungen zu machen. Besonders geben die Fallen der Appendicularien nur Aufschluss über das Vorkommen kleinster, kugeliger bis spindelförmiger Planktonformen von etwa 3-20 $\mu$ Durchmesser. Der Inhalt der Fangapparate entspricht sicher einer filtrierten Wasserquantität von weniger als 100 Kubikcentimeter. Genauere Vergleichung mit der Filtration durch Seidentaffet gibt sogar für die grossen Gehäuse von Oitiopleura albicans nur eine Zahl von etwa 50 Kubikcentimeter. So darf man annehmen, dass das im Fangapparat enthaltene Plankton stets weniger, als den Filterrickstand aus 0,1 Liter Wasser betrage. Zur Vergleichung der Filtration durch Seide und Appendicularien eignet sich die Betrachtung ron Organismen, die, wie die Coccolithophoriden, sich mit beiden Methoden gleich gut fangen lassen.

Eine Zusammenfassung der methodologischen Auseinandersetzungen fülırt zum Schluss, dass die Appendicularien die schonendste Filtrationseinrichtung besitzen und dadurch beim Studium der kleinsten, unbeschalten, einzelligen Planktonten uniibertreffliche Iienste leisten. Schon bei der Filtration durch Seidentaffet und mehr noch durch gelıärtete Papierfilter gehen die meisten nackten und auch gewisse schalentragende Protozoen und Protophyten zu grunde. Doch lassen sich mit dichtem Taffet bei quantitativen und qualitativen Bestimmungen kleiner Schalenträger gute Resultate erzielen. Endlich bildet Müllergaze $\mathrm{Nr}$. 20 bei der quantitativen Untersuchung von Metazoen und grössern Protozoen ein ausgezeichnetes Filtrationsmaterial. Die Verbindung aller geprüften Methoden liefert ein im ganzen klares Bild über die wirklich vorhandene Menge und die Zusammensetzung des marinen Auftriebs, wenn auch ein Rest kleiner Organismen ungefangen bleibt.

In einem dritten Abschnitt seiner Ablandlung vergleicht Verf. spezieller die einzelnen Methoden in bezug auf ihre Brauchbarkeit für den Fang der verschiedenen Planktonorganismen. Gleichzeitig gelangt er, gestïtzt auf kritische Erörterungen und Vergleiche zu Schlïssen über die Zusammensetzung des marinen Planktons und beschreibt kurz die bemerkenswertesten Auftrieborganismen aus den Gruppen der Protozoen und Protophyten. Besonders berücksichtigt werden die kleinsten, durch die Müllergaze nicht zurückgehaltenen Formen. Viele derselben sind neu. Sie gehören zu den Amöben, Eutlagellaten, Ciliaten, Yeridineen, Chrysomonadinen, Cryptomonadinen und Euglenen.

Neben den Metazoen, Protozoen und Protophyten werden bei der Besprechung auch die Blastomyceten, Bakterien und die Ruhezu- 
stände (Cysten) von Protisten nach ihrem qualitativen und quantitativen Auftreten beriicksichtigt.

Im allgemeinen lässt sich sagen, dass im Auftrieb des Meers alle Abteilungen der Protozoen vorkommen. Neben Foraminiferen und Radiolarien finden sich nackte Amöben und Heliozoen, neben Cystoflagellaten, Euflagellaten, neben Tintinniden und Vorticellen holotriche, hypotriche und heterotriche Ciliaten. Von diesem Reichtum fängt die Müllergaze nur die Cystoflagellaten vollständig, die Radiolarien nahezu vollständig, von den Foraminiferen und Tintinniden nur ${ }^{1 / 3}$ bis $1 / 4$, von allen übrigen höchstens zufällig vereinzelte Individuen.

Auf Seiden- und Papierfiltern bleiben alle Skeletträger und ein grosser Teil der widerstandsfähigern nackten Formen zurïck. Die meisten Euflagellaten und fast alle nackten Amöben dagegen gehen zu grunde. Nur in seltenen Fällen treten übrigens die nackten Protozoen in erheblichen Mengen auf; da sie sehr klein sind, machen sie einen nennenswerten Bruchteil der gesamten Planktonquantität nur aus, wenn sie in sehr grossen Zahlen erscheinen. Überhaupt nicht gefangen wurden die Schwärmer der Cystoflagellateu und Acineten, die Schwärmzellen der Radiolarien und die Sporen der Sporozoen.

Fänge mit Mïllergaze geben über die Rolle der Protophyten im marinen Auftrieb ein ganz unvollkommenes Bild. Die Anwendung von Seiden- und Papierfiltern bringt einen /uwachs von einigen Formen und zahlreichen Individuen. Durch die Untersuchung der Appendiculariengehäuse kommen neue Arten nicht dazu, doch wächst die Anzahl der Exemplare der nackten Organismen und auch diejenige einer sehr kleinen Diatomee bedentend.

Die Dezemberfänge bei Syrakus ergaben über die Wirksamkeit der verschiedenen Filter - Müllergaze, Papier, Seide, Appendicularienapparate - und über den Gehalt des Meers an Auftrieb etwa folgendes allgemeine Resultat. In 1000 Litern filtrierten Wassers lebten mehr als zwei Millionen Planktonpflanzen, von denen die Müllergaze nur 110000 fing, während jede der drei folgenden Filtrationsarten die Zahl um rund 650000 vermehrte. Tiere fanden sich in derselben Wassermenge nur ${ }^{1 / 3}$ Million; von ihnen blieben nur 9000 im Gazenetz zurück. Alle diese Zahlen verschwinden vollkommen neben den ungeheuren Nengen der auftretenden Bakterien. Die mühsame, aber wichtige Ausrechnung der im Neer damals vorhandenen Planktonmasse ergibt für 1000 Liter Wasser 52,4 Kubikcentimeter, von denen das Gazenetz nur 21 Kubikcentimeter fing. $60 \%$ der Auftriebmasse gingen durch die Müllergaze verloren.

Der Versuch Brandts, das Verhältnis zwischen Konsumenten 
und Produzenten, das auch im Meer bestehen muss, zur Bestimmung des beim Fang eintretenden Planktonverlusts zu benuitzen, scheitert an der Unkenntnis der hauptsächlichsten in Betracht fallenden Faktoren. Auch wenn die Müllergaze uns wirklich über die Masse der im Plankton lebenden Konsumenten aufklären könnte, so wäre doch die Möglichkeit ausgeschlossen, darnach den Auftriebverlust zu berechnen. Wie unzulänglich für I'lanktonuntersuchungen die Fänge mit Müllergaze sind, geht auch daraus hervor, dass $80 \%$ der auf diesem Wege erbeuteten Planktonmasse zu den Metazoen gehört; in Wirklichkeit aber bilden die Gewebetiere nur $55 \%$ des ganzen Auftriebs. Die Hauptmenge des Planktons wird uns erst durch Papierfiltration fassbar gemacht; Filtration durch Seide steigert die Masse pflanzlichen Planktons noch bedeutend, wïhrend die Untersuchung der Appendiculariengehäuse unsere Vorstellung rom Volumen des Auftriebs kaum verändert.

Die Gazefänge genïgen nicht, um die Fragen nach der Masse des Planktons, nach seinen qualitativen Eigenschaften, nach der Zusammensetzung aus Konsumenten und Produzenten zu lösen. Sie versagen aber auch ganz oder teilweise bei den für die Erkenntnis der Ökonomie der Meere so wichtigen Studien über die Vermehrungsgeschwindigkeit und die Grösse der Vernichtung, der jede Art durch ihre Feinde ausgesetzt ist. Endlich dürfen sie nur mit der grössten Vorsicht verwendet werden, wenn es gilt, die zahlreichen Fragen nach der zeitlichen und örtlichen Verbreitung der einzelnen Planktonorganismen zu entscheiden.

Am passendsten tritt an die Stelle der Müllergaze zur Filtration vertikaler Wassersäulen ein Netz aus dichtem Stoff. Die Anwendung eines solchen Apparats hat sich wesentlich vereinfacht, seitdem wir wissen, dass selbst in sehr planktonarmen Meeren die Filtration von weniger als 100 Liter Wasser genügt, quantitativ abzuschätzen, die ganz oder teilweise durch die Naschen der Müllergaze hindurchgehen.

Bei ruhiger See und in relativ geringen Tiefen kann das zu filtrierende Wasser mit Schlauch und Pumpe gewonnen werden. Im ganzen eignet sich aber diese, zudem zeitraubende und kostspielige Methode besser für Binnengewässer als für Meere.

Das Schöpfen von Wasserproben ron $1-5$ Liter aus verschiedenen Tiefen und die folgende Filtration durch dichte Filter gibt kein vollständiges Bild von der gesamten Planktonzusammensetzung. Grössere und seltenere Organismen werden nicht gefangen.

Nicht ausser acht zu lassen ist die Tatsache, dass durch die Konservierung manche Organismen zu grunde gehen. So empfiehlt 
sich möglichst ausgedehnte Untersuchung des lebenden Planktons. Über das Vorkommen der nackten Protisten klärt einzig der Inhalt der Fangapparate von Appendicularien-Gelaäusen genügend auf.

In den Schlussbemerkungen der äusserst sorgfältigen Alhandlung, deren so reicher Inhalt hier nur ungenügend skizziert werden konnte, hebt Verf. als Ergebnis seiner Untersuchungen lıauptsächlich drei Punkte hervor. 1. Ias Meer beherberyt einen bedentend reichern Auftrieb, als man annehmen konnte. Filtration kleiner Wassermengen genügt also, um das quantitative Auftreten der Planktonorganismen zu erkennen. 2. Die GleichmäBigkeit der marinen Planktonverteilung ist eine recht grosse; kleine, von einem Tag zum andern verschiedenen Tiefen entnommene Stichproben zeigen deutlich die Verteilung des Auftriebs in den verschiedenen Wasserschichten. 3. Känge mit Müllergaze geben kein richtiges Bild von der qualitativen und quantitativen Beschaffenheit des P'lankitons. Um irrige Vorstellungen zu vermeiden, müssen andere Filtrationsmethoden ergänzend und ersetzend Verwendung finden.

F. Zschokke (Basel).

340 Wesenberg-Lund, C., Sur l'existence d'une faune relicte dans le lac de Furesö. In: Bull. Acad. R. Sc. Lett. Danemark. Nr. 6. 1902. pag. 259-303. 1 carte.

Nach einer historischen Übersicht über die Entwicklung unserer Ansichten von .. Reliktenseen" und "Reliktenfaunen" definiert Verf. als .. Relikte" alle diejenigen marinen 'Tierformen, die auf irgend einem Weg in das Suisswasser eingewandert sind und sich demselben auf irgend eine Weise angepasst haben. Dabei bleibt es somit gleichgültig, ob die kinwanderung in ursprüngliche Meeresarme erfolgte, oder ob der Eintritt in die Seen durch Fliisse rermittelt wurde, sowie ob die neue Anpassung infolge von Isolierung von Meeresteilen sich vollzog, oder ob sie in den Wasserläufen während der Immigration einsetzte. Keitlich ist der Begriff der relikten Tiere ebenfalls weiter $z u$ fassen. Das Phämomen der Reliktenbildung begann lange vor der Glacialzeit, wie es z. B. die Gegenwart jurassischer Reliktenformen im Tanganyikasee beweist, und dauert heute noch weiter fort. So wäre .. relikt" jedes marine, in einem See isolierte Tier, das sich dem siissen Wasser zu irgend einer Keit angewöhnte.

Im dïnischen Furesö leben eine Reihe ron relikten Organismen, die in das Süsswasser wahrscheinlich direkt aus dem Meer während des Zeitabschnittes einwanderten, der uns von der Eiszeit tremnt. Mit ihnen beschäftigt sich Verf. in systematischer, geographischer und biologischer Beziehung. Es sind Mrysis oculata Fabr. var. relicta (Lovén) (i. O. Sars, Pontoporeia affimis Lindströn, Pallasiella quadri- 
spinosa G. O. Sars, Caligus lacustris Stp. u. Lkt., Neritina fluriatilis L. und Osmerus eperlanus L. Ob Pallasiella als glaciales Relikt zu gelten hat, bleibt fraglich. Sie ist, wie wahrscheinlich alle Süssmasseramphipoden, wohl eine eingewanderte Meerform, oder stammt doch ron marinen Vorfahren ab. Über die Zeit der Einwanderung und die spezielle Abstammung lässt sich indessen einstweilen nichts aussagen.

Der mit dem marinen Caligus curtus Müll. sehr nahe verwandte C. lacustris ist überhaupt nur aus den zwei dänischen Gewässern Furesö und Tjustrupsö bekannt. Er lebt gemein auf verschiedenen Fischen, am häufigsten auf dem Hecht. Seinen Import in den Furesö verdankt Caligus wohl Osmerus. Neritina fluciatilis drang vielleicht nicht in unmittelbar postglacialer Zeit in das Süsswasser ein; für sie ist auch passiver Import nicht ausgeschlossen. Osmerus eperlanus verwandelt sich in Seen, aus denen die regelmäBige Rückwanderung nach dem Meer allmählich unmöglich wird, unter wenigstens teilweisem Verlust des Wandertriebs und unter Grössenabnahme zum reinen Süsswasserfisch.

Die Fauna relicta des Furesös zerfüllt in zwei Cruppen: ältere, arktische Formen, die abyssal leben, sich wahrscheinlich in der kältesten Jahreszeit fortpflanzen und in weitentlegener Epoche direkt in den See eindrangen, und nicht arktischen Tieren, deren kinwanderung auf ein viel späteres Datum anzusetzen ist. Zur ersten Gruppe gehören Mysis und Pontoporcia, zur zweiten Pallasiella, Caligus, Neritina nnd Osmerus.

Die Gegenwart dor besonders interessanten arktischen Gruppe in dänischen Seen war unbekannt. Im allgemeinen bieten die seichten und warmen Wasserbecken Dänemarks polaren Tieren keine passende Heimat.

Über den Zeitpunkt und die Modalität der Besitznahme des Furesös durch die marinen Geschöpfe lassen sich blosse Conjekturen aufstellen. Als Basis hat denselben die in neuerer Keit vervollständigte Kenntnis der geologischen Verhältnisse von Nordseeland zu dienen. Eür die definitive Gestaltung des ganzen in Betracht

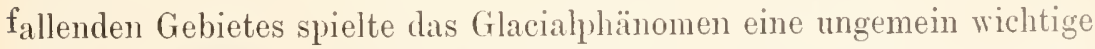
Rolle. Das Meer erreichte den Furesö nie. Es stellt also der See keinen abgetrennten Neeresarm dar; sein Bett verdankt den Ursprung wohl glacialer Erosion.

Als Nordseeland nach dem Rückzug des Eis sich mit einer einfachen, polaren Vegetation bedeckte, drang in die Ostsee, das "YoldictMeer" in seiner weitesten Ausdehnung, auch die arktische Fauna ein. Später zur „Birken-” und .Fichtenzeit“ des nördlichen Seeland ver- 
wandelte sich das baltische Meer zu dem gewaltigen, durch Hebung vom Ozean sich ganz abschnïrenden "Ancylus-See". Das weitgedehnte Wasserbecken verlor seinen Salzgehalt; die arktisch-marinen Insassen mussten sich dem Süsswasser anpassen, während gleichzeitig Süsswassertiere aus den russischen Flüssen in den See einwanderten. Fortschreitende Hebung fïhrte zur Abschneidung der schwedischen Golfe und zur Isolation ihrer Fauna.

Eine Senkung liess den Ancylus-See mit dem Ozean ron neuem in Beziehung treten. So entstand das "Littorina-Meer", das während der "Eichenzeit" bei fortgesetzter Senkung in die alten, glacialen Erosionstäler des nördlichen Seeland vordrang und sich so auch dem Furesö beträchtlich amnäherte. Die alhmählich sich einstellende, nene Hebung liess endlich das Meer wieder zurïckweichen.

Zur Einwanderung mariner Tiere in den Furesö, der niemals einen Meeresabschnitt darstellte, eignete sich die unmittelbare Postglacialzeit mit ihren stark fliessenden Schmelzwässern nicht. Seit einigen Jahrhunderten ist ferner der Fintritt von Tieren in den betreffenden See durch den Menschen rerlegt worden, der den Ausfluss fuir industrielle \%wecke in Anspruch nahm.

Während der langen Zwischenepocle bot sich der günstigste Moment zur Einfuhr mariner Faunenelemente in das Süsswasserbecken, als das Meer in Lanf der",Eichenzeit" weit gegen den Furesö vordrang. Vielleicht zog sich damals, als das Littorina-Neer entstand, die Fauna des westlichen Ancylus-Sees ror dem Eindringen des Salzwassers in die lihssmündungen und in die mit den Flïssen verbundenen Seen zurück. $/ 2 u$ dieser sich flüchtenden Tierwelt zählten auch arktisch-marine Elemente, die sich indessen bereits an das Sïsswasser des Ancylus-Sees angepasst hatten. Der Prozess der Einwanderung vollzog sich wahscheinlich im weiterer geographischerAusdehnung, besonders die norddeutschen Seen dürften ebenfalls durch ihn ihre marinen Relikten erhalten haben. Wesenberg-Lund stiitzt seine Hypothese rornehmlich dureh die Betrachtung der heutigen Verteilung der arktisehen Tierformen in der Ostsee und der speziellen Verteilung der beiden Mysis-Arten inr Sund und im baltischen Meer. Ostsee und Furesö heherbergen Mysis relictu, der Sund dagegen, nach Lönnberg als Bestandteil einer arktischen Reliktenfauna, $M$. oculatu, die Stammform ron $M$. relicte.

Mit den polaren Crustaceen MIysis und Pontoporeia erreichten walırscheinlich auch weitere marine Arten den Furesö. Andere aber wanderten viel später ein, zuletzt wohl Osmerus. Erst die menschliche Industrie gehot der Tiereinfuhr Halt. Jetzt ist der Import 
unmöglich, ebenso können unter den heutigen Verhältnissen Tiere aus dem See aktiv nicht mehr auswandern.

So wären im Furesö gegenwärtig folgende marine Fauna-Elemente isoliert:

1. Erste marine Einwanderer, wie Valcata, Bithynia usw., die zur sehr alten, fast kosmopolitischen Tierwelt des Süsswassers gehören. Sie passten sich dem Leben im süssen Wasser lange vor der Eiszeit an; ihre eigentliche Herkunft ist gänzlich unbekannt.

2. Mysis oculata var. relicta und Pontoporein affinis, zwei arktische Formen, die in die Ostsee einwanderten, während diese mit dem Eismeer in Verbindung stand. Sie gewöhnten sich in dem zum Ancylus-See gewordenen baltischen Meer an das Süsswasser an und zogen sich beim Anbruch der Littorinu-Zeit von Osten und Westen her auch in den Furesö zuriick. Später, nach dem liückzug des Meers aus den tiefen Erosionstälern Seelands, blieb nur noch der östliche Weg offen, den der Mensch endlich auch verlegte. M̈hnliche Ereignisse traten vielleicht an allen Ufern des Ancylus-Sees, besonders den westlichen ein.

3. Die iibrigen marinen Bewohner des Furesös entstammen wohl zum grössten Teil späterer Finwanderung. Aus der Gegenwart mariner Tiere im Furesö kann nicht geschlossen werden, dass das Wasserbecken früher mit dem Meer in direktem Zusammenhang stand. So erhält ein von Credner im allgemeinen ausgesprochener Satz eine weitere Bestätigung.

F. Zschokke (Basel).

\section{Parasitenkunde.}

341 Scott, Th., Notes on some Parasites of Fishes. In: T'wentieth Ann. Report Fishery Board Scotland, Glasgow 1902. pag. 288-303. pl. 12 u. 13.

In Ergänzung früherer Mitteilungen zälılt Verfo eine Reihe parasitischer Copepoden von Fischen der schottischen Gewässer auf (3 Ergasiliden, 4 C'aligiden, 5 Dichelestiden, 2 Chondracanthiden, 1 Lernaeiden und 2 Leruaepodiden). Fr beschreibt ausführlich die neuen und wenig bekannten Arten und legt ihre systematische Stellung gegenüber den verwandten Formen klar. - Die genaue Schilderung der Eudactylina acuta van Ben, von Rhina squatina hat zugleich als Typus-Definition des Genus Eudactylina zu gelten.

Als Species novae charakterisiert Scott Bomolochus onosi (Träger Onos mustelus und O. cimbrius), B. zeuglopteri (Zeuglopterus punctutus), Caligus labracis (Labrus mixtus und L. maculatus), Clavella cluthae (Ctenolabme rupestris) und Eudactylina similis (Raja radiata). Andere Formen waren an den schottischen Küsten unbekannt oder kommen in neuen Wirten vor.

Am Ende der Mitteilung bespricht Verf. noch zwei Trematoden, das für Schottland zum ersten Male nachgewiesene Callicolyle kroyeri Dies. aus der Kloake von Raja radiata und die neue Art Acanthocolylc montirellii von den Kiemen von Raja clavata.

F. Zschokke (Basel). 


\section{Coelenterata.}

342 Duerden, J. E., Boring algae as agents in the disintegration of corals. In: Bull. Americ. Mus. Nat. Hist. Vol. IVI. Article XXV. 1902. pag. 323-332. 1 Taf.

Queckett war der erste, der die Aufmerksamkeit auf die Tatsache lenkte, dass Kiorallen häufig in allen Richtungen von Röhren durchzogen sind, die die Folge des Wachsens fadenförmiger Pflanzen in dem Kalkskelett sind. Später haben andere Forscher ähnliche Röhren nicht nur bei Korallen, sondern auch in den Hornskeletten der Spongien, den Schalen der Foraminiferen, Mollusken und Brachiop oden nachgewiesen und gezeigt, dass bohrende Algen und Pilze die Ursache sind. Verf. untersuchte frisch gesammelte Korallen von Jamaika sowie die von Alexander Agassiz in den Jahren 1899-1900 gesammelten Korallen von den Riffgebieten des Pacific und fand ïherall fadenförmige Algen das Skelett durchzielien. Er hält den Prozess der Korrosion durch Algen für eine wichtige, wenn nicht für die wichtigste Ursache der Auflösung der Korallenmassen und glaubt, dass dadurch die Entstehung der Atolle im Murrayschen Sinne rerständlicher wird. Die physikalischen und chenischen I'rozesse, die dabei stattfinden, sind noch nicht völlig aufgeklärt Die korrodierende Wirkung ist wahrscheinlich ähnlich der, die beobachtet wird, wenn die Wurzeln lebender Pflanzen in Berihhung mit einer Marmorplatte kommen. W. II a (Karlssuhe).

343 Felix, Über zwei neue Ko rallengattungen aus den ostalpinen Kreideschichten. In: Sitzungsber. d. Naturf.-Ges. Leipzig. XXVI. u. XXVH. Jhrg. 1899 1900. pag. 37-40.

Im Jahre 1853 beschrieb Reuss eine neue Korallenart aus Gosau als Gyrosmitia edrardsi. Er bemerkt dazu, die Art sei sehr selten. 1857 führt Milne Edwards die Art in seiner Hist. nat. T. II, pas. 362 als Thecosmitiu eduardsi auf. An einem grossen, vom Terf. bei Gosau gesammelten Stock war nun die Struktur vorzüglich erhalten, und die Untersuchung dieses und anderer Exemplare ergab, dass die Koralle zu keiner der beiden obengenannten Gattungen gerechnet werden kann. Auch mit keiner sonstigen Gattung stimmt sie röllig überein, sondern ist vielmehr als ein neues Genus zu betrachten, für das Verf. den Namen Astrogyra vorschlägt. Es scheint in den Cosauschichten nur durch die eine obengenamnte Art edwardsi vertreten zu sein. Am nächsten steht es der Gattung Lasmogyra, von der Verf. כ́ Arten in den Gosauschichten nachweisen konnte.

Bei Untersuchung der Milirostruktur von Thamnastrapa multiradiatu Reuss liam Verf. zu der Uberzeugung. dass diese Art als 
Vertreter einer neuen Gattung anzusehen ist, für die er den Namen Astraraea vorschlägt. Diese Gattung soll koloniebildende Formen umfassen, die äusserlich einen thamnastracenartigen Habitus besitzen, deren Septen aber, wie bei Coscinarcaea, mehr oder minder unregelmäßig perforiert sind und keine Neigung zeigen, kompakt zu werden. Die beiden bis jetzt bekannten Arten stammen von Gosau und sind als Astraraea muttiratiata und A. mertia zu bezeichnen.

W. May (Karlsinhe).

\section{Vermes.}

Plathelminthes.

44 Sabussow, II., Tricladenstudien IV. Erster vorläufiger Bericht über die von HerrnW. Garjajew im Baikalsee gesammelten Pla-

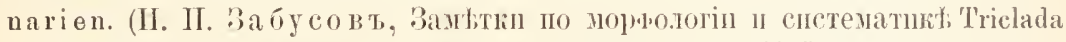

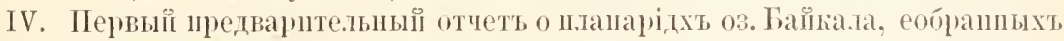
B. II. I'аряевымъ.) In: Arbeiten der Naturforscherges. bei der $k$. Univers.

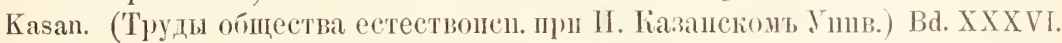
Heft 6. 1903. pag. 1-59. Taf. I. (Russisch mit dentscher Zusammenfassung). Die beschriebenen Tricladen wurden 1899-1901 von Garjajew gesammelt. Unter ihnen sind fast alle beschriebenen Arten neu. Vor allem bemerkenswert noch eine neve Rimacephalus-Art. $I_{i}$. punctalus unterscheidet sich von $l_{\text {. }}$. pulvinar Grube durch weisse Färbung, schärfer hervorstechende braune Flecke und ge. ringere Grösse. Die übrigen beschriebenen Arten sind: Idrocelis nigrofasciatus Grube, S. hepatizon Grube, T. grine Grube, S. fungiformis u. sp., S. lineatus n. sp., S. garjajewi n. sp., S. lencocephalus n. sp., P. lencocephalus var. bifasciatus var., S. guttaia Gerstf., Procotyles baicalensis n. sp., Planaria anyerensis Gerstf., Pl. anuta n. sp., $P l$. sibirica n. sp.. Pl. grubei n. sp., $P l$. rlybowskyi. Von allen beschriebenen Arten sind die Kopulationsorgane abgebildet. E. Scliultz (St. Petersburg).

\section{Arthropoda.}

Crustacea.

15 Scott, Thr, Notes on gatherings of Crustacea collected by the Fishery Steamer "Garland" and the Steam Trawlers "Star of Peace" and "Star of Hopo", of Aberdeen, during the year 1901. In: 'T'wentieth Ann. Rep. Fishery Board Scotland, Glasgow 1902. pag. 447-485. pl. 22-25.

Die Crustaceenausbeute, die auf den Streifziigen der schottischen Fischereidampfer gewonnen wurde, umfasste eine Reihe never oder seltener Forrien. Manche waren für die Küsten Schottlands und der Shetlandinsehn unbekannt. Wiederholt und sehr gründlich untersuchte Lokalitäten lieferten vorher dort nicht gefangene, auffällige Arten. So fanden sich im Firth of Forth der Schizopode Erythrops goesii G. O. Sars und der Macrure Calocaris macandreae. Das Auftreten dieser Formen erklärt sich vielleicht durch neue Zuwanderung.

Die Mehrzahl der gesammelten Crustaceen, die einlässlich aufgezählt und wo es nötig schien genauer beschrieben und systematisch sicher gestellt werden, gehört den Copepoden an. Für sie musste Verf. fünf neue Genera und 10 neue Species aufstellen.

Aus der Abteilung der Ascidicolidae stammt Plutypsyllus n. g. mit der Art 
P. minor n. sp. I'seudomesochra n. g. nimmt eine Mittelstellung zwischen Mesochra Boeck und Cletodes G. S. Brady ein, entfernt sich jedoch von beiden Gattungen durch den Bau des Mandibulartasters und des fünften Fusspaares. Die einzige bekannte Art ist 1 . longifurcata $\mathrm{n}$. sp. Leptopontia n. g. mit seiner Species $L$. curvicauda 11. sp. unterscheidet sich von den verwandten Mesochra Boeck und Tetrogoniceps durch die Abwesenheit eines sekundären Antennenasts, die Form der Mandibel und den Besitz eines einästigen Mandibularpalpus. An Cletodes G. S. Brady schliesst sich Fultonia n. g. (Art F. hirsuta n. sp.) an. Zu den Lichomolgidae gehört Pseurlopsyllus n. g. (P. clongatus n. sp.) mit Anklängen an Clausia Claparède und Hersitiodes Canu.

Neue Arten schon bekannter Gattungen sind Phoenna zetlandica, vielleicht identisch mit Ph. spinifcra Claus, die auf dem Anneliden Eulalia viridis parasitierende Tereicola concinna, Stenhelia confusn, welche St. hirsuta J. C. Thompson am uächsten steht, Ameira tennicornis und A. propinqua.

Als erwähnenswerte, für die schottischen Gewässer neue Funde liaben zu gelten, ein $q$ des nordischen Tanthocalanus borealis G. O. Sars, das bisher nicht beschriebene of von Scolecithrix brericomis G. O. Sars, Normanella altenuata A. Scott, Nannopus palustris G. S. Brady, Icontiophorns ornatus Brady and Robertson, Cribropontius normani Brady and Robertson, Cancerilla tubulata Dalyell und Salenskya tubcrosa Giard et Bomnier. Letztere parasitiert auf Ampelisca spinipes Boeck und fällt vielleicht mit Rhizorbina ampcliscae zusammen.

Beide Gattungen der Monstrilliden, Monstrilla Dana und Thanmaleus Kröyer besitzen an der schottischen Küste Vertreter, erstere M. longiremis Giesbr., letztere Th. thompsoni Giesbr. Von den Ostracoden nennt Verf. nur die zwei selteneru Eormen Sarsiella copsula Norman, deren ó er zum erstenmal beschreibt, und Conchoecea elegans G. O. Sars.

Kurze Notizen über die erbeuteten Branchiopoden (Podon), Amphipoden, Isopoden, Cumaceen, Schizopoden und Macruren schliessen die Arbeit ab.

F. Zschokke (Basel).

346 Sars, (4. 0., On a new south American Phyllopod, Eutimnadia brasiliensis G. O. Sars, raised from dried mud. In: Arch. Math. Naturvidensk. B. 24. Nr. 6. Kristiania. 1902. pag. 1-12. Taf. 1.

Aus getrocknetem Schlamm, der kleinen, brasilianischen Tümpeln entstammte, zog Sars die neue Art Eulimmatia brasitiensis auf. Mit ihr steigt die Zahl der aus Südamerika bekannten Phyllopodenformen auf 5 an.

Die genaue Beschreibung von o und zeigt, dass sich E. brasitiensis in einigen Beziehungen den indischen Verwandten E. chaperi Simon und E. gibba G. O. Sars nähert. Andere Merkmale erinnern an die europäische Limmadia lenticutaris L. und an Entimmadia dahti G. O. Sars aus Australien.

Wie in der Limmadia-Gruppe überhaupt, so sind auch bei $E$. brasitiensis die männlichen Exemplare äusserst selten. Es gelang, sogar ans vollständig ausgetrockneten, unbefruchteten Eiern der nenen Art frische Generationen aufzuziehen. 
An die Stelle der primären Bisexualität der Phyllopoden trat, nach $\mathrm{S}$ a r's, sekundäre Parthenogenesis, um in kleinen, leicht austrocknenden 'T'ümpeln eine möglichst rasche Vermehrung durchzuführen. Der Prozess der Verdrängung der einen Fortpfliınzungsweise durch die andere ist bei den verschiedenen Arten verschieden weit gediehen. Limnadia lenticularis L. ptlanzt sich gar nicht mehr bisexuell fort; bei Eulimnadia Packard erscheinen, gewissermalen als atavistischer Rïckschlag, sehr seltene Männchen, die für die Vermelırung kaum noch eine Bedeutung besitzen. Sie werden häufiger bei Paralimmalia G. O. Sars, wo indessen die Weibchen an Zahl noch bedeutend überwiegen. Beide Geschlechter treten endlich zu jeder Jahreszeit in ungefähr derselben Menge boi den Angehörigen der Estheriidae und Lynceidae (= Limnetidae) auf.

Für die Ostracoden lässt sich eine durchans parallele Reilhe der Ersetzung zweigeschlechtlicher Fortpflanzung durch Parthenogenesis aufstellen.

F. Tscholike (Basel).

347 Samter, M. und R. Heymons, D ie Variationen bei Lrtemia salina Leach und ihre Abhängigkeit von äisseren Einflüssen. In: Anhang z. d. Abhandlg. k. l'reuss. Akad. Wissensch. 1902. pag. $1--62$.

Studien an Artemia solinu aus den Salzhmanen bei Odessa hatten seiner Zeit Schmankewitsch dazu geführt, den Einfluss des wechselnden Salzgehalts auf den Körperbau des entomostraken Krebses in verschiedener Richtung als sehr tiefgreifend zu bezeichnen. Eine Verdünnung der Salzlösung sollte die Bildung scharf umschriebener Varietäten, die sich der Gattung Branchipus annähern, hervorrufen; eine Konzentration des Salzgehalts dagegen sollte A. salina in die Art A. mithauseni überführen. Diese Angaben blieben nicht unwidersprochen. Besonders Bateson machte darauf aufmerksam, dass die bei Artemia häufigen und verschiedenartigen Variationen und Veränderungen nicht durch den wechselnden Salzgehalt bedingt werden.

Es schien somit wïnschenswert, die Untersuchungen Sch mankewitschs unter möglichst engem Anschluss an die von ihm verwendeten Methoden zu wiederholen und so der Frage nahe zu treten, ob neue tierische Formen wirklich unter dem Einfluss eines einzigen äusseren Falitors, in diesem Fall des wechselnden Salzgehalts des bewohnten Mediums, sich herausbilden können.

Verfasser fanden das nötige Untersuchungsmaterial in den Sal\%lagunen von Molla Kary am Ostufer des Kaspischen Meeres. Grössere Seen und kleinere Tümpel, deren Salzkonzentration in ziemlich weiten Grenzen schwankte, lieferten Unmengen von Artemia. Die Tiere 
färbten zeitweise das Wasser rötlich. Während der Salzgehalt der verschiedenen in Betracht fallenten Gewässer voneinander abwich, gestalteten sich dagegen in allen Seen und Tümpeln die ïbrigen äussern Lebensbedingungen wesentlich gleichartig. Dieselben brauchten deshalb nicht berïcksiclitigt zu werden. Zur Untersuchung dienten nur Exemplare ron Artemic, die in Transkaspien in freier Natur gesammelt wurden.

Die Artemien von Molla Kary gehören zur Species $A$. satina Leach. Einige konstante Abweichungen ron ihren Artgenossen anderer Lokalitäten, besonders von denjenigen der Odessaer Limanen, stempeln sie zu einer transkaspischen Lokalrasse. Die Unterschiede liegen in der Länge der Individuen, im V'erhältnis ron Vorderkörper und Abdomen, in der Skulptur der Cuticula, der Zahl der Furkalborsten, der Gestalt der Kiemen u. a. m. Sie sind geringfïgig, aber konstant und charakteristisch. So erscheinen die Kírebse ron Odessa und Ilolla Kary als Lokalvarietïten oder lokale Subspecies von Artemia sulina.

Unter den tausenden von untersuchten Tieren fand sich ein einziges männliches Exemplar; alle andern waren Weibchen, die Latenzeier, Subitaneier oder Embryonen in der Bruttasche trugen. Schon Walter hatte früher an lerselben Lokalität keine Iännchon gefunden.

Diese Tatsachen sprechen gegen Schmankewitsch, der annimmt, dass der steigende Salzgelualt des bewohnten Wassers als äusserer, entscheidender laktor auf die Geschlechtsbestimmung von Artemia einwirke. Verfasser hätten in diesem Fall in den untersuchten, stark salzigen Gewässern unbedingt männliche Artemien finden müssen. Die bisherigen Erfahrungen an verschiedenen Tieren berechtigen übrigens kaum dazı, die Frage nach den Ursachen der geschlechtlichen Differenzierung als in so einfacher Weise lösbar darzustellen. Besonders ist es gewagt, das zeitweilige Auftreten männlicher Individuen bei gewöhnlich parthenogenetisch sich fortpflanzenden Geschöpfen auf die Rechnung des Einfluss dieser oder jener äussern Lebensbedingungen zu setzen. Viehmehr diurfte bei parthenogenetischen Metazoen die Notwendigkeit vorliegen, die Kxistenz der Species von Zeit zu Zeit durch die dureh Ei- und Samenzelle vermittelte Vermischung der Idioplasmen zweier Individuen zu sichern. Dadurch ergibt sich das Bedürfnis gelegentlicher Einschiebung gamogenetischer Generationen in die parthenogenetische Generationenfolge. Der Vorgang wiirde eine Parallele zur Konjugation der Protozoen bilden.

Wenn sich die parthenogenetischen 'Tiere nun an eine bestimnte Lebensweise anpassen, die unter dem Einfluss streng gesetzmäßig sich wiederholenden Wechsels der äussern Bedingungen steht, so 
kann das Auftreten der gamogenetischen Generationen in rhythmischer Folge wiederkehren. Damit erhalten äussere Falktoren einen gewissen, sekundären Einfluss auf die Geschlechtsbestimmung.

In Fällen aber, wo der Wechsel der Lebensbedingungen nicht regelmäßig eintritt, felltt auch eine genügend festgelegte Periodicität in Erscheinen der begattungsfähigen Individuen. I)ieselben treten, wie die sich konjungierenden Protozoen, in unregelmäßigen Intervallen auf. Die Gegenwart dieser kopulationsbedürftigen 'Tiere lässt sich einstweilen nur durch die hypothetische Annahme einer spezifischen, innern Organisation der Eltern, d. h. durch, dem eigentlichen Wesen nach unverständliche Ursachen deuten. Zur zweiten Kategorie parthenogenetischer Geschöpfe scheint Artemia zu gehören. Eine Gesetzmäßigkeit in der Geschlechtsbestimmung, in der sich der Einfluss äusserer Faktoren ausdrücken würde, lässt sich für den Krebs nicht erkennen. Besonders zweifelhaft bleibt es, ob das auslösende Moment zur Erzengung getrennt geschlechtlicher Individuen gerade in einer bestimmten Konzentrationsstufe der bewolnten Salzlösung zu suchen sei.

In den 15 mutersuchten Salz-Seen und -Tümpeln ron Molla Kary entwickelten sich die weiblichen Artemien in maximalen Individuenzalılen bei 10 bis $24^{\circ}$ Beaumé Salzgehalt. Die Variationserscheinungen der 'Tiere bildeten eine gleichmäßige Stufenleiter, die dem Grad der Salzkonzentration parallel lief. Mit steigendem Gehalt des Wohnorts an Kochsalz nimmt die Körperlänge der Artemien schrittweise ab; das Abdomen streckt sich relativ, indem sich das Verhältnis von Vorderkörper und Hinterleib verändert. Gleichzeitig verlängem sich einzelne Abdominalsegmente. Die l'urka wird absolut und relativ kleiner; die Zahl ihrer Borsten verringert sich von Grad zu Grad. Endlich werden die Kiemen relativ grösser, der Enddarm dagegen kïrzer. Diese Veränderungen treffen nur für die Gesamtsumme aller Individuen aus Gewässern ron derselben Salzkonzentration zu; nicht alle 'Tiere desselben Wasserbehälters verändern sich gleich stark. So bilden die Bewohner eines Tümpels keine einheitliche Kolonie, die sich von der Bevölkerung von Salzwasser anderer Konzentration scharf unterscheiden würde. In jeder Stufe ron Salzgehalt vielmehr finden sich nebeneinander alle möglichen Übergänge und Variationserscheinungen der betrachteten Merkmale.

So kommen die Verfasser zum Schlnss des speziellen Teils ihrer Arbeit, dass der Salzgehalt des umgebenden Wassers auf den Organismus von $A$. salina einen nachweisbaren Einfluss ausübe, der sich besonders in gewissen Umgestaltungen der Grössen- und Formverhältnisse des Körpers ausdriicke. Sie schliessen aber weiter, dass, die 
Einwirkung der Salzkonzentration eine relative sei. Die Mehrzahl der Individuen variiert in dentlich übereinstimmender Richtung, doch spielen individuelle Schwankungen immerhin eine ziemlich grosse Rolle, indem derselbe Salzgehalt nicht alle Artemien genan in derselben Weise und Stärke beeinflusst.

Der zweite, allgemeine Teil der Abhandlung bringt die eingehende Kritik der theoretischen Ansichten von Schmankewitsch, die sich etwa in folgenden Sätzen formulieren lassen. 1. Durch Einwirkung von Salzwasser ron bestimmter Konzentration werden bei Artemia salina bestimmte Varietäten gebildet. 2. Durch den Einfiuss starksalzigen Wassers gewinnt $A$. salina die Charaktere der Form $A$. mithanseni. 3. Durch den Einfluss schwachsalzigen Wassers nähert sich A. salina dem Genus Branchipus.

Schmankewitsch beschreibt eine beschränkte Anzahl (5) von Tarietäten von $A$. salina, die sich durch ganz bestimmte Merkmale charakterisieren und stets nur Salzwasser ron demselben Sättigungsgrad bewohnen. Solche festgelegte Varietäten könnten den Ausgangspunkt späterer Differenzierung von Subspecies und Species bilden.

Dem gegeniiber erbringen die Verf. den Nachweis, dass die fünf ron Schmankewitsch aufgestellten Formen nicht als wohlumschriebene Varietäten im zoologischen Sinne zu betrachten sind. Sie verbinden sich alle untereinander durch zahlreiche Übergangsstufen. Beim Versuch die streng gesetzmäßige Abhängigkeit der Körperform ron Artemia ron dem Grad der Salzkonzentration des ungebenden Mediums darzutun, verwickelte sich Schmankewitsch in eine Anzahl unlösbarer Widersprüche. „Bedingungslos an die Konzentration des Salzwassers geknüpfte Varietäten gibt es bei $A$. salina nicht; sie kommen zweifellos ebensowenig in den Limanen ron Odessa vor, wie wir sie in den Salzlagunen der transkaspischen Steppen auffinden konnten."

Artemia mithanseni, die schon Schmankewitsch nur als eine zweifelhafte Art ansah, fassen Samter und Heymons als eine der zahllosen Varietäten von A. salina auf. Bei ihr hat die Redultion der Borstenzahl und die Undeutlichkeit der abdominalen Segmentierung den :iussersten Grad erreicht. Ununterbrochene Übergänge verbinden A. mithauseni mit den übrigen Variationstypen von $A$ salina. Die Variation A. mithanseni entsteht unter dem Einfluss starksalzigen Wassers, ohne dass sie eine konstante Rasse oder gar eine eigene Art bilden wïrde. Als feststehende, selbständige Form gehört sie nicht in das System.

Der Varietätenbildung von Artemia in ihrer Abhängigkeit von der Lokalität näher tretend, führen die Verfasser aus, dass ohne Hinzn- 
treten weiterer Momente unter natürlichen Verlältnissen der Grad der Salzsättigung des bewohnten Wassers niemals hinreiche, um an einem Ort bestimmte, durch feststehende Merkmale gegenüber der typischen Artemia salina ausgezeiclnete Rassen oder Abarten zu erzeugen. Sie stellen sich dadurch wieder in prinzipiellen Gegensatz zu Schm an kewitsclı. Er glaubte in der Veränderung eines einzigen, äussern Faktors den Weg gefunden za haben, den die Natur einschlägt, um allmällich neue Formen zu schaffen. Samter und Heymons zeigen ausfülırlich, dass weitere, wesentliche Umstände mitwirken müssen, um an räumlich weit voneinander entfernten Lokalitäten formbeständige Rassen von Artemien hervorzubringen. Genaueres über die Bedingungen, welche die Entstehung eigentlicher Varietiiten begünstigen, ist bis lieute unbekannt. Doch kann in dieser Beziehung neben dem wechselnden Kochsalzgehalt an andere von Ort zu Ort verschiedene Verhältnisse, wie die chemische Zusammensetzung des Wassers, die Ernälırungsbedingungen, an klimatische Einflüsse, Intensität der Sonuenbeleuchtung usw. gedacht werden. Auch innere, konstitutionelle Ursachen, die sich durch Vererbung weiter übertrugen, mögen bei der Bildung von Lokalvarietäten maßgebend mitgespielt haben. Zu den zahlreichen bei dem in Frage stehenden Prozess notwendigen Faktoren gehört aber vor allem auch genügende räumliche Trennung der Wohnstätten der sich differenzierenden Varietäten. Sie sclıliesst Rïckschlagserscheinungen und Vermisclungen mit andern Lokalrassen aus.

In bezug auf das gegenseitige Verhältnis der Gattungen Artemia und Branchipus und ihre Abhängigkeit von äussern Lebensbedingungen ergibt sich, dass ein durchgreifendes, morphologisches Trennungsmerkmal für beide Genera kaum existiert. In allgemeinen liegen gewisse Verschiedenheiten in einigen Sexualcharakteren der Arten ler Artemia-Gruppe gegenüber denjenigen der Branchipus-Gruppe; eine scharfe und absolute Trennung lässt sich aber auch damit nicht durchführen. Erst die Verwertung einer ganzen Summe verschiedenartiger Merkmale, teilweise sogar solcher der innern Organisation, erlaubt eine Verteilung der Arten auf Artemia und Branchipus. Artemia besitzt im ganzen mehr primitive, larvale Eigenschaften, als Branchipus; sie bleibt auf tieferer Entwicklungsstufe stehen. Die Vermutung liegt nahe, dass die so unbedeutenden Gattungsunterschiede infolge der Aupassung an verschiedene Wohnorte, Salzwasser und Süsswasser, entstanden seien. Fü̈r diese Hypothese sprechen indessen einzig Wahrscheinlichkeitsgründe. Ein wirklich schlagender Beweis, dass nur der Einfluss eines bestimmten Salzorads des bewohnten Mediums die Trennung der beiden Genera bewirkte, fehlt 
vollständig. Heute haben sich die Gattungsmerkmale von Branchipus und Artemia schon in dem Grade fixiert, dass die natürliche oder künstliche Überführung der einen in die andere Form vollkommen ausgeschlossen ist. Die Fixation der Merkmale geht so weit, dass Arten beider Gattungen in Medien leben, die eigentlich dem andern Genus entsprechen, ohne dabei ihre generellen, typischen Eigenschaften einzubüssen.

F. Zschokke (Irasel).

\section{Arachuida.}

348 Schtschelkanowzew, S., Beiträge zur Anatomie der Pseudoscor-

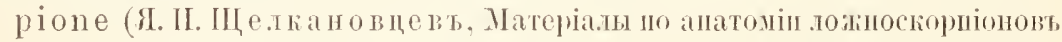
(Psendoscorpiones). In: Gelehrte Schriften d. K. Moskauer Univ.,

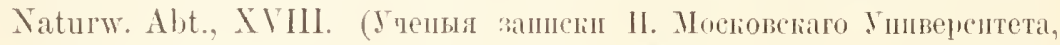
Огд. ест.-нет. Вын. XVII). 1903. pag. 1-202. 'Taf. 1-3. (russisch).

Das Gewicht dieser Arbeit liegt in der genauen monographischen Beschreibung einiger Arten des Genus Chernes, also in den Details; so dass Ref. hier nur weniges Allgemeinere hervorheben kann und sich auf Hinweise darauf, was in der Arbeit zu finden ist, beschränken muss. Es fellt nur die Reschreibung des Herzens und der Geschlechtsorgane, die rom Verf. an anderer Stelle gegeben wurde. Das skelett, der Cephalothorax und die Extremitäten werden ausführlich besehrieben. Ein sinnesorgan liegt in dem beweglichen und unbeweglichen Gliede der Chelicerenschere und besteht aus zwei Gruppen ron Zellen (Simnesganglien), die von einem rom obern Sclılundganglion ausgehenden Nerven versorgt werden. Diese sinnesorgane haben viel Ïhnlichkeit mit den von Sazepin und vom Rath beschriebenen Sinnesorganen der Iyriopodenfühler. Der im unbeweglichen Gliede liegende Teil wird rom Verf. als Geruchs- oder Geschmacksorgan angesehen, der Teil des Organes, der im beweglichen Gliede sich befindet, soll ein Tastorgan sein. Die Cheliceren sind deswegen hauptsächlich Träger der Siunesorgane und dienen, da die Tiere nur Hlissige Nalırung aufnehmen, nicht für die Zerkleinerung der Nahrung. Ihrem Charakter nach stehen sie den Fühlern der Myriopoden, Insekten und Crustaceen näher, als Kauorganen. Weiterhin schildert Verf. ausführlich die Gelenkbildungen und die Muskulatur der Extremitäten. Die Muskulatur des Cephalothorax weist darauf lin, dass derselbe nicht durch Verschmelzung von sechs, sondern von sieben Brustscliildern entstanden ist. Chemes fehlen viele Muskeln, die für die Skorpione beschrieben wurden, so viele die Coxalglieder bewegende Muskelı, was in der geringen Beweglichkeit derselben eine Erklärung findet. -- Das Chitin ist an Stellen, wo es dicker wird, von vielen 
Kanälen durthzogen; die grössern sind in geringerer Zahl vorhanden und münden in die Höhlung der über ihnen befestigten Haare oder auch frei, die dünnern Kanäle sind verzweigt. Es gibt zwei Arten von Haaren bei den Pseudoscorpionen, wovon die einen hohle Cylinder sind, die sich nach aussen und innen öftnen und deren verbreitertes zackenförmiges Ende somit nicht geschlossen ist. Unter jedem dieser Haare sitzt eine aus der Hypodermis gebildete Blase augenscheinlich eine Drüse, die ihr Sekret in den Kanal des Haares ergiesst. Dils Interessante ist, dass diese Drüsen, im Unterschiede von äbnlichen Drüsen der Inseliten, vielzellig sind. Ein Paar von Drüsenkomplexen liegt unter dem Cephalothoraxschilde und ihre Ausführungsgänge münden in die Auswïchse der Galea: es sind Spinndrüsen die sich bedeutend ron den Giftdrüsen der Spinnen unterseheiden. Die Coxaldrüsen sind in der Zahl von einem Paare vorhanden und sind in dieser Bezielıung den Seespinnen und niclıt den Spinnen, die zwei Paare haben, ähnlich. Ausser diesen Drüsen sind noch kleine Drüsenanhäufungen zwischen den Coxalgliedern der fünf Extremitätenpaare vorhanden. - Das Rostrum wird sehr ausfïhrlich beschrieben. In seiner untern Seite findet Verf. eine Urïse, die er einer ähnlichen Drïse am Rostrum der Spinnen homologisiert und Wassmannsche Drüse nennt. Eine obere Längsverdickung der Seitenwände des Rostrums wird als Geschmatksorgan gedeutet. Die zwei in der untern Wand des Rostrums gelegenen Drüsen nennt Verf. Speicheldrüsen, ihr Sekret soll die Fibrinbildung im Blute der Tiere hemmen, auf welchen Chernes parasitiert. Der ganze Ösophagus ist vollkommen rom Nervensystem umschlossen. Der Mitteldarm zerfällt in zwei Teile; im vordern erweiterten Chylusmagen finden wir drei taschenförmige Erweiterungen. Nur der kleinste hinterste Teil des Darmes, die sog. Kloake, entsteht als entodermale Einstülpung. Das den Darm umgebende Fettgewebe hat nach Ansicht des Verfs. die Aufgabe, die aufgesogene Nahrung, vielleicht dieselbe weiter verarbeitend, in das Blut überzuleiten. Die Tracheen werden sehr ausfülırlich beschrieben, doch müssen wir auch hier aufs Original verweisen. Das Nerrensystem wird nur topographisch, nicht histologisch beschrieben. Das obere Schlundganglion besteht aus drei Knotenpaaren, das erste Paar ist von geringer Grösse, das zweite bildet die Hauptmasse des Gehirnes, das dritte Knotenpaar bildet das Ganglion der Cheliceren. Die Sehnerven fehlen bei Chernes vollständig (gegen Kroneberg), somit sind die Nerven der Cheliceren, die in besonderen oben erwähnten Sinnesorginen enden, das erste abzweigende Nervenpar. Die Nerven der l'edipalpi entspringen rom Vorderrande des unteren Schlundganglions. Da der 
Cephalothorax mindestens aus sieben Netameren zusammengesetzt ist, vor dem Cephalothorax aber noch ein ganzer Kieferteil, das Rostrum, liegt, das mindestens aus zwei Teilen besteht, so treten in den Bestand des Cephalothorax von Chernes nicht weniger als neun Segmente; was nicht mit dem von Heymons für die Arachniden gegebenen Schema übereinstimmt (ein präoraler Teil und sieben postorale). Zuletzt folgen theoretische Betrachtungen über Gelenke und Tracheen.

E. Schultz (St. Petersburg).

\section{Insecta.}

34917 h Report of the state Entomologist on injurious and other insects of the State of New York. 1901. In: New York State Nuseum. Bull. 53. Entomol. 14. pag. 700-925. Fig. 1--29. 'Taf. 1-6.

Der Bericht behandelt zunächst eingehend die Hessenfliege, Cecidomyia destructor, die so verheerend auftrat, dass der durch sie angerichtete Schaden auf drei Millionen Dollars geschätzt wird. Dann folgen kürzere Notizen über andere scliädliche Insekten und zwar 1. Obstbauminsekten (Scolytus rugulosus, Fidia viticida, Colaspis brunnea, Saperda candida, Systcna frontalis, Clisiocampa disstria, Cenopis diluticostana, Typhlocyba comes var. vitis), 2. Schatten- und Forstbauminsekten (Galcrucella lutcola, Rhabdophaga salicis, Prionoxystus robiniae, Zeuzcra myrina, Bucculatrix canadensisella, Asterolccanium variolosum, Lccaninm nigrofasciatum, Pseudococcus aceris, (hermes pinicorticis), 3. Garten- und andere Insekten (Epicanta vittata, E. pennsylianica, E. cincrea, Systena tacniata, Phorbia fusciceps, Cacoecia parellcla, Anasa tristis, Smynthums hortensis, Cutcrebra euniculi, Mantis religiosus, Thyllodromia germanica). Win weiterer Abschnitt handelt über die Fortsetzung der Versuche, geeignete Mittel gegen die San José Laus zu finden. Dann werden die Beobachtungen entomologischer Liebhaber mitgeteilt, die sich hauptsächlich auf Clisiocampa disstria, Cl. americana und Cecidomyia destructor beziehen. Den Schluss des Heftes bilden ein Bericht und Katalog der entomologischen Abteilung der panamerikanischen Ausstellung des Jahres 1901.

W. M a yarlsruhe).

350 Tichomirofi, A., Ki nust 1 iche Parthenogrenese beim Seiden-

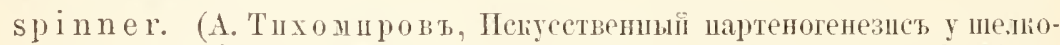
витнаго тервя.) In: Mittheil. d. Comités f. Seidenzucht d. Kais. Moskauer Landwirt. Ges. (Пзвғетія полтета пельоводства П. Московскаго общ. сельсlаго хозяїства.) Bd. I. Heft 10. 1903. pag. 3-10. 'Taf. I (russisch) ${ }^{1}$ ).

Verf. beruft sich auf seine schon 1885 erschienenen Beobachtungen über künstliche Parthenogenese bei dem Seidenspinner, die durch Einwirkung von Schwefelsäure, Reibung oder warmes Wasser hervorgerufen waren, woraus er schon seinerzeit schloss, dass Reize der verschiedensten Natur als Faktoren der kiinstlichen Parthenogenese dienen können. Dieses Resultat stelıt in Widerspruch mit der bekannten Auffassungweise Loebs und in Einklang mit den neuern Beobachtungen Delages. Verf. stellt neue ähnliche Versuche am Seiden-

$\left.{ }^{1}\right)$ Vgl. Zool. Zentr.-Bl. IX, 1902. Nr. 424. 
spinner an und findet, dass die parthenogenetische Entwicklung hier immer grössere oder geringere Abnormitäten aufweist. Bald sind die Zellen der Serosa von oft riesenhafter Grösse, bald ist die Entwicklung sehr verschnellert, was sich besonders aufs Ektoderm bezieht, während das Mesoderm und das Entoderm zurïckbleibt, in andern Fällen bleibt das Ektoderm allein in der Entwicklung zurück, es geschieht auch, dass die Zellen der Serosa als unregelmäßige Kette mitten im Dotter liegen. Diese Resultate widersprechen nach der Meinung des Verfs. der Ansicht Loebs, nach welcher das unbefruchtete Ei (des Seeigels) alle nötigen Elemente enthält, um eine normale Larve zu geben.

E. Schultz (St. Petersburg).

351 Felt, Ephraim Porter, Elm Leaf Beetle in New York State. In: New York State Museum. Bull. 57. Entomol. 15. 1902. pag. 1 -43. 2 Textfig. 8 Taf.

Der Ulmenblattkäfer Galerucella luteola Müller, hat so grosse Verheerungen an den Ulmen der Stäite und Dörfer längs des Hudson angerichtet, dass er als der wichtigste Feind der Schattenbäume jener Gegenden angesehen werden muss. Verf. gibt daher einen ausführlichen Bericht ïber die systematische Stellung, die Kennzeichen, die Verbreitung, Lebensgeschichte und Gewohnheiten dieses Käfers sowie Angaben zu seiner Vertilgung.

Das Insekt wird in einem grossen Teil Europas gefunden, doch tritt es dort in grosser /ahl und wirklich verheerend nur in den südlichen Teilen von Deutschland und Frankreich und in Italien und Österreich auf. Nach Amerika kam es etwa 1834. Seine Verbreitung am Hudson ist den Verkehrslinien gefolgt. 1879 war es häufig und zerstörend bei Newburg, 12 Jahre später bei Poughkeepsie, 1890 bei Hudson, 1891 bei New Baltimore, und 1892 hatte es Albany und Troy erreicht.

Die Käfer verbringen den Winter an geschützten Orten. Mit Beginn der wärmern Jahreszeit kommen sie hervor, Hiegen auf die Bäume und fressen unregelmäßige Löcher in die Blätter. Dann werden die orangegelben Eier an die Unterseite der Blätter in Haufen von 5-26 abgelegt. Etwa 5 oder 6 Tage nach der Eiablage kriechen die Larven aus und skelettieren die Unterseite der Blätter. Nach 15 bis 20 Tagen sind sie ausgewachsen, verlassen die Blätter und suchen einen geschützten Ort zur Terpuppung. Die Beobachtungen von 1896-1898 haben es ausser Frage gestellt, dass zwei vollständige und unter günstigen Umständen auch noch eine dritte unvollständige Generation in einem Jahre möglich sind.

Von den verschiedenen Ulmenarten leiden Ulmus campestris und 
$U$. montana am meisten, während $U$. americana ziemlich verschont bleibt. Ausser dem Ulmenblattkäfer ist es namentlich die Ulmenrindenlaus, Crossyparia ulmi Genff., die diesen Bäumen Schaden zufïgt. Die so geschwächten Bäume sind dann auch den Angriffen von Tremex columba L. und Saperda tridentata Oliv. ausgesetzt.

Unter den natïrlichen Feinden des Ulmenblattkäfers ist der Pilz Sporotrichum entomophitum Peck. einer der wichtigern. Doch ist er ebensowenig wie die tierischen Feinde des Käfers fähig, ihn genügend in seiner Vermehrung zu hemmen. Daher muss man zu künstlichen Vernichtungsmitteln greifen, unter denen die Besprengung der Blätter mit giftigen Flüssigkeiten am meisten zu empfehlen ist.

W. Ma y (Karlsruhe).

\section{Vertebrata.}

Pisces.

352 Studuicka, 1. K., Über das Epithel der II undlı̈hle von Chimaera monstrosa mit besonderer Berücksichtigung der Lymphbahnen der selben. In: Bibliogr. anat. 'Tome Xl. 1903. pag. 217-233. 5 'Textfig.

Verf. untersuchte das sehr dicke Epithel, welches die obere Wand und die Lippen von Chimaer monstrost auskleidet. Die Zellen sind mit mehr oder weniger dicken Exoplasmaschichten bedeckt, die da, wo das Epithel besonders hart ist, auch besonders stark entwickelt sind. Voneinander sind die Zellen durch dentliche Intercellularliicken getrennt und hängen miteinander nur durch fadenförmige Intercellularbrücken zusammen. Die basalen Zellen des Epithels sitzen der Membran mit glatter Fläche auf; sie teilen sich viel spärlicher als die Zellen der nuittlern Schichten, so dass der Epithelersatz offenbar von diesen ausgeht.

Das Epithel ist ron hellen Streifen - so erkennt man bei Anwendung schwacher Systeme - durchsetzt, die ron den untersten Zellschichten ausgehen und durch die ganze Dicke des Epithels bis zur Oberfläche führen. Es handelt sich hier um wandungslose Kanäle, d. h. um erweiterte Partien des im ganzen Epithel vorhandenen Lückensystems, in welche hinein von allen Seiten die engen Intercellularliicken münden. Sie stellen also Sammelräume des Lückensystemes dar. Diese Kanäle verlaufen entweder gerade oder nur wenig gekrimmt, haben überall die gleiche Breite und besitzen runden Querschnitt. Die basalen Abschnitte dieser Kanäle enthalten Leukocyten, die gerade durch das Epithel aufstrebenden, die Kamine, nur in den untersten Partien. Die Kamine münden frei nach aussen.

B. Rawitz (Berlin). 


\section{-347
Reptilia.}

353 Kunitzky, J., Die Entstelung und Lintwicklung der Cuticularhärchen auf den P'oten von Platylactylus maritanicus

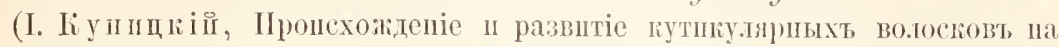
.ашкахъ гекоповь) (Platydactylus manitanicns). In: 'Travaux Soc. Imp. Natural. de St. Pétersbourg (Труды Ш. спо́. общ. естествопеп.) Vol. XXXIV. fase. 2. 1903. pag. 1-19. Tat. I (russisch nit deutschem Resumé).

Der I'rozess der Borstenbildung beginnt erst in vorgeschrittenern Entwicklungsstadien. Die Resultate des Verfs. stimmen mit denjenigen Brauns überein und nicht mit denjenigen Hases, der 3-4 Zellenreilien nit Fortsätzen vertreten sein lïsst, die el als Borstenanlage ansieht. Nach Meinung des Verfs. geht die Entwicklung der Borsten nur von einer Seite einer einschichtigen Zellenlage vor sich. Die äussere Schicht der embryonalen Epidermis (Epitrichium Herberts) wird bei der ersten Häutung abgeworfeu und nicht mehr erneuert. Die sog. Hornschicht bestelit aus Cuticula und Horusubstanz. Die innere cylindrische Zellenschicht bildet die cutikularen Borstenbündel. Jede Zelle trägt nur ein Borstenbündel; diese Cutikularbündel sind die veränderte Häutungshärchen (Cartier) und haben dieselbe Aufgabe wie diese, d. I. bei dem Abwerfen der alten Haut behilthich zu sein.

$$
\text { E. Schultz (St. Petersburg). }
$$

\section{Aves.}

354 Mudge, Geo. P., On the Myology of the Tongue of Parrots, with a Classification of the Order, based upon the Structure of the Tongue. In: Transact. zool. soc. Iondon. Vol. XVI. Part. 5. 1902. pag. 211-270. Taf. 26-29. 16 'Textfig.

Nach einer kurzen historisclıen Übersicht beginnt Terf. seine Schilderung mit dem

Musculus ceratoglossus und zwar mit dessen unterer Partie: a) Ceratoglossus inferior. Man kann bei diesem ungemein variablen Muskel neun verschiedene Ausbildungsstadien unterscheiden. Die Endglieder dieser letztern nennt Verf. „unipars" und „duopars"; jenes wird durch das erste, dieses durch die höchsten Stadien r'epräsentiert, zwischen denen die Übergänge in den mittlern Stadien sich finden.

Die primitivste Form (1. Stadium) wird bei Cucatua alba angetroffen. Der Muskel inseriert sich sehnig an den vordern lateralen Fortsatz des Os entoglossum wird Heischig rom linteren Rande des Basihyale und bleibt dies in der ganzen Ausdehnung des Uro- 
hyale, von dem er entspringt. Dieses Sicherstrecken des Ursprunges iiber die ganze Länge des Urohyale ist ein primitiver Zustand. Er findet sich ausser bei der oben erwähnten Species bei C. sulphurea und triton, Ara ararama in gleicher Weise ausgebildet und wird rom Verf. Ceratoglossus inferior anticus accessorius genamnt. Dieser Muskel besteht also nur ans einer vordern Portion, daher "nnipars".

Bei Cacatua galerita (2. Stadium) ist dieser Muskel insofern abweichend gestaltet, als die innere Partie teilweise von der äussern sich getrennt hat. Ferner teilt sich die ventrale sehnige Fascie in eine innere unl äussere Partie. Das 3. Stadium findet sich bei Stringops.s hubroptilus. Hier erstreckt sich der Muskel etwas ausgedehnter läng's des Hypobranchiale und dieser Teil ist abgetrennt von dem Hauptmuskel. Verf. nennt diese Partie Ceratoglossus inferior posticus. Ähnlich ist das Verhalten bei Cacatua leadbeatori, Calopsittacus nova-hollandiae und Nasiterna pusio. Das 4. Stadium charakterisiert sich durch eine geringe Rückbildung des innern Randes und des bintern Endes der innern Partie des C. inf. ant. und durch die Entwicklung in antero-posteriorer Richtung. So z. B. bei Ara macao, Wicroylossus aterimus, Cyanolyseus patagonicus und Chrysotis achrocephala. Stadium 5. Ein verdickter Strang in der Ventralfascie des Muskels, der früher nur angedeutet war, ist jetzt stärker hervorgehoben und hat sich teilweise ron der Fascie getremnt. Es besteht also die T'endenz des M. ceratoglossus inferior posticus, sich über das hintere Ende des Hypobranchiale hinaus zu erstrecken. Die Rückbildung der innern Partie des Ceratoglossus inferior anticus ist sehr ausgeprägt geworden. So findet man die Verhältnisse, von unwesentlichen individuellen Abweichungen abgesehen, bei Psittacus erithacus, Coracopsis rara, Palaeornis torquata usw. Im 6. Starlium zeigt die ventrale Fascie des Ceratoglossus inferior anticus nicht mehr den ausgesprochen sehnigen Charakter wie bisher. Der Ceratoglossus inferior posticus reicht ïber das hintere Ende des Hypobranchiale hinaus. Dies ist der Fall bei Clatycercus eximius, Coeocephalus rïpelli, Bolborhynchus lineolutus u. a. Das 7. Stadium zeigt keine sehnige Fascie mehr, daher sind die Sehnen der Muc. ceratoglossus inferior posticus und c. lateralis roneinander unabhängig. Die innere Partie des M. ceratoglossus inferior anticus ist völlig verschwunden. So bei : Pyrrhura lencotis. Nymphicus maeensis, Cyanorhampus anriceps usw. Stadium 8. Der M. ceratoglossus inf. post. ist allenthalben sehr deutlich: Lorius domicella, L. Alavopalliatus. Das 9. Stadium unterscheidet sich vom vorigen nur durch die Art, wie sich das hintere Sehnenende fächerartig ausbreitet: Eos ricimata. 
b) Ceratoglossus lateralis. Er entspringt fleischig von der dorso-lateralen Oberfläche des Hypobranchiale und setzt sich mit einer Sehne, die ihm mit C. inferior gemeinsam ist, an den vorderu lateralen Fortsatz des Os entoglossum. Über die verschiedenen Abweichungen von diesem Schema vgl. Original.

c) Ceratoglossus superior. Der Muskel entspringt von der dorsalen innern Fläche der vordern Hälite eines jeden Hypobranchiale, geht über die dorsale Fläche des Basihyale, von der er Zuzug bekommt, und inseriert sich an die dicke Scheide, welche eine in der dorsalen Aushöhlung des Os entoglossum gelegene konische Bindegewebsmasse einhüllt. Primitives Stadium (Cacatua, Ara, Calyptorhynchus und Calopsittacus usw.)

Musculi thyrohyoideus und thyrohyoideus accessorius. Ersterer zeigt sehr konstante Verhältnisse bei allen untersuchten Species. Er entspringt von der vordern Partie des l'arahyalfortsatzes und inseriert sich an die ventrolaterale Fläche des Thyroid.

Musculus thyroglossus. Die Ausbildung dieses Muskels geht von drei verschiedenen Anfangsstadien aus, die zu einem höhern Stadium konvergieren. Er' erscheint (A) als eine Abzweigung des Thyrohyoideus, oder (IB) bei beginnender Teilung des letztern trennt sich der Thyrogl. nicht unmittelbar von ihm, oder endlich (C) der Thyroglossus erscheint als eine nach vorn gerichtete Ausdehnung eines Teiles des Thyrohyoideus. Die Ursprungsmethode A oder B beraubt den Muskel gewissermalien seiner Selbständigkeit, bei der Methode C leitet die entoglossale Entstehung die Selbständigkeit des Muskels ein. Bezüglich der sehr komplizierten Einzelheiten, die sich zu einer referierenden Wiedergabe nicht eignen, sei auf das Original verwiesen.

Musculus hypoglossus. Verf. unterscheidet hier zwei Muskeln: a) h. obliquus. Er bietet zahlreiche Variationen dar, entspringt zum Teil vom Hypobranchiale, zum Teil von den ventralen und dorsalen Oberflächen des Körper's des Basihyale und inseriert sich an die Innenfläche des Hinterrandes des Processus laterulis posterior ossis entoglossi. b) h. rectus entspringt von der äussern Fläche des zuletzt genannten Processus und inseriert sich sehnig teils in der Spitze der Zunge, teils an die Fascie des Mesoglossus.

M. mylohyoideus. Auch dieser Muskel besteht aus zwei Partien.

a) Mylohyoideus anterior wird von einer oberflächlichen vordern und einer tiefen hintern Partie gebildet. Beide Partien entspringen gemeinsam am vordern dorsalen Horn des Unterkieferastes, 
genau hinter der Linie, welche das Schnabelende bezeichnet. Beide Partien vereinigen sich in der Mittellinie, indem sie teils zusammenfliessen, teils in gemeinsame Sehne übergehen. Der vordere Teil des Muskels geht niemals ans Hyoid, sondern bleibt ventral ron ilm; der hintere Teil inseriert sich an einem linorpligen oder knöchernen Knnötchen, das mit der ventralen Fläche des Urohyale artikuliert.

b) Mylohyoideus posterior besteht ans einem innern hintern Teil, dem Serpihyoideus, und einem äussern vordern, dem Stylohyoideus. Beide entspringen gemeinsam rom lintern Ende der Mandibula; der erstere inseriert sich an das vorhin erwähnte Knötchen des Urohyale, der letztere inseriert sich an die laterale äussere Fläche des Parahyale.

M. sternoly yide us entspringt vom rordern Ende des ventralen Randes des Brustbeinkiels und inseriert sich rückwärts längs dem Körper des Basihyale und reicht auch etwas auf das Hypobranchiale über.

M. geniohyoideus ist bei manchen Gattungen aus zwei 'T'eilen, bei den meisten aber aus dreien zusammengesetzt, von denen der dritte durch Längsspaltung des vordern jener zwei entstanden ist. Die hinterste Partie entspringt entweder vom ventralen Rande der Mandibula oder ron deren Aussenfläche. Die beiden 'Teile der vordern Partie entspringen gemeinsam von der innern Fläche des anterodorsalen Abschnittes des Unterkiefer's. Jene Partie inseriert sich an der Dorsalfläche des Ceratobranchiale, die vordere an das hintere Ende des Hypobranchiale.

1I. genioglossus, paarig, von der Innenfläche des hintern Endes des Unterschnabels zu einem dïnnen Grat, der die Dorsalgrenze des hintern lateralen I'ortsatzes des Os entoglossum liennzeichnet.

M. c erat ohy o ide us entspringt in einigen Fällen ron der Scheide des Urohyale, in andern teils von dieser und teils vom hintern Rande der Urohypobranchialselıne, in ganz wenigen Fällen teils won der letzterwähnten Stelle, teils von einem Knötchen an der ventralen Fläche des Uroliyale.

1I. m es oglossus ist dreieckig mit der Spitze nach hinten und mit den obern Ceratoglossi verbunden. Er liegt in der dorsalen Höhlung des Entoglossum und verbindet sich am einen Linde mit den Ceratoglossi, am andern mit dem Hypoglossus und der Membran der Zunge.

(Diese wenigen Notizen mögen genïgen; bezüglich der reichen Einzelangaben des V'erfs. sei auf die sehr sorgfältige Arbeit selber verwiesen).

B. Rawitz (Berlin). 
Suschkin, P., Zur Morphologie des Togelskelettes. Vergleicliende Osteologie der Tagraubvögel (Accipitres) und Klassificationsfragen. Theil I: Grundlagen der Einteilung der Accipitres. Theil II: Die Falken und ihre nächsten Verwandten. (II. Cунцинт. - lís мортологіп скелета птпц. Сравиптельная остеологія диевныхъ хпщпыхт птиц пा вопросы

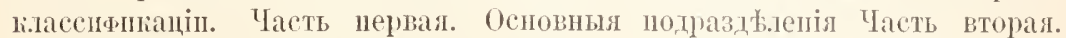

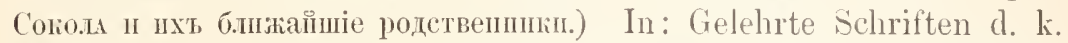

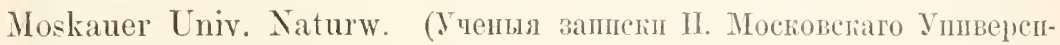
тета. Отд. естеств.-петор.) Heft XVII. 190\%. pag. 1-414. Taf. I-IV und 56 Fig. im Texte (russisch).

Eine neue, auf osteologische Merkmale gegründete Kklassifikation der Accipitres wird uns hier geboten, da ja bis jetzt die Stellung der Gattungen zueinander sehr streitig war. Verf. hat zu diesem Zwecke in verschiedenen Museen Europas Skelette ron 80 Gattungen, also ${ }^{4} / 5$ aller Gattungen der Accipitres, untersucht. Er teilt auf Grund dieser Untersuchnngen die ganze Unterordnung der Accipitres in zwei Familien: Falconidae (Falcones, Microhieraces, Polybori, Micrastur, Herpetotheres) und A quilidae (alle iibrigen) und führt ausführlich 47 osteologische und myologische Merkmale an, durch die sich diese beiden Familien unterscheiden. Auch Unterschiede im Bau der Luftröhre und des Schnabels werden gefunden. Nach einigen Merkmalen sind die Falconidae eine fortgeschrittenere Gruppe, nach andern die Aquilidae, woraus Ref. folgert, dass keine direkte genetische Verbindung zwischen diesen beiden Familien existiert, sondern nur eine Verbindung durch Abstammung von einem gemeinsamen Stammvater.

Im II. Teile behandelt Verf. die Falconidae spezieller und gibt eine ausführliche Osteologie der eigentlichen Falken, der Geierfalken, zwischen denen er eine nalıe Verwandtschaft findet, bespricht alle osteologischen Merkmale der Gattungen der echten Falken, vergleicht Timmunculus alandarius Gray und Falco peregrinus T'Tunst., wobei letzterer als weiter differenzierte Gattung angegeben wird, bespricht das Genus Harpe, welches Falco peregrims näher stehen soll als Tinnunculus; Harpe wird als primitivste Form mnter allen lebenden ecliten Falken angegeben und ist der am wenigsten typische Falke; er hat sich von jenem genetischen Stamme abgetrennt, der zu Falco peregrims und seinen nächsten Verwandten fülıt. Die geographische Verbreitung von Harpe steht damit in gutem Zusammenhange, da sich diese Form auf Neu-Seeland beschränkt, wo sie von aller Konkurrenz ausgeschlossen, ron einigen Ausnahmen abgesehen, fast als höchstes warmblütiges Tier, spezialisiert Vögel im Fluge zu fangen, 
wie alle Falken, gut bis auf unsere Zeit fortleben konnte. Hieracidea ist Tinmunculus sehr ähnlich, weniger Harpe. Eine Reihe exotischer Timmunculus-Arten wird osteologisch verglichen und der Verf. kommt zu dem Resultate, dass dieses Genus eine vollkommen natiirliche Gruppe bildet. Die Osteologie des Hypotriorchis subbuleo L. und seiner Verwandten zeigt, dass diese Gruppe seitwärts von allen oben erwähnten steht, ihr primitiver Charakter weist nur anf ihre Entstehung und Nähe zu dem gemeinsamen Stammvater aller Falken. Erythropus Brehm ist ein Nebenzweig des Stammes, der zu Hypotriorchis führt. Aesalon, Hierofalco, Dissodectes, Stales, Rhynchofalco Rdgway werden weiter besprochen. Nur Dissodectes und Rihynchofalco konnten nicht osteologisch untersucht werden, so dass sich der Verf. nicht näher über ihre genetischen Beziehungen auszusprechen berechtigt sieht. Was Microhierax, Patiohierax und Speziupleryx betrifft, die ron allen Ornithologen in die Nähe der echten Falken gestellt werden, so stehen sich Microhierax und Paliohierax sehr nahe, müssen aber zusammen in eine besondere Gruppe gesondert werden, die der Verf. Microhieraces nennt. Unter den Polyborinae wird Mituag, Polyborus untersucht. Micrastur und Herpetotheres bilden die primitivste Gruppe in der Familie der Falconidae, die Mitte zwischen den Falken und Microhieraces einerseits und den Polyborinae andererseits bildend. Somit ist die Gruppe der Herpetotheres die Grundlage aller uns bekannten Formen der Familie Falconidae. Alle diese Schlïsse sind auf detailliert abgebildeten osteologischen Nerkmalen aulgebaut. Somit gruppiert der Verf. alle zur Familie Falconidae gehörenden Gattungen in vier durch anatomische und äussere Merkmale gut charakterisierte Gruppen, ron denen die echten Falken und die Polyborinae auch von frülıern Forschern angefïhrt wurden, es treten nur noch die zwei neuen Gruppen - Paliohieracinae und Herpetotherinae hinzu. Diese vier Gruppen sind als Subfamiliae anzusehen. Es folgt eine Tafel zur Bestimmung der Unterfamilien und Gattungen der Falconidae nach äussern Merkmalen. Die genetischen Beziehungen, deren nähere Darlegung auf osteologisehen Merkmalen im 'Texte nachgesehen werden muss, finden ihren Ausdruck in nebenstehender Stammtafel:

Die Familie der Falconidae und der Aquilidae wird als von einem gemeinsamen Stamme entsprossen angesehen.

Was die geographische Verbreitung der Falconidae betriftt, so ist der grosse Reichtum derselben in der neotropischen Region bemerkenswert. Die primitiven Formen sind nur auf der sïdlichen Halbkugel der neotropischen Region anzutreffen (Herpeto- 

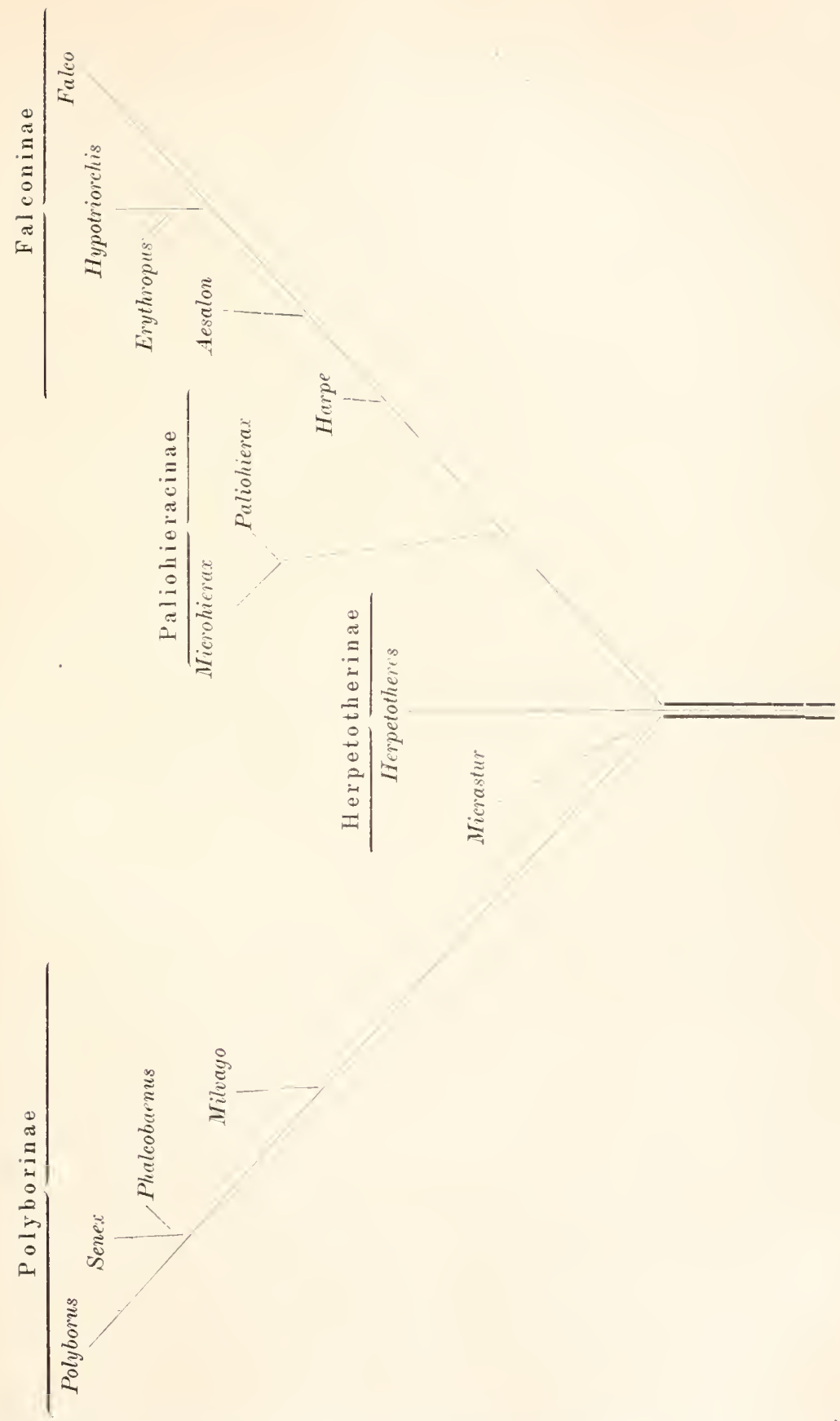

the rinae, Milvago). In Nord-Amerika und besonders Europa sind die Falconidae erst sehr spät - in posttertiärer Zeit - auf- 
getaucht. Nach allem zu urteilen lag die Heimat der Falconidae in der südlichen Hemisphäre, in Süd-Amerika oder Neu-Seeland oder einem früher mit ihnen verbunden gewesenen Gebiete, das später verschwunden ist. Ein solches Gebiet konnte der antarktische Weltteil gewesen sein, auf dessen Existenz zur Zeit des Endes der mesozoischen und Anfanges der cenozoischen Ära die Verbreitung vieler Tiere hinweist. Neues Festland trat in Verbindung mit Süd-Amerika, Neu-Seeland und Australien. Das Faktum, dass der primitivste echte Falke auf Neu-Seeland zu finden ist, erlaubt anzunehmen, dass die Isolation der erste Anstoss zur Ausarbeitung des Typus der Unterfamilie Falconinae war, im Verein mit dem Fehlen der Säuger. Die Verbreitung dieser differenzierteren Unterfamilie rief wohl das Hinwelken der Paliohieracinae hervor, die sich wahrscheinlich über Afrika, welches zur ersten Hälfte der 'Tertiärzeit durch eine Inselkette mit Brasilien einerseits und dem Osten andererseits verbunden war, verbreiteten. Die Herpetotherinae und Polyborinae (mit einer Ausnahme) blieben ganz in den Grenzen des neotropischen Gebietes, was Verf. durch die reiche Tertiärfauna der Aquilidae in West-Europa und Nord-Amerika erklärt, die den oben genannten Gruppen eine grosse Konkurrenz war. Andererseits wird das Fehlen ron Astur in der neotropischen Region nur dadurch erklärt, dass hier früher Micrastur, dem ersten in Bau und Lebensgewohnleit analog, entstanden war. E. Schultz (St. Petersburg).

\section{Mammalia.}

356 Jakobi, Arnold, Der Ziesel in Deutschland nach Verbreitung und Lebensweise. In: Arch. f. Naturgesch. 1902. Bd. I. Heft 3. pag. 199-238. 3 Fig.

In dem ersten Abschnitt „Systematische Bemerkungen über Spermophitus citellus (L.)" verbreitet sich Verf. namentlich über die Zahl und Anordnung der Gaumenfalten, über die Färbung und über die systematische Bezeichnung des Ziesels. Die Färbung ändert ab nach Individuum, Alter und Vorkommen, doch sind die Abänderungen nicht erheblich, und man muss die Art als eine solche ansehen, die innerhalb des Verbreitungsgebietes ihre Kennzeichen unter geringen Schwankungen festhält. - Die bisherige Schreibweise des Namens Spermophitus citillus (L.) ist hinsichtlich des Speciesnamens nicht ganz richtig. Die älteste und folglich festzuhaltende Benennung rührt von Linné her und lautet: Mus citellus. Sie geht jedenfalls auf die von Albertus Magnus, Gesner und Schwenkfeld gebrauchte Latinisierung des Vulgärnamens zurück. In der XIII. von Gmelin besorgten Ausgabe des Systema naturae ist die zweite Hälfte 
des Linnéschen Namens in citillus umgewandelt worden, welche Form Pallas und alle spätern Schriftsteller beibehalten haben. Nach den Regeln der ersten Namengebung muss indessen die ursprüngliche Linnésche Schreibart festgehalten werden, weshalb der wissenschaftliche Artname des Ziesels Spermophilus citellus (L.) zu lauten hat.

Der zweite Abschnitt handelt über die Verbreitung des Ziesels. Wir kennen den Ziesel aus Ober- und Niederösterreich, dem grössten Teile von Böhmen und einem anstossenden kleinen Bezirke von Sachsen, ferner findet er sich in österreichisch und preussisch Schlesien sowie in Mähren. Ungarn beherbergt ihn südlich und westlich der Karpathen bis zur Drau. In den Balkanstaten ist er an der nordund südöstlichen Grenze Serbiens nachgewiesen und häufig in Bulgarien bis zum Kamme des Despotodagh. Von diesem Gebiete scheinen mehrere Kolonien, von denen wir mindestens eine im türkischen Macedonien, tief im Süden bei Saloniki und eine zweite bei Konstantinopel kennen, ganz abgetrennt zu sein. Weiterhin findet sich der Ziesel anscheinend im ganzen Königreich Rumänien, also in der Wallachei, Dobrudscha und Moldau. Im Norden folgen als Wohngebiet die Bukowina und einige unmittelbar anstossende kleine Bezirke des nördlichen Bessarabien und Podolien. In Westgalizien endlich bedarf das Vorkommen noch genauerer Bestätigung.

Betrachtet man die Verbreitung vom physisch-geographischen Standpunkte, so hat man als Lebensbezirk des Ziesels im grossen Ganzen das Becken der Donau von iłrem Mittellauf an bis zur Mïndung anzusehen. An manchen Stellen freilich greift das Areal weiter aus. So ist das ganze Gebiet der Oberelbe bis zum Durchbruch durch das Gebirge samt den Zuthïssen rom Ziesel bewohnt, und ebenso ist es mit dem halben Stromlauf der Oder gehalten. Die Stelle, an der er sich neben dem Dniestr angesiedelt hat, ist andererseits sehr beschränkt und dürfte von dem Gebiete am Pruth, einem Donauzufluss, abgezweigt sein. Dagegen gehören die Siedelungen auf dem Rhodopegebirge, bei Saloniki und am Bosporus gänzlich zum Entwässerungsgebiet des ägäischen Meeres und besitzen mit dem grossen Donaubecken keinerlei Zusammenhang.

Die Frage, ob der Ziesel in frühern erdgeschichtlichen Zeiten bereits solche Gebiete inne gehabt hat, in denen er jetzt fehlt oder in die er neuerdings erst wieder einwandert, ist verneinend zu beantworten. Er hat wahrscheinlich vou Anfang an nur das Donaugebiet und dessen nächste Nachbarschaft bewohnt, ohne während des Pleistocäns die nördlichen und westlichen Steppengebiete zu betreten, und seine vom vorigen Jahrhundert an unternommene Einwanderung in Schlesien ist als völlig nene Besiedelung anzusehen. 
Der dritte Abschnitt der Abhandlung beschäftigt sich mit Aufenthalt und Lebensweise des Ziesels. Alle Beobachter betrachten ihn als ein Charaktertier der Steppe. Sein Gebundensein an die Steppenformation des Bodens hindert ihn aber durchaus nicht im Gebirge, ja sogar im Hochgebirge zu wohnen. In Schlesien sucht er sich das Gelände aus, das seinen Aufenthaltsorten im Osten am meisten gleicht, die vom Menschen geschaffene Kultursteppe, das offene waldentblösste und trockene Land mit gleichmäBiger niedriger PHanzendecke, also Wiesen und Felder. Eine Ursache für das Einwandern der Ziesel in unsere Tierwelt darf wohl darin erblickt werden, dass in Schlesien seit dem vorigen Jahrhundert die Entblössung des Bodens rom Waldwuchse und der Ersatz durch die Kunltur der Gräser grosse Fortschritte gemacht hat.

Bei der Schilderung der Lebensweise des Ziesels legt Verf. die Verhältnisse im Falkenberger Kreise Schlesiens, insbesondere aut dem Lamsdorfer Schiessplatze zu grunde. Die Ansiedlungen sind auf der kahlen Heide des Platzes überall vorhanden und zwar sowohl aut höher gelegenen Stellen wie in der Tiefe mit Ausnahme der weniger mit Binsen bestandenen feuchten Flecke. Unter den Bauen lassen sich eigentliche Wohn- und Brutbaue ron den blossen Spiel- und Zufluchtsbauen unterscheiden. Die Nahrung des Ziesels besteht aus Gras, Sämereien und Wurzeln, aber er plïndert auch die an den Platz grenzenden Felder erheblich. Vielfach werden Kartoffelknollen und Rüben angefressen und fallen dem Verderben anheim. Neben diesem direkten Schaden macht sich ein anderer geltend. Er besteht darin, dass die zahlreichen Löcher den Boden nachgiebig machen, so dass Pferde, Zugtiere und selbst Menschen die Decke durchtreten können und zu Falle kommen.

Die Bekämpfung des Ziesels richtet sich fast immer gegen die im Bau befindlichen Tiere, wiewohl es möglich ist, bei geduldigem Ansitzen einen Ziesel auch im Freien mit der Flinte zu erlegen. Man fängt ihn mit Klappfallen oder Schlingen, die man vor der Wohnung aufstellt. Nächstdem ist das Ausgiessen mit Wasser beliebt, zumal wenn man das Tier lebendig in die Hand bekommen will. Ferner hat man versucht, dem laäufigen Vorkommen der schädlichen Tiere durch künstliche Erregung seuchenartiger Krankheiten zu steuern, erzielte aber nur einen scheinbaren und vorübergehenden Erfolg. Dagegen erwies sich das Einbringen eines mit Schwefelkohlenstoff getränkten Lappens in jede befahrene Röhre als ein durchaus wirksames Vertilgungsmittel.

W. M a y (Karlsruhe). 


\section{Zoologisches Zentralblatt}

unter Mitwirkung von

Professor Dr. O. Biitschli

in Heidelberg

herausgegeben von
Professor Dr. B. Hatschek

in Wien

\section{Dr. A. Schuberg}

a. 9. Profeseor in $\mathrm{Heidelberg.}$

Verlag von Wilhelm Engelmann in Leipzig.

5. Juni 1903.

No. 11.

Lu boziehen durch alle Buctihandlungen und Postanstalten, sowie darch die Verlagsbuehhandlung. Jährlich 26 Nummern im Umfang von 2-3 Bogen. Prois für den Jahrgang M. 30. - Bei dirokter Zusendung jedor Nummer unter Streifband erfolgt ein Aufschlag von 11. 4._- nach dem lnland nnd von X. 5. - nach dem Ausland.

Referate.

Lehr- und Handbïcher. Sammelwerke. Vermischtes.

57 Sherborn, (․ I)., Index an imalium sive index nominum quae ab A. I). MIC'ClNIIl generibus et speciebus animalium imposita sunt. Sectio prima, a Kalendis Jan. MDCCLVIII usige ad finem Decembris MDCCC. pag. I-LIX; $1-1195$.

Wer selbst erfahren hat, wie schwierig die Feststellung der ältesten Namen von Tieren in vielen Fällen ist, wird ein Werk wie das vorliegende zu schätzen verstehen. Der erste Band enthält die Namen, die von 1758 bis 1800 einschliesshich veröffentlicht sind. Die auf den über 1200 eng gedruckten Seiten enthaltene Fïlle ron Namen stellt eine gewaltige Arbeit dar. Die Arbeit wurde 1890 begonnen, da aber Vert. mehrere Jahre durch Krankheit verhindert wurde, zu arbeiten, hat die Arbeit tatsächlich nur 8 Jahre in Anspruch genommen. Diese Zeit freilich riickt die Erfüllung des Wunsches eines jeden systematisch arbeitenden Zoologen, auch die im neunzehnten Jahrhundert publizierten Namen in gleicher Weise gesammelt zu sehen, in bedenkliche Ferne; denn man kann wohl annehmen, dass fast ron Jahr zu Jahr mehr neue Namen gemacht worden sind.

Der Zweck des Werkes ist, eine vollständige Liste aller veröffentlichten Namen zu geben, das genaue Datum jeder einzelnen Publikation.zu ernitteln und in jedem Falle ein Allen verständliches vollständiges Citat zu geben. Nicht nur die den rezenten, sondern auch die den fossilen Tieren gegebenen Namen sind berücksichtigt worden. Ganz besonderes Gewicht ist auf die Eruierung der genauen Daten gelegt worden. Im ganzen waren 1300 Bücher zum Nach- 
schlagen erforderlich, ron denen der Autor oder die Mitglieder des von der "Royal Society" zur Förderung des Buches ernannten Spezialcomités nur 19 nicht selbst laandhaben konnten. Die Liste der auf pag. X genannten 19 ... libri desiderati“ enthält aber meist unwichtige Bücher, ron denen es zweifelhaft ist, oh sie systematische Namen enthalten. Auf die Liste der „libri desiderati“ folgt die der im Buche genannten Büclıer, mit kurzen Angaben darïber, ob sie systematische Zoologie, binäre Nomenklatur und neue Namen enthalten oder nicht. Diese Bücherliste allein ist von lohem Werte für systematische \%oologen und alle, die sich für Literatur interessieren. Dass sie absolut vollständig sei, wird wohl kaum jemand glauben, der die Schwierigkeit solcher Arbeiten liennt, sie ist es aber sicher bis zu einem noch nicht dageresenen und geradezn bewundernswerten Grade. Bedauerlich ist es, dass die Titel deutscher Werke in einigen Fällen Druckfehler (oder Schreibfehler?) enthalten - z. B. sind a und ä, u und ii häufig nicht unterschieden, -- auch reigt die Art, wie die Titel abgekïrzt sind, in melurern Fällen eine mangelnde Kenntnis der deutschen Sprache. Der Hauptteil des Bandes, der "Index nominum animalium", pag. 1-1195, ist durchaus alphabetisch geordnet, nicht nur die Gattungs-, sondern auch die Arten- und Varietäten-Namen. Dies ist ron besonderm Werte, da man oft nicht genau weiss, unter welchem Gattungsnamen ein gegebener Art- oder Varietät-Name znerst veröffentlicht worden ist. Die folgenden Details mögen besonders bemerkt werden.

"Nomina nuda“ sind durch den Zusatz [n. n.] gekennzeichnet, nomina nuda in Verbindung mit Abbildungen durch [n. et f.]. Der Verf. führt logisch ans, dass der Name auf einer Tafel nomen nudum bleibt, bis der begleitende Text erscheint. Nichts beweist, dass das abgebildete Tier wirklich das vom Antor benamte ist. Die Tafel $i_{\text {st das }}$ Werk des Künstlers, nicht des Schriftstellers, oft ist die auf Tafeln gegebene Erklärung fehlerhaft gewesen und in vielen Fällen hat später der Autor die dort gemachten Fehler richtig gestellt. Das Publikationsdatum sollte daher stets das der Beschreibung sein, nicht das der Abbildung, obwohl letztere oft jahrelang vorher erschienen sind. Die Daten ron Separatabdrïcken sind mit Recht nicht beriicksichtigt worden. Unsicheres Datum ist in allen Fällen als solches gekennzeichnet. Alle adjektivischen spezifischen Namen sind in der alphabetischen Anordnung behandelt, als ob sie männlichen Geschlechtes wären, doppelte Anführung (nnit Hinweisung anf das volle Citat in dem einen Falle) ist gemacht, wo sich die Geschlechter sehr wesentlich unterscheiden.

Kein Versuch, die Synonymie der Namen zu ergründen, ist ge- 


\section{- $359-$}

macht. Das ist die Sache von Spezialisten und kann unmöglich von einem einzigen Manne befriedigend unternommen werden.

Auf alle Fälle muss jeder systematisch arbeitende Zoologe dem Autor Dank wissen und mit Erwartung den fernern Bänden des eine grossartige Arbeit enthaltenden Werkes entgegensehen.

E. Hartert (Tring).

\section{Zellen- und Gewebelehre.}

58 Beard, John, The Germ Cells. Part I. Thaja batis. In: Zool. Jahrb. Abt. f. Anat. u. Ontog. 16. Bu. 1902. pag. 615-702. 2 Taf. 3 Textabbildgn.

Beards grosse Abhandlung enthält, wie alle Mitteilungen des Autors, eine Fülle von wichtigen Funden und durchaus originellen Anschauungen: doch gesteht Ref. offen, dass die Lektüre der $\Lambda$ bhandlungen des Verfs. ihm weit schwerer fällt, als die anderer englischer Autoren. Die Vorrede und Einleitung wenden sich gegen die herrschende Anschauung von der Entstehung der "Lieim"- oder ."Geschlechtszellen" aus dem Bauchlı̈hlenepithel. Der nächste Abschnitt behandelt die Untersuchungsmethode. Es wurde Eisenhämatoxylinfärbung angewandt. Die folgenden Kapitel behandeln die Keimzellen, nach Lage, Form und Zahl in Embryonen ron $32 \mathrm{~mm}$, von 10-12 $\mathrm{mm}$, von $6-8 \mathrm{~mm}$, von $14 \mathrm{~mm}$, von $21-22 \mathrm{~mm}$ und von $26 \mathrm{~mm}$. Die Keimzellen charakterisieren sich durch ihr helles, glasiges, sich wenig färbendes Protoplasma, in dem noch zahlreiche Dotterkörner liegen. Sie haben meist eine unregelmäßige Form und zeigen intra vitam offenbar amöboide Bewegungen. Der Kern wird oft durch die Dotterkörner ganz verdeckt, er ist meist, wenn nicht immer (pag. 660) zweilappig, was Verf. im Sinn von R ückert und Haecker auf die Autonomie der mütterlichen und väterlichen Kernbestandteile bezieht. Sehr wesentlich ist das Felılen jeder Mitosen in den primären Keimzellen; sie machen offenbar ein langes Ruhestadium (wohl Wanderungsstadium Ref.) durch. Sie besitzen ziemhich gleiche Grösse, etwa $20 \mu \mathrm{im}$ Durchmesser, während die Leibeszellen des Embryos zu dieser Zeit etwa $12 \mu$ messen. Aber es kommen auch einzelne grosse $36-56 \mu$ dicke, „Megasplären“ (R ii ckerts) ror, die Verf. mit Sicherheit für Kieimzellen erklärt, die sich nur etwa zweimal weniger geteilt haben, wie die normalen. Die Keimzellen stammen nach des Verfs. Überzengung direkt von den Furchungszellen ab, sie sind sicher schon vor der Embryonalanlage da und liegen später unter der Embryonalanlage. Von da wandern sie in den Embryo an die Stelle der künftigen Keimdrüsenanlage ein. Verf. hält 512 
Keimzellen für die Normalzalıl bei weiblichen, 256 bei männlich werdenden Embryonen. Verf. fand aber bis zu $30 \%$ aller Keimzellen den eigentlichen Bestimmungsort nicht erreichen und verirrte Keimzellen darstellen. Selten verirren sie sich in die Anlage des Zentralnerrensystems, nicht häufig in die Hautanlage, öfters ins Darmepithel, das Pericard oder irgend welche Stellen des Mesoblast, namentlich in der Umgebung ihres eigentlichen Bestimmungsortes, (vgl. R ü ckerts "Gononephrotom"). Im Kopfteil des Embryos sind sie seltener, im Schwanzende gar nicht zu finden. Die primären Keimzellenkerne verharren im Ruhestadium, bis der Lmbryo etwa $42 \mathrm{~mm}$ lang ist, dann verdauen sie ihre Dotterkörner und teilen sich in die sekundären Kieimzellen, die kleiner sind. Auch die verirrten primären Keimzellen sind nur bis zu diesem Entwicklungsstadium nachzuweisen. Ein besonderer Abschnitt ist der Diskussion der Cohnheimschen Teratomentstehungshypothese gewidmet. Verf. glaubt, durch seine Entdeckung der zahlreichen verirrten Keimzellen diese Hypothese sicher gestützt zu haben, und meint, dass sie auch auf solche Teratome passe, die nicht in den Geschlechtsorganen ihren Sitz haben. Das darauf folgende Kapitel hehandelt ausfiihrlicher die Degeneration der verirrten Keimzellen. Ein 'Teil von ihnen degeneriert jedenfalls und zwar entweder durch einfache Atrophie oder unter Bildung konzentrierter Zellnester, die durch multipolare Teilungen entstehen. Bei beiden obengenannten Arten der Degeneration spielt die Chromatolyse eine Rolle. In der Regel tritt ein deutlicher Zerfall des Kernes in zwei Hälften ein, offenbar eine Trennung des väterhichen und mütterlichen Anteiles, die, im Leben mehr oder weniger lose miteinander verbunden, im Tode getrennt werden. - Bei der gewöhulichen Mitose entfernen sich die Zellen meist voneinander, bei der pluripolaren bleiben sie in Nestern beisammen; die erstere kann daher ,centrifugal“, die letztere „centripetal" genannt werden. - Den Schwerpunkt der Abhandlung legte Verf. in die letzten Abschnitte, die mit aller Entschiedenheit auf Grund der zum Teil vou den Autoren selbst anders gedeuteten Befunde von Balfour, Beard, Boveri, Eigenmann, Haecker, Nussbaum, Rabl und R i ckert beweisen sollen, dass die Keimdrüsenanlage eigentlich nicht dem Embryo selbst angehört, sondern in ihn erst einwandert. Die lieimzellen sind direkte Furchungszellen und eine derselben bildet durcl successive Teilungen den Embryo, während die andern draussen warten, bis ihre künftige Schutzstätte einigermaßen aufgebaut ist, dann wandern sie in die Behausung ein. Der Embryo, das Metazoon, ist also eigentlich steril, nur eine vorübergehende, vergängliche Hülle für die sich selbständig 
als einzellige Organismen fortpflanzenden Keimzellen, die bei Gelegenheit zur Kopulation „unsterblich" genannt werden können. Das Keimplasma ist also stets mabhängig, niemals mit dem Somatoplasma verbunden, die Keimzellen sind ganz unabhängige Zellen, durchaus keine Ablömmlinge irgend welcher somatischer Fpithelien. Noch konkreter spricht übrigens der Verf. seine Anschauungen in dem auf vorstehende Abhandlung in den zoolog. Jahirb. folgenden Aufsatz über die Geschlechtsbestimmung (s. Ref. Nr.361) aus. Er sagt, man habe sich den Vorgang etwa so zu denken: Nach der fünften Furchungsteilung, also auf dem 32-Zellenstadium, repräsentiere eine Zelle die Urkeimzelle, die übrigen 31 stellten gewissermaßen nur das Substrat, die Larve oder das Phorozoon dar, auf dem sich später der Einbryo entwickle. Die Urkeimzelle teile sich dann rasch hintereinander viele mal, bei Raja batis z. B. neunmal, so dass $2^{9}=512$ „primäre Keimzellen“ entständen. Von diesen gibt dann also nach Verfs. oben referierter Ansicht eine Zelle ihre Selbständigkeit als einzelliger Organismus auf und liefert den Embryo. R. Fick(Leipzig).

9 Beard, John, The Germ cells of Pristimus. In: Anat. Anz. 21. Bd. Nr. 2. 1902. pag. $50-61$.

Beard hat jetzt auch eine grössere Zahl von Pristiums-Embryonen untersucht und die primäre Keimzellenzahl bestimmt; doch gibt el' selbst zu, dass es sich mehr um eine gewissenhafte Schätzung handelt, als um eine genaue Zählung. Dazu komnt, dass ein Teil der Kieimzellen auch degeneriert, sogar schon vor der Entstehung des Embryos. Die Zällung gelingt ïberlaupt nur bei Embryonen von $5 \mathrm{~mm}$ Länge an bis zu $16 \mathrm{~mm}$ Länge. Bei ganz kleinen Embryonen sind die Keimzellen im Keimzellennest zu eng aneinander gepresst; in ältern Embryonen tritt schon die Teilung der primären Keimzellen in die sekundären ein. Die Keimzellenzahl schwankt bei den rom Verf. untersuchten Embryonen von 100-153, das Mittel ist 127,3. Verf. meint, die Zahl müsse eine Potenz von 2 sein, vermindert um 1 (also $2^{\mathrm{n}}-1$ ), weil eine Zelle der ursprünglichen Keimzellen den Embryo bilde (s. vorstehendes Referat). Bei Pristiurus fand Verf. $2-11 \%$ verirrte Keimzellen. - Verf. betont, dass die Verwandlung einer Keimzelle in eine gewöhnliche embryonale Epithelzelle ein Wunder ohne gleichen wär'e.

R. Fick (Leipzig).

60 Bearl, Johu, The numerical law of the germ cells. In: Anat. Anz. 21. Bd. Nr. 6/7. 1902. pag. 189-200.

Auch in dieser Mitteilung des Verfs. finden wir Andeutungen seiner Anschauungen iiber die Herkunft der Keimzellen und die Un- 
ablıängigkeit vom Embryo. Ausserdem gibt Verf. einen interessanten Bericht über die Anzahl der lieimzellen in einigen ron ihm beobachteten Missbildungen. In einem einseitig im Wachstum zurückgebliebenen Raja batis-Embryo waren auf der „normalen“ Seite, ausser zwei in der Leibeshöhle verirrten Kieimzellen, überhaupt keine Keimzellen. In einem zweiten, ähnlichen Fall waren auch auf der normaler entwickelten Seite nur sehr wenig Kieimzellen. Ein dritter Fall ist eine Missbildung, der die Vorderkopf-Anlage felltt. Dieser Embryo enthielt merkwürdigerweise 26 "Megaspliären“ an den sonst von den gewöhnlichen Kieimzellen auf ihrer Wanderung oder Verirrung eingenommenen Stellen und nur zwei gewölıntiche Keimzellen und diese am eigentlichen Bestimmungsort. (Ein normaler, etwas grösserer Embryo hatte 64 Megasphären, 70 gewöhnliche Keimzellen.) Ein dritter abnormer Embryo hatte auch auf der normalen Seite nur wenig (11) Keimzellen, daron nur vier in normaler Lage. Bei einem vierten Fall waren aber umgekehrt auf der normalen Seite mehr (46) Keimzellen als auf der verkümmerten (14). Ein fïnfter am Vorderkopf verkümmerter Embryo zeigte auch nur wenig gewöhnliche Keimzellen, statt dessen viele Negasphären. - Die zweite Hälfte der Abhandlung enthält Angaben für die normale Keimzellenanzahl bei verschiedenen Selachiern und andern Tieren: Rana esculenta 8 . Petromyzon 32, Acanthias vulgaris 6t (\%), Scyllium canicula 128, Pristiums melanostomus 128, Tiaja batis o 256, Raja batis +512 . (Cyctops 2, Ascaris 2, Cecidomyia 4, Chironomus 8.) Wie schon in der vorstehend referierten Arbeit angedeutet, kommt Verf. zu dem Schluss, dass die Kémzellenarzahl $2^{\mathrm{n}}-1$ sei (s. oben). (Diesem "Gesetz" gegeniiber vergl. des Autors im vorstehend referierten Aufsatz selbstgemachte Angaben über die Ungenauigkeit der Zählungen. Ref.)

R. Fick (Leipzig).

361 Beard, John, The Determination of Sex in animal development. In: Zool. Jahrb. 16. Bd. 1902. pag. 703-764. 1 Taf. u. 3 Textfigg.

362 - The Determination of Sex in animal derelopment. In: Anat. Anz. 20. Bd. Nr. 22. 1902. pag. 556-561.

Die zweite Abhandlung enthält die Hauptresultate der ersten, die in folgende Abschnitte abgeteilt ist: Vorrede, Einleitung. I. Geschlechtsthesen, Hermaphroditismus, Parthenogenese. II. Die Geschlechtszellen der Metazoen. Die vier Arten von Gameten und die drei funktionierenden Arten derselben. Pseudo-Hermaphroditismus. III. Der vermeintliche Einfluss der Befruchtung auf das Geschlecht. IV. Die Äusserung der Creschlechtsbestimmung. V. Die Geschlechts- 
basis. VI. Strasburgers Untersuchungen über diöcische Gewächse. VII. Die Bedeutung der Chromosomenreduktion. VIII. Die Geschlechtsbestimmung. IX. Der Ursprung der Geschlechtlichkeit bei den Metazoen. X. Die Regulierung des Gescllechts in der Natur.

Den Hauptanstoss zur Abllandlung erhielt Verf. dadurch, dass er bei Raja batis eine selır verschiedene Zahl von primären Keimzellen fand, die, wie er meint, um zwei Normalzahlen lierum schwanken nämlich entweder um 5̃12 oder 2气̌6. Die erstere soll die Normalzahl bei solchen Embryonen sein, die später weibliches Geschlecht zeigen, die Zahl 256 soll die Normalzahl für männliche Embryonen sein. (Bezüglich der Sicherheit dieser Grundlage vergl. die eigene Angabe des Verfs. über die grosse Zälılungsschwierigkeit in der Abhandlung iiber Pristimus s. o. Ref.) Nach des Verfs. Meinung sollen bei fast allen Metazoen vier Arten ron Geschlechtszellen gebildet werden: zwei Arten von Samenfïden, vergl. die haar- und die wurmförmigen bei Paludimu und zwei Arten von Eiern, „männliche" und „weibliche". Bei sehr vielen Tieren kommt es allerdings nicht zur vollkommenen Ausbildung der zweiten Spermatozoenart, was sehr erklärlich sei, weil sie niemals zur Befruchtung verwendet werde. „Da es das Ei ist, was sich entwickelt, und nicht der Samenfaden, so fällt die Aufgabe, die Rasse zu erhalten, dem weiblichen Metazoon zu, oder besser, den Keimzellen, die im weiblichen Metazoon hausen. D azu ist die Differenzierung von zwei Gametenarten, männlichen und weiblichen Eiern nötig. Die Keimzellen des weiblichen Körpers sorgen so nicht nur für einen neuen Schub von weiblichen, sondern anch von mämmlichen Eiern. Andererseits liefern die Keimzellen des männlichen Kö̈rpers nur eine Forın voll funktionierenden Gameten. Die Geschlechtshestimmung für die nächste Generation wohnt somit bei den Keimzellen des weibliclıen Metazoon.“ „Bei der gewöhnlichen Annahme nur einer Art von Eiern ist nur eine Form der Individuen möglich, wie der gewöhnliche Hermaphroditismus beweise, denn hier sind alle Individuen, die durch die Vereinigung zweier Gameten entstehen, einander gleich. Für die dauernde Lintstehung von zwei Formen (Geschlechtern) sind mindestens drei Gametenarten nötig".

„Die Geschlechtsbestimmung beginnt bei der Teilung der primären Keimzellen zu den sekundären, sie wird rollendet bei der Oocytenund Spermatocyten-Bildung und sie wird offenkundig bei der Zahlenreduktion der Chromosomen in ilmen." Nur der weibliche Körper kann hermaphrodit werden. In allen Fällen, wo Eier und Hoden beschrieben sind, handelt es sich um spermatocytische Vorstadien der zweiten, nicht funktionierenden Art von Samenfäden. Eine aus- 
führliche Besprechung wird der Bienenentwicklung gewidmet, Verf. hält für bewiesen, dass die Befruchtung nicht das geschlechtshestimmende Moment bei den Bieneneiern ist. Als Facit aus seinen Untersuchungen zieht Terf. den Schluss, dass niemals durch irgendwelche äussere Imstände eine Geschlechtsbeeinflussung herrorgebracht werden kam.

R. Fick (Leipzig).

363 Delage, Yres, Les Thénries de la Fécondation. Conférence faite au Congrès international de Zoologie (Session de Rerlin, août 1901). In: Revue générale des Sciences pures et appliquées, 12. Jahr'g. Nr. 19. I’aris. pag. $861-874$.

In wahrhaft klassischer Klarheit spricht Verf. iiber die rorliegenden Untersuchungen auf dem Gebiete der Ei- und Samemreifung, sowie der Befruchtung und künstlichen Parthenogenese und kommt dabei in logisch zwingender Weise zu den höchst bemerkenswerten Folgerungen, dass wir über die Phylogenese der Befruchtungsplü̈nomene nichts genaues wissen, dass die Chromosomen nicht bleibende Individuen sein können, (vgl. R. Fick, Zool. Zentralbl. 6. Bd. pag. 946), dass ihre Zahl für bestimmte Zellen eine charakteristische ist, die sich bei kïnstlicher Veränderung von selbst reguliert, und dass die Reifungsteilungen daher nicht erforderlich sind zur Zahlenredulition, ein Siatz, den Ret. schon im Jahre 1893 anfstellte. Verf. führt Tatsachen an, die beweisen, dass die Befruchtung auch nicht von der Menge des Chromatins abhängt, dass die Reifungsteilungen also auch nicht zur lieduktion der Chromatinmasse nötig sind (ebenfalls bereits 1893 von lief. ausgesprochen). Terf. weist ferner ditrauf him, dass die Reifungsteilungen übrigens bei Ei und Samen sehr verschieden funktionieren, indem beim Ei eine relatire Massenredultion des Chromatins, beim Samen eine relative und absolute des Zellprotoplasmas stattfindet. Mit schärfster Logik weist er weiter nach, dass, falls wirklich eine qualitative Reduktion bestehen sollte, diese durchaus nicht an die Querspaltung der Clnomosomen bei einer der Reifungsteilungen gebunden wäre und dass diese Querteilung, falls sie wirklich ein Charakteristikum für die Reifungsteilung wäre, nicht durch die Notwendigkeit einer qualitativen Reduktion erklärt würde. Lie Chromosomen seien nämlich in querer Richtung nicht homogen, die Entwicklungsgeschichte zeige rielmehr, dass die Tochterzellen einer Mutterzelle, trotzdem sie durch Längsspaltung der Chromosomen entstanden sind, doch ganz verschieden differenzierten Charakter haben können, also qualitatir verschieden seien. Bei Besprechung der Befruchtung trennt Verf. auch ganz scharf die Amphimixis und die Entwicklungserregung oder wie er sagt die Embryogenese. Er kommt auf Grund 
der entwicklungsmechanischen Experimente, die zeigen, dass durch allerlei mechanische, chemische oder physikalisch-chemische Eingriffe künstlich eine Entwicklungserregung (, Embryogenese“) hervorgerufon werden kann, zu dem grundlegenden Resultat, dass die Reifungsteilungen usw., kurz die morphologisch charakteristischen Vorgänge, nur indirekt an der Entwicklungserregung beteiligt sind und offenbar wesentlich der Amplimixis dienen. Verf. hat z. 13. jüngst bewiesen, dass Reifungsteilungen vom Ei noch nicht ausgeführt zu sein brauchen, um es cntwicklungsfïhig zu machen, es muss nur das Kémbläschen geplatzt sein, so dass der Kernsaft ins I'rotoplasma austreten kann. Die Aufsaugung dieses Kernwassers durch den dadurch anfquellenden Samenkern betrachtet Verf. als den Hauptentwicklungsreiz bei der normalen Befruchtung.

R. Fick (Leipzig).

64 Friedmanu, Hermann, Über die Chromosomen als Träger der Vererbungssubstanzen. In: Biol. Centralbl. (1902). Nr. 24. pag. $778-780$.

65 - Zur Physiologie der Vererbung. In: Biol. Centralbl. 22. Bd. 1902. Nr. 24. lag. 773-778.

Die beiden kleinen Aufsätze des Verf's. entlıalten interessante Betrachtungen ïber die Unzulänglichkeit unserer bisherigen Auffassungen des Vererbungsmechanismus. Sehr interessant ist die angefiihrte Tatsache, dass bei Krystallmisehugen der Formcharakter nur selten der bei der Miselung quantitiv am meisten beteiligten Grundsubstanz entspricht. Manchmal tritt sogar das Gegenteil ein. Es gibt rhomboedrische Hisehungen von $\mathrm{IgCO}_{3}$ und $\mathrm{FeCO}_{3}$, deren Polkantenwinkel um so schärfer wird, je mehr $\mathrm{Mg}$ in der Mischung ist, obwohl der Polkantenwinkel der Grundverbindung $\mathrm{MgCO}_{3}$ stump fer als der von $\mathrm{FeCO}_{3}$ ist.

R. Fick (Leipzig).

66 Hicker, Valentin, Ïber das Schicksal der elterlichen und grosselterlichen Kernanteile. Morphologische Beiträge zum Ausbau der Vererbungslehre. In: Jenaische Ztschr. f. Naturwiss. 37. Bd. N. F'. 30. 1902. 104 pag. + Taf. 16 Textabb.

In ausserordentlich griindlicher und doch zugleich übersichtlicher, klarer Weise setzt Verf. seine Befunde und Anschaumgen über das Schicksal des väterlichen und miitterlichen Kernanteils auseinander, das er bei den Copepoden jetzt bis zu den Reifeteilungen, also bis zur Lntstehung der Enkelzellen verfolgen zu kömnen glaubt. Überdies enthält die Ablandlung wichtige neue Funde über die Reifungsteilungen bei Cyclops und sehr bemerkenswerte Betrachtungen über das Wesen der Befruchtung und üher die Geschlechtsbestimmung, 
bei denen Yerf. einen heutzutage besonders angenehm auffallenden vornehmen Ton in der Diskussion auch den Gegnern gegenïber hochhält. - Das erste Kapitel enthält biologische Bemerkungen über die Copepoden des Titisees, das zweite Kapitel entwicklungsgeschichtliche Mitteilungen über die Centrop agiden. Verf. glaubt, dass bei Diaptomus donticomis im zweiten Abschnitt der Fortpflianzungsperiode "I anereier" erzengt werden. Die Keimbahnzellen zeichnen sich durch vier Merkmale von den gewöhnlichen Furchungszellen aus: 1. durch die Autonomie der elterlichen Kernhälften, 2. durch die Heterotypie der Kernteilung, 3. die zunehmende Verlatngsamung der 'l'eilungsgeschwindigkeit (Phasendifferenz), 4. das Auftreten von Aussenkörnchen (Ektosomen). Verf. hält die Aussenkörnchen, ähnlich wie die Nucleolen für temporäre, nicht strukturierte Ausscheidungen oder Zwischenprodulte des Kern-Zelle-Stoffwechsels. Die Ektosomen werden bei der T'eilung jeweils der kleinern schwesterzelle, nicht der grosskernigen Kieimbahnzelle ïberliefert und werden während der Kernuhe aufgelöst. Im Ruhezustand bildet der Kern der Keimbahnzellen bei Iliaptomus (etwa 8) Teilbläschen, die Verf., obwohl die Zahl der Bläschen nicht mit der Chromosonıenzahl (32) übereinstimmt, „Idiomeren“ nennt. Sehr rasch rerschmelzen die etwa acht Idiomeren zu zwei gleichgrossen Bläschen, die Verf. .Gonomeren" nennt, da er sie für die beiden elterlichen Anteile hält. Die Gonomeren enthalten fädiges Gerüstwerk. Bei Diaptomus erhält sich der Doppelbau übrigens nach des Verfs. eigener Angabe im Ruhezustand nicht wie bei Cyclops, sondern beide Gonomeren verschmelzen sehr rasch zu einem einheitlichen oroiden liern. Dafür aber treten "mit vollständiger Regelmärigkeit" an dem dem spindelrest zunächstliegenden Kernpol zwei anfänglich gleichgrosse Nucleolen aul. Dieselben verschmelzen dann allerdings miteinander und vorübergehend zeigen sich bei ältern furchungszellen auch erhebliche Grössendifferenzen zwischen beiden. Rei den sekundüren Urgenitalzellen und den Entodermzellen zeigt sich übrigens manchmal auch nur ein einziger, doppelt grosser Nucleolus. Bei Cyclops finden sich auch zwei Nucleolen und liegen je in einer Abteilung der "Doppelkerne". Freilich kommen kleine Nebennucleolen vor. Öhnlich ist es bei Crepidula nach Conklin. Die Symmetrie der Nucleolen zeigt sich auch in der primären Urgenitalzelle und in den Kernen der beiden sekundären (definitiven) Urgenitalzellen, die zur Zeit des neunten 'T'eilungsschrittes der Blastodermzellen entstehen. Nachdem die beiden sekundären Urgenitalzellen mit dem Blastoporus-I'fropf der Entodermzellen in đie Tiefe der Furchungshöhle gedrängt worden sind, verschmelzen allerdings beide Nucleolen und bleiben während 
der langen Ruhepause der Urgenitalzellen, die erst im Larvenstadium mit drei Schwimmfusspaaren ihr Fnde nimmt, verschmolzen. Erst bei der folgenden, die Gonadenbildung einleitenden Teilung treten wieder symmetrische Nucleolen auf. Bei der spätern Differenzierung seien die Zeichen des Doppelbaues überhaupt wieder dentlicher. Er zeige sich noch mindestens bis zu den jungen Samen-Mutterzellen wenigstens bei den jungen Männchen. İhnlich ist es bei den jungen Weibchen, wo auch in den Keimbläschen der jungen Ovocyten noch symmetrische Nucleolen die Gonomerie andeuten sollen. Über die Reifungsteilungen bei Cyclops ist Verf. jetzt zu ganz anderen Deutungen der Gruppierung gelangt wie früher. Er glaubt jetzt, dass sich die 12 Vierergruppen, deren jede ein Chromatinelement darstellt, zeitweise in der zentralliegenden Richtungsspindel der ältesten Ovidukteier in zwei Schichten zu je sechs aufreihen und dass diese zwei Schichten die beiden elterlichen Kérnanteile darstellen. An den Eiern, die eben den Eileiter verlassen haben und besamt sind, sieht man hingegen, wie Verf. schon 1895 beschrieben, ein linsenförmiges, „sekundäres K eimbläschen", das durch eine Scheidewand getrennt noch je zwei sechszählige Chromosomenreihen enthält, die sich in je zwei "Tangential- oder Äquatorialebenen" gegenüberliegen. (Nach des Ref. Meinung liegt hier, falls sich der Befund als normal bestätigt, eine höchst interessante Abweichung vom sonst ausschliesslich beobacliteten Spindelverhalten vor, indem hier die zentrale Spindel mit „:ïuatorialer" Chromosomenanordnung an den Pol in gerader Richtung aufsteigt, dann gewissermaßen in perverser Richtung linsenförmig komprimiert wird, und dass die Chromosomen noch ihre dem $\ddot{A} q u a t$ or parallele Stellung beibehalten, obwohl die Längsachse der Linse oder Spindel ebenfalls tangential oder äquatorial liegt, und dass danach erst noch die Spindel sich schräg stellt, dann erst sich zur radiären Schlussstellung dreht. Bei allen andern Eiern liegen die Chromosomen in der aufgestiegenen, ,tangential" liegenden Spindel zuerst nmgekehrt wie hier, in ra diären Ebenen. Ref.) Das „sekundäre Keimbläschen" lässt eigentümliche, vom peripheren zum zentralen (breiten) "Pol“ der Linse durchlaufende Plasmabalken erkennen, die Verf. jetzt für eine Art Segmentierung des Kernes in eine der Chromosomenzahl entsprechende Anzahl ron Kammern liält. (Sehı' beachtenswert erscheint dem Ref. der Umstand, dass diese Kammerwände den Kern nicht den väterlichen in mütterlichen Chromosomen des Verfs. entsprechend teilen, sondern in der darauf senkrechten Richtung, so dass je 1-2 väterliche mit 1-2 mütterlichen Chromosomen in eine Kammer zu liegen kämen. Ref.) Von den 1895 an den spitzen Linsenpolen beobachteten sphärenähnlichen Plasma- 
sternen (vgl. Zool. Zentr.-Bl. 3. Bd., 1896, pag. 299 ff.) spricht Verf. jetzt nicht mehr. Verf. nimmt (im Gegensatz zu Rückert, Ref.) an, dass vor der ersten Reifungsteilung keine "Äquatorialplatte" von den Chromosomen gebildet wird. Die Metakinese soll sehr rasch rerlaufen, so dass Verf. dieselbe nicht zu Gesicht bekam. Infolge der sonderbaren Chromosomengruppierung in dem linsenförmigen „sekundären Keimbläschen" in zwei gonomeren Fronten, ist Verf. gezwungen anzunehmen, dass die väterlichen und mütterlichen Elemente zwischen einander durchpassieren, ..in einer ganz gesetzmäßigen, quadrillenähnlichen Ordnung". (In Fig. 34 bildet V'erf. eine Spindel ror der Metakinese ab. In ihr ist eine Andeutung einer Scheidewand zwischen den beiden übereinander liegenden väterlichen und mütterlichen Chromosomengrupen; Ref. kann nicht umhin zu bemerken, dass diese Scheidewand, wie auch die des .,sekundären Keimbläschens" in Fig. 31/32 einer Zellplatte ähnlich sieht, die auf eine bereits vollendete Metakinese hinweisen würde. Es wäre vorteilhaft gewesen, wenn Verf. die Möglichkeit dieser Auslegung, die der eigenen, friihern (1892) Auffassung des 'íerfs. entspricht, ausdrücklich widerlegt hïtte. Ref.) Die erste Richtungsteilung stellt nach dem Verf. eine „Äquationsteilung dar, bei der die „Spalthälften“ der 12 Vierergruppen sich auf Reifungszelle und Eizelle verteilen. Beide enthalten unmittelbar nach der Teilung je 12 einfache Schleifen, die allerdings .biralent" sind. Diese verdicken und verkürzen sich zu plumpen Winkeln und legen sich paarweise zusammen und zwar zu $6 \mathrm{X}$ - oder $\mathrm{H}$ - ähnlichen Figuren. Die beiden Parlinge sind .nahezu sicher” die dem Ei zunächst verbleibenden Hälften der in der ersten Richtungsspindel einander opponiert gewesenen miitterlichen und väterlichen Vierergruppen. Hier komnt es also nach dem Verf. endlich zu einer richtigen Vereinigung des mütterlichen und väterlichen Chromatins, während bis dahin im ganzen Leben die beiden Gonomeren sich höchstens scheinbar vermengt, in Wahrheit aber doch immer getrennt roneinander gehalten haben. Bei der Äqnatorialplatte der zweiten Reifungsspindel stellen sich die 6 X-Figuren nach dem Verf. so auf, dass nicht das väterliche $\sigma^{7}$ mach dem einen Pol, das miitterliche n nach dem andern Pol gerichtet ist, sondern so, dass ron jedem der eine Schenkel über, der andere Schenkel unter dem Äquator liegt

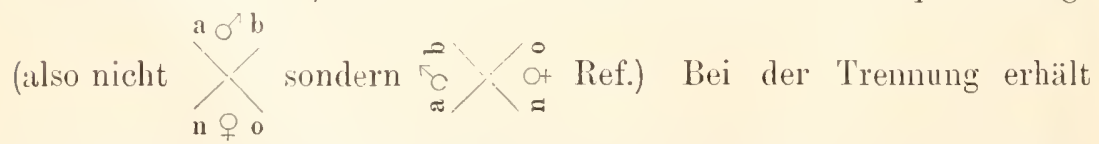
also sowohl die zweite Reifungszelle als die Eizelle je einen mütter- 
lichen und väterlichen, bezw. grossväterlichen und grossmütterlichen Schenkel der X-Figuren zugeteilt. Diese beiden Schenkel vereinigen sich untereinander fest, so dass der Eikern sechs einfache feste Schleifen enthält, die aber aus zwei grosselterlichen Hälften zusammengesetzt sind. Die zweite Reifungsteilung ist also wohl eine Reduktionsteilung. Infolgedessen im Verein mit der Bivalenz der ursprünglichen /Komponenten der X erhält natürlich das Ei nicht nur noch die Hälfte der grosselterlichen Iden, sondern auch seiner Idanten, z. B. nur noch a und $n$, während $b$ und $o$ in die Richtungszelle übergegangen sind. Ref.). Das sechste Kapitel entliält eine sehr interessante Aufzälllung einer Fülle von Objekten, an denen nach dem Verf. sich der "gonomere Kernzustand" schon hat nachweisen lassen, wobei "die zwei symmetrisch gelagerten Nucleolen" bei den meisten Beispielen als Kriterium für die Heranziehung bestimmend gewesen sind. Die Beispiele beziehen sich auf Conjugaten, F'ucus, Gefässkryptoganen, Gymnospermen, Ingiospermen, Plathelminthen, Ascaris, Annelicler, Echinodermen, Arthropoden, Mollusken, Tunicaten, Selachier, Amplibien, Säuger (Mensch).

Im allgemeinen Teil weist Verf. daranf hin, dass der Zweck der Befruchtung nicht eine "Kernverschmelzung", sondern im Gegenteil die "Schaftung eines Doppelgebildes", die Schaftung zweikerniger Fortpflanzungszellen sei. Aus der Vereinigung der Gonomeren zu den X-Figuren schliesst Verf. auf eine sexuelle Affinität oder Chromotaxis, die aber erst ,am Sehluss der Kinder-Generation zur .Geltung kommt". In geistreicher Weise sucht Verf. gewisse Erscheinungen an Tier- und PHanzenbastarden mit dem Ausbleiben dieser grosselterlichen Amphimixis zu erklären. Ein besonderer Abschnitt behandelt die Individualität der Chromosomen, für die Verf. lebhaft eintritt. Verf. verschliesst sich aber durchaus nicht den Gründen der Gegner und meint, dass eventuell wenigstens an der Kontinuität der achromatischen Chromosomengrundlage festzuhalten sei. (Diese Anschaung des Verfs. oder "Achromatin-Individualitätshypothese Häckers“, wie wir sie nennen kömnen, ist jedenfalls schwerer zu widerlegen wie die Chromatinindividualitätslehre. Ref.) Der letzte Abschnitt gibt eine sehr prägnante Besprechung der progamen, syngamen und epigamen, d.h. vor, bei oder nach der Befruchtung stattfindenden Geschlechtsbestimmung. Verf. meint mit Rauber, dass bei manchen Organismen mit pro- oder syngamer Geschlechtsbestimmung durch Verschiedenheit der Ernährung doch ein anderes Geschlecht erzeugt werden könne. Im Hinblick auf Boveris neue Annahme der Qualitätsunterschiede zwischen den einzelnen Chromosomen hält Verf. es für möglich, „dass es im Kern männliche und 
weibliche Untereinheiten gibt und dass jeweils die Majorität derselben ausschlaggebend ist."

R. F i ck (Leipzig).

367 IIertwig, Richard, Über Wesen und Bedeutung der Befruchtung. In: Sitzber. math. phys. Cl. d. k. hayer. Akad. d. Wiss. 32. Bd. 1. Heft. 1902. pag. $57-73$.

Verf. gibt zuerst einen ausserordentlich klaren Überblick ïber die wesentlich verschiedenen Befruchtungshypothesen und verweist dabei auf seine frühern Feststellungen über die Unabhängigkeit der Befruchtung von der Vermehrung (s. \%ool. Zentralbl. 7. Bd. pag. 787 f.). Er gelangt dabei zu einer äusserst präzisen Fragcstellnng und zur Antwort, dass die Kernkopulation eine Kräftigung, nicht etwa eine "Verjüngung" der Kopulationszelle herbeiführt. Verf. sieht diese Kräftigung nun in einer Verstirkung bezw. Ergänzung der regulierenden Kräfte, wobei er sich auf umfangreiche Versuche an Actinosphïrien, die er der Überfütterung aussetzte, stützt. Die überfütterten Actinosphärien teilen sich ïbertrieben oft, der Chromatinreichtum wird zu gross, so dass eventuell das ganze Chromatin in Chromidien verwandelt wird, die ins Plasma und schliesslich aus der Zelle ausgestossen werden, wodurch die Zelle damn zu grmnde geht. Verf. sieht darin eine "funktionelle Degeneration". Fr nimmt an, dass die in ganz aussergewöhnlicher Weise gesteigerten Lebensfunktionen das Gleichgewicht der \%ellteile erschüttern, die regulatorischen Vorgänge schïdigen bis zum völligen Zusammenbruch der Zelle.

$$
\text { R. Fick (Leiprig). }
$$

368 Hertwig. Richard, Über die Korrelation von Zell- und Kerngrösse und ihre Bedeutung für die geschlechtliche Differenzierung und die Teilung der Zelle. In: Biol. C'entralbl. 23. Bd. 1903. pag. 40-62; pag. 108-119.

Aus diesem an Gedanken und tatsïchlichen Mitteilungen reichen Aufsatz sei folgendes hervorgehoben: „Die Befruchtung ist kein excitatorischer, sondern ein regulatorischer Vorgang." Die Einführung eines fremden Elementes, wie es der Spermakern ist, miisse auf das Ei einen hemmenden Einfluss ausüben, insofern er noch nicht wie der Eikern anf das Protoplasma abgestimmt ist. .. Bei Inzuclit und der ihr entsprechenden grossen Gleichartigkeit der Kerne wird diese Hemmung zu gering ausfallen, bei zu bedeutender I)ifferenz der beiden Erzenger zu gross, so dass die geschlechtliche FortpHanzung bei einem mäßigen Unterschied der Eltern ihr Optimum findet." Die Versuche Boveris und Gerasimoffs haben für Tier und Pfianze gezeigt, dass Zellen bei gleicher morphologischer Bedeutung 
die Halbierung der Kernmasse zu Zellen von halber Grösse führt, die Verdoppelung der Kermmasse dagegen eine Vergrösserung der Zelldimension zur Folge hat, dass also die Kerngrösse die Zellgrösse bestimmt. Andererseits kann Schwund des Plasmas zu einer Kíernverkleinerung führen. Hertwig nimmt daher an, dass jeder Zelle eine normale Kern-Plasmarelation zukommt. Es ist ilm und Kasanzeff aber gelungen, durch monatelange Fütterung bezw. Hunger eine "Umregulierung“ zu bewirken, z. B. eine dauernde relative Kernvergrösserung. In beiden Reichen sind aber nach des Verfs. Meinung die Sexualzellen das interessanteste Beispiel einer Umregulierung der gewöhnlichen Kernplasmarelation, die einen kardinalen, ja geradezu den ausschlaggebenden Charakter der Sexualität darstellt.

Daraus, dass die sexuelle Differenzierung schon bei den einzelligen Organismen vorkommt, ist zu schliessen, dass die Ursachen zur Sexualität in den Stoffwechselvorgängen der 'Zelle selbst gegeben sind. Durch seine Erfahrungen an Protozoen wird Verf. zu dem Resultat geführt, „dass energische Zellfunktion zu einer Steigerung der Kernmasse führt und so eine Fntwicklungsrichtung begünstigt, die im Ban der nännlichen Geschlechtszelle ihren Höhepunkt erreicht." Die Zellteilung ist weder eine direkte Folge des Hungerns, noch der Fiitterung oder des Wachstums, sondern die Folge eines bestimmten Spannungszustandes der \%ellbestandteile, der sowohl durch Hunger wie durch Futter herbeigetïhrt werden kann, je nach der jeweiligen Beschaffenheit der Zelle. Im „Normalzustand“ der Zelle befinden sich Kern und Protoplasma im Gleichgewicht, indem das Protoplasma nichts mehr an den Kiern abgibt, der Kern nichts mehr aus ihm aufnimmt. "Tritt nun Ernährung ein, so wïchst das Protoplasma heran, es bildet sich ein Spannungszustand zwischen beiden Zellbestandteilen ans, bis derselbe so gross wird, dass es zur Teilung kommt." Die Frage des plötzlichen Aufhörens der Furchung, des Einsetzens der Organbildung soll später ausführlicher behandelt werden.

$$
\text { R. Fick (Leipzig). }
$$

369 Lubosch, Wilhelm, Über die Eireifung der Metazoen, insbesondere über die Rolle der Nukleolarsubstanz und die Erscheinungen der Dotterbildung. In: Merkel-Bonnets Ergebnisse. 9. Bd. 1901. Wiesbaden 1902. pag. 709-783.

Verf. hat in seinem sehr willkommenen Bericht hauptsächlich die Literatur von 1894-1902 inklusive berïcksichtigt. Als Einleitung gibt er eine Übersicht über die verschiedenen Anschauungen in der Eireifungslehre, namentlich über die von Rückert-Born einerseits, 
Carnoy-Lebrun andererseits. Den eigentlichen Referaten ist noch eine Übersicht iiber die beobachteten Tatsachen und ein Schlusskapitel: „Theoretisches über die Eireifung" beigegeben.

R. Fick (Leipzig).

370 Schultze, Bernhard S., Zum Problem der geschlechtsbestimnenden Ursachen. In: Kentralbl. f. Gynäkologie 1903. pag. $1-4$.

Verf. stellt fest, dass er bereits im Jahıre $185 \overline{5}$ sich für die Annahme der progamen Geschlechtsbestimmung ausgesprochen habe, auf Grund der Tatsache, dass alle eineiigen Zwillinge und Monstra gleiches Geschlecht zeigen. Neuerdings ist aber durch Hofacker und Sadler bewiesen, dass das relative Alter ron Vater und Mutter auch geschlechtsbestimmenden Einfluss hat, insoferne, je älter der Vater im Vergleich zur Mutter ist, desto mehr iiberwiegt der Knabenüberschuss das mittlere Verhältnis der Geschlechter. Ferner ist es eine von den Tierzüchtern sicher festgestellte Tatsache, dass das stärker zum Belegen in Anspruch genommene Zuchttier verhältnisıäßig mehr Männchen erzeugt, als ein seltener bespringendes.

In äusserst geistvoller Weise setzt Verf. auseinander, dass diese 'Tatsachen durchaus nicht, wie Döderle in meint, ausschliessen, dass das Ei das Geschlecht bestimmt. Nan braucht nämlich nur anzunehmen, dass die das Ovar rerlassenden „männlicheu Eiev“' der jüngern Frau inehr Anziehung auf die Samenfäden des ältern Nannes ausïben als die weiblichen Eier und dass die männlichen Eier der Stute usw. die frisch aus dem Hoden kommenden Samenfäılen des Hengstes mehr anziehen als die weiblichen Eier, während die weiblichen Eier durchschnittlich zugänglicher sind für Samenfäden, die schon länger im Hoden verweilt haben. Diese Annahmen beseitigen jeden Widerspruch.

R. Fick (Leipzig).

371 Strasburger, Eduard, Üb e r Befrucht ung g. In : Botanische Zeituug 1901. Nr. 23. Sep. pag. 1-8.

Verf. betont in ähnlicher Weise wie R. Il ertwig (s. oben Referat Nr. 367) die Unabhängigkeit der Fortpflanzung oder der "vegetativen Befruchtung" von der Qualitätenkombination oder "generativen Befruchtung". Er weist auch Winklers und Ho fme isters Angaben zurïck, dass die Befruchtung nur ein chemischer Yorgang sei; er sieht darin vielmehr die Vereinigung organisierter Elemente. Der letzte Teil wendet sich gegen Correns' Aufstellungen ïber den Ort (Embryosackmutterzellen) der Farbenbestimmung bei rot- oder weissblühenden Epilobien usw. 
372 Wedekind, W., Die Parthenogenese und das Sexualgesetz.

In: Verhandlg. d. V. Internationalen Zoologen-Congresses z. Berlin. (1901). 1902. p. 403-409.

373 - Junge oder Mädchen? Wodurclı entsteht das verschiedene Geschlecht der Kinder? Wie kimn man nach Belieben Knaben oder Mälchen lıervorbringen. Berlin. (Wedekindl 1900. 30 pag.

Verf. vertritt die 'Theorie der .gekreuzten Geschlechtsvererbung", d. h. den Standpunkt, dass das Ei an sich eine Zelle mit männlichen Figenschaften ist, der Samenfaden eine solche mit rein weiblichen. Er glaubt daher, dass Kiräftigung der Frau gegenüber dem Manne Knaben erzeuge, Kräftigung des Mannes gegenïber der Frau Mädchen. Das parthenogenetisch sich entwickelnde Ei sei hermaphroditisch wie schon siebold vermutete. Inaher zeige es, je nachdem das männliche oder weibliche Prinzip die Oberhand gewimne usw., Arrhenotokie, Amphotokie oder Thelytokie.

R. Fick (Leiprig).

\section{Protozoa.}

374 Eutz, Géza, Nélúiny patagoniai véglény röl. (Ueber einige patagonische Protozoen.) In: Matlı. és Természettudományi F́rtesitö. Bi. XX. Budapest 1902. pag. 442-469. 7 Textabbild. 2 T'af.

Das rom Verf. bearbeitete Suisswasser-Plankton wurde ron Filippo Silvestri in den Jahren 1899--1900 gesammelt. Die darin gefundene, aus 23 Arten besteliende kleine Protozoen-Fauna stimmt im ganzen selır überein mit den Protozoen des europäischen Plankitons; unter den bekannten Arten fand sich jedoch, und zwar in ungeheurer llenge, auch eine neue Acineta, die Verf. als A. tripharetrata bezeichnet und eingehend beschreibt. Die hauptsächlich an Daphnien vorkommende neue Art steht Acineta jolyi Maup. nalie, welche Maupas an marinen Hydroiden, Bryozoen etc. entdeckt hat. Im System sind diese beiden Acineten als nahe Verwandte, jeclenfalls unnittelbar nebeneinander anzuführen. Bei $A$. tripharetrata sind die in drei Bündel vereinigten Suctellen, welche in der Rindenschichte zwei in entgegengesetzter Richtung gewundene Fibrillen besitzen, nicht regellos zerstreut, sondern in einer schneckengangartigen Windung angeortnet. Das Protoplasma enthält zweierlei Einsclılüsse, und zwar farblose und grüne Körperchen; erstere sind Assimilationsprodukte, letztere symbiotische Algen (\%oochlorellen), von welchen Verf. auch einige, wahrscleinlich in Teilung begriffene Formen beobachtete. Die Zoochlorellen gelangen vermutlich durcli Vermittlung der als Nahrung dienenden Colacien in das Inmere der Acinete. 
Interessant ist die Struktur des Zellkerns. Innerhalb der Kernmembran sind in der homogenen Grundsubstanz mehr weniger scharf umschriebene Körperchen wahrzunehmen, welche der Grösse nach in Schichten angeordnet sind; unterhalb der Kernmembran liegen die kleinsten Körperchen, tiefer folgen die Schichten immer grösserer Körperchen; die in einem Niveau liegenden gleich grossen Körperchen aber sind so angeordnet, dass jedes derselben auf die Ecke eines gleichseitigen Dreiecks fällt. Bei genauerer Untersuchung stellt es sich heraus. dass diese Körperchen nicht Kü̈gelchen sind, sondern winzige Zapfen. welche senkrecht zur Oberfläche stehen und zwei parallel lanfende feine Plasmalıäutchen miteinander verbinden; diese Zapfen entspringen also von einem nach innen stehenden Plasmahäutchen und heften sich mit scheibenartig verbreitertem Ende an dem darüberliegenden äussern Plasmahäntchen an. In dem äussern Plasmalä̈tchen ziehen mit den Zäpfchen zusammenfallende Linien, feine Fäden ron konsistenterer Substanz hin, welche einander in drei Richtungen unter einem Winkel ron $60^{\circ}$ durchschneiden und miteinander ein in gleichwinkelige Dreiecke geteiltes Netz bilden. Die Netzfärlen der nmmittelbar nebeneinander liegenden Schichten laufen nicht parallel, insofern die Netzfäden jeder schicht gegen die Richtung der Fäden der oberhalb liegenden Schicht in einem Winkel von $30^{\circ}$ verschoben sind, demznfolge nur die Fäden jerler zweiten Schicht parallel miteinander laufen. Diese feine Struktur ergibt bei einer Einstellnng auf das Netz und das distale Ende der Zäpfchen das Trugbild, als ob die Zäpfchen durch Speichen-Fäden miteinander verbunden wären (Heitzmannsche netzige I'lasmastrulitur); ein aus lem Net\% und dem optischen Querschnitte der Schichten kombiniertes Bild aber lässt die Silche so erscheinen, als wären die einzelnen Schichten, gleich den Bienenwaben, aus winzigen Kammern aufgebaut (Bütschlis wabige Plasmastruktur). Diese Struktur des \%ellkerns, welche auch an andern Protozoen erkennbar ist, ist nicht an allen Exemplaren ron A. triphuretrata gleichmäßig ausgebildet; bei vielen Exemplaren erleidet die Struktur eine Veränderung dadurch, dass sich in seiner Substanz, wahrscheinlich rom distalen Teile der Zäpfchen, kleinere oder grössere, mehr minder scharf umschriebene rundliche Körperchen differenzierten. welche zuweilen das ganze Kernplasma ausfüllen, oft aber in kleinern oder grössern Zwischenräumen regellos zerstreut liegen und so die eigentliche Struktur verwischen.

Yeben dem Zellkern zeigen sich in der Regel $1-4$ Körperclien, von welchen es unbestimmt ist, ob sie Micronucleen, PseudoMicronucleen (Sand), oder Tinctin-Körper (Plate) sind; nach dem Verf. spricht alles dafür, dass sie den Micronucleen der 
Ciliaten homolog sind. Bei konjugierten Paaren sind sie in der Regel in grösserer Anzahl wahrnehmbar und erinnern dann ansserordentlich an die Spindel der in Teilung begriffenen Hicronucleen der Ciliaten.

Das interessanteste, was Verf. an A. tripharetruta zu beobachten vermochte, ist die Kopulation, von welcher ilum zwar nur die Anfangs- und Endstadien bekannt wurden, die indessen keinen Zweifel zulassen, dass der Körper der konjugierten Paare vollständig verschmilzt und sich dann zu unzweifelhaft längerer Ruhe encystiert. I) Beobachtung dieser, mit vollständiger Verschmelzung schliessenden Kopulation ist hauptsächlich deshalb wichtig, weil sie, „obgleich mehıfach behauptet, noch nirgends sicher erwiesen wurde" (Bitschli, Bromns Kklassen und Ordnungen etc., Protozoa, lrag. 1914) und bisher bloss die abermals nit einer 'Trennung endigende Konjugation der Zygoten sicher bekannt war.

A. Gorka (Budapest).

75 Entz, Géza, Az ázalékállatkák variálásáról. (Über die Tariabilität der Infusorien.) In: Pótfüzetek a 'Természettudományi Közlönyhöz. Állattani Közlemények. Bd. XXIII. Budapest. pag. 241 - 256. Mit zehn Gruppenbildern.

Der Verf. bespricht auf Grnud vieljähriger Erfahrungen einige Richtungen der Variation der Infusorien und mehrere nachweisbare Gründe der Variabilität.

1. Fa rbenvariation. Abgesehen von den selır mannigfaltigen Farbennnancen, welche durch die im Körper der Infusorien angehäuften Reservestoffe und Spaltungsprodukte des Stoftwechsels verursacht werden, kennt man zahlreiche Infusorien, welche beständig farbig oder aber gelegentlich gefärbt sind. Die Farbe ist in der Regel an rundliche oder linsenförmige lïrperchen gebunden und nur selten im Protoplasma gleichmäßig verteilt. In der Färbung zeigt sich eine grosse Mannigfaltigkeit. So ist Blepharisma lateritiu (Ehrbg.) zuweilen ganz farblos, zuweilen blass, - oft dunkel pfirsichblütenfarbig, es ist jedoch auch eine ziegelrote Varietät bekannt. Ophryoglena atra Ehrbg. ist selten farblos, gewöhnlich bräunlich oder olivengrün in verschiedenen Nuancen, oft aber rauchschwarz bis dunkel sammtschwarz. Bei den Nassula-Arten steigert sich das blasseste Ziegelrot bis zum lebhaftesten Orangegelb. Die Farbe ron Stentor. coeruleus Ehrbg., Folliculina ampulla (Müll.) und Climacostomam stepanoui Entz schwanlit zwischen rein blau und grünlich blau und schlägt bei Folliculina zuweilen ins Violette oder dunkle Purpurrot ïber. Stentor niger Ehrbg. ist schwarz, allein es gibt auch braune und ziegelrot gefärbte Formen. Holosticha flarorubra Entz ist in einer Varietät strohgelb, in der andern ziegelrot mit in Längsreihen 
stehenden blutroten Flecken. Urostyla gracilis Entz ist bald fleischfarbig, bald dunkel purpurrot. Die Färbung der Infusorien längt anch von den in ihrem Innern symbiotisch lebenden einzelligen Algen, den sog. Zoochlorellen ab. Bei manchen Arten (z. B. bei Stentor polymorphus, Euplotes patella) sind die grünen und farblosen Formen gleich häutig, bei andern wieder sind die farblosen (Coleps hirtu. Ehrbg.), bezw. die grüinen Variationen (Paramaecium bursaria Ehrbg.) die häufigen. Dies hängt übrigens vom Fundort ab; so fand Verf. bei Kolozsvír niemals grüne Climacostomm vivens, wogegen die budapester gedrängt voll mit Zoochlorellen waren. Die Färbung der Infusorien rührt nach dem Verf. teils von den symbiotischen Zoochlorellen, teils von dem reinen - oder modifizierten Chlorophyll der Nahrung (Algen) her. d. i. die Farbenvariation ist stets rom physiologischen Zustand bedingt und selbstverständlich weder als Warnungs-, noch als mit der Umgebung iibereinstimmende Schutzfarbe zu betrachten.

2. Die Grössenvariation bewegt sich in viel weiteren Grenzen, als bei den meisten Metazoen. Ihre häufigste Ursache bildet das Alter der Generationen. Oft steht sie im Zusammenhang mit der V'ermehrung; so entwickelt sich bei den Vorticelliden nur aus einzelnen Individuen eine \%werg-Generation, deren Individuen bestimmt sind, die normal grossen Exemplare zu befruchten (knospenförmige Konjugation). An den baumartig rerzweigten Kolonien des Genus Zoothummium entwickeln sich auch einige riesige Individuen, welche die liestimmung hahen, von der Kolonie abgelöst, an geeigneten Stellen neue Kolonien zu griinden. Auch die reichliche Nahrung verursacht ein übermäßiges Anwachsen. so z. B. bei den räuberischen Arten ron Enchelys, Amphiteptus. usw. Ferner wird die Grössenvariation auch durch die räumlichen Verhältnisse der Ansiedelung beeinflusst, so z. B. sind die an dünnen Algenfäden sesshaften Individuen von Cothurnia crystallina Zwerge gegen diejenigen. welche auf Algen mit dickern Fäden geraten sind. Schliesslich können auch symbiotische Algen den Körper des Wirtstieres vergrössern; die grünen Exemplare von Frontonia lences (Ehrbg.) sind stets beträchtlich grösser, als die farblosen.

3. Die übermäßig progressive oder regressive Entwicklung einzelner Organe oder die gehemmte Entwicklung derselben. Bei manchen Infusorien schwankt die Grösse und der Entwicklungsgrad des Peristoms; z. B. erreicht das Peristom von Spirostomum ambigun Ehrbg. in der Regel nicht die Hälfte der Körperlänge, es finden sich jedoch auch Exemplare, deren Peristom sich bis zum hintern Körperdrittel oder - Viertel hinzieht. Auch die Länge des 
Stiels der Vorticelliden ist veränderlich, weshalb das Verhältnis zwisclien Körper und Stiel keinen verlässlichen Artcharakter bildet. Der Stiel derjenigen Individnen ron Torticella comallaria Ehrbg., welche sich an schwebende Gegenstände festsetzen, ist 4-8 mal länger, als der Körper, bei lang anhaltendem Regenwetter aber, wenn sie an der Oberfläche des Wassers keine geeigneten Gegenstände finden, schwimmen sie entweder olme Stiel nmher, orler aber ilur Stiel wird 20-30mal länger, als der Kï̈rper. Von Cothumia crystallima und $C$. maritima fand Verf. relativ langgestielte Exemplare an solclien Algenfäden, welche mit Synerlia- und Leptothrix-Fäden bewachsen waren; hier wnrde die Verlängernug des Stiels offenbar deshalb zur Notwendigkeit, damit die Colhumia sich ïher das Dickicht erheben könne. Der Halsteil von Lacrymaria olor (Mïll.) lässt sich in der liegel zweimal, lıöchistens 4-6iual so lang ansstrecken, als der Körper des Tieres ist; Verf. beobachtete indessen wiederlolt auch solche Exemplare, welche den Halsteil 15-20 ma länger auszustrecken rermochten. Letztere hatten sich einer eigentïmlichen Lebensweise angepasst; sie schwammen nämlich nicht frei, sondern batten sich in leeren Sclialen von Arcella, Cyphoderia usw. angesiedelt und dadurch wurde die iibermäPige Verlängerung des Halses notwendig. In Überschwemmungs-Pfüitzen kann man Exemplare von Vorticella concallaria Ehrbg. und V. lmaris Nü̈ll. in Menge finderr, die Generationen hindurch keinen Stiel besitzen. Zoothumium parasita Stein bildet in der Regel an kleinen Entomostraken Kolonien, lebt aber auch oftmals isoliert und bildet keine Kolonien. Nach den Untersuchungen des Verf. ist das Saville K entsche Genus Rhabdostylu nichts anderes, als rerschiedenartige Epistylis, bei welchen die Stielund Koloniebildung unterblieben ist. Die an Asellus lebende Vorticella crassicalis S. Kent ist eine isoliert lebende For'm eines noch nicht beschriebenen Carchesium.

4. Die Vervielfältignng einzelner Körperanhänge. Hastatella radians Erlang. besitzt ausser den Cilien des Wimperkranzes anch am Glockenrand und im hintern Körperdrittel kräftige, dicke und lange Borsten, gewöhnlich je vier an der Zahl, es kommen indessen auch solche Exemplare vor, welche mit 8, 12, 16 oder 24 Borsten tragen. Es sind diese, nach dem Verf., insgesamt Varietäten von Astylozoon fallax Engelmann, welche Form, abgesehen von der Schwanzborste, gänzlich borstenlos ist.

5. Die Variation der Torsion des Körpers. Das instruktivste Beispiel hierfïr ist Metopus sigmoides Clap. et Lachm., dessen extremste Varietäten jüngst als selbständige Arten beschrieben worden sind. Vert. studierte diese Varietäten wiederholt und schliesst sich 
der Ansicht von Eberhard, Biitschli u. a. an, und betrachtet diese stets zusammen vorkommenden Formen nicht als eigene Arten.

6. Die Variation der Gehäuse. Die Ursache derselben ist zumeist nocl gänzlich unbekannt, oftmals aber lässt es sich sicher nachweisen, dass der erste Anstoss zur Variation von den äussern Einwirkungen ausgeht, auf welche die Infusorien häufig mit sehr auffallenden Veränderungen reagieren, welche sich dann von Generation auf Generation vererben. In diese Kategorie gehört z. B. die Entwicklung einer Terschlussrorrichtung der Gehäuse, sowie die Anpassung festgewachsener Geläuse an die räumlichen Verlältnisse der Basis. So ist z. B. das chitinöse Gehäuse der an die Schwanzborsten von Canthocamptus fixierten Exemplare von Lagenophrys raginicola stein einem nach hinten verschmälerten keulenförmigen Schlanch ähnlich, während das Gehäuse der an Ostracoden befestigten ganz rund ist. Die in der Regel an fremden Gegenständen haftenden Infusorien mit Gallerthïllen leben häufig Generationen hindurch frei ohne Gehäuse. Yerf. fand in Innern des gallertigen Thallus einer Alge (Chaetophora pisiformis Ag.) massenhaft Stichotricha secumla Perty, bei welchen, infolge der geschickten Ausniitzung des gallertigen Algen-Thallus, die Bildung einer gallertigen Rölıre ausblieb. Anch die deckelartigen Klappen gewisser Cothurnien, mit welcher sie sich gegen das Eindringen der räuberischen Enchelyden und Acineten, sowie gegen Diatomeen u. a. schützen, sind variabel. Das Gehäuse der Cothurnien ist nach Verf. gleich demjenigen anderer Protozoen an der Innenwand mit einem feinen Protoplasmaläutchen bedeckt. Auf dieser Protoplasmamembran, welche die Forscher bisher nicht bemerliten, bilden sich zufolge der Reizung eindringender fremder Organismen die später erhärtenden deckelartigen Kilappen. Das Sarille lientsche Genus Thuricola ist nach dem Verf. nichts weiter, als eine Cothmmia mit Deckel. und die von Vejdorsky beschriebene Thuricola gruberi vermutlich identisch mit der gedeckelten Form ron Cothumia crystallina. A. Gorka (Budapest).

\section{Spongiae.}

376 sollas, Jg. B. J.. On the Sponges collected during the ${ }_{n}$ Skeat Expedition" to the Malay Peninsula 1899-1900. In: Proc. Zool. Soc. London. Jabrg. 1902 (Bd, 2). pag. 210-221. Taf. 14-15.

In der vorliegenden Arbeit werden die von Fvans in Pulau Bidang in der Neuninselgruppe gegenüber der Westküste der malayischen Halbinsel, und bei der. Grossredang Insel gegenüber der Ostküste derselben am Strande gesammelten Spongien beschrieben. Einer Anzahl (9) von Formen, namentlich Renieren, werden keine Namen beigelegt. Benannt werden zwanzig. Zehn von diesen sind nere Arten. Im ganzen werden 5 Tetractinelliden, 21 monactivellide Kieselschwämme und 3 Hornschwämme aufgefülırt.

R. v. Lendenfeld (Prag). 
377 Topsent, k., Sur les larves curassées de Thoosa armuta. In: Arch. \%ool. expér., sér. 4. Bd. 1. Nr. 1. (notes et rev.) 1903. 3 pag. Topsent hat in einem Korallenskelett, welches von der MonacoExpedition in den Azoren ans einer 'Tiefe von 599 m heraufgeholt worden war, ein Exemplar des ron ihm früher (1888) als Thoosa crmatu beschriebenen bohrschwammes gefunden, welches zahlreiche, verschieden weit entwickelte Larven enthielt. Der Schwamm besitzt keine Megasclere. Die friiher von 'lopsent als solche beschriebenen Stabnadeln gehören nicht dem Schwamm sellsst an. Die Microsclere sind: dornige Pseudosterraster. knorrige Ampliaster, schlankstrahlige Imphiaster und Oxyaster. Das Bemerkenswerte ist nun, dass die Larven ein gan\% anderes Skelett haben als der ausgebildete Schwamm. Zuerst treten in den oberflächlichen Zellen derselben paratangential gelagerte liieselscheiben auf, welche dann, in einfacher Lage angeordnet und mit den Rändern einander etwas ïbergreifend, einen Hautpanzer bilden. Etwas später als diese entstehen im Innern zarte Stabnadeln, die zu grossen Stylen auswachsen. Diese Style orlnen sich radial an und ragen schliesslich so weit ïber die Obertläche vor, dass die ganze Larve - samt diesem Nadelpelz - einen grössern Durchmesser hat als die weitesten Ausfuhrkanäle. Bei den zweien am meisten ausgebildeten von den beobachteten Larven waren diese Style nicht radial, sondern in der Weise angeordnet, dass sie dem einen Ende der ovalen Larve tangential dicht anligen, über das andere aber in Gestalt eines langen Schopfes lierrorragten: diese Änderung der Lage der Style ermöglicht es, wie Topsent wohl mit Recht bemerkt, diesen Larven geboren zı werden. Ausser jenen Scheiben und diesen S sylen, welche beide dem ausgebildeten Schwamme fehlen, finden sich in ältern Larven auch noch zarte Jugendformen der knorrigen Amphiaster der erwachsenen Thoos armata. Diese Beobachtung spricht für die Richtigkeit der von 'Topsent schon friiher vertretenen Meinung „que nombre de Clionides adultes ne conservent qu'une spiculation incomplete".

R. V. Lendenfeld (Prag).

\section{Echinoderma.}

378 Joeb, Jacques, Über Eireifung, natürlichen Tod und Verlängerung des Lebens beim unbefruchteten Seesternei (Asteria: Forbesii) und deren Bedeutung für die Theorie der Befruchtung. In: Pflügers Archir f. d. ges. Physiol. 93. Bd. 1902. pag. $59-76$.

Verf. berichtet über Beobachtungen von grundlegender Bedeutung für die Frage, ob es einen natïrlichen Tod gibt, und für die Be- 
fruchtungslehre. Er hat durch Versuche festgestellt, dass reife, unbefruchtete Seesterneier auch in sterilem Seewasser schnell, also wohl durch innere U'sache, eines natïrlichen Todes sterben, während unreife oder kiinstlich in der Reifung verzögerte oder befruchtete Eier länger oder dauernd am Leben bleiben. Versuche zeigten, dass Samerstoff und freie Hydroxyl-Ionen die Reifung beschleunigen, Sauerstoffarmut aber die Reifung hemmt. Verf. meint, dass bei der Eireifung der natürlichen parthenogenetischen Eier vielleicht nebenbei ein katalytisch wirkender Stoff im $\mathrm{Ei}$ gebildet werde, während er bei befruchtungsbedürftigen Eiern erst von aussen eingeführt werden miisse. Ferner stellte er fest, lass dieselbe Säurebehandlung, die reife Seestemeier zur kïnstlichen Parthenogenese veranlasst, den Reifungsvorgang meist hemmt. Dem Reifungsvorgang scheinen demnach andersartige chemische Prozesse zu grunde zu liegen, wie dem .. liefruchtungsrorgang" (besser, der ..Entwicklungserregung" Ref.). Verf. meint, bei der Entwicklungserregung spielten offenbar katalytisch auf synthetische Prozesse wirkende Stoffe eine Rolle, bei der Eireifung handle es sich aber offenbar um destruktive, autolytische Vorgänge.

R. Fick (Leipzig).

\section{Vermes.}

\section{Plathelminthes.}

379 Janicki, C. v., beziehungen zwischen C'hromat in und Nucleolen während der Furchung des Eies von ciyroductylus elegans ron Nordu. In: Zool. Anz. 26. Bd. 1903. pag. 241-243. 4 Textfig.

Verf. bestätigt die direkten Beziehungen der Nucleolen, Karyomeriten, Chromosomen und Chromatinkörnchen, die Goldschm id t bei Polystomm gesehen hat, (vgl. Zool. Zentr.-Bl. 9. Bd. 1902, pag. 398-399), die gut stimmen zu den Anschaungen CarnoyLebruns und des Ref.

R. Fick (Leipzig).

\section{Aunelides.}

380 Bretscher. K., \%ur Biologie und Faunistik der wasserbewohnenden Oligochäten der Schweiz. In: Biol. Centralbl. XXIII. 1903. pag. 31-47, 119-128.

Die (iesamtzahl der in Betracht fallenden Arten beläuft sich auf 116; sie gehören 40 Genera an. Von Seen wurden bis jetzt 13 untersucht; ihr Artenbestand sthwankt (ohne die Lumbriciden) zwischen 1 und 41 und die Befunde deuten darauf hin, dass fast jeder von ihnen ihm eigentuimliche Formen besitzt, für welche er als Entstehungsherd angesehen werden kann. Von einer eigenartigen 
Tiefseefauna kamm hinsichtlich der Borstenwiirmer nicht gesprochen werden.

Die Untersuehung eines Sumpfgebietes ergab in 10 verschiedenen Bächen, Tümpeln und Gräben eine benerkenswerte Differenz der Fauna der einzelnen Gewässer, lie 2 - 8 Arten vergesellschaftet enthielten. Diese Unterschiede lassen sich nicht durchans auf den differenten Charakter dieser Gewässer, ihre Hodenverhältnisse und Beptlanzung zurïckführen. sonderm macht Besiedelung durch passive Transportmittel wahrscheinlich. Deswegen hat die Faunistik die unscheinbarsten Gewässer zu berïcksichtigen.

Auch die Fauna ron Bächen, Mooren, feuchtem Bolen zeigt oft eine eigenartige Zusammensetzung. I ie Trubificidae, Lumbriculidae, Enchytraeidae legen Neigung an den Tag, auch grössere Höhen aufzusuchen, während die Naididae in atusgesprochenem Maße das Flachland berorzngen. Die kosmopolitischen Arten gehören auch den verschiedensten Regionen an, während wiederum andere Formen und besonders auffällig die Enchytraeidae, eine entschiedene Tenden\% zu Vorkommen an vereinzelten beschränkten Standorten bekunden.

K. Bretscher (Zürich).

\section{Arthropoda.}

Crustacea.

381 Petrunkewitsch, Mexander, Die Reifung der parthenogenetischen Eier von Artemia salina. (Aus dem zool. Institut der Universität Freiburg i. B.) In: Anat. Anz. 21. Bd. Nr. 9. 1902. pag. 256-263. \& Textabbildgn.

Verf. isolierte die eiertragenden Weibchen, um sicher jede Befruchtung auszuschliessen. Im Keimbläschen der Ovarialeier fand er 84 chromatische Zweiergruppen. Bei der Reifungsteilung tritt eine Vierergruppenbildung auf, so dass das Ei und die Reifungszelle jede 84 \%weiergruppen bei der Teilung erhalten. Ein zweiter Richtungskörper wird bei normalen parthenogenetischen Eiern nicht gebildet. An infizierten kranken Eiern fand er Bilder, die an kopulierende Vorkerne erinnerten, und riesige, geblähte ('entrosomen. Bei normalen Eiern soll zuerst beim Keimbläschen ein strahlenloses Centrosom zu sehen sein, das sich bei Eintritt der Reifung rom Keimbläschen trennt, ins Eiinnere wandert und Strahlen entwickelt. Nach Abstossung des Richtungskörpers wandert der Eikern ins Innere zum Centrosom.

R. Fick (Leipzig).

\section{Myriopuda.}

382 Bouin, P'. und M., Réduction chromatique chez les Myria- 
podes. In: Compt. Rend. Assoc. Anatomist. IV. session. Montpellier 1902. pag. 74-78.

Die Verff. haben die Spermatogenese ron Lithobius forficutus und Geophilus linearis untersucht und kommen dabei zu sehr bemerkenswerten Folgerungen. Vor allem zeigt ihre Untersuchung, dass beim Heranwachsen der spermatogonien zu Spermatocyten I. O. eine etwa 50-100 fache Chromatiuvermehrung eintritt, so dass also die spermatiden trotz der zwei rasch aufeinander folgenden Teilungen nnd dem Übertritt von überschiissigen Chromatin in das Protoplasma doch noch hei weitem mehr ('hromatin besitzen als die Spermatogonien: von einer "Halbierung der Normalchromatinmasse“ ist also gar keine Rede. Die Verff. schliessen aus ihren Untersuchungen, dass das Chromatin sich wohl kaum als idioplasmatische Substanz selbständig erhalten wird während der ()ntogenese und der Entstehung der Geschlechtsprodukte.

R. Fick (Leipzig).

\section{Insecta.}

383 Farkas, Kálmain, A selyemhernyó energia forgalmáról metamorphosisa közben. (Der Energiewechsel der Seidenraupe während der Metamorphose.) In: Állatorvosi Lapok. Bd. XXVI. Nr. 2. Budapest 1903. (Auch separat als Inaug.-Dissert.)

Die Untersuchungen des Verf. beziehen sich auf den Energiewechsel in drei Lebensperioden der Seidenraupe. Die erste Periode beginnt mit der Inangriffnahme des Einspimnens und dauert so lange, bis die Verpuppung vollständig stattgefunden hat, was nach dem Verf. mit dem Anftreten der normalen braunroten Färbung der l'uppe erfolgt. Die zweite Periode beginnt mit der Verpuppung und endigt mit dem Ausschliipfen des Schmetterlings, damert also ca. 13-14 Tage. Die Dauer der dritten Periode aber währt vom Ausschliipfen des Schmetterlings bis zum spontanen Umkommen desselben, ist mithin veränderlich. In der ersten Periode, d. i. während des Verspinnens und der Verpupung werden von der im Körper der Raupe befindlichen 'Trockensubstanz $12,02^{\circ}$, 0 , von der Energie aber $13,27^{\circ} \%$ verbraucht. Im Körper der Puppe sind von der ursprünglichen Energiemenge der liaupe 52,78\%, also etwa über die Hälfte enthalten; $29.69 \%$ wurden zu Seide verarbeitet. ferner sind $4,26 \%$ in der abgestreiften Haut und in den entleerten Fäces nachweisbar. In der zweiten Periode, d. i. in der Zeit, während welcher siclı aus der Puppe der Schmetterling entwickelte, sind ron der in der Puppe enthaltenen Trockensubstanz $9,71^{\%} \%$ zerfallen, wobei $13,93^{\circ} \%$ der Energie befreit wurden. In der dritten Periode, d. i. während des Zeitraums der Paarung und Eierablage, sind von der im Körper des 
Schmetterlings befindlichen urspriinghichen 'Trockensubstanz $12,54^{\circ} \circ$, von dem Energiegehalte aber 16,37\% verwendet worden.

Eine Raupe, deren Körper durchschnittlich 2,726 g wiegt, rerbraucht vom Verspinnen bis zum Ausschlïpfen des Schmetterlings 795 Kalorien enthaltende $0.1171 \mathrm{~g}$ Trockensubstanz, d. i. 20,59\%o ihrer Trockensubstanz und 25.350 ihrer Energie. Bis zum spontanen Verenden des Schmetterlings verbrennen $30,55^{\circ} 0$ der ursprünglichen Trockensubstanz der Raupe, wobei 37,56\% Energie frei werden. Zur Billung der Eier werden 9,1200 der ursprïnglichen Trockensubstanz der liaupe verwendet.

Bemerkenswert ist es, dass die männlichen Individuen bei ihrer Metamorphose um ${ }^{1}$ s T'eil mehr T'rockensubstanz und ${ }^{1} 6$ Teil mehr Energie verbrauchten, als die weiblichen. Auch im Falterzustande weicht der Stoff- und Energieverbranch des Männchens wesentlich ab von dem des Weibchens. Iner spezitische Energiegchalt des ausgeschlüpften Weibchens heträgt nämlich 5976 Kalorien, der des Männchen aber 6411 Kalorien, hingegen jener des nach der kierablage, bezw. nach der Paatung umkommendeu Weibchens 5:336 Kalorien, der des Männchens aber 5224 Kalorien. Es scheint, dass die Männchen während der lebhaften Körperbewegung vor der Paarung und hei der Paarung weit mehr energiehaltige Stofte rerbrennen und ausscheiden als die Weibchen, und hierbei den verwendbaren EnergieVorrat mehr erschöpfen. Es ist wohl eine Folge davon, dass die Männchen alsbald nach der Paarung absterben, während die Weibchen auch nach der Eierablage noch einige Tage an leben bleiben können.

A. Gorka (Budapest).

384 Wucke, Ad.. Die stachellosen Bienen (Mclipona IIl.) von Para. In: Zool. Jahrb. Syst. XVII. Bd. 1902, pag. 285-328. 1 Taf. u. 17 Abbild.

Diese sehr fleissig gearbeitete Monographie umfasst die Beschreibung von 42 Arten (incl. Trigona); eine analytische Übersicht der Subgenera und Species (q) wird voransgeschickt. Bei einigen Arten werden biologische Mitteilungen spez. bezüglich des Blütenbesuches gemacht; auch Nester werden beschriehen.

K. W. v. Dalla Torre (Inusbruck).

385 Forel, A., und H. Dufour, İber die Empfindlichkeit der Ameisen für Ultraviolett und Röntgensche Strahlen. In: Zool. Jahrh. Syst. XVII. Bd. 1902. pag. 335̃-338.

Nach einer Auseinandersetzung bezüglich der methodischen Durchfiihrung dieser Frage konstatiert Verf.: Lasius flacus zeigte eine mangelhafte Reaktion und beachtete weder die ultravioletten noch die andern Strahlen des Spektrums, während er auf diffuses Sonnenlicht reagiert hatte. 1)agegen gelang das Experiment bei Formicu 
sangutine mit Sklaven $(F$. fuscet) und P'uppen zweimal ganz gut: nach Einwirkung der reinen, isolierten ultravioletten Strahlen von $H$ nach $\mathrm{C}^{\top}$ und weiter während etwa einer Viertelstunde waren die in einer Ecke der Schachtel mit ihren Puppen konzentrierten Ameisen alle in den rom Spektrum nicht getroffenen Teil der Schachtel geHohen. Das Experiment beziiglich der Frage, ob die Ameisen für Röntgensche Strahlen empfänglich seien, ergab ein entschieden negatives Resultat.

K. W. v. I) alla Torre (Innsbruck).

386 Mncsiry. S. et (i. Szepligeti. Hymenoptera. In: Zool. Eirgebn. der dritten asiatischen Forschungsreise des Grafen Eugen Zichy, Bd. II Budapest. (V. Hernyansky). Leipzig (K. W. Hiersemann). 1901. $4^{0}$ pag. 121-169.

Ein Verzeichnis von 499 Arten und 17 Varietäten, welche von E. Csiki in Kaukasus (9), im europäischen Russland (283), in Sibirien (260), in der Mongolei (14) und in China (7) gesammelt wurden. Ausser den beiden obigen Autoren, welche sich in der Bearbeitung teilten, wirktell auch André, Emery, Friese, Kohl und Konow mit. Im ganzen wurden 53 neue Arten, eine Unterart und sieben Varietäten beschrieben, die zumal auf die "Entomophagen" fallen. Das interessanteste 'Tier ist Odyncrus aurantiacus Mocs., welches bisher nur aus ZentralUngarn bekannt war, nun aber auch in der Mongolei gefunden wurde. Das interessanteste Gebiet scheint Südsibirien zu sein. Für viele Arten werden wichtige Daten über die geographische Verbreitung beigebracht.

K. W. v. Dalla Torre (Innsbruck).

387 Ruzsky, M., Neue Ame isen a us Russland. In: Zool. Jahrb. Syst. XVII. Bd. 1902. pag. $469-482.8$ Abb. im Text.

Eine grössere Arbeit über die russischen Ameisen in russischer Sprache in Aussicht stellend, verzeichnet Verf. folgende neue Fornien: Kyrmecocystus cursor var. caspius n., F. ruibarbis subspec. subpilosa n., $F$. cinerea Mayr. var. imitans n., Myrmica bergi n. sp., M. stangcana n. sp., Leptothorax serviculus n. sp., L. safunini n. sp., L. pamiricus n. sp., Curdiocondyla koshcwnikori n. sp., Tctramorium caespitum I. var. reticulixentre n. Ausserdem wird ein neues Genus Myrmoxems n. g. beschrieben und die Art $M$. gordiagini n. sp. abgebildet; ferner wird die Beschreibung des bisher unbekannten Männchens von Formica rufibarbis subspec.clara For. gegeben.

K. W. v. Dalla Torre (Innsbruck).

388 Csiki. E., A Magyar birodalom Anophthalmusai. (Die AnophthalmusArten des Ungarischen Reiches. - In: Allattani Közlemények. Bd. I. Budapest 1902. pag. 43-58; 91-104. Mit 2 Abbildungen.

Der Verf. betrachtet das Genus Anophthalmus als scharf charakterisierte, eigene Gattung, nicht aber als Subgenus des Genus Tiechus, und zwar wegen des gänzliclıen Augenmangels der hierher gehörigen Käfer und auf Grund der Analogie, wie man nämlich die blinden Spalax-Arten von ihren sehenden Verwandten der Gattungen Rhyzomys und Tachyoryctes getrennt hat. Auf dem Gebiete des Ungarischen Reiches kommen, nach Verf., dreierlei Anophthalmus-Arten vor: 1. Solche, welche nur in Höhlen; 2. solche, welche im Freien, besonders im höhern Gebirge, untel Steinen; 3. solche, welche hier, wie dort leben. Demzufolge hat der Verf. dieselbe in folgenden drei Gruppen geordnet:

I. Gruppe: Anophthalmus budae Kend., A. herculis J. Friv., A. paroceus J. Friv., 
A. reiseri Ganglb., A. reitteri Mill., A. eurydice Schauf., A. dalmatinus Mill., A. amabilis Schauf., A. ganglbaneri Pad., A. kiesenuetteri Schm., ab. oszailensis Bedel, ab. rectangularis Schauf., ab. likanensis Schauf,, ab. rexator Schauf., A. paganetti. Ganglb., A. apfelbecki Ganglb.

11. Gruppe: A. bielzi Seidl., var. pilosellus Mill., .1. cavifuga Ganglb., A. dietli Ganglb., A. dacicus J. Friv., var. malomvizensis Ganglb., A. hegediisi J. Friv., 1. pilifer Ganglb., A. treseavicensis Ganglb., A. speiseri Ganglb., 1. merklii J. Friv., A. deubeli Ganglb., 1. malleszii C'siki.

III. Gruppe: A. biclzi var. trenssylvanicus Csiki, +1. cognatus J. Friv., 1. milleri J. Friv., A. redtenbacheri K. et J. Friv., A. priveli Csiki.

Der Verfasser gibt einen guten Bestimmungsschlüssel der Arten.

A. Gork a (Budapest).

389 Csiki, Lrust, Cole opteren. In: Zool. Frgebnisse d. dritten asiatischen Forschungsreise des Grafen Eugen Zichy. Band II. (Budapest und Leipzig). 1901. pag. 76--120.

Verf. gibt ein Verzeichnis der auf obiger Reise gesammelten Coleopteren, welches im ganzen 832 Arten und $6+$ V arietäten enthält. Davon entfallen auf den Kaukasus 74, auf das europäische Russland 455, auf Sibirien 381, die Mongolei 72 und auf (hina 27 Arten. Neu sind darunter 39 Arten, ron welchen die meisten (20) ans der Mongolei stammen. Abgesehen von diesen neuen Arteu, welche in ungarischer und lateinischer Sprache beschrieben werden, zählt das Verzeichnis noch viele recht seltene und interessante Formen auf, wie z. I. Lionedrya mongolica Motsch, Necrophorus jakonleni Reitt., Trox eximius Fald., Sphenoptera fissifrons Mars., Chrysobothris lieremannsi Ab. usw.

K. Escherich (Strassburg).

390 Ganglbauer, L., Systemat isch-coleopter o log is che Stud i en. In: München. coleopterol. Zeitschr. Bd. I. 1903. pag. 271-319.

Dass das Latreillesche Coleopterensystem, welches die Zahl der 'Tarsen zur Grundlage lat, recht unnatürlich ist, beweisen die vielen Versuche, die zu seiner Umgestaltung unternommen wurden. In der vorliegenden Arbeit unterzielıt Ganglbauer die neuern Klassifikationen der Coleopteren von Leconte und Horn, Sharp, Lameere und lílbe einer kritischen Bespreehung und geht dann zur Aufstellung und Begründung seines eigenen Systems iiber. Er hält es vor allem für unabweisbar, die Coleopteren in zwei Unterordnungen zu teilen, die Adephaga und Polyphaga (sensu Emery); denn die Adephagen differieren von allen iibrigen Coleopteren nicht nur durch das Flügelgeäder der Inıgines und die zweigliedrigen Tarsen der Larven, sondern anch durch die meroistischen Ovarien und die einfachen tubulösen Hoden. Diese Merkmale lassen es zugleich auch als zweifellos erscheinen, dass die 
Adephagen die tiefere phylogenetische Stellung einnelmen. Sie umfassen 10 Familien, die Carabiden, Cicindeliden. Uytisciden, Gyriniden, Halipliden, Hygrobiiden, Amplizoiden, Pausiden, Rhysodiden und Cupesiden.

I) 2. Unterordnung, die T'olyphagen, teilt Ganglbaur in 6 gleichwertige Familienreihen, nämlich 1. Staphylinoidea, 2. Diversicornia, 3. Heteromera, 4. I'hytophaga, 5. Rhynchophora. 6. Lamellicornia. - Ton diesen nehmen entschieden wiederum die Staphylinoidea phylogenetisch die tiefste Stufe ein; demı ihr Flïgelgeäder lässt sich direkt von dem der Adephagen ableiten, und sodam herrscht unter ihnen die ursprïngliche campodeoide Larvenform ror oder dieselbe zeigt wenigstens lieine so weitgehenden Moditikationen wie bei den ïbrigen Familienreihen.

Mit den IDiversicorniern begimen die Familienreihen, deren Flïgelgeäder sich auf das der Malacodermen zurückführen lässt. Unter diesen Familienreihen erweisen sich die IDiversicornier und die Heteromeren nach den Larven, dem Nervensrstem, dem einfachen Bau der Hodenfollikel als die phylogenetisch tieferstehenden, und die Phytophagen, Rhynchophoren und Lamellicornier als die höherstehenden. Die Diversicornier (Cantlariden, Cleriden, Elateriden, Buprestiden, Anobiiden, Nitiduliden, Lathridiiden, Endomychiden, Coccinelliden und riele andere) lassen sich von einer, den hentigen Canthariden oder Malacodermen nahegestandenen (irundform direkt oder vermittelt ableiten. Die Wurzel der Phytophagen und Lamellicornier dagegen ist nicht mehr zu erkennen: jedenfalls dürfte sie nicht unter den Diversicorniern zu suchen sein. I ie l'hytophagen mit Cerambyciden. Chrysomeliden und Bruchiden bilden eine äısserst natürliche Familienreihe, in der die Cerambyciden und chrysomeliden einander so nahe stehen, dass weder Leconte und Horn, noch Bedel im stande waren, zwischen beiden Familien durchgreifende Unterschiede festzustellen. - Die vermutlich ron den Sagrinen unter den Chrysomeliden abgezweigten Bruchiden führen zı der Familienreihe der Rhynchophoren, die nach dem Tarsalbau und den Larven als eine allerdings scharf begrenzte Modifikation des Phytophagen-Typus zu betrachten ist. Durch die Verschmelzung der Gularnähte und den Bau der Vorderbrust unterscheiden sich aber die Rhynchophoren so charakteristisch ron den Phytophagen, dass sie zweifellos als selbständige Familienreihe neben letztern beizubehalten sind. Die Rhynchophoren enthalten 4 Familien, deren naturgemäße Anordnung folgende ist: 1. Anthribidae, 2. Brenthidae, 3. Curculionidae und 4. Scolytidae.

Die 6. Familienreihe, die Lamellicornia, nehmen zweifellos die höchste Stufe unter den Coleopteren ein, welche Ansicht übrigens 
schon Burmeister ansgesprochen und hinreichend begrïindet hat (Handbuch d. Entom. III. 1892. pag. 1-3). In diese Familienreilıe gehört nur eine einzige Familie, welche den Namen Scarabacidae zu führen lat und welche in die 4 Unterfamilien Lucanini, Passalini, Scarabaeini und Melolonthini zerfällt.

Dieses hier kurz angeführte Ganglbauersche System, welches auf breiter vergleichend-morphologischer Grundlage beruht, berleutet nach Ansicht des Ref. einen gewaltigen Fortschritt und kommt zweifellos der natïlichen V'erwandtschaft der Coleopteren näher als alle bisher aufgestellten Systeme. Hoffentlich findet dasselbe in nicht allzu langer Zeit auch in den Lehrbüchern der Zoologie, in welehen vielfach unbegreitlicherweise immer noch das Latreillesche Tarsalsystem (trotz des ungleich bessern Leconte-Hornschen!) angenommen ist, die gebülırende Beachtung.

K. Escherich (Strassburg).

\section{Vertebrata.}

Pisces.

91 Czermak, W., Das ('entrosoma im Befruchtungsmomente bei den Salmoniden. Vorlüufige Mitteilung. In: Anat. Anz. 22. Bd. Nr. 19. 1903. pag. 393-400. ó Textfig.

Die Schlüsse des Verfs. lauten: ,1. Das weibliche Centrosom existiert bei den Salmoniden. 2. Bei der Beriilırung der beiden Vorkerne legt sich die weibliche Spluäre (das Centrosoma ist in diesem Moment im Wirrwarr der Fäden, Takuolen und Körner nicht mit Sicherheit zu erkennen) dem einen Pole der männlichen Vorkernspindel an, so dass nur dieser Pol - also nur eine der beiden ersten Blastomeren - eine vollständige Befruchtung erleidet." Dadurch wird diese zu fortdauerndem Leben fähig, während die andern wahrscheinlich sogar die drei andern ersten Blastomeren - vom mütterlichen Organismus nur liernteile, aber keine C'entrosomateile bekommen und dadureh wahrscheinlich zur Produktion der sterblichen somatischen Zellen bestimmt sind." "Mitochondrale Doppelfäden dringen aus dem Bildungsdotter in den Kern ein und gehen in die sich bildenden Chromosomen über. Mitocentra bilden also die Ursache der Erscheinung, dass alle Enden der Chromosomen im Stadium des Monasters sich zur P'eripherie wenden." R. Fick (Leipzig).

92 Schneider, Guido, Ichthyologische Beiträge II. Fortsetzung der Notizen über die an der Suidküste Finnlands vorkommenden Fische. In: Acta Soc. pro Fauna et Flora Fennica 21. Nr. 1. 1901. 1 Taf. 
In diesem zweiten Teile seiner ichthyologischen Studien bringt der Verf. neue Ergebnisse seiner und K. M. Levanders fortgesetzten Untersuchungen über die Biologie der in der inmern Ostsee vorknmmenden Brackwasserfische. Sein Beobachtungspunkt für den Sommer 1901 befand sich auf einer kleinen Insel in der Nähe des Cap Porkala etwa $40 \mathrm{~km}$ westlich ron Helsingfors. Hier wird ein ergiebiger Sprottenfang getrieben und daher fand Verf. hier eine gute Gelegenheit, die Lebensverhältnisse dieses wichtigen Fisches genaner zu sturtieren, als ihm im vorhergehenden Jahre möglich gewesen war. Auch weitere Lücken im ersten Teile soll vorliegende Arbeit nach des Verf. eigenen Worten möglichst schnell ausfüllen und damit Missdeutungen vorbeugen, die leicht durch Verallgemeinerung von Daten entstehen kïnnen, welchen unzureichendes Material zu grunde lag.

Ausser dem Sprott (Chuper sprathe L.) sind es daher namentlich Pleuronectiden, Esociden und (ypriniden, über welche zahlreiche neue Beohachtungen gesammelt wurden. Für diese speziellen Ergebnisse ist jedoch auf das Original zu verweisen. Yur sei hier in bezug auf den Sprott die Tatsache erwälnt, dass derselbe unzweifelhaft auch im Brackwasser der Ostsee, im Finnischen Meerbusen selbst, laicht und zwar im Sommer (Juni, Juli, August). Wichtig ist, dass die Sprotteier im Brackwasser um vieles grösser sind, als die der nämlichen Fischart im salzigen Wasser, welcher Cirössenunterschied in erster Linie durch die Bildung eines grossen perivitellinen Raumes hervorgerufen wird.

Aus dem allgemeinen Teil der Arbeit sei hervorgehoben, dass, wie übrigens schon von Möbius und Heincke betont wurde, die Brackwasserformen ursprünglich mariner Fische im ginzen kleiner sind als die Neeresbewolmer. Ihr Rumpf ist höher, die Bewaffnung des Körper's mit Stacheln und ähnlichen Hautbildungen ist schwächer. Ferner tritt bei einem Teile der ursprünglichen Meeresfische die Laichzeit im Brackwasser später ein als im Salzwasser. Da das Leben im Brackwasser bei allen Meeresfischen mehr oder weniger dieselben Veränderungen in ciestalt und Lebensweise hervoruft, könnte man erwarten, dass ungekehrt bei süsswasserfischen, wemn sie ins Brackwasser oder sogar in das Neer hinauswandern, genau das Entgegengesetzte eintreten müsse. Es müssten also bei letztern der Rumpf schlanker und die epidermalen Bildungen stärker werden. Sodann müssten sie durchschnittlich grösser sein als die im Süsswasser zurïckgebliebenen Artgenossen und früher als diese laichen.

Letzteres ist jedoch nicht der Fall und zwar schon ans dem einfachen Grunde, weil der Finnische Busen im Frühjahr das Eis oft längere Zeit behält als die Flüsse und kleine Seen des Festlandes, 
die Fische daher in letztern früher zu laichen anfangen. Daher sind die Fortpflanzungsverhältnisse der Süsswasserfische im Brackwasser nicht wesentliclı verändert.

Die iibrigen körperlichen Eigenschaften konnten in dieser Beziehung noch nicht eingehend genug studiert werden. Zwar scheinen für einzelne Arten (Osmerus eperlanus, Perca fluviatitis) die angedeuteten Unterschiede durchgehend zu existieren. Bei den Cypriniden jedosh kann, wie es scheint, von richtigen Brackwasserrassen noch keine liede sein.

Hinsichtlich der Nahrmng, welcher Verf. wie im vorigen 'Teile seine besondere Aufmerksamkeit zuwendet und über welche er viele wichtige Details mitteilt, finden sowohl die Meeresfische als auch die Süsswasserfische im Brackwasser wesentlich veränderte Bedingungen vor, welche auch auf die Körperform ron Einfluss sein mögen. Die Nahrung der Meeresfische ist, wie zahlreiche Untersuchungen des Magen- und Darminhalts beweisen, im Brackwasser einförmiger als im Ozean, besonders deshalb, weil die meisten ursprïnglichen Meeresfische die aus dem Siisswasser stammenden Insekten und Mollusken verschmähen oder viehmehr nicht an die Jagd auf Siisswassertiere, welche meist am Ufer zwischen Steinen und P'tlanzen leben, angepasst sind. Eine Ausnahme macht nur der Strömling (Cl. harengus var. membras L.), der viel Insektenlarven frisst.

Die Nahrung der Cypriniden ist im allgemeinen im Brackwasser mehr animalisch, im süsswasser mehr regetabilisch. Dies gilt nicht nur für die erwachsenen, sondern, wie es scheint, anch für die Jungfische.

H. C. Redelie (Helder).

\section{Amphibia.}

393 Lubosch, Wilhelm, Über die Nicleolarsubstanz des reifenden Tritoneies nebst Betrachtungen über das Wesen der Eireifung. (Habilitationsschrift der mediz. Fak. Jena.) In: Jen. Ztschr. f. Naturw. N. F. Bd. 30. 1903. 80 pag. 5 Taf.

Es handelt sich hier um eine sehr gründliche, auf tiefer Durchdringung des Gegenstandes basierte Abhandlung, die z. T. noch unter Borns Leitung im Breslauer anatomischen Institut entstand. Dieselbe enthält viele sorgfältig selbstgezeichnete Abbildungen und Photographien. Sie wurde unternommen, um die Angaben der grossen Arbeiten Carnoy-Lebruns auf ihre Richtigkeit zu prüfen; diese Prüfung ergab eine glänzende Bestätigung der Hauptentdeckung der belgischen Autoren, der periodischen Nucleolenauflösung. Born selbst hatte wie der Ref. bei den bizarren "Figuren" CarnoyLebruns zuerst an Kunstprodukte durch die Sublimatfixierung ge- 
dacht (s. Zool. Zentr.-Bl., 5. Bd. pag. 66/67), deshalb untersuchte Verf. in erster Linie den Einfluss der Fixierung und verschiedener Färbung auf die Eireifungsbilder. Seine Ergebnisse dieser Untersuchung sind folgende: Die Chromsäure verdeckt einen Teil der feinern Kernstruktur, sie macht den Kiern glasig und opak, unter gleichzeitiger Hervorhebung der dichtern Chromatinanhäufungen; die Schrumpfungen sind am geringsten. Das Gilsongemisch fällt den Kerninhalt gleichmäßiger. Es zeigt da distinkte Chromosomen, wo bei Chromsäure nur verquollene Wolken zu seben sind. In ältern Eiern tritt öfters bei Gilson stärkere Schrumpfung auf. Flemmings Lösung setzt stärkere Schrumpfungen, lässt aber besonders gut färben. Für die Färbung zeigt die progressive Hänatoxylinfärbung nach Carıoy mehr Details als Differenzierungsmethoden, bei denen leicht Details verloren gehen. Verf. zeichnet am Keimbläschen stets bucklige Auswïchse (die zum Teil entschieden pseudopodienähnlich genannt werden mïssen. Ref.). Sehr verdienstlich ist des Verfs. Bestreben, das Chaos der von Carnoy-Lebrun, jetzt auch von ihm genau so beobachteten ,Figuren" in eine gewisse Ordnung zu bringen. Er unterscheidet: Ruhende Nucleolen, einfacl vakuolisierte Nucleolen, Nucleolen mit veränderter Form, zu denen er auch die Kapsel-oder Mantelnucleolen, die zum Teil knäuelförmigen oder schaumigen Inhalt haben, rechmet, sodann direkt zerfallende oder fädig zertliessende Nucleolen, die chromosomenähnliclıe Figuren produzieren. Er erwähnt auch die vom Ref. "Nucleolenschatten", und die von Born ,blasse Flecke" benannten abgeblassten Nucleolen. Seine Untersuchungsergebnisse der Nucleolenauflösungen sind im wesentlichen absolut dieselben wie die von Carnoy-Lebrun, d. h. Verf. hält es auch für wahrscheinlich, dass von der Kieimbläschen-Peripherie schubweise Nucleolen ins Innere wandern, und für sicher; dass sie sich auflösend chromosomenälinliche, Figuren" bilden. Auch er lommt zur Annahme, dass andererseits auch im Innern des Keimbläschens neue Nucleolen entstehen und sich zur Keimbläschen-Peripherie begeben. Das vierte Kapitel bringt eine ausführliche kritische Besprechung der Eireifungsarbeiten Carnoy-Lebruns, in der Verf. sich gegen einige allzu „,sichere" Schlüsse der Autoren wendet. Der Hauptdifferenzpunkt ist der, dass Carnoy-Lebrun aus ihren Befunden den Schluss ziehen, dass alle chromosomenähnlichen Gebilde im reifenden Kieimbläschen aus den Nucleolen stanmen, während der Verf. überzeugt ist, dass das nur für einen Teil von ihnen gilt, während er die übrigen für Reste des ursprünglichen chromatischen Kerngerüstes hält. Der Verf. gibt freilich offen zu, dass er den Beweis dafür ebensowenig erbringen könne wie Carnoy-Lebrun für ihre An- 
schauung. Im zweiten Abschnitt des Kapitels bespricht Verf. die Mitteilung über die Froscheier von R. Fick von 1899 (s. Zool. Zentr.-Bl. 6. Bd. pag. 946 f.). (Verf. nimmt dabei aus Versehen an, die Mitteilung beziehe sich nicht auf eigene Untersuchung, sondern nur auf Carnoys Präparate, was nach Hitteilung des Verfs. daraus entstanden ist, dass R. F ick in der seinen Vortrag begleitenden Demonstration auch ein Originalpräparat Carnoys den Anwesenden demonstrierte, s. Verh. Tübingen, Demonstrationen, pag. 133. Ref.) Verf. glaubt (mit Recht, Ref.), dass er mit seiner Anschaumg Fick nicht allzufern stehe. Im dritten Abschnitt des Kapitels ist ,Rolle der Nucleolensubstanz während der Eireifung der Metazoen anf Grund der neuern Literatur" behandelt. - Ein besonderer Abschnitt bringt eine kurze wichtige vorläufige Mitteilung über eine Untersuchung des Verfs. über das reifende Neunaugenei. Dasselbe enthält einen Riesennucleolus, der mit dem Chromatingerüst in innigem Zusammenhang steht und mehrere Jahre lang sich unverändert erhalten soll.

Das fünfte Kapitel enthält die Theorie der Eireifung. Verf. hält den Austritt von Nucleolen aus dem Keimbläschen in das Eiprotoj)lasma für noch nicht einwandfrei bewiesen. Die Dotterbildung ist nach dem Verf. nicht vom Kieimbläschen abhängig, sondern geht nur vom Follikelepithel aus. Verf. nnterscheidet in der chromatischen Substanz die idiochromatische und die trophochromatische Substanz; letztere ist die Nucleolensubstanz. Verf. hält es nicht für ausgeschlossen, dass die eigentümlichen Formveränderungen der Nucleoolen durch die chemischen Prozesse in diesen, von R. Fick direkt "Nucleinlaboratorien" genannten Gebilden durch Platzen von Blasen, Wirbelbildungen beim Ein- und Ausströmen usw. zu stande kommen.

R. F ick (Leipzig).

\section{Reptilia.}

394 Gough, Lewis Henry, On the Anomalous Snakes in the Collections of the Zoological Institute Strassburg. In: Zool. Jahrb. Syst. XVII. 3. 1902. pag. 457-468.

Der Terf. hat die bei den Schlangen der oben erwähnten Institutssammlung rorkommenden Abnormitäten, die sich fast ausnahmslos auf solche der Beschuppung und hiervon wieder vorwiegend auf solche der Kopfschilder beschränken, zusammengestellt. Dem Ref. will es scheinen, als ob der Ausdruck "Abnormität" hier nicht immer passen würde. Wenn eine Schlange statt 21 oder 23 Schuppenreihen deren 19 besitzt, so ist dies keine Abnormität, sondern die Variationsbreite der Art ist eben grösser, als dies gewöhnlich an- 
genommen wird. Auch wäre es in vielen Fällen, namentlich bei den Oberlippen- und Okularschildern, unschwer zu eruieren gewesen, welche Schilder gespalten oder verschmolzen sind, und hätte dies die Arbeit jedenfalls über eine blosse Aufzählung erhoben. IDie grosse Zahl von Abnormitäten erklärt sich leicht aus dem Faktum, dass, wie der Ref. schon im Jahre $1893^{1}$ ) ausführte. die Variationstendenz immer grösser ist, je grösser die absolute Anzahl der Schilder einer Kategorie ist. Deshalb konnte auch der Verf. von den wenig beschilderten $\mathrm{C}$ al amarien und verwandten Formen nur sehr wenige Fälle anführen. Ob lie Schlange mit einem voun Auge getreunten Loreale (pag. 467) wirklich Tarbophis fallar ist, will Ref. dahingestellt sein lassen. - Jerlenfalls bietet aber die Arbeit gutes Material zum Studium der Tariabilität bei den Schlangen und ist als solche hoffentlich die V'orläuferin ähnlicher. Die meisten Schlangen, namentlich ältern Datums, welche in kleinern Museen sich rorfinden, sind ja infolge ihrer vorwiegenden Fundortlosigkeit und mangels anderweitigen Interesses wohl ausschliesslich nur auf diese ITeise wissenschaftlich rerwertbar.

F. Werner (Wien).

895 Kiritzescu, Const., Sur la présen e d'Eryr jaculus en Rounanie. Iı: Bull. Soc. Sci. Bucarest. 1003. An XI. No. 5 et 6, pag. 620 - 626

Die Herpetologie Rumäniens macht in letzter \%eit sehr erfreuliche Fortschritte und der Verf. hat das Seinige dazu redlich beigetragen. Während man vor wenigen Decennien aus Rimänien nicht viel mehr Arten kannte, als steindachner aus der Dobrudscha aufrählt (Terh. Zool. bot. Ges. XII. 1863. pag. 1123-1123), sind in den letzten Jahren u. a. Lacerta taurica und maticola, Coluber samomates (quatuorlineatus var.) und Zamenis caspius (gemonensis var.) ron dort nachgewiesen worlen; hierzu kommt noch die Entdeckung einer LremiasArt, der E. arguta Pall. (wohl der westlichste Fundort in Europa), und nun auch der Sandschlange, Eryx jaculus L. durch r. Dombrows ky und zwar bei Cernavoda und Giuvegea in der Iobrudscha. - Der Autor gibt nicht nur eine ausführliche Beschreibung der Dimensionen, Körpergestalt, Beschuppung und Färbung der bisher gefundenen rumänischen Exemplare, von denen ein junges eine sehr merkwürdige Färbung der Oberseite zeigt (helle Flecken in zwei Reihen, die nach hinten in schmale Querbinden übergehen, auf dunklem, schwärzlichen Grunde), sondern auch biologische Angaben (nach Dombrowsky) unter denen eine, der zufolge diese als Säugetier- nud Eidechsenfresserin bekannte Schlange in der Dobrudscha sich lıauptsächlich von kleinen Schnecken ernährt, besonders erwähnt werden möge.

1) Biol. Zentr.Blatt XIII. Nr. 3, pag. 92. 
Schliesslich wird die Verbreitung der Art besprochen und die Frage diskutiert, ob dieselbe aus dem kaspisch-kaukasischen Gebiete über Südrussland oder von Süden aus nach der Dobrudscha gekommen sei. Der Verf. lässt die Frage, als nach dem gegenwärtigen Stande unserer Kenntnisse noch nicht mit Sicherheit zu beantworten, noch often mo er tut Recht damit, denn die Griinde, welche für die eine oder die andere Annahme sprechen, lialten eimander die Wagschale. (Das Vorkommen ron Eryx in der T'ïrkei wird aber mit Unrecht rom Verf. bezweifelt, da sie ron Elsner an den süssen Wässern bei Konstantinopel gefunden wurde.) Die Beantwortung wird ja besonders dadurch erschwert, dass viele Reptilien rund um das Schwarze Meer vorkommen. Jedenfalls ist der Verf. berechtigt, in dem Schlusspassus seiner Arbeit die Ansicht auszusprechen, dass nach diesem Fund die Dobrudscha als der nördlichste Vorposten der Mediterranregion anzusprechen sei.

F. Werner (Wien).

96 Siebenrock, Friedrich, Zur Systematik der Schildkrötenfamilie Trionychidae Bell nebst der Lieschreibung e iner neuen Cyctanorbis-Art. In: Sitz.-Ber. Ak. Wiss. Wien Bd. XCI. Abth. 1. Okt. 1902. pag. 807-846. 18 Fig.

Der Verf. hat die Beschaffenheit des Plastrons der Trionychiden studiert und darin wertvolle und sichere Unterscheidungsmerkmale nicht nur für die sechs Gattungen, sondern für alle Arten, von denen das Plastron iiberhaupt abgebildet, oder dem Verf. durch eigene Anschauung bekannt war, gefunden. Er weist nach, dass die Unterscheidung nach dem Riickempanzer allein manchmal sogar für die Gattungen (Cycloderma und Cyclanorbis) nicht möglich ist, und dass Arten, welche bisher nur nach der Färbung unterschieden wurden (Trionyx spinifer und ferox, T. gangeticus, hurum und leithi, sowie Emyda granosa und rittata) im Bau des Bauchpanzers keinerlei Verschiedenheit aufweisen und zusammenzuziehen sind. Als wesentlichste Unterscheidungsmerkmale konnten ausser den schon bekannten und in der Systematik verwendeten Eigentümlichkeiten des Plastrons noch die Ausbildung und Zahl der Zacken des Hyo-, Hypo- und Xiphiplastrons, die Form der Epiplastra und des Entoplastrons, die Grösse, Zahl und Form der plastralen Callositäten, die Art und Weise der Verbindung der einzelnen Stiicke des Plastrons miteinander, sowie der Grad der Annäherung der parigen Stücke in der Medianlinie benützt werden und die sehr klaren und instruktiven Abbildungen im Texte machen die Unterscheidung der Arten, die bisher bei Spiritusexemplaren, namentlich wenn sie noch dazu den Kopf eingezogen haben, oft sehr schwierig, ja geradezu unmöglich war, vollständig sicher und mühelos. 
Wie gross der Unterschied in Bau des Plastrons bei äusserlich sehr schwer zu unterscheidenden Arten ist, lehrt z. B. ein Blick auf die Abbildungen von T. subplanus Geoffr. und cartilagimens Bodd.

Nebstdem wird auch eine neue Art ron Cyclanortis, die $C$. otigotylus genannt wird, beschrieben und das Plastron abgebildet. Die Art stammt aus Nubien und wurde von Kotschy am obern Nil gesammelt.

F. Werner (Wien).

Ares.

397 Grant. W. R. O., and H. O. Forbes. Birds of Sokotra and Abd-elKuri. In: Natur. Hist. of Sokotra and Abd-el-Kuri. pag. 21-63, Tab. III-VIl.

Die beiden Forscher machten vor einigen Jalıren eine wissenschaftliche Forschungsreise nach Sokotra und Abd-el-huri. Sie sammelten auf ersterer Insel 396, auf letzterer 41 Vögel. Vier neue Arten, Fringillaria insularie, $F$. socotrana, Caprimulgus jonesi und Scops socotranus wurden auf Sokotra, drei, Amydrus rreaghi, Passer hemileucus, Motacilla forwoodi auf Abd-el-Kuri, eine, Phalacrocorax nigrogularis, auf beiden Inseln erbeutet, und es wurden sonstige für die Inseln neue Arten erlangt und beobachtet. Die Identität von Rhynchostruthus ricbechi und Rh. socotranus wurde mit Sicherheit festgestellt, das bis dahin unbekannte Weibchen von Amydrus frater entdeckt. Den einzelnen Arten sind eingehende biolo. gische Beobachtungen von Grant beigefügt. Die Tafeln exthalten wohlgelungene Darstellungen der seltenern endemischen Arten. E. Hartert (Tring).

398 Iteinroth, 0., Ornithologische Ergebnisse der „I. Deutschen Südsee-Expedition ron Br. Mencke." In: Journ. f. Orn. 1902. pag. 390-457. Tab. VIII, IX. 1903. pag. 65́-127.

Im Juli 1900 verliess die Dampfyacht „Eberhard“ Hamburg; berührt wurden Ceylon, Singapore, Java, Amboina, Neu-Guinea; die Haupttätigkeit aber wurde auf den Inseln des Bismarck-Archipels entfaltet. Die erfolgreiche 'Tätigkeit auf der vorher unerforschten Insel St. Matthias wurde bekanntlich durch den Überfall und die Tötung des Expeditionschefs und anderer Mitglieder jäh unterbrochen.

Die Arbeit des Verfs. zeichnet sich vor vielen andern ornithologischen Arbeiten durch die vielseitige Behandlung des Stoffes aus. Ausser einer Aufzählung der gesammelten Arten und Beschreibungen neuer Formen (alle binär benannt), gibt V'erf. eingehende Beobachtungen über die Lebensweise, über die Mauser, die Brutzeit, Gewichtsangaben, grob anatomische Verhältnisse der Haut u. a. 1n., sowie auch oft sehr ausgedehnte Mitteilungen über das Leben in der Gefangenschait. Aus der Fülle des Interessanten möge folgendes hervorgeholen werden.

Die Fruchttauben (Carpophaga) brechen ilıre aus Früchten bestehende Nahrung im Freien stets ab, es ist daher liaum möglich, sie an das Aufnehmen von Futter zn gewöhnen. Die Erweiterungsfähigkeit des Schlundes ist enorm, die Unterkieferäste treten wie 
bei fressenden Schlangen auseinander. Der Fussbau ist ganz und gar für das Baumleben eingerichtet. Die Carpophagen klammern sich klettenartig fest an. Für das ungeheuer dichte, leicht ausfallende Gefieder der Tauben und den unglaublich dicht befiederten Bürzel der Campephagiden hat Verf. auch keine plausible Erklärung. Die von anderer Seite versuchten Erklärungen sind gänzlich unbrauchbar.

Bei zwei Weibchen von Astur dampieri fand Terf. beide Eierstöcke entwickelt. Die als "Spechtpapageien" bezeichneten zwerghaften Nasiterna pusio nähren sich ron einer an der Baumrinde befindlichen Masse, vielleicht einer Art Manna. Die schon oft erwïhnte Beobachtung, dass bei Centropus nur ein Hode, und zwar immer der rechte, entwickelt ist, wurde auch wieder rom Verf. bestätigt. Über diese, von allen europäischen Vogelarten so ganz verschierlene Gattung sind hochinteressante Lebensbeobachtungen mitgeteilt. Verf. hat sehr Recht, wenn er die grosse Verschiedenheit der "Centropinae" von den "Cuculinae" hervorhebt.

Halcyon tristami ist Brutrogel im Bismarckarchipel, der ähnliche H. sanctus dagegen nur Zugrogel aus dem Süden. Halcyon nusae und H. mathiue sind nene Formen ron Nusa und St. Matthias. Merops sulvadorii ist Brutvogel, $\boldsymbol{M}$. ornatus Zugrogel aus dem Süden. Die den Bismarck-Archipel bewohnende Rabenart (eine kleinere Subspecies von Coreus orru, Ref.) wird als (orrus insularis beschrieben.

Monarcha mencliei und Rhipidura matthiae sind prachtrolle neue Arten von der Matthias-Insel.

Hervorragend sind die biologischen Notizen über Philemon cockerelli. Cimnris frenata ftara wird als neue Subspecies ron Neupommern beschrieben.

Einige allgemeine Bemerkungen enthalten allerlei Beaclitenswertes, besonders das über zweckmäßige Färbung gesagte.

Ein in Makassar lebend gekaufter Vogel wird zum Schlusse als Acrocephutus celebensis sp. nov. beschrieben.

\section{E. Hartert (Tring).}

399 Salvadori, T., Contribuzioni alla ornitologia delle Isole del golfo di Guinea. I. Uccelli dell' Isola del Principe. In: Memorie Accad. R. Sc. Torino, ser. 2, vol. LIII. ann. 1902-1903. pag. 1-16.

Nach einleitenden Bemerkungen ünd einer Übersiclnt der ornithologischen Erforschung und Literatur von "Ilha do Principe" inl Golf von Guinea, gibt Verf. eine vollständige Liste der bekannten Arten, mit allen auf die Insel bezüglichen Literaturangaben, Aufzählung der von T ea erbeuteten Exemplare und kritischen systematischen Bemerkungen. In ganzen sind 43 sichere Arten bekannt, vier weitere sind vermutlich fälschlich angegeben und drei unsicher bestimmt. 
Ein grosser Prozentsatz der Arten ist der Insel eigentümlich. Mehrere bisher mit Sicherleit allein von der Prinzeninsel bekannte Arten (Parinia lcucophaca, Cuphopterus dohni, IIyphantornis princeps, Lamprocolius ignitus) sind wohl mit Unrecht auch für das westafrikanische Festland angegeben worden, meist durch die in ihren Fundortsangaben notorisch unzuverlässigen Pariser Ornithologen Gebr. Verreaux. Turdus xanthorhynchus ist eine neue von Fea entdeckte Art.

E. H a r tert (Tring).

400 salvalori, T., Contribuzione alla ornitologia delle Isole del Golfo di Guinea. Il. Uccelli dell' Isola di San 'T'homé. ln: Memorie Accad. R. Sc. Torino. ser. 2. vol. LIII. 1902-1903. pag. 17-45.

Auf der Insel St. Thomé im Golf von Guinea haben Weiss, Moller, Francesco $\mathrm{Newton}$ und neuerdings $\mathrm{Hocquerys}$ und Fea gesammelt. 6.3 Arten sind bis heute sicher als Bewohner von St. 'Thomé bekannt, von denen mindestens 22 der Insel eigentümlich sind, 17 Arten sind mit grösster Wahr. scheinlichkeit irrtümlicherweise für St. Thomé verzeichnet, meist durch Allen und Thomson, die ihre Sammlungen unzuverlässig etikettiert und auf diese Weise manche Irrtümer in die Wissenschaft eingeführt liaben, den unzuverlässigen Gujon und Lopez de Lima. Einige Arten scheinen auf einen kleinen Teil der Insel beschrïnkt zu sein, so z. B. ist die Fringillide Neospiza concolor (Bocage) und die merkwürdige Nectariniide Elacocevthia thomensis (Bocage) nur von Newton, der Cypselide Chactura thomensis Hart. nur von Mocquerys erbeutet worden. Der kleine geläubte Alcedinide ist von Salvadori mit Recht als Corythornis thomensis unterschieden worden. Man kann annelımen, dass die Vügel von St. Thomé jetzt grösstenteils bekannt sind, aber die hohen Berge im Innern der Insel scheinen noch nicht erforscht zu sein und dürften noch ganz unbekannte Formen bergen.

E. Hartert (Tring).

\section{Mammalia.}

401 Van der Stricht, 0., Le Spermatozö̈le dans l'oeuf de cluavesouris ( $V^{r}$. roctula). In: Verh. Inat. Vers. Halle a. S. 1902, Ergänzungshft. d. Anat. Anz. 21. Bd. pag. 163-168. 1 Textal,bildg.

Dieser kleine Vortrag enthält selır interessante Befunde am Fledermausei. Er wurde durch vorzügliche Präparate illustriert. Der Samenfaden dringt ganz in das Ei ein und zwar an beliebiger Stelle und erhält sich lange Zeit färbbar, auch noch nach Ausbildung des Samenkernes. Am vordern Centrosom des Verbindungsstiickes bildet sich die Samenstrahlung aus. In der Eiperipherie fand Verf. eine relativ bedeutende Chromatinmasse, die keine Beziehungen zu den Torkernen hat, die er als Pseudochromosomen betrachtet. Verf. gab im Vortrag an, dass keine Drehung des Samenfadens im Ei stattfinde, eine Angabe, mit der sich R. Fick in der Diskussion nicht einverstanden erklären konnte, da er gerade an einem der schönen Präparate des Verfs. eine solche Knickung des Samenelementes deutlich erkennen zu können glaube.

R. F i ck (Leipzig). 


\title{
Zoologisches Zentralblatt
}

unter Mitwirkung von

Professor Dr. O. Bütschli

in Heidelterg and Professor Dr. B. Hatschek

herausgegeben von

\author{
in Wien
}

\author{
Dr. A. Schuberg \\ a. o. Professor in Heidelberg.
}

Verlag von Wilhelm Engelmann in Leipzig.

X. Jahrg.

19. Juni 1903.

No. 12.

Lu beziehen durch alle Buchhandlungen und Postanstalten, sowie durch die Verlagsbuchhandlung. Jährlich 26 Nummern im Umfang von 2-3 Bogen. Preis für den Jahrgang M. 30. - Bei direk ter Zusendung jeder Nummer unter Streifband erfolgt ein Aufschlag von L1. 4.- uach dem Inland uud von 11.5 . - nach dem Ausland.

\section{Referate.}

\section{Lehr- und Handbuicher. Sammelwerke. Vermischtes.}

402 Gardiner, J. Stanley, On the Unit of Classification for Systematic Biology. In: I'roceed. of the Cambridge I'hilos. Soe. Vol. XI. Pt. VI. 1902. pag. 423-427.

V'erf. polemisiert gegen eine von Bernard vorgeschlagene neue Methode der Klassifikation. Nach dieser sollen die Exemplare einer Sammlung in Formen für jede Lokalität eingeteilt werden, und jede Form soll bezeichnet werden X. loc, 1, 2, 3, 4, 5, usw. in Übereinstimmung mit der Zahl der Formen in dieser Lokalität.

Verf. glaubt, dass sich gegen diesen Vorschlag so schwere Bedenken geltend machen lassen, dass seine Annahme unmöglich ist. Vor allem hat Bernard keinen Versuch gemacht, genau zu definieren, was er unter einer "Form" versteht. So viel aus seiner Schrift hervorgeht, scheint sie fast dasselbe zu sein wie eine Varietät. Wenn dies der Fall ist, so hat sie eine wissenschaftliche Basis, wenn sie aber eine der Varietät untergeordnete Kategorie bezeichnen soll, so entbehrt sie einer solchen Basis. Die einzige wirkliche Grundlage einer tiefer stehenden Kategorie ist die Summe der Charaktere jedes einzelnen Exemplares, wie dies von den meisten Systematikern angenommen ist. Die gegenwärtige Methode entspricht keineswegs allen Anforderungen, aber Bernard hat keine bessere an ihre Stelle gesetzt.

W. May (Karlsiuhe).

\section{Zellen- und Gewebelehre.}

403 Boveri, Th., Über nehrpolige Mitosen als Mittel zur Analyse des Zellkerns. In: Verh. phys. med. Ges. Würzburg. N. F. Bd. 35. 1902. pag. 67--90. 
Terf. hat früher (durch unveröffentlichte Untersuchungen) an normal befruchteten Eiern von Seeigeln durch Unterdriickung der ersten Furche dasselbe erzielen können, wie Driesch an doplelt befruchteten Eiem: die Bildung von vier anstatt zweier Zentren, simultane Vierteilung und pathologische Entwicklung (in Stereoblastulae). - Dass bei Doppelbefruchtung die pathologische Entwicklung wirklich eine Folge der Dispermie ist (und nicht etwa eines schon vorher vorhandenen pathologischen Zustandes der Eier), beweist Verf. durch einen Versuch, der auf seiner früher gemachten Erfahrung beruht, dass nämlich der Prozentsatz doppelt befruchteter Eier in hohem Maße von der Spermamenge abhängig ist. "Tadellose Eier eines Weibchens wurden in zwei Portionen geteilt; der einen wurde sehr wenig, der andern sehr viel Sperma zugesetzt; eine Untersuchung nach dem Auftreten der ersten Furche ergab, dass die erstere Portion sehr wenige, die letztere sehr viele disperme Eier enthielt. Der Prozentsatz pathologischer Larven in beiden Zuchten entsprach genau dem der Dispermie."

Verf. hat durch Verfolgung der Entwicklung ron isolierten Blastomeren des vierzelligen Stadiums bei normaler Entwicklung feststellen können, dass aus jeder derselben sich ein Pluteus entwickeln kann. Anders verhält es sich mit den isolierten Blastomeren eines doppeltbefruchteten, simultan viergeteilten Eies: diese entwickeh sich - mit verschwindenden Ausnahmen - nicht zu Plutei. Doch liefern viele von ihnen mehr oder weniger normale Gastrulae in so hohem Prozentsatz, dass auf je zwei disperme Eier im Durchschnitt eine 1 Gastrula trifft, so dass also gewisse Viertel einzeln mehr leisten als alle vier Zellen vereint. .Während also die vier Blastomeren eines normal geteilten Eies einander genau gleichwertig sind, zeigen sich die Eigenschaften derjenigen eines doppelt befruchteten in mannigfaltiger Weise, mehr oder weniger hochgradig, voneinander verschieden." Wie nach diesem Ergebnis zu erwarten war, entwickeln sich auch in den ganzen dispermen Keimen liäufig die vier Viertel in verschiedener Weise (oft begimnen z. B. in der polar differenzierten Blastula ein oder zwei zwischen zwei Meridianen gelegenen Quadranten Zellen in das Innere abzugeben, so dass dieser Abschnitt bald trüb erscheint). Mitunter können die dispermen Eier sich simultan in drei anstatt in vier Zellen furchen (wemn nämlich das eine Spermozentrum - infolge von Schïtteln — sich nicht geteilt hat) und die Tendenz zu normaler Entwicklung ist in diesen Dreiern eine weit grössere als in den Simultanvierern; aus jenen erhält man einen ganz erheblichen Prozentsatz von Plutei, von denen einzelne vollkommen 
normal sind (meistens sind dieselben abnorm, asymmetrisch). Weit seltener entwickeln sich Plutei aus den Simultanviereru.

Die Bedingung für diese merkwürdigen Variationen in der Entwicklungsweise sowohl der ganzen dispermen Eier wie der einzelnen Blastomeren sieht Verf. in der Verteilungsweiso der Chromosomen, und zwar nicht der Mengen-, sondern der Qualitätenverteilung. Dass die Mengenverteilung nicht maligebend ist, lïsst sich auf (irund einer vom Verf. frïher gemachten Erfahrung darlegen: dass nämlich die Kerngrösse bei den Seeigellarven proportional der Cahl der Chromosomen ist. Nun finden sich in einigen aus "Simultandreiern" gezüchteten Iarven einige fast normale Plutei, bei denen einige Bezirke grössere, andere kleinere Kerne enthielten, ohme dass dies die normale Form beeinträchtigte; umgekehrt findet man hochgradig pathologische Larven, bei denen Grössenunterschiede der Kíerne nicht nachweisbar waren. Aus dieser Annahne der Verteilungsweise der Chromosomen als bedingenden Momentes erklïrt sich auch die erwähnte 'T'atsache, dass die Simultandreier viel mehr' annähernd normale Larven ergeben als Simultanvierer ${ }^{1}$.

Indem Verf. nun seine Betrachtungen weiter ausspinnt, kommt er zu der Amahme, dass die einzelnen Chromosomen verschiedene Qualitäten besitzen müssen (entgegen seiner frühern Ansicht, dass dieselben essentiell gleichwertige, nur individuell verschiedene Bildungen seien); „damit ist ein erster Schritt getan zur Erforschung der physiologischen Konstitution des Zellkerns. Der Unterschied unserer Versuche iiber den Kern von den frühern liegt darin, dass bis jetzt nichts anderes ausführbar war, als den ganzen Kern zu entfernen und die Folgen dieses Fehlens zu ermitteln."

In speziellen bemerkt Verf., dass die Anfangsvorgänge bis zum Stadium der Blastula von der Qualität der Kernsubstanz unabhängig sind; die Notwendigkeit bestimmter Chromosomen zeigt sich erst an mit der Bildung des primären Mesenchyms. Verf. opponiert gegen die Angaben von I riesclı (vergl. Zool. Zentr.-Bl. Bd. 5. 1898. pag. 707), dass alle Larvencharaktere mit Ausnahme des Skeletts rein miitterlich seien; nach Untersuchungen des Verfs. seien nicht nur Form und Skelett des Pluteus, sondern auch die Gestalt der Larve ror der Ausbildung des Skeletts, die Menge des Pigments, die Anordnung des Pigments und die Zahl der primären Mesenchymzellen vom Spermatozoon beeinflussbar.

1) Teils nämlich, weil unter der Annahme einer Qualitätenverschiedenheit der Chromosomen die Wahrscheinlichkeit, dass eine bestimmte Qualität in jede Blastomere gelangt, in den "Dreiern" um vieles grösser ist als in den "Vierern", teils weil bei drei Polen in jede der Spindeln ein vollständiger Vorkerı gelangen kann. 
Die Struktur des Eiplasmas besorge nach Verf. nur das "Promorphologische": die Polarität, die Bilateralität hängen von ilır ab, und alle auf die Achsenbildungen bezüghichen Missbildungen beruhen auf Protoplasmastörungen oder Protoplasmadefekt. Geringfügige Plasmaverschiebungen am vegetativen Pol führen zu Doppelbildungen, und aus verlagerten Blastomerenhaufen erhält man, falls die eingetretenen Verschiebungen nicht rückgängig gemacht werden, öfters Larven mit doppeltem resp. sogar dreifachem Urdarm. „Der Echinidenkeim ist sonach nichts weniger als ein harmonisch-äquipotentielles System" (gegen Driesch).

Verf. berichtet zuletzt vorläufig, dass es ilmm gelungen ist, in einzelnen bestimmten Blastomeren (so in einer der ${ }^{1 / 2}$ oder ${ }^{1 / 4}$ Blastomeren, in den Nacromeren und Mesomeren) mehrpolige Teilungsfiguren hervorzurufen und damit den hieraus hervorgehenden Keimbereich pathologisch zu machen: die pathologischen Zellen treten früher oder später ins Innere, kleine ,Geschwülste" bildend; Verf. weist auf die Bedeutung hin, welche solche Beobachtungen möglicherweise für die İtiologie der Geschwiilste lıaben liönnten ${ }^{1}$ ).

$$
\text { R. S. Bergh (Kopenhagen). }
$$

\section{Faunistik und Tiergeographie.}

404 Amberg, 0., Biologische Notiz über den Lago di Muzzano. In: Forschungsber. Biol. Stat. Plön. Teil 10. 1903. pag. 74-85.

Der kleine, südlich von Lugano gelegene Lago di Muzzano stellt ein 23 ha messendes und nur $3-4 \mathrm{~m}$ tiefes Seebecken von $342 \mathrm{~m}$ Höhenlage dar. Im Winter friert der See oft zu, im Sommer erbebt sich seine Temperatur bis zu 20 und $25^{\circ}$. Grund und Oberflächentemperatur weichen nur unwesentlich voneinander ab. Das stark verunremigte, wenig transparente Wasser enthält viel gelöste Humusstofte; seine Erneuerung vollzieht sich nur sehr langsam. An Nahrung für das Plankton herrscht Überfluss.

Untersuchungen an der limnetischen Tier- und Pflanzenwelt, die in Frühjahr, Herbst und Winter vorgenommen wurden, charakterisierten den Lago di Muzzano nicht als See, sondern als Teich. Für eine solche Einreihung spricht das Fehlen der typisch eulimnetischen Diatomaceen, die Gegenwart vieler Chlorophyceen, die konstant auftretende Wasserblüte von Schizophyceen, das pelagische Vorkommen von Brachionus und die sehr bedeutende Planktonmenge. Zudem deckt sich die

1) Noch seien folgende Sätze des Verfs. angeführt: „Vielfache Zentren in einer Zelle sind so lange für den schliesslich entstehenden Zellkomplex unschädlich, als immer nur je zwei Pole zu einer karyokinetischen Figur zusammentreten und der ursprüngliche oder die ursprünglichen Kerne normal waren“. „Pathologischen Effekt haben mehrfache Zentren nur dann, wenn sie sich zu mehr als zweien in die vorhandene Kernsubstanz teilen; denn dann fehlt jede Garantie oder gar die Möglichkeit, allen Zellen einen Anteil an sämtlichen durch die einzelnen Chromosomen repräsentierten verschiedenen Qualitäten zu vermitteln". 
Zusammensetzung der freischwebenden Flora und Fauna mit dem von Z a charias gegebenen Verzeichnis des Heleoplanktons.

Eine tabellarische Zusammenstellung erlaubt einen Einblick in die qualitativen Verhältnisse des Planktons während der verschiedenen Untersuchungsmonate und gibt Aufschluss über die Häufigkeit der einzelnen limnetischen Geschöpfe. Die Gesamtsumme der 71 Planktonkomponenten zerlegt sich in 29 Algen, 13 Mastigophoren, 8 Protozoen, 13 Rotatorien und 9 Crustaceen.

brachionus pala Ehrenb. ist eine echte Frühlingsform. Selten fehlt Polyarthra platyptcra. Alle andern Rotatorien traten nur hin und wieder auf. Von Cladoceren war Ceriodaphnia pulchclla Sars am häufigsten. F. Zschokke (Basel).

405 Amberg. O., Anhang zur vorstehenden Abhandlung über den Lago di Muzzano. Untorsuchung einiger Planktonproben vom Sommer 1902. In: Forschungsber. Biol. Stat. Plön. Teil 10. 1903. pag. 86-89.

Ergänzende Fänge im Lago di Muzzano gaben Aufschluss über die im Sommer herrschenden Planktonverhältnisse. Dieselben kennzeichnen sich, wie in andern seichten Gewässern zn derselben Jahreszeit, durch massenhaftes Auftreten von Cratium und Abnahme der Pflanzen gegenüber den Tieren. Phytound Zooplankton halten sich im Sommer quantitativ das Gleichgewicht, während in den andern Zahreszeiten die freischwimmende Flora an Masse überwiegt. Diese Erscheinung lä̈nt mit der starken sommerlichen Prodnktion der Copepoden zusammen.

Über das Auftreten der einzelnen Planktonkomponenten in den Sommermonaten gibt Verf. eingehender Auskunft. Einige Formen erscheinen in der warmen Jahreszeit neu (Brachionus urceolaris Ehrbg., Schizocerca diversicomis Daday, Daphnia pulex L., Alona rostrata Koch, A. costata Sars, Cyclops fuscus Jur., C. insignis Ces.).

F. Zschokke (Basel).

406 Marsion, II, Die Fauna und Flora des verschmutzten Wassers und ihre Beziehung zur biologischen Wasseranalyse. In: Forschungsber. Biol. Stat. Plön. Teil 10. 1903. pag. $60-73$.

Die Verunreinigung der Gewässer durch fäulnisfähige und faulende Substanzen - Abwasser von Wohnstätten und Fabriken - ruft eine durchans eigentümliche, aquatile Fauna und Flora hervor. So gewinnt die biologische Analyse Gewicht bei der Beurteilıng des Wassers. Verf. zeigt, wie die verschiedenen Influvien das Wasser und seine pflanzliche und tierische Bevölkerung beeinflussen.

Vergiftung des Wassers kündet sich schon durch das gleichzeitige $\mathrm{Ab}$ sterben der Fische aller Arten und des verschiedensten Alters an, eine Erscheinung, die durch Fischepidemien nicht verursacht wird. In giftigen Abwässern gehen auch die Mollnsken zu grunde. Schnecken und Muscheln können gleichzeitig als Leitorganismen für den Grad der Verunreinigungen dienen, indem die verschiedenen Arten sich gegenüber der Verschmntzung als verschieden empfindlich erweisen. Am wenigsten von den Vernnreinigungen beeinflusst wird Limnaca auricularia. Ende und Anfang einer Schädigung lässt sich biologisch an dem Grade des Wohlbefindens der einzelnen Species feststellen. Dabei kommen auch Spongillen und Bryozoen in Betracht.

Besonders scharfe Kriterien für die Wasserbeschaffenheit liefert das Ver. balten der Flora. Als ganz charakteristische "Leitpflanzen" haben vor allem die Wasserpilze, die Oscillatorien, die Diatomeen u. a. m. zu gelten. Verf. setzt die Bedentung der Microflora für die Wasseruntersuchung eingehend auseinander 
und bespricht dann die für faulende Gewässer typischen Protozoen. Manche charakterisieren durch ihre Gegenwart durchaus bestimmte Arten der Wasserverunreinigung.

Überall wo Füulnisprozesse, wenn auch in engstem Bezirk, stattfinden, stellen sich Ciliaten ein, am häufigsten Colpidium colpoda und Chilodon cucullulus. Auf eine stärkere Wasserverumreinigung deuten hin Paramaccium caudatum, $P$. putrinum und $P$, aurelia. Vorticclla mierostoma und Epistylis coarctata leben in sehr faulem Wasser, Carchesium lachmanni in stinkender Jauche. Nach der Quantität der Leitorganismen kann sich der Experte ungefähr ein Bild über die Mengen von stickstoffhaltigen, organischen Stoffen entwerfen, die im Abwasser an einer bestimmten Stelle vorbeigefiossen sind. Darin liegt ein Vorteil der biologischen Analyse gegenüber der chemischen Untersuchung.

Neben einer grossen Zahl weiterer Ciliaten spielen auch die Achromatoflagellaten als Leitformen für faulende Gewässer eine gewisse Rolle. Ferner ist zu beachten das Auftreten freilebender Nematoden, von denen z. B. Diplogaster rivularis eiıen hohen Grad von Fäulnis erträgt. Etwas empfindlicher sind im allgemeinen die Oligocbäten. Auch einige Rotatorien verdienen bei der Wasseruntersuchung Berücksichtigung.

Für die Schlammbeurteilung hat die Gegenwart von manchen Insektenlarven - Chironomus plumosus - ihre Wichtigkeit. Daphnia pulex findet sich in stark verumreinigten Teichen, Gammarus pulcx und Ascllus aquaticus können in schlechtem Wasser aushalten, vorausgesetzt, dass demselben durch Strömung oder Wasserpflanzen neuer Sauerstoff zugeführt werde.

Endlich gestatten die Planktonverhältnisse Rïckschlïsse auf die Wasserbeschaffenheit. Die Zusammensetzung der limnetischeu Organismenwelt weist auf bestimmte Verunreinigungsherde hin. Auch das Verhältnis zwischen Zoound Phytoplankton ist bei den in Frage stehenden Untersuchungen oft von Wichtigkeit. Je nach ihrem eruährungsphysiologischen Bedürfnis erscheinen die einzelnen Organismen nur im Wasser von bestimmten Eigenschaften.

\section{F. Zschokke (Basel).}

407 Monti. R., Le condizioni fisico-biologiche dei Laghi Ossolani e Valdostani in rapporto alla Piscicoltura. In: Mem. R. Istit. Lom. bardo. Marzo 1903. pag. 1-51. $13 \mathrm{Abb}$. im Text.

Verf. beschreibt eine Anzahl hochalpiner Wasserbecken des Gebiets von Aosta und Ossola nach ilıren physikalischen, geologischen, hydrographischen und biologischen Eigenschaften. Die Seen liegen in Höhen von 1267-2553 m; sie besitzen eine Fläche von 1 Hektar bis ${ }^{1 / 2}$ Quadratkilometer und verdanken ihren Ursprung fast ausschliesslich dem Glacialphänomen (Moränenseen und glaciale Erosionsseen).

Faunistisch werden die bemerkenswertern Funde zusammengestellt. Weite Verbreitung geniesst der rotgefärbte Diaptomus denticornis Wierz. Neben ihm kommt im Lebendunersee $(2153 \mathrm{~m})$ D. gracilis Sars vor. Neu für Italien ist die Hydrachnide Arhenumes neumanni Piersig.

Der Lago di Antillone, mit 1267 m Höhenlage, beherbergt eine Fauna, die in qualitativer und quantitativer Beziehung an die Tierwelt der Gewässer des Flachlands erinnert. Auffallender ist es, dass im untern Lago Zyole, trotzdem er bei $2521 \mathrm{~m}$ liegt, eine äusserst reiche Gesellschaft sonst nur in bedentend tieferer Lage vorkommender Tiere lebt. Sie besteht aus Mydrometra costac, Notonecta glanca, Hydroporus-Arten, Ephemeriden, Phryganiden und was be- 
sonders ins Gewicht fällt, aus den Dendrocoelen der Ebene: I'olycclis nigra, $P$. cornuta, Dendrocoelum lacteum, Planaria gonocephala, während die typische Planarie des Hochgebirgs, die auch im Untersuchungsgebiet weit verbreitete $P l$. alpina, vollständig fehlt. Für den See auf der Passhöhe des Grossen St. Bernhard bestätigt Verf. die faunistischen Angaben des Referenten. Das Wasser des kleinen Beckens wird durch die Abfälle aus dem Hospiz verunreinigt, was in der Zusammensetzung der Fauna seinen Ausłruck findet.

Im höchstgelegenen der untersuchten Seen, dem Lago Licone, $2553 \mathrm{~m}$, fanden sich Hclophorus glacialis, zahlreiche Larven von Chironomus, Phryganiden, Ephemeriden und Planaria alpina. Pelagisch wurden erbentet Alona affinis, Plenroxus cxiguus, Crepidoccreus setiger, Sida cristallina, Candona candida und ein unbestimmter Diaptomus. Im Untergrund lebten Diffugia spiralis, D. urccolate und Stentor spec. Dagegen fehlen Fische.

Abschliessend untersucht Verf., welche der hochalpinen Wasserbehälter, physikalisch und biologisch geeignet wären, Fische aufzunehmen, und welche Fischarten in ihnen mit Erfolg ausgesetzt werden könnten. F. Zschokke (Basel).

408 0stwald, W., Ueber eine neue theoretische Betrachtungsweise in der Planktologie, insbesondere über die Bedeutung des Begriffs, der inneren Reibung des Wassers" für dieselbe. In: Forschungsber. Biol. Stat. Plön. 'Teil 10. 1903. pag. $1-49$.

Verf. macht den höchst interessanten Versuch, die I'lanktonbewegungen, besonders die vertikalen Wanderungen, auf physikalischem Weg zu erklären. Dadurch führt er in die Planktologie einen neuen Gesichtspunkt ein, dessen Beachtung für die Zukunft die reichsten Friichte verspricht.

Die allgemeinste und durchaus typische Eigenschaft des Planktons liegt in seiner Schwebefühigkeit; sie allein unterscheidet die limnetischen Wesen prinzipiell von andern Organismengruppen. Die Eigenschaft der Schwebefähigkeit ist daher in den Mittelpunkt der planktologischen Betrachtungsweise zu stellen.

Erst eine genaue Analyse und Definition des Schwebebegriffs wird es erlauben, eine Reihe von auf das Plankton bezïglichen Tatsachen zu erklären. Unter Schweben versteht Verf. diejenigen Gesclıehnisse, welche sich als Sinkvorgänge von ausserordentlich geringer Sinkgeschwindigkeit auffassen lassen.

Da „Sinken" als Oberbegriff von „Schweben" zu gelten hat, beziehen sich die Schlüsse über Sinkvorgänge auch auf Schwebegeschehnisse. Die nähere Definition des Schwebens hat somit mit der Untersuchung der Sinkgeschehnisse zu beginnen. Es erheben sich zunächst drei Hauptfragen:

1. Welches sind die physikalischen Bedingungen, unter denen Sink- resp. Schwebevorgänge stattfinden und wie hängen die letztern Geschehnisse von diesen Bedingungen ab? 
2. Welche speziellen Schwebebedingungen finden wir bei den Planktonorganismen?

3. In welcher Weise reagiert das Plankton auf Veränderungen der Schwebebedingungen?

Neben dem spezifischen Gewicht und dem Übergewicht, das selbst von der Temperatur und dem Gehalt des Wassers an gelösten Stoffen abhängt, spielt bei Sinkvorgängen der ,Formwiderstand" des sinkenden Körpers eine wichtige Rolle. Füir den Formwiderstand kommen zwei Falitoren in Betracht, die ,relative oder spezifische Obertläche“ des sinkenden Köörpers, d. l. das Verlıältnis von absoluter Oberfläche und Volumen, und seine ,Projektionsgrösse“. In bezug auf die let\%tere lässt sich sagen, dass diejenigen Körper langsamer sinken, welche eine grössere Vertikalprojektion oder einen grössern Querschnitt besitzen.

Übergewicht und Formwiderstand stellen die beiden biologischen Faktoren der Sinkgeschwindigkeit dar. Ins Spiel tritt aber noch ein äusserer, für die Planktonvorgänge sehr wichtiger Faktor, der im Medium liegt und den die Physik längst liennt: die spezifische Zähigkeit oder innere Reibung des Wassers. Dieselbe steht offenbar mit der chemischen Beschaffenheit des Mediums und seiner Temperatur in enger Beziehung. Geschehnisse, die durch spezielle Eigenschaften der innern lieibung bedingt werden, weichen prinzipiell von den Vorgängen ab, die sich infolge besonderer Verhältnisse der spezifischen Gewichte ron sinkendem Körper und von Flïssigkeit einstellen. Unter Berücksichtigung aller Faktoren lässt sich die Antwort auf die erste der drei gestellten Fragen etwa folgendermaßen formulieren: Damit ein Sinkrorgang zu einem Schwebevorgang wird, damit ein Körper schwebt, muss der Quotient aus Übergewicht und innerer Reibung mal Formwiderstand ein Ninimum sein.

In der speziellen Anwendung dieser Schwebeformel auf die Planktonorganismen diskutiert Verf. zuerst die zwei biologischen Faktoren. Er zälılt Einrichtungen auf, die der Erlangung eines möglichst geringen Übergewichts dienen (Wasserreichtum der Organismen, Gegenwart ron Vakuolen, die Stoffe von geringerem spezifischen Gewicht, als Protoplasma oder sogar Wasser enthalten, Entwicklung von Fetten, Ölen, Gasen usw.).

Oft verändern sich die beiden Faktoren des Formwiderstandes so, dass derselbe extrem anwächst. Die spezifische Oberfläche dehnt sich durch Anlage zahlreicher Stacheln, Dornen, Borsten, Haare; zudem können diese Schwebewerkzeuge noch horizontal ausgebreitet werden. Ebenso geht die Projektionsgrösse Veränderungen ein.

Für die Schwebegeschehnisse ron Planktonkörpern sind aber noch 
weitere Eigenschaften ron Wichtigkeit, Faktoren, die im Wesen jener Körper als Organismen liegen. Störend und komplizierend fiir die theoretische Deutung der Sink- und Schwebevorgänge wirkt die Eigenbewegung eines grossen Teils des Zooplanktons. Ferner besitzen die Mitglieder des Planktons, wie alle Organismen, die beiden biologischen Qualitäten der dynamischen Stabilität nnd der Anpassungsfähigkeit. Beide stehen untereinander in engem Zusammenhang, wenn auch ihre Tendenz zum Teil direkt entgegengesetzt ist. Die dynamische Stabilität erlaubt es den Organismen, die Änderungen der Aussenbedingungen, im speziellen Fall besonders der Temperatur und der Konzentration des Wassers, nur innerhalb gewisser Grenzen zu ertragen. Verf. bespricht diese den lebenden Wesen zukommenden Eigenschaften in ihrer Bedeutung für die Schwebeverhältnisse des Planktons näher.

In Beantwortung der dritten Frage geht Ostwald den Veränderungen nach, die in den Schwebebedingungen überhampt stattfinden können und in der freien Natur wirklich eintreten. Als der weitaus variabelste Faktor erweist sich die innere Reibung des Wassers, sie trïgt gleichzeitig zum Schwebe- resp. Sinkvorgang am meisten bei.

In der grossen Mehrzalıl der Fälle kann bei der Betrachtung der Reaktionen des Planktons auf Veränderungen der Scliwebebedingungen einfach von Reaktionen gegenüber veränderter innerer Reibung gesprochen werden. Der Begriff der innern Reibung rückt so planktologisch in eine zentrale Stellung. Seine Anwendung gestattet die Deutung einer grossen Anzahl bisher mnerklärlicher Tatsachen; ebenso lassen sich neue ordnende Gesichtspunkte, die eine schärfere Umschreibung bis jetzt unlösbarer Planktonprobleme erlauben, gewinnen.

Nach der Art und Weise, wie das Plankton auf eine Veränderung der innern Reibung reagiert, lässt sich der Stoff in zwei Gruppen teilen. In ersten Fall handelt es siclı um biologische Reaktionen durch Veränderung eines oder der beiden iibrigen Faktoren der aufgestellten Schwebeformel. Solche Reaktionen haben ihre Gültigkeit in weitem Maße für das , Planliton im allgemeinen Sinne", das siclı aus Individuen, Entwicklungen, Generationen, Varietäten, Arten usw. zusammensetzt. Die in der zweiten Gruppe eintretenden Reaktionen tragen keinen oder nur einen unzureichenden biologischen Charakter. Das Plankton muss vielmelır seine räumliche Orientierung ändern; es antwortet mit Variationen der Sinkgeschwindigkeit, d. h. mit passiven Wanderungen auf die Veränderung der innern Reibung. Diese Art der Reaktion kommt liauptsächlich dem „Individuenplankton" zu. Darunter versteht Verf. die Summe aller etwa an einem Tag in einem 
Wasserbecken vorhandenen, oder in einem Fang erbeuteten Planktonindividuen.

Den passiven Wanderungen wendet Verf. zunächst sein Augenmerk zu. Er zeigt ihre Abhängigkeit von der Veränderung der inneren Reibung und betont, dass die passiven Ortsbewegungen des Planktons, besonders die Vertikalbewegungen nach abwärts, sich als einfaches Postulat der Schwebebedingungen ergeben. Erst sekundäre Anpassung und Verrollkommnung der pelagischen Lebensweise bringt Einrichtungen hervor, die augenblicklich oder doch im Lauf der Zeit die Sinkgeschwindigkeit so regulieren, dass ein Minimum zu stande kommt.

Die Benützung des Begriffs der innern Reibung gestattet die Anfstellung einer neuen Theorie der Wanderungen des Planktons, besonders seiner periodischen Verschiebuug. Praktisch üben indessen ausser der innern Reibung noch andere Faktoren ihren Einfluss auf die Sinkgeschwindigkeit und die räumliche Orientierung der schwebenden Lebewesen aus. Sie müssen bei der Erklärung der periodischen Planktonbewegungen mit in Betracht gezogen werden. Hierher gehören vor allem die aktiven horizontalen und vertikalen Ortsreränderungen des Planktons. Weitaus die wichtigsten von ihnen sind die nach oben gerichteten. Ausserdem spielen bei den besprochenen Erscheinungen die verschiedenen Tropismen, sowie chemische und physikalische Nebengrössen, Strömungen, Winde, Wellen, chemische Wasserbeschaffenheit, Gestalt des Wasserbeckens eine teils fördernde, teils hindernde Rolle. Dazu treten ferner biologische Faktoren, wie Nahrungserwerb, Fortpflanzungstrieb, Beziehung zwischen pflanzlichem und tierischem Plankton, sowie innerhalb des animalen Planktons.

Alle Theorien aber, die sich nur auf die ebengenannten Faktoren stützen, reichen zur Erklärung der periodischen Wanderungen des Planktons nicht hin. Auch die Tropismen und die aktiven Eigenbewegungen treten bei der Erzeugung jener Erscheinungen in den Hintergrund.

Die Vertikalwanderungen des Planktons sind vielmehr theoretisch einer rein physikalischen Deutung zugänglich. Erniederung der innern Reibung, hervorgebracht besonders durch Erhöhung der Temperatur, gibt den zum Sinken des Planktons nötigen Anstoss. Extreme Zunahme der innern Reibung aber kann niemals eine aufsteigende Bewegung auslösen. Der Aufstieg wird rermittelt durch Diffusionsströme und aktive Wanderung.

Die Betrachtung der in den Gewässern eintretenden Temperaturschwankungen lässt eine Theorie der periodischen V'ertikalwanderungen des Planktons aufstellen. Entsprechend dem Gang der Temperatur 
finden sich in der freien Natur zwei Gruppen von Wanderungen, die täglichen und die jährlichen.

Dies zeigt Verf. zunächst an dem theoretischen Beispiel eines Normaltags mit Durchschnittstemperatur und absoluter Temperatur von mittlerer Höhe, an einem Normalsee von mittlerer Lage, Tiefe, Grösse usw., in dem das vertikal gleichmässig verteilte Plankton überall minimale Sinkgeschwindigkeit besitzen und auch sonst die gleichen Lebensbedingungen finden wïrde. Die Einwirknng des Temperaturverlaufs auf die innere Reibung und damit auf die Sinkgeschwindigkeit des Planktons ruft ein Absteigen der pelagischen Lebewesen während der vorgeschrittenen Tagesstunden hervor, Diffusionsströme usw. bewirken ein Aufsteigen in der zweiten Hälfte der Nacht, gegen den Morgen.

Nach der verschiedenen Beschaffenheit der das Plankton zusammensetzenden Organismen, nach dem rerschiedenen Grad der aktiven Schwimmfähigkeit und besonders des Formwiderstands verlaufen die Wanderungen abweichend. Durch Beleuchtung dieser Punkte erklärt sich eine Fülle ron Einzelerscheinungen. Die guten Schwimmer erreichen die Oberfläche zuerst und verlassen dieselbe zuletzt; grössere Organismen sinken bei eintretender Erwärnung schneller und frïher und verweilen lïnger in der Tiefe; kleinere Wesen, besonders Jugendformen und Entwicklungsstadien im allgemeinen wandern passiv zuerst nach oben, zuletzt nach unten usw.

Ausser nach den biologischen Einflüssen richtet sich die Wanderungsperiode in ihrem regelmäbigen, täglichen Verlauf nach einer grossen Zahl äusserer, physikalischer Faktoren. So beeintlusst der Salzgehalt des Wassers die Tiefenerstreckung der Wanderungen; die Durchsichtigkeit spielt eine Rolle, weil die Erwärmung zum Teil von ihr abhängt. Wind und Wellen, Beschaffenheit der Gewässer üben ebenfalls einen Druck aus, ohne dass sich einstweilen allgemeine Gesetze über den Einfluss dieser Faktoren aufstellen liessen.

Nach der Besprechung und theoretischen Deutung der täglichen Planktonwanderungen wendet sich $\mathrm{O}$ st w a ld zu den jährlichen Perioden der Vertikalbewegungen. Er geht dabei wieder von normalen Vittelverhältnissen aus und zeigt, dass die Temperaturkurve des Jahrs und die von ihr abhängenden Diffusionsströmungen besonders in einem Punkt von derjenigen des einzelnen Tags abweicht. In Jahresverlauf erreichen die Diffusionsströme theoretisch zweimal ein Maximum, in der Tageskurve nur einmal. Dem entsprechen faktisch zwei maximale, jährliche Auftriebperioden, eine im Frühjahr und eine im Herbst. Die Einzelheiten in der Gestaltung dieser Maxima stimmen mit den Forderungen der aufgestellten Theorie gut überein. Dem mit den 
Planktonfragen und ler Planktonliteratur einigermaßen Vertrauten wird es ïberhaupt nicht entgehen, dass die empirischen Beobachtungen eine weitgreifende Bestätigung der physikalisch-theoretischen Deduktionen des Yerfassers enthalten, ohne dass derselbe nötig hätte, den speziellen Beweis dieser Übereinstimmung ron Theorie und praktischer Erfahrung zu erbringen. Durch die Anwendung der neuen begrifflichen Hilfsmittel ist aber gleichzeitig auch eine Menge neuer Probleme, denen Ostwald später näler zu treten verspricht, aufgestellt worden.

Den Fällen, in welchen das Plankton auf Ïnderungen der Schwebefähigkeit infolge Herabsetzung der innern Reibung nicht biologiseh antworten konnte, stehen solche gegenüber, bei denen die regulierende Reaktion biologischen Charakter besitzt. Nach der Schwebeformel kann es sich dabei nur um Ïnderungen des Ïbergewichts, oder des Formwiderstands, oder beider genannter Fiktoren gleichzeitig handeln. Die Regulation sucht die Planktonindividuen an dem eimmal eingenommenen Ort, der gewöhnlich einem Optimum der Lebensbedingungen entspricht, zu erhalten.

Unter den diesbezüglichen physikalischen, auf das Individuenplankton sich beziehenden Erscheinungen hebt Verf. das Verhalten der manchen Planktonwesen zukommenden Gasblasen herror. Bei steigender 'Temperatur wird der durch Abnahme der innern Reibung vermehrten Sinkgeschwindigkeit ein physikalischer Compens durch Zunahme des Auftriebs der Gasblase gegenübergestellt. So erhalten besonders viele Vertreter des Phytoplanktons eine sehr praktische und leicht zu erwerbende Regulation.

Als Beispiel der Veränderung des Formwiderstands im Anschluss an eine Ïndermng des spezifischen Gewichts durch Volumenvergrösserung führt Verf. u. a. das Pseudopodienspiel an.

Das Individuenplankton reagiert ferner physikalisch gegenüber chemischen Veränderungen des Wassers, besonders Variationen seines Salzgehalts. Bei Abnahme des Salzgehalts und damit der innern Reibung und Zunahme der Sinkgesthwindigkeit stellt sich eine regulierende Herabsetzung des spezifischen Gewichts des Planktonkörpers durch Wasseraufnahme ein. Umgekehrt folgt der Erhöhung des Salzgehalts und der innern Reibung auch eine solche des spezifischen Gewichts durch Wasserabgabe.

Änderungen der beiden biologischen Faktoren, besonders aber des Formwiderstands, geben Anlass zur Temporal-, Saison-, Lokalusw. -Variation des Planktons. Diese biologischen Anpassungen der schwebenden Organismen an Veränderungen der innern Reibung werden vom Verf. final, d. h. in bezing auf ihre Bedeutung für die 
Schwebefähigkeit besprochen. Die Theorie verlangt, dass die Sommervariationen einen grössern Formwiderstand besitzen müssen. Diesem Ziel führen zwei Wege entgegen, die von der Natur in der Tat auch betreten werden: die starke Zunahme der absoluten Oberfläche und die mehr direkte Zunahme der spezifischen Oberfläche. Auch die Tatsache, dass Kolonien bildende Planktonten im Sommer anders aussehen als im Winter, lässt sich von dem durch den Verf, eingenommenen Standpunkt aus deuten. So kann die Frage bejaht werden, ob die zeitlichen Planktonveränderungen den veränderten Schwebebedingungen entsprechen.

Variationen, die mit einiger Bestimmtheit auf die Einwirkung äusserer Faktoren bezogen werden können, sind ferner Veränderungen des Formwiderstands infolge wechselnden Salzgehalts des Mediums. Damit mag die Tatsache in Zusammenhang stehen, dass süsswasservarietäten einen bedeutend grössern Formwiderstand besitzen Auftreten von Borsten, Dornen, Stacheln usw. - , als in Salzlösungen lebende Variationen.

Für eine weitere Gruppe ron Variationen gewisser Planktonformen, besonders für lokale Änderungen, ist der bedingende Falitor einstweilen unbekannt. Es zeigt sich dabei deutlich, dass die Planktonorganismen neben der Anpassung an die Schwebefühigkeit noch eine solche an eine Menge anderer Lebensgeschehnisse (Ernährung, Fortpflanzung usw.) besitzen. Doch verknüpfen sich die allgemeinen biologischen Eigenschaften mit der speziellen Planktonqualität der Schwebefähigkeit oft sehr eng. Namentlich die Fortpflanzung steht oft in interessintem \%usammenhang mit den Schwebegeschehnissen (Dissogonie der (tenophoren, Verhalten der Bosminen u. a m.).

Der Schwerpunkt der ganzen Abhandlung liegt in der Entwicklung der physikalischen Begriffe und in der entsprechenden Definition der Schwebevorgänge. Aus dieser nähern und genauern Definition des Scliwebens gehen in letater Linie alle Resultate hervor, die von dem neuen Gesichtspunkt Ostwalds aus gewonnen werden können. Alle ausgesprochenen theoretischen Gedanken sind priifbar, zum Teil sogar experimentell. Für das wahre Verständnis der Planktonvorgänge aber dürfte die Aufstellung der pliysikalischen Theorie Ostwalds einen sehr bedeutungsvollen Wendepunkt bezeichnen.

$$
\text { F. Zschokke (Basel). }
$$

109 Voigt, M., Das Zooplankton des kleinen Uklei- und Plussees bei Plön. In: Forschungsber. Biol. Stat. Plön, Teil 10. 1908. pag. 105-115.

1 Abb. in Text.

Die beiden nicht zum Flussgebiet der Schwentine gehörenden Seen weichen biologisch in mehrfacher Hinsicht von den übrigen Wasserbecken der Plöner 
Gegend ab. Der in Laub- und Nadelwald liegende Plussee erreicht bei 13 ha Fläche $29 \mathrm{~m}$ Maximaltiefe, während der von Buschholz ungebene Ukleisee nur 2,5 ha Fläche und $15 \mathrm{~m}$ Tiefe misst. Beiden Behältern fehlen sandige Ufer. Der geringe Kieselsäuregehalt erlaubt nur eine dürftige Entfaltung der Diatomeen.

Neben der Aufzählung der limnetisclien Tiere und der Darstellung ihrer Periodicität im Jahreslauf berïcksichtigt Verf, auch die Zusammensetzung der Uferfauma der zwei Seen.

Das Zooplankton des Ukleisees ist arm; viele pelagische Tiere der benachbarten Gewässer fehlen oder treten nur während ganz kurzer Zeit auf, wie manche Rotiferen. Organismen, die in einem Jahr massenhaft vorkommen, erscheinen im nächsten Jahr gar nicht. So erleidet der Verlauf der Planktonperiodicität eigentümliche Schwankungen. Die ärmliche Entwicklung des Phyłoplanktons, besonders der Diatomeen, dürfte in erster Linie die quantitative und qualitative Armut der limnetischen Tierwelt bedingen.

Biologisch näher verwandt mit den äbrigen Seebecken des Untersuchungsgebiets ist der Plussee. Störungen im periodischen Auftreten der Planktonten fallen weniger auf, als im Ukleisee. Dagegen ist die Tatsache beachtenswert, dass gewisse Rotatorien, wie Flosculuria mulabilis Bolton und Gastropus stylifer, die in den andern Plöner Seen zu den Sommerformen gehören, im Plussee auch im Winter ausdauern.

F. Zschokke (Basel).

410 Kacharias. O.. Biologische Charateristik des Klinkerteichs zu Plön. In: Forschungsber. Biol. Stat. Plön. Teil 10. 1903. pag. 201-215. 1 Abb. im Text.

Ein wenig tiefer Teich von mäßjigem Unfang, der viel Abwässer aufnimmt, erwies sich bei der im Laufe von 9 Jahren wiederholt vorgenommenen biologischen Untersuchung als arm an Algen und wenig reich an Tieren. Nur die Bakterien gedeihen üppig.

Die faunistische Liste umfasst 24 Protozoen, 34 Rotatorien und 6 Crustaceen. Über das lokale und temporale Auftreten, die Häufigkeit und Biologie der einzelnen Arten führt Verf. kurze Beobachtungen an. Beachtung verdient die Gegenwart des sonst nur aus Norwegen bekannten Peridinium laeve Huitfeldt-Kaas und des seltenen Phascolodon vorticclla Stein. Chilodon cucullulus Ehrenb. parasitiert auf jungen Fischen; das sehr anpassungsfähige Infusorium lebt aber auch in ganz heterogenen Medien, wie in dem von gewissen Cikaden abgeschiedenen Schaum (Kuckucksspeichel). Neu ist die anf Rädertierchen und seltener auf Crustaceen sitzende Rhabdostyla congregata.

Die Rotatorien machen den Hauptbestandteil des vorhandenen, an Gesamt. menge nur spärlich vertretenen 'T'eichplanktons aus. F. Zschokke (Basel).

411 Zacharias, O.. Zur Kenntnis der niederen Flora und Fauna holsteinischer Moorsümpfe. In: Forschungsber. Biol. Stat. Plön. Teil 10. 1903. pag. 223-289. Taf. 2. 8 Abb. im Text.

Die bis jetzt wenig bekannte Tier- und Pflanzenwelt der Torfgewässer findet in Zacharias einen Bearbeiter, der im Sommer, Herbst und teilweise im Winter kleine Tümpel, grössere Lachen, Moorteiche, Torfgräben, torfige Waldsümpfe der Plöner Gegend floristisch und faunistisch untersuchte. Den Organismenlisten der einzelnen Lokalitäten lässt Verf. die Schilderung der neuen Formen und Bemarkungen über Auftreten, Häufigkeit, Periodicität, Biologie und Morphologie der bekamnten Arten folgen. 
Ein kleiner, von Sphagnum durchwaclisener seichter Tümpel lieferte zwei neue Arten von Chlorophyceen, Selenococeus farcinalis und Atractinium schmidlei, sowie das in Genus und Species unbekannte Bakterium Pseudospirillum nliginosum. Im faunistischen Verzeichnis figurieren als neu Cryptodiffngia turfacea Zach., Vorticella sinnata Zach. und das dem Stenostoma lemnae Duj. nahestehende, doch keine Otolithenbläschen besitzende St.turgidum. Zu den seltenern Formen zählt das ausfïhrlicher beschriebene Heliozoon IIeterophrys myriopoda Archer. Polyarthra platyptera fand sich in einer sehr beweglichen Zwergvarietät. Selten war Cathypna ligona Dunlop, häufig dagegen traten auf Chactonotus succinctus Voigt und Ch. chuni Voigt und die weitverbreitete Oribatide Notaspis lacustris Mich.

Im ganzen mmfassen die Listen 60 Algen und 77 Tiere (24 Amöbinen, 3 Heliozoen, 15 Mastigophoren, 7 Ciliaten, 1 Suctorie, 19 Würmer, 5 Arthropoden) Amöben und Flagellaten spielen die Hauptrolle, während die Ciliaten an Bedentung zurücktreten. Ein eigentliches Plankton fehlt.

Mit dem Eintritt herbstlicher und winterlicher Temperaturen ging das tierische Leben sehr stark zurück, auch die meisten Pflanzen wurden seltener. Eine Moorlache von 3-4 Aren Fläche und 2-3m Tiefe beherbergte eine durch Entomostraken und Insektenlarven, sowie durch eine geringe Protozoenvertretung

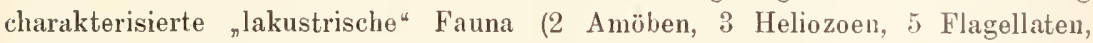
2 Ciliaten, 1 Turbellarie, 5 Cladoceren, Insektenlarven). Interesse verdient die Gegenwart von Sphaerastrum fockei Arch. und der festsitzenden Flagellate Histiona zachariasi Voigt. Simocephains vetulus war reichlich mit Amocbidium parasiticum Cienk. besetzt, dessen Bau, Fixationsweise und Bildung amöbenhafter Sporen Verf. bespricht.

In einem grössern und tiefern Noorteich fanden sich drei neue Varietäten der Alge Raphidium polymorphum und Mallomones fastigata nov. spec. Eine schwebende Flora und Fauna trug den Cliarakter des Heleoplanktons mit dem typischen Vorkommen von Brachionus und zahlreichen Rotiferen und Chrysomonadinen. Neu für das Plankton ist Bursaria truncatella O. F. M. Im Januar nahm die Planktonquantität bedeutend ab, während die qualitative Zusammensetzung der freischwimmenden Organismenwelt bunt blieb.

Der an den untersuchten Teich sich anschliessende Torfgraben lieferte 5 Sarkodinen, 3 Heliozoen, 21 Flagellaten, 11 Ciliaten, 1 Iydra, 1 Turbellarie, 5 Rotatorien, 2 Chaetonotinen, 2 Oligochäten, 2 Cladoceren, 1 Hydrachnide. Davon werden als neu beschrieben die 2 Flagellaten Menoidium falcatum und Heteronema tremulum und die zwei Ciliaten Leptodesmus tenellus n. g. n. sp. und Spirostomum teres Clap. et Lachm. var. caudatum n. var.

Der holotriche Leptodesmus tencllus schliesst sich an die Trachelinen an und steht vielleicht der Gattung Dileptus am nächsten. Wenigstens besass ein Exemplar über der Mundöffnung einen rüsselförmigen Fortsatz, den Z a ch arias als atavistischen Rückschlag auf Dilcptus deuten möchte.

Erwähnenswert ist auch das Vorkommen der schlammbewohnenden Cladocere Iliocryptus agilis Kurz und die für Moorgewässer im allgemeinen geltende Seltenheit der Hydrachniden.

Gewisse Algen färben sich im Moorwasser komplementär zur Farbe des einwirkenden Lichtes. Sie gehen einen Anpassungsprozess, die „chromatische Adaption“ im Sinne Engelmanns ein. Wie die Züchtung von Oscillatoric sancta bewies, vererbt sich die neuerworbene Färbung.

Torfige Waldsümpfe zeichneten sich durch Reichtum an Diatomeen (78 Arten) aus. Für Deutschland wurde in ihnen zum ersten Male Ceratinm curvirostre Huit- 
feldt-Kaas gefunden, das sich morphologisch zwischen $C$. hirundinella und $C$. cornutum einschiebt. Ein Exemplar von Mesostoma viridatum M. Sch. trug ein ahnorm grosses, mehrere Embryonen umschliessendes Ei.

Endlich bestimmte Verf. Material aus nicht bei Plön gelegenen, doch meistens norddeutschen Torftümpeln. Es fand sich darin u. a. der skandinavische Moorbewohner Difflugia ollciformis Lagerh.

F. Zsehokke (Basel).

112 Zacharias, O.. Über die jahreszeitliche Variation von Hyalodaphnia kahlbergensis Schoedl. In: Forschungsber. Biol. Stat. Plön. Teil 10. 1903. pag. 293-295. 2 Abb. im Text.

Die Herbstgenerationen von Hyalodaphnia kahlbcrgensis verkürzen gegeniuber der Sommerform derselben Art die Länge von Kopf und Schalenstachel bedeutend. Die Verkürzung des Kopfs vollzieht sich auf dem Weg der Häutung. Experimen. telle Untersuchungen von W. Ostwald deuten indessen darauf hin, dass die Temperatur des bewohnten Wassers das Längenwachstum des Kopfhelms von Hyalodaphnien direkt beeinflusse. F. Zschokke (Basel).

413 Zacharias, O.. Über Grïn-, Gelb- und Rotfärbung der Gewässer durch die Anwesenheit mikroskopischer Organismen. In: Forschungsber. Biol. Stat. Plön. Teil 10. 1903. pag. 296-303.

Verf. stellt nach eigener Erfahrung und nach der Literatur Fälle zusammen, in welchen Organismen die Buntfärbung von Wasseransammlungen bewirkten. Eine biologisch bedeutsame Rolle spielen besonders die grünfärbenden Algen, da sie während des Tags den Sanerstoffgehalt des Wassers gewaltig zu steigern vermögen. Neben zahlreichen rein pflanzlichen Organismen fallen in dieser Richtung auch manche Flagellaten in Betracht.

Gelbfärbung wird hauptsächlich durch Diatomeen hervorgerufen: daneben wirken älnlich massenhaft auftretende Exemplare von Ceratium hirundinella und von Dirobryon-Kolonien.

Für die Rotfïrbung sind verantwortlich zu machen Euglena sanguinea, Astasia haematoides und IIacmatococeus pluvialis. Doch sind auch Fälle bekannt, wo Entomostraken und Hydrachniden (Daphnia pulex, Diaptomus, Cyclops, Diplodontus decipiens) die rote und gelbe Farbe hervorbrachten. Starke Färbung des Meers durch rötliche Organismen - Peridinium, Protococeus - fiel mehrem Beobachtern auf. F. Zschokke (Basel).

414 Zacharias, O.. Einige Beobachtungen an der sog. „Stadtpfütze"zu Hohenmölsen. In: Forschungsber. Biol. Stat. Plön. Teil 10. 1903. pag. $304-308$.

Fin kleines Bassin, das auf dem Marktplatz zu Hohenmölsen (Prov. Sachsen) als Wassersammler dient und häufig Verunreinigungen enthält, beherbergt neben einigen Entomostraken und Rotiferen (Daphnia magna Straus, D. obtusa Kurz, Graptoleberis testudinaria Fischer, Cyclops strenuus Fischer, Triarthra mystacina Ehrbg., Brachionus urecolaris Ehrbg.) auch Ceratium hirundinclla O. F. M. und die stiellose Vorticella vaga Römer, sowie ihre dickwandigen Dauercysten. Im Bodenschlamm lebten, ausser vielen Bakterien und Cevcomonas elavata Perty, die bisher für Deutschland unbekannte Diffugia ollcifermis Lagerh. und Amocba proteus Ehrbg. Eine grosse Amöbe, die sich vermittelnd zwischen Pelomyxa palustris Greeff und 1 '. villosa Leidy einschiebt, beschreibt $\mathrm{Z}$ acharias als $P$. intermedia nov. sp.

$$
\text { F. Zschokke (Basel). }
$$




\section{Coelenterata.}

15 Stevens, N. M., Regeneration in Antemularia ramosa. In: Arch. f. Eutwmech. Bd. 15. Heft 3. 1902. pag. 429-447. 12 Textfig.

Antermularia ramosa ist namentlich dadurch von der von J. L o e b auf die Regeneration untersuchten A. anteminc verschieden, dass der Stamm reichlich verzweigt ist, und die Regenerationsvorgänge erscheinen auch wesentlich verschieden. Die Art und Weise der Regeneration wird bei der von der Verfasserin untersuchten Art nicht durch Polarität bestimnt, auch nicht durch die Orientierung des Stiickes in bezug auf die Schwerkraft oder durch Verhältnisse, die an andern Ende des Stïcks bestehen, wenn nicht bei normaler Anheftung des 'Tieres; eher sind die bestimmenden F'aktoren in der Topographie der Stiicke zu suchen, indem gewisse Stengelstiicke die Tendenz haben, Wurzeln, andere dagegen Stämme herrorzubringen: basale Stiicke bringen meistens Stämme herror, Stïcke aus der Mitte erzeugen Wurzelı, Stïcke aus der Spitzenregion (dem Wachstumsbezirk) haben die Neigung, den Stamm nach unten fortzusetzen. Stïcke, denen es nicht gelungen ist, sich mittelst ihrer Wurzeln festzuheften, oder welche durch wiederholtes Hervorbringen von Wurzeln erschöpft sind, erzeugen schliesslich einen oder mehrere Stämme an den Enden oder seitlich.

Das Cönosark besitzt in den rerschiedenen Regionen (Wurzeln und Stämmen) durchaus einförmigen Bau, so , dass man es einer Wachstumsform entziehen und zu einer andern bringen kamn, ohne dass neues Gewebe produziert wird". - Die Regeneration bei dieser Art scheint, wenigstens in den frühern Stadien, mehr Anpassung des (önosarks an neue Bedingungen und Zwangsverhältnisse darıustellen, als dass dabei unter Kellwucherung der Aufbau nener Gewebsteile veranlasst wird. - „Das Cönosark kann von allen Pinnae und Neubildungen hinweg auf den alten Stamm zurückgebracht werden und bleibt dann wochenlang untätig - wenigstens zwei Monate - dann treibt es anf einmal schnell neue Wurzeln und Stämme an den Seiten und Enden des Stengels".

R. S. Bergh (Kopenhagen).

416 Gardiner, J. Stanley, South African corals of the genus Flabellum, with an account of their anatomy and development. In: Marine Investigations in South Africa. Vol. II. 1902. pag. 113-154. Taf. I-IV.

Die vorliegende Arbeit bildet den ersten 'Teil eines Berichtes über eine schöne Korallensammlung vom Kap der guten Hoffnung.

Zoolog. Zentralbl. X. Jahrg.

- Nr. $415-416$. - 
Diese Sammlung ist deshalb von besonderm Interesse, weil dieselben Formen wiederholt in mehr oder weniger verschiedenen Lokalitäten gedredgt worden sind, wodurch die Möglichkeit gegeben ist, die lokale Variation zu beurteilen und mit den physikalischen und andern Bedingungen in Beziehung zu bringen.

Nach einer allgemeinen Charakteristik der Gattung Flabellum gibt Terf. eingehendere Beschreibungen von Flabellum paronimum und Fl. rutrum sowie eine ausführliche Darstellung der gröbern und feinern Anatomie der Polypen von Fl. mbum. Dann folgen Mitteilungen über die postlarvale Entwicklung ron Fl. rubm. Den Schluss bildet eine Zusammenfassung der Hauptresultate.

$$
\text { W. Ma y (Karlsruhe). }
$$

417 Gardiner, J. Stanley, Some notes on variation and protandry in Flabellum rubum, and senescence in the same and other corals. In: Proceed. Cambridge Philos. Soc. Vol. XI. Pt. VI. 1902. pag. 463-471.

Verf. erhielt vom Südafrikanischen Museum in Kapstadt einige Hundert Exemplare ron Flabellum zur Bestimmung. Ton diesen gehörten 8 zu $F$. pavonimum, alle iibrigen - iiber $500-$ zu $F$. rubum, mit dem $F$. cumingii, elongatum, crassum, crenulatum, elegans, spheniscum. mofundum, irregulare und transiersale synonym sind. Verf. standen ferner Exemplare von den Maldiven und die Sammlung des Britischen Museums zur Verfügung. Auf Grund der Untersuchung dieses reichen Materials gelangte er zu der Überzeugung, dass die bisher getrennten Arten Flabellum rubrum, $F$. stokesi und $F$. (Blastotrochus) mutrix als Varietäten einer einzigen Species anzusehen sind. Es ist dies der erste Fall von unterbrochener Variabilität bei den Madreporarien. Gemäß den Regeln der Nomenklatur muss die Species als $F$. rubum bezeichnet werden, die beiden Varietäten als var. stokesi und var. mirix. Diese Bezeichnung beweist den unglïcklichen und undehnbaren Charakter jener Regeln. Denn die Benennung einer typischen Form unter den drei genannten Formen ist augenscheinlich nicht wünschenswert. Die zuerst beschriebene Form repräsentiert nur einen besondern Fall normaler Variabilität, der wahrscheinlich durch die Einfliisse der Umgebung hervorgerufen worden ist, wie gewöhnlich bei den Korallen.

Verf. schildert sodann die Entwicklung der Genitalorgane bei Flabellum rubrum, die Bildung der Hoden, ihre Verdrängung durch die Ovarien, die Entlassung der Eier und deren Ersetzung durch nene Eier. Es geht aus dieser Darstellung der protandrische Charakter der Species hervor. 


\section{- $415-$}

Den Schluss der Abhandlung bildet eine längere Auseinandersetzung über das Absterben der Korallen, zu der Yerf. durch seine Beobachtungen bei Flabellum rubmum angeregt wurde. Das Ảbsterben ist eine gewölnliche Erscheinung auf den Riffen und ist von den meisten Korallenforschern beokachtet worden. In manchen Fällen ist es der Entblössung vom Wasser zu verdanken, in andern der Verschlammung oder einer zu hohen Temperatur, aber in solchen Fällen werden nicht nur eine oder zwei Species von Korallen beeinflusst, sondern das Korallenwachstum auf dem ganzen Gebiet. Im Gegensatz dazu steht das Absterben, das nicht auf äussere Ursachen zurïckgeführt werden kann, wo einzelne Kolonieen absterben oder eine Anzahl von Kolonieen einer einzelnen Species in einem abgesonderten Gebiet. Einzelne tote Kolonieen werden oft gefunden, wo benachbarte Kolonieen derselben Species in Blïte stelien. Dies ist jedenfalls dirauf zurückzuführen, dass das Wachstum der Kolonieen durch innere, in den Organismen selbst liegende Ursachen beschränkt ist, in ähnlicher Weise wie das Wachstum der Bäume. Es wird ein Maximum der Produktivität erreicht, dann wird der elterliche Organismus allmählich weniger fruchtbar und stirbt schliesslich ab. Doch bietet die Tatsache des Absterbens der Korallen noch viel Un. erklärtes und erfordert weitere Untersuchung. W. May (Karlsruhe).

418 Morolf, Th., Studien über Octocorallien. In: Zool. Jahrb. Abt. f. Syst. Bd. XVII. Heft 3. 1902. pag. 363-410. Taf. 14-18.

Der erste Teil dieser Arbeit handelt iber die Pennatulaceen des Münchener Museums, der zweite über einige nene Gorgonaceen aus Japan.

Die Ordnung der Pennatulaceen ist in der Münchener Sammlung durch eine verhältnismäßig begrenzte Zahl von Exemplaren vertreten, die zu verschiedenen Zeiten teilweise von privaten Sammlern, teilweise von der \%oologischen Station in Neapel erworben wurden. Neuerlich wurde diese Gruppe bedeutend vermehrt durch das Material, welches Doflein aus Californien und Haberer aus Japan mitgebracht haben. Ganz nenerdings ist dem Muinchener Museum die grosse Sammlung Köllikers zugefallen, die aber für die vorliegende Arbeit nicht mehr benutzt werden konnte.

Die grösste und wichtigste Arbeit über die Pennatuliden hat Kölliker geliefert, und er verdient die vollste Anerkennung für seine sorfältige Bearbeitung des damals existierenden Materials. Als eine endguiltige Gattungs- und Artabgrenzung dïrfte seine Monographie aber kaum angesehen werden können, da viele Arten und manche Gattungen nach sehr ungenügendem Material aufgestellt 


\section{$-416-$}

worden sind. Es scheint, als ob die Arten dieser Gruppe viel mehr veränderlich sind, als dies angenommen wurde; es dürfte dalier die vergleichende Untersuchung eines genügend zahlreichen Naterials viele Arten und manche Gattungen wieder verschwinden machen. Anch scheint man die richtigen Artunterschiede, auf Grund deren die einzelnen Arten charakterisiert werden sollten, nicht besonders glïcklich herausgefunden zu haben.

Verf. beschreibt 23 Arten, die sich in folgender Weise auf die einzelnen Familien verteilen: Pteroididae 5, Pennatulidae 6, Virgularidae 5, Stylatulidae 1, Funiculinidae 1, Kophobelemnonidae 2, Renillidae 1, Lituaridae 2. Unter diesen 23 Arten sind folgende neun neu: Ptcroides sagamiense (Japan), Pt. rhomboidale (Japan), Pennatula americana (Massachuselts), Ptilosarcus quadrangularis (Californien), Tirgularia rigida (Philippinen), Pavonaria dofteini (Californien), P. californica (Californien), Acanthoptilum scalpellifolium (Californien), Carernularia habereri (Japan).

Die 4 neuen aus Japan stammenden Gorgonaceen, die V'erf. im zweiten Abschnitt beschreibt, sind: Pleurocorallium confusum, Pleurocoralloides formosum, P'aramurice procera und Plexamides asper.

iV. M a y (Karlsiuhe).

\section{Echinoderma.}

419 Stevens, N. M., Experimental Studies on Eggs of Echimes microtuberculatus. In: Arch. f. Entwmech. Bd. 15. Heft 3. 1902. pag. 421-428. Taf. 13.

Die Aufgabe war folgende: Seeigeleier in einer Anaphase der ersten Teilung in Stücke, die weniger als die normale Chromosomenzahl enthielten, zu zerschneiden und ihre weitere Entwicklung zu verfolgen, um festzustellen, ob die verkleinerte Anzahl der Chromosomen sich auch während der weitern Teilungen erhalte, oder ob die normale Zahl wieder hergestellt werde. Die Ergebnisse, zu denen Verfasserin durch diese Untersuchungen gelangte, sind folgende:

Ein Teil eines Echinus-Eies, welcher ein Centrosoma und eine kleine Anzahl von (Chromosomen ( $4-12$; die normale Zahl ist 18) enthält, kann in der Entwicklung bis zur fünften oder sechsten Teilung nach der Operation vorschreiten, ohne zu der konstitutionellen Anzahl von Chromosomen zurückzukehren (gegen Delage). Chromosomen können sich wiederholt teilen, ohne dass eine Spindel vorhanden zu sein oder Kern- und Zellteilung einzutreten braucht. Centrosomen können ganz ron neuem in einer Blastomere erscheinen, aus der das Centrosom während der Anaphase der ersten Teilung entfernt worden ist. - Die erste Furchung wird von Stücken, welche die entsprechende Teilungsebene einschliessen, die Spindel aber nicht enthalten, gewöhnlich rollendet; bei Stücken aber, die jene Teilungs- 
ebene nicht enthalten, tritt nur dann Zellteilung ein, wenn Chromosomen und Centrosomen gegenwärtig sind.

\author{
R. S. B e rgh (Kopenhagen).
}

\title{
Vermes.
}

\section{Nemathelminthes.}

420 r. Linstow, O., Parasiten aus Siam. In: Arch. mikrosk. Anat. Bd. 62. 1903. pag. 108-121. Taf. V.

Es werden beschrieben Ascaris infundibulicola n. sp. aus Python reticulatus, Lippen mit Zahnleisten und Zwischenlippen; 1. solitaria n. sp. aus dem Magen von Dipsadomorphus dendrophilus, Lippen wie bei voriger Art; A. dipsadomorphi n. sp., eine Larve mit Bohrzahn aus dem Mesenterium von Dipsadomorphus den. diophilus; Heterakis rimula n. sp. aus Centropus sinensis, Saugnapf am männlichen Schwanzende langgestreckt und schlitzförmig; IIeterakis circularis n. sp. aus Centropus sinensis, Saugnapf kreisförmig; Cheilospirura ophthalmica aus dem Auge von Tunix taigor; Männchen am Schwanzende mil zahlreichen, dichtgedrängten Papillen vor der Cloake; Cheilospirura siamensis n. sp. aus Centropus sinensis das Genus Cheilospinira gehört zu den Secernentes und die Arten leben im Auge von Vögeln und Säugetieren; Oxyuris siamensis n. sp. aus dem Magen von Liolepis bellii, am Kopfende sechs Lippen mit je drei Papillen; Oxyuris coronata n. sp. aus dem Dickdarm von Galeopithecus rolans, am Kopfende mit sechs an der Spitze nach aussen gebogenen Lamellen; Oxysoma tuberculatum n. sp. aus dem Darm von Megalophrys montana, Cloakenöffinung des Männchens prominent, davor eine polsterartige Erhebung, beide von Stäbchen eingefasst; Filaria longicirrata n. sp. unter der Haut von Galcopithecus volans, das eine Spiculum sehr lang; Filaria sciuri n. sp. unter der Haut von Sciurus caniceps gefunden; Angiostomum brachylaimus n. sp. aus Bufo melanostictus, hermaphroditische Weibchen, wahrscheinlich aus der Lunge; Lissonema rotundatum n. gen.; n. sp. aus Centropus sinensis, niedrige und breite Seitenfelder ohne Gefäss, ein Porus excretorius fehlt, Männchen mit zwei gleichen Spicula, vor der Cloake nur eine unpaare Papille; gehört zu den Resorbentes.

o. v. Linst ow (Göttingen).

421 Looss, A., Weiteres über die Einwanderung der Ankylostomen von der Haut aus. In: Centralbl. f. Bakter., Parask. u. Infkr. I. Abth. Orig. Bd. XXXIII. 1903. pag. 330-343.

Verf. untersuchte durch Wochen hindurch die Darmentleerungen eines Mannes und fand sie ohne Ankylostomum-Eier; dann wurden ihm einige Tropfen eines stark larvenhaltigen Wassers auf den Arm gebracht; die Haut rötete sich später an den befeuchteten Stellen und 71 Tage darauf traten Ankylostomum-Eier in den Fäces auf, die von da an Zahl zunahmen. Auch Pieri wiederholte dies Experiment mit positivem Erfolg; 75 Tage später traten Ankylostomum-Eier in seinen Exkrementen auf und durch eine anthelminthische Kur wurden Ankylostomen entleert. Trotzdem ficht Pieri und mit ihm Grassi die Loosssche Beobachtung an und erklärt den Erfolg seines Experiments für Zufall. L,ooss entfernte von einer Hautstelle bei 
einem Hunde die Haare und brachte Kotkohlenbrei auf den Ort mit zahlreichen Larven von Ankylostomum caninum Erc.; nach 2 Stunden wurde die Hautstelle gereinigt; 10 Tage darauf war der Hund tot und zeigte im Darm kleine Hämorrhagien und in ihnen zahlreiche ganz junge, zum Teil in Häutung begriffene Ankylostomen. Zwei andere Hunde wurden ebenfalls mit Ankylostomum-Larven infiziert, der eine in der angegebenen Weise, der andere per os; der erstere starb am 10., der andere am 12. Tage nach dem Versuch und beide enthielten zahlreiche ganz junge Ankylostomen im Darm, die noch kein Blut gesogen hatten; der Tod der Hunde war also durch Giftwirkung der Parasiten erfolgt. Eintrocknen vertragen die Ankylostomum-Larven nicht.

o. v. Linstow (Göttingen).

422 Low, G. C., Fitaria perstans. In: Brit. med. Journal London. 1903. No. 2204. pag. 722-724. Fig. 1-2.

Filaria perstans Manson erzeugt die Schlafkrankleit in British Guiana, an der Westküste von Afrika, aber auch in Ostafrika, wie in Uganda, auf den Sese-Inseln, in Bulemezy, IIugema, Unyoro, Wadelai. Die Embryonalform im Blute des Menschen ist 0,203-0,205 mm lang und $0,0042 \mathrm{~mm}$ breit und hat ein abgerundetes Schwanzende; sie erscheint in den Hautkapillaren des Menschen bei Tage wie des Nachts; die Embryonalform von Filaria bancrofti Cobbold, welche in den Hautkapillaren nur nachts erscheint, wird bis $0,3 \mathrm{~mm}$ lang, die Breite beträgt $0,008-0,010 \mathrm{~mm}$ und kann, da sich am Tage die Hautkapillaren bis auf einen Durchmesser von $0,0075 \mathrm{~mm}$ kontrahieren, nur nachts im Schlafe in sie eindringen; das Schwanzende der Embryonalform von Filaria bancrofti ist spitz. Die Geschlechtsform von Filaria perstans findet sich im Bindegewebe an der Basis des Mesenteriums; das Kopfende ist etwas verdickt, am kugelförmig verjüngten Schwanzende stehen zwei dreieckige Fortsätze; Länge des Männchens $34 \mathrm{~mm}$, Breite $0,104 \mathrm{~mm}$; am Schwanzende jederseits eine post- und vier präanale Papillen dicht gedrängt; Weibchen $50 \mathrm{~mm}$ lang und $0,160 \mathrm{~mm}$ breit, Vulva $1,22 \mathrm{~mm}$ vom Kopfende, Anus $0,160 \mathrm{~mm}$ rom Schwanzende. Die Geschlechtsform ron Filaria bancrofti ist grösser, Länge des Männchens etwa 40, des Weibchens 76-90 mm; Schwanzende breit abgerundet.

\section{O. v. Linstow (Göttingen).}

423 Shipley, A. E.. On the Nematodes parasitic in the earthworm. In: Arch. de parasitol. T. VI. 1902. pag. 619-623.

Verf. stellt die in Lumbricus terrestris gefundenen Nematoden zusammen und nennt: 1. Pelodera pellio Schneider, eine Art, die als Larve ein Parasit von Lumbricus ist, als Geschlechtsform aber durch Fäulnis des Regenwurms frei geworden 
in der Erde lebt. 2. Ascaris spec.?, eine von Le uckart in den Muskeln des Maulwurfs gefundene Larve, die auch im Magen desselben mit verzehrten Regen. würmern zusammen gefunden wird. 3. Dicclis filaria Dujardin, eine geschlechtsreife Nematodenart, die in den Hoden des Regenwurms vorkommt. 4. Spiroptera turdi Molin, eine zwischen den Magenbäuten von Turdus pilaris, T. iliacus, $T$. merula, T. musicus und Sturmus vulgaris lebende Art, deren Larve in den ventralen Blutgefässen von Lumbricus terrestris durch Cor i gefunden wurde; die Übertragung in Drosseln und Stare ist leicht verständlich, weil Regenwürmer eine beliebte Nahrung für sie sind.

O. v. Linst ow (Göttingen).

424 Shipley, A. E., On a collection of parasites from the Sudan. In: Arch. de parasitol. T. VI. Paris 1902. Nr. 4. pag. 605-612. Taf. VII.

Verf. führt neun bekannte Nematodenarten aus dem Sudan an, Filaria sudanensis v. Linstow ist eine neue Art, die unter der Haut von Felis leo und Hyaenc? striata gefunden ist; das unvollständige Mänuchen war 4 mm lang und $0,39 \mathrm{~mm}$ breit; die Spicula sind sehr ungleich und messen 0,23 und $0,57 \mathrm{~mm}$; jederseits finden sich sechs prä-, eine par- und drei postanale Papillen; Weibchen $162 \mathrm{~mm}$ lang und $0,51 \mathrm{~mm}$ breit; der Ösophagus misst ${ }^{1 / 21}$, die Vulva liegt ganz vorn, der Anus mündet fast terminal, die Eier sind 0,01 mm lang und 0,0052 mm breit.

O. v. Linstow (Göttingen).

425 v. Zykofr. W. P., Materialien zur Wolga-Fauna und der Hydrofauna des Saratowschen Gouvernements. In: Bull. soc. Imp. natur. Moscou. 1903. Nr. 1. pag. 60-64. Tab. I.

Verf. erwähnt an parasitischen Nematoden Ascaris bidentata v. Linstow und Cystoopsis acipenseris Wagn., beide aus Acipenser ruthems, und an freilebenden Dorylaimus striatus v. Daday und Pseudomermis zykoffi n. gen; n. spec. Letztere Art ist im Schlamm der Wolga gefunden und wird nach einem jungen Weibchen beschrieben. Länge $11 \mathrm{~mm}$, Breite $0,11 \mathrm{~mm}$; die Haut zeigt nicht die bei Mermis bekannten zwei sich kreuzenden Liniensysteme; am abgerundeten Kopfende stehen im Kreise in den Submedianlinien vier grosse, kreisförmige Papillen; dicht linter ihnen finden sich in den Laterallinien querovale Seitenorgane; das abgerundete Schwanzende trägt, wie bei den Larren von Mermis albicans und anderen MermisLarren, ein kurzes Horn. Die Längsfelder, welche die Muskulatur unterbrechen, sind aus Reihen quadratischer, grosser Zellen mit rundem Kern gebildet; das Dorsal- und Ventralfeld besteht aus einer Reihe, die Dorsolateralfelder sind aus zwei Reihen solcher Zellen gebildet, die Ventrolateralfelder sind undeutlich; die Mundhöhle führt in ein chitiniges Ösophagusrohr, das zuerst in der Mittelachse verläuft und sich dann nach der Bauchfläche wendet, um mit dem Beginn des zweiten Körperviertels aufzuhören. Darm und Anus fehlen; ein Fettkörper erfüllt fast den ganzen Innenraum; ein Porus excretorius, die Ausmündung einer grossen Ventraldrïse, liegt 
$0,18 \mathrm{~mm}$ vom Kopfende; in derselben Gegeni sieht man auch den Nervenring; die weibliche Geschlechtsöffnung ist ein querer Spalt, der etwa in der Mitte des Körpers liegt. O. v. Linstow (Göttingen).

\section{Annelides.}

426 Janda. Victor, Über die Regeneration des centralen Nervensystems und Mesoblastes bei Rhynchelmis. In: Arb. Instit. f. Kool. u. vergl. Anat. Prag in Jahre 1902. (Vejdovský). pag. 1-59. Taf. 1-3. 6 Textfig. Auch in: Sitzungsber. d. k. bölım. Akad. d. Wiss.

Verf. amputierte die Würmer ohne Narkose. Ausser Rhynchelmis untersuchte er gelegentlich Tubifex, Limmodritus und Lumbriculus, Nereis, Capitella und Emice. Fixierung hauptsächlich in Platinchloridsublinat, Färbung in Delafieldschem oder Heidenhainschem Hämatoxylin und Eosin, Säurefuchsin oder Orange G.

Die von H. Randolph bei Lambriculus bei der Regeneration des Hinterendes nachgewiesenen T'elostichen im Ektoderm findet Verf. wieder und bildet sie sehr deutlich ab; nur findet er nicht wie die genannte Verfasserin fünf, sondern vier jederseits. Über das Schicksal derselben berichtet Verf. folgendes: die inneren (medianen) verschmelzen zur Bildung des Bauchstrangs; einen Nervenplexus, wie sie Ref. bei den Embryonen fand, hat Verf. bei der Regeneration nicht nachweisen können; die alten Nervenelemente nehmen keinen Anteil an der Bildung des neuen Bauchstrangs. Was die drei äussern Telostichen betrifft, so flachen sie sich ab und rerwachsen miteinander, so dass sie nicht ganz scharf auseinander zu halten sind; über das Schicksal derselben berichtet Verf. - ohne genügende Beweise zu bringen und sich offenbar seiner Sache nicht ganz sicher fühlend - dass aus der zweiten wesentlich die innern, aus der vierten die äussern Borstensäcke herrorgehen, während die dritte Reihe wesentlich die Seitenlinie entstehen lässt, (über die Bedeutung der letztern, ob nervöser oder muskulöser Natur, ist Verf. nicht klar; die wichtige Arbeit von $\mathrm{H}$ esse erwähnt er nichts bei der Gelegenheit). Über die Entwicklung der Nephridien ist Verf. zu keinen sichern Ergebnissen gekommen. Am Hinderende der Telostichen kommen Teloblasten nicht vor; dass jene nichts destoweniger den ähnlichen Gebilden bei Embryonen entsprechen, ist aber dem Verf. (wohl mit Recht) über allen Zweifel erhoben.

Der "Mesoblast" bildet sich bei der Regeneration des Hinterendes wesentlich aus den grossen (mitunter kolossalen), von $\mathrm{R}$ a n dolph beschriebenen "Neoblasten"; diese treten konstant in der Spalte zwischen dem Bauchstrang und den ventralen Borstenfollikeln auf; 
sie teilen sich lebhaft mitotisch. Die weitere Differenzierung des Mesoblasts stimmt mit der von Vejdovský für die Embryonalentwicklung geschilderten überein. Paarige "Promesoblasten" wie bei den Embryonen treten nicht auf. Bei der Regeneration des Kopfes treten keine Neoblasten auf; das Mesoderm entsteht hier aus. kleinern, unregelmäPig zerstreuten Zellen.

Bei der Regeneration des Kopfes tritt das Gehirn bedeutend früher auf, als die meisten Autoren es angeben; die Anlagen desselben sind anfangs ventrolateral gelegen; der erste sich entwickelnde Teil des Bauchstrangs ist der distalste, d. h. das untere Schlundganglion. Die Bildung der Dissepimente geht bei der Regeneration des Hinterendes der Gliederung des Bauchstrangs roraus; umgekehrt bei der Regeneration ủes Vorderendes. Die Ringmuskelfasern entstehen aus dẹm Ekitoderm.

Die Autotomie ist meistens mit dem allmällichen Absterben des Individuums verbunden; sie kann an der vordern Körperhälfte viel schwieriger hervorgerufen werden als an der hintern. „Die AutotomieErscheinungen können bei Rhynchelmis keine reelle Bedeutung für die Erhaltung und Verbreitung der Gattung (wie bei Lumbriculus) besitzen".

Einmal fand Verf. am Vorderende ein heteromorphes Schwanzstück als Regenerat; ein andermal wurde (von Mrázek) Bifurkation des Hinterendes beobachtet.

Über die Regenerationsfähigkeit der einzelnen Regionen macht Verf. folgende Angaben: 1. „Es werden am Vorderende ron einem gewissen Minimum, ron 2, 3, 4 bis 5 Segmenten angefangen, fast regelmïßig weniger Segmente regeneriert, als abgeschnitten wurden. 2. Nur in dem Falle, wenn nicht mehr als 2, 3, 4 bis 5 Segmente weggeschnitten wurden, können (jedoch nicht müssen) alle regenerieren. 3. Die Zahl der durch die Regeneration neu entstandenen Segmente steigt von dem angeführten Minimum angefangen nicht proportional mit jener der abgeschnittenen. 4. Es regenerieren 1, 2, 3, 4, manchmal auch 5 Segmente, das Peristom nicht gezählt. 5. Die Regenerationsvorgänge am Vorder- und Hinterende sind roneinander unabhängig und können gleichzeitig stattfinden. 6. Die Regeneration des Hinterendes verläuft viel schneller als die des Vorderendes. 7. Eine scharfe Grenze für die Regeneration des Kopfes lässt sich nicht bestimmen (am 15.-20. Segment scheint sie aufzuhören) $)^{6}$. Die Reparationsgeschwindigkeit ist bei verschiedenen Individuen sehr verschieden - es dürfte dies wohl wenigstens zum Teil mit ihrem Alter zusammenhängen (Ref.). R. S. Bergh (Kopenhagen). 
427 Torrey, J. C., The early development of the Mesoblast in Thalassema. In: Anat. Anzeiger. Bd. 21. 1902. pag. 247-256. 3 Fig.

Wie bei vielen Anneliden, so lässt sich nach Terf. auch bei Thalassema ein , larrales Mesenchym" unterscheiden, welches elitodermalen Ursprungs ist und gänzlich mabhängig von den von dem „primären Mesoblasten" sich herleitenden Mesodermstreifen.

Thalassemu hat anfangs äquale Furchung, welche zwischen den Extremen des rein radialen und des ausgesprochen spiraligen Typus variiert, sehr ähnlich der Furchung von Podarke. Der primäre Mesoblast nimmt seinen Lrsprung in gewöhnlicher Weise von der Zelle $4 \mathrm{~d}$ (die hinterste Zelle des 4. Quartetts); wenn diese sich in eine reclite und linke Zelle geteilt hat, sinken diese in die Tiefe und sprossen hier ein paar kleinere Zellen, die an dem Aufbau der Darmwand teilnehmen, bevor sie anfangen, die Mesolermstreifen zu produzieren (in Überstimmung mit E. B. Wilson u. a. fiir verschiedene Anneliden und Mollusken).

Der larvale Mesoblast oder Ektomesoblast nimmt seinen Ursprung aus den drei ersten Quartetten von, Ektomeren", namentlich aus dem dritten. $\mathrm{Er}$ besteht wenigstens aus 20 ,primären $/ \mathrm{ellen} \ldots$; ron diesen degenerieren wenigstens 10 (teils aus dem ersten, teils aus dem zweiten Quartett herstammend) und werden schliesslich von Entodermzellen resorbiert, ohne in irgend welche Funktion jemals einzutreten; die übrigen (rom ersten und dritten Quartett abstammend) bilden das larvale Mesenchym; ein guter Teil von diesem scheint in dem erwachsenen Tier zu persistieren (wohl als Muskeln).

Eine Kopfniere existiert nicht bei Thalassema (in Übereinstimmung mit Conn); die exkretorische Funktion scheint durch, several large floating cells of ectomesoblastic origin" ausgeführt zu werden, von denen einige an die larvalen Muskeln angeheftet werden.

In der theoretischen Deutung der Verhältnisse des Mesoderms schliesst sich Verf. Conklin und Wilson an.

R. S. Bergh (Kopenhagen).

428 Sukatschoff, B., Beiträge zur Entwicklungsgeschichte der Hirudineen. II. 巳̈ber Fnrchung und Bildung der embryonalen Anlagen bei Nephelis vulgaris Moq. Tand. In: Zeitschr. f. wiss. Zool. Bd. 73. 1903. pag. 321-367. Taf. 22-24.

Die Eier wurden in Chromessigsäure oder in Flemmingscher Lösung fixiert; fïr Schnitte wurde Sublimat mit Zusatz ron $3-5 \%$ starker (40\% /0-iger) Salpetersäure benutzt. Färbung in Delafieldschem IIämatoxylin. - Die wesentlichsten Ergebnisse sind folgende: 
Durch eine totale, inäquale Furchung - schon die ersten zwei Furchungskugeh sind nicht ganz gleich an Grösse - entsteht eine achtzellige Blastula, welchẹ aus vier Micro- und vier Macromeren besteht, indem (wie auch bei andern Würmern, Mollusken u. s. w.) jede Blastomere des vierzelligen Stadiums je eine Micromere liefert. Im Innern findet sich ein kleiner Hohtraum, die sog. Furchungshöhle, die aller Wahrscheinlichkeit nach sich später zu der Darmhöhle ausbildet. Nach Verf. sei diese Höhle jedoch nicht ,einer eigentlichen Furchungshöhle gleichzustellen, weil diese durch Auseinanderweichen der Ekto- und Entodermzellen entstehe"; da Verf. jedoch zugibt, dass die drei Macromeren den drei bei Clepsine in den Aufbau der Darmwand eingehenden Macromeren homolog sind und also entodermaler Natur sind, ist Ref. dieser Einwand nicht verständlich. Übrigens, wie Kleinenberg sagt: Loch ist Loch in der ganzen Welt. I)ie eben erwähnten drei grossen Zellen verhalten sich, wie schon von frïhern Autoren angegeben, während der weitern Entwicklung ganz passiv und werden schliesslich wahrscheinlich von wandernden Zellen der Larve allmählich resorbiert.

Bei der weitern Entwicklung bilden die Micromeren das Ektoderm des Kopfaapfens, sowie die Schlundwand und die Muskulatur des Larvenschlundes. Diese letztere ist also ektodermalen Ursprungs (in Übereinstimmung mit Ed. Meyer für Polychäten). Überhaupt geht der Kopfzapfen ganz und gar - die Kopfkeime ausgeschlossen - aus den vier Micromeren hervor.

Die vierte Micromere bildet durch ihre weitern Teilungen folgende Anlagen: Zuerst teilt sie sich in zwei Zellen $\left(\mathrm{D}^{1}\right.$ und $\left.\mathrm{D}^{2}\right)$, von welchen jede eine Entodermzelle in die Tiefe abschnürt; dann erzeugt die vorderste $\left(\mathrm{D}^{1}\right)$ noch zwei kieine Zellen, die den Micromeren anliegen und sich längere Zeit hindurch passiv verhalten und dann je eine Zellenreihe in den Rumpflieim geben, nämlich die sog. Neuralreihe; diese beiden Zellen sind also die Neuroblasten. Weiter teilen sich die zwei Zellen $\left(D^{1}, D^{2}\right)$, indem jede eine Querzellenreihe an dem vegetativen Pol des Eies erzeugen. Die zwei Endzellen der hintern Reihe sind die zwei Mesoblasten von Whitman und bilden die sog. ,innern Muskelplatten". Aus den in der Mitte der hintern Zellenreihe am vegetativen $\mathrm{Pol}$ liegenden Zellen entstehen durch Abspaltung nach aussen flache Zellen, die das Ektoderm des Rumpfes der Larve geben; die tiefer bleibenden Zellen gehen in das Entoderm und bilden die hintere Darmwand der Larve unter Umbildung in „Deutolecithzellen". Die vordere Zellenreihe geht vollständig in die Bildung des Keimstreifens auf, indem die vier Zellenpaare, aus welchen sie besteht, sich folgendermaßen anordnen: zwei tiefer in 
der Mitte liegende, durch Abspaltung entstandene Zellen möclite man als Anlage der Kopfkeime betrachten; die sechs höhern - doch nicht an der Oberfläche liegenden, obwohl ihre Urzelle frei nach aussen lag - gehen in die Bildung der drei Paar lateralen Zellenreihen ein, aus welchen nacls Ref. „nach Abgabe einiger zur Bildung der Ringmuskułatur bestimmten Zellen die ganze definitive Epidermis des Rumpfes der Kieferegel" entsteht.

Zwischen den beiden Zellenreihen am regetativen Pol des Eies kann man noch zwei symmetrisch liegende Zellen wahrnehmen, deren Ursprung Verf. unklar geblieben ist. "Sie entsprechen ihrer Lage nach dem dorsalen Zellstrang der etwas spätern Stadien. Aus diesem Zellstrang entsteht ein Teil der Muskel-, Nerven- und wandernden Mesenchymzellen der Larve".

Die Kopf- und Rumpfkeime entstehen nach Verf. aus einer gemeinsamen Anlage von der vierten Macromere aus (mit Bütschli, gegen Ref.) und verlieren ihren Zusammenhang miteinander durch starke Grössenzunahme des Rmmples der Larve. Später verwachsen sie wieder miteinander.

Die Mundöffnung der Larve entsteht auf frühern Furchungsstadien als Spalte zwischen den Ektodermzellen (mit Filat off). Der Schlund wird durch Abspaltung von Zellen in die Tiefe gebildet. - Entgegen Ref. meint Verf., dass die Ringmuskelfasern der Larve in die definitiven Ringmuskeln sich entwickeln.

Verf. hält (mit Whitman und Ref., gegen Brandes) den Entwicklungsmodus von Clepsine für primitiver als denjenigen der Kieferegel.

R. S. Bergh (Kopenhagen).

\section{Arthropoda.}

Crustacea.

429 Bigelow, M. A., The early development of Lepas. A Study of Cell-lineage ans Germ-layers. In: Bull. Mus. comp. \%ool. Harvard Coll. Cambridge. Vol. 40. Nr. 2. pag. 61-144. 12 Taf.

Verf. untersuchte hauptsächlich die Entwicklung von Lepas fascicularis, anatifera und pectinata, nebenbei beriicksichtigte er auch Lepas hillii, Pollicipes polymerns und Sacculina. Als bestes Fixierungsmittel erwies sich eine gesättigte Lösung von Pikrinsäure in 5\% Essigsäure; zur Färbung wurde Boraxkarmin sowie (für Schnitte) Delafieldsches Hämatoxylin mit oder ohne Eosin oder Orange G benutzt. Die Eierlamellen wurden in Nełkenöl zerzupft, wodurcl die Eier leicht isoliert wurden.

Die Ausstossung des ersten Richtungskörperchens findet etwa 
an dem Zeitpunkt statt, an dem die Eier den Ovidukt verlassen. Um diese Zeit sind die Eier kugelig; etwa gleichzeitig mit der Bildung des zweiten Richtungskörperchens wird das Ei aber oval, und es sammelt sich der Nahrungsdotter an dem einen Pol an; durch eine provisorische, später sich ausgleichende Furche wird sogar interimistisch ein Dotterlappen abgegrenzt. Das Spermatozoon dringt wahrscheinlich vor der Bildung der Dotterhaut, etwa zur Zeit der Ausstossung des ersten Richtungskörpers, ein; doch konnte Verf. hierüber (so wenig wie seine Vorgänger) Sicherheit erlangen.

Verf. gibt folgende allgemeine Schilderung der Entwicklung. Die Furchung ist ,total, inäqual und regulä1"“; Stadien von 2, 4, 8, 16, 32 und 62 Zellen werden normalerweise gebildet. Zellen aus irgend einer Generation können ihren Schwesterzellen in der Teilung vorauseilen; aber eine nene Teilung solcher Zellen tritt nicht ein, bevor alle andere Zellen entsprechende Furchungen durchgemacht und die gleiche Generation erreicht haben.

Die erste Furche liegt am Anfang des Prozesses fast in der längern Achse des länglichen Eies und geht durch den animalen Pol; nun findet aber während des weitern Verlaufs eine Rotation des ganzen Eies um $90^{\circ}$ statt, so dass die Furche schliesslich quer steht; das zweite Richtungskörperchen liegt während des ganzen Vorgangs in der Furche. Durch diese erste Furchung entsteht eine kleinere vordere und eine grössere hintere, dotterreiche Zelle (Micromere, Nacromere). Die zweite Furchungsebene steht senkrecht auf der ersten; durch sie wird die Micromere in gleiche, die Macromere in ungleiche Zellen geteilt, so dass nun drei Micromeren und eine Macromere vorhanden sind. Die dritte Furchungsebene ist wiederum senkrecht auf den beiden ersten; noch eine Micromere wird von der Ilacromere abgetrennt, welche von da ab rein ,mesentoblastisch" ist. Die Micromeren enthalten das ganze ektodermale Material und bilden durch wiederholte Teilungen das ,Blastoderm“. Doch geben gewisse Zellen, die von den ersten zwei Micromeren abstammen, einen T'eil des Mesoderms den Ursprung, so dass jene Micromeren nicht rein ektodermaler Natur sind; die dritte Micromere ist dies aber. In der vierten Furchung wird eine ,Mesoblastzelle" von der Macromere abgetrennt, welche von da ab rein entodermaler Natur ist.

Das 16 zellige Stadium ist somit aus 14 Abkömmlingen der drei Micromeren, einer Mesoblastzelle und einer Entoblastzelle (Dottermacromere) zusamnengesetzt. Die entoblastische Dottermacromere ist nahezu von den das ,Blastoderm" zusammensetzenden kleinern Zellen eingeschlossen; nur ein kleiner 'Teil des Entoblasts liegt am 
Blastoporus frei. Die einzelne Mesodermzelle liegt am hintern Rande des Blastoporus und würde: wenn ihre weitere Geschichte nicht verfolgt wäre, als "Blastodermzelle" aufgefasst werden. Bei der fünften Furchung teilt sich jede der 16 Zellen; die resultierenden zwei Mesodermzellen liegen noch an der Oberfläche; bei der sechsten Furchung teilen sich alle Zellen mit Ausnahme der zwei Entodermzellen, so dass ein Stadium mit 62 Zellen liervorgeht. Während der sechsten Furchung sinken die zwei Mesodermzellen vor ihrer Teilung unter das „Blastoderm" hinein, und dieses umwächst das Entoderm und verschliesst den Blastoporus. An demselben Zeitpunkt teilen sich vier an den vordern und lateralen Rändern des Blastoporus liegende Zellen parallel zur Oberfläche; die vier solchermaßen abgeschnittenen tiefern Zellen konstituieren einen Teil des Mesoderms. Dieses entstammt somit teils einer rom Entoderm während der vierten Furchung abgetrennten Zelle, teils vier Zellen, die sich während des sechsten Stadiums rom "Blastoderm" sondern "). - Die Gastrulation gehört dem epibolischen Typus an; der Blastoporus repräsentiert den ventralen und hintern Teil des künftigen Embryos.

In der Nomenklatur der Furchungszellen folgt Verf. (mit einigen notwendigen Änderungen) dem System von Kofoid.

Verf. bestätigt Grooms Beobachtungen darin, dass die Mesodermstreifen in spätern Stadien mehr nach der Dorsalseite zu gelagert sind, und dass hier die Nauplius-Extremitäten hervorwachsen. Ebenso bestätigt er den genamnten Verf. in bezug auf die Entwicklung des Darmkanals.

Schliesslich vergleicht Verf. die Furchung mit derjenigen anderer Typen (er hebt namentlich den Unterschied gegenüber Anneliden und Mollusken hervor, dass das Entoderm durch eine einfache Zelle, niclıt durch ein Quartett repräsentiert ist) und die Ḱeimblätterbildung mit derjenigen anderer Crustaceen und findet wesentliche Ähnlichkeiten und Übereinstimmungen in der Lage des Blastoporus und in der Bildung des Mesoderms und Entoderms. Eine Furchungstabelle wird gegeben.

In einem "Addendum" sprechen E. L. Mark und W. E. Castle aus, dass ihnen die Furchung von Lepas ein gutes Beispiel ron modifizierter Quartettfurchung darstellt. R. S. Bergh (Kopenhagen).

\section{Arachnida.}

430 Oudemans, Dr. A. C., Über eine sonderbare Art von Über-

1) Bei der siebten Furchung teilen sich alle Zellen mit Ausnahme der Kntodermzellen, sodass ein Stadium mit 122 Zellen resultiert. 
winterung einer Milbe. In: \%ool. Anz. Bd. XXY. 1902. pag. 218-219.

Der Verf. beschreibt eine eigenartige, einer Knospenschuppe ähnliche Überwinterungscyste, die in sich einen erwachsenen Erythraeus (= Rhyncholophus) barg. Da der Darm des eingeschlossenen Tieres mit zahlreichen schwarzen Partikelchen angefüllt war, so muss man annehmen, dass dieses sich nicht unmittelbar aus der Nymphe entwickelt hat, sondern kürzere oder längere Zeit ein Freileben führte und Nahrung zu sich nahm. Auch die Beschaffenheit der Überwinterungscyste beweist, dass sie keine Nymphenhaut sein kann. Sie ist ganz glatt, nicht gewellt oder mit Linien versehen. Am Hinterende weist sie zahlreiche, sehr kurze, stabförmige Haare oder haarförmige Gebilde auf; einzelne daron finden sich über den übrigen Teil der Membran verstreut. Bei einer 600 fachen Vergrösserung erkennt man, dass die letztere von unzähligen, dicht nebeneinander stehenden winzigen Poren durchbrochen wird. Reste von Beinen, Ansatzstellen derselben, Hüftplatten und Analöffnung wurden an der Cystenhïlle nicht aufgefunden. Der Verf. kommt zu dem Schluss, dass wir hier vor einem Problem stehen, dessen Lösung vielleicht nur möglich ist durch Zïchtung von Erythraeus-Arten und durch dabei ausgeführte sorgfältige Beobachtung ihrer Gewohnheiten und Handlungen, insbesonder'e gegen den Winter hin.

Die encystierte Form ist neu. Sie nähert sich dem $E$. phalangioides (de Geer), E. acis (Berlese) und E. regalis (C. L. Koch) und weicht ron diesen Arten ror allen Dingen durch ihre völlig glatten Haare ab. Der Verf. nennt sie Erythraeus hibernans.

R. Piersig (Annaberg, Erzgeb.).

431 Thor, Sig., South A frican Hydraclinids. In: Ann. South African Museum. Bd. 2. 1902. Part. XI. Nr. XIV. pag. 447-465. 'Taf. XVI-XXI.

Der Verf. beschreibt zehn neue Hydrachniden, die von Purcell und R. M. Lightfoot in Süd-Afrika besonders in Brackwasser- und Südwasserteichen des "Cape Peninsula* neben schou bekanuten Arten (Eulais voeltzkowi Ḱoen., Diplodontus despiciens (Müll.), Oxus stuhlmanni Koen., Capobates sarsi Thor, Piona (-Curripes) coccinca (Koch) $=$ notata (Müll.) und Atax crassipes (Müll.) in grosser Anzahl erbeutet wurden. Die meisten Species gehören der artenreichen Gattung Eulais Latr. an. E. purcelli Thor erreicht eine Länge von $3-4 \mathrm{~mm}$, sie gehört also zu den grössten Vertretern ihrer Gattung. Der Gestalt der Augenbrille nacl gehört sie in die Gruppe der Eulais-Formen, die bisher durch E. megalostoma Koen. und E. georgei Soar vertreten wurde. Die Augenkapseln sind kurz. Der Verbindungssteg (Augenbrücke) ist lang und nach rückwärts gebogen. Die beiden Haarborsten entspringen an den Enden des Augensteges. Es fehlen die vier linsenförmigen Höckerchen, die Koenike bei E. megalostoma beschreibt. Die Maxillartaster sind lang und dünn. Die einzelnen Glieder verhalten sich in ihrer Länge wie $17: 23: 26: 50: 32$. Das dritte Glied besitzt nur eine unbedeutende innere Anschwellung am distaleı 
Beugeseitenende. Man zählt auf derselben sechs kleine Borsten. Auf der Aussenseite des vierten Gliedes sitzen acht Dornborsten in doppelter Reihe, während zwej Fiederborsten das distale Ende eimnehmen. Die lnnenseite ist mit $20 \mathrm{z}$. T. gefiederten Borsten besetzt. Am Endgliede fällt eine Verengerung der Mitte besonders auf. Das reicl mit Borsten versehene distale Ende erscheint deshalb schwach kolbig angeschwollen. - Eulais lightfooti Thor wird 3-4 mm lang und erinnert an $E$. miilleri Koen. Bezüglich der Färbung, Körpergestalt und Ausstattung des Epimeralgebietes und der Beine gleicht sie der $E$. purcelli Thor. Die kurze, nach der Mitte zu verschmälerte Augenbrücke verbindet die Augenkapseln etwa in der Mitte, so dass zwischen denselben vorn und hinten fast gleich tiefe Einbuchtungen entstehen. In der Mitte des Vorderrandes bemerkt man einen klaren, nach vorn gerichteten Vorsprung. Die Länge der Maxillartasterglieder wird durch die Zalılenreihe 15, 20, 20, 40, 20 ausgedrückt. Wie bei $E$. prreclli ist die Verdickung an dem distalen Innenende der Beugeseite des dritten Gliedes sehr unbedeutend und trägt nur vier kurze Borsten. Das vierte Glied hesitzt an der Aussenseite drei lange Dornborsten und eine Fiederborste, die an das distale Ende des Gliedes herangeriickt ist. Auf der Innenseite bemerkt man zelın Borsten, von denen fünf kurz gefiedert sind und zwei nahe der Streckseite entspringen. -Eulais variabilis Thor ist etwa $2-3 \mathrm{~mm}$ lang. Sie ist in der Form der Augenbrilke sehr veränderlich, so dass man mehrere Varietäten unterscheiden muss. Die typische Augenbrille ähnelt am meisten dem entsprechenden Gebilde von E. mïlleri Koen. und E. dividuus Soar. Bei der einen Spielart E. r. var. magna ist die an sich breite Augenbrücke noch mehr verbreitert und die mediane Einbuchtung des Vorderrandes merkbar tiefer und ofiener als bei der Stammform. Die zweite Varietät $E$. var. var. intermcdia verjüngt sich der Augensteg sehr stark. Die Maxillartaster ähneln ungemein denen von E. degenerata Koen. Die Glieder verhalten sich zueinander wie 10:16:18:28:18. Bemerkenswert ist noch, dass die Unterseite des Capitulums, (Maxillarorgans) mit dem hintern Teile des Plarynx verschmolzen ist.

Für eine Art hält es der Verf. für nötig eine Untergattung zu schaffen, die er mit dem Namen Capculais belegt. Als wichtigste Kennzeichen derselben werden neben abweichender Körperform (Verdıckung des Hinterleibes) noch angeführt: Maxillartaster und Beine sind ungemein stark verdickt. Erstere besitzen nur wenige Borsten der gewöhnlichen Art. Dafür treten zwei ausserordentlich dicke und kräftige Dornen am vierten und fünften Gliede auf, die nahe an das distale Ende derselben gerïckt sind. Die einzige Form Capeulais crassipalpis Thor bat nur eine Länge von 1,6-2,1 mm. Die Augenbrille erimert an das gleiche Gebille bei Eulais occulta Thor. Der sehr kurze Steg verbindet fast in der Mitte die beiden Augenkapseln; sein Vorderrand springt bogig vor, während die hintere Ausbuchtung der Augenbrille in der Tiefe gerundet abschliesst. Die kurzen, stämmigen Palpenglieder verhalten sich zueinander wie $8: 17: 13: 24$ : 13 . Auf der innern des zweiten Seite und dritten Gliedes in der Nähe des distalen Endes zählt man je vier kurze, dicke Dornen, vier andere stehen mehr in der Mitte. Während die innere Seite des vierten Palpengliedes zwei lange Dornen und drei Fiederbor'sten trägt, bemerkt man auf der Aussenseite unweit des distalen Randes ein dolchartiges Chitingebilde, das unwillkürlich an den an gleicher Stelle stehenden Fortsatz bei Tiphys C. L. Koch, Piona (.Curipes) C. L. Koch usw. erinnert. Von den stämmigen, gedrungenen Beinpaaren ist besonders das vierte ungemein dick, fast doppeIt so dick wie die andern Füsse und dicker als die Maxillartaster. 
Limnesia africana Thor ähnelt in der Struktur der L. undulata (Müll.). Thre Grösse beträgt nur 560-800 „1. Auf der Beugeseite des vierten Maxillartastergliełes erlıben sich, etwas über die Mitte nach vorn gerückt, zwei Haarhöcker, die in ihrer Entwicklung an die gleichen Gebilde bei den meisten Arten der Gattung Piona (Curripes) C. L. Koch erinnern. Diese Ausstattung finden wir auch bei Limnesia aspera Koen., von der die neue Art durch die Beschaffenheit der Haut, die Bildung der Hüftplatten und des Genitalhofes merkbar abweicht. Letzterer besitzt auf jeder nach hinten verbreiterten Genitalplatte drei Näpfe, von denen der mittlere in unmiltelbarer Näbe des dritten stelit und durclı einen grossen Abstand vor dem vordersten geschieden ist. Die vierte Epimere ist selır kurz und an Hinterende breit abgerundet. Die von dem Verfasser irrtümlicheweise immer noch als "Curvipes" bezeiclnete Gattung Piona C. L. Koch wird in der vorliegenden Sammlung durcl eine neue Art "P. tridens Thor" vertreten. Sie weist eine grosse Verwandtschaft mit $I^{\prime}$. nodata (Müll.), var. coccinea C. L. Koch, P. stjördalensis Thor und $P$. controversiosa Piersig auf. Das vierte Glied des Maxillarstasters trägt jedoch drei Haarhöcker, von denen der mittlere am längsten ist, während der vorderste, viel kleinere, unmittelbar hinter dem am distalen Gliedende gelegenen Chitinstift sich erhebt. An dem Aussenrande der Schamlefzen sitzen je zwei Borsten. Jede der zu beiden Seiten der hintern Hälfte der Gescllechtsöffnung gelegenen mäßig grossen Napfplatten trägt 12-15 Genitalnäpfe. Die Körperhant ist liniert.

Von den Parzermilben unter den Hydraclmiden wird nur eine Gattung (Arrhcnurus Dag.) mit drei neuen Arten anfgeführt. Zwei derselben sind nur im männlichen und eine nur im weiblichen Geschlechte vertreten. - A. purcelli Thor erreicht eine Länge von $580 \mu$. Der Gestalt nach gehört dieser zu den Verwandten von A, integrator (Müll.). Der von oben gesehene elliptische Körper ist vorn und hinten eingebuchtet. Während jedoch die Einbiegung der Stirnseite eine flache Einsattelung darstellt, bildet die hintere Einbuchtung einen Ausschnitt, dessen Rand von beiden Seiten lıer zunächst flach verläuft, in der Mitte jedoch plätzlich umbiegt und eine schmale mediane Einkerbung entstehen lässt, in deren Tiefe ein winziges Zäpfclıen zu bemerken ist. Auf der Innenseite des zweiten Palpengliedes befinden sich nahe der Beugeseite zwei hintereinander gestellte Borsten. Das klauenartige fünfte Glied ist deutlich gespalten. Die Körpergrösse des 'Tieres beträgt 580 ॥.

Eine zweite neue Arhenurus. Art gehört in die Gruppe der Petiolurus. Die Körpergestalt erinnert am meisten an diejenige eines noch nicht voll entwickelten Männchens von $A$. maculator (Müll.). Die Eckfortsätze des schmalen Körperanhanges springen nur wenig über dessen Hinterrand hervor, auch tragen sie nichts zur Verbreiterung des Anhangsendes bei. Wie bei A. virens Neuman (= A. crassipetiolatus Koenike) ist der Petiolus hinten löffelförmig abgerundet. Vou der Seite gesehen, erscheint er oben stärker verlängert als unten, seine Dicke nimmt deshalb nach dem freien Ende hin lediglich auf Kosten der Unterseite ab. Der Verf. erwähnt bei der Beschreibung des Petiolus noch ein senkrechtes, stift. förmiges, nicht chitinöses Gobilde, das sich auf der Oberseite desselben erhob, sich jedoch von selbst ablöste. Er vermutet deshalb, dass es sich hierbei um ein fremdes Anhängsel handelt. Die gekrümmten Borsten zu beiden Seiten des Petiolus ragen ein wenig uiber ihn hinaus. Über dem Petiolus springt ein nach hinten verbreitertes, mit scharfen Hinterecken ausgestattetes hyalines Häutchen vor. Auf dem Rücken beobachtet man vier niedrige Rundhöcker, von denen das vordere Paar ausserhalb, das linter Paar innerhalb des Rückenbogens 
sich erbebt. Der vierte Fuss besitzt einen Sporn. Das von Thor Arrh. copensis genannte Tierchen misst 1,.05 mm.

Die dritte Arrhenurus-Form, A. meridionalis Thor, liegt nur als Weibchen vor. In der Gestalt erinnert sie an A. maximus Piersig. Die Genitainapfplatten des etwa $1,95 \mathrm{~mm}$ grossen Tierchens stimmen bezüglich der Gestalt annähernd mit denen von 1. tricuppidator (Mïll.) Bruzelius überein, nur reichen sie nicht viel weiter nach den Seiten als die innern Hinterrandborsten.

Als letzte Arrhemurus-Species beschreibt der Verf, ein braungefärbtes, 1,35 mrn grosses Weibchen, cessen Körperumriss grosse Ähnlichkeit mit demjenigen von A. stecki aufwejst. Die Genitalplatten bilden mitsamt den Schamlefzen annähernd einen nicht zu breiten Kreisabschnitt, dessen Selıne den Hinterrand des Geschlechtsfeldes darstellt. Der Verf. ist sich nicht ganz sicher, ob er die eben beschriebene Form in das Subgenus Truncaturus oder Petiolurus eingliedern soll. Eine bestimmte Entscheidung wird erst die Auffindung des Männchens herbeiführen.

R. Piersig (Annaberg, krzgeb.).

\section{Insecta.}

432 Felt, l. P. Crude l'etroleum as an Insecticide. In: I'roc. $23^{d}$ Annual Meeting of Soc. for Promotion Agricultural Science. 1902. pag. $1-10$.

Der Wert der mineralicchen ()le als Insektenvertilgungsmittel ist bis auf die letzten Jahre ïbersehen worden, und das Verdienst. die Aufmerksamkeit darauf gelenkt zu haben, gebiilnt dem Staitsentomólogen von New Jersey J. B. Simith, der in melurem Bulletins die Resnltate seiner Experimente mitteilte. In dem Bulletin von 1900 kommt er zu dem Ergebnis, dass rolies Petrolem von guter ()ualiät und richtig angewendet ein verhältnismäßig sicheres, billiges und wirksames Mittel zur Kontrolle der San Josi-Schildlaus darstellt. Mit diesem Irteil stimmen andere Reobachter teils überein, teils halten sie weniger von den Wirkungen des Petroleums. Felt teilt die Resultate dieser Untersuchungen im einzelnen mit und fasst am Schlnss das Gesamtergebnis der lieobachtungen der letzten 4 . Iahre in 7 Thesen ïbersielıthch zusammen. Aus diesen geht liervor, dass die Anwendung des Petroleums viel Umsicht und Berïcksichtigung spezieller Verhältnisse erfordert, wem sie nicht nu die Vernichtung des schädlichen Insekts herbeifülıren, sondern anch olıne Schaden für die ron dem Inselit befallenen I'tlanzen sein soll.

$$
\text { IV. Nay (Karlsruhe). }
$$

433 schenk, ()., Die antennalen Hautsinnesorgane einiger Lepidopteren und Hymenopteren. Mit besonderer Berücksichtigung der sexuellen Unterschiede. (Aus dem Zool. Inst. Jena.) In: Zool. Jahrb. Abt. f. Anat. u. Ontog Bd. XVII. 1903. lag. 573-618. Taf. 21-22. 4 Abb. im Text. 
An Lepidopteren wurden vom Verf. solche Arten zur Untersuchnng verwendet, die schon mit freiem Auge grosse Verschiedenleiten im Ban der Fühler beider Geschlechter erkennen liessen: von Geometriden: Fidonia piniaria I., Kiefernspanner, ron Bomby ciden: Orgyia untiqua L., Bürstenspimner, Psyche unicolor Hfn. Sackspinner und von \% y gaeniden: Tno prmi Esp. Schlehenwidderchen. Lis ergab sich, dass die geschlechtlichen Unterschiede im Bau der Antennen hiluptsächlich quantitativer Natur waren, dass es sich mit Ausnahme eines Falles nur um eine rerschiedene Menge ron Sinnesorganen handelte. Ferner konnte festgestellt werden, dass die Unterschiede im makroskopischen Bau der Antemnen in inniger Beziehung zur Ansbildnng gewisser Sinnesorgane stehen, und dass sich die ganze bifferenzierung der Antennen ron der Lebensweise der beiden Geschlechter abhängig zeigte. Von sinnesorganen finden sich an den Lepidopterenfühlern :

1. Sensilla coeloconica Grubenkegel: In die Cuticula eingesenkte, dïnnwandige, an der Spitze geschlossene auf einem kugligen ('hitinblïschen (Köppel Kraepelin) aufsitzende Kégel, die bald mehr hitarförmig zngespitzt, bald an ihrem Ende abgerundet erscheinen. Der in den Kegel eindringende Achsenfadenstrang bildet sich aus den Nervenfasern einer unter dem Kegel liegenden (wahrscheinlich zweizelligen) Gruppe ron sinneszellen, die ihrerseits durch einen zarten Strang mit dem das Fiederchen durchzielıenden Hauptnerven rerbunden sind.

2. Sensilla basiconica, ebenständige simneskegel, die ein ans dickem Chitin bestehendes, an der spitze abgerundetes, in der Chitindecke beweglich eingelenktes Gebilde darstellen. Der nervöse Endapparat dieser Organe konnte nicht rerfolgt werden.

3. Sensilla styloconica, Endzapten, Kolben. Sie stellen $0,0035 \mathrm{~mm}$ lange Kegelchen dar, die anf $0,02 t-0,028 \mathrm{~mm}$ langen Zapfen sitzen, welch letztere ron ältern Autoren für das Sinnesorgan gehalten worden sind, bis sie Nagel als hohle Auswüchse der Fühlerglieder erkannt hat, die nur dazu dienen können, das Organ über die Fühleroberfläche zu erheben. Die nervösen Endapparate komiten auch hier nicht weiter verfolgt werden.

4. Sensilla chaetica, borstenartige Sinnesorgane: Spitz ausgezogene, borstenartige, hohle, dickwandige Gebilde, die an den distalen Enden der Gilieder und an den Spitzen der Fühlerfiedern stehen. Sie sind verschieden gross und in den Chitinpanzer beweglich eingelenkt. An einigen Stellen konnten mit Sicherheit unter den borsten Sinneszellen wahrgenommen werden.

5. Sensilla trichodea, haarartige sinnesorgane: hohle, etwas 
gebogene, dunkel pigmentierte, beweglich eingelenkte Haare, die beim Weibchen beträchtlich kürzer sind wie beim Männchen, bei beiden jedoch alle andern Sinnesorgane an Grösse übertreffen. Zu jedem Haar gehört nur eine einzige Sinneszelle von langgestreckter Gestalt und mit ziemlich grossem Kern. An diese Zelle tritt der dem Sinnesorgan zukommende Nerr heran und die Zelle entsendet einen feinen Fortsatz, den Terminalstrang (vom Rath) in das Haar. Wie bei den Sensilla coeloconica, so tritt anch hier die Sinneszelle aus der sehr flachen Hypodermis heraus.

Was die physiologische Funktion der genannten antennalen Sinnesorgane betrifft, so kommt Schenk $z 11$ folgendem Ergebnis:

... D) Die Sensilla coeloconica sind als Geruchsorgane zu deuten, da sie bei den Männchen derjenigen Arten ihre grösste zalılenmäßige Ausbildung und die giinstigste Verteilung an der Antenne zeigen, bei welcher die Lebensweise eine derartige ist, dass die Männchen die Weibchen nach dem Geruch auffinden müssen.

$\beta$ ) Die sensilla styloconica sind gleichfalls Geruchswerkzeuge. Sie spielen vor allem eine Rolle bei dem rulhig sitzenten Tier, bei dem die Sensilla coeloconica infolge Mangels der Bewegung nicht in der genïgenden Weise mit den in der Luft suspendierten Riechstoffpartikeln in Berührung kommen.

y) Die Ausbildung der Sensilla trichodea steht in Korrelation mit der Bewegungsfähigkeit der Tiere, insofern als sie bei den äusserst lebhaften Männchen der untersuchten Arten vorzüglich entwickelt bei den ruhig sitzenden Weibchen dagegen fast ganz rückgebildet sind. Sie bringen dem Tier eine Empfindnng von der bewegungsgrösse der Luft oder ihrer selbst bei.

d) Die Sensilla chaetica und die Sensilla basiconica percipieren sonstige mechanische Reize."

Bei den Hymenopteren entsprechen die Sensilla basiconica in ihrem Bau rollkommen den Sensilla coeloconica der Lepidopteren, von denen sie sich nur durch ilnre Hächenständige Lage unterscheiden. Sie dienen dem Geruchsinn. Die Sensilla placodea oder Porenplatten der Apiden und Vespiden stellen mehr oder weniger dicke Platten dar, die durch eine ringförmige, dïnne Nembran allseitig fest nit der Fühlerdecke verbunden sind. Jede l'orenplatte ist mit einem Terminalstrang verbunden, der von einer Ganglienzellengruppe ausgeht, die ihrerseits mit dem den Fuihler durchziehenden Hauptnerven durch einen feinen Seitenast verbunden ist. Der anatonische Bau dieser Sensillen weist mehr auf eine mechanische als auf eine Geruchstunktion hin.

Die Sensilla coeloconica dienen dagegen wieder dem Geruch- 
sinn. Ihrer Gestalt nach wurden sie ron Forel als Champagnerpfropfenorgane bezeichnet.

Die Sensilla ampullatea orler Forelsehen Flaschen sind vermutlich Hörorgane. Aus dem Bau des Nervenapparates glaubt der Verf. ammelmen zu dürfen, dass sie aus andern Organen dureh Funktionswechsel hervorgegangen sind.

Die Sensilla trichodea erinnem in ihrem Bau an die Sensilla chaetica der Lepidopteren und dienen wie diese der lerception verschiedener mechaniseher Reize.

M. v. Lind en (Bonn).

434 Felt, E. P., Grapevine Root Worm. In: New York State Mnseum. Bull. 59. Ent. 16. 1902. pag. 49-84. I'late 1-6.

Der Weintraubenwurzelwurm (Fidic riticida Walsh) gehört zur Fanilie der Blattkäfer (Chrysomelidae). Er wurde zuerst 1866 in Kentucky und Illinois bemerkt, im folgenden Jahr auch in St. Louis und Bluffton. Damals bezeichnete man den Käfer als eines der dem Weinbau schädlichsten Insekten, grïndete aber dies Urteil lediglich auf die Verwiistungen der Kïfer an den 13lättern, die heute von geringer Bedeutung erachtet werden im Vergleich mit den Verheerungen der Larven an den Wurzeln. In den letzten Jahren sind besonders in den Weinbergen von Ohio ungeheure Verwüstungen angerichtet worden.

Was die Lebensgeschichte des Käfer's betrifft, so verbringen die faist ausgewachsenen Larven den Winter in oralen Höhlungen im Boden. Beim Herannahen des warmen Wetters bewegen sie sich aufwärts und werden danm dicht miter der Obertläche des Bodens gefunden. Die Verpuppung erfolst in der Zeit rom 1. bis 20. Juni, etwa zwei Wochen später liommt der Käfer aus und befrisst die Blätter. Die Eier werden von Ende Juni bis Ende Juli unter lose Rinde gelegt, nach zwei Wochen schliipfen die Larven aus. Diese fallen auf den lockern Boden und gelangen zu den feinern Wurzeln, wo sie unter gïnstigen Bedingungen rasch wachsen. Sodann greifen sie die grössern Wurzeln an, indem sie lange Rindenstreifen ablösen. Viele der Larven erlangen fast volle Grösse Ende August oder Anfang September. Im Spätlrerbst gehen sie im Boden in beträchtliche Tiefen, bauen ihre ovalen Zellen und verbringen darin den Winter.

Unter den natürlichen Feinden des Schädlings sind besonders die Eierparasiten Fidiobia flatipes Ashm. und Brachysticha firliae Ashm. zu erwähnen. Ferner nähren sich Lasius brumens Webst. var. aliemes. Tyroglyphes plyyllorerce P. and R. und Hoplophora arctate Riley von den Eiern. Larven von Lauflä̈ern und die Ima- 
gines von Staphylims rulpinus Nordm. machen Jagd auf die Lalien.

Von kïnstlichen Vertilgungsmitteh lıben sich bis jetzt folgende bewährt: Reuten des Bodens zu der \%eit, wenn die Mehrzahl der Käfer sich im P'uppenstadium betindet, sanmeh der Käfer während der ersten Woche ihres Erscheinens, Besprengen der P'flanzen mit arsenigen Giften, wenn der Käfer zu elscheinen beginnt.

$$
\text { IV. M a y (Karlsruhe). }
$$

435 l'etri. Karl, Monographie des Coleopteren-Tribus Hyperini. Herausgegeben ron dem Siebenbürgischen Verein fiur Naturwissenschaften zu Hermannstadt. Berlin (R. Friedländer und Sohn in ('ommission). 1901. 208 pag. 3 Tat. u. 5s 'extfiguren. I'reis 7,00 M.

Verf. liefert eine austüllliche Monograplie des CurculionidenTribus der Hyperini, welches, zu den schwierigsten Partien aul dem Gebiete der Coleopterologie" gehört. Das Tribus zerfällt nach dem bau der Epimeren der Mittelbrust usw. in die zwei Subtribus der Cepuriden und Iy yeriden. Ton len erstem wird nur eine Gattung (Fronto n. g.) mit einer Art behandelt, ron den letutern sieben Gattungen mit zahlreichen Arten. Von der Gattung Hypro z. B. werden nicht weniger als 93 paläarktische Arten besprochen, von Phytonomus 81. Jede Art wird ziemlich austührlich beschrieben und atusserdem wird die Bestimmung auch noch durch dichotomische Tabellen sehr erleichtert. Als spezitisches Unterscheidungsmerkmal wird in erster Linie die Art der Behaarung oder Besehuppung der Flïgeldecken verwendet, dann die Form des Halsschildes und der Flügeldecken usw. Auch die Form der männlichen (ienitalanhänge erweist sich systematiseh als sehr branchbar und wird auch bei den mcisten Arten beschrieben, wobei aber Vert. stets nur rom ,Forceps spricht. Es wäre doch nun wirklich an der Zeit, dass man auch in rein systematischen Arbeiten diesen nichtssigenten Terminus durch die präzisen Ausdriicke ,P'enis" und ,Parameren" ersetzte.

K. Escherieh (Strassburg).

\section{Vertebrata.}

Cyclostomi.

436 Plate. I.. Studien ïber Cyclostomen. I. Systemat ische Revision der Petromyzonten der südlithen Halbkugel. In: Kool. Jahrb. Suppl. Y: I. Plate, Fauna Chilensis. Kweiter Band. Heft 3. 1902. pag. 651-674. 1 Tat.

In dieser ersten Studie bringt der Verfasser als Torarbeit für weitere anatomische und phylogenetische Studien über Cyclostomen 
ausführliche, rein systematische und deskriptive Erörterungen über zwanzig Exemplare vou Neunaugen aus Australien und Chile, welche teils ron andern, teils von ihm selbst gesammelt und in Aliohol konserviert wurden.

Die \%wanzig gehören zwei verschiedenen Gattungen an: Gootria uni Mordacia. Ausser diesen beiden Gattungen und dem Genus Exomegas, welche Terfasser nicht aus eigener Anschaumng kennen lernte, sind alle l'etromyzonten-Gattungen der südlichen Hemisphire zil streichen.

Für die detaillierten Beschreibungen der unterscheirlenden Merkmale dieser Gattungen ist auf das Original zu verweisen.

Von der Art Geotria chilensis Gray standen ansser mehrem erwachsenen auch acht jugendliche Exemplare zur Verfügung, die sämtlich aus chile stammten und sich ungezwungen als verschiedene Altersstadien aneinander schlossen. Es liessen sich vier Stadien der Verwandlumg erkennen, welche der Verf. muterscheidet als: 1. Laivenoller Aumocoetes-Starlium (mit zwei Mundlappen, Auge kaum siclıtbar, Farbe selı hell); 2. erstes Vrrwandlungsstadim (runder Saugmund ohne Zäilıne und ohne zwei Tentakel, Auge etwas dentlicher. Farbe sehr liell); - 3. zweites Verwandlungsstadium (runder Saugmund ohme Ziihne aber mit zwei 'Tentakeln, Cirren, Auge sehr gross und deutlich. Farbe: rotbrauner libickenstrich, an den Seiten und unten silberglänzend); - 4. Ingendstadium = Macrophthatmia chilonsis P'late, (runder Saugmund mit Yähnen und zwei 'l'entakeln. Auge sehr gross und dentlieh, Farbe oben schwarzblau, Geiten und Banch stark silberglïnzend). Fis liegen hier somit im grossen und ganzen die näulichen Verhïltnisse vor wie bei unserm J'etromyzon.

$$
\text { H. ('. Liedeke (Itelder). }
$$

\section{Mammalia.}

437 Szakill, (ryula, A földi kutya (Spalar typhlus I'all.) szeme. (I) as Auge der Blindmaus.) In: Allattani Közlemények. Bid. I. Budapest 1902. pag. $80-91.1$ Taf.

Der Augapfel (Bulbus oculi) liegt bei gänzlichem Mangel der Lidspalte so anf dem Grunde des abgeschlossenen Schlauches der Conjunctiva, dass die Lichtstrahlen nur die normal gebaute Hant durchdringend hinein gelangen können. Der histologische Aufbau der Angen eines entwickelten 'Tieres weist darauf hin, dass die einzelnen Teile des Augapfels rorhanden sind, ihre Differenzierung aber auf einer so primitiven Stufe stehen geblieben ist, dass in dem entwickelten Auge: a) Die vordere - und hintere Basalmembran (Bowmann- und Descemetsche Haut) (ler Hornhant (Cornea) fehlt; 
b) die Aderhaut (Chorioidea) ebenfalls gänzlich fehlt, weshalb man innerhalh der Sklera alsbald auf die Netzhaut (Retina) stösst: c) der Strahlenkörper (Corpus ciliare) - mit Ausschluss jeglichen MesenchymGewebes - ausschliesslich durch die Falten der Pigmentschicht der Netzhaut gebildet wird.

/\%wischen den einzelnen Schichten der Netzhaut ist es ïnsserst schwierig, eine scharfe Grenze zu ziehen, weil ihre Differenzierung primitiv ist; demungeachtet lassen sich, trotzdem sie teilweise in fötalem Zustande rerblieben sind, die einzelnen Schichten dennoch auffinden. Die innern (ianglienzellen, deren Anzahl eine höchst geringe ist, liegen nicht in einem Nivean, sondern bald in der Nervenfaserschicht, laald wieder höher: in der innern retikulären Schicht. bilden somit keine vollständig zusammenhängende Schicht.

Die Kristallinse wird durch eine zusammenhängende Masse unregelmäßig geformter, kleiner oder grösserer, oftmals im Zerfall begriffener Zellen gebildet; zuweilen wird sie erset $/$ t durch eine Linsenblase, welche ron den in einer Schirht liegenden unregehmäBigen Zellen umschlossen ist, allein in beiden Fällen nimmt die rudimentäre Linse denjenigen Teil der Höhlung des Augapfels ein, welchen der stralılenkörper hinter der Netzhant frei lässt. I)ie vordere Wand der Linse grenzt unmittelbar an die Obertiiche der Hornhaut.

Die Arterie des Glaskörpers ist als Überrest des Fötalalters jederzeit nachweisbar. I)ie Augenmuskehn fehlen gänzlich, dagegen ist eine Irüse des Conjunctivalschlauches, nämlich die Hardersche Drüise, so mächtig entwickelt, dass sie mit dem rudimentiiren Augapfel durchaus in keinem Verhältnis steht. Mit Riiicksicht auf den rerkümmerten Augaprel lässt sich die mächtige Entwicklıng dieser Irüse etwa so erklären, dass nach dem Verf. ilne Sekrete, die in die Nasenhöhle gelangen, zum Abwaschen der dahin eingedrungenen fremden Stoffe dienen, was bei der eigentümlichen Lebensweise des T'ieres wirklich notwendig erscheint.

A. Gorka (Budapest). 


\title{
Zoologisches Zentralblatt
} unter Mitwirkung von

\section{Professor Dr. O. Bütschli}

In Heidelberg

\author{
herausgegeben von
}

Professor Dr. B. Hatschek

in Wion

\section{Dr. A. Schuberg}

a. 9. Protessor in Heidelberk.

Verlag von Wilhelm Engelmann in Leipzig.

\section{Referate.}

\section{Geschichte und Literatur.}

438 Fickel, Johannes, Die Literatur über die Tierwelt des Königreichs Saclisen. Zwickau 1902. 71 pag. Mk. 2.-.

Als wissenschaftliche Abhandlung des Jahresberichts des Vereins für Naturkunde zu Zwickau hat Fickel eine sehr sorgfältige Zusammenstellung der Schriften über die sächsische Tierwelt gegeben, die woll als um so vollstïndiger gelten kamn, als der Verf. bereits acht Jahre früher den gleichen Gegenstand in einem Schulprogramm behandelte und inzwischen aufs eifrigste zu ergänzen bestrebt war. Er geht über die ïblichen Anforderungen der wissenschaftlichen Zoologie hinaus, indem er selbst die Tagesblätter berïcksichtigt, meiner Meinung nach mit Recht, da manche faunistischen Einzelvorkommnisse nur so festzulegen sind. Ferner beschränkt sich Fickel nicht auf die Literatur, die Sachsen speziell behandelt, sondern sucht anch in allgemeinern Werken alle anf das Königreich bezüglichen Stellen zusammen, eine schwierige Aufgabe. In dieser Hinsicht war es wohl kaum möglich, vollikommenen Abschluss zu erreichen. Die Reichhaltigkeit ergibt sich aus dem engen Druck, die Seiten sind in zwei Spalten gegliedert, jeder Nummer ist eine kurze Inhaltsgabe in Petitdruck beigefügt. Auf Kritik lat sich Fickel nicht weiter eingelassen, wenigstens nicht durchgängig. Der Bemerkung, dass die Leipziger Lerchen deshalb besonders delikat seien, weil sie sich von dem daselbst massenhaft auf den Feldern wachsenden Knoblauch nährten, konnte inmerhin die sachliche Berichtigung beigefügt werden, dass der Bärlauch sich auf die Auewälder beschränkt, wo er allerdings in Übermaß wuchert. Die Anordnung folgt dem System, zunäichst Allgemeines, dann die 
Wirbeltiere mit ihren fünf Klassen, die Insekten mit den alten sieben Ordnungen usw. Ein Autoren- und Ortsregister beschliesst die fleissige Arbeit. Sie wird eine Fundgrube bleiben für die Geschichte der Tierwelt in Sachsen wie für liünftige faunistische Arbeiten.

\section{H. Simroth (Leipzig).}

\section{Lehr- und Handbuicher. Sammelwerke. Vermischtes.}

439 Matzlorff, C., Tierkunde für den Unterricht an höhern Lehranstalten. Ausgabe für Realanstalten, auf Grund der preussischen Lehrpläne von 1901 bearbeitet. In sechs Teilen. Teil I-IV. Breslau (Ferd. Hirt) 1903. kart. Mk. 4.15.

Bei der Beurteilung der vorliegenden Bücher, zu denen die beiden letzten Teile noch folgen sollen, hat man erst den Standpunkt zu wählen; entweder man sielıt sie bloss von den gegebenen Lehrplänen aus an oder man fragt, ob wirklich die neue Methode die beste ist; und dann kommt man zu allerlei Zweifeln. Gut ist auf jeden Fall die Forderung, die Biologie immer mehr zu berücksichtigen, was von Matzdorff meist in ausreichender Weise geschehen ist, wenn man unter Biologie die Lebensweise, sowie etwa die Abhängigkeit des Körperbaues von äussern Verhältnissen, zum mindesten die Harmonie zwischen Bau und Lebensweise versteht. Fraglich aber ist mir, ob der sogenannte konzentrische Lehrgang der vorteilhafteste und anregendste ist, zum mindesten in der vorliegenden Form. Es liegt die Gefahr vor - und ihr scheint mir der Verf. in mehrfacher Hinsicht unterlegen zu sein - das alte, mittelalterliche Schema der grammatikalischen Ausbildung auf die Naturwissenschaften zu ibertragen und "statt der lebendigen Natur" den Geist in spanische Stiefeln einzuschnüren. Man verzeihe mir, wenn ich möglichst freimütig rede. Ich erkenne zunächst die ausserordentliche Arbeit von Matzdorff willig an, die grosse Mühe methodischer Auswahl, die Hereinziehung moderner Disziplinen, wie sie sich in der Tiergeographie, in der Karte der europäischen Zugstrassen der Vögel, in den Farbentafeln für Schutzfärbung und Nimicry ansspricht, die Verdeutschung technischer Ausdrücke, die konsequente Durchführung der lateinischen Bezeichnungen nach den neuen Nomenklaturregeln (z. B. Flusskrebs, Potamobius astacus, die Garnate, Crangon crangon), die reiche Ausstattung mit guten Habitusbildern, anatomischen und histologischen Zeichnungen, schematischen Durchschnitten u. dergl. Nebenbei mag ich etwa darauf hinweisen, dass zum Seepferdchen wohl ein Habitusbild gehört hätte, da von einer so charakteristischen Form die Beschreibung keine genügende Vorstellung geben kann. 
Doch nun zur Begründung meines über die Methode absprechenUrteils! Die drei ersten Jahrgänge sind den Wirbeltieren gewidmet. In Sexta werden eine Anzahl bekanntester Säuger und Vögel besprochen. Daran wird ein zweiter Abschnitt gefügt: Frläuterungen und Zusanmenfassungen; und darin steckt zum ersten Male das pedantische Schema. Wir finden 3 Abschnitte: A. Allgemeines, B. Säugetiere, C. Vögel; unter A folgende Rubriken: I. Begriffsbebestimmungen, II. Aufenthalt, III. Bewegung, IV. Ernälırung; unter B. : I. Allgemeines, $\$ 27$ Körperabschnitte, $\$ 28$ Vordergliedmaßen, $\$ 29$ Hintergliedmaßen, $\$ 31$ Lormen des Auftretens, II. Körperbedeckung, III. Bewegung, $\$ 36$ Knochen, $\$ 37$ Vordergliedmaßien, \$ 38 Hintergliedmaßen, IV. Ernährung, V. Fmpfindung, VI. Fortptlanzung; unter C.: I. Allgemeines, \$ 53 Körperabschnitte, \$54 Vordergliedmaßen. ș 5 5 Hintergliedmaßen, II. Körperhedeckung, III. Bewegung, $\$ 62$ Vordergliedmaßen, $\$ 63$ Hintergliednaßen, $\$ 64$ Schwanz- und Steuerfederu, IV. Ernährung, V. Finptindung, VI. Fortpflanzung. Hier haben wir die schönste grammatikalische Gliederung. Meiner Meinung nach gehörte sichs, in der Zusammenfassung die Vergleichung durchzuführen, die Ernähırung also A. IV., B. I und C. IV unter einen Gesichtspunkt zu bringen und in den Verschiedenheiten darzulegen; ebenso gehïrten A. III, B. I, bezw. erst recht mit den Vordergliedmaßen und Hintergliedmaßen, B. III die Knocheu der Gliedmaßen, C. I $553-5 \check{5}$, und C. III zusammen usw. Freilich fallen dann die Paragraphen weg und die Möglichkeit, immer wieder durch die verschiedenen Bändchen hindurch scharf auf den Wortlaut und die Rubrik zu verweisen. Im Quintanerkurs erhalten wir wieder eine Anzahl Säugetiere, an Stelle der Hauskatze von Band I tritt der Löwe auf, eine Anzalıl Vögel, 2 Reptilien, 2 Lurche und 3 Fische. Auch kommt der Mensch in erster anatomischer Betrachtung daran. Dann folgt wieder ein zweiter Mbschnitt: Erläuterungen und Zusammenfassungen. A. Allgemeines. I. Körperform, II. Körperbedeckung, III. Bewegung, IV. Ernährung, V. Verwandtschaft, VI. Verbreitung (diese ganz erfreulich, wie oft das Einzelne). Dann kommen wieder dieselben liubriken, diesmal bei den 5 Wirbeltierklassen, abermals mit Tordergliedmaßen und Hintergliedmaßen usw., natürlich etwas genauer und erweiterter, aber konzentrisch! Band III., Quarta, schliesst die Wirbeltiere ab. Wieder neue Tierbeschreibungen, für Hauskatze und Löwe z. B. treten 'Tiger und Jaguar auf; die systematische Einteilung wird vollendet, worauf ich gleich zurückkomme. Dann abermals der zweite Abschnitt mit derselben Gliederung. Den Jungen werden zweifellos die neuen Tierformen, die er jetzt bekommt, wieder interessieren; aber ob er als Sextaner, der den zoologischen 
Garten kannte, nicht anch bereits Löwe und Tiger als grosse Katzen aufzufassen im stande war, mag der natürliche Verstand entscheiden. Freilich die Systematik darf ja erst im dritten Jahre kommen, in konzentrischer Erweiterung! In der Quinta hat er den Begriff der Verwandtschaft gelernt, leider nicht im geringsten im Sinne der Blutsrerwandtschaft und Descendenz (das kïnnte wohl Anstoss erregen), sondern als Gliederung in Typen, Klassen, Unterklassen usw., wiewohl an Stelle der schematischen Wiederholungen Raum genug gewesen wäre für gelegentliche Abschweifung - doch die passt nicht zu spanischen Stiefeln. Nun einige Beispiele ron Systematik; ich entnehme sie den Vögeln. Hier sind deutsche Kollektivnamen in ganz anderm, wenn auch vielleicht modernern Sinne genommen, als bisher, sodurch nur Verwirrung entstehen kamn. Aber es genïgt dem Verf. nicht, fïnfzelın Ordnungen aufzustellen, die Ordnungen werden erst wieder in sieben Reihen zusammengefasst. So gehören Reiher und Flamingo zur Ordnung der Schreitvögel, Kranich und Bekassine zur Ordnung der Lautrögel, beide bilden die Reihe der Stelzrögel. Die Reihe der Schwimmvögel umfasst die Ordnungen der Leistenschnäbler, Seeflieger, Ruderfüsser und Taucher. Abgesehen davon, dass als Parallele zum botanischen Unterricht besser der Begriff der Familie anzuführen oder doch die Zusammenfassung in Reilien wegzulassen war, warum musste der alte Begriff der Laufvögel, bezw. Brevipennes, jetzt anf den Kranich ïbertragen werden! Das gibt nur Verwirrung. Was aber sollen wir sagen, wenn, einer möglichst scharfen Begriffsbestimmung zu Liebe, von der Reihe der Stelzrögel zum Unterschiede von den Schwimmrögeln wiederholt betont wird, dass sie ihre Nahrung a uf dem Lande suchen? Auch der besonders beschriebene Fisch. reiher? Hat es für Quartaner Zweck, zu lernen, dass man Scharrvögel und Raubrögel als Unterklasse Fänger zusammenstellen kann? Hinter Pfau und Perlhuhn findet er: Reihe der Fänger gleich als Kapitelüberschrift. Solche Dinge gewinnen erst dann Wert, wenn der Begriff der Descendenz erläutert ist. Auch genügte wohl, für Scharrvögel zu sagen: Hühner oder Hiihnervögel. Die Pädagogik der Naturgeschichte sollte darauf hinausgehen, auf möglichst einfache Weise möglichst viel Kenntnisse und wahres Verständnis beizubringen, aber nicht mit der mïhsamen Erlernung einer Art Klaviatur das Gedächtnis z.u belasten. Es sollte nichts in ein Naturgeschichtsbuch, was bloss auswendig zu lernen ist, ohne Beziehung zu den Besonderheiten des Lebens, mag es deshalb auf wissenschaftlicher Höhe stehen oder nicht. Was fängt der Schüler mit dem Namen Cranyon crangon an, ohne jede Ahnung von der Entstehung und Entwicklung der binären Nomenklatur? Danit sind wir beim vierten Cursus, bei den Gliedertieren, 
angelangt. Hat es Zweck, hier beizubringen, dass die Tiere bilateral gebaut sind und eine genaue Erklärung dieses Begriffes zu geben? Bilateralität gehört erst an die Stelle, wo andere, radiäre, Formen auftreten, so gut wie der Begriff der Farbe wegfiele, wenn es bloss den Gregensatz von hell und dunkel gäbe, wie ihn die Nachttiere haben. Nachher macht sichs spielend. Für die systematische Qual ein Beispiel. Der erste Teil, die Tierbeschreibungen, bringen sechs Spinnentiere: Skorpion, Weberknecht, Kreuzspinne und 3 Milben, dafür sind zu lernen: 1 Klasse, 2 Unterklassen und 4 Ordnungen, also mehr taxonomische Begriffe als Arten. Der zweite allgemeine Teil bringt bei C Spinnentiere unter VII. ,Verwandtschaft" eine erweiterte kurze Übersicht des Systems (beiläufig mit verschmitzten lateinisehen Namen, wie Phryniscus creniformis als Vertreter der Geisselspinnen, welche , ,3,3 cm lang" sein sollen), unter I. ,Allgemeines" wird aber bereits die Gliederung genau angegeben: „Der Hinterleib besteht bei den Walzenspinnen aus 9 oder 10, bei den Geisselspinnen aus 11 oder 12, bei den Skorpionen aus 13 , bei den Afterskorpionen aus 6 bis 8 , bei den Afterspinnen aus 6 Ringeln". Das sollen die Jungen lernen, ohne nähere Kenntnis der Formen. Von der gesetzmäßigen V'erkürzung und Verschmelzung kein Wort! Nebenbei die merkwürdige, wiederholt betonte Auffassung, den Spinnentieren fehlte das erste Kieferpaar, dafïr benutzten sie die Fühler, daher ,Kieferfühler". Noch eine andere Bemerkung betr. der Systematik. Sobald in einer Zusammenfassung die geschilderten Tiere aufgezällt werden, wird möglichst eine Bestimmungstabelle aufgestellt, oft für 2 und 3 Tiere. Die Tabelle hat doch bloss \%weck für die Bestimmung, wenn das Tier noch umbekannt ist, hinterher mutet sie einen wieder an wie eine / $/$ wangsjacke, in die der Schiiler hinein muss. Auf weitere Einzelheiten verzichte ich. Ich bitte Interessenten, sich die Bücher, von deren verschmitzten überreichen Verweisen ich nichts näheres bringen will, nach den angegebenen Gesichtspunkten anzusehen. Sie werden wohl mit mir zu dem Schlusse kommen, dass auf diese Weise der Nachwuchs schwerlich für die Zoologie zu begeistern ist.

H. Sini roth (Leipzig).

\section{Zellen- und Gewebelehre.}

440 Boveri, Marcella, Ueber Mitosen bei einseitiger Chromosomenbindung. In: Jenaische Zeitschr. Bd. 37. 1903. pag. 401-446. Taf. 21-23. 25 Textfig.

Verfasserin hat die ron Th. Boveri beschriebenen abnormen Mitosen, bei denen die ganze Kernsubstanz in die eine Tochterzelle gelangt, während die andere nur ein Centrosoma mit Sphäre erhält, 
genauer analysiert. Diese Abnormität kann nicht willkürlich hervorgerufen werden: sie ist eine seltene Ausnahme und wurde nur in solchen befruchteten Fragmenten ron Echinideneiern gefunden, denen der Eikern fehlt; ausserdem kommt sie in ganzen Eiern und kernhaltigen Fragmenten an jedem isolierten Spermakern zu stande (wenn im Falle der Dispermie der eine Spermakern mit seinem Spermozentrum selbständig bleibt, so entsteht nach Verdopplung der Sphäre die gleiche einseitige Figur, während ans dem andern Spermakern, der mit dem Eikern kopulierte, eine normale Spindel hervorgeht). In den abnormen Fällen stehen die beiden Sphären viel weiter voneinander $a b$, als sie im normalen Fall bei gleichen Protoplasmadimensionen und auf gleichem Stadium tun. Dabei macht Verf. auf folgende interessante Verhältnisse aufmerksam: Grösse und Abstand der Sphären sind nicht allein von dem Stadium abhängig, sondern auch von der Menge des Protoplasmas (je kleiner das Fragment, um so kleiner die Sphären; je mehr Sphären in einem polysperm befruchteten $\mathrm{Ei}$ vorhanden sind, desto kleiner sind sie). Weiterhin gelangt sie zu dem wichtigen Resultat, dass der normale erste Furchungskern eine zusammenhaltende Wirkung auf die Splrären ausübt, die dem selbständigen Spermakern in den erwähnten Fällen fehlt:

„Diese Attraktion muss es offenbar sein, die bewirkt, dass Sphären, die einen Kern zwischen sich haben, nicht so weit auseinander weichen, wie unverbundene es tun. Wir sehen hier zwei einander widerstreitende Tendenzen: die Zentren suchen sich bis auf einen gewissen Abstand voneinander zu entfernen, der uns aus den Fällen, wo sie nicht rerbunden sind, bekannt ist, und den wir ihre Gleichgewichtslage nennen wollen. Der Kern muss diesem Bestreben folgen, er kommt ihm durch seine Vergrösserung und vor allem durch Streckung bis zu einem gewissen Grad nach. Von da an aber hält er nun seinerseits die Sphären fest und verhindert sie, ihre Gleichgewichtslage wirklich zu erreichen.

In unsern Fragmenten, die nur einen Spermakern enthalten, siegt in diesem Widerstand die Entfernungstendenz der Sphären. Zur Erklärung wird man vor allem an die Kleinheit des Spermakerns zu denken haben, wobei man zu folgender Vorstellung käme. Die Sphären suchen sich voneinander zu entfernen, der Kern sucht mit beiden in Kontakt zu bleiben. Da er dies nicht kann, weil er so klein ist, bleibt er je nach dem Zufall an einer ron beiden hängen, während die andere unabhängig geworden ist. So können die Sphären hier bis zu ihrer Gleichgewichtslage auseinander weichen. Diese Auf- 
fassung würde zugleich die oben besprochene Tatsache erklären, dass der Spermakern fast stets gegen die freie Sphäre gerichtet ist".

In bezug auf die Mechanik der Teilung macht Verf. auf das Abgedrängtwerden der Chromosomen von den Zentren und auf ihre Verstremung (gegenseitige Abstossung) aufmerksam; bei ausschliesslicher Einwirkung von einer Sphäre weisen sie nie einen so grossen Abstand rom Zentrum auf wie bei der Einwirkung zweier. „Es muss also im letzten Fall ein Zug von der Gegenseite stattfinden, der in keiner Sphäre eine so starke Annäherung der Chromosomen an das Zentrum gestattet, wie es den Wirkungen dieser Sphäre allein entspräche". Weil in den beschriebenen Abnormitäten die Sphären von Anfang an ihre Gleichgewichtslage eimnehmen, weichen sie später nicht weiter anseinander. In bezug auf die Bedeutung der Spindelfasern als Zugfasern schliesst Verf. an Th. Boveri an. Auch in bezng auf die Zahl der Chromosomen ist sie mit diesem Forscher und nicht mit Delage in Übereiustimmung.

In den beschriebenen Fällen fand in der kernlosen Blastomere nur Vermehrung der Sphären statt - ihre Zahl entspricht derjenigen des gefurchten Bereiches - aber keine Zellteilung. Verf. diskutiert die von Zi egler und E. B. Wilson beschriebenen, anders verlaufenden Fälle und die Ansichten ïber das Fintreten der Zellteilung an kernlosen Zellen; doch muss in bezug hierauf auf das Original verwiesen werden.

R. S. Bergh (Kopenhagen).

41 Sutton, Walter S., The Chromosomes in Heredity. In: Biol. Bulletin IV. Bd. Nr. 5. April 1903. pag. 231-251.

Verf. stellt sehr interessante Betrachtungen ïber die Kombinationsmöglichkeit der väterlichen und mütterlichen Chromosomenübertragung bei der Befruchtung an unter Berücksichtigung der verschiedenen Qualität der einzelnen Chromosomen usw., wobei er sich im wesentlichen auf die botanischen Erfahrungen bei Kreuzbefruchtung usw. stützt.

R. Fick (Leipzig).

442 Ziegler, H. E., Experimentelle Studien über die Zelltheilung. Fortsetzung. In: Arch. f. Entwmech. Bd. 16. 1903. pag. 15็ - 175. 30 Textfig.

Verf. ist früher durch das Studium der Furchung von Beroë zu der Ansicht gelangt, dass die im Grunde der einschneidenden - bekanntlich einseitig sich ausbildenden - Furche gelegene V'erdickung der äussern Protoplasmaschicht die nächste mechanische Ursache der Durchschnürung sei, dass also die Zellteilung durch eine Veränderung der protoplasmatischen Aussenschicht bewirkt wird, welche durch eine zur Zeit 
nicht genauer bestimmbare Fernwirkung der Centrosomen hervorgerufen ist, und dass die Strahlen der Kernteilungsfigur weder kontraktile Fäden sind noch durch ihren Zug die Zellteilung bewirken. Gegen diese Anschauungen wurde von Fischel sowie von Rhnnbler Opposition erhoben, und Verf. sucht seine Ansicht durch neue Beobachtungen zu erhärten.

Zunächst wird mitgeteilt, dass man in dem DurchströnıungsKompressorium ein Ei recht Hach drüicken kanm, ohne dass der Fortgang der Teilung gestört wird, was bei einem zentrierten Radiensystem nicht möglich wäre. „Wenn man sich die Zelle mit dem gedachten Radiensystem körperlich vorstellt, so ist es einleuchtend, dass ein Zusammendrücken der Zelle zahlreiche Radien entspannen und andere iibermäßig anspannen würde. Es müsste die schwerste Störung des Zellteilungsvorgangs eintreten, was aber keineswegs der Fall ist" (ausserdem reichen die Radien nicht weit genug und kömnen unmöglich geradlinig zwischen den grossen Dotterballen verlaufen).

Auch bei Seeigeleiern findet sich nach Verf. eine dünne protoplasmatische Aussenschicht - schon vor vielen Jahren von Selenka beobachtet - und anch hier verdickt sich vor Beginn der Teilung diese Aussenschicht an der Stelle der entstehenden Furche, wälırend sie an den übrigen Teilen der Zelloberfläche sich bis zur Unkenntlichkeit verdünnt (all dieses ist nur an lebenden Eiern zu beobachten). Demgemäß deutet Verf. die Teilungsvorgänge auch hier in ähnlichem sinne wie bei Beroë.

Interessant ist eine vom Verf. mitgeteilte, auf seine Anregung von Schmauss ausgeführte Untersuchung über die Einwirkung von Bleiessig auf die Seeigelfurchung: sie wird dadurch verlangsamt, und die Furche bildet sich einseitig, so dass die Physiognomie der Teilung derjenigen der Furchung von Beroë recht ähnlich wird.

R. S. Bergh (Kopenhagen).

\section{Vergleichende Morphologie, Physiologie und Biologie.}

443 Driescli, Hans, Neue Antworten und neue Fragen der Entwickelungsphysiologie. In: Ergebnisse d. Anat. u. Entwgesch. Bd. 11. 1901. pag. 784-945.

In der Einleitung hält Verf u. a. an seiner Verwerfung des theoretischen Begriffs Homologie und der vergleichenden Methode der Morphologie fest und verlangt die Anerkennung nicht nur eines Art-, sondern eines "Rangunterschiedes" zwischen "Wissenschaft $\mathrm{Nr}$. 1" (das Rationelle), „Wissenschaft Nr. 2“ (die Klassifikation) und ,Wissenschaft Nr. 3“" (die Historie). Die Historie als ein so geringes Objekt menschlicher Geistestätigkeit aufzufassen, sogar geringer als die 
Klassifikation mag als Ausdruck eines bestimmten Gieschmacks eines bestimmten sehr begabten Experimentalforschers gelten; darïber hinaus hat die Drieschsche ,Klassifikation" der "Wissenschaften" keinen Wert.

Danach behandelt Verf. sehr eingehend die grosse nevere Literatur iiber ,das erste Problem der Entwicklungsphysiologie" (die prospektive Potenz der Blastomeren); weiter folgt eine ,Orientierung über die Finzelprobleme der Lntwicklungspliysiologie" (selbständige, allgemeine Betrachtungen des Verfs. enthaltend, die sich nicht in Kürze wiedergeben lassen) und ein Abschnitt, ,von der Verteilung der Potenzen im Keimganzen" (Analyse der neuern Studien über Regulationen). Ferner behandelt Verf. die ,äussern Mittel der Formbildung (Licht, Wärme, Sauerstoff, osmotischen Druck und chemische Vittel), sowie die ,,innern" Mittel der ,Formbildung" (Aggregatzustand und Verwandtes, Histogenese, Zellteilung, „organbildende Stofle", Latalyse), sowie die .,Mittel sekundärer Regulationen" und die Ursachen der Formbildung (gegebene strukturelle Ursachen, Richtungsreize und formative Reize, Selbstdifferenzierung und Reize, welche sekmndäre Formregulationen hervorrufen). Lis folgt ein Abschnitt: "von der Spezifität ontogenetischer Effekte" (u. a. behandelt Terf. hier die Konstanz der Grösse und Form von Zellen und höhern Einheiten sowie das entwicklungsfähige Keimesminimum und die Beendigung morphogener Elementarprozesse). Schliesslich folgen liurze Betrachtungen ïber ,das Ganze der Ontogenese, den Cyklus der Formbildung erbung.

Diese ausführliche Abhandlung, die wesentlich als Referat neuerer Untersuchungen herrortritt, enthält - wie in einer Arbeit von I) riesch selbstverständlich - eine Anzahl selbständiger Erörterungen und Betrachtungen. Da ein Eingehen auf dieselben in Kürze nicht gut tunlich ist, musste sich Ref. auf die obige Angabe dos Inhalts beschränken.

R. S. B ergh (Kopenhagen).

444 Fischel, Alfr., Entwickelung und Organ-D ifferenzierung. In: Arch. f. Entwmech. Iid. 15. 1903. pag. 679-750. 21 Textfig.

Verf. geht bei seinen Betrachtungen ron den Ergebnissen der früher von ihm selbst und von andern angestellten Experimente an den Beroë-Eiern aus: es war durch dieselben erwiesen worden, dass schon in (ungefurchten) Ei eine bestimmte Menge eines ganz bestimmten Anlagematerials rorhanden sei, und dass dieses Material bei der Furchung in ganz gesetzmäßiger Weise auf die einzelnen Plastomeren verteilt werde. Die Ursache dieser Differenzierung liegt nach Verf. nicht so sehr im Kern, sondern wesentlich in der Organisation des 
Zellleibes, und Vert'. stellte eine Reihe neuer Versuche an, um zu entscheiden, ob dieses Anlagematerial iiber das ungefurchte Ei gleichmäßiq ausgebreitet oder nach einem ganz bestimmten Typus eingelagert sei. Es war zu ermitteln, ob die Ausschaltung bestimnter Teile des Fies stets auch das Ausbleiben der Entwicklnng bestimnter Teile des Larvenkörpers im Gefolge hat, ol, es also auch in der ungefurchten Eizelle eine (nnd welche?) genane Topographie von etwaigen organbildenden lieimbezirken gibt.

Die Versuche ergaben wesentlich folgendes:

Eier, denen die oberste Protoplasmaschicht an animalen Pol, oberhalh des Kerns weggenommen wurde, entwickelten sich nicht weiter; höchstens fuihrten sie die /weiteilung zu Ende. Wenn dagegen seit lich nahe am obern Pol Protoplasmastiicke abgeschnitten werden, entwickeln sie sich meistens weiter; die Operation hat aber dann stets Rippendefekte zur Folge. Die Fintnahme nicht allzu grosser Stiicke ans dem seitlichen nntern Abschnitte des Fies behindert dagegen nicht tie Entwicklung einer ihren Organen und ihrer Gesamtform nach völlig normalen Larve; ebenso das Abschneiden des untersten T'eils des lies (entsprechende Ergebnisse wurden anch an den zwei ersten Furchungskugeln erzielt, indem die Protoplasmadefekte hier durch Operationen herrorgebracht wurden).

Schon dem nngefurchten Ctenophorenei fehlt demgemäß die Fähigkeit, sich nach jeder Richtung hin zum Ganzen auszugleichen; die verschiedenen Bezirke des Lies sind ihrer Beziehung zur Organbildung nach ungleichwertig: lür die Lehre von der Isotropie der Eimasse bildet das (tenophorenei keine Stuitze. Die Rippenentwicklung ist nicht direkt und ausschliesslich ron epigenetischen Eintiüssen beherrsclit; es muss eine besondere ripenbildende Substanz in einer bestimmten Menge, in einem bestimmten Bezirk lokalisiert, vorhanden sein und, einmal ein Teil daron dem Ei entnommen, kann sich der Rest nicht wieder zur normalen Menge regulieren. Sie ist im obern seitlichen Abschnitte des ungefurchten Eies enthalten. Auch die übrigen sich entwickehnden Teile haben die für sie bestimmte Substanzen in bestimmter Weise im ungefurchten Ei lokalisiert: in dem an obern Pole liegenden protoplasmatischen Rindenmaterial sei das materielle Substrat für das Mesoderm enthalten; der zentrale (bez. auch unterste) Eiabschnitt stelle das Material für die Macromeren, aus denen sich das Entoderm herleitet, dar. - Weiter diskutiert Verf. die Frage, ob schon im unbefruchteten Ei diese topographisch bestimmte Organisation sich vorfinde, und kommt zu dem Ergebnis, dass diese Annahme wahrscheinlich sei.

Weiter sucht Verf. dar'zulegen, wie in der Entwicklung jedes 
Organs der Ctenophoren sowohl epigenetische wie evolutionistische Momente sich geltend machen. Nan müsse dahin kommen, bestimmte, organogene, präformierte Stoffe im Ei anzunehmen, wie solches sich in einigen Fällen (Ilyanassa und namentlich Myzostoma) sich direkt wahrnelımen lässt. Es seheint ihm nun, dass jene für die erwähnten Eiarten teils sicher erwiesene, teils sehr wahrscheinliche genetische Beziehung zwischen einer besondern Plasmaschichtung des (ungefurchten) Eies und den ans ihm entstehenden Organen in Prinzipe allen Eiarten zukommt, und dass der Unterschied zwischen ,Regulationseiern" und ,Mosaikeiern" nur ein ganz gradueller sei (dass das als typisches Regulationsei angenommene Seeigelei kein solches ist, haben die Untersuchungen Boveris erwiesen). Verf. stellt als allgemeinen Satz auf, dass „die Anlagen der l'rimitivorgane des Embryos schon in der ungefurcliten Eizelle, und zwar in deren verschiedenen, materiell und potentiell ungleichwertigen plasmatischen Zonen rorbereitet enthalten sind. Die Eizelle selbst ist demnach, im Prinzip, nicht als ein isotropes (iebilde anzusehen, und in keinem Falle kann die Entwicklung als ,reine Epigenese" angenommen werden."

Verf. stellt schliesslich eine lieihenfolge der Eier auf, soweit sie anf ihre Regulationsfähigkeit untersucht sind (dabei bildet das Ctenophorenei ein Verbindungsglied zwischen den reinen Mosaikeiern und den ïbrigen); er hebt hervor, dass je strenger die Mosaikarbeit durchgefülurt ist, desto starrer der Furchungstypus sei (welcher Satz wohl übrigens kaum neu sein dürfte), und desto grösser auch die chemischen Differenzen innerhalb des Eies seien. Er nimmt an, dass die Teilung der Centrosomen von den Kermen umabhängig, von den Plasmaschichten aber beeinflusst sei. - Die Schlussbetrachtungen des Verfs. lassen sich nicht gut in Kürze wiedergeben.

R. S. Bergh (Kopenhagen).

445 Korschelt, E. und K. Heider, Lehrbuch der vergle ichenden Entwicklungsgeschichte der wirbellosen 'Thiere. Allgemeiner Theil. Zweite Lieferung. Jena (G. Fischer) 1903. pag. 539-750. 87 Textfig. Mk. 5.50.

Mit erwiunschter Schnelligkeit ist die zweite Lieferung des allgemeinen Teils des Korschelt-Heiderschen Werkes, in der Verff. die Eireifung, Samenreifung und Befruchtung sowie die Theorieen der Vererbung behandeln, dem ersten Heft gefolgt. Sie besitzt durchaus dieselben Vorziige wie dieses: gediegene, eingehende Darstellung der Tatsachen und der auf sie gegründeten Theorieen, genaue Kenntnis und Berücksichtigung der Literatur und objektive Beurteilung strittiger Fragen. 
Ein kurzer Hinweis auf den Inhalt muss hier genïgen.

Zunächst schildern Verff. die Bildung und Abschnürung der Richtungskörper und besprechen ausführlich die Theorieen, die man über ihre Bedentung formuliert hat: dann folgt ein entsprecbendes Kapitel uiber die Samenreifung, und hieran schliessen Verff. ein grosses Kapitel „Die Reifungsteilungen im Hinblick auf die Reduktionsfrage"; in bezug auf letatere Frage kommen im tatsächlichen Verlanf der Reifungsteilungen verschiedene Modi vor, welche Verff. als „eumitotische Reifungsteilungen" (Boverischer Modus, Bildnng der ('hromosomen-Tierergruppen durch zweimalige Längsspaltung) und ..pseudomitotische Reifungsteilung" (Bildung der Vierergruppen durch einmalige Längsspaltung und entweder - .P'ostreduktionsteilung“6 oder Weismannscher Modus - einmalige Querteilung oder Aneinanderlegung je zweier ('hromosomempare - l'räredulitionsteilung oder Korscheltscher Modus); endlich komme mögticherweise (nach Julin bei Ascidien) Unterdrückung beider Iängsspaltungen vor. Es folgt eine Iriskussion ïber Wesen und liedeutung der Chromatinreduktion und ein Abschnitt über die Reifung parthenogenetischer Eier.

Zur Lehre von der Befruchtung übergehend, behandeln Verff. zunächst das Ëndringen des spermatozoons in das Ei, sowie die Ausbikung des Spermakerns, die lieeinflussung des Ooplasmas durch die Befruchtung, Auftreten und Herkunft der C'entrosomen (aus dem Spermatozoon), das Verhalten der achromatischen Substanz (Attraktionssphären, Radiensysteme und Spindelfasem aus dem Ooplasma), weiter die Vereinigung der Geschlechtskerne und das Verhalten der chromatischen Substanz; Geschlechtsbestimmung, Keimzellendifferenzierung und Polyspermie. Die Ansichten über Wesen und Bedeutung der Befruchtung werden auseinandergesetzt, und hieran schliesst sich ein grosser Anhang über die Theorieen der Vererbung.

Auch dieses Heft ist mit einer reichlichen Auswahl von Figuren ausgestattet und mit einem sehr vollständigen Literaturverzeichnis versehen.

R. S. Bergh (Kopenhagen).

446 Wedekind, W., Eine rudimentäre Funktion. In: Zool. Anz. 26. Bd. Nr. 692. 1903. pag. 203-204.

Verf. glaubt, man könne ebenso wie man in der vergl. Anatomie von "rudinentären Organen" spreche, in der vergl. Physiologie von "rudimentären Funktionen " sprechen. Als eine solche betrachtet er die Möglichkeit parthenogenetischer Entwicklung der Echinodermeneier usw., die für gewöhnlich durch das Absterben der Eier vorzeitig abgebrochen werde, durch künstliche Eingriffe (wie in L o ebs Versuchen) aher zur Wirksamkeit gebracht werden kömne. R. Fick (Leiprig). 
447 ron Fïrth, 0tto, Vergleichende chemische P'hysiologie der nieder en Tier e. Jena (G. Fischer) 1903. gr. $8^{0}$. 670 pag. Mk. 16.-.

Das Bedürfnis nach physiologischen lienntnissen macht sich in den Kreisen der Zoologen von Jahr zu Jahr mehr geltend, fühlen es doch schon viele, dass der Stern der Morphologie in sinken begriffen ist. Und andererseits ist die Zahl der I'hysiologen, die sich bemühen, ihre theoretischen Anschaungen nicht mehr lediglich auf die Erfahrungen an einigen Wirbeltieren zu grïnden, sondern auch die formenreichen Kreise der Wirbellosen lreranzuziehen, in stetigem Znnehmen begriffen. Dem Zoologen ist bei seinem Streben die geringe Kenntnis der oft zerstreuten physiologisehen Literatur hinderlich, dem I'hysiologen die mangelnde I'bersicht ïber die Formenfülle des Tierreichs. Unter solchen Umständen muss ein Buch wie das rorliegende von ausserordentlich vielen mit Freude begrüsst werden, es füllt eine sehr empfindliche Liicke in der literatır ans, und, was gleich betont werden mag, es füllt diese lïcke rortrefflich aus. Mit unsäglichem Fleisse ist ans den entlegemsten Winkehn in- und ansländischer Literatur ein Material zusammengetragen, das chen so sehr durch seine Reichhaltigkeit in Erstamen setzt, wie lar'h seine übersichtliche Anordunug praktisch rerwendbar wird.

Ein kurzer Abriss der organischen Clyemie, der dem rigentlichen Werke vorangesetat ist, macht anch für den chemiscle minder geschulten die Lektiire möglich.

F' ii r h behandelt zunäichst die grossen Kapitel: Rilnt, Atmung, Ernährung und Exkretion, dann folgt ein liöchst interessanter Abschnitt über tierische Gifte. Das Kapitel ,Sekrete besonderer Art" enthält n. a. reichhaltige Angaben über das Tintensekret der Cephalopoden, den I'urpur, die Seide, das Wachs. Die nächsten Abschnitte behandeln die Muskeln und die Gerüstsubstanzen. Das schwierige Kapitel der Farbstoffe der Gewebe findet eine klare kritische Darstellung. Eigene Abschnitte sind endlich noch gewidmet den Reservestoffen und Aschenbestandteilen, den P'rodukten der Sexualdrüsen und den chemischen Existenzbedingungen wirbelloser Tiere.

Diese wenigen Angaben mögen eine ungefähre Vorstellung von dem reichen Inhalt des Werkes geben, auf den im einzelnen natiirlich nicht näher eingegangen werden kam. Sicher hat sich fi iith durch diese Zusammenfassung nnseres gegenwärtigen Wissens von der Chemie der Wirbellosen, die mit kritischer Schärfe die engen Grenzen desselben zeigt, ein grosses Verdienst erworben, und es ist zu lioffen, dass das Bneh, dem man nur die weiteste Terbreitung wünschen kamn, anregend zn exakten Arbeiten anf dem writen Felde 
der vergleichenden physiologischen (hemie der Wirbellosen wirken wird.

A. P iit ter (Göttingen).

448 Webster, Raph W., A Contribution to the physical analysis of the phenomena of absorption of liquids by animal tissues. In: The Decennial P'ublications, University of Chicago. Vol. X. 1902. 32 pag.

Die vorliegenden Intersuchungen beschäftigen sich hauptsächlich mit den Erscheinungen der Absorption von Flüssigkeiten durch den Muskel (Gastrocnemius des Frosches). Verf. kommt zu dem Ergebnis, dass derselbe aus hyper-, iso- und hypotonischen Lösungen von Elektrolyten und Nicht-Elektrolyten Flïssigkeit absorbieren kann. Das Sarkolemma ist für die untersuchten Ionen in beiden Richtungen durchgängig, jedoch viel stärker in der Richtung nach auswärts, als nach einwärts. Bei diesen Absorptionsvorgängen sollen nach Webster osmotische Wirkungen nur bei der Absorption von Wasser und Rohrzuckerlösungen in Betracht kommen, im iibrigen sollen Ionenwirkungen eine grosse Rolle spielen. Die Absorption aus isosmotischen Lösungen liängt ab 1. von der Natur der gelösten Substanz, 2. von der Zeit der Einwirkung der Lösung, 3. der relativen Permeabilität des Sarkolemms, 4. dem physikalischen Zustande des Muskels und 5. der Temperatur, bei welcher die Absorption stattfindet.

Über weitere Angaben betreffend die Wirkung der Anionen und Kationen mag das Original verglichen werden.

A. P'üter (Göttingen).

\section{Faunistik und Tiergeographie.}

449 Adams, C'l. C., Southeastern United States as a center of geographical distribution of flora and fauna. In: Biolog. Bulletin. Vol. III. 1902. pag. 115-131.

450 - Postglacial origin and migrations of the life of the north-eastern United States. In: Journ. of Geogr. Vol. I. 1902. pag. 303-310: 352-357. 1 Kartenskizze.

Verf. bringt zunächst in dem an erster Stelle angeführten Aufsatze eine ausführliche Darstellung seiner in einer kurzen rorläutigen Mitteilung ${ }^{1}$ ) bereits niedergelegten Ergebnisse tiergeographischer Studien. Fine nähere Untersuchung der Reptilien- und Amphibienfauna von Illinois fühıte zunächst zu einer Ableitung dieser Fauna ans dem Suidosten, das gleiche fanden andere Forscher für zahlreiche P'flanzen der nordwestlichen Gebiete, das gleiche gilt weiter für die Unionidenfauna von Michigan und des Mississippi, sowie für manche

$\left.{ }^{1}\right)$ Vergl. Zool. Zentr.-BI. IX. Jahrg. 1902. Nr. 691 pag. 679. 
andere Tierformen, und nur die typisch nordischen Vertreter der Fauna und Flora machen eine Ausnahme von dieser Regel. Es würde also im Südosten der Vereinigten Staaten ein Entwicklungszentrum zu suchen sein, für dessen Gegenwart auch Reichtum und Mannigfaltigkeit der Pflanzen- und Tierformen sprechen, letzteres namentlich hinsichtlich der Süsswassermollusken und Wirbeltiere. Daneben enthält das Gebiet zahlreiche Relikten älterer Faunen, so einmal solche asiatischer Verwandtschaft, insofern eine Reihe von Pflanzen des östlichen Nordamerika sich gleichzeitig in Japan und Ostasien wiederfinden, und von Tieren namentlich ein Alligator, Amphibien und Fische, weiter Krebse, Insekten, Bryozoen und Unioniden auf eine nahe Verwandschaft beider Gebiete hinweisen. Zu erklären würden diese Erscheinungen dadurch sein, dass die allmählich rordringende Vereisung diese Organismen aus gemeinsamen nördlichen Wohngebieten in die südlicher gelegenen Teile beider Liontinente hinabdrängte. Als Reste einer zweiten alten Fauna sind weiter gewisse Fische und Insekten anzusehen; sie sind dadurch ausgezeichnet, dass sie keinerlei Verwandtschaft mit asiatischen Formen erkennen lassen. -Ein zweites Entwicklungszentrum ist übrigens nou im Südwesten der Vereinigten Staten und auf dem Hochplatean von Mexiko gelegen, es enthält im Gegensatze zu dem feuchten Suidosten die Organismen der trockenen Steppen- und Wüstengebiete.

Verf. stellt sodann in zehn Punkten die Hauptcriterien zusammen, welche aus den biologischen Verhältnissen der rezenten Formen für die Aufstellung und Beurteilung eines Entwicklungszentrums gewonnen werden können, um schliesslich wieder auf den speziellen Fall zuriickzukommen und die Hauptverbreitungslinien anzugeben, welche von dem südöstlichen Entwicklnngszentrum ausgehen. In erster Linie erfolgte die Ausbreitung längs des Tales des Mississippi und seiner Nebentlüsse, ein zweiter Weg verlief längs der Kiiste des atlantischen Ozeans nach Norden, Sïden und Westen, ein dritter führte dem Appalachiantal entlang nach Norden.

Zum Schlusse geht Verf. endlich näher auf die Bedeutung ein. welche fiir diese Fragen das Studium der Variationen der einzelnen Formen längs dieser Verbreitungslinien gewinnen würde. Vom Entwicklungszentrum aus nehmen die Organismen nach der l'eripherie hin an Grösse ab, nimmt weiter die Konstanz der Formen ab, während umgekehrt die Neigung zur Bildung von Variationen wächst. Dabei ist die Kontinuität solcher Variationen längs der Verbreitnngslinien eine sehr vollkommene, und ihr Studium bietet zugleich ein wichtiges Hilfsmittel zum Verständnis der verwandtschaftlichen Beziehungen im einzelnen dar. 
Einen etwas andern Ansgangspunkt wïhlend, kommt Verf. in der zweiten Abhandlung zu ganz ïhlichen Schlussfolgerungen linsichtlich der Ableitung der Fauna der Vereinigten Staaten. Die nrsprüngliche Fauna und I'lora des nortöstlichen Teiles von Nordamerika wurde durch die Eiszeit zum grossen Teile in die südöstlichen Gebiete zurïckgedrängt, dessen jetzige Organismenwelt muss demnach postglacialen Ursprnngs sein. Eine erste Neubesiedlung des Gebietes fand nach dem Zurïckweichen der Gletscher durch die Organismen statt, die sich am Rande des Eises aufhielten, demselben beim Zurückweichen nachfolgten und so teils nach Norden zogen, teils an den Abhängen der isolierten Gebirgsketten emporstiegen und sich hier als lieliktenformen erhalten haben. Ion dieser ersten. üher den Nordosten linwegziehenden Tierwelle laben sich nmr wenige Vertreter bis heute erhalten, sie sind durch ihr nordisch-alpines (iepräge gekennzeichnet. Ihr folgte eine zweite Welle nach, die man als subarktisch oder subalpin bezeichnen kann, sie hat sich am ansgeprägtesten in den Koniferenwäldern Kanadas erhalten. In grösserm Abstande rom Eisrande rückte die dritte Welle heran, sie zeigte den Typus der gemäBigten Zone, wie er heute noch in Illinois, Indiana und Ohio vertreten ist. Die erste Welle ging über das (rebiet hinweg; die ihr angelörigen Formen weisen eine circumpolare Verbreitung anf, das gleiche gilt für einen grossen Teil der Vertreter der zweiten Tierwelle, die ansserdem noch die höchsten Spitzen der Berge zn erreichen vermochten, die dritte ist am beschränlitesten in ihrer Ansdehnung, sie reichte nicht so weit nach Norden und machte in den Tiefländern Halt. Die Angelörigen der beiden ersten Tierwellen sind nördlichen Ursprungs, entstanden unter nordischen Pedingungen, bei der dritten gilt dies nur für ihre präglacialen Vertreter, während die postglacial entstandenen Formen südlichen Ursprungs sind. Und diese südlichen Formen entstammen in erster Linie dem südöstlichen Entwicklungszentrum, von welchem oben ansführlich gesprochen wurde, zum geringern Teile nur, dem namentlich die Organismen der Prairiegebiete zuzurechnen sind, dem trockenen Siidwesten.

$$
\text { J. Ne is en heimer (Marburg). }
$$

451 vou Erianger, Carlo Freiherr, \%oogeographie und Ornithologie von Abyssinien, den Galla-nnd Somali-Ländern. In: Bericht Senckenberg. Naturf. Gesellsch. Frankfurt 1902. pag. 155-169. 1 Karte.

Verf. teilt das von ihm bereiste Gebiet, welches das südliche Abyssinien, die Galla- und Somali-Länder mmfasst und im Westen bis zum nördlichen 'Teil der afrikanischen Seeenkette reicht, in sechs 
zoogeographische Bezirke. In dem ersten derselben, dem nördlichen Somaliland, spielen in den Küstengebieten paläarktische Formen noch eine bedeutsame Rolle, während nach dem terrassenförmig ansteigenden, gebirgigen Innern hin tropische Formen schnell an Zahl zunehmen. Das abyssinische Hochland zerfällt in zwei weitere tiergeographische Gebiete, einmal in das Gebiet zwischen Hanasch und blauem Nil und dann in die Länder südlich und südöstlich vom Hauasch, die Abdachung nach den Somaliländern darstellend. Nördlich rom Hauasch treten lediglich schoanische Formen auf, die südlich davon zum grossen Teil verschwinden und durch neue ersetzt werden. Verf. charakterisiert das ganze Gebiet näher hinsichtlich seiner maninigfirchen Landschaftsformen, nach seiner Vegetation und seiner Tierwelt, letzteres unter besonderer Berïcksichtigung der Vogelwelt. Einen vierten Bezirk stellt das längs der ostafrikanischen Seeenkette sich hinziehende abtlusslose Gebiet dar, welches zu beiden Seiten von Ausläufern der abyssinischen Gebirge begleitet wird und dessen nördlicher Teil von der Expedition geographisch genauer durchforscht und aufgenommen wurde. Faunistisch ist der ungeheure Reichtum an Wasservögeln bemerkenswert, während zugleich neben noch vorhandenen abyssinischen Formen auch die grossen Säuger Ostafrikas zahlreich auftreten, so dass wir uns hier in einem faunistischen Nischgebiet befinden. Das fünfte Gebiet ist das Südsomaliland mit einem starken Überwiegen ostafrikanischer (nicht dagegen nordostafrikanischer) Formen sowie mit einer ganzen Reihe besonderer Typen, von denen es der Expedition gelang, zahlreiche für die Wissenschaft neve Tiere und Pflanzen zu erbeuten. Das sechste Gebiet endlich würde das ostafiikanische Kï̈stengebiet darstellen, welches ohne scharfe Grenze in das soeben geschilderte Hinterland übergeht.

J. Me is enheimer (Marburg).

452 Oberhummer, E., Die Insel Cypern. Eine Landeskunde auf historischer Grundlage. Gekrönte Preisschrift. Erster T'eil: Quellenkunde und Naturbeschreibung. München 1903. XVI. pag. 1-488. Mit 3 Kiarten und einem geolog. Profil. Mk. 12.-

In dem vorliegenden geographischen Werk wird versucht, ,das Naturbild der Insel zu zeichnen, mit allen Veränderungen, die es im Laufe der Jahrhunderte mit oder ohne Zutun des Menschen erfahren hat". Mit besonderer Vorliebe ist der Abschnitt über die Tierwelt ausgeführt, der in lïnderkundlichen Werken am meisten vernachlässigt zu werden ptlegt. Im Gegensatze zu den absprechenden Worten des Geographen Philippson: ,die Tierwelt bat für die Landeskunde nur eine untergeordnete Bedeutung:, mißt V'erf. derselben einen 
hohen Wert zu, und auch der Tiergeograph und Zoologe wird in der ausführlichen Darstellung des Verfs., die die Fauna eines Gebietes und einzelne Hauptrertreter historisch zu behandeln versucht, vielerlei Anregendes finden.

Besonders gilt dies für die Säugerfauna, spez. für das der Insel eigene Muflon, über das alle frühern Quellennachrichten mit Angaben grösserer Verbreitung sorgfïiltig zusammengestellt sind. Auch die Frage, ob Raubtiere der Insel ursprünglich fehlen, oder vielleicht erst durch den Menschen ausgerottet sind, wird auf Grund ron historischen Quellenschriften geprüft. Eine besondere Hasenart des Gebirges wird erwähnt, ferner werden die Haussäugetiere, die Viehzucht, das Kamel und auch die Zucht der sog. Cyperkatze, die schon in mittelalterlichen Quellen erwähnt wird, besprochen. Ausführliche Darstellung findet besonder's die Vogelwelt, deren lieichhaltigkeit und Wechsel schon frühern Besuchern aufgefallen ist. Cypern liegt auf einer der 4 Zugstrassen der Wandervögel über das Nittelmeer ,und die vermittelnde Stellung der Insel tritt nicht bloss in den örtlichen Formen der PHanzen- und Tierwelt, sundern auch in deu Wanderungen der Zugrögel deutlich hervor". Von den Reptilien werden die Schlangen besonders besprochen: von Süsswasserfischen ist bei der Wasserarmut der sog. , Huss"läufe, die im Sommer fast versiegen, wenig zu sagen. Desto wichtiger sind einige Gruppen der Wirbelloseı, auch für den Menschen, die Wanderheuschrecken als Schädlinge, worüber Verf. sehr viel interessantes Material, aucl über die Bekämpfung zusammengetragen hat, und die Bienen, mit eigener Rasse, als Nutztiere. Diese Rasse ist auch bei Verpflanzung sehr konstant und, ,gibt in tiergeographischer Beziehung ein selten bemerkenswertes Beispiel von einer durch die insulare Abschliessung wie durch Klima und Vegetation begünstigten Ausbildung und Lebenskraft einer besonderen Varietät". Andere Beispiele besonderer Ausprägungen, sowie allgemeine Bemerkungen über die Biologie spez. der niedern Fauna, über Sommerschlaf, Zusammendrängung in Oasen usw. werden nach den Mitteilungen des Ref. gegeben, der ebenso wie Verf. selbst einen lïngern Aufenthalt auf der Insel genommen hat. Ebenso findet die Meeresfauna, der Schaum vom Paphos usw. nach Angaben des Ref. Berïcksichtigung. Da auch Klima, P'flanzenkleid usw. ausführliche und historische Besprechung finden, so sind die tiergeographischen Angaben für den Zoologen von erhöhtem Interesse.

O. M a as (München).

453 Scharfi, R. F., Some remarks o n the Atlantis problem. In: The Geolog. Magazine. N. S. Dec. IV'. Vol. IX. 1902. pag. 455 -456 . 
Yon den auf das klassische Altertum zurückzuführenden Überlieferungen über einen alten atlantischen Kontinent ausgehend und nach einem kurzen Überblick der für und gegen eine solche Landverbindung zwischen Europa und Nordamerika sprechenden wissenschaftlichen Gründe der Gegenwart tritt Vert., gestützt auf eine Anzalıl neuer tiergeographischer Tatsachen, fuir eine atlantische Landbrïcke zwischen beiden Kontinenten ein. Madeira und die Azoren sind als die Reste eines alten, tertiären Kontinentes anzusehen, der urspringlich und wiederholt mit Luropa in Verbindung stand und erst seit dem l'leistocïn definitiv von ihm geschieden wurde. Die eigentliche Landbrïcke mit Amerika muss siidlich von diesem Kontinent gelegen haben, sie ist heute kaum noch durch einige, aus grossen Tiefen aufragende Inselchen gekennzeichnet.

$$
\text { J. Me is en heimer (Narburg). }
$$

4 Schnee, Einiges zur 'T'ierwelt' in der Jaluit-Lagune. In: Zoolog. Garten. 44. Jahrg. 1903. pag. 14-15.

Enthält einige biologische Notizen über die Korallen, die Fischfauna und die Seevögel der zu den Marshall-Inseln gehörigen Jaluit-Lagune.

\section{J. M e is en heimer (Marburg.)}

\section{Invertebrata.}

Leon, N., Prophysema Haeckelii. In: Zool. Anz. Bd. 26. 1903. pag. 418 -419 .

Leon hat bei der Insel Radö nördlich ron Bergen einen in die Häclielsche Gattung Prophysema (früher Haliphysema) gehörigen Organismus gefunden, ein $2 \mathrm{~mm}$ langes Gebilde von Kieulenform, welches mit einem Stiele festsitzt und am freien Ende eine runde Öffnung hat, die in den innern Hohlraum des Körpers hineinführt. Die Körperwand ist ein, imen nit Geisselzellen bekleidetes Syncytium, enthält Sandkörner und Spongiennadeln, namentlich viele "sternförmige Spicula“" und wird nicht von Poren durchbrochen. Durch die Solidität des Stieles und jene sternförmigen Spicula unterscheidet sich diese von anderı Prophysema-Arten. Auf Grund der Befunde seiner Untersuchung dieses Organismus gibt Leon $\mathrm{Häckel}$ Recht, Prophysema als einen Gasträaden anzusehen, und er weist den Vorwurf von Delage zurïck, dass Häckel die Foraminifere Haliphysema als Gasträaden beschrieben hätte und dass seine bezüglichen Angaben "ne correspondent à rien de réel".

$$
\text { R. v. Lendenfeld (Prag). }
$$

\section{Spongiae.}

156 Ijima, I., Nate on Walteria leuckarti Ij. In: Annot. Zool. Japon. Bd. 4. Pt. 4. 1902. pag. 119-122. 
Die Untersuchung einiger in ihren obersten Teilen gut erhaltener Stücke dieses Schwammes hat Ijima in den Stand gesetzt nachzuweisen, dass Walteria lerckarti ein kleines Osculum am Scheitelende seines Stammes trägt, welches aber durch eine Masse von Nadelgewebe von dem grossen innern Gastralraume getrennt wird und mit letzterm nur durch enge, jenes Nadelgewebe durchsetzende Kanäle in Zusammenhang steht.

R. v. Lendenfeld (Prag).

457 Lendenfeld, R. V., Eine biologische Notiz über Spongilla fragitis Leidy. In: Arch. f. Naturg. Jg. 1903. Bd. 1. pag. 181-182. Taf. 10 .

Im Aquarium aus Genmulae gezogene Stücke dieses Süsswasserschwammes wuchsen in 12 Tagen zu lappig begrenzten Krusten von $3 \mathrm{~cm}$ Durchmesser heran und hatten, 18 Tage alt, sclion eine nene Gemmulageneration gebildet. Während der Gemmulabildung verschwand der Weichkörper des Schwammes. Unter den die Gemmulae dieser Aquarium-Spongillen einhüllenden, dornigen Rhabden fanden sich verhältnismäßig viele bis zur Ringform gekriummte. Bei den freilebenden stücke, von dem sie abstammten, waren jene Nadeln im allgemeinen weniger stark gekrümmt und Ringformen sehr selten.

$$
\text { R. r. Lendenfeld (Prag). }
$$

458 Schulze, F. E.. Chaulophacus arcticus (Armauer Hansen) und Calycosoma gracile

F. E. Sch. nov. spec. In: Abh. Ak. Berlin. Jg. 1903. 22 pag. 2 Taf.

Sclulze hat die Original-Exemplare des früher von A. Hansen als Hyalonema arcticum beschriebenen Schwammes nachuntersucht und auf Grund dieser Untersuchung eine neue und ausführliche Beschreibung desselben geliefert. Dabei hat sich gezeigt, dass es sich da um eine Canlophacus-, und nicht um eine IIyalonema-Art haudelt. Ferner wird eine neue Calycosoma-Art aus dem Malayischen Gebiete beschrieben, welche der einzigen bisher bekannten, atlantischen Art dieser Gattung sehr ähnlich ist.

R. v. Lendenfeld (Prag).

459 Whitelegre. Th.. Notes on Lendenfeldstypesdescribed in the Catalogue of Sponges in the Australian Museum. In: Records Austral. Mus. Bd. 4. Nr. 7. 1903. pag. 274-288.

In der vorliegenden Arbeit veröffentlicht Whitelegge die Ergebnisse einer genauern Untersuchung des vor 18 Jahren vom Referenten vorläufig und zum Teil nur flüchtig bestimmten Materials an Spongien im Australischen Museum in Sydney. Er berichtigt einige Irrtümer, die da unterlaufen sind und gibt genauere Beschreibungen mehrerer Renieren, Halichondrien und anderer Monoceratina.

R. v. L e nd enfeld (Prag).

\section{Coelenterata.}

460 Gast, R. und E. Godlewski, Die Regulationserscheinungen bei Pemaria Cacotinii. In: Arch. f. Entwmech. Bd. 16. 1903. pag. $76-116$. Taf. 2-3; 22 Textfig.

Wenn man grossen Stämmen mit zahlreichen Seitenästen von 
Pennaria alle Hydrantlien wegschneidet, so nimmt der Regenerationsvorgang folgenden Verlauf. Er fängt am apicalen Ende des Stammes und an den distalen Enden der Seitenäste an und schreitet basalwärts resp. proximalwärts vor; im Nittel regenerieren $67 \%$ der abgesehnittenen Hydranthen. Diese regenerierten Polypen degenerieren aber nach 24--48 Stunden, und zwar geht diese Degeneration den umgekehrten Weg wie die Regeneration: sie verläuft basal-apicalwärts (resp. proximal-distalwärts).

Was die intimeren Vorgänge bei diesen Bildungs- und Rückbildungsprozessen betrifft, so spielen die Zellteilungen bei der Regeneration der Hydranthen keine oder wenigstens eine ganz unbedeutende Rolle; die Hydranthenentwicklung ist als ein Transformationsprozess aufzufassen, wobei die verlagerten Cönosarkzellen direkt zu Bestandteilen der in Bildung begriffenen Hydranthen werden. Die Degenerationserscheinungen beruhen dagegen hauptsächlich auf Zerfall der Zellelemente, wobei der grössere Teil der Zerfallsprodukte (Körner) dnrch Strömung in das Stammlumen überzugehen und ron den Entodermzellen resorbiert zu werden scheint (dabei wird der Mund meistens geschlossen; bei Verzögerung dieses Vorgangs strömen die Körner aus dem geöffneteu Mund heraus). Die Degeneration der IIydranthen ist also nicht als direkte Transformation der Zellen in Elemente des Stammes aufzufassen.

Nach dem Abfall der Polypen lockert sich nun an den distalen Teilen der Seitenïste der Zusammenhang des Cöno- und Perisarks, und das Cönosark zieht sich weiter nach unten zurück. Dieser Vorgang muss als ein regulativer aufgefasst werden; das Material wird dabei verlagert. Die Verlagerungsprozesse, die auf aktiven Kontraktionen des Cönosarkstammes mit gleichzeitigen Umordnungen der Zellelemente beruhen, finden immer statt, wenn formative I'rozesse an einem andern Punkte des Organismus vor sich gehen sollen. Wenn nun das aus einem Seitenaste sich zurückziehende Cönosark an irgend einer Stelle des Seitenastes Halt gemacht hat, trennt es dort die leere, vou ihm verlassene Perisarkröhre ab. Es gewinnt zunächst wieder an seiner Spitze Kontakt mit dem Perisark, und ,an dieser ringförmigen Kontaktstelle gruppieren sich Ektodermzellen in bestimmter Weise, scheiden ein Perisark lösendes Sekret aus, wodurch die Bildung einer rings um das Perisark verlaufenden Rinne an der innern Perisarkfläche veranlasst wird. Da diese Rimne bis zur OberHäche des Perisarks vordringt, bricht der leere, distale Abschnitt des Perisarkrohres ab. Nach diesem ,spontanen Abtrennen“" des leeren Perisarkrohrabschnittes findet entweder an der Bruchstelle Hydranthenregeneration statt, oder das Cönosark zieht sich weiter stammwärts 
zurïck, um an einem andern Punkte das Abtrennen des wieder verlassenen Abschnittes des I'erisarkrohres zu wiederholen".

I)ieses spontane Abtrennen leerer Perisarkröhrchen lïsst sich als ein für die weitere liegenerationstätigkeit des Tieres vorteilhafte Regulationseinrichtung deuten: es ermöglicht, trotzdem das bildungsmaterial durch die vorhergehenden liegenerations- und Resorptionsprozesse ziemlich erschöpft wurde, doch eine weitere Regenerationsleistung, indem es die Tierdimensionen verkleinert und somit die Menge des vorlandenen Zellmaterials für regenerative P'rozesse genügend wird. Aus dem Mechanismus des Abtrennens der leeren Perisarkröhrchen lässt sich ersehen, dass , dieselben Fktodermzellen, welche das l'erisark ausscheiden, unter gewissen liedingungen die entgegengesetzte Tätigkeit, nämlich Perisark zu lösen, leisten können". I)iese perisarklösende Eigenschaft der Ektorlermzellen findet auch Verwendung bei der Verwachsung von Stolonen verschiedener Stiucke.

Bei den regenerativen und heteromorphotischen Vorgängen bei Pemaria treten die Polaritätserscheinungen selnr deutlich hervor und äussern sich besonders in dem Neigungswinkel der neuentstandenen Seitenäste. ,Hildet sich am apicalen stammende regenerativ eine Stammverlängerung, so liegen die sich daran bildenden Seitenhydranthen resp. Äste in derselben Ebene wie die alten Scitenäste und billen denselben Winkel nit dem stamm. Bildet sich am basalen Stammende heteromorphotisch ein Hydranth und gehen von diesem anch neue Seitenlydranthen resp. Ïste aus, so liegen sie zwar ebenfalls in aler Ebene der alten seitenäste, laben aber umgekehrte Richtung, wie die alten: der spitze Seigungswinkel ist dem hasalen Fndhydranthen zugewendet.. Dic Art der Regeneration äussert sich etwas rerschieden, je nachilem es sich um ein apicales oder nm ein basales Stück handelt: die basalen Stammstücke haben die Tendenz, Stammverlängerungen zu bilden, und diese Tätigkeit nimmt apicalwärts ab: dagegen haben die apicalen Teile grössere Neigung, an den Seitenästen Hydranthen zu regenerieren, und diese Fähigkeit nimmt wiedermm basalwärts in den einzelnen Regionen des Stocks ab.

Stämme, denen alle Seitenäste abgeschnitten wurden, regenerieren an allen Wundstellen Hydranthen mit ihren Stielen, niemals aber die ganzen abgeschnittenen Ïste. Ganz kleine Stammstücke olme Seitenäste bringen nie Hydranthen, aber nur kurze Stolonen hervor, etwas grössere können auch Hydranthen hervorbringen. Abgeschnittene Seitenäste regenerieren meistens nicht die proximalen Hydranthen, 
sondern nur die distalen und an der Abtrennungsstelle vom Stamm einen Hydranthen.

Lichtmangel hat keinen ungünstigen Finfluss auf die Regenerationstätigkeit ganzer Stämme.

R. S. Bergh (Kiopenhagen).

461 Friedemann, 0., Untersuchungen iiber die postembryonale Entwicklung ron Aurelia aurita. In: Zeitschr. wiss. Zool. 71. Bd. 1902. pag. 227--267. Taf. XI-XII.

Die Arbeit des Verfs. ist die zeitliche Fortsetzung der Heinschen frühern Arbeit iiber Auretia und soll, ron dem Stentakeligen Scyphostoma an bis zur Epliyra fortschreitend, die schon früher zwischen Claus und Goette erörterten Fragen der Discomedusenmorphologie noch einmal beleucliten. Auch werden eine Anzahl histologischer Details gebracht.

Im Fuss der Larve sind besondere I)rüsenzellen mit Pseudopodien wahrzunehnen, die die Festleftung besorgen. Bei starker Lntwicklung der Nesselwülste (z. B. in den 'Tentakeln) wird das Ektoderm mehrschichtig. Von den Nesselkapseln gehen Fortsïtze aus, die bis in die Stiitzlamelle und zur Verbindung mit Ganzlienzellen verfolgt werden können. Es gibt zweierlei Arten von Nesselkapseln, grosse und kleine, ohne Übergäinge. Ain Nesselfaden finden sich ausser den basalen Widerhaken noch, Häkschen kleinster Art" in regelmïßiger Verteilung in ganzen Verlauf. Das Entoderm in der I'roboscis liat einen ganz andern Charakter wie im Gastralraum. Hier kann Verf. sowohl eine extracelluläre wie eine intracellıläre Verdauung walınehınen. Er sucht in verschiedenen Bildern zu zeigen, wie die einzelnen Zellen ein Sekret entleeren, das den Frendkörper umfliesst und auflöst. lerner aber nehmen die phagocytïren Zellen Nahrungskörper auf und man kann den Vorgang der Verarbeitung am I'rotoplasma Schritt für Sclıritt verfolgen. Die Muskeln sind im Ektoderm des Tentakels längsrerlaufend nul sehr stark, im Entoderm sehr fein, circulär angeordnet und mit gelegentlicher Verzweigung. Beide Arten sind quergestreift. Die Zellen in der Stuitzsubstanz, die zuerst in achtarmigen Stadium auftreten und ein typisches faseriges Bindegewebe erzeugen, entstammen sowohl dem Elitoderm wie dem Entoderm.

Die morphologisch-embryologischen Angaben des Verfs. sind ron den Befunden Go et tes nicht überall rerschieden: entfernen sich aber auch da, wo sie übereinstimmen, stets in der Deutung. Die Darstellung der Septalmuskeln gelit parallel der Goetteschen, und auch die Trichter sind, wenn auch in anderm Sinne als bei Goette, auf allen Stadien rorhanden. Der Trichter zeigt sich bei ältern Scyphostomen interradial als röllige Neubildung, an welche der Muskel 
distal sich anschmiegt. Er ist auch histologisch rom Septalmuskel verschieden; Verf. schlägt vor, ihn mit dem indifferenten Namen ,Peristomtrichter" zu bezeichnen anstatt Septaltrichter. Er ist laut Verf. nur wenig tief, reicht also nicht. wie Goette angibt, in den Sticl, sondern nur dureh etwa 1/5-1/4 des Recherabschnittes der Larve. Er liefert auch nicht die Subgenitalhöhle, sondern ist nur eine vorübergehende ektodermale Einwucherung in die Täniole. An der freischwimmenden Ephyra ist er noch mit einem Muskelrest nachzuweisen. Das Vorhandensein eines ektodermalen Schlundrohrs wird durchaus in $\Lambda$ brede gestellt. Die Zellwucherung am äussersten Rand der Darntïniolen ist rein entodermal. Magentaschen im sinne Goettes sind ,aul" ganz frühen Stadien“ nicht vorhanden, sondern nur durch die Täniolen bedingte Magenrimnen. Beim achtarmigen Scyphostoma treten zuerst 4 mit echtem Entoderm ausgekleidete Magentaschen auf. Nach Bildung der Septalostien zeigen sich die 8 Lappentaschen. Die Strobilation ist, wie andere Vorgainge, in der Zeit ihres Auftretens sehr variabel und hat dadurch zu mannigfachen Kontroversen Anlass gegeben. Die Rückbildung der Tentakel, die sich zuerst in den Ordnungszahlen 4, 8, 16, 24 vermehrt haben, geschieht teils durch Abwerfen, teils durch Schrumpfung mit Hilfe phagocytärer Zellen. Die Simneskörper sind nicht die umgewandelten basalen 'T'eile der Tentakel, sondern Nenbildungen am subumbrełlaren Rand der 8 Lappentaschen.

O. Maas (München).

462 Hein, W.. Untersuchungen über die Entwicklung von Cotylorkiza tuberculuta. In: Zeitschr. f. wiss. Zool. Bd. 71. 1902. pag. 302-320. Taf. XX und XXI.

Die vorliegende Studie soll eine Ergänzung bilden zu des Verfs. früherer Arbeit über Aurelia (s. \%.Z.-BI. VII. 1900, Nr.590) und wendet sich wie diese gegen die Go ettesche Annahme eines Scyphulastadiums in der Discomedusenent wicklung und gegen die daraus gefolgerten llomologieen zwischen Acalephen und Anthozoen. Es ist jedoch hervorzuheben, dass eine Anzahl anderer Angaben Goettes, wenn auch nicht stets mit den Folgerungen, vom Verf. bestätigt werden. Die am Muttertier befindlichen Blastulae zeigen lieine polare Differenzierung; es beginnt an ihnen eine multipolare Einwanderung von Zellen, die jedoch (entgegen den Angaben Ida Hydes usw.) mit der Entodermbildung nichts zu tun hat; viehmehr gehen die betreffenden Zellen zu grunde, und das Blastocöl erscheint nach kurzer Zeit wieder frei. Die Gastrulation ist eine typische Invagination; aber der Blastoporus schliesst sich, so dass das spätere Prostoma nicht wie laut Verf. bei Auretia aus dem Urmund entsteht, sondern eine Neubildung ist. 
Die Abscheidung der „Stützlamelle“ oder Gallertschicht soll beiden Blättern der Planula zufallen. Die freischwimmende Larve zeigt geringe polare Differenzierungen: das Festsetzen ist zeitlich grossen Schwankungen unterworfen, so dass man von der gleichen Brut iu selben Behälter sowohl ältere Planulastadien schon festgeheftet, als junge Scyphostomen nocl frei umherschwimmend antreffen kann.

Am neugebildeten Prostoma der festgesetzten Larve ist eine selır rege Zellteilung zu bemerken; beide Blätter sind histologisch schwer voneinander zu unterscheiden. Es entsteht cine „muldenförmige Vertiefung", aber die Einstülpung früherer Autoren konnte V'erf. "nicht in dem gleichen Maße" beobachten. Er hïlt also trotz der erwähnten Eigentümlichlieiten daran fest, dass (gegen Goette) kein ektodermales Schlundrohr vorhanden ist, sondern der Mund des Seyphostoma eine einfache Verbindung des Cölenterons mit der Aussenwelt darstellt, an dessen Rändern beide Kieimblätter aneinander stossen. Auch die folgenden. vom Verf. sehr kurz belıandelten Stadien lassen keinen Vergleich mit den Anthozoen zu, was auch, wie Verf. hervorhebt, durch Ap pell ö fom Standpunkt der Actinienentwicklung aus ausgeschlossen wird. "Die "Scyphula“ sowie der anthozoenähnliche Bau fehlt dem jungen Scyphostoma gänzlich, und die junge Larve zeigt vor Entwicklung der Magenfalten und der später in dieselben sich einsenkenden Längsmuskelstränge einen vollkommen bydropolypenähnlichen Bau." Danach erscheinen die Beziehungen zwischen Scyphopolypen und Hydrozoen enger als es nach Goette anzunehmen wäre.

O. Maas (Mïnchen).

463 Maas, 0., Die Scyphomedusen der Siboga-Expedition. Monogr. XI. aus: Siboga-Expeditie. Leiden 1903. 4º pag. 1-91. Taf. I-XII.

Unter 19 Gattungen mit 21 Arten, die die Expedition mitgebracht hat, sind zwei Gattungen, vier Arten, mehrere Varietäten neu; ferner finden sich darunter mehrere Arten, die bisher verschollen oder selten waren und andere, die erst von der gerade rorhergehenden deutschen 'Tiefseeexpedition bekannt geworden sind. Von morphologischem Interesse sind besonders Formen, die aus grösserer Tiefe stammen und der Gruppe der Coronaten angehören. Dabei ist zunächst die Gattung Pericolpa zu erwähnen, die nur 4 Tentakel und nur 4 Randkörper, alternierend zwischen $\&$ Randlappen, aufweist. Eine so einfache Anordnung kommt sonst in der ganzen Gruppe niclit vor, da Nausithoe und Verwandte 8 Tentakel und \& Randkörper, Periphylla usw. 12 Tentakel und 4 Randkörper mit 16 Randlappen alternierend besitzen, ebenso wie auch die Ephyralarve, die einfachste 
Form. in der alle Discomedusen zuerst erscheinen, schon 8 Tentakel und 8 Randkörper mit 16 Lappen aufweist. Diese seit $\mathrm{Haeckels}$ Medusenwerk nicht mehr gefundene Form wird deswegen für die verwandtschaftlichen Beziehungen der Scyphomedusen und die Verknüpfung mit den primitiveren festsitzenden Formen, sowie den Charybdeiden von hoher Wiclıtigkeit. In älnnlicher Hinsicht ist eine neue Gattung Paraphyllina zu erwähnen, die wie Periphylla 12 Tentakel und 4 Rhopalien hat, bei der aber letztere nicht interradial, sondern perradial den Magenecken entsprecliend stehen. Die Sinnesliörper zeigen eine vermittelnde Stelhung zwischen Nauithoe der Oberfläche und Periphylla der Tiefe. Von Periphylla selbst sind ebenfalls mehrere Exemplare gefunden, was Gelegenheit gibt, auf die "Augen"struktur zurïckzukommen, die durch das entodermale Pigment am Sinneskolben erscheint. Durch eigentümliche Gliederung des Schirmkranzes, Tiefenherkunft und Struktur der Rhopalien ist Atorella (6 Tentakel, 6 Sinneskolben mit 12 liandlappen) bemerkenswert. die bisher nur in eine m mäßig erhaltenen Exemplar ron der deutschen Tiefseeexpedition bekannt war. Yon Atolla. und zwar der spec. raldiriae. wurden an sechs Stellen eine Reihe ron Exemplaren verschiedenster Grösse gefischt. Die jüngsten zeigen bereits die für die Gattung clarakteristische grosse Antimerenzahl. Alle stanmten aus grösserer Tiefe. Diese sowie die vorher erwähnten Arten geben Gelegenheit, die Frage nach dem Torkommen wirklicher' Tiefseemedusen bejahend zu beantworten, in Anknüpfung an des Verfs. Befunde bei den Medusen des Fürsten ron Monaco sowie Vanhöffens bei der deutschen Tiefseeexpedition.

Ton Obertiachenformen ist Linerges draro zu erwähnen, an dem $7 \mathrm{~mm}$ erstenmal an gut konserviertem Material manche abweichende Organisationsverhältnisse beschrieben werden konnten; von Semaeostom en sind Arten ron Aurelia, Cyanea, Pelagia gefischt worden; besonders reich ist aber. wie sich in diesem wärmern Meer erwarten liess, das Material ron Rhizostomen. Es sind sowohl neue wie verschollene Gattungen gefunden worden; in mehreren Fällen wurden ganze Entwicklungsserien ron der Ephyralarve an bis zum erwachsenen Tier gefischt; ron allen Unterabteilungen sind Vertreter darunter, und es war dadurclı mögliclı, eine eingehende Revision des so vielfach erörterten Systems der Rhizostomen vorzunehmen. Das H a e ckelsche Hauptmerlimal, die Beschaffenheit des Subgenitalraums. wird für die Trennung grosser Gruppen verworfen, wenn es auch in einzelnen Fällen zur Trennung von Genera dienen kann, die Bedeutung der Armform und Verzweigung anerkannt und auf $\mathrm{Claus}$ und Vanhöffen zurückgegriffen. Doch wird dabei herrorgehoben, 
wie man die dreifliigelige Form von der zweiflügeligen ableiten kann und wie alle andern Formen, die Riemenform, die mit Schulterkrausen usw. nur spezielle Morlifikationen der dreiflügeligen sind, die untereinander in sehr verschiedenem Terhältnis stehen. Die sog. Genitalostien oder Atemhöhlen werden im Gegensatz zum Porticus als systematisch bedeutsam erkannt, ebenso das periphere Kanalsystem, das gewisse gruppenweise stets wiederkehrende Verzweigungstypen zeigt. In grossen Gruppen übereinstimmend ist ferner die Anordnung der Subumbrellarmuskulatur, ferner zeigen auch die Sinneskolben, wenn auch im ganzen nach demselben Crundtypus gebaut, doch gewisse gruppenweise wiederkehrende Eigentiimlichkeiten. Es werden nach allen diesen Merkmalen unterschieden:

\section{Rilizostomata :}

A. A rcadomyaria. Nuskulatur in Fiederarkaden. Nundarme unregelmäßig gefiedert (,pinnata" Vanh.) Kanalsystem mit doppeltem Ringkanal usw, Subgenitalostien eng, kreisrund, in vier getremnte Hühleı fülırend. Rhopalien olıne Ange und ohne äussere Sinnesgrube.

Hierher: Cassiopeidae.

B. Radiomy aria. Muskulatur in Radiärzügen, zirkul. \%üge selı schwach. Arme zweigábelig (,dichotoma"Vanlı.), charakteristisclıes Kanalsystem; Ostien eng, trichterförmig. Rilopalien mit Pigmentfleck und äusserer Simnesgrube.

Hierher: C'epheidae.

C. Cyclomyaria. Muskulatur ringförmig angeordıet. Armform dreiflügelig oder davon ableithar (,triptera + trigona, scapulata, lorifera" Vanlı.) Ostien schlitzförmig oder sehr weit.

1. 16 zum Schirmrand gehende Radiärkanäle, dazwischen blind endendes Anastomosennetz. Arme mit Schulterkrausen. Ostien schlitzförmig, durch Klappen geteilt. Khopalien ohne Ocellus, aber mit äusserer Sinnesgrube.

Hierher: Rhizos tomidae.

2. \& zum Schirmrand, 8 zn einem Ringkanal gehende Kanäle, anssen enges Netz, innen wenige Maschell.

a) Arme dreitlïgelis mit seitlichen Fiederästen. Ostien schlitzförmig. Rhopalien mit Ocellus mnd änsserer Grube mit Radiärfalten.

Hierher: Is y chnor hizidae.

$\beta$ ) Arme stark verlängert, mit Fortsatz. Ostien klaffend.

Leptobrachidae part.

3. 8 zum Schirmrand, 8 nur zum Ringkanal gehende Kanäle, aussen enges, innen weiteres Netz bildend.

a) Arme stark verlängert. Ostien weite Querschlitze.

Hierher: Leptobrachidae.

$\beta$ ) Arme dreiflügelig, nicht verlängert. Ostien weit. Rhopalien mit Ocellus und äusserer Grube ohne Radiärfalten.

Hierher: Catost ylidae.

O. Maas (Miinchen).

464 Cardiner, J. Stanley, On the coral islands of the Maldives. In: Nature. Tol. 64. 1901. pag. 587-588.

Die Gruppe der Maldiven im Sïdwesten Ceylons besteht aus 
einer langen Reihe verhältnismäßig niedriger Bänke, die voneinander durch Kanäle von etwa 170 Faden (etwa $310 \mathrm{~m}$ ) Tiefe getrennt sind. Sie erstreclien sich nordwärts und südwäits als eine in der Mitte doppelte Kette ron 550 Meilen Länge. Alle sind mit Korallenriffen bedeckt, die sich bis zur Oberfläche erheben. Einige Bänke haben auf ihrem Umkreis einzelne ringförmige Riffe oder rollkommene Atolle, während andere mit zahlreichen kleinen isolierten Riften besetzt sind, ron denen viele kreisförmig sind mit seichten Lagunen. Die zwei Klassen von Bänken gehen ineinander über, und die bis heute ror sich gehenden Veränderungen berechtigen zu der Vermutung, dass die Atolle durch die Verschmelzung der kleinern Riffe entstanden sind. Alles Land in der Gruppe rerdankt seinen Ursprung direkt oder indirekt der Erhebung. Gegenwärtig deutet alles auf einen Zustand der Ruhe. Es zeigt sich keine Spur ron Ausfüllung der Lagunen, im Cregenteil sind Anzeichen für ilıre Erweiterung und Tertiefung und die allmähliche Zerstörung der Bänke und des Landes innerhalb der Riffe vorhanden. Die Maldivengruppe bezeichnet die Existenz eines alten Landgebietes, aber die vor sich gehenden Veränderungen sprechen nicht für die Ansicht, dass die Riffe durch Senkung des Landes gebildet wurden. Die rerschiedenen Riffe scheinen vielmelır einzeln auf leichten Erhebungen eines gemeinsamen Plateaus in einer Tiefe ron 1500 Faden gewachsen zu sein, während das Plateau selbst durcl das Wegwaschen des ursprünglichen Landes durch Wellen und Strömungen gebildet worden ist. W. May (Karlsruhe).

465 Kikenthal, W., Über eine neue Nephthyidengattung aus dem siidatlantischen Ozean. In: Zoolog. Anz. Bd. XXVI. 1903. pagr. $272-275$.

Aus dem südatlantischen Ozean waren bis jetzt noch keine Nephthyiden bekannt. Verf. untersuchte eine grössere Anzahl Alcyonaceen des Hamburger Museums, die ron Paessler bei Bahia gesimmelt wurden und zweifellose Nephthyiden sind. In vielen äusserı Charakteren stimmen sie rollständig mit Spongodes überein, und Verf. wiurde niclit anstehen, sie trotz des isolierten Vorkommens in diese indopacifische Gattung einzureihen, wenn ihm nicht die Untersuchung der innern Organisation einen wesentlichen Unterschied aufgedeckt hätte. Es sind nämlich die Kanäle, die Stamm und Hauptäste durchzichen, ganz eigentümlich angeordnet. Nur wenige weite Kanäle finden sich ror, jeder von zwei nahe beieinander liegenden Mesenterien durchzogen, die als Fortsetzungen der dorsalen Mesenterien der freien Polypen erkannt wurden, während die sechs andern Mesenterien an der Basis des freien Polypen endigen. Die Kíanäle 
sind nun so angeordnet, dass sie radiär um eine ventrale Achse liegen, die zwar zart und irregulär, aber ziemlich dicht mit Spicula erfüllt ist. Auf diesen Charakter gründet Kükenthal die neue Gattung Neospongodes. Die ïberraschend grosse Ähnlichkeit des iibrigen Baues von Neospongodes mit Spongodes hält er tür eine Konvergenzerscheinung, insbesondere glaubt er, dass das Stützbïndel bei beiden Gattungen unabhängig voneinander entstanden ist, als ein Schutz des Polypenköpfchens gegen das Abgefressenwerden durch gewisse Fische.

Verf. charakterisiert die neue Gattung durch folgende Diagnose: "Nephthyiden von baumartigem Habitus. Polypen vereinzelt oder in Bündeln, mit Stützbïndeln. Kranalwände im Zentrum von Stamm und Ïsten eine unregehmäßige Achse bildend". Er heschreibt zwei Arten, die beide von Paessler bei Bahia gesammelt wurden: $N$. atlantica und $N$. bahiensis. Die zweite Art unterscheidet sich von der ersten durch rigidern Bau, mehr rechtwinkligen Abgang der Ïste und durchweg stärkere Bedornung der Spicula. Auch sind die Spicula der untern Stammrinde in beiden Arten sehr verschieden.

$$
\text { W. Ma y (Karlsruhe). }
$$

466 Lendenfeld, R. v., Die Arbeiten von Agassiz über die Korallriffe der Fidschiinseln. In: Biol. Centralbl. Bd. XXII. 1902. pag. 82-96.

Die Fidschiinseln sind geologisch deshalb besonders interessant, weil sie zu den wenigen Eilanden des tropischen Pacifik gehören, die nicht ausschliesslich aus jungrulkanischem Gestein oder rezenten Korallenbauten bestehen. I) arid unterscheidet auf Grund der Untersuchungen von Agassiz und Andrews sieben Gesteinsstufen re1schiedenen Alters in den Fidschiinseln.

Das älteste dort vorkommende Gestein ist ein harter, blaugrauer, geschichteter Kalkstein ohne makroskopisch sichtbare Fossilien, der vielleicht demselben Horizont angehört wie die Globigerinenkalke der Salomoninseln und Neukaledoniens. Dann folgen vulkanische, sphernlitische Rhyolite and diabasische Dolerite. Die dritte Stufe wird durch drei verschiedenartige Gesteine repräsentiert, die wohl als verschiedene, demselben Horizont angehörige Facies aufgefasst werden können: 1. die geschichteten, nicht koralligenen Kalksteine des Singatokatales, 2. kalkige, vulkanische Konglomerate, die stellenweise in Seifenstein übergehen, und 3. der Fidschier Seifenstein, ein submarin gebildeter vulkanischer Tuff, der vielfach in foraminiferenhaltigen und auch in koraligenen Kalkstein iibergeht und mit echten Korallenriffen wechsellagert. Die vierte Gesteinstufe besteht aus korallenhaltigem Kalkstein. Dieser ist bedeutend, jedoch in ver- 
schiedenen T'eilen der Inselgruppe sehr verschieden hoch gehoben worden. Der höchste bisher aufgefundene 'l'eil liegt 320 un über dem Meeresspiegel. Die fünfte Stufe setzt siclı aus Andesiter und Korallenkonglomeraten zusammen, die sechste besteht aus Olivia-Basalt, und die sicbente wird ron den rezenten Riffen gebildet.

Alle Kï̈sten der Fidsehiinseln werden von lebenden Korallriffen eingefasst, und ausserdem gibt es noch zahllose andere, grössere und kleinere, in der Ungebung der Inseln sich erhebende, isolierte Riffe. Den Kï̈sten entlang ziehen Strandriffe ron wechselnder Breite, die vielerorts, weiter vom Ufer sielı entfernend, zu Wallriffen werden. Die Lagunen linter den Walliffen und imerhalb der Atolle haben zum 'T'eil recht bedentende Dimensionen. Auch die 'Tiefe einiger' Lagunen ist recht beträchtlich, in grossen Lagunen in der Regel bedeutender wie in kleinen.

Über die Neigungsverhältnisse der äussern Riffböschungen sagt $\Lambda$ gassiz eigentlich nichts. Immerhin lassen die T'iefenangaben der Seekarten den Schluss zu, dass vielerorts die äussere Riffböschung hoch und auch ziemlich steil ist. Agassiz betont, dass bei den Korallriffen im allgeneinen und besonders auch bei den Riffen des Fidschiarchipels die Riffkrone nicht in dem Maße, wie Dana und andere annehmen, einen wirklichen Damm bildet und nur in verhältnismäßig geringem Grade die Wasserbewegung hemmt. Die Breschen in den Strandriffen und den küstemnahen Wallriffen pflegen sehr genau den Ausmündungen jener Schluchten an Ufer gegeniiber zu liegen, durch die die Wildwässer zur Regenzeit Schlamm und Sand ins Neer hinaus führen.

Die riffbauenden Korallen gedeihen an den imnern Riffböschungen in Tiefen zwischen $5^{1 / 2}$ und $14^{1} 2 \mathrm{~m}$. An den äussern Riffböschungen reichen sie bis zu 30 oder $36^{1 / 2} \mathrm{~m}$ herab. Gegen die untere Grenze der Zone des Riffkorallenwachstums stehen die einzelnen Korallenstöcke weit voneinander entfernt; nach oben hin drängen sie sich dichter zusammen. Gegen die obere Grenze des von ihnen eingenommenen Gürtels werden sie kleiner.

Darwin und Dana fassen die Fidschiriffe als Beispiele von Korallenbauten anf, die während einer P'eriode positiver Strandverschiebung gebildet wurden. Demgegenïber behauptet Agassiz, dass die rezenten Fidschiriffe nicht während einer Periode positiver Strandverschiebung gebildet worden seien und dass die letzte Strandrerschiebung, die in jenen Gebieten stattgefunden hat, eine negative war. Lendenfeld unterzieht diese Agassizsche Ansicht einer kritischen Priifung.

Aus einer Reihe von Lrscheinungen liann man mit ziemlicher 
Sicherheit schliessen, dass die Fidschiinseln im allgemeinen sehr häufigen und bedeutenden Niveauveränderungen und sonstigen tektonischen Störungen ausgesetzt gewesen sind. Ganz sicher haben seit der Bildung des Korallenkalkes eine oder mehrere negative Strandverschiebungen stattgefunden. Agassiz meint, dass zwischen und nach diesen negativen Bewegungen keinerlei positive Bewegung stattgefunden habe. Er fülırt aber keine Tatsache an, die die Richtigkeit dieser Behauptung zu stützen geeignet wäre. Lendenfeld sieht durchaus keinen Girund, warum wir nicht annehmen sollen, dass im Fidschigebiet oscillatorische Bewegungen stattgefunden haben und noch stattfinden, dass dort Perioden positiver Strandverschiebung mit I'erioden negativer Strandverschiebung abwechselten und noch abwechseln. Manche Eigentümlichkeiten des Bodenreliefs scheinen ihm die Amahme jüngst stattgefundener positiver Bewegungen höchst wahrscheinlich zu machen.

Verf. sucht an dem Beispiel ron Totoya zu zeigen, dass die Agassizsche Erklärung seiner Entstehung mit den Tatsachen vielfach im Widerspruch stelit und dass durch blosse Abrasion und Atmosphärilienwirkung die Erscheinungen, die uns in der Gestaltung ron 'Totoya entgegentreten, niclit erklärt werden könnelı. Dagegen wïrden unter Annahme einer positiven strandverschichung die 'Tatsachen leicht verstïndlich sein.

Agassiz selbst lält es für höchst wahrscheinlich, dass der Korallenkalk, der die vierte Stufe der in den Fidschiinseln beobachteten Gesteinslagen bildet und stellenweise eine Mächtigkeit von bedeutend über $200 \mathrm{~m}$ erreicht, während einer Periode positiver Strandverschiebung gebildet worden ist. Warum sollte denn dann, meint Lendenfeld, der rezente Riftkalk nicht auch während einer solchen Periode gebildet worden sein? Stellenweise hat Agassiz gesehen, dass das rezente Riff dïnn ist. Daraus schliesst er, dass es nirgends eine bedeutendere Mächtigkeit habe, doch sicher kein zulässiger Schluss. Er macht auch keinen Versuch, die Steilheit der äussern Riffböschung auf Grund seiner eignen Rifftheorie zu erklären. Die in den Fidschiriffen ausgezeiclnet entwickelten Lagunen und Lagunenkanäle führt er auf die ausspülende Wirkung des bewegten Meeres zurück. Wenn dies richtig wäre, so müssten in allen Meeren und in allen Breiten, nicht bloss in den von Korallen besiedelten Gebieten, atollähnliche Bildungen zu stande kommen, müssten z. B. Sandbänke und andere Untiefen auch in der Mitte ausgetieft werden. Bei Annahme einer positiven Strandverschiebung während der Riffbildung ist dagegen die Entstehung der Lagunen leicht erklärt.

Die meisten der aus altem Korallenkalk bestehenden Inseln des 
Fidschiarchipels sind breit blockförmig und haben steile Seitenabstürze und flache Scheitel. Bei manchen ist die Scheitelfläche in der Mitte mehr oder weniger stark eingesenkt. Friihere Autoren und jetzt auch I) arid halten diese Inseln für trocken gelegte Atolle. A gassiz dagegen glaubt, dass die Scheiteldepressionen erst sekundär, nachdem die Inseln schon trocken gelegt waren, infolge der Einwirkung des atmosphärischen Wassers auf den Kalkstein entstanden sind. Lendenfeld schliesst sich der Davidschen Auffassung an und sieht in jenen Inseln gehobene Atolle. Wenn sie aber alte Atolle darstellen, so sind es solche, die wegen ihrer Mächtigkeit, Isoliertheit und geringen Horizontalausdehnung nur während einer Periode positiver Strandverschiebung gebildet werden komnten.

Agassiz hat somit den Nachweis, dass die Korallriffe der Fidschiinseln nicht während einer Periode positiver Strandverschiebung entstanden sein können, nicht nur nicht geliefert, sondern durch die neuen, ron ihm mitgeteilten 'latsachen nur neue Beweise für die Richtigkeit der Darwinschen Senkungstheorie erbracht.

W. M a y (Karlsruhe).

467 Pratt, Edith M., The mesogloeal cells of Alcyonium. In: Zool. Anz. Bd. XXV. 1902. pag. 545-548. + Textfig.

Bei der Untersuchung einer zur Gattung Lobophytum gehörigen Fiorallenspecies fand Verf., dass die stern- und spindelförmigen Zellen und Fasern, die den sog. mesogloealen Nerrenplexus bilden, auffallend zahlreich und gross sind. Um die Funktion dieses Zellensystems zu erkennen, machte Verf. Experimente an lebendem Material von Alcyonium digitatum, da lebende Exemplare von Lobophytum in England nicht zu erhalten waren. Es wurden an dünnen Schnitten amöboide Bewegungen der Zellen beobachtet. Ferner wurden die Polypen mit Karminpulver gefüttert und dann geschnitten. Nach 4-7 Tagen fanden sich Karminpartikel: 1. in den Zellen der Entodermkanäle der Mesogloea, 2. in den Zellen der soliden Entodermstränge der Mesogloea, 3. in den stern- und spindelförmigen Zellen der Mesogloea. Die Überführung solider Karminpartikel aus der Höhlung des Coelenterons eines Polypen zu solchen Teilen der Kolonie, die entfernt von den Polypen sind, die Tatsache, dass die Entodermzellen häufig amöboid werden. und der amöboide Charakter der mesogloealen Zellen liefern den Beweis, dass die sog. Nervenzellen der Mesogloea Entodermzellen sind, die amöboid geworden und in die Mesogloea eingewandert sind. Es ist wahrscheinlich, dass das System der amöboiden Zellen zur Vermittlung ron Impulsen dient, aber die Gegenwart von Karmin in diesen Zellen lässt vermuten, dass sie auch 
Nahrung oder Exkrete aufnehmen. Sie können als Neurophagocyten angesehen werden.

W. M a y (Karlsruhe).

\section{Vermes.}

\section{Plathelminthes.}

168 Fídoror, N., I'a anémie bothriocéphalique. In: Areh. de Parasitol. Tome VI, no. 2. 1902. pag. 207-24t.

Es ist eine bekannte 'Tatsache, dass die an perniciöser Anämie leidenden Menschen auch meist mit Helminthen, hauptsächlich Bothriocephalen infiziert sind. Man hat sich deshalb gefragt, besteht zwischen dieser Krankheit und der Parasiteninfektion eine bestimmte Beziehung, oder handelt es sich nur un eine einfache Coincidenz? Die Ansichten sind getrennt.

Reyler und Runeberg und mit diesen fast alle Autoren, welche in Russland ihre lieobachtungen gemacht haben, sind der Ansicht, dass das erstere der Fall sei. Sie liaben an zahlreichen Beispielen gezeigt, wie der Patient von der Anämie geheilt wurde, wenn er erst von seinen Eingeweidewïrmern befreit war. Wenn nun auch daraus nicht geschlossen werden darf, dass Bothriocephalus eventuell auch ein anderer Helninth die Anämie allein hervorruft, so ist doch mit Sicherheit anzunehmen, dass er eine Ursache der perniciösen Anämie ist. Den russischen Forschern ptlichten die Beobachter nicht bei, welche in Deutschland und in der Schweiz die Frage studiert haben. Biermer, Quincke, Immermann, Litten u. a. können durchaus keinen Zusammenhang zwischen Blutarmut und Bandwurm finden. An eine befriedigende Lösung der Kontroverse konnte erst gegangen werden, als $\mathrm{H}$ a yem auf die Notwendigkeit der Blutanalyse hinwies. Untersuchungen, welche sich auch auf diese ausdehnten, lieferte Schauman. Sie haben die unbedingte Identität der Bothriocephalus-Anämie mit der perniciösen Anämie dargetan.

Es ist also sicher, dass der Grubenkopf eine schwere Blutarmut erzeugen kann. Aber auf welche Weise bringt der Schmarotzer die tiefe Veränderung zu stande?

Nach Botkine sollte er eine reflektorische Wirkung auf das Blutbildungszentrum ausiiben. Da aber ein solches Zentrum noch problematisch ist, so wurde diese Theorie verlassen. Sie erklärt ja auch keineswegs, warum nicht alle ron Bothriocephalen behafteten Individuen anämisch werden.

Reyher glaubt das Saugen von Blut und Chylus von seiten des Parasiten könnte die Krankheit verursachen, oder man hätte an eine leichtere Infektion mit Microorganismus bei Vorhandensein des Bandwurmes zu denken. Állein bei Bothriocephalus kann von einem wirk- 
lichen Saugen nicht die Rede sein. Die Beobachtungen, welche man bezüglich der Nicrobeninfektion gemacht hat, sind noch so spärlich, dass eine Erklärung der Krankheit aus dieser Ursache nicht möglich ist.

Die Ansicht, welche am meisten Anklang gefunden hat, rührt von Schapiro her. Die Anämie wird nach diesem Autor dadurch hervorgerufen, lass der Bandwurm unter gewissen Bedingungen eine toxische Substanz ausscheidet, die ins Blut dringt und eine Zerstörung der roten Blutkörperchen verursacht. In der Tat haben die Versuche Schaumans und Tallquists die Vermutung bestätigt. Die perniciöse Anämie befällt bekanntlich nur einen kleinen Teil der mit Bothriocephalen behafteten Individuen. Schapiro und mit ihm Viltshur und Ehrlich nehmen daher an, dass nur der kranke oder tote Wurm gefährlich wird, oder, dass die Zersetzung abgefallener Proglottiden genügt, um die Krankheit zu erregen.

Die geographische Verbreitung der perniciösen Anänie deckt sich nicht durchaus mit derjenigen der Bothriocephalen.

Die Krankheit ist in der Schweiz verhältnismäßig selten, während der Bothriocephalus in ihr sehr stark verbreitet ist. IIan kenut ferner die Bothriocephalus-Anämie weder in Schweden noch in Norwegen. Häufig ist sie dagegen in Finnland. Man beobachtet sie auch in den baltischen Provinzen und im übrigen Russland, in Rumänien und selbst in Nordamerika.

Es ist nicht ausgeschlossen, dass auch andere Helminthen die Anämie erzeugen können. Incinaria duodenatis soll z. B. in dieser Art wirken. Nicht nur, dass sie durch ihre Haken eine stete Blutung in der Mucosa verursacht, sie scheidet auch, wie Lussana und Rohland gezeigt haben, eine toxische Substanz ans, die auf das Blut einen zerstörenden Eintluss hat. Nach den Versuchen Mingazzinis, Messineas und Calamidas findet durch Tänien eine Intoxikation mit nachfolgender Anämie nicht statt.

$$
\text { E. Riggenbach (Basel). }
$$

469 Kholodkorsky. N., Contributions à la connaissance des Ténias des Ruminants. In: Arch. de Parasitol. Tome VI. no. 1. 1902. pag. 145-148. Die Anoplocephalidengattung Thysanosoma umfasste bis jetzt nur zwei Arten T. giardi Stiles und $T$. actinoides Diesing. Mit einer dritten Species T. pygargi macht uns der Verf. in der vorliegenden Arbeit bekannt.

T. pygargi wurde von Silantiev in Sibirien aus Capreolus pygargus Pallas gesammelt. Der 1-1,5 m lauge Bandwurm besitzt einen rundlichen Skolex, dem ausser del Saugnäpfen jegliche Bewaffnung felılt. An den ziemlich langen Halsteil setzen sich sehr kurze Proglottiden an. Die Strobilation ist undeutlich, nur die hintersten Glieder sind scharf voneinander getrennt. Die Kette erreicht ungefähr in der Mitte eine maximale Breite von $4 \mathrm{~mm}$. In dieser Region treten die 
Anlagen der Genitalorgane auf. Über ihren Bau gab das Material nur spärlich Auskunft. Die Hodenbläschen sind in grosser Zahl vorhanden. Sie liegen zwischen der Anlage der weiblichen Geschlechtsdrüsen und den Längsgefässstämmen. Die weiblichen Genitalorgane nehmen den medianen Teil der Proglottis in Anspruch. Die Geschlechtsgänge wenden sich bald dem rechten, bald dem linken Seitenrande zu und öftinen sich an demselben etwas hinter der Mitte. Der Wechsel in der Lage ist ziemlich regelmäßsig. Ein am Hinterrande des Gliedes transversal verlaufender Kanal erweist sich als der junge Uterus. Seine vordere Wand ist mehrfach sackartig gebuchtet. In den ältern Gliedern scheint er sich ganz in isolierte Kapseln aufzulösen. Die Eier sind rund und entbehren des birnförmigen Apparates.

T. pygargus gehört in die Familie der A noplo ceplıalidae. Ob sie innerhalb derselben in das Genus Stilesic oder Thysanosoma zu stellen ist, mag bei dem schlechten Erhaltungszustande des Originalmateriales schwer zu entscheiden sein. Die Bildung der Uteruskapseln woist auf die Gattung Thysanosoma hin; der Parasit von Capreolus pygargus dürfte also bis auf weiteres am elesten in diesem Genus untergebracht werden.

E. Riggen bach (Basel).

470 v. Linstow, O., Drei neue 'Taenien a us Ceylon. In: Centrbl. Bakt. Par. u. Infektkr. I. Abt. Originale. Bd. XXXIII. Nr. 7. 1903. pag. 532-535.

Da der Beschreibung eine genanere Schilderung der anatomischen Verhältnisse nicht eingefügt ist, so beschränken wir uns auf die Wiedergabe des Inhaltes in der knappen Form der Diagnose.

Taenia polycalcaria n. sp. aus dem Darm von Felis pardus. Länge $108 \mathrm{~mm}$, Breite $1,5 \mathrm{~mm}$ vorn, 6,71 $\mathrm{mm}$ hinten. 2.19 Haken. Hebelast kurz, senkrecht zur Hauptrichtung, bei den kleinern Formen ungespalten. Genitalöffnungen von einem wulstigen Rande umgeben, unregelmäßig alternierend, in der Mitte des Gliedrandes liegend. Parenchym mit ausserordentlich zahlreichen, dicht gedrängten Kalkkörperchen.

Tacnia maeander n. sp. aus IIipposideros. 18,2 mm lang; vorne 0,12 mm, hinten $0,99 \mathrm{~mm}$ breit. Maximale Breite $1,42 \mathrm{~mm}$, Rostellum mit 24 Haken. Proglottiden durchwegs kürzer als lang. Genitalporen randständig, einseitig. Hodenbläschen zum Teil zwischen den beiden Längsmuskelschichten eingelagert. Dotterstock in der Mitte des Gliedes. Keimstock in der Marksubstanz. Kalkkörperchen fehlen.

Acanthotaenia shipleyi n. gen. n. sp. aus dem Darm von V'aranus salvator. Länge $13,8 \mathrm{~mm}$, Breite $0,11 \mathrm{~mm}$ vorn, $0,49 \mathrm{~mm}$ hinten. Proglottidenbildung vorne gar nicht, hinten nur schwach angedeutet. Geschlechtsöffnungen unregelmäßig abwechselnd in der Mitte des Gliedrandes gelegen. Cuticula des ganzen skolex und der Strobila bis 1,76 $\mathrm{nm}$ nach hinten mit dichten feinen Borsten besetzt. Rostellum ohne Haken. Etwa 50 Hodenbläschen in jedem Gliede.

E. Rigg e $\mathrm{nbach}$ (Basel).

471 Liilıe, M., Eine nomenclatorische Berichtigungbetr. die Cestodeng at tung Amphitretus R. BI. In: Centralbl. Bakt. Par. und Infektkr. I. Abt. Orig. Bd. XXXIII. Nr. 8. 1903. pag. 608-609.

In seinen Arbeiten über Buthriocephaloideen hat der Verf. mehrfach den von Blanchard 1894 aufgestellten Gattungsnamen Amphitretus gebraucht. Es hat sich nun aber herausgestellt, dass dieser Name von W. E. Hoyle für einen pelagischen Cephalopoden der Challenger Expedition bereits 1885 angenommen 
wurde. Die B anchardsche Gattung muss also ungetauft werden. Sie sol] nummehr Acanthophallus nom. nov. heissen. Die Neubenennung bringt für das Bothriocephaloideensystem folgende Änderung mit sich:

Fam. A canthophallidae nom. nov. syn. mit Amphitretidae Lühe 1902, Braun 1902 und Hoyle 1886.

Gen. Acanthophallus nom. nov. syn. mit Amphitrctus R. Blanchard 1894, Lühe 1899, Braun 1900, Lühe 1902 und $1902 \mathrm{a}$; syn. mit Diplogonoporus Stiles 1896; syn. mit Amphitretus Hoyle 1885; syn. mit Diplogonoporus Lömberg 1892 und Lühe 1899.

Typische Art: Acanthophallus wageneri (Montic. 1890) syn. Amphitretus wageneri R. Bl 1894.

E. Riggenba ch (Basel).

472 Kostanecki, Ras., Über die Reifung nnd liefruchtung des Eies von Cerebratulus marginatus. In: Bull. Acad. Krakau. Mai 1902. pag. 270-277. Taf. 18-21.

Verf. berichtet kurz über die Untersuchung melıerer Serien künstlich befruchteter Eier von Cerobratulus bei Perennyi- bezw. Sublimat-Eisessigfixierung und Eisenlämalaunfärbung. Verf. kommt zu ähnlichen Resultaten wie Coe in seiner vortrefflichen Arbeit (vgl. Zool. Zentr.-Bl. VI. Bd. pag. $474 \mathrm{f}$. Ref.) Die Richtungsteilungen erfolgen karyokinetisch mit wohlausgebildeten Strahlungen und Centrosomen. Der Nucleolus verschwindet bis zur Ausbildung der Richtungsspindel vollständig. Die Chromosomen der Kichtungsspindeln bilden 16 Vierergruppen. Die Chromosomen des zentralen Pols der ersten Richtungsspindel teilen sicl oft schon vorbereitend für die zweite Reifeteilung. Das erste Richtungskörperchen teilt sich sehr häufig in zwei. Die zweite Spindel bildet sich ,in typischer Weise" aus den Resten der ersten. Der Sanenfaden dringt ganz in das Ei ein; die Eintrittsstelle hat sehr wechselnde Lage. Centrosom und Drehung lassen sich am Samen faden nicht feststellen. Das Centrosom und die Strahlung treten erst neben dem bläschenförmigen Samenkern auf. Die Samenstrahlung und Samencentrosomen verdoppeln sich lange vor der Kopulation. Die von der zweiten Richtungsteilung her dem Ei verbliebenen 16 Chromosomen bilden 16 kleine bläschenförmige Kerne, die schliesslich zu einem einzigen, zuerst lappigen, dann runden Kern zusammenfliessen. Beide Geschlechtskerne verschmelzen bei der Kopulation zu einem einzigen Keimbläschen. Wälırend des Bläsihenstadiums des Eikerns verschwindet das Eicentrosom, die Strahlung bleibt aber noch eine Zeitlang erhalten bis zur Annäherung des Samenkernes mit seiner mächtigen doppelten Strahlung, dann verschwindet auch sie. Ohne Zweifel stammen also bei Cerebratulus beide erste Furchungscentrosomen vom Samenfaden ab, obwohl auch hier nach völliger Annäherung der Geschlechtskerne die 
Strahlung eine Zeitlang „undeutlich wird und die Centrosomen infolgedessen nicht gefunden werden können".

R. Fick (Leipzig).

473 Kostanecki, Ras., Über abnorme Richtungskörpermitosen in befruchteten Eiern von Cerebratulus marginatus. In: Bull. Acad. Krakau. Nai 1902. pag. 363-387.6 Taf.

Verf. macht sehr interessante, namentlich für die Zellteilungslehre wichtige Mitteilungen über eigentümliche Abnormitäten an seinem grossen, sonst normalen Material. Er fand in manchen Eiern vielfache Strahlensysteme mit Zentralkörperchen und mehrpolige Mitosen, die zum Teil zur Abstossung überzähliger Richtungskörperchen geführt haben. Die Strahlensonnen sind wohl durch Teilung aus der Eikernstrahlung hervorgegangen, nicht aus Nebensamenfäden, obwohl die Mehrzahl der abnormen Eier auch polysperm befruchtet waren.

R. Fick (Leipzig).

\section{Annelides.}

474 Attems, Carl Graf, Beiträge zur Anatomie und Histologie von Scololepis fuliginosa Clap. In: Arb. zool. Inst. Wien. Bd. 14. 1902. pag. 173-210. Taf. 6-9.

Verf. hat, hauptsächlich an Sclinittpräparaten, die Anatomie und Histologie des Spioniden Scololepis fuliginosa Clap. untersucht. Die Epidermis, die typisch ein einschichtiges Epithel ron wechselnder Dicke, an einigen Stellen aber mehrschichtig ist, besteht aus indifferenten oder Stützzellen, Driisenzellen, Wimperzellen - die auf den Kiemen und in je zwei Querreihen auf der Dorsalseite jedes Segmentes angebracht sind - und Nervenzellen. Letztere sind mit einem subepithelialen Plexus von Nervenfasern verbunden. Auf den Stützzellen liegt eine Cuticula, die an der Ventralseite etwas dicker ist. Der Kopflappen trägt auf seiner Dorsalseite zwei als Cerebralcirren angesehene Frontalhörnchen. Das Nervensystem ist von der Epidermis nicht scharf getrennt. Das Gehirn lässt ein unpaares Mittelhirn, das die vier Augen trägt, und je zwei paarige Teile, ein Vorder- und ein Hinterhirn unterscheiden, letztere mit den Nuchalorganen verbunden. In dem durch die Schlundring-Kommissuren zusammenhängenden Bauchmark findet Verf. kleinere und riesige Ganglienzellen und zwei grosse, das Organ der Länge nach durchziehende Neurochorde. Für die Augen führt er Hesses Beschreibung an. Die Nuchalorgane bestehen aus schmalen, an den Präparaten nicht mehr mit Wimpern besetzten Zellen. Die vier vordersten Segmente tragen auf der Dorsalseite jederseits zwei Wimperorgane. Die Parapodien werden kurz beschrieben. Vom Blutgefässsystem konnten nur die zentralen Teile näher 
untersucht werden, ein Darmsinus, der sich in den Segmenten 20-30 in ein Herz fortsetzt; von diesem, das nach vorn wieder in einen dïnnwandigen Sinus übergeht, entspringt in der Gegend des Ösophagus ein mit einem rudimentären Herzkörper ausgestattetes Rïckengefäss. Jede Kieme ist durch ein zu- und ein abführendes Gefäss mit dem Darmsinus verbunden. Das Bauchgefäss wies keine Seitengefässe auf. Die Kiemen sind schlauchförmig mit je zwei Gefässen. In bezug auf die Muskulatur und deren Histologie sei auf das Original verwiesen. Am Verdaungstraktus wird ein Ösophagus mit einer rudimentären Pharynxtasche, ein Mitteldarm und ein kurzer Enddarm untersehieden. Das Peritoneum besteht ans verschiedenen Zellen. Nephridien sind zu je zweien in allen Segmenten mit Ausnahme einiger der vordersten vorhanden. Jedes beginnt in einem Segment mit einem Wimpertrichter und zieht mit seinem aus verschiedenen Abschnitten gebildeten Kanal in das folgende, in dem es ausmündet. Ilmen liegen die Ovarien und die Hoden an.

J. W. Spengel (Giessen).

\section{Enteropneusta.}

475 Menon, K. Ramumi, Enteropneusta from Madras. In: Quart. Journ. microse. Sc. (N. S.) Tol. 47. 1903. pag. 123-131. pl. 10.

Verf. hat beim Dredgen vor der Madras-Küuste u. a. Enteropneusten gefunden, je einen Vertreter der Gattungen Glossobalams. Glandiceps und Dolichoglossus. Ein einziges für eine genauere Untersuchung des ersteren brauchbares Individumm sieht Verf. als ein kleines Exemplar von Gl.minutus an; nur die Farbe war mehr weiss als bei den Neapler Exemplaren.

Die 2. Form, durch einige männliche Exemplare vertreten, ist der bisher nur aus Japan bekannte Glandiceps hacksi [durch einen Druckfehler in der Ablandlung immer hackii genannt!|. Länge bis $\mathrm{zu} 45 \mathrm{~mm}$; Eichel $6^{1} / 2 \mathrm{~mm}$ lang, $4 \mathrm{~mm}$ breit, etwas iber $3 \mathrm{~mm}$ dick (dorso-ventral), vorn breiter als hinten; Maße des Liragens $2^{1 / 2}, 4^{1 / 2}$ ) und $4 \mathrm{~mm}$; Rumpf vorn $3^{1 / 2} \mathrm{~mm}$ breit, $4-4^{1 / 2} \mathrm{~mm}$ dick, nach hinten breiter (bis $5^{1 / 2} \mathrm{~mm}$ ) und flacher werdend. Die hintersten Körperabschnitte scheinen gefehlt zu haben. Färbung ähnlich wie von Spengel für [die jungen Exemplare von] Gl. hacksi beschrieben [dem die Art auch in den Maßen nahe kommt].

Über die innere Organisation macht Verf. nur folgende Angaben. Der Wurmfortsatz des Eicheldarms, ron dem Spengel nur den proximalen Teil habe sehen können [was nur für das aite Tier gilt, während er für das junge auf Taf. 20 Fig. 1 in seiner ganzen Länge ron etwa $0,8 \mathrm{~mm}$ abgebildet ist], sei bei einem grossen Exemplar nur wenig über $0,1 \mathrm{~mm}$ lang gewesen und bei dieser Art daher sehr 
reduziert, während das dorso-ventrale Septum sich weiter nach vorn erstreckt. Chondroides Gewebe sehr stark entwickelt; Schenkel des Eichelskeletts bis ans Hinterende des Kragens reichend. Am Kragen. mark ist vorn und hinten eine in dieses sich einsenkende Vertiefung vorlıanden, von denen Verf. nicht einsehen kann, warum sie nicht Neuroporen genannt werden sollen. Der vordere ist jedenfalls keine Epidermistasche, da eine solche ausserdem vorhanden ist. |Auf der Fig. 1, Taf. 20, der Monographie des Ref. weist der Strich ron ept $=$ Epidermistasche irrtiimlich auf die erwälınte vordere öffnung statt auf die rechts daneben gelegene Epidermistasche.] Ton Darmpforten waren im Gegensatz zu Spengels Angaben, der 9 umpaare und in einiger Entfernung dahinter 3 paarige fand, bei dem rom Verf. auf Querschnitten untersuchten Exemplar etwa 60 unpaarige und 6 paarige vorhanden, die erstern bald rechts, bald links; gelegentlich beiderseits gelegen. Die (männlichen) Gonaden erstrecken sich von der Nälıe des Vorderendes der Kiemenregion [bei Spengels Exemplar beginnen sie erst am 13. und 14. Kiemenporus] bis in den Anfang der Leberregion.

[Es ist nach den in dieser unvollständigen Beschreibung herrortretenden Unterschieden wenig wahrscheinlich, dass diese Art mit Glandiceps hacksi (Marion) identisch ist.]

Von der 3. Art, Dolichoglossus boumei n. sp., waren zwei Yorderkörper (Eichel, Kragen und ein bis zu $18 \mathrm{~mm}$ langes Stiick der Kiemenregion) vorhanden. Eichel lebend bis 9, konserviert $6 \mathrm{~mm}$ lang, deprimiert, aber nicht mit einer Längsfurche wie bei $D$. sulcatus und $D$. otagoensis, an der Basis fast $2 \mathrm{~mm}$ breit. Hals der Fichel sehr dünn. Kragen $1 \mathrm{~mm}$ lang, $1^{1 / 1} / 2 \mathrm{~mm}$ breit, mit 3 Ringfurchen. Kiemenregion $1^{1 /} / 2 \mathrm{~mm}$ breit. Beide Exemplare weiblich, hellbraun, Spitze der Eichel und líragen gelblich.

Über den innern Bau werden folgende Angaben gemacht. Eichel: Ringmuskulatur schwach, Längsmuskulatur nicht in konzentrischen Ringen angeordnet, also wie bei $D$. otagoensis. In der ganzen Länge ein rorn ziemlich weiter, im lintern Drittel sehr enger Hohlraum. Die basalen Organe reichen nur über etwa $1 / 10$ der Eichellänge, das Mesenterium aber bis an den weitern Teil der Höhle reichend. Spitze des Eicheldarms wie bei $D$. kowalewskii dorsal gewandt. Eicheldarm hohl, Hohlraum im vordern Teil äusserst eng; Hals sehr lang und weit hinten in die Krragenhölıle mündend. Zentraler Blutraum sehr deutlich. Herzblase sehr klein. Körper des Eichelskeletts lang, sich bis in den hintern T'eil des Kragens erstreckend; chondroides Gewebe sehr schwach; Schenkel bis ans Hinterende des Kragens reichend. Eichelporus links von der Medianlinie am hintern 
Ende des Eichelhalses. Kr ragen: Dorsales Mesenterium in der ganzen Länge, ventrales in der hintern Hälfte des Kragens. Quermuskeln an der ventralen Wand der Perilı̈malräume. Keine Peribranchialräume. Kragenmark mit zahlreichen kleinen Höhlen. Tiefe vordere Epidermistasche mit gefalteten Wänden. Kragenpforten wie gewölınlich. Rumpf: Keine Ringmuskulatur. Lä̈ngsmıskeln bilden eine dicke Lage, rentral treten einige Fasern anf die Darmwand ïber. Radiärnuskeln zwischen Kiementaschen und Haut. An der lypobranchialen Wand des hintern T'eils der Kiemenregion eine dünne Lage von Ringmuskeln. Wimperepithel der Kiemen wie bei Harrmania liupfferi aus sehr dünnen hohen Zellen gebildet, deren Kerne in verschiedener Höhe liegen. Aussenwand der Kiemenzungen nicht eingefaltet. Ovarien auf das vordere Ende der Kiemenregion beschränkt, keine medianen; fettähnliche Körperehen zwischen den Eiern; Genitalporen aussen von den Kiemenporen.

Ausserdem fand Verf. zwei Formen von Tornarien im Auftrieb. Eine, Tornaria krohmii, war sehr gemein. Da dieselbe Art im Mittelmeer vorkommt, neigt Verf. zu der Ansicht, dass es die Larre von Glossobalanus mimutus sein möchte. Die andere Art, die etwa $1^{1 / 2} \mathrm{~mm}$ lang ist, bildet Verf. vom Riicken und rom Bauch schematisch ab und beschreibt sie nach Spengels Terminologie, ohne ihr' einen Namen zu geben. Gelbliche Pigmentflecke gleichen in der Färbung denen von Glandiceps hacksi, zu den vielleicht die Larve gehöre (während Willey in allen Tornarien Larven von P'tychoderiden vermutet).

J. W. Spengel (Giessen).

\section{Arthropoda.}

\section{Crustacea.}

476 Ischikawa, C. . Über das rhythmische Auftreten der Furchungslinie bei Atyephira compressa de Haan. In: Arch. f. Entwmech. Bd. 15. 1902. pag. 535̃-5̌+2. Taf. 19.

Die erste Furchungslinie tritt an den Eiern des oben genannten kleinen Krebstieres anfangs einseitig auf; nachdem sie das Ei in zwei Zellen geteilt hat, wird sie wieder total verwischt, so dass das Ei wie ungeteilt aussieht; vor der zweiten Teilung tritt sie wieder anf. Auch nach der zweiten Teilung versehwinden die Furchungslinien wieder, beide aber nicht gleichzeitig, sondern zuerst die zweite und dann die erste; vor der dritten Furchung treten sie wieder auf. Nach dem achtzelligen Stadium verschwinden die Furchungslinien nicht mehr, obwohl die Abtlachung der Furche nach jeder Teilung der Blastomeren sehr deutlich zu bemerken ist.

An Schnitten hat Verf. nachweisen können, dass dieser eigentüm- 
liche Rhythmus in dem Auftreten der Furchungshinien mit dem Zustande des Kerns in Relation steht, und zwar so, dass ,die Furchung am prägnantesten ist, wenn der Kern die Teilung vollendet hat, und seine Chromatinelemente in lockern Kinäueln sich befinden. Geht der Kiern aber in sein völliges Ruhestadium über, so verschwindet auch die Furchungslinie. Das Auftreten der ersten Furchung macht sich bemerkbar, wenn der Kern sich in Spindelform befindet, und seine Chromosomen ron der $\ddot{A} q u a t o r i a k b e n e$ sich voneinander zu entfernen beginnen. Diese Furche wird nun altmählich deutlicher, bis die 'Tochterkerne völlig geformt sind". Wit der Umwandlung des Kerninhalts in das Ruhestadium verschwinden auch die Furchungslinien.

Ähnliche Erscheinungen habe auch Brooks, wem auch weniger ausgesprochen, an Süsswasser-Puhnonaten und an Leucifer beobachtet.

R. S. Bergh (Kopenhagen).

\section{Arachnida.}

477 Soar, C. I., Note on the ocurrence of living Hydrachnid Larvae in the stomach of a 'Trout. In: Journ. Quekett Nicr. Club, Ser. 2. Vol. VIII. Nr. כ̃2. 1903. pag. 463--46t. Fig. $1-4$.

Wie der Verf. berichtet, wurde in dem Magen einer im See Rannoch gefangenen Forelle eine grosse Menge lebender Hydrachnidenlarven aufgefunden. Trotz genauer Untersuchung gelang es nicht, festzustellen, zu welcher Gattung und Art diese Larven gehören. Der Verf. glaubt sie in die Nähe der Gattung Neumania stellen zu müssen. Koenike vermutet in ihnen das Entwicklungsstadium einer dicklüutigen, gepanzerten Süsswassermilbe (A\%hemur?) und gründet seine Meinung auf das Vorhandensein deutlicher Rï̈kenplatten. Nach Ansicht des Ref. ist diese Auffussung irrig. Auch die im geschlechtsreifen Alter weichhäutigen Hydrachniden entwickeh sich in der Regel aus Larven mit Dorsalschild. Um Amhenum-Larven kann es sich im vorliegenden Falle nicht handehn, da nach den beigegebenen Zeichmungen ersichtlich ist, dass Bau und Ausstattung der Palpen und des Analfeldes nicht den bei diesen vorkommenden Verhältnissen entsprechen. Alle bisher untersichten Arrhemurus-Larven - und es sind deren nicht wenige - kennzeichnen sich durch den Besitz einer an der Unterseite des vorletzten I'alpengliedes eingelenkten, körperlangen, deutlich gefiederten Borste. Weiter ist bei ihnen die zweite Epimere von der dritten bis zur Mittelfurche durch eine Naht deutlich abgegliedert, während bei der von Soar dargestellten Form nach innen zu eine Verschmelzung eingetreten ist. Das Analfeld zeigt eine andere Gruppierung der beiden Borstenpare um die sog. Analötfnung. Allem 
Anscheine nach gehört die neue Larvenform, wie schon Soar vermutet, zu einer der Gattung Neumania nahestehenden Hydrachnidenart.

R. P'iersig (Annaberg, Erzgeb.).

478 Thor, sig., Zwei neue Spcrchon-Arten und eine neue Aturus-Art aus der. Schweiz. In: Zool. Anz. Bd. XXVI. 1902. pag. 151-159. Fig. 1-5.

Nach den in den letzten Jahren veröffentlichten Arbeiten Koenikes und 'J'h o r's zu urteilen, scheint die Gattung Sperchon einen ähnlichen Formenreichtum zu besitzen wie Eulais und Lebcrtia. Bei der Aufstellung und Abgliederung der zahlreichen neuen Arten sind freilich oft Abweichungen in der Beborstung und Ausstattung der Maxillartaster und Beine sowie im Bau des Geschlechtsfeldes und des Epimeralgebietes als spezifische Unterscheidungsmerkmale verwendet worden, die es recht zweifelhaft erscheinen lassen, ob die betreffenden Arten zu Recht bestehen, oder ob wir es nicht hierbei mit Spielarten und lokaten Varietäten einer bestimmten Stammform zu tun laben. Die in der vorliegenden Arbeit 'Thors beschriebenen Sperchon-Arten kennzeichuen sich jedoch durch solche charakteristische Eigentümlichkeiten, dass ilıre Sonderstellung als berechtigt anerkannt werden muss. Sperchon vaginosns Thor erreicht etwa eine Länge von 900 "1. Die Körperdecke ist wie bei Sy. hispidus Koen. und Sp. elupeifer Piersig netzartig gefeldet. Auf dem Rücken bemerkt man einen Panzer. Das Maxillarorgan (Capitulum) besitzt einen schmalen, langausgezogenen Mundteil. Die Seitenwandungen tragen zwei kleine, wulstartige Fortsätze. Die Palpen erinnern in manchen Stücken an die gleichen Gebilde von P'seutosprrchon verrucosus (Protz). Der Zapfen auf dem ungemein reich beborsteten zweiten Palpenglieder ist weit nach vorn gerückt und selrr lang, besonders auf der Aussenseite, ausserhalb der Insertionsstelle der Degenborste, die von zwei feinen Härchen begleitet wird. Die Seitenwandungen des dritten Gliedes setzen sich distalwärts über die Einlenkungsstelle des nächsten Gliedes breit zungenfürmig fort, eine Erscheinung, die wir ähnlich bei den meisten Vertretern der Gattung Arrhenurus Dug. vorfinden. Auf der Beugeseite des vorletzten, kurzen und stämmigen Gliedes treffen wir etwa zwischen der Mitte und dem distaien Ende des Gliedes zwei grosse, sehr eng zusammengerückte Taststifte. Am Vorderrande der Innenfläche entspringt neben mehrern feinen Härchen ein kurzer kräftiger Chitinstift, der an das ähnliche Gebilde von Piona (=Curipes) C. L. Koch erinnert, nicht aber mit den kurzen, dolchartigen Fortsatz bei den Laminipes-Arten verwechselt werden darf. Das für die lier vorliegende Art am charakteristischste Merkmal ist eine scheidenartige Erweiterung des distalen Endes einzelner Beinglieder ähnlich wie beim dritten Palpengliede, doch ist der Vorderrand dieser Seitenklappen häufig gezackt. Weibchen und Nymphe der neuen Art ist noch unbekannt.

Sperchon plumifer 'Thor' gehört wie die vorige Art nach der Beschaffenheit der Haut zur Untergattung Hispidosperchon Thor. Die Maxillarpalpen sind lang und schmal und nur sparsam mit Borsten besetzt. Die zwei Taststifte des vorletzten Gliedes liaben kaum die Grösse der entsprechenden Gebilde bei Sp. brcvirostris lioenike; sie sind dem distalen Gliedende sehr nalıe gerückt. Das eigentïmlichste Merkmal dieser neuen Art besteht in dem Haarbesatz der Beine. Auf der Aussenseite des dritten, vierten und fünften Gliedes tritt eine Längsreihe von Fiederborsten mit auffallend breiter Fahne auf, wie sie noch bei keiner Sperchon. Art beobachtet wurde. Männclien und Nymphe sind noch unbekannt.

Im Anschluss an die Beschreibung der beiden neuen Sperchon-Arten teilt 
der Verf. noch mit, dass bei Spcrchon papillosus Thor die mit Papillen besetzte Haut ebenfalls eine netzartige Felderung aufweist.

Aturus crinitus 'Thor of wird etwa 500 "lang. Fr kennzeichnet sich besonders durch die Bauart und Ausstattung des Hinterfusses, der zwar stark verlängert ist, aber in der Entwicklung demjenigen von Aturus mirabilis Piersig und $A$. scaber Kramer nachsteht. Das zweite Glied ist am meisten verlängert und zeigt eine starke Krümmung. Das vierte Glied besitzt die Länge des dritten und trägt am mäßig verdickten distalen Ende vier grössere und einige kürzere Borsten; zwei derselben überragen sogar das fünfte Beinglied; die längste ist lanzettlich verbreitert. Das fünfte Glied besitzt im Gegensatz zu A. protzi Piersig keine schaufelförmigen oder gezackten Borsten, sondern am proximalen Ende der Beugeseite 8-10 dicke, steife, halblange Borsten. Das dritte Beinpaar trägt keine Schwimmhare. - Der Genitalhof ist jederseits der Geschlechtsöffnung längs des Körperrandes mit etwa 32 in einer Doppelreihe angeordneten (ienitalnäpfen ausgestattet; ausserdem liegen noch auf der Baucliseite rechts und links von der Schamspalte fünf Paar Genitalnäpfe ohne Haare und drei Paar kleine, auf Höckerchen stehende Borsten. Der Hinterrand des Körpers gewährt ein ähnliches Bild wie bei 1. mirabilis Piersig, doch sind die sogenannten Zwiebelborsten bei $A$. crinitus 'Thor viel länger $(500$ u) und nicht nach aussen, sondern nach innen gekrümmt. Im Gegensatze zu A. natangensis Protz, A. intcrmedius Protz und 1. protzi Piersig treten auf der Rückseite am medianen Einschnitt des Hinterrandes nur zwei keulenförmige Bläschen auf, die bei lebenden Individuen aufwärts gerichtet sind. - Das Weibchen unterscheidet sich von denen anderer Arten besonders dadurch, dass neben dem Genitalhof keine Chitinplättchen vorhanden sind. Die Genitalnäpfe (etwa 14-18 Paare) stehen wesentlich in einer Reihe.

An die Beschreibungen der eben charakterisierten neuen Arten schliesst der Verf noch einige Bemerkungen über die von $\mathrm{K}$ o e n ike angezweifelte Berechtigung der Gattung Ijartdalia. In Übereinstimnung mit dem Ref. findet er, dass die von Aturus abweichende Bildung des Rückenpanzers, des vierten männlichen Beines, der Maxillarpalpen und des Genitallıfes die Aufstellung einer neuen Gattung völlig berechtigt erscheinen lassen.

R. Piersig (Annaberg, Erzg.)

479 Wasmann, E., Zur Kenntnis der myrmecophilen Antemophorus und anderer anf Ameisen und Termiten reitenden Acarinen. In: \%ool. Anz. Bd. XXV. Nr. 661. 1902. pag. 66-76.

In der rorliegenden Arbeit beschäftigt sich der Verf. zunächst mit der Synonymie der von G. Haller 1877 beschriebenen neuen Gamaside, Antennophorus uhlmami., die als Parasit auf Ameisen lebt. Auf Grund vergleichender Untersuchungen weist er nach, dass ron derselben zwei neue Species abzugliedern sind, die läufig mit der Hallerschen Form rerquickt wurden. Wasmann schlägt für beide die Bezeichnung A. pubescens und A. foreli vor. Die drei Antennophorus-Arten unserer Fama unterscheiden sich dadurch, dass A. foreli Wasm. im Gegensatze zu A. uhlmanni Haller und A. pubescens Wasm. ein sehr stark gewölbtes, halblugelförmiges Rückenschild aufweist, dessen Oberfläche mit langen, aber zerstreut stehenden Haaren besetzt ist. Das Zentralfeld des Rückenschildes 
fällt durch seinen Mangel an Glanz auf, während das Marginalband ebenso poliert erscheint wie bei den beiden andern Species. Diese weichen besonders durch die Struktur und die Ansstattung des sog. Zentralfeldes voneinander ab. A. uhtmami besitzt ein solches mit sehr dichter und feiner Granulierung, während dasjenige ron 1. pubescens Wasm. eine ungemein feine Runzelung aufweist. Letztgenamte Art besitzt ausserdem noch ein breiteres, weitläufiger punktiertes und stärker glänzendes Marginalband. Nach den Feststellungen Wasmanns schmarotzt $A$. uhtmami Haller auf Lasius fuliginosus Latr., Lasius mixtus (Nyl.) und L. umbratus Nyl., A. mubescen. Wasm. auf $L$. Alavus Deg. und $A$. foreli Wasm. auf L. niger und $L$. alienus Först. Die auf dem zuletzt genannten Wirte schmarotzenden Individuen sind ein wenig kleiner und etwas dichter behaart als diejenigen auf $L$. niger.

Der Verf. berichtet dann über ausländische AntennophorusArten, von denen die eine sich durch ihre aussergewöhnliche Grösse auszeichnet und auf der Wanderameise Eciton maedator Fr. Sm. (= omirorm Wasm.) in Südbrasilien lebt. Sie wurde von dem Verf. schon früher eingehend beschrieben und erhielt den Namen A. barlatus Wasm. Die andere Form, A. wheeleri Wasm., besitzt eine kreisrunde, sehr schwach gewölbte Gestalt. Sie lebt in Nordamerika (Connecticut) auf Lasins aphidicola Walsh. Im Gegensatze zu $A$. burbutus Wasm., dessen Rïckenschild queroval, also bedentend breiter als lang ist, weist die nordamerikanische Art ein solches von kreisrunder Gestalt auf. Die bis jetzt bekannten europäischen Arten haben alle annähernd dreieckige Rückenschilder.

Auch bei den Termiten kommt eine Acaride vor, die grosse Ïhnlichkeit mit 1. wheeleri Wasm. erkennen lässt, aber stärker gewölbt ist. Ihr hellbraunes, Hach gewölbtes Rückenschild ist ebenfalls vollkommen kreisförmig, glatt, glänzend und unbehaart, auch ohne Narginalborste. Der Verf. nennt diese auf Termes tubicola Wasm. in Siidafrika schmarotzende Form, deren genaue Einordnung in das System erst nach der genauen Untersuchung der Morphologie der Mundteile und des Geschlechtsapparates erfolgen kann, vorläufig Antemophorws brounsi Wasm.

Eine merkwirdige, mit Antennophorus nahe verwandte, aber nach der Ansicht des Verfs. wahrscheinlich eine neue Gattung bildende, grosse, rotbraune, halbkugelige Gamaside ist der auf Plagiolepis custodiens Sm. (= fallax Mayr) gefundene A. raffrayi.

Der Verf. gibt auch einen Überblick über die ron ihm und andern Forschern (Berlese, Leonardi, Escherich und Michael) gemachten Beobachtungen über einige, der Gattung Antemophorus 
nicht zugehörige, ebenfalls auf Ameisen reitende Acarinen. Bei Neoberlesia equitans Berl., die auf Pheidole pallidula in Südeuropa und Kleinasien rorkommt, bestätigt er die Angaben früherer Beobachter. Bei Iphis equitans (= Loelaps), den Michael auf dem Kopfe ron Tetramorium caespitum L., subsp. meridionale Em., bei Ajaccio auf Korsika reitend fand, fügt der Verf. ergänzend linzu, dass er diese Acarine, gleich Loelaps oophilus Wasm., frei in Neste herumlaufen oder auf den jungen Larven der Ameisen sitzen sah. Loelups oophilus befällt ausserdem noch die Eierklumpen der Wirte.

Über die Lebensweise von Antemophorus hat der Verf. zahlreiche Beobachtungen im Freien und in Beobachtungsnestern gemacht ${ }^{1}$. Sie bilden eine vortreffliche Ergänzung zu den Angaben Janets. Nach der Auffassung Wasmanns ist das Verhältnis dieser Schmarotzermilbe zu den Ameisen nicht so sehr eine Übergangsstufe des Parasitismus zum echten Gastrerhältuis (Symphilie), sondern vielmehr ein parasitisches Zerrbild des letztern; der $A$. wird von seinem Wirte widerwillig geduldet und widerwillig gefüttert. Das Verhältnis der symphilen Coleopteren Atemeles, Lomrchusa und Claviger ist dagegen als ein wirkliches Gastrerhältnis mit gegenseitigen Leistungen aufzufassen. Die Pflege der echten Gïste durch ilure Wirte hat nichts zu tun mit der widerwilligen Duldung, die den Antennophorus-Arten seitens der Ameisen zu Teil wird.

R. Piersig (Annaberg, Erzgeb.).

\section{Insecta.}

480 Sjöstedt, Yngve, Monographie der T'ermiten Afrikas. In: Kongl. Srenska Vetensk. Akad. Handling. Bd. 34. Nr. 4. Stockholm 1900. 236 pag. 9 T'af.

481 Wasmann, E., Einige Bemerkungen zu Y. Sjöstedts, Monographie der Termiten Afrikas". In: Biol. Centralbl. XXII. 1902. pag. $713-716$.

482 Silvestri, Filippo, Contribuzione alla conoscenza dei Termitidi e Termitofili dell' America meridionale. In: Redia Bd. I. Portici 1901. pag. 1-234. 6 Taf.

Unsere Kenntnisse über die Systematik und Biologie der Termiten sind im Vergleich zu denen der übrigen sozialen Insekten noch sehr lückenhaft. Es ist deshalb mit Freuden zu begrüssen, dass in den letzten Jahren mehrere Forscher sich dem Studium dieser so überaus interessanten Tiere mit grossem Eifer zuwandten. Ausser Haviland und W asm ann (vgl. Zool. Zentr.-Bl. 1899 pag. 799, und 1898,

1) Vergl. Zool. Zentr.-Bl. IX. 1902. Nr. 892. pag. 861 . 
pag. 412) haben sich in jüngster Zeit vor allem Sjöstedt und Silvestri eingehend mit den Termiten beschäftigt, und umfangreiche Mlonographieen darüber geliefert, welch letztere hier kurz besprochen werden sollen.

Sjöstedts Monographie (480) behandelt die Termiten Afrikas auf (irund eines sehr reichhaltigen Materials, das teils von des Verfs. Reisen in Kamerun, teils von verschiedenen grössern Museen stammte. Es werden 82 Arten ausführlich beschrieben, teilweise auch abgebildet und ausserdem deren Biologie, soweit bekannt, mitgeteilt. Dit afrikanischen 'Termiten umfassen sechs Gattungen: Hodotermes Hag., C'alotermes Hag., Rininotermes Hag., Lcanthotermes sjöstedt, Termes (L.) Hag., und Eutermes (Heer) Hag. - Auf der höchsten Stufe der Fntwicklung steht Hodotermes, indem hier sowohl die Soldaten als auch die Arbeiter gut entwickelte Facettenaugen besitzen. Bei Calotermes sind die Augen dieser Stände schon schwächer ausgebildet, um bei den übrigen Gattungen gänzlich zu verschwinden oder sich nur durch einen hellen Fleck markiert zu zeigen.

Am leichtesten sind die einzelnen Termitenarten an ihren Soldaten zu unterscheiden, da diese die grössten Verschiedenheiten aufweisen und zwar vor allem bezüglich der Form des Kopfes und der Mandibeln. Besonders auffallend erseheinen die Mandibeln bei Eutermes socialis, haculi, hospes und capricornis, indem sie bei diesen Arten bandförmig, ganz unregelmäßig gebogen oder stabförmig sind. Eine besondere Soldatenform stellen die sogenanuten Nasuti vor, welche einen retortenförmig ausgezogenen Kopf, in dessen Spitze eine grosse Drüise mündet, besitzen. Diese Drüse bildet wohl das Hauptverteidigungsorgan, zumal die Mandibeln bei den Nasuti mehr oder weniger verkimmert sind. Nur in ganz wenigen Fällen (bei Eutermes lateralis und truncatus) besitzen die Soldaten sowohl gut entwickelte Mandibeln als auch eine "Nase"; man kann diese Formen gewissermaßen als Zwischenglieder zwischen den gewöhnlichen Soldaten und den Nasuti anselren.

Trotzdem die Soldaten meistens gute Anhaltspunkte zur Erkennung der verschiedenen Arten darbieten, hält es der Verf. für unrichtig; sie zur Aufstellung eines Systems zu verwenden, wie es Wasmann getan hat. Denn die Soldaten seien Anpassungsformen und ihre Verschiedenheiten lediglich Anpassungscharaktere an eine verschiedene Lebensweise. Es seien deshalb auch die Übereinstimmungen der Soldatenformen nicht immer ein Beweis für eine wirklich genetische Terwandtschaft, sondern vielfach als auf Konvergenz beruhend anzusehen. - Vert. sucht daher auf Grund anderer Merkmale, und zwar der Fühlerbildung und des Flügelgeäders der 
Imago zu emer natïrliclien Gruppeneinteilung der artenreichen Gattungen Termes und Eutermes zu gelangen.

Die Funktion der Soldaten besteht darin, die Gesellschaft gegen Ameisen und andere Feinde zu verteidigen; einigen, wie den Nasuti, soll auch die Hauptarbeit bei der Zerstörung des alten Holzwerkes zufallen. - Die Arbeiter haben hauptsächlich den Bau und den Unterhalt des Nestes zu besorgen. Bei einigen Arten, Termes lilljeborgi u. a. schneiden sie auch Gras- und Blattstuickchen ab, welche für den Pilzbau verwendet werden.

Das Aussehen und die Lage der Tester ist bei den afrikanischen 'Termiten sehr verschieden. Der Bau ist immer gut gegen das Eindringen des verhassten Lichtes, gegen Ameisen und andere Feinde geschiitzt. Zuweilen scheint eine Gesellschaft mehrere Nester zu laben, von denen nur eines von Geschlechtsindividueu bewohnt ist; von diesem werden dann die Eier und Larven nach den andern gebracht. Es werden eine ganze Anzahl von Ternitenuestern eingelıend beschrieben (turmähnliche, zapfenförmige, pilzförmige, mehrstöckige usw.) und einige davon auch auf 'laf. VI-IX selr gut abgebildet. Näher kann aber lier auf die einzelnen Formen nicht eingegangen werden. Den Schluss des schönen und v'rdienstvollen Werkes bildet ein Verzeichnis der gesanten 'Termitenliteratur, welches sehr vollkommen ist; es füllt nicht weniger als 11 Druckseiten.

Wasmann (481) weudet sich in seinen "Bemerkungen zu Sjöstedts Monographie* gegen die oben mitgeteilte Anschauung des Verfs. betreffs der systematischen Verwendbarkeit der Soldaten, und hält es für vollkommen berechtigt, die Terschiedenheit der Soldatenform gleichsam als Wegweiser für die generische und subgenerische Einteilung der Termiten zu benüitzen. Die Soldatenform sei die hochgradigst spezialisierte Kaste im Termitenstaat; man könnte sie sogar als eine sekundäre Imagoform bezeichnen. Ein Vergleich der 'Termiten verschiedener Erdteile zeige f'erner, dass die natürlichen Verwandtschaftsverhältnisse, durch welche die auf verschiedene Erdteile zerstreuten Arten jener Gattungen miteinander verbunden werden, gerade in der Soldatenform ihren prägnantesten Ausdiuck erhalten. Auch seien die verschiedenen Soldatenformen, welche bei ein und derselben 'Termitenart vorkommen, niemals qualitativ, sondern stets nur quantitativ verschieden usw. Ausdrïcklich betont aber Wasmann, dass man neben den Soldaten natiulich auch die übrigen Stände berücksichtigen müsse.

In ganz ähnlicher Weise wie Sjöstedt die Termiten Afrikas, behandelt Silvestri (482) die Termiten Südamerikas. Seine 234 Seiten und 6 'Tafeln umfassende Monographie zerfällt in zwei Teile, von 
denen der erste der Systematik und Biologie der'Termiten, und der zweite den Termitophilen gewidmet ist. Die Termiten Südamerikas, von denen in der rorliegenden Arbeit 65 Arten behandelt werden, gehören zwei Subfamilien an: den Calotermitinae, deren Gesellschaften nur aus Geschlechtstieren und Soldaten bestehen, und den Termitinae, die ausserdem auch noch gewöhnliche Arbeiter besitzen. Die ersteren werden wiederum in 4 Genera eingeteilt, die letzteren in 14 Genera, wobei anch die Wasmannschen. hauptsächlich auf die Soldatenform begründeten Subgenera der alten Gattung Termes (Cornitermes, Copto-, Rhino-, Eu-. Armi-, Capri-, Miro- Sprini- nnd Anoplotermes) anerkannt und in den Rang ron Gattungen erhoben werden. - Die eimzelnen Arten sind meist ausfülılich beschrieben und ausserdem sind die charakteristischen Nerkmale teils im Text (Fliigelgeäder), teils auf den ersten vier Tafeln recht gut abgebildet. Den Schluss des rein systematischen Ahschnittes bildet ein Katalog aller bis jetzt in Siidamerika festgestellten Termitenarten, wobei auch die Synonymie und geographische Verbreitung berïcksichtigt ist.

Im zweiten Abschnitt des ersten 'Teils berichtet Silvestri iiber die biologischen Beobachtungen, die er während seines Aufenthaltes in Siidamerika angestellt hat. Besonders eingehend werden die Nestbauten der Termiten behandelt, von denen viele nach photographischen Aufnahmen dargestellt werden. Auch ïber die sonstigen Lebensgewohnheiten der 'Termiten werden viele Einzelheiten mitgeteilt, worüber früher schon an dieser Stelle berichtet wurde (vgl. Zool. Zentr.-Bl. 1902. pag. 743).

Im zweiten Teil werden die Termitophilen, welche Silvestri in Siidamerika beobachtet hat, beschrieben: Es sind nicht weniger als 39 verschiedene Arten, von denen 5 den Acarinen, 3 den Diplopoden, 2 den Thysanuren, 2 den Hemipteren, 3 den Dipteren, 7 den Hymenopteren und 17 den Coleopteren angehören.

Dic meisten der aufgefundenen Arten erwiesen sich als neu. Auch über die Biologie, d. h. über die Beziehungen der Gäste zu ihren Wirten machte Silvestri, so gut es eben auf Reisen geht, Beobachtungen (teils direkt in der Natur, teils in künstlichen Nestern), und gibt darüber eingehende Mitteilungen. Der Verschiedenheit der Gäste entspricht auch die Verschiedenheit ihres Verhältnisses zu den Termiten: die einen leben als Ektoparasiten, die andern als indifferent geduldete Gäste und wieder andere als „echte Gäste" in den Termitenbauten. Silvestri führt für die verschiedenen Kategorieen trotz der Wassmannschen treffenden 
Bezeichnungen wieder neue griechische Termini ein: Alloicoxeni, Parassitoxeni, Cleptoxeni, Synoicoxeni und Euxeni. - Diese vielen Termini dürften aber das Gegenteil von dem, was sie sollten, erreichen, indem durch sie das Verständnis, anstatt erleichtert, nur erschwert wird (vgl. Zool. Zentr.-Bl. 1903. pag. 238). Im übrigen ist die Silvestrische Monographie ein sehr verdienstrolles Werk, durch welches unsere Kenntnisse über die Termiten Siidamerikas eine wesentliche Bereicherung erfahren. K. Es c h e r i ch (Strassburgi. Els.).

483 Wasmamn, k., Zur näheren Kenntnis des echten Gastrerhältnisses (Symplijlie) bei den Ameisen- und Termitengästen. In: Biol. Zentral-Bl. Bd. XXIII. 1903. pag. 63-72; 195 - 207; 232-248; 261-276; 295-310. 27 Fig. im Text.

Die ..echten Gäste“" der Ameisen und Termiten besitzen eine Reihe morphologischer Anpassungsscharaktere, aus denen man mit grosser Sicherheit auf die Reziehungen der Cäste zu den Wirten schliessen kann. \%u den anffallendsten dieser Cliaraktere gehören die Exsudatorgane, welchen die Funktion zufüllt, ein den Wirten angenehmes Exsudat zu produzieren. Bisher kamte man nur den äussern Bau dieser Organe, d. h. die Trichome nnd die Gruben oder Poren des Hautskeletts, wïhrend man von der feinern histologischen Beschaftenheit der Lxsudatbildner selbst noch gar nichts wusste. Wasmann stellte nun, um diese Lïcke auszufïllen, eingehende histologische Untersuchungen an eiler ganzen Reihe von Symphilen an und teilt seine diesbezïglichen Ergebnisse in vorliegender Arbeit mit.

Verf. fand stets unterlaalb der Trichome oder den Exsudatgruben auffallend mächtige Schichten von Fettgewebe. Ausserdem liessen sich aber bei einer Anzahl von Symphilen zwischen letzterm und der Hypodermis auch einzellige Hautdrüsen nachweisen, welche mit den äussern Exsudat-Organen in Verbindung stehen; und ferner fanden sich bei einigen physogastren T'ermitophilen auch sehr ausgedehnte Blutmassen zwischen Fett und Hypodermis. Aus diesen Befunden ergibt sich, dass das Exsudat der Symphilen teils ein direktes, teils ein indirektes Fettprodukt ist. Ein direktes Fettprodukt ist es in jenen Fällen, wo das Fettgewebe allein dominiert; ein indirektes dagegen in den übrigen Fällen, in welchen zwischen Fettgewebe und äussern Exsudatorganen noch Drüsen oder massig entwickeltes Blutgewebe eingeschaltet ist. Denn das Blutgewebe sowohl als auch die eigentümlichen einzelligen Drüsen, deren vakuolenreiches Protoplasma und chromatinarme Kerne eine grosse Ähnlichkeit mit den Fettzellen bekunden, sind wohl zweifellos als 
Abkömmlinge des Fettgewehes zu betrachten. Die Inrïsen bezeichnet Verf. deshalb auch als ,adipoid".

Die Ausscheidung des Exsurlates geschieht entweder durch feine P'orenkanäle, welche die ('uticula durchsetzen, oder durch membranöse. eimen Ausführgang mmschliessenden Ilautzipfel (Lomechnsa usw.). Fis können aber aucl besondere Ausführgänge ganz fehlen und an ilıe Stelle ausgedehnte dïnne membranöse Cuticularbezirke, durch welche die Terdunstung des Exsudates stattfinden kann, treten. Meistens sind die Exsudatstellen mit dichten gelben Harbiischeh oder Haarpinseln oder Borstenreihen ('Trichomen) beset/t. Diese Trichome stellen aber nicht etwa Drüsenhaare dar, welche innen hohl und an der Spitze mit einer Öffinung versehen sind, sondern sie sind vollkommen massiv und stehen mit Sinneszellen in Verbindung. Zweifellos dienen sie daher als Reizborsten, indem sie bei Beleckung durch die Wirte gezerrt werden und dadnlch einen Reiz auf die innern Exsudatorgane ausüben und so die Absonderung des Exsudates vermehren und beschleunigen. Ansser dieser Funktion kommt den Trichomen auch die Rolle von Verdunstmugsorganen zu, indem sie durch die Vergrösserung der Verdunstungsobertläche die raschere Verdunstung des Exsudates ermöglichen. Sekundär dienen die stark entwickelten Haarbïschel dann auch noch als 'Transporte und als Schutzorgane, so dass diese Gebilde ihren Trägern also einen recht vielseitigen Nutzen gewähren.

Im speziellen Teil beschreibt Terf. eingeliend den feinern histologischen Bau der Exsudatorgane von folgenden Symphilen: Lomechusa strmmosa (Larve und Imago), Clariger testacens, Hetaerins ferruginens, P'anssus cncmllatus, Chartopisthes heimi, Orthogomins schammi (Imago und Larve), Nenogaster inflata und Termitorenia. Auf die vielen Einzelheiten dieser Beschreibungen kann hier nicht näher eingegangen werden und sei in dieser Beziehung auf das Original verwiesen.

Mit den defensiven Analdrüsen der Ca rabiden, Paussiden, Staplıy iniden haben die adipoiden Drüsen der Exsudatorgane gar keme Beziehungen. Entsprechend dem diametral entgegengesetzten biologischen Zweck dieser beiden Driisenarten ist atuch die Natur des Sekretes eine ganz verschiedene. Bei den Analdrüsen handelt es sich um eine ibbelriechende oder an der Luft gasförmig explodierende Flüssigkeit, bei den Exsudatdrüsen dagegen um ein öliges, „den Produkten des Fettgewebes verwandtes" Sekret. Da ferner bei den defensiven Analdrüsen eine grössere Menge des Sekretes plützliclı ausgestossen werden muss, lassen diese Drüsen ilı Sekret durch einen gemeinsamen Lianal zunächst in ein eigenes, mit einem Ejakulations- 
apparat verbundenes Reservoir, welches aber bei den İxsudatorganen stets fehlt.

Am Schluss macht W asmann noch einige Bemerkungen über die phylogenetische Entwicklung der Symphilie, worin er sich hauptsächlich gegen die Ansichten des Ref. (vergl. Zool. Zentr.-Bl. 1902, pag. 85̆9) wendet. Er hält an der Annahme eines besondern .Symphilieinstinktes" und einer besondern Selektionsform, der "Amikalselektion" fest. Wenn Formica sangumea die Larven der Lomechusa dadurch, dass sie sie genan so behandelt, wie die eigenen Larven, zu grunde richtet, so sei dies kein beweis gegon einen besondern Symphilieinstinkt, sondern zeuge nur dafiir, dass der Symphilieinstinkt in diesen Punkte nicht vollkommen entwickelt sei. Ind die Amikalselektion sei von der Natmralselektion dadurch rerschieden, dass sie auf einer positiven Auslese ron seiten der Ameisen beruhe, wïlsrend letztere rein negativer Natur sei. Die Anikalselektion sei dalier von der Naturalselektion ebenso zu tremen wie die sexualselektion Darwins.

Auch gegen des Rief. Auffassung der Symphilie als einseitiges Verhältnis wendet sich IV a sm a nn, indem er in der Vergesellschattung ron Ameise und Symphilen ein wechselseitiges (reziprokes) Verlältuis sieht. Bei der Benrteilnng der Natur einer Gesellschaft seien nicht nur die morphologisclıen, sondern auch die biologischen Anpassungen zu berücksichtigen. So zeigten z. B. die Ameisen, welche in Trophobiose mit Blattlänsen lebten, nicht die geringsten morphologischen Anpassungscharaktere an dieses Verhältnis, obwohl sie doch einen grossen Nutzen, ja sogar vielfach die Hauptuahrungsquelle daraus zögen. - Ref. wird an anderer Stelle auf diese Ausführungen W a s m at n n näher eingehen.

K. Esclı erich (Strassburg).

484 Bammgartuer, W.J.. Spermatid Transformations in Gryllus assimilis, with special reference to the Nebenkern. In: Kansas Lniv. Sc. Bull. Vol. I. 1902. pag. 47-61. '2 Tf.

Die Umwandlung des Spermatidenkerns ron Gryllus assimilis in den Spermienkopf bietet nichts besonderes; ein ,accessorisches Chromosom", das anch hier vorhanden ist, verhält sich entsprechend der Darstellung ron Mc Clung für Xiphidium. Naclı der letzten Spermatidenteilung liegt neben dem Kern ein Rest der Spindel, deren Fasern zu dickern Strängen zusammengetlossen sind. Dieser Rest wandelt sich in einen Nebenkern von eigenartigem Aussehen um; er liegt neben dem Spermatidenkern als eiförmiger Körper, der eine regelmäßige Querstreifung zeigt, etwa wie ein Fass mit seinen Reifen. Es lässt sich mit Sicherheit zeigen, dass die Streifen nicht der optische 
Ausdruck durchgehender Wände sind. Diese Streifen lösen sich auf und der Körper besteht jetzt aus einer dunklern innern Masse, die von einem äussern Ring durch einen hellen Raum geschieden ist. Beim Answachsen des Achsenfadens legt sich der Nebenkern diesem an und zerfällt allmählich in Partikel, die diesen als Hülle umgeben. Ein Akrosom, dessen Entstelıung nicht rerfolgt wird, tritt im Lanfe der Entwicklung auf und wandelt sich in das Spitzenstïck der Spermie mm. Das Verhalten der ('entrosomen wurde nicht verfolgt. Am ansgebildeten Spermatozoon ist hemerkenswert, dass der liopt eine von einer stark gefärbten Wand eingeschlossene Röhre darstellt.

Auf Grund dieser nnd anderer Darstelhnngen der Entstehnng des Nebenkerns kommt Verf. zam Schhıss, dass die IIïllen des Spermatozoenschwanzesanf zwei verschiedene Arten entstehen können, nämlich ans einem Mitochondrienkörper (M e ves) und ans einem echten Nebenkern (Spindelrestkörper). Ref. möclıte bemerken, dass weder die Darstelhng noch die Abbildnngen dies zn beweisen seheinen und ist überzeugt, dass anch hier ein echter Mitochondrienkörper vorliegt.

R. Goldschmidt (Nürnberg).

485 P'antel, J. et R. de Sincity, Sur l'évolution de la Spermatide chez le Notonectu glanca. In: Compt. Rend. Ac. Sc. T. 135.1902. pag. $997-1000.12$ 'Textfig.

486 - Sur l'érolution de l'acrosome dans la spermatide du Notonecte. In: Compt. Rend. Ac. Se. 'T. 135. 1902. pag. $1124-1126$.

487 - Snr l'origine du Nebenkernet les monvements nucléiniens dans la spernatide de Notonecta glanca. In: Compt. Rend. Ac. Sc. T. 125. 1902. pag. 135̃9-1362.

In der jungen Spermatide findet sich ausser dem kleinen Kiern das Nebenkernmaterial in Form verdichteter Stränge, die den Kern umgeben (unabhängig rom Spindelrest); ferner die .,seknndären Idiozomkörperchen", kleine Körnchen, die in der \%elle zerstrent liegen, schliesslich Chromatinkörnchen nnd ausgewanderte Plasmosomen, die sich auch in den psendopodienartigen Auswiichsen des Zellkörpers finden. Im folgenden Stadium erscheinen die "Hauptidiozomkörper" als zahlreiche, kleine liyaline Kügelchen, die zu wenigen grossen verschmelzen; um diese ordnen sich kranzförmig die sekındären Idiozomkörperchen an. Schliesslich haben wir einen grossen hyalinen Kö̈rper, der sich auf der entgegengesetzten Seite wie der lamellär gewordene Nebenkern dem Kern anlagert. Die Chromatinkörnchen lagern sich in Form ron Kalotten dem Kern an und werden in diesen aufgenommen. Im Kern verdichtet sich das Chromatin zu einen Karyosom, 
während Plasmosomen in das Plasma auswandern, wie deutlich festgestellt werden kann. Darauf geht die Drehung des Kernes und Idiozoms ror sich, die die Umwandlung zum Spermatozoon einleitet. Das Idiozom umwächst wie eine Kappe den Kern zum grössten Teil, verlängert sich kegelförmig, wobei es eine gleichnäßig intensive Färbbarkeit annimmt und wird so zum Akrosom. Aus der hintern Partie der Kernmembran entsteht das Zwischenstïck (?), in dem sich der Endknopf des Achsenfadens findet.

Verff. betonen, dass durch den Nachweis der idiozomalen Entstehung des Akrosoms eine weitere Übereinstimmung zwischen der Insekten- und Wirbeltierspermatogenese erwiesen ist. I) Entstehung des Idiozoms fassen sie anders auf als Meres, indem sie es sich unabhängig von Sphärensubstanz aus zwei rersehiedenen Substanzteilen des Cytoplasmas entwickeln lassen.

Verff. fassen den Nebenkern auf Grund ilirer oben referierten Darstellung seiner Entstehung als Mitochondrienkörper im Sinne von Meves auf. Der Spindeliest hat nur insofern etwas mit diesem Gebilde zu tun, als das Material der letzten achromatischen Figur gewissermaßen als Orientierungsentrum für die Zusammenballung der Mitochondrien dient, ohne substantiell an der Bildung des Körpers beteiligt zu sein. Interessant erscheint ferner der Stoffaustausch zwischen Kern und Kelle (Chromatinkörner) und auch, wie es scheint, Kern und Akrosom, was an die Verhältnisse der Ovocyte erinnert und vielleicht einen wichtigen Faktor der sexuellen Differenzierung darstellt.

R. Goldsch midt (Niirnberg).

488 Trägardh, Ivar, Beiträge zur Kenntnis der Dipterenlarven. 1. Zur Anatomie und Entwicklungsgeschichte der Larve von Ephydra riparia Fall. In: Arkir f. Zoologi. Bd. 1. 1903. pag. 1-42. 'Taf. $1-4$.

Verf. gibt eine eingehende Schilderung der Larve von Ephydra riparia Fall., welche an der schwedischen Küste in kleinen salzhaltigen 'Tümpeln nicht selten rorkommt. Naclı einer kurzen Beschreibung der äussern Körperform und des Integunentes werden die Nundteile und das Cephalopharyngealskelett ausfülırlich behandelt. Die Mundteile bestehen aus zwei kräftig entwiekelten, dorsoventral abgeplatteten löffelförmigen Mundhaken, welche, dorsal gelegen, nach hinten in lange Stäbe sich fortsetzen und an ihrem hintern Ende zu einer Gelenlitläche sich erweitern. Yon letzterer Stelle aus gehen ventralwärts zwei schmale Chitinstäbchen, als Stïtzen des Unterrandes der Nundöffnung, ab. Diesen Mundteilen folgt nach linten las sog. Schlundgerüst, welches aus einem komplizierten System von Gräten 
und Stïbchen, welche Verdickungen der Schlundwand-Intima darstellen, besteht. In den Seitenwänden des Schlundes liegen zwei kräftige Gräten, die Hauptstützen des ganzen Geriistes, welche mit den Basalteilen der ,Mundhaken" gelenkig verbunden sincl. In der dorsalen Schlundwand liegt eine diinne Platte (Epipharyngealplatte), welche lateral nittelst schmaler Brücken mit obigen Gräten zusammenlängen, und in der ventralen Wand endlich finden sicls zwei transversale lialbzirkelförmige und zwei longitudinale Chitinstäbchen. - Auf den Schlund folgt als dritte Abteilung der Pharynx, welcher ron zwei ohern und zwei untern longitudinalen, durch mehrere Briicken miteinander verbundenen Platten gestützt wird.

Fine Vergleichung des Cephalopharyngealskeletts der EphydraLarve mit demjenigen der Larve ron Musca vomitoria zeigt, dass die einzelnen Teile in den jüngern Larvenstadien leicht zu homologisieren sind, dass sich aber während der weitern Entwicklung die Verhältnisse sehr ändern und der Bau des Skeletts bei beiden I)ipterenlarven stark abweichend wird. Bei ganz jungen Larven von Musea sowohl wie ron Ephylra sind die "Mundhaken" sehr klein und volliommen isoliert, d. h. stehen mit dem iibrigen Skelett nicht in \%usammenlang. \%wischen und etwas hinter demselben befindet sich ein nimparer Zahn, welcher nach hinten in zwei schmale divergierende Stäbchen (Schenkel) sich fortsetzt. Bei Kjhylra wird nun in ältern Stadien der unpaare Zahn abgeworfen, während der grösste Teil der "Schenkel" zurïckbleibt. $11 m$ mit den inzwischen kriftig entwickelten Mundluaken in gelenkige Verhindung zu troten. Bei Musea, Galliphor: usw. dagegen wird mit den unpaaren Zahn zugleich auch der grösste Teil der Schenkel reduziert, so dass diese also für die Befestigung der Mundhaken keine Bedeutung mehr besitzen. Diese Rolle wird uun ron dem sogr. X-förmigen Stïck W eismauns, welches wohl den Interschlundstäben der Ephydra-Larve entspricht, ïbernommen. Bei der Musco-Larve treten also die Mundhaken mit ventralen, bei der Ephyrha-Larve dagegen mit dorsalen resp. lateralen Skeletteilen in Verbindung. Verf. sucht diesen Unterschied durch die verschiedene Lebensweise zu erklären, indem die Mundhaken bei der fusslosen Musca-Larve auch als Lokomotionsorgane zn funktionieren haben, während sie bei den mit kräiftigen Abdominalfüssen verselıenen Ephydra-Larve lediglich dazu dienen, Algen usw. ron Boden der Gewässer loszukratzen.

Ein weiteres Kapitel behandelt Mundhöhle, Schlund und Pharynx, welches aber wenig neues enthält. An der Grenze zwischen Schlund nnd Pharynx befindet sich dorsal ein Büschel kräftiger, nach hinten gerichteter Borsten; gerade gegenüber davon in der Ventralwand 
mündet der gemeinsame Ausführgang der Speicheldrüsen. Der Pharynx hat ein viel weiteres Lumen als der Schlund und trägt ventral neun längslaufende ,dicht kammförmig geteilte"Chitinleisten. Die Funktion dieser Leisten sowohl als der Borsten sieht Terf. darin, feste Partikeln der Nahrung von Flüssigkeiten zu trennen. - Der Darmkanal hietet keine besondern Eigentiimlichkeiten dar, ebensowenig das Nervensystem. Von den Sinnesorganen rerdient Eines besondere Erwähnung, welches in Form von zwei Ganglien der obern Pharynxplatte dicht anliegt. Dasselbe ist schon früher von I' antel bei Thrixion und von Wandolleck bei Platycephala gefunden und von diesen als Schmeckorgan gedeutet worden. Verf. schliesst sich dieser Auffassung an, zumal er die betreffende Stelle der Pharyngealplatte mehrfach durchlöchert fand.

Das folgende Kapitel ist dem Tracheensystem gewidmet. Verf. fand die Ephydra-Larve im Gegensatz zu Fr. Brauer amphipneustisch. Das vordere Stigmenpaar sitzt auf dem Prothorax; die Filzkammern enden mit je drei gestielten fingerähnlichen Knospen, an denen keine öffnung nachgewiesen werden konnte. Die beiden hintern Stigmen befinden siclı an den Spitzen des gregabelten Atemrohres, an welchen, un das Flottieren aul der Obertläche des Wassers zu ermöglichen, $3-4$ äusserst feine Chitinbliatter angebracht sind. Besondere, demselben Zweck dienende 0 Jldrüsen, wie sie $\mathrm{W}$ ahl bei Lristalis gefunden, sind hier nicht vorhanden. Der Verlauf der Tracheenäste ist ganz ähnlich wie bei Eristulis. Die beiden Hauptstämme sind aber nur durch eine vordere Kommissur verbunden. Die ron den Hauptstämmen abgehenden Ïste kann man wie bei Eristalis in ,äussere" (ventrale) und ,innere" (dorsale) einteilen; von ersteren gibt es 10 Paare, von letatern nur 8. Von den äussern ist die letzte sehr stark entwickelt und zu einer besonderen Darmtrachee ausgebildet. An der Fettlörpertrachee des 6. äussern Astes findet sich ein eigentiimliches Gebilde, welches schwarz pigmentiert und ron birnförmiger Gestalt ist. In diesem ,Tracheenkörper", dessen Funktion ganz unklar ist, fehlt die regelmäßige Spiralstreifung und es scheint, als ob die 'Tänidien zickzackförmig gingen. - Die Verpuppung geschieht an Boden des Wassertümpels und zwar in der Weise, dass die Larve mit denı 7. und 8. Beinfusspaar die Wurzel eine Wasserpflanze umfasst. - Bezüglich der Veränderungen endlich, welche das Tracheensystem im Puppenstadium durchmacht, stimmt Ephydra mehr mit Musca als mit Eristalis ïberein, indem der ganze zwischen dem 1. und 6. äussern Ast gelegene Teil der beiden Hauptstämme bestehen bleibt. Die Stigmenhörner der Puppe, welche je zwei Öffnungen besitzen, durchbohren, da die V'erwandlung unter der 
Wasseroberfläche stattfindet, natürlich nicht das Puparium. Die Puppenzeit beträgt 6-7 Tage. Die Fliege sprengt das Puparium in der Weise, dass sich ein Deckel auf der Oberseite der drei Thorakalund des ersten Abdominalsergmentes loslöst. Vie Naht, längs welcher die Loslösung stattfindet, ist bei der Larve nicht präformiert.

K. Escherich (Strassburg).

489 Voinov, D. N., I a spermatogénèse clıez le Cybister Roesplii. In: Compt. Rend. Ac. Sc. T. 135. 1902. pag. 201-203.

Bei Cybister kommen ebenso wie bei Paludina, Pygaera und Staphylimus zwei verschiedenartige Spermatozoenformen vor, die sich verschieden entwickeln und auch zu differenten Jahreszeiten entstehen. Hier wird nur die Entwicklumg der normalen Formen geschildert. In dem Synapsisstadium der Spermatocyten 1. Ordu. findet sich ein Chromatinnucleolus (Montgomery), der während der 'Telophase Tetradengestalt annimmt, wälırend die andern Chromosomen längsgespalten werden. In den ruhenden Spermatocyten finden sich stark lichtbrechende Kugeln, die als ,Pseudoparasiten" bezeichnet werden (nach ähnlichen Bildungen in Krebszellen), da sie später ausserhalb der '/elle liegen. Die C'entrosomen sind $V$ förmig und auch während der Ruheperiode beweglich; sie begleiten die "Pseudoparasiten“ auf ihrem Weg zur Zellobertläche. In die 1. Reifungsteilung gehen 12 Chromosomen ein; der Chromatiunucleolns liegt neben der Spindel und wird nicht in den Spermatidenliern aufgenommen, der 6 Chromosomen enthält. Der grosse Nebenkern entsteht aus den stark entwickelten peripheren spindelfasern.

R. Goldsch mi dit (Nürnberg).

490 Agassiz, G., Ftude sur la coloration des ailes des papillons. Lausanne (H. Valloton et 'Toso) 1903. pag. 1--31.

Die vorliegende kleine Schrift fasst in übersichtlicher Darstellung unsere Kenntnisse der Färbungsphänomene bei den Schmetterlingen zusammen. Der Verf. bespricht darin den Bau der Schuppen, ihre Färbungsursachen (Pigment- und Strukturfarben), die physikalischen 'Theorieen der Farbenerscheinungen, die Regeln, welche Farben und Farbenverteilung beim Schmetterling beherrschen, und die äussern Einflüsse, unter denen sich Abänderungen in Färbung und Zeichnung der Falter vollziehen. Das letzte Kapitel der Abhandlung macht uns mit den ältern Untersuchungsergebnissen über die ontogenetische Entwicklung der Zeichnung in der Puppe, mit der Farbenfolge auf dem Schmetterlingsflïgel bekannt und beschäftigt sich ferner mit den wesentlichsten Resultaten der experimentellen Lepidopterologie. Im 
einzelnen kommt Agassiz zu dem Schluss, dass die verschiedenen Schmetterlingsfarben als Unıwandlungsprodukte eines hellen Pigmentes anzusprechen sind, das ursprünglich im Blut oder der Hämolymphe der Puppen enthalten ist. Es scheint dem Verf. wahrscheinlich. dass dieses, auch den Farbstoffen der Raupenhaut zu grunde liegende Mutterpigment in seiner organischen Beschaffenheit identisch ist mit den durch die Nahırung in den Insektenkörper eingeführten Pflanzenfarbstoffen. Von äussern Einfliissen, die a uf Zeichnung und Färbung der Schmetterlinge abändernd einwirken können, ist ausser dem Licht, der Temperatur, der Nahrung, der Trockenheit und Feuchtigkeit, der Elektrizität auch die Entwicklungsdauer des Schuetterlings in der Puppe von Bedeutung. Der letztere Umstand soll auch die Grösse der Falter beeintlussen.

M. v. Linden (Bonn).

491 v. Linden, Grïin I., Die Farben der Schmetterlinge und ihre Ursachen. In: Leopoldina. Heft XXXVIII. 1902. pag. 1-10.

Die Frage nach der chemischen Beschaffenheit, der Bildungsweise, dem Bildungsort der in den Schuppen der Schmetterlinge eingelagerten l'igmente haben eine Rieihe von Arbeiten gezeitigt, deren Resultate, wenn auch von einer endgiiltigen Lösung des Problems immer noch weit entfornt, dennoch von allgemeinem wissenschaftlichen Interesse sind. Es schien mir nicht umnuitz, durch Zusammenstellung dieser Untersuchungsergebnisse einen Überblick über den Stand unserer Kenntnisse zu geben und gleichzeitig heranzuzichen, was auf dem Gebiet der Pigmentierungsfrage bei den ïbrigen wirbellosen Tieren und den Wirbeltieren erforscht worden ist. Zum Schluss sind auch die Ergebnisse meiner eigenen Untersuchungen über den roten Farbstoff der Vanessen erwähnt, die gezeigt haben, dass es sich in ihm um ein Eiweisspigment handelt, das im Darmkanal der vor ihrer Verpuppung stehenden Raupe gebildet und durch den Blutstrom im Körper verbreitet wird. Aber auch die Torstufen dieses roten Farbstoffes, grünliche oder gelbgrünliche Pigmente, werden in der Epidermis der Schmetterlingsraupe und Puppe abgelagert und können unter bestimmten Verhältnissen auch hier in roten Farbstoff verwandelt werden.

Der rote Farbstoff ist sowohl durch seine Kristallform wie auch durch sein charakteristisches Absorptionsspektrum ausgezeichnet. Das letztere ist dem des Cochenillefarbstoffes sehr ähnlich. Die Lösungen des roten Farbstoffes sind lichtempfindlich und werden besonders durch die chemisch wirksamen Strahlen in ihrem Farbenton verändert. Eine Lösung des Farbstoffes von sherrygelber Farbe nimmt, wenn sie im Licht steht, schon nach 14 Tagen einen grünlichgelben Ton an. 
Erlı̈hung der Temperatur rerdunkelt zuerst die Farbe der Lösung, bewirkt indessen nach längerer Einwirkmng ebenfalls die Entfärbung des wässerigen Auszugs.

il. r. Linden (Bonn).

\section{Moliusca.}

Gastropoda.

492 Ancel, P., Histogénèse et structure de la glande liermaphrodite d'Hetix pomatia. (L.) In: Arch. Biol. T. XIX. 1903. pag. 389-652. $7 \mathrm{Tf}$.

Verf. hat sich in vorliegender umfangreichen Arbeit die verdienstliche Aufgabe gestellt, die Histogenese einer Zwitterdrüse von ihrem ersten Auftreten bis zur Geschlechtsreife zu verfolgen. Die Kíeimdrüse ron Helix pomatia entsteht kurze Zeit ror dem Ausschlüpfen des Embryos durch Zusammenschluss einer Gruppe von Mesodernzellen, mabhängig ron den bereits rorhandenen Anlagen von Eiweissdrüse, Uterus und Yas deferens. Bald darauf bildet sich als ein Strang im Mesoderm, der sich dann aushöhlt, der Zwittergang, der sich zunächst mit der Keimdrüse, die ein Lumen gewinnt, verbindet und dann erst mit den andern Ausfïhrwegen verlötet. Aus hohlen Knospen der Keimdrüse bilden sich weitere Follikel, die wieder eben solchen den Ursprung geben. Indem sich an der Oberfläche der Driise die Zellen epithelartig zusammenschliessen, kommt ein primitives Keimepithel zu stande, das aus völlig gleichartigen Zellen besteht. Von diesen beginnen nun einige zu wachsen und rerwandeln sich unter gewissen V'eränderungen der Kernstruktur in ,indifferente Vorkeimzellen". Unter weiterm Wachstum und Änderungen in der Anordnung des Chromatins gehen diese in die „männlichen Utrkeimzellen" (frïher sog. Primordialeier) über. Aus diesen gehen durch indirekte Teilung mit der Chromosomenzahl 48 die Spermatogonien 1. Ordn. hervor, deren Körper in das Lumen des Follikels ragt und durch stiele an der Wand befestigt ist. Durch weitere Teilungen entstehen aus diesen dann die Spermatogonien 2. Ordn. Während dieser Vorgänge hat sich das Keimepithel in zwei Lagen angeordnet. Die Zellen der innern Schicht, deren Kernstruktur unverändert bleibt, kennzeichnen sich durch das Anftreten von Fetttröpfchen im Cytoplasma als Nährzellen. Jetzt erst wachsen auch die Zellen der äussern Schicht, erreichen das Stadium der indifferenten Vorkeimzelle und gehen nun unter Veränderung der Kernstruktur und starker Zunahme des Cytoplasmas direkt in Orocyten über, ohne ein Primordialei- und Orogonienstadium zu durchliufen. Die Entwicklung rollzieht sich also in folgender regelmäBiger Reihenfolge: 1. männliche Geschlechtszellen, 2. Nährzellen, 3. weibliche Ge- 
schlechtszellen. Hieraus schliesst Verf, dass die Ausbildung der weiblichen Geschlechtsprodulite aus den indifferenten Urkeimzellen ledingt wird durch die Unwandlung einiger Epithelzellen in Nährzellen, die ein spezifisches Nährmaterial produzieren; gestützt wird diese Ansicht durch einige abnorme Fälle, in denen sich Orocyten statt Spermatogonien und umgekehrt gebildet latten. Diese Hypothese wird damn zur Erlilärung des in allen Tierklassen beobachteten gelegentlichen Hermaphroditismus herangezogen: Geschieht bei getrennt geschlechtlichen Tieren die Differenzierung der Keimepithelzellen zuerst zu Nährzellen, dann zu Geschlechtszellen, so entstehen nur weibliche Geschlechtszellen, ist die Reihenfolge der Differenzierung umgekehrt, so entstehen nur nännliche Zellen, beginnt die Iffferenzierung zu Sexualzellen vor jener zu Nährzellen und endet erst später als diese, so kommt der accidentelle Hermaphroditismus zu stande. Die urspriinglich indifferente Keimzelle wird zur männlichen oder weiblichen Geschlechtsyelle je nach den Bedingungen (Vorhandensein der Nährzellen und ihrer Produkte), die sie bei ihrem Auftreten in der Geschlechtsdr iise findet. Wegen der interessanten Einzelbegrïndung dieser Ansichten sei auf das Original rerwiesen.

In der jungen Orocyte ist das Cluromatin in form kleiner Nucleolen an der Peripherie des Kerns angeordnet; auf ilıre Kosten bildet sich ein Kernnetz, das dann wieder in unregelmäßige Sträuge zerfällt, die miteinander zu chromatischen Klumpen verschmelzen. Aus diesen bildet sich dann wieder ein neues Kerngerüst. Mit dem Auftreten der peripheren Chromatimnucleolen waren auch parachromatische Nucleolen sichtbar geworden, die nun miteinander verschmelzen, bis ein grosser Nucleolus vorhanden ist. Dieser verändert seine clıemische Natur und wird plasmatisch; in den oben erwähnten Chromatinklumpen des kerens tritt nunmehr parachromatische Substanz auf, die sich dem grossen Nucleolus anlagert und so die verschiedensten Formen des gemischten Nucleolus hervorbringt (?! Ref.). Nach beendeter Wachstumsperiode stellt der Nucleolus dann nur noch ein Abbauprodukt dar. Auch das Cytoplasma zeigt während dieser Periode einige Besonderheiten. In dem Plasma der jungen Ovocyten liegen körnige Fäden verteilt, die sich anders färben als das erstere. Sie konzentrieren sich allmählich zu einer peripheren Zone, die sich stetig rerkleinert, während das ïbrige Plasma eine alveoläre Struktur annimmt. In der Nähe des Kerns treten nun färbbare Stäbchen und Bröckchen auf, die schliesslich in Kügelchen übergehen, die Plasmafarben annehmen, siclı dann in der Zelle verteilen und schliesslich verschwinden. Sodann ist noch der Ei- 
follikel zu erwähnen, der sich erst nach Beginn der Wachstumsperiode aus den Zellen der äussern Schicht, der ja auch die Ovocyten entstammen, entwickelt. Diese Zellen unwachsen die Eizellen, platten sich völlig ab und trennen so die Orocyte von den Nährzellen. Die der Wand anliegenden Follikelzellen sind grösser, werden aber nicht, wie Platner und Obst angeben, von der Ovocyte aufgenommen und verdant, das Nährmaterial für die Eizelle wird vielmehr nur von den Nährzellen geliefert.

Ein letztes Kapitel ist dem Studium der Spermatogenese gewidmet. V'erf. kommt zu der Ansicht, dass auch bei Helix eine Zahlenreduktion stattfindet (gegen Bolles Lee), indem er bei den bisher übersehenen männlichen Vorkeimzellen die Normalzahl von 48 Chromosomen nachweist. (Die gleiche Zahl findet sich in den Furchungszellen.) Dadureh wird er veranlasst, die weitern Stadien anders anzurordnen als L ee. In den Spermatogonienkernen treten vor Beginn der Mitose 48 Clronıtinfäden auf, die zu je zweien während eines Synapsisstadiums miteinander verschmelzen, wodurch die 24 bivalenten Chromosomen der Spermatogonien entstehen. Auch die 24 Chromosomen der Spermatocyten 1. Ordn. entstehen durch Verschmelzung ron je zweien; die weitern Vorgänge entsprechien der Schilderung von L,ee. Besonders eingehend wird zum Schluss noch der Nebenkern behandelt. In den jungen Spermatocyten liegen im Plasma zerstreut färbbare Fäden, auf deren Kísten der Nebenkern entstelit, der im Anfang der Mitose wieder verschwindet. Er ist den in der Orocyte beschriebenen Gebilden vergleichbar und hat weder mit der Spindel, noch mit der Attraktionssphäre oder dem Kern etwas zu tun. R. Golds chmidt (Nürnberg).

493 Robert, A. Pecherches sur le développement des Troques. In: Arch. Zool. expér. et génér. 3 sér. Tome X. 1902. pag. 269 - อ̃38. Taf. $12-18.19-42$. 25 Fig. im Text.

Die Untersuchungen des Verfs. haben die frühere Entwicklung einer ganzen Reihe von Vertretern der Gattung Trochus zum Gegenstande, namentlich in Rücksicht auf den Verlauf der Furchung sowie hinsichtlich der Ableitung der einzelnen Körperregionen aus den Furchungselementen. Nach einigen Bemerkungen über das Vorkommen der einzelnen Species, ihr Verhalten in der Gefangenschaft, die Aufzucht der jungen Larven sowie die Konservierungsmethoden gibt Verf. zunächst eine ausführliche Darstellung der Eiablage. Die Zeit derselben scheint eine schwankende zu sein, insofern sie fast über das ganze Jahr verteilt ist, jede Species aber eine besonders bevorzugte Jahreszeit aufweist. Einige Species, wie Trochus magus und 
cineratus legen ihre Eier frei ins Wasser ab, andere, wie Trochus striatus, granulatus, conulö̈des, hüllen dieselben in eine Gallertmasse; beide Modi werden in ihren z. T. recht interessanten Einzelheiten näher geschildert. Eine eigentliche Dotterhaut fehlt, dagegen umgibt in einem grössern Abstande eine zarte, mit einer Vicropyle versehene Membran den jungen Kieim. Die Crösse der Eier schwankt innerlaalb recht bedeutender Grenzen, die kleinsten $(105-125 \mu)$ besitzt Trochus magus, die grössten $(260-300 \mu)$ Trochus commö̈les. Während die Entwicklungsdauer der einzelnen Formen sich ziemlich gleich verhält, ist der Zeitpunkt des Ausschlüpfens der jungen Larve sehr verschieden, je nachdem die Eier frei oder von einer Gallertmasse umgeben abgelegt werden (nach 20 Stunden bei Trochus mayns, nach 180 Stunden bei Trochus comulö̈les). Die Befruchtung ist eine äusserliche, indem beide Geschlechter ihre Geschlechtsprodukte ins Wasser abgeben.

Der zweite Hauptabschnitt behandelt im einzelnen den V'erlauf der Furchung. Die erste Furchungselene teilt das Ei in zwei gleich grosse Hälften, von denen die eine im Verhältnis zum spätern Embryo links und vorn, die zweite rechts und linten gelegen ist. Auch das vierzellige Stadium besteht noch aus durchaus gleich grossen Elementen, zwei derselben (B und D) werden von der spätern Sagittalebene der Larve halbiert, die beiden andern (A und C) liegen rechts und links und etwas näher dem animalen Pole. Die Polarfurchen an beiden Polen verlaufen in der Regel einander parallel, können aber auch senkrecht aufeinander stelien, und zwischen diesen beiden extremen Möglichkeiten gibt es alle Übergänge. Die Teilungsrichtung verläuft hier bereits typisch laeotropisch. Verf. verbreitert sich des nähern über die mechanischen Ursachen, welche diese im Tierreich weit verbreitete Anordnung der vier ersten Furchungszellen hervorrufen könnten; es gelang ihm für dieses sowie für dic folgenden Stadien (bis zum 16 zelligen) die verschiedenen Zustände durch Seifenblasen nachzuahmen, woraus er den Schluss zieht, dass dieselben wolıl im allgemeinen auf Kapillarvorgängen beruhen, im einzelnen Falle aber durchaus von der Lage und Richtung der Spindel abhängig sind. - Eine dexiotropische Teilung führt zum achtzelligen Stadium über, in abwechselnder Lagerung liegen nun vier Micromeren den Macromeren auf: Die obere Polarfurche verläuft zwischen $1 \mathrm{a}$ und $1 \mathrm{c}$ und bildet mit der untern einen bestimmten Winkel. Indem sich diese acht Zellen laeotropisch teilen, entsteht das sechzehnzellige Stadium, zuweilen unter Einschaltung eines zwölfzelligen, insofern die Macromeren unter Bildung der zweiten Micromerengeneration sich zuerst teilen, und die Teilung der ersten Micromeren- 
generation naclifolgt. Das zwanzigzellige Stadium gestattet zum erstennal eime Orientierung des jungen Keimes, und zwar mit Hilfe eines Fortsatzes, den die hintere Macromere $\mathrm{D}$ in der Achse des Embryos nach vorn und oben aussendet. Vorher teilten siclı die Macromeren bereits dexiotropisch unter Abgabe der dritten Micromerengeneration: indem sich sodann unmittelbar darauf alle ïbrigen Zellen des Keimes in der gleichen Richtung teilen, wird nacheinander ein 24 zelliges (2. Generation) und ein 32 zelliges (1. Generation) Stadium erreicht. Bemerkenswert ist auf diesem Stadium die geringe Grösse der nnmittelbar un den animalen Pol gelegenen vier Zellen (Scheitelzellen). Es schliessen sich hieran die schwach laeotropischen, fast radialen Teilungen von $1 \mathrm{a}^{1.2}-1 \mathrm{~d}^{1.2}$, während die fast gleichzeitig erfolgende erneute Teilung sämtlicher Zellen der zweiten Generation zn einem 44 zelligen Stadium überführt. Durch die erste Teilung der dritten Generation wird ein 48 zelliges Stadium erreicht und die weitere Teilung der unmittelbar am animalen Pol gelegenen Zellen sowie der Macromeren 3 A, 3 B, 3 C unter Bildung der viertem Generation ergibt schliesslich ein 55 zelliges Stadium. Die Zellen der zuletzt gebildeten vierten Generation unterscheiden sich von den vorhergehenden durch ihre ausserordentliche Grösse, während die eigentlichen Macromeren an vegetativen I'ole an Umfang sehr verloren haben.

Nachdem sodann noch weitere T'eilmngen von $1 \mathrm{a}^{2.1}-1 \mathrm{~d}^{2.1}$ und $1 a^{2.2}-1 d^{2.2}$ sich vollzogen haben (63zelliges Stadium), führt uns eine sehr wichtige Teilung, welche die Bildung der Urmesodermzelle zur Folge hat, zum 64 zelligen Stadium über, nämlich die Teilung von $3 \mathrm{D}$. Die bisher regelmäßig nach dem spiraligen Typus verlaufende Furchung erleidet die ersten Abweichungen hiervon auf dem Übergang zum 72 zelligen Stadium (durch Teilung von $2 \mathrm{a}^{1.2}-2 \mathrm{~d}^{1.2}$ und $\left.2 \mathrm{a}^{2 \cdot 1}-2 \mathrm{~d}^{2 \cdot 1}\right)$. Der animale Pol beginnt sich allmählich abzuplatten und schliesslich sogar einzusenken, un sich allerdings bis zum 145 zelligen Stadium hin wieder auszugleichen. Von diesem spätern Verlaufe der Furchung ist vor allem noch die fast bilaterale, ganz wenig dexiotropisch gerichtete erste Teilung der sich ins Innere verlagernden Urmesodermzelle auf dem 89zelligen Stadium hervorzuheben, sowie die erneute Teilung dieser beiden Urmesodermzellen unter Abgabe zweier kleiner Zellen nach rorn und oben auf dem 118 zelligen Stadium. Das letzte Stadium, bis zu welchem V'erf. die Teilungen in ununterbrochener Reihe verfolgen konnte, besass 145 Zellen. Ein fünftes Nicromerenquartett (unter Ausschluss des hintern Quadranten D) ist aufgetreten, es beginnt sich mit dem vierten sowie den ursprünglichen IIacromeren ins Innere einzusenken; die Urmesodernzellen 
(4. $d^{1.2}$ und $4 d^{2.2}$ ) teilen sich ron neuem. Die Beobachtung einer Anzahl weiterer, noch unvollendeter Teilungen lässt Verf. schliesslich noch das 159 zellige Stadium mit Sicherheit rekonstruieren.

Im dritten Hauptabschnitt gibt Verf. eine Schilderung des weitern Schicksals der einzelnen Zellgruppen des Furchungskeimes sowie des Anteiles derselben am Aufbau des Larvenkörpers. Das erste Micromerenquartett bildet an animalen Pole die bereits wiederholt für Mollusken wie Anneliden beschriebene Krreuzfigur, in deren Struktur sich Trochus im einzelnen am nächsten an Lsnochiton, Umbrella und die Amneliden anschliesst. Iie erwähnte rorübergehende Vertiefung am animalen Pole scheint ein rudimentäres Scheitelorgan darzustellen, zumal Verf. kurze Cilien an dieser Stelle beobachtet zu haben glaubt. Der grösste Teil der Kreuzfigur geht in der unpaaren Anlage der Cerebralganglien auf. Weiter leiten sich ron der ersten Micromerengeneration die T'entakel ab, an deren äusserm Rande die Augen als zwei P'igmentflecke sich anlegen. Von der ersten Micromerengeneration wird endlich auch das Velum in seinen Hauptbestandteilen gebildet. Der Prozess verläuft hier ganz in derselben Weise, wie er zıerst ron einigen Inneliden (Amphitrite und Clymenella) bekannt geworden ist, d. h. die primären Trochoblasten $\left(1 \mathrm{a}^{2}-1 \mathrm{~d}^{2}\right)$ liefern zunächst durch zweimalige Teilung je vier \%ellen in jedem Quadranten, welche sich nicht mehr weiter teilen. Verbunden werden diese vier Zellgruppen in den drei vordern Quadranten durch je drei Zellen der zweiten Micromerengeneration, im hintern Quadranten dagegen bleibt eine Lücke. Später erhalten diese Zellen Cilien, ordnen sich regelmäbig in zwei und noch später in eine Zellenreihe an und bilden nun das typische Velum der Larve, bis es gegen Ende der Larvenperiode wieder rïckgebildet wird. Ein V'ergleich mit den zahlreichen andern, bisher genauer in dieser Hinsicht untersuchten Mollusken und Amneliden führt Verf. zu dem Schlusse, dass dieses Organ nicht iiberall röllig homolog ist, dass nur die primären Trochoblasten lionstant vertreten sind, zu diesen aber noch mancherlei fremde Elemente hinzutreten können.

Die zweite und dritte Nicromerengeneration, welche in ihrer Ausbildung nochmals in Zusammenhange besprochen werden, sind zusammen mit der ersten Generation die alleinigen Bildner des Ektoderms. Die Gastrulation vollzieht sich in erster Linie durch Epibolie, wenn auch das Einsinken der grossen Zellen $4 a-4 d$ sowie der Macromeren auf eine leichte Invagination noch hinweist. Der Blastoporus verengt sich immer mehr, und an seiner Verschlussstelle tritt eine Einstülpung auf, welche Mund und Ösophagus liefert und, in Übereinstimmung mit andern Mollusken und Anneliden, im wesent- 
lichen aus Elementen der dritten Generation und nur zun kleinern Teil aus solchen der zweiten sich zusanmensetzt. Im hintern Quadranten tritt, gebildet aus Derivaten von $2 d$, eine starke Wachstumszone auf, die eine Verschiebung der Körperachsen des Embryos zur Folge hat, insofern Blastoporus, bezw. der an seiner Stelle auftretende spätere Mund und Velum, welche beide ursprïnglich an entgegengesetzten l'olen des lieimes lagen, aufeinander zu rücken, so dass der Blastoporus schliesslich in den vordern Teil der Ventralseite zu liegen kommt. Auch die Schalendrüse leitet sich sehr wahrscheinlich von jener hintern Wachstumszone ab, sie tritt in Form einer flachen Einsenkung auf, die sich bald wierler ausgleicht und ein feines Schalenhäutchen abscheidet. Ein Wulst am Torderrand der Schale stellt die erste Anlage des Nantels dar, zwischen ihm und den Fuss entsteht als Querspalt in der Mitte der Ventralseite die Mantelhöhle. Der Fuss, dessen einzelne Komponenten nur schwer noch mit Sicherheit festzustellen sind, geht aus den hinter dem sich schliessenden Blastoporus gelegenen Zellelementen herror; er weist zuweilen eine leichte Zweiteilung auf, die wohl auf eine V'erschmelzung aus zwei ursprïnglich getrennten, symmetrisch gelagerten Hälften zurïckzuführen ist.

Das primäre Nesoderm, dessen Entstehung oben bereits geschildert wurde. ordnet sich in zwei symmetrisch auf beiden Seiten gelegene Mesodermstreifen an, deren Ausbildung im einzelnen noch etwas weiter verfolgt werden konnte. Es werden hierbei die entsprechenden Terhältnisse anderer Mollusken sowie der Anneliden herangezogen, dabei auf die grosse Übereinstimnung in der Mehrzalıl der Fälle hingewiesen, abweichendes kritisch besprochen. Ein sekundäres Mesoderm, wie es als Abkömmling der 2. oder 3. Generation bei verschiedenen Formen beschrieben wurde, liess sich hier bei Trochus nicht nachweisen. Nachdem V'erf. sodann noch näher das spätere Schicksal der Entomeren und ihren Anteil an Aufbau des Darmtractus geschildert hat, geht er schliesslich auf die Beziehungen ein, welche zwischen den beiden Furchungsebenen und der spätern Sagittalebene der Larve bestehen. Letztere halbiert bei Trochus den Winkel, welchen beide Furchungsebenen miteinander bilden. Die Angaben über diese Beziehungen sind für die einzelnen Typen sehr verschieden, indessen sind diese Verschiedenheiten allein zurückzıführen auf die wechselnde Grösse der Furchungselemente und auf dadurch bedingte Verschiebungen am Kern; in Wirklichkeit liefern stets die gleichen Furchungselemente die gleichen Körperregionen und Organe.

In einem weitern Abschnitt geht Verf. näher auf das Zustande- 
kommen der Torsion ein, die sich an dem zunächst bilateral symmetrischen Embryo durch eine Drehung des umfangreichern hintern hörperabschnitts um den vordern, aus Velum, Fuss und Nund bestehenden Teil vollzieht. Die Drehung selbst beträgt $180^{\circ}$, sie erfolgt innerhalb von $6-8$ Stunden um eine auf dem Velarfeld senkrecht stehende Längsachse. Nachdem Verf. eine genauere Beschreibung der Torsion in ihren äussern Verhältnissen gegeben hat, wendet er sich einer Besprechung der bisherigen Theorieen zur Erklärung derselben mit grosser Ausführlichkeit zu. Die Entstehung der eigentlichen Asymmetrie der jungen Veligerlarve sucht Verf., wie schon Conklin getan, auf die Vorgänge während der Furchung zurückzuführen und findet die Ursachen derselben bereits bei der Entstehung des 5. Quartetts in einem asymmetrischen, stärkern Wachstum dieser Zellenelemente auf der rechten hintern Seite der spätern Larve.

Weiter kommt Verf. aut die links gewndenen Formen zu sprechen, sowie auf die bei jenen Formen stattfindende Umkehr der Spindelrichtungen, und erörtert dieselben des nähern in Riicksicht auf die eben besprochenen Verhältmisse. Tachdem solann noch eine Reihe von Einzelheiten ïber die Ausbildung der äussern Körperteile, der Sinnesorgane, des Finsses und semer Anhänge, der Mantelhöhle, der Kieme und der Schale Beachtung gefunden laben, entwickelt Verf. nach einer km\%en Zusammenfassung seiner Hauptergebnisse einige allgemeinere Schlussfolgerungen, in denen er zunächst auf die nahen Beziehungen hinweist, in welchen Mollusken, Anneliden mnd I'olycladen durch den Furchungsmodus zu stehen scheinen, und die schliesslich enden mit einer Erörterung der bestimmenden Ursachen des Verlaufs der Furchung. sowie des Einflusses, welchen der letztere auf die spätere Organisation des Embryos ausübt.

$$
\text { J. Me is en he iner (Marburg). }
$$

\section{Cephalopoda.}

494 Schweikart, A., Über die Bildung der Mikropyle und des Chorions bei den Cephalopoden. (Aus d. Zool. Inst. Marburg.) In: Zool. Anz. 26. Bd. Nr. 692. 1903. pag. 214-221. 2 T'extfig.

Die Untersuchung des Verfs. schliesst sich an die W. Bergmanns (s. Zool. Zentralbl. 10. Bd. p. 281) an. Er untersuchte ein junges Orar von Todaropsis rerasii und Längsschnitte durch junge Oocyten von Eledone moschata und Rossia macrosoma. Terf. konnte im wesentlichen die Angaben Bergmanns bestätigen, die Differenzen wird er später in der ausführlichen Darstellung seiner Befunde besprechen. Die Chorionbildung teilt er in 3 Stadien ein. Im 1. Stadium zeigen die Follikelepithelzellen gegen das Ei lin Vakuolen, die offenbar die 
Vorstufen der blassen Chorionkügelchen (s. Zool. Zentral-B1. 10. Bd. pag. 283) darstellen. Im 2. Stadium färben sich die Chorionpartikelchen mit Eisenhämalaun schwarz und erhärten wohl. Im 3. Stadium werden sie grösser und verschmelzen miteinander, während die Vakuolisierung des Follikelepithels verschwindet. Die Micropyle macht sich zuerst dadurch bemerkbar, dass die Eizelle am animalen Pol einen Plasinafortsatz in eines der radiären "Porenkanälchen" zwischen den Chorionpartikelchen hinein entsendet, so dass sich hier das Chorion nicht schliessen kann. Das Keimbläschen liegt zuerst direkt unter der Micropyle, später verschiebt es sich etwas seitwärts.

R. Fick (Leipzig).

\section{Tunicata.}

495 Goldschmidt, R., Notiz über die Entwickelung der Appendicularien. In: Biol. Centr.-Bl. Bd. 23. 1903. pag. 72-76.

Über die Entwicklung der Appendicularien ist bis jetzt so gut wie nichts bekannt. Kowalersky und Fol erwähnen zwar, dass sie Embryonalstadien von Copelaten untersucht hätten, aber abgesehen von der Mitteilung, dass die beiden Spiraculargänge aus zwei Ektodermeinstülpungen entstehen, denen zwei Entodernausbuchtungen entgegenwachsen, fehlen alle weitern Angaben. Es ist daher als besonders erfreulich zu hegriissen, dass es dem Verf. gelungen ist, den allgemeinen Entwicklungsverlauf wenigstens in grossen Zügen festzustellen. Die Furchung rerläuft sehr schnell: nach etwa zwei Stunden ist ein liugelähnlicher, etwas abgeflachter \%ellhaufen entstanden. Dieser nimmt später eine birnförmige Gestalt an und teilt sich durch eine ringförmige Einschnuirung in zwei Abschnitte. Im hintern erscheint sehr bald die Chorda als eine Reihe heller. stark lichtbrechender Zellen, und im vordern differenziert sich früh das sehr grosse Gehirn mit dem zwei Hörsteine enthaltenden Otolithenbläschen. Infolge seines Längenwachstums krümmt sich der Embryo innerhalb der Eihülle in einer ähnlichen Weise, wie der Ascidienembryo, nur besitzt dieser einen längern Schwanzabschnitt und erscheint daher schlanker. Hat der Appendicularienembryo eine bestimmte Grösse erreicht, so beginnt er Bewegungen auszuführen und streckt sich gerade, wobei die Larvenhaut zunächst nicht gesprengt werden, sondern sich dicht der nunmelir freischwimmenden Larve anschmiegen soll. Am Hinterende des Schwanzes zieht sich die Larvenhaut in einen borstenförmigen Fortsatz aus, der ungefälır die Länge der Larve erreichen kann (\%). Von besonderer Wichtigkeit ist der Nachweis, dass das Schwanzmesoderm älterer Larven jederseits aus zelın grossen. in einer Reihe liegenden Zellen besteht, die den 
spätern „Segmenten“ entsprechen. Im Rumpfabschnitt entstehen die beiden Spiraculargänge zunächst als umfangreiche Ektodermeinstülpungen, die erst später in den Kiemendarm durchbrechen. Sehr auffallend und, wie ich glaube, noch nicht hinreichend begrïndet, ist die Ansicht des Verfs., dass der Kiemendarm vielleicht in seiner ganzen Ausdehnung, mindestens aber in seinem vordern durch den Endostyl bestimmten Bereich durch Ektodermeinstülpung entstehen soll. Erst verhältnismäßig spät tritt die Verbindung zwischen dem respiratorischen und verdauenden Darmabschnitt (Kiemendarm -- Mitteldarm) ein, während bei Ascidien durchweg der letztere aus dem erstern durch Ausstülpung hervorgeht.

\section{O. Seeliger (Rostock).}

496 Hartmeyer, R., Holosome Ascidien (Ascidiacea holosomata). In: Meeresfauna von Bergen. 1901. pag. 17-63. 23 Textfig.

Der Verf. liefert eine vorzürgliche Beschreibung von 24 durch Appellöf bei Bergen gesammelten Monascidien. Nur zwei Arten (Pelonaia corrugata und Cynthia pyriformis Rathke) fanden sich in der Sammlung nicht ror, obwohl sie frühere Autoren auch in jener Gegend an der skandinavischen Küiste beobachtet hatten. Molgula koreni Traustedt hält der Verf. für eine zweifellafte Art, wenigstens glaubt er, sie atus der Liste der norwegischen Formen streichen zu müssen. Als neu wird Molgula kiaeri Hart. angefülırt.

Ein grosser Teil der beschriebenen Arten wird durch Textfiguren illustriert, die in hall schematischer Weise die markantesten Figentümlichkeiten der Species klar zur Anschauung bringen, so dass dadurch die Bestimmung einer fraglichen Art wesentlich erleichtert wird.

O. Seeliger (Rostock).

497 Magnus, R., Die Bed e ut ung des G anglions bei Ciona intestinalis. In: Mitth. Zoolog. Stat. Neapel. Bd. 15. 1902. pag. 483-486.

Die ältern Versuche Loebs hatten ergeben, dass bei Ciona auch ohne Vorhandensein des zentralen Nervensystems eine Reizleitung stattfindet, nur ist die Reizschwelle dann erhöht. Nach Exstirpation des Ganglions beobachtete dieser Forscher Kontraktionen der Leibesmuskeln und der Muskulatur der Siphonen, wenn das Tier von bestimmten Reizen getroffen wird, und er ist geneigt, eine Fortleitung der Erregung von Muskel zu Muskel anzunehmen. Der Verf. nahm die Loebschen Versuche wieder auf, kommt aber zu ganz andern Ergebnissen; denn er behauptet, dass die Exstirpation des Ganglions in Wirklichkeit den "Reflex" der Ascidie aufhebt und nur noch lokale Reaktionen bestehen lässt. Wenn zwei Tage nach 
der Exstimpation das Tier sich erholt hat, kontrahiert sich, wenn die In- oder Egestionsöffnung berïlırt wird, immer nur ein Sipho allein, oder es kontrahiert sich bei sehr starken Reizen in manchen T'ieren gleichzeitig auch die Iuskulatur des Rumpfes, aber stets nur lıalbseitig, so dass die Ascidie sich hornförmig krümmt. Eine Fortleitung des Reizes ron einem Sipho auf den andern findet also nicht statt; erst 2-3 Wochen nach der Operation, wenn das Gehirnganglion regeneriert ist, rerhalten sich wieder die Tiere normal. So wie die intakten Ciona erweisen sich anch die operierten sehr empfindlich gegen Erschïtterungen; es treten daher leicht allgemeine Leibeskontraktionen ein, wenn die Versuche nach der Loebschen Methode in der Weise angestellt werden, dass fallende Wassertropfen als Reize angewendet werden. Die leichte Reizbarkeit durch Erschiitterungen, auch nach Entfernung des Gehirns, ist immerhin eine sehr auffallende Erscheinung, und deutet, wie der Ref. annimmt, auf das Vorhandensein nerröser Nebenzentra hin, die unverletzt geblieben sind. In liokainisierten Tieren ist das Nerrensystem ausgeschaltet; daher fehlen Reflexe und Erregungsleitungen und bei elektrischen Reizen erfolyt nur lokale Kontraktion der Muskulatur.

O. Se liger (Rostock).

\section{Vertebrata.}

Pisces.

498 Retzius, G.o Über einen Spiralfaseraplarat am Kopfe der spermien der Selachier. In: Biol. Unters. N. F. Bd. X. 1902. pag. $61-64.1$ Tf.

Verf. beschreibt an den spermatozoen ron Acunthius culgaris ein durch Naceration dargestelltes Spiralband, das sich um den ganzen Kopf zieht und vorn in den Spermienspiess uiberzugehen scheint. Es ist sehr resistent und bleibt, auch wenn der Kopf geplatzt ist, in Zusammenhang erhalten; manchmal werden auch zwei solche Spiralfasern beobachtet, die parallel miteinander verlaufen. Ferner wird noch im Innern des Verbindungsstücks ein spiralig verlaufender Faden beschrieben, der sich an deu distalen Zentralkörperring anset/t und als proximaler \%entralkörper aufgefasst wird.

R. Goldschmidt (Nürnberg).

499 Eigenmann, C'. H., and Clanence Kennedy, Unilateral C'oloration with a Bilateral Effect. (Contribut. \%ool. Laborat. Indiana Univers. Nr. 45). In: Science. N. S. rol. XIII Nr. 334. May 24. 1901. pag. 828-830.

Die Verff. funden unter den Leptocephalen des United - Nr. 497-499. - 
States National Inseum zwei eigentiimliche gefleckte Individuen, welche zu zwei verschiedenen Species gehören könnten, wahrscheinlich jedoch verschiedene Stadien der nämlichen Art, von den Autoren Leptocephalus diptychus benannt, sind. Jedes der beiden Individuen besass acht grosse schwarze Flecken: einer über dem Darm etwas vor dem After, die andern auf den beiden Körperseiten. Jeder dieser Flecken stellt eine einzige, riesige Chromatophore dar, welche sich der Länge nach über drei oder vier somiten erstreckt. Eigentümlich ist, dass die Flecke sich insofern asymmetrisch rerhalten, als die der einen Seite mit denjenigen der andern Seite alternieren, wodurch bei der grossen Durchsichtigkeit der Tiere eine Reihe ron sieben in annäherend gleichen Abständen stehenden Flecken vorgetänscht wird. Die Verff. betrachten das hier geschilderte Verhalten fï̈ das normale und erblicken darin eine besondere Anpassungserscheinung (.,mutual adaptation").

H. C. Redeke (Helder).

500 Lampert, R., Teber die Nahrung der liachforelle und des Bachsaiblings. In: Algemeine Fischerei-\%eitung 1900. 7 palg. In der angenehmen Form einer .. ('auserie" schildert Verf. den in ökologischer Hinsicht wichtigen Unterschied zwischen der iippigen Tierwelt eines geschlossenen T'eiches und der verhältnismäßig armen Fauna eines schnell dahinfliessenden Gehirgsbaches. In der einen eine reichliche Anhäufung höherer und niederer Ptlanzen und Tiere in der Uferregion und am Boden des Gewässers und namentlich ein üppiges Plankton. welches für vick Fische eine Hauptnahrung bildet. Dem rasch fliessenden Gebirgsbach dagegen fehlt in der Regel die schilf- und pitanzenbewachsene Uferzone und mit ihr die ganze dort heimische Tierwelt. Besonder's aber tritt das Plankton der fliessenden Gewässer im Gegensatz zu dem l'lankton der stehenden Gewässer an Masse und Artenzahl granz bedentend zurück; in stark fliessenden Wasserläufen fehlt es so ziemlich ganz und kommt als Fischnahrung gar nicht in Betracht.

Nach Schilderung der \%usammensetzung der Tierwelt einiger Bäthe und Flïsse des schwar\%waldes, wobei es scheint, dass die in stehenden Gewässern so vielfach verbreiteten Moostiere und Schwämme vollständig fehlen und bekanntlich auch die Infusorien und Rädertiere sehr zurücktreten. betont V'erf. ausdrücklich, dass die Untersuchung des Mageninhaltes der Fische an sich nicht genüge zur Lösung der Frage nach der Nahrung der Fische. Die Untersuchung der Tierwelt der Gewässer und die Untersuchung des Mageninhaltes müssen Hand in Hand gehen.

Es standen zul Verfügung die Mägen von 12 Forellen und 
7 Bachsaiblingen. In drei Forellen fanden sich Fischreste, daneben wirbellose Tiere, welche im allgemeinen die Hauptnahrmg darstellen. Darunter finden sich so ungefähr alle Tiere, welche iiberhaupt in den Bächen angetroffen wurden, namentlich aber (und dasselbe gilt für den Bachsaibling) Köcherfliegenlarven, sogenannte Sprockwürmer, die trotz ihres Gehäuses verschiedenen Fischen zur Nahrung dienen, Larven von Eintagsfliegen und Frühlingstliegen, sowie die Larven verschiedener Fliegenarten, besonders der Zuckinücken (Chironomus).

Neben diesen Organismen kommen auch die Mollusken (Ancylus fluiatilis und Limnaea truncutula) als Nahrung in Betracht. Ganz vereinzelt finden sich auch, entsprechend dem Vorkommen derselben, Flohkrebse.

Schliesslich werden Forellen und Bachsaiblinge sicher noch eine ganze Anzahl anderer Tiere als Nahrung aufnehmen, die aber dank der raschen Verdauung und dem Mangel erhaltungsfähiger Teile bei der Untersuchung nicht mehr nachzuweisen sind.

Die vielleicht etwas kärgliche Nahrung, welche das tliessende Wasser zu bieten vermag. wird wesentlich ergänzt durch eine Zufuhr rom Lande. Die rerschiedenartigsten Landtiere fiunden sich im Mageninhalt der untersuchten Fische: Frïhlingstliegen, Köcherfliegen, Honigbienen, Schmetterlingsraupen, besonders von Spannern, allerhand Käfer, sogar Mistkäfer, Ameisen, Asseln, Spinnen, Regenwürmer. Ein Saibling hatte sogar ein Vogelei gefressen, jedenfalls das eines Wasservogels, von welchem noch ein Stiick Eischale und die innere Eihaut vorhanden waren.

Diese Untersuchungen vervollständigen in erfreulicher Weise die Ende 1899 ron $\mathrm{Hock}$ veröftentlichten Studien ïber die Lebensweise und die Nahrung der jungen Lachse im obern stromgebiet.

$$
\text { H. C. Redeke (Helder). }
$$

501 Zenneck, J., Reagieren die Fische a uf Töne? In: Pflügers Arch. f. d. ges. Physiol. Bd. 95. 1903. pag. 346-356. 6 Texttig.

Die Frage, ob Fische auf 'Tonschwingungen reagieren, d. h. auf solche elastischen Wasserschwingungen, deren Sclıwingungszahl und Dämpfung in demjenigen Gebiet liegt, innerhalb dessen Luftschwingungen vom menschlichen $\mathrm{Ohr}$ als Töne rezipiert werden, diese Frage ist neuerdings verneint worden, als sich die alte Behauptung, dass Fische ein Glockensignal hören könnten, durch Kreidls Untersuchungen als irrig erwies. Zenneck brachte bei seinen Versuchen eine ziemlich grosse Glocke, deren Klöppel elektromagnetisch betrieben wurde, unter Wasser an. Die mechanischen Schwingungen wusste er durch geschickte Versuchsanorinung anf ein Ninimum zu reduzieren, 
und durch verschieden abgeänderte Versuche den Nachweis zu bringen, dass dieses Minimum lieine Reaktion bei Fischen bewirkte. Unter solchen Kautelen angestellte Versuche gaben unzweideutige Beobachtungsresultate: stets reagierten die $\mathrm{F}$ ische lebhaft auf den Ton der Glocke. Auch die Möglichkeit, dass es nicht die einfachen Sinusschwingungen sein kïnnten, die bei Fischen die Reaktion hervorrufen, sondem die Stossschwingungen, die beim Beginn des Tönens einer Stimmgabel (ebensowohl einer Glocke) auftreten, konnte ausgeschlossen werden.

Zenneck konmt also doch zu dem Resultat, dass Flussfische - es wurden Leuciscus rutilus, L. dobula und Alburnus lucidus benutzt - auf Tonschwingungen reagieren können.

\section{A. P ü t ter (Göttingen).}

\section{Amphibia.}

502 Wolterstorff, W., Über die Eiablage und Entwicklung von Triton

(Pleurodeles) Iraltlii und Triton (Euproctus) Rusconii. In: Zool. Anz. Nr. 694. 23. II. 03. pag. 277-280.

Verf. beobachtete das Liebesspiel und die liablage an Plcurodeles im Aquarium. Vom 23. III. an bis zum Sommer legte ein Weibchen weit über 1000 Eier ab. Ihr Durehmesser ist $1^{3}+\mathrm{mm}$, jedesfalls unter $2 \mathrm{~mm}$ (Carnoy-Lebrun fanden die reifen Ëier 1,4-1,5 mm gross, vgl. Zool. Zentr.-Bl. V. 1898. pag. 63. Ref.), Verf. vergleicht sie mit den Axolotleiern. Im selken Frühjahr beobachtete er auch bei Titon rusconii die Ablage von 13 Eiern von 1-2 kleinen Weibchen; die Fier sind doppelt so gross wie die von Pieurodeles (Carnoy-Lebrun wiesen anch schon auf diesen Grössenunterschied hin a. a. O. Ref.) Verf. macht darauf aufmerksam, dass schon die Larven von Tr. walllii und rusconii sehr verschieden sind.

R. Fick (Leipzig).

\section{Mammalia.}

503 Cohn, Franz, Zur Histologie und Histogenese des Corpus luteum und des interstitiellen Ovarialgewebes. Inaug. Diss. Breslau 1903. 35 pag.

Verf. untersuchte gelbe Körper beim Kaninchen 201/2, 22, 221/2, $42,42^{1 / 2}, 44^{1} / 2,48^{1 / 2}, 68$ Stunden, $5,8,13$ und 15 Tage post coitum. Er lıält die Luteinzellen für hypertrophierte Granulosazellen und kommt auf Grund der histologischen Beschaffenheit der Zellen zur selben Annahme wie Born aus andern Gründen (vgl. Zool. Zentr.-Bl. 9. Bd. pag. 164. Ref.), dass nämlich der gelbe Körper eine Drüse mit innerer Sekretion sei. Bezïglich der interstitiellen Eierstockszellen kommt er zu ähnlichen Resultaten wie Limon (vgl. Zool. Zentr.-Bl. 10. Bd. pag. 138. Ref.). Verf. emptiehlt warm die Färbung mit phosphor-wolframsaurem Hämatoxylin nach $\mathrm{Plessen-Rabinovicz.} \mathrm{-}$

R. Fick (Leipzig). 
504 Retzius, G., Weitere Beiträge zur Kenntnis der Spermien des Menschen und einiger Säugetiere. In: Biol. Unters. N. F. Bd. X. 1902. pag. 45-60. 3 T't. 5 Textfig.

Verf. beschreibt zunächst noch einmal eingehend den Bau der normalen menschlichen Spermien. Hervorzuheben ist daraus das Vorkommen sehr kleiner, stark färbbarer Körner im Kopf, die Lage der Zentralkörperderivate im Halsstïck (sie können proximal, in der Mitte und distal liegen und auch in zwei Paaren vorkommen), die Unmöglichkeit, mit Sicherheit eine Spiralhülle des Verbindungsstückes nachzuweisen. Von den anormalen Spermien verdienen besonderes Interesse die doppelschwänzigen, die in allen Stadien der Ausbildung bis zur vollständigen Trennung der beiden Schwanzfäden beschrieben und abgebildet werden. Der Kiopf dieser Formen bietet nichts besonderes dar. In dem Halsstiick finden sich, auch wenn es doppelt ist, in der Regel nur zwei Zentralkörperkörner. eines für jede Teillälfte. Nur in einem Fall konnten 3 Körner nachgewiesen werden. Besonders aus dieser T'atsache schliesst Verf., dass die Doppelschwänze durch Spaltung des Schwanzfadens in жwei präformierte Teilfäden entstehen. Dafür spricht aucl das Vorhandensein aller Zwischenstadien vom einfachen zum doppelten Faden, besonders der Doppelfäden mit gemeinsamem Endstück. Daneben können die Doppelschwänze wohl auch auf die von Broman ${ }^{1}$ ) angegebene Weise entstehen.

Ein weiterer Abschnitt befasst sich mit ähnlichen Spermien bei Sängetieren. Beim Meerschweinchen kommen Doppelschwänze vor. die in jedem Verbindungsstiick die drei für diese Form charakteristischen Zentralkörperkörner zeigen, was also für B rom a ns Auffassung spricht. Die Doppelschwänze vom Stier verhalten sich wie die des Menschen, indem jedes Verbindungsstiick nur ein Zentralkörperkorn besitzt; das gleiche gilt für die Kiatze.

R. Goldschmidt (Nürnberg).

$\left.{ }^{1}\right)$ S. Zool. Centr-Bl. IX. 1902. No. 604. 


\section{Zoologisches Zentralblatt}

unter Mitwirkung von

\section{Professor Dr. O. Bütschli \\ In Heidelberg \\ and \\ Professor Dr. B. Hatschek \\ in Wien}

herausgegeben von

\section{Dr. A. Schuberg}

a. o. Professor in Heidelberg.

\section{Verlag von Wilhelm Engelmann in Leipzig.}

\section{Jahrg.}

14. August 1903.

No. $15 / 16$.

Lu beziehen durch alle Buchhandlangen und Postanstalten, sowie durch die Verlagsbuchhandlung. Jährlich 26 Nummern im Umfang von 2-3 Bogen. Preis für den Jahrgang M. 30. - Bei direkter Z asendung jeder Nummer unter Streifband erfolgt ein Aufschlag von II. 4.- nach dem Inland and von I. 5.- nach dem Ausland.

\section{Referate.}

\section{Zellen- und Gewebelehre.}

505 Schuberg, A., Über Kellverbindungen. Vorlüufiger Bericht. I. In: Verhandl. Naturhist. med. Ver. Heidelberg. I. F. VII. Bd. 190ะ. pag. $395-404$.

506 - Untersuchungen über Zellverbindungen. I. Theil. In: Zeitschı. wiss. Zool. Bd. LXXIV. pag. 155-325. Taf. IX-XV.

'Trotz der Bedeutung, welche der Frage nach dem Zusammenhang der zelhigen Elemente im tierischen Organismus zukommt, sind die Kenntnisse auf diesem Gebiete teils noch verhältnismäfig dürftige, teils unsichere. Die Verbindung der Zellen des „Bindegewebes“ zwar wird als ein so feststehendes Axiom hingenommen, dass es deshalb in neuerer '/eit nur wenige Nachprüfung erfuhr; die Verbindung der ZeHen der Epithelien gilt mit Recht als für viele Fälle genügend erwiesen; über die Verbindung der \%elten des Nervengewebes, sowie die des Muskelgewebes bestehen dagegen noch zahlreiche Meinungsverschiedenheiten; und Verbindungen zwischen Zellen verschiedener Gewebe schliesslich werden, obwohl solche wiederholt beschrieben wurden, fast allgemein mit grossem Misstrauen betrachtet. So hat denn auch die Ansicht, dass alle oder wenigstens zahlreiche Zellenelemente des tierischen Organismus in kontinuiertichem Zusammenbang stünden, bisher keine allgemeine Anerkennung finden können, obwohl diese Ansicht wiederholt anfgestellt worden war und mit den herrschenden Anschaungen vom Bau und den Leistungen, wie von der Abstammung der vielzelligen tierischen Organismen in guter Ubereinstimmung zu stehen schien.

Die vorliegenden „Untersuchungen“, iiber welche rom Verf. zum 
erstenmal in den Jahren 1891 und 1893 berichtet worden war, haben den Zweck, die Frage der Zellverbindungen einer gründlichen Priifung 7u miterwerfen. Sie suchen dies in objektiver' Weise zu tun. Obwohl dem Verf. die Kontinuität der lebenden Substanz mit der Auffassung des vielzelligen Organismus als „Zellenstaat" am besten übereinzustimmen sclieint, ist er iiberzeugt, dass es zweifellos Ciewebe gibt, in welchen eine Kontinuitit der Zellen nicht besteht, nnd dass anch die Zellen verschiedenartiger Gewebe durchaus nicht in allen Fällen miteinander in Zusammenhang stehen. Sein „Bestreben ist also nicht, Zellverbindungen zufinden, sondern zu nntersuchen, ob solche vorhanden sind".

Zur Einleitung in die eigenen Untersuchungen wird eine .. Üb e r. sicht ïber den gegenwärtigen Stand der Frage nach dem Vorkommen von Zellverbindungen im tierischen Organ is mu s" gegeben, wobei die Entwicklung unserer Anschauungen über die .. Verbindungen zwischen den Zellen der Bindesubstanzen" etwas eingehender beriicksiclstigt wird, da sie für die Beurteilung der Zellverbindungen überhaupt vorbildlich geworden sind. Nach einem kurzen Überblick iber ,Gang und leitende Gesichtspunkte der eigenen Untersuchungen“ werden sodann „die Verbindungen von Epithel-und Bindegewebszellen, sowie der Bindegewebszellen untereinander, in der Haut des Axolo tls" dargestellt.

Veranlassung zur Untersuchung dieser Salamandridenlarve gaben Beobachtungen Ley digs an den Larven der einheimischen Salamandra maculosa, die allerdings bisher so gut wie keine Beachtung gefunden hatten.

Da bei den bisherigen Beschreibungen von Zellverbindungen, namentlich von denen zwischen Zellen vers chiedener Gewebe, öfter ni chtzellige Elemente des Coriums als Zellverbindungen gedeutet wurden oder anderweitige Irrtümer rorkamen, so erschien es notwendig, das gewählte Objekt möglichst nach allen Richtungen hin zu untersuchen, also besonders das Verhalten aller im Corium vorkommenden Gewebselemente festzustellen, um derartigen Täuschungen zu entgehen: ein Verfahren, das Verf. bei Untersuchung allgemein histologischer Fragen für un so mehr geboten hält, als die modernen elektiven Fürbungen ganz besonders dazu verleiten, die nicht im Vordergrunde des Interesses stehenden Gewebselemente und Strukturen zu vernachlässigen. Hierdurch wurde allerdings der Gang der Untersuchung bedeutend in die Länge gezogen und andrerseits mussten Dinge geprüft werden, die mit ihr nur in indirektem /usammenhang stehen, dafür aber selbst manche bemerkenswerte Resultate ergaben. 
Zum Nachweis der Zellverbindungen wurde ror allem mit gutem Erfolge eine I) a h liafärbung mit nachfolgender Fixierung der Färbung durch Tannin und Brechweinstein benützt; sie kann nur an Sublimatorler Alkoholmaterial angewandt werden, da bei Vorbehandlung mit P'ikrinsïure, Chromsümre, Chrom- oder Platinsalzen die fibrillären Elemente des Bindegewebes derartig mitgefärbt werden, dass die sonst scharfe Protoplasmafärbung hierdurch undeutlich wird(vgl. das Original).

Die Untersuchung der Verbindungen der Bindegew e bszellen untereinander ergab zwar nichts wesentlich Neues, war aber schon aus dem Grunde nicht ganz nebensächlich, weil gerade dadurch die angewandte rärbungsmethode anf ilnen Wert und ihre Zurerlässigkeit geprüft werden konnte.

Auf die Literatur wird hinsichtlich der Zellrerbindungen in deur vorliegenden Teile im wesentlichen nur insoweit genauer eingegangen, als sie sich speziell auf den Axolotl bezieht.

1. Bau und Entwicklung des Coriums im allgemeinen. Um den Bau des Coriums des Axolotls richtig zu rerstehen, ist es notwendig. auf jüngere Stadien zurïickzugreifen.

bei Tieren his zu etwa $50 \mathrm{~mm}$ Länge besteht es aus einer einheitlichen Lage, die gegen die Kante der Flossensäume zu an Dicke allmählich abnimmt. Vit der Ausbildung der grossen Hautdrüsen beginnt eine Differenzierung in drei Lagen, die als innere, mittlere und änssere Corium-Lage bezeichnet werden. Bei mittelgrossen und erwachsenen Axolothn ist diese Sonderung des Coriums am Rumpfe deutlich vollzogen. Die innere Lage, welche mit den "derben wagerechten Lagen" nach Leydig identisch ist, besitzt die grösste Dicke; die mittlere schwankt ihrer Dicke nach bei dem gleichen Individuum an verschiedenen Stellen und bedingt vor allem die Dickenzunalıme des Coriums wälırend des Wachstums. Die äussere Lage wurde bisher nur ron Paulicki richtig als solche erkannt und sonst bei andern Amphibienlarven äbersehen oder als Basalmembran beschrieben. Dass es sich in Wirkliehkeit nur um eine äussere Lage des Coriums handelt, geht nicht nur daraus hervor, dass sie bei andern Amphibien, z. B. Proteus und Ichthyophis, eine grössere Dicke und dann den gleichen Bau wie die Innenlage besitzt, sondern auch daraus, dass sich an den Flossensäumen die innere und äussere Coriumlage zu einem einheitlichen Corium vereinigen, ron der gleichen Art, wie es hei den jüngern Tieren sich rorfindet. Die Entwicklung des Coriums zeigt, dass sich die mittlere, locker gebaute Lage mit der Entwicklung der sackförmigen Irüsen in das ursprünglich einheitliche Corinm einschiebt. Schon C. Rabl und II u ree haben richtig an- 
gegeben, dass gleichzeitig mit der Ausbildung der Drüsen die Hauptmasse des eigentlichen Coriums von der Epidermis ..abgedrängt" wird; doch haben sie die äussere Coriumlage übersehen. Die äussere Coriumlage am liumpfe und das einheitliche Corium der Flossensäıme sind natürlich diejenigen Stellen, welche fïr die Untersuchung der Verbindungen von Epidermis- und Bindegewebszellen ron Wichtigkeit sind, während Verbindungen der Bindegewebszellen untereinander in der innern und mittlern Coriumlage des liumpfes und in dem einheitlichen Corium der Flossensäume angetroffen werden.

2. Bindegewebsbïndel. - I)ie Hauptmasse des Coriums wird durch die "Bindegewebsbündel" dargestellt. In der innern Coriumlage sind sie in zur Hautobertläche parallelen Schichten angeordnet, in deren jeder die .. Fibrilken" im allgemeinen in der gleichen Richtung verlaufen; die Richtungen aufeinanderfolgender Schichten kreuzen einander jedoch unter etwa rechtem Winkel. Stets vereinigen sich die zerteilten Enden rerschiedener „Bündel“, um durch ihre Vereinigung wieder neuen Bündeln den Trsprung zu geben, so dass sie also in Wirklichkeit ein kompliziertes Maschenwerk darstellen. In solcher Weise verbinden sich nicht nur die Bündel der gleichen Schicht untereinander, sondern auch die ibereinander gelagerten Schichten können in ähnlicher Weise durch spitzwinkelig abtretende Fibrillen miteinander verbunden sein. Bei jüngern Tieren sind die Bündel dünner als bei ältern, woraus hervorgeht, dass beim Wachstum des Coriums nicht nur einfach eine Anlagerung never Bïndel erfolgt, sondern dass die Bïndel selbst an Dicke zunehmen. Ausser den die Hauptmasse der innern Coriumlage darstellenden, parallel zur Hautoberfläche ziehenden Bündeh sind in ihr noch senkrecht aufsteigende Bündel vorhanden; sie biegen in das Corium entweder rechtwinkelig aus dem Unterhantbindegewebe ein oder steigen senkrecht aus letzterm auf. Die Innenlage durchsetzen sie entweder in gleichmäßiger Dicke, um erst in der mittlern Coriumlage sich zu verzweigen, oder sie geben schon innerhalb der erstern seitliche Stränge $a b$, welche riemlich scharf umbiegen und sich mit den parallel zur Hautobertläche ziehenden Bündeln vereinigen. Von Herrick und Coghill sind diese anfsteigenden Bündel zum Teil für Nervenfasern gehalten worden: mit den ..senkrecht aufsteigenden Zïigen", wie sie von Ascherson, Leydig u. a. aus der Haut des Frosches und anderer Amphibien bescluieben wurden, sind sie nicht identisch. Bei jenen handelt es sich viehmehr um Stränge „lockern" Bindegewebes, welche die dichter und straffer gebaute innere Coriumlage durchsetzen und die aufsteigenden Nerven und Blutgefässe einschliessen. Beim Axolotl treten Nerven und Bhutgefässe durch die 
innere Coriumlage hindurch, ohne deren Anordnung irgendwie zu verändern.

In der mittlern Coriumlage, welche in die innere allmählich ïbergeht. sind die Bindegewebsbündel weniger regelmäßig angeordnet. In ihrer innern Partie sind sie noch ziemlich dicht, doch in den verschiedensten Richtungen durcheinander geflochten, während in der äussern Partie viele von ihnen gegen die äussere Coriumlage zu gerichtet sind, der sie unter welligem Verlaufe und vielfach auseinanderstrahlend zustreben; sie werden durch eine gallertige Grundsubstanz voneinander getrennt. Enter den srossen Hautdrüsen finden sich in der Riegel besondere, stiirkere Ziige von säulenartig aufsteigenden Bindegewebsbündeln, welche sich, wie auch die gegen die Aussenlage zustrebenden Bündel, meist in die aufsteigenden Bündel der Innenlage verfolgen lassen. Wie in einem spätern 'T'eile der „Untersuchungen"s auseinanderzusetzen sein wird, sind durch die mittlere Coriumlage anfsteigende Bindegewebsbündel anderer Amphibien ron gewissen Seiten fälschlicherweise als "\%ellverbindungen" beschrieben worden.

Die äussere ('oriumlage folgt (auf' senkrechten Hautsclmitten hetrachtet) der Innenseite der Epidermis als ein relativ dünner. ziemlich gleichmäbiger Saun. Sie lïsst (von der liäche gesehen) sehr feine, einander ïberkreuzende Fasersysteme erkennen, welche den Bau der Innenlage im grossen und ganzen zu wiederholen scheinen.

Das einheitliehe Corium der Flossensäume, das nach deren Kiante zu an Dicke abnimmt, stimmt im wesentlichen mit der innern Coriumlage des Rumpfes überein; nur sind die Bindegewebsbïndel dïnner und die Schichtung erscheint demgemäl. feiner. Gegen die Kante der Flosse zu verfeinern sich die Baurerhältnisse derart, dass sie hier mehr mit denjenigen der prinzipiell ja gleich gebauten Aussenlage vom Corium des Rumpfes übereinstimmen. Die senkrecht in das ('orium der Flossensäume aufsteigenden Bindegewebsbündel sind Fortsetzungen oder Zweige der das Gallertgewebe der Säume in querer lichtung durchsetzenden Bündel.

3. Elastische Fasern. - Wie Bindegewebsbündel haben auch die elastischen Fasern gelegentlich Anlass zu irrtiimlichen Anschauungen gegeben, indem man Verbindungen zwischen ihnen und Epidermiszellen festgestellt haben wollte; sie waren deshalb ebenfalls genauer zu untersuchen. Entsprechend dem larvalen Charakter der Axolothlhat sind elastische liasern in ihr noch recht schwach entwickelt; sie beschränken sich fast ausschliesslich auf senkrecht durch die Innenlage und die Mittellage des Coriums aufsteigende Fasern, während die Aussenlage des Rumpfcoriums und das einheitliche Coriun 
der Flossensänme noch frei von ihnen sind. Eine Verwechshung elastischer Fasern mit Verbindungen zwischen Epidermis- und Bindegewebszellen ist daher beim Axolotl schon aus diesem Grunde ansgeschlossen.

4. Bindegewebs\%ellen. - Die hamptsächlich zur Anwendung gebrachte Methode der Dalıliafürbung erlaubte, die Bindegewebszellen bis in ihre feinsten Auslänfer hinein zu verfolgen. Die hierdurch gewonnenen Bilder spiegeln im allgemeinen die Anordnung der Bindegewebsbündel wieder.

Der Innenlage des Coriums liegen an der Grenze gegen das Interhautbindegewebe zweierlei \%ellen an, die jedoch durch Übergangsformen miteinander verbunden sind: platte, an der Grenze flach ausgebreitete Zellen und solche. welche nit ihrem halbkugeligen oder birnförmigen Körper mehr oder weniger weit in das Unterhauthindegewebe hinein vorspringen; letztere fürben sich besonders stark, liegen oft gruppenweise znsanmen („subcutane Zellen und Zellennester") und gehen nach innen zu keinerlei Terbindungen ein. Beiderlei Zellen entsenden in die Innenlage des Coriums Fortsätze, welche sich mit denen anderer Zellen netzförmig verbinden. Die ,subcutanen Zellen“" lesitzen in der Regel einen senkrecht in die Innenlage aufsteigenden Fortsatz, von welchem meist mehrere, parallel zur Hautoberfläche ziehende Ausläufer abgehen, in der Art, dass der ganze in der Innenlage befindliche Teil der Zelle die Form eines 'T mit einfachem oder' mehrern Querbalken besitzt. Die autsteigenden Zellfortsätze liegen in der Regel anfsteigenden Bindegewebsbündeln an. Gewisse Beobachtungen machen es wahrscheinlich, dass diese Zetlen in die Innenlage des Coriums einwindern; man findet nämlich Übergangsformen zwischen den noch teilweise in das Unterhautbindegewebe hineinragenden und den ganz in der Innenlage des corimms liegenden Zellen, deren Körper parallel zur Hautobertï̈che sich ausbreitet. Die letzteren Zellen bilden flache P'latten, deren ausgefranste Rïnder in zahlreiche feine Ansläufer sich fortsetzen; die gleiche lorm besitzen, von der Fläche betrachtet, auch die parallel zur Hautobertläche verlaufenden Teile der in die Innenlage hereinragenden „subcutanen“ Zellen. Alle diese Ausläufer bilden ein kontinuierliehes Netz- und Maschenwerk, dats in Flächenansicht in weitgehendem Naße mit dem ans der Cornea der Wirbeltiere bekannten Zellennetze iibereinstimmt, indem die Ausläufer, entsprechend der Anordumng der Bindegewebsbündel, in zwei einander durchkreuzenden geradlinigen Hauptrichtungen angeordnet sind. Fie V'erbindung der übereinander liegenden Schichten von Zellen und Zellenausläufern erfolgt trils durch spitzwinklig, teils aber anch durch rechtwinklig aufstei- 
gende Fädchen, wie aus senkrecht zur Hautoberfläthe geführten Schnitten hervorgeht. An allen Verzweigungsstellen der Zellen finden sich stets kleine Protoplasmaansammlıngen mit bogigen Begrenzungslinien, was auf die zähtlüssige Natur des I'rotoplasmas hindeutet.

In der mittlern Coriumlage, wo die Ciestalt der Bindegewebszellen unregelmäßiger ist, wurde die Verbindung der feinen Zellausläufer ebenfalls nachgewiesen. Die Drüsen, sowie die ,säulenartigen“ Zïge der Bindegewebsbündel bedingen gewisse Modifikationen in der Form und Anordnung der Zellen. - In Zellen der mittlern Coriumlage (wie übrigens auch in solchen des Unterhautbindegewebes und von andern Orten) werden häufig kleine Pigmenteinlagerungen angetroffen, welche aus drei, vier, bis etwa zu einem Dutzend kleiner Körnchen bestehen ${ }^{1}$ ).

Unter der äussern Coriumlage, ilı z. T. dicht anliegend, bilden die Bindegewebszellen ein Netz, dessen Masehen von breitern Auslänfern gebildet wird. Wenn die äussere Coriumlage eine gewisse Dicke erreicht hat, wird sie ron feinen, aus diesem Netze entspringenden Fädchen durchsetzt, die sich mit dreieckig vorspringenden Fortsätzen der basalen Epidermiszellen kontinuierlich verbinden. Bei jüngern Tieren mit noch dünnerer Aussenlage sind die basalen Ejidermiszellen (quer abgestutzt und besitzen anscheinend keine Verbindungen mit den Bindegewebszellen.

Besonders deutlich nnd zahlreich sind solche Verbindungen jedoch in dem einheitlichen Corium der Flossensäume nathzuweisen. Im allgemeinen stimmt die Anordnung der Bindegewebszellen unter und in dem Corium der Flossensäume mit den fïr die Innenlage des Rumpfes geschilderten Verhältnissen äberein; die Zellen und Zellenausläufer bilden auch hier ein Maschenwerk, das an das der Corneazellen erinnert. Auch den „subcutanen" Zellen entsprechende Elemente sind hier vorhanden, deren Einwandern in das Corium durch Auftindung aufeinander folgender Stadien hier noch wahrscheinlicher gemacht werden konnte. I) as Netz der unter und in dem Corium gelegenen Bindegewebszellen nun ist durch zahlreiche, senkrecht aufsteigende Ausläufer mit den basalen Epidermiszellen verbunden, die sich mit ihren spitzen Fortsätzen oft tief in das Corium einsenken. Diese Verbindungsfäden können das ganze Corium senkrecht durchsetzen, entspringen dann also von den dem Corium nach innen anliegenden Zellen oder gehen von den

1) Prowazek hat an Bindegewebszellen der Salamanderlarve die gleiche Beobachtung gemacht. 
horizontal übereinander geschichteten, dem Corium eingelagerten Bindegewebszellen und deren Ausläufern ab. Die Zahl der Fortsätze, durch welche eine einzelne Bindegewebszelle mit der Epidermis in Verbindung steht, ist eine verhältnismäBig grosse; sie verbindet sich dabei nicht bloss mit einer, sondern mit mehrern Epithelzellen. Andererseits besitzen diese letztern nicht immer bloss einen, sondern oft auch mehrere in das Corium sich einsenkende und die Verbindungen herstellende Fortsätze. Die V'ereinigung der Ausläufer der Bindegewebszellen mit den Epidermiszellen ist eine kontinuierliche; eine Grenze zwischen beiderlei Elementen in den Verbindungsfädchen istnicht wahrunehmen, aus theoretischen Grïnden aber eine solche anzunehmen, besteht keine Veranlassung.

5. Pigmentzellen. - Mehrfach waren, auch für Amphibien und Amphibienlarven, Verbindungen zwischen Epidermiszellen und Pigmentzellen des Coriums besclrieben worden. Schon aus diesem Grunde war daher die Untersuchung der Pigmentzellen notwendig, die um so weiter ansgreifen musste, als die Zahl der strittigen Probleme für diese Zellenart eine noch recht beträchtliche ist. \%u einzelnen dieser Fragen, die noch in den letzten Jahren z. T. sehr verschieden beantwortet wurden, wurde anf Grund der Beobachtungen des Verfs. sowie früherer Autoren in bestimmter Weise Stellung genommen. Dies gilt vor allem für die Frage nach der $\mathrm{Natur}$ der Pigmentzellen. Noch jetzt werden diese Elemente häufig einfach als "Bindegewebszellen” aufgefasst, die sich von den gewöhnlichen „fixen Bindegewebszellen“ nur durch den Pigmentgehalt unterscheiden sollen; nach einer andern Anschauung wären sie dagegen, Wanderzellen ", modifizierte Leukocyten. Erst neuerdings wurde die zuerst von C. Rabl angedeutete Ansicht, dass die P'igmentzellen eine besondere Zellenart darstellen, eingehender zu begründen versucht (Ehrmann). Diese Ansicht seheint Verf. dadurch bewiesen zu werden, dass die Pigmentzellen im Epithel in den Intercellularräumen, in Corium in den Lymphspalten gelegen sind, dass sie im letztern Falle dem Körper oder den Ausläufern von Bindegewebszellen oft streckenweise dicht und parallel angelagert sind — was bei einer Identität mit Bindegewebszellen ausgeschlossen sein muss -, und dass sie schliesslich schon bei Larven durch mitotische Teilung sich vermehren (Flemming, Zimmermann). Die Verschiedenheiten der Form bei Pigmentzellen der Fpidermis und des Coriums kommen durch die Verschiedenheiten der örtlichen Bedingungen, d. h. durch die verschiedene Gestaltung der epithelialen Intercellularräume und der bindegerebigen Lymphspalten, zu stande. 
An der Grenze der Innenlage des Coriums und des Unterhantbindegewebes sind Pigmentzellen zahlreich vorhanden; in ersterer selbst wurden dagegen nur einzelne, senkrecht hindurchtretende Ausläufer gefunden, welche meistens von Zellen entsprangen, die selbst in der mittlern Coriumlage gelegen waren. Hier sind sie, wie lange bekannt, sehr zallheich: besondere Erwähnung verdienen die dicht unter der Aussenlage und parallel zu ihr sich hinziehenden Pigmentnetze. In den Flossensäumen finden sich solche nicht nur unter, sondern auch in dem geschichteten Corium. Die Netze der unter der Aussenlage des Riumpfes und unter dem Corium der F'lossensäume gelegenen I'igmentzellen sind unregelmäPig, während die innerhalb des letztern liegenden Netze und Ausläufer gleiclı den Bindegewebszellen die regelmäßige Anordnung der Bindegewebsbündel wiederspiegeln. Ter'bindungen der Pigmentzellen mit Epidermiszellen oder bindegewebszellen wurden niemals wahrgenommen und sind mit Sicherheit auszuschliessen. Die vorliegenden Angaben über Verbindungen ersterer Art beruhen auf einer falschen Deutung von Pigmentzellen, welche in die Epidermis eintreten, und zwar in deren Intercellularräume, was deutlich beobachtet werden konnte.

6. Farblose Pigmentzellen. - In der ïussern Partie der mittlern Coriumlage des Rumpfes, dicht unter der änssern Coriumlage, ferner in und unter dem Corium des Rumpfes, sowie in rereinzelten Fällen in der Epidermis fanden sich Zellen, welche nach ihrer Grösse, Art der Verzweigung und Netzbildung, sowie ihrem Vorkommen in den Lymphspalten und in den Intercellularräumen der Epidermis an I'igmentzellen erinnern. Das schwach färbbare P'rotoplasma ist mit zahlreichen blassen Körnchen erfüllt, welche sich nur mit gewissen Farbstoffen nachweisen liessen. In manchen solchen Zellen findet naan neue Pigmentkörnchen, welche mit den gewöhnlichen schwarzen Pigmentkörnchen, sowie nit den eben erwähnten farblosen Granula gleiche Grösse besitzen. Dieser Gehalt an Pigment kinn so weit gehen, dass annähernd gleich viel schwarze und ungefärbte Granula in der Zelle vorhanden sind. Dieser Umstand, wie die sonstige Übereinstimmıng mit den gewöhnlichen Pigmentzellen, machen es wahrscheinlich, dass die blassen Körnchen farblose Pigmentkörnchen, die \%ellen selbst also farblose Pigmentzellen darstellen. Wie Reinke gezeigt hat, lassen sich bei Salamanderlarven die Pigmentkörnchen rom Pigment befreit als kleine Granula darstellen, woraus hervorgeht, dass das Pigment an ein, auch im pigmentfreien Zustande nachweisbares Substrat gebunden ist. Diese Beobachtungen scheinen mir meine Auffassung wesentlich zu unterstützen. Von Mastzellen sind die farblosen Pigmentzellen durclı die 
verschiedenartige lieaktion der Körnchen gegen basische Anilinfarben sowie durch die Form verschieden; doch ist es nicht unmöglich und dafür spricht die gelegentliche Beobachtung in den Intercellularräumen der Epidermis - dass sie mit den Langerhansschen Zellen der Epidermis identisch sind. Yerbindnngen der farblosen P'igmentzellen mit Epidermis-oder Bindegewebszellen sind nicht vorhanden.

7. Mastzellen. - Über den Begriff der sog. .Mastzellen" herrseht in der Literatur vielfach noch eine ziemlich grosse Verwirrung, zumal die Lehrbücher auf diesen Gegenstand wenig einzugehen pflegen. Ans diesem Grunde war es notwendig, den Begriff und die Terminologie der Mastzellen einigermafen klarzulegen, wobei sich, z. T. in Übereinstimmung mit andern Autoren, ergab, dass ein Teil der "Plasmazellen" Waldeyers, die .. Iastzellen" Ehrlichs und die "Clasmatocyten" Ranviers identisch sind. Sie finden sich im Integument les Axolotls im Unterhautbindegewebe, in der äussern lockeren l'artie der mittlern Coriumlage und im Gallertgewebe der Schwanztlosse oft in ziemlicher Menge. Sie bestehen aus einem kleinen, meist oroiden, den Kern umschliessenden Hauptteil, ron dem nur wenige, lange Ausläufer absehen. Diese geben gleichfalls nur wenige, in ziemlich weiten Abständen abtretende Seitenzweige $a b$, welche weder miteinander, noch mit denen anderer Zellen sich vereinigen. Die Ausläufer und ibre Seitenzweige besitzen oft ziemlich dicht aufeinander folgende spindelförmige oder kugelige Anftreibungen und endigen in der Regel mit rundlichen, tröpfchenartigen Anschwellungen. Die Zellen sind dicht mit kleinen Körnchen erfüllt, welche nit basischen Anilinfarben die von Ehrlich für sie nachgewiesene metachromatische lärbung zeigen. In die Aussenlage des Coriums wie in das Corium der Flossensäume oder gar in die Epidermis dringen die Mastzellen niemals ein, können also schon deslıalb keinen Anlass zur etwaigen Vortäuschung von Zellverbindungen geben. Von Herrick und Coghill sind sie in der Haut des Axolotls irrtïmlicherweise als Ganglienzellen beschrieben worden.

8. Leukocyten. - Im Corium, insbesondere in der mittlern Lage, kommen regelmäßig verschiedenerlei Formen von Leukocyten ror, sowohl mehrkernige grannlafreie, wie granulahaltige. Von letztern finden sich zwei Arten: einkernige mit grössern und mehrkeruige mit kleinern Granula; die Granula dieser beiden Arten verhalten sich auch färberisch verschieden. Einkernige, granulafreie Leukocyten wurden auch bei der Durchwanderung der äussern Coriumlage angetroffen, so dass ilır Körper teils in der mittlern Coriumlage, teils in den Intercellularrämmen der Epidermis liıg. Eine Verwechslung solcher 
Torkommnisse mit Verbindungen zwischen Epidermis- und Bindegewebszellen ist ausgeschlossen.

9. Nerven. - Die markhaltigen Nerven treten, unter Verlust der Markscheide, in die Epidermis ein. An den Flossensäumen kann man gut verfolgen, wie sie das Corium senkrecht durchsetzen; von den Verbindungen der Epidermis- und Bindegewebszellen sind sie, schon durch ihre grössere Dicke, leicht zu unterscheiden. Die von Herrick und Cogh ill aus der Haut des Axolotls beschriebenen „Nerven“ sind grossenteils Bindegewebsbündel, ihre "Ganglienzellen" dagegen, wie schon oben erwähnt, Mastzellen.

Ein Vergleicl der beschriebenen Verbindungen zwischen Epidermis- und Bindegewebszellen mit allen iibrigen im Corium, insbesondere an dessen Grenze gegen die Epidermis zu vorkommenden Gewebselementen zeigt ebenso, wie die ganze Natur jeller Verbindungen an sich, dass eine Verwechslung mit irgend welchen andern Dingen ausgeschlossen ist und dass in der Haut des Axolotls, insbesondere aber in derjenigen der Flossensäume, Verbindungen zwischen Fpidermisund Bindegewebszellen unzweifelhaft rorlanden sind.

A. Schuberg (Heidelberg).

\section{Vergleichende Morphologie, Physiologie und Biologie.}

507 Schultze, Oskar, Was lehren uns Beobachtung und Experiment überdie Ursachen männlicher und weiblicher Gesehleehtsbildung bei T'ieren und Pflanzen. In: Sitzber. phys. merl. Ges. Wiirzlog. 13. XI. 1902. 9 pag.

Vorf. stellt in gedrängter Kürze die wichtigsten bisherigen Ergebnisse der Autoren übersichtliclı zusammen. Diese zeigren, dass bei zahlreichen niedern P'flanzen (Firnen und Equiseten) die Produktion der weiblichen Geschlechtszellen einer höhern Leistung des ()rganismus bei besserer Ernährung usw. entspricht, als die der mämnlichen Geschlechtszellen. Ebenso bei Monokotylen (Mais). Bei zweihäusigen Dikotylen hingegen ist im Samenkorn bereits das Geschlecht der Pflanze rorgebildet und scheint auch durch die Ernährung der Mutterptianze nicht beeinflussbar. Bei Hydra und bei den Aphiden liegen die Verhältnisse ähnlich wie bei den Kryptogamen. Auch bei Hydatina sentu gelang es Nussbaum, das Gesclılecht der sich bildenden Eier durch gute oder schlechte Frnährung des Muttertieres zu beeinfiussen, indem bei guter Ernährung weibliche, bei schlecliter männliche Brut entsteht. Verf. hat nun selbst zwei Jahre lang sehr umfangreiche, wohldurchdachte 
Versuche an Mäusen ausgeführt. Es ergab sich, dass Hof ackerSadlers Hypothese rom Einfluss des Alters der Erzeuger bei der Maus sicher keine Geltung hat. Auch die Behauptung, dass die stärkere geschlechtliche Inanspruchnahne eines der beiden Erzeuger einen Eintluss auf das Geschlecht habe, erwies sich bei der Maus als sicher falseh. Auch durch mehrere Generationen daternde Inzucht hatte keinen Einfluss auf das Geschlecht, auch sonst keinen schädigenden Eintluss bei guter Ernährung der Zucht. Auch günstige oder karge Ernährung der Mäuse erwies sich als einflusslos auf das Geschlecht sowohl der direkten Nachkommen, als der spätern Generationen. Verf. schliesst daraus, dass ganz sicher die Eier bereits gesthlechtlich differenziert sind und zwar wahrscheinlich schon zur Zeit der (ieburt des betr. Weibchens. Also könnte höchstens znr Zeit der embryoualen Entwicklung dieses Weibchens in seiner Mutter (also der ..Grossmutter") das (ieschlecht der künftigen Enkel beeinflusst werden. Iber bei den Mäusen scheint auch das unmöglich zu sein.

R. Fick (Leipzig).

\section{Descendenzlehre.}

j0s Wettstein, R. v., Der Neo-Lamarckismus und seine lieziehungen zum D)arwinismus. Jena (G. Fischer). 1908. 30 pag. 11. 1.-.

Diese Schrift gibt den durch einige Zusätze und Literaturnachweise erweiterten Wortlaut des Vortrags wieder, den der Wiener Botaniker auf der Naturforscherversammlung in Karlsbad 1902 gehalten hat.

Verf. bekennt sich als Anhänger sowohl des Darwinismus (Selektionsprinzip) als auch des Lamarckismus (Prinzip der direkten Anpassung), da er ,von der Gültigkeit beider Lehren vollkommen iiberzeugt" ist: sein Eintreten für den Lamarckismus in der vorliegenden Publikation bedeutet daher keinerlei Stellungnahme gegen die Selektionshypothese, erfolgt viehmehr nur deshalb, ,weil von beiden Lehren gerade die lamarckistische hente noch vicle Gegner und nur wenige überzengte Anhänger hat“. Dem Verf. erscheinen „die bisher aufgestellten Lehren über die Entstehung neuer formen im 'Tier- und Ptlanzenreich nicht so sehr als der Abschluss von Forschungsrichtnngen, sondern vielmehr als melur oder minder unfassend begriindete Thesen, deren Prüfung iu einzelnen erst erfolgen muss".

v. Wettstein unterscheidet Organisations- und Anpassungsmerkmale; erstere charakterisieren die Organisationshöhe in der Stufenleiter der Formen und werden von Generation zu Generation erblich festgehalten, letztere dagegen treten unter den Orga- 
nismen derselben Organisationshöhe auf und erweisen sich als Anpassungen an bestimmte (äussere) Faktoren und sind erblich unheständig. Neue Formen können nun durch Abänderung entweder ron Organisations- oder von Adaptionsmerkmalen entsteheu. Den erstern Weg machen Kreuzung und Mutation (de Vries) ,mit oder olme \%uhilfenahme der Selektion" verständlich. Mutation und Kreuzung erklären indes wohl die Mannigfaltigkeit der Organismenwelt, nicht aber die fortschreitende liomplikation in der Organisation. Letztere .,steht nit fortgesetzten Anpassungen an neue Funktionen und neue Lebensbedingungen in einem unverliennbaren Zusammenhange". So werden wir auf die Anpassungsmerkmale hin. gewiesen, hinsichtlich welcher sich Darwinismus und Lamarckismus gerade schroff gegenüberstehen.

Durch eigene eingehende Studien an Phamzen wurde Verf. zu der Überzeugung geführt, „dass in den untersuchten Fällen der Selektion eine nur untergeordnete Bedeutung zukommt," bei der Artbildung vielmehr - im Ptlanzenreich wenigstens - dem lamarckistisehen Faktor der Hauptanteil zufällt, verstanden als ,die Fähigkeit der Individuen, unter den jeweilig herrschenden Verhälmissen zweckmäßjige Veränderungen zn erfithren und die so erworbenen Eigentïmlichlieiten zu vererben". Das erstere Moment, die einfaclie Fähigkeit zur Anpassung ist Erfahrungstatsache, das zweite, die Erblichkeit der adaptiv erworbenen Merkmale, erscheint unserm Autor ebenso sicher. Für die letztere Ansicht werden indirekte und direkte lielege beigebracht, die hier selbstredend nur angedentet werden können. Als indirekte Beweise werden angeführt: die besondere Verbreitungsweise mancher l'tlanzen, die ., in sich gegenseitig ausschliessenden Arealen vorkommen", wobei die vicariierenden Arten an den Grenzen ihrer Areale stets durch zahlreiche Übergangsformen nicht hybrider Art miteinander verbunden sind, welche in ihren Merkmalen ebenso erbliche Konstanz zeigen“, ferner die Existenz ernährungsphysiologischer liassen oder Arten, die 'Tatsachen der sog. Konvergenzerscheinungen und endlich die rudimentären Organe. Direkte Beweise für die Vererbung erworbener Eigenschaften erblickt $r$. Wettstein im Verhalten vieler Microorganismen, speziell der Spaltpilze, bei welchen es mögliclı ist, "durch fortgesetzte, zahlreiche Generationen umfassende Kultur unter bestimmten Vegetationsbedingungen Eigentümlichkeiten herrorzurufen, die erblich festgehalten und erst wieder infolge eines nenen analogen Anpassungsprozesses abgestreift werden," ferner in ähnlichen Erfahrungen mit Hefen sowie in dem Nachweis der Möglichkeit, auch vielzellige Pilze an veränderte Ernährungsbedingungen so anzupassen, dass die erworbene nene Ernährungsweise erblich ïbertragen wird; 
endlich werden noch klimatische und Standortsverschiedenheiten im Bereiche der Blütenpflanzen (Weizen, Lein, Waldbäume. Enzian) herangezogen. Sohin kommt Verf. zu dem Ergebnis, dass „die Fähigkeit des Organismus, die durch direkte Anpassung erworbenen Ligentiimlichkeiten zu vererben, als zutreffend bezeichnet werden kann"(? Ref.).

Das Verständnis für die Wirksamkeit der direkten Anpassung findet man nach v. Wettstein in der Auffassung derselben als ..funktionelle Anpassung". "In der Zunahme oder Erwerbung der Funktionsfähigkeit liegt mithin das Wesen der Anpassung." Da ist die nächste Frage: ändert sich zuerst das Organ und dann die Funktion, oder ist das Umgekehrte der Fall: ., ersteres ist die Voraussetzung der Selektionslehre, letzteres die der Lehre von der direkten Anpassung." Verf. hält beide Geschehensweisen für möglich, meint aber, „dass in der Regel die l'unktion die Ausbildung eines ()rgans, beeinflusst," womit , eine annähernde Erklärung für die individuelle Ampassungsfähigkeit" gewonnen wäre.

lieziiglich der als zutreffend erachteten V'ererbung der adaptiv erworbenen Eigenschaften bietet auch r. Wettstein keinen Erklärungsversuch, sondern muss sich mit dem Hinweis auf die dunklen Tatsachen der Korrelation bescheiden, die „die Beeinflussung der Fortpflamzungsorgane durch adaptive Veränderung somatischer Körperteile ganz gut denkbar" erscheinen lassen (sollen Ref.).

$$
\text { F. r. Wagner (Giessen). }
$$

509 Ziegler, H. F., Ueber den derreitigen Stand der Descendenzlehre in der \%oologie. Jena (G. Fischer). 1902. 54 pag. M. 1.50 .

Von den auf der Naturforscherversammlung in Hamburg 1901 gehaltenen drei Vorträgen ïber den gegenwïrtigen Stand der Entwicklungslehre ${ }^{1}$ ) bringt die vorstehend angezeigte Publikation den zoologischen Teil. Während der botanische Redner (de Vries) im

1) Ref. gebraucht (nach Häckels Vorgange) den Ausdruck „Entwicklungslehre", da die Worte "Descendenzlehre" und "Darwinismus" vielfach synonym im universellen Sinne für Abstammungs- und Zuchtwahllehre verwendet werden, zugleich aber auch in dem beschränkten Sinne, dass Descendenztheorie nur die Abstammungslehre, Darwinismus nur die Selektionshypothese bezeichnet, woraus demn naturgemäß乃 zahlreiche Missverständnisse resultieren. Dass eine schärfere Scheidung dieser Begriffe bei der heutigen Sachlage besonders geboten erscheint, bedarf keiner nähern Begriindung. Die Verwendung des Ausdrucks „Entwicklungs-

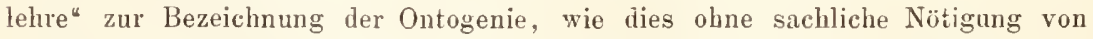
O. Hertwig geschieht (vergl. Handb. d. vergl. u experim. Entwicklungs leh re der Wirbeltiere), ist ein Missbrauch und selbstredend nur geeignet, die Konfusion zu vergrüsseru. 
wesentlichen seine originale Mntationstheorie darbot und der paliontologische Berichterstatter (Koken) seiner extrem nnd zndem eigenartig subjektiv gefärbten lamarckistischen Öberzengung Ausdruck $\left(\right.$ gab $\left.^{1}\right)$, hat Verf. als zoologischer Referent seine Aufgabe wohl am richtigsten aufgefasst, indem er unter tunlichster Ausschaltung alles subjelitiven Beiwerks ein unparteiisches Bild von der hentigen Sitnation der Entwicklungslehre in der wissenschaftlichen Tierkunde zu entwerfen versnchte.

Der ursprïingliche Vortrag erscheint hier in einem durch zahlreiche Literaturnachweise und Belegstellen in Anmerkungen und zudem durch sechs Zusätze erweiterten Gewande. In den letztern setzt sich der Verf. unter anderm mit G. Wolffs angeblicher Widerlegung des Darwinismus und desselben sowie Reinkes Neovitalismns auseinander und widmet dem Iuboisschen Pithecanthropms eine eingehendere Besprechung. Der Vortrag selbst belıandelt nacheinander die Descendenztheorie (Abstammungslehre), den eigentlichen Darwinismus (Selektionshypothese), das V'ererbungsproblem und die Anwendung der Abstanmungslehre auf den Menschen. Selbstredend sind die Darlegungen Zieglers mit Rïcksicht anf die einem Vortrage gesteckten Schranken kur\%, melı skizziert als ausgefülırt nnd beschränken sich auf das wesentlichste in These und Beispiel. Trotzdem sind dieselben klar und leicht verständlich und greben wohl auch, soweit dies auf so engem Raume ïberhaupt möglich ist, eine zutreffende, jedenfalls sichtlich objektir gehaltene Charakteristik des dermaligen Zustandes der Entwicklungslehre anf zoologischem Gebiete, so dass die lileine Schrift zur Orientierung auch weitern biologisch interessierten Kreisen empfohlen werden kann.

$$
\text { F. v. Wagner (Giessen). }
$$

\section{Faunistik und Tiergeographie.}

510 Shitkow, B., und S. Buturlin, Im Norden Russlands. Rericht an die Kaiserl. Gesellschaft ron Freunden der Naturwiss, der Anthropologie und Ethnographie über eine in deren Auftrage ausgeführte Reise ins Archangeler Gouvernement, und die Inseln Kolgujew und Nowaja Semlja im Jahre 1900, Moskau 1901. pag. 1-178. 4 Karten. 2 Tafeln und 11 Abbildungen im Texte (russisch).

Die Verff. besuchten die Mündung der nördlichen Dwina. Das Delta wird beschrieben, die Mïndungsarme Nikolskoje, Pudoshemskoje, Murmanskoje und Beresowoje. Ferner der Arm Maimaksa und der Lapominskaja Hafen. Die Inseln Reuschinskij, Lysunow, Tschaïtschij

1) Vergl. Zool. Zentr.-Bl. IX. Jahrg. 1902. pag. 432. 
und Tshishow - ihre Flora und Fauna wird besprochen, Beobachtungen an der Vogelwelt des Deltas mitgeteilt.

Bei einer Fahrt an den periodisch verschwindenden See Sjamgo wurden Beobachtungen an dessen Ichthyofauna und an jener der Nachbargewässer angestellt. Die Jagdtiere und das Vogelwild der Ungebung wird belrandelt (Alces palmatus Klein, Rangifer tarandus L., Ptevomys volans L., Fetis tynx L., Trtiastes bonasa L., Tetruo wogullus L., Tet. tetrix L., Lagopus albus (im.). Der See liegt im Kreise Onega. Ferner wird genauer eingegangen auf die Togelwelt dieser Gegend, wie sie sich nach reinem Nadelwald, gemischtem Bestand und Ackerland, den Waldtüsschen, den Seeufern verteilt.

Weiter wird die Fahrt nach Kolgujew gerichtet. Ausser rein geographischen Daten wird die Flora und Fauna der Insel besprochen. Lemminge (Myodes) fehlen, aber Camis inlpes L., Cam. lagopas L. leben hier beständig, $C a n$. lupus L. findet sich übers Eis zuweilen ein. Hin und wieder stattet Trsus marimus L. den Ufern einen besuch ab. Wilde Ren (Rumgifer tarandus. L.) fehlen, zahme sind vorlianden. Thoca foetila Fabr., Ph. babata Fabr. und Th. groenlandica Nils. werden an den Ufern gejagt. Trichechus rosmarus L. zeigt sich höchst selten.

Im folgenden Ḱapitel werden die Vögel der Insel behandelt und eine Listeder ron 'Trevor-Batty, P'earson und Feilden, sowie den ron Verff. daselbst gefundenen Arten gegeben. wobei zu den von den frülern Reisenden getundenen folgende durch die Verff. neu hinzugefügt werden: Fulmarus glaciatis L. (nistet aber nicht), Lanus marims L., Sterna macrura Xaum., Sommateria motissima L. (؛); im ganzen werden ó 4 Arten namhaft gemacht.

Ton Nowaja Semlja wird ebenfalls eine Besclureibung verschiedener l'unkte gegeben, die Beröllierung geschildert. Auf den KarmakulInseln gibt es Vogelberge (hauptsächlich ron Tria brïmichi bewohnt); die Durchfahrt Matotschkin Schar, das Flïsschen Matotschka wurden besucht und besclirieden. Von Säugern Nowaja Semljas werden als fuir die Jagd wichtig aufgeführt: Ursus maritimus L., Camis lagopus L., aber selten C'am. vulpes L., Can. Tupus L.; ferner Rangifer. taramlus L. auf beiden Inseln zahlreich; Mlyodes torquatus Pall. und die südlichere Form $M$. obensis Pall.; die umliegenden Meere bewohnen Trichechus rosmarus I., Phoca foetida Fabr., Ph. barbuta Fabr., und Ph. groentandica Nils. An Fischsäugern werden genannt Delphinapterns lencas, Balaenoptera laticeps Gray, Orea gladiator. Bonat. An Fischen werden gefangen Salmo alfims L. (am Westufer, ron der Karischen Pforte bis zum Matotschkin Schar) und Coregoms omml Pall. (in der Karischen Pforte). Eine Liste der er- 
beuteten Stücke und Felle der aufgefïhrten Tiere, die zur Ausfuhr kommen, schliesst das Kapitel. Dann folgt eine speziell über die Avifauna von Nowaja Semlja. Wir nennen hier die beschriebenen Arten, wie sie im Buche der Reihe nach besprochen sind: Tria brïnnichi Sab., Somateria spectalitis L., Stercorarius pomatorhinus Tenm., Cygnus bevicki Yarr., Anser allifions Scop., Tringa alpïna L.; Tr. mimuta Liesl., Larus glaucus O. Fabr., Tringa maritima Brünn., Charadrius hiatiala L.; Otocoris alpestris L., Plectrophanes nicalis L. (sehr gemein), Alle alle L., - alle diese wurden an der BelushjaBucht beobachtet. Bei Malyje Karmakuly wurden gesehen Cepphus mandti Licht. und einige der schon aufgezählten Arten. Eine eingehende Beschreibung wird einem jungen. noch nicht Hüggen Exem. plar ron Otocoris alpestris gewidmet. Hier wird auch Colymbus arctims L. getroffen. Höclıst selten kommt bei Malyje Karmakuly Fratercula arctica L. vor. Aus Mitteilungen einiger angesessener intelligenter Jäger komnte das Yorhandensein von Fuligula nigra L., Fulig. glacialis L., Nyctea niven L., konstatiert werden. Passer domesticus Briss. war zuweilen im Sommer, olne zu nisten, und eines Winters (1899-1000), C'orns comix L. im Sommer 1899 und ebenso 1900 beobaclitet worden. Am Matotschkin Schar: Cepphus mandti Licht., Somateria spectalilis nnd molissima L., zahllose I'ria brïmichi Sab., Larms gluncus Fabr., Stercorarius parasiticus L., Colymbus adumsi Gray, Rissa tridactyla L. (:), Frotercula arctica L. (:); im Tale des Flusses Matotschka: Charadrius hiaticula L., Tringa mavitima L., Hirundo rustica L. (auch friiher beobachtet), Pugophila obunea Phipps., Nyctea niea L., Plectrophanes niralis L. nistet vielleicht zweimal in Sommer hier!); am Meeresufer an der Miindnug: Fuligula fuscu L. und Ful.glaciulis L. Von hier ging es zurück nach Archangelsk.

C. Grevé (Moskau).

\section{Protozoa.}

511 A werinzew, S., Über die Struktur der Kalkschalen mariner Rhizopoden. In: Zeitschr. wiss. Zool. Bd. 74. 1903. pag. 478-490. 'Taf. 24.

Verf. bestätigt die Befunde R h n mblers betreffs der Perforation der Embryonalkammer der sonst imperforierten Peneroplis pertusus. Er beobachtet eine ähnliche echte Perforierung auch in der Enıbryonalkammer der spiraligen Varietät [nicrosphaerischen Ref.] von Orbitolites complanata; bei der einfachen Varietät (megalosphärischen Form, Ref.) war ähnliches nicht zu finden. „Die Porosität der Embryonalkammer ist somit so wenig allgemein verbreitet, dass sie, meiner 
Meinung nach, vorerst keinen Anhaltspunkt für die Ableitung der Inperforata von ursprünglich perforierten Formen bilden kann." [In dieser Richtung werden sich wohl auch kaum Anhaltspunkte finden lassen, da eine derartige Ableitung wegen der im allgemeinen viel höher stehenden Organisation und dem rorwiegend spätern paläontologischen Erscheinen perforater Formen von vornherein unwalıscheinlich und auch meines Wissens nach ron keiner Seite behauptet worden ist. lief.]

Die Untersuchungen des Verfs. erstrecken sich dann vorwiegend auf die Microstruktur der Schalenwandsubstanz, wobei aus den imperforaten Formenkireisen ausser T'eneroplis noch Orbiculina, ferner eine Miliolina, und rou perforaten Formen ausserdem Polystomella, Discorbina, Operatina und Hastigerina einer eingehenden microskopischen Prüfung unterworfen werden. Teils wurden in Wasser eingebettete Schalenbruchstiicke oder Dïnnschliffe oder getrocknete Schaknsplitter in zähem Kanadabalsam ohne weiteres untersucht, teils wurden die Schalen einer Vorbehandlung unterworfen, nämlich auf höhere Temperatur erhitzt, oder nach einer Anweisung Bïtschlis in Jodkalium (Schmelzpunkt bei $634^{\circ}$ (') eingeschmolzen, das vor der Untersuchung wieder aufgelöst wurde, oder die Schalen wurden entkallit. Irgend eine der genannten Methorlen oder auch gleichzeitig mehrere von ilınen liessen bei ausreichender Vergrösserung iiberall eino wabige oder eine globulitiscli-wabige oder globulitische Struktur. mit allen von Bitschli auch bei andern organischen und anorganischen kolloidalen und sphäıo-kristallinischen Abscheidungsprodukten konstatierten Kombinationen und Besonderheiten -, mit ausreichender Sicherheit erkennen.

Eine Behandlung der entkalkten Schalenhaut von Peneroplis mit Millons Reagens sowie die Xantloproteinrealition zeigten, dass die organische Grundmasse der Schalensubstanz ein Albuminoid sein muss, also nicht etwa aus ('hitin besteht.

In polarisierten Licht verhielt sich jede Einzelkammer (als Ganzes) ron Globigerina bulloides, Hastigerina, Discorbina sps., Planorbulina mediterranea, wie ein einheitlicher. negativer Sphärokristall mit gan. regelmäßigem schwarzen Kreuz. das nur bei Heterostegina der Längsrichtung der Kammern entsprechend verzert war, während die Gesamtschalen ron Orbitolites und Peneroplis ron der Breitseite betrachtet dagegen optisch positiven Sphärokristallen (mit allerdings nur wenig scharf hervortretendem schwarzem Kreuz) glichen, wie durch Anwendung des Gipsplättchens erster Ordnung an der Farbenverteilung gut erkennbar war. Bei Orbitolites liess sich an Dïnnschliffen konstatieren, dass sich die konzentrischen Kammerwïnde optisch unge- 
kehrt verhalten wie die radiär gerichteten. Daraus folgt, „dass die optischen Achsen in den verschiedenen Schalenbestandteilen nicht stets gleich orientiert sind, dass raher der optische Gesamtcharakter der Schalen jedenfalls ein Ergebnis der vorherrschenden Richtungen ist". Es darf daher auch nicht geschlossen werden, dass die kohlensaure Kalksubstanz von Peneroplis und Orbitolites ron umgekehrt optischem ('harakter sei, wie die der übrigen; es wird sich viehmehr nur um eine andere Anordnung ihrer Elemente handeln.

Als Gesamtergebnis der in B iitschlis Institut ausgefuihrten Arbeit erscheint hiernach folgendes: Die Microstruktur der kalkigen Foraminiferenschale ist eine direkt wabige oder wenigstens eine von nrspringlicher Wabenstrulitur ableitbare globulitische, aber die Strukturclemente sind nicht immer gleich gelagert.

L. Rhumbler (Göttingen).

\section{Spongiae.}

12 Cotte, J., I Les Éponges élaborent-elles de l'Amidon? In: Compt. rend. Soc. Biol. Paris. lid. 55. 1903. pag. 674-676. (Bull. mens. Réun. Biol. Marseille. Bd. 2. pag. 4-46.)

Viele Autoren haben angegeben, dass in Spongien Stärke vorkomme. Nicht wenige Spongien leben symbiotisch mit Algen. Die Untersuchung solcher kamn keinen Aufschluss über die Frage nach dem Vorlandensein der Stärke in Spongien geben, weil in diesen etwa vorgefundene Stärke ron den symbiotischen Algen stammen kitun. Cotte glaubt zwar nicht, dass die Stïrke in eine lösliche Form gebracht wird, dann ans den Algenzellen heraus difundiert, und schliesslich im Schwamngewebe wieder in ethte, unlösliche Stärlie verwandelt wird: hat aber bei einer Spongelia beobachtet, dass die Phagocyten die in ihr lebenden Oscillarien auffressen und dann eine Zeitlang - die Stärke jener Algen in sich nachweisen lassen. Untersucht man algenfreie Spongien, so muss man, um Fehler zu rrmeiden. zunächst die Lipochrome mit Ïther-Alkohol ausziehen, weil einige von diesen, gerade so wie lie Stärke, vom Jod blau gefärbt werden. Cotte hat eine grössere Anzahl von verschierlenen Spongienarten und diese zu verschiedenen Jahreszeiten unter Anwendung jener Vorsichtsmaßregel untersucht und gefunden, dass in ihnen keine Stärke enthalten ist. Nur einmal wurde mit dem Jod eine Blaufärbung bei Sponyelia pallescens er'ielt. Ia aber dieser Schwamm, wie erwähnt, gewöhnlich symbiotisch mit Algen lebt, kann dieser Befund die Richtigkeit des Ergebnisses, dass die Spongien keine Stärke erzeugen, nicht erschüttern.

R. v. Lendenfeld (Prag). 
513 Cotte, J., Contribution à l'ótude de la nutrition chez les spongiaires. In: Bull. Scient. France Belg. Bd. 38. 1903. pag. 420-573. 10 Fig.

Diese Arbeit ron ('otte ist keineswegs ein blosser Beitrag zur Kenntnis der Nahrungsaufnahme der Spongien, sondern eine monographische Darstellung ihrer Physiologie, in welcher neben der Nahrungsaufnahme auch die Exkretion, die Pigmente und die allgemeinen chemischen Eigenschaften des Weichkörpers behandelt. werden. Die einschlägigen Arbeiten früherer Autoren sind in selı. vollständiger Weise berücksichtigt, kritisch geprüft und verwertet worden. Die Beobachtungen des Verfassers selbst sind teils morphologisch-cytologische, teils physiologisch-chemische.

Zunächst werden der Wasserstrom und die Einrichtungen besprochen, die ihn erzeugen. Der Wasserstrom geht bei den Bohrschwämmen (Vioa oder (Tiona), die auch zuführende Kammerporen besitzen, geradeso wie bei den andern Spongien, durch die Geisselkammern hindurch. Die Schwingung der Geisseln der Kragenzellen ist eine wellenförmige und führt dazu, dass die festen, im Wasserstrom enthaltenen Teilchen mit den, an den Wänden der rieisselkammern sitzenden Leibern der liragenzellen in Berührung kommen. Ein wesentlicher Faktor bei der Entstehung des Stromes ist der Grössenunterschied zwischen den zufïhrenden Kammerporen und dem austiihrenden Kammernund. Die zuweilen im Innern der Geisselkammern höherer spongien und des Gastralraumes der Asconiden rorkommenden \%ellen oder Zellgruppen sind Elemente des Schwammes, welche, wenn derselbe abstirbt, ansgestossen werden und so in jene Ilohlräume gelangen.

Die A ufnahme der Nahrung wird bei den Spongien von den Kragenzellen besorgt, welche dabei wie festsitzende Phagocyten furktionieren. ('otte hat die Aufnahme ron Bruchstiicken von Stärkekörnern und von Bakterien durch die Kragenzellen beobachtet. Er benützte zu diesen Fütterungsversuchen fein zerriebene Reisstärke und einen in Glukose, l'epton und Meerwasser kultivierten Bacillus mesentericus. Die Kragenzellen strecken platte, pseudopodienartige Fortsätze nach diesen, durch die Geisselbewegung an sie herangebrachten Körper aus und nehmen sie in grosser Menge in sich auf. Der Verfasser glaubt aus diesen Beobachtungen den Schlıss ziehen zu diirfen, dass sich die Spongien grossenteils von kleinen, festen. im Wasser schwebenden Körpern nähren. Die Verdauung der von den líragenzellen aufgenommenen Nahrungsteilchen ist eine intracelluläre. Sie wird bei den Kalkschwämmen von den Kragenzellen selbst besorgt. Bei den Silicea sind wahrscheinlich die Zellen der 
Zwischenschicht. an welche die Kragenzellen die aufgenommenen Nahrungsteilchen abgeben, die eigentlich rerdanenden Elemente. Die Verdauung wird durch ähnliche Diastasen. wie sie bei andern Tieren vorkommen, bewirkt. Die Diastasen einiger Spongien machen die Milch gerinnen, ein Prozess, der durch Zusatz von etwas Chlorcalcium beschleunigt wird. Eiweisskörper werden von allen Spongien, die cotte untersucht hat, durch das Suberipsinferment gelöst. Dieses ist eine Art Trypsin und wird ron 'Tyrosin ohne Tryptophan erzeugt. Ënige spongienarten scheinen Pepsin zu besitzen, welches jenem basophilen Fermente beigefügt ist. Kohlehydrate (Stärke, Zucker) und lette werden von vielen Spongien gelöst. Laccase ist nicht nachweishar, wohl aber Tyrosinase. Die (iemmulae von Suberites dommunculd üben eine kräftigere. oxydierende Wirkung ans. als der ausgebildete Schwamm.

Cotte hat nachgewiesen, dass die spongien einen sehleim absondern, welcher dem schleim anderer Tiere sehr ähnlich ist. Kr uekenbergs Angaben über die Beziehungen zwischen den Lipochromen und dem ('holesterin werden bestätigt. Vielleicht kommen neben den Lipochromen auch kleine Mengen ron Lecithinen vor.

Die verschiedentlich als Körnchenballen, Knollenzellen, Rosettenzellen, Kugelzellen, ('ystencytes. ('hondrencytes. Collencytes, Thésocytes und Cellules sphèruleuses bezeichneten Elemente der \%wischenschicht, betrachtet cotte als ein und dasselbe nnd beniitat für alle den Namen Cellules spheruleuses. Er ist der Ansicht, dass diese Elemente Drüsenzellen sind. Sie entstehen aus Wanderzellen, füllen sich mit Tröpfchen oder Kügelchen des Sekrets und werden schliesslich vom Schwamme ausgestossen. Dieser, schon früher in einzelnen rällen beschriebene Prozess der Ausstossung ist ron Cotte nun genau verfolgt worden.

Stärke nnd Glykogen fehlen den Spongien, dagegen scheint Limiera simulans Butter- und Ölsäure zu enthalten. Der beim Stoffwechsel zur Ausscheidung gelangende Stickstoff wird grossenteils in Ammoniakverbindungen ausgestossen. Freie Cholinbasen wurden nicht beobachtet. Die unbrauchbaren Nahrungsreste werden auf verschiedene Art beseitigt. Die Kragenzellen geben sie unmittelbar an das die Geisselkammern durchströmende Wasser ab. Diejenigen, welche in die Zwischenschicht gelangen, werden grossenteils durch die Grundsubstanz, eine Anzahl auch durch die Wanderzellen und Cellules sphèruleuses zu den Kanalwänden gebracht und dort ausgestossen.

Insofern sie keine Stärke bilden, gleichen die Spongien den andern Tieren. Ihre intracelluläre Verdatuung sowie ihre allgemeinen Bauverhältnisse weisen darauf hin, dass sie am untern Ende 
der Stufenleiter der Tiere „à côté des Coelentérés proprement dits" einzureiken sind. In der Grundsubstanz finden zwei Strömungen statt, eine das Wasser und die darin gelösten Stoffe von den Wänden des Kanalsystems in sie hineintragende, centripetale; und eine, die Ausscheidungsprodukte. Kugelzellen etc. zn den Kanälen hintragende, centrifugale. Die Energie dieser Strömungen ist veränderlich. Zuweilen haben sie den (harakter von osmotischen Diffusionsströmen und sind damn bloss von der ()bertlächenspannung ablï̈ngig, zuweilen werden sie aber von vitalen Einwirkungen, ron Zellenliontraktionen beeinflusst. Viese Strömungen entspreehen den Strömungen des Chylus, der Lymphe und der Exkrete der höhern Tiere. Die Grundsubstanz der Spongien könnte daher gewissermafien als die phylogenetische Grundlage angesehen werden, von welcher ans die Organsysteme, in denen sich bei höhern 'Tieren jene Stoffe bewegen, entwickelt worden sind. "Rendons permanents les courants qui traversent la substance fondamentale des Spongiaires, recourrons de cellules les cavités qu'ils traresent, et nous aurons réalisé la disposition qui se montre chez les Coelomates les plus évolnés". R. v. Lendenfeld (Prag).

514 Ijima, I., Studies on the llexactinellida. III. (Placosome, a new Euplectellid: Leucopsacidae and (aulophacidae). In: Journ. Coll. Sei. Tniv. Tokyo. Bd. 18. Art. 1. 1903. $12+$ pag. 8 Taf.

In dieser Arbeit beschreibt $\mathrm{Ij}$ ima eine nene, massige, auf schlankem Stiele sitzende Euplectellide und stellt für sie das Genus Plucosoma auf. Hieran schliesst er eine Besprechung der Familie Euplectellidae und schlägt eine neue Diagnose für sie vor. Fïr einen 'Teil der frïher ron ilm in der Lnterfamilie Leucopsacinae vereinten Formen stellt er num. wegen der Besonderheiten ilures Dermalskelettes, eine eigene Familie, Leucopsacidae, auf und gibt eine Diagnose derselben. Aulocalys und Euryplegma sollen aus dieser Gruppe und überhaupt aus dem Rossellidenformenkreise ausgeschieden, und zu der dictyoninen Familie Dactylocalycidae gestellt werden. Dre zwei ron ihm früher schon anfgestellten Lencopsucus - Arten werden nochmals beschrieben. Über die Larven, welche er in einer derselben fand, macht Ijima genauere Angaben. Diese Larven bestehen vermutlich aus einer cylinderzellenlage an der Oberfläche und einer dichten Masse von Zellen im Innern. Zellgrenzen sind zwisehen den letztern nicht nachweisbar. ihre Kerne aber sind deutlich. Diese Larven dürften aus den von ihm schon früher beschriebenen "Archaeocyten" - Haufen hervorgehen. Die ersten Nadeln, die in den Larven auftreten, sind Stauraetine (Vierstrahler) und nicht Hexactine, wie man a priori hätte er- 
warten sollen. Die Stauractine liegen paratangential im oberflächlichen 'Teile der zentralen Zellmasse, in einer Schichte. Ihre Strahlen krümmen sich beim Längenwachstum so, dass sie die konvexe Seite nach aussen gegen die ebenso konvexe Oberfläche der Larve kehren. Die älteste beobachtete Larve war kugelig und hielt $100 \mu \mathrm{im}$ Durchmesser, die Strahlen ihrer Stauractine waren mehr als halb so lang als das. I jim a beschreibt auch die früher von ilım aufgestellten Chaunoplectclla-Arten sehr eingehend. Er ist der Ansicht, dass die Familie Asconematidae aufgelassen werden und ihre Angehörigen unter die Rossellidae und die neue Familie CauIophacidae aufgeteilt werden sollen. In der letztern bringt er die Gattungen Caulophacus, Aulascus und Sympagella unter. Die beiden letztgenannten werden miteinander vereint. Die systematischen Merkmale der hierher gehörigen Spongien werden in eingehend kritischer Weise behandelt nnd es wird eine Liagnose der neuen Familie gegeben. Ton Canlopharns und Sympagella wird je eine neue Art heschrieben. Am sichlusse werden die systematischen Anschaumgen Schrammens einer liritik unterzogen und die Tatsache festgestellt, dass die in der vorliegenden Arbeit aufgestellte neue simmpagellaArt (S. anomala) dem kürzlich von l’. E. Sichulze unter dem Namen Culyeosoma grarile beschriebenen Schwamme ungemein nahe steht. li. r. Lendenfeld (Prag).

515 Lendenfeld, R. v., T'etraxonia. Das Tierreich. 19. Liefg. Berlin (Friedländer) 1903. 168 pag. 44 Fig.

Das Manuskript für diese, jetzt erschienene Lieferung des Tierreiches ist in 1899/1900 gesehrieben worden und es ist demzufolge die Literatur nur bis Mitte 1900 berücksichtigt. Als T'etraxonia werden im allgemeinen diejenigen nicht hexaktinelliden Silicea (Incalcarea) angesehen, welche tetraxone Megasclere besitzen. Von Sprongien olne solche Xadeln wurden die skelettlose (Iscarellu suwie liejenigen Lithistiden zu den Tetraxonia gestellt, welche keine vierachsigen Nadeln haben. ()scarella hält der Referent für eine zweifellose Verwandte der Plakiniden, die dort stehen muss, wo diese untergehracht werden. Die tetraxonlosen Lithistiden aher hat er nur aus Opportunitätsgründen den Tetraxonia eingereiht und liält Schrammens Anschauung, nach welcher sie aus dem Formenkreise der Tetraxonia auszuscheiden und zu den Monaxonia zu stellen wären, für eine wohl begründete. Innerhalb der T'etraxonia werden die beiden bekannten Ordnungen Tetractinellida und Lithistida unterschieden. Die erstern zerfallen in drei Unterordnungen: Astrophora, Sigmatophora und Megasclerophora. Die don Te- 
tilliden ungemein nahe stehenden (von Sollas teilweise sogar mit ihnen vereinten) microsclerenlosen 'Tethyopsilliden, für welche der Referent früher die Gruppe Megasclerophora aufgestellt hatte, werden jetzt, als Familie, den Sigmatophora einverleibt. Die, die Plakiniden und Oscarclla umfassende Gruppe, welche er frïher Microsclerophora genanut hatte, erscheint jetat unter dem Namen Megasclerophora, weil der Referent zu der Ansicht gelangt ist, dass die Nadeln dieser Spongien, wenngleich microscler in bezug auf die Grösse, doch nicht als Microsclere in dem jetzt gebrïuchlichen Sinne des Wortes angesehen werden können, sondern den Megascleren anderer T'etraxonia gleichzustellen sind. Die L it h is t iden werden in die bekannten Gruppen Hoplophora und A noplia eingeteilt. Im ganzen werden 2 Ordnungen, 5) Unterordnungen, 17 Familien, 48 sichere und 1 fragliches Genus, 320 sichere Arten, ron denen 2 in 10 Unterarten zerfallen. und 66 unsichere Arten unterschieden. Die strenge Anwendung der Nomenklaturregeln lat es notwendig gemacht, an Stelle des Gattungsnamens Cramiella, Tethya zu setzen, Papyrula in anderm Simne wie fiulıer zu gebrauchen und noch einige andere Namen zu änderu: so muss die bekanute, grosse, adriatische Geodie Geodia mïlleri (statt G. cydomium), die strlletta dorsiggra St. boglicii heissen, und dergleichen mehr.

In der Einleitung werden der Bau der Tetraxonia kur\% geschildert und eine ansführliche, reich illustrierte liste der bei denselben vorkommenden Nadelformen mit den für sie angewendeten Namen gegeben. Einige ron den Abbildungen sind Originale, welche, wie die Zeichnungen der Sterraster, ein genaueres Bild ihrer Gestalt geben als die früher rom lieferenten und andern veröffentlichten Abbildungen.

R. v. Lendenfeld (Prag).

516 Urban, F., Teber das Dermalepithel der Kalkspongien. In: Verh. Ges. D. Naturf. u. Aerzte. (7t). Jg. 1902. Teil 2. pag. 159. 1903.

Urban hat das äussere Epithel eines kalifornischen, der $\mathrm{Ho}_{0}$ mandra ähnlich gebauten Kíalkschwammes genauer untersucht. Die Zellen, welche dasselbe zusammensetzen, sind zum Teil langgestreckt, wie die ron Bidder als Flaskzellen beschriebenen Elemente, zum Teil niedriger und mehr paratangential ausgebreitet. Ihres innern Baues wegen hält der Verf. diese Zellen für Drüsenzellen, nicht für kontraktile Elemente, und er glaubt, dass die Unterschiede ihrer Gestalt darauf beruhen, dass die einen (niedrigen) erst anfangen Sekret in sich aufzuspeichern, die andern (höhern) aber sich anschicken, das in ihnen angesammelte Sekret nach aussen zu entleeren. Urban lat dieselben Elemente auch bei vielen andern Kalkschwämmen gefunden 
und hält es für nicht unwahrscheinlich, dass sie die Exkretionsorgane ler Spongien seien.

I. v. Lendenfeld (Prag).

\section{Vermes.}

517 Rizzo. Agostino, La fanma elmintologica dei rettili nella provincia di Cat ania. In: Arch. parasitol. T. VI. 1902. pag. 26-41. c. 11 fig.

Unter den beobachteten 30 Arten, welche in Reptilien Catanias leben, wird ausführlicher beschrieben: Anchitrema mutabile (Mol.) aus der Gallenblase von Lacerla agitis und .1scalabotes mauritanicus, und Distomum acerrocalcifcrum Gast., welche Art bisher nur encystiert aus liana csculcntu bekannt war; sie wird im hintern 'Teile des Jarmes von Tropidonotus, natrix reif. Nen sind Oryuris anmulate aus dem Darm von Ciongylus occllatus, Strongylus catancnsis aus der Lunge vou Tropidonotus nutrix und Coluber viridiflaus, Trichosoma mingazzinii aus dem Enddarm von Tropidonotus natrix, Filaria parromucronata aus der Leibeshöhle von Coluber viridiflavus und eine nicht benannte Strongylide ans dem Darm von lacerte agilis und Lacerta viridis, die wahrscheinlich auch bei Scps chalcidcs lebt. Die beobachteten Helminthen verteilen sich anf 6 'T'rematoden-, 5 Cestoden-, 16 Nematoden- und 3 Acunthocephalen-Arten.

M. Brau n (Königsherg Pr.).

\section{Plathelunintlies.}

518 Ariok. V.. Contributo per un a monografia de Didymozoon. I. Dirlymozoon, parassiti del tonno. In: Arch. parasitol. 'T. VI. 1902. pag. 99-108. 11 Fig.

Es gibt wolnl keine 'I'rematodengruppe, die so wenig bekannt ist wie die von 'I'aschenberg als Didymozoon bezeichneten Formen, welche parweise in Cysten auf der Körperoberfläche oder au den Kiemen mariner Fisclie leben. Unter den hei Thynmus vorkommenden unterschied schon W a gener 1858 drei verschiedene Formen, denen er den von Wedl 1855 gegebenen Namen (Monostoma bipartitum) beliess. Wie der Verf. zu begründen versucht, handelt es sich in ilınen nicht nnr um verschiedene, auclı durch ilıren Befestigungspunkt siclı unterscheidende Arten, sondern auch um Vertreter verschiedener Gattungen. Für die zweite Form W a gener's, das Didymozoon thynni T'schbg. (abgebildet in Trematodes, Bronns Kl. u. Ord. d. Tierr. Taf. XXVI. Fig. 6 E) wird die neue Gattung Didymocystis aufgestellt (D. reniformis n. $110 \mathrm{~m}$.) und ihr noch eine an den Kiemenblättchen selbst lebende Art, die dritte Form Wageners (abgebildet in Trematodes 1. c. Fig. 6D) als Didymocystis uedli n. sp. eingereilht. Monostoma bipartitum Wedl =.Won. micropterygis Rich. 1901 (- erste Form Wageners, Fig. 6 B und 7 bei Bronn) wird Didymostoma bipartitum (Wedl) genannt - sie lebt auf den vordern und hintern Kiemenanhängen bei Thynnus vulgaris, Eine vierte und zwar neue Art ist Didymozoon prctiosus (!), anf den Kiemenbögen von Thynnus vulyaris in länglichen Cysten lebend und bisher nur einmal vom Verf. in Neapel gefunden. Der Verf. hat eine Charakteristik der Gattungen leider unterlassen, und so wird man weitere Mitteilungen abwarten müssen, ehe man sich ein Urteil bilden kann.

M. Braun (Königsberg Pr.).

519 Bossuat, E., Les helm inthes dans le foie. In: Arch. parasitol. T. VI. 1902. pag. 161-206 (avec 13 Fig.).

Ausgehend von einem genau geschilderten Funde von larvalen 'Tetrarynchen in der Leber von Orthagoriscus mola, für welche der 
alte, kaum je in Gebrauch gewesene Name Floriceps saccatus Cuv. hervorgeholt wird, bespricht der Verf. andere Helminthen. welche die Leber ihrer Wirte bewohnen; er unterscheidet hierbei normal in der Leber vorkommende und verirrte Arten und gruppiert die ersteren, je nachdem sie sich in der Leber als Larven oder als erwachsene T'iere vorfinden. Der Verf. berücksichtigt auch die Veränderungen in dem befallenen Organ, welche durch lie Parisiten bedingt werden. ohne freilich hierbei Vollständigkeit zu erreichen - so fehlen z. I;. die Beziehungen zwischen Lebercarcinomen und Opisthorchis felinens, welche Askanazy hierorts festgestellt hat, auch schreibt Verf. dem Ref. zu, die ron Winogradoff in der Leber des Menschen zuerst beobachteten Egel als eine neue Species betrachtet und sie Distommm. sibiricum genannt zu huben, während in Wirklichkeit dieser Nanı ron Winogradoff stammt und Ref. die Identität der sibirischen Form mit dem zuerst aus Italien bekannt gewordenen Distomum felinemm nachgewiesen hat. Der Schwerpunkt der vorliegenden Arbeit liegt jedoch in der Beschreibung des Floriceps succutus, der, wie Moniez 1891 feststellte, in einem Hai (Oxyrhina) gesclileclitsreif wird. Trotz der Massenhaftigkeit des Auftretens des Floriceps bei Orthagoriscus, wo er stets im Leberparenchym, nie in den Blut-oder Gallengefässen gefunden wird, sind die von ihm bedingten Störungen geringfïgigerer Natur und beschränken sich auf die Ausbildung einer Cyste sowie auf eine stellenweise auftretende Wucherung des Lebergewebes. Die ïberwiegende Mehrzahl der als Larven die Leber bewohnenden Helminthen gelangen in dieses (Irgan durch die Vena portarum, die geschlechtsreif vorkommenden Arten dagegen durch die Gallenwege.

M. Braun (Königsbergr Pr.).

520 Cohn, Ludwig. Zwei neue Distomen. In: Ctrbl. f. Bact., Par. u. Inf. I. Abth. Orig. XXXII. 1902. pag. 877-882 mit 5 Abb.

Beide neue Arten sind auch Vertreter neuer Gattungen; die eine derselben (Liolope copulans n. g. n. sp. aus Magen und Darm von Cryjtobranchus japonicus) kann den Harmostominen eingereiht werden, wenngleich der Verlauf des Uterus ein anderer ist als bei Harmostomum. Von besonderm Interesse ist, dass der Verf. ein Pärchen in Copula gefunden hat, derart, das der Cirrus des einen Individuums in den La ure rschen Kanal des andern eingeführt war. Dass es sich hier um eine wirkliche Kopulation gehandelt lıat, dürfte aus dem Umstande sicher sein, dass alle untersuchten Individuen bis auf eins Eier im Uterus noch nicht führten.

Die zweite Art (Leptophyllum stenocotyle n. g. n. sp.) entstammt dem Enddarm eines alten Sammlungsexemplars von IIcrpetodryas fuscus (Siidamerika); die trotzdem gut erhaltene Organisation der ganz platten, nur wenig über $1 \mathrm{~mm}$ lang werdenden Tiere veranlasst den Autor, diese Gattung in die Nähe von EnodioIrcma zu stellen, womit jedoch die Verwandtschaft kaum richtig ausgedrückt ist.

N. Braun (Könıgsberg Pr.).

- Nr. 519-5:0. 
521 Goldschmill, Richarl, Über Lau und Embryonatentwick I ung von Zoogonus mirus Lss. In: Ctrlbl. f. Bact, Par. u. Inf. I. Abth. Orig. XXXII. 1902. pag. $870-876$. 6 Abb.

Verf. machte seine interessanten Beobachtungen in der zoologischen Station zu Rovigno, wo er den von Looss zuerst in Labrus merula zu Triest auf'gefundenen Zoogoms mirus wiederfand. Die Untersuchung der Tiere ergab eine erwünschte Ergänzung zu der bisherigen Beschreibung, besonders in bezug auf Cenitalapparat, Darm und Exkretionsblase, die an ihrem Grunde mit einer Lage einzelliger, drüsenähnlicher Gebilde bedeckt ist; es ergab sich ferner, dass der von Odhner 1902 beschriebene Zoogonus: rubellus (Olss.) wohl mit der Loosssclien Art identisch sein dïrfte, welch letatere dann den älteren Namen (rubellux) zu führen lrätte. Vorzugsweise kam es aber dem Autor darauf an, die Embryonalentwicklung zu studieren, die trot\% der schönen Arbeit von Schauinsland noch viele dunkle I'unkte birgt. Den aus dem Keimleiter in den Uterus iibertretenden und mit einem Dotterkern versehenen Eizellen hängt sich auf diesem Wege ein Spermatozoon an; dann stossen zu ihnen paarweise miteinander verschmelzende Zellen, die aus dem Iotterstock stammen, jedoch der Dotterkörnchen entbelıren; ein solches Zellenpaar legt sich einem Pole der ovalen Eizelle an und umwächst von hier aus mit einer diinnen l'lasmalage die Eizellen, deren Hiillmembran bildend (!). Nach Findringen des Spermatozoons und Zerfall des Dotterkernes stösst die kizelle zwei Richtungskörperchen ab: dann vereinigen sich Samen- und Eikern und die Furchung beginnt, während die bis dahin an dem einen Eipol nachweisbaren Kerne der verschmolzenen Dotterzellen an den Ïquator des Eies nach gegeniiberliegenden Stellen sich begeben. Die Furchungszellen sondern sich in eine ohertlächliche Lage kubischer \%ellen (Ektoderm) und das nur aus wenigen Zellen bestehende Entoderm. Von ersterem wachsen neun Zellen in die lireite und werden plattenförmig; ihre Kerne sind gross und ehromatinarm. Acht von ihnen geben die spätere Epidermis des Miraeidiums, die neunte, polständige hat mehr zapfenförmige Gestalt und zeigt das Vorderende an (Rüsselzelle). Die iibrigen Ektodermzellen bleiben klein und liegen mit ihren chromatinreichen Kernen vorzugsweise an den Polen des Kernes, von wo sie in einem Strange nach innen wandern; die wenigen Entodermzellen sondern sich in zwei Gruppen: eine aus etwa vier \%ellen bestehende bildet den Mitteldarm, die andere, zwei Zellen enthaltende die Urgeschlechtszellen. Aus der vordern Ektodermeinwanderung entsteht der Vorderdarm, aus der hintern der Exkretionsapparat; andere vom Ektoderm vorn und hinten sich einschiebende Zellen mit kleinen 
Kernen geben das Mesenchym, drei andere, dorsal gelegene das Ganglion. Das fast reife Miracidium, das in der von den Dotterzellen herrührenden Hüllmembran eingeschlossen ist, besitzt also eine aus acht platten \%ellen bestehende Epidermis, während die neunte, dorsal über der Mundöffnung gelegene, den einzelligen Rïissel darstellt. Am Darm unterscheidet man den Vorderdarm mit einer Anzahl Retraktorund Drüsenzellen, sowie den etwa kubischen Mitteldarm: hinter diesem liegen die beiden Exkretionsorgane, die, abweichend von dem Verhalten der Miracidien anderer Arten, einen gemeinschaftlichen, am Hinterende mündenden sammelgang besitzen. In der Furchungshöhle finden sich nur wenige Iesenchymzellen, die meisten liegen tler Innentläche der Epidermis an. Zwischen den Exkretionsorganen trifft man die beiden Urgeschlechtszellen und dorsal rom Mitteldarm das Ganglion.

II. liraun (Königsberg I'r.).

522 Hollack, Johanne, \%ur Kenntnis der sexuellen Amphitypie bei Dicrocoeliinen. In: ('trlbl. f. Bact., Par. u. Inf. I. Abtl. Orig. XXXII. 1902. pag. 867-869.

Die Verf. hat 666 Exemplare von Dicrocoelium lanceutum st. et Hass. (= Distomum lanceolatum Mehl.) in bezug auf Amphitypie der Genitalien untersucht und in genau der Hälfte der Fälle den vordern Hoden rechts vom Uterus, den hintern Hoden und den Keimstock links daron gefunden; man kann daher hier nicht, wie in allen andern bisher bekannten Fällen, die zusammengestellt werden. ron einer Majorität und Ninorität, resp. einer Norm und einem abnormen Verhalten reden. Amphitypie der Genitalien ist dann noch bei Distomum mutabile Mol. und Dicrocoelium concinum Brn. konstatiert worden; sie kommt ausser bei Dicrocoeliinen noch bei Opisthorchiinen und einigen andern Formen vor.

II. B raun (Königsberg Pr.).

523 Looss, A., Die Distomen-Unterfamilie der Haploporinae. In: Arch. parasitol. T. VI. 1902. pag. 129-143 mit Textfig.

Die vier neuen Gattungen der ebenfalls neuen Unterfamilie umfassen sieben Arten, von denen nur eine, Distomm benedemi Stoss. (1587) bisher bekannt war. Alle Arten, die sich wegen ihrer sehr geringen Körpergrösse den bisherigen Untersuchern entzogen haben, bewohnen den Darm von Mugil-Arten der Adria, in denen noch Distomum pachysomm Eysenh., der Vertreter der Gattung Haplosplanchmus, und das zu den Allocreadien gehörige Distomum brusinai Stoss. lebt. Die II a ploporinen sind kleine, resp. sehr kleine Fascioliden, deren Vorderleil, flach ist, während der Hinterkörper 
einen kreisrunden Querschnitt zeigt. Besonders im Vorderende ist die Cuticula von zahlreichen, feinen und schlanken Stacheln durchsetat. Die beiden Saugnäpfe sind kräftig und verhältnismäßjig gross: Pharynx und Ösophagus vorhanden, Darmschenkel weit, aber kurz; Exkretionsblase sackförmig. Genitalporus in der ventralen Mittellinie dicht vor dem Bauchnapf gelegen; Fndteile der Geschlechtswege in einen voluminösen, anscheinend nicht muskulösen Beutel eingeschlossen (Pseudocirrhusbeutel), der in das verlängerte, mit Längsund Ringmuskeln versehene Genitalatrium mündet. Stets ist nur e in ziemlich grosser Hoden vorhanden, der in der Regel links liegt doch kommt anscheinend bei allen Arten auch gelegentlich Amphitypie, also rechtsseitige Lage des Hodens vor; der sehr kleine, sackförmige Keimstock liegt stets median und vor dem Hoden; ein Receptaculum seminis fehlt stets, dagegen dürfte der Laurersche Kanal allen Arten zukommen. Sehr schwach sind die paarigen Dotterstöcke ausgebildet; sie liegen in der Höhe der Schalendrüse. Der dünnwandige Uterus füllt den Hinterkörper fast vollständig aus. Die Eier sind verhältnismäßig gross, sehr dünnschalig und bei vier Arten sicher von einer hyalinen Gallerthïlle ungeben, die roraussichtlich auch den Eiern der drei andern Arten nicht fehlen wird. Stets enthalten die reifen Eier ein bewimpertes, bei einigen Arten mit AugenHecken versehenes Miracidium.

Die vier Gattungen sind am leichtesten an dem verschiedenen Verhalten der Dottersäcke auseinander zu halten, die bei einer Gattung (Dicrogaster n. gen.) so dicht beisammen liegen, dass ihre \%wcizahl nicht ohne weiteres zu erkennen ist, während bei den drei andern der paarige Aufbau der Dotterstöcke gleich zu sehen ist; bei der einen (Haploporus n. gen.) liegen sie innerhalb, bei den beiden andern ausserhalb der Darmschenkel und sind bei Succocoetium n. gen. unregehäßig dreieckig, schwach eingekerbt, bei Lecithobotrys n. gen. in sieben deutliche Follikel zerfallen. Dazu kommen noch weitere Unterschiede in anderen Organen.

Von Lecithobotiys ist bisher nur eine Art (L. putrescens n. sp.) bekannt, deren Niracidien Augentlecke besitzen; die andern Gattungen sind durch je zwei Arten vertreten. 'Typus von Dicrogaster wird D. perpusillus n. sp. (Miracidien mit Augenflecken); ihm schliesst sich eine zweite Art (D. contractus n. sp.) an, deren Miracidien Augen nicht entwickeh. Distomum benedeni Stoss. wird Typus der Gattung Haploporus: die andere etwas schlankere Art bekommt den Namen H. Iateralis n. sp.; auch hier unterscheiden sich beide Arten dadurch, dass die Miracidien des Typus Augenflecke besitzen, die der andern sie entbehren. Von den beiden Saccocoelium-Arten wird der häufigere 
(S. obesum 11. sp.) zum Typus erhoben: ilıe Niracidien sind ebenso wie die der zweiten Art (S. tensum n. sp.) mit Augen versehen.

Alle Arten sind abgebildet und zum grössern Teil nicht nur in Rïcken-, sondern auch in Seitenlage.

\section{Braun (Königsberg Pr.).}

524 Markow, Mich., Sur le nouveau représentant du genre Prosthogonimus - Pr. anatimus n. sp. Charkow 1902. 8 ${ }^{0} .11$ pag. 1 'Taf. - Sep. Abdr. aus: Arb. d. nat. Ges. b. d. Kíais. Inir. Charkow. 'T. XXXYII. Russ. mit franz. Resumé.

Diese in der Bursa Fabricii ron Hausenten zu Charkow gefundene neve Art des Lüh eschen Genus Prosthogonimus schliesst sich in der Körperform an Pr. oratus (liud.), in der Anordnung der innern Organe mehr an Mr. japonicus Brn. an. Wie hier liegt nämlich der stark gelappte lieimstock hinter dem recht grossen Banchmapf, noch weiter nach hinten symmetrisch die beiden ovalen Hoden nnd in deren Höhe die verhältnismäßig kleinen Dotterstäcke nach aussen ron den bogenförmig ziehenden Darmschenkeln. Der Genitalporus findet sich neben dem Mundnapf auf einer vorspringenden Ecke, die auch bei der japanischen Art ausgebildet ist. Eigentümlich ist der neuen Art die geringe Entwicklung des Uterus im Hinterleibe, wo kaum die Darmschenkel überschritten werden, welch letzteres Merkmal wieder an Proxthogonimus rarus Prn. erinnert, der aber wieder schon durch die 'Tremung der weiblichen ron der männlichen Geschlechtsöflnung von Pr. anatima abweicht. Der Verf. hat auch die Exkretionsblase beobachtet, welche sich vorn in zwei fast his zum Pharynx reichende Zipfel spaltet, also Y-förmig ist.

M. Braun (Königsberg Pr.).

525 Palona e Monticelli. Sui generi Placunclla e Trochopus. In: Monit. Zool. ital. Ann. Xill. 1902. Suppl. pag. 46-48.

Die Verff. kommen zu dem Schluss, dass die Hesse-van Benedensche Gattung Placunella zu gunsten der ältern Diesingschen Gattung eingezogen und für Placunella rallei eine neue Gattung (Ancyrocotyle) begründet werden muss; es gehören nunmehr zu Trochopus: Tr. tubiporıs Dies., Tr. differens Sons., Tr. lincalus Scott., Tr. pini v. Ben. et Hesse, Tr. rhombi v. Ben. et Hesse und $T_{r} r$. hexacantha Parona et Perugia.

II. Braun (Kürigsberg Pr.).

\section{Nemathelminthes.}

526 Giarl, A.. Evolutions métamorphiques chez les Ascarides des poissons (groupe de l'Ascaris adunca Rud.) In: Compt. rend. soc. biol. 'T. LV. Paris 1908. pag. 677-680. Fig. I-III.

Verf. findet im Darm von Clupea harengus Ascaris adunca Rud., eine Art, welche identisch ist mit $A$. clupeae van Bened. Sowohl Larven wie geschlechts- 
reife Folmen wurden beobachtet, auch in Häutung begriffene Exemplare; die Geschlechtsform trägt am äussersten Schwanzende charakteristische Spitzen. während das Schwanzende der Larve glatt ist, und bei den sich häutenden Larven sieht man unter der glatten Cuticula am Schwanzende, welche demnächst abgestreift werden wird, die der Geschlechtsform eigenen Spitzen.

O. v. Linst ow (Göttingen).

27 Stiles. C. W.. The significance of the recent americain cases of hookworm disease (Uncinariosis, or Anchylostomiasis) in man. In: 18. Annual Report Bur. anim. ind. for 1901. Washington 1902. pag. 183 -219. Fig. 113-196.

Das im Südosten von Nordamerika vorkommende Ankylostomum amcricanum Stiles wird beschrieben und eingehend über die Verbreitung und die durch den Parasiten hervorgerufenen Krankheitserscheinungen berichtet. Das Männchen ist 7-9, das Weibchen 9-11 mm lang; die Bursa des ersteren hat einen kurzen dorsalen, unparren Mittellappen, der von zwei am Ende gegabelten Rippen gestuitzt wird, während die grossen Seitenlappen vier Rippen führen, von denen die erste schmal und die zweite und vierte verdoppelt sind: die Vulva mündet heim Weihchen dicht vor der Mitte.

O. v. Linstow (Göt ingen).

\section{Arthropoda.}

Arachinida.

28 Froggatt, Walter, The Fow l'Tick (Aigas amerieame Packardt). In: Agricult. Gazette of X. S. Wales. Miscell. P'ublic. Nr. 520. 1901. pag. 1-5. Fig. 1-2.

Der Verf. berichtet ron einer Zecke, die im Jahre $1896 \mathrm{zum}$ ersten Male als ein geführlicher Feind der IHülnerzucht in Neu-SüdWales von ('. Fuller in der gleichen Zeitschrift (Vol. 3, pag. 593) aufgeführt wurde. Als Verbreitungsgebiete werden von dem ohen erwähnten Autor Nyngan, Bonrke, Lonth. Deniliquin und Sydney genannt, doch glaubt der Verf., dass bezïglich des letztgenannten Ortes ein Irrtnm obwaltet, da alle ihm zugeschickten Exemplare dieses Schmarotzer's aus dem trockenen Innern des Landes, niemals aber von der feuchten Küuste stammten. Allem Anscheine nach ist die als Hühnerzecke bezeichnete Milbe schon vor längerer Zeit in Neu-SüdWales sowie in andern australischen Kolonien eingeschleppt worden, denn mur so lässt sich ihre weite Verbreitung und ihr massenhaftes Auftreten erklären. Unterstiitzt wird diese Ansicht durch die Tatsache, dass schon im Jahre 1887 Michael lebende Exemplare von Adelaide erhielt, die er jedoch irrtiimlicherweise auf Argas persicus bezog. Eine zweite Sendung von dort kam 1892 in seine Hände. Zwei Jahre vorher hatte sich in Victoria die Zeckenplage für Hühnerhöfe recht verhängnisvoll erwiesen. Da Argas americanus in Nord-Amerika, besonders in 'Texas, heimisch ist, so steht zu vermuten, dass von hier aus die Einschleppung in die australischen Staaten erfolgt ist. Es 
ist dies um so eher anzunehmen, als ja die Handelsbeziehungen zwischen dieseı und den Vereinigten Staaten ziemlich umfangreich sind und ein reger Warenaustausch stattfindet. Packardt lat die Hühnerzecke im Jahre 1873 in Geological Survey von Texas (pag. 740) znerst beschrieben. Welch gefährlicher Schmarotzer Argas umericanus ist, hat jedoch erst C. M. Weed im Jahre 1883 festgestellt. Er erkannte in dieser \%ecke den Urheber der sogenannten Hühnerpest (pest in fowl-yards or to poultry). Kugleich empfiehlt er im .Prairie Farmer" .coal oil" als das beste Mittel, die Hühner von diesen l'arasiten $z u$ befreien. Im Jahre 1893 und 1895 veröftentlichte die Zeitschrift ..Insect Life" (Vol. 5, pag. 267 und Tol. 7. pag. 417) Berichte über den gewaltigen Schaden, den Argas americams auf den Farmen T'exas angerichtet latte. Der Verfasser des zweiten Artikels, Elrhorn, fuihrt in seiner Arbeit einige Beobachtungen über die Lebensgeschichte der Hülnnerzecke an. Er stellte fest, dass die Weibchen ihre Eier in grossen Massen in die Ritzen und Spalten der Wände des Hülınerliauses absetzten. Die Larven und Nymphen schmarotzen dann anf jnngen Hühnern und Kü̈chelchen, auf denen man sie bei 'Tag und Nacht antreffen könnte. Um das Gefligel zu retterl, gebrauchte Elrhorn mit grossem Erfolge "creozozone".

Lounsbury veröffentlichte zwei Arbeiten über das Auftreten und die Verbreitung einer Hühnerzecke im Kapland. Auch diese Form ist höchst wahrscheinlich mit Argas americamus identisch, wenigstens konnte der obengenannte Forscher keinen Unterschied zwischen Exemplaren aus der Kapkolonie, aus Australien und Amerika anffinden. In Südafrika wird die Zecke von den Farmern als .., wand luis" (Wandlaus) oder .ampan" bezeichnet. Lounsbur'y gibt all, dass die jungen Zecken während ihres Larvenstadiums, das etwa fünf Tage dauere, stäıdig auf den jungen Hïhnern schmarotzten. Nach dieser /eit verkröchen sie sich, um sich zu verpuppen. Der Verf. wendet sich nach diesem historischen Überblick der Beschreibung von Argas americanus zu. Die erwachsenen Zecken erreichen eine Länge von einem halben englischen \%oll. Junge Exemplare sehen grau aus, im Laufe der Zeit wird jedoch die Färbung immer dunkler, sich nach und nach abtönend vom hellsten liot bis zunı dunkelsten Braun. Der Rumpf ist oval. Die Rückenfläche zeigt eine geringe Wölbung. Die Haut ist unregelmäßig punktiert und erscheint deshalb etwas runzelig und rauh. Die Mundteile bestehen aus einem Paar kurzer viergliedriger Palpen, die mit einer Anzahl zerstreut stehender Borsten besetzt sind. Auf jeder Seite des Schnabels befindet sich ein Anhängsel, das eine Art Scheide bildet, die sich nach rorn öffnet nnd daselbst mit einem kurzen Haken bewaffnet ist. '/wei weitere 
Haken mit stärkerer Krümmung sitzen am äussern Rande. Das Rostrum ist an der Spitze breit abgerundet. Mit einer deutlichen Mediannalit ausgestattet, trägt es zu beiden Seite der Längslinie je eine doppelte Reihe zurïckgekriimmter, gedrungener 'Zähne. Die Beine sind ziemlich lang; an ihren Endgliedern bemerkt man zwei lange, scharfe Krrallen und ein kleines Polster oder Kissen. Die Geflügelzecke weist :̈hnliche Gewohnheiten auf wie unsere Bettwanze. Des Tags über in dunklen Ritzen und Klingen verborgen, da sie trotz ihrer Blindheit sehr lichtscheu ist, verlässt sie des Nachts ihre Schlupfwinkel, um ihre Beute aufzusuchen und Blut zu saugen. Wie die Wanzen, hält sie viele Monate ohne Nahrung aus. Auf diese Weise iberdanert sie ruhend den Winter. Sie übt ihr Schmarotzertum nur in den lieissen Monaten aus. Die von der Zecke befallenen Tiere werden unrthig und magern ab. Ihre Kämme und Lappen werden hellfarbig. Schliesslich fallen die Tiere vom Stengel und verenden.

Am Schlusse seiner Abhandlung verbreitet sich der Verf. darïber, auf welche Weise man die Einschleppung von Argas americanus verhiiten und ihr Auftreten bekiampfen kann. Fiir den letztern Fall wird die Anwendung von Teer und Lichtöl (Kérosen) besonders empfohlen.

R. I'iersig (Annaberg, lirgeb.).

29 'Thor, Sig.. Untersuclungen übor die Haut verschiedener dickhäutiger Acarina. In: Arbeit. \%ool. Instit., Wien, Bd. XIV. 1902. Heft 2. pag. 291-306. 'Taf. XIII. Fig. 1-11.

Der Verf. lat bei mehrern Milbenformen ganz andere, viel konpliziertere Hantstrukturen gefunden, als bisher von frïheren Autoren beschrieben wurden. Die angestellten, infolge der Härte und Sprödigkeit des Materials ungemein schwierigen Untersuchungen zeigen die dritte, chitinisierte Milbenhaut in einem neuen Lichte Die starren, toten Verhärtungen sind ron zahlreichen lebendigen Gewebselementen auf die mannigfiltigste Weise durchsetzt. Um dieselben sicher nachzuweisen, bedurfte es der verschiedensten Färbungsversuche. Als besonders vorteilhaft und gïnstig erwies sich die Behandlung der Schnitte mit Thionin, doch waren Nachfärbungen mit Eosin oder Säurefuchsin und Orange G häıfig notwendig. Das untersuchte Naterial stammte teilweise aus Norwegen und aus der Schwarzbach bei Zweibrïcken. Ee wurde mit verschiedenen Fliissigkeiten (Sublimat, $70 \%$ igem Alkohol, verdünntem Eisessig, Formol und P'ereny is (iemisch) fixiert und später in $80-90 \%$ igem Alkohol konserviert.

In Übereinstimmung mit Pagenstecher fand der Verf. bei Trombidium holosericeum (L.) drei Hautschichten: 1. Eine chitinisierte, fein linierte, biegsime und ziemlich weiche Aussenlage (Epiostracum), 
in der verdickte Haarpapillen eingelagert sind und mit ihren verschmälerten Aussenenden über die Oberfläche der eben genannten Schicht emporragen. 2. Eine dïnnere aber festere, chitinähnliche, netzartige Membran (Ektostracum), die sowohl für das Fpiostracum als auch für die darunter liegende dritte Schicht (die eigentliche Hypodermis = Matrix $=$ Endostracum) als Stütze dient. Letztere bildet eine grosse, helle Innenschicht, die durch querlaufende Linien in grosse Räume oder Lücken eingeteilt wird. Nach den rom erwachsenen Tiere gewonnenen Schnitten setzt sie sich nicht, wie bei manchen andern Milben, aus gewöhnlichen protoplasmareichen \%ellen zusammen, sondern man bemerkt feine Jinien. durch welche sie in grosse Räume zerlegt wird, in denen teils Körnchen und grosse Kerne, teils andere Zellen und Stränge sich rorfinden. Gewöhnlich ist einer der grossen Kerne in jeder Abteilung mit einem Nucleolus versehen. Von einer grossen Anzahl anderer Kerne strahlen Protoplasmafäden sternförmig aus. Nach der Auffassung des Verfs. bildet jeder grosse, von den erwähnten Linien gebildete Raum eine Hypodermiszelle, ron der wesentlich nur der Kern. Querschnitte der Zellenmembran (eben die Linien), diurftige Protoplasmareste und Fettmoleküle zu sehen sind. Der grösste Teil des protoplasmatischen Inhalts ist entweder verschwunden oder durchsichtig geworden. Diese Ansicht findet ihre Stütze nicht allein darin, dass die vorhandenen Kerne ziemlich regelmäBig verteilt sind, sondern anch in dem Auftreten zahlireicher „Molekiile“ (nach Pagensteclıer Fetttröpfchen). die schwer erklärlich sind, wenn man diese Schicht zum Ektostracum rechnen wollte. Zwischen Epiostracum und Ektostracum befindet sich ein /wischenraum von etwa $2 \mu$ oder mehr Dicke. Er wird durch eine feine Membran ausgefüllt, die der Verf. für die obere Grenztläche der Hypodermiszellen ansieht, weil sie mit den querlaufenden Linien in Verbindung steht. Ausser den schon angeführten Kernen und ...Molekülen" (?) treten noch in der Hypodermis vereinzelt grosse Lymphzellen (Leukocyten) auf, die wahrscheinlich aus den tiefer liegenden Geweben eingewandert sind. Weiter bemerkt man feine Strïnge, die hier und da schwache Anschwellungen aufweisen. T'hor erklärt sie für Nervenfasern. Eine Verbindung derselben mit. dem \%entralganglion konnte er jedoch nicht feststellen. Nach oben zu verlaufen sie in die Haare in eigentiimliche Elemente, für die der Verf. die Bezeichnung „Papillenzellen“ anwendet. Anscheinend ungebildete Hypodermiszellen, kennzeichnen sie sich durch eine längliche Gestalt. Sie durchsetzen die ganze Haut ron der basalen Grenztläche aus bis zum Epiostracum, wo sie die Haarpapille bis ans Haar durchlaufen. Man könnte sie als Haarbildungs- oder Nährzellen bezeichnen. Der Verf. glaubt, dass 
sie Sinneswahrnehmungen vermitteln. Sinnesorgane und Sinneszellen, bei Astacus in den Palpen aufgefunden, haben eine grosse $̈$ hinlichkeit mit den erwähnten Einrichtungen bei Trombilium. Was die Dicke der ganzen Haut bei den untersuchten Tieren anlangt, so schwankt dieselbe zwischen $28-10 \mu$ (Epiostracum $5-8 \mu$, Ektostracum $2 \mu$ und Hypodermis $20-30 \mu$.

Über den Bau der Haut von Arhemm berichtet der Verf. etwa folgendes: Wie bei Trombidium holosericem Latr. besteht die Körperdecke bei Arhemm pustulator (Miill.) aus den drei gewöhnlichen Schichten. Auch bei den andern mit zur Untersuehung lierangezogenen Arten (A. nemani Piersig, A. caudatus (de Geer) und A. globator (Müll.)) ist das der Fall. Die durchschnittliche Dicke der Körperdecke beträgt $50-60 \mu$ (Epiostracum :3 $\mu$, Ektostracum $25-28 \mu$ und Hypodermis $: 0-50 \mu$ respr. $10-20 \mu$. Die unterste Schicht bildet bei jungen Tieren zunächst ein netzartiges Gewebe mit grossen, runden Lücken. Es sind noch keine ektostracumbildende Matrixzellen vorhanden, doch treten oft eingelagerte Lymphzellen auf. Später bildet sich das Ektostracum schichtenweise, wobei die Lïcken des Hypodermisnetzes sich zu den scheinbaren l'oren des Hantpanzers umgestalten. Bei ältern Individuen rerschwindet schliessliclı die Sthichtenbildung, und das Ektostracum wird eine lomogene Masse. Die Hypodermis zerfällt nach den Angaben des Verfs. in die eigentlichen Matrixzellen, in eingelagerte Lymphzellen, feine Fasem, Pigmentkörperchen und Fetttropfen und in die sogenannten Porenzellen. Letztere zeigen im Verein mit den I ymphzellen und den feinen Fasern einen Haschenförmigen Umriss. Die Matrixzellen haben prismatische oder zylindrische Form. Sie bilden eine dicke Schicht, die aut einer Grenzlamelle von Bindegewebsfasern aufliegt. In Gemeinschaft nit den feinen Fasern treten noch zartere Stränge auf, die rom Verf. als Nervenfäden aufgefasst werden. Ähnliche Fasern bemerkte er in den Hautporen. Man kann sie bis ans Ektostracum verfolgen. Hier scheinen sie angeheftet zu sein, auch stehen sie oft nit einem Kern in Verbindung. Da das ganze Gebilde grosse Übereinstimmung mit dem von von $R$ a th dargestellten Membrankanal aus der Antenne eines Ichneumons anfweist, so glaubt der Verf., dass die Panzerporenplatten mitsant den Porenzellen und Fasern bei der Gattung $A r$ rhenmes (wie die Haare und Papillenzellen bei Trombidium) Sinnesorgane darstellen. Diese Annahme sehliesst nicht aus, class dieselben anch noch andere Funktionen ausüben.

Die Haut von Lebertia obscura 'Thor kennzeichnet sich besonders dadurch, dass sie ausser den gewöhnlichen Schichten noch eine vierte besitzt. Diese letztere schiebt sieh zwischen das Ektostracum und 
die Hypodermis ein. Der Verf. gibt ihr den Namen „Hypostracum“. Das Dickenverhältnis der vier Schichten wurde bei erwachsenen Tieren folgendermaben festgestellt: Epiostracum $4-8 \mu$, Ektostracum $20-30 \mu$, Hypostracum 20-27 $\mu$ und Hypodermis 4- $5 \mu$. Die dünne Iypodermis setzt sich wie bei Prona (-Curipes), Limmexia, Hygrolutes und Acerchs ans kleinen, Hachen Zellen zusammen. Xach der Angabe des Verfs. treten des öteren Tracheen in diese Hautschicht hinein. I)iese sind hohl und nicht von Kiernen und Lymphzellen begleitet. Obgleich sie gewöhnliclı nach den Hautporen hin verlanfen, konnte der Verf. eine Verbindung zwischen ihnen nicht feststellen. Unter der Hypodermis liegen vereinzelt oder in Gruppen geordnet Leukocyten mit kömigem luhalte. Die Leukocyten sind meist grösser als die Hypodermiszellen. lieobachtungen an lebenden Tieren veranlassen den Verf. zu der Amnahme, dass eine Anzahl Tracheen ausserhalb der Leukocyten und der Itypodermiszellen bis in die Cuticula vordringen. Sie scheinen ganz unregelmäßig zu enden, anch unterscheiden sie sich von den 'lracheen der Insekten durch den Mangel an Spiralfiuden und ihren ungeteilten Verlanf. Cowohl Hypostracum als Ektostracum lassen eine deutliche Schichtenbildung erkennen. Durch diese Fehichten dringen die Ilautporen, die jedoch hier viel kleiner sind, als bei der Gattmug Arhemuns. Die Innenwandung der loren ist mit spiralfäden ansgekleidet und orscheint deshalb in Ihurchschnitt zackig. Nach anssen sind die oben genamnten Gebilde durch die diime Schicht des Epiostracums verschlossen. Der Innenraum der I’ore ist ron einer Substan\% ausgefiillt. die eine fadenfömige Struktur anfweist. Auch das Epimerengebiet wird ron P'oren dnrehsetzt. Iliese laben grosse C̈hnlichkeit mit den entsprechenden Gebilden bei Arhemm,s, doch zeigen sie sich noch stärker verästelt als bei dieser Gattung. Durch diese Verästelnng werden die polygonalen l'orengruppen, die durch netzartig verlaufende Zwischenräume voneimander geschieden sind, hervorgorufen. Die IIiftplatten gewinnen dadurch ein gefeldertes Ansehen. Beziiglich der sogenamnten Genitalnäjfe schliesst sich der Verf. der Ansiclat 'Thons und Hallers an. Die drei P'atr Genitalnäpfe liegen bei Trombidium mter den Genitalklappen versteckt. In ihrem Imeren befinden sich ähnliche Gebilde, wie in den Haurpapillen. Die Haarpapillen auf den Genitalklappen besitzen langgestreckte Zellen, die nich Ansicht des Verfs. gleichfalls nervöser Natur zu sein scheinen. Er meint deshalb: ,wenn die Genitalnäpfe Sinnesorgane sind, dann können auch diese Hare (die von ihm anch bei Limnesia nnd Eulais anfgefunden wurden) Simnesorgane sein". Nerven hat el in diese Haarellen nicht eintreten sehen. 
Die Genitahäpfe bei Arhemur sind bedentend kleiner als die Ilautporen. Thor erblickt in ihnen umgebildete Panzerporen, die jedoch als Genitalnäpfe fungieren. Jede der Genitalporenzelle schickt in die äussere Erweiterung der Pore ein Faserbündel, das sich ähnlich verbreitert, wie bei Hygrobates, Piona und andern Hydrachnidenformen mit unbedeckten, äussern Genitalnäpfen. Das faserige Aussehen und die beständige Form des sogenannten Bündels, das regelmäßig rom Epiostracum abgerückt ist, spricht dagegen, dass es sich hierbei um ein Sekret handelt, der Verf. erblickt vielmehr in diesen Umständen den Beweis für die nervöse Natur dieser Gebilde. Bei Trombidium wurden Faserbiindel nicht beobachtet. - Nebenbei erwälnt der Verf. noch, dass Lebertia obsenra eine selbständige Art ist. Sie unterscheidet sich von L. porosa Thor durch die dunkle Färbung der Hüftplatten und die grosse Dicke der IIaut. Die Haut von L. obsema erreicht cine Dicke von 50-75 $\mu$. das ist 20-35 $\mu$ mehr als bei L. porosa. Noch dïnner ist die Kïrperdecke ron L. Ireripora 'Thor (etwa $18 \mu$ ) nnd $L$. inaequalis (Koch) (etwa $11 \mu$ ). Schon nach der verschiedenen Dicke des Integnments könnte man also melirere Arten der (iattmug Lebertia unterscheiden.

R. Piersig (Annaberg, Ermgeb.).

\section{Insectit.}

530 Gross, I., Untersuchungen ïher die Ilistologie des Insektenovariums. lu: Zool. Jahrb. Abt. Anat. Ontog. Bd. XVIII. 1903. pag. $71-186$. Taf. 6-14.

Seit der Arbeit ron Ko rschelt, mit welcher die ()oblastentheorie Wills widerlegt wurde, sind rergleichende Untersuchungen ïher die Histologie des Insektenovariums nicht mehr vorgenommen worden. Ausgedehnte Intersuchungen dieser Art haben Verf. daher noch zu manchen neuen Ergebnissen führen können.

Es werden von Gross 6 verschiedene Haupttypen von Ovarien unterschieden: 1. Ovaria fasciculata. 2. O. ramosa. 3. 0. racemosa. 4. O. pectinata. 5. Ovarium impar duplicatopectinatum nur bei einigen Brachyelythren und bei Trichopteryx vorkommend. 6. O. a rculum bei Sialis und namentlich bei $\mathrm{Per}$ liden. Die Eiröhren werden in "panoistische" ohne, und in "meroistische" mit Nährzellen eingeteilt. Die meroistischen zerfallen in "polytrophe" mit mehreren Nährkammern und in "telotrophe" mit einer endständigen Nährkammer.

Die spezielle Beschreibung des histologischen baues bezieht sich auf die Orarien von Thysanuren, Orthopteren, Odonaten, Plecopteren, Hemipteren, Neuropterens.str., Panor paten, 
Siphonapteren, I ipteren. Lepidopteren, Coleopteren und Hymenopteren. Auf die grosse Zahl ron Einzelbeobachtungen kann hier nicht eingegangen werden.

In einem Anhang zum speziellen 'Teil wird die Muskulatur der peritonealen Hiille behandelt, welche schon seit langem bekaunt ist und bisher als quergestreift galt. Verf, weist nach, dass die betreffenden Muskeh entweder glatt oder unvollkommen quergestreift sinr. Eine eigentiimliche Modifikation dieser Muskulatur zeigt sich bei den Pa norpaten und auch bei den meisten ('o leopteren und Hymenopteren. Es handelt sich um glatte Muskeln, die sich in Form eines Netzes rer⿳weigen, in dessen linoten die \%ellkerne sitzen.

Kontraktionen nach allen Richtungen, die sich den feinsten Formveränderungen der Eiröhre anschmiegen können, sind auf diese Weise ermöglicht.

In allgemeinen Teile werden die Untersuchungsergebnisse unter Heranziehung der Befunde frïherer Autoren im Zusammenhange besprochen. Unter den 'Thysanuren hieten. Japy.r' und Machilis das primitisste Verhalten dar, während Campodea. bei der jederseits nur eine polytrophe Eiröhre existiert, mehr spezialisiert ist.

Bei den Orthopteren finden sich bei wechselndem anatomischen Bau stets nur panoistische Eiröhren. Im Follikelepithel ist Amitose weit rerbreitet. Dasselbe gilt für Odonaten.

Den Hemipteren kommen büschelförmige Ovarien mit telotrophen Eiröhren zu.

Die siphonapteren laben büschelförmige Ovarien und sind unter den holometabolen Insekten die einzigen, welche noch den panoistischen Typus der Eiröhren zeigen. Ton den sog. Neuropteren schliesst sich siulis durch das hufeisenförmige Ovarium an die P lecopteren an. Die Eiröhren sind telotroph ohne Dotterstränge.

Chrysopa hat büschelförmige Ovarien mit je 8 langen polytrophen Eiröhren. Derselbe Typus findet sich auch in den kammförmigen Ovarien von Panorpa.

Bei den Dipteren sind zwei Typen zu unterscheiden, die Nematoceren mit langen schlauchförmigen Eikelchen und zahlreichen Eiröhren, und die Brachyceren und Pupiparen mit biischelförmigen Ovarien. Die Lepidopteren haben mit wenigen Ausnahmen je vier lange polytrophe Eiröhren.

Die Coleopteren weisen sehr weitgehende Modifikationen auf. Die adephagen Käfer, zu denen anth in diesem Punkte wieder die Paussiden gehören, haben polytrophe Eiröhren mit äusserlich abgegrenzten Ei- und Nährkammern. Alle iibrigen Käfer sind dagegen 
im Besitze von telotrophen Eiröhren. Verf. ist geneigt, den letztern Typus von dem erstern abzuleiten.

Die Hymenopteren haben allgemein büschelförmige Ovarien mit langen polytrophen Eiröhren.

Konvergenzerscheinungen spielen bei der Ausbildung der verschiedenen Eiröhrentypen sicherlich eine grosse Rolle. So sind die polytrophen Eiröhren sicher polyphyletisch entstanden, ähnlich ist es bei den telotrophen, die bei Hemipteren und höhern Coleop teren sich unabhängig ausgebildet haben müssen.

Schliisse auf die Verwandtschaftsbeziehungen ier verschiedenen Insektenorehnugen untereinander lassen sich anf Grund des Studiums der Anatomie und Histologie des Ovariums nicht ziehen. Sicher ist, dass das Ovarinm der I'uliciden weder eine Verwandtschaftsbeziehung der Flöhe zu den Coleopteren noch eine solche zu den Dipteren andeutet.

Hinsichtlich der Entstehung der zelligen Elemente im Insektenovarium schliesst sich Verf. der ältern, von Leydig begründeten Auffassung an, dass die Epithelzellen und Eizellen verschiedenen Ursprungs seien, eine Auffassung, die anch mit den embryologischen Resultaten übereinstimmt. Die Nährzellen der meroistischen Ovarien sind als abortive Eier anzusehen.

Das Chorion der Insekteneier wird nach Art einer Cuticula rom Follikelepithel gebildet, es entsteht also nicht durch direkte I'mwandlung des letztern.

Die genannte Bildungsweise gilt auch für Pyrhocoris, bei welcher Form Verf́. die früher ron ihm in Zweifel gezogenen ältern Beobachtungen von Kors chelt bestätigt.

In einem Nachwort hebt Verf. herror, dass die zweikernigen Zellen in Follikelepithel bei Hemipteren durch Amitose entstanden sind.

Die Kweikernigkeit kann also nicht als Gonomerie aufgefasst werden und für die Theorie der Selbständigkeit der väterlichen und miitterlichen Kernanteile verwertet werden.

R. He y mous (Berlin).

531 Kelntner. L., Over eenige insectenplagen bij de Cacaocultuur. Semarang-Soerabaia 1901. $8^{0} .23$ pag.

532 - Proefstation voor Cacao te Salatinga. Bull. Nr. 1. 1901. 10 pag. Nr. 2. 1902. 23 pag. 1 Taf. Nr. 3. 1902. 16 pag. 1 Taf.

Der durch seine exakten Forschungen über die Schädlinge des Zuckerrohres bekannte Verf. wendet sich nunmehr auch jenen Insekten zu, welche die Kakaokulturen Javas bedrohen. Die vorliegenden kleinen Arbeiten handeln über die ${ }_{n}$ Kakaomotte", eine nicht näher bezeichnete Tineide, dann über 3 Arten gleich- 
falls noch nicht benannter liäfer und über die bekannten Wanzen IIclopeltis antonii Sign. und theivora Waterh., deren Entwicklung nicht mehr als 9-17 Tage erfordert. Hingehender behandelt werden die $\mathrm{Col}$ o opteren Glcnea novemguttala Cast., Aracecmes fasciculatu. De Geer und Catarantha gigantea (?), dann die Le pidopteren Zeuzera coffeae Nietner und Orthocraspeda trima Moore.

A. Handlirsch (Wien).

533 Bredlin, (4., Die Hemipteren von Celeles. Ein Beitrag zur Faunistik der Insel. In: Abhandl. Ges. Halle. XXIV. 1901. 213 pag. 1 Taf.

Die Untersuchung des reichen ron den Vettern F. und I'. Sarasin auf Celebes in mustergïltiger Weise gesammelten Hemipteren-Materiales nebst einigen kleinern Sammlungen anderer Herkunft ermöglichten es dem Verf., ein übersichtliches Bild der Fauna genannter Insel zusammenzustellen. Trotz der relatir geringen Zahl der bisher auf' ('elebes gefundenen Arten (221), kommt Verf. doch zu einer lieihe ron Schlïssen iiber die Entstehung der Fauna:

..Celebes ist oder enthält ein grösseres Reststiick einer in tertiären Zeiten bestehenden Neuguinea mit Südost-Asien verbindenden Landbrïcke. Diese Landbriicke zeigt eine charakteristische Mischung und gegenseitige Durchdringung der beiden extremen Faunen, die sich hier begegneten, der papuasisch-iustralischen und der hochasiatischen. selbstrerständlich der Art, dass auf den Philippinen die asiatischen, auf den Molukken die australischen Einflüsse stärker hervortreten: jedoch sind zweifellos anstralische Typen, deren Ausbreitung sich lïngs dieser Brïcke vollzogen habeu muss, noch bis zu den Philippinen und Formosa deutlich nachauweisen, ja, wenn man will, auch in .lapan noch zu erkennen.

In diese eigentiimliche Fauna dringt nun in einer anscheinend spätern Zeit auf neu auftauchenden Seitenstrassen rorrückend rom Südwesten des malayischen Gebietes lier eine Flut von fremden Elementen ein. Angehörigen einer hochentwickelten, reichen Fauna etwas jüngern (repräges. Besonders in ('elebes ist diese jüngere Finwanderung (von Java her) so ergiebig, dass sie das ursprïngliche Faunenbild sehr stark trübt."

Den Systematiker bringt die vorliegende Arbeit ausser vielen kritischen Notizen und guten Beschreibungen 10 neue Genera und 66 nene species.

A. Handlirsch (Wien).

534 Cholodkorsky, x., Üher den Hermaphroditisu us bei ChermesArten. In: \%ool. An\%. XXV. 1902. pag. 521-522.

Der normale Geschlechtsapparat der Chermes-Arten besteht beim Männchen aus zwei Hoden, zwei Vasa deferentia, einem Ductus ejacu- 
latorius, zwei Anhangsdrüsen und einem Penis - beim Weibchen aus einer einzigen Firöhre, einem Oviduct mit Vagina und zwei Anhangsdrüsen, nebst dem Oripositor. Ausnahmsweise finden sich weibliche Indiriduen mit zwei Eiröhren und eine genaue Untersuchung hat gezeigt, dass bei solchen an der Vagina noch ein Vas deferens mit den zwei dazu gehörigen Hodenfollikeln und einer männlichen Anhangsdrüse liängt. Es handelt sich also hier um hermaphroditische Individuen.

A. Handirsch (Wien).

535 Cholodkorsky, N., Über den biologischen Cyclus ron Chermes riridanus Chololk. In: Rerue Russe d'Entomol. 1902. Nr. 3. pag. $139-147$.

Chermes vividams entwickelt sich olme Migration und pflanzt sich ausschliesslich parthenogenetisch fort. Während sogar bei den auf Fichten lebenden, ansschliesslich partlenogenetischen Arten (abietis Kalt. und lapponicus ('holod.) mindestens zwei verschiedene Generationen in Jahre vorkommen, finden wir hei dem auf Lärchen lebenden riridams, jülmlich nur eine (ge Hiigelte) Generation, also keine Spur mehr ron der fiir die I'lylloxerinen so clarakteristischen Heterogonie.

A. II andlirsch (Wien).

5.6 Iistant, W. I.. The Fauna of hritish India, including Ceylon and Burma. Rhyuchota. Vol. I. (Heteroptera). London, s". 1902. 438 pag.

Der rorliegende stattliche Band des gross angelegten Werkes umfasst erst einen Teil der IJeteropteren und zwar die Pentatomiden und Coreiden, welche in dem belandelten Faunengebiete, soweit bekannt, durch 247 Genera und 675 Speeies vertreten sind. Von diesen sind 40 resp. 180 von I)istant als neu aufgestellt. Besonderen Wert erhält die Arbeit durch den Tinstand, dass der Verf. die meisten Typen von Walker n. a. Autoren untersuchen konnte. Von jeder Gattung wurde ein Vertreter ahgebildet, was die Bestimmnng indischer formen fortan wesentlieh erleichtern wird.

A. Handlirsch (Wien).

537 Froggatt, W. W.. Notes on Australian Hemiptera. From Agricultural Gazette of N. S. IV. Misc. Publicat. Pt. I. Nr. 538. 1901. pag. 10. Pt. II. Nr. 538. 1902. pag. $1-7$.

In dieser Arheit gelangen alle häufigen Hemipteren Australiens nit ihren Lehensgewolnhleiten zur Besprechung. Wir ertahren, wie so manche Art auf eingeführte Pflanzen übergeht und auf diese Weise Schaden anrichtet; z. B. die Scutelleride Peltophora pedicellata Kirhy, welche die Kirschen den einheimischen Früchten vorzieht, oder llautia affinis Dall - die Reiswanze, Cuspirona simplex Walk - die Kartoffelwanze 11. v. a.

A. Handirsch (Wien). 
538 Froggat, $\boldsymbol{W}$. W., The Limitations of Parasites in the Destruction of scale Insects. From.: Agricult. Gazette N. S. W. Misc. Publ. No. 603. 1902. pag. 1-7.

Verf. bespricht ausfïhrlich die beiden unter den amerikanischen Entomologen herrschenden Meinungen über den Wert parasitischer Tiere und PHanzen füir die Bekämpfung kulturschädlicher Insekten.

Nach der Ansicht der östlichen Gruppe - mit Einschluss How ards sei den Parasiten ein gewisser Wert bei der Bekämpfung der Schädlinge nicht abzusprechen. doch genüre ihre Tätigkeit nur selten. Man könne daher die künstlichen Mittel (Bespritzen. Waschen usw.) nicht entbehren. Die westliche Gruppe der Statsentomologen dagegen vertritt die Anschaunng, jedes schädliche Insekt habe seinen natiirlichen Feind, wenigstens in seiner urspringlichen Heimat, nnd es sei daher Aufgabe der Fintomologen, in erster Linie diese ursprüngliche Heimat und dann auch den natürlichen Feind zu finden, einzufuihren nnd ihm alles andere zn überlassen.

I' roggat schliesst sich den Insichten Howards an und führt als Beweis für ihre Richtigkeit eine Reihe von Beispielen an: Coloradokïfer, Hessenfliege, Chinch-bug usw.

Auch bei cocciden sei die Wirkmng der natürlichen l'einde eine beschränkte und betrage kaum mehr als $50^{\circ} 0$.

\section{A. Handlirsch (Wien).}

539 Frogmatt. W. W.. A ustralian Psyllidae. II. In: Proc. Linn. Soc. N. S. W. 1901. pag. 242-29s. Taf. 14-16.

In diesem Teile der Arbeit kommen die Subfamilien Psyllinae, Triozinae und Prionocneminae zur. Besprechung. Hierher gehören die Genera Psylla mit einer bekannten und neun neuen Arten, Mycopsylla n. g. mit einer bekannten und einer neuen Art, Eucalyptopsylla n. g. mit zwei neuen, Eriopsylla n. g. mit zwei neuen Arten, Syncarpiolyma n. g. mit einer neuen Art, Brachypsylla n. g. mit einer neuen Art. Trioza mit einer bekannten und sieben neuen Arten und Tyora mit zwei neuen Arten. Es ist also fast alles neu.

A. Hand lirsch (Wien).

540 Crossaud. H. A., Two Pe a ch ścales. In: Florida Agric. Exper. Stat. Bull. 61. 1902. pag. 470-49s.

Diese Arbeit behandelt die zwei den Pfirsichkulturen vorzugsweise schädlichen Cocciden Aspidiotus pcrniciosus und Thaspis pcntayona. Bezü̈lich der ersten - der beriuchtigten San José-Laus - wird darauf hingewiesen, dass in deren Heimat (China und Japan) ein lä̈er die ühermäßige Vermehrung der Laus verlindere. Man hofft nun diesen Käfer - Chilocorus simili - auch in Amerika fortzubringen.

A. Handlirsch (Wien).

541 IIieber. Th., Catalogus insectorum faunae germanicae. Hemiptera, Heteroptera. Systematisches Verzeichnis der deutschen Wanzen. Berlin 1902. 8". 40 pag. 
Dieses Verzeichnis ist dazu bestimmt, dem deutschen Anfänger, welchem Putons neuester, 120 Seiten starker Katalog zu gross sein sollte, als bequemeres Handbuichlein zu dienen.

Ausser den bereits innerhalb der Reichsgrenzen gefundenen Arten sind anch noch jene ans den Nachbarländern aufgezählt, welche möglicherweise die Grenzpfähle bei ihren Wanderungen ïbersehen könnten.

Nähere Angaben über Verbreitung und Vorkommen enthält der Katalog nicht, die Synonyme sind knapp anfgezählt und Citate vollkommen vermieden, so dass das Biichlein wohl hauptsächlich für Tausch und Ordnungszwecke beniitzbar sein wird. Als ,deutsch" werden nur 647 Wanzenarten anerkannt.

\section{A. Handirsch (Wien).}

542 Kellogg. Vern. I. and Kuwana. Shinkai 1.. Papers from the Hopkins Stanford Galapagos Expedition 1898-1899. X. Entomological Results (8). M a 110 phaga from Birds. In: Proc. Washington Acal. Sc. IV. 1902. pag. 457-499. Pl. 28-31.

Die Untersuchungen erstreckten sich auf 36 Vogelarten und lieferten 45 Mallophagenarten, von denen nicht weniger als 28 für die Wissenschaft neu sind. Von Gattungen sind vertreten: Docophorus (11 Arten), Nirmus (10 Arten), Lipeurus (10 Arten), Coniocotes (1 Art), Eurymetopus (1 Art), Giebelia (1 Art), Physosiomum (1 Art), Ancistrona (1 Art), Colpocephalum (3 Arten), Menopon (6 Arten).

A. Handlirsch (Wien).

543 Kirkaldy, (G. W., Fauna Hawaiiensis. Vol. III. Hemiptera. 1902. pag. 93-174. Tab. 4-5.

Die Hemipterenfauna der Hawaii-Inseln - bisher so gut wie unbekannt - wird in der vorliegenden Publikation eingehend behandelt und in bezug auf ilıren Ursprung untersncht.

Verf. interscheidet kosmopolitische und endemische Elemente, australische Einwanderung und zufällige Einschleppungen.

Als kosmopolitische Elemente werden die Arten der Gattungen Tetiponia, Bythoscopus. Oliams, Triphleps, Lasiochitus, Psallus, Orthotylus. Acanthia, Corixa, Anisops. Ploiariodes, Reduriolus, Microcelia, Orthoen. Nysius und Rhopalus betrachtet.

Endemisch sind die Genera Metrarga. Sulamita und Pseudoclerada, ferner Coleotichus blaclibumiae. die auffallendste Form der ganzen, ziemlich unscheinbaren Fauna.

Als Belege für eine Einwanderung ans Australien werden Oechalia consociale, griseus, Lutera-Arten, Orthoea nigriceps und HyalopeplusArten angeführt, als zufällig eingeschleppt Zchus, Alloeocranum und Astemma.

A. H and lirsch (Wien). 
544 Kuwana. S. I. Coceidae from the Galapagos Islauds. lu: Journ. N. I. Entomol. Soc. X. 1902. pag. 28-33. Taf. 4-5.

Diese Arbeit enthält die ersten Nachrichten üher Cocciden der GalapagosInseln. Es wurden gefunden: Orthezia galapagoensis n. sp., Astcrolccanium pustulans, Lceanium hemisphacrium, Lecanium hesperidun pacificum n. var., Aspidiotus. Intaniae, A. smilacis.

Alle diese Arten gehören zu weit verbreiteten Gattungen.

A. H andlirsch (Wien).

545 Kuwana, S. I. Coceidae of Japan. In: Contrib. Biol. Hopkins Seaside Laboratory of the Leland Stanford Ir. University. 1902. pag. 43-94. Taf. 7-13.

Die Arbeit erstreckt sich anf 76 vom Verf. selbst gesammelte Arten, von denen sich 20 als neu erwiesen. Dazn kommt eine Liste von 40 bereits früher in Japan gefundenen Schildläusen, so dass die Zahl der bisher in dem Inselreiche beobachteten Arten 116 betrạ̈t Von diesen wurden 71 znerst nach japanischen Exemplaren heschrieben, und wir können annehmen, dass diese die autochthonen Formen sind.

A. Handirsch (Wien).

546 Matsmumpr. S., Mo nographie der Jassinen Japans. In: T'ermesz. Füzet. XXV. 1902. pag. 3.73-404.

Die in der Arbeit hesprochenen 39 Jassinen formen lapans verteilen sich anf 13 Genera, welche fast alle in der paläaktischen Region weit verbreitet sind. 26 Arten sind neu, vier waren schon friher aus Japan und 9 ans Europa beschriehen.

Die Verteiluns der Arten auf die Gattungen ist folgende: Guathodus Fieb. 5, Cieadula Zett. 4. Thamnotetlix Zett. 4. Athysanus Burm. 6, Nephotettix n. g. 1. Eutettix Van Inzee 1, Phlepsins Fieb. 1, Scrphoideus Uh1. 1, Aconura leth. 1, Peralimnus It. g. 2, Ieltocephalus Burm. 10, Jassus Fabr. 1, Nestocephalus Van Duzee 1.

A. Handlirsch (Wien).

547 Melichar, I., Monographie der Acanaloniiden und Flatiden (Homoptera). In: Anmal. Hofmus. Wien. XVI. 1901. pag. 178-258. XVII. 1902. pag. 1-253. 'Tat. 1-9.

Mit dieser Arbeit, welche sich in bezug anf Methode und Form eng an des Verfs. Monographie der Ricaniiden anschliesst, wirl wieder ein hetrïchtlicher Teil der prachtvollen Fulgoriden formen unserer Kienntnis näher gebracht.

Verf. unterscheidet die Hamptgruppen in folgender W eise: I. Deckflügel ohme Quernerven am Kostalrande mu ohne Tuberkeln im Clavns; Clavus am Ende stets geschlossen. Hinterschienen ohne Dornen. Subfam.: A canaloniidae. II. DeckHïgel mit Quernerven in der dentlich begrenzten Kostalmembran; Clavus stets mit Tuberkeln besetzt und an der Spitze znmeist offen. Hintersehienen mit 1-3 Dornen. Subfam.: Flatida e. A hörper von der Seite zusammengedriickt, die Deckfliigel stark vertikal gestellt, die Kostalränder derselhen unterhalb des Körpers znsammenstossend oder einander sehr genähert. Gruppe: Flatinae. B. Körper von oben nach unten zusammengedrückt, die Deckflïgel daher horizontal oder flach dachförmig gestellt, die Apicalränder zuweilen aneinander geschlossen. Gruppe: Flat oidin a e.

Alle Gattungen sind genan und ausführlich beschrieben, ebenso 
die Arten, von denen die auffallendsten auf den neun gut ausgeführten Lichtdrucktafeln zur Anschaumug kommen. Synonymie, Kritik und geographische Verbreitung sind in gleicher Weise behandelt wie in der Monographie der Ricaniiden.

Zur lieurteilung des reichhaltigen Inhaltes mag folgende kurze Übersicht der Gattungen dienen:

Acanaloniidae: Amphiscepa Say. 22 Arten, Acanatonia Spin. 16 Arten, davon 3 neu, Chlorochara Stal 1 Art, Batusa n. g. 4 Arten, davon 2 neu, Thiscia Stal 1 Art, Parathiscia n. g. 1 Art neu.

Flatidae:

Flatinae: Inyraca Stal 7 Arten, 5 neu, Flata Guér. 20 Arten, 4 neu, Flatima n. g. 8 Arten, 7 neu, Pereflate n. g. 1 Art, Ceryuia Stal 6 Arten, 3 neu, Concstra Stal 2 Arten, Copsyrna Stal 1 Art, Bythopsyrna n. g. 7 Arten, 2 nen, IIansenia Kirk. 2 Arten, 1 neu, Adrxia n. g. 3 Arten, 2 neu, Doria n. g. 1 Art, Lechaca Stal 5 Arten, 3 neu Poccloflate n. g. 4 Arten, 1 neu, Poekilloptera Latr. 6 Arteu, 4 neu, Scarpania Stal 3 Arten, Scrorpaulina n. g. 1 Art, neu, Flulosoma n. g. 2 Arten, 1 neu, Dermoflata n. g. 1 Art, neu, Flatida Hagl. \& Arten, 2 neu, F'latoptera 11. g. 2 Arten, 1 neu, Walkeria n. g. 2 Arten, Psendoftala (inér. 1 Art, Cyaria Stal 3 Arten, 1 neu, ('yarina n. g. 1 Art, C'acsonia Stal 1 Art, Arelute Stal 1 Art, Latois Stal 4 Arten, 2 nen, I'hleboptemu Stal 3 Arten, 2 nen, Siscin Stal 1 Art, Aulophorus Karsch 1 Art, Eurypessthus Karseh 1 Art, l'herdolus Karsch 1 Art, Aftata n. g. 1 Art, nen, Acropheen n. g. 1 Art, neu, Calamia stal 1 Art, Wirroflutu n. g. 1 A t, neu, Bigllis Stal 2 Arten, Phoutin Fieber 10 Arten, 1 neu, Mimophantia Matsum. 1 Art, Rihinophentia n. g. 1 Art, Mesophantia n. g. 1 Art, neu, Cryptoflata n. g. 10 Aiten, 4 nen, P'aranotns liarsch 3 Arten, 22 nen, licishe Kirkialdy 2 Arten. Helume Stal 1 Art, neu, Flutomorphu n. g. 1 Art, nen, Sarmurus II. g. 2 Arten, nen, Carthacu Stal 5 Arten, 2 nen, Carthatomorpha II. g. 4 Arten, 2 neu, Siphanta stal 4 Arten 1 neu, Euphenta 11 g. 3 Arten, 2 neu, Sulurnis Stal 2 Arten, ('blobesthes A. S. 2 Arten, Phyma II. g. 10 Arten, 5 neu, Ory.ra n. g. 2 Arten, 1 nen, Flutopsis n. g. 2 Arten, 1 neu, Mesophylla n. g. 2 Arten, neu, I'hyllypharta A. $\therefore .3$ Arten, P'aracromua II. g. \& Arten, Cromna Walk. 8 Arten, 4 nen, Flatula n. g. 1 Art, neu, C'amennin n. g. 1 Art, neu, Ormonis Stal 77 Arten, 43 neu, Nephesa A. S. 11 Arten, 6 neu, Colgar hirk. 29. Arten, 9 neu, P'eratella 1. g. 13 Arten, 8 nen, Sephena 11. g. 17 Arten, 12 neu, Sccerposa Uhl. 1 Art.

Flatoidinat: Zarudnya 11. g. 2 Arten, nen, Neocerus 11. g. 1 Art, nen, Cyarda Walk. 6 Arten, 1 neu, Seliza Stal 11 Arten, 4 ueu, Farona 1r. g. 1 Art, neu, Dascalu Stal, 22 Arten, 13 neu. Dascrima n. g. 4 Arten, nen, Eurima n. g. 1 Art neu, Derisa n. g. 1 Art, neu, lixoma n. g. 1 Art, neu, Anidora n. g. 1 Art, neu, Mussiia Walk. 2 Arten, I'xautis Stal 11 Arten, 7 neu, I'rana n. g. 1 Art neu, Lichena n. g. 1 Art, Porophloens In. g. 6 Arten, 5 neu, Fladoilles Guér. 90 Arten, 49 neu.

Wie wir sehen, enthält also die Monographie nicht weniger als 91 Genera nnd 523 Species, von denen rund die Hälfte als neu zu betrachten ist. Der Verfasser hat es vermieden, selbst irgend welche allgemeine Betrachtungen tiergeographischer oder phylogenetischer Natur anzustellen, liefert aber durch seine Arbeit eine sehr brauchbare Basis dazu, die hoffentlich recht bald benutzt werden wird.

A. Handlirsch (Wien). 
548 Reh, I., Biologisch-statistocche Untersuchungen an amerikanischen()bst-Schildläusen. In: \%oul. Jahrb. Syst. XVII (2). 1902. pag. $237-284$.

Diese Untersnchungen erstrecken sich anf Aspidiotus ancylus, camelliar, forbesi, perniciosus, Chionaspis furfura, Mytilaspis pomonum mnd auf eine Zeit ron drei Wintern. Untersucht wurde das Zahlenverhältnis zwischen jungen und erwachsenen Läusen, zwischen toten und lebenten und die Terteilung der Tiere über die Frucht. Ein weiteres Kapitel ist den von Cocciden erzengten Flecken und Vertiefungen gewidmet. ein anderes dem geneinsamen Vorkommen mehrerer Arten.

Wie der Verf. selbst hervorhebt, haben seine miiherollen Untersuchnngen nnr wenige allgemeine Lrgehnisse geliefert, jedoch wieder den Beweis erbracht, dass alle morphologischen Unterschiede von entsprechenden biologischen und physiologischen Initerschieden begleitet werden.

\section{A. Handlirsch (Wien).}

549 smith. J. B., The Rose Scale. New Jersey Agricultural Experiment Stations Bull. 159. 1902. 14 pag.

Diaspis rosae Bouché rerursacht in New Jersey auf kultivierten Rosen nicht unbeträchthichen Schaden, indem sie in grossen Massen auftritt und die jüngern Zweige der hosenstöcke aussaugt. Als Gegenmittel wird eine Waschung mit 'Transeife empfohlen.

A. Handlirseh (IVien).

550 Froggatt, W. W.. The Codling Moth (Carpocapar pomonella l..). In: Agricult. Ga\%. N. S. Wales. Miscell. Public. Nr. 521. Novemb. 1901. lag. 1-9. 1 Taf.

Der Apfelwickler hat sich von Europa ans iiber die ganze Welt verbreitet, so dass es nach den Zusammenstellungen des Verfs. kaum ein Gebiet gibt. auf dem Apfelläume wachsen, das von dem Schmetterling rerschont geblieben wäre. In Amerika wurde der Wickler zuerst 1817 beobachtet. Seither hat er sich in der neuen Welt mit ungeheurer Geschwindigkeit verhreitet, so dass sowohl in Amerika wie in Süd-Australien, Victoria, Queensland und Westaustralien Gesetze ansgearbeitet worden sind, nm durch eine strenge Kontrolle der Obstaus- und -Einfuhr und der Obstanlagen den Verheerungen, die alljährlich durch das Insekt angerichtet werden, Einhalt zu tum. Der Verf. hat durch eingehendes Studium der Lebensweise des Schädlings und durch Versuche zu seiner Vertilgung die Nittel an die Hand gegeben, un den Gartenban gegen die Verwïstungen des Wicklers zu schützen.

Der Apfelwickler fliegt in Australien in zwei Generationen. 
Die Imagines der ersten Gieneration gelangen in den ersten 'Tagen des Oktober zur Entwicklung aus iiberwinterten Raupen. Nach erfolgter Paarung legt das Weibchen in die zu dieser \%eit aufbliihenden Apfelblüten je ein Ei. Die kleine liaupe dringt in den Fruchtknoten ein, wächst auf Kosten des jungen Apfels heran nnd bohrt sich schliesslich einen Gang nach aussen, durch den sie, wenn ausgewathsen, den Apfel verläisst, indem sie sich an einem Seidenfaden rom baum auf den Boden herablässt frorausgesetzt. dass der in-

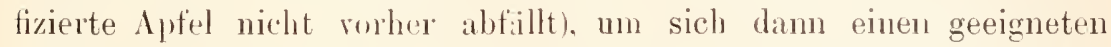
Platz zur Verpuppung zu suchen, den sie in den Ritzen der Borke des Banmstammes findet. In wammen Sommern Hiegen die aus diesen Raupen hervorgegangenen Schmetterlinge schon Anfing Januar. Nach dem 5. März war jedenfalls keine Puppe melı zu tinden. Die im Jannar ansgetlogenen Wickler legen ilne Eier in die halloreifen $\mathrm{Apfel}_{\text {, }}$ oft mehrere Eier in einen Apfel, mol aus diesen entwickelt sich die zweite Generation des Sclmetterlings, deren lianpen im April oder Juni erwachsen sind und ibberwintern. Die Raupen iiberwintern in der Mehrzahl in den Obstlagern, wo sie die ̈̈pfel vertassen nnd sich an geschiitzten Stellen einspinnen, nm dann im daranffolgenden Friiljalur, was in den (1) tober tïllt, als schmetterling in den Ohstpitanzungen wierler zu erscheinen.

Tin den Verwüstungen des Apfelwicklers zu stenern, hat es sich als nïtzlich erwiesen, die bamminde abzukratzen, mm rissige borken, Moos und Flechten zu entfernen, Fangringe um die baumstänme zn legen, unter denen sich die erwachseneu Raupen und l'uppen gerne ansammeln, und besonders auch die baumblüte in beginn des Fruchtansatzes mit giftigen Substanzen (Pariser (irüu) zu besprengen. und zwar zweimal im Friblyhr und eimmal vor dem Erscheinen der zweiten Raupengeneration. Auch das Mblesen der gefallenen wurmstichigen Apfel wie grïndliche Desinfektion der Lagerräume und die Üherwachung der Obstaus- und - Einfuhr laben sich als wichtige Mabregeln erwiesen, un einer Vernehrmng und Weiterverbreitung des Schädlings Einhalt zu tun. M. v. Linden (Bonn).

551 Giard, A.. Evolut ion a'Acherontia atropos. In: Feuille jeun. natural. IV. Ser. 33. Ann. Nr. 391. 1903. pag. 1-4.

Es ist schon öfters die lrage erörtert worden, ob die in Frïhjahr (April, Mai) da und dort aufgefundenen schmetterlinge von Acherontia atropos als überwinterte Weibchen der Herbstgeneration (Oktober) anzusehen seien.

Réa umur hält dies für sehr wahrscheinlich und nimmt an, dass es befruchtete Weibchen seien, die sich in den Winterschlaf hegeben, 
ım bei Eintritt der wärmeren Jahreszeit zı erwachen und ihre Brut abzusetzen. Inzwischen sind die verschiedenen beobachtungen in dieser lichtung angestellt worden, die zeigen, dass die lirage, ob eine Überwinterung der Atropos-Imagines stattfinde oder nicht, keineswegs so leicht gelöst werden kann. Gegen ein solches Übcrwintern der Weibchen spricht, wie Gi ard ausfïhrt, schon der Umstand, dass eigentlich noch nie wälnend der Wintermonate lebende Atropos-Falter bei nus angetroffen worden sind. Ausserden ist bekannt, dass die Herbstgeneration bei ihrem Erscheinen noch nicht geschlechtsreif ist, dass also von vorneherein eine Begattung vor Eintritt des Winters auszuschliessen ist. Wie sollte sich aber wälırend des Winterschlafes die Entwicklung zur geschlechtsreifen Generation vollzielon? Der Verf. hält es für wahrscheinlicher, dass die Herbstgeneration nördlicher Bezirke siidliche Lïnder anfsucht und im Frülıjalır als geschlechtsreife Generation wiederkehrt. Lelior re hat anch beobachtet. dass sich in Oktober die Atropros-Schmetterlinge in ähnlicher Weise gesammelt haben. wie es die Zugrögel zn tun pflegen, ehe sie ilne Wanderung antreten. Dass ausserdem im Sommer Ziige der Schmetterlinge der dcherontia atropos von Siiden nach Norden stattinden, ist eine bekannte 'Titsaehe.

Auch in bezng auf' den Wechsel der Finterpthinze ron Acherontia atropos in den rerschiedenen Ländern und Landstrichen, in denen die Rampe angetroffen wird. teilt mo (iiard Interessantes mit. Im Norden ron Frankreich wird die Riaupe fisst ausschliesslich auf $S_{0-}$ lamm lubrenzm, der Líartoffel. gefnnden. In Südosten und Südwesten von frankreich machten l'érez und siepi die Beobachtung. dass die Raupen des schmetterlings von den Blittern der Esche leben und fast nur als graue Varietät vorkommen, in Portugat schliesslich bildet nach Giard das solamm dulcumane die normale Futterptlanze der Atropos-liaupe.

Was in allgemeinen die Entstehung von Fürbungsvarietäten der kaupen betriflt. so stellt der V'erf. fest, dass die gratue Varietait besonders häufig in südlichen Ländern angetroffen wird.

I. v. Linden (Bomn).

552 crüuberg, K., Untersuchungen über die Kieim- und Nährzellen in den Hoden und Ovarien der Lepidopteren. Ein Beitrag zur Kenntnis del Entwicklnng und Ausbildung der Keimdrüsen bei den Insekten. In: Keitschr. wiss. \%ool. Bd. 74. 1903. pag. 327-395. Taf. $16-18$.

Durch die Untersuchungen von Verson über die Spermatogenese beim Seidenspinner ist eine im Hoden der Raupen gelegene eigen- 
artige grosse Kelle bekannt geworlen, die später auch hei Vertretern anderer Insektenordnungen gefunden wurde und den Namen V e rsonsclıe Zelle erlıalten hat. Üher ilıre Herkunft und Bedeutung gehen die Ansichten der Autoren weit auseinander. Hierüber Kilarheit zu gewimnen, war die Veranlassung zu den Tntersuchungen von Gr ii nberg.

Als Ausgangspunkt seiner Studien wählt V'erf. die jüngsten, zum 'Teil noclı den Eiern entrommenen Raupenstadien von Bombyx mori. Die zelligen Elemente der Keimdrüsen sind in diesem Stadium bei beiden Geschlechtern noch ïbereinstimmend. Ein geschlechtlicher Unterschied gibt sich aber in der Insertion der Ausführungsgänge \%u erkennen, wie Grünberg unter Bestätigung der Angaben ron 'I'oy a ma hervorhebt. (Fs mag an dieser Stelle an die Verlienste von Herold erinnert werden, der 1815 bereits diesen Geschlechtsunterschied bei den Raupen entdeckt lıat. Ref.)

Beim Männchen ist sehon an der embryonalen Geschlechtsdrüse am Ende eines jeden der Hodensclilüucle eine auftallend grosse Zelle differenziert (Versonsche \%elle), der V'erf. den treffenden Namen „Apikalzeller gilst. Letrtere entsteht nicht aus der bindegewebigen Hülle, sondern ist als eine umgewandelte Keimzelle anzusehen. 'Teilungen sind an der Apikialzelle nicht nachweisbar. Hie Bedeutung der Apikalzelle liegt darin, dass sie eine Nährelle ist. Eine Anzahl der in ihrer Nachbarschaft hefindlichen Siermatogonien werden anfgelöst und ilue /erfallprodukte, die daun als schwarze Nahrungskörner in ihrem I'lasma sichtbar werden, den ührigen Spermatogonien zngiinglich gemacht.

Auch durch Vermittelung der äusseren bindegewebigen Huille des Hodens wird der Apikalzelle ans der umspoulenden Bluttlüssigkeit Nährmaterial zugeführt. Unter diesen Umstiinden kann sich Verf. nicht mit der Meinung Versons einverstanden erklären, dass die Apikalzelle Spermatogonien produziere, deren lierne in ilrem Protoplasma entstehen sollen. '/u dieser Meinung hat offenbar eine V'erwechselung der Nahrungskörner mit Spermatogonienkernen die Veranlassung gegeben.

An der Apikalzelle machen sich schon bei erwachsenen Raupen Anzeicluen der beginnenden Degeneration bemerkbar, welche schliesslich zu ihrer Autlösung führen. Auch die innere Schicht der Hiillmembran des Hodens degeneriert. Mit dem Erlöschen der Nährtäitigkeit der Apikalzelle gelangen auch keine neuen Keimzellen mehr zur Entwicklung:

Der nächste Abschnitt der Arbeit behandelt die Orarien. Am vorderen blinden Ende eines jeden der Eischläuche (Ovariolen) ist 
schon während der Embryonalzeit die Anlage einer Apikalzelle nachweisbar, welche gleichfalls als eine modifizierte lieimzelle anzusehen ist, obwohl sich ihr Kern frühzeitig ron denjenigen der Oogonien unterscheidet. Wenn auch an der Homologie der Apikalzellen im Hoden und Ovarium kein Zweifel obwalten kanı, so scheinen diese Zellen in der weiblichen Geschlechtsdrïse niemals eine besondere Bedeutung zu gewinnen, sondern sie beginnen, ohne wichtige Veränderungen zu erlangen, bei verpuppungsreifen liaupen zu degenerieren. Mit jeder Apikalzelle geht eine Anzahl Keimzellen zu Grunde.

$\mathrm{Zu}$ entsprechenden Resultaten gelangte Grïnberg bei I'ntersuchung von Phalera bucephala. bei welchem Insekt namentlich die secernierende Tätigkeit der Apikalzelle im Hoden in den Vordergrund tritt. Ferner werden ähnliche Beobachtungen an Frastropacha rubi. Pieris brassicae und Vanessa io mitgeteilt.

In den Schlussbetrachtungen weisst Verf. darauf hin, dass die hauptsächliche funktion der Apikalzelle im larvalen Hoden stattfindet, und dass ihr Kern sich sowohl bei ihrer secernierenden 'Tätigkeit als Nährzelle wie an den assimilatorischen Vorgängen durch Gestaltsveränderungen nsw. lebhaft beteiligt. Der Grund, weswegen die Apikalzelle im Ovarium nicht die entsprechende wichtige Rolle spielt, wie im Hoden, ist darin zu suchen, dass die männlichen Kieimzellen nur eine geringe Menge ron Xïlırsubstanz zu ilırer Entwicklung brauchen. welche sehr wohl ron einer einzigen \%elle besclrafft werden kann, während in Orarium für die gross werdenden Oogonien eine anderc Ernährungweise Platz greifen muss.

Die Genealogie der Zellelemente der Keimdrüsen wird durch folgendes Schema veranschaulicht:

$\mathrm{Hod} \theta \mathrm{n}$

Urkeimzellen

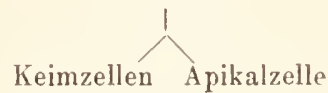

(Spermatogonien)

Spermatocyten Cystenzellen
Ovarie II

Urkeimzellen

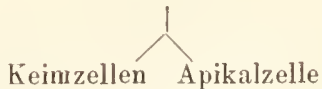

(Oogonien) (funktionslos)

Der zweite Hauptteil der Arbeit betrifft die postembryonale Entwickelung der Ovarien bei Bomby mori und Pieris brassicae. Iiei den jüngsten Raupenstadien wie bei den Embryonen zeigen sich die Eischläuche noch mit gleichartigen Urkeimzellen erfüllt. Zwischen den Eischläuchen und dem Ausführungsgange finden sich aber bereits kleinere Kerne vor, die im weiteren Entwicklungsverlaufe in epithelialer Form an die Wand sich zurïckziehen und zum Epithel des Eiröhrenstiels werden. Wenn später die Differenzierung der Keim- 
zellen siclı daun vollzogen hat, werden von dem letztyenannten Epithel ans die Follikelzellen geliefert.

Keimzellen und Follikelzellen leiten sich also bei Bombyx mori und Pievis brassicae von zwei schon im embryonalen Orarium deutlich unterscheidbaren \%ellenarten her, ein Resultat, das mit den Ergebnissen von Heymons an Orthopteren und Dermapteren im Einklange stelit. Auch darin, dass bei Rombyre und Pieris die Follikelzellen und Zellen des Ausführungsganges genetisch gleichwertig sind, stimmen die genannten Lepidopteren mit den ()rthopteren überein.

An der Richtigkeit dieser Ergebnisse lässt die eingehende Schilderung von Griin.berg einen \%weifel nicht aufkommen.

Die histologische Differenzierung der Ovarien gelit bei Bomlyx rascher, bei Pieris langsamer ror sich. In weiter fortgeschrittenen Stadien sind an jeder Eiröhre vier verschiedene \%onen zu unterscheiden: 1. Keimzone, in welcher ausser undifferenzierten Keimzellen auch schon Follikelzellen entlıalten sind, 2. Synapsiszone, die Kerne der Keimzellen sind in das Kinäuelstadium übergegangen, auch hier sind zwischen den Kieimzellen liegende Follikelzellen zu sehen, 3. Differenzierungszone, in welcher die lieimzellen in Oocyten und Nährzellen sich sondern, 4. Wachstumszone im engeren sinne.

Durch diese Beobachtungen wird erwiesen, dass die aus den $\mathrm{L}^{\mathrm{r}}$ keimzellen hervorgehenden Oogonien nur Oocyten und Nährzellen liefern.

R. Heymons (Berlin).

553 Levrat, M. M. D., et $\mathbf{\Lambda}$. C'onte. Sur l'origine de la coloration naturelle des soies de Lepidoptieres. In: Compt. rend. Ac. Se. Laris T. CXXYV. Nr. 17. 1902. pag. 700-702.

Verff. haben sich die Frage gestellt, ob es möglich sei, durch Fütterung der Schmetterlingsraupen mit Farbstoffen die von den Raupen produzierten Gespinste zu färben. Zu den Versuchen wurden Raupen von Attacus orizalia (Westwood) und von den in Frankreich kultivierten Rassen des liomlygx mor $i$ mit gelben bezw. mit weissen Seidengespinsten verwendet. /ur Fütterung der Raupen dienten wässerige Lösungen ron Neutralrot (rouge de toluyline), Methylenblau B X und Pikrinsïure, mit denen die Blätter der Futterpflanzen befeuchtet wurden. Bei Attacus orizaba ergab sich, dass nicht nur Raupen, welche ganz jung mit Neutralrot gefärbte Blätter zu fressen bekamen, sondern auch ältere Raupen, die z. B. erst nach der vierten Häutung zu den Experimenten verwendet worden waren, den Farbstoff in das Blut aufnehmen und lebhaft rot gefärbte Gespinste lieferten. Weniger leicht wurde der blaue Farbstoff resorbiert und die Seide der mit Methylenblatu gefürbten Blättern gefütterten Raupen 
zeigte sich nur leicht blau gefärbt. Mittolst I'ikrinsäure wurde gar kein Erfolg erzielt. Rot gefïbte Gespinste waren indessen auch zu erhalten, sobald eine Tentrahotlösung der Raupe subkutan eingespritzt wurde.

Zu allen diesen Versuchen eigneten sich die liaupen von Attacus: orizaba besser, wie diejenigen von Bombyx mori; das Experiment hat aber auch bei den letztern erwiesen, rass die in der Nahrung enthaltenen Farbstoffe durch den Darm resorbiert, in das Blut der Raupen aufgenommen werden und schliesslich den Gespinstfäden ihre Farbe verleihen. Die natürlich grïn erscheinenden Seidenfärlen des Spinners Antherara yama erhalten ihre natuirliche Farbe von dem mit der Nahrung anfgenommenen Ptlanzenfarbstoff, von dem Chlorophyll, dessen Gegenwart im Blut des schmetterlings durch den Verf: spektroskopisch nachgewiesen wurde. I)as gelbe l'igment, welches im Blut der die gelbe Seide produzierenden Spinnerraupen angetroffen wird, entspricht ebenfalls einem gelben Farbstoff ihrer Nahrungspthanzen. Diese interessanten Versuche über natürliche Seidenfärbung sollen von den Verff. noch weiter fortgesetzt werden, un festzustellen, inwieweit diese Methode. gefärbte Seide herzustellen, für die Technik in Betracht kommen kann.

II. v. Linden (Bonn).

554 Smith, J. B.. New Noctuids and Notes. In: Journ. New York Entom. Soc. Vol. VIl. Nr. 4. Dez. 1899. pag. 224-234.

S mith beschreibt 12 neue Noctuidenarten, die sieben Genera angehören, von denen eines (Cobalos) neu aufgestellt werden musste. Was die Beziehungen der neuen Formen zu den bekannten Arten und ihre örtliche Verteilung anbetrifft, so ergibt sich aus der Zusammenstellung folgendes:

Cobulos angclicus n. sp. von Los Angelos, California, und Cobalos franciscanus, San Francisco County, California, sind verwandt mit den Vertretern der Genera Iyppa und I'aleria. Tacniocampa pluriannula n. sp, Glenwood Springs, Colorado, ähnlich der T. alia. T. reliqua n. sp., Park County, Colorado, erinnert an T' trifascia. Nylomiges pallidior n. sp. New Westminister, British Columbia, ähnlich mit $T$. simplex. Tylina torrida n. sp. Washington, Colorado, N. W. British Columbia, Sodasprings, California. Die heller gefärbten Exemplare erinnern an X. tepida, die dunklern an X. antennata. Xylina dentilinea n. sp. Senator, Arizona, Denver, Garfield, Colorado; Fort Collins Tylina pomona n. sp. Almeda County, California; Olympia, Washington. Nylina longior n. sp. Glenwood Springs, Colorado. Iylina itata n. sp. Colorado. Eucalyptera pectinicornis n. sp. Phoenix, Arizona. In der Flügelform ähnlich mit E. bipunctata, im Bau der. Palpen stimmt sie sowohl mit den Vertretern des Genus Eucalyptera wie auch mit denen von Scolecocampa überein. Epizcuxis suffusalis 11. sp. Santa Rita Mts., Arizona.

M. v. Linden (Bomn).

555 Sinitl. J. B.. New Noctuids from British North Anerica, with notes on some others. In: The Canadian Entomologist Vol. XXXII. Nr. 8. August 1900. pag. 217-225. 1 Taf. 
Sämtliche hier beschriebenel Arten stammen aus British America, und zwar: Auytus obscums n. sp. von Edge Calary ist ähnlich privatus. Anytus profundus n. sp. von Brandon, Manitoba, ist vielleicht als geographische Varietät von priratus anzusehen. Mamestra negussa 1. sp. von Calgary, Canada, fliegt zusammen mit Crussata, hat aber weniger schwarz in der Zeichnung. Hudena cerivana n. s]. Calgary, Canada, Juni, ist Finitima sehr ähnlich.

Nephelodes pectinatus n. sp. British Columbia erinnert an minians, die östlicher vorkommende nah verwandte Art.

Cosmia punctirena n. sp. Glenwood Springs, Colorado, September. Yellow. stone Park, Wyoming, August; Cartwright, Manitoba.

Tanthia pulchella n. sp Livingston, Vancouver; British Columbia. Diese Art ist näher mit den europäischen Formen verwandt wie nit den amerikanischen. Sie ist in die Reihe von Vulpecula und Citrago zu stellen. Drasteria conspicua n. sp. Calgary, Canada, IIai bis Juni. Erinnert in der Flügelzeichnung an Erchtca. Die 'Tafel enthält die photographischen Abbildungen sämtlicher 'Typen.

$$
\text { M. v. Linden (Boun). }
$$

556 Sinith. J. B., Acronycta and Types. In: Canadian Entomologist Vol. XXXlll.

1901. Angust. pag. 232-234.

Smith entsclieidet die Fragen: 1. wie Artnamen beurteilt werden sollen, die auf Grund einer Zeiclınung gegeben sind, die nach einem Original angefertigt wurde, das der spätere Beschreiber der Art nie gesehen hat, oder das überhaupt nicht melı vorhanden ist. 2. kömnen unter diesen Umständen die von Abbatt gezeichneten und von Gue née beschriebenen Imagines von Acronycta-Arten als Typen betrachtet werden, oder sollen die auf die zugehörigeu Larven sich beziehenden Beschreibungen zur Artbestimmung verwendet werden. Smith ist der Ansicht, dass eigentlich nur solche Abbildungen berticksichtigt werden dürften, von denen die Originale noclı vorhanden sind, und dass in Fällen, wo es zweifelhaft ist, ob die abgebildete Raupe und die lmago zusammengehören, stets die letztere als Repräsentant der Art zu betrachten sei. M. v. Linden (Bonn).

557 Smith. J B., Three new noctuids from British North America. In:

The Canadian Entomologist. Vol. XXXIV. Nr. 2. 1902. pag. 29-32

Es werden drei neue Eulenarten beschrieben, von denen die eine Semiophora youngii n. sp. bei Ottawa, Ontario und Canada gefangen wurde und sich durch grosse Variabilität auszeichuet. Ein Exemplar des Schmetterlings erinnert an I'latagrotis condita, ein anderes an Adelphayrotis stellaris. Auch frühere Entwicklungsstadien des Schmetterlings sind bekannt. Die zweite Art, Cameades infusa n. sp., stammt von Cartwright, Manitoba; Black Hills und Wyoming. Der Färbung und Zeichnung nach stimmt diese Art mit obeliscoides überein, ist aber kleiner wie diese. Hyppa brumeicrista n. sp. erinnert in Gestalt und Zeichnung an $\boldsymbol{X}$ ylinoides, ist aber dunkler gefärbt. Als Fundort ist angegeben: Calary, Alberta, Head of Pine Creek; Fundzeit: Juni und Juli. M. v. Linden (Bonn).

558 Smith, J. B., New species of Noctuidae for 1902. In: Journ. New York entomol. Soc. Vol. X. March 1902. pag. 33-53.

Der Verf. gibt uns die Bearbeitung von 24 neuen aus verschiedenen Teilen der Vereinigten Staaten stammenden Noctuidenarten, die dadurch um so wertvoller sind, weil sie die genauen Angaben des Fangortes und der Fangzeit entlualten. Smith gelangt zu dem Ergebnis, dass dis Noctuide n selı viele Lokal- 
varietäten bilden und dass es nur an einem sehr umfangreichen Material (100 Exemplare von beiden Geschlechtern einer Lokalität) möglich ist, einigermafien sichere Merkmale aufzustellen.

Als neue Arten bezw. Varietäten sind aufgefülırt: Euthyatira pennsylvanica n. var. Pennsylvanien, 29. April bis 5. Mai. Varietät von Thyatira mudens. Cyathissa pallida sp. nov. Walters Station, California. April. Älnnlich der C.percara aus Texas, aber grösser und verschieden gefärbt. Noctua sprcta sp. nov., Hastings, Florida. Grösse und Gestalt wie lubricans, aber obne Schwarz.

Feltia subgothica Haw.. Calary, Alberta, Het Springs, New Mexico, 'Texas, Corvallis, Oregon, Washington, Vancouver, Island. Unterscheidet sich durch die Gestalt der Antennen von ovanidalis Gurt.

Feltia edcntata sp. nov. Pullmann, Washington, 13. August, steht der tricosa Lintner selır nahe, hat aber auch Beziehungen zu subgothica.

Luperina trigona sp. nov. Smith County Tenn,, 6., 7., 21. August. Selrr nalie verwandt mit passer, aber kräftiger gebaut. Hadena macerata sp. nov. Cartwright, Manitoba, 11. Juli. Winnipeg, Manitoba, 7. Juli, sehr ähnlich miscloides.

Hadena unicineta sp. nov. Sodasprings, 27. August, California; Sierra Nevada, California. Flïgelform wie diversirolor, Zeichnung wie claudens. Mamestra circumciadis sp. nov. Head of Pine Creek, Calary, Alberta, 21. Juli, verwandt mit chartaria und defcssa. Mamestra van-orbicularis $11 . \mathrm{sp}$, Corvallis, Oregon, 21. Juni. Zeichuung wie bei norerca und goorlclli, der Kürperbau aber kräftiger wie bei den genannten Arten. Oncocnemis balteata sp. nov. Ponclia springs, Colorado, 14. August. Zeigt seine Zugehörigkeit zu Lcvis. Oncocnemis regina, n. sp., Regina N. W. P.

Helotropha obtusa sp. nov., Ashleys Ferry Claremont N. H1. 17. August, 3. September, hat auch Beziehungen zu den Vertretern der Gattung Enplcxia. Eucalyptera strigata sp. nor. Hackley, Texas, 29. Mai, 1.-18. September. Von dieser Art sind die Weibchen sowohl in hezug auf die Zeichnung wie auch beziiglich ihrer Grösse sehr verïnderlich.

Platysenta albipuncte sp. nov. Harris Co., Texas, Colorado Springs, 5. Augnst Colorado, steht nahe zu videns. Tueniocampa alurina sp. nov. bei Chicago, Illinois, 27, 28. April. Ist der alia sehl ähnlich, die männlichen Genitalorgane erinnerı am meisten an die e uropä ische incerta. I'odagra grassipes gen. now., sp. nov. Quartsite, Ymma County, Arizona, März. Walters Station, Colorado, Desert, California, 20. April. C'rimona pallimedia gen. nov., sp. nov., Walters Station, California, April. Steht der Fala ptygophora am nächsten.

Oryenemis fusimacula sp. nov. Quartzsite, Iuma Co., Arizona, März. Walters Station, California, April. Verwandt mit arlena Girt. Leontia nivereollis sp. nov. Walters Station, California, März. Art zwischen lanccolata und gonclla zu stellen. Acontia seniatra sp. nov. Quartzsite, Yuma Co., Arizona, März. Zeigt sehr wenig Beziehungen zu andern bekannten Arten, am nächsten steht die Art ihrer Erscheinung nach der arizonce. Lcontia tcmucsecns sp. nov. Lake Worth, Florida, muss zu rirginialis Grt. und binocula Grt. gestellt werden. M. v. Linden (Bomn).

559 Heath. E. Firmstome. A few notes on the Lepidoptera of 1901 in Southern Manitoba. In: The Canadian Entomologist. Vol. XXXIV. Nr. 2. 1902. pag. $33-36$.

Verf. hat Beobachtungen darüber angestellt, dass verschiedene Lepidopterengenera in einem Jahre plötzlich auftreten, sehr häufig werden, um dann ebenso unvorliergesehen zu verschwinden, um andern bisher seltenen Genera und Arten 
Platz zu machen. 1897 war z. B. Aeronycta in 10-12 Arten vertreten. Im darauffolgenden Jahre verschwand die Gattung fast ganz, an ihre stelle trat das Gienus Agrotis. 1901 waren im Wachsen begriffen: Pyrameis eardui, Pieris rapac, Homogloea hireina, Biston ursainu, Peridroma saueia, Plusia precationis, Hybernia tiliaria, Ufeus plicatus. Weniger häufig wurden beobachtet die Vertreter der Gattungen: Theela, Pamphila, Iyeaena, Cacenllia intermedia, Mamestra farnhami, alle Noctuiden, viele G e o m etriden und die im Herbst fliegenden Plusia-Arten. Die Sphingiden waren in gewöhnlicher Artenzahl vertreten.

M. v. Linden (Bonn).

560 Petrukewitsch, Alexander, Die Richtungskörper und ihr Schicksal imbefruchteten und unbefruchteten Bienenei. (Aus d. zool. Inst. d. Univ. Freiburg i. Br.). In: Zool. Jahrb. Abt. f. Anat. u. Ontog. d. Tiere. 14. Bd. 1901. pag. 573-603. 4 Taf. 561 - Das Schicksal der Richtungskörper im Drohnenei. lin Beitrag zur Kenntnis der natiorlichen Parthenogenese. Ibid.: 17. Bd. 1903. jag. 481-5̃16. 'Taf. 11-13.

Wie Resultate der ersten Abhandlung fasst Verf. kurz in folgende Sätze zusammen:

1. Die ron der Königin in die Drohnenzellen abgesetzten Eier sind immer befruchtet.

2. Wie in den befruchteten, so auch in den parthenogrenetischen Fiern wird der erste Richtungskörper nach einer Äquationsteilung abgetrennt.

3. Bei der Abtrennung des zweiten Richtungskörpers findet in allen fällen eine Reduktion der ('lromosomenzahl um die Hälfte statt.

4. Ebenso teilt sich immer der erste Richtungskörper mit einer lieduktion in zwei Häliten, von denen die periphere aus dem Ei entiernt wird und zu grunde geht.

5. Die Herstellung der Chromosomenzahl im weiblichen l'ronucleus der Drohneneier geschieht vermutlich durch Längsspaltung der C'hromosomen mit einem Ausbleiben der entsprechenden Teilung in zwei Tochterkerne.

6. Die zentrale Hälfte des ersten Richtungskörpers kopuliert regelmäßig mit dem zweiten Richtungskörper und gibt so einen Richtungskopulationskern mit nomaler \%ahl der Chromosomen.

7. Im Drohnenei entstehen aus diesem Richtungskopulationskern durch dreifache Teihung acht \%ellen mit doppelten Kernen.

8. In befruchteten Eiern, sowie in Arbeitshrohneneiern bildet sich der Richtungskopulationskern zu einer spindel um, diese geht aber einfach zu grunde oder liefert $1-4$ \%ellen, die aber immer Zerfallserscheinmongen des Chromatins aufweisen und schliesshich auch zu grunde gehen.

In der zweiten Ablandlung wendet sich Verf. gegen Dickels 
"C̈bertragungstersuche", die beweisen sollen, dass auch die Drohneneier befruchtet sind. Terf. weist u. a. nach. dass Dickels Zeitangaben unzuverlässig sind. Verf. hat schon friilıer festgestellt, dass im Drohnenei „der zweite Richtungskörper mit der innern Hälfte des ersten zusammenfliesst und den sog. Richtungskopulationskern mit der normalen Zahl (16) von Chromosomen bildet. Lus diesem Kern gehen endlich acht doppelkernige Zellen im Blastoderm ant dor Bauchseite des zukïnftigen Embryos hervor, die ins Innere des Eics einwandern. Diese Zellen vermehren sich karyokinetisch, wandern und sammeln sich auf dem Räcken an. Später dringen sie in das Lumen der Mesodermröhren ein mol bilden hier die Anlage der Geschlechtsdrüsen. Im befruchteten Bienenei hingegen gehen die Richtungskörper zu grunde, die Urgeschlechtszellen stammen hier vom Mesoderm ab. Bei lihopalosiphum nymphaeae scheint sich der erste Richtungskörper zu teilen und seine innere Hälfte mit dem zweiten Richtungskörper zu verschmelzen. Ëine weitere P'rüfung der bei der Biene aufgeworfenen Fragen war bei den Aphiden nicht möglich. Ein besonderer Abschnitt behandelt die Frage der \%weckmäßigkeit des rom Verf. beschriebenen Entstehungsmodus der Geschlechtszellen bei den Drohnen. Er glaubt, dass durch die Richtungsliernkopulation die T'erschiedenheit der Chromosomen garantiert werde. Bei Entstehung der männlichen Geschlechtszellen aus dem unbefruchteten Eikern würden sie sehr bald nmr identische ('hromosomen enthalten. Der letzte $\Lambda$ bschnitt enthält interessante Betrachtungen über natürliche und künstliche l'arthenogenese. Mit Recht tritt Verf. dafür ein, die letztere für einen ganz besondern, werler mit der natürlichen l'arthenogenese, noch mit der Befruchtung direkt gleichwertigen Yorgang zu halten.

R. Fick (Leipzig).

\section{Vertebrata.}

562 Fiirbringer, M., Morphologische Streitfragen. 1. Nervus trochlearis. 2. Rabls Methode und Behandlung ler Extremitätenfrage. In: Morph. Jahrb. Bd. XXX. 1902. paig. $85-274$.

Veranlasst dureh scharfe Angriffe von seiten Dohrns und Rabls gibt Verf. seinen Auffissungen über den Nervus trochlearis (1. Abschnitt der Arbeit) einen präziseron Ausdruck, als dies in seiner Abhandlung ,yüber die spino-occipitalen Nerven der Selachier usw." (Festschrift für Geg enbaur) geschehen.

Der Nervus trochlearis des II enschen und der Säuger entsteht aus dem Stillingschen Trochleariskern. Von dessen dorsaler und literaler Circumferenz geht die Trochleariswurzel ab, welche 
nach kompliziẹrtem Verlaufe, im Niveau des caudalen Endes der hintern Vierhügel, dorsomedianwärts zum Anfinge des Velum inedullare zieht. Hier tritt sie auf die Gegenseite über, krenzt sich init der Wurzel des Gegennerven und tritt neben dem Frenulum veli medullaris ultradorsal aus dem Gehirn. Yon hier geht der Nervus trochlearis in die Orbita; es innerviert somit der vom rechten 'Trochleariskern kommende Ner den linken Musculus obliquus superior und umgekehrt. Entgegen seiner frühern Auffassung, wonach Vert. den Trochlearis als medial-motorischen Nerven betrachtete, hält er ihn jetzt für einen lateral-notorischen. Ton Anfang an nimmt sein lirsprungsschenkel einen dorsolateralen Verlauf und tritt dadurch in P'arallele zu den lateral-motorischen Wurzeln des Trigeminus, Facialis usw. Der gewöhnlich dorsal vom hintern Längsbiindel gelegene liern des Nerven findet sich bei verschiedenen Säugern an dieses Bündels ventraler Seite. Mas Mittelstïck seiner Wurzel, beim Menschen median ron der absteigenden Trigeminuswurzel gelegen, geht bei vielen Säugern innige Verflechtungen nnit der letztern ein, ja kann sogar lateral von ihr verlaufen. Diese Beziehungen zur absteigenden 'Trigeminuswurzel sind es, die den Verf. zur seiner jetzigen Auffassung führen.

Die dorsale Kreuzung beider Nerven - Austrittskreuzung lält Vert. fïr bedingt durch periphere Ursathen.

Tiei sa uropsiden liegen nach der Melırzahl der Autoren die Verhältnisse wie beim Menschen.

Bei $A$ mphibien, Fischen und Cyclostomen liegt nach der Mehrzahl der Autoren der Trochleariskern dorsal vom hintern Lingsbiindel in mittlern oder caudalen Abschnitte des Mittelhirns; er schliesst sich direkt an das caudale Ende des Oculomotoriuskernes an. Die Wurzel geht von hier aus zur totalen dorsalen Austrittskreuzung. Verf. urgiert daher mit Schäre den ganz eigenartigen Charakter des Nervus trochlearis, namentlich seinen Gegensatz zunı Oculomotorius und Abducens.

In Anschlusse an diesen anatomischen 'T'eil des Abschnittes ïber den 'Trochlearis gibt Verf. eine Zusammenstellung der Ergebnisse der ontogenetischen Arbeiten über die Augenmuskelnerven und die Augenmuskeln. Dem ihm gemachten Vorhalte gegenüber, dass die vergleichende Anatomie in diesen Fragen zu keinem einwandfreien Krgebnisse gekommen sei, zeigt Verf. durch seine Zusammenstellung, dass die ontogenetische Methode noch viel weniger zu sichern, eindeutigen Ergebnissen führe. Denn die verschiedensten, einander ausschliessenden Auffassungen werden von den verschiedenen Forschern als die allein richtigen bchauptet. 
Im fünften Kapitel gibt Verf. einige Notizen über die l'arietalorgane und kommt dann, unter Heranziehung aller ron ihm selber oder von andern Autoren herrührender Angaben, zu dem Schlusse, den er bereits in einer frühern Arbeit ausgesprochen, diss der Trochlearis einst Beziehungen zu den I'arietalorganen gehabt habe und dass seine intradorsale Kreuzung dadurch zu stande gekommen sei, dass die von ihm innervierten Muskeln mit der Rüickbildung der Parietalorgane zu den antimeren Lateralaugen gewandert seien.

Der zweite Abschnitt der vorliegenden Abhandlung ist gegen ., liabls Methode und Behandlung der Extremitätenfrage" gerichtet und daher wesentlich polemischer Natur. Es ist nicht möglich, die einzehnen I'hasen des rom Verf.' als Vertreter der Ge $\underline{g}$ en ba u r schen schule gegen Rabl und die Ontogenetiker mit grossem Geschick geführten Kampfes referendo wiederzugehen. Es ist dies wohl auch nicht die Anfgabe eines Rieferates. Daher sei nur in aller Küurze darauf hingewiesen, dass der zweite Abschnitt der vorliegenden Abhandlung trotz seines kriegerischen Aussehens eine rorzügliche Ïbersicht über den gegenwärtigen Stand des Extremitätenproblems der Vertebraten gibt. Die Ansichten der vergleichenden Anatomen und die der Embryologen werden einander scharf gegenuibergestellt und so wird jedem die Möglichleit gewährt, sich in diesen nicht gerade leichten Problemen zu orientieren und, dank einer rorzüglichen Literaturzusammenstellung, ron hier aus event. zu eigenen Untersuchungen fortzuschreiten.

B. Rawitz (Berlin).

563 Levaliti, C.. Le Leucocyte et ses granulations. In: Scientia. Sér. biol. Nr. 15 und 16. Paris 1902. 159 lag. mit Tabellen.

Das rorliegende Werkchen, das ron Ehrlicli mit einem Vorwort begleitet wird, behandelt in zehn Kapiteln das Thema der leukocytären Granulationen. Nach allgemeinen einleitenden Betrachtungen, nach einer Angabe der Methodik, bei der sehr wertvoll ist das genaue liezept ron Ehrlichs Triacid (Verf. ist ein Schïler Ehrlichs), werden die Morphologie und die färberischen Reaktionen der Granuli der Leukocyten geschildert. Dann folgen die Besprrechungen der Arten der Leukocyten, der hämatopoetischen Organe. der Beziehungen der verschiedenen Leukocytenformen zueinander, der Entstehung der granulierten Leukocyten, ihrer zahlenmäßigen Variabilität und der verschiedenen Arten der Eosinophilie. Endlich geben die beiden letzten Kapitel Aufschlüsse über die Mastzellenleukocytose. und über die Wichtigkeit der leukocytären Granulationen und über ihren spezifischen Charakter. Am Anfange steht ein genaues Literaturverzeichnis. 
Seinen Zweck, nämlich eine erschöpfende Orientierung über den Stand der Leukocytenfrage und über deren biologische Bedeutung zu geben, erfüllt das gefällig geschriebene Werkchen vollkommen und dalıer sei es Interessenten aufs Wärmste empfohlen.

B. Ii witz (Berlin).

564 Meres, Fr., Zur Struktur der roten Blutkörperchen bei A mphibien und Säugetieren. In: Anat. Anz. Bd. 23. 1903. Nr. 8 und 9. pag. 212-213.

I) elı ler hatte an Erythrocyten ron Hühnerembryonen einen sich besonders fürbenden Randreifen beschrieben. Verf. hat die gleiche bildung bei Erythrocyten ron Salamanderlarven gefunden und kann folgende Einzellıeiten mitteilen. Der Randreifen hat ausgesprochen fibrilläre Struktur. besteht aus einer grossen Zahl parallel verlaufender feinster Fäden oder auclı aus einem einzigen, zu einer dicken Locke aufgewundenen Faden. Bei der Mitose der Erythrocyten verlagert sich der Randreifen unter starker Anflockernng ins Innere, verschwindet als solcher und wird offenbar zum Aufbau der achromatischen Figur verwendet. Die Interfilarmasse, ron der Filarmasse des Randreifens geschieden, entlı̈llt das Hämoglobin.

Die Frythrocyten der Sïugetiere laben keinen liandreifen, sondern eine nach innen von der Aussenwand gelegene Membran, die vol P'oren durchsetzt ist.

B. Rawitz (Berlin).

56.5 Schaniusland, H., Beiträge zur Entwicklungsgeschichte und Inatomie der Wirbeltiere I, II, III. In: Zoologica, herausgeg.

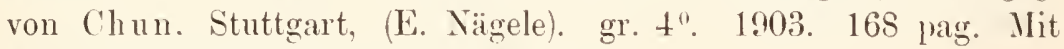
45 Abbildungen auf 56 Taf. M. 80.-

l)er erste Teil dieses schönen Werkes betrifft die Entwicklung eines Holocephalen (Callorhynchus antarcticus) und zweier Reptilien (Sphenodon punctatum mi Chamaeleo vulgaris), die beiden folgenden Teile enthalten entwicklungsgeschichtliche Beobachtungen an zahlieichen Vögeln. sowie an Sphenodon. Das Werk enthält 56 vorziiglich ausgeführte Tafeln. Ein Teil derselben bietet genauere Abbildungen zu frühern P'ublikationen des Verfs.; daher ist der Text nur kurz, und wird die Literatur nur teilweise berücksichtigt.

Die Entwicklungsstadien ron Callorhynchus wurden ron dem Verf. auf den Chatam-Inseln und auf Neuseeland gesammelt. Die friihen Stadien sind denjenigen anderer Selachier älnlich. Der jüngste der beschriebenen Embryonen zeigt eine Keimscheibe mit Embryonalschild (nahezu dem stadium B ron Balfour entsprechend). Die folgenden Figuren könnten den Stadien G-K (nach Balfour) zugerechnet werden. 
Die älern Embryonen weichen immer nelır von den entsprechenden Stadien anderer Selachicer ab; insbesondere fällt die knollenähnliclıe Giestalt des Rostrums auf. Bei den ailtesten der abgebildeten Embryonen sind die Kiemen ausgebildet und mit zahlreichen laugen äussern Kiemenfäden versehen; num beginnt der Kriemendeckel iber die Kiemen lierüberzuwachsen. - Von allen diesen Embryonen werden schöne Abbildungen geboten, welche auch manche der schwierigern Einzelheiten erliennen lassen, z. B. die Teuromeren, die Anlagen der Ganglien der grossen Gehirmnerven, die Muskelknospen an den Extremitätenanlagen usw. Die Beschreibung ist kurz gehalten, wohl aber ist eine ausführliche Tafelerklärung beigefügt.

Das embryonale Kopfskelett von C'allorhynuhus ist von dem Verf. nach der Bornschen Platten-Modellier-Methode in zwei stadien körperlich reproduziert und selır hïbsch abgebildet worden. Bei den jüngern Stadium ist nur die Basis des Kinorpelschädels verknorpelt, die übrigen Teile sind noch durch Vorknorpel repräsentiert. 'Trotzdem findet man das Palatoquadratum schon mit dem Schidel verwachsen, in der präorbitalen Gegend völlig mit ilm vereinigt, nur an dem eigentümlichen postorbitalen Fortsatz, einigermaßen von der Ohrgegend des Schädels abgesetzt. Eigenartig sind die Knorpelteile der Nasengegend, was viclleicht mit der sonderbaren Gestalt des Rostrums zusammenhängt. Im Innern der Schädelhöhle springt die Sattellehne (welche die Spitze der Chorda enthält) sehr stark nach oben vor, und davor liegt eine tiefe Grube, entsprechend der starken Entwicklung des Infundibularteils des Kwischenlirns und der Hypophyse.

Der Hyoidbogen des Cullorhynchus-Embryos ist ganz ähnlich gebaut, wie die folgenden Kiemenbögen. Median besitzt er eine Copula; an diese schliesst sich ein Ceratobranchiale (= Hyoid). daran ein Epibranchiale (= Hyomandibulare) und oben findet man noch ein kleines Pharyngobranchiale. Die Strahlen am Hyoidbogen bilden das Skelett des Kriemendeckels. - An Unterkieter wurde median ein kleiner umparer Kinorpel gefunden; deshalb spricht der Verf. die Hypothese aus, dass dieser Knorpel der Copula eines Kiemenbogens entspreche, der Unterkiefer dem des Ceratobranchiale, der vordere Teil des Palatoquadratums dem Epibranchiale, der nach hinten gerichtete 'Teil desselben dem Plaryngobranchiale.

Kum Vergleich mit Callorhymchus werden Schädel und Visceralskelett von Triaenodon obesus (Riip).) aus Laysan abgebildet.

Interessant sind die Reihen von Hautzähmen, welche auf der sonst nackten Haut von Cullorhynchus-Embryonen stelsen, zwei 
Reihen an der Oberscite des Kopfes, eine Reihe jerlerseits nehen der Merlianlinie des Rïclens vor der zweiten Rückenflosse und eine ̈̈hnliche Reihe hinter lieser Flosse.

Bei den Zahnplatten im Munde von Callorhynchus lässt sich ontogenetisch keine Verschmelzung aus Einzelzähnchen nachweisen, sondern sie entstehen einheitlich; die dichte Lamelle an der Oberflïche der Zahnplatten ist als Vitrodentin. nicht als Schmelz anfzufassen.

Die Wirhelsäule entwickelt sich in ähnlicher Weise wie bei andern Selachiern. An der Oberfläche der Chorda entsteht eine dicke zellenlose Chordascheide. An den Stellen der spätern untern und olsern Bögen häufen sich auf der Chordascheide Mesenchymzellen an und bilden vier Längsleisten auf derselben. Ein Teil dieser Mesenchymzellen wandert in die Chordascheide ein. ohne aber in iln segmentale Wirbel (primäre Wirbel) zu bilden. Wenn die línorpelbildung an der Wirbelsäule beginnt, gelıeı aus den erwähnten Leisten die obern und untern Bogen hervor.

Der Verf. hat auch das Gehirn von Callorhynchus in verschiedenen Entwicklungsstadien algebildet, sowie die sehwierigen Verhältnisse der Hirnnerven beschrieben nnd durch mehrere Figuren erläutert. Das Vorderhirn steht in engster Beziehung zu den selır starken Riechnerven, das Mittelhirn ist sehr gross, die Hirnbeuge selır ausgeprägt.

Gehen wir nun zur Entwicklungsgeschiehte der Reptilien über. Es gelang dem Verf., eine Reihe junger Stadien von Sphenodon (= Hutteria) muctatum zu sammeln. Das vorliegende Werk entluält Obertlächen- und Schnittbilder der wichtigsten Stadien, rom Beginn der Urdarmeinstülpung bis zum Schluss der Amnionbildung. Auch von späteren Stadien sind schöne Abbildungen gegeben, insbesondere von nahezu reifen Embryonen. an welchen die eigentümliche Fürbung des ausschliipfenden Tieres zu sehen ist (dunkle Querbänder auf Rumpf und Schwanz, sowie auf den Extremitäten, Längsstreifung an der Kehle, Tüpfelung anı Bauch).

Da der Verf. schon in einer frülıern Publikation (Anat. Anz. 15. Bd. 1899. pag. 309 u. f.) die einzelnen Stadien kurz beschrieben hat, ist hier anstatt einer Beschreibung nur eine ausführliche Tafelerklärung beigefügt. Zur Zeit, wenn die Urdarmeinstülpung ausgebildet und in die geräumige Subgerminalhöhle durchgebrochen ist, findet man hinter der Urdarmeinstuilpung eine Zellenmasse, welche dem Primitivstreifen der Vögel entspricht und Primitivplatte genannt wird. In ihr hängen alle Keimblätter zusammen, und das Mesoderm wuchert von hier aus lateralwärts weiter (Mesodermsichel). In der 
dorsalen I'rdarmwand findet man zu dieser Zeit noch eine gleichartige \%ellenplatte. in welcher dann das Entoderm, das Mesoderm und die Chorda durch Differentiation sich sondern. Es tritt also bei der Lintstehung des Mesoderms keinerlei Faltenbildung auf.

Ferner hat der Verf. eingehende Studien iiber die Entwickhung des Skelettes von Sphenolon gemachit. worüber er zum Teil schon früher berichtete ${ }^{1}$ ). Die Entwicklung des Schädels wurde durch plastische Rekonstrulition in drei Stadien klargelegt. Man sieht den knorpeligen Primordialschädel in verschiedenen Entwicklungsstufen. sowie die Anlagen der Deckknochen. Das Quadratım liängt ursprïnglich mit der Columella kontinuierlich zusammen und sondert sich später von ilır, indem die beiden linochen selbständige Verknöcherungszentren enthalten. Ferner besitzt das knorpelige Quadratum einen Fortsatz, welcher nach vorn zu dem Pterygoid und dem Transversum sich erstreckt und dauernd knorpelig bleibt. Das Guadratum ist beim Embryo mit dem Squamosum durch ein Gelenk verbunden. während später eine starre Verbindnng besteht. Hinsichtlich der eigentümlichen Verhältnisse am obern Teil des Hyoidbogens, wie auch am Squamosum usw. muss auf das Original verwiesen werden und auf des Verfs. friihere l'ublikation, welche die genauere Beschreibıng enthält. Dasselbe gilt von der Entwicklung des Schultergürtels und Beckengürtels und der Extremitïten.

Der Verf. beobachtete auch die friihen Entwicklungsstadien eines andern Reptils. nämlich Chamaelo rulgaris; er stellte melnere Stadien durch P'lattenmodelle dar. Sehr auftällig ist bei Chamaeleo die frïhe Entwicklung des Amnions. Schon lange vor der Entstehung der Crdarmeinstülpung bildet sich am Umfang des kreisförmigen Embryonalschildes eine ringförmige Amnionfalte, welche rasch den Schild iiberwächst und ïber der Mitte desselben zum Schluss kommt. Der Verf. hält diese Art der Aunnionbildung für die ursprünglichste. Das Amnion ist eine durch Zuchtwahl erworbene Einrichtung, welche zum Schutze des Embryos dient und diese Funktion um so eher erfüllen kam, weun es so friih entsteht. - Bei Chamaeleo schreitet auch die Unwachsung des Dotters durch das Ektoderm sehr rasch fort, so dass der Dotter zur Zeit der ringförmigen Amnionfalte schon fast gänzlich umwachsen ist. - Dagegen tritt die Urdarmbucht sehr spät anf. Vorlier wird der P'rimitivstreifen gebildet, welcher sich als eine Wucherung des Ektoderms darstellt und nach den Seiten hin die Mesodermplatten entsendet. Der vorderste Teil des Primitivstreifens („Kopffortsatz") verbindet und rermischt sich mit dem Entoderm. Nun

1) Weitere Beiträge zur Entwicklung von Hatteria (Skelettsystem, schallleitender Apparat, Hirnnerven usw.). In: Arch. mikr. Anat. 57. Bd. 1900. 
erst erscheint die Urdarmbucht am vordern Teile des Primitivstreifens und geht (schief ron hinten oben nach rorn unten) durch den vordersteu Teil des Primitivstreifens (..Kopffortsatz") hindurch, bis sie in die subgerminale Höhle sich öffnet ${ }^{1}$ ).

Vom grössten Interesse sind die zahlreichen Beobachtungen an Vögeln. Der Verf. gibt schöne Abbildungen junger Embryonen rom Albatros (Diomedea immutabilis Rothsch.), von einer Seeschwalbe, Hatiplana fuliginosa Gm., von Tölpeln (Sula cyanops Sunder. und Sula piscatrix L.), rom Fregattrogel (Fregatta aquila L.), von einem Tropikrogel, (Phaeton rubricauda Bodd.) und von einem Sturmtaucher Puffime cumeatus Salv.), sowie vom Star (Sturmes rulgaris L.) und vom Sperling (Passer domesticus L.). Es sind meistens die Stadien des Primitirstreifens und der Urmundeinstïlpung, sowie diejenigen des Schlusses des Medullarrohrs dargestellt. Die Urmundeinstülpung, aus welcher der Canalis neurentericus hervorgeht, ist bei allen den genannten Vögeln zu sehen, sie bricht aber beim Sperling und bein Star nicht in die Subgerninalhöhle durch. [Bekanntlich fehlt die $\mathrm{U}_{1}$ darmeinstülpung gerade beim Hühnchen, welches allzulange als I'aradigma der Yogelentwicklung galt. Ref.]. -- Die Mesodermentwicklung geht von dem Primitivstreifen aus; wie bei den Reptilien fasst der Verf. auch bei den Vögehn den Primitirstreifen als Ektoderm auf und leitet daher das Mesoderm vom Ektoderm ab.

Besondere Aufmerksamkeit wurde dem Amniongang und dem vordern Amnionzipfel gewidmet. Der erstere kommt nicht nur Schildkröten und Sphenodon zu, sondern auch rerschiedenen Vögeh; er entstelit dadurch, dass die hintere Amnionfalte nicht auftritt oder klein bleibt, die vordere Amnionfalte aber immer weiter nach hinten vorrückt; dadurch wird der Amnionnabel an das hintere Ende des Embryos verlegt und schliesslich zu einem Gang ausgezogen, welcher vom Embryo ans eine Strecke weit nach hinten verläuft. Dieser Gang ist der Amniongang. - Der vordere Amnionzipfel wurde ron dem Verf. bei einigen Vögeln gefunden; am grössten ist er bei Dio-

1) In bezug auf die theoretische Betonung dieser Befunde kann ich dem Verf. nicht ganz folgen. Ich erkläre das relativ späte Auftreten der Urdarmbucht als cänogenetische Verzögerung und halte daher die späte Verbindung des Primitivstreifens mit dem Entoderm auch für cänogenetisch. Ich kann also der Tatsache, dass das Mesoderm bei Chamaeleo scheinbar allein vom Ektoderm gebildet wird, keine theoretische Bedeutung beilegen. Auch bin ich der Ansicht, dass man die Ausdrücke Ektoderm und Entoderm im morphologischen Sinne erst dann an. wenden darf, wenn die gastrale Einstülpung entstanden ist. Ich sehe den Primitivstreifen der Amnioten ebenso wie den Urmundrand der niedern Wirbeltiere als ein indifferentes Gebiet an, in welchem alle Keimblätter sich vereinigen (vergl. mein Lehrbuch der Entwicklungsgeschichte, Jena 1902, 10. Kapitel). Ref. 
meden und Phaeton ausgebildet. Der vordere Teil der Amnionfalten ist ursprünglich mesolermfrei, die Leibeshöhlensäcke dringen dann von beiden Seiten her ein, und es entsteht, wenn sie median zusammentreffen, vor dem Embryo eine mediane Scheidewand (älnnlich dem dorsalen Mesenterium des Darmes); in diese ragt eine zipfe]förmige Fortsetzung der Amnionhöhle hinein.

\section{H. E. Ziegler (Jena).}

\section{Reptilia.}

566 Kaschtschenko. N. Th.. Ueber die Wechselbeziehungen zwischen der gemeinen Otter (Pelius bents L.) und Renards Otter (I'el. renardi Christoph.) In: Isvestija der ostsibirischen Sektion der kais. russ. geogr. Geselischaft. Bd. XXXIII. 1902. pag. 1-12 (russisch).

Die gemeine Otter scheint, mit Ausnahme des liöclisten Nordens, im ganzen russischen Reiche vorzukommen. Die Frage über ihr Vorkommen im Turkestan bleibt offen. Nikolski lässt sie hier fehlen, da sie durch I'el, renardi vertreten wird. Aber im südlichen Teil des Tomsker Gouvemements fand Verf. beide Arten. Strauch salı Pel. renardi nicht als besondere Art an ${ }^{1)}$ und erst 1893 hat G. A. Boulenger in den Proc. of the Zool. Soc. London einige erginzzende wichtige Unterscheidungsmerkmale gegeben. Renards Otter geht von den Wolgasteppen (Sarepta) bis zu den Westgrenzen des Altai (Smeinogorsk) im Osten, doch ist sie lier noch nicht ganz sicher festgestellt. 1898 und 1900 beobachtete Verf. sie im Zentral-Altai, im geschlossenen Tale des Uimon und zwar Exemplare mit sehr scharf ansgeprägten Charaktermerkmalen. Selten traf man sie nördlich vom Altai, sogar bei der Stadt Tomsk. Da ıun nach einigen von Strauch in seiner Arbeit „die Schlangen des russischen Reichs“ (pag. 213) gegebenen Beschreibungen von Kreuzottern auf das Vorkommen von $P$. renardi in Ostsibirien geschlossen werden darf, gibt Verf. erst die Unterscheidungsmerkmale beider Furmen. Er weist auf Ausnahmen hin, die dieselben zulassen, auf Übergangsformen, die er 1900 in den Steppen westlich vom Altai fand (wo in Turkestan, der Kirgisensteppe, im Zentral-Altai - also in der Nachbarschaft die typische $P$. renaidi haust). Man dürfte also für Ostsibirien sicher auf diese letztere rechnen und doch ergab die Durchsicht ostsibirischen Materials ein überraschendes Resultat: die meisten glichen nur äusserlich der P. renardi - alle spezielleren Kennzeichen (Suprarostralschilder, Form des Kopfes, Grösse und Lage der Nasenlächer) weisen auf die gemeine Otter hin. Wahrscheinlich sind dies ebenfalls Übergangsformen, weil wohl südlicher, in Transbaikalien, der Mandschurei die lienardsche Otter vorherrschen dürfte. Verf. hält beide Arten für selbständig, da er im geschlossenen Uimontale typische Vertreter von P. berus sowohl, wie $P$. renardi beieinander fand.

C. Grevé (Moskau.)

\section{Mammalia.}

567 Bolk, L., Beiträge zur Affen-Anatomie. IV. Das Kleingehirn der Neuweltaffen. In: Morphol. Jahrb. Bd. 31. 1902. pag. $44-84$. Taf. II. 26 'Textfig.

Im Gegensatz zu den Katarrhinen zeigen die Platyrrhinen hin-

1) A. Strauch, Die Schlangen des russ. Reichs, St. Pet. 1873 u. Synopsis aer Viperiden, St. Petersb. 1869. 
sichtlich ilures Cerebellums eine natïrliche Entwicklungsreihe, in der das Genus Hapale auf der niedersten Stufe steht. Die höchste Entwicklung findet sich bei Atcles. Verf. untersuchte die Gehirne folgender Genera: Hapale, Midas, Chryothrix, Nycetes, Cebus. Ateles. Die Reihenfolge, in der die Gattungen aufgezählt wurden, gibt anch die morphologische Stufenfolge wieder.

Verf. beginnt mit einer vergleichenden Beschreibung des Medianschnittes; dabei ergibt sich eine so rollständige Übereinstimmung zwischen Hapale und Midas, dass deren gesonderte Schilderung nicht nötig ist. Vier Flächen sind an dem meist viereckigen Medianschnitte des Cerebellums zu unterscheiden: eine vordere, eine obere, eine hintere und eine untere. Die untere krümmt sich in ihrer Mitte nach oben und bildet dadurch die Begrenzung des Tentoriums. Die Grenze der hintern Fläche, die bei Chrysothri, eingeknickt ist, gegen die obere und untere ist allenthalben sehr scharf. fast winkelig; die rordere Fläche hat dagegen eine runde L'mbiegung. Mit Ausnahme von Chrysothrir ist die hintere Cerebellarflïche flach und fast genau senkrecht zur Achse des Hirnstammes orientiert. I a eine Falx cerebelli bei den Platyrrhinen fehlt. liegt die lintere Fläche des Organs des Squama occipitis unmittelbar an; das Tentorium steht senkrecht und das Cerebellum ist iiberall vollständig vom Grosshirn iiberlagert. Die obere Hä̈che des Cerebellums ist bei Hapale und Wycetes flach, bei Chrysothrix und Crbus mehr gewölbt. Die Vordertliche legt sich an die Corpora quadrigemina an und ist diesen entsprechend konkav eingedrückt. Die Unterfläche endlich wird durch das Fastigium in einen vordern kürzern und hintern längern Abschnitt geteilt. Das Fastigium ist eine schmale Spalte, welche tief eindringt, lateral sich erweitert und dabei allmählich sich vertlacht. Es ist bei Hapale, Midas, Chryothrix, Cebus und Ateles senkrecht zum Boden des Sinus quartus orientiert, wïhrend es bei Nycetes nach hinten und oben gerichtet ist. Nach oben reicht das Fastigium an die untere Seite des unregelnüßigen, viereckigen Markkernes.

Zur Schilderung der Form des Cerebellums übergehend, verwirft Verf. die Bezeichnung ,Wurm" vollkommen und betrachtet das Organ als zusammengesetzt aus zwei Lobi: L. anterior und L. posterior. Denkt man sich bei Platyrrhinen das Tentorium nach oben durch den Markkern verlängert, so gelangt man in eine Furche, die von $\mathrm{K}$ u ith an als Sulcus primarius bezeichnet wird, von dem nach vorn der Vorder-, nach hinten der Hinterlappen des Cerebellums gelegen ist. Am Medianschnitte ist es leicht den Sulcus primarius zu finden, sehr schwer dagegen bei Betrachtung der obern Fläche des Cerebellums, da er nicht likafit. 
An der obern Fläche des Lobus anterior sind vier Ränder zu unterscheiden: ein vorderer, ein hinterer, zwei seitliche. Der vordere Rand ist bei den Arctopitheciden wellenförmig gebogen, zeigt ein ähnliches Verhalten bei Chrysothrir, während er bei Mycetes. C'obus. und Ateles konkar gestaltet ist. Seitlich stösst der Lobus anterior an eine Partie des Lobus posterior, die Verf. als Formatio vermicularis bezeichnet. Die Betrachtung der Faltungen der Kileinhirnoberfläche führt Verf. zu folgender Schlussfolgerung: ., Es besteht in Lobus anterior cerebelli der Neuweltaffen ein bestimmtes Wachstumszentrum, welches in der Medianlinie seine höchste Intensität besitzt, dessen Wirksamkeit laterahwärts alluählich schwächer wird. Folglich ist die Oberflächenzunahme der Rinde am meisten intensiv in der Medianlinie, am geringsten an den Seitenwänden des Lobus anterior". (pag. 63)

Dem Lobus posterior ist die Hauptmasse des Cerebellums zuzurechnen. Daher erscheint sein medialer Teil zuweilen in mehr oder minder beträchtlichem Grade eingesunken. So tritt also eine Art Dreiteilung des Lobus auf. Er zeigt bei den verschiedenen Species nicht unbeträchtliche Differenzen. Am einfachsten ist er bei Hupule. ihm schliesst sich der ron Mycetes an, am meisten differenziert ist er bei Ateles. (Die Einzellıeiten vgl. Original.)

B. R aw itz (Berlin).

568 Kaschtschenko. X. Th.. Siagetiere, 'ges ammelt von P. G. Ignatows Altaiexpedition 1901. In: Ann. Musée zool. de l'Acad. Impér. des Sc. de St. Petersb. T. VII. 1902. pag. 1-16 (russisch).

Die Sammlung entbält 60 Exemplare (29 Spirituspräparate ganzer Tiere, 12 Bälge mit Schädeln, 9 Schädel und 10 Stück Diverses - Bälge ohne Schädel Geweihe, Hörner). Diese Zahl umfasst eine Fledermaus, I'espertilio mystacinus Leisl.; drei Insektenfresser, Sorex pygmaeus Pall., Crossopus fodiens L., Talpa altaica Nikolski (mit Mafstabelle); fünf Raubtiere, Putorius nivalis L., Put. evers. manni Lesson, Meles amurensis altaicus Kaschtschenko, Vulpes alopex L., Ursus arctos L. (mit Maßtabelle der beiden Schädel); vier Huftiere, Capreolus pygargus Pall., Rangifer tarandus L., Ovis ammon L., Capra sibirica Meyer; acht Nager, Sciurapterus volans L., Tamias asiaticus Gmel., Spermophilus evcrsmanni Brandt, Lagomys alpinus Pall., Sminthus subtilis Pall., Microtus terrcster L., Micr. eversmanni Poljakow, Mus tscherga Kaschtschenko.

Verf. bezweifelt, dass ein strenges Scheiden von Talpa europaca und $T$. altaica aufrecht zu erhalten sei (auch schon in seiner Arbeit „Resultate der zool. Altaiexpedition 1898, in: Iswestija der Univ. Tomsk, Buch 16, 1900, pag. 13 russisch). Obwohl die beiden Ursus-Schädel die Typen von Fversmanns $U$. cadaverinus und $U$. formicarius s. longirostris repräsentieren, gehören doch beide einer Art an, da das lokale Material alle möglichen Übergänge bietet.

Méhely hat neuerdings (Dritte asiat. Forschungsreise d. Grafen E. Zichy, 1901) Capreol. pygargus leptocerus und pachycerus nach dem Gehörn unterschieden. Erstere Rasse soll den Ebenen West-Sibiriens und des Kaukasus, letztere den Bergen Sibiriens angehören. Abgesehen davon, dass das Reh jetzt den Ebenen

-. Nr. 567--568. 
West-Sibiriens fehlt und nur in bergigen Gegenden getroffen wird, findet Verf. das Material Zichys zu ungenügend, um darauf sogar nur Rasseunterschiede zu begründen. Capra sibirica der Sammlung hat Hörner, die nach hinten konvergieren - ein Merkmal, woraufhin Blyth seine $C$. sakeen aus dem Himalaya von dieser Art abtrennte, das jedoch für sehr unzuverlässig von Verf. gelralten wird.

Nach den vorhandenen Spermophilus ercrsmanni-Bälgen kann festgestellt werden, dass der Wechsel des Sommerkleides gegen das Winterkleid im August erfolgt (im Altai) und zu Ende des Monats vollendet ist.

Mus tscherga hatte Verf. nach zwei Exemplaren aufgestellt (Resultate d. zool. Altaiexped. 1898, l. c. pag. 46) - die hier vorliegenden acht Spiritusexemplare verlangen einige Frgänzungen des dort Gesagten. Es werden Maßstabellen gegeben, Zurechtstellungen in den Merkmalen geboten und schliesslich

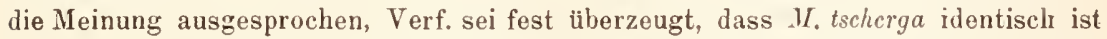
mit $M$. chevrieri M. Hdw., sowie mit M. sylvaticus Radde (welche beide letzteren $\mathrm{B}$ ü chner identifiziert (Wissensch. Resultate von $\mathrm{Prz} e w a l s k i s$ Reisen, B. I. Lief. 3. 1889. pag. 92).

C. Lirevé (Moskau).

569 Weimberg, R., Fossile Hirnformen. 1. Anchilophus desmaresti. In: Zeitschr. wiss. Zool. Bd. 74. 1903. pag. 491-500. Taf. 25.

Verf. war in der Lage, versteinerte Kerne der Schädelhöhle ausgestorbener Säugetiere zu untersuchen. hatte daher zum Studium die Oberfläche eines fossilen Säugetiergehirnes in solcher Naturtreue, wie sie die gelegentlich ausgeführten kïinstlichen Ausgüsse fossiler Schädel nie zeigen können. Bei schlichtfurchigen Säugetiergehirnen gibt die Schädelkapsel auf ihrer Innentläche ein vorziigliches Negatir der Grosshirnhemisphären.

Der Steinkern der Schädelhöhle, den Verf. beschreibt, gehörte einem Anchilophus desmaresti, einem oligocänen Unpaarhufer, und stammt aus dem Mergel ron Castres im siidfranzösischen Departement Taru. Verf. nahm das am Steinkern haftende fragmentarische Frontale fort - ein fragmentarisches Stïck rom Parietale haftete zu fest und liess sich nicht entfernen - und überblickte dann die dorsolateralen konvexen Flächen der Grosshirnhemisphären. Das Gehirn ist nach rorn hin leicht verschmälert und zeigt nur in der Gegend des Sulcus suprasylvius eine leichte Einschnürung.

Über die Gyri an der dorsalen und dorsolateralen Fläche ist folgendes zu sagen:

Ein schmaler Saum des Gyrus cinguli, zum Teil rom Parietale bedeckt, ist rechts zu erkennen; links verschwindet er ganz unter dem Parietalerest. Seine Grenzfurche, der Sulcus splenialis, ist sehr deutlich. Der Gyrus marginalis zieht in sagittaler Richtung vom Occipitalgebiet her nach vorn und verläuft in den vorderen zwei Dritteln der Hemisphären randständig. Er ist links hinten quer eingeschnürt und besitzt rechts eine starke Verbindungsbrücke 
zum Gyrus suprasylviacus. Nach rorn stösst der Gyrus an den Sulcus cruciatus an. Der Gyrus suprasylvius ist in ganzer Ausdehnung zu erkennen und erscheint typisch für die kleinen schlichthirnigen Ungulatengehirne. Der Gyrus ectosylvius scheint mit dem Gyrus sylviacus eine einzige zusammenhängende Masse zu bilden.

So finden sich an dem eocänen Gehirn die typischen Windungen des Gehirns rezenter kleiner Ungulaten.

Hinsichtlich der Sulci zeigt sich, dass keine röllige Symmetrie zwischen beiden Hemisphären vorhanden ist.

An der rechten Hem is ph äre beschreibt Verf. folgende Furchen:

Sulcus acuminis vor der Längsmitte in die Substanz des Pallium einschneidend; Verlauf rein transversal. Sulcus su prasylvius (Fissura Sylvii nicht erhalten) ruft deutliche Einkerbung des Konturs hervor, erscheint im Profil als eine tiefe dreieckige Grube, spaltet sich in zwei Äste, einen distalwärts ziehenden und einen zum Sulcus ansatus gehenden. Sulcus lateral is entsprechend dem Verhalten rezenter Ungulaten weit nach aussen; Vorderende 'T förmig, trichterartig vertieft. Sulcus splenialis von typisch rezentem Verhalten. Sulcus coronalis einwärts konvex, in der Längsmitte medialwärts geknickt, an beiden Enden T förmig gespalten. Sulcus cruciatus deutlich rorhanden, mit dem Sulcus coronalis zusammenhängend. Sulcus praesylvius in einer dem rezenten Ungulatengehirn typisch gleichenden Weise, tritt mit dem Sulcus coronalis nicht in Verbindung.

Die linke He m is phä re bietet folgende Eigentümlichkeiten dar. Sie ist schmächtiger und nach vorn mehr verjüngt als die rechte.

Sulcus lateralis (S. splenialis ron Parietalerest verdeckt) gibt rechten Seitenzweig ab, geht, was rechts nicht der Fall, zum Sulcus ansatus. Sulcus suprasylyius hat stärkern Bogen als rechts. Sulcus acuminis Transversalfurche wie rechts. Sulcus praesylvius kürzer als rechts. Sulcus coronalis stärker als rechts, verbindet sich mit dem Sulcus cruciatus.

Das Gehirn ist also ein typisches Ungulatengehirn und gehört zu den Traguliden.

B. R awitz (Berlin). 


\section{Zoologisehes Zentralblatt}

unter Mitwirkung von

Professor Dr. O. Bütschli and Professor Dr. B. Hatschek

in Heidelt,erg

herausgegeben von

in Wien

Dr. A. Schuberg

a. 9. Professor in Heidelberk.

Verlag von Wilhelm Engelmann in Leipzig.
X. Jahrg.
4. September 1903.
No. 17.

Lu bezielen durch alle Buchhandlungen und Postanstalten, sowie durch die Verlagsbuchhandlung. Jăhrich 26 Nummern im Unfang von 2-:3 Bogen. Preis' für den Jahrgang 11. 30 . - Bei direkter Zusendung jeder Nummer onter Stroifband erfolgt ein Aufschlag von i. $4 .-$ nach dem lnland und von II. 5.- nach dem Ausland.

\section{Referate.}

\section{Zellen- und Gewebelehre.}

70 Meves, F., lichtongskärperbildung in der Spermatogenese. In: Mitt. Ver. Schlesw.-Holst. Irzte. V. XI. 1903. 2 pag.

Kurze Mitteilung üher merkwiirdige spermatocytenteilungen im Drohnenhoden. Die Teilung erfolgt in eine grosse nud eine winzig kleine \%elle; beide beginnen sich zn sinermien umzuwandehn, let/tere degenerieren damn wahrscheinlich. Verf. behält sich nühere Untersuchung des Gegenstandes ror.

li. (ioldsch midt (Nïrnberg).

71 Rohle, L., Untersuchungen ïber den bia der zelle. I. Kern und liernkörper. In: Ztschr. wiss. Zool. Bd. 73. 1903. pag. 497 -682.9 'lf.

Verf. untersuchte den Bau zahlreicher lierne ron Ei-, Epithel-, Ganglien-, Bindegewebszellen usw. der verschiedensten Tiergruppen vor allem auf ihr Verhalten rot-blanen larbstoffgemischen gegenüber. Er kommt dabei mogefülı zu folgenden Anschaunngen über den Bau des Kernes. Der Kern besitat ein netzförmiges Plistingerüst, dem Nucleinkörper und Nucleolen eingelagert sind. Dazwischen ist ein flüssiges Enchylema, das sich mit Jodgrünfuchsin grrün färbt und Nuclein enthält. Die Nucleinkörper sind in jungen Zellen stark phosphorhaltig (grün färbbar), was bei Drüsenzellen und multinucleolären Ganglienzellen erhalten bleibt, bei andern, z. B. Eizellen, schwindet. (Violettfärbung.) Ihrer Form nach zerfallen die Nucleinkörper in Nicrosomen und Macrosomen, die auseinander hervorgehen. Die Nucleolen der Metazoen sind erythrophil, färben sich mit rotblanen Farbstoffen rot. Sie entstehen während des Wachstums der Zelle aus intensiv grün- 
färbbaren. phosphorreichen Nucleolen, die ihrerseits auf Microsomen zurückzuführen sind. Ein Rest dieses Nucleins bleibt oft als grïn oder violett färbbare \%one erhalten. Bleibt reichlich Nuclein in den Nucleolen erhalten (multinucleoläre Eier), damn zerfallen sie öfters periodisch in Dicrosomen und banen sich aus diesen wieder auf. In den uninucleolären Eiern und (ianglienzellen geht das Nuclein im Hauptnucleolus ganz verloren und es kommt ror allem eine sekretorische Tätigkeit, durch Vakuolenbildung gekennzeichnet, zum Aus(lruck $\left.{ }^{1}\right)$. Eine besondere Einwirkung auf den Zelleib ist den Nucleolen zuzuschreiben, auch sollen sie mit der Zellmembranbildung zusammenhängen, weil besonder's in den Eiern der Säugetiere Hatuptnucleolus und Zellmembran eine fraplante Übereinstimmung in der Färbbarkeit zeigen (s.!) In gewissen Fïllen (bei Gastropodenganglienzellen) sollen sogar die Nincleolen aus dem Kern und dem Kellleib auswandern, wobei sicl etwas Kellplasma mit alsehnürt, und hieraus neue Zellen eutstehen. (s.'?) Resonder's eingehend werden die Nucleolen des Amphibieneies in Riicksicht auf Carnoys liefunde behandelt. Verf. glaubt. dass die mannigfachen Figuren, die dieser Autor innerhalb des Nucleolus entstehen lässt, durch Kónospung usw. vom Nucleolus ans entstelien.

R. Goldschmidt (Niirnberger).

572 Rhumbler, L., Mechanische Erklärung der Ïbulichkeit zwischen nagnetischen Kraftiniensystemen und Kellteilungsfiguren. In: Arch. Entwmech. Bil. 16. 1903. pag. 476; -535. 36 Textfig.

Verf. unterzieht die bekannte Ähnlichkeit zwischen magnetischen Kraftliniensystemen und Zellteilungsfiguren einer eingehenden Analyse, um festzustellen, ob beiden Erscheinungen gleiche mechanische Faktoren zu grunde liegen. Dass in der Zelle nicht etwa auch magnetische Erscheinungen vorliegen können, wird von vornherein durch das Vorkommen dreipoliger Mitosen mit Spindeln zwischen je zwei P'olen ansgeschlossen. Die mechanische Analyse zeigt nun, dass magnetische wie auch andere Kraftliniensysteme (z. B. in Roux 'Modell) \%ug und Drucktrajektorien darstellen, denn sie sind die Folge von Spannung längs der Kraftlinien, Pressung in der Richtung senkrecht zu ihnen. Wie verhält sich dies nun in der Zelle? Dort sind die gleichen Faktoren nachzuweisen, vorausgesetzt, dass dem Plasma ein wabiger Ban zukommt und die Kentren bei der Kellteilung in der Art wirken, wie es Verf. früher im Anschluss an Biitsclıli dargestellt hat. Die im

$\left.{ }^{1}\right)$ Die gerade das Gegenteil beweisenden Angaben von Wilson. Hartmann, dem Ref. scheint Verf, nicht zu kennen. (Ref.) 
Dyasterstadium stark anschwellenden Centrosomen entnehmen zunächst dem umliegenden Hyaloplasma Flüssigkeit, wodurch die ihnen anliegenden Sphärenteile und die ausstralılenden Radien optisch dichter werden. Nun zieht nach den Gesetzen der Oberflächenspannung, wie Verf. friiher näher ausfülıte, dichteres Hyaloplasma weniger dichtes an sich heran, wenn beide miteinander in Kontinuität stehen; IJand in Hand damit geht eine Repulsion ron Enchylema, Dotter usw. ron der Sphäre weg, in der Richtung der Radien, und diese Substanzen diosmieren in die interradialen Waben. Durch den Volunverlust streben aber die radialen Waben sich zu rerkiirzen, d. h. sie sind in Longitudinalspannung, die interradialen dagegen blähen sich auf und bewirken so den senkreeht gegen die Trajektorien pressenden Widerstand. "Der mechanische Grund der Übereinstimmnng ron magnetischen Kraftinienspindeln und . . a andern Trajektoriensystemen mit Keruteilungsspindeln liegt darin, dass bei allen in Vergleich gestellten Trajektoriensystemrn die Trajektorien in Längsspannung begrifien sind nnd dass senkrecht gegen die Trajektorien pressende kröifte wirken."

Die so nachgewiesene Longitudinalspanumog stellt anch nicht, wie man glauhen kïnnte, ein Hindernis für die Zellteilnng dar, sie leitet sie viehmelır sogar ein. inden in Kelliänator die am wenigsten widerstandsfïligen Stellen der am stärlisten gespannten Trajektorien liegen. Auch die bisweilen am Ende der Zellteilung anftretende Kraltlinientigur, die der "Zipfelkreuzfigur" des magnetischen (ileichpolsystems entspricht, findet unter den gleichen Gesichtspunkten ihre Erlilïrung, werm man annimmt, dass die Zugtätigkeit der Zentren noch narh ter äquatorialen Trennung anhält; dann werden die intertrajektoriellen T'eile nach dem $\ddot{I}_{\text {quator }}$ (dem locns minoris resistentiae) gerluängt und von dort radiair durch die Bijtschlischen Raimme (eine ringförmig die Spindel umgebende Wabenpartie) angesangt, wobei die Radien passir mit nach aussen gebogen werden.

Der Mevossche Finwand, dass die Strahlenkreuzung der Zellteilungsfiguren beweise, dass kein Kraftliniensystem vorliegen liönne, wird auch hier wieder zuritkgewiesen, intem gezeigt wird, dass die Krenzung dureh ungleichzeitiges Einsetzen der Zngwirkung der sphären (anch beim Magneten entsprechend) oder durch lokale Störungen im Zugfelde (Dotter usw.) zu stande kommen können. Z/um Schluss wird noch bewiesen, dass die ja anch im Magnetfelde cintretende fontänenartige Biegung der Polarradien nur unter der Annahme des Wabenbaues des Plasmas mönlich ist: „Den Schlïssel zu einer einheitlichen mechanischen Frklärung der Kellteilung 
liefert die Wabenlehre. Die Ähnlichkeitsbeziehnngen zu magnetischen Kraftlinienfiguren weisen mit Entschiedenheit daraul hin, dass bei der Aufdeckung der Zellteilungsmechank die dynamische, anf den Wabenbau gegrindete kontraktionstheorie, die sich in jüngster \%eit wieder in E. B. Wilson (01) und Conklin (102) nene, gewichtige Vertreter erworben lat, den sieg iiber likartheorien und Expansionstheorien behalten wird". Quod felix fanstumgue sit!

R. Goldschmidt (Nürnberg).

573 Staufracher, Heh., Einiges iiber \%ell-und hernstrukturen. In: Ktschr. wiss. Zool. Bd. 73 1903. pag. 368-76. 1 Tf. 4 Textfig.

Verf. glaubt an verschiedenen Zellarten von Cyclas cornea sehen zu kömnen, dass die in Strängen angeordnete achromatische Substanz des Kerns sich durch die Kernwand in die Zolle fortsetzt und hier das cytoplasmatische Netzwerk bildet. (?!)

R. Goldschmidt (Nürnberg).

\section{Faunistik und Tiergeographie.}

574 Forbes, S. A. Illinois State Laboratory of Natural History. Biennial Report of the Director for 1899-1900. Urbana 1901. pag. 1-21.

Die biologische Station von Illinois stellte sich in den letzten Jahren die Beobachtung der im Staatsgebiete vorkommenden Fische zur Hauptaufgabe. Berücksichtigt wurden die Häufigkeit und Verteilung, die Wanderungen, die Brutzeiten und Brutplätze, das Verhalten und die besonderen Gewohnheiten der Fische in verschiedenen Gewässern, die Farbvariationen, das Wachstum zu verschiedenen Jahreszeiten. Die Daten entstammen neun verschieden gelegenen Stationen. Mlit Firfolg wurde die statistische Methode der Plankton-Biologie auf die Ichthyologie angewendet.

Es liessen sich im allgemeinen faunistisch nach Vorkommen, Lebensweise und Ban im süssen Wasser drei Fischgruppen, die Bewohner von Fluss, See und T'eich, unterscheiden. Die Flussfische selhst bilden verschiedene Untergruppen im schlammigen und klaren Wasser, doeh indert sich die Verteilung mit dem Wechsel der äussem Bedingungen. Im Frühjahr mischen sich die Gruppen durch flussaufwärts ins Seichtwasser gerichtete Brutwanderungen.

Zwei weite Exkursionen nach dem Osten, Westen und Sidwesten von Illinois dienten zur allseitigen Ausdehunng der Kenutnisse über die Fischfauna und zur Vermehrung der Sammlung. Die ichthyologischen Resultate werden in rinem grossen Bilderwerk niedergelegt.

Mit den Fischstudien ging Hand in Hand die Fortsetzung der seit dem Jahr 1894 begonnenen Beobachtungen über die Planktonverhältnisse des Illinois-Riversystems, sowie Arbeiten iiber die Wasserinsekten und Hirudineen. An 20 Schulen wurde im Meer und Süsswasser gesammeltes Unterrichtsmaterial verteilt.

Die Station verfügt ïber einen Stab wissenschaftlicher Mitarbeiter und über eine gute Bibliothek, die einen regen 'Tauschverkehr' unterlıält.

F. Zschokke (Basel). 
575 Lohmanu, II., Untersuchungen über die Tier-und Pflanzenwelt sowie ïber die Bodensedimente des Nordatlantischen Ozeans zwischen dem 38. und 50. Grade nördlicher Breite. In: Sitzber. Kgl. Preuss. Akad. Wiss. Bd. 26. 1903. pag. 560-583. Taf. I.

Eine im Mai und Juni auf einem Kabehdampfer unternommene Iieise, die nach den Azoren und nach New-York und auf demselben Wege zurückführte, gab) Verf. Gelegenleit zu mannigfaltigen und ergebnisreichen biologischen Untersuchungen an Organismen der Veeresfliche und des Meeresgrundes. sowie zu Peobachtungen ïber die Bodensedimente.

Fïr die Lebewelt der Oberflïche schlägt L. die praktische Einteilung in "Auftriel," und .. Wirbeltiere" vor, mit der Bemerkung, dass eine ganz scharfe Trennung nicht durchfïlubar sei.

I) grossen Auftriebformen, deren Vorkommen von Bord aus zu brobachten war, verteilten sich in dem durchfalurenen rebiet geset\%mäPig. Lhre Individuen- und Artenzalıl veränderte sich mit dem Wechsel der physikalischen Verhältnisse und unter dem Einfluss der Jahreszeiten. Im ginzen heriihrte die Reise drei Gebiete, ron denen sich jedes durch bestimmte grosse Auftrieborganismen charakterisierte: ein westliches mit P'ly ysalien und treibendem frolfkrant, eine östliche, bis zum 20. Iü̈ngegrad sich ausdehnente \%one mit P'olagien und Salpa scutigera-conforderata, und einen bis zur europäischen Kiiste sich erstreckenden Abschnitt, den ein fast völliger Mangel an grö̈ssern, freischwebenden Lebewesen kennzeichnete.

Nach einer biologischen und faunistisch-floristischen Schilderung der drei Bezirke, einer nngeführen Bestimmung ihrer Grenzen und nach Angaben und die Häufigkeit und die I)ichtigkeit des Auftretens der einzelnen (Organismen, frägt Verf. nach der Bedeutung der auffälligen Verteilung der grossen Auftriebformen und nach den Girïnden ilıres Wechsels auf der Hin- und Riiickreise. Er sieht in dieser V'erteilung den Ausdruck allgemeiner hydrographischer und biologischer Verhälnisse der durchfahrenen Strecke des atlantischen Ozeans, unablüügig von voriibergehenden Einttüssen von Wind, Wetter und Tageszeit. Die drei Gebiete entsprechen wohl drei verschiedenen Abschnitten des Golfstroms. So lässt sich die allgemeine Verteilung der fraglichen ()rganismen durch Strömungsverhältnisse erklären, wenn sich auch der Deutung mancher Einzelerscheinung noch zahlreiche Schwierigkeiten in den Weg stellen.

Besonders fällt die scharf gezogene Grenze zwischen den beiden westlichen Gebieten auf, sowie die Konzentration der verschiedenen Arten ron Auftriebformen am Nordrand des Pelagien- und Salpen- 
gebiets. Steigerung der Zeugming und Strömungshemmung verursachen wahrscheinlich dureh ihre Zusammenwirkung jene 'Tieranhäufung.

Eigentlichen "Schwärmen" begegnete der Kabeldampfer nicht.

Volle Bedeutung besitzt der Nachweis eines ausgesprochenen, jahreszeitlichen Wechsels in der Zusammensetzung des Grossplanlitons für das beriihrte Neeresgebiet. Der Wechsel erklärt sich aus den Veränderungen der Existenzbedingungen im grossen, nordäquatorialen Stromzirkel wälırend eines rollen Kreislaufs. Könnte man mit dem Wasser einen solchen Kreislanf mitmachen, so würde sich für das I'lankton unfehlbar eine gesetzmäbige, bei jedem Umlauf periodisch wiederkehrende V'eränderung ergeben. Komplizierend tritt noch der jahreszeitliche Wechsel dazu. Er wird gegeben durch die Verschiedenheit der Existenzbedingungen, denen das Plankton in den rerschiedenen Jahreszeiten am Ort der ungünstigsten Verhältnisse unterworfen ist. l'ür den nordäquatorialen Stromzirkel liegt diese Stelle da, wo sich seinen Wasser südlich von der Neufundlandbank der polare Labradorstrom beimischt.

Für die Beurteilung des Yorkommens kleinerer, indessen mit Müllergaze noch fangbarer Auftrieborganismen verfügt $I$. über neun quantitative Netzzüge. Die betreffenden Planktonvolumina blieben immer klein, ein Resultat. das sich mit früher im Nittelmeer und atlantischen Ozean gesammelten Erfahrungen deckt.

Besonderes Interesse bot die Planktonzusammensetzung im westlichen Teil des Gebiets des Golfkrauts und der P'hysalien. Auf der Ansreise fehlten dort die Oscillarien, während auf der Rückfahrt Ieliotrichum in grosser Nenge auftrat. Mer Wechsel beschränkte sich auf das hocherwärmte Golfstromwasser. Wasser von $13^{\circ}$ beherbergte ein Plankton, das demjenigen des Warmwassers im allgemeinen entsprach, doch mit starker Reduktion der Artenzahl. Von arktischen Formen fanden sich nur wenige. meistens tote Exemplare. Auffallend war die Armut an Tintinnen. Das Kaltwasser charakterisierte sich, neben dem Fehlen von Heliotrichum, durch das reichliche Auftreten leerer Gehäuse nordischer, im Labradorstrom und in der Davisstrasse bäufiger Tintinnoiden und einer Ptychocyclis-Art.

Trotz der grossen Entfernung rom Kontinent erschien am Westrand des Golfstroms eine freischwimmende, wahrscheinlich den Molguliden zugehörende Ascidienlarve. Sie geht aus schwimmenden Eiern hervor, zeigt indessen keine besonderen Anpassungen an selbständiges, pelagisches Leben. Bei den Molguliden verkürzt sich sonst die Schwärmzeit stark.

An der Nordgrenze des Pelagien- und Salpenbezirlis lebten am 15. Juli grosse Mengen von Chio myramidata L. Die europäische und 
amerikanische Flachsee zeichnete sich aus durch die enorme Hänfigkeit ron Guinardia und durch das zahlreiche Vorkommen ron Cortomella ientricosa und ron Muschellarven. Vor New York war Thalassiosir $\iota$ charakteristisch.

Filtration des Auftriebwassers durch dichten Seidentaffet erlaubte schliisse ïber das Auftreten kleinster, durch Miillergaze nicht mehr fangbarer Plankitonten. Im allgemeinen ergab sich eine Bestätigung der von L. für das Mittelmeer festgestellten Verhältnisse in bezug auf die \%usammensetzung des kleinsten Auftriebs, das Auftreten, die V'erteilung und die Häufigkeit der einzehnen Formen. Gy mnodinien und C'hrysomonadinen spielten wieder die Hauptrolle; Ciliaten und Zooflagellaten erschienen in spärlicher \%ahl. Das Fehlen der $\Lambda$ pendicularien-Geläuse verhinderte leider die Untersuchung der Fangapparate, so dass eine im Nittelmeer trefflich luewälnte Kontrollmetlıode wegfallen musste.

Ein weiterer Abschnitt der Arbeit umschliesst die ïber die Wirbeltiere - Vögel, C'etaceen, Chelonier, Fische während ler Fahrt aufgezeichneten Reobachtungen. Das Gebiet der Pelagien und Salpen erwies sich als bedentend reicher an schwimmenden Vertebraten, als die beiden andern durelıkenzten Bezirke. Bei der Besprechung ron Orthagorisens mola fügt Verf. Notizen iiber den sehr stark entwiekelten Knorpel der lörperwand ein, der, spezifisch leichter als Meerwasser, lem Fisch mülueloses Schwimmen und Ruhe auf der Oberfläche erlaubt.

Die allgemeinen Resultate über die Sedimente Res Meeresgrundes und ihre Zusammensetzung entspredhen den friiher anf der Lotungsfalurt der ..Britamnia" festgestellten Tatsachen. Sürllich ron Nenfundland und Teuschottland boten sich besonders interessante. teilweise unbekannte Verhältnisse.

Der rote Ton, wie der blane Mud umschlossen dort immer grosse, oft sehr zahlreiche Exemplare ron Coscinodiscus radiatus. Ehrbg., einer in nordischen und arktischen kïistengebieten weitrerbreiteten Form. Dagegen waren Radiolarien äusserst selten. Die betreffenden Sedimente liegen an der Tierïhrungslinie von Golfstrom und Labradorstrom, so dass man mit der Annahme wohl kaum fehl geht, die ('oscinodisken sinken vom Warmwasser getötet zu Boden. Thre dicken Schalen bleiben in den Sedimenten erhalten, während die skelette zarterer Diatomeen zn grunde gehen.

Eine eigentïmliche Schichtung der Sedimente im westlichen Übergangsgebiete des roten Tons in den Globigerinenschlamm deutet darauf hin, dass neben der T'iefe noch ganz andere, einstweilen unbekannte 


\section{- 584 -}

Tmstände bei der Umwandlung der am Meeresgrund sich ablagernden Sitoffe zu den verschiedenen Sedimentformen mitwirken.

Fis bestätigte sich ferner, dass ein Bruchteil der zartern, pelagischen I)iatoncen bis zmm Meeresboden in mehr als $3600 \mathrm{~m}$ gelangt. Doch werden diese Algen wahrscheinlich anfgelöst, bevor sie eine ruhige Ablagerung erfahren. Bathybius: wurde nicht gefunden.

(' o c colithen fehlten in keinen Schlammproben; sie traten weitans am zahlreichsten im Globigerinenschlamm anf und liessen sich his zu $69+1 \mathrm{~m}$ Tiefe nachweisen. Quantitativ stellten die Coccolithen hei $43^{\circ} 32^{\prime}$ lir. und $19^{\circ} 49^{\prime}$ L. $68^{\circ} \%$ des Gesamtgewichts und $71^{\%} \%$ des Gesamtrolumens der Sedimente dar. Der Name .Coccolithenschlamm" wïre also herechtigter als "Globigerinenschlamm". Über das Vorkommen und die Verbreitung der einzelnen Coccolithenformen spricht sich Verf. eingehender aus. Wr hetont auch, dass die relativ kleine Menge der lebenden Exemplare an der Meerestlïche in keinem Verhältnis znr grossen Häufigkeit der toten Skelette auf dem Meeresgrund zu stehen scheine. Bei der Beurteilung dieses scheinbaren Missverhältnisses ist zu bedenken, dass verschiedene Tiere auf Coccolithennahrung angewiesen sind und dass während der Entwicklung ron den C'occolithen alte Schalen wiederholt abgeworfen und durch neve ersetzt werlen.

Manche Protozo en der Oberfläche und des Grundes, besonders Codonella, verstärken oder bekleiden ihse Schalen mit Coccolithen.

F. Zschokke (Basel).

576 Zykoff. W., Bemerkung über das Winterplankton der Wolga hei Saratow. In: Zool. Anz Bd. 26. Nr. 703. 1903. pag. 544-546.

Unter dem Eis der Wolga fanden sich bei schneller Strömung im Jammar 4 llicrophyten, 4 Protozoen, 6 Rotatorien und 7 Crustaceen. Mclosira dominierte; im Gegensatz zur Oder traten in der Wolga Diatomeen im Winterplankton typisch hervor.

Von Rotatorien war Anuraca aculeate am häufigsten, ilır folgte Notholca longispine. Alle Crustaceen blieben vereinzelt. Für die Bosminen prägt sich in der Wolga der Saisondimorphismus deutlich aus. R. longirostris-cormute erschien in der Winterform.

Die allgemeine Planktouarmut erklärt sich durch die Ungunst der Jahreszeit und durch die schnelle Strömung.

F. Zschokke (Basel).

\section{Protozoa.}

577 Mrgutiusky, P., Malariastudien. In: Arch. mikr. Anat. Entwg. lid. LIX. 1901. pag. 315-35t. Taf. 18-21.

Verf. hat die im Blute malariakranker Kinder zu Kasan zu beohachtenden Entwicklungsstadien des Tertianparasiten genauer unter- 
sucht. Er konnte dreierlei verschiedene Formen von einkernigen Parasiten unterscheiden:

1. Zellen mit relativ reichlichem und grobem Pigment und mit reichlichem knänelförmig angcordneten, wie ein vielfach vertlochtener Faden erscheinenden Chromatin, welehes in nach Romanowsky gefärbten l'räparaten ron einer ungefärbt gebliebenen \%one umgeben und ron dem im Gegensatz zu andern l'arasitenformen mehr grïnlich als blau gefärbtem Protoplasma hufeisenförmig umgeben war. Verf. hält diese Formen für dic Microgametocyten. Sie fandon sich bei sämtlichen malariakranken Kindern und fielen am meisten in die Augen, trotzdem sie sich von den andern Formen durch etwas geringere Grösse unterscheiden. Ihre Häutigkeit war zwar gewiscen Schwankungen unterworfen, liess jedoch keine Beziehung zum Fieberverlauf erkennen.

2. Kellen mit sehr spärlichem, liönigem, peripher gelegenem Chromatin und grossem, eine gesättigtere blaue Farbe ammehmendem Protoplasmakörper. Vorkommen wie bei den vorigen. Verf. hält diese Formen fïr Macrogameten.

3. Zeilen mit einem bläschenförmigen Kern. der ein dentliches Karyosom erkennen lässt. Viel seltener als die andern formen und namentlich auf der Höhe des Fieberanfalls nur ganz vereinzelt anzutreffen. von $A \mathrm{r}$ ut insk mit Rücksicht anf diese letzterc Erscheinung in ihrer uberwiegenden Mehrzahl für schizonten gehalten, zum Teil allerdings auch für noch nicht fertigr ausgebildete Microgametocyten bez. Macrogameten.

Die Vermehrung der Schizonten beginnt nach dem Verf. mit einer Zweiteilung des Karyosoms, dem die Teilung des ganzen Kernes folgt. Die entstehenden 'Tochterker'ne sind anfänglich wie der Mntterkern blïschenförmig, sollen sich jedoch nachträglich (: Ref.) umformen. indem in jedem von ihmen das Kiaryosom sich spaltet und auflockert und zu einer Anordnung des Chromatins in einer Anzahl von nicht allzu kuzen Fïden führt, so dass ein an eine Mitose erinnernder Bau der Kerne entsteht. In einem weiter vorgeschrittenem Stadium fanden sich Kerne mit wenigem. kompaktem Chromatin und unregelmäßiger, eckiger, stacheliger Form. Haben die Kerne ihre definitive oder beinahe definitive Zahl erreicht. so erscheinen sie noch kompakter. färben sich intensiver und sind regelmäbiger rund bez. ellipsoid gestaltet. Kerne mit einer Einschnürnng, hantelförmige Kerne und je zwei durch eine kurze, feine Verbindungsbricke noch in Zusammenhang stehende Kerne weisen darauf hin. dass die Kernteilung jetzt eine direkte ist und keinerlei Ähnlichkeit mehr mit einer Mitose hat. (Diese Angaben sind inzwischen von Schandinn bestätigt und 
erwitert worden. Ref.) Erst nach Abschluss der Kernteihno findet die Teilung des Protoplasmakörpers statt.

Gelegentlich will Yerf. T'eilungsvorgänge anch bereits bei sehizonten beobachtet halen, die man iluer Kleinheit wegen noch für ganz jung und unreif hätte halten sollen.

Lie Parasiten sollen nach dem Verf. nicht imnerhalb der roten lihthörperchen liegen, sondern ihnen nur äusserlich angehefted sein. und zwar nicht nur in ihrer . Ingend. sondern danerus bis zur vollendeten Vermehrung. Diese Angabe. welle bisher von \%eit an \%eit immar wieder gemacht wurde, darf wohl inzwischen als endgiiltig widerlegt angesehen werlen, nathdem Sehaudinn das Eindringen der P'arasiten in die Blutkörperchen direkt rerfolgt hat.

M. I. ï he (Königsberg i. I'r.).

578 Irgutiusky. I'. Malariastudien. \% wo ite Mitteilnng: \%

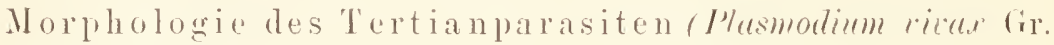
et Fel.). In: Arch. mikr. Anat. lintwg. lin. LXI. 1902. patg. 331-347. Taf. XYIII.

Verf. betont, dass die ibbliche Ilerstellung ron blutaustrichen durch lrocknenlassen einer möglichst dünnen Blutschicht und nichheriges F̈ixieren Forn und Struktur von Kern nnd Protoplatsma der Malariaparasiten erheblich rerändert. Ererlangt deshalb Fixierung des nocli fenchten lilutausstriches (am besten mit (Osmiundaimpfen), behandelt aber den Ausstrich nmm nicht feucht weiter, sondern lässt ihn unmittelbar mach der Fixierung doch wieder trocknen, derart dass sogar die Entfernung des ïherschüssigen ()smiums durch Wasserstoffsuperoxyd erst nach diusem Trocknen rorgenommen wird. An die Möglichkeit. dass auch bei dieser Methoule das Trocknen Kunstprodukte herbeiführen kann, wird oftenbar gar nicht gedacht. woll aber erklärt der Verf. alle bei der ïblichen Methode des Fixierens nach vorherigem Trocknen erzielten Bilder, welche er bei seiner jetzigen Methode nicht zu Ciesicht bekommen hat, olme weiteres für limstprodukte. So z. B. die Ringbildung, welche fïr die jungen Malariaparasiten charakteristisch ist und welche doch auch am lebenden objekt ebensowolil nachweisbar ist. wie an Priparaten, die niemals trocken gewesen sind. sondern fencht fixiert und feucht weiter behandelt werden. Jedenfalls hat Verf. in den nach seiner Methode behandelten Präparaten Ringe nie beobachtet und ferner fand er, im Gegensatz zn den Angaben anderer Autoren. dass der Kern der Malariaparasiten relativ seln gross ist und rollkommen kompakt und strukturlos erseheint ohne .achromatischen Bezirk." Entsprechend dieser Angahe lassen die Abbildungen des Verfs. starke Überfärbung des liernes erkennen. Bei 
den sich durch starke amöhoide leweglichkeit anszeichmenden Entwicklungsstadien soll auch der liern eine mehr oder weniger ausgesprochene Abweichung ron der runden Gestalt zeigen, als Ausdruck seiner lieteiligung an den amöboiden Bewegungen des I'lasmakörpers.

Eine besondere Pesprechung findet auch noch die Struktur der Macrogameten und Microgimetocyten, welche Verf. jetzt auf Grund der veränderten Methodik nicht unwesentlich anders schildert, als in seiner vorstehend besprochenen ersten Mitteilung. Namentlich hat Verf. bei seiner neuen und angeblich besseren Hethode eine struktur des Kernes auch bei den Microgametocyten nicht nachweisen kïmnen. IIatte Verf. in seiner rorstehend besprochenen I'ullikation (auf pag. 337) die Schizonten ausdriicklich als ,.ebenso gross wie die Macrogameten” bezeichnet. so werden nummehr die Macroganete'n als , die grössten unter den Parasiten" bezeiclnet. Während I lontinsky an den Nicrogametocyten niemals eine Indeutung von amöboiden Fortsiitzen gesehen hat, liessen die Macroganeten leichte amöhoide Gestaltsreränderungen erkennen - lieobachtungen, die mit (ntsprechenden Angaben Schaudinns in vollem Einklang stehen.

M. I ülı (Königsherg i. P'r.).

579 Lankester. L. Lay, ()n a Confenient Terninology for the Varions Stages of the Malaria l'arasite. In: Proceed. lioy. Soc. London. Vol. LXX. 190" Ne.460. pag. 7t-79.

580 - - In: Nature. Vol. LIV. 1902. Nr. 1691. pag. 499--501.

581 - - In: Lirit. ned. Journ. Vol. I. for 1902. Nr. 2150) par. (552-653.

882 - In: Reports to the Malaria Committee. Roy. Soc. London. VII. Ser. 1902. pag. $47-52$.

Ray Lankester liat in dem British Museum eine lieile ron Modellen aufstellen lassen, welche den Entwicklnngsomg der Malariaparasiten reranschaulichen sollen, und empfand bei deren Etiketticrung das Bediurfnis nach einer 'T'erminologie ..so einfach und klar als möglich". Ausdricke wie "Sporozoiten", "Ookineten", ...chizonten" usw. wirkten zum Teil rerwirrend; sie hätten wohl Platz zu finden in Besprechungen der allgemeinen Morphologie und Lebensgeschichte der Sporozoen, seien aber .,erfahrungsgemäb. wenig geeignet für den ummittelbaren Gebrauch bei der Schilderung oder Erwähnung der Entwicklungsstadien des Malariaparasiten. Anstatt ron .,Sporozoiten“ will er daher von „Exotosporen“ sprechen, da dieselloen ausserhall, des menschlichen Körpers gebildet werden; mit Riïckicht auf ihre Form kömnte man allerdings auch an Namen wie ..Oxyspore" oder ,liaphidiospore" denken. Die Merozoiten sollen digegen ... Bulıemosporen" genannt werden, die amöboid beweglichen Schizonten "Amoebulae". 
Für die Crametocyten erscheine die Benennung ..Halbmond"‘ am besten bez. bei denjenigen Arten. wo dieselben nicht halbmondförmig sind, ,Halbmond-Späre" (crescent-sphere). Die reifen Macrogameten werden als ..Fizellen“, die Microgametocyten nach ihrer Überführung in den Miickenmagen als ... Spermamntter\%ellen". die Microgameten als ..Spermatozoen" bezeichnot. Aus der Vereinigung von „Eizelle" und ..Spermatrzoon" geht die ..'Yygote" oder ..Embryozelle" hervor, welche sich zum ..Vermieulus" streckt und nach ihrer Einwanderung in die l)armwandung der Miicke zur ..Sporencyste" umwandelt. Die in dieser gebildeten Sporoblisten (Schandin n. L ïhe u. a.) be\%. Sporoblastoiden ( i rass i) endlich werden .,Sporenmutterzellen" genamut.

Ob die vom V'erf. vorgeschlageneu lienennungen wirklieh so praktisch sinrl, dass die abermalige Vermehrung der bereits iberreichen Fïlle ron Namen für ein und dieselben Objekte als ein Fortschritt angesehen werden muss, bleibe dem Urteil des Lesers überlassen.

M. Lii he (Köngsberg i. Pr.).

583 Griy. St Geo. The MaIaria l'arasite. In: Brit. med. Journ. Vol. I. for 1902. No. 2157. pag. 1121.

In vorstehend hesprochener l'ublikation hatte Ray la ankester unter anderm auch geäussert. dass es nicht möglich sei, die männlichen und weiblichen IIalbmonde, solange sie noch im menschlichen Blute sich befänden, mit Sicherheit zu unterscheiden. Nach den Erfahrungen des Verfs. ist dies jedoch in der Mehrzahl der Fälle keineswegs schwierig. Abgesehen ron der bereits von andern Autoren betonten Verschiedenheit in der Fürbbarkeit des Plasmas findet Verf. anch das l'igment in den männlichen Halbmonden zerstrenter, weniger intensir schwar\% (? Ref.) und in der Regel exzentrisch. dem einen Iol mehr genähert als dem andern, in den weiblichen dagegen mehr konzentriert und in der Regel in Gestalt eines Rings im Zentrum des Halbmondes gelagert.

Aus Anlass einer andern Äusserung La nkesters bemerkt Verf. ferner noch, dass er bei der Reifung der Nacrogameten fast stets die Bildung von zwei ,l'olkörperchen" beobachtet habe.

\section{Lïhe (Königsberg i. P'r.).}

584 Sambon, $\boldsymbol{L}$. W. Remarks concerning the nomenclature, etiology, and prophylaxis of the intermittent fevers. In: Brit. med. Journ. Vol. II. for 1902. Nr. 2178. pag. 964.

Verf. unterscheidet abweichend von der Mehrzahl der Malariaforscher 4 verschiedene Formen der Malaria, ausser Quartana, Tertiana, ,Subtertiana* ( $=$ Herbstsommerfieber, Tropenfieber oder Perni- 
(ciosa) anch noch eine Quotidiana und nennt die diese rerschiedenen Formen hervorrufenden Parasitenarten: Hacmamoda golgii (nomen norum: = Plasmodimm malariae! Ref.), Haemamoeba rirax, Haemamoeba larerani Labbé e. po (= Lareramia malariae Girassi bez. Plasmodium immaculatum f(ir. et. Fel.| Schaudinns) und "Haemamoeba

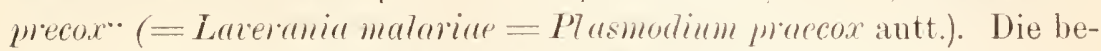
sondere Gattung Larerania (= Hacmomenas lioss) sei iibertlïssig, der Name Plasmodium als ungeeignet (..inappropriate*) zu verwerfen (letzteres ist freilich nicht statthaft. Ref.). Weiterlnin wendet sich Verf, gegen die oben besprochenen Vorschlige von $L$ a n kester. Speziell die nenen Bezeichnungen ... Exotospore" und ..Exhämospore" erklärt Verf. für iibertlïssig, die erstere auch direkt fiul . absurd” und tritt (als Mediziner dem Zoologen gegeniiber! lief.) fïr die ..wohlbegrïndeten zoologischen Ansiriicke" Sporozoit und Merozoit ein.

II. L ï lıe (Königsberg i. Pr.).

85 Schaudinn, Frity, Studien ïber k ranklieitser regende P'rotozoen - Il. Plasmodium rifax (Grassi d Feletti). der Erreger des T'ertiantiebors beim Menschen. In: Arb. a. d. Kaiserl. Gesundheitsante. IBd. XIX. IIft. 2. 1902. pag. 169-250. Taf. IV-VI.

Die vorliegende Arbeit muss zweifellos als die wiehtigste von allen morphologischen Malariaarbeiten bezeichnet worden, welche seit dem Erscheinen von $G_{1}$ assis imfangreichem Buche veröflentlicht worden sind. Wemn Lang in seinem Lehrbuch der vergleichenden Anatomie (2. Aufl., 2. Lief., pag. 219) Sc la udinns Arbeit über den Generationswechsel der Coccidien als ..technisch und methodisch mustergültig" bezeichnet, so lat dieses Urteil nicht nindere borechtigung fïr die jetzige Arbeit, in welcher der bekamte P'rotozoenforscher eine genaue Schilderung des Tertianparasiten liefert. Zum nicht geringen T'eil hängt der grosse l'ortschritt, welchen die vorliegende Arbeit bedeutet, damit zusammen, dass der Verf. im Gegensatz zı dem in der Malariaforschung in letzter \%eit fast allgemein herrsehenden Gebrauch sich nicht damit begniigt hat. die im fixierten und gefärbten l'räiparat gefundenen Stadien zu cinem Gesamtbilde zu kombinieren, sondern dass er vielmehr alle Beobachtungen und Schlussfolgerungen auch am lebenden Objekt kontrolliert, alle Entwickhungsvorgänge im Leben verfolgt hat.

Von den hierbei erzielten Riesultaten können als die wichtigsten wohl diejenigen angesehen werden, welche die Geschlechtsindividuen betreffen. Diese treten bereits verhältnismäßig früh nach dem Ausbruch der Krankheit auf; denn bei einer frisehen Infektion ron 
typischer Tertiana begann die Differenziermug der Macrogameten mul Microgametocyten bercits nach dem dritten Fieberanfall. Das Wachstum beider erfolgt wesentlich langsamer als disjenige der Schizonten und beansprucht mehr als die dophelte Zeit. Hieraus erklärt Verf. die dichtere Strulitur des l'rotoplasmas und die reichlichere Anbänfung des l'igments, welch letatere das am frïhesten sichtbar werdende Interscheidmgsmerkmal gegenïber den schizonten ist. Zeichnen sich doch bereits die juingsten stadien der lieschlechtsindividnen, welche in Form und birösse noch fast rollkommen den freien bez. eben in rote Bhuthörperchen eingedrungenen Verozoiten gleichen, durch den Besitz von l'igment ans, während solehes len gleichgrossen Schizonten noch algeht. (ileichfalls bereits anf fribhen Stadien int der Kern der Geschlechtsindividuen grösser als derjenige der Schizonten mo bei weiterm Warhstum zeigt er eine immer mehr zunehuende Auflockerung. Die lebhafte amoboide liewewlichlieit nnd die die lingform hedingende Ennährungraknole fehten den heranwachsenden fieschlechtsindividuen vollständig. Nur der Macrogamet lïsst finc Zeitlang noch eine im Vergleich zum Schizonten auffällig träge amöboide lieweglichlieit erkennen; bein Nicrogametocyten scheint auch dicse zu fehlen. Lei den Nicroganetocyten ist die Anflockerung und Vergröissermug des liernes noch stärker nnd frülıer ausgeprägt als bei len Macroganeten und auch in der l'lasmastruktur zeigen die beiden Gesehlechter Unterschiede voneinander. liei den Microganetocyten erscheint das Plasma im Leben auffällig blass mol schwach lichtbrechend und im fixierten Präparat färbt es sich mit keinem l'arbstofí so intensiv, wie dasjenige des schizonten. Ingekehrt ist ein leicht erkennbares Mlerkmal der Macrogameten in Gegensatz zn den schizonten sowohl wie zu den Nicrogametocyten die auffallend dunklere Färbung des Plasuas, welche bei Anwendung der verschiedensten larbstoffe hervortritt. Während $A r^{2} u t i n s k y^{1}$ ) ausdrïeklich betont, dass bei den ron ihm in Kasan mintersuchten Tertianparasiten Macrogameten und Schizonten gleich gross sind. Fand Schaudinn in Istrien die Marrogameten stets erheblich grösser wie die Schimonten.

Verschieden wie ilne Struktur ist anch das spütere Schicksal der Nacrogameten und Microgametocyten, wenn dieselben in der Bhutbahn rerbleiben und somit ihren Reifungsprozess nicht durchmachen können. Die Microgametocyten scheinen relativ rasch zu grunde zu gehen. In 2 Füllen konnte deren allmähliche $A$ bnahme rom 4. bis 6. Tage nach dem letzten Fieberanfall direkt festgestellt werden und in allen Fïllen, in welchen 3 bis 6 Wochen nach dem letzten Fieberanfall überhaupt

1) In seiner vorstehend besprochenen ersten Mitteilung. Vergl. aber anch das Referat über die zweite Mitteilung Argutinskys. Ref. 


\section{- 591}

noch Parasiten im Bhlute nachweisbar waren, handelte es sich ansschliesclich um Macrogameten. Die Langlebigkeit dieser letzteren ist überhaupt eine sehr grosse unil sie ist es, welche im V'erein mit der Fähigkeit derselben Macrogameten, sich unter Einliissung eines 'Teiles ihres Kernes und ihres I'lasmas zu Schizonten zurückzubilden, das Auftreten der Rezidive nach scheinbar iiberstandener Malariainfelition bedingt. Schandinn konnte nämlich in einem fralle die speziellen liedingungen feststellen. welche bei dem betreffenden Patienten stets zum Aufteten von Malariarezidiven führten. Als sulche sind im allgemeinen Erkältung, Öberanstrengung n. dol. bekannt. In rorliegenden Fall handelte es sich mm einen zu gewissen Keitpunkten eintretenden und mit vermehrter Arbeitsleistung verbundenen Aufentlaltswechsel. Als diese bedingungen nun wieder einma! gegeben waren, wurden alle 2 Stunden lilutprohen des betreftenden l'atienten untersucht. Fis fanden sich hierhei eigentimmliche Formen von Macrogameten, welche an Trilungsstadien erinnerten. nud welehe in ihrer Gesamtheit keinen Zwrifel lassen, dass die Macroganneten siell inäqual teilten in eine dem Untergang geweilite Irälite, in welche auch ein Teil des ursprïnglichen Macrogametenkernes eintrat, nnd eine andere, die sich zu rinem Schizonten umwandelt nnd dureh typische Schizogonie weiterteilt. Bald daranf trat anch in der Tat ein Mal-

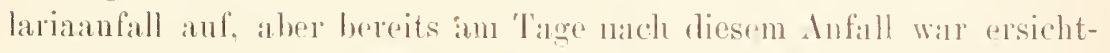
lieh, dass die meisten Merozoiten zin Gameten heranwudhen nnd in der Tat erwies sich anch die Zahlıl der noch gebildeten schizonten als zu klein, ın noch einen zweiten fieberanfall herbeizuführen.

bas verschiedene Schicksal, welches die im Bhute \%nrïckgebliebenen (iametocyten erleiden, erscheint anch physiologisch lecicht rerstïndlich. Der Microgametocyt mit seinem grossen liern und wenigg dichten Plasma lïsst ane so hohe Spezialisierung seines bines elkennen, die zugleich so deutlich auf den Bernf der Micrugametenbillung hinweist, dass es physiologisch schwer rorstellbar ist, wie er in diesem augenscheinlich sehr lahilen Zustande lange verharen kann. In Gegensatz hierzu besteht die S.jezialisierung der Macrogameten vor allem in ihrem dichten, offenbar reich mit Reservestoften beladenen Protoplasma, welches ihnen eine grössere Widerstandsfähigkeit verleiht und sie zu einem längern Leben befïhigt erscheinen lïsst. Ihre Umwandlungen bei Auftreten eines Rezidives fasst Schaudinn direkt als ein Zurïicksinken auf den Schizontenzustand auf. infolge einer Schwächung durch langen -Aufenthalt im Blute oder durch andere Einflüsse.

Bringen diese Angaben prinzipiell neues, so enthïlt die Arbeit ausserdem noch eine Fïlle neuer Detailangaben. welche unsere Kennt- 
nisse wesentlich erweitem, auf welehe hier in einzelnen näller einzugehen jedoch zn weit führen wïrde. Es sei deshalb nur benerkt, dass Sclandinn anch Ban und Beweglichlieit der Sporozoiten, das am lehenden objekt rerfolgte Eindringen der aus der Speicheldriise eines Anopheles entnommenen Sporozoiten in rote Iintkörperchen des Menschen und die in letaterm erfolgende I mwandlung des Sporozoiten zum jungen Schizonten, ferner Wachstum. Bau. Beweglichkeit und Vermehrung der Schizonten, die Bilhnng der Microgameten, die Kopulation und die T'uwandlung der Copula zum Oukineten ansführlich schildert. Nur auf das Eindringen des ()okineten in die Darmwandung der Miicke und die weitere Entwicklung bis zur Einwandermng der Sporozoiten in die Speicheldrïsen geht Sclla ndinn nicht nälıer ein, da er bezïglich dieser Fragen den Angaben G rasis in der zweiten umgearheiteten Anflige von dessen Malariawerk nichts wesentlich neues hinznzusetzen hat. Yon besondernu Interesse ist dic Schilderung der Kernteilung in Schizonten, da es sich bei derselben wieder um eine Art ron primitiver Mitose handelt, wie dieselbe in den letzten Ialren, nicht zum wenigsten durch die Untersuchngren Sehandinns bereits von einer ganzen Reihe ron Protozoen bekannt geworden ist, wemn sic anch bei verschiedenen Arten stets in etwas anderer Weise verläuft. Namontlich die erste Kernteilung im Schizonten des T'entianparasiten hat eine anffallige Ïhnlichkeit mit der typischen Mitose (Auftreten achromatischer Fasen mnd einer Ïquatorialplatte, spaltung der letztern in zwei 'Tochterplatten), währent bei weiterm Fortschreiten der Kernvermelıung diese $̈$ Hhnlichkeit allmählich undentlicher wird und die letzten Kernteilungen als einfache I) rohschnïrungen des Kernes erscheinen. Frwähuung verdient anch noch die praktisch wichtige leststellungr, dass das Pigment des Malariaparasiten in polarisierten lichte doppelt brechend erscheint, und dass Schaudinn die Ringform der jungen Schizonten, wie bereits oben gelegentlich angedentet wurde, auf den Besitz einer „Ernihrungsvacuole" zurückführt.

Ansser der besprochenen Sehilderung des Entwicklnngsganges des Tertianparasiten enthält die Arbeit noch Angaben über eine ron ('hinin noch nicht beeinflusste Malariaepidemie in einem istrischen Dorfe und einen Abschnitt ïber die wissenschaftlichen Speciesnamen der verschiedenen menschlichen Malariaparasiten.

M. Liille (Königsberg i. Pr.).

586 Holmes, S. J., Plototaxis in Toleox. In: Biol. Bull. Vol. IV. Nr. 6. May 1903. pag. 319-326.

Nen sind die Beobachtungen der Verfs. iher die I'hototaxis ron 
Tolvor dem Wesen nach nicht, seine Absicht ist, die Bedeutung der roten Pigmentflecke, die am Vorderpol der Kolonie grösser sind, als an andern Stellen, für das Zustandekommen der richtenden Lichtwirkung zu betonen. Die Abweisung der Oltm annsschen Anschauung, dass nicht die Riehtung des Lichtstrahls, sondern der Intensitätsabfall die Ursache der phototaktischen Bewegungen sei, ist gänzlich unbegrïndet, da der Verf. gar keinen V'ersuch gemacht hat, diese beiden Momente, die bei gewöhnlicher Versuchsanordnung gleichsinnig wirken, experimentell zu trennen und daher aus seinen Befunden gar nichts für oder gegen diese Anschauung deduzieren kann.

A. P'itter (Göttingen).

37 Jennings, II. S., Studies on Reactions to stimuli in unicellular Organisms. IX. On the behavior of fixed Infusoria (Stentor and Iorticella), with special reference to the modifiability of Protozoan reactions. In: Amer. Journ. Physiol. Vol. VIIl. 1902. 1ag. 2:3-60. 10 'T'extfig.

Die Untersuchungen, welche sich auf Stentor, Tortirma. Epistylis und Carchrsium beziehen, ergeben viele Ïhnlichlieiten in den Reaktionen dieser festsitzenden Infusorien.

Typisch ist folgender lieizerfolg, der zuerst bei der meclanischen lieizung von Stentor roeselii beschrieben wird: Das Tier neigt sich zunächst von der Reizquelle fort: gelingt es ihm dadurch nicht aus ihrem Bereich zu kommen, so erfolgt eine kurze Umkehr der Richtung des (wirksamen) Cilienschlages, was gegebenenfalls einige Male wiederholt wird. Dauert der lieiz noch weiter fort, so kontrahiert sich das Tier, wobei es sich in seine Rï̈lre zurückzieht; dies wiederholt sich bei dauernder Reizung oftmals und die Perioden der Kontraktion werden gewöhnlich länger. Endlich löst es sich von der Unterlage ab, schwimmt davon und baut sich an anderer Stelle, wo es ron dem Reiz befreit ist, ein neues Gehäuse.

Die Variationen dieses Reaktionstypus bei verschiedenen Reizen und verschiedenen Species mögen im Original nachgesehen werden. Bemerkenswert sind noch die Angaben über "Reizgewöhnung" bei den untersuchten 'Tieren: Von einer Reihe von mechanischen Reizen war nur eine gewisse Zeit hindurch jeder wirksam, dann folgten mehr oder minder lange P'erioden, in denen eine, zum T'eil recht bedentende Zahl von Einzelreizen unwirksam war, bis dann wieder eine Kontraktion erfolgte. Der Vorgang scheint grosse $̈$ h̆nlichleit mit der Erscheinung des sog. "Refraktärstadiums" des Muskels zu haben.

A. Pätter (Göttingen). 
588 Jennings, II. S., and Clara Jamieson, Studies on reactions to stimuli in unicellular organisms. X. The movements and reactions of pieces of Ciliate Infusiora. In: Biol. Bull. Yol. III. Nr. 5. ()kitober 1902. pag. 225-234. 4 Textfig.

Bei den löher differenzierten Ciliaten haben die verschiedenartigen Gruppen von Cilien offentrar verschiedene Funktion. nehmen ainen ungleichen Anteil an dem Zustandekommen der einzelnen Bewegungen. Jennings und .J amieson haben num die Frage in Angriff genommen. in wie weit Iruchstïcke von Ciliaten die typischen oder abweichende Bewegungs- und Realitionserscheinungen darbieten. Als Objelite dienten Stylonychia, Stentor, Sprirostomum und l'aramaecimm. Unter dem Braus-Drün e rehen T'räpariermikroskop wurden durch Kerschneiden der 'Tiere isolierte Vorder- und Hinterlälften, Mittelstücke, rechte und linke IIälften hergestellt.

Das liesultat der Untersuchungen war, dass alle Bruclistiicke, wemn sie nicht gar zu klein und unregelnübig gestaltet waren, dieselben liowegungstypen zeigten wie die ganzen Tiere. Sie schwimmen in Spiraltouren, von bestimmter Drelrichtung, und wenden sich bei Reizung in derselben Weise zur Seite wie normal. Die Verff. kommen so zu dem Schlnss, dass die Körpergestalt, der Sit\% des P'eristoms und die Arbeitsteilung zwischen den verschiedenen Ciliengruppen n i cht die hohe Bedentung für das \%ustandekommen der charaliteristischen spontamen und Reaktionshewegungen haben könnten, der diesen Faktoren von andern Autoren zugesprochen wird (\%).

Leviler fehlen genauere Angaben dariber. w i e dem nun die ('ilien aler Bruchstücke, in ne u e r Loordination schlagend, die gl ei chen lieaktionen hervorbringen, wie sie beim kompletten Tier zu beobachten sind, und dic allgemeine Angabe, dass noch keine Arbeitsteilung der (ilien stattgefunden habe, dass sie alle einander gleichwertig seien, hilft ïber diesen Mangel nicht hinweg, sondern lässt die Resultate doch vorlïutig als ungewiss nnd nicht ganz wahrscheinlich erscheinen.

A. Piitter (Göttingen).

589 Maier, Hermann Nicolaus, Über den feinern Bau der Wimperapparate der Infusorien. (Aus. d. Zool. Institut 'Tübingen.) In: Arch. Protistenk. II. Bd. 1903. pag. 73-179. 'Taf. 1-2. (Auch: Dissertat. Naturwiss. Fakult. 'Täibingen. 1902.)

Verf. unterwarf den feinern Bau des Wimperapparates der Infusorien, insbesondere auch die Terbindungen mit dem Zellkörper, einer genauern Untersuchung, welche ihm namentlich für die Beurteilnng der von Lenhossék und Henneguy aufgestellten Ansicht, dass die Basalkörperchen der Metazoenflimmerzellen Derivate der 
Centrosomen darstellten, ron Interesse zu sein schien. Konserviert wurde meist mit Sublimatalkohol, gefärbt (nach Paraffineinbettung) fast ausschliesslich mit Eisenhämatoxylin. Untersucht wurden folgende Ciliaten: Opalina ranarum, Prorodon teres, Chilodon cucullulus, Ch. meinatus (var.?), Coleps hivtrs, Glancoma scintillans, Paremaccirm candatum, Ophylgoglena Hara (Art nicht ganz sicher bestimmt), Nyctotheres cordiformis. Bursaria truncatella, Stentor niger (sowie St. coentens, polmmorphus, ropsetii), Sprivostommm umbignum, S1. teres, Stylonichin histrio, Carchesinm polypimum.

Die Resultate des Verfs., die er in einem .. allgemeinen T'eil“" zusammenstellt, sind folgende:

"Die Cilien der Infusorien stellen äusserst feine, haarartige Fädchen ron plasmatischer Substanz vor und sind als kontraktile Primitivfibrillen oder Myofibrillen (Apathy) aufzufassen." Sie sind rollkommen homogen (gegen 'Tönniges, der bei Opalina regelmä̈rig ahwechselnde hellere und dunklere Abschnitte erkannt haben wollte) laufen, wenigstens bei den vom Verf. mitersuchten Arten. anscheinend an Ende stets fein aus und sind in der Regel in Furchen angeordnet, welche der Körperstreifung der Infusorien entsprechen. Nur bei Paramaecium bedecken sie den Körper „gleichmälig, aber stets in gleichen Abständen roneinander entfernt", und stehen in der Mitte regelmäßig begrenzter, gr'ubenförmig vertiefter Feldchen. Die ..̈̈ussern Ektoplasmaschichten" werden von den Cilien durehsetzt, und zwar bei Anwesenheit einer Alveolarschicht derart, dass die Cilie innerhath einer Alveolarkante verläuft (I'rorodon, Bmsaria). An der Wurzel der Cilien wurden bei sämtlichen darauf geprüften Infusorien Basalkörperchen gefunden, von der gleichen Art, wie sie bei den Flimmerzellen der Metazoen bekannt sind; sie färben sich mit Eisenhämatoxylin intensir schwarz und halten den Farbstoff beim Differenzieren mit Eisenalaun lange fest. Ihre Grösse ist verschieden (die grössten wnrden bei Nyctotherus gefunden). ihre Gestalt bald kugelig (Chitodon, (boleps, Paranaecium, Nyctotheru, Bussaria), bald eiförmig (Opatima, Glancoma, Stentor, Sprirostomum), bald birnförmig (Prorodon, Ophryoglena). „Die Basalkörperchen liegen im ('ortikalplasma, wo ein solches gut ausgebildet ist (Opatima, Prorodon, Paramaecium, Ophryoglena). 'Tritt das Ektoplasma nur in Form einer dïnnen Pellicula auf (Coleps. Chilocion, Stylonychia), so finden wir sie direkt unter dieser. Bei Infusorien, welche nur eine einheitliche, dicke Ektoplasmalage, die allen drei Ektoplasmaschichten anderer Ciliaten entspricht, aufweisen (Nyctotherus, Bursariu, Stentor), haben sie ihre Lage in diesem Ektoplasma“.

"Als 'Tastborsten bezeichnet man bei den Ciliaten cilienartige 
Gebilde, die als starre Borsten dem Körper eingepflanzt und keiner Tewegung fähig sind." Sie besitzen wie die Cilien Basalkörperchen (Rückenborsten ron Stylonichia histrio (). F. M., hinterer Wimperbiischel von Prormaccium randatum Ehrbg., randständige Borsten von Loxodes rostrum (O. F. M.) und werden in Übereinstimmung mit Maupas, Bïtsclıli u. a. als umgewandelte Cilien aufgefasst.

Bei den undulierenden Membranen, an denen die schon von frïhern Autoren beobachtete Längsstreifung und die Karfaserung in einzelne Fibrillen (Starki) bei den getüteten 'Tieren, vom Turf. bestätigt werden. konnte unter jeder einzehen Fibrille den basalkïrperchen entsprechende Gobilde nachgewiesen werden, dic in ihrer Gesantheit den .Pasalsaum” bilden. Bei stylonichio foräorale Nembram) liegen sie in einfacher Reihe, hei r'orhesium und Torticella (an den beiden parallel verlaufenden undulierenden Menbranen des Vestibulums) in dreifacher lieilıe; in (puerschnitt des basalsamms der peroralen Membran von Glaucoma scintillums Ehrbg. finden sich fünf, und im (puerschnitt des Basalsaums der endoralen Membran des gleichen 'Tieres sogar „mindestens zehn“ Basallïrperchen nebeneinander. Wie schon frïhere Autoren, nimmt auch Verf. an. dass die undulierenden Menbranen durcl Verklebung von Cilienreilien entstanden seien; je nach der Anzalıl der auf den Querschnitt nebeneinander liegenden basalkörperchen war hierbei eine verschiedene Anzahl von Cilienreihen beteiligt. An der basis mancher undulierenden Mombranen konnten ,homogrne, ektoplasmatische Verdickmngen" festgestellt werden, die Terf. als .. I a sa llamellen"1) bezeichnet und auf deren änsserem Teile die Basalkörperchen des Basalsaumes liegen. Ile undulieronden Membranen zeigen somit ähnliche V'erhältnisse, wie sie z. 'T'. schon früher von andern Autoren für die Membranellen nachgewiesen worden waren.

Für die Membranellen ron buraria trmatella hatte zuerst Selinberg gezeigt, dass bei Einwirkung von Sodalösung im optischen Durchschnitt zwei Punktreihen sichtbar werden, die auf' eine /usanmensetzung aus zwei Cilienreihen hindenten. Die gleiche Beobachtung machten biitschli und Schewiakoff an den Nembranellen von Stentor coeruleus; Schuberg bestätigte sie ebenfalls bei dieser Form, sowie bei Chimacostomum virens und einigen Hypotrichen. Der Verf. kam allgemein zu den gleichen Ergebnissen; es gelang ihm aber ferner. den bei manchen Formen schon von früher'n Forschern - znerst ron Engelmann bei Hypotrichen - nachgewiesenen Basal-

$\left.{ }^{1}\right)$ Im Anschluss an die vom Ref, bei den Membranellen von Stcutor entdeckten „Basallamellen“. 
sa um als aus zwei Reihen von Basalkörperchen zusammengesetzt zu erkennen, entsprechend der Struktur der Membranellen selbst.

„Die Membranellen sitzen mit ihrem Basalsaum dem Infusorienkörper meist vermittels einer ektoplasmatischen Verdickung auf." Bei Nyctotherus springt längs der ganzen adoralen Zone das stark verdickte, homogene Ektoplasma wulstförmig in das Endoplasma ror (..Basalwuls t"); meist jedoch finden sich unter jeder Membranelle gesonderte "Basallam ellen" (Schuberg 1891). Bei Bursura hatten Schuberg (18S6) und Biitschli (1889) sie als einfache Verdickungen der Alreolarwände angesehen, und noch als ., Basalsaum* bezeichnet: nach den Verf. jedoch handelt es sich bei dieser Form um "von diesen wohl zu unterscheidende Bildnngen." Die Verbindungen der Basallamellen mit dem "Peristomband" (Schuberg) werden bustiitigt und dieses selbst im Inschluss an Schuberg als eine elastische Stiitze des P'eristomrandes anfgefasst. Iie ron sclı. als möglich hingestellte kontraktile Natur der obertlächlichen Fibrillen des Peristonbandes wird dagegen in Abrede gestellt. Für Stentor wird , die eigenartige Beriehung der Membranellen zum l'lasmaleibe", wie sie sch uborg beschrieb, nach Beobachtungen an St. miger ., his ins lileinste Detail bestätigt"; unter jedem Ibasalsaum einer Membranelle senkt sich eine dreieckige ,Hasallamelle* ins Lndophasma ein, die in ein feines „Endfïdchen“" ausläuft; alle Endfädchen der adoralen \%one vereinigen sieh mit einer unter dieser in ilnrem ganzen Verlanfe hinziehenden Basalfibrille. Bei Sprostomm sind die Verhältnisse in wesentlichen die gleichen. Die .,Basalsämme" hält Verf. mit Schuberg für liefestigungsapparate, desgleichen die „Basallamellen"; die „Endfädchen“ und , die Basalfibrille“ dagegen fasst er wie A. Iirauer, der diese Gebilde schon teilweise beobachtet hatte, als kontraktile, keinesfalls aber als nerröse Elemente auf ${ }^{1}$ ). Bei Hypotrichen (Stylonichia histrio O. F. M.) , ,erstreckt sich von dem in eine homogene Basallamelle eingebetteten Basalsaum einer jeden Membranelle aus ein haarförmiger Fortsatz, die „.. Basalfaser"., in das Endoplasma hinen. dlle Basalfasem scheinen gegen einen Punkt auf der linken Seite des Peristoms in der Nälle des Anfangs der adoralen Zone gerichtet, endigen

1) Verf. spricht an einer Stelle von der Ansicht Schubergs, dass wir ${ }_{n}$ die basalen Apparate der Membranellen als nervös aufzufassen haben“". Wie Verf. an anderer Stelle richtig anführ't, habe ich ausdrücklich bemerkt, dass „hierzu die nötigen Beweise mangeln“. Ich habe aber nicht nur das bemerkt, sondern schliesse meine Ausführungen ïber die Funktion des basalen Apparates der Membranellen mit den Worten: "Leider ist mein Resultat hinsichtlich der Funktion ein negatives; keine der angeführten möglichen Vermutungen scheint mir genïgend wahrscheinlich gemacht, um mit einiger Sicherheit angenommen werden zu können". 
aber nach kurzem V'erlauf in Endoplasma frei. Sie scheinen die Funktion von Stuitzgebililen zu haben."

Als ,.Membrannla $\mathrm{e}^{6}$ bezeichnet Verf. die membranellenartigen Wimpergebilde des hintern Wimperkranzes der Vor ticellinen (Carchesium und rorticella); sie bestehen nur aus einer einzigen lieihe von Fibrillen und ihr schief zur Längsachse des Tieres gerichteter Basalsaum ist nur aus e in er Reihe von Basalkörperchen zusammengesetzt. Daraus wird geschlossen, dass sie. im Unterschiede ron den ,Membranellen" durch Verklebung einer einziggen Cilienreihe entstiuden. Die , Wimperkränze“ mehrerer IJolotrichen(Jinophryna, I)idymium) scheinen den Membranulae zuzurechnen oder nahe verwandt zu sein.

Auch an der Basis der Cirren von Hypotrichen (Stylonichic histrio) gelang es Basalsäume nachzuweisen, die aus einer grossen Anzahl in einer Platte angeordneter Basallïrperchen bestelıen. Die zuerst von Engelmann beschriebenen, an der Basis der Cirren inserierenden intracellulären Fasern - ,Basalfasern" - lassen sich durch die Schwarzärbung nit Eisenhänatoxylin deuthich machen. Wie Bïtschli und Schuberg liält Verf. die von Èngelmaun für sie angenommene ,nerröse Funktion“ nicht für wahrscheinlich; er erblickt vielnehr in ihnen ,Stützgebilde." Die Cirren selbst scheinen ihm aus einem Bïndel verklebter Cilien zu stande gekommen zu sein.

Ein Vergleich mit den Flinmerzellen der Metazoen ergibt dem Verf., dass sich sowohl bei diesen wie bei den Infusorien an der Basis der Cilien je ein mit Eisenhämatoxylin schwarzgefärbtes Basalliörperchen nachweisen lässt. Den ,Wimperwurzeln“ der Metazoen entsprechende Einrichtungen felılen den einfachen Cilien der Infusorien; dagegen besteht eine entsprechende Übereinstimmung zwischen den Membranellen der Infusorien, besonders von Stentor und den sog. Eckzellen der Kímen von Anodonta (B ii s chli, Schuberg). Ein Unterschied besteht nur darin, ,dass der basale Stiitzapparat bei der Eckzelle aus einzelnen Fasern gebildet wird. während er bei Stentor lomogen ist." Auch die ron andern Autoren beschriebenen basalen Verhältnisse der Geisseln von F la gellaten und der Cilien ron Algenschwärmsporen werden vergleichsweise besprochen.

Die Funktion der Basalkörperchen fasst der Verf. anders auf, als es in der letzten \%eit für die Flimmerzellen der Metazoen vichfach üblich geworden war. Er sieht in ihnen nicht ..kinetisclse \%entren" für die Flimmerbewegung (Verworn, v. Lenhossék), sondern in Übereinstimmung mit Eismond (1900) St ützapparate für die Cilien, eine Auffassung, dic für die ,Basalsäume“ der Membranellen 
von Stentor frïher schon Sclu u erg (1891) vertreten hatte. ${ }^{1}$ ) Für die kinetische Funktion der Basalkörperchen kann nicht nur kein einwandsfreier beweis erbracht werden, sondern es sprechen sogar verschiedene Tatsachen gegen eine solche. ,In allen Fällen, wo man glaubte, dass dieser Beweis erbracht sei, konnte nachgewiesen werden, dass dabei eine Einwirkung des Protoplasmas durchaus nicht ausgeschlossen war. Die 'Tatsache aber', lass wir Basalkörperchen an der Basis unbeweglicher Ciliengebilde, nämlich bei Sinneshaaren und am Borsten- oder Stäbchensaum antreffen. spricht entschieden gegen eine motorische Bedeutung ler Basalkörperchen."

Zum Schlusse bespricht der Verf. noch die, Entstehung der liasalkörperchen" und kommt dabei zu dem Ergelonis, dass die Hypothese von v. Lenhossék und Henneguy, wonacl die liasalliörperchen der Flimmerzellen aus Centrosomen hervorgehen sollten, nicht zutrifft. Wenn auch namentlich einige Tatsachen aus der Spermatogenese sie zu beweisen scheinen, so ,spricht gegen die centrosomale Entstehung der Basalkörperchen vor allem der Nachweis von ('entrosomen in Flimmerzellen, der jetzt bei d'n verschiedenston Wimperepithelien gegliickt ist"6; ferner die Reobachtungen Gurwitschs, wonach die basalkörperchen wahrscheinlich, ,aus den liasalteilen der Flimmerhare durch Verdichtung und Differemzierung ihrer Substanz entstehen", schliesslich aber auch .,das Vorhandensein von Basalkörperchen an den Wimperapparaten der Infusorien, bei denen ja nichts von einem centrosomaähnlichen Gebilde bekannt ist”. „Die Basalköpperchen der Wimperzellen entstehen wahrscheinlich als cytoplasmatische Gebilde an der Zelloberfläche und sind als besondere Verdichtungen an der Wurzel der Cilien aufzufassen, die sich dank ihrer dichten Beschaffenheit stark fïrben."

In dem, dem allgemeinen Teile der Arbeit vorangestellten ,speziellen 'Teile" schliesst sich bei den einzelnen Formen an die Schilderung des ,Wimperapparates" jedesmal ein Abschnitt ïber, ,Morphologisches", ,in welchen verschirdene Beobachtungen über den Körperbau des betreffenden Tieres, die sich im Verlaufe der Lntersuchungen gewissermaßien nebenbei ergaben, angeführt werden." Hiervon sei nur das Folgende erwähnt:

Im Ektoplasma von Opalina lassen sich zwei Schichten unterscheiden. Die äussere entspricht der Pellicula und Alveolarschicht anderer Infusorien und besitzt eine eigentiunliche, komplizicrte Obertlächenstruktur (vgl. Original); von Zeller wurde sie als eine Lage eng aneinander schliessender ,muskulöser l'änder"6 aufgefasst,

$\left.{ }^{1}\right)$ Es war mir allerdings nicht gelungen, dio Basalsäume in einzelne Basalkörperch en aufzulösen. 
was dann schon Bïschli in Abrede stellte. Die innere Sclicht, das ,Cortikalplasma", besitzt einen feinwabigen Ban. - Am Munde von Coleps hictus findet sich ein wohlentwickelter Reusenapparat, der sich aus einem Kranze von ca. 13 Stäbchen zusammensetzt und sich fast bis an das Hinterende erstreckt. - Die Trichocysten von I'aramaccium cuudutum Elirhg. werten im wesentlichen so gefunden, wie sie $\mathrm{Maupas}$ und neuerdings Kölsch schilderten. Der ron Ma up a beschriebene ,harfömige" Fortsatz ist schon beim lebenden Tier an der ruhenden Trichocyste zu beobachten und scheint mit der Pellicula in imnigerem Zusammenhange zu stehen: "r stellt einen besonders differenzierten Teil der Trichocyste dar, der bei ausgeschnellten Trichocysten als "T'mknickung des Fadenendes" erscheint. - Bei Bursaria truncatella kamen in Ektoplasma, in die Alveolarkanten eingebettet, ,trichocystenartige" körperchen vor; vielleicht hat A. Brauer an einigen stellen diese Gelilde ror sich gehabt, die ..möglicherweise nur lokal oder nur an einzelnen Individuen auftreten". und wude dadurch zu der von Schuberg widerlegten Auffassung des alveolären Ektoplasmas als Trichocystenschicht veranlasst. Das um die Mundspalte gelegene Plasma zeigte eine besondere Differenzierung. - Die von Bü schli heschriebene Alveolarschicht ron Stentor und den Kanal, in welchem nach B. hei dieser Form die Myoneme verlaufen. konnte Verf. nicht beobachten. - liei Srirostomm ziehen zu beiden Seiten der adoralen \%one stärkere ..zonale" Myoneme, welche wohl die bei der Kontraktion der 'liere eintretende 'Torsion bewirken. - Eine fibrilläre Struktur des Stielmuskels konnte weder bei C'archesimm polypimm, noch bei Irovticolla nchulifera nachgewiesen werden. Die Myoneme, welche an der Ursprmasstelle des Sticlmuskels gegen den hintern Wimperkranz ziehen, verbinden sich nicht mit diesen, sondern ziehen. wie schon A. Brauer richtig angab, in einiger Entfernung von diesem ..nach oben".

\section{A. Schuberg (Heidelberg).}

590 Neresheimer, Eugen Robert. Ïber die Höhe histologischer Differenzierung bei holotrichen ciliaten. In: Arch. Protistenk. 2. Bd. 1903. pag. 305-324. 'Taf. III. 1 Textfig.

verf. untersuchte Stentor coeruleus vor allem mit der von II allory angegebenen Dreifachfärbung $\left.{ }^{1}\right)$. .. Um möglichst grosse Stiicke des losgelösten Ektoplasmas zu erhalten, empfiehlt es sich,

$\left.{ }^{1}\right)$ Norfärbung mit Säurefuchsin, Beizung mit Phosphormolybdänsäure, Nachfärbung mit einem Gemisch von Anilinblau, Orange G, Oxalsäure und dest. Wasser." 
die lebenden Stentoren in schwach mit Methylenblan gefürbtes Wasser zu bringen und den Zeitpunkt abzupassen, in dem das Tier das ganze Ektoplasma abwirft und abstirbt. Die abgeworfenen Ektoplasmastiicke, die sich bald auflösen, fixiert man sofort und fürbt sie nach der angegebenen Methode." Verf. bemerkt selbst, dass sich "bei all diesen gewaltsamen Nethoden natïrlich leicht Verzerrungen und Verlagerungen der Elemente ergeben, so dass es schwer ist, den normalen Verlauf der Fibrillen genau zu verfolgen." Seine Methoden mahnen allerdings gar selır zu einer vorsichtigen Beurteilung seiner morphologischen Beobachtungen und lassen diese der Bestätigung bedürftig erscheinen. Für den normalen Verlauf der "Zwischenstreifen“ (Biitschli) werden im allgemeinen die Angaben Schubergs bestätigt ${ }^{1}$. In der hintern Hälfte des Tieres nun fand Verf. Fasern, welche „direkt oberhalb der Myophane mit diesen parallel verlaufen, und

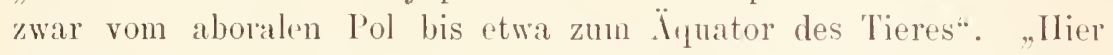
endigen viele mit einem etwas verdickten línöpfchen, andere scheinen dünner und schwächer zu werden und verschwinden schliesslich ganz. Auf Querschnitten fand V'erf. die Querschmitte dieser ron ilm als "Neurophane" bezeichnoten l'asern etwas peripher ron denen der Myophane. "Zn fast jeden Myonem gehört ein Nenrophan"; einige Myophane aber scheinen ron lieinem Neurophan begleitet zu sein; ror allem fehlen sie ganz den Myophanen des Stirnfeldes. Auch bei spirostomm ambignm glaubte Verf. .in einzehen Fallen” .eine Y'erdoppelung der in den Kwisehenstreifen hinziehenden Fibrillen zu crkennen", während er bei Carhesimm und Epistylis nichts analoges finden konnte.

Den Beweis für die nervöse Natur seiner ..Neurophane" glauht Verf. durch toxikologische Experimente erbracht zu haben. ..Gelingt der Nachweis, dass gewisse Gifte, die bei Metazoen notorisch die Nerven affizieren, bei Strntor und Sprirostomem im Gegensat\% zun andern Protozoen eine analoge Wirkung ausüben, so ist das Vorhandensein nervöser Organellen bei diesen hochdifferenzierten (iliaten anzunehmen. Es wird dann mindestens sehr wahrscheinlich sein, dass die Träger der nervösen Funktion eben die bei andern (Ciliaten nicht nachzuweisenden Neurophane scien." Die angestellten Tersuche, bei welchen Paramacciam, Stylonichia, Didinium nasutum und Amoeba moteus als Kontrolltiere benutzt wurden (betr. der Einzelheiten rgl.

1) Verf. behauptet, ich erwähne nicht die Beobachtung Steins, dass einzelne, vom aboralen Pol ausgehende Streifen die Wimperspirale nicht erreichten. Ich sage jedoch in meiner Arbeit (Zool. Jahrb. Abt. Anat. 4. Bd. 1890. pag. 199): "Schon Stein berichtet, dass nicht immer alle Streifen das Vorder- oder Hinterende erreichen". 
das Original), scheinen dem Verf. "bei Stentor coeruleus und Spirostomum ambigumm zweifellos eine so auffallende Übereinstimmung mit den Wirkungen auf die Nerven höher organisierter Tiere festzustellen, dass wir wohl unbedingt das Vorhandensein nervöser Organellen bei diesen Tieren annehmen miissen."

Die Schilderung Schubergs von der Befestigung der Membranellen im Körperinnern hält Verf. für nicht ganz richtig. Jede Membranelle „scheint“" zwei verschierlene Fortsätze (..Basallamellen") ins Körperinnere zu senden, ., wo sie sich ganz verschieden verhalten“. l)ie ..Basalfibrille”, welche nach Schubergg die Endfädchen der Basallamellen miteinander verbindet, wird dadurch vorgetïuseht, dass .. die ganze Zone rom Randstreif' bis zu den hakenförmigen Umbiegungen der Endfädchen aus einer Art ron Membritn besteht" nnd dass ... diese ganze niembranöse Zone sich bei losgelïsten P'eristomfeldern oft nach innen umschlägt" 1). Die Vergiftungsversnche ergaben keinerlei Anhaltspunkte für eine nerröse Funktion des basalen Apparates der. Nembranellen.

A. Schuberg (Heidelherg).

591 Siedlecki, Michel, L'Mcrpelophrya astoma n. g. 11. sp., infusoire parasite des Polymnios. In: Bull. Ac. Sc. Cracovie. Cl. sc. math.-11at. 1902. pag. 365 -362. 'Taf. XXXII.

Unter dem Namen Herpetophrya astoma beschreibt Verf. ein neues holotriches Infusorium aus der Leibeshöhlenflüssigkeit von Polymnia nebulosa (Golf von Triest). Der ovale Körper' ist linten abgerundet, vorne dagegen in einen kleinen Rüssel ausgezogen, der allein unbewimpert ist. Das Ektoplasma besitzt eine senkrechte Strichelung, welche jedoch nicht einfach auf einen Alveolarsaum zu bezielen ist. Verf. glaubt vielmehr, dass die Streifen rreprésentent une structure ressemblant à celle décrite dans des cellules épithéliales à cils vibratiles ( $\mathrm{n}$ gel mann)". T'rotz der tebhaften Gestaltsveränderungen, deren das Tier fähig ist, sind Myoneme nicht nachzuweisen. Mund, Peristom und kontraktile Vakuolen fehlen. Im Endoplasma fatlen vor allem grosse Vakuolen auf, deren Flüssigkeit aus der Leibeshöhlenflüssigkeit der Polymnien zu stammen scheint. Macronucleus und Micronucleus wurden nachgewiesen. Die Schwimmbewegungen der Tiere sind selır lebhaft. Die Fortpflanzung erfolgt durch Teilung.

Seiner systematischen Stellung nach ist Herpctophrya in die Familie der Opalinidae einzureihen, innerhalb deren sie den Gattungen Anoplophrya St. und Monodontophrya Vejd. am nächsten steht.

A. Scli uberg (Heidetberg).

\section{Coelenterata.}

592 Alers, W. M., Über die T'eilung ron Protohydra Lncharti. Beiträge zur Kenntnis der Spermatogenese bei den

$\left.{ }^{1}\right)$ Ich muss gestehen, dass mir die Auffassung des Verfs. weder aus seiner Beschreibung noch aus seinen Abbildungen verständlich geworden ist. Vgł. hierzu ïbrigens das Ref. Nr. 589 ïber die Arbeit Maiers, welcher meine Darstellung durchaus bestätigt. Ref. 
Coelenteraten. In: Ztschr. wiss. Zool. Bd. 74. 1903. ¿ 'Taf.

19 Textfig. (Inaug.-Diss. Marburg).

Der 'Teilungsvorgang von Protohydra geht ähnlich vor sich, wie die einfache Querteilung der Hydra; die dargestellten Details bieten wenig Bemerkenswertes.

Die zweite Abhandlung gibt zunächst eine Darstellung von der Entstehung und Ausbildung der Hoden von Hydra vividis, durch starke Wucherung der interstitiellen Zellen des Ektoderms, die an Ort und Stelle entstehen, nicht einwandern. Beim Heranwachsen des Hodens zum bekannten mammaförmigen Gebilde lassen sich nacheinander die Spermatogonien und Spermatoryten I. und II. Ordn. dureh die \%ell- und Spindelgrösse unterscheiden; Chromosomenzählung war nicht möglich. Weiterhin werden Mitteilungen gemacht über Nährzellen in den männlichen Gonaden ron Amolia amita. Die Hodenacini dieser Meduse sind ron einer kontinuierlichen Entodermlamelle überzogen. Von den kubischen \%ellen dieser Schicht fallen einige durch die stärkere Färbbarkeit ihres lierns auf. Bald verdichtet sich anch das I'lasma und num wandern diese Nährzellen mit Hilfe ron Pseudopodien dureh die Gallertschichte, die die Hodenacini umgibt, und durch die Stiitzlamelle hindurch in den Hoden ein. Hier lagern sich ihnen die Spermatomenköpfe dicht an, ja dringen in sie ein und dann beginnt die allnähliche I)generation zuerst des I'lasmas, dann des Kerns. Der degenerative Charakter derselben zeigt sich auch in der regehnäbig eintretenden amitotischen V'ermehrung.

R. Goldsehmidt (Nürnberg).

\section{Arthropoda.}

\section{Crustacea.}

98 Brian, A., Sostituzione di nome a I nuovo genere di Crostaceo Ler. neide: Silvestria mihi (= Leptotrachelus miki). In: Zool. Anz. Bd. 26. Nr. 703. 1903. pag. 547.

Da der Name Silvestria schon vergeben ist, tauft Verf. die von ihm beschriebene Lernaeidenform s.. truchae, die auf der patagonischen Pcrcichthys trucha leht, in Leptotrachelus truchae um. Der Krebs bewohnt den Magen seines Wirts, den Kopf in las Epithel einsenkend.

F. Zsehokke (Basel).

994 van Douwe, C., '/ur Kenntnis der Sisswasser-Harpacticiden Deutschlands. In: \%ool. Jahrb. Abt. Syst. Geogr. Iiol. Bd. 18. Ilft. 3. 1903. pag. 383-400. 'Taf. 20.

\%ur Systematik und Biologie der deutschen Süsswasser-Harpacticiden liefert van Dou wes Arbeit einen schätzenswerten Beitrag. Sie beschreibt genau, nach Material aus den oberbayerischen Mooren, den sonst atus Norwegen und böhmen bekannten Canthocamptus gracilis 
Sars, unter hesonderer Beriicksichtigung der Geschlechtsunterschiede. Die Art kennzeichnet sich auffallend durch deu schlanken Habitus, durch die Länge und Haltung des vierten Fusses und durch den bial des fünften männlichen Fusses. Dieser weicht von den entsprechenden Verhältnissen hei allen übrigen Canthocamptus-Arten dadurch ab, dass die beiden verschmolzenen Basalsegmente einen vollkonmen glatten Ring olne Verbreiterung und Bewehrung bilden; das wohl ausgebildete Endsegment dagegen trägt vier liorsten.

Fïr C. wierzejzkii Mrizek, den Mrizek in Töhmen, van Douwe in einem Quelsumpif des Isartals bei München fand, wird die frïhere Beschreibung des ergänzt und berichtigt. Als typische Erkennungsmerkmale liaben zu gelten die Form der Furka und ein beutelartig verbreitertes Segment der mïmmlichen Vorderantennen.

Auch die Diagnose ron ('. rejolow Mryi Mrák erfilurt Erweiternngen. Die aus Böhmen, lem Plöner See und den oberbayerischen Iforen bekannte Art charakterisiert sich besonder's durch den selur typischen Bau der weiblichen Furka.

C. cusprilutus, den Schmeil ans den Rhätikongewässern beschrieb, lebt auch in feucliten Wiesen dos Isartals.

Eine genaue Beschreibung widmet Verf. der nenen Art Moraria schmoilii, als deren Erkennungszeichen er die Innemrandborste der weiblichen lurka, den lian des rritten Innenastsegments des 2. bis t. Fusses, sowic die struktur des 5 . weilolichen Fussparars angibt.

Schmeils Verzeichnis der dentschen süsswasser-Harpacticiden breichert sich betrïchtlich. Fis sotzt sich nun \%usammen aus 14 Vertrotern des Genus Canthocamptus, 3 von Woraria, je 2 von Vitocre mnd Wolterstorffia, je 1 von Laophonte. Apsteinia, Ectinosoma und Ihyllogmathopus.

Biologisch passen sich diese Cupepoden den verschiedensten Lebensbedingungen an. Sie bewohnen das Ufer grosser Gewässer, rie Moospolster kleiner Quelkümpfe, Hache Wiesenbäche und in 'Trockenstarre sogar die Mooskrusten stark besounter Felsen. Dem verschierlenen Wolmort entsprechen Abweichungen in Grösse, Bau und Erscheinung der einzelnen Arten. Das Bediirfnis nach bestimnten Wasserquantititen bindet manche Harpacticiden-Species an gewisse, unter gegebenen Feuchtigkeitsbedingungen vorkommende , WirtspHlanzen". So bewohnt Canthocamptus ascholikei volzugsweise Hymmm crista-castrensis, (!. pygmacus das Lebermoos Ficgatella conica, $C$. vierajskii das submers wachsende Tastigobryum tiblobatum. Immer aber werden lebende, reichlich Sauerstoff spendende P'Aanzen, nie der schlamm aufgesucht. Daher stellen sich auf den Harpacticiden, im Gegensatz zu manchen Cyclopiden, die faules Wasser bewolmen, nur 
selten Ektoparasiten ein. In Betracht konmt einzig Metucinetu mystacina auf Canthocamptus gracitis.

F. Zschokke (Basel).

95 van bouwe, C.. Zur Kenntnis der freilebenden Sisswasser-Copepoden Deutschlands: Cyclops crassicaudis Sars. In: Zool. Anz. Bd. 26. Nr. 700. 1903. pag. 463-465. 3 Fig. im Text.

Der aus dem Norden und aus Bölınen bekannte Copepode lebt auch im Bodenschlamm der Isar bei München. Das $q$ trägt am Innenrand des zweiten Basalsegments des vierten Fusspaars eine Anzalnl Dornen, die dem of und den Verwandten ans dem Süsswasser fehlen. Etwas ähnliches kehrt bei marinen Formen (Miracia) wieder. Zu den charakteristischen Eigenschaften gehört die (iestalt des Receptaculum, die auffallende Grösse der Spermatophoren und die kreideweisse Färbung. Form und Bewehrung des rudimentären Fusses entspricht den für die bicuspidatus-Gruppe geltenden Verläiltnissen. Die weibliche V'rorderantenne zählt zwölf Glieder.

C. crassicandis gehört zu den kleinem Vertretern der Gattung. Fr bewegt sich ähnlich wie C. bisctosus, $C$. langnidus und $C$. phaleratus in dïnner Wasserschicht. Sein Abdomen führt auffälige Seitenlewegungen aths.

F. Kschokke (Basel).

96 van Douwe, (.., Beitrag zur Kenntuis der Copepodenf a ua Bulgariens.

In: \%ool. Anz. Bd. 26. Nr. 703. 1903. pag. 550-553.

Von 11 Lokalitäten - 'Tümpeln, liraben, Bächen - werden 10 Cyclopiden, 1 Harpacticide (Canthocomptus stuphylinus) und 1 Centropagide (Diaptomus wierzejskii) anfgezählt. Häufig treten die offenbar osteuropäischen Arten Cyclops diaphanus und C. masinus anf.

F. Zschokke (Basel).

697 Holmes, F. J., Death-lieigning in terrestrial Amphipods. In: Biol. Bull. Vol. IV. Nr. 4. March 190:3. pag. 192-196.

Der Verf. teilt einige lieobachtmngen ïber das "Sichtotstellen" bei An phipoden mit. Am typischsten ansgebildet findet er diese Eigentiimlichkeit hei der strandhewolınenden Form Telorchestia longicomis; Orchestia agilis, zeigt bei Berührung mit festen Körpern eine starke Beeinthussung der liewegung. wie Holmes meint, ... a sort of hypnotic effect apparently", ein eigentliches, sichtotstellen" kommt niclit zu stande.

Orchestia palustris stellt eine Zwischenstufe zwischen den beiden genannten Arten dar, ihre Reaktionen sind stärker, als die ron 0 . agilis. Diese Unterschiede in der Reaktion auf Beriihrungsreize sucht Verf. ethologisch zu verstehen und malt nach dem bekannten Schema des Selektionsprinzips die phylogenetische Fntwicklung derselben aus. Nach Holmes Auffassung ist das, Sichtotstellen" ein Instinkt, der in vielen Gruppen des Tierreichs entstanden ist.

Von physiologischem Standpunkt aus muss gegen die Auffassung der .,Scheintodreaktion" als .. Instinkt** entschieden Einspruch erhoben werden, es landelt sich hier sicher m einen sog. , L, ag e- 
reflex", einen .Reflextonus." Die Beschreibung, die Verf. von dem ganzen Verlauf der ..Scheintodreaktion" gibt, stimmt Zug für Zng mit den Erscheinungen des Reflextonus iiberein, wie wir ihn besonders durch V erworns ${ }^{1}$ ) Untersuchungen bei Wirbeltieren kemnen gelernt haben, und leicht kïnstlich erzeugen können, bei Arten, denen jeder derartige ..Instinkt" fehlt. Von Erscheinungen ,hyjmotischer" Natur liann gar keine Rede sein. Die ethologische krklärung vorliert hierdurch wohl auch wesentlich an Wahrscheinlichlieit.

A. P'iitter (Göttingen).

\section{Arachida.}

598 Kobert, R., Beiträgezur Kenntnis der Giftspinnen. Stuttgart (F. Enke) 1901. 191 pag. $1+$ Fig. im 'lext.

Der Verf. gibt eine ausführliche Darstellung der Entwicklung unserer Kemntnisse von den Giftspinnen, eine kritische Darlegung des gegenwärtigen Wissensstandes und eine grosse Rieihe experimenteller Beiträge zur Lösung bis dahin schwebender Fragen. Es mögen kurz die Hauptresultate der Arbeit folgen:

Die Solpugen sind ungefälırlich, ihr Biss (es handelt sich hauptsächlich um (Galcodes) hat für Menschen und Tiere wohl keine grösscre Ledeutung, als etwa ein Bienenstich. Eine Ciftdrüse fehlt allen darauf untersuchten Arten (die Angaben zum Teil nach brieflichen Mitteihngen vor: Alfred Walter). und die nach dem Bisse anftretenden lokalen Reizerscheinungen berulien teils auf der mechanischen Reizung durch den Biss, teils auf der Wirkung des Speichels der Tiere.

Über die Gefährlichkeit der Mygaliden liegen nur spärliche Beobachtungen vor, immerhin scheint es nach diesen, dass die Myydle: Species für den Menschen sogar lehensgefälnlich werden können, und Nemesia curmenturia nicht nur schmerzhafte Geschwiilste bei Mensch und Tieren bewirken, sondern gleichfalls gelegentlich den 'Tod herbeifülıren kann.

Harmlos erscheinen wieder die Taranteln. Sowohl nach den Angaben in der neuern Literatur, wie nach Versuchen mit Extrakten russischer Taranteh (Lycosa singoriensis Laxmam) konmt Kobert zu dieser Anschanung. Die mittelalterlichen Epidemien des 'T'arantismus sieht Verf. als Beispiele psychischer Ansteckung an, wie wir sie ja heute noch beim Veitstanz (Chorea) beobachten, jedenfalls haben sie nichts mit dem Biss der Spinne zu tun.

Der Hauptteil des Buches ist den Erscheinungen der LathrodectesVergiftung gewidmet. Überall wo die Lathrodcctes-Arten vorkommen, kennt man ihre Gefährlichkeit für den Menschen und die Haustiere.

1) Leiträge zur Physiologie des Zentralnervensystems. Jena 1898. 
Über das Krankheitsbild des Bisses der ,Malmignatte" (Italien und Griechenland; Luthrodectes tredecimguttutus, und $L$. conglobutus) und der ,Karakurte" (Russland, Taurien, Turkestan usw. L. erebus) liegen eine Reihe ron Berichten vor, die noch wesentlich ergänzt werden, durch die Ergebnisse von Fragebogen, die Kobert in den fraglichen Gouvernements Russlands verteilt hat. Auch aus Australien (XenSeeland und Suidaustralien) liegen Angaben über den Biss des ,Kratipo“ (Lathrodectes scelio und hasseltii) ror, dessen Folgen fast genau so beschrieben werden, wie die des Bisses der Malmignatte und Karakurte. Nach allen. gut ïbereinstimmenden Perichten ist das Krankheitsbild beim Menschen folgendes: Der Gebissene fühlt augenblicklich den Biss wie einen Bienenstich. Anschwellung der kaum geröteten Bissstelle ptlegt nieht zu erfolgen. Auch die rasch einsetzenden rasenden Schmerzen bevorzugen die Jissstelle keineswegs, sondern lokalisieren sich auf die Gelenke der untern Extremitit und die Hüftgegend. Die Patienten sind unfähig sich a ufrecht zu erhalten, sie brechen kraftlos zusammen, kalter Schweiss bedeckt den Körper, die Atmung wirl dyspnoisch, lä̈nfig ist Oppressionsgefühl in der Herzgegend vorhanden. Urin- und Stuhlentleermng sind angehalten. Nach \&3 'T'agen tritt gewöhnlich erhebliche liessermug ein, doch sind auch Todesfälle beohachtet worden.

Um eine genanere Vorstellung von dem Virus zu bekommen, das diese Erscheinungen einer schweren Vergiftung erzeugt. hat Verf. eine grössere Reihe von Versuchen mit Auszïgen von taurischen Karakurten angestellt. Aus ilınen geht herror, dass das Gift nicht nur in den Gifthriisen, sondern im ganzen Körper der erwachsenen Spinnen sowohl, wie der eben ans dem Ei geschliipften. und auch in den unentwickelten Eiern enthalten ist, und zwar überall etwa in gleicher Wirksamkeit. Seine Giftigkeit wurde an Süugetieren (Hund, Katze, Meerschweinchen, Kaninchen, Igel usw.), an Vögeln (Sperling, Fink) und an Fröschen sowie an Blutegeln erprobt. Immmn erwies sich keins der mitersuchten Tiere, doch zeigte der Igel eine erhellich grössere Widerstandsfähigkeit, als die übrigen Tiere. Für Katzen und Kaninchen liegt die tödliche Dosis unter $2 \mathrm{mg}$ pro Kilogramm Körpergewicht. Auf das isolierte Froschberz wirkt der Kochsalzauszug von Kiarakurteneiern noch in einer Verdünumg von 1:100000 abtötend. Die Symptome sind überall ganz ähnlich denen, die bei schweren Fällen von Lathrodectes-Biss beim Menschen beobachtet sind: Herz und Zentralnervensystem werden mit oder ohne vorhergehende Erregung der motorischen Zentren gelähmt.

Von besonderm Interesse sind die Nitteilungen über einige ge- 
lungene Fälle ron $\mathrm{I} m \mathrm{~mm} \mathrm{n}$ s i erung gegen das Spinnengift durch Vorbehandlnng mit sehr geringen Quantitäten.

I)as Gift wird durch Hitze sowohl, wie durch Alliohol und andere Fïllnngsmittel fïr Eiweissliörper unwirksam gemacht, löst die roten Blutkörperchen anf, nnd befördert ausserordentlich die Cierinnung, so dass man es als ein Toxalbumin oder giftiges Enzym anselıen muss.

I)as Schlusskapitel enthält einige Angaben iiber die Giftigkeit von Chivacanthimm mutrix: Walck. und Versuche über die Giftigkeit der Kreuzspinne. Sie ergaben, dass die Epeira im ganzen löorper und während der ganzen Entwickhnng vom Ei an ein Gift enthält, das in seiner Wirkung dem Lathrodectes-Gift ansserordentlich älmlich ist; es erwies sich aber als widerstandsfähiger gegen physikalische und chemische Manipulationen, so dass es möglich war, ein Albumin zu fïllen, das den wirksamen Restandteil mitriss. Das Fällungsprodukt hatte allerdings eine selı abgeschwïlite Wirkung. Die Wirknng eines frischen lireuzspimnen-Extraktes muss man wohl als eine recht kräftige hezeichnen. wenn man hört, dass die Giftmenge. welche e in e einzige Spimne liefert, hinreichen wïrde, um etwa 1000 halbwïchsige Katzen (1600 bis $1800 \mathrm{~g}$ Gewicht) zn töten.

Extrakte aus andern eimheimischen Spinnen, Tegenaria, Eucharia, Diassus usw. Waren durchweg völlig wirlsungslos anf die Versuchstiere.

$$
\text { A. Pütter (Göttingen). }
$$

\section{Insecta.}

599 Gridin von linden. M., Morphologische und physiologischchomische Untersuchnngen iiber die l'igmente der I.epirlopteren. 1. Diegelben nud roten Farbstofte der Yanessen. In: Arch. ges. Physiol. Bd. 98. 1903. 1)ag. 1-89. Mit 3 'lextfig. n. 1 'Taf.

In der genannten Arbeit habe ich mir die folgenden Fragen vorgelegt: welcher chemischen Natur sind die roten und gelben Farbstoffe, die in den schuppen, im Blut, im Darm und in den Excrementen unterer Tanessa-Arten anftreten? In welcher liezielnung stehen die verschiedenen Farbentöne zneinander? Wie und wo bilden sich die P'igmente und welche liedentung haben sie für den Stoffwechsel des Insekts? Die Ergebnisse dieser Untersuchungen waren kurz zusammengefasst die folgenden:

Die roten Farbstoffe der Vanessen sind in die Gruppe der Eiweisskörper zu stellen. Hierfür spricht 1. ihr Verlıalten gegen Lösungsmittel: Alle roten und gelben l'igmente sind wasserlöslich, sie werden sowohl ron heissem wie ron kaltem Wasser anfgenommen, ebenso ron Zuckerlösungen und ron Glycerin. 
Ausserdem können die Farbstoffe durch konzentrierte Mineralsäuren in Lösung übergeführt werden. Wenig löshich sind sie in verdünnten Lösungen der $\mathrm{N}$ e utralsalze, sehr wenig in Chloroform.

Unlöslich sind die Farbstoffe in konzentrierten Salzlösungen, in Alkohol und $\ddot{A}$ ther usw.

2. Die Fällbarkeit des Farbstoffs a us seiner wässerigen Lösung: Sümtliche Nittel, welche Eiweisskörper aus ihren Lösungen niederschlagen, bewirken auch die Fällung der roten Vanessenpigmente. Hierler gehören: Alkohol, verdïnnte Mineralsäuren, Essigsäure, konzentrierte Lösungen der Nentralsalze, die Salze der schweren Metalle, Tannin, NatronKalilauge und Ammoniak, Kohlensäure.

3. I) ie Farbenreaktionen der roten Vamessenpigmente. Die lösungen des Farbstoffs geben sowohl die für die Gegenwart von Eiweisskörpern charakteristische $1 /$ illo n sche lieaktion sowie auch die Xanthoproteinreaktion. Aucl der von Adamkiewicz beschriebene, für Eiweisskörper charakteristische Farbenwechsel tritt ein, sobald der Farbstofflüsung Schwefelsäure zngesetzt wird. Es bilden sich an der Berührungsstelle beider Flïssigkeiten zuerst ein roter, dann ein violetter und schliesslich ein blauer ling.

Da durch salzsauren Alkoliol eine Spaltung des roten Vanessenpigmentes in eine ungefärbte oder wenig gefärbte wasserlösliche und in eine gefärbte alliohollösliche Komponente möglich ist, so muss angenommen werden, dass es sich in dem larbstoff um die Verbindung eines Eiweisskörpers mit cinem P'igment handelt, ähnlich wie es bei dem Bhutfarbstoff, dem Hämoglobin der Fall ist, das durch den Einfluss von Säuren in (ilobin und alkohollösliches H ämatin zerlegt wird.

Nach seinen lieaktionen zu urteilen, gehört der Eiweisskörper. an den der rote Vianessenfarbstoff gebunden ist, in die Gruppe der Albumosen. Beweisend ist hierfür, dass der durch Salpetersäure bewirkte Niederschlag des l'igments in der Wärme löslich ist und in der liäle wiederkehrt, dass dasselbe ferner durch konzentrierte Salzlösungen gefällt werden kann, und dass auch Kupfersulfat einen Niederschlag hervorruft (primäre Albumosen). Eigentiimlich für den gefärbten Körper ist seine Eällbarkeit dureh Kohlensäure, eine Eigenschaft, die er mit den Globulinen gemein hat. Der Schuppenfarbstoff kann indessen durch Kohlensäure nicht ausgefällt werden. Fällung des Farbstofṫs erzielen wir ferner durch Ammoniak, wenn derselbe in eine salzsaure Lösung des Pigmentes eingetragen wird; in dieser Reaktion 
zeigt der Körper eine anffallende Ähnlichkeit mit den Histonen, von denen er sich indessen dnrch sein Verhalten gegen Essigsäure (Histone werden durch Essigsüure nicht ansgefüllt) nnd gegen Neutralsalzlösungen (Histone werden schon durch verdünnte Neutralsalzlösungen niedergeschlagen) unter'scheidet. Die färbende Komponente des Eiweisskörpers ist cine Sän re, sie ist, wie wir sahen, alkohollöslich und wird von Chloroform aufgenommen.

Die ('hloroformlösung des roten Farbstoffs ist gelb nund gibt anf Zusatz ron einigen Tropfen lionzentrierter Salpetersäure, die etwas salpeterige Sänre enthält, das Furbenspiel der für Gallenfarbst of fe charakteristischen Gmelinschen Reaktion. Der Farbstoff durfte demuach den Bilirubin nahe stehen, wofü auch seine Kiristallform, seine Farbe und sein optisches Verhalten sprechen.

Der rote Vamessenfarbstoff ist kristallisationsfälig. Die Fristalle stellen klinorhombische I'lättchen dar. Diese I'lättchen fülıren zn feinen abgeplatteten Nadeln üher, dis oft zu federförmig verzweigten Drusen oder zu Doppelbiischeh veroinigt sind. Ihre Farbe ist Gelbrot, \%wiebelrot oder Karminrot, daneben finden sich aber anch grüngelbe, ja selbst farblose Kristalle von ähnlicher (iestalt und ähnlichem optischen Verhalten. Ausser in wohlausgebildeten Kristallen fällt der Farbstoff anch in unregelmäßjig begrenzten l'latten aus, die zu dentritisch verzweigten Gebilden zusammentreten. Die Farbstoffkristalle sind doppelbrechend und dichroitisch. Bei holer Einstellung erscheinen sie unter dem Mikroskop gelbrot mit einem deutlichen Stich ins Grine, bei tiefer Einstellung sind sie blaurot. Es besteht also hier ein Dichroismus. der lebhaft an ten der Hämoglobinkristalle erinnert, die bei auffallendem Liclit scharlachrot, hei durchfallendem bläulichrot erscheinen. Auch die Doppelbreclung haben sie mit jenen gemeinsam.

Der rote Vanessenfarbstoff besityt sowohl in Lösung wie anch in Substanz ein tharakteristisches Absorptionsspektrum. Dasselbe besteht aus einer Endabsorption des Cltraviolett, aus drei schmälern Absorptionsstreifen im Violett und Indigo, die aber nur auf der photographischen Platte zur Geltung kommen, und a us einem breiten, sehr charakteristischen Band im Blaugrïn zwischen b und F, und eines besonders bei dem karminroten Farbstoff in Substanz sehr deutlichen Streifens bei I). Mittelst des Spektrookulars lassen sich nnr die Absorptionen im Blangrïn und im Orange beobachten. Die schmälern Absorptionsbänder im Violett und Indigo treten nur auf der photographisehen Platte und da besonders bei der schwefelsauren, purpurrot gefärbten Lösung des Pigmentes deutlich hervor. Wird die Farbstofflösung mit reduzierenden 
Mitteln behandelt, so tritt neben Farbenänderung eine sehr charakteristische Terschiebung in dem Absorptionsspektrum ein. Die Endabsorption im Ultrariolett und Violettwird ungefährdoppelt sobreit, wie bei normalen lösungen, während das Absorptionsband im Blangrün fast ganz verschwindet. Im Spektroskop besehen erscheint das Absorptionsspektrum der Farbstofflösungen identisch mit demjenigen von Urobilin- (Harnfarbstoff) oder Hydrobilirubinlösungen, je nachdem der Streifen bei D vorhanden ist oder nicht. Wird der Pigmentlösung Ammoniak zugesetzt, so verändert sich dieselbe in ähnlicher Weise wic die Lösungen des Harnfarbstoffs, indem das Band in Blaugrün schmäler, aber schärfer begrenzt erscheint, während sich gleichzeitig die bisher rote Farbe der Lösung in gelb verwandelt. Die Verwandtschaft des roten Schmetterlingspigmentes mit dem Urobilin zeigt sich anch darin, dass seine Lösungen wie die des Harnfurbstofts nach Zusatz ron Chlorzink und A mmoniak schöne grüne Flu o rescenz erhalten.

Wie das Hämoglobin, so hat auch der rote Darm-Exkremente und Fpidermisfarbstoft' der Vanessen die Ligenschaft, den Sauerstoff der Luft locker zu binden, d. l. ihn, wie es beim Bhutfurbstoff der Fall ist, leicht anfzunehmen und leicht abzugeben. Oxydation und Reduktion der Farbstofflösungen sind stets mit einem Farbenwechsel verbunden. Der frische rubinrot gefürbte wässerige Auszug des roten Vinessenpigmentes wird durch oxydierende Mittel griinlichgelb gefürbt und durch reduzierende Agentien in eine hochgelb gefürbte l'hiissigkeit verwandelt, die wieder rot wird, sobald sie neuen Sauerstoff aufnimut. Durch fortgesetate Oxydation kann eine rote Farbstotelösung vollkommen entfärbt werden. Es ist höchst eigentiumlich, dass Farbstofflösungen der Schuppenpigmente sowie auch Ausziige des Darm- und Exkrementefarbstoffs, die lïngere Zeit der Luft ausgesetzt waren, weniger leicht reduzierbar sind. Er scheint somit in beiden Fïllen die Verbindung des larbstoff́s mit dem Sauerstoff eine festere geworden zu sein, eine Veränderung, wie sie sich im Blut bei dem Übergang des $0 \mathrm{xy}$ hämoglobins in Methämoglobin vollzieht. Diese Veränderungen sind bei dem Vanessenpigment auch von Farbenwechsel begleitet, die schwer reduzierbaren Lösungen sind nicht mehr rubinrot, sondern sherrygelb gefärbt. Auch rot gefärbte Farbstofflösungen, die auf etwa $40^{\circ} \mathrm{C}$. erwärmt werden, verlieren ihre rote Farbe und werden gelblich; ein ähnliches Verhalten zeigt unter denselben Verhältnissen der Blutfarbstoff, der in das gelb oder gelbbraun gefärbte Methämoglobin übergeht. 
Ausser durch oxydierende und reduzierende Mittel wird der rote Vanessenfarbstoff auch noch durch das $\mathrm{L}$ i cht und durch Wärme in seinem Farbenton beeinflusst. Die chemischen Strahlen des Sonnenlichtes wirken wie oxydierende Agentien, die ihrem Einfluss ausgesetzten gelbbraunen Lösungen werden gr ï 1 lichgrau, sie nehmen die Farbe verdorrten Grases an.

Die Wärme wirkt erst verdunkelnd auf den Farbstoff ein, es treten in der Lösung ausgesprochen rotbraune Töne auf, bleibt die Lösung indessen längere /eit gleichuäßiger Wärme ausgesetzt, so schwindet die intensivere Färbung und sie gewinnt das Aussehen der am Licht gebleichten Farbstoffansziige.

Oxydations- und Reduktionsvorgänge scheinen auch im Organismus des Schmetterlings für die bildung verschiedener Farben makgebend zu sein, wenigstens tritt im Insektenorganismus der Farbstoff in verschieden pigmentierten Modifikationen auf, die mit gleichzeitig im Organismus rerlaufenden Oxydations- und Reduktionsvorgängen in Zusammenhang zu bringen sind.

Für die Beurteilung der physiologisehen Rolle, welche der Farbstoff im Organismus der Inseliten spielt, ist es wichtig zu wissen, dass derselbe Eisen und freien '/ucker entlält. Der Beweis für die Gegenwart des Eisens konnte durch Ferrocyankalium und Salzsäure erbracht werden. War der Farbstoff in Lösung, so wurde er nach Zusatz der beiden Reagentien ausgefällt, Niederschlag und iiberstehende Flïssigkeit fürbten sich nach kurzer Zeit tief blan. Auch die Asche ergab, nach derselben Methode behandelt. lösliches Berlinerblaul.

Der / uckernachweis gelang sowohl mit Fehlingscher Lösung, alkalischer Silbernitratlösung wie auch durch die P'henylhydrazinprobe. Im einen Fall zeigte die Bildung von K upferoxydul und Silberspiegel, im andern das Zustandekommen von Osazonkristallen die Gegenwart eines Zuckers an.

Ls wurde bereits erwähnt, dass es möglich ist den Farbstoff der I Tanessen, dessen rote Modifikation in dieser Arbeit zum Ausgangspunkt der Untersuchungen genommen wurde, durch Oxydations- und Redultionsprozesse in rerschieden gefürbte P'igmente ibberzufülıren; da alich im Insektenkörper neben dem roten grïne, gelbe und gelbrote Pigniente angetroffen werden, so liegt es sehr nahe, auch hier die Entstehung der Farbstoffe ähnlicheu Ursachen zuzuschreiben. Das Experiment zeigt, dass die grïnlichgelben Pigmente in der Raupenoder Puppenepidermis in karminroten Farbstoff verwandelt werden können und umgekehrt, dass es möglich ist, die so entstandenen Farbstoffe auch wieder künstlich auf ihre ursprüngliche Färbung zurïck- 
zufïhren. Wird z. B. eine Rampe ron Vanessa urticae ins Wasser geworfen und dieses bis zum Sieden erhitzt, so sehen wir, dass in demselben Augenblick, wo die allgemeine Muskelstarre die Gerinnung des Körpereiweisses anzeigt, die Farbe ihrer Epidermis in tensiv k arminrot wird. Fine ähnliche Verfärbung tritt ein, wemn Raupen oder Puppen trockener Hitze ausgesetzt oder mit Chloroformdämplen betäubt werden. Die so verfärbten Granulationen in den Epidermiszellen können nun durch oxydierende Mittel, und wenn sie längere Zeit der Luft ausgesetzt sind, in bramgelbe, grelbe und grünliche Körnchen zurïckverwandelt werden. Wir sehen somit, dass die verschiedenen im Insektenorganismus, besonders in den Epithelien und Epithelbildungen vorliommenden Farbstoffe alle künstlich ineinander iibergeführt werden können und, wie uns die Ontogenese der Farben während der Fintwicklung des Fies, der Raupe und des schmetterlings lehrt, auch wirklich auseinander hervorgehen.

Als Bildungsort der Körperfarbstoffe haben wir den l) arm der R a 1 pe, als Bildungsstoffe die mit der Nahrung aufgenommenen Pflanzenpigmente zu betrachten. Fis lässt sich verfolgen, wie im barm der Raupe das Chlo rophyll der Nahrung gelöst, ron den Darmzellen als Chlorophyllan resorbiert und unter bestimmten Bedingungen in einen gelben oder roten Farbstoff ungewandelt wird. Während des Raupenlebens geht der Farlsstoff in seiner grüngelben Modifikation in die Gewebs ïler und wird unter normalen V́rlältnissen erst in der Epidermis in rötlich gefäbte Produkte verwandelt. Dass die gelben und roten Farbstoffe tatsächlich aus dem Chlorophyllkorn stammen, lässt sich an der Hand von mikroskopischen Präparaten beweisen. Ich fand, dass in den Brennesselzellen, welche den Darminhalt hungernder Raupen gebildet liatten, nach Verlaut von zwei Jahren die Chlorophyllkörner zun grossen 'Teil in Chlorophyllan und roten Farbstoff verwandelt waren. Der rote Farbstoff war teils amorph, teils wie der rote Darmfarbstoff kristallisiert und zu schönen Drusen vereinigt. Die Priparate waren in Glyceringelatine eingeschlossen und im Dunkeln aufbewahrt worden. Die Bildung des roten Farbstoff's geht mit einem Zeriall der Chlorophyllkörper Hand in Hand und kamn von Stufe zu Stufe verfolgt werden. Es scheint dabei der ganze Chlorophyllkörper in den Farbstoff uberzugehen. Farbe, Kristallform und spektrales Verhalten des in der Pthanze gebildeten Farbstoffs entspricht vollkommen demjenigen des Vanessenfarbstoffis. Diese 'Tatsachen bestätigen, was uns P oulton schon längst durch den Versuch gezeigt hat, dass nämlich die Schmetterlingsraupen ilıe bunten Farben nur dann bilden können, wemn ihre Nahrung Chlorophyll oder Etiyolin enthält. 
Was nun die physiologisclie Rolle betrifft, die der Farbstoff im Körper des Insektes zu leisten hat, so ist diese durch seine chemische Beschaffenheit bestimmt und durch die Eigenschaft des l'igmentes, mit dem Sauerstoff der Luft lose Verbindungen eingehen zu können. Der Zucker- und Eiweissgehalt der gefärbten Substanz deutet darauf hin, dass ihm eine wichtige Rolle bei der Ernährung der Raupe, der Puppe und des Schmetterlings zukommt. Hierfür spricht auch die Bildungsstätte der Pigmente. Auch die Beobachtıng, dass die in den Schmetterlingspuppen lebenden parasitischen Insektenlarven den Farbstoff in sich aufnehmen, dass ihr Darm davon prall erfüllt ist. dass er aber wïhrend der Puppenruhe dieser Insekten verbrancht wird, lässt darauf schliessen, dass der Farbstoff als Reservenahrung sehr geeignet ist und als solche dic Lebensrorgänge unterstïtzt, die sich während der Metamorphose des Insekts vollziehen.

Die Verteilung der Pigmente im Insektenkörper, ilır Verhalten, wenn künstliche Reduktions- oder Oxydationsvorgänge eingeleitet werden. knrz die Eigenschaft des Farbstoffs. sich mit dem Sauerstoff der Luft leicht verbinden. denselben aber auch leicht wieder abgeben zu können, legt es nahe anzmnehmen, dass dem P'igment im Insektenkörper auch ane respiratorische Funktion zukommen muss.

Cranz besonders scheinen mir die l'igmente im stande zu sein in ihrer gr üng elben Fürbung, die sich im Experiment als ilhre hochoxydierte Modifikation darstellt, den Sauerstoff lange aufspeichern zu können und dem Inselit gleichsam als Sauerstoffreservoir zu dienen. So erklärt es sich, dass sogar die Raupen, die bekanntlich einen äusserst intensiven Stoffwechsel haben, ïberraschend lange Zeit in Sauerstoff-freicr I ult (Kohlensäure- oder Leuchtgasatmosphäre) am Leben bleiben, dass sich aber gleichzeitig die grüne Färbung ihrer Haut mehr und mehr verliert und einer blauroten. der Farbe des reduzierten Farbstoft's Platz macht. Dieses Verhalten der Schmetterlingspigmente ist $u m$ so interessanter, weil hier der respiratorische Farbstoff des Tieres aus dem respiratorischen Pigment der Pflanze hervorgeht. Nicht weniger wichtig ist es indessen, dass der rote Schmetterlingsfarbstoff ganz ansgesprochene Verwandtschaft mit dem Bilirubin und Urobilin zeigt, mit zwei Farbstoffen, die ihrerseits wieder als Umwandlungsprodukte des Blutfarbstoffs, des respiratorischen Pigments der Wirbeltiere zu betrachten sind.

M. v. Linden (Bonn a. Rh.). 


\section{Vertebrata.}

Pisces.

300 Tower, R. W. 'The Gas in the Swim-Bladder of Fishes. In: Bull. U. S. Fish Commiss. Yol. XXI. for 1901. Washington 1902. pag. $125-130$.

Verf. hat bei einer Anzahl von "Sinueteagues" (Cynoscion regulis) den Gehalt der Schwimmblaseuluft an Sauerstoff und Kohlensäure bestimmt und zieht aus dem relativen Mengenverhïltnis beider Gase Schliisse auf den ('asaustausch zwisehen Schwimmblasenluft und Blut. bei normalen Fischen schwankte das Mengenverhältnis Kohlensäure: Samerstoff zwischen 0,061-0,104:1. Bei asphyktischen Tieren aber stieg dasselbe, um nach dem Tode 0,2 tó-0,295:1 \%u betragen. Verf. schliesst hieraus auf einen aktiven Respirationsrorgang; welcher während der Asphyxie in der Schwimmblase Platz greife. I) il der Prozentgehalt der Schwimmblasenluft an satuerstoff bei verschiedenen Tieren sehr verschieden sein kann, auch wenn diesetben sich unter völlig gleichen Bedingungen befanden - in einer Serie ron Individuen sehwankte dieser Prozentgehalt \%. B. zwischen 19,0 und 5.55\% — so spricht Verf. sich des weitern für die Auffissmg aus, dass die Alsseheidung des Gases nicht ein einfacher Diffusionstorgang ist, sondern durch aktive sekretion erfolgt.

Ausser den "Sifueteagues" wurden anch noch einige Exemplare eines in wrössern T'iefen lebenden lisches (Lopholatilus chamaeleonticeps) untersucht und hierbei in C̈hereinstimmung mit ältern Beobachtungen anderer Autoren ein relativ hoher Gehalt an Sanerstoff und nur sehr geringe Mengen von Kohlensiure gefunden. Bei einem Exemplare aus 5.) Faden Thefe wurden $6505 \%$ sanerstoff in der Schwimmblasenluft gefunden, bei einem andern aus 70 laden Tiefe $69 \%$, während von Kohlensäne in heilen Fällen nur spuren vorhanden waren. '/un Vergleich wird daran erimnert, dass nach Biot bei einer Trigla Tyra aus 500 Faden Tiefe $87 \%$, bei einem Sparus aryenteus aus 65 Faden $50 \%$, bei einem Sparus dentex aus 20 Faden $40 \%$ Sanerstoff in der Schwimmblasentuft enthatten waren. In tieferm Wasser scheint also stets der Sauerstoflgehalt der Schwimmblasenluft zuzunehmen bez. das rom Verf. in den Vordergrund der Betrachtungen gerückte Verhältnis zwischen Kohlensäure- und Sauerstoffgehalt abzunehmen.

I. L ï he (Königsberg i. Pr.).

\section{Amphibia.}

601 Kasehtschenko, N. Th., Uebersicht der Reptilien und Amphibien des 
Tomsker Gebietes. In: Isvestija der kais. Universität Tomsk. 1902. pag. 1 -24. Separatdruck (russisch).

Die Arbeit besteht aus zwei Teilen: einer Bestimmungstabelle für die Reptilien des Tomsker Gebietes und seiner Amphibien und einer systematischen Aufzählung der daselbst vorkommenden Arten, mit Fundortsangaben und Aufführung etwa bekannt gewordener Subspecies und Varietäten. Die Literatur über die in diesem Gebiete gefundenen Arten wird ebenfalls verzeichnet. Für Nichtspezialisten wird eine Erklärung der vorkommenden Merkmalsbezeichnungen gegeben. Das systematische Verzeichnis enthält folgende Arten: ? Testudo horsfieldii Gray, Tropidonotus natrix L., ?rop. tesselatus Laur., Coluber dione Pall., ? Taphrometopon lineolatum Brandt, ? Eryx jatulus L., . Ineistrodon intermedius Strauch, Aneist. blumhoffi Boje, ? Ineist. haly: Pall., I'clias berus I., Pel. renardi Christoph, Lacerta agilis L., B. vivipara Jaeq., Eremias arguta Pall., ? Phrynocephalus helioseopus Pall., Salanandrella keyserlingii Dybowsky, Ranodon sibirieus Kessler, Molge vulgaris L., Bufo vnlgaris Laur., Bufo virilis Laur., Rana arvalis Nilss., R. muta Laur., - Rana esculenta L. und IIyla scheinen zu fehlen.

C. Grevé (Moskau).

602 Montgomery, Tohs. H. jun., The heterotypic maturation mitosis in Amphibia and its general significance. In: Biol. Bull. 'T'. IT. 1903. pag. 250-269. 8 'Textfig.

Verf. mitersuchte die Anfangsstadien der Spermatogenese ron Plethodon rinerrus Greev. und Itemognathus fiscus Raf., nm nachzuweisen (gegen Fl e m m ing, Meresusw.), dass auch bei den Amphibien eine echte Reduktionsteilumg vorliege. Die normale Chromosomenzahl ist 24: in den Kermen der Spermatocyten 1. (rod. treten aber nur 12 auf, die als zweiwertig aufgefasst werden, entstanden durch Verschmelzung zweier einwertigen mit ilıen Enden zu einer U-förmigen Schleife. Der Längspart, der in diesen anftritt, ist die Andeutung der Ïquationsteihng bei der zweiten Reifungsmitose. Bei der ersten Spermatocytenteilung werden dann diese zweiwertigen Chromosonnen in zwei einwertige zerlegt, was eine echte Reduktion vorstellte. Xach Verf. ist die heterotypische 'Teilung somit nichts anders als eine Reduktionsteilung, wodurch eben ilure Besonderheiten bedingt werden.

R. Goldschmidt (Nïrnberg). 


\section{Zoologisches Zentralblatt}

unter Mitwirkung von

Professor Dr. O. Bütschli In Heidelberg

\section{herausgegeben von}

Professor Dr. B. Hatschek

in Wien

\section{Dr. A. Schuberg}

a. 9. Profeseor in Heidelberg.

Verlag von Wilhelm Engelmann in Leipzig.

\section{Jahrg.}

2. Oktober 1903.

No. $18 / 19$

Lu beziehen durch alle Buchhandlungen und Postanstalten, sowie durch die Verlagsbuehhandlung. Jahrlich 26 Nummern im Umfang von 2-3 Bogen. Preis für den Jahrgang II. 30 - Bei direkter Zusendung jeder Nummer anter Streilband erfolgt ein Aufschlag von M. 4.- nach dem Inland und von II. 5.- nach dem Ausland.

\section{Zusammenfassende Übersicht.}

\section{Die Coeeidien-Literatur der letzten vier Jahre.}

Zusammenfassende Besprechung von Dr. M. Lühe, Königsberg i. Pr.

603 Blanchard, Raphaïl, Les coccidies et leur role pathogène. Causeries scientif. Soc. Zool. France. Amuce 1900. 80. 40 pag. 12 figs.

604 Bonnet-Eymand, G.. Sur l'évolution de l'Eimeria noca. In: Compt. rend. Soc. Biol. Paris T. LII. 1900. Nr. 24. pag. 659-661.

605 Burchardt, Engen, Beiträge zur Kenntnis des Amphioxus lanceolatus, nebst einem ausführlichen Verzoichuis der bisher über Amphioxus veröffentlichten Arbeiten. V. Branchiocystis amphioxi, ein Coceidium im Epithel der Kiemenbogen. In: Jenaische Zeitschr. Naturw. Bd. XXXIV. (N. F. Bd. XXVII.) 1900. pag. 779-784. Taf. XIX. Fig. 9-11. 'Taf. XX. Fig. 1-9. 606 Chatin, Joannes, Altérations nucléaires dans les cellules coccidiées. In: Compt. rend. Soc. Biol. Paris. T. LII. 1900. Nr. 14. pag. $345-346$.

607 Cnénot, L., Legerclla testiculi nov, spec., Coccidie parasite du testicule de Glomeris. In: Arch. Zool. exp. gén. 3. sér. T.X. 1902. Notes et Revue. Nos. 4/5. pag. XLIX-LIII. 6 figs.

608 Irago, Umberto, Coccidium seyllii n. sp. In: Ric. Laborat. Anat. norm. R. Univ. Roma ed in altri Laborat. biol. Vol. IX. 1902. fasc. 1. pag. 89-94. 7 fig. 609 Giglio-'Tos, E., Une coceidie parasite dans les thrombocytes de la grenouille. In: Arclr. Ital. Biol. T. XXX. 1898. fase, 1. pag. 130-137. 6 figs.

610 Grinow, A., Ein Fall von Protozoen-(Coccidien?-) Erkrankung des Darmes. In: Arch. exper. Pathol. u. Pharmakol. Bd. XLV. 1901. Hft. 3.4. pag. 262-271. Taf. I.

611 Jacquemet, Marcel, Sur la Systématique des Coccidies des Cépha lopodes. In: Arch. Protistenk. Bd. II. 1903. Hft. 1. pag. 190-194.

612 Laverau, A., Au sujet des altérations cellulaires produites par les coccidies. In: Compt. rend. Soc. Biol. Paris. T. LII. 1900. Nr. 15. pag. 378 -380 .

613 Laveran, A., et F. Mesuil, Sur la coceidie trouvée dans le rein de la Rana esculenta et sur. l'infection générale qu'elle produit. In: Compt. rend. Acad. Sci. Paris. T. CXXXV. 1902. Nr. 2. pag. 82-87. 11 figs. 
614 Laveran, A., et Fesnil. Sur deux Coccidies intestinales de la "Riana eseulenta". In: Compt. rend. Soc. Biol. Paris T. LIV. 1902. No. 24. pag. $857-860.9$ figs.

615 - - Sur quelques Protozoaires parasites d'une Tortue d'Asie. (Damonia Iiecesii). In: Compt. rend. Acad. Sci. Paris T. CXXXV. 1902. No. 16. pag. 609-614. 14 figs.

616 Léger, Louis, Essai sur la Classification des Coceidies et description de quelques espèces nouvelles ou peu connues. In: Bull. Mus. Marseille. T. I. 1898. Fasc. 1. pag. 71-122. pl. V-VIII.

617 - Sur la présence d'une coccidiecoelomique chez Oloerates abbreviatus O1. In: Arch. Zool. Expér. gén. 3. ser. T. VIlI. 1900. Notes et Revue. No. 1/2. pag. I-11I.

618 - Sur le genre Eimeria. In: Compt. rend. Soc. Biol. Paris. T. LII. 1900. No. 22. pag. $575-576$.

619 - Le genre Eimcria et la classification des Coccidies. Ibid. pag. 576 $-577$.

620 - et O. Dnbosiq. Les Grégarines et l'épithélium intestinal chez les 'Traclı́ates. In: Arch. de Parasitol. T. VI. 1902. No. 3. pag. 377-473, avec planches $1 \mathrm{I}-\mathrm{Vl}$ et 18 figs. dans le texte.

621 Liihe, M., Ergebnisse der neueren Sporozoenforschung. Zusammenfassende Darstellung mit besonderer Berücksichtigung der Malariaparasiten und ihrer nächsten Verwandten. I. Entw ckelungeyklus der Coccidien. In: Centrbl. Bakt. I. Abtlg. Bd. XXV1I. 1900. Nr. 10/11. pag. 368-384. 9 Fig.

622 - Ergebnisse der neueren Sporozoenforschung usw. Erweiterter Abdruck aus dem Centralbl. f. Bakter. usw. Jena ((i. Fischer). 1900. ১0. IV. 100 pag. $35 \mathrm{Fig}$.

623 - Über den Schrotausschlag der Scluweine und das sogenannte „Coccidium fuscmu". In: Centralbl. Bakter. I. Abtlg. Bd. XXIX. 1901. pag. 693 -698. 7 Fig.

624 - Ưber Geltung und Bedeutung der Gattungsnamen Eimcria und Coccidium. In: Centrbl. f. Bakter. 1. Abtlg. Originale Bd. XXXI. 1902. Nr. 15. pag. $771-773$.

625 - Über Befruchtungsvorgänge bei Protozoen. In: Schrift. Physik.Ökon. Gesellsch. Königsberg i. Pr. Jahrg. XLIII. 1902. Sitzber. pag. 3-6.

626 Mesnil. F., Coccidies et Paludisme. - I. Partie. Cycle évolutif des Coccidies. In: Revue Génér. Sci. X. Année. 1899. No. 6. pag. 213-224. 10 figs.

627 - Essaisurla classification et l'origine des Sporozoaires. Extr. du Cinquantenaire Soc. Biol. Paris 1S99. S $^{0} 17$ pag.

628 - Sur la conservation du nom générique Eimeria et la classification des Coccidies. (A propos des communications de I. L. Léger faites à la précédente st́ance.) In: Compt. rend. Soc. Biol. Paris. T. LII. 1900. No. 23. pag. 603-604.

629 Metzuer, Rud., Untersuchungen an Coecidium eunieuli. I. T'eil. In : Arch. Protistenk. Bd. Il. 1903. Hft. 1. pag. 13-72. Taf. II.

630 Mousis, G. et (i. Marotel, Sur une coecidiose du mouton. In Recueil de Méd. Vétérin. 8. sér. T. VIIT. 1901. No. 24. [Annexe: Bull. Soc. Centr. Méd. Vét. Séance du 28 Novbr.] pag. 470-474.

631 - Sur nne coccidiose intestinale du mouton. In: Compt. rend. Soc. Biol. Paris. T'. LIII. 1901. No. 39. pag. 1087-1089. 
32 Moussu, G. et G. Marotel, La coccidiose du Mouton et son parasite. In: Arch. Parasitol. T. VI. 1902. No. 1. pag. 82-98. 12 figs. dans le texte.

335 Pérez, Ch.. Sur une Coccidie nouvelle, Adelea mesnili (n. sp.), parasite coelomique d'un Lépidop tère. In: Compt. rend. Soc. Biol. Paris T. T.I. (11. sér. T. I.) 1899. pag. $694-696$.

34 - Le cycle évolutif de l'Adelea Mesnili, Coceidie coelomique parasite d'un Lépidoptère. In: Arch. f. Protistenkde. Bd. II. 1903. Hft. 1. pag. 1-12. Taf. I. 4 Textfig.

35 Pianese, G.. Le fasi di sviluppo del coceidio oviforme e le lesioni istologiche che induce. In: Arch. Parasitol. T. II. 1899. pag. 397-449. Taf. $4-5$.

36 - Über ein I'rotozoon des M eerschweincliens. In : Zeitschr. f. Hygiene. Bd. XXXVI. 1901. pag. 350-367. T'af. X-XI.

37 Schanlinu, F., Der Generationsweclrsel der ćoccidien und Haemosporidien. Eine Zusammenfassung der neueren Forscliungsresultate. In: Zool. Centr.-Bl. VI. Jahrg. 1899. Nr. 22. pag. 765-783.

38 - Untersuchungen über den Generationswechsel bei Coccidien. In: Zool. Jalurb. Abt. f. Anat. u. Ontog. Bd. XIII. 1900. Hft. 2. pag. 197-292. Taf. $13-16$.

39 - Studien über kranklreitserregende Protozoen. I. Cyclospora caryo_ lytira Sclıad, der krreger der perniciösen knteritis des Maulwurfs. In: Arb. kais. Gesundheitsamt. Bd. XVHI. 1902. Hft. 3 pag. 378-416. 'Taf. XII-XIII. 1 Textfig.

40 Sergent, Eumond, Snr une coceidie nouvelle parasite du Caméléon vulgaire. In: Compt. rend. Soc.'Biol. Paris. 'T. LIV. 1902. No. 31. pag. 1260-1261.

41 Siedlecki, Michael. Étude cytologique et cycle évolutif de Adelea ovata Schn. In: Ann. Instit. Pasteur. T. XIII. 1899. pag. 169-192. Taf. I-III. 42 - Cycle évolutif de la Caryotropha mesnilii, coccidie nouvelle des Polymnies. Note préliminaire. In: Bull. Acad. Sci. Cracovie. Cl. Sci. matl. nat. 1902. pag. 561-568. 5 [6] fig.

43 Simond, P. L., Note sur une Coccidie nouvelle, Coccidium Scrmorganti, parasite de Gavialis gangeticus. In: Compt. rend. Soc. Biol. Paris. 'T. LIII. 1901. Nr. 16. pag. $483-485.6 \mathrm{flg}$.

34 - Note sur une Coccidie nouvelle, roccidium Legeri, parasite de ryptopus granosus (Emyda granosa). Ibid. pag. 485-486. 6 fig.

345 Suith, Theobald and Herhert P'. Johnson, On a Coceidium (Kossiella muris gen. et spec. nov.). Parasite in the Renal Ep ithelium of the Mouse. In: Journ. Exper. Med. Vol. VI. 1902. No. 3. pag. 303-316. plate XXI-XXIII.

46 stiles. Ch. Warlell, Eimeria sticdac (Lindemann 1865) corlect name of the hepatic coccidia of rabbits. In: U. S. Departm. Agricult. Bureau Anim. Ind. Bull. Nr. 35: Eleven Hiscellaneous Papers on Animal Parasites. Washington 1902. pag. 18.

947 - Eimeriella, new genus of Coccidia. Ibid. pag. 18-19.

648 Thomas, J. J., A case of bone formation in the human brain due to the presence of Coccilia oviformia. In: Journ. Boston Soc. Med. Sc. Vol. IlI. 1899. pag. $167-169$ ').

i) Citiert nach gleichlautenden Releraten von G. II. F. Nuttall in Baumgartens Jahresbericht üb. d. Fortschr, i. d. Lehre v. d. pathog. Mikroorganismen. XV. Jahrg. 1899 pag. $647-648$ und in Centralbl. f. Bakter. 1. Abtlg. Bd. XXVIII. 1899. Nr. 25. pag. $852-883$. 
649 Toirin. Tal., Zur Morphologie und Biologie einiger Coccidien, Coccidium oviforme Le uckart und Coccidium fuscum Olt. In Zool. Jahrb. Abt. Anat. Ontog. Bd. XIV. 1900. Hft. 1. pag. 61-106. 'I'af. V.

\section{Inlaltsiibersicht:}

Einleitung.

I. Systematisches.

Il. Entwicklungsgeschichtliches.

1. Nenes zur Entwicklung von Arten der Gattung Eimeria.

2. Entwicklung von Arten der Gattmg Isospora.

3. Cyclospora caryolytica Schaud.

4. Die Gattungen Adclea, Klossia und Legerella.

5. Die Gattung Eucoccidiun.

6. Caryotropla mesnili Siedl.

7. KTossiella muis Smith und Johnson.

1II. Zur Pathologieder Coccidien-Infektion.

1) ie ansführliche Arbeit Sch a u dinns (638) iiber den Generationswechsel der c'oceidien. welche ror nun bald 4 , Jahren erschien und wekhe La ang in seinem Lehrbuch der rergleichenden Anatomie (Liefg. 2, pag. 219) als ".technisch und methodisch mustergültig" bezeichnet. kann insofern als epochemachend angesehen werden, als sie die der Entuleckung jenes (ienerationswechsels gewidmete l'orschungsperiode zu einem gewissen Abschhns brachte, nachdem bereits in den Jahren vorher von Schaudinn selbst und andern eine Reihe wichtiger Entdeckungen auf diesem Gebiete bekannt gegeben waren. Diese Bedeutung der Sch a udinnschen Untersuchungen fand ihren äussern Ausdruck darin, dass im Anschluss an dieselben von drei verschiedenen Seiten der V'ersuch unternommen wurde, den gesamten Zeugungskreis der Coccidien in für weitere Leserkreise bestiumten, zusammenfassenden Übersichten darzustellen: von Schaudinu (637) selbst in diesem Zentralblatt, zwar noch vor lisscheinen der erwähnten ausführlichen Arbeit, aber doch uniter Berücksichtigung der in ihr niedergelegten liesultate, sowie bald darauf und fast gleichzeitig miteinander von $\mathrm{B}$ lan ch ard (603) und Lï he $(621,622)$, nachdem bereits zu Anfang des Jahres 1899 Mesnil (626) den Reigen dieser zusammenfassenden Übersichten eröffnet hatte.

Seitdem aber hat unsere Kenntnis ron den Coccidien nicht unwichtige weitere Fortschritte gemacht und es soll deshalb im folgenden im Anschluss an die genannten zusammenfassenden Übersichten, insbesondere an die in diesem Zentralblatt erschienene, über diese in den letzten vier Jahren erzielten Fortschritte berichtet werden. Dieselben sind namentlich nach der Richtung hin wichtig, dass im An- 
schluss an die Publikationen von Sch au dinn und Si ed lecki, welche in den Jahren 1898-1900 erschienen sind, bei einer Reihe von weitern Coccidienarten der Zeugungskreis mehr oder weniger vollkommen aufgedeckt wurde und bei dieser Gelegenheit rerschiedene neue Modifikationen in der Entwicklungsweise der Coccidien bekannt wurden. Diese Resultate sind grösstenteils bei den Untersuchungen neuaufgefundener Arten erzielt worden und da ausserdem anch eine Reihe von Coccidiengattungen aus prioritätsrechtlichen Grïnden Inderungen ihrer Namen hahen erfahren müssen, so scheint es zweckmäßig, im folgenden zunächst die Fortschritte zu besprechen, welche die Systematik der Coccidien gemacht hat, um alsdann, auf der so gewonnenen Grundlage fussend, des nähern auf die Entricklungsweise der genauer untersuchten Arten einzugehen.

\section{Systematisehes.}

Das von Léger (616) geschaffene und seitdem in spinen (irundziigen allgemein angenommene ('occidiensystem, welches auf der Zahl der in einer Oocyste gebildeten Sporocysten und Sporozoiten berulit, ist mehrfach als provisorich bezeichnet worden (rergl: Schand inn, 1337). Mit liiicksicht hierauf verdient es hervorgehoben zu werden, dass auch die seitdem erzielte genanere Kenntnis der Entwicklungsweise einer grössern Zahl von Coccidienarten Änderungen in der Tmgrenzung der Gattungen bisher nicht erforderlich gemacht hat. Indessen hat Léger (619) selbst gewisse Ïnderungeu in der Anordnung der Gattmngen im System vorgenommen, nachdem er eine bis dahin erst sehr ungeniigend bekannte Coccidienart wieder aufgefunden hatte und bei deren Untersuchung hatte feststellen können, dass dieselbe in ihrem Zengungskreise eine bisher umbekaunte Modifikation der typischen Coccidienentwicklung darbietet (vergl. Léger, 618). Es handelt sich um die ron Aimé Schneider 1881 beschriebene Eimeria nora, welche in den I alpighisclien Gefässen von Glomeris schmarotzt und seit ihrer ersten Entdeckung nicht wieder beobachtet war. Fis stellte sich nun heraus, dass der Entwicklungsgang dieser von Léger wiedergefundenen Art insofern ron demjenigen aller andern bisher genauer untersuchten Coccidien abweicht, als es innerhalb der Oocyste nicht zur Bildung mehrerer Sporocysten kommt, sondern eine doppelte Oocystenschale direkt zahlreiche Sporozoiten umschliesst ${ }^{1}$.

$\left.{ }^{1}\right)$ Ich setze hier und im folgenden stets die in diesem Zentralblatt erschienene Übersicht von Sehaudinn (687) und die dort gebrauchte Nomenklatur als bekaunt voraus. - Doflein (Protozoen als Parasiten und Krankheitserreger. Jena 1901. pag. 99) hat die Bezeichnung "Sporocyste" verworfen, weil dieser Name bereits an ein Entwicklungsstadium der Trematoden vergeben sei. Ich gebe zu, dass es 
Fin derartiges Ausbleiben der Sporocystenbildung war ein IIanptmerkmal der Gattung Fimeria Aimá Schn. gewesen; aher eines der wichtigsten Ergehnisse ler in Scha ud in $\mathrm{ns}$ (63i) Übersicht besprochenen Arbeitun hatte darin bestanden. dass die nach dem sogenannten Eimeria-'iypus sich fortptlanzenden Coccidienformen nur als rine andere Generation derselben Arten erkannt worden waren. welche sich auch unter sporocystenbildung (nach dem (oocidium-Typus) vermehren. Es war deshall, die (iattung Eimera ans der Liste der selhstäudigen Gattungen gestrichen worden. Nachdem jetat Líger bei einer Art dieser frühern Gattung das Aushleiben der Sporocystenbildung anch bei der sporogonie nachoewiesen hatte, shlaubte er daraufhin die Ciattung Eimerire wieder herste Hen zu sollen. Gleichzeitig reformierte er sein friileres ('occidiensrstem (vergl. die Schandinnsche Thersicht), wolches in erster Linie auf der /ahl der in eincr Oocrste gebildeten sporocysten und erst in zweiter Linie auf der Zahl der in jeder sporocrste gebildeten Sporozoiten beruhte. ITn der neuen Lieobachtung liechnumg zu tragen, stellte er jetat die Kahl der Sporo\%oiten in den Vordergrund und gestaltete sein System, wie folgt (vergl. Légèr, 619):

mit Rücksicht hieranf keine selı glückliche Wahl gewesen ist, auch ein Stadium ler Coccidien so zu nennen. Es ist dies indessen nun eimmal geschehen und da der Name sich eingebuirgert lat, so halte ich es nicht für notwendig ihn durch einen neuen zu ersetzen. Die Überfülle von Namen für die rerschiedenen Entwicklungsstadien der 'T'elosporidien ist wahrlich schon gross genug. (Vgl. Lii he, 622, pag. 60-61.) Am allerwenigsten aber kann ich es fül zweckmäßig laalten, jene Benenuung, deren schaffung trotz des zuzugebenden Missgriffs in der Wahl des Namens, einen entschiedenen Fortschritt bedeutete, wieder durch die alte, indifferente Bezeichnung s. Spore ${ }^{*}$ zu ersetzen, wie dies Doflein tut. Der Ausdruck "Spore wird von verschiedenen Autoren in so verschiedenem Simne gebraucht, dass er einer präzisen Beguffsbestimmung entsclieden hinderlich ist und dass im Vergleich lierzu der Ausdruck, Sporocyste", selbst wenn man ihu in dem angedeuteten zweifachen sinne gebraucht, loch immer noch viel weniger missverständlich ist, bei der Unmöglichkeit, Trematoden und Coccidien bezw. die Sporo. cysten der eiuen und die Sporocysten der andern direkt miteinander zu vergleichen.

Doflein führt freilich noch einen zweiten Grunä für die Verwerfung der Bezeichnung Sporocyste an. Indessen liegt diesem nur ein tatsächlicher Irtum zu gimde. Doflein glaubt nämlich, dass die genannte Bezeichung nur angewandt sei „für Sporen, welche mehrere Keimlinge (Sporozoiten) einschliessen " und also entbehlich sei, da eine derartige Unterscheidung natïrlich nicht sehr wichtig ist. Dies ist, wie gesagt, ein Irrtum. Wo in der modernen Coccidien-Literatur von Sporocysten die Rede ist, ist liese Bezeichnung stets in demselben Sinne angewandt, in welchem Doflein den Ausdruck Spore gebraucht, d. h. für die beschalten Gebilde, welche aus den Sporoblasten hervorgehen, ganz gleichgïltig, ob in ihnen nur ein einziger oder zahlreiche Sporozoiten gebildet werden. 


\section{$-623-$}

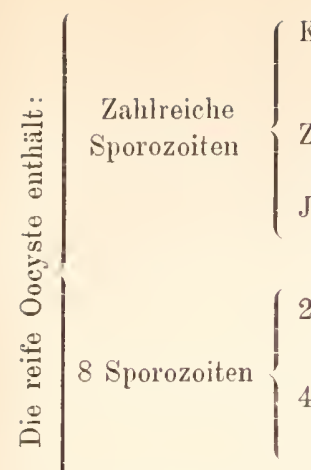

Keine Sporocysten.

Anprocystidea.

Gen. Eimcria

Zahlreiche Sporocysten,

Polysporocystidea.

Jede Sporocyste enthält

$\begin{cases}1 & \text { Sporozoit } \\ 2 & \text { Sporozoiten } \\ 3 & \text { Sporozoiten } \\ 4 & \text { Sporozoiten }\end{cases}$

Barroussia

Adelea

Benerlenia

Klossia

2 Sporocysten mit je 4 Sporozoiten

Disporocysticlea

Diplospora

4 Sporocysten mit je 2 Sporozoiten

Tetrasporucysticlea

Coccidium

4 Sporozoiten, welche sich zu je 2 auf 2 Sporocysten verteilen,

Cyclospora.

An diesem Systeme sind mmn jedenfalls einige formelle İnderungen vorznnehmen, da nicht weniger wie die Hälfte der von I.éger angewanlten Gattungsnamen dem Prioritätsgesetz widerstreiten.

Wenn Lreger in sein System die Gattnng Isoxpore Aimé Schn., welche er im Jahre 1 s.s noch noben Jiplospora Labbé beibehalten latte, nicht mehr anfgenommen hat. so ist dies wohl nur dahurch zu erklären, dass er inzwischen chenso wie La veran und schaudinn (rgl. Schandinns (Thersicht 6:37) zu der Überzengung gelangt ist, dass die beiden genannten Gattungen sich nach unsern heutigen Kenntnissen nicht auseinanderhalten lassen. Dann aber hat nicht der Name Isospora, sondern der Tame Diploxpora zu fallen, diu ersterer Priorität liat und dieses formale Prioritätsrecht durch nnsere ungenügenden Kenntnisse ron der ursprïnglich einzigen Art der Gattung Isospora nicht beeinträchtigt wird. In der Tat wirl anch von allen andern neuern Coccidien-Forschern mit Ausnahme Légers der Name Isospora angewandt. V'ergl. \%. L. Seha u dinn (637, 63:35), I, a veran und Mesnil (613), Sergent (640).

Den andern formalen Ïnderungen, welche légers System erfordert, entsprechen neuerdings rorgenommene Untanfen dreier (iattungen.

Zunächst hat Blanchard (603) darauf hingewiesen, dass die Gattung Benedenia Aimé Schn. 1855 umgetauft werden muss, da Diesing bereits im .Jahre 1858 diesen Gattungsnamen rergeben hatte. Blanchard hat für die Schneidersche ('occidien-Gattung den Namen Legeria vorgeschlagen. Unglïcklicherweise ist aber auch dieser Gattungsname bereits vergeben, da Labbé in seiner Bearheitung der Sporozoen für das . Tierreich" eine Gregarinen-Gattung mit demselben belegt hat. Infolgedessen hat Lïlı e (624) die in Rede stehende Coccidien-Gattung Eucoccilium genannt. Später hat I a cqueme t (B11) 
aus demselben Grunde für die gleiche Gattung den Namen Legerina vorgeschlagen, der jedoch als synonym zu dem prioritätsberechtigten Encoccitium in Fortfall gerät. Jacquemet hat aber gleichzeitig auch noch die Unterschiede zwischen den beiden Arten von 'Tintenfisch-Coccidien besprochen: Eucoscidium ortopiamum aus Octopus mlgaris und Eledone moschate hat 10-12 Sporozoiten, Eucoccidium eberthi aus Sepin offirimatis dagegen nur :3-4 Sporozoiten in jeder Sporocyste.

Weiter hat Mesnil (628) darauf aufmerksan gemacht, dass auch die Gattung Eimrria in dem jetzigen Simne Légers nicht aufrecht erhalten werden kann. In der' Tat hat Schneider die Eimerin nora. auf welche Léger die Gattung basieren will, erst nachträglich im Jahre 1881 in die bereits im Jahre 1875 für eine ganz andere Art geschaffene Gattung eingereilit. Auf Grund des Prioritätsgesetzes ist daher die durch Eimeria nora Aimé Schn. 1881 vertretene Gattung ron Mesnil in Legerella ungetanft. Aus demselben (irunde hat später Stiles (647), ohne Kenntnis der Publikation von Mesnil, für dieselbe Gattung den Namen Eimeriella in Vorschlag gebracht, welcher jedoch als synonym zu Legerellı einzuziehen ist. Fine zweite Art dieser Gattung ist übrigens, wie gleich hier bemerkt sei, inzwischen durch ('uénot (607) bekannt gegeben und nach dem Wohnsitz Legerell testiculi genannt (rgl. unten im entwicklungsgeschichtlichen T'eil die nähern Angaben).

Endlich haben Liihe (624) und Stiles (646) annähernd gleichzeitig und nnabhängig voneinander betont, dass die Gattung Eimeria bisher zu Unrecht als synonym zu Coccidium eingezogen sei. Vielmehr hat die im .Jahre 1875 aufgestellte Gattung Eimcrir Aimé Schn. (Typus: Eim. falciformis) l'riorität vor der erst 1879 aufgestellten Gattung Coccitim Leuck. (Typus: Coce oriforme). Es muss daher im Gegensatz zu dem bisherigen Ciebrauche Coccidium als synonym zu Eimoria einbezogen werden, und diese auf Crund des Prioritätsgesetzes notwendige Entscheidung hat gleichzeitig den grossen Vorteil. dass der bisher bereits häufiger für die ganze Ordnung als fuir eine bestimmte Gattung gebrauchte Name .Coccidien"1) seine bisherige Doppel-Bedeutung. welche leicht zu Missrerständnissen führen kann, rerliert und nunmehr nur für die ordnung reserviert bleibt. Stiles (646) weist aher gleichzeitig auch noch darauf hin, dass auch der Speciesnamen der am längsten bekannten Coccidien-Art einer

1) Vergl. z. B. in dem vorstehenden Literatur-Verzeichnis die Titel der Arbeiten von Burchardt (605), Cuénot (607), Jacquemet (611), Léger (616), IT esuil (626, 628), Pérez $(633,634)$, siedlecki (642), Smith und Johnson (645) Stiles $(646,647)$. 
Änderung bedarf. Das Coccidium oriforme Lenck. 1879, welches erst kürzlich von Labbé anf Grund des Prioritätsgesetzes in Coccidium cmiculi (Riv. 1878) umgetauft und daher auch noch von $L$ ü he (624) Eimeria cmicuii genannt wurde, muss fortan Eimeria stiedae (Iindem. $1865)$ heissen. Hat doch bereits im Jahre 1865 Lindemann diese Art auf Grund ciner von Stieda in Virchows Archiv (Bd. 32. 1865. pag. 132-139 und Taf. 3. Fig. + und 5) publizierten Beschreibung und Ablildung Monocystix stiedae getauft. (Tergl. Lindemann, Karl, Weiteres über Gregarinen. In: Bull. Soc. Imp. Nat. Moscou. Tome XXXYII. 1865. 2. Partie. Nr. 4. pag. 381-387. - Dic Charakteristik der hier erwähnten Art steht auf pag. 385-386.)

Dieser Gattung Eimeria, deren wichtigstes Merkmal die Bildung ron 4 Sporocysten mit je 2 Sporozoiten in jeder Oocyste darstellt. gehören nun eine Reihe ron Arten an, welche erst in den letzten Jahren neu in die Wissenschaft cingefuihrt sind. Auf zwei ron diesen Arten. Eimeria famei (Mouss. it Mar.) aus dem I)ünndarm ron Oi is aries jux. und Eimeria mitraria (Lav. of Mesn.) aus dem Dickdarm von Damonir rectesi. wird unten in entwicklungsgeschichtlichen Teil zurückzukommen sein. so dass lier ihre cinfuche Erwähnung genïgt. Zwei weitere zur Gattming Eimeria gehörende Arten liat S im ond $(643,644)$ beschrieben. Von diesen ist Eimeria kermoryanti ans $G a-$ rialis gangeticus (Si mond gebraucht noch den Gattungsnamen Cocriflim an Stelle von Eimeria) nicht nur deswegen bemerkenswert, weil es das erste Coccid aus cinem Krokodil ist, sondern mehr noch deswegen, weil es in der Milz gefunden wurde, also eincm Organ, welches eines zur Lntleerung der Oocysten befähigten Ausfïhrungsganges cntbehrt. Fine Erklärung dieser auffälligen Tatsache ist zur Zeit 11 m so weniger möglich, da der Darm des infizierten Gavial überlaupt nicht untersucht werden konnte ${ }^{1}$. Die andere ron Simond entreckte Art, Eimeria legeri aus Cryptopus granosus, zeigt grosse Ähnlichkeit mit der Eimeria liermorganti, von welcher sie sich hauptsächlich durch ilıre geringere Grösse, sowie durch dic etwas andere Lagerung der Sporozoiten in der Sporocyste unterscheidet. Sie fand sich ausschliesslich in der Leber der infizierten Schildkröten.

Gleichfalls zur Gattung Eimeria grehört eine Art, welehe kürzlich von $\mathrm{L}_{\text {averan }}$ und Mesnil (614) beschrieben worden ist und welche fortan den Namen Eimeria ranarum (Lav. et Mesn.) zu führen hat (= Karyophagus ranarmm Labbé 1894 nomen nudum = Coccidimm ranarmm Lav. et Mesn. 1902). Sie schmarotzt im Dünndarm ron

$\left.{ }^{1}\right)$ Vergleiche jedoch hierzu weiter unten die Besprechung der Entwicklung von Isospora licberkiihni (Iabbé) Lav. at Mesn. 


\section{- 626}

Rama esculenta und ist nahe verwandt mit Eimeria mropra (Aimé Schn.) ans Molye-Arten.

Eine zweite Coccidienart, welche dieselben Autoren im Darm von Recuce esculenta fanden, schliesst sich zwar auch noch dem Formenkreise der Eimerien an, mnterscheidet sich jedoch ron den typischen Arten dieser Gattung dadurch, dass die Sporocystenhülle nachträglich wieder anfgelöst wird (näheres hierüber folgt weiter unten). Die Verff. betrachten sie deshalb als Vertreter einer besondern Untergattung, welche sie Paracocidium nennen. Die Art hiesse hiernach Eimeria (Paracoccidium) meroti (Lav. et Mesn. ').

Noch eine dritte Coccidienart lebt in Rana esculenta und zwar speziell in der Niere dieses Frosches, woselhst sie bereits 1854 ron Lieberkühn entdeckt worden ist. Später hat Labbé diese Art wiedergefunden nud Hyaloklowsia lieberkïhmi genannt. Laveran und II esnil (11) fanden nun kürzlich gleichfalls in der Niere von Rama esculentu Coccidien, welche sie trotz wesentlicher Differenzen zwischen ihren Beobachtungen nnd den ältern Angaben für identisch mit der genannten Art halten. Sie lassen jedoch die auf diese eine Art begründete Gattung Hyalokilossia fallen und stellen die Art vielmehr zu Isospora Aimé Schn., Lar. emend. (= Diplospora Labbé), da sie nach ihren Feststellungen die charakteristischen Merkmale dieser Gattung besitzt ( 2 Sporocysten mit je 4 Sporozoiten).

Ausser den bereits genannten sind in dem letzten Jahre noch drei weitere neue Coccidienarten genaner beschrieben worden, Cyclospora caryolytica schaudinn n. sp, K7ossiplla muris Smith \& Johnson n. gen. n. sp. ${ }^{2}$ ) und Canyotropha mesnili siedl. n. gen. n. sp. Auf alle drei muss weiter unten im entwicklnngsgeschichtlichen Teil näher eingegangen werden, so dass hier ihre einfache lirwähnung genügt.

Dagegen sind hier als weitere neue Arten noch anzuführen einige Coccidien (?) -Formen, deren Schilderungen leider einen genïgenden Einblick in die Lebensgeschichte der betreftenden Arten noch nicht zu geben vermögen.

P i a n es e (636) beschreibt ein ..Sporozoarium rom Genus der Coccidieu" aus der Niere des Meerschweinchens. Gameten und Oocysten wurden nicht beobachtet. Die Vermehrung, welche Verf. inter An-

$\left.{ }^{1}\right)$ Laveran und Mesnil selbst geben zwar ihrer Ansicht dahin Ansdruck, dass Paracoccidium nur als Untergattung aufgefasst werden solle, bezeichnen dasselbe jedoch an andrer Stelle als , $n$. gen. ou subgenus“ und gebrauchen den Namen stets als Gattungsnamen.

$\left.{ }^{2}\right)$ Leider schaffen die Verf, bei Aufstellung der neuen Gattnng auch gleich ein Synonym zu dem von ihnen gewählten Gattungsnamen, indem sie anführen, dass sio anfänglich die Absicht gehabt hätten, die Gattung Microklossia zu nennen. Ref.

- Nr. 603-649. - 


\section{-627
-6}

wendung einer eigenen Terminologie des nähern zu schildern versucht, soll grosse $̈$ İnlichkeit mit der Schizogonie von Eimeria cuniculi laben und ,durch einen Sporulationscyklus mit Merozoiten und Micromerozoiten" erfolgen.

Ferner fand Burchardt (605) gelegentlich einer Untersuchung ïber Imphioxus lanceolatus im Epithel der Kiemenbögen parasitische Organismen, welche er als Coccidien auffasst und Branchiocystis amphioxi n. gen. 11. sp. nennt. Untersucht wurden dieselhen freilich nur auf zu andern Zwecken gefertigten Schnittserien durch ihren Wirt und der Verf. hält daher selbst seine „Präparate für die Scheidung verschiedener Entwicklungsarten nicht für ausreichend“, wenngleich er einen Zerfall des Parasiten in zahlreiche eifürmige bis kugelige Körperchen als Sporoblastenbildung auffasst. In der Tat reichen denn anch seine Angahen in keiner Weise zu einem sichern Urteil über die Branchiocystix aus und können nur insofern einen Wert beanspruchen, als sie auf die Existenz des fraglichen Parasiten aufmerkmerksam machen. In dieser Hinsicht sind sie freilich um so auffälliger, als Branchiocystis danach durchaus nicht selten zu sein scheint. Nur in wenigen Lanzettfischen wurde sie rom Verf. ganz vermisst, während hänfig die lufection eine ausserordentlich starke war.

Auch das von Drago (608) beschriebene Coccillium scyllii n. sp. wurde nur zufällig gefunden in einer ebenfalls zu ganz anderm \%weck hergestellten Schnittserie durch einen Teil des Spiraldarms eines Scyllirm stellare. In den Epithelzellen der Spiralklappe fanden sich zahlreiche einzellige P'arasiten von ovaler Gestalt, deren Kern ein verhältnismäfig grosses, intensir färbbares Karyosom erkennen liess. Daneben fanden sich auch andere Formen, welche augenscheinlich Stadien einer multiplen Vermehrung dieses Parasiten darstellen, indem der Zellleib ${ }^{1}$ ) in zahlreiche, rundliche, intensir färbbare Körperchen zerfallen schien. Kugelige Pakete ron zahlreichen sichelförmigen Körperchen, welche, wenn ich die Darstellung des Verfs. recht verstehe, einen zentralen Restkörper umschliessen, werden als ein späteres Stadium jenes Vermehrungsprozesses gedeutet. Es wïrde sich hiernach augenscheinlich um eine Schizogonie handeln. Ausser den bisher erwähnten Formen des Parasiten fanden sich nun aber auch noch langgestreckte, keulenfürmige und intensiv färbbare Gebilde in den Epithelzellen und auch in dem diesen Zellen aufgelagerten Darm. schleim. Die Deutung derselben erscheint dem Verf. selbst noch ganz rweifelhaft, doch wird ron ihm an die Möglichkeit gedacht, dass es sich um Gameten handeln könne.

$\left.{ }^{1}\right)$ Oder der Kern? Verf. betrachtet auch das Karyosom als eine Differenzierung des Protoplasmas und erwähnt von Kernen überhaupt nichts im Text seiner Arbeit. 
Ist schon die Zugehörigkeit ron Branchiocystis amphioxi Burchardt und Coccirlim scyllii. Drago zur Zeit noch etwas hypothetischer Natur ${ }^{1}$ ). so erscheinen die Coccidien, welche Grunow (610) gefunden haben will, in noch zweifelhafterem Lichte. Es handelt sich um rundliche bis orale, $6-13 \mu \mathrm{im}$ Iurchmesser haltende, .,aus einem leicht grünlich schimmernden, homogenen Innenkörper und einer zarten Hülle" bestehende Körper, welche sich bei einem Falle von letal endender Enteritis in den Fäces und in der Darmschleimhaut fanden. Der Verf. hält dieselben für Protozoen und rermutet ihre Zugehörigkeit zu den Coccidien, speziell zu der Limeria bigemina (Stiles). Diese Vermutung steht aber auf recht schwachen Füssen, zumal sich auf Grund der Formverhältnisse der beobachteten durchweg unbeschalten Gebilde die weitere Vermutung anschliesst, dass fast ausschliesslich Macrogameten und zwar Macrogameten mit dem doch nurim Moment der Kopulation vorhandenen Empfängnishïgel zur Beobachtung gelangten (sic!). Verf. gibt denn auch selbst die Konsequenz seiner Auffassung, dass lie Macrogameten vor Ausbildung der Dauercysten mit den Fäces nach aussen entleert wïrden, als „etwas gewagt" zn (und doch kommt gerade dies letztere bei einzelnen Coccidienarten vor - rergl. nnten die Besprechung der Entwickhng ron Cyclospora caryolytica Schaud.). Jedenfalls ist die Beschreibmng Grunows für eine sichere Beurteilung seines Fundes nicht ausreichend, zomal Stadien der Fortpflanzung und Vermehrung nicht heobachtet wurden, wenn man nicht etwa den angeblichen Empfängnishügel als solches ansehen will.

Kaum minder zweifelhaft ist ein Coccid, welches Giglio-Tos (609) in den Thrombocyten eines Frosches gefunden haben will. Da dasselbe nur zufällig in einem mit Methylenblau gefärbten Iiluttrockenpräparat entdeckt wurde und trotz alles Suchens nie wieder gefunden werden konnte, so mussten die Angaben ïber dasselbe notwendigerweise sehr liickenhaft bleiben. Es handelt sich um ovale Gebilde von $6 \mu$ Iänge und $3 \mu$ Breite, welche sich bei der Behandlung mit Methylenblau gleichmäßig dunkel gefärbt hatten, mit Ausnahme einiger kugeliger, völlig ungefärbt gebliebener Einschlïsse.

Im Anschluss an diese melır oder weniger zweifelhaften Formen ist auch noch des Coccidium fuscum. Olt zu gedenken, welches neuer-

1) Um Missverständnissen vorzubeugen, sei ausdrícklich betont, dass das hier ausgesprochene Urteil ausschliesslich auf den citierten Publikationen beruht. Es ist nämlich richtig, dass im Spiraldarm von Scyllizm Coccidien schmarotzen, welche der Gattung Eimeria angehören. Ich hoffe auf diese meines Wissens zuerst von Schaudinn gesehenen Coccidien an anderm Orte des näheren eingehen zu können. 
dings von Voirin (649) untersucht worden ist. Dasselbe soll in den Schweissdrüsen des Schweines schmarotzen und den durch eine cystische Degeneration dieser Driisen charakterisierten Schrotausschlag hervorrufen. Indessen sucht $L$ ïh e (623) auf Grund der vorliegenden Angaben über dies angebliche Coccid den Nachweis zu führen, dass es sich um alles andere eher als un Coccidien handelt.

Schliesslich sei hier noch angeführt, dass Mesnil (627) bereits 1899 den Begriff der Coccidien erweitert hat, indem er die Hänosporidien - welche sich ja ron den typischen Coccidien im wesentlichen nur dadurch unterscheiden, dass die Sporoblasten direkt, ohne vorherige Umwandhung zu Sporocysten, in die Sporozoiten zerfallen und dass der Zeugungskreis durch das Auftreten des Wirtswechsels kompliziert ist - eben wegen der relativen Geringfügigkeit dieser Unterschiede nur als Unterordnung der Coccidien auffasste ${ }^{1}$ ). Durch L égers oben erwähnte Angaben über Lorgerella noc ist M esnil (628) in dieser Auffassung bestärkt worden, da er anscheinend in den Hämosporidien, welche zwar mehrere Sporoblasten, aber keine Sporocysten bilden, eine Art von C̈bergangsform zwischen Legerellaund den typischen Coccidien sielıt. Er gelangt darauf hin zn folgendem Coccidien-Systene, welches durchaus dem La b béschen System der (iregarinida cephalin a entspricht:

I. Asporocystées.

1. Asporoblastées (? ou monosporoblastées.) (Gien. Legcrella.)

2. Sporoblastées (= Haemosporidia.)

II. Sporocystées (die typischen Coccidien mit Sporocystenbildung, deren System gegen früher unverïndert bleibt. Vergl. Schaudinus Übersicht 637).

Gegen die Natürlichkeit dieses Systems lassen sich freilich sehr gewichtige Einwendmngen erheben. Die Ïhmlichkeit zwischen Legerella und den Hämosporidien ist doch wohl viel zu gering, um die erstgenamte Gattung von allen andern Coccidien zu trennen und mit den Hämosporidien zu vereinigen. Im (iegenteil lehren uns die entwicklnngsgeschichthichen Untersuchungen ron Bonnet-Ey ma r d (604) dic nächsten Verwandten von Legerella in den ('occidien-Gattungen Adelea und Klossia kennen, mit welchen die erstgenannte unter anderm die der Kopulation der Gameten vorausgehende Konjugation der Gametocyten gemein hat (rgl. hierzu unten Abschnitt II, 4 dieser Übersicht). Von den beiden übrigen dnrch die Bildung zahlreicher Sporozoiten charakterisierten Coccidien (vgl. das oben wiedergegebene System Légers) nimmt dann Encoccidtum Lhe. (= Benedenia Aimé

1) Eine ähnliche Auffassung hat später auch Doflein (Protozoen als Parasiten und Krankheitserreger. Jena 1901) vertreten, indem er, anscheinend ohne Kenntnis der hier besprochenen Arbeiten Mesnils, Coccidien und Hämosporidien als die beiden Unterordnungen einer Ordnung Coc cidio morph a bezeichnete. 
Schn. nec Dies. = Leyeria R. Bl. nec Labbé = Leyerina .Jacuuemet) eine verhältnismäPig isolierte Stellung ein, nicht nur wegen des Ausfalls der Schizogonie, sondern auch wegen der langgestreckten Fadenform der geissellosen Microgameten. Barrous;ia schliesst sich zwar beziiglich der Nicrogameten ebenso eng an Eimeria Aimé Schn., Lhe. (=Cocridium Leuck.) an. wie sie sich ron Eucoccitium sowohl wie von Adelea, Klossia und Legerella entfernt, doch würde es bei unsern jetzigen Kenntnissen noch verfrüht sein, nur mit Rücksicht auf die Form der Geschlechtsindividuen und die Kopulation die Gattungen Eimeria und Barroussia als nahe miteinander verwandt ansehen zu wollen. Wenn dagegen Léger in seinem oben wiedergegebenen Systeme die Gattung Isospora Aimé Schn. (= Diplospora Labbé) als nächstrerwandt mit Eimeria Aimé Schn., nec Léger (= Coccidium Leuck.) ansieht, so enthalten die unten zu besprechenden entwicklungsgeschichtlichen Angaben ron Laveran und Mesnil (613) bezw. Sergent (640) über zwei Isospora-Arten wenigstens nichts, was jener Annalıme widerstreitet.

Ton der Fattung Cyclospora Aimé Schn. waren bisher nur die durch den Besitz von vier Sporozoiten charakterisierten reifen Oocysten bekannt. Nach einer Arbeit yon Schaudinn (639), welche uns eine neue Art dieser Gattung kemnen lehrt (vgl. unten unter II. 3), scheint dieselbe eine Art ron Mittel-Stellung zwischen Eimeria einerseits und Adclea nebst verwandten liormen andererseits einzunehmen.

\section{Entwicklungsgeschichtliches.}

1. Neueszur Entwieklung ron Arten der Gattung Eimeria.

Wie für die Coccidienforschung ïberhaupt, so ist auch gerade speziell für die vollkommene Aufdeckung des Entwicklungsganges der Eimeria-Arten Scha udinns Arbeit ïber den Generationswechsel der Coccidien epochemachend gewesen. Aus den seither erschienenen Mitteilungen, welche entwicklungsgeschichtliche Angaben ïber Arten jener Gattung enthalten, sei hier zunächst die von Laveran und Mesnil (614) publizierte Schilderung von Eimeria (Paracoccidium) prevoti Lar. et Mesn. hervorgehoben, da diese Art eine bisher unbekannte Modifikation der Coccidienentwicklung darbietet. Die Schizogonie bietet keine Besonderheiten gegenüber den typischen Fimerien, die Kopulation erfolgt in ganz ähmlicher Weise wie bei Eimeriu schubergi (Schaud.) und auch der Ablauf der Sporogonie entspricht anfänglich durchaus demjenigen anderer Eimerien. Sobald indessen in der Ooçste die Sporozoiten gebildet sind, verschwindet die Hiill- 
membran der 4 Sporocysten und in den reifen Oocysten sind daher die 8 Sporozoiten nicht mehr zu je zwei mit je einem Restkörper auf die 4 Sporocysten verteilt, sondern liegen vielmehr ebenso wie die von jedem der 4 Sporoblasten gebildeten Restkörper (reliquats sporauxj frei in der Oocystenschale, welche ausserdem auch noch einen bei der Bildung der Sporoblasten übrig gebliebenen Restkörper (reli(uuat kystal) enthält. Augenscheinlich handelt es sich hierbei nur um eine sekundïre Modifikation der Entwicklung, d. h. Eimeria (Paracoccidium) preroti stammt ron typischen Eimerien ab.

Das zweite Coccid aus dem Darmkanal des Frosches, welches La veran und Mesnil (61t) schildern, die Eimeria ranam (Lav. et Mesn.), bietet keine entwicklungsgeschichtlichen Besonderheiten. Es sei deshalb hier nur angeführt, dass im regensatz zu Eimeria schubergi und Paracoccidium meroti, dagegen in Übereinstimmung mit Eimeria propria (Aimé Schn.) (aus Molge-Arten), die Oocystenhïlle nicht erst nach der Kopulation auftritt, sondern bereits den reifen unbefruchteten Macrogameten umschliesst und eine Micropyle besit durch welche bei der Kopulation der Nicrogamet eindringt.

Simond $(643,(544)$ schildert bei den beilen ron ihm beschriebenen und bereits oben erwälnten neuen Fimeriu-Arten nur die Sporogonie, welche ron derjenigen anderer Eimeria-Arten lieine wesentlichen Abweichungen zeigt. Stadinn der Schizogonie wurden bisher nur bei einer von beiden Arten beobachtet, loch geht der Verf. nicht näher auf dieselben ein.

Bemerkenswerte Abweichungen gegenüber allen andern Coccidien fanden Laveran und Mesnil (615) bei der gleichfalls bereits unter den neuen Arten namhaft gemachten Eimeria mitrariu (Lav. \& Mesn.). Einmal hat die Oocyste dieses Coccids eine selır wunderbare Form, insofern als sie an eine Mitra erinnernd an einem Pole in eine Spitze ausgezogen ist, an dem entgegengesetzten Pole dagegen breit endet, aber nicht gleichmäPig stumpf abgerundet, sondern in 3 (seltener 4) nebeneinander gelegene, konische Spitzen ausgezogen erscheint. Eine weitere Abweichung gegenüber allen andern Coccidien besteht, wenn Laveran und Mesnil recht berichten, darin, dass das Coceid ausschliesslich extracellulïr zu leben scheint. Die französischen Gelehrten haben nämlich ausser den erwähnten Oocysten auch Schizonten in allen Vermehrungsstadien, Microgametocyten in allen Stadien der Microgametenbildung und Macrogameten in allen Wachstumsstadien beobachtet. Aber alle diese Stadien wurden ausschliesslich frei im Dickdarm der infizierten Schildkröte gefunden. Auch auf Schnitten durch die Darmwandung wurde kein einziges intracellulär gelegenes Coccid gefunden. Alle beobachteten Wachstums- und Differenzie- 
rungsstadien erschienen vielmehr nur dem Epithel oberflächlich aufgelagert. La veran und Mesnil nehmen daher an, dass wenn intracellulär gelegene Stadien überhaupt existieren, dieselben nur von sehr kurzer Dauer sein können. Die erwähnten Fortsätze an der Oocyste werden vermutungsweise auf "Pseudopodien" zurïckgeführt, welclıe zur Ernährung der Coccidien auf Kosten der Darmepithelien dienen sollen.

Bei der gleichfalls bereits erwähnten Eimeria faurei, welche Moussu und Marotel $(630,631,632)$ im Darmkanal ron Lämmern fanden, weist die Sporogonie, welche in mit Wasser angesetzten Kulturen verfolgt wurde, keine Besonderheiten auf. W'enn es dagegen den Verff. wirklich gelungen ist, auch die Schizogonie auf den von ihnen hergestellten Schnittpräparaten durch den infizierten Darm zu beobachten, so wiirde diese nicht unerhebliche Abweichungen von dem Verhalten anderer Coccidien zeigen, infolge der erheblichen Grösse der Schizonten und Nierogametoeyten. welche bis zu 250-300 $\mu \mathrm{im}$ Durchmesser erreichen sollen, und der relativen Kileinheit (Länge von $5-6 \mu$ bei einer Breite ron $2 \mu$ der Merozoiten. Schon bei makrosliopischer betrachtung des infizierten Darmstückes hatte dieses, gegen das Licht gehalten, wie durchlöchert ausgesehen. Die Verff. hatten anfänglich vermutet, dass es sich hier um Coccidienherde handele, fanden aber auf Schnitten nur je einen parasitischen Organismus von den angegebenen Mafen mit zahllosen spindelförmigen Keimen, derart. dass das ganze Gebilde an sporenerfüllte Sarcosporidien erinnerte. Diese verhältnismäßig riesigen Bildungen gehen hervor aus kleinen einkernigen Insassen ron Zellen der L i e be r k iu li nschen Drüsen. Ihre Zugehörigkeit zu dem Coceid scheint den Verff., selbst noch nicht völlig sicher zu sein, doch wissen dieselben keine andere Deutung ihrer Befunde, zumal die angeführte İhnlichkeit mit Sarcosporidien nur für die anscheinenden Schizonten gilt, nicht dagegen für andere Gebilde ron denselben Dimensionen, die als Microgametocyten gedeutet werden, da ihre sprösslinge fast nur aus Chromatin bestehen. Bemerkt sei noch, dass diese als Microgameten gedeuteten Gebilde im Innern des Mutterindividuums zu 8-15 Gruppen vereinigt sind, derart, dass in dieser Hinsicht eine gewisse Analogie mit der unten zu besprechenden Caryotropha mesnili zu bestehen scheint.

Schliesslich liegen auch noch zwei neuere Arbeiten vor über das Coccid der Kaninchen, die Eimeria stiedae (Lindem.) Stiles $(=$ Coccidium oriforme Lenck.). Noch kurz vor dem Erscheinen ron Schaudinns ausführlicher Arbeit über den Generationswechsel der Coccidien ist ron Pianese (635) eine ziemlich nmfangreiche Arbeit veröffentlicht worden. deren entwicklungsgeschichtliche Angaben sich zum 
Teil mit unsern sonstigen Kenntnissen kaum in Einklang bringen lassen, deren Verständnis aber freilich auch dadurch erschwert wird, dass der Verf. für die verschiedenen Entwicklungssphasen eine Menge besonderer Benennungen anwendet, welche zum Teil erst von ihm gebildet "), zum Teil von ilm in anderm Sinne als ron andern Autoren gebraucht werden ${ }^{2}$ ). Die von dem sonst bekannten abweichenden Angaben Pianeses betreffen namentlich folgende Punkte:

1. Die Schizogonie soll in zweierlei form auftreten und entweder zahlreiche "Micromerozoiten" oder weniger zahlreiche ..Macromerozoiten" entstehen lassen. Die Bedeutung dieser Verschiedenheit wird jedoch nicht erörtert und ilır tatsächliches Vorhandensein bedarf zum mindesten der Bestätigung.

2. Die Oocysten sollen unter Umständen unter Wasserverlust sich zu Formen umwandeln, welche Terf. als . Pseudonavicellen" bezeichnet und als besondere Entwicklungsstadien ansieht, welche jedoch zweifellos nur auf artifizieller Schrumpfung von ('ysten beruhen, deren Inlalt abgestorben (bezw. degeneriert: ${ }^{3}$ ) ist.

3. Die durch Sporogonie erzeugten Sporozoiten sollen sich, nachdem sie ein intracellulïres "Stadium gregariniforme" durchgemacht haben, direkt encystieren und zur Bildung von Dauercysten führen können, eine Angabe, welche mit den Resultaten der modernen Coccidienforschung unvereinbar ist.

4. Die Infektion der Kaninchen soll durch junge Oocysten erfolgen, in welchen sich der Sporont kugelig kontrahiert, aber noch nicht (oder kaum ?) zur Teilung angeschickt hat (,nello stadio di cisti matura giovane, almeno nella fase della sfera madre"), eine Angabe, welche trotz der durch das beigefügte „almeno" bedingten Unbestimmtheit zu allen sonstigen Erfahrungen in so schroffem Widerspruche steht, dass ihre Richtigkeit gleichfalls bezweifelt werden darf ${ }^{4}$ ), zu-

$\left.{ }^{1}\right)$ Z. B. nemnt Pianese die Sporogonie ,megalocyclische“, ,monomorphe“ oder ,plionomorphe“, die Schizogonie ,microcyclische“, ,polymorphe" oder ,,mionomorphe“ Entwicklung, die Oocysten ,cisti mature“, die Schizonten „, cisti nude" odel" ,cisti giovini“" (nicht zu verwechseln mit den ,,ciste mature giovini“"d. h. jungen Oocysten) usw.

$\left.{ }^{2}\right)$ Wenn Pianosez. B. angibt, dass in den "Sporocysten" bis zu 30 und mehr „Sporozoiten“ entstehen können, so können hierbei nur Schizonten, welche Merozoiten bilden, gemeint sein, nicht aber dasselbe, was andere Autoren als Sporocysten bezw. Sporozoiten bezeichnen.

${ }^{3}$ ) Vergl, unten Cyclospora earyolytica.

4) Braun (Die tierischen Parasiten des Menschen. 3. Aufl. Würzburg 1903 pag. 73. Anm.) hat bereits mit Recht darauf hingewiesen, dass eine Infektion nach Verfütterung junger Oocysten nur dann vorstellbar wäre, wenn man amühme, ,dass die aufgenommenen Oocysten den Darm passiert, im Freien sporuliert und dann von neuem von den Versuchstieren aufgenommen worden sind." Dass aber junge 
mal in Rïcksicht auf die sogleich zu besprechenden Untersuchungen Metzners. C̈brigens hat Pianese auch einige Experimente angestellt zur Stütze der Anschaumg, dass die Sporozoiten durch die Gallenwege in die Leber eindringen ${ }^{1}$ ).

Ohme Kenntnis dieser Arbeit Pianeses hat Metzner (629) sehr griindliche Untersuchungen über das Kanincheneoccid angestellt, deren Resultate freilich erst zum 'Teil publiziert sind und zwar soweit es sich um die V'erfolgung der Sporogonie und die Feststellung des Infektionsmodus gehandelt hat.

Metzners Schilderung setzt ein bei der "sporulationsfähigen" ()ocyste, in welcher der Sporont sich bereits zu einer liugeligen Protoplasmamasse zusammengezogen lat, während der'/wischenraum zwischen der ovalen Oocystenhïlle und der eingeschlossenen kugeligen \%elle von einer halbflüssigen Gallertmasse ausgefüllt wird²). Die Oocystenhïlle selbst besitzt eine Micropyle und ist an ihrer Aussentlïche noch ïberlagert won einer diinnen Gallert- oder Schleimlsiille, welche L e u ck a r t zwar auch bereits an unreifen ('ysten beohachtet, an reifen Cysten dagegen vermisst hatte, so dass er infolgedessen zu der Auffassung kam, die ('occidien machten eine IIäutung durch. Metzner hat diese äussere (iallert- oder Schleimhiille jedoch auch noch bei reifen ('ysten, welche bereits sporozoiten enthielten, beobachtet, andererseits aber festgestellt, dass dieselbe schwindet, wenn man die Cysten längere Zeit in Flüssigkeiten aufhebt. Ihre Dicke ist wechselnd und besonders gross an Cysten aus der Gallenblase, so dass Metzner vermutet, es handele sich nicht um eine von den Coccidien selbst gebildete Hülle, sondern um eine Schleimhülle, welche dem Medium entstamnt, in dem die Coccidien sich befanden. Am dicksten ist diese äussere Hiille stets in der Nachbarschaft der Microyple, vor welcher sie eine Art liupe von wechsehder Grösse und häufig, namentlich bei jungen Cysten, ron gelblich-bräunlicher Färbung bildet, der

Oocysten wirklich den Darm passieren können, ohne in ihrer Entwicklungsfähig. keit Einbusse zu erleiden, erscheint un so unwahrscheinlicher, als ja bekanntlich die Schalen reifer Coceidien-Oocysten sich unter dem Einfluss der Darmsäfte des Wirtes öffnen, um den Sporozoiten den Austritt zu gestatten. Ich nehme daher zur Erklärung der Pianeseschen Infektionsversuche an, dass unter dem verfütterten Material sich auch reife Oocysten befunden haben müssen, wenn auch in so geringer Anzahl, dass Pianese sie ïbersehen hat.

1) In dem Neapler" „Zoologischen Jahresbericht" für 1900 (Protozoa pag. 11) sind in diesem Zusammenhange wohl nur versehentlich "Merozoite" angeführt worden, jedenfalls auch ein Beweis für die wenig klare Darstellungsweise Pi a neses.

$\left.{ }^{2}\right)$ Metzner bezeichmet diese ,sporulationsfäligen Cysten“ auch als ,reife Oocysten". Ich würde denken, dass als reife Oocyste nur eine solche zu bezeichnen wäle, welche die Sporogonie durchgemacht hat und ausgebildete Sporozoiten enthält. 
Vermutung Metzners zufolge bedingt durch die Reste von nicht eingedrungenen, der Oocyste ïusserlich angeklebten Microgameten. Hat doch Sclıaudinn (638) solche Nicrogametenballen an den Oocysten von Eimeria schubergi regelmälig gefunden.

Die Weiterentwicklung dieser Cysten hat Metzner dann mit Hilfe einer sehr zweckmäßigen Methode in möglichst zahllreichen Fällen an ein und demselben Individuum durch alle Stadien hindurch verfolgt. Dagegen gelang es ihm bisher nicht, befriedigende Färbungen der Cysten zu erzielen. Infolgedessen hat er bisher auch über die feinern Vorgänge bei der Kernteilung im Sporonten noch keine Klarheit gewinnen können. Die Sonderung der 4 Sporoblasten erfolgte ca. 30 Stunden nach der Entnahme der Cysten aus dem Kíote des Rectums bei Darmcoccidiose oder aus der Gallenblase bei Lebercoccidiose. Die Kernteilungsvorgänge scheinen ca. 10 Stunden frïher einzusetzen, da zu diesem Keitpunkt der Kern des lebenden Coceids undeuthich wird. Das in diesen Zeitangaben sich dokumentierende langsame Tempo der Sporogonie im Vergleich zu Eimeria schubergi, bei welcher die Sporoblastenbildung nur 4 Stunden orfordert, bleibt anch weiterhin bestehen, denn nacls den Untersuchungsprotokullen Metzners sind die Sporozoiten erst 42 stunden nach dem Beginn der äusserlich erkennbaren Sporoblastenbildung bez. 69-70 Stunden nach der Anfertigung des Präparates gut zu erkennen.

Von besonderm Interesse sind in Netzners Arbeit die Angaben iiber Veränderungen, welche an den Sporoblasten auftreten, bevor dieselben sich durch Abscheidung einer Itiille zu sprorocysten umwandeln. Es handelt sich hierbei namentlich $11 m$ die schon von ältern Autoren gesehene voribergehende Zuspitzung der Sporoblasten, welche M e tzner als "Pyramidenstadium" bezeichnet, sowie $u$ die ron Schuberg als Schncidersche bez. Sti edasche Körperchen bezeichneten Gebilde, alles Erscheinungen, die bisher noch nicht (iegenstand genauer Untersuchungen gewesen sind, trotzdem Schuberg solche bereits 1895 für wünschenswert erklärt und die Coccidienforschung seitdem so ungeheure Fortschritte gemacht hat.

Nach ll etzners Schilderung bleibt in den Sporoblasten der Kern nur kurze Zeit dentlich und bald nach seinem Undeutlicherwerden tritt an der Peripherie jedes Sporoblasten und zwar auf der dem ideellen Gesamtmittelpunkt aller 4 Sporoblasten abgewandten Seite ein helles Polfeld auf, aus welchem im Verlauf einer Viertelstunde ein kleiner Höcker hervorwächst. Dieser spitzt sich alsclann zu einer kleinen, allmählich immer grösser werdenden, hellen Pyramide zu, indem ein kleines stark lichtbrechendes Körperchen herausgepresst wird, welches dic Spitze der Pyramide bildet. und bereits von Schuberg bei der Eimeria

$$
\text { - Nr. 603-649. - }
$$


falciformis der Mäuse gesehen wurde. Gleichzeitig mit dem Auftreten dieses Kïrperchens wird aine feine Streifung bemerklich, welche von dem "Spitzenkörperchen” divergierend zur Basis der Pyramide verläuft und eino zarte Halbspindel bildet. Auf der Höhe ihrer Ausbildung, welche die Pyramiden in ca. ${ }^{3} / 4$ Stunden erreichen, bleiben sie eine Zeitlang stehen; dann ziehen sie sich relativ rasch wieder zurüick, aber unter Zurücklassung des Spitzenkörperchens, dessen Ausstossung aus dem Sporoblasten augenscheinlich das wesentliche des ganzen Vorganges ist. Die nähere Deutung desselben ist noch nicht ganz sicher, da der Nachweis noch fehlt, ob das Spitzenkörperchen vom Chromatin des liernes stammt. Anscheinend sind aber die Spitzenkörperchen den von Aimé Schneider bei Cyclospora glomericola beobachteten ..Schneiderschen Körperchen" vergleichbar.

Nach der Rückbildung der Pyramiden runden sich die Sporoblasten wieder ab, ilure Struktur ist nunmehr aber eine andere als vor der Pyramidenbildung, eine Verwechslung beider Stadien bei aufmerksamer Untersuchung somit ausgeschlossen. Die Sporoblasten werden dann zunächst oral, um sich hierauf an einem Pole zuzuspitzen, während gleichzeitig eine scharfe liontur auftritt als \%eichen für den Deginn der Bildung der Sporocystenhülle. I)er körnige Inlıalt der Sporocyste weicht alsdann ron dem spitzern Ende etwas zurïck, und an der Spitze des jetzt durchsichtigern Teiles erscheint ein dunkleres Gebilde, das dieses linde quer abstutzt, das „S t i e d a sche Körperchen.“ Während Schuberg semerzeit angenommen hatte, dass dieses Körperchen aus dem bereits erwähnten Spitzenkörperchen hervorgehe, mond während andere Autoren das Stiedasche Körperchen für eine lokale Verdickung der Sporocystenhülle gehalten hatten, weist Metzner nunmehr nach, dass dasselbe nur vorgetäuscht wird durch eine AbHachung der Hüllmembran an dem zugespitzten Ende der Sporocyste und die dort befindliche Micropyle, deren Vorhandensein durch die Untersuchungen ïber das Ausschlïpfen der Sporozoiten sicher gestellt werden konnte. Gegenüber den abweichenden Angaben L a b bés stellt Metzner fest, dass bei dem Kaninchencoccid ausser den 4 Sporocysten-Restkörpern auch bereits bei der Sporoblastenbildung ein Restkörper gebildet wird.

Von besonderm Interesse sind die Angaben Metzners über die Bedingungen, unter welchen die Sporogonie sowie das Ausschlïpfen der Sporozoiten erfolgt.

So rasch und sicher die Sporogonie ron Eimerict stiedae im feuchten, an der Luft liegenden Kote oder in dem in feuchter liammer mit Luftzutritt ausgebreiteten läsigen Inhalt der Leberknoten, ebenso wie in der an der Luft stehenden coccidienhaltigen Galle vor sich 
geht, so wenig konnte dieselbe bisher im Darm oder in der Leber der Kaninchen beobachtet werden. Metzner stellt nunmehr anf experimentellem Wege fest, dass es vornehmlich der Iangel an Sanerstoff ist, welcher die Sporogonie im Innern des infizierten Wirtes verhindert. Daneben ïbt auch die hohe Körpertemperatur des Warmblüters eine hemmende Wirknng aus; denn die Beobachtıng von R. Pfeiffer, dass die Sporogonie im lirutschrank zwar einsctzt, aber unvollständig bleibt und ihren normalen Abschluss nicht erreicht, wird von Metzner bestätigt und weiterhin festgestellt, dass dieselbe bereits im heissen Sommer ein wenig langsamer verlief, als bei mittlerer Temperatur von $15-20^{\circ}$ C. Speziell für die Leber-Coccidien spielt aber auch the hohe Kohlendioxyd-Spannung in der Leber eine wichtige Rolle. Metzner konute nämlich experimentell nachweisen, dass ein längeres Verweilen in einer Kohlendioxyd-Atmosphäre die Coccidiencysten tr̈tet, wälnend ein kiirzeres Verweilen in derselben einen atypischen Verlanf der Sporogonie Kreiteilung anstatt gleichzeitiger Entstehung aller vier Sprorohlasten 11. dgl.) bedingt. Dieser selbe atypische Verlauf der Sporogonie komnte auch an Cysten beobachtet werden, die solchen Tieren entstanmten. welehe bereits seit lïngerer Zeit eine Lebercoceiliose besassen, niclit dagegen an Darmcoccidien, da der Aufenthalt der (yrsten im Darm nicht lang genug ist, um eine schädigende Wirkung des Kohlendioxyds zu ermöglichen. Durch diese Feststellungen finden anch die ältern Angaben über \%weiteilung bei Kaninchencoceidien, deren Richtigkeit in nenerer Zeit bestritten war, ihre naturgemäße Erklärung.

Das Ausschliip,fen der Sporozoiten erfolgt nicht im Magen, sondern erst im Dnodenum, und zwar ist hierbei das Pankreassekret das wirksame Agens, derart, dass der Einfluss des Inlualtes des Duodenums surf die Coccidien-('ysten ein verschiedener ist, je nach seinem Gehalt in P'ankreassekret. Ist dieser Gehalt ein relativ grosser, so schliipfen die sporozoiten durch Eigenbewegungen zunïchst durch die Nicropyle der Sporocyste, darauf durch diejenige der Oocyste. Hierbei bleibt aber die Erweichung und Fältelung der Oocystenhiille ans, welche bei lïngerm Verweilen der ('ysten im Magensafte sich rinstellt und von frïhern Antoren für das Anfangsstadium der Sporozoiten-Befreiung gehalten wurde.

\section{Entwicklung vou Irten der Gattung Isosponer.}

Bisher waren ron keiner der zur Gattung Isospora Aimé Schn., Laveran emend. (= Diplospora Labbé) gehörigen Arten nähere entwicklungsgeschichtliche Daten bekannt. Schon allein aus diesem Grunde wïrden die Angaben, welche Laveran und Mesnil (613) 
über die von ilnen zu dieser Gattung gestellte Isospora lieberkïhni (Labbé) (= Hyalolilossia lieberkï̈hni Labbé) machen, besonderes Interesse verdienen, und dieses Interesse erhöht sich noch durch die Feststellung einer bisher unbekannten und nicht unwichtigen Abweichung von der Lebensgeschichte anderer ('occidien.

Die Art hewolnt, wie bereits oben erwälnnt, die Niere von liana ceculentr. Die jüngsten Stadien des Parasiten, welche dort gefunden wurden, waren noch relativ jugendliche Macrogameten sowie Microgametoeyten. deren kern sich bereits in zahlreiche, an die Obertläche gerückte Tochterkerne geteilt hatte (Einleitung zur Bildung der Microgameten). Ije reifen Microgameten besitzen wie diejenigen ron Eimeria, Barrouxia und Cyclospora (bez. letzterer vergl. den nächsten Paragraphen) zwei Geisseln. Die Reifung des Macrogameten erfolgt, anscheinend ähnlich wie bei Ëmeria schubergi (Schaud.) durch Ausstossung des Karyosoms, vor der Befruchtumg.

Während die Gametocyten noch z. 'T. in den Nierenepithelien sclumarotzen, erfolgt die Befruchtnug sowie die Entwicklung der (Oocysten im Lumen der Harnkanälchen. Wie bei Eimeria schubergi ist der Matrogamet im Momente der Befruchtıng noch nackt und bildet die zur Schale der Oocyste werdende Hüllmembran erst nach dem Findringen des Microgameten. Dr Kopulationskern (das Synkaryon Langs) bildet zunächst eine ähnliche aus Filamenten zusammengesetzte Spindel, wie sie Siedlecki (6+1) bei ddelea outa geschildert hat und wie sie allgemein für dieses Stadimm im Zeugungskreise der Coccidien charakteristisch zu sein scheint. Nach seiner Abrundung teilt sich alsdann der Kern durch wiederholte Zweiteilung in vier Tochterkerne, lierauf erst erfolgt die Teilung des I'rotoplasmas und Bildung zweier zweikrniger Sporoblasten. Diese wanteln sich alsbald durch Abscheidung einer Hiille zu dein Sporocysten um und lassen aus sich nach nochmaliger Kweiteihng der Kerne je vier Sporozoiten und einen Restkörper hervorgehen.

Der Weg, anf welchem die Infektion der Niere erfolgt, wurde durch Fïterungsexperimente festgestellt. Die Sporozoiten schlïpfen wie bei andern ('occidien unter dem Einfluss der Darmsïfte des Wirtes aus, sind auch 20 Stunden nach Fïtterung von reifen Oocysten wenigstens z. $\mathrm{T}$. in den Darmepithelzellen nachweisbar. Wenige Stunden später aber findet man bereits Coccidien in den Blntgefässen. Bei einem Frosch wurde dann 48 Stunden nach der Fiitterung eine allgemeine Infektion festgestellt. In den Lungen, den Nieren, dem Fettkörper, in Leber, Milz und Dickdarm fanden sich zahlreiche Coccidien und zwar fast ausschliesslich in den Blutgefässkapillaren. 
sei es frei im Lumen derselben, sei es in den Endothelzellen. In den Nieren fanden sich die Parasiten hauptsächlich in den Glomeruli.

Die Entwicklung der Parasiten innerhalb der Blutbahn ist noch nicht vollkommen aufgekiärt. Bereits 24 Stunden nach der Infektion wurden Macrogameten sowie Microgametocyten in Stadien der Microgameten-Bildung in der Blutbahn gefunden. Man könnte infolge dieses frühzeitigen Auftretens der Geschlechtsindividuen daran denken, dass ähnlich wie bei Eucoccitium octopiamm die Schizogonie ausgefallen ist. Hierfür könnte eventuell anch geltend gemacht werden, dass bei den natürlich infizierten Fröschen alle Coccidien ein und desselben Wirtes stets auf fast dem gleichen Entwicklungsstadium standen. Trotzdem hat jene Annahme zur Zeit noch keine genügende Stiitze und das um so weniger, als die Verff. in der Bhutbahn kïnstlich infizierter Frösche auch noch kleine Formen fanden, welche sie als Merozoiten denten. Die Fintstehung dieser Merozoiten wurde allerdings bisher noch nicht sicher beobachtet und nur ein Stadium wird erwähnt, welches möglicherweise als Schizont aufzufassen wäre bezw. bei welchem es zweifelhaft ist, ob es sich um einen Schizonten in einem frühen Stadium der Merozoiten-Bildung oder um einen Microgametocyten in einem frïhen Studium der Microgameten-Bildung handelt.

Jedenfalls ist nach den Untersuchungen von Laveran und Mesnil der Weg, auf welchem dic Coccidien in die Niere des Frosches gelangen, die Blutbahn. Wenn in letzter \%eit wohl gelegentlich die Hämosporiden bezeichnet worden sind als an das Leben im Blute angepasste Coecidien, so lernen wir nunmehr ein typisches Coccid kennen, welches einen T'eil seiner Entwicklung gleichfalls im Blute durchmacht, ohne doch trotz dieser Übereinstimmung sich im ïbrigen den Hämosporidien melır zu nähern, als andere C'occidien. Abgesehen von dem allgemeinen Interesse, welches diese Feststellung hat, sei hier aber auch noch auf einen speziellen I'unkt hingewiesen. Die Arbeit von Laveran und Nesnil könnte nämlich vielleicht auch Bedeutung gewimen für die Dentung der Resultate, zu welchen $\mathrm{I}_{\mathrm{u}} \mathrm{tz}$ bei seinen Untersuchungen über die Drepanidien der Schlangen gelangt ist. Ich habe bereits in meinem Referate über die Arbeit von Lutz (Zool. Zentr.-BI. Bd. IX. 1902. Nr. $19 / 20$ pag. 613 f. Ref.) darauf hingewiesen, dass ein Teil der von $L$ ut z beobachteten Eormen Coccidien angehören dïrfte. Als ich jenes Referat niederschrieb, war die Arbeit von Laverau und Mesnil noch nicht erschienen und ich stellte mir die Sache so vor, dass der normale Sitz jener hypothetischen Coccidien vielleicht die Leber sei und dass von dort aus die Coccidien gelegentlich in die Blutbahn geraten und mit dieser

Nr. 603-649. 
verschleppt werden konnten, 1 m dann in der Regel bereits in den Kapillaren des Lungenkreislaufs hängen zu bleiben. Wenn ich nunmelır geneigt bin, in der Arbeit von Laveran und Mesnil eine Bestätigung meines Grundgedankens zu erblicken, so eröffnet die selbe doch andererseits die Möglichkeit, dass es sich bei den von $\mathrm{Lutz}$ in brasilianischen Schlangen gefuntenen und als Entwicklungsstadien von Hämogregarinen gedeuteten ('occidien gleichfalls um Formen handelt, welche normalerweise einen Teil ihrer Entwicklung im Bhute durchmachen. Es ist vielleicht nicht ïberflüssig, die durchaus hypothetische Natur dieser Deutungen noch besonders zu betonen. Vielleicht kann aber trotzdem oder vielmehr gerade deswegen das Aussprechen derartiger Gedanken für den wissenschaftlichen Fortschritt von Nutzen sein.

Im Anschluss hieran sei auch noch einmal an die bereits oben angeführte Beobachtung ron Simond elimert, wonach Eimeria kermoryanti in der Milz seines Wirtes (Gariulis yanyeticus) gefunden wurde. Auch diese Angabe rïckt durch die Entdeckung von Laveran und Mesnil in eine ganz neue Beleuchtung, freilich ohne deshalb bereits eine ausreichende Erklärung finden zu können. Ist doch kein Weg vorstellbar, auf welchem die reifen Sporozoiten aus der Milz nach aussen gelangen können, und ist doch deshalb auch die Nilz wohl kaum als der normale Wohnsitz jenes c'occids anzusehen. Haben doch auch Laveran und Mesnil ausnahmsweise die Sporogonie von Isospora lieberkithni auch in der Lunge erfolgen sehen, obwohl sie als normalen Wohnsitz nur die Niere ansehen.

Aus nenester Zeit liegt nun noch eine zweite Mitteilung über eine Tsospora-Art ror, welche gleichfalls den Zengungskreis der betreffenden Art in Kürze schildert. Es handelt sich um die von Sergent (640) als nene Art beschriebene Isospor mesnili des Chamäleons. welche im Gegensatz zu der vorstehend besprochenen Isospora lieberliühni ausschliesslich im Darmkanal und zwar in den Kernen der Epithelzellen des Dickdarms schmarotzt. Liessen Laveran nnd Mesnil es noch zweifelhaft, ob bei Isospora liebertiihni ein Generationswechsel rockomme, so hat Sergent einen solchen bei Isospora mesnili nachgewiesen. Aus seinen kurzen Angaben hierüber geht herror, dass wie bei Eimeria Schizonten, Macrogameten und Microgametocyten sich durch rerschiedene Struktur unterscheiden. Die Zahl der von einem Schizonten gebildeten Merozoiten soll relativ sehr erheblich schwanken $(10-30)$ und die Microgameten sollen nicht so schlank sein, wie bei andern Coccidien, sondern relativ kurz und dick (.trapus et non effilés"). 


\section{Cyelosponer rerleyglytice Schaul.}

Von der im Jahre 1881 von Aimé Schneider aufgestellten Gattung Cyclospora, bezw. von deren einziger Art, Cyclospora glomericola Aimé Schn. waren bisher nur die Dauercysten bekannt, welche durch den Einschluss ron nu 2, je 2 Sporozoiten enthaltenden Sporocysten charakterisiert sind. Kïrzlich hat uns jedoch S c h a ud in $(6394)$ in einer wichtigen Arbeit den Entwicklungsgang ron einer andern, dieser Gattung znzuzählenden Art kennen gelehrt, der Cyclospora caryolytica Schaud. des Maulwurfs. Es ergaben sich hierbei einige nicht unwichtige Abweichungen von den Fortpflanzungsverhïltnissen anderer Coccidien.

Auch bei Cyclospora caryolytica findet sich ein typischer Generationswechsel. In ähnlicher Weise wie dies für die überwiegende Nehrzahl der genauer untersuchten Coccidien gilt, dient eine ungeschlechtliche Fortpttanzung (Schizogonie), welche in mehrfacher Wiederholung auftritt, der raschen Vermehrung der Individuen innerhalb eines bereits infizierten Wirtsindividums, während eine geschlechtliche l'ortpflanzung zur Bildung der Dauercysten führt. welche die Infektion neuer Wirte rermitteln. Die von Schandinn untersuchte Cyclorpora unterscheidet sich aber dadurch wesentlich ron den Fimerien, dass die Schizogonie in zweierlei Form anftritt. Die durch Sporogonie erzeugten Sporozoiten. welche in den Cysten und auch noch frei im Darmkanale des Nanlwurfs noch keinerkei wahrnehmbaren Dimorphismus zeigten, beginnen bereits bald nach ihrem Eindringen in die Darmepithelzellen Unterschiede aufzuweisen, um alsdann zwei verschic'denen Formen-Reihen den Ursprung zu geben, welche wir als of und q unterscheiden können, da die eine später die münnlichen, die andre die weiblichen Geschlechtsindividuen aus sich hervorgehen lässt. Dieser sexuelle Dimorphismus während der ungeschlechtlichen Fortpllanzung bildet das wesentlichste Charakteristicum der Cyclospora caryolyticn im Vergleich zu Eimeria. Die beiden nachstehenden tabellarischen Übersichten werden dies am besten erkennen lassen: 
Entwicklungsgang vo n Eimeria $\left.{ }^{1}\right)$.

\begin{tabular}{|c|c|c|c|}
\hline $\begin{array}{c}\text { Schizo- } \\
\text { gonie } \\
\text { (mehrfach }\end{array}$ & $\begin{array}{l}\text { Sporozoit } \\
=\text { Schizont } \\
\mid\end{array}$ & & \\
\hline $\begin{array}{l}\text { wieder- } \\
\text { holt). }\end{array}$ & $\begin{aligned} & \text { Merozoit } \\
= & \text { Schizont }\end{aligned}$ & & - \\
\hline $\begin{array}{c}\text { Merozoit } \\
=\text { Schizont } \\
\mid \\
\text { usw. } \\
\text { (Schizogonie } \\
\text { bald }\end{array}$ & $\begin{array}{l}\text { Merozoit } \\
=\text { q Nacro- } \\
\text { gametocyt } \\
=\text { q Nacro. } \\
\text { gamet }\end{array}$ & $\begin{array}{c}\text { Merozoit } \\
=\text { J Micro- } \\
\text { gametocyt } \\
\text { | } \\
\text { gicro- } \\
\text { gamet }\end{array}$ & $\begin{aligned} & \text { Merozoit } \\
= & \text { Macr } \\
\text { gametocy } & \\
= & \text { Y Macr } \\
& \text { gainet }\end{aligned}$ \\
\hline & Sporogonie & $\begin{array}{r}\mathrm{Co} \\
=\text { Sporor } \\
\text { Spor } \\
=\mathrm{Sp} \\
\text { Spd } \\
=\mathrm{S}\end{array}$ & $\begin{array}{l}\text { pula } \\
\text { it (Oocyste) } \\
\text { | oblast } \\
\text { orocyste } \\
\text { | rozoit } \\
\text { chizont }\end{array}$ \\
\hline
\end{tabular}

Entwicklungsgang von Cyclospora.

$$
\begin{aligned}
& \text { Schizo- Sporozoit } \\
& \underset{\text { gonie }}{\text { gonfach }} \mid=\text { Schizont }
\end{aligned}
$$

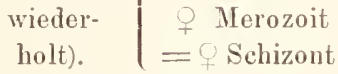

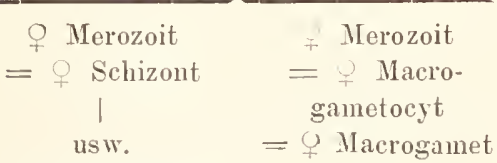

(S.hizogonic

bald erlöschend).

$$
\begin{aligned}
& \text { Sporozoit } \\
&= \text { Schizont } \\
& \text { | Merozoit } \\
&=\text { Schizont }
\end{aligned}
$$

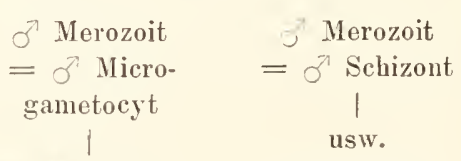

(Schizogonie bald erlöschend).

$$
\text { Sporogonie } \begin{gathered}
\text { Copula } \\
=\text { Sporont (Oocyste) } \\
\text { Sporoblast } \\
=\text { Sporocyste } \\
=\text { Sporozoit Schizont }
\end{gathered}
$$

Von nähern Details ans dem Entwicklungsgange von Cyclospora caryolytica sei folgendes hier angeführt:

1) Etwas modifiziert nach Lühe $(621,622)$. 
Die weiblichen Schizonten wachsen sehr rasch heran (sie haben bereits in 4-5 Stunden ihr Wachstum vollendet), speichern keinerlei Reservestoffe im Plasma auf und zeigen daher eine grob-vakuoläre Struktur. Die der Schizogonie vorausgehende K'ernvermehrung erfolgt nach demselben Typus (einer Art ron primitiver Mitose) wie bei Eimeria schubergi and andern Arten. Die sich entwickelnden Merozoiten springen an der ()berflïche des Schizonten knospenähnlich vor und strecken sich bei ihrer weitern Entwicklung stark in die Länge, derart, dass sie schliesslich mit dem zentral-gelegenen, stets sehr kleinen Restkörper eine sonnenblumenähnliche Figur bilden. Der Kern dieser Merozoiten liegt stets in d $m$ dem Restkörper moewandten, hintersten Drittel der \%elle.

Die männlichen Schizonten wachsen etwas langsamer heran als die weiblichen und zeichnen sich ferner durch den Gehalt ron stark lichtbrechenden Körnchen aus, welche in verdïnnten Sänren und Alkalien, in $̈$ ther, Chloroform und Alkohol gleich unlöslich sind und im Gegensatz zu den dotterartigen Reservestoffen der Macrogameten ihr starkes Lichtbrechnngsvernögen anch in Kanadabalsam beibehalten. und deren Zahl im Laufe des Wachstums der Selizonten eine starke Vermehrmng erfüht. Die Kernvermelrung erfolgt ebenso wie bei den weiblichen Schizonten; abweichend verhält sich dagegen die Schizogonie selbst, welche bis \%u einem gewissen Grade an die superficielle Furchung erinnert. Wie sich entwickelnden Merozoiten wölben sich nicht über die Obertläehe der Schizonten vor, sondern treten viehmehr zuerst dadurch in die Erscheinung, dass zwischen den an die Oberfläche gerückten Kernen feingranulierte Plasmastreifen sichtbar werden, welche zu den einzelnen Kernen gehörige polygonale Höfe umgrenzen. Von diesen Plasmastreifen aus schreitet die Segmentierung weiter nach innen zu fort, derart, dass jeder einzelne Merozoit einen T'eil der zentral angehäuften lichtbrechenden Körnchen erhält und ein Restkörper nicht übrig bleibt. Ausser durch den Gehalt an diesen Kö̈nchen unterscheiden sich die mämnlichen Merozoiten von den weiblichen auch noch durch ihre etwas gedrungenere Form und die Lage des Kernes im rordersten Drittel der Zelle.

Die Gametocyten treten erst am 4.- כ. Tage nach der Infektion anf, wenn die Krankheit des Wirtes ihren Höhepunkt erreicht hat und in ihr kritisches Stadium eintritt, um, wenn dieses gliicklich ïberstanden, in rasche Heilung überzugehen. Männliche und weibliche Schizonten beginnen gleichzeitig Gametocyten zu bilden und dies erfolgt so rasth und allgemein, dass bereits am 6. Tage nach der Infektion der ganze Darmkanal mit Geschlechtszellen in allen Stadien 
der Differenzierung überschwemmt ist und nur noch ganz vereinzelte Schizonten angetroffen werden.

Während des Wachstums der jungen Microgametocyten erwirbt deren Plasma eine stärkere Affinität zu Kernfarbstoffen (Aufspeicherung von Chromatin im Plasma mit Riicksicht anf die enorme Kernrroduktion bei der Microgametenbildung?) und gleichzeitig werden die stark lichtbrechenden Körnchen, welche der Merozoit mitgebracht hatte, allmällich resorbiert. Dieselben sind also anscheinend Reservestoffe, die bei der Differenzierung der Microgameten gebraucht werden.

Die liildung der Microgameten wird durch eine multiple Kiernteilung in dem Microgametocyten eingeleitet, welche in sehr charakteristischer Weise verläuft. Das Karyosom wächst nicht wie bei den Schizonten zu einem grossen kugeligen hörper lieran, sondern teilt sich durch wiederholte /weiteilung in zahlreiche kleine 'lochterkaryosome, während gleichzeitig das ausser diesen Karyosomen noch im Kiern vorhandene Chromatin immer feinkörniger wird. Wenn die Kernteilung vollendet ist, sind die einzelnen Tochterkaryosome in gleichmäßigen Abständen an der Oberlïche der Zelle verteilt mnd je von einem Hofe kleiner Chromatinkörnchen umgeben. Auf einem etwas spätern Stadium der Microgameten-Bildung wird dann aus allen Microgametenkernen annähernd gleichzeitig das Karyosom ausgestossen. (Bei Eimoria schubrgi geht das nngeteilt gebliebene liarysom des Microgametocyten schon vor der Bildung der Microgameten-Kerne zu grunde, bei Eimeria lacazci bleibt es ungekeht noch bis nach der Kopulation in den Nicrogameten erhalten, scheint dann aber auch zil grunde zu gehen.)

Die ausgebildeten Microgameten sind wie bei den Eimerien und bei Barrouxia zweigeisselig, lassen jedoch wegen ihrer betriichtlichen Grösse einige feinere Details besscr erkennen. Ton besonderem Interesse ist der Nachweis eines Basalkörperchens der Geisseln, entsprechend dem Basalkörperchen der Gieissel bei Trypanosomen (bezw. der einzelnen Wimpern bei Flimmerzellen).

Die Macrogametocyten wachsen von allen Formen am langsamsten und bleiben auch am kleinsten, vielleicht in Zusammenhang damit, dass sie einen grossen Teil des aufgenommenen Nährmateriales in Gestalt reichlicher dottcrartiger Reservestoffe aufspeichern, anstatt es direkt zum Aufbau ihres Körpers zu verwenden. Auch in den Macrogametocyten entstehen durch wiederholte Zweiteilung des Karyosoms zahlieiche Tochterkaryosomen, doch verdichten sich dieselben nach-

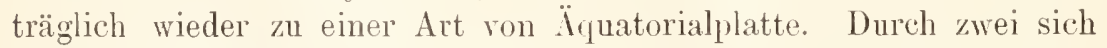
hieran anschliessende liernteilungen, welche an die Richtungskürperchen-Bildung bei Metazoen und Heliozoen erinner'n und von welchen 
die erste an eine Mitose erimnert, die zweite dagegen eine einfache Durchschnïlung darstellt, entstehen im ganzen drei Kerne, von welchen zwei allmählich resorbiert werden, während der dritte den Kern des nunmehr befruchtungsfähigen Macrogameten bildet.

Diese lieduktionsteilungen finden unter den Coccidien unr bei den Microgametocyten von Adelea orata eine gewisse Analogie, da dort durch zweimalige Zweiteilung 4 Microgameten gebildet werden, von welchen nur einer zur Kopulation gelangt. Sonst verläuft die Chromatinreduktion bei den genauer untersuchten Coccidien-Arten in wesentlich anderer Weise: Bei dem Macrogameten ron Adelea oratu wird vor der Befruchtung ein Teil des Kernes (aber nicht das Karyosom) ausgestossen; bei Eimeria schuberyi wird dagegen das Karyosom ausgestossen und zwar gleichfalls vor der Befruchtung; bei Eimeria lacuzei erfolgt die Auflösung des Karyosoms und Ausstossung eines T'eiles des Kiernes erst kurz nach der Befruchtung und bei Eimeria mopria anscheinend noch etwas später. Die Ausitossung des Karyosoms aus den Microgametosyten bezw. Microgameten wurde bereits oben besprochen.

Bei der Befruchtung wird wie bei Eimeria schubryi ein Empfängnishügel gebildet. Während aber die Cystenhülle, die bei Eimeria propria und Eimeria ranam schon dem reifen, befruchtungsfähigen Macrogameten zukommt, bei Eimeria schubergi im Momente des Eindringens des Microgameten gebildet wird. tritt bei Cyclospora caryolytica diese Cystenhülle erst sehr spuit auf, so dass Polyspermie die liegel ist. Ausser dem einen zur Kópulation gelangenden Microgameten dringen in den Macrogameten noch 8-1t weitere Microgameten ein; indessen gehen diese normalerweise zu grunde und werden wie die lieduktionskerne allmählich resorbiert.

Bei besonders heftigem Krankheitsverlauf werden nicht selten noch unreife Gametocyten mit dem Kote entleert, ohne in iln'er weitern Entwicklung hierdurclı gehemmt zu werden.

Die weitere Entwicklung der Cyclospora von der Kopulation bis zur Bildung der Sporozoiten bietet gegenüber andern Coccidien keine wesentlichen Besonderheiten. Erwähnt sei hier deshalb nur, dass bei besonders heftiger Infelition nicht selten eine eigentümliche Degeneration der Sporonten eintritt, an Stelle der normalen Weiterentwicklung. Bezüglich der Details dieser Degeneration, welche von Schaudinn mit der von R. Hertwig geschilderten senilen Degeneration bei Actinosphatium in eine gewisse Parallele gestellt wird und welche vielleicht auch für die Erklärung der bösartigen Geschwülste des Menschen Bedeutung gewinnen kann, sei hier auf das Original verwiesen. 
Mit Rücksicht auf das frühe Anftreten des geschlechtlichen Dimorphismus wurde bereits bei den Sporozoiten nach Geschlechtsdifferenzen gesucht, indessen ohne Erfolg. Eine Stunde jedoch, nachdem diese Sporozoiten in den Zellkernen des I)armepithels zur Ruhe gelangt sind, treten jene Differenzen bereits deutlich hervor, indem die männlichen Schizonten nicht nur bereits merkbar im Wachstum zuriickgeblieben sind. sondern auch bereits die oben erwähnten stark lichtbrechenden Körnchen zu bilden begonnen haben.

Bald nach dem Eindringen der Sporozoiten kommt es auch durch Auftreten des Plastins und Verschmelzung desselben mit einem aus Verdichtung des Chromatimnetzes hervorgegangenen zentralen Chromatinklumpen zur Ansbildung des Karyosoms, welches wie bei allen C'oceidien den Sporozoiten (und iberhaupt allen Stadien der Sporogonie) abgeht, bei den Kernteilungen der Schizonten dagegen eine wichtige Rolle spielt.

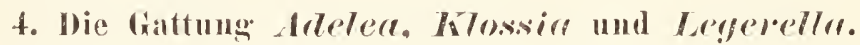

Ein ähnlicher sexueller I)imorphismus während der Schizogonie, wie er sich nach rorstehender. Schilderung bei Cyclospor a caryolytica findet, war bisher nur von den Arten der Gattung Adelea A imá Schn., sowie von Legerella nora bekannt und bei Adelea oidu am genauesten untersucht worden. Sclia u dinn (639) glaubt nun freilich in dieser Hinsicht noch einen Untersehied zwischen Adrloa ovata und Cyclospon ca curyolytica konstatieren zu können; denn .,bei Adelea orctu soll nach Siedlecki die Differenzierung der mämnlichen und weiblichen Formen erst nach mehrern (?) undifferenzierten Generationen von Schizonten auftreten und nicht schon die Sporozoiten sich wïhrend des Wachstums differenzieren." Auch würde dies in der Tat der Schilderung entsprechen, welche Siedlecki in seiner gemeinsam mit Schandinn unter dem 'Titel .. Beiträge zur Kenntnis der Coccidien" in: Verhdlg. Dtsch. Zool. Ges. VII. (Kiel) 1897. pag. 192-204 veröfentlichten vorläufigen Mitteilung entwirft. In seiner ausführlichen I'ublikation, welche auch in anderer Beziehung mehrfach eine andere Auffassung wiederspiegelt wie die 2 Jahre früher erschienene vorläufige Mitteilung, erklärt Si ed le cki (641, rag. 189) jedoch ansdrüicklich: „Les sporozoïtes des sporocystes se développent, dans les cellules épithéliales de l'intestin du Lithobius, les uns en individus mâles, les a utres en indiridus femelles"1)! Der sexuelle Dimorphismus besteht also anch hier von Anfang an und entspricht in jeder Beziehung demjenigen der Cyclospora caryolytica. In einer andern Hinsicht macht es sich freilich jetzt geltend, dass die sorgfältige Arbeit Siedleckis die erste ansführliche Mitteilung über den Generations-

1) Im Original nicht gesperrt

- Nr. 603-649. 
wechsel einer Coccidienart war. Auf etwaige Verschiedenheiten zwischen den Schizonten einer-, den Gametocyten andererseits wird in Text so wenig Pïcksicht genommen, dass man glauben könnte, dieselben seien in ihrem Bau völlig identisch und es hinge von Zufälligkeiten ab, ob das erwachsene Coccid sich durch Schizogonie rermehre oder die Rolle eines Gametocyten ïbernähme. Zwischen den männlichen Schizonten und den Macrogametocyten lassen allerdings bereits die Abbildungen Siedleckis deutliche Untersehiede erkennen. Bei den weiblichen Schizonten und den Microgametocyten ist dies dagegen nicht der Fall und doch möchte ich annehmen, dass sicherlich auch zwischen diesen gewisse Unterschiede bestehen. Nach dieser Richtung diirfte also eine Nachuntersuclung der Adelea ovata wïnschenswert sein.

Ausser durch den Dimorphismus während der Schizogonie unterscheidet sich Adelea ovata von der Mehrzahl der bisher genauer untersuchten ('occidien auch durch den Verlauf der liefruchtungsvorgänge, insofern als der Kopulation von Macro- und Microgamet eine Aneinanderlagerung der Gametocyten voranggeht. Erst nachden diese erfolgt ist, wandelt sich der Macroganetocyt durch Chromatinredulion zum befruchtungsfähigen Macrogameten un und gleichzeitig teilt sich der Microgametocyt in 4 (einen Riestkörper übrigg lassende) Microgameten, von welchen dann einer die Kopnlation mit dem Macrogameten vollzieht. Lühe (625) weist darauf hin, dass dieser verhältnismäßig komplizierte Ablauf des Befruchtungsvorganges einen Fingerzeigr dafür abgibt, in welcher Weise wir die Konjugation der Infusorien von der Kopulation anderer Protozoen abzuleiten haben. Wenn wir nämlich die Aneinanderlagerung der Gametroyten bei Adelea mit der Konjugation der Infusorien vergleichen, so entspricht die 'leilung des Micronucleus der Infusorien in 4 Tochterkerne durchaus der Microgametenbildung bei Ldclea, d. h. die Teilprodukte jenes Micronucleus, von welchen einer die Kiopulation mit dem andern Konjuganten vollzieht, sind vom vergleichend-morphologischen Standpunkt aus durchaus homolog den Microgameten der Coccidien, obwohl sie niemals wie diese letztern das Stadium selbständiger Zellen erreichen.

Die übrigen Arten der Gattung Adelea scheinen sich in ihrem Entwicklungsgange im wesentlichen ähnlich zu verhalten wie Adeleu orata. Allerdings hatte Pérez (633) in seiner, bereits in Schaudinns Übersicht (637) berüicksichtigten rorläufigen Mitteilung das Fehlen des sexuellen Dimorphismus der Schizonten bei Adelea mesnili Pérez behauptet. In seiner ausführlichen Arbeit (Pérez 63t) hat er jedoch diese Angabe nicht unwesentlich eingeschränkt. Er schildert zunächst verhältnismäßig ausführlicher Schizonten. welche meist 20-30, seltener 
mehr oder weniger $(10-40)$ lang gestreckte Merozoiten (15 $\mu$ lang und $2 \mu$ breit) mit ovalem Kerm bilden, und erwähnt dann noch kurz Schizonten, die durch geringore \%ahl der ron ilmen gebildeten Merozoiten (hüchstens 10), gedrungenere Gestalt dieser Merozoiten (nur 7--S $\mu$ lang bei $4 \mu$ Breite), sowie die runde Kernform derselben, nach der Abbildungen zu urteilen, auch durch (im Text nicht hervorgehobene) geringere Grösse der ganzen Schizonten von den ausführlicher geschilderten Formen abweichen.

Er denkt daher jetzt an die Möglichkeit, dass diese letztgenannten Schizonten und Merozoiten als mimmliche, die vorher erwähnten als weibliche anzusehen seien. Der entwicklungsgeschichtliche Beweis für diese Termutung ist freilich noch nicht erbracht. wenn auch die angeführte Verschiedenheit sicherlich nicht bedeutungslos sein wird und die beobachteten Unterschiede in den Mafo- und /ahlverhältnissen P'érez" Deutung zu stïtzen geeignet sind. Aucl bei drlelea orata sind nämliclı die männlichen schizonten kleiner als die weiblichen und sind die von den männlichen Schizonten gebildeten Merozoiten weniger zahlreich und gedrungener als die von den weiblichen Schizonten gebildeten. Was den weitern Unterschied anbetrifft, dass bei Adelea ovata die weiblichen Schizonten einen Restlïrrper übrig lassen, die männlichen dagegen nicht, so scheinen die diesbezüglichen V'erhältnisse bei Adclca mesniti gleichfalls ähnlich zu liegen, wenn sie auch noch nicht genügend klargelegt sind. Jedenfalls wird bei den als männliche gedeuteten Schizonten ein Resthörper nicht erwähnt, wohl aber bei denjenigen, welche als weibliche gedeutet werden. („A l'état frais, on distingue aux pôles du barillet quelques granules incolores réfringents, qui constituent sans doute un reliquat éliminé.")

Einen ganz analogen Dimorphismus von Sclizonten und Merozoiten hat aber aucl bereits Léger (616) bei den von ihm untersuchten Adclo-Arten beobachtet. Danach wird bei Adelea dimidiata Aimé Schn. ganz wie bei ddelea oruta bei der Bildung einer gedrungeneren Merozoitenform kein Restkörper übrig gelassen, während andere, schlankere Merozoiten um einen Restkörper angeordnet sind. Adelea alidium Léger soll mit Ausnahme der Grösse der Oocysten und der Zahl der Sporocysten, also wohl auch bezüglich des Dimorphismus bei der Schizogonie, vollkommen mit Adelea dimidiata übereinstimmen und für Adelea tipulae Lég. wird der Dinorphismus wieder direkt hervorgehoben durch die Angabe, dass ein Teil der Schizonten 15-20 Merozoiten bilde, ein anderer 'T'eil dagegen eine beträchtlichere Anzahl liteinerer Merozoiten. In diesem Falle allerdings lielt es Léger noch nicht für sicher, sondern nur für wahr- 
scheinlich, dass es sich um einen sexuellen Dimorphismus handele, wie bei Adelea ovata und dimidiata.

Ebenso wie dieser Dimorphismus der ungeschlechtlich durch Schizogonie sich vermehrenden Generationen scheint aber auch die weitere Eigentiimlichkeit allen Adeleu-Arten gemeinsam zu sein, dass der Kopulation von Macro- und Microgamet eine Aneinanderlagerung (Konjugation) des noch unreifen Macrogameten und des Microgametocyten rorausgeht, Übereinstimmungen, die um so mehr Beachtung verdienen, als die Gattung Adelea nur auf die Zahl der Sporozoiten und Sporocysten in der reifen Oocyste basiert ist.

Pérez (634) weist darauf hin, dass in einigen von Léger publizierten Abbildungen den Oocysten von Adelea dimidiata Ainé Schm. und Adelea alidium Lég. ein Körper angelagert ist, welchen Léger selbst als „corps de réduction nucléaire" bezeichnet, welcher jedoch nach Pérez nicht unwahrscheinlicher V'ermutung ein Nicrogametocyt, bezw. der Rest eines solchen ist ${ }^{1}$ ). Nit noch grösserm Recht kann auf die von Pérez nicht erwähnten Abbildungen hingewiesen werden, welche Léger ron Adelea timulae Lég. publiziert hat. Wir werden auf Grund unserer heutigen Kenntnisse mit zienlicher Sicherheit behaupten köunen, dass die Elemente, welche Léger (616, Taf. VIII. Fig. $21-24$ ) als "Mierogameten" von Aclea tipulae bezeichnet, in Wahrheit nicht solche, sondern vielmehr Microgametocyten sind, ganz wie bei Adelea ovutu limé Schn. Bei einer weitern Adelea-Art endlich, der Adelea mesnili Pérez hat P'ére\% $(633,634)$ selbst den Befruchtungsvorgang in allen Details verfolgt und die vollkommene Analogie mit Adelea orata feststellen können. Als eine Abweichung, die für den Vergleich mit andern ('occidien nicht ohne Interesse ist, verdient jedoch hervorgehoben zu werden. dass die Konjugation von Macrogamet und Microgametocyt bei Adelea mesnili lieine conditio sine qua non für die Nicrogametenbildung ist. Letztere kann vielmehr auch bei isolierten Nicrogametocyten stattfinden, was bei Adelea oiata nicht beobachtet worden ist. Allerdings vermutet l'érez, dass in solchem lalle die Nicrogameten nicht zur Kopulation gelangen. Nicht selten wurde dann auch beobachtet, dass zwei oder mehr Microgametocyten, welche ohne vorherige Konjugation zur Nicrogametenbildung schritten, aneinander gelagert waren. Doch glaubt Pérez

1) Inzwischen haben Léger und Dubosq (620) in einer Arbeit über Gregarinen eine Abbildung publiziert, welche einen Schnitt durch den Darm eines Scolopenders darstellt, und in welcher auch ein Macrogamet von Adelea dimidiata mit angelagertem Microgametocyten abgebildet ist, so dass nummehr die der Kopulation der Gameten vorausgehende Konjugation der Gametocyten auch für diese Art sicher gestellt erscheint. 
diesem Verhalten keine besondere physiologische Bedeutung zuschreiben zu sollen, er führt es vielmehr nur auf zufällige multiple Infektion der betreffenden Wirtszelle zuriick.

Wie aber Adelea hinsichtlich des sexuellen Dimorphismus der sich ungesehlechtlich vermehrenden Schizonten nicht allein steht, so auch nicht hinsichtlich der Konjugation der noch unreifen Gametocyten. Bereits in Schaudinns mehrfach citierter Übersicht (637) konnte darauf hingewiesen werden, dass auch bei Klossin helicina die Befruchtung nach Laveran in analoger Weise verläuft wie bei Adelea orutu, dass auch bei der Kr lossiu der Nicrogametocyt sich anlagert an den noch unreifen Macroganeten (den man nach Analogie mit ... Microgametocyt" wohl als ..Macrogametocyt" bezeichnen kann) und erst hiernach die zur Microgametenbildung führende Kiernteilung beginnt. Das gleiche ist inzwischen von Léger (61S) und BounetEymard (604) anch für Legerella nora ( $=$ Eimeria nora Aimé Schn.) nachgewiesen worden, und währeud bei Klossia holicina sexueller Dimorphismus der Schizonten nicht gefunden wurde, stimmt Logerella nork, wie bereits oben erwähnt, atuch in dieser bezielıng mit Adelen orata iiberein. Anch bei Lugerella norn sind ebenso wie bei ddelea orata die weiblichen Schizonten grösser wie die männlichen (man könnte also eventuell nach Analogie der Macro- und Microgameten auch von Macro- und Microschizonten sprechen). Anch darin stimmen beide Arten überein, dass bei der Schizogonie der weiblichen Schizonten eine ziemlich erhebliche Zahl ron Merozoiten gebildet wird (20-40 bei Adelen orata, etwa 30 bei legerella) und ein Restiörper übrig bleibt, wogegen die männlichen Schizonten in eine geringere \%ahl von Merozoiten (S-12, selten 14 bei Adelea orata, $6-8$ bei Leycrella) zerfallen, ohne einen Restkörper übrig zu lassen. Die Konjugation der Gametocyten erfolgt bei Legerella mitunter bereits vor Beendigung des Wachstums der Macrogametocyten. Die Folge hiervon ist, dass dieser alsdann den Microgametocyten noch teilweise umwächst, so dass letzterer in eine grubige Tertiefung des Nacrogametocyten eingebettet erscheint. Die Vierzahl der Microgameten findet sich bei Legerella ebenso wie bei Adelou.

Die Sporogonie von Legerella nor a ist noch nicht genau verfolgt, obwohl gerade sie allem Anschein nach besonderes Interesse verdient wegen des Endresultates, zu welchem sie führt und welches eine bereits am Eingang dieser Übersicht erwähnte bemerkenswerte Abweichung gegeniiber andern C'occidien anfweist. Die reife Oocyste enthält nämlich nicht wie bei den andern Coccidien mehrere Sporocysten, sondern viehmehr nur die $30-40$, vollkommen nackt erscheinenden Sporozoiten. Léger $(618,619)$ hat hieraus die Schluss- 
folgerung gezogen, dass bei Eimeria die Encystierung der Sporoblasten d. h. die Bildung der Sporocysten unterbliebe, ähnlich wie dies ja auch bei den Malariaparasiten der Fall ist. Die bisher vorliegenden Angaben lassen aber meines Erachtens noch eine andere Deutung zu. Da nämlich die Art der Teilung und Vermehrung innerhalb der Oocyste bisher noch nicht verfolgt werden konnte, so ist auch noch in keiner Weise der Nachweis geliefert, dass wirklich melrere gleichwertige Sporoblasten gebildet werden. Es ist vielmehr sehr wohl denkbar, dass es sich um Entwicklungsvorgänge handelt, bei welchen nur ein einziger Sporoblast zur Ausbildung bezw. Funktion gelangt, ähnlich etwa wie die Amöbosporidien abweichend von andern Gregarinen nicht zahlreiche, sondern nur einen einzigen Gameten (sog. Sporoblasten) ausbilden ${ }^{1}$. Für diese Deutung, die zwar noch hypothetisch ist, aber doch der l'rüfung wert erscheint. könnte eventuell geltend gemacht werden, dass nach Bonnet-Eymard (604) die Oocyste von Legerella eine doppelte (ystenwand besityt mnd dass in der reifen Ooeyste die Sporozoiten nicht in mehrern Gruppen angeordnet sind, etwa wie hei der (iregarinen-Gattung Porowpore, sondern an die Anordnung der Merozoiten erimern. welche bei der Schizogonie durch die multiple Teilung eines einzigen Mutterindiridums entstanden sind. Wenn nämlich die Sporozoiten auch nicht immer ein einziges Bïndel bilden, so kommt eine etwaige Sonderung in zwei Gruppen doch nur durch die Zwischenschaltung des Restlörpers zu stande und macht also die Annahme der Abstammung der Sporozoiten von mehrem Sporoblasten in keiner Weise erforderlich.

Die hier aufgeworfene Frage ist auch durch die Entdeckung einer zweiten Lagerella-Art von seiten Cuénots (607) nicht entschieden. Diese Leyprella testiculi Cuénot schmarotzt in dem Hoden von Glomeris und unterscheidet sieh ansser durch diesen Wohnsit\% von Legerella nora (Aimé Schn.) unter anderm durch die ovale Gestalt der Oocysten. welche bei $L$. nor k kugelig sind, und durch die geringere Anzahl der in einer Oocyste gebildeten Sporozoiten (15 bis 28). Ilie Ancinanderlagerung von unreifem Macrogamet und Microgametocyt erfolgt wie bei Adelea mesmili Pér. bereits auf frühem Wachstumsstadium, so dass auch hier der Microganetocyt vom Macrogameten zum Teil umwachsen wird. Bemerkenswert ist die anscheinend nicht selten gemachte Peobachtung, dass einem Macrogameten mehrere, bis zu vier Microgametocyten angelagert waren, ohne dass sich jedoch über die Bedeutung dieses Vorkommnisses be-

1) Vergl. Léger, L., La réproduction sexuée chez les Ophryocystis. In Compt. rend. d. 1. Soc. d. Biol. Paris. T. LII. 1900. No. 34. pag. 927-930. Diskussion: Mesnil, Ibidem pag. 930. 
reits ein Urteil fällen liesse. Die Reduktionsvorgänge am Macrogameten wurden beobachtet. die Beobachtung der Kopulation gelang dagegen nicht. Die die Sporozoiten umschliessende Cystenlı̈̈lle ist bei Legerella testiculi nicht nur doppelt wie bei Legerella nova, sondern sogar dreifach, so dass hier der Vergleich mit den durch ihre multiple Cystenhïlle ausgezeichmeten Amöhosporidien, soweit der prinzipiell verschiedene Ablauf der Befruchtungsvorgänge bei Coccidien einer- und bei Gregarinen andererseits einen solchen Vergleich überhaupt zulassen, noch nälser liegt wie bei Logerella nora. Im iibrigen sei hier nur noch bemerkt, dass nach ('uénots Angaben auch bei Leyerlla texticuli ein sexueller Dimorphismus bereits während der Schizogonie besteht, dass derselbe aber anscheinend nur wenig ausgeprïigt ist.

\section{Die Gattung Eurocreidium.}

(= Benetenia Aimé Schn., nec Dies., = Legeria R. Bl., nec Labbé $=$ Legerina Jacquemet $=$ Klossia Labbé e. p.

Unsere Kemntnis ron dem Entwicklungsgange der Arten der Gattung Eucoccilium the. berulit anch heute noch wio bereits vor vier Jahren auf der in den Amnales de l'Institut Pasteur erschienenen Arbeit Siedleckis ${ }^{1}$, welche bereits Scluaudinu (637) in seiner zusammenfassenden Übersicht berïcksichtigt hat. Wohl hat die Gattung in der Zwischenzeit mehrfach ihren Namen wechsehn miissen, wie dies bereits oben erwähnt wurde. Angaben über die Intwicklung hierher gehöriger Arten finden sich jedoch nur noch bei flacquemet (611), insofern dieser die Existenz zweier Arten bestätigt, welche durch die rerschiedene Zahl der ron einem Sporoblasten gebildeten Sporozoiten charakterisiert sind. Wohl hat bereits Aimé Schneider bei seiner ersten Beschreibung der Benedenia octopiana angegehen, dass jede Sporocyste 8-15 Sporozoiten enthalte, als er aber später bei Sepria officinatis nur 3 oder höchstens 4 Sporozoiten fand, scheint er selbst an die Möglichkeit eines Irrtums bei seiner ersten Beohachtnng gedacht zu haben. Trotzdem damn inzwischen Mingazzini auch bei Coccidien aus Octopus nur 3-4 Sporozoiten gefunden hatte, hat Labbé auf Grund der verschiedenen Sporozoitenzahl zwei Arten unterschieden: Klossia octopiana (Aimé Schn.) aus Octopus und Klossia eberthi n. sp. aus Sepia. (Übrigens findet sich diese systematische Unterscheidung noch nicht in Labbé, Sur le noyau et la division nucléaire chez les Benedenia, in: Compt. rend. de l'Acad. des Sci. 'T. 120, 1895, pag.

1) Siedlecki, M., Étucle cytologique et cycle évolutif de la Coccidie de la Seiche. In: Ann. Inst. Pasteur I.-XII. 1898 pag. 799-836, avec pl. VII-IX. - Dortselbst bezw. bei J a c ${ }^{\prime}$ u e met (611) die Citate der nachfolgend erwähnten aber nicht citierten Publikationen. 
381-383, wie es nach dem Citat in Labbés Bearbeitung der Sporozoen für das Tierreich (pag. 5̃) den Anschein hat, sondern erst in Labbé, Recherches zoologiques, cytologiques et biologiques sur les coccidies, in: Arch. de Zool. expérim. 3. sér. T. IV. pag. 535, wo für Klossia eberthi auch gleich noch dis im ..Tierreich " nicht aufgeführte, totgeborene Synonym Klossia sepiana gebildet wird.) Léger (616) hat die Labbésche Auffassung acceptiert, Siedlecki dagegen neigt mehr zu der Annahme, dass Aimé Schneider sich wirklich getäuscht habe, und nennt daher das von ihm untersuchte Coccid aus Sepia officinatis Klossia octopiana und im Anschluss an ihn haben auch Blanchard (603), D oflein (Die Protozoen als Parasiten und Kranklieitserreger, Jena 1901) und Lühe $(622$, 623) dieselbe Art Legeria octopiana bez. Benedenia octopiana genannt. Anch haben Blanchard (603) und $L$ ï he $(621,622)$ in die Gattungsciagnose ausdrücklich die Dreizahl der Sporozoiten aufgenommen. Durch die Untersuchungen von J a cqu e met (611), welche diese IBesprechung hier veranlassen, ist nun aber in der Tat festgestellt, dass in dieser Beziehung innerhalb der Gattung Eucoccidium entwicklungsgeschichtliche Differenzen bestehen. Während der ron Siedlecki untersuchte Parasit von Sepia officinalis, der fortan den Namen Eucoccillium elerthi (Labbé) zu führen hat, nur 3, selten 4 Sporozoiten in jeder Sporocyste bildet, finden sich bei dem Coccid ans Octopus rulgaris, dem Eucoccidium octopianum (Aimé Schn.) tatsächlich mehr, 6-12 Sporozoiten in jeder Sporocyste. Auch die weitere ältere Ingabe von Labbé, dass bei den Eucoccidien verschieden grosse Sporocysten vorkommen, wird von Jacquemet (611) bestïtigt. Auch letzterer spricht, wie bereits Labbé, von ...Macrosporocysten" und ... Microsporocysten". Am grössten sind die Unterschiede zwischen beiden bei Eucoccidium octopianum s. str., woselbst die Macrosporocysten im Mittel 20 " im Durchmesser messen und je 10-12 Sporozoiten enthalten, die Microsporocysten dagegen nur $10 \mu$ im Durchmesser messen mnd nur 6 Sporozoiten enthalten. Bei Lucoccidium eberthi bestehen entsprechende Grössenunterschiede, indem die Macrosporocysten $12 \mu$, die Microsporocysten nur $6 \mu$ im Durchmesser messen, aber hier enthalten beide Arten von Sporocysten die gleiche Zahl (3, selten 4) sporozoiten. Die Bedeutung dieser Verschiedenheiten ist aber bisher $11 \mathrm{~m}$ so weniger aufgeklärt, als Ja cquemet (611) ausdrïcklich betont, dass die beiden verschiedenen Formen durch Ubergänge verbunden sind. Im iibrigen ist Jacque net auf den Zeugungskreis von Eucoccidium octopianum s. str. nicht näher eingegangen, da derselbe im allgemeinen dem von Si ed leck i für Lucoccidium eberthi festgestellten durchaus analog sei. 


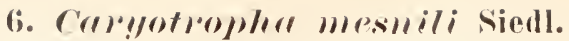

Eine ron derjenigen anderer Coceidien wesentlich abweichende Entwicklungsweise lehrt uns eine Arbeit von Sie lle cki $(642)$ bei Caryotropha mesnili n. g. n. sp. kennen. Bei dieser Form sollen nämlich dieselben ..erwachsenen, indifferenzierten Individuen" sowohl den Ausgangspunkt für die ungeschlechtliche Vermehrung durch Schizogonie wie anch fïr die Bildung der Geschlechtsindividnen bilden. Es sollen aber ferner, und das ist noch wichtiger, bei der Vermehrung durch Schizogonie zwei ungeschlechthiche Generationen miteinander abwechseln und entsprechend auch bei der Bildung der Microgameten zwei Generationen beteiligt sein. Wenn wir dies ähnlich wie oben bei Eimeria und Cyclospora in Stammbaumform darstellen wollen, erhalten wir folgendes Schema:

\section{Sporozoit}

$=$ erwachsenes, undifferenziertes Individuum.

\section{Schizonten}

\begin{tabular}{|c|c|}
\hline $\begin{array}{l}\text { Merozoiten } \\
=\text { erwachsene, undifteren- } \\
\text { zierte Individuen } \\
\text { Schizonten } \\
\text { | } \\
\text { usw. }\end{array}$ & 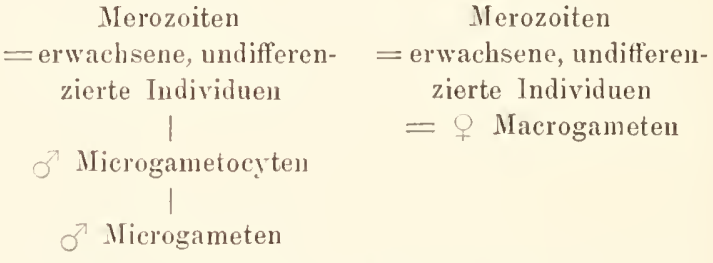 \\
\hline bald erlöschend) & $\begin{array}{c}\text { Copula }(1 \text { o }+1+) \\
=\text { Oocyste } \\
\mid \\
\text { Sporoblasten } \\
=\text { Sporocysten } \\
\mid \\
\text { Sporozoiten. }\end{array}$ \\
\hline
\end{tabular}

Wenn das .erwachsene, molifferenzierte Individnumı", welches aus dem die Infektion rermittelnden Sporozoiten oder aus einem Merozoiten durch Wachstum hervorgegangen ist, sich zur Schizogonie anschickt, so teilt es sich zunächst nach wiederholter Zweiteilung des liernes in 10-15 grosse, rundliche Tochterindividuen, welche in ihrer weiteren Entwickhng sich wie die Schizonten anderer Coccidien verhalten, indem jedes ron ihnen sich in 20-30 Merozoiten teilt. Dieser ganze 2 Generationen umfassende Entwicklungsgang spielt sich innerhalb ein und derselben, zuerst von den Sporozoiten bez. Merozoiten befallenen Wirtszelle ab. Das Endresultat der Vermehrung durch Schizogonie ist also. dass die Wirtszelle 10-15 Bündel von je 20-30 Merozoiten enthält. 
Die Macrogameten entstehen aus den „erwachsenen, undifferenzierten Individuen" durch eine einfache Umwandlung, indem in dem Plasma nachträglich noch Reservestoffe aufgespeichert werden, an der Oberfläche eine von einer Micropyle durchbohrte Cystenhülle abgeschieden wird und an dem Kern charakteristische Veränderungen auftreten, welche wie bei der Macrogametenreifung bei allen andern Coccidien in der Ausstossung eines Teiles der Kernsubstanz gipfeln. Diese letztere soll bei der Caryotropha dadurch eingeleitet werden, dass sich das chromatische Netzwerk des Kernes in Chromatinfäden auflöst und gleichzeitig das Karyosom sich mehrmals durch Kínospung teilt, so dass mehrere kleine Karyosome entstehen. Inwieweit diese letztern dann etwa noch bei der Ausstossung eines Teiles der Chromatinsubstanz aus dem ('occid beteiligt sind, wird nicht angegeben.

Die Bildung der Microgameten ist im Ciegensatz hierzu an einen Vermehrungsvorgang gebunden, wie dies ja anch bei allen andern Coccidien der Fall ist. Wie aber bereits eingangs bemerkt wurde, tritt auch bei dieser Microgametenbildung ganz wie bei der Schizogonie eine Generation mehr anf, als bei allen anderu bisher untersuchten Coccidien. Das ,erwachsene. undifferenzierte Individum". welches sich zur Nicrogametenbildung anschickt, teilt sich in ähnlicher Weise, als wenn es sich durch Schizogonie vermehren wollte, zunïchst in 10-15 grosse, runde Zellen und diese \%ellen sind es, welche dann ihrerseits durch abermalige mnltiple Teilung die Nicrogameten aus sich hervorgehen lassen und welche also den Microgametocyten anderer Coccidien entsprechen, obwohl sie nieht wie letztere direkt durch Wachstum aus den Merozoiten hervorgegangen sind. Inwieweit sich diese Microgametocyten von Garyotropha ron den Schizonten unterscheiden, hat Siedlecki noch nicht angegeben.

In der Oocyste, welche wie bei allen andern C'occidien aus der Vereinigmg ron Macro- und Microgamet resultiert, entwickeln sich etwa 20 Sporocysten mit je 12 sporozoiten.

Siedleckis Nitteilmg über Caryotrophe ist ausdrïcklich als vorläufige Mitteilung bezeichnet und wir diirfen daher erwarten, dass ihr eine ausführlichere Arbeit folgen wird, welche auch die bisher noch offen gelassenen liragen beriicksichtigt. Berlauerlich ist dagegen, dass Siedlecki, ähnlich wie dies oben bereits von l'ianese angegeben wurde, Benennungen, welche in der Protozoenforschung bereits üblich geworden sind. in wesentlich anderm Sinne gebraucht als alle andern Autoren. Schandinn bezw. Grassi haben dasjenige Stadium der Coccidien und Malariaparasiten, welches durch seine ungeschlechtliche Vermehrung (Schizogonie bezw. Monogonie) die Merozoiten bildet, Schizont hezw. Monont genannt und seither ist ron 
allen Protozoenforschern einer dieser beiden Namen acceptiert worden. siedlecki aber belegt jetzt mit denselben Namen das Endprodukt des ungeschlechtlichen Vermehrungsrorganges, die Merozoiten. Diese unnötige und nur zu Verwirrung Anlass gebende Ïnderung der Begriffe "Monont" bezw. .Schizont" führt denu auch dazu, dass das Mutterindividuum der Merozoiten, welches ich in vorstehender Schilderung im Anschluss an Schaudinns Nomenklatur als Schizont bezeichnet habe, von Siedlecki mit dem neugeschaffenen Namen ..Nonontocyt ou Schizontocyt" belegt wird. Bei dieser Gelegenheit sei bemerkt, dass ich bei der morphologischen Schilderung des Entwicklungsganges der Coccidien (und ähnlich der Malariaparasiten) die Bezeichnungen Schizogonie bezw. Schizont und Sporogonie bezw. Sporont den Bezeichnungen Monogonie bezw. Monont und Amphigonie bezw. Amphiont deswegen rorziehe, weil erstere sich auf bestimmte morphologisch charakterisierte Stadien beziehen, während letztere sehr viel weitere, biologische Begriffe darstellen. Ist doch der Sporoblast oder der Nicrogametocyt ebensogut ein Monont wie der Schizont! So wertvoll daher die Begriffe Monogonie bezw. Monont und Amphigonie bezw. Amphiont für rererbungstheoretische und ähnliche Erörterungen sind, so wenig scheint mir die Art der Anwendung dieser Begriffe auf die Coccidien und Malariaparasiten, wie sie von Grassi und Lang rersucht worden ist, im Sinne Haeckels, des Schöpfers jener Legriffe, zu liegen. Wenn ich aber gerade an dieser Stelle auf diese Frage zu sprechen komme, so geschieht dies, weil mir scheint, dass jene ron Grassi und Lang versuchte Anwendung durch die Bildung des Wortes ...Monontocyt" ron seiten Siedleckis gänzlich ad absurdum geführt ist. Diss dieses Wort gebildet werden konnte, beweist meines Erachtens besser als alle Erörterungen, dass die Haeckelschen Begriffe durch den Gebrauch, welchen Grassi und Lang von ihnen gemacht haben, ihres biologischen Sinnes und damit auch ihres Wertes für die Wissenschaft entkleidet werden.

\section{Klossiello mmis Smith and Johnson.}

Bereits im Jahre 1889 hatte Theobald Smith in der Niere von Mäusen ein (occid beobachtet ${ }^{1}$ ) und gelegentlich seiner wichtigen Untersuchungen über das Sarcosporid der Mäuse ${ }^{2}$ ) hat er dasselbe so häufig wiedergefunden, dass es möglich wurde, etwas genanere An-

1) Smith, Th., in: Journ. of Comparative Med. a. Surg. Vol. VI. 1889. pag. 211. -- Citiert nach Smith u. Johnson (645).

2) Smith, Th., The production of sarcosporidiosis in the mouse by feeding infected muscular tissue. In: Jonrn. of Experim. Med. Vol. VI. 1901. No. 1. pag. 1 -21. Taf. $1-4$. 
gaben über seine Vermehrungsweise zu machen (vergl. Smith und Johnson 645).

Das Coccid, welches den Namen Klossiella muris n. g. n. sp., daneben leider aber auch gleich als Mitgift den synonymen Gattungsnamen Microklossia nov. nom. erhält, fand sich ausschliesslich bei erwachsenen Mäusen. Die infizierte Niere ist etwas vergrössert und hat eine leicht nnebene Oberfläche. welche mit kleinen, eben noch sichtbaren gramen Fleckchen besät erscheint. Die jüngsten Parasiten, welche beobachtet wurden, sind $7 \mu$ im Durchmesser haltende, ligelige Organismen, welche im I'lasma der Epithelzellen der T'ubuli contorti schmarotzen. Ihr Kern besitzt ein, seltener zwei und zwar dann verschieden grosse Karyosome. Wenn der Parasit sich zur Termehrung anschickt, ist er so stark herangewachsen, dass er $40 \mu \mathrm{im}$ Durchmesser misst. Die Kernvermehrung erfolgt anscheinend durch wiederholte \%weiteilung, die Tochterkerne rücken an die Oberfläclıe (dieses Stadium wird als . Mutter-Sporoblast" bezeichnet) und die folgende '/ellteilung führt zur Bildung von $6-14$, selten mehr. kugeligen Tochterzellen (,Tochter-Sporoblasten“): welche anfänglich in Gestalt einer Rosette zusammenhängen, sich aber bald von einander lösen, ohne jedoch die Wirtszelle zu verlassen. Freilich ist von dieser Wirtszelle fast nur noch eine dünne Membran iibrig geblieben, welche eine grosse Vakuole unschliesst. In jeder so entstandenen Tochterzelle schreitet die Kernvermehrung durch wiederholte Zweiteilung aber noch weiter fort und fülurt zur Bildung ron je 30-35) .. Sporozoiten".

Wie Smitl und Johnson bei ihrer Schilderung dieser Vermehrungsvorgänge die Ausdriicke .. Sporoblast" und "Sporozoit" gebrauchen, so bezeichnen sie auch das junge Coccid, welches den Ausgangspunkt der geschilderten Vermehrung bildet, als "Sporont" und die Vermehrung selbst als "Sporogonie" — ob mit Recht, erscheint mir zweifelhaft. Eine Kopulation ist jedenfalls ebensowenig beobachtet worden wie eine Encystierung und dass das Coccid vor Beginn der Vermehrungsvorgänge so erheblich heranwächst, spricht doch wohl entschieden dafür, dass es sich um eine ungeschlechtliche (monogone) Fortpthanzung handelt. Smith und Johnson scheinen zu der gegenteiligen Auffassung nur dadurch bestimmt worden zu sein, dass das Coccid nicht direkt in Merozoiten zerfällt, dass vielmehr deren Bildung zwei Generationen erfordert, wie dies bisher nur von der Bildung der Sporozoiten bekannt war, inzwischen aber von Siedlecki bei Caryotropha mesnili anch für die Merozoiten gefunden wurde. In der Tat lassen auch die Abbildungen, durch welche Smith und Johnson ihre Schilderung erläutern, eine gewisse $̈$ hlnlichkeit er- 
kennen mit den Abbildungen, welche in Siedleckis Arbeit die Schizogonie von Caryotropha wiedergeben.

Ausser den bisher berïcksichtigen Stadien, welche die gewundenen Nierenkanälchen bewohnen, fanden Smith und Johnson nun aber auch noch andere Formen in den Glomerulis mancher infizierten Nieren, woselbst sie in den Epithelzellen der Bowmanschen Kapsel schmarotzen und zwar meist in denen des visceralen Blattes. Es sind unregelmäßig lappige Körper, welche bei ihrer Vermehrung zur Bildung zahlreicher sichelförmiger Körper führen. Ihre Bedeutung ist noch unsicher. Für ihre Zugehörigkeit zu K7ossiella muris führen Smith und Johnson die Tatsache ins Feld, dass sie ausschliesslich in Nieren gefunden wurden, welche mit K7ossiella infiziert waren. Andererseits wurden sie in manchen nur schwach infizierten Nieren vermisst.

Die Einwanderung der Coccidien in die Niere kann wohl nur auf dem Wege der Blutbalm erfolgen. ̈̈lınlich wie dies Laveran und Mesnil für Isospora liebertiühni (L a bbé) nachgewiesen haben.

\section{Zur Pathologie der Coceddien-Infektion.}

Die präzisesten Angaben über den Einfluss der Coccidien anf die Gewebe des Wirtes hat in neuerer Zeit schaudinn gemacht. In seiner Arbeit über die im Darm von Lithobius schmarotzenden Coccidien betont Schaudinn (638), dass in demselben Maße, in welchem die Coccidien heranwachsen, die Wirtszelle degeneriert. Anfänglich beginnt dieselbe infolge der von dem Parasiten ausgeïbten Reizung zu hypertrophieren; auch der Zellkern erfährt eine Vergrösserung. In Zusammenhang damit, dass die Zelle mehr Nahrungsstoffe herbeischafft, als der Parasit verzehren kann, steht auch die fettige Entartung der Zelle, welche sich in der Ansammlung grosser fettähnlicher Kugeln im Plasma derselben äussert. Bald aber ändert sich dies Verhältnis: die Zelle wird durch den andauernden Reiz seitens des Parasiten und durch die schnelle Entziehung der Nahrung beim rapiden Wachstum desselben so geschwächt, dass sie nicht mehr assimilieren kann. Sie stirbt allmählich ab und das Coccid resorbiert alsdann anch noch fast den ganzen Rest der infizierten Epithelzelle, von welcher nur der zu einem kompakten Chromatinklumpen zusammengeschumpfte Zellkern und geringe Spuren von Plasma ïbrig bleiben. Iiese letzten Reste der Zelle fallen schliesslich mit dem Parasiten in das Lumen des Darmes, um dort ganz resorbiert zu werden.

Da demnach die infizierte Zelle unfehlbar zu grunde geht, so kommt es, wenn die Zahl der Parasiten sehr gross ist, zu einer schweren Darmerkrankung. Es kann rorkommen, dass kaum eine 
Fpithelzelle frei von Parasiten bleibt, in manchen sich sogar melırere ( $2-4)$ ansiedeln, so dass also fast das ganze Darmepithel zerstört wird. Bei solcher Masseninfektion kann es sogar vorkommen, dass die jungen Merozoiten in erwachsene Coccidien einer andern Art eindringen; z. B. wurde mehrfach Einnistung ron Eimeria schubergi in Adelea orata heobachtet.

Diese Überschwemmung des Wirtsdarmes mit Coccidien setzt aber deren Schizogonie eine Grenze. Sie bedingt das Auftreten der Geschlechtsindividuen und dieses fülırt durch die sich anschliessende Sporogonie zu einer Reinigung des Darmes; mit andern Worten: das akute Stadimm der Krankheit ist nicht von langer Dauer und, wenn dasselbe überstanden ist, tritt auch baldige Besserung und Spontanheilung ein.

Bei Cyclospora caryolytica ist nach Schaudinn (639) der allgemeine Gang der Infektion der gleiche, die Erkrankung allerdings noch büsartiger, da die Mehrzahl der infizierten Maulwïrfe stirbt. Ein besonderes Interesse bietet jedoch die Cyclospora dadurch dar, dass sie ausschliesslich in den Kernen der Darmepithelzellen schmarotzt. Auch die Sporozoiten und Merozoiten der Coceidien von Lithobins dringen zwar in der Regel bei ihrer Einwanderung in die Epithelzellen bis an den Kern vor, aber nicht in diesen hinein. Letzteres war bereits bekannt von den früher zur Gattung Karyophagus Steinh., em. Labbé vereinigten Arten Eimeria sulamandrae und Eimeria momia, aber diese Arten können ebensogut auch bereits im Plasma halt machen: Ihr Kernparasitisuns ist nur fakultativ und nicht obligatorisch, wie bei Cyclospora caryolytica. Nenerdings haben uns jedoch Lavera n und Mesnil (614) in Eimeria ranarm und Sergent (640) in Isospora mesnili gleichfalls Coccidien mit obligatorischem Kernparasitismus kennen gelehrt.

Der andere Sitz der Cyclospora bedingt nun anch einen andern Ablauf der Zelldegentration wie bei den Lithobins-Coccidien. Der eindringende Sporozoit bezw. Merozoit bringt schon anf einfach mechanischem Wege durch seine Rewegungen eine Verschiebung und Zerstörung des Kerngerïstes hervor. Beim Wachstum des Parasiten, das zunächst auf Kosten des Zellkerns und dann auch des l'lasmas stattfindet, wird allmällich das fein alveoläre Liningerüst im Kern gelöst. Es treten grössere Vakuolen auf, das Volumen des Kernes wird unter Flüssigkeitsaufnahme aus dem Plasma vergrössert, oft um das 6-10 fache seines ursprünglichen Durchmessers (bei Eimeria salamandrae und Eimeria momia ist letzteres nicht der Lall). Das Clromatin wird viel langsamer gelöst, wie die achromatischen Kernbestandteile; es rerschmilzt zu grössern Kklumpen, wird allmählich 
nach der Peripherie des Kernes zusammengedrängt und an der Kernmembran in siebartig durchbrochenen Platten oder groben, netzförmig angeordneten Strängen niedergeschlagen. Schliesslich wird der ganze Kern in eine riesige Vakuole verwandelt, in deren Innerem der Parasit schwimmt. Die Kernmembran mit spärlichen anhaftenden Chromatinresten bildet den ganzen Überrest des Kernes. Das Plasma der infizierten Zelle macht während der gewaltigen Ausdehnung des Kernes einen entgegengesetzten Prozess dureh; es wird resorbiert und schrumpft zusammen. Zu Hypertrophie der ganzen Zelle kommt es ebenso wenig wie zu fettiger Entartung. Mehrfache Infektion eines Zellkernes ist sehr häufig und die rapide Epithelzerstörung, der die Regeneration nicht die Wage halten kamn, bedingt die Schwere der Frkrankung.

Ton weitern, auf eigenen Untersuchungen beruhenden Angaben über die Pathologie der Coccidieninfektion sind seit Ende 1899 folgende zu erwähnen:

Die Angaben von Chat in (606) über dic Degeneration der von Coccidien infizierten Leberzellen des Kaninchens, sowie die allgemeiner gehaltenen Angaben von Laveran (613) enthalten nichts wesentlich neues. Laveran berichtet jedoch bei dieser Gelegenheit, dass er eine ähnliche Kernhypertrophie, wie sie manche Coccidienarten in Beginu der Zellinfelition hervorrufen, auch bei roten Blutkörperchen ron Crotalus homillus beobachtet hat, welche mit Hämosporidien infiziert waren.

Auch Pianese (635), 636) betont die vollkommene Zerstörung der ron Coccidien infizierten Kellen in der Kaninchenleber und der Meerschweinchenniere. Nur die, ,Kellmembranen" sollen erhalten bleiben und ein Netzwerk bilden, in dessen Maschen die Coccidien liegen. Ein solcher Cocridienhaufen erhält die besondere Benennung „,cistonido“. Die Wucherung der infizierten Epithelien erfolgt unter typischer und atypischer Karyokinese. In übrigen wird die pathologische Degeneration der infizierten Zellen nicht wirklich beschrieben, sondern nur durch Termini technici wie ,Karyolise, Karyorexis, Nucleinlise, Nucleinrexis, Protoplasmalise usw." und durch den Vergleich mit der Zelldegeneration in Carcinonen cluarakterisiert.

Die von $\mathrm{Smith}$ und.J o hnson (645) untersuchte Klossiella muris ruft ähnlich wie Eimeria schubergi (Schaud.) eine Hypertrophie der infizierten Epithelzelle hervor, die zu einer abnormen birntörmigen Gestalt der Zelle fïhrt und woh' auch die Ursache ist, dass die infizierten Zellen sich leicht aus dem epithelialen Terbande der Nierenkanälchen lösen. Spriugt doch in vorgeschrittenern Wachstumsstadien die infizierte Zelle weit in das Lumen des Nierenkanälchens vor, nur noch mit relatis dïnnem Stiele bis an die Basalmembran des Epithels 
heranreichend. Anscheinend stets befindet sich jedoch der Parasit nicht in direkter Berührung mit dem Protoplasma der Wirtszelle, vielmehr liegt er in einer Vakuole eingeschlossen. Auch bei doppelter Infektion einer Epithelzelle liegt jeder Parasit in seiner eigenen Vakuole. Das Plasma der Wirtszelle wird schliesslich so vollkommen aufgezehrt, dass ron der ganzen Zelle, wie bereits oben erwähnt, fast nur noch eine dünne Membran übrig bleibt, welche die den Parasiten bergende und nit zunehmendem Wachstum des I'arasiten natülich gleichfalls immer grösser gewordene Vakuole wie eine (ystenhiille umschliesst. Der Iruck, welchen die stark vergrösserte, infizierte Zelle ausïbt, fuhrt anch znm Schwunde des benachbarten Epithels.

Die bereits früher erwälnten grauen Fleckchen, welche sich in der linde infizierter Mäusenieren finden, entstehen durch Verödung der Nierenkanälchen und Proliferation des interstitiellen Bindegewebes. Ihr ätiologischer Zusammenhang mit der coccidieninfektion ist nicht sichergestellt. wird aber durch das regelmäbige gleichzeitige Vorkommen wahrscheinlich gemacht. Gemiib der Auffissmg von Smith und Johnson handelt es sich $n$ m alte, rerïlete C'occidienlierde.

Léger und Dubosq (620) erwähnen gelegentlich in ihrer grossen Gregarinenarbeit eine eigentïmliche Beobachtung, welche sie bei Adelea dimidiata Aiméschn. gemacht haben. Sie fanden nämlich bei dem Nacrogameten dieser Art einen eigentümlichen rüsselartigen Fortsatz, welcher in der infizierten Epithelzelle des scolopenderdarmes bis an die Basalmembran reichte. Sie vermuten, dass dieser Fortsatz ähnlich wie der auch in der Form ihm älnelnde Epimerit von Pyximia möbuszi Lég. \& I ub. dazn diene, um Nahrung aus dem Bhute anfzusaugen, welches den I)armkanal des Scolopender's umspïlt. Eine Nachprïung dieses bisher bei den Coccidien ohne Anologie dastehenden Befundes scheint mir jedoch noch wünschenswert.

Der anscheinend durchweg extracelluläre Aufenthalt von Eimeria mitraria ist bereits oben im entwicklungsgeschichtlichen Teil besprochen. Dagegen ist hier noch die Arbeit von Thomas (648) zu erwähnen, welche mir im Original allerdings nicht bekannt ist. Bei einer an Lungenentziindung gestorbenen 40 jälırigen Frau wurde eine ,, Ḱnochenbildung" innerhalb des Gehirns beobachtet, in deren Innerem sich eine körnig-nekrotische Masse fand. Diese letztere enthielt zahlreiche ovale Körperchen, welche etwa $2-3 \mathrm{mal}$ so gross waren wie rote Blutkörperchen und als Schalen von Eimeria stiedae (L i nd e m.) (=Coccidium oriforme Lckt.) gedeutet werden - eine Deutung, die doch wohl im höchsten Maßje problematisch ist. 


\section{Referate.}

\section{Zellen- und Gewebelehre.}

650 Saint-Hilaire, K., Untersuchungen über den Stoffwechsel in der Zelle und in den Geweben. Erster Theil. (li. li. Centw-

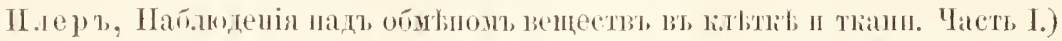
In: 'Trav. Soc. Imp. Nat. St. Pétershourg. (Т'руды H. C'L. общ. Еетестопеп.) T. ХХХІІІ. fasc. 2. 1903. pag. 1-232. Taf. I-Y. (russisch mit deutschem Résumé).

Der erste Teil der L'ntersuchungen ist den säureausscheidenden Speicheldrüsen der Molhsken gewidmet. Die Histologie dieser Drüsen wird bei Opisthobranchiaten (Oscanins, Pleurobranchaea) und Prosobranchiaten (Dothum, Caswilaria, Tritonimm), besonders soweit sie den l'rozess des Secernierens erleuchten kann, ausführlich geschildert. Lei allen untersuchten Arten sind diese I) rüsen nach ein und denselhen 'Typus gebaut. Das Protoplasma der Drüsenzellen hat eine Schaumstruktur; im Netzwerke desselben liegen Kö̈nchen, die sich zu Vakuolen entwickeln, miteinander verschmelzen und an dem freien Teil der Zelle hinaufsteigen und dort entleest werden. Ausserdem sind zwischen den Zellen intercelluläre Zwischenräume vorlıanden, in diesen findet man die Schwefelsäure, innerhalb der \%ellen ist sie dagegen weder durch Indikatoren noch durch Bil und $\mathrm{Pb}$ nachzuweisen. Die Schwefelsäure bildet sich nach Meinung des Verfs., indem $\mathrm{CaSO}_{4}$ des lilutes unter Einwirkung der Kohlensïure sich in $\mathrm{Ca}^{(} \mathrm{O}_{3}$ und $\left.\mathrm{H}_{2} \mathrm{SO}\right)_{4}$ zerlegt. ( $\mathrm{Ca}^{\prime} \mathrm{O}_{3}$ wird von den Kalkzellen absorbiert, welche in der Nähe der Drüsenkanälehen gelagert sind, und nach der Entferuung von ( $\mathrm{CCC}_{3} \mathrm{kann}$ die Reaktion sich wieder fortsetzen. Der Bildungsherd der Säure sind die erwähnten intercellulären Zwischenräume. Der Prozess der Säurebildung hat hier viel Ïhnlichkeit mit der Bildung der Säure im Magen der Wirbeltiere. Verf. fülırt noch einige andere räle ron Säureausscheidung bei Tieren an, so in der Haut von Plenrobranchaea und Oscanius und im Magen, wo gleichfalls Kalkzellen die Bildung der Süure beeinflussen; der Mantel der Ascidien, der Stiel von Rhopalea.

Ein anderer Teil der Untersuchung ist dem Magenepithel von Plemobranchns und Oscanims gewilmet und dem l'rozesse der Sekretbildung in diesen Zellen. Die Alveolen und Körner in den Epithelzellen sind in der Zellachse parallel verlaufenden lieihen geordnet, was daher kommt, dass ron den Seiten die Zellnnembran dünne Falten nach dem Innern der Zelle entsendet. Die Ausscheidungstätigkeit der Zelle besteht im Ablïsen von Protoplasmateilen in die Darmlı̈hle, 
ähnlich wie es bei Insekten, in der grünen Drüse der Crustaceen und in den Nierenkanälchen beobachtet worden ist.

Weiterhin gibt der Verf. eine Untersuchung der DicyemidenZellen. Die Achsenzelle hat alveoläre Struktur, zwischen den Alveolen liegen kleine Körnchen, die gleichsam ein Netzwerk bilden. Die Membran der Achsenzelle ist an einigen Stellen durchlöchert. Die Bläschen in der ausgewachsenen Achsenzelle stammen auch hier aus den oben erwähnten Körnern. Die Deckzellen besorgen den Stoffwechsel.

In einem andern Kapitel untersucht Verf. die Speicheldrüsen einiger keine Säure ausscheidenden Mollusken (Dolium, Cassidariu, Tritonim, Cmbrella, Aplysia). Hier findet Verf. einen scharfen Unterschied zwischen oxyphilen und basophilen Kellen. Auch hier entstehen die grossen Sekretkörner aus kleinsten Körnchen. Endlich findet man Basalfilamente und fadenähnliche Elemente, die in die Kellen dringen und an die Trophospongien Holmgrens erimnern.

Auch die Zellen der Darmanhä̈nge einiger I'olychäten (Hemione, Alhrodite) erimnern in ilnem Batu an die oben geschilderten Drüsenzellen. Auch hier besteht das Protoplasma aus einem Netzwerk von Körnchen, in dessen Maschen _Bläschen und Klï̈npchen eingeschlossen sind. Die Körnchen wachsen anch hier zu grossen Sekretkörnern aus.

In den Zellen des barmes ron Tenebrio molitor weisen Einschlüsse im Protoplasma ('hromatinkörnchen, Kernfragmente, Kiristalle, die gewöhnlich im kern zu treffen sind) auf eine Entstehung aus dem Kerne hin, und wirklich gelang es dem Verf., den Vorgang der Loslösung von Kernteilen und ihre Verwandlung in I'rotophasmaeinschliisse zu verfolgen.

E. Schultz. (St. Petersburg).

\section{Faunistik und Tiergeographie.}

1 Chun, C., Aus den Tiefen des Weltmeers. Schilderungen von der deutschen Tiefsee-Expedition. 2. Auflage. Jena (Gustav Fischer). 1903. gr. 8. 592 pag. 6 Chromolithographien, 8 Heliogravïren, 32 Vollbilder, 3 Kirten. 482 Abbildg. im T'ext Mk. 18.-

Chus Werk schildert in ungemein fessehuder und ansprechender Weise den Verlauf und die wissenschaftliche Bedeutung der Valdivia-Expedition. Es führt den Leser kurz in die Geschichte der Tiefseeforschung ein, macht ihn bekannt mit dem Personal und der biologischen und ozeanographischen Ausrüstung der deutschen Expedition und verfolgt die rom August 1898 bis Mai 1899 danernde Fahrt der Valdivia. Dieselbe führte bekanntlich zunächst nach Edinburgh und nach den Faroer, damn nach den Kanaren und Kapverden unter bedeutender Amnäherung an die afrikanische Kïste. Reiche Gelegenheit zu wissenschaftlicher Beobachtung boten die nord- und südäquatorialen Strömungen und der Guineastrom. Im weitern Verlauf er- 
reichte das Suhiff Liamerun, von wo ein Ausflug landeinwärts auf dem Wurifluss nnternommen wurde, die Congomündung und die grosse Fischbai. Reiche Ausbeute, von bedentendem Interesse in tiergeographischer Hinsicht, lieferte die Südafrika rorgelagerte Aegulhasbank. Ein Vorstoss nach Süden, in das antarktische Meer, fülırte zur Wiederentdeckung der bonvet-Insel und bis an die Eisgrenze unter dem $64^{\circ} 14,3^{\prime}$ südl. Breite und $54^{0} 31, t^{\prime}$ östl. Länge. Die Rïckfalıt brachte einen Aufenthalt auf den Kerguelen, über deren Klima, Geschichte, landschaftliche Scenerie, 'Ticr- und Pflanzenleben das Buch ein ungemein lebendiges Bild entwirft. St. Paul und Neu-Amsterdam bildeten weitere Stationen auf dem Weg nach Sumatra. Zwischen der Südwestküste dieser Insel und der vorgelagerten Inselkette lieferten die Schleppnetzzïge im Mentaweibecken überraschend mannigfaltige, zoologische Ernte. Die Fahrt der Valdivia wurde daher bis nach Atschin und zu den Nikobaren ausgedehnt. Üher ('eylon nähorte sich das Schiff den Maldiren und Diego Garcia; seine Lotungen stellten die Gegenwart eines unterseeischen Verbindungsriickens zwischen der Chagosgruppe und den Maldiven fest. Endlich wurden die Seychellen, die ostafrikanische Kü̈ste mit Dar-es-Salâm und Sansibar, sowie Aden berïhrt.

Die stimmungsrollen Bilder, die Chun ron Land und Meer zu entwerfen versteht, sowie die anziehenden ethnographischen Schilderungen, die er ausgiebig einstrent, wissen den Leser immer von neuem zu fesseln. Landschafts- und Vegetationstypus treten aus der Beschreibung packend hervor. So zeichnet uns der Verf. in vorzïghicher Weise die Kanaren, Kamerun, den Kongo und die Fischbai; er beschreibt anschaulich den antarktischen Charakter der wiederanfgefundenen Bonvet-Insel und führt uns das südpolare Meer mit seinen Eisbergen und seinem 'Treibeis fasslich vor die Augen. Als tropischer' Gegensatz mögen vor allem die präclıtigen landschaftlichen und ethnographischen Schilderungen von Sumatra, der Nikobaren, von Diego Garcia und der Seychellen gelten.

Einen breiten Raum nehmen natiurlich die Betrachtungen der ozeanographischen und zoologischen Pesultate der Expedition in Anspruch. Sie sind Muster populärwissenschaftliclıer Darstellung, ob sie nun das Vogelleben der Farver, die Jagden auf Haifische und auf Globiocephalus melas bei den Kapverden oder die Landfauna der Kerguelen betreffen. Von dort erhalten wir hauptsïchlich Aufschlüsse über den einzigen Landvogel der antarktischen Region, Chionis minor, über den Schopfpingnin, Eudyptes chrysocoma, über Phalacrocorax iervucosus und MLavorhims leoninus. Es werden aber auch dit Hügel. losen Insekten, speziell die Fliege Calocopteryx moselcyi berücksich- 
tigt. Robben und Wasservögel der Kerguelen ernähren sich auf Kosten einer äusserst reich entfalteten Strandfamna. Von ihren Vertretern treiben merkwürdigerweise manche Brutptlege. Dies gilt auch für Angehörige von Tiergruppen, bei denen Aufzucht der Jungen im mütterlichen Körper bisher unbelsannt war, wie für die Alitinie Marsupifer valdivice. Von den iibrigen, zahlveichen biologischen Schilderungen, die, von prïchtigen Abbildungen begleitet, in den Text der eigentlichen Reisebeschreibung eingeschoben sind, kann hier nur noch weniges angedentet werden. Es sei etwa hingewiesen auf die Kennzeichnung der pelagischen Tiefenfauna, wie sie im Golf von Guinea, auf der Fahrt nach den Maldiven und später besonders zwischen den Seychellen und Ostafrika erbeutet wurde. An der letztgenannten Lokalitiit schwebten direkt über dem Grund Copepoden und Radiolarien und hïuften sich in erstaunlicher Menge die leeren Schalen ron 'lintinnen, Globigerinen und Radiolarien an. Die Vertikalnetzziige zwischen ('eylon und den Maldiren förderten als Planktonten der grössern Tiefen Fische, Cephalopoden, Sergestiden, Atolla, Pelagonemertes und eine riesige Carinaria ron $53 \mathrm{~cm}$ Länge zu Tage. Dort wurde auch die Beobachtung gemacht, dass der Fisch Glyphidodon bengalensi: in leeren Nautilusschalen Zuttucht sucht.

Auch das Obertlächenplankton erfährt an verschiedenen Stellen des Werks eine nähere Würdigung in zoologischer und. nach Schimpers liefunden, in botanischer Richtung. Es wird auf seine an der Grenze ron Kalt- und Warmwassergebiet sich vollziehende Veränderung hingewiesen und besonders seine Zusammensetzung, Verteilung und Tiefenverbreitung im antarktischen Meer besprochen. Freischwebende P'flanzen beleben nur die obcrsten Wasserschichten von etwa $400 \mathrm{~m}$ Tiefe.

Die ergebnisreichen Schleppnetzzüge im Mentaweibecken geben Anlass zu einer ausführlichern Charakterisierung der in jenem Meeresabschnitt lebenden Tiefenfanna. Sie zeichnet sich ans durch den Reichtum an Hexactinelliflen, Isideen und Steinkorallen. Eine Art von Flabellum erreicht ungewöhnliche Dimensionen.

Höchst interessante Vertretung finden die Echinodermen in der zuerst nordisch bekannten Gattung Brisinga, in violetten Tiefseeholothurien, in mit Giftstacheln bewehrten Arten des Lederigels Phormosoma. Dazu gesellen sich Palceopneustes aus dem Nord-Niaskanal, sowie neue Vertreter der indischen Gattungen Porocidaris, Dorocidaris und Stereocidaris und vier vorher unbekannte Crino iden. Aus der Fülle von Crustaceen ragen Tiefseegarneelen mit monströs verlängerten Beinen (Nematocarcims) und Arten ron Aristaeus und fristaropsis hervor, deren Fühler den Körper an Länge 10 bis 12 mal 
iibertreffen. Andere Funde ron grosser Seltenheit sind eine gigantische ( ixripedie (Sralpellum stearmsi Pils.) mnd ein lebendes Fxemplar von Sprivula aus 594 m Tiefe. Endlich vertienen Erwähnumg die Schnecke Xmophora, die andere Schneckenschalen in regelmäßiger Anordnung auf ihrem Gehäuse befestigt, und eine grosse Schar von Fischen hauptsächlich aus den Gattungen Lamprogramma, Comgermurasna. Chamax, Dibramchns, Teoscopelas und Echiostoma. Alle diese 'Tiefenbewohner der Mentaweisee leben in buntem Nebeneinander zusammen, wïhrend im atlantischen ()zean an den einzelnen Lokalitäten jeweilen bestimmte Tierformen rorherschen. Ihre Ernährung wird bereitet durch eine selir stark entfaltete oberflächenflora.

Tom Mentaweibecken nach den Nikobaren steigerte sich noch der Reichtum an $\mathrm{H}$ exactinelliden. Hier gingen auch zahlreiche Fixemjlare ron Ilatymaja "ry ille-thomsoni Miers ins Netz, eine Krabbe. von der die Challengerexpedition nur ein Exemplar crhentete.

Dredschzïge im äquatorialen indischen Ozean lieferten wichtiges Material an Umbelluliden, l'ennatuliden, Antipathiden, ferner Dematortiadema und Drachiopoden mit fein verästeltem Fuss.

Nur voribergehend mag an die iiberaus anziehenden Schilderungen der Sargassum-Fauna im sumatranischen Neere, der Strandberilkelung von T)iegro Garcia, der reichen Tiefenfauna der Bouvetinsel, des iiprigen Tierlebens in und an der grossen Fisclibai, wo Heere von Fischen einer iberreichen niedern 'lierwelt nachgehen und selbst wieder zahllosen Wasservögeh zum ()pfer fallen, erinnert werden.

Nas Vogeltreiben an der Eiskante des Südens, der Fischreichtum und die Pinguine ron St. P'aul, die terrestrische Tierwelt von Diego (xarcia und der Seychellen (Testudo plefantima) liefern Vorwürfe zn ansprechenden Bildern.

Die wenigen aus dem /usammenhang gerissenen Beispiele haben bereits gezeigt, dass die lieschreibung der V'aldiviafaht immer wieder durch biologische und ozeanographische Darstellungen unterbrochen wird, die auch für den Fachzoologen grösstes Interesse besitzen. Den Schluss des Buches aber bildet eine Zusammenfassung der über den Charakter und Biologie der Tiefenbewohner und den Bau ihrer Vertreter erhaltenen Resultate. Sie bringt dem Zoologen eine iberraschende Fïlle ungeahnter Aufschlïsse tiergeographischer, biologischer und systematischer Art und lässt vorausahnen, welchen Reichtum an neuen Gesichtspunkten die wissenschaftliche Verarbeitung des Valdiviamaterials enthïllen wird. Die \%usammenfassung wird mit ihrem klargeschriebenen 'Text und ihren rahlreichen, ausgezeichneten Abbildungen auch den Laien in die Kenntnis der Rewohnerschaft tiefster Meeresgriinde 
gut einführen. Auf diese wichtigen Schlusskapitel des C hun schen Werks sei noch kurz eingetreten.

Die konsequente Anwendung der Vertikalnetze und die Ausfiihrung von Stufentängen erlaubte die Finteilung der Tiefseefauna in eigentliche Grundbewohner und in Plankton der lichtlosen Wasserschichten. Viele Organismen, von denen man frïher annahm, dass sie den Meeresboden bewohnten, leben in Wirklichkeit pelagisch. Immerhin lässt sich die Scheidung einstweilen nicht in allen Fällen, besonders für Fische und macrure Krebse, scharf durchführen. Ebenso lält es schwer, die Lage der Grenzschicht zwischen Obertlächen- und Tiefenfauna zu bestimmen. Die Grenze liegt im allgememen da, wo das Sonnenlicht zu schwach wird, un das (iedeihen assimilierender PHanzen zu gestatten und wo die Temperatur zugleich sich von derjenigen der oberfläche bodentend entfernt. Assimilierende Algen leben etwa bis zu 350 m Tiefe, unter den Tropen noch wwas tiefer. Sie stellen sich in srösster Menge bis zur 'Tliefengrenze von $80 \mathrm{~m}$ ein, ron dort bis $300 \mathrm{~m}$ fügen sich nur noch wenige formen zu einer ..Schattentlora" zusammen. Echte Tiefenorganismen finden sich fast ausschliesslich von $400 \mathrm{~m}$ an.

Als Grundbewolner erbentete die .. Vallivia" u. a. massenhaft riesige Rhabdammina-Arten am atlantischen Abfall der Algullıasbank, $56+\mathrm{m}$ tief, und nackte foraminiferen von betıächtlicher Grösse an der Küiste Ostafrikas bei 2959 m Tiefe.

Glanzoll sind in den Fïngen die Hexatinelliden vertreten. Die ersten wurden nordwestlich von Schottland $(1626 \mathrm{~m})$ erbeutet. dazu gesellten sich bald zahlreichere Arten zwischen den Kanaren und Kapverten. Einige neu Formen stehen Euplectella nalıe. Eine weitere unbekannte Art sass wenig tief auf der Algulhasbank. Der Dredschzug ror Enderbyland lieferte Vertreter der zwei nenen Gattungen Holascus und Caulophacus aus einer Tiefe von 4636 11. Besonders reich an Hexactinelliden waren die Westkiiste ron Sumatra, wo massenlaft Aphrocallistes auftrat. und die Yikobaren. So ergab ein einziger Fang am Westeingang zum Sombrerokanal bei $805 \mathrm{~m}$ T'iefe nicht weniger als fünf Arten, unter denen durch Grösse zahlreiche Exemplare ron Pheronema raphams hervorragten. Benachbart $(752 \mathrm{~m}$ tief) lebte eine neue Form ron der Gestalt eines antiken Mischkrugs, etwas weiter siidlich $(362 \mathrm{~m})$ die cylindrische, bis $80 \mathrm{~cm}$ lange Semperella cucumis. Unter der überraschend reichen Ausbeute in der Nähe Ostafrikas zeichnen sich besonders zwei neue Glasschwämme aus der wohlbegrenzten Gruppe der Amphidiscophora aus: Platylistrum platessa alumt die Gestalt einer Schöpfkelle nach und Monoraphis he- 
nützt eine gigantische Kieselnadel, die wohl 3 Meter lang werden kamn, zur Verankerung.

Auch die Hydropolypen der grossen Tiefen charakterisieren sich teilweise durch riesige Dimensionen. Bei Monocautus imperator der ostafrikanischen Küiste $(1019 \mathrm{~m})$ misst der Stamm und Basalabschnitt mehr als $1 \mathrm{~m}$. Das in roten Tönen gefürbte Tier trägt zwei bilateral-symmetrisch angeordnete 'T'entakelkränze, zwischen den Tentakeln liegen die Gonophoren.

Von den zahlreichen, neuen und oft interessant gebauten Alcyonarien verdient die zuerst im Norden entreckte, an der Bouvet-Insel und im ganzen indischen Ozean wiedergefundene LTmbellula Erwäl-nung. Der ostafrikanischen Kïste entstammt eine neue eigenartige Familie der Pennatuliden, Kükenthals Verticelladeae. Die meterlangen l'olypare tragen Wirtel von 2 bis 3 dunkelvioletten Einzelpolypen; am freien Ende des hatrfein ausgezogenen Stammes sitzt der älteste Polyp. Aus der Anordnung der Tiere ergibt sich lilar das linospungsgeset\%. Reich vertreten sind im Dredschmaterial schön gefärbte G orgon i d e n (Isis, Isidigorgia, I) (syygryia, Leptoptitum, (hrysogorgia), neue Alcyoniden, besonders von der Bouret-Insel, antarktische, durch hochrote Farbentöne fesselnde Alitinien. Die grosse Tiefe ron $5248 \mathrm{~m}$ bewohnt noch ein violetter, in filziger Hülle steckender Cerimthrs, die Algulhasbank eine Riesenform ron Isozoanthus. Viele Alstinien, wie z. I. die hochrote Bolocera, können ilıre knopfförmig verkürzten Tentakeln abschnüren.

Das erbeutete steinkorallen-Material gibt wertvolle tiergeographische Aufschlïsse. Atlantische Formen verbreiten sich auch im indischen Becken; westindische Arten erscheinen wieder an den Nikobaren. Besonders die Funde bei St. Paul und Neu-Amsterdam werfen ein Licht auf den Zusammenhang der atlantischen und indischen Tiefenfauna.

Ungemein ausgiebige und wichtige V'ertretung finden in der Valdiviansbente die Echinodermen. Sieben von den acht aus der Tiefe gelolten Crinoiden-Arten sind neu. Ein neues Genus wurde nicht entdeckt. Bei Enderbyland ergab die Tiefe ron $4636 \mathrm{~m}$ je einen Hyocrims und einen Bathycrims; dazu fügte das Mentaweibecken drei Repräsentanten von Pentacrims und einen von Metacrims. Die Somalikuiste beherbergt bei $1600 \mathrm{~m}$ Tiefe einen Rhizocrimus, der rom bekannten Th. lofotensis durch Grösse ind Struktur abweicht. Antecton motixa und A. phalangium bedeckten massenhaft die Faroerrimne und die Josephinenbank; Endiocrinus n. sp. gehört Ostafrika bei $1289 \mathrm{~m}$ Tiefe an.

Erstaunlich ist der Formenreichtum an Asteroiden. 
Einzig die Ophiuriden der Valdivia umfassen etwa 30 rattungen und 220 Arten: von 115 Grundnetzfängen enthielten St Schlangensterne. Mehrere Genera und viele Arten sind neu. Als eigentümlich seien angeführt Ophiocreas, Astrophime ron der Algulhasbank und die Brutpflege treibende Ophioglypha hexactis von den Kerguelen.

Im atlantischen Ozean traten die Stelleriden weniger in den Vordergrund. Immerhin verlangen Beachtung die interessanten Formen Zoroaster fulgens, Hyphalaster raldiviae aus $5000 \mathrm{~m}$ Tiefe und verschiedene Vertreter der Porzellanasteriden. Wichtiger werden die Seesterne auf der Algulhasbank mit dem in geringer Tiefe erbeuteten Dipsacuster sladeni Alcock, der früher bei den Indamanen gedredscht wurde. Die Ophiuriden und Stelleriden der Bouvet-Insel beanspruchen tiergeographisches Interesse.

Das Mentaweibecken lieferte neue Formen der Irisingiden und Zoroasteriden, sowie Arten von Prarchaster, Puntastor, Psendarchaster, Aphroditaster, Persephonaster, Dictyaster und Nymphaster. Aus dem zentralen indischen Ozean ( ̈̈̆uatorialkanal $2250 \mathrm{~m}$ ) bildet Chun Pentagonaster abyssalis ab. Lesonders reich und interessant fiel die Stelleridenbeute längs der ostafrikanischen Kïste aus. Die neue Art und Gattung der Porzellanasteriden I'ertimiliscus ammar erinnert in anffallender Weise an das antarktische Crenus Ctenorliscus, weicht ron demselben indessen dadurch ab, diss die Randplatten in jedem Armwinkel mit einer unparen I'latte begimnen. Dasselbe Ciebiet zeichnet sich durch grossen Reichtum verschiedenster Archasteriden. Astropectiniden, Pentagonasteriden und Porzellanasteriden ans. Nanches erwies sich als nen. Pentagonaster excellons n. sp. von der Somalikïste war mit einer ektoparasitischen Schnecke besetzt.

Unter den etwa fünfrig Arten ron seeigeln haben ungefülı zwölf, zum grössern 'T'eil dem indischen Ozean angehörende Formeı als neu zu gelten. Tnbekannt war auch die Eupatagus nahestehende Gattung Gymmoputagus von der Somaliküste. Auf der Algulhasbank stossen indische, atlantische und antarktische Echiniden zusammen. In mancher Richtnng Interesse erwecken wieder die Seeigel aus dem indischen Gebiet. An der afrikanischen Ostküste lebt die erst vor wenigen Jahren im Atlantik entdeckte Echinothuride Sperosoma. Ostafrikanisch ist auch das einzige von Astheno:oma erbeutete Exemplar; es steht den japanischen A. Tongispimm nahe. Phormosoma war in oft riesigen Exemplaren im Mentaweibecken und längs ()stafrika zu Hause. Vom Kapland bis Sumatra verbreiten sich zahlreiche Angehörige ron Stereocidaris und Dorocidaris, deren Stacheln blattartige Längsrippen tragen. Wichtigkeit ist dem Auftreten ron Aspidodiadema 
und Dermatodiartema im indischen Ozean beizumessen. \%u den interessanten Seeigehn des indischen Gebiets geliört Palaropnerstes n. sp. aus dem Süd-Niaskanal, während die atlantische Gattung Poutalesir zu fehlen scheint.

Einen sehr typischen Bestandteil der Grundfauna machen auch die Crustaceen aus. Ton Brachyuren fand die Taldivia fast alle interessantern, durch frïhere Expeditionen bekanut gewordenen Gattungen wieder auf. Zahlreich sind die Oxylhynchen, von denen Scyramathia. Matymaja und Cyrtomaja sntmmi Miers Beachtung verdienen. Letztere Art enthob die Iredsche sieben Stellen der sumatrensischen und ostafrikanischen see $(650-1362 \mathrm{~m}$ tief), während der Challenger und Investigator je nur ein Exemplar erbeuteten. Von wichtigern Krabben seien noch angefülirt Trichopelterium alcocli n. sp. Dotl., Tietroplmma notopms Alcock und Anders., die aus dem Golf von Bengalen bekannt war und num auch bei Sumatra entdeckt wurde und Goryon paulensis n. sp. Ioth., einer der südlichsten Vertreter der Brachyuren. Wie die arktische, so zeichnet sich auch die antarktische Region durch Armut an kurzschwänzigen Dekapoden aus. Aus grösserer Tiefe stammt die Schwimmkrabbe Benthochascon hemingi Alcock und Anders. Endlich tührt ( Thun als nennenswerte Funde eine mit sicheren am hintersten Thorakalfusspar bewehrte Homolide von del ostafrikanischen Küste und die Gattungen Lithodes und Echimoplar an.

Die Färbung dor Tiefseekrabben bewegt sich vorzugsweise in verschiedenen Abstufungen von Rot, die Grösse ihrer Eier legt den Schluss auf abgekiirzte Metamorphose nahe.

Ton den besonders an der Somalikiiste und im Mentaweibecken zahlreich auftretenden Paguriden bewohnte eine Art die Schalen grosser J)entalien. Xylopagmus nistet sich in Holzstïclien ein und verschliesst die hintere Öffning durch eine deckelartige, harte V'erbreiterung der letzten Körpersegmente. Häufig vollzieht sich Vergesellschaftung der Einsiedlerkrebse mit Adamsia und Epizoanthus, wobei der letztere die bewohnte Schneckenschale auflöst, dem Iírebs aber durch knorpelige Beschaffenheit und oft riesige Grösse genügenden Schutz gewährt.

Unter den Galatheen stellen die Gattungen Mmida und Mrmidopsis typische 'Tiefseevertreter. Ihr prachtroll rotes Kolorit weicht in grösserer. 'Tiefe zart-fleischfarbenen Tönen; gleichzeitig schwindet das Pigment der Augen. Die Astaciden senden in die Tiefe Nephrops und Tephropsis. Tephrops andamenicus des Investigator lebt im Mentaweibecken zusammen mit einer Nephropsis- 
Art, die $N$. occidentalis von der pacifischen Kïste Amerikas nahe steht und nur pigmentlose Augenrudimente besitzt.

Von den altertümlichen, bis in den lithographischen schiefer zuriuckreichenden Eryoniden umschliesst die Ausbeute der Valdivia mehrere Formen. Die blutroten, mit guten Augen und zum Teil monströsen Antennen versehenen Garnelen scheinen in gewissen Arten unnittelbar ïber dem Crumd zu schwimmen. Hierher gehört u. a. ein Aristuropsis von der Somalikuiste $(977 \mathrm{~m})$, dessen Körperlänge $28 \mathrm{~cm}$ beträgt, während die Antennen 1,5 m messen. Bei dem über dem Boden schwebenden Nematocarcims laufen die spimnenartig verlängerten Fïisse in Büschel von Simnesborsten aus.

Bereits erwähnt wurde die gigantische Cirripedie aus dem SüdNiaskanal; sie übertrifltt alle Verwandten beträchtlich an Grösse. Unter den zahlreichen Pycnogoniden finden sich 14 neue Arten. Schon die Netzzïge bei den Faroer lieferten Riesenformen der Gattung Colossendeis: abenteuerlich geformte, blutrote Pycnogoniden von gigantischem Wuchs entstammen auch der Bouvet-Insel und dem Kerguelenplateau.

Das Bild der grundbewohnenden lierwelt erginzt siclı durch eine Fülle von Mollusken, besonder's dem Meeresboden angepasste Cephatopoden. Ostafrika und teilweise auch das Mentaweibecken spendeten Riesen von Heteroteuthis und Opisthoteuthis. Den bemerkenswertesten Fund aber macht ein hellvioletter, achtarmiger 'Tintentisch von der Somaliküste aus. Er erinnert an Eledone; doch tragen die Arme an der den Saugnäpfen abgewendeten Seite breite Flossensïume, in die sich das Tier, wie in einen zweiten Mantel, einhüllen kann.

Die Grundfische rekrutieren sich alus meistens auch an der Oberfläche verbreiteten Familien. Nene Gattungen und Arten fehlen nicht: so lieferte Ostafrika in $1840 \mathrm{~m}$ einen unbekannten 'liet'seehai und bei $823 \mathrm{~m}$ eine neue, grosse Art von Torpedo.

Ton den Knochenfischen spielen die Hauptrolle dic Makruren, Ophidiiden, Pediculaten, Muraeniden, Gadiden und die schuppenlosen Alepoceplualiden. Einige ïbertreften an gigantischen Dimensionen alle Verwandten. Im allgemeinen zeichnen sich die echten 'Tiefseefische aus durch geringe Entwicklung der BauchHossen, langen, spitz zulaufenden Schwanz, ventral gelegenes Maul, Abplattung des Körpers, Umwandlung der Flossen in Stützorgane und in seltenen Fällen durch Verkïmmerung der Augen und durch Pigmentmangel.

Weit über 100 Schliessnetzfänge und zahlreichste Stufenfänge, die mit aller Torsicht ausgeführt nnd gedeutet wurden, bewiesen mit 
voller Klarheit die Existenz einer pelagischen Tiefenfauna. Keiner dieser Züge kehrte ohne lebende Organismen zurück; in fast allen fanden sich Acanthometriden, Phaeodarien, Challengeriden, die für die Tiefe typischen Tuscaroriden, Ostracaden und Copepoden. In mittlern Schichten, 1000-3000 m unter der OberHäche, leben Sagitten. Wurmlarven, Tomopteriden, Typhloscoleciden, zu denen Trachomedusen, Siphonophoren, Amphipoden, Euphausiden und nicht selten Pteropoden und kleine Scopeliden (Cyclothonc) kommen. Von allen genannten Tierabteilungen wurden auch Larven erbentet; aus T'iefen von $4-5000 \mathrm{~m}$ stammende Coprepodennauplien erreichten die Oberfliiche noch lebend. Von $800 \mathrm{~m}$ Tiefe an scheint eine proportional der Entfernung yon der Oberfläche fortschreitende Tierverarmung einzutreten.

Wenn auch die Ausbeute der Schliessnetzfänge nur aus kleinern Formen bestand, darf doch nach dem Ergebnis der vertikalen Stufenfänge als sicher angenommen werden, dass anch grosse Tiere in unbelichteten Tiefen schweben. Die interessantesten Vertreter der freischwimmenden Tiefenfauna setzen erst bei einer Entfernung von 600 bis $800 \mathrm{~m}$ von der Neerestläche rin.

Bleiben die lebenden Foraminiferen in tiefern Wasserschichten selten. so erfüllen dieselben dagegen zahlreichste R ad iolarien. Yeben ihnen rbeutete die Valdivia 14 Gattungen und 21 Arten acraspedoter Medusen, ron denen sich drei Genera und neun Species als neu erwiesen. Als wirkliche Tiefenformen haben besonders Atolla und Periphylla zu gelten. Eine ganze Reilue von Craspedoten, die sich zum Teil auf neue Gattungen und Arten verteilen, gehören dem Tiefenplankton an. Echt tiefenpelagisch sind ferner einige Siphonophoren, besonders bis zu 4 m lange Rhizophysen und dunkelviolette Physophoriden.

Eine abgeplattete, $4-5 \mathrm{~cm}$ breite Mertensia aus dem atlantischen und indischen Ozean, in welcher der schwärzlich-riolette Nagen auffïllt, und eine blutrote Cydippe mit samtschwarzen Nagen führen auch die Ctenophoren in die Bevölkerung tiefer Wasserschichten ein.

Zu den zartesten und glanzvollsten Mitgliedern des Tiefenplanktons aber ist Pelagothuria ludwigi n. sp. ('h., die im indischen Ozean in Tiefen ron $800-2000 \mathrm{~m}$ gefangen wurde. zu rechnen. Ihr widmet Chun eine nähere Beschreibung und mehrere Abbildungen.

Zn1r Vervollständigung des Bildes vom Plankton lichtloser Regionen tragen bei grosse Sagitten. seltener rote und orangefarbene Typhloscoleciden, antarkitische, fingerlange T o mopteriden. durchsichtig bis auf die rosa gefärluten Parapodien. und Pelagonemortes. Aus dem Heer meist stark bewehrter Crustaceen. die bisweilen blind sind, 
häufiger aber gewaltige Augen und Fühler tragen und phosphorescierende Organe besitzen, können nur wenige Formen spezieller aufgezählt werden. Die Ha lo cypriden finden Vertretung in der riesigen, $1 \mathrm{~cm}$ langen Gigantocymis aus dem atlantischen und indischen Ozean. Während dem Tier die Angen fehlen, trägt die orangerote Schale am Kópfabschnitt zwei perlmutterglänzende Reflektoren.

Auch die stark vertretenen Amphipoden zeigen häufig rerschieden weitgehende Rückbildung der Augen. Das andere Extrem stellt der durchsichtige Thammatops mit gigantischen Sehorganen dar.

Tnter den Schizopoden berorzugen besonders die Euphausiden tiefe Wasserschichten: Nematoscelis und Stylocheiron stellen sich von $500 \mathrm{~m}$ Tiefe an in ungeheurn Schwärmen ein. Die Riesenform Gnathophansia schwamm 1000-2000 m iiber dem Grund. Bei den sehr charakteristischen Sergestiden, denen die Augen nur selten abgehen, übertreffen die Fühler die Körperlänge wieder um das Kelin- bis Zwanzigfache.

Zum Tiefenplankton sind endlich zahlreiche nene Dekapoden zu rechnen. Dies gilt ror allem anch für gewisse Eryoniden (Eryoniscus).

Durch Bau und Grösse ausgezeichnete Pteropoden und Heteropoden fingen sich in den schwebenetzen; besonders reich aber entfalten sich unter" $1000 \mathrm{~m}$ Tiefe die Cephalopoden. Sie passen sich in wunderbaren nenen Formen dem tiefenpelagischen Leben an. Die durch das Valdiviamaterial bedingte Vermehrung der Kenntnis kommt hauptsächlich der Gruppe der Cranchiaden zu gut. Auf den seltenen Fang einer lebenden Spimla wurde schon hingewiesen.

Bei der Annäherung an das Kapland zog das Netz aus einer Tiefe ron $2000 \mathrm{~m}$ zwei gigantische, $8.5 \mathrm{~cm}$ lange lxemplare einer Appendicularie, Bathochordatus charon Ch. Chuns nähere Beschreibung der Tiere zeigt, dass dieselben iiber die Beziehungen der Tunicaten zu den Vertebraten kaum neuen Aufschluss liefern werden.

An pelagischen Tiefenfischen förderten die Vertikalnetze „eine ganze Welt von neuen Formen" zutage. Die 180, meistens neuen Arten verteilen sich besonders auf die Scopeliden, Stomiatiden, Lophiden und Mraeniden. Viele dieser Fische sind monströs gestaltet und verraten in ihrer Erscheinung eigenartige Anpassung an das Leben in dunkeln Tiefen. Ihr schwarzes Kleid weicht selten dem Silberglanz oler bunter l"ärbung. Die meisten verfüigen iiber Leuchtorgane. Der Valdivia gelang der Nachweis, dass viele Fische. die man als typische Grundbewohner betrachtete, pelagisch leben und oft Tausende ron Metern vom Meerboden sich entternen (Melanocetus). 
Zufälle können solche bizzare Tiefenfische passiv an die Oberfläche gelangen lassen (saccopharynx ampullaceus).

Auf ihrer Fahrt beriihrte die Valdivia vier tiergeographische Gebiete, die arktische, atlantische, indische und antarktische Region. Für den atlantischen Bezirk liessen sich im allgemeinen die schon früher bekannten faunistischen Züge bestätigen. Tierformen der amerikanischen Küisten wurden auch am Rande Westafrikas erbentet. In der Tiefenfauna der bonvet-Insel tritt speziell eine grosse Kahl eigener antarktischer Formen auf. Namentlich die Anthozoen, Ophiuriden, Stelleriden und Crustaceen gewinnen dort geographische Bedeutung.

Das Nentaweibecken zeigt faunistisch manche Übereinstimmung mit dem vom Investigator durchforschten (iolf ron Bengalen. Ïhnliches gilt für den zentralen, indischen Ozean und für die ostafrikanische Kïiste, wenn anch die letztere eine Fiille neuer, eigenartiger Formen beherbergt.

Bei dieser scheinbaren liegrenzung tiergeographischer liegionen muss nach den Valdiviaresultaten nachdriicklich betont werden, dass zahlreiche atlantische Tierformen in den indischen Ozean übergreifen und Südafrika so keine starke faunistische Scheidewand zwischen den beiden grossen Meerbecken bildet. Auf der Algulhasbank treften die Vertreter von drei Gebieten zusammen. So wäre es zum mindesten verfrüht, schon jetzt entscheidon zu wollen, ob die vier Becken eigene, zoogeographische Tiefenregionen bilden.

Auch die Frage nach der Bedeutung der Konvergenz ron arktischeu und antarktichen Tierformen erscheint noch nicht spruchreif. Eine Ïhnlichkeit in Gesamtcharaliter der nord- und südpolaren Fauna, und auch in einzelnen Vertretern derselben lässt sich kaum in Abrede stellen, (Umbellula der Bonvet-Insel und arktische $U$. encrinus, Arcturus und Antarcturus). Es wird zu entscheiden sein, ob in den weiten Zwischengebieten zwischen Arktis und Antarktis in der Tiefsee Tiere leben, welche die konvergierenden Formen des Nordens und Siidens verwandtschaftlich verbinden, oder ob solche Zwischenglieder fehlen. Im ersten Fall wäre eine in der Tiefe sich vollziehende Wanderung ron einem Pol zum andern anzunehmen, im zweiten behielten Murray und Pfeffer mit der Ansicht recht, dass eine einheitliche Tertiärfauna den Meeresgrund bedeckte und sich später, bei Veränderung der Lebensbedingungen in deu äquatorialen und gemäfigten Regionen, nach den beiden P'olen zurückzog.

Wesentlich anders als für die Grundfauna liegen die Verbreitungsverhältnisse für das Tiefenplankton. Es trägt, nach den Befunden der Valdivia, in allen Heeresgebieten einen überraschend gleichartigen 
Charakter, der sich auf alle Tierstämme erstreckt. Dagegen wechselt die \%usammensetzung des Oberflächenplanktons, und speziell sein Bestand an niedern, assimilierenden Pflanzen, von Ort zu Ort in weitem Maße. Auch viele Oberflächentiere reagieren äusserst fein anf die weehselnden bedingungen in den verschiedenen Stromgebieten. Neben diesen lokalisierten Organismen erscheinen periodisch an der MeerHäche gewisse Planktontiere, die gegen Veränderungen in Belichtung, 'Temperatur und Salzgehalt in hohem Grad unempfindlich sind. Sie treten oberflächlich zu bestimmten Jahreszeiten auf, vermehren sich gewaltig, staten sich in grossen Mengen an, un dann ebenso rasch wieder zu verschwinden. In der \%wischenzeit beleben diese Organismen, wenigstens teilweise, die grössern, kühlern Tiefen. Die Valdiviafahrt hat die Vorstellung von auch in freien Ozean sich abspielenden, periodischen Vertikalwanderyngen verstärkit.

Solche Wanderungen erklären auch die kosmopolitische Verbreitung periodisch an der Obertiäche auftretender Tiere. Durch Austausch des Tiefenwassers werden die vertikal den Standort verändernden 'l'iere gemischt, während die stationären Obertlächenbewohner diesem Schicksal entgehen. Es liegt darin aber auch eine Erliärung einer gewissen, den Gesantcharakter betreffenden Konvergenz in der Zusammensetzung von arktischem und antarktischem I'lankton.

In beiden Polargebieten treten sogar identische Obertlächenformen auf (Sayitta hamata, Diphyes arctica), die den trennenden, ungeheuren Warmwasser"zonen rollkommen fehlen. Im kalten Thiefenwasser tropischer Gebiete vollzieht sich, wie Schliessnetzbefunde lehren, ein Austausch zwischen arktischen und antarktischen Planktonformen, die periodischer Vertikalwanderungen fühig sind.

In sehr ansprechender Weise behandelt Chun endlich die Anpassung der Tiere an die Existenzbedingungen der T'iefsee. Er wendet sich zinerst zu der graduell zu verfolgenden Riuickbildung der Augen leei Fischen und ('rustaceen und umschreibt die Verbreitung dieser Erscheinung bei Grundbewohnern und pelagischen T'iefenformen. Sodann spricht er vom Auftreten wohlentwickelter, oft ungewöhnlich vergrösserter Selıorgane. I) l'rage nach der Lichtyuelle der Tiefsee führt zur Besprechung der phosphorescierenden Organe und ihrer Verteilung in den rerschiedenen Tiergruppen. Berührt wird das Vorkommen eigentümlicher Schnauzenorgane bei vielen Fischen, deren phosphorescierende Bedeutung noch nicht genïgend festgelegt ist. Unter den vielen neuen Beohachtungen finden sich solche über das Leuchten bei Gnathophansia und die wunderbare Phosphorescenz von Lycoteuthis diadema Ch. und von andern Cephalopoden. Den biologischen Wert der Lenchtorgane möchite Chun ror allem auch in 
der Möglichkeit des Anlockens der Beute durch den Lichtschein suchen. I) Verschiedenheit der Organe in (irösse, Lage und Bau bei den einzelnen Tierformen und sogar auf ein und demselben Tierkörper lässt ohne weiteres an einen verschiedenen biologischen Wert der einzelnen Lichter und Laternen denken. Jeder pelagische Tiefenfisch erhält durch die Verteilung der Leuchtorgane eine bestimmte, ihm eigene Zeichnung, die das Zusammenfinden der Geschlechter und die Schwarmbildung erleichtern wird.

Bereits früher waren für pelagische A mphipoden nnd Schizopoden der tiefern Wasserschichten .,Teleskopaugen“" bekannt: eine ähnliche Augenumbildung gilt nun anch für viele $\mathrm{F}$ ische und Cephalopoden des Tiefenplanktons. Über das Vorkommen und die Verbreitung dieser Erscheinung und uiber den Umbildungsprozess, der rom normalen Kugelauge ausgehend durch zahlreiche Zwischenstufen das gestreckte l'ernrohrauge erreicht, gibt Ch u n nähern Aufschluss. In der Jugend kehrt das Kugelauge wieder. Das hochgradig kurzsichtige Teleskopauge, das immerhin auch auf etwas weiter entfernte Gegenstände eingestellt werden kann, bedeutet eine Anpassung an die Bedingungen der Tiefsee. Fs ist konvergierend in verschiedenen nicht näher verwandten Tiergruppen entstanden.

Anschliessend erwähnt ('hun die biologisch schwer zu deutenden Stielangen ron jungen Fischen und Cephalopoden aus der indischen und antarktischen Tiefsee, um endlich das ansserordentlich inhaltsreiche Kapitel durch die Darstellung der räuberischen Organisation und die Steigerung des Orientierungsapparates der Tiefenbewohner abzusehliessen. Er betont in einen Schlusssat\%. dass auch die bizarrste Erscheinung der 'T'iere tiefer Wasserschichten nur auf U'mformung von Bekanntem und auf Anpassung au nene Lebensbedingungen zurückzutühlıen sei.

F. Zschokke (Basel).

\section{Vermes.}

\section{Plathelminthes.}

652 Curtis, W. C., The life history, the normal fission and the reproductive organs of Planaria maculate. In: Proc. Boston Soc. Nat. Hist. Pd. 30. Nr. 7. 1902. pag. 515—559. 10 Taf.

Die an den verschiedenen Lokalitïten gesammelten Individuen von Planaria maculata weisen in der Art ihrer Fortptlanzung merkwïrdige Verschiedenheiten auf. An einigen Stellen vermehren sich die Tiere ansschliesslich durch Teilung, an andern wieder ausschliesslich auf geschlechtlichem Wege. Ausserdem gibt es Plätze, wo zn gewissen Jahreszeiten beide Fortptlanzungsweisen vorkommen, und zwar überwiegt bald die geschlechtliche, bald die ungeschlechtliche 
T'ermehrung. V'erf. nimmt zur Erklärung dieser Erscheinung an, lass bei $P$. maculata zeitweilig die geschlechtliche Fortpflanzung für ine Rieihe von Jahren durch die V'ermehrung durch Teilung ersetzt verden kann.

Interessant ist, dass an den Individuen vor Eintritt der T'eilung niemals irgend ein Zeichen entdeckt werden kounte, das auf den zommenden Teilungsprozess hingewiesen hätte; auch gelang es niemals, lie T'eilung durch_kïnstliche Reizung oder Verletzungen der Tiere 1erbeizuführen. Sie erfolgt viehmehr nur bei gut gefütterten, in rischem Wasser gehaltenen Tieren und zwar röllig spontan, indem lie 'Tiere regelmäßjig an einer bestimmten Stelle hinter dem Pharynx u zwei Stiicke zerfallen, die unmittelbar darauf auseinander kriechen. Die Regeneration der fehlenden Organe beginnt sowohl in dem Kopfwie in dem Schwanzstiick erst nach vollzogener Teilmng; in kurz nach der Teilung konservierten und auf Schnitten untersnchten Teilstücken waren niemals irgend welche Anlagen der zu regenerierenden organe noch sonst irgend welche Zeichen histologischer Veräinderungen, die ler T'eilung vorausgegangen wären. zu finden. Die Regeneration aller Organe geschieht anscheinend auf Ḱosten sog. Bildungszellen, die wïhrend der Teilungsperioden innerhalb des sonst anscheinend yucytialen Parenchyms in sehr grosser Kahl unterscheidbar sind und zahlreiche Mitosen zeigen. Diese Auffassung steht in direktem Gegensatz zu einer knrz vorher erschienenen Arbeit ron E. Schultz (vgl. das Referat Zool. Zentral-Bl. Bd. 9. 1902. pag. 677), die dem Verf. noch nicht bekannt gewesen ist. Nach Schultz sollen während der Regeneratiousvorgänge bei den 'Tricladen niemals Mitosen zu beobachten sein : ferner soll nach ihm die Regeneration des Ektoderms rom Ektoderm aus stattfinden, während bei der Regeneration des Parenchyms nicht die sog. Bildungszellen, sondern gerade die syncytiale Masse ansschlaggebend seiti soll. Ref. muss sich jedoch uach der vorsichtigen, alle Spekulationen rermeidenden Darstellung des Verf., vor allem aber auf Grund seiner Abbildungen, unbedingt an ihn (Curtis) anschliessen.

Der Geschlechtsapparat ron P. maculata, den Verf. hier zum ersten Male beschreibt, obwohl die Art bereits $18+4$ von Leidy aufgestellt wurde, stimmt im wesentlichen mit dem von $P$. lugubris O. Sch. und $P$. polychroa $O$. Sch. bekannten Typus überein. Nach der Eiablage degenerieren seine einzelnen Organe in einer bestimmten Reihenfolge; zuerst gehen die Hodenfollikel zu grunde, diun folgen die Vasa deferentia und Dotterstöcke und schliesslich auch das Atrium genitale, Penis, Orar und Ovidulite. Ehe noch die zuletzt genannten Organe völlig verschwunden sind, beginnt die Vermehrung durch T'eilung, und zwar geschieht die Teilung genau an der Stelle des 
alten Atriums. Die Geschlechtsorgane entstehen beim jungen Tier ebenfalls aus dem Parenchym und zwar in zwei getrennten Komplexen, von denen der eine die keimbereitenden Organe, der andere das Atrium und die dazu gehörigen Organe umfasst. Wegen der Einzelheiten, die auch hier wieder, was die letzteren Organe betrifft, mit den Angaben ron Schultz nicht ïbereinstimmen, sei auf das Original verwiesen.

Verf. hat ferner auch die Entwicklung von P. maculuta studiert, aber keine wrsentlich neuen Resultate gegenüber den ron andern Tricladen her bekannten Befunden erhalten. Wichtig ist jedoch, dass er feststellen konnte, dass der definitive Pharynx nicht an der gleichen Stelle wie der Embryonalpharynx, sondern neben demselben entsteht. E. Bresslau (Strassburg, Els.).

65. v. Graff, I.., Vorläufige Mitteilungen über Rhabdococliden. I. Die Geschlechtsverhältnisse von Gymator hermaphroditus Ehrbg. In: Zool. Anz. Bd. 26. Nr. 686. 1902. pag. 39-41.

654 - - II. Die Acoelen von I'uerto Orotava. Bergen und Alexandrowsk. In: Zool. Anz. Bd. 26. Nr. 688 u. 689. 1902. pag. $110-112 ; 121-123$.

In der ersten der beiden Mitteilungen beschreibt Verf. das Vorhandensein zweier weiblicher Geschlechtsötthnngen hei Gyrator hermaphrortitus, von denen die eine der Copula, die andere der Eiablage dient. Erstere - bereits ron $\mathrm{Hallez}$ erkannt - ist dorsal gelegen und führt in das gleiclneitig als Rursa copulatrix dienende Receptaculum seminis, das an seinem andern (rentralen) Ende durch einen engen Kanal mit dem Atrium genitale in Verbindung steht. I)ieses selbst, in das von vorne her Uterus und Dottergang, von der Seite her der Keimstock und eine Anzahl einzelliger Drïsen münden, öfinet sich an der Ventralseite des Körpers durch einen der weiblichen Geschlechtsöffnung der iibrigen digonoporen Turbellarien entsprechenden, rom Mund etwa doppelt soweit als rom Hinterende entfernten Porus. Verf. erwähnt ferner, dass er bei einzelnen der Grazer Exemplare von Gyrator hermaphroditus den Keimstock paarig (rechts stärker wie links) entwickelt angetroffen hat, was nach Langerhans bei den marinen Exemplaren die Regel ist. Ref. möchte hinzufügen, dass er bei Strassburg ebenfalls vereinzelte Tiere dieser Art mit doppelten Keimstöcken gefunden hat.

Die zweite Mitteilung bringt ansser famistischen Notizen Ergünzungen zu der Beschreibung dreier bisher nicht genügend bekannter Acoelenarten. Von der ersten derselben, Aphanostoma rhomboides (Jens.), die Verf. sowohl bei liergen wie hei Alexan- 
lrowsk (Pala Guba) antraf, konnte er feststellen, dass sie mit den eiden ebenfalls von Jensen aufgestellten Species Aphanostoma legans und Mecymostoma agile identisch ist. Die beiden andern Arten, das von Oersted t entdeckte Aphanostoma virescens (Bergen) and ebenso die rom Verf. früher beschriebene Comroluta langerhansi Puerto Orotava) haben sich bei genauerer Untersuchung als zum ien. Amphichoerus v. Graff gehörig erwiesen, das gleichzeitig eine neue Abgrenzung gegeniber der vou Mark anfgestellten Gattung Dolychoerns erführt. Als Unterschied zwischen den beiden Gattungen alt bisher die Anzahl der (hitinmmndstücke des Bn'sa seminalis, die ïr Amphichorns auf zwei (gelegentlich 2 überzählige) für Polychoems uf $6-50$ angegeben war. Dieser Unterschied wird jedoch durch lie beiden neu zur Gattung Amphichoerus gezogenen Species, Amphihocms virescens und langerhansi. verwischt, inden erstere 14, letztere 11 Bursamundstiicke besitzt. Dennoch sind beide Gattungen nicht niteinander zu rereinigen, da zwischen ihren weiblichen Geschlechtsuparaten tiefgreifende Tnterschiede bestehen. Die Gattung Amplichoerns besitzt einfache ()varien olne Spur einer Scheidung in Keimand Dotterstöcke, sowie Eileiter olne distinkte Wandung, in der rattung Polychoerus dagegen sind (nach G a ldiner) die Ausfülırungsänge der Keimstöcke zu weiten, mit einem Epithel von Dotterzellen ungekleideten Säcken umgestaltet. Fiir diese eigenartigen Bildungen. lie sich morphologisch von den Dotterstöcken aller iibrigen Turbellarien unterscheiden, bringt Verf. den Namen Vitellarien in Anwendung. E. Bresslau (Strassburg, Els.).

Iarkow, M., Zur Turbellarienfauna der Umgegend von Charkow (S üdrussland). In: Zool. Anz. Bd. 26. Nr. 692. 1903. pag. 221-223.

Verf.hat in den süssen Wässern des $\mathrm{Ch}$ ark ow schen Gouvernements während es Frïhlings und Sommers 190222 Rhabdocoelen- und 2 Tricladenspecies gefunden, ie sämtlich bekannten Arten angehören. Ausser den beiden Tricladen waren isher aus Südrussland nur 4 Rhabdocoelenarten beschrieben.

E. Bresslau (Strassburg, Els.).

. Stummer-Traunfels. R.. Eine Süsswasser-Polyklade aus Borneo. In : Zool. Anz. Bd. 26. Nr. 690. 1902. pag. 159-161.

Die Arbeit enthält die vorläufige Beschreibung einer durch ihr Vorkommen n stehenden Süsswasserlachen Borneos vor den sonst durchweg marinen Polyladen ausgezeichmeten Leptoplanide, die Verf. nach ihrem Entdecker Shelfordia orneensis benennt. Ein eingehenderes Referat soll folgen, sobald die ausführliche, nit Abbildungen versehene Arbeit erschienen ist.

E. Bressla u (Strassbnrg, Els.).

Lacharias, O., Eine neue Tn rbellarienspecies (Stenostoma turgidum). In Zool. Anz. Bd. 26. Nr. 686. 1902. pag. 41-42.

Stenostoma turgidum, am nächsten wahrscheinlich St. lemnae verwandt, aber

- Nr. 654-657. - 
von diesem durch das Fehlen des Otolithenbläschens unterschieden, ist ausgezeichnet durch mebrere wellige Anschwellungen des nach vorne sich verschmälernden Kopflappens, sowie durch eine an der ventralen Seite desselben kurz vor der Mundöffnung gelegene, halbkreisförmige, wulstige Verdickung, die von einer Anzahl kurzer Längsriefen durchschnitten wird und verlängerte Cilien trägt.

E. Bresslau (Strassburg, Els.).

658 Bergendal, I), Zur K enntniss der nordischen Nemertinen. In: Bergens Mus. Aarb. 1902. Nr. 4. 22 pag. 1 Taf.

659 - Studien über Nemertinen. II. Valencima bahusiensis Bergendal, ein Beitrag zur Anatomie und Systematik der Heteronemertinen. In: Kongrl. Fysiogr. Sällsk. Lund Handl. Bd. 13. Nr. 3. 1902. 104 patg. 2 Dopleltaf. 18 'Textfig.

660 - Bemerkungen über einige Angaben, den Kopf einiger Heteronemertinen betreffend. In: Zool. Anz. Bd. 26. Nr. 693. 1903. pag. $254-257$.

661 - Überdie Nemertinengattung Callimera Bgdl. In: Verhandlg. $\mathrm{V}$. internat. Zool. Kóngr. 1902. pag. 739-749. 2 Taf.

In der ersten der 4 obenstehenden Abhandlungen (65\%) gibt Verf. die vorläufige Beschreibung כ̃ neuer Nemertinenspecies, von denen 3 (Carinella grönlandica n. sp. . Carinella théeli n. sp., Hulnechtella dubia n. g. n. sp.) den Paläonemertinen. die beiden andern (Oxypolella punetti n. g. 11. sp., Talencinura bahusiensis n. g. n. sp.) den Heteronemertinen angehören. Carinella grönlandica n. sp. war rom Verf. bereits 1890 an der Kiüste ron Nordgrönland gefunden und auf Grund ihrer äussern Erscheinumg mit Carinella linearis (Montagu) Mc Intosh identifiziert worden. Die Intersuchung der aus dem einzigen gefundenen Exemplar gefertigten Schnittserie ergab jedoch. trotz der äussern vollkommenen Übereinstimmung in Form, Farbe und Körperbeschaffenheit, eine bedeutende Verschiedenheit der innern Organisation in einer Reihe wesentlicher I'unkte. Die imnere Ringmuskelschicht ist ror der Nephridialregion am stärksten und setzt sich weit nach hinten über diese und über die Phynchocölomgegend hinaus bis in den hintern Abschnitt der Mitteldarmregion fort, während die Ringmuskelschicht des Rhynchocölons dagegen hinter den Nephridialporen keine nennenswerte Terstärknng zeigt. Die Lage und Anordnung der Gefässe, besonders in der Koptspitze, ist eine vollkommen andere als bei $C$. linearis und auch das Nervensystem soll interessante Verhältnisse darbieten, auf die Verf. hier jedoch noch nicht näher eingeht.

Carinella théeli 1n. sp., vom Verf. in der Nähe der schwedischen zoologischen Station Kristineberg (in Bohuslïin) entdeckt, ähnelt in ihrer äussern Erscheinumg ('. polymorpha (Renier) Hubrecht. Ihre 
Farbe ist braun, ihr Kopf nicht deutlich vom Körper abgesetzt und niemals breiter wie dieser. Die Muskelkreuze sind, wie bei der zuerst beschriebenen newen Art, in der Nephridialgegend sehr stark entwickelt; die Blutgefässe entbehren der ventralen Kommissur in der Gehirngegend und ror dem Munde, dorsal finden sich vor dem Gehirn, sowie in der Gegend der Rüsselöffnung einfaclıe Anastomosen, aber keine grossen Blutlakunen, auch fehlen die Verzweigungen der Seitengefässe in der Mundgegend. Was das Gehirn betrifft, so liegt seine Fasermasse der Imnenseite der wenig stark entwickelten Grundschicht des Epithels dicht an, seine Ganglienzellen liegen dagegen imnerhalb der basalen Zellmassen der Grundschicht selbst, so dass also $C$. théeli (und vielleicht auch $C$. linearis) in diesem Punkte wwischen den Gattungen Procarinina und Carimina, deren Gehirn rollstïndig im Epithel gelegen ist, und den ibrigen Arten der Gattung Carinella, bei denen das Gehirn in die innern Körperschichten verlagert ist, vermittelt. Als Unterschied gegen C. polymorplaa ist noch hervorzuheben, dass die Geschlechtsdrüisen, die dort unehrern übereinander lagern, hier nur in einfacher Reihe jederseits vorhanden sind.

Hubrechtella dubia n. g. n. sp. ist eine kleine weissliche Nemertine mit zugespitztem Kopf, der seitlich Andeutungen von Längsfurchen zeigt. Die Mundöffnung liegt kurz linter dem Gehirn, der Darm ist taschenlos. Die Cerebralorgane sind tiefliegend, ihre lintern, von Blutgefässen umgebenen, einen mächtigen Kanal einschliessenden Anschwellungen liegen zwischen 2 Zipfeln des obern Ganglions. Die Nervenstämme und das längliche, starke Kommissuren besitzende Gehirn finden sich zwischen der Epithelgrundschicht und der Ringmuskelschicht der Körperwand, auf die nach inmen eine Längsmuskelschicht folgt; eine äussere Längsmuskelschicht felılt dagegen vollständig. Im Kopf sind die beiden Muskelschichten des Riumpfes wohl entwickelt. Der dünnwandige Rüssel enthält in seinem Epithel grosse Mengen von Rhabditen und anscheinend auch Nesselkapseln. Verf. hielt das sehr jugendliche Tier anfangs für eine junge Micrura, sah sich aber wegen des Fehlens der äussern Längsmuskelschicht, die bei den Ileteronemertinen gewöhnlich am allerstärksten entwickelt ist und auch sehr frïh aufzutreten pflegt, sowie mit Rücksicht auf den Bau des Kopfes, der fast ganz von den beiden innern Muskelschichten gebildet wird, dazu veranlasst, es vorläufig als eine neue, selbständige, zu den Heteronemertinen hinüberleitende Form unter die Paläonemertinen einzureilıen, vorbehaltlich einer Bestätigung dieser Ansicht durch die Untersuchung ausgewachsener Exemplare. Die Iteteronemertine Oxypolella pumetti n. g. n. sp. wird ca. $3 \mathrm{~cm}$ 
lang, ihr rundlicher Vorderkörper erscheint weiss, die Mitteldarmregion platter und braunrot, das Hinterende ist zugespitzt. Die Rhynchodäalöffnung liegt ventral in der Mitte zwischen dem Vorderende und der Mundöffnung. Der Kopf kann eingezogen werden, kur'z vor dem Mund findet sich eine ringförmige Wimperfurche, an seinem Vorderende trägt er eine kleine Erhebung, die das Frontalorgan vorstellen soll. Der Rü̈ssel ist fast so lang wie der Körper und zeigt in seinen verschiedenen Abteilungen einen sehr verschiedenen Bau seiner Wand. Das Gehirn ist sehr lang, die Cerebralorgane gross, ihre hintern Anschwellungen dringen in Blutgefässe ein. Die Blutgefässe des Kopfes bilden vor und über dem Rhynchodäım eine dorsoventral abgeplattete, von zahlreichen Gewebsbalken durchzogene Lakune. Oxypolella gehört zur Familie der Eupoliiden und erseheint der Gattung Oxypolia Punnet verwandt, von der sie sich jedoch durch den Bau der Cutis unterscheidet. Bei Oxypolia besitzt dieselbe eine äussere, driisenfreie gallertartige Schicht, die hier fehlt; vielmehr ist bei Oxypolella die Cutis besonders im Vorderkörper beinahe vollständig von Druisenzellen erfiillt.

Die fünfte der neu beschriebenen Arten, die Heteronemertine Valencinura bahusiensis n. g. n. sp., die auch den Gegenstand der zweiten ausfülırlichen Monographie (659) bildet, wurde vom Verf. ebenfalls bei Kristineberg (Bohuslän) gedredscht. Sie erreicht eine Länge von $5-6 \mathrm{~cm}$ bei $0,25 \mathrm{~cm}$ Breite und gehört nach ihrer äussem Körpergestalt in die Nähe der Gattung Íalencinia, mit der sie auch das Fehlen der Augen, sowie einen verwandten Bau des Blutgefäss- und Nephridialapparates gemein hat. Sie unterscheidet sich aber von ihr sofort durch den Besitz eines Schwanzanhanges, in den hinein sich von den innern Organen nur 2 seitliche Nervenstämme, ferner Ausläufer der innern Ring- und Längsmuskelschicht und eine zentrale Blutlakune fortsetzen. Eine derartige Schwänzchenbildung war bisher nur aus der Familie der Lineiden (Gattung Cerebratulns, Micrura, Micrella, Zyygupolia) bekannt, sie hat also eine weitere Verbreitung unter den Heteronemertinen, als bisher angenommen wurde.

Besonderes Interesse verdienen die Ergebnisse der Untersuchung des Hautmuskelschlauchs, des Kopfes, Rüssels und des Nervensystems ron T'ulencimura, in deren eingehender Darstellung der Schwerpunkt der an zweiter Stelle genannten monographischen Arbeit berulit. Der II a t m uskelschla u ch von Valencimma ist dadurch ausgezeichnet, dass sich sowohl im vordersten Abschnitt der Vorderdarmgegend wie in der Übergangsregion zwischen Vorder- und Mitteldarm nach innen von den 3 typischen Muskelschichten der Het eronemertinen noch eine innere Ringm uskelschicht ausgebildet findet, deren Vor- 
kommen bisher nur ron den Paläonemertinen (Proto- + Mesonemertini Bürger) bekannt war ${ }^{1}$ ).

In der Vorderdarmregion besitzt diese, am Innenrande der hier mächtig entwickelten innern Längsmuskelschicht gelegene und gegen das Parenchym scharf abgesetzte Schicht die Eigentiimlichkeit, dass ihre Fasern nur scheinbar ringförmig verlaufen, in Wirklichkeit aber fast sämtlich tangential zum Aussenrande des Parenchyms angeordnet sind und daher mit ihren beiden Enden jeweils in die innere Längsmuskelschicht, seltener auch in die äussere Ring- und Längsmuskelschicht ausstrahlen. Infolge dieses Faserverlaufs ist die Schicht daher weniger kompakt, als es bei schwacher Vergrösserung den Anschein hat, um so mehr, da ihre Fasern infolge der gegenseitigen Durchkreuzung nach aussen zu in der Regel kleinere Inseln ron Längsmuskelfasern einschliessen. In der dorsalen Mittellinie ist diese gegenseitige Durchkreuzung etwas stärker ausgebildet und erinnert daher bis zu einem gewissen Grade an die dorsalen Muskelkreuze der Paläonemertinen. Viel deutlicher zeigt sich die Ringnatur der Schicht in der Übergangsregion zwischen Vorder- und Mitteldarm, indem sie hier, besonders ventral, mächtig entwickelt den Ilarm stark einschniurt und daher eine Art Sphinkter darstellt. Aber auch hier gehen zahlreiche schräg ins Parenchym und in die innere Längsmuskelschicht ausstrahlende Fasern ron ihr ab und bilden vielfach einen deutlichen Übergang zu den dorsoventralen Muskelfasern, die sich weiter nach hinten finden. Bemerkenswert ist, dass iibrigens auch die äussere Ringmuskelschicht in der Gegend des Mundes zahlreiche sclı̈äge ind sich gegenseitig durchkreuzende Fasern besitzt, was beweist, dass auch in einer unzweifelhaften Ringmuskelschicht ein derart eigentiimlicher Faserverlauf rorkommt.

Im Kopf ron Valencimura zeigt sich auf Querschnitten ein zentraler Gewebscylinder, imnerlalb dessen die drei typischen Muskelschichten des Nemertinenkörper's deutlich als besondere Schichten ausgebildet sind. Dieser Befund ist insofern ron Wichtigkeit, als bisher ganz allgemein die Anschauung bestand, dass nur bei den Proto- und Metanemertinen der Kopf dieselben Muskelschichten wie der Rumpf besässe, bei den Heteronemertinen dagegen die Muskulatur des Kopfes von der des Rumpfes vollkommon verschieden sei. Verf. hat zum Vergleich noch einige weitere Heteronenertinen daraufhin untersucht und bei einem Teil derselben (Valencinia longirostris, Micrura purpurea, Lineus lacteus und bilineatus, Cerebratulus

1) Die Zugehörigkeit dieser Schicht zum Hautmuskelschlanch hat Verf. in einer kurz vorher erschienenen Arbeit (vgl. das Referat Zuol. Zentr.-BI., IX. 1902. pag. 502) zu erweisen gesucht. 
fuscus und marginatus) ebenfalls die rerschiedenen Muskelschichten des Rumpfes im Kopfe mehr oder minder deutlich nachweisen können, während er bei andern allerdings kaum etwas von ihnen entdecken konnte. Es besteht also auch in diesem Punkte kein prinzipieller Gegensatz zwischen den Heteronemertinen und den ïbrigen Nenertinen, sondern nur der Unterschied, dass in der Reihe der erstern eine allmähliche Reduktion und Umbildung der innern Muskelschichten des Kopfes stattfindet. Die Ur'sache hierfiir erblickt Verf. in der starken Entwickelung der Kopfdrüse und der Cutisdrüsen ausserhalb der Ringmuskelschicht und der dadurch bedingten Ausbildung von Bindegewebe und Muskelfasem in der Cutis.

Der $R$ ii ssel zeight bei Iralencinura, was den Bau seiner Muskulatur betrifft, ausserordentliche Mannigfaltigkeit, indem mindestens drei Hauptabteilungen an ihm unterschieden werden müssen, in denen die Muskelanordnung jeweils eine völlig andere ist. Besonders ist dabei zu beachten, dass sich vielfach drei deutliche Muskelschichten und stellenweise Andeutungen von Muskelkreuzen finden, Merkmale, die bisher unter den Heteronemertinen als charakteristisch für die Familie der Lineiden galten, wogegen für die Familie der Eupoliiden - zu der nach der bisherigen Systematik die Gattung Valencinia gehört und auch Valencinura zu stellen wäre - nur zwei Muskelschichten in Rüssel olne Muskelkreuze angegeben wurden. Verf. bat infolgedessen den Bau des Rïissels in den einzelnen Gattungen der Eupoliiden einer Nachprïfung unterworfen und dabei festgestellt, dass mindestens drei von den sechs bisher bekannten Gattungen derselben (Parapolia, Orypolia und Orypolella) in Riissel ganz sicher drei Muskelschichten besitzen und auch bei einzelnen Arten aus der Gattung Valencinia ( $V$. rubens) sich Andeutungen davon finden, so dass also unmöglich für die Eupoliiden. wie bisher angenommen, ein zweischichtiger Muskelschlauch des Rüssels charakteristisch sein kann. Als besondere Eigentiimlichkeit für den Rïssel von Valencimura ist noch zu erwähnen, dass sich in ihm grosse, mit Sekretkörnern und Sekretkörner füihrenden Zellen gefüllte Höhlen finden, Bildungen, die sonst nicht ron Nemertinen bekannt sind. Das Rhynchocölom ist sehr lang und reicht bis fast an das Hinterende des Körpers, ist aber hier sehr eng.

Vom Nervensystem der Valencinura endlich sei nur erwähnt, dass das Gehirn einen verhältnismäßig primitiven, an die Pa lä onemertinen erinnernden Bau zeigt und dass siclı ausser dem obern Riickennerven mit typischem Verlauf noch ein dorsaler Muskelnerv findet, der in seiner ganzen Länge mitten in der äussern Längsmuskelschicht verläuft. Einen älınlichen Nerven, der allerdings 
ausserhalb der äussern Längsmuskelschicht liegt, hat kïrzlich Punnet (vgl. das Ref. Zool. Zentral.-Bl. Bd. IX. 1902. pag, 201) beschrieben. Durch die rom Verf. bei Talencimura festgestellten Befunde werden die Heteronemertinen den Paläonemertinen bedentend genähert. Bürger hatte die erstern von den letztern durch die Vermittlung der Gattung Eupolia abgeleitet, von der alle übrigen Eupoliiden und weiterhin die Lineiden abstammen sollten. Verf. ist nun der Ansicht, dass umgekehrt die Eupoliiden vom Lineidenstamme sich abzweigten und zwar durch Vermittlung der Gattungen Valencimu'a und Valencinia, die eine niedrigere Organisation aufweisen wie Eupolia. Gleichzeitig nimmt er Veranlassung, die Bürgersche Familie der Eupoliiden in die zwei Familien Valencinidae und Eupoliidae aufzulösen, wie sie ursprünglich von $\mathrm{Hubrecht}$ aufgestellt waren. Zu den Valenciniden würden die Gattungen Valencimia, Valencinura, Oxypolella, Oxypotia und Parapolia, zu den Lupoliiden die Gattungen Eupoliu und Poliopsis gehören.

In der dritten der hier zu besprechenden Abhandlungen (660) führt Verf. nachtragsweise zur Bestätigung seiner in der vorigen Arbeit auf Grund der Befunde an Valencimora bahusiensis ${ }^{1}$ ) entwickelten Anerkennungen ïber den bau des Heteronemertinenkopfes aus der Literatur zwei Angaben von Pun net über Micrella rufa und Thompson über Zygeupoliu litoralis an, die seiner Ansicht nach für das Vorhandensein der inneren Muskelschichten in der Kopfspitze dieser Formen sprechen, obwohl die beiden Autoren selbst dies nicht ausdrücklich hervorheben. Verf. legt diesen Angaben deshalb besonderes Gewicht bei, weil die betreffenden beiden Formen in vielen Beziehungen eine niedere Stufe unter den Heteronemertinen einnehmen. Als weitern Beleg seiner Ansicht citiert Verf. einen in der Bürgerschen Nemertinenmonographie (Tat. 18. Fig. 25) abgebildeten Querschnitt durch die Kopfspitze von Lineus bitineatus, der ebenfalls die Andeutung einer Schichtenbildung im Innern derselben zeigt.

I) ie letztgenannte Arbeit (661) verdankt ihre Entstehung dem I'mstand, dass Yerf. kurze Zeit nach Fertigstellung seiner grossen Abhandlung über Callinera bïrgeri (vgl. das Ref. \%ool. Zentral-Bl. IBd. IX. 1902. pag. 364 ${ }^{2}$ ) vier z. T. allerdings stark beschädigte Exemplare einer Callinera zur Intersuchung erhielt, die sich von der erstgenannten Form äusserlich durçh ihre bedeutendere Grösse, durch das Vorhanden-

1) Verf. schreibt in dieser Arbeit $V$. bohusiensis.

$\left.{ }^{2}\right)$ Auf Wunsch des Verf, trage ich zu diesem von Jägerskiöld-Upsala verfassten Referat nach, dass der das wichtigsie Merkmal der Gattung Callinera bildende, als M uskels ack bezeichnete, hinterste Abschnitt des Rhynchocoeloms dadurch charakterisiert ist, dass hier die dorsale Wand der Rüsselscheide bis auf 
sein einer Halseinschnïrung und ausserdem durch das Vorhandensein weisslicher Flecke in der Halsgegend, die auf den Besitz von Cerebralorganen (bei C. biirgeri fehlend!) hindeuten, unterscheidet. Auch scheint hier der Mund relativ viel kleiner zu sein als bei $C$. biirgeri. Da infolge des Erhaltungszustandes der Tiere eine vollständig erschöpfende Untersuchung nicht möglich war, lässt es Verf. dahingestellt sein, ob es sich um eine nene species oder nnr um eine Varietät von C. lüiggeri handelt, und beschränkt sich zunächst nur auf die vorläufige Besprechung einiger besonders interessanter l'unkte. Hierher gehört, von einigen Bemerkungen über den Hautmuskelsclilauch und den eigentiimlichen Muskelsack der Rïisselscheide abgesehen, die Beobachtung, dass der Umstand, ob der Riissel ausgeworfen ist oder nicht, anscheinend die Lage und Gestaltung der Blutgefässe der Vorderdarmregion und des Kopfes nicht unerheblich beeintlusst. In gleicher Weise findet Verf., dass das Gehim der Tiere mit ausgeworfenem Riissel viel kleiner ist, als das der Exemplare, die den Riissel enthielten, was auf eine ähnliche Beeinflussung liindeutet, wenngleich schwer einzusehen ist, wie das Auswerfen des Rïssels auf die Form des Gehirns einzuwirken vermag. Stets ist die ventrale Kommissur der Gehirnhïlften hier viel grösser als bei C. biirgeri, die sich gerade durch die auffallende Kürze der beiden Kommissuren. besonders der ventralen. bei mächtiger Entwickelung des Gehirns auszeichnet. Ein weiterer Unterschied liegt darin, dass der bei C. bïrgeri kurze und konstant unpaare Schlundnerv hier konstant paarig gefunden wird. Besonders merkwiirdig ist bei den neu gefundenen T'ieren das Verhalten der ebenfalls ein Hauptmerkmal der Gatt. Callinera darstellenden subepithelialen \%ellenschicht des Kopfes, die Verf. früher, nach den Befunden bei C. bürgeri, mit der Nervensehicht von Hubrechtia verglichen hat. Nach den hier vorliegenden Verhältnissen, wegen deren Einzelheiten jedoch auf das Original verwiesen werden muss, ist aber auch die Frage aufzuwerfen, ob in derselben nicht auch eine eigentiimliche Ausbildung einer Kopfdrüse vorliegt.

E. Bressla u (Strassburg, Els.).

\section{Arthropoda.}

\section{Crustacea.}

662 Sars, G. 0., The P'olyphemidae of the Caspian Sea. In: Annuaire Mus. Zool. Acar. Imp. Sc. St. Pétersbourg. T. 7. 1902. pag. 1 -24. pl. 1-4.

eine etwas verstärkte Grundschicht völlig geschwunden ist, während die ventrale Wand ganz ausserordentlich verdickt ist und aus bogenförmigen Muskelbändern bestelıt, deren Masse so kolossal werden kanu, dass sie auf Querschnitten fast die Hälfte der Körperdicke (bei C. biirgeri) beträgt. 
Seit Sars im Jahre 1897 einige Polyphemiden aus dem Kaspischen Meer beschrieb und darauf hinwies, dass sich die einen mehr den Süsswasserformen, die andern mehr den marinen Arten annähern, hat sich aus Planktonproben, die zum grössern Teil den siidöstlichen $\mathrm{Ab}$ schnitten des betreffenden Gewässers entstammen, ergeben; dass der Polyphemidenreichtum in dem grossen Bimensee ein höchst bedeutender ist. Nicht nur wurden neue nnd interessante Arten entdeckt, sondernn auch der allgemeine Nachweis erbracht, dass die im Meer und Süsswasser sonst so formenarme Entomostrakengruppe sich im Kaspischen Meer glänzend entfaltet und offenbar noch weiter progressiv entwickelt. Seit der See sich vom Ozean lostrenute, blieb er bis heute ein Schöpfungszentrum für Arten von Mollusken und wenigstens für gewisse Gruppen niederer Crustaceen. Ïnderungen physikalischer und biologischer Natur, die während der allmählichen Abtrennung des Kaspischen Meers Platz griffen, rerbunden mit der fortschreitenden Isolierung der Tiere, übten wohl auf manche Species einen tiefgehenden, umwandehden Einfluss aus. Der heute noch in den obern Wassersehichten ron Ort zu Ort stark variierende Salzgehalt bewirkt weitgehende Divergenz ron Tierformen, die, wie die Polyphemiden, nahe der Obertläche wohnen. Dies gilt für die Gattung Evadne in dem Grade, dass die Abgrenzung der einzelnen Formen äussert schwierig wird und manche derselben als Subspecies, oder noch besser, als im Entstehen begriffene Arten zu betrachten sind.

Sars zählt alle aus dem Kaspischen Meer bekamnt gewordenen Polyphemiden auf, schildert die nenen Species und Subspecies, gibt Notizen über ihr Vorkommen und sucht besonders den phylogenetischen Zusammenhang der einzelnen Formen klarzulegen.

Das Genus Cercopagis G. O. S. stammt von der nahestehenden Gattung Bythotrephes ab. Aus den nördlichen Zuflïssen wanderte voraussichtlich eine Bythotrephes-Art in dic Laguneu des Kaspischen Meers ein, um dort, an Stellen, wo sich heute noch in kaum brakischen Wasser eine echte Sïsswasserfauna aufhält, die nötigen Existenzbedingungen zu finden. Von den Flussmïndungen schweifte der betreffende Entomostrake in das salzigere Wasser des offenen Sees hinaus. Aupassung an die neuen Verhältnisse und daran sich anschliessende Differenzierung liess aus der Stammform - wohl eher Bythotrephes cederströmi Schödeler, als B. longimana Leydig - die Gattung Cercopagis entstehen.

Diese zerlegte sich viel später und ausschliesslich im Kaspischen Neer in zahlreiche Arten. Eime auch im Asowischen Meer lebende Species, C. nconilae G. O. S. verdankt ilne Gegenwart in dieser sekun- 
dären Heimat wahrscheinlich dem zufälligen, passiven Transport durch Togelflug.

Neben der wenigstens im offenen Wasser häufigsten Art Cercopragis robmsta G. O. S., von der sich wahrscheinlich die ïbrigen ableiten lassen, bewohnen das Kaspische Meer C. microny.r G. O. S., (. motonyatn G. O. S., C. tenern G. O. S., C. anomyx G. O. S., C. neonitae G. O. S. und C. gracillima n. sp.

Selbständig ans einer Bythotrephes-Art, vielleicht B. Tongimana Leydig, diirfte die Gattung Apayis mit den hente bekannten Arten A. cylindrate (., O. S. und A. Tongicandata G. (). S. entstanden sein.

Von dem im süssen Wasser der nördlichen Hemisphäre weitverbreiteten Polyphemus pediculus stammt zweifellos die Art des Kaspischen Meers P. exigms G. O. S. ab.

Eradne Lorén stelıt mit dem selnr nahe verwandten Genus Porton Lilljeb. in enger phylogenetischer Beziehung; dabei hat Podon als primitiverer Vorfahrentypus zu gelten. Beide Gattungen diurften auf einen Polyphemus des Süsswassers zurïckzuführen sein. Mit den sehr zahlreichen Eradnr-Formen des Kaspischen Meers bilden die drei wohl umschriebenen marinen Arten desselben Genus keinen engern Verband. Die kaspischen Vertreter von Eradne weisen auf einen alten Siisswasser-Yorfahren, in letater Linie vielleicht auf Polyphemus pediculns zmrïck, dessen direkter Nachkomme, P. exigmus, noch jetzt das Kaspische Meer berölkert und ans dem wahrscheinlich auch die marinen Poton- und Exalne-Arten hervorgingen.

Für den sehr rezenten Ursprung der Eradne-Formen im Kaspischen Meer, den Sars postuliert, spricht die Unbeständigkeit der Charaktere mancher derselben im scharfen Gegensatz z.l den marinen Gattungsgenossen.

Evadne anomyr G. O. S. und E. producta G. O. S. betrachtet Sars wegen ihrer sehr nahen V'erwandtschaft nur noch als Varietäten oder besser Subspecies derselben Art. $E$. anomyx ist die gemeinste und verbreitetste kaspische Form der Gattung Evadne; sie zeigt dentlich die Tendenz, sich in neve, entstehende Arten zu spalten. Wohlbegründet stehen E. maximoritschi n. sp. und E. hircus n. sp. da. Letztere erzeugte wahrscheinlich eine Nebenform im Asowischen Meer. Endlich finden sich noch E. comptony.x G. O. S. und E. trigona (r. O. S., um deren typische Mittelform sich eine grosse Anzahl ron Subspecies, oder von im Werdeprozess begriffenen Arten gruppieren.

F. Zschokke (Basel).

\section{Insectil.}

663 Sutton, Walter S., On the Morphology of the Chromo- Nr. 662-663. - 
some Group in Brachystola magna. In: Biol. Bull., 4. Bd. Nr. 1. Dez. 1902. pag. 2ł-39. 11 Textabbildgn.

Verf. beschreibt in den Iletaphasen der Spermatogonien und Spermatocytenteilungen an Schnitt- und Quetschpräparaten Ungleichheiten in der Chromosomengrösse, aus der er den Schluss auf die Erhaltung der Chromosomenindividuen und physiologische Qualitätsunterschiede zieht. Verf. meint, bei der Eireifung sei das gleiche der Fall und jedem männlichen Chromosomenindividum entspräche bei der Refruchtung ein bestimmtes weibliches. Die Bestimmung des Geschlechtes sei auf ein (bei den Orthopteren nachweishares) überzähliges Chromosom zurückzufülıren, das bei der Samenzellenteilung nicht halbiert werde, sondern immer nur in die eine T'ochterzelle übergehe. - (Vielleicht deuten die Unterschiede im Aussehen der Chromosomen, namentlich in Fig. 5 des Verfs. darauf hin, dass auch fiir Brachystola Lebruns Entdeckung der allmälılichen Chromosomenausarbeitung bei den Amphibieneiern gilt (s. Zool. Zentr.-Bl. 9. Bd. pag. 804; Ret.).

R. Fick Leipzig).

664 von Hormuaki, Constuntin Freiherr, lepidopterologische Beobachtungen in ler Bukowina. In: Entomol. Nachr. Jahrg. XVIII. 1892. Ni. 20 u. 21. pag. $305-321$.

665 - Bemerkungen über Varietäten einiger in der bukowina einheimischer Grosschmetterlinge. In: Vorhandl. d. K. K. \%ool.-Bot. Ciesellsch. Wien. Jahrg. 1895. pag. 1-30. 1 Textfig.

666 -Die Schmetterlinge (Lepidoptera) der Bukowina. Ibid. Jahrg. 1897. pag. 1-210. 1 Kiarte.

667 - Beobachtungen an der Melitaeengruppe Athalia Iiott., Aurplia Nick. und Parlhenie Borkh. In: Entomol. Keitschr. Iris. 1898. pag. $1-13$.

668 - Neuere Macrolepidopterenfunde aus Rumänien. In: Verhandl. d. K. K. zool.-bot. Gesellsch. in Wien. Jahrg. 1902. pag. $563-567$.

Die in den ersten drei Arbeiten (664-666) niedergelegten Ergebnisse sind das Resultat langjühriger systematisch betriebener Forschungen und geben uns ein sehr vollständiges Bild von der Lepidopterenfauna der Bu kow in a an sich und von ihren Beziehungen zu der del Nachbarländer. Es ergibt sich daraus, dass sich die Lepidopterenfauna der Bukowina aus Formen zusammensetzt, die in dem zentralen Europa ebenfalls angetroffen werden, sie ist aber dadurch sehr charakteristisch, dass neben diesen Lokalrassen vorkommen, die den nordasiatischen Formen nahe stehen oder ihnen vollkommen gleichen. Eigentümlich 
ist es ferner, dass verhältnismäßig viele Arten entweder höchst heschränkte Standorte bewohnen, oder aber nur ganz sporadisch in Jehrzahl erscheinen, un nach 1-2 Jahren spurlos zu verschwinden. So erreichen z. B. Papitio podalivius. Sphin.r Tigustri, Suturnia pylri usw. schon in geringer Höhe ihre obere Grenze. während Melitafa aurinia, Sphinx pinastri, Satumia paronia usw. ausschliesslich im Gebirge angetroffen werden. Wir begegnen indessen auch dem Umgekehrten. So fliegen z. B. ron ausgesprochen montanen Formen Pamussius memnosyne. Erebia acthiops usw. zusammen mit Fermen der subalpinen Region und des Tieflandes.

Wie für die Vegetation, so zeint es sich auch für die Lepidopterenfauna, dass die baltische und pontische Region gut begrenzte natürliche Gebiete darstellen. Die pontische Region nimmt den Nordosten, die baltische den südwesten der Bukowina ein. Vergleicht man die Lepidopterenfamna des pontischen Hügel- mo Tieflandes und der montanen baltischen Region. so trifit man ganz ähnliche Verhältnisse an, wie bei der Vegetation. Nanche Arten werden ant das eine oder andere dieser Gebiete heschränkt, in andern Fällen macht sich bloss ein Vikariieren bemerkbar, so dass ron gewissen nahe miteinander verwandten Arten, die eine in der baltischen Region vorherrscht und in der pontischen nur vereinzelt anftritt, oder umgekehrt.

Es ist für die Verbreitung der schmetterlinge wichtig, dass bei solchen Arten. bei denen man früher eine von NO nach SW ziehende, den Kontinent in ziemlich gerader Linie lurchschneidende Äquatorialgrenze annahm, diese Linie in Wirklichkeit oinen andern Verlauf hat. Anfangs ziemlich regelnüBig rom Wolgagebiet und den südlichen Ausläufern des Ural ausgehend, dann der Scheide zwischen dem Waldund Steppengebiet in Sïdrussland folgend, wir die Süilgrenze mancher nördlicher Lepidopterenirten, sobald sie in Ostgalizien die Karpathen trifft. entsprechend dem Zug dieses Gebirges fust rechtwinkelig nach Südosten abgelenkt und dringt dann längs der Karpathen nach Süden vor bis in die Bukowina, Molda u und Wallachei. Bei manchen Arten scheint sich die Arealgrenze mit dem Gebiet der baltischen Flora senau zu decken und schiebt sich in dieser Gegend zungenförmig nach Siiden und Sïdosten ror. Hierbei bezeichnen die Karpathen die Äquatorialgrenze der betreffenden Arten. Umgekehrt kommen wieder die in der Bukowina und gleichzeitig in Ungarn und siebenbürgen eimbeimischen pontischen Formen im Karpathengebiet ebensowenig vor, ats in Mitteleuropa z. B. Argynnis pandora, Smerinthus quercus: usw. Zahlreiche mittel- und selbst nordeuropäische Lepidopteren erreichen z. T. in der Bukowina, meist aber erst in 
Rumänien den südlichsten Punkt ihrer Verbreitung in Europa. Das Gebirge zeigt klimatisch grössere Ähnlichkeit mit dem nördlichen Nitteleuropa wie das Tiefland. da das Klima in den Bergen ebenfalls ein gleichnäßiges ist, und diese Beziehungen kommen auch in der Fauna zum Ausdruck. Die Eigentiumlichkeiten der Bukowiner Lepidopterenfauna, die diese von derjenigen Mitteleuropas unterscheiden, sind daher auch im Tiefland am deutlichsten ausgeprägt. Die Fauna der montanen, baltischen Schmetterlinge, die aus vielen weitverbreiteten Arten besteht, weichen von den mitteleuropäischen Formen liauptsächlich darin ab, dass viele von ihnen in eigenen, mitnuter den sibirischen Formen nahe verwandten Lokalrassen auftreten, sie bilden geradezu eine Mittelform zwischen den beiden extremen Variationen, von denen die eine auf Mitteleuropa, die andere auf sibirien beschränkt ist. Bei einer geringen Zahl von Lepidopteren tritt die östliche Rasse nur im Tiefland, in der montanen Region hingegen die mitteleuropäiscle (baltische) Grundform auf. So fliegti z. B. Parnassins dorilis $f$ bei Czeruowitz nur in der Varietis orientalis Stgr, in (iehirge dagegen in der typischen Form.

Ein genaues V'erzeichnis der in der $B$ uk ow in thegenden sichmetterlinge mit Angaben ïber die F'ugzeit, die Häufigkeit und das Verbreitungsgebiet jedes einzelnen derselben und eine übersichtliche Karte der klimatischen Floren- und Famen-Gebiete der Bukowin a vervollständigen lie verdienstrollen nach den verschiedensten Richtungen interessanten Untersuchungen Hormuzakis.

Bei den in der Bukowina Hiegenden Melitueen beobachtete Verf. eine sehr grosse Variationsfähigkeit (667). Besonders konstant war eine auf ilurer Oberseite $\boldsymbol{M}$. dictyma ähnliche atrelia-Form, die er als var. dictynnoides beschreibt. Diese Varietit weicht sowohl durch die rötliche Beschuppung ihrer I'alpen wie auch durch ihre Flügelform und Zeichnung in charakteristischer Weise ron der Melitaea aurelia und II. uthalia ab. Da sie stets in grosser Individuenzahl angetroffen wird, und zwar weit verbreitet, auch an Stellen. an denen M. athatia nicht vorkommt, so kann nicht angenommen werden, dass tictymoides durch direkte Hybridation ans aurelia-athatia herrorgeht. Hhr häufiges Vorkommen schliesst es auch ans, die dictynnoides als blosse Aberration aufzufassen, ebensowenig kann sie als lokale rasse angeselien werden, weil sie stellenweise an denselben Flugplätzen mit athatia, aurelia und parthenie angetroffen wird.

Viel wahrschemlicher erscheint es dem Verf., dass die fragliche Varietät in einer frühern Zeitperiode durch Kreuzung zwischen athatia und anelia, vielleicht auch parthenie oder dictymna liervorgegangen sein könnte. und falls nur die drei erstern Arten in 
Betracht kämen, dass sich dann die Zeichnung der Oberseite unter den dortigen klimatisclien Verhältnissen selbständig in der erwähnten Richtung abgeändert hätte. Danach wäre dictymnoides eine junge, aber gut begrenzte und fixierte Form; die gleichzeitig mit ihr vorkommenden athatia-, ametia- und parthenie-Arten sind damn die Nachkommen der z. T. ganz verdrängten ältern Formen; die unter dictymnoides Hiegenden zweifelhaften, d. h. sich der einen oder andern Stanmart nähernden stücke können entweder neue unmittelbare Hybriden oder aber atavistische Formen darstellen.

Das in 668 enthaltene Verzeichnis bildet eine Ergänzung der durch E. F le c k verfassten zusammenfassenden Darstellung der Lepidopterenfauna Rumäniens, die im Buletinul Societatii de sciinte (Bd. VIII. 1899. Heft 6. Iid. IX. 1900 Heft 1 und Jahrg. XI. Heft 1 bis 2. 1902 ) erschienen ist. Horm $\mathrm{u}_{\mathrm{k}} \mathrm{k} \mathrm{i}$ hebt ganz besonders hervor, dass einzelne asiatische Arten und noch mehr solche Lokahassen in Rumänien ihren einzigen europäischen Fundort besitzen.

$$
\text { M. v. I. ind en (Bonn). }
$$

\section{Vertebrata.}

\section{Mammalia.}

669 Satuniu, K. A., Neue Nagethiere aus Centralasien. In: Annuare Mus. Zool. Acad. Imp. Sc. St. Pétersbourg, T. VII. 1902. pag. 1-43. Separatabdruck (deutsch).

Verf. bearbeitete die Sammlungen des Museums der Akademie in St. Petersburg an Nagetieren, besonders das von P. K. Koslow von seiner dreijährigen Reise in Zentralasien mitgebrachte Material. Es werden die unten folgenden nelien Arten genau beschrieben und ihre Maß3e sorgfältig angegeben: Sciuropterus bucchueri sp. nov. ( 7 und 3 f) aus Gausu; Spermophilus pallidicauda 7 sp. n. Gobi-Altai; Gerbilius koslowi sp. n. $(2 \circ, 3$ ) unteres Kobdo, Altain-Nuru, Cbaljumgol im GobiAltai (4200' hoch); Gerb. tamaricinus satschouensis subsp. nov., f, Oase Satschou;

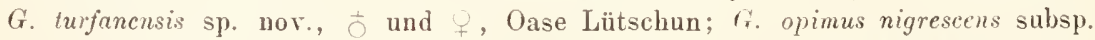
nov., 3 f, See Orok-Noor im Gobi-Altai; Mus giyas sp. nov, Setschuan; M. (Leggada) gansuensis sp. nov., (1 f 1 juv.) Kloster Tschoitentau, Fluss Chi-tschju (System d. Blauen Fluss) $7100^{\prime}$ und $13000^{\prime}$ hocb; Cricetulus phaeus griseirentris subsp. nov. Altain-Nuru am Bisschengol-Fluss; $C_{\text {. }}$. dichrootis sp. nov., 2 + Nanschan, Gorbanangyr-gol-Fluss; C. koslowi sp. nov., $q$, Satschou; C. roborovskii sp. nov., 1 ? juv., 1 a ad., Nanschan, Scharogol-dschin-Oberlauf; Urocricetus subsp. nov., $U$. kemensis sp.n., + (Kam = Nordost-Tibet), Moktchyun-Fluss, Mekong.Gebiet; Microtus nanschanicus sp. n., +, Scharagold-schin-Oberlauf; M. limnophilus tlaviventris subsp. nov., $\sigma^{\top}$, Kloster Tschortentau $\left(7100^{\prime}\right)$; 11 . tsaidamensis sp. nov., Tosso-noor-See. Tsaidam; Nicrot, kasnakovi sp. nov., Chi-tschju (Oberlauf des Blauen Flusses); Cardiocranius gen. nov., C. paradoxus sp. nov., Springmaustypus, - , Scharogol-dschin, Nanshan. Im Anhang wird eine neue Ratte aus Turkestan beschrieben: Mus turkestanicus sp. nov., von Assambob in Ferghana, gefunden vom Akademiker K o rźin s ky.

C. Grèè (Moskau). 


\title{
Zoologisehes Zentralblatt
}

unter Mitwirkung von

\author{
Professor Dr. O. Bütschli and Professor Dr. B. Hatschek \\ in Heidelherg \\ in Wien
}

herausgegeben von

Dr. A. Schuberg

a. 9. Professor in Heidelbers.

Verlag von Wilhelm Engelmann in Leipzig.

X. Jahrg. 30. Oktober $1903 . \quad$ No. 0/1.

Zu beziehen durch alle Buchhandluagen and Postanstalten, sowle durch die Verlagsbuehhaudlung. Jährlich 26 Nummern im Unfaug von 2-3 Bogen. Preis für den Jahrgang M. 30. - Bei direkter Zusendang jeder Nummer unter Streitbaud erfolgt ein Aufschlag von M. 4.- nach dem Inland and von H. 5. - ach dem Ausland.

\section{Referate.}

\section{Descendenzlehre.}

670 Dïlerlein, I., Leber die Bezielungen nahe verwandter "T'ierformen" zu einander. In: Keitschr. Morph. Anthrop. 4. Bid. 1902. pag. 394-442.

Eine vortreffliche Abhandlung. die nicht lebhaft genug der Beachtung der Fachgenossen empfohlen werden kann. Ihr reicher Inhalt gliedert sich in drei Kapitel, von welchen das erste den Pegriff ..Art." oder .Species" darlegt, das zweite sich ïber die verschiedenen innerhalb einer Gattung oder älınlichen Gruppe zu unterscheidenden 'Tierformen verbreitet und das dritte von Variabilität und Vagilität handelt.

Grundlegend ist der erste Abschnitt. Neue Erfahrungen, speziell an Riffkorallen, haben die alte Wahrheit bestätigt, dass es in der \%oologie keinen Begriff gibt, mit dem in der Praxis so frei und willkürlich geschaltet wird, wie mit dem der .Art”. Die Auffassung der "Art" ist gegenwärtig eine so differente, dass fast in jeder Tiergruppe andere Gesichtspunkte für dieselbe maßgebend sind. Die liffkorallen einerseits und die Vögel andererseits stellen in dieser Beziehung Extreme dar, zwischen welchen sich in den mannigfaltigsten Abstufungen die Auffassung des Speciesbegriffs bei den ïbrigen Tiergruppen bewegt.

Welche Auffassung ist nun die richtige? Oder ist es überhaupt einerlei, wie man hierin verfahren mag? Für "reine Museumszwecke* vielleicht, für wissenschaftliche niemals, denn der Faunistiker und der Tiergeograph, der Systematiker wie der vergleichende Anatom oder Embryologe sind in gleicher Weise daran interessiert, ,einen 
Ausdruck zu besitzen für die kleinsten Tiergruppen, welche sämtliche Individnen mmfassen, die einerseits auf Grund von morphologischen Merkmalen sich ron denen anderer derartiger Gruppen noch scharf trennen lassen, andererseits ohne Krang und Willkür eine scharfe Trennung in zwei oder mehrere Gruplen micht mehr gestatten".

..Fs muss einen Begriff geben für die engsten noch znverlüssig abgrenzbaren natiirlichen Tiergruppen, die möglich sind, $11 m$ eine ..systematische Einheit" zn erhalten, mit der die Forschung sicher zu operieren vermag. Dieser Begriff ist die Linnésche Species und von ihm ,müssen wir das praktisch Brauchbare und Wichtigste, die scharfe I'nterscheidbarkeit, behalten, mögen wir im ïbrigen von ihm denken, was wir wollen." Eine Art als systematische Einheit muss dennach eine Formengruppe darstellen, .die von andern scharf abgegrenzt werden kann", und in jedem der ihr subsummierten Individuen die Interscheidungsmerkmale zn! Anschaumg bringt. In typischen Exemplaren wohl unterscheidbare, aber durch C̈bergänge rerbundene und infolgedessen zuverlässig und ohne Willkür nicht trenubare Tierformen miissen daher als .Varietäten“ betrachtet werden.

Fiir den Descendenztheoretiker ist es selbstrerständlich, dass die Linnesschen Arten keine natürlich unschriebenen Formengruppen darstellen, deren Grenzen seit jeher und für immer feststehen, und in diesem Simne ist es zweifellos richtig, dass es keine natülichen Arten gibt. .. Wir leben aber in der Wirklichkeit nnd haben in erster Linie mit den tatsächlich vorliegenden Verhältnissen zu rechmen: und hier finden wir zahllose scharfe Grenzen zwischen den nns bekannten Organismenformen. Jede dieser scharfen Grenzen bedentet eine Lücke in unserer Kenntnis vom Zusammenlang der Formen; und jede dieser Liicken ist eine Artengrenze. So riele Lücken wir also haben in mnserem gegenwärtigen Wissen vom Zusammenhang der Formen von Lebewesen, so viele Arten müssen wir anerkennen."

Inter einer .Art" muss man sonach "nicht nur die Gesamtheit aller Individuen rerstehen, welche iibereinstimmend die gleichen Merkmale aufweisen, also Vertreter einer einzigen Form sind, im Falle diese scharf von andern Formen sich unterscheiden lässt, sondern es fallen unter eine Art auch ganze Reihen von verschieden ausgebildeten Formen, sofern sie nur ohne scharfe Grenze ineinander übergehen und in ihrer Gesamtheit sich schart von ander'n Formen oder Formengruppen unterscheiden lassen." Der Umfang einer Species kann mithin ansserordentlich 
verschieden sein und es wird einförmige, formenarme und formenreiche Arten geben.

Das Gesagte zusammenfassend haben wir uns die verschiedenen Arten einer Tiergruppe vorzustellen ..als die einzelnen uns bekannten Bruchstïcke vom Stammbaum der Gruppe, soweit diese miteinander nicht in direkten $/$ us ammenhang zu bringen sind, da die Verbindungsstiicke bisher nock unbekannt blieben". Daraus ergeben sich für den Gang der systematischen Erforschung einer Tiergruppe die folgenden Etappen:

"1. Stufe: Beginnende Kenntnis der Gruppe, gektnnzeichnet durch wenige, scharf voneinander getrennte, formenarme Arten.

2. Stufe: Bei fortschreitender Kenntnis wächst die Kahl der Arten immer mehr, ihre Interscheidung stösst mitunter auf Schwierigkeiten, manche ron ihnen sind ziemlich formenreiclı.

3. Stufe: Weit fortgeschrittene Kenntuis der Grupe, dadurch gekennzeichnet, dass zahlreiche der bisher unterschiedenen Arten sich zn lückenlosen Formenreihen und Formenketten zusammenfügen lassen, so dass die Zahl der scharf unterschiedenen Arten sich sehr verringert hat. viele Irten sehr formenreich geworden sind.

4. Stufe: Vollständige Kemntnis der (iruppe. Einzelne Arten sind nicht melr zu unterscheiden. sämtliche Formen reihen sich lïckenlos ancinander und bilden einen zusammenläingenden Stammbaum."

Man kann sagen. dass zur Zeit die Kenntnis dor meisten Tiergruppen sich auf der zweiten Stufe bewegt, manche freilich auclı noch auf der ersten verharren und nur wenige mehr oter weniger erfolgreich den Schritt zur dritten Stufe zu vollziehen streben.

In dem dargelegten Sinne erweist sich das Wesen der Art als ein nur von unserem augenblicklichen Wissen abhängiger Begriff, den man unter Beriicksichtigung des Haupterfordernisses, seiner praktischen Verwendbarkeit, nach Inhalt und ITmang etwa so bestimmen liann: "\%u einer Art gehören sämtliche Exemplare, welche der in der liagnose festgestellten Form entspreclien, ferner sämtliche davon abweichende Exemplare, die damit duch $/$ wischenformen so innig verbunden sind, dass sie sich ohne Willkür nieht scharf davon trennen lassen, endlich a uch alle Formen, die mit den vorgenannten nachweislich in genetischem \%us ammenhang stehen." Nun gibt es aber nicht wenige Formen, die scharf unterscheidbar sind, deren Tnterschiede aber nur ganz 
geringfügiger Natur sind, so dass es vom praktischen Standpunkte nicht wünschenswert erscheinen mag, sie als getrennte Arten zu behandeln; solche Formen sind dann als subspecies oder Unterarten zu bezeichnen und durch trinäre Benennung kenntlich zu machen.

Im zweiten Kapitel bezeichnet Verf. „die engsten natürlichen Individuengruppen, mit denen überhaupt gerechnet werlen kann" als ..Formen“. Eine „Form” ist ganz allgemein jede Gruppe von Individuen, ..welche solche Übereinstimmung in ihren morphologischen Merkmalen aufweisen, dass sie in einen gewissen Gegensatz zu andern ,Formen" treten, gleichgültig, ob die Unterschiede von andern Formen gross oder klein sind, ob sie mehr oder weniger scharf sind." Wollte man in diesen „Formen" etwa natürliche Arten erblicken, so bedeutete dies ron vornherein Verzicht leisten auf scharfe Trennbarkeit und damit auf \%uverlässigkeit bei der praktischen Verwendung. Trotzdem sind diese ,Formen" von grosser Wichtigkeit, denn die Natur arbeitet tatsä.chlich mit ihnen und man kann innerhalb natürlicher Gruppen (z. B. einer ciattung) in der Regel eine Anzahl "Formen" von gleichem oder ungleichem systematischen Wert unterscheiden, ..deren gegenseitige Beziehungen höchst verschiedener Natur sein können", Verhältnisse. die für die Frage nach der Eutstehung der Arten von erheblicher Bedeutung sind.

Man hat zunächst zwischen selbständigen Formen, das ist den Varietäten und Arten, und den unselbständigen oder ,.\% uständen" zu unterscheiden. Erstere „sind nicht voneinander ablı̈̈ngig, d. h. sie stehen nicht in direkter genetischer Beziehung zueinander," letztere lingegen ...treten innerhalb einer oder mehrerer Generationen einer selbständigen Form in gewisser Regelmäßigkeit immer wieder auf als die direkten Nachkommen einer bestimmten Ausgangsform, welche umgekehrt auch unter ihren eventuellen Nachkommen regelmäßig wieder erscheint."

Unter den "Zuständen“ sind zu unterscheiden diejenigen Formen, „in welchen dasselbe Individuu m innerhalb seiner Lebensdauer erscheinen kann" (z. B. die Cysticercus-Form von Taenia solium) und die untereinander genetisch verbundenen, ,welche, durch verschiedene Individuen dargestellt, innerhalb des Generationscyklus einer selbständigen Form in regelmäßigem Wechsel oder gelegentlich auftreten können," Vorkommnisse, die bekanntlich als Polybzw. Dimorphismus bezeichnet werden. Hierin unterscheidet Döderlein den alternierenden Polymorphismus (einschliesslich Saisondimorphismus). den sozialen (Insektenstaaten etc.), den sexuellen 
Dimorphismus und den fakultativen Polymorphismus, zu welchem die polyandrischen, polygynen, polychromen (bzw. dichromen), dichotomen und proteischen Arten zählen. Die selbständigen Formen umfassen die konstanten Formen, also Varietäten und Arten: „Die Übereinstimmung der wesentlichen Merkmale einer konstanten Form beruht auf Vererbung und ist nicht direkt abhängig von den äussern L,ebensbedingungen. Durch Kreuzung verschiedener konstanter Formen kann eine Änderung der Nerkmale erzielt werden." Die selbständigen Formen zerfallen wieder in die geographischen. stratigraphischen, faciellen, culinischen und physiologischen Formen. Die Charakteristik dieser und der rorher anfgeführten Formengruppen kann hier nicht gegeben werden und ist darüber das Original einzusehen.

/wischen selbständigen und unselbständigen Formen vermitteln, von den sog. individuellen Formen (Aberrationen), wie sie sich in Abnormitäten und Monstrositäten kundgeben, abgesehen - besonders die ..adaptiren Formen." Dei diesen ..weisen eine grosse Anzahl ron Individuen, die nebeneinander unter den gleichen Lebensbedingungen existieren, übereinstimmend die gleichen Merkmale auf, durch welche sie von andern Formen sich unterscheiden: auch die Nachkommen können diese gleichen Merkmale zeigen. Die Übereinstimmung der wesentlichen morphologischen Merkmale bei allen Induriduen einer adaptiven Form beruht nicht auf Vererbung, sondern ist direkt abhängig ron der Ïbereinstimmnng der äusser n Lebensbedingungen. Eine Kreuzung verschiedener adaptiver Formen miteinander würde demnach eine Ïnderung der Merkmale nicht hervorrufen können." Das markanteste Beispiel adaptierter Formen bietet die Artemia salina mit Artemia milhanseni.

Der letzte (3.) Abschnitt ist der Erörterung der Faktoren gewidnet, welche die rerschiedenartigen Schwierigkeiten bei der Formenunterscheidung bewirken. Man kann sagen, dass der Grund jener Schwierigkeiten entweder in der verschiedenen Höhe der Organisation, oder in der verschiedenen individuellen Variabilität der Merknale, endlich auch in der verschieden grossen Neigung zur Ausbildung geographischer und adaptiver Formen bei den verschierlenen Tiergruppen" zu finden ist. Yon den Faktoren, welche hierfür als bewirkende Ursachen in Betracht zu ziehen sind, behandelt Verf. der lieihe nach unter Beifïgung erläuternder Beispiele die Plastizitat der Organe, die Vagilität als Fähigkeit des Ortswechsels und die indiriduelle Variabilität; von letzterer wird eine ,endogene" und eine 
.. ektogen e unterschieden, je nachdem es sich um eine .in der Natur der betreffenden Form liegende, erbliche, inlï̈rente Anlage zur Abänderung der einzelnen Merkmale" handelt oder eine "Reaktion auf bestimmte äussere Lebensbedingungen, die anf den Organismus einwirken und eine Abänderung einzehner Merkmale veranlassen," vorliegt. Ref. muss sich mit diesen flüchtigen Imrissen begnïgen und im iibrigen anf das Original verweisen.

Eine I'rüfung des gewonnenen Standpunktes an den Vögeln einerseits und den Riffkorallen, deren Studium dem Verf. den Anlass zu del ganzen Darlegung gegeben hat, andererseits beschliesst die von ausgebreitetster Sachkenntnis zeugende und durchaus ron modernem Geiste getragene schöne Arbeit. Schade. dass dieselbe an einem Orte veröffentlicht worden ist, an dem sie gerade die interessierten Kreise wohl niemals suchen werden. F. r. IV agner (Giessen).

671 Pauly, A., Walıes und Falsches a 1 Da rwins Le hre. München (E. Reinliardt). 1902. 18 pag. M. - .80.

Verf. versteht unter...Darwins Lehre" Descendenztheorie und Zuchtwahllehre. Erstere lässt er gelten, letztere lehnt er ab, indem er nachzuweisen sucht, dass die Selektionshypothese den 'Tatsachen des Natmrlebens nicht entspreche mol ganz und gar unfähig sei. die sog. ZweckmäPigkeit der Organismen irgendwie zu erklären. Der .Zufallstheorie" I) a r w ins, die zudem einen "ungehenerlichen Verstoss gegen die Logik.' bedenten soll. setzt Verf. daher ..die Antwort der Natur" entgegen. Diese besteht nach unserm Autor darin, dass alles Zweckmäfige nach Bedarf vom ()rganismus selhst .in seiner Aktivitit" herorgebracht wird und zwar kraft eines .nrteilenden Prinzips, das im Innern des Organismus liegt. eine Fähigkeit der organischen Materio ist", also ..ein psychologisches sein nuss". Näheres hierüber mögen Interessenten im Original einsehen. Rief. möchte nur folgendes bemerken: Es kinn nicht zugegeben werden, dass die ron Verfasser der \%uchtwahllelıe gewidmeten kritischen Bemerkungen das gefällte absprechende Urteil begriindeten: allerdings scheint derartiges in neuester Zeit überhaupt nicht mehr fiir nötig gelıalten zu werden. Bezüglich der positiven Aufstellungen ist Ref. durchaus der Ansicht des Verf., dass es ein L'mrecht wäre, von dem Ersatz der Selektion durch das nene psychologische Prinzip „einen Angriff auf einige der festesten Säulen, welche die Wissenschaft aufgerichtet hat*, zu befürchten und ..die Riickkehr vertriebener Irrtiiner" zu besorgen.

F. v. Wagner (Giessen).

\section{Faunistik und Tiergeographie.}

67 Daday. E. von. Mikroskopische süsswasserfauna a us Kleinasien. 
In: Sitzungsber. kais. Akad. Wiss. Wien. Math.-nat. K]. Bd. 112. Abt. I. März 1903. pag. 139-167. 2 Fig. in Text. Taf. 1 u. 2.

Aus zwei Seen des nördlichen Kleinasıens, dem Albullonia-Gül und dem Isnik-Göl, bestimmte D. 12 Protozoen, $18 \mathrm{~W}$ ürmer, zum grossen Teil Rotatorien und 13 Crustaceen. Die grosse Mehrzahl der gesammelten Tiere sind weitverbreitete Kosmopoliten, von denen die meisten allerdings aus Kleinasien unbekannt waren. 7 Arten gelı̈ren nach dem momentanen Stand der Kenntnisse nur kleinasiatischen Fundorten, 7 weitere ausserdem nur noch europäischen Lokalitäten an.

Als neue Formen beschreibt Verf. besonders ausführlich Mastigocerca heterostyla, die $M$. bicomis und $I /$ cornuta am nächsten steht, Brachionns rubens Ehrbg. var. werneri nov. var., Canthocamptus spec., Onychocamptus heteropus und Limneythere dubiosa.

Auch die Aufzäblung der bereits bekannten Arten wird von Angaben über Vorkommen, Häufigkeit, geographische Verbreitung, sowie von systematischen und morphologischen Notizen begleitet.

Tintimopsis ovalis, die D. früher aus siebenbürgischen Teichen beschrieb, schiebt sich verbindend zwischen Tintinnopsis lind Codonella ein. Adactyla verrucosa Barr. lad. scheint die Gewässer Kleinasiens zu charakterisieren. Notops maerures Barr. Dad. ist, entgegen der Ansicht Rousselets, mit $N$. brachionus nicht identisch. Als Synonyme oder liöchstens Varietäten von Brachionus budapestinensis Dad. lraben 1 . punctatus Hempei und $B$. lineatus Skorikow zu gelten.

F. Zschokke (basel).

673 Daday, E. von, Mikroskopische Sïsswasserthiere der Umgebung des Balaton. In: Zool. Jalırb. Abtlg. Syst. Geogr. Biol. Bd. 19. Heft 1. 1903. pag. 37-98. 'T'af. 5 u. 6. 3 Abbildg. im 'Text.

Verf. zählt in systematischer leihenfolge 209 Arten niederer 'Tiere (Protozoen, Hydren, Turbellarien, Nematoden, Rotatorien, Crustaceen und Hydrachniden) auf, die in zalılreichen, grössern und kleinern stehenden Gewässern der Umgebmng des Plattensees gesammelt wurden. Er berücksichtigt dabei Fundorte und Häufigkeit der betreffenden Formen und besonders lhr Vorkommen oder Fellen im Balaton seibst und in Ungarn. Für den Plattensee erwiesen sich 124 Arten als unbekannt, davon sind 43 für die ungarische Fauna überhaupt neu. Die Mannigfaltigkeit der äussern Lebensbedingungen in den untersuchten Wasseransammlungen bedingt, nach Verf,, ihren Reichtum an Tierformen, die im nahe gelegenen Plattensee fehlen.

Eıngehendere systematisch-morphologische Benerkungen widmet D. besonders den Cladoceren Plenroms laevis Sars, Alona rectangula Sars, Alonopsis ambigua Lillj., Leydigia acanthocercoides Fisch., L. quadrangularis Leydig, Scapholeberis bispinosa De Geer, Moina micrura Kurz und der interessanten, aus Ungarn früher als Macrothrix servicaudata Dad. beschriebenen Bunops serricaudata Dad. Erwähnenswert ist das Vorkommen des patagonischen Plenroxus scopulifer Ekm. Dada y schliesst indessen die Möglichkeit nicht aus, dass die genannte Cladocere nur eine Varietät des weitverbreiteten Pl. aduneus sei. Camptoccrcus lilljeborgi Schödl. fand sich in einer von den schwedischen Exemplaren abweichenden Form, die füglich als Varietät betrachtet werden könnte.

Weitere neue Varietäten sind Graptoleberis testudinaria Fisch. var. pannonica n. var. und von den Ostracoden Eucandona csilii Dad. var. pannonica n. var., die den Übergang zu Candona fabaeformis G. IV. M. bildet. 
Endlich stellt Verf. auf: Wlassicsia pamonica n. gen., n. spec., Dunheredia neglecta n. spec. und Scapholebcris erinaceus n. sp.

Das Genus Wlassicsia reiht sich durch den Besitz von Darmcoeca am Magen an die Gattungen Ophryoxus Sars und Grimaldma Rich. an. Es unterscheidet sich von Ophryoxus durch die Abwesenheit der Darmschlingen, von Grinaldina durch die Fussstruktur und die Gegenwart eines Abdominalfortsatzes. W. pannonica steht am nächsten der im Kongogebiet gefundenen Grimallina brazzai Rich.

Die auch in Asien vorkommende Dunhevedia neglecta dürfte in Ungarn weitverbreitet sein. Sie nähert sich sehr $D$. odontoplax G. O. S.

Seapholeberis erinaceus erinnert im allgeneinen Habitus an s. bispinosa var. mucronata und an S. microcephala, durch die Bedornung der Schale dagegen an S. spinifera var. brevispina Rich. aus Chile.

F. Zschokke (Basel).

674 Lo Bianco, S., Le pesche abissali eseguite da F. A. Krup col Yacht l'uritannelle adiacenze di Capried in altre localiti del Mediterraneo. In: Mitthl. Zool. Stat. Neapel. Bd. 16. Heft 1 u. 2. 1903. pag. 109-279. 1 Tabelle. Taf. 7-9.

Die rom Februar bis Mai zum grössten Teil suidlich ron Capri ausgeführten Fänge der I ampfyacht .. Luritan" bedenten eine sehr wesentliche Bereicherung unserer lienntnisse üher Zusammensetzung, Verteilung und Lebensweise von Plankton und Benthon in Nittelmeer. Zu den gïnstigen Resultaten trug hauptsächlich auch die Anwendung einer Anzall neu konstruierter Apparate und Tetze bei.

In eingehenden Tabellen verzeichnet Verf. alle pelagischen Fänge und Grundfänge unter Angabe von Zeit, Ort, Tiefe, Fangart, Richtung des Netzzuges und unter Aufzählung der erbenteten Tiere. Er gibt sodann eine ausfülırliche Übersiclit über die einzelnen Species, die eine reiche Fülle ron Notizen über zeitliches und örtliches Auftreten, Häufigkeit, geographische Verbreitung, Entwickhng, Systematik und Morphologie enthält. Ausführlicher werden Jugendstadien und neue Formen beschrieben. Trotzdem die Arbeit nur den Charakter einer vorlünfigen Jitteilung tragen soll, umschliesst ihr spezieller Teil eine solche Menge von Einzelbeobachtungen, dass ein lieferat eine genügende Orientierung über diesen Abschnitt der Originalabhandlung nicht geben könnte.

Dagegen mögen die allgemeinen liesultate, zu denen Lo Bianco gelangt, kurz berïhrt werden. Von der Obertiäcle bis zu den grössten erreichten Tiefen lebt in den untersuchten Meeresabschnitten eine relativ reiche velagische Organismenwelt. In Betracht fallen, ausser den zahlreichen Fängen mit rerschiedenen Netzen bei Capri, einige Züge an den aeolischen Inseln und an der französischen Küste.

Unter 500 m Tiefe vermindert sich das pelagische Tierleben quantitatir etwas, wälıend es qualitativ sehr mannigfaltig bleibt. Nach der Intensität des einfallenden Lichts glietert sich das P'lankton 
in rertikal übereinander liegende Zonen oder Schichten. Zu unterscheiden wäre eine oberste sehr lichtreiche Region, die von der Oberfläche bis zu etwa $30 \mathrm{~m}$ 'Tiefe reicht, eine Schattenzone, deren untere Grenze bei etwa $500 \mathrm{~m}$ Tiefe, mit dem Erlöschen der letzten eindringenden Strahlen des Sonnenlichtes zusammenfällt, und eine mächtige Schicht vollständiger Dunkelheit, $500 \mathrm{~m}$ unter der Meeresfläche beginnend und bis zu den grössten, bewohnten Tiefen reichend. Die den verschiedenen bathymetrischen Zonen entsprechenden Planktongrupen nennt T'erf. Phaoplankton. Kinephoplankton und Skotoplankton: für alle Tiere, die ohne Unterschied ron der Oberfläche bis zum tiefsten Grund pelagisch leben können, fiihnt er den Namen Pantoplankton ein.

Den beiden bauptsächlichsten Lichtzonen entsprechen ungefähr auch zwei Temperaturzonen, indem die Wasserwärme des Mittelmeers rom Meeresspiegel bis zu $500 \mathrm{~m}$ 'Tiefe sehr stark schwankt (an der Obertläche von $13^{\circ}-26^{\circ}$ ), in tiefern Schichten aber fast konstant bei $13^{\circ}$ stehen bleibt. - Der obern mehr oder weniger durchlenchteten und variabel warmen Region gehört das l'hao- und linephoplankton an, der dunkehn Zone ron konstanter 'Temperatur das Skotoplankton. Indessen ïht die Temperatur, im Gegensatz zum Licht, keinen direkten Einfluss anf die Vertikalverteilung des Planktons aus. Nur die Elemente des skotoplanktons sind an Schichten von ungefälı gleichbleibender Wärme gebminden.

Die eigentlichen Bestandteile des Phaoplanktons tummeln sich stark positiv heliotropisch mnter intensiverm Sonnenlicht und bei sehr wechsehnder Temperatur an der Meeresoberfäche. \%u ihnen gesellen sich während der Entwicklmng und Metamorphose Eier und Larven von Benthon-Tieren, die erwachsen das Tfer und geringe Tiefen bewohnen. Sie machen mit manchen Copeproden zusammen die Hauptmenge des betreffenden Planktons aus. Das Phaoplankton entfaltet sich am reichsten im Frühjahr, der Zeit der lebhaftetesten Vermehrung; seine Znsammensetzung wecliselt im Jahreslauf. Die Gegenwart so zahlreicher Larven benthonischer Geschöpfe erklärt sich, nach Beobachtungen, die Verf. hiuptsächlich an Plutei von Avbacia pustulose anstellte, durch Wind- und Strömungsverhältnisse.

Fast das ganze Jahr hindurch finden sich im Phaoplankton Larven von Tieren, welche adult ausschliesslich dem Skotoplankton angehören. Hierher zählen die Luphausiden bis ihre Leuchtorgane funktionsfähig sind, Amalopenaens elegans Smith bis zum Mysis-Stadium, die Eier von Macrurus, die Larven der Scopeliden, alle Larrenstadien der Sergestiden, Jugendzustände ron Calocaris, von Echiurus usw. Das Auftreten ihrer Eier und Larven nahe der Oberfläche besitzt 
Bedentung für die horizontale V'erbreitung skotoplanktonischer Tiere durch Winde und Strömungen.

Nanche Vertreter des Phaoplanlitons zeichnen sich durch geringen Umfang aus. Nit der Tiefe nimmt im allgemeinen die Grösse vieler lelagischer Organismen zu. Genera, die in verschiedenen Tiefen typische Arten besitzen, treten immer in den kleinsten species am nächsten an der Oberfläche auf. Aus kleinsten Repräsentanten der Genera und Familien setzt sich so die Hauptmenge des Phao1) lanktons zusammen.

Nachts häuft sich das litorale Phaoplankton in der tiefsten ihm zugänglichen Zone an, verstärlit durch Tiere. die während des Tages auf dem Grund oder in den Algen verborgen leben. Vom Plaoplankton der Küste weicht dasjenige der Hochsee durch zahlreiche typische Formen ab. (Sphatrozoen, Thalassicollen, die Copepoden Pontella und Anomalocera, Pelagia noctituca, Telella, Porpita). Dieselben gelangen nur zufäHlig an das Lfer, wo sie zu grunde gehen.

Das Knephoplankton sucht eine Zone auf. die von 20 bis $30 \mathrm{~m}$ Tiefe bis zur untersten Grenze des eindringenden Lichts reicht. Es findet dort, dem Wellenschlag und dem direkten Sonnenlicht entrïickt, günstige Wohnortsverhältnisse. Immerhin schwankt in der obersten, dem Knephoplankton zugänglichen Schicht die Temperatur in weitem IIaße $\left(13-24^{\circ}\right)$.

Als eine Folge der günstigen Lebensbedingungen darf der grosse Reichtum der vom Knephoplankton bewohnten Schicht an tierischen und ptlanzlichen Organismen angesehen werden. In die Augen fällt die Gegenwart von Eiern und Larven der meisten Benthonformen, neben solchen, die Skoto- und Panteplanktonformen angehören. Die meisten Vertreter des Kinephoplanktons übertreffen die Pliaoplanktonten an Grösse; sie besitzen selten liompliziertere Leuchtorgane. Manche derselben steigen vielleicht nachts in die Zone des l'haoplanktons empor. Nach Stïrmen, besonders im Winter und Frühjahr, werden Mitglieder des Knepho- und P'antoplanktons durch Tiefenströme an die Neerobertläche getragen und ron da durch den Wind in die Kïstenströme getrieben.

Ton $500 \mathrm{~m}$ Tiefe an bis zum Neeresgrund wohnt in lichtloser Region, bei einer konstanten Temperatur von $13^{n}$, das Skotoplanktom. Die Grösse seiner, oft mit mehr oder weniger komplizierten Leuchtorganen ausgeriisteten und lebhaft gefärbten Vertreter entspricht im allgemeinen derjenigen der Knephoplanktonten. oder wird etwas bedentender. Während die Larven der dem Skotoplankton angehörenden Organismen oft in höheren Schichten leben, halten sich die 
erwachsenen Tiere in der Tiefe auf. Sie gelangen nur zufällig und passiv an die Oberfläche. Gewisse Skotoplankton-Formen allerdings nähern sich nachts mehr oder weniger dem Wasserspiegel und werden etwa, vom Licht überrascht, an die Kïiste geworfen, wo sie umkonmen. So vielleicht Nyctiphanes norvegica G. O. S. bei Capri.

Die ganze Wassermenge, von der Fläche bis zu den grössten Tiefen, erfüllt das Pantoplankton. Einige seiner Komponenten machen indessen, wenigstens während des Tags, schon in der Schattenzone Halt. Während z. B. Diphyes sieboldii Koell. ron der Oberfläche bis bis zum tiefsten Abgrund auftritt, stellt sich Tomopteris liefersteimii Greeff erst von 20 bis $30 \mathrm{~m}$ Tiefe an ein und bleiben Pulculina und Coelodendrum noch bedeutend tiefer znrück. Die meisten P'anteplanktonten sind durchsichtig, farblos; unter gewissen Bedingungen werden indessen manche opak; selten verfügen sie iiber hochdifterenzierte Lenchtorgane.

In einer Schlusshemerkung macht Verf. darauf aufunerksam, dass starke und kontinuierliche Winde auf die Verteilung des Planktons nicht ohne Einfluss bleiben. Passives Emporwandern des Tiefenplanktons, bedingt durch Strömungen und Stiirme, scheint eine allgemein verbreitete Erscheinung zu sein. Dafür sprechen beobachtungen bei Messina; auch bei Neapel liess sich zu verschiedenen Jahreszeiten eine ähnliche Wirkung der Suidost- und Südweststürme feststellen. 'Typische Bestandteile des Knepho-, Skoto- und Panteplanktons er'scheinen nach starkem Sturm in den Kïistenströmungen.

Lo Bi a n cos Untersuchungen erlauben auch den vorläufigen Schluss, dass das Mittelmeer den grössten T'eil seiner pelagischen Tiere mit dem atlantischen Ozean teile. Die Strasse von Gibraltar vermittelt wahrscheinlich einen gegenseitigen Planktonaustausch.

48 gesammelte Tierformen waren für das Mittelmeerplankton, 20 weitere für die Imgebung des Golfs ron Teapel unbekannt. Als Species novae werden eingeführt: Echinospira compressa, Plesionilia capreensis, Eryonicus pmitanii. Gaetams krupuii, zwei Arten von Spongodrymus und Agrosphuera pellucida.

Auch die im zweiten Teil der Arbeit besprochenen Tiefenfänge, die besonders südlich ron Capri und im Gebict der Bocca grande ausgeführt wurden, lieferten viel für das Mittelmeer neue Ergebnisse, obwohl mit den vorhandenen Apparaten fast ausscliliesslich die weniger beweglichen Tiere erbeutet werden konnten.

Die Zusammensetzung der Kalkablagerungen auf dem Grund des Mittelmeers entspricht derjenigen in den grossen Tiefen des atlantischen und pazifischen Ozeans (Pteropoden- und Orbulina-Schlamm). 
So kann die tiefste Zone im Mittelmeer sowohl nach der Bodenbeschaffenheit, als nach dem Charakter der Tierwelt, physikalisch und biologisch, als typisch „abyssal" bezeiclmet werden. Entgegen frühern Ansichten und in Bestätigung der hauptsächlich durch Giglioli gewonnenen Resultate, erwies sich die grundbewohnende Fauna in den grössten untersnchten 'T'iefen als sehr reich. Doch erlauben die einstweilen allzu beschränkten Kenntnisse keine sichere Beantwortung der Frage nach dem Zusammenhang zwischen atlantischer und mediterraner Abgrundfamna. Bemerkenswert bleibt indessen die 'Tatsache, dass bei Neapel zahlreiche Tiefenformen des nördlichen Atlantik, speziell der norwegischen Kï̈sten (Lototen) gefangen wnrden. Vert. vermutet, dass eine seln grosse Zahl von Organismen iiberhaupt allen Veeren des Erdballs gemeinsam sei.

Die von L. aufgestellte Liste der Grundbewohner umfasst 128 Species; 68 davon waren für das Nittelmeer unbekannt, 9 sind nene Arten (Krappomenia minima n. g. n. sp., Auchistin lornii, Richardina fiedericii. Cmmonisens limumii, Prodajus lolinancoi. Medenophthatmus minutus, Phascolosoma spere, Spadella musculosa, sp. pro funda). Zwölf weitere Arten wurden zum erstenmal im Bereich des Neapler Golfs gefunden.

F. Zschokke (Basel).

675 Albert I., Prince de Monileo, Sur la quatrieme campagne de la Princesse Alice II. In: Compt. Rend. Acad. Sc. Paris, T. 136. pag. 211-215 1 Fig. in Text.

Anf der vierten Fahrt der ,Princesse Alice" wurden im Mittelmeer und im nordatlantischen (Ozean zwanzig Tiefseefänge mit verschiedenen Apparaten bis zu $5930 \mathrm{~m}$ 'Tiefe ansgeführt. Die reiche zoologische Ausbente nmschliesst miter anderm bis meterlange Alcyonarien. Scirpenta flagellum und S. ocherece, die auf der Josephinenbank $\left(36^{\circ} 41^{\prime}\right.$ N. B., $16^{\circ} 32^{\prime}$ W. L.) einen eigentlichen Wald bildeten. Derselbe Fang lieferte viele Spongien, Ophiuren. Crustaceen, unter letztern besonder's einen Inachus mit violetten Fiissen.

In $4275 \mathrm{~m}$ Tiefe lebten zwischen der Josephinenbank und den Azoren Psendostichopus villosus, mit als Commensalen daraufsitzenden Actinien, Hymenuster giboryi, Paragonaster subtiic und vielleicht neue Arten von P'hutomaster und Hyphalaster. Vor S. Miguel förderte das Netz ans 1187 m neben vielen Fischen - Bathyyadus melanobranchus, Macrurus aequalis - ein prächtiges Fxemplar von Aristens splendens zutage. Derselbe Krebs kehrte bei Fayal $(950 \mathrm{~m})$ und zum erstenmal in männlichen Individuen bei Sùo Jorge $\left(\begin{array}{ll}1095 \\ \mathrm{~m}\end{array}\right)$ wieder. Bei $42^{\circ} 53^{\prime}$ N. B. und $30^{\circ} 51^{\prime}$ W. L. wnrde ein bathypelagischer, Cyclothone elongata nahestehender, mit Lenchtorganen 
häufiger zu werden. Meist war gleichzeitig Lankesterella monilis rorhanden, die nur in 12 ron den 372 Fröschen vermisst wurde. (Ob es sich wirklich um diese europäische Art gehandelt hat und nicht um eine andere, welche vicariierend für dieselbe eingetreten ist? oder vielleicht gar nur um Formen, welche auch in den Zengungskreis der rom Verf. als neu geschilderten Art gehören! Ref.). Bei 27 Fröschen will Verf, ausserdem noch Danilewslya krusei (= Drepanidium magnum) gefunden haben und bei 40 ein Trypanosoma. Zwischen den beiden Wirtsspecies wird bei diesen Angaben nicht unterschieden.

Die nene Art, welche noch nicht benannt wird, ist etwa $26-28 \mu$ lang bei einer grössten Breite ron ungefähr $4,0-5,5 \mu$. Sie erscheint an ihrem hintern Pole zugespitzt, am vorderen abgerundet und liegt in der Regel nicht direkt in stroma des roten Blutkörperchens, sondern in einer ..stark lichtbrechenden, farblosen Kapsel, welche das Ansehen einer Cylinderröhre hat. an welcher das eine Ende keulenförmig ausgetrieben ist." Daneben wurden, wenn auch nur in geringer Zahl, andere Formen ohne solche Kapsehn gefunden, welche dem Drepanidium magnum sehr ähnlich waren und den Erythrocytenkern an einer seiner langen Seiten, ein wenig um die P'ole einbiegend, dicht einschlossen und deren Plasma sich nach der Romanowskyschen Methode nur sehr schwach mit Methylenblau färbte.

Vermehrungsstadien wurden auch bei Untersuchung von Leber, Milz, Lungen und Knochenmark nicht gefunden.

Die den Arbeiten beigefügten T'a feln enthalten die Reproduktion einer Anzahl von Microphotogrammen. Die der später erschienenen deutschen Arbeit beigefügte Tafel ist neu lıergestellt, enthält ein Microphotogramm mehr und ist auch etwas schärfer als die Tafel des russischen Originals. Die Verbältnisse der ..Kapsel“, auf welche Yerf. bei seiner Schilderung besonderes Gewicht legt, treten jedoch auf keiner von beiden Tafeln dentlich hervor. Einige bedauerliche Druckfehler, welche sich in die Figurenerklärung der deutschen Arbeit eingeschlichen haben. sind wenigstens zum Teil auch ohne Vergleich mit dem russischen Original verständlich. Trotzdem dürfte es wünschenswert sein, hier darauf hinzuweisen, dass ebenso wie Fig. 5 und 6 (nicht 4 und 5) ..freie Parasitenformen" darstellen, in Fig. 7 -9 (nicht 6-8) ...jüngere Formen inkapsulierter Parasiten" abgebildet sind und Fig. 7 (nicht 8) ausserdem noch ein ,Drepanidium monitis" enthält, während "Damilerskyg knusei" nur in Fig. 10-12 (nicht 9-12) dargestellt ist. Allerdings felılt auf der deutschen 'Tafel die auf der russischen vorhandene Nummerierung der einzelnen Figuren, so dass die Figurenzahl dureh Abzählen zu ermitteln ist.

II. L ii h e (Königsherg i. Pr.). 
678 Durham, H. B., Drepanidium in the Toad. In: Report of the Yellow Fever Expedition to Parà of the Liverpool School of Trop. Med. and Med. Parasitol. (Liverpool School Trop. Med. Mem. VII.) Liverpool 1902. pag. 78-79.

Gelegentlich der Expedition, welche im Jahre 1900 zur Lrforschung der Ïtiologie des gelben Fiebers nach Parà entsandt wurde und die Übertragung desselben durch Stegomyia fasciata sicherstellte, wurde auch in verschiedenen Tieren nach etwaigen Blutparasiten gesucht. Solche wurden namentlich bei einer kleinen Kröte und zwar regelmäßig gefunden. Die Vitteilungen hierüber sind von einem gewissen allgemeinern Interesse, trotzdem eine Bestimmung der Kröte nicht versucht worden zu sein scheint und auch die Schilderung des der Gattung Drepanidium zugezählten Parasiten nicht ausreichend ist. um sie für die Systematik zu verwerten.

Es wurden in den roten Blutkörperchen rerschiedene Formen von Parasiten gefunden, ron welchen eine dem gewöhnlichen Drepanidium entsprach, die andere der von Labbé als Dactylosoma bezeichneten Form. Beide Formen werden, noch ohne Kenntnis der Arbeit von Hintze (vergl. \%ool. \%entr.- Bl. IX. 1902., Nr. 5ૅ1), dersebben Parasiten-Art zugeschrieben nnd zwat wird die durch die Untersuchungen Hintzes als berechtigt erwiesene Vermutung anfgestellt, dass die Diepanidium-Form die Gameten darstelle, die Dactylosoma-Form dagegen die sich ungeschlechtlich in der Kröte vermehrende Generation.

Im cirkulierenden Blute wurde eine Vermehrung der InepranidiumForm nicht beobachtet, wohl aber eine solche des Dactylosoma-Form. Während aber Hintze glaubt festgestellt zu haben, dass die Hämosporidien der Frösche sich olne Wirtswechsel entwickeln, ist D u rham (wohl mit Recht, vergl. das nachstehende Referat! Ref.) davon überzeugt, dass auch bei diesen ein Wirtswechsel vorliegt. Als zweiter Wirt wird mit Wahrscheinlichkeit eine Zecke (Ixodes) angesehen, mit welcher fast alle Kröten behaftet waren. Die Hauptaufgabe der Expedition gestattete freilich nicht, auf die Verfolgung dieser Frage viel Zeit zu rerwenden. Auch waren keine parasitenfreien Kröten für künstliche Infektionsversuche zu erhalten. Indessen wurde doch folgendes festgestellt:

Wenn eine grössere Quantität dem Herzen der Kiröte entnommenen Blutes direkt mit Sublimatlösung fixiert wurde, wurden niemals freie Parasiten gefunden, sonderu ausschliesslich solche, welche in rote Blutkörperchen eingeschlossen waren. Wurde jedoch das Blut frisch untersucht, so konnte nach einiger Zeit ungekehrt kein einziger endoglobulärer Parasit der Drepanidienform mehr geïunden werden, alle 
waren freigeworden. Ein Vergleich mit dem ähnlichen Verhalten der Gametocyten der Malariaparasiten liegt nalie. Bei I'ntersuchung der Zecken wurden eigentümliche Cysten gefunden von einer Grösse bis zn $60 \mu$. Es wurde feruer konstatiert, dass die lewegungen der freien Irepanidien in den Magensäften der Kecken viel lebhafter waren als im Kiötenblut. Endlich wurden Vorgänge beobachtet, welche die Vermutung einer im Magen der Zecken erfolgenden Copulation weckten, auf die aber nicht näher eingegangen wird. I) jedoch Material für weitere Untersuchungen konserviert worden ist, so werden wir vielleicht noch genanere Mitteilungen erwarten dïrfen.

M. Lïh l (Königsberg i. Pr.).

679 siegel. C.. Die geschlechtliche Entwickelung von Haemogregarina stepanori im Riisselegel Placobchella catemigera. In: Arch. f. Protistenkde. Bd. II. 1903. Hit. 3. pag. 339-342. Mit 7 Fig.

Vorliegende Arbeit bedeutet einen wichtigen schritt vorwärts in unserer Kenntnis der Hämosporidien. Waren bisher Gienerationsund Wirtswechsel nur von den Malariaparasiten des Menschen und von einem der beiden Hämosporidien der Tögel bekannt, so hat Si egel nunmehr einen durchans analogen Zeugungskreis auch für eine der zahlreichen. in Kaltblütern schmarotzenden Hämosporidienarten nachgewiesen. Die rorliegende vorlänfige Mitteilung bringt nur eine kurze Übersicht iiber die erzielten Resultate. Hiernach ist der zweite Wirt der in Emys Intraria häutigen Haemogregarina stepanori ein Egel, Placobulla catenigera. In den Magenblindsäclien derselben bleiben die roten Blutkörperchen der Schildkröte sowohl wie die darin eingeschlossenen IIämo-poridien monatelang unverändert. Nur eine geringe (quantität des Blutes gelangt täglich in den I)arm. Die in diesem enthaltenen bohnenförmigen Parasiten werden nur wenig verändert und noch schön färbbar mit den Kote wieder ausgeschieden, wogegen die schlangenförmigen Parasiten die Infektion des Egels bewirken, indem sie sich zwischen den Zotten des Darmes z. $\mathrm{T}$. in Macrogameten z. T. in Microgameten verwandeln. Bemerkenswert ist die ausserordentliche Kleinheit des Microgameten. wie sie ähnlich auch bereits Hintze bei Lankesterella minima gefinden hat (vol. Zool. Zentr.-Bl. IX 1902. Nr. 541.). Aus der Kopnlation geht wie bei den Malariaparasiten ein langgestreckter Ookinet hervor, welcher in den die Darmdivertikel umschliessenden Bluträumen und weiterhin im Herzen des Egels wiederzufinden ist und schliesslich in die Zellen der Ösophagusdrüsen gelangt, die kurz hinter dem Rïssel gemeinsam ausmünden. Erst hier runden sich die Ookineten, in denen die Kern- 
vermehrung bereits vorher begonnen hatte. ab, wachsen unter gleichzeitiger weiterer starker Vermehrung der Kerne erheblich heran und lassen schliesslich eine grosse Zahl spiralgewundener Fäden ans sich hervorgehen, welche frei werden und in das Lmmen der Drïse gelangen. Es sind die Sporozoiten, welche die Infektion der Schildkröten bewirken, in deren Blut sie bei dem Saugeakt gelangen.

Bemerkenswert ist, dass nicht nur alle daranflin untersuchten ausgewachsenen Egel diese Sporozoiten in ihren Ösophagusdrüsen enthielten, sondern dass dieselben Sporozoiten auch bereits in den kaum entwickelten Ösophagusdrüsen der noch unreifen, vom Dotter lebenden Embryonen nachweisbar waren. Es muss also hier eine germinative Infektion des Egeleies stattgefunden haben, ähnlich der von Balbiani entdeckten Infektion der Seidenraupeneier mit dem die Pebrine erregenden Microsporid Tosema bombycis und der von F. E. Schulze entdeckten Infektion der Eitr ron Spongelia pallescens mit der in diesem Schwamme niemals fehlenden parasitischen Alge.

Aus einer "Anmerliung des Herausgebers", welche dieser Mitteilung Siegels beigefügt ist, muss noch hervorgchoben werden, dass Schaudinn den Wirtswechsel auch bereits bei einem zweiten Kaltblüterhämosporid festgestellt hat. Infektionsversuche, welche Schaud in $n$ angestellt hat, ergaben nämlich, dass das als Karyolysus bekannte Eidechsen-Hämosporid durch die Larren und Nymphen von Irodes ricims übertragen wird. Schaudinn hat auch bereits die Befruchtung und die Entstehung der Ookineten im Darm der Kecken verfolgt und ferner ermittelt, dass die İbertragung auf die Eidechsen sowohl durch dieselbe (ieneration der sich infizierenden Zeckenlarven, wie auch durch deren Tochtergeneration erfolgen kann.

Dass durch diese Untersuchungen nunmelir bei zwei verschiedenen Arten von Kaltbliiterhämosporidien ein Wirtswechsel nachgewiesen ist. kann auf die Beurteilung der, einen solchen Wirtswechsel bei der Lankesteiclla der Frösche in Abrede stellenden Arbeit Hintzes ( $\mathrm{rgl}$. Zool. Zentr.-131. IX. 1902. Nr. 541) nicht ohne Einfluss bleiben. Der bereits in dem eben citierten Referat ron mir geäusserte Verdacht, dass die von Hintze im Darm der Frösche beobachteten Oocysten nicht in den Zeugungskreis der Lankesterella gehören, gewinnt nunmehr einen sehr hohen (irad ron Wahrscheinlichkeit, wie dies auch Schaudinn in der von ihm der Arbeit des Verfassers beigefügten Anmerkung direkt ausspricht.

Zum Schluss sei noch darauf hingewiesen, dass die Feststellung der Infektionsvermittelung durch die Tochtergeneration derjenigen Egel bezw. Zecken, welche sich durch parasitenhaltiges Blut direkt 
infiziert hatten, auch mit Riucksicht auf die seit langem bekannte entsprechende Übertragung von P'roplasma boris (Babes) noch grössere Beachtung verdient, als dies an sich schon der Fall ist.

M. Lii he (Königsberg i. Prr.).

680 Grassi, B., Document iriguardanti lastoria della scoperta del modo di trasmissione della malaria umana. Roma 1903. $\mathrm{S}^{0} .103$ pag.

Vorliegende Publikation enthält, abgesehen ron einem kurzen Vorwort und einer am Schlusse folgenden historischen Zusammenfassung, beide von wesentlich polemischer Tendenz, Abdruicke der Publikationen von Grassi und Ross uber die Entwicklung der Malariaparasiten des Menschen im Körper der Mücken, soweit diese Publikationen bis September 1899 inkl. erschienen sind. Der Wert, welchen sie durch diese Zusammenfassung einer grösseren Zahl zerstrenter einzelner Arbeiten hat, wïrde freilich grösser sein, wenn sie auch die Arbeiten von Ross iiber die entsprechenden Entwicklungrorgänge des Plasmodium muecox der Tögel (bekannter nuter dem Namen Proteosoma) enthielte. Dass diese, zwar nicht die menschlichen Malariaparasiten behandelnden, aber gleichwohl fïr die neuere Malariaforschung grundlegenden Arbeiten ron Ross fehlen, hängt jedoch mit der Tendenz der ganzen Publikation zusammen, die mit den unerfreulichen Prioritätsstreitigkeiten, in welche der Verf. verwickelt ist, insofern in Zusammenhang steht, als der V'erf. seine eigenen Verdienste möglichst in den Vordergrund zu riicken bestrebt ist.

I. L, ii he (Königsberg i. Pr.).

681 Laveran, A., Sur quelques Hémogregarines des Ophidiens. In: Compt. rend. Acad. Sci. T. CXXXY. 1902. Nr. 23. pag. 1036. -1040. 13 Fig.

Verf. macht in vorliegender Arbeit Mitteilung von einigen neuen Hämogregarinen aus verschiedenen schlangen.

1. Haemogregarina najae n. sp. ans Naja tripudians. Der ams. einen Ende abgerundete, an andern zugespitzte l'arasit ist im gestreckten Zustande 21-22 lang und am abgerundeten Ende 3 " breit. Innerhalb des roten Blutkörperchens ist er in bekannter Weise zweischenklig zusammengebogen und infolge dessen nur etwa $14 \mu$ Jang. Hypertrophie des Erythrocytenkernes, wenn iiberhaupt auftretend, nur gering.

2. Hacmogregarina zamenis n. sp. aus Zamenis hippocrepis. Gleichfalls am einen Linde abgerundet, am andern zugespitzt, aber plumper als die vorige Art. Breite etwa 4 «, Länge des zweischenkelig 
zusammengebogenen Stadiums $18 \mu$. Daneben fanden sich auch noch kleine orale Parasiten in den roten Blutkörperchen, von ähnlicher Form und Grösse wie der Erythrocytenkern. Dieselben werden als Jugendformen gedeutet. Hypertrophie des Erythrocytenkernes häufig beobachtet. Nicht selten streckt sich dieser Kern so in die länge, dass er fast ebenso lang wird wie der neben ihm gelegene Parasit: trotzdem erscheint er niemals randständig. bez. überhaupt nur erheblich aus der Mitte des roten Bhtkörperchens verdrängt.

3. Haemogregarina crotali n. sp. aus Crotalus confluentus. Zweischenkelige Formen nicht beobachtet. Grösste Parasiten $15-16 \mu$ lang und $5-6 \mu$ breit, an beiden Polen abgerundet, bohnenförmig bis langgestreckt oral. Der Kiern des befallenen Erythrocyten ist stets und häufig sehr erheblich hypertrophiert und wandständig. Seine Länge kann die des Parasiten noch iibertreffen.

4. Hamogregarina mocassini n. sp. ans Ancistrodon piscivorus. Jugendform schlank. gestreckt, nicht zweischenkelig. Zweischenkeliges Stadium im zusanmengebogenen Znstande 12-17 $\mu$, im gestreckten Zustande 20-25 "lang. Breite nicht angegeben, aber nach den Abbildungen zu erteilen nur gering und ungefähır derjenigen ron Haemogregarimu najae entsprechend. Erythrocytenkern verlagert und abgeplattet, aber nicht hypertrophiert. der befallene Erythrocyt selbst jedoch häutig etwas verlängert.

In einem Schlusswort betont Verf. die Schwierigkeit der systematischen Unterscheidung der Hämosporidien der Schlangen, solange deren Entwickelung noch so gänzlich mbekannt sei. Er glanbt jedoch nicht, dass es berechtigt ist. alle diese Formen verschiedener Wirte mit L u tz (vergl. \%ool. Zentr.-131. 1X. 1902. Nr. 19/20 pag. 623) zu einer einzigen Art zusammenzufassen. Endlich gibt er seiner Überzeugung dahin Ausdruck. dass anch die Hämosporidien der Schlangen jedenfalls durch Ektoparasiten übertragen werden.

M. Lïhe (Königsberg i. Pr.).

682 Laveran, A. et F. Mesnil, Sur quelques Protozoaires parasites d'une T'ortue d'A sie (Damonia reeresii). In: Compt. rend. Acad. Sci. Paris 'T. CXXXV. 1902. pag. 609-614.

Die Verff. haben mehrere Exemplare von Dumonia recresi, welche angeblich aus Ceylon, wahrscheinlich aber aus China oder Japan stammten, auf parasitische P'rotozoen untersucht und deren auch nicht weniger wie 5 verschiedene Arten gefunden. Im Darmkanal schmarotzte ein (occid (Coccidium mitrarium n. sp.), dessen Schilderung bereits in der vom Ref. verfassten zusammenfassenden Übersicht über die nevere Coccidienliteratur (pag. $631 \mathrm{f}$ ) berücksichtigt ist. In den Nieren 
fand sich ein Myxosporid, welches mit dem in den Nieren von Emys Jutraria gemeinen Myxidium tamilerskyi identificiert wird. 1)ie anderen drei Parasiten schmarotzten im Blute und zwar lisndelt es sich um zwei Hämosporidien und ein Trypanosoma.

1. Haemogregarina stepanowiana 11. sp).. so genannt wegen seiner Ïhnlichkeit mit $H$. stepanori, welche bei den bohnenförmigen Stadien besonders gross ist. Auf dem zweischenkeligen Starlium ist die Speciesverschiedenheit dagegen dentlich, da der eine der beiden Schenkel stets erheblich dünner und kürzer ist als der andere. Wenn dieses Stadium aus dem roten Blutkörperchen ausgetreten ist und sich streckt, ist es mit einer Länge ron 18-20 « und einem grössten Durchmesser (nahe dem einen Ende) von etwa $5 \mu$ erheblich kürzer und breiter als das entsprechende Stadium ron Hacmogregurina stepanori. Vermehrungsstadien wurden nie im peripheren Blute, wolıl aber in der Leber beobachtet. Sie sind wieder ähnlich wie bei Haemogregarina stepanowi. Der Parasit, welcher sieh zur Vermehrung anschickt, nimmt orale Gestalt an. Sein Kern teilt sich durch dreimal wiederholte Zweiteilung, so dass \& Tochterkerne entstehen, darauf folgt die Teilung des ganzen Parasiten in 8 Tochterindividuen. - Diese Hämosporidienart wurde ron den Verff. in allen 4 daraufhin untersuchten Exemplaren von Damonia reeresi gefunden. Ls sei deshalb die Bemerkung gestattet, dass lief., der denselben Parasiten in der gleichen schildkröte kurz ror dem Erscheinen der hier besprochenen Publiliation gleichfalls gefunden hat. iln hei Untersuchung melırerer Exemplare auch nie vermisst hat.

2. Haemogregarina rara n. sp. wurde nicht ganz so häufig (dreimal bei 4 schildkröten) gefunden. Sie ist kiirzer und schlanker als H. stepanowiana, in Mittel $15 \mu$ lang und $2-3 \mu$ breit, ihr Hauptunterschied gegeniber $H$. stepanowiana liegt aber nach Laveran und Mesnil im Kern. Dieser ist nämlich bei $H$. stepanowiana rundlich bis oval, mit der grössern Achse häufig quer zur Längsrichtung der Hämogregarine gestellt. Bei $H$. rava dagegen ist der Kern sehr lang gestreckt, cylindrisch, wenigstens ${ }^{2 / 3}$ so lang wie das ganze Hämosporid und an seinen heiden Enden in der Regel kolbig verdickt.

Dass es sich bei den beiden vorstehend charaliterisierten Formen um zwei verschiedene Arten und nicht un einen mit geschlechtlicher FortpHanzung in Zusammenhang stehenden Dimorphismus handle, begründen die Verff. damit, dass 1 . beide Formen nicht immer gleichzeitig gefunden wurden - 2. dass Sim ond (vergl. Zoolog. Zentr.-Bl. 1902. Nr. 18 pag. 562), welcher doch verschiedene Hämosporidienarten aus Schildkröten beschrieben habe, keine der Haemogregarina rara 
,analoge" Form erwähne -- 3. dass die der $H$. stepanoviana so ähnliche $H$. stepanowi keine Geschlechtsfornen besitze [dies ist ein Irrtum; wenn dieselben auch bisher noch nicht bekannt oder vielmehr richtiger erkannt waren, so sind sie doch inzwischen von Siegel studiert worden; vergl. das Referat Nr.679. Ref.] - 4 . dass die Existenz von Geschlechtsformen für Hämogregarinen überhaupt noch nicht nachgewiesen sei [dieser. Satz ist mir mit Rücksicht auf die Arbeit von Hintze - vergl. \%ool. Zentr.-B1. IX. 1902. Nr. 18. pag. 550 - nicht rerständlich, da ja L a veran auch die Hämosporidien der Früsche zur Gattung Haemogregarina rechnet - vergl. Zool. Zentr.-Bl. 1902. Nr. 18 pag. 5̆̉ 1 Ref.].

3. Trypanosoma damonue n. sp. ist schlanker als das Trupanosoma rotatorium der frösche, aber weniger schlank als die Trypanosomen der Fische und der Säuger. Vermehrungsstadien wurden nicht beobachtet, auch waren die Trypanosomen in den beiden Schildkröten, in welchen sie gefunden wurden, sehr selten. Länge einschliesslich der Geissel 32 $\mu$, Breite etwa $4 \mu$.

1. Lü̈lı (Königsberg i. Pr.).

683 Laveran, I. et F. Mesnil, Sur les Hámatozoaires des Poissons marins. In: Compt. rend. Acad. Sci. Paris. '1'. 135. 190\%. Nr. 15. pag. $567-570$.

Die Verff. machen Angahen ïber dic Häufigkeit der beiden bereits frïher von ihnen geschilderten Hämogregarinen (vgl. Zool. Zentr.-Bl. IX. 1902. Nr. 18. pag. 554 f.), sowie eines Trypanosoms in den zn Roscoff und in der Anse Saint-Martin untersuchten Exemplaren ron Solea rulgaris hez. verschiedener Blennus-Arten. Speziell die Huemogregurina simonli wurde in Solen vulguris nur selten vermisst, was Ref. auch für Rovigno und Triest bestätigen kaun. Haemogregarina biyeminu wurde in der Anse Sirnt-Martin in zahlreichen Exemplaren von Blemins thotis und Blennius montami (der letztere Wirt war in der vorigen, an der eingangs citierten stelle referierten Arbeit der Verff. versehenthich als Bl. gattorugine bezeichnet worden) fast stets gefunden, in Roscoff dagegen nur in 4 von 11 untersuchten Blennius mehrerer, einzeln nicht angeführter Arten. Tiyponosoma soleae fand sich im ganzen in 3 von 14 untersuchten Seezungen. Anschliessend an diese Angaben werden auch noch sämtliche Knochenfischarten angeführt, welche vergeblich auf Blutparasiten untersucht wurden und zwar mit Angabe der untersuchten Individuenzahl.

Die Verff. laben nunmehr aber auch in Selachiern Bhtparasiten nachgewiesen und schildern kurz zwei neue Arten:

1. Haemogregarina delagei nov. sp. in Raja punctata und Raja 
mosaica, in Form und Grösse an Haemogr: bigemina erinnerud, int Mittel $13 \mu$ lang bei einer maximalen Breite ron $2 \mu$, am einen Ende abgerundet, am andern zugespitzt, in rasch fixierteı Präparaten stets endoglobulär und nicht selten zu zweit in einem Erythrocyten. Ausser dem ovalen Kern, der etwa in der Mitte des Körpers liegt und aus einem Haufen einzelner Chromatinkörnchen bestehen soll, wurden noch einzelıe Chromatinkörnchen im Plasma beobachtet.

2. Trypanosoma scylliumi nov. sp. [soll wohl scyllii heissen! Ref.] aus Scyllium stellare, 70 - $80 \mu$ lang, wovon $14-20 \mu$ auf die Geissel entfallen. und $5-6 \mu$ breit, ähnlich dem bereits früher von den Verff. geschilderten Tryp. rajae. von welchem es sich hauptsächlich dadurch nnterscheidet, dass bei der neuen Art das hinter dem Basalkörperchen der Geissel gelegene Hinterende linrz nnd stmmpf abgerundet ist, bei Tryp. rajae dagegen lang und zugespitzt, so dass es mitnnter sogar eine zweite Geissel vortänscht.

Zum Schluss äussern sich die Verff. noch zur Frage des Infektionsmodus. Sie haben in Roscoff auf allen intizierten Seezungen in grosser Zahl einen Ichtyobdelliden gefunden (Hemibdella soleae van Ben. et Hesse) und vermuten daher. dass dieser die Infektion vermittele. Auf der Haut ron Blennien haben sie dagegen nie I'arasiten gefunden. Sie denken daher an die Möglichlseit, dass die Hurmogregurina bigemina durch einen in der Anse Saint-Martin häufigen Isopoden uibertragen werde, welcher zeitweise auf den Kiemen der Blemnien schmarotzt (Praniza spec.).

M. L ï he (Königsberg i. Pr.).

684 Maurer, G., Die II alaria perniciosa. Beitrag zur Biologie und Morphologie ihres Erregers. In: Centrbl. f. Bakter. ete. I. Abtlg. Bd. XXXII. 1902. Originale. Nr. 10. pag. 695-719. Mit 3 Tateln.

Verf., welcher bekanntlich ebenso wie Ref. das sogen. Sommerherbstieber oder 'Tropenfieber als Perniciosa bezeichnet, macht in vorliegender Mitteilung Angaben über die Fntwicklnng des Parasiten dieser Malariaform, der Lacerania malariae. Die für die jungen Stadien charakteristische Ringform hatte Verf. früher im Anschluss an Il annaberg dadurch erklärt. dass er den Hohlramm des Ringes als Kern und das sich nach Romanowsky rot färbende Gebilde nur als „Kernkörperchen“ ansah. Jetzt jedoch hat er sich iiberzeugt, dass nicht das geringste Zeichen für die Znsammengehörigkeit der beiden genannten Elemente sich finden lässt. Da andererseits das Plasma des Parasiten sich stets in scharfer Kreishinie gegen den ungefärbten Innenraum abgrenzt und der Kern im mikroskopischen Bilde anstatt in dem Protoplasma des Ringes anch innerhalb des zentralen 
farblosen Teiles des Parasitenkörpers erscheinen kann, da ferner sich Bilder beobachten lassen, nach welchen der Ring zur Hälfte in das Blutkörperchen einzuschneiden, zur andern Hälfte frei in das Blutplasma sich vorzuwölben scheint, während der ungefärbte Binnenraum wieder eine genau kreisrunde Scheibe darstellt - so muss die Ringform des Parasiten scheinbar und der Binnenraum eine von Flüssigkeit (aus dem Blute aufgenommener Nahrung) erfüllte Nährvakuole sein. Diese Auffassung, welche auch dem Ref. allein möglich erscheint, hat ja auch Schaudinn in seiner kïrzlich referierten Arbeit vertreten, freilich ohne eine Begründung für nötig zu halten. In den Merozoiten ist [entgegen den Angaben Ewings, Ref.] ein nngefärbt bleibender Teil noch nicht vorhanden und nur das Auftreten der Nährvakuole scheint anfünglich die Volumzunahme des jungen Parasiten zu bedingen. Diese jungen Parasiten sollen nun nach Ma urer nicht in sondern a u den roten Blutkörperchen leben, was auch "schon lange bekannt" sei — rom Ref. aber trotzdem entschieden bezweifelt wird.

Von den ..kleinen Ringen" mit schmalem Protoplasmastreif werden die ..grossen Ringe" unterschieden, in welchen der Kern und namentlich das Protoplasma an Mitsse zugenommen habe, die Vakuole dagegen eher etwas kleiner als grösser geworden sei. Auch noch diese grossen liinge sollen dem Blutkörperchen nur a ufliegen und nicht selten das Blutkörperchen am liande umgreifen.

Auf einem noch späteren Stadium soll dann endlich der Parasit in das rote Bhutlörperchen eindringen (wie ihm das jetzt noch möglich ist, nachdem er bereits zu einen relativ grossen, rundlichen Gebilde herangewachsen ist, wird freilich nicht rerraten) und wird ron nun an als ,interner Schizont" bezeichnet. Da das Pigment in den grossen Ringen noch wenig hervortritt, bei den "internen Schizonten“ dagegen ,plötzlich als anselnnliche Masse" auffüllt, so wird ferner angenommen, dass der P'erniciosaparasit „den grössten Teil seines Pigmentes während des Eindringens in seinen Wirt" bilde und es im Gegensatz zu dem Quartan- und Tertianparasiten sammle, bevor die Teilung des Kernes begonnen liabe.

An den rou dem l'erniciosaparasiten befallenen roten Blutkörperchen hat II a urer eine charaliteristische Fleckung nachgewiesen, welche er auffasst als Ausdruck von ..Substanzveränderungen resp. -verlusten auf der Oberfliiche des Erythrocyten, die eine Folge sind ron Angriffen des (noch nicht in das Blutkörperchen eingedrungenen) Parasiten, welche dieser unternimmt, um sich an seinem Träger festzuhalten und sich Nahrung zu verschaffen." Mit der Anzweiflung des Sitzes der Parasiten a u dem roten Blutkörperchen statt in dem- 
selben wird natiurlich auch diese Deutung der fraglichen Flecken unannehmbar (rgl. hierzu das folgende Referat).

Jie Gametocyten sollen sich ron den Schizonten unter anderm dadurch unterscheiden, dass sie reichlicher Pigment bilden. Dieso Beobachtung, welche mit den Angaben Schaud in ns über den Tertianparasiten in gutem Einklang steht. wird von Na urer dadurch erklärt, dass , diejenigen kleinen liinge, die sich zu Gameten umbillen, frühzeitig in das Immere der Blutscheibe eindringen" und dort, .von Nahrungssubstanz umgeben, sich bequem mit dem Nötigen rersorgen" kömnen, .. während der aut dem Blutkörperchen lebende Schizont die Nahrung von seinem Wirte in sehr geringen Portionen bezieht." Die oben erwähnte Fleckumg wucde bei roten blutkörperchen, welche Halbmonde enthielten. nicht beobachtet und ihr Fehlen oder Vorhandensein wird deshalb zm Differentialdiagnose zwischen jungen Schizonten und jungen Gametocyten benutzt (vgl. hierzu jedoch das folgende lieferat). Als charakteristisch für die Halbmonde wird dagegen ein sich intensiv rot fïbender samm bezeichnet, der Ausdruck einer "Kapsel"bildung um den Parasiten, welche die lolge ist von Veränderungen des stronas des Erythrocyten. Die beiden fieschlechter der Gimetocyten unterscheiden sich schon durch ihre Form. Der Macrogamet ist länglich, schlank, leicht gekrümmt: der Microgametocyt kürzer und breiter, mehr bohnen- oder nierenförmig als halbmondfömig. Der grosse Kern des Microgametocyten ist ,.ans locker geschlungenen, wirr durchemander liegenden oder in dentlich getrennten Zügen angeordneten Fäden zusamnengesctzt" und nur von einem schmalen Protoplasmasaume umgeben. Der ..aus dicht geschlungenen Faden bestelıende" liem des Macrogameten dagegen ist kleiner und liegt innerhalb cines grossen Protoplasmakörpers, welcher im Gegensat\% zu allen andern Ingaben (rgl. z. B. das folgende Referat oder die kiur\%lich referierte Publikation von (iray) sowie zu eigenen Beobachtungen des Ref. als ..sehr wasserreich und daher mur schwach bläulich gefärbt" bezeichnet wird. Einen ausschlaggebenden Lnterschied in der Form und Anordnung des Pigmentes hat Manrer im Gegensatz zu andern Angaben (\%. B. Gray) nie finden kömnen, wenngleich natürlich infolge der erheblichern Grösse des Kernes bei den Microgametocyten das Pigment häufig mehr zerstrent liegt.

Ton besonderm Interesse sind emige Angaben iuber die Entstehung der Rezidive, welchen eine ähnliche beobachtung zu grunde liegt, wie sie Scha udin heim 'lertianparasiten gemacht hat. Fis wurde nämlich (allerdings nur in einem einzigen Falle) ein Halbmond beobachtet, bei welchem das I'rgment ebenso zentral zusammengedrängt war wie bei den vor der Teilung stehenden schizonten und bei 
welchem der Kiern in Teilung begriffen zu sein schien. Schon frïher einmal hatte Ma urer in einem andern Falle eine Teilungsfigur beobachtet, welche ihm nur erklärlich schien durch die Annahme eines sich schizogenetisch teilenden Halbmondes. Da nun auch bei Fällen von Perniciosa, bei welchen es nicht zur Halbmondbildung gekommen war, die Rezidive ausblieben, so kommt Ma urer zu dem Schlusse. dass die Halbmonde, abgesehen von ihrer geschlechtlichen Funktion, auch noch „Dauerformen“ darstellen, „d. l. Formen. die der Parasit annimmt, um gewissen schädlichlieiten zu entgehen, und die er so lange beibehält, bis die Gelegenheit zur Weiterentwicklung durch 'Teilung rïnstiger wird."

Es folgen noch eine Besprechung der klinischen Erscheinungen der P'erniciosa. sowie Angaben über' die Färbetechnik.

\section{Lïlı e (Königsberg i. I’r.).}

685 Irgulinsky, P., 7ur Kenntnis des Tropicaparasiten (Plasmodium pracou Gr. n. Fel. - D i e 'Tüpfelung der Wirtszellen der Halbmonde. In: ('entrbl. f. Baliter. etc. I. Abtlg. Pid. XXXIV. 190\%. Orig. Nr. 2. pig. 144 149. 1 'Taf.

Terf. hat neuerdings ciolegenleit gehabt, in Anschlnss an seine Untersuchungen ïber den l'ertianparasiten anch den P'orniciosa- oder 'Iropica-Parasiten zu untersuchen und bespricht in voriegender Arbeit speziell eine charaliteristische 'lïpfelung der von Halbmonden bewohnten Erythrocyten, sowie dic Geschlechtsunterschiede bei den Halbmonden. Diese Geschlechtsunterschiede entsprechen denen, welche Sclla dinn in seiner küzlich referierten Arbeit über den 'Tertianparasiten ausfühlich geschildert hat. Die ausgewachsenen männlichen Halbmonde besitzen ein hyalines, bei färbung nach Romanowsky sich blassbläulich färbendes, mitunter sogar fast farblos bleibendes Protoplasma und einen relatir grossen liern, „Aer den grössten T'eil des Halbmondes einnimmt." Sic sind kürzer und breiter, der sie umhüllende Frythrocytensaum ist fist immer schmäler als bei den weiblichen Halbmonden. Diese letztern liaben ein dunkleres, sich gesättigt blau färbendes Protoplasma, welches nach den Enden des Halbmondes zu noch dunkler wird, und einen kleinen, runden oder ovalen Kern. Diese Lnterschiede sind so prägnant, dass Verf. in seinen l'räparaten die beilen Geschlechter stets auf den ersten Blick unterscheiden kann. Die 'Tüpfelung des rom Halbmond bewolnten Erythrocyten war in nach der üblichen Trockenmethode hergestellten Präparaten nicht darstellbar, trat aber sehr schön hervor in l'räparaten, welche nach der vom Verf. in seiner kürzlich referierten zweiten 'lertiana-Arbeit angegebenen Methode behandelt waren. Feuchte 
Fixierung in Osmiumdämpfen, darauf trockneu lassen, Behandlung mit offizineller Wasserstoffsuperoxyd-Lösung 30 Ninuten lang, darauf Auswaschen während 12-24 Stunden in mehrfach gewechseltem destilliertem Wasser; Färben mit altem Sodamethylenblau-Losin mit nach folgender Differenzierung in angesïuertem Alkohol. Anstatt reiner Osmiumsäure benutzt Terf. jetzt ein Osmiumessigsäure-Gemisch. In entsprechend behandelten Präparaten mit Tertiamparasiten ist die T'ïpfelung der infizierten Erythrocyten nicht mehr nachweisbar. Andererseits zeigt sich in Präparaten, in welchen durch gewöhuliche Fixierung und Färbung die Tertianatüpfelung dargestellt ist. bei gleichzeitiger Infektion mit Halbmonden keine spur einer Tüpfelung der diese letztern bergenden roten Blutkörperchen. Diese Terschiedenheit im färberischen Verhalten fasst Verf. in dem Satze zusammen: ... Die Tropicatiipfel färben sich also schwerer als die der Tertiana, aber einmal gefärbt, halten sie bei Differenzierung der Färbung mit sanrem Alkohol die Farbe stärker zurück und entfärben sich schwerer als die Tertianatiipfel, was vielleicht mit der Aufquellung der von Tertianparasiten befallenen Erythocyten und der etwaigen Schrumpfung der Blutzellen bei Tropicainfektion im Zusammenhang stehen mag." Abgesehen aber von diesem I'nterschied erscheint die Tüpfelung der ron Halbmonden befallenen Lrythrocyten der von Schüftner entdeckten ..Tertianatiipfelung" durchaus analog. Ausser Halbmonden hat Verf., dem nur einige leichte Erkrankungen in Kasan das Material lieferten, nur noch kleine Ringe (d. h. junge Schizonten) beobachtet und bei diesen war keinerlei l'iipfelung nachweisbar. Dagegen vermutet Verf., dass die von Ma urer (rgl. vorstehendes lieferat) bei ..grossen Ringen" und reifen Schizonten beobachteten Flecken ebenfalls als Tüpfelung aufzufassen seien, sowie dass die „Kapsel des Halbmondes", welche Ma urer auf Grund von stark tingierten Präparaten beschreibt, ein Kunstprodukt infolge rou C̈berfärbung sei und beim vorsichtigen Ausziehen der Farbe sich als der vom Verf. in vorliegender Arbeit besprochene getüpfelte ., Saum"-artige Rest des Erythrocyten erweisen würde.

I. Lühe (Königsberg i. Pr.).

686 Ruge, R., Untersuchungen iiber das deutsche Proteosoma. In: Centralbl. f. Bakter. I. Abtlg. Bd. XXIX. 1901. Nr. 5. pag. 187-191. Mit 2 Kurven.

687 Ruge, R., Researches on the Proteosoma in Germany. Transletad by P. Falcke. In: Journ. Trop. Med. Yol. IV. 1901. Nr. 7. pag. $107-119$, mit 2 Kurven.

Verf. macht Mitteilungen über Proteosomen, welche er bei Berlin in Sperlingen gefunden hat, speziell uiber deren Häufigkeit in 
verschiedenen Jahreszeiten und iiber einige entwicklungsgeschichtliche Einzelheiten.

Am häufigsten war die Infektion der Sperlinge mit den Proteosomen im Herbst (in Oktober 1899 waren von den untersuchten Sperlingen 20\% infiziert. im September $190030 \%$ und im Frïhjahr (im April 1900 27\% ). In Dezember 1899 und Januar 1900 wurde ïberhaupt keine Infektion bei frisch gefangenen Sperlingen beobachtet und selten war dieselbe anch in . Iuni 1900 (nur 5\% 5 ). Eine graphische Darstellung dieser Schwankungen lässt eine gewisse Ihnlichkeit mit dem Verlauf der in Norddentschland (z. B. Wilhelmshafen) beobachteten Malaria-Ejidemien erkennen.

Gegenuiber dem in Italien beobachteten Proteosoma soll das von Ruge bei Berlin gefundene in zwei Punkten Unterschiede erkennen lassen, insofern als die sporozoiten ..viel feiner" waren und als ferner die Ookineten mehr Ïhnlichkeit mit denen des Hulteridium als mit denen des italienischen Proteosoma zeigten. Die Sporogonie in der Mücke erfolgte lei einer zwischen 16 und $24^{\circ}$ C schwankenden Temperatur langsamer als bei $24-30^{2} \mathrm{C}$.

Der Krankheitsverlauf bei den Kanarienrögeln soll rerschieden sein, je nachdem die Infektion durch Injektion proteosomenhaltigen Blutes oder durch Stiche infizierter Miicken hervorgerufen war. Ïhnliche noch unaufgeklärte Verschiedenheiten fand R uge anch bezïglich der Bildung der "Ross schen Keime (black spores)" im Körper von Culex pipiens. Diese fanden sich nämlich ziemlich häufig, ., wenn Mïcken an Sperlingen gresogen hatten, die an einer natürlichen Proteosoma-Infektion litten. Hatten die Miicken aber an künstlich (scil. durch Injektion, Ref.) infizierten Kanarienvögeln gesogen, so kamen die Rossschen Körpercheu (blitck spores) sehr selten, hatten sie an durch Mïckenstiche (scil. experimentell, Iief.) infizierten Kanarienvögeln gesogen, so liamen sie selten zur Beobachtung."

Ausser den ..black spores" fand Ruge in den Cysten an der Magenwand der Mïcken auch ,braune Sichelkeime“ und .. Formen, welche den Ïbergang zwischen diesen braunen Sichelkeimen und den black spores vermittelten." Er glaubt daher „das bewiesen zu haben, was Ross von vorn herein vermutet laatte, dass nämlich die black spores aus den Sichelkeimen herrorgehen," er hat jedoch ..nicht feststellen können, ob sie eine Danerfor'm oder eine Degenerationserscheinung darstellen." Diese Angaben sind nur verständlich durch mangelnde Kenntnis der grundlegenden Arbeiten Grassis iiber die Malariaparasiten. Hat doch Grassi bereits ein Jahr vor Erscheinen der Rugeschen. Arbeit nicht nur den Nachweis erbracht, dass die "black spores" z. T. in der Tat aus Sporozoiten (= "Sichelkeimen“ 
bei li ngel, z. 'T' aber anch ans Restkörpermasse hervorgehen, sondern auch den weiteren Xachweis. dass sie keine Lanerformen, sondern Degenerationserscheinungen sind und dadurch entstehen, dass in der geplatzten Oocrste zurückgebliebene Sporozoiten und Iiestkörper von einer bramen Masse eingekapselt werden, welche in älnlicher Weise anch andere in Mückenkïrper befindliche Fremdkörper einkapsehn kann.

II. Lii he (Königsberg i. P'r.).

688 ron Wasielewsky, Impfrersuche mit Haemamoeba spec. inc. (syn. Proteosoma). Vorläufige Mitteilung. Ans: Hygien. Rundschau 1901. N1. 14. Sep.-Abdr. 2 pas.

689 - Ïber die Verbreitung und kïnstliclıe Übertragnng der Vogelmalaria. In: Arch. f. Hre. Bd. XII. 1901. pag. $68-84$.

Verf. stellt die bisherigen Angaben über das Vurkommen des Proteosoma zusammen. Er sellsst hat dasselbe mehrfach bei Halle und Berlin gefunden, in Strix otus, Emberiza projer. Fringilla coelebs, Fringilla chloris und Passer domesticus. Über das Trorkommen in Spatzen wird zur Ergänzung der rorstehend besprochenen l’ublikation ron Rnge mitgeteilt. dass im , Juli und August 1900 ron 40 spatzen aus Treptow bei Berlin $5=12,5^{0} 0$, im März 1901 von 30 Spatzen aus Rixdorf bei Berlin 2 , also ebenfalls 12.500 infiziert waren. Diese Zahlen passen sehr gut in die ron linge veröffentlichte Tabelle des zeitlichen Torkommens von Proteosoma. Ansführlicher bespricht Verf. den (von ihm stets chronisch befundenen) Infektionsverlauf bei Kanarienvögeln, welche durch Ïberimpfung einer Anfschwemmung parasitenhaltigen Blutes in steriler Nährbonillon kïnstlich mit Proteosoma infiziert worden waren. Mit Riücksicht hierauf unss hier jedoch auf das Original rerwiesen werden.

In der Einleitung zu seiner ausführlichen Arbeit bespricht Verf. auch die Frage der Nomenklatur der Vogelhämosporidien. Vit rollem Recht macht er darauf aufmerksam, dass die ron Kr r use 1890 unter dem Namen Haemomoteus danilewsky und unter Beifïgung guter Abbildungen geschilderte Art unzweifellaft mit der später von Labbé als Halteridium bezeichneten Larerania danilerskyi Grassi und Feletti 1889 identisch ist und nicht mit der unter dem Labbéschen Namen Proleosoma am besten bekannten Hacmamoebu maecox Grassi und Feletti 1889, dass dilher der K r u sesche Gattungsname Haemon'oteus auch nicht. wie dies Labbé in "Tierreich" (Liefg. 5. Sporozoa. pag. 79) rersucht hat, für Proteosoma wieder eingefuihrt werden darf, sondern dass vielmehr jener ältere Gattungsname an die stelle von Halteridium zu treten hat. Weniger gliicklich scheint nir dagegen Verf. in der Frage 
der Benennung des Proteosoma gewesen zu sein. Er will für dieses anf Grund des Prioritätsgesetzes den Namen Cytosporon malariae Tanil. einführen. Ref. hat dem gegenüber bereits an anderer Stelle (Baumgartens .Jahresbericht XVII. 1901. pag. 669) betont, dass in den D a nilewskyschen Publikationen für die Hämosporidien der Vögel überhaupt keine präzisen Speciesnamen aufzufinden sind, auf welche das Prioritätsgesetz anwendbar wäre. Der älteste Speciesname für das Proteosoma ist rielmehr Haemamoeba maecox Grassi et Feletti, der prioritätsrechtlich allein zulässige Name daher Plasmodium praecox (Gr. et Fel.) — oder, wenn man für diesen I'arasiten eine besondere Gattung bilden will, was Ref. jedoch ebensowenig für notwendig hält wie Schaudinn in seiner kürzlich referierten Tertiana-Arbeit: Proteosoma pracer: (Gr. et Fel.). M. L ï he (Königsberg i. I'r.).

690 Ruge, Reinhold, Fragen und Probleme der modernen Ma lariaforschung. In: Centr.-Bl. Pakter. Bd. XXXII. 1902. Originale. Nr. 11. pag. 776--799. 1 Taf. und 1(8) Fig. im Text.

In vorliegender Arbeit liat der lekannte Malariaforscher sich vor allem die Aufgabe gestellt, die Entwicklung der Gametocyten des 'Tertianparasiten klarzulegen, und ist hierbei z. T'. zu älınlichen. z. T. freilich anch zu etwas anderen liesultaten gelangt als schandinn in seiner annähernd gleichzeitig erschienenen nud kïrzlich referierten Arbeit (vergl. Nr. 17 pag. 589). Er bezeichnet als charaliteristisch für die Gametocyten in Gegensatz zu den Schizonten. dass das Chromatin. nicht im Plasma direlit, sondern innerhalb eines Plasmaringes liege. Auch die Art des Wachstums sei bei Schizonten und bei Gametocyten nicht durchweg die gleiche. Da die Untersuchungen ausschliesslich an gefürbten Präparaten angestellt zu sein scheinen, so fallen bei Ruge unter den Begriff verschiedener Wachstumsformen allerdings. auch Verschiedenheiten in der amoeboiden Bewegliclikeit.

Von diesem Gesichtspunkt aus steht es dann aber in Einklang mit den Beobachtungen von Schaudinn und Argutinsky (rergl. Zool. Zentr.-131. X. 1903. Nr. 17 pag. 584-592), wenn Rug e betont, dass ,jenes Plasmawachstum, durch das der halberwachsene 'T'ertianparasit einer Amöbe gleicht, die in dem Augenblicke, als sie alle ihre Fortsätze ausstreclite, erstarrte, fast nur ausschliesslich bei Schizonten und nur in seltenen Fällen bei Gameten auftritt.

Die Gameten haben vielmehr die Neigung, ruhige, starre, wenig gegliederte Plasmaformen zu bilden." Auch Nacrogamet und Microgametocyt lassen jedoch nach Ruge ein ,rerschiedenes Wachstum des Plasmas erkennen. Bei den Microgametocyten soll nämlich der Tertianaring in der Regel als solcher wachsen, ohne seine Form 
wesentlich zu verändern. Bei den Maerogameten dagegen soll das Wachstnm vorwiegend einseitig erfolgen und zwar .. von der äussern Umrandung der mondsichelförmigen Verdickung des linges". Auch diese Angahen nnterscheiden sich nur durch den Ausdruck von den Feststellungen Schaudinns in seiner mehrerwähnten Arbeit, dass der Liern bei den Microgametocyten in der Regel annähernd zentral, bei den Macrogameten dagegen oberHächlich liegt. In Übereinstimmung mit Scha ud in n betont $\mathrm{R}$ uge ferner die sehr schwache Fürbharkeit des Mlasmas der Microgametocyten, den grossen Chromatinreichtum derselben im Gegensatz zu den Macrogameten und den reichlicheren (iehalt beider Geschlechtsformen an Pigment im Vergleich zu den Schizonten. Dass dieser stärkere (iehalt an Stoftivechselprodukten an sich sehon für ein höheres Mlter spricht, hat liuge freilich nicht erkaunt. Li glanbt vielmehr konstatiert zu haben, dass bei jedem Fieberanfall die Hauptmenge der bis dahin gebildeten Geschlechtsformen zerstört wird und lass die neue Generation ron (ieschlechtsformen sich während der Apyrexie genau so wie die neuen Schizonten entwickele, also anch in 48 Stunden heranwachse. Nach Schandinn's einwandsfrei erscheinenden Beobachtungen brauchen die Ganetocyten des Tertianparasiten dagegen ungefähr die dopjelte Zeit. Ref.] Ruge ist zu seiner Anffassung dadurch gekommen, dass er durch Zählung der Parasiten feststellen konnte, dass die Gametocrten nach dem Fieberanfall allmählich sehr erheblich an Kahl abnahmen. um kurz vor be\% bei Beginn eines neuen Anfalls wieder nngefähr in derselben Zahl aufzntreten wie bei lieginn des vorliergehenden Anfalls. Während in der Zwischenzeit in derselben Zahl junge Formen gefunden wurden, wekche mit Wahrscheinlichkeit (wegen der Lage des ('hromatins innerhalb des l'lasmaringes) als heranwachsende Gametocyten gedeutet werden. I)ieselben Zählungen ergaben übrigens noch zwei andere liesultate, welche namentlich mit lïicksicht anf Schaudinns Angaben über das Schicksal der im menschlichen Blute rerbliebenen Gametocrten von Interesse sind. I uge find nämlich erhebliche Schwankungen in dem Zahl-Verhältnis zwischen Macrogameten und Microgametocyten. Häufig (und zwar bei fast allen daraufhin untersuchten Rezidiven) waren die Vicroganetocyten viel spärlicher als die Macrogameten und wo die Geschlechtsformen nur vereinzelt nachweisbar waren. wurden die Microgametocyten vollkommen vermisst. Andererseits wurden die Geschlechtsformen bei Rezidiven relativ zahlreicher gefunden als bei Neuerkrankungen.

Wenn Ruge noch ausdriicklich betont, dass auch die Jugendformen der Gametocyten bereits Kieme besitzen gegen stephens und Christophers. The malarial infection of native children. In: 
Royal Society, Reports to the Malarial Committee. III. Series. London 1900. pag. 4-14, Pl. I) und dass beim Heranwachsen der Geschlechtsformen der Kiern sich zwar auflockere aber nicht teile, so erscheint beides rom zoologischen Standpunkt aus ja als selbstrerständlich.

In der Einleitung zu seiner Arbeit bespricht Ruge ausführlich die von Laveran für die Anschaung von der Species-Einheit der menschlichen Malariaparasiten ins Feld geführten Gründe, welche er sämtlich als nicht stichhaltig bez. als durch die nevere Malariaforschung entkräftet hinstellt. In einem Schlussabschnitt endlich werden einige epidemiologische Tatsachen besprochen zwecks erneuter Bekräftigung der Auffassung. dass die Infektion des Menschen auschliesslich durch die Anophelen erfolgt.

II. Lühe (Kïnigsberg i. I’r.).

\section{Spongiae.}

691 Kirkpatrick, R., Description of South A frican sponges. Part. II. In: Marine-Investigation in Suth Africa. Cape of Good Hope. Dep. of Agriculture. Jhrg. 1902. Nr. 14. pag. 171-180. Taf. 4.

In dieser Mitteilung werden fünf neue sïdafrikanische T'etraxonia be. schrieben und die neuen Lithistidengattungen Microsclerorlerma, Lithobactrum und Monanthus aufgestellt. Bezüglich der hallkugligen Tetilla casula wird eine Bemerkung von Gilchrist mitgeteilt, wonach dieser Schwamm mit seiner flachen Seite dem Sande des Meeresgrundes auflegt; wie die Beobachtung lebender Stücke im Aquarium gezeigt lat, verhindert die Flachleit der I'nterseite ihr Einsinken $\mathrm{n}$ den weichen Grund.

R. v. Le unde nfeld (Prag).

\section{Coelenterata.}

692 Bernarl, Henry M., Catalogue of the Madreporarian Corals in the British Museum (Natural History). Vol. IV. The Family Poritidae. I. The Genus Gomiopora. London 1903. VIII und 206 pag. 14 Taf.

Der Katalog beginnt mit einer Darstellung der Geschichte unserer Kenntnis der Poritiden. Daran schliesst sich die Charakteristik des Genus Goniopor a rom historischen, morphologischen, systematischen und geographischen Gesichtspunkt. Dann folgt die Beschreibung von 152 Formen, die nach den Fundorten bezeichnet und in 14 geographische Gruppen eingeordnet sind. Fünf Tabellen enthalten ferner die Lokalitait. Tiefe und den geologischen Horizont der beschriebenen Formen, die geographische und geologische Verbreitung der Gattung, eine Übersicht über die Verbreitung der bekannten Variationen in der Art des Wachstums, eine Übersicht über die Verteilung der leichter zu definierenden Typen des Kielches und eine solche über die typi- 
schen Septalformein. Den Schlnss bilden allgemeine Bemerknngen über die Vorteile des Gebrauchs der geographischen Bezeichnmmgen. W. May (Karlsruhe).

693 Duerden, J. E.. West Indian Madreporarian Polyps. In: Mem. Nat. Acad. Sc. Vol. VIII. Seventlı .Jemoir. 1902. pag. 399-597. 25 Taf. 18 Textfig.

Die Arbeit zerfällt in zwei Teile. einen morphologisclıen und einen systematischen. Der morphologische behandelt in grosser Ausführlichkeit und Gründlichkeit die Anatomie und Ontogenie der Korallenpolypen im allgemeinen, soweit das vorliegende Material es erlaubte. Verf. beschrïnkt sich dabei absichtlich auf die Beschreibmng der Weichteile, weil diese bisher durchams vernachlässigt wurde, während die harten Skeletteile bereits gründliche Darstellungen gefunden haben. Die angefügten Bemerkungen ïher die Larven und postlarvale Entwicklung bezeichnet zirar Terf. sellst als mrollständig, doch machen sie riele Eigentümlichkeiten des erwachsenen Organismus verstïndlich. In ausgedehntem Mafe versucht Verf. Vergleiche mit den besser bekannten Actiniarien. Hie Polypen beider Gruppen sind so ähnlich, dass die Kenntnis der ('haraktere der einen oft Licht auf die der andern wirft.

Im zweiten oder systematischen 'Teil beschreibt Verf. 16 bereits oberflächlich bekannte Arten austührlich in bezug auf äussere Charaktere, Anatomie und Histologie. Er versucht zum ersten mal generische Diagnosen anf Grund des Baues der Polypen.

IT. II a y (Karlsruhei.

694 Hickson. Sidney J., The Alcyonaria of the Maldives. I'art. I. In: The Fauna and Geography of the Maldive and Laccadive Archipelagoes. Vol. II. Part. 1. 1903. pag. 473-502. Taf. XXVI - IXVIII.

695 Pratt, Edith M., The Alcyonaria of the Maldives. Part. II. Ibid. p. 503-539. Taf. XXVIII-XXXI.

Diese Sammlung von Alcyonarien ist ron mehr als gewöbnlichem Interesse. In den meisten Fällen sind die Species der Alcyonarien auf ein einziges Exemplar oder auf zwei oder drei Exemplare gegründet worden, die von einer einzigen Lokalität erlangt wurden. Das Interesse der hier bearbeiteten Sammlung liegt in der Tatsache, dass Exemplare durch eine beträchtliche Anzahl von Dredgeziigen erlangt wurden, die in mehrern der Atolle oder der Riffe eines sehr ausgedehnten Archipels gemacht wurden. Sie bieten daher Gelegenheit zum Studium der Form, Farbe und anderer Eigenschaften innerhalb der Grenzen eines weiten Gebiets. 
Der erste von $\mathrm{Hicks}$ on bearbeitete Teil behandelt die Gattungen Xenia, Telesto, Spongodes, Nephthya, Paraspongodes, Chironephthya, Siphonogorgia, Solenocaulon und Melitodes, der zweite von Pratt bearbeitete Teil die Gattungen Sarcophytum, Lobophytum, Sclerophytum und Alcyonium. Neu sind folgende 10 Arten: Telesto rulra, Chironephthya variabilis, Sarcophytum roseum, S. tenuis, Sclerophytum capitale, Sc. hirtum, Sc. palmatum, Sc. gartineri, Se. durum, Sc. querciforme. Neu ist auch das Genus Sclerophytum, in das Pratt das Genus Simlaria eimbezieht. Die Diagnose des neuen Genus lautet: "Kolonie gelappt und in der Form ziemlich ähnlich Lobophytum. Corallum oft hart und körnig. Kolonien gewöhnlich dimorph, aber die Siphonozooide sehr klein und mit deutlichen Zeichen der Riickbildung. Autozooide gewöhnlich kleiner als bei Sarcophytum, Lobophytum und Alcyonium und zuweilen schwach rïckgebildet. Zwei deutliche Kanalsysteme, ein oberflächliches und ein inneres. Die oberflächlichen Kanäle in den meisten Species gross und zahlreich, das innere Kanalsystem in vieler Hinsicht ähnlich dem bei Sarcophytum und Lobophytum und bis zur Basis der Kolonie sich erstreckend. Spicula gewöhnlich verschieden von denen bei Sarcophytum und Lobophytum, meist gross und ron rerschiedener Form. Habitus sehr verschieden."

Sehr beachtenswert sind Hicksons Bemerkungen über das Genus Spongoules und die wahıscheinliche grosse Variabilität seiner Species.

W. May (Karlsruhe).

696 Kiikenthal, W.. Versuch einer Revision der Alcyonarien. II. Die Familie der Nephthyiden. 1. Teil. In: Zool. Jahrb. Abt. f. Syst. Bd. XIX. Heft 1. 1903. pag. 99-172. Taf. 7-9.

K ükenthal gibt in dieser Arbeit eine Revision der weniger unfangreichen Gattungen der Nephthyiden, der die Bearbeitung der grossen, besonders schwierigen Gattungen Spongodes und Eunephthya sowie der neuen Gattung Neospongodes bald folgen soll.

Die erste ausführliche Bearbeitung der Familie gaben Wright und studer 1859. Sie legten das Hauptgewicht auf den baumförmigen Aufbau und die Ḱanalanordnung. Nach der grössern oder geringern Zahl der Spicula in den Kanalwandungen unterschieden sie 2 Unterfamilien: Spongodinae und Siphonogorginae. 1896 erhob Kïkenthal die Siphonogorgiidae zum Rang einer Familie und zweigte sie von den Nephthyiden ab. Innerhalb der Familie der Nephthyiden betrachtete er als wichtigstes Merkmal, ob die Polypenköpfchen terminal auf ihrem Stiele sitzen oder seitlich davon. Letzterer Fall tritt dann ein, wenn sich auf einer Seite ein Bïndel Spicula besonders stark 
entwickelt: das Stïtzbïndel. Er unterschied demnach 2 Unterfamilien, von denen die eine Polypen aufweist, die mit einem Stiitzbündel versehen sind und seitlich an den Stielen sitzen, während bei den andern die Polypen keine Stützbïndel haben und terminal sitzen. Als weiteres Einteilungsprinzip rerwendete er die Vereinigung der Polypen in Kätzchen oder Läppchen oder ihr Auftreten in kleinern Bündeln oder vereinzelt. So ergaben sich ihm 4 Gattungen: Nephthya, Spongodes, Ammothea und Paraspongodes.

Die Hauptprinzipien dieser Einteilung hat $K$ ïkentla al in seiner nenen Arbeit gewahrt, die Zahl der Gattungen aber auf 8 rermehrt. Der Gattung Paraspongodes hat er den ihr nach den Regeln der neuen Nomenklatur zukommenden ältern Namen Eumephthya Verrill gegeben. Die Gattung Ammothe hat den ihr zukommenden ältesten Namen Lithophytum Forsk. erhalten. Paranephthya Wr. et Stud. ist identisch mit Capmella Gray, welcher ältere Name die Priorität hat. Die 8 Gattungen lauten nun: Lithophytum Forsk., Eunephthya Verrill, Capmella Gray, Lemnatia Gray, Scleronephthya Wr. et Stud., Nephthya Sav., Spongodes Less, Neospongodes Kïkth.

K ïkenthal gibt dann folgende Familiendiagnose der Nephthyiden: .Alcyonaceen, deren Kolonien anfrecht verzweigte haumoder strauchartige Stöcke bilden, die in einen mehr oder minder sterilen kompakten untern Stammteil und einen verschieden verästelten obern polypentragenden 'Teil gesondert sind. Die Gastralhöhlen der' freistehenden Polypen verlängern sich in Kanäle; die grossen Kanäle des Stammes und der Hauptäste kommen von den primären Polypen. Die seliundären. tertiären und andern Polypen liefern meist blind endigende Kanäle, welche mit den Kanälen der primären Polypen durch Röhren verbunden sind. In den Scheidewänden der Kanäle liegen fast stets Spicula, mit denen auch die äussere Oberfläclie mehr oder weniger dicht besetzt ist. Die Spicula der Polypen stehen im allgemeinen in 8 mehr oder minder deutlichen nach oben zu konvergierenden Doppelreihen."

Es folgt dann die Charakterisierung der Gattungen und Arten auf Grund der Untersuchung eines umfangreichen Materials. Die Arten verteilen sich auf die Gattungen wie folgt: Lithophytum: 16, Capnella: 5, Lemnalia: 7, Scieronephthya: 1, Nephthya: 24. Neu sind darunter 15 Arten: Lithophytum confcrtum (Viti), L. formosanum (Stiller Ozean, westlich von Formosa), L. armatum (Port Denison), Capnella fungiformis (Ind. Ozean, Küste von Dar es Salaam), Lemnalia umbellata (Duke of York), Nephehya thujaria (Stiller Ozean, Karolinen), N. expressiformis (Stiller Ocean, Palauinseln), N. erecta (Stiller Ozean, Tongainseln), N. pacifica (Stiller Ozean, Viti), N. formosana (Stiller Ozean, westlich von Formosa), $N$. tongaensis (Tongainsehn), N. splaerophora (Fundort unbekannt), N. brassica (Tongainseln), N. striata (Rotes Meer), N. crassa (Stiller Ozean, Port Denison).

W. May (Karlsruhe). 


\section{Vermes.}

\section{Plathelminthes.}

97 Haswell, W. A.. On a Cestode from Cestracion. In: Quart. Journ. Micr. Sc. (N. S.) Vol. 46. Part. 3. 1903. pag. 399-415.

Die neue Species Phyllobothrium vagans gehört zu jenen Bandwürmern, die ihre hintern Proglottiden lange vor der Reife abschniuren. Man findet daher im Darm des Cestracion neben der sehr beweglichen Strobila isolierte Glieder in grosser Zahl, die ähnlich wie eine Ligula umherkriechen. Die Kette selbst ist 9-10 cm lang. Ilır Skolex trägt vier ungeteilte Bothridien mit je einem kleinen Saugnapf. Die Ränder der Bothidien sind äusserst dehnbar'. die Sangnäpfe scheiren mehr der Fortbewegung als der konstanten Fixierung zu dienen. Der frühzeitige Verlust der hintern Proglottiden hängt offenbar mit der grossen Beweglichkeit der Strobila zusammen, denn diese wird nur schwer die mit Eier beladenen Glieder nach sich ziehen können.

Im anatomischen Ban zeigt Phyllobothrium ragans keine nennenswerten Besonderheiten. In den abgelösten Proglottiden sind die zahlreichen Hodenbläschen zentral gelegen. Sie ziehen sich rom sog. Halsteil bis hinter die Gonitalöfhnungen. Das Vas deferens bildet zugleich die Vesicula seminalis. Es mündet in einen Cirrus, der mit feinen Härchen bedeckt ist.

Das zweiflügelige Ovarium ist von einer Membran eingehïllt, die wite eine Kondensation des P'arenthyms aussieht, vielleicht aber auch muskulösen Charakters ist. Der Oridukt beginnt mit einem wohl entwickelten Schluckapparat, der durch rhythmisch pulsierende Bewegungen die Eier in den Ovidukt befördert. Damit diese nicht wieder ins Ovarium zurïckgleiten, ist der Ovidukt auf eine Strecke weit mit Haaren besetzt, die nur eine lewegung der Eier in der Richtung rom Sehluckapluarat weg zulassen. Das Endstïck des Oviduktes ist ein cylindriseher, durch unregelmäßige Ausweitungen vergrösserter Tubus, den man als primären Uterus bezeichnen kann, da er die schon fertigen Eier enthält. Der sekundäre Uterus ist eine ungeteilte Kammer, die ron dem Nivean der Genitalöffnungen bis zum Ovarium sich ausdehnt. $\mathrm{Er}$ hat keine naturliche Öffnung. Aus einem, durch Zerreissen der Wandung entstehenden rentralen Schlitz entweichen die Eier.

In primären Iiterus sind die Eier unsegmentiert. Sie werden von einer spindelförmigen Schale unhüllt, die aus einer äusseren homogenen und einer inneren fibrillären Schicht besteht. Die Eier des sekundären Tterus sind bereits segmentiert, sie enthalten aber 
noch keinen Embryo. Dieser scheint sich erst zu entwickeln, wenn die Eier mit den Fäces aus dem Wirtstiere ausgewandert sind.

E. Riggenbach (Basel).

698 Coe, W. R., The Nemertean Parasites of Crabs (Carcinonemertes). In: Amer. Natural. Bd. 36. Nr. 426. 1902. pag. 431450. $9 \mathrm{Fig}$.

699 - The Genus Carcinonemertes. In: Zool. Anz. Bd. 25. Nr. 672. 1902. pag. 404-414. 2 Fig.

An Platyonychus ocellatus der Kiiste Neu-Englands findet sich gewöhnlich eine kleine parasitische Metanemertinenform, die im Jugendznstand an den Kiemen dieser Krabbe lebt, nach Eintritt der Geschlechtsreife aber auf die Eierballen derselben wandert. Die Form ist identisch mit dem von Kölliker 1844 in Messina an den Eiern von Carcinus maenas entdeckten Nemertes carcinophilos. Joubin und nach ihm Bürger hatten die Art zur Gattung Eunemertes gestellt. Verf. begrïndet für sie und eine andere ron ihm an den Eiern von Epialtus productus der kalifornischen Kïste entdeckte Species, das Genus Carcinonemertes. Das Hauptmerkmal der neuen Gattung ist der ïberaus geringe Ausbildungsgrad des Rüsselapparates, dessen hinteres Ende eine liurze Strecke hinter dem Gehirn gelegen ist. An dem äusserst kurzen und schmalen Rïssel selbst sind drei Abschnitte zu unterscheiden, ron denen der rorderste weder die Muskelschichten und Nerven noch das drüsenreiche Epithel besitzt, das sich sonst bei den meisten Nemertinen findet. Auch der zn einer dïnnen Membran ungebildeten Rüsselscheide fehlt jegliche Muskulatur. Der Stiletapparat besteht aus einem einzigen, sehr kurzen Angriffsstilet $(1 / 2-1 / 3$ der etwa $0,3 \mathrm{~mm}$ langen Basis), Reservestilets sind nicht vorhanden. Nur zwei Augen, die gelegentlich in vier zerfallen. Es fehlt die für die Angehörigen der Gattung Ennemertes charakteristische Neigung, sich zusammen zu knäueln; statt dessen findet man die Tiere oftmals in scharfem Knick gefaltet, so dass die vordere und hintere Körperhälfte parallel verlaufend einander berühren. Carcinonemertes carcinophila (Kölliker) und C. epialti n. sp. unterscheiden sich in ihren Maßverhältnissen sowie durch kleinere Differenzen im Bau des Rüsselapparates. Beide Arten sind ovipar, doch kann bisweilen ein Teil der Eier sich im Muttertier entwickeln. Die anfangs frei schwimmenden Larven verlieren später ihr Wimperepithel und suchen alsdann kriechend ihre Wirte auf, ohne eine weitere Metamorphose durchzumachen.

$$
\text { E. Bresslau (Strassburg, Els.). }
$$




\section{Nemathelminthes.}

00 Jerke, Eine parasitische Anguillula des Pferdes. In: Arch. wissensch. u. prakt. Tierheilk. Bd. XXIX. 1903. pag. 113-127. 'Tab. I.

Verf. hält Oxyuris curvula Rud. und O. mastigodes Nitzsch für verschiedene Arten: bei curvula ist das Männchen 9-15, das Weibchen 39-65 mm lang und letzteres ist hell- bis ockergelb gefärbt, bei mastigodes aber ist das Männchen 12-16 und das Weibchen 105 bis $273 \mathrm{~mm}$ lang und letzteres ist blau- bis dmnkellaubgrün. Die Oxymeris cicipara Probstmayer genannte Art, ron Perroncito zu Thabdonema gestellt, gehört, wie schon Railliet fand, zu Anguillula. Die Art lebt, mitunter zn Millionen, im Blind- und Grimmdarm von I'ferd und Esel: bisher waren nur die Weibchen bekannt. Die Cuticula ist fein quergeringelt; der Nervenring umgibt den Ösoplagus in seinem vordern Drittel; die beiden Gefässe in den Seitenfeldern vereinigen sich vorn, um dicht vor dem Hinterende des (i)sophagus in einen auffallend gebildeten l'orus zu münden: am Kopfende stehen 3 Lippen: der Ösophagus ist bei einem 2,8 langen Exemplar 0,462 mm lang, das hintere Viertel ist ein flaschenförmiger Bulbus mit Ventilzähnen: der Schwanz ist bei beiden Geschlechtern lang und fein zugespitzt; bei jungen Exemplaren misst er $\frac{1}{2, \bar{b}}$, bei ältern ${ }_{3,7}^{1}$ der ganzen Länge. Das Männchen ist 2,6 $\mathrm{mm}$ lang und 0,084 $\mathrm{mm}$ breit, die Cirren sind gleich, schwach gekrümmt, an der Basis doppelt geknöpft und 0,072 $\mathrm{mm}$ lang; der Hoden ist einfach. Das Weibchen ist $2.9 \mathrm{~mm}$ lang und $0,095 \mathrm{~mm}$ breit, die Vulva liegt in der Mitte des Körpers, das Geschlechtsrohr ist doppelt: die reifen Eier sind 0,560 $\mathrm{mm}$ lang und $0,06+\mathrm{mm}$ breit; das Weibchen ist vivipar und man tindet 2-3 Embryonen von 1,8t $\mathrm{mm}$ im Uterus. Sie werden in den Darm des Wohntieres geboren, wo sie sich weiter entwickeln und daher riihrt die oft ungeheure Menge des Parasiten, der keines Zwischenwirts bedarf.

o. r. Linst ow (röttingen).

\section{Annelides.}

01 Crossland, Cyril, On the marine fauna of Zanzibar and British East Africa, from collections maid by Cyril Crossland in the years 1891 and 1892. - Polychaeta. Part I. In: Proc. Zool. Soc. London 1903. Vol. 1. pag. 109-176. pl. 16-17. Von den während einer Reise nach Zanzibar und Britisch OstAfrika gesammelten etwa 150 Polychäten-Arten beschreibt Verf. in dem vorliegenden 1. Teil die Gattung Phyllochactopterus mit den zwei neuen Arten $P h$. elioti und $P h$. pictus. Von der erstern Art 
gibt er nach einer Schnittserie eine Anzahl von anatomischen Angaben.

Das Nervensystem ist in Berührung mit der Haut. Das Gehirn ist eine einfache Anschwellung der Schlundkommissuren. Die AugenHecken sind ein Paar von Zellengruppen mit schwarzen Pigmentkörmchen, in Zusammenhang mit den Nervenzellen des Gehirns, aber vor und dorsal von dessen faserigem Teil. Das Cölom besteht im Vorderkörper aus zwei grossen ventral und lateral rom Darm gelegenen Teilen und einem dorso-medianen Abschnitt, der sich nach hinten zu in einen das Rückengefüss umschliessenden Kanal fortsetzt. Hinten wird das Cölom normaler, durch dorsale und rentrale Mesenterien in zwei Hältten geschieden. Das Gefässsystem besteht aus einem dorsalen und einem ventralen Gefäss, ersteres an der Basis des Kopflappens in drei Äste aufgelöst und hinten in einen grossen Sinus auf der dorsalen Seite des Darms übergehend. Darmkanal: Der Mund ist reich bewimpert; in seinem Epithel einige Flecken ron schwarz-grünem Pigment, die im Darm des ersten Körperabschnittes fehlen. in dem des zweiten und dritten aber wieder reichlich auftreten. Die Notopodialkiemen enthalten einen Cölomraum und in dessen Kentrum ein Borstenbündel. An den Ründern liegt eine von Drüsenzellen mit langen Wimperhaaren eingefasste liinne. I. W. Spengel (Giessen).

702 Fauvel. P., Annélides polychètes de la Casamance, rapportées par. H. Aug. Chevalier. In: Bull. Soc. Linn. Normandie (5) Vol. 5. (1901) 1902. pag. 59-105. 54 Fig.

Verf. beschreibt aus dem Mündungsgebiete des Casamance (Senegambien) folgende 12 Polychäten, von denen 7 neu sind: Euniciden: Marphysa sanguinea Mont., Diopatia neapolitana; L y coriden: Nereis gravieri n. sp.; Neph thyiden: Nephehys lyrochaeta n. sp.; Glyceriden: Glycera africana Arwidsson; Cirratuliden: Cirratulus filiformis Keferstein; Spioniden: Nerine perrieri n. sp.: Ariciiden: Aricia cheralieri n. sp.; Opheliiden: Armandia intermedia n. sp.; Maldariden: Clymene monilis n. sp.; Terebelliden: Loimia medusa Lav.; Serpuliden: Potamilla casamancensis n. sp. J. W. Spengel (Giessen).

703 Faurel, Pierre, Les otocystes des Annélides Polychètes. In: Compt. rend. Ac. Sc. Paris, T'. 135. 1902. pag. 1362-1365.

Die mit Otocysten ausgestatteten Polychäten gehören zu den Familien der Sabelliden, Terebelliden, Arenicoliden, Ariciiden und Alciopiden. Davon hat Verf. untersucht 6 Sabelliden: Branchiommra vesiculosum Mont., Jasmineira elegans Saint-J., Oria armandi Clp., Amphiglena mediterranea Leyd., Myxicola aesthetica Clp.. M. infundibulum Mont.: + Arenicoliden: Arenicola marina L., A. ecaudata Johnst., A. grubii Clp., A. cristata Stimps.; 2 Terebelliden: Lanice conchilegu Pall., Amphitrite edwurdsi Qtfg. 
Die bei Amphitrite edwardsi von de Sa in t-J oseph angegebenen Otocysten auf dem Gehirn existiren nicht, sind viehmehr durch encystierte Distomen rorgetäuscht. - Bei Lanice conchilega sind zwei unmittelbar unter dem dicken Drüsenwulst gelegene Organe, ausgekleidet mit Wimperhaaren und mit zahlreichen unregehmäfigen ()tolithen ron 3-9 $\mu$ (wahrsclieinlich Quarzkörnchen) vorhanden: beim erwachsenen Tiere, wo sich Spuren eines atrophierten Kanals finden, weniger entwickelt als bei dem jungen. - Bei Branchiommra vesiculosum kommunizieren die bewimperten Otocysten durch einen langen, deutlich bewimperten Kanal mit der Aussenwelt und enthalten zahlreiche unregehmäßige Otolithen (Quarzkörnchen). - Ebenso bei Arenicola marina. - Bei den ïbrigen sind die ()tocysten geschlossen, mit kugeligen organischen Otolithen. Bei Oria armandi, Arenicola cristata, Jusmineria elegans, Myxicola infundibulum und M. aesthetica, ist ein einziger Otolith vorhanden, bei Amphiglena mediternanea, Arenicola ecundata und A. grubii sehr zahlreiche. Abgesehen von den beiden letzten Arten werden die Otolithen durch Wimperhaare bewegt. Bei den zwei Arenicola-Arten fehlen solche gänzlich, obwohl die Bewegung der Otolithen schr lebhaft ist; sie rührt von Brownscher Bewegung her. Jede Otocyste enthält gewöhnlich einen oder mehrere Otolithen von 15-30 $\mu$. eine Anzahl mittelgrosse und eine Menge kleine, von $1-3 \mu$; die im Zentrum gelegenen grössern werden durch die kleinen peripherischen in Bewegung versetzt. Bei Arenicola marina, grubii und ecauduta werden die Sinneszellen durch Methylenblau gefärbt. Der Nerv zur Otocyste ist der vorderste von drei Nerren, welche die Schlundconnective vor ilırer Vereinigung abgeben.

$$
\text { J. W. Spengel (Giessen). }
$$

704 Fanvel, Pierre, Le tube des P'ectinaires (Annélides l'olychètes Sédentaires). In: Mem. pontificia Accad. nuovi Lincei. Vol. 21. 1903. 28 pag. 7 Fig.

Vert. hat die Röhren von Amphictene anricoma IIiill. und Pectinaria (Lagis) koreni Mgr. untersucht. Die Krrümmung ist für eine Species konstant. Die Röhre besteht aus einer einzigen Lage ron Körnchen (Quarz, kleine Kiesel, Schalenbruchstücke, Kieselnadeln), deren Beschaffenheit von der Lingebung abhängt und keine spezifische Bedeutung hat. Die Körnchen sind durch ein weisses alveoläres Zement verbunden, das innen die Unregehmäßigkeiten ausgleicht. Es lat keine Affinität zu Farbstoffen, wird von kalten Säuren nicht angegriffen, von Ammoniak und Ätzkali gequellt und erweicht, von Eau de Javelle in Körperchen zerlegt. Nach innen davon findet sich eine farblose blass gelbe oder rötliche feine Membran, die aus 
mehrern übereinander gelegenen Schichten von faseriger Struktur besteht und sich in Schleimfarbstoffen färbt, dagegen in Plasmafarbstoffen ungefärbt bleibt, von Alkalien nicht angegriffen wird, in Säuren quillt. Sie ist das Erzeugnis der Schleimdrüsen des Schildes, wo hingegen das Zement ron grossen ovalen milchweissen \%ementrrüsen erzeugt wird. Letztere bestehen aus grossen Zellen und sind rou einem Muskelfilz bekleidet. Die Pectinarien rerlassen die Riöhren nicht und sind nicht im stande sieh eine neue zu bauen. Die Röhren sind an ihrem schlankern Ende mit einem Schlammpfropfen versehen, in dem häufig der Spionide Polydora ciliata lebt und der ron einem Kanal durchzogen ist, welcher sich in eine zarte hinfällige und oft elneuerte Anhangsröhre ron schleimiger Beschaffenheit fortsetzt. Die Pectinarien führen ein nächtliches Leben, tagsiiber im Sande verborgen, nachts ragt die Spitze der Röhre teilweise hervor. Sie bohren sich mittelst ihrer Palen, den Kopf nach unten, in den Sand. Peristaltische liörperbewegungen erzeugen in der Röhre Wasserströmungen von wechselnder Richtung. Das Wachstum der Röhre ist langsam und kontinuierlich. Dia das schlankere Ende leicht abbricht; ist der Durchmesser an offenen Fnde wichtiger als die Länge.

I. IV. Spengel (Giessen).

705 Oppenheimer, Adele, Certain sense organs of the proboscis of the polychaetous Annelid Rhynchobolus dibranchiatus. In: Proc. Amer. Acad. Art. Sc. Vol. 37. 1902. pag. 5อ5-562. 6 'laf.

Verf. gibt im Anschluss an Ehlers (1864-68) zuerst eine Beschreibung des Rïssels von Rihynchobolus und heschreibt dann. unterstiitzt durch zahlreiche Abbildungen, den Bau von zahlreichen Sinnespapillen, welehe den grösseren Teil der Aussenwand des ausgestülpten Rüssels bedecken und in denen sie durch Methylenblau-Fürbung ansser je zwei Stiitzzellen je 2-3 Sinneszellen nachweist, welche einerseits mit einem Fibrillenbüschel peripherisch entspringen, andererseits zentralwärts eine Faser entsenden, welche direkt oder indirekt (durch ein Nervengeftecht) in einen der 18 längsnerven des Riissels ïbergeht. Beiläufig beschreibt sie die vier unvollständigen Diaphragmen oder "Lappen" (Ehlers), die vom Rüssel ins Cölom hineinhängen (in der Erklärung von Taf. 2 Fig. 1 ,Lemnisci“ genannt), und Ganglienzellen und Fasern enthalten, grossenteils aber aus Zellen bestehen, die ron Ehler's nicht erwähnt sind, aber auch von der Verf. nicht näher beschrieben werden.

J. W. Spengel (Giessen).

706 Pratt, Elith M., A collection of Polychaeta from the Falkland - Nr. 704-706. - 
Is la nds. In: Mem. Proc. Manchester lit. phil. Soc. Vol. 45 (1900-1901) 1901.

Nr. 13, 18 pag. pl. 4.

Verf. behandelt folgende Arten: Aphroditidaea: Hermadion magalhaensis Kinberg; Phyllodociden: Etcone spathocephala Ehlers; Sylliden: Autolytus: simplex Elılers; Nereiden: Platynereis magalhaensis Kinberg; Goniadiden Goniada norvegica Örsted var. falklandica n. var.; Spioniden: Polydora polybranchia Haswell: Arenicoliden: Arenicola claparedii (einige postlarvale Formen an der Oberfläche); Cirratuliden: Promenia jucunda Kinberg; Hermelliden: Sabellaria macropalea (Schmarda) = Patlaxia sexungula Ehlers (1896); Telebelliden: Thelepus spectabilis Verrill; Sabelliden: Sabella ceratodaula Schmarda: ? Bispira mariae Lobianco; Serpuliden: Spirorbis borealis Daudin. Eingehend beschrieben wird die var. falklandica von Goniada norvegica, welche sich von den norwegischen Exemplaren hauptsächlich durch die Zahl der V-förmigen Zähne des Rüssels (4 gegenüber 17-18) unterscheidet. Ferner wird ein Vergleich der Parapodien mit denen der westafrikanischen Artell angestellt.

Die Sanimlung umfasst danach 4 Gattungen (Etcone, Polydora, Promemia und Bispira), welche auf die nördlich€n und südlichen extratropischen Meere beschränkt sind, und 7 kosmopolitische; auch Autolytus ist fast ausschliesslich extratropisch. Von den Species sind 4 (Goniada norvegica, Polydora polybranchia, Arenicola slaparedii nnd Bispira mariae extratropisch, nur 1 (Spirorbis borealis) kosmopolitisch.

$$
\text { J. W. Spengel (Giessen). }
$$

\section{Arthropoda.}

Insecta.

707 Richter v. Binnenthat, Friedrich. I)ie Rosenschädlinge aus dem Tierreiche, deren wirksame $A b w e h r u n d$ bekämpfung. Stuttgart, (Eugen Ulmer). 1903. 80. 392 pag. 50 Textfig. M. 4.-

Das Buch beginnt mit einer Einleitung über die typischen Formen der Pflanzenbeschädigung durch Tiere. Daran schliessen sich allgemeine Erörterungen über den Stamm der Giliederfüsser, die Einteilung, Fortptlanzung, Metamorphose und den Körperbau der Insekten. Dann wird die Abwehr und Bekämpfung der Schädlinge besprochen, zunächst die dabei in Betracht kommenden allgemeinen Gesichtspunkte, dann die Vertilgungsmittel im einzelnen, und zwar: 1. Mittel, deren Bestandteile ganz oder vorwiegend dem Pflanzenreiche entnommen sind (Tabakabsud, Nessle r sche Flüssigkeit, Koch sche Quasinholz- und Schmierseifenbrïhe, Insektenpulver, verschiedene andere PHanzenstoffe, Terpentinöl, Presshefe), 2. Verbindungen des Kohlenstoft's mit Wasserstoff (Petroleum, Karbolsäure, Krresol. Naphtalin), 3. anorganische Stoffe aus der Klasse der Metalle und Metalloide (Schweinfurter Grïn, Ïtzkalk, Schwefelkalium und Schwefelcalcium, Quecksilberchlorid, Schwefelkohlenstoff, Kainit, Chilisalpeter, Kupfermittel, Eisenvitriol), 4. die Trokenbestäubung: 5. die Räucherung, 6. Geheimmittel. Dann geht Verf. zur Besprechung der einzelnen Rosenschädlinge ïber, die in folgender Ordnung betrachtet werden: I. Gliederfiisser. A. Insekten: 
1. Käfer. 2. Hauttliigler, 3. Schmetterlinge, 4. Zweitlügler, 5. NetzHiugler. 6. Geradflügler, 7. Schnabelkerfe, 8. spinnentiere. II. Würmer. Ein ausführliches Sachregister erleichtert die Benutzung der sehr Heissigen, mit Benutzung aller einschlägigen Literatur ausgefïhrten Arbeit.

W. II a y (Karlsruhe).

708 Ruibsatamen, Ew. H., Mitteilung über die von Herrn J. Bornmiiller im Oriente gesammelten Zoocecidien. In: Zool. Jahrb. Syst. Bd. XVI. Heft 2. 1902. pag. 243-336. 39 Textfig. Taf. $12-16$.

Unter den 143 hier besprochenen Gallen befinden sich 58 gan\% neue und 50 bekannte, zu denen neue substrate anfgefunden wurden. Der Bequemlichkeit wegen sind die Gallen in alphabetischer Reihenfolge, nach den Ptianzen geordnet, aufgeführt, ohne Riieksicht auf die Erzeuger, doch findet sich am Schlusse ein kurzes, nach den Erzeugern geordnetes Verzeichnis mit jedesmaligem Hinweis auf die Nr., unter der die Beschreibung der Galle zu finden ist. Ton den 143 beschriebenen Gallen werden 40 von Gallmilben, 42 von Dipteren, 36 von Cynipiden, 10 von Aphiden, 4 von Psylliden, 1 von Cocciden, 1 von Käfern und 4 von Schmetterlingen hervorgebracht.

W. II a (Karlsruhe).

709 Metaluikoff, S. J., Beiträge zur Kenntnis der Anatomie der Raupe von Galleria melonella (Vorläuf. Mitt.). In: Zool. An\%. XXVI. Bd. 1903. pag. 619-623.

Der Verdaumngsapparat der sich von Wachs ernährenden Raupe der Wachsmotte zeichnet sich durch gewisse Eigentümlichkeiten in seinem Bau aus. Die Ringmuskulatur des Vorderdarmes besteht aus epithelartig angeordneten grossen Zellen, die die Speiseröhre ringartig umformen und neben einem ausserordentlich grossen Kern eine grosse Anzahl quergestreifter Muskelfibrillen enthalten. Der Verdauungsprozess geht unter alkalischer Reaktion vor sich. Die Malpighischen Gefässe beginnen in Gestalt zweier kurzer Kanäle zu beiden Seiten des Darmes und mündell an der Grenze zwischen Mittel- und Enddarm in das I)armlumen ein. In geringer Entfernung vom Darm teilt sich jeder Kanal in zwei Ïste, von denen sich der eine nochmals gabelt. Auf diese Weise entstehen jederseits drei Gefässe, die anfangs in der Richtung nach dem Kopfende hin verlaufen, hierauf nmbiegen und bis zum Enddarm herabsteigen. Eines der Gefässe bildet eine Erweiterung, eine Art Blase, worauf alle drei Gefässe in die Wandung des Enddarmes eindringen.

Das Tracheensystem setat sich aus 10 Paaren grosser Tracheen- 
blasen zusammen, die zu beiden Seiten des Darmkanals gelegen sind und die Darmwand mit Luft versorgen. Eine jede dieser Blasen ist von länglicher cylindrischer Gestalt und giebt zahlreiche Ästchen an die Wandungen des Darmes ab.

Vom Verfasser ausgeführte physiologische Injektionen mit ammoniakalisehen Karmin und mit Indigokarmin hatten zur Folge, dass das Indigokarmin von den Malpighischen Gefüssen ausgeschieden und das ammoniakalische Karmin durch die Pericardialzellen aufgenommen wurde. Die zu beiden Seiten des Herzens auf den Hïgelförmigen Muskeln angeordneten Pericardialzellen nelımen bereits einige Stunden nach der Injektion die grelle rote Karminfärbung an. Die Gestalt der Pericardialzellen ist bei Gallevia sehr mannigfaltig. Neben kleinen, einkernigen Zellen finden sich riesige vielkernige, welche schon mehr an Syncytien erinnern. Die letztern entstehen aus den kleinen Zellen, deren Kern sich teilt (direkte Kernteilıng). sodann bilden sich im Plasma Spalten, die die Zelle in mehrere abgesonderte Zellen teilt, die untereinander durch plasmatische Fortsätze in Verbindung bleiben. Schliesslich nähern sie sich einander, verbinden sich miteinander und verwandeln sich in grosse Syncytien. Vor Beginn der Verpuppung ist eine Degeneration der grossen Pericardialzellen zu beobachten. Es treten Vakuolen in ilnen auf, die Kerne nelımen an Grösse zu und erhalten ein verschwommenes Aussehen. Während der Puppenruhe erfolgt ein allmällicher Zerfall der Zellen unter Beililfe von Leukocyten, welche sich zu dieser Zeit in ungelieuerer Anzahl in der Nïhe der Pericardialzellen ansammeln. Die Leukocyten beladen sich dann auch mit dem Karmin, das ursprünglich in den Pericardialzellen abgelagert war. Die kleinen P'ericardialzellen werden niclit zerstört, sie vermehren sich wälırend der Puppenruhe durch einfache direkte Teilung und aus ihnen bilden sich die Pericardialzellen des ausgebildeten Insekts. Auch der in den kleinen Pericardialzellen aufgestapelte Karminvorrat wird durch die Kellteilungen stark vermindert, so dass bei dem ausgebildeten Insekt im Innern der Pericardialzellen nur noch Spuren von Karmin beobachtet werden. Bei grossen ausgewachsenen Raupen, Puppen und Faltern fanden sich die Pericardialzellen auch an den innern Wandungen des Herzens, was auch bei andern Schmetterlingen beobachtet wird. M. von Linden (Bonn).

710 Zander, Enoch, Beiträge zur Morphologie der männlichen Geschlechtsanhänge der Lepidopteren. In: Zeitschr. wiss. Zool. Bd. 74. Heft 4. 1903. pag. 5̌57-615. 1 Taf. 15 Fig. im Text.

Die vorliegende Arbeit ist ein weiterer Beitrag des Verfs. zur Nr. 709--710. 
Lösung der Frage: „ob die im entwickelten Zustande so grundverschieden erscheinenden Kopulationsapparate der Insekten einen einheitlichen Plan ihres morphogenetischen Aufbaues erkennen lassen oder nicht". Untersucht wurden zahlreiche Species aus allen grössern Lepidopterengruppen und es ergab sich, dass bei sämtlichen untersuchten Lepidopteren ein gemeinsamer Bauplan des abdominalen Hautskelettes und der Geschlechtsanhänge festzustellen war, der sich im wesentlichen mit dem stile der Trichopteren deckt. Hier wia dort ist das Abdomen von zehn dentlich unterscheidbaren Chitinringen umgürtet, die dem 4.--13. Körlersegment angehören. Abgesehen vom ersten Abdominalsegment, wo eine Bauchschupe stets fehlt, sind die übrigen stets deutlich in Banch- und Rïckenschuppe differenziert. Bei dem 10. und 11. Segment ist die Form dieser Skelettelemente oft wesentlich moditiziert; so wird besonders der 11. Segmentring zum Träger verschieden gestalteter Anhänge. Wie hei den 'Trichopteren, so tritt auch bei den Lepidopteren das 12. und 13. Segment in engste Beziehung zu den Geschlechtsanhängen. Die ventralmediane l’artie des 12. Segmentrings trägt einen den Trichopteren fehlenden, für den Geschlechtsapparat der Lepidopteren sehr charakteristischen Anhang, den Saccus. Das Aftersegment (13) wird dorsal und rentral ron meist beckenförmigen Anhängen überragt, dem dorsalen Uncus und dem ventralen Scaphium. Bisher wurde Uncus und Scaphium als Riicken- und Banchschuppe gedeutet, was indessen unrichtig ist, da sie nur sekundäre Anhänge vorstellen, die von der dorsalen bezw. ventralen Basis des konischen Afterkegels rorwachsen.

Die Geschlechtsanhänge der Lepidopteren liegen innerhalb des 12. Segmentringes und rentral vom Aftersegment ind sind innig mit diesen Hautskelettelementen rerbunden: man unterscheidet wie bei den Trichopteren: Penistasche, Penis und Vulvae. Die Vulvae stellen sehr verschieden gestaltete Klammerorgane dar, die im Gegensatze zu den Trichopteren stets beweglich mit dem postsegmentalen Rand des 12. Segmentrings verbunden sind. In einzelnen Fällen sind die Vulvae klein und unscheinbar, so dass sie ihre Bedeutung als Klammerorgane verlieren (Micropteryx, Sparmannella, Adela, Degeerella). Bei einzelnen Butaliden finden wir die ventralen Vulvaränder so verwachsen. dass nur an der Basis ein Spalt für den Hindurchtritt des Penis frei bleibt. Die Penistasche stellt eine Tasche dar, die sich, wenn man das Abdomen ron hinten betrachtet, ron dem postsegmentalen Rande des 12. Segmentringes und der ventralen Afterlippe tief in das Abdomen einsenkt. Sie besitzt die Gestalt eines sehr festwandigen Trichters, an dem sich eine mehr oder weniger tief muldenförmig gestaltete Randzone und ein enger schlauch- 
förmiger zentraler Bezirk unterscheiden lässt. Die Grenze dieser beiden Abschnitte ist meist sehr deutlich und oft dadurch noch schärfer ausgesprochen, dass sich der Rand des engen Taschengrundes in Gestalt einer ringwallartigen, den Penis umziehenden Hautduplikatur erhebt. In dem engen schlauchförmigen Abschnitt der Penistasche steckt der Penis, der bedeutend länger ist, als man bisher glaubte und die Form eines langen Chitinschlanches besitzt. Man kann an dem Penis einen membranösen oralen und einen stark chitinisierten terminalen Abschnitt unterscheiden. Der orale Teil bildet in seiner vordern Hälfte eine ventral offene Rinne. Das Längenverhältnis der beiden Abschnitte variiert stark, ebenso die Form des chitinisierten Endstiicks. Axial wird der Penis ron dem in seiner ganzen Ausdehnung von einer zarten Chitinlamelle ausgekleideten Luctus ejaculatorius durch\%ogen, der kurz ror seinem Eintritt in die Penisbasis die Vasa deferentia aufnimmt.

Während Zander auf Grund der vergleichend anatomischen Untersuchung zu dem Ergebnis gelangt, dass der männliche Geschlechtsapparat nur in der Ausbildung seiner Komponenten, nicht aber in seinem Bauplan von dem der 'Trichopteren abweicht, fasst er die Resultate der entwicklungsgeschichtlichen Untersuchumg in folgenden Sätzen zusammen: sowohl bei den Hymenopteren, wie bei den Trichopteren und Lepidopteren verdanken die Geschlechtsanhänge ihre Entstehung morphogenetisch durchaus gleichartigen Anlagen. Diese Homologie kommt zum Ausdruck: „1. in der Anlage einer, der Form nach verschiedenen postsegmentalen Einsenkung (Genitaltasche) der zwölften Bauchschuppe, 2. in der Entwicklung eines Paares einfacher Primitizzapten am Grunde der Genitaltasche, 3 . in der sekundären spaltung jedes Zapfens in ein laterales (Vulva) und mediales (Penis) Stück, 4. in der Entstehung des Penis aus ursprünglich paarigen Anlagen". Das spätere Schicksal der Genitaltasche und der Zapfenpare ist jedoch bei Hymenopteren einerseits, Trichopteren und Lepidopteren andererseits ein vollkommen verschiedenes. Die Geschlechtsanhänge der Hymenopteren verharren auf einer primitivern Stufe der Entwicklung und lassen die ursprüngliche Anlage weit klarer erkennen als diejenigen der Trichopteren und Lepidopteren.

M. v. Linden (Bonn).

711 Stuhlmann, Franz, Über den Kaffeebohrer in Usambara. In: Berichte über Land- und Forstwirtschaft in Deutsch-Ostafrika. Bd. I. Heft 2. 1902. pag. 154-161. Taf. III.

Seit einiger Zeit macht sich auf den KaffeepHlanzungen in Usambara ein Bohrer in recht unangenehmer Weise bemerkbar, der einer 
grossen Anzahl von Kaffeebäumen schon das Leben gekostet hat, dessen Natur aber bisher noch unbekannt geblieben war. Stullmann identifiziert ihn jetzt auf Grund eines sehr vollständigen, aus Larven, Puppen und zwei in Bohrloch auf Magrotto gefundenen Käfern bestehenden Materials mit dem 1893 ron ihm auf der französischen Missionsstation Morogoro in Ukami gefundenen Anthores lenconotus Pascoe. Es handelt sich demnach 1 m kein mit der Kaffeekultur neu eingeführtes 'Tier, denn der Käfer ist seit langem aus Natal. Caffrarien. Nord-Transvaal, Delagoa-Bay. Ovampo in Südwestafrika bekannt und in Ostafrika ausser in Morogoro auch schon in Usambara gesammelt worden.

Nach den bisherigen Befunden muss man annelmen, dass das Kïferweibchen seine Eier an den Wurzelhals oder bis $1 / 2 \mathrm{~m}$ iber der Erde an die Rinde legt, wahrscheinlich immer nur wenige Eier einzeln an jeden Baum legend und vor Baum zu Baum gehend, bis die Eierstöcke erschöpft sind. Daraus ist das platzweise \%usammenstehen der kranken Bäume zu erklären. Die I arve frisst nach dem Ausschlüpfen im saftreichen Cambium hin und her, einen breiten, fast obertlächlichen rang bildend, um, wenn sie fast ausgewachsen ist, sich in das Stammholz und den Markkanal, neist nach oben geliend, zu fressen, dort ihre letzte Entwickhung durchzumachen und ihre Puppenwiege lierzustellen. Die Käifer Hiegen wah'scheinlich am Ende der Trockenzeit und Beginn der Regenzeit, um besonders in letzterar Periode, wenn der Saftgehalt der Rinde am grössten ist. ihre Eier abzulegen.

Die Bekämpfung muss sich hamptsächlich gegen die Hiegenden und eierlegenden Käler und die auskriechenden Larven richtell. Fs müssen 1. alle erreichbaren Larven durch Verbrennen der Bäume vernichtet werden: 2. die Hiegenden ausgebildeten Käfer eingesammelt und gefangen und besonders 3 . durch Vergiften der Stämme die eierlegenden Weibchen ferngehalten und die jüngsten Larven getötet werden. Genaues Studium der Lebensgewohnheiten des Käfers und sachgemäPe Bekämpfung wird sicher zum Ziele führen.

$$
\text { W. II a } \text { (Karlsruhe). }
$$

712 Cholodkorsky, N., Über den Spinnapparat der Lyrla. In: Allg. entom. Zeitschr. VI. 1901. pag. 17-19. Fig.

Verf. untersuchte hauptsächlich Lyda erythrocephala L. und erweitert die Befunde K. Ecksteins (1890) wesentlich. Die Wandungen der Driisenschläuche bestehen aus einer Lage Hacher. voneinander nicht deutlich abgegrenzter Epithelzellen. und aus grossen saftreichen secernierenden Zellen, welche mit ihrem Halse in den Hauptstamm einmïnden: nach vorne zu verschwinden dieselben 
allmählich. Jeder der beiden Hauptstämme verbindet sich am Kopfe mit je einer Filippischen Drüse. Diese stellt einen ziemlich langen unregelmäfig gelappten, am blinden Ende gegabelten Schlauch dar, dessen Lumen sehr eng und stark cuticularisiert ist. Ausserdem enthält der Spinnapparat bei Lyda noch zwei büschelförmige Drüsen (Glandulae multifidae), welche glashell sind, dichotomisch verästelt erscheinen und blasig ausmünden. Über die Rolle dieser einzelnen Teile wird nichts gesagt.

K. W. r. Dalla Torre (Innsbruck).

713 Cobelli, R., Il senso del gusto nel Lasius marginatus Oliv. In: Verh. zool. bot. Ges. Wien. LII. 1902. pag. 25+-257.

Aıs Fütterungsversuchen mit den verschiedenartigsten Lösungen und Flüssigkeiten ergab sich:

1. $L$. e. verschmäht die Lösung von Chinin-Bisulfat und verdiinnter Schwefelsüure, auch wenn sie in gleichen Mengen mit Honig gemischt sind. 2. Sie verzehren reinen Honig und ebenso solchen, welcher in gleicher Menge gemischt ist mit Wermuttinktur. gesättigter Magnesiumsulfat-Lösung, Enziantinktır, Quassiatinktur, Assa foetida'Tinktur, Joltinktur, 3 prozentiger Borsäurelösung, gesättigter Sodaoder Kochsalzlösung, verdiinnter Essigsäure, Glycerin und Naphthalin. Nur dem letzten (iemenge wird reiner Honig vorgezogen. 3. In reinem Zustande werden alle diese substanzen zurückgewiesen. Daraus geht hervor, dass $L$. e. ein wenig entwickeltes, oder wenigstens ein von unserm sehr abweichendes Geschmacksrermögen besitzt.

K. W. v. Dalla Torre (Innsbruck).

814 cobelli, R., I. releni ed il Lasius emarginatus Oliv. In: Verh. zool. bot. Ges. Wien. LIII. 1903. pag. 18-21.

Verf. reichte dieser Ameisenart reinen Honig, dann Gemische von Honig und gleichen Mengen ron Atropinsulfat $(0,01: 2)$, Belladonnatinktur, Cocaintinktur $(0,05: 2)$, Morphiumhydrochlorat $(0,05: 2)$, Opiumtinktur, wässerige Codeinlösung $(0,05: 2)$, Pilocarpinhydrochlorat (0.05:2), Fowlersche Arsenlösung, kaltgesättigte wässerige Lösung ron Strychninnitrat, Aconitumtinktur, Colchicumtinlitur, Digitalistinktur und alkolıolische Lösung von Veratrin $(0,02: 2)$ - und alles wurde aufgenommen. In reinem Zustande aber wurde alles verschmäht. Somit ist diese Ameise gegen alle diese dem Menschen so gefährlichen Gifte widerstandsfähig und verrät auch ihren besondern Geschmack.

K. W. v. Dalla Torre (Innsbruck).

715 Dedekind, A., A ltägy ptisches Bienen,wesen im Lichte der modernen Bienenwirtschaft. Berlin. (Mayer \& Müller). 1901. 8º 32 pag.

Nach einem Papyrus Waris Nr. 1 erscheint das Bild der Bienen- 
königin als ,das Bild der Herrschaft", stets in Verbindung mit Königsnamen, daher „unaussprechbal“. Die Biene stellt gewissermaßen das Land selbst vor und heisst ab-en-ebio $=$ „Fliege des Honigs" $[$ Apis mellifera $=$ mellifica $]$. König Ramses III. habe während seiner Regierung den Tempeln grosse Mengen von Honig und Wachs gespendet, [es wird auf $10964 \mathrm{~kg}$ Honig abgeschätzt] letzteres weniger als ersteren, weil die Bereitung des Wachses den Bienen viel mehr Kraftverbrauch kostet, etwa ${ }^{1} / 2 \mathrm{~kg}$ Wachs soviel wie $5-7^{1} / 2 \mathrm{~kg}$ Honig.

K. W. v. Dalla Tore (Innsbruck).

716 Iickel, Ferd., Die Ursachen der geschlechtlichen Differenzierung im Bienenstaat. (Ein Beitragzur Vererbungsfrage.) In: Arch. ges. Physiol. XCV. 1903. pag. 66-106. Fig.

Unter Anführung der einschlägigen Literatur, ausschliesslich aber auf dem Wege selbständiger Fxperimente (I.-XII.) gelangte Verf. zu einer Reihe von sehr interessanten, für die Geschlechtsfrage der Biene grundlegenden Resultaten, von denen die Haupt-Schlussätze in folgenden aufgeführt werden mögen: .. Die Mutterbiene vermag weder zu leben, noch Eier zu produzieren, ohne Aufnahme von Bildungssubstanzen, welche im Organismus der Arbeitsbiene bereits eine weitgehende chemische Umgestaltung erfahren haben und von hohem Wert als Zellenbildungsstoffe sein müssen. Die direkte und ausschliessliche Beteiligung der Arbeitsbiene am Aufbau und der Gestaltung der Nachkommen tritt mit dem Augenblicke ein, wo das Ei den Mutterleib verlässt."

Die als Hïchtig erscheinenden hellen Substanzen sind es, welche die ersten Entwicklungserscheinungen im Ei veranlassen. („Einspeicheln" der Imker.) ..Eier, die meist regelmäßig abgelegt oder möglichst bald dem Einfluss der Bienen entzogen werden, entwickeln sich nie zu Larven."

„Die gesamten Entwicklungserscheinungen legen den Schluss sehr nahe, dass es sich um eine Anfeuchtung der Eier mit denselben Stoffen handelt, welche anch die Entstehung ron dreierlei Zellenformen veranlassen und die die Entwicklungsrichtung der Eier bestimmen."

„Die zellenformbestimmende und tierformbestimmende Substanz ist die gleiche und ist charakterisiert durch Geruchsqualitäten, welche bei den am Aufbau der Tiere beteiligten Bienen durch Vermittlung des Geruchssinnes die gleichartige Absonderung veranlasst." („Geschlechtsbestimmende Substanz" und "volumenbestimmende Substanz".)

.. Im reifen Bienenei an sich sind nur die Anlagen zur männlichen Formbildung vorhanden“ - ; , erst durch das Sperma wird die Anlage zur weiblichen Formbildung, wie zur Entstehung von Arbeitern, dem Ei zugefülırt." "Aus unbefruchteten Bieneneiern geht, auch 
unter den sonst günstigsten Bedingungen, kein Lebewesen hervor, wenn es in die erste Mutterzelle abgesetzt und daher von rornlerein durch die Arbeitsbienen auf Heranbildung des Weibchens beeintlusst wird. Die Anlage zur weiblichen Formbildung ist somit an das Sperma gebunden."

..Die normalen Drohneneier sind auch befruchtet." --- Als wichtigste Störungsursachen sind zu bezeichnen: Mangel an Gelegenheit für die Arbeiter, ihre geschlechtsbestimmenden Produkte in der Gestalt abzusetzen, wie es der bezeichnete Normalzustand verlangt, und anhaltende Einwirkung von Wärmegraden, welche die Grenze der Normalblutwärme der Bienen nach oben zu ibberschreiten droht. Hiermit gelıt in der Regel eine mangelhafte Zufuhr genügend sauerstoffhaltiger Luft Hand in Hand."

..Durch den Verlnst der Mutterbiene wird der Trieb nach Erzeugung der beiden Geschlechtstiere bei den Bienen rege und die 'Tiere sind tatsächlich fähig, diese heranzubilden, wenn ihnen Arbeiterlarven und Fier in gleicher Entwicklungsrichtung in Drohnenzellen zu Gebote stehen." .. Die Embryonen tïr Arbeitsbienen müssen bis zu einer gewissen Entwicklnngshühe geschlechtlich nach beirlen Ricltmogen hin entwicklnngsfähig, also noch nentral sein. Die Bienenzelle in ihrer heutigen Gestalt als liegulator der Geschlechtsentwicklung bei den Bienennachkommen kamn nichts Ursprïngliches sondern muss etwas Erworbenes sein.“ "Fs ist nur ein Ergebnis des Entwicklungsverlaufs der Bienenkolonie, wenn hr'ute in derselben normalen Weise anstatt vieler Weibchen nur eines geduldet wird."

Ias Schlussresumé lautet: "Aus Arbeitereiern kann man Drohnen erzichen und umgekehrt. Die ron der normalen Iutterbiene abgesetzten Eier miissen daher auch alle befruchtet sein, mnd somit kann von ihr die Geschlechtshestimmung nicht abhängig sein. Da man ferner dmch sekretübertragung die /ukunft des Eies bestimmen kann, so ist dieses das Ausschlaggebende."

Übrigens ist die Arbeit auch in anderer Kichtung sehr lesenswert. Sie enthält nämlich eine Menge eingestreuter Beolsachtungen und Angaben über Biologie, Physiologie und P'sychologie der Honisbiene, die man in bisherigen Lehrbïchern ganz anders dargestellt findet.

K. W. V. Dalla Torre (Innsbruck).

717 Ducke, Adr., beobachtungen ïber lïthenbesuch, erscheinungszeit etc. der be i Paravorkommenden Bienen. In: Keitschr. f. Hymenopterol u. Dipterol. I. 1901. pag. „25-32. 49-65 (I): in: Allg. Keitschr. f. Entom. VII. 1902 pag. 321-325. (II) $360-368 ; 400-405 ; 417-422$. 
Verf. gibt in der Einleitung eine Übersicht über die biologischen Verhältnisse der Blumen und der sie besuchenden Bienen. Ersteren sei folgendes entnommen:

... Überdies bietet hier die Beobachtung der Bienen unvergleichlich grössere Schwierigkeiten, als in Europa, da hier zu Lande sehr viele Bienen die Blüten hoher Bäume aufsuchen und sich so der Beobachtung entziehen. So z. B. sind die Dipterix-Arten, wenn sie in Blüte stehen, von unglaublichen Mengen von Bienen besucht, deren Gesumm trotz der grossen Höhe $(30 \mathrm{~m}$ und mehr) dieser Bäume auf den am Boden stehenden Beobachter den Eindruck des Sansens eines starken Windes macht.

Der notorische Blütenmangel der Tropenländer in Vergleiche zu Europa bewirkt es, dass sich ein ausschliesslicher Besuch gewisser Bliiten hier seltener und weniger scharf ausgepräigt vorfindet, als dort. Doch besncht hier z. B. die prachtvolle Schmarotzerbiene Acanthopus splendidus F. ganz ausschliesslich die Blüten der Liane Thoclea lasiocarna Nart. und der obzwar in eine andere Familie gehörigen. aber denen der genannten Pflanze sehr älnnlich aussehende Blïten besitzenden Monina spec., in letztern Falle vielleicht getäuscht, da bei der Seltenheit der Momina jedenfalls die häufige Dioclea als eigentliche Nährptlanze anzuselien ist. Ausserhalh der Blïtezeit der genannten Pflanzen (Nai bis September) habe ich den Acanthopus nie auf Blüten angetroffen, obwohl die $q$ das ganze .Jahr hindurch nicht ïbermäßig selten sind.

Von den Bienen bevorzugte I'flanzenfamilien sind: vor allem Papilionaceae, hier wie in Europa die am stärksten frequentierte, dann Solanaceae, deren europäische Vertreter merkwiirdigerweise ron den Bienen geradezu gemieden werden, dann Caesalpiniaceae. Apocynaceae, Flacourtiaceae, Verbenaceae, Malraceae. Convolvulaceae, Compositae, Marantaceae.

(Oft werden die einzelnen Species gewisser P'flanzengenera von sehr rerschiedenartigen Bienenarten bevorzugt; am auffallendsten ist dies bei Solamem. So wird Solanum grandiflorum Ruiz et Par. von Centris rustica, C. personata, C. flavilabris, C. Alarifrons, C. mbella, C. mlumipes und Oxaea festira besucht, Solamm toxicarium nie von diesen, dafür aber gerne von Euglossa-Arten, während ein drittes hier häufiges, hlaublühendes und stacheliges Solamum, dessen Speciesname mir nicht bekannt ist, von keiner der genannten Bienenarten, und iiberhaupt nur von solchen Bienen aufgesucht wird, die keine bestimmten Blüten bevorzugen. als: Bombus, Halictus nnd einige Melipona-Arten.

Die besonders ron Kolibris frequentierten scharlach- oder 
orangeroten Blumen, die hier sehr hänfig sind, werden von allen Bienen absolut gemieden mit alleiniger Ausnahme der Melpiona fulvirentivis Guér., die ausser an verschiedenen andern auch an solchen Blïten häufig angetroffen wird. z. B. an Passiflora coccinea, Heliconia psittacorum und an scharlachrotblïhenden Acanthaceen(Jacobina spec.)."

Bei Bienenarten mit zwei Generationen mit scharfluegrenzter Erscheinungszeit hat jede einzelne Generation bevorzugte Nährpflanzen. So Hiegt z. B. die Märzgeneration der Centris maculata an einer Ipomoea spec, die Septembergeneration besonders an Petraea volubitis."

Die meisten Arten Hiegen wohl un bei Sommenschein aus, doch beobachtete ich 7. I3. die $\sigma^{7}$ ron Eucera auch bei recht trübem Wetter und die o von Euglossa fusciata und E. dimidiata flogen am Morgen des 17. März 1900 trotz des herrschenden Landregens in grossen Schwärmen an Catasetum macrocarpm Rich."

Wie bekannt. besnchen die lienen mit hochentwickelten Mundteilen zumeist hochdifferenzierte, jene mit einfachen Mundteilen einfache Blüten. Von letztern erinnern manche durch ihren Honigduft an die Umbelliferen Europas und werden wie diese anch mit Vorliebe von den Grabwespen aufgesucht (Sapindaceen, besonders Paullinia, Erythroxylon coca, Micamia scamens). Meliponen aller möglichen Arten findet man oft in grosser Menge an sehr pollenreichen Bliiten beisammen, die M. ruficrus fand ich sogar mit dem Einsammehı des Pollens einer Scleria sp. beschäftigt (Cyperaceae!), die sonst ron Insekten überhaupt nicht besncht ist. - Ine Cyperacee Rymchospora cephalotos Valıl, die hier ron kleinen Halictus-Arten nul Faltenwespen besucht wird, seheint zu den insektenbliitigen Pflanzeı zı gehören.“

..Grosse Bienen mit schnellem Fluge - vor allem Centris besuchen fast ausschliesslich die hoch über dem Boden befindlichen Blïten verschiedener Bäume und Sträncher; kleine Arten, die schlechte Flieger sind - z. B. Tetrapedia - findet man besonders an niedrigen Kräntern."

„Bisweilen besuchen die einzelnen Geschlechter einer und derselben Art ganz verschiedene Blüten. So Hiegen bei manchen Euglossa-Arten die mit Vorliebe an Orchideen, nie fand ich aber anch nur ein einziges $q$ an einer solchen P'flanze. Von Centris personata findet man die $\sigma^{7}$ besonders an Diocler, die $P$ an Solanum grandiflorum, von C. lineolata erstere an Dioclea, letztere an Cassia alata. Bei manchen Arten, wo man das eine ter Geschlechter auffallend seltener findet, mag dasselbe vielleicht die Blüten hoher Bäume besuchen und sich auf diese Weise der Beobachtung entziehen." 
An Schlusse folgt eine Liste ron Pflanzenarten (oft auch nur das Genus genannt) mit den an denselben beobachteten Apiden, allerdings ohne Angabe, wie der Besuch heschaffen ist.

Inı II. Teile werden diese Beobachtmngen weiter ausgeführt, namentlich in Hinsicht auf die Biologie der blumenbesuchenden Hymenopteren. So bemerkt er, dass bei gewissen Bienenarten z. B. bei Euglossa comlata von einer Frscheinungszeit nicht die liede sein kann, da sie bei Para das ganze Jahr hindurch mit gleicher Häufigkeit angetroffen wird, soweit eben das Gebiet des Regenwaldes reicht.

In den Campesgegenden ist zur Zeit der Dürre das Bienenleben sehr gering. Zugleich mit der Bliitenentwicklung (.Iuni, Juli) beginnt dann erst der Hauptbienenflug wieder: Jannar und Februar weist das Minimum anf. Eigentümlich erscheint es, dass riele Pflanzen keine eigentliche Blütezeit haben nnd dass oft mehrere . Iahre verstreichen können. ohne dass ein bestimntes Exemplar einer I'Hanze in volle Bliite kommt. Danit steht auch der Bienenbesuch in engstem Zusammenhange.

Hierauf folgt wieder eine Liste von I'flanzenarten mit Angabe ihrer Besucher. Den schluss der Arbeit bildet eine ungemein reiche Liste ron blumenbesnchenden Apiden mit rielen biologischen und systematisch wichtigen Angaben: anch nene Arten werden beschrieben. Ferner wird der Nestbau ron Euglowst-Arten geschillert. Er besteht ans durch Gummi aneinandergefügten Rindenspänen - nicht aus Gummi allein (E. muragdona), bei E. cordata ans Harzmasse. Im ganzen werden 32 (iattungen behandelt.

K. W. r. Dalla Torre (Inusbruck).

T18 Forel, A., Die Sitten und Nester einiger $\Lambda$ meisen der Sahara bei Tugust und Biskra. Beobachtet ron Dr. A. Wiehl, mitgetheilt von A. Forel. In: Mittheil. Schweiz. entom. Ges. X. Heft 10. 1903. pag. 453-459.

Sehr interessante Vitteilungen über den Nestbau und das biologische Verhalten folgender Ameisenarten: Myrmecoeystus bombylans Royer, M. albieans Roy.. M. albicans v. riutioides André, M. riaticus r. desertorum For., Camponotus muculatus v., casium For.. 11. var. cognato-casimm For. Pheidole pallidula Nyl., Solenopsis Ton n. sp., Acantholopis franenfeldi Mayr, bipartita smith.

Mehrfich wertvoll scheint mir folgende Stelle zu sein: Messor babarus ist ein mächtiger Stamm beim Ameisenvolke: seine kriegstüchtigen Eigenschaften machen ilm gefürchtet, wie folgende Spielerei zeigt. Ich setzte einen grossköpfigen Arbeiter mit starken Mandibeln 
an den Eingang eines Mymecocystus-riaticus-Nestes, alle Bewohner flohen eiligst in das Nest. I er eine barbarus behauptete den ganzen Eingang, kein Nestbewohner kam heraus, keiner hinein. Die Heimkelırenden wichen beim Anblick des Belagerers schon auf $30 \mathrm{~cm}$ Entfernung zuriick und liefen gestört umher, bis schliesslich eine ganze Schar der Heimkehrenden das Nest im grossen Umkreis ängstlich unruhig umliefen. Dem barbarus setzte ich zwei Cienossen bei zur Hilfe. Die Myrmecocysti verwehrten nun von innen den Eingang, indem sie stossweise Sandkiigelchen vorwarfen und aufhängten. Die babari lanerten; wenn ein Bein oder Fühler herauskam, schnappten sie darnach mud griffen zornig an. Da der Eingang trotz allem bald von innen her zugebaut war, ging der stärkste barbarus um die Öffnung herum auf die Höhe des Gewölbes, kroch herum und zerwiihlte trotz aller Angriffe der bedrängten Insassen die ganze Mauer. Ein ganz kleiner barbarus vertrieb einen der grössten Myrmecocysti aus der Nestregion. Die geistige Bildnng und Vielseitigkeit scheint den baburus zum überlegenen zu machen; schlau und listig. auslanernd ist er, wie keine andere Art. die ich sah. Die Silberameise (Myrmecocystus bombylans Roy.) lat mehr Mut. aber nie gleiche Überlegung.

K. W. v. Dalla 'Torre (Innsbruck).

19 Frohawk, J. W.. Attitude of Hybernating Wasp. In: Entomologist. XXXVT. 1903. pag. 33-34.

Verf. traf eine Wespe am 12. Dezember in ihrer Winterruhe an. Beine und Fühler waren dem Körper eng angelegt, die Flïgel gefaltet. Eine Bewegung zeigte sich nicht, nur der Hinterleib liess ein schwaches Klopfen beobachten. In der Lage der Extremitäten und Flügel erblickt Verf. einen Schutz vor feindlichen Angriffen.

K. W. v. Dalla Torre (Innsbruek).

20 Ilarington, Ernest, Male $\mathrm{Wasp}$ with Female Antennae. In: Canad. Entomol. XXXV. 1903. pas. 37-38.

Ein Thyreopus latipes Milh., im männlichen Geschlechte an der sclreiben. förmigen Erweiterung der Tibien leicht zu erkennen, zeigte die einfache Fühler. form des. +, ïberhiupt neigte die ganze Kopfform diesem Geschlechte zu. Das Tier stammt aus St. John, NB.

K. W. v. Dalla Torre (Innsbruck).

21 Ï̈ppner, Jos., Weitere Beiträge zur Biologie nordwestdeutscher Hymenopteren. In: Allg. Zeitschr. f. Entom. VI. Bd. 1901. pag. 33-35 (I.), 132-134. (II.), 291-293. (III.). VII. Bd. 1902. pag. 134-136. (IV.), 180-184. (V.), 298-301. Mit Fig. im Text; Taf. II.

I. Encera difficitis Dufour legt einen Zweigbau an; die Wände sind durch den erhärteten Speichel geglättet. Sie entwickelt sich im ersten Jahre bis zur Ruhelarve; als solche überwintert sie in einem 
selbst gesponnenen Cocon. Im folgenden Jahre entwickelt sie siclı weiter bis zur Imago, die Ende Mai, Anfang Juni des nächsten Jahres ausschlïpft. Sie ist zweijährig.

II. Über das Torkommen mehrerer Bombus-Arten in einem Nest. Aus Beobachtungen an Bombus acloarum und B. armicola Thoms., sowie melireln andern Hummelarten schliesst Verf.: 1. In einem Hnmmelnest. welches einen Teil (den grössern) seiner $q$ verloren hat und dadurch geschwächt ist, werden $q$ einer andern Art aufgenommen.

2. Geht (in Hummelnest durch irgend einen Uimstand plötzlich zu grumde, so suchen die Überlebenden $q$ bei in der Nähe bauenden Hummelarten unterzukommen.

III. Prosopis liviechlammeri Först. Verf. beschreibt sehr genau die Nestanlage im Marke ron Phraymites commurs, einem Grase, an welchem eine Fliege Lipara hucons Gallen erzeugt, welche von dieser Biene bewohnt werden. Dieselbe wird auch genau boschrieben.

IV. Wird der Deckel der I'rosopis-Zellen ron den Larven oder ron den Mättern hergestellt? Beobachtungen an meluern ProsopisArten, P. dilatata, I'. kriechbameri Först., I'. brecicomis Nyl., P. rucki Ciorsky. P'. confusa Nyl. und an mehr als $50 \mathrm{im}$ Bau begriffenen Nestern ergaben den Satz, dass nicht Prosopis-Larven, sondern das Prosopis-Weibchen den Zelldeckel rerfertigt.

Y. Odynerus (Microdymerus) exitis S. Verf. vergleicht den Bau dieser Art nit jenem ron $O$. laeripes. Er baut keine Lehmzellen, sondern nistet in Rübenstengehn; nur die einzelnen Zellen sind durch Querwände aus Sand und Lehm romeinander geschieden. Der Cocon ist oval, nicht fingerhutartig: der häutige Terschlnssdeckel ist deutlich von dem Wandcocon getrennt. Es werden einige Angaben Nielsens berichtigt.

VI. Über einige Testbauten des Bombus sorvensis Fabr. var. proters Gerst. Nach dem Verf. kommt in Nordwestdeutschland die weissafterige Form des $B$. sorensis nicht vor. In den Nestanlagen findet man nur die rotafterige Form proteus Gerst., sehr selten auch die var. sepulchralis Schecke. Die Nester werden unterirdisch, mäßig tief, mit Vorliebe ganz orler teilweise in alten, abgestorbenen Bamstiimpfen angelegt. Der Zellenklumpen wird ron einer dichten Hülle aus zerbissenen Halmen, Moos 1. dergl. umgeben. \%uweilen ist das Nest anch noch teilweise durch eine Wachsdecke geschïtzt. Tolkreiche Nester dieser Art fertigen auch aus einel wachsartigen Masse Honigtöpfe an.

K. W. r. Dalla 'Torre (Innsbruck). 
722 Kolll, Fr. F., Über einen Fall von frontaler Gynandromorphie bei Ammophila abbreviata. In: Verh. zool. bot. Ges. Wien. L1. 1901. pag. 405-407. Kopf und Thorax mit ihren Anhängseln sind in allen Teilen weiblich, das Abdomen zeigt bei der robusteren Form des weiblichen Hinterleibes die Segmentzalıl des männlichen und einen Genitalapparat, der sich in nichts von jenem normaler Männchen unterscheidet. Die Beine erscheinen in allen Teilen gedrungener, die Besaumung der Taster ist reicher. Das Tier stammt aus Amerika.

K. W. v. Dalla Torre (Innsbruck).

723 Nielsen, J. C.. Biologische Studien über einige Grabwespen und solitäre Bienen. In: Allg. Zeitschr. f. Entom. VI. 1901. pag. 307-30s: Fig.

Verf. fand Nester von Ceratophorus morio in morschem Holz ron Populux. Das Nest besteht aus drei oder mehrem parallelen Gängen von 15-80 $\mathrm{mm}$ Länge; in ihnen finden sich mehrere Lellen mit den Cocons. Diese sind wieder mit zwei Deckelchen versehen, einemi äussern fast harten und einem innern weichen Gespinnst. Daraus schliesst Verf., dass das Deckelehen der l'em phredonen aus zwei voneinander unabhängigen liestandteilen zusammengesetzt ist, ron denen einer der Gruppe eigen ist. während der andere als ein rudimentärer Cocon zu deuten ist; doch stellen einige Arten auch einen vollständigen Cocon her. Jene Arten nun, welche in dürrem Holz, mamentlich in dürıen \%weigen wohnen, erscheinen coconlos, da die Larven schon durch diese Umhüllung vor Feuchtigkeit geschützt sind; bei den erdbewohnenden Diodontus-Arten dagegen ist ein Cocon als Abschluss nach aussen nötig. Ebenso findet sich bei den Arten in lebendem Mark ein solcher (Isen atratus). Selbst ein und dieselbe Art, die Blattwespe Poccilosoma mulerata lietz.. Kam sich in dieser beziehung verschieden verhalten, indem sie in lebendem, feuchtem Marke ron Fraximus, Sambuans einen cocon anlegt, im trockenen derselben PHanzenarten aber keinen.

$$
\text { K. W. v. Dalla Torre (Innsbruck). }
$$

724 Undenans, J. T., Ein merkwürdiges Nest von l'espa vulgaris L. In: Allg. Zeitschr. Entom. VI. 1901. pag. 97-100; 119-122. Taf. II.

Das in Rede stehende Nest stammt von Vespa vulgaris L. und war etwa $2,50 \mathrm{~m}$ vom Erdboden entfernt, in dem niedrigen Raum zwischen einem Plafond (Badezimmer) und einem Bretterboden (Dachkammer) an einem Wasserleitungsrohr befestigt. Es war stark depress, dafül aber horizontal auffallend vergrössert, im Durchschnitt fast dreieckig. Die Gesamthöhe dïrfte $25,5 \mathrm{~cm}$ betragen haben, das Gesamt-Volumen über $36000 \mathrm{ccm}$; sein Gesamtgewicht etwa $700 \mathrm{~g}$. Die Hülle war ungemein stark entwickelt, die Zahl der Waben betrug nur 6 mit dem Ansatz einer siebenten. Eine Wabe hing frei von der Innenseite der Hülle herab. Im Gegensatze zu den normalen Nestern, bei denen die Waben ihr Maximum an Grösse und Zellenzahl in der Mitte aufweisen, stellte sich das Verhältnis bei dieser Wabe folgendermaß3en: 


$\begin{array}{rccc} & \text { Oberfläche in } \mathrm{cm}^{2} & \text { Zahl der kleinen Zellen } & \text { Zahl der grossen Zellen } \\ \text { I. } & 190 & 1185 & - \\ \text { II. } & 467 & 2685 & - \\ \text { III. } & 415 & 2387 & - \\ \text { IV. } & 330 & 1897 & 752 \\ \text { V. } & 501 & 1380 & 1198 \\ \text { VI. } & 416 & - & 200(?) \\ \text { VII. } & 70(?) & - & 95\end{array}$

Somit betrug die Anzahl der Zellen etwa 12000. Die Gestalt der Waben war mit Ausnahme der I. und VIII. sehr unregelmäßig, die II. bis VI. zeigte seitlich angesetzte Hörner; die VIII. freie stand auf der Höhe der VII. Im ganzen zeigt das Nest, dass die Tiere genau im Verhältnisse des zugemessenen Raumes arbeiteten. K. IV. v. Dalla Torre (Innsbruck).

725 Porgande, T.. The ant-decapitating Fly. In: Proc. Entom. Soc. Washington. IV. 1901. pag. 497-501.

Verf. beobachtete wiederholt, dass mitten in ihrer 'Tätigkeit befindliche Ameisen der Art C'amponolus pennsylvanicus Degeer von einer Fliege verfolgt wurden, einmal beobachtete er auch einen Kampf zwischen beiden und wiederholt fand er am Eusse von Baumstiicken, an denen Ameisen verkelırten, isolierte Köpfe am Boden. Schliesslich ergab die Zucht, dass eine Phoride, Apocephalus pergandei n. g. Coquillet n. sp. diese Köpfung durch das Belegen mit Fiern veranlasst. In Europa scheint Formica essecta in dieser Weise gefährdet zu sein.

K. W. v. Dall a Torre (Innsbruck).

726 Platean, F., Expériences sur l'attraction des insectes par les étoffes colorées et les objects brillants. In: Ann. soc. entom. Belg. XIII. 1900. pag. 174-18s.

Verf. experimentierte zuerst $(\$ 1)$ mit gefärbten Stoffen, indem er an einer mit Ampelopsis hederace überkleideten Wand, in deren Nähe Lilac und anderes Gesträuch das Grün ausfülite, mit Blumen versah. Beim 1. Tersuche wurden benutzt: Symphoricarpus racemosus Michx. (rosenrot). Dahlia iavialitis Desf. (rot und orange), Rudbectia laciniata L. (gelb), I'entatemon hartwegii Benth. (rosenrot und rot). Es hatte lebhaft rot: $516+228 \mathrm{~cm}^{2}$, gelb: $495 \mathrm{~cm}^{2}$, lebhaft violett: $234+234 \mathrm{~cm}^{2}$ und himmelblau: $176 \mathrm{~cm}^{2}$. Die antliegenden Insekten waren Apis mellifica L., Megachite ericetomm Lep., Pieris napae L., Eiristalis tenax L., Sypihus balteatus Deg., Calliphora romitoria L. und Musca domestica L.

Beim 2. Versuche unter denselben V'erhältnissen erschienen tags darauf nebst den Insekten am Vortage noch Bombus hypuorum L.. Odynetus quadratus Panz. und Symhus vibesii L.

Beim 3. Versuche wurde eine stark besonnte Wand mit Pfirsichlaubwerk ohne Bliiten und Früchte derselben, aber mit zahlreichem Jasminum officinale in Bliite gewählt. Am Grunde waren vorhanden: 
Chrysanthemum hybridum (weiss), Gaillardia drummoudii DC. (orange), Coreopsis auriculata L. (gelb), Salvia hormimm L. (rosenrot und blau). Es zeigten sich folgende Insekten: Anthidium manicatum L., Megachile oricetorum Lep., Anthophora quadrimaculata Panz. Apis mellifica L. selten, Odynterus quadratus P'anz. selten, Eristalis tenax L., Syrphu. balteatus Deg., S. ribesii L., Pioris rapae I.

Beim 4. Versuche wurden die Farben geändert und es erhielten dieselben folgende Ausmafe : feuerrot: $516 \mathrm{~cm}^{2}$, blutrot: $561 \mathrm{~cm}^{2}$, azurblan: $722 \mathrm{~cm}^{2}$, rosenrot: $722 \mathrm{~cm}^{2}$, gelh: $703 \mathrm{~cm}^{2}$. Dabei zeigten sich folgende Insekten: Apis mellifica L. zahlreich, Megachile ericetorum Lep. desgl., Anthophora quadrimaculata Panz. selten, Halictus spec., Eristatis tenax L. zahlreich, Tolucella bomlyllans L., Syrphus pyrastri L.. Melanostoma mellimm L., Musca domestica L., Pieris rapae L., zahlreich Gonionteryx rhame L.

5. Lenchtende ()bjekte. Zwischen Blumen wurden silberne und metallisch glänzende Kugeln aufgehängt; diese wurden von folgenden Insekten besucht:

Apis mellifica L. zahlreich .

Megachile cricetorum Lep. desgl.

Bombus terrestris I. häufig

Bombus museorum Fabr. desgl.

Odynerus quadratus Panz.

Eristalis tenax L. zahlreich

Syrphus balteatus Deg.

S. pyrastri L.

Pieris rapae L. häufig

Pararga megaera L.
Anziehung an der Glaskugel

$4 \mathrm{mal}(-)$

3 .. (1)

$1,,(-)$

$3, \quad(1)$

$2, \quad(3)$

1 , (-)
Anziehung an der gefärbten Metallkugel

- mal (1)

$1,,(-)$

j, (1)

2 , (2)

2 - (1)

Die fruien Zahlen bedeuten sichere, die eingeklammerten zweifelhafte Fälle von Anziehung.

$\$ 3$ behandelt das Verhalten der Insekten zu farbigen Stoffen in der Nähe von durch Blattwerk verkleideten Blumen.

4. Der Duft der Dahlien. Verf. konstatiert, dass scheinbar duftlose Bliiten, wie die der Dahlien, in der Tat einen auch von Menschen wahrnehmbaren Duft entwickeln, wenn man ihn von einer Anzahl Blïten in geschlossenem Gefässe ausströmen lässt.

s. 5ersuche mit Dahtia variabitis Desf. und Rudbeckia laciniata L., deren Köpfchen (zusammen 16) mit Jungfernrebe maskiert wurden.

$\$$ 6. Schlussätze: 1. Lebhafte Farben ziehen im allgemeinen die Insekten so wenig an, dass man hieraus unmöglich einen Beweis zu gunsten ihver Anlockung durch Blütenfarben ableiten kann. 
2. Gefärbte Stoffe, welche neben durch Blätter verdeckte Blüten befestigt werden, ïben nicht mehr Anziehungskraft auf die Insekten aus, als wenn sie sich neben freien Blüten befinden.

3. Metalliseh glänzende Gegenstände scheinen eine etwas grösserc Anziehung auszuïben, so dass man sehliessen kann, die Anziehung, welche bisweilen andere Giegenstände als Blumen erkennen lassen, rühren wahrscheinlich vou dem Unterschicde in der Masse des von dem Laube, bezw. diesen Gegenständen reflektierten Lichtes her.

K. IV. v. Halla Torre (Innsbruck).

727 Platea, F., Nouvelles recherches sur les rapports entre les insectes et les fleurs. 'Troisicme luatie. Les Syrphides admilent-ils les couleurs desteleurs? In: Mén. soc. zool. France. XIII. 1900. pag. 266-285. - Extr.: Illustr. Zeitschr. f. Entom. VI. pag. 170.

1. Kap. Geschichtliches. $\$ 1$ Die Theorie. $\$ 2$. Die Literaturcitate.

II. Kap. Beobachtungen und Versuche seitens des Verfassers. s. Wert der sog. Beweise der Verwumderung. \$ 4. Die syrphiden schweben über allerlei Objekten, a) syrphus myastri I., b) S. corollae I.. S. balteatus Deg., d) S. ribesii I.., e) Melanostoma mellimm I.. 5. Derselbe Gegenstand (Versuche).

III. Kap. III. Schlussätze: „1. die \%ahl der Fäile, in welchen Insekten durch blütenfarbige Objekte wirklich getäuscht wurden, ist sehr beschränkt und reduziert sich vielleicht im ganzen auf 7 unter tausenden ron Beobachtungen seitens einer Anzalıl von Forschern.

2. Die einzigen derartigen Insekten sind die Syrphiden, also Insekten mit bedeutend geringeren geistigen. Fähigkeiten als die Hymenopteren.

3. Nach meinen eigenen Beobachtungen zeigen die Syrphiden regelmäßig ihre Gewohnheit, über den Blumen zu schweben, nicht nur bei solchen ohne auffallende Farben. sonder'n auch bei grïinen und grïnlichen und bei blattähnlich getälbten.

4. Nach meinen eigenen Beobachtungen und den Beobachtungen anderer, deren Namen im Text genannt worden sind, finden Bliitenbesuche seitens der Syrphiden zahlreicl statt und es wurden solche an 35 grünen oder griunlichen Pflanzenarten festgestellt, welche zu 22 verschiedenen Familien gehören. Diese Fliegen konnten also nicht durch lebhafte Färbungen, welche ja gänzhich fehlen, angelockt werden.

5. Tach meinen Beobachtungen schweben Syrphiden häufig auch über irgend welchen andern PHlanzenkörpern, als über Blïten, so über 
grïnen Blättern, über geschlossenen und griüen Kinospen, uiber griinen Friichten, über grünen und braunen Zweigen.

6. Meine Versuche zeigen weiter, dass die Syrphiden tatsächlich auch ïber Objekten schweben, welche weder mit Blumen noch mit andern Pflanzenkörpern die geringste Ïhnlichkeit haben: über dem Finger oder der Hand des Experimentator's, über einem Stabe, einem Möbelstiick, einem Band (,filet:).

7. Somit fehlt den Insekten zweifellos ein Farbensinn."

Die entgegengesetzte Ansicht beruht nach dem Autor auf irrtümlicher Auslegung einzelner Fälle.

$$
\text { K. W. v. Dalla Torre (Innsbruck). }
$$

728 Plateau, Felix, Observations sur le phénoméne de la constance chez quelques Hyménoptèces. In: Ann. soc. entom. Belg. XLV. 1901. pag. ว́t-83. (Extı: Bot. C. LXXXVI. pag. $364)$.

Verf. erörtert zunächst len Begriff der Konstanz des Blımenbesuches. Nach ihm sind in ihren Besuchen konstant diejenigen Iymenopteren, welche zwar die rerschiedensten Blumen besuchen (also polytrop' sind!), aber während eines Austluges rom Nest aus ilne 'Tatigkeit auf die Ausbeutung einer einzelnen I'Hanzenart beschränken. Nilch ihm ist die Honigbiene schon Iristoteles als konstant bekannt gewesen. indem er sclneibt: "Auf jedem Austluge fliegt die Biene nicht von einer Blume auf die einer andern st, sondern geht z. B. von einer violetten zu einer andern violetten, ohne eine andere Blume zu berïhren, bis sie wieler in ilıren Bau zuriekgekelırt ist." "C̈hnlich schreiben ilı Bennet und Christy eine fast absolute Konstanz, Bulman und () r l ziemliche Inkonstanz zu; ähnlich differierende Ansichten ergeben auch dic Beobachtungen von andern Forschern bei andern Aiten. Die eigenen Beobachtungen werdeu zunäclist in Tabellenform mitgeteilt, dann werden die allgemeinen Folgerungen gezogen.

a) Bombus tervestris, B. hortorum, B. muscorum, B. hypnorum und $B$. lapidarius zeigen aus t2 Beobachtungen, dass die Hummeln sehr inkonstant sind und auf einem einzigen Austluge 3-5 mal die Pflanzenart wechseln. Dabei gehen sie von schwerzugänglichen Blumen und solchen mit verborgenem Honig unvermittelt zu solchen mit offenliegendem Honig, und wechseln fast ausnahmslos - eine Ausnahme tritt ein, wenn sie eine beträchtliche Anzahl ausbeutereicher Blumen derselben Art zur Verfügung haben - alle Farben ohne jegliche Spur einer bestimmten Reihenfolge. Die Höhe der Inkonstanz hängt ron besondern Umständen ab. 
b) Anthidium manicatum L. ist selır konstant, und wenn Labiaten etwas isoliert und in Blüten stehen, sammeln sie selbst tagelang nur auf solchen. Weiter besuchen sie mit Vorliebe Ranunculaceen, Papilionaceen, Compositen und Scrophulariaceen. Verf. beobachtete bei Hunderten von Individuen nur 8 Fälle von Inkonstanz.

c) Megachile und Coelioxys sind ziemlich inkonstant und besuchen nacheinander sehr verschiedene Blumen.

d) Apis mellifica erscheint auch nach den Beobachtungen des Verf. sehr konstant. Die beobachteten Individuen besuchten nicht nur lange Zeit hindurch Blumen derselben Art mnd liessen sich durch die Gegenwart anderer Pflanzen ror der liückkehr in den stock nicht nur nicht beirren, sondern kehrten stets, wenn sie sich verirrt hatten, sofort. nachdem sie den Irrtum bemerkt hatten, zur früheren Pflanze zurïck. Verf. glaubt, dass stets die Vorliebe tiir eine bestimmte Nektarsorte die Ursache der Konstanz sei, nicht die Blumenfarbe und sagt: nur wenn eine Blumensorte nicht ansreicht, um eine Tracht Nektar oder P'ollen zu liefern, oder wenn wenig Blunen derselben Art auf isolierten Stellen wachsen usw., geht die Bieue auf andere Blumen ïber, um auf diesen ilne Lathng voll zu mathen. Wahei lassen sich die Bienen weder durch den Bau, noch durch die Bliitenfarbe abhalten. Doch beobachtete Verf. innerhalb 3 Sommer nur 14 Fälle von Inkonstanz.

Die Bedentung der Konstanz liegt nach Darwin darin, thass die Insekten bei dem Besnch von Bliiten derselben Art den Mechanisnums besser kennen lernen, somit schneller arbeiten können. und Christy glaubt geradezu, dass die Bienen vermöge iherer höheren Intelligenz ihre Zeit besser anszunitzen verstehen, als die geistig inferioren Hummeln. Nach dem Verf. aber ist der Grad der Ermüdnng, nicht die Zeit, das Maß für ihre Muskeltätigkeit und dadurch, dass die Iusekten unnötige Ermüdung meiden, kommen sie zur Konstanz des Bliitenbesuches. Die Inkonstanz der Hummeh beim Blütenbesuche ist dagegen auf ihre grössere Arbeitsfahigkeit resp. auf ihre grössere Resistenz gegen Ermüdung zuriickzuführen. So trägt z. B. Bombus terrestris $0,15 \mathrm{i} \mathrm{g}, \mathrm{B}$. lapidarius $0,094 \mathrm{~g}$, Ipis mellifica $0,075 \mathrm{~g}$ (per 1.2 Stücke).

Die Schlusssätze lauten also:

1. Keine beobachtete Apide der Gattungen Bombus, Apis, Meyachile, Anthidium. Coetioxys ist absolut konstant; selbst die konstantesten verlasseu ab und zu eine besuchte Pflanze und begeben sich auf eine davon abweichende Art.

2. Bombus ist sehr inkonstant und bleiben selten längere Zeit hindurch bei derselben Blumenart. 
3. Anthidium manicatum und Apis mellifica zeigen ziemliche Konstanz, doch machen auch sie Ausnahmen.

4. In allen Fällen der Inkonstanz fliegen Hymenopteren von einer bestimmten Blumenart und -farbe auf andere Blumenarten. oft ron solchen anderer Familien und anderer Farben; dabei ist ihnen sowohl der Bliitenbau als auch die Blumenfarbe ganz und gar gleichgültig. Tur der Besitz von Nektar und Pollen ist ihr einzixes Motiv.

5. Der Unterschied im Verhalten der konstanten und inkonstanten Apiden ist keineswegs das Resultat der Überlegung der erstern, also eine höhere geistige Fähigkeit, sundern - "peut-être" eine physische Differenz; die konstanten Arten meiden rielmehr instinktmäBig die Ermuidung, indem sie auf derselben Ptlanze bleiben. um dadurch ihre Bewegungen, somit ihre Ausgaben auf ein Minimum bringen.

6. Die Konstanz führt eine grosse Geschicklichkeit in der Ansbeutung von Nektal und l'ollen herbei und lïsst sie dadurch Zeit gewinnen. Doch ist die erworbene Geschicklichkeit und die gewonnene Zeit nur die Folge und keineswegs die Absicht des Tieres.

li. W. r. Dalla Torre (Inusbruck).

729 Prowazek, Si., Pteromalidenlarven in schildläusen. In: Allg. Zeitschr. f. Entom. VI. 1901. pag. 289--291. Taf. IV.

Verf. beschreibt die Larve einer in Schildläusen auf Exomymus japonica bei Triest anfgefundenen Schildlausart und beohachtete im Li eine Teilung des Kerns in Fnrchungs- und eigentliche \%ellkerne. Dieselben sehen anf gewissen Stadien dicht aus und erseheinen grannhert, später werden sie mehr hell nnd gerüstartig. Im weitern Verlauf folgt das Ei der ron $k$ nlagis fiir Mlatyguster festgestellten Entwicklung. Die \%ucht ergab Pteromalus coccorm. welche also anch eine Hypermetamorphose zeigt, wie die verwandten Gattungen Platyguster u. Teleas. Im Imagozustande kriechen sit namentlich auf der Interseite der Blätter und erscheinen an warmen Nachmittagen lebhafter. Da sich in jedem ('oceidenindividum 1--3 Stücke Larven rorfanden, darf man amnehmen. dass sie an der Vernichtung dieser Schädlinge kräftigen Anteil nelımen, welche durch ihr Ansaugen Blattflecken und durch die Häutungsprodukte Verunzierungen der Biäter hervorrufen. K. W. v. Dalla Torre (Innsbruck).

730 Reichenbach, W., Über Parthenogenese bei Ameisen und andere Beobachtungen an Ameisen nnd künstlichen Nestern. In: Biol. Centralbl. XXII. 1902. pag. 461-464.

Verf. konstatiert, dass aus unbefruchteten Arbeitereiern von Lasius niger 16 Arbeiter entstanden. Im übrigen war die Kolonie 
normal. Bemerkenswert ist das dreimalige zeitliche \%usammentreffen (1899, 1900, 1901) des Auftretens von Männchen mit typischer Schwärmezeit im Freien (letzte Juliwoche). Das Alter der Arbeiter wird im Mittel anf 4 Jahre geschätzt. Aus dem sehr interessanten, wiederholt beobachteten Verhalten beim Beziehen des Nestes schliesst Verf., dass Formica sungminea. u. F. fused die Fïhigkeit haben, auf Grund von gemachten Erfahrungen ihre Handlungen zu modifizieren: .Retlexmaschinen sind zu solchem Verhalten nicht fähig."

$$
\text { K. IV. r. Dalla Torre (Innsbruck). }
$$

731 Robertson, Ch., Flower vis its of oligotropic Bees III. In: Bot. Gaz., XXXII. 1901. pag. 367 .

Den bisher bekannten oligotropen Bienen fügt Verf. noch 3 Arten hinzu: Andrena krigiana sammelt nur auf Krigia amplexicaulis, Entechnia taurea nur auf Ipomoea pandurata und Anthedon compta nur auf Oenothera bicnnis.

Melissodes, welche nur den zarten Pollen der Compositen sammelt, bat dichte und geschlossen behaarte Beine. Emphor, Xenoglossa und Entechnia dagegen, welche die grossen Pollenkörner von Hibiscus lasiocarpus, Cucurbita pepo und Ipomoea pandurata sammeln, hat nur lose und dünn behaarte Beine. Die enge Verwandtschaft $\mathrm{zwischen}$ flnthedon und Melissodes und die Beobachtung, dass das Männchen an den Hinterschienen gefiederte Haare besitzt. lässt schliessen, dass die Bürste des Weibchens erst in jüngster Zeit die Bebartung verloren und einfache Borstenhaare erlangt habe. Die Untersuchung ergab, dass die Pollen. körner von Oenothera biennis gross, dreilappig und spinnwebig verbunden sind; es sind daher einfache Borstenhaare zum Pollensammeln ausreichend.

Andrena nasoni ist nicht oligotrop.

In der Umgebung von Carlinville (Illinois) sind, ausschliesslich der ohnehin nicht sammelnden Inquilinen, $30^{\circ}$ o der Bienenarten oligotrop.

$$
\text { K. W. v. Dall a Torre ([nnsbruck). }
$$

732 schrottky, C.. Biologische Notizen solitärer Bienen von St. Paulo

(Brasilien). In: Allg. Zeitschr. f. Entom. VI. 1901. pag. 209-216.

Angeregt durch die Arbeit von Ducke veröffentlicht der Verf. seine Beobachtungen in St. Paulo, welche z. T. jenen entsprechen, z. T. aber auf den klimatischen Unterschieden beruhende veränderte Lebensbedingungen und abweichendes Verhalten der Bienen beim Blütenbesuch aufweisen. Die Flora der beiden Gebiete scheint sehr verschieden zu sein. Von einem wirklichen Blütenmangel kann man hier in keinem Monate sprechen und dementsprechend finden sich auch in den kältesten Junitagen Bienen aus den Gattungen Bombus, Meli. pona, Trigona. Am besuchtesten sind auch hier die Blüten von Papilionaceen, Caesalpiniaceen und Solanaceen, letztere allerdings nur gelegentlich, da in den meisten Fällen nur die $q$ daran zu finden sind.

Von den aufgeführten Pflanzen seien hier nur jene erwähnt, welche für die betreffende Bienenart als „Futterpflanze“ bezeichnet werden; über die Tätigkeit der Bienen in der Blüte teilt Verf. nichts mit.

Vernonia spec. mit Colletes rufipes Sm.

Teeoma ipé Mart. mit Xyloeopa colona Lep.

Leonurus sibiricus L. mit Anthidium manicatum L.

Stachytarpheta dichotoma Vahl mit Thalestria smaraydina Sm. 
Passiflora spec. mit? Nylocopa brasilianorum L.

Liihea pannieulata Mart. mit Epicharis schrottkyi Friese.

Conepia grandiflora Benth. mit Euglossa nigrita Lep.

Eriobotrya japonica LindI. mit Megacilissa eximia Sm.

Cassia splcndida Vog. mit Centris discolor Sm.

C. bicapsularis L. mit C. collaris Lep., C. xanthocnemis Per., C. paulö̈nis Friese. Crotalaria paulina Schum. mit zahlreichen der Gattung Centris verwandten Gattuingen und Arten.

C. vitellina Ker. var. minor mit Eucera und Exomalopsis spec.

K. W. v. Dalla Torre (Innsbruck).

738 Silvestri. Fil., Contribuzione alla convicenza dei Meliponidi del bacino del Rio de La Plata. In: Riv. patol. veget. X. 1902. pag. 121 -170.2 Taf.

Die Meliponiden sind stachellose, gesellig lebende Bienen, von denen man über 200 Arten kennt; sie sind in der südlich gemäßigten und heissen Zone zu Hause und namentlich in Südamerika sehr zahlreich vertreten. Im Stromgebiete des La Plata allein konnte Verf. 24 Arten genau studieren (darunter 4 neue) und Beobachtungen ïher die Lebensweise, den Nestbau und die Honigtracht machen. Die meisten nisten in Baumstämmen oder Mauernischen, viele unterirdisch, doch scheint keine Art an eine ganz bestimmte Nistweise gewöhnt zu sein; anch in Termitenbauten wurden nene beobachtet (Trigona kohli bei Euternus ripperti). In den Nestern sind besondere Zellen für àie Brut und besondere für die Vorräte, welche in Honig und Pollen bestehen; bei $T$. silrestrii sind auch diese letztern in abweichend gestalteten Trögen untergebracht. Der Honig wird je nach der Bienenart von ganz bestimmten Blumen gesammelt; T. cupira nahm zu diesem Zwecke die zuckerhaltigen lixkremente einer Cicadenlarve (Acthalion reticulatum) auf, manche setzen sich am Körper des Menschen fest und lecken Schweiss; $T$. timida lebt mit einer Lecaniide symbiotisch. Die meisten sind harmlos; einige beissen, T. flareola soll beim Biss Ameisensäure in die Wunde bringen, wodurch Entzündungen entstehen. Del Honig gilt als Arznei- und Nahrungsmittel. Einige Nestbauten, auch morphologisches Detail ist anf der Doppeltafel abgebildet.

K. W. v. Dall a Torre (Innsbruck).

734 Skottsberg, r. Einige blï tenbiologische Beobachtungen im arktischen Teil von schwedisch Lappland. 1900. In: Bihang Svenska Vetensk.-Akad. Handl. XXVII. Afd. 3. Nr. 2. 1901. 19 pag. 2 Taf.

Über die „Insektenwelt des Gebietes und ihr Verhältnis zur Pflanzenwelt" schreibt V'erf.: Man möchte denken, dass die kümmerliche Insektenwelt der Sarjekgegend sowohl an Arten als auch an Individuen arm, nicht für die grosse Anzahl von Alpenpflanzen genügen sollte, die durch die Farbe, Exposition, Honigabsonderung usw. für Bestäubung durch Insekten deutlich eingerichtet sind. Sicherlich würde eine ganze Menge Alpenpflanzen des nördlichen Europas oder wenigstens innerhalb der von mir berïhrten Gegenden steril bleiben oder nur spärlich fruktifizieren, wenn nicht, wie von 
mehr als einem Forscher hervorgehoben ist. Autogamie in grossem Maßstabe vorkïme.

Für eine richtige Auffassung von der Bedeutung der Inseliten für die Vertreter der Alpentlora sind Beobachtungen über Insektenbesuche natiurlich von Wert. Mir war deshall, daran gelegen. die Inselitenbesuche genau zu notieren, welche zu beobachten ich sellost (ielegenheit gehabt.

Lepidopteren, Hymenopteren und Dipteren kïnnen innerhalb des fraglichen Gebietes einige Rolle bei der liestiubung der Alpenblmmen spieten. Von den erstgenannten darf man nicht viel erwarten: ich habe nur ; Arten: digymis pales Schiff.; Evebia Tampona Esp. und Colias hecla Let. Blmmen besuchen sehen. Die Coleopteren, welche auf den Weiden allgemein rorkommen. kömen vielleicht für diese I'tlanzen eine Bedentung als Überbringer des l'ollens haben. Die Fliegen besuchen oft Bhumen, insbesonders salices. Unter allen Insekten spielen die Hummehn fiir die liestäubungsarbeit die vielleicht sxösste Rolle. Aber auch sie kommen nur spärlich vor; die gemeinste Art ist Bombus lapponicus Fabr. Auch diese habe ich nicht so oft gresehen: wenn das Wetter es erlauht, erscheinen die Hummeln. aber immer einzeln. Ion B. lapponicus sind vielleicht in allem wo Besuche ron ms wahroenommen, die maisten anf Drapensia und aut den Myrtithe-Arten. Li. consobrims I)bm. und L. scrimshiram.s lbbm. sind weit seltener: ron diesen habe ich viel weniger Besuche geselien, inshesonders rom letztern (kaum 10) . . .

In Allgemeinen sind die Insekten gezwnngen, sich in den geschützten Tälern aufzuhalten; dort ist anch die Vegetation am reichsten: löher auf den Gijpeln kommen die Insekten immer späirlicher vor: die Vegetation ist da recht kïmmerlich, d. h. von wenigen Arten zusammengesetzt. .. .

K. W. v. Da lla Torre (Innshruck).

\section{Vertebrata.}

Pisces.

785.5 Kerr, J. Graham. On the male genito-uriuary organs of the Lepidosiren and Protopteries. In: I'roc. zool. Soc. London 1901. pag. 48t-498. pl. $27-28.6$ 'Texttig.

736 - The genito-nrinary organs of Dipnoan Fishes. In: Proc. Cambridge philos. Soc. Tol. 11. 1902. pag. 329-333.

In der ersten Abhandlung (735) berichtet Verf. über die Anatomie des Hodens und der Samenwege ron Lepidosiven und Protopterns. Bei Lepridosiren scheidet sich der Hoden in einen die Spermatozoen produzierenden vordern Teil — formativer 'Teil - von beträchtlicher 
Lainge und etwa cylindrischer Gestalt und einen etwa ${ }^{1}{ }_{4}$ der Gesamtlänge einnehmenden hinteren Teil, in dem keine Spermatozoen gebildet werden, der dagegen einen der Länge nach durchziehenden Hohlraum ron unregelmäfiger (iestalt umschliesst - vesikulärer Teil - und von (dem allein) und zwar von seiner hinteren Hälfte die Vasa efferentia zur Niere (Mesonephros) treten. Liese sind etwa 5-6 Kanäle, die sich gegen die Viere 7.0 in mehrere Ïste spalten und durch diese mit ren zu Klumpen angehäuften Valpighischen Körperchen rerbinden. So gelangt das Sperma durcli die letzten Sammelkanäle der Niere. deren je einem ein Vas efferens nach seiner Lage etwa entsuricht. in den Harnleiter (Wolffschen (iang). Eine direkte Ausmiindung des hohlen Hodenabschnitts in den Harnleiter oder in lic Kloak ist nicht rorhanden. Die beiden Harnleiter münden auf je einer Papille in den Koloakenblindsack. Dieser entstelst ontogenetisch aus einer Erwaiterung der miteinander verschmolzenen distalen Abschnitte rer Ilarnleiter. Ini emen „jïhrigen Tier fanden sich Cherreste der Viillerschen (rïnge. die hei dem ansqewachsenen bis aut die Abdominaltrichter greschwunden sind.

liei P'rotopterus sind die Verhältnisse weentlich die gleichen. doch tinden sich folgende linterschiede. Der vesikuäre Teil nimmt nur etwa '⿳a der Länge des Hodens ein. Hinten verschmelzen beide mitcinanier. aber sine (iffnung in den .. Trogenitalsinus" (l'allier) ist nicht vorhanden. Fs ist jederseits nur ein V'as efferens in Gestalt eines unregelmäfig gestaltoten nnd mit Fortsätzen besetzten sinus vorhanden. del ans dem Hinterende des resikulairen Hodenteils entspringt. Die mit ihm lommmizierenden lintern Abschmitte der beiden Nieren berïhren sich in der Mittellinie. Von den Müllerschen Gängen bleiben die (ölomtrichter und die hintern Teile erlıalten: letztere vereinigen sich linten und endigen blind im Innern der Rasis der Trogenitalpapille.

Auch Cerutodus scheint :̈hnliche Verhältnisse aufznweisen. Die von G ïnther beschriehenen Vasa deferentia dürften die Mïllerschen Gänge sein.

Als eine weitere Fortbildung dieses bei den Dipnoern getrofienen Zustandes will Verf. denjenigen ron Polypterus ansehen, bei dem der resikuläre Hodenabschnitt nicht mehr durch Nierenkanäle ausmïndet, sondern sich direkt in den Harnleiter öffnet, und daron wären dann die Teleosteer abzuleiten.

Die zweite Abhandlung (7:36) enthält eine kurze Vitteilung über die Entwicklung des Pronephros und des Mesonephros bei Lepidosiren. Der Pronephros tritt als eine anfangs solide, über zwei Myotome sich erstreckende Mesoblastmasse auf, von der der Vornieren- 
gang als ein ebenfalls zunächst solider Stah ausgeht. Süiter erscheint in der Gegend des Nephrotoms ein Spalt und jeder Pronephros erhält zwei Tephrostomen. wie bei den Trodelen. Ihnen gegenüber wachsen in einer Tornierenkammer, die mit dem übrigen cölom danernd in Verbindung bleibt, die beiden Glomera hervor: Die Kianäle des Mesonephros treten zuerst streng metamer auf. nehmen aber bald an Kahl so zu, dass sie etwa doppelt so zahlreich wie die Myomeren derselben Körperabschnitte werden. Sie münden mit ilırm einen Ende in den Vornierengang, währond das andere sich zu einem Malpighischen Körperchen ausweitet und etwas später auch einen Glomerulus erhält. Zur Bildung von Nephrostomen kommt es nicht. Fïu aritter Abschnitt dieser schrift ist vin knrzer Anszug des Inlalts der ersten Abhandlung (735).

.J. W. spengel (Giessen).

\section{Mammalia.}

737 Bichner, E. Przewalskis Pferd in der liearheitung des Akademikers $\mathbf{W}$. W. Salensky ${ }^{1}$. Fine kritische liemerkung. St. Petersburg 1903. pag. $1-40$ (russisch).

Eugen Büchner, der anfängliche Bearbeiter der von X. I'rzewalski aus Zentralasien mitgebrachten Säugetiere, von welchem wohl eine genaue Bekanntschaft mit dem im Museum der Akademie \%n St. Petersburg rorhandenen Materiale zu erwarten ist, liefert lier eine sachliche, wenn auch scharfe liritik der learbeitung des interessantesten Ohjekts der Sammlung, des Equms maewalskii Pol. durch den Akademiker Wr. Sa lensky. Nach des Verfs. Ausspruch konnte die Kritik nur negativ ausfallen, weil salensky, als Koologe, nicht Systematiker, seine Kräite in dieser lieziehung überscliätzte und als erste Probe einer systematischen Arbeit eine so schwere Aufgabe sich stellte, wie die Bearbeitung des Materials zu Equms przewalslii.

Hauptsächlich wirft Verf. dem Bearbeiter Folgendes vor: Ungenaue Citation der 'Titel im Literaturnachweis, Aufführung von Arbeiten, die niemals im Iruck erschienen, Ignorierung andererseits von solchen, die vor allen Dingen Beachtung verdient hätten; bei Behandlung des vorhandenen Iuseumsmaterials vermisst man die erforderliche Genauigkeit, wodurch Nummerverwechslungen nicht nur, sondern auch andere Irrtïmer begangen werden, so dass eine Ausnutzung des Materials zu Schlussfolgerungen diesen jede sichere Basis entzieht; zur Vergleichung hätte Verf. dem Wildpferde näher stehende mongo-

1) Wissenschaftliche Resultate von den Reisen N. M. Przew alskis in Zeutralasien. Zoologischer Teil. Band I, Säugetiere, Teil 2, Huftiere, Lief. 1, Equus Przewalskii Pol., bearbeitet vom Akademiker IV. Salensky. St. Petersb., 1902 (russisch und deutsch). Vgl. Z. Zentr.-Bl. X. 1902. Nr. 69. 
lische Hausplerdrassen und nicht europäische Rasspferde heranziehen sollen, wie auch die Anwendung der Nathusiusschen Malie hier kaum zulässig erscheint; die äussern Merkmale sind nicht vollständig durchgearbeitet; Verwechshungen in bezug auf Bezeichnungen für Vorderund Hinterextremitäten kommen wiederholt vor; ein und dasselbe Exemplar wird an verschiedenen stellen unter verschiedenem Alter und Geschlecht erwähnt; bei den geographischen Angaben merkt man, dass Verf. die Karten nicht zu hate gezogen, da im entgegengesetzten Falle die augenfälligen Irrtümer nicht blos auf Nomenklatur, sondern auch in bezug auf Längen und Breiten vermieden worden wären, Stidte nicht als Seen, Landschaften nicht als Fliisse figurieren wiirden; bei liesprechung der systematischen Stellung des Przewalski-Pferdes werden die Meinungen westenropäischer Gelehrter, die nie Gelegenheit hatten, das Tier zu sehen oder zu studieren, in Petracht gezogen, die Ansichten russischer Forscher (Poljakow, Tschersky, T'ichomirow, Anutschin) nur fliichtig oder gar nicht beriihrt.

Daher kommt es denn, dass der Verf. an verschiedenen stellen seiner Monographie zu ganz entgegengesetzten schliissen gelangt.

Der deutsche Paralleltext zeugt ron mangelhafter Beherrschung dieser Sprache durch den I'bersetzer', da sonst nicht solche ('uriosit möglich wären, wie dass der Kunlan zwei Quasten an Schwanze habe, wie man aus der darauf berüglichen, ziemlich unklaren Stelle entnehmen miisse. Alle seine Vorwïrfe stiitzt E. Biichner durch genaue Citation ron Belegstellen.

Wie uns bekannt geworden, will E. Büchner-da der deutsche 'Text eine Menge anderer Irrtiumer aufweist - anch cine deutsche Kritik der Arbeit erscheinen lassen.

C. Grevé (Moskau).

738 Kennel, J., C̈ber eine stummelschwänzige Hatkatze und ihre Nachkommenschaft. Ein Beitrag zur Lehre von der Variation der Tiere. M. 2 Abb. i. Text. In: Zool. Jalırb. Abt. Syst., (ieogr., Biol. 15̃. Bd. 2. Heft. 1901. pag. 219-242.

Der 'Tatbestand ist folgender: Eine stummelschwänzige Katze warf 1897 in Frühjahr 6 Junge, 4 mit und 2 ohe Schwanz, in Herbst 4, daron 2 mit und 2 ohne Schwanz. Der Frühjahrswurf des folgenden Jahres brachte 5 .Junge, ron welchen 1 geschwänzt war. 3 schwanzlos und je 1 einen rudimentären Schwanz besass. Der nachfolgende Herbstwurt ergab unter 4 Jungen 1 geschwänztes Männchen und 3 ungeschwänzte Weibchen, wobei die letztern zum ersten Male nicht mehr die bis dahin festgehaltene Zeichnung der Nutter zeigten. 18!!) wurden zunächst 4 Junge geworfen, 2 geschwänzte und 2 stummelschwänzige, im Herbst endlich vater 5 .Jungen 


\section{$-760$}

2 mit normalen Schwänzen, 1 stummelschwïnzige und ¿ schwanzlose: diese sind dem Verf. zugesandt worlen. Die Stammmutter war eine sog. Maskenkatze, die ..als kleines Tier in völlig verwahrlostem Zustande auf dem Felde gefangen worden" war. liei keinem ihrer Würfe kann ..ein stummelschwänziger oder schwanzloser Kater der Yitwirkung bezichtigt werden", so dass Inzucht für die anfeinanderfolgenden Bruten ausgeschlossen und der Charakter der letztem in der angegebenen Richtung von der Stamumutter bedingt erscheint. Wie aber diese letztere zu ilrem stummelschwanz gekommen war, liomite nicht entschierlen werden und fehlt damit selbstredend gerade die enticheidende Grumdlage für dic theoretische lieurteilung des Falles. Vielleicht bringen die von Velt. in Anssicht genommenen Zuchtrersuche mit einem stummelschwänzigen und einem schwanzlosen Kater des letzten Wurfes einigen Lisatz für dieses Manko.

Iit stummelschwänzige nud gir schwanzlose Katzen - abgesehen ron gewissen fiegenden dapan. Insel Man, in denen sie endemisch als lionstante liassen seit langem rorkommen - nur sch selten beobachtet werden, muss dis lier in of (ienerationen yutage getretene partielle Vererhung von stunmelschwïnzigkeit. resp. Schwanzlosigkeit jedenfalls auffällig erschemen. Für die Frkliirung kümen drei Möglichkeiten in Retracht, entweder Import ron auswärts oder zufillige Verstïmmelung oder ...prungweise" Variation seitens der Stammmutter. Vorf. entscheidet sich für die zuletzt genamnte Auffassung und kniipt daran eine Reihe theoretischer, vornehmlich gegen I'late gerichteter Betrachtungen. die hier nicht referiert werden kömnen.

Zum Schlnsse berichtet der Verf. über die Verschiedenheiten im anatomischen Befunde der Wirbelsäule einer stummelschwänzigen und einer schwanzlosen Katze im Verhältnis zum normalen Ban dieses ()rgans. F. r. Wagner Giessen). 


\title{
Zoologisches Zentralblatt
}

unter Mitwirkung von

Professor Dr. O. Bütschli

In Heideltierg and

herausgegeben von
Professor Dr. B. Hatschek

in Wien

\author{
Dr. A. Schuberg
}

a. 9. Profoser in Heidelberg

Verlag von Wilhelm Engelmann in Leipzig.

\section{Jahrg.}

17. November 1903.

No. 2223.

Lu bezehen durch allo Buchhandlumen und Postanstalton, sowie ilurch die Verlagsbuelihanillung. Wảirlich 26 Ninmern in Uulang von 2-3 Bogen. P'reis fïr don Jahrgang Nl. 30 . - Bei direkter \%usond ung jeder Nominer uner Streifband erfolet ein Aufschlag von il. 4.- nach lem Inland und von H. $\overline{0},-$ nach dern Ausland.

\section{Referate.}

\section{Lehr- und Handbiicher. Sammelwerke. Vermischtes.}

739 Nalepar, I., Grundriss der Xaturgeschichte dos l'ierreiches fïr die unteren Klassen der Mittelschulen und reswandter Lehranstalten. Mit hesonderer lierïcksichtigung der beriehnngon \% wischenkörperban und Lebensweise. Wien 1902. 220 pag. 2!n; Holzchnite. :3 kol. Tarf. 1 Erdkarte. Geb. M. 2.60.

Das Buch nimmt in der einschlägigen pädagogisclen Literatur eine eigenartige Stelle ein, man kann wohl sagen, durch seine Finfachheit, und das erachte ich für einen wesentlichen Vorteil, so sehr anch mancher Schulmann, ler in einer fein ausgetiiftelten Methode alles Heil erblickt, die Vase rümpfen mag. Ls wird vieles weggelassen, was in der Tat entbehrlich erscheint, zunächst die lateinischen Namen, sodann alle klassitikatorischen Termini, die über Kreis, Klasse und Ordnmo hinausgehen. In ler Tat wird das Verstïndnis dafür am ersten bei der Botanik gewomnen, in der das system, womöglich mit einigen Bestimmungsübungen, zur Besprechung gelangen muss; da genügt ein Hinweis auf die Zoologie vollkommen. Weiterhin halte ich für praktisch, dass den Schülern vor allen I)ingen Inschaung und Tatsachen ïhermittelt werden an Stelle ermüdender Abstraktionen. Vielleicht geht hier Nalepa etwas weit, wenn er, ahgesehen ron einer kurzen taxonomischen Übersicht der Ǩlassen am Schluss, die einleitenden Bemerkungen zu den Gruppen auf die Säuger und Vïgel beschränlit, im weiteren aber die Unterschiede ganz allein aus der monographischen Schilderung einzelner Vertreter lervorgehen lässt. Hier kann aber der Lehrer recht wohl nachhelfen. 
Freilich ist in diesem Sinne auch die Erdkarte, die dem Buche beigegeben ist, olne irgendwelche zoogeographischen Einzeichnungen, ïbertlïssig. Sie mag als Wandkarte im Klassenzimmer hängen. Dass die bunten Tafeln nur Schmetterlinge und deren Entwickelıng vorführen, ist wohl etwas knapp, entspricht aber den natiurlichen Verhältnissen insofern ganz gut, als sich daran in der Schule die Bedentung der Farben immer am besten erläutern lässt. Auffallend ist es wohl, dass die Forficuliden als Lederfliggler die letzte Insektenordnung bilden hinter den Länsen. Die Abbildungen sind selır gut and meist hiologisch: wiedermu nit änsserster Beschränkung wissenschaftlicher Zutaten. Nur ein Slielett nnd einige Schädel sind darunter. Ïhnliche Peschränking in der Answalıl sowohl als in der Zısammenfiassung. In ersterer Hinsicht fehlt z. 13. Amphioxus, von den Stachelb:intern werden nur der ,gemeine" Seestern und der "gemeine" Seeigel besprochen, in letzterer worden Schwimm- und Wasscrkäfer(I)yticiden und Hydrophiliden) zusammengefasst. Unter den Trtieren konnten wohl ausser den Infusorien noch die Foramin iferen als "Kreidetierchen" beachtet werden. Doch das sind Kileinigkeiten.

Im grossen und ganzen wird man das Bnch, auch ohne dass ein Vorwort über die Absichten des Verfs. Anfschluss gähe, als einen gnten Schritt zur Bewältigung les riesigen Materials in den Unterlilassen oder Mittelklassen, nm eine Basis zu gewinnen für moderne Anschaunngen, betrachten dïrfen. Freilich muss dabei noch Spielraum bleiben für weiteren Ausbau, sei es in len folgenden Kilassen, sei es auf Crund rertiefter Anschaung unit den Mitteln der Schulsammlıng. sei es dnrch gelegentliche Einschaltungen an geeigneter Stelle (z. B. Descendenz bei den Hunderassen). Die Dnrchbildung und Persönlichkeit des Lehrers wird stets die Hauptsache bleiben.

H. Sim rot lı (Leipzig-Gautzsch).

\section{Zellen- und Gewebelehre.}

740 Vejdorsky, F. und A. Mrizek, U mbildung des Cytoplasma während der Befruchtung und Zellteilung. Nach den Untersuchungen am Rhynchelmis-Eie. In: Arch. f. mikr. Anat. Bd. 62. 1903, pag. 431-579. 6 'lf. 11 Textfig.

Verft. haben die in der cytologischen Literatur viel zu wenig berïcksichtigten Untersuchungen Vejdorskys am Rhynchelmis-Ei einer eingehenden Neunntersuchung mit modernen Nethoden unterzogen und durch Beobachtungen an verwandten Formen ergänzt. Die angewandten Methoden sind die in der Zellenforschnng üblichen. die gegen A. Fischers Angriffe lebhaft verteidigt werden. Thas dicht mit Dotterkugelı erfïllte Rhynchelmis-Ei ist von einer peripheren Proto- 
plasmaschicht überzogen. die nach aussen von einem Alveolarsaum begrenzt wird. Noch im Mutterleib bildet sich ans dem exzentrisch gelegenen Kern die erste Reifungsspindel. an deren Polen grosse Centroplasmen (= Centrosomen Boveri) mit deutlichen Centriolen liegen. (Die Entstehnng der spindel aus dem Kern wird für Ilyodritus näher geschildert.) Der Kernanteil der spindel bleibt immer gesondert und tritt nicht in Terbindung mit den Centroplasmen. Die spindel enthält $32 f$-förmige Chromosomen. Nunmelır steigt sie unter lebhaften, wellenförmig ron Pol zu Pol fortschreitenden Gestaltsveränderungen des sehr plastischen Eies zur Oberflïche auf. (Noch stiirmischer verlaufen die Gestaltsverändermngen unter Pseudopodienbildung bei Tubifer.) An dem peripheren Spindelpol ist in der dichten Plasmamasse, die hier muter der Oberfläche liegt, Centroplasma und Centriol nicht melı zu erkennen. Das proximale Centroplasma behält seine Grösse bei und auch das Centriol verdoppelt sich nicht während der Abstossung der Polzelle; es sind das bedentende Unterschiede gegenüber dem Verhalten der ('ontren in den l'urchungszellen. Die : Reifungsspindel, deren Entstehung nicht verfolgt wude, bictet nichts besonderes. I) blëschenfürmig nmgewandelten Chromosomen (Karyomeren) vereinigen sich zu (incm maulheerförnigen Eikern, der ins Innere rückt, wobei ihm ein Stück weit der plasmatische liest von Sphäre nnd Spindel kometenschwanzförmig folgt.

I le lie samung, d. h. das Eindringen des Spermatozoons in das Ei, bietet interessante Einzellıeiten. Die Spermien kïmnen an jedem I'unkt der Oberfläche in den Alveolarsaum eindringen und hier die Bildung eines "Pesamungskegels" hervorrufen, von denen aber nur einer sich weiterentwickelt. Der Alveolarsaum verdickt sich an einer solchen Stelle beträchtlich, wobei er die radiale Streifung. den Ausdruek dor Alveolen, beibehält. Die darunterliegende periphere P'rotoplasmaschicht wird kappenförmig von dem in toto eindringenden Spermatozoon vorgedrängt und deshalb im ausgebildeten líegel auch als "Kegelkappe" bezeichnet. "Wwischen diesen und dem Derivat des Alveolarsaums findet sich eine protoplasmatische Masse, die aus dem eigentlichen Eiplasma hieher diffundiert sein soll und bei dem weitern Heranwachsen des Kegels in das Ei deutlich wabig wird. Das aufgequollene Alveolarsehichtderivat des Kegels kann schliesslich als grosser Zapfen über die Eiobertläche ragen. Die Bedeutung des ganzen Gebildes ist, eine Leitstrasse für das Eindringen des Spermatozoons zu bilden. Verff. möchten aus diesen Beobachtungen schliessen, dass auch in den Fällen, wo dem Spermatozoon entgegen ein Empfängnishügel gewölbt werden soll, dies erst auf den Reiz des Spermatozoons 
him reschieht (:). Sobald seine Funktion orfiillt ist, verschwindet der Besamumgkegel schnell wieder durch Zerfall mol liesorption.

An hinteren Ende des noch fadenförmigen Spermatozoons tritt jetzt das Zentralkorn auf. U'm dieses sammelt sich Plasma an, von dem strahlen zwischen die momgehenden Dottrumassen ansaghen. Die Strahlen sollen Plasmaströme sein, aus denen sich das C'entroplasma denn dies ist die das Zentralkorn umgebende Plasmamasse - aufbaut. Fs sind also die Strahlungen schon vor den C'entroplasma [= C'entrosom (I,overi)] vorhanden. welch letzteres sich erst nnter dem Eintluss des Centriols bildet. Es zeigt jetzt hereits eine dentlich alveoläre Struktur. Der Spermakopf hat sich inzwischen kondensiert nnd wird ron ener Scheide umgeben, die wohl aus der frotoplasmatischen Umhiillnng des ersteren hervorgegangen ist: eine I)rehung um $180^{\circ}$ fiihrt er nicht aus. Inzwischen ist die Centroplasmakngel bodentend herangrwachsen und ron einer stralıligen, ans Alveolen zusammengesetzten Hiille (Boveris Archiplasma) umgeben. Fs soll diese aus den oben beschriobenen Plasmastrahlen hervorgegangen sein und ilıc Struktur durch Imwandlung ron Microstmen in Alveolen erlangt haben (?). Das ('entroplasma wird immer grösser und seine Alveolen immer güber, so dass schliesslich bei der Konserverung die Wände reissen. Der Spermakern, der mit dem Arehiplasmanantel durch eine eigenatige spindel verbmulen ist, verlässt diese. div resolbiert wirel, mud tritt in das riesige Centroplasma ein. in dem sich das Contriol geteilt hat. Tm das C'entriol differemziert sich jetzt bereits ein 'Tochtercentroplasma, für das das Muttercentroplasma, dessen Alreolen stralilig angeorinet sind, den Arehiplasmamantel abgibt. l)ie Grenze des Mutterentroplasmas ist durch ein Mikrosomenstratmm angerlentet. Währemel sich num die zweipolige spindelfigm ausbilket, wathsen die 'Toehterentroplasmen wieder unter Vergrösserung ilner Aleolen heran, so dass sie schliesslich das Muttercentroplasma verdrängen nud in der ausgebildeten Furchungsspindel als mit hlossem Auge sichtbare Kugeln imponieren. Die Furchungcentroplasmen [=Centrosome (Boveri)] entstehenalso nicht durch Teilung einesspermacentrosoms, sondern werden von dem sich allein teilenden Centriol neugebildet. An den im \%entrum der Strahlenfigur lieg»nden spermakern tritt jetzt der Eikern heran und aus hoiden hilden sich die Chromosomen und die Kermspindel aus. Während in der ganzen Teihngsfigur die Strahlungen ausschliosslicl durch radiale Anordnung der Alveolen bedingt werden und ron Faden oder Fibrillen nirgends die Rede sein kann, wie immer wieder betont wird, wird fïr die eigentliche Kernspindel, die immer scharf abgesetzt erscheint, die Möglichkeit von echten Fibrillen. entstanden 


\section{$-765$}

durch fädige Ausziehung der zähen Kernsubstanz, zugegeben, weun anch hier bisweilen Querverbindungen beobachtet wurden. In diesem Stadium zeichnet sich auch das Centroplasna durch eine Besonderheit aus; es schickt nämlich zu dem Ende der Kernspindel eine Protuberanz, die aus denselben grossen Alveolen aufgebaut ist, die aber der Spindel entsprechend in lieihen angeordnet sind. Auch ist die strahlige Archiplasmaschicht jetat besonders mächtig und in ihrer innern Lage stark verdichtet. Es können nummehr zwei Wege eingeschlagen werden. Leim 1. Typus teilt sich das Zentralkorn, wobei in seinem Umkreis. innerhalb des Centroplasmas, seine Strahlungen anftrrten, die durch ein Zuströmen ron Wabenwandsubstanz zum C'entriol gebilket werden. Eine durch die Anordnung der Alveolen bedingte feine Zentralspindel rerbindet die Centriolen. verschwindet aher, sobald die letztern anseinanderrïcken. hat also gar keine Bedentung. Aus dem zun Centriol fliessenden „Hyaloplasma“ bilden sich die neuen Enkelcentroplasmen, die wieder eine sehr faine alveoläre Struktur erlangen. lieim ¿. 'Typus, der als der normale angesehen wird, bildet sich um das nngeteilte C'entriol ein neues f'entroplasma, das sich einschnïrt. aber noch nach rollzogener 1. Furchmeg nicht geteilt ist, während sich in seinem Innern sehon die neuen Enkelcentroplasmen gebildet haben. die dam die Pole der 2. Furchnngsspindel eimnelmen. (Die lioverische "Reduktion des Centrosoma" hat also жwoimal stattgefunden.) In der 2. Furchungsspindel sieht man besonders schön die Überkreuzung der Strahlen, die beweisen, ..dass bei mabweislich bloss aheolïrer struktur tatsächlich Kreuzungserscheinnngen sich zeigen und zeigen miissen." Es wiederholen sich num die gleichen Vorgänge der Bildung von Tochter- und Enkelcentroplasmen, also der doppelten "Reluktion des Centrosons"; allerdings werden mit dem Ḱleinerwerden der Zellen die Vorgänge auch weniger deutlich und dadurch denı gewöhnlich beschriebenen Verhalten ähnlicher. Je geringer die Dimensionen der Zellen werden, um so mehr verändert sich das Grössenverhältnis der achromatischen und chromatischen T'eile zu Gunsten des letztern. Dadurch wird es dann auch ermöglicht, die Eintstehung der Kernspindel, die immer deutlich abgegrenzt bleibt, zu verfolgen. Bisweilen, nicht regelmäbig, ist eine ungleiche Grösse der beiden Sphären an den Polen nachzuweisen, die aber hier ein anormales Verhalten darstellt, niicht der Grösse der beiden Furchungszellen proportional ist, wie bei Polystomum (Ref.). Der allgemeine Teil enthält vor allem eine Diskussion der Centrosomenfrage, die in dem Satze gipfelt, „dass das "Centrosoma“ Boveris, unser Centroplasma, keine selbständige persistierende Zellorganelle darstellt, sondern dass dasselbe 
periodisch stets rollkommen neu entsteht und zwar immer endogen innerhalb des alten Centroplasmas.". Das Centrosom erbt sich nicht durch Teilung von Zelle zu Zelle fort, sondern bildet sich unter dem Ëinfluss des Centriols immer wieder neu durch Umbildung des l'lasmas. Verff. glauben schliessen zu dürfen, dass auch in allen andern Objekten (Echinodermen, Ascoris usw.) die Torgïnge die gleichen sind.

Vorliegende Untersuchung. deren Fedentung für die Lebre ron den sog. achromatischen Zellbestandteilen die ansfïhrlichere Wiedergabe der Resnltate rechtfertigt, ist einmal ats cin neuer, anf exakte Tatsachen gegriindeter Erfolg der dynamischen \%ellteilungstheorien und der Lehre von dem Wabenbau des I'rotoplasmas zu begrüssen; sodam wird sie aber anch vor allem dazu beitragen, dass die Centrosomenfrage wohl in Bälde definitir erledigt werden kann.

li. Cioldschmidt (München).

\section{Vergleichende Morphologie, Physiologie und Biologie.}

741 Pfeffer, W., Pflanzenphy siologie. Ein Handbuch der Lehre vom Stoffwechsel und Kraftwechsel in der Pflanze. \%weite völlig ungearbeitete Auflage. \%weiter Band: Kraftwechsel. 1. Hälfte (Bogen 1-22). Leiprig (W. Engelmann). 1!101. gr. 8. 353 jag. 31 Textfig. M. 11.-.

Wenn ein Forscher, der Jahrzehnte lang den hervorragendsten Anteil an der Entwicklung der Pflanzenpliysiologie genommen laat, der so unendlich vieł zur Vertiefung ihrer P'roblemstellung, zur Lösung wichtiger Fragen beigetragen hat, den Wissensbestand. die Ziele und Wege seines Arbeitsgebietes zusammenfassend darstellt, so darf man einem solchen Werke gegeniber grosse Erwartungen hegen, und mam wird sie in Pleffers l'tianzenphysiologie vollauf erfüllt finden. Die zweite Auflage stellt ein fast röllig neues Werk dar. so dass eine Bezugnahme auf die erste Auflage übertliissig erscheint.

Die erste Hälfte des zweiten Bandes, über die lier berichtet werden soll, enthält ein überreiches Tatsachenmaterial. das, unter dem Gesichtspunkte des Kraftwechsels behandelt, in 10 Kapiteln seine Darstellung gefunden hat. Einen breiten Raum nimmt die Lelıre von der Wachstumstätigkeit ein: Die Wachstumsbewegung, die Mechanik des Wachsens, Wachstum und Zellvermehrung, die Elastizitäts- und Kohäsionsverhältnisse des Pflanzenkörpers, die Gewebespannung und die Beeinflussung der Wachstumstätigkeit durch die Aussenbedingungen finden in eigenen Kapiteln eingelıende Darstellung. 
Ein ïberaus inhaltsreiches und beachtenswertes Kapitel ist den innern Ursachen der spezifisehen Gestaltung gewidmet. Variation und Erblichkeit finden nur eine kurze Besprechung, da ein Eingehen auf die Fragen der Artbildung nicht im Plane des Werkes lag. Findlich ist ein Abschnitt der Rhythmik der Vegetationsprozesse gewidmet und das letzte Kapitel behandelt die Widerstandsfähigkeit gegen extreme Einfliisse.

Ein Referat über dies Werk im Zoologischen Zentralblatt darf wohl besonders den Wert der pflanzenphysiologischen Forschung, deren Ergehnisse uns hier von Meisterhand vorgeführt werden, für die Fragen betonen, die dem Zoophysiologen nahe liegen, und die al $\lg _{\mathrm{g}} \mathrm{n} \mathrm{e}$ in physiologisches Interesse beanspruchen dïrfen.

Man sagt gewöhnlich, dass die hohe Stufe der Entwicklung der Pflanzenphysiologie wesentlich durch die geringe Kompliziertheit der gegebenen Verhältnisse ihre Erklärung finde; aber es drängt sich gerade bei dem Studium der Pfefferschen Ptlanzenphysiologie unwiderstehlich der Eindruck auf, als hahe noch ein, auch scheinbar äusserliches Moment lier wesentlichen Einfluss geiibt: die l'tlanzenphysiologie ist in ilurer freien wissenschaftlichen Entwicklung nie durch dic starken und ganz einseitigen lediurfnisse der l'ruxis gehemnt worden, wie die P'hysiologie der l'iere, die noch heute grossenteils ant's engste an der speziellen Plysiologie des Menschen und einiger Wirbeltiere orientiert ist.

Wenn man sielıt, wie anf dem (iebiete der P'llanzenphysiologie gearbeitet wird, so erkennt man, dass eine allgemeine Vertrautheit mit der Formenfuille des Ptlanzenreiches bei einen: I'flanzenphysiologen eine Solbstrerständlichlieit ist, und dass sich so ganz ron selbst eine vergleichende behandhng der Probleme ergeben musste.

Die Forscher, welche sich nit Lebenserscheinungen der Tiere beschäftigten. waren dagegen bis in die neueste Zeit entweder Zoologen, und dann fehlte ihnen meist die genügende physiologische Bildung, oder sie waren P'hysiologen, und das bedentete meist, dass sie vom 'Tierreich nur ein knappes Dutzend Wirbeltiere in erwachsenem Zustande kannten. Die hierans entspringende Einseitigkeit in der Behandlung der Probleme ist leider ein sehr hervorstechendes Charakteristicum der zoophysiologischen Arbeiten gegenüber den phytophysiologischen.

Nur ein Beispiel mag diese Behauptung erläutern: Wir erleben heute in der Physiologie der Tiere das seltame Schauspiel, dass die Berechtigung einer Cellularphysiologie von manchen Seiten bestritten wird, dass man ihr allen Wert, oder doch jede allgemeinere Bedeutung absprechen zu können glaubt. Eine solche Meinungsverschiedenheit, die auf dem Boden einer speziellen Wirbeltierphysiologie erwuchs, 
hat in der Pflanzenphysiologie keine Bedeutung: theoretisch und maktisch finden wir iiberall das selbstrerstïndlich erscheinende Bestreben, die an ganzen l'Hanzen lionstatierten Vorgänge als Funlition der Kellen, der Protoplasten, darzustellen, die l'tanzemphysiologie cellula l'physiologisch zu behandeh.

So verdankt die I'flanzenplyysiologie ihre wissenschaftliche töhe wohl weniger der grössern ..Einfalchheit" ihner objekte, ein begrift. der lebenden Gebilden gegenüber ïberhaupt mit arosser Vorsicht zu verwenten ist, sondern dem Lmstande, dass die Arbeit, due in ilır geleistet wurde, wirklich in der Richtung auf l'robleme angewandt. ward, dass die Objekte und Mothoten dem Problem entsprechend gewälıtt wurden und nicht, wie so häutig in der Tierphysiologie, die l'robleme nach den eben modernen Methoden und Aplatraten und den wenigen stereotypen (o)jekten.

Wenn zmm Schlusse noch auf einiges spezielle hingewiesen werden darf, so sind es vor allem zwoi lieihen ron l'roblemen, deren Behandhng in der Pflanzenplyysiologie sehon viel weiter gediehen ist, als in der l'hysiologie der There: die Lehre von der formativen Wirkung der Reize nnd die I'hysiologie der Formbildung nnd Entwicklung ïberhaupt.

Die Erfahrungen ïber ".Morphosen”, d. h. formative lieizwirkungen, sind bei 'lieren wenig zahlreich und weit zesstreut in der Literatur, fiir l'Hanzen weist I' feff'er bei fast jeder Reizqualitait solche Erscheinmogen nach, besonders über dic photomorphotischen und chemomorphotischen Wirkungen finden sich wichtige Angaben. Was die Physiologie der Entwicklnmg. die formative Itetminierung der /ellen und der Organe anlangt, so sind diesclhen bet' 'ieren fast ausschliesslich von Forschern studiert, denen es an physiologischer Inrchbildung gebrach, bei Pflanzen aber sind eine Menge hochwichtiger 'Tatsachen mit all der kritischen Schärfe moderner physiologischer Arheitsweise gesichert, und müssen von jeden in rollem Lmtange gewïrdigt werden, der über diese Probleme eine Anschauung gewinnen will, von der man nicht schon a priori als gesichert ansehen muss, dass sie derbunten Fülle des Lebens nicht gewachsen sein kann, weil sie eben grosse Gebiete seiner Manifestationen unbericksichtigt gelassen hat.

I'feffers l'Hanzenphysiologie ist in hohem Grade geeignet als das Band zu dienen, welches Tier- mnd Pflanzenphysiologie vermäge ihrer gemeinsamen Probleme rerknïpten muss, um heide ror Einseitigkeit zu bewahren, ein Band, das zur 'Leit so locker ist, dass nur eine geringe Übertreibung dazu gehört, wollte man behaupten, es sei gar nicht vorhanden, sondern erst zu erstreben. Die ausführlichen Litera- 
turangaben machen es leicht, sich über jede Frage von Wiehtiglieit zu orientieren, mit den Originaldarstellungen vertraut zu werden.

A. Pïtter (Göttingen).

742 Rádl, Eim., Untersuchungen ïber den I'hototropismus der T'iere. Leipzig, (W. Engelmann). 190\%. gr. 8. 188 pag. M. 4.-.

Der Verf. beabsichtigt, allgemeine Anschaungen ïber die optischen () rientierungserscheinungen der Tiere zu entwickeh. oder mit andern Worten, über das Selıen, soweit es der Orientierung im Raume dient. In diesem letztern, sehr weiten Begriff fasst er das Wort I'hototropismus.

Die speziellen Untersuchungen bringen eine grosse Anzahl interessanter lieobachtungen und Versuche.

Oir sind zunächst die Untersuchungen iiler die Reaktionen der Tiere auf der Drehscheibe zu erwähnen. Schon l'nrkinje war bei seinen Untersuchungen über den Drehschwindel zu der Anschanung gelangt, dass er das Produkt zweier Faktoren sei: der Augenberegungen einerseits und der Leistung noch eines in liopf gelegenen Organes andererseits. Xachdem das Labyrinth als das fraglicle zweite Organ erkinnt worden war, hat es sich der fast auschliesslichen beachtung der Forseher zil erfoeuen gehalt. sobald es sich um die Frage der Orientiermng landelte, die Bogengänge, iiberlaupt das häutige Labyrinth gilten als "Orienticungsorgan” par excellence.

Líidl hat nun versucht, die Erscheinungen der Orientierungsbewegungen gegen das Licht, als welche or die Znckingen der Angen der Wirbeltiere auf der Drehscheibe ansieht, bei Arthropoden nachzuweisen, bei denen sie ja selbstverständlich nicht vom Labyrinth herrühren könnten. Er glaubt, alle die gerichteten Bewegungen der Insekten aui der Trehscheibe als Folge der Orientierung gegen den Lichtstrahl ansehen zu dürfen, und kommt zu dem satze: ..wenn sich das lnselit in einem beleuchteten Raume bewegt, so muss dasselbe optisch orientiert sein." "Der Lichtstrahl vertritt bei den Insekten die Rolle der Schwerliraft."

In demselben Sinne deutet der Verf. auch seine lieobachtungen über die kompensierenden liopfbewegungen der Insekten. In ilmen glaubt er eine P'arallelerscheinung les . Fixierens" der Wirbeltiere gefunten zu haben. Das Auge der Daphnia ist nach seinen Angaben bestrebt, stets die gleiche Richtung gegen das Licht zu erhalten, was teils durch die Bewegungen der Augenmuskeln, teils durch Körperbewegungen erreicht wird.

Unter den Filiegen bot die Asilide Laphria flaca ein Beispiel, dass ancl sie bestrebt sind, eine feste Orientierung ihrer Augen 
zu erhalten, dass sie also einen Punkt fixieren, nur dass sie es nicht durch Augen-, sondern durch Kopfbewegungen erreichen. Auch bei Libellen konnten eigenartige Orientierungsbewegnngen gegen das Licht festgestellt werden, die anf eine lieeintlussung der Muskelspannung durch das A rom Labyrinth ausgeaibt wird. Wenn also Wundt in diesem sinne das Labyrinth der Wirbeltiere und die Statocysten der Wirbellosen als .toniscle sinnesorgane* bezeichnet, so ist auch das Auge der Insekten ein solches "tonisches Sinnesorgan." Auch die Erscheinungen eines deutlichen Kopfnystagmus bei Insekten bestätigen die Insicht des Verfs. von der liedeutung des Auges, die er dann noch weiter zu stïtzen sncht dnrch Versuche mit Insekten, denen ein Auge gesclwäizt war, und bei denen daraufhin viclfach der Kopf die symmetrische Lage gegen den Körper verliert (wie bei Zerstörung eines Labyrinthes, Ref.).

Es würde zu weit führen den speziellen Ausführungen Rádls im einzelnen weiter zu folgen. Noch mehrere Probleme, so z. B. das des Fluges der 'Tiere in die Flamme usw., werden literarisch und anf Grund eigener Beolachtungen behandelt. Die Literatur wird eingehend gewiurdigt, und manche Beobachtung ist von ethologischen und physiologischen Interesse.

Viel weniger wertroll elscheint der zweite, allgeneine 'Teil des buches. In ilm versucht der Verf., nach Besprechung der bisherigen Theorien des I'hototropismus und der .'Tropismen" iberhaupt, eine neue Theorie für beide Escheinungskonplexe aufustellen. Dieselbe in extenso mitzuteilen, scheint nicht von Interesse, es sei nur durch einige Proben das allgemeine theoretische Niveau gekennzeichnet. So z. B. "nicht nur die Einstellung der Insekten mit den Kopf gegen den Lichtstrahl, vieler pelagischer Tiere gegen den Wasserstrom usw. ist eine rheotropische Erscheinung, sondern anch der Flug eines Vogels“ u. ä. [vom Ref. gesperrt]. Die Vorstellung über die Art und Weise, wie der Lichtstralıl als Reiz wirkt, nennt Rádl selbst "recht phantastisch," und diesem Urteil wird wohl niemand widersprechen, der hört: (ler Lichtstralıl „muss eine Druckkraft ${ }^{1}$ ) auf den Organismus ausüben, ich glaube eine ähnliche Druckkraft, wie auf uns etwa der Luftstrom driickt." "Das Auge ist möglicherweise ein solches Organ, dessen Elemente unmittelbar auf den Druck der Lichtstrahlen ${ }^{1}$ ) reagieren.

Eine grosse Ungewandtheit in der Handhabung der deutschen Sprache erschwert die Lektiire des Buches wesentlich.

$$
\text { A. Piitter (Göttingen). }
$$

1) vom Ref. gesperrt. 
743 Ostwall, W., Theoret is che Planktonstud ien. In: Zool. Jahrh. Abtlg. Syst. Geogr. Biol. Bd. 18. Heft 1. 1903. pag. 1-62. 4 Kurrentafeln. 2 Abbldg. im Text.

In der Schwebeformel, die Verf. frïher für Planktonorganismen aufstellte (s. Ref. \%ool. Kentr.-131. Bid. 10. 1903. pag. 403) sind drei Faktoren enthalten: Formwiderstand, Ïbergewicht und innere Reibung des Wassers. Die heiden ersten hängen von dem betreffenden Organismus ab, während der letzte ein rein physikalisch-chemischer, vom Organismus unahhängiger, äusserer Faktor ist. Als sehr wenig veränderlich erweist sich das Übergewicht; stark variiert dagegen der Formwiderstand; weitaus an rariabelsten aber ist die innere Reibung. Sie verändert sich ganz besonder's unter dem Einfluss wechsehnder Temperatur und rerschiedenen Gehalts des Wassers an gelösten Stoffen. Verf. nimmt sich nun ror. diejenigen Fälle näher zu untersuchen, bei denen Teränderungen der Schwebebedingungen durch Variation in der Menge der im Wasser gelösten Stoffe hervorgerufen werden.

In einer ersten Abhandlung prifit er gemeinsam mit $\mathrm{A}$. Genthe den Einfluss der in biologischer Richtung hauptsichlich in betracht kommenden Salz- unl Gaslösungen auf die innere Reibung des Wassers. Teben dem weitaus wichtigsten Kochsal\% erstrecken sich die Intersuchungen noch auf die im Meerwasser sich in etwas grössem Prozentsätzen findenden Salze Mg( $I_{2}, K_{C}, M_{g S O}$ und ('aSO), sowie anf die Gaslösungen von $\mathrm{O}, \mathrm{N}, \mathrm{CO}_{2}$ und $\mathrm{CH}_{4}$.

Die innere Reibung einer Fliissigkeit definieren die Verti. als die Reibung der Flüssigkeitsteile aneinander, d. h. als eine physikalisch-chemische Gröse, die sich jeder Bewegung der Flüssigkeit liemmend entgegenstellt. Kur Messung dieser Grösse dient die Bestimmung der Geschwindigkeit cines sinkenden Körpers, oder der Auslaufszeit eines gewissen Volumens der betreffenden Flüssigkeit. Die letztere, von ihnen mit Hilfe eines mehrfach abgeänderten Ost waldschen Apparats angewandte Methode beschreiben 0 . und $G$. näher.

Im allgemeinen ergab sich eine Bestätigung des Satzes, dass bei Konstanz der chemischen Beschaffenheit der gelösten Stoffe die innere Reibung des Lösungsmittels mit der Kónzentration der untersuchten Lösungen gleichsinnig wächst. Es verändert sich ferner die innere Reibung in umgekehrtem Sinn, wie die Temperatur. Daher müssen Messungen zur Restimumug des Konzentrationseinflusses einer Lösung bei konstanter 'Temperatur geschehen. Für rerschiedene Temperaturen aufgestellte Kurven laufen miteinander nicht parallel. Um den Einfluss der Lösungskonzentration auf die innere Reibung unter Berücksichtigung der Temperatur graphisch darzustellen, wäre eine 
Raumkurve mit den drei Koordinaten innere Reibung, Konzentration, 'Temperatur zu konstruieren. Praktisch genügen indessen in den meisten Fällen vier parallel aus dieser Raumkurve innerhalb der ersten $30^{0}$ geschnittene Ebenen, da die Abhängigkeit des Konzentrationseinflusses von der Temperatur eine sehr stetige und nicht allzu grosse ist.

Die P̉erechnung der imern Reibung von Kochsalzlösungen nach Prozenten lieferte namentlich für die höhern lonzentrationsstufen erwünschte Ligänzungen zu frühern, unvollstïndigen Messungen. Es zeigte sich, dass der lionzentrationseinfluss auf die innere Reibung stetig wächst: diasselbe gilt rom T'emperatureinfluss gegenüber dem lonzentrationseinfluss. Der Durchschnittswert für die Zunahme der innern Reibung schwankt infolge des Linflusses der T'emperatur von 1.7-3,6. Er unterliegt für die ersten $10^{\circ}$ etwa einer Steigerung von 3) Einhriten, für die zweiten $10^{\circ}$ ungefühır einer solchen von 2,5 Einheiten; Temperaturen von $20-30^{\circ}$ zeigen eine Durchschnittszunahme von 2 Einheiten pro $1^{0}$.

Entsprechend den geringen Konzentrationen bleibt der Einfluss der übrigen güüsten Salze auf die innere Rieibung unerheblich. Auch die gelösten Gase spielen in dieser Bezichung in allgemeinen keine bedeutende Rolle. Den grössten Einfluss besitzt noeh Stickstoff, der bei $+20^{\circ} \mathrm{im} \mathrm{V}^{\top}$ orgleich zu reinem Wasser eine Zunahme von einer Einheit zeigt. Verff. bemerken, dass der Eintluss der gelösten Gase auf die innere lieibung, namentlich vergliehen mit dem Einfluss der gelösten Salze, so gering sei, dass er nicht eine messende, sondern nur eine abrundende Berücksichtigung speziell für biulogische \%wecke finden könne.

I ie erste Abhandlung schliesst mit einer Anleitung zum Gebrauche der T'afeln. Inieselben sollen für ozeanographische Zwecke; vor altem fïr das Verständnis der Verbreitung pelagischer Organismen genügen.

In der zweiten, umfangreichern Abhandlung bespricht Ostwald den Einfluss des Salzgehalts der Gewässer auf das Plankton.

Einleitend führt er aus, dass biologisch in erster Linie die Beeinflussung der innern Reibung durch Kochsalz in Betracht falle, da $\mathrm{XaCl}$ so ziemlich der einzige Stoff sei, der, in grössern Mengen gelöst, doch noch die Existenz eines l'lanktons gestatte. Er will sich vor allem mit den Einflüssen des wechsehnden Salzgehalts der Gewässer auf die Schwebefähigkeit, die Ifaupteigenschaft des Planktons, befassen und sich dabei auf die in der ersten Abhandlung gewonnenen Resultate über die Bedeutung des Kochsalzes für die innere Reibung des Wassers stiitzen. Indessen darf nicht ausser acht gelassen werden, dass neben dem Salzgehalt noeh andere Faktoren die innere 
Reibung und damit die schwebefähigkeit des Planktons verändern kömmen. In hohem Maße wirkt in dieser Richtung die Temperatur. Ferner spielen, wie hei allen biologischen Geschehnissen, Ernährung, Fortptlanzung, Beziehmngen der einzelnen I'lanktonorganismen untereinander usw. eine komplizierende Rolle. So hält es oft schmer zu entscheiden, welchem Einfluss diese oder jene Reaktion des Planktons zuzuschreiben sei. Terf. will nur diejenigen Tatsachen näher prïfen, welche wahscheinlich durch den wechselnden Salzgehalt des Wassers bedingt werden, oder bereits experimentell auf diesen Faktor zurückgefïhrt worden sind.

Fis handelt sich dabei um Planktonreaktionen rerschiedener Art. Besonders sind, wie in der frïhern Arbeit Ostwalds, so auch hier wieder" .Individuenplankton" nnd .. Plankton im allgemenen Sinne" auseinander zu lialten. Beide Gruppen unterscheiden sich durch die Bedeutung des \%eitfaktors; beide reagieren im allgemeinen auch sehr verschiedenartig auf durch weehselnden Salzgehalt bedingto Veränderung der innern Wasserreibung. Beim . Plankton im allgemeinern Sinn" tritt die Anpassungsfähigkeit der Organismen weit mehr in den Vordergrund, als beim Individuenplankton.

Den Hauptteil seiner Ahhandlung gliedert 0 . in drei Kanitel nit den Titeln:

Allgemeine physikalisch-chemische Einfliisse verschieden konzentrierter Salzlösungen; Eintliisse wechselnder Konzentrationen auf das Individuenplinkton; Finflüsse wechselnder Konzentrationen auf das Plankton im allgemeinen Sinn.

Unter den allgemeinen lieaktionen, die jeder sich im Wasser befindliche Körper in mehr oder weniger hohem Maße zeigt, treten, wenn nicht als die einzigen, so doch als die wichtigsten und am schärfsten definierbaren, die osmotischen Erscheinungen und die Ïnderungen der Oberflächenspannung hervor. Sie haben als die hauptsächlichen allgemeinen physikalisch-chemischen Eintlüsse zu gelten, die olme Gefährdung des Lebens und olme weitergehende Berïcksichtigung der Zeit und der räumlichen Orientierung auf das spezifische Gewicht und den I'ormwiderstand einwirken können. Fine nähere Prüfung der osmotischen Wirkungen von Salzlösungen rerschiedener Konzentration auf Schwebegeschehnisse, wobei das Verhalten von Noctiluea in Meerwasser und Süsswasser als Beispiel herangezogen wird, berechtigt dazu, den Satz aufzustellen: .. Das spezifische Ciewicht der Planktonorganismen wird im allgemeinen bei stäkern Salzkonzentrationen des Wassers erhöht, bei schwächern erniedrigt." Einstweilen steht uns allerdings kein genaneres Mittel zu Gebot, die Änderungen, die im spezitischen Gewicht der Kellen im Anschluss an 
Wechsel der Salzkonzentration eintreten, direkt nachzuweisen oder zahlenmäPig auszudriicken.

Nicht so einfach liegen die Verhältnisse betreffend die Variationen des Formwiderstands unter osmotischen Einflïssen. Um die I)iskussion zu erleichtern, führt Verf. für den Begriff ..Q Qnotient von Obertläche und Tolumen" den Namen ..relative oder spezifische Oberfläche eines Körpers ein". Es ergibt sich das Resultat, dass die spezifische Oberfläche im allgemeinen bei stärkerer Salzkonzentration des Aussenwassers wächst, bei schwächerer abnimmt. Neben der spezifischen Oberfläche muss indessen vor allem noch in der . Vertikalprojektion" eines Körpers ein wichtiger Faktor seines Formwiderstands gesucht werden. Für unregelmäßig gestaltete Körper bleibt einstweilen eine feinere Abschätzung der osmotischen Variationen des Formwiderstands unmöglich.

Übrigens letont Verf., dass die osmotischen Wirkungen verschieden starker Salzlösungen für die Betrachtungen der Schwebevorgänge des Planktons nur berichtigend und in zweiter Linie in Frage kommen. Wo Hüssiges oder halbthïssiges Protoplasma das Aussenwasser unmittelbar, ohne Einschiebung einer Zellmembran. berührt, gewinnen Änderungen der Oberflächenspannung. d. h. eine weitere Gruppe physikalisch-chemisch definierbarer Eirscheinungen, eine gewisse Bedeutung für die Schwebegeschehnisse. Sie drücken sich in dem Bestreben Hüssiger oder halbflüssiger Körper aus, die Kugelgestalt anzunehmen. Auf Planktonorganismen wirken die EinHlïsse der Oberflächenspannung wiederum wesentlich durch Veränder'ung der Zahlen des spezifischen Gewichts und des Formwiderstands. Allgemein Gültiges lässt sich jedoch in dieser Hinsicht wegen der ansserordentlichen Mannigfaltigkeit der Fälle nicht sagen. An Wichtigkeit stehen die Oberflächenspannungs-Erscheinungen hinter den osmotischen Vorgängen schon deshalb zurïck, weil nur bei relativ wenig zahlleichen Planktonten das Protoplasma frei nach aussen tritt.

In Anhang an die Besprechung der allgemeinen physikalischchemischen Einflïsse verschieden konzentrierter Salzösungen macht Verf. auf die Beobachtung aufmerksam, dass viele in MeerwasserAquarien gehaltene Tiere (Ctenophoren, Radiolarien) an Grösse stark abnehmen. Er fasst die Schrumpfung als Resultat osmotischer Yorgänge auf, welche durch die wasserentziehende Wirkung des infolge von Verdunstung stärker konzentrierten Meerwassers bedingt werden.

Das Individuenplankton, dessen Beeinflussung durch wechselnde Kionzentration des bewolnten Mediums das nächste Kapitel gewidmet ist, kann auf Ïnderungen der innern Reibung kaum durch Veränderungen des Übergewichts oder des Formwiderstands reagieren. Die 
Reaktionen driicken sich viehmehr in passiven Wanderungen aus. Beispiele lehren, dass der Grad der Salzkonzentration die räumliche Orientierung des Planktons wirklich beeinflusst. Hier können u. a. angefülnt werden die Beobachtnngen ron Verworn und von Chun an Ctemophoren, die Experimente, die Meyer und Moebius an verschiedenen Tieren - auch Fisehen - durch Versetzung aus dem Ostseewasser in Nordseewasser anstellten, besonders aber die ïber das Flottieren der eine Eigenbewegung entbehrenden Fischeier bei verschiedener Wasserkonzentration gesammelten Daten (Hensen, Sars, Malmgren).

Ïltere Erklärungen all dieser Beobachtungen liessen den Formwiderstand und besonders die innere Reilung vollstïndig unberücksichtigt. Gerade der letatgenannte Faktor aber besitzt in seinem wechsehden Wert die grösste Wichtigkeit für die riehtige Dentung der fraglichen Vorgänge; Abtrieb und Auftrieb, d. l. die positiven oder negativen Differenzen der spezifischen Giewiehte, treten bei den genannten Erseheinmgen natiirlich auch ins Spiel. In den meisten Fällen aber bleibt ihr Eintluss anf die Sinkgeschwindigkeit gegentiber demjenigen der innern Reibung unverhältnismäßig klein und kann so vielfach vernachlïssigt werden. Der in seinem Effekt anf die Schwebefähigkeit gleichsinnig mit der Veränderung des spezifischen Gewichts verlaufende Wechsel der inuern Reibung bringt die citierten Modifikationen im Schweben von Planktonkürper'n zım grössten T'eil hervor.

Nähere Ïberlegung zeigt, dass sich die Einflüsse der Konzentration auf das Individuenplankton hanptsächlich in der räumlichen Orientierung ausdrücken. Unmittelbar treten sie zutage in Variationen der Sinkgeschwindigkeit oder Schwebefühigkeit; allgemeiner handelt es sich um passive Wanderungen in vertikaler und horizontaler Richtung. Als Ergebnis dieser Bewegungen ergiebt sich die Planktonverteilung, die somit vom Gesichtspunkt der Veränderung des Salzgehalts aus zu betrachten ist.

Direkt durch Konzentrationswechsel bedingte passive Vertikalbewegungen des Planktons treten in der freien Natur selur selten ein. Dagegen vermögen Veränderungen der Salzlösung schon bestehende Vertikalwanderungen zu modifizieren, besonders abzuschwächen. Als Beispiel dient die Abwärtswandermng des Hochseeplanktons bei Sonnenschein, oder in den Mittagsstunden. Diese Bewegung verdankt ihren Ursprung wahrscheinlich der dureh Temperaturerhöhung hervorger'ufenen Abnahme der innern Reibung des Oberflächenwassers; doch lässt sich wenigstens theoretisch die Beteiligung der Salzkonzentration an der Erzeugung des gedachten Vorganges ableiten. Höhere Salzkonzentration 
wirkt in rerschiedener Weise hemmend anf die Ansgiebigkeit orter Weite der Vertikalwanderungen des Planktons. Der Satz erhält gute Stiitzen durch die analytische Prüfung der jährlichen Planktonperiodizität.

Auf den Einflnss verschiedener Salzkonzentration leitet sich auch der Umstand zuriek, dass unter sonst gleichen Verhïltnissen das I'lankton in stärker salzigem Wasser länger an roer Oberfliche bleibt und kïrzer in der 'Tiefe verweilt. Schwebende Organismen salzreicher Gewässer mussten sich dem physikalisch-chemisch notwendigen Verhalten biologisch anpassen und dabei höhere Temperatmren nnd grössere Lichtstïrken ertragen lernen.

In der vertikalen Planktonverteilung lïsst sich der schichtenweise sortierende Einfluss wechselnden Salzgehalts rerschiedener Wassertiefen nicht verkennen. Sehichtungen des Wassers nach Salzkonzentration bringen ihrer verschiedenen immern Pribung entsprechende Schichtungen des I'lanktons nach Arten, Individuen, Entwicklungsstufen, Grössen, spezifischen fiewichten, aber anch Lebensweisen. Stoffwechselarten usw. hervor. Jit vielen andern lieispielen spricht für diesen satz die von (' l u n und Sch imper im Eismeer beobachtete Vertikalverteilung der pelagischen Flora.

Die Kombination des Salzgehalts mit andern Faktoren, von denen besonders die T'emperatur Nennung verdient, liefert eine Fülle rerschiedenartiger Lebensbedingungen, welche einen tiefen Einfluss auf die Verteilnng des Planktons ausïben. \%weckmäßigerweise muss bei Untersuchungen iiber vertikale und lorizontale Anordnung der Organismen die gesamte innere Reibung, die sich aus Einfliissen von Temperatur und Salzgehalt zusammensetzt, berüicksichtigt werden.

Wohl noch ausgiebiger als anf die rertikale Bewegnng und Verbreitung wirkt der Grad der Salzkonzentration auf die horizontale Verschiebung und Verteilung des Planktons. Doch lassen sich hier die hetreffenden Einflüsse noch schwieriger abschätzen. Vor allem ist wieder die gesante innere lieibung. und nicht einzelne Faktoren derselben, in Rechumg zu ziehen. Ton der chemisch-physikalischen Schwebeformel ansgehend bespricht Verf. theoretisch den Simn des Einflusses wechselnden Salzgehalts auf die Wanderungen und Verteilungen in horizontaler Richtung. Er sieht die letzten Wirkungen der beiden wichtigen Faktoren, Temperatur und Salzgehalt zusammengenommen u. a. in dem grössern Planktonreichtum der Nordsee und westlichen Ostsee gegenüber der östlichen Ostsee und auch in den Wanderungen des Nektons, speziell der Heringe.

Das Plankton im allgemeineren Sinn, d. h. die Summe ron Generationen, Entwicklungsstufen, Arten, Tarietäten, die man gewöhnlich Plankton nennt, zeichnet sich vor dem Individuenplankton durch viel 
grössere Variabilität der einzelnen Lebenseigenschaften und daher auch durch grössere Anpassungsfähigkeit derselben aus. Dieser Umstand kann sich in der Schwebeformel im Übergewicht oder im Formwiderstand ausdrücken. Auf Veränderungen der Schwebebedingungen, besonders auf ungünstige, antwortet das Plankton im allgemeinen Sinn durch Herabsetzung des Übergewichts und durch Erhöhung des Formwiderstands. Es sucht so ein Optimum der Schwebefühigkeit wieder herbeizuführen. Bedeutungsvoller führt sich bei diesen Vorgängen der sehr veränderliche Faktor Formwiderstand ein. Anpassung an Veränderungen der innern Reibung spricht sich im Lauf der Generationen nur noch als Variation des Formwiderstands aus. So könnte geradezu ein „biologischer" Faktor dem „äussern“ Faktor der innern Reibung entgegengestellt werden.

Damit die betroffenen Planktonindividuen ihre Lebensfähigkeit nicht einbüssen, müssen die Einflüsse verschiedener Salzkonzentrationen, welche Variationen des Fornwiderstandes hervorbringen, bestimmte Eigenschaften besitzen. Sie dürfen vor allem nicht zu stark und zu plötzlich eintreten. Sodann ist zu unterscheiden zwischen Einflüssen, die nur kur\% erfolgen, und solchen, welche während der Fortptlanzung, Entwicklung u. s. w. wirken, konstant sind, oder in konstantem Sinne sich ändern. Im wesentlichen kommt mur die zweite Gruppe von Einflüssen in Betracht; nur sie erzeugt in der Regel rererbbare $\mathrm{Ab}$ änderungen.

An diese mehr allgemeinen Ansfülırungen schliesst sich die spezielle Besprechung der Ïnderungen des Formwiderstands unter dem Druck wechselnder Sal\%konzentration. Unter den Begriff Formwiderstand fallen die zwei Grössen spezifische Oberfläche und Projektionswert der Form des Organismus. Beide lassen sich bis heute kaum messen; iiber sie kann nur Augenschein und Schätzung entscheiden. Die beiden Grössen stehen in engster gegenseitiger Bezielıung, so dass am besten wieder ganz allgemein von Variation des Formwiderstands gesprochen wird.

Für Planktonorganismen stehen zwei Wege zur Veränderung des Formwiderstands offen, die beide wohl ungeführ in demselben Umfang benützt werden: Veränderungen des Volumens und Veränderungen der absohuten Oberfläche. Nie werden indessen die beiden Modalitäten einseitig angewendet, sie sind von einander abhängig. Verf. setzt auseinander wie Variationen des Formwiderstands als Endergebnis einer ganzen Reihe verschiedener Vorgänge, die selbst wieder durch Modifikation der Salzlösung bedingt werden, aufzufassen seien. Dabei stellen sich Stoffwechsel- und Wachstumsprozesse als unbedingt nötige, primäre Erscheinungen ein. Bei der Verschiebung der Schwebe- 
fähigkeit infolge von Konzentrationsänderungen wird immer ein Kompromiss geschlossen zwischen den physiologischen und allgemein biologischen Eigenschaften des Planktons und dem Formwiderstand. Daraus resultiert wieder ein Optimum der Lebensbedingungen und der Lebenstätigkeiten. Tariationen des Formwiderstands vollziehen sich viel häufiger in der Richtung der Vergrösserung desselben als umgekehrt.

Die physikalisch-chemischen, speziell osmotischen Eintlüsse verschiedener Salzkonzentrationen auf den Formwiderstand der Planktonorganismen sind zweckmäßige. Ebenso führt die finale Prüfung der Veränderungen, wie sie im Formwiderstand durch Wachstum, Entwicklung u. s. w. entstehen, zu positiven Resultaten. Hamptsächlich Schmankewitschs Tntersuchungen über den Einfluss von verschiedenen Salzlösungen auf Entomostraken liefern für die angeführten theoretischen Sätze praktische Beispiele. Sie zeigen, wie der lormwiderstand mit der Salzkonzentıation sich ändert.

Eine kausale, physikalisch-chemische Erklärung der final gedeuteten Erscheinungen steht einstweilen noch aus.

Nachdem Ostwald die Variationen des Formwiderstands bei abnehmender Salzkonzentration des Mediums näher beleuchtet bat, berührt er kurz die entsprechenden Erscheinungen bei zunehmendem Salzgehalt. Er weist auf gewisse Gegensiitze im Plankton ron Hochsee und Sïsswasser hin und betont, dass in salzreichen Gewässern grössere Planktonformen auftreten, als in salzarmen. Meist sind indessen die Variationen des Formwiderstands bei /unahme von Salzgehalt und Schwebefähigkeit nicht selı augenfällig. Diese Tatsache sucht Verf. zu erlïären, zum Teil sich wieder auf die Untersuchungen Schmankewitschs stïtzend.

Ein Anlang beschäftigt sich endlich mit .den weitern physiologischen Einflüssen wechselnder Konzentrationen". Ausser den direkten Einflüssen, welche die Veränderung der inneren Reibung, bedingt durch wechselnden Salzgehalt des Wassers, auf die räumliche Orientierung des Planktons und die Variation der Gestalt ausiibt, lässt sich auch eine Beeinflussung von Eigenschafien erkennen, welche mit der Schwebefähigkeit des Planktons nur indirekt in Beziehung stehen. Vor allem wird der grosse Prozess des Stoffwechsels durch Veränderungen von Salzgehalt und innerer Reibung in Mitleidenschaft gezogen. Leider lässt sich bei unsern heutigen, ungenügenden Kenntnissen des Stoffwechsels niederer Organismen iber die Art der betreffenden Abhängigkeit nichts Bestimmtes sagen. In das Gebiet der Beziehungen zwischen Salzgehalt und Stoffwechsel gelı̈rt, nach V'erf., die von Schmankewitsch beobachtete Erscheinung der verschiedenen 
Färbung des südrussischen Branchipus im Sommer und im Herbst. Auf demselben Boden lässt sich vielleicht deuten, warum Artemien in Wasser von stiirkerm Salzgehalt eine tiefere, optimale Temperatur besitzen, als in einem weniger salzigen Medium. Endlich erhält die Fortpflanzungsweise mancher Planktonorganismen, unter der Beriicksichtigung der vermehrten innern Reibung salzreicher Gewässer, eine neue Beleuchtung. Dissogonie und Parthenogenesis dürften sich so teilweise erklären.

F. Zschokke (Basel).

\section{Faunistik und Tiergeographie.}

44 Petersen, C. G. J., Report of the Danish Biological station to the Board of Agriculture. X. 1899 und 1900. In: Fiskeri Beretn. for 1900-01. Kjobenhavn 1901. pag. 1-37. 1 Karte.

An der Hand eines reichen statistischen Materials über die Zahl und Verteilung der Aal-Fangstätten in Dänemark möchte Verf. entscheiden, woher die im Herbst während der Wanderung an den dänischen Küsten gefangenen Aale stammen, in welcher Richtung ihr Zng gelıt, in welcher Menge sie auftreten, und ob die Aalfischerei nicht weiterer Entwicklung und Ausdehnung fähig wäre.

Als unrichtig erweist sich dabei die alte Annahme vom grossen Aalreichtnm der Ostsee. In vielen Bezirken und Zufliissen des baltischen Meers sind die Fische selten, in manchen fehlen sie ganz. Sie nehmen mit dem weitern Tordringen in die Ostsee an Zalıl ab, an Grösse dagegen zu. Ihre Laichplïtze liegen nicht in dem genannten Neer.

Die in den dänischen Fjorden erbenteten Aale sind an derselben Lokalität aufgewachsen, die Aale der Belte wandern von den dänischen und schleswig-holsteinischen Fjorden her zu; nur der Sund erhält seine Aale hauptsächlich aus der Ostsee.

Dänemark stellt sich in bezug auf die Aalfischerei sehr günstig; seine Seen beherbergen die betreffenden Fische in grosser /ahl und seine sandigen und seichten Ufer erlauben einen ausgiebigen und auf verschiedene Weise betriebenen Fang. Derselbe könnte indessen noch technisch vervollkommnet werden und lässt auch an kräftiger Durchfïhrung und Ausdehnung zu wünschen übrig.

Kleinere Notizen beschäftigen sich mit dem Erfolg des Einsetzens junger Schollen in den Limfjord, mit dem Auftreten von Haifischen in den dänischen Gewässern, mit der Bedeutung von Asterias mbens für die Schollenfischerei und mit der Lage der Laichplätze des Herings.

Acanthias vulgaris tritt zu gewissen Jahreszeiten an der Westküste ron Jïtland sehr häufig auf; er erscheint nicht selten, wahr- 
scheinlich als weitziehender Wanderfisch, im Grossen Belt. Wie Fangresultate und besonders Intersuchungen des Mageninhalts el'geben, beeinträchtigt sein Auftreten die Fischerei.

Asterias rubens, der im Limfjord massenhaft lebt, wird als Nahrungskonkurrent der jungen Schollen schädlich. Seine Verwendung als Diinger wird angeraten.

Entgegen der Annahme von Heincke laicht der Frïhlingshering nicht ausschliesslich in Brackwasser und Buchten oder Flussmündungen.

F. Zschoklie (Basel).

745 Richard, J., Campagne scientifique du Yacht ..Princesse Alice" en 1902. In: Bull. Soc. Zool. France, Année 1903. 'T. 28. pag. $63-79$.

Über die zoologischen Resultate der vierten Forschungsfahrt der "Princesse Alice" berichtet ausfïlnlicher Richard. Aus seinen Zusammenstellungen, die an famnistischen Einzelheiten ungemein reich sind, mögen einige bemerkenswerte Daten als Ergänzung des vorhergehenden Referats hervorgehoben werden. Nach einigen Exkursionen in das Mittelmeer, welche hauptsächlich der Erprobung nener Apparate und Netze dienten, verliess die Yacht am 18. Juli Monaco, durchfulır vorziiglich die Region der Azoren, unter ausgiebiger Anwendung der verschiedenen Fangmethoden, und erreichte Havre am 18. September.

Die Ergebnisse gruppiert R. nach Stationen und nach Fangarten.

Besonders ausgiebigen Ertrag lieferten die Schleppnetzziige. So wären von der Josephinenbank bei Tiefen von etwa $200 \mathrm{~m}$ u. a. schöne Antipathiden (Aphanipathes?) und der Seeigel Centrostephamus longispinosus zu nennen. Zwischen der genannten Bank und den Azoren kamen eine neue, grosse Species von Cocculina, Turcicula alicei und der Fisch Coryphaenoides gigas vor.

Reich war die Tiefe ron Sâo Miguel $(1187 \mathrm{~m})$. Ihr entstammen z. B. Flabellum alabastrum Epizoanthus hirondellei, vergesellschaftet mit Parapagurus pilosimams, Asthenosoma hystrix, die auf Dorocidaris sitzende Cirripedie Paecilasma aurantium, eine auf Bimssteinen festgewachsene Verruca, zahlreiche Exemplare von Scyramathia carpenteri und viele Fische (Symaphobranchus mimnatus, Nettastoma, Macrurus güntheri, $\boldsymbol{M}$. осca, Hymenocephalus spec.).

Als kaum weniger mannigfaltig bevölkert erwies sich die Tiefe von $3018 \mathrm{~m}$ zwischen S. Miguel und Terceira; sie beherbergte u. a. eine neue Varietät von Farrea occa, eine äusserst zarte Chrysogorgia und die gewaltige Pycnogonide Colossendeis gigas. 30 Meilen westlich von Terceira lebten bei $1805 \mathrm{~m}$ Stephanotrochus aliadema, der 
lebhaft violette Seeigel Sperosoma grimaldii. die Gephyree Phascolion hirondellei in Dentalienschalen, Gigantocym is neben zahlreichen Fischen, von denen eine neue Varietät von Bathypterois dubius nnd der im Gebiet der Azoren in Tiefen von 1000-3000 m überhaupt häufige Halosamropsis macrochir spezielle Nennung verdienen.

Die letzterwähnte Art trägt an jeder Flanke eine Reihe von etwa 64 Leuchtorganen, deren Licht nur schräg nach unten geworfen werden kann.

Fin bei Fayal erbeutetes Exemplar von Flabellum alabastrum befand sich in Teilmng. Von derselben Station stammt ein Exemplar der 1888 durch die .Hirondelle" bei den Azoren entdeckten Chirothentis grimaldii. Die ïber den Körper des Cephalopoden verteilten, eigentiimlichen Organe deutet Joubin als "thermoskopische Augen", geeignet gewisse Strahlen des Spektrums, besonders die dunkeln, kalorischen, wahrzunehmen. Vielleicht erfiullt das Seitenauge des Copepoden Pleuromma denselben Zweck. Neu ist die äusserst bizzare Form Cirroteuthis grimaldii .Joubin.

Aus der Tiefe von $1095 \mathrm{~m}$ bei S. Jorge wurde die Hexactinellide Pheronema grayi gezogen; einen Vertreter der bathypelagischen Meduse Atolla ergab der Fang zwischen Pico und S. .Jorge.

Uubekannt in der Fauna der Azoren war der seltene, zwisehen S. Miguel und Terceira $(992 \mathrm{~m})$ getroffene Fisch Chiasmodon niger; dort leite auch eine neue Murex-Art und der tiefenpelagische Argyropelecus hemigymms.

Weniger ergebnisreich als früher gestalteten sich die Reusenfänge. Sie bereicherten das gesammelte Material u. a. nördlich ron S. Miguel $(3020 \mathrm{~m}) \mathrm{um}$ schöne Macruriden (Coryphoenoides) und zwischen l'ico und S. Jorge um einen grossen Synapholranchus, der parasitische Isopoden, Livoneca, in der Mundhöhle trug.

Mit gutem Erfolg wurde dagegen der Fang mit Grundschnüren und zum 'Teil die Obertlächenfischerei betrieben. Die letrtere verschaffte etwa 30 Exemplare von Thymms alulonga, deren Magen mit dem Amphipoden Brachyscelus crusculum gefüllt war, ferner Polyprion cernium und einen Balistes capriscus, dessen Mageninhalt aus Nautilograpus minutus und Lepas anatifera bestand.

Wiederholt stiess man auf Hyperoodon. Von der sonst so seltenen Leachia cyclura, einem gelatinösen, durchsichtigen Calmar, trieben an der Meerfläche ziemlich häufig tote, männliche Exemplare. Die Arme fehlten regelmäßig, so dass der Tod wohl nach erfolgter Fortpflanzung eintrat. Der Tintenfisch trägt an der Interfläche der Augen fünf goldglänzende, vielleicht lichterzengende Flecke. Als 
sehr seltener Fund muss ein Exemplar ron Onychotcuthis rerzeichnet werden.

An der Obertläche flottierten von Fischen besonders Stermoptyx diaphana. Argyropelecus olfersi, A. hemigymms und Capros aper.

Es erscheint nicht ausgeschlossen, dass die vulkanischen Ereignisse auf den Antillen eine Rückwirkung auf dem Meeresgrund der Azoren fanden, die sich in letzter Linie auch in gewissen Störungen des 'Tierlebens ausdricickte.

F. Zschoklie (Basel).

746 Richarl, J., Sur l'état actuel du Musée océanograplique de Monaco et sur les travaux qui s'y poursuivent. In: Bull. Soc. Zool. France. 'T'. 28. 1903. pas. 57-62.

Von dem ozeanographischen Museum in Monaco, das seiner baulichen Vollendung entgegengeht, sind die meisten in Untergrund gelegenen, gegen das Meer offenstehenden Räumhichkeiten dem Betrieb bereits übergeben worden. So wurde der grosse Aquariumsaal, der neben sechs Meter langen Behältern kleinste Glasbecken zur Aufnahme und Beobachtung wenig umfangreicher Tiere besitzt, bezogen. Zwei Pumpen heben das ihm zuströmende Wasser vom Meer aus auf $65 \mathrm{~m}$ Hühe.

Dem Aquarium entspricht an Umfang ein Saal für Skelettier- und Ausstopfearbeiten mit darunter liegenden Macerierräumen. Ferner fanden Platz die Bibliothek, Magazine, Abteilungen, die dem Präparieren und Ordnen der Samm? lungsgegenstände dienen, ein besonderer Raum für die Publikationen und sechs Arbeitszimmer fül wissenschaftliche Forschung. Zwei derselben besitzen eine für physikalische, biologisch-chemische und physiologische Forschungen bestimmte Ausrüstung, die andern sind mehr auf zoologische, botanische und histologische Untersuchungen berechnet. Alle verfügen über Heizung, Beleuchtung, Meer- und Süsswasser, sowie ïber bewegliche Aquarien mit laufendem Wasser. Endlich fehlt nicht ein photographisches Lahoratorium.

Als eine seiner Aufgaben betrachtet das Museum die schon jetzt ins Werk gesetzte möglichst genaue ozeanographische und biologische Erforschung der an Monaco angrenzenden Meeresteile. Aber auch die Landfauna des Fürstentums soll, unter Mithilfe zahlreicher Spezialforscher, vollständig festgestellt werden. Vor allem aber müchte die gross gedachte und angelegte Anstalt zu einer Zentrale der Ozeanographie im weitesten Sinne sich entfalten.

F. Zs chokke (Basel).

747 Sauerwein, Ch., L' Océanographie. In: Publication de la Soc. d' Océanogr. Golfe de Gascogne. Bordeaux 1903. 37 pag.

In populärer Form gibt Verf. einen Überblick über Geschichte, gegenwärtigen Stand, Zweck und Mittel der Ozeanographie im weitesten Sinn. Er bespricht die Teilnahme der verschiedenen Nationen an der marinen Forschung und weist auf den gewaltigen Impuls hin, den die ozeanographischen Studien durch die Entdeckung der T'iefenfauna erhielten. An Beispiel der letzten Reise der "Princesse Alice“, die vom 17. Juli bis 17. September 1902 frülser begonnene Studien im Gebiet der Azoren fortsetzte, drei ungenïgend umschriebene 
Bänke (Gorringebank, Josephinenbank, Princesse-Alice-Bank) genauer erforschte und eine submarine Depression ron $6000 \mathrm{~m}$ Tiefe untersuchte, wird der Mechanismus einer ozeanographischen Expedition in allen Phasen seiner 'Tätigkeit geschildert. S. macht uns bekannt mit den verschiedenen Instrumenten und Apparaten und ihrer Anwendung (Sonden, Schlamm- und Wasserfasser, Tiefenthermometer, Dredschen, Reusen, Grundschnïre); er entwirft Bilder von der Jagd auf Orea gladiator und von den verschiedenartigen Tiefenfängen und schildert kurz einige Hauptvertreter der abyssalen Fauna. Daran schliesst sich die Besprechung der rein ozeanographischen Arbeiten, Entnahme der Wasser- und Schlammproben und Temperaturbeobachtungen, deren wissensehaftliche Bedeutung eingehend gewürdigt wird. Weitere Intersuchungen galten dem Vorkommen von Bakterien in tiefen Wasserschichten und dem Arsenikgehalt von Meertieren.

Die reine Ozeanographie, wie die marine Biologie, verdanken ihre ersten Resultate der individuellen Initiative. An ihre Stelle trat später auf nationaler Basis organisierte Arbeit. In neuester Zeit hat die T'bereinkunft seefahrender Mächte in Kopenhagen dem wissenschaftlichen Betrieb der Ozeanographie eine internationale Grundlage gegeben. Frankreich hat seit den Fahrten des Travailleur und des 'Talisman auf' ozeanographischem Gebiet manches versäumt, doch mehren sich gegenwärtig dort die Zeichen steigenden Interesses an der Meereskunde.

F. Z L chokke (Basel).

748 Kykoff, W., bemerkung über das Plankton der Altwässer des oberen Jenissees. In: Zool. Anz. Bd. 26. Nr. 705. 1903. pag. 626-628.

Das Plankton von mit dem Hauptstrom in oflener Verbindung stehenden Altwässern des Jenissees $\left(51^{\circ} \mathrm{n}\right.$. Br., $93^{\circ} 30^{\prime}$ o. L. ) erwies sich im August als qualitativ arm. Auch seine Zusammensetzung bietet kaum besonderes Interesse. Am häufigsten waren Dinobryon sertularia und Polyarthra platyptera. Bosmina longirostris-comuta trat in der Winterform auf; Ceriodaphnia pulchella befand sich in Ephippienbildung; Daphnia fehlte.

F. Zs chokke (Basel).

\section{Palaeontologie.}

749 Arnoll, Ralph, The Paleontology and Stratigraphy of the Marine Pliocene and Pleistocene of San Pedro, California. In: Mem. Californ. Acad. Sc. III. 1903. 420 pag. 37 'Taf.

Diese sehr bemerkenswerte, ausführliche Monographie der jungtertiären, pleistocänen und post-pleistocänen Meeresfauna von San Pedro an der californischen Küste hat nicht nur paläontologisches, sondern hervorragend zoologisches Interesse. Über die Herkunft der 
lebenden Fanna der pacitischen Küïste wird in erster Linie diejenige der jüngst verflossenen Erdperioden Aufschluss geben kïmnen.

Bei San Pedro sind drei verschiedene Ablagermugen mit drei Famnen verschiedenen Alters iibereinander vorhanden: pliocän, altpleistocän nnd jungpleistocän. Es haben hier also sicher pliocäne mnd postpliocäne, bedeutende Hebungen stattgefunden. Der Verf. hält das Gebiet sogar für eines der ansgedehntesten Schichtentblössnngen des Pliocïns auf der Erde.

Eine lange Tabelle der ansserordentlich zahlreichen fossilen Reste von Sam P'edro lässt die Faunen der einzehnen Etagen äbersichtlich erkennon und gibt an, wieweit die Formen hentzntage ausgestorben sind, wieweit dieselben heute noch bei San Pedro leben, wieweit sie nördlich oder südlich San l'edro leben oder ob sie hente bei C'atalinaisland leben. Die Tabelle. auf welche ich im Original verweise, nennt mehr als 400 Arten.

Im Anschluss an dieses Vorkonmen bespricht der Verf. dann ähnliche Schichten anderer Lokalitäten der pacifischen Kü̈ste; ror allem lat die Umgebung von San Diego reiche Faunen geliefert.

Von den pliocänen Formen leben 18.5\% hente nördlich San Pedro; die meisten andern Arten lehen noch jetzt dort; immerhin ist der Schluss unabweisbar, dass in spätpliocäner Zeit das Klima Galiforniens ein kühleres war als das jetzige. Im untern I'leistocän ist das Kilima nahezu das gleiche gewesen, nur dürfte es veränderlicher gewesen sein. $17,4^{\circ} \%$ kommt heutzutage nur nördlich San Pedro ror, aber $3,4 \%$ nur südlich. Erst in der spätpliocinnen Zeit wird das Klima wärmer; hier sind $14,2 \%$ Arten vorhanden, welche hente nur süllich vorkommen, aber noch $6,1 \%$ sind Nachzügler aus der voraufgegangenen Zeit und sind heute nur nördlich zu finden.

Interessant ist die nahe Verwandtschaft zwisehen der jungtertiären und pliocänen Fauna Californiens und Japans, welche die rezente Fauna nicht mehr in dem Mafe erkemnen lässt. Die Verbreitung von Haliotis ist dafïr ein gutes Beispiel; diese Form tritt in Californien erst in dem alten Pliocän auf. während sie in Japan beträchtlichälter ist. Auf die genane Speciesbeschreibung, welche von zahlreichen Tafeln begleitet ist, kann hier nicht eingegangen werden.

A. Tornquist (Strassburg i. E.).

750 Boili. F.. Die Fauna der Pachycardientuffe der Seiser Alp. In: Palaeontogr. 50. 1908. pag. 145-227. 11 Taf.

Die Beschreibung einer neuen und einer der best erhaltenen Triasfaunen enthält die vorliegende Monographie. v. Zittel hat im Jahre 1899 in eingehender Weise das Volkommen dieser Fauna und ihre stratigraphischen Beziehungen ge- 
schildert. Der Fundpunkt befindet sich unweit der Tschiapitbriacke auf der Seiser $A l_{p}$ in Südtirol.

Die Abhandlung enthält die Beschreibung sämtlicher gefundenen Versteinerungen mit Ausschluss der Gastropoden und Cephalopoden. Es werden 157 Arten behandelt; davon sind 4 Crinoiden, 13 Echiniden, 18 Brachiopoden und 122 Lamellibranchiaten.

Die Pachycardientuffe stelien ihrem Alter nach zwischen den Cassianer- und Raibler-Schichten. Die in diesen beiden Horizonten auftretenden Crinoiden finden sich gleichfalls in den 'Tuffen. Bei den Echiniden liegt die Blütezeit, soweit man von 'Triasechiniden von Blütezeit überhaupt sprechen kann (Ref.), in der Cassianerzeit; in den Tuffen treten auch zahlreiche Cidaris-Arten auf. Die Brachiopoden sind ganz autfallend schwach vertreten; die äussern Existenzbedingungen müssen den kleinen dünnschaligen Brachiopoden in ilırer Entwicklung hindernd in dem Weg gestanden haben. Die Tuffe müssen sich in einem lebhaft bewegten Seichtwasser gebildet haben; denn die Lamellibranchiaten finden sich in meist stark abgerollten, einschaligen Exemplaren eingebettet. Die Lamellibranchiaten zeigen den Übergang zwischen den Cassianer- und Raibler-Schichten besonders rein.

Die vorzüglich gezeichneten 'Táfeln geben von der Fauna ein ausgezeichnetes Bild.

A. 'Tornquist (Strassburg i. E.).

\section{Protozoa.}

751 (ireely, Inthur White, The artificial production of spores in Monas by a reduction of the temperature. In: 'The Decennial Publications. Chicago 1902. Vol. X. 7 pag. 5) Texttig. lis ist clem Verf. schon frülıer gelungen, durelı Ablïlılumgr bei Protozoen Cystembildung zu bewirken. Dasselbe liat er jetzt bei Monas durch líultivieren der Tiere bei $4-6^{\circ} \mathrm{C}$. erreicht. Küllte er aber noch weiter ab, auf $1^{\circ} \mathrm{C}$., so beobachtete er nach $5-7$ 'Tagen das Auftreten ron Sporen, die zu 2 oder 3 bis zu 25 in einem Individuum entstanden.

Während nach der Angabe des Autors die Cysten nur teilweises Austrocknen ertragen, sind die Sporen selbst gegen vollständigen Wasserverlust beständig und können bei Erhöhung der Temperatur siclı im Laufe einiger Tage wieder zu den Flagellaten-Zuständen von Monas entwickeln.

Bei der geringen Kenntnis, die wir noch von der formativen Wirkung der Reize, besonders der nicht spezifischen haben, beansprucht die Mitteilung allgemeines Interesse.

A. Pütter (Göttingen).

\section{Spongiae.}

752 Baar, R., Hornschwämme aus dem Pacific (Ergebnisse einer Reise nach dem Pacific, Schau insland 1896,97). In: Zool. Jahrb. Syst. Bd. 19. 1903. pag. $27-36.1$ Fig. 
In dieser Arbeit werden 13 Arten, von denen 2 (zusammen) in 6 Varietäten zerfallen, aufgeführt. Eine Siclospongia-Art ist neu. Diese wird ausführlicher beschrieben. 1 Art stammt von Honolulu, 4 Arten (1 davon mit 2 Varietäten) von Adelaide, 7 Arten von den Chatham-Inseln und 2 Arten (1 davon mit 4 Varietäten) von Laysan. Die verhältnismäßig grosse Zahl von Hornschwämmen von den Chatam-Inseln ist eiı neuer Beweis fül den merkwürdigen Reichtum dieser kleinen Inselgruppe an Hornschwämmen; ein Reichtum, der umso auffallender ist, als das benachbarte Neuseeland sehr arm an Hornschwämmen zu sein scheint.

R. v. Lendenfeld (Prag).

753 Preiwisch. J.. Kalkscbwämme a us dem Pacific (Ergebnisse einer Reise nach dem Pacific, Schauinsland 189697). In: Kool. Jahrb. Syst. Bd. 19. 1903. pag. 9-26. Taf. $2-4$

In dieser Arbeit werden 5 neue Kalkschwämme, 2 Leucetten, 2 sycaudren und eine Ebnerclla beschrieben. Irei von diesen stammen von den Chatam-Inseln und diese, namentlich Lcucetta schaninslandi, zeichnen sich durch den Besitz nngewöhnlich dickstrabliger Nadeln aus. $\quad$ i. v. Lendenfeld (Prag).

754 Thicle, J.. Beschreibung einiger unzureichend bekannten monaxonen Spongien. In: Arch. Naturg. Jg. 1903. Bd. 1. pag. 375--398. Taf. 21.

Thiele luat Originalstücke einer Anzaht der von O. Schmidt beschriebenen Monaxoniden des Nordostatlantik nachuntersucht und in der vorliegenden Arbeit darïber berichtet. Durch diese Studien werden die Begriffe, die man mit 27 von Schmidt benützten Monaxoniden-Namen zu verbinden hat, sicher gestellt. R. v. Lendenfeld (Prag).

\section{Vermes.}

\section{Nemathelminthes.}

755 C'ancrano. L., Descrizione di una nu ova speciedi Chordodes del Congo. In: Bollet. Mus. zool. anat. comp. 'Torino. Vol. XVII. 1902. Nr. 426. 2 pag.

Chordodes yariazzi ist eine neue Art vom Congo; das Mänuchen ist $240 \mathrm{~mm}$ lang und 1,5 mm breit. Der Körper ist braun mit schwärzlichen Flecken; die Cuticula zeigt folgende Areolen: 1. maulbeerförmige, 2. papilläre in Gruppen von 2-4, von denen eine eine keulenförmige Verlängerung trägt, 3. einzelne papilläre mit ähnlichen Verlängerungen, 4. grössere, dickere, papilläre, mit ovalem Querschnitt, umgeben von 12-17 kleinern, 5. einzelne, lange, dornförmige Verlängerungen.

O. v. Linst ow (Göttingen).

756 Camerano, L.. Gordiens nouveaux ou peu connus du Musée Zoologique de l'Acad. Imp. des sc. de St. Pétersbourg. T. VIII. 1903. pag. $1-8$.

Beschreibt Chordodes skorikovi n. sp. aus Ceylon: Cuticula mit folgenden Areolen: 1. maulbeerförmigen, 2. ähnlichen dunklern in Gruppen von 2-4, 3. ähnlichen mit einer kleinen Veslängerung, 4. maulbeerförmigen zu 7-8, welche 2 grössere umgeben, die eine Krone kurzer, sehr feiner Verlängerungen tragen, 5. dornförmigen, besonders in der Ventrallinie. Es werden ferner besprochen Parachordodes kaschgarieus Cam.; P. pleskci Cam.; P. pustulosus Baird, P. violaceus Baird; P. varius Leidy, Gordius villoti Rusa, G. pioltii Cam. und G. robustus Leidy.

O. v. Linst ow (Göttingen). 
757 v. Linstow, ()., Helminthologische Beobachtungen. In: Centralbl. Bakt., Parask. u. Infkr. Bd. XXXIV. 1. Abth. Orig. 1903. pag. 520-531. 7 Fig. Ankylostomum americanum Stiles wird beschrieben aus Simia troglodytes in Afrika, von Stiles massenhaft im Menschen im südöstlichen Nordamerika gefunden, wo der Parasit eine ähnliche verderbliche Rolle spielt, wie Ankylostomunt duodenale an andern Orten; vermutlich ist er durch den Menschen von Afrika nach Amerika verschleppt und hat sich hier ausgebreitet. Mermis mirabilis ist eine neue Art von den Hawaii-Inseln; Länge 43 und $85 \mathrm{~mm}$, Breite 0,21 und $0,35 \mathrm{~mm}$. Das grössere Exemplar ist ein Weibchen, das kleinere ein Hermaphrodit mit zwei Geschlechtsöffnungen, einer weiblichen dicht hinter der hörpermitte und einer männlichen $0,22 \mathrm{~mm}$ vom Schwanzende, wo 2 gleiche Spicula und 3 Papillenreihen sichtbar sind. Die Eier beider Exemplare sind 0,061 mm lang und 0,037 nmm breit. Die innere Hülle ist kugelförmig, die äussere an den Polen habbkngelförmig verdickt. Mermis nigra ist eine neue Larvenform von brauner bis schwarzer Farbe; die Länge beträgt $44-200 \mathrm{nmm}$, die Breite 0,25$0,35 \mathrm{~mm}$; von der Gegend des Nyassa-Sees in Südafrika. Die Larve von Mcrmis nigreseens Doj. lebt auch in Forficula acanthopygia und die von Mermis albicans v. Sieb. auch in Agrotis orbona. Die Gattungen Nermis, Peremermis, Hydromermis, und Pseudomermis werden besprochen. O. v. Linstow (Göttingen).

758 Weinlanl, E., Über Energiegewinnung durch Zersetzung von Kohlehydrat ohne Sauerstoffzufulu bei Ascuris lumbricoidcs. In: Sitzungsher. Ges. Morph. I'hysiol. München, B., XVII. 1902. pag. 1.

Parasitische Würmer, besonders Asearis lumbricoides, haben einen sehr hohen Gehalt an Glykogen; sie vermögen in 1\% iger Kochsalzlösung völlig ohne Sauerstoff längere Zeit zu leben, so auch in Wasserstoff und Kohlensäure; das Kohlehydrat nimmt dabei stetig ab unter Bildung von Kohlensïure und Valeriansäure; es landelt sich hier demmach um einen gärungsartigen Prozess.

O. v. Linstow (Göttingen).

\section{Annelides.}

759 Bretscher, K., Tiergeographisches über die Oligochäten. In: Biol. Centralbl. Bd. 23. 1903. pag. 618-625; 634-639.

Die Tatsache, dass einzelne Arten der limicolen Oligochäten nur in ganz beschrïnkten und zerstreuten Lokalitäten auftreten, erklärt sich durch ihre Ausbreitung mittelst passiven Transportes durch Tiere. Zur erfolgreichen Verbreitung müssen eine ganze Reihe von Bedingungen zusammentreffen, so dass sie nur ausnahmsweise erfolgen kann. Daher hat im Laufe der Zeit auch nicht eine grössere Uniformität und Ausgleichung der Faunenbestände Platz gegriffen. Speziell Arten, die bis jetzt nur von einer Fundstelle bekannt geworden sind, bewohnen die Seeufer in Material, das zum Transport durch Tiere sich nicht eignet; daher ihre ausgesprochene Lokalisierung. 
Fïr die Regenwïrner geht aus einer /usammenstellung der Fundstellen der für die Schweiz endemischen Arten mit Wahrscheinlichkeit hervor, dass die Feuchtigkeits- resp. Nienterschligsverhïlnisse eine wichtige Rolle spielen, indem diese Formen fast ausnahmslos entweler an gut bewässerten Orten oder an solchen mit grossen Niederschlagsmengen getroffen wurden. Da diese Fundorte aucl innerhalb der Grenzen der Tereismng während der letzten V'ergletschermngsperiode liegen, sind sie als seitherige und verhältnismäßig junge Bildungen aufzufassen.

K. Bretscher (\%ürich).

760 Bretsher, Oligochäten aus Graubünden. (J. Carl, Fauna der rhätischen Alpen, Ill. Beitrag.. In : Revue suisse zool. Bd. 11. 1903. pag. 113-122.

Im ganzen gehören der bïndnerischen Fauna bis jetzt 53 Oligochäten an, nämlich $1 \mathrm{Naidom}$ orpha, 5 Tubificidae, $3 \mathrm{~L}$ umbriculidae, 29 Encluy traeidae, 1 Haplotaxida, 14 Lumbricidae. Für die Schweiz neu ist Buchholzia sarda Cogn; als neue Arten wurden 1 Henlea und 2 Fridericia aufgestellt, von denen nur jene bis jetzt anderswo nicht gefunden wurde.

K. Bretscher (Zïrich).

761 Bretscher, K., Beobachtungen über die Oligochäten der Schweiz. VII. Folge. In: Revue suisse zool. Bd. 11. 1903. pag. 1-21. 1 Taf.

Die fortgesetzten Uutersuchungen ergaben nicht neue, dagegen die Bestätigung bereits aufgestellter Gesichtspunkte. Im Genfersee wurden 2 weitere limicole Formen konstatiert, im obern Murgsee, 1825 in. ui. M. 11, im mittlern, $1815 \mathrm{~m}, 3$; im untern, $1678 \mathrm{~m}, 7$ Arten nachgewiesen. Die Fauna des Ägeri. sees, $450 \mathrm{~m}$, dagegen zeigte 27 Species. Die untersuchten feuchten Böden, Torferde, Streuerieder, zeigten Gesellschaften von 5-7 Enchytraeiden und ihre Individuenzahl kann auf 25000 per $1 \mathrm{~m}^{2}$ sich belaufen. Von den neuen Species gehört 1 (Naidium) den Naidomorpluae, 5 (1 Henlea, 2 Marionina, 1 Mesenchytraeus, 1 Fridericia) den Enclutraeiden, 1 den Lumbriciden (Allolobophora) an.

K. Bretscher (Zürich).

\section{Prosopygia.}

762 Cumings, E. R., The Morphogenes is of Platystrophia. A Study of the Evolution of a paleozoic Brachiopod. In: Amer. journ. sc. XV. 1903. pag. 1-48; 121-136.

Der Verf. dieser sehr sorgfältigen und ausführlichen Arbeit führt ein Beispiel von Variabilität der Arten einer altpaläozoischen Brachiopodengattung vor; für solche, welche ein spezielles Interesse haben, die Variabilitätsverhältnisse, welche von lebenden Arten oft dargestellt worden sind, bei einer silurischen Gattung kennen zu lemen, sei auf diese Arbeit verwiesen.

Platystrophia ist eine im Silur sehr verbreitete Gattung; die ersten Stadien von Platystrophia-Schalen haben eine solche Ähnlichkeit mit Orthis lenticularis, dass eine Abstammung der Gattung von 
Orthis keinem Zweifel unterliegt. Es bilden sich schon im untersten Silur zwei Formenreihen und, als Ausgänge dieser, zwei scharf getrennte Arten, P. lymx und $P$. biforata. Aus der ersten Art bilden sich nacheinander: $P$. costata, laticostata, acutilivata und amicostatu, letztere schon dem mittleren Untersilur angehörend. Von P. li forrta stammen dagegen $P$. Aentata und fissicostata ab.

Von allgemeinerem Interesse ist die Beobachtung, dass die Formen his zum mittlern Untersilur schnell an Grösse zunehmen, dass dann die grossen Arten aussterben, während die mittlern weiter bestehen. dass die Grösse von nun bis zum Aussterben aber wieder abnimmt.

Die Untersuchung erstreckte sich auf das gesamte Material Nord-Amerikas; un die I'ntersuchung aber gegen alle Einwände zu sichern, müssten die europäisthen Platystrophien einer gleichen l'rüfung unter"zogen werden.

Die Schlussfolgerungen, zu welchen der Verf. kommt, lituten num folgendermaBen: Ilatystrophia besitzt zur /eit ihres ersten Aufretrons den höchsten Gral von Variabilität. Die Variabilität nimmt damn mit der \%eit ah und erstreckt sich zugleich immer mehr und melı auf Charaktere olme physiologische Bedeutmng. Die systematische Bewertung der Variabilität müsste also mit dem Alter der Gattmng langsam abnehmen.

Es wurden denmach in der ersten Zeit des Bestehens der Gattung auch selu viele nene Arten gebildet. Es sind aber auch in der ersten \%eit sehr zahlreiche /wischenformen zwischen den einzelnen Arten vorhanden, welche später ganz fehlen. Der Anstoss zu neuen Variationen und Arten findet immer dann sclmell statt, wenn eine besonders starke Form gebildet worden war. Ilatystrophia bietet ferner für die „Intrinsic evolution“ d. h. für die morphologische äquivalenz und Analogie, ein ausgezeichnetes Beispiel.

$P$. lymx und $P$. biforata sind zwei nebeneinander hergehende, aber ganz verschiedene Arten, ilı Vorkommen und ihre Vergesellschaftung mit denselben Faunenelementen haben aber bewirkt, dass die ältesten Formen der lymx in Amerika beständig mit der biforata verwechselt worden sind, während die jüngsten biforata in Russland stets als lynx bestimmt worden sind. Trotz der äussern $̈$ hnlichkeit der beiden Arten sind beide doch in wesentlichen Merkmalen verschieden, so in der Ausbildung der Branchien.

Die der Abhandlung beigegebenen zahlreichen Abbildungen und Stammbäume helfen ausserordentlich zum Verständnis des Textes.

A. Tornquist (Strassburg i. E.). 


\section{Arthropoda.}

\section{Crustacea.}

763 Lkman, S., Cladoceren und freilebende Copepodon a us A egypten und dem Sudan. In: Results Swedish Zool. Expedit. to Egypt and the White Nile 1901 under the Direction of L. A. J ̈̈gerskiöld. Nr. 26. 1903. pağ. 1-18. 11 Fig. im 'Text.

Die Untersuchung ron in İgypten und im Sudan gesammelten Entomostraken ergab für manche Arten eine weitgehende Variationsfähigkeit, die für die systematische Einreihung der betreffenden Formen ron Wichtigkeit ist. So tritt Diaphanosoma excisum Sars in der näher beschriebenen nenen Varietät longiremis auf. Aneh Intuhir longispina Leydig bildet eine eigene, besonders im männlichen Geschlecht rom Typus abweichende form ans. Sie erfiillte im Januar einen Tïmpel bei liairo in beiden Geschlechtern; die + trugen teilweise Sommereier, teilweise Wintereier. Variationserscheinungen liessen sich ferner beobachten an Ceriorlaphmia rigaudi Rich.,

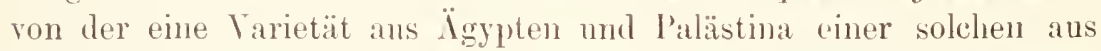
Südafrika gegeniibergestellt werden kann, an Moina dubia de Guerne et Rich., Basmima longirostris s. str. Lillj., Macrothrix laticormis. mit einer Form für das sïdöstliche Mittehmeergebiet, Lynceus cambonei de Guerne et Rich. und ganz besonders für den ungemein variabehn, vom Verf. genau geschilderten $L$. bulobensis Weltner. Derselbe wurde zuerst in Deutsch-Ostafrika entdeckt: el schliesst sich an engsten an den neuserländischen $L$. encostatu. Sars an.

Die Gattnngsbezeichnung Lyncons führt Verf. an Stelle von Alomu nach dem Prioritätsgesetz weiter; er lält auch gegenüber Daday an der Tarietät patayonica von Lynoms cambonei fest.

Ton den Copepoden variieren in gewissen Beziehungen ausgiebig Diuptomus galchi Barrois und Cyclops sermlatus Fisch.

Faunistisch erfährt die Kenntnis der niedern Tierwelt des Niltals durch die rorliegende Arbeit einige Bereicherung. Gleichzeitig wird die kosmopolitische Verbreitung vieler Entomostraken des Süsswassers durch neue Beispiele belegt. So lebt Diaphanosoma excisum Sars, ausser im weissen Nil südlich ron Omdurman, anch im VictoriaNyansa und in Gewässem ron Nord-Queensland. Ceriodaphnia rigaudi war schon frïher aus Tonkin, I'ałästina, Sumatra und rom Kap der gaten Hoffnung bekannt; Lyncens cambonei kommt in Ïgypten, Palästina und Südamerika vor.

F. Zschokke (Basel).

764 Ficott. Th.. On some new and rare Crustacea collected at various times in connection with theinvestigations of the fishery board for Scotland. In: Twenty-first Ann. Rep. Fishery Board Scotland being for the year 1902. Glasgow 1903. pag. 109-134. pl. 2-6. 
Scotts Mitteilung beschäftigt sich ausschliesslich mit in den schottischen Gewässern zu verschiedenen Zeiten und an verschiedenen Lokalitäten gefangenen Copepoden. Sie bringt Notizen über Vorkommen, geographische Verbreitung, Systematik und Morphologie schon bekannter Arten und schildert ausführlich die Species novae nach Bau, Verwandtschaft, typischen Zügen und Wohnort.

Parastcphos pallidus G. O. S. gehört auch der britischen Fauna an. Eucalanus crassus Gieshr. und Stephos scotti wurden an neuen schottischen Fundorten erbeutet; von der letztgenannten Ait traten auch ouf.

Für Parastephos pallidus, den Sars nur in einem männlichen Exemplar kannte, beschreibt S. beide Geschlechter; ebenso gibt er die nähere Beschreibung des of und q von Dactylopus debilis Giesbr.

Die Liste der neuen Formen setzt sich wio folgt zusammen: Amicra pusilla, 1. ambigua, Delaralia minntiswima. Tetragoniceps mygmacus, Lapplronte gracilis, Cletodes nuglerta, Enhydrosoma gracile, E. minutum, Dartylopus littoralis, D. iararensis, D. mirlus and Paranthessius dubius.

Das neue Cienus I'uranthessius gehört zu den Lidiomolgiden; seine einzige Species ist nur im männlichen reschlecht bekannt. Für die meisten neuen Arten fehlt einstweilen die Kenntnis des j; nur von Tetrugoniceps pygmaers, Cletoles neglecta und Enhytrosoma gracilc wurden leide Cieschlechter gefunden.

F. Zsclooke (Basel).

765 v. Daday, l.., Eine neue Cladoceren-Ciattung aus der Familie der Bosminiden. (Vorl. Mitt.) In: 7ool. Anz. Bd. 26. Nr. 704. 1903. pag. 594 -597. 3 Fig. im 'Text.

$\mathrm{Zu}$ den bis jetzt bekannten beiden Gattungen der Bosminiden Bosmina Baind und Bosminopsis J. Rich., fügt Verf. nnter näherer Besclireibung die aus Paraguay stammende liosminella anisitsi 1 . @., 11. sp. Sie ähnelt in der äusseru bischeinung Bosmina und entfernt sich gleichzeitig von Bosminopsis durch die Abwesenheit einer Einkerbung zwischen Rumpf und Kopf. Dagegen erinnert an die letztgenannte Gattung die Lage des ersten Antennenpaars an der Spitze des stark verlängerten Rostrums, sowie die Struktur des zweiten Antennenpars und des Abdomens. Bei Bosminopsis gliedern sich indessen die ersten Antennen vom Rostrum ab, während sie bei Bosminella mit demselben vollständig verschmelzen.

F. Zschokke (Basel).

766 Merkel, F., Ueber Limnadia gigas (Hermann) (Limnatia hermami, Brongniart). In: Mittlgn. Bad. Zool. Ver. Nr. 16. Karlsruhe 1903. pag. 3-16.

Anknüpfend an den Fund verhältnismäßjig zahlreicher Exemplare der in Zentralemropa sehr selten beobachteten Limmadia gigas in einem ephemeren, wenig tiefen, $20-24^{\circ} \mathrm{C}$. warmen Tïmpel bei Walldorf (Baden) stellt Verf. Notizen über die bis jetzt bekannten Fundorte des Phyllopoden und über die Geschichte seiner Einreihung in das System zusammen. Er gibt eine kurze Beschreibung des Krebses, aus der folgende Angaben hervorgehoben werden mögen. Die Länge der sehr durchsichtigen, von kohlensaurem Kalk vollkommen freien Schalen betrug $13-15 \mathrm{~mm}$, die Höhe 9-11 mm; die Zahl der An- 
wachsstreifen schwankte von 5-9. Für den ventralen, längern Ast der zweiten Antennen zählte Verf. S-12, für den dorsalen, kürzern Ast 7-10 Glieder. An demselben 'Tier verhalten sich die Antenneniste ron rechts und links in bezug auf die Gliederzahl verschied.n. Gewöhnlich ist die betreflende $/$ ahl am ventralen, linken Ast grösser. als am entsprechenden rechten.

Kiemlich weiten Schwankungen unterliegt auch die Anzahl der Kiöpersegmente und ihrer Anhangsorgane. Verf. stellte sie in manchen Fällen auf 23 fest. Die 10 ersten Spaltfusspare besitzen ungefähr dieselbe Länge; rom elften Bein an tritt eine merkliche Verkürzung ein, die fuir die vier letzten Extremitatenpare anfallend wird. Männchen wurden keine gefunden.

Limmadia gigas bewohnt seichtes, roich mit Pllanzen durchwachsenes Wasser. Während der Krebs bei hoher Wasserdurchwärmung lebhaft und graziös umherschwimnt. bleibt er bei sinkender 'Temperatur versteckt, an Grashalmen hängend oder auf der Seite liegend, wobei durch ausgiebige Fussbewegung ein Wasserstrom erzeugt wird. Eine Benützung des am Kopf liegenden sogenannten Haftorgans konnte nicht beobachtet werden, ebenso wenig, entgegen den Angaben früherer Autoren, ein Schwimmen auf dem Rïcken. Bei der Häutung fällt mit der Körperhülle auch die Schalencuticula weg.

l. \%schokke (basel).

Sharpe, R. W., Report on the Fresli-Water Ostracoda of the United $\mathrm{States} \mathrm{National} M$ useum, including a revision of the subfamilies and genera of the family Cyprididae. In: Proc. U.S. Nat. Mus. Vol. 26. pag. 969-1001. pl. 64-69.

Die Arbeit enthält die nähere Beschreibmig von 9 im Nationalmuseum der Vereinigten Staaten aufbewahrten Arten von Süsswasser-Ostracoden inter Berücksichtigung der Literatur, Synonymie, Systematik, der Differenzen gegenüber verwandten Formen und europäischen Artgenossen und unter Angabe der über die ganze Union verteilten Fundorte. Zwei Arten und die Gattung Spirocypris sind neu; 3 Genera und 5 Species waren für die Vereinigten Staten und mit Ausnahme der auch in Mexiko gefundenen Chlamydotheca, für Amerika überhaupt unbekannt.

In Betracht fallen Chlamydotheca mexicana n. sp., Ch. azteca Saussure, IIerpetocypris reptans Baird, spirocypris passaica n. sp., Cypris virens Jurine, C. mbera O. F. M., C. pellucida Sharpe, Potamocypris smaragdina Vavra und Cypria exsculpta.

Ausserdem umfasst die Abhandlung einen Schlüssel zur Bestimmung aller Gattungen und Untergattungen der Cyprididen, sowie die Diagnosen derselben und von Limnicythere und Darwinula. Teilweise, besonders wo es sich um amerikanische Formen liandelt, werden auch die Arten systematisch berïcksichtigt.

Cyprinotus hat als blosses Subgenus von Cypris zu gelten, da die aufgestellten Unterschiede, Art der Fortpflanzung und Gegenwart einer Reihe von Hökerchen auf dem Schalenrand, nicht genügendes generelles Gewicht besitzen. 
Dieselbe Stellung gegenüber Cypris nehmen Hetcrocypris und Amphicypris ein. Provisorisch muss noch ein weiteres Subgenus mit Cypris grandis Chambers als Typus aufgestellt werden. Über seinen definitiven Bestand werden weitere Forschungen entscheiden. Alle Cypris - Formen, die den gevannten vier Untergattungen nicht angehören, reihen sich in das Subgenus Cypris ein.

Spirocypris n. g bildet mit Cypridella und Cypricercus eine durch die vorn in der Schale gelegenen, kreisförnig angeordneten Hoden ausgezeichnete Gruppe. Am nächsten steht sie Cypricercus, von dem sie indessen durch Schalencharaktere und Gestalt der Furca abweicht.

Polamocypris Brady erhält eine schärfer gefasste Diagnose; als synonym mit der genaunten Gattung erklärt Verf. Candonclla und Cypridopsclla.

F. Zs chokke (Basel).

\section{Insecta.}

768 Nroggat, W. W. Typical Insects of Central Australia. In: Agricult. Gaz. N. S. Wales. 1901. Nisc. Public. Nr.511. 10 pag. $1 \mathrm{pl}$.

Der zentrale 'Teil von Australieu (das Gebiet, welcles etwa 100 Meilen vou der Kiiste entfernt ist) besteht meist ans mit Gras bewaclisenen Ebenen, "Busch", unfruchtbaren Niederungen, Gebirgsketten, Sandhügelı oder nackten Flächen, aus denen sich vereinzelte Granit- oder Kalkhïgel erlieben; das Gebiet ist mur schwach bewaissert, die Stromketten meist trocken, doch erfolgen alle par Jalue mächtige Regengiisse, welche grandiose C̈berschwemmnngen zur Folge haben; dann verwandelt sich die Sandwiiste binnen weniger Tage in sinen Gras- und Blumengarten, welcher wie durch \%auberkunst mit einer reichen Fauna bevökert wird. Für gewöhnlich bietet das rauhe unfruchtbare Land, dessen wenige Pflanzen sich durch Härte der Rinde und Mangel an Blätern auszeichnen, der Insektenwelt wenig Amuehmlichkeiten und diejenigen Formen, welche darinnen aushalten kounten, mussten notgedrungen im Kampf ums Dasein manche Umwandlungen durchmachen, bis sie sich der wenig gastfreundlichen Natur angepasst hatten. In neuerer Zeit ist jedoch die Insektenfauna Zentralaustraliens, infolge der fortschreitenden Kultivierung des Gebiets und der Einführung von Rindern und Scluafen, im Begriff sich wesentlich zu verüindern, indem viele der ursprïnglichen PHanzen im Aussterben begriffen sind und mit ihnen auch gewisse Insektenarten verschwinden; auch durch die Verbreitung des Kianinchens und der Honighiene erhält die Flora, und mit ils auch die Fiuna ein verindertes Aussehen.

Was zunächst die Ordnung der Lepidoptera betrifft, so sind die Tagschmetterlinge nur spärlich vertreten (Papilus, Terias, Danais, Junonia usw., meist gelb oder braun gefärbt) : hïufiger sind L y c a e $\mathrm{n}$ iden. (Die schneckenartigen Jalmcmus-Raupen scheiden ein klebriges Sekret aus, durch welches Ameisen angelockt werden; letztere schiitzen wahrscheinlich die Raupen gegen Feinde.) Als charak- 


\section{$-794 \quad-$}

teristischsten Schmetterling bezeichnet Froggatt Picris teutonica, welcher in grossen Mengen auftritt und dessen Raupen auf Capparidenarten leben. Von andern Schmetterlingen sind Teara contraria, Doratifera vulncrans und Limacodes longeraus (schöngefürbte Raupen mit Stacheln), Anthroea encalypti usw. zu erwähnen. Noctuidenlarven zerstören oft den ganzen Graswuchs.

Unter den Coleoptera sind die Carabiden und Curculioniden am stärksten vertreten; Cicindela-Arten fehlen ganz; bemerkenswert sind die grossen, metallisch glänzenden Vertreter der Gattungen Megacephala und Tetracha. Grosse, gedrungen gebaute Scarabaeiden ohne Flugorgane, aber mit wollentwickelten Grabfüssen, auf und unter der Rinde lebende Heteromeren (Chalcopterus, Hapaulax, Tlelaens), Curculioniden, welche auf dem Boden und unter Steinen leben (Amycterides, Cubicorrhynchus u. a.), einige Buprestiden (Merimna atrata, welche die eigentimliche Gewohnheit hat, selbst am 'T'age direkt in das Lagerfeuer zu fliegen, Diadorns, Frenclla, Cesseis, Ethon, Mclobasis), grosse Prioniden (Phoracantha) cylindrisch geformte Lamien, einige Cleriden (Trogodendron), wenige Lamellicornier (Anoplognathus, Bolbocerus) gehöreu mit zu den typischen Käfern Zentralaustraliens.

Unter den H y moptera spielen die Ameisen die hervorragendste Rolle; Iridomyrmex purpurens, in uugeheuern Scharen schwärmend und komplizierte unterirdische Nester bauend, die gefleckte Podomyrmex gratiosa, die bekannten ,Honigameisen" u. a. m. bewohnen Einöden und Wälder und sind nicht selten der Schrecken der Ansiedler. Von andern Hautflïglern (deren australische Vertreter noclı so gut wie unerforscht geblieben sind) erwähnt der Verf. die Wespen Ammophila suspiciosa und Pelopaeus lactus, Abi:pa cphippium (bekannt durch ihren Angriff auf die Expedition des Majors M itchell), zahlreiche Hutilliden, einige Bienen (Anthophora cinguluta, Megachilus).

Die Hemiptera sind u. a. vertreten durch Mictis. Arten mit auffallender Zeichnung, die Gattungen Gardena, Geobia, Adrisa, Mononyx, Galgulus (kleinere pflanzenfressende Arten wiegen vor), ferner durch Cicaden (IClampsalta, die grossen Arten sind mehr Küstenbewohner), Eurymela-Arten (auf Eucalyptus schmarotzend, die Larven secernieren den von Ameisen hochgeschätzten „Honigtau“), zalllreiche Psylliden (deren Larven zum 'T'eil merkwürdige Hüllen aus zuckerartigen Ausscheidungen bilden). Die Larven gewisser Aleurodiden machen Vertiefungen in junge Eucalyptusblätter; Cocciden siud zahlreich auf Akazien, Eiche und $\mathrm{Cy}^{-}$ presse, wähond die Brachyscelidae durch ihre grossen Gallen, in welchen sie aufwachsen, ausgezeichnet sind.

Von dell Orthoptera sind es hauptsächlich Acridiodeen und Blattodeen, welche für das Gebiet charakteristisch sind; erstere (Epacromia terminalis, Pachytylus terminalis u. a.) zeigen gute Schutzfärbung, treten in ungeheuern Schwärmen auf, letztere sind meist ungeflügelte, grosse Tiere und nicht selten prachtvoll gefärbt (Folyzosteria, Geoscapheus). Gryllen (namentlich Gryllotalpa coarctata) fiuden sich meist da, wo artesische Brunnen angelegt wurden.

Diptera. Zu den grössten Plagen gehört eine Musca-Art (,bush fly“) welche weder Mensch noch Tiere mit ihren Stichen verschont; ferner sind die Gattung Comptosia (einige Arten parasitieren bei _lbispa, deren Brut sie verzehren), zahlreiche Sylphiden und vor allem riesige Asiliden (Craspodia coriaria, Phellus glancus, $1^{3}{ }_{4}$ Zoll lang) zu erwähnen.

Unter den Neuroptera fiuden wir Odonaten, Myrmeleontiden und vor allem Termiten. Zum Schluss erwälnt der Verf. noch den Reichtum an Vertretern der 'Thysanoptera, welche meist Gallen bilden.

Der kurze, aber gedräingte Bericht des Verf's. gibt viele wissenswerte An- 
gaben über die Lebensweise der für Zentralaustralien typischen Insekten. Zahlreiche Druckfehler in den lateinischen Namen hätten wohl vermieden werden können. Die Tafel enthält Abbildungen von vier Coleopteren und zwei Blattodeen.

N. v. A delung (St. Petersburg).

769 Silvestri F., Circa alcuni caratteri morfologici di Projapyx e loro importanza filogenetica. In: 1Boll. Mus. Zool. Torino. Vol. XVI. 1901. pag. 1-3. (Auch in: Boll. Soz. ent. ital. Vol. XXXIII. (1902), pag. 204-212).

Es ist dem Verf. gelungen, neuerdings in Argentinien (Misiones), Paraguay und in Matto Grosso Exemplare der von Cook aus Liberia beschriebenen Gattung Projapyx zu erbeuten, welche ein genaueres Studium dieses seltenen Objekts erlaubten. Dasselbe ergab, dass Projapyx als das primitivste der bis jetzt bekannten Insekten gelten könne; die hauptsächlichsten Merknale hiefür sind folgende: Es sind 3 thorakale und 7 abdominale Stigmenpaare vorhanden; der erste Abdominalsternit trägt zwei Styli und zwei cylindrische Anhänge: zwei Drüsen, welche sich längs des Enddarms erstrecken, münden durch die Cerci hindurch an deren Spitze nach aussen und zwar vermittelst eines ausstïlpbaren Ausfülırgangs. Diese Drüsen sind denjenigen der s y nphyla und der Diplopoda analog, die Papillen der letzteren den Cerci.

Die Mundteile entsprechen denen ron Japyx, mit welchem die nene Gattung die meiste Ïhnlichkeit hat; die Abdominalblasen fehlen. Fis sind 5 kurze Malpighische Gefässe rorhanden.

Silvestri stellt fiir Projapyx die Familie Projapygidae auf (Projapygidae + Japygidae = Dicell ura Hal.).

Zum Schluss gibt der Verf. die Beschreibung einer hypothetischen Thysanure, ron welcher alle gegenwärtigen Thysanuren abstammen würden.

N. v. A delung (St. Petersburg).

770 Silvestri, F., Descrizione di un nuovogenere di Projapygidae (Thysanura) trovato in Italia. In: Ann. Sc. Sup. Agricoltura Portici. Vol. V. 1903. pag. 3-8. 1 Abb. i. T.

771 - Sull Anajupyx resiculosus Silv. (Projapygidae, Thysanura). In: Fauna Napoletana. Ann. Mus. Zool. Univ. Napoli. Vol. I. 1903. pag. $1-5$. 1 Abt. i. T.

Der Verf. hat in Portici eine neue Thysanure (Anajapyx resicuiosus n. sp.) gefunden, für welche er die neue Gattung Anajapys $x$ n. g. aufstellt. Von der nahe verwandten Gattung Projapy $x^{1}$ ) unterscheidet sich die neue Gattung durch den Besit\% von ausstïlpbaren Blasen (resi-

1) Vgl. Nr. 769 . 
culae abdominales) am 2.-7. Abdominalsternit, das Fehlen von Stigmen im Prothorax und durch die Gestalt der Labialtaster. Das neue Insekt hat nur $2 \mathrm{~mm}$ Länge und lebt in der Erde; bis jetzt wurden 11 weibliche Exemplare gefunden. Neben einer genauen Beschreibung der äussern Körperform finden sich auch anatomische Einzelheiten. Die Zahl der Stigmenpare beträgt 9. Im hintern Körperabschnitt fehlt die Queranastomose der 'Tracheenstämme, welche bei den J a p ygidae besteht; nur die mit Stigmen versehenen Abdominalsegmente weisen querverlaufende Anastomosen auf. Die Terzweigungen der 'Tracheen sind ansfïhrlicher besclurieben. Der Vorderdarm ist stark entwickelt und erstreckt sich bis zum 4. Abdominalsegment, der Mitteldarm nur vom 5.-7. Segment; dasselbe findet sich auch bei Projumyx Silv. I)as letzte der 7 Abdominalganglien zeichuet sich durch besondere Grösse ans.

In der Gattung Anujupyx sind die Merkmale der Symphylen, der Diplopoden, Campodeiden, Japygiden und Lepismatiden vereinigt. Anajapyx zeigt einen noch primitivern Charakter als Projapyx und soll jener primitiven Form an nächsten stehen, welche vom den Vorfahren der Progoneata (Symphyla und Diplopoda) ausging, und von woleher die Thysanura abstammen.

Fiir Japyx iscubllae Grassi stellt der Verf. die neue Gattung Parajamyx n. g. auf. welche in der Zall und Lage der Stigmen mit Anajapyr übereinstimmt und sich durch die Gestalt der Mandibeln, die fehlenden Labialtaster. den besitz ron Ventralblasen im 2. und 3. Abdominalsegment usw. von elanyx unterscheidet.

$$
\text { N. v. Adelung (St. Petersburg). }
$$

772 Finot, A., Sur le genre Euhymia de la tribu des Acridiidae, Famille des Acridiodea, Ordre des Insectes Orthoptères. In: Am. Soc. Ent. France. 1903. pag. 620-636. 13 Abb. i. T.

Die Gattung Euhymia wurde von Stâl für zwei Arten (ans Borneo und Madagaskar) aufgestellt; ron Brancsik wurde eine weitere Art aus Nossibé beschrieben. Finot macht weitere sechs Arten dieser Gattung bekiunt, von denen eine aus Südindien, fünf voll Madagaskar stammen (E. kirbyi, kraussi, brunneri, scudderi, saussurei, bolivari nn. spp.). E. brunncri zeichnet sich durch Höckerbildungen auf dem Pronotum aus und dürfte zweifellos zur Aufstellung einer neuen Gattung berechtigen, was der Verf. auch andeutet. E. melanocerca Stial wird neu beschrieben und eine dichotomische Tabelle zur Bestimmung aller bekannten Arten aufgestellt, womit eine Monographie der Gattung geliefert wird, welche bei dem auffallenden Mangel an ähnlichen Zusammenstellungen innerhalb der Familie der Acridiidae (der Verf. fasst diese noch als Tribus, die Unterordnung Acridiodea dagegen als Familie auf) einen sehr schätzenswerten Beitrag zur Orthopterologie bildet, zumal da die Diagnosen, wie stets bei dem Vert, selır ansfühlich und präzis verfasst sind.

N. v. Adelung (St. Petersburg). 
773 Child, C. M., and A. N. Young, Regeneration of the Appendages in Nymphs of the Agrionidae. In: Arch. Entwmech. Bd. XV. 1903. pag. 543-602. Taf. XX-XXII.

In rorliegender Arbeit hat Young die Beobachtungen und den experimentellen Teil übernommen, während die Deutung der erzielten Resultate Child zum Verfasser hat. Als Material dienten nicht näher bezeichnete Agrioniden aus der Umgebung von Chicago. Sowohl die Beine als auch die Trachealanhänge wurden an verschiedenen Stellen, von deren Spitze bis zur Basis, unter Chloroformnarkose, operativ entfernt und die darauf eintretende Autotomie und Regeneration im Vergleich mit den unversehrten Anhängen untersucht. Von den dabei erzielten Resultaten sei folgendes mitgeteilt:

Die Beine und Trachealanlänge regenerieren stets, in welchem Niveau sie auch durchschnitten sein mögen. Autotomie tritt bei Verletzung der Trachealanhänge und der distalen Beinbezirke ein, wobei in 'Trochanter ein besonderer Mechanismus hierzu vorhanden ist. Gleichförmigkeit und Geschwindigkeit der Regeneration erreichen ihr Maximum da, wo die Beschädigung der Gewebe am geringsten ist ('Troclanter-Femur-Artikulation). Bei der Regeneration ist keine Anpassung in bezug auf Verletzungen melı unterworfene Stellen der Anhänge und leine zu bemerken. Wird eine grössere Portion der Beine entfernt, so erfolgt die Regeneration deshalb doch nicht relativ rascher als bei Amputation einer kleinen Portion. Mit der letzten Häutung ist die Regeneration unterbrochen; das regenerierte Bein der Imago bleibt auf dem Stadium stehen, welches es beim Auskriechen derselben erreicht hatte. Bei der Regeneration der Beine findet eine progressive Differenzierung seiner Abschnitte statt. Die T'arsalklauen erscheinen im allgemeinen ror den Gelenken, letztere erst nachdem die für ihre Bewegung notwendigen Muskeln rorhanden sind, und zwar zuvor an der Seite der ersten Selmenanheftung. Die Gelenke repräsentieren Faltenbildungen der Körperbedeckung, wahrscheinlich infolge des Zuges an den Selmenanheftungsstellen; sie treten im allgemeinen zuerst in den proximalen Bezirken des regenerierenden Beines auf, wie auch die Muskeln, Sehnen usw.

Nach Schnitten durch das Tibio-Tarsal-Gelenk sind die Klauen bei der nächsten Häutung meist gelenkig mit dem Tarsus verbunden, während dies bei Schnitten durch den Tarsus noch nicht der Fall ist. Wird der Schnitt durch die zwei distalen Drittel der Tibia geführt, so erscheint das Klauengelenk nach der ersten Häutung, liegt der Schnitt noch höher, so bleiben die K'lanen iiberhaupt gelenklos, da bei einer vollständigen Neubildung der Kilauemmuskeln die Sehnen 
die Klanen nicht erreichen, sondern sich mit den Tarsalnuskeln verbinden.

Bei Regeneration ohne Bildung eines Gelenkes zwischen Tarsus und Klanen gelangt meist nur eine der letztern und zwar fast immer die hintere zur Ausbildung, während die andere in Gestalt eines Anhanges bestehen bleibt; dies Verhalten ist wahrscheinlich dem UnIstande zuzuschreiben, dass bei fehlendem Klauengelenk diese hintere Klaue stärker benützt wird. Endlich zeigt das distale Tarsusglied bei fehlendem Kklauengelenk noch die Eigentiimlichkeit, dass es konisch (und nicht cylindrisch) gebildet ist und allmählich in die Klaue übergelıt. Bleibt die regenerierende Klaue gelenklos, so fehlt ihr im Imagostadium der charakteristische Zahn, welcher normalerweise bei der letzten Häutung auftritt.

Die vorliegende Arbeit bietet um so melır Interesse. als iiber die Regeneration bei Odonaten so gut wie nichts bekannt war.

$$
\text { X. v. A delung (St. Petersburg). }
$$

774 Enderlein, G.. Zur Kenntnis europäischer P'sociden. In: Zool. Jahrb. Syst. Bd. XVIII. 1903. pag. 365-382. Taf. 19. 9 Abb. i. T'.

775 - Zur Kenntnis amerikanischer Psociden. Ibid. pag. 352-364. Taf. 17, 18.

An der Hand eines sehr bedentenden Vergleichsmaterials, welches in verschiedenen Gegenden Deutschlands und Skandinaviens gesammelt wurde, kommt der Verf. zu dem Schluss, dass die von Kolbe anfgestellten Arten (und Gattungen): Tichobia alternans und Cerobasis muraria Entwicklungsstadien der ebenfalls ron Kolbe beschriebenen "Hlïgellosen" Psocide Hyperates guestfalicus darstellen. wobei erstere der Larve, letztere der Nymphe dieser Art entspricht. Das vordere Flügelpaar der letzteren ist ganz rudimentär (etwa $1 / 20 \mathrm{~cm}$ lang) und mit Borsten besetyt. Das Insekt lebt nach den Beobachtungen Enderlein's nicht nur an verschiedenen Coniferen, sondern auch an Laubhölzern, wobei es von Flechten und Iloos überzogene Bäume bevorzugt.

Des weitern gibt Verf. eine erste Liste der auf der Insel Rügen vorkommenden Psociden (gesammelt wurde im Winter, Frühling, ferner im Juni und September); konstatiert wurden die Gattungen Amphigcrontia Kolbe (2 sp.), Psocus Latr. (3 sp.), Graphopsocus Kolbe (1 sp.: Gr. cruciatus L., dessen Weibchen verkürzte Flügel haben), Stenopsocus Hag. (1 sp.), Caecilius Curt. (4 sp.), Plerodela Kolbe (2 sp.), Pt. livida n. sp. an Eichen), Leptella Rent. (1 sp.: L. helvimacula Enderl., bisher nur aus Fimnland und in wenigen Exemplaren aus der Umgebung von Berlin bekannt), Peripsocus Hag. (3 sp.), Elipsocus Hag. (2 sp.; Verf. weist darauf hin, dass E. moebiusi Tet. of zu E. westwoodi Mc Lachl. $O$ gehört und dass $E$. hyalinus Steph. von Kolbe mit E. westwoodi verwechselt worden ist; 
E. brcvistylus Rent. soll identisch sein mit $E$. hyalinuss), Philotarsus Kolbe (1 sp.), Hypcrctcs Kolbe (1 sp.), Troctes Burm. (1 sp.)

Den Schluss des ersten Aufsatzes bildet die Aufzählung von 11 in Dänemark und Schweden erbeuteten Psocidenarten; hervorzuheben ist der seltene, bisher nur in England, in Holstein (2 Exempl.), in Leipzig (1 Exempl.) und in zwei Fällen bei Berlin nachgewiesene Caccilivs atricornis Mc Lachl., welcher nunmelır auch aus Dänemark beschrieben wird.

Aus Südamerika beschreibt Enderlein folgende neue Arten: Ischnoptcry.x Enderl. cincta n. sp. (Amazonas); P'socus Latr. brasilianus n. sp. (Espiritu Santo), P.s simplex 11. sp. (Porto Allegro); Dcndroncura n. g., (Ptilopsocinae, ausgezeichnet durch das dendritische Aussehen des Geäders) ramulosa n. sp. (Peru), Caecilius Curt. thicmei sp. n. (Columbien) und pubes n. sp. (Surinam): IIemicaecilius n. g. bogotanus n. sp. (Columbien); Dcipmopsocus n. g. (verwandt namentlich mit Rhyopsocus Hag. von den Kerguelen) spheciophilus n. sp. (Peru, in einem Nest der Wespe Chartergus apicalis Fabr., Flügelspannung nicht ganz $2 \mathrm{~mm}$ ).

Zum Schlusse werden zwei neue Trochus Burm. aus Nordamerika (Tr. ncedhami und Tr. bicolor n. sp. aus Illinois) beschrieben.

Durch vorliegende Aufsätze hat der Verf. wiederum einen dankenswerten beitrag zmr henntnis der namentlich fïr aussereuropäische Gebiete so wenig erforschten I'socidenfauna geliefert.

$$
\text { r. v. Adelung (St. I'etersburg). }
$$

776 Trägirdh, J., T'ermiten ans dem Sudan. In: Results Svedish \%ool. Expedit. to Egyjt and the White Nile 1901 under the Direction of L. A. Jägerskiöld. Nr. 12. Upsala 1903. 47 pag. 3 Talf. 8 Abb. i. T.

Die in vorliegender Schrift mitgeteilten Beobachtnngen wurden im Februar und März zwisehen Chartum und Faschoda unter relativ mngïnstigen Bedingungen angestellt, so dass sie, wie der Verf. selbst bemerkt, auf Vollständigkeit keinen Anspruch machen können. Immerhin ist es Trägådh gelnngen, eine ganze Anzahl interessanter Tatsachen, namentlich beziiglich des Baues der Nester, zu beobachten; ansserdem hat er erstmals das betreffende Gebiet ernstlich auf Termiten untersucht und dabei drei newe Termitenarten entdeckt. Im ganzen wmrden sieben Arten beobachtet, welche nachstehend kurz besprochen werden sollen. Es sei noch bemerkt, dass die vier bereits bekannten Arten ausser dem sndan noch teils in Natal, an der Goldküste, in Kamerun usw. vorkommen, was auf eine weite Verbreitung hindeutet. Alle beobachteten Arten leben in der Erde, was der Verf. durch die wenig Schatten gebende Baunvegetation erklärt; Termitenbauten wurden nur auf einem verhältnismäßig schmalen Vegetationsgebiet der Ufer, und zwar in gewisser Höhe, gefunden.

Für die sieben Arten werden zwei Tabellen aufgestellt, von denen die eine auf morphologischen Merkmalen der "Soldaten“, die andere 
auf der Nestform begründet ist, wobei folgende vier Unteral,teilmngen angenommen werden: 1. Grosse Erdhügel mit Pilzkulturen; Trmes natulensis Har. (P'ilzkulturen nur in peripherischen Kammern) und T. affiris n. sp. (Pilzkulturen in allen Kammern). 2. Kleinere Erdhügel, ohne Pilzkulturen: Eutrmes occonomus n. sp. colme spezielle Königimnenzelle) und $E$. parms IIar. (mit besonderer Königinnenzelle). 3. Unterirdische Nester, Ausführgänge mit Propfen: E. terricola n. sp. 4. Keine eigenen Tester: E. baculi Sjöst. (durch das Leben mit den Wirten umgewandelt) und $E$. insertus Hag. (in besondern Liammern des Wirtsnestes lebend).

Termes natalcnsis Har, ist nächst $T$. bellicosus Sm. die in Afrika an wei. testen verbreitete Art; die Nester haben eine Höhe von über 2 m (nach Haviland nur 4'); die Oberfläche junger Nester ist grobkörnig, mit Erhöhungen, diejenige alter Nester glatt und eben. In der äussern Wand verlaufen breite Gänge, welche nur unterhalb der Erdoberfläche mit dem innern System von Gängen in Verbindung stehen; nach aussen münden diese Gänge nur bei im Bau begriffenen Hügeln und scheinen zum Transport von Erde zu dienen. In der Masse der kompakten äussern Wand liegen unregelmäligige Kammern, welche Gebilde von korkähnlicher Masse enthalten, - die Pilzgärten. Diese Gebilke bilden ein Konglomerat von ursprünglich kugelförmigen Klümpchen und bestehen anscheinend nur aus vegetabilischer Substanz, welche von Mycelfilz überzogen sind; stellenweise finden sich an den Innenwänden woisse, ans einer kompakten Masse von verzweigten Mycelfäden bestehende Kügelchen. Die Oidienbildung erfolgt nicht so vollkommenerweise, wie dies von Holtermann beschrieben wurde. Im Innern der Hügel findet sich ein labyrinthähnliches System unregelmäßig geformter Kammern und Gänge, welche nach innen zu an Grösse zunehmen; besondere Kammern für Weibchen und Männchen (Haviland) konnte der Verf. nicht finden ${ }^{1}$ ), ebenso befindet sich nach seinen Beobachtungen im obern T'eil des Hügels kein besonderer "Dom"; was Smeathman als solchen bei $T$. bellicosus beschreibt, hält Träg à $\mathrm{rdh}$ für das Resultat zufälliger Zerstörung des Kammersystems. Das Kammersystem erstreckt sich mindestens $1 \mathrm{~m}$ tief in die Erde und reicht seitlich bis über $100 \mathrm{~m}$ weit. Beim Mauern würgten die Arbeiter mit Sekret durchtränkte Erde aus, welche sie an geeigneter Stelle ablegten und durch Bewegungen des Kopfes festdrückten. Exkremente oder Bruchstücke des Baues wurden beim Mauern niemals verwendet. Die ausgew ürgte Erde stammt nach des Verfs. Ansicht aus dem Darmkanal anderer Arbeiter, aus welchem sie bei drohender Gefahr (Eingriff seitens des Menschen oder von Tieren) durch Streicheln ,hervorgelockt" wird, während beim Bauen unter normalen Verhältnissen die Erde einfach direkt aus dem After abgelegt wird. Es erscheint dem Ref. nicht einleuchtend, warum das kompliziertere Verfahren von den Arbeitern gerade dann angewendet werden soll, wenn rasche Abwehr von Feinden geboten ist.

Termes affinis n. sp.; T. vulgaris Hav. nahestehend -, die Hügel gleichen äusserlich denjenigen der vorhergehenden Art, doch sind die Pilzgärten enthaltenden Kammern von regelmäß3iger Gestalt und nehmen den ganzen oberirdischen Teil

1) Derartige Kammern finden sich nach Ansicht des Verfs. nur bei solchen Arten, deren Kammern sehr eng sind und daher für die Weibchen speziell hergerichtet und erweitert werden müssen. 
ein; die Pilzkammern stehen nur durch enge Gänge mit einander in Verbindung (kein Labyrinth). Die Pilzgärten haben die For'm von unten konvexen Badeschwämmen und bestehen gewissermafen aus dünnen, lalbkugelförmigen, konzentrisch aufeinandergelegten Scheiben. Das Material zu neuen, obern Schichten wird dem Boden des Pilzgartens entnommen; die in den äussern Schichten der weissen Kügelchen entlıaltenen Zellen sind kleiner als die des lnnern; beide waren teils leer, teils mit Plasma angefüllt.

Eutermes oeconomus n. sp., mit E. geninatus Wasm. und E. trincrius (Ramb.) verwandt, mit grössern und kleinern Nasuti (bei letztern ist das dritte und vierte Flügelglied meist vorschmolzen). Erdhügel klein, mit völlig ,gleichartigem, homogenem System von labyrinthartig gewundenen Gängen“. In den peripheren l'eilen des Hügels Vorräte von kurzgeschnittenen Pflanzenteilen und Samen. Königinnen wurden nicht beobachtet. Die Larven nähren sich wahrscheinlich von Exkrementen der Arbeiter (wie dies schon Grassi beschrieben lat).

Eutermes pareus (Hav.). Die Dimensionen der Königin und Arbeiter übersteigen die von $\mathrm{Haviland}$ und Sjöstedt gegebenen Malie. Hügel regelmäßig konisch, etwa $50 \mathrm{~cm}$ hoch, das Nest ragt nur $20 \mathrm{~cm}$ in die Erde hinoin, gegen welche es scharf (konisch) abgegrenzt ist. Dio Hügel bestehen aus einer $3-4 \mathrm{~cm}$ dicken äussern Erdschicht, im übrigen aus einer braunen, vegetabilischen Masse, welche von aus Sand bestehenden Streifen durchzogen wird. Die Gänge verlaufen konzentrisch un die etwas unterhalb der Erdoberflache gelegene Königinuenzelle; mehrfuch wurden zwei Königinnen nebeneinander angetroffen.

Tcrmes incertus: Hag. Die Mandibeln sind fein sügeartig gezähnt, nach Haviland und Sjöstedt ungezähnt. Ein Nest befand sich in einem Baumstumpf, ohne Spur von Pilzgärten, die iibrigen in Bauten von T. natalensis Hav. und $T$. affinis $\mathrm{n}$. sp. (uach $\mathrm{H}$ agen in Hügeln von $T$. bellicosus), in den Wänden zwischen den grössern Wirtskammern. In einigen Kammern enthaltene braungelbo Gebilde hält der Verf. (gegen Haviland) nicht für Pilzkulturen, sondern für Material (Holz), welches aus den Pilzgärten der Wirte gestohlen wurdo und als Nahrung dient.

Eutcrmes tcrricola n. sp. Nur Soldaten, vou denen die kleinern nur 12.gliedrige Fülıler besitzen, die grössern 13-14-gliedrige. Die unterirdischen Nester stehen durch 4-5 mm weite, durch Pfropfen verschlossene Gänge mit der Oberfläche in Verbindung. Der Bau der Nester konnte wegen der harten Konsistenz des Bodens leider nicht näher untersucht werden.

Eutermes baculi Sjöst. Es wurde ein Exemplar in einem Hügel von $T$. affinis 11 . sp. gefunden.

Der Verf. hat in einem Fall die Inrasion von ardern Insekten (T'enebrioniden und andere Käfer, Microlepidopteren) in einem Termitenbau konstatieren können. Der obere Teil des Baues war vou den 'Termiten verlassen worden (ob vor oder nach der Invasion?), die Pilzgärten von den Eindringlingen zerstört.

Bezïglich der Rolle der Soldaten hebt der Verf. mit Recht herror. dass dieselbe nie unter normalen Verhältnissen beobachtet wird, sondern meist bei gewaltsamer Zerstörung des Nestes. Unter normalen Bedingungen füllen die Soldaten mit ihrem stark entwickelten, rechtwinklig herabgebogenen Kópf die zu verteidigenden Gänge, wobei sie beim Nahen des Feindes den Kopf in die Höhe werfen (wozu ein 
besonderes Gelenk hestelıt) und die Mandibeln z.nsammenklappen. Zwischen den verschiedenen Mandibelformen der 'T'ermiten-Soldaten und der Natur ihrer Feinde existiert sicher eine Weclsselbeziehung (mit Silvestri gegen Sharp).

Die Entstehnngsweise der Hiigel denkt sich Träg Znerst wird bein Anlegen des ursprïnglich ansschliesshich nnterirdischen Nestes durch einen vertikalen Gang Erde an die Erdoberfläche geschafft, der Gang verschlossen und dann erst in dem so entstandenen Hïgel Rïume angelegt, wohei die fortzuschaffende Erde an der Oberfläche des Hügels abgelegt wird. Durch peripher verlanfende Ginge wird neues Material ans der Erde heraufgebracht (die anstralischen Termiten legen nach Froggatt ilne Hiigel direkt als Wohnnngen an, wobei sie Erde rings nun den Hügel anf dem Boden sammeln: eine Verallgemeinermng dieser Bauweise ist nach den Beobachtungen 'Trägă rd lıs nicht zulässig). Die Zwischenwände im Innern des Baues bestehen entweder aus Erde und sind dann mit einer diimmen vegetabilischen Schicht belegt (E. occonomus), oder aus rein vegetabilischer Substanz mit Erdstreifen durchsetzt (E. parrus). indem die urspriinghich rein erdigen Wände allmählich immer dicker mit vegetabilischer Substanz ansgekleidet werden, während gleichzeitig die Erde allmählich weggeschafft und durch vegetabilische Substanz ersetzt wird.

Bau und Entstehung der Nester werden durch gnte Abbildungen veranschauliclit.

N. v. A del $n$ ng (St. Petershurg).

777 Willianson, F. B., Faun a and Flora of Winona Lake: B. Additions t o the Indiana list of Drogon Flies. Nr. II 1). In: „Proc. Indiana Ac. Sc. 1901. Reports from the Biolog. Station." Indianopolis 1902. pag. 119125. Pl. 1.

Einer früher erschienenen Liste der Indiana-Odonaten werden sechs weitere Arten hinzugefügt, wodurch die Zahl der aus diesem Gebiet bekannten Arten auf 97 erhöht wird. Ferner werden mehrere Angaben der ersten Jiste berichtigt und vervollständigt, was Fundort und Datum betrifft. Enallagma cyathigerum (Europa) und E. annexum (Nordamerika) hält der Verf. für identisch; Ophio. gomphus designatus ist in die Gattung Herpetogomphus zu stellen, Gomphus albistylus zu Letnthus. Gomphus sp. (pag. 294) ist G. viridifrons Hine; G. deseriptus ist von der Liste zu streichen; G. segrcgans Needh. ist ein Synonym von G. spiniecps Walsh. Die Eiablage von Sympetrum vicimum wird beschrieben. Die Füllung der Samenblase mit Samen erfolgt nach den Beobachtungen des Verfs. bei den Gattungen Caloptery:x, Argia und Enallagma, nachdem das Männchen das Weibchen ergriffen hat, mit einem Male, bei Lesehna und Dromogomphus wahrscheinlich während des Fluges.

N. v. A delung (St. Petersburg).

1) Nr. I hat dem Ref. nicht vorgelegen. 
778 Banks, Nathan, The eastern species of Psychoda. In: Canad. Entomol. Oct. 1901. pag. 278-275.

Der Aufsatz enthält eine analytische 'Tabelle nebst Bemerkungen über die im östlichen Teil der Vereinigten Staten vorkommenden Psychoda-Arten.

\section{.J. C. H. de M eijere (Hilversum).}

779 Becker, Th., Die Phoriden. In: Abhdl. k. k. Zool. Bot. Ges. Wien.

I. 1. 1901. pag. 1-100. M. 7,60.

Der durch mehrere hervorragende Arbeiten über die Systematik der europäischen Dipteren rühmlichst bekannte Autor hat sich jetzt auch mit der schwierigen Gruppe der P h o ri d e n beschäftigt. Das beziigliche Material vieler öffentlicher und Privatsammlungen wurde in Betracht gezogen und namentlich möglichst viele Typen der älteren Autoren, zur Richtigstellung der Synonymie, untersucht. Der Autor fand, dass frösse und Farbe nur sekundäre Merkmale sind, dass aber die Beborstung, namentlich von Stirn und Schienen, gute Merkmale darbietet, sowie auch das Flügelgeäder, obgleich doch die Entfernung der verschiedenen Adern weniger konstant ist, als Winnertz meinte. Letzterer hat in einer nie veröffentlichten Monographie der Phoriden viel zu viele Arten auf ganz geringfügige und variable Verhältnisse des Geäders begründet. In der Deutung der Adern schliesst der Verf. sich der Auffassung Girschners an, sowie er auch iiberhaupt der Ansicht dieses Forschers, die P'horiden seien die nächsten Verwandten der Mycetophiliden, beizuptlichten geneigt ist, was dem Ref. anch wegen der ganz verschiedenen Larven doch noch ungenïgend begründet erscheint. Ver grüsste Teil der Arbeit fällt der Crattung Phora zu, von welcher 65 europäische Arten aufgefiihrt werden.

Was die iibrigen Gattungen anlangt, so erachtet Verf. die Aufstellung der Familie der Stethopathiden von seiten Wandollecks, für einige derselben, als ïberflüssig, was besonders aus dem Verhalten der bezüglichen Männchen hervorgehen soll. Nur von den abweichenden und noch ungenau bekannten Gattungen Platyphora und Aenigmatias bleibt es dahingestellt, ob sie richtig in den rom Verf. fixierten Formenkreis hineinpassen.

Über die Larven wird nur sehr weniges mitgeteilt; aus ältern Angaben wird der Schluss gezogen, dass eine bestimmte Art nicht an ein bestimintes Wohntier oder an eine besondere Nahrung gebunden ist, sondern dass die verschiedenartigsten Ernährungsverhältnisse bei einer und derselben Art beobachtet wurden.

Die Arbeit enthält auch ein Verzeichnis der aussereuropäischen Phoridenarten, oder besser gesagt, ron dem verschwindend kleinen Teile derselben. welcher bis jetzt erbentet und beschrieben worden ist. 
In fünf schönen Tafeln, zum Teil von der berufenen Hand $\mathrm{R}$ ii bsa amens, sind manche Einzelheiten, namentlich Flïgel und änssere Genitalien, bilılich dargestellt, ein löbliches Verfahren gegeniiber mehrern ältern Dipterologen, welche etwaige Abbildungen beizugeben fast zu fürchten schienen. J. C. II. de Meijere (Hilversum).

780 Giard, Alfred, Sul' l'éthologie des larves de Sciara medullaris. In: Compt. rend. Ac. Sc. Paris. T. (XXXIV. 1902. pag. 1179 -1185 .

Die Larven wurden rom Verf. im Mark der Stengel ron Senecio jacobaca L. getroffen; in ersten Stadium sind sie metapneustisch, indem nur das 11. Segment stigmen trägt, später peripneustisch, wie gewöhnlich bei Mycetophiliden-Larven der Fall.

Obgleich die Larren positiv hydrotropisch sind, so zeigten sie andererseits stark ausgesprochene Anhydrobiose. Während 3 Wochen ganz getrocknet gehaltene Exemplare waren wenige Stunden, nachdem sie wieder angefenchtet wurden, wieder ganz normal, und es gelang, Exemplare zehn Tage hindurch täglich einmal unter dem Objektglase trocknen zu lassen und immer wurden sie bei Anfeuchtung wieder munter.

Gegen den Zeitpunkt der Verpuppung ändert sich der Hydrotropismus ganz um; infolgedessen findet man die P'uppen gerade rings un etwaige Löcher im Marke, welche mit der Aussenwelt in Verbindung stehen, grupliert: nach diesem Verhalten hat gerade eine andere Art, Sciara conceryens Perris, ilnen Namen erhalten. Dass die betreffenden Stengel immer zuerst von Lixus punctiventris durchbohrt worden sind, hat nach Giard nicht die Bedeutung, dass die Sciarct. Larven sich etwa von den Exkrementen dieses Coleopterons ernähren, sondern findet darin seine Erklärung, dass weder die jungen Larven, noch die zarten Mücken unversehrte Stengelteile zu durchbohren im stande sind.

J. C. H. de Meijere (Hilversum).

781 Goeldi, Emilio, Os Mosquitos no Pará, encarados come una Calamidade publica. Belem, Pará, Imprensa official. 1902. pag. $1-57$.

Eine Streitschrift aus Brasilien gegen die Moskitos, von der Hand Goeldis, des Direktors des Museums in Belem in Pará. Das spanisch geschriebene Schriftchen enthält I. allgemeine Orientierung über den Bau der Stechmiicken, besonders der daselbst vorkommenden Arten, II. Beschreibung der Biologie, III. die Bedentung der Stechmiicken in hygienischer Hinsicht, IV. notwendige Gegenmittel. Wenn wir beachten, dass an dem Wohnorte des Verf. nicht weniger 
als drei gefährliche Krankheiten von Mücken ïbertragen werlen können - Malaria von Anopheles argyrotarsis Desv., Filariosis von Culex fatigans Wied. und gelbes Fieber ron Stegomyia fasciata F., so lïsst sich das pathetische "Caveant consules" am Schlusse ganz gut begreifen.

.J. C. H. de Meijere (Hilversum).

82 Grimshaw, P. H., Diptera. In : Fauna Hawaiiensis. Vol. II. Part. 1. 1901. pag. $1-77$.

83 Grimshaw, P. II. und P. Speiser, Diptera (Supplement). Ibid. Part. 2. 1902. pag. 79-92.

Von der bisher fast unbekannten Dipterenfauna der SandwichInseln wird durch das ron Perkins gesammelte und von Grimshaw bearbeitete Material sogleich ein bedentender Teil der Wissenschaft übergeben. Lis werden in der Arbeit 172 Arten, dazu in Supplement noch 16 Arten, verzeichnet und diese ergaben sich bis anf 22 alle als neu.

Die Arten gehören den verschiedensten Familien an, und liessen sich grösstenteils in schon bekannten Gattungen unterbringen. Anffälligerweise sind die Ioosophiliden sehr reichlich vertreten, es werden nicht weniger als 40 Arten ron Ihosophila aufgetiihrt, welche alle neu sind, und dazu werden noch 8 weitere Arten erwählnt, welche aber zur Besthreibung untauglich waren. Dagegen wirden () rthorriapha brachycera fast nicht erbentet (nur 1 Sargus, 11 Dolichopodidae, 1 eingeführter Scenopinus). Auch Tipuliden s. str. fehlten in der Sammlung ganz; die Limnobiiden dagegen sind namentlich durch mehrere Dicranomyiae vertreten, welche wieder alle neu waren. Bei weitem die Mehrzahl der erbeuteten Dipteren-Arten fand sich nur je auf einer der die Gruppe zusammensetzenden Inselı.

Die eigentümlichste, im Supplement beschriebene Art ist eine fast flïgellose, mit Chrysotus verwandte Dolichopodide (Emperopter a mirabitis 11. sp.).

Von Pupiparen erwïhnt Speiser drei Arten, unter welchen eine neue; die beiden iibrigen weisen nach dem amerikanischen Kíontinent hin.

J. C. H. de Meijere (Hilversum).

784 Ilendel, Fr., Revision der paläarktischen Sciomyziden. In: Abhandl. k. k. Zool.-Bot. Ges. IVien II. 1. 1902. pag. 1-93.

Die Arbeit bildet eine ausgezeichnete Monographie eines Teils der palïarktischen Dipterenfauma.

Als Sciomyziden fasst der Verf. die Tetanocerinen und Sciomyziden zusammen und fügt noch die früher bei den Dryomyzinen untergebrachte Gattung Lucina hinzu. Letztere Familie, sowie auch die Sapromyziden werden durch neue Merkmale den Sciomyziden gegenüber charakterisiert und 
auch die Phycudromiden und die abweichenden Gattungen Trigonometopus, Neoltiophilum, Cyrtonotum und Prosopomya werden in vergleichender Weise besprochen. Wegen der noch ganz vorhandenen Stirmmittelleiste und der Anorduung der Borsten stellen sich die Tetanocerinen als primitiver als die Sciom yzinen heraus. Bei letzteren hat sich die Stirnmittelleiste schon zum Ocellendreieck reduziert.

Die Arten sind äber eine grosse Anzahl Gattungen (27, wovon viele neue), verteilt. Im speziellen Teil werden nur die 13 ersten eingehend belrandelt und die Arten derselben ansführlich beschrieben. Die meisten übrigen Gattungen wurden schon früher vom Verf, bearbeitet.

Ref. möchte darauf hinweisen, dass er an der pag. 9 zitierten Stelle in den Zool. Jahrb. nicht die Stigmen der Larve, sondern der Puppe von Scpedon sphegeus $\mathrm{F}$. beschrieben hat.

J. C. H. de Meijere (Hilversum).

785 Kellogg. Vernon L., An exftraordinary new maritime Fly. In: Biol. Bull. Vol. I. Nr. 2. March 1900. pag. 81-87.

Zu den auf sehr absonderlich gebaute Dipteren begründeten Familien der Stethopathidae (TWandolleck) und Stenoxenidae (Coquillet) fügt Verf. noch eine dritte, die der Eretmopteridae. Sie wurde errichtet für Erctmoptera browni Kell., eine au den von der Ebbe zurückgelassenen Pfützen an der Küste von Kalifornien erbeutete Art. Die Flügel sind kurz und sehr schmal und ohne Ader, derb, die Halteren schuppenartig; die Antemnen des Männchens zeigen 6, die des Weibchens 4 Glieder; die 'Taster sind viergliedrig. Durch die Mundteile und durch die der Atemhörner ganz entbehrende Puppe ist die Fliege mit den niederen Nematoceren verwandt. [Auch mehreren Chironomiden-Puppen gehen die Atemhörner ab. Ref.] Leider wurden die Larven bis jetzt noch nicht beobachtet. Walnscheinlich werden diese wohl eine Entscheidung über die richtige Stellung des Tierchens im System ermöglichen und dann wird es vielleicht nicht nötig sein, die neue Familie beizubehalten, ebensowenig wie die der Stethopathidae.

J. C. H. de Meijere (Hilversum).

786 Kellogg, Vernon I., Notes on the life-history and structure of Blepharocera capitata Loew. In: Entomol. News. Vol. X1. 1900. Nr. 1. pag. 305-318.

787 - The net-winged Midges (Biepharoceridae) of NorthA merica (Contributions to biology Hopkins Seaside Laborat. Leland Stanford Jr. Univers. XXX). In: Proceed. Californ. Ac. Sci. (3), \%ool. III. 1903. pag. 187-232.

Die Blepharoceriden bilden eine im Imago- und im Larvenstadium gleich interessante kleine Dipterenfanilie, von welcher jetzt etwa 20 Arten, aus Europa, Ceylon und namentlich aus Amerika, bekannt sind.

Während in der erstangeführten Abhandlung eine derselben in ihren verschiedenen Stadien belenchtet wird, finden sich in der zweiten alle nord-amerikanischen Arten besprochen und auch in eine analytische Tabelle zusammengestellt. '/unächst werden vier nene 
Arten aus Kalifornien beschrieben, sowie zwei Larven, deren Imagines noch unbekannt blieben. Bei der Anordnung der Arten zu Gattungen wird mehr auf das Flügelgeäder, weniger anf die früher als besonders wichtig hervorgehobene Bildung der Augen geachtet. Die Mundteile weisen ein primitives Verhalten auf, welches sich dem der ..beissenden Insekten" wohl näher anschliesst als bei irgendwelcher andern Dipterenfamilie. Mandibeln finden sich nur bei den Weibchen; diese nähren sich von kleinen Insekten, namentlich Chironomiden.

Die Fazettenaugen sind meistens zweiteilig, wie ebensolche auch bei mehreren männlichen Ephemeriden beobachtet werden. Die Ommatidien des dorsalen T'eiles, welcher bei den Männchen viel kleiner und weniger auffällig ist als bei den Weibchen, sind doppelt so breit und doppelt so lang, aber weniger stark pigmentiert, als die der unteren Hälfte.

Die Larven finden sich in stark Hiessendem Wasser mit ihrer medianen Reihe von sechs Saugscheiben festgehaftet an Steinen. Diese Saugscheiben werden nur von dem Integument gebildet; dureh Zurückziehung einer im Zentrum liegenden linsenartigen ('hitinverdickung entsteht ein Vakuum.

Die Larven zeigen äusserlich sechs Abteilungen; das erste derselben entspricht Kopf und 'Thorax. Die Tiere atmen vermittelst zweier' Reihen an der Ventralseite befindlicher Tracheenbüschel. I)as erste bis fünfte Abdominalsegment entluält davon jederseits ein Büschel, welches aus fünf bis sechs kurzen İsten bestelıt; am letzten Segmente kommen überdies noch zwei Paar fingerförmiger Anhänge vor. Sie ernähren sich von den an den bezügliehen Stellen üppig wachsenden Diatomeen. Die Puppen finden sich an denselben Stellen, also auch unter Wasser festsitzend. Ihre Unterseite ist ganz flach; die Prothorakalhörner bestehen je aus vier, wie die Blätter eines Buches nebeneinander liegenden Platten.

Wegen des stark fliessenden Wassers ist das Auskriechen für die sehr zarten Imagines eine sehr missliche Geschichte, bei welcher auch wirklich nach Kelloggs Beobachtungen viele den Tod finden. Damit die Schwierigkeit etwas verringert wurde, finden sich die Flügel zuletzt in voller Grösse, nur stark gefaltet, in der Scheide vor, und von diesen Falten soll nach Kellogg die sekundäre Aderung herrühren, welche für diese Familie charakteristisch ist.

P'hagocytose spielt auch hier während der Entwickelung eine ausgedehnte Rolle, wie es sich auch bei der starken Spezialisierung der Larven erwarten lässt.

J. C. H. de Meijere (Hilversum). 
788 Kellogg, Vermon Is., The anatomy of the la r'va of the Giant Cranefly, Holomsia mbiginosa. In: I'syche. Vol. IX. 1901. pag. 207-213.

789 - The histoblasts (imaginal buds) of the wings and legs of the Giant Cranefly. Ibid. Tol. IX. 1901. pag. 246-250.

Beide Abhandlungen bezwecken, eine Einleitung zu liefern in das Studium weniger bekamnter Verhältnisse bei den Insekten. Der Autor hat zunächst die, eine Länge ron $5-6 \mathrm{~cm}$ erreichende Larve von Holontsia mbiginosa gewählt, einer Tipulide, welche auch iiberhaupt das grösste bekannte I)ipteron ist. In der ersten Abhandlung werden die rerschiedenen Organsysteme kurz beschrieben und anch das Präparationsverfahren angegeben.

Die zweite Abhandlung ist den bei diesen grossen Tieren makroskopisch aufzufindenden Imaginalscheiben gewidmet. Letzterer Name wird rom Autor als unzutreffend bei Seite gestellt, weil nicht alle als solche bezeichneten Gebilde Organe für die Imago, einige auch solche für die l'uppe liefern, was allerdings richtig ist; doch scheint es Ref. nicht ganz notwendig, für diese Ausnahmefälle die gelänfige Bezeichnung aufzuopfern.

.J. C. H. de Meijere (Hilversum).

790 Kerteisz, Koloman, Diptera. In: Zool. Ergebn. 3. asiat. Forschungsreise des Grafen Eugen Zichy. Bd. II. Budapest 1901. pag. 181-201.

In erfreulicher Weise hat Ernst Csiki, der Zoolog der Zichyschen Expedition, auch auf die Dipteren geachtet und dadurch unsere bezüglichen Kenntnisse, namentlich was Sibirien anlangt, sehr gefördert. Das Velzeichnis enthält im ganzen 237 Arten; davon wurde eine Art im Kaukasus, 150 in Russ. land, 111 in Sibirien und 4 in der Mongolei gesammelt.

Die Ausbeute an neuen Arten war auffällig gering, es sind deren 4 aus Sibirien (Nemotelus zichyi, Stcnopogon csikii, Acemyia csikn und IIylemyia megatrich $($ ) und 1 aus Russland (Dolichopus angustipennis) angefïhrt. Überdies werden ('eratopogon bicolor Meig., Therioplectes tarandinus L., Dioctria lata Lw., Dioctria mefipes de G., Laphria gilea L., Anthrax blandus L., Chrysotoxum sibiricum Lw., IIylemyia penicillaris Rond., Oncomyia distincta Meig. und Acidia spcciosa Lw. besonders besprochen, zum Teil da sie durch mehr oder weniger abweichende Exemplare repräsentiert sind.

J. C. H. de M eijere (Hilvorsum).

791 Melander, A. I., Gynandromorphism in a new species of Hilara. In: Psyche. Tol. IX. 1901. pag. 213-215.

Inter mehreren Exemplaren der neuen Empide Hilara whecleri beobachtete Verf. eines, welches nach dem Abdomen ein Weibchen sein sollte, dessen Torderfüsse aber die für die Männchen charakteristische Erweiterung des Metarsus aufwies. Für solche Fälle schlägt er den den Zeitverhältnissen sicher gut entsprechenden Namen: .tandemhermaphroditism" vor. Obgleich über die imnern Genitalorgane nichts angegeben wird, so sind sie im obigen Falle doch nach aller Wahr- 
scheinlichkeit ganz weiblich, so dass es doch allerdings besser erscheint, gar nicht von Hermaphroditismus zu reden', sondern von Gynandromorphismus.

J. C. H. de Meijere (Hilversum).

792 Nuttall, G. II. F., and Arth. Shipley, Studies in relation to Malaria. The structure and biology of Anopheles. In: Joum. Hyg. Vol. II. No. 1. 1902. pag. 58 84. Vol. III. No. 2. 1903. pag. $166-215$.

Die Entdeckung der Beziehungen zwischen Anopheles und der Malaria hat eine wirkliche Lawine von Abliandlungen veranlasst über alles, was mit dieser Frage in Verbindung steht, und es haben dieselben nicht nur der Hygiene, sondern auch der Zoologie eine reiche Ernte an neuen Tatsachen geliefert. So ist auch die Anatomie und Biologie der in Betracht kommenden Miicken in eingehender Weise durchforscht worden. An obengenannter Stelle geben Nuttall und Shipley eine reichlaaltige Znsammenstellung ron dem, was hierüber bokannt wurde und fügen noch manche eigene Beobachtung hinzu. Besonders interessant erscheint der 'rst citierte Teil. Zum Beweis sei hier nur einiges, ohne nälıeren Zusammenhang, herrorgehoben.

Im allgemeinen gilt fïr die Gattung Anopheles, dass der Riissel mit dem Körper eine gerade Linie bildet und dass die 'T'iere in der Ruhelage einen spitzen bis rechten Winkel mit der Interfliche bilden. Bei Culex zeigt sieh \%wischen Rïissel und Kürper ein stumpfer Winkel und das Tier sitzt der Unterfläche parallel, oder der hintere T'eil des Körpers nähert sich sogar derselben. Anophcles maculipennis wurde in fast ganz Europa, Kanada, den Veremigten Staaten und Palästina beobachtet. Die Culicidate fliegen nicht weit ron den Brutstellen, die Verbreitung findet hauptsächlich in passiver Weise, so z. B. durch den Wind, Schiffe, Eisenbalmen usw. statt. Grosse Wanderzïge wurden bei Anopheles nicht, ausnahmsweise bei ein Paar andern Arten beobachtet. - Nur ron Anopheles bifurcatus überwintern die Larven; in dieser Jahreszeit finden sich ron dieser Art nur ganz wenig Imagines, dagegen wurden die ron A. maculipemis oft im Winter beobachtet, aber nur Weibchen. - Im Sommer gelang es, letztere Miicke mit Pisang und Wasser längere Zeit, bis etwa acht Wochen, am Leben zu erhalten. - Befruchtung scheint nicht möglich zu sein, bevor die Weibchen Blut zu sich genommen haben. Eine Kopulation geniigt für mehrere Eierablagen, aber vor jeder derselben muss wieder Blut aufgenommen werden. Bei blosser liütterung mit Pisang fand wenigstens keine Ablage ron Eiern statt.

Bei einer leider nicht näher bestimmten Art beobachtete Kellogg 
einen Fall von Parthenogenesis. Die aus den bezüglichen Eiern hervorgegangenen Larven erreichten fast ihr volles Wachstum. - Männchen und Weibchen sind fast in gleicher Anzahl rorhanden. - Jährlich finden sich in Nordamerika, wie auch in Italien, etwa zwei Generationen. - Oft wurde beobachtet, dass Miicken sich von Früchten, Blumensäften usw. ernährten, bisweilen auch von Insekten oder sogar sehr jungen Fischen. Bei einigen Arten saugen auch die Männchen Blut, bei andern nur ausnahmsweise.

Entgegen Grassi fanden die Autoren, dass auch die Männchen von A. maculipemis Nahrung zu sich nehmen. Fïr die Weibchen scheint es notwendig, hin und wieder Blut zu saugen: dadurch wird ibre Lebensdaner bedeutend verlängert. - Getrocknete Datteln bilden ein ausgezeichnetes Nährmittel für gefangene Culiciden. - 1. maculipennis fliegt etwa von Sonnenunter- bis Somnenaufgang. - Iiese Art wird an meisten von dunkelblauen Gegenständen angezogen. am wenigsten von hellen Farben, namentlich nicht von weiss, orange und gelb. - Die Bewegung der Flügel bringt einen Laut hervor, welcher um so liöher wird, je mehr man vom distalen Ende des Fliigels wegschneidet.

I)er zweite 'Teil der obigen Abhandlung befasst sich mit der Anatomie. Der ganze Darmtraktus mit seinen Anhängen, besonders die drei, auch nach den Experimenten der beiden Autoren als Futterbehälter fungierenden Säcke am Ende des (i)sophagnis und die Speicheldrüsen werden eingehend beschrieben und in instruktiver Weise abgebildet.

Allerdings noch nicht abgeschlossene Versuche über die Wirkung des Speichels lassen es doch schon als nicht wahrscheinlich erkennen, dass der'selbe sich der Koagulierung des Bluter's entgegenstellt. Ein ausgedehntes Verzeichnis der Malarialiteratur bildet den Schluss der Arbeit.

J. C. H. de Meijere (Hilversum).

793 smith, John. B., The salt-marsh Mosquito. In: New Jersey agricult. exp. Stat. spec. Bull. T. July 8. 1902. pag. 1-10.

Es handelt sich hier um Culex sollicitans, eine in New .Jersey und andern am Meeresgestade liegenden Ortschaften Nord-Amerikas besonders lästige Art. Bei derselben scheinen die Eier nicht immer im Wasser abgelegt zu werden und nur in diesem Stadium findet die Überwinterung statt. Die Larve findet sich in nur bei besonders bohen Fluten von Wasser erreichten, dann aber längere Zeit wasserhaltigen Gruben, daselbst aber oft in ungehenerer Anzahl. Als nächstliegendes Gegenmittel wird also die Auffüllung derartiger Pfützen empfohlen. Besonders von dieser Art ist beobachtet, dass ganze Wolken von Weibchen sich vom Winde verschleppen liessen.

J. C. H. de Meijere (Hilversum).

794 Thomas, Fr., Die Dipterocecidien von 
mit Bemerkungen über Blattgr übchen und über terminologische Fragen. In: Marcellia. Riv. int. di Cecidologia. 1902. pag. $146-161$.

Nachdem zunächst zwei von Cecidomyiden an der genamiten I'flanze hervorgebrachte Gallen, resp. knorpelig verdickte Blattrandrollung und spindelförmige Deformation der Triebspitze besprochen sind, ist weiter ron einer dritten Deformation, den Blattgrübchen die Rede. Letztere wurden rom Verf. im Thüringerwalde und in den Alpen, im ganzen an vier Fundorten beobachtet und rïhren auch von einer Gallmücke her. Die Griibchen werden nicht durch etwaige Hypertrophie, sondern durch einseitige lokale Henmung des Wachstums veranlasst. In diesen blattoberseitigen, länglichrunden, durch einen grossen, farbigen Hof umgebenen Beulen wird die Mückenlarve durch einen klebrigen Schleim festgehalten.

Von ebensolchen Grübchen sind zur Zeit etwa 18 Fälle bekannt, welche sich auf 10 Pflanzengattungen rerteilen. Ton ihnen finden sich 2 auf Acer; die eino entsteht durch Hypertrophie, wälırend die zweite sich wie die Grübchen ron Vuccinimm rerlält; oh es sich hier bei Acer um zwei verschiedene Arten landelt, bleibt dahingestellt, ist aber doch wahrscheinlich.

Für ebensolche lypertrophielose, im übrigen aber die Merkmale eines C'ecidiums tragenden Pflanzendeformationen sclıägt Thomas den Terminus: Iseudocecidien vor. Bei den echten C'ecidien ist gerade immer Neubildung, zum Nutzen des Erzeugers, im Spiel.

Zuletzt weist Verf. darauf hin, dass .. ('ecidiologie" linguistisch ganz gut zulässig ist, obgleich es zweckmässig erscheint, sich der ühlichen Bezeichuung .Cecidologie" anzuschliessen. "Die C'ecidie" statt „das Cecidium" wird aber entschieden als unrichtig zurïckgewiesen. J. C. H. de Meijere (Hilversum).

795 vou Buttel-Reepen, If., Die stammesgeschichtliche Ent stehung des Bienenstaates, sowie Beiträge zur Lebensweise der solitären und sozialen Bienen (H um meln, Meliponinen etc.). Vortrag gehalten auf dem Zoologen-Kongress in Giessen 1902, erweitert und mit Anmerkungen und Zusätzen herausgegeben. Leipzig (Georg T'hieme) 1903. 132 pag. 20 Fig. Preis M. 2.40.

Der Verf. hat sich die hohe Aufgabe gestellt, das wunderbare Leben des Bienenstaates nach den Prinzipien der Deszendenzlehre aus der phylogenetischen Entwicklung zu erkläreu. Wohl haben schon frühere Autoren (Darwin, We ismann, Herbert Spencer u. a.) gelegentlich über die vermutliche Entstehung dieser merkwürdigsten Form des tierischen Gesellschaftslebens gesprochen, aber eine 
so eingehende und auf so spezielle Kenntnisse gegrïndete Erklärung ist bis jetzt noch nie gegeben worden. Bei dem Verf. rerbinden sich die Erfahrungen eines rollkommenen Imkers mit der theoretischen Bildung eines modernen Zoologen ${ }^{1}$ ), und ausserdem kommen ihm seine persönlichen Beziehungen zu dem Entomologen Heinrich Friese zugute, welcher einer der besten Kenner der solitiiren und der sozialen Bienen ist.

Der erste Abschnitt betrifft die solitären Bienen nnd gewisse Anfänge des sozialen Zusammenlebens bei denselben. Bei den solitären Bienen werden die Zellen von der Mutterbiene gebaut. und gewöhnlich verlässt diese den Bau, nachdem sie in jede Zelle die Nahrung gebracht und das Ei dazu gelegt hat. Eine Gesellschaftsbildung, welche sich zu derjenigen der Honigbiene in Beziehung setzen lässt, kann erst dann angenommen werden, wenn die Mutterbiene bei dem Bau verbleiht und mit den ausschlüpfenden jungen Bienen zusammenkommt. In dieser Hinsicht sind die Verhältnisse bei Halichus quadricinctus sehr bemerkenswert. Diese Biene gräbt einen Schacht in die Erde und baut am untern Ende desselben eine grosse Tahl von Zellen (bis zu 24) übereinander; sie fertigt dann ringsum eine Höhlung, ein kleines Gewölbe, so dass die Luft un die Zellen zirkulieren und die Erdfeuchtigkeit, welche die Schimmelpilze begünstigen würde, nicht so leicht an den Bau kommen kann. Das Muttertier bleibt bei der Wabe und bewacht sie, damit Schmarotzer und tierische leinde nicht an sie gelangen können; die Mutterbiene ist zur Zeit des Ausschlïpfens der Jungen noch vorhanden, es würde also ein Anfang sozialen Lebens entstehen, wenn die ausschliipfenden Jungen einige Zeit bei dem Bau verweilen würden. - Bei manchen Halictus-Arten folgen sich mehrere Generationen in einem Jahr, und eine dieser Generationen besteht nur ans Weibchen, die sich dam parthenogenetisch fortpflanzen. Man kann sich also die Entwicklung der Geselligkeit leicht in der Weise denken, dass in dem Bau, welchen das Muttertier im Friihjahr anlegte, eine Generation von Weibchen entstelit, welche der Befruchtung nicht bednrften, sondern ihre Bauund Legeinstinkte bei dem heimatlichen Bau betätigten, anch eventuell ihren Fütterinstinkten beim Anblick der noch offenen Zellen gehorchten und Nahrung herbeitrugen, also sozusagen in jeder Hinsicht der Mutter behilflich waren.

1) Von den frühern Publikationen des Verf. mag hier nur die Herausgabe der 5. Auflage des bekannten Datheschen Buches iiber die Bienenzucht (1892) erwähnt werden, sowie die Schrift „Sind die Bienen Reflexmaschinen“ (Ieipzig bei Arthur (ieorgi, 1900), in welcher die Lebensweise der Bienen mehr von der physiologischen Seite betrachtet wird. 
Ein derartiges Verhältnis besteht tatsächlich bei den Hummehn. I)as befruchtete Weibchen ïberwintert und legt im Frühjahre das Nest an. Die ersten ausschlüpfenden jungen Hummeln sind kleine Weibchen, die danı beim Nestbau und beim Füttern. sowie auch am Eirrlegen sich beteiligen. Sie bleiben unbefruchtet, und aus den parthenogenetischen Eiern entstehen nur Männchen ${ }^{1}$ ). In weitern Terlaufe des Sommers kriechen auch grössere befruchtungsfähige Weibchen aus, welche nach der Befruchtung sich zur Überwinterung in ein Versteck zurückziehen, während die iibrigen Individuen des Staates im Siätjahr absterben. - Der Hummelbau bildet in mehrfacher Hinsicht ein Bindeglied zwischen den solitären und den sozialen Apiden; wie bei erstern werden zum Bau der Zellen allerlei pflanzliche Bestandteile verwendet z. B. Moos, Gras, Blätter, Holzfasern, aber als Bindemittel dient das Wachs, dessen Erzeugung bei den solitären Bienen kaum mit befriedigender Sicherheit nachgewiesen ist, aber bei den sozialen Apiden eine so hohe Bedeutung gewinnt. Wie Hoffer beobachtete, werden die ersten Zellen im Frühjahr ganz ebenso angelegt wie man es bei den solitären Bienen zu sehen gewöhnt ist; es werden nämlich geschlossene Zellen gebaut, deren jede einen Futtervorrat und ein Ei enthält. Aber nach einer Reihe von Tagen öffnet das Weibchen die ersten Zellen, bringt den Larven neues Futter und schliesst dann die Behälter wieder. Dies wird unter Umständen mehrfach wiederholt. Wir sehen also hier ein Beispiel für das biogenetische Grundgesetz, nämlich zuerst die phylogenetisch ältere Ernährungsweise der Larve (Futteryorrat in der geschlossenen Zelle) und dann die phylogenetisch jüngere Fütterungsweise (Atzung der heranwachsenden Larve). Letztere wird bei den Hummeln im Laufe des Sommers zur alleinigen. Wächst nämlich das Volk stark heran, so tritt Arbeitsteilung ein, die Königin beschränkt sich fast nur noch auf die Eiablage und fliegt gar nicht mehr aus. Die kleinen Weibchen, die sogenannten Arbeiterinnen, übernehmen das Bauen, Fuittern und das Einsammeln der Nahrungsmittel, die jetzt durch die vermehrte Zahl der Kräfte so reichlich zufliessen, dass ein Deponieren von Vorrat in die Brutzellen nicht mehr nötig ist und nicht mehr stattfindet.

Ein wichtiger Unterschied zwischen dem Hummelstaat und dem Bienenstaat liegt darin, dass die "Arbeiterinnen" der Hummeln anatomisch und morphologisch vollkommene Weibchen sind, die sich

1) Dass aus parthenogenetischen Eiern nur Nännchen entstehen, ist eine Eigentünlichkeit verschiedener Abteilungen der Hymenopteren. Es gilt für Tenthrediniden (Blattwespen), für die Vespiden und die sozialen Apiden. 
von der Königin meist nur durch die geringere Grösse unterscheiden, (was durch die schwächere Ernährung der Larve bedingt ist). Aber bei den Arbeiterinnen der Honigbiene sind die Geschlechtsorgane rudimentär, und es finden sich bei ihnen manche Organe in besonders starker Ausbildung: die bei der Königin nur rudimentär oder in schwächerer Entwicklung vorhanden sind, wie z. B. die Organe der Wachserzeugung, der Sammelapparat, die besonders kräftige Ausbildung der Speichelılrüsen, der längere Rïssel u. s. w. Auch sind die Instinkte der Arheitsbiene von denjenigen der Königin sehr erheblich verschieden. Alle diese Interschiede kïnnen nicht einfach auf schlechte Ernälırung der Larven zurückgeführt werden. Wir müssen lier mit Weisma n $n$ annehmen, dass im Bienenei dreierlei Anlagen vorhanden sind, die durch besondere Einflïsse ausgelöst werden können. während in einem Hummel- oder Wespenei nur zweierlei Anlagen (nämlich männliche und weibliche) rorhanden zu sein brauchen. Die Differenzierung der Arbeiterinnen war fiir den Stock ron grossem Vorteil und wurde daher durch die natürliche Zuchtwahl befördert ${ }^{1}$ ).

Das Vorkommen echter Arbeiterinnen, welche von den Weibchen linsichtlich des anatomischen baues wie auch in den Instinkten verschieden sind, ist nicht allein für die Honigbienen ( A p in a e) charakteristisch, sondern wird auch bei den stachellosen Bienen (Gattungen Metipona und Trigona) getroffen. Bei diesen gibt es in dem Stock eine Königin, deren Taitigkeit sich lediglich auf die Eiablage beschränkt, während Arbeiterinnen, die von ihr anatomisch verschieden und nicht begattungsfähig sind, alle andern Geschäfte besorgen; daneben kommen oft noch jungfräuliche Königinnen im Stock vor, bei welchen es unsicher ist, ob sie sich an der Eiablage beteiligen. Bei den Meliponen und Trigonen werden die Zellen von den Arbeiterimnen gebaut und mit Pollen und Honig gefüllt, worauf die Königin das $\mathrm{Ei}$ in die Zelle legt, die dann von den Arbeiterinnen verschlossen wird ${ }^{2}$ ).

1) In diesem Sinne schrieb ich früher einmal: „Die natürliche Selektion begünstigte diejenigen Stöcke, in welchen die Arbeitsbienen am besten für ihre Tätigkeit angepasst waren, und infolgedessen entstanden die zwischen Arbeiterinnen und Königinnen bestehenden (fast alle Organe betreffenden) Verschiedenheiten; es kam zu einer Vervollkommnung der Arbeitsbienen hinsichtlich der zum Sammeln notwendigen Instinkte wie hinsichtlich der dazu dienenden Apparate, während bei der Königin die Fruchtbarkeit zunahm und die Sammelinstinkte verkümmerten." (H. E. Ziegler. Die Naturwissenschaft und die sozjaldemokratische Theorie, Stuttgart 1893, pag. 131). Ref.

2) Beiläufig mag erwähnt werden, dass in dem nenesten Heft der ,Zoologischen Jahrbücher", Syst. Abt., ein interessanter Bericht von H. v.Ihering über brasilianische Meliponen und Trigonen erschienen ist. Ref. 
Nach dem Vorstehenden wird uns der Polymorphismus ind die Arbeitsteilung im Stock der Honigbiene nicht mehr unbegreitlich erscheinen. Aber einer Erklärung bedarf noch das auf so merkwiirdigen Instinkten beruhende Schwärmen.

Um diesen Vorgang zu verstehen, muss man die Lebensverhältnisse tropischer Honigbienen zum Vergleich beiziehen, welche Friese ${ }^{1}$ ) vor kurzem beschrieben hat. Die grosse indische Biene Apis dorsata baut eine einzige, rertikathängende, oft $1 \mathrm{~m}$ lange Wabe

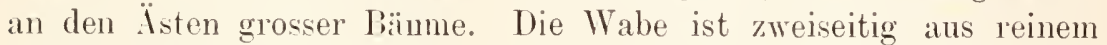
Wachs angefertigt wie eine echte Bienenwabe; jedoch besteht der Unterschied, dass bei Apris dorsatu nur einerlei \%ellen gebant werden, also die Differenzierıng der Drohnenzellen, Arbeiterinzellen und Königinzellen noch nicht vorhanden ist; auch die Honigzellen, welche oben an der Wabe stehen, haben denselben Durchmesser wie die andern Zellen, nur werden sie länger gebaut als diese. Die Apis dorsatu ist eine Wanderbiene; sie baut ilıre Wabe dort, wo Nahrung vorhanden ist. Es kann vorkommen, dass die alte Königin mit dem grössten 'Teil der Arbeiterinnen abzieht, um an anderer Stelle, wo sich zur Zeit reichliche Nahrung findet, eine nene Wabe zu banen, oder dass von der alten Wabe aus in der Nähe Kolonien angelegt werden, welche die alte oder anch junge Königinnen erhalten. Aus solchen Verhältnissen lässt sich das Schwärmen unserer Ilonigbiene leicht ableiten.

Ebenso interessant ist die kleinste indische Biene Apis florea. Sie bant ebenfalls eine vertikal hängende, doppelseitige Wachswabe, aber die Zellen sind von ungleicher Grösse und ihre Anordnung ist von besonderer Bedeutung. Oben an der Wabe findet man die Honigzellen, welche $4 \mathrm{~mm}$ im Durchmesser haben und beträchtlich tiefer als die übrigen Zellen sind. Der grösste Teil der Wabe besteht aus Arbeiterinnen-Zellen, welche nur 2,7 mm messen. Am untern Teil der Wabe folgen die Drohnenzellen mit $4 \mathrm{~mm}$ Durchmesser und ganz unten findet man als Abschluss des Zellenzylklus die beträchtlich grössern und vertikal abwärts stehenden Weiselzellen. Wir sehen also hier auf einer einzigen Wabe alle Bestandteile rereinigt, welche man bei unserer Honigbiene auf melıreren hintereinander hängenden Waben findet ${ }^{2}$ ). Da die Wabe mit der Anlage der Weiselzellen ihr Ende

1) H. Friese, Über den Wabenbau der indischen Apis-Arten. In: Allg. Zeitschr. f. Entomol. 7. Bd. 1902. p. 198-200.

2) Die Wabe von Apis florea zeigt insofern eine gewisse Analogie zu dem Bau eines Wespennestes als bei letzterm die Zellen der künftigen Königinnen auf der untersten Wabe sich befinden, also auch gewissermaßen den Abschluss des Baues bilden. Ref. 


\section{$-816-$}

findet, ist es wahrscheinlich, dass die Lebensweise der Biene (die nicht genauer beobachtet ist) einen periodischen Bau einer Wabe und ein periodisches Verlassen derselben mit sich bringt. Wir dürfen also annehmen, dass die Königin, wemn die letzten Zellen der Wabe mit Eiern versehen sind, mit einem Teil der Arbeiterinnen abzieht, un an einem andern Ort eine neue Wahe zu bauen, ein Vorgang, welcher dem Erst- oder Vorschwarm bei unserer Honigbiene entsprechen würde. Darauf mögen dann junge ausschlüpfende liöniginnen ebenfalls mit einem Teil der allmählich ausschlïpfenden Arbeiterinnen die Wabe verlassen, wie wir dies bei den Nachsclıärmen unserer Honigbiene zu sehen gewölnt sind.

Nachdem der Verf. in seiner stufenartigen Betrachtung ron den solitären Bienen, den Hummeln und den wilden Honigbienen zu den Verhältnissen unserer Honigbiene anfgestiegen ist, fügt er noch eine Reihe ron Zusätzen bei, welche verschiedene, mit dem Hauptthema in Beziehung stehende Nebenfragen betreffen und teils biologischer, teils physiologischer, teils morphologischer Art sinci. Der Inhalt dieser Darlegungen lässt sich kaum liurz wiedergeben, und muss ich also hinsichtlich der Zusätze auf das Original verweisen.

Versuchen wir schliesslich die wichtigsten Eigentiimlichkeiten des Bienenstaates im Sinne der Ausführungen des Verfassers aus primitiven Verhältnissen herzuleiten. I)ie Untätigkeit der Drohnen erklärt sich daraus, dass schon bei den solitären Bienen die Männchen niemals am Bau der Zellen sich beteiligen. Die Existenz der Königin erinnert daran, dass bei den ältern sozialen Bienen und Wespen der Bau des Nestes ron einem einzigen Weibchen ausgeht, welches allein alle Eier legt (oder wenigstens alle befruchteten Eier). Die Entstelung der Arbeiterinnen ist aus einem solchen Zustanıl lervorgegangen, wie wir ihn bei den Hummeln sehen, wo unbefruchtete Weiluclien neben der Mutterbiene (Königin) als Hilfsarbeiter tätig sind. Der Bau mehrerer Waben hintereinander ist an die Stelle des Baues einer einzigen Wabe getreten, eine Anpassung an beschränkten Raum (hohle Bäume, Felskliifte). — Das Schwärmen mit dem Alozug der alten Königin ist aus dem periodischen Verlassen des Baues herzuleiten, was durch den Abschluss des Cyklus auf der Wabe (vergl. Apis florea) oder durch periodische Verlegung des Aufenthaltes bedingt war.

H. E. Ziegler (Jena).

796 Marschall, Paul, Le cycle érolut if du Polygnotus minutus. In: Bull. Soc. Ent. France. 1903. Nr. 4. pag. 90-93.

In der Larve von Cecidomyia destructor beobachtete Verf. Eier der obengenannten Proctotrupide und fand, dass aus denselben 
je mehrere Larven herrorgehen. Meistens findet sich nur ein Ei, immer im Magen der I)ipterenlarve, bisweilen aber 2-4: aus denselben entwickeln sich je 10-12 Blastulae, welche zunächst durch eine gemeinsame Masse Ernährungsprotoplasma zusammengehalten werden. Später kommen sie frei und durchbohren auch die Magenwand. Wir haben es hier also mit einen ähnlichen Entwicklungsmodus zu tun, wie derselbe früher von der Chalcidide Encyitus firscicollis beschrieben wurde. Was hei der Entwicklung der Embryonen letzterer als Amnion gedentet wurde, ist nur eine rom Wirte herrührende Adventiveyste. Bei den frei im Magen liegenden Kieimen ron Polygnotus hommt eine ebensolche nicht zur Entwicklung.

$$
\text { J. C. H. de Meijere (Hilversum). }
$$

797 Rouget, (harles, La Phagocytose et les leucocytes hématophages. In: Compt. rend. Soc. biol. Paris. T. III. 1900. pag. $307-309$.

Der Verf. betont, dass er schon in 1874, also lange vor Metschnikoff, die Phagocytose der weissen Blutkörperchen beobachtet und Angaben ibber dieselhen publiziert hat. Derselbe teilt weiter mit. dass diese Gebilde bei Batrachierlarven die roten Bluthörperchen nicht angreifen, so lange diese ganz normal sind, sondern nm solche, welche einmal angefangen haben, abzusterben. Nach den Angahen von Anglas scheinen bei Insekten die Lencocyten auch ganz normale Elemente anzugreifen.

J. C. H. de Meijere (Hilversum).

798 Ruzsky. M., Die Ameisenfauna der Astrachanischen Kirgisensteppe. In: Horae Soc. Entom. Ross. T. XXXVI. 1903. pag. 294-316. (Russisch).

Aus dem Gebiet der Kirgisensteppe waren nur 8 Ameisenarten bekannt. Ruzsky hat, zum 'T'eil auf Grund eigner Nachforschungen, diese Zahl auf 33 Arten (mit 40 Formen) gebracht, welches Resultat er jedoch noch nicht als erschöpfend betrachtet. Die Zusammensetzung dieser Ameisenfauna bietet Interesse auch in zoogeographischer Hinsicht: sie bestelt aus südeuropäischen, mediterranen und Formen des zentralen und südwestlichen Asiens, welch' letztere spezifische Bewohner der Wüstengebiete sind, aus Zentralasien stammen und z. 'T. wohl neuern Ursprungs sind und sich als charakteristisch für die Aralo-kaspisehe Niederung erweisen dürften. 10 der aufgefïhrten Formen gehören der asiatischen Fauna an, nur 2 Arten sind typisch für die europäische Fauna, die übrigen gehören dem Mittelmeergebiet an. Ein sehr auffälliger Fund ist Camponotus hereuleanus lignipcrda Latr., eine typische Waldform.

Bei der Aufzählung seiner Arten berücksichtigt der Verf. in lobenswerter Weise ilrre Lebensweise sowie die Natur des Fundorts.

Neu aufgestellt werden: Camponotus marginatus Latr. nov, var. kamensis, nov. subg. Proformica für Formica nasuta Nyl. (auf Grund der abweichenden Stirnstruktur, der Gestaltung der Fühlerglieder usw.; Ruzsky beschreibt die bisher unbekannten geflügelten Geschlechtstiere dieser Art), Tetramorium cnespitum Lin. 
nov. var. ferox, Leptothorar semenovi n. sp., Myrmica rugosa Mayr nov. var. Lirgisica (Diagnosen auch in deutscher Sprache). Die ganze Liste unfasst folgende Gattungen: Myrmceocystus $2 \mathrm{sp}$., Camponotus $3 \mathrm{sp}$., Formica $3 \mathrm{sp}$, Lasius $4 \mathrm{sp.,}$ Plagiolepis 1 sp., Acantholepis 1 sp., Bothriomyrmex 1 sp., Tapinoma 1 sp., Dolichoderus 1 sp., Solcnopsis 2 sp., Tetramorium 1 sp., Strongylognathus 1 sp., Pheirlole $1 \mathrm{sp}$., Leptothorax $2 \mathrm{sp}$., Cardiocondyla $2 \mathrm{sp}$., Myrmica $3 \mathrm{sp}$., Messor $2 \mathrm{sp}$., Monomorium 1 sp., Crematogaster 1 sp.

N. v. A delung (St. Petersburg).

799 Sladen, F. W.. A recent producing organ in the worker of Apris mellifice. In: Entom. Monthly Magaz. XXXYIII. 1903. pag. 20S-211. Fig.

Beobachtungen und mikroskopische Tntersuchungen ergaben, dass der von $\mathrm{Yassonoff}$ i. I. 1883 auf dem Hinterleibe ron Apis mellifica beschriebene "Kanal" mit kleinen offenen Drüsen, in welchen $/$ oub a reff Flïssigkeitströpfchen wahrnahm, ein lnftapparat sei; allerdings zeigte nicht jedes Exemplar diese Frscheinung. Der Kanal liegt auf dem Riicken des 6. Segmentes. Isbende stïcke zeigen beim Ausströmen eine besondere Körperlaltung und eine damit verbundene auffallende Flïgelbewegung. K. W. v. Dalla 'Torre (Imnsbruck.)

s00 L'le, E., Ameisengärten im Amazonagebiet. In: Botan. Jahrb. XXX. 1901. Beibl. Nr. 68. pag. 45-52. Taf. XXIII.

Verf. führt aus, dass Ameisen Blütemptlanzen auf Sträuchern und Bäumen ansäen und sie zum Schutze ihrer Wohnungen aufziehen und pflegen, also wirklich „schwebende crärten" anlegen, die er Ameisengäiten nennt. Diese, den Ilumusepiphyten am nächsten stehenden PHanzen nennt er Ameisenepiphyten. Tert. erblickt für die betreffenden Pflanzen insofern einen Vorteil, als dieselben sonst nicht wïrden bestehen können; dafüı ermöglichen sie den Ameisen den Bau von Testern auf den Bäumen, die durch diese Epiphyten Halt vor den heftigen Regengïssen bekommen und ausserdem auch oft vor den sengenden Strahlen der Sonne geschützt sind. Trotzdem ist dies Kusammenleben nach dem Verf. nicht eine Schutz-, sondern eine Raumsymbiose. Ton den beobachteten Gattungen nehmen die Bromeliaceen (Nidularium, Portea) und Anthurium meln das Zentrum des Nestes ein. Gesneriaceen und Ficus breiten sich nach aussen aus und Peperonia hängt mit ihren langen Zweigen abwärts. An einem Batum, "Arvore do tachi“. laufen die Ameisen eilig am Stamme umher und bewachen ihn; auch am boden lassen sie in einem gewissen Umkreise um den Stanm keine andere Pflanze aufkommen.

K. W. v. Dalla Torre (Innsbruck). 


\section{Tunicata.}

S01 Isert, A., Untersuchungen ïher den Bau der I)rüsenanhänge des I)armes bei den Monascidien. In: Arch. f. Naturg. 69. Jahrg. 1903. pag. 237-296. 'Taf. 12-15.

Den weitaus umfangreichsten Abschnitt der Abhandlung bildet eine genaue Schilderung der Leher der Monascidien. Der anatomische und histologische Bau dieses Organs wurde bei 13. zu 3 verschiedenen Familien gehörenden Spezies eingehend untersucht (Microcosmus vulyaris, Cynthia papillosa, C. dura, C. echinata, Molgula occulta, 1I. appendiculata, M. nana, M. macrosiphonica, Styelopsis grossularia, Ciona intestinalis, Ascidiella rirginea, Ascidia mentula, A. cristuta). Wo überhaupt ron einer Leber bei Ascidien die Rede sein kamn, erweist siclı das Organ hervorgegangen aus Ausstiilpungen des vordem Darmtractus beziehungsweise der Magenwand. Im einzelnen bestehen aber nicht unwichtige Intersehiede zwischen den verschiedenen Arten. Während bei den acht ersten der angeführten Spezies die Leber als ein mehr oder minder scharf und deutlich rom Darmkanal abgegrenztes Gebilde sofort auffallt, sind es bei den folgenden Arten besondere Teile des Darmrohres selhst, die eine eigenartige Inifferenzierung erfahren. ohne sich gleichzeitig von den benachbarten Regionen des Darmepithels bei äusserer Betrachtung sellarf abzuheben. Es ist das Verdienst des Verfs., in allen diesen räillen das Torkommen von typischen Leberzellen an bestimmten Stellen der Darmwand iiberzeugend nachgewiesen zu hahen. Bei Styelopsis sitzen die Leberzellen vornehmlich in den Längsfalten des Magens, und auch bei Ciona haben sie eine ähnliche Lage; bei Ascidia und Ascidiella finden sich die die Leberfunktion ausiibenden 'Zellen nicht nur in der Magenregion, sondern in einem grossen Teil des Intestinums zerstreut.

Im zweiten Abschnitt wird die darmumspimnende Driise von Microcosmus vulyaris behandelt. Es gelang, die Trsprungsstelle des ausserordentlich rerzweigten Kanalsystems aus dem Darnurohr nachzuweisen; sie liegt ungefäln $1 \mathrm{~cm}$ hinter dem Pylorus. Der hier entspringende Hauptkanal ist ausserordentlich kurz (beträchtlich länger ist er bei Cynthic dura und C. echinata), so dass er kaum die Bezeichnung als besonderer Mündungskanal verdient, und gabelt sich sofort in zwei Stämme.

O. Seeliger (Rostock).

802 Riedlinger, R., Untersuchungen über den Bauvon Styelopsis grossularia der Ostsee. In: Nova Act. Acad. C. L. Nat. Cur. Tol. 81. 1892. pag. 1-62. Taf. 1-6.

Der Verf. gibt eine eingehende Darstellung des anatomischen 
und histologischen Baues der Styclopsis. Es wulden aussehliesslich aus der Ostsee stammende Individuen untersucht, während die frühern Autoren, so in besondern. Julin und Lacaze-Duthiers und Delage in der Nordsee oder im Ozean gefischte Exemplare beobachtet hatten, die sich durch eine bedeutendere Grösse auszeichnen. Es mag sein. dass auch gewisse histologische Verschiedenheiten, die sich ans den Angaben der verschiedenen Autoren ergeben, auf lokaler Tariabilitiat beruhen. Lacaze und l)elage hatten zwei scharf getrennte Varietäten der Styclopsis unterschieden: eine solitïre und eine soziale Form. In ler Ostsee bestehen nicht diese zwei formtypen unvermittelt nebeneinander, sondern die Species erweist sich in allen ihren Individuen melı oder minder variabel, und es finden sich Exemplare, in denen die einen Organe nach dem .. solitären Typus“, die andern nach dem "sozialen Typus" gestaltet sind. Ebenso zeigen Form und Grösse des Körpers alle möglichen ITbergangsstadien zwischen den extremen Gliedern der ganzen Formenreihe.

An den naturgetrenen Abbildungen ist nur das eine auszusetzen, dass sie nicht alle in ibbereinstimmonder Weise und grösstenteils sehr unzweckmäßig orientiert sind. Angenscheinlich war die Anordnung der Figuren vom Verf. für yuerliegendes Format und nicht fïr Längstafeln vorbereitet worden.

(). Seeliger (Rostock).

S03 Van Name, W. G., The Ascidians of the Bermuda Islands. In: Transact. Connecticut Acad. Vol. XI. 1902. pag. 325-412. Taf. 46-64.

Die Challenger- Expedition fand an den Bermudainseln nur 6 Ascidienarten. darunter die unsichere Species Didemnum inerme. Dieser Herdmanschen Liste fügte später Verrill noch 7 andere Arten hinzu, unter diesen wohl irrtümlich die Stycla canopoides Heller. Sicher bekannt waren also nur 11 Species. Unter dem von Van Name untersuchten Material fanden sich diese Formen wieder; nur das interessante Symplegma viride Herdman fehlte, was um so bedauerlicher ist, als diese Ascidie seit der Challenger-Expedition iaberhaupt nicht wieder beobachtet worden ist. Dagegen führt Verf. 27 andere Ascidienarten an, deren Vorkommen an den Bermudainseln bisher unbekannt war, und unter diesen sind nicht weniger als 21 Species neu für die Wissenschaft (Distoma capsulatum, D. convexum, D. obscuratum, D. olivaccum, D. clarum; Cystodytes violaceus; Distaplia bermudensis; Amarocium bermudae, A. cxile; Didemnum solidum, D. atrocanum, D. porites, D. lucidum, D. orbiculatum; Polysyncraton amethysteum; Diplosoma lartcum, D. atropunctatum, Diplosomoides fragile; Echinoclinum verrilli; Michaclscnia tincta; Diandrocarpa botryllopsis). Am bemerkenswertesten sind die Formen, für die neue Gattungen aufgestellt werden mussten, und zwar führt der Verf. vier neue Genera an, die zwar wohl nicht den Bermudainseln eigentümlich sein werden, mit Sicherheit aber an andern Orten noch nicht nachgewiesen wurden. Ausser Echinoclinum, Michaelsenia und Diandrocarpa wird auch Rhodozona als neuer Gattungsname genannt. Dieses neue Genus ist für eine bereits von Verrill als Diazona picta beschriebene Form gebildet worden. Ob der Verf. bei der Schaffung neuer Gattungen nicht vielleicht das eine oder andere Nal zu weit gegangen ist, 
wird die Folgezeit lehren. Jedenfalls sind die neuen Species so gerau und treffend beschrieben, dass ihre Wiedererkennung keine Schwierigkeiten bieten kann. Von fast allen Arten gibt der V'erf. eine gute Abbildung, die die charakteristischen Merkmale deutlich hervortreten lässt.

O. Seeliger (Rostock).

\section{Vertebrata.}

804 Dïlerlein, L., Ueber die Erwerbung des Flugrermögens bei Wirbeltieren. In: Zool. Jalırb. Abt. Syst., Geogr., Biol. 14. Bd. 1900. pag. 49-61.

Über $60 \%$ aller lebenden Tierarten besitzen Flugorgane. Von zwei Fischgattungen abgesehen haben nur Landbewohner die Kunst des Fliegens erworben und unter diesen lediglich Angehörige der zwei Stämme der Arthropoden und Vertebraten. Von den letztern sind etwa $64 \%$ mit Flugorganen ausgestattet, woraus schon die grosse Wichtigkeit des Flugrermögens für diese Tiere erhellt.

In 12 verschiedenen Gruppen der Wirbeltiere sind Flugorgane zur Ausbildung gekommen, aber nur bei dreien, den Vögeln, Fledermäusen und fossilen Flugsauriern echte Flügel; die Flugwerkzeuge der andern Gruppen zeigen verschiedeuartigen, aber stets primitiveru Bau und wirken nur als Fallschirme. Tert. untersucht die Frage, „welches wohl die Voraussetzungen waren, unter denen imerhalb der einzelnen Gruppen ron Wirbeltieren Flugfähigkeit erworben werden konnte."

Der F alls chirm-(Patagium-) Typus der Flugorgane entsteht dadurch, ,dass am Körper grössere seitliche Hautfalten auftreteu, die gewöhnlich von bestimmten Skeletteilen gestuitzt und ausgespannt werden können." Da der Fallschirm nur zu funlitionieren vermag, wenn sein Träger mehr oder weniger von der Unterlage abgehoben ist, dies aber nicht selbst bewirken kann, so müssen die betreffenden Tiere entweder sich in die Höhe zu schnellen oder durch Klettern auf Bäumen etc. die erforderliche Fullhöhe zu erreichen befähiggt sein; ersteres trifit bei den fliegenden Fischen (Exocoetus und DactyTopterus) zu, letzteres gilt von alleu Landwirbeltieren mit Fallschirmen. V'erf. erörtert der Reihe nach die hierher gehörigen Vorkommnisse: den fliegenden Frosch (Rhacophorus), die Flugdrachen (Draco), den Hiegenden Gecko (Ptychozoon homalocephahum) und unter den Säugern die Flugbeutler (Petanroides, Petams und Acrobates) und Flughörnchen (Pteromys und Sciuropterws), ferner die sogenannten "Flugbilche" (Anomaluns und Iclimus) unter den Nagetieren, sowie den in mehrfacher Beziehung isoliert stehenden Flugmaki (Galeopithecus).

Ech te Flüg el, die nicht nur als vorzügliche Fallsehirme fungieren, sondern zugleich auch im stande sind, durch ilıre aut- und abschwin- 
genden Bewegungen, „den Körper in die Höhe zu heben," finden sich. wie schon bemerkt, bei den Pterosauriern, Vögeln und Chiropteren; zweifollos in jeder (iruppe selbständig entstanden und besonder's geartet ergibt sich doch „das Gemeinsame, dass als Hauptstiitze fuir das Flugorgan die rordern Gliedmafien ausgebildet sind."

..Der morphologische Interschied zwischen Fallschirm und Flügel erscheint nur als ein gradueller, und man kann sich wohl vorstellen, dass aus dem Fallschirm eines Säugetieres, etwa des Galeopithecus, _ _ - - schliesslich ein Fliigel nach Art der Chiropteren oder der Pterosaurier wird." Demnach müssten die Vorfahren der fliegenden Wirbeltiere Klettertiere gewesen sein. Für die Fallschirmtiere kann es keinem Zweifel begegnen, dass solche Formen, abgesehen rom V'lugmaki, dessen Verwandtschaftsverhältnisse überhaupt dunkel sind, nur in den (iruppen zur Ausbildung gekommen sind, die mehr oder weniger gewandte Banm- und Klettertiere numfassen. Aber auch bei den echten Filiegern finden sich noch deutliche Anklïnge an einen vordem erheblichern (irad ron Kiletterfertigkeit; so leben die Fledermäuse, wenn sie nicht fliegen, als behäbige Klettertiere mit Hilfe ihrer starken Krallen an lyumen mo Hinterbeinen, eine Eigenschaft, deren Besitz auch den Flugsauriern der Vorwelt ohne Zweifel eine gewisse Kletterfertigkeit zuzuerkennen gestattet. Für die Vögel freiliclı muss zugegeben werden, dass heute kein einziger ausgewa chsener Vogel typische Kletterfähigkeit zeigt. Indes ist neuestens ron einer brasilianischen Vogelart (Opisthocoms: hoazin) festgestellt worden, dass die Jugendformen derselben an den Flïgeln Kirallen besitzen, die sie ..tatsüchlich und ausgiebig zum Klettern" benutzen. Ind ron drhueopteryx ist bekannt, ,dass an den bereits zu Flügeln gewordenen Vordergliedmaßen 3 rïinger noch grosse, auffallend kräftige Krallen getragen haben, die den Eindruck erwecken. dass das Tier noch bedeutende Fertigkeit im Klettern besessen haben dürfte". Trotz alledem kann nicht in Abrede gestellt werden, dass auch das Klettervermögen der Flugsaurier und Fledermäuse hinter der Flinkheit und Geschicklichkeit, mit welchen die Fallschirmtiere sich bewegen, beträchtlich zurïcksteht. ,Wälırend eben bei diesen letztern Formen grosse Gewandtheit und Schnelligkeit im Kklettern und Springen notwendige Voraussetzung für die Ausnutzung des Fallschirms ist, ist für die Ausübung des Fliegens Klettergewandtheit überhaupt nicht mehr erforderlich. Der Flügel ersetzt die Kletterorgane und macht sie überflïssig".

F. v. Wagner (Giessen). 


\section{Pisces.}

805 Nordquist, 0., Some biological reasons for the present distribution of Freshwater-Fish in Finland. Lecture held at the Meeting of the .. Geograph. soc. of Finland", April 25. 1903. In: Fennia. 20. \&. Helsingfors 1903. pag. 1-29. 6 Verbreitungskarten.

Anf die geographische Verteilung der 'Tiere und damit auf die Znsammensetzung der Fauna eines bestimmten (rebiets üben biologische Faktoren einen bedeutenden Finfluss aus. Sie erklären, wie Verf. es zeigen will, z. B. zum gnten Teil die heutige Verbreitung der Süsswasserfische in Finnland. Keine derselben haben als endemisch oder autochthon zu gelten; alle Fische müssen in die finnischen Süsswïsser seit dem Riickgang der letzten, grossen Vereisung, die das ganze Land bedeckte, eingewandert sein. I lirekt auf die Lauma des ansgedehnten, mmittelbar postglacialen Joldir-iees, welcher den grössten Teil ron Fimnland einnahm, gehen Cottus quadricomis. Salmo salur, S. trutta. Coregone lararetus, C. allumla. Gasterostas aculeatus, Gr. mungitius. Osmerns pirblams und P'etromyzon thriatitis zurïck. Sie alle leben noch im weissen Meer. dessen 'lierwelt nit der Iolnlir-Fauna nahezu überemstimmt. Etwas anders verhält es sicl nit Salmo mmbla. Er findet sich in Seebecken, die das Weisse Mcer umgeben und demselben lente noch tributär sind, oder früher wahrscheinlich tributïr waren. Eine Einwanderung des Saiblings in diese Gewässer rom Weissen Meer aus kam als sicher angenommen werden. Dagegen diirfte Salmo umbla in Ladoga- und Onega-Gebiet der Yoldiasee entstammen.

Esor, Perea und Lota maculosa, die im Südwesten, siiden und Osten Fimmlands eine weite Verbreitung geniessen, stellten sich gegen Ende der Yoldiu-Zeit ein, als beim liückgang des Eises das Kilima schon etwas milder wurde und der Salzgehalt des Wassers bedentend abgenommen hatte. Gleichzeitig mit den drei genannten Fischen erschienen wohl in den finnischen (iewässem Thymallus rulgaris, Phoximes aphya und Idus molanotus. Thymallus ging in seinem Vordringen wahrscheinlich ron Osten aus.

Etwas suäter, nach einer weitern Erhöhung der 'T'emperatur, trafen als siidliche Einwanderer Allumms lucidus und wohl auch Abramis brama ein.

In den grossen, ausgesüssten Aucylus-See, der sich bildete, als sich die Yoldia-See durch Hebung des Festlands vom Weissen Meer abtrennte, und der iiber Zentralschweden mit dem Skagerrack in Verbindung stand, wanderten, wie angenommen werden darf, aus der pontokaspischen Region, Aspius rapax, Abromis ballorus, A. vimba, 
Pelecus cultratus, Stizostedium lucioperea, Cyprinus carassins und vielleicht anch gleichzeitig Scardinins erythrophthatmus ein. Erst gegen das Ende der Aucylus-Periode gesellten sich Leuciseus cephalus und Tince rulyaris zur finnischen Fischfamna.

I) Einwanderungsepoche und die folgende Verbreitung der Fische steht in engstem Zusammenhang mit dem Wärmebedürnis der betreffenden Arten. Dieses selbst aber richtet sich wieder nach bestimmten biologischen Eigenschaften. Unter den biologischen Faktoren, welche die Verbreitung der Süsswasserfische rom Klima ahlıängig machen, spielt der Eintritt der Laichzeit die Hauptrolle.

Im allgemeinen gilt der Satz, dass, von der gemäfigten Zone ausgehend, nach der arktischen liegion sich linbewegend die Zahl der im Süsswasser laichenden Fische abnimmt. Im lesonderen aber vermindert sich die l'rozentzahl der Frühlingslaicher, während diejenige der Herbstlaicher in derselben Richtung zunimmt. Parallele Verhältnisse ergeben sich beim Anstieg rom Flachland in das Gebirge.

Von den F'rühlingslaichern erreichen diejenigen den höchsten Norden, die ihre Eier zuerst im Frühjahr und bei der tiefsten Temperatur ablegen (Esor, Perca, Thymallus). Ihr Laich erweist sich als gegen Temperaturstuirze sehr unempfindlich. Dagegen besitzen später und bei höherer Wassertemperatur laichende Fische gegen eintretende Kälte äusserst empfindliche Eier. Sie schreiten überhaupt nicht zur Laichablage, bis das Wasser eine gewisse Minimalwärme besitzt; so dass an ihrer nördliclisten Verbreitungsgrenze in ungünstigen Jahren ihre Vermehrung mterbleibt (Alramis brama).

Die Jmngbrut früh laichenter Fische befindet sich ferner im Vorsprung, weil ihr Gelegenheit geboten wird, während eines längern ersten Sommers Reservenahrung für die winterliche Fastenzeit aufzunehmen.

Am besten aber an ein kaltes Klima und an einen kurzen Sommer sind die Herbstlaicher biologisch angepasst. Ihre Eiablage vollzieht sich bei tiefer 'Temperatur, etwas früher oder später, je nach der Gunst der Jahre. Auch die Entwicklung der befruchteten Eier und der jungen Brut rerlangt kaltes Wasser; sie geht umso langsamer vor sich, je mehr die Temperatur sinkt. Wenn im Frühjalır die niedere Wasserfama zu crwachen beginnt, ist die Brut der Ilerbstlaicher gerade soweit entwickelt, dass sie von der Aussenwelt Futter verlangen muss. Sie verliert keinen Teil des nahrungsreichen Sommers zn ihrer weitern Entwicklung.

Diese biologischen Erwägungen finden ihre Bestätigung in der heutigen Verteilung der Fische im Süsswasser Finnlands.

Coregoms albula z. B. verbreitet sich in den fimnischen Seen 
bedeutend nördlicher, als Osmerus eperlanus, obschon der erstgenannte Fisch nicht früher als der zweite einwanderte und sich gegenüber Osmerus auch nicht durch grössern Wanderinstinkt auszeichnet. Die Erklärung liegt darin, dass Coregomes als Herbstlaicher den nördlichen Klimaten biologisch besser angepasst ist, als der im Friihjahr laichende Osmerus. Gegenüber andern Frühlingslaichern, wie Barsch und Hecht, bleibt Osmerus südlicher zurück, weil seine langsame Entwicklung im ersten Jahr es ihm nicht erlaubt während des kurzen lappländischen Sommers stark genug zu werden, um den langen, planktonarmen Winter zu überleben. Osmerus trägt eben den biologischen Charakter eines Meer-oder Wanderfischs. Nahrung und Temperatur bleibt im Meer das ganze Jahr viel gleichmäßiger, so dass auch die Entwicklung der Fische sich nicht so rasch abzuspielen braucht, wie im Süsswasser. Reinen Bewohnern von See und Fluss (Esox, Perea) hilft ihre raschere Entwicklung und der Unstand, dass sie nicht auf l'lankton allein angewiesen sind, zu weiterer Verbreitung.

Der Frühlingslaicher Thymallus vulgaris geht im Norden von Lappland und Finnland weiter, als im Sürlen. Biologisch erklärt sich dies durch sein Bedürfnis nach kaltem Wasser, seine rasche Entwicklung und seinen Aufenthalt in Flüsen, die auch im Winter Nahrung liefern. Von der Sommerlänge ist Thimmullus somit weniger abhängig, als die Bewohner von Seen.

Bei Phoximus aphya, der erst in der zweiten Sommerhälfte seine Eier ablegt und sich trotzdem bis zum Eismeer verbreitet, wird der späte Eintritt der Laichzeit durch rasche Entwicklung kompensiert.

Von Fischen, die später laichen und wärmeres Wasser beanspruchen, gehen Alramis brama und Stizostedium lucioperea am weitesten nach Norden. Sie überschreiten indessen nur vereinzelt eine Linie, welche einer mittlern Iulitemperatur von $15^{\circ} \mathrm{C}$. entspricht. Das sporadische Vorkommen nördlich von dieser Isotherme weist auf eine durch frïhere lilimatische Verhältnisse begünstigte weitere Verbreitung von Abramis und Stizostedium im Norden.

Neben dem Eintritt der Laichzeit und der Entwicklungsdauer von Eiern und Jungbrut tragen auch andere biologische Faktoren dazu bei, die Ausdehnung der Süsswasserfische nördlich zu begrenzen.

In Betracht fällt etwa die von dem betreffenden Fisch verlangte Nahrung, doch ist zu bedenken, dass ihre Quantität und Qualität mehr vom individuellen Charakter eines Sees abhängt, als von seiner geographischen Lage. Höhere Bedeutung besitzt der Umstand, dass gewisse Fische, besonders die Cypriniden, bei sinkender Temperatur die Nahrungsaufnahme einstellen. So werden manche Fische aus Gebieten ausgeschlossen, in welchen ein allzu kurzer Sommer ihnen 
die Aufnahme genügender Nahrungsreserve für den Rest des Jahrs verbieten wiirde.

Verf. bespricht endlich die Veränderungen. welche die Zusammensetzung der Fischfauna der finnischen Süsswässer im Lauf der Zeit erfahren hat. Er zeigt besonders an Beispielen ron Zander, Sail)ling, Wels, Brachsen, wie an manchen Orten Spezies verschwanden, die den äussern Verhältnissen nicht mehr genügend biologisch angepasst waren. Eine Verarmung der Ichthyofanna war mit den in geologischen Zeiten sich vollziehenden Veränderungen der Seen und des Ḱlimas rerknuipft.

Der passive Transport übte auf die Verbreitung und Zusammensetzung der Fischfauna im Süswasser Finnlands keinen nemenswerten Einfluss aus. Auch durch die Eingriffe des Menschen wurden die allgemein für die Fischverbreitung geltenden Gesetze nicht gestört. F. Zscliokke (Basel).

Amphibia.

806 Boulenger, G. A., On a Collection of Batrachians and Reptiles from the Interior of Cape Colony. In: Ann. Mag. Nat. Hist. (7) Xil. 1903. pag. 215-217. Taf. XVI-XVII.

Enthält eine Aufzählung von Arten aus Deelfontein im Richmond-Distrikt, 32 Meilen südlich von De Aar und 25 östlich von Victoria West, in der Mitte eines meilenweit nach jeder Richtung ausgedehnten, dürren und wasserarmen Gebietes. Die vier Batrachier, von denen eine Art (Bufo granti, verwandt $B$. regularis, pag. 216, Taf. XVI) neu ist, finden sich in Quellen oder Brunnen. Auch eine Schildkröte (T'estudo seimundi, pag. 216, Taf. XVII) die der gleichfalls dort vorkonmenden T. tentoria Bell nahe verwandt ist, liat sich als neu für die Wissenschaft erwiesen. Ausserdem findet sich noch eine Land- und eine Wasserschildkröte, 13 Eidechsen- und 3 Schlangenarten im Gebiete; von ihnen mögen nur Agama brachyura Blngr., Eremias puichella Gray und Mabuia sulcata Ptrs. hervorgehoben werden.

F. Werner (Wien).

807 Kiritzescu. Const. Contributions à la faune des Batraciens de Roumanie. In: Bull. Soc. Sc. Bucarest-Roumanie. An. XII. Nr. 3 et 4.1903. $23 \mathrm{pp}$.

Diese Arbeit bringt sehr wertvolle Beiträge zur Kenntnis der Batrachierfauna Rumäniens und ist wohl die erste, die dieselbe ebensowohl ausfihlilich wie gründlich behandelt. Ausser einer kurzen Liste war bisher nicht die kleinste zusammenfassende Arbeit darüber bekannt und so ist es nicht verwunderlich, dass BouIengers Verbreitungskarten (in: The Tailless Batrachians of Europe, London 1897) gerade in bezug auf Rumänien wegen Mangel an Literatur und Material ungenau oder sogar unrichtig sind. Der Verf, begnügt sich nicht damit, die rumänischen Fundorte der einzelnen Arten aufzuzählen, sondern gibt auch genaue Maßstabellen und Angaben über Färbung etc.

Nachgewiessen sind folgende Arten: Rana esculenta L. var. ridibunda Pall. (die typische Form fehlt vollständig); Rana temporaria L. mit var. longipes F. Müll. (nur im Gebirge), Rana agilis Thomas (gemein in der Ebene und im Hügel- 
land), Bufo vulgaris Lam., B. variabilis Merr. (viel häufiger als vulgaris), Pclobates fuscus Laur. (selten, bisher nur an zwei Punkten des Landes gefunden; die Südgrenze, welche Boulenger angibt, wird als durchaus künstlich verworfen und die Donau als solehe betrachtet): Bombinator igneus Laur. und pachypus Bp., Hyla arborca L. (die var. oricntalis Bedr. ist unhaltbar), Salamandra maculosa Laur. (nur in grossen Gebirgswäldern, zwischen 500 und $1200 \mathrm{ml}$ ); Thiton vulgaris L, cristatus Laur. mit var. dobrogicus n. (durch längere Finger und Zehen, schlankere Gestalt und die Färbung unterschieden), alpestris Laur. (im Gebirge, nur zur Paarungszeit im Wasser): montandoni Blngr. (nur in den Karpathen, geht bis $1000 \mathrm{~m}$ ).

- Rana arralis Nilss. fehlt in Rumänien vollständig.

F. Werner (Wien).

\section{Reptilia.}

808 Lönnberg, Einar, () 11 the adaptation to a molluscivorous diet in Tarmus niloticus. In: Ark. för \%ool. K. svensk. Vetensk. stockholm. Band 1. 19)3. pag. 65-83. 5 Fig. im Text.

Der Verf. gibt Kunde ron einer bemerkenswerten Abweichung eines I a raniden in der Ernährungsweise und der dadurch bedingten Veränderung im Schädelbau und namentlich im Gebisse. Es handelt sich un den Varanus niluticus von Kamerun. von welcher Art Verf. den Schädel eines grossen Exemplares erhielt. dessen Giebiss sich durch die grossen Molaren, mit abgerundeten Kronen anszeichnete, während ja sonst die Varaniden sich durch schlanke, nach riickwärts gerichtete, zugespitzte, an die der Boiden erinnernde Zähne kennzeichnen. Terf. vermutete, dass sich diese Art in Kamerun ron Landschnecken (Ach a tinen etc.) eruähre. Eine Sendung aus Kamerun, den Darmtraktus eines I aramus-l'atres in Formalin enthaltend, brachte die Bestätigung dieser Annahme. Es ergab sich auch, dass der Trramu. die Schnecken vor dem Verzehren so weit als möglich der Schalen entledigt, dass er aher Nacktschnecken und Heuschrecken unzerteilt verschlingt, dass also kein Kaualit stattfindet. Die Achatinen etc. hatten nur mehr geringe, schwierig ablösbare Schalenrudimente an sich, was nicht durch die Autlösung der Schale durch den Magensaft erklärt werden kanu, da die Weichteile der Schnecken fast unversehrt waren. Durch dieses mächtige, zum Zermalmen der Achatina-Schaten dienende Gebiss ist aber die Verstälkung der sichädelknochen notwendig geworden und so kommt es, dass der Schädel des Kamerun-T arams fast dreimal so schwer und viel höher ist, als ein gleich langer eines normal sich ernährenden Traramus ( $T^{r}$. salcator). Besonders die Kiefer haben an Dicke und Stärke beträchtlich zugenommen. (Ref. möchte hier bemerken, dass auch bei Exemplaren vom Kongo dieselbe Erscheinung zu bemerken ist, so dass diese oft an den südlichen, kurzköpfigen $V$. albigularis Daud. erinnern). Terf. gibt nun vergleichweise die Masse der Schädelknochen bei $r$. niloticus 
und salvator, woraus nur erwähnt werden soll, dass der Unterkiefer bei salcator (Schädellänge $134 \mathrm{~mm}$ ) 5, bei nitoticus (Schädellänge 136) aber $11 \mathrm{~mm}$ Höhe hat (am hintern Teil der Dentalgegend); ähnlich sind anch die Lickenverhältnisse und sogar bei Knochen, die mit dem Kieferapparat in keiner nähern Beziehung stehen, wie beim Tasalfortsatz des Prämaxillare, ist dies zu bemerken (Breite $2^{1} \mathrm{~mm}$ bei niloticus. $1 \mathrm{~mm}$ bei saliator an der schmalsten Stelle). Sehr bemerkenswert ist auch die Erscheinung, dass der Zwischenraum zwischen den Pterygoiden bei $\mathrm{r}$. saliator mehr als doppelt so breit ist wie bei $T^{r}$. nitoticus, was darauf zurïcligeführt wird. dass ersterer grosse Beutetiere unzerteilt verschlingt und daher die Vergrösserung des Rachenraumes ron Vorteil ist, während bei niloticus das nahe Zusammenrücken der Pterygoide in der Medianlinie einen Schut\% gegen die Beschädigung der Gehirnkapsel durch die zermalmten scharfen Schalenstïcke bildet. Der Umstand, dass der grösste Durchmesser der elliptischen Basis der Molaren schief zur Längsache des Kiefers steht. wird damit erklärt, dass auf diese Weise die Zähne bei gleicher Cirösse dichter stehen kömen, als bei einem andern (Yuerschnitt und daher bei dem gelegentlichen Zahnwechsel die Lüicken nicht so fühlbar sind. $\%$ erwähnen wäre auch noch. dass bei dem jungen 1. niloticus die Verhältnisse ganz ähnlich sind wie bei sulvator, der also ein phylogenetisch älteres Stadium der Gebiss- und Schädelentwickelung vorstellt. Aus der eingehenden Besprechung des Darmkanals möge nur hervorgehoben werden. dass der Ilickdarm sich durch seine liürze auszeichnet. was auch wieder auf die Ernährungsweise zurïckzuführen sein dürfte.

Der Verf. erwähnt nicht den sehr ähnlichen Fall bei Triony. sinensis Wiegm.. ron welcher Art eine molluskenfressende Form mit breiten, stumpfen Kieferrändern neben einer räuberisch lebenden mit scharfen hiefern existiert.

Es würde zu weit fuhren. die wesentlichen Veränderungen, welche in der Gestalt des C'nterkiefers, des Parietale, in der Richtung der Basipterygoidfortsätze. der Basisphenoide usw. zwischen dem Schädel ron $T$. niloticus und sulrator bestehen und die rom Verf. ausführlich und mit Bezug auf den Zusammenhang mit der veränderten E1nährungsweise des Kamerun- Y arans behandelt werden. hier anzuführen.

Jedenfalls wird dieser Fall von so weitgreifender Anpassung nicht verfehlen. Aufmerksamkeit in zoologischen hreisen zu erregen.

$$
\text { F. Werner Wien!. }
$$




\section{Zoologisehes Zentralblatt}

unter Mitwirkung von

Professor Dr. O. Bütschli

In Heidaltierg

herausgegeben von

Dr. A. Schuberg

a. P. Profasent in Heidelberg

\author{
Dr. B. Hatschek
}

in Wien

Verlag von Wilhelm Engelmann in Leipzig.

X. Jahrg.

1. Dezember 1903.

No. 24.

Zu beziehen durch alle Buchhandlungen und Postanstalten, sowie durch die Verlagsbuehhandlung. Jährlich 26 Nummern im Cmfang von 2-3 Bogen. Preis für den Jahrgang M. 30. - Bei direk. ter Zusendung jeder Nummer unter Streifband erfolgt ein Aufschlag von land und von II. 5.- nach dem Ausland.

\section{Referate.}

\section{Geschichte und Literatur.}

09 Köppen, Tli., Gustay I wanowitsch Radde. In: Jonrnal des Ministeriuns iler Volksautliärung. St. Petrishurg 1903. pag. 109-128.

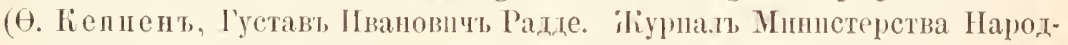
паго Iросвнщенія.)

Der in Mär\% dieses lahres in Tittis verstorbene Direktor des Kankasischen Musemus, (r. I. liadde. einer der bedentendsten und erfolgreichsten Erforscher Sibiriens und der Kaukasusländer in geographischer wie naturgeschichtlicher Hinsicht, komte auf einen Lebenslauf zurückblicken, wie er so reich an fruchtbringender wissenschaftlicher Arbeit und an Erfolgen jeder Art nur wenigen beschieden ist. Am 15/27. Norember 1831 als Sohn eines unbemittelten Schullehrers in Danzig geboren, benchte Gustav Ferdinand Richard Rad de die dortige liealschule, um sodann infolge mangelnder Mittel als Lehrling in eine Apotheke einzntreten. Von Kindheit an ein begeisterter Naturfreund, verwandte Radde alle freien Stunden zu theoretischen und praktischen Studien der Zoologie und Botanik, wobei er von seiten des Professors Menge in fürsorglichster Weise unterstiitzt wurde. Nach dem Tode seiner Eltern beschloss er seinen längst gehegten Wunsch, die Krim behufs naturhistorischer Studien zu bereisen, zur Ansführung zu bringen, verschaffte sich Empfehlungen an den am Südufer der Halbinsel lebenden Akademiker P. Köppen und machte sich 1852 auf den Weg, von der Danziger naturforschenden Gesellschaft mit einem kleinen Reisestipendium ausgerïstet. Am Ziele der Reise angelangt fand Radde freundliche Aufnahme bei dem bekannten Botaniker und Entomologen Ch. Steven, 
welcher ilım Gelegenheit bot, sich mit den reichen Naturschätzen des Landes bekannt zu machen, und sodann bei dem Gutsbesitzer Schatiloff. auf dessen Gute er aus eigenen Kräften ein lokales ornithologisches Museum begrïndete und seine ersten Schriften über die Ptlanzen- and Tierwelt Tauriens, sowie über dessen eingeborene Bevölkerung verfasste. 1 Sว̆ gelang es Radde, in der Eigenschaft eines Naturforscher's der von der russischen geographischen Gesellschaft nach Ostsibirien ausgerüsteten Expedition zugezählt zu werden. Im Verlauf dieser, fün Jahre dauernden Forschungsreise untersuchte er unter anderm den Baikalsee und dessen Ufer, Daurien (der äusserste nordöstliche Teil der Wüste Gobi), die Ufer der Schilka und des Amur, wo er 14 Monate in der Einöde, begleitet ron nur zwei Kosaken, zubrachte, und den östlichen Teil des Sajangebirges. Da wo die Kette des kleinen Chingan an den Amurtluss herantritt, gründete Radde die Kosakenkolonie Raddowka. welche seitdem zu einer bedeutenden Ansiedelung herangewachsen ist. Die reichen naturwissenschaftlichen, geographischen und ethnographischen Resultate dieser Reise gaben ilum Veranlassung zu einer Reihe von Veröftentlichungen, vou denen namentlich folgende von Bedeutung sind:

"Gustar Raddes Vorlesungen iiber Sibirien und das Amurland, gehalten im Saal der Kais. Univers. zu St. Petersburg, März 1S60:6 (l'etermanns geogr. Mitt. 1860, 1861), „Berichte über Reisen im Süden von Ost-Sibirien, im Auftrage der K. Russ. Geogr. Ges. ausgefiihrt in den .Iahren 1855 bis incl. 1859 von Gustar Rad de." St. l'etersburg 1861, $8^{0}$ XXII und 719 pp. mit Atlas. (Beitr. z. Kenntn. d. Russ. Reiches etc., Hd. 23). "Neue Sängetier-Arten aus Ost-Sibirien" (Bull. Ac. Imp. Sc. St. Petersb. T. 4, 1862); "Reisen im Süden von Ost-Sibirien in den Jahren 1855-59 etc." Bd. I. Die Säugetierfauna: Bd. II. Die Festlandsornis des südöstlichen Sibiriens. St. Petersburg $186^{\circ} / 1863,4^{0}$.

Seit seiner Riuckkehr aus Sibirien als Konservator am zoologischen Museum der Akademie in St. Petersburg angestellt, ging $\mathrm{P}$ add e 1863 nach dem Kaukasus, dessen Erforschung in biologischer und geographischer Hinsicht er sich bis zu seinem Lebensende widmete, fast alljährlich (oft in Gesellschaft anderer Forscher) Reisen nach verschiedenen Seiten hin unternehmend, und über die Resultate derselben berichtend. Ausserdem unternahm der unermüdliche Gelehrte $1886^{\circ}$ eine Forschungsreise in das Transkaspigebiet und hegleitete ferner 1890-91 die Grossfursten Alexander und Sergius Michailowitsch auf einer Seereise in das tropiscle Asien und 1895 und 1897 den verstorbenen 'Thronfolger auf Rundfahrten auf dem Mittelländischen Meere. 
Ausser etwa 50, in rerschiedenen \%eitschriften (namentlich auch in Petermanns geogr. Mitteilungen) erschienenen kürzern Aufsätzen, in welchen Radde über seine Forschungsreisen im Kaukasus berichtete, erschienen noch folgende umfangreichere Schriften aus seiner Feder: „Wissenschaftliche Ergebnisse der im Jahre 1886 in T'ranskaspien ron Dr. G. Radde, Dr. A. Walter und A. Konschin ausgeführten Expedition. Bd. I. Zoolog. Abteilung. Jena 1889". R a d de G. und Koenig E, Das Ostufer des Pontus und seine kulturelle Entwicklung im Verlaufe der letzten dreissig Jahre." (Peterm. geogr. Mitt. 1894); "Die Fauna und Flora des suidwestlichen Kaspi-Gebietes." Leipzig 1886. "Zwei Fahrten in das Nittelmeer in den Jahren 1895 und 1897, auf den Kais. russischen Yachten Polarstern und Zarniza." (Deutsche Rundschau für Geogr. etc. 1898); ..Ornis Caucasica. Die Vogelwelt des Kaukasus, systematisch und biologisch geographisch beschrieben. Kassel 1854. $4^{0}$ (59) pp. mit 26 Tafeln): „Grundzüge der Pflanzenverbreitung in den Kaukasusländern, von der untern Wolga ïher den Manytsch-Scheider bis zur Scheitelfläche Hocharmeniens." Leipzig $1899.8^{\circ}$ (XII und 500 pp.. billet den 3. Teil won Engler und Drude, Die Vegetation der Ercle).

Ein grosses Verdienst hat sich Radde ferner durch die Gründung und Verwaltung des ..Kaukasischen Museums" in Titlis erworben, welches er zu einem mustergültigen Institut gemacht hat. In Verein mit mehrern andern Gelehrten hat er in den letaten Jahren seines Lebens eine Beschreibung der Schätze des von ihm geleiteten Museums unternommen, welche 5 grosse Quartbände unter dem Titel „Wie Sammlungen des kaukasischen Museums, im Vereine mit Spezialgelehrten bearbeitet und herausgegeben ron Dr. Gustar li adde (Titlis 1899-1902), umfasst. Der 4. Band, welcher die Geschichte des Museums sowie eine Autobiographie Raddes enthalten soll, ist noch nicht erschienen.

Radde war ein Selfmademan in des Wortes vollster Bedentung; der arme Apothekerlehrling hat es dank seiner eisernen Energie und seiner glïhenden Liebe zur Natur zu einem hochangesehenen Gelehrten gebracht, dessen Arbeiten und Schöpfungen nie der Vergessenheit anheimfallen werden; auch an Anerkennungen aller Art hat es Radde nicht gefehlt, so ist er von der Universität Dorpat zum Magister hon. causa, ron der Universität Breslan zum Doctor philosophiae ernannt worden. Der bis zu seinem Lebensende gesellige und stets lebensfrohe Forscher hinterlässt zahlreiche Freunde unter den Berufsgenossen seiner alten wie seiner neuen Heimat.

$$
\text { N. v. A delıng (St. Petersburg). }
$$


810 Szilíly, Zoltìn, A magyar àllattani irodalom is nu e retése. (Bericht über die ungarische zoologische Literatur während der Jahre 1891-1900.) III. Bd. 1891-1900. Budapest. 1903. Herausgegeben v. Kgl. Ung. Naturwissensch. Gesellseh. pag. I- YI. $1-505$.

Verf. bietet weit mehr, als nach dem 'Titel seines Werkes zu erwarten wäre, denn er bringt nicht nur den Titel und kurzen Inhalt der im Zeitraum 1891-1900 in ungarischer sprache erschienenen wissenschaftlichen und populären zoologischen Werke. sondern auch die Besprechung der Aufsätze ungarischer Autoren in jedweder Sprache. sowie der Publikationen ausländischer Zoologen, insofern sie in Ungarn erschienen sind und insotern sie die ungarische Fauna oder ungarische Forscher und deren Arbeiten betreffen. Die l'ublikationen in kroatischer Sprache bespricht Ottokar Ka di $\check{c}$.

Die Einteilung des Werkes ist eine übersichtliche und dasselbe deshalb leicht zu handhaben; die besprechungen sind zuweilen ku1'\%, aber immer klar; sehr gehoben wird die Brauchbarkoit des Werkes dadurch, dass es zum Schlusse eine übersichtliche Gruppierung derjenigen ungarischen neuen Arten und neuen Varietïten gibt, welche in den in vorliegendem Werke verzeichneten I'ublikationen beschrieben sind. Sehr zweckmäfig und wünschenswert wäre es, wenn Verf. in den künftig erscheinenden Bänden die besprechungen in zwei Teile trennen und in den einen Teile diejenigen I'ublikationen, welche wissenschafthichen Wert haben und neve Daten enthalten, in dem andern Teile aber die rein populären Werke aufführen wiurde. Dann könnte er hinsichtlich der im ersten Teile enthaltenen Werke mit wissenschaftlicher Kritik vorgehen und wïrde dieser 'Teil ein wichtiges Hilfsbuch für ungarische und ausländische Forscher bilden, während der zweite 'Teil denjenigen Fingerzeige böte, die sich iiber irgend eine zoologische Frage in ungarischer sprache Belehrung verschaffen wollen.

A. Gorka (Budapest).

\section{Lehr- und Handbiicher. Sammelwerke. Vermischtes.}

811 Schultz, Eug., Zo o logie. Populäre Vorlesungen. (Е. ІЦульц, Зоологія). In: (Семейный университеть. Нзданіе Кімарскаго. С. Петербургь). 1900-1903. pag. 1-196. 250 Textfig. (russisch).

Diese populär gehaltenen 12 Vorlesungen, die systematisch alle Tierklassen durchgehen, jkönnen nur in der Richtung das Interesse des Spezialisten erwecken, dass hier der Biologie und Ökologie als Erklärung der Tierformen ein weiter Raum gelassen worden ist. Dem Buch liegen Werke wie Langs, ,Festsitzende Lebensweise" und Siml'o ths .. Entstehung der Landtiere" zu grunde. Die Tierformen werden

$$
\text { - Nr } 810-811 \text {. - }
$$


als Anpassingserscheinungen aufgefasst und der Einfluss des Parasitismus, der festsitzenden Lebensweise, des Wasser- oder Landlebens, des Siisswassers. der 'Tiefsee etc. ausführlicher auseinandergesetzt. Im einzehnen musste vieles sehr kurz ausgedriickt werden, was das Verständnis für den Laien leider verdunkelt mnd ihm das Lesen des Buches nnerquicklich maclit.

E. Schultz (St. Petersburg).

\section{Vergleichende Morphologie, Physiologie und Biologie.}

12. Marshall, W.. Gesellige Tiere. Nr. 1. Allgemeines. Tiergesellschaften ohne Arbeitsteilung. In: Hochschul-Vorträge f. Jedermann. Leipzig (Seele u. Co.) 1901. Heft XXII u. XXIY. S $^{0} .47$ pag. N. - 60.

13: - Nr. 2. Die Arbeitsteilung, ilır Wesen und ilır Wirken. Ibid. 1901. Heft XXY. $8^{0} .27$ pag. M. - 30.

14 - Nr. 3. Allgemeines ïber den Insektenstaat. Die l'apierwespen. Ibid. 1902. Heft XXVI. $8^{\circ} .30$ pag. I. - 30. 1.i - Nr. 4. Allgemeines ïber den Insektenstaat. Hummeln und Meliponen. Ibid. 1902. Heft XXVIl n. XXYlI $8^{\circ} .42$ pag. II. - 130 .

Der Inhalt der obengenannten Hefte, der auf sechs Vorträge verteilt ist, wird durch die Titel der einzelnen Jefte im wesentlichen gekennzeichnet.

Yon 'Tiergesellschaften olne Arbeitsteilung werden im ersten Hefte abgehandelt: die nicht differenzierten "Tierstöcke", wie sie bei vielen Spongien, Hydroiden, Korallen, Bryozoen gefunden werden, ferner die ..Gesellschaften von körperlich getrennten Einzelwesen" (Schwärme. z. B. von Copepoden, Henschrecken, Fischen, Vögeln, Walen), und schliesslich die Gesellschaften, welche durch die Vereinigung ron Individuen verschiedener Tierarten gebildet werden (wie z. 1). Strausse und Equiden u. dgl.). Sodann werden die Ursachen für die Entstehung der Geseltschaften besprochen, die ebenso verschieden sind, wie diese selbst.

Im zweiten Hefte wird zunächst die Arbeitsteilung zwischen den einzelnen Zellen des vielzelligen Organismus geschildert, woran sich die Darstellung der Arbeitsteilung und ihrer Bedeutung bei den zusammenhängenden Tierstöcken oder Kiormen. namentlich für die Fintstehung des Polymorphismus, sowie die Besprechung der Arbeitsteilung bei den Gesellschaften von freilebenden Individuen anschliesst. Bei letztern werden insbesondere die durch die Fortpflanzung und die Brutpflege bedingten Erscheinungen ( $V$ ögel, Fische, Amphibien usw.) berïcksichtigt. 
Das 3. und 4. Heft sind ganz den Staatenbildungen der Insekten, speziell den Papierwespen, Hummeln und Meliponen gewidmet.

In allen Vorträgen, die in gutem sinne populär gehalten sind, werden zahlireiche biologische Verhältnisse in der ansprechenden Weise geschildert, durch die sich die populären Darstellungen des Verfs. mit Recht in weiten Kreisen beliebt gemacht haben.

$$
\text { A. Sc ch uberg (Heidelberg). }
$$

\section{Protozoa.}

816 Minkiewicz, R., Études sur les P'rotozoaires de la Mer Noire. I: Lorganisation, la multiplication et la positions ssté-

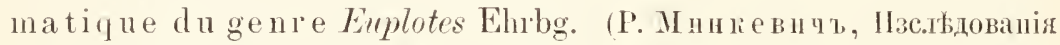

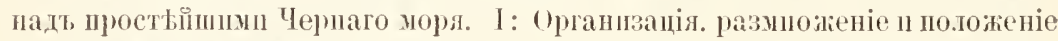
въ системы рода Euplotes Ehrbg.). In: 'Trav. Soc. Nat. Kasan (Tpyды

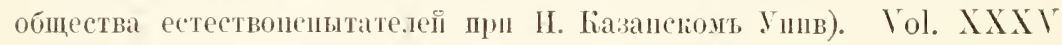
livr. 1. 1901. pag. 1-67. Taf. I-II (russ. mit franz. Resumé).

Nach einer geschichtlichen Einleitung über das (ienus Euplotes untersucht Verf. ausführlich die Organisation und die Teilung von Euplotes vamus O. F. Müller $(=E$. longipes Cl. L. oder E. extensus Fres.). Die äussere Körperform ist sehr variabel, gleichfalls das Peristomfeld; der Pharynx stark entwickelt, tubulös und sein Ende umgebogen. I)ie Cirren könnte man als in vier oder auch in fünf Linien geordnet ansehen oder endlich in sechs von vorne nach hinten ziehenden Bogenlinien. Letztere Einreihung ist die einzig rationelle, da sie auf der Entwickelung nach der Teilung beruht und uns erlaubt, phylogenetische Schlüsse zu ziehen. Die Cirren lassen sich durch Osmiumsïure in immer feinere Fibrillen zerlegen. Die „,sternförmigen Gebilde" liegen zwischen dem Ekto- und Endoplasma und sind harte, wahrscheinlich kristallische Körper und keine Vakuclen. Der Kern hat eine feine Alreolarstruktur, das Chromatin ist in feine Stäbchen geordnet. Zwischen den beiden konjugierenden Individuen ist immer ein Unterschied zu bemerken, der sich in der Länge des Körpers, seiner Breite und cier Zalıl der Candalcirren liund tut. Dieses ist der Anfang eines Sexualdimorphismus. E. charon, den Verf. gleichfalls untersuchte, bietet keine besonderen anatomischen Unterschiede von E. cumms. Bei der Teilung von E. unterschejdet Terf. sieben Stadien. Das I'eristom wird nicht ganz neugebildet, nur die adorale Zone entsteht neu, während der innere Rand des Peristoms direkt aus demjenigen des Muttertieres herrorgeht. Die Cirren erscheinen als sechs Längsreihen, die sich darauf in zwei Gruppen teilen: die anale und frontale. Bei den Oxytrichina finden wir analoge sechs Reihen und das gleiche Auseinanderweichen dieser Gruppen. E. Schultz (St. Petersburg). 


\section{Coelenterata.}

817 Schydlowsky, A., Matériaux relatifs à la faune des polypes hydraires des mers arctiques. I. Les Hydraires de la Mer Blanche le long du littoral des îles solowetzky.

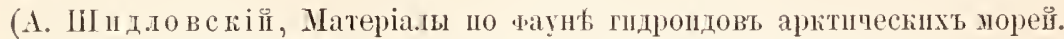
I. Гидроиды Бъ.аго Моря у береговъ Соловецихъ острововъ.) In: Trav. soc. nat. Univ. Kharnew. (Труды общества исиытателей шрироды при Харыіовсконь Университеть). Т. ХХХІІ. 1902. pag. 1-276. Tab. I- I (russisch mit lateinischer (harakteristik der Arten und Resumé).

Zuerst werden die hydrologischen Eigentümlichkeiten des Weissen Veeres und der Kiisten der Solowetzkyschen Inseln rom Verf. ausführlich geschildert.

Dem systematischen 'Teile gehen morphologische Betrachtungen über die Thecophora voraus. Das ganze Hydrosom ist ein System besonderer morphologischer Einheiten, die der Autor Hydromedusoide neunt; dieses ist eine Form. die in einem bestimnten Bezirke im Fitoderm eine Höhle hat - die Vestibularhöhle. Die die Höhle nach aussen bedeckende Ektodermschicht ist das Velum; der Teil des (önosarks mit einschichtigem Ektoderm ist die Hydrumbrella des Hydromedusoides. So ist die Vestibularhöhle zu gleicher Zeit Subumbrellarhöhle. Ein Teil der Subumbrella differenziert sich in ein Hydromanubrium. Das Hydromedusoid ist nicht den anderen Medusen- und Medusoidstadien der Hydrozo: homolog, die künstlich in den Hydromedusentypen vereint werden, der aus einigen selbstïndigen 'ypen besteht und sich selbständig zur Ausgangsform. dem Hydropolypen, verhält. Das Hydromednsoid ist einer dieser selbständigen 'Typen, der sich durch die Spaltung des Ektoderms in bestimmten bezirken und die Bildung einer Höhle in demselben auszeichnet. Von diesem Moment hört der Zustand des primären Hydropolypen auf und es beginnt das Stadium des Hydromedusoides. Das Hydromedusoid tritt in drei Variationen auf: 1. als entokodones Hydromedusoid (geschlechtliche Medusoidlinospen der Hydroiden) - in ihm ist das den Vestibularraum enthaltende Ektoderm als Glockenkern gesondert, 2. als einfaches Hydromedusoid und 3. als rudimentäres Hydromedusoid. Die vom Verf. entworfenen Schemata entsprechen durchaus nicht dem allgemein angenommenen Schema von Claus-Hertwig. Das Hydromedusoid ist der einzige medusoide Typus der Hydroiden, den ausnahmslos alle Teile des Hydrosonas der Thecophora in ihrer Entwicklung durchmachen. Das Hydromedusoidensystem, welches das Hydrosom zusammensetzt, ist nach dem Typus der Strobila gebaut: die Hydrorhiza ist ein einfaches Hydromedusoid, dessen Hydromanubriun die Pasis des Hydrocaulus bildet: der Hydrocaulus ist eine 
Reibe rudimentärer Hydromedusoide, das Hydrostyl endlich ist ein System zweier apilial liegender Hydromedusoiden, der untere ist rudimentär, der obere einfach. Bei den Sertularidae entwickelt sich das Hydromanubrium des zweiten Hydromedusoids zu einem dritten. terminalen Ilydromedusoid (Hydrant). - Das Hydromedusoid ist das Individuum der Kolonie. Der Ban der Thecophora ist das Resultat seines Wuchses und seiner línospung. Der Staum verlängert sich durch apikales Wachstum, während die Gymnoblastea ein zonares liaben. Die Transformation der Wachstumsspitze in ein Hydromedusoid beendet das Wachstum. Ioch kann dieselbe vorerst eine axiale linospe ergeben, die die Bedentung einer nenen Wachstumsspitze erhält; so erhalten wir ein ununterbrochenes Wachstum der Achse. Das Hydrostyl entsteht durch (Querteilung dor Wachstumsspitze, wobei jedes der beiden T'eile zu einem Hydromedusoid des Hydrostyls wird. Die die undifferenzierte spitze bedeckende Chitinhülle ist die Hydrotheca primordialis. Wenn dabei die Wachstumsspitze eine spezielle terminale Knospe bildet, so ist die Hydrotheca rom Hydrocaulus durch eine Einschürung getrennt, die den Fundus der Hydrotheca bildet, andernfalls hat sie keinen boden, wie \%. B. bei allen Sertulatidae. Die Querteilung der allgemeinen Anlage des Hydrostyls wird ron der Biłhung neuer ('hitinschichten in innern der primären Hydrotheca begleitet und es bildet sich ein Diaphragma. Die Gruppe der Sertularidale weist folgende Eigentiimlichkeiten anf: Die Wachstumsspitze ist in zwei oder mehrere Teile längsgeteilt, von denen nur einer zur Wachstumsspitze wird, die übrigen werden Hydrostyle. Eine weitere Eigentiimlichkeit ist das Insymmetrische der folgenden I'rozesse. Die dritte Eigentümlichkeit ist, dass das Hydromanubrium des zweiten Hydromedusoids seinerseits ein selbständiges Hydromedusoid bildet: dieses ist das dritte Hydromedusoid des Hydrostyls.

Der systematische Teil besteht aus einer systematischen Beschreibung der gefundenen Formen, worunter neun neve Species und zwei neue Varietäten sind.

L. Schult z (St. Petersburg).

\section{Vermes.}

\section{Plathelninthes.}

$818 \mathrm{v}$. Rátz. Istrín. Uj és kevéssé ismert hazai mételyek. (Neue und wenig bekannte ungarische Egel.) In: Allattani Közlemények. Bd. II. Budapest 1903. pag. 83-88. 1 Taf.

Verf. beschreibt zwei Arten des Genus Opisthorchis. Die eine ist Opisthorchis tcnuicollis Rud., welche nach dem Verf. in Budapest in den Gallenwegen der Katze ziemlich selten und in geringer Anzahl vorkommt. Die vom Verf. untersuchten Exemplare stimmen nit dem typischen Opisth. tenuicolis Rud. vollständig iiberein und unterscheiden sich von ihm bloss durch die Lage des 
Dotterstockes hinter den Ovarien und die Kleinheit der Eier. Die andere neue Art kommt in der Gallenblase des roten Reihers (Ardea purpurca) vor. Verf. bezeichnet sie mit dem Namen Opisthorchis entzi und gibt ihre genaue Beschreibung nebst guter Abbildung. Hinsichtlich der anatomischen Struktur gleicht diese Art dem $O$. tenuicollis, noch mehr aber dem $O$. longissimus Linstow, ist jedoch von beiden scharf untersclieden durch die charakteristische Form und durch die eigentümliche Anlage der innern Organe. Thre auffallendsten Merkmale sind: die Lancettenform des Kopf- und Halsteiles, sowie die ungleiche Entwicklung des Dotterstockes, dessen eine Hälfte immer länger ist und deshalb weit mehr nach vorn gerückt ist, als die andere.

A. Forka (Budapest).

\section{Arthropoda.}

Insecta.

19 II inds, Warren Elmer, Contribution to a monograph of the Insects of the order Thysanoptera inhabiting North America. In: Proc. U. S. Nation. Mus. Yol. XXVI. 1092. pag. 79 -242. Pl. I-XI.

Der vorliegende Versuch einer monographischen Bearheitung der nordamerikanischen Thysanopteren ist nicht nur für die genauere Kenntnis der betreffenden Fauna, welcher bisher nur wenig Aufmerksamkeit geschenkt wurde, von grosser bedeutung, sondern wird auch als Beitrag zur Kenntnis dieser interesanten Insektenordnung ïberhaupt willkommen sein. Das I'rogramm, welches $\mathrm{H}$ inds sich bei seiner Arbeit gestellt hat, ist ausführlich und eingehend bearbeitet und enthält mehrfach eigene Beobachtungen, namentlich ïber die Lebensweise; in vieler Hinsicht kann diese Arbeit als Ergänzung zu der vortrefflichen Monographie von $\mathrm{U}_{\mathrm{ze}} \mathrm{l}^{1}$ ) dienen. Was den systematischen Teil der Arbeit betrifft, so ist nicht nur die bedeutende Bereicherung der nordamerikauischen Thysanopterenfauna an neuen Arten hervorzuheben, sondern auch der Imstand, dass es dem Verf. möglich war. die meisten 'Typen der ron frühern amerikanischen Autoren beschriebenen Arten zu studieren und neue, ansführlichere Diagnosen für dieselben zu geben. Von den früher bekannten 26 in Nordamerika vorkommenden Arten betrachtet Hinds 4 (Limothrips tritici Pack., shlocothrips mali F'itsch, Pht. earine Fitsch und Thrips phylloxerce liil.) als nicht wiedererkennbar, 6 andere erwiesen sich als Synonyme; hierzu kommen 18 von $\mathrm{Hinds}$ beschriebene neue Arten. Von den 18 neven Arten stammen 16 ron einem sehr beschränkten, dem „Massachusetts Agricultural College” gehörigen Areal: dies beweist wiederum, wie wenig bis jetat für die Erforschung der Thysanopterenfauna geschehen ist. und wie gross die Kahl aller Arten dieser Ordnung sein muss.

1) Vergl. Zool. Zentr.-Bl. III, 1896, pag. 845. 
Der Verf. bespricht zuvor die systematische Stellung der 'Thysanopteren, welche er mit Jordan zwischen die Corrodentia und Rhynchota, den Homoptera am nächsten stehend, einreilat. Weiterhin werden Ratschläge für das Sammeln und Konservieren der zarten kleinen Insekten mitgeteilt: zu erwähnen ist hieraus, dass Hinds vor der Montierung von Dauerpräparaten (für 'Tlysanopteren die einzig mögliche Konservierungsmethode) in Glycerin warnt, in welchem sich Kristalle (wahrscheinlich Phosphate aus dem Insektenkörper') bilden und welches das dunkle Pigment der Iugen auflöst, wodurch die Präparate nach wenigen Monaten unbrauchbar wurden. Hinds empfiehlt, die frisch getöteten Tiere direkt in Xylol und dann in Kanadabalsam zu bringen, was tadellose Präparate geben soll. Alkohol bewirkt eine starke Deformation und soll nur zur Aufbewahrung von Doubletten leicht erkenubarer Arten verwandt werden.

Die äussere Anatomie wird auf 23 seiten besprochen und durch zahlreiche Abbildungen erläutert; auch dieser Ibschnitt enthält vielfach neue Beobachtungen des Verfs. und ist daher auch von allgemeinerm Interesse ${ }^{1}$ ). Hervorzuheben ist die Beschreibung der Mundteile (Asymmetrie, nach (rarman), der Brust, Flïgel und sekundären Genitalcharaktere.

Die ökonomische Bedeutung scheint ziemlich bedeutend zu sein; Thysanopteren schaden, nach amerikanischen Autoren, den Erdbeeren, Ijpfeln und andern Früchten, ferner der Baumwollstaude, Warmhauspflanzen usw. Meist erfolgt der Schalen durch Beschädigung der Blumen (Griffel usw.), wodurch Befruchtung und Ansetzen der Frucht unmöglich gemacht werden: im allgemenen jedoch ziehen die Thysanopteren nach Hinds grüne I'Hanzenteile als Nalurung vor; die Angabe Burmeisters und Pergandes, der Nelitar diene den Thysanopteren als Nahrung, erscheint Hinds hinf:illig, indem diese Insekten auf Blumen sich stets von Pflanzensäften nährten. Was das Torkommen von Thysanopteren in Gallen anderer Insekten betrifft, so vermutet $H i n d s$, dass erstere in vielen Fällen zufällig (des Schutzes wegen oder dergl.) dahin gelangt sind, wobei sie sich ganz wohl in Gesellschaft der wahren Gallenbewohner von PHanzensäften nähren könnten (Tubulifera). Walsh hatte ein solches Torkommen in Crallen damit erklärt, dass die Thysanopteren auf Kosten der Gallen erzengenden Insekten lebten. Dagegen unterliegt es keinem 7weifel, dass manche Arten andern Insekten vder deren Eiern nach-

1) Pag. 95 beklagt sich der Verf. darüber, dass Uzel in seiner bekannten Monographie den gesamten anatomischen Teil in ,,ungarischer" Sprache geschrieben hat; es muss natiirlich heissen , in tschechischer Sprache“. 
stellen, so z. B. gewissen Phylloxera-Arten, Sclmetterlingseiern, Milben, Rüsselkäfereiern, Schildläusen; diese Arten werden dadurch zu nützlichen Insekten.

Von Feinden der 'Thysanopteren sind zu erwähnen: Triphleps insidiosts, Megilla maculata, Chrysopa- und Syphlhts-Larven, Trombidium-Larven (nach Hinds), Nematoden, ferner von ptanzlichen Parasiten Entomophthora sphaerosperma. Macrosporium. Der grösste Schaden wird den Thysanopteren jedoch durch legenschaner zugefügt, nach welchen sie zeitweilig ganz verschwinden.

Die Bekämpfung schädlicher Arten mit Insecticiden wird in den Vereinigten Staaten energisch betrieben: von diesen schädlingen sind Thrips tabaci, Euthrips tritici und Anaphothrips striatus die gefährlichsten und werden mit . Whale-oil"-Seife, I'etroleum und „rose leaf insecticide" bekämpft. In Treibhäusern war die Anwendung einer Nikotinlösung am wirksamsten. Sehr wichtig und in vielen Fällen allein wirksam ist das Verbrennen der befallenen Kulturen (Zwiebeln, Gras).

Der systematische Teil der Monographie beginnt mit der algemeinen Charakterschilderung der Ordnung und der Besprechung der bei den Thysanopteren vorkommenden individuellen Abweichungen in der F̈̈̈rbung nnd im Körperbau (Kahl der Antennenglieder, Dimensionen des Abdomens); letzterer Abschnitt ist wohl geeignet, namentlich dem Anfänger wichtige Fingerzeige bei der Bestimmmng der Arten zu geben. Es folgt die Besprechung der Unterordnungen, Fitmilien, Gattungen und Arten, welche wir hier kurz wiedergeben wollen:

I. Subordo Terebrantia. 1. Fam. A eolothripidae. Gen. Aeolothrips Hal. 2 sp. (Ae. bieolor n. sp.). 2. Fan. Thripidao. Gen. Chrothrips Hal. 3 sp (Ch. crassus und obcsus nn. spp.), Limothips Hal. (L. arenae n. sp.), Sericothrips Hal. $2 \mathrm{sp}$. (S. cingulatus n. sp.), Pseudothrips n. g. für Thrips inaequalis Beach, Euthrips Targ.-L'ozz. (für l'hysopus Am. Serv., welcher Nane von Leach schon 1817 für ein Neuropterengenus verwendet wurde) 4 sp., (E. fuscus n. sp.), Scolothrips n. g. für Thrips b-maculatus Perg., Raphilothrips Uz. (F. fuscipennis 11. sp.), Anaphothips Uz. 1 sp., Aptinothrips Hal. 1 sp., ICliothips Hal. 4 sp. (H. faseictpennis n. sp.), Parthenothrips Uz. 1 sp., Thrips L. 2 sp. II. Subordo 'T'ubulifera. Fam. Phloeothripidae. Gen. Anthothips Uz. 2 sp. Trichothrips Uz. 2 sp. (Tr. ambitus und beachi nn. spp.), Cephalothrips Uz. (C. yuccae n. sp.), Phloeothrips Hal. 2 sp. (Phl. uzeli und pergandei nn. spp.), Acanthothrips Uz. (A. magnafcmoralis n. sp.), Malacothips n. g. (M. zonatus n. sp.), Eurythrips n. g. (E. ampliventralis und osborni nn. spp.), Cryptothrips Uz. (Cr. adspersus n. sp.), Idolothrips Hal. 1 sp. Hierzu kommen noch $5 \mathrm{sp}$, deren Ǩlassifizierung $\mathrm{H}$ in ds nach der Beschreibung allein nicht möglich erscheint. Von fossilen Formen werden angeführt Melanothrips Scudd. 1 sp., Lithadothrips Scudd. 1 sp. und Palaeothrips Scudd. 1 sp.

Die Diagnosen sind sehr ausführlich, mit Beriicksichtigung aller rein morphologisclıen Merkmale; so ist z. B. bei sehr vielen Arten 
die relative Länge der Antennenglieder angegeben. Der oft sehr repwickelten amerikanischen wie europäischen Synonymie ist vollanf Rechnnng getragen. Rereits bekannte Species sind vielfach neu beschrieben, die Fundorte auch für Europa angeführt. Zn bemerken ist, dass der Verf. bei der Benennung newer Species nicht immer ganz glïcklich gewesen ist: Namen wie fusciapenmix, magnafemoratis und amplirentralis klingen nicht gut und hätten sehr leicht richtiger gebildet werden können.

Ein besonderes Kapitel ist der Phylogenie gewidmet. Ausgehend von einer bypothetischen Stammform "Prothysanopteren" findet II inds. dass die Tubulifera sich durch veränderte Lebensweise viel weiter (und frïher) von dieser Stammform differenziert haben als die Terebrantia. während die Aeolothripidae sich in der nrsprünglichen Richtung weiter entwickelten und der Stammform am ähnlichsten geblieben sind. Die Thripidae haben sich später abgezweigt, wobei sie in gewissem Sinn der Entwickhngsrichtung der Phloeothripidae folgten, im grossen ganzen jedoch einen selbständigen, eigenartigen Zweig bildeten.

Den Beschluss der vortreft lichen Arbeit $\mathrm{H}$ ind s' macht ein bibliographisches Verzoichnis ron 480 Nummern. Hierbei ist der Verf. entschieden viel zı grïndlich rerfahren, indem er nicht nur vielfach Referate ron citierten Arbeiten mit anfgenommen hat (a. d. Zoologischen .Jaluesberichten. Bertka usw.). sondern anch z. B. Artikel von wenigen Zeilen anfüihrt, in welchen zum Sammeln von Thysanopteren anfgefordert wird n. dgl.m. Da die Titel der in Zeitschriften erschienenen Aufsätze nicht mitgeteilt werden. wird der Ciebranch der Hindsschen Liste durch so vielen uniüzen Bullast erheblich erschwert.

N. r. A delnng (St. P'etersburg).

820 Lósy, Jozsef, A méh és méhtetï egyïttélése. (Commensalismus der Biene und Bienenlans.) In: Kisérletügyi Közlemények, Bd. V. Budapest 1902. pag. 163-204. 6 Textabbild. und 3 Taf.; (auch in: Rorartani Lapok. Bd. IX. Budapest 1902. pag. 153-156; 175-180 5 Textabbild.).

Verf. studierte die Lebensweise der sogenannten Bienenlaus (Braula coeca Nitzsch.), einer eigentümlichen Fliegenart, die ron Réaumur. Taschenberg. Hess. Cirard, Mäggenburg u. a. einfach für parasitiseh, von andern, wie l'eréz und bílint für kommensalistisch gehalten wurde, ohne aber positive Beweise rorbringen zu kömnen. Laut Verf. ïherwintert die Bienenlans in den Bienenkörben und beginnt im Frühling sich fortzuptlanzen, was bis zum Spätherbst fortgesetzt wird. so dass die \%ahl bedentend anwächst. 
Die Parasiten halten sich meistens auf der Königin anf und gehen erst auf di rbeiter über, wenn diese die Fütterung der Larven besorgen, wobei sie von der Nahrung naschen, welche denselben zugefiihrt wird. Sobald die Fiitterung beendigt ist, finden sich alle auf der Königin ein, auf welcher auch die Paarung stattfindet. Ihre Zahl nimmt bis Ende November so bedeutend zı, dass die Königin in die Gefahr kommt, derart geschwächt zu werden, dass sie noch im Spätherbst umkonmt; bei hochgradiger Infektion (in unrein gehaltenen Körben) kann dies sehon in sommer erfolgen, was zum Verfall des ganzen Stockes fuilıren kann.

Die Mundteile der Bienenlaus sind von jenen der übrigen Dipteren wesentlich verschieden. Das Labrum ist eine halbkreisförmige Platte. Die Sangröhre bilden die zwei oftenen Hälften des Labrums, die dem Lobus externus entsprechen können. Das Labellum ist im Vergleich zu dem der Dipteren sehr einfach. Die Maxillen bestehen aus zwei kräftigern Chitinplatten und aus membranartigen Teilen, welche die eigentliche Saugröhre gurtartig ungeben. Die Vaudibeln sind breite bogenförmige Platten, die geschlossen die Saugröhre oben schliessen. An der Basis der Mundteile bleibt noch eine kleine Öffnung, die ron der l'latte des Labrums geschlossen wird. In der verschliessbaren Röhre der Unterlippe liegt die Zmuge, welche aus zwei T'eilen besteht: der obere. ans zwei Lamellen zusammengesetzte, bogige T'eil ist der Epipharynx, der untere der Hypopharynx, zwischen denen der saugkanal läuft.

Die Mundteile von Bratula bilden ein Saugorgan, das sich, lant dem Verf.. den Iuntteilen ler Biene in erstaunlicher. Weise angepasst hat. Die Funktion der eigentiimlichen Mundorgane ist die folgende: Die Bienenlaus sangt ihre Nahrung aus den ausgestreckten Mundteilen der Biene. Sicherlich ninumt sie das Geräusch walır, welches beim Saugen oder durch die Bewegung der Chitinskeletteile des Sangmundes entsteht und welches ihr andeutet, dass sie nunmehr in die Muntteile der Biene eindringen kann. Denn stets läuft sie zn solcher \%eit üher die Stirn zu den Mundteilen, wenn die Biene, nach dem Anfsaugen der Nahrung die Zunge ausgestreckt haltend, die Nahrung vollends aufsaugt und verschlingt, oder aber dann, wenn sie den in den Drüsen der Bienen erzengten süssen Nährstoff in die Zellen der Jungen träufeln lässt. Die Bienenlans bleibt anf dem sich öfnenden Oberkiefer und der Oberlippe stehen. Gleichzeitig sind anch die Unterkiefer im Begriffe sich voneinander zu teilen, so dass die äussere Saughöhle oben offen ist. Die T'eilung wird durch Braula dadurch befördert, dass sie ihre mit bürstenartigen Borsten rersehenen Kiefer zwischen sie einkeilt und 
sie trennt; sodann streckt sie den Rïssel aus und reicht damit bis zur rïckseitigen Oberfläche der Zunge. Da jedoch die Zunge der Biene moch in Bewegung ist, so gelangt endlich die horizontal gehaltene Riusselspitze der Braula in die Höhlung der gleichzeitig hervorrringenden Zungenwurzel; hier zwängt sie sich unter die I'araglossen, rerbreitert sich, ihre Borsten sträuben sich empor, mit den charakteristischen zwei Stützborsten der Unterlippen spreizt sie die beiden Paraglossen auseinander und verhindert anf diese Weise einerseits fas Zuriickziehen der Zunge, andererseits aber hält sie den Basalteil der Zunge offen. Letzteres aus dem Grunde, weil sich hinter der Zungenbasis die Ausleitungsöffnung der Speichelausspritzungskanäle (der Ampullen der Sieboldschen II. und III. Drüsensysteme) befindet; durch diese Drüisenöffnung wird anf den Reiz des eingedrungenen fremden Körpers und fremden Speichels retlektorisch Speichel ausgespritzt, welchen Branla aufsaugt. Nach den Untersuchumgen des Verfs. trachtet Braula in erster Reihe den Speichel der Biene zu erwerben und in zweiter Reihe erst den Honig, den sie sich auch auf andere Weise verschaffen könnte. Branta ist also e in Parasit, der sich dem Organismus der Bienenkönigin angepasst hat und in erster lieihe dieserzur Last und Qual ist.

A. Gorka (Budapest).

821 Kohaut, Rezio, Magyarország bolhái. (Die Flöhe Ungarns.) In: Állattani Közlemények. Bd. If. Budapest 1903. pag. 25-46; 53-68. 5 Taf.

Die auf dem Gebiete Unsarns vorkommenden Flöhe teilt Verf. in folgende sechs Genera ein: Pulex, Chactopsylia nov, gen., Ceratophyllus, Typhlopsylla, Ctcnopsylla und Ceratopsylla. Neu ist hiervon das Genus Chaetopsylla, dessen lateinische Charakteristik Verf. folgenderma ßen zusammenfasst: ,Sexus forma capitis ab invicem differunt; oculi prope marginem inferiorem capitis siti; margo inferior foveae antennalis in sexu utroque ad pleuras extenditur; sexui utrique antennarum articulus tertius strobiliformis. Palpi labiales quinque articulati. Caput et margo posticus prothoracis sine ctenidiis. Forceps maris palettae formis. Processibtis articularibus et unciformibus haud bene explicatis. Setae in articulo tertio tarsorum ita collocatae, sicut in genere Pulcr L." In dies Genus gehören: Ch. globiceps Taschenberg, sowie die zwei neuen Arten: Ch. trichosa und $C h$. rolhschildi. Die beiden neuen Arten gleichen dem Ch. globiceps, sind aber hinsichtlich der Haftzangen, des Tarsus und der Behaarung des Männchens wesentlich verschieden von ihm, so zwar, dass sie schon ,auf den ersten Blick zu unterscheiden sind". In Ungarn hat Verf. das Vorkommen folgender Arten konstatiert: Pulex irritans L., P. canis Curt., P. felis Bouché, P. erinacci Bouché, Chactopsylla globiceps Taschenberg, Ch. trichosa n. sp., Ch. rothschildi n. sp., Ceratophyllus fasciatus Bose D'Antic, C. sciurorum Bouché, C. melis Walker, C. gallinae Schrank, Typhlopsylla assimuiis Taschenberg, T. typhlus Motschulsky, T. bisoetodentata Kolenati. T. gracilis T'aschenberg, Ctenopsylla musculi Dugès, Ceratopsylla elongatus Curt., Cer. jubata Wagner, Cer. wagneri n. sp., Cer. hexuctena Kolenati, Cer. pentactena Kolenati, Cer. dictena Kolenati und Cer. unipectinata Taschenberg. 
Die 2-2,5 mm lange neue Art: Ceratopsylla wagneri lebt an der gemeinen Fledermaus (Myotis myotis Bechst.) und gleicht der Ceratopsylla octoctena Kol., allein die Haftzange des Männchens ist verschieden und an der äussern und innern Seite des Femurs zeigt sich je eine Reihe von Borsten, an der Tibia trägt in der äussern Reihe das Männehen 12, das Weibchen 9-10, an der innern Reihe das Männchen 16, das Weibchen aber 10-11 Borsten.

A. Gork a (Budapest).

322 Shipley, A. E., and Elwin Wilson, On a possible stridulating organ in the mosquito. (Anopheles maculipemis Meig.) In: Transact. Roy. Soc. Edinburgh. Vol. XI. Part. II. Nr. 18. 1902. 1). $367-372.1$ Taf.

Die Verff. liaben an den Flügeln von Anopheles nahe deren Ansatzstelle am Thorax eigentümliche Strukturverhältnisse gefunden, welche sie als ein Stridulationsorgan auffassen. Es handelt sich um eine gezähnte Leiste, welche einer Reibplatte aufliegt. Ton den Details der ziemlich komplizierten Strukturverhältnisse wird die beigefügte Abbildung eine bessere Anschaung gewähren, als ein Aus-

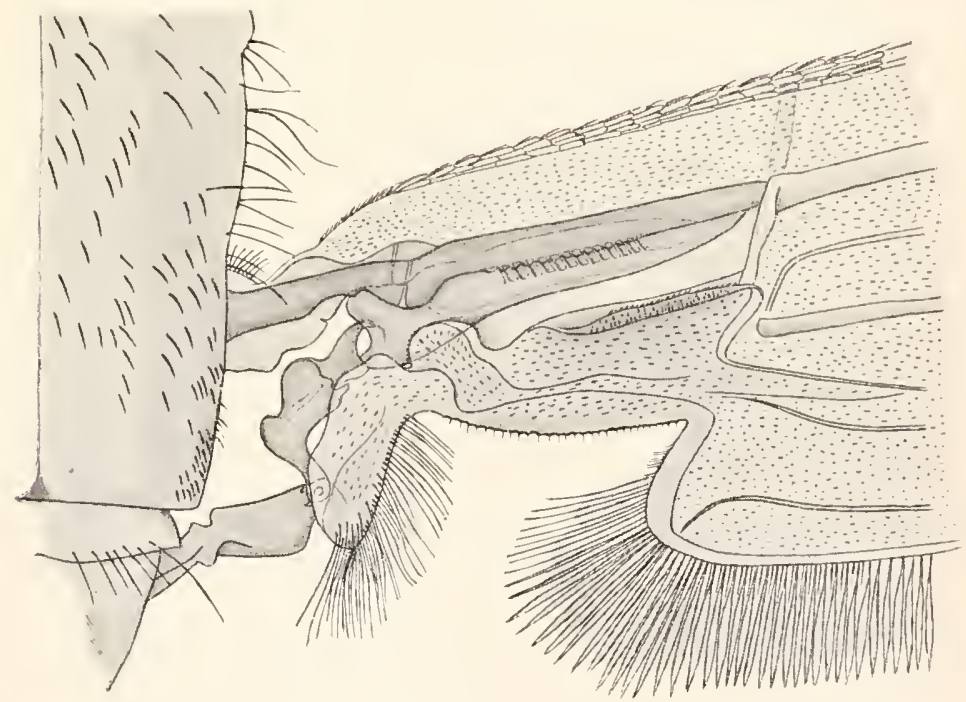

zug aus der von den Verff. gelieferten Beschreibung. Da die Flügel am Thorax nicht in einer horizontalen Ebene, sondern in leicht schräger Richtung befestigt sind, so scheint eine Bewegung der Zahnleiste auf der Reibplatte während des Auf- und Abschlagens der Flügel möglich und die Verff. nehmen an, dass diese Bewegung bei der Entstehung des summenden Tones beim Fluge der Mücken beteiligt ist.

M. Lühe (Königsberg i. Pr.) 


\section{Mollusca.}

\section{Amphineura.}

82: Thiele, Joh., I i e systematische Stellung der Solen ogas tren und die Phylogenie der Mollnsken. In: Zeitschr. wiss. Zool. Bd. 72. 1902. pag. 249 466. 10 Taf. 21 Textfig.

Die inhaltreiche Arbeit bringt einerseits eine Reihe nener anatomischer Tatsachen ans Licht, welche primitive Weichtiergruppen betreften, Solenogastres. A cmaeiden, altertümliche Gastropoden und Lamellibranchien, sowie Anneliden, andrerseits gibt sie -... nnd das ist die Hanptleistung - gewissermassen den vergleichend zoologischen Niederschlag von Thieles langjährigen Molluskenstudien. Thiele rermeidet es, viel zu polenisieren. er sucht vielnehr unter knrzer kritischer Beleuchtung entgegenstehender Insichten anfzuhauen. Da ist es nicht ganz leicht, ihm überall zu folgen, am wenigsten vielleicht dem Referenten, der, von der Pendulationstheorie ans, zu vielfach bis in den Grund hinein abweichenden Anschanungen gekommen ist. Ich will versuchen. Thieles Firgebnisse möglichst objektir darznstellen.

Der erste Abschnut bringt .. Beiträge zur lienutnis der Solenogastren". Ihe kleine Notomenia cluviger hat eigentiimlich geringelte Spicnla, wobei die Ringelung auf die Kalkschicht entfällt. Das Innere ist nit fürbbarer Substanz ausgefüllt. Sie stehen nur in schwacher ('uticnla, weshalb die Form wohl neben Lepidomeniu den Myzomeniiden einzureihen ist, wiewohl der Vorderdarm sich wesentlich anders verhält. Kopulations- und Reizorgane fehlen; die beiden keimdriisen stehen nur durch das P'ericardium miteinander in Verbindung. Receptacnlum seminis und Schalendrüse werden an den Ausführwegen dargestellt. Die rentrale Flimnerrinne reicht nicht bis zur Kloake, die hier weiter nichts darstellt als eine Enddarmtasche. Der charakteristische Vorderdarm ist eine enge kurze Röhre, von der ein enges kurzes Blindsäckchen unter dem Schlund „wohl” als Radulascheide anzusehen ist. Die Erhaltung erlaubte oft über ein ..wohl" und ...scheint" nicht hinauszugehen. Genaue Schilderungen erhalten Proncomenia australis Thiele und Pr. sluiteri $\mathrm{Hubrecht}$, mit welcher letzteren die von mir abgetrennte $P r$. langi zusanmengefasst wird, da die von mir zur Unterscheidnng benutzten Merlimale variabel zu sein scheinen. Die erstere hat verschiedene Spicula, gewöhnliche spiralförmige, teils in der Haut gekreuzt, teils radiär, ohne Kusammenhang mit den Hypodermisfortsätzen in der Cuticula, die. solange sie noch nicht nach aussen geöffnet sind, Sinnesfunlition liaben dïrften. Besondere Spicula, gegenüber den vorigen mehr oder weniger solid, ungeben die Körpereinstülpungen, die lakenförmigen neben 
dem After dienen wohl als Haftorgane bei der Copula. Von der Hautmuskulatur ist besonders die Längsfaserschicht bemerkenswert: sie ist. von oben nach unten an Stärke zunehmend, nur als innere Lage ausgebildet, wälırend andere Arten unten neben der Flimmerrinne noch eine äussere Lage besitzen. Über dem Hinterende der Vorkammer liegen die Blutzellen unter der Körperwand dicht in einem Haufen zusammen, so dass man an eine Blutbildungsdrüse denken kann. Am Pericard liegt möglicherweise der Anfang von Pericardialdrüsen vor. Von Proneomenia sluiteri, mit welcher die Art in der beträchtlichen Länge von $9 \mathrm{~cm}$ übereinstimmt, unterscheidet sie sich besonders durch das Fehlen spiculatragender Fortsätze in der Cuticula, durch die viel schwächere Ausbildung der analen Gruben mit den liakenförmigen Spicula, durch den sehr weiten Vorderdarm und die ganz verschiedene Radula, die nur aus zwei Reihen spitzer Zähne bestelit, durch das Fehlen eines vorderen Mitteldarmfortsatzes, durch die Vielzahl der Receptacula seminis und die fast getrennten Schenkel der Schalendrüse. Von Pron. thulensis, die mit ihr die Vielzahl der Receptacula gemeinsam hat, ist sie durch die bedentendere Grösse und die ganz andere Ausbildung des Vorderdarms und der liadula verschieden.

Eine Nachuntersuchung der nordischen Neomenia carinata, die u. a. proterandrisch zu sein scheint, liess das dorsale Sinnesorgan, das bisher rermisst wurde, auffinden und ergab, von allerlei Einzelheiten abgesehen, eine Reihe von Differenzen gegenüber der Neapeler N. grandis: geringere Grösse, andere Form der hintern Sinneswerkzeuge, weniger scharfe hintere Begrenzung der Flimmerrinne, verschiedene Form des Vorderdarms, der bei $\mathrm{N}$. grandis länger ventral geschlossen, mit besser entwickelten Drüsen und einem dorsalen Wulst versehen ist.

Bemerkungen über Chaetoderma nitidulum führen zu dem Ergebnis, dass die ausstuilpbare Mundhöhle andern Solenogastren entspricht, unter Verlust des Cirrenapparates. Der ...Mundschild," die flache, von einer kräftigen Cuticula bekleidete Ungebung der Mundöffnung, ist eine besondere Erwerbung, ein Tastorgan, als Folge der grabenden Lebensweise. Der grösste Teil der ihn innervierenden Ganglien ist sicher den vordern Anschwellungen anderer Gattungen homolog. Das interessante Chaetoderma raduliferum, das Kowale vsky aus dem Marmarameer beschrieb, will Thiele als Gattung "Prochaetoderma" abgliedern, gekennzeichnet durch die Kiefer, durch das Verhalten der Radula und vielleicht durch die beiden Lippen an Stelle des Mundschildes.

Die allgemeinere Vergleichung ergibt, dass Chactoderma unter 
den Solenogastren am weitesten umgebildet, Neomenia dagegen am primitivsten ist. Als primitive Merkmale von Neomenia kann man betrachten:

mäßig dïnne Cuticula mit einfacheren Hypodermisfortsätzen. radiäre Anordnung der Spicula,

gute Ausbildung der vorderen Fussdriise, die bei andern oft schwindet,

ein dorsales, in der Mitte verdïnntes Längsmuskelbündel unter der

Hant, das auch den Chitonen zukommt,

die Kiemen als Radialfalten der Dorsalwand der Kloake,

der Vorderdarm, ohne .Andentıng von verlorenen sackförmigen

Speicheldriisen oder einer einst vorhandenen Radula," das frei im I'ericardium gelegene Her\%,

die Komplikation der Geschleehtswerkzenge, die sich in der Zusammensetzung der Gonade aus zahlreichen, hintereinander angeordneten Säcken, in dem schwellbaren Kopulationsorgan der Vagina, in den beiden Penisstacheln mit ihrer Driise ausspricht, die letzteren bei anderen Formen verkümmernd, infolge von Selbstbefruclitung?

Da Chactoderma sekundär hoch entwickelt und abgewichen ist (Abtrennung eines Kiopfes, Erwerbung des Mundschildes, V'erlust der Bauchrinne. Vergrösserung und Verschmelzung der Ganglien, Sonderung der Leber u. dergl. m.), da keine 'Zwischenform mehr vorhanden ist, lässt sich nicht entscheiden, ob die bei ihrer Lage zwischen After und Genitalporus liegenden und daher den gleichnamigen Organen anderer Molluskeln nicht homologen Kiemen reine Neubildungen sind oder nicht.

Ein längerer Abschnitt .zur Systematik und Phylogenie der Chitoniden" bringt zunächst vereinzelte Beiträge, die Radula und die Haut, Schale und Stacheln betreffend. Der Radula legt Thiele mehr systematischen Wert bei, als dem Integument. Er korrigiert manche von seinen früheren Angaben, so dass z. B. die Radula, die er von Beanella rissoi beschrieb, in Wahrheit von Lepidopleurus algesirensis herrührt, ebenso Fehler anderer Autoren, unter andern den, dass der von Cos ta beschriebene Chiton rubicundus in zwei Arten zerfällt, so dass Callochiton doriae und laevis zu trennen sind, contra l'ilsbry. Middendorffic wird als Untergattung zu Nuttallina gestellt, mit einer neuen Art Nutt. simrothi, die ich an den Azoren sammelte. Acanthochites fascicularis (L.) und discrepans (Brown) sind zwei durch die bald runden und dichtstehenden, bald weiter getrennten und länglich eiförmigen Körnchen auf der Schale leicht zu unterscheidende Species, nur dass erst noch die richtige 
Zuteilung der Namen zu entscheiden ist, u. dergl. kritische Bemerkungen mehr.

Die Untersuchung von Schalenschliffen zeigt manche 'Besonderheiten iiber Verteilung und Zusammenfassung der Aestheten, führt aber namentlich zu einem allgemeineren Resultat: Die Schalenschichten der Chitonen, besonders der Lepidopleuriden, die in Übereinstimmung mit wohl allen einschlägigen Autoren als ursprïnglichste gelten, sind nicht so scharf voneinander getrennt, dass man für sie eine ganz verschiedene Entstehung annehmen müsste; sie sind wohl nur Differenzierungen in einer ursprünglich einheitlichen Cuticularbildung, welche durch Kalkeinlagerung zu einem festen Hautpanzer geworden ist. Dieser bedeckt die ganze Dorsalseite einschl. Kopf, das Notaeum dagegen sitzt seitlich an, in immer stïkerer Massenentwicklung von den Lepidopleuriden gegen Cryptochiton und Cryptoplax hin (allerdings eine wunderliche Verschiebung der Nomenklatur, ,ein seitlicher Riicken“ Srth). Von der dorsalen Bekleidung wird als vereinzelte Tatsache angegeben, dass die langen gebogenen Kalkspicula von Callochiton doriae in sehr tiefen Einstülpungen der Hypodermis gebildet werden, ans denen sie vernutlich später heransrüicken, um schliesslich in der Cuticula zu wureln. Besonders sensibel ist die Lateralfalte, welche die Kiemenhöhle ron der starken Cuticula des Notaeums trennt, bei Lepidopleums cajetamus \%. li. mit zahlreichen Sinneszellen, (ob freilich für Tastemptinılung? Sith.), ebenso mit Sinneshïgeln oder Seitenorganen, die aber nicht, wie I'late will, eine N tuerwerbung der Lepidopleuriden sind, sondern primitiv, vielleicht Reste eines zusammenhängenden Sinnesepithels. Las Fehlen bei anderen Formen beruht auf Schwund.

Beziiglich des Nervensystems sind die Formen mit zahlreichen Lateropedalkonnektiven die ursprünglichen; ihre Fortsetzungen gehn zum Nantel, die Mantelnerven sind die ältesten, die Lateralstränge bilden das Innervierungszentrum des Notaeums, die Ǩiemen mit ihren Nerven dagegen sind sekundäre Bildungen. Die vordern Buccalganglien sind bei Callochiton doriae mit dem obern Schlundring verwarhsen, wohl ein alter Rest, denn sie dürtten in der l'hylogenie von ihm stammen, wie die hintern aus dem Epithel des Stomodaeums. Die Hinterenden der Kopffalte werden ron den Lateralsträngen nach ihrer Abtrennung rom Schlundring innerviert.

Das ausstülpbare Subradılarorgan, eine sensible, wohl schmeckende Unterzunge, ist ohne Irüse, contra B. Haller. Dagegen wird der hintere Teil des Subradularsacks von driisigem Epithel ausgekleidet, zum Schutze gegen die Radula. 
Die Mundhöhle hat vor und hinter der innern öffnung ein sehr hohes, kutikularisiertes Epithel, doch noch ohne Kieferbildung.

Speicheldruisen fehlen. Was Plate so nennt, sind muköse Aussackungen der Mundhöhle. Die Knorpel der Zunge um die eigentïmlichen Blasen wechseln nach Ausbildung und Anordnung. Von den 17 Platten jeder Radulaquerreihe sind zumeist nur noch 7 mit Schneiden versehen; und von diesen ïberragt jederseits die Hakenplatte die andern so sehr, dass sie schliesslich noch allein funktioniert. Man kann die Radula recht wohl phylogenetisch verwenden, ausgehend etwa von Lepidopleurus alyesirensis mit dreizähniger Hakenplatte ohne inneren Fligel; sie kann schon in derselben Gattung einen oder zwei ihrer Zähne verlieren, geht aber andererseits dreizähnig auf die Ischnochitonen über und erhält sich in verschiedenen Entwicklungsreihen bis zu Cryptoplax und Cryptochiton. In anderer Richtıng erhält sie Flügel und wird schliesslich vierzähnig wie bei Lucilima und Schizochiton. - Schlundsäcke und Zuckerdıüsen sind nicht zusammen zu werfen, sondern von wesentlich verschiedenem Ursprung, die Schlundsäcke, mit Stützzellen in dem Irüsenepithel, sind ektodermal, die Zuckerdruisen, ohne Stiitzzellen, entodermal. Die sekundäre Leibeshöhle existiert nicht, contra Haller. Wenn die Lepidopleuriden die primitivsten sind, so ist der Lmstand, dass die innern Eileiterteile in grosser Länge drïsenfrei sind, keine Folge sekundärer Erwerbung, wie P'late will, sondern ursjü̈nglich; die drüsige Natur ist vom Ektoder'n her ansgebildet.

Der.. Vergleich zwischen Solenogastren und Chitoniden" führt zu dem Ergebnis, dass die erstern primitiver sind, contra Pelseneer, unter vielen wichtigen Einzelheiten. Die Flimmerrinne hat dieselbe Länge wie die Fusssohle primitiver Chitonen, daher kann sie nicht der Mantelhöhle entsprechen. Da die Fussmuskulatur der Chitonen grösstenteils aus Transversalmuskeln besteht, die von der Schale zur Sohle herabziehen, während in der Mitte die Längsfasern völlig fehlen, wie in der Kanalrinne der Solenogastren, so reicht das Homologon des Chitonfusses bei den Solenogastren weiter, so dass zum mindesten noch deren äussere ventrale Längsmuskeln den Seitenteilen des Chitonfusses entsprechen. Damit stimmt die Innervierung iberein, insofern diese Teile bei beiden Gruppen von den Pedalsträngen versorgt werden. Die Cuticula der Haut, die ursprünglich auf die Dorsalseite beschränkt war, griff bei Solenogastren wie bei Chaetopoden und Nematoden weiter herum und liess nur die Flimmerrinne frei. Die Falten dieser Rinne entsprechen denselben in der Byssushöhle der Lamellibranchier und auf dem Fuss ron Janthina. Dazu stimmt endlich die Drüsenversorgung der Bituch- 
rinne. Die KKloake ist eine ähnlich erworbene ektodermale Einstïlpung der Analgegend, wie bei den Rotatorien, die den Darm und die Geschlechtsöffnungen umfasst und respiratorische Fältchen bildet. Da die Stacheln der Solenogastren im Gebiete der Lateralstränge keine Differenzierungen zeigen, um so mehr aber bei den Chitonen, so fordert deren Notaeum besondere Deutung. Thiele denkt sich die Lateralfalte der letzteren ursprünglich als seitlichen Körperrand. Fr zog sich immer mehr gegen den Fuss auf der Unterseite zurïck, indem ungekehrt das Notaeum aut diese Unterseite ïbergriff, womit dann $₫$ Im den Fuss herum eine tiefe Rinne entstand. Damit verschoben sich an der Unterseite die radiär gestellten Spicula in eine annähernd tangentiale Lage. Während der Seitenrand jetzt durch Cuticula und Spicula genïgend geschiitzt war, entwickelte sich auf dem Rïicken, der sich über den wichtigsten Organen immer mehr emporwölbte, ler härtere Kalkpanzer. Die Hypodermisfortsätze der Solenogastren entsprechen den İstheten der Chitonen. Die Schale entsteht also durch folgende Vorgänge:

1. Die Cuticulat verkalkt,

2. die Epithelpakete verlängern sich bis zur Obertlïche, wo sie die Kappen der Ïstheten erhalten.

3. die Spicula bilden sich zurück.

Das Articulamentum ist nicht, wie P'late will, durch V'erschmelzung der Spicula entstanden, sondern durch Differenzierung der ursprünglich gleichartigen kalklaltigen substan\%. wie das Hypostricum.

Der Cirrenapparat in der Mundhöhle der Solenogastren entspricht keineswegs dem Subradularorgan der Chitonen. sonderner ist deren zusammengefasste und weiter entwickelte Kopffalte. Beide umfassen den Mund hufeisenförmig; die Mundhöhle der Solenogastren ist also eine sekundäre Einstülpung.

Fïr die Muskulatur ergeben sich folgende Vergleiche:

Ausser dem vierschichtigen Hautıuskelschlauch besitzen die Solenogastren:

1. in regehnässiger Folge an der Bauchrinne entspringende Transversalmuskelzïge in zwei Gruppen,

a) hoch am Riicken entspringend, ventral nicht gekreuzt,

b) seitlich entspringend, ventral gekreuzt.

2. eine Reihe unter dem Darm verlaufender Querbänder,

3. bei Neomenia neben dem Dorsalgefüss ein I'aar Längsmuskeln. Ganz dieselben Verhältnisse hat Chiton:

1. Die Lateropedal-Muskeln, a) dorsal näher der Mitte ent- Nr. 823. - 
springend und nicht gekreuzt, b) mehr seitlich entspringend und gekreuzt: 2 und 3 genau wie oben.

Der Hautinuskelschlauch der fSolenogastren erscheint bei den Chitonen riickgebildet bis auf die Muskeln, welche die Schalenstücke verbinden. Nur die von der Schale in das Notaeum ausstrahlenden Radiärmuskeln scheinen Neubildungen zu sein.

Das Nervensystem stimmt bei beiden Gruppen gut überein, ausser in den vordern Teilen. Die Subradularganglien fehlen den Solenogastren, bei denen sich umgekehrt C'erebralganglien differenziert haben; bei den Chitonen haben sich dagegen die Lateralstränge mit der Verlïngerung des Notaeums vorn auf dem Lopfe bis zur Mittellinie fortgesetzt, und dieser vorderste 'leil ist mit der obern Hälfte des Schluudringes verschmolzen, woraus sich abweichende Innervierungen erklären.

Am Darm sind selbstrerständlich die Unterschiede sehr stark, Mundhöhle (s. o.), Subradularorgan, Radula, /ungenknorpel etc. am Vorderdarm; für den Mitteldarm der Chitonen kann man etwa folgende Umwandlung vornehmen:

Verengerung und Verlängerung, damit Aufwindung und Differenzierung der drüsigen Anhänge nach Form und Funktion, indem sie entweder baumförmig verästelte Gebilde wurden (Leber), oder sich zu sackförmigen, nach innen eingefalteten Anliängen umgestalteten (Zuckerdrïsen). Ein Leberacinus mag einer Aussackung eines Solenogastren entsprechen, eine Zuckerdriise einer Mehrzahl.

Eine Homologie der Kiemenhöhlen besteht nicht, so wenig wie eine solche der Kiemen. Diese bedingen auch die verschiedene Ausgestaltung der Vorhöfe. Das Gefässsystem in seiner Verzweigung ist natürlich wesentlich verschieden, so wie auch die Solenogastren allein rote Bhutkörperchen haben. In bezug auf Pericard und Gonale zeigen die Solenogastren die einfacheren Verhältnisse (contra Pelseneer). Die gesonderten Geschlechtswege der Chitonen dürten wohl so entstanden sein, dass sie ursprünglich von der Keimdrüse ausgingen und bis ans Epithel reichten, worauf sich an den Enden ektodermaler Urüsenbelag hinzugesellte.

Als .. die ältesten Gastropoden " sieht Thiele die \%ygobranchien mit Spiralschale an, zumal die beiden Gattungen Pleurotomaria und Haliotis (auch Haliotis mit dem abweichenden schalenmuskel und ohne Operculum? Srth.). Tie freie Nackenkieme der Acmaeiden betrachtet er als Neuerwerbung. Ihr ähnlich ist auffallenderweise die Kieme der Neritiden beschatfen (man kann wohl Taliata hinzufügen, Srth.). Die grosse Entwicklung des Epipodiums bei Haliotis beweist, dass hier ein altererbtes Organ vor- 
liegt, auf das der Vert. nun besonders eingeht. Die Bezugnahme auf alle die vereinzelten Sinnesstreifen und ihre Innervierung lässt sich im Auszug kaum referieren. Der Mangel des subpallialen Sinnesorgans spricht den Acmaeiden eine abgeleitete Stellung zu gegenüber den Patellide n, die es haben. Die Angenbecher der Patelliden sind schon reduziert gegenüber denen ron Haliotis, da sie unter der Schale liegen, die Riiickbildung ist vollständig bei den Lepetiden, Cryptobranchic alba liat an ilirer Stelle bloss ein Paar enger pigmentloser Epitheleinstiilpungen. Das Subradularorgan von Chiton und Dentalium fehlt allen Gastropoden, wenngleich die entsprechenden Nerven aus den I abialganglien bei Hatiotis, Emarginula und Docoglossen rorkommen. Von den l'edalsträngen gehen ventral die Fussnerven aus, die sich iiber der Sohle verzweigen, dorsal die zalılreichen Epipodialnerven, ausserdem aher, worauf besonders Wert gelegt wird, viele dorsalwärts gerichtete Nerven, die im mittlern Teile den Spindelmuskel, weiter hinten den dorsalen Teil des Fusses innervieren, also Organe, die iiber dem Epipodium gelegen sind. Man hat anzunehmen, dass die Cerebropedalkonnektive ursprünglich die einzigen Verbindungen der Cerebral- und Pedalganglien waren wie bei den ('hitonen; die C'erebropleuralkonnektive sind erst später entstanden. Haliotis hat noch ein sehr primitives, aus einem reichen Gettecht gangliöser Stränge bestehendes Epipodialnervensystem, das sich wie bei andern zuriickbildet.

Die ältesten Gastropoden sollen jederseits einen Komplex von Muskeln zwischen Schale und Fuss gehabt haben, von denen der linke allmählich rückgebildet ist, - also kein einheitlicher Spindelmuskel. (Musste nicht bei der Torsion viehmehr ein einheitlicher Muskel um die Spindel gewissernassen zusammengeknebelt werden, so dass die Verhältnisse von Haliotis u. a. durch halbe Sessilität in der Brandung, oder, wie bei Neritiden in Hiessendem Wasser sekundär zu erklären sind? Srth).

In der Iundhöhle rerschiedene Sinnesepithelien. Die Subradularnerven verlanfen auf der Dorsalseite des Subradularsacks. Ein Sublingualsack bei Docoglossen ist von Willcox ebenso fälsclılich als Subradularorgan gedeutet, wie es frïher von $\mathrm{Haller}$ bei Gastropoden beschrieben wurde. Es handelt sich vielmehr um allerlei Furchen und Wülste in wechselnder Ausbildung bei den verschiedenen Formen, die in ihrem Lesatz mit glatter oder gezähnter Cuticula eine Art Ergänzung zur Radula bilden und diese beim Abschaben der Nahrung von den Uferfelsen unterstützen. bei Patelliden mehr nach Art eines Baggers, bei Acmaeiden nach Art einer Raspel. Ähnlich diurfte der rudimentäre Kiefer der Neritiden wirken, er 
besteht aus einer seitlichen Cuticula, die \%. T. zahlreiche kleine Zälne trägt, mit nach innen gerichteten Spitzen; sie mögen dem 'liere dazu dienen, Nahrungsteile festzuhalten und mit Hilfe der Radula ins Innere zu befördern. Andere Bemerkungen sind dem Vergleiche der Kieferstrukturen gewidmet, ebenso der Radula. Die rerschiedenen accessorischen Zungenknorpel sind Sondererwerbungen der einzelnen Familien und nicht, wie Amaudrut glaubt, homolog. Bei Acinaeiden und Lepetiden ist den $\mathrm{Patellen}$ gegenüber eine starke Konzentration eingetreten. Den Ausgangspunkt der ganzen Reihe soll auch hier wieder Hatiotis bilden.

Die von $\mathrm{H}$ aller und Amandrut beschriebenen Speicheldrïsen der Neritiden. die zwischen Magen und Kropf liegen sollen, münden ganz anders, als die Autoren angaben, nämlich an der Ventralseite, dem Deckel gegenüber. Thiele nimmt an, dass sie beim Aufbau des Operculums beteiligt sind, und nennt sie Deckeldrüsen. Die Grenze des ektodermalen Vorderdarms gegen den entodermalen Mitteldarm wird durch das hohe Epithel unter den zungenförmigen Klappen bezeichnet. (Ich habe auf dem letzten Zoologenkongress eine andere Ansicht vorgetragen. Srth.).

Das Herz der Patelliden in seiner verschobenen lage sucht T'hiele von den symmetrischen Verhältnissen der Fissurelliden abzuleiten.

Die Ungleichheit der Haliotis-Nieren erklärt sich aus der verschiedenen Beziehung zu den Nachbarorganen; die rechte stösst überall an Eingeweide, zwischen die hinein sie sich ausdehnt; die linke, zwischen Pericard und Mantehöhle eingeschlossen, kann die Vergrösserung nur durch innere Vorsprünge erreichen und wird zum Papillarsack.

Fissurelliden und Docoglossen sind von Formen abzuleiten. bei denen bereits die rechte Niere das Übergewicht hatte. Die weitere Umbildung wird bei einzelnen weiter verfolgt.

Bei den monobranchen Rhipidoglossen überwiegt umgekehrt die linke Niere. Die rechte verkümmert immer mehr. Doch sind die Beziehungen zwischen der einzigen Taenioglossenniere und denen der Rhipidoglossen noch dunkel; wesentlich ist, dass hereits Trochus cinerarius an der linken Niere eine deutliche Nephridialdrüse hat, ähnlich der ron Littorina und Natica; daher die Homologie dieser Niere als sicher gelten kann.

Das Schicksal der rechten Niere blieb zn untersuchen. Sie tritt bei Trochiden, bei Pleurotomaria, bei F issurelliden und Docoglossen bekanntlich in Beziehung zur Keimdrüse, bei der ersteren steht der Oridukt durch den Endteil der Niere mit einem ektoder- 
malen Drüsengang. wohl einer Schalendriise, in Verbindung, und mündet dadurch erst nach aussen. Nun hat Thiele die Genitalwegt: verschiedener Neritiden, Nerita, Naricella und Scutellina, untersucht und ist zu höchst interessanten Resultaten gekommen. Das Wesentliche kommt darauf hinaus. dass der urspriingliche weibliche Geschlechtsgang, mit Eiweiss- und Schalendrüse ausgestattet. für sich mïndet, dass er aber durch einen Verbindungsgang mit der rechten Niere verbunden ist, welche eine neue äussere Öffnung erhalten hat und als Receptaculum seminis dient. In männlichen Geschlecht geht sie einfach verloren; hier hat der Samenleiter seinen entsprechenden Drüsenbesatz; das Sperma wird dann auf der Aussenseite des Leihes durch Flimmerung zum Penis geleitet, so weit er rorhanden ist. Die gewölnnliche Anschaunng, wonach die rechte Niere zu dem Geschlechtsorgan geworden sein soll, ist dahin zu korrigieren, dass sie bloss als Receptaculum einen Anhangsteil zu ihm darstellt. (So sehr ich dieser Ableitung zustimmen muss, so scheint mir doch der Vert. selbst damit in Widerspruch zu stehen, insofern er schon beim noch ungedrehten Trgastropod die Geschlechtswege durch die Niere münden lässt, s. u. Srth.). Bei verschiedenen Neritiden liegt in der Mantelhöhle eine lappige Inüse unbekannter liunktion, die ler Lage nach als Hypobranchialdrüse bezeichnet wird. Thieles Deutungen stiitzen sich auf die Histologie der verschiedenen Abschinitte.

Ha llers Darstellung der Neritenu iere wird korrigiert. Bei Naricella hat der Renopericardialgang ein Epithel mit besonders starken Geisseln und, wie es scheint, muskulös kontraktilem \%ellplasma. Fine sekundäl'e Leibeshöhle existiert nirgends, contra Haller. Von den Verhältuissen, die das erweiterte Pericarlium ron Naricella zeigt, kann man leicht zu denen der Cejhalopoden kommen. Deren "Leibeshöhle“ ist durch starke Erweiterung des Herzbeutels und Verschnnelzung desselben mit den inneren Teilen der Geschlechtswege entstanden zu denken.

Der "Vergleich zwischen Gastropoden und Chitonen* (meiner Meinung zu stark auf Maliotis gestiutzt, Srth.) stellt folgrende Punkte in den Vordergrund:

Nur die schmale Mantelkante der ('hitonen entspricht dem Mantelrande der Sclinecken.

Dem Epipodium entspricht das Notaeum, beide gehen auf den liopf iiber, beide haben gleiche Sinnesorgane, die Seitenorgane von Haliotis und Lepidoplemus. Das epipodiale Nervensystem entspricht vollkommen den Lateralsträngen der Chitonen. Auch die Kiemenarterie zeigt ähnliche Feziehungen zum Gefässsystem des Fusses. 
Der Deckel der Schnecken ist erst nach der Drehung entstanden.

Deren Schale war antangs rundlich, daher sie nicht, wie die längliche der Chitonen, sich gliedern konnte, hinten mit zwei Lappen, wenig verkalkt. U'm diese Unterschiede auszudrücken, schlägt Thiele den Namen Test a für alle Holluskenschalen ror, den Namen Concha für alle mit Ausnahme der Chitonen, - entsprechend Testacea und Conchifera.

Kiemen und Kiemenhöhle sind nicht homolog. Die Urform hatte wahrscheinlich noch keine Ctenidien.

Die Tentakel sind erst bei den Gastropoden entstanden, sie sind am Kopf und Epipodium gleichwertig.

I) larvalen Chitonangen sind wohl den Haliotis-Augen lomolog, einige Lepidopleuren scheinen noch an den Zipfeh der Kopffalte in erwachsenem Zustande Reste zu haben als kleine Einstiilpungen, in deren Grunde die Zellen etwas pigmentiert sind.

Die Kopfialte ist vorn das älteste Sinnesorgan.

Homologa der Osphradien von Gastropoden haben die Chitonen nicht (contra Plate), ebenso fehlt die Hypobranchialdrüse.

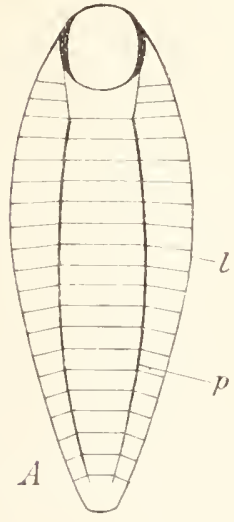

Fig. 1. Schema des Nervensystems (ohne die Buccalganglien). A von Chiton, B von der Urconchifere. l Lateralstränge, p Pedalstränge, $\checkmark$ Visceralkommissur.

Die Otocysten sind erst ron Conchiferen erworben. In der Kopfmuskulatur ron Haliotis scheinen die vier Schichten der Solenogastrenhaut erhalten.

Von der ausführlichen Vergleichung der Nerven bemerke ich. dass die Mantelnerven von Haliotis als vordere dorsale Nerven von den Pedalsträngen gelten sollen. Neu ist die Visceralkommissur der Gastropoden, bedingt durch die Entstehung der Ctenidien und der sie deckenden Mantel - Lappen.

Über den Ort der Abzweigung geben am besten die vergleichenden Figuren Anfschluss, die ich hier reproduziere.

Die Radula der Rhipidoglossen ist die primitivste.

Chitonen haben nur Buccal-, noch keine Speicheldrüsen.

Im Gefäisssystem stimmen die neuralen Fussarterien, Kiemenarterie von Chiton und Epipodialgefäss von Haliotis, mediane Fussgefässe 
und Eingeweidehöhle überein; Eingeweidearterien dagegen, Mantel-, Nieren- und Kiemengefässe sind verschieden.

Das Urogenitalsystem wird wieder am besten durch die beigegebene Textfigur erläutert. Bei den Chitonen ursprünglich doppelte Keimdrüsen, bei den Gastropoden hat sich die anfangs rechte zurückgebildet (war eine zweite vorhanden? Alle Welt nimmt es an, ohne jeden Beweis. Schon bei Turbellarien kommit Verschmelzung in der Mittellinie vor. Srth.). Die Mündungen ergeben sich von selbst.

Als "die primitivsten Lamellibranchien" haben nicht nur die $\mathrm{Nuculiden}$ zu gelten, sondern in vieler Hinsicht noch mehr die A r c i d en, wiewohl die einzelnen Charaktere vielfach in ihrer Ausbildung durcheinandergehen (wie iiberall, Srth.). Die zahlreichen einzelnen Korrekturen, die auf Pelseneers, Stempells, Grobbens Angaben bezug haben, übergehe ich, unn nur die Schlussresultate des Abschnittes zu geben. Die Ausgangsform ist ein breites, flaches Tier mit gerader Dorsallinie, äusserm Ligament, das als unverkalkter Teil des Ostracums zu gelten hat, und taxodontem Schloss, dorsal
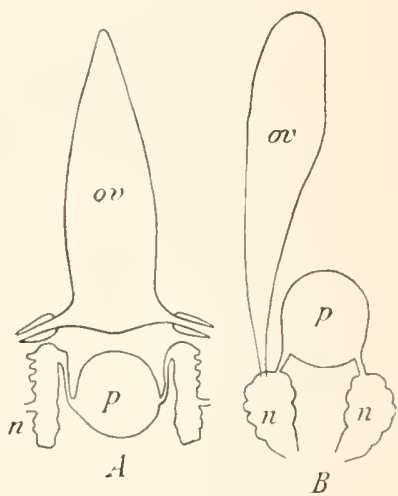

Fig. 2. Urogenitaltystem. A von Chitonen, $\mathrm{B}$ voln Urgastropod. n Nephridium, ov Gonade, p Fericardium. vorn rundlich, hinten zugespitzt, mit einer Kiemenkante, wie bei Arca, deren Schale nach verschiedenen Arten, nach den Hilfsbändern des Ligaments usw. ausfülırlich beschrieben wird. Die Wirbel wölben sich ïber den Geschlechtsdrüsen auf. Der Mantel ist ganz offen, am Rande mit drei Falten, von denen eine für das Ostracum da ist, die andern das l'eriostracum zwischen sich nehmen, wie bei Arcu, doch ohne besondere Sinneswerkzenge.

Die Fusssohle zeigte eine vordere Fussdrüse, eine Mucusdrüse dahinter. dann eine visköse (Byssus-) Drïse und hinten noch eine muköse Drüse; sie war noch zum Kriechen verwendbar, doch hauptsächlich zur Anheftung an fester Unterlage. Die Kiemen mögen ähnlich gewesen sein wie bei Nucula, und die Mundlappen, wie diese, einen Anhang gehabt haben, mit einer Rinne, in die sich die Kiemenenden legen, um ein Rohr zu bilden, das die Nahrung dem Munde zuführt. Yon Sinneswerkzengen waren ausser diesem Anhang rorhanden: ein Paar . adorale" Sinnesorgane, ein Paar Otokrypten, ein Paar Augenrudimente, für deren Vorkommen neue Fälle angegeben werden, ein Paar Osphradien und ein Paar abdominale Sinnesorgane. 
Die Konnektive zu den Pedalganglien waren vorn gespalten. Fine Labialkommissur fehlte (contra Pelseneer). Die Muskulatur war wohl ähnlich wie bei Arca, ein schwächerer vorderer, ein stärkerer hinterer Fussretraktor, dariuber Muskelschichten. Der Vorderdarm zeigt eine Andeutung zweier Seitentaschen, der Magen erhält das Lebersekret durch zwei sehr kurze, weite Gïnge, der Hinterdarm war in eine ventrale Schlinge gelegt. Die Urogenitalorgane waren einschliesshch der Pericardien rollkommen paarig. die Kiemendrïsen münden unmittelbar vor den Nierengängen aus und die I'e ricardialgänge mit diesen zusammen, also nicht in die Niere selbst. I) Nieren sind Säcke mit gefalteten Wänden und vorderen Mündungen. In jedem Pericardium liegt ein Herz. das nur als muskulöser Teil des arteriellen Gefässsystems aufgefasst werlen darf; der Vorhof liegt seitlich, die Kammer median; jeder Aortenstamm teilt sich in einen vordern und einen hintern Ast, von dem sich der erstere mit dem der Gegenseite üher dem Darm, der letztere unter ihm vereinigt, so dass um den Traktus ein Aortenriner gebildet wird.

Der .. Vergleich zwischen Gastropoden und Lamellibranchien" führt schliesslich zur Konstrulition einer Urform. Die primitive Concha war flach und rundlich mit zwei lappenförmigen Fortsätzen ïber den beiden Kiemen, noch wenig verkalkt und biegsam, wohl perlmuttern. Die Lappen entsprechen der hintern Hälfte der Muschelschale. Ein vorderer schmaler Mantelrand verbreitert sich mit der Zunahme der Kiemen nach rorn. Alduktoren, aus dem Hantmuskelschlauche gebildet, teilten die schale in zwei Kkappen. Der Mautel der Lamellilranchien ist also nicht, wie Thiele früher meinte, der Summe ron Mlantel und Epipodium gleich. das Epipodium fehlt. Die Kiemen der Schnecken und Muschehn sind homolog, wenn auch die Art der Blutzufuhr bei den Xuculiden noch strittig ist, nach den Angaben ron Pelseneer, I) rew u. a. Der hintere Teil des Muschelkörper's ist durch den Schalenmuskel vergrössert. Die Kopffalte von Huliotis ist homolog den vordern Mundlappen, auf deren Enden bei Area die Augen liegen. Die Mundtentakel der Tuculiden entsprechen wohl den Tentakeln der Haliotis. Verschwunden ist die Schnauze mit dem ektodermalen Anteil des Schlundes und der Buccalganglien, infolge veränderter festsitzender Lebensweise (ich laabe mehr an den Aufenthalt im Schlamm gedacht. Srth). Das obere Schlundganglion der Muscheln ist Cerebropleuralganglion, wobei der cerebrale Teil in der Mitte liegt. Die hintern Ganglien in der Visceralkommissur der Muscheh entsprechen, bis in ihre (iliederung, den gangliösen Einlagerungen bei Haliotis. Die gangliösen Einlagerungen, die Babor bei Dreissensin als Parietalganglion deutete, sind spätere 
Erwerbungen. Der Hautmuskelschlauch besteht bei beiden an manchen Stellen noch aus vier Schichten. Die Fussdruisen von Haliotis geben den Ausgangspunkt für die Byssusdrüsen der Lamellibranchien. Wahrscheinlich sind auch die Hypobranchialdrüsen von Nucula und Haliotis homolog. Die paarigen, seitlich gelagerten Gonaden von Arca entsprechen den ursprünglichen Verhältnissen, abgesehen von der gesonderten Ausmündung, neben welcher auch die Nierenpori nach vorn gerückt sind. Endlich entsprechen sich die renösen Teile des Kreislaufes.

Hiernach wird die folgende Urconchifere, wie Thiele statt Prorhipidoglossum sagt, konstruiert:

Der Körper niedrig und breit, mit Kiriech- und Saugsohle, mit dünner, völlig Hacher, länglicher Perlmuttersehale mit linterm Einschnitt, die Kopf und Seitenränder freiliess. Der Mantel vorı und seitlich sehr schmal, nur linten mit zwei Lappen über den gefiederten Kiemen. Die lussdrüsen wie bei Haliotis. nur die vordere stärker entwickelt. Von Sinneswerkzeugen eil l'aar becherförmige Augen und eine Kopffalte dazwischen, zahlreiche Taster an den Seitenrändern, der vorderste neben den Augen, zahhreiche, auf den Seitenteilen des Körpers zerstreute Simneshiugel, ein Paar Sinnesstreiten über dem Vas efferens als Osphradien, vermutlich ein Paar abdominale Sinneshügel neben dem After, vielleicht auch vorn unter dem Nantel ein subpallialer Sinnesstreifen, ein Paar Otokrypten, unter der Radula ein subradulares Sinnesorgan. Neben den Kiemen eine Hypobranchialdrïse. Der vierschichtige Hautmuskelschlauch bildete sich unter der Schale und im Fusse zurück. Das Nervensystem ähnlich dem ron Haliotis. Die Mundöffnung an Ende eines kurzen Rïssels. Kuřer Lippenteil. Weite Mundhöhle mit Radula, Zungenknorpeln, Kiefer und zwei drüsigen Säcken. Die Radulaplatten noch gleichförmig. Entodermaler Vorderdarm mit zwei drüsigen Säcken (Kropf), Magen mit paariger Leber und hinterm Blindsack. Der Enddarm bildet eine ventrale, nach vorn gerichtete Schlinge, mit zwei ventralen Längswïlsten im Innern. After zwischen den Kiemen. Wohl kein ektodermaler Enddarm. Urogenitalorgane lateral vom Darm; die lappigen Gonaden neben der Leber', die Ausführgänge führen in die Nieren. Keine Begattungswerkzeuge. Jedes Pericardium mit Renopericardialgang zum vorderen Nierenende, z. T. mit exkretorischem Epitliel. Nieren sackförmig, mit gefalteter Wandung, Mündung nahe dem After zwischen den Kiemen. Jedes Pericard mit Kammer und seitlicher Vorkammer, vordere und hintere Aorta jederseits, weiterhin vereinigt. Die vordere rersorgt den ganzen Körper mit Ausnahme der hintern Mantellappen. Das Blut sammelt sich in einem Venensinus und geht 
durch die Nieren zu den Kiemen, deren zuführendes Gefäss ventral vom abführenden verläuft. (Ich frage gegenüber allen diesen Konstruktionen, namentlich bei derartiger Detaillierung: worin liegt der Beweis, dass eine solche Abstraktion je gelebt hat? Hier spuken Adam und Eva nach, oder etwa die künstlichen Konstruktionen von Atomen und Molekülen. Jene Merkmale brauchen keinesfalls in einer einzigen Tierform rereinigt gewesen zu sein. Ganze Faunen, d. h. Tiergruppen haben sich verändert. Die Rechnung, die eine Klasse auf eine Stammart zurückführen will. muss stets trïgen. Srth.).

Von der Urconchifere werden einerseits die scaphopoden abgeleitet, wobei als neu im Fuss von Cadulus ein Hohlraum, wohl eine Byssushöhle, beschrieben wird.

Der Cephalopodentrichter entspricht der Sohle. nicht Epipodien, contra Pelseneer, die Arme sind Neubildungen vom Fuss aus. (Ich branche wohl nicht zu erwähnen, dass ich mich neuerdings auf der Giessener V'ersammlung der deutschen zoolog. Ges. über die Herleitung der Cephalopoden ganz ander's ausgesprochen habe). Der Zusammenhang zwischen Gonade und Pericard ist nicht primitiv, sondern sekundär erworben. Die Kiemen sind Ctenidien. das zweite Paar von Nautilus beruht anf Neubildung. Ein näherer Zusammenhang existiert nur mit der Urconchifere, nicht mit Chiton.

Um "die Beziehungen der Chitonen zur Urconchifere* aufzuklären, wird als gemeinsamer Ausgangspunkt das Urmollusk konstruiert (ein neues l'latosches Bild, strth.). Beide Wege von hier aus werden geschildert, der zu den Chitonen sowie der zur Urconchifere. Dabei wird überall ein wesentlicher Unterschied gemacht zwischen den mit Sicherheit und den mit Wahrscheinlichkeit durchlaufenen lypothetischen İbergangsstufen, als ob irgendwo sicherheit bestände. Wir haben hier ein Huster vergleichend anatomisch phylogenetischer Methode in scharfer Konsequenz (Srth.). Ich will wenigstens rom Urmollusk Wesentliches herausgreifen. Dorsal ganz Hach, unten Kriechsohle, vorn Kopf mit Falte und Becheraugen. hinten Analregion, wahrscheinlich mit respiratorischen Fältchen. Tollständiger, vierschichtiger Hautmuskelschlauch, nur über der Sohle unterbrochen; von ihr zogen zahlreiche Transversalmuskeln zum Iä̈cken empor, der Darmtrakt ruhte auf einer Reihe ventraler Quermuskeln. Nervensystem ganz gangliös, Schlundring. zwei Paar Buccal- und ein Paar Subradularganglien etc. "Von Fussdrüsen war eine vordere mit einer Einstülpung und zahlreiche Schleindrüsenzellen im Epithel vorhanden, 
und zwar muköse am Vorderrand, visköse im grössten Teile der Sohle. “1) Keimdrüsen getrennt geschlechtlich.

Die ,Bezielıungen der Solenogastren zum Ermollusk“ erfordern abermals eine hypothetische Lrform zwischen beiden. Diese Ausgangsform wird in folgender Weise angedeutet.

Ein flaches, scheibenförmiges Tier mit dorsaler Cuticula, aus welcher vielleicht stacheln hervorragten, ventral mit Flimmerepithel, ohne Trennung ron Kopf und Fuss, doch mit einer an Drüsenzellen reichen Fusssohle. Cm die Mundötfnung eine lunfeisenförmige Sinnesfalte, um die Analöffnung wohl strahlige, respiratorische Fältchen. Augen zweifelhaft. Körperwand sensibel, darunter vielleicht Sinneshügel. Vierschichtiger Hautmuskelschlauch, zahlreiche Transversalmuskeln zwischen den Säcken des Mitteldarms, ventrale Quermuskeln. Pauriges, oberes Schlundganglion, zwei Buccalganglien, zwei Paar Längsnervenstämme, dazwischen gangliöser Plexus. Torderdarm vielleicht schon vorstülpbar. Einfachste Radula. Der Vorderdarm mündet von unten in den Mitteldarm. Seitliche Zwitterdrïsen, Säcke mit Längsgängen, die sich hinten zum Iterus erweitern; Endteil = Schalendrise. Ton den Kiemenfältchen je ein Blutgefäs zum Hirn, Fxkretionsorgane fehlten vielleicht (wahrscheinlich nicht, srth.).

Daraus haben sich die Solen og a stren durch veränderte Lebensweise entwickelt (ich habe sie wohl znerst so erklärt, Srth.).

Der Abschnitt über verwandtschattliche Beziehungen der Solenogastren zu den . W ̈̈rmern" bringt ausser weitgelıenden, gedrängten Erörterungen nicht wenige eigene Beobachtungen über Polychaeten, die ich nur kur\% berühren kann. Die Stammform der Solenogastren und Mollusken weist auf die Turbellarien hin, speziell auf die Polycladen. Die Blutgefässe mögen im Zusammenhange mit den Kiemen entstanden sein, liese als Folge der Cuticula. Das Blut wird zunächst zu den sauerstoffbedürftigen Organen gebracht, zum Hirn und wohl zu den Gonaden. Pharynx und Darm sind leicht aufeinander zu beziehen, vielleicht auch die Kopulationsorgane. Ob Solenogastren noch Protonephridien haben, mag bei der schwierigen Erkennung auf Schnitten noch zweifelhaft sein. Die Sinnesfalte entspricht den Randtentakeln. Der Hautmuskelschlauch ist gleich, das Nervensystem sehr ähnlich. Die Sohle ist nicht aus dem Saugnapf entstanden, sondern aus der Bauchfläche vor den Geschlechtsorganen. Das parenchymatöse Gewebe hat sich grossenteils

1) Wie kann man von der Beschaffenheit der einzelnen Drüsen etwas aussagen wollen? Amalia marginata hat z. B. auf dem ganzen Körper firnisartiges, zäh fadenziehendes, „visköses" Sekret, Am. gagates klaren Schleim. Srth. 
in Blut umgewandeit durch Verflüssigung der Intercellularsubstanz. Vielleicht sind die Rhabditen der Turbellarien zu Stacheln geworden.

Die Nemertinen zeigen mit der $/$ wischenform zwischen len l'urbellarien und der Stammform von Solenogastren und Crmollusken einige Übereinstimmung, haben aber den liüssel für sich und stehen durch die Trennung der Keimdrüsen und des Geschlechtes höher.

Die Gastrotrichen stehen durch die dorsalen Cuticulargebilde nahe, sind aber vereinfaclit und rïckgebildet.

Die Rotatorien stehen nicht ganz so nahe: sie sind an eine voribergehend testsitzende Lehensweise angepasst. Nicht sessile Formen sind sekundär modifiziert, besonders Hexurthra und Trochosphaera. Die 'Trochophora ist scharf von Trochosphaera zu trennen, schon wegelı ganz verschiedener Lage des zentralen Nervensystems und der sinnesorgane. Die Rotiferen stehen bereits hoch und fül sicls, mit Gastrotrichen zusammen von einer iiber den Turbellarien stehenden Ansgangsform abgezweigt.

Auch die Nematoden leiten sich von ähnlichen Tiortornen ab, wie solenogastren und Gastrotrichen. Die Ventraldrüse der Meeresnematoden entspricht vielleicht der Drïse in der Bauchgrube von Neomenia.

Betreff's der' Anneliden wendet sich 'Thiele zunächst in ausführlicher Begrïndung gregen die anch von ilun früher vertretene Ansicht, dass das Cölon mit dem Nephridialapparat dem Urogenitalsystem entspricht. Vielmehr sind die zunächst unter dem Endothel gelegenen Keimstofte durch dieses hindurch in den Hohlraum gelangt. Die Dissepimente entstanden aus Muskelı und Bändern zwischen den Darmsidcken. Die thimmernde Bauchfurche von Protodrilus und Serpuliden ist der der Solenogastren homolog. Die Dissepimente bewirken wohl die äussere Segmentierung, Parapodien etc., deren Borsten mögen mit den stacheln unserer Übergangsform und der Gastrotrichen auf dieselbe Anlage zurückgehen. Die Tentakel von Prototritus sind der Kopflalte homolog, ebenso die beiden dorsalen Tentakel ron Ophryotrocha. Die Cerebralcirren, als Äquivalent der Parapodialcirren, sind ebenso ein Derivat der Seitenlinie, wie die Kopftentakel der Gastropoden. Die Otocyten der Polychate $n$ sind denen der Mollusken dagegen nicht homolog. Im Hautmuskelschlauch der Anneliden sind bei der schlängelnden Bewegung die Längsmuskeln verstärkt, die diagonalen unterdrückt. Das Tervensystem von Polychaeten (Diopatra) und Solenogastren stimmt im ganzen überein. Die Untersuchung der Mundhöhle von Euniciden fïhrt zu einer Vergleichung des Kiefers mit der Radula. Der Hauptunterschied ist die starke Entwickelung des Kieferapparates 
bei den Anneliden; dadurch ist älnlich wie bei Mollusken der Pharynx auf Kosten des vordern Abschnittes sehr vergrössert, die Radula würde dem Oberkiefer entsprechen, über dessen blindsackförmigem Hinterende die Buccalkommissur verläuft. Die Segmentalorgane sind, wie oben erwälınt. ohne Homologon bei den Mollusken, deren Nieren aus den Geschlechtsorganen entstanden sind und nicht aus Protonephridien (wie passt letzteres zu dem Verhalten der Neritiden? Srth.). Die Gonaden der Anneliden haben ihre Ausführungen verloren. Paarige Aorten sind den Euniciden und dem Trmollusk gemein. Somit sind die I'olychäten der Zwischenform zwischen Turbellarien und Solenogastren ziemlich nahe verwandt. Auch die Gordiiden und Dimophilus stehen in der Nähe, die ersteren haben namentlich die weiblichen Genitalorgane sehr ähnlich denen der Neomeniu.

Das Schlusskapitel . die Phylogenie des Molluskenstamues" führt die Wurzel bis auf die C'tenophoren zurïck. Die Cydippiden sind dasjenige pliyletische Stadium, das den Flimmerlarven der lö̈heren Tiere entspricht. Cnidarier und Spongien sind von cydippenähnlichen Formen abgezweigt. Durch kriechende Lebensweise sind aus denselben die 'Turbellarien entstanden (meiner Meinung nach umgekeirt. Srth.). Die Acoelen sollen durch Verbindung mit Zoochlorellen rïclgelsildet sein (es existiert meines Wissens keine Tierform, die durch symbiose mit Algen regressiv beeinflusst würde, liadiolarien, In f́usorien, l'olypen, Schwämme, Anneliden. Srth.). Den Hauptstamm für weitere Verzweigung bilden die Polycladen. Ans Turbellarien hat sich weiter jene Gruppe von Würmern entwickelt, welche die Gastrotrichen und liotatorien, die Dinophiliden und Gordiiden, die Nematoden und Anneliden, endlich die Solenogastren unfasst. „Man kann sie alle von einer ausgestorbenen Form herleiten, welche durch den Besitz eines After's, eines zusammenlängenden Hohlraumes ron dem Mitteldarm durch Cutikularisierung des dorsalen Epithels, wenn auch walırscheinlich nicht in ganzer Ausdelınung, und veruutlich durch Stachelbildungen, besonders an den Seiten des Körpers, durch ein paar drüsige Zacken am Hinterende, vielleicht auch durch den Besitz zweier Längsgefässe, die in einigen der genannten Gruppen rückgebildet sein können, sich über den Kreis der Turbellarien erloben hatte." (Also ein neuer, noch grossartigerer, konstruktiver Sammeltypus. Wann und wo lebte er? Es kann sich doch nicht um eine Hiichtige, rergängliche Form gehandelt haben, sondern um eine konservative, zähe, die immer und immer wieder zur Verfügung stand für Weiterschöpfungen, wandelbar und zïh zugleich, ein Proteus, der nie existiert hat (Srth.). Erst iiber die Solenogastren hinaus 
wird der Schritt zum Urmollusk getan. Das nebenstehende Schema drückt die Verhältnisse aus. Ihre nähere Erörterung bringt naturgemäß neben neven Gesichtspunkten viele Wiederholungen, die sich also zum Referat nicht eignen. Yon der Flimmerlarve der Mollusken

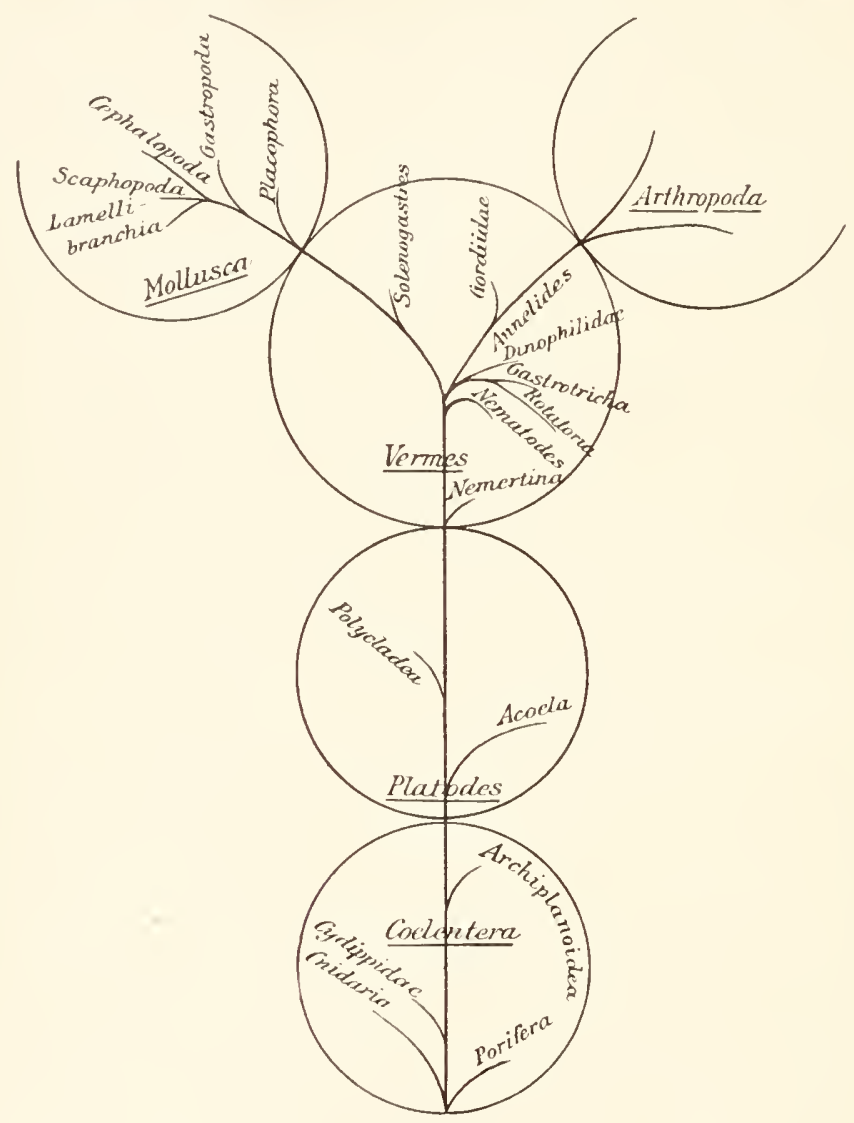

Fig. 3.

sagt Thiele, dass sie in der Hauptsache dem Ctenophorenstadium entspricht und dass besonders die Larvenniere dem Turbellarienstadium entnommen ist.

Nachdem sich Thiele nochmals gegen die Trochophoratheorie gewendet, präzisiert er die Stellung der Solenogastren dahin, dass sie eine mit Gordiiden und Anneliden nächst verwandte Gruppe von Würmern sind, welche durch die Beziehung, in welche der Uterus zum Herzen getreten ist, sowie durch Anfänge einer Radulabildung zu den Mollusken hinüberführen, unter denen die Chitoniden besonders durch die Erhaltung der Lateralstränge ihnen am nächsten stehen. 
Ich bemerke schliesslich, dass meine Einwürfe sich weit mehr gegen eine allgemein verbreitete Methode wenden, die auch ich lange genug befolgt habe, als gegen den Autor.

H. Si m roth (Leipzig-Gautzsch).

\section{Gastropoda.}

4 Nordenskiöl, Erland, Üb e r die Trockenzeitanpas sung eines Ancylus von Südamerika. In: Zool. Anz. 26. 1903. pag. $590-593$.

Im bolivianischen Chaco, wo die Flïsse von den Anden feinen Schlamm hinabbringen, bilden sich in der Regenzeit zahlreiche 'Tïmpel, die in der 'Trockenzeit austrocknen. Hier leben zwei Ancylus-Arten, die eine gehört wohl zı $A$. uncinatus Ancey, die andere zu A. moricaudi d'Orb. Diese letztere zeigt eine wunderbare Anpassung an die Trockenperiode. Der Mantel bildet nämlich von hinten her eine schwach nach :ussen rorgewölbte Verschlussplatte, welche die Mïndung so verengert, dass in höchster Steigerung nur noch vorn eine kleine Mïndung bleibt für Kopf und Fuss. Die Schale erscheint damn fast als eine Hach gedrïckte Riöhre mit umlaufender scharfer Kante. Die Verschlussplatte gleicht nicht etwa einem Winterdeckel von Helix pomatia, sondern scheint Schalenstruktur zu haben. Ganz kleine Tiere bilden die Verschlussplatte ebenso aus wie grosse. Nordenskiöld fragt nit Recht nach dem Schicksal der Platte während der nächsten Regenzeit. Hat die Schnecke die Fähigkeit, die sekundäre Platte wieder aufzulösen oder gehen die kleinen Tiere zu grunde? Der Umstand, dass grosse Schalen gefunden wurden mit einer deutlichen Zuwachslinie, wohl in mittlerer Höhe, also mit einer Unterbrechung des Wachstums, wird zu Gunsten der ersten Alternative gedeutet. Die sichere Entscheidung könnte indes nur durch Beobachtung während der Regenzeit gefunden werden, wozu der Verf. indes keine Gelegenheit hatte. - Mir scheint die Sache nicht nur biologisch höchst interessant. sondern auch systematisch. Gundlachia unterscheidet sich von Ancylus im wesentlichen durch ein horizontales halbmondförmiges Septum, das im hinteren Schalenumfang angebracht ist. Es liegt nahe, dieses auf eine solche Anpassung zu beziehen, d. h. auf den Rest einer Verschlussplatte, der Dauer erhalten hätte. Jedenfalls liegt hier ein Hinweis vor, wie vorsichtig man mit konstruktiven Deutungen, die in diesem Fall auf einem Teil einer früheren spiralschale hinauslaufen wïrden, sein muss.

H. Sim ot h (Leipzig-Gautzsch). 


\section{Tunicata.}

825 Herdman, W. A., 'Tunicata. In: Report on the Collect. of Nat. Hist. made in the antarctic regions during the voyage of the ,Southern Cross" 1902. pag. 190-200. Taf. $19-23$.

Das vorliegende Ascidienmaterial stammt zum grössten Teil von der Küste des Victoria-Landes. ungefähr vom $720 \mathrm{~s}$. Br. (Kap Adare) und enthielt 2 Arten Monascidien, 6 Synascidien und eine grössere Anzahl Kettentiere der Salpa ru." cinata-fusiformis. Vier zur Familie der Polycliniden gehörende Species werden als neu aufgeführt: Tylobranchion antarclicum, Polyclinum adarcanum, Psammaplidium nigrum, Ps. antarcticum. Auf der Challenger-Expedition war eine sehr eigenartige Synascidie aufgefunden worden, die $\mathrm{Herdman}$ infolge der ungünstigen Konservierung nicht sicher bestimmen konnte und unter der Bezeichnung - (?) ignolus anführte. Zahlreiche Bruchstücke dieser Ascidie, die der "Southern Cross" im antarktischen Meer fischte, ermöglichten jetzt die Gattungsbestimmung ais „Distaplia" (ignota), und Herdman ist der Ansicht, dass diese Species mit Calmans Julinia australis identisch ist. Bewahrheitet sich das, so müsste der letzte Gattungsname wieder eingezogen werden.

O. Seeliger (Rostock).

826 Salensky, W.. Etudes anatoniquessur les Appendiculaires. I. Oitoplema ianhoeffeni Lolmann. In: Mém. Acad. imp. sc.

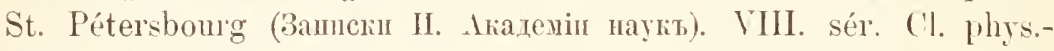
math. Yol. XIII. Nr. 7. 1903. (französisch). jag 1-44. 5 'Taf. 3 Textfig.

Die vom Verf. untersuchte Appendicularienart, welche im nördlichen Eismeere vorkommt, unterscheidet sich durch ihre Grösse (4 mu, der Schwanz $2.8 \mathrm{~mm}$ ) und durch bedeutende Interschiede im innern Bau. Die Absonderung der Schale geht in der Weise vor sicl, dass dieselbe sich gleich von den Sekretionszellen abhebt, worauf auch die entsprechenden \%ellen sich von den anliegenden lösen und nachher von den Nachbarzellen ersetzt werden. Die Buccaldrisen der Oiliopleura können als Prototyp der Haftgruben der Ascidienlarven angesehen werden. Die Appendicularien sind demnach, nach der Meinung des Verfs., der Urform nahestehend und haben sich erst später in festsitzende Tiere ungewandelt; das Vorhandensein der Buccaldrüsen bei ihnen weist auf eine Neigung zur festsitzenden Lebensweise hin, d. h. sich an Cregenstände am Meeresboden ron \%eit zu Zeit festzusetzen. Da Fritillaria und Kowalewskaja keine Buccalganglien haben, sieht Verf. Oikoplewra als die älteste dieser Formen an. Vom Nervensystem beschreibt Verf. nur das Kopfganglion. Links am Ganglion sitzt eine Sinnesblase, deren Lumen sich in das Ganglion fortsetzt: sie wird gewöhnlich als Gehörblase beschrieben, doch finden sich hier ausser einer Blase mit Otolithen, an der obern Wand ein sphärischer linsenförmiger Körper, unter dem sich eine Lamelle erstreckt, die V'erf. als perzipierenden Apparat ansieht, den Körper 
als Linse deutet und somit in dem ganzen Gebilde, trotz des Fehlens von Pigment, ein Auge sieht. Die Wimpergrube, die rechts vom Ganglion liegt, soll sich erst sekundär mit diesem verbunden haben. Sie ist ron bedeutender Grösse. Die basalen Zellen der Grube sind ron enornrer Grösse, die höher gelegenen Reilıen tragen sehr lange Wimperbïschel. Das ziemlich bedeutende Endostyl wird ausführlich beschrieben; ebenso die Zellen des Magens. Im letzteren findet Verf. vier Arten von Zellen: Zylindrische Schleimzellen, becherförmige Zellen, polyerlrische dunkelfarbige Zellen, zylindrische Zellen, in denen sekretorische Natur noch nicht sichtbar ist. Nach der Zahl der Zellen zu urteilen, wären die zylindrischen Schleimzellen mit den Hauptzellen der Fundusdrüsen der Vertebraten zu honologisieren, die dunkelfarbigen Zellen mit den Belegzellen. Die Cardioprocardialorgane bestehen aus zwei Säcken, die rom Pharynx mit gemeinsamem Rohre beginnen. Das rechte Procardium ist kleiner und bildet nach rechts eine membranöse Erweiterung - die rechte Procardialmembran, die das Rectum ventral und rechts umgibt. Das linke Procardium ist bedeutender und bildet nur eine unbedeutende Membran zum Magen zu, die aus kontraktilen Muskelfasern bestelrt. Ein Her\% im eigentlichen Sinne fellt damit der Oikoplenra, nur die kontraktile Wand des linken Procardiums wirkt bei der Zirkulation des Blutes zwischen den verschiedenen Organen mit. ist aber keine Pumpe, die das Blut durch ihre Hölrlung hindurch jagt. l)as Herz von Clarellina entwickelt sich nach E. ran Beneden und $J$ ulin, indem der Pharynx zwei Divertikel bildet - die Procardien. die siclı an ihren blinden Enden rereinigen und einen medianen Sack bilden, dieser Sack bildet den Beginn des Pericardiums, das durch eine Einstülpurg, wie bekaunt, das Her'z bildet. Die beiden P'rocardien der Oikopleura entsprechen den beiden genannten l'harynxdivertikeln. Ob die unpaarige Mündung der Procardien bei Oikopleura eine sekundäre oder primäre Erscheinung ist, lässt der V'erf. ungelöst. Bei Oikopleura bleibt die Entwicklung vor der Bildung des Pericardes stehen. Die Muskelschicht in der Wand des linken Procardiums hat dieselbe rentrale Lage, wie die Pericardialeinstülpung, die das Herz der Tunicaten bildet, und ist diesem homolog. - Im Ovarium findet Verf. ausser den Eizellen noch Zellen mit grossen Kernen ohne Chromosomen mit pseudopodienartigen Fortsätzen, in deren Protoplasna man netzförmige Verzweigungen sieht. Ton diesen Pseudopodien ungeben liegen die Eier, und werden nach Ansicht des Verfs. von ihnen ernährt, so dass diese Zellen hier dieselbe Rolle spielen, wie die Follikelzellen bei den Ascidien.

E. Schultz (St. Petersburg). 
827 Heine, P., Untersuchungen über den Bau und die Entwicklung des Herzens der Salpen und der Ciona intestinatis. In: Zeitschr. wiss. Zool. Bd. 73. 1902. pag. 429-495. Taf. $29-31$.

Im ersten Teil seiner Untersuchung giht der Verf. eine eingehende Darstellung des anatomischen und histologischen Baues des Salpenherzens. Untersucht wurden die Solitär- und Kettenformen der Salpa africana-maxima, S. mucinata-fusiformis, S. democraticamucronata und Kettentiere der S. bicaudata. Bekanntlich bestehen überall bei Salpen und Ascidien die Wandungen des zentralen Gefässapparates aus einem äussern flachen Pericardialblatt und dem innern Myocard. Die spindelförmigen Herzmuskelzellen und die Fibrillen des Myocards verlaufen, wie es scheint bei allen Salpen, quer zur Längsachse des Herzens. Die peristaltischen Kontraktionswellen, die von hinten nach vorn zu oder in umgekehrter Richtung über das Herz hinweglaufen, kommen also dadurch zu stande, dass die vordern und hintern Muskelzellen und Fibrillen nicht gleiclızeitig, sondern nacheinander sich liontrahieren. Bei den meisten untersuchten Formen fand der Verf. ein deutliches endotheliales Endocard, das sich allerdings nur auf bestimmten Strecken an der Innenseite des Myocards ausbreitete.

Der zweite Abschnitt behandelt das Ciona-Herz. Im Gegensatz $z u$ den Salpen verlaufen die F̈̈brillen im Myocard in der Längsrichtung des Herzens von dem einen Ostium gegen das andere zu, ohne allerdings durch die ganze Länge der Muskelwand sich hindurch zu erstrecken. Immerhin ist es bemerkenswert, dass trotz dieser Verschiedenheit die Art und Weise der Herztätigkeit bei Ascidien und salpen im wesentlichen die gleiche zu sein scheint. Ein besonderes Herzendothel konnte bei Ciona nicht nachgewiesen werden. Ein im Pericardialraum bereits von frühern Autoren beobachteter „weisslicher Körper" wurde vom Verf. auf Grund gewisser listologischer Eigentümlichkeiten als drüsiges Organ, "P'ericardialdrüse“, in Anspruch genommen.

In einem dritten Abschnitt beschreibt der Terf. die Entwicklung des Herzens im Embryo der Salpa democratica. Die erste Anlage, die zur Beobachtung kam, war ein kleiner Zellhaufen, der in seinem Zentrum ein winziges Lumen, die Pericardialhöhle, erkennen liess. Das Gebilde stand einerseits mit dem Entoderm, andererseits mit dem Mesoderm in engstem Zusammenhang. so dass eine sichere Entscheidung, welchem Keimblatt die Herzanlage entstammt, nicht möglich war. Die weitere I'mbildung des Bläschens zu einem doppelwandigen 
Sack und die Differenzierung in Herz und Pericardialschlauch vollziehen sich in bekannter Weise.

O. Seeliger (Rostock).

\section{Vertebrata.}

828 Steinach und Kahn, Echte Contractilität und motorische Innervation der Blutcapillaren. In: Pfliigers Arch. ges. Physiol. Bd. 97. 1903. pag. 105-133. Taf. II.

Die bisherigen Anschanungen über die Teränderungen im Kaliber der Blutkapillaren stïtzen sich wesentlich auf die Untersuchungen von Stricker und Biedl, velche zu dem Resultat gekommen waren, dass die Verengung des Lumens durch Verbreiterung der Wand, die Erweiterung durch Dünnerwerden der Wand bewirkt wïrde, ein Vorgang, der also auf einer Zellvergrösserung beruht und etwas wesentlich anderes ist, wie eine ,aktive Kontraktion der Kapillaren", unter welchem Namen sich die Erscheinung in der Literatur eingebiirgert hat.

Die Verff. haben nun an besonders günstigen Objekten, an der Nickhaut, an der Membrana perioesophagealis des Frosches und am Onentum junger Katzen und Neerschweinchen den Vorgang der Kaliberveränderung der Krapillaren verfolgt, und sind zu Resultaten gelangt, die der alten Anschaung durchaus widersprechen.

Nach ihrer Darstellung, die auf umsichtig angeordneten Versuchen basiert ist. kommt es bei jeder Kontraktion einer Kapillare zn einer auffälligen Verkleinerung nicht bloss der Lichtung, sondern des Gesamtquerschnittes. Diese Reduktion des Querschnittes kann bei maximaler Kontraktion zu völliger Aufhebung des Lumens führen, die Kapillare wirl zu einem Strang. Bei der Zusammenziehung entstehen, der Längsachse der Kíapillare entsprechend, feine Falten oder liunzeln der Zellhant, welche beim Aneinanderrïcken der Kapillarwandung an Zahl, Deutlichkeit und Ausdehnung zunehmen, bei Dilatation des Gefässes wieder vollkommen rerstreichen. Es ist dies der Beweis für die Existenz einer ecliten Kontraktilität der Kapillar rand, die ihren sitz in Ciebilden haben muss, welche die Kapillarwand ringförmig umgeben, analog der Anordnung der glatten Muskelfasern an den grossen Gefässen. Solche Grebilde sind nun in der Tat histologisch nachgewiesen. Schon 1873 wurden sie von Rouget beschrieben, aber die Beobachtung wurde der Vergessenheit erst entrissen als S. Mayer 1902 die Gebilde wieder auffand. Nach der Darstellung dieser Forscher ermangeln die Kapillaren durchaus nicht der glatten Muskulatur, die den Gefüssen so allgemein zukommt, sondern sie werden von Zellen umsponnen, deren Kerne in der Längsachse der Kapillare liegen, und 
deren Zellsubstanz senkrecht rom Kern ausstrahlend feine Fädchen entsendet, die, sich öfters teilend, das Gefässröhrchen „wie Fassreifen" umspannen. Die Abbildung Rougets haben Steinach und Kí h h reprodnziert, und sie stehen nicht an, den beschriebenen Zellen die Rolle einer Kapillar-Muskulatur zuzusprechen.

Den Schluss der interessanten Arbeit bildet der Nachweis der motorischen Innervation der Kapillaren. Es gelang die Verengung des Lumens durch Reizung vom Grenzstrang des Sympathicus ans zu erhalten, wobei die Beobachtung zu machen war, dass die kontraktilen Kapillarwandzellen bei indirekter Reizung träger ansprechen als die Muskelfasern der grössern Gefässe, während bei direkter Reizung das Latenzstadium für beide etwa dasselbe ist ( $1-3$ Sekunden).

A. Piit ter (Göttingen).

\section{Amphibia.}

829 Königstein, Hans, Die Funktion der Muskulatur in der Amphibienlunge. I. Anatomischer Teil. In: Pfliigers Arch. f. Pliysiol. Bd. 95. Heft 11 12. 1903. pag. 616-624. Taf. III.

Verf. hat die Menge, Anordnung und Verlaufsrichtung der glatten Inskelfasern in der Lunge von verschiedenen Amphibien, namentlich von Cryptobranches japonicus untersucht, nm darauf Schlïsse iiber ihre Wirkungsweise aufzubanen. Die Mnskulatur ist derart in die Septen eingelagert, dass sie in deren verdickten Kämmen am mäcltigsten ist nnd gegen die Basis der Septen zu immer mehr abnimmt. Auf diese Weise entstehe der Anschein, als ob der Binnenran der Lunge von einem muskulösen Yetzwerk ansgekleidet ist, durch dessen Mischen man in die Vorräume und die peripher gelegenen Alveolen gelangt. I urch die Verlaufsrichtnng parallel zur Richtung der Septen ist dieses Balkenwerk befähigt, den Binnenraum der Lunge suwohl wie den Eingang zu den Vorräumen der Alveolen zu verengern. Durch diese Verkleinerung des zentralen Bimnenraumes muss aber die Kontraktion des Balkennetzes bei geschlossenem Aditus laryngis die Luft aus dem Binnenritum in die peripher gelegenen Alveolen treiben. Die Amphibien besitzen daher nach Ansicht des Verfs. in der glatten Lungenumskulatur einen Apparat. welcher ihnen die "partienweise" Verwenłung der in der Lunge angesammelten Luft ermögliche. '/um Beweise dafïr. dass die Lungenmnsknlatur in der 'Tat so wirke. fülrt Königstein eine Beobachtung von Kahn an. Wonach die Lunge bei den Reptilien „unter gewissen Verhäitnissen nach jedem Glottisschlıss ohne dass die Möglichkeit einer Exspiration gegeben ist, ihr Volumen za verkleinern trachtet." Verf. erblickt in diesen von Kahn bei Eidechsen festgestellten Vuskelkontraktionen bei geschlossener 
Glottis eine Bestätigung seiner Auffassung, da es sich bei ihnen um eine rhythmische Verkleinerung des Lungenbinnenraumes mit verteilender Wirkung auf die darin enthaltene Luft gehandelt habe.

M. Lüh e (Königsberg i. Pr.).

\section{Reptilia.}

830 (iross, J., ت̈ber die Sehnervenkreuzung bei den Rejtilien. In: Zool. Jhrb. Anat. u. Ontog. Bd. 17. Htt. 4. 1903. pag. 763 -788; Taf. 35 u. 36.

Bei Anguis fiugilis findet sich stumpfwinkelige Kreuzung. Der eine Nerv zerfällt dabei in drei, der andere in zwei Blätter, wobei die individuelle Differenz sich zeigt, dass bald der rechte. bald der linke Nerr eine Drei- bezw. Kweiteilung erkennen lassen. Bei drei Blättern ist das mittelste das stärkste, bei zwei sind beide gleich stark. Im Chiasma nur spärliche Gliazellen. Bei Lacerta agitis spitzwinkelige Kreuzung; jeder Ners in drei Blätter geteilt, woron das dorsale am stärksten, das ventrale am schwächsten; die Blätter des linken Nerven unter denen des rechten gelegen. Im Chiasma Gliazellen. Lacertu viridis: Fast rechtwinkelige Kreuzung; bald der rechte Nerv in drei, der linke in zwei Blätter zerfallend, balı umgekehrt; bei drei Blättern das mittlere am schwächsten, dorsales und ventrales gleich stark. Im Chiasma viele Gliazellen. Platydactylus maneturicus: Stumpfwinkelige Kreuzung: jeder Ner in drei Blätter zertallend, dorsales anl schwächsten, dir beiden andern gleich stark. In Chiasma fust gar keine Gliazellen. Chamaeleo mlgaris: Verf. untersuchte zwei Tiere, welche abweichende Verhältnisse darboten. Bei dem einen: Krreuzung fast rechtwinkelig; Chiasma zerfaillt in zwei ziemlich gleich starke Hälften, ventrale von einem dicken Blatte des Nerven gebildet, das linke unterhalb des rechten gelegen; dorsale Hälite in zalılreiche Blätter und Bündelchen zerfallen, die einander kreuzen. Beim zweiten liere ventrale Partie aus zwei Blättern bestehend; linke Nerven zielıen unter den rechten. Im Chiasma viel Gliazellen. Tropidonotus nutrix: Stumpfwinkelige Kreuzung; jeder Ners in zwei ungleich dicke Blätter zerfallend, rechts das dorsale, links das ventrale Blatt dïnner. Rechte Blätter ïber den linken gelegen. In (hiasna reichlich Gliazellen. Zamenis riridoftarus: Stumpfwinkelige Kreuzung: Yerven in je vier Blätter zerfallend, die sich stumpfwinkelig kreuzen. bald die rechten Blätter über den linken liegend. bald umgekehrt. Emys europaer: Die Angaben früherer Beobachter werden bestätigt, wonach zahlreiche, sich durchflechtende Bündel vorhanden sind. Kreuzung spitzwinkelig. Testudo graeca: Sehr stunpfiwinkelige Kreuzung; strohmattenähnliche Verflechtung 
zahlreicher Bündel, in der ventralsten Partie dagegen nur ein Blatt auf jeder Seite. Im Chiasma auffällig wenig Gliazellen. Alligutor lucius: Spitzwinkelige Kreuzung: jeder Opticus in zahlreiche dünne, alternierend sich kreuzende Blätter zerfallend. Im Chiasma zahlreiche Gliazellen.

Bei Anguis, Platydactylus, beiden Lacerten. Tropidonotus und Zamenis ist eine totale Ḱrenzung der Opticusfasern vorhanden. Bei den untersuchten Cheloniern und bei Chamaeleo ist die totale Krenzung wahrscheinlich. Die einzige Schnittserie von Alligator, die dem Verf. zur V'erfügung stand, war schräg ausgefallen, konute daher für die Entscheidung der Frage, ob totale oder partielle Kreuzung, nicht verwendet werden.

B. Rawitz (Berliu).

831 Kovatscheff". W. 'T.. Beiträge zur Kenntnis der. Reptilien-und Amphibienfauna Bulgariens. In: Verhd. Zool.-bot. Ges. Wien 1903. pag. $171-173$.

Die herpetologische Erforschung der östlichen Balkanlïnder hat in den letzten Jahren sehr grosse Fortschritte gemacht und haben die Ergebnisse nicht nur unsere Kenntnisse von der Verteilung und Ausbreitung der Arten sehr bereichert, sondern auch manche Überraschung gebracht. Der lèf. erwähnt ausser den vom Ref. bereits im Jahre 1899 nach den Sammlungen Othmar Reisers aufgezählten Arten noch folgende: INemidactylus turcicus L. (in den Häusern und der Ungebung Philippopels), Ophisaurus apus Pall. (Varna, Sosopol), Ablepharus pannonicus Fitz. (Rustschuk), Zamenis dahlii Fitz. (Sosopol), Zamenis gemonensis Laur. var. caspius Iwan (Rustschuk); Rana esculenta L. (jedenfalls var. ridibunda Pall.) (im Rustschuker Kreise und wahrschemlich in ganz Bulgarien), Rana agiiis Thomas (Rustschuk); R. temporaria L. (dem Ref. noch etwas zweifellaft) (TatarPazardjik); Bufo mlgaris Laur. (Tatar-Pazardjik; im Burgaser Kreise an der türkischen Grenze); Iyla arborea L. (Rustschuk, Tatar-Pazardjik); Bombinator igneus Laur. (Rustschuk, T'Tatar-Pazardjik); Molge cristata Laur. (Rustschuk, Sistov, Tatar-Pazardjik); Salamandra maculosa Laur. ('Tatar-Pazardjık, Weg zum Petrochan).

So sind also jetzt zwei Arten von Schildkröten, 10 Eidechsen (Ref. kann nämlich auch noch Gymnodactylus kotschyi Stdchr. für Rustsclınk anführen) 9 Schlangen und 9 Batrachier von Bulgarien nachgewiesen. Einige Arten, wie Testudo ibera, Eryx jaculus, Bombinator pachypus, Holge vulgaris und alpestris sind wohl noch mit Sicherheit zu erwarten.

F. Werner (WVien).

832 Siebenrock, Friedrich, Schildkröten des üstlichen Hinterindiens. In: Sitz. Ber. Ak. Wiss. Wien. math. nat. Kl. Bd. CXIL. Abth. 1. Iai 1903, pag. 333-352. Taf. I-II.

Der Verf. hat die Schildkröten-Ausbente bearbeitet, welche ron H. Fruhstorfer von 1899-1901 in den Küistenstrichen von Annam, Cochinchina, Siam und 'Tonkin gesanmelt wurde. Da ïber die Schildkrötenfauna dieser Länder nur sehr wenig bekannt ist. so bietet die Ausbente sehr Bemerkenswertes. Von den 12 Arten werden 6 (Ocadia sinensis Gray, Clemmis bealii Gray var. quadriocellata n., 
Cyclemys dhor Gray, C. amamensis n. sp., Triomyx sinensis Wiegm. und Pelochelys cantoris Gray) von Annam, Damonia subtrijuga Schl. u. Müll., Cyclemys amboinensis Daud., Notochelys platynota Gray, Testudo elongata Blyth von Cochinchina, Damonia subtrijuga Schl. u. Müll. Trionyx cartilaginens Bodd. von Siam, schliesslich Pyxidea mouhotii Gray, Testudo elongate Blyth und Trionyx cartilagineus Bodd. von Tonkin erwähnt.

Was die einzelnen Arten anbelangt, die ausfülırlich beschrieben werden, so wäre zu erwähnen, dass Ocadia sinensis für Annam neu ist; desgleichen auch die nur in zwei Exemplaren und nur aus China bekannt gewesene Clemmys bealii. Die beiden früher zu Cyclemys gestellten Arten C. mouhotii Gray und C. platymota Gray werden dem Verf. auf Grund osteologischer und andrer Merkmale aus dieser Gattung entfernt. Beide haben die Haut am Hinterkopt in kleine Schilder geteilt, Cyclemys platynota hat konstant mindestens sechs Vertebralschilder und muss daher ebenso von Cyclemys getrennt werden, wie Thalassochelys Fit\% mit 6 oder mehr Costalschildern von Chelone L. mit nur 4 Costalschildern; Veri. schlägt für diese Art den bereits von Gray dafür gebrauchten Gattungsnamen Notochelys vor.

Weit wichtiger sind aher die Unterschiede, welche zur Abtrenuung der $C$. mouhotii, nötigen: das Foramen palatinum posterius, welehes bei Cyclemys s. str. gross und längsoral ist und von Palatinum, Maxillare und Pterygoid begrenzt wird, ist bei $E$. mouhotii, für welche der Graysche Gattungsname Pyxidea restituieut wird, klein und liegt im Palatinum selbst. Der P'ostorlitalbogen, der bei den echten Cyclemys-Arten ein breites Linochenblatt vorstellt, ist bei C. mouhotii nur eine schnnale Spange. Auch im Ban der Hinterfüsse. die nur eine I'halange der fünften \%ehe besitzen und den Kilumpfüssen der Landschildkröten ähnlich sind, unterscheidet sich die Gattung Pyxidea deutlich von Cyclemys, welche schwimnfüsse und zwei Plıalangen ler fünften, zum Spannen der Schwimmhaut benutzte Zehe besitzt. Verf. gibt auch eine erweiterte Synopsis der Gruppe P der Familie Testudinidae (Boulenger, Cat. Chel. pag. 49) und eine solche der Arten der Gattung Cyclemys (sensu stric.); von dieser sind C. Ahor, C. amamensis n. s]). und $C$. amboinensis in der Coll. Fruhstorfer vertreten, alle neu für die Crebiete, in denen sie gefunden wurlen, was auch fïr Notochelys und Pyxidea gilt. Auch der Fundort "Tonkin" für Testudo elongate und Trionyx cartilagineus und "Annam" für T. sinensis und Pelochelys ist nen.

Die eingehende Beschreibung der seltenen und nur ungenïgend bekannt gewesenen Schildkröten dieser Kollektion und die schönen Abbildungen von Clemys bealii var. quadriocellata (ron oben und 
unten, Taf. I), Pyxidec mouhotii (Schädel von unten und von der Seite ebenda) und Cyclemys annamensis (von oben nnd unten sowie Kopf ron der Seite) machen die kleine Arbeit zu einer der wesentlichsten, die ïber die Systematik der Chelonier in den letaten Dezennien erschienen sind und diese selbst reiht sich würdig den frühern trefflichen Arbeiten des Verf. an.

F. Werner (Wien).

\section{Mammalia.}

833 Fish. Pierre A., The cerebral Fissures of the atlantic WaJrus. In: Proceed. I. St. Nat. Mus. Vol. 26. pag. 675688. Taf. 28 und 29.

Verf. fasst die Ergebnisse seiner an zwei Walrossgehirnen (Trichechus rosmarus) angestellten ('ntersuchungen in folgende Sätze \%usammen. Hinsichtlich seiner Oberflächengestaltung gleicht im grossen ganzen das Gehirn des Walross dem gleichen Organ eines Carnivoren. Wie bei Katze, Hund und Bär ist die praesylvische Partie ausgedehnter als die postsylvische. Die Epiphyse zeigt eine sehr beträchtliche Auslildung. Die Bulbi olfactorii gleichen denen der Seehunde, erreichen also nicht die gleiche Ausbildung wie bei den Carnivoren. Die einzelnen Fissuren (supersylvische, laterale, coronaria, cruciata) haben ziemliche Übereinstimmung mit Raubtieren, doch so, dass das Gehirn nicht einer bestimmten Gruppe sich direlit anschliesst, sondern in dem einen Punkte dieser, in lem andern jener gleicht.

B. Ria witz (Berlin).

834 Grönberg, Gösta, Wie Ontogenese eines niedern sïugergehirns nach Untersuchungen an Erinacens enropaeus. In: Zool. Jahrb. Anat. u. Ontog. Ba. 15. Heft 1 und 2. 1901. pag. 261--384. Taf. 14-19. 18 Textfig.

Verf. untersuchte die Entwicklung des Igelgehirns an 7 Lmbryonen, von denen der jüngste eine Länge ron $4 \mathrm{~mm}$, der älteste eine solche ron $37 \mathrm{~mm}$ hatte. In Kap. 1 schildert er die allgemeine äussere Form des Gehirns aut den verschiedenen Stadien. Auf dem jüngsten Stadium ( $4 \mathrm{~mm}$ Länge) tindet sich deutlich die Dreiteilung in primäres Vorderhirn, Mittelhirn und Hinterhirn. während von einer Zerlegung des ersteren in sekundäres Vorderhirn und Zwischenhirn nichts zu selıen ist. Auch das Hinterhirn ist eimheitlich. Die Scheitelkrümmung ist gut ausgebildet, die beiden andern Hirnkrümmungen nur angedeutet. Das Hirnrohr auf diesem Stadium bildet fast einen rechten Winkel. Die Augenblasen stellen sich als kleine Blindschläuche dar.

Das zweite Stadium (8 mm Länge) unterscheidet sich zunächst und hauptsächlich von dem vorigen durch das Auftreten der Hemisphärenbläschen und durch die stärlere Ausbildung der Briicken- 
krümmung. Die Augenstiele sind schärfer abgeschnürt, die Recessus infundibnli haben sich gebildet. Eine Differenzierung des Hinterhirns in Kleinhirn und verlängertes Mark ist noch nicht angedeutet; doch zeigt sich eine Verschiedenheit im Dach der Hinterhirnblase. Das vordere Fünftel ist dick und nerrös, es wird zum Cerebellum; die übrigen vier Fünftel sind dünn und epithelial, sie werden zur Tela chorioidea ventriculi IV. Be i E m b r y o von $11 \mathrm{mmLänge} \mathrm{erscheint} \mathrm{das}$ Hinterhirn nicht mehr so gross, wie in den beiden vorigen Stadien. Der Schädelbalken ist verdünnt gegen früher, die dem Schädel anliegenden Gehirnteile sind einander nähergeriickt. Die Scheitelkrümmung hat ihr Maximum erreicht; die Nackenkrümmung ist sehr stark ausgebildet. Die Grenze von Zwischenhirn und Mittelhirn wird dırch seitliche Einschnürungen markiert. Die Hemisphärenblasen haben langgestreckte Form erhalten, weil ihr Längenwachstum stärker war als ilı Breitenwachstum. Die Augenstiele sehen nicht mehr wie Hirnteile, sondern wie Hirnnerven aus. Embryo von $15 \mathrm{~mm}$ Länge. Die Brückenkrïmmung hat jetzt spitzwinkelige Gestalt, während die Scheitelkrïmmung unverändert geblieben ist und die Nackenkrümmung eine Rückbildung durch Stumpfwerden ihres Winkels erkennen lïsst. Charakteristisch für dieses Stadium ist ein stärkeres Wachstum des Mittelhirnes und der Hemisphäreublasen, während das Kawischenhirn mehr und mehr zwischen die Hemisphären eingekeilt wird. Der Recessus infundibuli entspringt ganz im Winkel zwischen der hintern Wand des Zwischenhirnes und dem rentralen Boden. Die Augenstiele sind jetzt typische Nervi optici. Embryonen von $20 \mathrm{~mm}$ L ïnge zeigen eine geringere Brücken- und Nackenkrümmung. Bei $26 \mathrm{~mm}$ L änge zeigen alle Hirnkrümmungen deutliche Abnahme. Die Hemisphärenblasen zeigen am medialen Rande eine deutliche Knickung; des fernern differenzieren sich bereits deutlich die Isobi olfactorii. Das Zwischenhirn ist noch weiter in die Tiefe gerückt als auf dem vorigen Stadium. $37 \mathrm{~mm}$ Länge. Fortdauernde Rückbildung der Hirnkrümmungen; bedeutendes Wachstum der Grosshirnhemisphären mit noch stärkerer Differenzierung der Bulbi olfactorii. Eine Fissura rhinica ist an der äussern dorso-lateralen Fläche des Nantels aufgetreten als Grenze zwischen dem dorsalen Pallium und dem ventralen Rhinencephalon. Ventral ist ebenfalls eine Furche erschienen, die laterale Grenze des Tuberculum trigoni olfactorii. Während das Zwischenhirn wiederum mehr in die Tiefe gerïckt ist, hat das Mittelhirn an Grösse zugenomuen. Auch die Ausbildung des Cerebellum zeigt einen schnellern Fortschritt. Am Gehirn des neugebor enen Tieres ist die Entwicklung des lateralen Teiles des Lobus pyriformis sehr auffallend. Das Zwischenhirn ist von dorsal her kaum. 
zu erkennen, da es die Hemisphären fast völlig verdecken.

Das

Mittelhirn ist breiter als lang und lässt eine Vierteilung erkennen, die Corpora quadrigemina. Das Cerebellum lässt deutlich die Einteilung in laterale und mediale Partien sehen: an der letztern treten bereits Querfurchen auf.

In zweiten Kapitel beschreibt Verf. das Hemisphärenhirn und zwar: Corpus striatum, Pallium und Lobus olfactorius mit Ganglion olfactorium.

Corpus striatum. Bei 8 mm langen Embryonen ist in der Wand der Hemisphärenblasen da, wo beide Wände ineinander umbiegen, eine Verdünnung vorhanden. wälırend am Übergang der ventrolateralen Wand in die Seitenwand des Zwischenhirns ein Verdickung sich bemerkbar macht. Letztere ist die Anlage des Corpus striatum und zugleich des ventralen Abschnittes des Thalamus opticus. Das Foramen Monroi bildet eine weit offene Verbindung zwischen Hemisphärenblasen und III. Ventrikel. Allmählich nimmt das Corpus striatum an Jjmfang zu unter gleichzeitiger Verengung des Foramen Monroi.

Am Pallium mnterscheidet Verf. die mediale Hemisphäıenwand von dem Pallium s. str. oder der dorsolateralen Wand. An der media len $\mathrm{Hemisphärenwand} \mathrm{ist} \mathrm{ein} \mathrm{vorderer} \mathrm{und} \mathrm{hinterer} \mathrm{Abschnitt}$ zu erkennen. In der Wand entstehen die Fissura chorioidea, die Fissura arcuata sowie die Fornix-Kommissur, das Corpus callosum und die Commissura anterior. Im Pallium s. str. entwickelt sich aus dichtgedrängt in vielen Reihen stehenden \%ellen die Textur der Hirnrinde.

Der Lobus olfactorius erscheint zuerst als differenziertes Gebilde bei einer Embryolänge ron $15 \mathrm{~mm}$. Gesondert von ihm tritt etwas früher zwischen Riechgrube und Gehirn in Form einer kleinen Zellanhäufung die erste Anlage des Ganglion olfactorium auf. Den Zeitpunkt der Tereinigung beider Gebilde hat Verf. nicht beobachten können.

In Kap. 3 bespricht Verf. das Zwischenhirn und die Hypophyse. Bei ersterm zieht Verf. die Commissura posterior zum Mittelhirn. Die Epiphyse tritt zuerst bei einer Embryolänge von $11 \mathrm{~mm}$ auf und erscheint als eine solide Ausbuchtung des Daches, die erst bei einer Embryolänge von $37 \mathrm{~mm}$ Hohlsprossen aussendet. Mit der Ausbildung der Epiphyse hält gleichen Sclıritt die der Commissura superior, die vor jener gelegen ist. Vor der Kommissur legt sich die Tela chorioidea media an. Zwischen der Verwachsungsplatte, die einen Teil des Hemisphärenhirns repräsentiert, und dem Chiasma ist eine diinne Partie rorhanden: Lamina terminalis. Hinter 
dem Chiasma legt sich der Recessus postopticus an und dahinter der Processus infundibuli. Bei $15 \mathrm{~mm}$ langen Embryonen ist die Haubenanlage zu erkennen. (Abweichungen von der bekannten Reihenfolge, in der sich die Teile des Zwischenhirns anlegen, scheinen nicht vorhanden zu sein. Das Gleiche gilt für die Hypophyse.)

Dem Mittelhirn ist das 4. Kapitel gewidmet. Es ist beim Embryo von $4 \mathrm{~mm}$ eine einfache Blase, die vom Hinterhirn scharf abgeschniirt ist, gegen das primäre Torderhirn sich nur durch seichte laterale Einkerbungen markiert. Auf dem Boden sind drei Einbuchtungen vorhanden; von einer Segmentierung aber ist keine Spur zu erkennen. Bei $8 \mathrm{~mm}$ Länge erscheint das Mittelhirn eiförmig, die Anlage der Commissura posterior erscheint in Dach, während die Buchten auf dem Boden verschwunden sind. Die Wand hat sich im allgemeinen rerdickt. Iie Entwicklung bis zum Embryo ron $37 \mathrm{~mm}$ zeigt weiterhin keine Besonderheiten.

Das Kleinhirn (Kap. 5) entsteht aus einem unberdentenden Teil der einheitlichen Hinterhirnblase ( $\mathbf{L}$ a mina cerebelli). Diese Lamelle zeigt anfänglich sich aus dicht gedrängten grosskernigen Zellen zusammengesetzt, aus denen schon auf dem nächsten Stadium (8 mm) 3 getrennte Schichten entstanden sind. Diese differenzieren sich allmählich zur bekannten Textur des Cerebellum.

Die Medulla oblongata (Kap. 6) zeigt auf dem friihesten Stadium eine vierseitige Dachplatte, deren nach rorn gerichtetes Dreieck stumpfwinkelig, deren nach hinten gerichtetes spitzwinkelig ist. Die Rautenform der Dachplatte ändert sich sehr bald.

Mit dem Kap. 7 beginnt der rergleichende Teil der Arbeit. Verf. bespricht der lieihe nach: Einteilung des Säugetiergehirnes, das Hemisphärenhirn, Zwischenhirn, Mittelhirn, Kleinhirn und Medulla oblongata, entsprechend der Kapitelsonderung des ersten Teiles. Die Ausfïhrungen dieses Abschnittes eirnen sich, wegen ihrer Verflechtung mit den Angaben früherer Autoren, nicht zu einem Referate.

B. Raw it z (Berlin).

35 Szakáll, Gyula, A 11 agyar földi kutya (Spalax hungaricus Nhrg.) hallókésziiléke. (Das Gehörorgan der ungarischen Blindmaus.) In: Állattani Közlemények. Bd. II. Budapest. 1903. pag. 69-83. 2 Taf.

Das innere Ohr der Blindmaus ist in gewisser Hinsicht vollkommener, als dasjenige aller bisher untersuchten Säugetiere, was darauf zuriickzuführen ist, dass, wenn irgend ein Sinnesorgan eines Tieres verkümmert, dafür, als Ersatz, sich ein anderes vollkommener entwickelt, obgleich hierbei auch eine gewisse Rückbildung bemerkbar 
ist, besonders was die Muskeln der Gehörknöchelchen betrifft; denn sowohl der M. tensor tympani als auch der M. stapedius fehlt gänzlich. Die topographischen Verhältnisse der einzelnen Teile des Labyrinths sind so leicht zu überblicken, wie bei keinem einzigen Nager, bezw. Säuger, denn dieselben liegen Mangels des kompakten Kinochenbestandes des Felsenbeins sozusagen vollständig frei. Es ist sehr auffałlend, dass an der innern Oberfläche des Felsenbeins der Hiatus subarcuatus so übermäßig entwickelt ist. wie es in diesem Grade bisher nur von den Vögehn bekannt war. Die knöcherne Schnecke ist $0,19 \mathrm{~cm}$ hoch und hat $3^{1 / 4}$ Windungen.

Zwischen der untern und obern Abteilung der Schnecke ist das Höhenverhältnis sehr auffallend; in der basalen Windung ist es noch kaum ausgesprochen, von der zweiten Windung an aber ist die Scala vestibuli doppelt so hoch, als die Scala tympani. Für die Seitenwandung des Schneckenganges (Ductus cochlearis) ist sehr charakteristisch die mächtig entwickelte und mit P'igmentkörnchen reichlich besetzte Stria vascularis, welche von dem ligimentum spirale so ausgesprochen differenziert ist, wie bei keinem einzigen andern Säuger. Dem Verf. nach ist es wahrscheinlich, dass die Endolymphe des Schneckenganges hier austritt. Die Membrana basilaris ist nicht zwischen der Lamina spiralis und dem Ligamentum spirale ausgespannt, sondern zwischen dem Lig. spirale und dem Limbus spiralis, wetch letzterer die Lamina spiralis ossea weit überragt.

Auf Grund seiner Untersuchungen lält Verf. die sog. Membrana. tectoria Cortii, im Gegensatze zur Ansicht von Ayers (Anat. Inzeiger, Bd. VI. pag. 219) nicht für das Produkt der Haarzellen, sondern für dasjenige der in innern Limbus spiralis hefindlichen Zellen. Charakteristisch für das Cortische Organ ist es, dass von den Haarzellen die innern $\mathrm{nur}$ in einer, die äussern dagegen in drei bis fünf Reihen stehen, so zwar, dass sich in der Basalund Spitzwindung vier, bezw. drei, in der zweiten und dritten aber stets fünf Reihen vorfinden. Diese Zahl ist eine so hohe, wie sie kein anderes Säugetier aufweist; denn bekanntlich sind in der Schnecke des Menschen nur vier, in derjenigen anderer Säuger nur drei Haarzellenreihen bekannt. Mit der Zahl der Haarzellen stimmen die Deitersschen Stützzellen überein. Die Paukenhöhle ist mit einem flachen Epithel überzogen; auch an der Öffnung der Ohrtrompete (Tuba auditiva Eustachii) fehlt das Flimmerepithel.

A. Gorka (Budapest). 


\section{Zoologisches Zentralblatt}

unter Mitwirkung von

Professor Dr. O. Bütschli

In Heidelberg and

herausgegeben von
Professor Dr. B. Hatschek

in Wien

\section{Dr. A. Schuberg \\ a. o. Protagar in Heidelberg}

Verlag von Wilhelm Engelmann in Leipzig.

\section{Referate.}

\section{Vergleichende Morphologie, Physiologie und Biologie.}

36 Loeb, Jacques, Zusammenstellung der Ergebn isse einiger Arbeiten über die Dymanik des thierischen Wachsthu m. In: Arch. f. Entwmech. Bd. 15. 1903. pag. 669-678.

Verf. verweist, veranlasst durch eine Arbeit ron Sch a per (im Arch. f. Entwmech. Bd. 14) anf seine frïhern Mitteilungen (namentlich auf seine „Untersuchungen zur Morph. u. Phys. der Tiere". Heft 2. 1891), in denen er durch eine lieihe von Versuchen wahrscheinlich gemacht hat, dass bei dem tierischen wie bei dem ptlanzlichen Wachstum die Wasseraufnahme und der durch dieselbe bedingte 'Turgor der \%ellen eine grosse Rolle spielen, was auch spätere Verfasser, meistens ohne seine Angaben zu kennen, behauptet haben. Schliesslich warnt er doch aus verschiedenen Gründen davor, den Zellenturgor als einzig maßgehendes Moment zu betrachten.

R. S. Bergh (Kopenhagen).

37 Roux, Wilh., Ueber die Selbstregulation der Lebew esen. In: Arch. f. Entwmech. Bd. 13. 1902. pag. 610-650.

Dieser Aufsatz ist zum grössten Teile ein Abdruck aus frühern Schriften des Verfs. in bezug auf die Theorie der Regulation; Verf. hat sich veranlasst gefühlt, denselben vorzunehmen, weil er seine Anschauungen in der Schrift von Driesch: "Die organischen Regulationen" nicht genügend berïcksichtigt findet. Im Anschluss hieran stellt er den Satz auf, dass „der Kampf unter verschiedenen Gewebsqualitäten ein viel heftigerer und daher viel ausmerzender sein muss, als der Kampf der Individuen" (denn sie leben dichtest gedrängt 
beieinander und fressen alle aus demselben Napfe), und dass, selbst wenn Darwins Selektionstheorie ron der Entstehung der Arten sich als nicht stichhaltig erweisen sollte, die Zü̈htung der rom Verf. charakterisierten allgemeinen (iewebsqualitäten doch bestehen bleibe. Zum Schluss folgt eine lange Polemik gegen Driesch in bezug auf "funktionelle Anpassung" und "Kampf der Teile im Organismus".

$$
\text { Ti. S. Bergh (Kopenhagen). }
$$

838 Stolé, Antonín, Versuche betreffend die Frage, ob sich auf ungeschlechtlichem Wege die durch mechanischen Eingriff oder das Milieu erworbenen Eigenschaften vererben. In: Arch. f. Entwmech. Bd. 15. 1903. pag. 638-668. 26 Textfigg.

Die Individuen ron Aeolosoma hempichii sind normal ,sechszählig“; indem sie nämlich sechs Doppel-Paare von Borstenbündeln besitzen: bei der ungeschlechtlichen Vermehrung liefern sie wieder sechszählige Nachkommen. Verf. fand nun, dass verschiedene Teile solcher Ketten, welche man durch mechanische Abtrennung von der Kette erhalten kann, mit Hilfe der Regeneration oder ohne dieselbe wieder ungeschlechtlich durch Knospung sich vermehrende Individuen liefern; solche Individuen besassen in der Regel eine andere Anzahl der Doppelpaare von Borstenbündeln als die normalen Individuen. Terf. verfolgte nun die Nachkommenschaft solcher Individuen mit Rïcksicht auf die Frage, ob die neu acquirierte Eigenschaft der abweichenden Segmentzahl sich vererben wiirde. I)ie (gänzlich negativen) Piesultate fielen so aus:

Stücke, die den Kiopf und fünf oder vier Doppelpaare von Borstenbündeln besitzen, fangen, ohne sich selbst zu regenerieren, an, Ketten zu produzieren, und die ron diesen sich ablösenden Tochterindividuen haben schon sechs borstentragende Segmente. Stücke, die den Kopf und zwei oder drei Borstenbündelpaare besitzen, regenerieren sich erst zu .. fünfzähligen" und bilden dann Ketten, von denen sich wiederum ... sechszählige" Individuen ablösen. Stücke, die aus dem Kopf und nur einem borstentragenden Segment bestehen, sind der Regeneration und der Kettenbildung unfähig.

Verf. hat noch die Versuche in der Weise variiert, dass er (hintere) Stïcke eines Mutterindividuums zusammen mit der Knospe abgeschnitten hat. ()ft kommen dabei Verschmelzungen vor, wodurch achtzählige Indivituen entstehen können; aber wenn Regeneration und Kettenbildung eintritt, wird die Nachkommenschaft wieder sechszählig.

Weiter hat Verf. gefunden, dass bei den in einem alten Kultur- 
wasser lebenden Individuen nach einer bestimmten Zeit die Intensität der Vermehrung abnimmt, bis dieselbe eventuell ganz aufhört. Die Knospungszone wird undeutlich, und die Einkerbungen, welche die Knospen voneinander trennen, schwinden. Werden nun solche Ketten in frisches, häufig erneuertes Wasser übertragen, so treten Veränderungen auf, die schliesslich wiederum zur ungeschlechtlichen Vermehrung hinführen. Auch bei diesen Vorgängen findet man das Muttertier mitunter mit überzähliger Segmentzahl; auch hier werden aber die Descendenten der Tochterindividuen sechszählig (die Tochterindividuen selbst sind mitunter fünfzählig). Die abnormen Segmentzahlen können also entweder auf Reduktion oder auf Summation (Verschmelzung) beruhen.

Verf. zieht aus seinen Versuchen folgenden Schluss: ..die durch einen einzelnen, also nicht wiederholten mechanischen Eingriff oder durch einen nicht wiederholten Einfluss des Mediums erworbenen Eigenschaften werden bei ungeschlechtlicher Vermehrung nicht vererbt."

R. S. B ergh (Kiopenhagen).

\section{Coelenterata.}

39 King, Helen D., Further Studies on Regeneration in Hydra viridis. In: Arch. f. Entwmech. Bd. 16. 1903. pag. 200-242 Taf. $4-6$.

Verfasserin hat zunächst den Einfluss des Lichtes auf die Anzahl der sich nach Wegnahme eines Kopfes neubildenden Tentakel untersucht nnd positive Ergebnisse hierüber erzielt. Werden nämlich die Polypen während der ganzen \%eit ihrer Regeneration ununterbrochen im Dunkeln gehalten, so entwickeln sich weniger Tentakel, als es der Fall ist, wenn die Polypen dem Einfluss des Lichtes ausgesetzt waren. Immerhin ist der Entwicklungsgrad der Tentakel in beiden Fällen derselbe.

Der weitaus grössere Teil der Arbeit handelt von Pfropfungen, welche Verf. in vielfach variierter Weise angestellt hat. Die wesentlichsten Ergebnisse sind folgende:

Wenn bei seitlichen Vereinigungen das aborale Ende des einen Polypen der Seite des anderen eingefügt wurde, so sind die Beziehungen der Achsen beider Komponenten ein wichtiger Faktor für das Schicksal des aufgepropften Stückes und für die Art und Weise seiner Trennung vom Stock in denjenigen Fällen, in denen die Vereinigung keine dauernde wird, nämlich: a) Bilden die Achsen der Teile oberhalb der Vereinigungsstelle der beiden Komponenten gleiche Winkel mit dem gemeinsamen Stamm, so wandert das aufgepfropfte Stück allmählich bis an den Fuss des Stockes, woselbst es zur Ab- 
schnürung und schliesslich zur Trennung kommt; b) wird die Stockachse an der Pfropfungsstelle nicht gebogen, dann bildet das aufgepfropfte Stück einen Fuss am aboralen Ende und trennt sich bald rom Stock, ohne anscheinend eine Abwärtswanderung unternommen zu haben; c) schwingt sich die Achse des aufgepfropften Stückes in gleicher Richtung mit der Stockachse herum, so vereinigt sich das aufgepfropfte Stiick dauernd mit dem Stock, und ein T'eil des letztern schnürt sich von seinem eigenen Stamme ab und wird mit dem Pfropfstück zu einem selbständigen Individuum.

Das Abwärtswandern eines aufgepfropften Stiickes entsteht weder unter dem Einflusse der Schwerkraft noch durch Spaltung des Stockes. Jener Vorgang stellt lediglich eine Bewegung des Pfropfstückes dar und bedingt keinerlei Gewebsverschiebungen am Stocke selbst.

„Das Schicksal eines Pfropfstuickes hängt nicht von dem Grade seiner Spezialisierung $a b$, sondern von seiner Grösse, von der relativen Lage seiner Achse zu der des Stockes und von seiner Stellung an letzterm. Wird las Kopfende eines Polypen in der Nähe des oralen Endes eines andern Polypen angefügt, so verschmilzt das Pfropfstïck vollständig mit dem Kopf des Stockes und die abnorm grosse Tentakelzahl wird durch Verschmelzungs- und Resorptionsvorgänge so weit reduziert, bis sie innerhalb der normalen Variationsbreite liegt. Wird ein grosses Stiick von einem Polypen irgendwo entlang dem Stamm eines andern Polypen angefügt, so trennt es sich früher oder später als selbstïndiges Individuum von dem Stock. Ein kleines Stïck aus der Körperwand eines Polypeu wird an jeder beliebigen Stelle eines andern Polypen von dem Stock desselben resorbiert: ein Polypenkopfstück lässt sich aber lediglich dem oralen Ende des Stockes inkorporieren."

Wird das orale Ende eines des Kopfes beraubten Polypenstammes der Mitte eines andern Polypen eingefügt, so wandert das Pfropfstück nach dem aboralen Stockende und schnürt sich ab als selbständiges Individuum, das Hypostom und Tentakel zur Entwicklung bringt. Entfernt man den Fuss des Pfropfstückes an einer solchen Vereinigung durch einen Querschnitt, so bildet sich ein neuer Fuss und das Pfropfstïck löst sich ab. Hat der Schnitt alles bis auf ein kleines Stïck des Pfropfstiickes entfernt, so findet schrittweise Resorption des Pfropfstuickes seitens des Stockes statt, und es entsteht ein normaler Polyp.

Wird nach Entfernung von Hypostom und Tentakeln das orale Ende eines Polypen der Mitte eines andern eingefügt, und wird dann der Fuss des Pfropfstiickes entfernt durch einen Querschnitt, dem ein Längsschnitt durch das Pfropfstiick und quer durch den Stock 
sich erstreckend nachfolgt, so teilt sich letzterer in ein vorderes und ein hinteres Stiick, deren jedem ein langes, schmales Stück des Pfropfstückes anhaftet. Sclıwingt sich die Pfropfstückhälfte des vordern Stockteiles so herum, dass seine Achse mit der des Stockes zusammenfällt, so wird die Vereinigung des Pfropfstïckes mit dem Stock zu einer dauernden, indem das Pfropfstück einen Fussteil regeneriert und das aborale Ende eines normalen Polypen wird. Bleibt die Achse des Pfropfstuickes unter fast rechtem Winkel zur Achse des Stockes stehen, so schnürt sich dasselbe als selbständiges Individuum ab. Besitzt ein dem hintern Stockteil angeheftetes Pfropfstück genügende Grösse, so trennt es sich stets ab: wenn klein, wird es dem Stock einverleibt.

Wird der Fuss eines Polypen entfernt und mit seinem Hinterende einem andern in der Mitte angeheftet, und wird darnach der Kopf des Pfropfstiickes und der unterhalb der Vereinigungsstelle gelegene T'eil des Stockes dırch einen Querschnitt entfernt, so hängt das Schicksal des Pfropfstïckes ron seiner Grösse und von der Beziehung seiner Achsen zu der des Stockes ab. Ist nänlich das P'fropfstück gross und bleibt seine Achse unter nahezu rechtem Winkel zu der des Stockes stehen, so bilden sich an seinem obern Ende Tentakel und es trennt sich eventuell ab; ist es aber klein, so stellt es sich in der Längsrichtung des Stockes ein, bildet einen Fuss am aboralen Ende und wird bleibend zum aboralen Ende des Polypen. - Auch in dem Falle, dass der kopflose Stamm eines Polypen mit dem oralen Ende der Mitte eines andern eingefügt wird, und wenn darnach sowohl der Fuss des Pfroptstiickes wie der obere Teil des Stockes entfernt wird, hängt das Schicksal des Pfropfstiickes von seiner Grösse ab. Wenn gross, regeneriert es aboral einen Fuss und trennt sich eventuell ab; ist es dagegen klein, wird es von seinem Träger resorbiert.

Die Tentakelzahl, die nach der Entfernung des Kopfendes von einem Polypen regeneriert wird, erfährt keine Vermehrung durch Aufpfropfen des Polypen auf' einen andern, trotzdem dadurch, wenigstens eine Zeitlang, sein Volumen vergrössert wird.

Der Regenerationsvorgang der Komponenten einer endständigen Verbindung ist wenigstens z. T'. durch die Grösse derselben bedingt. Sind beide gross, so regeneriert jeder; die den verlorenen entsprechenden Teile trennen sich eventuell als selbständige Individuen. Ist der eine Komponent viel kleiner als der andere, so wird er entweder von diesem resorbiert oder er geht mit ihm eine bleibende Verbindung ein. Im letztern Falle wird seine Polarität, falls es nötig ist, zu Gunsten der Erzeugung eines normalen Polypen derart 
ungekehrt, dass sich an der Schnittläche die entsprechende Neubildung entwickelt.

Ls gelingt nicht, eine bleibende Vergrösserung des Stammdurchmessers durch „tangentiale Einpfropfung“ zu erreichen. Eine Zeitlang können solche Bildurgen bestehen bleiben, früher oder später kommt es aber zur Bildung eines oder mehrerer normaler Individuen. - Die Regulation bei durch besondere Methoden vierköpfig gemachten Hydren erfolgt wie bei den zweiköpfigen dadurch, dass sich der Körper in getrennte Individuen teilt; gewöhnlich bilden sich so viele Individuen, wie zu Anfang des Versuchs Köpfe vorhanden waren: mitunter können aber auch zwei Köpfe verschmelzen und aus dieser Verschmelzung ein Polyp sich bilden.

Wenn nur ein kleines, dreieckiges Stück der Körperwand des Stockes an einer Knospe hängen bleibt (wie weit diese immer entwickelt war), so schnürt sich eventuell die Knospe von ihm ab: niemals wird ein solches Stiick der Knospe einverleibt. - Die Trennung einer Knospe von dem elterlichen Tier kann verzögert, aber nicht verhindert werden, indem man das Kopfende der Knospe unmittelbar nach Auftreten der Tentakel entfernt.

Wird eine Knospe der Länge nach mitten durchgeschnitten und der Schnitt durch das Elterntier verlängert, so ist es möglich, eine bleibende Verbindung zwischen dem Hinterteil des Elterntieres und dem an ilım gebliebenen Teil der Knospe herbeizufuihren, nämlich dann, wenn die Knospe sich bis zum Zusammenfallen der beiderseitigen Achsen herumbiegt (mit $\mathrm{l}$ iand). Dagegen scheint es unmöglich, eine bleibende Vereinigung des Vorderendes des Elterntieres mit dem ihm anhängenden Knospenteil zu erzielen.

R. S. B ergh (Kopenhagen).

840 Morgan, T. H., Some Factors in the Regeneration of Tubularia. In: Arch. f. Entwmech. Bd. 16. 1903. pag. 125-154. 16 Textfig.

In bezug auf die Regenerationsfähigkeit kommen individuelle Unterschiede zwischen aufeinander folgenden, kurzen Stücken verschiedener Stämme vor, welche nach Verf. möglicherweise mit der relativen Dicke des Cönosarks zusammenhängen. Diese Dickenunterschiede des Cönosarks könnten teilweise auch das verschiedene Verhalten der verschiedenen Bezirke desselben Stammes erklären.

In bezug auf die Unterschiede bez. der Bildung ,einfacher oder doppelter Strukturen“ (d. h. der Bildung von Polypenköpfen an einer oder an beiden Schnittflächen der Stammstücke) scheinen in sehr kurzen Stücken zwei nahezu einander die Wage haltende, entgegen- 
gesetzte Faktoren tätig zu sein: „der reduzierende Faktor, welcher die Grösse des hydranthbildenden oralen Bezirkes entsprechend der Grösse des Stückes als Ganzes zu regulieren sucht, und der Einfluss des aboralen Schnittendes, der dort einen Hydranthen zu bilden strebt. Man kann noch einen dritten Faktor erkennen, nämlich die zu Missverhältnis führende Änderung des radialen Durchmessers, der aus der Vereinigung von Cönosark und Perisark herrührt und der die Entstehung von Bildungen in normaler Grösse begünstigt. Entsprechend dem Vorherrschen des einen oder andern von diesen Faktoren ergibt sich: a) der Länge nach verkürzte, in sich proportionierte Bildungen oder b) Doppelbildungen, c) unvollständige Bildungen mit Organen in voller (irösse."

Werden sehr kurze Stücke mit dem einen Ende in den sand vergraben, so bringen sie an dem freien Ende ganze oder unvollständige Bildungen hervor, olne Rücksicht darauf. ob jenes das orale oder das aborale ist. Doppelbildungen gelangen selten zur Entwicklung.

Die Zalıl der von einem Stammstïck hervorgebrachten T'entakel hängt hauptsächlich von dem querunfange des Stückes ab. In sehr kurzen Stiicken kann die Hydrathanlage der Länge nach eine erhebliche Reduktion erfahren, olme dass in radialer Richtung eine entsprecliende Reduktion der T'entakelzabl stattfände. Verf. sieht dies als Folge der engen Vereinigung von Cönosark und Perisark an, welche das Cönosark zn voller Grösse ausgedehnt erhält. „Es zeigt sich somit, dass eine regulatorische Reduktion der Organisation nach einer Dimension stattfinden kann. ohne dass dies nach der andern der Fall zu sein braucht. Ein einfacher physikalischer Faktor, nämlich die Vereinigung von Cönosark und P'erisark, ist für den Regulationsmangel in radialer lichtung verantwortlich zu machen."

Das schräge Abschneiden von stammstïcken am proximalen Ende veranlasst nicht die Entstehung einer schıägen Anlage des distalen Hydranthen, selbst wenn sich der letatere bis in den schrägen Bezirk hinein erstreckt. Die Tentakeln können an der schrägen Oberfläche dort in der Entwicklung 7urückbleiben, wo das schräge Ende zum Verschluss sich heriiberlegte.

Einfache Köpfe (nur an dem einen Ende entwickelt) kann man dadurch hervorbringen, dass man das orale Ende sich für $1-3$ Stunden schliessen lässt und dann ein kleines Stück von diesem Ende abschneidet, letzteres regeneriert dann meistens mit einem $\mathrm{Hy}$ dranthen; die Ursache dieses Ergebnisses scheint der Vorsprung zu sein, welchen das eine Ende vor dem andern hat.

..Wenı ein langes Stammstück abgeschnitten und dem Ende er- 
laubt wird, sich zu schliessen, und wenn dann nach einer, zwei, drei oder mehr Stunden das Stiick in der Mitte entzwei geschnitten wird, so wird die Entwicklung der proximalen Hydranthen des proximalen Stiickes oft beschleunigt. l)ies scheint auf der dem proximalen gegenüber dem distalen Stïck desselben Stückes gegebenen Entwicklungsbeschleunigung zu beruhen."

Vert. hat weiter lange Stammstiicke durch einen Faden in Winkel gebogen und eingeschniirt. Dadurch wird die Bildung des proximalen Hydranthen crheblich beschleunigt, obgleich das Cönosark des gebogenen Stiickes an der Biegung nicht zertrennt ist. Verf. nimmt an, dass dieses Ergebnis den Fortfall des behindernden Einflusses zuzuschreiben ist, welchen der sich entwickelnde distale Hydranth auf die Entwicklung des proximalen Kopfes hat: vielleicht beruhe dieser Fortfall auf Störung der Spannmmgsverhältnisse des Stïckes.

Wird der Länge nach ein grösseres Stiick aus einer Seite eines Stammstiickes herausgeschnitten, so kann sich an jedem Ende des Schnittbezirkes ein Hydranth entwickeln, wenn auch die ganze Schnittregion ein zusammenhängendes Cönosark besitzt, indem dieses sich iiber die Schnittfläche zusammenbiegt. Das Freistehen der schrägen Enden des ('önosarks ist für dieses Ergebnis verantwortlich.

Unter mehrern ganz kleinen unvollständigen Regeneratbildungen war die kleinste ein Riussel mit einem distalen 'T'entakel.

"Die eigentiimliche Erscheinung bei der Regeneration der Tubularia, nämlich die Entstehung distaler. unvollständiger Bildungen, erklärt sich als die Folge der eigenartigen 'orbedingung, welche der Stamm dafür liefert, nämlich der Verschmelzung von Cönosark und Perisark. Infolge daron behält das Cönosark seine volle Ausdehnung und infolgedessen ist die Tendenz zur Bildung distaler Strukturen voller Grösse stärker als die 'lendenz zur radialen Reduktion, d. h. Regulation, der Neubildung auf eine der Länge des Stiickes entsprechende (irösse." R. S. Bergh (Kopenhagen).

S41 Hazen, Annah P., Regeneration in the Anemone Sagartia luciae. In: Arch. f. Entwmech. Bd. 16. 1903. pag. 365̄-376. 11 Textfig.

Tentakeln regenerieren an oralen Ende von Stiicken, welche in verschiedener Höhe ahgeschnitten wurden, auch an sehr kurzen Stïcken. Doch erfolgt die Regeneration schneller, wenn die Schnittfläche nahe an der Mundscheibe gelegen war. - Die Abwesenheit der Fussscheibe bei einem Stiick hat auf die Regeneration der Tentakel keinen EinHuss: auch ist die zur Regeneration einer nenen Fussscheibe erforderliche Zeit grösser als die zur 'Tentakelregeneration nütige. - Ein 
Schnitt durch die Columna oder den Mundring veranlasst kein Tentakelwachstum, es sei denn, dass im letztern Falle deren einige verloren gegangen sind. Sind Tentakel entfernt worden, so regenerieren sich im allgemeinen deren neue an der Schnittstelle, sie können aber im Umkreise des Mundringes in Intervallen eingeschoben werden. Eine Fussscheibe regeneriert sich stets nur am aboralen, Tentakel nur an oralen Ende eines Stückes (mit Ausnahme einiger heteromorphischer Tentakel an ganz kleinen oralen Stiicken. - Weder Schwerkraft noch Kontakt iiben auf die Regeneration ron Tentakeln oder auf die Orientierung der Individuen einen Einfluss aus (z. T. entgegen einem frïhern Schluss der Verfasserin). Eine scheinbare Orientierungsänderung findet man lediglich bei sehr kleinen Stiicken; anch diese jedoch nehmen mit Hilfe rapiden Wachstums an der Schnittstelle schliesslich dieselbe Orientierung an wie die Individuen. von denen sie abgetrennt wurden, und zeigen auf diese Weise, dass selbst den kleinsten Stïcken eine ausgesprochene Polarität innewohnt.

R. S. Berg li (Kopenhagen).

\section{Echinoderma.}

842 Loeb, Jacques, On a method by which the eggs of a Seaurchin (Strongylocentrotus mumuratus) can be fertilized with the sperm of a Starfisli (Asterias ochracea). In: Univ. of ('alifornia l'ublic. Pliysiol. Vol. 1. Nr. 1. 1903. pag. 1-3.

In normalem Seewasser lassen sich die Eier des oben genannten Seeigels nicht mit Seestern-Sperma befruchten; in gewissen Lösungen (dieselben sind bei der Kürze der Nitteilung nicht angegeben) lässt sich aber Bastardierung der genannten Arten vornehmen. Das Seewasser enthält Substanzen, welche, wenn jenen Lösungen beigegeben. die Bastardierung verhinderı. Umgekehrt werden in jenen Lösungen die Seeigeleier unempfänglich fïr die Befruchtung mit dem Samen ihrer eigenen Species gemacht, können aber wieder hierfür empfänglich gemacht werden durch Zusatz jener Stoffe, welche die Bastardierung verhindern.

Etwa 50\% der durch Seesternsperma befruchteten Seeigeleier bilden Membran und entwickeln sich, die ïbrigen nichti. Die Entwicklung schreitet bis zum Blastula- und Gastrulastadium vor; einige blieben mehr als eine Woche am Leben und zeigten Differenzierung des Darms, hildeten aber kein oder ein rudimentäres Skelett (vielleicht enthalten die Seeśternsperınatozoen Stoffe, welche die Skelettbildung verhindern).

R. S. B ergh (Kopenhagen).

843 Boveri, Th., Über den Einfluss der Samenzelle auf die 
Larvencharaktere der Echiniden. In: Arch. f. Entwmech. Bd. 16. 1903. pag. 340-363. Taf. 15. 3 Textfig.

Bekanntlich hat vor Jahren Driesch ausser für das Skelett eine Beeinflussung der Larvencharaktere der Echiniden durch das Spermatozoon geleugnet. Verf. hat die Richtigkeit dieses Schlusses bezweifelt und deshalb zur Priifung desselben neue Versuche angestellt. Dieselben ergaben im wesentliclien folgendes:

1. Die Zahl der primären Mesenchymzellen ist, wie schon Driesch gezeigt hat hei den verschiedenen Arten verschieden (bei Echimus microtuberculatus 5̄̄-60, bei Strongylocentrotus lividus gegen 50, bei Sphaerechimus gramularis gegen 40). Bei Bastardierungen zwischen Echimus und Sphaerechimus zeigte sich deutlich eine Veränderung der Mesenchymzellenzahl in Richtung der väterlichen Larvenform; doch steht die Durchschnittszahl der Bastardzuchten dem miitterlichen Typus näher, woraus im allgemeinen auf einen etwas grössern Einfluss des Eies zu schliessen wäre (auch ist grosse Variabilität in bezug anf die Mesenchymzellenzahl bei den Bastardlarven vorhanden.

2. In bezug auf die Larvenform meinte Driesch, dass die Form der Bastardlarve nur insofern väterliche (haraktere aufweise, als sie durch die Konfiguration des Skeletts bestimmt sei. Auch dieser Schluss ist nach Boveri nicht richtig, weil die Form der Bastardlarve schon zu einer Zeit, wo das Skelett als formbestimmender Faktor noch nicht wirksam sein kann, väterliche Charaktere anfweist (die Sphaerechinus-Larve ist mehr ballonförmig aufgetrieben, während die Strongylocentrolus-Larve etwa dreieckigen Umriss liat); die Bastardlarve lässt sehr früh die Mischung erkenuen. Schon vom Stadium der fertigen Gastrula an trägt die Larve väterliche Charaktere zur Schant.

3. Auch die Piginentierung der Larven hatte Driesch als rein miitterlichen Charakter hingestellt. Verf. stellte verschiedene Versuche hierüber an. Erstens wurden Eier eines Echinus $q$ in acht annähernd gleiche Portionen geteilt und jede Portion mit Sperma eines andern Echimus o befruchtet; die Pigmentierung der Plutei war in jeder einzelnen /ucht ziemlich gleichartig, in den rerschiedenen Zuchten dagegen variabel. Ähnliches ergaben auch Bastardierungsversuche, bei denen sowohl Eier von einem Echinus of wie von einem Sphaerechinus $q$ in drei Portionen geteilt und jede Portion mit dem Samen eines andern Strongylocentrotus of befruchtet wurde, indem immer für je eine Echimus- und eine Sphaerechimus-Bastardierung das gleiche Strongylocentrotus $0^{7}$ verwendet wurde; die Resultate entsprachen ganz denen des vorigen Versuches; aus dem letzten 
lässt sich aber zugleich ersehen, dass gleiches Sperma in verschiedenen Eiern, sogar solchen von zweierlei Arten, die Pigmentierung in gleicher Weise beeinflusst. Und zwar ist es sowohl die Menge der Pigmentzellen als auch der Pigmentgehalt der einzelnen Zellen, wie endlich deren Anordnung, welche vom Spermatozoon beeintlussbar sind.

4. Selbst die Grösse der Larven kann unter Umständen voi der Samenzelle beeinflusst werden, was wohl darauf beruhen muss, dass dieselbe auf den Grad der Wasserimbibition einen Einfluss ausiiben kann.

Verf. unterwirft die Resultate von Driesch einer genauen kritischen Analyse und kommt schliesslich auf allgemeine Fragen zu sprechen. Als rein mütterliche Charaktere bleiben nur die Furchungsmerkmale und der Habitus der Blastula iibrig, und es erscheint „,selbstverständlich, dass, wenn das ungeheure miitterliche $\ddot{C}$ bergewicht, welches der Menge nach in den Keim eingeht. überhaupt überwindbar ist, es nur allmählich überwunden werden kam und dass wir also in den ersten Vorgängen mütterliche Merkmale in $\mathrm{nm}$ so grösserer Reinheit antreffen müssen, je näher wir auf das Ei zurückgehen“" Die ontogenetischen Charaktere müssen nach V'erf, in prätormierte Qualitäten des Eiplasmas und in epigenetische Qualitäten geschieden werden (zu erstern gehören eben der Furchungstypus und der Habitus der Flirchungs- und der Blastulazellen). - Verf. spricht sich schliesslich - jedoch mit einiger Reserve - für den Kern als Vererbungsträger aus. In bezug hierauf muss aber auf das Original verwiesen werden. $\quad$ R. S. Bergh (Kopenhagen).

44 Morgan, T. H., 'The Gastrulation of the Partial Embryos of Sphaerechinus. In: Arch. f. Entwmech. Bd. 16. 19103. pag. $117-124$.

Die Untersuchung bezielit sich wesentlich auf die Zellenzahl der Zwerglarven. In bezug hierauf war Verf. früher zu dem Resultat gelangt, dass die frïher gastrulierenden eine relativ normale, die später gastrulierenden eine relativ grössere Anzahl von Zellen für die Bildung des Urdarms verwenden. Die neuen Untersuchungen ergaben folgendes:

„Die ganzen Halbei- und Viertelei-Larven von Sphacrechims enthalten nur die Hälfte und bezw. ein Viertel der Totalanzahl von Zellen in den Ganzei-Larven. Diese Zellen sind daher, in entsprechendem Verhältnis, zwei- und viermal zu gross. Eine Regulation in der Zellengrösse gibt es nicht. - Der Urdarm ist oft, ganz besonders in den frühzeitig gebildeten Gastrulae, sehr exzentrisch, was wahrschein- 
lich auf einer unvollständigen Regulation beruht; es zeigt dies, dass noch eine Erinnerung an die eigentlich normalen Bauverhältnisse besteht. - Die Halbei- und Viertelei-Blastulae, welche gleichzeitig nit oder bald nach den Ganzeiblastulae die Gastrula bilden, verwenden eine verhältnismäßig entsprechende Anzahl von Zellen für den Irdarm, nämlich ein Zelıntel der Gesamtzahl. Die später gastrulierenden Eiteilgastrulae stiilpen verhältnismäßig mehr Zellen ein, als ein Zehntel der (iesamtzahl. wie bei Toromeustes. Wenn die Gastrulation erst halb rollendet ist. haben sie manchmal mehr als die verhältnismäßige Zellenzahl im Lrdarm. Ein noch grösseres Feld der Urdarmplatte wird in den spätem Teillarven eingestiilpt, und der Itrdarm ist oft, speziell bei den V'ierteleigastrulae, zu gross. Für strongylacentrotus scheinen dieselben Regeln zu gelten, denen die anderı reeigelarten folgen. Er stülpt etwa ein Zehntel der gesamten Kellenzahl ein. und nicht die Hältte, wie Boveris Lirgebnisse anzudeuten scheinen. $\quad$ R. S. Bergh (Kopenhagen).

845 Teichmann, Ernst, Üher die Beziehnngen zwischen Astrosphärenund Furchen. Experimentelle Lntersuchungen am Seeigelei. In: Arch. f. Entwmech. Bd. 16. 1903. pag. 243-327. Taf. $7-13$.

Verf. wurde zil dieser Arbeit veranlasst durch den Widerspruch z.wischen den Versuchen Boveris und Wilsons, die über Teilung der Seeigeleier nach Unterdrückung der ersten Furchen bestehen: war die erste Furche durch I'ressumg oder durch Kälte (Boveri) oder durch Schütteln (Wilson) unterdriickt worden, so erfolgte Zweiteilıng (mit zweikernigen Zellen): war die Unterdrückung mittelst Ätherisierung (Wilson) bewirkt worden, so erfolgte simultane Vierteilung. Verf. stellte sich folgende Fragen: „Sind es die Astrosphären oder bestimmte Teile derselben, welchen die Fähigkeit, Furchen zu bilden, innewohnt, oder füluren sie nur denjenigen Znstand herbei. der der Furchen bildenden Kraft das Angreifen ermöglicht? Welches ist dann dieser Zustand und welcher Kraft haben wir das Vermögen der Furchenbildung zuruschreihen ?’” Er führte seine lieobachtungen ausschliesslich an lebende 1 Material (Eiern von Echims microtuberculatus) ans.

Die Methoden, die Verf. zur Unterdrïckung der ersten Furche benutzt hat, sind dieselben wie die ron Boveri und Wilson: Kälte, Ätherisierung und Schütteln: aber das Verhalten der Eier erwies sich unabhängig davon, welche dieser Methoden angewandt worden war: dieselben Erscheinungen können in allen drei Fällen auftreten: die Mehrzahl der Eier mit unterdrückter 
erster Furche teilt sich doch immer bei der zweiten Kernteilung in zwei Zellen mit je zwei Kernen. Verf. analysiert genauer den Verlauf der Teilung in verschiedenen Variationen und kommt durch diese Analyse zu folgenden Schlüssen in bezug auf die Beziehungen zwischen Sphären und Furchen: „1. Je grösser die Entfernung ist, die sich im Laufe der Theilungsvorgänge zwischen zwei Strahlungen legen kann, desto tiefer rermag die zwischen ihnen auftretende Furche einzuschneiden, desto grösser wird auch die Aussicht, dass es zu Abtrennung von Zellen kommt. Dies lässt sich auch folgendermaßen ausdrücken: die Tiefe einer Furche kann dem grössten Abstand ihrer Pole proportional gesetzt werden. 2. Furchen vermögen nur gradlinig zu verlaufen, indem sie senkrecht zur Verbindungslinie ihrer Pole einschneiden. Wenn also in einer Zelle mehr als zwei Zentren vorhanden sind, so kann eine Teilung durch eine Furche nur da bewirkt werden, wo die durch den Mittelpunkt der Verbindungslinie zweier Pole senkrecht zu ihr gelegte Ebene weder eine andere Verbindungslinie zweier Zentren noch auch ein Zentrum selbst schneidet. l)iese Bedingung wird im allgemeinen selten erfüllt sein. Ist sie nicht erfülit, was in den weitaus meisten Fällen zutreffen wird, so darf gesagt werden, dass 'Teilungen in Zellen mit mehr als zwei Zentren nur durch das \%usammenwirken mehrerer Furchen zn stande kommen (hierzu auch mathematische Ausfiihrungen). Die simultane Vierteilung wird nach Verf. durch folgende drei laktoren bewirkt: 1. die grössere Entfernung zwischen den Teilungszentren und die davon abhängige ..Fähigkeit der Furche, tiefer einzuschneiden": 2. die durch die Bewegung ler Kernspindelpole herbeigeführte gleichzeitige und gleichmäPige Vergrösserung des Abstandes jedes Zentrums von jedem andern und die dadurch ermöglichte Gleichzeitigkeit des Entstehens und Gleichmäßigkeit des Vordringens der Furchen und 3. die grössere Anzahl der bei der Abtrennung jeder Zelle mitwirkenden Furchen und das damit gegebene Minus an aufzuwendender líaft.

Bei den erwähnten Vorgängen wird die bekannte O. Hertwigsche Regel, dass sich die Kernspindel in der Richtung der grössten Protoplasmamasse einstellt, oft nicht befolgt; der ausschlaggebende Faktor ist die Eistruktur.

Weiter hat Verf. mit disperm befruchteten Eiern experimentiert, in denen es bekanntlich häufig zur Bildung eines Tetrasters und in dessen Folge zu simultaner Vierteilung kommt. Es kann aber auch der Fall eintreten, dass der eine Spermakern mit seiner Sphäre gesondert bleibt und eine gesonderte Spindel ausbildet. Meistens kommt es dann zu einer Teilung in zwei zweikernige Zellen; während der 
spätern Furchung können sich dann einkernige Zellen (auf verschiedenen Zeitpunkten) abtrennen und gelegentlich kann es (selbst bei vollkommen gesonderten Spindeln) zu simultaner Vierteilung kommen. All dieses beweist, dass die Cnterdriickung der ersten Furche (in jenen früher erwähnten Fällen) in keinem kausalen Zisammenlıang mit den später eintretenden Teilungen steht; jene Furche tritt nicht mehr auf (mit Boveri, gegen Wilson). „Nur wenn ein Kieim, dessen erste Furche unterdrïckt worden ist, mittelst eimes Tetrasters, dessen vier Centra in der karyokinetischen Ebene liegen, simultan in vier materialgleiche Zellen zerlegt wird, kann derselbe Eftekt erreicht werden, den die reguläre Furchung im Gefolge hat. Aber selbst in diesem Falle wird man der unterdrückten ersten Furche keinen irgendwie aktiven Anteil an der Furchenbildung zuschreiben wollen, indem man annimmt, dass sie sich restituiere; auch hier ist es vielleicht richtiger, in der Furche, die an der Stelle der ersten entsteht, eine nene Bildung zu sehen." (Der Ernst, mit dem dies behandelt ist, erinnert Ref. ein wenig an den berühmten Ḱleinenbergschen Ausspruch: "Loch ist Loch in der ganzen Welt.") Terf. gibt auch Analysen von einigen deformierten, dispermen Eiern, in denen die Astrosphären durch ihre Stellung teils eine Wirkung hervorbringen, die der Teilung zuwiderlänft, teils umgekehrt eine ganz ausserordentliche simultane Teilungsfähigkeit bewirken.

In einem dritten Kapitel teilt Verf. seine Erfahrungen mit über die schon ron einigen andern Autoren erwähnten Fälle von der Bildung kernloser Zellen während der Furchung. Es kann dieser Yorgang entweder so stattfinden, dass noch spindeln gebildet werden und ron den Teilungszentren das eine ein Kernspindelpol ist, oder so, dass die Zellteilung ohne jede Spindelbildung sich abspielt; (einmal waren es zwei Monaster, das andere Mal ein Spermakernpol vor der Auflösung und ein Eikern in dem Rekonstruktionsprozess, das dritte Nal ein sich wiederbildender Kern und eine leere Strahlung, welche als Zentren der Teilung fungierten). „Es ist von prinzipieller Bedeutung, dass die Furchung vor sich geht, während die I'lasma ansammehnde und verdichtende Tätigkeit der Kerne anhält. Während dieser ganzen Zeit ist der Zellinhalt in demjenigen Zustande, der für die Teilung geeignet ist." Aber wenn dies richtig ist, darf man auch der leeren Strahlung die Plasma ansammelnde und rerdichtende Tätigkeit nicht absprechen und .. hieraus folgt ohne weiteres, dass das Centrosom während seiner ..kinetischen Periode" (Boveri) eine Attraktion auf das umgebende Plasma ausuibt. "Allerdings ist diese Wirkung bei isolierten Centrosomen nie so stark wie dort, wo sich ein Kern an ihr beteiligt." 
In dem ,allgemeinen Teil- legt Verf. folgende Auffassung dar. Die Entstehung einer Furche im Seeigelei sei durch das Zusammenwirken zweier Faktoren bestimmt. "Der eine derselben ist in dem Zustand zu suchen, in den die Zellsubstanzen durch die Wirkung der \%entren versetzt werden. Dieser Zustand charakterisiert sicls als eine Plasmaansammlung und Verdichtung um zwei Mittelpunkte, die eine Auflockerung des substanzgefüges in den zu den Zentren peripherischen 'leilen mit sich bringt. Der andere Falitor liegt in der veränderten Druckrichtung in der Oberfïche. Während der Aktivi. tätsperiode der Zentren kann der Kohäsionsdruck in der Oberfläche nicht auf den geometrischen Mittelpunkt der \%elle grerichtet sein: seine Riclıtung ist vielmehr durch die zentripetale Bewegung des Plasmas bestimmt und läuft gegen die beiden Mittelpunkte dieser Bewegung; in der interzentralen Grenzsclicht steht er als Riesultante der auf die beiden Zentren hin gerichteten Brücke senkrecht zu dem Mittelpunkte ihrer Verbindungslinie“. Verf. sucht nachzuweisen, dass diese Auffassung mit den Erscheinungen der normalen (ersten) \%ellteilurg des Seeigeleies im Einklang steht. - Eine ziehende oder stemmende Wirkung der Strahlen der Astrosphären weist Verf. bestimmt ab; die Strahlen sind nach ihm nur Ausdruck der Ansammlung, der zentripetalen Bewegung des I'lasmas.

Schliesslich zieht Verf. folgendes allgemeines Facit: „Die \%ellteilung ist aufzufassen als Produkt aus einem imnern und einem äussern Faktor. Ersterer lässt sich ganz allgemein als ein \%ustand des /ellinhaltes bezeichnen: er ist dadurch charakterisiert, dass sich das gesamte Material der \%elle um zwei \%entren gruppiert, welchen die Kraft innewohnt, diese Gruppierung für eine bestimmte \%eit aufrecht zu erhalten. Die Gruppierung wird folgendermassen erreicht: 1. das Plasma der \%elle wird in und am Kern (durch die vereinte Tätigkeit von Kern und Centrosomen) angesammelt und verdichtet. woraus eine Auflockerung des peripherischen Substanzgefiiges notwendigerweise folgt. Während dieser Periode nimnt die Strahlung zunächst kontinuierlich zı, um wieder schwächer zu werden, wenn die Anläufung des Plasmas ihrem Maximum entgegengeht. 2. Das gesamte, so in der mittlern Zellregion angesammelte Material wird an die beiden aus der Teilung des Spermacentrosoms hervorgegangenen Verdichtungszentren verteilt. Dies geschieht, indem sich der Kern auflöst und mit seinem Inhalte, soweit er aus Plasma besteht, zum Aufbau der Astrosphären das Wesentliche beiträgt. Mit abnehmender Grösse des Kerns und seiner Spindel wachsen die Sphären und Strahlen, bis die ganze Plasmamasse in sie eingegangen ist. 3. Die Chromosomen sind um diese Zeit an den Sphären angelangt. Damit 
ist die Zweiteilung des gesamten Zellmaterials vollendet. In diesem Zustande wird die Zelle durch die sich rekonstruierenden Tochterkerne festgehalten. Dies geschieht dadurch, dass die Kerne das Plasma ihrer Umgebung an sich ziehen und aufnehmen und so neuerdings eine zentripetale Bewegung hervorrufen, die erst erlischt, wenn die Kerne ihre Maximalgrösse erlangt haben und das Plasma wieder in der mittlern Zellregion angehäuft ist (Abnahme der Strahlungsintensität). Während dieser Zeit wirkt der äussere Faktor, den wir als einen Druck (Kohäsionsdruck) charakterisieren zu müssen glaubten. Er bringt die Durchtrennung der Zelle zu stande, indem er den beiden, von den Zentren beherrschten Gruppen zu der unter den gegebenen Umständen kleinstmöglichen Oberflïche verhilft. Zum Ausdruck kommt das durch die Streckung des Keimes, das Auseinandergedrängtwerden der Sphären und das Durchschneiden der Furche".

R. S. Bergh (Kopenhagen).

\section{Vermes.}

\section{Plathelminthes.}

846 Bardeen, Ch. R., Factors in Heteromorphosis in Planarians. In: Arch. f. Entwmech. Bd. 16. 1903. pag. 1-20. 18 'Textfig.

In einer frühern Arbeit hat Verf. folgende Ergebnisse in bezug auf die Regeneration erlangt: 1. Die neuen ..Ektodermzellen“ entstehen aus den alten durch direkte Teilung. Die neuen Nervenzellen, Darmzellen, möglicherweise auch Muskelzellen, scheinen ebenso aus präexistierenden durch direkte Teilung zu entstehen. Doch ist es möglich, dass diese Gewebe aus grossen, im Parenchym gelegenen Zellen embryonalen, Cliarakters entstehen. Aus den letztern entstehen die übrigen Gewebe hauptsächlich. - Die P'olarität ist durch den in dem Stück enthaltenen Teil des Nervensystems bestimmt. Der neue Pharynx entsteht hinter der Region, in welche die Darmcontenta durch allgemeine Muskelkontraktion gedrängt werden, und als Antwort auf Stimuli, die von jener Region ausgehen. - Ein neuer Kopf wird nur regeneriert in Gewebe, das an einer Schnittläche erzeugt wird, und mit bestimnten axialen Beziehungen zu jener Fläche. Der direkte Stimulus zur Kopfbildung geht von einer exponierten "chief coordinating" Region des Zentralnervensystems aus. Der Kopf bildet sich mit "radialer Symmetrie" auf der Spitze des sich bis an die Schnittfläche erstreckenden Hauptdarmastes und in der Nähe des exponierten Nervensystems. Nachdem Kopf und Pharynx sich differenziert haben, markieren sich sehr deutlich die Tendenzen, das Fragment in einen Wurm von normaler Form und Proportionen zu 
entwickeln. - Während der Regeneration werden hoch differenzierte Gewebe zerstört, falls sie nicht direkt in die Bildung der nenen Teile herïbergenommen werden.

In der nenen Arbeit stellt Verf. nun zunächst fest, dass die angeführten Sätze in gleicher Weise auf die Erscheinungen der Heteromorphose angewendet werden können. Ferner: "Wenn das Hauptkoordinationszentrum eines gegebenen Bezirkes bei einer Planarie an einer Schnittfl̈che frei liegt, dann kann ein nener Kopf gebildet werden und zwar a) hinter einem Gewebsring, welcher nichts rom Gewebe des Zentralnervensystems enthält, oder b) hinter einem mehr nach vorn zu gelegenen, aber teilweise abgelösten Bezirk". Heteromorphosen (d. h. ganze oder unvollständige neue Köpfe) können auch an abgeschnittenen seitlichen Streifen entstehen. - Bei kurzen, quer abgeschnittenen Stuicken, die so abgetrennt sind, dass die in die Pharynxtasche führende Öffnung die Nitte der Bauchfläche einnimmt. werden gewöhnlich an beiden Schnitttlächen nene Köyfe gebildet; ein solcher kann sich aber auch nur an der vordern oder nur an der hintern Schnittfläche entwickeln. Ein neuer Jharynx bildet siclı gewöhnlich in Znsammenhang mit dem vordern Kopt.

Ein nener, umgekehrt gestellter Kopf kann auch am Hinterende vorn intakter Individuen auftreten, vorausgeset $/$, dass der hintere Bezirk nur an einer Seite mit dem vordern zusammenhängt.

Wenn bei der allgemeinen Körperkontraktion sich die Darmcontenta nach zwei oder mehr Punkten lin anhäufen, so entstehen zwei oder mehr Phaı ynxe. Ein nener Pharynx kann auch ,in dem Verbindungsbezirk zwischen vorderm und hinterm Abschnitt eines halbierten Wurms" auftreten. R. S. Bergh (Kopenhagen).

7 Chilu, ('h. M., Studies on Regulation. I. Fission and Regulation in Stenostoma. In: Arch. f. Entwmech. Bd. 15. 1902. pag. $187-237 ; 355-420$. Taf. $5-7$.

8 - Studies on Regulation. II. Experimental Control of Form-Regulation in Zooids and Pieces of Stenostoma. In: Arch. f. Entwmech. Bd. 15. 1903. pag. 603-637. Taf. 23-24.

I. Verf. fasst Stenostoma auf als im wesentlichen aus zwei Hohlcylindern oder Hohlkegeln bestehend, die einer in dem andern stecken und von denen sich der innere (= Darm und Pharynx) an seinem Vorderende nach aussen öffnet, während der äussere (= die Körperwand) geschlossen ist. Die beiden genannten Cylinder hängen durch zahlreiche feine Stränge von Bindegewebe, welche das Pseudocöl durchkreuzen, zusammen. Das Stïck hinter dem Darm (der Schwanz) besteht nur aus der ein enges Pseudocöl umschliessenden Körper- 
wand. - Bei Stenostoma grande zieht sich die hintere Pharynxregion in Falten und die einzelligen Pharynxdrüsen erstrecken sich nach hinten nicht bis in den Faltenbezirk; bei st. leucops faltet sich die Pharynxwand nicht und die Drüsenzellen kommen bis ans hintere Ende des I'harynx vor. - Der dorsal am Darm liegende Nephridialkanal geht unter dem Gehirn durch und kehrt in sich selbst zurïck: der Nephroporus liegt meistens an der Ventralfläche des Schwanzes, doch ist seine Lage variabel. Die Wimpergrübchen stehen mit grossen Ganglien in enger Beziehung.

Die Ausbildung einer Teilungsebene wird durch die Bildung des Gehirns des hinteren Individuums eingeleitet: die Entwicklung des neven Gehirns und Pharynx verursacht eine Einschnürung des Darmes, welcher schliesslich so eng wird. dass der Durchgang von Nahrung nur schwierig geschieht: der Darm bekommt an der Teilungsstelle keine spezifisch differenzierte Struktur. I)ie Zusammenschnürung der Körperwand ist nicht bloss das Ergebnis einer Ringmuskelkontraktion, sondern auch das von Strukturveränderungen, welche waluscheinlich zum Erscheinen des neuen Gehirns in Korrelation stehen. Septa fehlen. Während der Entwicklnng des neuen (iehirns und l'harynx verlängert sich die Pharynxregion, wahrscheinlich infolge der Verlängerung des Pharynx; auch die eingeschnürte I)armpartie wird dadurch gestreckt. - Bei der Trennung der Zooide (oder seltener vorher) reissen der Darm und der Nephridialkanal durch. In dem hintern Teilgliede bleibt das vordere Darmende eine Zeitlang als eine Art Cöcum bestehen, wie solches bei Wicrostoma zeitlebens vorhanden ist: allmählich jedoch verkürzt sich dieser Blindsack und schwindet, wahrscheinlich als das Ergebnis der Druckwirkung des ausgedelunten Pharynx, und schliesslich endet der Darm querabgeschnitten am hintern Pharynxende. Der zerrissene Nephridialkanal wächst in dem rordern Individuum in den neu sich bildenden Schwanz aus und bildet sich einen neuen Nephroporus, .. der jedoch während der spätern Stadien seine Lage in gewisser Ausdehnung zu verändern vermag“.

Stenostoma kann kriechen oder schwimmen, kann sich auch mit der Bauchtläche und namentlich mit dem Schwanz an die Unterlage anheften; auf der Bauchtläche gibt es einen durch sein Aussehen markierten medianen Streifen („Bauchstreifen“), der in umgekehrter Richtung (nach vorne) schlagende Cilien besitzt. Diese Cilien dienen zur Verlangsamung oder Rückwärtsbewegung. Der Bauchstreifen sondert wenig oder keinen Schleim ab. Auf jeder Seite desselben liegt ein „Bauchseitenstreifen“, der kräftige, nach hinten schlagende Wimpern besitzt, die sowohl zum Schwimınen wie zum 
Kriechen benutzt werden; die Bauchseitenstreifen sondern schleim ah. Der Bauchstreifen kann konkav gestaltet werden, so dass die Seitenstreifen die Ränder der Konkavität bilden; solchermaßen kann die Bauchtläche als Saugorgan für die Anheftung an die Interlage dienen; die ventrale SchwanzHäche ist eine Fortsetzung des Bauchstreifens und dient par excellence als Saugorgan. - Die Seiten- und Rückenwimpern dienen meist zum Schwimmen (sie schlagen nie in ungekeluter Richtung), sind aber überhaupt meist in Bewegung, obwohl die Bewegungsintensität wechselnd sein kann. Ist das Tier festgesaugt, bewirken die Bewegungen dieser Wimpern eine Streckung des Körpers.

Die Fassumgsfähigkeit des Darms hängt stark von der Körperform ab, aber nicht umgekehrt, wenn auch starke Ausdehnung des Darmes Veränderung der äusseren Form verursachen kann. In Ermangelung von fester Nahrung enthält der Darm Wasser und kollabiert infolgedessen nicht. Der Darminhalt verteilt sich anf die rerschiedenen Darmgegenden durch peristaltische Kontraktionswellen, die den Körper luäufig überlaufen. Durch dieselben wird oft ein so starker Druck ausgeübt, dass es gelegentlich zur Ruptur der Darmund Körperwand kommen kann. Pharynx und Darm tragen Wimpern. welche die fliissigen Darmcontenta in Bewegung erhalten.

In einem zweiten Abschnitt unterscheidet Verf. zwischen „reaktiver und mechanischer Regulation“. . Die typische oder ..normale“ Form des Organismus kann teilweise mechanisch durch die typische oder normale Spamung oder den Druck auf die Gewebe, veranlasst durch normale Bewegungen oder andere mechanische Momente, bestimmt werden, und nach Beeinträchtigung oder Zerstörung der normalen Form kann die Fortdaner der normalen Einwirkungen, oder der Versuch, sie fortdauern zu lassen, mechanisch zu einer mehr oder weniger vollständigen Riegulation, d. h. zu einer Wiederherstellung der .normalen“ Gestalt führen." Mechanische und reaktive Regulation sind oft miteinander kombiniert. Worauf es ankommt, ist, ob die mechanische Formänderung den Ausgangspunkt für andere Regulationsveränderungen bildet, ob die Gestaltveränderung selbst einen Reiz zu reaktiven Prozessen abgibt.

Diese Betrachtung findet nun auf die Bewegungen des Stenostoma ihre Anwendung (Verhältnis der Körperform zur Anheftung, Cilienbewegung und Schleimabsonderung, peristaltische Muskelkontraktionen und Menge des Darminhalts; auch Unterschiede in der Schnelligkeit und Art der Bewegungen sind bei den mechanischen Gestaltänderungen wichtig). Gestaltregulation und Wachstum können gleichzeitig vorgehen. Wird die Gestalt von Stenostoma durch Spannungen, denen 
das ganze Tier oder Stücke ausgesetzt sind, geäindert, so muss die Veränderung am Hinterende am stärksten sein, da hier die Spannung am stärksten ist (iibrigens ist vieles ron diesem Abschnitte in Original nachzusehen).

In einem dritten Abschnitt berichtet Verf. weiter: Gestaltregtlation oder Morphollaxis in Stiicken oder \%ooiden ron Stenostoma besteht gewöhnlich in Längenzunahme und Breitenabnahme (mehr oder weniger ausgesprochen); der Vorgang beginnt am IInterente und schreitet nach vorn über den Körper hin: die Form wird dabei eine mehr oder weniger ausgesprochen kegelförmige. Die Geschwindigkeit, mịt der die Gestaltveränderung vor sich geht, hängt in erster Linie von der Häufigkeit des Festheftens ab, da die Längsspanmung bei festgehefteten Stiicken am grössten ist. bei koptiosen oder nur schwache Kopfanlage aufweisenden stiicken kommt es selten zur Anheftung. .,Solche Stiicke, namentlich die nahe dem Hinterende der Mutterkette entnommenen, bei denen die aus der Inheftuug sich ergebende Längsspannung grösser war, als bei den weiter nach vorn gelegenen, unterliegen entwerler langsamern Formverianderungen als Stïcke mit vollentwickelten Köpten, oder können infolge der Spannungrsverminderung sograr kiirzer werden, his die Entwicklung der Kopfgegend die Vervollkommmung der charakteristischen Bewegungen ermöglicht".

In Stücken, die aus mehr als einem \%ooid gebildet sind, beschränkt sich die Gestaltveränderung hauptsächlich auf das lintere Kooid (als Resultat der mechanischen spannung). Kurze Stücke unterliegen einer grössern Gestaltverändermig als lange (t'alls keine grossen Aktivitätsunterschiede bestehen). .. Findet während des Riegulationsprozesses keine Nahrungsiufnahne statt, so hängt die Querschnittgrösse des Stückes von der Grösse des Gehirns ab. Das Gehirn ist ein nur wenig plastischer Körperteil, der nur geringer Gestaltverïnderung ausgesetzt ist." Nahrungsaufuahme während des Regulationsprozesses kann die Gestaltreränderung maskieren. Die Verlängerung der Pharynxregion während der Entwicklung des Pharynx ist wahrscheinlich wenigstens teilweise das Resultat mechanischer Dehnung der Körperwand durch die Pharynxbewegungen.

"Streng genommen besitzt Stenostoma keine "normale“ Gestalt, d. h. bestimmte Proportionen“; die Bedingumgen der Körperform sind: Aktivität des Individuums, Häutigkeit der Anheftung, Menge des Darminhalts, Häufigkeit und Stärke der P'eristaltik, Grösse des Gehirns und des Stïckes. .Charakteristische Wachstumsweisen existieren offenbar, aber die Form des Ganzen ist das kombinierte Resultat aus diesen nnd den oben erwähnten Faktoren“. Die Morphol- 
laxis bei Stenostoma besteht wesentlich in einer Formänderung, die sich aus den Verschiedenheiten der mechanischen Spannung ergibt, welchen das Stiick im Vergleich zum Ganzen unterliegt. - Formregulationen gehen bei der erwähnten Form sehr rasch vor sich. Olne Fütterung kann bei gewöhnlicher Laboratoriumstemperatur in wenigen Stunden die Länge der Stücke verdoppelt und die cylindrische in eine konoidische verändert werden. Die Regulation ist bimnen 24 Stunden oft zum grössten Teil vollendet.

II. In dieser Studie lat Verf. die rorhin erwähnten Ergebnisse über die Regulationen einer experimentellen I'rüfung unterworfen, indem er die stücke oder \%ooide verhinderte. mit Oberflächen in Berïhrung zu kommen oler sich über dieselben hin zu bewegen. Hierdurch gelang es Verf. festzustellen, dass die Entwicklung des Schwanzes primär das Ergebnis mechanischer Bedingungen ist: seine Bildung kann verhindert, verzögert oder beschleunigt werden. indem man experimentell die Spannungsverhältnisse dieser Körpergegend ändert, nämlich das Stiick oder Zooid an der Berührung mit oder an dem Kriechen über eine Fläche verhindert oder solches in geringerm oder grösserm Maße zulässt. In ihıen frühern Entwicklnngsplhasen lıängt die Form des Schwanzes ab ron den Bedingungen, denen der hintere Abschnitt des Stïckes unterworfen war.

Schliesslich stellt Verf. folgende Sütze auf: .. Die Formregulation ist nicht die Reaktion der (iewebe auf liontaktreize, sondern ist das Ergebnis der durch die Bewegungen des Tieres, Stiicke oder Zooide auf die plastisehen Gewebe ausgeübten \%ugspannung. Der hauptsächlichste Faktor bei der Erzeugung der Formveränderung ist die Längsspannung, welche die lieniitzung der Banchfläche, speziell ihres Hinterendes. als Haftorgan rerursacht, während the Wimpern der Riucken- und Seitenregion zu schlagen fortfahren. Die peristaltischen Kontraktionen üben einen gewissen Druck auf den Darminhalt und damit indirekt auf die Körperwand aus, wodurch wahrscheinlich eine weitere Tendenz zur Körperverlängerung entsteht. Die umgekehrte Bewegungsrichtnng der Wimpern des Bauchstreifens mag gleichfalls einen gewissen Grad ron spannung in der Bauchgegend verursachen nud somit die Verlängerung und Formveränderung begiinstigen."

R. S. Bergh (Kopenhagen).

49 v. Gronkowski, Const. Zum feineren Bau der Trematoden. In: l'oln. Arch. biol. u. med. Wiss. I. Lemberg 1902. 29 pag. 1 Tafel.

Nach den Untersuchungen Blochmanns und seiner Schüler über die Natur der sogenannten Subcuticularschicht der Cestoden und ihr 
Verhältnis zur hörperbedeckung lag es nahe. die Verhältnisse bei Trematoden einer erneuten Prütung zu untelziehen. Der Verf. bediente sich hierbei in Formol konservierter Exemplare von Distommm hepaticum, lanceolatum, rariegatum und Imphistomum conicum, deren Schnitte er mit der Kaliumhypermanganat-Nethode nach H e n n e guy, jedoch zur Kontrolle auch mit andern Färbemitteln, behandelte. Es ergab sich auch hier, dass die Cuticula das Produkt eines Epithels ist, dessen Elemente in Gruppen oder einzeln (je nach den Arteu) durch die Basalmembram lindurch in das Parenchym eingesunken sind und durch Ausläufer mit der Cuticula in Verbindung stehen. Vielfach sind diese Kellen von andern Autoren gesehen, aber meist anders gedeutet worden; andererseits sind aber auch Elemente als Subcuticularzellen bezeichnet worden, deren Natur eine andere ist (Myoblasten). Der Verf. untersuchte ferner auch noch das Parenchym; es erwies sich ilım beim Leberegel bestehend aus einem mascligen Gerüstwerk (Grundgewebe), aus kleinern Kemen an den Wänden der Maschen und aus multipolaren Zellen in den Lücken zwisclien den Maschen; bei Amphistomum conicum kommen ausserdem noch grosse, runde und mehrkernige Zellen vor. Bei Cercarien aus Limnatus stagnalis findet man das ganze Innere des Körpers mit grossen, u1verästelten und mehrkernigen Zellen erfïllt (Blasen- oder Urparenchymzellen), die ailem Anschein nach zwischen sich erst das Grundgewebe abscheiden und dabei meist selbst bis auf die Kerne zu grunde gehen. Da ferner bei andern Cercarien (aus Paludina vicipara) zwischen den Blasenzellen fast immer noch multipolare Zellen vorhanden sind, so darf dies auch für den entsprechenden Zustand des Leberegels angenommen werden; sie erhalten sich hier bis in das geschlechtsreite Stadium und bilden im Grundgewebe ein wohl trophische Bedeutung besitzendes Netz. Die grossen Zellen des Parenchyms von Amph. conicum sind mehrkernig gewordene Blasenzellen.

II. Braun (Königsberg, Pr.).

850 Haswell, W. A., On two remarkable sporocysts occurring in Mytilus latus, on the coast of $\mathrm{New}-\mathrm{Zeal}$ and. In: Proc. Linn. Soc. New-South-Wales 1902. pag. 497--5̃15. 2) pl.

In mehr als $10 \%$ der untersuchten Mytilus latus fand der Verf. in grossen Mengen besonders in den Geschlechtsdrüsen und Bojanusschen Organen bis $3 \mathrm{~mm}$ lange Sporocysten, die einige furcocerke Cercarien von $4 \mathrm{~mm}$ Länge einschlossen. Es kann keinem Zweifel unterliegen, dass hier die Jugendform eines Fascioliden gefunden ist, der mit Distomm laticolle Rud. (aus Carane trachurus, Seriola dumerili und Corvina nigra) nahe verwandt ist: der Vorder- 
körper der Cercarien trägt alle Merkmale dieser Art und besitzt auch schon die Geschlechtsdrüsen sowie den Uterus, der median in der Höhe des sehr kurzen Ösophagus (also hinter dem cylindrischen Pharynx) ausmündet; die Dotterstöcke fehlen noclı. Die Exkretionsblase ist langgestreckt, vorn ror dem Keimstock gegabelt und windet sich S-förmig zwischen den beiden hintereinander gelegenen Hoden hindurch. Der Schwanz der C'ercarien ist am Vorderende aufgetrieben und vielfach eingekerbt, jedoch nicht zur Aufnahme des Vorderkörpers eingerichtet. Aus dem Cmstande, dass immer eine sehr grosse Zahl von sporocysten vorhanden sind, schliesst der Verf. auf eine Vermelurung derselben durch Knospung oder Abschnürung. Tur einmal fand der Verf. in verzweigten Sporocysten typische Bucephalen, die Jngendzustände einer Ciasterostomum-Art.

II. Bra un (Königsberg, Pr.).

851 Johnston, S. J.. Contributious to a knowledge of a ustralian entozoa. Nr. II. On a new species of Distomum from the Sawfish Shark (Pristiophoms cirratus Lath.). In: Proc. Cinn. Soc. New-South-Wales 1902. pag. 326-330. $1 \mathrm{pl}$.

Distomum pristiophor 11. s $\mu$. wurde nur in 3 Exemplaren in der Leibeshöhle von Pristiophorus cirratus bei sydney gefunden, einmal jedoch auch noch TrematoderEier, die wegen ihrer charakteristischen Dickschaligkeit $(0,008 \mathrm{~mm})$ und Form $(0,077: 0,062 \mathrm{~mm})$ wohl zu derselben Art gehöıen; sie wird $25 \mathrm{~mm}$ lang, $6 \mathrm{~mm}$ breit und erinnern $n$ vielen Punkten ihrer Organisation an Distomum tereticolle, den 'Typus von -1zygia Looss.

II. Bir a un (Königsberg, Pr.).

852 Louss. A.. Zur Kenntniss der Trematodenfiauna des Triester Hafens. II. U eber Monorehis Mont. und Maplosplanchnus n. g. In: Ctrbl. Bact., Par. u. Inf. I. Abth. Oig. XXXII. 1902. pag. 115-122. 4 Abb.

Der Verf. gibt zunächst eine genaue Beschreibung von Distomum monorchis Stoss. (aus Cantharns orbicularis), das mit dem Dist. taitinii stoss. (aus Oblata melanura), wie die Untersuchung der Originale ergab, zusammenfällt. Für die genannte Art, sowie für Dist. pachysomum war voll Monticelli die Untergattung Monorchis anfgestellt und von Stiles und Hassal Dist. monorchis zum Typus der Gattung Monorchis gemacht worden, deren Charaktere der Verf. nummehr festlegt. Kine zweite Art derselben Gattung (Mon. parus n. sp.) kommt in den Appendices pyloricae und im Anfangsteil des Dünndarms von Sargus annularis und S. rondeletii zu Triest vor. Nach den heutigen Anschauungen kanm aber Dist. pachysomum Eysenh. infolge seiner abweichenden Organisation nicht mehr bei Nonorchis bleiben, wenn es auch gleich diesem nur eimen Hoden besitzt. Der Verf. stellt daher für diese Art, die er einer erneuten Untersuchung unterzog, die neue Gattung IIaplosplanchnus auf, in der er ein Bindeglied $\mathrm{zwischen} \mathrm{Fascioliden} \mathrm{und} \mathrm{Aspidobothriiden} \mathrm{zu} \mathrm{seben}$ glaubt.

M. Br a u (Königsberg, Pr.).

853 Luos:- A. Notizen zur Helminthologie Egyptens. V. Eine Revision der Fasciolidengattung Heterophyes Cobb. In: Ctrb!. f. Bact., Par. u. Inf. I. Abth. Orig. XXXII. 1902. pag. 886-891.

- $\mathrm{Nr} .850-85.3$. 
Wenn es richtig ist, dass Cobbold in seinem Werke "Tapeworms" (London 1866 pag. 6) den Gattungsnamen IIeterophyes für Distomum heterophyes v. Sieb. aufgestellt hat, dann werden die auf derselben Species beruhenden Namen Cotylogonimus Lhe. und Coenoyonymus Looss Synonyme. Eine neue Revision der in Ägypten vom Verf. gesammelten Heterophyes-Exemplare, unter denen er 2 Arten: Dist. heterophyes (aus Mensch, Hund, Katze, Fuchs und Mirus aegyptius (=M. parasiticus)) und Dist. fraternum (aus dem Pelikan, aus Hund und Katze) unterschied, ergab die Existenz mehrerer Arten. Der Name /Icterophyes fratermus wird auf Formen aus dem Darm des Pelikans beschränkt, deren Cuticula sehr dicht mit längern, schmalen Schuppen besetzt ist, während der Genitalnapf - an Grösse dem Bauchnapf gleich, beide aber grösser als der Mundnapf - mit 65-75 gekrümmten Stäbchen besetzt ist und die Darmschenkel stets bis hinter die Hoden reichen. Untermischt mit dieser Art, gelegentlich aber anch bei Milvus acgyptius. vorkommend, findet sich beim Pelikan eine kleinere Art ( $I$. inops n. sp.) mit kurzen, breiten und nicht dicht stehenden Schuppen in der Cuticula, kurzen, meist nur bis an den Vorderrand der Hoden reichenden Darmschenkeln und mit 25-35 kleinen Stäbchen am Genitalnapf, der im eingezogenen Zustande ein wenig kleiner als der Mundnapf ist, während der Bauchnapf letztern übertrifft. Ähnlich dieser Art ist Heterophyes aequalis n. sp. der Katze und des Hundes, doch doppelt so lang werdend $(0,9 \mathrm{~mm})$ und ferner durch branne Farbe der Eischale unterschieden (II. inops hat hellfarbige Eier). Im Hund, nur vereinzelt in der Katze, lebt IIeterophyes dispar n. sp. mit einem Banchnapf, der 2-3 mal den Nundnapf übertrifft; Eier tief dunkelbraun, Darmschenkel bis an den Hinterrand der Hoden oder bis an die Exkretionsblase reichend; Zahl der Genitalstäbchen $=30$; Hantschuppen sehr gross, in relativ weiten Abständen.

Was bisher als Distomum heterophyes bezeiclınet wurde, schliesst sich in bezug auf die dicht gedrängt stehenden schmalen llautschuppen und den grossen, mit 70- 0 gekrümmten Stäbchen besetzten Genitainapf an Hcterophyes fratermu: des Pelikans an. Es ist dies $I I$. hrterophycs (v. Sieb.) und II. pallidus n. sp.; letztere Art ist bisher nur bei Milus acyyptius gefunden und nach dem Verf. trotz aller Ähnlichkeit mit Divt. hetcrophyes von diesem spezifisch verschieden. Die typische Art des Genus ist die gewöhnlichste Form beim Hund, die einzige ron den bisher bekannten Hcterophycs-Arten, die auch den Menschen bewohnt, die endlich, wenn auch nur selten, in der Katze vorkommt.

Der Verf. ist der Überzeugung, dass die bisher charakterisierten Arten niemals verkannt werden können; inmerhin kummen aber, und zwar oft in Massen, Individuen vor, über die selbst Looss ein sicheres Urteil nicht abgeben kann. Die eine Gruppe dieser Formen schliesst sich im innern Bau vollkommen an Hetcrophycs dispar, die andere an $H$. hetcrophycs an; sie unterscheiden sich aber von den genannten Arten äusserlich durch geringere Körpergrösse und ein anderes Grössenverhältnis der Saugorgane, was ausschliesslich durch abweichende Grösse des Bauchuapfes bedingt wird. Die erstgenannte Gruppe ist bisher in relativ wenigen Exemplaren nur in der Katze, die andere massenhaft in demselben Wirt (Hauskatze) und selten im Hund gefunden worden. Da jedoch Übergangsformen zu den typischen Species vorkommen, so bleibt es zweifelhaft, ob man es in ihnen, wie Looss trotz allem persönlich überzeugt ist, mit selbständıgen Arten oder mit Entwicklungszuständen zu tun hat; der Verf. bezeichnet daher einstweilen die eine Gruppe als ,limatus-Form des Het dispar", die andere als ,sentus-Form des Het. hetcrophyes".

M. Braun (Königsberg, Pr.). 
54 Shipley. A. E., On a collection of parasites from the Soudan. In: Arch. de parasitol. VI. 1902. pag. 604-612. 1 pl.

Ansser einer Aufzählung der (wenigen) Helminthen gibt die vorliegende Notiz eine Beschreibung von Filaria sudanensis n. sp. (v. Linstow) aus Felis leo und Hyaena sp. und eines larvalen, beim Serval beobachteten Bothriocephatiden, der nicht benannt wird und zu den von Diesing als Sparganum bezeichneten Formen gebört. Von einer als Cotugnia polyacantha? Fuhrm. benannten Art wird der Kopf abgebildet.

I. Braun (Königsberg, Pr).

55 stafford, J.. The american representatives of Distomum cygnoidcs. In: Zool. Jahrb. Abth. f. Syst. XVII. 1902. pag. 411-424. 1 pl.

Schon durch Bensley (1897) war bekannt geworden, dass unter den nordamerikanischen, bisher als Distomum cygnoides bezeichneten Trematoden zwei ab. weichende Formen vorkommen, die bald darauf Looss (1899) zu besondern Arten (fiorgodera amplicava und $G$. simplex) erhoben hat. Der Verf. hat es sich nun angelegen sein lassen, canadische Amphibien auf die Bewohner ihrer Harnblase genauer zu ustersuchen und dabei noch drei Arten entdeckt, die ebenfalls als zu Frorgodera gehörig angesehen werden. Gorg. translucida n. sp. wurde in Isufo lenliginosus und liana virescens, Gorg. opaca n. sp. nur in ersterer und Gorg. attenuata in $R$. virescens und $F$. catesbiana gefunden; Gorg. simplex lebt in liana catesbiana, hier auch 6 . amplicara. Alle Arten werden beschrieben und abgebildet.

M. Braun (Königsberg, Pr.).

6 Stafford. I., On the american representatives of Distomum rariegatum.

In: Zool. Jahrh. Abth. f. Syst. XVI. 1902. pag. 895-\$12. 1 pl.

Während in unsern Amphibien 3 Hacmatolockus-Arten, die Looss zu unterscheiden gelehrt hat, vorkommen resp. his jetzt bekannt geworden sind, führen neue Untersuchungen über die T'renatoden der Lunge nordamerikanischer Amphibien den Verf. zur Aufstellung von funf neuen Arten, die z. T. den europäischen recht nahe verwandt siud Es sind folgende: 1. H. longiplexus n. sp., die häufigste Art bei Iiana catcsbiana; 2. II breviplexus n. sp., selten bei der eben genannten Art, häufiger bei Rana virescens; 3. H. varioplexus n sp., nur bei Rana catesbiana gefunden; 4. H. similiplcrus n. sp. bei Rana virescens und Pufo lentiginosus und 5. II. medioplcxus n. sp. in denselben heiden Arten. Andere, allerdings in geringercr Anzahl untersuchte Anuren-Arten Nordamerikas waren frei von Lungenfascioliden.

M. Braun (Köönigsberg, Pr.).

7 Wilson. Elm. B., Experiments on Cleavage and Localization in the Nemertine-egg. In: Arch. f. Entwmech. Bd. 16. 1903. jag. 411-460. 11 Textfig.

Das Ei von Cerebratulus lacteus, an dem Verf. experimentiert hat, hat sich als ein vorzügliches Objekt für solche Studien bewährt. Fis macht einen typischen „mosaikartigen, spiraligen Typus der Furchung durch, ist Operationen gegenüber ebenso widerstandsfähig wie Seeigeleier, bildet lieine Befruchtungsmembran, sondern besitzt nur eine lose Hülle, die leicht abgeschüttelt werden liann, so dass die Eier leicht in Fragmente geschüttelt oder geschnitten werden können. Ausserdem sind die Eier leicht zu orientieren, indem sich 
gegenüber dem animalen Pole, wo die Richtungskörper sich bilden, eine kleine konische Protuberanz meistens vorhanden ist. - Die ersten vier Furchungszellen sind sich ganz gleich; bei der dritten Furchung werden die vier Zellen am untern Pol kleiner als die an obern. Es bildet sich eine Rosette mit dem Apicalorgan, aber das „Kreuz" der Annelidenlarven scheint zu fehlen. "\%wei Crmesoblastzellen schieben sich vor der Invagination in die Furchungshöhle; Verf. hält sie eher für den "Ektomesoblast" als dem "Coelomesoblast" entsprechend. - Was Verf. hauptsächlich untersuchen wollte, war die Entwicklung befruchteter Eifragmente im Vergleich \%u der Entwicklung isolierter Furchungszellen und es stellten sich dabei äusserst interessante Resultate heraus.

Zunächst hat er festgestellt, dass in der Reifungs- und Befruchtungsgeschichte des Eies zwei "kritische Perioden" existieren, in denen die Konstitution des Eiplasmas geändert wird; die eine wird durch die Auflösung der Wand des Keimbläschens, die zweite durch das Eindringen des Spermatozoons bezeichnet, (die Richtungskörperchen erscheinen erst nach dem letztern Vorgang). Wenn nämlich Eier in dem Stadium, wo das Keimbläschen noch scharf begrenzt ist, zerschnitten oder zerschüttelt werden, so entwickeln sich immer nur die kernhaltigen Fragmente; die kernlosen sind nicht befruchtungs- oder entwicklungsfähig. Ist dagegen das Keimbläschen schon undeutlich geworden, so können sowohl kernhaltige wie kernlose Fragmente befruchtet werden und sich entwickeh. Nitch der Befruchtung entwickelt sich aber - wenn die Eier in Fragmente zerteilt werden immer nur ein Stïck, nämlich dasjenige, welches Ei- und Sperm:kern enthält; die andern sind einer Wiederbefruchtung und darauf folgender Entwicklung nicht fähig.

Was nun den Vergleich zwischen der Entwickhung von Eifragmenten und isolierten Furchungszellen betrifft, so stellte sich heraus, dass die kragmente, a us welcher Region des Eies sie a uch hergenommen wurden, immer, in jedem letail sich wie ein ganzes Ei von verminderter Grösse furchen. Die isolierte Furchungszelledagegen furcht sich nie wie ein ganzes Ei, sondern wie der Teil eines solchen: als ob nämlich diefehlenden Schwesterzellen gegenwärtig wären. In beiden Fällen kommt aber ein vollständiges Pilidium von geringerer Grösse zu stande. Die untere Volumengrenze, welche noch zur Bildnng eines vollständigen Pilidinm hinreicht, beträgt ungefähr ein Viertel des ganzen Eirolumens. Die kernhaltigen Fragmente behalten sicher, die kernlosen wahrscheinlich ihre Polarität (ersteres kann daraus ersehen werden, dass die Furchungsebenen die- 
selben Beziehungen zu den Richtungskörperchen haben, wie in ganzen Eiern). - Bei der Furchung isolierter Zellen des ersten Stadiums wird die zweite, bei derjenigen isolierter Zellen des zweiten Stadiums die erste Teihung inäqual. Alle diese isolierten Zellen geben weiter mehr oder weniger weit offenen Blastulis Trsprung, in extremen Fällen sogar nahezu flachen Platten; doch können aus allen diesen Formen Pilidien hervorgehen, von denen die aus den becherförmigen Blastulis hervorgegangenen normale Gestalt haben kömen, während die cus den plattenförmigen gewöhılich (immer?) unsymmetrisch sind.

Bruchstücke von ganzen Blastulis können normal gestaltete Zwergpilidien hervorbringen, doch zeigen die Larven dann gewöhnlich Asymmetrie oder Defekte. Fragmente von der animalen Hälfte besitzen stets das Scheitelorgan, doch ist der Trdarm oft (vielleicht immer) von relativ geringer Grösse. Fragmente der vegetativen Hälfte entbehren häufig (immer:) des Scheitelganglions und der scheitelgeissel und das Archenteron ist gewöhnlich (immer:) von abnormer Länge.

Die Ektodermzellen des prätrochalen Bezirks sind bei allen Larven von annähernd derselben Grösse, sei es bei normalen oder aus Fragmenten, oder endlich aus isolierten Blastomeren entstandenen. Dasselbe scheint für die Mesenchymzellen zuzutreffen. Fs scheint also wohl die Zahl, aber nicht die Grösse der Zellen der Larvengrösse proportional zu sein.

An die erwähnten wichtigen Tatsachen knüptt nun Vert. sehr interessante Betrachtungen, die er in folgenden Sätzen zusammenfasst:

„Die vorstehenden Tatsachen zeigen, dass die Lokalisationen der Keimbezirke ein progressiver (epigenetischer) P'rozess sind. Vor der Reifung sind die Keimbezirke des Nemertineneies äquipotent in bezug auf die Faktoren der Furchung und der Lokalisaton. Diese Faktoren werden in der Periode zwischen Reifungsbeginn und Vollendung der ersten Furche in einer gewissen Ausdehnung lokalisiert, doch kann vermöge eines Regulationsprozesses ein vollständiger Embryo noch aus einem einzigen Blastomer hervorgehen".

„Der Lokalisationsprozess wird primär hervorgebracht durch eine Neuverteilung und eine Absonderung spezifischen Cytoplasmamaterials, ein Vorgang, der wälırend der Reifungsperiode beginnt (möglicherweise in manchen Fällen noch eher) und in den Blastomerenindividuen während der Furchungsperiode sich fortsetzt. Die Furchung spielt, obwohl sie an sich nicht die Ursache der Differenzierung ist, doch als ein Mittel zur Isolierung bei der Lokalisation eine wichtige Rolle. Das Furchungsmosaik ist ein wirkliches Mosaik von (unter sich) spezi- 
fisch differenten Cytoplasmamaterialien und infolgedessen ein Mosaik von mehr oder weniger ausgeprägten Entwicklungstendenzen."

„Mit der fortschreitenden Bildung, Abscheiden und Trennung solcher (unter sich differenten) Materiale während der Furchmng wird das Zellmosaik fortschreitend komplizierter und hestimmter. Die Begrenzung der so in den einzelnen \%ellen lervorgebrachten (spezifischen) Potenzen varijert wahrscheinlich in ihrer Höhe und endet entweder in völliger Spezifizierung oder nicht. Im letztern Falle können die Zellen immer noch komplexe Potenzen unter metabolischer Regulation iibrig behalten. im erstern ist die Zellpotenz durch den Ansfall solcher Regulationsfähigkeit begrenzt. In beiden Fällen kamn der Embryo als Ganzes immer noch insofern Regulationfähigkeit behalten, als sich ein Bruchstïck (eine \%ellgruppe) selhst zu einem Ganzen umbilden kann."

R. S. Bergh (Kopenhagen).

\section{Nemathelminthes.}

858 Martini, Erich, Über Furehung und Gastrulation bei Cucullanus elegans Zed. Rostocker Iiss. 1903. 60 pag. 3 Tat'. \& Textfig. (Auch in: Zeitschr. f. wiss. Zool. Bd. 74. Heft 4).

I)ie Untersuchung wurde angestellt. um zu erfahren, wie sich die Ontogenie des Cucullams. die früher namentlich von Bütschli untersucht wurde, sich zu den durch Boveri und Zur Strassen ermittelten Daten über die Ascaris-Entwicklung verhält. Zur Fixierung wurde namentlich 2\% ige Essigsäure (in physiologischer Kiochsalzlösung gelöst), I'ikrinessigsäure und P'ikrinschwefelsäure, zur Färbung Boraxkarmin benutzt: das zum Schneiden bestimmte Material wurde mit rom Rathschen Gemisch, nit Pikrinessigsäure oder Formol fixiert; Färbung bei dem ersten Gemisch in rohem Holzessig, in den beiden letztern Fällen mit dünnem Hämatoxylin oder Alaunkarmin.

Die Furchungszellen besitzen, wie schon von Bütschli angegeben, eine helle Hautschicht und ein granuliertes Innenplasma. Bei der Kernteilung in den somatischen Zellen konnte Verf. nie Diminutionsvorgänge beobachten; , doch scheinen die Chromosomen in den somatischen Zellen ïlterer Embryonen in der Form von denen bei jüngern verschieden. Die Länge erscheint im Verhältnis zur Dicke viel geringer bei den erstern" (sie sind kaum noch stäbchenförmig zu nennen). Ihre Anzahl ist 12.

In bezug auf die Zellgenealogie stimmen die Resultate Verfs. mit Boveris und Zur Strassens bis auf geringe Abweichungen überein, die in Kürze nicht anzugeben sind und im Original nachge- 
schen werden müssen. Eine Furchungshöhle existiert in keinem Stadium; schon auf dem 12 zelligen geht die dorsoventrale Abplattung an, welche bei Cucullamms viel stärker ist als bei Ascaris.

In seinen theoretischen Erörterungen über Furchung und Zellgenealogie hebt Verf. u. a. folgendes hervor. WVenn \%ur St rassen bei Ascaris fand, dass, die Furchungsenergie der ein\%elnen Zellgruppen zumeist von der der ibrigen verschieden ist, imnerhalb derselben '/ellgruppe aber für alle aufeinander tolgenden Furchungen dieselbe bleibt" (was auf die Tererbung der Teilnngsenergie ron der Mutterzelle auf die 'lochterblastomeren zurückgeführt wird), so trifft dies vielleicht meistens zu, doch konnte sich Verf. bei seinem Objekt nicht überall davon iiberzeugen, sondern fïhrt verschiedene Abweichungen von jener liegel auf. Vert. meint, dass die .rerschiedenen 'Teilungsenergien der nen entstandenen Familien (s. \%ellgrupuen) doch wieder eine Furchungsgeschwindigkeit ergeben, die ungefähr der der gremeinsamen Mutterzelle gleich ist. \%wei solche Mutterzellen, oder noch mehr zwei Familien, die ron derselben \%elle abstammen, ergeben wieder als Mittel ihrer spezifischen Teilumgsgeschwindigkeiten ungefähr die jener gemeinsamen Grossmutterzelle und so fort." Bei den Nematoden findet sich das ungewönliche Verhalten, dass sich bei der inäqualen Furhung die grössern \%ellen friher teilen als die kleinen; bei Ascuris, Rhabditis und Strongylus passt die gewöhnliche Erklärmug, dass es die Dottermengen seien, die, als tote Masse mitgeschleppt, eine Last fiur die \%elle seien, welche sie an rascher Teilung hindern; bei Cucullamus sei diese Hrklärung wegen des Dottermangels ausgeschlossen und doch teilen sich immer, in allen Phasen, die grösseln \%ellen frülıer als die kleinern. Hier stehe man vor einem Rätsel.

Verf. schildert ausführlich die Zusammenkrümmung der Placula zur Gastrula und die Stellung der einzelnen Zellgruppen dabei. Die Tollendung der Gastrulation rollzieht sich durch Epibolie. „Hierbei schieben sich zunächst ron beiden Seiten die Mesenchymanlagen, die ursprïnglichen Seitenränder der I'latte ïber die Entodermzellen und die Geschlechtsanlige in der Mitte zusanmen und wieder über sie weg die grossen Ektodermzellen bis zur Berïhrumg in der ventralen Mittellinie. Vorn legen sich die Seiten der Rinne aneinander und bilden das Rohr des Stomodäum."

Eine ganz so frühzeitige Sonderung der Anlagen für die hauptsächlichsten Organsysteme wie bei Ascaris findet sich nach Verf. bei Cucullamus nicht, trotz der überraschend grossen Übereinstimmung der ersten Entwicklungsstadien. - Verf. sucht die so sehr ausgeprägte Plattenform der Cucullanus-Embryonen mit den Ernährungs- 
verhältnissen in Zusammenhang zu bringen (die Eier haben fast keinen Nahrungsdotter, sondern sollen durch die intrauterine Flüssigkeit ernährt werden). $\mathrm{Ob}$ die Placula als zusammengedrïickte Blastula oder als ausgebreitete Gastrula aufzufassen sei, lässt Verf. dahingestellt.

R. S. Bergh (Kopenhagen).

\section{Arthropoda.}

\section{Insecta.}

859 Ribalga, C.. Osservazioni circa l'anatomia del Trichopsocus dalii IIc. Lachl. In: Rivista Patol. Yeget. Yol. IX. 1901. pas. 129-176. Tab. I-VI.

Der immere Bau der Psociden ist bisher nur ron einigen wenigen Forschern zum Gegenstand ihrer Studien gewählt worden, und infolgerlessen verhältnismäBig sel» wenig bekannt, was den Verf. der rorliegenden Árbeit bewogen hat, die Anatomie einer neapolitanischen Art genauer zu untersuchen. (Es möge hier bemerkt werden, dass Ribaga bei der Aufzählung der drei bisher erschienenen Arbeiten über einzelne innere Organe der Psociden die alte Arbeit ron Nitsch „über das Fingeweidesystem der Bücherlaus“ nicht anführt.) Der Verf. hat sämtliche Organsysteme untersucht und durch zahlreiche gute Abbildungen erläutert.

Indem wir die Beschreibung der Muskulatur, der Mundteile und der Speicheldrüsen übergehen, deren Inhalt sich schwer kurz fassen lässt, wollen wir nur einige Befunde ïber den Ban der Verdaunngsorgane, der Geschlechtsorgane und des Nervensystems mitteilen.

Der Übergang des Pharynx in den (̈)sophagus ist nur durch die Beschaffenheit der Ringmuskulatur zu erkennen, welche an ersterm viel stärker entwickelt ist. Der Ösophagus verläuft in gleicher mäbiger Dicke bis zum Metathorax, wo er sich plötzlich zu einer Ampulle erweitert, welche sich nach hinten zu rasch verengert; eine dem Kropf entsprechende Bildung wurde nicht beobachtet. Der darauf folgende Mitteldarm hat die Gestalt eines länglichen, nach hinten erweiterten Sackes, welcher im Abdomen eine doppelte Schlinge bildet. Anhänge des Mitteldarmes fehlen. Der Enddarm nimmt die halbe Länge des Abdomens ein und zerfällt in drei Abschnitte: einen kurzen cylindrischen mit starker Ringmuskulatur, einen längern, breitern, ausdehmbaren Mittelteil und einen Endabschnitt, welcher proximal und distal cylindrisch, in der Mitte aher erweitert und durch 6-7 kreisförmig von ihm ausstralılende starke Muskelbündel an den hintersten Abdominalbögen befestigt ist. Die beiden cylindrischen Teile des letzten Abschnitts sind aussen 
von starken Ringmuskeln bekleidet. Die Malpighischen Gefässe sind in der Vierzahl rorhanden und münden unmittelbar hinter dem Mitteldarm in den Fnddarm. Pharynx, Ösophagus, Mittelund Enddarm sind mit Längsmuskeln, der hinterste Ahschnitt des Rectums mit Retraktoren rersehen. Epithel und Intima des Vorderdarms zeigen nichts besonderes. Die Epithelzellen des Mitteldarms sind cylindrisch. sehr hoch. äusserst zahlreich, eng gedrängt und ron einer Intima ausgekleidet: an engen Stellen springen diese Zellen gruppenweise in das Darmlumen ror. Das Epithel des Enddarms zeichnet sich durch die Anwesenheit ron sehr zarten und kleinen, nach rïckwärts gerichteten Dörnchen auf der Intima aus. 12 Zellansammlungen im erweiterten Teil des Enddarms springen in das Lumen desselben vor (Rektaldrüsen\%). Was die Speicheldrüsen betrifft, so sei hier nur erwähnt, dass Ribaga das dritte Paar der von Bertkau beschriebenen speicheldrïsen bei seiner Art nicht gefunden hat.

I) innern männlichen Genitalorgane zeichnen sich durch einfachen liau aus und bestehen aus zwei mäßjig grossen, ovalen, sackförmigen Hoden mit kurzen Vasa deferentia ohne accessorische Drüsen. Einen komplizierten Bau reigt dagegen das Kopulationsorgan. Dasselbe ist im ganzen von konischer Gestalt und liegt hinten zwischen dem Anus und den letzten Ventralhalbringen und besteht aus den Weichteilen, welche den Samenausfiihrgang umgeben, den harten, die Einfuilurung des Samens in die weiblichen Geschlechtswege ermöglichenden (hitinstïcken und den die letztern bewegenden sowie das Ausspritzen des Samens bewirkenden Muskeln. Der basale feil des Organs, „vescicola seminale“, entliält vier, von Cylinderepithel ausgekleidete Kammern. Dieser Teil ist ron einer starken Schicht quergestreifter Ringmuskeln ungeben, welche zum 'Teil rer Länge, zum Teil der Quere nach verlaufen und die Fjakulation des Spermas bewirken. Die \%ellen sind ron einem dicken Cylinderepithel ausgekleidet, welches auch die doppelten Zwischenwände liefert: dieses Epithel ist stark färbbar und liefert nach Ansicht Ribagas ein Sekret, welches in den vier Kammern rorgefunden und mit dem Sperma ausgespritzt wird. Dies Sekret gerinnt unter der Einwirkung fixierender Flüssigkeiten zu einer fast homogenen Masse. Die Spermatozoen finden sich in den beiden dorsalen Kammern, wohin die beiden Vasa deferentia einzeln in der Nähe der Medianlinie durch das Epithel hindurch einmünden. Aus den Kammern dringt das Sperma bei der Kontraktion der die Vesicnla seminalis umgebenden Muskulatur durch zwei enge Kanäle in ein kleines Atrium und ron hier in einen, durch den apicalen (zugespitzten) Abschnitt des liopulationsorgans fülırenden 
Kanal. Die Wandungen dieses Heischigen Abschnitts (Penis) sind aussen und nanentlich innen von einer grossen Menge klemer, chitinöser nach hinten gerichteter Dornen besetzt. Das Lumen dieses Abschnitts ist durch zwei Vorsprünge T-förmig gebildet; der Stiel des $T$ dient als Ductus ejaculatorius; dieser wird nach oben zu von einem chitinösen stachelförmigen Gebilde abgeschlossen, welches durch die ganze Länge des konischen Abschnitts hindurchgeht und die Einführmg in die weibliche Geschlechtsöffnung erleichtert. Die beiden Vorsprünge rereinigen sich weiter hinten zu einem medianen Gebilde, der "Radula". Dorsal und ventralwärts von dem Endabschnitt des "Penis" finden sich starke chitinöse Platten. Eine genaue Beschreibung des merkwïrdigen Kopulationsorgans ist ïbrigens ohne Abbildungen kaum möglich.

Die weiblichen (ienitalorgane bestehen aus zwei längs dem Darm gelegenen, je von 4 Ovarialtuben zusammengesetzten Orarien; die je etwa $\check{5}$ Eier enthaltenden Tuben sind durch ein Filament gemeinsam am ersten Dorsalhalbring befestigt. Die beiden kurzen () vidukte vereinigen sich in einem gemeinsamen Endstück, welches in das Atrium der Scheide mündet; hierher mündet anch der chitinöse Kanal einer runden, dorsal gelegenen Samentasche; die Wandungen der Ovidukte und der Samentasche bestehen aus niederm Ptlasterepithel, welches aussen mit einer Ringmuskelschicht, innen mit einer diinnen Intima bedeclit ist. Die äussern weiblichen Genitalorgane bestehen aus der letzten Ventralplatte, auf welcher das Atrium der V'ulva nach aussen mündet, zwei viereckigen seitlichen, nach linten gerichteten und mit gegabelten Anhängen versehenen Platten und jederseits zwei unter der letzten Ventralplatte hervorragenden langen stilettförmigen Gebilden. Von Muskeln fand Ribaga drei Paare: querverlaufende Dilatatoren der Vulva, zwei längsgerichtete Retraktoren des Rectums und ein Paar Retraktoren oder Abduktoren der gegabelten Anhänge.

Am Nervensystenı beschreibt Ribaga das Supraösophagealganglion mit grossen Lobi optici, zwei starken Antennennerven, Nerven nach dem Gesichtsteil und nach dem Hinterkopfe. Das sympathische Tervensystem besteht aus einem Querbogen (Vereinigung zweier lateraler rom Gehirn kommender Filamente), ron welchem ein starker medianer unterer Strang nach hinten verläuft und seitlich jederseits drei Nerven (nach dem Pharynx), zwei feinste Nerven nach der Oberlippe und andere Nerven nach den Mundteilen und dem Pharynx, ausgehen. Yom Subösophagealganglion gehen zwei Nerven nach der Unterlippe und jederseits drei Nerven nach den Maxillen und deren Tastern (vielleicht auch nach der Mandibel). Die Nervenkette besteht aus dem kleinen prothorakalen, dem grossen meso + metathorakalen und dem 
kleinen abdominalen Ganglion, welch letzteres an der Grenze von Thorax und Abdomen gelegen ist. Alle Ganglien sind untereinander durch kurze, verhältnismäßig dicke Komnissuren verbunden. Die beiden thorakalen Ganglien geben Nerven an die Anhänge der Brust, das abdominale zwei lange Nerven ab, welch' letztere je drei verästelte Zweige nach den Seiten des Körpers (Muskulatur) aussenden.

Das Tracheensystem (namentlich an .Jugendstadien in Glycerin gut zu sehen) weist drei thorakale und 6 (vielleicht auch 7) abdominale Stigmenpaare auf. Die Längsstämme sind gut entwickelt und geben zahlreiche Verästelungen nach den verschiedenen Organen ab. Querlaufende Tracheenstïmme hat der Verf. bei Trichopsocus nicht beobachtet.

N. v. Adelung (St. Petersburg).

260 Wagner, J., Apluanipterologische Studien V. ${ }^{1}$. In: Horae Soc. Entom. Ross. T. XXXVI. 1903. pag. 125-156. Tab. Il.

Den Gegenstand der vorliegenden Studie bildet .,der gegenseitige Bezug der Gruppen Aphaniptera und der der Sängetiere und über die Einteilung der Gattung Typhlopsylla Tasch." Der Verf. betont die Natur der Aplianipteren als stäudige Parasiten, deren Organismus unter dem Ëinfluss dieses Parasitismus sich sehr stark verändert hat, und spricht die Vermutung aus, dass die Eier einiger Floharten in der Vermehrungsperiode der Wirte und während des Winterschlafs derselben abgelegt wurden, was für den jungen Parasiten den Vorteil bieten würde, sofort einen neuen Wirt und während der Paarung der Wirte Artgenossen zu finden, welche sich aus andern Larven entwickelt hatten. Die Zahl der Generationen schätzt der Verf. in den meisten Fällen auf mindestens zwei, wobei die Vermehrung der auf wilden T'ieren lebenden Flöhe wohl mit derjenigen der Wirte zusammenfällt. Charakteristisch sind die Flöhe nur für Säugetiere. während sie auf Vögeln nur eine Ausnahme bilden. Da die Huftiere kein Lager bauen, so haben sie auch keine Flöhe zu Parasiten. Zudem sind die meisten Floharten durch ihre Organisation und Vermehrungsverhältnisse an eine bestimmte Säugetierart gebunden, und man kann in Anbetracht des relativ hohen Alters der Gruppe und deren weiter Verbreitung wohl voraussetzen, "dass die Ausarbeitung der Floharten parallel gewesen ist der phylogenetischen Entwicklung der Sängetiere"; die natürliche systematische Einteilung der Flöhe muss daher der biologischen und systematischen Gruppierung der Säugetiere entsprechen.

Auf Grund obiger Gesichtspunkte hat der Verf. eine kritische Revision der Gattung Typhlopsylla (was deren paläarktische For-

1) Vergl. Zool. Zentr.-B]. Bd. VIII. 1901. pag. 528. 
men betrifft) vorgenommen, deren Vertreter auf kleinen Nagetieren, Insektenfressern und Mhstela-Arten leben. Dabei weist der Verf. anf den Tmstand hin, dass die meisten Floharten ihre Wirte zeitweilig verlassen, um anf Sängetiere einer andern Art iiberngehen, was namentlich daun eintritt, wemn der Wirt ron einem andern Tier gefressen wird, oder sich im Lager eines solchen aufhält. Steht der neue Wirt dem frühern nahe, so kann der Floh längere Zeit anf ersterem verweilen, ja bei völlig gleichen Lebensverhältnissen sogar ganz anf demselhen bleiben. Hierfür werien Beispiele angeführt: Thyphlopsylla ag!ntes Hell. z. B. ist ein ständiger P'arasit und hat als echten Wirt Whs sylraticus oder Aricola arcalis. als zufällige Wirte dagegen

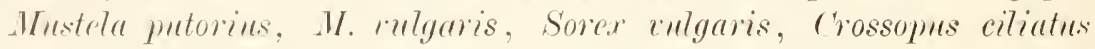
und Tulpu enropuen, welchen die erstgenannten Nager als Nahrmug dienen. Ferner geht Ceratophyllus melis Walk., ein zweifelloser Parasit des Dachses, zufällig auf Füchse ïber, und umgekehrt geht ein l'arasit des Fuchses, Pulex gloliceps Tasch., auch auf Dachse ïber: es ist bekannt, dass Füchse häufig rerlassene und auch noch bewohnte Dachshane aufsnchen. Alle Angaben iiber die Wirte von Floharten müssen daher sorgfältig geprüft werden.

Es sind 12 Arten der Gattung Typhlopsylla bekannt, von welchen zwei auf Insektenfressern und fünf auf klemen Nagern leben, wälrend für die übrigen Arten der echte Wirt noch nicht mit Sicherleit bekannt ist. Von der Betrachtung ausgehend, dass die Insekienfresser phylogenetisch älter sind als die Nagetiere, suchte der Verf. die Arten der Gattung Typhlopsylla auf Grund indifferenter, also beständigerer Merkmale (namentlich der Beborstung), dem Alter nach zu gruppieren, was auch vollständig gelungen ist: Die Gattung lässt sich auf Grund verschiedener Merkmale in drei Gattungen zerlegen, von welchen die eine, Palacopsylla n. g., die ältesten Charaktere aufweist, und drei auf Insektenfressern parasitierende paläarktische Arten umfasst ( $T$. dasycnemus Rothsch., T. gracilis T. n. T. sibirica Rotlısch.); die zweite (iattung Ncopsylla n. g. enthält die paläarktischen Arten $N$, bidentatiformis W., $N$, altaica W. und $N$. pentacanthus Rothsch. (Parasiten vou Nagern), die dritte Gattung, Typhlopsylla s. str. die Arten T. cal• casica T., T. assimilis T., T. orientalis W., T. agyrtes Hell., T. bisoctodentata K., T. uncinata $\mathrm{W}$. und 'T. proxima $\mathrm{n}$. $\mathrm{sp}$.

Auf Grund der Zahl der paarigen Borsten am Metatarsus steht Palaeopsylla mit vier Paaren seitlicher Borsten obenan (nahe? bei Ceratophyllus), von ihr zweigen ab Typhlopsylla s. str. mit drei Paaren solcher Borsten und Neopsylla olne Nebenborsten. Es folgt eine dichotomische Tabelle der Gattungen und Arten sowie eine genaue Besprechung zweier Arten, welcher wir Folgendes entnehmen: N. setosa W. ist Synonym von $N$. bidentatiformis W. (Ziesel, Süd- und Südostrussland), deren beide Geschlechter genauer beschrieben werden; T. proxima 11. sp. vom Kaukasus, erbeutet anf Crocidura aranea und Mus sylvaticus, steht T. agyitcs nahe, von welcher sie siclı durch den Bau des männlichen Haftapparates interscheidet.

Ferner bespricht der Verf. die nahestehende Gattung Ctenopsylla, deren Vertreter auf kleinen Nagern leben, und beschreibt den Haftapparat von Ct. taschen- 
bergi W. Im ganzen sind sieben paläarktische Arten dieser Gattung bekannt; die von Baker beschriebene Ct. mexicana (auf Mus decumanus in Mexiko erbeutet) ist nach Wagner identisch mit der gemeinen enropäischen Ct. musculi.

Den Beschluss des interessanten Aufsatzes bildet die Beschreibung einer neuen Gattung Typhloceras n. g. ( $T$. poppei n. sp.), welche nach einigen Merkmalen der Typhlopsylla-Gruppe, nach andern Merkmalen Ciratophyllus nahesteht. Der einzige Vertreter der Gattung wurde von Poppe bei Vegesack auf Mus sylraticus gefangen, welche jedoch wohl kaum als dessen echter Wirt anzusehen ist (Abbildung der neuen Art).

N. v. Adelung (St. Petersburg).

61 Bolle, J., und II. Richter, Studien über die Ursache der Schlafsucht der Seidenraupe. In: Keitschr. f. d. Landw. Versuchswesen in Österreich 1903. pag. 287. (Referiert in Centr.-IB]. f. Bact., Parasitenk. u. Infectionskr. I. Abt. Ref. Nr. 23. Iid. XXXIII. pag. 735 - 736.)

Verf. haben sich die Frage zur Entscheidung vorgelegt, ob die schlafsucht der Seidenraupe, wie von verschiedenen Forschern behauptet worden ist, durch Bakterien hervorgerufen wird, die sich in dem Magen von auf diese Weise erkrankten Raupen gefunden hatten. Zu diesem \%week unterwarfen sie die auf dem Maulbeerbatum vorkommenden bakterien der Reinkultur. Es konnten sechs Arten streng differenzierbarer Microorganismen und zwei Arten Hefepilze gezïchtet werden. Mit den sehr konzentrierten Lösungen sämtlicher lieinkulturen wurde frisches Laub infiziert und dieses an die Raupen sowohl bei vollem wie bei leerem Magen verfüttert. Die Raupen blieben dabei gesund. l)asselbe war der Fall, wenn den Raupen Futter verabreicht wurde, das mit lieinkulturen ron Bakterien rerumreinigt war, die sich im Iageninhalt von Raupen gefunden hatten, die vor ihrer vierten bezw. kurz nach ihrer dritten Häutung untersucht worden waren. Auch Fütterungsversuche, die mit Bakterien aus dem Magen- und Yarminhalt ausgesprochen schlafsiichtiger Raupen angestellt wurden, verliefen grösstenteils resultatlos, wenn auch bei einigen offenbar prädisponierten Raupen, die dem Versuch bei leerem Magen unterworfen worden waren, Schlafsuchtsfälle rorkamen. Danach kamen die Verf. zu dem Schlusse: Dass die Microorganismen auf den Blättern des Iaulbeerbaumes sowohl im Verdaungskanal gesunder wie kranker Raupen angetroffen werden und dass dieselben selbst dann, wenn sie den Raupen in Reinkulturen zugeführt worden waren, keine Schlafsuchtserkrankung hervoriufen.

11. v. Linden (Bonn).

62 Hermes, 0., Nachtschwärmer in Rovigno. In: Koolog. Garten. Jahrg. XLIII. 1902. Nr. 4. pag. 128-132.

Im ()ktober 1902 wurden an einem in der Nähe der Zoologischen 
Station gelegenen Haus durch den Bau eines Bienenschwarmes, der sich zwischen Fenster und Jalousien an einem Treppenfenster des zweiten Stockwerkes eingenistet hatte, in grosser /ahl Schmetterlinge von Acherontia atropos L. angelockt und im ganzen 15+ Fxemplare des Schwärmers gefangen. Am ersten Oktober allein waren 100 Totenköpfe gesammelt worden, ron da an kamen täglich 4-5 Stiick in Gefangenschaft und nachdem einige 'Tage nicht nachgesehen worden war, wuchs die Ausbente wieder auf 36.

Noch läufiger wie Acherontia atropos wurde vom Verf. Sphin. convoluti L. beobachtet, der sich besonders durch den Duft der unmittelbar vor der Station angeptlanzten Mirabilis galopa anlocken liess. Mit Leichtigkeit liessen sich innerhalb einer Viertelstunde 10-15 Schmetterlinge fangen und obgleich dies eine Woche hindurch geschah, schien die allabendlich sich einstellende Zahl des Schwärmer's nicht abzunehmen. Da Verf. seit einer Reihe von Jahren dieselbe Beobachtung gemacht hat, so kamn lifer an ein nur periodisch massenhaftes Auftreten des Windenschwärmers nicht gedacht werden.

II. v. Linden (Bomln).

863 Hirschler, Jan, Studien über Regenerationsrorgänge bei Lepidopterenpuppen. In: Anatom. Anz. XXIII. Bd. 1903. Nr. 24. pag. 612-627. 5 Abbildg.

Experimentiert wurde an I'uppen von Notodonta tremulae, Vanessu levana und Samia momethea. Die Versuche wurden in der Weise ausgeführt, dass Verf. die drei letzten Segmente der I'uppe mittelst einer Schere oder eines Rasiermessers entfernte und die Puppe sogleich nach der Verwundung in Hïssiges $50^{\circ}$ C. warmes Paraffin tanchte. Die Wunde bedeckte sich auf diese Weise mit einer luftdicht abschliessenden Kruste, die indessen nicht so fest der Wundfäche aufsass, lass der Regenerationsprozess dadurch beeinträchtigt worden wäre, da der nach dem Schneiden herausquellende hellflüssige Körperinhalt allmählich durch liesorption verschwindet und zwischen Schnitttläche und Paraffindecke einen Hohlraum erzeugt, der allmählich durch die regenerierenden Gewebe ausgefüllt werden kann. Der Regener:itionsprozess wird dadurch eingeleitet, dass an der A ussenfläche der W unde viele Gewebe, hauptsächlich aber das Fettgewebe in Zerfall geraten. Dieser Gewebszerfall tindet am schnellsten in den äussern Partien der Wunde statt, später nnd langsamer in den tiefern Schichten nnd bewirkt, dass die Wunde von einer ziemlich dicken, kompaliten, fein granulierten Masse bedeckt wird, die den ersten $W$ undverschluss darstellt. Etwa 2+ Tage nach der Operation fand sich die erste Bildung von Narbengewebe, das sich ïberwiegend aus epithelialen Elementen 
(Hypoderm und Tracheenmembran), teilweise aus Leukocyten aufbant. Das epitheliale Narbengewebe erscheint zuerst am Wundrande, von wo es in der Richtung gegen die Mitte der Wunde wïchst, das leukocytäre sehen wir hingegen am frühesten und am stärksten in der Witte der Wundfäche entstehen. Beide (iewebe wachsen sich somit entgegen und vereinigen sich zu einer dicken Schicht, welehe die Wunde bedeckt und deren Ausläufer in den Körper der Puppe eindringen. Dieses Zusammenschliessen beider Gewebe zu einen einheitlichen Narbengewebe hält Verfasser für den zweiten provisorischen Wundverschluss. Der definitive Wundverschlnss wird durch Regeneration der Hypodermis bewirkt. Die regenerierten Hypodermelemente entstehen zuerst am Wundrand und verdanken ihre Entwicklung dem alten Hypoderm. Sie bilden einen Übergang ron einem sehr hohen Fpithel (Rand der Wunde) zu einem platten mit ovalen, gestreckten Kernen (Mitte der Wunde). Bevor das neu regenerierte Hypoderm die Wunde ganz verschlossen hat, bildet sich eine (hitinschicht aus, die anfangs sehr dïnn und durch Eosin leicht färbbar ist. Die am Raud der Wunde sich regenerierende Hypodermis bildet ron Anfang an eine, selten zwei ringförmige, tiefe lalten. welche denjenigen zwischen andern Abdominalsegmenten entsprechen und somit auf eine Neubildung von einem resp. von zwei Segmenten hinweisen. Was sich regenerierende Hypoderm bedeckt nicht alles Narbengewebe von aussen her, es dringt teilweise in die verhältnismäßig dicke Schicht hinein und schliesst nach seiner Verwachsung einen Teil dieses Gewebes gïnzlich voin Puppenleib aus.

Was nun die Regeneration einzelner Organe anbetrifft, so fand Verf. folgendes: Schon 24 Tage llach der Operation war eine Verbindung des Nittel- und Enddarmes zu beobachtell. Lis muss angenommen werden, dass der Enddarm nur aus Elementen der Pylorusimaginalseheibe hervorgeht, da die larvalen Epitheheste mit den abgeschnittenen Segmenten entfernt wurden. Das Endstiick des Rectmms samt Anus wurde dureh proctodäumähnliche hypodermale Einstïlpungen gebildet.

Auch die liegeneration der Ansführungsgänge der Geschlechtsorgane vollzieht sich verhältnismäßig raseh (37. Tag) und zwar entsteht ein bedentender Teil derselben durch Ausstïlpungen des Iypoderms, also aus ektodermalem Baumaterial, wie es auch bei der normilen Entwickhung beobachtet wurde.

Wie bei der Regeneration des Banchnervenstranges der Amneliden, so komte auch bei der Regeneration der von dem letzten Ganglion der Schmetterlingspuppen abgehenden Nervenstränge eine Beteiligung ron Hypodermiselementen konstatiert werden. 
An den Stellen nämlich, wo sich die Nervenabzweigungen der Hypodermis nähern, haben alle Hypodermiszellen lange zahlreicle Fortsätze, die gegen die Nerven zn gerichtet sind. Man sieht anch einzelne Hypodermzellen austreten und in Form langer gestreckter Kellen, bisweilen zu mehrern kleine Bündel bildend, die Strecke zwischen dem Hypodern und den Nervenendigungen ausfüllen. In demselben Maß, wie die Regeneration fortschreitet, lïsst sich eine l)egeneration des Narbengewebes nachweisen.

Der Verfasser stellt noch eine ansfïhrlichere Arbeit ïber diesen (regenstand in Anssicht, in der auch die Regenerationsvorgänge am vordern Körperende beriicksichtigt werden sollen.

I. v. Linden (Bonn).

\section{Vertebrata.}

\section{Reptilia.}

864 v. Méhely, Iajos, Lacerte taurica Pall, a magyar fauna uj gyikja (L. tamica Pall, eine neue Eidechse der ungarischen launa). In: Allattani közlemények. Bd. I. Budapest. 1902. pag. 58--63. 3 Orig.-Textabbild.

Verf. berichtet über das Vorkommen der für Ungarn neuen Eidechsenart Lacerta taurica Pall. Seiner Ansicht nach ist L. taurica im Donau-Theiss-Becken des ungarischen Tieflandes überall leimisch geworden und sicherlich im Donautale aus Rumänien, bezw. aus der taurischen Halbinsel nach Ungarn eingewandert. In der liegel kommt sie auf lose gebundenem Sandboden ror. Sie erscheint Mitte April und lebt während des Sommers in schief angelegten röhrenartigen Erdlöchern von $1,5 \mathrm{dm}$ Tiefe. In der Gefangenschaft beginnen die Weibchen Mitte Juni je 4-5 Fier abzulegen. Die grössten Eier waren $14 \mathrm{~mm}$ lang und $7.7 \mathrm{~mm}$ breit. Das Farbenkleid dieser Eidechse ist sowohl hinsichtlich der Grundfarbe als auch der Zeichnung in den Details je nach der Gegend verschieden und in geringerm oder höherm Maße der Umgebung angepasst. Ein schönes Beispiel hiefür erwähnt Verf. aus der P'uszta Bugacz bei Kecskemét. Ein 'Teil derselben ist mit einer rotbraun blühenden schwärzlichen Zwergbinsenart (Schoenus nigricans L.) bestanden und auf diesem Gebiete ist das Grün des Rïckenfeldes der Eidechse sehr schmal mit schmutzig gräulichem Anthug, die RandHecken sind aber sehr ausgedehnt und der Binsenblïte entsprechend schwärzlich rotbraun gefärbt, so dass das unbeweglich sitzende Tier vom schärfsten Auge nicht wahrgenommen werden kann, und wenn es sich dennoch regt, so meint man, die Binsenköpfe seien erschüttert worden. An andern Stellen der l'uszta, wo das Gras spärlich wächst und umsomehr gelber Sand vorhanden ist, zeigt auch die Eidechse 
eine andere Färbung. Das Rückenfeld ist breit und glänzend grasgrïin, die Randflecken sind klein und auffallend blass gelblich braun gefärbt. Das ganze Farbenkleid des 'l'ieres ist somit ein Ebenbild der Umgebung.

A. Gorka (Budapest).

86.5 v. Mihely, Lajos, Adatok a delibláti homokpuszta és a Lokva hegység faunájához. (Beiträge zur Fauna der Sandsteppevon Deliblít und des Lokva-Gebirges.) In: Allattani Közlemények. Bd. II. Budapest 1903. pag. 93-105.

Verf. berichtet über eine in der zweiten Hälfte April 1903 unternommenen Sammelexkursion in die $396 \mathrm{~km}^{2}$ umfassende Sandsteppe von Deliblát und in das Lokva-Gebirge im südungarischen Komitate Temes, bezw. KrassóSzörény. Die wichtigste der zahlreichen Beobachtungen ist diejenige, dass Lacerta taurica Pall. in allen Sandsteppen Ungarns vorkommt und charakteristisch für dieselben ist. Nachdem I. taurica in Ungarn lïngs der untern Donau von Baziás bis Orsova nicht vorkommt, G. v. Horváth aber auch bei Vranja in Serbien einige Exemplare sammelte, so spricht Verf., darauf fussend, die Meinung aus, dass dies Tier aus Rumänien nach Serben und von da nach Ungarn gelangt sei, u. z. zunächst in die Sandsteppe von Deliblát, von wo ans es sich dam auch in westlicher und nordwestlicher Richtung, im Donan - Theiss - Becken verbreitet habe und bis Budapest vorgedrungen sei. Eine interessante Beobacl:tung ist es ferner, dass Lacerta praticola Eversm., welche Verf. vor 8 Jahren bei Herkulesbad anfgefunden hat, von Herkulesbad bis Zlaticza, mithin in ganzen Gebirg längs der Donau verbreitet ist und eine charakteristische Art dieser fiebirgsgegend bildet, insofern sie in andern Gegenden Ungarns überhaupt nicht vorkommt.

A. Gorka (Budapest).

Ares.

s66 Sharpe, R. B., A Monograph of the Turdidae or family of 'Thrushes, by the late II enry Seebohm. Bd. 1. 1898. pag. 1-337, Tab. 1-78. Bd. 2. 1902. pag. 1-250, Tab. 79-149.

In Jahre 1895 starb der berïhnte englische Ornithologe Henry Seebohm und hinterliess die Mehrzahl der in vorliegendem Werke erschienenen Tafeln fertig gedruckt und koloriert, sowie ein kleines Manuskript, die Beschreibungen der Gattung Geocichla enthaltend. R. Bowdler Sharpe ïbernahm es, das Werk im Sinne des Verstorbenen zu vollenden. Es sind also mehr denn drei Viertel des Werkes von Sharpe allein geschrieben. Es sind in dem Werke nicht weniger als 221 Formen behandelt, nämlich 51 der Gattung Geocichla, 89 von Turdus, 82 von Merula und 7 von Mimocichla. Wissenschaftlich ist diese Einteilung in 4 Gattungen nicht, da man eine scharfe Grenze zwischen Geocichla, Turdus und Merula nicht ziehen kann; man sollte also eigentlich nur Turdus und Mimocichla anerkennen, aber bei der grossen Anzahl der Arten scheint das Bedïrnis nach Einteilung in sogenannte Gattungen sehr gross zu sein. 
I) ie grosse Anzahl sogenannter Arten ist nur dadurch zu stande gekommen, dass Verf. alle trinär benannten Unterarten als Arten, bin̈̈r benannt, behandelte, soweit er sie anerkannt hat. lief. bedauert ein solches Verfahren, da es unbedingt zum Widerspruch reizen muss. Schwer zu unterscheidende, oder gar wenig ausgeprägte, nicht immer konstante, lokale Formen muissen beachtet werden, niclst nur, weil es eine Vernachlässigung von Tatsachen in der Yatur ist. wenn man es nicht tut, sondern auch weil gerade sie geeignet sind, uns Fingerzeige für das Entstehen verschiedener Arten zu geben. sie sollten aber mach Ansicht des Ref. nur als Unterarten behandelt werden. Die Bebandlung der einzelnen Arten ist folgendermaßen: Dem (immer binären) wissenschaftlichen Namen ist ein meist "gemachter" englischer Name beigefügt, worauf ein Synonymen-Yerzeichnis folgt, das alle Kombinationen ron Gattungs- und Speciesnamen enthält, aber kein Literaturver\%eichnis. I)ann kommt eine kurze lateinische Diagnose. In dem darauf folgenden Hauptalsschnitte sind Verbreitung, Aufenthalt, alles was über Lebensweise. Fortpflanzung und Nahrung bekannt ist. angegehen, und schliesslich folgt eine englische Beschreibung der verschiedenen Gefiederzustïnde. Eine knappe Angabe über die Verbreitung unmittelbar linter der Diagnose wäre von grossem Nutzen gewesen, da es bei der getroffenen Anordnung, die mehr oder minder in erzihlendem Tone gehalten ist, immerhin einige Zeit erfordert, ein genaues Bild der geographischen Verbreitung zu gewinnen. Fiir die Vollständigkeit und Zuverlässigkeit des Werkes bürgt der Name des Verfassers, beziehungsweise Herausgebers. Die Bilder sind meist vortrettich, doch lässt bei einigen noch zu Lebzeiten Seebohms fertig gestellten Tafeln das Kolorit zu wünschen übrig, ein Fehler, der nur teilweise wieder gut gemacht werden konnte. Die Maße sind nach Art fast aller englischen Ornithologen immer noch in englischen Zoll gegeben. Nit dem Abschlusse dieses Werkes, wie es deren so viele älnnliche in englischer Sprache gibt, ist wieder eine grosse (iruppe von Vögeln nicht nur in guten Bildern, sondern auch in rollständigen Reschreibungen dem Verständnisse eines Jeden näher gebracht.

E. Hartert (Tring). 


\section{Zoologisches Zentralblatt}

unter Mitwirkung von

Professor Dr. O. Bütschli and Professor Dr. B. Hatschek

in Heidelberg

herausgegeben von

in Wien

Dr. A. Schuberg

a. o. Professor in $H_{\theta}$ idelberg

Verlag von Wilhelm Engelmann in Leipzig.

29. Dezember 1903.

No. 26.

Zu beziehen durch alle Buchhandlangen und Postanstalten, sowie durch die Verlagsbuehhandlung. Jahrlich 26 Nummern im Umfang von 2-3 Bogen. Preis für den Jahrgang M. 30. - Bei direk ter Zusendung jeder Nummer unter Streifband erfolgt ein Aufschlag von i. $_{\text {4. }}$ - nach dem Inland and von 31 . 5.- nach dem Ausland.

\section{Referate.}

\section{Faunistik und Tiergeographie.}

867 Davenport, C. Bo, The animal ecology of the Cold Spring sand spit, with remarks on the theory of adaptation. In: Decennial Publicat. Univers. of Chicago. Vol. 10. 1903. pag. 1-22. 7 Textfig.

Gegenstand dieser biologischen Untersuchung ist eine sandige Landzunge, welche als quer vorgelegte Barriere den Hafen von Cold Spring Harbor auf Long Island in einen kleinen Innenlafen und einen weit umfangreichern Aussenhafen zerlegt. Die Landzunge selbst ist $660 \mathrm{~m}$ lang und $40 \mathrm{~m}$ durchschnittlich breit, der höchste Punkt liegt etwa $1 \mathrm{~m}$ über der mittlern Flutgrenze. Der Boden besteht im wesentlichen aus Sand, der aussen grobkörniger, nach innen feiner ist, während an der Innenseite Schlammablagerungen sich finden. Vegetation tritt nur an der Innenseite und auf dem Kamm auf (Spartina-Gras). Nach diesen äussern Verhältnissen zerlegt Verf. das ganze Gebiet in drei Regionen, in den Aussenrand, den Kamm und den Innenrand.

Der Aussenrand weist zunächst eine unterseeische Zone auf, die nur bei sehr tiefer Ebbe vom Wasser freigelegt wird; sie beherbergt einmal festsitzende Formen, darunter vor allem Lamellibranchiaten (Ostrea virginiana, Pecten irradians, Anomia simplex, Arca, Mactra usw.), die hier einen sehr günstigen Weidegrund finden, weiter kriechende Formen, darunter namentlich Gastropoden (Nassa obsoleta besonders häufig), Seesterne nnd Crustaceen (Brachyura, Eupagurus und Limulus polyphemus); einen dritten Bestandteil bilden wühlende Tiere, wie Synapta, Balanoglossus, Cerebratulus und Anneliden,

Zoolog. Zentralbl. X. Jahrg.

- Nr. 867. - 
und einen letzten endlich die schwimmenden Formen, die teils Aasfresser, teils Riauber sind und in wesentlichen aus Krebsen und Fischen sich zusammensetzen. - An die unterseeische Zone schliesst sich der untere Abhang des Aussenrandes an, der sehr ungünstige Existenzbedingungen darbietet, da er im Bereich der Gezeiten gelegen ist und abwechselnd ron Land und Wasser bedeckt wird. Das Pflanzenleben ist auf einzellige Algen beschränkt, ron Tieren findet sich hauptsächlich eine Anzahl arktischer Collembolen, weiter im Juni zahlreiche Weibchen von Limulus polyphemus. die hier ihre Eier ablegen, und endlich ein grosser Annelid, Nereis Timbata. - Der obere Abhang des Aussenrandes setzt an der obern Flutgrenze an und ist ron Trümmern organischen und anorganischen Ursprungs bedeckt, welche die See auswirft und die eine reiche Nahrungsquelle darbieten. Zunächst treten P'Hanzenfresser auf in einigen dem Landleben angepassten Amphipoden (Orchestra und Talorchestia). weiter in Staphyliniden (Bledius) und in einem Regenwurm (Enchytraens albidus), Aasfresser stellen Ameisenarten, Fliegen (Sarcophagu connaria), Necrophorns sowie die Larven ron Dermestiden dar, als Räuber kommen hinzu einige Spinnen (Lycosa cinerca), Asiliden und Cicindela. Am obern Rand dieser Zone treten einige höhere Pflanzen rereinzelt anf und mit ilmen Heuschrecken, die weiss wie der Sand gefärbt sind, und Grillen.-- Am obersten Raud des äussern Abhanges finden sich bereits grössere Mengen von Spartina-Gras, zwischen dem breite Kanäle zum Abthiessen der überschlagenden Flut gelassen sind, und hier haben sich zahlreiche Mollusken angesiedelt (MLdioldArten, Mytilus edulis. Nasea obsoleta, Littorina).

Am Innenrande finden sich mächtige Schlammablagerungen sowie eine reiche Vegetation von Spartina-Gras, in der Nähe der obern Flutgrenze halten sich hier vor allem Brachyuren (Gelasimus pugnax und pugitator) auf. - Zwischen Innen- und Aussenrand liegt endlich eine trockene Landzone mit einer dauernden Pflanzenvegetation, und hier tritt uns eine reine Landfauna entgegen, wie sie eine Wiese in einiger Entfernung rom .Jeere gleichfalls darbieten wïrde, und die sich aus pftanzenfressenden Kü̈fern, Aphiden, Heuschrecken, Spinnen, Ameisen usw. zusammensetzt.

Um nun festzustellen, bis zu welehem Grade die Fauna des Meeresstrandes ron den äussern Existenzbedingungen abhängig ist, vergleicht Verf. die geschilderte Fauna mit derjenigen der Seeküste des Michigansees bei Chigaco, wo zwischen einem unterseeischen Bezirk und einer Landzone zu unterscheiden ist. Der erstere besitzt naturgemäß gänzlich andere Species als der Meeresstrand, im übrigen aber finden sich anch hier festsitzende (Nuscheln), kriechende (Schnecken 
und Crustaceen) und schwimmende Formen (Fische und Krebse) vor. Die Fauna jenseits der Wasserlinie, wo ganz die gleichen Verhältnisse wie am Aussenrand der Landzunge herrschen, besitzt ebenfalls ginz die entsprechenden Formen des Meeresstrandes, nur fehlen die typisch marinen Vertreter. Es spricht dies für die ausserordentlich hohe Bedeutung, welche die Existenzbedingungen einer Lokalität für die Zusammensetzung ihrer Fauna besitzen, während die geographische Lage von weit geringerer Wichtigkeit ist. Zum Schlusse wendet Verf. die Ergebnisse seiner Entersuchungen auf die Lehre von den Anpassungserscheinungen an und findet, dass ein Organismus ron einer bestimmten Oroanisation bei stetig stattfindender Selektion stets danach strebt, den Ort aufzusuchen, dessen Existenzbedingungen für eben diese Organisation am zusagendsten sind, woraufhin dann naturgenüß乃 eine mächtige Entwicklmog dieser Form stattinden kamm.

J. Me is en h e imer (Marburg).

868 (Halvagni. Wgon, Beiträge rur Kennthiss der Fauna einiger dalmatinischer Inseln. In: Verhandl. k. k. zool-botan. Gesellsch. Wien. 52. Bd. 1902. pag. 362-388.

Als Ergebnisse einer Reise nach den dalnatinischen Inseln (Lisna. Mellisello, Lagosta und Pelagosa) gibt Verf. zunächst einen Überblick ïber die bodenplastisch('n und geologischen Verhälnisse der einzelnen Inseln sowie ïber die \%usamnenset\%ung ilner Tegetation und wendet sich sodann einer nähern Schilderung der Tierwelt zu. Die westlichen Inseln zeigen starke Anklänge an die Fauna Italiens, eigentïmliche Formen treten vor allen unter den Landschnecken und einzelnen Lacerten auf. Is felitt die giftige Vipera ammodytes, welche auf den weiter istlich, näher dem Festlande gelegenen Inseln häutig ist. Bei der Betralchtung der einzelnen Inseln schildert V'erf. namentlich etwas eingehender das Insektenleben auf Lissa, hebt die rerhältnismäßig grosse Insektenarmut ron Lagosta hervor und weist schliesslich auf die interessante Erscheinung hin, dass auf der Pelagosa-Gruppe die ungetlïgelten Inseliten an Individuenzahl gegenüber den gefliggelten Formen stark überwiegen. Bemerkenswert ist auf derselben Inselgruppe das Vorkommen eines Seehundes, des Mlonachis albienter Gray. Am Schlusse der Abhandlung findet sich in längern Verzeichnissen eine /usammenstellung der auf den einzelnen Inseln gefundenen Arten der Myriopoden, der einzelnen Insektenordnungen. der Molluslien und der Reptilien (von Spezialisten der betreffenden Gruppen bearbeitet).

J. M e is en he imer (Marburg).

869 IIicker, V., Koologische Reiseeindrïcke a us Norwegen. 
In: Jahreshefte Vereins für Naturk. Württemberg. 1903. pag. LXVI-LXXV.

In kurzen Zügen schildert Verf. die Eindrücke einer Reise in das Fjordgebiet zwischen Bergen und Trondhjem, wobei zunächst die Vegetation etwas eingehender behandelt wird. Faunistisch interessant ist vor allem ein Haustier, das Fjordpferd, dessen ursprüngliche Stellung im Verhältnis zu den wilden Vorfahren des Pferdes näher erörtert wird. Charakteristische Vögel sind namentlich die Waldhühner mit ihren zahlreichen Bastarden, von denen die bekannteste und häufigste Form das Rackelhuhn (Tetrao medius) ist. Bemerkenswert erscheinen Verf. weiter die zahlreichen Albinos nordischer Vögel im Bergener Museum, wobei er einige Bemerkungen über diese Erscheinung sowie über die normale Weissfärbung der Vögel hinzufügt. Zum Schlusse finden sich einige Angaben über die Fischfauna, wie sie Verf. auf dem Fischmarkte, im Bergener Museum sowie im Aquarium der biologischen Station zu beobachten Gelegenheit hatte.

J. M e is enhe imer (Marburg).

S70 Kiikenthal, W., Zusammenfassung der zoologischen Ergebnisse einer Reise in den Molukken und in Borneo. In: Abhandlungen Senckenberg. Naturf. Gesellsch. Frankfurt. Bd. 25. 1903. pag. 971-988.

Nachdem die Bearbeitung des gesamten Sammelmaterials der Reisen des Verfassers ihren Abschluss gefunden hat, gibt er uns nunmehr eine Zusammenstellung der Ergebnisse dieser Untersuchungen. Was zunächst das tatsächliche Material angeht, so stammen die Meeresformen derselben fast ausschliesslich von dem Litoral, welches dem Städtchen Ternate vorgelagert ist; es zeigten sich darunter von Schwämmen namentlich die Kieselschwämme reich vertreten, von Cölenteraten die Alcyonarien, ebenso lieferten die meisten übrigen Gruppen der Wirbellosen neue Formen in grösserer oder geringerer Zahl, sehr wenige dagegen die Fische. Für die Fauna des Süsswassers wie des festen Landes kommen als Sammelorte in erster Linie Halmahera, sodann die kleinen Inseln Batjan und Ternate in Betracht, in geringerm Maße Celebes, Borneo und Java. Im speziellen ist über diese Fauna zu bemerken, dass die Oligochäten nur dürftige faunistische Beziehungen der nördlichen Molukken zu den umgebenden Gebieten erkennen lassen, die Schmetterlinge dagegen auf eine nahe Verwandtschaft mit den Formen der südlichen Molukken hinweisen. Neue Formen ergaben in besonders grosser Zahl die Orthopteren, die Spinnen schliessen sich eng an das übrige indoaustralische Gebiet an; neue Arten lieferten wieder eine Bearbeitung der Myriopoden und 
der Landmollusken. Wenig zahlreich sind die Süsswasserfische Halmaheras, sehr reich dagegen war die Ausbente an Batrachiern und Reptilien, darunter eine ganze Reihe endemischer Formen; die Vögel lieferten keine neuen Formen, wohl aber die Säugetiere einige wenige.

Das vorliegende Material benutzt Verf. nun zu einer Charakterisirung der tiergeographischen Stellung der nördlichen Molukken. Er schildert zunächst, gestiitzt auf die Forschungen von P. und F. Saras in sowie von $\mathrm{Max}$ W eber, den angenblicklichen Stand unserer Kenntnisse über die tiergeographischen Beziehungen des indo-australischen Archipels und hebt dabei vor allem die völlige Bedeutungslosigkeit der sog. Wallaceschen Linie hervor. Eine speziellere Darlegung der Stellung der nördlichen Molukken stösst noch auf grosse Schwierigkeiten, da wir von den umliegenden Gebieten zu wenig wissen. Der Totaleindruck der Fauna Halmaheras ist ein mehr australischer, wie es sich weniger in der ausserordentlich armen Säugetierfauna als in der Vogelwelt ausdrückt. Es muss also eine Landverbindung der nördlichen Molukken mit Neu-Guinea bestanden haben, wenn auch die Unterbrechung schon so lange zurückliegt, dass zahlreiche neue Arten und selbst einige neue Gattungen sich herausbilden konnten. Zu den gleichen Sclılïssen nötigt die Verbreitung der Reptilien und Amphibien, und in der Armut an Süsswasserfischen schliesst sich Hahmahera dem ganzen übrigen Osten des indoaustralischen Archipels an. Als westliche Verbindung nimmt Verf. darin ganz den Ausfïhrungen ron P'. und F. Sarasin folgend, eine Landbrücke nach Celebes hinüber an, weniger einfach scheinen ihm die Beziehungen zu den Philippinen zu sein, während iber einen Zusammenhang mit den südlichen Gebieten der Molukken noch kein Material vorliegt. Die Fauna der nördlichen Molukken ist mithin als eine Mischfauna ron östlichen und westlichen Formen anzusehen, von denen erstere im allgemeinen überwiegen. Die weitern Aufgaben zur Lösung der vorliegenden Fragen glaubt Verf. vor allem in der Erforschung von Buru und Ceram sowie der Sulu-Inseln suchen zu mïssen.

J. Meisenheimer (Marburg).

871 Mrízek, Al., Ein Beitrag zur Kenntnis der Fauna der Wa rmhäuser. In: Sitz.-Ber. k. böhm. Gesellsch. Wissensch. Math.-naturw. Cl. 1902. XXXVII. 21 pag.

Von den zahlreichen, durch den Handel nach Europa gebrachten exotischen Tierformen gehen die meisten wohl ohne weiteres infolge der ungïnstigen Existenzbedingungen zu grunde, und nur da, wo sie den Tropen entsprechende Verhältnisse aufzufinden vermögen (höhere 
Temperatur und höhern Wassergehalt der Luft vor allem), sind Aussichten für ein weiteres Fortkommen vorhanden. Geboten werden nun solche vor allem in unsern Warmhäusern, und es kommt so hier eine eigentümliche Fauna zu stande, der naturgemäß Wirbeltiere und sonstige grössere Tierformen zwar fehlen, die aber unter solchen Formen, die in feuchter Erde, unter Steinen, Laub usw. leben, eine beträchtliche Zahl von Vertretern aufweist. - In den Süsswasserbassins der von Verf. untersuchten Warmbäuser des botanischen Gartens zu Prag fanden sich zwar keine exotischen Formen ror, zahlreiche Vertreter lieferte dagegen die Untersuchung der terricolen Fauna. Zunächst ist es sehr wahrscheinlich, dass die zahlreichen, an feuchten Stellen lebenden Acariden, kleinen Arachniden, Thysanuren usw. manche fremdländliche Form enthalteı, wenn auch Verf. sie nicht näher darauf hin untersuchte; als typisch exotische Formen wurden dagegen festgestellt eine japanische Heuschrecke, Diestramena marmorata, sowie ron Myriopoden der sehr gemeine Paradesmus gracilis und eine Species von Chordeuma. Von terricolen Oligochäten ist anzuführen eine Species der Gattung Pheretima, von Landnemertinen die iiberaus häutige Geonemertes chalicophora, ron Landplanarien drei verschiedene Arten, Placocephalus kevensis, Rhynchodemus bilineatus und Microplana humicola, welch letztere Form indessen hauptsächlich in der freien Natur Mitteleuropas weit verbreitet zu sein scheint und wohl nur mehr zufällig in die Treibhäuser gerät.

Auf eng umgrenztem lokalen Gebiet tritt uns also hier eine selbständige Fauna entgegen, die sich aus zwei verschiedenen Bestandteilen zusammensetzt, einmal aus allochthonen Formen, die in der Fremde günstige Existenzbedingungen gefunden haben, und dann aus einheimischen Arten, die gleichfalls Zutritt fanden und sich diesen speziellen Verhältnissen anpassten. Dabei scheint diese Warmhausfauna eine ausserordentlich grosse Einheitlichkeit zu besitzen, ïberall tritt sie aut, wo die Bedingungen für sie gegeben sind, ihre Verbreitung erfolgt rein passir durch den Pflanzentransport.

Im Anschluss an diese speziellern Untersuchungen wendet sich Verf. nunmehr einer allgemeinern Betrachtung zu, die im wesentlichen die Methodik bei der Behandhung tiergeographischer Probleme zum Gegenstand hat. Zunächst handelt es sich hierbei un die objektive Feststellung der tatsächlichen Verbreitung, nnd Verf. ist der Ansicht, dass die Tiere überall da, wo alle zu ihrer Existenz notwendigen Bedingungen erfüllt sind, auch wirklich existieren. Namentlich gilt dies für die Süsswasserfauna, deren Formen ganz gleichmäßig über alle passenden Lokalitäten verbreitet sind; ungleichmäßig verteilt sind nur 
die verschiedenartigen Lokalitäten. Getrennt hierson wiirden sodann weiter die Ursachen der Verbreitung (Vorhandensein von Nahrung usw.) und endlich die Mittel und Wege der Verbreitung zu behandeln sein. Namentlich in letzterm Punkte übt Verf. Kritik an den bisher zumeist gebräuchlichen Methoden und wendet sich gegen die Überschätzung aktiver und passiver Verbreitungsmittel gegenüber dem starken Einfluss der phykalischen Bedingungen einer Lokalität auf die Zusanmensetzung ihrer Fauna. Die Ausstreuung von Tieren und ihren Keimen findet so massenhaft statt. dass dieselben leicht iilerall hin gelangen können, aher an der betreffenden Lokalität findet dann eine Auslese statt, und nur die den speziellen physikalischen Verhältnissen angepassten Formen erhalten sich. Schliesslich polemisiert Verf. gegen die häufig ungenauen Ansdricke, wie ..kosmopolitisch“, "selten“, "häufig" usw., und betont die Notwendigkeit rerbesserter Fangmethoden, wodurch faunistische Angaben sehr an Zuverlässigkeit und Wert gewinnen wïrlens.

I. I eisenheimer (Marburg).

872 Römer, F., Die Meeresfauna von spitzbergen und ihre Beziehungen zu den Meeresströmungen. In: Bericht Senckenberg. Yaturf. Gesellsch. Frankfurt. 1002. I. Teil. pag. $139-143$.

Verf. schildert zunächst den physikalischen Charakter der Küsten Spitzbergens, die im ()sten und Westen eine fundamental verschiedene Gestaltung anfweisen. Im Westen hat die Kïste Fjordcharakter, der Boden ist von Schlamm bedeckt. im Osten herselit Strassenbildung vor, d. h. die Küiste ist in zahılreiche Inseln aufgelöst, deren Zwischenkanäle von einer rapiden (iezeitenströmung durcheilt werden, der Boden ist steinig. Weiter steht die Westkïste unter dem Einflusse des Golfstromes, der hier nur noch wenige Planktonorganismen mit sich führt, sie ist mithin nahrungsarm; die Ostküste dagegen wird von dem I'olarsirom bespült, der sehr reich an kleinsten Organismen, namentlich Diatomeen, ist, sie zeigt somit Überfluss an Nahrung. Der Einfluss dieser verschiedenen Existenzbedingungen auf die Verteilung der Tierwelt ist ganz unverkennbar. Der Westen ist in Arten-wie Individuenzahl ärmer an Tieren als der Osten, im Westen ïberwiegen kriechende Formen (Echinodermen), im Osten die festsitzenden (Cölenteraten, Bryozoen), welch letztere eine ganz au-serordentlich ïppige Entfaltung aufweisen. Eine Eigentümlichkeit aller um Spitzbergen gelegenen Gebiete ist das Fehlen einer Litoralfauna bis zu etwa $10 \mathrm{~m}$ Tiefe, da im Winter dieser Streifen zugefroren ist, im Sommer das Eis hier unausgesetzt den Boden schenert und eine tierische Ansiedehung unmöglich macht. Im Norden von Spitzbergen trat eine 
vom übrigen Spitzbergenmeer gänzlich abweichende Tiefseefauna auf, die durch ihren Reichtum an Hexactinelliden ausgezeichnet ist. Die Planktonuntersuchungen ergaben für den Sommer 1898 ein abnorm hohes Aufsteigen des Golfstromes und ein starkes Zurücktreten des Polarstromes, wie es sich in der geringen Beteiligung der für die kalte Ströme charakteristischen Diatomeen an der Zusammensetzung des Planktons aussprach. Charakteristisch für das Plankton der Arktis ist die Armut an Larvenformen, welche Erscheinung darauf zuriickzufuihren ist, dass die meisten Tiere infolge der hier herrschenden, für junge Organismen so sehr schädlichen Existenzbedingungen zur Brutpflege ïbergegangen sind. Bemerkenswert ist endlich noch, dass die Planktontiere, welche in südlichern Breiten bei Tag niedersinken und nachts emporsteigen, in diesen hohen Breiten das gleiche tun, trotzdem während des arktischen Sommers eine Dunkelheit überhaupt nicht eintritt.

J. M e is en heimer (Marburg).

Sis Sehuster, Wilhelm, Eingebürgerte Fremdlinge im Mainzer Becken. In: Zoolog. Garten. 43. Jahrgang. 1902. pag. 380-389. Das fruchtbare, infolge seiner geschiitzten Lage eine höhere Wärme als die Umgebung besitzende Mainzer Becken weist eine nicht unbeträchtliche Zahl fremder, dem Süden angehöriger Tierformen auf, die teils durch das Nahetal, teils durch die Niederung des Oberrheins eingewandert sind. Terf. zählt eine ganze Reihe von Schmetterlingen, namentlich Schwärmer, auf, die hierher zu rechnen sind, weiter einige Heuschrecken (vor allem Oedipoda caerulescens und stridula), eine Anzahl Hymenopteren, den zu den Ameisenlöwen gehörigen Ascalaphus meridionalis, zwei Eidechsen (Lacerta viridis und muralis), die Würfelnatter (Tropidonotus tessellatus) und endlich die ron den Römern eingefïhrte Äsculapschlange (Coluber longissimus) bei Schlangenbad, sie alle stammen aus siidlichern Regionen.

$$
\text { J. Me is enheimer (Marburg). }
$$

\section{Spongiae.}

S74 Sollas, J.. On Haddonella Topsenti, gen. et sp. n., The structure and development of the Pithed Fibres. In: Ann. Mag. Nat. Hist. ser. 7, Bd. 12. 1903. pag. 557-563. Taf. 28, 29.

In dieser Mitteilung beschreibt Fräulein Sollas einen Schwamm aus der 'Torresstrasse, welcher ein aus Sponginfasern bestehendes Skelett besitzt. Die Fasern sind aus einem zellenlosen Mark und einem zellenhaltigen Aussenteil zusammengesetzt und gleichen in dieser Hinsicht den Skelettfasern der Janthella-Arten. Da sie aber nicht wie diese zur Bildung eines netzartigen Gerüstes zusammentreten. 
stellt die Verfasserin für diesen Schwamm ein neues Genus (Haddonella) auf. Die Untersuchung der Fasern ergab folgendes. An ihrer Vegetationsspitze grenzt das zellenlose Mark unmittelbar an die hier aus zahlreichen, ïbereinanderliegenden Lagen bestehende Spongoblastenhülle. Übergangsformen zwischen den Spongoblasten, die aussen der Faser anliegen und den dem Spongin des Faseraussenteils eingebetteten Zellen finden sich nicht. Die letztern sind in verschiedener Tiefe verschieden. Die nahe der Faseroberfläche gelegenen sind grösser, reich an kugeligen Einlagerungen und füllen den Hohlraum in der Sponginmasse, in dem sie sitzen, vollständig aus. Nach Innen. gegen die Faserachse hin, werden diese Zellen ärmer an jenen kugeligen Einlagerungen, kleiner, und füllen die Höhlen nicht mehr aus. Zwischen dem Spongin-Aussenteil und dem Mark findet sich eine granuläre und etwas fibrilläre Übergangszone, welche ebenfalls Zellen entlält.

R. v. Lendenfeld (Prag).

875 Wilson. H. V., The Sponges collected in Porto Rico in 1899. In: U. S. Fish Comm. Bull. Bd. 2. 1902. pag. 375-411.

In dieser Arbeit gibt Wils on gute, aber leider nicht durch Abbildungen erläuterte Beschreibungen vor 47 Spongien von Porto Rico. Es werden 16 nene Arten und 3 neue Varietäten aufgestellt. Den systematischen Beschreibungen ist eine mit Textfiguren ausgestattete Liste der verwendeten Termini technici, namentlich der Nadelbezeichnungen, vorangestellt. Die Namen der Nadeln sind nicht einheitlich. Einige (Triaene, Strongyle) haben englische, andere (Sigma, Chela) lateinische kndungen. Die Monactine werden Mon a tinal, die Pentactine aber Pentact genannt. Die Silbe Sphaer wird das eine Mal (Sphaerohexaster) Sph a er, andere Male (Spheraster, Spherule) Spher geschrieben. Zwischen Singular- und Pluralformen wird nicht scharf unterschieden. Solche formale Ungleichheiten in den Bezeichnungen sollten nicht vorkommen. Die Zeichnung des Sphaerohexasters (Fig. 18), der nach der Abbildung nur vier statt sechs Strahlen hätte und der Sterraster (Fig. $23 \mathrm{~b}$ und $23 \mathrm{c}$ ), deren strahlen nach den Abbildungen eine zonale statt der wirklichen, gleichmäßig verteilten Anordnung hätten, sind mangelhaft.

R. v. Lendenfeld (Prag).

\section{Vermes.}

Plathelminthes.

876 Curtis, W. C., Crossobothrium laciniatum and developmental stimuli in the Cestoda. In: Biol. Bull. Mar. Lab. Woods Holl. Vol. V. 1903. pag. 125-142.

Crossobothrium laciniatum bewolnt die Spiralklappe des Carcharias littoralis. Die Proglottiden lösen sich meist früh von der Strobila und bewegen sich dann wie selbständige Wesen zu hunderten in Chylus des erwähnten Darmteiles. Eine bemerkenswerte Durchsichtigkeit der Gewebe lässt schon an Totalpräparaten fast alle Einzel- 
heiten des anatomischen Banes erkennen. Man sieht, wie aus den in der vordern Hälfte angehänften Hodenbläschen die Vana efferentia zum Vas deferens sich vereinigen, wie dieses in zahlreichen Windungen dem Seitenrande zustrebt und dort in einen bestachelten Cirrus ausläuft. Leicht zu verfolgen sind auch die weiblichen Geschlechtswege. Die Vagina liegt unmittelbar vor dem Penis. In Hachen Bogen läuft sie zum median gelegenen, keulig verästelten Ovar. nachdem sie noch vorher zu einem Receptaculum seminis sich erweitert hat. Beiderseits ziehen sich dnrch die ganze Proglottis die Bänder der Dotterstockfollikel.

Wesentliche Besonderheiten der Geschlechtsdrïsen sind nicht zu finden. Eigentümlich ist nur, dass der Uterus gegen die Bauchfläche des Gliedes vorgewölbt ist. Auf der Mitte der Wölbung steht ein warzenartiges (iebilde. Durch dieses treten bei der Eiablage die reifen Eier aus. Ein Vergleich mehrerer freier Glieder zeigt, dàss̀ sie sowohl in Grösse als in der Zahl der Eier, wekhe der Uterus enthält, merklich differieren. Die grössern Exemplare sind offenbar die älteren; denn nur sie schreiten, sobald sie ins Meerwasser gebracht werden, zur Eiablage. Sie rerfallen dabei in krampfartige Bewegungen. Vorder- und Hinterende biegen sich so zueinander, dass das erstere oft in einen Winkel des letztern zu liegen kommt, die Proglottis also zum geschlossenen Ring wird. Wiederholte Biegungen bewirken das Bersten des warzenförmigen Körperchens auf der nach aussen gekehrten Bauchfläche. Die Eier treten ans. Erst wenn alle entleert, rermindern sich die Kontraktionen, die Proglottis bleibt aber noch 1-2 Tage am Leben. Die Iterusiuptur tritt bei den reifen Gliedern regehmäßig auf. wenn die Nährtlüssigkeit durch Meerwasser ersetzt wird. Unreife Proglottiden entleeren ihre Eier gewöhnlich nur, wenn sie gedrückt werden. Was fül die reifen P'roglottiden im Experiment zu beobachten ist. wird sich auch in der Natur abspielen. Sie verfallen in Kontraktionen. wenn sie mit den Fäces aus dem Darm ins Meer gelangen.

Da diese Bewegungen sofort beim liontakt mit dem Wasser eintreten, so wird die Infektion des Zwischenwirtes nicht durch Aufnahme ganzer Proglottiden, sondern zahlreicher Fier zu stande kommen. Ein Zwischenwirt ist zur Zeit nicht bekannt. Verfasser vermutet aber, dass eine in Cymoscion regal is lebende Lar've das Jugendstadium des Crossobothrium laciniatum sei. Wahrscheinlich entwickelt sich das Ei nur bis zum sechshakigen Embryo, ehe es in ein Wirtstier gelangt.

Der Besprechung des Crossobothrum fügt der Verf. eine Be- 
trachtung über "Developmental stimuli in the Cestoda" an, deren Resultat kurz folgendermaßen wiedergegeben werden kann. Die Entwicklung eines Cestoden ist abhängig von verschiedenen Stimuli. Jeder derselben ist in seiner Wirkung begrenzt. So verleiht bei vielen Cestoden die Vereinigung des Keimplasmas dem Ei die Kraft, sich bis zu einem gewissen Grade zu entwickeln. Dann folgt ein Ruhestadium. Dieses wird erst überschritten, wenn ein zweiter Stimulus. der Kontakt mit dem Wasser, einsetzt. Jetzt baut sich das Ei bis zum sechshakigen Embryo aus. Hier angekommen bedarf das sich entwickelnde Wesen einer weitern Einwirkung. Diese findet statt, wenn der Zwischenwirt bezogen wird. Aus dem Embryo kam sich nun die larvale Cestodenform entwickeh. Als letzten Stimulus bedarf der unfertige Wurm der C̈berführung in den Hauptwirt.

$$
\text { E. Riggenbach (Basel). }
$$

877 Zschokke, F., Ein neuer Fall ron Dipylidium caminum (L.) beim Menschen. In: Centrahl. Bakt. Par. u. Infelit. I. Abt. Bd. XXXIV. 1903. pag. 42-43.

Unter den Darmparasiten des Hundes und der Katze ist Dipylidium canimum (L.) einer der häufigsten. Hin und wieder ist er auch schon im Menschen gefunden worden, in Russland z. B., in Schweden, Dänemark, Schottland, Frankreich, Dentschland und in der Schweiz. Insgesamt sind 34 Fälle bekannt geworden. Da Dipylidium cumimm aber in Menschen keine merkhichen Krankheitserscheinungen hervoruft, so wird der Parasit wohl häufiger im Menschendarm zu finden sein, als nach den spärlichen Befunden vermutet werden kamm. Dipylidium canimm findet sich hauptsächlich bei Kindern, selten bei Erwachsenen. In den oben genannten Ländern die Schweiz ausgenommen — wurde es nur 2 mal in Erwachsenen, 24 mal aber in Kindern angetroffen. In der Schweiz verteilen sich ungekehrt die Fälle nur zweimal auf Kinder, alle ïbrigen auf Erwachsene Der Bandwurm wird durch die Hundelaus Trichodectes canis, liäufiger noch durch Pulex serraticeps, den Hundefloh, auf den Menschen ïbertragen. Auch Pulex irituns soll hin und wieder das cysticerkoide Stadium der Tänie bergen. Eine direkte Übertragung scheint nicht ausgeschlossen.

E. Riggenbach (Basel).

\section{Nemathelminthes.}

878 Montgomery, T. H., The adult organisation of Paragordius varius (Leidy). In: Zool. Jahrb. Abt. Anat. Ontog. IBd. XVIII. Heft 3. 1903. pag. $387-474$. Taf. $37-43$. 
Verf. beschreibt in eingehender Weise die Geschlechtsform von Paragordius varius Leidy, dessen Larve in der Leibeshöhle ron Acheta (Gryllus) abmreriata lebt: die Art ist im östlichen Nordamerika häufig: das Weibchen mit 3 lappigem Schwanzende kann eine Länge von $290 \mathrm{~mm}$ erreichen. Das helle Kopfende ist schräg abgestutzt und trägt einen schwarzen Cervikalring; die Mundöffnung liegt vorn ventral. Die Cuticula und die Hypodermis werden geschildert; die Muskulatur besteht aus longitudinalen Zellen; der Darm ist gebildet wie bei Gordius; beide Geschlechter haben eine dorsale und ventrale Leibeshöhle, das Weibchen ausserdem zwei laterale; der Bauchnervenstrang entspringt von dem Kopfganglion und endigt mit einem Cloacal-Ganglion; es lassen sich chromophile und chromophobe Nervenzellen und -Fasern unterscheiden; in der Hypodermis verlaufen besonders in der V'entrallinie Längsnerven, ferner radiäre, die vom Hauptnervenstrang ausstrahlen und, vorwiegend in der Dorsalgegend, in sensorielle Nervenzellen endigen; das periphere Nervensystem ist reich entwickelt und wird als motorisches (chromophobisch) und sensorielles (chromophil) unterschieden. Als Auge fasst Verf. die ganze dorsale Kopflälfte auf und unterscheidet vorn einen Hypodermis-Wall, darunter eine Retina und eine mit Flïssigkeit gefüllte Höhlung, die hintere Grenze bildet eine Augenkapsel; dorsal rom Darm liegt ein Supraintestinal-Organ; beim Männchen münden beide Horden durch 2 Vasa deferentia in die Kloake; die weiblichen Genitalorgane bestehen aus 2 ()varien, die 3000-4000 paarige Segmente bilden, ans 2 Cteri und 2 Oridukten mit Cilien-Epithel. die in das Atrium treten; in dieses mündet vorn das ventral gelegene Receptaculum seminis, und ron der Dorsalseite geht der Darm in das Atrium über, welches sich nach hinten in eine $6 \mathrm{~mm}$ lange Kloake fortsetzt. Die Gordien bilden eine isolierte Gruppe und sind weder degenerierte Anneliden, noch modifizierte Nematoden; als Parasiten wurden Coccidien in ihnen gefunden.

O. v. Linstow (Göttingen)

879 Noè, Gr. Studi sul ciclo evolutivo della Filaria labiatopapillosa Alessandrini. In: Rendic. R. Acc. Lincei, class. sc. fis. mat. nat., 5. ser. Vol. XII. 1903. fasc. 9. 7 pag.

Verf. macht die Entdeckung, dass die embryonale Larvenform von Filaria labiato-papillosa Alessandrini = Filaria cervina Dujardin = Fitaria terebra Diesing ans der Leibeshöhle von Cerrus und Bos in Blute der Wohntiere lebt, wenngleich nur in geringer Menge; Stomoxys calcitrans Lin. sticht die von den Flarien bewohnten Tiere an und saugt mit deren Blut auch Blutfilarien auf, welche dann, ähnlich wie die von Filaria bancrofti Cobbold und Filaria immitis 
Leidy in Anopheles, einen Entwicklungsgang in Stomoxys durchmachen und vermutlich durch Stich auf die genannten Süugetiere wieder übertragen werden; etwa $3-4$ Prozent der StomoxysExemplare enthielten die Larven; es sind dieselben, welche Ref. im Jahre 1875 im Rüssel von Stomoxys calcitrans gefunden und unter dem provisorischen Namen Filaria stomoxeos beschrieben und abgebildet hat.

O. Linst ow (Göttingen).

\section{Arthropoda.}

\section{Insecta.}

80 Pomerantzer, D., Der Ha inbuchensplintkäfer (Scolytus carpini Rtzb. auf der Haselstaude (Corylus avellana L.) (д. По иеранцевъ, Грабовыі сколитъ на лещинь). In: Horae Soc Entom. Ross. T. XXXVI. 1903. pag. 118-124. Taf. I. (Russisch.

Der Verf. hat 1900 im Chersonschen Gouvernement das Auftreten des Hainbuchensplintkäfer's an Haselnussstauden beobachtet. Die Käfer begannen Ende Mai (alt. Stils) auf ausgelegten Fanghölzern zu erscheinen, das Maximum der Kopulation und der Eiablage fiel auf den 24. Juni. Die Männchen bleiben bei der Kopulation auf der Rinde sitzen; die Weibchen legen unter Flechten usw. die Eingangsöffnung an und fressen dann kurze $(10-20 \mathrm{~mm})$ zweiseitige (selten einseitige) wagrechte líuttergänge nit beiderseits sehr dicht gedrängten Eiergrübchen, worauf sie meist in der Eingangsöffnung sitzen bleiben und hier absterben, so ihren Gang vor Feinden verschliessend. Die Eiablage danert sehr lange (etwa 1 Monat). Die Dauer des Eistadiums konnte nicht bestimmt werden, ist aber jedenfalls sehr kurz. Die jungen Larren fressen Längsgänge, welche späterhin wirr durcheinander laufen und eine Länge von $80-90 \mathrm{~mm}$ erreichten. Es wurden auch sehr kurze Muttergänge mit nur 3-4 Larvengängen gefunden.

Einige Käfer legten nach der Eiablage an denselben Stämmen radiär ausstrahlende und etwas tiefer eindringende Niniergänge an, wobei mehrere Weibchen die gleiche Eingangsöffnung beniitzten. An der Hainbuche sind die Muttergänge länger (bis $40 \mathrm{~mm}$ ) und die Puppenwiegen liegen tiefer im Stamm als an Haselstauden. Die Überwinterung erfolgt im Larvenstadium. Schaden richtete Sc. carpini nur an der Hainbuche, nicht aber an der Haselstaude an.

Im Zimmer gelang es dem Verf. Parasiten des Schädlings zu erziehen und zwar eine Schlupfwespe, Dendrosoter protuberans Nees. Das Ausschlüpfen der Weibchen dieser Art aus dem Holz (dieser Akt danert $1 \frac{1}{1} 2$ Stunden) und das Gebahren der dasselbe erwartenden Männchen wird sehr anschaulich geschildert.

$$
\text { N. v. Adelung (St. Petersburg). }
$$


881 Semenov, .., Sur la structure et le rôle du pédoncule mésothoracique (pediculus mesothoracis) chezcertains Coléoptères. In: Rerue Russe d'Entomol. T. III. 1903. pag. 85-88. 1 Abb. і. T. (А. Семеновт, О строеніп п вначеніи пейliп среднегруди (pediculus mesothoracis) у пъкоторыхъ тесткокрылыхт.) (Russisch.)

Bei einigen Carabiden (z. B. Scarites, Clivina, Dyschirius, ferner Broscus u. a. m.) ist der vordere T'eil des Mesothorax zu einem halsoder stielfür'migen Abschnitt umgewandelt, was der Rïckenfläche des Brustabschnitts ein fremdes Aussehen gibt. Namentlich fällt es auf, dass hier zwischen den Suturen der Elytren scheinbar kein Seutellum zur Entwicklung kommt. Der Verf. beschreibt den Bau des Mesonotums und der Elytren solcher Kïfer, wobei er darauf hinweist, dass der Rïickenteil des Stiels sowohl von den Bestandteilen der Mittelbrust als auch von den basalen Abschnitten der Elytren gebildet wird: letztere sind durch eine Einschnürung von den Rückenabschnitten getrennt, stark in der Längsrichtung ausgezogen und liegen niedriger als letztere. Dieser abweichende Bau der Elytren bedingt das scheinbare Fehlen eines Scutellums, welches jedoch in Wirklichkeit anch bei diesen Kü̈ern \%wischen den Suturen der Elytren eingekeilt liegt.

Die morphologische Bedeutung der halsartigen Verlängerung der Mittelbrust fühırt der Verf. auf den Vorteil grösserer Beweglichkeit des Prothorax zurück. Die betreffenden Käfer leben nämlich in selbstgegrabenen Gängen im Sande, indem sie den Kopf zur Öffnung des Ganges herausstrecken, auf Beute spälien und vorbeilaufende Käfer usw. (selbst ron bedentender Grösse) ergreifen. Die ebenfalls im feuchten Sande lebenden Epactius-Arten mit breitaufsitzendem Prothorax bedürfen der Beweglichkeit des letztern in geringerm Grade, da sie ihre Beute im Laufen resp. Fliegen ergreifen. während der stark und breit eingelenkte Prothorax nebst fiopf beim Graben der Gänge wichtige Dienste leistet (vertikales Auf- und Abwärtsbewegen.

N. r. A delung (St. Petersburg).

\section{Vertebrata.}

882 His, Wilhelm, Über Zellen-und Syncytienbildung. Studien am Salmonidenkeim. In: Abhandl. matl.-physik. Classe k. Sächs. Gesellsch. Wissensch. Leipzig. 1898. Bd. 24. pag. 401-468. 41 Textfiguren.

883 - Protoplasmastudien am Salmonidenkeim. Ibid. 1899. Bd. 25. pag. 159-218. 3 Tafeln und 21 'Textfiguren.

884 - Lecithoblast und Angioblast der Wirbelthiere. Histo- 
genetische Studien. Ibid. 1900. Bd. 26. pag. 173-326. 102 Textfiguren.

Die erstgenannte Abhandlung enthält Studien über die Beziehungen zwischen Keim und Dotter bei jugendlichen Lachs- und Forelleneiern. Auf der frühesten ovarialen Entwicklungsstufe stellt das Ei der Ḱnochenfische eine das Keimbläschen umschliessende protoplasmatische Vollkugel dar. In sie treten in zunehmendem Maße Elemente des Nebendotters oder Deutoplasmas ein, welche den ursprünglichen Protoplasmakörper durchsetzen, an die Peripherie drängen und schliesslich in drei wohlgesonderte Abschnitte scheiden, in den verdickten Keim, die periphere Rindenschicht und in die im Innern den Dotter durchsetzenden Plasmafortsätze. Der scheibenförmige Keim enthält den Furchungskern und an ihm erfolgt die Furchung: er enthält zudem bei Lachs und Forelle fast das gesante Plasma, während Rindenschicht und Plasmafortsätze nur selır schwach entwickelt sind. Noch vor Beginn der Furchung hebt sich der Keim liügelförmig über seine Umgebung empor und setzt sich durch eime ringförmige Furche gegen die Interlage ab, seine Ränder gehen in eine rasch sich verjüngende \%one der Rindenschicht iiber. Diesen ringförmigen Plasmasaum, der den eigentlichen Kieim umgibt, bezeichnet $\mathrm{H}$ is als Properiblast. Die ersten Furchen schmeiden nur in den obern Teil des Keimes ein, und sind in den untern Bezirlien allein durch lielle Strassen lockerer gefügten Protoplasmas erkennbar. Auf der zweiten Furchungsstufe besteht der Keim ans drei Lagen von Blastomeren, rou welchen die obersten allseitig abgegrenzt erscheinen, die mittlern dagegen mit den untern und die letztern wieder untereinander im Zusammenhang stelıen, mithin noch ein Syncytium darstellen. Wie auf der ersten Stufe, so sind auch jetzt sämtliche Zellen von deutlichen Strahlungen erfüllt. Zwischen den Strahlensystemen der untern Zellenelemente sind als Trennungslinien nur hellere plasmatische Strassen (Diasteme) nachweisbar; dieselben besitzen also keinen peripheren $\mathrm{Ab}$ schluss, weshalb $\mathrm{H}$ is diese Gebilde als Plasmochoren bezeichnet, die in ihrer Gesamtheit ein Syncytium bilden, im Gegensatz zu einem Plas modium. Bei letzterm ist eine Abgrenzung der einzelnen, das Plasmodium zusammensetzenden Bestandteile nicht möglicl, wohl aber beim Syncytium. Auf dem folgenden Stadium nimmt die Zahl der Zellenschichten des Keimes rasch zu, zahlreiche Spalträume durchziehen sie namentlich in den untern Schichten, lebhafte amöboide Bewegungen zeichnen die Zellen im lebenden Zustande aus. Das Syncytium an der Keimbasis ist niedriger geworden, zugleich unterscheidet es sich äusserlich von dem blassen zelligen Keim durch seine dunklere Färbung. Auf der vierten Stufe erfolgt endlich eine 
schärfere Scheidung der syncytialen Zellen von den obern, allseitig abgegrenzten Furchungszellen durch einen Spalt, die Keimhöhle. Die dünnen, auf dem Dotter zurückbleibenden Plasmaschichten bilden den basalen Periblast oder das Keimlager, es setzt sich nach aussen fort in den oben erwähnten ringförmigen Properiblast, der den peripheren Periblast oder den Keimwall aufbaut. Nur am Grunde der Randfurche besteht noch eine Verbindung zwischen dem zelligen Kieim und dem Periblast, der den Charakter eines Syncytiums noch immer bewahrt, ebenso wie seine dunklere Färbung und sein dichteres Plasmagefüge. Die Strahlungszentren der Plasmochoren erreichen jetzt ihre stärkste Entwicklung, sie können untereinander in Verbindung treten und so zu pluripolaren Mitosen Veranlassung geben. Es tritt dann eine Ruheperiode in den Teilungen ein, und die Kerne liegen in Gruppen zu zwei bis fünf innerhalb dunkler, durch hellere Zwischenräume roneinander getrennter Höfe. Schliesslich sind an den Kernen des Periblasts zwei Gruppen zu unterscheiden, einmal die einzelstehenden Kerne und Kerngruppen und sodann die Kernkonglomerate und Riesenkerne, erste hervorgehend aus einer fortschreitenden Verschmelzung von Kerngruppen.

Den Schwerpunkt seiner Abhandlung legt Verf. nach diesen mehr speziellen Erörterungen nun in die Frage nach der Entstehung und Organisation von Syncytien. Es werden deslaalb zunächst eine Reihe von allgemeinen Sätzen über Zell- und Kernteilung aufgestellt, von denen folgendes herrorgehoben sei. Alle Teilungen setzen bewegende Kräftesysteme roraus, deren sichtbaren Ausdruck die zentrierten Plasmastrahlungen darstellen, und die sich $\mathrm{H}$ is als rom Zentrum ausgehende Anziehungen und Abstossungen vorstellt. Jede Strahlung umschliesst bei ungehemmter Entwicklung einen Kugelraum, die Astrosphäre, deren Durchmesser die Ausdehnung des einzelnen Kräftegebietes angibt. Bei jeder Kernteilung berühren sich nun die Astrosphären der beiden Strahlungen in einer Ebene, die den Äquator der Teilungsspindel enthält; ihre Strahlen, die sich überallhin ausbreiten, durchkreuzen sich und bilden die Spindel, welche also nichts anders ist als ein sekundär besonders differenziertes Teilstück der Astrosphären. Diese Kräftezentren beherrschen weiter vollständig sämtliche Umbildungs- und Verlagerungserscheinungen des Chromatins während der Kernteilung; in den Astrosphären sind die primären, in den Chromatingebilden die sekundären Vorgänge zu suchen. An der Astrosphäre selbst unterscheidet Verf. den hellen Innenhof, einen dunklen, ringförmigen Verdichtungshof und endlich den Strahlenhof, der sich in das diffuse Plasmagerüst fortsetzt; es wird weiter das gegenseitige Verhältnis dieser Teile, ihre verschiedene Ausdehnung 
während der einzelnen Teilungsperioden aufs genaueste geprüft, und Verf. kommt so zur Annahme besonderer Kontraktions- und Expansionsphasen der Astrosphären, die mit Pro- und Metaphase, bezüglich Anaphase der Teilung zusammenfallen. Es spielen sich also eine Reihe von Bewegungsvorgängen im Plasmagerüst während der Teilung ab. Verf. glaubt dieselben durch eine besondere Plasinastruktur erklären zu können, insofern er sich letztere als ein Gerüstwerk weicher, pseudopodienartiger Substanzstränge vorstellt, die fortwährend Form und Verbindungsweise ändern und so auch in die mannigfachen Formen der Astrosphären sich anordnen können.

Unabhängig von den Astrosphären entstehen die membranösen Grenzschichten plasmatischer Gebilde, und zwar bei den Furchungszellen aus dem peripher gelegenen diffusen Plasmagerïst durch lokale Verdichtung seiner Bälkchen (Zellplatte). Bildung von Syncytien tritt nun dann auf, wenn die Membranbildung verzögert wird, oder wenn nachträglich bereits getrennte Zellen wieder verschmelzen. In ersterm Falle kann es leicht zur Bildung von tripolaren und pluripolaren Spindelsystemen kommen, indem benachbarte Spindelgebiete ineinander übergreifen, letzterer Fall tritt namentlich nach reichlicher Nalırungsaufnahme der Zellen und damit verbundener Ausweitung des Plasmas auf, also beispielsweise bei lecitophagen \%ellen. Syncytien sind also nicht eine besondere Gewebsform, sondern uur bestimmte Entwicklungszustände plasmatischer Gebilde. Und ganz analog der Bildung von Syncytien durch verzögerte Zellteilung können durch verzögerte pluripolare Kernteilung Kernkonglomerate und Riesenkerne entstehen, die Verf. in entsprechender Weise als Syncaryen bezeichnen möchte.

Enge an diese Ausfülırungen schliesst sich der Inhalt der zweiten Abhandlung an, die sich mit Protoplasmastudien an geöffineten frischen Salmonideneiern beschäftigt. Noch schärfer als früher unterscheidet Verf. an dem lebenden Protoplasma einen mehr hyalinen Teil, das Hyaloplasma, und einen körnigen Teil, das Morphoplasma. Auf jungen Stadien überwiegt das Morphoplasma, später dagegen das Hyaloplasma. Letzteres bildet gewöhnlich eine äussere Mantelschicht um die körnige Binnenmasse, ohne dass indessen eine absolut scharfe Grenze zwischen beiden zu ziehen wäre. Unmittelbar nach der Befruclitung bildet das Keimplasma eine flache Scheibe, die sehr allmählich in Dotter- wie Rindenschicht übergeht; während der ersten Stunden des Aufenthaltes im Wasser konzentriert sich indessen das Plasma zu einem Hügel und bei Beginn der Furchung ist dieser gewölbte Hügel aus Keimplasma scharf von Dotter und Rindenschicht geschieden. Das Plasma selbst stellt eine undurchsichtige, von gröbern 
und feinern Körnchen durchsetzte Masse dar. Äusserst lebhaft sind die Bewegungen der Blastomeren junger Keime nach dem Öffnen des Eies, sie strecken Fortsätze von hyalinem Plasma aus, körniges Plasma strömt nach, und schliesslich wird das Ganze wieder in den Körper eingezogen. Auf etwas ältern Stadien nehmen diese buckelförmigen Fortsätze häufig die Gestalt langgestreckter, fingerförmiger Ausläufer an und zeichnen sich dann durch das starlie Überwiegen von Hyaloplasma aus.

Verf. geht nun auf die Organisation des Protoplasmas jugendlicher Zellen ein. Dieselben sind im Innern erfüllt von einem morphoplasmatischen Gerüstwerk, welches nach innen das Kerngebiet mit umfasst, nach aussen in den membranösen Grenzschichten seinen Abschluss findet; die Maschen dieses Gerüstes sind von der durchsichtigen, zähen Flüssigkeit des Hyaloplasmas ausgefüllt, welche gegen Fällungsmittel völlig indifferent erscheint. Sekundär verändert kann das reine Plasma dadurch werden, dass sich Fremdstoffe in Form von Sekreten, Dotterkörnern oder Fetttropfen einlagern. Ist das P'lasma auf grosse Strecken hin völlig gleichartig aus feinsten Maschen aufgebaut, so bezeichnet Verf. seinen Bau als isotyp, ist das Gerïst ungleich dicht und verschiedenartig angeordnet oder treten Strahlungen auf, so ist es anisotyp. Die membranösen Grenzschichten entstehen durch Verschmelzung von Morphoplasmabälkchen, sie sind ein Teil der lebenden Substanz und schliessen die Zelle mit ihrem Inhalt nach aussen organisch ab. Betreffs des Anteils der einzelnen Plasmabestandteile an dem Zustandekommen der Bewegungserscheinungen glaubt Verf., dass das morphoplasmatische Gerüst mit seiner komplizierten Struktur das aktive Agens sei, während das strukturlose Hyaloplasma eine mehr passive Rolle spiele.

Die Organisation der lebenden Substanz mit ihrer gesetzmäßigen räumlichen Anordnung ist einem ständigen Wechsel unterworfen. Die Verteilung von Morphoplasma und Hyaloplasma erleidet starke Verschiebungen bei den amöboiden Bewegungen der Blastomeren sowie im Verlauf der Teilungen, wie Verf. bereits in der erstgenannten Abhandlung ausführlich geschildert hat. Weiter geht Verf. auf die Rekonstruktion der Kerne in den Blastomeren des Salmonidenkeimes ein; sie erfolgt in der Weise, dass die Chromatinkörnchen der sich auflösenden Chromosomen an den Strassen des Plasmagerüstes entlang wandern, zunächst also an den Hauptstrahlen längsgerichtete Stäbchen bilden, innerhalb des Verdichtungshofes aber. wo das Strahlengerüst sehr engmaschig wird, sich zu kleinen Schläuchen oder Bläschen anordnen (Chromocyklen), die schliesslich zur Bildung des 
Kernes verschmelzen. Es handelt sich also hier nicht um eine blasenartige Aufquellung der Chromosomen.

Unbefruchtete Salmonidenkeime können in fliessendem Wasser wochenlang aushalten, ohne abzusterben. Verf. beschreibt genauer ihr Verhalten im einzelnen, ihre plasmatischen Bestandteile sowie ihre Zerfliessungserscheinungen. Im Verlaufe einiger Wochen nimmt das Plasma an Menge allmählich ab, sein Inneres wird von Fetttropfen und Dotterkugeln durchsetzt. Besonders interessant ist das Auftreten von Sphären, die im Mitteljunkt ein kleines Centrosoma enthalten, sie sind wohl von dem ursprünglich vorhandenen Ovocentrum abzuleiten, dagegen ist von Chromosomen oder Kernanlagen keine Spur zu finden, wie überhaupt das Schicksal des Eikernes hier noch besonderer Untersuchungen bedarf.

Die letzte, umfangreiche Abhandlung bringt ergänzende Studien zu den Arbeiten des Verfassers auf entwicklungsgeschichtlichem Gebiete, die ihn seit Jahren beschäftigen und die ihn vor allem zur Aufstellung der Parablastlehre geführt hatten. Wir finden zunächst einen Überblick ïber die Dotterbestandteile der meroblastischen Eier in ihren mannigfachen Erscheinungsformen, wobei unter Dotter oder Deutoplasma nur das unorganisierte Material zu verstehen ist, das ausserhalb des Keimes angehäuft oder in Plasmagebilden des letztern eingeschlossen ist. Ihım steht gegenüber die organisierte Substanz, der Keim, der aus Blastoderm und Lecithoblast besteht. Nur das Blastoderm ïbernimmt den eigentlichen Aufbau des Embryos, der Lecithoblast hat keinen unmittelbaren Anteil daran. Dem Lecithoblasten zuzurechnen sind der Keimwall der Vögel- und Reptilieneier, der zellige Inhalt des Dottersackes der letztern, der sog. Dotterkern der Amphibieneier sowie der P'eriblast der Selachier und Knochenfische. Ehe Verf. nun näher auf die einzelnen Formen des Lecithoblasten eingeht, gibt er zunächst eine allgemeine Schilderung desselben. Es ist darunter ein mehr oder minder ungegliederter Teil des protoplasmatischen Keimes zu verstehen, der die Aufbewahrung und Verarbeitung des Dotters übernommen hat. Beim dotterarmen Säugetierei wird er vertreten durch den Trophoblasten, Ze!len der äussern Körperschicht, die mit der äussern Umgebung eine enge Verbindung eingehen, zwecks Gewinnung und Verarbeitung der notwendigen Nahrungsstoffe für den Embryo.

Bei der Einzelbetrachtung schildert Verf́. nun zunächst den Lecithoblasten des Hühnchens, dargestellt durch den sogenannten Keimwall am Rande der Kieimscheibe, wo lockere Hypoblastzellen unter sehr reichlicher Aufnahme von Dotterkörnern sich zu einer dem Dotter dicht anliegenden, später mehrschichtigen Zellenlage um- 
wandeln und die Verarbeitung des Dotters iibernehmen. Eine ähnliche Keimwalibildung weisen die Reptilien auf, auch hier legen sich die durch Dotteraufnahme stark vergrösserten Zellen des Randwulstes zu einer zusammenhängenden Platte aneinander, indessen finden sich Abweichungen insofern. als der ganze Inlaalt des Dottersackes schon frïhzeitig von Zellen durchsetzt und in den Lecithoblasten einbezogen wird. Bei den Selachiern hält Verf. gegen Rückert an der Ansicht fest, dass der Periblast hier dadurch gebildet wird, dass sich die dem Dotter zunächst liegenden Blastomeren unter Aufnahme reichlicher Dottermengen und unter Auflösung ilırer Grenzschichten zu einem Syncytium vereinigen. Endlich wird noch näher auf den Bau der Periblastkerne eingegangen, zunächst sind sie sehr durchsichtig und blasig, dann nimmt das Chromatin allmählich zu und ordnet sich dabei entweder zentriert in wenigen Kernkörpern an oder zeigt eine eigentümliche feinkörnige Verteilung über den ganzen Kerninhalt. \%wischen beiden Typen finden sich mancherlei Übergangsformen. Amitosen kommen im P'eriblast nicht vor.

Von besonderer Bedeutung ist das Verhältnis des Periblasts zu den Schichten des Blastoderms. Der Periblast bildet zusammen mit dem Endoblast den Hypoblast und Verf. geht nun zunächst näher auf den Endoblasten und seine Bestandteile ein. Der Endoblast gliedert sich in Darmendoblast (embryonaler Mesoblast + Darmendoderm) und in Dotterendoblast (ausserembryonales Mesenchym, Gefässkeim oder Angioblast und Dottersackepithel); gestiitzt auf Untersuchungen an Selachiern verfolgt Verf. die Bildung aller dieser einzelnen Keimbezirke nun in eingehender Darstellung. Es wird zunächst die Entstehung des Darmendoblasten durch eine lippenartige Vorwölbung des hintern Blastodermrandes geschildert, weiter dessen Sonderung in Endoderm und Mesoblast. Nach der vollzogenen Anlage des Keimes sind an demselben ein embryonaler und ein ausserenbryonaler Bezirk zu unterscheiden, zu ersterm gehört ausser der eigentlichen Fmbryonalanlage noch ein hinterer und seitlicher. durch das Vorhandensein eines Darmendoblasten charakterisierter Randbezirk, die als sog. Caudallappen durch ihre beiderseitige Verschmelzung den Axialsclıluss des Körpers herbeiführen. Der ausserembryonale Keimbezirk, der ursprünglich nur die vordere Keimhälfte umfasste, umwächst gleichzeitig mit diesen Vorgängen den ganzen Keim und umfasst ihn schliesslich rings an seiner Peripherie vollständig. In der vordern Hälfte des ausserembryonalen Zellengerüstes liegt eine geräumige Höhlung, die Balfoursche Höhle, welchen Namen Verf. infolge der unsichern Deutung dieses sich später wieder sehr stark reduzierenden Gebildes allen andern vorzieht. Durchsetzt ist der ausserembryonale Keim- 
bezirk von einem mesenchymatösen Zellengerüst (Protenchym), welches in seiner Gesamtheit den Dotterendoblasten bildet. Die zelligen Anlagen desselben sind schon vor der Bildung des Darmendoblasten vorhanden; sie stammen zum Teil von tiefer gelegenen Zellen des gefurchten Keimes, zum grössern Teile indessen von sich loslösenden Zellen des Periblasts, wie Verf. an einer grossen Zahl von Figuren ausführlich erörtert. Der Periblast, der mit dem eigentlichen Keime nur an der Peripherie noch in Verbindung stand, und dessen Riesenkerne und Ǩerngruppen sich auf Flächenbildern als dunkle Flecken, sog. Brutnester, bemerkbar machten, tritt später mit dem Endoblast in nähern Zusammenhang, beide bilden eine einheitliche, gegen den Dotter scharf abgegrenzte Platte, ein gemeinsames Syncytium, das sich in den Lagen verschiedener Herkunft etwas verschieden verhält. Erst nachdem sich von dieser gemeinsamen Schicht eine epithelartig angeordnete Zellenlage als Dottersackepithel abgeschieden hat, tritt auch der Periblast wieder schärfer abgegrenzt hervor und bildet nun eine stetige Quelle für die Bildung neuer Epithelzellen.

In der Region des Aussenhofes sondert sich vom peripherischen Randgebiete des Dotterendoblasts als eine selbständige, zwischen Ektoderm und Entoderm gelegene Gewebsschicht, das Randmesoderm ab, welches in zwei scharf zu sondernde Anlagen, in das Randmesenchym und den Gefässkern oder Angioblasten zerfällt. In dem Randmesenchym treten zwischen dessen ursprünglich dichter gelagerten Elementen bald grössere Lückenräume auf', die miteinander und mit den Lücken des anstossenden embryonalen Mesoblasts zur Bildung des Cöloms verschmelzen. Unter dieser Mesenchymplatte liegt der Gefässkeim. der zunächst aus linsenförmigen, verdickten Blutinseln besteht. Die oberflächlich gelegenen Zellen dieser Blutinseln plätten sich, verschmelzen zu einer Endothelhaut und enthalten nun die übrigen, sich zu Blutkörperchen umwandelnden Zellen im Innern. Von den Blutinseln ausstrahlende, zackenförmige Fortsätze sind die ersten Gefässsprossen, die nach allen Seiten hin auswachsen und schliesslich in das allgemeine Gefässsystem ïbergehen. Die bei der Ausbildung des Mesoblasts sich abspielenden Vorgänge, die im wesentlichen mit den Darstellungen anderer Forscher in Einklang stehen, nötigen Verf., entgegen seiner frühern Anschauung, den Ausführungen Rabls sich anzuschliessen und die Bindesubstanzanlagen nicht mehr mit den Gefässanlagen zu vereinigen, sondern für erstere besondere Anlagen aus den verschiedensten Teilen des Mesoblasts anzunehmen. Es schliessen sich hieran mehr anhangsweise einige Erörterungen histologischen Inhalts über Mesenchymgewebe, Endothel und Epithelien an, nament- 


\section{- $938-$}

lich wird der Begriff der letztern an der Entwicklung des Keimes schärfer präzisiert.

Alle diese Untersuchungen über die Differenzierung des Keimes bezogen sich auf die Selachier, nunmehr wendet sich Verf. auch den übrigen Wirbeltieren unter besonderer Berücksichtigung der Gefässbildung zu. Anı vollständigsten sind seine Beobachtungen an Hühnchen, wo in wesentlichen die gleichen Verhältnisse anzutreffen sind wie bei den Selachiern; für die Reptilien stand ein ausreichendes Untersuchungsmaterial nicht zur Verfïgung. Auch für die Kinochenfische enthalten die Beobachtungen des Verfassers mancherlei Lücken, sicher ist indessen anzınehmen, dass die Gefässbildung auch hier von anfangs soliden, netzförmig zusammentretenden Zellensprossen ausgeht, dagegen scheint der Angioblast, vor allem die intermediäre Zellenmasse, hier einen andern Lrsprung zu besitzen; Verf. glaubt, ihn vom Darmendoblast ableiten zu müssen. Es folgen noch einige Bemerkungen über die (iefässbildung bei Batrachiern sowie bei Säugetieren, und sodann wendet sich Verf. einigen histogenetischen Verallgemeinerungen zu. Er erörtert nochmals genauer die Gegensätze von Epithelien, Protenchymen und Mesenchymen in ihren mannigfachen Erscheinungs- und Übergangsformen und gibt endlich zum Schlusse einen zusammenfassenden Überblick der gewebsbildenden Leistungen der einzelnen Keimschichten. Der Epiblast liefert Nerrengewebe und Horngewebe, der Hypoblast gliedert sich in embryonalen Mesoblast (Muskelgewebe, Genitalapparat, embryonale Bindesubstanzen), ausserembryonales Mesenchym, Angioblast (Blut und Blutkapillaren) und Endoderm (Epithelien und Drüsen des Eingeweiderohres). Wo ein Lecithoblast zur Ausbildung gelangt, stellt er einen Teil des Hypoblasten dar.

J. Me is en he ime r (Marburg).

885 Jaquet, H., Anatomie comparée du système sympathique cervical dans la série des vertébrés. In: Arch. sc. méd. 1900. pag. 163-229. 29 Textfig.

Verf. untersuchte an Repräsentanten sämtlicher Vertebratenklassen das sympathische Nervensystem und kam dabei zu folgenden Resultaten:

Während beim Menschen der Cervikalteil des sympathischen Systems eine wohl umschriebene Einheit bildet, ist eine gleiche Charakterisierung dieses Teiles nicht bei allen Säugern vorhanden. Bei der Nehrzahl vielmehr ist der Sympathicus mit dem Vagus vereinigt und zwar liegen beide Nerven in gemeinsamer Scheide, um sich erst bei ihrem Eintritt in den Thorax voneinander zu trennen. Es ist daher 
bei vielen Säugern nicht leicht. das Ganglion cervicale superius des Sympathicus vom Ganglion vagi zu unterscheiden. Auch das Ganglion inferius des Sympathicus ist vielfach nicht klar getrennt, sondern häufig entweder mit dem Ganglion thoracale primum der sleichen oder dem Ganglion cervicale medium der andern Seite vereint.

Bei den $V \ddot{o g}$ eln ist das Ganglion cervicale superius nervi sympathici deutlich unterschieden. Von ihm geht nach hinten ein Nerv ab, der mit jedem Spinalnerven der Cervikalgegend durch Rami communicantes sich verbindet. Er ist dem Vertebralnerven der Sänger vergleichbar. Längs der ventralen Fläche der Wirbelsäule läuft ein zweiter, von diesem Ganglion entspringender Nerv, der ron äusserster Feinheit ist, mit dem der Gegenseite sich vereinigt und so einen unpaaren Nerven herstellt, der sich bis zum neunten oder zehnten Wirbel verfolgen lässt. Auch dieser Nerv verbindet sich mit jedem Spinalnerven. Das untere Cervikalganglion ist nicht deutlich erkennbar.

Bei den Crocodilieru liegen die Verhältnisse ähnlich wie bei den Vögeln, nur dass die den unpaaren Yerven zusammensetzenden Zweige mit dem gemeinsamen, dem Glossopharyngeus und Y'agus gehörigen Ganglion in Verbindung stehen. Bei den andern Reptilien verschwindet das Ganglion cervicale superius, das man nur noch höchst selten bei Cheloniern wiederfindet.

Bei den Anuren ist. der Cervikalsympathicus sehr reduziert, eigentliche Cervikalganglien gibt es nicht. Bei den Urodelen (Salamandrinen) sind die ('ervilialganglien deutlich zu unterscheiden und stehen in ausgiebiger Verbindung mit den Spinalnerven. Der Sympathicus kommt bei allen Amphibien aus der Nerveumasse, welche melireren Hirnnerren gemeinsam ist oder aus denen nur der Vagus entspringt.

Die K n o clu enf ische beweisen die Hypothese, dass die Schädelnerven ursprünglich den Spinahnerven glichen. Denn bei ilınen fehlt ein Cervixteil des Sympathicus und der in der Kopfregion befindliche Abschnitt dieser Nerven gelıt fast mit allen Schädelnerven, wie im übrigen Verlaufe mit den Spinalnerven, Verbindungen ein. - Man kanı also nicht sagen, dass bei allen Vertebraten eine Einteilung des Sympathicus in eine Pars cephalica, cerricalis. thoracica, abdominalis und caudalis deutlich rorhanden ist; namentlich der Cervikalteil ist nur bei wenigen Formen klar ausgebildet. B. Rawitz (Berlin).

\section{Cyclostomi.}

886 Haack, W., Über Mundhöhlendrüsen bei Petromyzonten. In: Zeitschr. wiss. Zool. Bd. 75. pag. 112-146. Taf. 15 u. 16. Bei Petromyzon planeri liegt, wie Verf. in Übereinstimmung mit 
friihern Untersuchern angibt, die Mundhöhlendrüse, die parig ist, unter der Augenhöhle eingebettet im ventralen Abschnitt des M. basilaris. Sie ist ein oraler Sack, der im hintern Drittel hantelartig eingeschnürt ist. Kurz vor der Spitze der Drüse entspringt der Ausführungsgang, der auf einer dorsal vom zweiten Hauptzahn des Gaumens gelegenen Papille mündet. Bei Petromyzon fluviatitis sind die Verhältnisse genau die gleichen. Petromyzon marime zeigt dagegen etwas veränderte Situation. Die Drïse ist grösser als bei den andern Species und stelit einen ovalen glatten Sack dar. Der Drïsengang entspringt ventral an der Innenseite des Organs und mündet, ohne den Zungenknorpel zu durchbohren, auf einer wie bei Petromyzon planeri gelegenen Papille.

Die Drüse besitzt ihre eigene quergestreifte Muskulatur: glatte Muskulatur fehlt an ihr wie am Ausführungsgange.

Ammocoetes hat keine derartige Driise; sie entwickelt sich bei ihm aus dem Mundhöhlenepithel als solider Zellstrang.

Histologisch zeigt die Drüse sehr einfache Verhältnisse; auf feiner Membrana propria sitzen Cylinderzellen in einfacher Schicht, während der Ausfülıungsgang ein zweischichtiges Plattenepithel trägt.

Verf. gibt ferner einige kursorische Notizen über den Kiemendarm der Petromyzonten und wendet sich dann zur Physiologie der Drüse. Ein mucinöses Seliret liefert sie nicht, sondern ist eine Eiweiss verdauende Drüse und zwar sondert sie ein pepsinartiges Ferment ab. Eine gleiche Funktion haben die Drïsen des Kiemendarmes.

Verf. zog schliesslich noch jene Driisen in Betracht, die an den für die Geschlechtsfunktion umgehildeten Flossen der männlichen Selachier sich finden. Er untersuchte Acronthias vulgaris, Scyllium catulus und canicula, Raja clarata und batis.

B. Rawitz (Berlin).

\section{Pisces.}

887 Boeke, J., Beiträge zur Entwicklungsgeschichte der Teleostier. I. Die Gastrulation und Keimblätterbildung bei den Muraenoiden. In: Petrus Camper. Dl. II. Afl. 2. pag. 135--210. Taf. 2-3. 18 Figuren im Text.

Die Eier der M ura enoiden schweben als durchsichtige, wasserklare Gebilde frei im Wasser, und zwar erscheinen sie im Golfe von Neapel von August bis November. Ausgezeichnet sind sie durch ihre Grösse, den grossen perivitellinen Raum, die glatte, glashelle Eikapsel ohne Poren, durch die blasige Beschaffenheit des Dotters sowie durch einen oder mehrere dem Dotter eingelagerte ÖItropfen, deren Zahl 
wie Gruppierung von grossem diagnostischen Wert ist. Werden die Eier früh morgens gefischt, so zeigen sie bisweilen noch das Stadium der einfachen Blastodermkuppe, nie mehr ein Furchungsstadium, öfter dagegen die schon eingeleitete Invagination. Im Verlaufe des ersten Tages erfolgt dann die Umwachsung des Dotters, deren Verlauf sich infolge der konstanten Lage der Öltropfen sicher verfolgen lässt, am Anfang des zweiten Tages schliesst sich der Blastoporus, differenzieren sich die ersten Urwirbel und die Gehirnanlage, im weitern Verlaufe des zweiten Tages treten Augen- und Ohrenblasen, Kiemenspalten und Herzanlage auf und am Ende des zweiten Tages macht sich eine blasige Erweiterung des Darmkanals, die sog. Borsa stomacale, bemerkbar, die zur Respiration dient. Am dritten Tage fängt das Herz zu pulsieren an, Gehirn und Rückenmark haben sich weiter gegliedert, Leber und Wolffsche Gänge bilden sich aus. Am Ende des vierten. oder aber, wie es meist erst geschieht, am fünften Tage schlïpfen die jungen, langgestreckten, glashellen Larven aus, die noch der Mundund Afteröffnung entbehren. Die Öltropfen liegen am Vorderende des langegezogenen Dottersackes unter dem Herzen, und nur wenn sie zahlreicher waren, sind sie unregelmäßig zerstreut. In den nächsten Tagen bilden sich dann die ïbrigen Teile der jungen Larve aus, vor allem ist die Umgestaltung des Mundes und das Herrorwachsen der Zähne für dieses Alter charakteristisch. Aın 9. oder 10. Tage gehen sie nach völliger Resorption des Dotters durch Tahrungsmangel meist zu grunde; nur schwierig gelingt es, sie in einzelnen Fällen durch dargebotene Planktonnahrung etwas länger am Leben zu halten. Das Material des Verfassers umfasste im ganzen sieben verschiedene Species, von denen im Vergleiche mit den ron Raffaele aufgestellten Species eine genaue Differentialdiagnose gegeben wird.

Verf. geht nun zu einer nähern Schilderung der innern Entwicklungsrorgänge ïber. Sein jüngstes Stadium hatte nach vollendeter Furchung das Blastoderm, welches als konische Kuppe dem Dotter aufsitzt, bereits völlig ausgebildet. Dasselbe unschliesst eine geräumige Furchungshöhle, seine äussere Zellenschicht wandelt sich zu einer regelmäßigen, aus kubischen Elementen bestehenden Deckschicht um, die sich später stark abflacht, die untern Zellenlagen sind ron gleichartigem, lockeren Gefüge. Unter dem eigentlichen Keime liegt der Periblast, eine dicke, protoplasmatische, kernhaltige Schicht, die sich an den Rändern zum Keimwall verdickt und aussen als sehr dünne Protoplasmalage die ganze Dottermasse umschliesst. Yon diesem Periblast vermögen sich Zellen loszulösen und nach oben dem Blastoderm anzuschliessen, wie Verf. glaubt auf das Bestimmteste nachweisen zu können. Verf. geht nälıer auf die feinere histologische Struk- 
tur sowie die Teilungsmodi der Periblastzellen ein, bemerkenswert ist auf spätern Stadien vor allem das Auftreten eigentümlicher, zarter Röhrchen an dem nach aussen angrenzenden Syncytienrand und später an dem vom Blastoporusrand umgebenen Dotterloch, welche nach aussen zu münden scheinen und wahrscheinlich als intracellulare Selretkapillaren eine exkretorische Funktion besitzen. Auch der Cilienbesatz, der sich häufig an den gleichen Stellen findet, mag nit diesen Erscheinungen in Zusammenhang stehen.

Die Gastrulation wird durch Abtlachung des konischen Keimes an der einen Seite, sowie durch eine Verdickung des Blastoderms an der gleichen Stelle eingeleitet. Währeıld dann die Deckschicht fest am Periblast haftet, schlägt sich die lockere Blastodermmasse, am Hinterrande beginnend, nach innen um, und schliesslich bildet der invaginierte Teil eine zungenförmig unter dem Embryonalschild nach vorn sich erstreckende Zellenmasse, aus der allein Cborda und Nesoderm hervorgehen. Das Darmentoderm ist völlig unabhängig ron dieser Anlage, seine erste Andeutung ist in einer Verdickung am Hinterrande des Keimes zu suchen, an der Stelle, wo die oberflächliche Zellenlage des Blastoderms den Periblast beriihrt. Die Zellen werden zunächst umfangreicher, cylindrisch und geben endlich durch Teilung Tochterzellen ins Innere ah. Es entsteht so schliesslich eine zwischen den umgeschlagenen Blastodermteil und den Periblast sich einschiehende, zungenartige Zellenmasse, die sog. Prostomalverdickung (Su mer). Diese Zellenmasse nun liefert allein das Darmepithel, sie leitet sich nach Verf. nicht von den Zellen der Deckschicht ab. wie șmner annimmt, sondern von dem unmittelbar an dieselbe angrenzenden Periblast. Eine Beteiligung anderer Zellelemente am Aufbau des Darmepithels hält Verf. für sehr unwahrscheinlich. Nach der Bildung der Prostomalverdickung nimmt der Periblast keinen Anteil mehr am Aufbau des Embryos, er besitzt nur noch die Funktion eines Dotterorganes. Das Darmentocierm wächst ebenso wie die Chorda-Mesoderm-Anlage weit nach vorn aus und während die Dotterumwachsung sich vollzieht, scheidet sich zunächst in der Mittellinie. von hinten beginnend, die Chorda vom Mesoderm ab. Die zu beiden Seiten liegenden Streifen des Mesoderms fangen erst spät an, sich in Urwirbel zu gliedern, bei Schluss des Blastoporus sind erst $\check{5}-10$ Paare rorhanden. In der Ausbildung der K upferschen Blase stimmen die Befunde des Verfassers in allen wesentlichen Punkten mit denen Sumners überein, herrorzuheben ist nur das stark variable Verhalten, welches die Muraenoideneier in der Entstehung wie der definitiven Ausbildung der Kupfferschen Blase 
aufweisen, so dass diese bald nahezu völlig von einem E Eithel umgeben ist, bald zentral gänzlich vom Periblast begrenzt erscheint.

In einigen allgemeinen Betrachtungen über den Gastrulationsvorgang kommt Verf. zu dem Schlusse, dass der ursprïngliche Prozess, bestehend in einer Verlagerung von Darmentoderm, Chorda- und Mesodermanlage ins Innere des Keimes sowie in der Ausbildung einer Gastrathölıle zwischen diesen beiden Zellenlagen, bei den Teleosteern derart modifiziert erscheint, dass der ganze Torgang in zwei Phasen verläuft, zunächst in den Umschlag der Chorda-Mesodermanlage und sodann in der Abfurchung des Darmentoderms (als Prostomalverdickung) vom Periblast. Die Gastralhöhle ist völlig geschwunden, sie wurde dargestellt durch den virtuellen spalt zwischen den Umschlagszellen und der Prostomalverdickung. Erst sekundär bildet sich innerhalb der letztern eine Höhlung aus, eben die Kupffersche Blase, aber diese von allen Seiten rom Darmentoderm umgebene Höhlung kann nun nicht mehr als ein 'Teil der Crastralhöhle angesehen werden, sondern nur als ein Abschnitt der wirklichen Darmhöhle.

$$
\text { J. Meisenheimer (Marburg). }
$$

\section{Amplibia.}

888 Boulenger, G. A., Report on the Batrachians and Reptiles. In: Fasc jculi Mla layenses, Zoology. Vol. I. October 1903. pag. 131-176. Taf. V-X. Figuren im Text.

Die malayische Reptilien- und Batrachierfauna, deren Kenntnis seit den Zeiten Cantors namentlich in den letzten Jahren einen gewaltigen Aufschwung genommen hat, erfahrt in der vorliegenden Arbeit abermals wieder eine wesentliche Bereicherung, nicht nur an Formen, die neu für die malayische Halbinsel sind (Mabuia siamensis, Lygosoma quadririttatum, Dibamus norae guineae) und an solchen, die überhaupt zum ersten Male hier beschrieben sind (zwei neue Frösche. zwei Schildkröten, eine Eidechse und eine Schlange), sondern auch in systematischer und namentlich biologischer Beziehung, da die beiden Sammler des Materials (Annandale und Robinson) nicht nur auf die Färbung der beobachteten Tiere im Leben achteten, sondern der Biologie derselben eingehende Aufnerksamkeit schenkten, so dass das Werk in jeder Beziehung eine wesentliche Ergänzung der Arbeiten S. S. Fl o wer s (vergl. Jalırg. VII. 1900 p. 160; VIII. 1901 p. 135) vorstellen.

Melır oder weniger ausfülıliche Bemerkungen finden wir bei: Megalophrys montana Kuhl var. aceras n., Taf. V, Fig. 1. (Bemerkungen über die merkwürdigen Larven), Bufo asper Gravh., nelanostictus Gthr. parrus Blngr., Callula pulchra Gray, Microhyla ornata UB., Oryglossus lima Gravh., Rana macrodon DBd., tigrina Daud., limnocharis Boie, erythraea Schleg., Rhacophorus leucomystax Gravh., Rh. robinsoni n. sp. (von Bukit Besar, Taf. V, Fig. 2), Rh. nigropaimatus Blngr. (Taf. VI, kig. 1), Ixalus larutensis Blngr. (Taf. V, Fig. 3 und 4), horridus sp. n. (Bukit Besar; Taf. VI, Fig. 2), Batagur baska Gray, Damonia subtrijuga Schleg. u. Müll., Cyclemys amboinensis Daud, platynota Gray, annandalii n. sp. (Kampong Jalor; abgeb. Taf. VI und VIII), dhor Gray, Geocmyda spinosa Gray, Testudo pseudemys n. sp. (Batang Padang District, Süd. Perak, 1000-2000 Fuss; abgeb. Taf. IX, Schädel pag. 145), 
elongata Blyth., Chelone imbricata und mydas L., Tomistoma borncensis Schleg. und Miill., Crocodilus porosus Sclın., Gymnodactylus marmoratus Kuhl, pulchellus Gray, Gonatodes affinis Stol., Hemidactylus frenatus DB., platurns Schn., Gehyra mutilata Wiegm., butleri Blngr., Giecko verticillatus Laur, stentor Cant., monarchus DB., Ptychozoon homalocephalum Crev., Draco fimbriatus Kuhl, munctatus Blngr. (Taf. X, Fig. 1), melanopogon Blngr., formosus Blngr., blanfordii Blngr., Gongocephalus borneensis Sehleg., herveyi Blngr., grandis Gray, 1canthosanva asmata Gray, Calotes cristatellns Kuhl, rersicolor Daud., emma Gray, Liolepis bellii Gray (Jugendform abgeb. Taf. X, Fig. 2), Iraranns ncbulosus DB., salvator Laur., Tachydromes sexlincatus Daud., Mabuia macularia Blyth., rugifera Stol., multifasciata Kuhl, siamensis Gthr., Lygosoma pracsigne Blngr., bowringii Gthr., quadrivittatum Ptr's., chalcides L., miodactyhım n. sp. vom Semangko Pass, Selangor-Pahang-Grenzgebiet, 2700 Fuss (abgeb. Taf. X, Fig. 3), Dibamns novac-guincac DB., schliesslich: Typhlops braminus Daud., nigroalbus DB., P'ython reticulatus Schn.; von den Colubriden möge nur die beim Verzehren des Laichs von Ixalns horridus betroffene Tropidonotns chrysargus Schleg., ferner Lycodon laoensis Gthr., fzamcnis korros Schleg., die Höhlenschlange Coluber taeniurns Cope, C. radiatus Sehleg., Dendrophis pictus Gmel., Calamaria parimentata DB., Hypsirhina plumbea Boie und boconrti Jan, Dipsadomorphus dendrophilus Boie var. melanotus Blkr., cynodon Boie, pallidns n. sp. von Jalor (Kopf abgeb. pag. 165), Dryophis prasinns Boie, Chrysopelea ornata Shaw, Thalessophis annandalei Laidlaw, Enhydris valakadien Boie, Naia tripudians Merr., bungams Schleg. (Bissfall beschrieben) und Doliophis intestinalis Laur. erwähnt worden, ausserdem noch Haplopeltura boa Boie, Amblycephalus mocllendorffi Bttgr., Ancistrodon rhodostoma Boie (Verbreitung wie Damonia subtrijnga: Siam, Malayische Halbinsel, Java; Biss nach Aussage der Eingeborenen nicht gefährlich).

Den Schluss der Arbeit bildet ein vollständiges Verzeichnis aller bis jetzt von der malayischen Halbinsel bekannten Reptilien und Batrachier, woraus wir ersehen, dass 60 Batrachier (darunter 3 Apoden), 23 Schildkröten (incl. 4 Seeschildkröten), 3 Krokodile, 71 Eidechsen und 129 Schlangen (darunter 22 Hydrophiinen) von dort bekannt sind, also um 16 Batrachier und 37 Reptilien mehr, als Flowers Verzeichnis von 1896 ausführt. F. Werner (Wien).

\section{Reptilia.}

889 Mocquart. F., Notes herpétologiques. In: Bull. Mus. hist. nat. 1903. Nr. 5. pag. $209-220$.

Diese Arbeit besteht aus drei Teilen. In dem ersten werden einige nete Arten des Pariser Museums beschrieben, nämlich Crotaphytus fasciolatus $(=C$. fasciatus Mocq. nee Hall.), Monopeltis unirostralis (vom Gabun), M. boveei (Fernand Vaz, Französisch-Congo), Helminthophis canellci (Isthmus von Panama), Tropidonotus obalskii (Black Lake, Canada), Phrynonax faucherei (Holländisch-Guyana), Bufo decorsei (Brazzaville, Französisch-Congo). - Im zweiten Teil weist der Verf. nach, dass Chamaeleon parsoni Cuv. entgegen der Annahme des Ref. im weiblichen Geschlechte keinerlei 'Rostral-Apophysen besitzt, dass beim $\sigma^{7}$ dieser Art (wie auch bei Ch. oshaugnessyi und globifer) eine postkloakale Verdickung an der Unterseite des Schwanzes fehlt, und dass $q$ dieser Art nur äusserst selten in den Sammlungen sich vorfinden. Letzterer Umstand wird aber weder durch die Annahme, dass sie von den Sammlern wegen ihrer Hornlosigkeit geringgeschätzt und daher nicht mitgenommen werden, genügend erklärt, da bei den nahe verwandten vorerwähnten Arten, bei denen beide Geschlechter in ziemlich gleicher Zahl in den Museen vertreten sind, weder eine wesentlich verschiedene Lebensweise des $q$ 
anzunehmen, noch auch trotz der genau gleichen sekundären Sexualcharaktere bei diesen Arten eine Bevorzugung durch die Sammler zu konstatieren ist. Der dritte Teil behandelt die Variabilität einiger Merkmale von Sternothaerus sinuatus Smith und bestätigt im wesentlichen die Beobaclitungen von Siebenrock, bringt also nichts Neues über diesen Gegenstand.

F. Werner (Wien).

890 Dollo, L., Eochelone brabantica, Tortue marine nouvelle du Bruxellien (Écoènemoyen) de la Belgique et l'Evolution des Chéloniens marins. Bruxelles 1903. 62 pp.

In einer überaus anregend und klar geschriebenen Abhandlung nimmt der ausgezeichnete belgische Paläontolog die Beschreibung einer neuen Seeschildkröte zum Ausgangspunkt, um aus dem Vergleich mit den bekannten lebenden und fossilen Cheloniden mit umfassender Benützung sowohl der osteologischen als der biologischen (ethologischen) Forschungsergebnisse die P'hylogenie der Cheloniden zu entwickeln. In erster Linie ist die Lage der Choanen, die Länge der Unterkiefersymphyse, der Bau der Vorderextremität in Betracht gezogen. Die präzise Darstellung und die streng logische Ableitung der verschiedenen Seeschildkrötenformen voneinander muss als mustergültig betrachtet werden und ein Auszug gibt keinen Begriff ron der Eigenart dieser Publikation, auf welche daher die Zoologen nur aufmerksam gemacht werden mögen.

F. Werner (Wien).

891 Siebenrock. F.. Schildkröten von Madagascar und Aldabra, gesammelt von Prof. Dr. A. Voeltzkow. In: Abh. Senckenbg. naturf. Ges. Bd. XXVII. Heft 2. Frankfurt a. M. 1903. pag. 241-259. Thaf, XXXIII-XXXV.

Die Schildkrötenfauna von Madagaskar umfasst sieben Arten, die sich auf sechs verschiedene Gattungen verteilen. Von diesen sind zwei (Pyxis und Acinixys) auf Madagaskar beschränkt, ebenso sind die beiden madagassischen Arten der Gattung Testudo endemisch; ausserdem findet sich die sonst südamerikanische Gattung Podocnemis durch eine Art (P. madagaseariensis) vertreten. Mit dem afrikanischen Festlande sind nur zwei Arten (Stemothaerus nigricans Donnd. und Pelomedusa galeata Schpfi.) gemeinsam. Von der nach B oettger auf Madagaskar gegenüber Nossi Bé in grossen Mengen vorkommenden Cinixys belliana Gray wurde von Voeltzkow an eben dieser Stelle und auch sonst in Madagaskar keine Spur gefunden, so dass diese Art für die Insel zu streichen ist. Merkwürdigerweise fehlt auch Trionyx vollständig, obwohl T. triunguis Forsk. ïberall in Afrika und sogar noch in Syrien mit dem Crocodilus niloticus vergesellschaftet ist oder war, während auf Madagaskar zwar das Krokodil häutig ist, Trionyx aber nicht einmal noch fossil gefunden wurde.

Der Verf. gibt nun eine ausfülurliche Beschreibung von Pyxis arachnoides Bell, sowie von Acinixys planicauda Grand., die auf Taf. XXXIII und XXXIV auch farbig abgebildet ist. Bei Testudo radiata Shaw und T. yniphora Vaill. (letztere auf Taf. XXXV abgebildet) wird die Strahlenzeichnung des Panzers von einer gemeinsamen Stammform abgeleitet und auch osteologisch dargetan, dass beide Arten, trotz des langen vordern Plastrallappens und des ungeteilten Gulare 
bei $T$. yniphora einander nahe stehen und diese mit $T$. angulata nur eine geringe Verwandtschaft besitzt. Bei Besprechung der Gattung Sternothaerus kommt Verf. auch auf die Verschiedenheit des Verschlussmodus der Schale bei Emys, Cistudo und Cyclemys einer, Cinosternum andererseits, sowie bei Testudo zu sprechen und bringt neues Beweismaterial für die von Tornier angezweifelte Artverschiedenheit von St. nigricans von St. sinuatus Smith. Von Pelomedusa wird vornehmlich die sehr variable Färbung beschrieben und bezüglich der madagassischen Podocnemis der Beweis erbracht, dass sie eine Übergangsform zwischen den Gattungen Podocnemis Wagl. und Peltocephalus DB. ist, indem sie mit der erstern Gattung die Maßsverhältnisse der medianen Plastralnähte, das geteilte Supracaudale und die Beschuppung des Schwanzes, mit der letztern das Fehlen einer Stirnrinne und die gleiche Schläfenbeschilderung gemeinsam hat. Durch die Art der Verbindung des Jugale mit dem Quadratum in verschiedenen Altersstufen verbindet sie beide Gruppen, unterscheidet sich aber andererseits von beiden durch die geringere Zahl der Neuralplatten und die konstant konvexe Form des Plastrons beider Geschlechter, die sich aber durch den Besitz eines deutlichen Hakens mitten am Oberkieferrand beim $\sigma^{7}$, del beim $q$ fehlt oder höchstens angedeutet ist, unterscheiden. Alle drei Wasserschildkröten scheinen sehr häufig zu sein, während von den Landschildkröten nur $T$. radiata in grossen Mengen vorkommt.

Die (farbigen) Abbildungen sind sehr hübsch, wenngleich sie deutlich erkennen lassen, dass sie nach ausgestopften Exemplaren angefertigt sind.

F. Werner (Wien).

\section{Mammalia.}

892 Bensley, R. R.. 'The cardiac glands of mam mals. In: Americ. Journ. Anat. Vol. 2. 1903. pag. 105-15்6.

Verf. untersuchte die Drüsen der Cardia beim Menschen, beim Schwein und bei mehrern Rodentia und kam dabei zu folgenden Resultaten: Die Cardiadrüsen sind Mucindrïsen. Die /ellen dieser Gebilde unterscheiden sich beträchtlich von den Hauptzellen der Fundusdrüsen. Die Cardiadrüsen sind retrogressive Bildungen der Fundusdirisen. Den letztern Satz zu beweisen, fügt Verf. längere Betrachtungen über die Phylogenie der Cardiadrüisen an.

B. Raw itz (Berlin).

893 Me Clure, Ch. F. W., AContribution to the anatomy and development of the venous system of Didelphys marsupialis L. Part. I Anatomy. In: Americ. Journ. Anat. Vol. 2. 1903. pag. 371-404. Taf. $1-5,11$ Textfig.

Verf., welcher 101 Tiere der Art Didelphys marsupialis untersucht hat, gibt zunächst die Anatomie des Herzens. Eine Fossa ovalis, ein Annulus ovalis und Ductus arteriosus fehlen bei Didelphys und allen andern erwachsenen Marsupialiern. vielleicht mit Ausnahme von P'erameles, wie dies bereits öfters beschrieben. Die rechte Valvula atrio-ventricularis besteht aus einem medialen orler septalen und zwei lateralen Zipfeln, die alle drei an der Basis zusammenhängen. Der 
linke laterale Zipfel ist der ausgedehnteste, der rechte der schmalste von den dreien; die beiden lateralen Zipfel hängen durch Chordae tendineae mit drei Musculi papillares zusammen, während die Chordae tendineae des septalen Zipfels direkt an die Herzwand (Septum) gehen. Verf. vergleicht die Resultate mit denen, die andere Autoren an andern Species gefunden haben, und konstatiert, dass bei Marsupialiern die Zahl der Ḱlappenzipfel zwischen zwei und fünf schwanken kann. Im Gegensatz dazu zeigen die Mitralis und die Semilunarklappen völlige Übereinstimmung mit den höhern Mammalia.

Die Pulmonalven en vereinigen sich gewöhnlich zu einer T'ena pulmonalis communis vor ihrer Einmündung in das linke Atrium.

Die Venae coronariae bestehen aus einer dorsalen und einer ventralen Gruppe. Erstere besteht aus einer grossen und mehrern kleinern Venen, die auf dem linken Ventrikel gelegen sind und in die linke Vena praecara münden. Die gleiche Zusammensetzung besitzt die rentrale Gruppe. Ihre kleinen V'enen münden direkt in das rechte Atrium, die grosse V'ene, $V$. cordis magna, geht erst nach einem sehr komplizierten Verlaufe in die Cava sup. (praecava).

Die Kopf- und Nackenvenen. Mit Ausnahme ron Belideus breviceps haben alle Marsupialier zwei Venae praecavae. Bei Didelphys entsteht eine jede ron ihnen aus der Vereinigung vou drei Venen: Vena subclavia, I. jugularis communis und V. costovertebralis. Zu der Praecava gehen: I. mammaria interna, I. azygos (links) und die hintere Gruppe der Coronarvenen. Es seien aus den fernern sehr sorgfältigen Angaben nur folgende Besonderheiten referendo wiedergegeben. Die Vena jugularis externa bildet jederseits einen venösen Ring, in dem die Clavicula gelegen ist. Beide Jngulares externae anastomosieren miteinander in der Medianlinie (Vena anastomotica). und zwar kommt von jedem Halbring einer Jug. ext. je eine Vene, im ganzen also vier, die sich in einem besondern Gefäss vereinigen, oder zwischen den zwei ventralen Halbringen der Jug. ext. ist ein einfaches Gefäss vorhanden.

Die Venen des Vertebralkanals und die tiefliegenden Venen der Cervikal- und Thorakalregion. Die Venae columnae vertebralis bilden zwei breite Sinus. Die bereits erwähnte V. costovertebralis hat selır enge Beziehungen zu diesem V'enensystem. Die erste Interkostalvene geht entweder in die Costovertebralis oder in die Praecava. Die Vena vertebralis geht ebenfalls in die Costovertebralis. Die Vertebralvene und die tiefe Interkostalvene erinnern in ihren Beziehungen zur Wirbelsäule, zu den Jugular- und Subclavialvenen an die vordere und hintere Vertebralvene der Vögel.

Die Vena azygos. Gewöhnlich ist nur eine solche, linksge- 
legene Vene vorhanden, die von hinten nach vorn an Umfang zunimmt. Das caudale Ende verbindet sich mit der Vena postcava (cava inferior) etwa in der Gegend des zweiten Lumbalwirbels. Das craniale Ende mündet in die linke Praecava in der Gegend des Köpfchens der dritten Rippe. Bei $30 \%$ der untersuchten Tiere war auch eine kleine rechte Azygos zu finden.

Die Vena postcara (V. cara inferior). Der prähepatische und der hepatische Abschnitt dieser Vene bieten keine Besonderheiten dar. Auch der renale Abschnitt zeigt keine Abweichungen und nur das wäre zu erwähnen, dass die rechte Nebenniere der dorsalen Fläche der Vene fest aufliegt und dass das craniale Ende des Organes in den kaudalen Lappen der Leber eingebettet ist.

Der postrenale Abschnitt nimmt zwei oder drei Paar Venae lumbales, die V. spermaticae internae und die V. iliacae auf. Ebenso mündet in ihn das caudale Ende der Azygos. Gleichwie bei allen andern bisher untersuchten Marsupialiern, mit einziger Ausnalıme von Petaurus taguanoides nach Hochstetter, so liegt auch bei Didelphys marsupialis der postrenale Abschnitt der Postcava ventral von der Aorta. Dagegen unterscheidet sich die vom Verf. untersuchte Species durch die Variabilität der Vereinigung der V. iliacae, und zwar lassen sich drei Typen der Postcava-Entstehung unterscheiden.

In ersten Typus vereinigen sich die $V_{v}$. iliacae internae mit den iliacae externae, ventral von den Arteriae iliacae communes oder ventral von der Aorta.

Im zweiten Typus findet die Vereinigung der Vv. iliacae internae mit den externae dorsal ron den Arteriae iliacae communes statt oder dorsal von der Aorta.

Im dritten Typus endlich treten die Vv. iliacae internae mit den externae zur Bildung der Postcava sowohl dorsal und ventral von den Art. iliacae communes, wie dorsal und ventral von der Aorta zusammen.

In 99 von den untersuchten 101 Tieren fand Verf. einen der drei Typen ausgesprochen. Nur in zwei Fällen glich die Bildungsweise der Postcava und ihr Verhältnis zur Aorta nicht dem bei Marsupialiern gewöhnlich zu beobachtenden, sondern zeigte die Verhältnisse der höhern Mammalia.

(Über die sehr interessanten und wichtigen Einzelheiten des Venenverlaufes vgl. Original.) B. Rawitz (Berlin). 


\section{Register.}

Bearbeitet von cand. zool. R. Loeser.

Alle Ziflern beziehen sich anf die Nummern der Referate!

\section{Autoren-Register.}

Die fett gedruckten Zablen beziehen sich auf Referate über Arbeiten der betr. Autoren, die in kleiner Schrift gedruckten Zahlen anf Zitate, die kursiv gedruckten Zahlen geben die Arbeiten an, ïber die von den Genannten referiert wurde.

Nr. Nr. Nr.

Abbatt 556 .

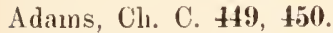

Adelung, N. v. $5,31-46,49$ $-51,54,56,57,98,107$ $-117,144,115,118-171$, $175,176,21 \%, 768-777$, $795,80 \%, 819,8.59,860$, 8811,881 .

Aders, W. M. 5̈:.2.

Adler 259.

Adlerz, G. $\mathbf{3}(\mathbf{i 9}$.

Agassiz, A. 342, 466.

Agassiz, G. 490.

Alismead, R. 31

Albertus Magnus 356.

Allen 400.

Allmann 18.

A maudrut 289, 8:3.

Anberg, O. $\mathbf{4 0 4}, \mathbf{4 0 5}$.

Aricel, P. 49:.

Arcey 116.

André, Ern. 214, 386.

Andrews 466.

Anglas 797.

Anuandale $\$ 88$.

Anutschin 737.

Apátlyy 589 .

Appeliöf 462 .

Apstein 284.

Argutiusky, P. 577, 578, 585, 6 5. 690.

Ariola, V. 85, 91, 518.

Aristoteles 728 .

Arnold 64.

Arnold, Ralple $\mathbf{7 4 9 .}$
Arrigoni degli Oddi, E. 64. Bensley, R. R. 855, $\mathbf{8 9 2}$.

Ascherson 506 .

Askanazy 519.

Attems, C. Graf 28, $\mathbf{4 7 4 .}$

Awerinzew, S. ill

Ayers 83.5 .

Azam, J. :3:3.

Batar, Ki. 7o.

Babor 823 .

Bachmetjew, P. 145.

Baker 860.

Balbiani 94, 335, 679.

Balfour 199, 358, 565, 884.

Bálint 820 .

Ballowitz 335 .

Banks, N. 50, 51, 778.

Bardeen, Ch. R. \$16.

Barrett, O. W. 39, 40.

Bartliels, Ph. 57.

Bataillon 9.

Bateson 347.

Baumgarten 9.

Baumgartner, W. J. 184.

Beard, J. 125, 358 -362.

Bechstein 325 .

Becker, Th. 779.

Bedel 390.

Beer 297.

Bell, F. J. 75, 76.

Benda 335.

van Beneden 525.

van Beneden, E. 187, 188, 826.

Bennet 728 .

- Autoren-Register.
Berestneff, N. M. (476, 677. Berg, I. 171.

Bergendal, D. 6.58 - 661.

Bergh, R. S. 99-105, 106 , $106,10.3,415,119, \pm 26$, $42 \pi, 428,428,429,440$, $442-445,460,476,836$ $-845,857,859$.

Bergmann, C. 1.

Bergmann, W. 296, 494.

Berlepsch, H. (io.).

Berlese, A. 26, 27, 25, 29, $92,311,479$.

Bernard 402.

Bernand, H. M. 692.

Berthold, A. A. 1, 3.

Bertkau 819, 859 .

Bertrand, L. ' 185.

Bethe, A. 215, 216, 21S, 229, $231-233,236-238,240$, $252,254,259-260,265$.

Betten, C. $\mathbf{3 1}$.

Bianchi, V. L. 111, 17 .

Bidder 516.

Hiedl 828 .

Biermer 468 .

Bigelow, M. A. $\mathbf{4 0 9}$.

Biro 262, 263.

Bisclioff 332 .

Blainville 177.

Blanchard, R. 471, 608 .

Blochmann 849 .

Blumenbach, J. Fr. 1.

Blyth 568 . 
Boas, J. H. V. 90.

Boeke, J. $\mathbf{5 8 7}$.

Boettger 891 .

Boili, F. 750 .

Bojanus 850 .

Bolivar 109, 110.

Bolk, L. 567.

Bolle, J. S6il.

Bonnet 116, 313, 332.

Bonnet-tyymard. G. 604.

Bonz 194.

Born 211, 369, 393, 503, 565.

Bossuat, F. 519.

Butkine 468.

Bouin, M. 335, :35.

Bouin, P. 335, 35.

Boulenger, $(\mathrm{i}$ A. 19S, 199, $203,566,806,807,8: 12 \mathbf{s 8}$.

Bourne 30.

Boutan 289.

Boverı, M. $\$+0$.

Boveri, Th. 94, 358, 366, 368, 10:3, 440, 444, 445, 740, 84:3, 844, 845, 858.

Bowdich, B. S. 32:3.

Bowman 645 .

Bowmann 437 .

Brancsik 772.

Brandes 106, 428.

Brandt 339 .

Brauer, A. 589.

Brauer, F. 144.

Braun, iI. 91, 353, 517, 514, $519,519-525,635,849-$ 8.56 .

Brauns, H. 271.

Braus 588.

Breddin, G. j:33.

Brelım 213, 288, 325.

Brehm, V. 28t.

Bresslau, H. 69S, 699, 652 -661 .

Bretscher, K. 380, 350, 759, 759, 760, 760, 7(\$1, 76i1.

Brewster, W. (i6.

Brian, A. 59:3.

Broman 504.

Bromn 148, 518.

Brooks 476.

Brunner v. Wattenwyl, 46 , $111,114$.

Bryan, W. A. 205.

Bichner, E. 568, 7:35.

Büchner, L. 130 .

Budgett, J. S. 94, 9g2.

Buffa, P. 285.

Bühler, A. :313, 31t.

Bulman 728.

Burchardt, E. 605.

Burckhardt 288.

Bürger, 0. 106; 659, 660, 698, 699.
Burmeister 111, 819.

Burr, M. 107, 108, 109.

Buitschli, 0. 1, 3, 289, 374, 375 , 428, 511, 572, 589, 590,858 .

Buttel-Reepen, H. v. 216, 79\%)

Büttner, C. W. 1.

Buturlin. S. 510.

Calamida 468.

Call 334.

Calman 825.

Camerano, L. 755, $\mathbf{7 5 6 .}$

Canestrini, 4. 92, 311.

Cantor 888.

Canu, E. 337 .

Carl, J. 760.

Carlsson, A. 175.

Carnoy 94, 174, 300, 369, 379, $393,502,571$.

Cartier 353.

Castle. W. E 429.

Caudell, A. N. ::H.

Cerfontaine, P. 100.

Chatin, J. 606.

Chevalier, A. 305.

Chevreux, E. 337.

Child, C. M. 77:3, $847,845$.

Cholodkowsky, N.83, 54, 117,

146, 176, 217, 49(5, 5i34, 5ino, 71:.

Christophers 690.

Christy 728.

Cliun, C. 219, 286, (5i)1, 743.

Claparède 92.

Clark, H. L. Ss.

Claus, C. 1, 461, 463, 817.

C'lieny, A. 337 .

Cobbold 853 .

Cobelli, R. 21s, 270, 71:3, 714.

Coe, IV. R. 472, (6)s, 609.

Coghill 506.

Colin, Fr. 50:3.

Cohn, L. 190, 520.

Cohnheim 141. 358.

Couklin 94, 366, 427, 49:, 572.

Comn 427.

Conte, A. .inis.

Cook 206, 769.

Coquillet, D. W. 31, 785.

Cori 423.

Correns 371.

Corti 835.

Costa 823 .

Cotte, J. 19:3, 150-15.5, 512, 513.

Credner 340.

Creplin 91, 190.

Croneberg, A. 194, 195.

Crossland, C. 701 .
Csiki, E. 356. 359, 790.

Cuénot, L. 116, (00\%.

Cumings, E. R. $\mathbf{7 6 2 .}$

Curtis, W. C. (502, sio.

Cyrilio 111.

Czermak, W. 385, 391.

Czerniawsky 23.

Daday, E. v. (;7:2, (79:3, 76.5, 76 .

Daffiner, Fr. 130.

Dahl, Fr. 21!.

Dalla Torre, K. IV. v. 983, $197,351-397,712-7.34$, $7.95,8110$.

Dana 466.

Danilewsky 689 .

Darling, .J. F. 198.

barwin, Ch. 4, 466, 483, 671, $7: 28,795,837$.

Dathe 795 .

Davenport, C. B. 291 , \$67.

David 466 .

Dedekind, A. 71.5.

Desland 325.

Dehler 564.

Deiters 835.

Delage, Y. 2, 10:2, 350, :36;3. $419,440,455,-02$.

Dendy, A. 1s, 143 .

Descemet $4: 37$.

Dickel. F. 170, 561, $\mathbf{7 1 6}$

Diesing 91, 525, 603, 454 .

Dionisi 9 .

Distant, W. L. :3:36.

Döbel 325 .

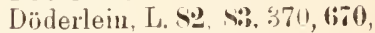
() 4 .

Dotlein 418, 622, 627 .

Doherty, W. $20 \overline{6}$.

Dohrn 56\%.

Dole 20:5.

Dollo, L. $\$ 90$.

Dombrowsky, v. 39...

van Donwe, C. 59t-5.)(i.

Doyère 177 .

Drago, U. 608.

Drew \&23.

Driesch, H. 3, 403, $\mathbf{4}: \mathbf{3}, 837$, 843.

Drude 809.

Drummond, J. M. .s.?.

Driiner 5\8.

Dubois 509 .

Dubosq, 0. 290), (;20.

Ducke, A. :s4. 717, 732 .

Duerden. J. E. :34:2, (;9:3.

Dnfour, H. 247. 35.

Dugès 311 .

Duruam, H. B. tizs. 
$\mathrm{Nr}$.

Eherlard 375 .

Eckstein, K. 712.

Ehlers, H. 1, 1, 20, 23, 304, 70.5 .

Ehrlich 468, 506, 563.

Ehrmann 506.

Eigenmann, C. H. 358, 499. Eisig 22.

Eismond 589.

Kkman, S. v. 306, 76:8.

Eirhorn 528.

Elsner 395.

Emery, C. 200-20s, 278, 386 , 390.

Enderlein, G. 774, 755.

Engelmann 411, 589, 591.

Engler 809.

Enriques, P. 141.

Entz, (4. 337, 375.

Erlanger, C. v. 116, 4.i1.

Erlanger, R. v. 289.

Erxleben, J. C. P. 1.

Escherich, K. 55, 5S, 59, $214-224$, 려), 229, 2:30, $231-278,245,38 \%, 391$, $135,479,450-492,483$, $15.3,498$.

Evans 376.

Eversmani 568.

Ewing 684.

Exner 297, 323.

Evibricius, J. C. $27,111$.

Farkas, K. :38:3.

Fatio, V. 62.

Fauvel, P. :305, 702-704.

Fea $399,400$.

Fédorov, N. $\$$ is.

Fedtschenko 171.

Feilden 510.

Felix :343.

Felt, E. P. 31, :351, 432, $4: 34$.

Fick, R. 94, \%4, 132, $17 \%$, 1't. 187, 18\%, 185, 15\%, $296,294,299,300,300$, $301,302,302,305,312$, $313,314,321,322,332$ - $335,358-.362,263,363$ $-373,378,379,381$, $352,391,393,393,401$, $101,441.146,472,473$, $49 t, 502,503,507,560$, $561,663.3$.

Fickel, J. 4:35.

Fieber 111.

Ficld, A. M, 231-23:3.

Fielding-Ould, R. 14.

Filatoff 428.

Filippi 712 .

Finot, A. 116, 7\%.
Finsch 205.

Fischel, A. 315, 442, 444 .

Fischer, A. 740.

Fischer.Waldheim 111.

Fish, P. A. 833.

Fleck, F, 668.

Flemming 94, 334, 506, 602.

Flower, S. S. 888 .

Fol 495 ,

Foot, Kath. :301, :302.

Forbes, H. O. 199, 397.

Forbes, S. A. 574.

Forel, A. 216, 219, 233, $\mathbf{2 9 4}$ -247, 266, 273, 355, 438, 718.

Foulke 29.

Fowler "2.

Francotte 189.

Frandsen, P. .91.

Frazar, M. A. 66.

Frech, Fr. (i1.

Frey, H. 1.

Friedemann, O. 461 .

Friedmann, H. :364, :36.5.

Friese, H. 386, 795.

Froggatt, W. W. 528, 537 -5.3!), 5.50, 765, 776.

Frohawk, J. W. 719.

Fruhistorfer, H. 832.

Fuchs 201.

Fuller, C. 528.

Fïrbringer, M. $5(1 \%$.

Fintll, $O$. v. 47 .

Gadd, G, 52

Gadean de Kerville, H. 3335.

Galli-Valerio, B. 91.

Galvagni, E. 204, sis.

Ganglbauer, I. 890.

Gardiner, J. St. $76, \mathbf{4 0 2}, \mathbf{4 1 6}$, 417, 464, 654 .

Garjajew, IV. 344.

Garman 819.

(iast, R. 460.

Gatterer, Clrr. IV. 1.

Gegenbaur, K. 2, 562.

Gemminger 93.

Genthe, A. 743.

Geoffroy 311.

Gerasimoff 368 .

Gerould 143 .

Gervais 177.

Gesner 356.

Giacomini, E. 115-123, 127, 172.

Giard, A. 23, 526, 551, 580.

Giglioli, H. H. :324, 674 .

Giglio-'Tos, E. (609.

Gilchı ist 691 .

Gilson 187.
Ginzberger 204.

Girard 820 .

Girschner 779.

Glasunow, D. 154.

Gmelin 356, 599.

Godlewsky, E. jr. 101.

Godlewski, E. 460.

Godron 4.

Goeldi, E. A. 71, 200, 781.

Goette $94,461,462$.

Goldschmidt, R. 131, 147, 379, $484-487,489,492,495$, $498,504,521,5 \div 0,571$, $571-573,592,602,740$.

Göppert 297.

Goriajeff 23.

Gorjanovic-Kramberger, K. 63. 202.

Gorka, A. 374, 375, 383, $385,437,810,815,820$, $8: 1,835,864,865$.

Gossard, H. A. 510.

Gough, L. H. 394.

Gounelle. E. 245.

Graaf 313.

Graber 233.

Graf, A. 106.

(iraff, I. v. $297, \mathbf{6 5 3 , 6 0 4} 4$.

Gram, Chr. s.

Grandidier 30.

Grant, W. R. O. 397.

Grassi, B.9, 9, 421, 579-582, $585,642,6 \times 0,686,687$, $776,792$.

Gravenhorst, J. L. C. 1.

Gravier, Ch. 20 - 23.

Gray 684, 832 .

Gray, (7. D. 10.

Gray, St. Geo 58:3.

Greely, A. IV. 751 .

Green 199.

Grenacher, H. 1.

Grevé, C. 510, 566, 568, 601, $669,737$.

Grieg, J. A. 77.

Grimshaw, P. H. 7s:, 7s:3.

Grobben 823.

Grönberg, G. S34.

Gronkowski, C. v. S49.

Groom 429.

Gross, J. 530, \$80.

Grube 20.

Grum-Grshimailo, Gr. 148, 149.

Grünberg, K. 147, 312, 5:3.

Grunow, A. 610.

Gudden 92.

Guenée 556.

Gujon 400.

Gundlach 323.

Giünther 735 .

Gurwitsch 589 . 
Haack, W. SS6.

Haase, E. 192, 353.

Haberer, K. 70, 418.

Haeckel, E. 2, 455, 463, 509, 642.

Haecker, V. 300, 308, 358, 366, \$69

Hagen, 50, 776 .

Haginann, G. 71, 200.

Haller, A. v. 1.

Haller, B. உ, 823.

Haller, G. 92, 479, 529.

Hallez 653.

Hammar, J. A. 17s.

Hancock, J. L. 110.

Handilirsch, A. 531-5. $1 . \%$

Hansen, A. 458.

Hanstein, v. 231-233.

Harmer 2.

Harold, Br. E 93.

Harrington, E. 7.0.

Hart, A. Ch. \$9.

Hartert, E. 64-67, 205, 206, 07, 20\%, 20s, 2018, 209, $209, \bullet 10,210,323-3.31$, $35 \%, 39 \%-400,866$.

Hartlaub, C. 18, 18.

Hartniann, M. 300, 571.

Hartmeyer, R. 496.

Hassal 852 .

Haswell, W. A. 69\%, \$50.

Hatschek 297.

Haviland 480, 776 .

Hayem 468.

Hazen, A. P. $\mathbf{\$ 1 .}$

Heath, E. F. 50.

Heidenhain, M. 189.

Heider, K. 2, $\mathbf{1 4 .}$.

Hein, W. $\mathbf{4 6 2}$.

Heincke 319, 392, 744.

Heine 67.

Heine, P. Sะ7.

Heinroth, O. 39S.

Heitzmann 374.

Helmboltz 297.

Hendel, Fr. $7 \mathrm{~S}$.

Henneguv 589, 849.

Hensen 293, 297, 339, 743.

Fenshaw, H. IV. உ06.

Herbert 353.

Herbst, C. 3, 103.

Herbst, F. G. 1 .

Herdman, IV. A. 803, \$ㅎ.5.

Helmann 187, 188, 189, 311.

Hermes, O. S6\%

Herold 552.

Hérouard, E. 75, S9, 143.

Herrick 506.

Hertwig, O. 300, 509, 845.

Hertwig, R, 94, 300, 367, 3(is, 371, 639, 817 .

Hess 820 .
$\mathrm{Nr}$.

Hesse, R. 2, 297, 297, 309, $315-317,320,336,426$, $471,525$.

Heyden, v. 311.

Heymons, R. 347, 348, 5:31, 552,552 .

Hickson, S. J. 694.

Hinds, IV. E. \$19.

Hintze 678, 679, 682.

Hirschler, J. S6:3.

His, IV. 295, \$\$2-\$84.

Hitclicock 67.

Hochstetter 893 .

Hoek 500.

Hofacker $370,50 \%$.

Hoffer 795.

Hoffmaun, R. W. 990.

Hofmeister 371.

Hollack, J. 50?.

Holmes, F. J. 597

Holmes, S. J. 5\$6.

Holmgren, N. 5.), 650 .

Holtermann 776 .

Höppner, J. $7 \mathbf{2 1}$.

Hormuzaki, C. Frh. ₹. $6 \mathbf{6 4}-$ 66 .

Horn 390.

Horvath, G. v. 865 .

Howard 538 .

Hoyle, IV. H. 471.

Hïeber, Th. $\mathbf{5} \$ 1$.

Hyde, J. 462.

gnatow, P. G. 175, 568.

lhering, H. v. 79\%.

Ijima, J. 456 , 514.

Immermann 468.

Ischikawa, C. $\$ 76$.

Isert, A. S01.

Iacobson, G. G. 111.

Jacquemet, N. 611.

Jaekel 81.

Jägerskiöld, L. A. 763, 776 .

Jagodowskij 338.

Jakobi, A. 356 .

Jakowleff, B. E. 155-157.

Jamieson, Cl. J̌SS.

Janda, V. 4:26.

Janet, Ch. 249, 479.

Janicki, C. v. 379.

Jaquet, M. 56, 57, S5.5.

Jenniugs, H. S. 58j, 5ss.

Jensen, A. S. 72, 92, 6.54.

Jerke 700 .

Johnson, H. P. 303, 645.

Johnston, G. 311.

Johnston, S. J. \$51.

Jordan 819.

Josephi, W. 1.
Joubin 698, 699, 745.

Julin $445,802,826^{\circ}$.

Ka dič, O. 810 .

Kahn S2S, 829.

Kalinowski, J. 65.

Karawaiew 5.5 .

Karpelles 27.

Karsch 112 .

Kasanzeff 368 .

Kaschtschenko, N.'Th. $\mathbf{6 5}, \mathbf{0}(\mathbf{6 6}$, 566. 601 .

Keferstein, IV. 1.

Keibel, Fr. 30.

Keller 140.

Kellogg, V. L. 542, 75.5-789, 792.

Kennedy, Cl. 49!).

Kennel, J. 23, 73:.

Kent, S. 375.

Kerr, Gr, J. 29:, 294, 735, 736.

Kel'remans 155 .

Kerschbaumer, Fr. 11.

Kertész, K. $\mathbf{7 9 0 .}$

Kerville, H. G. de :3:7.

Kessler 315.

Keulemans 207.

Kholodkovsky, N. s. Clrolodkowsky.

Kieschnick 186.

Kinberg 20.

King, H. D. 94, 17t, 205, 301 , siis.

Kiritzesea, C. 395, $\$ 07$.

Kirkaldy, G. IV. 5t:3.

Kirkpatrick, R. 134, (691.

Klein 325.

Kleinenberg 428, 845.

Klinkowström, v. 189 .

Klynens, J. 7.

Knipowitsch, N. M. 98, :335.

Kobelt, W. $\mathbf{2 7 9 .}$

Kobert, R. 598 .

Koch, C. L. 194, 311.

Koehler, R. \$ 4 .

Koelliker 4, 128, 296, 41. 698,699 .

Koenig, H. 809.

Koenike, F. 푸, 194, $\mathbf{3 1 0}$, $431,477,478$.

Kofoid 429 .

Kohaut, R. S21.

Koll, Fr. Fr. 93, 197, 386, 72.2.

Koken 509.

Kokujew, N. 16s, 16:9.

Kolbe 390, 774, 775.

Kollmann 178.

Kölsch, K. A. 589.

Königstein, H. Sy. 
Konow 386.

Konschin, A. 809 .

liöppen, P. 809.

Köppen, Th. so\%.

Kopsch, Fr. 17:3, 245.

Korff, v. 131.

Korjinsky, S. 4 .

lisorschelt, E. 2, 73, 445, 530 .

Korzinsky 669.

Koslow, P. K. 669.

Kostanecki, R. 47: 473.

kovatscheff, TV. 'T'. \$:31.

Kowalevsky, A. 53, 495, 823 .

Krabbe 91.

Kraepelin 433.

Kramer, P. 92, 311.

Krämer, J. C. A. 1.

Krauss, H. A. 112, 11:, 114.

lireidl 501.

Krendowsky 194.

kironeberg 348.

Kruckenberg 518.

Krulikowsky, L. 150.

Kírimmel 339.

Krupp, F. A. 286, 674.

Kruse 688, 689.

Kuhlgatz, Th. 250.

Kuitlian 567.

Kükenthal, W. 186, 4(65), 651, (6) 6 ; 870 .

Kulagin, N. 170.

Kulagis 729.

Kunitzky, J. 3isis.

Künkel 291.

Kunz, H. :

Kupffer, v. 128, 887

Kuwana, S. J. 5t2, jtt, 5t,

Kuznetzoff, J. D. 98.

Iablué $6,603,613,616,624$, $629,637.678,688,689$.

Jacaze-Duthier's 802.

Lagerheim, G. 20 .

Lameere, A. உّĭ1, 390.

Tampe, E. :01.

Lampert, R. 500.

Lang, A. 585, 613, 638, 642 , 811.

Langerhans 172,653 .

Lankester, E. Ray 297, 59$552,583,554$.

Latreille 311, 390.

Lauber, H. 320.

Laveran, A. 612-615, 637, 645, 6\$1, 6S:, 6S3, 690.

Lazear, J W. 1:.

Lebrun, H. 94, 94, 174, 300, $369,379,393,502,663$.

Leconte 390.

Lee, A. B. 131, 492.
Léger, L. $\mathbf{2 9 S , ~} \mathbf{2 9 9}), 616-600$, 628,634 .

Leidy 23, 652 .

Lelièvre 551 .

Lendenfeld, R. v. 133-140, $140,182-180,376$, $377,455,456,457,457-$ $45 \%, 466,512,513.511$, 515, 515, 516, 691, 752$751,474,875$.

Lenhossék, M. v. 73, 316, 589.

Leon, N. 45\%.

Leonardi 479.

Lerat, P. :30S.

Leuckart, R. 1, 423, 629.

Levaditi, C. 5ti3.

Levander. K. M. 392.

Levrat, М. М. D. 5is?.

Leydig 506, 530, 662 .

Lieberkühn 613, 630-632.

Lightfoot, R. M. 431.

Lillie 302.

Limon, M. :33:3, :3:4, 503.

Lincecum 266.

Lindemann, K. 646.

Linden, M. v. $146,433, .190$, 491, 191, 550, 551, 553559, 599, 599, 66.t-668, $7(19,710), 86 ; 1-86.3$.

Lindholm, IV. A. ㅃ01.

Tinné 115, 356. 670.

Linstow, 0, v. 191, $4: 0,120-$ $425,470,526,52 \%, 7101$, $755,756,757,757,758$, 478,479

Litten 468.

l.o Bianco, S. פsti, 674 .

Loeb, J. 85, 94, 102, 103, $350,375,415,446,497$. Si3i, 812

Loewenthal. N. 179.

Lohmann, H. 286, :339, 575.

Long, WV. H. ฉ(i7.

Lönnberg, E. 18, 95, 340, sos.

Looss, A. 4021, 521, 503, S522,

853, $855,856$.

Lopez de Lima 400.

Lósy, J. \$20.

Lounsbury 528.

Low, G. C. 4.2.

Loweg, 'Th. 96.

Lubbock 233, 247, 266.

Lubosch, W. 369,

Ludwig, H. 75- $49,141,142$, $142,143,143$.

Lïhe, M. $6-/ 7,190,+71$, $524,577,579,579,579-$ $545,600,603-620,621-$ (625, 621-6.19, 676-682,
$\mathrm{Nr}$.

683, 68.3, 684, 6.4-685,

$689,649,690,822,829$.

Iussana 468 .

Lutz 58, 613, 681 .

Mas, $0.152,461,462$, 46:3, 163 .

Mac Clendon, J. F. 27s.

Mac Clung 484.

Mac Clure, Ch. F. IV. 893.

Mac Cock 240.

Mac Crady 18.

Mac Farland 189

Macgillivray, A. D. 31.

Mackenzie 130.

Magnus, R. 497.

Maier, Herm. Nic. „59, 590.

Malaquin 303.

Mallory 590 ,

Malmgren 20, 743.

Ilannaberg 684 .

Marceau, F. 6, 124, 125, 126.

Mark, E. I. 429, 654.

Markow, M. 50t, $\mathbf{6 5 5}$.

Marotel, (i $6: 30-6: 32$.

Marschall, P. $\mathbf{0 6}$.

Marshall 116, S1:)-\$15.

Marsson, M. $\{06$.

Martini, H. s.5s

Massait, J. 251.

Matsumura, S. 546.

Matzdorff, ('. 4:3!).

Maupas 7, 374, 589.

Maurer, F. 506.

Maurer, (1. 13, 69t.

May, IV. 342, 343, 319, 351 , 3.5 $(j, 102,416,417,418$, $132,131,46.1-467,692$ $-696,707,708,711$.

Mayer, P. 337.

Mayer, S. 828 .

Mayr, G. 271.

Meek, A. S. 210 .

Végnin 92.

Méliely, I. v. 568, s(j4, \$6.5.

Meijere, J. C. H. de $\mathbf{8 6}, 778$ - 791, 796, 79\%.

Meisenlleimer; J. ‥)․, 27925.) 2 $49-295,318,319$, $449-451,45.3,454,493$, $567-873,894$.

Meissner, G. 1.

Meissner, W. $\mathbf{3 0 7}$.

Melander, A. L. $\mathbf{7 9 1 .}$

Melichar, L. 547.

Mencke, Br. 398.

Menge 809 .

Menon, $\mathrm{Kr}$. $\mathbf{4 7 5}$.

Merkel, F. $76 \mathbf{6}$.

Merrem, B. 1. 
$\mathrm{Nr}$.

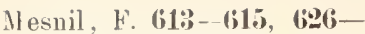
638, 645, 652, 653.

Messinea 468 .

Metalnikuff, S. 503, 709 .

Metschnikoff 797.

Metzner, R. (6:2!).

Meves, Fr. 94, 335, 484-487, $5(i 4,50,572,602$.

Meyer 339, 743.

Meyer, Ed. 428.

Meyer, F. A. A. 1.

Michael, A. D. 27, 92, 479, 528.

Michailowitsch, A. 809 .

Michailowitsch. S. 809.

Millon 511.

Milne.Edwirds 343 .

Vingazzini 468, 637.

Minkiewicz, R. s16.

Mitchell 768.

Möbius 392, 749.

Möbusz 55.

Mocquart, F. S5\%.

Mocquerys 400 .

Moesáry, S. 356.

Nokrzetzki, S. A. 5, $15 \%$.

Moller 400.

Monaco, Albert Fürst v. 463, (i75.

Moniez 2, 519.

Montgomery, 'Ih. H. jr. 789, 602 , s7s

Monti, R. 407 .

Monticelli 190, 505, 852.

Mordwilko 5.

Morgan, 'T. H. 104, \$\$0, \$4t.

Moroff, Th. \pm 18

Morrihy, C. B. 9.

Morse, A. P. 36, :37, :35.

Mortensen 81 .

Moussu, G. 6:30-6:2.

Mrázek, A. 426, 594, 7ł0, 870.

Muckermann, H. :7\%, $27: 3$.

Mudge, G. P. 354.

Müggenburg 820.

Mülberger, M. 116.

Mïller, Jolı. 297.

Müller, W. 220, 267, 286.

Murbaclı, L. 18.

Murray, 342, 651.

Nagel 433.

Nägeli 117.

Nalepa, A. 92, 7:39.

van Name, IV. (i. $189, \mathbf{8 0 3 .}$

Nassonott 799.

Natlusius 69.

Needbam, J. G. :1, 49.

Neher, E. M. :309.

Neresheimer, H. R. 5not.
Neuman 194.

Newton, Fr. 400.

Nielsen, J. C. 721, 7:3.

Nikolski 566 .

Nikolsky, A. M. 98.

Nitseh 559 .

Noè, G. 9, sт.).

Nopesa, Fr. v. 202.

Nordenskiöld, E. SEt.

Noldquist, $\mathrm{O}$. $\mathbf{S 0 . 5}$.

Nusbaum, J. 23.

Nussbaum 358, 507.

Nuttall, G. H. F. 79:.

Dates, E. IV. :3: $\mathbf{6}, \mathbf{: : 0 7}$.

Oberholser, H. C. 33:

Oberlummer, E. 45.

Obst 300, 492.

Oahner 521.

Oerstedt 654 .

Ogilvie-firant 199.

oka 106.

Oken. Lor. 1.

Oppel 95.

Oppenheimer, A. 705.

Ord $72 s$.

ustergren. Hj. 77, 14:2, 143.

Ostwald, W. 408, 412, 743.

Ottmann 586.

Oudemans 9:, 311.

Oudellans, A. C. $4: 30$.

Oudemans, J. Th.

Packardt 528 .

Paessler 465.

Pagenstecher 529.

Palacky, J. !)

Paljak off $6 \%$.

Pallas 144, 356.

Pantel, J. 455-457.

Parker 7:35.

Parona 5.5.

Paulicki 506.

Pauly, A. (j71.

Pealson 510.

van Pée, P. 315.

Peiser, A. 211.

Pelseneer 289, 82:\%.

Pérez, Ch 551, 6:3:3, 6:34, 637, 8:20.

Pergande, 'I. 7ฆ5, 819.

Perkins 782, 783 .

Perkins, H. F. 18, 291.

Perrier, E. 14:3.

Perrier, R. 14:3.

Perroncito 700.

Petermann 809.

Petersen, C. G. J. 744

Petri, K. 4:in.
$\mathrm{Nr}$.

Petrunkewitsch, A. 170, :\$1, j)(i0, 5061.

Pettersson 338.

I'feffer, IV. 6.51, $7 \pm 1$

Pfeiffer, R. 629.

Pflüger 73

Philippi, E. 6l.

Philippson 452.

Pianese, G. (6ij), (6:3);

Pickel 54.

Pieri 421.

Piersig, R. 25-27, 92, 194, 19. 195, 196; 310, 3111 $311,130,131,17 \%, 475$ $178,47 \%, 528,539$

Pilsbry 823 .

Pittaluga, (1. 9 .

Plate, L. 289, 374. \$;3;, 738, 823.

Plateau, F. 706-72s.

Platner 492.

Plato 823.

Poljakow 737.

Poinerantzev, D. s>0.

Poncy, M. 56.

Poppe 860.

Porta, 1. 5s, j9.

Portsehinsky, J. A. 14t, 1;1, 1.5.

Potts 23.

Poulton 599.

Pratt. E. M. :304, $467 \%$, (205), 706;.

Pieble, E. A. 201.

Preiwisch, J. Gi:.

Prenant 335.

Protz 310.

Plowazek, S. 250, 506, 729.

l'rewalski, N. 69, 568, 737.

Punnet 660.

Purcell 431.

Purkinje 712.

Puton 541.

Püitter, A. $3,7 \ddot{2}, 73, \quad 71$, 130, 4ti, 4t5, .511, 5iti $-585.597,5.48,7+1,742$, $751,428$.

Pyeraft, IV. P. 3:os.

Quecket 342 .

Quincke 468.

IRahl, C. 178, 21, 317, 358, $506,562,884$.

Radde, G. J. 809.

Rádl, E. 74:.

Raffaele 887.

Railliet 700 .

Rand 839.

Randolph, H. 426. 
Rankin, W. M. 79.

Ranvier 506.

Rialp 178.

vom Rath $348,438,529,858$.

Rátz, .J. v. S1s.

hawitz, B. 11s-12s,172,17s, tis, 150, 211, 352, 35t, $.562-564,567,56 \%, 830$, $833,83 \%$, 455, 856, $89 \%$, $(4 \%)$

Réaummr 551. 820.

Rebel, H. 145.

Redeke, H. C. 39:, 4:36, 499 , .)

Redtenbacher, J. 111, 114.

Reh, L. 5.ts.

Rehn, .I. :39, 40, 41, 111.

Reibisch, J. :\$19.

Reichenbach, H. 1. 205.

Reichenbach, W. Fi30.

Reithenow 67.

Reinke 506,509.

Reiser, 0. 8:11.

Reitter 160.

Riejsek 320 .

Rellard 566.

Retterer 178.

Retzius, (4. 498, 504.

Reuss $34:$.

Reyher 468.

Rhimbler, L. :3, 72, 442, 511, $57 \div$

Ribaga, C. :06, s.5!).

Riccioli, 14. 9.

Richard, J. 745, 7ft5.

Richmond, C. IV. (67.

Richter, M. S61.

Richter v. Biunenthal, Fr. 707.

Richter's, F. 1.

Riebeck 199.

Riedlinger, R. s0:.

Rigrenbach, b. 91, ,11, 1:\%, $191, .65-171,697,676$, 87.

Rizzo, А. 517.

Robert, A. 49:3.

Robertson, Ch. 7:31.

Rothinson 88s'.

Rohde, E. 5it.

Robland 468.

Romanowaky 577, 676, 677, 684,685 .

Bïmer, F. (;2, 71, 96, 98, $47,129,177,181,212$, 8.9.

Ross. R. 7, 14, 680, 686, 687.

Rossikow, K. N. 1.5, 181.

Rothschild, W. 205, 210.

Rouget, Ch. 7!) 828 .

Rousselet 672.

Roux 3, 57\%.

Roux, W. \&:3.
$\mathrm{Nr}$.

Ruibsaamen, E. IV. 70S, 779.

Rückert 94, 308, 358, 366, $369,884$.

Ruge, G. 150, 314.

Ruge. R. 7, 15, 16, 686, 657, $688,689, \mathbf{6 9 0}$.

Runeberg 468.

Russo, A. 50, \$1, 87.

Ruzsky, M. 171, 357, 795.

Sabussow, H. :34.

Sadler 370, 507.

Saint Hilaire, K. (650).

Saint-Joseph, de 20,708.

Salensky, W. (69), 737, Sะ6.

Salomon 213.

Salvadori, T. 3901, 400.

Sambon. L. W. Est.

Samter, M. :34.

Sand 374.

Sander 112.

Sarasin 226\%

Sarasin, F. 283, 533, 570 .

Sarasin, P. 283, 533, 870.

Sars, G. O. 18, :\$6;, $66^{\circ}=$ 743,764 .

Satunin, K. A. (669).

Sauerwein, Ch. 747.

Saussure : 80.

Sazepin 348.

schäffer, C. ㅁot.

Schaper 836.

Schapiro 468

Scharff, R. F. 4583.

Schatiloff 809.

Schaudiun, Fr. 7, 11, 577,

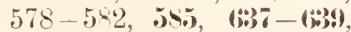
$642,659,684,655,689$, 690 .

Sehauinsland, H. 106, 521, 5(6), 752,753 .

Schaumam 468 .

Schenk 73.

Schenk, O. 4333.

schewiak off $5-9$.

Schimkewitsch, IVI. 9:. 181.

Schimper 219, 651, 743.

Schlosser, It. 70.

Schlotthauber, F. A. 1.

Schmankewitsch 347,743 .

Schmauss 44:

Schmeil 594.

Schmidt 29.

Schmilt, A. Th. 297.

Schmidt, Fr. 24 .

Schmidt, J. 129.

Schmidt, O. 137, 754 .

Schmitt, J. 267.

Schnee 454 .

Sclineider 185.
Schneider, Aimé 616, 629, 637,639 .

Schneider, Guido :39:.

Schockaert, R. 187, 185, 1s9.

Schoo, H. J. M. 17.

Schrammen, A. 13:5, 1:36, 514,515 .

Schreiner, J. Th. 21:3

Schreiner, K. H. 318.

Schrottky, C. 732.

Schtschelkanowzew, S. :34S.

Schuberg, A. 505, 505, 505, $506,506,506,589,559$ $590,590,591,629,812$ 815.

Stchïffner 685 .

Schultz, E. 1, 19, 24, 52, 5.3, 6.5, 199, 338, 34.t, 348 $3511,353, .355,650,652$, \$11, $811,816,817,826$.

Schultze, B. S. 370.

Schultze, 0. 94, 300, 313, 507.

Schulze, F. E. 18, 100, 135, 4.5. $514,679$.

Schuster, W. 3330, s73.

Schweikart, A. 4!4.

Schwenkfeld 356.

Schydlowsky, A. \$17.

Scott, 'I'l. 341, 345, 764 .

Scudrer, S. H. $42-45,111$, 11.5.

Sedlaczek 55 .

Seebohm, H. 866 .

Seeliger, 0. 81, 465-19\%, s(i) - $903,825,827$.

Selenka, E. 1, 442

Semenow, A. 169, \$81.

Semoll, R. 114.

Sergent, fi. (640).

Sharp 390. 776.

Sharpe 205.

Sharpe, R. B. S66t.

Sharpe, R. W. 7tiz.

Sherborn, C. D. 357.

Shicharew. N. 338.

Shipley, A. H. $40: 3,404,792$, s.2., 5.54.

Shitkow, B. 510.

Siebenrock, Fr. 0:3, 396, \$3:2, 889, \$91.

Siebold 37\%, 373, 820 .

Siedlecki, M. 591, 613, 637, 639, (i41, 642, 645 .

Siegel, C. 679, 682.

Siepi 551.

Silantiev 469.

Silantjeff, A. A. 98, $17 \mathbf{6 i}$.

Silvestri, F. 26, 28, 99,374 ,

45., 73:3, 7(39-771, 776 .

Simond 682

Simond, P. L. 613, 64t. 
$\mathrm{Nr}$.

Simroth, H. 132, 291, 43S, 439, 73.), 811, 823, 823, $82 \%$

Sinéty, R. de 4S5-457.

Sjöstedt, Y. 450, 481, 776.

Skottsberg, C. 734

Sladen, F. W. 2, 799.

Sluiter 143.

Smeathman 776.

Smith, J. B. 432, 54!), 5.545.58, 793.

Smith, P. 198.

Simith, 'Th. 6tă.

Smitt, F. A. 98.

Soar, C. D. 477.

Sobotta 313 .

Sollas, J. si4.

Sollas, Jg. B. J. 376, 515.

Somina, O. M. 111.

Speiser, P. 78:3.

Spencer, H. 795.

Spengel, .I. W. 2, 201) 2-3, $3113-3115,174,475,475$ $7111-7116,735,736$.

Spépligeti, G. 356.

Staden 2.

Stafford, J. 85.5, 856 .

Stâl 109, 111, $112,772$.

Stauffacher, Heh. 573.

Stein 590.

Steinach S:S.

Steindachner 395.

Steinmann 103.

Stempell 823.

Stephens 690.

Sterki 589.

Sternander, R. ㄱof(;.

Steven, Ch. 809.

Stevens, N. M. 415, 419.

Stieda $646,629$.

Stiles, C. WW. 507, (646, 647, $757,852$.

Stilling 562.

Stöhr 178.

Stolě, A. Siss.

Stolzmann, J. (5i).

Strasburger, E. 361, 871.

Strauch 566.

van der Stricht, O. 187-189, $335,401$.

Stricker 828.

Strobell, E. Ch. 301, 30:.

Stromeyer, Ed. 1.

Stscherbakoff, A. M. 46.

Studer 696.

Studnicka, F. H. 350.

Stuhlmann, Fr. 711.

Stummer-Traunfels, R. v. 656.

Sukatschoff, B. 40s.

Sumner 887.

Suschkin, P. 355.
Sutton, W. S. 441, 6033.

Svenander, G. 9.;.

Swinhoe 328.

Szakáll, (1. 43i, 83\%.

Szilâdy, Z. 810.

'Tallquist 468.

Taschenberg 213, 518, 820 .

Teichmann, E. 845.

Thacher, H. S. 104.

Théel 143.

Thiele, J. 186, 7.54, 8*3.

Thienemann 325.

Thilenius, G. 28:.

Thomas, Fr. 794.

Thomas, J. J. 648.

Thompson 660 .

Thomson 400.

Thon 529 .

Thor, Sig. 310, \$11, 431, 475, 5.29.

Tichomiroff, A. \$300, 737.

Tönniges 589.

Topsent, E. 137-139, 3375.

Tornatola 315 .

Tornier 891.

Tornquist, A. 61, 6.3, 70, $749,7501,762$.

Torrey, J. C. 427.

Tower, R. W. 2, 600.

Toyama 147, 552.

'Trügårdh, J. 27, 458, 776.

Treadwell, A. R. 105.

Tretiakow, D. 1!).

'Treub 219.

Trevor-Batty 510.

Trimen 225.

Trinchese 100 .

Tristram 210.

Trouessart, E. 27, 97, 311, 337.

Tschersky 737.

Tschitscliérine, T. 159-167.

Tschusi zu Schmidhoffen, V. v. 331 .

Tümpel, R. 111.

Tutt, J. W. 25.s.

Cle, E. 800.

Urban, F. .j16.

Uzel 819.

Vallentin 304.

Vallon, Gr. 324.

Vanhöffen 463.

Vejdovsky, F. 426, $7 \mathbf{4 0 .}$

Verhoeff, K. 20, 29, 30, 47, $47,48,48,130,60,192$, $192,193,193$.
Vernhout, J. H. 140.

Verreaux 399.

Verrill 803.

Verson 312, 5i2.

Verworn, M. 74, 589, 597, 743.

Viehmeyer, H. 256.

Viltshur 468.

Virchow 646

Voeltzkow 891.

Voigt, M. 409.

Voinov, D. N. 459.

Voirin, Val. (6t9.

Vosmaer, G. C. J. 140.

Vosseler, J. 111, 116.

Vries, de 508, 509.

Wagener 518 .

Wagner, F. v. 5(1s, 5119, 6it), (;71, 738, s01

IVagner, J. S60.

Wagner, N. 52.

Wagner, Rud. 1.

Waldeyer 506 .

Walker 111, 536.

Wallace $283,870$.

Walsh 819.

WValter 347.

Walter, A. 598, 809.

Wandolleck 192, 488, 779, $78 \%$.

Warpachowsky, H. A. 98.

Warris 715 .

Wasielewsky, von (iss, (is9).

Wasmann, L. 257-260, 479, 4\$1, 482, 45:3.

Waterhouse 67.

Waterstradt, .J. 208.

Weber 213.

Weber, M. 283, 870.

Webster, R. IV. $4 \mathbf{4 8}$.

Wedekind, W. 3720, $\mathbf{3 7 3}$ 446.

WVedl 518.

Weed, C. M. 528.

Weinberg, R. 569.

Weinland, E. 758.

Weismann 94, 189, 445, $488,795$.

Weiss 400.

Werner, E.198-2013,204,211.1, $394,391,39.5,391 ;$, s116S०8, 831, 832, S46-891.

Wesenburg-Lund, C. 284, 340.

Westwood 39, 40.

Wettstein, R. v. 508.

Wetzel, G. :32:.

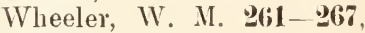
977, 278.

Whitelegge, Th. 459. 
Whitman 94, 106, 428.

Will 530.

Willcox 82:.

Willem, V. :3:.

Willemoes-Suhm, R. v. 1.

Willey 475.

Williamson, E. B. 787.

Wilson 94.

Wilson, E. B. 427, 440, 571 , $572, \times 2,845,80$.

Wilsou, H. V. 575.

Wilson, Sc. 205.

Winckler 92.

Winkler 371.

Wimertz 779.

Winogradoff 519.

Wolcott, H. R. 196.
Nr.

Wolff, G. 509.

Wolterstorff, W. 502.

Wright 696 .

Wundt 742 .

loung, A. N. 773.

Fung, Em. 265.

Zacharias, O. 297, 255, 404, $410-+14,15.57$.

Zander, E. 710.

Zelintner :30, 5:31, 5:3:.

Zelinka 2.

Zeller 589.

Zenneck, J, 501.

Zichy, Graf Eugen 386, 568, 790 .
$\mathrm{Nr}$.

Ziegler, H. E. 295, 440, $\mathbf{4 2}$, $509,565,795.795$.

Zimmermann 506.

Zittel 97, 750.

Zoubareff 779 .

Zschokke, F. 284, 28t$245,3116,317,310$, $337,339,341), 341,345$, $346,345,+101-414,57 t-$ $576,59 \%-596,651,662$. $672-675,743-748,763$ $-767,815,87$.

Zubowsky 111.

Zürn, J. 3366.

Zir Strassen 8.58

Zykoff, IV. P. v. 425, 576, $7 \pm 5$. 


\section{Sach-Register.}

Nr.

\section{I.}

Aberration 146, 324, 670.

Achromatin 94, 366, 44., 485-4>7, 564, $573,578,585,639,740$.

Iquatorialplatte 94. 174, $366,585,639$.

Amitose 99, 530, 577, 592. 709, 884.

Anpassung 49, 116. 347, 375, 415, 480, 48.3, $499,505,651,662,743,768,773,795$. $805,811,824$.

Autonomie (d. Kernbestandteile) 358, 366, 472,580

Autotomie 116, 426, 779.

\section{I3.}

Befruchtung 7, 73, 85, 94, 102, 170, 173, $242,243,275,298,299,361,362,363$, 366. 367. $3188,371,378,391,401,440$, $441,445,472,493,560,561,610,613$, 633, 634, 637, 639. 641, 716, 730, 740, $792,795,840,857$.

Berattung 92, 94, 212, 275, 301, 347, 520. Bewegung 291.

Bindegewene 178, :313-317, 505, 506, 884 . Biologie 279, 339, 406, 408, 811 .

Blastula 2, 102, 103, 332, 403, 428, 462, $796,842,843,857,858$

Blutgefäss-System 124, 125, 126, 828,884 .

Blutkörperehen 116, 8\%3, 884.

Brutpflege (Allg.) 872, - (Coelent.) 651, (Ins.) $214,220,230,233-235,263$, (Pisces) $813,-$ (Amphib.) 813, - (Rept.) $200,-$ (Aves) 813.

\section{c.}

Centrosom 94. 174, 187, 188, 189, 298, 302, $381,391,401,419,440,442,444,445$, $472,473,484,489,572,589,740,845$, 88:.

Chemomorphose 741.
Chemotaxis 182 .

Chromatin 55, 94. 105, 132, 187, 188, 290, $296,298,299,300,322,363,366,367$, 379. $381,382,393,401,445,476,485-$ $487,489,492,521,560,577,629-632$, $628,639,641,642,650,683,690,740$, $816,882,853,884$.

Chromatophoren 293, 294, 499.

Chromosomen 94, 174, 187, 188, 189, 298, $300,308,361-364,366,379,391,393$, $403,419,440,441,445,472,476,489$, $492,560,561,592,602,663,740,826$, $845.858,883$.

Commensalismus 820 .

Conjugation s. Konjugation.

Copulation s. Kopulation.

\section{1).}

Degeneration 94, 99, 109, 103, 104, 1乞7, $188,259,312,322,334,358,359,367$, $460,552,570,592,606,689,686,687$, 709.

Deszendenzlehre 130, 132, 508, 509, 670, 671,79 ;.

Dimorphisinus 64, 73, 110, 234, 235, 278, $326,327,433,576,604,607,611,616$, $618,633,634,639,641,670,685,816$.

Domestikation 330 .

\section{E.}

Eibildung 106, 296, 359, 362, 492.

Eireifung 94, 102, 105, 174, 187, 188, 189, $298,299,300,308,363,369,378,381$, $393,429,445,472,521,560,561,663$, $740,857$.

Eizelle 72, 92, 102, 10.5, 132, 147, 170, 173 , $174,187,188,200,2 \times 6,290,295,296$, $298,299,300,312,313,314,321,322$, $322,335,347,350,361,362.363,366$. $368,370,372,373,378,379,381,392$, 


\section{\begin{tabular}{l}
$-\quad 959$ \\
\hline
\end{tabular}}

$\mathrm{Nr}$.

$\mathrm{Nr}$.

$393,401,40 \%, 419,429,4: 3.540,442$, $444,445,446,469,472,473,476,492$, $493,494,502,503,507,521,530,552$, $560,561,571,598,651,66 \%, 697-700$, $716,725,729,730,740,74:, 757,795$, $796,826,842-845,8.77,864,876,882$, $85.3,884,887$.

Ektoderm 2, 19, 7ฬ, 99, 101, 178, 293, 294, $303,350,426,428,429,460,461,462$, $493,495,521,565,592,652,817,82.3$, $846,857,858,884$.

Entoderm 2, 19, 49, 101, 106, 350, 366, $427,428,429,444,460,461,462,463$. $467,495,521,565,592,823,827,858$, $881,887$.

Entwickelungsgeschichte $44 ;, 415$.

Epithelgewebe $118,12 \%, 127,12 \%, 141,178$, 296, 297, 31:-317, 3201, :352, 358, 359, $492,505,506,516$.

Erytluocyten 8, 128, 46׳, 564, 57\%, 585, $598,61:, 64 \times, 676-679,6 \times 1,682,6=4$, $6 \times 5,797$.

\section{I.}

Flugvermügen 801 .

Forstliche Zoologie 1;,1, 158, :49.

Fortpflanzung (geschl.) 1:2, $358-364,366-$ $368,370,372,373,652$.

Fortptlanzung, ungeschl. (Coel.) 18, (PJatlielm) 65:, - (Ansel.) :30:;, 138.

Furchung 2, 19, 94, 102, 103, 10\%, 173 , $290,295,3: 2,335,358,366,368,379$, $41 !, 427,428,429,440,442,444,476$, $492,493,495,521,729,740,845,857$, $858,852,883,887$.

\section{G.}

Gastrula 2, 85, 842. $843,844,858$.

Gastrulation 2, 429, 462, 493, 844, 8., 887.

Gedächtnis 232, 237, 238, 275 .

Gehör 129, 237, 238, 493.

Generationswechsel 117. 604, 605, 610, 611, $613-615,618,619,627,629-637,639-$ $641,643,6+4$.

Geotropismus 100, 291.

lieruch 232, 233, 237, 238, 258, 348, 433, 716.

Geschmack 218, 237, 238, 270, 348, 713, 714.

liesichtssinn 233, 237, 238, 247, 256, 258.

II.

Häutung 92, 110, 116, 430, 766, 861.
Heliotropismus 674.

Hermaphroditismus $361,362,372,373,420$, 534, 535, 757. 791.

Heterogenese 4.

Heteromorphose $100,426,460,846$.

L.

Instinkt 237, 238, 258, 259, 597.

\section{II.}

Keimblätter $19,2,6 \%$.

Kern 55, 74, 92, !1, 99, 105, 127, 128, 131, $132,147,187,188,189,290.295,296$, 298, 299, 800, 312, 313, $314,322,33 \%$, 358, 368, 366, 567, 568, 374, 381, 391, $398,401.408,425,4: 3,4+0,444,445$, $47,473,476,484-487,492,514,521$, $529,590,552,560,561,571,573,577$, $578,585,591,592.602,608,613,629$, $63+$, fi.3-642. 645. 650, 67!, 651685, $690,70 !, 729,740,816,826,843$, $44,849,85 \%, 8 \times 2,88 \%, 884$.

Kernteilung 94, 105, 131, 366, 419, 484, $577,58.7,699,639,482,729,816,845$, 858,852 .

Knospung (Coelent.) 100, 651, - (Turbell.) 847, - ('l'remat.) 850 , - (Amnel.) 303 , 838 .

Konjugation (b. Protozoen) 7, 13ะ, 347, 374, 634,816 .

Kopulation $14,29 \Re, 374,610,613,614$, $616,634,639,641,645,679$

Korallen-Inseln 464, 466 .

\section{1.}

Landwirtschaftliche Loologie 5, 152, 153 , $158,213,349,351,356,432,435,528$, $531,532,538,549,550,707,711,715$, $\$ 19$.

Leibeshölıle 2, 106, 141, 292, 296, 313, 701, $705,823$.

Leukocyten 53, 95, 128, 178, 293, 294, 314, $352,506,529,563,709,797,863$.

II.

Mastzellen 506, 563.

Mesoderm 2, 99, 106, 128, 293, 294, 315$317,350,426,427,429,444,492,493$, $495,561,565,827,88 t, 887$.

Metamorphose 261, 286, 38:, 435. 
Mimikry 439.

Misshildung 360 .

Mitose 94, 99, 101, 106, 121, 122, 132, 298, $821,339,358,403,426,440,472,473$, $476,506,561,564,572,577,585,6012$, $639,652,845,882-884$.

Muskelgewehe 124, 125, 126, 448, 505, 506, 530 .

Myrmecophilie $236,240,259,265,269,276$, 479.

\section{N.}

Nebenniere 118-123.

Nervenendigung 12:3, 291, 297.

Nervengewebe 505,506 .

Nucleolus 94, 174, 187, 188, 290, 296, 298, $366,369,379,393,472,489,492,529$, 571,684 .

\section{I.}

Paläontologie $24,61,63,70,97,136,202$, 343, 569, 749, 750 .

Parasitismus 606, 613, 685, 6:86, 638, 639, $645,645,811$.

Parthenogenese 73, 85, 102, 117, 170, 259. $275,284,346,347,350,361,362,863$, $872,373,378,381,445,446,560,561$, $730,743,792,795$.

l'hagocyten 461. 467, 512, 513, 786, 797.

Photomorphose 741.

Phototropismus 102, 291, 586, 742.

Plyylogenie 823.

Physiologie $446,447,741$

Pigment 94, 103, 129, 297, 314, 403, 437, $463,490,491,518,529,553,577,583$, $5 \times 5,586,599,651,684,690,701,819$, $826,835,843$.

Pigmentzellen 293, 294, 297, 506.

Plankton, marines 339, 408, 575, 651, 674, 743 .

Plankton, des Süsswassers 284, 285, 287. $288,307,374,404-414,500,574,576$, 743,748 .

Planula 462.

Polymorphismus 110, 224, 225, 228, 234, $235,259,261-263,277,480,481,48 \%$, $670,716,776,795.813$.

Polyspermie 403, 440, 445, 473, 845.

Proterandrie 417, 823.

Protoplasmastruktur 3, 72, 94, 300, 37t, $571,572,578,589,650,740,883$.

\section{R.}

Reduktion (der Chromosomen) 94, 187, 188,
$189,299,361,362,363,366,382,445$, $492,560,561.60^{\circ}, 607,639,641,740,858$. Regeneration (Coelent.) $100,101,415,460$, 889, 840, 841, - (Turbell.) 104, 652, 846, - (Annel.) 305, 426, 427, 838, - (In. secta) $773,86:$ ).

Regulation (Allg) 443, 837, - (Coelent.) 101, 444, 460, 839, 840, - (Echinod.) 844, - (Turbell.) 847, 848, - (Nemert.) 857.

Reifungsteilung 94, 189, 363, 366, 381, 445,472

Richtungskörperchen s. Eireifung.

Schutzfärbung $110,113,116,439,768,864$. Schwebevorrichtungen 408,743 .

Sehorgan 293, 294, 297, 309, 315-317. $320,336,4: 37,742$.

Selektion 48., 508, 509, 597, 671, 795, 837. Sinnesorgane $43:), 742$.

Spermatogenese 29, 94, 106, 131, 308, 363 , $382,445,481-487,492,552,570,592$. 602,663

Spermatozoen 73, 102, 110. 116, 132, 147, $170,296,298,299,302,812,347,361$. $362,363,368,370,: 872,401,403,429$, $440.445,472,473,481-487,489,498$, $504,521,570,592,716,735,740,84 \%$, $843,845,857,859$.

Sphäre (Attraktions- und Centro-) 94, 105, $187,188,189,300,366,391,401,440$, $442,445,472,473,492,572,740,845$, $882,883$.

Statische Organe 742.

Stereotropismus 100.

Stoffwechsel 74, 94, 290, 366, 375, 650, $741,713,758$.

Symbiose 217, 219, 236, 240, 255, 259, 265, $271.374,375,512,733,745,800,823$.

Symmetrie-Verhältnisse 2, 289.

Symphilie 479, 482, 483.

\section{'T.}

'Tastsinn 237, 238, 291, 348, 433.

Termitophilie 259, 479, 482.

Thigmotaxis 182, 291.

Tiefseefauna $84,286,463,575,651,674$, $745,811,872$.

Tiergeographie 5, 116, 145, 279-2১4, 337, $338,355,356,395,438,439,449-454$, $510,575,651,672-675,744,745,768$, $805,867-870,872,873$.

Tierwelt des Meeres 286, 337. 339, 340, $575,651,674,675,745,747,805,811$, $867,872$. 
Tierwelt des Süsswassers $31,307,340,380$, $404-407,410,411,414,805,811$.

Tud 74, 378, 417.

Tropismen 21, 742.

\section{V.}

Variabilität 4, 146, 294, 291, 347, 375, 394, $417,449,450,667,670,738,741,743$, 762.

Vererbung 363, 364, 365, 441, 445, 508, $509,670,716,738,741,838,843$.
W.

Wachstum 130, 225. 741, 836 .

Wanderung $145,250,279,340,356,439$, $449,450,452,743,805$.

Wanderzellen 358, 428, 506, 513.

Z.

Zellstruktur s. Protoplasmastruktur.

Zellteilung s. a. Kernteilung, s. Mitose bezw. Amitose :368, 419, 440. 442, 473, 572, 740. Zellverbindungen $352,505,506,709$. Zellwanderung 358, 428 . 


\section{Geographisches Register.}

$\mathrm{Nr}$.

A.

Afrika 20, 30. 109, 112, 113, 116, 156, 163 , $166,199,201,203,207,227,305,331$, $355,397,399,400,422,424,451,480$, $481,651,654,701,702,706,711,745$, $755,757,769,776,808,889,891$.

Alpen 62, 193, 284, 285, 287, 288, 343, 407, $594,750,794$.

Amerika 111, 113, 148, 149, 152, 219, 248, $250,265,278,351,453,538,548,550$, $767,775,786$.

Asien 23, 111, 116, 148, 149, 152, 158, 15. $157,161-164,169,199,279,283,328$, $449,533,601,66 t-666,668,763,792$, 798,891 .

Atlantischer Ozean 18, 20, 27, 32, 77, 89, $134,138,142,143,256,304,305,387$, $340,345,377,416,449,453,455,458$, 46.), 496, 575, 651. 658, 6744, 675, 68. 691, 693, 702, 706, 743, 745, 746, 79:?, $802,803,893,867,875$.

Australien 114, 166, 167, 283, 304, 355, 436, $459,528,53: 3,537,539,543,550,598$, (99s, 699. 752, 763, 768, 851, 874.

Azoren 138, 143, 377, 453, 575, 745, 746.

\section{8.}

Baikal-See 23, 344.

Balkan-Halbinsel 56, 57, 63, 145, 204, 331, $356,395,468,585,596,598,664-668$, $807,831,864,685,86$.

C.

Ceylon 108, 109, 259, 398, 464, 470, 475, $536,651,682,756,786$.

China $20,70,148,149,162,386,389,540$, 682.

\section{D.}

Dänemark 340, 744, 774, 877.

Deutschland 1, 73, 136, 194, 201, 206, 219, $250,279,280,284,310,325,330,351$, $356,394,409-411,414,498,468,500$,
$509,529,541,576,594,595,653,686$ $-689,721,744,766,774,794,860$, $878,877$.

w.

Europa 64, 77, 98, 109, 111, 116, 145, 152, $153,154,160,171,176,203,234,235$, 259, 273, 279, 328, 351, 355, 374, 439, $453,479,550,575,664-666,672,676$, $677,717,725,734,737,762,766,774$, $779,786,792,798,860,871$.

\section{F.}

Farüer 651.

Finnland 111, 306, 392, 468, 774, 805.

Frankreich 18, 20, 27, 152, 163, 300, 305. 337, :351, 551, 558, 569, 674, 6775, 683, $745,746,877,889$.

G.

Galápagos 330, 542, 544.

Grönland 79, 658 .

Grossbritannien 77, 92, 206, 341, 345, 477, $651,738,764,774,877$.

II.

Hawaii $205,206,543,757,782,783,825$.

I.

Indien 20, 23, 30, 107, 109, 155, 156, 164, $208,326,327,331,376,398,417,419$, $464,536,676,677,763,795,832,888$. Indischer Ozean 20, 76, 134, 186, 199, 283, $376,397,417,418,458,464,465,475$, $651,684,685,696,701,870$.

Italien $9,28,29,116,173,193,250,285$, $286,300,304,324,330,331,384,404$, $405,407,418,479,517,519,598,674$, 683, 686, 687, 698, 699, 770, 792, 868. 
Nr.

\section{J.}

Japan $82,83,109,236,418,449,475,520$, $524,533,540,545,546,682,788,749$, 871.

\section{K.}

Kanaren 331, 651.

Kaspisches Meer 347, 395, 662.

Kaukasus 23, 111, 151, 152, 181, 331, 386, $389,395,568,654,790,809,860$.

Kerguelen 651, 775.

Kleinasien $145,157,391,452,479,672$.

\section{M.}

Madagaskar 30, 109, 112, 163, 165, $17 \%$ $259,271,772,891$.

Marmara-Meer 395, 823.

Mittelamerika $110,113,115,259.889$.

Nittelmeer 27, 33, 118, 116, 137, 143, $193,204,286,300,304,30 \%, 331,839$, $3 \%, 418,452,479,521,523,575,674$, $675,683,698,699,745,746,798,809$, $85 \%, 868,887$.

\section{N.}

Neu-Guinea 107, 114, 226, 283, 398, 399, $533,870,874$.

Neu-Seeland 18, 28.2, 304, 355, 565, 598, $752,76.), 8.50$.

Niederlande $17,73,890$.

Nordafrika 113, 116, 137, 155, 156, 2:0, $245,251,259,265,279,325,381,396$, $675,715,718,768,776,853,854$.

Nordamerika 23, 31, 34, $36-45,49-51$, $66,77,88,94,96,110,115,152,196$. $197,234,285,259,261,262,261,265$, $266,267,273,277,278,279,281,303$, $304,306,309,328,349,8.1,355,418$, $432,454,449,450,458,468,479,499$, $516,527,528,538,540,549,554,555$, $557,558,559,574,575,698,699,731$, $749,757,762,767,775,775,777,778$, $785,787,792,793,819,855,856,860$, $867,878,889$.

Nördliches Eismeer 77, 79, 340, 510, 658, $817,826,872$.

Österreich 63, 193, 202, 250. 284, 287, 288, $351,356,521,585,594,595,683,729$, $750,852,861,871$

Ostsee 269, 339, 340, 392, 743, 744, 802.

\section{P.}

Philippinen 20, 210, 226, 418, 583, 870.

Polynesien 210, 219, 282, 283, 330, 398,
$454,466,565,696$.

Nr.

Pyrenäenhalbinsel 116, 381, 551.

\section{IR.}

Rotes Meer 20, 305.

Russland 4, 5, 24, 46, 9ৎ, 111, 148, 149, $150,151,158,158,162,168,194,195$, $215,279,306,307,338,340,347,356$, $386,387,3 \vee 9,425,468,510,524,566$, $576,577,585,598,654,655,790,805$, $809,860,877,880$.

Schwarzes Meer 395, 662, 816.

Schweiz 62, 236, 241, 310, :980, 468, 478. $594,759,760,761,877$.

Sibirien 4, 27, 68,9९, 148, 149, 175, 306, $386,389,469,519,566,568,601,748$, 790,809 .

Skandinavien 18, 27, 77, 95, 142, 269, 276, $306,338,340,411,455,468,496,529$, $594,654,658,673,674,706,734,774$, $805,869,877$.

Spitzbergen 27.

Stiller Ozean 18, 20, $82,83,88,205,206$, $282,28 ., 303,304,418,454,465,466$. $475,516,674,691,696,698,699,752$, $753,785,825,870,874$.

Südafrika 112, 124, 156, 166, 198, 201, 225, $259,271,286,305,416.417,431,479$, $528,651,691,757,763,806$.

Suidamerika $20,21,23,26,65,71,109,113$, $163,164,166,200,209,248,259,304$, $346,355,374,384,4: 6,465,479,482$, $520,593,613,673,678,706,717,732$, $733,763,765,769,775,781,800,824$ $8 \div 9,891$.

Suidliches Eismeer 75, 651, 743. 825.

Sunda-Inseln 30, 107, 109, 114, 163, 186, $201,208,226,283,398,458,531-538$, $651,656,772,870,808$.

\section{I.}

Ungarn $63,107,356,875,386,388,664-$ $666,673,810,818,821,835,864,865$.

\section{W.}

Weisses Meer 338, 510, 805, 817.

Westindien 23, 110, 115, 32:3. 342, 693, 803,875 .

Zentralasien 69, 111, 116, 144, 148, 149, $154,155,157,161,168,171,208,279$, $386,389,566,568,598,669,737,790$, 798, 509 . 


\section{Systematisches Register.}

\section{Protozoa}

Syst. 7, 285--288, 374, 410, 411, $414,455,579-582,584,585,591,603$, $605,607,608-611,613,614,616,619$, $621-624,627,628,636-640,642-645$. $647,649,672,673,676,677,678,681$, $682,683,686-690,739,74$.

Faun. 9, 11, 13, 17, 28t-245, 389, 374. $405,407,410,411,414,466,575,576$, $577,585,591,651,672,673,674,676$, $677,678,682,683,686-689,748$.

Biol. 8, 9, 17, 284-288, 389, 342, 374 $375,405,406,407,410,411,413,414$, $575,576,585,607,613,615,629,639$ $640,643,645,651,674,676,677,681$, $684,686-689,743,748,751,823$.

Paras. $6-17,89,299,410,411,577,578$, $583,585,591,603-649,676-690$, 878.

Morph. 12, 2!s, 299, 374, 375, 411, 511, $577,578,589,585,589,590, .991,604$, $605-611,615,616,615,629-632,634$, 699. 642, 6i45, 676, 677, 681, 682, 684 $-687,690,816$.

Schale und Gehäuse $3,72,342,375,511$, Cysten 6, 89. 295. 339, 414, 604. 610, $629,635,639,642,645,676,677,751$, 816.

Beweg. Org. 375, 587, 588, 589, 639.

Kontrakt. Vakuole 591.

Kern 132, 298, 299, 374, 577, 578, 585, $591,608,6130629.634 .638-642,645$, $679,681-685,690,816$.

Fortpflanzung $6,7,10,13,14,15,17,132$, $298,299,339,347,367,368,374,411$, $577-585,591,604,605,610,611,613-$ $615,618,619,627,629-637,639-641$, $643,644,676-679,684-687,690,816$.

Physiol. 3, 17, 342, 368, 374, 375, 5ธ6, $587,588,590,606,613,620,634-636$, $638,645,648,751$.

Fossil 511.

Phylog. 132.

Sarcodina $3,72,285,286,288,339,342$, 367. $375,404,407,411,414,455,466$, $511,575,590,639,651,674,739,743$, 823.
Nr.

Rlizopoda 3, 72, 285, 286, 339, 342,375 , $407,411,414,455,466,511,575,590$, $651,674,739$

Heliozoa 288, 339, 367, 411, 639 .

Radiolaria $286,399,575,651,674,74 \%$, 82:.

Sporozoa $6-17,89,298,299,3999,577$, $60: 3-649,676-690,878$.

Coccidiaria 7, 603-649, 682, 878.

Gregarinida 298, 299, 607, 620.

Haemosporidia $6-17,577-585,613$, $619,642,676-690$.

Mastigophora 284, 287, 288, 399, 404, $405,410,411,413,414,575,586,584$, $743,748,751$.

Flagellata 287, 288, 339, 410, 411, 413, $575,586,589,748,751$.

Dinoflagellata $284,287,288,405,411$, $41:, 414$.

Cystoflagellata 339,749 .

Infusoria 132, 287, 339, 374, 375, 406, $407,410,411,414,575,587-591,641$, $651,739,816,82: 3$.

Holotricha $339,375,406,411,589,590$, 591 .

Peritricba $339,375,406,407,411,414$, $575,587-590,651$.

Hypotricha $389,375,406,410,588,589$, 590,816 .

Heterotricha 339, 375, 411, 587-590. Suct or i a $339,374$.

\section{Spongiae}

Syst. 134-140, 185, 337, 376, 458, 459, 514. 515, 651, 691, 745, 752, 758, 754, 874,875 .

Faun. 134, 136, 137, 138, 186, 337, 376, $377,458,459,651,675,691,745,752$, $758,754,870,872,874,875$.

Biol. 138, 139, 387, 342, 377, 406, 457, $512,651,675,691,745,812,823,872$. Paras. 679.

Morphol. 138, 139, 140, 377, 456, 457, $514,691,874$.

Kanalsyst. 138, 140, 377, 456, 513, 516. Skelettgebilde $138,138,140,186,342$, $377,455,456,514,515,651,753,874$, 875 . 
Histol. $513,516$.

Gemmulae 133, 185, 457, 513.

Entwicklg. 377, 514.

Physiol. 182-185, 342, 512, 513.

Fossil. 1:36.

Phylog. 2, 1:32, 823.

Calcarea $2,182,513,516,753$.

Silicosa $134,135,137-140,183-186$, $376,377,406,456-459,513-515,651$, $675,691,745,754.870,872$.

Cer atos a $342,376,459,512,679,752$, 874.

\section{Coelenterata}

$2,18,106,101,286,297,397,339,342$, $345,874,377,411,415-418,442,444$, $454,460-467,507,575,592,651,670$, $673,674,675,692-696,743,745,812$, $817,823,839,870,872$.

H y d rozoa

Syst $18,337,411,651,673,817$.

Faun. 18, 387, 339, :374, 411, 575, 673, $674,817$.

Biol. 18, 100, 389, 374, 411, 415, 507, $575,674,812,82:)$

Morphol. 18, 415, 6.)1, 817.

Gastrovasc.-Syst. 18.

Geschl. Org. 18, 100, 592, 651.

Histol. 18, 592 .

Entwicklg. 2, 18, 100, 462, 592, 651.

Pliysiol. 100, 101, 415, 460, 507, 839, 840.

Phylog. 2, 462.

Hydroidea 2, 18, 100, 101, 937, :374, 411, 415, 460, 507, 592, 651, 673, 812, 817, $82: 3,839,840$.

Siphonophora '286, 339, 575, 651, 674.

Scy hozoa

Syst. 286. 3:37, 342, 416, 417, 418, 463, $465,651,670,6912-696,745$.

Faun. $286,3: 37,342,346,416,417,418$, $454,46:-466,575,651,675,692-$ $696,745,870$.

Biol. 286, 339, 342, 377, 416, 454, 463, $464,465,575,651,675,743,812$.

Morphol. $343,416,417,461,463,465$, $651,692-696$.

Gastrovasc. - Syst. 461, 462, 463, 46.5, $694,695,696$.

Skelettgebilde 2, $100,342,46 i 5,693-$ 696.

Nesselkapseln 461.

Muskeln 461.

Nervensyst. $461,467$.

Sinnes-Org. 297, 461, 463.

Geschl.-Org. 417, 463, 592.

Histol. 297. 461, 462, 467, 693.

Entwicklg. 2, 417, 442, 444, 461, 462, 463, 693.

Physiol. 100, 297, 342, 417, 461, 467, 841.

Phylog. 2, 297, 462, 823 .
Acalepha 2, 297, 339, 461, 462, 463, 575, $592,651,745$.

Anthozoa 2, 100, 337, 342, 343, 377, 416, $454,462,464-467,651,670,675,692$ $-696,745,812,841,870$

Octocorallia $337,418,462,465,467,651$, 670 .

Hexacorallia 100, 342, 343, 416, 417, $651,675,692-696,745,841,870$.

Ctenophor a 286, 442,444, 651, 743, 823 .

\section{Echinoderma}

Syst. 2, 75, 76, 77, 79, 82, 83, 84, 86, $88,89,142,143,337,651,739$.

Faun. $75,76,77,79,82,83,84,86,88$, $89,142,143,337,651,674,675,744$, $745,867,872$.

Biol. 84, 378, 651, 674, 675, 744, 745, 867,872 .

Paras. 85, 89, 651.

Morphol. 75, 78, 80, 81, 86, 87, 141, 143,651 .

Intgmt. 78.

Skelett. 75, 78, 80, 86, 103, 143, 403, $651,842,843$.

Muskeln 87, 103.

Nervensyst. 80.

SinnesOrg. 297.

Ernähr.Org. 80, 141, 842

Ambul.-Syst. 80, 81, 86, 87, 143.

Blut-Gf.Syst. 78, 80, 141 .

Geschl.Org. 80, 81, 102, 300, 842 .

Histol. 78, 80, 87, 141, 297, 403, 740, 845.

Entwicklg. 2, 75, 78, 80, 85, 102, 103, $300,350,366,378,403,442,444,446$, $674,740,842-845,857$.

Physiol. 85, 102, 108, 141, 297, 378, 403, $419,842-845$.

Fossil. 80, 81, 86, 750 .

Phylog. 2, 80, 86, 143 .

Crinoidea $2,76,77,79,80,81,651$, 750.

Cystoidea 80,81 .

Blastoidea 80 .

Asteroidea $75,76,77,79,80,82,102$, $297,300,378,651,675,739,744,842$.

Ophiuroidea $2,75,76,77,79,80,83$, $84,300,651,675$.

Ech inoidea $75,76,77,79,80,85,86$, $102,103,350,403,419,442,444,651$, $674,739,745,750,842-845,857$.

Hol othurioidea $75,77-81,87,88,89$, $102,141-143,651,867$.

\section{Vermes}

$2,5,19-23,31,73,90,91,94,100,104$ $-106,132,158,187-191,284-$ $288,296,297,301-305,337,342$, $344,345,360,366,374,379,380,404$ $-407,409,410,411,414,420-$ $429,449,450,468-475,493,500,507$, $517-527,574,576,591,598,642,650-$ 
$661,670,672,673,674,679,683,697-$ $707,740,745,750,755-762,812,818$, $819,823,838,846-858,863,867,870$, $871,872,876-879$.

\section{Plathelminthes}

Syst. 2, 73, 90, 91, 190, 344, 411, 469, $470,471,517-521,523,524,525,654$ $-660,670,673,697-699,818,850-$ 856,376 .

Faun. $344,407,411,468,469,470,517$, $519,520,521,523,524,651,653-$ $656,658,659,670,673,698,699,818$, $851-856,867,871,877$.

Biol. 407, 411, 468, 518, 519, 520. 651, $652,653,660,697-699,847,867,871$, $876,877$.

Paras. 90, 91, 190, 191, 468, 469, 470, $517-521,523,524,697-699,703,818$, $849-856,876,877$.

Morphol. 90, 91, 190, 191, 344, 469, 470, $520,521,523,524,653,654,657-660$, $697-699,818,823,847,850,852,853$, 854,876 .

Intgmt. 190， 523， 657-660, 697-699, $823,849,853$.

Drüsen 521, 659, 660, 698, 699, 847.

Haft-Or. . 2, 190, 191, 469, 470, 523, 524, $697,823,848,853$.

Musk. 521, 658, 659, 660, 697-699, 823, $846-848$.

Nerv.Syst. 297, 521, 658, 659, 660, 698, $699,023,846,847,848$.

Sinn.Org. 297, 523, 657, 659, 698, 699.

Ernähr.Org. 10t, 521, 523, 52t, 652, 658, $659,846,847,848,850,855$.

Blt.Gif.Syst. 658, 659, 660, 823 .

Exkr.Org. 521，523，524, 658, 659, 823, 847,850 .

Geschl.Org. 90, 104, 190, 191, 344, 469. $470,520-524,652,653,654,697,818$, $823,850-853.876$.

Histol. 2, 104, 187-191, 297, 652, 658$661,740,823,847,848,849$.

Entwcklg. 90, 187-189, 191, 366, 379, $472,473,493,521,523,652,658,697$ $-699,740,846,849,850,857,876$, 877.

Physiol. 297, 379, 468, 652, 846-848, 857. Phylog. 2, 132, 823.

Turbellaria $73,104,132,187-189,297$, $344,407,411,493,652-657,673,823$, $846-848,871$.

Rhabdocoela $411,653,654,655,657,847$, 848.

Dendrocoela 104, 187-189, 344, 407, 493, $652,655,656,823,846,871$.

Trematodes $2,379,517-525,703,740$, $818,849-856$.

Dicyemida e 650 .

Cestodes 2, 90, 91, 190, 191, 468$471,517,519,670,697,849,854$, $876,877$.
Nemertina $472,473,651,658-661,698$, $699,823,857,867,871$.

\section{Rotatoria}

Syst. 2, 73, 285, 287, 288, 409, 410, 411, $414,672,67.3$.

Faun. 284, 285, 287, 288, 404, 405, 409, $410,411,414,576,672,679$.

Biol. 285, 257, 288, 40t, 405, 406, 409, $410,411,414,507,576,823$.

Morphol. 823.

Intgmt. 823.

Nerv.Ayst. 2, 823 .

Sinn.Org. 82?.

Entwcklg. 2, 823.

Plysio!. 507.

Phylog. 2, 823.

\section{Gastrotricha}

Syst. 411

Faun. 411.

Biol. 411.

Intgmt. 823.

Phylog. 823.

\section{Nemathelminthes}

Syst. 2, 420-425, 517, 526, 673, 700, 755 , $756,757,878,879$.

Faun. 5, 420, 422, 424, 425, 517, 527, $673,755.756,757,879$.

Biol. 5, 406, 421-425, 527, 700, 757, 819,879 .

Paras. 5, 158, 420-425, 517, 526, 527, $700,757,758,819,854,878,879$.

Morphol. 420, 422, 425, 526, 527, 700, $755,756,757,878$.

Intgmt. $420,422,425,526,700,755,756$, 823,878 .

Haft.Org. 420 .

Musk. 19, 425, 828, 878.

Nerv.Syst. $19,700,878$.

Sinn.Org. 297, 878 .

Ernähr.Org. 19, 425, 700, 878.

Exkret.Org. 425, 700.

Geschl.Org. 420, 422, 425, 527, 700, 757, 858,878 .

Histol. 297, 740.

Entwcklg. 19, 94, 360, 366, 421, 423, $526,700,740,757,858,879$.

Physiol. 94, 297, 421, 422, 758.

Phylog. 2, 823.

Nematodes $5,19,94,158,297,360,366$, 406. 420-425, 517, 526, 527, 673, 700, $740,755-758,819,823,854,858,878$, 879.

A canthocephala $158,517$.

\section{Chaetognatha}

Syst. 2, 286, 651 .

Faun. 286, 651, 674.

Biol. 286, 651, 674 .

Nerv.Syst. 297.

Sinn.Org. 297.

Histol. 297. 
Entwicklg. 651.

Phylog. 2.

\section{Annelides}

Syst. 2, 20, 22, 23, 286, 304, 305, 337, $380,411,651,701,702,706,759-761$.

Eaun. 20-23, 286, 303, 304, 305, 337, $380,411,574,651,674,701,702,706$, 759-751. 867, 870, 871.

Biol. 21-23, 286, 301, 303, 380, 406, $411,500,574,598,651,674,704,759$, 82:, 867, 871.

Paras. 345, 423, 591, (142, 679, 68:), 703.

Morphol. 20, 22, 303, 474, 701, 703, 823 .

Intgmt. u. Borsten 20, 22, 303, 426, 474, $701,823$.

Drüsen $301,474,650,703$.

Gehäuse 704 .

Musk. 106, 303, 427, 428, 474, 823.

Nerv.Syst. $106,303,426,428,474,701$, 703. 705, 823, 863 .

Sinn.Org. 2, 297, 303, 474, 701, 703, 705 , 823.

Ernähr.Org. 20, 303, 428, 474, 679, 701, 823.

Blt.Gf.Syst. $106,303,474,701,823$.

Respir.Org. 20, 22, 474, 823.

Exkret.Org. 106, 303, 426, 427, 474, 650, 823.

Geschl.Org. 22, 106, 296, 302, 303, 474, 823.

Histol. 106, 297, 302, 426, 427, 428, 474, $650,701,705,740,82 \%$.

Entwcklg. 2, 105, 106, 296, 30.3, 366, $427,428,429,498,651,740,863$.

l'hysiol. 105, 297, 309), 426, 427, 598, 650, $838,863$.

Pliylog. 2, 823.

Chaetopoda $2,20,105,106,286,296$, $297,301-305,337,345,380,406,411$, $423,426-429,474,493,500,591,642$, $650,651,674,701-706,740,759-761$, $823,838,867,870,871$.

Oligochaeta $297,301,302,3 \times 0,406,411$, $423,426,500,740,759-761,838,867$, 870,871 .

Polychaeta 2, 20, 105, 286, 296, 297, $303,304,305,337,345,426,427,428$, $474,493,591,642,650,651,674,701-$ $706,823,867$.

Echiurida 286, 427,674.

Myzostomida 444 .

Hirudine a $106,297,337,428,574,598$, 679, 683.

\section{Prosopygia}

Syst. 337, 745, 762 .

Faun. 337, 374, 449, 450, 651, (i74, 745, $762,872$.

l3iol. 342, 374, 406, 651, 674, 745, 812, 872.

Gehäuse 342.

Nerv.Syst. 2.
Eruähr.Org. 2.

Blt.Gf.Syst. 2.

Exkret-Org. 2.

Entwcklg. 2.

Physiol. 100, 342.

Fossil 750, 762 .

Phylog. 2, 762.

Sipunculacea $2,674,745$.

Phoronidea 2, 100.

Bryozoa $2,337,374,406,449,450,812$, 872.

B $1^{\circ}$ a chio p od a $342,651,750,762$.

\section{Enteropneusta}

Syst. 475.

Faun. 475, 867.

Biol. 867.

Morphol. 475.

Intgint. 475 .

skelett 475 .

Musk. 475.

Nerv.Syst. 475.

Nutritor.Darm 475.

Respirat.Darm 475.

Blt.Gf.Syst. 475.

Geschl.Org. 475.

Histol. 475.

Entwcklg. 475.

\section{Arthropoda}

$2,5,7,9,10,14,15,17,18,24-60,92$, $93,98,106-117,133,144-171,192-$ $197,214-280,284-287,297,299,306$ $-312,337,338,340,341,345-351,360$, $366,374,375,381-390,392,404-407$, $410-414,429-435,438,439,444,449$, $450,452,476-491,500,507,528-561$, $574,576,585,593-599,607,620,633$, $634,638,641,650,651,662-668,670$, $672-675,678,679,680,683,686,687$, 690, 698, 699, 707-734, 739, 742, 743, $745,748,757,763-800,812,814,815$ $859-863,867,868,870,871,873,877$ -881 .

\section{Crustacea}

Syst. 2, 286, 287, 298, 306, 307, 337, 338, $341,345,346,347,366,411,414,439$, $593-596,651,662,670,672,673,745$, $748,763-767$.

Faun. 31, 284-288, 306, 307, 337, 338, $339,341,345,346,347,374,404,405$, $407,411,414,449,450,576,593-596$, $651,662,672-675,745,748,763,764$, 766, 767, 867.

Biol. 18, 31, 139, 279, 284-288, 306, 307, $309,337,338,339,341,345,346,347$, $366,374,375.404-407,410-413,500$. $576,593,594,595,597,651,662,670$, $674,675,743,745,748,763,766,767$, 812, 867.

Paras. 341, 345, 410, 411, 593, 594, 683, $698,699,745$. 
Nr.

Morphol. 306, 337. 347, 412, 594, 595, $651,673,764-767$.

Fxtrem. u. Mlundwkzg. 2, 306, 345, 347, $412,429,594,595,651,672,765,766$, 767.

Intgint. u. Schale $347,412,594,595,651$, $673,766,767$.

Drüsen 306, 650 .

Nerv Syst. 297, 306, 309.

Sinn.Org. 297, 309, 529, 651, 745.

Ernähr.Org. 2, 52, 306, 347, 429, 673.

Resuir.Org. 306, 347.

Exkret.Or. 52, 306, 650.

Geschl.Org. 2, 284, 306, 308, 246, 489, $595,651,767$.

Histol. 297, 306, 309, 650 .

Entwcklg. 286, 306, 308, 347, 360, :366, $381,429,476,4-9,651,674$.

Phrsiol. 2, 347, 381, 412, 597, 650, 742, 743.745.

Fossil 651.

Phylog. 2, 306, 662.

Eintomostrac a 2, 284, 285, 286. 288, $306-308,337,340,341,345,341 ;, 347$, $360,366,374,375,381,404-407,411$ $-414,429,476,576,593-5 ! 66,651$, $662,670,673,674,742,743,745,748$, $763-767,812$.

l'hyllopoda 284, 285, 288, 306, 30\%, 345, $346,347,374,381,404-407,411-$ $414.576,651,662,670,673,742,743$, 748, 763. 765, 766.

Ostracoda $286,307,345,346,375,651$, 673,767 .

Copepoda 284, 285, 286, 307, 308, 337. $340,341,345,360,366,375,407,413$, $414,593-596,651,674,745,763,764$ 812 .

Cirripedia 2, 2\$6, 429, 651, 745

M a l a costrac a 2. 18, 52, 133, 286, 30!, $337,338,340,345,375,406,439,476$. $500,529,597,651,674,675,683,698$, $699,745,867$

Leptostraca 337.

Arthrostraca 52, 286, 337, 340, 345, 375, $406,500,597,651,683,745,867$

Amphipoda 52, 286, 337, 340, 345, 406 , $500,597,651,745,867$

Isopoda $286,3: 37,345,375,406,500$, 683,745 .

'Thoracostraca 2, 18, 133, 286, 309, 337 , $338,340,345,439,476,529.651,674$, $675,698,699,745,867$.

Cunnacea 345.

Schizopoda 286, 337, 345, 651. 674.

Decapoda 2, 18, 133, 286, 309, 337, 338 , $340,345,439,476,529,651,674$,

\section{Palaeostraca} $675,698,699,745,867$.

\section{Syst. 24.}

Faun. 24, 867.

Biol. 867
Fossil 24.

Plivlog. 2.

Trilobita 2, 24.

Xiphosura 2, 867 .

Gigantostraca 2.

\section{Protracheat:}

Sinn.Org. 297.

Histol. 297.

Phylog. 297.

\section{Myriopoda}

Syst. 28, 29, 30, 193, 3:37, 769, 770.

Faun. 28, 29, 30, 193, 337, 86ช, 870, 871.

Biol. 30, 193, 263, 279, 492, 865, 871.

Paras. 7, 299, 607, 620, 639, 641.

Morphol. 29, 30, 192, 193.

Extrem. u. Mundwkzg. 28, 29, 192, 348.

Intgint. 30 .

Drüsen 29.

Musk. 29, 192.

Nerv.Syst. 47.

Sinn.Org. 297. 348 .

Ernähr.Org. 52.

Respil.Org. 29.

Exkr.Org. 52.

Geschl.Org. 29, :30, 3-2

Histol. 297.

Eutwcklg. 382.

Physiol. 297, 342.

Chilopoda 7, 47, 299, 352, 620, 638, 641.

Symphyla 28. $769,770$.

Pauropoda 28, 29.

Diplo poda 2ะ, 30, 192, 193, 482, 607, $769,770,871$.

\section{Arachnida}

Syst. 25, 26, 27, 29, 92, 194-196, 310, $311,337,348,411,430,431,499,477$, $478,479,673,745$.

Faun. 26, 27, 29, 93, 194 196, 280, 810, $337,407,411,4.31,477,478,479,526$, $673,745,867,870,871$.

Biol. 27, 92, 110, 279, 280, 310, 337, 348, $407,411,413,430,431,434,477,479$, $482,500,528,598,707,708,745,819$, 867,871 .

Paras. 92, 348, 479, 528, 678, 679, 707, 708.

Morphol. 25, 26, 92, 194, 195, 196, 310, $311,348,430,431,439,477,478,479$, 528,651 .

Extrem. u. Mundwkzy. 25, 26, 27, 92, $194,196,310,311,348,430,431,439$, $477,478,479,528,651$.

Intgmt. 25, 26, 92, 194, 195, 196, 310, $311,348,430,431,477,478,479,528$, 529.

Drïisen 2, 92, 348, 598.

Musk. 92, 348.

Nerv.Syst. 92, 297, 348, 529.

Sinn.Org. 92. 297, 348, 529.

Ernähr.Org. 2, 52, 92, 34১. 
Blt.Gf.Syst, 348.

Respir Org. 2, 348.

Exkr.Org. 52, 92.

Geschl.Org. $25,26,92,194,196,310$, $348,430,431,478,479,529$.

Histol 92, 297, 348, 529 .

Entwcklg, 27, 92, 310, 444, 477, 478, $5: 8$.

Physiol. 92, 279, 348, 430, 598.

Phylog. 2, 439.

Scorpionidea $2,29,279,297,34,439$.

Pseudoscorpionidea $348,439$.

Pedipalpi $2,439$.

Solifugae 439, 59s.

Phalangidae 439.

A raneina $2,110,279,280,29-, 348,439$, $500,707,867,870$.

A c arina $25-27,29,92,110,194,195$, $196,310,311,337,407,411,413,430$, $431,434,439,477-479,482,528,529$ $598,679,678,679,708,819,871$.

Pantopoda $937,651.745$.

\section{Insecta}

Syst. 7, 32, 39, $34,36-51,56,57,93$, $107-116,144,145,148-150,154-157$, $159-169,171,197,214,220,222,225-$ $227,234,235,241,249,259,261-263$, $267,269,271,277,387,338,384,386-$ $390,411,434,4: 35,438,480,481,482$, $533, \quad 236,539,541-547,554-559.664 t$ $-6168,670,708,718,721,731-733$, $739,768-772,774-779, \quad 7 \div 2-786$, $790,798,819,821,860$.

Faun. 5, 9, 31, 32, 38. 34, 36-46, 49, $50,51,56,57,98,107-116,144,145$, $148-169,171,197,214,219,225-227$, $230,234-230,240,241,245,248,2,01$, $251,259,261,262,264-267,269,271$, $27 \cdot, 276-280,337,339,349,351,384$, $.866-389,407,411,432,434,435,449$, $450,452,4>0,482,488,531,532,533$, $536,537,53 \%, 540,541,543-546,550$, $551,554,555,557-559,574,651,664$ $-668,708.711,715,717,718,721,722$, $725,731-734,769,770,772-779,781$, $782,785,786,790,792,793,798,-100$, $819,821,860,862,867$, ᄃ68, 870, 871, 880.

Biol. 5, 7, 11, 17, 27, 31, 49, 58, 60, 93, $98,110,113,114,116,117,144,151-$ $153,158,171,214-280,337,349,350$, $351,382,384,388,392,406,407,410$, $411,432,434,479,480,482,483,488$, $490,507,528,531,532,537,538,540$, $548.550,551,559,574,585,598,651$, $664-668,670,707.708,711,715-719$, $721,723-728,730-734,768,773,774$, $776,777,780,781,785,786,791-793$, $795,796,798-800,808,812,814,815$, $819,820,822,859,860,861,862,867$, $868,871,879,880,881$.
Nr.

Paras. 5, 7, 9, 11, 14, 15, 17, 31, 98, $144,151-153,158,479,482,531,532$, $535,537,598,540,542,548,549,550$, $585,633,684,679,680,686,687,690$, $707,708,711,717,729,757,779,794$. $796,819,820,860,877-880$.

Morphol. 7, 15, 34, 35, 37, 47, 48, 60, 93, $110,114,116,154,192,214,220,225$, $227,230,234,235,261,263,269,277$, $278,351,390,433,435,480,481,482$, $483,458,547,599,667,707,709,710$, $720,722,731,769,770,772,776,779$, $783-786,788,792,795,798,819-$ $822,859,881$.

Extrem. und Mundwkzg. 49, 60, 192, 225, $230,232,234,235,259,278,345,390$, $480,488,547,667,717,719,720,722$, $731,768,770,771,773,776,779,785$, $786,791,795,798,819-822,859$.

Intgmt. 60, 116, 220, 221, 225, 278, 390, $433,435,4-3,488,490,491,547,599$, $6667,710,731,774,775,779,786,821$, $82.2,851$.

Drïsen $85,52,14,55,58,116,219,348$, $783,483,585,650,712,769,792,795$, $499,859$.

Musk. 52, 116, 192,530,709,859.

Nerv.Syst. 47, 23ะ, 297, 390, 433, 488, $770,859,868$

Ninn.Ory 232-235, 237, 233, 256, 258, $270,277,297,348,438,430,529,713$, 714,786

Ernilhr.Org, 7, 52, 53, 55, 58, 59, 488, $594,709,76 ! 4,770,792,859,863$.

Blt.Gf.Syst. 51. 58, 106, 116, 599, 709.

Respir.Org. 2, 488, 529, 709, 769-771, 773, 7E11, 784, 786, 859.

Exkr.Orw. 52, 53, 55, 483, 599, 709, 859. Geschl.Org. 48, 114, 116, 147, 192, 231$233,262,263,265,308,312,390,435$, $454-487,489,530,534,535,552,560$, $561,570,663,710,720,722,777,779$, $791,819,859,863$.

Histol. 35, 52, 53, 54, 55, 58, 116, 147, $297,312,350,433,483,490,491,529$, $530,552,599,650,709,712$.

Entwcklg. 7, 11, 49, 106, 110, 144, 147, $152,153,158,242,249,275,308,312$, $350,351,360-362,390,392,484-$ $489,532,535550,551,55 \%, 560,561$, $570,663,707,709,711,716,721,723$, $729,779,780,786,789,796,859,863$, 880 .

Physiol. 53, 54, 55, 58, 59, 93, 116, 117, $146,170,218,231-233,237,238,242$, $248,256,258,260,263,266,270,275$, $297,350,361,362,383,385,433,483$, $490,491,507,552,553,598,599,650$, $709,713,714,716,726-728,742,768$, $773,780,791,792,795,797,822,861$, 863. 
$\mathrm{Nr}$.

Phylog. 2, 32, 221, 234, 278, 390, 769, $770,795,819,860$.

A pterygota $2,32,192,280,297,349$, $482,530,769-771,867,868,871$.

Orthoptera $33-48,107-116,192,279$, $349,452,484,530$. 552, 663, 707, 739, $757,768,772,808,812,867,870,871$, $873,878$.

Pseudoneuroptera 31, 49, 51, 111, $259,277,279,280,407,479-483,530$, $733,742,768,773-777,7<6,819,859$.

Neuroptera $5,31,50,51,116,297,407$, $530,707,710,768,819,873$.

Heteroptera $110,111,407,482,485-$ $487,528,530-533,536,537,541,543$, $707,768,819$.

Ho moptera $52,349,410,533,543,546$, $547,733,768,819$.

Phyt ophthires $5,117,217,255,271,280$, $349,351,432,483,507,533,584,535$, $538,539,540,543-545,548,561,707$, $708,729,738,768,819,867$.

A ptera $533,542,739,877$.

Diptera $5,7,9,11,14,15,17,27,31$, $53,111,144,151,158,266,279,297,337$, $349,360,406,407,482,483,488,500$, $530,538,585,651,680,686,687,690$, $707,708,721,725-727,734,742,768$, $778-794,796,819,820,822,867,879$.

A phanipter a $297,530,821,860,877$.

Lepidoptera 5, 116, 145-153, 279, 312, $349,350,383,433,490,491,500,530-$ $532,550-559,599,633,534,664-668$, $679,707,708,710,726,734,739,757$, $768,776,819,861-863,870,873$.

Cole optera $5,47,55-60,111,151$, $153-167,192,219,230,345,279,349$, $351,388-390,407,434,435,479,482$, $483,489,500,530-532,588,540,650$, $707,708,711,734,739,7688,776,780$, $819,867,880,881$.

H y m en op ter a $5,31,54,93,110,151$, 153. 168-171, 197, 214-278, 280, 361, $362,384-387,433,434,452,479,480$, $482,483,500,529,530,560,561,570$, $598,707,708,710,712-726,728-734$, $768,795,796,798-800,814,815,820$, $862,867,873,880$.

\section{Mollusca}

$2,31,49,61,94,131,133,136,219,283$, $286,289-291,296,297,300,337,339$, $340,342,361,362,366,392,395,406$, $428,429,447,449,450,471,476,489$, $492-494,500,571,573,575,589,611$, $650,651,662,674,675,745,749,750$, $805,808,823,824,849,850,867,868$, 870 .

\section{Amphineura}

Syst. 337, 823 .

Faun. 337, 823.

Biol. 823.
Morphol. 823.

Intgmt. 823.

Schale und Mantel 823.

Radula 823.

Drüsen 823.

Musk. 823.

Nerv.Syst. 823 .

Sinn.Org. 823.

Ernähr.Org. 823.

Blt.Gf.Syst. 823 .

Respir.Org. 823.

Geschl.Org. 823.

Histol. 23.

Entwcklg. 49:3, 823.

Phylog. 823.

Solenogastres 823 .

Placophor a 493, 823 .

\section{Gastropoda}

Syst. 337, 745, 823.

Faun. 337, 339, 340, 651, 745, 749, 805, 867,868 .

Biol. 133, 219, 291, 339, :40, 395, 106, $493,500,651,745,808,823,824.867$, 868.

Paras. 651, 849.

Morphol. 289, 291, 823, 824.

Intgint. 291, 823.

Schale u. Mantel 133, 289, 493, 823, \&24.

Radula u. Kiefer 823.

Fiihler 291.

Driisen 493, 650, 823.

Musk. 823.

Nerv.Syst. 289, 291, 297, 493, 82:.

Sinn.Org. 291, 297, 493, 823.

Ernähr.Org. 289, 290, 291, 493, 82:3.

Blt.Gf.Syst. 289, 823 .

Respir.Org. 493, 823.

Exkr.Org. 289, 823.

Geschl.Org. 131, 361, 362, 489, 492, 493, 823.

Histol. 297, 492, 650, 828 .

Entwcklg. 94, 289, 290, 300, 361, 362, $366,476,489.492 .493,823$.

Physiol. 290, 291, 297, 650.

Fossil. 749, 750 .

Phylog. 289, 823.

Prosobranchia 94, 132, 289, 290, 297, $339,340,361,362,366,489,495,650$, $745,749,82: 3,849,867$.

Heteropoda 651 .

Opisthobranchia $493,650$.

Pulmonata $131,219,291,297,300,340$, $406,476,492,500,805,808,824,849$, 868.

\section{Pteropoda}

Faun. 575, 651, 674.

Biol. 575, 651, 674 .

Entwcklg. 651.

\section{Scaphopoda}

Syst. 74.5

Faun. 651, 745 . 
Biol. 651, 745

Morphol. 823.

Intgint. 823.

Schale und Mantel 651.

Nerv.Syst. 823 .

Entwcklg. 823 .

Phylog. 823.

\section{Cephalopoda}

Syst. 337, 471, 651, 745.

Faun. 286, 337, 6.1, 675, 745.

Biol. 286. 651, 675, 745 .

Paras. 611.

Intgmt. 82?.

Schale u. Mantel 651.

Drüsen 447.

Sinn.Org. 297, 651, 745.

Blt.Gf.Syst. 296, 823 .

Exkr.Org. 923.

Geschl.Org. 2, 296. 494, 571, 823.

Histol. 297, 494, 571.

Entweklg. 2965, 494, $82: 3$.

Physiol. 297, 447, 651, 745.

Fossil. 136, 750 .

Phylog. 2, 823.

Tetrabianchia $297,651,823$.

Dibranchia $2,286,296,297,447,494$, $611,651,675,745,823$.

\section{Lamellibranchia}

Syst. 61, 337, 825.

Faun. 61, 136, 337, 340, 449, 450, 805. 867.

Biol. 337, 340, 406, 82:3, 867.

Paras. 850.

Morphol. 823.

Intgmt. 823.

Schale u. Mantel 823.

Driisen $82 \%$.

Musk. $82:$

Nerv.Syst. 823.

Sinn.Org. 297, 823.

Ernähr.Org. 823.

Blt.Gf.Syst. 823 .

Respir.Org. 589, 823.

Exkr.Org. 823.

Gieschl.Org. 823.

Histol. 297, 573, 589.

kintwcklg. 823.

Physiol. 297.

Fossil. 61, 136, 750.

Phylog. 61, 823.

\section{Tunicata}

Syst. 337, 496, 651, 803, 825 .

Faun. 286, 337, 339, 496, 575, 651, 802, $803,825,826$.

Biol. 286, 339, 575, 651, 802, 826 .

Morphol. 339, 495, 801, 802, 826, 827.

Intgmt. 650,826 .

Driisen. 650, 801, 826, 827.

Musk. 497, 826, 827.

Nerv.Syst. 495, 497, 826 .

Sinn.Org. 297, 495, 826.
Nutritor.Darm 339, 495, 801, 826.

Respirator.Darm 495.

Blt.Gf.Syst. 826, 827 .

Geschl.Org. 826 .

Histol. 297, 801, 802, 826, 827.

Entweklg. 297, 366, 445, 495, 575, 801, $826,827$.

Physiol. 297, 497, 826, 827.

Phylog. 826.

A p pendiculacea $286,297,339,495,575$, 651,826

Thaliacea $297,575,825,827$.

Ascidiace a $445,495-497,575,650,801$ $-803,825,826,827$.

Vertebrata 1, 2, 3, 5-17, 31, 49, 58, $62-70,72,73,90,91,94-99$, $103,110,116,118-130,132,144,153$, $172-181,187,188,190,191,198-213$, $237,238,258,259.279,281,282.283$, $285,286,292-295,297,300,308,313-$ $338,340,341,352-356,358,370,372$, $373, \quad 391-401,406,410,420-425$, $436-439,448-452,454,465,468-$ $471,477,485-487,498-507,509,510$, $517-521,523,524,526,527,528,542$, $562-569,571,574,575,577,543,585$, $593,597,598,600-602,605,608-610$, $613-615,621,62 \%, 629-632,636,639$ $640,643-646,648,650,651,663,669$, $670,674-690,697,700,717,733,735-$ $739,741-745,757,768,776,792,797$, $804-809,812,813,818,823-835,850$ $-856,860,864-871,873,876,877$, $882-893$.

\section{Leptocardii}

Syst. 739.

Paras. 605.

Sinn.Org. 297.

Respir.Org. 605.

Histol. 297.

Physiol. 297.

Phylog. 297.

Cyclostomi

Syst. 436.

Faun. 436, 805.

Biol. 805 .

Morphol. 127, 292, 313, 436.

Drüsen. 127, 172, 886.

Musk. 127.

Nerv.Syst. 118, 562 .

Sinn.Org. 436.

Ernähr.Org. 127, 172, 436, 886.

Respir.Org. 127, 886.

Exkr.Org. 118, 292.

Geschl.Org. 292, 313.

Histol. 118, 127, 172, 313.

Entwcklg. 313, 360, 393, 436.

Physiol. 886.

Phylog. 436.

Pisces

Syst. 63, 198, 285, 337, 338, 392, 439, 651,745 . 
Nr.

Faun. 63, 98, 198, 279, 283, 285, 286, $337,338,340,392,439,449,450,452$, $454,510,574,575,651,674,675,744$, 745. $805,867,869,870$.

Biol. 31, 49, 98, 110, 173, 279, 285, 286, $319,338,340,392,406,410,439,454$, $465,477,499,500,574,575,600,651$. $674,675,743,744,792,804,805,812$ $813,867,869$.

Paras. 190, 341, 410, 4.5, 518, 519, 521, $523,526,593,608,682,683,697,745$, $792,850,851,852,876$.

Morphol. 124, 292-294, 318, 392, 439 $499,565,600,651,804$.

Extrem. 292, 565. 651, 804.

Intgrmt. u. Zähne 293, 294, 352, 392, 499, 565.

Skelett 292, 318, 565, 887.

Musk. 124, 565.

Drüsen 293, 294, 886.

Nerv.Syst. 293, 294, 318, 358, 562, 565, $885,887$.

Sinn.Org. 293, 294, 317, 651, 887.

Krnälı.Org. 293, 294, 500, 600, 887.

Blt.Gf.Syst. 124, 128, 887.

Respir. Org. 128, 565, 887.

Urogen-Syst. $119,120,173,292,313,358$, $359,361,362,498,735,736,857$.

Histol. 103, 119, 120, 124, 128, 293, 294, $313,317,335,352,358,360,391,498$, $565,887$.

Entwcklg. 128, 173, 286, 292-295, 313, $317,318,319,335,358-362,366,391$, $565,736,805,88 \%-884,887$.

Physiol. 103, 173, 319, 361, 362, 391, $392,501,600,887$.

Fossil. 63, 29.2.

Phylog. 262, 735.

Chondropterygi i 119, 12๖, 190, 292, $317,335,341,352,358-362,498,562$, $565,608,651,675,683,697,744,851$, $876,884.886$

Holocephala 352,565 .

Plagiostoma $119,128,190,292,317,835$, $341,358-362,366,498,519,562,565$, $608,651,675,683,697,744.851,876$, 884,886 .

Ganoidei $292,318,425,735$

Teleostei $63,98,120,173,190,198,279$, $283,285,286,292,295,313,319,340$, $341,391,392,499,500,501,510,518$, $519,521,523,526,575,593,600,651$, $674,675,683,735,743,744,745,804$, $805,850,852,882-885,887$.

Dipnoi $293,294,735,736$.

\section{Amphibia}

Syst. 1, 2, 198, 201, 204, 281, 439, 601, $806,807,831,888,889$.

Faun. 5, 31, 62, 94, 198, 201, 204, 281, $439,449,450,601,806,807,831,870$, 888,889
Biol. 5, 31, 73, 94, 110, 279, 439, 502 $598,804,807,813$.

Paras. $14,420,520,609,613,614,676$ $-679,682,855,856$.

Morphol. 124, 292, 439, 506.

Extrem. 292.

Intgmt. 505, 506.

Skelett 292

Muskel 124, 448, 828, 829 .

Nerv.Syst. 121, 122, 293, 294, 506, 562, $828,885$.

Sinn.Org. 317, 320.

Bit.6f.Syst. 121, 12:, 124, 314, 320, 506, $564,828$.

Respir.Org. 829.

Urog.Syst. 94, 121, 122, 308, 313, 314, $321,571,602,66: 3$.

Histol. 121, 122, 124, 187, 188, 313, 314, $317,320,321,505,506,564,571,828$, 829.

Entwcklg. 72, 73, 94, 174, 187, 188, 300, $308,313,314,317,321,360,366,393$, $502,602,663,884$.

Physiol. 3, 58, 73, 94, 279, 448, 598, 797, $828,829$.

Fossil. 292.

Phylog. 292.

Steg ocephala 292

Urodela 2, 3, 62, 72, 94, 121, 122, 187, 188, 201, 279, 292-294, 314, 3ะ0, 393, $502,505,506,520,564,601,602,(\mathrm{j} 14$, $807,829,831,845,888,889$.

An u r a $3,5,58,62,72,73,94,110,121$, $122,124,174,198,201,204,281,314$, $360,393,420,448,506,598,601,609$, $613,614,676-679,682,797, \succ 04$, ๖ 6 , $807,828,831,855,856,870,885,888$.

\section{Reptilia}

Syst. 1, 198, 199, 201-204, 394, 395, 396, $439,566,601,806,831,832,864,865$, $888-891$.

Faun. 198-201, 203, 204, 279, 282, 283, $395,439,449,450,452,566,575,601$, $651,675,806,808,831,832,864,865$, $868,870,873,888-891$.

Biol. 110, 116, 200, 279. 395, 439, 566, $575,651,675,804,808,864,868,873$, $889,890$.

Paras. 6, 19l, 420, 470, 517, 520, 615, $640,643,644,679,681,682$.

Morphol. 124, 353, 394, 395, 439, 565, $566,804,808,832,889,890,891$.

Extrein. 202, 832, 890.

Intgmt. u. Schuppen 353, 394, 395, 396, $565,832,889,891$.

Skelett 202, 396, 565, 805, 832, 890, 891 .

Musk. 124.

Nerv.Syst. 562, 8:30, 885.

Sinn.Org. 317.

Zähne 808 .

Bit.Gf.Syst. 124. 
Respir.01'g. 829.

Urogen.Syst. 200, 322.

Histol. 124, 317, 322, 353, 565, 8:30.

Entweklg. 317, 353, 565, 884.

Physiol. 279, 808, 829.

Fossil. 202, 890.

Phylog. 890.

Chelonia $198,199,203,204,396,265$, $575,601,615,644,651,675,679,682$ $806,808,830,8931,832,885,888-891$.

Crocodilina $199,200,449,450,643,830$, $885,888,891$.

Sauria 6, 116, 124, 198, 199, 202, 204, $2 \times 3,358,395,470,517,565,601.640$, $679,804,806,808,829,830,831,864$, $865,873,885,888,889$.

Rhynchoceph alia $282,565$.

Op hidia 110, 124, 191, 198, 199,201, 204,279, $317,322,394,395,420,452,517,520$, $566,601,681,806,808,830,831,868$, $873,885,888,8 \times 9$.

Pterosauria 804

Pythonomorpli a 202.

\section{Aves}

Syst. 1, 64-6i7, 175, 176, 20.)-210, 223 . $324,326-329,331,338,354,355,397$ $-400,439,670,739,866$.

Faun. $64-67,98,175,205-210,281$, $282,283,323-328,330,331,338,355$, $397-400,439,451,452,454,510,575$, $651,717,809,866,869,870$.

Biol. 5, 64, 95, 98, 116, 153, 175, 206, $279,323-327,330,331,355,398,43 \times$ $439,454,500,510,528,575,598,651$. $717,804,812,813,860,866,869$.

Paras. $420,423,524,528,542,674,680$, $686-689,818,853,860$.

Morphol. 64, 95, 328, 329, 354, 355, 398 $439,804$.

Extrem. 64, 176, 439.

Intgmt. und Federn 64, 329, 398, 439.

Skelett. 354, 355, 398, 439.

Musk. 95, 125, 354, 355 .

Drüsen 95

Nerv.Syst. 123, 562, 565, 885.

Sim. Org. 317.

Ernähr.Org. 95, 354, 355.

Blt.Gf.Syst. $123,125,564$.

Urogen.Syst. 123, 398.

Histol. 95. 123, 125, 317, 564, 565 .

Entwcklg. 64, 99, 317, 565, 88t.

Physiol. 398, 598.

Fossil. 804.

Phylog. 355.

Odontornithes 804 .

Imponnes $175,439,510,651$.

Long ipennes $95,175,330,439,510,565$.

Steganopodes $95,175,397,439,565$, $651,853$.

Lamellirostres $95,129,125,175,930$, $439,510,524$.
C i c o n i a e $95,175,205,206,330,397$ $439,818$.

Gralla e 65, 66, 95, 175, 205, 206, 281, $325,3: 30,439,510,651$.

Cursores 283 , 812.

Gallinace a $65,95,49,123,125,175$, $208,209,281,317,326,327,320,420$, $439,510,528,564,565,869,884$.

C o l n m bin a e 95, 128, 209, 398.

R a p t atores $66,95,123,175,208,210$, $324,329,330,355,398,439,510,625$ $689,853$.

Passeres $65,95,123,125,15 \%, 175$, $205-210,279,281,283,328,330, ;: 31$. $397-400,42 \%, 438,510,565,598,686$ $-689,866$

Cypsel o in orpla a $65,95,123,125$, $397,400,717$.

P i c i $65,95,209$.

C o c с y o morplia e 65, 9., 175, 210, $398,400,420$.

Ps ittal ci $95,210,32 \%, 354$.

\section{Mammalia}

Syst. $1,69,70,97,177,356,439,568$, $669,737.739,745,747,860$,

Faun. 5, 62, 68, 69, 70, 97, 98, 14t, 213, 281, 28:3, $356,439,452,510,568,575$, $651,669,675,737,738,745,747,768$, $809,868,869$.

Biol. 5, 68, 96, 98, 130, 144, 213, 279, $330,356,395,439,507,56 \times, 575,651$, $669,675,733,738,745,747,776$, ๖04 812. $860,868, \varepsilon 69$.

I'aras. 7-17. 90, 91, 144, 191, 420

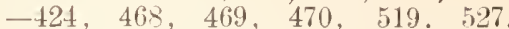
$577,583,585,610,621,623,629-632$, $636,639,645,616,648,679,680,682$, $684,685,690,700,757,818,853,854$, $860,877$.

Morphol. 6!) 129, 130, 177, 178, 212, 356, $439,737,738,804$.

Extrem. 130, 439, 737.

Intemt. und Haare 69, 96, 129, 181, 356, 439.

Skelett. 69, 177, 181, 439, 738, 835 .

Musk. 125, 126, 129, 177, 181, 828, 835.

Drüsen $180,211,437,503,892$.

Nerv.Syst. 130, 177, 179, 336, 437, 562, $567,569,828,833,834,885$.

Sinn.Org. 129, 178, 212, 315, 316, 317, $336,437,835$.

Errnähr.Org. 130, 177, 178, 180, 211.

Zähne $69,130,177,181$.

Blt.Gf Syst. 125, 126. 128, 180, 564, 828, $892,893$.

Respir.Org. 130.

Urogen.Syst. 313, 332-335, 503,504, 571.

Histol. 96, 121, 122, 125, 126, 128, 178 , $179,181,211,315,316,317,332-336$. 401, 437, 503, 504, 564, 567, 571, 828. 892. 
Nr.

Entwicklg. 73, 96, 126, 130, 178. 212, $313,315,316,317,332,335,366,370$, $372,373,401,738,834,893$.

Pliysiol. 58, 73, 130, 370, 372, 373, 421, $422,468,507,598,741,828,892$.

Fossil. 6×, 70, 97, 509, 569.

Pliylog. 69, 97, 509, 860.

M o notrem a 283.

M a r s upia li a $90,288,804,893$.

Ceta cea $97,510,575,651,675,745$, $747,812$.

Sirenia 97.

Un g u l a t a $7,69,70,129,144,178,181$, $191,212,279,281,315,316,317,332$, $336,856,370,452,469,504,510,568$, $569,623,630-632,700,737,768,812$, $860,869,892$.

Perissodactylia $69,70,129,336,356$, $370,569,700,737,812,869$.

Artiodactylia non ruminantia $70,129,178$, $191,212,317,336,623,892$.

Artiodactylia ruminantia 7, 70, 129, 144, $178,181,279,281,315,316,317.382$, $326,452,469,504,510,568,569,630-$ $622,768$.
Proboscidea $68,70$.

Rodentia $5,7,58,62,96,129,144,178$, $179,212,279,281,283,315,316,317$, 333, 334, 356, 420, 437, 452, 503, 504, $507,510,568,598,629,636,645,646$, $669,768,804,828,835,860,892$.

In sectivor a $96,177,178,179,213$, 279, 283, 383, 423, 568, 598, 639, 834, 860 .

Carnivor a $70,91,129,177,178,279$, $281,316,336,421,424,439,452,470$, $504,510,568,598,738,818,828,833$, $853,854,860,877$.

Pinn i ped i a $97,510,651,833,868$.

Ch i ro p t er a $279,333,335,401,568,804$.

I'rosiun i a $129,180,420,804$.

Pithe ci 129, 180, 509, 567, 757.

Prim a tes $7-17,68,70,73,91,126$, $128,129,130,144,179,180,211,212$, 237, 238, 258, 259, 313, 316, 317, 330. $336,356,366,370,372,373,421,422$, $439,468,504,519,527,56 \prime, 577,589$, $585,598,610,621,689,648,679,680$, $684,685,690,783,741,757,768,776$, $835,853,877,885,892$. 


\title{
V. Genus- und Familien-Register.
}

\author{
A. \\ Nr. \\ Llerida 109, 111, 116. \\ Acrididae 111. \\ A cridid ae $34,109,111$, \\ 772. \\ A cridiode a $33,36,39,40$, \\ $42,46,114,116,768,772$. \\ Acridium 111, 116. \\ Acrobates 804. \\ Acrocephalus 330, :398. \\ Acrocrinus 2. \\ Acronyeta 556, 559 . \\ Acrophaca 547. \\ Acrotylus 111, 116. \\ Letaeosurus 202. \\ Actinosphacrium 367, 639. \\ A cupalpin i 159, 161 . \\ Adactyla 672. \\ Adalia 5. \\ Idamsia 651. \\ Adela 710. \\ Idelea 604, 607, 616, 619, \\ 620, 625, 633, 634, 637, \\ 639,641 . \\ Adelophagrotis 557. \\ Adexia 547. \\ Allonia 5. \\ Idriosaurus 202. \\ Idrisa 768. \\ Acrialitis 65. \\ Legoecros 181. \\ denigmatios 779. \\ Acnictus 227. \\ Acolosoma 8is8. \\ A eolothripidae 819. \\ Leolothrips 819. \\ - Lequorea 300. \\ 1csalon 35.5. \\ Aeschna 49, 777. \\ A eschnidae 49. \\ Acthalion $7: 33$. \\ Aethalium 72. \\ Ajlate 547. \\ Agalena 280. \\ 1 gama 806. \\ A grionidae 77?. \\ Igriotes 5. \\ Nr. \\ Agriotypidae 93. \\ Agrosphaera 674. \\ Igrotis 5, 559, 757. \\ Aidemona 39, 40. \\ A igialos a uridae 202 . \\ Ligialosenrns 202. \\ Alaopone 227. \\ Alauda 438. \\ A laudidae 175 . \\ Albarues 501, 805. \\ Alcedinidae 400 . \\ 1lecs 510. \\ 1lchyonice 143. \\ Aleicephalus 70. \\ Alciopidae 297, 703. \\ Alcyonidae 651 . \\ Alcyonium 467, 695 . \\ Ale pocephalida e 651 . \\ Ileurobius 92. \\ Aleurodidae 768. \\ Alitter 20. \\ Illantis $\$ 9,142,143$. \\ Alle 510. \\ 1lligator 449, 830 . \\ 1llococranum 543. \\ Allolobophora 301, 302, 761. \\ Alloporus 30. \\ Illotettix 110. \\ Alona 255, 405, 407, 673, 763. \\ Alonopsis 673. \\ Alosa 279. \\ .1lpheus 286. \\ Alycus 311. \\ Alysiidae 31 . \\ .lytes 94. \\ Amalia 828. \\ Amalopcnaens 286, 674. \\ Amaroccium 803. \\ Amblycephahus 888. \\ Amblyomma 26. \\ Amblyopsis 279. \\ Amblystoma 314, 502, 505, \\ 506. \\ Ameira 345. \\ Amia 292, 318. \\ Amiera 764.
}

Abacetus 164.

ibispr 768 .

Ablepharws \&31.

1 bramis 805 .

Acanalonia 547.

A canalonidace 547.

1eanthaclisis 51.

Acanthia 543.

Acanthias $360,498,744,886$.

Icanthochites 823.

Acanthocotyle 341.

Acanthocystis 288.

Acantholepis 251, 798.

Acantholopis 718.

Acanthometridae 651 .

Acanthophallidae 471.

Icanthophallus 471.

Acanthoptilum 418.

Leanthopus 717.

Acanthosaura 888 .

Icanthostichus 220.

icanthotacnia 470.

Leanthotermes 480.

Acanthothrips 819 .

Acaridae 479, 871.

Acarus 27, 311.

deaulis 18.

Accmyia 790.

Acer 281, 794.

Accratherium 70

Acercus 194, 529.

Achatina 808.

Acherontia 551, 862.

Acheta 115, 878.

Achorntoides 32.

Achurum 109.

Acidia 790.

Acineta 339, 374.

Acinirys 891.

Acipenser 425.

A c maeidae 823 .

Acontia 558.

Acontiophorus 345.

deonura 546.

Genus- und Familien-Register. 


\section{Nr.}

Ammococtes 118, 436, S86.

A $m m o d i s c i d$ a e 72 .

Ammonia 311.

Ammophila 722, 768.

Ammothea 696.

- Imnicola 19.

Amocba 3, 72, 414, 590.

1nocbidium 411.

Amonia 34.

Ampelisera 34\%.

Ampelopsis 726 .

Amphichoerns 654.

Amphicremno 109.

Amphictene 704.

Amphicypris 767 .

-1mphidiscophora 651.

Amphigerontia 774.

Amphiglena $70 \%$.

Amphilepis $7 \%$.

Amphileptus 375.

1mphingus 297, 605, 739.

Imphiscepa 517.

Imphistomum 849 .

Amplitretida 471.

Imphitrctus 471.

Amphitritc 498, 703.

Amphizoidae 390.

Amycterides 768.

Amyens 109.

Amydrus 397.

Anabolia 297.

An actinopoda 14 ?

Anajapyx 770, 771

Anamastigona 28.

Ananchytidae 66 .

Inaphothrips 819.

Anapns 288.

Inas 95, 123, 125, 524 .

Inase 349.

Anatidae 175.

Anax 49 .

Anchilophus 569.

Anchustia 674.

Anchitherium 70 .

Anchitrema 517.

Ancistrodon 601, 681, 885.

- incistrogaster $39,40$.

Ancistrona 542.

- Inconia 34.

Ancylus 340, 500, 805, 824.

Ancyrocotyle 5:5.

Andiena 731.

Anergates 259.

Angiostomum 420.

Anguilla 120, 279, 744 .

Anguillula 700 .

Anguis 830.

Anidora 547.

An is odactylini $159,161$. Anisogamia 111.

Anisolabis 10s, 116.

Anisoplia 5.

Nr.

Nr.

Anisops 543.

Anisoptera $31,49$.

inkylostomum 421, 527. 757. Ankiroderma 143.

A nobiida e 390 .

Aluodonta $5 \times 9$.

Anomalocera 674.

Inomalurus s04.

Inomia 867.

Inomma 214, 225.

A nomocladinidae 135. Anopheles 7, 11, 14, 15, .55, $781,792,822,879$.

Anophthalmus $3 \mathrm{~K}$.

inoplocephala 90.

A noploceplialida 469.

Anoploceplialinae 90 .

Anoplognathus 768 .

Inoplophiya 591.

Inoplotermes 259, 482.

- Inser 125, 510.

Intarctobilum 16:9.

Intarcturus $6 \vdots 1$.

Intedon 79-81, 651.

Antennophorus 479 .

Antemularia $\$ 15$.

Intherlon 731 .

Intheraca 5.53.

A nthicid a e 56 .

Anthislium 726, 728, 732.

Anthophora 726, 768.

Inthores 711.

Anthothrips \&19.

Antlerar 790.

A lut hribida e 390 .

Authroea 768 .

Anthurinm $v 00$.

Antilnpe 129, 144.

Antilopinar 70 .

Intimora 67.5.

Antipathidae 651.745.

inuraea 284, 285, 288, 576.

Anurida 32.

Inurophorus 32

Anytus 555.

Apagis 662 .

Ipanteles 151.

Aphaenogaster 171

Aphanipathes 745.

Aphanopoia 86.

Aphanostoma 6.54 .

A phidae 217, 250, 507, $708,867$.

Aphidius 31.

Aphis 255.

Aphlebia 111.

Aphoromma 32.

Aphrocallistes 138, 651 .

Aphroditaster 651 .

Aphrodite 650 .

A phroditidae 706 .

Aphrophora 52.
Aphiona 5.

Iphylla 49.

A pidae 93, 433, 717, 795, 815.

A pinae 79.5

Lion 55.

Apis $170,361,362,452,500$,

$560,561,570,598,715$,

716, 726, 728, 795, 799,

820 .

1 plysia 6.50.

Apocephalus 725 .

Aporia 151.

Ipotettix 110.

Aprion 114.

Apscustodon 166.

Apseudes 286.

Ipsteinia 594 .

Apterygida 89. 40, 107, 108

Aptinothrips 819.

A q 11 ilidale 35.5 .

Ira 354.

A r a c lı nida e $\$ 37$.

1 rachnomysis 286.

Araccerus 531, 532.

Aracopteryx 34.

Arbacia 55. 674.

1rca $297,823,867$.

Arcella 375

Archaeouterys 804.

Archasteridae 651 .

A recidae 823 .

Arctia 14s.

Arctiidae 150 .

Arctomys 279.

A retopithecidae 567 .

Arcturus 651.

Arcyptera 111.

Irdea 95, 439, 818.

Ardeida e 175.

Arelate 547.

Irenicola 304, 703, 706.

Arenicolidae 703,706 .

Arcte 20.

Argas 528.

Argia 777.

Argusianus 208.

Argutoridius 163.

Argymis 664-666, 734.

Argyropelecus 745.

Aricia $305,70 \%$.

A riciidae 702, 703 .

Aristacopsis 651 .

Aristaeus 651.

Iristeus 675.

Iristida 266.

Irmandia 305, 702.

Armitermes 482.

Arphia 39, 40.

Arrenurella 26.

Arrenurus 25.

Arhenurella 26. 
$\mathrm{Nr}$.

Arrhenurus 25, 26, 194, 195, 407, 431, 477. 478, 529.

Arsenorenus 163.

Artabas 162.

Artema 306, 347, 381, 670, 743.

Arvicola 5, 62, 144, 279, \$60.

A sa phida e 24.

Asaphus 24.

Asenlabotes 517 .

A scala phida e 51

Ascalaphus 873.

Ascaridae $\$ 26$.

Ascaris 94, 360, 420, 423, $526,740,758,85 \%$

Ascidia 801.

Ascidicolidae 34.5.

Ascidiella 801.

A sconematidae 514 .

Asellus 375, 406.

A silidae 742, $768,867$.

Asio 329.

Asionidae 329 .

Asioninae 329 .

Aspidiotus 540, 541, 548.

Aspidium 117.

Aspidobothridae 852.

Aspidodiarlemu 651.

Aspius 805.

1.splanclina 284.

Astacidae 651 .

Astasia 413.

A sterida e 2.97.

Astemma 54:.

Lsterias $75,79,82,102,103$,

300, 378, 744, 842 .

Asterolecanium 349, 544.

Asthenosoma 6.51, 745.

- Istraraca 348.

Astrogonium 82.

Astrogyra 343.

Hstroides 100.

Astropeeten 82.

Astropectinjdae 651 .

Astrophiure 84, 651.

Istrophyton 83.

Astropyga 86.

Astur 210, 355, 398.

istylozoon 375.

1tax 194, 431.

1teles 180, 567.

Atelodus 70.

Atcmeles 479.

Athene 123, 324.

Ithous 5.

Ithysanus 546.

Atolla 463, 651, 745.

Atorella 463.

Atruetides 25.

Itraetinium 411.

Atractoles 31.

Atraetomorpha 111.
Atta 219, 234, 235, 240, 244.

Ittaeus 553.

Aturus 310, 478.

Alyephira 476.

Aucella 61.

Aularantha 286.

Aulacodus 96.

Aulaseus 514.

Iulastoma 106.

Aulia 209.

Aulocaly. 514.

Aulophorus 547.

Aurlia 2, 297, 461, 462, 46\%. 592.

Aulolytus 304, 706.

Axinoderma 139.

Azoricidate 135.

Azteca 219.

Laygia 8.51.

\section{3.}

Bacillidae 111.

Bacillus 111, \$13.

Bacteria $39,40$.

Baetis 31.

Bakewellia 61.

Balaenoptera 510.

Balanoglossus 867.

Balistes 74.5.

Barbus 120, 198.

Barroussia 613, 619, 637.

Barroneria 613, 619. 637.

Basiaesehna 49.

Basteria 311.

Batagur SE8.

Bathochordatus (551.

Bathybius 575.

Bathyerinus 2, 651 .

Bathygalus 675.

Buthyplotes 113.

Bathypterois 745.

Bat rachidina e 110 .

Batrachoseps 2.

Batrachotetrigini 111 .

Batrachotetrix 111.

Batusa 547.

Bdella 27, 92, 311.

Bdellidae 27, 310, 311.

Beanella 823.

Begonia 4.

Belideus 893.

Belone 295.

bencdenia 603, 611, 619, 622, $623,637$.

Benthochascon 651 .

Benthodytes 143.

Benthogonc 143.

Benthothuria 143.
Beroë 442, 444.

Betula 280.

Bibos 70 .

Bibracte 114.

Biemma 186.

Biloculina 286 .

Bimichäilia 311.

Bison 70.

Bispire 304, 706.

Biston 559.

Bithynı 3.0.

lilarina 281.

Blastotrorhes 417.

Blatta 114.

B'lattidae $35,47$.

Blattodea $39,39,40,48$, $114,116.768$.

Bledius 867

Blennidius 163.

B lennidae 173.

Blennius 6s:3.

Blepharisma 375.

Blepharocera $786,787$.

liepharoceridae $\quad 786$, 787.

Boetis 51 .

B o id a e 808 .

bolbocerus $76 \mathrm{~s}$.

Bolborhynchus 35t.

Boloeera 6:51.

liombinator 122, 807, 831.

Bombus 717, 721, 726, 728, $732,734,795$.

B $0 \mathrm{mb}$ y ces 145 .

$130 \mathrm{mby}$ cidae 438.

Lomby: 147, 312, 350, 383. $552,553,1779$, \&61.

Bomolochus 341.

lios 7, 70, 129, 178, 316, $336^{\circ}, j 04,879$.

Bosmina 284, 288, 408, 576, $748,763,765$.

Bosminella 765.

Bosminidae 765 .

Bosminopsis 307, 765.

Bostry chida e 56 .

Bothriocephalidae 854 .

Bothrioceplealus 91, 468.

Bothrionurmex 798.

Bothriopterus 165.

Bothynoproetus 163.

Botys 153.

Bournellum 30.

Boyeria 49.

Brachiomus 285, 404, 405, 411, 414, 672.

Brachycolus 5.

Braehylabis 108.

Brachynemurus 51.

Brachypsylla 539.

Brachyscelidae 768 .

Brachyseelus 745. 
Brachysticha 434.

Brachystola 663.

Brachystropha 31.

$\mathrm{Br}$ aconidae $5,31,93$, 151, 153, 168, 169.

Branchiocerianthus 18.

Branchiocystis 605 .

Branchiomma 297.

Branchiommra 708.

Branchioplryme 286.

Brancli iopodidae 306.

Br anchipus 306, 947, 743.

Liraula $\$ 20$.

Bremia 5.

Brenthidae 390 .

Brephidae 150 .

Brisinga 651.

Broseus 881.

B ruchida e 56,390 .

Brunnerella 111.

Brutomysis 206.

Bryorlema 111.

Bubo 66, 32!.

Bubonidae 175 .

Buchholzia 760.

Bucculatrix 34!)

Bufo 5, 94, 122, 174, 204, $314,420,601,806,807$, $831,855,856,888,889$.

Bunops 673.

Buprestida e $56,15-15 \%$, $390,768$.

Bursaria 411, 589.

Butalidae 710 .

Byllis 547.

B y r l i d a e 56 .

Bythopsyrna 547.

Bythoscopus 543.

Bythotrephes 2ษ4, 662 .

\section{(}

Cacatua 354.

Caroecia 349.

Cacomantis 210.

Calulus 823 .

Caccilius 774, 775.

C'aecullia 559.

Caesonia 547.

Caiman 200.

Calamaria 201, 394, 888.

Calamus 109.

Calauria 547.

Calcarius 281.

Caligid a e 341.

Caligus 340, 341.

Calliboetis 51.

Callicotyle 341.

Callinera 661.

Calliphora 488, 726.
Nr.

Calliptamns 111.

Callizonclla 286.

Callochiton 828.

Callocystites 81 .

Callorhymchus 565.

Callula 8.8.

Calocaris 286, 345, 674.

Calopsittacus 354.

Caloptenus 111, 116.

Calopteryx 651, 77.

Calosoma 153.

Calotermes 51, 480.

Caloterm it in a 482.

Calotes 888.

Calycosoma 458, 514.

Calyptorhynchus 354 .

Camelopardalis 70 .

Camelus 452.

Camerunia 547.

C'a m peph agida e 398.

Campodea 530.

Campodeidae 770,771 .

C'amponotus 171, 219, 242, $243,24,251,259,265$, $718,725,798$.

Comptocercus 673.

Canachites. 281.

Canccrilla 345 .

Candona 407, 673.

Candonclla 767.

Canestriniinae $9: 2$.

Can idae 70, 129.

('anis 129, 178, 336,421 , $510,598,789,853,877$.

Cantharidae 5.5, $56, \quad 390$.

Cantharus 8.52.

Canthocamptus 285. 375,594 , 596,672 .

Caobangia 28.

Capculais 481.

Capitella 22, 426.

Capite 11 id a e $22,23$.

Capnella 696.

Capnobntes 39, 40.

Capobates 431.

Capra 129, 181, 336;, 568.

Caprella 337.

Caprcolus 469, 5fis.

Caprimulyus 95, 125, 397.

Capritermes 452.

Capros 745.

Cartabidae 56, 159, 154, $159-167,390,483,768$, 881.

Caranx ti3, 850 .

Carcharias $=76$.

Carchesium 375, 406, 587, 589, 590.

Careinonemertes 698, 699.

Carcinophora 108.

Carcinus 698, 1999.

Cardiocondyla 171, 387, 798.
Cardiocranius 669.

Caretta 675.

Carinaria 651.

Carinella 6.58 .

Carinina 658.

Carncades 557.

Carpocapsa 5, 550 .

Carpophaga 398.

Carpoglyphus 92.

Carsosaurus 202.

Carthaea 547.

Carthacomorpha 547 .

Caryotropha 642, 645.

Cassia 717, 732.

Cassidaria 650.

Cassiopeidae 463 .

Catantops 112, 114.

Catara 114.

Cathaxantha 581, 532.

Cathypna 411.

Catostylidae 463 .

Canlopla eida e 514 .

Caulophacus 514, 651.

Cucrumlaria 418.

Cavia 129, 179, 33., 504, 598, 636,828 .

Cebus 180, 567.

Cccidomyia 5, 117, 349, 3611, 538, 796.

Cecidom y idae 5, 794.

Cecropia 219.

C'eles 111.

Celor 169.

Cenestra 547.

Cenopis 349 .

C'entris 717, 732.

Centropagidae 366, 596.

Centrophorus 675.

C'entropina e 398.

Centropus 398, 420.

Centropyris 285.

Centroscymnus 675.

Centrostephanus 745.

Cephalothrips 819.

Cephalotyspis 161.

Ceph eidae 463.

Cepphus 510.

Cepurida e 435.

Cerambycidae $56,390$.

Cerastcs 279.

Ceratium 284, 287, 405, 411, $413,414$.

Ceratocephala 20.

C'cratoccphalus 20.

Ceratodus 735.

Ceratonereis 20.

Ceratophorus 723 .

Coratophyllus 821, 860 .

Ceratopogon 790.

Ceratopsylla 821.

Ceratopsyllus 297.

Cereomacra 209. 
Cercomonas 414.

Cerropayis 662.

Cerebramius: 472, 473, 658, $659,857,867$.

Cerianthus 651.

Ceriodaphnir 404, 748, 763.

Cerobasis 774.

Cervarus 70.

Cervus 70, 129, 332, 879.

Cerynict 547.

Cesseis 768.

Cestracion 697.

Cetasetum 717.

Cey.x 210.

Chaetauchenium 16:?

Chaetoderma 823.

Chatonotus 411.

Chatophora 375.

('inctopisthes 4\$?).

rhatop:ylla 821 .

Chactoptcous 105, 297.

Chaeiospania 117.

Chrietura 400.

Chatcididae 93, 796.

Chaleopterus 768.

Chaleochrous 166.

Chalicotherium 70 .

Challenteridae (j.). 1 .

Chamacleo 199, 565, 640, 830 , 889.

Chare :s.

Charadridae 175.

Charadrius 510.

Cherora 111.

Chertergus 77.

Charybdaea 297.

Charybdeidae 463 ,

Chauliodus 286.

Chaulopharus 458.

Chaunax 651.

Chamonolus 207.

Channoplectclla :514.

Chcilospinum 4:0.

Chelifer 311.

Chelisoches 108.

Chelone 199, 832, 889.

Chelonida e 890 .

Chermes 117, 349, 534, 535.

Chernes 34५.

Cheyletus::11.

Chiasmodon 745.

Chiloeorus 50.

Chilodon 406, 410, 589.

Chimaera 352.

Chionaspis 548.

Chionis 651.

Chiracanthium 598.

Chiriquia 110.

Chironephthya 694.

Chironomidae 31, 785 , 787.

Chironomus 360, 406, 407, 500.
Chirolheutis 745.

Chirothrips 819.

Chiton 828.

Chitoniciae 823.

Chlamydotheca 767.

Chlorochara 547.

Chlorodrepanis 205, 206.

Chlorophoneus 207.

Chologaster 279.

Chondracanthidae 341 .

Chordeuma 871.

Chordodes 75.5, 756 .

Choriphyllem 110.

Chorotypidae 111.

Chorolypus 111.

Chorlogryphus 92.

Chroicoptera 112.

Clirotogonus 111.

Chrysuthemum 726.

Chrysididae 93.

Chrysoblemma 156.

Chrysobothris 389.

Chrysochraon 111.

Chrysogorgia 651, 745.

Chrysomela 538.

Chrysomelidae 56,390 , 434.

Chrysomonadina 339. $411,575$.

Chrysopa 51, 530, 819.

Chrysopelea sis.

Chrysophrys 63.

Chrysopidae 5, 51 .

Chrysothrix 567.

Chrysotis 354.

Chrysotoxum 790.

Chrysotus 788.

Cicalula 546.

Cieindela 768, 867.

Cicindelida e 56, 390.

Cirlaris 750 .

Cinisys 891.

Cimnyris 398.

Cinosternum 891.

Ciona 497, 801, 827.

Cirplute 114.

Cirratulidat 702, 706

Cirratulus 305, 702.

Cimonereis 20.

Cirrotcuthis 745.

C'istuclo 891.

Citrego 55.5.

Clad o morphidae 111.

Ciladonotina 110.

Cladonotus 111

Cladopeltidae 195.

Cladorhiza 139.

Cladolrichum 250.

Claries 198 .

Clatyeercus 354

Clausia 345

Clavella 341
Nr.

Nr.

Clavellina 826.

Claviger 479, 483.

C] a valina 140.

Clerleobia 5.

Clcmurys 8.32.

Clepsine 106, 428.

Cle ridate $390,768$.

Cletodes 345, 764 .

Climacia 31.

C'limacostomem 375, 589.

Clin 575.

Cliona 513.

Clio n ida e $1+0$.

Clisiocampa $151,349$.

Clitum nid a e 111.

Clivina 881.

Clupea 63, 392, 526, 743, 744.

Clymene 305, 700.

cliymenella 493.

C'ypeaster 86.

Clypeotettix: 110.

Cobalos 554.

Coccidae 280, 588, 540, $544,545,548,708,768$, 819.

Coccilliurn 7. 608, 614, 619, 629, 124, fi29, 635, 6397, $643,644,646,648,649$, 158:

Corcinella 5. 5 .

Coceinellidae 56, 390.

Coceulina 745.

Cochleophoris: 194.

Cochylis :5.

Codonclla 575, 672.

Coclioxys $72 \mathrm{~s}$.

Coclodendrum 674.

Coclodus 63.

Coenogonymus 853.

Coeocephalus 354.

Colaspis 349.

Colcoticlius 543.

Coleps 375, 589.

Colyar 547.

Colias 148, 734.

Colletes 793 .

Colobesthes 547.

Colobopsis 251.

C'olossendeis 651, 745.

Colpulium 406.

Colporephalum 542.

Coluber 204, 395, 517, 601, 873, 888 .

Colubrida e 888 .

Columba 95, 123, 209.

Columba e 95.

Colymbidae 175 .

Colymbres 510.

Comptosia 768.

Conehoeeea 345.

Conehoecia 286. 


\section{- 980}

Congermuraena 651.

Coniopterygida e 51.

Coniopteryx 51.

Conoceplialidae 36.

Conocephalus: 39, 40.

Conopleyma 111.

Conozoa 111.

Conurus 323.

Convoluta 654.

Coppatias 186.

Copsyrna 547.

Coptotcrmes 482.

Coptottetix 114.

Coracopsis 354.

Corcgomus 98, 313, 510, 805.

Cor'eid a e $5: 36$.

Corcopsis 726.

Corixa 543.

Comitermes 482.

Corvida e 175, 330 .

Comine 850.

Corvus 598, 510.

Corydalis 51.

Corylus 880.

Corymorpha 18.

Corymorphidae 18.

Coryphaenoides 745.

Corystes 18.

Corythornis 400.

Coscinaraea 843.

Coscinodiscus 575.

Cosmia 555.

Cosmophoneus 207.

Cosmorhipis 111.

Cosmorhyssa 111.

Cossidae 150.

Cossus 145, 148.

Cothurnia 375.

Cottus 805.

Cotngnia 854.

Cotyloyonimis 85\%.

Cotylorhiza 462.

Conepia 732.

Cranaë 114.

Crangon 439.

Craniella 186, 515.

Craspedoprion 209.

Craspedosomidae 28.

Craspodia 768.

Craterocarus 161.

Creciscus 65.

Cremastus 169.

Crematogaster 171, 234, 235, 259, 271, 798 .

Crenilabrus 295.

Crepidocercus 407.

Crepidula 94, 366.

Cribrella 82, 186.

Cribropontius 345.

Cricetulus 669.

Cricctus 5, 279.

Crimona 558.
Criniger 208.

Crinorliza 139.

Criotctir 111.

(risticeps 17:), 295.

Crocilura ¿60.

Crocodilus 199, 888, 891.

C'romna 547.

Crossobothrium 876.

Crossolus 568, 860.

Crotalaria 732.

Crotalus 612, 681.

Crotaphytus 889.

Cryptobranchia 823.

C'ryptobranchus $820,520,829$.

Ciyptochiton 823.

Cryptodifflugia 411.

Cryptoflata 547.

Cryptognathis 311.

Cryptoleon 50.

Cryptomona din a 339.

Cryptoplax 822.

Cryptopus 644.

Cryptopygus 32.

Cryptothrips 819.

Crypturus 209.

Cienoclecticus 116.

Ctenodisens 651.

C'tenolabrus 341 .

Ctenopsylla 821, 860.

Cubiceps 675 .

Cubiocorrhynchus 768.

Cuculidae 175.

Cuculinae 398.

Cucullanus 858.

Creulligera 111.

Cuculus 95.

Cucumaria 75, 81, 143.

Cucurbita 731 .

Culex 11, 15, 53, 686, 687, $781,792,793$.

Culicidae 11, 15, 792.

C'umoniscus 674.

Cuncexa 311.

Cunaxidae 311.

Cupesidae 390.

Cuphopterus 399.

Curculionidae $55, \quad 390$, $435,768,819$.

Curvipes 196, 431, 478, 529.

Chspicona 537.

Cuterebra 349.

Cyanea 463.

Cyanolyseus 354.

Cyanorhamphus 354.

Cyarda 547.

Cyaria 547.

Cyarina 547.

Cyathissa 558.

Cybister 489.

Cyecthra 75.

Cyclanorbis 396.

Cyclas 573.
Cyclemys 832, 888, ¿91.

Cycloderma 396.

Cyclopidae 594, 596.

Cyclops 284, 308, 360, 366, $405,413,414,595,596$, 763.

Cyclospora 613, 619, 629, 637, $639,641,642$.

Cyclothone 286, 651, 675.

Cydippe 651.

Cydippidae 823.

Cydonium 1:4.

Cygnus 510.

Cymatophoridae 150 .

Cymbidae 150.

Cynipida e 95, 708.

Cynoscion 600, 876.

Cynthia 496, 801.

Cyornis 208.

Cyphoderia 285, 375.

Cyphomyrmex: 236.

Cypria 767.

Cypricercus 767.

Cypridelia 767.

Cy pridida $\theta 767$.

Cy prinida e $392,805$.

Cypridopsella 767.

Cyprinotus 767.

Cyprinus 120, 805.

Cypris 767.

Cypselidae 40ú.

Cypselus 123.

Cytomaja 651.

Cyrtonotume 784.

Cysta 311.

Cystodytes 803.

Cystoopsis 425.

Cystosira 18.

('ytosporon 689.

Cyta 311.

\section{D.}

Dactylocalycidae 514 .

Dactylopius 5.

Dactylopterus 804.

Dactylopus 764.

Dactylosoma 678.

Dacytes 55.

Dahlia 726.

Damonia 615, 682, 832, 888.

Danais 768.

Danilewshya $676,677$.

Daphnia 284, 285, 405, 406, $413,414,742,748,763$.

Daphnida e 500 .

Daptini 159.

Derwinula 767.

Dasealia 547.

Dascalina 547. 
Dascillidae 56 .

Dasychone 297.

Dasỳgorgia 651.

Decticus 116.

Degcerella 710.

Deima 89.

Deimatidae 143.

Deipnopsocus 775.

Delavalia 764.

Delphinapterns 510.

Deltocephaius 546.

Demiegretta 205.

Dendrochir ota 143.

Dendrocoelum 407.

Dendronereis 20.

Dendroneura 775.

Dendrophis 201. 888.

Dendrosoter 880.

Denisonia 201.

Dentalium 651, 745, 823.

Dericorys 111, 116 .

Derisa 547.

Derm a p tera $33,39,49,48$.

Dermatodiadema 86,651 .

Dermestida e 56,867 .

Dermotlata 547.

Derocalymma 112.

Derocorys 111, 116.

Derocorysta 111.

Derocorystes 111.

Desmacella 186.

Desmognathus 602.

Desmophyllum 675

Desmoptera 114.

Deudora 156, 157.

Dexia 5.

Diaulorus 768.

Dialychone 297.

Diandrocarpa SU3.

Diapensia 734.

Diaphanosoma :307, 763.

Diapheromera 45.

Diaphoropus 286.

Diaptomus 284. 366, 407, 413, 596,763 .

Diaspis 540, 549 .

Diastatomma 4!.

Diazona 803.

Dibamus 888.

Dibranchus 651 .

Dicelis 423 .

Dichelestidae 341.

Dichopetala 39, 40.

Dichthadia 225.

Dicorypha 114.

Dicraniomyia 782.

Dicrocoelium 522.

Dierogaster 523.

Dierostony. 281.

Dietyaster 651.

Dic y e mida e 650 .

Didelphys 893.
Didemnum 803.

Didinium 590.

Didymocystis 518.

Didymostoma 518.

Didymozoon 518.

Diemyctilus 94.

Diestramena 871.

Diexis 111.

Difflugia 3, 407, 411, 414.

Dileptus 411.

Diloba 5.

Dinobryon 288, 413, 748.

Dinophilidae 823.

Dinophilus 73, 823.

Dinophrya 589.

Dioclea 717.

Dioctria 790.

Diodontus 723.

Diomedea 565.

Diopatra 305, 702, 823.

Diphyes 286, 651, 674.

Diplatys 108.

Diplectrona 51.

Diplodontus 194, 413, 431.

Diplogaster 406.

Diplogonoporus 471.

Diplosoma 803

Diplosomoides 803.

Diplospora 613, 619, 637.

Dipoides 70.

Dipsacaster 651.

Dipsadomorphus 420, 888.

Dipterie 717.

Dipylidium 877.

Discopus 2.

Discorbina 511.

Disparipes 92

Dissemurts 208.

Dissodectes 355.

Distaplia 803, 825.

Distoma 803.

Vistyla 285.

Dis to min i 159,161 .

Distomum 190, 517, 519, 522, $523,849-853,855,856$.

Ditypophis 199.

Docophorus 542.

Dolichoderus 241, 798.

Dolichoglossus 475.

Dolichopodidae 782 , 783.

Dolichopus 790.

Dolichosauridae 202.

Dolichosaurus 202.

Doliophis 888.

Dolium 650.

Donatia 184, 185, 186.

Doratifera 768.

Dorcadion 5.

Doria 547.

Dorocidaris 651, 745 .

Dorocordulia 31.
Nr.

Doryctes 168.

Dory ctin a e 168 .

Dorylaimus 425.

Do rylidae 234, 235 .

Dorylinae $220,222,227$, 234, 235, 261-263, 266, 267.

Dorylus 214, 225-227.

Dorymyrmex 234.

Draco $804,888$.

Drassus 598.

Drasteria 555.

Dreissensia 823.

Drepanidae $150,206$.

Drepanidium 676, 677, 678.

Drimostoma 166.

Dromogomphus 49, 777.

Drosophila 782.

Drosophilidae 782.

Dryo myzina e 784 .

Dryoph is 201, 888 .

Dryoscopus 207.

Dunhevedia 673.

Duronia 111, 116.

Dybou'seella 23.

Dynatus 197.

Dyschirins 881.

Dystacta 112.

Dyticida e 739 .

D y t is cida e 56,390 .

\section{$\mathbf{E .}$}

Earias 148

Ebnerclla 753.

E c h i in id a $\theta 843$.

Echinobrissus 86.

Echinochalina 186.

Echinoclinum 803.

Echinococcus 191.

Echinocyamus 86.

Echinoplax 651.

Echinorhynchus 158.

Echinosoma 108.

Echinospira 674.

Ech ill oth uridae 651 .

Echinus 75, 86, 103, 403, $419,442,843,845$.

Echiostoma 651.

Echis 199, 279.

Echiurus 286, 674.

Eciton 220, 222, 234, 235, 261, 267, 479.

Ectinosoma 594.

Ectobia 111.

Ecty i o n in a 186.

Edoliisoma 210.

Egnatioides 116. 
Eynatius 111

Eimeria 604. 608.610. 613615,61 ․, 619, 624, 628$632,635-640,642-644$, $646-648$.

Eisigiella 22, 23.

Fil a chistida e 150 .

Elacocerthia 400.

El a te rid a $\theta 56,390$.

Eledone 494, 611, 651.

Elcphas 68, 70.

Elimaca 114.

Elipsocus 774.

Elpidia 143.

E. $\mathrm{p}$ i d i i d a e $14 \%$

Elpidi in a e 89 .

Elpidiogone 143.

Emargulina 823.

Emberisa 688, 689.

Emperoptera 783.

Eniphor 731.

E m p i d a e 791 .

E m p id id a e 31 .

Empusa 111.

Emyda 396, 644.

Emys 204, 679, 682, 830, 891.

Enallagma 777.

Enchelys 375 .

Enchodus 63.

Enchytracus 867.

Finchy tra eida e 380,760 , 761.

Encyrtus 796.

Endiocrinus 6\%1.

Eud om y chidae $56,390$.

Endospermum 219.

Enhydris 888.

Enhydrosoma 764.

Enicognathus 201.

Enodiotiema 520.

Entechnia 731.

Entomophthora 813.

Entomoscelis 5 .

Enypniastes 143.

Eochelone 890

Eos 354.

Eosteropus $16 \%$.

Epacromia 111. 116, 768.

Epactius 881.

Epcira 2, 439, 598.

Ep hem e r id a e $31,51,407$, $500,787$.

Ephippigera 116.

Ephydra 488.

Epicueschna 49.

Epialtus 698, 699.

Epicauta 349.

Epicharis 732.

Epicometis 5 .

Epicrates 201.

Epilampra 114.

Epilobium 371.
Epistylis 375, 406, 587, 590.

Epizeuxis 554.

Epizoanthus 651, 745.

Epoccus 259.

Equida e 812 .

Equus 69, 70, 129, 336, 356, $370,700,737,869$.

Erebia $664-666,734$.

Erebomyrma 277.

Eremiaphila 116.

Eremias 199, 395, 601, 806.

Eremobiini 111.

Eremobia 111, 113, 116.

Eremocharis 111.

Eremogryllus 113, 116.

Eremoleon 51.

Eremopsyche 51.

Erethizon 96.

Eretmoptera 785.

Eretmopteridae 785.

Ereynetes 311.

Ergasilidae 341.

Erica 271.

Frinacels 178, 179, 279, 333, $592,834$.

Eriabotrya 732.

Eriocampa 5.

Eriocraniidae 150.

Eriocypas 161.

Eriophonus 161.

Eriopsyila 539.

Eristalis 488, 726.

Eryonicus 674.

E ry on idae 651 .

Eryoniseus 651.

Erythraeus 430.

Erythrius 4.

Erythrops 345.

Erythropus 355.

Erythroxylon 717.

Erylus 137.

Eryx 395, 601, 831.

Es o c id a e 392.

Eso: 1:0, 340, 805.

Esperella 186.

Estheriidae 346.

Eteone 304, 706.

Ethon 768.

Etiella 5.

Eucalanus 286, 764.

Eucalyptera 554, 558.

Eucalyptopsylla 539 .

Eucalyptus 768.

Eucamptognathus 164.

Eucandona 673.

Eucera 717, 721, 732.

Euchaeta 286.

Eucharia 598.

Eucharis 286.

Eucoccidium 611, 614, 624, 637.

Eudactylina 341.
Nr.

Eudromus 16.'.

Eudyptes 651.

Eugaster 116.

Euglena 339, 413.

Euglossa 717. 732 .

Eniris 26, 194, 195, 431, 47٪, 529 (s. auch Eylois).

Eulatia 345.

Eulimnadia 346.

Eunapius 111, 116

E'unemertes 698, 699.

Eunephthya 696.

Euncreis 20.

Eunice 297, 436.

É nicid a e $23,702,823$.

Eupagurus 867.

Eupalus 311.

Eupratagu: 651 .

Euphante 547.

Euphausia 286.

Euph a usida e 651,674 .

Euphronides 143

Euplectclla 6.51.

Eupleres 177.

Euplectellida e 514 .

Euplexia 558.

Euplotes 375, 816.

Eupodes 311.

Eupodidae 311 .

Eupodinae 311.

Eupodisma 111.

Eupolia 659 .

Eu polidat $6.8,659$.

Euprepoenemis 111.

Euproctus 122, 502 .

Eupronoё 286.

Eurete 138, 675.

Eurime 547.

Eury a lid a e 2, 83.

Euryenema 114.

Eurycorypha 112.

Euryercon 5, 153.

Eurydice 286.

Eurymela 768.

Eurymetopus 54:.

Euryplegma 514.

Euryprosthius 547.

Eurypteridae 2 .

Eurypyga 65.

Eurythrips 819.

Euscorpius 439.

Eutanys 163.

Eutermes 259, 480, 482, 733, 776.

Eutettix 546.

Eutririps 819.

Euthyatira 558.

Euthymia 772.

Evadne 662.

Evaniidae 93.

Evonomys 729.

Exochomus 5. 
Exocoetus 804.

Exoma 547.

Exomalopsis 732.

Exomegas 436.

Eylais 26, 194, 195 (s. auch Eulais).

\section{F.}

Fala 558.

Falco 95, 355 .

Falconidae 137, 355 .

Falconina e 355 .

Farona 547.

Farrea 745.

F a s c i o lid a e 523,850,852, $853,856$.

Feyatella 594.

Felida e 91, 129.

Felis $70,91,129,178,316$, $336,424,439,452,470$, $504,510,598,738,828$, $853,854,877$.

Feliria $310,558$.

Feroniola 163.

Festuea :5.

Fibularia 86.

Ficus 800.

Fidia 349,434 .

Fidiobia 434.

Fidonia 438.

Filaria 420, 422, 424, 425, 517, 854, 879.

Fimbriaria 90.

Finitima 555.

Fischeria 116.

Fissurellidae 823 .

Flabellum 416, 417, 651, 745.

Flata 547.

Flatidu 547.

Flatidae 547 .

Flatina 547.

Flatinae 547 .

Flritoides 547.

Flatoid in a e 547 .

ITlatomorpha 547.

Flatopsis 547

Flatoptera 547.

Fleitosoma 547.

Flaiula 547.

Floriceps 519.

Floscularia 409.

Folliculina 375.

Forcipula 108.

Forficula 111, 116, 757.

Forficulid ae 739 .

Forficulodea 116.

Formica 171, 233-236, 244, 247, 258, 259, 268. 269, $271,273,385,387,483$, $725,730,798$.
Nr.

Ge ometra e 14.5 .

Geometridae $150, \quad 4533$, 559.

Geonemertes 871.

Gcophilus 382.

Ceoscapheus 768.

Geotria 436.

Geotrupes 47, 60, 500.

Gerbilius 669.

Gervilleia 61.

Geryon 651.

Gesonia 114.

Giebelia 542.

Gigantocypris 651, 745.

Glandiceps 475.

Gla re olidae 175 .

Glaucoma 589.

Glauconia 199.

Glenea 581, 582.

Globigerina 511. 575, 651.

Globiocephalus 651. 675.

G l o in erida e 30 .

Glomeris 193, 607.

Glossobalanus 475.

Glycera 305, 702.

G l y c e ri d a e 702 .

ilycyphagus 92.

Glyphanus 111.

Glyphidodon 651

Gilyphuclonus 109.

G I y p t i n i 159 .

Gly phiptery gidate 150 .

Gnathodus 546.

Gnathophausia 65il.

Gobius 295.

Gom phida e 49.

Gomphocerus 111.

Gomphomastax 111.

Gomphomasticini 111 .

Gomphus 31, 49, 777.

Gonatodes 888.

Gongocephalus 888.

Gongrocnemis 39, 40.

fongylus 517.

Cioniada 304, 706.

Goniadidae 706 .

Goniocotes 542.

(ronionemus 18 .

Goniopora 692.

Goniopteryx 726.

Conostoma 286.

Gonypeta 33, 112.

(iordiid a e 823 .

Gordins 19, 756, 878.

Gorgodera 855.

Gorgonida e 651 .

Gorgonocephalus 83.

Gossyparia 351.

Gracilatiida e 150 .

Graphoscopus 774.

Graptoleberis 414, 673.

Gratidia 111. 
Graucalus 208, 210.

Grimaldina 673 .

Grus 439.

Gryllocris 114.

Gryllodea $33,39,40$, $114,116,768,867$.

Gryllomorpha 116.

Gryllotalpa 768.

Gryllus 35, 39, 40, 44, 113, $115,116,484,878$.

Guinardio 575.

Gundlachia 824.

Gussata 555 .

(iymnodactylus 831, 888.

Gymnogryllus 114.

Gymnopatagus 651.

Gyrator 653 .

Gy rin id a e 390.

Gyrodactylus 379.

Gyrosmilia 343.

\section{I.}

Haddonella 874.

Hadena 558.

Hadenia 555.

Haemamoeba 584, 688, 689.

Haematococcus 418.

Hacmatoloechus 856.

Haemogregarina 679, 681, $682,683$.

Haemomenas 584.

Haemoproteus 689 .

Hagenius 49.

$\mathrm{H}$ a l a c a ri d a 337 .

Halacarns 337.

Halcyon 398.

Haleremita 18.

Halictus 717, 726, 795.

Haliotis 297, 749, 823.

Haliphysema 455.

Haliplana 565.

Haliplanes 286.

Halipli da e 390.

$\mathrm{Hal}$ oc y p ridae 651 .

Halosauropsis 745.

Halotydens 311.

Halteridium 14, 686, 687, 689.

Hamigera 186.

Hansenia 547.

Hapale 567.

Hapaulax 768.

Haplogenius 51.

Haplootropis 111.

Haplopeltura 888.

$\mathrm{H}$ a ploporina e 523.

Haploporus 523.

Haplosplenchmus 523, 852.

Haplotaxida e 760 .
Harmostomum 520.

Nr.

Harpacticidae $594,596$.

H a rp a l in i 159-162.

Harpalues 57, 161, 162.

Harpe 355.

IIarpyia 148.

Harrimania 475.

Hastatella 375.

Hastigerina 511.

Hatteria 282, 565.

Hediste 20.

Hedyle 20.

Helaeus 768.

Heliastus 39, 40.

IIeliconia 717.

Helieopsyche 51.

Helioscirtus 111, 116.

Hcliothrips 819.

Heliotrichum 575.

Helix 131, 492, 824.

Hclminthophis 889.

Helocordulia 31.

Helopeltis 531, 532.

Helophorus 407.

Helotropha 558.

Hemerobiidae $31,51$.

Hemiaster 75.

Hemibdella 683.

Hemicaecilius 775.

Hemicalanus 286.

Hemidactylus 199, 204, 831, 888.

Hemignathus 206.

Hemimerus 48.

Hemipedina 86.

Hemisarcoptes 92.

IIenlea $760,761$.

H e p ialid a e 150 .

Hcpialus 148.

Hericia 92.

Hermadion 706.

Hermellida e 706.

Hermione 650.

Herpestina e 177.

Herpctocypris 764.

Herpctodryas 520.

Hcrpetogomphus 777.

Herpetophrya 591.

Herpetotheres 355.

Herpetotherina e 355.

Hersiliodes 345.

Herus 39, 40.

Hesione 296.

Hesperiida e 150 .

Hesperotettix 34, 36.

Hetaerius 483.

Heterakis 420.

Heteraprium 114.

Heterocypris 767.

Hetcrogamia 111, 116.

Heteronema 411.

Heterophrys 411.
Heterophrysus 286.

Heterophyes 853.

Heteroplectron 51.

ITeteropternis 111.

Heterostegina 511.

Heterostephanus 18.

Heteroteuthis 651.

Heterotrypus 114.

Hexarthra 823.

IIibiscus 731.

Hicracidea 355.

Hierodula 114.

Hierofalco 355.

Hilaria 791.

Himatione 205.

Hipparion 70.

ITippiscus 34, 42.

IIippocampus 439.

Hippopotamus 70.

Hipposideros 470.

Hirudo 106, 297.

Hirundin ida e 175.

Hirundo 279, 510.

Hispidosperchore 478.

$\mathrm{Hi}$ is terid a e 56.

Mistiogaster 92.

IIistiona 411.

Histiostoma 92.

$\mathrm{H}$ is t i o s to m in a 92 .

Hjartdalia 309, 478.

Hodotermes 480.

Hoernesia 61.

Holascus 651.

Holcocerus 148.

Holcomyrmex 251.

Holorusia 788, 789.

Holosticha 375.

IIolothuria 75, 141, 143.

Holothuriidae 143.

Homalosoma 166.

Homandra 516.

Homo 7, 12-15, 68, 70, 91, $126,128,129,130,144$, $178,180,211,212,313$, $316,317,330,336,356$, $370,372,373,421,422$, $439,452,468,504,509$, $519,527,562,577,579-$ $5 \times 3, \quad 585,598,610,639$, $648,679,680,684,685$, $690,713,714,757,853$, $877,885,892$.

Homocogamia 39, 40.

Homogloea 559.

Homolampas 86.

Hom olj d a e 651 .

Homopus 198.

Hoplandrocnema 156.

Hoplauchenium 163.

Hoplistura 156.

Hoplophora 434.

Hubrechtclla 658.

- Genus- und Familien-Register. 
Hubrechtia 661.

Hyaena 70, 424, 854.

Hyaenarctos 70 .

Hyalodaphnia 412.

Hyaloklossia, 613.

Hyalonema 458.

Hyalopeplus 543.

Hyalopteryx 109.

IIybernia 559.

Hybocodon 18.

Hydatina 73, 507.

Hydra 2, 18, 411, ј07, 592, 839.

Hydrachna 26, 194.

Hydrachnidae 26, 92 , $194,195,310,411,413$. $431,477,529$.

Hydriphantes 194.

Hydromermis 757.

Hydrometra 407.

Hydrophilidae 56. 739.

IIydrophis 201.

Hydroporus 407.

IIydropsyche 51 .

Hydropsychidae 51 .

Hygrobates 194, 529.

Hy grobiidae 390 .

Hyla 12\%, 601. 609, $807,831$.

Hylemyia 790.

IIylophilus 209.

Hymenaster 675.

IIymcnocephalus 745 .

Hyocrinus 651.

Hypera 435.

Hyperates 774.

Hyperborea 148 .

Hyperetes 774.

Hyperia $2 \$ 6$.

Hyperidae 286. 43.5.

Hy perini 435 .

Hyperoodon 745.

IIyphalaster 651, 675 .

IIyplantornis 399.

Hурnит 594.

Hypocharmosyna 210.

Hypodoryctes 168.

IIypolytus 18.

IIypopte 148.

Hypotriorchis 355.

Нуруа 554, 557.

Hypsicomus 297.

Hysirhina 888.

\section{I.}

Ichneumonidae 98,151 , 169.

Ichnotropis 198.

Ichthyophis 506.

Irterus 281.
Idiomelas 159.

Idiurus 804.

Idolomorpha 116.

Idolothrips 819.

Idume 547.

Idus 805.

Iliocryptus 411.

Illex 296.

Ilyanassa 444.

Ilyodrilus 740 .

Inachus 675.

Ino 148, 433.

Inoceramus 61, 136.

Iole 208.

Iphinereis 20.

Iphis 479.

Ipomoea 717,731 .

Iridomyrmex $219,768$.

Iris 116.

Irpa 143.

18chnochiton 82:3.

Ischnopteryx: 775.

Isidogorgia 651.

Isis 651.

Isnochiton 493.

Isops 137.

Isospora 613. 619, 637, 638, 640.

Isotelus 24.

Isotoma 32.

Isozoanthus 651 .

Ityraca 547.

lixalus 888.

Ixodes 678, 679.

Ixodidae 26.

\section{J.}

Jacobina 717 .

Jalmenus 768 .

Janthella 874.

Jantlina 823.

Japygida e $769-771$.

Јарух 530, $769-771$.

Jasmineira 703.

Jasminum 726.

Jassina e 546 .

Jassus 546.

Julinia 825.

Julus 30.

Juncus 271.

Junonia 768.

Jynx 95.

\section{K.}

Karyolysus 6, 679.

Karyophagus 614.
Nr.

Kittacincla 208.

Klossia 608, 604. 611. 616, $619,6: 37$.

K'lossiella 645.

Kolga 89, 143.

Kophobelemnonidae 418.

Kowalewskaja 826.

Krigia 731.

kruppomenia 674.

Labco 198.

Labia 107, 108.

Labidoplax 142.

Labidura 108, 116.

Labidus 222.

Labrar 295.

Labrus 341, 521.

Lacerta 6, 204, 395, 517, 601, $830,864,86.), 873$.

Lachesis 191.

Lachnus 217.

Lacrymaria 375.

Lactista 39. 40.

Laetmogone 143.

Lagenophrys 375 .

Lagis 704.

Lagomys 144, 568.

Lagopus 281, 510.

Lagridae 56.

Lamellicornia 768 .

Laminipes: 478.

Lampra 18.

Lamprocolius 399.

Lamprogramma 651.

Laniarius 207.

Lanice 703.

La niidae $175,20 \%$.

Lanius 207.

Lankestcrella 676, 677, 679.

Lanthus 49.

Laophonte 594, 764.

Laphria $742,790$.

Laridae 175 .

Larus $95,510$.

Lasiaster 77.

Lasiocanpidae 150 .

Lasiocephala 51.

Lasiochilus 543.

Lasioptera 5.

Lasius 171, 218, 2:37, 2:38, $249,250,255,270,274$, $275,278,385,434,479$, $713,714,730,798$.

Lasmogyra 343.

Lates 63.

Lathria 209.

Lathridida $e 390$

- Genus- und Familien-Register. 
Lathrodectes 2:9, 598.

\section{Latois 547 .}

Laverania 584, 684, 689.

Leaehia 675, 745 .

Lrbertia 25, 194, 478, 529.

Le c a n i i d a e 733 .

Lecanium 349. 544.

Lechaea 547.

Lecithobotrys 523.

Legerella 604, 607, 619. 628.

Legeria 603. 62:, 62:3.

Legerina 611.

Lemnalia 696.

Lentungulinae 92.

Leonnates 20.

Leontis 20.

Leonums 732

Lepas 429, 745.

Le petida e $82 \%$.

Lepidomenia 823.

Lepidopleurida e 823 .

Lepidopleurus 82:3.

Lepidopus 286.

Lepidosiren 293, 294, 735, 736.

Lepidosten.s 318.

Lepisma 192.

Lopism atida e 770, 771.

Leptella $7 \%$.

Leptobrachida 463 .

Leptocella 51 .

Leptocephalus 286, 499.

Le ptoceridae 51 .

Leptocerus 51.

Jeptochone 297.

Leptodesmus 411

Leptodira 201.

Leptodora 284. 307.

Leptogenys 262, 263.

Leptonema 51 .

Leptonereis 20.

Leptophyllum 520.

Leptoplanidae 656 .

Leptopontia 345.

Leptopternis 111, 116.

Leptoptilum 651.

Leptoscirtus 111, 116.

Leptothorax 251, 256, 258, 259, 265, 357. 798.

Leptothrix 375.

Leptotrachelus 593.

Lepus 7, 58, 178, 212, 279, $315-317,333.334,452$, $503,598,606,613,629$, 635,646 .

Lerna eida e $341,593$.

Lernaepodidae 341.

Leucetta 753.

Leucifer 476.

Leuciscus 120, 501, 805.

Leucochrysa 51.

J,eucopsacidae 514 .
Leucopsacina e 514.

Leucopsacus 514.

Leucorrhinia 31.

Leuctra 31.

Leydigia 673.

Libellulidae 742 .

Lichena 547.

Lichomolgidae 345, 764 .

Lima 297.

Limacodes 768.

Limax 291.

Limnadia 346, 766 .

Limnaed 406, 500 .

Limnaeus 849 .

Limnesia 26, 431, 529.

Limnetidae 346.

Limnicythere 672, 767.

Lim ll ob i idae 782 .

Limnodrilus 426.

L, i nu ophilidae 51 .

Limosa 281.

Limothrips 819.

Limulus 867.

Lina 5.

Lineidace $658,659$.

Linerges 463.

Lineus 659, 660 .

Linopncustes 86.

Linopodes 311.

Liocellus 161.

Liolepis 420, 888 .

Liolope 520.

Lionedrya $3 \& 9$.

Liopasa 166.

Lipara 721.

Lipephile 20.

Lipeurus 542.

Lissonema 420.

Lithadothrips 819.

Lith istidae 135.

Lithobactrum 691.

Lithobius 7, 382, 638, 641.

Lithodes 651.

Lithophytum 696.

Littorina $340,823,867$.

Lituaridae 418 .

Livoneca 745.

Lixus 780 .

Lobobrachus 166.

Lobophytum 467, 695 .

Loboptera 116.

Locustodea $33,36,37$, $39,40,46,114,116$.

Loelaps 479.

Loimia 305, 702.

Lomechusa 479, 483.

Lonchodidae 111.

Lo phiidae 651.

Lopholatilus 600.

Lorius 354

Lota 805 .

Loxodes 589.
Nr.

Lorotropa 259.

Lucanidae 56 .

Lucanini 390.

Lucifuga 279.

Lucilina 823.

Iucina 784.

Lïhea 732 .

L. um bricidae $\quad 297, \quad 380$, 760,761 .

Lumbriconereis 23.

Lumbriculidae 380,760 .

Lumbriculus 426.

Lumbricus 423.

Iuperina 558.

Luteva 543.

Lutra 70.

Lycaena 145. 148, 5.59.

Lyc aenid a e 150,768 .

Lycastis 20, 21, 23.

Lychnorhizidae 463.

lycodon $8 \& 8$.

Lycoridae 20. 702 .

Lycoris 20.

Lycosa 598, 867.

Lycoteuthis 651 .

Lyda 54, 712.

Lygosoma es8.

Ly mantriidae 150 .

Lymexylonidae 56 .

Ly ne eidae 346 .

l.ynceus 763.

Lynx 281

Lyonetiidae 150 .

Lysiopetalum 30.

I.

Mabuia 199, 806, 88.

Machaerocera $39,40$.

Nachaeridia 109.

Jachairodus 70.

Machetes 95.

Machilis 192, 297, 529.

Macrocorax 210.

Macronena 51.

Macrophonus 161.

Macrophthahnia 436.

Macropus 90.

Macrorhinus 651.

Wacrosporium $\$ 19$.

Macrothrix 673. 763 .

Macruridae 651. 745.

Macrurus 286, 674, 675, 745.

Mactra 867.

Maelia 92.

Malacodermidae 56.

Malaconotus 207.

Malacoptila 65.

Malacothrips 819.

Maldanidae 702

- Genus- und Familien-Register. 
Mallomonas 411.

Mamestra 555, 55<, 559.

Manayunkia 23.

Mantidae 47.

Hantis 112, 114, 116, 349 .

Mantispa 51.

Mantispidae 51 .

Mantodea 33, 39, 40, 114 . 116.

Maracanda 50.

Margelidae 18 .

Margelopsis 18.

Marionina 761 .

Marphysa 305, 702.

Marsupifer 6.51.

Massila 547.

Mastacidae 111 .

Mastax 111.

Mastigobryum 594.

Mastigocerca 288, 672.

Mastigonereis 20.

Mastodon 70.

Mecynostoma 654 .

Mecostethus 111.

Medenophthalmus 674.

Megacephala 768.

Megachile 726, 728 .

Megachilus 768 .

Megacilissa 7.92.

Megalocercus 286.

Megalophonus 162.

Megalophrys 420. 888.

Megaly id a e 93.

Megahizin idae 135

Megascops 66.

Megilla 819 .

Melampsalta $76^{-}$.

Melandryidac 56.

Melanocêtus 651 .

Melanopli 36.111.

Melanoplus 34, :9, 40, 111.

Melanostoma 726,727 .

Melanothrips 819 .

Meleagris $12:$.

Meleoma 51.

Meles 70, 279, 568, 860.

Melipona $3-4,717,732,795$.

Meliponida e 733 .

Melissodes $7: 31$.

Melitaca 664-667.

Melitodes 694.

Melobasis 768 .

M e loidae 58.

Melolontha 158.

Melolonthini 390.

Melosira 576.

Melospiza 328.

Menopon 542.

Menoidium 411.

Meraula: 163.

Merimna 768.

Mermis 425, 757.
Merocestus 190.

Merops 398.

Merotettix 110.

Mertensia 651.

Merula 866.

Mesenchytraeus 761.

Mesochra 345.

Mesoleptos 202.

Mesophantia 547.

Mesophylla 547.

Mesostoma 411.

Mesothuria 89, 142, 143.

Ucssor 718, 798.

Metacineta 594

Mctacrinus 651.

Metamelanius $16: 3$.

Metopa 337.

Metopus 375.

Mctrarga 54:.

Metrodorina e 110 .

Micania 717.

Michailia 311.

Michaclsenia 803 .

Micrastur 355.

Mierella 658, 660 .

Microcosmus 801 .

Microdynerus 721 .

Microflata 547.

Microglossus 354.

Microharpalus 161.

M icrohieraces 355 .

Microhierax 355.

Microhyla 888.

Mirroklossia 645.

Mieroleon 51

Micronereis 20.

Microniscus 286.

Micromotus 110.

Microphthalmus 5.

Microplana 871 .

Micropteryx 710 .

Micropyga 86.

Microeclevoderma 691.

Microstoma 847 .

Hicrotus 568, 669.

Microvelia 543.

Micrura 658, 659.

Mictis $76 \mathrm{~s}$.

Midas 567.

Middendorffia 823.

Miliolina 511 .

Milvago 355.

Milvus 853.

Mimocichla 866.

Mimophantia 547

Miogryllus 43.

Mioscyrtus 111.

Mirabilis 862 .

Miracia 595.

Mirotermes 482.

Mitrephanes 209.

Mitrocoma 2.
Nr.

Modiola 867.

Moina 307, 673, 763.

Molge 601, 614, 831.

Molqula 496, 801.

Molgulidae 575 .

Molgus 311.

Molpadiidae 143.

Momotus 65.

Monachus 868.

Monanthus 691.

Monarcha 398.

Monas 751.

Monilia 5.

Monina 717.

Monocaulus 18. 651.

Monocystis 646.

Monodontophrya 591.

Monomorium 171, 259, 265, 798.

Mononyx 768.

Monopeltis 889.

Monoraphis 651.

Monorchis 852.

Nonostoma 518.

Monostomum 190.

Monstrilla 345.

Monstrillidae $: 345$.

Mora 675.

Moraria 594.

Mordacia 436.

Mordellidae 56.

Worhippolyte 286.

Morrhua 63.

Motacilla 397.

Motacillidae 175.

Mugil 523.

Munida 651.

Munidopsis 651.

Muraenidae 651 .

Muraenoidae 887 .

Iurex 13:3, 745.

Mus 7, 178, 179, 338. 356, $507,568,629,645,669,860$.

Musca 488, 726, 768.

Vustela 281, 860 .

Mutillidae 768.

Mycale 186.

Mycetes 567.

My cetophilidae 779,780 .

Mycopsylla 539.

Myelophilus 117.

Hyersia 286.

Nygale 598.

Mygalidae 598.

Myodes 510.

Iyopotamus 96.

Myotis 821.

Myrina 675 .

Myriothela 18.

Myriotiochus 142.

Myrmerocystus 171, 230, 245, $251,387,718,798$. 
Nr.

Myrmecodia 219.

Myrmeleon 51, 116.

My ${ }^{\circ} \mathrm{mele}$ enida e 50,51 .

Myrmeleontidae 768 .

Myrmica 171, 237, 238, 265, $387,798$.

Myrm icinae 277 .

Myrmotherula 209.

Myrmoxenus 387.

Myrillus 734.

Mysis 286, 340, 674 .

Mytilaspis 548 .

Mytilus $850,867$.

Myxicola 297. 703.

Myxidium 682 .

Myxine 313.

Myzomela 210.

Myzomeniidae 823.

Myzostoma 444

\section{$\mathbf{N}$}

Naidida e 380 .

Naidium 761.

Naidomorphae $760,761$.

Naja 198, 279, 681, 888.

Nandinia 177.

Nannopus 345.

Nasiaeschna 49.

Nasiterna. 210, 354, 398.

Nassa 290, 867.

Nassula 375.

Natica 823.

Naumachius 20.

Nauorchestes :311.

Nansithoe 463.

Nautilograpus 745.

Nantilus 297, 651, S23.

Navieella 823.

Neanthes 20.

Neanurini 32 .

Nebria 154.

Necrophorus 3ะ9, 867.

Nectarinida e 400 .

Nectochaeta 286.

Nematocarcinus 651 .

Nematoscelis 286, 651 .

Nemertes 695, 699.

Nemesia 598.

Nemopsis 18.

Nrmotelus 790.

Neoberlesia 479.

Ncocerns 547.

Neolampas 86.

Neolobophora 108

Neomenia 823.

Neopeltidae 135.

Neopsylla 860.

Neoscopelus 65I.
Neospiza 400.

Neospongodes 465, 696 .

Neotettix 110.

Nrottinphilum 784.

Nephelis 106, 428.

Nephelodes 555.

Nephesa 547.

Nephotettix 546 .

Nephrops 651.

Nephropsis 651 .

Nephthya 694, 696.

Nephthyidae 465,696 , 702.

Nephthys 305. 702.

Nereicola 345.

Nereida e 20, 23. 706 .

Nereilepas 20.

Nereis 20, 297, 305, 426, 702, 867.

Nerine 305, 702.

Nerita 823.

Neritida e 82 .

Neritina 340.

Nesacinopus 159.

Nesaea 194.

Nettastoma 745.

Neumania 194, 477.

Neuromus 51.

Newelstoia 148.

Nidularium 800

Ninox 210, 329.

Niobc 24.

Nirmus 542.

$\mathrm{Nit}$ i dulida e 390 .

Nitncra 337, 594.

Nocarodes 111.

Noctiluca 743.

Noctua 558.

Noctuae 145.

Noctuidae 116, 150, 554, 558, 559, 768.

Noerneria 311.

No lidae 150.

Nonotettix 110.

Nornianella 345.

Nosema 679.

Notaspis 411.

Notholca 284, 285, 576.

Notochelys 832.

Notodonta 863.

Notogonia 285.

Notomenia 823.

Notonecta 407, 485-487.

Notontidae 150 .

Notophallus 311.

Notopleura 113, 116.

Notops 672.

Tucula 823.

$\mathrm{N}$ uculida e 823 .

Numenius 281.

Numida 439.

Nuttallina 828.
Nyctea 510.

Nycticorax 205.

Nyctiphanes 286, 674.

Nyctotherus 589.

Nymphalidae 150 .

Nymphaster 651.

Nymphicus 354.

Nysins 543.

\section{0.}

Oblata 852 .

Ocadia 832.

Ochetotettix 110.

Ochrilidia 111, 116.

Ocneria 151.

Ocneroles 116.

Octopus 611.

Odonata $31,49,768,773$, 777.

Odontaster 75.

Odontomachus $262,26:$.

Odontomelus 109.

Odontoperna 61.

Odontophorus 209.

Odontoxiphidium 36.

Odontura 116.

Odynerus 386, 721, 726.

Oecanthus 39, 40 .

Oechalia 543.

Oecophylla 219.

Oedalens 111, 1!6.

Oedemagena 144.

O ed e m erida e 56.

Oedipoda 111, 116,873.

Oed i podida e $42,111$.

Oenothera 731.

Oestromyia 144.

Oikopleura 286, 339, 826.

Oikopleurina e 339 .

Olemira 51.

Oliarus 543.

Olocrates 617.

Onchidium 297.

Onchometopus 24.

Oncocnemis 558.

Oncomyia 790.

Oneirophanta $14 \%$.

Onos 341.

Onuphis 296.

Onychocamptus 672 .

Onychoteuthis 745 .

Oodeopus 286.

Opalina 589.

Opalinidae 591 .

Operculina 511.

Opetiosaurus 202.

Opheliudae 702 .

Ophiacantha 77 . 
Ophiactis 7.5.

Ophidiidae 651.

Ophioacthiops 76.

Ophiocreas 6.51.

Ophioglypha 75. 84, 300, 651.

Ophiogomphus 777.

Ophiomusium 75, 84 .

O p h i o n id a e 169.

Ophionotus 75.

Ophiopholis 2.

Ophiophycis 84.

Ophiopteron 76.

Ophiostcira 75.

Ophiozona 75.

Ophisaurus 204, 831.

Ophiura 300.

Ophomala 111.

Ophonus 162.

Ophryoglena 375, 589.

Ophryotrocha 297, 823 .

Ophryoxus 673.

Opisthocomus 804.

Opisthocosmia 107, 108.

Op is thorch i illa e 52.

Opisthorchis 519,818.

()isthotcuthis 651 .

Opsomala 111.

Orbiculina 511.

Orbillus 112.

Orbitolites 72, 511 .

Orbulina 674.

Orca 510, 675, 747.

Orchclimum 37.

Orchestia 597, $86 \%$.

Oreula 142.

Orcomyza 205.

Orgyia 433.

Oria 703.

Or ibatidae 92 .

Ormenis 547.

Orphulclla $39,40$.

Orthagoriscus 519,575

Ortheria 544.

Orthis 762 .

Orthocladius 337.

Orthocraspeda 531, 5.32.

Crthoca 543.

Orthoyonius 483.

Oithomorpha 30 .

Orthotylus 543.

Oryxa 547.

Oscanius 650

Oscarella 515.

Oscillatoria 411.

Osmerus 340, 392, 80..

Osmia 274.

Ostrea 867.

Ot id ida e 175.

Otis 325 .

Otocoris 328, 510 .

Otumba 110.

Ovibos 281.
Ovis 129, 178, 315, 317, 336, $452,568,6: 30-632$.

Oxaea 717.

Oxus 194, 431.

Oxya 111.

Oxycnemis $55 \mathrm{~s}$.

Oxyglossns 885 .

Oxyolena 109.

Oxypolella 658, 659 .

Oxypolia 658, 659.

Oxyrhina 519.

Oxysoma 420.

Oryuris $420,517,700$

I'.

Pachastrellidae 135.

Pachycalamus 199.

Pachycondyla 262, 263.

Pachydactylus 198.

Pachynematus :31.

Pachytilus 116.

Pachytylus 111, 279, 452. 768.

Paecilasma 745.

Pagophila 510.

Pagurus 133

Paelopatides 89.

Pagurida e 651.

Palaemonetes :309.

Palaeomcryx 70.

Palacopncustes 86, 651.

Palaeopsylla 860.

Palacoreas 70.

Palaeornis 354.

Palaeothrips 819.

l'alhyacna 70.

Paliohieracinae 355.

Paliohicrax 355.

Pallasiella 340.

Palndina 94, 289, 361, 362, 489,849

Pa m p ha ida e 111, 116.

Pamphagus 111, 116.

Pamphila 559.

Pandalus 338.

Pancsthia 114.

Pannychia 89.

Panorpa 530.

Papilio 664-666.

Papilionidat 150 .

Papilus 768.

Papyrula 515.

Paracaloptenus 111.

Paracamelus 70.

Parachalcides 199.

Parachordodes $756^{\circ}$.

Paracinema 111.

Paracletus 5.
Paracoccidium 614.

Paracromna 547.

Paradesmus 871.

Paraflata 547.

Paragonaster 675.

Paragordius 878.

Parajapyx 770. 771.

Paralimnadia 346.

Paralimnus 546.

Paramaecium 375, 406, 585590.

Paramermis 757.

Parametopa 337.

Paramuricea 418.

I'aranephthya 696.

Paranortes 163.

Paranotus 547.

Paranthessius 764.

Paranurus 166.

Parapagurus 745.

Paraphyllina 463 .

l'arapleurus 111.

Parapodium 197.

Parapolia 659

Pararchaster 651 .

Pararga 726 .

Paraspongodes 694, 696.

Parastephos 764 .

Paratella 547.

Paratettix $39,40,110,111$. 116.

Parathiscia 547.

Parbosclaphns 70.

Parelpidia 143

Parcuprepocnemis 111.

Parinia 399.

Parnassius 664-666

Parnidae 56 .

Paroriza 89.

Parthenothrips 819.

Parus 281.

Pasiphaea 286

$\mathrm{Pas}$ s a $\mathrm{l}$ in i 390.

Passer 123, 330, 331, 397, $510,565,598,686-689$.

Passiflora 717, 732.

Patella 297.

Patellida e 823.

Patlaxia 706.

Paullinia 717.

$\mathrm{P}$ a us s i d e $390,483,530$.

Paussus 483.

Paía 439.

Pavonaria 418.

Paxilla 110.

Pecteu 297, 867.

Pectinaria 704.

Pectinidiscus 651.

Pectunculus 297.

Pedicellina 2.

Ped i c u l a t i 651 .

Pedinosoma 286. 
Pelagia 463, 575, 674.

Pelagohydra 18.

Pelagoby dridae 18.

Pelagonemertes 651.

Pelagophlus 161.

Pelagothuria 651.

Pelecanus 853.

Polecinid a e 93

Pelecus 805.

Pelias 322, 566, 601.

Pelicinizes 207.

Pelmatellin i 159.

Pelobates 807.

Pclochelys 832.

Pelodera 423.

Pelomedusa 891.

Pelomyxa 414.

Pelonaia 496.

Pelopaeus 768.

Pelopatides 143.

Peltocephalus 891.

Peltophora 537.

Penelope 65.

Peneroplis 72. 511.

Peniagone 143.

Pennaria 18, 100, 460.

Pennaridae 18

Pennatula 418.

Pennatulida e $418,651$.

Pennula 205.

Pentacrinus 651.

Pentagonaster 651.

Pentagonasteridae 651 .

Pentaphis 5.

Pentatemon 726.

Pentat omida e 536.

Penthaleus 311.

Pentodon 5.

Pentophonus 161.

Peperonia 800.

Perameles 893.

Perca 295, 392, 805.

Percichthys 59:3.

Percosteropus 163.

Periamma 143.

Pericolpa 463.

Pericrocotus 208.

Peridinea e 339.

Peridinium 284, 288. 339, $410,413$.

Pcridroma 559.

Perigonimus 18.

Perinereis 20.

Peripatus 297.

Periphylla 463, 651.

Periplaneta 39, 40, 114, 116.

Peripsocus 774.

Perixerus 39, 40.

Perlida e 51.

Perna 61.

Persephonaster 651.

Petaloptera 39, 40.
Petal urid a $\theta 49$.

Petauroides 804.

Petaurus 804, 893.

Pctiolurus 431.

Petraca 717.

Pctromyzon 118, 127, 172, $313,360,393,436,805$, 886.

Pezotettix 111.

Phaedolus 547.

Phaeton 565.

$\mathrm{Ph}$ a l a crocoracida e 175.

Phalacrocorax 95, 397, 651.

Phalanger 283.

Phalangium 439.

Phalaropus 281.

Phalcobaenus 355.

Phalcra 147, 552.

Phaneropteridae 36.

Phantia 547.

Phascolion 745

Phascolodon 410.

Phascolosoma 674.

Phasianidae 175 .

$P h$ a $s m i d a \theta 45$.

Phasmode a 39, 40, 114.

Pheidole 171, 251, 265, 479, 718,798

Phellus 768.

Pheretima 871.

Phcronema 651, 745.

Philemon 398.

Philopotamus 51.

Philotarsus 774.

Phlcboptcrum 547.

Phlepsius 546.

Phlocerus 111.

Phloe othripidae 819 .

Phlocothrips 819.

Phlyctaenodes 153.

Phoca 510.

Phoenicopterus 439 .

Phocnna 345.

Phora 779

Phoracantha 768.

Phorbia 349.

Phoridae 725, 779.

Phornosoma 86, 651.

Phoronis 100.

Photodilus 329.

Phoxinus 805.

Phragmites 721.

Phrissocystis 86.

Phrixa 39, 40.

Phronimella 286.

Phryganeidae 500 .

Phryganidae 407.

Phryniscus 439.

Phrynocephalus 601.

Phrynonax 889.

Phycodromida e 784.

Phycopsis 186.
Phyllirhoe 300.

Phyllobothrium 697.

Phyllochaetopterus 701.

Phyllodactylus 199.

Phyllodocidae 706 .

Phyllodromia 349.

Phyllognathopus 594.

Phyllonotus 110.

Phyllopertha 158.

Phyllophora 114.

Phyllophorus 142.

Phylloptera 39, 40.

Phylloxera 819.

Phyllyphanta 547.

Phyma 547.

Phymateus 111.

Phymateidae 111 .

Phymatidae 111 .

Phyniatodesmus 30.

Physalia 575.

Physophoridas 651 .

Physopus 819.

Physostomum 542.

Phyionomus 43.).

Phy to ptidae 92, 708.

Pica 123.

Picidae 65.

Picumnus 209.

Pieus 95.

Pieridae 150 .

Pieris 147, 312, 552, 559, 726, 768 .

Pilidium 857.

Piona 194, 196, 431, 478, 529.

Piroplasma 679.

Piscnoe 20.

Pisorhina 208, 329.

Pitta 210.

Pittasoma 209.

Pithecanthropus. 509.

Placobdclla 679.

Placocephalus 871.

Placosoma 514.

Placospongia 140.

Placunella 525.

Plagiolepis 171, 251, 479, 798.

Plagioplatys 163.

Plakinidae 515.

Planaria 104, 344, 407, 652.

Planorbulina 511.

Plasmodium 17.577, 578, 594, $585,680,685,689$.

Platagrotis 557.

Plataleidae 175.

Platyblcmmus 116

Platycephala 488.

Platycleis 116.

Platydactylus 353, 830.

Platygaster 729.

Platylabia 107, 108.

Platylistrum 651.

Platymaja 651. 
Platynereis 20, 304, 706.

Platyonychus 698, 699.

Platyphora 779.

Platyphylax 51.

Platyphyma $1 \mathrm{J6.}$

Platypsyllus 345.

Platypterna 111, 113.

Platysaums 198.

Platysenta 5.58.

Platysma 163, 165, 166. 167.

Platysmatin i $163-167$.

Platystolus 116.

Platystrophia 762.

Platythorus 110.

Plantia 537.

Plecoptera 31.

Plectronotus 110.

Plectrophanes 510 .

Ptcetrotettix 39, 40.

Plerocercus 191.

Plesiadda. 70.

Plesionika 674.

Plesiozonus 86 .

Plcthodon 602.

Pleuariodes 543.

Pleurobranchaea 650.

Pleurocorallium 418.

Pleurocoralloides 418

Pleurodeles 502.

Pleuromma 745.

I'leuronectes 319, 744.

Pleuronectida e 392.

Pleurosauns 202.

I'lcurotomaria 8:3.

Pleuroxus 407, 673.

Plexaurides 418.

Ploceus 208.

Thusia 559

Plutellida e 150 .

Plutonaster 675.

l'odagra 558.

Podarke 105, 427.

Podargid a e 210 .

Podargus 210.

Podicipedidae 175.

Podismea 111.

Podismini 111.

Podium 197.

Podoenemis 891.

Podomyrmer 768.

Podon 345, 662

Podoscirtus 114.

Poceilocerus 111.

Poceilofata 547.

Poecilosoma 723.

Pockilloptera 547.

P'ogonomyimex 266.

Polichne 114.

Poliopsis 659.

Pollicipes $4 \times 9$.

Polyartenia 306.

Poly artemiidae 306.
Polyarthra 284, 285, 404, 411, 748.

Poly borina e 355 .

Polyborus 355.

Polyeelis 407.

Polycentropus 51.

Polychaetus 285.

Polychoerus 654.

Polyclinidae 825 .

Polyclinum 825.

Polydesmidae 30 .

Polydora 304, 704, 706.

Polyergus 233,236,258,259,261.

Polygnotus 796.

Polymnia 591.

Polyodontophis 201.

Poly phemidae 662 .

Polyphemus 662.

I'olyphylla 5, 158.

I'olypodium 18.

Polyprion 745.

Polypterus 292, 735.

l'olystomella 511.

l'olystomum 379, 740.

Polysyneraton 808.

I'olyzosteria 114.768.

Ponera 262, 263.

Ponerina e 220, 221, 234, $262,263,266$.

Pontaster 651.

Pontella 674.

Pontobdclla 297.

I'ontoporcia 340.

Pontosaurus 202.

Poraniomorpha 77.

Poritidae 692

Porocidaris 86, 6.51.

Poroplulocus 547.

I'orpita 674.

Portea 800.

I'orthesia 151.

Porzellanast erida 0651 .

Potamilla 305, 702.

Potamobins 439.

Potamocypris 767.

Pourtalesia 651 .

Pourtalesiidae 86 .

Praniza 683.

Praxithea 20.

Prionidae 768 .

Prionocneminae 539.

Prionoxystus 349.

Pristiophorus 851.

Pristiurus 335, 359-362.

Pristurns 190.

Procarimina 6.58.

Procell a riida e 330.

Prochactoderma 823.

Procotyla 344.

Proctotrupidae 93,259 , 776.
Prodajus 674.

Prodiens 28.

Proformiea 798.

Progomphus 49.

Proja pygidae 769.770 , 771.

Projapyx 769-771.

Promenia 304, 706.

Pronematus 311.

Proncomenia 823.

Prophyscma 455.

Prorodou 589.

Prorospora 604.

Prosobothrium 190.

Prosopis 721 .

I'rosopomyia 781

Prosthogonimus 524.

Proxymna 201.

Protankyra 14:3.

Proteosoma 14, 680, 686689.

Protetraecros 70

Proteus 279, 506.

Protococeus 41:3.

Protodrilus 82:3.

Protohydra 592.

Protopterus 293, 7.,5.

Prumna 111.

Prunus 151.

Psalis 108.

Psallus 549.

Psammaplidinm 825.

Pseu 723.

Pseudarchaster 651.

Psendobos 70.

Psendoceles 111.

Psendocheylus 311.

Pseudoclerada 543.

Pseudococens 349.

Pseudodiehthadia 222, 2:34.

Psendollata 547.

Pseudomernis 42:, $75 \%$

Pseudomesochra 345 .

Pseudomyima 237.

Pseudonereis 20.

Pseudoperla 51 .

Psendopsyllus 345.

Psenuloptymx 210.

Pseudosperchon 478.

Pscudospirillum 411.

Pscudostichopus 89, 143, 675.

Pseudothrips 819.

Psittaeus 3.54

Psittirostra 206.

Psocida e 51, 280, 774 775.859

Psocus 51, 774, 775.

Psolus 14:.

Psophus 111.

Psyche 43:.

$\mathrm{Ps}$ y ch i d a e 150

Psychoda 778. 
Paychropotes 89, 143.

Psychropotidae 143.

Psylla 539.

P sy 11 i d a e 539, 708, 768.

Psyllinae 539 .

Pteris 117.

Ptcrnoscirta 111.

Ptcrocephalus 299.

Pterodela 51, 774.

Pteroides 418.

Pteroidid a e 418.

Pterolichus 92.

Pteromalidae 729.

Pteromalus 729.

Pterumys 510, 804.

Pterophoridae 150.

Pterostichus 167.

Ptetica 111.

Pteruthins 208.

Ptilopsocina e 775 .

Ptilosarcus 418.

Ptychocyclis 575.

Ptychoder idae 475.

Ptychozoon 804, 888.

Puffinus 565.

Pulex 821, 860, 877.

$\mathrm{Pul}$ icida e 530.

Pulvulina 674.

Pupa 291.

Putorius 568.

Pycnogonidae 357, 651, 745 .

Pycnonotus 208.

Pygacra 48?.

Pygidicrania 108.

Pygodon 30.

Py ralid a e 150, 15.3.

Pyrameis 559.

Pyrgocorypha 39, 40.

Pyrgodera 111.

Pyrgomorpha 33, 111, 112, 116.

Pyrgomorphida e 111 .

Pyriglena 209.

Pyrochroidae 56.

Pyrrhocoris 530.

Pyrrhula 208.

Pyrrhura 354.

Python 420, 888.

l'yxidea 832.

Pyxinia 620.

Pyxis 891.

\section{Q.}

Quercus 281.

Quirogesia 111.

IR.

Raja 128, 341, 358, 360-302, $675,683,886$.
Rapidae 317 .

$\mathrm{Nr}$

Rallida e 175 .

Rallus 65, 205.

Ramburia 111.

Rana 3, 58, 62, 72, 73, 94, 122, 198, 204, 314. 360 , 393,448 . 506, 517, 598, $601,613,614,676,677$, $807,828,831,85 \%, 8.66$, 888.

Rangifer 281, 510, 568.

Ranodon 601.

Raphidium 411.

Raphidothrips 819.

Reduviolus 543.

Reniera 185, 376, 459, 513.

Renillid a e 418 .

Retropluma $65 \mathrm{~L}$.

Rhabdammina 651.

Rhabdamminida e 72 .

Rhabdastrella 186.

Rhabditis 858.

Rhabdoncma 700.

Rhabdophaga 349 .

Rhabdostyla 375, 410.

Phachidorus 114.

Rhachotropis 286.

Rhacoclcis 116.

Rhaconotus 168.

Rhacophorus 804, 888.

Rhadinotatum 109.

Rhagidia 311.

Pheinardius 208.

Rhina 341.

Rhinoceros 70.

Rhinocricus 30.

Rhinophantia 547.

Rhinoternes 480, 482.

Rhipicephalus 26.

Rhipidura 398.

Rhizarcha 31.

Rhizocrinus 651.

Rhizoglyphus 92.

R h i z o m orin ida e 135 .

Rhizophysidae 651.

Rhizorbina 345.

Rhizostoma 463.

$\mathrm{R} \mathrm{hiz} \mathrm{os} \mathrm{t} 0 \mathrm{mid}$ a 8463 .

Rhizotrogus 158.

Rhodacanthis 206.

Rhodozona 803.

Rhombodera 114.

Rhomalea 39, 40.

Rhopalea 650.

Rho paloe ra 145.

Rhopalodinida e 143.

Rhopalosiphum 561.

Rhopalus 543.

Rhozites 240.

Rhyacophila 51.

Rhy a c o philidae 51 .

Rhynchelmis 426, 740 .
Rhynchitcs 5.

Rhynchobolus 296, 705.

Rhynchocyclus 209.

Rhynchodcmus 871.

Rhynchofalco 355.

Bhyncholophus 27, 430.

Rhynchortyx 209.

Rhynchostruthus 397.

Rhyopsocus 775.

Rhy s odida e 390 .

Rhyzomys 388.

Ri can i i d e 547.

Richardina 674.

Rimacephalus 344.

Riissa 510.

Roederiodes 31 .

Rossellida e 514 .

Rossia 494.

Rudbeckia 726.

Ruticilla 330.

Rynchospora 717.

Sabella 297, 304, 706.

Sabellaria 304, 706.

Sabellida e 703, 706 .

Saecocoelium 523.

Saccopharynx 651.

Sacculina 429.

Sagartia 841.

Sayitta 286, 651.

$\mathrm{Sag}$ rinae 390 .

Saiga 144.

Salamandra 94, 122, 314, 317, $505,506,564,807,831$.

Salamandrella 601.

Salamandrina 322.

Salenskya 345.

Salmo 98, 279, 285, 500, 510, 805.

Salmonida e $295,319,391$, $882-854$

Salpa 575, 825, 827.

Salurnis 547.

Salvia 726.

Sambucus 723.

Samia 863.

Sanurus 547.

Saperda 349, 351,

Saproglyphus 92.

Sapromyzidae 784 .

Sarcophaga 867.

Sarcophytum 695.

Sarcoptes 92.

Sarcoptidae 92.

Sargus 782, 852.

Sarsia 100.

Sarsiella 345.

Saturnia 664-666. 
Saturniida e 150.

Scalpellum 651 .

Sca phididae 56.

Scaphoideus 546.

Scapholeberis 673.

Scarabaeida e $56, \quad 390$, 768.

Scal'abaein i 390 .

Scardinins 805.

Scaria 110.

Scariles 881.

Scarpanta 547.

Scarpantina 547 .

Scarposa 547.

Scelionidae 31 .

Sceloglaux 329.

Scenopinus 782.

Schistocerca 34, 39, 40, 111 , 113. 116.

Srhizocerca 405.

Schizochiton 823 .

Schoenus 864.

Sciara 780.

Scintharista 1'1, 116.

Seionlyzidae 784.

Sciomyzinae 784 .

Scirpearia 675.

Scirnla 311.

Scirus 311.

Scinrapterns 568.

Scinropterus 669, 804.

Sciurus 178, 420.

Sclcria 711.

Scleritoderm idae 135.

Scleronephthya 696.

Scleropliytum 695.

Sicolecitlirix 345.

Scolecocampa 5.54.

Scoliorhaphinidae 135.

Scololepis 474.

Scolopar 330.

Seolopendra 299.

Scolothrips 819.

Scolytus 349. 880.

Scoly tidae 56,390 .

Scombresox 675.

Sco pelid a e 286, 651, 674 .

Scopelus 286.

Srops 829, 397.

Scotonnassa 89, 148.

Scotoplanes 89, 143.

Scudderia 36, 39, 40.

Scutelleridat 537 .

Scutcllina 823.

S c y lli i d a e 292.

Scyllium 360, 608. 688, 886.

Seyramathia 651, 745.

Sebastes 675.

Selenococens 411.

Seliza 547.

Semiophora 557.

Semperella 651 .
Senccio 780 .

Sencx 355.

Sepedon 31, 784.

Sephena 547.

Sepia 2, 611.

Sepiola 286, 296.

Seps 517.

Septoria 5.

Septosporium 250.

Sergestidae 674.

Sergia 286.

Sergestidae 651 .

Sericostomatidae 51.

Sericothrips 819.

Serinus 686-689.

Serpa 204.

Serpulidae 23, 702, 706, 823.

Sertularidae 817 .

Sesiidae 150.

Setella 286.

Shelfordia 656.

$\mathrm{S}$ i a lid a e 31,51 .

Sialis 51, 530.

Sida 407.

Silphidae 56 .

Silvestria 593.

Simia 757.

Simocephalus 201, 411.

Sinularia 695.

Siphanta 547.

Siphnens 70.

Siphonogorgia 694.

Siphonogorgida e 696 .

Siphonogorginae 696.

Siphonophora 5.

Siphonostoma 296.

Sipunculus 2.

Siscia 547.

Sisyra 31.

Sitotroga 152.

Sitta 208.

Siva 208.

Sivatheriina 70 .

Simerinthus 664-666.

Sminthurus 349.

Sminthus 568.

Solanum 551, 717.

Solaster 77.

Solea 683.

Solenocaulon 694.

Solenopsidii 277.

Solenopsis $171,240,259,265$, $277,718,798$.

Somateria 510.

Sorcx 62, 568, 860 .

Sorocelis 344.

Spadella 297, 674.

Spalax 388, 437, 835.

Sparganum 854.

Sparattia 39, 40.

Sparidae 63.
Sparmannella 710.

Spartina 867.

Sparus 600.

Sipelerpes 122.

Sperchon 478.

Spermophilus 5, 356, 568, 669 .

Sperosoma 651, 745.

Speziapteryx 355.

Sphaerastrum 411.

Sphaercchinus 103, 843, 844.

Sphaeromimus 30.

Sphaeropaeus 30.

Sphaerotheriida 30 .

Sphaerotherium 30.

Sphaerothuria 143.

Sp ha erozo id a e 674 .

Sphagnum 411.

Sphecina e 197.

sph e g i d a e 93.

Siphenarinm 39, 40.

Sphenodon. 565.

Sphenoptera 155-157. 389.

S p h i n g e s 145.

S p hingida e 116, 150, 559,873 .

Sphingonotus 111, 113, 116.

Sphin. 66t-666, 862.

Sphodromerus 111, 113.

Sphodropoda 114.

Spinitermes 48\%.

Sp i o n id a e 702, 704, 706.

Spirocypris 767.

Spiromanes 30.

Spiromimus 30.

Spiroptera 423.

Spirorbis 304, 706.

Spirostomum 375, 411. 588590.

Spirostreptus 30.

Spirostrophus 30.

Spirula 651.

Spondilus 297.

Spongelia 512, 679.

Spongilla 185, 457.

Spongiphora 107.

Spongocardium 134.

Spongodes 465, 694, 696.

Spong od ina e 696 .

Spongodrymus 674.

Sporotrichum 351.

Squ a li d a e 317.

Sqnalius 190.

Stachytarpheta 732.

Stagmomantis 39, 40.

Staphylinidae 56,483 , 867.

Staphylinus 434, 489.

Stanrocephalus 296

Stauronotus 111, 113, 116.

Steenstrupia 18.

Stegodon 70.

Stegomyia 678, 781.

- Genus- und Familien-Register. 
Stegosoma 286.

Siellctta 515.

Stelospongia 75?.

Stenamma 231-233, 251.

Stenhelia 345.

Stenobothrus 33, 111, 116.

Stenomorphini 159.

Sicnopelmatus 39, 40.

Stenopogon 790.

Stenopsocus 7Tt.

Stenostoma 411, 657, 817, 848.

Stenoteuthis 675 .

Stenolhoe 337.

Stenotlo ida e 335

Stenox en id a e 785 .

Stentor 375, 467, 537-590.

Steph a n id a e 93.

Stcplianotrochus 745 .

Stephos 764 .

Stereopneustes 86.

Stercorarius 510.

Stereocidaris 651.

Sterna 510.

Sternopatagus 86.

Stcrnoptyx 745.

Sternothaerus 203, ๖ธ9, §91.

Sietheophyma 111.

Stethopat hidae $779,785$.

Stethophyma 116.

Stichopus 89, 142, 143.

Stichotricha 375.

Stigmatomma 263.

Stilesia 469.

Stilpnochlora 39, 40.

Stipa i.

Stizostcdium 805.

St o miatidat 6.51 .

Stomoxys 879.

$\mathrm{Str}$ at iom y ida e 31 .

Stratonice 20.

Strepsiceros 70.

Strigida e 330.

Stringops 354.

Strix 95, 329, 330, 688, 689.

Strongylocentrotus 102,842 , $843,844$.

Strongulognatius $236, \quad 259$, 798.

Strongylus 517, 858.

Stropis 114.

Strumigenys 26.5.

Strumiger 111.

Stryx 123.

Sturnidae 175.

Sturnus 423, 56.5.

Styela 803 .

Styclopsis 801, 802.

Stygia 148.

Stylaria 297.

Stylatulidae 418 .

Stylocheiron 651.

Stylonychia 588, 589, 590.
Stylopyga 114.

Stylorhynchus 29s.

Suberites 133, 183-185, 513.

Sula 565.

Sulamila 543.

Sus 70, 129, 178, 191, 212, $317,336,623,649,892$.

Suya 208.

Sycandra 182.753.

syllidae 706 .

Syllideat 308 .

Syllis 297, 30:.

Sylviidae 175 .

Symmetropleura 39, 40.

Sympagclla 514.

Sympetrum 757.

Symphoricarpus 726.

Sympiegma 803 .

Synallactes 143.

Sylla llactidae 143.

Syrallact inae 89.

Synaphobranchus 745.

Synapta 14:. 867.

Sy naptidae 143 .

Syncarpiolyma 539.

Syncorync 100.

Synedra 375.

Syntechna 39, 40.

Syrbula 39. 40.

Syrnimm 329.

Syrphidae $5.727,768$.

Syrphus 726, 727, 819.

Systena $34 y$.

'.

Tachinae 1 jol.

Tachycineta 66.

Tachydromus 888.

Tachyophonus 161.

Tachyoryctes 388.

Tacnia 191, 470, 670.

Taeniocampa 554, 558.

Taenioporla 39, 40.

Tagalina 107.

Talorchestia 867.

Talpa 213, 333, 423, 568, 639,860 .

Tamias 568.

Tanymecus 5.

Taonius 675.

Taphrometopon 601.

Tapinoma 171, 251, 798.

Tapirus 70, 129.

Tarbophis 204, 394.

Tardinulus 208.

Tarsonemidae 92 .

Tauschira 114.

Taxonus 31.

Teara 768.
Tecoma 732.

Tegenaria 598.

Teleas 729.

Telenomus 31.

Tclesto 694

Telmatcti: $39,40,110$.

Telorchestia 597.

Telyphonus 2.

Tcrebrio 650.

Tenebrioniade $56,776$.

Tenthredinidae 31,54 , 93,795 .

Teracolus 148.

Terebellidae 702, 703, 706.

Terias 768.

Termes 479, 480, 482, 776.

T e r m it id a e 51, 768 .

Term it in a e 480 .

Termitoxenia 483.

Testudinldate 832.

Testudo 199, 601, 651, 806, $830-832,888,891$.

Tet a ll o cerilla e 784 .

Tethya 184, 185, 186, 515.

Tetilla 691 .

'T'etillia a e 134,515

Tetrabothriidae 190 .

Tetracha 768.

Tetracladinidae 135.

Tetragoniceps 345, 764 .

Tetramornum 171, 251, 259, 387, 479, 798.

Tetrao 510, 869.

Tetrapedia 717.

Tetrastes 510.

Tetrigidae 111.

Tetrix 111.

Tettigidae 110.

Tettigidea 39, 40, 110.

Tettig in a e 110.

Tettigonia 543.

Tettig o n id a e $39,40$.

Tettix 110.

Thalassema 427.

Thatassicolla 6it4.

Thalassiosira 575.

Thalassochelys 199, 832.

Thalassophis 888.

Thalestria 732.

Thalcstris 337.

Thalpomena 111.

Thamnastraea 343.

Thamnophilus 209.

Thamnotettix 546 .

Thaumaleus 345.

Thaumatops 651 .

Thecla 559.

Thecosmilia 343.

Thecosiphonin 136.

Thelcpus 304, 706.

Theneidae 135. 
Thesclytes $39,40$.

Therioplectes 790 .

Thiscia 547.

Thisoecctrus 111.

Thisoicetrus 116.

Thoosa 377 .

Thorsa 20.

Thripidae 819.

Thrips 819.

Thrixion 488.

Thryonomys 96.

Thuja 153.

Thuricola 375.

Thyas 92.

Thyatira 558.

Thymallus 80.5 .

Thynnus 518, 675, 745.

Thyone 75, 14.3.

Thyreopus 720.

Thyromygus 30.

Thyrsoccra 39, 40.

Thysanopoda 286

Thysanosoma 469.

Thysanozoon 187, 188, 189.

Tiare 15.

Tiarclla 18.

Tichobia 77 t.

Tifia 158.

Timarcha 58.

Tinamus 209.

Tilica 120, 805.

Tineidae $150,531,532$.

Tinnunculus 35.5 .

Tintinuidae 339 .

Tintinuopsis 672.

Tintinnus $\div 5$, 651 .

Tiplia .).

Tipleys 194, 431.

Tipulidae 782, 788.

Titropis 114.

Imethis 111.

Tolaropsis 494.

Tomistoma 888.

Tomognathus 259.

Tomonotus 39, 40.

T o mopteridae 651 .

Tomopteris 674.

Tornaria 475.

Torpedo 119, 651.

Tortricida e 150 .

Totanus 66.

Toxopncustes 844.

Trachelina 411 .

Trachelophyllum 287.

Trachurus 675.

Tragoceras 70 .

Tragulida e 569 .

Trcchus 388.

Tremer 351.

Triaenodon 565.

Triarthra 284, 414.

Trichcchus 510, 833 .
Trichodectes 87\%.

Trichopelterium 651 .

Trich opselaphin i 159.

Trichopsocus 859.

Trichopteryx 530.

Trichosoma 517.

Trichostemma 139.

Trichotarsus 92.

Trichothrips 819 .

Tricorythus 51.

Tridactylus 116.

Trigla 600.

Trigona 384. 732, $733,795$.

Trigonalida e 93.

Trigoniulus 30.

Trigonocephalus 279.

Trigonometopus 784.

Trigonopsis 197.

Trilophidia 111.

Trimerophorella 193.

Trimerophoron 193.

Trimcrotropis $3439,40$.

Trinchus 111.

Tringa 510.

Trionyx s08, 832

Triplilcps 543, $\$ 19$.

Triplotaenia 90.

Triou y chida e 396 .

Trionyx 396, 891.

Trioza 589.

Triozina e $5: 39$.

Triton 3. 62, 72. 94, 122, 314, 393, 502. 807 .

Tritonium 650 .

Trochalopteron 20 .

Trochidae 823.

Trochilidae 6.5, 717.

Trochophrra 297.

T'rochopus 525.

Trochosphacra 823 .

Trochostoma 143.

Trochus 493, 823.

Troctes 774.

Troctus 775.

Troglodytes 65.

Trogodendron 768.

Trombididae 92 .

Trombidiida e $92,311$.

Trombidium 529, 819.

Tromopteris 286 .

Tropeopeltis 156 .

Troprdauchen 111.

Tropidocerus 163.

Tropidodcrus 114.

Tropidonotus 201, 317, 517, $601,830,873,888,889$.

Tropidopola 111.

Tror 389.

Truncaturus 431.

Trutta 295, 477, 500, 882.

'Tuxalidae 113.

Truxalis 39, 40, 109, 111.
Nr.

Trypanosoma $676,677,6<2$, 683.

Trypanosylli; 303.

Tryxalidae 111.

Tryralis 109, 111.

Tubcrcularium 30.

Tubifex 426, 740 .

$\mathrm{Tu}$ bificidae 380,760 .

Tubularia 18, 101, 840.

Tubularidae 18 .

Turcicula 745.

Turdida e 175, 866.

Turdus 399, 423, 866.

Turnix 420.

Tuscaloridae 651 .

Tydeus 311.

Tylenchus 5.

Tylobranclion 825.

Tylorhynchus 20.

Tylotettis 110.

Tyora 539.

Typhlatta 234, 235.

Typhlichthys 279.

Typhloceras 860

Typhlocyba 349 .

Typhlopone 234, 235.

Typhlops 199, 888.

Typhlopsylla 821, 860.

Typliloscolecida e 651 .

Typsilharpalus 161.

Ty rogly phidae 91.

'Tyrogly phinae 92 .

Tyrogliphus 92, 434.

I.

Ufcus 559.

Ulmus 281, 3 šl.

Ulula 51.

Umbellula 651.

Umbellulidae 651 .

Umbrella 493, 650 .

Uncinaria 468.

Unionidae 449.

Urana 547.

Uria 510.

Uroceridae 93.

Urocricctus 669 .

Urostyla 375.

Ursus 70, 279, 510, 568.

Uxantis 547.

\section{V.}

Vaccinium 794

Valcncinia 658, 659

Valencinida $\theta 659$.

Valencinura $658,659,660$. 
Valeria 554.

Valrata 340, 823.

Vanellus :330.

Vanessa 146, 147, 491, 552, $599,863$.

$\mathrm{V}$ aranidae $202,808$.

Varanus 199, 202, 470, 808, 888.

Vates 39, 40.

Velella 674.

Veronia 732.

Verruca 745.

Verticelladeae 651.

Vespa 724.

Vespertilio 279, 333, 385, 568 .

Vesperugo 401.

Vespida e $93, \quad 438, \quad 795$, 814.

Vioa 513.

Vipera 279, 868.

Virgularia 418.

Virgularidae 418.

Viverridae 177.

Viverrinae 177.

Volucella 726.

Volvox 586.

Vorticella 339. 375, 406, 411, $414,587$.

Vorticellidae 375.

Vulpecula 555 .

Nir.

Vulpes 70, 281, 568, 853, Nylocopa 732. 860.

W.

Wageneria 190.

Walkeria 547.

II'alteria 456 .

Wlassiesia 673.

Wolterstorffia 594

\section{I.}

Tanthia 555.

Tanthippus 42.

Xanthocalanus 345.

Tenia 694.

Tenobalanus 675.

Tenodermus 201.

Tenogaster 483.

Tenoglossa 731.

Yenophora 651.

Testocephalus 546.

Xiphidiini 37.

Yiphidium 36--40, 484.

Xiphocera 111.

Tylina 554.

Tylinoides $55 \%$.
Tylomiges 554.

Xylopagurus 651.

Nr.

Y.

Yoldia 340,805 .

Yponommeutidae 150 .

Ypsilothuria 143.

z.

Zabrachia 31.

Zamenis 199, 201, 204, 395. $681,830,831,888$.

Zarudnya 547.

Zelus 543.

Zenaidura 281.

Zeuglopteris 341.

Zeuzera 148, 349, 531, 532.

Zoogonus 521.

Zoothamnium 375.

Zoroaster 651 .

Zostera 18.

Zosterops 210.

Z y ga enid a e $150,437$.

Zygeupolia 658, 660 .

Z ygoptera 31 .

Zygothuria 143. 


\section{Berichtigungen.}

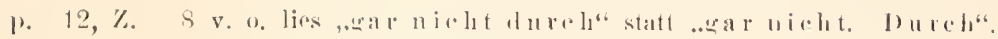

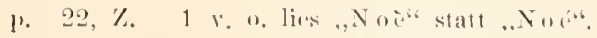

1. 62, \%. 2 r. o. lime ,degialites" statt ,Aegrimlitis".

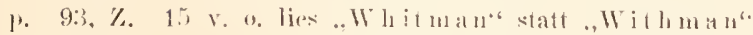

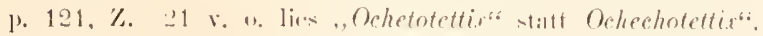

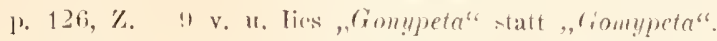

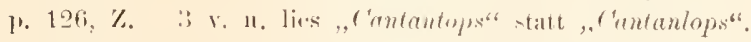

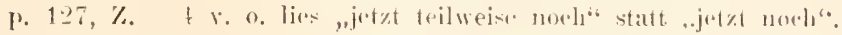

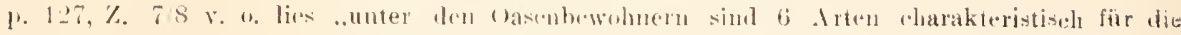

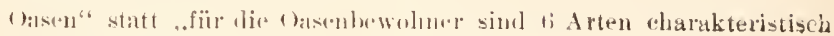
fiir thireltren".

1. 127. \%. 11 v. o. lies ,Sehistocereu" statt ,. Schirocerect".

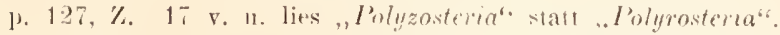

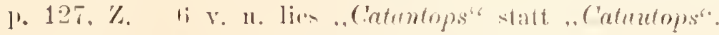

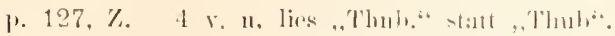

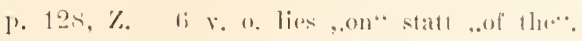

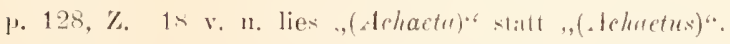

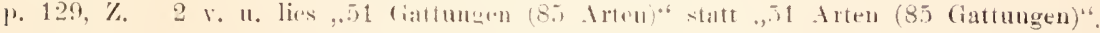

1. 180, \%. 15 v. 11. lies ., tunctamus." statt .lunetunus".

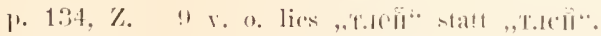

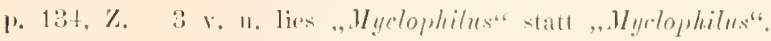

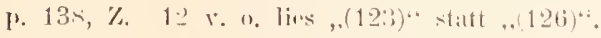

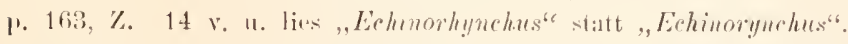

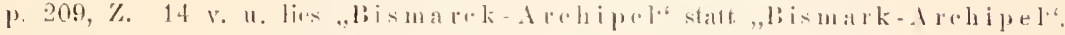

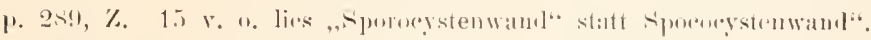

p. 294, \%. 26 r. o. lies ..kkman. s... statt , Wkman. S. vom".

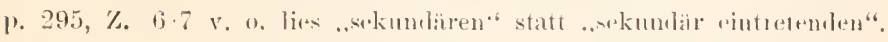

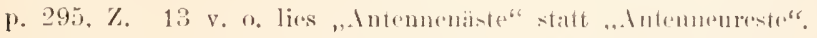

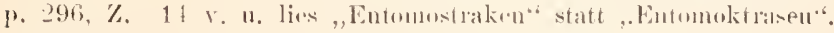

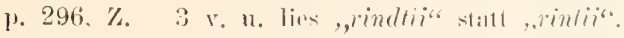

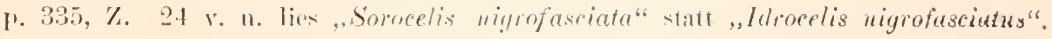

p. 335, \%. .2:3 v. u. lies, ,S. tigrima statt "T. grime".

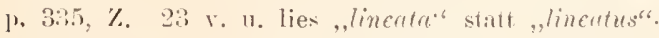

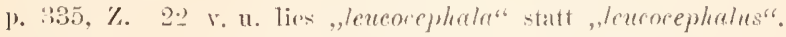

p. 33., Z. 2.1 v. u. lies "Irocotylu" statt. "Procolyles".

p. 335, \%. 21 ฯ. u. lies, "urmeta" start, "anuta".

p. 342, \%. !) r. o. lies, , I" statt, , s". 




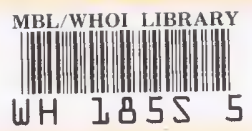


est 